\title{
LA-UR-17-24162
}

Approved for public release; distribution is unlimited.

Title:

33 Shafts Category of Transuranic Waste Stored Below Ground within Area $\mathrm{G}$

Author(s): $\quad$ Hargis, Kenneth Marshall

Monk, Thomas $\mathrm{H}$

Intended for: Report

Issued: 
Disclaimer:

Los Alamos National Laboratory, an affirmative action/equal opportunity employer, is operated by the Los Alamos National Security, LLC for the National Nuclear Security Administration of the U.S. Department of Energy under contract DE-AC52-06NA25396. By approving this article, the publisher recognizes that the U.S. Government retains nonexclusive, royalty-free license to publish or reproduce the published form of this contribution, or to allow others to do so, for U.S. Government purposes. Los Alamos National Laboratory requests that the publisher identify this article as work performed under the auspices of the U.S. Department of Energy. Los Alamos National Laboratory strongly supports academic freedom and a researcher's right to publish; as an institution, however, the Laboratory does not endorse the viewpoint of a publication or guarantee its technical correctness. 


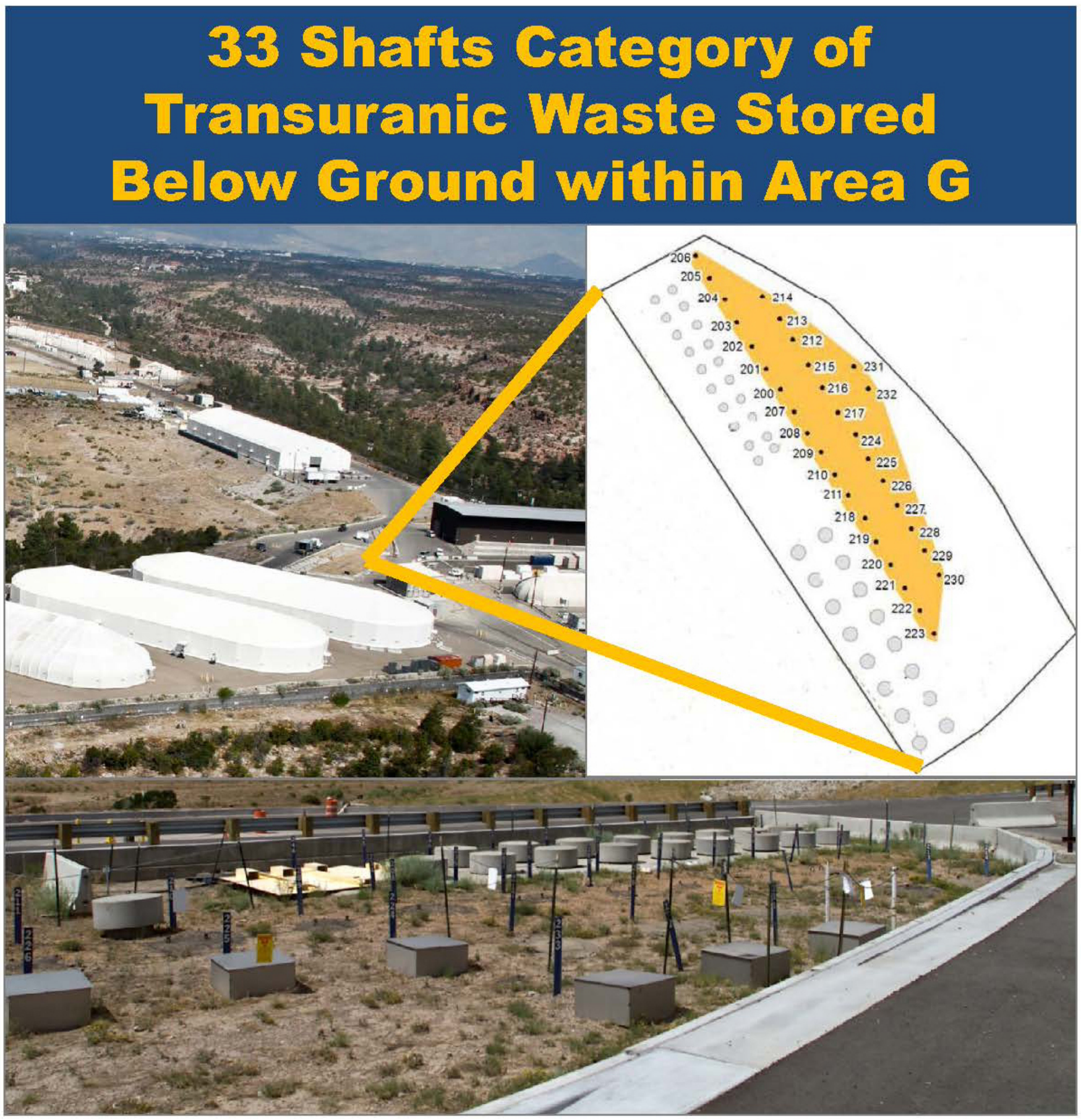

J anuary 2014 
This page intentionally left blank.

UNCLASSIFIED 
UNCLASSIFIED

Reviewing

Official:

Teri Tingey, REG-SP

Date: $1 / 23 / 2014$

\section{Shafts Category of Transuranic Waste Stored Below Ground within Area G}




\section{Authors}

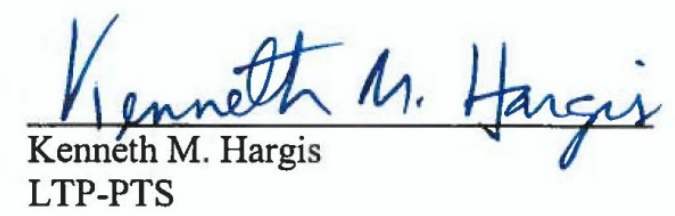

Kenneth
LTP-PTS

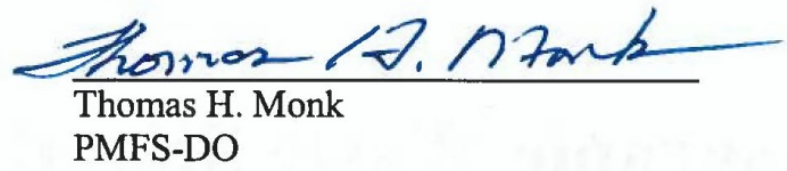

\section{Reviewers}

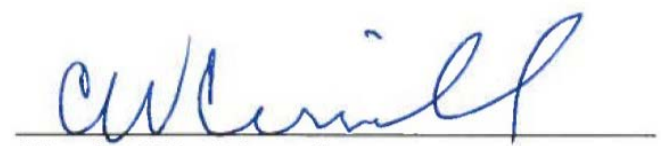

Charles W. Criswell

LTP-PTS

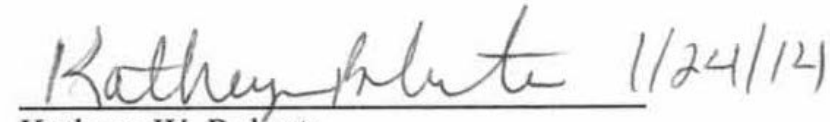

Kathryn W. Roberts

REG-SP 


\section{Table of Contents}

Table of Contents iii

Abbreviations and Acronyms

$\mathbf{v}$

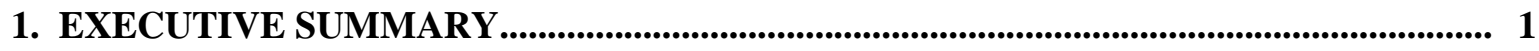

2. INTRODUCTION

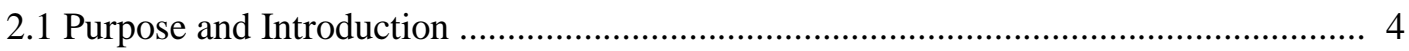

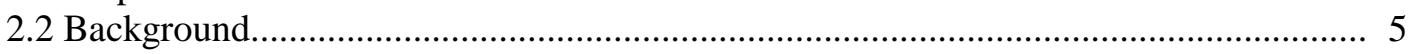

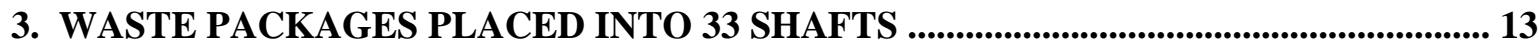

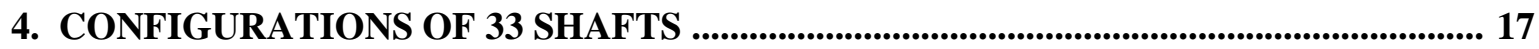

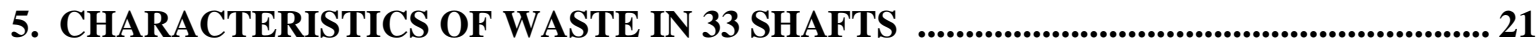

6. SOURCES AND LIMITS OF INFORMATION ON 33 SHAFTS ................................ 23

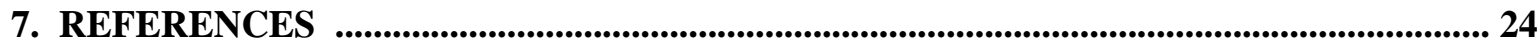

APPENDIX A, 33 Shafts Waste Data Fact Sheets ......................................................................... A-1

APPENDIX B, Engineering Drawings with 33 Shafts Locations and Coordinates ............... B-1

APPENDIX C, Radioactive Solid Waste Disposal Record Forms for 33 Shafts .................. C-1

APPENDIX D, Portions of Weston Report Relevant to 33 Shafts ........................................... D-1

APPENDIX E, Letter and Questionnaire regarding RH TRU Waste Storage at LANL ..... E-1

APPENDIX F, Disposal Log Book for Shafts 200-232, TA-54 Material Disposal Area G ... F-1

APPENDIX G, LAMPRE Reactor Decommissioning Report ............................................. G-1

APPENDIX H, Portions of Field/Del Mar Report Relevant to 33 Shafts ............................. H-1

APPENDIX I, Portions of Vance/Leonard Report Relevant to 33 Shafts .............................. I-1

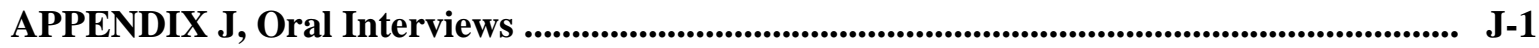

APPENDIX K, Portions of 1986 TRU Inventory Work-Off Plan Relevant to 33 Shafts ..... K-1

APPENDIX L, Portions of CCP AK Report for 16 RH Canisters Relevant to 33 Shafts..... L-1

\section{Index of Figures}

Figure 1. Location and Aerial Photo of TA-54 Area G 
Figure 3. MDA G from the East with Locations of BG TRU Waste Storage Areas .................... 7

Figure 4. LANL Planned TRU Waste Disposition Timeline ...................................................... 9

Figure 5. Site Plan of Shaft Field with Locations of 33 Shafts ................................................. 10

Figure 6. Ground Surface Above the 33 Shafts (from the East) ................................................... 11

Figure 7. Ground Surface Above the 33 Shafts (from the Southeast) …...................................... 11

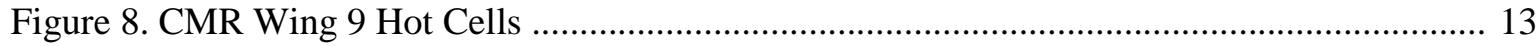

Figure 9. CMR Hot Cells Waste Packaging …............................................................................. 14

Figure 10. Photographs (L to R) of Welded Steel Can, Rigid Plastic Liner, and Paint-Type Can .. 14

Figure 11. Truck with Shielded Cask Used for Waste Packages from CMR Facility ..................... 15

Figure 12. LAMPRE Reactor Vessel Waste Package .................................................................. 16

Figure 13. Placement of Cask with LAMPRE Reactor into Shaft 212 ...................................... 16

Figure 14. Shaft Configurations within 33 Shafts ................................................................. 17

Figure 15. Photograph of Top of Configuration A Shaft ............................................................. 18

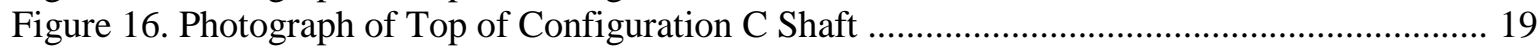

Figure 17. Photograph of Latching Lid and Lifting Ring …..................................................... 19

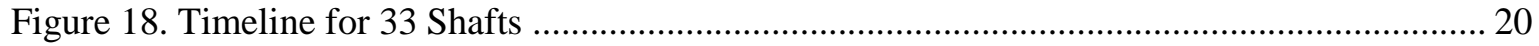

\section{Index of Tables}

Table 1. Overview of Below-Ground TRU Waste Categories ..................................................... 8

Table 2. Summary of Waste Content for 33 Shafts ...................................................................... 22 


\section{Abbreviations and Acronyms}

\begin{tabular}{|c|c|}
\hline AEC & Atomic Energy Commission \\
\hline BG & below ground \\
\hline CFR & Code of Federal Regulations \\
\hline $\mathrm{CH}$ & contact handled \\
\hline CMP & corrugated metal pipe \\
\hline CMR & Chemistry and Metallurgical Research facility (Building 3-29) \\
\hline Co-60 & cobalt-60 \\
\hline Consent Order & New Mexico Environment Department Compliance Order on Consent \\
\hline DOE & U.S. Department of Energy \\
\hline EPA & U.S. Environmental Protection Agency \\
\hline $\mathrm{ft}$ & feet \\
\hline $\mathrm{ft}^{3}$ & cubic feet \\
\hline FY & fiscal year \\
\hline gal & gallon \\
\hline HEPA & high-efficiency particulate air (filter) \\
\hline in & inch \\
\hline LAMPRE & Los Alamos Molten Plutonium Reactor Experiment-I \\
\hline LAFO & Los Alamos Field Office \\
\hline LANL & Los Alamos National Laboratory \\
\hline LANS & Los Alamos National Security, LLC \\
\hline $\mathrm{lb}$ & pound \\
\hline $\mathrm{m}$ & meter \\
\hline $\mathrm{m}^{3}$ & cubic meters \\
\hline MAR & material at risk \\
\hline MDA & Material Disposal Area \\
\hline MFP & mixed fission products \\
\hline $\mathrm{mrem} / \mathrm{hr}$ & milliroentgen equivalent man per hour \\
\hline $\mathrm{nCi} / \mathrm{g}$ & nanocuries per gram \\
\hline NEPA & National Environmental Policy Act \\
\hline NMED & New Mexico Environment Department \\
\hline NNSA & National Nuclear Security Administration \\
\hline NNSS & Nevada National Security Site (formerly the Nevada Test Site) \\
\hline PE-Ci & plutonium-239 equivalent curies \\
\hline Pu-239 & plutonium-239 \\
\hline $\mathrm{R}$ & rad \\
\hline RCRA & Resource Conservation and Recovery Act \\
\hline RH & remote handled \\
\hline RSWD & Radioactive Solid Waste Disposal Record \\
\hline
\end{tabular}


TA

TRU

U-235

WAC

WIPP
Technical Area

Transuranic (elements with atomic number greater than 92)

uranium-235

Waste Acceptance Criteria

Waste Isolation Pilot Plant 


\section{Executive Summary}

A large wildfire called the Las Conchas Fire burned large areas near Los Alamos National Laboratory (LANL) in 2011 and heightened public concern and news media attention over transuranic (TRU) waste stored at LANL's Technical Area 54 (TA-54) Area G waste management facility. The removal of TRU waste from Area $G$ had been placed at a lower priority in budget decisions for environmental cleanup at LANL because TRU waste removal is not included in the March 2005 Compliance Order on Consent (Reference 1) that is the primary regulatory driver for environmental cleanup at LANL. The Consent Order is an agreement between LANL and the New Mexico Environment Department (NMED) that contains specific requirements and schedules for cleaning up historical contamination at the LANL site. After the Las Conchas Fire, discussions were held by the U.S. Department of Energy (DOE) with the NMED on accelerating TRU waste removal from LANL and disposing it at the Waste Isolation Pilot Plant (WIPP).

In January 2012, the DOE National Nuclear Security Administration (DOE/NNSA) and the NMED announced the issuance of the Framework Agreement: Realignment of Environmental Priorities (Framework Agreement). The Framework Agreement is a non-binding agreement that outlines DOE/NNSA commitments to further accelerate TRU waste disposition at LANL (Reference 2). Commitments under the Framework Agreement related to TRU waste include a commitment to develop by December 31, 2012, a schedule with pacing milestones for disposition of below-ground (BG) TRU waste requiring retrieval at Area G based on projected funding profiles.

Within the schedule for disposition of BG TRU waste submitted to the NMED in December 2012 (Reference 3), the DOE/NNSA committed to disposition of six BG categories of TRU waste no later than September 30, 2018. These six categories were identified as (1) Pit 9; (2) Trenches A-D; (3) Corrugated Metal Pipes (CMPs); (4) Hot Cell Liners; (5) Tritium Packages; and (6) $17^{\text {th }}$ Remote-Handled (RH) Canister. The DOE/NNSA will work to meet cumulative pacing milestones to disposition $250 \mathrm{~m}^{3}$ by September 30, 2015; $1,000 \mathrm{~m}^{3}$ by September 30, 2016; 1,750 $\mathrm{m}^{3}$ by September 30, 2017; and 2,395 $\mathrm{m}^{3}$ by September 30, 2018. Approximately $99.86 \%$ of the total estimated waste volume of 2,399 $\mathrm{m}^{3}$ and approximately $99.9 \%$ of the total radioactive Material at Risk (MAR) of 110,751 plutonium-239 (Pu-239) equivalent curies (PE-Ci) in all below-ground TRU waste that may require retrieval is contained within these six categories.

For a seventh BG category that may require retrieval, the 33 Shafts, DOE/NNSA committed in the Framework Agreement to complete (1) a determination as to whether this category contains TRU waste that requires retrieval; and (2) to the extent necessary, its decision process under the National Environmental Policy Act (NEPA) regarding retrieval, by no later than September 30, 2015.

The 33 Shafts category is comprised of waste contained within Shafts 200-232 located near the east end of Area G, and this category contains a total waste volume of approximately $3.4 \mathrm{~m}^{3}$ and total MAR of approximately 97 PE-Ci. The 33 Shafts received waste from 1979 to 1987, but waste in all but four of the shafts was emplaced before the November 18, 1985, effective date of 40 CFR 191 Subpart B, Environmental Standards for Disposal of TRU waste (Reference 4). Waste in Shafts 224, 228, 231, and 232 was emplaced after the effective date of 40 CRF 191.

Waste placed in 32 of the 33 shafts (all but Shaft 212) was generated in hot cell operations at the LANL Chemistry and Metallurgy Research (CMR) facility that involved examination of irradiated fuels from the DOE Liquid Metal Fast Breeder Reactor program and other advanced-fuel efforts, including development of nuclear rocket engines under Project Rover. Information for a single waste package in one shaft indicates that materials from the Three Mile Island facility may also have been examined. Generator records indicate the CMR waste packages contain residual samples, spent equipment, and waste materials typical of hot cell operations such as spent plastic bottles, glassware, towels, polishing cloths, and paper. Shaft 212 contains the 
reactor vessel from a small research reactor called the Los Alamos Molten Plutonium Reactor Experiment (LAMPRE).

Under the WIPP Waste Acceptance Criteria (WAC), TRU waste containers that have an external radiation dose equivalent rate greater than 200 milliroentgen equivalent man (mrem) per hour (hr) at the surface of the container are considered to be RH waste (Reference 5). Waste packages placed into the 33 Shafts were reported to have external radiation dose equivalent rates of $1,750 \mathrm{mrem} / \mathrm{hr}$ to $1,200,000 \mathrm{mrem} / \mathrm{hr}$ at the time that they were emplaced into the shafts, and were calculated to have external dose rates up to 569,000 $\mathrm{mrem} / \mathrm{hr}$ when decayed to 2009.

The 33 Shafts have been identified as the "lined shafts" in some documents because waste was placed inside metal pipes that stand vertically within the shafts. The shafts were constructed by boring a vertical hole (reported as 3 feet in diameter and about 18 feet deep in Reference 7) into the tuff. Waste packages were placed into the 33 shafts in three different configurations, identified as Configurations A, B, and C. Configurations A and B, which apply to 24 of the 33 shafts, have waste packages encased in concrete inside metal pipes that are too large to be shipped to WIPP. These shafts contain about $93 \%$ of the waste volume and $83 \%$ of the MAR for the 33 shafts.

Because the waste in the 33 shafts is remote-handled waste, the retrieval and processing of the waste has a high-risk in terms of technical complexity and estimated cost. Worker risk for retrieval and processing of the 33 Shafts category is highly uncertain until specific work activities and controls are defined, but radiation exposure to workers is of concern because of the very high radiation levels of waste packages placed into the 33 Shafts. The DOE/NNSA is evaluating alternatives that range from leaving all or some subset of shafts in place at MDA G to retrieval, processing, characterization, and shipping all or some subset of the waste within the 33 shafts to WIPP.

This report compiles information to support the evaluation of alternatives and analysis of regulatory paths forward for the 33 shafts. The historical information includes a form completed by waste generators for each waste package (Reference 6) that included a waste description, estimates of Pu-239 and uranium-235 (U-235) based on an accounting technique, and calculations of mixed fission products (MFP) based on radiation measurements. A 1979 letter and questionnaire (Reference 7) provides information on waste packaging of hot cell waste and the configuration of disposal shafts as storage in the 33 Shafts was initiated. Tables of data by waste package were developed during a review of historical documents that was performed in 2005 (Reference 8). Radiological data was coupled with material-type data to estimate the initial isotopic content of each waste package and an Oak Ridge National Laboratory computer code was used to calculate 2009 decay levels. Other sources of information include a waste disposal logbook for the 33 shafts (Reference 9), reports that summarize remote-handled waste generated at the CMR facility (Reference 10) and placement of waste in the 33 shafts (Reference 11), a report on decommissioning of the LAMPRE reactor (Reference 12), interviews with an employee and manager involved in placing waste in the 33 shafts (References 13 and 14), an interview with a long-time LANL employee involved in waste operations (Reference 15), a 2002 plan for disposition of remote-handled TRU waste (Reference 16), and photographs obtained during field surveys of several shafts in 2007. The WIPP Central Characterization Project (CCP) completed an Acceptable Knowledge (AK) summary report for 16 canisters of remote-handled waste from the CMR Facility that contains information relevant to the 33 Shafts on hot-cell operations and timeline (Reference 17).

Overall, the content and accuracy of the data are typical for legacy waste generated from 1979 to 1987. Waste information during this period has gaps and is sometimes inconsistent between various records and reports. Where data were inconsistent, information from generators was judged to be more reliable with regard to waste packages and content, while information from TA-54 operators was judged to be more reliable with regard to shaft configuration and placement of waste packages into the shafts. 
Waste data fact sheets for the 33 shafts (Appendix A) were prepared using information that was judged to be the most reliable and accurate available. These include a summary fact sheet and a specific fact sheet for each of the 33 shafts. The specific fact sheet for each shaft includes a short description of shaft contents and configuration, figures of shaft configuration and location, and tables with more detailed data on waste packages and content of each shaft, including available data on radiation levels of waste packages. 


\section{Introduction}

\subsection{Purpose and Introduction}

Purpose of Report. This report compiles information regarding the 33 Shafts, which is a group of 33 vertical shafts augered into the ground at LANL TA-54 Material Disposal Area (MDA) G (the belowground portion of Area G) that potentially contain TRU waste that may require retrieval. Evaluation of these shafts to determine whether they contain TRU waste requiring retrieval was included in a schedule for below-ground TRU waste that was submitted to the NMED in December 2012 (Reference 3) pursuant to the Framework Agreement for Realignment of Environmental Priorities with the NMED that was announced in January 2012 (Reference 2). Information has been compiled to support the evaluation of alternatives and analysis of regulatory paths forward for the 33 shafts.

Framework Agreement. A large wildfire called the Las Conchas Fire burned more than 150,000 acres south and west of LANL in late June and July 2011. The fire came within about 3.5 miles of TA-54, Area G, and heightened public concern and news media attention of TRU waste storage at Area G. Following the fire, New Mexico Governor Susana Martinez asked the DOE to provide sufficient funding for cleanup of defense legacy wastes from LANL and for TRU waste disposal at WIPP.

The primary regulatory driver for environmental cleanup at LANL is the Compliance Order on Consent, a 2005 agreement between LANL and the NMED that contains specific requirements and schedules for cleaning up historical contamination of the LANL site, and has a final deliverable date of December 2015 (Reference 1). The Compliance Order on Consent does not address requirements and deliverables for removing TRU waste from the LANL site, which placed TRU waste removal at a lower priority in budget decisions. Removal of TRU waste stored aboveground at Area G and belowground within pits, trenches, and shafts within MDA G is required before a remedy for cleanup of MDA G can be implemented under the Consent Order. After the Las Conchas Fire, discussions were held with the NMED on accelerating TRU waste removal from LANL.

In January 2012, the DOE/NNSA) and the State of New Mexico Environment Department (NMED) announced the issuance of the Framework Agreement: Realignment of Environmental Priorities. This document includes commitments by DOE/NNSA to further accelerate TRU waste disposition at LANL (Reference 2). Commitments under the Framework Agreement related to TRU waste include:

- Removal of all non-cemented above-ground TRU waste stored at Area G as of October 1, 2011, by no later than June 30, 2014. This inventory was defined as 3,706 cubic meters $\left(\mathrm{m}^{3}\right)$ of material;

- Removal of all newly-generated TRU waste received in Area G during FYs 2012 and 2013 by December 31, 2014;

- Based on projected funding profiles, develop by December 31, 2012, a schedule with pacing milestones for disposition of below-ground TRU waste requiring retrieval at Area G; and

- Removal of the above-ground cemented TRU waste in an efficient and effective manner protective of human health and safety of workers and the public.

Within the schedule for disposition of below-ground TRU waste submitted to the NMED in December 2012, the DOE/NNSA determined that there are seven below-ground waste unit categories within MDA $G$ that potentially contain TRU waste that may require retrieval (Reference 3). These seven categories were identified as (1) Trenches A-D; (2) Pit 9; (3) Corrugated Metal Pipes; (4) Hot Cell Liners; (5) Tritium Packages; (6) $17^{\text {th }}$ RH Canister; and (7) the 33 Shafts. The seven categories have an approximate total volume of 2,399 $\mathrm{m}^{3}$ and approximate radioactive MAR of 110,751 plutonium-239 equivalent curies (PE-Ci). Of these seven categories, approximately 99.86\% of the waste volume and approximately 
99.9\% of the MAR is contained within the first six categories. The DOE/NNSA concluded that these first six categories may include below-ground TRU waste that requires retrieval. For the remaining category, the 33 Shafts (which have a total approximate volume of $3.4 \mathrm{~m}^{3}$ and total approximate MAR of 97 PE-Ci), additional evaluation is warranted.

The DOE/NNSA committed to disposition the below-ground TRU waste in the first six categories no later than September 30, 2018, and will work to meet cumulative pacing milestones to disposition 250 $\mathrm{m}^{3}$ by September 30, 2015; 1,000 $\mathrm{m}^{3}$ by September 30, 2016; $1,750 \mathrm{~m}^{3}$ by September 30, 2017; and 2,395 $\mathrm{m}^{3}$ by September 30, 2018.

For the 33 Shafts, DOE/NNSA committed to complete (1) a determination as to whether this category contains TRU waste that requires retrieval; and (2) to the extent necessary, its decision process under NEPA regarding retrieval, by no later than September 30, 2015.

\subsection{Background}

Historical Perspective._Radioactive waste has been generated at LANL since the 1940's during research and development activities for nuclear weapons, nuclear reactors, and plutonium science. Historically, radioactive waste was buried in shallow landfills at LANL called MDAs; MDA G at TA-54 (belowground portion of Area $G$ ) first received radioactive waste in 1957 and has served as the primary radioactive solid waste management facility at LANL since 1959 (Reference 18). Figure 1 shows a highlevel aerial photograph of TA-54 Area G and location of Area G on a map of LANL and the surrounding area.

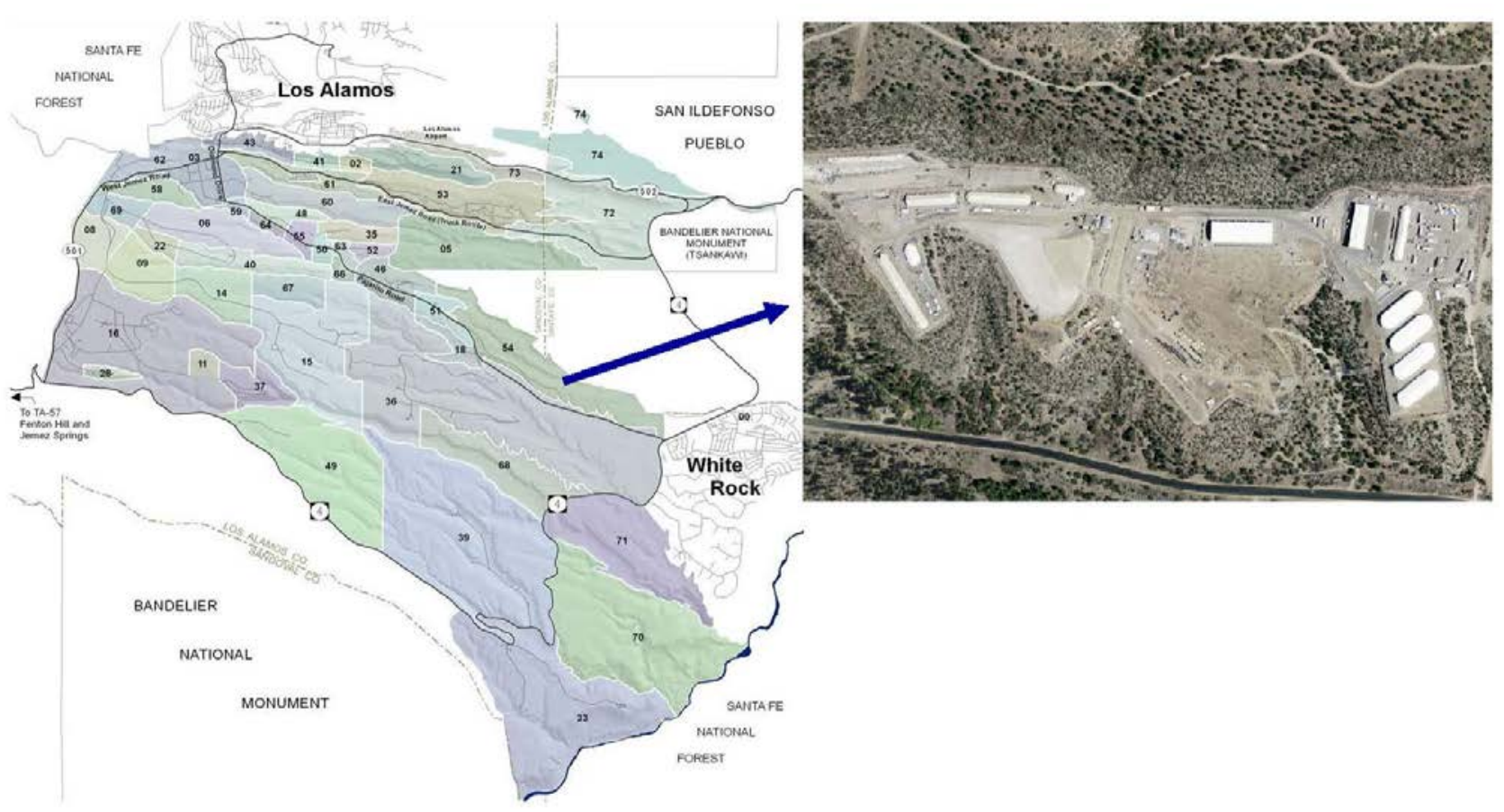

Figure 1. Location and Aerial Photo of TA-54 Area G

In 1970, the Atomic Energy Commission (AEC) issued Immediate Action Directive 0511-21 that directed AEC sites to segregate wastes with "known or detectable concentrations of transuranium 
nuclides" and that such wastes be "packaged and buried in such a fashion that they can be readily retrievable as contamination-free packages within an interim period of 20 years; beyond that period retrievability should continue to be possible" (Reference 19.) This waste was to be stored for disposition in a future deep geologic repository (ultimately, WIPP).

The segregation limit for TRU waste was changed in 1973 with issuance of the Atomic Energy Commission Manual, Chapter 0511, "Radioactive Waste Management” to material contaminated with certain alpha-emitting radionuclides and activity greater than10 nanocuries per gram (nCi/g) for plutonium-239 (Pu-239) and uranium-233 (U-233). Both Pu-238 and Pu-241 were excluded unless indicated by Pu-239 impurities or when required by local burial criteria. The value of $10 \mathrm{nCi} / \mathrm{g}$ was derived from the upper range of concentrations of radium-226 in the earth and was "subject to modification based on long-term studies of nuclide migration in soil” (Reference 20). In 1982, the TRU waste segregation limits were changed to $100 \mathrm{nCi} / \mathrm{g}$ for all TRU isotopes with a half-life of 20 years or longer (including Pu-238) by DOE Order 5820.1, Management of Transuranic Contaminated Material (Reference 21).

Like a number of DOE sites, LANL initially developed storage configurations for TRU waste that involved placing the waste containers in trenches, pits, and shafts that were excavated into the ground surface (Reference 18). Remote-handled TRU waste was stored in shafts. LANL also began storing TRU waste in large fabric-covered storage domes in 1985 (white structures in the aerial photograph in Figure 1). By the time that WIPP opened in 1999, LANL had built up an inventory of about 9,100 cubic meters $\left(\mathrm{m}^{3}\right)$ of TRU waste at Area G, with about 2,416 $\mathrm{m}^{3}$ stored below ground in trenches, pits, and shafts and about 6,700 $\mathrm{m}^{3}$ stored above ground (Reference 22).

No specific criteria were initially identified for RH TRU waste. The approach established for RH TRU waste that is described in this report allowed safe transfer, placement, and storage of waste packages from the CMR hot cells to TA-54 and minimized radiation doses to workers. These high-dose waste items (described in Section 3) not only contained estimated concentrations of alpha-emitting TRU isotopes to qualify for retrievable storage, but also contained beta-gamma emitting isotopes that required radiation shielding for worker safety.

The current WIPP Waste Acceptance Criteria (WAC) specify requirements for contact-handled (CH) TRU waste and RH TRU waste (Reference 5). The external radiation dose equivalent rate of individual payload containers of $\mathrm{CH}$ waste shall be $\leq 200$ milliroentgen equivalent man (mrem)/hour (hr) at the surface, and the external radiation dose equivalent rate of individual payload containers of RH waste must be $\geq 200 \mathrm{mrem} / \mathrm{hr}$ and $\leq 1,000,000 \mathrm{mrem} / \mathrm{hr}$ at the surface.

TRU Waste Disposition. Through September 30, 2013, LANL had shipped a total of 6,091 $\mathrm{m}^{3}$ of TRU waste to WIPP. A total of $1,333 \mathrm{~m}^{3}$ of TRU waste that was reclassified to MLLW after radioassay showed TRU isotope concentrations less than $100 \mathrm{nCi} / \mathrm{g}$ was also shipped off-site to commercial facilities for treatment and disposal at the Nevada National Security Site (NNSS), formerly the Nevada Test Site. Total disposition of TRU waste through September 30, 2013, was 7,575 $\mathrm{m}^{3}$. There isn't a oneto-one correlation between TRU waste volumes shipped to WIPP, or reclassified and shipped as MLLW, and inventory reduction because some containers were over-packed into standard waste boxes or repackaged into multiple drums because of their high activity.

The LANL TRU Program is currently engaged in a campaign to ship 3,706 $\mathrm{m}^{3}$ of higher risk TRU waste stored above ground by June 30, 2014, and will also complete shipment of all newly-generated TRU waste received in FYs 2012 and 2013 by December 31, 2014. 
Although the focus of shipments of TRU waste from LANL to WIPP has been on TRU waste stored above ground, LANL retrieved and shipped below-ground RH waste in 16 shafts (Shafts 236-243 and 246-253) with a total volume of about $17 \mathrm{~m}^{3}$ to WIPP in 2009. Unlike waste in the 33 Shafts, the RH waste in these 16 shafts was packaged after the WIPP WAC for RH waste was available, waste containers were vented, and containers were placed into canisters that could be retrieved and loaded into the WIPP RH-TRU 72-B shipping cask for RH TRU waste. All other waste segregated and stored below ground as TRU waste remains below ground.

Below-Ground TRU Waste. Figure 2 presents a high-level aerial photograph of Area $\mathrm{G}$ with the locations of the seven remaining below-ground waste categories. These locations are shaded in red and labels identify the 7 categories.

Figure 3 shows locations of the below-ground TRU waste categories on an aerial photograph taken from the east of Area $\mathrm{G}$ that shows more detail of the TRU waste storage domes and other structures in the vicinity of the 33 Shafts category of below ground TRU waste.

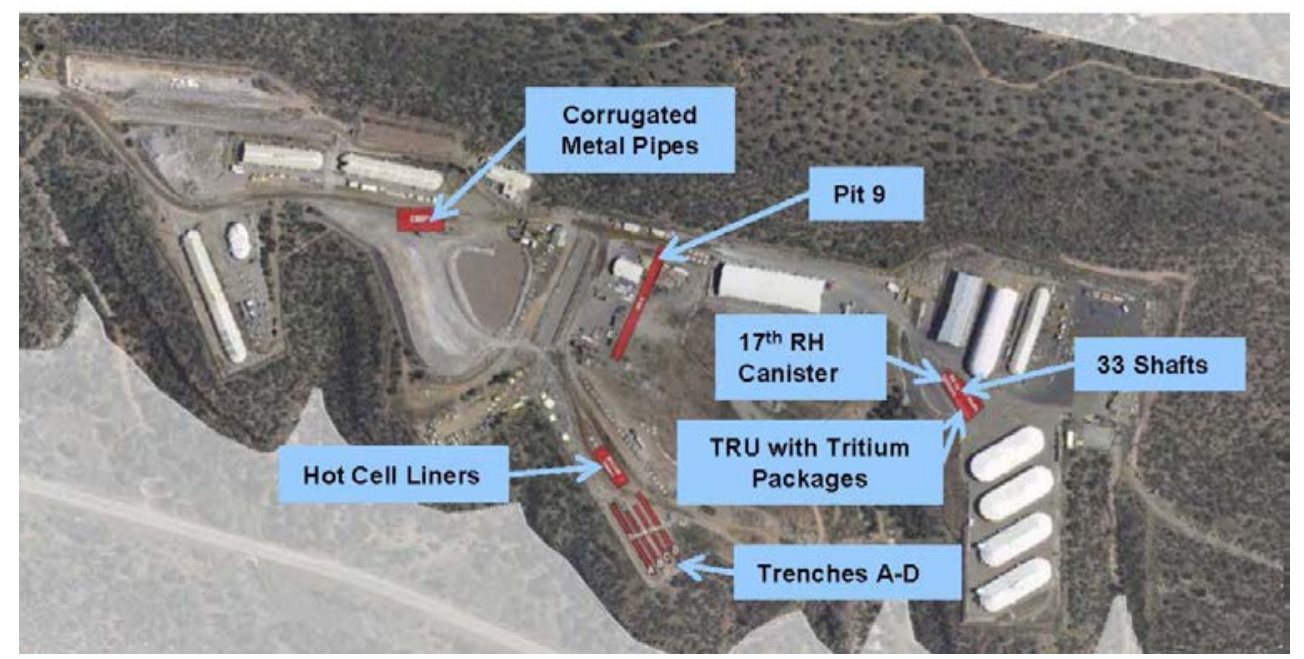

Figure 2. Aerial Photo of Area G with Below-Ground TRU Waste Storage Areas Shaded in Red

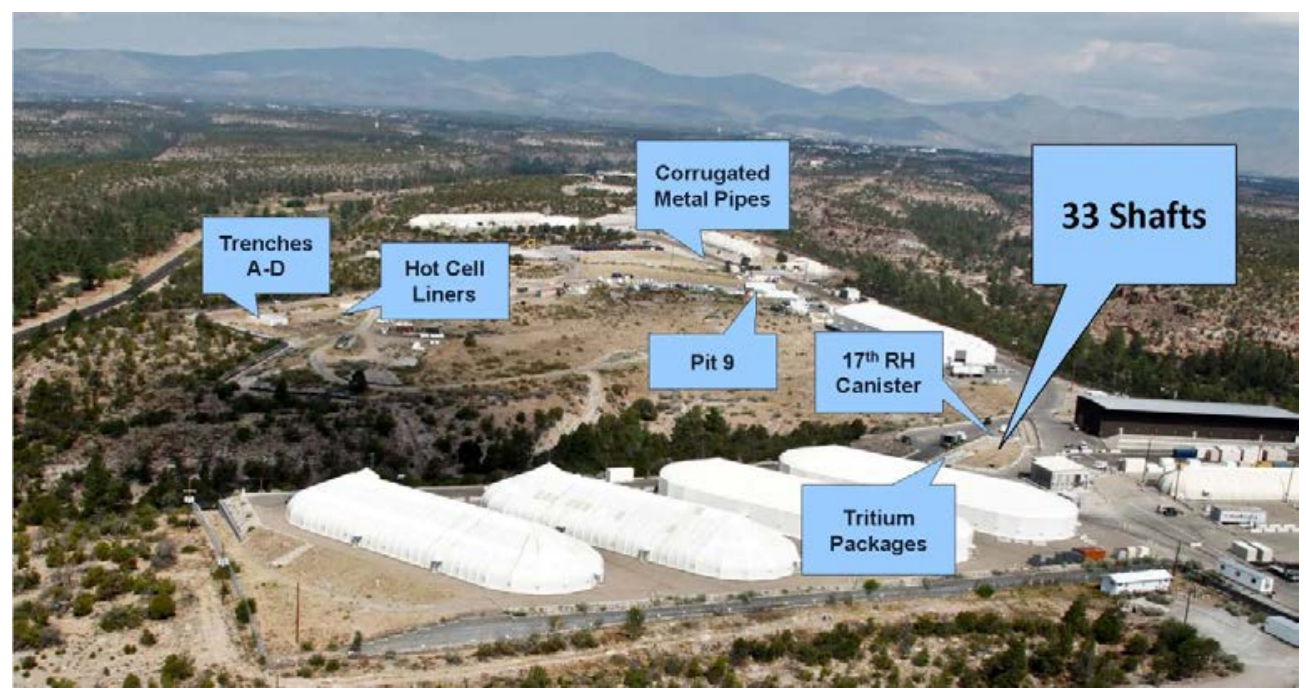

Figure 3. Area G from the East with Locations of Below-Ground TRU Waste Storage Areas 
Table 1 presents a summary of the seven TRU waste categories stored below-ground at MDA G. The table provides a general description of each category, the approximate volume of each category and the percentage each category makes up of the total volume of the seven below-ground categories, and the approximate MAR of each category and the percentage each category makes up of the total MAR of the seven categories. The first six categories (Trenches A-D, Pit 9, CMPs, Hot Cell Liners, Tritium Packages, and $17^{\text {th }}$ RH Canister) that are scheduled to be retrieved and dispositioned in the FY 2015 to FY 2018 period, make up $99.84 \%$ of the total volume and $99.92 \%$ of the total MAR of the seven categories. The 33 Shafts make up only $0.14 \%$ of the total volume and $0.09 \%$ of the total MAR of the seven below-grade categories.

TABLE 1

Overview of Below-Ground TRU Waste Categories

\begin{tabular}{|c|c|c|c|c|c|}
\hline Category & General Description & $\begin{array}{l}\text { Approximate } \\
\text { Volume }\left(m^{3}\right)\end{array}$ & $\begin{array}{c}\text { Percentage } \\
\text { Total } \\
\text { Volume }\end{array}$ & $\begin{array}{l}\text { Approximate } \\
\text { MAR (PE-Ci) }\end{array}$ & $\begin{array}{c}\text { Percentage } \\
\text { Total } \\
\text { MAR }\end{array}$ \\
\hline Trenches A-D & $\begin{array}{l}\text { Approx. } 710 \text { 30-gal. drums in } 4 \\
\text { trenches }\end{array}$ & 335 & 14.0 & 93,870 & 84.8 \\
\hline Pit 9 & $\begin{array}{l}\text { Approx. } 3,88255 \text {-gal., 30-gal. and } \\
85 \text {-gal. drums, } 191 \text { fiberglass- } \\
\text { reinforced plywood boxes, and } 6 \\
\text { other containers }\end{array}$ & 1,560 & 65.0 & 6,019 & 5.4 \\
\hline $\begin{array}{l}\text { Corrugated Metal Pipes } \\
\text { (CMPs) above Pit } 29\end{array}$ & $\begin{array}{l}158 \mathrm{CMP} \text {, each } 30 \text { in. diameter } \\
\times 20 \mathrm{ft} \text {. long }\end{array}$ & 442 & 18.4 & 10,775 & 9.7 \\
\hline Hot Cell Liners (RH Waste) & $\begin{array}{l}5 \text { Shafts with glovebox liners } \\
\text { from hot cells, each in a steel box } \\
6 \mathrm{ft} . \times 6 \mathrm{ft} . \times 10 \mathrm{ft} \text {. long (Shafts } \\
302-306 \text { ) }\end{array}$ & 51 & 2.1 & 0.5 & 0.005 \\
\hline Tritium Packages & $\begin{array}{l}4 \text { tritium packages, each } \\
\text { containing } 355-\text { gal. drums, and } \\
\text { one tritium tank that is } 20 \mathrm{ft} \text {. long } \\
\text { (Shafts 262-266) }\end{array}$ & 6.7 & 0.3 & 8 & 0.01 \\
\hline $17^{\text {th }}$ RH Canister & $\begin{array}{l}\text { Canister containing } 355 \text {-gal. } \\
\text { drums (Shaft 235) }\end{array}$ & 1 & 0.04 & 1.5 & 0.001 \\
\hline 33 Shafts (RH Waste) & $\begin{array}{l}32 \text { lined shafts with pipes } \\
\text { containing } 1 \text { or } 2 \text { gal. cans of hot- } \\
\text { cell debris; } 1 \text { shaft with reactor } \\
\text { vessel (Shafts 200-232) }\end{array}$ & 3.4 & 0.14 & 97 & 0.09 \\
\hline Total & & 2,399 & $100 \%$ & 110,751 & $100 \%$ \\
\hline
\end{tabular}

Figure 4 presents LANL's planned TRU waste disposition timeline for all TRU waste stored at MDA G based on the Framework Agreement, current budget targets and the schedule for below-ground TRU waste. Major milestones for TRU waste disposition in the timeline consist of completion of the 3,706 $\mathrm{m}^{3}$ Campaign for higher-risk above-ground TRU waste by June 30, 2014; completion of disposition of newly-generated TRU waste received in FYs 2012 and 2013 by December 31, 2014; removal of the lower-risk (non-3706 Campaign) above-ground TRU waste by September 30, 2016; and completion of disposition of all of the below-ground TRU waste categories by September 30, 2018. Analyses will be completed and a Federal Decision whether to retrieve the 33 Shafts category of below-ground TRU waste is expected to be completed by September 30, 2015. If a decision is made that the 33 Shafts category requires retrieval, then a capital project would likely be initiated to implement this decision. 


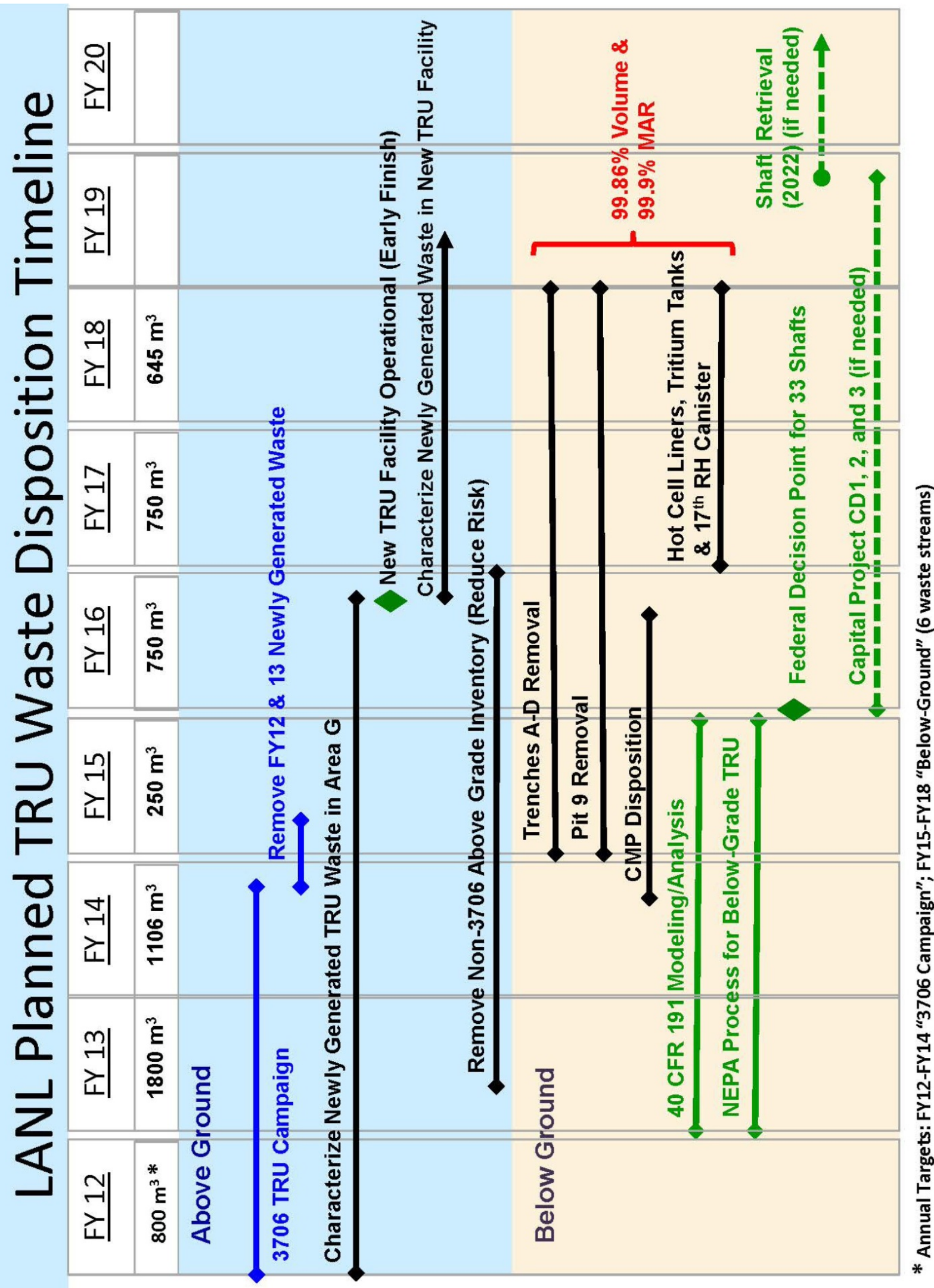

Figure 4. LANL Planned TRU Waste Disposition Timeline 
33 Shafts. The 33 Shafts waste category consists of RH waste that was placed into Shafts 200 through 232 in Shaft Field B at MDA G from 1979 to 1987. The 33 Shafts have been identified as "lined shafts" in some documents because waste was placed inside metal pipes that stand vertically within the shafts. The shafts were constructed by augering a vertical hole (reported as 3 feet in diameter and about 18 feet deep in Reference 7) into the tuff in the shaft field. Figure 5 presents a site plan that shows locations of Shafts 200 through 232 in the shaft field (arrows on the site plan are discussed below). Engineering drawings with dimensions of shaft locations in the shaft field and a shaft location site plan with the specific coordinates of each of the shafts are provided in Appendix B.

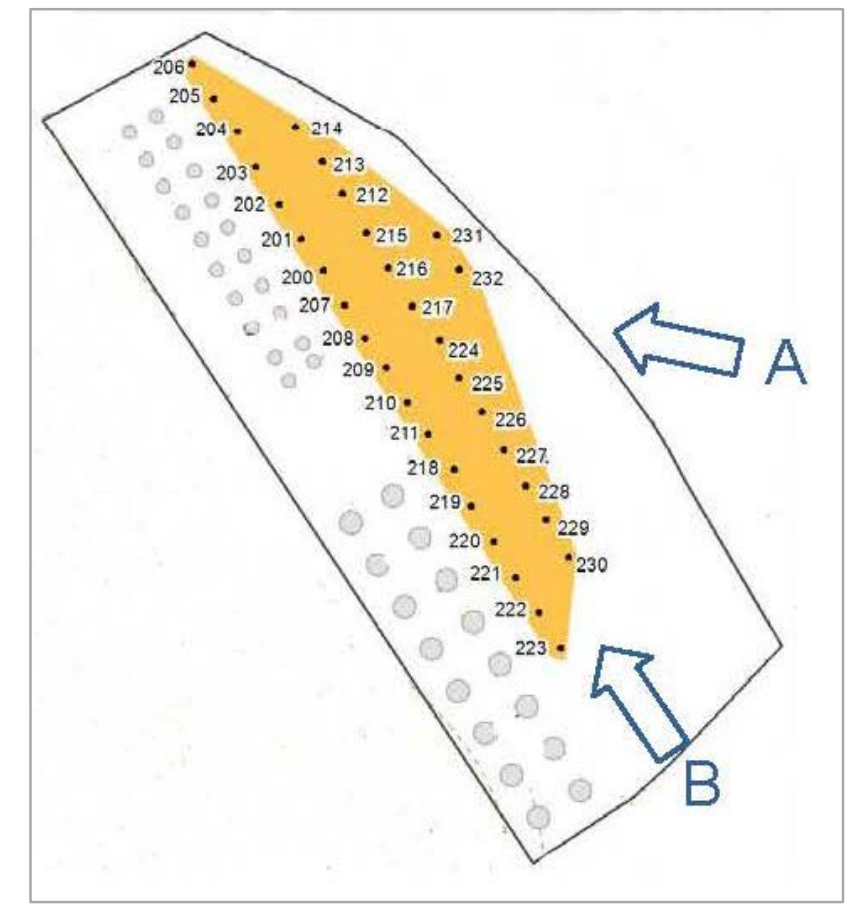

Figure 5. Site Plan of Shaft Field with Locations of 33 Shafts

Figure 6 presents a photograph of the ground surface of the shaft field as seen from the location of the arrow with Letter A on the site plan in Figure 5. The 33 shafts are in the area at the bottom and just inside the retaining wall and asphalt at the right side of the photograph, and are located in the foreground of shafts with cylindrical covers. Vertical blue stakes about three feet high had been placed at each shaft and show the number of that shaft (the blue stakes were removed since this photo was taken but provide perspective on spacing of shafts in the photo). The rectangular boxes shown in the photo sit on top of Shafts 224, 225, 226, 231, 232, and 233; however, Shaft 233 is not included in the 33 Shafts category. The rectangular box on the far left of the photo sits above Shaft 226 and the box just behind the yellow radiation sign at the left sits above Shaft 225.

Figure 7 presents a photograph of the ground surface of the shaft field as seen from the location of the arrow with Letter B on the site plan in Figure 5, and the view is between the rows of shafts that make up all of the 33 shafts except Shafts 231 and 232. The concrete mound with a metal knob just below the Danger sign in the foreground is Shaft 223 and the first rectangular box to the right sits above Shaft 230 . Additional cover was added since this photo was taken, and the metal knobs are no longer visible.

Thirty-two of the 33 shafts (Shafts 200 through 211, and Shafts 213 through 232) contain hot cell debris waste packaged in one-gallon (gal) or two-gal cans from Wing 9 of the CMR Facility (Building 3-29) at 


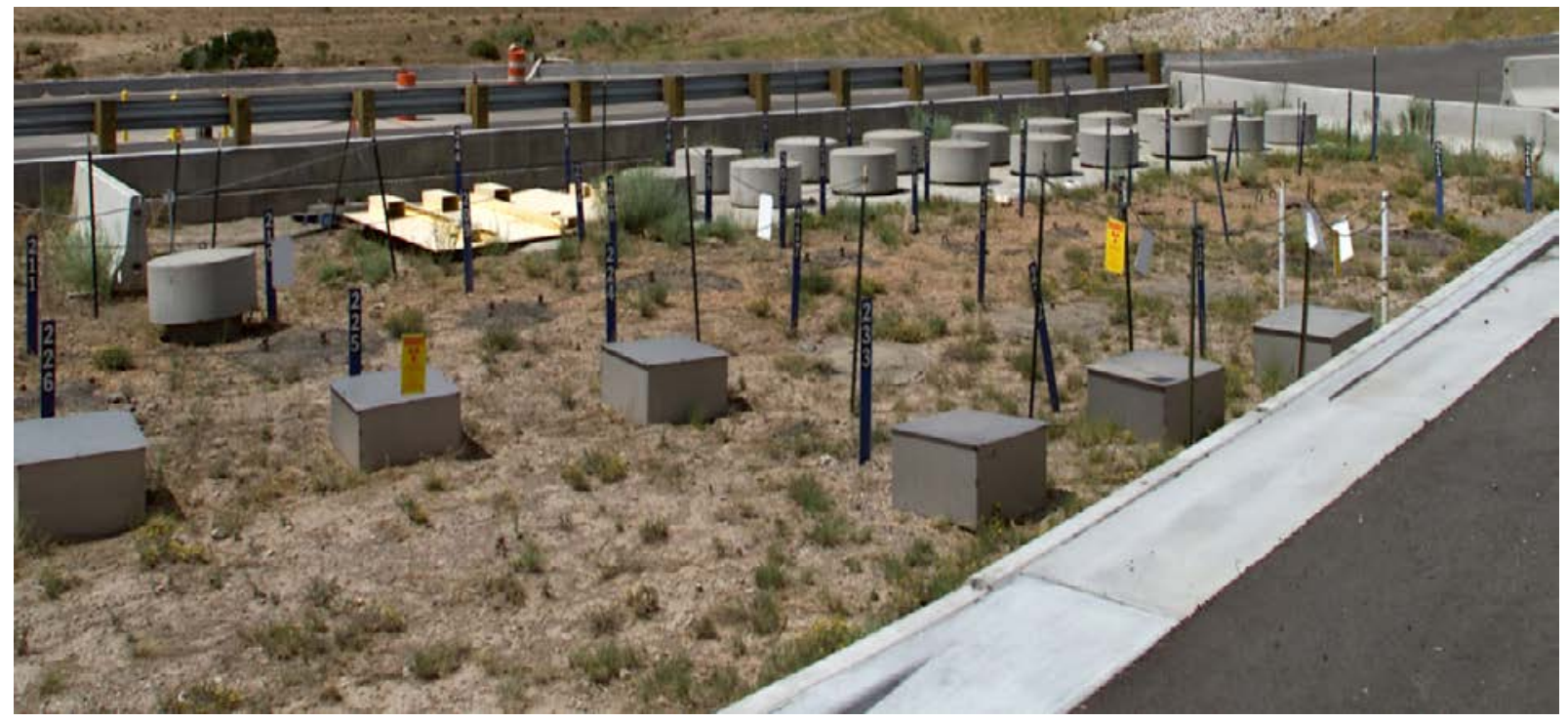

Figure 6. Ground Surface Above the 33 Shafts (from the East)

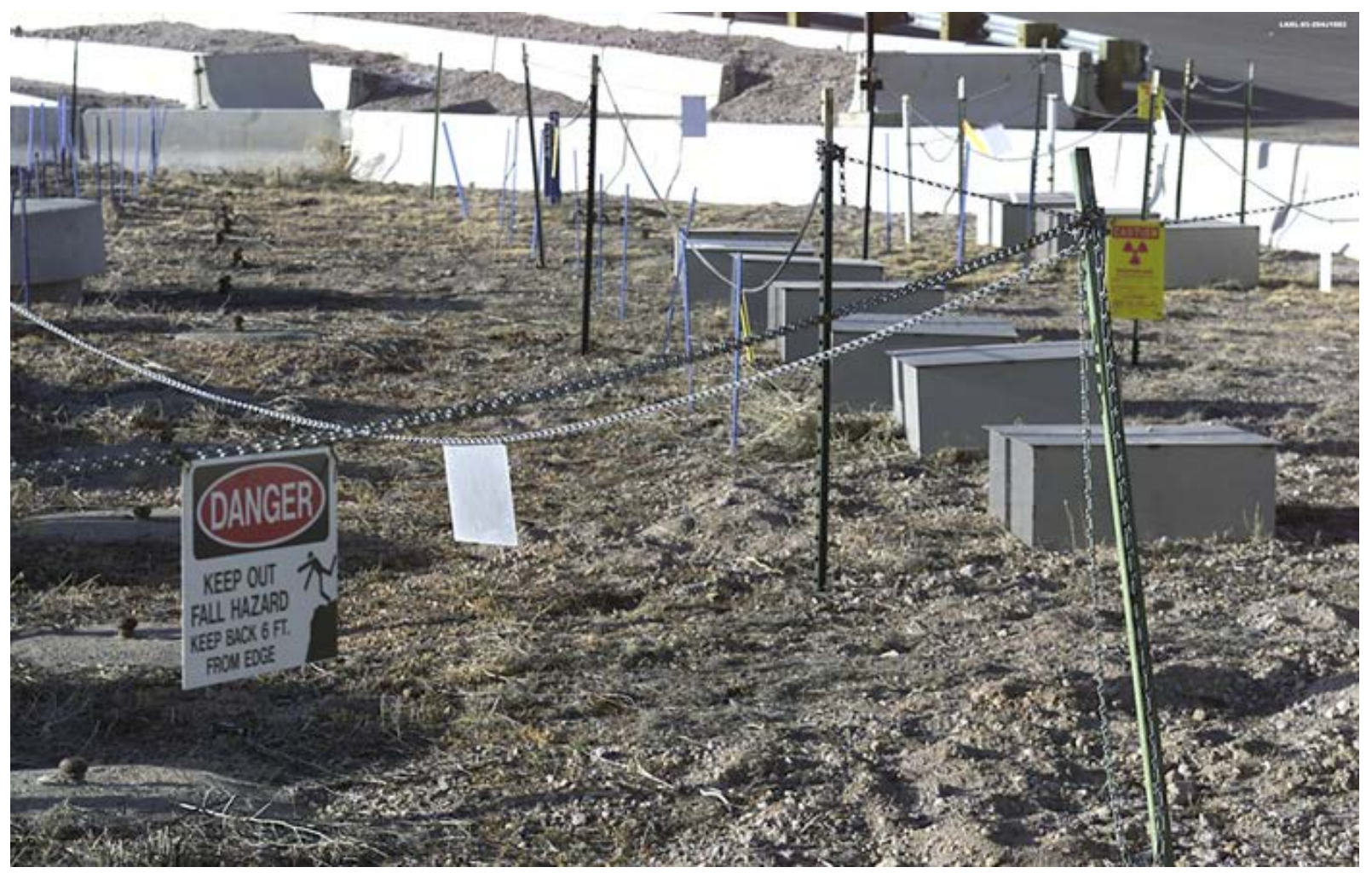

Figure 7. Ground Surface Above the 33 Shafts (from the Southeast)

LANL. Primary radioactive contaminants listed by the waste generator for the hot cell debris consist of Pu-239, U-235, and MFP. Shaft 212 contains a small reactor vessel from the LAMPRE research reactor that was removed from Building 35-2. Primary radioactive contaminants listed by the waste generator for the reactor vessel consist of Pu-239 and cobalt-60 (Co-60). 
Section 3, Waste Packages Placed into 33 Shafts, provides more detail on the waste packages. Several types of packaging were used for the waste generated in the hot cells at the CMR facility, and these are described and shown in photos and figures in Section 3. Waste was placed into the shafts in three different configurations that are described in Section 4, Configurations of 33 Shafts, which begins on Page 17. Appendix A, 33 Shafts Waste Data Fact Sheets, presents both summary and detailed information on the waste packages and configuration of each of the 33 shafts.

Waste in all but four of the shafts (Shafts 224, 228, 231, and 232) was emplaced before the effective date of radiation protection standards for disposal of TRU waste promulgated by the U.S. Environmental Protection Agency (EPA) in 40 CFR 191 Subpart B, Environmental Standards for Disposal (Reference 4). 


\section{Waste Packages Placed into 33 Shafts}

The primary source of information for waste packages placed into the 33 Shafts is the Radioactive Solid Waste Disposal (RSWD) Record Form that was prepared by the waste generator before a waste package was approved for transport and receipt at TA-54 Area G. The RSWD forms are one-page forms that have a unique identifying number and provide information such as the date the form was completed, origin of the waste (LANL organization, technical area, building, and room if applicable), waste code, waste description, number and type of waste packages, gross volume, package radiation at surface and at 1 meter (m), gross weight, additional description of packaging and packaging materials, radionuclide content and basis (analysis, measurement, estimate) and accountable material write-off if applicable. The form also has sections completed at TA-54 that show the date the package was disposed and disposal/ storage location. Not all sections were completed on all RSWD forms for the 33 shafts (some gaps in information exist).

Copies of a total of 193 RSWD forms for the 33 Shafts were compiled by RSWD number in 2009 by the Acceptable Knowledge Team for the Central Characterization Project (Reference 6), and are also compiled by shaft number and attached to this report as Appendix C. There are 192 RSWD forms for waste packages placed into the 33 Shafts that were generated in the hot cells at the CMR Facility (Building 3-29) and one RSWD form for the reactor vessel from demolition of the LAMPRE research reactor located within Building 35-2.

In general, for waste placed into the 33 Shafts, an RSWD form was completed for each waste package (which for hot cell waste generated at the CMR Facility typically consisted of two 1-gal cans from 1979 to 1982, one two-gal can from 1982 to 1983, and one 1-gal can from 1984 to 1987). Information from six RSWD forms for six waste packages placed into Shaft 202 and six RSWD forms for six waste packages placed into Shaft 203 were transferred to a single RSWD form for each shaft in April 1980. Although the TA-54 Area G log book for the 33 Shafts (Reference 9) includes the original RSWD numbers, those RSWD forms are not available in the LANL RSWD records system; only the forms onto which information was transferred are available. Waste data fact sheets for each shaft in Appendix A show the numbers and type of waste packages for each shaft as described in the RSWD forms.

Figure 8 shows a photograph of the hot cells in Wing 9 at the CMR Facility (from Reference 23). The hot cells provide shielding and remote handling capabilities for work on highly radioactive materials. Work in the CMR hot cells at the time that waste packages were placed into the 33 Shafts involved examination of irradiated fuels from the DOE Liquid Metal Fast Breeder Reactor program and other advanced-fuel efforts, including development of nuclear rocket engines under Project Rover. Information for a single waste package in Shaft 232 indicates that materials from the Three Mile Island facility may also have been examined. Waste packages from the CMR Facility include residual samples, spent equipment, and waste materials typical of hot cell operations such as spent plastic bottles, glassware, towels, polishing cloths, and paper (Reference 8).

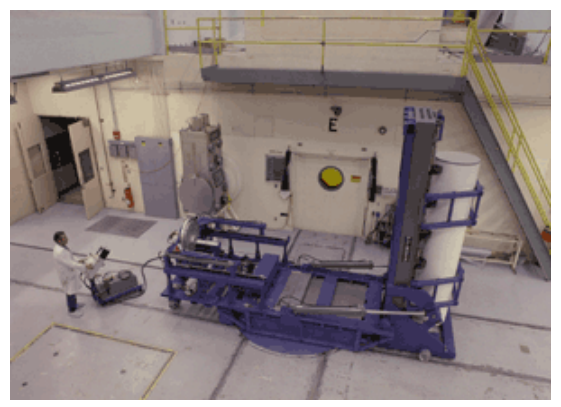

Figure 8. CMR Wing 9 Hot Cells 
Figure 9 shows a diagram of the two types of packaging that were used for CMR hot cell waste. Waste packages for Shafts 200-211 and 213-223 typically consisted of 1-gal metal paint-type cans with no lid placed inside 1/8 inch (in) thick plastic containers with pressed lids, which were sealed inside two plastic bags (Reference 16). Most waste packages contained two 1-gal cans but a few waste packages contain only one can. The RSWD forms for some waste packages state that 2-gal cans were used during 19821983, but no other information on two-gal cans was located. Waste placed into Shafts 224-232 was placed inside an open 1-gal metal paint can, inside a rigid plastic container with a lid, and placed inside a welded $1 / 8$ in thick steel can (Reference 11).

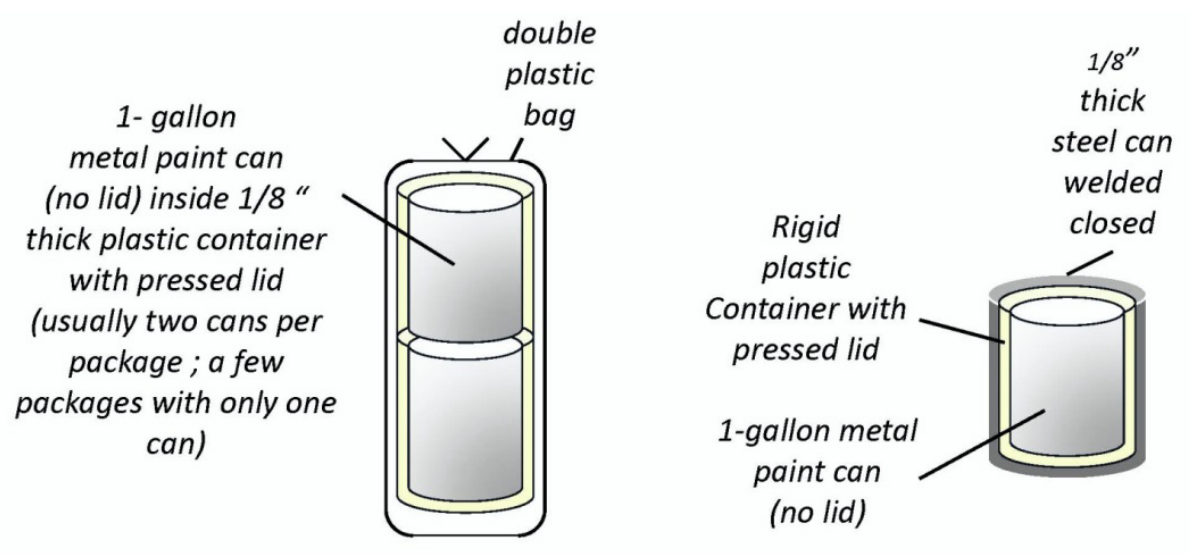

Shafts 200-211

and 213-223

Shafts 224-232

Figure 9. CMR Hot Cells Waste Packaging

Figure 10 contains a photograph of a 1-gal metal paint-type can (on the right), the rigid plastic container (in the middle) and welded steel can (on the left) used for waste packages from the CMR hot cells in 1984 to 1987 (Shafts 224-232). It is unknown whether the plastic container described for the earlier waste packages from the CMR hot cells and placed into Shafts 200-211 and 213-223 is the same as that shown in Figure 10.

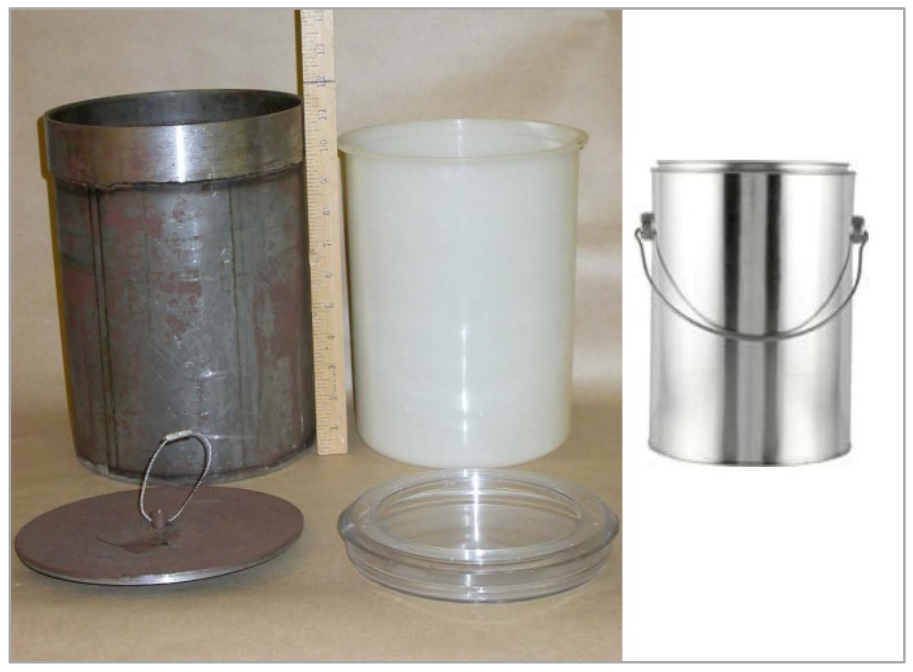

Figure 10. Photographs (L to R) of Welded Steel Can, Rigid Plastic Liner, and Paint-type Can 
Waste packages from the CMR hot cells and placed into Shafts 200-211 and 212-232 were transported to Area $\mathrm{G}$ inside a shielded cask on a flat-bed truck shown in Figure 11. The shielded cask had a guillotinetype sliding door on the bottom that was closed during transport. A large funnel was placed into the pipe inside the shaft and the truck was maneuvered so that the door to the shielded cask was above the funnel. The door was then opened and the waste package dropped into the funnel and down the pipe inside the pipe within the shaft. A long pole was used to dislodge waste packages that did not freely fall into the pipe. Lead shot was sometimes added to the pipe to reduce radiation levels at the top of the shaft (Reference 13). After all waste packages were placed into a shaft, a concrete cap was placed on top of the shaft. Additional information on shaft configurations is presented in the next section.

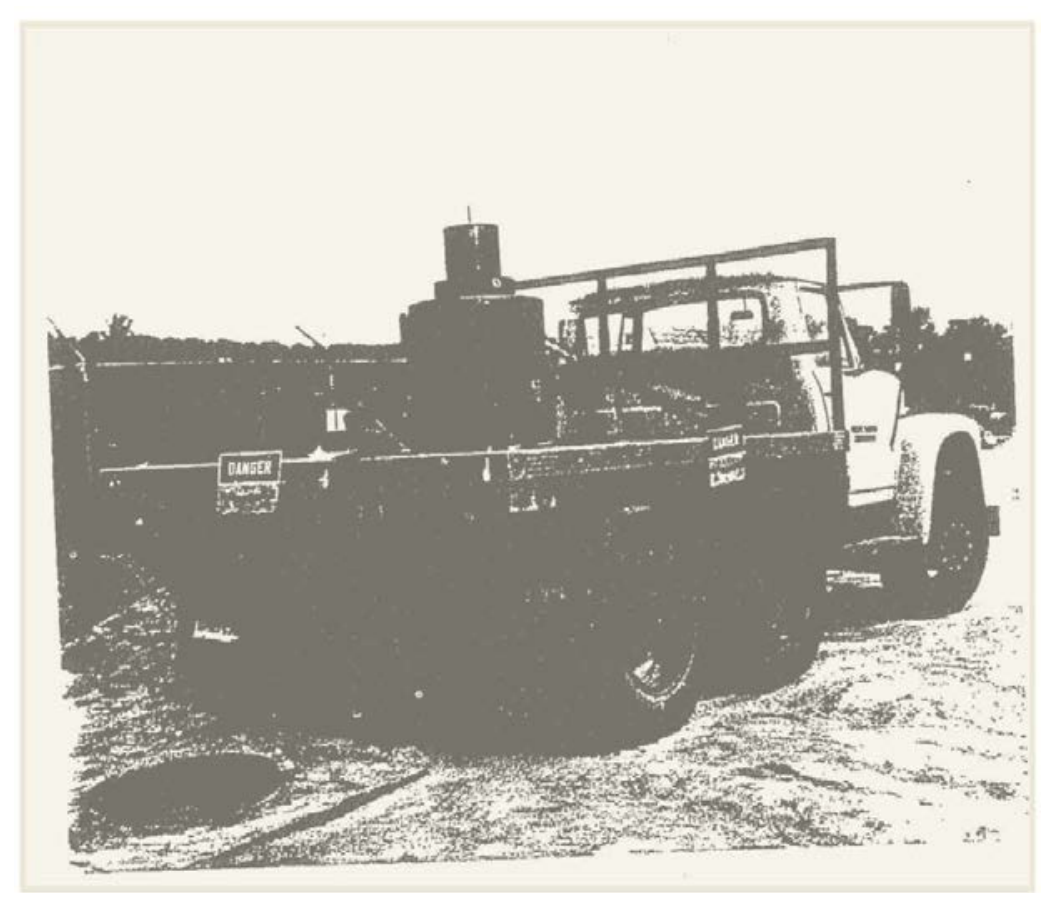

Figure 11. Truck with Shielded Cask Used for Waste Packages from CMR Facility

Shaft 212 contains the reactor vessel from a small research reactor called the LAMPRE reactor located at TA-35 Building 2, which was a sodium-cooled reactor built and operated in the early 1960's to develop plutonium fuels for fast breeder applications. The reactor was retired and defueled in the mid-1960s. The fuel from the LAMPRE reactor was shipped to the Savannah River Site and processed in F-Canyon in late 1966 to early 1967 (Reference 24).

During decommissioning of the reactor in 1980, expanding polyurethane foam was injected into the pipes used to carry sodium into the reactor vessel, the pipes were cut near the reactor vessel and cans with roofing tar were placed over the pipes going into the reactor vessel. All supports for the reactor vessel were removed and the reactor vessel (approximately $1 \mathrm{ft}$ in diameter and $121 / 2 \mathrm{ft}$ in length) was placed into a cask constructed of a steel pipe ( $1 / 4$ in thick wall, 32 in diameter and $14 \mathrm{ft}$ in length) with a steel plate welded onto the bottom of the pipe. The space between the reactor vessel and the cask was filled with concrete (Reference 12). The reactor vessel may contain residual sodium metal as well as an estimated 12 PE-Ci of activity. Figure 12 shows a diagram of the waste package (cask) for the LAMPRE reactor vessel. 


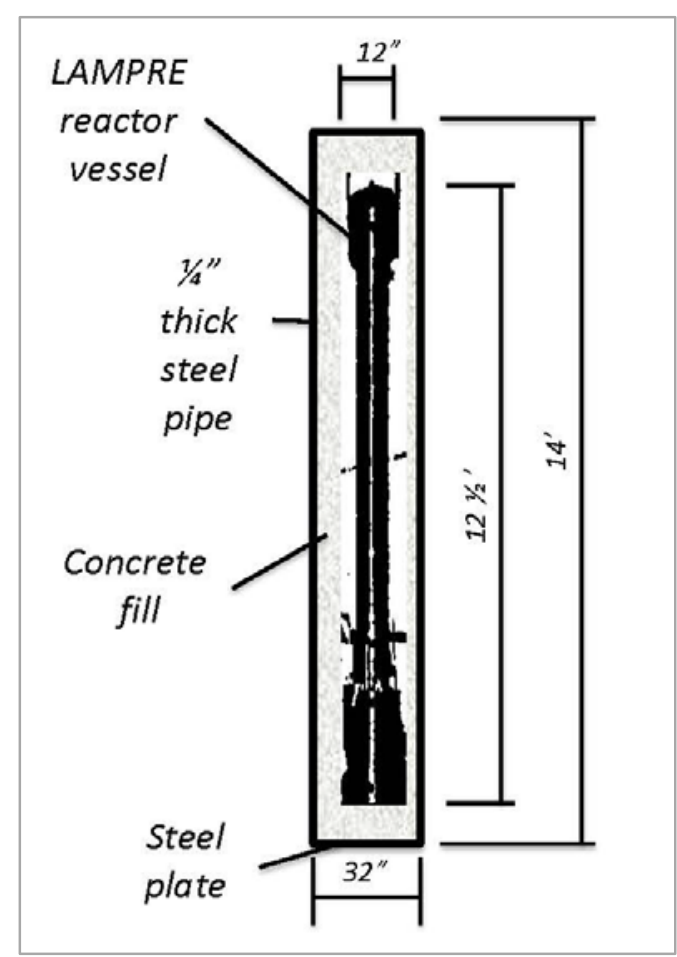

Figure 12. LAMPRE Reactor Vessel Waste Package

The cask, with a volume of 75 cubic ft (about $2 \mathrm{~m}^{3}$ ), was transported to Area G and placed into Shaft 212 in April 1980. Figure 13 contains a photograph of the cask with the LAMPRE reactor vessel being lowered into the shaft.

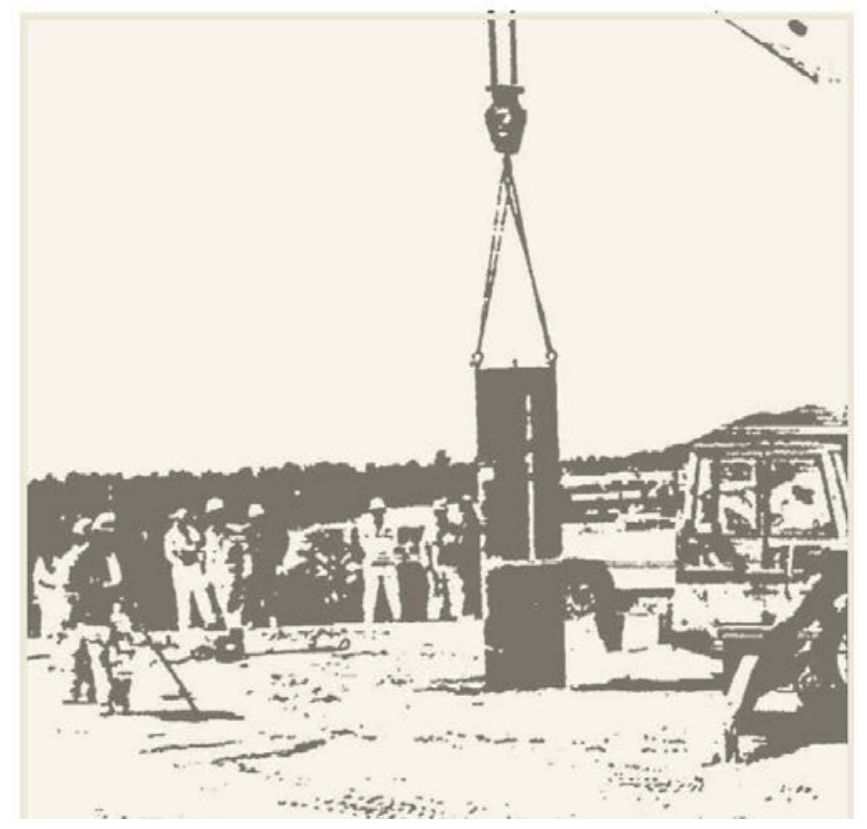

Figure 13. Placement of Cask with LAMPRE Reactor into Shaft 212 


\section{Configurations of 33 Shafts}

Waste packages were placed into the 33 Shafts in three configurations, which have been identified as Configurations A, B, and C. Figure 14 shows the three configurations.

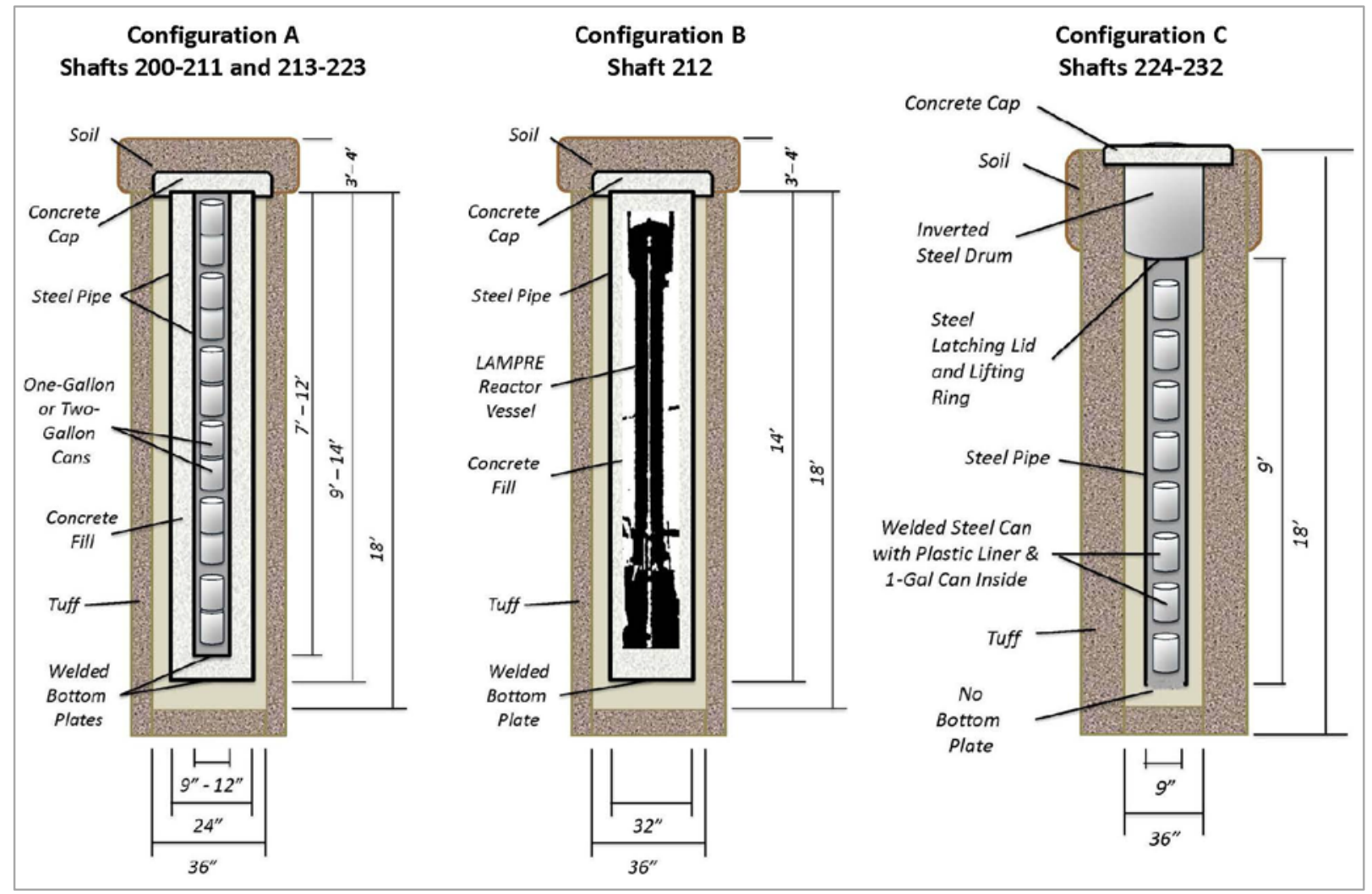

Figure 14. Shaft Configurations within 33 Shafts

Construction of shafts in all of the configurations was initiated by augering a 3-ft diameter vertical hole to a depth of about $18 \mathrm{ft}$ into the tuff in the shaft field. In Configuration A, a 24-in diameter metal pipe (1/4 in wall thickness) with a length of 9 to $14 \mathrm{ft}$ in length with a metal plate welded to the bottom was inserted into the vertical hole and centered within the hole. Both smooth wall and corrugated metal pipes were used (Reference 11). A $1 \frac{1}{2}$ in thick, smooth-wall inner pipe with a diameter of 9 to 12 in and 7 to 12 $\mathrm{ft}$ in length with a plate welded to the bottom was centered in the larger pipe with a small amount of concrete to provide vertical alignment of the inner pipe and outer pipe. A large metal funnel was inserted into the inner pipe and waste packages were dropped into the inner pipe from a shielded transport cask moved into position above the shaft.

Configuration A was used from 1979-1983 for waste that was emplaced in Shafts 200-211 and 213-223, a total of 23 shafts. Waste from the CMR hot cells was packaged in one- or two-gallon metal paint-type cans, and waste packages from 1979-1983 typically consisted of two gallons of waste inside a double plastic bag. The paint-type cans were overpacked in a plastic container before being placed into the plastic bags. Shafts filled during this period (Shafts 200-211 and 213-223) contain 8 to 14 gallons of hot cell waste, but typically contain about 12 gallons of hot cell waste. Shafts 200-214 typically contain waste packages composed of two 1-gal cans, and Shafts 215-223 typically contain waste packages composed of 2-gal cans. In some shafts, lead shot was added on top of waste packages to reduce radiation dose at the ground surface. After all waste packages were placed, concrete was placed in the annular space between 
the pipes, and the top of the pipes and the shaft bore hole were capped with 3-4 inches of concrete. The result is that the pipe containing the waste packages in Configuration A is completely encased in concrete, with about 6 inches of concrete on the sides and at least one $\mathrm{ft}$ of concrete on the bottom and top. The volume of the entire cask with both pipes is about 45 cubic feet $\left(1.3 \mathrm{~m}^{3}\right)$ with a weight of about $4,000 \mathrm{lb}$, mostly concrete (Reference 7).

A field study was conducted in August 2007 in which the concrete cap was removed from one of the shafts in Configuration A. Figure 15 shows a photograph of the top of the outer corrugated metal pipe that is filled with concrete and lifting rings embedded into the concrete. The space between the outer pipe and the wall of the shaft has no concrete.

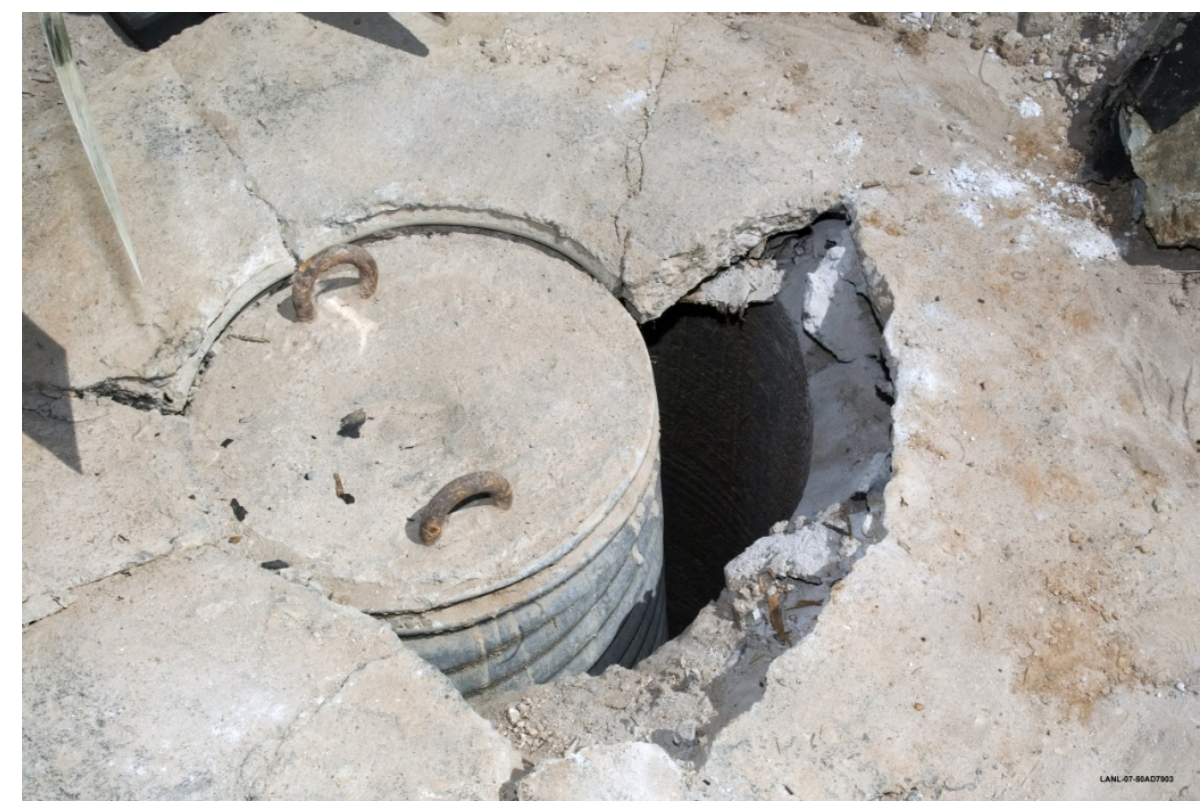

Figure 15. Photograph of Top of Configuration A Shaft

Configuration B was used only for Shaft 212, which contains the cask with the LAMPRE reactor vessel. A 36-inch diameter vertical shaft was augered into the tuff to a depth of about 18 feet. A steel cask, composed of a pipe of $1 / 4$ inch wall thickness that is 32 inches in diameter and 14 feet in length with the reactor vessel encased in concrete inside the pipe, was lowered into the shaft. Estimated weight of the cask is about 16,000 lb. A concrete cap was constructed on top of the shaft after the cask was emplaced.

Configuration C was used from 1984-1987 for CMR hot cell waste emplaced into Shafts 224-232, a total of nine shafts. Vertical shafts of 3 feet in diameter and 18 feet in depth were augered into the tuff in the shaft field. A $1 / 4$ inch wall pipe of 9-inch diameter and 9 feet in length was centered in the shaft and the space between the pipe and the shaft filled with crushed tuff. An interview with the manager of the Area $G$ waste operations at the time the waste was emplaced (Reference 14) indicates that the pipe in the shaft had a metal plate welded to the bottom, but a 1986 report that described the configuration does not mention a bottom plate for this configuration (Reference 11). Waste packages from the CMR hot cell facility that were dropped into the pipe centered in the shaft were composed of a 1-gal metal paint-type can inside a rigid plastic container that was inside a 1/8 inch wall welded steel can. The welded steel cans were described as being HEPA filtered in the interview with the Area G manager (Reference 14), but the 1986 report that described the packages does not indicate that the welded cans were filtered (Reference 11). Shafts in Configuration C contain from 3 to 8 waste packages, but most contain 8 waste packages with a total of 8 gallons of waste. After all waste packages were placed into the pipe, a latching lid with a 
lifting ring was placed onto the top of the pipe, and a cut-down 55-gallon drum with a lid was placed above the pipe. Soil was placed around the drum, and cement and soil were placed above the drum lid.

Figure 16 shows a photograph of the top of a Configuration $C$ shaft that was uncovered during a June 2007 field study. The rectangular metal box above the shaft was removed, as was a small amount of soil and concrete that was on top of the lid for the 55-gal drum that sits on top of the shaft. Soil is present on the outside of the 55-gal drum to the top of the drum. The metal pipe with a latching lid that holds the waste packages is surrounded by crushed tuff.

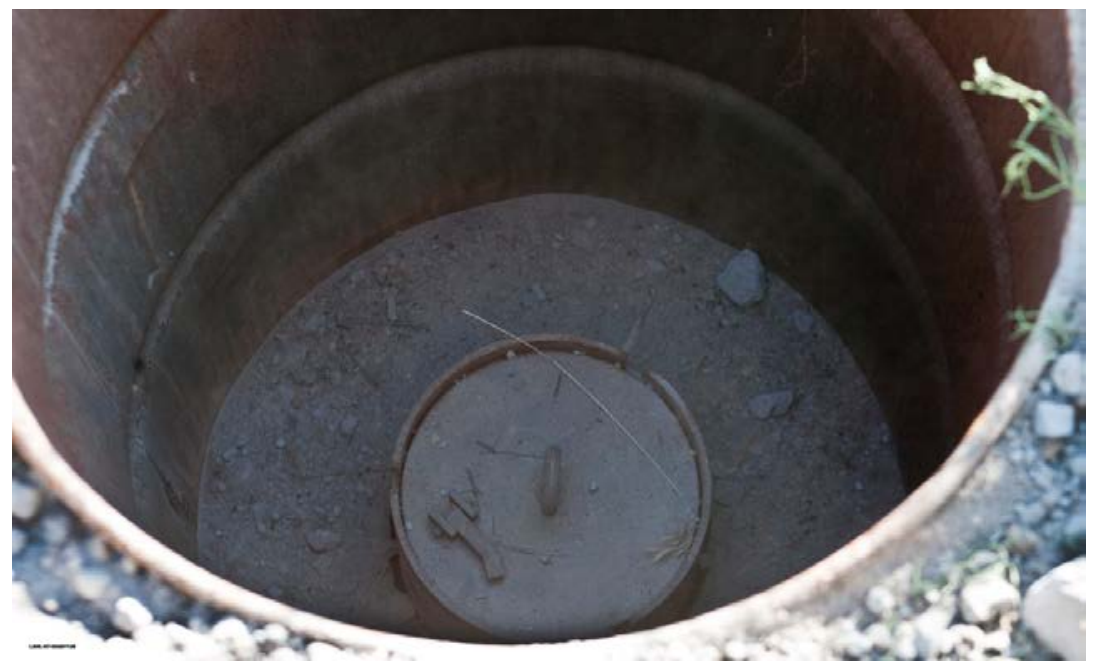

Figure 16. Photograph of Top of Configuration C Shaft

Figure 17 shows a close-up photograph of the latching lid and lifting ring at the top of the pipe containing the waste packages. No attempt was made to open the lid during this field study.

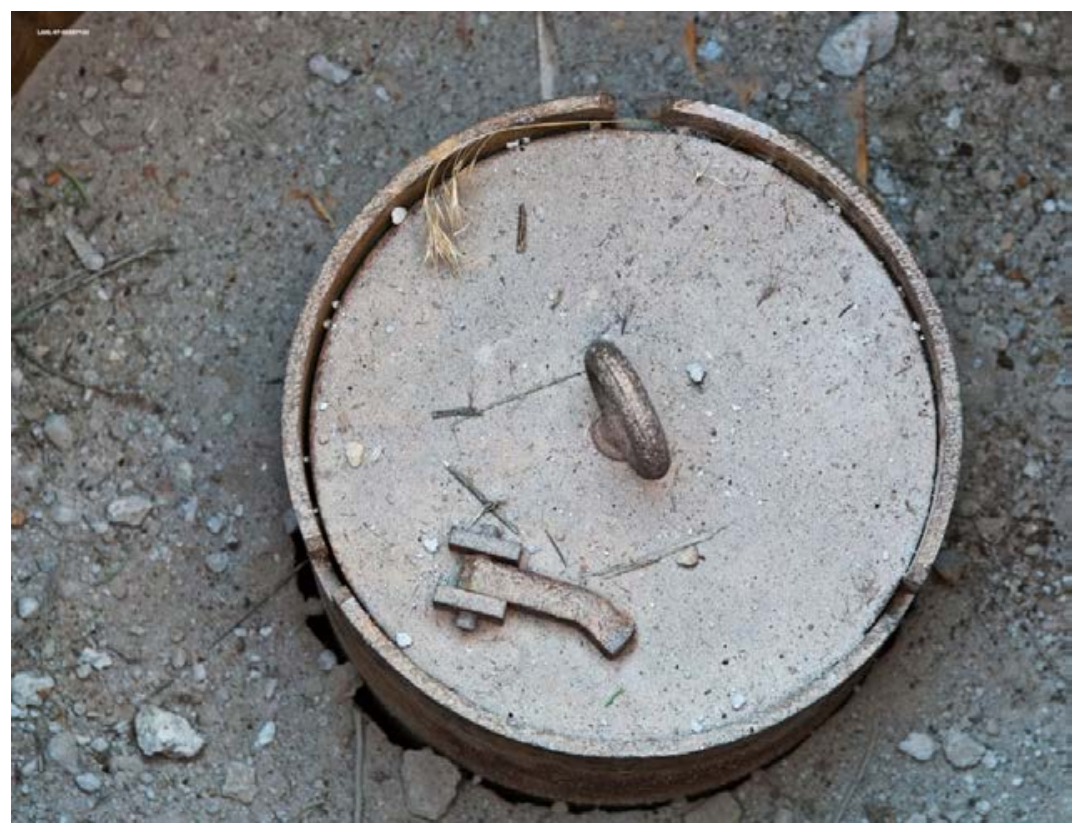

Figure 17. Photograph of Latching Lid and Lifting Ring 
Figure 18 presents a timeline for the 33 Shafts that shows the configuration of each shaft and the year that waste was emplaced in each of the shafts. Waste packages with CMR Wing 9 hot cell waste were emplaced in 23 of the shafts in Configuration A between 1979 and 1983. The LAMPRE reactor vessel was emplaced in Configuration B in 1980. Waste packages with CMR hot cell waste were emplaced in 9 of the shafts in Configuration C between 1984 and 1987.

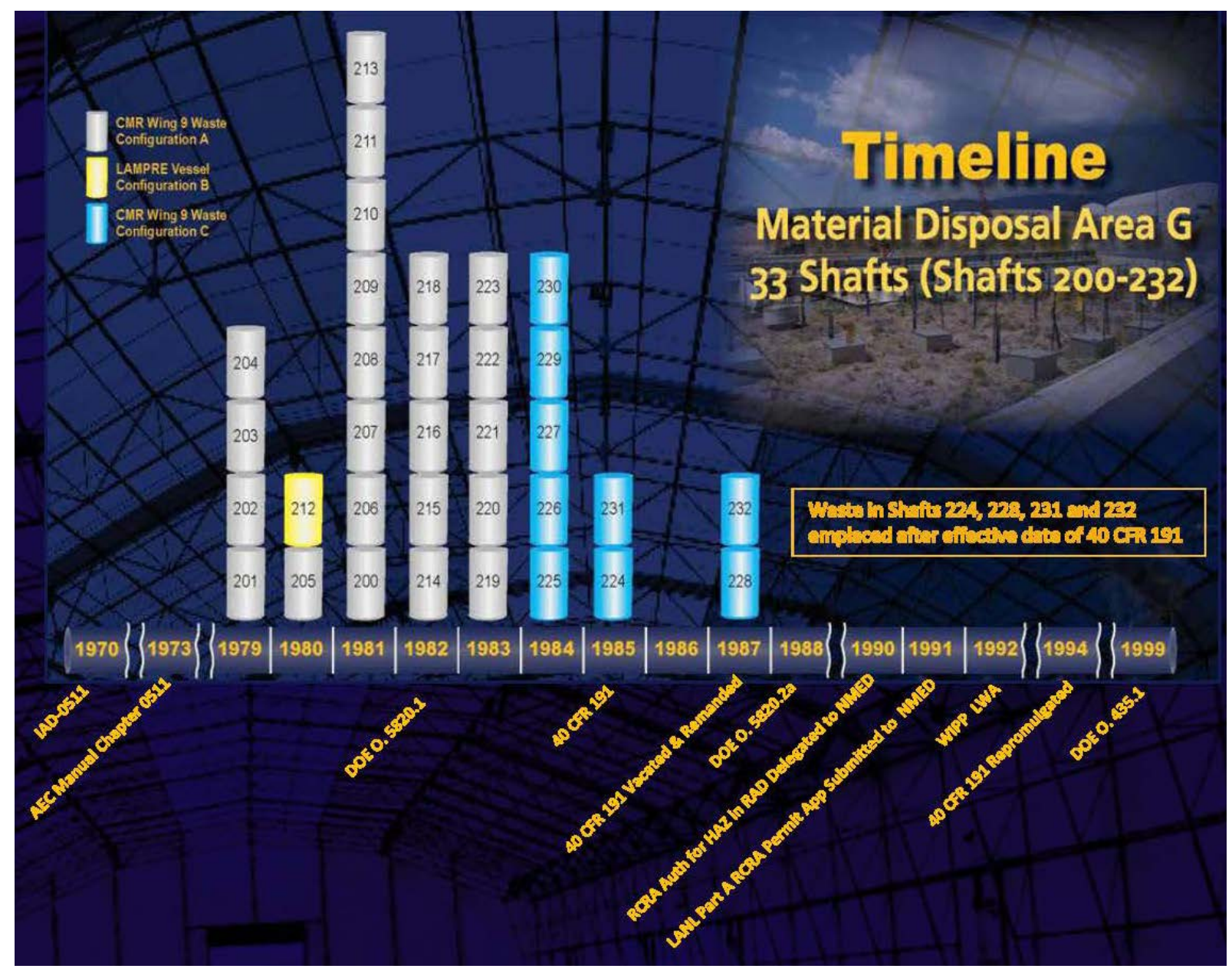

Figure 18. Timeline for 33 Shafts

Figure 18 also includes dates of statutory and regulatory actions that are relevant to the 33 Shafts. All of the waste packages in the 33 Shafts were emplaced after the AEC Directive and AEC Manual Chapter 0511 that directed AEC sites to segregate waste with transuranic isotopes. Waste in 19 of the 33 Shafts was emplaced before DOE Order 5820.1, Management of Transuranic Contaminated Material. Waste in 29 of the 33 shafts was emplaced before the effective date of the 40 CFR 191 radiation protection standards for disposal of TRU waste. Waste in Shafts 224, 228, 231 and 232 was emplaced after the effective date of the 40 CFR 191 radiation protection standards for disposal of TRU waste. 


\section{Characteristics of Waste in 33 Shafts}

Waste placed in 32 of the 33 shafts (all except Shaft 212) was generated in hot cell operations at the LANL CMR facility that involved examination of irradiated fuels from the DOE Liquid Metal Fast Breeder Reactor program and other advanced-fuel efforts, including development of nuclear rocket engines under Project Rover. Information for a single waste package in Shaft 232 indicates that materials from the Three Mile Island facility may also have been examined.

The RSWD record forms (Reference 6 and Appendix C) provide the primary information on the characteristics of the hot cell waste. As noted, the hot cell waste is contained in either 1- or 2-gal cans. Weights of the waste packages are also provided for almost all of the waste packages. The waste packages contain residual samples, spent equipment, and waste materials typical of hot cell operations such as spent plastic bottles, glassware, towels, polishing cloths, and paper. Contaminants listed on the RSWD forms for these wastes are Pu-239, U-235, and MFP. Contaminant levels were estimated for Pu239 and U-235 based on an accounting technique, and calculated for MFP based on a radiation measurement (References 6 and 7). Radiation levels at the exterior surface of the waste package and at 1 $\mathrm{m}$ are provided on most of the RSWD record forms.

Shaft 212 contains the reactor vessel from the LAMPRE reactor. The RSWD record form for the waste package includes the estimated gross volume and weight of the cask containing the reactor vessel, and estimates of the Pu-239 and Co-60 content of the cask.

Table 2 provides a summary of the waste content for the 33 Shafts. Information is provided on the volume of waste; the weight of the waste packages; shaft fill dates (year in which waste was emplaced in the shafts); minimum and maximum contact dose of the waste packages at the time they were placed into the shafts; and total curie (Ci) content of the waste packages. Calculations for radiation parameters decayed to 2009 are also provided for total $\mathrm{Ci}$ and PE-Ci content, and contact doses and dose at $1 \mathrm{~m}$ from the waste packages. All of this information is provided for all 33 Shafts. However, information for Shaft Configuration $\mathrm{C}$ is divided into a column for the shafts in which waste was emplaced before the effective date of the EPA 40 CFR 191 radiation protections standards for TRU waste disposal (Shafts 225-227 and 229-230), and a column for the shafts in which waste was emplaced after the effective date of the EPA 40 CFR 191 radiation protections standards for TRU waste disposal (Shafts 224, 228, 231, and 232).

Waste volumes in the table for all of the shafts except Shaft 212 are based on the volume of the numbers of 1-gal and 2-gal cans described in the RSWD forms, and not on the volume of the double-wall pipes and concrete in Shafts 200-211 and 213-223 or the volume of the pipes that contain the waste packages in Shafts 224-232. The volume used for Shaft 212 in the table is the reported volume of the cask that contains the LAMPRE reactor vessel. The volumes for the retrievable waste configurations in both Shaft Configuration A (Shafts 200-211 and 213-223) and Shaft Configuration B (Shaft 212) are too large to fit into any of the approved transport containers for shipments to WIPP. Although the pipes containing the waste packages in Configuration $\mathrm{C}$ would fit into the WIPP RH-TRU 72-B waste cask, available information is inconsistent on whether the pipes in Configuration $\mathrm{C}$ have a bottom plate that would allow retrieval of the pipe assembly.

Weights presented in the table are based on the weights provided in the RSWD record forms. As noted in one of the footnotes to the table, weights for waste packages in three of the shafts (Shafts 202, 203, and 211) appear questionable because the weights are reported in tons while similar packages in all of the other shafts total only about $100 \mathrm{lb}$ per shaft. The original RSWD forms for Shafts 202 and 203 were transferred to one form for each shaft and it is possible that an error occurred in transfer of the information. However, the five waste packages for Shaft 211 are reported on the RSWD forms as $880 \mathrm{lb}$ 
each, even though all appear similar to waste packages in other shafts that are typically reported as $20 \mathrm{lb}$ each or less. Weights were also not reported for two of four waste packages in the RSWD forms for Shaft 210.

TABLE 2

Summary of Waste Content for 33 Shafts

\begin{tabular}{|c|c|c|c|c|c|c|}
\hline & & $\begin{array}{c}\text { Shafts } \\
200-211 \\
\& 213-223\end{array}$ & $\begin{array}{l}\text { Shaft } \\
212\end{array}$ & $\begin{array}{c}\text { Shafts } \\
225-227 \\
\& 229-230\end{array}$ & $\begin{array}{c}\text { Shafts } \\
224,228,231 \\
232 *\end{array}$ & All 33 Shafts \\
\hline \multicolumn{2}{|l|}{ Volume } & $\begin{array}{l}271 \text { gallons } \\
\left(1.02 \mathrm{~m}^{3}\right)\end{array}$ & $\begin{array}{c}75 \mathrm{ft}^{3} \\
\left(2.12 \mathrm{~m}^{3}\right)\end{array}$ & $\begin{array}{l}39 \text { gal } \\
\left(0.15 \mathrm{~m}^{3}\right)\end{array}$ & $\begin{array}{c}27 \mathrm{gal} \\
(0.10 \mathrm{~m} 3)\end{array}$ & $3.39 \mathrm{~m}^{3}$ \\
\hline \multicolumn{2}{|l|}{ Weight (pounds) } & $16,279 * *$ & 16,000 & 1,137 & 815 & 34,231 \\
\hline \multirow{2}{*}{ Shaft fill dates } & Start & 1979 & 1980 & 1984 & 1985 & 1979 \\
\hline & Finish & 1983 & 1980 & 1984 & 1987 & 1987 \\
\hline \multicolumn{7}{|l|}{ At Emplacement: } \\
\hline \multicolumn{2}{|l|}{ Total Ci } & 3,656 & 42 & 114 & 149 & 3,847 \\
\hline \multirow{2}{*}{$\begin{array}{l}\text { Contact Dose } \\
\text { (mR/hr) }\end{array}$} & Max & $1,200,000$ & 1,750 & 400,000 & 500,000 & $1,200,000$ \\
\hline & Min & Not Available & 1,750 & 10,000 & 3,000 & NA \\
\hline \multicolumn{7}{|l|}{ Decayed to 2009} \\
\hline \multicolumn{2}{|l|}{ Total Ci } & 1,868 & 13 & 64 & 70 & 2,015 \\
\hline \multicolumn{2}{|l|}{$\mathrm{PE}-\mathrm{Ci}$} & 66 & 12 & 7.4 & 8.5 & 93.9 \\
\hline \multirow{2}{*}{$\begin{array}{l}\text { Contact Dose } \\
\text { (mR/hr) }\end{array}$} & Max & 569,000 & 40 & 212,000 & 543,000 & 569,000 \\
\hline & Min & NA & 40 & 5,300 & NA & NA \\
\hline \multirow{2}{*}{$\begin{array}{c}\text { Dose at } 1 \mathrm{~m} \\
(\mathrm{mR} / \mathrm{hr})\end{array}$} & Max & $\sim 4,000$ & $\sim 0$ & $\sim 1,500$ & $\sim_{3,800}$ & $\sim 4,000$ \\
\hline & Min & $\sim 0$ & $\sim 0$ & $\sim 40$ & NA & NA \\
\hline
\end{tabular}

\footnotetext{
* Waste in these shafts emplaced after effective date of 40 CFR 191 Subpart B

** Reported weights for packages within 3 shafts are questionable because the packages are reported in tons while similar packages in other shafts total only about 100 pounds per shaft
}

Of note in the table are the estimated contact radiation levels that are as high as $569,000 \mathrm{mR} / \mathrm{hr}$ even when decayed to 2009. Estimated radiation levels at $1 \mathrm{~m}$ are also estimated to be as high as about 4,000 $\mathrm{mR} / \mathrm{hr}$ when decayed to 2009. These levels would require remote handling of the waste packages.

Because the waste in the 33 shafts is remote-handled waste, the retrieval and processing of the waste has a high-risk in terms of technical complexity and estimated cost. Worker risk for retrieval and processing of the 33 Shafts category is highly uncertain until specific work activities and controls are defined, but radiation exposure to workers is of concern because of the very high radiation levels of the waste packages. The DOE/NNSA is evaluating alternatives that range from leaving all or some subset of shafts in place at MDA G to retrieval, processing, characterization, and shipping all or some subset of the waste within the 33 shafts to WIPP. 


\section{Sources and Limits of Information on 33 Shafts}

Information has been compiled to support the evaluation of alternatives and analysis of regulatory paths for the 33 shafts. The historical data includes a RSWD record form completed by waste generators for each waste package (Reference 6) that included a waste description and estimates of Pu-239, U-235, and MFP. The RSWD record form for Shaft 212 also includes an estimate of Co-60 contamination. Tables of data by waste package were developed during a review of historical documents that was performed in 2005 (Reference 8). Radiological data in this review was coupled with material-type data to estimate the initial isotopic content of each waste package and an Oak Ridge National Laboratory computer code was used to calculate 2009 decay levels. Other sources of information include a waste disposal logbook for the 33 shafts (Reference 9), reports that summarize remote-handled waste generated at the CMR facility (Reference 10) and placement of waste in the 33 shafts (References 7 and 11), a report on decommissioning of the LAMPRE reactor (Reference 12), interviews with an employee and manager involved in placing waste in the 33 shafts (References 13 and 14), an interview with a long-time LANL employee involved in waste operations (Reference 15), a 2002 plan for disposition of remote-handled TRU waste (Reference 16), and photographs obtained during field surveys of several shafts in 2007. The WIPP CCP completed an AK summary report for 16 canisters of remote-handled waste from the CMR Facility that contains information relevant to the 33 Shafts on hot-cell operations and timeline (Reference 17). The waste packaged in the 16 canisters was packaged later than the waste emplaced in the 33 Shafts, and the 16 canisters contained waste generated during cleanout of the hot cells and decommissioning activities.

Overall, the content and accuracy of the data are considered typical for legacy waste generated from 1979 to 1987 . Waste information during this period has gaps and is sometimes inconsistent between various records and reports. Where data were inconsistent, information from generators was judged to be more reliable with regard to waste packages and content, while information from TA-54 operators was judged to be more reliable with regard to shaft configuration and placement of waste packages into the shafts.

Waste data fact sheets for the 33 shafts (Appendix A) were prepared using information compiled to date that was judged to be the most reliable and accurate available. These include a summary fact sheet and a specific fact sheet for each of the 33 shafts. The specific fact sheets for each shaft include a short description of shaft contents and configuration, figures of shaft configuration and location, and tables with more detailed data on waste packages and content of each shaft, including available data on radiation levels of waste packages. 


\section{References}

1. Compliance Order on Consent, Los Alamos National Laboratory, New Mexico Environment Department, March 1, 2005.

2. Los Alamos National Laboratory Framework Agreement: Realignment of Environmental Priorities, Department of Energy National Nuclear Security Administration and State of New Mexico Environment Department, January 2012.

3. Los Alamos National Laboratory Schedule for Disposition of Below-Ground Transuranic Waste Requiring Retrieval, LA-UR-12-26765, December 10, 2012; submitted in letter from Jeff Mousseau, Associate Director Environmental Programs, LANL, and Peter Maggiore, Assistant Manager Environmental Projects Office, Los Alamos Site Office, National Nuclear Security Administration, to Jim Davis, Division Director, Resource Protection Division, New Mexico Environment Department, EP2012-0288, December 10, 2012.

4. Section 191.17, Effective Date, in Subpart B, Environmental Standards for Disposal, Code of Federal Regulations, Title 40-Protection of the Environment, Part 191-Environmental Radiation Protections Standards for Management and Disposal of Spent Nuclear Fuel, HighLevel and Transuranic Radioactive Wastes, US Government Printing Office, Washington, DC

5. Transuranic Waste Acceptance Criteria for the Waste Isolation Pilot Plant, DOE/WIPP-02-3122 Rev. 7.4, U.S. Department of Energy, Carlsbad Field Office, April 22, 2013.

6. Radioactive Solid Waste Disposal (RSWDs) Forms for LANL RH Waste in 33 Shafts (RH AKM167), RSWD No. and Date Ranges: S791472, February 7, 1979 - S874134, February 4, 1986, Los Alamos National Laboratory, Environmental Programs Document Control System, ERID506471.

7. J. Warren, Letter to R. M. Greinetz with attachment, Remote Handled Stored TRU Waste at LASL, H7-79-176, Los Alamos Scientific Laboratory, April 17, 1979.

8. Historical Emplacement Data Review for Remote-Handled and Contact-Handled Transuranic Waste at Los Alamos National Laboratory, prepared by Weston Solutions, Inc., December 22, 2005, Environmental Programs Document Control System, ERID-5226716.

9. RH Waste 33 Shafts, LANL CMR Notebook No. S-3873, Aug. 1978-Dec. 1991, Los Alamos National Laboratory, Environmental Programs Document Control System, ERID-506580.

10. L.R. Field and P. Del Mar, Survey of RH-TRU Waste at Los Alamos National Laboratory, TWCP-443, Environmental Programs Document Control System, ERID-130442.

11. J. L. Warren and A. E. Dross, Final TRU Waste Inventory Work-Off Plan, Los Alamos National Laboratory, August 1986 (Revised December 15, 1986), LA-UR-86-862932, Environmental Programs Document Control System, ERID-132782.

12. J. R. Harper and R. Garde, Decommissioning the Los Alamos Molten Plutonium Reactor Experiment (LAMPRE I), LA-9052-MS, Los Alamos National Laboratory, November 1981.

13. T. H. Monk, Charles Villareal Interview regarding 33-Shafts, May 23, 2012.

14. T. H. Monk, John Warren Telephone Interview regarding 33- Shafts, June 8, 2012.

15. T. H. Monk, Davis Christensen Interview regarding 33-Shafts, November 15, 2012.

16. J. N. Vance and L. E. Leonard, LANL Remote-Handled Transuranic (RH-TRU) Waste Disposition Plan, April 10, 2003, Los Alamos National Laboratory, Environmental Programs Document Control System, ERID-125088.

17. Central Characterization Project Acceptable Knowledge Summary Report For 16 Canisters of Remote-Handled Transuranic Debris Waste From Los Alamos National Laboratory Chemistry and Metallurgy Research Facility, Waste Stream; LA-MHD03.002, Revision 3, CCP-AK-LANL500, June 5, 2007.

18. M. A. Rogers, History and Environmental Setting of LASL Near-Surface Land Disposal Facilities for Radioactive Wastes (Areas A, B, C, D, E, R, G, and T), LA-6848-MS, Vol. 1, June 1977. 
19. R. E.Hollingsworth, Immediate Action Directive 0511-21, Policy Statement Regarding Solid Waste Burial, U.S. Atomic Energy Commission, March 20, 1970.

20. AEC Manual, Chapter 0511, Radioactive Waste Management, U.S. Atomic Energy Commission, September 19, 1973.

21. Management of Transuranic Contaminated Material, DOE Order 5820.1, U.S. Department of Energy, Washington, D.C., September 30, 1982.

22. K. M. Hargis, D. V. Christensen, and M. D. Shepard, De-Inventory Plan for Transuranic Waste Stored at Area G, EP2012-5025, Rev. 0, LANL, January 2012.

23. S. Bodenstein, S. Helfinstine, R. Romero, and J. Ledbetter, "Wing 9 Hot Cells Support Work Involving Highly Radioactive Materials,” The Actinide Research Quarterly, $1^{\text {st }}$ Quarter 1999, LANL, Spring 1999.

24. B. Crooks, LAMPRE fuel - processed at Savannah River between 1966-67, e-mail from B. Crooks to M. Lee Bishop, September 26, 2013. 
Appendix A

33 Shafts Waste Data Fact Sheets

Page A-1 
This page intentionally left blank.

Page A-2 


\section{Material Disposal Area G}

\section{Shafts Waste Data Fact Sheets}

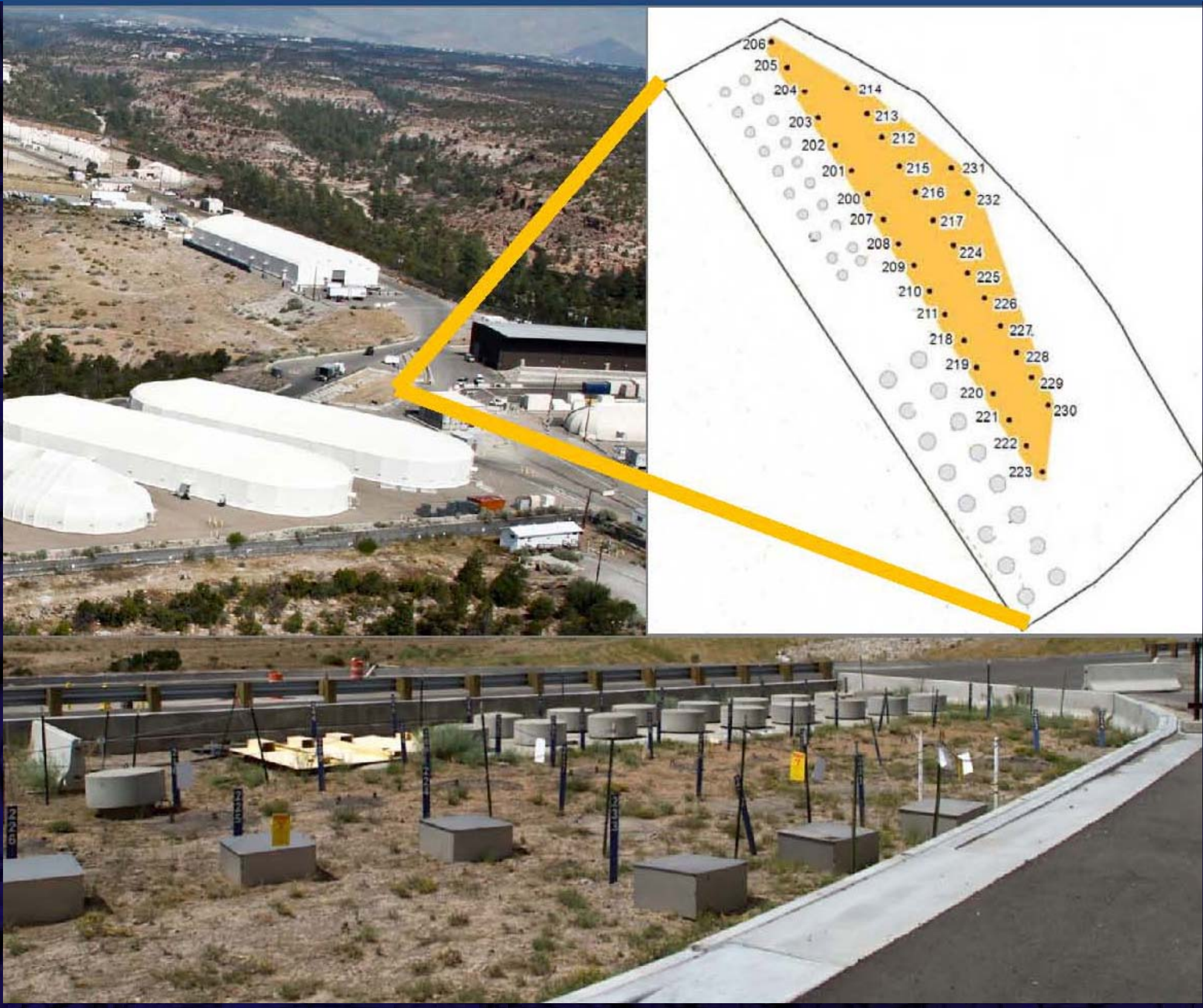

The 33 Shafts in MDA-G are augured vertical holes with three distinct configurations containing waste packages. Thirty two of the shafts contain waste packages from irradiated fuel examination and a single shaft contains a small reactor vessel.

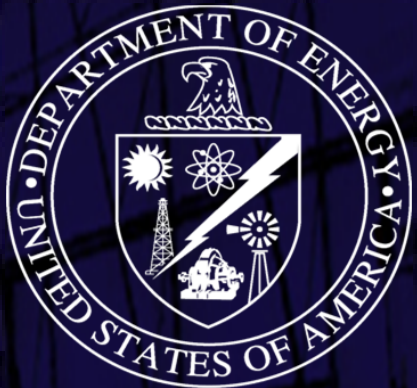




\section{Shafts}

\section{Waste Characteristics Summary}

\section{Contents}

The 33 shafts are comprised of Material Disposal Area G shafts 200-232. Remote handled transuranic (TRU) waste was placed into these shafts from 1979-1987. The waste in the 33 shafts was generated in hot cell operations at the Chemistry and Metallurgy Research (CMR) facility, except for shaft 212 which contains the reactor vessel from a small research reactor called the Los Alamos Molten Plutonium Reactor Experiment (LAMPRE).

CMR waste was generated from examination of irradiated fuels from the Liquid Metal Fast Breeder Reactor and other advancedfuel evaluation efforts, including the ROVER space propulsion program. A single waste package in shaft 232 suggests that materials from Three Mile Island also may have been examined. Generator records indicate the waste includes residual samples, spent equipment and waste materials typical of hot cell operations.

\section{Shaft Data}

An extensive review of historical documents in 2005 included waste generator records that described the waste and quantity of Pu$239, \mathrm{U}-235$, and mixed fission products. Other data sources also were examined. The content and accuracy of the data are typical for legacy waste generated from 1979-1987. The initial isotopic content of each package was estimated from radiological data coupled with material-type data, and an Oak Ridge National Laboratory computer code calculated 2009 decay levels.

\section{RCRA Status}

All wastes in the 33 shafts were emplaced before the effective date of RCRA mixed waste regulations. Therefore, the 33 shafts are not regulated as RCRA treatment, storage or disposal units. Any wastes retrieved from the shafts would be subject to the RCRA waste characterization requirements for newly-generated wastes. The 33 shafts were identified by LANL as a solid waste management unit for the purposes of RCRA corrective action. Any releases of RCRA hazardous constituents from the shafts are, therefore, subject to the corrective action requirements of the 2005 Compliance Order on Consent (Consent Order). This Consent Order does not regulate the radionuclides present in the shafts.

\section{CFR 191}

Waste in Shafts 224, 228, 231, and 232 was emplaced after the November 18, 1985, effective date of 40 CFR 191 Subpart B, Environmental Standards for Disposal. Waste in the remainder of the 33 shafts was emplaced before 1985.

\begin{tabular}{|c|c|c|c|c|c|c|}
\hline \multicolumn{2}{|l|}{ Shaft Data } & $\begin{array}{c}\text { Shafts } 200-211 \text { and } \\
\text { Shafts } 213-223\end{array}$ & Shaft 212 & $\begin{array}{l}\text { Shafts } 225-227 \\
\& 229-230\end{array}$ & $\begin{array}{c}\text { Shafts } 224,228, \\
231,232 *\end{array}$ & All 33 Shafts \\
\hline \multicolumn{2}{|l|}{ Shaft Configuration } & A & B & C & C & $A, B$, and $C$ \\
\hline \multicolumn{2}{|l|}{ Volume } & $\begin{array}{c}271 \text { gallons } \\
\left(1.02 \mathrm{~m}^{3}\right)\end{array}$ & $\begin{array}{c}75 \mathrm{ft} 3 \\
\left(2.12 \mathrm{~m}^{3}\right)\end{array}$ & $\begin{array}{c}39 \text { gal } \\
\left(0.15 \mathrm{~m}^{3}\right)\end{array}$ & $\begin{array}{c}27 \mathrm{gal} \\
\left(0.10 \mathrm{~m}^{3}\right)\end{array}$ & $3.39 \mathrm{~m}^{3}$ \\
\hline \multicolumn{2}{|l|}{ Weight (total pounds) } & $16,279 * *$ & 16,000 & 1,137 & 815 & 34,231 \\
\hline \multicolumn{2}{|l|}{ Shaft Fill Dates } & $1979-1983$ & 1980 & 1984 & $1985-1987$ & 1979-1987 \\
\hline \multicolumn{7}{|l|}{ Properties at Disposal } \\
\hline \multicolumn{2}{|l|}{ Total Curies } & 3,656 & 42 & 114 & 149 & 3,847 \\
\hline \multirow{2}{*}{$\begin{array}{l}\text { Reported Contact Dose of } \\
\text { Waste Packages (mRem/hr) }\end{array}$} & Maximum & $1,200,000$ & 1,750 & 400,000 & 500,000 & $1,200,000$ \\
\hline & Minimum & 50,000 & 1,750 & 10,000 & 3,000 & 3,000 \\
\hline \multicolumn{7}{|c|}{ Estimated Properties Decayed to 2009} \\
\hline \multicolumn{2}{|l|}{ Total Curies } & 1,868 & 13 & 64 & 70 & 2,015 \\
\hline \multicolumn{2}{|c|}{ Plutonium-239 Equivalent Curies (PE-Ci) } & 66 & 12 & 7.4 & 8.5 & 93.9 \\
\hline \multirow{2}{*}{$\begin{array}{l}\text { Calculated Contact Dose of } \\
\text { Waste Packages (mRem/hr) }\end{array}$} & Maximum & 569,000 & 40 & 212,000 & 543,000 & 569,000 \\
\hline & Minimum & 0 & 40 & 5,300 & 0 & 0 \\
\hline \multirow{2}{*}{$\begin{array}{l}\text { Calculated Dose of Waste } \\
\text { Pkgs. at } 1 \text { meter (mRem/hr) }\end{array}$} & Maximum & $\sim 4,000$ & $\sim 0$ & $\sim 1,500$ & $\sim 3,800$ & $\sim 4,000$ \\
\hline & Minimum & $\sim 0$ & $\sim 0$ & $\sim 40$ & $\sim 0$ & $\sim 0$ \\
\hline
\end{tabular}

* Waste in these shafts emplaced after effective date of 40 CFR 191 Subpart B

** Reported weights for packages within 3 shafts are questionable because total weights are about ten times higher than similar packages in other shafts 


\section{Shafts \\ Configurations}

Configuration $\mathrm{A}$

Shafts $200-211$ and $213-223$

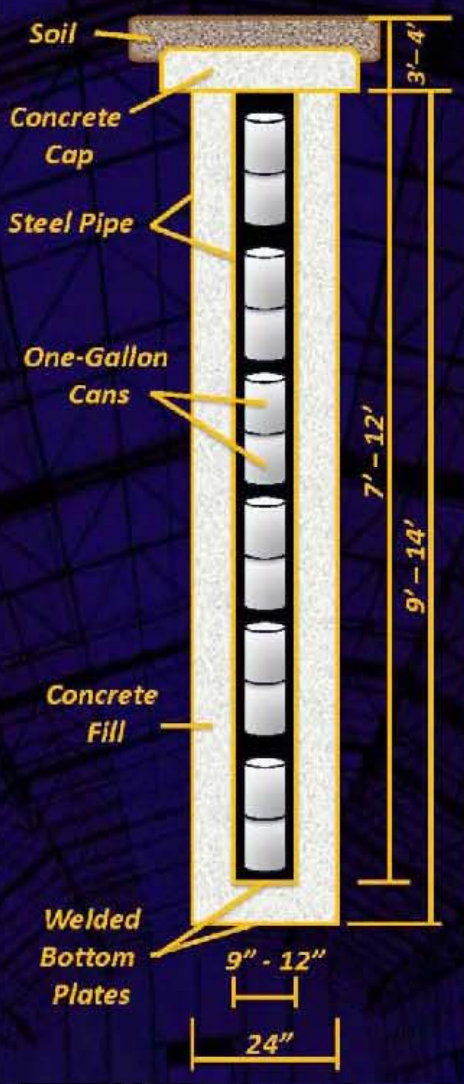

\section{Configuration A}

Waste packages in the inner pipe of configuration A shafts typically consist of a plastic bag containing one or two 1-gallon or 2-gallon metal paint-type cans filled with waste. Some cans may also be inside a plastic bucket.

\section{Configuration B Shaft 212}

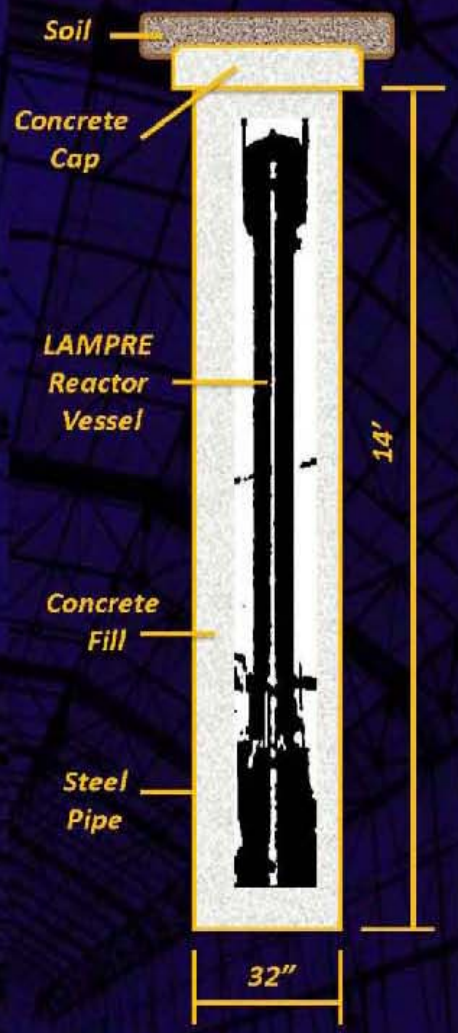

\section{Configuration B}

Shaft 212, Configuration B, contains a single waste package, a metal pipe with a welded bottom with the LAMPRE reactor vessel encased in concrete.
Configuration $\mathrm{C}$ Shafts 224-232

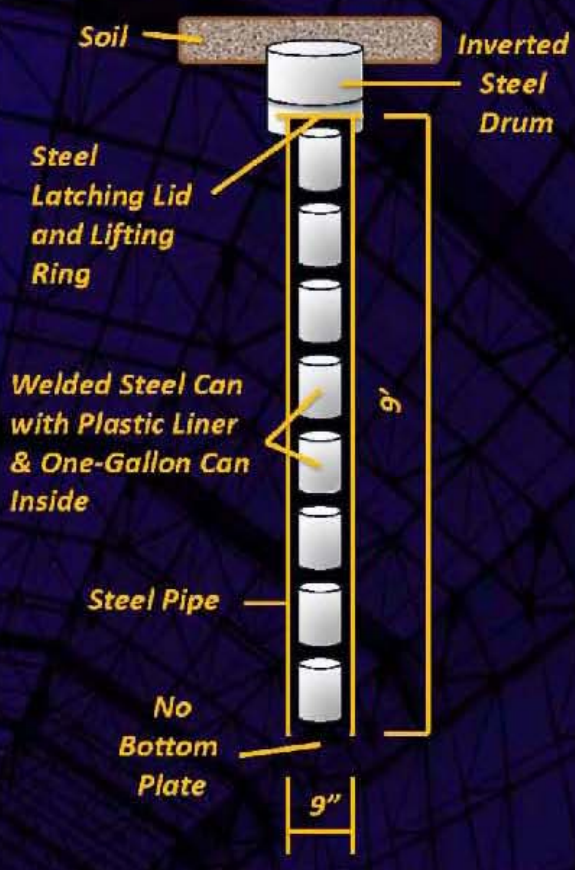

\section{Configuration C}

Configuration $\mathrm{C}$ waste

packages consist of a steel can, sealed with a welded-on lid, and typically contain a plastic bucket with a one-gallon steel paint-type can inside. 
Material Disposal Area G, 33 Shafts

\title{
Waste Data Fact Sheets for
}

Shafts 224, 228, 231, 232

\author{
Waste Emplaced After \\ Effective Date of 40 CFR 191
}


This page intentionally left blank 


\section{Material Disposal Area G, 33 Shafts Shaft 224 Waste Data Fact Sheet}

\section{Contents}

Shaft 224 contains eight packages of waste from the Chemistry and Metallurgy Research (CMR) Facility Wing 9 hot cells, with each package containing waste in a one-gallon paint-type can that is inside a rigid plastic liner that is inside a 1/8" wall welded steel can. Wastes include hot-cell trash, spent-fuel sample preparation residues, cladding, tissue, and small tools. Major radionuclides in the waste consist of plutonium-239, uranium235, and mixed fission products (MFP). Waste is considered to be remotehandled with the reported radiation dose at the surface of the packages at the time of generation ranging from 20,000 to $300,000 \mathrm{mrem} /$ hour. The eight packages of waste were placed into Shaft 224 in December 1985.

\section{Shaft Configuration}

Construction of Shaft 224 was initiated by augering a 36-inch diameter vertical hole into the mesa top. An 1/4 inch wall inner pipe of 9-inch diameter and 9 feet in length was centered in the shaft with crushed tuff used to fill the space between the pipe and the shaft. A large metal funnel was placed in the inner pipe, and waste packages were dropped into the inner pipe from a shielded transport cask moved into position above the shaft. After all waste packages were placed into the pipe, a latching lid with a lifting ring was placed onto the top of the pipe, and the shaft was protected by an inverted cut-down 55-gallon drum placed on top of the shaft.

\section{Shaft 224 Configuration}

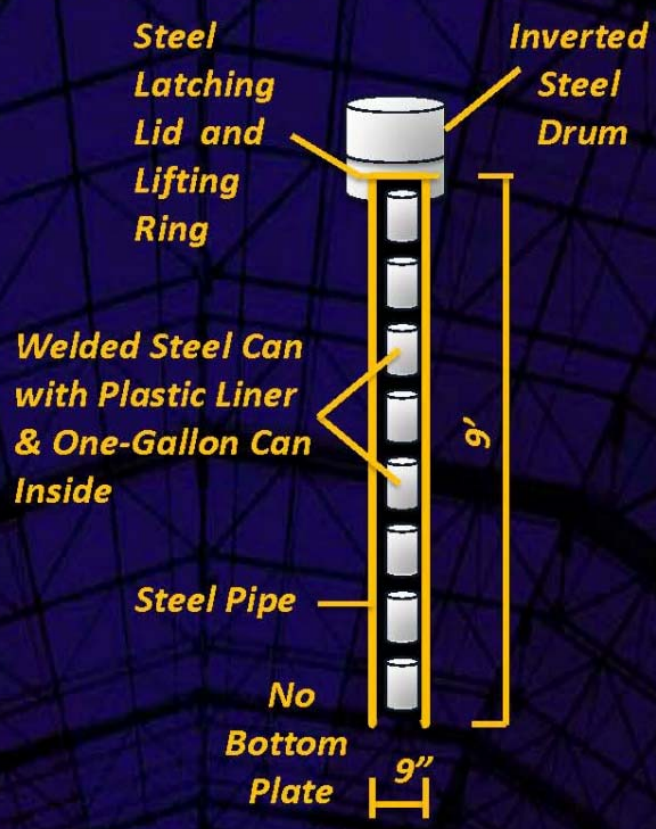

\section{Location in Shaft Field}

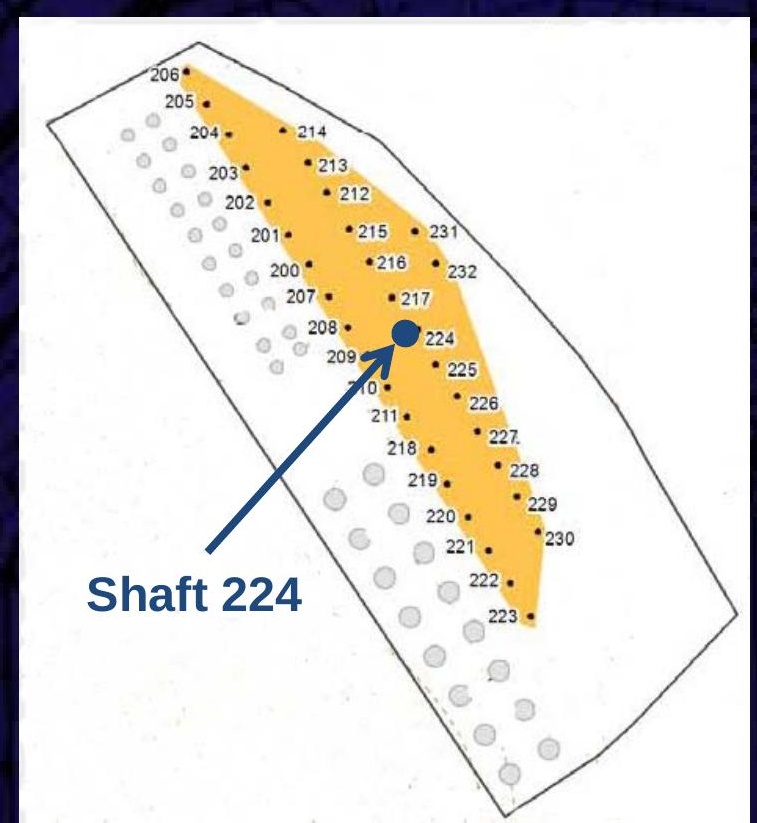

Waste Package Data Summary

\begin{tabular}{|c|c|c|c|c|c|}
\hline $\begin{array}{c}\text { RSWD } \\
\text { Number }\end{array}$ & $\begin{array}{c}\text { Volume } \\
\text { (gallons) }\end{array}$ & Radionuclides & $\begin{array}{c}\text { Total Curies } \\
\text { at Disposal }\end{array}$ & $\begin{array}{c}\text { Total Curies } \\
\text { Decayed to 2009 }\end{array}$ & PE-Ci \\
\hline S852326 & 1 & Pu-239, U-235, MFP & 4.00 & 2.19 & 0.0062 \\
\hline S852328 & 1 & Pu-239, U-235, MFP & 2.00 & 1.10 & 0.0062 \\
\hline S852332 & 1 & Pu-239, U-235, MFP & 4.00 & 2.19 & 0.0062 \\
\hline S852804 & 1 & Pu-239, U-235, MFP & 3.00 & 1.73 & 0.204 \\
\hline S855064 & 1 & Pu-239, U-235, MFP & 4.02 & 2.30 & 0.223 \\
\hline S855065 & 1 & Pu-239, U-235, MFP & 4.42 & 2.52 & 0.223 \\
\hline S855066 & 1 & Pu-239, U-235, MFP & 1.50 & 0.83 & 0.0062 \\
\hline S855068 & 1 & Pu-239, U-235, MFP & 1.50 & 0.83 & 0.0062 \\
\hline TOTALS for & 8 & Pu-239, U-235, MFP & 24.47 & 13.68 & 0.68 \\
\hline Shaft 224 & & & & & \\
\hline
\end{tabular}

* RSWD $=$ Radioactive Solid Waste Disposal record 


\section{Shaft 224 Totals}

\begin{tabular}{|c|c|c|}
\hline Total Number of Waste Packages & \multicolumn{2}{|c|}{8} \\
\hline Total Gross Weight (pounds) & \multicolumn{2}{|c|}{240} \\
\hline Total Pu-239 (grams) & \multicolumn{2}{|c|}{11} \\
\hline Total U-235 (grams) & \multicolumn{2}{|c|}{40.5} \\
\hline Total Mixed Fission Products at disposal (Ci) & \multicolumn{2}{|c|}{23.8} \\
\hline Dates of Disposal & \multicolumn{2}{|c|}{$12 / 30 / 1985$ to $12 / 30 / 1985$} \\
\hline Radiation at Surface of Waste Package ( $\mathrm{mR} / \mathrm{hr}$ ) & $\begin{array}{l}20,000 \text { to } 300,000 \\
\text { at disposal }\end{array}$ & $\begin{array}{l}11,000 \text { to } 163,000 \\
\text { decayed to } 2009\end{array}$ \\
\hline $\begin{array}{l}\text { Radiation at One Meter from Surface of Waste } \\
\text { Package }(\mathrm{mR} / \mathrm{hr})\end{array}$ & $\begin{array}{l}500 \text { to } 4,200 \\
\text { at disposal }\end{array}$ & $\begin{array}{c}80 \text { to } 1,150 * \\
\text { decayed to } 2009\end{array}$ \\
\hline
\end{tabular}

* Calculated using inverse square rule assuming a point source at the center of the waste package paint cans

\section{Detailed Waste Package Data at Disposal}

\begin{tabular}{|c|c|c|c|c|c|c|c|c|c|}
\hline $\begin{array}{l}\text { RSWD } \\
\text { Number }\end{array}$ & $\begin{array}{c}\text { Date } \\
\text { Disposed }\end{array}$ & $\begin{array}{c}\text { Gross } \\
\text { Weight } \\
\text { (lb) }\end{array}$ & Waste Description & $\begin{array}{l}\text { Additional } \\
\text { Description of } \\
\text { Packaging and } \\
\text { Packaging } \\
\text { Materials }\end{array}$ & $\begin{array}{l}\text { Nuclide } \\
\text { or } \\
\text { Material } \\
\text { Type }\end{array}$ & Amount & Units & $\begin{array}{l}\text { Package } \\
\text { Radiation } \\
\text { at Surface } \\
\text { (mR/hr) }\end{array}$ & $\begin{array}{c}\text { Package } \\
\text { Radiation } \\
\text { at } 1 \text { meter } \\
(\mathrm{mR} / \mathrm{hr})\end{array}$ \\
\hline \multirow{3}{*}{ S852326 } & \multirow{3}{*}{$12 / 30 / 1985$} & \multirow{3}{*}{30} & \multirow{3}{*}{$\begin{array}{l}\text { Cell \#11 waste plastic } \\
\text { can \#4088 }\end{array}$} & \multirow{3}{*}{$\begin{array}{c}300 \mathrm{R} / \mathrm{hr} @ \text { cont steel } \\
\text { can \#58 }\end{array}$} & Pu-239 & $1.00 \mathrm{E}-01$ & $\mathrm{~g}$ & \multirow{3}{*}{300,000} & \multirow{3}{*}{4,000} \\
\hline & & & & & $\mathrm{U}-235$ & $4.00 \mathrm{E}-01$ & $\mathrm{~g}$ & & \\
\hline & & & & & MFP & 4.00E+00 & $\mathrm{Ci}$ & & \\
\hline \multirow{3}{*}{ S852328 } & \multirow{3}{*}{$12 / 30 / 1985$} & \multirow{3}{*}{30} & \multirow{3}{*}{$\begin{array}{l}\text { Cell \#11 waste plastic } \\
\text { can \#4097 }\end{array}$} & \multirow{3}{*}{$\begin{array}{c}100 \text { R/hr @ cont steel } \\
\text { can \#61 }\end{array}$} & Pu-239 & $1.00 \mathrm{E}-01$ & $\mathrm{~g}$ & \multirow{3}{*}{100,000} & \multirow{3}{*}{2,000} \\
\hline & & & & & $\mathrm{U}-235$ & 4.00E-01 & $\mathrm{g}$ & & \\
\hline & & & & & MFP & $2.00 \mathrm{E}+00$ & $\mathrm{Ci}$ & & \\
\hline \multirow{3}{*}{ S852332 } & \multirow{3}{*}{$12 / 30 / 1985$} & \multirow{3}{*}{30} & \multirow{3}{*}{$\begin{array}{l}\text { Cell \#13 waste plastic } \\
\text { can \#4072 }\end{array}$} & \multirow{3}{*}{$\begin{array}{c}300 \mathrm{R} / \mathrm{hr} @ \text { cont steel } \\
\text { can \#32 }\end{array}$} & Pu-239 & $1.00 \mathrm{E}-01$ & $\mathrm{~g}$ & \multirow{3}{*}{300,000} & \multirow{3}{*}{4,000} \\
\hline & & & & & $\mathrm{U}-235$ & 4.00E-01 & $\mathrm{g}$ & & \\
\hline & & & & & MFP & 4.00E+00 & $\mathrm{Ci}$ & & \\
\hline \multirow{3}{*}{ S852804 } & \multirow{3}{*}{$12 / 30 / 1985$} & \multirow{3}{*}{30} & \multirow{3}{*}{$\begin{array}{c}\text { Cell } 14 \text { trash can } 3660 \\
\text { fuel inside }\end{array}$} & \multirow{3}{*}{$\begin{array}{l}\text { Steel can } 67100 \mathrm{R} \\
\text { contact }\end{array}$} & $\mathrm{Pu}-239$ & $3.30 \mathrm{E}+00$ & g & \multirow{3}{*}{100,000} & \multirow{3}{*}{2,800} \\
\hline & & & & & $\mathrm{U}-235$ & $8.70 E+00$ & $\mathrm{~g}$ & & \\
\hline & & & & & MFP & $2.80 \mathrm{E}+00$ & $\mathrm{Ci}$ & & \\
\hline \multirow{3}{*}{ S855064 } & \multirow{3}{*}{$12 / 30 / 1985$} & \multirow{3}{*}{30} & \multirow{3}{*}{$\begin{array}{c}\text { Cell } 14 \text { trash can } 3661 \\
\text { fuel inside }\end{array}$} & & Pu-239 & $3.60 E+00$ & $\mathrm{~g}$ & & \\
\hline & & & & $\begin{array}{c}\text { Steel can } 63100 \mathrm{R} / \mathrm{hr} \\
\text { contact }\end{array}$ & $\mathrm{U}-235$ & 1.49E+01 & $\mathrm{g}$ & 100,000 & 3,300 \\
\hline & & & & & MFP & $3.80 E+00$ & $\mathrm{Ci}$ & & \\
\hline & & & & & $\mathrm{Pu}-239$ & $3.60 E+00$ & $\mathrm{~g}$ & & \\
\hline S855065 & $12 / 30 / 1985$ & 30 & $\begin{array}{l}\text { Cell } 14 \text { trash can } 3662 \\
\text { fuel inside }\end{array}$ & $\begin{array}{l}\text { Steel can } 66300 \mathrm{R} / \mathrm{hr} \\
\text { contact }\end{array}$ & $\mathrm{U}-235$ & $1.49 \mathrm{E}+01$ & $\mathrm{~g}$ & 300,000 & 4,200 \\
\hline & & & & & MFP & $4.20 \mathrm{E}+00$ & $\mathrm{Ci}$ & & \\
\hline & & & & & Pu-239 & $1.00 \mathrm{E}-01$ & $\mathrm{~g}$ & & \\
\hline S855066 & $12 / 30 / 1985$ & 30 & $\begin{array}{c}\text { Cell } 14 \text { trash can } 3663 \\
\text { trash only }\end{array}$ & Steel can 65 & $\mathrm{U}-235$ & $4.00 \mathrm{E}-01$ & $\mathrm{~g}$ & 70,000 & 1,500 \\
\hline & & & & & MFP & $1.50 \mathrm{E}+00$ & $\mathrm{Ci}$ & & \\
\hline & & & & & Pu-239 & $1.00 \mathrm{E}-01$ & $\mathrm{~g}$ & & \\
\hline S855068 & $12 / 30 / 1985$ & 30 & $\begin{array}{c}\text { Cell } 14 \text { trash can } 3664 \\
\text { fuel inside }\end{array}$ & Steel can 64 & $\mathrm{U}-235$ & $4.00 \mathrm{E}-01$ & $\mathrm{~g}$ & 20,000 & 500 \\
\hline & & & & & MFP & $1.50 E+00$ & $\mathrm{Ci}$ & & \\
\hline
\end{tabular}




\section{Shaft 228 Totals}

\begin{tabular}{|c|c|c|}
\hline Total Number of Waste Packages & \multicolumn{2}{|c|}{8} \\
\hline Total Gross Weight (pounds) & \multicolumn{2}{|c|}{235} \\
\hline Total Pu-239 (grams) & \multicolumn{2}{|c|}{0.8} \\
\hline Total U-235 (grams) & \multicolumn{2}{|c|}{3.2} \\
\hline Total Mixed Fission Products at disposal (Ci) & \multicolumn{2}{|c|}{10.8} \\
\hline Dates of Disposal & \multicolumn{2}{|c|}{$12 / 23 / 1987$ to $12 / 23 / 1987$} \\
\hline Radiation at Surface of Waste Package ( $\mathrm{mR} / \mathrm{hr}$ ) & $\begin{array}{l}9,000 \text { to } 200,000 \\
\text { at disposal }\end{array}$ & $\begin{array}{c}0 \text { to } 114,000 \\
\text { decayed to } 2009\end{array}$ \\
\hline $\begin{array}{l}\text { Radiation at One Meter from Surface of Waste } \\
\text { Package ( } \mathrm{mR} / \mathrm{hr})\end{array}$ & $\begin{array}{l}120 \text { to } 2,500 \\
\text { at disposal }\end{array}$ & $\begin{array}{l}0 \text { to } 800 * \\
\text { decayed to } 2009\end{array}$ \\
\hline
\end{tabular}

* Calculated using inverse square rule assuming a point source at the center of the waste package paint cans

\section{Detailed Waste Package Data at Disposal}

\begin{tabular}{|c|c|c|c|c|c|c|c|c|c|}
\hline $\begin{array}{l}\text { RSWD } \\
\text { Number }\end{array}$ & $\begin{array}{c}\text { Date } \\
\text { Disposed }\end{array}$ & $\begin{array}{l}\text { Gross } \\
\text { Weight } \\
\text { (lb) }\end{array}$ & Waste Description & $\begin{array}{l}\text { Additional } \\
\text { Description of } \\
\text { Packaging and } \\
\text { Packaging } \\
\text { Materials }\end{array}$ & $\begin{array}{l}\text { Nuclide } \\
\text { or } \\
\text { Material } \\
\text { Type }\end{array}$ & Amount & Units & $\begin{array}{c}\text { Package } \\
\text { Radiation } \\
\text { at Surface } \\
(\mathrm{mR} / \mathrm{hr})\end{array}$ & $\begin{array}{c}\text { Package } \\
\text { Radiation } \\
\text { at } 1 \text { meter } \\
(\mathrm{mR} / \mathrm{hr})\end{array}$ \\
\hline \multirow{3}{*}{ S874123 } & \multirow{3}{*}{$12 / 23 / 1987$} & \multirow{3}{*}{30} & \multirow{3}{*}{ Cell 14 trash can 4032} & \multirow{3}{*}{$\begin{array}{l}\text { Steel can 54, was } \\
\text { RSWD } 852802\end{array}$} & Pu-239 & $1.00 \mathrm{E}-01$ & $\mathrm{~g}$ & \multirow{3}{*}{9,000} & \multirow{3}{*}{150} \\
\hline & & & & & $\mathrm{U}-235$ & 4.00E-01 & $\mathrm{g}$ & & \\
\hline & & & & & MFP & $1.50 \mathrm{E}-01$ & $\mathrm{Ci}$ & & \\
\hline \multirow{3}{*}{ S874124 } & \multirow{3}{*}{$12 / 23 / 1987$} & \multirow{3}{*}{25} & \multirow{3}{*}{$\begin{array}{l}\text { Cell } 13 \text { waste plastic } \\
\text { can } \# 4093 \text { steel }\end{array}$} & \multirow{3}{*}{$\begin{array}{c}\text { can } 55,20 \mathrm{R} / \mathrm{hr} \\
\text { contact, was RSWD } \\
\# 852325\end{array}$} & Pu-239 & $1.00 \mathrm{E}-01$ & $\mathrm{~g}$ & \multirow{3}{*}{20,000} & \\
\hline & & & & & U-235 & $4.00 \mathrm{E}-01$ & $\mathrm{~g}$ & & \\
\hline & & & & & MFP & $1.50 E+00$ & $\overline{\mathrm{Ci}}$ & & \\
\hline \multirow{3}{*}{ S874125 } & \multirow{3}{*}{$12 / 23 / 1987$} & \multirow{3}{*}{30} & \multirow{3}{*}{$\begin{array}{c}\text { Cell } 14 \text { waste can } 4164 \text {, } \\
\text { Steel can } 62\end{array}$} & \multirow{3}{*}{$\begin{array}{c}10 \mathrm{R} / \mathrm{hr} \text { contact, was } \\
\text { RSWD \#852811 }\end{array}$} & Pu-239 & $1.00 \mathrm{E}-01$ & $\mathrm{~g}$ & \multirow{3}{*}{10,000} & \multirow{3}{*}{120} \\
\hline & & & & & U-235 & 4.00E-01 & $\mathrm{g}$ & & \\
\hline & & & & & MFP & 1.50E-01 & $\mathrm{Ci}$ & & \\
\hline \multirow{3}{*}{ S874126 } & \multirow{3}{*}{$12 / 23 / 1987$} & \multirow{3}{*}{30} & \multirow{3}{*}{$\begin{array}{l}\text { Cell \#13 waste plastic } \\
\text { can \#4086, see RSWD \# }\end{array}$} & \multirow{3}{*}{$\begin{array}{l}\text { 852323, Steel Can \#57, } \\
200 \text { R/hr @ cont. }\end{array}$} & Pu-239 & $1.00 \mathrm{E}-01$ & $\mathrm{~g}$ & \multirow{3}{*}{200,000} & \multirow{3}{*}{2,500} \\
\hline & & & & & U-235 & 4.00E-01 & $\mathrm{g}$ & & \\
\hline & & & & & MFP & $2.50 \mathrm{E}+00$ & $\overline{\mathrm{Ci}}$ & & \\
\hline \multirow{3}{*}{ S874127 } & \multirow{3}{*}{$12 / 23 / 1987$} & \multirow{3}{*}{30} & \multirow{3}{*}{$\begin{array}{c}\text { Cell \#13 waste plastic } \\
\text { can \#4094, Was RSWD\# }\end{array}$} & & Pu-239 & 1.00E-01 & $\mathrm{g}$ & & \\
\hline & & & & 852324, Steel Can 56 & $\mathrm{U}-235$ & 4.00E-01 & $\mathrm{g}$ & & \\
\hline & & & & & MFP & $1.50 \mathrm{E}+00$ & $\mathrm{Ci}$ & & \\
\hline & & & & & Pu-239 & $1.00 \mathrm{E}-01$ & $\mathrm{~g}$ & & \\
\hline S874128 & $12 / 23 / 1987$ & 30 & $\begin{array}{c}\text { Cell \#11 waste plastic } \\
\text { can \#4092 }\end{array}$ & $\begin{array}{l}\text { Steel can \#60 See } \\
\text { RSWD \#852330 }\end{array}$ & $\mathrm{U}-235$ & 4.00E-01 & $\mathrm{g}$ & & \\
\hline & & & & & MFP & $1.50 \mathrm{E}+00$ & $\mathrm{Ci}$ & & \\
\hline & & & & & Pu-239 & 1.00E-01 & $\mathrm{g}$ & & \\
\hline S874129 & $12 / 23 / 1987$ & 30 & Cell \#11 waste plastic & Steel can \#59, see & U-235 & 4.00E-01 & $\mathrm{g}$ & 60,000 & 1,500 \\
\hline & & & & & MFP & $1.50 \mathrm{E}+00$ & $\mathrm{Ci}$ & & \\
\hline & & & & & Pu-239 & 1.00E-01 & $\mathrm{g}$ & & \\
\hline S874130 & $12 / 23 / 1987$ & 30 & Cell \#14 trash can & Steel can \#53, see & U-235 & $4.00 \mathrm{E}-01$ & $\mathrm{~g}$ & 80,000 & 2,000 \\
\hline & & & & & MFP & $2.00 \mathrm{E}+00$ & $\mathrm{Ci}$ & & \\
\hline
\end{tabular}




\section{Material Disposal Area G, 33 Shafts Shaft 231 Waste Data Fact Sheet}

\section{Contents}

Shaft 231 contains eight packages of waste from the Chemistry and Metallurgy Research (CMR) Facility Wing 9 hot cells, with each package containing waste in a one-gallon paint-type can that is inside a rigid plastic liner that is inside a 1/8" wall welded steel can. Wastes include hot-cell trash, spent-fuel sample preparation residues, cladding, tissue, and small tools. Major radionuclides in the waste consist of plutonium-239, uranium235, and mixed fission products (MFP). Waste is considered to be remotehandled with the reported radiation dose at the surface of the packages at the time of generation ranging from 3,000 to 1,000,000 mrem/hour. The eight packages of waste were placed into Shaft 231 in December 1985.

\section{Shaft Configuration}

Construction of Shaft 231 was initiated by augering a 36-inch diameter vertical hole into the mesa top. An 1/4 inch wall inner pipe of 9-inch diameter and 9 feet in length was centered in the shaft with crushed tuff used to fill the space between the pipe and the shaft. A large metal funnel was placed in the inner pipe, and waste packages were dropped into the inner pipe from a shielded transport cask moved into position above the shaft. After all waste packages were placed into the pipe, a latching lid with a lifting ring was placed onto the top of the pipe, and the shaft was protected by an inverted cut-down 55-gallon drum placed on top of the shaft.

\section{Shaft 231 Configuration}

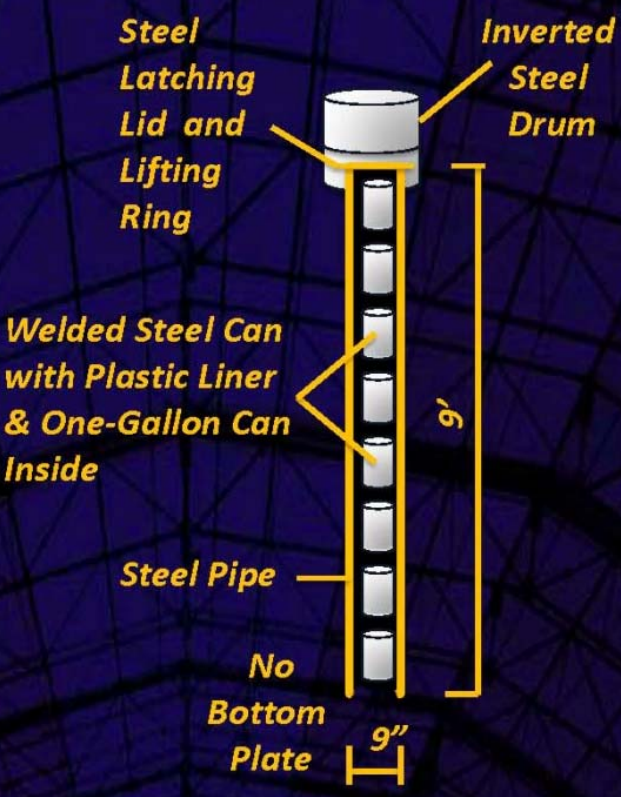

\section{Location in Shaft Field}

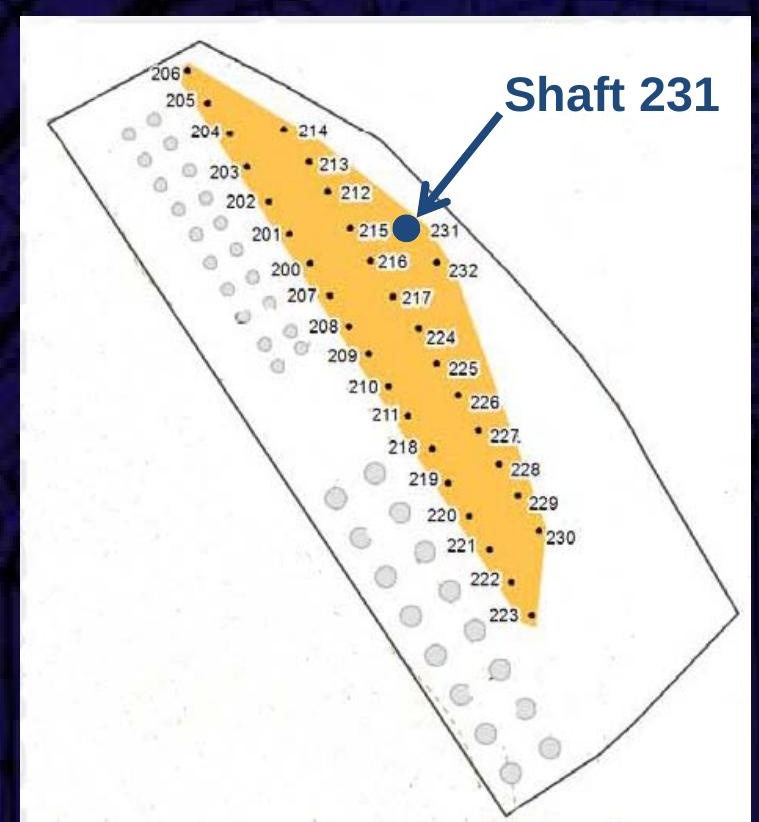

Waste Package Data Summary

\begin{tabular}{|c|c|c|c|c|c|}
\hline $\begin{array}{c}\text { RSWD * } \\
\text { Number }\end{array}$ & $\begin{array}{c}\text { Volume } \\
\text { (gallons) }\end{array}$ & Radionuclides & $\begin{array}{c}\text { Total Curies } \\
\text { at Disposal }\end{array}$ & $\begin{array}{c}\text { Total Curies } \\
\text { Decayed to 2009 }\end{array}$ & PE-Ci \\
\hline S855046 & 1 & Pu-239, U-235, MFP & 3.00 & 1.64 & 0.0062 \\
\hline S855047 & 1 & Pu-239, U-235, MFP & 3.00 & 1.64 & 0.0062 \\
\hline S855048 & 1 & Pu-239, U-235, MFP & 0.90 & 0.49 & 0 \\
\hline S855049 & 1 & Pu-239, U-235, MFP & 0.40 & 0.22 & 0 \\
\hline S856015 & 1 & Pu-239, U-235, MFP & 2.10 & 1.15 & 0.0062 \\
\hline S856016 & 1 & Pu-239, U-235, MFP & 6.00 & 3.28 & 0.0062 \\
\hline S856017 & 1 & Pu-239, U-235, MFP & 6.00 & 3.28 & 0.0062 \\
\hline S856018 & 1 & Pu-239, U-235, MFP & 1.01 & 0.55 & 0.0062 \\
\hline TOTALS for & 8 & Pu-239, U-235, MFP & 22.42 & 12.27 & 0.04 \\
\hline Shaft 231 & & & & & \\
\hline
\end{tabular}

* RSWD = Radioactive Solid Waste Disposal record 


\section{Shaft 231 Totals}

\begin{tabular}{|c|c|c|}
\hline Total Number of Waste Packages & \multicolumn{2}{|c|}{8} \\
\hline Total Gross Weight (pounds) & \multicolumn{2}{|c|}{235} \\
\hline Total Pu-239 (grams) & \multicolumn{2}{|c|}{0.6} \\
\hline Total U-235 (grams) & \multicolumn{2}{|c|}{26.1} \\
\hline Total Mixed Fission Products at disposal (Ci) & \multicolumn{2}{|c|}{22.4} \\
\hline Dates of Disposal & \multicolumn{2}{|c|}{$12 / 30 / 1985$ to $12 / 30 / 1985$} \\
\hline Radiation at Surface of Waste Package ( $\mathrm{mR} / \mathrm{hr}$ ) & $\begin{array}{l}3,000 \text { to } 1,000,000 \\
\text { at disposal }\end{array}$ & $\begin{array}{l}1,600 \text { to } 543,000 \\
\text { decayed to } 2009\end{array}$ \\
\hline $\begin{array}{l}\text { Radiation at One Meter from Surface of Waste } \\
\text { Package (mR/hr) }\end{array}$ & $\begin{array}{l}40 \text { to } 30,000 \\
\text { at disposal }\end{array}$ & $\begin{array}{c}10 \text { to } 3,840 \\
\text { decayed to } 2009\end{array}$ \\
\hline
\end{tabular}

* Calculated using inverse square rule assuming a point source at the center of the waste package paint cans

\section{Detailed Waste Package Data at Disposal}

\begin{tabular}{|c|c|c|c|c|c|c|c|c|c|}
\hline $\begin{array}{l}\text { RSWD } \\
\text { Number }\end{array}$ & $\begin{array}{c}\text { Date } \\
\text { Disposed }\end{array}$ & $\begin{array}{c}\text { Gross } \\
\text { Weight } \\
\text { (lb) }\end{array}$ & Waste Description & $\begin{array}{l}\text { Additional } \\
\text { Description of } \\
\text { Packaging and } \\
\text { Packaging } \\
\text { Materials }\end{array}$ & $\begin{array}{l}\text { Nuclide } \\
\text { or } \\
\text { Material } \\
\text { Type }\end{array}$ & Amount & Units & $\begin{array}{c}\text { Package } \\
\text { Radiation } \\
\text { at Surface } \\
(\mathrm{mR} / \mathrm{hr})\end{array}$ & $\begin{array}{c}\text { Package } \\
\text { Radiation } \\
\text { at } 1 \text { meter } \\
(\mathrm{mR} / \mathrm{hr})\end{array}$ \\
\hline \multirow{3}{*}{ S855046 } & \multirow{3}{*}{$12 / 30 / 1985$} & \multirow{3}{*}{30} & \multirow{3}{*}{$\begin{array}{l}\text { Plastic can } 3813 \text {, } \\
\text { vacuum cleaner motor }\end{array}$} & \multirow{3}{*}{$\begin{array}{l}\text { Steel can } 72,1000+ \\
\text { R/hr at contact }\end{array}$} & Pu-239 & $1.00 \mathrm{E}-01$ & $\mathrm{~g}$ & \multirow{3}{*}{$1,000,000$} & \multirow{3}{*}{30,000} \\
\hline & & & & & $\mathrm{U}-235$ & $4.00 \mathrm{E}-01$ & $\mathrm{~g}$ & & \\
\hline & & & & & MFP & $3.00 \mathrm{E}+00$ & $\mathrm{Ci}$ & & \\
\hline \multirow{3}{*}{ S855047 } & \multirow{3}{*}{$12 / 30 / 1985$} & \multirow{3}{*}{25} & \multirow{3}{*}{$\begin{array}{l}\text { Plastic can 4114, } \\
\text { manipulator boot }\end{array}$} & \multirow{3}{*}{$\begin{array}{c}\text { Steel can } 73,1000+ \\
\mathrm{R} / \mathrm{hr} \text { at contact }\end{array}$} & Pu-239 & $1.00 \mathrm{E}-01$ & $\mathrm{~g}$ & \multirow{3}{*}{$1,000,000$} & \multirow{3}{*}{6,500} \\
\hline & & & & & U-235 & $3.00 \mathrm{E}-01$ & $\mathrm{~g}$ & & \\
\hline & & & & & MFP & $3.00 E+00$ & $\mathrm{Ci}$ & & \\
\hline \multirow{3}{*}{ S855048 } & \multirow{3}{*}{$12 / 30 / 1985$} & \multirow{3}{*}{30} & \multirow{3}{*}{$\begin{array}{c}\text { Cell } 10 \text { trash, plastic } \\
\text { can } 3859\end{array}$} & \multirow{3}{*}{$\begin{array}{c}\text { Steel can } 74,100 \mathrm{R} / \mathrm{hr} \\
\text { at contact }\end{array}$} & Pu-239 & & & \multirow{3}{*}{100,000} & \multirow{3}{*}{900} \\
\hline & & & & & U-235 & $1.50 \mathrm{E}+01$ & $\mathrm{~g}$ & & \\
\hline & & & & & MFP & $9.00 \mathrm{E}-01$ & $\mathrm{Ci}$ & & \\
\hline \multirow{3}{*}{ S855049 } & \multirow{3}{*}{ 12/30/1985 } & \multirow{3}{*}{30} & \multirow{3}{*}{$\begin{array}{l}\text { Plastic can } 3651, \text { R B } \\
\text { Robinson fuel }\end{array}$} & \multirow{3}{*}{$\begin{array}{c}\text { Steel can } 75,3 \mathrm{R} / \mathrm{hr} \text { at } \\
\text { contact }\end{array}$} & Pu-239 & & & \multirow{3}{*}{3,000} & \multirow{3}{*}{40} \\
\hline & & & & & U-235 & $9.00 E+00$ & $\mathrm{~g}$ & & \\
\hline & & & & & MFP & 4.00E-01 & $\mathrm{Ci}$ & & \\
\hline \multirow{3}{*}{ S856015 } & \multirow{3}{*}{$12 / 30 / 1985$} & \multirow{3}{*}{30} & \multirow{3}{*}{ Plastic can 3649} & & Pu-239 & $1.00 \mathrm{E}-01$ & $\mathrm{~g}$ & & $t$ \\
\hline & & & & $\begin{array}{c}\text { Steel can } 68,1000+\text { at } \\
\text { contact }\end{array}$ & U-235 & 4.00E-01 & $\mathrm{g}$ & $1,000,000$ & 22,000 \\
\hline & & & & & MFP & $2.10 \mathrm{E}+00$ & $\mathrm{Ci}$ & & \\
\hline & & & & & Pu-239 & $1.00 \mathrm{E}-01$ & $\mathrm{~g}$ & & \\
\hline S856016 & 12/30/1985 & 30 & $\begin{array}{c}\text { Cells } 2 / 4 \text { waste plastic } \\
\text { can } 4113\end{array}$ & $\begin{array}{c}\text { Steel can } 69,20 \mathrm{R} / \mathrm{hr} \text { at } \\
\text { contact }\end{array}$ & U-235 & 3.00E-01 & $\mathrm{g}$ & 20,000 & 600 \\
\hline & & & & & MFP & $6.00 E+00$ & $\mathrm{Ci}$ & & \\
\hline & & & & & Pu-239 & $1.00 E-01$ & $\mathrm{~g}$ & & \\
\hline S856017 & 12/30/1985 & 30 & $\begin{array}{c}\text { Plastic can } 3626, \text { Cell } 9 \\
\text { trash }\end{array}$ & $\begin{array}{c}\text { Steel can } 71,500 \mathrm{Rhr} \text { at } \\
\text { contact }\end{array}$ & $\mathrm{U}-235$ & $3.00 \mathrm{E}-01$ & $\mathrm{~g}$ & 71,500 & 6,000 \\
\hline & & & & & MFP & $6.00 \mathrm{E}+00$ & $\mathrm{Ci}$ & & \\
\hline & & & & & Pu-239 & $1.00 \mathrm{E}-01$ & $\mathrm{~g}$ & & \\
\hline S856018 & 12/30/1985 & 30 & $\begin{array}{c}\text { Plastic \# } 3625, \text { Cell } 9 \\
\text { trash }\end{array}$ & $\begin{array}{c}\text { Steel can No } 70,350 \\
\text { Rhr at contact }\end{array}$ & $\mathrm{U}-235$ & 4.00E-01 & $\mathrm{g}$ & 350,000 & 7,000 \\
\hline & & & & & MFP & $1.00 E+00$ & $\mathrm{Ci}$ & & \\
\hline
\end{tabular}




\section{Shaft 232 Totals}

\begin{tabular}{|c|c|c|}
\hline Total Number of Waste Packages & \multicolumn{2}{|c|}{3} \\
\hline Total Gross Weight (pounds) & \multicolumn{2}{|c|}{105} \\
\hline Total Pu-239 (grams) & \multicolumn{2}{|c|}{0} \\
\hline Total Pu-53 (grams) & \multicolumn{2}{|c|}{16} \\
\hline Total Pu-55 (grams) & \multicolumn{2}{|c|}{27} \\
\hline Total Pu-56 (grams) & \multicolumn{2}{|c|}{12} \\
\hline Total Pu-57 (grams) & \multicolumn{2}{|c|}{14} \\
\hline Total U-21 (grams) & \multicolumn{2}{|c|}{48} \\
\hline Total U-25 (grams) & \multicolumn{2}{|c|}{7} \\
\hline Total U-235 (grams) & \multicolumn{2}{|c|}{135} \\
\hline Total U-238 (grams) & \multicolumn{2}{|c|}{60.2} \\
\hline Total Mixed Fission Products at disposal (Ci) & \multicolumn{2}{|c|}{0} \\
\hline Dates of Disposal & \multicolumn{2}{|c|}{$12 / 23 / 1987$ to $12 / 23 / 1987$} \\
\hline Radiation at Surface of Waste Package (mR/hr) & $\begin{array}{l}6,500 \text { to } 1,000,000 \\
\text { at disposal }\end{array}$ & $\begin{array}{c}0 \text { to } 14,000 \\
\text { decayed to } 2009\end{array}$ \\
\hline $\begin{array}{l}\text { Radiation at One Meter from Surface of Waste } \\
\text { Package }(\mathrm{mR} / \mathrm{hr})\end{array}$ & $\begin{array}{l}\text { Not Available } \\
\text { at disposal }\end{array}$ & $\begin{array}{c}0 \text { to } 100 * \\
\text { decayed to } 2009\end{array}$ \\
\hline
\end{tabular}

* Calculated using inverse square rule assuming a point source at the center of the waste package paint cans

\section{Detailed Waste Package Data at Disposal}

\begin{tabular}{|c|c|c|c|c|c|c|c|c|c|}
\hline $\begin{array}{l}\text { RSWD } \\
\text { Number }\end{array}$ & $\begin{array}{l}\text { Date } \\
\text { Disposed }\end{array}$ & $\begin{array}{c}\text { Gross } \\
\text { Weight } \\
\text { (lb) }\end{array}$ & Waste Description & $\begin{array}{l}\text { Additional } \\
\text { Description of } \\
\text { Packaging and } \\
\text { Packaging } \\
\text { Materials }\end{array}$ & $\begin{array}{c}\text { Nuclide } \\
\text { or } \\
\text { Material } \\
\text { Type }\end{array}$ & Amount & Units & $\begin{array}{c}\text { Package } \\
\text { Radiation } \\
\text { at Surface } \\
(\mathrm{mR} / \mathrm{hr})\end{array}$ & $\begin{array}{c}\text { Package } \\
\text { Radiation } \\
\text { at } 1 \text { meter } \\
(\mathrm{mR} / \mathrm{hr})\end{array}$ \\
\hline \multirow{3}{*}{ S874132 } & \multirow{3}{*}{ 12/23/1987 } & \multirow{3}{*}{35} & \multirow{3}{*}{$\begin{array}{c}\text { 3Mile Island waste can } \\
77 \text { - was on a }\end{array}$} & \multirow{3}{*}{ CWSR LA86110050600 } & Pu-239 & $0.00 E+00$ & $\mathrm{~g}$ & \multirow{3}{*}{6,500} & \\
\hline & & & & & U-25 & $7.00 E+00$ & $\mathrm{~g}$ & & \\
\hline & & & & & MFP & $0.00 E+00$ & $\mathrm{Ci}$ & & \\
\hline \multirow{6}{*}{ S874133 } & \multirow{6}{*}{$12 / 23 / 1987$} & \multirow{6}{*}{35} & \multirow{6}{*}{$\begin{array}{c}\text { Cell } 9 \text { waste fuel can } 79 \\
\text { - was on a }\end{array}$} & \multirow{6}{*}{$\begin{array}{c}\text { CWSR LA86110050601 } \\
>1000 \mathrm{R} / \mathrm{hr}\end{array}$} & $\mathrm{Pu}-53$ & $1.60 E+01$ & $\mathrm{~g}$ & \multirow{6}{*}{$1,000,000$} & \\
\hline & & & & & Pu-55 & $2.70 E+01$ & g & & \\
\hline & & & & & Pu-56 & $1.20 E+01$ & $\mathrm{~g}$ & & \\
\hline & & & & & Pu-57 & $1.30 \mathrm{E}+01$ & $\mathrm{~g}$ & & \\
\hline & & & & & U-235 & $1.35 \mathrm{E}+02$ & $\mathrm{~g}$ & & \\
\hline & & & & & U-238 & $6.02 E+01$ & $\mathrm{~g}$ & & \\
\hline \multirow{3}{*}{ S874134 } & \multirow{3}{*}{$12 / 23 / 1987$} & \multirow{3}{*}{35} & \multirow{3}{*}{$\begin{array}{l}\text { INC-11 Waste steel can } \\
78 \text { - was on a }\end{array}$} & \multirow{3}{*}{ CWSR LA86110050648 } & Pu-57 & $1.00 E+00$ & g & \multirow{3}{*}{29,000} & \\
\hline & & & & & U-21 & $4.80 E+01$ & $\mathrm{~g}$ & & \\
\hline & & & & & MFP & & & & \\
\hline
\end{tabular}


Material Disposal Area G, 33 Shafts

\title{
Waste Data Fact Sheets
}

for

Shafts $200-223,225-227, \& 229-230$

\author{
Waste Emplaced Before \\ Effective Date of 40 CFR 191
}


This page intentionally left blank 


\section{Material Disposal Area G, 33 Shafts Shaft 200 Waste Data Fact Sheet}

\section{Contents}

Shaft 200 contains six packages of waste from the Chemistry and Metallurgy Research (CMR) Facility Wing 9 hot cells, with each package containing waste placed inside two one-gallon paint-type metal cans and placed into a plastic bag. Some paint-type cans may have been sealed in a plastic container before being placed into the plastic bag. Wastes include hot-cell trash, grinding papers, kimwipes, and plastic. Major radionuclides in the waste consist of plutonium-239, uranium-235, and mixed fission products (MFP). Waste is considered to be remote-handled with the reported radiation dose at the surface of the packages at the time of generation ranging from 60,000 to 1,150,000 mrem/hour. The six packages of waste were placed into Shaft 200 in April 1981.

\section{Shaft Configuration}

Construction of Shaft 200 was initiated by augering a 36-inch diameter vertical hole into the mesa top. A 24-inch-diameter metal pipe (1/4 inch wall) with a length of 9 to 12 feet with a metal plate welded to the bottom was inserted into the hole as a liner. A 1/2 inch-wall inner pipe of 9- to 12-inch diameter and 7 to 12 feet in length with a metal plate welded to the bottom was centered in the larger pipe with a small amount of concrete to provide vertical alignment of the inner pipe in the outer pipe. Records with the specific dimensions for the pipes in Shaft 200 have not been located. A large metal funnel was placed in the inner pipe and waste packages were dropped into the inner pipe from a shielded transport cask moved into position above the shaft. After all waste packages were placed into the inner pipe, concrete was placed in the annular space between the pipes and the top of the shaft and auger hole were capped with 3 to 4 inches of concrete. The result is that the pipe containing the waste packages is completely encased in concrete.

\section{Shaft 200 Configuration}

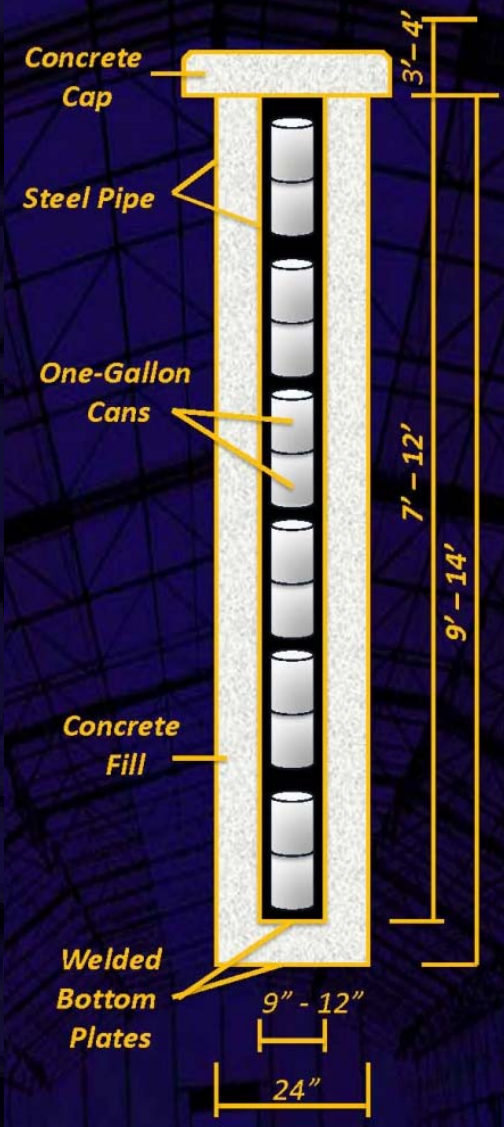

Waste Package Data Summary

\section{Location in Shaft Field}

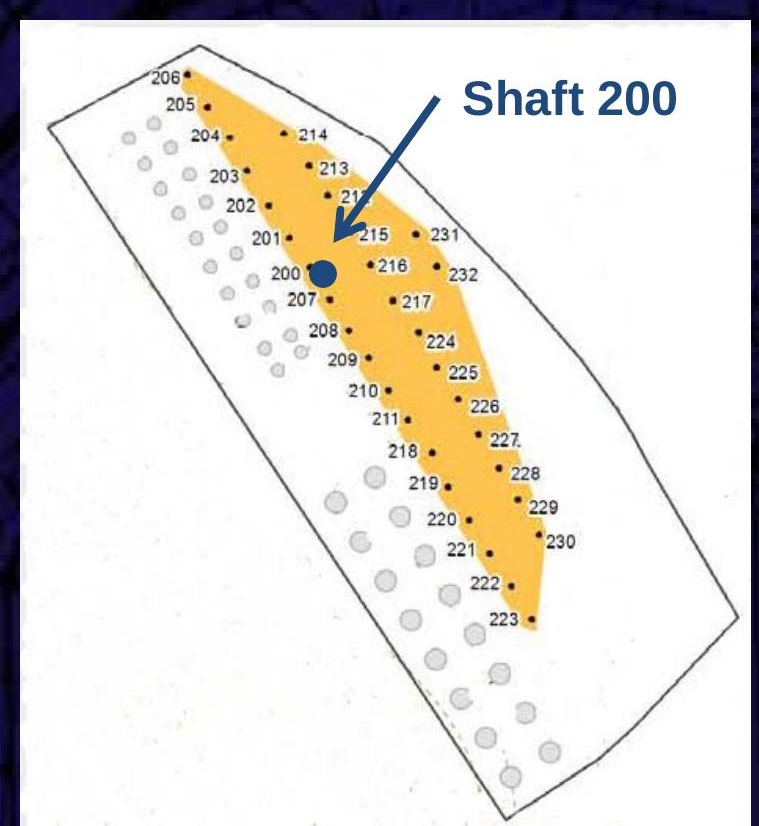

\begin{tabular}{|c|c|c|c|c|c|}
\hline $\begin{array}{c}\text { RSWD * } \\
\text { Number }\end{array}$ & $\begin{array}{c}\text { Volume } \\
\text { (gallons) }\end{array}$ & Radionuclides & $\begin{array}{c}\text { Total Curies } \\
\text { at Disposal }\end{array}$ & $\begin{array}{c}\text { Total Curies } \\
\text { Decayed to 2009 }\end{array}$ & PE-Ci \\
\hline S811387 & 2 & Pu-239, U-235, MFP & 3.75 & 2.49 & 1.25 \\
\hline S811390 & 2 & Pu-239, U-235, MFP & 6.62 & 3.60 & 0.62 \\
\hline S811396 & 2 & Pu-239, U-235, MFP & 0.60 & 0.30 & 0.01 \\
\hline S811398 & 2 & Pu-239, U-235, MFP & 0.85 & 0.55 & 0.25 \\
\hline S811471 & 2 & Pu-239, U-235, MFP & 3.47 & 2.12 & 0.77 \\
\hline S811473 & 2 & Pu-239, U-235, MFP & 20.3 & 10.3 & 0.31 \\
\hline $\begin{array}{c}\text { TOTALS for } \\
\text { Shaft 200 }\end{array}$ & 12 & Pu-239, U-235, MFP & 35.6 & 19.3 & 3.21 \\
\hline
\end{tabular}

* RSWD = Radioactive Solid Waste Disposal record 


\section{Shaft 200 Totals}

\begin{tabular}{|c|c|c|}
\hline Total Number of Waste Packages & \multicolumn{2}{|c|}{6} \\
\hline Total Gross Weight (pounds) & \multicolumn{2}{|c|}{93} \\
\hline Total Pu-239 (grams) & \multicolumn{2}{|c|}{51.8} \\
\hline Total U-235 (grams) & \multicolumn{2}{|c|}{132.98} \\
\hline Total Mixed Fission Products (Ci) & \multicolumn{2}{|c|}{32.4} \\
\hline Dates of Disposal & \multicolumn{2}{|c|}{$4 / 14 / 1981$ to $4 / 14 / 1981$} \\
\hline Radiation at Surface of Waste Package (mR/hr) & $\begin{array}{l}60,000 \text { to } 1,150,000 \\
\text { at disposal }\end{array}$ & $\begin{array}{l}30,000 \text { to } 569,000 \\
\text { decayed to } 2009\end{array}$ \\
\hline $\begin{array}{l}\text { Radiation at One Meter from Surface of Waste } \\
\text { Package }(\mathrm{mR} / \mathrm{hr})\end{array}$ & $\begin{array}{l}600 \text { to } 20,000 \\
\text { at disposal }\end{array}$ & $\begin{array}{l}200 \text { to } 4,000 * \\
\text { decayed to } 2009\end{array}$ \\
\hline
\end{tabular}

* Calculated using inverse square rule assuming a point source at the center of the waste package paint cans

\section{Detailed Waste Package Data at Disposal}

\begin{tabular}{|c|c|c|c|c|c|c|c|c|c|}
\hline $\begin{array}{c}\text { Waste } \\
\text { Package } \\
\text { RSWD } \\
\text { Number }\end{array}$ & $\begin{array}{l}\text { Date } \\
\text { Disposed }\end{array}$ & $\begin{array}{c}\text { Gross } \\
\text { Weight } \\
\text { (lb) }\end{array}$ & Waste Description & $\begin{array}{c}\text { Additional } \\
\text { Description of } \\
\text { Packaging and } \\
\text { Packaging } \\
\text { Materials }\end{array}$ & $\begin{array}{c}\text { Nuclide } \\
\text { or } \\
\text { Material } \\
\text { Type }\end{array}$ & Amount & Units & $\begin{array}{c}\text { Package } \\
\text { Radiation } \\
\text { at Surface } \\
\text { (mR/hr) }\end{array}$ & $\begin{array}{c}\text { Package } \\
\text { Radiation } \\
\text { at } 1 \text { meter } \\
(\mathrm{mR} / \mathrm{hr})\end{array}$ \\
\hline \multirow{3}{*}{ S811387 } & \multirow{3}{*}{ 4/14/1981 } & \multirow{3}{*}{16} & \multirow{3}{*}{ 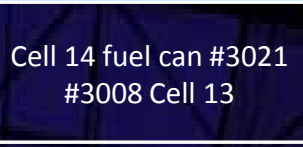 } & \multirow{3}{*}{$140 \mathrm{R}$ at contact } & Pu-239 & $2.02 E+01$ & $\mathrm{~g}$ & \multirow{3}{*}{140,000} & \multirow{3}{*}{2,500} \\
\hline & & & & & $\mathrm{U}-235$ & $8.08 \mathrm{E}+00$ & $\mathrm{~g}$ & & \\
\hline & & & & & MFP & $2.50 E+00$ & $\mathrm{Ci}$ & & \\
\hline \multirow{3}{*}{ S811390 } & \multirow{3}{*}{$4 / 14 / 1981$} & \multirow{3}{*}{16} & \multirow{3}{*}{$\begin{array}{l}\text { Cell } 13 \text { grinding papers, } \\
\text { kimwipes, plastic }\end{array}$} & \multirow{3}{*}{ Plastic cans 3061, 3053} & Pu-239 & $1.00 \mathrm{E}-01$ & $\mathrm{~g}$ & \multirow{3}{*}{60,000} & \multirow{3}{*}{600} \\
\hline & & & & & $\mathrm{U}-235$ & $3.80 E+01$ & $\mathrm{~g}$ & & \\
\hline & & & & & MFP & $6.00 E+00$ & $\mathrm{Ci}$ & & \\
\hline \multirow{3}{*}{ S811396 } & \multirow{3}{*}{ 4/14/1981 } & \multirow{3}{*}{16} & \multirow{3}{*}{$\begin{array}{l}\text { Cell } 13 \text { grinding papers, } \\
\text { kimwipes, plastic }\end{array}$} & \multirow{3}{*}{ Plastic cans 3061, 3053} & Pu-239 & $1.00 E-01$ & $\mathrm{~g}$ & \multirow{3}{*}{60,000} & \multirow{3}{*}{600} \\
\hline & & & & & U-235 & $4.00 \mathrm{E}-01$ & $\mathrm{~g}$ & & \\
\hline & & & & & MFP & $6.00 \mathrm{E}-01$ & $\mathrm{Ci}$ & & \\
\hline \multirow{3}{*}{ S811398 } & \multirow{3}{*}{ 4/14/1981 } & \multirow{3}{*}{20} & \multirow{3}{*}{$\begin{array}{l}\text { Cell } 13 \text { catch \& drain } \\
\text { pans, kimwipes }\end{array}$} & \multirow{3}{*}{$\begin{array}{c}120,000 \mathrm{mR} / \mathrm{hr} \text { surface, } \\
\text { cans } 3051 \text { \& } 3052\end{array}$} & Pu-239 & $4.00 \mathrm{E}+00$ & $\mathrm{~g}$ & \multirow{3}{*}{120,000} & \multirow{3}{*}{600} \\
\hline & & & & & U-235 & $1.60 \mathrm{E}+01$ & $\mathrm{~g}$ & & \\
\hline & & & & & MFP & $6.00 \mathrm{E}-01$ & $\mathrm{Ci}$ & & \\
\hline \multirow{3}{*}{ S811471 } & \multirow{3}{*}{ 4/14/1981 } & \multirow{3}{*}{9} & \multirow{3}{*}{$\begin{array}{l}\text { Cell } 14 \text { trash cans } 2864, \\
2846\end{array}$} & \multirow{3}{*}{$700 \mathrm{R} / \mathrm{hr}$ at contact } & Pu-239 & $1.25 \mathrm{E}+01$ & $\mathrm{~g}$ & \multirow{3}{*}{700,000} & \multirow{3}{*}{9,000} \\
\hline & & & & & $\mathrm{U}-235$ & $2.15 \mathrm{E}+01$ & $\mathrm{~g}$ & & \\
\hline & & & & & MFP & $2.70 E+00$ & $\mathrm{Ci}$ & & \\
\hline & & & & & Pu-239 & $5.00 E+00$ & g & & \\
\hline $58114 / 3$ & 4/14/1981 & 16 & \#2877 - 2863 & $1150 \mathrm{R} / \mathrm{hr}$ at contact & $U-235$ & $4.90 \mathrm{E}+01$ & $\mathrm{~g}$ & $1,150,000$ & 20,000 \\
\hline & & & & & MFP & $2.00 E+01$ & $\mathrm{Ci}$ & & \\
\hline
\end{tabular}




\section{Material Disposal Area G, 33 Shafts Shaft 201 Waste Data Fact Sheet}

\section{Contents}

Shaft 201 contains seven packages of waste from the Chemistry and Metallurgy Research (CMR) Facility Wing 9 hot cells, with six of the packages containing waste placed inside two one-gallon paint-type metal cans and placed into a plastic bag. One of the seven packages consists of a single-one gallon metal can placed into a plastic bag. Some paint-type cans were placed into a plastic container before being placed into the plastic bag. Wastes include hot-cell trash, grinding papers, kimwipes, and plastic. Major radionuclides in the waste consist of plutonium-239, uranium-235, and mixed fission products (MFP). Waste is considered to be remote-handled with the reported radiation dose at the surface of the packages at the time of generation ranging from 15,000 to 1,200,000 mrem/hour. The seven packages of waste were placed into Shaft 201 in June 1979.

\section{Shaft Configuration}

Construction of Shaft 201 was initiated by augering a 36-inch diameter vertical hole into the mesa top. A 24-inch-diameter metal pipe (1/4 inch wall) with a length of 9 to 12 feet with a metal plate welded to the bottom was inserted into the hole as a liner. A 1/2 inch-wall inner pipe of 9- to 12-inch diameter and 7 to 12 feet in length with a metal plate welded to the bottom was centered in the larger pipe with a small amount of concrete to provide vertical alignment of the inner pipe in the outer pipe. Records with the specific dimensions for the pipes in Shaft 201 have not been located. A large metal funnel was placed in the inner pipe and waste packages were dropped into the inner pipe from a shielded transport cask moved into position above the shaft. After all waste packages were placed into the inner pipe, concrete was placed in the annular space between the pipes and the top of the shaft and auger hole were capped with 3 to 4 inches of concrete. The result is that the pipe containing the waste packages is completely encased in concrete.

\section{Shaft 201 Configuration}

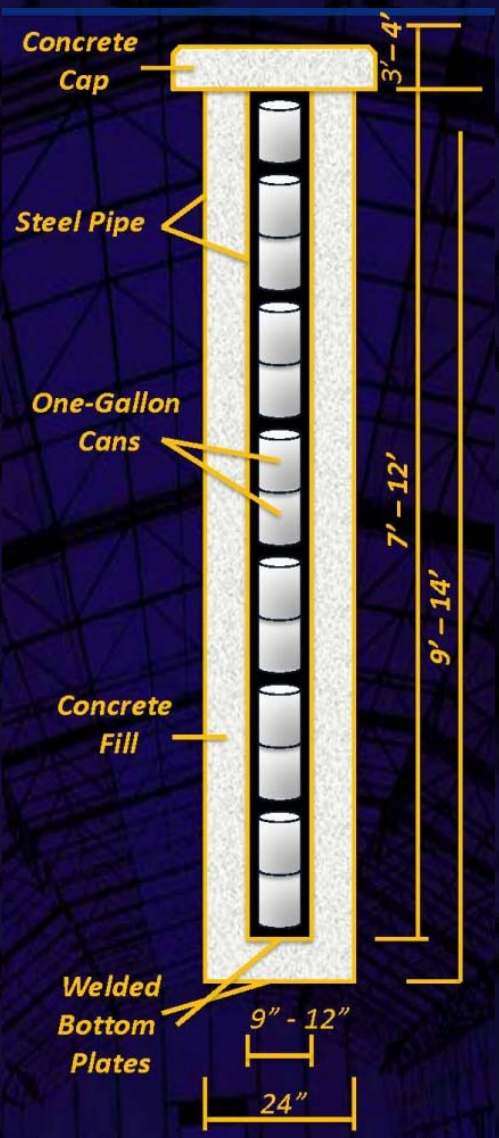

Waste Package Data Summary

\section{Location in Shaft Field}

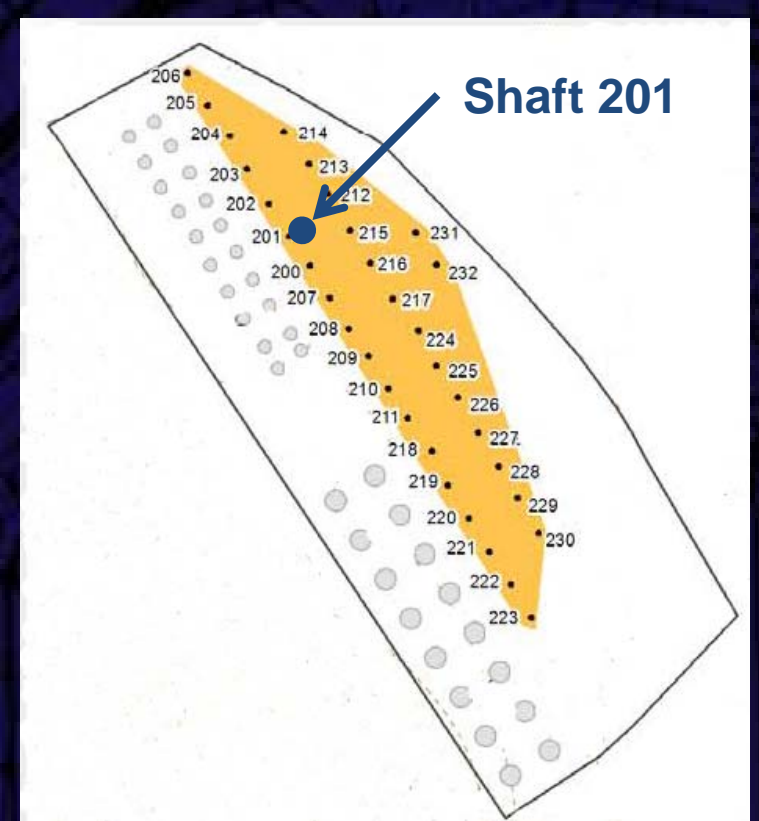

\begin{tabular}{|c|c|c|c|c|c|}
\hline $\begin{array}{c}\text { RSWD * } \\
\text { Number }\end{array}$ & $\begin{array}{c}\text { Volume } \\
\text { (gallons) }\end{array}$ & Radionuclides & $\begin{array}{c}\text { Total Curies } \\
\text { at Disposal }\end{array}$ & $\begin{array}{c}\text { Total Curies } \\
\text { Decayed to 2009 }\end{array}$ & PE-Ci \\
\hline S791484 & 1 & Pu-239, U-235, MFP & 4.18 & 2.08 & 0.19 \\
\hline S794215 & 2 & Pu-239, U-235, MFP & 11.03 & 5.25 & 0.03 \\
\hline S794216 & 2 & Pu-239, U-235, MFP & 8.14 & 3.93 & 0.14 \\
\hline S794218 & 2 & Pu-239, U-235, MFP & 1.15 & 0.63 & 0.16 \\
\hline S794219 & 2 & Pu-239, U-235, MFP & 1.39 & 0.71 & 0.09 \\
\hline S794220 & 2 & Pu-239, U-235, MFP & 34.20 & 18.40 & 4.21 \\
\hline S794221 & 2 & Pu-239, U-235, MFP & 43.66 & 25.30 & 8.67 \\
\hline $\begin{array}{c}\text { TOTALS for } \\
\text { Shaft 201 }\end{array}$ & 13 & Pu-239, U-235, MFP & 103.76 & 56.32 & 13.49 \\
\hline
\end{tabular}

* RSWD = Radioactive Solid Waste Disposal record 


\section{Shaft 201 Totals at Disposal}

\begin{tabular}{|c|c|c|}
\hline Total Number of Waste Packages & \multicolumn{2}{|c|}{7} \\
\hline Total Gross Weight (pounds) & \multicolumn{2}{|c|}{66 (weight for one package not available) } \\
\hline Total Pu-239 (grams) & \multicolumn{2}{|c|}{218} \\
\hline Total U-235 (grams) & \multicolumn{2}{|c|}{544} \\
\hline Total Mixed Fission Products (Ci) & \multicolumn{2}{|c|}{90.3} \\
\hline Dates of Disposal & \multicolumn{2}{|c|}{$6 / 29 / 1979$ to $6 / 29 / 1979$} \\
\hline Radiation at Surface of Waste Package ( $\mathrm{mR} / \mathrm{hr}$ ) & $\begin{array}{l}15,000 \text { to } 1,200,000 \\
\text { at disposal }\end{array}$ & $\begin{array}{l}7,100 \text { to } 567,000 \\
\text { decayed to } 2009\end{array}$ \\
\hline $\begin{array}{l}\text { Radiation at One Meter from Surface of Waste } \\
\text { Package }(\mathrm{mR} / \mathrm{hr})\end{array}$ & $\begin{array}{l}1,000 \text { to } 85,000 \\
\text { at disposal }\end{array}$ & $\begin{array}{c}50 \text { to } 4,000 * \\
\text { decayed to } 2009\end{array}$ \\
\hline
\end{tabular}

* Calculated using inverse square rule assuming a point source at the center of the waste package paint cans

\section{Detailed Waste Package Data at Disposal}

\begin{tabular}{|c|c|c|c|c|c|c|c|c|c|}
\hline $\begin{array}{c}\text { Waste } \\
\text { Package } \\
\text { RSWD } \\
\text { Number }\end{array}$ & $\begin{array}{c}\text { Date } \\
\text { Disposed }\end{array}$ & $\begin{array}{l}\text { Gross } \\
\text { Weight } \\
\text { (lb) }\end{array}$ & Waste Description & $\begin{array}{l}\text { Additional } \\
\text { Description of } \\
\text { Packaging and } \\
\text { Packaging } \\
\text { Materials }\end{array}$ & $\begin{array}{l}\text { Nuclide } \\
\text { or } \\
\text { Material } \\
\text { Type }\end{array}$ & Amount & Units & $\begin{array}{c}\text { Package } \\
\text { Radiation } \\
\text { at Surface } \\
\text { (mR/hr) }\end{array}$ & $\begin{array}{c}\text { Package } \\
\text { Radiation } \\
\text { at } 1 \text { meter } \\
(\mathrm{mR} / \mathrm{hr})\end{array}$ \\
\hline \multirow{3}{*}{ S791484 } & \multirow{3}{*}{$6 / 29 / 1979$} & \multirow{3}{*}{ NA } & \multirow{3}{*}{$\begin{array}{c}\text { Cell \#12 one fuel can } \\
\text { \#2171 }\end{array}$} & \multirow{3}{*}{$\begin{array}{l}\text { Tin can in plastic } \\
\text { container }\end{array}$} & Pu-239 & $3.00 E+00$ & $\mathrm{~g}$ & \multirow{3}{*}{17,500} & \multirow{3}{*}{4,000} \\
\hline & & & & & U-235 & $1.00 E+00$ & $\mathrm{~g}$ & & \\
\hline & & & & & MFP & $4.00 E+00$ & $\mathrm{Ci}$ & & \\
\hline \multirow{3}{*}{ S794215 } & \multirow{3}{*}{ 6/29/1979 } & \multirow{3}{*}{15} & \multirow{3}{*}{$\begin{array}{l}\text { Cell } 12 \text { trash \& fuel } \\
\quad \# 1854,1851\end{array}$} & \multirow{3}{*}{$266,000 \mathrm{mr}$ at contact } & Pu-239 & $5.50 \mathrm{E}-01$ & $\mathrm{~g}$ & \multirow{3}{*}{266,000} & \multirow{3}{*}{11,000} \\
\hline & & & & & $U-235$ & $2.00 E+00$ & $\mathrm{~g}$ & & \\
\hline & & & & & MFP & $1.10 E+01$ & $\mathrm{Ci}$ & & \\
\hline \multirow{3}{*}{ S794216 } & \multirow{3}{*}{ 6/29/1979 } & \multirow{3}{*}{15} & \multirow{3}{*}{$\begin{array}{l}\text { Cell } 12 \text { trash and fuel } \\
\text { can } \# 1798 \text { \& } 1953\end{array}$} & \multirow{3}{*}{$\begin{array}{c}261000 \mathrm{mr} / \mathrm{hr} \text { at } \\
\text { contact, cans in p-bags }\end{array}$} & Pu-239 & $2.25 \mathrm{E}+00$ & g & \multirow{3}{*}{261,000} & \multirow{3}{*}{85,000} \\
\hline & & & & & U-235 & $9.00 E+00$ & $\mathrm{~g}$ & & \\
\hline & & & & & MFP & $8.00 E+00$ & $\mathrm{Ci}$ & & \\
\hline \multirow{3}{*}{ S794218 } & \multirow{3}{*}{ 6/29/1979 } & \multirow{3}{*}{10} & \multirow{3}{*}{$\begin{array}{l}\text { Cell } 14 \text { fuel can no. } \\
2002 \& 2003\end{array}$} & \multirow{3}{*}{$\begin{array}{l}\text { tin cans in plastic cans } \\
\text { in p-bags }\end{array}$} & Pu-239 & $2.50 E+00$ & $\mathrm{~g}$ & \multirow{3}{*}{15,000} & \multirow{3}{*}{1,000} \\
\hline & & & & & $U-235$ & $1.00 \mathrm{E}+01$ & $\mathrm{~g}$ & & \\
\hline & & & & & MFP & $1.00 E+00$ & $\mathrm{Ci}$ & & \\
\hline \multirow{3}{*}{ S794219 } & \multirow{3}{*}{ 6/29/1979 } & \multirow{3}{*}{12} & \multirow{3}{*}{$\begin{array}{c}\text { Cell } 14 \text { fuel \& trash can } \\
\text { no. } 2004 \& 1992\end{array}$} & \multirow{3}{*}{$\begin{array}{c}\text { Tin cans in plastic cans } \\
\text { in p-bags }\end{array}$} & Pu-239 & $1.50 E+00$ & $\mathrm{~g}$ & & \\
\hline & & & & & $U-235$ & $5.00 E+00$ & $\mathrm{~g}$ & 27,000 & 1,300 \\
\hline & & & & & MFP & $1.30 E+00$ & $\mathrm{Ci}$ & & \\
\hline & & & & & Pu-239 & $6.80 \mathrm{E}+01$ & $\mathrm{~g}$ & & \\
\hline S794220 & 6/29/1979 & 6 & Hot trash met samples & $1200 \mathrm{R} / \mathrm{hr}$ at contact & U-235 & $1.47 \mathrm{E}+02$ & $\mathrm{~g}$ & $1,200,000$ & 30,000 \\
\hline & & & & & MFP & $3.00 E+01$ & $\mathrm{Ci}$ & & \\
\hline & & & & & Pu-239 & $1.40 E+02$ & $\mathrm{~g}$ & & \\
\hline S794221 & 6/29/1979 & 8 & Fuel samples from cells & $1050 \mathrm{R} / \mathrm{hr}$ at contact & $U-235$ & $3.70 E+02$ & $\mathrm{~g}$ & $1,050,000$ & 35,000 \\
\hline & & & & & MFP & $3.50 \mathrm{E}+01$ & $\mathrm{Ci}$ & & \\
\hline
\end{tabular}




\section{Material Disposal Area G, 33 Shafts Shaft 202 Waste Data Fact Sheet}

\section{Contents}

Shaft 202 contains six packages of waste from the Chemistry and Metallurgy Research (CMR) Facility Wing 9 hot cells, with each package containing waste placed inside two one-gallon paint-type metal cans and placed into a plastic bag. Some paint-type cans may have been sealed in a plastic container before being placed into the plastic bag. Wastes include hot-cell trash, grinding papers, kimwipes, and plastic. Major radionuclides in the waste consist of plutonium-239, uranium-235, and mixed fission products (MFP). Waste is considered to be remote-handled because of the source of the waste and the quantity of MFP (radiation dose at the surface of the packages placed into Shaft 202 was not reported.) The six packages of waste were placed into Shaft 202 in April 1980.

\section{Shaft Configuration}

Construction of Shaft 202 was initiated by augering a 36-inch diameter vertical hole into the mesa top. A 24-inch-diameter metal pipe (1/4 inch wall) with a length of 9 to 12 feet with a metal plate welded to the bottom was inserted into the hole as a liner. A $1 / 2$ inch-wall inner pipe of 9- to 12-inch diameter and 7 to 12 feet in length with a metal plate welded to the bottom was centered in the larger pipe with a small amount of concrete to provide vertical alignment of the inner pipe in the outer pipe. Records with the specific dimensions for the pipes in Shaft 202 have not been located. A large metal funnel was placed in the inner pipe and waste packages were dropped into the inner pipe from a shielded transport cask moved into position above the shaft. After all waste packages were placed into the inner pipe, concrete was placed in the annular space between the pipes and the top of the shaft and auger hole were capped with 3 to 4 inches of concrete. The result is that the pipe containing the waste packages is completely encased in concrete.

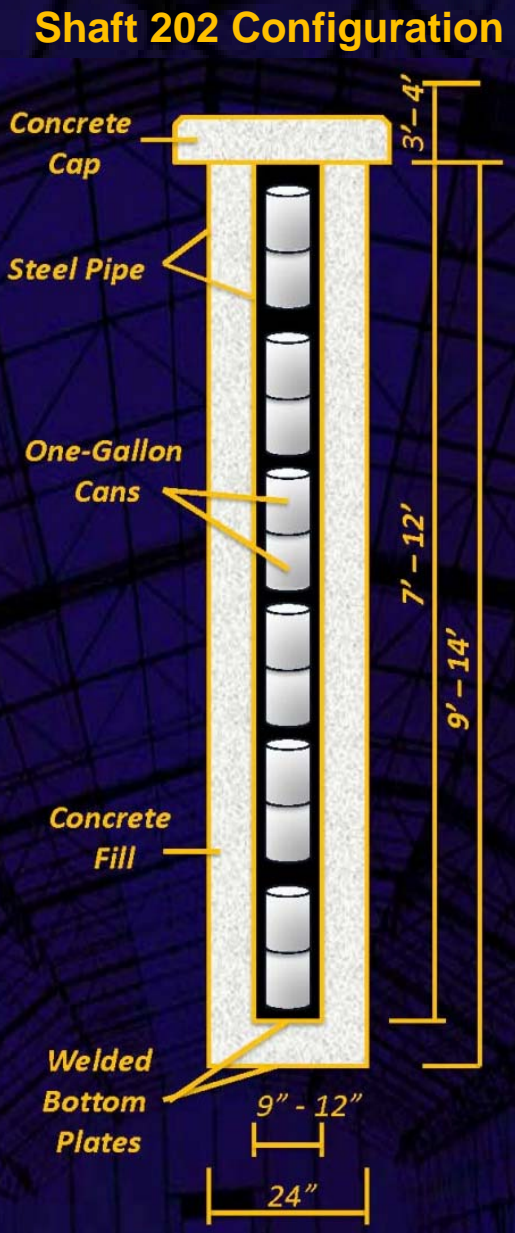

\section{Location in Shaft Field}

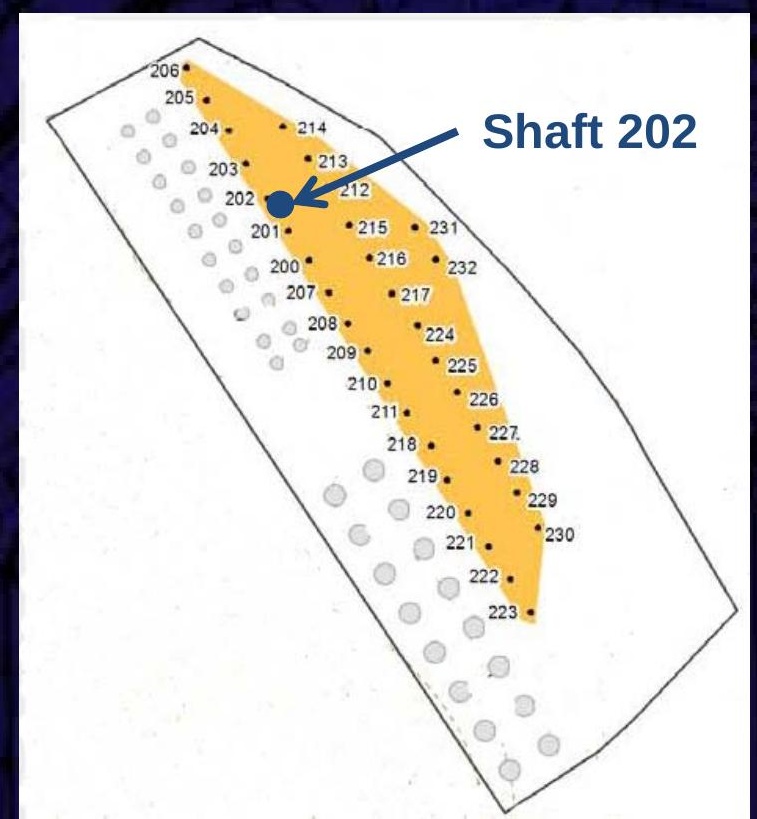

Waste Package Data Summary

\begin{tabular}{|c|c|c|c|c|c|}
\hline $\begin{array}{c}\text { RSWD * } \\
\text { Number }\end{array}$ & $\begin{array}{c}\text { Volume } \\
\text { (gallons) }\end{array}$ & Radionuclides & $\begin{array}{c}\text { Total Curies } \\
\text { at Disposal }\end{array}$ & $\begin{array}{c}\text { Total Curies } \\
\text { Decayed to 2009 }\end{array}$ & PE-Ci \\
\hline S803548 ** & 12 & Pu-239, U-235, MFP & 219 & 106 & 4.05 \\
\hline $\begin{array}{c}\text { TOTALS for } \\
\text { Shaft 202 }\end{array}$ & 12 & Pu-239, U-235, MFP & 219 & 106 & 4.05 \\
\hline
\end{tabular}

* RSWD = Radioactive Solid Waste Disposal record

** Six RSWD forms were transferred to one form; original forms are not available 


\section{Shaft 202 Totals}

\begin{tabular}{|c|c|c|}
\hline Total Number of Waste Packages & \multicolumn{2}{|c|}{6} \\
\hline Total Gross Weight (pounds) & \multicolumn{2}{|c|}{$4,600 *$} \\
\hline Total Pu-239 (grams) & \multicolumn{2}{|c|}{65.4} \\
\hline Total U-235 (grams) & \multicolumn{2}{|c|}{223} \\
\hline Total Mixed Fission Products (Ci) & \multicolumn{2}{|c|}{215} \\
\hline Dates of Disposal & \multicolumn{2}{|c|}{$4 / 30 / 1980$ to $4 / 30 / 1980$} \\
\hline Radiation at Surface of Waste Package (mR/hr) & Not Available & Not Available \\
\hline $\begin{array}{l}\text { Radiation at One Meter from Surface of Waste } \\
\text { Package ( } \mathrm{mR} / \mathrm{hr})\end{array}$ & Not Available & Not Available \\
\hline
\end{tabular}

* This weight is questionable because other characteristics of the six packages in Shaft 202 are similar to packages composed of two one-gallon cans in other shafts. Other shafts with similar packages are reported to have total package weights of about 75 to 130 pounds. The original six RSWD forms were transferred to one RSWD form at some time and an error may have occurred in transcription.

\section{Detailed Waste Package Data at Disposal}

\begin{tabular}{|c|c|c|c|c|c|c|c|c|c|}
\hline $\begin{array}{l}\text { Waste } \\
\text { Package } \\
\text { RSWD } \\
\text { Number }\end{array}$ & $\begin{array}{c}\text { Date } \\
\text { Disposed }\end{array}$ & $\begin{array}{l}\text { Gross } \\
\text { Weight } \\
\text { (lb) }\end{array}$ & Waste Description & $\begin{array}{l}\text { Additional } \\
\text { Description of } \\
\text { Packaging and } \\
\text { Packaging } \\
\text { Materials }\end{array}$ & $\begin{array}{l}\text { Nuclide } \\
\text { or } \\
\text { Material } \\
\text { Type }\end{array}$ & Amount & Units & $\begin{array}{l}\text { Package } \\
\text { Radiation } \\
\text { at Surface } \\
(\mathrm{mR} / \mathrm{hr})\end{array}$ & $\begin{array}{c}\text { Package } \\
\text { Radiation } \\
\text { at } 1 \text { meter } \\
(\mathrm{mR} / \mathrm{hr})\end{array}$ \\
\hline \multirow{3}{*}{ S803548 } & \multirow{3}{*}{$4 / 30 / 1980$} & \multirow{3}{*}{4,600} & \multirow{3}{*}{$\begin{array}{l}\text { Hot cell waste CMB1 - } \\
\text { CMB14 from 9/15/79 }\end{array}$} & \multirow{3}{*}{ thru $1 / 10 / 80$} & Pu-239 & $6.54 \mathrm{E}+01$ & g & \multirow{3}{*}{ Not Available } & \multirow{3}{*}{ Not Available } \\
\hline & & & & & U-235 & $2.23 \mathrm{E}+02$ & $\mathrm{~g}$ & & \\
\hline & & & & & MFP & $2.15 \mathrm{E}+02$ & $\mathrm{Ci}$ & & \\
\hline
\end{tabular}




\section{Material Disposal Area G, 33 Shafts Shaft 203 Waste Data Fact Sheet}

\section{Contents}

Shaft 203 contains six packages of waste from the Chemistry and Metallurgy Research (CMR) Facility Wing 9 hot cells, with each package containing waste placed inside two one-gallon paint-type metal cans and placed into a plastic bag. Some paint-type cans may have been sealed in a plastic container before being placed into the plastic bag. Wastes include hot-cell trash, grinding papers, kimwipes, and plastic. Major radionuclides in the waste consist of plutonium-239, uranium-235, and mixed fission products (MFP). Waste is considered to be remote-handled remote-handled because of the source of the waste and the quantity of MFP (radiation dose at the surface of the packages placed into Shaft 203 was not reported). The six packages of waste were placed into Shaft 203 in April 1980.

\section{Shaft Configuration}

Construction of Shaft 203 was initiated by augering a 36-inch diameter vertical hole into the mesa top. A 24-inch-diameter metal pipe (1/4 inch wall) with a length of 9 to 12 feet with a metal plate welded to the bottom was inserted into the hole as a liner. A 1/2 inch-wall inner pipe of 9-to 12-inch diameter and 7 to 12 feet in length with a metal plate welded to the bottom was centered in the larger pipe with a small amount of concrete to provide vertical alignment of the inner pipe in the outer pipe. Records with the specific dimensions for the pipes in Shaft 203 have not been located. A large metal funnel was placed in the inner pipe and waste packages were dropped into the inner pipe from a shielded transport cask moved into position above the shaft. After all waste packages were placed into the inner pipe, concrete was placed in the annular space between the pipes and the top of the shaft and auger hole were capped with 3 to 4 inches of concrete. The result is that the pipe containing the waste packages is completely encased in concrete.

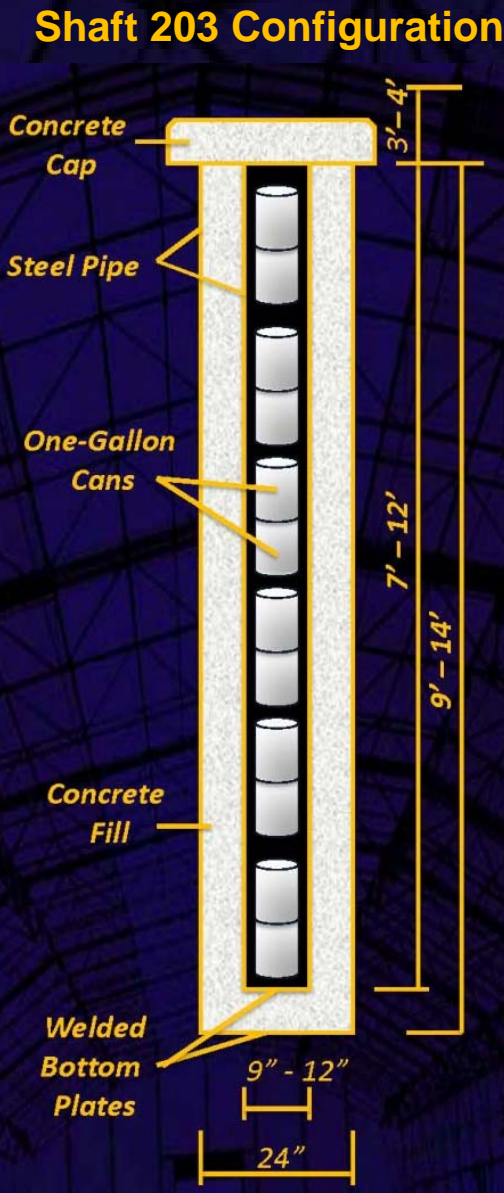

\section{Location in Shaft Field}

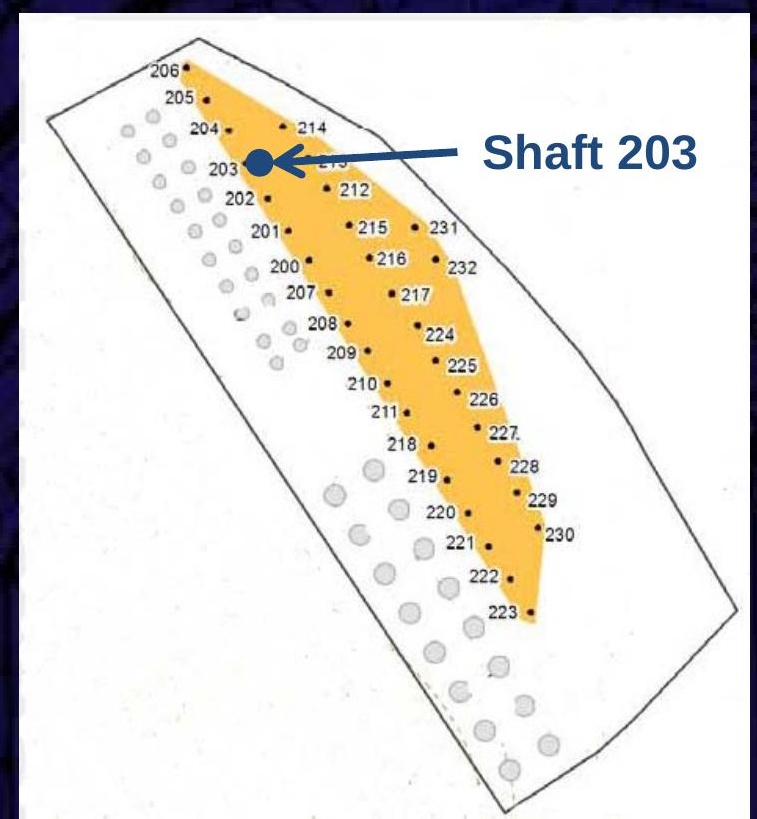

Waste Package Data Summary

\begin{tabular}{|c|c|c|c|c|c|}
\hline $\begin{array}{c}\text { RSWD } \\
\text { Number }\end{array}$ & $\begin{array}{c}\text { Volume } \\
\text { (gallons) }\end{array}$ & Radionuclides & $\begin{array}{c}\text { Total Curies } \\
\text { at Disposal }\end{array}$ & $\begin{array}{c}\text { Total Curies } \\
\text { Decayed to 2009 }\end{array}$ & PE-Ci \\
\hline S803547 ** & 12 & Pu-239, U-235, MFP & 111.05 & 53.9 & 2.32 \\
\hline $\begin{array}{c}\text { TOTALS for } \\
\text { Shaft 203 }\end{array}$ & 12 & Pu-239, U-235, MFP & 111.05 & 53.9 & 2.32 \\
\hline
\end{tabular}

* RSWD = Radioactive Solid Waste Disposal record

** Six RSWD forms were transferred to one form; original forms are not available

This fact sheet was compiled from information judged to be the most reliable and accurate available. Waste information from the 1970's and 1980's has gaps and is sometimes inconsistent between various records or reports. 


\section{Shaft 203 Totals}

\begin{tabular}{|c|c|c|}
\hline Total Number of Waste Packages & \multicolumn{2}{|c|}{6} \\
\hline Total Gross Weight (pounds) & \multicolumn{2}{|c|}{$4,600 *$} \\
\hline Total Pu-239 (grams) & \multicolumn{2}{|c|}{37.5} \\
\hline Total U-235 (grams) & \multicolumn{2}{|c|}{127} \\
\hline Total Mixed Fission Products (Ci) & \multicolumn{2}{|c|}{109} \\
\hline Dates of Disposal & \multicolumn{2}{|c|}{$4 / 30 / 1980$ to $4 / 30 / 1980$} \\
\hline Radiation at Surface of Waste Package (mR/hr) & Not Available & Not Available \\
\hline $\begin{array}{l}\text { Radiation at One Meter from Surface of Waste } \\
\text { Package ( } \mathrm{mR} / \mathrm{hr})\end{array}$ & Not Available & Not Available \\
\hline
\end{tabular}

* This weight is questionable because other characteristics of the six packages in Shaft 203 are similar to packages composed of two one-gallon cans in other shafts. Other shafts with similar packages are reported to have total package weights of about 75 to 130 pounds. The original six RSWD forms were transferred to one RSWD form at some time and an error may have occurred in transcription.

\section{Detailed Waste Package Data at Disposal}

\begin{tabular}{|c|c|c|c|c|c|c|c|c|c|}
\hline $\begin{array}{l}\text { Waste } \\
\text { Package } \\
\text { RSWD } \\
\text { Number }\end{array}$ & $\begin{array}{l}\text { Date } \\
\text { Disposed }\end{array}$ & $\begin{array}{l}\text { Gross } \\
\text { Weight } \\
\text { (Ib) }\end{array}$ & Waste Description & $\begin{array}{l}\text { Additional } \\
\text { Description of } \\
\text { Packaging and } \\
\text { Packaging } \\
\text { Materials }\end{array}$ & $\begin{array}{l}\text { Nuclide } \\
\text { or } \\
\text { Material } \\
\text { Type }\end{array}$ & Amount & Units & $\begin{array}{l}\text { Package } \\
\text { Radiation } \\
\text { at Surface } \\
(\mathrm{mR} / \mathrm{hr})\end{array}$ & $\begin{array}{l}\text { Package } \\
\text { Radiation } \\
\text { at } 1 \mathrm{~meter} \\
(\mathrm{mR} / \mathrm{hr})\end{array}$ \\
\hline \multirow{3}{*}{ S803547 } & \multirow{3}{*}{$4 / 30 / 1980$} & \multirow{3}{*}{4,600} & \multirow{3}{*}{$\begin{array}{l}\text { Hot cell waste CMB1 - } \\
\text { CMB14 from 12/13/ }\end{array}$} & \multirow{3}{*}{78 thru $8 / 15 / 79$} & Pu-239 & $3.75 \mathrm{E}+01$ & g & \multirow{3}{*}{ Not Available } & \multirow{3}{*}{ Not Available } \\
\hline & & & & & U-235 & $1.27 E+02$ & g & & \\
\hline & & & & & MFP & $1.09 \mathrm{E}+02$ & $\mathrm{Ci}$ & & \\
\hline
\end{tabular}




\section{Material Disposal Area G, 33 Shafts Shaft 204 Waste Data Fact Sheet}

\section{Contents}

Shaft 204 contains five packages of waste from the Chemistry and Metallurgy Research (CMR) Facility Wing 9 hot cells, with each package containing waste placed inside two one-gallon paint-type metal cans and placed into a plastic bag. Some paint-type cans may have been sealed in a plastic container before being placed into the plastic bag. Wastes include hot-cell trash, grinding papers, kimwipes, and plastic. Major radionuclides in the waste consist of plutonium-239, uranium-235, and mixed fission products (MFP). Waste is considered to be remote-handled with the reported radiation dose at the surface of the packages at the time of generation ranging from 50,000 to $140,000 \mathrm{mrem} / \mathrm{hour}$. The five packages of waste were placed into Shaft 204 in June 1979.

\section{Shaft Configuration}

Construction of Shaft 204 was initiated by augering a 36-inch diameter vertical hole into the mesa top. A 24-inch-diameter metal pipe (1/4 inch wall) with a length of 9 to 12 feet with a metal plate welded to the bottom was inserted into the hole as a liner. A 1/2 inch-wall inner pipe of 9- to 12-inch diameter and 7 to 12 feet in length with a metal plate welded to the bottom was centered in the larger pipe with a small amount of concrete to provide vertical alignment of the inner pipe in the outer pipe. Records with the specific dimensions for the pipes in Shaft 204 have not been located. A large metal funnel was placed in the inner pipe and waste packages were dropped into the inner pipe from a shielded transport cask moved into position above the shaft. After all waste packages were placed into the inner pipe, concrete was placed in the annular space between the pipes and the top of the shaft and auger hole were capped with 3 to 4 inches of concrete. The result is that the pipe containing the waste packages is completely encased in concrete.

\section{Shaft 204 Configuration}

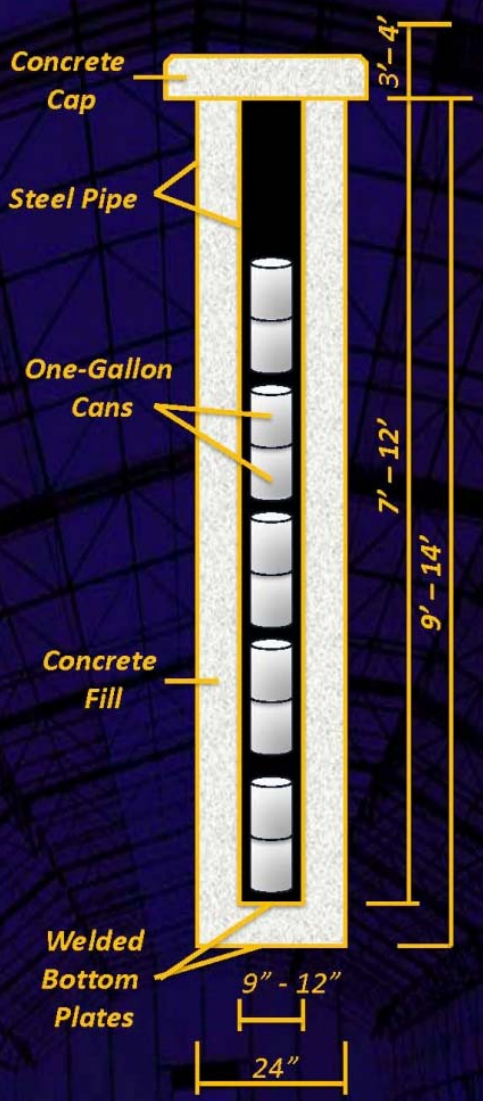

Waste Package Data Summary

\section{Location in Shaft Field}

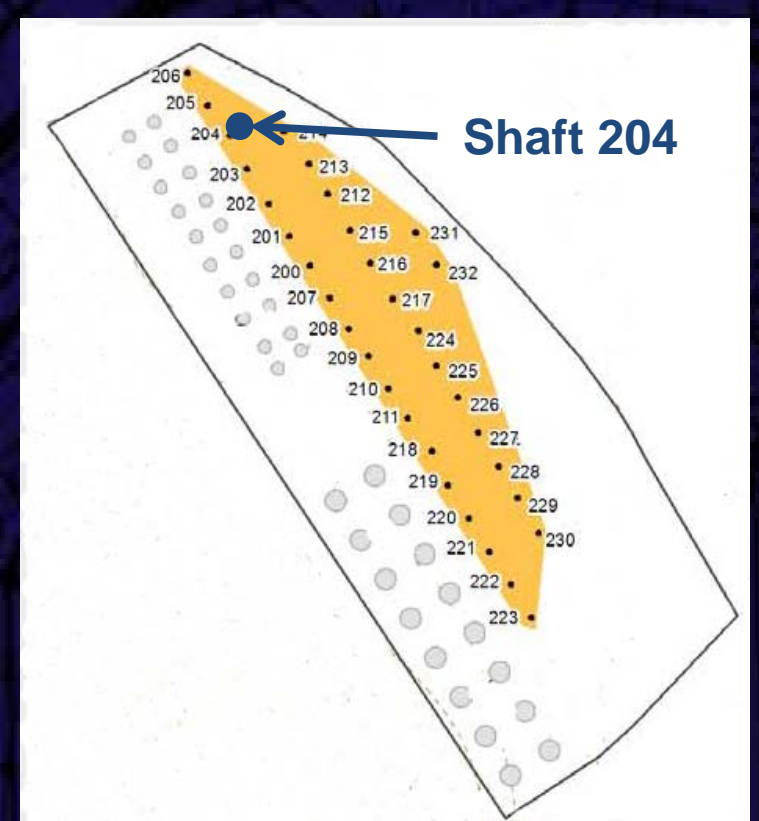

\begin{tabular}{|c|c|c|c|c|c|}
\hline $\begin{array}{c}\text { RSWD } \\
\text { Number }\end{array}$ & $\begin{array}{c}\text { Volume } \\
\text { (gallons) }\end{array}$ & Radionuclides & $\begin{array}{c}\text { Total Curies } \\
\text { at Disposal }\end{array}$ & $\begin{array}{c}\text { Total Curies } \\
\text { Decayed to 2009 }\end{array}$ & PE-Ci \\
\hline S791472 & 2 & Pu-239, U-235, MFP & 10.61 & 5.09 & 0.11 \\
\hline S791478 & 2 & Pu-239, U-235, MFP & 2.17 & 2.17 & 2.17 \\
\hline S791483 & 2 & Pu-239, U-235, MFP & 1.59 & 0.80 & 0.09 \\
\hline S794222 & 2 & Pu-239, U-235, MFP & 0.29 & 0.29 & 0.29 \\
\hline S794223 & 2 & Pu-239, U-235, MFP & 21.01 & 10.5 & 1.02 \\
\hline $\begin{array}{c}\text { TOTALS for } \\
\text { Shaft 204 }\end{array}$ & 10 & Pu-239, U-235, MFP & 35.67 & 18.87 & 3.68 \\
\hline
\end{tabular}

* RSWD = Radioactive Solid Waste Disposal record

This fact sheet was compiled from information judged to be the most reliable and accurate available. Waste information from the 1970's and 1980's has gaps and is sometimes inconsistent between various records or reports. 


\section{Shaft 204 Totals}

\begin{tabular}{|c|c|c|}
\hline Total Number of Waste Packages & \multicolumn{2}{|c|}{5} \\
\hline Total Gross Weight (pounds) & \multicolumn{2}{|c|}{86} \\
\hline Total Pu-239 (grams) & \multicolumn{2}{|c|}{59.5} \\
\hline Total U-235 (grams) & \multicolumn{2}{|c|}{193.55} \\
\hline Total Mixed Fission Products (Ci) & \multicolumn{2}{|c|}{30.5} \\
\hline Dates of Disposal & \multicolumn{2}{|c|}{$6 / 29 / 1979$ to $6 / 29 / 1979$} \\
\hline Radiation at Surface of Waste Package (mR/hr) & $\begin{array}{l}50,000 \text { to } 1,000,000+ \\
\text { at disposal }\end{array}$ & $\begin{array}{c}0 \text { to } 51,000 \\
\text { decayed to } 2009\end{array}$ \\
\hline $\begin{array}{l}\text { Radiation at One Meter from Surface of Waste } \\
\text { Package }(\mathrm{mR} / \mathrm{hr})\end{array}$ & $\begin{array}{l}10,500 \text { to } 140,000 \\
\text { at disposal }\end{array}$ & $\begin{array}{c}0 \text { to } 360 * \\
\text { decayed to } 2009\end{array}$ \\
\hline
\end{tabular}

* Calculated using inverse square rule assuming a point source at the center of the waste package paint cans

\section{Detailed Waste Package Data at Disposal}

\begin{tabular}{|c|c|c|c|c|c|c|c|c|c|}
\hline $\begin{array}{c}\text { Waste } \\
\text { Package } \\
\text { RSWD } \\
\text { Number }\end{array}$ & $\begin{array}{c}\text { Date } \\
\text { Disposed }\end{array}$ & $\begin{array}{c}\text { Gross } \\
\text { Weight } \\
\text { (lb) }\end{array}$ & Waste Description & $\begin{array}{c}\text { Additional } \\
\text { Description of } \\
\text { Packaging and } \\
\text { Packaging } \\
\text { Materials }\end{array}$ & $\begin{array}{c}\text { Nuclide } \\
\text { or } \\
\text { Material } \\
\text { Type }\end{array}$ & Amount & Units & $\begin{array}{c}\text { Package } \\
\text { Radiation } \\
\text { at Surface } \\
\text { (mR/hr) }\end{array}$ & $\begin{array}{c}\text { Package } \\
\text { Radiation } \\
\text { at } 1 \text { meter } \\
(\mathrm{mR} / \mathrm{hr})\end{array}$ \\
\hline \multirow{3}{*}{ S791472 } & \multirow{3}{*}{$6 / 29 / 1979$} & \multirow{3}{*}{20} & \multirow{3}{*}{$\begin{array}{l}\text { Cell } 12 \text { trash \& fuel } \\
\text { cans } 2127 \& 2150\end{array}$} & \multirow{3}{*}{$\begin{array}{l}108,000 \mathrm{mR} \\
\text { at contact }\end{array}$} & Pu-239 & $1.75 E+00$ & $\mathrm{~g}$ & \multirow{3}{*}{108,000} & \multirow{3}{*}{10,500} \\
\hline & & & & & $\mathrm{U}-235$ & $5.25 \mathrm{E}+00$ & $\mathrm{~g}$ & & \\
\hline & & & & & MFP & $1.05 E+01$ & $\mathrm{Ci}$ & & \\
\hline \multirow{3}{*}{ S791478 } & \multirow{3}{*}{$6 / 29 / 1979$} & \multirow{3}{*}{15} & \multirow{3}{*}{$\begin{array}{l}\text { Cell } 9 \text { hot trash cans } \\
2015,2117,1000+\text { Rhr }\end{array}$} & \multirow{3}{*}{$\begin{array}{l}\text { at contact } 140,000 \\
\mathrm{mR} / \mathrm{hr} \text { at meter }\end{array}$} & Pu-239 & $3.50 E+01$ & $\mathrm{~g}$ & \multirow{3}{*}{$1,000,000+$} & \multirow{3}{*}{140,000} \\
\hline & & & & & $\mathrm{U}-235$ & $1.21 \mathrm{E}+02$ & $\mathrm{~g}$ & & \\
\hline & & & & & MFP & & $\mathrm{Ci}$ & & \\
\hline \multirow{3}{*}{ S791483 } & \multirow{3}{*}{$6 / 29 / 1979$} & \multirow{3}{*}{15} & \multirow{3}{*}{$\begin{array}{c}\text { Cell } 12 \text { fuel cans } 2095 \\
\& 2167\end{array}$} & \multirow{3}{*}{ tin cans in plastic cans } & Pu-239 & $1.50 \mathrm{E}+00$ & $\mathrm{~g}$ & \multirow{3}{*}{50,000} & \multirow{3}{*}{15,000} \\
\hline & & & & & U-235 & $4.50 E+00$ & $\mathrm{~g}$ & & \\
\hline & & & & & MFP & $1.5 \mathrm{E}+? ? ?$ & $\mathrm{Ci}$ & & \\
\hline \multirow{3}{*}{ S794222 } & \multirow{3}{*}{$6 / 29 / 1979$} & \multirow{3}{*}{16} & \multirow{3}{*}{$\begin{array}{c}\text { Cell } 12 \text { fuel cans } \# 1790 \\
\& 1815\end{array}$} & \multirow{3}{*}{$100,000 \mathrm{R}$ at 1 meter } & Pu-239 & 4.75E+00 & $\mathrm{g}$ & & \multirow{3}{*}{100,000} \\
\hline & & & & & U-235 & $1.90 E+01$ & $\mathrm{~g}$ & & \\
\hline & & & & & MFP & & $\mathrm{Ci}$ & & \\
\hline \multirow{3}{*}{ S794223 } & \multirow{3}{*}{$6 / 29 / 1979$} & \multirow{3}{*}{20} & \multirow{3}{*}{$\begin{array}{l}\text { Cell } 9 \text { trash in } 1 \text { gal. } \\
\text { disposable cans }\end{array}$} & \multirow{3}{*}{$\begin{array}{c}\text { in plastic bag, can \#s } \\
1786 \& 1813\end{array}$} & Pu-239 & $1.65 \mathrm{E}+01$ & $\mathrm{~g}$ & & \multirow{3}{*}{20,400} \\
\hline & & & & & U-235 & $4.38 \mathrm{E}+01$ & $\mathrm{~g}$ & & \\
\hline & & & & & MFP & $2.00 E+01$ & $\mathrm{Ci}$ & & \\
\hline
\end{tabular}




\section{Shaft 205 Totals}

\begin{tabular}{|c|c|c|}
\hline Total Number of Waste Packages & \multicolumn{2}{|c|}{7} \\
\hline Total Gross Weight (pounds) & \multicolumn{2}{|c|}{132} \\
\hline Total Pu-239 (grams) & \multicolumn{2}{|c|}{117.1} \\
\hline Total U-235 (grams) & \multicolumn{2}{|c|}{386.1} \\
\hline Total Mixed Fission Products (Ci) & \multicolumn{2}{|c|}{866.7} \\
\hline Dates of Disposal & \multicolumn{2}{|c|}{$12 / 1 / 1980$ to $12 / 1 / 1980$} \\
\hline Radiation at Surface of Waste Package (mR/hr) & $\begin{array}{l}160,000 \text { to } 1,000,000 \\
\text { at disposal }\end{array}$ & $\begin{array}{l}77,000 \text { to } 483,000 \\
\text { decayed to } 2009\end{array}$ \\
\hline $\begin{array}{l}\text { Radiation at One Meter from Surface of Waste } \\
\text { Package }(\mathrm{mR} / \mathrm{hr})\end{array}$ & $\begin{array}{l}12,000 \text { to } 520,000 \\
\text { at disposal }\end{array}$ & $\begin{array}{l}550 \text { to } 3,400 * \\
\text { decayed to } 2009\end{array}$ \\
\hline
\end{tabular}

* Calculated using inverse square rule assuming a point source at the center of the waste package paint cans

\section{Detailed Waste Package Data at Disposal}

\begin{tabular}{|c|c|c|c|c|c|c|c|c|c|}
\hline $\begin{array}{c}\text { Waste } \\
\text { Package } \\
\text { RSWD } \\
\text { Number }\end{array}$ & $\begin{array}{c}\text { Date } \\
\text { Disposed }\end{array}$ & $\begin{array}{l}\text { Gross } \\
\text { Weight } \\
\text { (lb) }\end{array}$ & Waste Description & $\begin{array}{l}\text { Additional } \\
\text { Description of } \\
\text { Packaging and } \\
\text { Packaging } \\
\text { Materials }\end{array}$ & $\begin{array}{c}\text { Nuclide } \\
\text { or } \\
\text { Material } \\
\text { Type }\end{array}$ & Amount & Units & $\begin{array}{c}\text { Package } \\
\text { Radiation } \\
\text { at Surface } \\
(\mathrm{mR} / \mathrm{hr})\end{array}$ & $\begin{array}{c}\text { Package } \\
\text { Radiation } \\
\text { at } 1 \text { meter } \\
(\mathrm{mR} / \mathrm{hr})\end{array}$ \\
\hline \multirow{3}{*}{ S801483 } & \multirow{3}{*}{$12 / 1 / 1980$} & \multirow{3}{*}{20} & \multirow{3}{*}{$\begin{array}{c}\text { Cell } 9 \text { trash cans } 2875, \\
2926\end{array}$} & \multirow{3}{*}{$\begin{array}{l}+1000 \mathrm{R} / \mathrm{hr} \text { contact } \\
135 \mathrm{R} / \mathrm{hr} \text { at meter }\end{array}$} & Pu-239 & $1.00 \mathrm{E}-01$ & $\mathrm{~g}$ & \multirow{3}{*}{$1,000,000$} & \multirow{3}{*}{135,000} \\
\hline & & & & & $\mathrm{U}-235$ & $1.00 \mathrm{E}-01$ & $\mathrm{~g}$ & & \\
\hline & & & & & MFP & $1.35 E+02$ & $\mathrm{Ci}$ & & \\
\hline \multirow{3}{*}{ S801485 } & \multirow{3}{*}{$12 / 1 / 1980$} & \multirow{3}{*}{30} & \multirow{3}{*}{$\begin{array}{l}\text { Cell } 9 \text { trash can } 2928, \\
\qquad 2930\end{array}$} & \multirow{3}{*}{$\begin{array}{l}+1000 \mathrm{R} / \mathrm{hr} \text { contact } \\
170 \mathrm{R} / \mathrm{hr} \text { at meter }\end{array}$} & Pu-239 & $2.50 \mathrm{E}+01$ & $\mathrm{~g}$ & \multirow{3}{*}{$1,000,000$} & \multirow{3}{*}{170,000} \\
\hline & & & & & $\mathrm{U}-235$ & $9.50 \mathrm{E}+01$ & $\mathrm{~g}$ & & \\
\hline & & & & & MFP & $1.70 E+02$ & $\mathrm{Ci}$ & & \\
\hline \multirow{3}{*}{ S802244 } & \multirow{3}{*}{$12 / 1 / 1980$} & \multirow{3}{*}{15} & \multirow{3}{*}{$\begin{array}{c}\text { Cell } 14 \text { fuel \& trash cans } \\
2574 \& 2577\end{array}$} & \multirow{3}{*}{$\begin{array}{c}160000 \mathrm{mR} / \mathrm{hr} \text { at } \\
\text { contact }\end{array}$} & Pu-239 & $5.00 \mathrm{E}-01$ & $\mathrm{~g}$ & \multirow{3}{*}{160,000} & \multirow{3}{*}{41,000} \\
\hline & & & & & U-235 & $2.00 \mathrm{E}+01$ & $\mathrm{~g}$ & & \\
\hline & & & & & MFP & $4.10 E+00$ & $\mathrm{Ci}$ & & \\
\hline \multirow{3}{*}{$\$ 802246$} & \multirow{3}{*}{$12 / 1 / 1980$} & \multirow{3}{*}{16} & \multirow{3}{*}{$\begin{array}{c}\text { Cell } 14 \text { fuel can \# } 2604 \text { \& } \\
2584\end{array}$} & \multirow{3}{*}{$\begin{array}{c}\text { surface reading } \\
1,000,000 \mathrm{mR} / \mathrm{hr}\end{array}$} & Pu-239 & $1.75 \mathrm{E}+01$ & $\mathrm{~g}$ & \multirow{3}{*}{$1,000,000$} & \multirow{3}{*}{14,000} \\
\hline & & & & & U-235 & $7.00 E+01$ & $\mathrm{~g}$ & & \\
\hline & & & & & MFP & $1.40 E+00$ & $\mathrm{Ci}$ & & \\
\hline \multirow{3}{*}{ S802247 } & \multirow{3}{*}{$12 / 1 / 1980$} & \multirow{3}{*}{16} & \multirow{3}{*}{$\begin{array}{c}\text { Cell } 14 \text { fuel \& trash can \# } \\
2603 \& 2602\end{array}$} & \multirow{3}{*}{$\begin{array}{l}\text { surface reading } \\
615000 \mathrm{mR} / \mathrm{hr}\end{array}$} & Pu-239 & $5.00 E+00$ & $\mathrm{~g}$ & & \\
\hline & & & & & U-235 & $2.10 \mathrm{E}+01$ & $\mathrm{~g}$ & 615,000 & 12,000 \\
\hline & & & & & MFP & $1.20 \mathrm{E}+00$ & $\mathrm{~g}$ & & \\
\hline & & & & & Pu-239 & $1.20 E+01$ & $\mathrm{~g}$ & & \\
\hline S802259 & $12 / 1 / 1980$ & 15 & $\begin{array}{c}\text { Cell waste cans 2642, } \\
2669, \text { Cell } 9\end{array}$ & $\begin{array}{l}1000 \mathrm{R} \text { hr plus } \\
\text { bottom entry }\end{array}$ & $\mathrm{U}-235$ & $3.90 \mathrm{E}+01$ & $\mathrm{~g}$ & $1,000,000$ & 35,000 \\
\hline & & & & & MFP & $3.50 \mathrm{E}+01$ & $\mathrm{Ci}$ & & \\
\hline & & & & & $\mathrm{Pu}-239$ & $5.70 \mathrm{E}+01$ & $\mathrm{~g}$ & & \\
\hline S802287 & $12 / 1 / 1980$ & 20 & $\begin{array}{l}\text { Hot trash cell 9, cans } \\
2785.2646+1000 \text { Rhr }\end{array}$ & $\begin{array}{l}\text { contact } 520 \mathrm{Rhr} \text { at } \\
\text { one meter }\end{array}$ & U-235 & $2.36 \mathrm{E}+02$ & $\mathrm{~g}$ & $1,000,000$ & 520,000 \\
\hline & & & & & MFP & $5.20 E+02$ & $\mathrm{Ci}$ & & \\
\hline
\end{tabular}




\section{Shaft 206 Totals}

\begin{tabular}{|c|c|c|}
\hline Total Number of Waste Packages & \multicolumn{2}{|c|}{7} \\
\hline Total Gross Weight (pounds) & \multicolumn{2}{|c|}{94 (weight for one package unavailable) } \\
\hline Total Pu-239 (grams) & \multicolumn{2}{|c|}{282.503} \\
\hline Total U-235 (grams) & \multicolumn{2}{|c|}{790} \\
\hline Total Mixed Fission Products (Ci) & \multicolumn{2}{|c|}{370.2} \\
\hline Dates of Disposal & \multicolumn{2}{|c|}{$4 / 1 / 1981$ to $4 / 14 / 1981$} \\
\hline Radiation at Surface of Waste Package (mR/hr) & $\begin{array}{l}1,000,000 \text { to } 1,010,000+ \\
\text { at disposal }\end{array}$ & $\begin{array}{c}0 \text { to } 108,000 \\
\text { decayed to } 2009\end{array}$ \\
\hline $\begin{array}{l}\text { Radiation at One Meter from Surface of Waste } \\
\text { Package ( } \mathrm{mR} / \mathrm{hr} \text { ) }\end{array}$ & $\begin{array}{l}22,000 \text { to } 100,000 \\
\text { at disposal }\end{array}$ & $\begin{array}{c}0 \text { to } 3,500 * \\
\text { decayed to } 2009\end{array}$ \\
\hline
\end{tabular}

* Calculated using inverse square rule assuming a point source at the center of the waste package paint cans

\section{Detailed Waste Package Data at Disposal}

\begin{tabular}{|c|c|c|c|c|c|c|c|c|c|}
\hline $\begin{array}{c}\text { Waste } \\
\text { Package } \\
\text { RSWD } \\
\text { Number }\end{array}$ & $\begin{array}{c}\text { Date } \\
\text { Disposed }\end{array}$ & $\begin{array}{l}\text { Gross } \\
\text { Weight } \\
\text { (lb) }\end{array}$ & Waste Description & $\begin{array}{l}\text { Additional } \\
\text { Description of } \\
\text { Packaging and } \\
\text { Packaging } \\
\text { Materials }\end{array}$ & $\begin{array}{l}\text { Nuclide } \\
\text { or } \\
\text { Material } \\
\text { Type }\end{array}$ & Amount & Units & $\begin{array}{c}\text { Package } \\
\text { Radiation } \\
\text { at Surface } \\
\text { (mR/hr) }\end{array}$ & $\begin{array}{c}\text { Package } \\
\text { Radiation } \\
\text { at } 1 \text { meter } \\
(\mathrm{mR} / \mathrm{hr})\end{array}$ \\
\hline \multirow{3}{*}{ S812291 } & \multirow{3}{*}{ 4/1/1981 } & \multirow{3}{*}{10} & \multirow{3}{*}{$\begin{array}{c}\text { Cell } 13,15 \text { met } \\
\text { samples, cans } 2805 \text {, } \\
2806\end{array}$} & \multirow{3}{*}{$\begin{array}{l}\text { Bottom entry } 1000+ \\
\text { R/hr @ contact }\end{array}$} & Pu-239 & $1.23 \mathrm{E}+02$ & $\mathrm{~g}$ & \multirow{3}{*}{$1,000,000$} & \multirow{3}{*}{40,000} \\
\hline & & & & & U-235 & $3.21 \mathrm{E}+02$ & $\mathrm{~g}$ & & \\
\hline & & & & & MFP & $4.00 E+01$ & $\mathrm{Ci}$ & & \\
\hline \multirow{3}{*}{ S812292 } & \multirow{3}{*}{$4 / 1 / 1981$} & \multirow{3}{*}{10} & \multirow{3}{*}{$\begin{array}{l}\text { Cell } 13,15 \text { met samples } \\
\text { cans } 2801,2804\end{array}$} & \multirow{3}{*}{$\begin{array}{l}\text { Bottom entry } 1000+ \\
\text { R/hr @ contact }\end{array}$} & Pu-239 & $1.00 E+02$ & $\mathrm{~g}$ & \multirow{3}{*}{$1,000,000$} & \multirow{3}{*}{22,000} \\
\hline & & & & & $\mathrm{U}-235$ & $2.69 \mathrm{E}+02$ & $\mathrm{~g}$ & & \\
\hline & & & & & MFP & $2.20 \mathrm{E}+01$ & $\mathrm{Ci}$ & & \\
\hline \multirow{3}{*}{ S812293 } & \multirow{3}{*}{$4 / 1 / 1981$} & \multirow{3}{*}{20} & \multirow{3}{*}{$\begin{array}{c}\text { Cell waste cans } 2454, \\
2812, \text { cell } 14\end{array}$} & \multirow{3}{*}{$\begin{array}{c}1000 \mathrm{Rhr} \text { contact, } 108 \\
\text { Rhr meter }\end{array}$} & Pu-239 & $7.00 E+00$ & $\mathrm{~g}$ & \multirow{3}{*}{$1,000,000$} & \multirow{3}{*}{108,000} \\
\hline & & & & & U-235 & $2.80 E+01$ & $\mathrm{~g}$ & & \\
\hline & & & & & MFP & $1.00 E+02$ & $\mathrm{Ci}$ & & \\
\hline \multirow{3}{*}{ S812297 } & \multirow{3}{*}{ 4/14/1981 } & \multirow{3}{*}{20} & \multirow{3}{*}{$\begin{array}{l}\text { Cell } 14 \text { trash \& fuel } \\
\# 2829,2807\end{array}$} & \multirow{3}{*}{$\begin{array}{c}+1000 \text { Rhr contact } 100 \\
\text { Rhr at meter }\end{array}$} & Pu-239 & $2.20 \mathrm{E}+01$ & $\mathrm{~g}$ & \multirow{3}{*}{$1,000,000$} & \multirow{3}{*}{100,000} \\
\hline & & & & & U-235 & $8.6 \mathrm{E}+01$ & $\mathrm{~g}$ & & \\
\hline & & & & & MFP & 1.00E+02 & $\mathrm{Ci}$ & & \\
\hline \multirow{3}{*}{ S812298 } & \multirow{3}{*}{ 4/1/1981 } & \multirow{3}{*}{20} & \multirow{3}{*}{$\begin{array}{l}\text { Cell \#14 trash \& fuel } \\
\quad \# 2826 \& 2827\end{array}$} & \multirow{3}{*}{$\begin{array}{l}+1000 \mathrm{Rhr} \text { at contact } \\
100 \mathrm{Rhr} \text { at meter }\end{array}$} & Pu-239 & $2.20 E+01$ & $\mathrm{~g}$ & \multirow{3}{*}{$1,000,000$} & \\
\hline & & & & & U-235 & $8.60 \mathrm{E}+01$ & $\mathrm{~g}$ & & 100,000 \\
\hline & & & & & MFP & $1.00 \mathrm{E}+02$ & $\mathrm{Ci}$ & & \\
\hline & & & & & Pu-239 & $8.00 \mathrm{E}+00$ & $\mathrm{~g}$ & & \\
\hline S812302 & 4/1/1981 & 14 & $\begin{array}{c}\text { Cans } 2883,2865 \\
\text { Canh }\end{array}$ & 1010+R/hr @ contact & $\mathrm{U}-235$ & $2.30 \mathrm{E}-05$ & $\mathrm{~g}$ & $1,010,000$ & 82,000 \\
\hline & & & & & MFP & $8.20 E+00$ & $\mathrm{Ci}$ & & \\
\hline$\$ 812303$ & 4/1/1981 & $N A$ & & & Pu-239 & $5.03 \mathrm{E}-01$ & $\mathrm{Ci}$ & & \\
\hline & & & & & U-235 & $5.04 \mathrm{E}-05$ & $\mathrm{Ci}$ & & \\
\hline
\end{tabular}




\section{Material Disposal Area G, 33 Shafts Shaft 207 Waste Data Fact Sheet}

\section{Contents}

Shaft 207 contains five packages of waste from the Chemistry and Metallurgy Research (CMR) Facility Wing 9 hot cells, with four of the packages containing waste placed inside two one-gallon paint-type metal cans and placed into a plastic bag. One of the five packages contains waste placed inside three one-gallon metal cans placed into a plastic bag. Some paint-type cans were placed into a plastic container before being placed into the plastic bag. Wastes include hot-cell trash, grinding papers, kimwipes, and plastic. Major radionuclides in the waste consist of plutonium-239, uranium-235, and mixed fission products (MFP). Waste is

considered to be remote-handled with the reported radiation dose at the surface of the packages at the time of generation ranging from 3,600 to $290,000 \mathrm{mrem} / \mathrm{hour}$. The five packages of waste were placed into Shaft 207 in May 1981.

\section{Shaft Configuration}

Construction of Shaft 207 was initiated by augering a 36-inch diameter vertical hole into the mesa top. A 24-inch-diameter metal pipe (1/4 inch wall) with a length of 9 to 12 feet with a metal plate welded to the bottom was inserted into the hole as a liner. A 1/2 inch-wall inner pipe of 9- to 12-inch diameter and 7 to 12 feet in length with a metal plate welded to the bottom was centered in the larger pipe with a small amount of concrete to provide vertical alignment of the inner pipe in the outer pipe. Records with the specific dimensions for the pipes in Shaft 207 have not been located. A large metal funnel was placed in the inner pipe and waste packages were dropped into the inner pipe from a shielded transport cask moved into position above the shaft. After all waste packages were placed into the inner pipe, concrete was placed in the annular space between the pipes and the top of the shaft and auger hole were capped with 3 to 4 inches of concrete. The result is that the pipe containing the waste packages is completely encased in concrete.

\section{Shaft 207 Configuration}

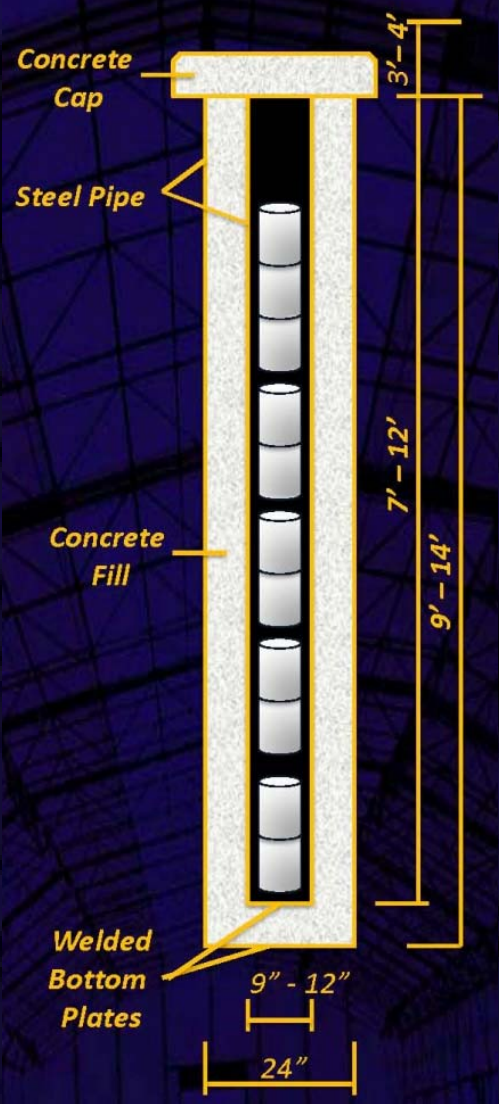

Waste Package Data Summary

\section{Location in Shaft Field}

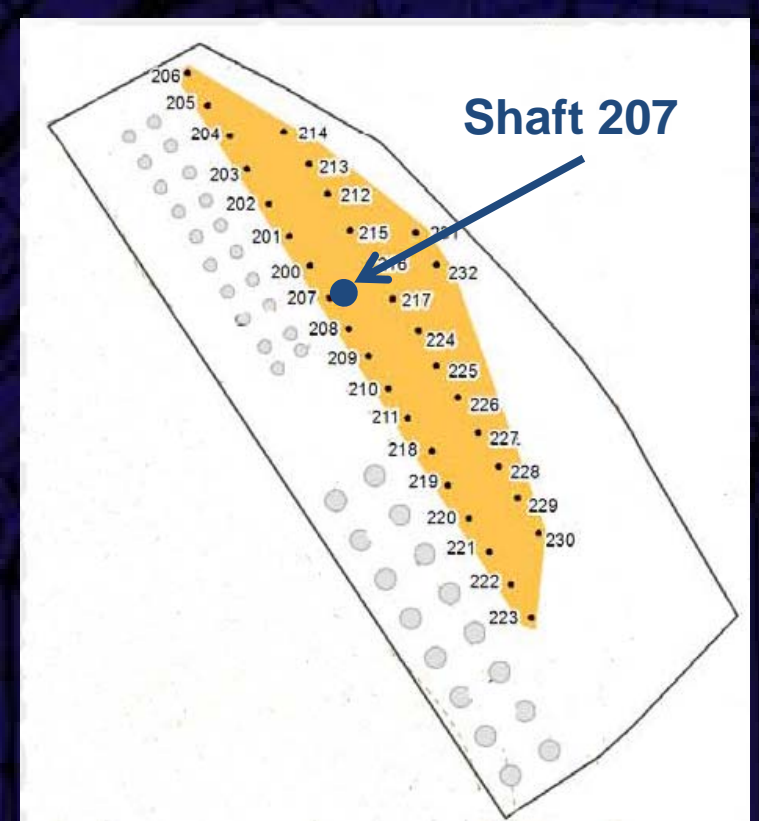

\begin{tabular}{|c|c|c|c|c|c|}
\hline $\begin{array}{c}\text { RSWD * } \\
\text { Number }\end{array}$ & $\begin{array}{c}\text { Volume } \\
\text { (gallons) }\end{array}$ & Radionuclides & $\begin{array}{c}\text { Total Curies } \\
\text { at Disposal }\end{array}$ & $\begin{array}{c}\text { Total Curies } \\
\text { Decayed to 2009 }\end{array}$ & PE-Ci \\
\hline S811397 & 2 & Pu-239, U-235, MFP & 2.00 & 1.00 & 0.0062 \\
\hline S811400 & 2 & Pu-239, U-235, MFP & 3.50 & 1.75 & 0.0062 \\
\hline S811401 & 2 & Pu-239, U-235, MFP & 5.20 & 2.63 & 0.0657 \\
\hline S811406 & 2 & Pu-239, U-235, MFP & 2.50 & 1.25 & 0.0062 \\
\hline S814978 & 3 & Pu-239, U-235, MFP & 0.18 & 0.09 & 0.0037 \\
\hline $\begin{array}{c}\text { TOTALS for } \\
\text { Shaft 207 }\end{array}$ & 11 & Pu-239, U-235, MFP & 13.40 & 6.72 & 0.09 \\
\hline
\end{tabular}

* RSWD $=$ Radioactive Solid Waste Disposal record

This fact sheet was compiled from information judged to be the most reliable and accurate available. Waste information from the 1970's and 1980's has gaps and is sometimes inconsistent between various records or reports. 


\section{Shaft 207 Totals at Disposal}

\begin{tabular}{|c|c|c|}
\hline Total Number of Waste Packages & \multicolumn{2}{|c|}{5} \\
\hline Total Gross Weight (pounds) & \multicolumn{2}{|c|}{76} \\
\hline Total Pu-239 (grams) & \multicolumn{2}{|c|}{1.42} \\
\hline Total U-235 (grams) & \multicolumn{2}{|c|}{5.68} \\
\hline Total Mixed Fission Products (Ci) & \multicolumn{2}{|c|}{13.33} \\
\hline Dates of Disposal & \multicolumn{2}{|c|}{$5 / 29 / 1981$ to $5 / 29 / 1981$} \\
\hline Radiation at Surface of Waste Package (mR/hr) & $\begin{array}{l}3,600 \text { to } 290,000 \\
\text { at disposal }\end{array}$ & $\begin{array}{l}1,800 \text { to } 143,000 \\
\text { decayed to } 2009\end{array}$ \\
\hline $\begin{array}{l}\text { Radiation at One Meter from Surface of Waste } \\
\text { Package }(\mathrm{mR} / \mathrm{hr})\end{array}$ & $\begin{array}{l}180 \text { to } 5,150 \\
\text { at disposal }\end{array}$ & $\begin{array}{c}10 \text { to } 1,000 * \\
\text { decayed to } 2009\end{array}$ \\
\hline
\end{tabular}

* Calculated using inverse square rule assuming a point source at the center of the waste package paint cans

\section{Detailed Waste Package Data at Disposal}

\begin{tabular}{|c|c|c|c|c|c|c|c|c|c|}
\hline $\begin{array}{l}\text { Waste } \\
\text { Package } \\
\text { RSWD } \\
\text { Number }\end{array}$ & $\begin{array}{c}\text { Date } \\
\text { Disposed }\end{array}$ & $\begin{array}{c}\text { Gross } \\
\text { Weight } \\
\text { (lb) }\end{array}$ & Waste Description & $\begin{array}{c}\text { Additional } \\
\text { Description of } \\
\text { Packaging and } \\
\text { Packaging } \\
\text { Materials }\end{array}$ & Nuclide & Amount & Units & $\begin{array}{c}\text { Package } \\
\text { Radiation } \\
\text { at Surface } \\
\text { (mR/hr) }\end{array}$ & $\begin{array}{c}\text { Package } \\
\text { Radiation } \\
\text { at } 1 \text { meter } \\
(\mathrm{mR} / \mathrm{hr})\end{array}$ \\
\hline \multirow{3}{*}{ S811397 } & \multirow{3}{*}{$5 / 29 / 1981$} & \multirow{3}{*}{16} & \multirow{3}{*}{$\begin{array}{l}\text { Cell } 13 \text { grinding papers, } \\
\text { kimwipes, plastic }\end{array}$} & \multirow{3}{*}{$\begin{array}{c}\text { Plastic can nos. } 3069 \\
\text { and } 3055\end{array}$} & Pu-239 & $1.00 \mathrm{E}-01$ & $\mathrm{~g}$ & \multirow{3}{*}{60,000} & \multirow{3}{*}{2,000} \\
\hline & & & & & U-235 & $4.00 \mathrm{E}-01$ & $\mathrm{~g}$ & & \\
\hline & & & & & MFP & $2.00 \mathrm{E}+00$ & $\mathrm{Ci}$ & & \\
\hline \multirow{3}{*}{ S811400 } & \multirow{3}{*}{ 5/29/1981 } & \multirow{3}{*}{16} & \multirow{3}{*}{$\begin{array}{l}\text { glass, paper, etc, can } \\
3046,3060 \text {, Cell } 14\end{array}$} & \multirow{3}{*}{$290000 \mathrm{mR} / \mathrm{hr}$ surface } & Pu-239 & $1.00 \mathrm{E}-01$ & $\mathrm{~g}$ & \multirow{3}{*}{290,000} & \multirow{3}{*}{3,500} \\
\hline & & & & & U-235 & 4.00E-01 & $\mathrm{g}$ & & \\
\hline & & & & & MFP & $3.50 \mathrm{E}+00$ & $\mathrm{Ci}$ & & \\
\hline \multirow{3}{*}{ S811401 } & \multirow{3}{*}{ 5/29/1981 } & \multirow{3}{*}{16} & \multirow{3}{*}{$\begin{array}{l}\text { Cell } 14 \text { can } 3065 \text { ? Fuel } \\
\text { plastic bottles }\end{array}$} & \multirow{3}{*}{$\begin{array}{l}\text { Cell } 16 \text { can } 3067 \\
170000 \mathrm{mR} / \mathrm{hr}\end{array}$} & Pu-239 & $1.06 \mathrm{E}+00$ & $\mathrm{~g}$ & \multirow{3}{*}{170,000} & \multirow{3}{*}{5,150} \\
\hline & & & & & U-235 & $4.24 \mathrm{E}+00$ & $\mathrm{~g}$ & & \\
\hline & & & & & MFP & $5.15 \mathrm{E}+00$ & $\mathrm{Ci}$ & & \\
\hline \multirow{3}{*}{ S811406 } & \multirow{3}{*}{$5 / 29 / 1981$} & \multirow{3}{*}{16} & \multirow{3}{*}{$\begin{array}{l}\text { Cell } 13 \text { (illegible) } \\
\text { Papers, kimwipes, } \\
\text { plastic }\end{array}$} & \multirow{3}{*}{$\begin{array}{c}\text { Plastic cans } 3103,3101 \\
150000 \mathrm{mR} / \mathrm{hr}\end{array}$} & Pu-239 & $1.00 \mathrm{E}-01$ & $\mathrm{~g}$ & \multirow{3}{*}{150,000} & \multirow{3}{*}{2,500} \\
\hline & & & & & $\mathrm{U}-235$ & 4.00E-01 & $\mathrm{g}$ & & \\
\hline & & & & & MFP & $2.50 \mathrm{E}+00$ & $\mathrm{Ci}$ & & \\
\hline \multirow{3}{*}{ S814978 } & \multirow{3}{*}{$5 / 29 / 1981$} & \multirow{3}{*}{12} & \multirow{3}{*}{$\begin{array}{l}\text { Cell } 15 \text { wipes, polishing } \\
\text { cloths, plastic }\end{array}$} & \multirow{3}{*}{$\begin{array}{c}\text { cans } 3104,3097,3099 \\
\text { also form } 4979\end{array}$} & Pu-239 & $6.00 \mathrm{E}-02$ & $\mathrm{~g}$ & \multirow{3}{*}{3,600} & \multirow{3}{*}{180} \\
\hline & & & & & U-235 & 2.40E-01 & $\mathrm{g}$ & & \\
\hline & & & & & MFP & $1.80 \mathrm{E}-01$ & $\mathrm{Ci}$ & & \\
\hline
\end{tabular}




\section{Material Disposal Area G, 33 Shafts Shaft 208 Waste Data Fact Sheet}

\section{Contents}

Shaft 208 contains seven packages of waste from the Chemistry and Metallurgy Research (CMR) Facility Wing 9 hot cells, with five of the packages containing waste placed inside two one-gallon paint-type metal cans and placed into a plastic bag. Two of the seven packages contain waste placed inside single one-gallon metal cans placed into a plastic bag. Some paint-type cans were placed into a plastic container before being placed into the plastic bag. Wastes include hot-cell trash, grinding papers, kimwipes, and plastic. Major radionuclides in the waste consist of plutonium-239, uranium-235, and mixed fission products (MFP). Waste is considered to be remote-handled with the reported radiation dose at the surface of the packages at the time of generation ranging from 1,000 to 80,000 mrem/hour. The five packages of waste were placed into Shaft 208 in June 1981.

\section{Shaft Configuration}

Construction of Shaft 208 was initiated by augering a 24-inch diameter vertical hole into the mesa top. A 24-inch-diameter metal pipe (1/4 inch wall) with a length of 9 to 12 feet with a metal plate welded to the bottom was inserted into the hole as a liner. A 1/2 inch-wall inner pipe of 9- to 12-inch diameter and 7 to 12 feet in length with a metal plate welded to the bottom was centered in the larger pipe with a small amount of concrete to provide vertical alignment of the inner pipe in the outer pipe. Records with the specific dimensions for the pipes in Shaft 208 have not been located. A large metal funnel was placed in the inner pipe and waste packages were dropped into the inner pipe from a shielded transport cask moved into position above the shaft. After all waste packages were placed into the inner pipe, concrete was placed in the annular space between the pipes and the top of the shaft and auger hole were capped with 3 to 4 inches of concrete. The result is that the pipe containing the waste packages is completely encased in concrete.

\section{Shaft 208 Configuration}

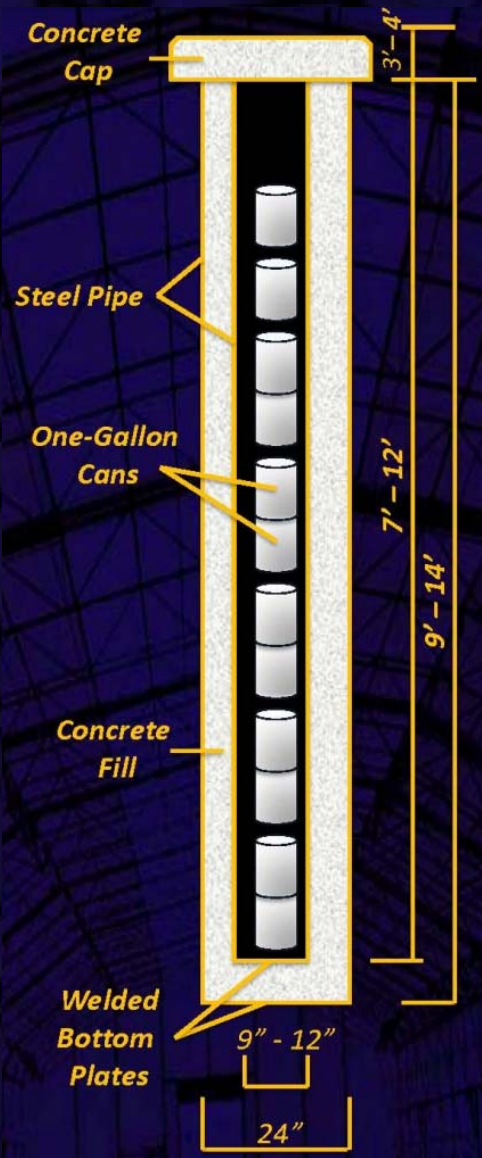

Waste Package Data Summary

\section{Location in Shaft Field}

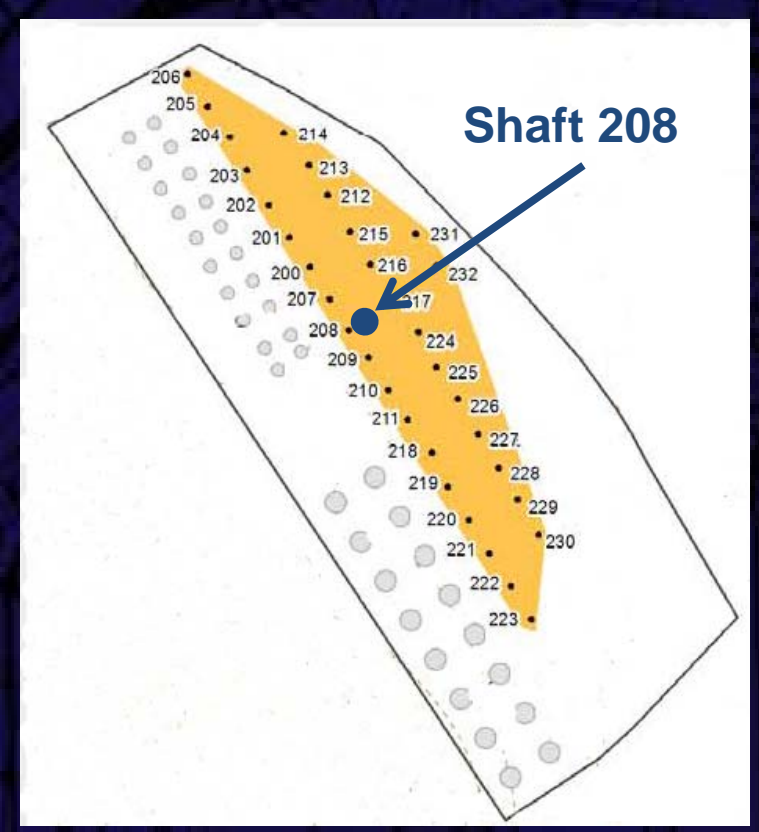

\begin{tabular}{|c|c|c|c|c|c|}
\hline $\begin{array}{c}\text { RSWD * } \\
\text { Number }\end{array}$ & $\begin{array}{c}\text { Volume } \\
\text { (gallons) }\end{array}$ & Radionuclides & $\begin{array}{c}\text { Total Curies } \\
\text { at Disposal }\end{array}$ & $\begin{array}{c}\text { Total Curies } \\
\text { Decayed to 2009 }\end{array}$ & PE-Ci \\
\hline S810794 & 2 & Pu-239, U-235, MFP & 101.63 & 51.6 & 1.75 \\
\hline S810802 & 1 & Pu-239, U-235, MFP & 0.07 & 0.04 & 0.0062 \\
\hline S811405 & 2 & Pu-239, U-235, MFP & 2.03 & 1.03 & 0.031 \\
\hline S811408 & 1 & Pu-239, U-235, MFP & 0.09 & 0.05 & 0.0062 \\
\hline S811409 & 2 & Pu-239, U-235, MFP & 2.10 & 1.05 & 0.0062 \\
\hline S811411 & 2 & Pu-239, U-235, MFP & 1.01 & 0.50 & 0.0062 \\
\hline S814979 & 2 & Pu-239, U-235, MFP & 0.12 & 0.06 & 0.00248 \\
\hline $\begin{array}{c}\text { TOTALS for } \\
\text { Shaft 208 }\end{array}$ & 12 & Pu-239, U-235, MFP & 107.05 & 54.29 & 1.81 \\
\hline
\end{tabular}

* RSWD = Radioactive Solid Waste Disposal record

This fact sheet was compiled from information judged to be the most reliable and accurate available. Waste information from the 1970's and 1980's has gaps and is sometimes inconsistent between various records or reports. 


\section{Shaft 208 Totals at Disposal}

\begin{tabular}{|c|c|c|}
\hline Total Number of Waste Packages & \multicolumn{2}{|c|}{7} \\
\hline Total Gross Weight (pounds) & \multicolumn{2}{|c|}{85} \\
\hline Total Pu-239 (grams) & \multicolumn{2}{|c|}{29.44} \\
\hline Total U-235 (grams) & \multicolumn{2}{|c|}{105.76} \\
\hline Total Mixed Fission Products (Ci) & \multicolumn{2}{|c|}{1004.36} \\
\hline Dates of Disposal & \multicolumn{2}{|c|}{$6 / 22 / 1981$ to $6 / 22 / 1981$} \\
\hline Radiation at Surface of Waste Package (mR/hr) & $\begin{array}{l}1,000 \text { to } 80,000 \\
\text { at disposal }\end{array}$ & $\begin{array}{c}500 \text { to } 40,000 \\
\text { decayed to } 2009\end{array}$ \\
\hline $\begin{array}{l}\text { Radiation at One Meter from Surface of Waste } \\
\text { Package ( } \mathrm{mR} / \mathrm{hr})\end{array}$ & $\begin{array}{l}60 \text { to } 2,100 \\
\text { at disposal }\end{array}$ & $\begin{array}{l}10 \text { to } 300 * \\
\text { decayed to } 2009\end{array}$ \\
\hline
\end{tabular}

* Calculated using inverse square rule assuming a point source at the center of the waste package paint cans

\section{Detailed Waste Package Data at Disposal}

\begin{tabular}{|c|c|c|c|c|c|c|c|c|c|}
\hline $\begin{array}{c}\text { Waste } \\
\text { Package } \\
\text { RSWD } \\
\text { Number }\end{array}$ & $\begin{array}{c}\text { Date } \\
\text { Disposed }\end{array}$ & $\begin{array}{c}\text { Gross } \\
\text { Weight } \\
\text { (lb) }\end{array}$ & Waste Description & $\begin{array}{c}\text { Additional } \\
\text { Description of } \\
\text { Packaging and } \\
\text { Packaging } \\
\text { Materials }\end{array}$ & $\begin{array}{c}\text { Nuclide } \\
\text { or } \\
\text { Material } \\
\text { Type }\end{array}$ & Amount & Units & $\begin{array}{c}\text { Package } \\
\text { Radiation } \\
\text { at Surface } \\
\text { (mR/hr) }\end{array}$ & $\begin{array}{c}\text { Package } \\
\text { Radiation } \\
\text { at } 1 \text { meter } \\
(\mathrm{mR} / \mathrm{hr})\end{array}$ \\
\hline \multirow{3}{*}{ S810794 } & \multirow{3}{*}{$6 / 22 / 1981$} & \multirow{3}{*}{16} & \multirow{3}{*}{$\begin{array}{l}\text { Cell } 9,13 \text { fuel trash } \\
\text { cans } 3123,3126\end{array}$} & \multirow{3}{*}{$\begin{array}{c}1000+\mathrm{R} / \mathrm{hr} \text { contact } 100 \\
\mathrm{R} / \mathrm{hr} \text { meter }\end{array}$} & Pu-239 & $2.85 \mathrm{E}+01$ & $\mathrm{~g}$ & & \\
\hline & & & & & U-235 & $1.02 \mathrm{E}+02$ & $\mathrm{~g}$ & & \\
\hline & & & & & MFP & $9.99 \mathrm{E}+02$ & $\mathrm{Ci}$ & & \\
\hline \multirow{3}{*}{ S810802 } & \multirow{3}{*}{ 6/22/1981 } & \multirow{3}{*}{5} & \multirow{3}{*}{$\begin{array}{l}\text { Cell } 13 \text { hot trash can } \\
3119\end{array}$} & & Pu-239 & $1.00 \mathrm{E}-01$ & $\mathrm{~g}$ & \multirow{3}{*}{1,000} & \multirow{3}{*}{60} \\
\hline & & & & & $\mathrm{U}-235$ & 4.00E-01 & $\mathrm{g}$ & & \\
\hline & & & & & MFP & $6.00 \mathrm{E}-02$ & $\mathrm{Ci}$ & & \\
\hline \multirow{3}{*}{ S811405 } & \multirow{3}{*}{$6 / 22 / 1981$} & \multirow{3}{*}{16} & \multirow{3}{*}{$\begin{array}{l}\text { Cell } 13 \text { catch pans, } \\
\text { grinding papers, } \\
\text { towels }\end{array}$} & \multirow{3}{*}{$\begin{array}{l}\text { plastic cans } 3096 \\
3102\end{array}$} & Pu-239 & 5.00E-01 & $\mathrm{g}$ & \multirow{3}{*}{80,000} & \multirow{3}{*}{2,000} \\
\hline & & & & & U-235 & $2.00 E+00$ & $\mathrm{~g}$ & & \\
\hline & & & & & MFP & $2.00 E+00$ & $\mathrm{Ci}$ & & \\
\hline \multirow{3}{*}{ S811408 } & \multirow{3}{*}{$6 / 22 / 1981$} & \multirow{3}{*}{8} & \multirow{3}{*}{$\begin{array}{l}\text { Cell } 15 \text { wipes, polishing } \\
\text { cloths, plastics }\end{array}$} & \multirow{3}{*}{ Can 3093} & Pu-239 & $1.00 \mathrm{E}-01$ & $\mathrm{~g}$ & \multirow{3}{*}{1,500} & \multirow{3}{*}{80} \\
\hline & & & & & $\mathrm{U}-235$ & 4.00E-01 & $\mathrm{g}$ & & \\
\hline & & & & & MFP & $8.00 \mathrm{E}-02$ & $\mathrm{Ci}$ & & \\
\hline \multirow{3}{*}{ S811409 } & \multirow{3}{*}{ 6/22/1981 } & \multirow{3}{*}{16} & \multirow{3}{*}{$\begin{array}{c}\text { Cell } 13 \text { catch pans, fuel, } \\
\text { grinding papers }\end{array}$} & \multirow{3}{*}{ plastic cans 3092,3110} & Pu-239 & 1.00E-01 & $\mathrm{g}$ & \multirow{3}{*}{32,000} & \multirow{3}{*}{2,100} \\
\hline & & & & & $\mathrm{U}-235$ & $4.00 \mathrm{E}-01$ & $\mathrm{~g}$ & & \\
\hline & & & & & MFP & $2.10 \mathrm{E}+00$ & $\mathrm{Ci}$ & & \\
\hline \multirow{3}{*}{ S811411 } & & & & & Pu-239 & $1.00 \mathrm{E}-01$ & $\mathrm{~g}$ & & \\
\hline & $6 / 22 / 1981$ & 16 & $\begin{array}{l}\text { Cell } 13 \text { grinding papers, } \\
\text { plastic, towels }\end{array}$ & $\begin{array}{l}\text { Plastic cans 3094, } \\
3116\end{array}$ & U-235 & 4.00E-01 & $\mathrm{g}$ & 29,000 & 1,000 \\
\hline & & & & & MFP & $1.00 \mathrm{E}+00$ & $\mathrm{Ci}$ & & 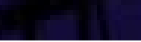 \\
\hline & & & & & Pu-239 & 4.00E-02 & $\mathrm{g}$ & & \\
\hline S814979 & 6/22/1981 & 8 & $\begin{array}{l}\text { Cell } 15 \text { wipes, polishing } \\
\text { cloths, plastic }\end{array}$ & $\begin{array}{l}\text { Cans } 3100,3109 \text { - see } \\
\text { form } \$ 814978\end{array}$ & $\mathrm{U}-235$ & $1.60 \mathrm{E}-01$ & $\mathrm{~g}$ & 2,400 & 120 \\
\hline & & & & & MFP & 1.20E-01 & $\mathrm{Ci}$ & & \\
\hline
\end{tabular}




\section{Material Disposal Area G, 33 Shafts Shaft 209 Waste Data Fact Sheet}

\section{Contents}

Shaft 209 contains six packages of waste from the Chemistry and Metallurgy Research (CMR) Facility Wing 9 hot cells, with each package containing waste placed inside two one-gallon paint-type metal cans and placed into a plastic bag. Some paint-type cans may have been sealed in a plastic container before being placed into the plastic bag. Wastes include hot-cell trash, grinding papers, kimwipes, and plastic. Major radionuclides in the waste consist of plutonium-239, uranium-235, and mixed fission products (MFP). Waste is considered to be remote-handled with the reported radiation dose at the surface of the packages at the time of generation ranging from 1,600 to 90,000 $\mathrm{mrem} / \mathrm{hour}$. The six packages of waste were placed into Shaft 209 in April 1981.

\section{Shaft Configuration}

Construction of Shaft 209 was initiated by augering a 36-inch diameter vertical hole into the mesa top. A 24-inch-diameter metal pipe (1/4 inch wall) with a length of 9 to 12 feet with a metal plate welded to the bottom was inserted into the hole as a liner. A 1/2 inch-wall inner pipe of 9- to 12-inch diameter and 7 to 12 feet in length with a metal plate welded to the bottom was centered in the larger pipe with a small amount of concrete to provide vertical alignment of the inner pipe in the outer pipe. Records with the specific dimensions for the pipes in Shaft 209 have not been located. A large metal funnel was placed in the inner pipe and waste packages were dropped into the inner pipe from a shielded transport cask moved into position above the shaft. After all waste packages were placed into the inner pipe, concrete was placed in the annular space between the pipes and the top of the shaft and auger hole were capped with 3 to 4 inches of concrete. The result is that the pipe containing the waste packages is completely encased in concrete.

\section{Shaft 209 Configuration}

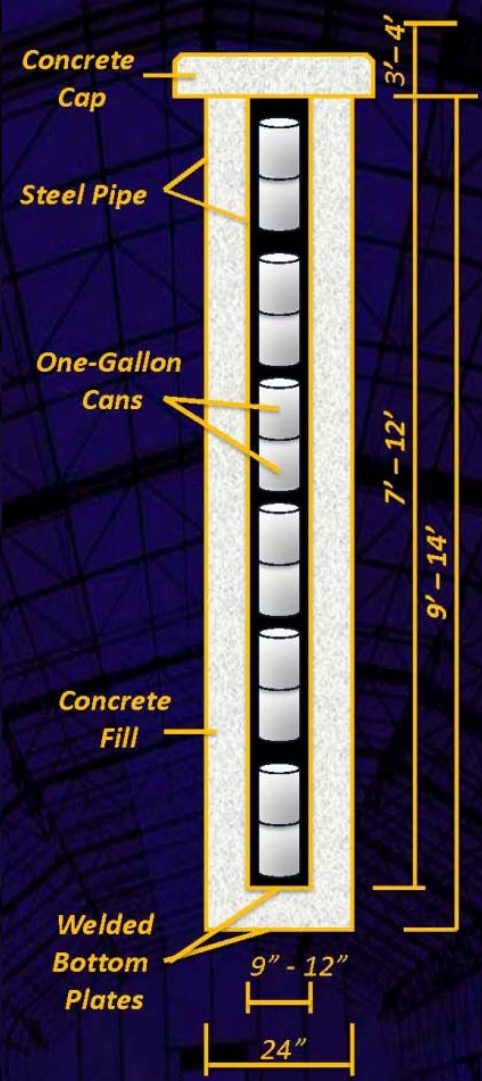

Waste Package Data Summary

\section{Location in Shaft Field}

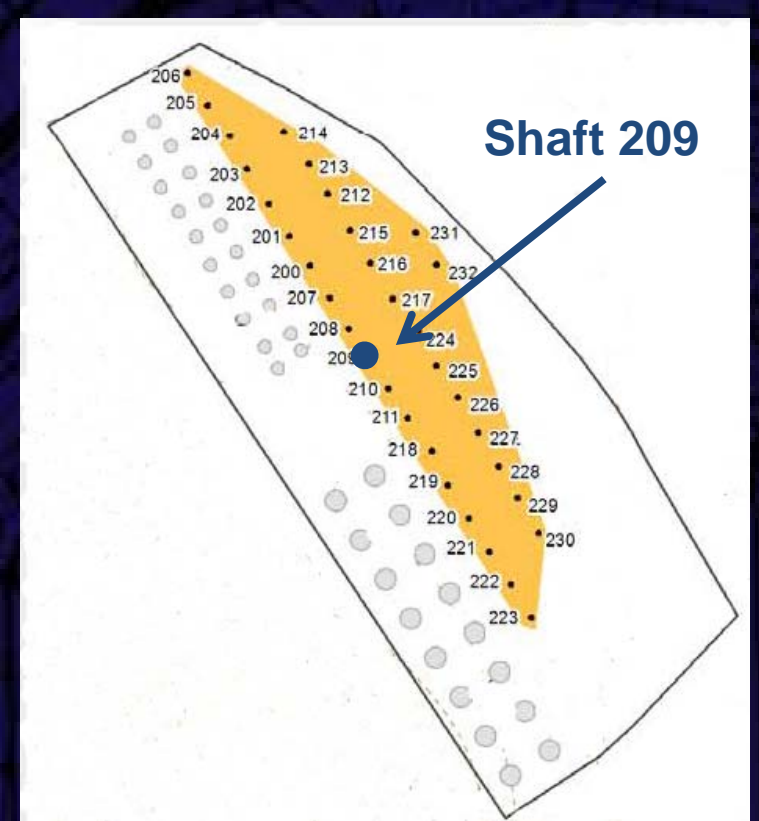

\begin{tabular}{|c|c|c|c|c|c|}
\hline $\begin{array}{c}\text { RSWD * } \\
\text { Number }\end{array}$ & $\begin{array}{c}\text { Volume } \\
\text { (gallons) }\end{array}$ & Radionuclides & $\begin{array}{c}\text { Total Curies } \\
\text { at Disposal }\end{array}$ & $\begin{array}{c}\text { Total Curies } \\
\text { Decayed to 2009 }\end{array}$ & PE-Ci \\
\hline S810787 & 2 & Pu-239, U-235, MFP & 0.41 & 0.20 & 0.0062 \\
\hline S810795 & 2 & Pu-239, U-235, MFP & 1.00 & 0.50 & 0.0062 \\
\hline S810798 & 2 & Pu-239, U-235, MFP & 0.21 & 0.11 & 0.0062 \\
\hline S810799** & 4 & Pu-239, U-235, MFP & 0.31 & 0.16 & 0.0062 \\
\hline S81412 & 2 & Pu-239, U-235, MFP & 2.00 & 1.00 & 0.0062 \\
\hline $\begin{array}{c}\text { TOTALS for } \\
\text { Shaft 209 }\end{array}$ & 12 & Pu-239, U-235, MFP & 3.93 & 1.97 & 0.03 \\
\hline
\end{tabular}

* RSWD $=$ Radioactive Solid Waste Disposal record

** Contains two packages of two one-gallon cans 


\section{Shaft 209 Totals}

\begin{tabular}{|c|c|c|}
\hline Total Number of Waste Packages & \multicolumn{2}{|c|}{6} \\
\hline Total Gross Weight (pounds) & \multicolumn{2}{|c|}{94} \\
\hline Total Pu-239 (grams) & \multicolumn{2}{|c|}{0.5} \\
\hline Total U-235 (grams) & \multicolumn{2}{|c|}{2} \\
\hline Total Mixed Fission Products (Ci) & \multicolumn{2}{|c|}{3.9} \\
\hline Dates of Disposal & \multicolumn{2}{|c|}{$6 / 22 / 1981$ to $6 / 22 / 1981$} \\
\hline Radiation at Surface of Waste Package ( $\mathrm{mR} / \mathrm{hr}$ ) & $\begin{array}{l}1,600 \text { to } 90,000 \\
\text { at disposal }\end{array}$ & $\begin{array}{c}790 \text { to } 45,000 \\
\text { decayed to } 2009\end{array}$ \\
\hline $\begin{array}{l}\text { Radiation at One Meter from Surface of Waste } \\
\text { Package }(\mathrm{mR} / \mathrm{hr})\end{array}$ & $\begin{array}{l}200 \text { to } 2,000 \\
\text { at disposal }\end{array}$ & $\begin{array}{l}10 \text { to } 320 * \\
\text { decayed to } 2009\end{array}$ \\
\hline
\end{tabular}

* Calculated using inverse square rule assuming a point source at the center of the waste package paint cans

\section{Detailed Waste Package Data at Disposal}

\begin{tabular}{|c|c|c|c|c|c|c|c|c|c|}
\hline $\begin{array}{l}\text { Waste } \\
\text { Package } \\
\text { RSWD } \\
\text { Number }\end{array}$ & $\begin{array}{c}\text { Date } \\
\text { Disposed }\end{array}$ & $\begin{array}{l}\text { Gross } \\
\text { Weight } \\
\text { (lb) }\end{array}$ & Waste Description & $\begin{array}{l}\text { Additional } \\
\text { Description of } \\
\text { Packaging and } \\
\text { Packaging } \\
\text { Materials }\end{array}$ & $\begin{array}{l}\text { Nuclide } \\
\text { or } \\
\text { Material } \\
\text { Type }\end{array}$ & Amount & Units & $\begin{array}{c}\text { Package } \\
\text { Radiation } \\
\text { at Surface } \\
(\mathrm{mR} / \mathrm{hr})\end{array}$ & $\begin{array}{c}\text { Package } \\
\text { Radiation } \\
\text { at } 1 \text { meter } \\
(\mathrm{mR} / \mathrm{hr})\end{array}$ \\
\hline \multirow{3}{*}{ S810795 } & \multirow{3}{*}{$6 / 22 / 1981$} & \multirow{3}{*}{16} & \multirow{3}{*}{$\begin{array}{l}\text { Cell } 13 \text { trash, plastic, } \\
\text { paint, vermiculite }\end{array}$} & \multirow{3}{*}{$\begin{array}{l}\text { Plastic cans } 3098, \\
\quad 3131\end{array}$} & Pu-239 & $1.00 \mathrm{E}-01$ & g & \multirow{3}{*}{15,000} & \multirow{3}{*}{1,000} \\
\hline & & & & & U-235 & $4.00 \mathrm{E}-01$ & $\mathrm{~g}$ & & \\
\hline & & & & & MFP & $1.00 \mathrm{E}+00$ & $\mathrm{Ci}$ & & \\
\hline \multirow{3}{*}{ S810797 } & \multirow{3}{*}{$6 / 22 / 1981$} & \multirow{3}{*}{16} & \multirow{3}{*}{$\begin{array}{l}\text { Cell } 15 \text { trash, wipes, } \\
\text { chips, plastic }\end{array}$} & \multirow{3}{*}{$\begin{array}{l}\text { Plastic cans } 3118 \text { \& } \\
\quad 3129\end{array}$} & $\mathrm{Pu}-239$ & $1.00 \mathrm{E}-01$ & $\mathrm{~g}$ & \multirow{3}{*}{2,800} & \multirow{3}{*}{400} \\
\hline & & & & & $\mathrm{U}-235$ & $4.00 \mathrm{E}-01$ & $\mathrm{~g}$ & & \\
\hline & & & & & MFP & $4.00 \mathrm{E}-01$ & $\mathrm{Ci}$ & & \\
\hline \multirow{3}{*}{ S810798 } & \multirow{3}{*}{$6 / 22 / 1981$} & \multirow{3}{*}{16} & \multirow{3}{*}{$\begin{array}{l}\text { Cell } 15 \text { vermiculite, } \\
\text { wipes, plastic, paint }\end{array}$} & \multirow{3}{*}{ Plastic cans 3111,3114} & Pu-239 & $1.00 \mathrm{E}-01$ & $\mathrm{~g}$ & \multirow{3}{*}{1,600} & \multirow{3}{*}{200} \\
\hline & & & & & $\mathrm{U}-235$ & 4.00E-01 & $\mathrm{g}$ & & \\
\hline & & & & & MFP & $2.00 \mathrm{E}-01$ & $\mathrm{Ci}$ & & \\
\hline \multirow{3}{*}{ S810799* } & \multirow{3}{*}{$6 / 22 / 1981$} & \multirow{3}{*}{30} & \multirow{3}{*}{$\begin{array}{c}\text { Cell } 15 \text { trash cans } 2125, \\
3108,3117,3130\end{array}$} & & $\mathrm{Pu}-239$ & $1.00 \mathrm{E}-01$ & $\mathrm{~g}$ & \multirow{3}{*}{5,000} & \multirow{3}{*}{300} \\
\hline & & & & & $\mathrm{U}-235$ & 4.00E-01 & $\mathrm{g}$ & & \\
\hline & & & & & MFP & $3.00 \mathrm{E}-01$ & $\overline{\mathrm{Ci}}$ & & \\
\hline \multirow{3}{*}{ S811412 } & \multirow{3}{*}{$6 / 22 / 1981$} & \multirow{3}{*}{16} & \multirow{3}{*}{$\begin{array}{c}\text { Cell } 13 \text { grinding } \\
\text { papers, plastic, glass }\end{array}$} & \multirow{3}{*}{ Plastic cans 3091,3115} & $\mathrm{Pu}-239$ & $1.00 \mathrm{E}-01$ & $\mathrm{~g}$ & \multirow{3}{*}{90,000} & \multirow{3}{*}{2,000} \\
\hline & & & & & $\mathrm{U}-235$ & $4.00 \mathrm{E}-01$ & $\mathrm{~g}$ & & \\
\hline & & & & & MFP & $2.00 E+00$ & $\mathrm{Ci}$ & & \\
\hline
\end{tabular}

\footnotetext{
* Contains two packages of two one-gallon cans
} 


\section{Material Disposal Area G, 33 Shafts Shaft 210 Waste Data Fact Sheet}

\section{Contents}

Shaft 210 contains six packages of waste from the Chemistry and Metallurgy Research (CMR) Facility Wing 9 hot cells, with each package containing waste placed inside two one-gallon paint-type metal cans and placed into a plastic bag. Some paint-type cans may have been sealed in a plastic container before being placed into the plastic bag. Wastes include hot-cell trash, grinding papers, kimwipes, and plastic. Major radionuclides in the waste consist of plutonium-239, uranium-235, and mixed fission products (MFP). Waste is considered to be remote-handled with the reported radiation dose at the surface of the packages at the time of generation ranging from 300 to $10,000 \mathrm{mrem} /$ hour. The six packages of waste were placed into Shaft 210 in June 1981.

\section{Shaft Configuration}

Construction of Shaft 210 was initiated by augering a 36-inch diameter vertical hole into the mesa top. A 24-inch-diameter metal pipe (1/4 inch wall) with a length of 9 to 12 feet with a metal plate welded to the bottom was inserted into the hole as a liner. A 1/2 inch-wall inner pipe of 9- to 12-inch diameter and 7 to 12 feet in length with a metal plate welded to the bottom was centered in the larger pipe with a small amount of concrete to provide vertical alignment of the inner pipe in the outer pipe. Records with the specific dimensions for the pipes in Shaft 210 have not been located. A large metal funnel was placed in the inner pipe and waste packages were dropped into the inner pipe from a shielded transport cask moved into position above the shaft. After all waste packages were placed into the inner pipe, concrete was placed in the annular space between the pipes and the top of the shaft and auger hole were capped with 3 to 4 inches of concrete. The result is that the pipe containing the waste packages is completely encased in concrete.

\section{Shaft 210 Configuration}

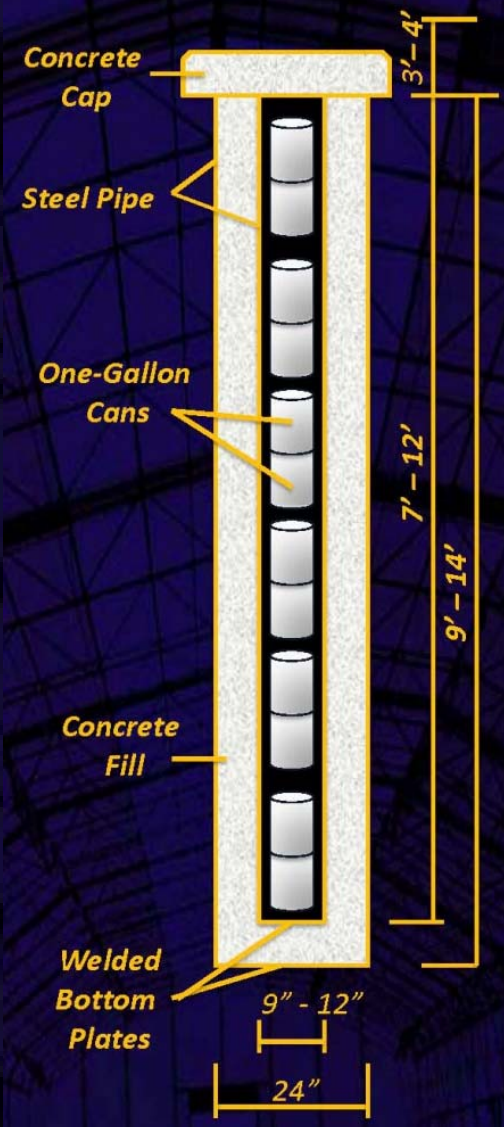

Waste Package Data Summary

\section{Location in Shaft Field}

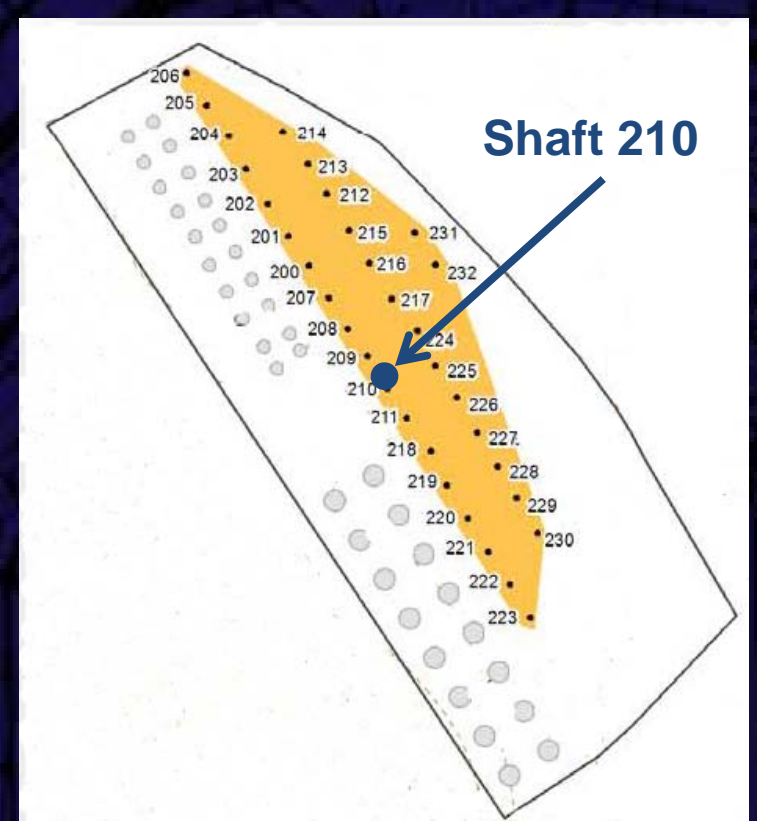

\begin{tabular}{|c|c|c|c|c|c|}
\hline $\begin{array}{c}\text { RSWD } \\
\text { Number }\end{array}$ & $\begin{array}{c}\text { Volume } \\
\text { (gallons) }\end{array}$ & Radionuclides & $\begin{array}{c}\text { Total Curies } \\
\text { at Disposal }\end{array}$ & $\begin{array}{c}\text { Total Curies } \\
\text { Decayed to 2009 }\end{array}$ & PE-Ci \\
\hline S810800 & 2 & Pu-239, U-235, MFP & 0.41 & 0.20 & 0.0062 \\
\hline S810804** & 4 & Pu-239, U-235, MFP & 0.21 & 0.11 & 0.0062 \\
\hline S810805** & 4 & Pu-239, U-235, MFP & 0.31 & 0.16 & 0.0062 \\
\hline S810806 & 2 & Pu-239, U-235, MFP & 0.03 & 0.02 & 0.0062 \\
\hline $\begin{array}{c}\text { TOTALS for } \\
\text { Shaft 210 }\end{array}$ & 12 & Pu-239, U-235, MFP & 0.94 & 0.48 & 0.025 \\
\hline
\end{tabular}

* RSWD = Radioactive Solid Waste Disposal record

** Contains two packages of two one-gallon cans

This fact sheet was compiled from information judged to be the most reliable and accurate available. Waste information from the 1970's and 1980's has gaps and is sometimes inconsistent between various records or reports. 


\section{Shaft 210 Totals}

\begin{tabular}{|c|c|c|}
\hline Total Number of Waste Packages & \multicolumn{2}{|c|}{6} \\
\hline Total Gross Weight (pounds) & \multicolumn{2}{|c|}{51 (weights not provided on two RSWD forms) } \\
\hline Total Pu-239 (grams) & \multicolumn{2}{|c|}{0.4} \\
\hline Total U-235 (grams) & \multicolumn{2}{|c|}{1.6} \\
\hline Total Mixed Fission Products (Ci) & \multicolumn{2}{|c|}{0.92} \\
\hline Dates of Disposal & \multicolumn{2}{|c|}{$6 / 22 / 1981$ to $6 / 22 / 1981$} \\
\hline Radiation at Surface of Waste Package ( $\mathrm{mR} / \mathrm{hr}$ ) & $\begin{array}{l}300 \text { to } 10,000 \\
\text { at disposal }\end{array}$ & $\begin{array}{c}150 \text { to } 4,900 \\
\text { decayed to } 2009\end{array}$ \\
\hline $\begin{array}{l}\text { Radiation at One Meter from Surface of Waste } \\
\text { Package }(\mathrm{mR} / \mathrm{hr})\end{array}$ & $\begin{array}{l}20 \text { to } 400 \\
\text { at disposal }\end{array}$ & $\begin{array}{c}1 \text { to } 35 * \\
\text { decayed to } 2009\end{array}$ \\
\hline
\end{tabular}

* Calculated using inverse square rule assuming a point source at the center of the waste package paint cans

\section{Detailed Waste Package Data at Disposal}

\begin{tabular}{|c|c|c|c|c|c|c|c|c|c|}
\hline $\begin{array}{c}\text { Waste } \\
\text { Package } \\
\text { RSWD } \\
\text { Number }\end{array}$ & $\begin{array}{c}\text { Date } \\
\text { Disposed }\end{array}$ & $\begin{array}{l}\text { Gross } \\
\text { Weight } \\
\text { (Ib) }\end{array}$ & Waste Description & $\begin{array}{l}\text { Additional } \\
\text { Description of } \\
\text { Packaging and } \\
\text { Packaging } \\
\text { Materials }\end{array}$ & $\begin{array}{c}\text { Nuclide } \\
\text { or } \\
\text { Material } \\
\text { Type }\end{array}$ & Amount & Units & $\begin{array}{l}\text { Package } \\
\text { Radiation } \\
\text { at Surface } \\
(\mathrm{mR} / \mathrm{hr})\end{array}$ & $\begin{array}{c}\text { Package } \\
\text { Radiation } \\
\text { at } 1 \text { meter } \\
(\mathrm{mR} / \mathrm{hr})\end{array}$ \\
\hline \multirow{3}{*}{ S810800 } & \multirow{3}{*}{$6 / 22 / 1981$} & & \multirow{3}{*}{$\begin{array}{l}\text { Cell } 13,15 \text { hot trash } \\
\text { cans } 3145,3147\end{array}$} & & Pu-239 & $1.00 \mathrm{E}-01$ & $\mathrm{~g}$ & \multirow{3}{*}{10,000} & \multirow{3}{*}{400} \\
\hline & & & & & $\mathrm{U}-235$ & 4.00E-01 & g & & \\
\hline & & & & & MFP & 4.00E-01 & $\mathrm{Ci}$ & & \\
\hline \multirow{3}{*}{ S810804 * } & \multirow{3}{*}{$6 / 22 / 1981$} & & \multirow{3}{*}{$\begin{array}{l}\text { Cell } 13,15 \text { hot trash } \\
\text { cans } 3139,3133,3135\end{array}$} & \multirow{3}{*}{ Cans, 3132} & Pu-239 & $1.00 \mathrm{E}-01$ & $\mathrm{~g}$ & \multirow{3}{*}{4,000} & \multirow{3}{*}{200} \\
\hline & & & & & U-235 & 4.00E-01 & $\mathrm{g}$ & & \\
\hline & & & & & MFP & 2.00E-01 & $\mathrm{Ci}$ & & \\
\hline \multirow{3}{*}{ S810805* } & \multirow{3}{*}{$6 / 22 / 1981$} & \multirow{3}{*}{35} & \multirow{3}{*}{$\begin{array}{c}\text { Cell } 13,15 \text { hot trash } \\
\text { cans } 3143,3146,2969 ;\end{array}$} & \multirow{3}{*}{3151 in suitcase cask } & Pu-239 & 1.00E-01 & $\mathrm{g}$ & \multirow{3}{*}{5,000} & \multirow{3}{*}{300} \\
\hline & & & & & U-235 & 4.00E-01 & $\mathrm{g}$ & & \\
\hline & & & & & MFP & 3.00E-01 & $\mathrm{Ci}$ & & \\
\hline \multirow{3}{*}{ S810806 } & \multirow{3}{*}{$6 / 22 / 1981$} & \multirow{3}{*}{16} & \multirow{3}{*}{$\begin{array}{l}\text { Cell } 13,15 \text { hot trash } \\
\text { cans } 3150,3153\end{array}$} & & Pu-239 & $1.00 \mathrm{E}-01$ & $\mathrm{~g}$ & \multirow{3}{*}{300} & \multirow{3}{*}{20} \\
\hline & & & & & $\mathrm{U}-235$ & 4.00E-01 & $\mathrm{g}$ & & \\
\hline & & & & & MFP & 2.00E-02 & $\mathrm{Ci}$ & & \\
\hline
\end{tabular}

\footnotetext{
* Contains two packages of two one-gallon cans
} 


\section{Material Disposal Area G, 33 Shafts Shaft 211 Waste Data Fact Sheet}

\section{Contents}

Shaft 211 contains six packages of waste from the Chemistry and Metallurgy Research (CMR) Facility Wing 9 hot cells, with each package containing waste placed inside two one-gallon paint-type metal cans and placed into a plastic bag. Some paint-type cans may have been sealed in a plastic container before being placed into the plastic bag. Wastes include hot-cell trash, grinding papers, kimwipes, and plastic. Major radionuclides in the waste consist of plutonium-239, uranium-235, and mixed fission products (MFP). Waste is considered to be remote-handled with the reported radiation dose at the surface of the packages at the time of generation ranging from 1,000 to 940,000 mrem/hour. The six packages of waste were placed into Shaft 211 in October 1981.

\section{Shaft Configuration}

Construction of Shaft 211 was initiated by augering a 36-inch diameter vertical hole into the mesa top. A 24-inch-diameter metal pipe (1/4 inch wall) with a length of 9 to 12 feet with a metal plate welded to the bottom was inserted into the hole as a liner. A 1/2 inch-wall inner pipe of 9- to 12-inch diameter and 7 to 12 feet in length with a metal plate welded to the bottom was centered in the larger pipe with a small amount of concrete to provide vertical alignment of the inner pipe in the outer pipe. Records with the specific dimensions for the pipes in Shaft 211 have not been located. A large metal funnel was placed in the inner pipe and waste packages were dropped into the inner pipe from a shielded transport cask moved into position above the shaft. After all waste packages were placed into the inner pipe, concrete was placed in the annular space between the pipes and the top of the shaft and auger hole were capped with 3 to 4 inches of concrete. The result is that the pipe containing the waste packages is completely encased in concrete.

\section{Shaft 211 Configuration}

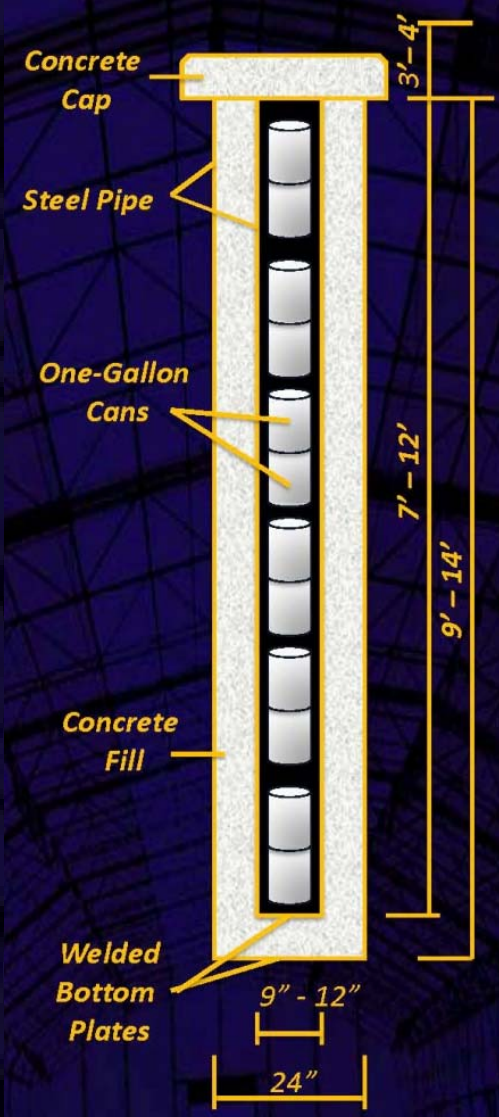

\section{Location in Shaft Field}

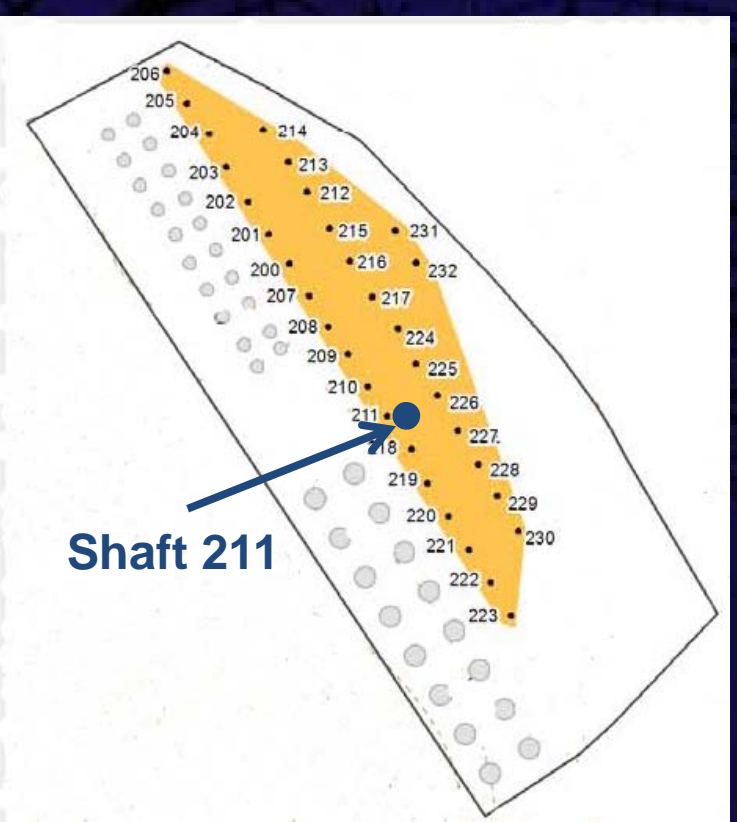

Waste Package Data Summary

\begin{tabular}{|c|c|c|c|c|c|}
\hline $\begin{array}{c}\text { RSWD } \\
\text { Number }\end{array}$ & $\begin{array}{c}\text { Volume } \\
\text { (gallons) }\end{array}$ & Radionuclides & $\begin{array}{c}\text { Total Curies } \\
\text { at Disposal }\end{array}$ & $\begin{array}{c}\text { Total Curies } \\
\text { Decayed to 2009 }\end{array}$ & PE-Ci \\
\hline S810807 & 2 & Pu-239, U-235, MFP & 0.71 & 0.35 & 0.0062 \\
\hline S810808 & 2 & Pu-239, U-235, MFP & 2.21 & 1.1 & 0.0062 \\
\hline S810809 & 2 & Pu-239, U-235, MFP & 4.00 & 2.00 & 0.0062 \\
\hline S810810** & 4 & Pu-239, U-235, MFP & 0.07 & 0.04 & 0.0062 \\
\hline S812669 & 2 & Pu-239, U-235, MFP & 11.40 & 5.88 & 0.406 \\
\hline TOTALS for & 12 & Pu-239, U-235, MFP & 18.38 & 9.36 & 0.43 \\
\hline Shaft 211 & & & & & \\
\hline
\end{tabular}

* RSWD = Radioactive Solid Waste Disposal record

** Contains two packages of two one-gallon cans 


\section{Shaft 211 Totals}

\begin{tabular}{|c|c|c|}
\hline Total Number of Waste Packages & \multicolumn{2}{|c|}{6} \\
\hline Total Gross Weight (pounds) & \multicolumn{2}{|c|}{4,400 * } \\
\hline Total Pu-239 (grams) & \multicolumn{2}{|c|}{6.96} \\
\hline Total U-235 (grams) & \multicolumn{2}{|c|}{27.6} \\
\hline Total Mixed Fission Products (Ci) & \multicolumn{2}{|c|}{17.96} \\
\hline Dates of Disposal & \multicolumn{2}{|c|}{$6 / 23 / 1981$ to $10 / 6 / 1981$} \\
\hline Radiation at Surface of Waste Package ( $\mathrm{mR} / \mathrm{hr}$ ) & $\begin{array}{l}1,000 \text { to } 940,000 \\
\text { at disposal }\end{array}$ & $\begin{array}{c}500 \text { to } 465,000 \\
\text { decayed to } 2009\end{array}$ \\
\hline $\begin{array}{l}\text { Radiation at One Meter from Surface of Waste } \\
\text { Package ( } \mathrm{mR} / \mathrm{hr} \text { ) }\end{array}$ & $\begin{array}{l}60 \text { to } 11,000 \\
\text { at disposal }\end{array}$ & $\begin{array}{c}10 \text { to } 3,300 * * \\
\text { decayed to } 2009\end{array}$ \\
\hline
\end{tabular}

* This weight is based on weights provided in the RSWD forms, but is considered questionable because other characteristics of the six packages in Shaft 211 are similar to packages composed of two one-gallon cans in other shafts. Other shafts with similar packages are reported to have total package weights of about 75 to 130 pounds.

** Calculated using inverse square rule assuming a point source at the center of the waste package paint cans

\section{Detailed Waste Package Data at Disposal}

\begin{tabular}{|c|c|c|c|c|c|c|c|c|c|}
\hline $\begin{array}{l}\text { Waste } \\
\text { Package } \\
\text { RSWD } \\
\text { Number }\end{array}$ & $\begin{array}{c}\text { Date } \\
\text { Disposed }\end{array}$ & $\begin{array}{l}\text { Gross } \\
\text { Weight } \\
\text { (lb) }\end{array}$ & Waste Description & $\begin{array}{l}\text { Additional } \\
\text { Description of } \\
\text { Packaging and } \\
\text { Packaging } \\
\text { Materials }\end{array}$ & $\begin{array}{l}\text { Nuclide } \\
\text { or } \\
\text { Material } \\
\text { Type }\end{array}$ & Amount & Units & $\begin{array}{l}\text { Package } \\
\text { Radiation } \\
\text { at Surface } \\
(\mathrm{mR} / \mathrm{hr})\end{array}$ & $\begin{array}{l}\text { Package } \\
\text { Radiation } \\
\text { at } 1 \text { meter } \\
(\mathrm{mR} / \mathrm{hr})\end{array}$ \\
\hline \multirow{3}{*}{ S810807 } & \multirow{3}{*}{$\begin{array}{l}6 / 23 / 1981 \\
10 / 6 / 1981\end{array}$} & \multirow{3}{*}{880} & \multirow{3}{*}{ Cell 13 \& 15 hot trash; } & \multirow{3}{*}{ cans plastic 3145,3147} & Pu-239 & 1.00E-01 & g & \multirow{3}{*}{16,000} & \multirow{3}{*}{700} \\
\hline & & & & & $\mathrm{U}-235$ & 4.00E-01 & $\mathrm{g}$ & & \\
\hline & & & & & MFP & 7.00E-01 & $\mathrm{Ci}$ & & \\
\hline \multirow{3}{*}{ S810808 } & \multirow{3}{*}{ 10/6/1981 } & \multirow{3}{*}{880} & \multirow{3}{*}{$\begin{array}{c}\text { Cell } 14 \text { cans } 3158 \\
\text { 3159, hot trash, glass; }\end{array}$} & \multirow{3}{*}{$\begin{array}{l}126 \mathrm{R} \text { at contact, } \\
\text { plastic, paper }\end{array}$} & Pu-239 & $1.00 \mathrm{E}-01$ & $\mathrm{~g}$ & \multirow{3}{*}{126,000} & \multirow{3}{*}{2,200} \\
\hline & & & & & $\mathrm{U}-235$ & 4.00E-01 & $\mathrm{g}$ & & \\
\hline & & & & & MFP & $2.20 E+00$ & $\mathrm{Ci}$ & & \\
\hline \multirow{3}{*}{ S810809 } & \multirow{3}{*}{ 10/6/1981 } & \multirow{3}{*}{880} & \multirow{3}{*}{$\begin{array}{r}\text { Cell } 13 \text { trash catch } \\
\text { pans, plastic wipes; }\end{array}$} & \multirow{3}{*}{$\begin{array}{l}\text { Plastic cans } 3162,3167, \\
160 \text { R/hr @ ct; }\end{array}$} & Pu-239 & 1.00E-01 & $\mathrm{g}$ & \multirow{3}{*}{160,000} & \multirow{3}{*}{4,000} \\
\hline & & & & & U-235 & 4.00E-01 & g & & \\
\hline & & & & & MFP & $4.00 E+00$ & $\mathrm{Ci}$ & & \\
\hline \multirow{3}{*}{ S810810* } & \multirow{3}{*}{ 10/6/1981 } & \multirow{3}{*}{880} & \multirow{3}{*}{$\begin{array}{c}\text { Cell } 15 \text { cold trash, } \\
\text { plastics, bottles, } \\
\text { wipes; }\end{array}$} & \multirow{3}{*}{$\begin{array}{c}\text { Can } 3160,3161,3168 \\
3169\end{array}$} & $\mathrm{Pu}-239$ & 1.00E-01 & $\mathrm{g}$ & \multirow{3}{*}{1,000} & \multirow{3}{*}{60} \\
\hline & & & & & $\mathrm{U}-235$ & 4.00E-01 & $\mathrm{g}$ & & \\
\hline & & & & & MFP & 6.00E-02 & $\mathrm{Ci}$ & & \\
\hline \multirow{3}{*}{ S812669 } & \multirow{3}{*}{$\begin{array}{l}10 / 6 / 1981 \\
8 / 3 / 1981\end{array}$} & \multirow{3}{*}{880} & \multirow{3}{*}{$\begin{array}{c}\text { Cell } 14 \text { cans } 3171 ?, \\
\text { 3179, fuel , OM?, glass, } \\
\text { etc }\end{array}$} & \multirow{3}{*}{$940 \mathrm{Rhr}$ contact } & Pu-239 & $6.56 \mathrm{E}+00$ & g & \multirow{3}{*}{940,000} & \multirow{3}{*}{11,000} \\
\hline & & & & & U-235 & 2.60E+01 & g & & \\
\hline & & & & & MFP & $1.10 \mathrm{E}+01$ & $\mathrm{Ci}$ & & \\
\hline
\end{tabular}

* Contains two packages of two one-gallon cans 


\section{Material Disposal Area G, 33 Shafts Shaft 212 Waste Data Fact Sheet}

\section{Contents}

Shaft 212 contains the stainless steel core of a small research reactor called the Los Alamos Molten Plutonium Reactor Experiment (LAMPRE I) that operated at LANL Technical Area 35, Building 2, in the early 1960s. The reactor was retired and defueled in the mid-1960s and decommissioned in 1980. The cylindrical reactor vessel was removed and placed into a cask constructed from a $1 / 4 / 4$ inch thick steel pipe that was 32 inches in diameter and 14 feet in length with a steel plate on the bottom. The reactor vessel was encased in concrete within the cask. The primary radionuclides in the waste are plutonium-239 and cobalt-60. Waste is considered to be remote-handled with the reported radiation dose at the surface of the package at the time of generation reported as 1,750 $\mathrm{mrem} / \mathrm{hour}$. The single package of waste was placed into Shaft 212 in April 1980.

\section{Shaft Configuration}

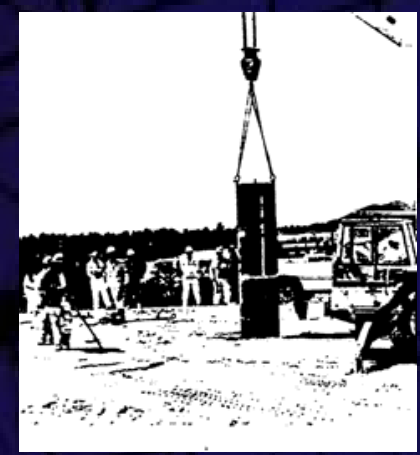

Construction of Shaft 212 was initiated by augering a 36-inch diameter vertical hole into the mesa top. The cask containing the LAMPRE reactor vessel encased in concrete was lowered into Shaft 212 and a cap of concrete was constructed over the shaft. $A$ photograph of the cask being lowered into the shaft is shown on the left.
Shaft 212 Configuration

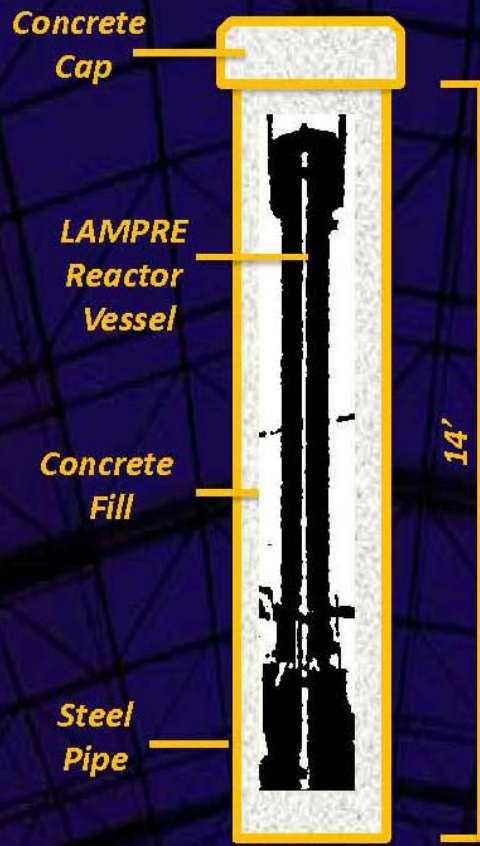

\section{Location in Shaft Field}

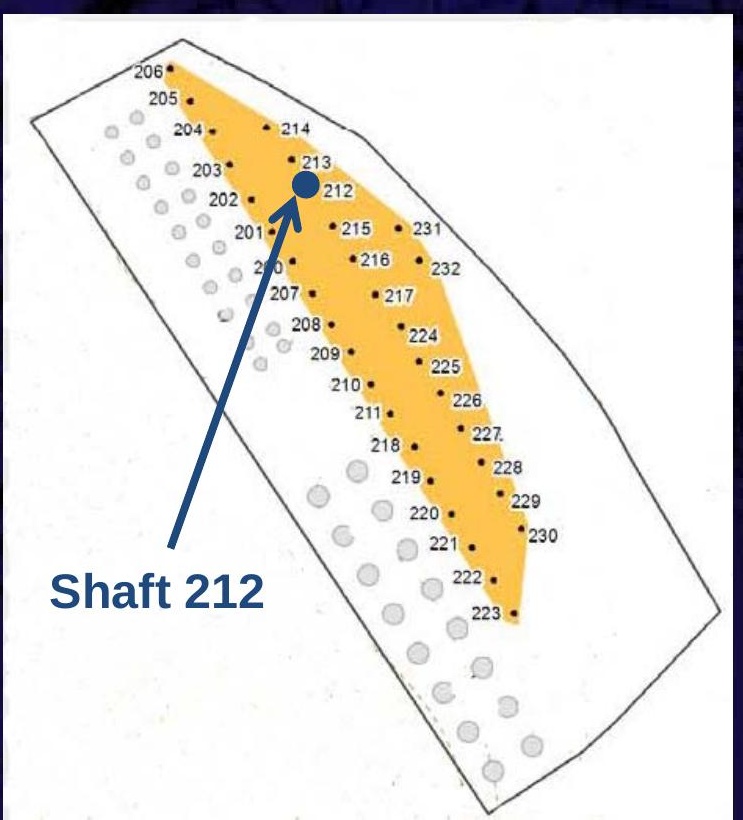

Waste Package Data Summary

\begin{tabular}{|c|c|c|c|c|c|}
\hline $\begin{array}{c}\text { RSWD * } \\
\text { Number }\end{array}$ & $\begin{array}{c}\text { Volume } \\
\text { (cubic } \\
\text { feet) }\end{array}$ & Radionuclides & $\begin{array}{c}\text { Total Curies } \\
\text { at Disposal }\end{array}$ & $\begin{array}{c}\text { Total Curies } \\
\text { Decayed to 2009 }\end{array}$ & PE-Ci \\
\hline S803758 & 75 & Pu-239, Co-60 & 42.40 & 13.06 & 12.40 \\
\hline $\begin{array}{c}\text { TOTALS for } \\
\text { Shaft 212 }\end{array}$ & 75 & Pu-239, Co-60 & 42.40 & 13.06 & 12.40 \\
\hline
\end{tabular}

* RSWD = Radioactive Solid Waste Disposal record

This fact sheet was compiled from information judged to be the most reliable and accurate available. Waste information from the 1970's and 1980's has gaps and is sometimes inconsistent between various records or reports. 


\section{Shaft 212 Totals}

\begin{tabular}{|c|c|c|}
\hline Total Number of Waste Packages & \multicolumn{2}{|c|}{1} \\
\hline Total Gross Weight (pounds) & \multicolumn{2}{|c|}{16,000} \\
\hline Total Pu-239 (grams) & \multicolumn{2}{|c|}{200} \\
\hline Total Co-60 (curies) & \multicolumn{2}{|c|}{30} \\
\hline Date of Disposal & \multicolumn{2}{|c|}{$4 / 09 / 1980$} \\
\hline Radiation at Surface of Waste Package ( $\mathrm{mR} / \mathrm{hr}$ ) & $\begin{array}{l}1,750 \\
\text { at disposal }\end{array}$ & $\begin{array}{c}40 \\
\text { decayed to } 2009\end{array}$ \\
\hline $\begin{array}{l}\text { Radiation at One Meter from Surface of Waste } \\
\text { Package ( } \mathrm{mR} / \mathrm{hr})\end{array}$ & $\begin{array}{l}300 \\
\text { at disposal }\end{array}$ & $\begin{array}{c}10 * \\
\text { decayed to } 2009\end{array}$ \\
\hline
\end{tabular}

* Calculated using inverse square rule assuming a point source at the center of the waste package paint cans

\section{Detailed Waste Package Data at Disposal}

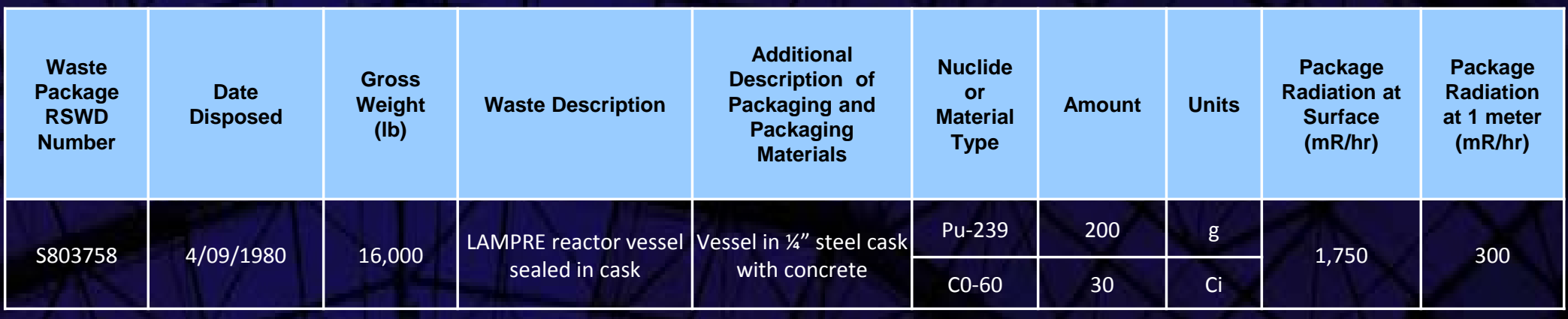




\section{Material Disposal Area G, 33 Shafts Shaft 213 Waste Data Fact Sheet}

\section{Contents}

Shaft 213 contains four packages of waste from the Chemistry and Metallurgy Research (CMR) Facility Wing 9 hot cells, with each package containing waste placed inside two one-gallon paint-type metal cans and placed into a plastic bag. Some paint-type cans may have been sealed in a plastic container before being placed into the plastic bag. Wastes include hot-cell trash, grinding papers, kimwipes, and plastic. Major radionuclides in the waste consist of plutonium-239, uranium-235, and mixed fission products (MFP). Waste is considered to be remote-handled with the reported radiation dose at the surface of the packages at the time of generation ranging from 160,000 to 1,000,000 mrem/hour. The four packages of waste were placed into Shaft 213 in November 1981.

\section{Shaft Configuration}

Construction of Shaft 213 was initiated by augering a 36-inch diameter vertical hole into the mesa top. A 24-inch-diameter metal pipe (1/4 inch wall) with a length of 9 to 12 feet with a metal plate welded to the bottom was inserted into the hole as a liner. A 1/2 inch-wall inner pipe of 9- to 12-inch diameter and 7 to 12 feet in length with a metal plate welded to the bottom was centered in the larger pipe with a small amount of concrete to provide vertical alignment of the inner pipe in the outer pipe. Records with the specific dimensions for the pipes in Shaft 213 have not been located. A large metal funnel was placed in the inner pipe and waste packages were dropped into the inner pipe from a shielded transport cask moved into position above the shaft. After all waste packages were placed into the inner pipe, concrete was placed in the annular space between the pipes and the top of the shaft and auger hole were capped with 3 to 4 inches of concrete. The result is that the pipe containing the waste packages is completely encased in concrete.

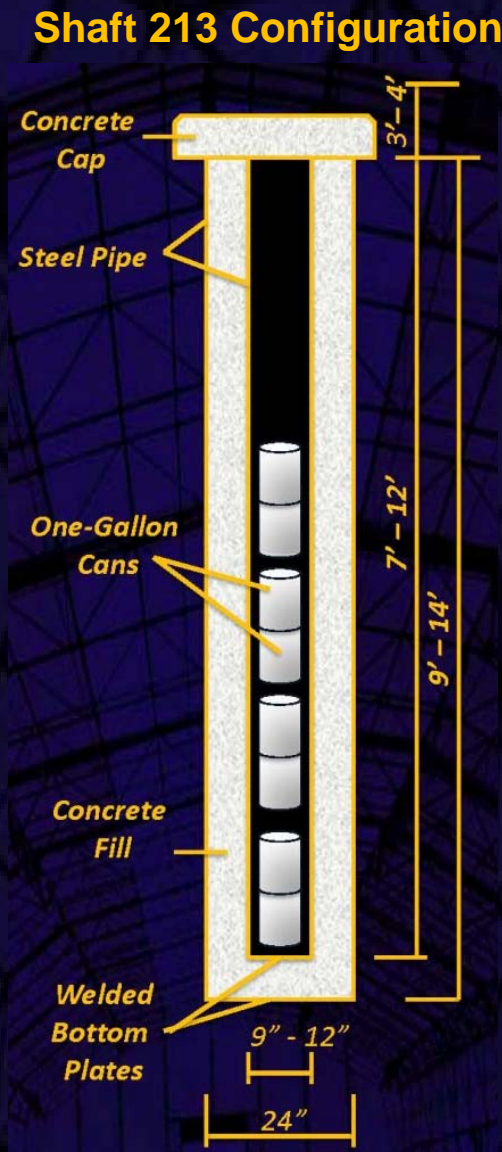

\section{Location in Shaft Field}

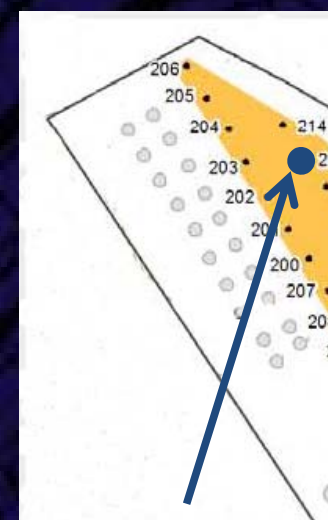

Shaft 213
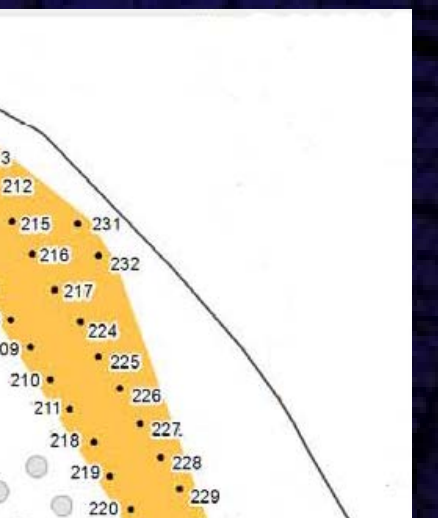
229
$\cdot 230$ $221 \cdot-230$ 222 . 223 .

Waste Package Data Summary

\begin{tabular}{|c|c|c|c|c|c|}
\hline $\begin{array}{c}\text { RSWD * } \\
\text { Number }\end{array}$ & $\begin{array}{c}\text { Volume } \\
\text { (gallons) }\end{array}$ & Radionuclides & $\begin{array}{c}\text { Total Curies } \\
\text { at Disposal }\end{array}$ & $\begin{array}{c}\text { Total Curies } \\
\text { Decayed to 2009 }\end{array}$ & PE-Ci \\
\hline S812684 & 2 & Pu-239, U-235, MFP & 42.77 & 22.3 & 2.02 \\
\hline S812686 & 2 & Pu-239, U-235, MFP & 7.26 & 3.75 & 0.27 \\
\hline S812688 & 2 & Pu-239, U-235, MFP & 101.71 & 51.0 & 0.79 \\
\hline S812689 & 2 & Pu-239, U-235, MFP & 2.81 & 1.40 & 0.01 \\
\hline $\begin{array}{c}\text { TOTALS for } \\
\text { Shaft 213 }\end{array}$ & 8 & Pu-239, U-235, MFP & 154.56 & 78.46 & 3.09 \\
\hline
\end{tabular}

* RSWD $=$ Radioactive Solid Waste Disposal record

This fact sheet was compiled from information judged to be the most reliable and accurate available. Waste information from the 1970's and 1980's has gaps and is sometimes inconsistent between various records or reports. 


\section{Shaft 213 Totals}

\begin{tabular}{|c|c|c|}
\hline Total Number of Waste Packages & \multicolumn{2}{|c|}{4} \\
\hline Total Gross Weight (pounds) & \multicolumn{2}{|c|}{64} \\
\hline Total Pu-239 (grams) & \multicolumn{2}{|c|}{49.93} \\
\hline Total U-235 (grams) & \multicolumn{2}{|c|}{243.2} \\
\hline Total Mixed Fission Products (Ci) & \multicolumn{2}{|c|}{151.6} \\
\hline Dates of Disposal & \multicolumn{2}{|c|}{$11 / 3 / 1981$ to $11 / 3 / 1981$} \\
\hline Radiation at Surface of Waste Package (mR/hr) & $\begin{array}{l}160,000 \text { to } 1,000,000 \\
\text { at disposal }\end{array}$ & $\begin{array}{c}0 \text { to } 247,000 \\
\text { decayed to } 2009\end{array}$ \\
\hline $\begin{array}{l}\text { Radiation at One Meter from Surface of Waste } \\
\text { Package }(\mathrm{mR} / \mathrm{hr})\end{array}$ & $\begin{array}{l}2,800 \text { to } 101,000 \\
\text { at disposal }\end{array}$ & $\begin{array}{c}0 \text { to } 1,750 * \\
\text { decayed to } 2009\end{array}$ \\
\hline
\end{tabular}

* Calculated using inverse square rule assuming a point source at the center of the waste package paint cans

\section{Detailed Waste Package Data at Disposal}

\begin{tabular}{|c|c|c|c|c|c|c|c|c|c|}
\hline $\begin{array}{c}\text { Waste } \\
\text { Package } \\
\text { RSWD } \\
\text { Number }\end{array}$ & $\begin{array}{c}\text { Date } \\
\text { Disposed }\end{array}$ & $\begin{array}{l}\text { Gross } \\
\text { Weight } \\
\text { (lb) }\end{array}$ & Waste Description & $\begin{array}{c}\text { Additional } \\
\text { Description of } \\
\text { Packaging and } \\
\text { Packaging } \\
\text { Materials }\end{array}$ & $\begin{array}{c}\text { Nuclide } \\
\text { or } \\
\text { Material } \\
\text { Type }\end{array}$ & Amount & Units & $\begin{array}{c}\text { Package } \\
\text { Radiation } \\
\text { at Surface } \\
(\mathrm{mR} / \mathrm{hr})\end{array}$ & $\begin{array}{c}\text { Package } \\
\text { Radiation } \\
\text { at } 1 \text { meter } \\
(\mathrm{mR} / \mathrm{hr})\end{array}$ \\
\hline \multirow{3}{*}{ S812684 } & \multirow{3}{*}{$11 / 3 / 1981$} & \multirow{3}{*}{16} & \multirow{3}{*}{$\begin{array}{c}\text { Cell } 9 \text { cell waste } \& \text { fuel } \\
\& \text { cell } 16 \text { waste }\end{array}$} & \multirow{3}{*}{$\begin{array}{l}\text { Plastic cans } 3248 \text { - } \\
1000+R / h r \text { surf. }\end{array}$} & Pu-239 & $3.26 \mathrm{E}+01$ & $\mathrm{~g}$ & \multirow{3}{*}{$1,000,000$} & \multirow{3}{*}{40,800} \\
\hline & & & & & $\mathrm{U}-235$ & $1.38 \mathrm{E}+02$ & $\mathrm{~g}$ & & \\
\hline & & & & & MFP & $4.08 \mathrm{E}+01$ & $\mathrm{Ci}$ & & \\
\hline \multirow{3}{*}{ S812686 } & \multirow{3}{*}{$11 / 3 / 1981$} & \multirow{3}{*}{16} & \multirow{3}{*}{$\begin{array}{l}\text { Cell } 14 \text { cans } 3245, \\
3246 \text {, fuel, glass, } \\
\text { towels }\end{array}$} & \multirow{3}{*}{$500 \mathrm{R}$ at contact } & Pu-239 & $4.33 \mathrm{E}+00$ & $\mathrm{~g}$ & \multirow{3}{*}{500,000} & \multirow{3}{*}{7,000} \\
\hline & & & & & U-235 & $1.73 \mathrm{E}+01$ & $\mathrm{~g}$ & & \\
\hline & & & & & MFP & $7.00 \mathrm{E}+00$ & $\mathrm{Ci}$ & & \\
\hline \multirow{3}{*}{ S812688 } & \multirow{3}{*}{$11 / 3 / 1981$} & \multirow{3}{*}{16} & \multirow{3}{*}{$\begin{array}{c}\text { Cell } 9 \& 13 \text { fuel \& hot } \\
\text { trash }\end{array}$} & \multirow{3}{*}{$\begin{array}{c}101000 \mathrm{mR} / \mathrm{hr} @ 1 \\
\text { meter, Cans 3273/3274 }\end{array}$} & Pu-239 & $1.28 \mathrm{E}+01$ & $\mathrm{~g}$ & & \multirow{3}{*}{101,000} \\
\hline & & & & & U-235 & $7.79 E+01$ & $\mathrm{~g}$ & & \\
\hline & & & & & MFP & $1.01 \mathrm{E}+02$ & $\mathrm{Ci}$ & & \\
\hline \multirow{3}{*}{ S812689 } & \multirow{3}{*}{$11 / 3 / 1981$} & \multirow{3}{*}{16} & \multirow{3}{*}{$\begin{array}{c}\text { Cell } 1314 \text { cell waste } \\
\text { cans } 3266,3272\end{array}$} & \multirow{3}{*}{ 160R/hr@ contact } & Pu-239 & 2.00E-01 & $\mathrm{g}$ & \multirow{3}{*}{160,000} & \multirow{3}{*}{2,800} \\
\hline & & & & & U-235 & $1.00 E+01$ & $\mathrm{~g}$ & & \\
\hline & & & & & MFP & $2.80 E+00$ & $\mathrm{Ci}$ & & \\
\hline
\end{tabular}




\section{Shaft 214 Totals}

\begin{tabular}{|c|c|c|}
\hline Total Number of Waste Packages & \multicolumn{2}{|c|}{6} \\
\hline Total Gross Weight (pounds) & \multicolumn{2}{|c|}{116} \\
\hline Total Pu-239 (grams) & \multicolumn{2}{|c|}{0.6} \\
\hline Total U-235 (grams) & \multicolumn{2}{|c|}{2.4} \\
\hline Total Mixed Fission Products (Ci) & \multicolumn{2}{|c|}{29.7} \\
\hline Dates of Disposal & \multicolumn{2}{|c|}{$4 / 1 / 1982$ to $4 / 23 / 1982$} \\
\hline Radiation at Surface of Waste Package ( $\mathrm{mR} / \mathrm{hr}$ ) & $\begin{array}{l}4,000 \text { to } 110,000 \\
\text { at disposal }\end{array}$ & $\begin{array}{l}2,000 \text { to } 56,000 \\
\text { decayed to } 2009\end{array}$ \\
\hline $\begin{array}{l}\text { Radiation at One Meter from Surface of Waste } \\
\text { Package }(\mathrm{mR} / \mathrm{hr})\end{array}$ & $\begin{array}{l}120 \text { to } 1,300 \\
\text { at disposal }\end{array}$ & $\begin{array}{c}10 \text { to } 400 * \\
\text { decayed to } 2009\end{array}$ \\
\hline
\end{tabular}

* Calculated using inverse square rule assuming a point source at the center of the waste package paint cans

\section{Detailed Waste Package Data at Disposal}

\begin{tabular}{|c|c|c|c|c|c|c|c|c|c|}
\hline $\begin{array}{c}\text { Waste } \\
\text { Package } \\
\text { RSWD } \\
\text { Number }\end{array}$ & $\begin{array}{c}\text { Date } \\
\text { Disposed }\end{array}$ & $\begin{array}{c}\text { Gross } \\
\text { Weight } \\
\text { (lb) }\end{array}$ & Waste Description & $\begin{array}{c}\text { Additional } \\
\text { Description of } \\
\text { Packaging and } \\
\text { Packaging } \\
\text { Materials }\end{array}$ & $\begin{array}{c}\text { Nuclide } \\
\text { or } \\
\text { Material } \\
\text { Type }\end{array}$ & Amount & Units & $\begin{array}{l}\text { Package } \\
\text { Radiation } \\
\text { at Surface } \\
(\mathrm{mR} / \mathrm{hr})\end{array}$ & $\begin{array}{c}\text { Package } \\
\text { Radiation } \\
\text { at } 1 \text { meter } \\
(\mathrm{mR} / \mathrm{hr})\end{array}$ \\
\hline \multirow{3}{*}{ S820057 } & \multirow{3}{*}{ 4/20/1982 } & \multirow{3}{*}{18} & \multirow{3}{*}{$\begin{array}{l}\text { Cell } 16 \text { trash can } 3338 \text {, } \\
\text { kimwipes, glassware; }\end{array}$} & \multirow{3}{*}{$\begin{array}{l}\text { Lucite can in steel } \\
\text { nipple }\end{array}$} & Pu-239 & $1.00 \mathrm{E}-01$ & $\mathrm{~g}$ & \multirow{3}{*}{15,000} & \multirow{3}{*}{300} \\
\hline & & & & & $\mathrm{U}-235$ & 4.00E-01 & $\mathrm{g}$ & & \\
\hline & & & & & MFP & 3.00E-01 & $\mathrm{Ci}$ & & \\
\hline \multirow{3}{*}{ S820058 } & \multirow{3}{*}{ 4/20/1982 } & \multirow{3}{*}{22} & \multirow{3}{*}{$\begin{array}{l}\text { Cell } 16 \text { trash can } 3351 \text {, } \\
\text { kimwipes, glassware; }\end{array}$} & \multirow{3}{*}{$\begin{array}{l}\text { Lucite can in steel } \\
\text { nipple; }\end{array}$} & Pu-239 & $1.00 \mathrm{E}-01$ & $\mathrm{~g}$ & \multirow{3}{*}{4,000} & \multirow{3}{*}{120} \\
\hline & & & & & $\mathrm{U}-235$ & $4.00 \mathrm{E}-01$ & $\mathrm{~g}$ & & \\
\hline & & & & & MFP & $1.20 \mathrm{E}-01$ & $\mathrm{Ci}$ & & \\
\hline \multirow{3}{*}{ S821822 } & \multirow{3}{*}{$4 / 21 / 1982$} & \multirow{3}{*}{30} & \multirow{3}{*}{$\begin{array}{l}\text { Cell } 13 \text { trash can } 3369 \text {, } \\
\text { kimwipes, paper; }\end{array}$} & \multirow{3}{*}{ Plastic bags \& bottles } & Pu-239 & $1.00 \mathrm{E}-01$ & $\mathrm{~g}$ & \multirow{3}{*}{25,000} & \multirow{3}{*}{400} \\
\hline & & & & & $\mathrm{U}-235$ & 4.00E-01 & $\mathrm{g}$ & & \\
\hline & & & & & MFP & 4.00E-01 & $\mathrm{Ci}$ & & \\
\hline \multirow{3}{*}{ S821823 } & \multirow{3}{*}{ 4/21/1982 } & \multirow{3}{*}{30} & \multirow{3}{*}{$\begin{array}{c}\text { Cell } 13 \text { trash can } 3373, \\
\text { paper, plastic; }\end{array}$} & & Pu-239 & $1.00 \mathrm{E}-01$ & $\mathrm{~g}$ & \multirow{3}{*}{30,000} & \multirow{3}{*}{450} \\
\hline & & & & & $\mathrm{U}-235$ & 4.00E- 01 & $\mathrm{~g}$ & & \\
\hline & & & & & MFP & $4.50 \mathrm{E}-01$ & $\mathrm{Ci}$ & & \\
\hline \multirow{3}{*}{$\$ 821826$} & \multirow{3}{*}{ 4/23/1982 } & \multirow{3}{*}{20} & \multirow{3}{*}{$\begin{array}{c}\text { Cell } 14 \text { can } 3378 \text {, glass, } \\
\text { plastic bottles; }\end{array}$} & & Pu-239 & $1.00 \mathrm{E}-01$ & $\mathrm{~g}$ & \multirow{3}{*}{20,000} & \multirow{3}{*}{400} \\
\hline & & & & & $\mathrm{U}-235$ & 4.00E-01 & $\mathrm{g}$ & & \\
\hline & & & & & MFP & 4.00E-01 & $\mathrm{Ci}$ & & \\
\hline \multirow{3}{*}{$\$ 823410$} & \multirow{3}{*}{ 4/1/1982 } & & & & Pu-239 & $1.00 \mathrm{E}-01$ & $\mathrm{~g}$ & & \\
\hline & & 16 & $\begin{array}{l}\text { Cell } 13 \& \text { Cell } 14 \text { hot } \\
\text { trash cans } 3307 \& \&\end{array}$ & $\begin{array}{c}110 \mathrm{R} / \mathrm{hr} @ \text { contact, } \\
\text { can } 3278\end{array}$ & $\mathrm{U}-235$ & 4.00E-01 & $\mathrm{g}$ & 110,000 & 1,300 \\
\hline & & & & & MFP & $1.30 E+00$ & $\mathrm{Ci}$ & & 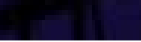 \\
\hline
\end{tabular}




\section{Material Disposal Area G, 33 Shafts Shaft 215 Waste Data Fact Sheet}

\section{Contents}

Shaft 215 contains seven packages of waste from the Chemistry and Metallurgy Research (CMR) Facility Wing 9 hot cells, with five of the packages containing waste placed inside five two-gallon paint-type metal cans and placed into a plastic bag. Two of the seven packages contain waste placed inside single one-gallon metal cans placed into a plastic bag. Some paint-type cans were placed into a plastic container before being placed into the plastic bag. Wastes include hot-cell trash, grinding papers, kimwipes, and plastic. Major radionuclides in the waste consist of plutonium239, uranium-235, and mixed fission products (MFP). Waste is considered to be remote-handled with the reported radiation dose at the surface of the packages at the time of generation ranging from 20,000 to 1,000,000 $\mathrm{mrem} / \mathrm{hour}$. The seven packages of waste were placed into Shaft 215 from January to June 1982.

\section{Shaft Configuration}

Construction of Shaft 215 was initiated by augering a 36-inch diameter vertical hole into the mesa top. A 24-inch-diameter metal pipe (1/4 inch wall) with a length of 9 to 12 feet with a metal plate welded to the bottom was inserted into the hole as a liner. A 1/2 inch-wall inner pipe of 9- to 12-inch diameter and 7 to 12 feet in length with a metal plate welded to the bottom was centered in the larger pipe with a small amount of concrete to provide vertical alignment of the inner pipe in the outer pipe. Records with the specific dimensions for the pipes in Shaft 215 have not been located. A large metal funnel was placed in the inner pipe and waste packages were dropped into the inner pipe from a shielded transport cask moved into position above the shaft. After all waste packages were placed into the inner pipe, concrete was placed in the annular space between the pipes and the top of the shaft and auger hole were capped with 3 to 4 inches of concrete. The result is that the pipe containing the waste packages is completely encased in concrete.
Shaft 215 Configuration

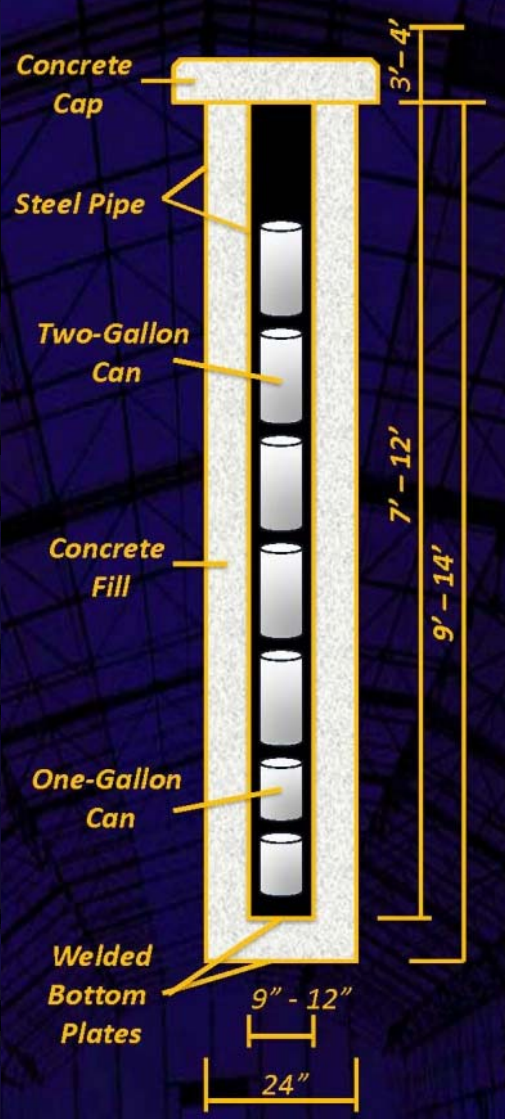

Waste Package Data Summary

\section{Location in Shaft Field}

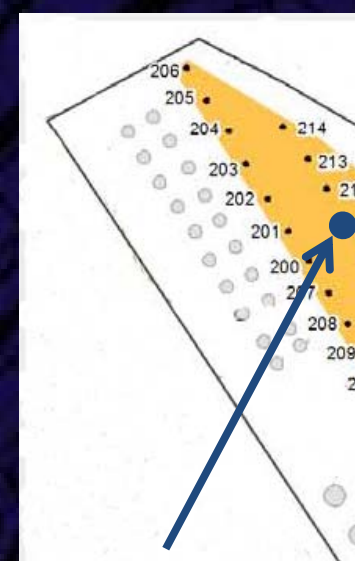

Shaft 215

\begin{tabular}{|c|c|c|c|c|c|}
\hline $\begin{array}{c}\text { RSWD * } \\
\text { Number }\end{array}$ & $\begin{array}{c}\text { Volume } \\
\text { (gallons) }\end{array}$ & Radionuclides & $\begin{array}{c}\text { Total Curies } \\
\text { at Disposal }\end{array}$ & $\begin{array}{c}\text { Total Curies } \\
\text { Decayed to 2009 }\end{array}$ & PE-Ci \\
\hline S820041 & 1 & Pu-239, U-235, MFP & 30.91 & 16.2 & 0.93 \\
\hline S820042 & 1 & Pu-239, U-235, MFP & 14.99 & 7.64 & 0.0062 \\
\hline S821832 & 2 & Pu-239, U-235, MFP & 2.00 & 1.03 & 0.0062 \\
\hline S821833 & 2 & Pu-239, U-235, MFP & 3.00 & 1.53 & 0.0062 \\
\hline S821834 & 2 & Pu-239, U-235, MFP & 2.00 & 1.03 & 0.0062 \\
\hline S821835 & 2 & Pu-239, U-235, MFP & 0.31 & 0.16 & 0.0062 \\
\hline S821837 & 2 & Pu-239, U-235, MFP & 2.00 & 1.03 & 0.0062 \\
\hline $\begin{array}{c}\text { TOTALS for } \\
\text { Shaft 215 }\end{array}$ & 12 & Pu-239, U-235, MFP & 55.22 & 28.60 & 0.97 \\
\hline
\end{tabular}

* RSWD = Radioactive Solid Waste Disposal record

This fact sheet was compiled from information judged to be the most reliable and accurate available. Waste information from the 1970's and 1980's has gaps and is sometimes inconsistent between various records or reports. 


\section{Shaft 215 Totals at Disposal}

\begin{tabular}{|c|c|c|}
\hline Total Number of Waste Packages & \multicolumn{2}{|c|}{7} \\
\hline Total Gross Weight (pounds) & \multicolumn{2}{|c|}{176} \\
\hline Total Pu-239 (grams) & \multicolumn{2}{|c|}{15.6} \\
\hline Total U-235 (grams) & \multicolumn{2}{|c|}{73.6} \\
\hline Total Mixed Fission Products (Ci) & \multicolumn{2}{|c|}{54.3} \\
\hline Dates of Disposal & \multicolumn{2}{|c|}{$1 / 06 / 1982$ to $6 / 09 / 1982$} \\
\hline Radiation at Surface of Waste Package (mR/hr) & $\begin{array}{l}20,000 \text { to } 1,00,000 \\
\text { at disposal }\end{array}$ & $\begin{array}{l}10,000 \text { to } 506,000 \\
\text { decayed to } 2009\end{array}$ \\
\hline $\begin{array}{l}\text { Radiation at One Meter from Surface of Waste } \\
\text { Package }(\mathrm{mR} / \mathrm{hr})\end{array}$ & $\begin{array}{l}800 \text { to } 30,000 \\
\text { at disposal }\end{array}$ & $\begin{array}{c}70 \text { to } 3,580 * \\
\text { decayed to } 2009\end{array}$ \\
\hline
\end{tabular}

* Calculated using inverse square rule assuming a point source at the center of the waste package paint cans

\section{Detailed Waste Package Data at Disposal}

\begin{tabular}{|c|c|c|c|c|c|c|c|c|c|}
\hline $\begin{array}{c}\text { Waste } \\
\text { Package } \\
\text { RSWD } \\
\text { Number }\end{array}$ & $\begin{array}{c}\text { Date } \\
\text { Disposed }\end{array}$ & $\begin{array}{c}\text { Gross } \\
\text { Weight } \\
\text { (lb) }\end{array}$ & Waste Description & $\begin{array}{c}\text { Additional } \\
\text { Description of } \\
\text { Packaging and } \\
\text { Packaging } \\
\text { Materials }\end{array}$ & $\begin{array}{c}\text { Nuclide } \\
\text { or } \\
\text { Material } \\
\text { Type }\end{array}$ & Amount & Units & $\begin{array}{c}\text { Package } \\
\text { Radiation } \\
\text { at Surface } \\
\text { (mR/hr) }\end{array}$ & $\begin{array}{c}\text { Package } \\
\text { Radiation } \\
\text { at } 1 \text { meter } \\
(\mathrm{mR} / \mathrm{hr})\end{array}$ \\
\hline \multirow{3}{*}{ S820041 } & \multirow{3}{*}{$\begin{array}{l}6 / 9 / 1982 \\
1 / 6 / 1982\end{array}$} & \multirow{3}{*}{18} & \multirow{3}{*}{ Cell 9 fuel can 3312} & \multirow{3}{*}{$1000+R h r$ at contact } & Pu-239 & $1.50 \mathrm{E}+01$ & $\mathrm{~g}$ & \multirow{3}{*}{$1,000,000$} & \multirow{3}{*}{30,000} \\
\hline & & & & & $\mathrm{U}-235$ & 7.12E+01 & $\mathrm{g}$ & & \\
\hline & & & & & MFP & $3.00 E+01$ & $\mathrm{Ci}$ & & \\
\hline \multirow{3}{*}{ S820042 } & \multirow{3}{*}{$\begin{array}{l}6 / 9 / 1982 \\
1 / 6 / 1982\end{array}$} & \multirow{3}{*}{18} & \multirow{3}{*}{ Cell 14 waste can 3307} & \multirow{3}{*}{ 140 R/hr @ contact, } & Pu-239 & $1.00 \mathrm{E}-01$ & $\mathrm{~g}$ & \multirow{3}{*}{140,000} & \multirow{3}{*}{15,000} \\
\hline & & & & & U-235 & 4.00E-01 & $\mathrm{g}$ & & \\
\hline & & & & & MFP & $1.50 E+01$ & $\mathrm{Ci}$ & & \\
\hline \multirow{3}{*}{$\$ 821832$} & \multirow{3}{*}{ 6/9/1982 } & \multirow{3}{*}{28} & \multirow{3}{*}{$\begin{array}{c}\text { Cell } 11 \text { trash can } 3393 \\
\text { hot trash }\end{array}$} & \multirow{3}{*}{$\begin{array}{l}\text { Lucite can in steel } \\
\text { nipple }\end{array}$} & Pu-239 & $1.00 \mathrm{E}-01$ & $\mathrm{~g}$ & \multirow{3}{*}{35,000} & \multirow{3}{*}{2,000} \\
\hline & & & & & $\mathrm{U}-235$ & 4.00E-01 & $\mathrm{g}$ & & \\
\hline & & & & & MFP & $2.00 E+00$ & $\mathrm{Ci}$ & & \\
\hline \multirow{3}{*}{$\$ 821833$} & \multirow{3}{*}{ 6/9/1982 } & \multirow{3}{*}{28} & \multirow{3}{*}{$\begin{array}{l}\text { Cell } 11 \text { hot trash can } \\
3300\end{array}$} & \multirow{3}{*}{ 100R @ contact } & Pu-239 & 1.00E-01 & $\mathrm{g}$ & \multirow{3}{*}{100,000} & \multirow{3}{*}{3,000} \\
\hline & & & & & $\mathrm{U}-235$ & 4.00E-01 & $\mathrm{g}$ & & \\
\hline & & & & & MFP & $3.00 E+00$ & $\mathrm{Ci}$ & & \\
\hline \multirow{3}{*}{ S821834 } & \multirow{3}{*}{ 6/9/1982 } & \multirow{3}{*}{28} & \multirow{3}{*}{$\begin{array}{c}\text { Cell } 13 \text { hot trash can } \\
3387 ?\end{array}$} & \multirow{3}{*}{200 R/hr @ contact } & Pu-239 & 1.00E-01 & $\mathrm{g}$ & & \\
\hline & & & & & $\mathrm{U}-235$ & 4.00E-01 & $\mathrm{g}$ & 200,000 & 2,000 \\
\hline & & & & & MFP & $2.00 \mathrm{E}+00$ & $\mathrm{Ci}$ & & \\
\hline & & & & & Pu-239 & $1.00 \mathrm{E}-01$ & $\mathrm{~g}$ & & \\
\hline S821835 & 6/9/1982 & 28 & $\begin{array}{c}\text { Cell } 13 \text { hot trash can } \\
3383\end{array}$ & $\begin{array}{c}\text { Grinding papers, kim } \\
\text { wipes }\end{array}$ & $\mathrm{U}-235$ & 4.00E-01 & $\mathrm{g}$ & 40,000 & 800 \\
\hline & & & & & MFP & 3.00E-01 & $\mathrm{Ci}$ & & 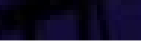 \\
\hline & & & & & Pu-239 & $1.00 \mathrm{E}-01$ & $\mathrm{~g}$ & & \\
\hline S821837 & 6/9/1982 & 28 & 3415 & Bottles, kimwipes & U-235 & 4.00E-01 & $\mathrm{g}$ & 20,000 & 2,000 \\
\hline & & & & & MFP & $2.00 E+00$ & $\mathrm{Ci}$ & & \\
\hline
\end{tabular}




\section{Material Disposal Area G, 33 Shafts Shaft 216 Waste Data Fact Sheet}

\section{Contents}

Shaft 216 contains six packages of waste from the Chemistry and Metallurgy Research (CMR) Facility Wing 9 hot cells, with each package containing waste placed inside a two-gallon paint-type metal can and placed into a plastic bag. Some paint-type cans may have been sealed in a plastic container before being placed into the plastic bag. Wastes include hot-cell trash, grinding papers, kimwipes, and plastic. Major radionuclides in the waste consist of plutonium-239, uranium-235, and mixed fission products (MFP). Waste is considered to be remote-handled with the reported radiation dose at the surface of the packages at the time of generation ranging from 8,000 to $200,000 \mathrm{mrem} /$ hour. The six packages of waste were placed into Shaft 216 in June 1982.

\section{Shaft Configuration}

Construction of Shaft 216 was initiated by augering a 36-inch diameter vertical hole into the mesa top. A 24-inch-diameter metal pipe (1/4 inch wall) with a length of 9 to 12 feet with a metal plate welded to the bottom was inserted into the hole as a liner. A 1/2 inch-wall inner pipe of 9- to 12-inch diameter and 7 to 12 feet in length with a metal plate welded to the bottom was centered in the larger pipe with a small amount of concrete to provide vertical alignment of the inner pipe in the outer pipe. Records with the specific dimensions for the pipes in Shaft 216 have not been located. A large metal funnel was placed in the inner pipe and waste packages were dropped into the inner pipe from a shielded transport cask moved into position above the shaft. After all waste packages were placed into the inner pipe, concrete was placed in the annular space between the pipes and the top of the shaft and auger hole were capped with 3 to 4 inches of concrete. The result is that the pipe containing the waste packages is completely encased in concrete.
Shaft 216 Configuration

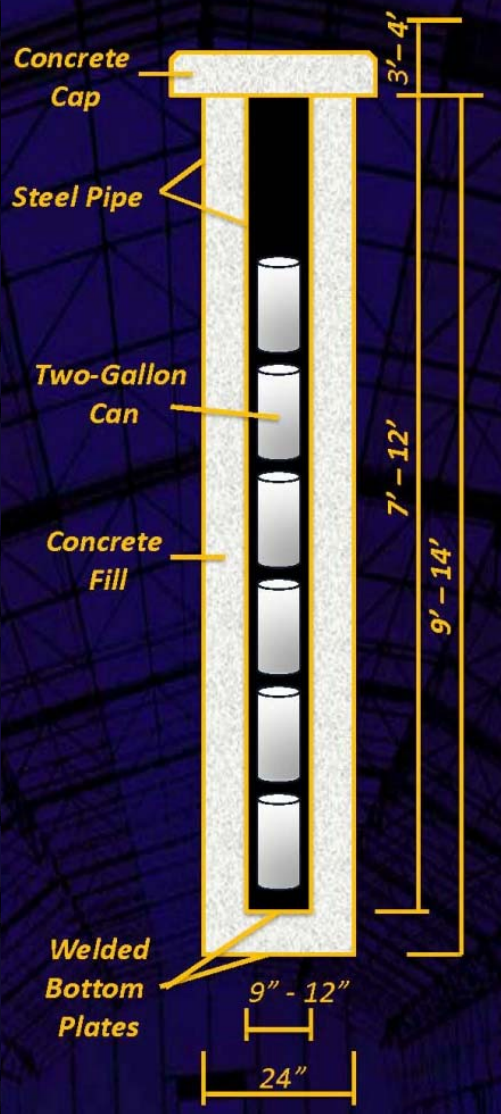

Waste Package Data Summary

\section{Location in Shaft Field}

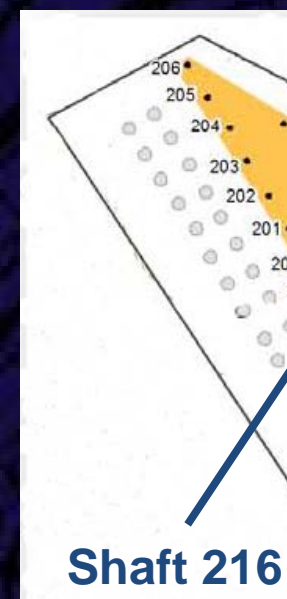




\section{Shaft 216 Totals}

\begin{tabular}{|c|c|c|}
\hline Total Number of Waste Packages & \multicolumn{2}{|c|}{6} \\
\hline Total Gross Weight (pounds) & \multicolumn{2}{|c|}{160} \\
\hline Total Pu-239 (grams) & \multicolumn{2}{|c|}{1.5} \\
\hline Total U-235 (grams) & \multicolumn{2}{|c|}{6} \\
\hline Total Mixed Fission Products (Ci) & \multicolumn{2}{|c|}{10} \\
\hline Dates of Disposal & \multicolumn{2}{|c|}{$6 / 09 / 1982$ to $6 / 09 / 1982$} \\
\hline Radiation at Surface of Waste Package ( $\mathrm{mR} / \mathrm{hr}$ ) & $\begin{array}{l}8,000 \text { to } 200,000 \\
\text { at disposal }\end{array}$ & $\begin{array}{l}4,000 \text { to } 101,000 \\
\text { decayed to } 2009\end{array}$ \\
\hline $\begin{array}{l}\text { Radiation at One Meter from Surface of Waste } \\
\text { Package ( } \mathrm{mR} / \mathrm{hr})\end{array}$ & $\begin{array}{l}200 \text { to } 4,000 \\
\text { at disposal }\end{array}$ & $\begin{array}{c}30 \text { to } 720 * \\
\text { decayed to } 2009\end{array}$ \\
\hline
\end{tabular}

* Calculated using inverse square rule assuming a point source at the center of the waste package paint cans

\section{Detailed Waste Package Data at Disposal}

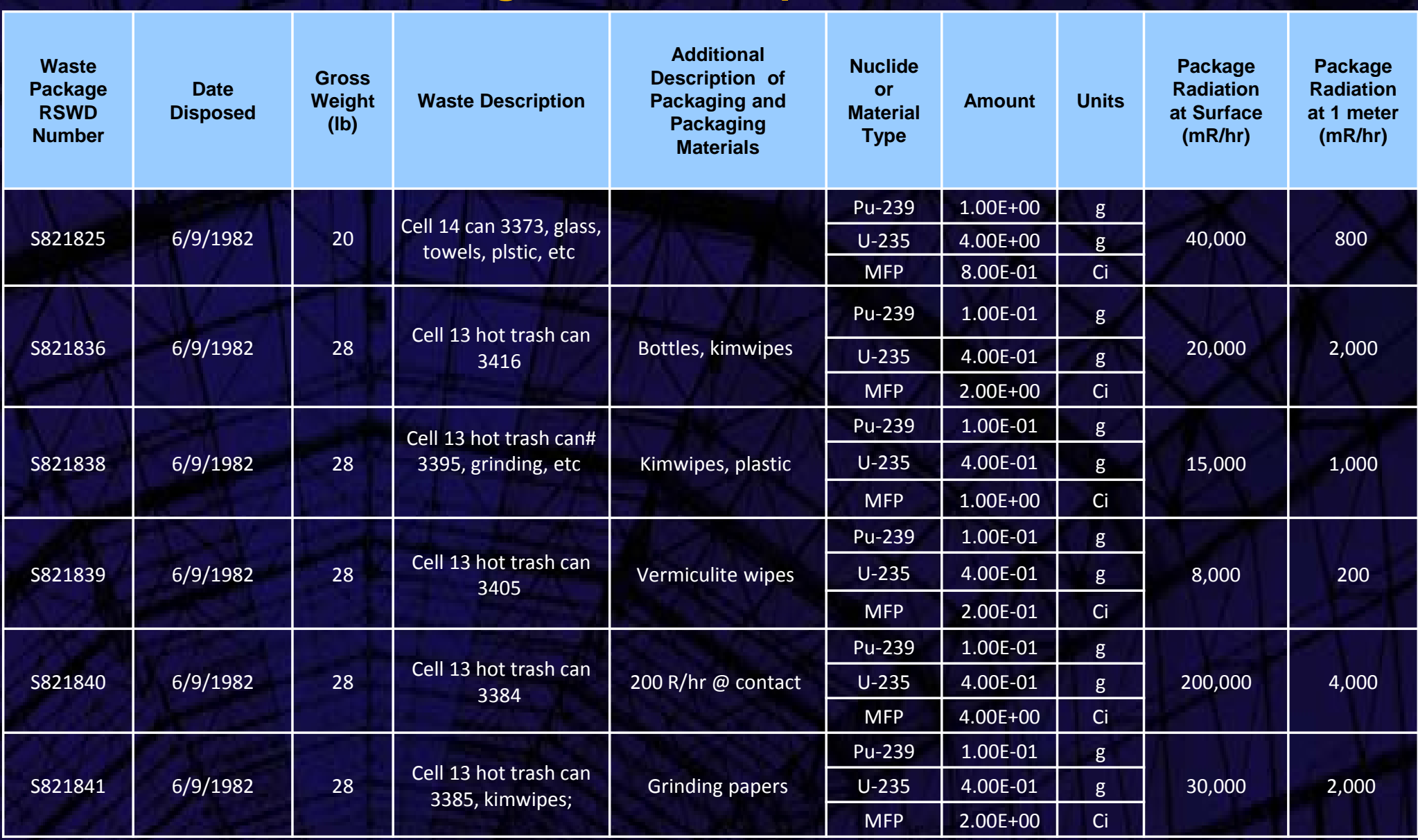




\section{Material Disposal Area G, 33 Shafts Shaft 217 Waste Data Fact Sheet}

\section{Contents}

Shaft 217 contains six packages of waste from the Chemistry and Metallurgy Research (CMR) Facility Wing 9 hot cells, with each package containing waste placed inside a two-gallon paint-type metal can and placed into a plastic bag. Some paint-type cans may have been sealed in a plastic container before being placed into the plastic bag. Wastes include hot-cell trash, grinding papers, kimwipes, and plastic. Major radionuclides in the waste consist of plutonium-239, uranium-235, and mixed fission products (MFP). Waste is considered to be remote-handled with the reported radiation dose at the surface of the packages at the time of generation ranging from 6,000 to 1,000,000 mrem/hour. The six packages of waste were placed into Shaft 217 in September 1982.

\section{Shaft Configuration}

Construction of Shaft 217 was initiated by augering a 36-inch diameter vertical hole into the mesa top. A 24-inch-diameter metal pipe (1/4 inch wall) with a length of 9 to 12 feet with a metal plate welded to the bottom was inserted into the hole as a liner. A 1/2 inch-wall inner pipe of 9- to 12-inch diameter and 7 to 12 feet in length with a metal plate welded to the bottom was centered in the larger pipe with a small amount of concrete to provide vertical alignment of the inner pipe in the outer pipe. Records with the specific dimensions for the pipes in Shaft 217 have not been located. A large metal funnel was placed in the inner pipe and waste packages were dropped into the inner pipe from a shielded transport cask moved into position above the shaft. After all waste packages were placed into the inner pipe, concrete was placed in the annular space between the pipes and the top of the shaft and auger hole were capped with 3 to 4 inches of concrete. The result is that the pipe containing the waste packages is completely encased in concrete.

\section{Shaft 217 Configuration}

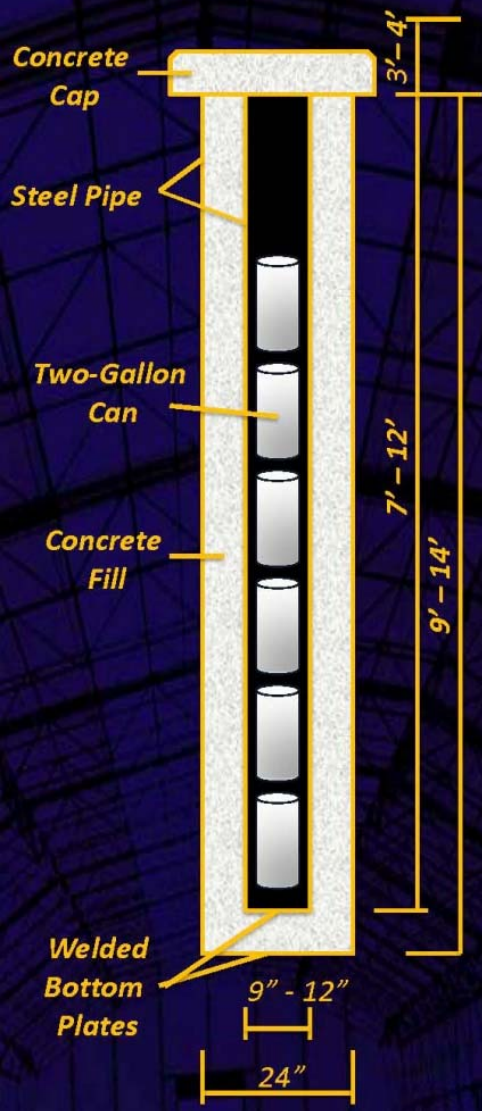

Waste Package Data Summary

\section{Location in Shaft Field}

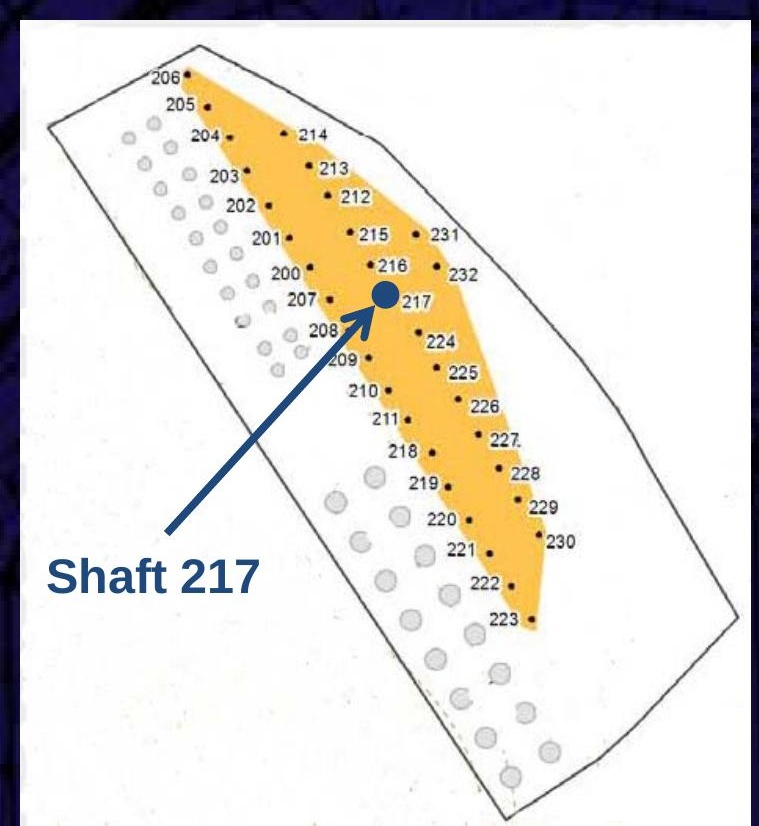

\begin{tabular}{|c|c|c|c|c|c|}
\hline $\begin{array}{c}\text { RSWD * } \\
\text { Number }\end{array}$ & $\begin{array}{c}\text { Volume } \\
\text { (gallons) }\end{array}$ & Radionuclides & $\begin{array}{c}\text { Total Curies } \\
\text { at Disposal }\end{array}$ & $\begin{array}{c}\text { Total Curies } \\
\text { Decayed to 2009 }\end{array}$ & PE-Ci \\
\hline S821870 & 2 & Pu-239, U-235, MFP & 0.19 & 0.10 & 0.0062 \\
\hline S821871 & 2 & Pu-239, U-235, MFP & 4.70 & 2.49 & 0.198 \\
\hline S821874 & 2 & Pu-239, U-235, MFP & 9.99 & 5.10 & 0.0062 \\
\hline S821882 & 2 & Pu-239, U-235, MFP & 1.01 & 0.52 & 0.0062 \\
\hline S821915 & 2 & Pu-239, U-235, MFP & 2.41 & $1.92 \mathrm{E}$ & 1.41 \\
\hline S821918 & 2 & Pu-239, U-235, MFP & 1.20 & 0.71 & 0.20 \\
\hline $\begin{array}{c}\text { TOTALS for } \\
\text { Shaft 217 }\end{array}$ & 12 & Pu-239, U-235, MFP & 19.49 & 10.83 & 1.82 \\
\hline
\end{tabular}

* RSWD = Radioactive Solid Waste Disposal record 


\section{Shaft 217 Totals}

\begin{tabular}{|c|c|c|}
\hline Total Number of Waste Packages & \multicolumn{2}{|c|}{6} \\
\hline Total Gross Weight (pounds) & \multicolumn{2}{|c|}{164} \\
\hline Total Pu-239 (grams) & \multicolumn{2}{|c|}{29.5} \\
\hline Total U-235 (grams) & \multicolumn{2}{|c|}{87} \\
\hline Total Mixed Fission Products (Ci) & \multicolumn{2}{|c|}{17.68} \\
\hline Dates of Disposal & \multicolumn{2}{|c|}{$9 / 13 / 1982$ to $9 / 13 / 1982$} \\
\hline Radiation at Surface of Waste Package ( $\mathrm{mR} / \mathrm{hr}$ ) & $\begin{array}{l}6,000 \text { to } 1,000,000 \\
\text { at disposal }\end{array}$ & $\begin{array}{l}3,000 \text { to } 456,000 \\
\text { decayed to } 2009\end{array}$ \\
\hline $\begin{array}{l}\text { Radiation at One Meter from Surface of Waste } \\
\text { Package }(\mathrm{mR} / \mathrm{hr})\end{array}$ & $\begin{array}{l}1,000 \text { to } 150,000 \\
\text { at disposal }\end{array}$ & $\begin{array}{c}20 \text { to } 3,200 * \\
\text { decayed to } 2009\end{array}$ \\
\hline
\end{tabular}

* Calculated using inverse square rule assuming a point source at the center of the waste package paint cans

\section{Detailed Waste Package Data at Disposal}

\begin{tabular}{|c|c|c|c|c|c|c|c|c|c|}
\hline $\begin{array}{c}\text { Waste } \\
\text { Package } \\
\text { RSWD } \\
\text { Number }\end{array}$ & $\begin{array}{c}\text { Date } \\
\text { Disposed }\end{array}$ & $\begin{array}{c}\text { Gross } \\
\text { Weight } \\
\text { (Ib) }\end{array}$ & Waste Description & $\begin{array}{c}\text { Additional } \\
\text { Description of } \\
\text { Packaging and } \\
\text { Packaging } \\
\text { Materials }\end{array}$ & $\begin{array}{l}\text { Nuclide } \\
\text { or } \\
\text { Material } \\
\text { Type }\end{array}$ & Amount & Units & $\begin{array}{c}\text { Package } \\
\text { Radiation } \\
\text { at Surface } \\
(\mathrm{mR} / \mathrm{hr})\end{array}$ & $\begin{array}{c}\text { Package } \\
\text { Radiation } \\
\text { at } 1 \text { meter } \\
(\mathrm{mR} / \mathrm{hr})\end{array}$ \\
\hline \multirow{3}{*}{ S821870 } & \multirow{3}{*}{ 9/13/1982 } & \multirow{3}{*}{20} & \multirow{3}{*}{$\begin{array}{c}\text { Cell } 14 \text { can } 3451 \text {, glass, } \\
\text { plastic bottles }\end{array}$} & & Pu-239 & $1.00 \mathrm{E}-01$ & $\mathrm{~g}$ & \multirow{3}{*}{15,000} & \multirow{3}{*}{1,500} \\
\hline & & & & & U-235 & 4.00E-01 & $\mathrm{g}$ & & \\
\hline & & & & & MFP & $1.80 \mathrm{E}-01$ & $\mathrm{Ci}$ & & \\
\hline \multirow{3}{*}{ S821871 } & \multirow{3}{*}{ 9/13/1982 } & \multirow{3}{*}{38} & \multirow{3}{*}{$\begin{array}{c}\text { Cell } 14 \text { can } 3452 \text {, fuels } \\
\text { scrap, card boxes }\end{array}$} & \multirow{3}{*}{$\begin{array}{c}100000 \mathrm{mR} / \mathrm{hr} \text { at } \\
\text { contact }\end{array}$} & Pu-239 & $3.20 \mathrm{E}+00$ & $\mathrm{~g}$ & \multirow{3}{*}{100,000} & \multirow{3}{*}{4,500} \\
\hline & & & & & U-235 & $1.29 \mathrm{E}+01$ & $\mathrm{~g}$ & & \\
\hline & & & & & MFP & $4.50 E+00$ & $\mathrm{Ci}$ & & \\
\hline \multirow{3}{*}{ S821874 } & \multirow{3}{*}{ 9/13/1982 } & \multirow{3}{*}{28} & \multirow{3}{*}{$\begin{array}{l}\text { Cell } 13 \text { hot trash, } \\
\text { grinding papers, etc }\end{array}$} & \multirow{3}{*}{ Bottom entry cask } & Pu-239 & $1.00 \mathrm{E}-01$ & $\mathrm{~g}$ & \multirow{3}{*}{80,000} & \multirow{3}{*}{1,000} \\
\hline & & & & & $\mathrm{U}-235$ & 4.00E-01 & $\mathrm{g}$ & & \\
\hline & & & & & MFP & $1.00 \mathrm{E}+01$ & $\mathrm{Ci}$ & & \\
\hline \multirow{3}{*}{ S821882 } & \multirow{3}{*}{ 9/13/1982 } & \multirow{3}{*}{30} & \multirow{3}{*}{$\begin{array}{c}\text { Cell } 13 \text { trash can \# } \\
3478\end{array}$} & & Pu-239 & $1.00 \mathrm{E}-01$ & $\mathrm{~g}$ & \multirow{3}{*}{6,000} & \multirow{3}{*}{1,000} \\
\hline & & & & & $\mathrm{U}-235$ & 4.00E-01 & $\mathrm{g}$ & & \\
\hline & & & & & MFP & $1.00 \mathrm{E}+00$ & $\mathrm{Ci}$ & & \\
\hline \multirow{3}{*}{ S821915 } & \multirow{3}{*}{ 9/13/1982 } & \multirow{3}{*}{10} & \multirow{3}{*}{$\begin{array}{l}\text { Cell } 9 \text { can } 3446 \text {, waste } \\
\text { fuel and cell trash }\end{array}$} & \multirow{3}{*}{$\begin{array}{c}1000+R \text { contact } 150 R \\
\text { at } 1 \text { meter }\end{array}$} & Pu-239 & $2.28 \mathrm{E}+01$ & $\mathrm{~g}$ & \multirow{3}{*}{$1,000,000$} & \multirow{3}{*}{150,000} \\
\hline & & & & & $\mathrm{U}-235$ & $6.00 \mathrm{E}+01$ & $\mathrm{~g}$ & & \\
\hline & & & & & MFP & $1.00 E+00$ & $\mathrm{Ci}$ & & \\
\hline \multirow{3}{*}{ S821918 } & \multirow{3}{*}{ 9/13/1982 } & & & & Pu-239 & $3.20 \mathrm{E}+00$ & $\mathrm{~g}$ & & \\
\hline & & 38 & $\begin{array}{l}\text { Cell } 14 \text { can } 343 / \text { tuel } \\
\text { scrap card boxes }\end{array}$ & 900 R/hr @ cont & U-235 & 1.29E+01 & $\mathrm{g}$ & 900,000 & 10,000 \\
\hline & & & & & MFP & $1.00 \mathrm{E}+00$ & $\mathrm{Ci}$ & & \\
\hline
\end{tabular}




\section{Material Disposal Area G, 33 Shafts Shaft 218 Waste Data Fact Sheet}

\section{Contents}

Shaft 218 contains six packages of waste from the Chemistry and Metallurgy Research (CMR) Facility Wing 9 hot cells, with each package containing waste placed inside a two-gallon paint-type metal can and placed into a plastic bag. Some paint-type cans may have been sealed in a plastic container before being placed into the plastic bag. Wastes include hot-cell trash, grinding papers, kimwipes, and plastic. Major radionuclides in the waste consist of plutonium-239, uranium-235, and mixed fission products (MFP). Waste is considered to be remote-handled with the reported radiation dose at the surface of the packages at the time of generation ranging from 200,000 to 1,000,000 $\mathrm{mrem} / \mathrm{hour}$. The six packages of waste were placed into Shaft 218 in September 1982.

\section{Shaft Configuration}

Construction of Shaft 218 was initiated by augering a 36-inch diameter vertical hole into the mesa top. A 24-inch-diameter metal pipe (1/4 inch wall) with a length of 9 to 12 feet with a metal plate welded to the bottom was inserted into the hole as a liner. A 1/2 inch-wall inner pipe of 9- to 12-inch diameter and 7 to 12 feet in length with a metal plate welded to the bottom was centered in the larger pipe with a small amount of concrete to provide vertical alignment of the inner pipe in the outer pipe. Records with the specific dimensions for the pipes in Shaft 218 have not been located. A large metal funnel was placed in the inner pipe and waste packages were dropped into the inner pipe from a shielded transport cask moved into position above the shaft. After all waste packages were placed into the inner pipe, concrete was placed in the annular space between the pipes and the top of the shaft and auger hole were capped with 3 to 4 inches of concrete. The result is that the pipe containing the waste packages is completely encased in concrete.

\section{Shaft 218 Configuration}

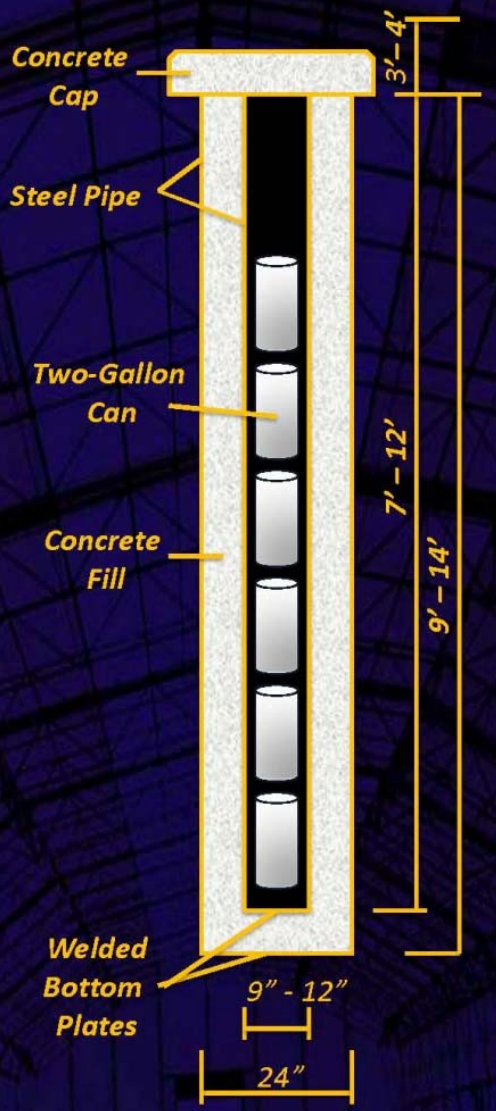

Waste Package Data Summary

\section{Location in Shaft Field}

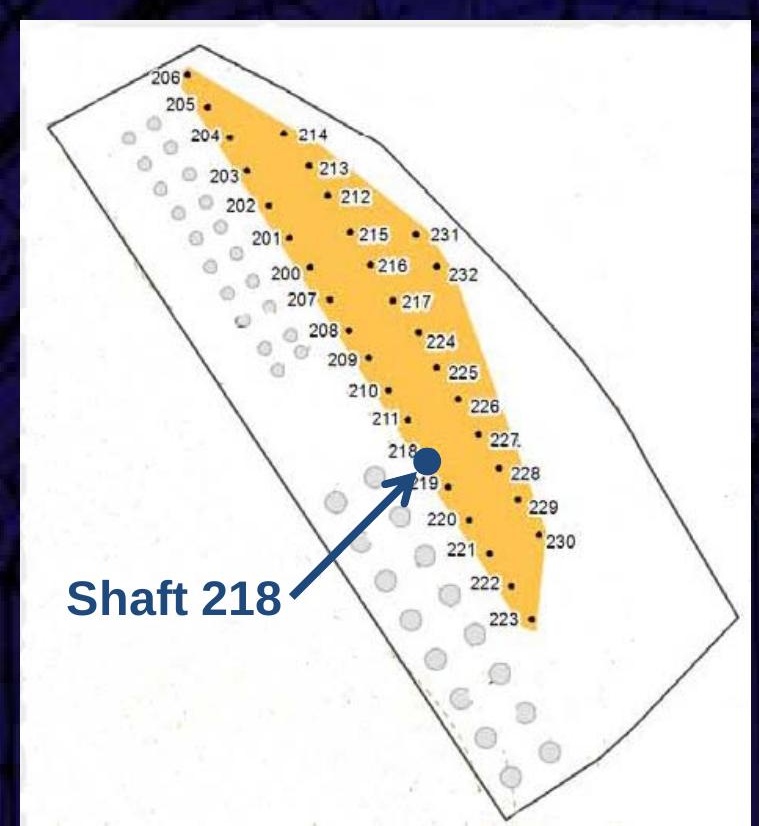

\begin{tabular}{|c|c|c|c|c|c|}
\hline $\begin{array}{c}\text { RSWD * } \\
\text { Number }\end{array}$ & $\begin{array}{c}\text { Volume } \\
\text { (gallons) }\end{array}$ & Radionuclides & $\begin{array}{c}\text { Total Curies } \\
\text { at Disposal }\end{array}$ & $\begin{array}{c}\text { Total Curies } \\
\text { Decayed to 2009 }\end{array}$ & PE-Ci \\
\hline S821875 & 2 & Pu-239, U-235, MFP & 19.99 & 10.2 & 0.0062 \\
\hline S821879 & 2 & Pu-239, U-235, MFP & 30.10 & 15.4 & 0.124 \\
\hline S821881 & 2 & Pu-239, U-235, MFP & 40.10 & 20.5 & 0.124 \\
\hline S821883 & 2 & Pu-239, U-235, MFP & 6.00 & 3.06 & 0.0062 \\
\hline S821916 & 2 & Pu-239, U-235, MFP & 32.48 & 17.8 & 2.5 \\
\hline S821917 & 2 & Pu-239, U-235, MFP & 6.00 & 3.06 & 0.0062 \\
\hline $\begin{array}{c}\text { TOTALS for } \\
\text { Shaft 218 }\end{array}$ & 12 & Pu-239, U-235, MFP & 134.67 & 69.95 & 2.77 \\
\hline
\end{tabular}

* RSWD = Radioactive Solid Waste Disposal record 


\section{Shaft 218 Totals}

\begin{tabular}{|c|c|c|}
\hline Total Number of Waste Packages & \multicolumn{2}{|c|}{6} \\
\hline Total Gross Weight (pounds) & \multicolumn{2}{|c|}{190} \\
\hline Total Pu-239 (grams) & \multicolumn{2}{|c|}{44.7} \\
\hline Total U-235 (grams) & \multicolumn{2}{|c|}{102} \\
\hline Total Mixed Fission Products (Ci) & \multicolumn{2}{|c|}{132} \\
\hline Dates of Disposal & \multicolumn{2}{|c|}{$9 / 13 / 1982$ to $9 / 13 / 1982$} \\
\hline Radiation at Surface of Waste Package ( $\mathrm{mR} / \mathrm{hr}$ ) & $\begin{array}{l}200,000 \text { to } 1,000,000 \\
\text { at disposal }\end{array}$ & $\begin{array}{l}101,000 \text { to } 456,000 \\
\text { decayed to } 2009\end{array}$ \\
\hline $\begin{array}{l}\text { Radiation at One Meter from Surface of Waste } \\
\text { Package }(\mathrm{mR} / \mathrm{hr})\end{array}$ & $\begin{array}{l}6,000 \text { to } 40,000 \\
\text { at disposal }\end{array}$ & $\begin{array}{l}700 \text { to } 3,200 * \\
\text { decayed to } 2009\end{array}$ \\
\hline
\end{tabular}

* Calculated using inverse square rule assuming a point source at the center of the waste package paint cans

\section{Detailed Waste Package Data at Disposal}

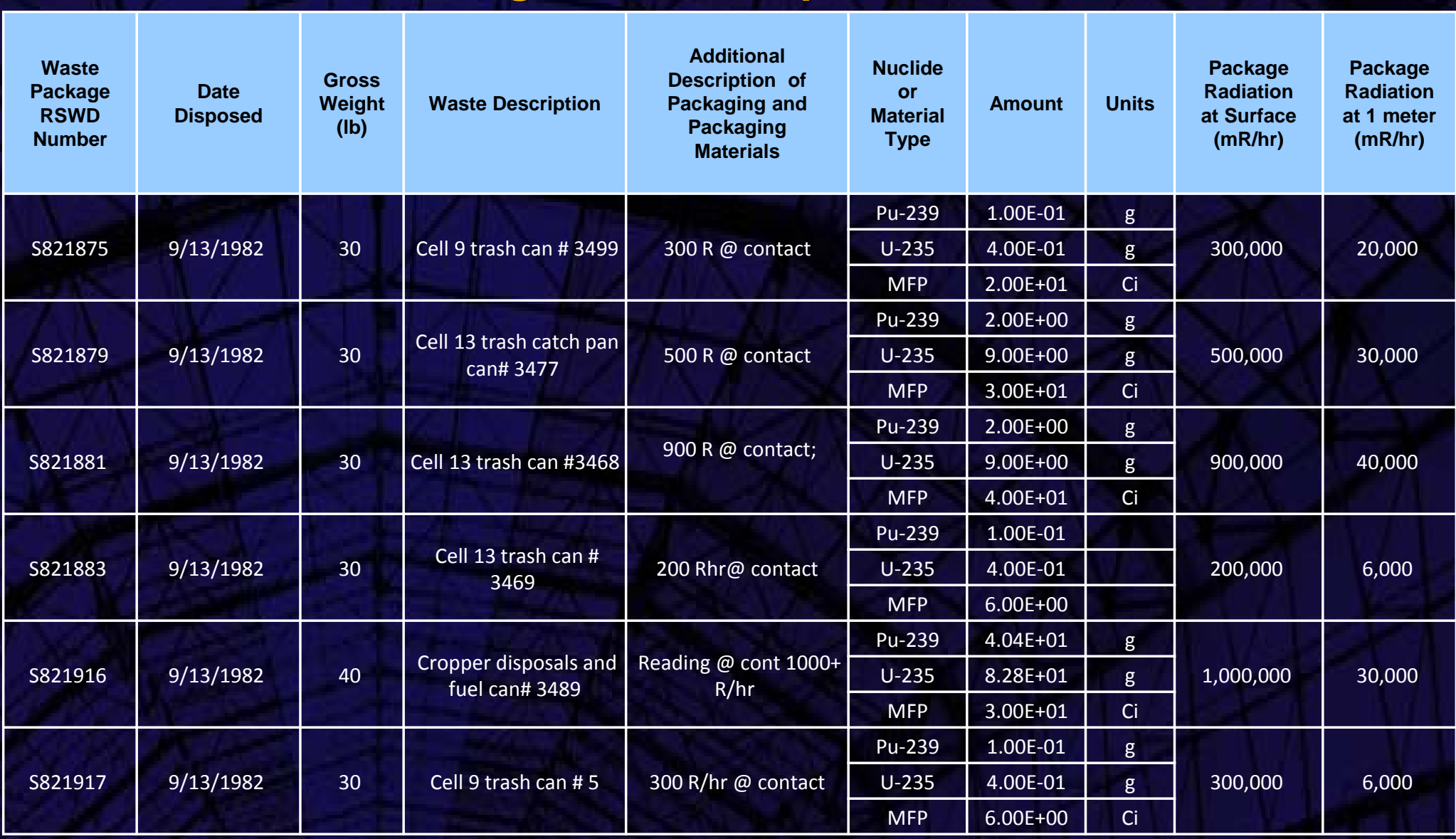




\section{Material Disposal Area G, 33 Shafts Shaft 219 Waste Data Fact Sheet}

\section{Contents}

Shaft 219 contains six packages of waste from the Chemistry and Metallurgy Research (CMR) Facility Wing 9 hot cells, with each package containing waste placed inside a two-gallon paint-type metal can and placed into a plastic bag. Some paint-type cans may have been sealed in a plastic container before being placed into the plastic bag. Wastes include hot-cell trash, grinding papers, kimwipes, and plastic. Major radionuclides in the waste consist of plutonium-239, uranium-235, and mixed fission products (MFP). Waste is considered to be remote-handled with the reported radiation dose at the surface of the packages at the time of generation ranging from 30,000 to 1,000,000 mrem/hour. The six packages of waste were placed into Shaft 219 in March 1983.

\section{Shaft Configuration}

Construction of Shaft 219 was initiated by augering a 36-inch diameter vertical hole into the mesa top. A 24-inch-diameter metal pipe (1/4 inch wall) with a length of 9 to 12 feet with a metal plate welded to the bottom was inserted into the hole as a liner. A 1/2 inch-wall inner pipe of 9- to 12-inch diameter and 7 to 12 feet in length with a metal plate welded to the bottom was centered in the larger pipe with a small amount of concrete to provide vertical alignment of the inner pipe in the outer pipe. Records with the specific dimensions for the pipes in Shaft 219 have not been located. A large metal funnel was placed in the inner pipe and waste packages were dropped into the inner pipe from a shielded transport cask moved into position above the shaft. After all waste packages were placed into the inner pipe, concrete was placed in the annular space between the pipes and the top of the shaft and auger hole were capped with 3 to 4 inches of concrete. The result is that the pipe containing the waste packages is completely encased in concrete.

\section{Shaft 219 Configuration}

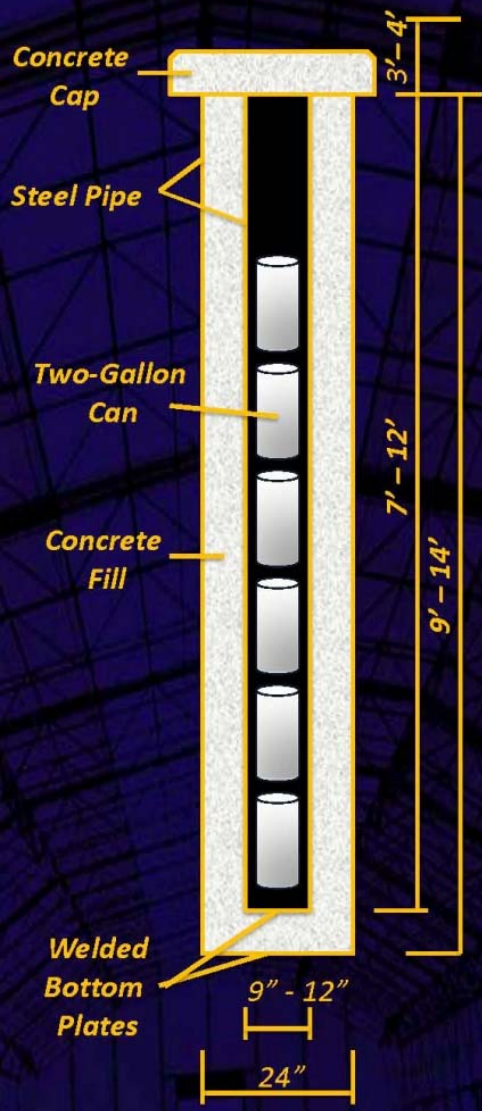

Waste Package Data Summary

\section{Location in Shaft Field}

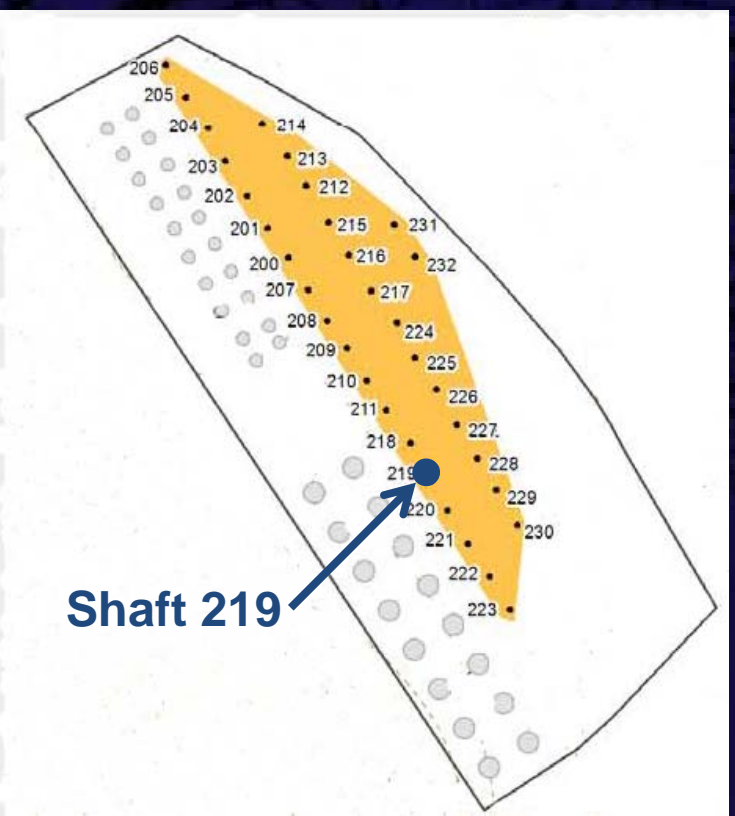

\begin{tabular}{|c|c|c|c|c|c|}
\hline $\begin{array}{c}\text { RSWD * } \\
\text { Number }\end{array}$ & $\begin{array}{c}\text { Volume } \\
\text { (gallons) }\end{array}$ & Radionuclides & $\begin{array}{c}\text { Total Curies } \\
\text { at Disposal }\end{array}$ & $\begin{array}{c}\text { Total Curies } \\
\text { Decayed to 2009 }\end{array}$ & PE-Ci \\
\hline S832830 & 2 & Pu-239, U-235, MFP & 19.99 & 10.4 & 0.0062 \\
\hline S832831 & 2 & Pu-239, U-235, MFP & 0.81 & 0.42 & 0.0062 \\
\hline S832832 & 2 & Pu-239, U-235, MFP & 152.39 & 80.6 & 2.51 \\
\hline S832833 & 2 & Pu-239, U-235, MFP & 29.98 & 15.6 & 0.0062 \\
\hline S832834 & 2 & Pu-239, U-235, MFP & 50.10 & 26.1 & 0.0062 \\
\hline S832835 & 2 & Pu-239, U-235, MFP & 100.19 & 52.4 & 0.309 \\
\hline $\begin{array}{c}\text { TOTALS for } \\
\text { Shaft 219 }\end{array}$ & 12 & Pu-239, U-235, MFP & 353.46 & 185.62 & 2.84 \\
\hline
\end{tabular}

* RSWD = Radioactive Solid Waste Disposal record

This fact sheet was compiled from information judged to be the most reliable and accurate available. Waste information from the 1970's and 1980's has gaps and is sometimes inconsistent between various records or reports. 


\section{Shaft 219 Totals}

\begin{tabular}{|c|c|c|}
\hline Total Number of Waste Packages & \multicolumn{2}{|c|}{6} \\
\hline Total Gross Weight (pounds) & \multicolumn{2}{|c|}{180} \\
\hline Total Pu-239 (grams) & \multicolumn{2}{|c|}{45.88} \\
\hline Total U-235 (grams) & \multicolumn{2}{|c|}{257.8} \\
\hline Total Mixed Fission Products (Ci) & \multicolumn{2}{|c|}{350.8} \\
\hline Dates of Disposal & \multicolumn{2}{|c|}{$3 / 10 / 1983$ to $3 / 10 / 1983$} \\
\hline Radiation at Surface of Waste Package (mR/hr) & $\begin{array}{l}30,000 \text { to } 1,000,000 \\
\text { at disposal }\end{array}$ & $\begin{array}{l}16,000 \text { to } 518,000 \\
\text { decayed to } 2009\end{array}$ \\
\hline $\begin{array}{l}\text { Radiation at One Meter from Surface of Waste } \\
\text { Package ( } \mathrm{mR} / \mathrm{hr})\end{array}$ & $\begin{array}{l}800 \text { to } 150,000 \\
\text { at disposal }\end{array}$ & $\begin{array}{l}100 \text { to } 3,700 * \\
\text { decayed to } 2009\end{array}$ \\
\hline
\end{tabular}

* Calculated using inverse square rule assuming a point source at the center of the waste package paint cans

\section{Detailed Waste Package Data at Disposal}

\begin{tabular}{|c|c|c|c|c|c|c|c|c|c|}
\hline $\begin{array}{c}\text { Waste } \\
\text { Package } \\
\text { RSWD } \\
\text { Number }\end{array}$ & $\begin{array}{c}\text { Date } \\
\text { Disposed }\end{array}$ & $\begin{array}{c}\text { Gross } \\
\text { Weight } \\
\text { (Ib) }\end{array}$ & Waste Description & $\begin{array}{c}\text { Additional } \\
\text { Description of } \\
\text { Packaging and } \\
\text { Packaging } \\
\text { Materials }\end{array}$ & Nuclide & Amount & Units & $\begin{array}{c}\text { Package } \\
\text { Radiation } \\
\text { at Surface } \\
(\mathrm{mR} / \mathrm{hr})\end{array}$ & $\begin{array}{c}\text { Package } \\
\text { Radiation } \\
\text { at } 1 \text { meter } \\
(\mathrm{mR} / \mathrm{hr})\end{array}$ \\
\hline \multirow{3}{*}{ S832830 } & \multirow{3}{*}{$3 / 10 / 1983$} & \multirow{3}{*}{30} & \multirow{3}{*}{$\begin{array}{l}\text { Cell } 13 \text { grinding waste } \\
\text { can } \# 3527\end{array}$} & \multirow{3}{*}{1000 R/hr @ contact; } & Pu-239 & $1.00 \mathrm{E}-01$ & $\mathrm{~g}$ & \multirow{3}{*}{$1,000,000$} & \multirow{3}{*}{20,000} \\
\hline & & & & & U-235 & 4.00E-01 & $\mathrm{g}$ & & \\
\hline & & & & & MFP & $2.00 E+01$ & $\mathrm{Ci}$ & & \\
\hline \multirow{3}{*}{ S832831 } & \multirow{3}{*}{$3 / 10 / 1983$} & \multirow{3}{*}{30} & \multirow{3}{*}{ Cell 11 trash can 3727} & \multirow{3}{*}{ Bottom entry cask } & Pu-239 & $1.00 \mathrm{E}-01$ & $\mathrm{~g}$ & \multirow{3}{*}{30,000} & \multirow{3}{*}{800} \\
\hline & & & & & U-235 & 4.00E-01 & $\mathrm{g}$ & & \\
\hline & & & & & MFP & $8.00 \mathrm{E}-01$ & $\mathrm{Ci}$ & & \\
\hline \multirow{3}{*}{ S832832 } & \multirow{3}{*}{$3 / 10 / 1983$} & \multirow{3}{*}{30} & \multirow{3}{*}{$\begin{array}{c}\text { Cell } 9 \text { fuel \& hardware } \\
\text { can } 3724\end{array}$} & \multirow{3}{*}{$\begin{array}{l}\text { 1000+R @ contact } \\
\text { 150R @ } 1 \text { meter; }\end{array}$} & Pu-239 & $4.05 E+01$ & $\mathrm{~g}$ & \multirow{3}{*}{$1,000,000$} & \multirow{3}{*}{150,000} \\
\hline & & & & & $\mathrm{U}-235$ & $2.36 \mathrm{E}+02$ & $\mathrm{~g}$ & & \\
\hline & & & & & MFP & $1.50 \mathrm{E}+02$ & $\mathrm{Ci}$ & & \\
\hline \multirow{3}{*}{ S832833 } & \multirow{3}{*}{$3 / 10 / 1983$} & \multirow{3}{*}{30} & \multirow{3}{*}{ Cell 9 waste can 3725} & \multirow{3}{*}{$200 \mathrm{R} / \mathrm{hr}$ contact; } & Pu-239 & $1.00 \mathrm{E}-01$ & $\mathrm{~g}$ & \multirow{3}{*}{200,000} & \multirow{3}{*}{30,000} \\
\hline & & & & & U-235 & 4.00E-01 & $\mathrm{g}$ & & \\
\hline & & & & & MFP & $3.00 E+01$ & $\mathrm{Ci}$ & & \\
\hline \multirow{3}{*}{$\$ 832834$} & \multirow{3}{*}{$3 / 10 / 1983$} & \multirow{3}{*}{30} & \multirow{3}{*}{$\begin{array}{c}\text { Cell } 9 \text { hot trash can } \\
3524\end{array}$} & \multirow{3}{*}{$\begin{array}{c}1000+R \text { contact } 50 R \text { at } \\
1 \text { meter }\end{array}$} & Pu-239 & $1.00 \mathrm{E}-01$ & $\mathrm{~g}$ & \multirow{3}{*}{$1,000,000$} & \multirow{3}{*}{50,000} \\
\hline & & & & & $\mathrm{U}-235$ & 4.00E-01 & $\mathrm{g}$ & & \\
\hline & & & & & MFP & $5.00 \mathrm{E}+01$ & $\mathrm{Ci}$ & & \\
\hline & & & & & Pu-239 & $4.98 \mathrm{E}+00$ & $\mathrm{~g}$ & & \\
\hline S832835 & 3/10/1983 & 30 & $\begin{array}{l}\text { Cell } 9 \text { hot trash can } \\
3495\end{array}$ & $\begin{array}{c}1000+R \text { contact } 100 R \text { at } \\
1 \text { meter }\end{array}$ & $\mathrm{U}-235$ & $2.02 \mathrm{E}+01$ & $\mathrm{~g}$ & $1,000,000$ & 100,000 \\
\hline & & & & & MFP & $1.00 \mathrm{E}+02$ & $\mathrm{Ci}$ & & \\
\hline
\end{tabular}




\section{Material Disposal Area G, 33 Shafts Shaft 220 Waste Data Fact Sheet}

\section{Contents}

Shaft 220 contains six packages of waste from the Chemistry and Metallurgy Research (CMR) Facility Wing 9 hot cells, with each package containing waste placed inside a two-gallon paint-type metal can and placed into a plastic bag. Some paint-type cans may have been sealed in a plastic container before being placed into the plastic bag. Wastes include hot-cell trash, grinding papers, kimwipes, and plastic. Major radionuclides in the waste consist of plutonium-239, uranium-235, and mixed fission products (MFP). Waste is considered to be remote-handled with the reported radiation dose at the surface of the packages at the time of generation ranging from 100,000 to 1,000,000 $\mathrm{mrem} / \mathrm{hour}$. The six packages of waste were placed into Shaft 220 in March 1983.

\section{Shaft Configuration}

Construction of Shaft 220 was initiated by augering a 36-inch diameter vertical hole into the mesa top. A 24-inch-diameter metal pipe (1/4 inch wall) with a length of 9 to 12 feet with a metal plate welded to the bottom was inserted into the hole as a liner. A 1/2 inch-wall inner pipe of 9- to 12-inch diameter and 7 to 12 feet in length with a metal plate welded to the bottom was centered in the larger pipe with a small amount of concrete to provide vertical alignment of the inner pipe in the outer pipe. Records with the specific dimensions for the pipes in Shaft 220 have not been located. A large metal funnel was placed in the inner pipe and waste packages were dropped into the inner pipe from a shielded transport cask moved into position above the shaft. After all waste packages were placed into the inner pipe, concrete was placed in the annular space between the pipes and the top of the shaft and auger hole were capped with 3 to 4 inches of concrete. The result is that the pipe containing the waste packages is completely encased in concrete.

\section{Shaft 220 Configuration}

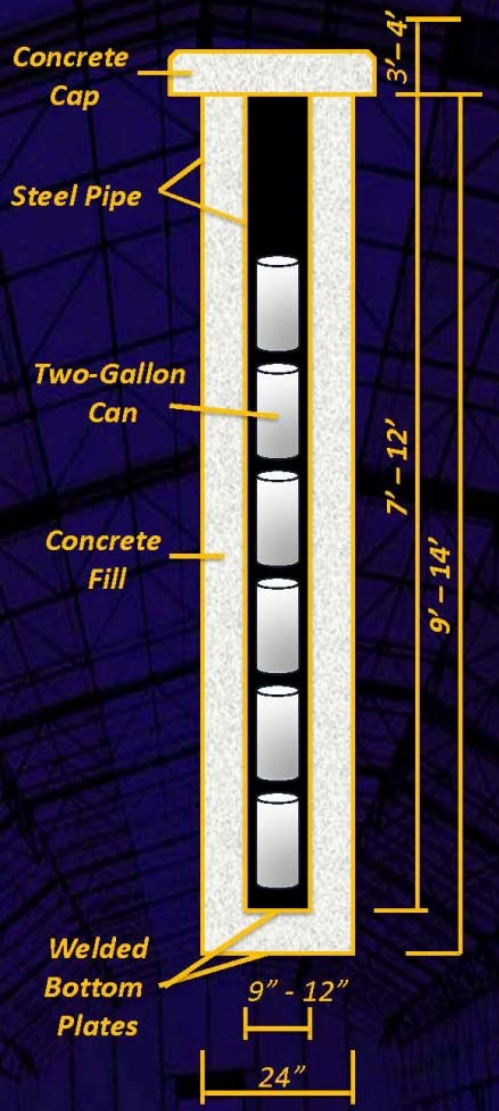

Waste Package Data Summary

\section{Location in Shaft Field}

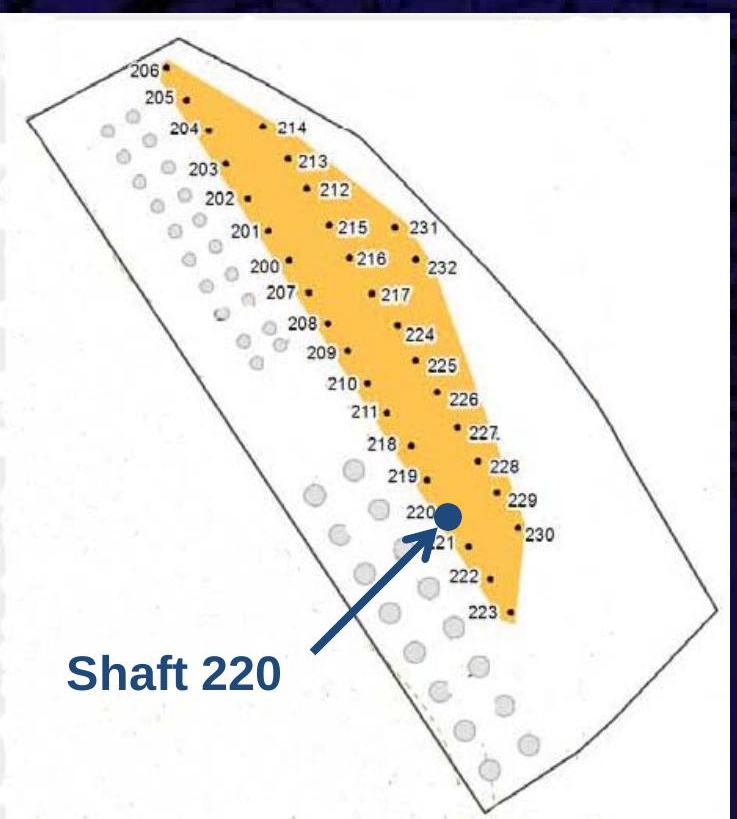

\begin{tabular}{|c|c|c|c|c|c|}
\hline $\begin{array}{c}\text { RSWD } \\
\text { Number }\end{array}$ & $\begin{array}{c}\text { Volume } \\
\text { (gallons) }\end{array}$ & Radionuclides & $\begin{array}{c}\text { Total Curies } \\
\text { at Disposal }\end{array}$ & $\begin{array}{c}\text { Total Curies } \\
\text { Decayed to 2009 }\end{array}$ & PE-Ci \\
\hline S832836 & 2 & Pu-239, U-235, MFP & 99.89 & 52.1 & 0.0062 \\
\hline S832837 & 2 & Pu-239, U-235, MFP & 99.89 & 52.1 & 0.0068 \\
\hline S832838 & 2 & Pu-239, U-235, MFP & 2.00 & 1.05 & 0.0062 \\
\hline S832839 & 2 & Pu-239, U-235, MFP & 8.01 & 4.18 & 0.0062 \\
\hline S832840 & 2 & Pu-239, U-235, MFP & 199.87 & 104 & 0.0062 \\
\hline S832841 & 2 & Pu-239, U-235, MFP & 50.10 & 26.1 & 0.0062 \\
\hline $\begin{array}{c}\text { TOTALS for } \\
\text { Shaft 220 }\end{array}$ & 12 & Pu-239, U-235, MFP & 459.76 & 239.78 & 0.038 \\
\hline
\end{tabular}

${ }^{*}$ RSWD $=$ Radioactive Solid Waste Disposal record

This fact sheet was compiled from information judged to be the most reliable and accurate available. Waste information from the 1970's and 1980's has gaps and is sometimes inconsistent between various records or reports. 


\section{Shaft 220 Totals}

\begin{tabular}{|c|c|c|}
\hline Total Number of Waste Packages & \multicolumn{2}{|c|}{6} \\
\hline Total Gross Weight (pounds) & \multicolumn{2}{|c|}{180} \\
\hline Total Pu-239 (grams) & \multicolumn{2}{|c|}{0.61} \\
\hline Total U-235 (grams) & \multicolumn{2}{|c|}{2.4} \\
\hline Total Mixed Fission Products (Ci) & \multicolumn{2}{|c|}{460} \\
\hline Dates of Disposal & \multicolumn{2}{|c|}{$3 / 10 / 1983$ to $3 / 10 / 1983$} \\
\hline Radiation at Surface of Waste Package (mR/hr) & $\begin{array}{l}100,000 \text { to } 1,000,000 \\
\text { at disposal }\end{array}$ & $\begin{array}{l}52,000 \text { to } 104,000 \\
\text { decayed to } 2009\end{array}$ \\
\hline $\begin{array}{l}\text { Radiation at One Meter from Surface of Waste } \\
\text { Package }(\mathrm{mR} / \mathrm{hr})\end{array}$ & $\begin{array}{l}2,000 \text { to } 200,000 \\
\text { at disposal }\end{array}$ & $\begin{array}{c}400 \text { to } 730 * \\
\text { decayed to } 2009\end{array}$ \\
\hline
\end{tabular}

* Calculated using inverse square rule assuming a point source at the center of the waste package paint cans

\section{Detailed Waste Package Data at Disposal}

\begin{tabular}{|c|c|c|c|c|c|c|c|c|c|}
\hline $\begin{array}{c}\text { Waste } \\
\text { Package } \\
\text { RSWD } \\
\text { Number }\end{array}$ & $\begin{array}{c}\text { Date } \\
\text { Disposed }\end{array}$ & $\begin{array}{c}\text { Gross } \\
\text { Weight } \\
\text { (Ib) }\end{array}$ & Waste Description & $\begin{array}{c}\text { Additional } \\
\text { Description of } \\
\text { Packaging and } \\
\text { Packaging } \\
\text { Materials }\end{array}$ & $\begin{array}{l}\text { Nuclide } \\
\text { or } \\
\text { Material } \\
\text { Type }\end{array}$ & Amount & Units & $\begin{array}{c}\text { Package } \\
\text { Radiation } \\
\text { at Surface } \\
(\mathrm{mR} / \mathrm{hr})\end{array}$ & $\begin{array}{c}\text { Package } \\
\text { Radiation } \\
\text { at } 1 \text { meter } \\
(\mathrm{mR} / \mathrm{hr})\end{array}$ \\
\hline \multirow{3}{*}{ S832836 } & \multirow{3}{*}{ 3/10/1983 } & \multirow{3}{*}{30} & \multirow{3}{*}{$\begin{array}{c}\text { Cell } 9 \text { waste etc can } \\
3728\end{array}$} & \multirow{3}{*}{$\begin{array}{c}100 \mathrm{R} / \mathrm{hr} @ 1 \mathrm{~m} 1000+ \\
\mathrm{R} / \mathrm{hr} @ \mathrm{con}\end{array}$} & Pu-239 & $1.00 \mathrm{E}-01$ & $\mathrm{~g}$ & \multirow{3}{*}{$1,000,000$} & \multirow{3}{*}{100,000} \\
\hline & & & & & U-235 & $4.00 \mathrm{E}-01$ & $\mathrm{~g}$ & & \\
\hline & & & & & MFP & $1.00 E+02$ & $\mathrm{Ci}$ & & \\
\hline \multirow{3}{*}{ S832837 } & \multirow{3}{*}{$3 / 10 / 1983$} & \multirow{3}{*}{30} & \multirow{3}{*}{ Cell 9 waste can 3491} & \multirow{3}{*}{$\begin{array}{c}100 \mathrm{R} / \mathrm{hr} 1 \mathrm{~m} 1000+ \\
\mathrm{R} / \mathrm{hr} \text { contact }\end{array}$} & Pu-239 & 1.10E-01 & $\mathrm{g}$ & \multirow{3}{*}{$1,000,000$} & \multirow{3}{*}{100,000} \\
\hline & & & & & U-235 & $4.00 \mathrm{E}-01$ & $\mathrm{~g}$ & & \\
\hline & & & & & MFP & $1.00 \mathrm{E}+02$ & $\mathrm{Ci}$ & & \\
\hline \multirow{3}{*}{ S832838 } & \multirow{3}{*}{ 3/10/1983 } & \multirow{3}{*}{30} & \multirow{3}{*}{ Cell 11 trash can 3706} & \multirow{3}{*}{$100 \mathrm{R} / \mathrm{hr}$ contact } & Pu-239 & $1.00 \mathrm{E}-01$ & $\mathrm{~g}$ & \multirow{3}{*}{100,000} & \multirow{3}{*}{2,000} \\
\hline & & & & & U-235 & 4.00E-01 & $\mathrm{g}$ & & \\
\hline & & & & & MFP & $2.00 E+00$ & $\mathrm{Ci}$ & & \\
\hline \multirow{3}{*}{ S832839 } & \multirow{3}{*}{$3 / 10 / 1983$} & \multirow{3}{*}{30} & \multirow{3}{*}{$\begin{array}{l}\text { Cell } 13 \text { grinding can } \\
3528\end{array}$} & \multirow{3}{*}{$200 \mathrm{R} / \mathrm{hr}$ contact } & Pu-239 & $1.00 \mathrm{E}-01$ & $\mathrm{~g}$ & \multirow{3}{*}{200,000} & \multirow{3}{*}{8,000} \\
\hline & & & & & $\mathrm{U}-235$ & 4.00E-01 & $\mathrm{g}$ & & \\
\hline & & & & & MFP & $8.00 \mathrm{E}+00$ & $\mathrm{Ci}$ & & \\
\hline \multirow{3}{*}{$\$ 832840$} & \multirow{3}{*}{ 3/10/1983 } & \multirow{3}{*}{30} & \multirow{3}{*}{$\begin{array}{l}\text { Cell } 13 \text { grinding can } \\
3522\end{array}$} & \multirow{3}{*}{$\begin{array}{c}200 \mathrm{R} / \mathrm{hr} 1 \mathrm{~m} 1000+ \\
\mathrm{R} / \mathrm{hr} \text { contact }\end{array}$} & Pu-239 & $1.00 \mathrm{E}-01$ & $\mathrm{~g}$ & \multirow{3}{*}{$1,000,000$} & \multirow{3}{*}{200,000} \\
\hline & & & & & U-235 & $4.00 \mathrm{E}-01$ & $\mathrm{~g}$ & & \\
\hline & & & & & MFP & $2.00 \mathrm{E}+02$ & $\mathrm{Ci}$ & & \\
\hline & & & & & Pu-239 & $1.00 \mathrm{E}-01$ & $\mathrm{~g}$ & & \\
\hline S832841 & 3/10/1983 & 30 & $\begin{array}{l}\text { Cell } 16 \text { Wire wrap can } \\
3726\end{array}$ & $\begin{array}{l}\text { SO K/nr } 1 \mathrm{~m} \text { loout } \\
\text { R/hr contact }\end{array}$ & $\mathrm{U}-235$ & 4.00E-01 & $\mathrm{g}$ & $1,000,000$ & 50,000 \\
\hline & & & & & MFP & $5.00 \mathrm{E}+01$ & $\mathrm{Ci}$ & & \\
\hline
\end{tabular}




\section{Material Disposal Area G, 33 Shafts Shaft 221 Waste Data Fact Sheet}

\section{Contents}

Shaft 221 contains six packages of waste from the Chemistry and Metallurgy Research (CMR) Facility Wing 9 hot cells, with each package containing waste placed inside a two-gallon paint-type metal can and placed into a plastic bag. Some paint-type cans may have been sealed in a plastic container before being placed into the plastic bag. Wastes include hot-cell trash, grinding papers, kimwipes, and plastic. Major radionuclides in the waste consist of plutonium-239, uranium-235, and mixed fission products (MFP). Waste is considered to be remote-handled with the reported radiation dose at the surface of the packages at the time of generation ranging from 60,000 to 1,000,000 mrem/hour. The six packages of waste were placed into Shaft 221 in March 1983.

\section{Shaft Configuration}

Construction of Shaft 221 was initiated by augering a 36-inch diameter vertical hole into the mesa top. A 24-inch-diameter metal pipe (1/4 inch wall) with a length of 9 to 12 feet with a metal plate welded to the bottom was inserted into the hole as a liner. A 1/2 inch-wall inner pipe of 9- to 12-inch diameter and 7 to 12 feet in length with a metal plate welded to the bottom was centered in the larger pipe with a small amount of concrete to provide vertical alignment of the inner pipe in the outer pipe. Records with the specific dimensions for the pipes in Shaft 221 have not been located. A large metal funnel was placed in the inner pipe and waste packages were dropped into the inner pipe from a shielded transport cask moved into position above the shaft. After all waste packages were placed into the inner pipe, concrete was placed in the annular space between the pipes and the top of the shaft and auger hole were capped with 3 to 4 inches of concrete. The result is that the pipe containing the waste packages is completely encased in concrete.

\section{Shaft 221 Configuration}

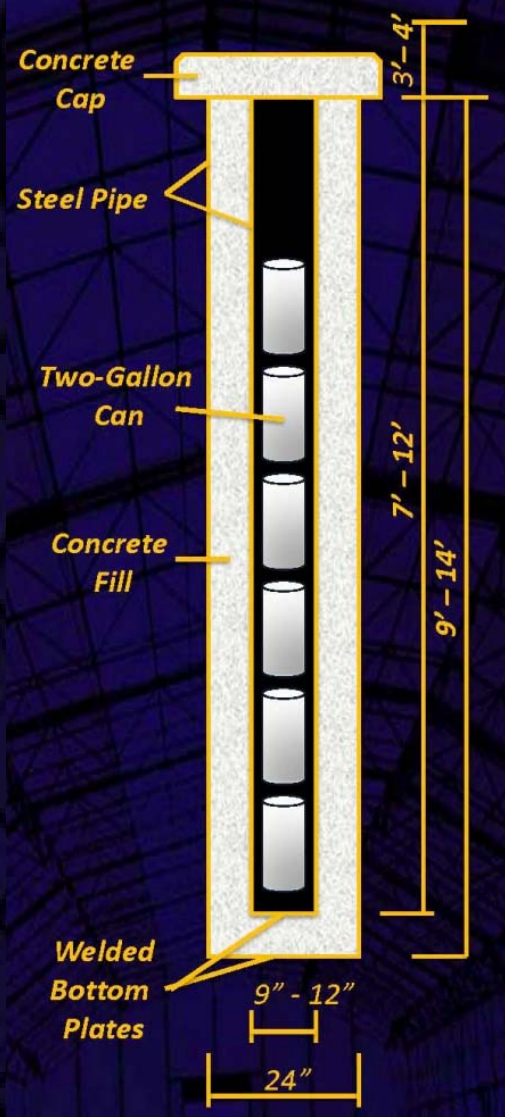

Waste Package Data Summary

\section{Location in Shaft Field}

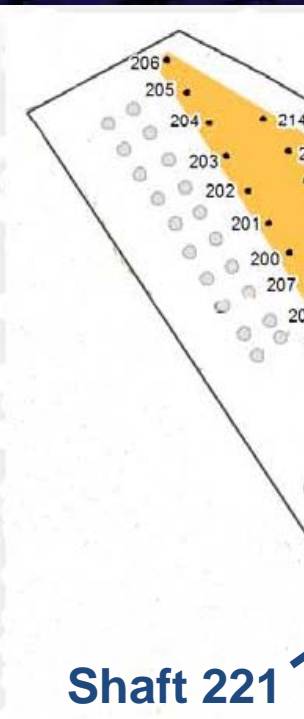

\begin{tabular}{|c|c|c|c|c|c|}
\hline $\begin{array}{c}\text { RSWD * } \\
\text { Number }\end{array}$ & $\begin{array}{c}\text { Volume } \\
\text { (gallons) }\end{array}$ & Radionuclides & $\begin{array}{c}\text { Total Curies } \\
\text { at Disposal }\end{array}$ & $\begin{array}{c}\text { Total Curies } \\
\text { Decayed to 2009 }\end{array}$ & PE-Ci \\
\hline S832842 & 2 & Pu-239, U-235, MFP & 14.99 & 7.82 & 0.0062 \\
\hline S832843 & 2 & Pu-239, U-235, MFP & 29.98 & 15.6 & 0.0062 \\
\hline S832844 & 2 & Pu-239, U-235, MFP & 39.98 & 20.9 & 0.0062 \\
\hline S832845 & 2 & Pu-239, U-235, MFP & 1.50 & 78.7 & 0.0062 \\
\hline S832846 & 2 & Pu-239, U-235, MFP & 59.98 & 31.3 & 0.0062 \\
\hline S832847 & 2 & Pu-239, U-235, MFP & 29.98 & 15.6 & 0.0062 \\
\hline $\begin{array}{c}\text { TOTALS for } \\
\text { Shaft 221 }\end{array}$ & 12 & Pu-239, U-235, MFP & 176.42 & 92.00 & 0.04 \\
\hline
\end{tabular}

* RSWD = Radioactive Solid Waste Disposal record 


\section{Shaft 221 Totals}

\begin{tabular}{|c|c|c|}
\hline Total Number of Waste Packages & \multicolumn{2}{|c|}{6} \\
\hline Total Gross Weight (pounds) & \multicolumn{2}{|c|}{180} \\
\hline Total Pu-239 (grams) & \multicolumn{2}{|c|}{0.6} \\
\hline Total U-235 (grams) & \multicolumn{2}{|c|}{2.4} \\
\hline Total Mixed Fission Products (Ci) & \multicolumn{2}{|c|}{176.5} \\
\hline Dates of Disposal & \multicolumn{2}{|c|}{$3 / 10 / 1983$ to $3 / 10 / 1983$} \\
\hline Radiation at Surface of Waste Package ( $\mathrm{mR} / \mathrm{hr}$ ) & $\begin{array}{l}60,000 \text { to } 1,000,000 \\
\text { at disposal }\end{array}$ & $\begin{array}{l}31,000 \text { to } 414,000 \\
\text { decayed to } 2009\end{array}$ \\
\hline $\begin{array}{l}\text { Radiation at One Meter from Surface of Waste } \\
\text { Package }(\mathrm{mR} / \mathrm{hr})\end{array}$ & $\begin{array}{l}1,500 \text { to } 60,000 \\
\text { at disposal }\end{array}$ & $\begin{array}{l}220 \text { to } 2,900 * \\
\text { decayed to } 2009\end{array}$ \\
\hline
\end{tabular}

* Calculated using inverse square rule assuming a point source at the center of the waste package paint cans

\section{Detailed Waste Package Data at Disposal}

\begin{tabular}{|c|c|c|c|c|c|c|c|c|c|}
\hline $\begin{array}{c}\text { Waste } \\
\text { Package } \\
\text { RSWD } \\
\text { Number }\end{array}$ & $\begin{array}{c}\text { Date } \\
\text { Disposed }\end{array}$ & $\begin{array}{c}\text { Gross } \\
\text { Weight } \\
\text { (Ib) }\end{array}$ & Waste Description & $\begin{array}{c}\text { Additional } \\
\text { Description of } \\
\text { Packaging and } \\
\text { Packaging } \\
\text { Materials }\end{array}$ & $\begin{array}{l}\text { Nuclide } \\
\text { or } \\
\text { Material } \\
\text { Tupe }\end{array}$ & Amount & Units & $\begin{array}{l}\text { Package } \\
\text { Radiation } \\
\text { at Surface } \\
(\mathrm{mR} / \mathrm{hr})\end{array}$ & $\begin{array}{c}\text { Package } \\
\text { Radiation } \\
\text { at } 1 \text { meter } \\
(\mathrm{mR} / \mathrm{hr})\end{array}$ \\
\hline \multirow{3}{*}{ S832842 } & \multirow{3}{*}{$3 / 10 / 1983$} & \multirow{3}{*}{30} & \multirow{3}{*}{ Cell 1 wire wraps 3554} & \multirow{3}{*}{$400 \mathrm{R} / \mathrm{hr}$ contact } & Pu-239 & $1.00 \mathrm{E}-01$ & $\mathrm{~g}$ & \multirow{3}{*}{400,000} & \multirow{3}{*}{15,000} \\
\hline & & & & & U-235 & $4.00 \mathrm{E}-01$ & $\mathrm{~g}$ & & \\
\hline & & & & & MFP & $1.50 E+01$ & $\mathrm{Ci}$ & & \\
\hline \multirow{3}{*}{$\$ 832843$} & \multirow{3}{*}{$3 / 10 / 1983$} & \multirow{3}{*}{30} & \multirow{3}{*}{ Cell 1 wire wraps 3507} & \multirow{3}{*}{$1000+R / h r$ contact } & Pu-239 & $1.00 \mathrm{E}-01$ & $\mathrm{~g}$ & \multirow{3}{*}{$1,000,000$} & \multirow{3}{*}{30,000} \\
\hline & & & & & U-235 & 4.00E-01 & $\mathrm{g}$ & & \\
\hline & & & & & MFP & $3.00 E+01$ & $\mathrm{Ci}$ & & \\
\hline \multirow{3}{*}{$\$ 832844$} & \multirow{3}{*}{ 3/10/1983 } & \multirow{3}{*}{30} & \multirow{3}{*}{ Cell 14 hot trash 3569} & \multirow{3}{*}{$800 \mathrm{R} / \mathrm{hr}$ contact } & Pu-239 & $1.00 \mathrm{E}-01$ & $\mathrm{~g}$ & \multirow{3}{*}{800,000} & \multirow{3}{*}{40,000} \\
\hline & & & & & $U-235$ & 4.00E-01 & $\mathrm{g}$ & & \\
\hline & & & & & MFP & 4.00E+01 & $\mathrm{Ci}$ & & \\
\hline \multirow{3}{*}{ S832845 } & \multirow{3}{*}{ 3/10/1983 } & \multirow{3}{*}{30} & \multirow{3}{*}{$\begin{array}{l}\text { Cell } 14 \text { hot trash can } \\
3722\end{array}$} & \multirow{3}{*}{ Bottom entry cask } & Pu-239 & $1.00 \mathrm{E}-01$ & $\mathrm{~g}$ & \multirow{3}{*}{60,000} & \multirow{3}{*}{1,500} \\
\hline & & & & & $\mathrm{U}-235$ & 4.00E-01 & $\mathrm{g}$ & & \\
\hline & & & & & MFP & $1.50 \mathrm{E}+00$ & $\mathrm{Ci}$ & & \\
\hline \multirow{3}{*}{$\$ 832846$} & \multirow{3}{*}{ 3/10/1983 } & \multirow{3}{*}{30} & \multirow{3}{*}{ Cell 14 waste can 3720} & \multirow{3}{*}{$200 \mathrm{R} / \mathrm{hr}$ contact } & Pu-239 & $1.00 \mathrm{E}-01$ & $\mathrm{~g}$ & \multirow{3}{*}{200,000} & \multirow{3}{*}{60,000} \\
\hline & & & & & U-235 & $4.00 \mathrm{E}-01$ & $\mathrm{~g}$ & & \\
\hline & & & & & MFP & $6.00 E+01$ & $\mathrm{Ci}$ & & \\
\hline & & & Cell 14 waste can & 200 Rhrontan & Pu-239 & $1.00 \mathrm{E}-01$ & $\mathrm{~g}$ & & \\
\hline S832847 & 3/10/1983 & 30 & \#3721 & $200 \mathrm{~K} / \mathrm{hr}$ contact & U-235 & 4.00E-01 & $\mathrm{g}$ & 200,000 & 60,000 \\
\hline & & & & & MFP & $3.00 \mathrm{E}+01$ & $\mathrm{Ci}$ & & \\
\hline
\end{tabular}




\section{Material Disposal Area G, 33 Shafts Shaft 222 Waste Data Fact Sheet}

\section{Contents}

Shaft 222 contains seven packages of waste from the Chemistry and Metallurgy Research (CMR) Facility Wing 9 hot cells, with four packages containing waste placed inside two-gallon paint-type metal cans and placed into plastic bags. Three of the packages contain waste placed inside one-gallon paint-type metal cans and placed into plastic bags. Some paint-type cans may have been sealed in a plastic container before being placed into the plastic bag. Wastes include hot-cell trash, grinding papers, kimwipes, and plastic. Major radionuclides in the waste consist of plutonium-239, uranium-235, and mixed fission products (MFP). Waste is considered to be remote-handled with the reported radiation dose at the surface of the packages at the time of generation ranging from 10,000 to 900,000 $\mathrm{mrem} /$ hour. The seven packages of waste were placed into Shaft 222 in December 1983.

\section{Shaft Configuration}

Construction of Shaft 222 was initiated by augering a 36-inch diameter vertical hole into the mesa top. A 24-inch-diameter metal pipe (1/4 inch wall) with a length of 9 to 12 feet with a metal plate welded to the bottom was inserted into the hole as a liner. A 1/2 inch-wall inner pipe of 9- to 12-inch diameter and 7 to 12 feet in length with a metal plate welded to the bottom was centered in the larger pipe with a small amount of concrete to provide vertical alignment of the inner pipe in the outer pipe. Records with the specific dimensions for the pipes in Shaft 222 have not been located. A large metal funnel was placed in the inner pipe and waste packages were dropped into the inner pipe from a shielded transport cask moved into position above the shaft. After all waste packages were placed into the inner pipe, concrete was placed in the annular space between the pipes and the top of the shaft and auger hole were capped with 3 to 4 inches of concrete. The result is that the pipe containing the waste packages is completely encased in concrete.

\section{Shaft 222 Configuration}

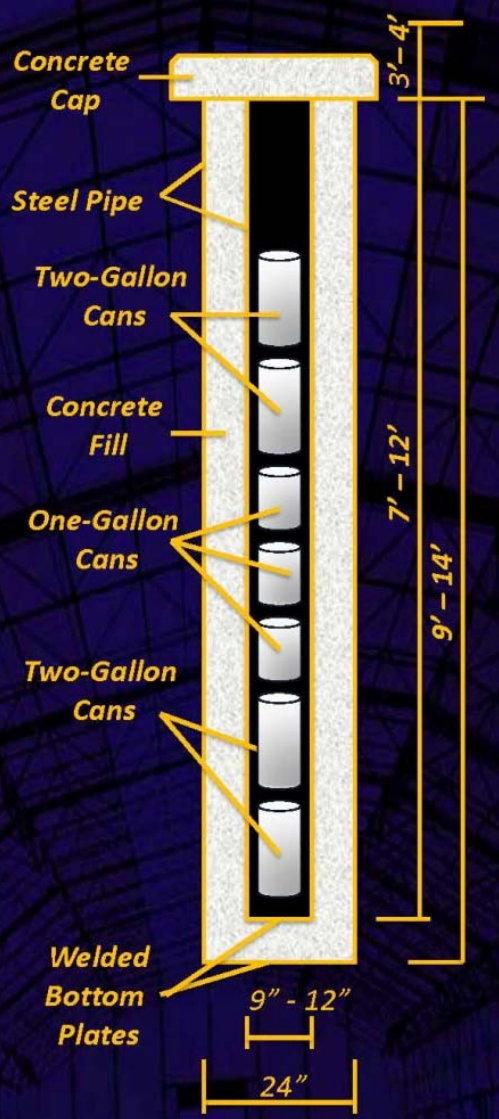

Waste Package Data Summary

\section{Location in Shaft Field}

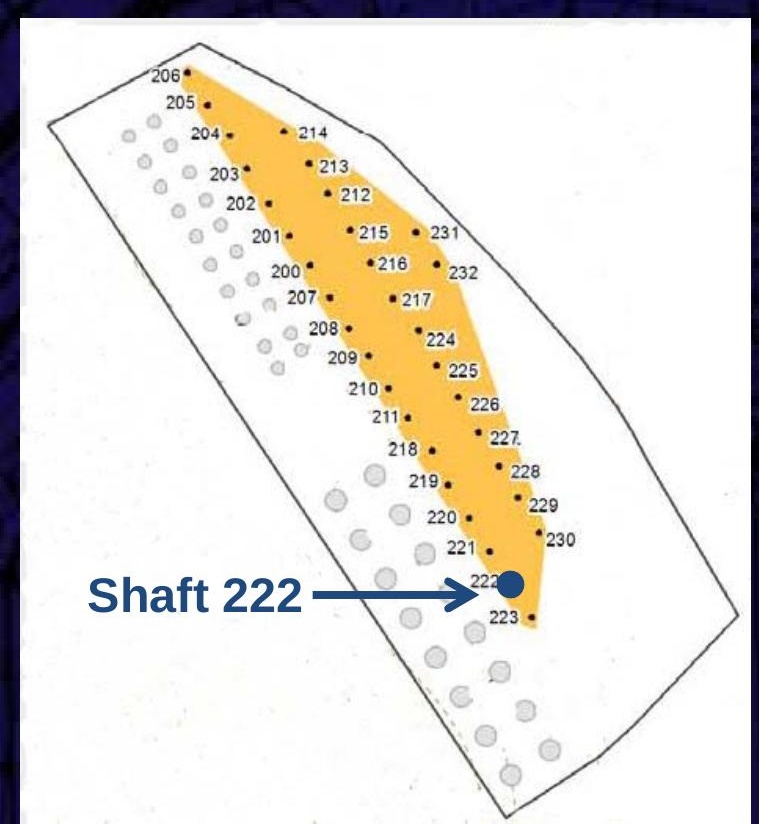

\begin{tabular}{|c|c|c|c|c|c|}
\hline $\begin{array}{c}\text { RSWD } \\
\text { Number }\end{array}$ & $\begin{array}{c}\text { Volume } \\
\text { (gallons) }\end{array}$ & Radionuclides & $\begin{array}{c}\text { Total Curies } \\
\text { at Disposal }\end{array}$ & $\begin{array}{c}\text { Total Curies } \\
\text { Decayed to 2009 }\end{array}$ & PE-Ci \\
\hline S830716 & 2 & Pu-239, U-235, MFP & 20.02 & 10.5 & 0.035 \\
\hline S830717 & 2 & Pu-239, U-235, MFP & 199.90 & $1.04 \mathrm{E}+02$ & 0.035 \\
\hline S830781 & 2 & Pu-239, U-235, MFP & 1.02 & 0.53 & 0.004 \\
\hline S830787 & 1 & Pu-239, U-235, MFP & 40.02 & 20.9 & 0.009 \\
\hline S830788 & 2 & Pu-239, U-235, MFP & 40.03 & 20.9 & 0.009 \\
\hline S830789 & 1 & Pu-239, U-235, MFP & 0.24 & 0.12 & 0.008 \\
\hline S830790 & 1 & Pu-239, U-235, MFP & 41.28 & 21.4 & 0.220 \\
\hline $\begin{array}{c}\text { TOTALS for } \\
\text { Shaft 222 }\end{array}$ & 11 & Pu-239, U-235, MFP & 342.52 & 178.53 & 0.32 \\
\hline
\end{tabular}

* RSWD = Radioactive Solid Waste Disposal record 


\section{Shaft 222 Totals}

\begin{tabular}{|c|c|c|}
\hline Total Number of Waste Packages & \multicolumn{2}{|c|}{7} \\
\hline Total Gross Weight (pounds) & \multicolumn{2}{|c|}{260} \\
\hline Total Pu-239 (grams) & \multicolumn{2}{|c|}{1.13} \\
\hline Total U-235 (grams) & \multicolumn{2}{|c|}{4.5} \\
\hline Total Mixed Fission Products (Ci) & \multicolumn{2}{|c|}{341.2} \\
\hline Total Pu-53 (grams) & \multicolumn{2}{|c|}{3.3} \\
\hline Total U-36 (grams) & \multicolumn{2}{|c|}{13.2} \\
\hline Dates of Disposal & \multicolumn{2}{|c|}{$12 / 14 / 1983$ to $12 / 14 / 1983$} \\
\hline Radiation at Surface of Waste Package ( $\mathrm{mR} / \mathrm{hr})$ & $\begin{array}{l}10,000 \text { to } 900,000 \\
\text { at disposal }\end{array}$ & $\begin{array}{l}5,200 \text { to } 466,000 \\
\text { decayed to } 2009\end{array}$ \\
\hline $\begin{array}{l}\text { Radiation at One Meter from Surface of Waste } \\
\text { Package }(\mathrm{mR} / \mathrm{hr})\end{array}$ & $\begin{array}{l}200 \text { to } 40,000 \\
\text { at disposal }\end{array}$ & $\begin{array}{l}40 \text { to } 3,300 * \\
\text { decayed to } 2009\end{array}$ \\
\hline
\end{tabular}

* Calculated using inverse square rule assuming a point source at the center of the waste package paint cans

\section{Detailed Waste Package Data at Disposal}

\begin{tabular}{|c|c|c|c|c|c|c|c|c|c|}
\hline $\begin{array}{c}\text { Waste } \\
\text { Package } \\
\text { RSWD } \\
\text { Number }\end{array}$ & $\begin{array}{c}\text { Date } \\
\text { Disposed }\end{array}$ & $\begin{array}{c}\text { Gross } \\
\text { Weight } \\
\text { (Ib) }\end{array}$ & Waste Description & $\begin{array}{l}\text { Additional } \\
\text { Description of } \\
\text { Packaging and } \\
\text { Packaging } \\
\text { Materials }\end{array}$ & $\begin{array}{c}\text { Nuclide } \\
\text { or } \\
\text { Material } \\
\text { Type }\end{array}$ & Amount & Units & $\begin{array}{c}\text { Package } \\
\text { Radiation } \\
\text { at Surface } \\
\text { (mR/hr) }\end{array}$ & $\begin{array}{c}\text { Package } \\
\text { Radiation } \\
\text { at } 1 \text { meter } \\
(\mathrm{mR} / \mathrm{hr})\end{array}$ \\
\hline \multirow{3}{*}{ S830716 } & \multirow{3}{*}{$12 / 14 / 1983$} & \multirow{3}{*}{30} & \multirow{3}{*}{$\begin{array}{l}\text { Cell } 14 \text { can } 3712 \text { fuel } \\
\text { scrap, paper, etc }\end{array}$} & \multirow{3}{*}{$900 \mathrm{Rhr}$ at contact } & Pu-239 & 5.64E-01 & $\mathrm{g}$ & \multirow{3}{*}{900,000} & \multirow{3}{*}{20,000} \\
\hline & & & & & $\mathrm{U}-235$ & $2.25 \mathrm{E}+00$ & $\mathrm{~g}$ & & \\
\hline & & & & & MFP & $2.00 \mathrm{E}+01$ & $\mathrm{Ci}$ & & \\
\hline \multirow{3}{*}{ S830717 } & \multirow{3}{*}{$12 / 14 / 1983$} & \multirow{3}{*}{30} & \multirow{3}{*}{$\begin{array}{l}\text { Cell } 14 \text { can } 3718 \text { fuel } \\
\text { scrap, paper, etc }\end{array}$} & \multirow{3}{*}{$\begin{array}{l}200 \mathrm{Rhr} \text { at one } \\
\text { meter+1000 Rhr } \\
\text { contact }\end{array}$} & Pu-239 & 5.64E-01 & $\mathrm{g}$ & & \\
\hline & & & & & $\mathrm{U}-235$ & $2.25 \mathrm{E}+00$ & $\mathrm{~g}$ & & \\
\hline & & & & & MFP & $2.00 E+02$ & $\mathrm{Ci}$ & & \\
\hline \multirow{3}{*}{ S830781 } & \multirow{3}{*}{$12 / 14 / 1983$} & \multirow{3}{*}{40} & \multirow{3}{*}{ Cell 14 trash 1 can } & \multirow{3}{*}{$\begin{array}{l}\text { Bottom entry, ST can } \\
\qquad \# 1\end{array}$} & Pu-53 & $5.00 E-02$ & $\mathrm{~g}$ & \multirow{3}{*}{20,000} & \multirow{3}{*}{1,000} \\
\hline & & & & & U-36 & 2.00E-01 & $\mathrm{g}$ & & \\
\hline & & & & & MFP & $1.00 E+00$ & $\mathrm{Ci}$ & & \\
\hline \multirow{3}{*}{ S830787 } & \multirow{3}{*}{$12 / 14 / 1983$} & \multirow{3}{*}{40} & \multirow{3}{*}{ Cell 9 trash 1 can } & \multirow{3}{*}{$\begin{array}{l}\text { Bottom entry steel can } \\
\quad \# 10200 \mathrm{R} / \mathrm{hr} \mathrm{C} .\end{array}$} & Pu-53 & $1.20 \mathrm{E}-01$ & $\mathrm{~g}$ & \multirow{3}{*}{200,000} & \multirow{3}{*}{40,000} \\
\hline & & & & & $\mathrm{U}-36$ & 5.00E-01 & $\mathrm{g}$ & & \\
\hline & & & & & MFP & $4.00 E+01$ & $\mathrm{Ci}$ & & \\
\hline \multirow{3}{*}{ S830788 } & \multirow{3}{*}{$12 / 14 / 1983$} & \multirow{3}{*}{40} & \multirow{3}{*}{ Cell 14 trash 1 can } & \multirow{3}{*}{$\begin{array}{l}\text { Bottom entry steel can } \\
\text { \#6 } 100 \mathrm{R} / \mathrm{hr} \text { cont. }\end{array}$} & Pu-53 & 1.20E-01 & $\mathrm{g}$ & \multirow{3}{*}{100,000} & \multirow{3}{*}{40,000} \\
\hline & & & & & $\mathrm{U}-36$ & $5.00 \mathrm{E}-01$ & $\mathrm{~g}$ & & \\
\hline & & & & & MFP & $4.00 E+01$ & $\mathrm{Ci}$ & & \\
\hline & & & & & Pu-53 & $1.00 \mathrm{E}-01$ & $\mathrm{~g}$ & & \\
\hline S830789 & $12 / 14 / 1983$ & 40 & Cell 14 trash 1 can & Steel can \#8 & U-36 & 4.00E-01 & $\mathrm{g}$ & 10,000 & 200 \\
\hline & & & & & MFP & 2.00E-01 & $\mathrm{Ci}$ & & \\
\hline & & & & & $\mathrm{Pu}-53$ & $2.91 \mathrm{E}+00$ & $\mathrm{~g}$ & & \\
\hline$\$ 830790$ & $12 / 14 / 1983$ & 40 & Cell 14 trash 1 can & $\begin{array}{c}\text { soel can } H 9 \text { cou } \\
\text { cont }\end{array}$ & U-36 & $1.16 \mathrm{E}+01$ & $\mathrm{~g}$ & 200,000 & 40,000 \\
\hline & & & & & MFP & 4.00E+01 & $\mathrm{Ci}$ & & \\
\hline
\end{tabular}




\section{Material Disposal Area G, 33 Shafts Shaft 223 Waste Data Fact Sheet}

\section{Contents}

Shaft 223 contains six packages of waste from the Chemistry and Metallurgy Research (CMR) Facility Wing 9 hot cells, with each package containing waste placed inside a two-gallon paint-type metal can and placed into a plastic bag. Some paint-type cans may have been sealed in a plastic container before being placed into the plastic bag. Wastes include hot-cell trash, grinding papers, kimwipes, and plastic. Major radionuclides in the waste consist of plutonium-239, uranium-235, and mixed fission products (MFP). Waste is considered to be remote-handled with the reported radiation dose at the surface of the packages at the time of generation ranging from 60,000 to 1,000,000 mrem/hour. The six packages of waste were placed into Shaft 223 in December 1983.

\section{Shaft Configuration}

Construction of Shaft 223 was initiated by augering a 36-inch diameter vertical hole into the mesa top. A 24-inch-diameter metal pipe (1/4 inch wall) with a length of 9 to 12 feet with a metal plate welded to the bottom was inserted into the hole as a liner. A 1/2 inch-wall inner pipe of 9- to 12-inch diameter and 7 to 12 feet in length with a metal plate welded to the bottom was centered in the larger pipe with a small amount of concrete to provide vertical alignment of the inner pipe in the outer pipe. Records with the specific dimensions for the pipes in Shaft 223 have not been located. A large metal funnel was placed in the inner pipe and waste packages were dropped into the inner pipe from a shielded transport cask moved into position above the shaft. After all waste packages were placed into the inner pipe, concrete was placed in the annular space between the pipes and the top of the shaft and auger hole were capped with 3 to 4 inches of concrete. The result is that the pipe containing the waste packages is completely encased in concrete.

\section{Shaft 223 Configuration}

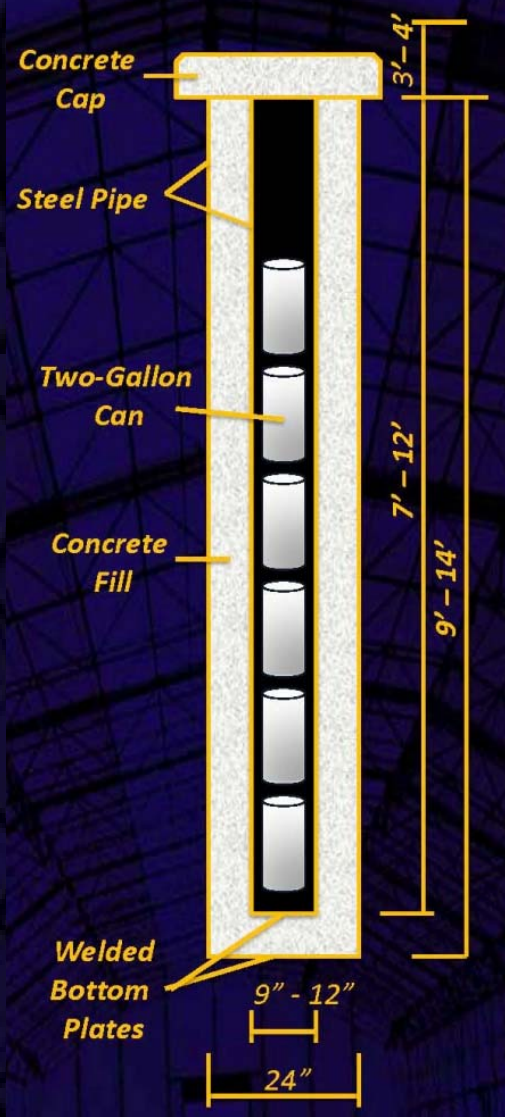

Waste Package Data Summary

\section{Location in Shaft Field}

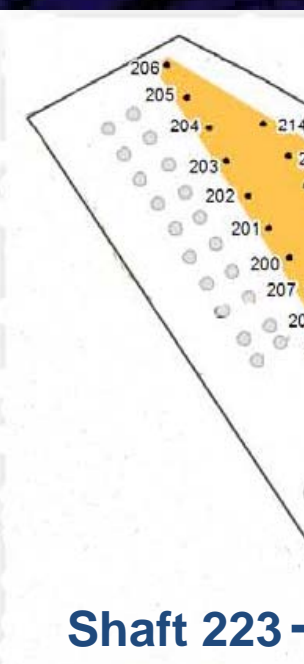

\begin{tabular}{|c|c|c|c|c|c|}
\hline $\begin{array}{c}\text { RSWD * } \\
\text { Number }\end{array}$ & $\begin{array}{c}\text { Volume } \\
\text { (gallons) }\end{array}$ & Radionuclides & $\begin{array}{c}\text { Total Curies } \\
\text { at Disposal }\end{array}$ & $\begin{array}{c}\text { Total Curies } \\
\text { Decayed to 2009 }\end{array}$ & PE-Ci \\
\hline S830782 & 2 & Pu-239, U-235, MFP & 25.01 & 13.0 & 0.004 \\
\hline S830783 & 2 & Pu-239, U-235, MFP & 3.04 & 1.58 & 0.008 \\
\hline S830784 & 2 & Pu-239, U-235, MFP & 3.04 & 1.58 & 0.008 \\
\hline S830785 & 2 & Pu-239, U-235, MFP & 3.04 & 1.58 & 0.008 \\
\hline S830786 & 2 & Pu-239, U-235, MFP & 1.52 & 0.79 & 0.004 \\
\hline S830791 & 2 & Pu-239, U-235, MFP & 1.54 & 0.80 & 0.008 \\
\hline $\begin{array}{c}\text { TOTALS for } \\
\text { Shaft 223 }\end{array}$ & 12 & Pu-239, U-235, MFP & 37.20 & 19.37 & 0.04 \\
\hline
\end{tabular}

* RSWD = Radioactive Solid Waste Disposal record 


\section{Shaft 223 Totals}

\begin{tabular}{|c|c|c|}
\hline Total Number of Waste Packages & \multicolumn{2}{|c|}{6} \\
\hline Total Gross Weight (pounds) & \multicolumn{2}{|c|}{240} \\
\hline Total Pu-239 (grams) & \multicolumn{2}{|c|}{0} \\
\hline Total U-235 (grams) & \multicolumn{2}{|c|}{$\mathbf{0}$} \\
\hline Total Mixed Fission Products (Ci) & \multicolumn{2}{|c|}{37} \\
\hline Total Pu-53 (grams) & \multicolumn{2}{|c|}{0.5} \\
\hline Total U-36 (grams) & \multicolumn{2}{|c|}{2} \\
\hline Dates of Disposal & \multicolumn{2}{|c|}{$12 / 14 / 1983$ to $12 / 14 / 1983$} \\
\hline Radiation at Surface of Waste Package ( $\mathrm{mR} / \mathrm{hr}$ ) & $\begin{array}{l}20,000 \text { to } 100,000 \\
\text { at disposal }\end{array}$ & $\begin{array}{l}10,000 \text { to } 52,000 \\
\text { decayed to } 2009\end{array}$ \\
\hline $\begin{array}{l}\text { Radiation at One Meter from Surface of Waste } \\
\text { Package }(\mathrm{mR} / \mathrm{hr})\end{array}$ & $\begin{array}{l}1,500 \text { to } 25,000 \\
\text { at disposal }\end{array}$ & $\begin{array}{c}70 \text { to } 370 * \\
\text { decayed to } 2009\end{array}$ \\
\hline
\end{tabular}

* Calculated using inverse square rule assuming a point source at the center of the waste package paint cans

\section{Detailed Waste Package Data at Disposal}

Waste

Package

RSWD

Number

\begin{tabular}{|c|c|c|c|}
\hline S830782 & $12 / 14 / 1983$ & 40 & Cell 14 trash 1 can \\
\hline S830783 & $12 / 14 / 1983$ & 40 & Cell 14 trash 1 can \\
\hline S830784 & $12 / 14 / 1983$ & 40 & Cell 14 trash 1 can \\
\hline S830785 & $12 / 14 / 1983$ & 40 & Cell 14 trash 1 can \\
\hline S830786 & $12 / 14 / 1983$ & 40 & Cell 14 trash 1 can \\
\hline S830791 & $12 / 14 / 1983$ & 40 & Cell 16 trash 1 can \\
\hline
\end{tabular}

Date

Disposed

Gross

Weight

(Ib)

Waste Description
Additional Description of

Packaging and

Packaging

Materials

Bottom entry $100 \mathrm{R}$ contact can \#5

Bottom entry steel can

\#3

Bottom entry steel can

\#4

Bottom entry steel can

\#7

\begin{tabular}{c} 
Steel can \#2; \\
\cline { 2 - 2 } \\
Bottom entry steel can \\
$\# 11$
\end{tabular}

Nuclide

or

Material

Type

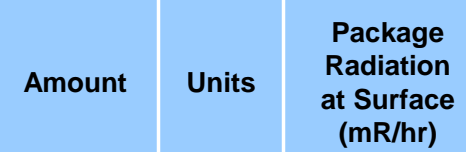

at Surfac
(mR/hr)

\begin{tabular}{|c|c|c|}
\hline Pu-53 & $5.00 E-02$ & $\mathrm{~g}$ \\
\hline $\mathrm{U}-36$ & $2.00 \mathrm{E}-01$ & $\mathrm{~g}$ \\
\hline $\mathrm{MFP}$ & $2.50 \mathrm{E}+01$ & $\mathrm{Ci}$ \\
\hline
\end{tabular}

100,000

25,000

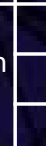

\begin{tabular}{|c|}
\hline Pu-53 \\
\hline U-36 \\
\hline MFP \\
\hline
\end{tabular}

\begin{tabular}{|c|c|}
\hline Pu-53 & \\
\hline U-36 & \\
\hline MFP & \\
\hline
\end{tabular}

\begin{tabular}{ll}
$3.00 \mathrm{E}+00$ & $\mathrm{~g}$ \\
\hline
\end{tabular}

$1.00 \mathrm{E}-01$

\begin{tabular}{|l|}
$1.00 E-01$ \\
\hline $4.00 E-01$
\end{tabular}

$3.00 \mathrm{E}+00$

\begin{tabular}{|c|}
\hline Pu-53 \\
\hline U-36 \\
\hline MFP \\
\hline
\end{tabular}

\begin{tabular}{|c|}
\hline $4.00 \mathrm{E}-01$ \\
\hline $3.00 \mathrm{E}+00$
\end{tabular}

Pu-53

\begin{tabular}{ll}
$5.00 \mathrm{E}-02$ & $\mathrm{Ci}$ \\
\hline
\end{tabular}

\begin{tabular}{|c|c|c|}
\hline $\mathrm{U}-36$ & $2.00 \mathrm{E}-01$ & $\mathrm{~g}$ \\
\hline $\mathrm{MFP}$ & $1.50 \mathrm{E}+00$ & $\mathrm{Ci}$ \\
\hline $\mathrm{Pu}-53$ & $1.00 \mathrm{E}-01$ & $\mathrm{~g}$ \\
\hline $\mathrm{U}-36$ & $4.00 \mathrm{E}-01$ & $\mathrm{~g}$ \\
\hline $\mathrm{MFP}$ & $1.50 \mathrm{E}+00$ & $\mathrm{Ci}$ \\
\hline
\end{tabular}

32,000

Package

Radiation

at 1 meter

(mR/hr) 


\section{Material Disposal Area G, 33 Shafts Shaft 225 Waste Data Fact Sheet}

\section{Contents}

Shaft 225 contains eight packages of waste from the Chemistry and Metallurgy Research (CMR) Facility Wing 9 hot cells, with each package containing waste in a one-gallon paint-type can that is inside a rigid plastic liner that is inside a 1/8" wall welded steel can. Wastes include hot-cell trash, spent-fuel sample preparation residues, cladding, tissue, and small tools. Major radionuclides in the waste consist of plutonium-239, uranium235, and mixed fission products (MFP). Waste is considered to be remotehandled with the reported radiation dose at the surface of the packages at the time of generation ranging from 10,000 to $105,000 \mathrm{mrem} /$ hour. The eight packages of waste were placed into Shaft 225 in November 1984 to December 1984.

\section{Shaft Configuration}

Construction of Shaft 225 was initiated by augering a 36-inch diameter vertical hole into the mesa top. An 1/4 inch wall inner pipe of 9-inch diameter and 9 feet in length was centered in the shaft with crushed tuff used to fill the space between the pipe and the shaft. A large metal funnel was placed in the inner pipe, and waste packages were dropped into the inner pipe from a shielded transport cask moved into position above the shaft. After all waste packages were placed into the pipe, a latching lid with a lifting ring was placed onto the top of the pipe, and the shaft was protected by an inverted cut-down 55-gallon drum placed on top of the shaft.

\section{Shaft 225 Configuration}

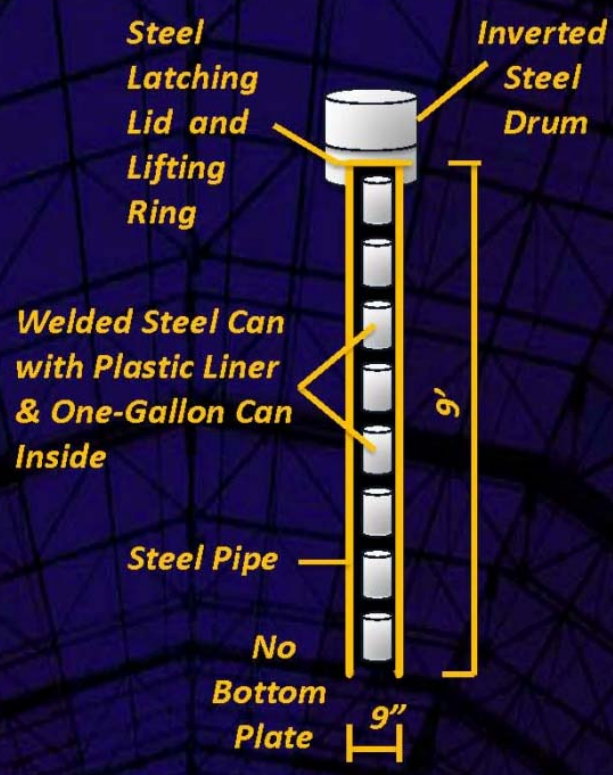

\section{Location in Shaft Field}

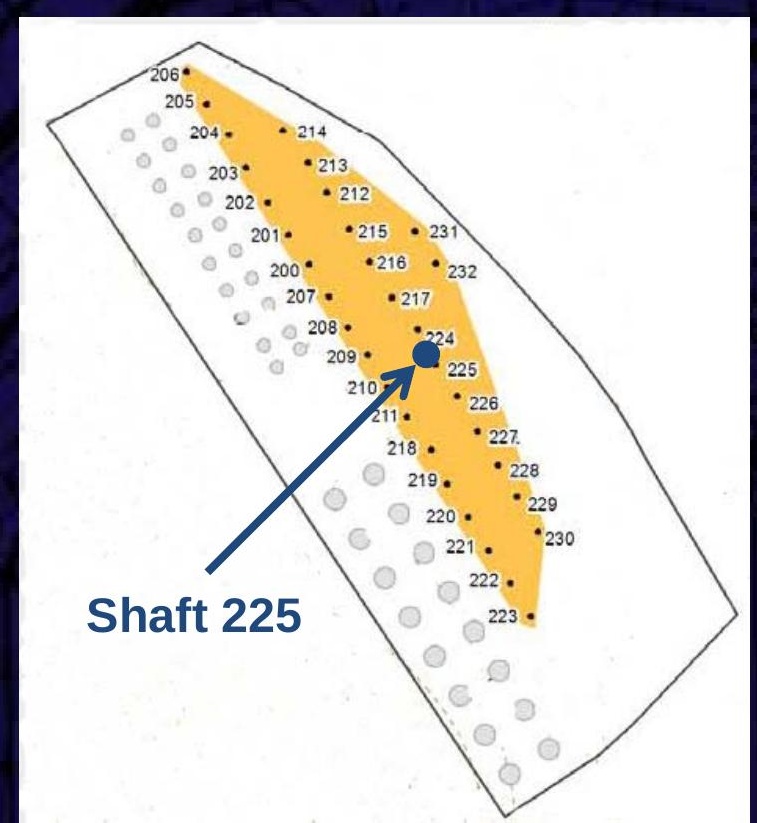

Waste Package Data Summary

\begin{tabular}{|c|c|c|c|c|c|}
\hline $\begin{array}{c}\text { RSWD } \\
\text { Number }\end{array}$ & $\begin{array}{c}\text { Volume } \\
\text { (gallons) }\end{array}$ & Radionuclides & $\begin{array}{c}\text { Total Curies } \\
\text { at Disposal }\end{array}$ & $\begin{array}{c}\text { Total Curies } \\
\text { Decayed to 2009 }\end{array}$ & PE-Ci \\
\hline S840848 & 1 & Pu-239, U-235, MFP & 0.41 & 0.22 & 0.0062 \\
\hline S840854 & 1 & Pu-239, U-235, MFP & 1.50 & 0.81 & 0.0062 \\
\hline S840856 & 1 & Pu-239, U-235, MFP & 1.50 & 0.81 & 0.0062 \\
\hline S840857 & 1 & Pu-239, U-235, MFP & 3.00 & 1.61 & 0.0062 \\
\hline S840863 & 1 & Pu-239, U-235, MFP & 0.09 & 0.05 & 0.0062 \\
\hline S840864 & 1 & Pu-239, U-235, MFP & 0.31 & 0.17 & 0.0062 \\
\hline S840867 & 1 & Pu-239, U-235, MFP & 0.41 & 0.22 & 0.0062 \\
\hline S840874 & 1 & Pu-239, U-235, MFP & 0.21 & 0.11 & 0.0062 \\
\hline TOTALS for & 8 & Pu-239, U-235, MFP & 7.42 & 3.99 & 0.05 \\
\hline Shaft 225 & & & & & \\
\hline
\end{tabular}

* RSWD = Radioactive Solid Waste Disposal record

This fact sheet was compiled from information judged to be the most reliable and accurate available. Waste information from the 1970's and 1980's has gaps and is sometimes inconsistent between various records or reports. 


\section{Shaft 225 Totals}

\begin{tabular}{|c|c|c|}
\hline Total Number of Waste Packages & \multicolumn{2}{|c|}{8} \\
\hline Total Gross Weight (pounds) & \multicolumn{2}{|c|}{240} \\
\hline Total Pu-239 (grams) & \multicolumn{2}{|c|}{0.8} \\
\hline Total U-235 (grams) & \multicolumn{2}{|c|}{3.2} \\
\hline Total Mixed Fission Products at disposal (Ci) & \multicolumn{2}{|c|}{7.38} \\
\hline Dates of Disposal & \multicolumn{2}{|c|}{$11 / 16 / 1984$ to $12 / 31 / 1984$} \\
\hline Radiation at Surface of Waste Package ( $\mathrm{mR} / \mathrm{hr}$ ) & $\begin{array}{l}10,000 \text { to } 105,000 \\
\text { at disposal }\end{array}$ & $\begin{array}{l}5,300 \text { to } 56,000 \\
\text { decayed to } 2009\end{array}$ \\
\hline $\begin{array}{l}\text { Radiation at One Meter from Surface of Waste } \\
\text { Package ( } \mathrm{mR} / \mathrm{hr})\end{array}$ & $\begin{array}{l}80 \text { to } 3,000 \\
\text { at disposal }\end{array}$ & $\begin{array}{c}40 \text { to } 400 * \\
\text { decayed to } 2009\end{array}$ \\
\hline
\end{tabular}

* Calculated using inverse square rule assuming a point source at the center of the waste package paint cans

\section{Detailed Waste Package Data at Disposal}

\begin{tabular}{|c|c|c|c|c|c|c|c|c|c|}
\hline $\begin{array}{l}\text { RSWD } \\
\text { Number }\end{array}$ & $\begin{array}{c}\text { Date } \\
\text { Disposed }\end{array}$ & $\begin{array}{c}\text { Gross } \\
\text { Weight } \\
\text { (lb) }\end{array}$ & Waste Description & $\begin{array}{l}\text { Additional } \\
\text { Description of } \\
\text { Packaging and } \\
\text { Packaging } \\
\text { Materials }\end{array}$ & $\begin{array}{l}\text { Nuclide } \\
\text { or } \\
\text { Material } \\
\text { Type }\end{array}$ & Amount & Units & $\begin{array}{c}\text { Package } \\
\text { Radiation } \\
\text { at Surface } \\
\text { (mR/hr) }\end{array}$ & $\begin{array}{c}\text { Package } \\
\text { Radiation } \\
\text { at } 1 \text { meter } \\
(\mathrm{mR} / \mathrm{hr})\end{array}$ \\
\hline \multirow{3}{*}{ S840848 } & \multirow{3}{*}{$\begin{array}{l}12 / 31 / 1984 \\
11 / 19 / 1984\end{array}$} & \multirow{3}{*}{30} & \multirow{3}{*}{$\begin{array}{l}\text { Cell } 13 \text { waste plastic } \\
\text { can } \# 4076\end{array}$} & \multirow{3}{*}{ Steel can \#21 } & Pu-239 & $1.00 \mathrm{E}-01$ & $\mathrm{~g}$ & \multirow{3}{*}{40,000} & \multirow{3}{*}{400} \\
\hline & & & & & $\mathrm{U}-235$ & 4.00E-01 & $\mathrm{g}$ & & \\
\hline & & & & & MFP & $4.00 \mathrm{E}-01$ & $\mathrm{Ci}$ & & \\
\hline \multirow{3}{*}{ S840854 } & \multirow{3}{*}{$\begin{array}{l}12 / 31 / 1984 \\
11 / 16 / 1984\end{array}$} & \multirow{3}{*}{30} & \multirow{3}{*}{$\begin{array}{l}\text { Cell } 13 \text { waste plastic } \\
\text { can } \# 4033\end{array}$} & \multirow{3}{*}{ Steel can \#24 } & Pu-239 & $1.00 \mathrm{E}-01$ & $\mathrm{~g}$ & \multirow{3}{*}{50,000} & \multirow{3}{*}{1,500} \\
\hline & & & & & U-235 & 4.00E-01 & $\mathrm{g}$ & & \\
\hline & & & & & MFP & $1.50 \mathrm{E}+00$ & $\mathrm{Ci}$ & & \\
\hline \multirow{3}{*}{ S840856 } & \multirow{3}{*}{$\begin{array}{l}12 / 31 / 1984 ? \\
11 / 16 / 1984 ?\end{array}$} & \multirow{3}{*}{30} & \multirow{3}{*}{$\begin{array}{l}\text { Cell } 13 \text { waste plastic } \\
\text { can } \# 4043\end{array}$} & \multirow{3}{*}{ Steel can \#31 } & Pu-239 & $1.00 \mathrm{E}-01$ & $\mathrm{~g}$ & \multirow{3}{*}{90,000} & \multirow{3}{*}{1,500} \\
\hline & & & & & $\mathrm{U}-235$ & $4.00 E-01$ & $\mathrm{~g}$ & & \\
\hline & & & & & MFP & $1.50 \mathrm{E}+00$ & $\mathrm{Ci}$ & & \\
\hline \multirow{3}{*}{ S840857 } & \multirow{3}{*}{$12 / 31 / 1984$} & \multirow{3}{*}{30} & \multirow{3}{*}{$\begin{array}{l}\text { Cell } 13 \text { waste plastic } \\
\text { can } \# 4035\end{array}$} & \multirow{3}{*}{$\begin{array}{c}105 \mathrm{R} / \mathrm{hr} @ \text { cont steel } \\
\text { can \#30 }\end{array}$} & Pu-239 & $1.00 \mathrm{E}-01$ & $\mathrm{~g}$ & \multirow{3}{*}{105,000} & \multirow{3}{*}{3,000} \\
\hline & & & & & U-235 & $4.00 E-01$ & $\mathrm{~g}$ & & \\
\hline & & & & & MFP & $3.00 E+00$ & $\mathrm{Ci}$ & & \\
\hline \multirow{3}{*}{ S840863 } & \multirow{3}{*}{$\begin{array}{l}12 / 31 / 1984 \\
11 / 19 / 1984\end{array}$} & \multirow{3}{*}{30} & \multirow{3}{*}{$\begin{array}{l}\text { Cell } 13 \text { waste plastic } \\
\text { can } \# 4046\end{array}$} & & Pu-239 & $1.00 \mathrm{E}-01$ & $\mathrm{~g}$ & & \\
\hline & & & & Steel can \#40 & U-235 & $4.00 E-01$ & $\mathrm{~g}$ & 10,000 & 80 \\
\hline & & & & & MFP & 8.00E-02 & $\mathrm{Ci}$ & & \\
\hline & & & & & Pu-239 & $1.00 \mathrm{E}-01$ & $\mathrm{~g}$ & & \\
\hline S840864 & $\begin{array}{l}12 / 31 / 1984 \\
11 / 19 / 1984\end{array}$ & 30 & $\begin{array}{l}\text { cen \#4044 } \\
\text { castic }\end{array}$ & Steel can \#34 & $\mathrm{U}-235$ & 4.00E-01 & $\mathrm{g}$ & 25,000 & 300 \\
\hline & & & & & MFP & 3.00E-01 & $\mathrm{Ci}$ & & \\
\hline & & & & & Pu-239 & $1.00 \mathrm{E}-01$ & $\mathrm{~g}$ & & \\
\hline S840867 & $12 / 31 / 1984$ & 30 & $\begin{array}{l}\text { can \#4054 } \\
\text { calc }\end{array}$ & Steel can \#38 & U-235 & 4.00E-01 & $\mathrm{g}$ & 30,000 & 400 \\
\hline & & & & & MFP & 4.00E-01 & $\mathrm{Ci}$ & & \\
\hline & & & & & Pu-239 & 1.00E-01 & $\mathrm{g}$ & & \\
\hline S840874 & $\begin{array}{l}12 / 31 / 1984 \\
11 / 20 / 1984\end{array}$ & 30 & Cell 14 trash can 4051 & Steel can \#43 & $\mathrm{U}-235$ & $4.00 \mathrm{E}-01$ & $\mathrm{~g}$ & 15,000 & 200 \\
\hline & & & & & MFP & 2.00E-01 & $\mathrm{Ci}$ & & \\
\hline
\end{tabular}




\section{Material Disposal Area G, 33 Shafts Shaft 226 Waste Data Fact Sheet}

\section{Contents}

Shaft 226 contains eight packages of waste from the Chemistry and Metallurgy Research (CMR) Facility Wing 9 hot cells, with each package containing waste in a one-gallon paint-type can that is inside a rigid plastic liner that is inside a 1/8" wall welded steel can. Wastes include hot-cell trash, spent-fuel sample preparation residues, cladding, tissue, and small tools. Major radionuclides in the waste consist of plutonium-239, uranium235, and mixed fission products (MFP). Waste is considered to be remotehandled with the reported radiation dose at the surface of the packages at the time of generation ranging from 15,000 to $300,000 \mathrm{mrem} /$ hour. The eight packages of waste were placed into Shaft 226 in November 1984 to December 1984.

\section{Shaft Configuration}

Construction of Shaft 226 was initiated by augering a 36-inch diameter vertical hole into the mesa top. An 1/4 inch wall inner pipe of 9-inch diameter and 9 feet in length was centered in the shaft with crushed tuff used to fill the space between the pipe and the shaft. A large metal funnel was placed in the inner pipe, and waste packages were dropped into the inner pipe from a shielded transport cask moved into position above the shaft. After all waste packages were placed into the pipe, a latching lid with a lifting ring was placed onto the top of the pipe, and the shaft was protected by an inverted cut-down 55-gallon drum placed on top of the shaft.

\section{Shaft 226 Configuration}

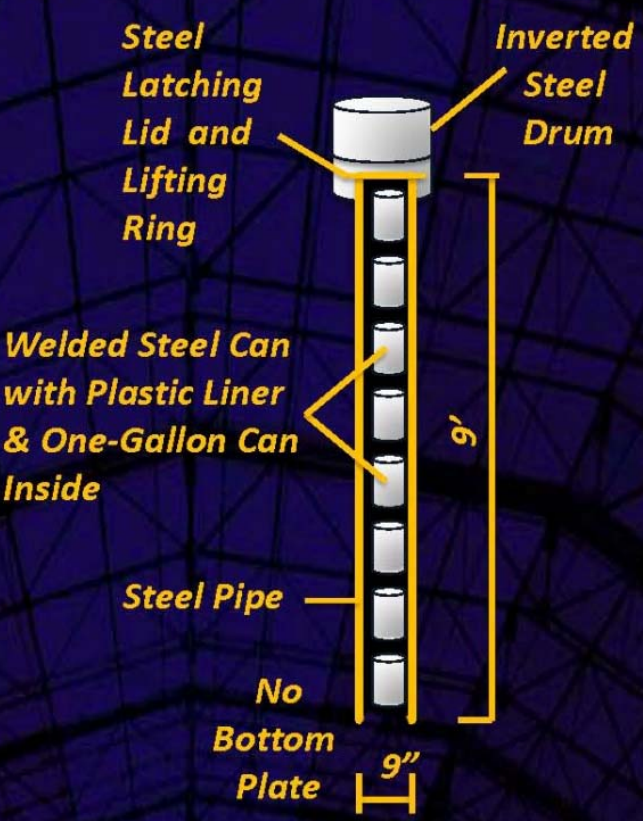

\section{Location in Shaft Field}

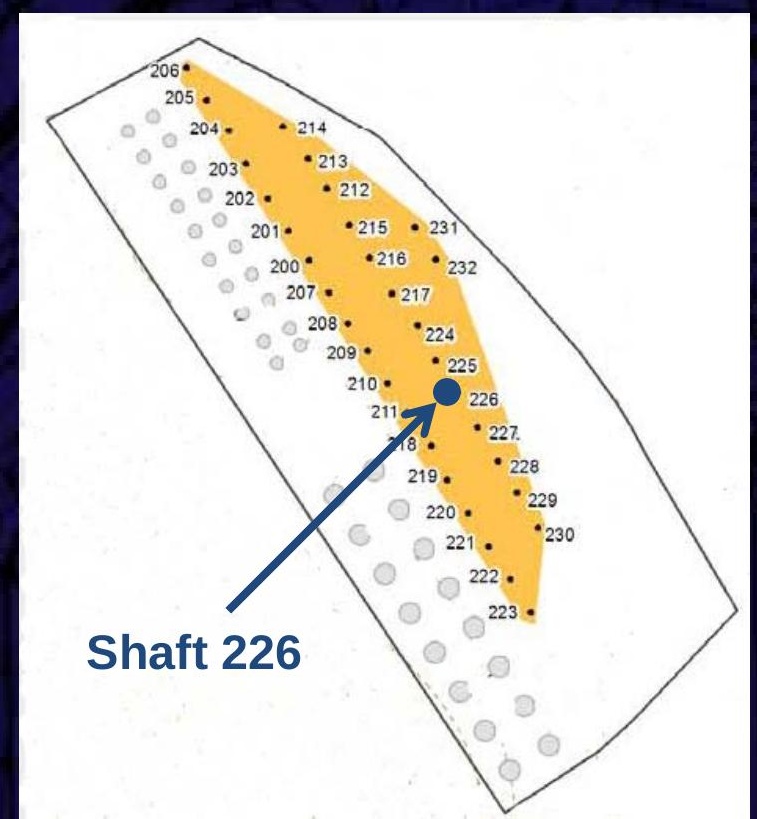

Waste Package Data Summary

\begin{tabular}{|c|c|c|c|c|c|}
\hline $\begin{array}{c}\text { RSWD } \\
\text { Number }\end{array}$ & $\begin{array}{c}\text { Volume } \\
\text { (gallons) }\end{array}$ & Radionuclides & $\begin{array}{c}\text { Total Curies } \\
\text { at Disposal }\end{array}$ & $\begin{array}{c}\text { Total Curies } \\
\text { Decayed to 2009 }\end{array}$ & PE-Ci \\
\hline S840842 & 1 & Pu-239, U-235, MFP & 2.00 & 1.07 & 0.0062 \\
\hline S840843 & 1 & Pu-239, U-235, MFP & 2.00 & 1.07 & 0.0062 \\
\hline S840844 & 1 & Pu-239, U-235, MFP & 1.50 & 0.81 & 0.0062 \\
\hline S840845 & 1 & Pu-239, U-235, MFP & 0.31 & 0.17 & 0.0062 \\
\hline S840846 & 1 & Pu-239, U-235, MFP & 5.02 & 2.67 & 0.0062 \\
\hline S840847 & 1 & Pu-239, U-235, MFP & 1.50 & 0.81 & 0.0062 \\
\hline S840862 & 1 & Pu-239, U-235, MFP & 0.21 & 0.11 & 0.0062 \\
\hline S840868 & 1 & Pu-239, U-235, MFP & 0.31 & 0.17 & 0.0062 \\
\hline TOTALS for & 8 & Pu-239, U-235, MFP & 12.85 & 6.88 & 0.05 \\
\hline Shaft 226 & & & & & \\
\hline
\end{tabular}

* RSWD $=$ Radioactive Solid Waste Disposal record 


\section{Shaft 226 Totals}

\begin{tabular}{|c|c|c|}
\hline Total Number of Waste Packages & \multicolumn{2}{|c|}{8} \\
\hline Total Gross Weight (pounds) & \multicolumn{2}{|c|}{240} \\
\hline Total Pu-239 (grams) & \multicolumn{2}{|c|}{0.8} \\
\hline Total U-235 (grams) & \multicolumn{2}{|c|}{3.2} \\
\hline Total Mixed Fission Products at disposal (Ci) & \multicolumn{2}{|c|}{12.8} \\
\hline Dates of Disposal & \multicolumn{2}{|c|}{$11 / 14 / 1984$ to $12 / 31 / 1984$} \\
\hline Radiation at Surface of Waste Package ( $\mathrm{mR} / \mathrm{hr}$ ) & $\begin{array}{l}15,000 \text { to } 300,000 \\
\text { at disposal }\end{array}$ & $\begin{array}{l}8,000 \text { to } 159,000 \\
\text { decayed to } 2009\end{array}$ \\
\hline $\begin{array}{l}\text { Radiation at One Meter from Surface of Waste } \\
\text { Package }(\mathrm{mR} / \mathrm{hr})\end{array}$ & $\begin{array}{l}200 \text { to } 5,000 \\
\text { at disposal }\end{array}$ & $\begin{array}{l}60 \text { to } 1,130 * \\
\text { decayed to } 2009\end{array}$ \\
\hline
\end{tabular}

* Calculated using inverse square rule assuming a point source at the center of the waste package paint cans

\section{Detailed Waste Package Data at Disposal}

\begin{tabular}{|c|c|c|c|c|c|c|c|c|c|}
\hline $\begin{array}{l}\text { RSWD } \\
\text { Number }\end{array}$ & $\begin{array}{c}\text { Date } \\
\text { Disposed }\end{array}$ & $\begin{array}{c}\text { Gross } \\
\text { Weight } \\
\text { (lb) }\end{array}$ & Waste Description & $\begin{array}{l}\text { Additional } \\
\text { Description of } \\
\text { Packaging and } \\
\text { Packaging } \\
\text { Materials }\end{array}$ & $\begin{array}{l}\text { Nuclide } \\
\text { or } \\
\text { Material } \\
\text { Type }\end{array}$ & Amount & Units & $\begin{array}{c}\text { Package } \\
\text { Radiation } \\
\text { at Surface } \\
\text { (mR/hr) }\end{array}$ & $\begin{array}{c}\text { Package } \\
\text { Radiation } \\
\text { at } 1 \text { meter } \\
(\mathrm{mR} / \mathrm{hr})\end{array}$ \\
\hline \multirow{3}{*}{ S840842 } & \multirow{3}{*}{$\begin{array}{l}12 / 31 / 1984 \\
11 / 14 / 1984\end{array}$} & \multirow{3}{*}{30} & \multirow{3}{*}{$\begin{array}{l}\text { Cell } 13 \text { waste plastic } \\
\text { can } \# 4056\end{array}$} & \multirow{3}{*}{ Steel can \#20 } & Pu-239 & $1.00 \mathrm{E}-01$ & $\mathrm{~g}$ & \multirow{3}{*}{90,000} & \multirow{3}{*}{2,000} \\
\hline & & & & & $\mathrm{U}-235$ & $4.00 E-01$ & $\mathrm{~g}$ & & \\
\hline & & & & & MFP & $2.00 E+00$ & $\mathrm{Ci}$ & & \\
\hline \multirow{3}{*}{ S840843 } & \multirow{3}{*}{$\begin{array}{l}12 / 31 / 1984 \\
11 / 14 / 1984\end{array}$} & \multirow{3}{*}{30} & \multirow{3}{*}{$\begin{array}{l}\text { Cell } 13 \text { waste plastic } \\
\text { can } \# 4045\end{array}$} & \multirow{3}{*}{ Steel can \#26 } & Pu-239 & $1.00 \mathrm{E}-01$ & $\mathrm{~g}$ & \multirow{3}{*}{80,000} & \multirow{3}{*}{2,000} \\
\hline & & & & & $\mathrm{U}-235$ & 4.00E-01 & $\mathrm{g}$ & & \\
\hline & & & & & MFP & $2.00 \mathrm{E}+00$ & $\mathrm{Ci}$ & & \\
\hline \multirow{3}{*}{ S840844 } & \multirow{3}{*}{$\begin{array}{l}12 / 31 / 1984 \\
11 / 14 / 1984 ?\end{array}$} & \multirow{3}{*}{30} & \multirow{3}{*}{$\begin{array}{l}\text { Cell } 13 \text { waste plastic } \\
\text { can } \# 4023\end{array}$} & \multirow{3}{*}{ Steel can \#19 } & Pu-239 & $1.00 \mathrm{E}-01$ & $\mathrm{~g}$ & \multirow{3}{*}{70,000} & \multirow{3}{*}{1,500} \\
\hline & & & & & $\mathrm{U}-235$ & 4.00E-01 & $\mathrm{g}$ & & \\
\hline & & & & & MFP & $1.50 \mathrm{E}+00$ & $\mathrm{Ci}$ & & \\
\hline \multirow{3}{*}{ S840845 } & \multirow{3}{*}{$\begin{array}{l}12 / 31 / 1984 ? \\
11 / 14 / 1984 ?\end{array}$} & \multirow{3}{*}{30} & \multirow{3}{*}{$\begin{array}{c}\text { Cell } 13 \text { waste plastic } \\
\text { can } \# 4034\end{array}$} & \multirow{3}{*}{ Steel can \#22 } & Pu-239 & $1.00 \mathrm{E}-01$ & $\mathrm{~g}$ & \multirow{3}{*}{21,000} & \multirow{3}{*}{300} \\
\hline & & & & & U-235 & $4.00 E-01$ & $\mathrm{~g}$ & & \\
\hline & & & & & MFP & 3.00E-01 & $\mathrm{Ci}$ & & \\
\hline \multirow{3}{*}{ S840846 } & \multirow{3}{*}{$\begin{array}{l}12 / 31 / 1984 \\
11 / 15 / 1984\end{array}$} & \multirow{3}{*}{30} & \multirow{3}{*}{$\begin{array}{l}\text { Cell } 13 \text { waste plastic } \\
\text { can } \# 4024\end{array}$} & & Pu-239 & $1.00 \mathrm{E}-01$ & $\mathrm{~g}$ & & 6 \\
\hline & & & & $\begin{array}{c}300 \text { R/hr @ cont Steel } \\
\text { can \#25 }\end{array}$ & U-235 & $4.00 E-01$ & $\mathrm{~g}$ & 300,000 & 5,000 \\
\hline & & & & & MFP & $5.00 \mathrm{E}+00$ & $\mathrm{Ci}$ & & \\
\hline & & & & & Pu-239 & 1.00E-01 & $\mathrm{g}$ & & \\
\hline S840847 & $\begin{array}{l}12 / 31 / 1984 \\
11 / 15 / 1984\end{array}$ & 30 & $\begin{array}{l}\text { Cell } 13 \text { waste plastic } \\
\text { can \#4022 }\end{array}$ & Steel can \#23 & $\mathrm{U}-235$ & $4.00 E-01$ & $\mathrm{~g}$ & 70,000 & 1,500 \\
\hline & & & & & MFP & $1.50 \mathrm{E}+00$ & $\mathrm{Ci}$ & & \\
\hline & & & & & Pu-239 & $1.00 E-01$ & $\mathrm{~g}$ & & \\
\hline S840862 & $\begin{array}{l}12 / 31 / 1984 \\
11 / 14 / 1984\end{array}$ & 30 & $\begin{array}{l}\text { can \#4027 } \\
\text { calic }\end{array}$ & Steel can \#39 & $\mathrm{U}-235$ & 4.00E-01 & $\mathrm{g}$ & 15,000 & 200 \\
\hline & & & & & MFP & 2.00E-01 & $\mathrm{Ci}$ & & \\
\hline & & & & & Pu-239 & $1.00 \mathrm{E}-01$ & $\mathrm{~g}$ & & \\
\hline S840868 & $\begin{array}{l}12 / 31 / 1984 \\
11 / 15 / 1984\end{array}$ & 30 & $\begin{array}{l}\text { cell } 13 \text { Waste plastic } \\
\text { can \#4025 }\end{array}$ & Steel can \#35 & $\mathrm{U}-235$ & $4.00 \mathrm{E}-01$ & $\mathrm{~g}$ & 35,000 & 300 \\
\hline & & & & & MFP & 3.00E-01 & $\mathrm{Ci}$ & & \\
\hline
\end{tabular}




\section{Material Disposal Area G, 33 Shafts Shaft 227 Waste Data Fact Sheet}

\section{Contents}

Shaft 227 contains eight packages of waste from the Chemistry and Metallurgy Research (CMR) Facility Wing 9 hot cells, with each package containing waste in a one-gallon paint-type can that is inside a rigid plastic liner that is inside a 1/8" wall welded steel can. Wastes include hot-cell trash, spent-fuel sample preparation residues, cladding, tissue, and small tools. Major radionuclides in the waste consist of plutonium-239, uranium235, and mixed fission products (MFP). Waste is considered to be remotehandled with the reported radiation dose at the surface of the packages at the time of generation ranging from 15,000 to $400,000 \mathrm{mrem} /$ hour. The eight packages of waste were placed into Shaft 227 during November to December 1984.

\section{Shaft Configuration}

Construction of Shaft 227 was initiated by augering a 36-inch diameter vertical hole into the mesa top. An 1/4 inch wall inner pipe of 9-inch diameter and 9 feet in length was centered in the shaft with crushed tuff used to fill the space between the pipe and the shaft. A large metal funnel was placed in the inner pipe, and waste packages were dropped into the inner pipe from a shielded transport cask moved into position above the shaft. After all waste packages were placed into the pipe, a latching lid with a lifting ring was placed onto the top of the pipe, and the shaft was protected by an inverted cut-down 55-gallon drum placed on top of the shaft.

\section{Shaft 227 Configuration}

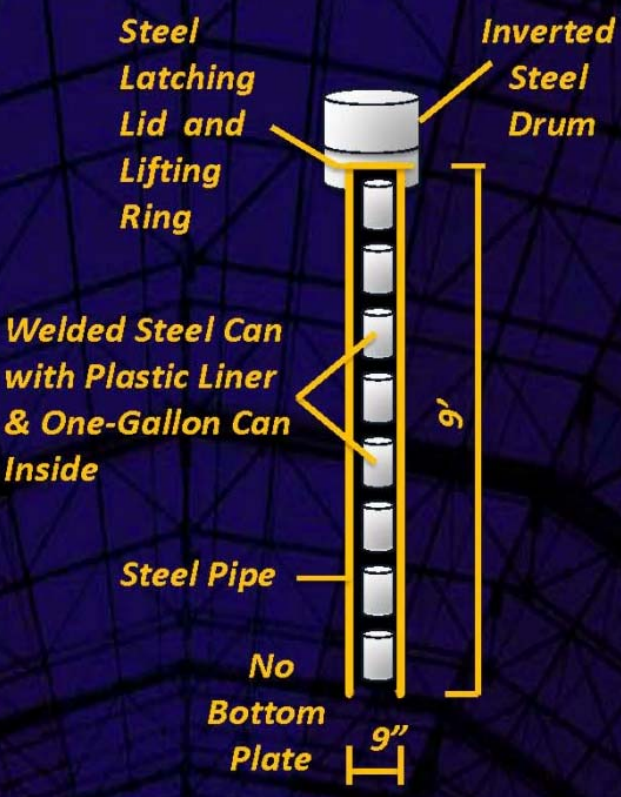

\section{Location in Shaft Field}

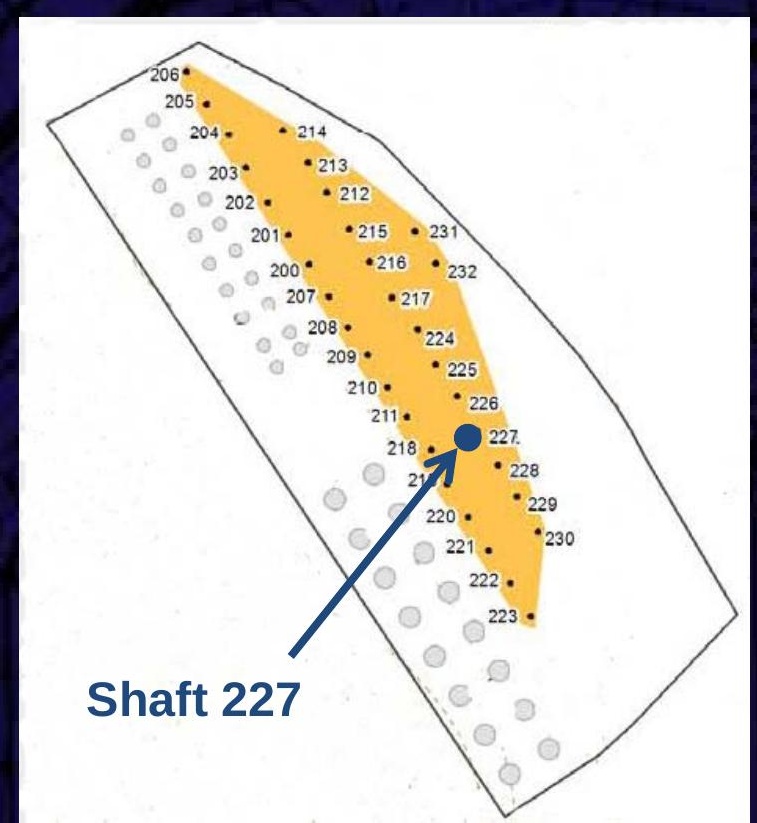

Waste Package Data Summary

\begin{tabular}{|c|c|c|c|c|c|}
\hline $\begin{array}{c}\text { RSWD } \\
\text { Number }\end{array}$ & $\begin{array}{c}\text { Volume } \\
\text { (gallons) }\end{array}$ & Radionuclides & $\begin{array}{c}\text { Total Curies } \\
\text { at Disposal }\end{array}$ & $\begin{array}{c}\text { Total Curies } \\
\text { Decayed to 2009 }\end{array}$ & PE-Ci \\
\hline S840877 & 1 & Pu-239, U-235, MFP & 1.63 & 0.94 & 0.136 \\
\hline S840878 & 1 & Pu-239, U-235, MFP & 2.69 & 1.53 & 0.192 \\
\hline S840879 & 1 & Pu-239, U-235, MFP & 4.19 & 2.33 & 0.192 \\
\hline S840880 & 1 & Pu-239, U-235, MFP & 2.69 & 1.53 & 0.192 \\
\hline S840881 & 1 & Pu-239, U-235, MFP & 3.19 & 1.79 & 0.192 \\
\hline S840883 & 1 & Pu-239, U-235, MFP & 2.00 & 1.07 & 0.0062 \\
\hline S840885 & 1 & Pu-239, U-235, MFP & 6.19 & 3.40 & 0.198 \\
\hline S840886 & 1 & Pu-239, U-235, MFP & 0.81 & 0.43 & 0.0062 \\
\hline TOTALS for & 8 & Pu-239, U-235, MFP & 23.40 & 13.01 & 1.11 \\
\hline Shaft 227 & & & & & \\
\hline
\end{tabular}

* RSWD = Radioactive Solid Waste Disposal record

This fact sheet was compiled from information judged to be the most reliable and accurate available. Waste information from the 1970's and 1980's has gaps and is sometimes inconsistent between various records or reports. 


\section{Shaft 227 Totals}

\begin{tabular}{|c|c|c|}
\hline Total Number of Waste Packages & \multicolumn{2}{|c|}{8} \\
\hline Total Gross Weight (pounds) & \multicolumn{2}{|c|}{240} \\
\hline Total Pu-239 (grams) & \multicolumn{2}{|c|}{18} \\
\hline Total U-235 (grams) & \multicolumn{2}{|c|}{77.9} \\
\hline Total Mixed Fission Products at disposal (Ci) & \multicolumn{2}{|c|}{22.3} \\
\hline Dates of Disposal & \multicolumn{2}{|c|}{$11 / 28 / 1984$ to $12 / 31 / 1984$} \\
\hline Radiation at Surface of Waste Package ( $\mathrm{mR} / \mathrm{hr}$ ) & $\begin{array}{l}15,000 \text { to } 400,000 \\
\text { at disposal }\end{array}$ & $\begin{array}{l}8,000 \text { to } 212,000 \\
\text { decayed to } 2009\end{array}$ \\
\hline $\begin{array}{l}\text { Radiation at One Meter from Surface of Waste } \\
\text { Package }(\mathrm{mR} / \mathrm{hr})\end{array}$ & $\begin{array}{l}800 \text { to } 6,000 \\
\text { at disposal }\end{array}$ & $\begin{array}{c}60 \text { to } 1,500 * \\
\text { decayed to } 2009\end{array}$ \\
\hline
\end{tabular}

* Calculated using inverse square rule assuming a point source at the center of the waste package paint cans

\section{Detailed Waste Package Data at Disposal}

\begin{tabular}{|c|c|c|c|c|c|c|c|c|c|}
\hline $\begin{array}{l}\text { RSWD } \\
\text { Number }\end{array}$ & $\begin{array}{c}\text { Date } \\
\text { Disposed }\end{array}$ & $\begin{array}{c}\text { Gross } \\
\text { Weight } \\
\text { (lb) }\end{array}$ & Waste Description & $\begin{array}{l}\text { Additional } \\
\text { Description of } \\
\text { Packaging and } \\
\text { Packaging } \\
\text { Materials }\end{array}$ & $\begin{array}{l}\text { Nuclide } \\
\text { or } \\
\text { Material } \\
\text { Type }\end{array}$ & Amount & Units & $\begin{array}{c}\text { Package } \\
\text { Radiation } \\
\text { at Surface } \\
\text { (mR/hr) }\end{array}$ & $\begin{array}{c}\text { Package } \\
\text { Radiation } \\
\text { at } 1 \text { meter } \\
(\mathrm{mR} / \mathrm{hr})\end{array}$ \\
\hline \multirow{3}{*}{ S840877 } & \multirow{3}{*}{ 12/31/1984 } & \multirow{3}{*}{30} & \multirow{3}{*}{$\begin{array}{l}\text { Cell } 14 \text { trash can } 4050, \\
\text { fuel inside }\end{array}$} & \multirow{3}{*}{ Steel can 42} & Pu-239 & $2.20 E+00$ & $\mathrm{~g}$ & \multirow{3}{*}{80,000} & \multirow{3}{*}{1,500} \\
\hline & & & & & $\mathrm{U}-235$ & $8.90 E+00$ & $\mathrm{~g}$ & & \\
\hline & & & & & MFP & $1.50 \mathrm{E}+00$ & $\mathrm{Ci}$ & & \\
\hline \multirow{3}{*}{ S840878 } & \multirow{3}{*}{$12 / 31 / 1984$} & \multirow{3}{*}{30} & \multirow{3}{*}{$\begin{array}{l}\text { Cell } 14 \text { trash can, fuel } \\
\text { inside, can } 4042\end{array}$} & \multirow{3}{*}{$\begin{array}{c}250 \text { R/hr @ contact, } \\
\text { Steel can } 46\end{array}$} & Pu-239 & $3.10 \mathrm{E}+00$ & $\mathrm{~g}$ & \multirow{3}{*}{250,000} & \multirow{3}{*}{2,500} \\
\hline & & & & & $\mathrm{U}-235$ & $1.44 \mathrm{E}+01$ & $\mathrm{~g}$ & & \\
\hline & & & & & MFP & $2.50 \mathrm{E}+00$ & $\mathrm{Ci}$ & & \\
\hline \multirow{3}{*}{ S840879 } & \multirow{3}{*}{$\begin{array}{l}12 / 31 / 1984 \\
11 / 28 / 1984\end{array}$} & \multirow{3}{*}{30} & \multirow{3}{*}{$\begin{array}{l}\text { Cell } 14 \text { trash can } 4041, \\
\text { fuel inside }\end{array}$} & \multirow{3}{*}{$\begin{array}{c}300 \mathrm{R} / \mathrm{hr} \text { contact, Steel } \\
\text { can } 44\end{array}$} & Pu-239 & $3.10 E+00$ & $\mathrm{~g}$ & \multirow{3}{*}{300,000} & \multirow{3}{*}{4,000} \\
\hline & & & & & U-235 & $1.44 \mathrm{E}+01$ & $\mathrm{~g}$ & & \\
\hline & & & & & MFP & $4.00 \mathrm{E}+00$ & $\mathrm{Ci}$ & & \\
\hline \multirow{3}{*}{ S840880 } & \multirow{3}{*}{$\begin{array}{l}12 / 31 / 1984 \\
11 / 29 / 1984\end{array}$} & \multirow{3}{*}{30} & \multirow{3}{*}{$\begin{array}{l}\text { Cell } 14 \text { trash can } 4048, \\
\text { fuel inside }\end{array}$} & \multirow{3}{*}{$\begin{array}{l}\text { Steel can } 45 \text {, contact } \\
\text { reading } 350 \mathrm{R}\end{array}$} & Pu-239 & $3.10 E+00$ & $\mathrm{~g}$ & \multirow{3}{*}{350,000} & \multirow{3}{*}{2,500} \\
\hline & & & & & $\mathrm{U}-235$ & $1.44 \mathrm{E}+01$ & $\mathrm{~g}$ & & \\
\hline & & & & & MFP & $2.50 E+00$ & $\mathrm{Ci}$ & & \\
\hline \multirow{3}{*}{ S840881 } & \multirow{3}{*}{$\begin{array}{l}12 / 31 / 1984 \\
11 / 28 / 1984\end{array}$} & \multirow{3}{*}{30} & \multirow{3}{*}{$\begin{array}{l}\text { Cell } 14 \text { trash can } 4057, \\
\text { fuel inside }\end{array}$} & Contact 200 R/hr, Stee & Pu-239 & $3.10 \mathrm{E}+00$ & $\mathrm{~g}$ & & \\
\hline & & & & can 51 & $\mathrm{U}-235$ & $1.44 \mathrm{E}+01$ & $\mathrm{~g}$ & 200,000 & 3,000 \\
\hline & & & & & MFP & $3.00 E+00$ & $\mathrm{Ci}$ & & \\
\hline & & & & & Pu-239 & $1.00 \mathrm{E}-01$ & $\mathrm{~g}$ & & \\
\hline S840883 & $\begin{array}{l}12 / 31 / 1984 \\
11 / 29 / 1984\end{array}$ & 30 & Cell 14 trash can 4064 & $\begin{array}{c}\text { Contact } 100 \mathrm{R} / \mathrm{hr} \text {, Steel } \\
\text { can } 48\end{array}$ & $\mathrm{U}-235$ & 4.00E-01 & $\mathrm{g}$ & 100,000 & 2,000 \\
\hline & & & & & MFP & $2.00 \mathrm{E}+00$ & $\mathrm{Ci}$ & & \\
\hline & & & & & Pu-239 & $3.20 E+00$ & $\mathrm{~g}$ & & \\
\hline S840885 & $\begin{array}{l}12 / 31 / 1984 \\
11 / 28 / 1984\end{array}$ & 30 & $\begin{array}{l}\text { Cell } 14 \text { trasn can } 4156, \\
\text { fuel inside }\end{array}$ & $\begin{array}{c}\text { Contact } 400 \mathrm{R} / \mathrm{hr} \text {, steel } \\
\text { can } 49\end{array}$ & U-235 & $1.06 \mathrm{E}+01$ & $\mathrm{~g}$ & 400,000 & 6,000 \\
\hline & & & & & MFP & $6.00 \mathrm{E}+00$ & $\mathrm{Ci}$ & & \\
\hline & & & & & Pu-239 & $1.00 \mathrm{E}-01$ & $\mathrm{~g}$ & & \\
\hline S840886 & $\begin{array}{l}12 / 31 / 1984 \\
11 / 29 / 1984\end{array}$ & 30 & Cell 14 trash can 4084 & Steel can 50 & $\mathrm{U}-235$ & $4.00 \mathrm{E}-01$ & $\mathrm{~g}$ & 15,000 & 800 \\
\hline & & & & & MFP & 8.00E-01 & $\mathrm{Ci}$ & & \\
\hline
\end{tabular}




\section{Material Disposal Area G, 33 Shafts Shaft 229 Waste Data Fact Sheet}

\section{Contents}

Shaft 229 contains seven packages of waste from the Chemistry and Metallurgy Research (CMR) Facility Wing 9 hot cells, with each package containing waste in a one-gallon paint-type can that is inside a rigid plastic liner that is inside a 1/8" wall welded steel can. Wastes include hot-cell trash, spent-fuel sample preparation residues, cladding, tissue, and small tools. Major radionuclides in the waste consist of plutonium-239, uranium235 , and mixed fission products (MFP). Waste is considered to be remotehandled with the reported radiation dose at the surface of the packages at the time of generation ranging from 10,000 to $200,000 \mathrm{mrem} /$ hour. The seven packages of waste were placed into Shaft 229 during November and December 1984.

\section{Shaft Configuration}

Construction of Shaft 229 was initiated by augering a 36-inch diameter vertical hole into the mesa top. An 1/4 inch wall inner pipe of 9-inch diameter and 9 feet in length was centered in the shaft with crushed tuff used to fill the space between the pipe and the shaft. A large metal funnel was placed in the inner pipe, and waste packages were dropped into the inner pipe from a shielded transport cask moved into position above the shaft. After all waste packages were placed into the pipe, a latching lid with a lifting ring was placed onto the top of the pipe, and the shaft was protected by an inverted cut-down 55-gallon drum placed on top of the shaft.

\section{Shaft 229 Configuration}

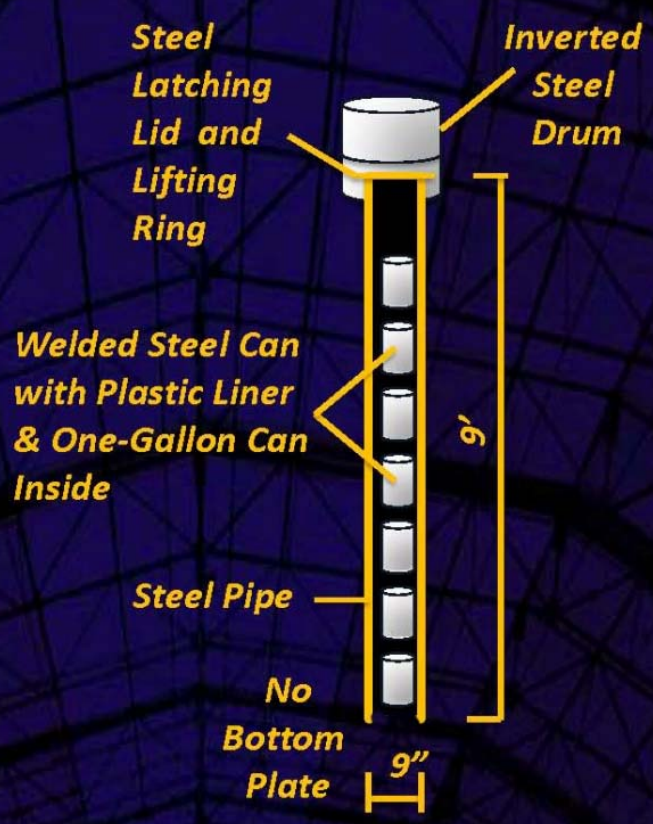

Waste Package Data Summary

\section{Location in Shaft Field}

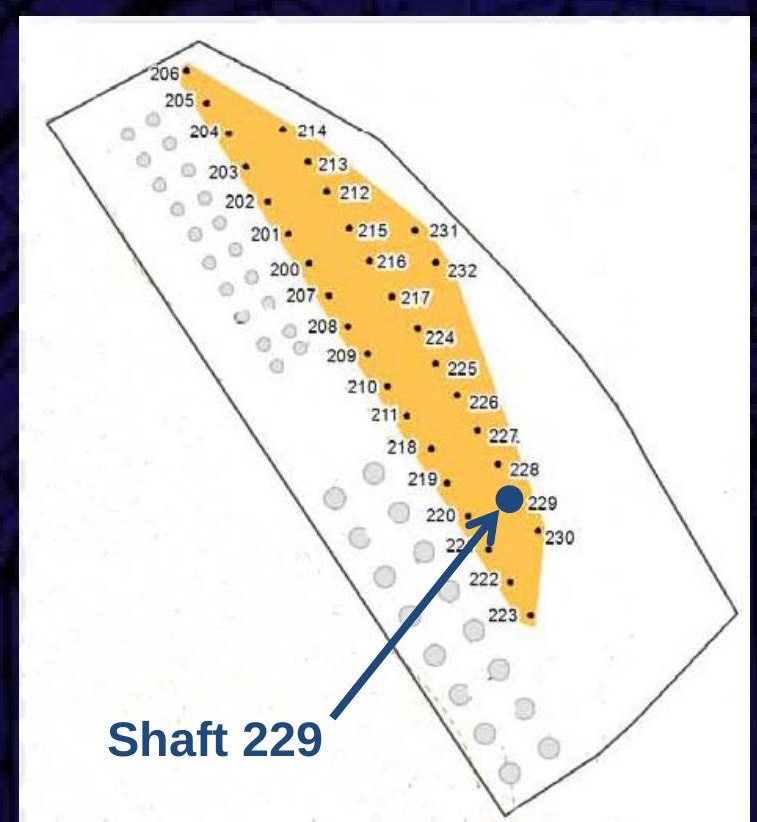

\begin{tabular}{|c|c|c|c|c|c|}
\hline $\begin{array}{c}\text { RSWD } \\
\text { Number }\end{array}$ & $\begin{array}{c}\text { Volume } \\
\text { (gallons) }\end{array}$ & Radionuclides & $\begin{array}{c}\text { Total Curies } \\
\text { at Disposal }\end{array}$ & $\begin{array}{c}\text { Total Curies } \\
\text { Decayed to 2009 }\end{array}$ & PE-Ci \\
\hline S840851 & 1 & Pu-239, U-235, MFP & 3.00 & 1.61 & 0.0062 \\
\hline S840855 & 1 & Pu-239, U-235, MFP & 1.01 & 0.54 & 0.0062 \\
\hline S840860 & 1 & Pu-239, U-235, MFP & 2.00 & 1.07 & 0.0062 \\
\hline S840865 & 1 & Pu-239, U-235, MFP & 0.11 & 0.06 & 0.0062 \\
\hline S840873 & 1 & Pu-239, U-235, MFP & 2.18 & 1.25 & 0.186 \\
\hline S840882 & 1 & Pu-239, U-235, MFP & 0.31 & 0.17 & 0.0062 \\
\hline S840888 & 1 & Pu-239, U-235, MFP & 0.16 & 0.09 & 0.0062 \\
\hline $\begin{array}{c}\text { TOTALS for } \\
\text { Shaft 229 }\end{array}$ & 7 & Pu-239, U-235, MFP & 8.77 & 4.79 & 0.22 \\
\hline
\end{tabular}

* RSWD $=$ Radioactive Solid Waste Disposal record 


\section{Shaft 229 Totals}

\begin{tabular}{|c|c|c|}
\hline Total Number of Waste Packages & \multicolumn{2}{|c|}{7} \\
\hline Total Gross Weight (pounds) & \multicolumn{2}{|c|}{210} \\
\hline Total Pu-239 (grams) & \multicolumn{2}{|c|}{3.6} \\
\hline Total U-235 (grams) & \multicolumn{2}{|c|}{14.4} \\
\hline Total Mixed Fission Products at disposal (Ci) & \multicolumn{2}{|c|}{8.55} \\
\hline Dates of Disposal & \multicolumn{2}{|c|}{$11 / 19 / 1984$ to $12 / 31 / 1984$} \\
\hline Radiation at Surface of Waste Package ( $\mathrm{mR} / \mathrm{hr}$ ) & $\begin{array}{l}10,000 \text { to } 200,000 \\
\text { at disposal }\end{array}$ & $\begin{array}{l}5,300 \text { to } 106,000 \\
\text { decayed to } 2009\end{array}$ \\
\hline $\begin{array}{l}\text { Radiation at One Meter from Surface of Waste } \\
\text { Package (mR/hr) }\end{array}$ & $\begin{array}{l}100 \text { to } 3,000 \\
\text { at disposal }\end{array}$ & $\begin{array}{c}40 \text { to } 750 * \\
\text { decayed to } 2009\end{array}$ \\
\hline
\end{tabular}

* Calculated using inverse square rule assuming a point source at the center of the waste package paint cans

\section{Detailed Waste Package Data at Disposal}

\begin{tabular}{|c|c|c|c|c|c|c|c|c|c|}
\hline $\begin{array}{l}\text { RSWD } \\
\text { Number }\end{array}$ & $\begin{array}{c}\text { Date } \\
\text { Disposed }\end{array}$ & $\begin{array}{c}\text { Gross } \\
\text { Weight } \\
\text { (lb) }\end{array}$ & Waste Description & $\begin{array}{l}\text { Additional } \\
\text { Description of } \\
\text { Packaging and } \\
\text { Packaging } \\
\text { Materials }\end{array}$ & $\begin{array}{c}\text { Nuclide } \\
\text { or } \\
\text { Material } \\
\text { Type }\end{array}$ & Amount & Units & $\begin{array}{l}\text { Package } \\
\text { Radiation } \\
\text { at Surface } \\
(\mathrm{mR} / \mathrm{hr})\end{array}$ & $\begin{array}{c}\text { Package } \\
\text { Radiation } \\
\text { at } 1 \text { meter } \\
\text { (mR/hr) }\end{array}$ \\
\hline \multirow{3}{*}{ S840851 } & \multirow{3}{*}{$12 / 31 / 1984$} & \multirow{3}{*}{30} & \multirow{3}{*}{$\begin{array}{l}\text { Cell } 13 \text { waste plastic } \\
\text { can \#4028 }\end{array}$} & \multirow{3}{*}{$\begin{array}{c}200 \mathrm{R} / \mathrm{hr} @ \text { cont, Steel } \\
\text { can \#28 }\end{array}$} & Pu-239 & $1.00 \mathrm{E}-01$ & $\mathrm{~g}$ & \multirow{3}{*}{200,000} & \multirow{3}{*}{3,000} \\
\hline & & & & & U-235 & $4.00 \mathrm{E}-01$ & $\mathrm{~g}$ & & \\
\hline & & & & & MFP & $3.00 E+00$ & $\mathrm{Ci}$ & & \\
\hline \multirow{3}{*}{ S840855 } & \multirow{3}{*}{$\begin{array}{l}12 / 31 / 1984 \\
11 / 29 / 1984\end{array}$} & \multirow{3}{*}{30} & \multirow{3}{*}{$\begin{array}{l}\text { Cell } 13 \text { waste plastic } \\
\text { can } 4145\end{array}$} & \multirow{3}{*}{ Steel can \#27 } & $\mathrm{Pu}-239$ & $1.00 \mathrm{E}-01$ & $\mathrm{~g}$ & \multirow{3}{*}{40,000} & \multirow{3}{*}{1,000} \\
\hline & & & & & U-235 & 4.00E-01 & $\mathrm{g}$ & & \\
\hline & & & & & MFP & $1.00 \mathrm{E}+00$ & $\mathrm{Ci}$ & & \\
\hline \multirow{3}{*}{$\$ 840860$} & \multirow{3}{*}{$\begin{array}{l}12 / 31 / 1984 \\
11 / 29 / 1984\end{array}$} & \multirow{3}{*}{30} & \multirow{3}{*}{$\begin{array}{l}\text { Cell } 13 \text { waste plastic } \\
\text { can } \# 4026\end{array}$} & \multirow{3}{*}{$\begin{array}{c}150 \mathrm{R} / \mathrm{hr} @ \text { cont, Steel } \\
\text { can \#36 }\end{array}$} & Pu-239 & $1.00 \mathrm{E}-01$ & $\mathrm{~g}$ & \multirow{3}{*}{150,000} & \multirow{3}{*}{2,000} \\
\hline & & & & & U-235 & $4.00 \mathrm{E}-01$ & $\mathrm{~g}$ & & \\
\hline & & & & & MFP & $2.00 E+00$ & $\mathrm{Ci}$ & & \\
\hline \multirow{3}{*}{ S840865 } & \multirow{3}{*}{$\begin{array}{l}12 / 31 / 1984 \\
11 / 20 / 1984\end{array}$} & \multirow{3}{*}{30} & \multirow{3}{*}{$\begin{array}{c}\text { Cell \#13 waste plastic } \\
\text { can } \# 4055\end{array}$} & \multirow{3}{*}{ Steel can \#37 } & $\mathrm{Pu}-239$ & $1.00 \mathrm{E}-01$ & $\mathrm{~g}$ & \multirow{3}{*}{10,000} & \multirow{3}{*}{100} \\
\hline & & & & & $\mathrm{U}-235$ & $4.00 \mathrm{E}-01$ & $\mathrm{~g}$ & & \\
\hline & & & & & MFP & $1.00 \mathrm{E}-01$ & $\mathrm{Ci}$ & & \\
\hline \multirow{3}{*}{ S840873 } & \multirow{3}{*}{$\begin{array}{l}12 / 31 / 1984 \\
11 / 19 / 1984\end{array}$} & \multirow{3}{*}{30} & \multirow{3}{*}{ Cell 14 trash can 4065} & \multirow{3}{*}{$\begin{array}{c}100 \text { Rhr contact, Steel } \\
\text { can } 41\end{array}$} & Pu-239 & $3.00 E+00$ & $\mathrm{~g}$ & & \\
\hline & & & & & U-235 & $1.20 E+01$ & $\mathrm{~g}$ & 100,000 & 2,000 \\
\hline & & & & & MFP & $2.00 E+00$ & $\mathrm{Ci}$ & & \\
\hline & & & & & $\mathrm{Pu}-239$ & $1.00 \mathrm{E}-01$ & $\mathrm{~g}$ & & \\
\hline S840882 & $\begin{array}{l}12 / 31 / 1984 \\
11 / 27 / 1984\end{array}$ & 30 & Cell 14 trash can 4066 & $\begin{array}{l}\text { Steel can } 4 /-4.1 \mathrm{ft} 3 \\
\text { shaft }\end{array}$ & $\mathrm{U}-235$ & 4.00E-01 & $\mathrm{g}$ & 18,000 & 300 \\
\hline & & & & & MFP & 3.00E-01 & $\mathrm{Ci}$ & & \\
\hline & & & & & $\mathrm{Pu}-239$ & $1.00 E-01$ & $\mathrm{~g}$ & & \\
\hline S840888 & $\begin{array}{l}12 / 31 / 1984 \\
11 / 26 / 1984\end{array}$ & 30 & Cell 14 trash can 4075 & Steel can 52 & $\mathrm{U}-235$ & $4.00 \mathrm{E}-01$ & $\mathrm{~g}$ & 10,000 & 1,500 \\
\hline & & & & & MFP & $1.50 \mathrm{E}-01$ & $\mathrm{Ci}$ & & \\
\hline
\end{tabular}




\section{Material Disposal Area G, 33 Shafts Shaft 230 Waste Data Fact Sheet}

\section{Contents}

Shaft 230 contains eight packages of waste from the Chemistry and Metallurgy Research (CMR) Facility Wing 9 hot cells, with each package containing waste in a one-gallon paint-type can that is inside a rigid plastic liner that is inside a 1/8" wall welded steel can. Wastes include hot-cell trash, spent-fuel sample preparation residues, cladding, tissue, and small tools. Major radionuclides in the waste consist of plutonium-239, uranium235, and mixed fission products (MFP). Waste is considered to be remotehandled with the reported radiation dose at the surface of the packages at the time of generation ranging from 30,000 to 1,000,000 $\mathrm{mrem} / \mathrm{hour}$. The eight packages of waste were placed into Shaft 230 in December 1984.

\section{Shaft Configuration}

Construction of Shaft 230 was initiated by augering a 36-inch diameter vertical hole into the mesa top. An 1/4 inch wall inner pipe of 9-inch diameter and 9 feet in length was centered in the shaft with crushed tuff used to fill the space between the pipe and the shaft. A large metal funnel was placed in the inner pipe, and waste packages were dropped into the inner pipe from a shielded transport cask moved into position above the shaft. After all waste packages were placed into the pipe, a latching lid with a lifting ring was placed onto the top of the pipe, and the shaft was protected by an inverted cut-down 55-gallon drum placed on top of the shaft.

\section{Shaft 230 Configuration}

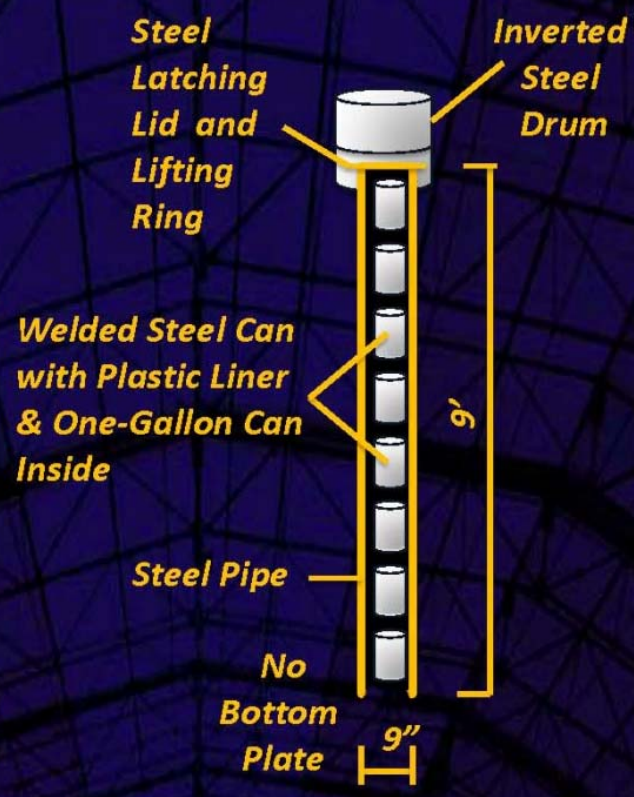

\section{Location in Shaft Field}

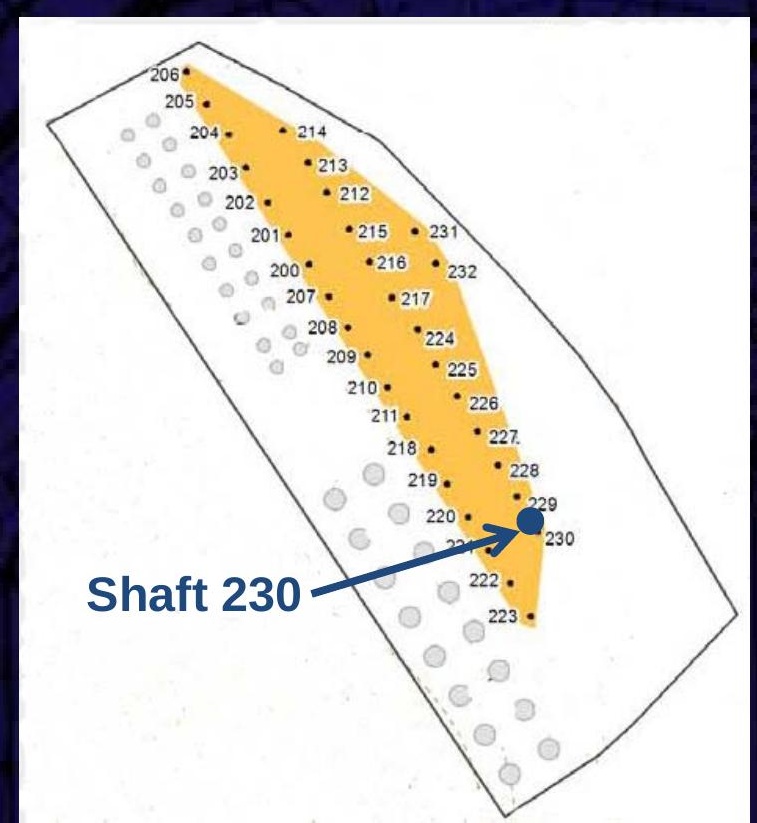

Waste Package Data Summary

\begin{tabular}{|c|c|c|c|c|c|}
\hline $\begin{array}{c}\text { RSWD } \\
\text { Number }\end{array}$ & $\begin{array}{c}\text { Volume } \\
\text { (gallons) }\end{array}$ & Radionuclides & $\begin{array}{c}\text { Total Curies } \\
\text { at Disposal }\end{array}$ & $\begin{array}{c}\text { Total Curies } \\
\text { Decayed to 2009 }\end{array}$ & PE-Ci \\
\hline S840831 & 1 & Pu-239, U-235, MFP & 40.90 & 24.60 & 5.95 \\
\hline S840835 & 1 & Pu-239, U-235, MFP & 9.99 & 5.34 & 0.0062 \\
\hline S840836 & 1 & Pu-239, U-235, MFP & 0.41 & 0.22 & 0.0062 \\
\hline S840838 & 1 & Pu-239, U-235, MFP & 5.02 & 2.67 & 0.0062 \\
\hline S840839 & 1 & Pu-239, U-235, MFP & 1.50 & 0.81 & 0.0062 \\
\hline S840840 & 1 & Pu-239, U-235, MFP & 1.01 & 0.54 & 0.0062 \\
\hline S840841 & 1 & Pu-239, U-235, MFP & 0.71 & 0.38 & 0.0062 \\
\hline S840859 & 1 & Pu-239, U-235, MFP & 1.01 & 0.54 & 0.0062 \\
\hline TOTALS for & 8 & Pu-239, U-235, MFP & 60.57 & 35.12 & 5.99 \\
\hline Shaft 230 & & & & & \\
\hline
\end{tabular}

* RSWD = Radioactive Solid Waste Disposal record

This fact sheet was compiled from information judged to be the most reliable and accurate available. Waste information from the 1970's and 1980's has gaps and is sometimes inconsistent between various records or reports. 


\section{Shaft 230 Totals}

\begin{tabular}{|c|c|c|}
\hline Total Number of Waste Packages & \multicolumn{2}{|c|}{8} \\
\hline Total Gross Weight (pounds) & \multicolumn{2}{|c|}{240} \\
\hline Total Pu-239 (grams) & \multicolumn{2}{|c|}{96.7} \\
\hline Total U-235 (grams) & \multicolumn{2}{|c|}{247.8} \\
\hline Total Mixed Fission Products at disposal (Ci) & \multicolumn{2}{|c|}{54.6} \\
\hline Dates of Disposal & \multicolumn{2}{|c|}{$10 / 05 / 1984$ to $12 / 31 / 1984$} \\
\hline Radiation at Surface of Waste Package (mR/hr) & $\begin{array}{l}30,000 \text { to } 1,000,000 \\
\text { at disposal }\end{array}$ & $\begin{array}{l}16,000 \text { to } 212,000 \\
\text { decayed to } 2009\end{array}$ \\
\hline $\begin{array}{l}\text { Radiation at One Meter from Surface of Waste } \\
\text { Package ( } \mathrm{mR} / \mathrm{hr})\end{array}$ & $\begin{array}{l}400 \text { to } 35,000 \\
\text { at disposal }\end{array}$ & $\begin{array}{c}110 \text { to } 1,500 * \\
\text { decayed to } 2009\end{array}$ \\
\hline
\end{tabular}

* Calculated using inverse square rule assuming a point source at the center of the waste package paint cans

\section{Detailed Waste Package Data at Disposal}

\begin{tabular}{|c|c|c|c|c|c|c|c|c|c|}
\hline $\begin{array}{l}\text { RSWD } \\
\text { Number }\end{array}$ & $\begin{array}{c}\text { Date } \\
\text { Disposed }\end{array}$ & $\begin{array}{c}\text { Gross } \\
\text { Weight } \\
\text { (Ib) }\end{array}$ & Waste Description & $\begin{array}{c}\text { Additional } \\
\text { Description of } \\
\text { Packaging and } \\
\text { Packaging } \\
\text { Materials }\end{array}$ & $\begin{array}{l}\text { Nuclide } \\
\text { or } \\
\text { Material } \\
\text { Type }\end{array}$ & Amount & Units & $\begin{array}{l}\text { Package } \\
\text { Radiation } \\
\text { at Surface } \\
(\mathrm{mR} / \mathrm{hr})\end{array}$ & $\begin{array}{c}\text { Package } \\
\text { Radiation } \\
\text { at } 1 \text { meter } \\
(\mathrm{mR} / \mathrm{hr})\end{array}$ \\
\hline \multirow{3}{*}{$\$ 840831$} & \multirow{3}{*}{$12 / 31 / 1984$} & \multirow{3}{*}{30} & \multirow{3}{*}{$\begin{array}{l}\text { Cell } 9 \text { hot waste can } \\
\# 4017 \text {, Steel can 13; }\end{array}$} & \multirow{3}{*}{$\begin{array}{l}\text { +1000 Rhr contact, } \\
35 \mathrm{Rhr} \text { at meter ; }\end{array}$} & Pu-239 & $9.60 E+01$ & $\mathrm{~g}$ & \multirow{3}{*}{$1,000,000$} & \multirow{3}{*}{35,000} \\
\hline & & & & & U-235 & $2.45 E+02$ & g & & \\
\hline & & & & & MFP & $3.50 E+01$ & $\mathrm{Ci}$ & & \\
\hline \multirow{3}{*}{ S840835 } & \multirow{3}{*}{$\begin{array}{l}12 / 31 / 1984 \\
11 / 08 / 1984\end{array}$} & \multirow{3}{*}{30} & \multirow{3}{*}{$\begin{array}{c}\text { Cell } 13 \text { waste plastic } \\
\text { can } 4153\end{array}$} & \multirow{3}{*}{$\begin{array}{c}100 \mathrm{R} / \mathrm{hr} @ \text { contact, } \\
\text { Steel can } 16\end{array}$} & Pu-239 & $1.00 \mathrm{E}-01$ & $\mathrm{~g}$ & \multirow{3}{*}{100,000} & \multirow{3}{*}{1,000} \\
\hline & & & & & U-235 & $4.00 \mathrm{E}-01$ & $\mathrm{~g}$ & & \\
\hline & & & & & MFP & $1.00 E+01$ & $\mathrm{Ci}$ & & \\
\hline \multirow{3}{*}{ S840836 } & \multirow{3}{*}{$\begin{array}{l}12 / 31 / 1984 \\
10 / 05 / 1984\end{array}$} & \multirow{3}{*}{30} & \multirow{3}{*}{$\begin{array}{c}\text { Cell } 13 \text { waste plastic } \\
\text { can } 3974\end{array}$} & \multirow{3}{*}{ Steel can 15} & Pu-239 & $1.00 \mathrm{E}-01$ & $\mathrm{~g}$ & \multirow{3}{*}{30,000} & \multirow{3}{*}{400} \\
\hline & & & & & U-235 & 4.00E-01 & $\mathrm{g}$ & & \\
\hline & & & & & MFP & 4.00E-01 & $\mathrm{Ci}$ & & \\
\hline \multirow{3}{*}{ S840838 } & \multirow{3}{*}{$\begin{array}{l}12 / 31 / 1984 \\
11 / 08 / 1984\end{array}$} & \multirow{3}{*}{30} & \multirow{3}{*}{$\begin{array}{c}\text { Cell } 13 \text { waste plastic } \\
\text { can } 4154\end{array}$} & \multirow{3}{*}{$\begin{array}{l}400 \mathrm{R} / \mathrm{hr} @ \text { cont, } \\
\text { Steel can } 14\end{array}$} & Pu-239 & $1.00 \mathrm{E}-01$ & $\mathrm{~g}$ & \multirow{3}{*}{400,000} & \multirow{3}{*}{5,000} \\
\hline & & & & & U-235 & $4.00 \mathrm{E}-01$ & $\mathrm{~g}$ & & \\
\hline & & & & & MFP & $5.00 E+00$ & $\mathrm{Ci}$ & & \\
\hline \multirow{3}{*}{ S840839 } & \multirow{3}{*}{$\begin{array}{l}12 / 31 / 1984 \\
11 / 09 / 1984\end{array}$} & \multirow{3}{*}{30} & \multirow{3}{*}{$\begin{array}{c}\text { Cell } 13 \text { waste plastic } \\
\text { can } 4155\end{array}$} & & Pu-239 & $1.00 \mathrm{E}-01$ & $\mathrm{~g}$ & & \\
\hline & & & & Steel can 18 & U-235 & 4.00E-01 & $\mathrm{g}$ & 90,000 & 1,500 \\
\hline & & & & & MFP & $1.50 E+00$ & $\mathrm{Ci}$ & & \\
\hline & & & & & Pu-239 & $1.00 \mathrm{E}-01$ & $\mathrm{~g}$ & & \\
\hline$S 840840$ & $12 / 31 / 1984$ & 30 & $\begin{array}{l}\text { Cell } 13 \text { waste plastic } \\
\text { can } 4037\end{array}$ & Steel can 29 & U-235 & 4.00E-01 & $\mathrm{g}$ & 90,000 & 1,000 \\
\hline & & & & & MFP & $1.00 E+00$ & $\mathrm{Ci}$ & & $t^{2}$ \\
\hline & & & Cell 13 waste plastic can & & Pu-239 & $1.00 \mathrm{E}-01$ & $\mathrm{~g}$ & - & \\
\hline S840841 & $\begin{array}{l}12 / 31 / 1984 \\
11 / 09 / 1984\end{array}$ & 30 & 4036 & Steel can 17 & U-235 & 4.00E-01 & $\mathrm{g}$ & 90,000 & 1,000 \\
\hline & & & & & MFP & $1.00 E+00$ & $\mathrm{Ci}$ & & \\
\hline & & & Cell 13 waste plastic can & & Pu-239 & $1.00 \mathrm{E}-01$ & $\mathrm{~g}$ & & \\
\hline S840859 & $\begin{array}{l}12 / 31 / 1984 \\
11 / 13 / 1984\end{array}$ & 30 & 4031 & Steel can 33 & $U-235$ & 4.00E-01 & $\mathrm{g}$ & 60,000 & 700 \\
\hline & & & & & MFP & 7.00E-01 & $\mathrm{Ci}$ & & \\
\hline
\end{tabular}





\section{Appendix B}

Engineering Drawings with 33 Shafts Locations and Coordinates

Page B-1 
This page intentionally left blank.

Page B-2 


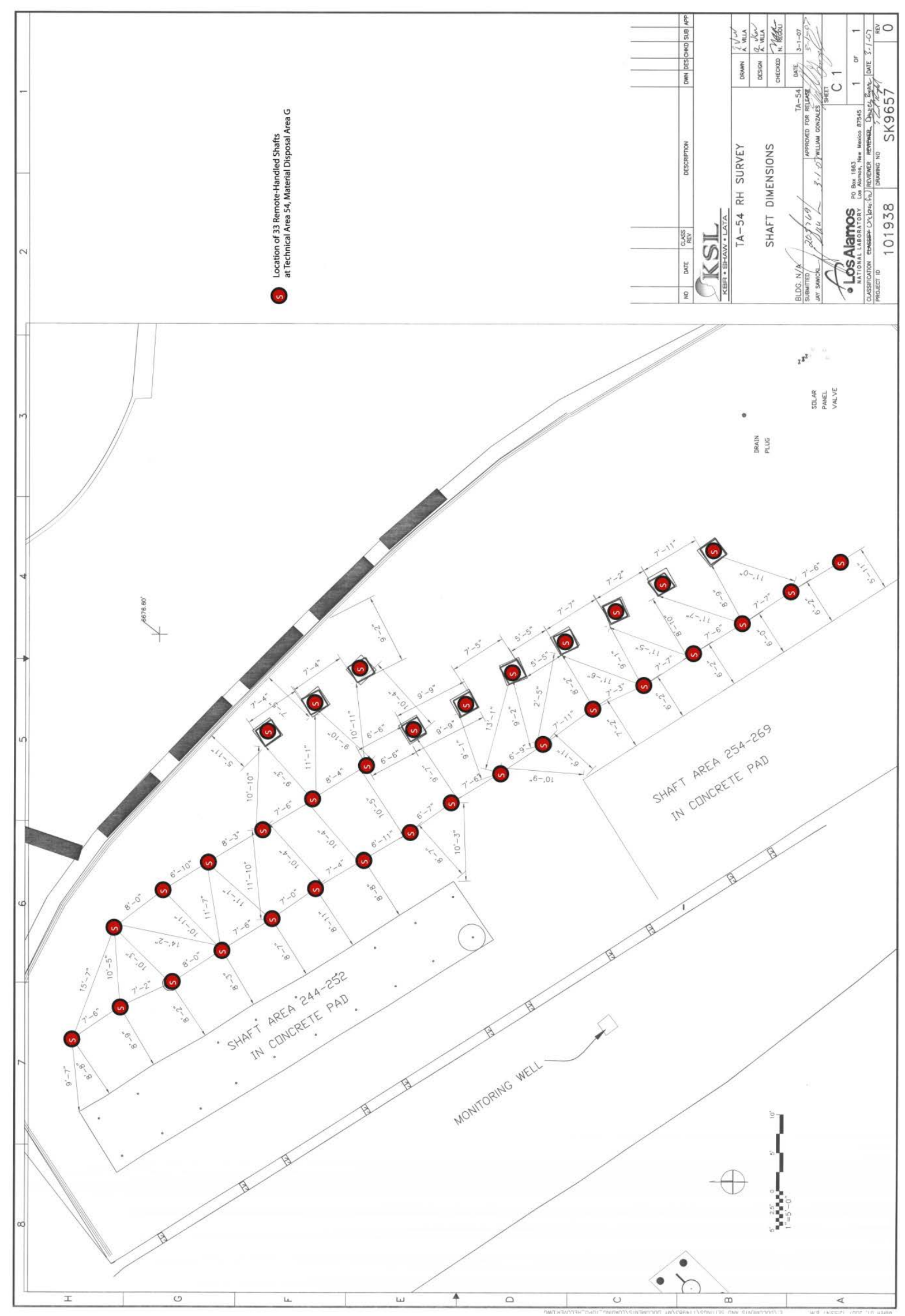

Page B-3 
This page intentionally left blank.

Page B-4 


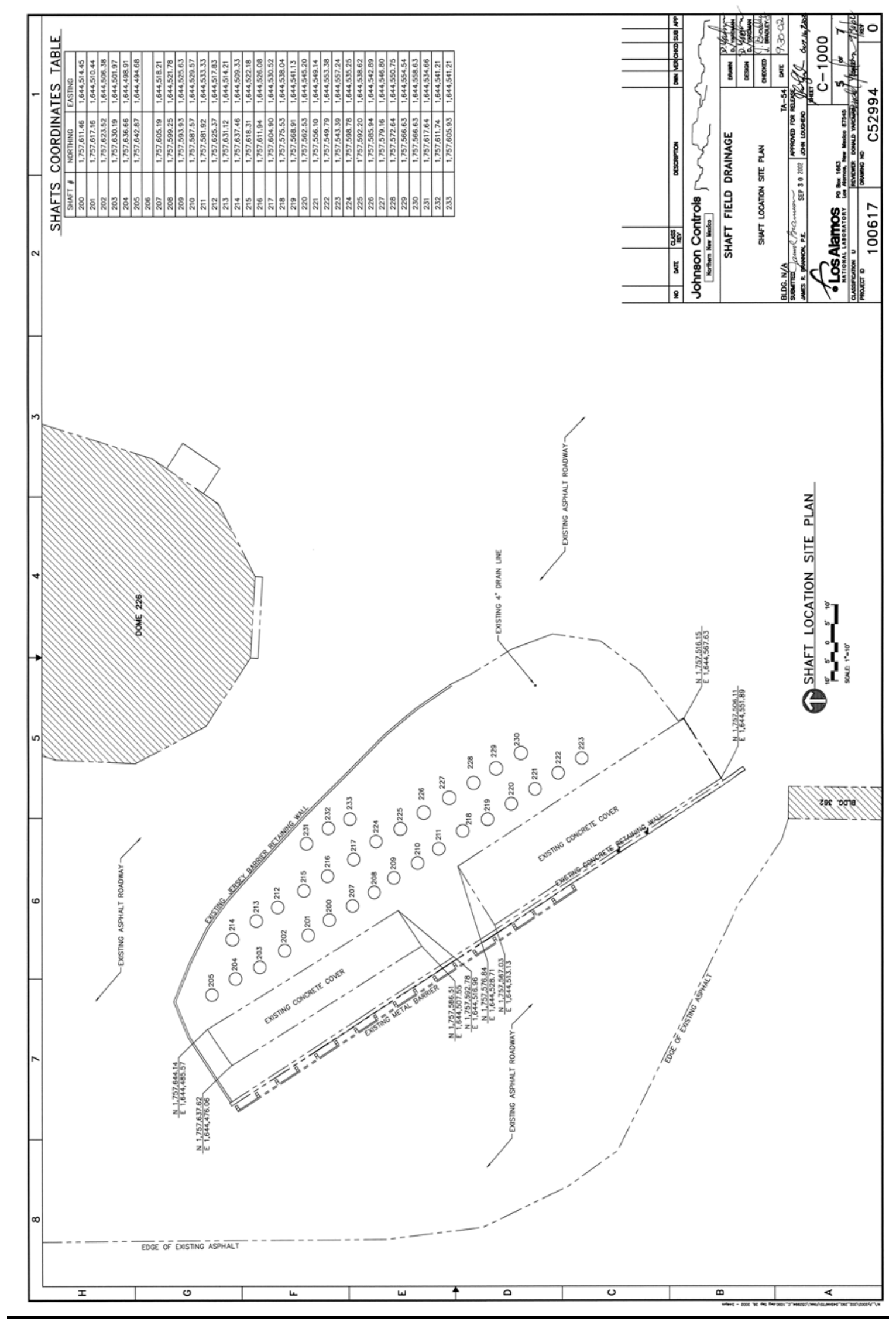

Page B-5 
This page intentionally left blank.

Page B-6 



\section{Appendix C}

\section{Radioactive Solid Waste Disposal Record Forms for Waste Packages Placed into 33 Shafts}

Compiled from ADEP Document Control System May 2013 
This page intentionally left blank.

Page C-2 
RADIOACTIVE SOLID WASTE DISPOSAL RECORD FORMS

FOR

SHAFT 200

MATERIAL DISPOSAL AREA G 


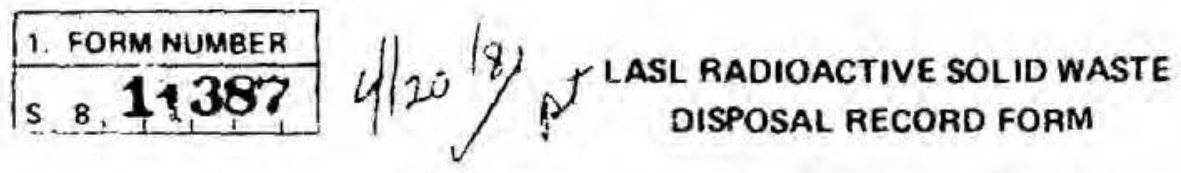
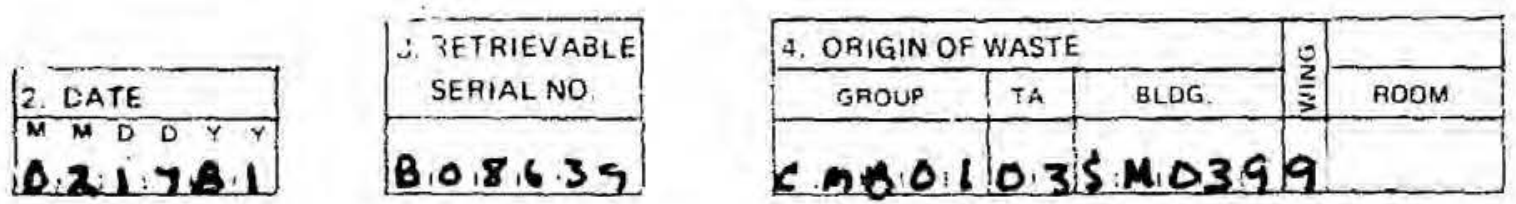

$\begin{array}{r}\text { 5. VIAST } \\ \text { CODE } \\ \hline A, 4,6\end{array}$

6. WASTE DESCRIPTION

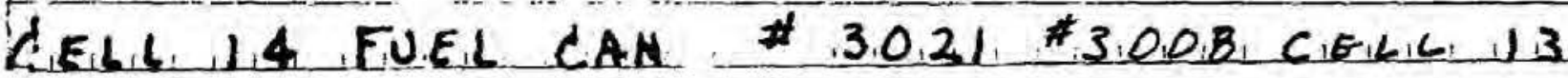

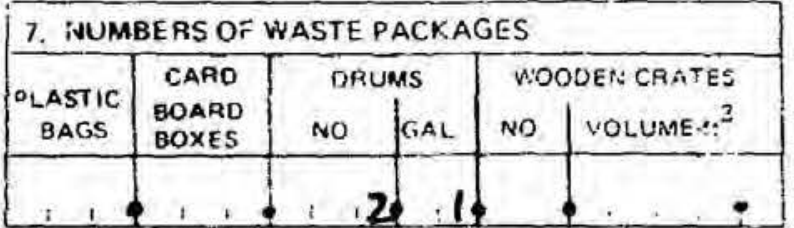

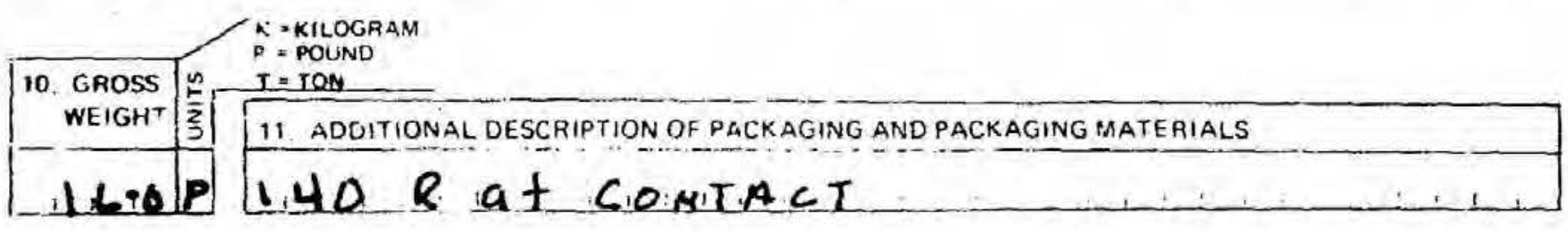

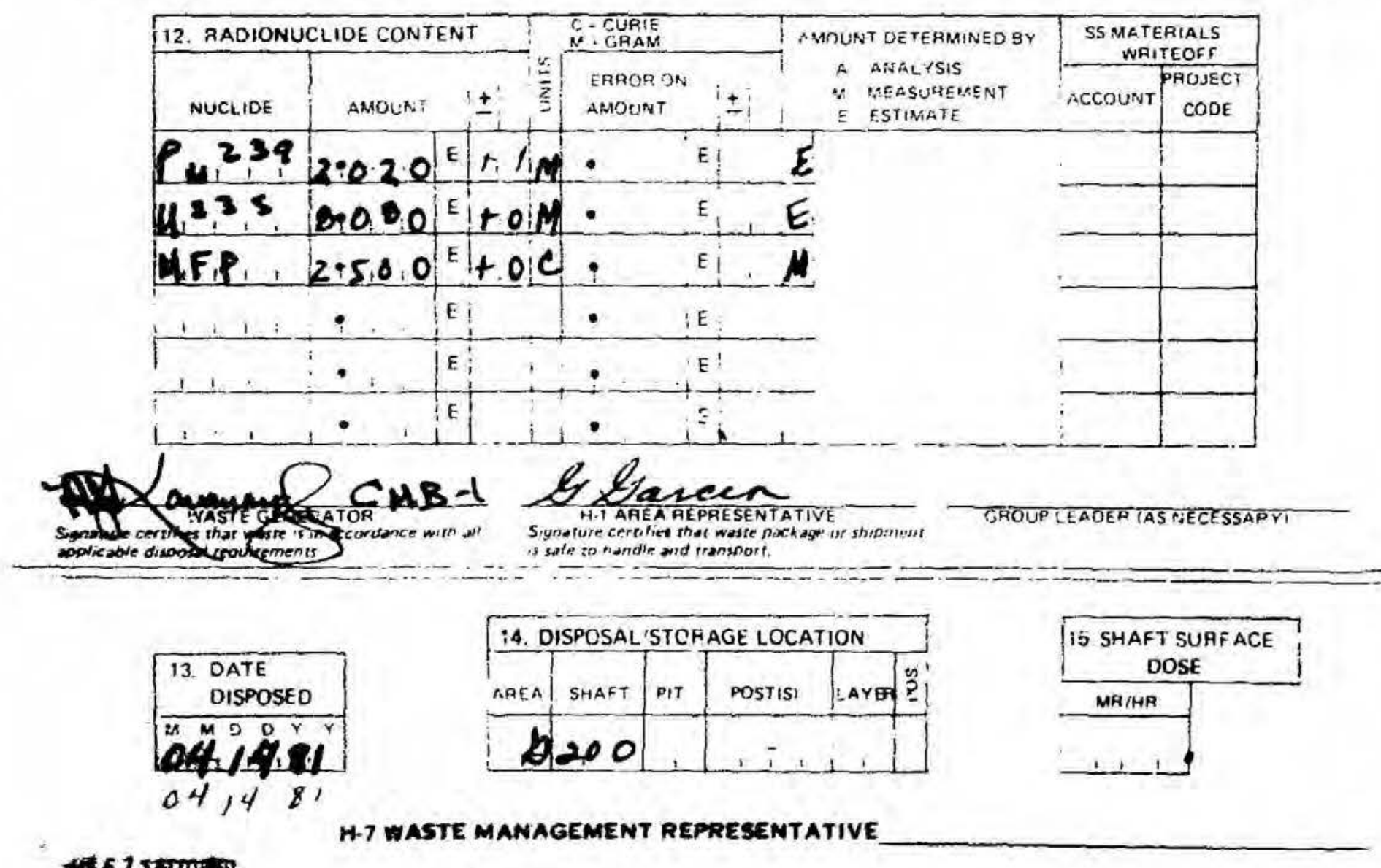




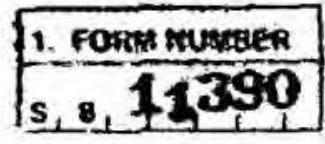

2. DATE

H

extiare.1
$4 / 20^{181} \mathrm{pi}^{12}$

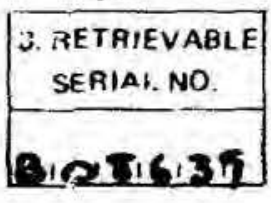

LASL RADIOACTIVE SOLID WASTE DISPOSAL RECORD FORM
H.7 Wasie Managpmen:

\{xi 5095 MS. 59 ?

\section{WASTE DESCRIPTION}

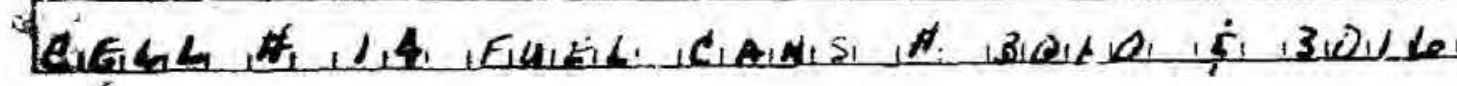

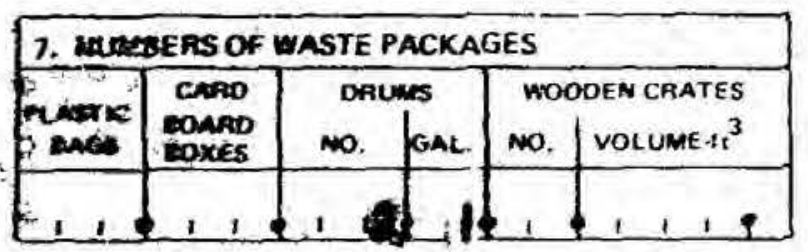
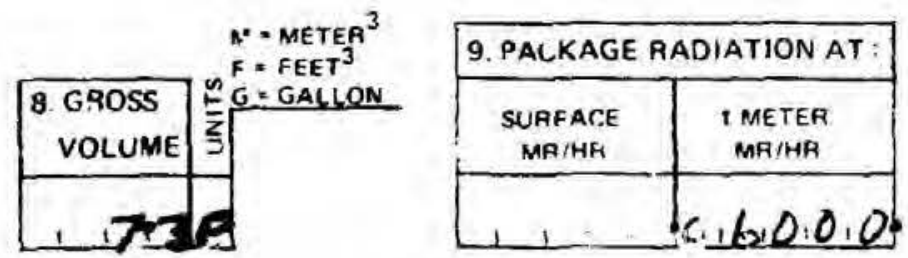

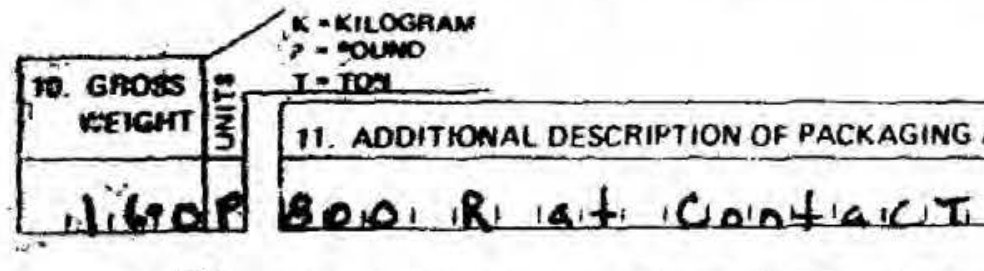

\begin{tabular}{|c|c|c|c|c|c|c|c|c|c|}
\hline \multicolumn{3}{|c|}{ 12. REDHOAUCL HE CONTENT } & \multicolumn{4}{|c|}{$\begin{array}{l}C=\text { CUARE } \\
M=\text { GRM }\end{array}$} & \multirow{2}{*}{$\begin{array}{l}\text { AMOUNT DETERMINED BY: } \\
\text { A = ANALYSIS } \\
M=\text { MEASUREMENT } \\
E \text { - ESTIMATE }\end{array}$} & \multicolumn{2}{|c|}{$\begin{array}{c}\text { SS MATEAIALS } \\
\text { WRITEOFF }\end{array}$} \\
\hline muculoe & 1. Amount & $1 \pm$ & $\frac{n}{5}$ & $\begin{array}{l}\text { EAROA ON } \\
\text { AMOUNT }\end{array}$ & & \pm & & ACCOUNT & $\left\{\begin{array}{l}\text { COOA } \\
\text { COOT }\end{array}\right.$ \\
\hline $\operatorname{lm}^{2}{ }^{3}$ & $\angle P O: D:\rfloor$ & E & & 111. & E & & E & & \\
\hline & $3,8,04$ & E & H & 1,1 & E & & है & & \\
\hline A. Fip. & $\operatorname{cis}, 00$ & $E$ & IC & 1,1 & E & & A & & \\
\hline 11.1 & 9,1 & E & & $\because \quad 1$ & E & & & & \\
\hline 111 & 112 & E & & $\therefore+1$ & E & & & & \\
\hline & $\bullet, 1$ & E & & 1,1 & E & & & & \\
\hline
\end{tabular}

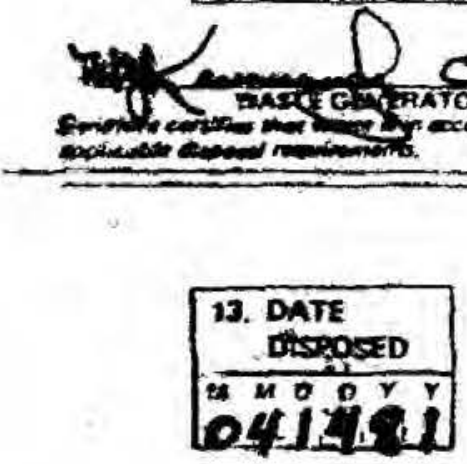


PLEASE READ INSTRLCTIONS ON BACK CAREFULLY
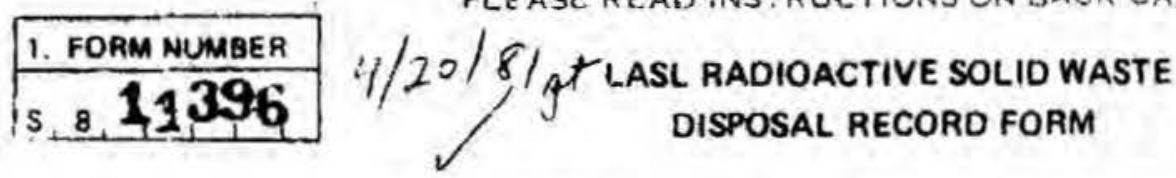

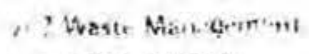

$1 x^{\prime} \div 295$ US $58 \%$
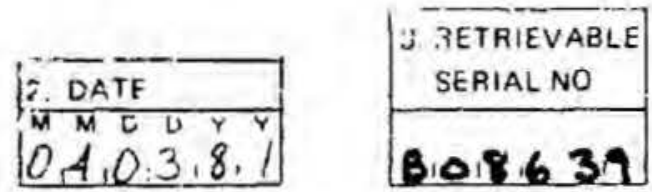

\begin{tabular}{|c|c|c|c|c|}
\hline 4. ORIGIN OF WASTE & \\
\hline GROUP & TA & BLDG & $\frac{2}{3}$ & AOOM \\
\hline$M_{1} B_{1} / 1,4$ & 0,3 & S, $M_{12}, 9$ & 9 & \\
\hline
\end{tabular}

\begin{tabular}{|r|}
\hline 5. WASTE \\
CODE \\
\hline$A, 4,0$ \\
\hline
\end{tabular}

6. WASTE DESCRIPTION

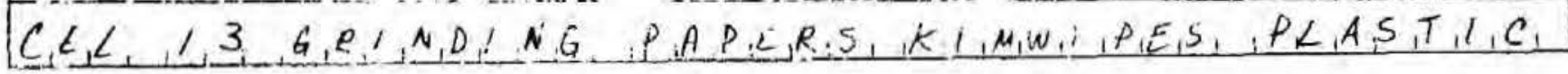

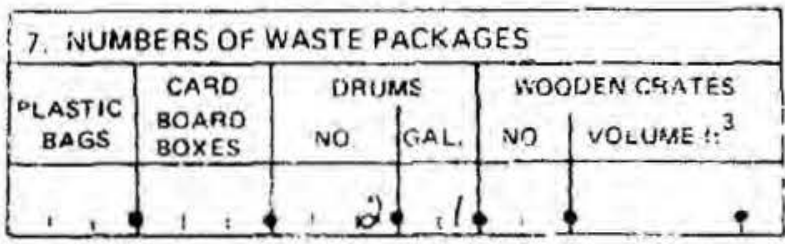

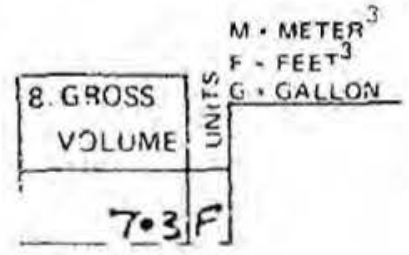

\begin{tabular}{|l|l|}
\hline 9. PACKAGE RADIATION AT: \\
\hline $\begin{array}{c}\text { SURFACE } \\
\text { MAIHR }\end{array}$ & $\begin{array}{c}\text { 1 METER } \\
\text { MRIHR }\end{array}$ \\
\hline G.0.00 & $16.0,0$ \\
\hline
\end{tabular}

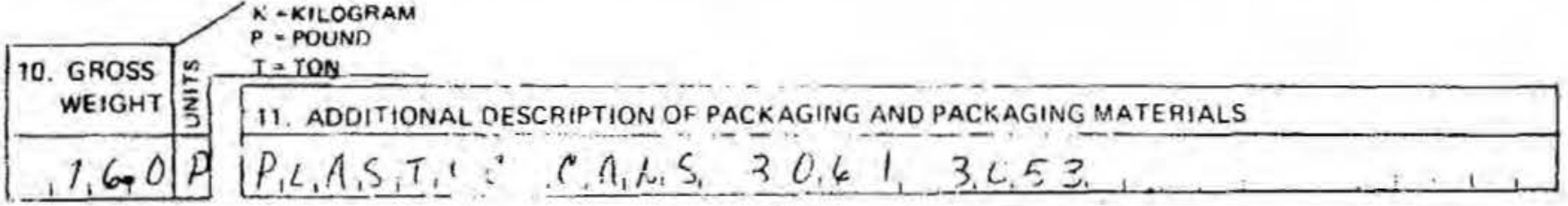

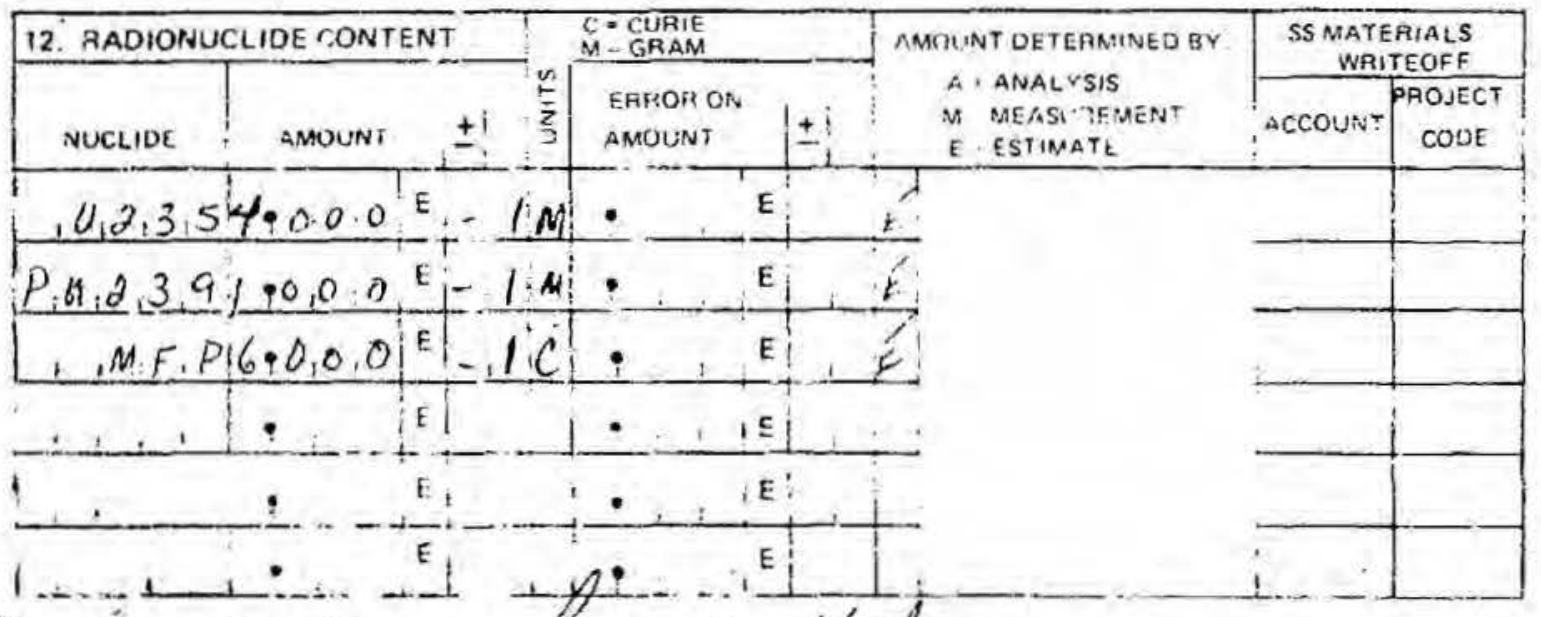

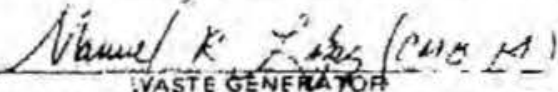

Segnature certuties that wast as in ded

apolicable doswosed requarements.

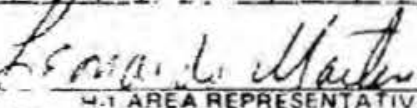

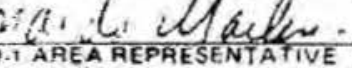

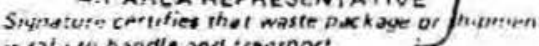

sats: to handie and transport:

CROUP LEADEA IAS NECESSARYI

=- $=-.$.

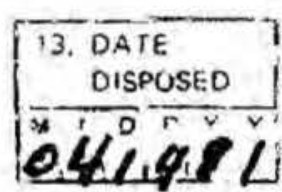

$(4148)$
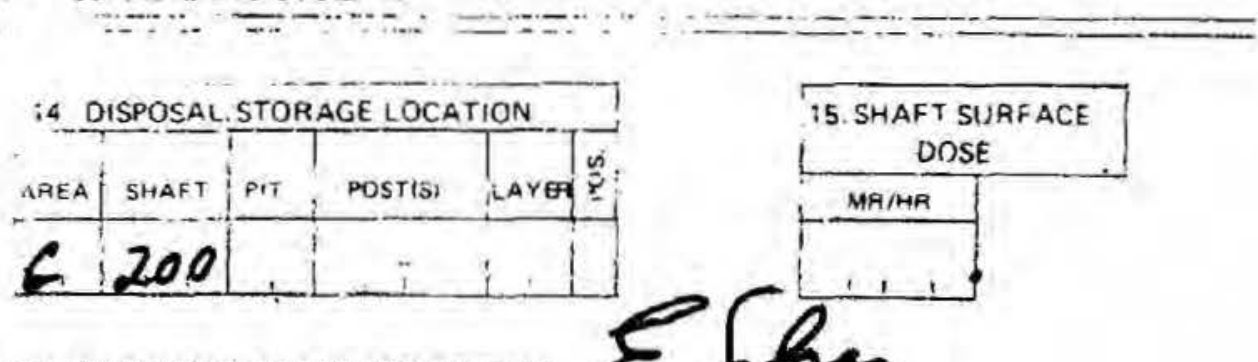
PLEASE RFAO INSTRUCTIONS ON BACK CAREFULLY

1. Fominumes $4 / 20 / 81$
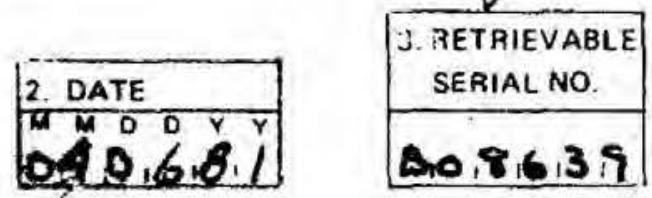

SL. RADIOACTIVE \$OLIO WASTE DISPOSAL RECORD FORM
Hi) Wastr Manazaturem ExI 6095 MS.592

\begin{tabular}{|c|c|c|c|c|}
\hline \multicolumn{3}{|c|}{ 4. ORIGIN OF WASTE } & \multirow{2}{*}{$\frac{2}{3}$} & \multirow[b]{2}{*}{ ROOM } \\
\hline GROUP & TA & BLDG. & & \\
\hline$C_{1} M_{1} B_{1}$ & $\frac{2}{1}$ & $5 M=$ & & \\
\hline
\end{tabular}

$\begin{array}{r}\text { 5. WASTE } \\ \text { CODE } \\ \hline A, 4,0 \\ \hline\end{array}$

\section{6. maste DESCRLPTION.}

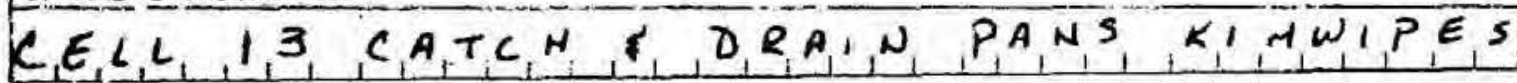

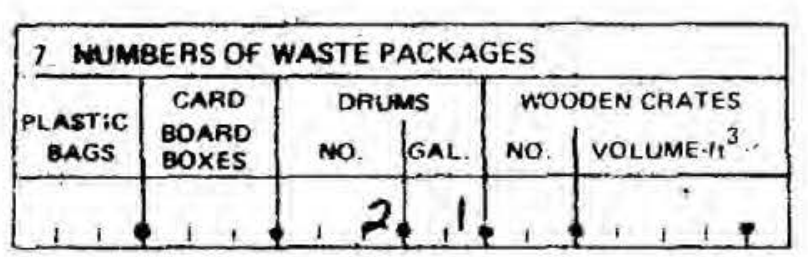

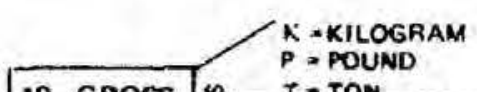

10. GROSS \& $\begin{aligned} & \mathrm{T} \text {-TON } \\ & \text { in }\end{aligned}$

WEIGHT 盗 11. ADDITIONAL DESCRIPTION OF PACKAGING AND PACKAGING MATERIALS

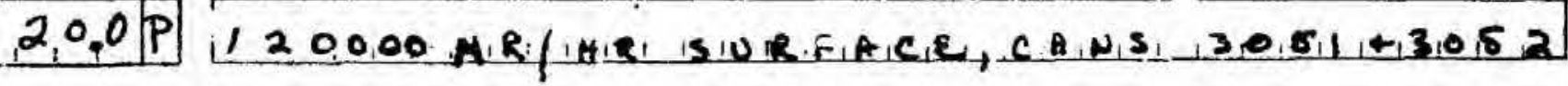

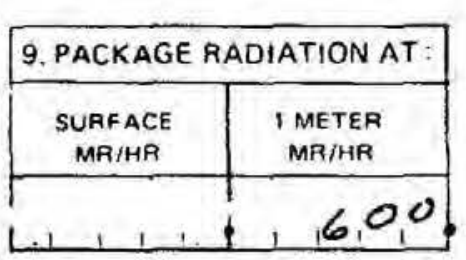

$F=F E E T^{3}$

\begin{tabular}{l|l} 
8. GROSS \\
VOLUME
\end{tabular}

$7 \cdot 3 \cdot 5$
$M=M E T E R^{3}$

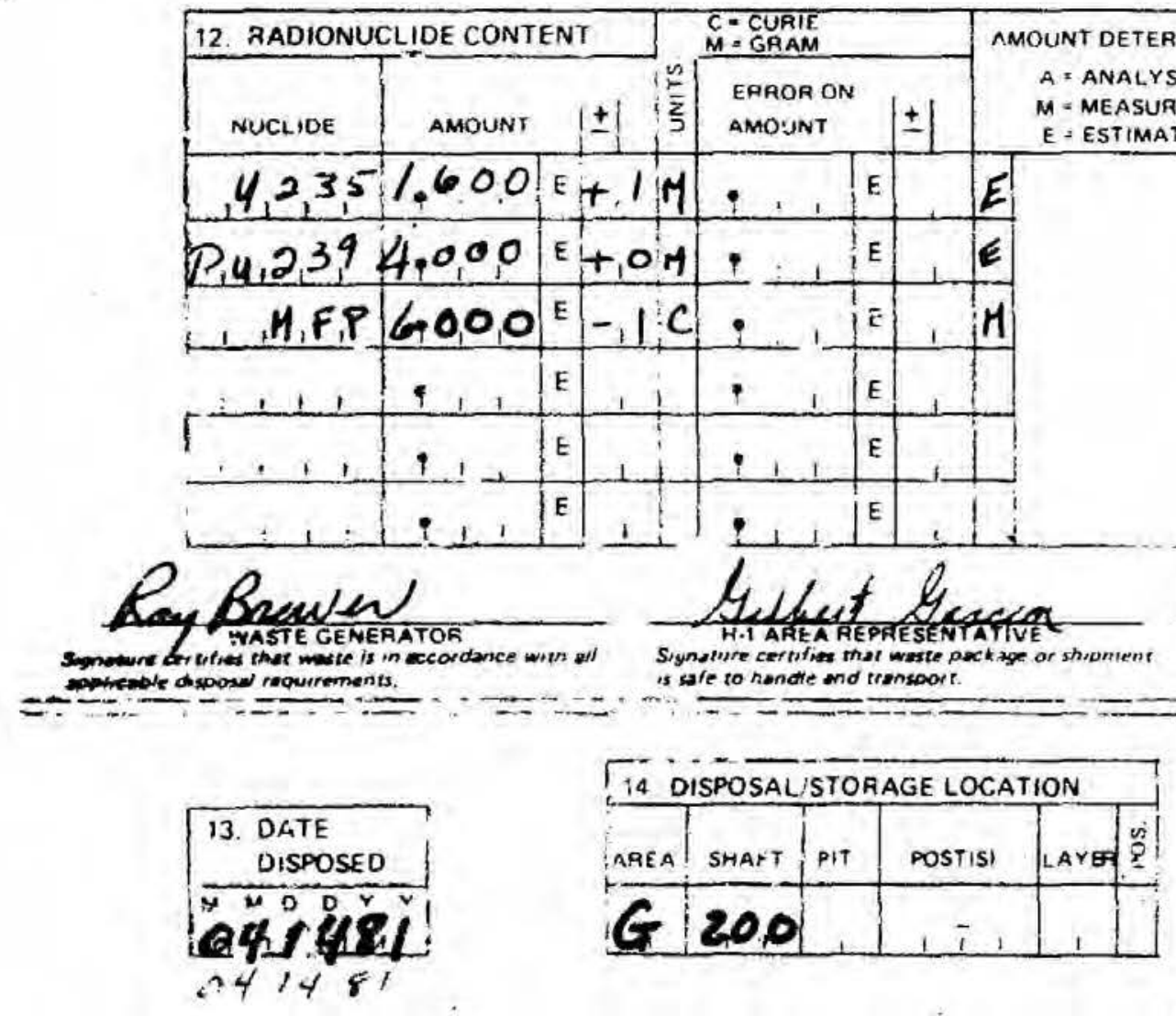

H-7 WASTE MANAGEMENT REPRESENTATIVE 


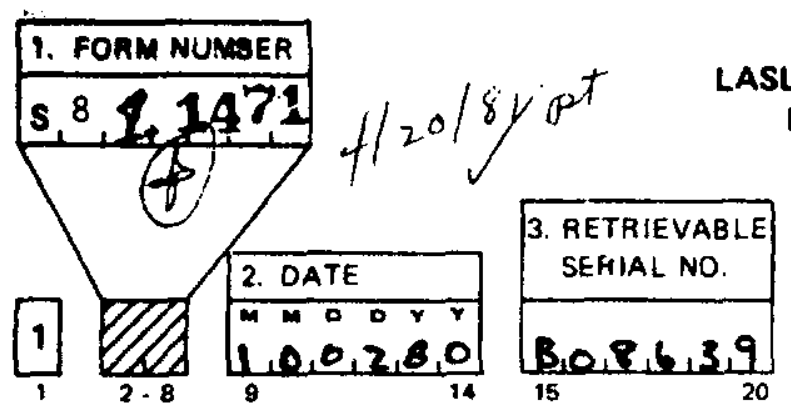

\section{LASL RADIOACTIVE SOLID WASTE DISPOSAL RECORD FORM}

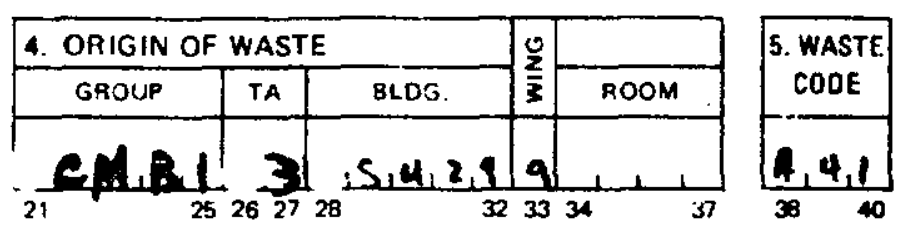

6. WASTE DESCRIPTION

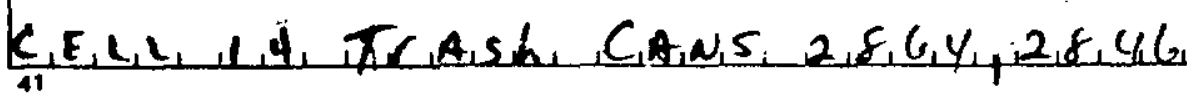
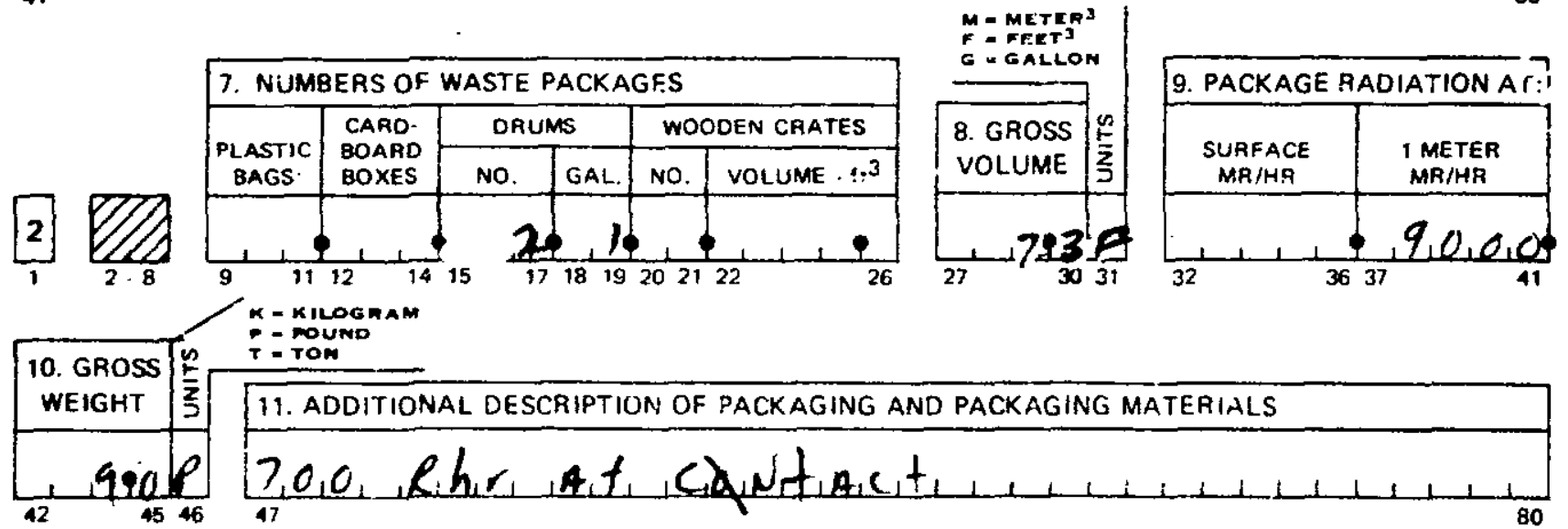

\section{K = KILOGRAM}

- Mouno

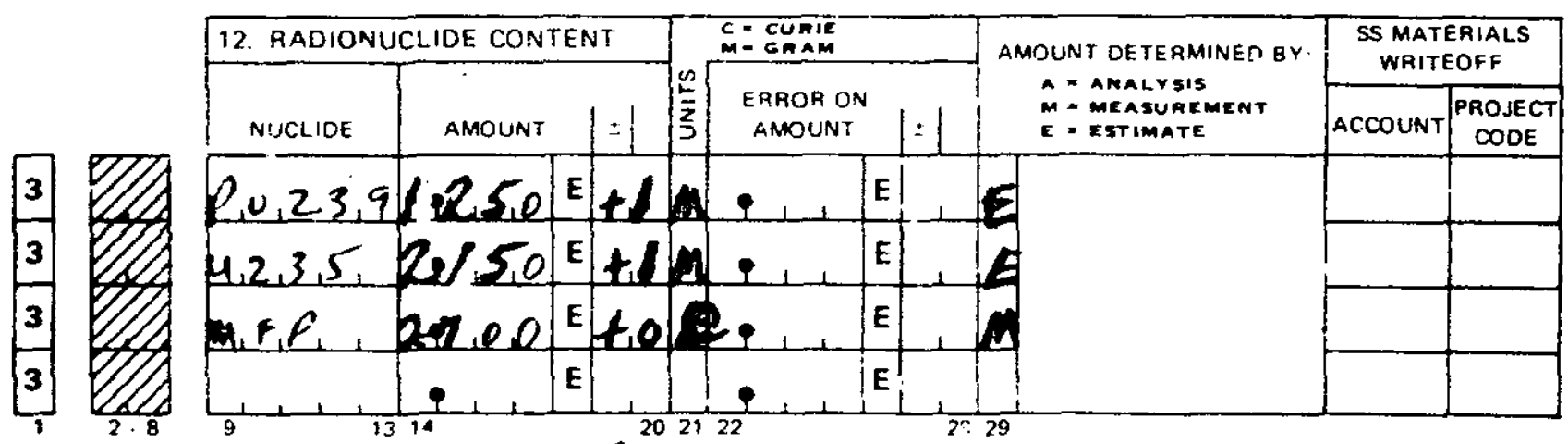

Unaste Geneatiof
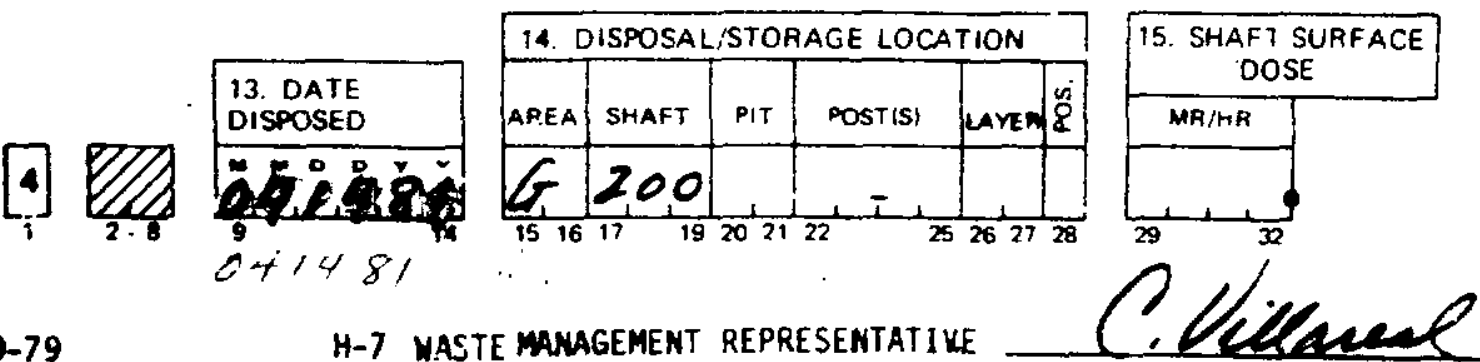


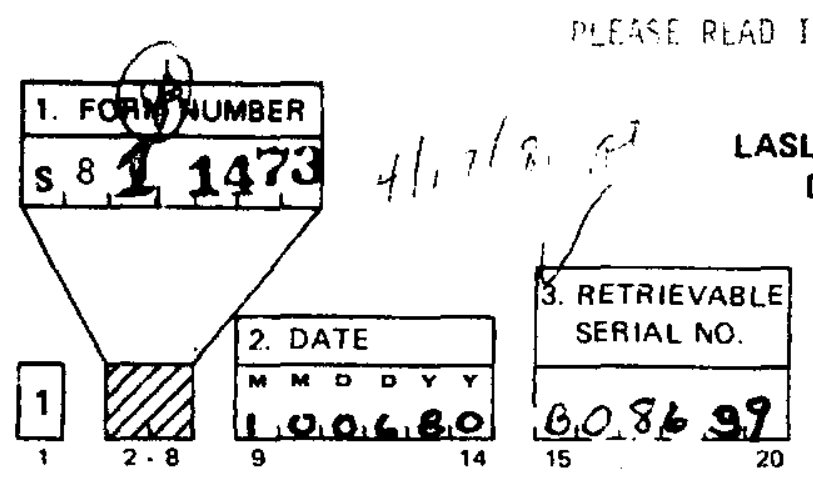

\section{LASL RADIOACTIVE SOLID WASTE DISPOSAL RECORD FORM}
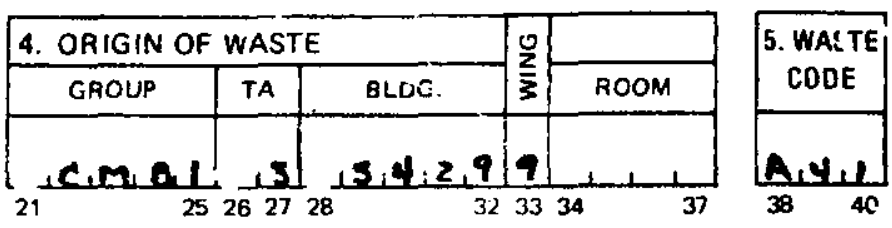

6. WASTE DESCRIPTION

$\#, 2,8,7,2,2,6,3,3,1,1, \frac{1}{80}$
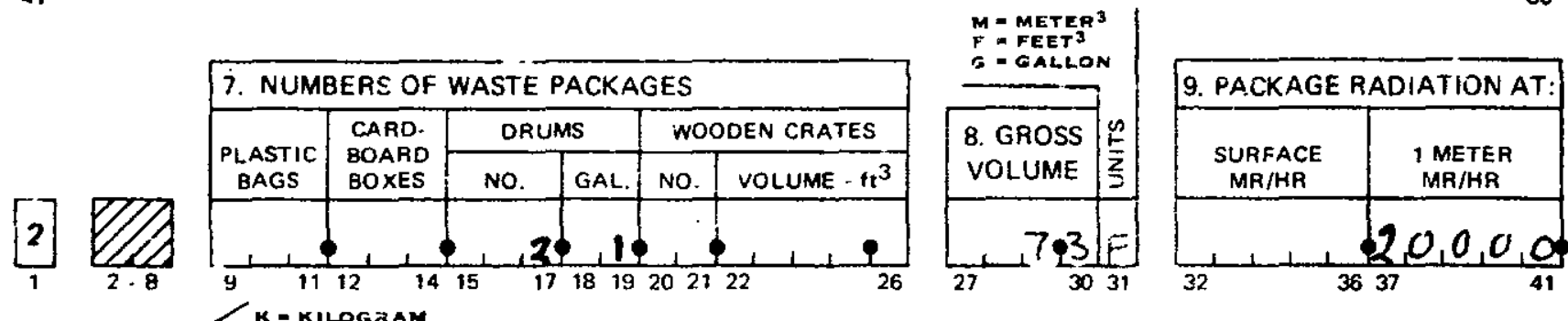

H-7 Waste Managemen

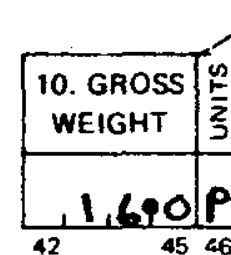

K= KILOGAAM

$T=$ TON

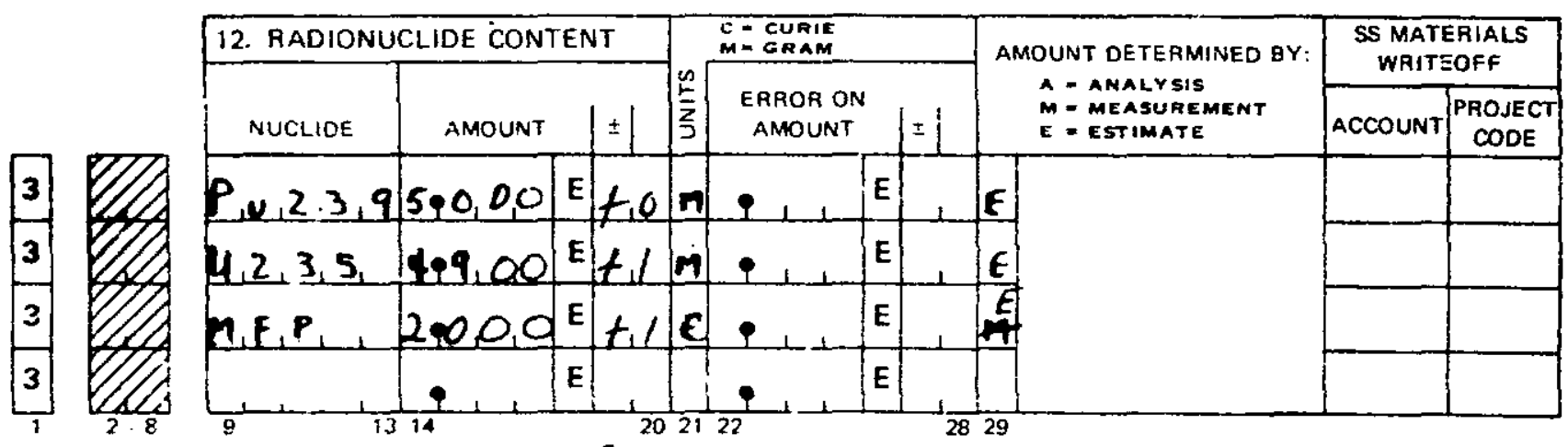

nol $2003-1$

J WASTE GREPATOR

signd ture cetifife: inat wate is in accorcance

11. ADDITIONAL DESCRIPTION OF PACKAGING AND PACKAGING MATERIALS

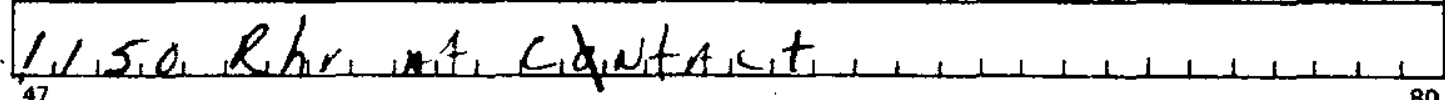

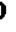

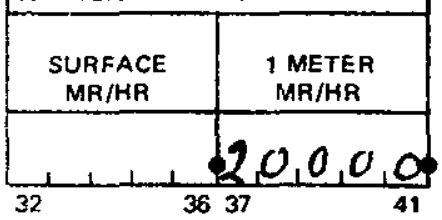


RADIOACTIVE SOLID WASTE DISPOSAL RECORD FORMS

FOR

SHAFT 201

MATERIAL DISPOSAL AREA G 


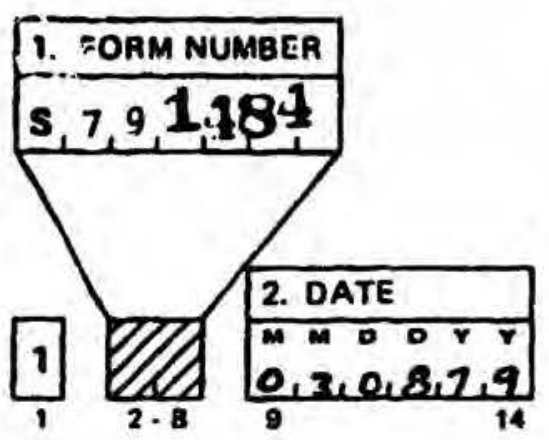

\section{PLEASE READ INSTRUCTIOAS ON BACK GourtrkLLY LASL RADIOACTIVE SOLID WASTE DISPOSAL RECORD FORM}
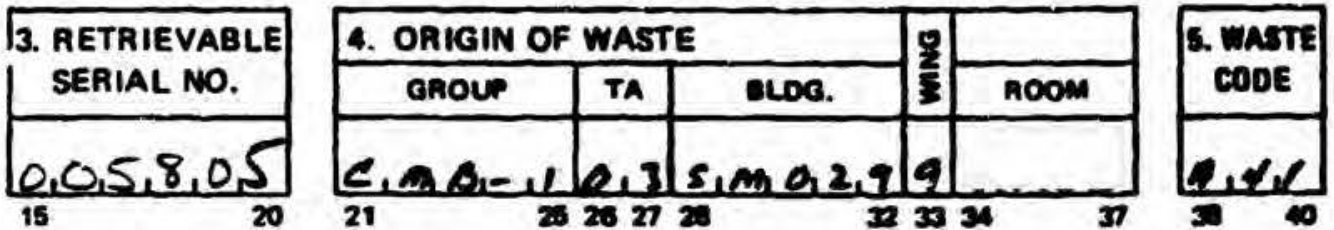

\section{WASTE DESCRIPTION}

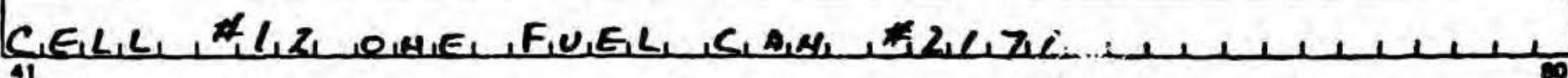

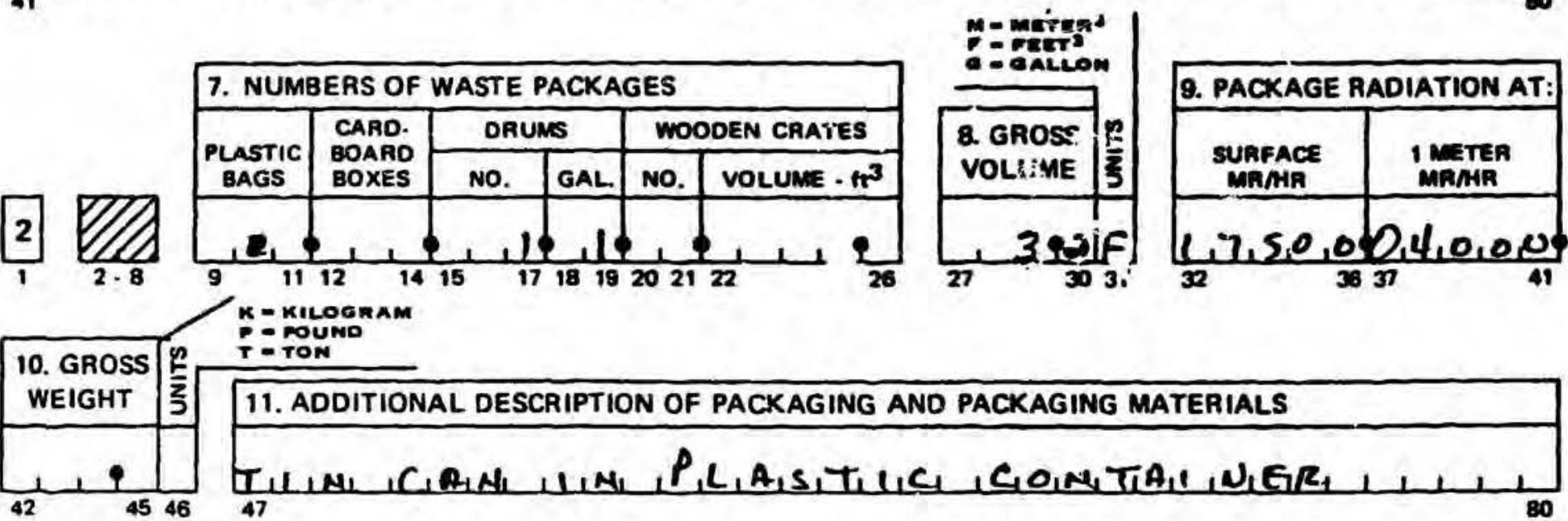

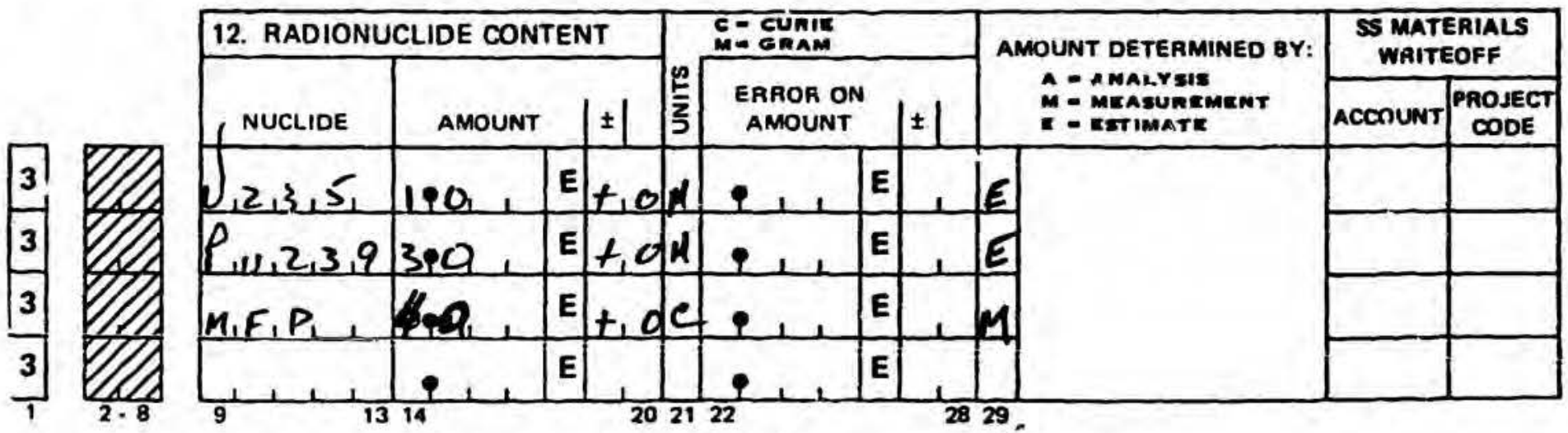

WASter geNERATOR
ignature certifies that waste is in accordance
ith all applicable disposal requirements.

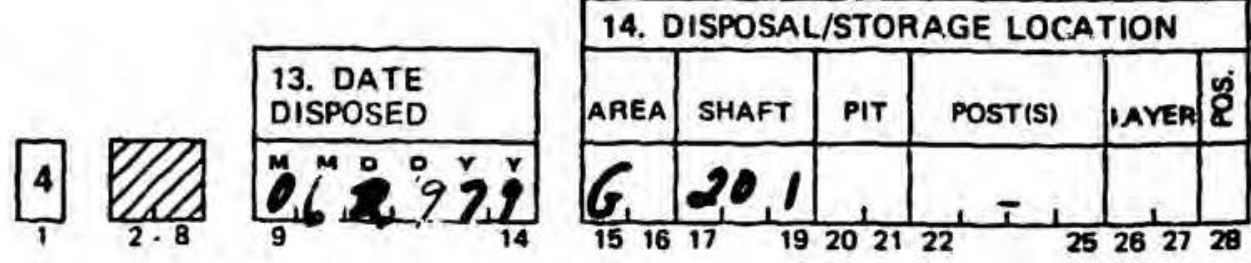

H-7 WASFF

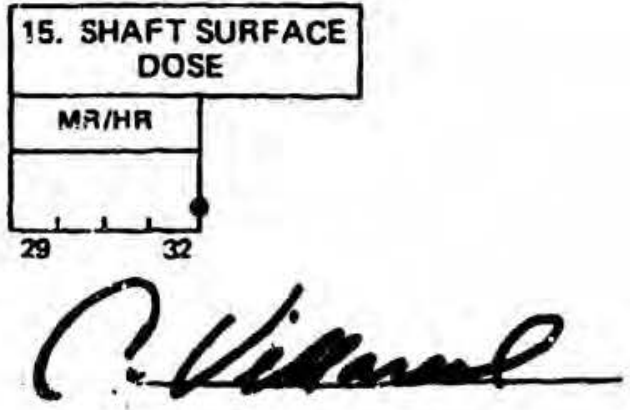




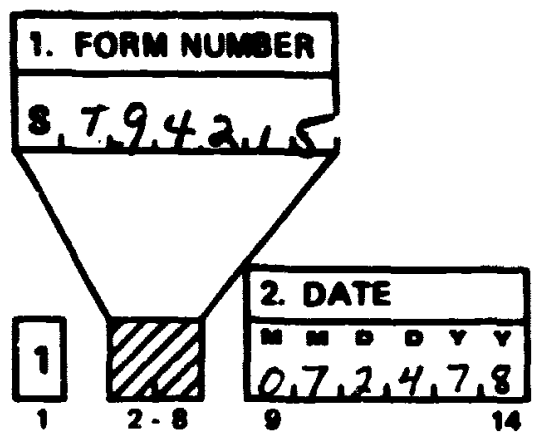

\section{LAL AMDOACTIVE OLD MASTE disual Recond Fom}

n. ... Haragemont

Ext sC9: $\mathrm{N}: 282$
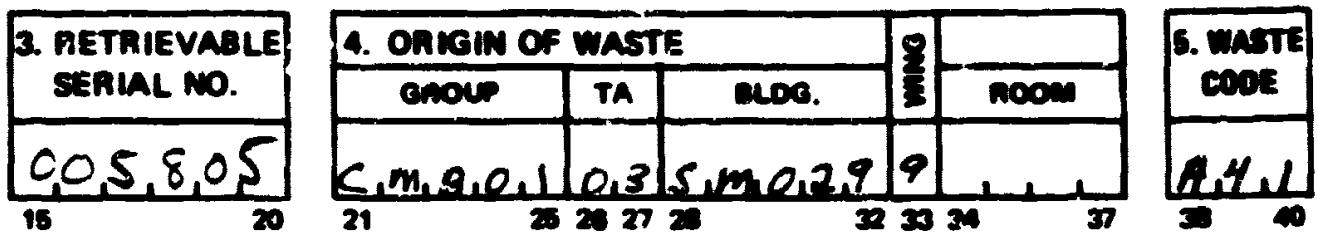

\section{WASTE DESCRIPTION}

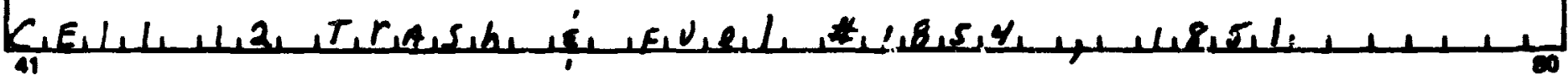
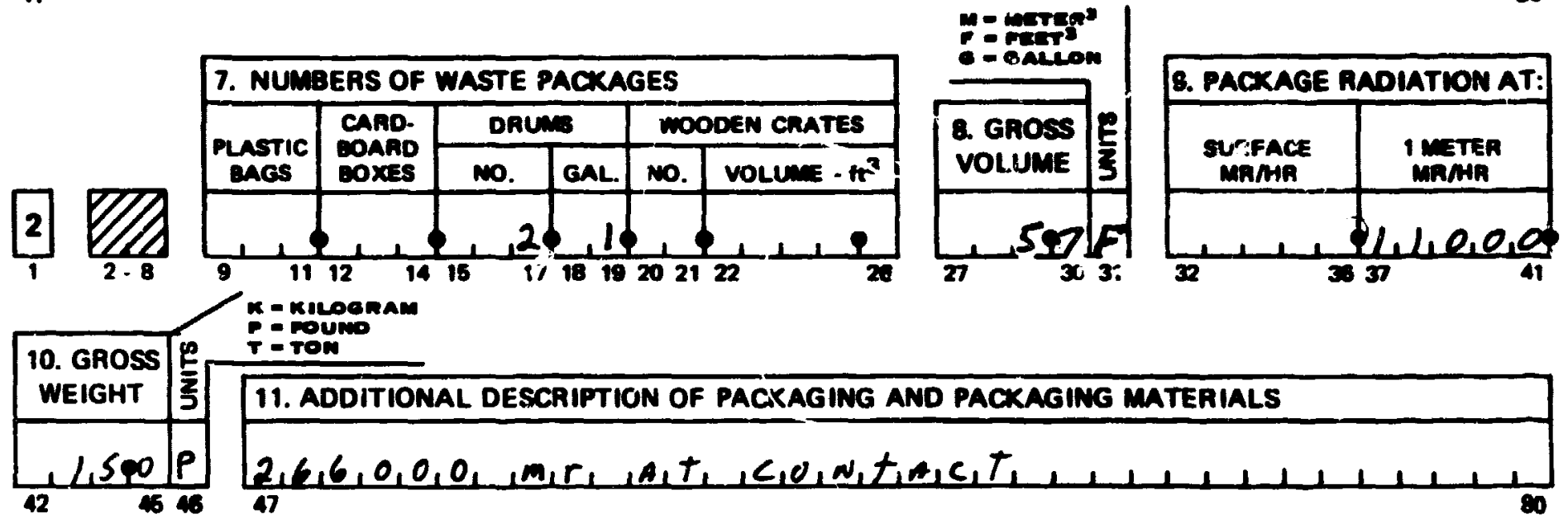

- Kusognam

T = TON
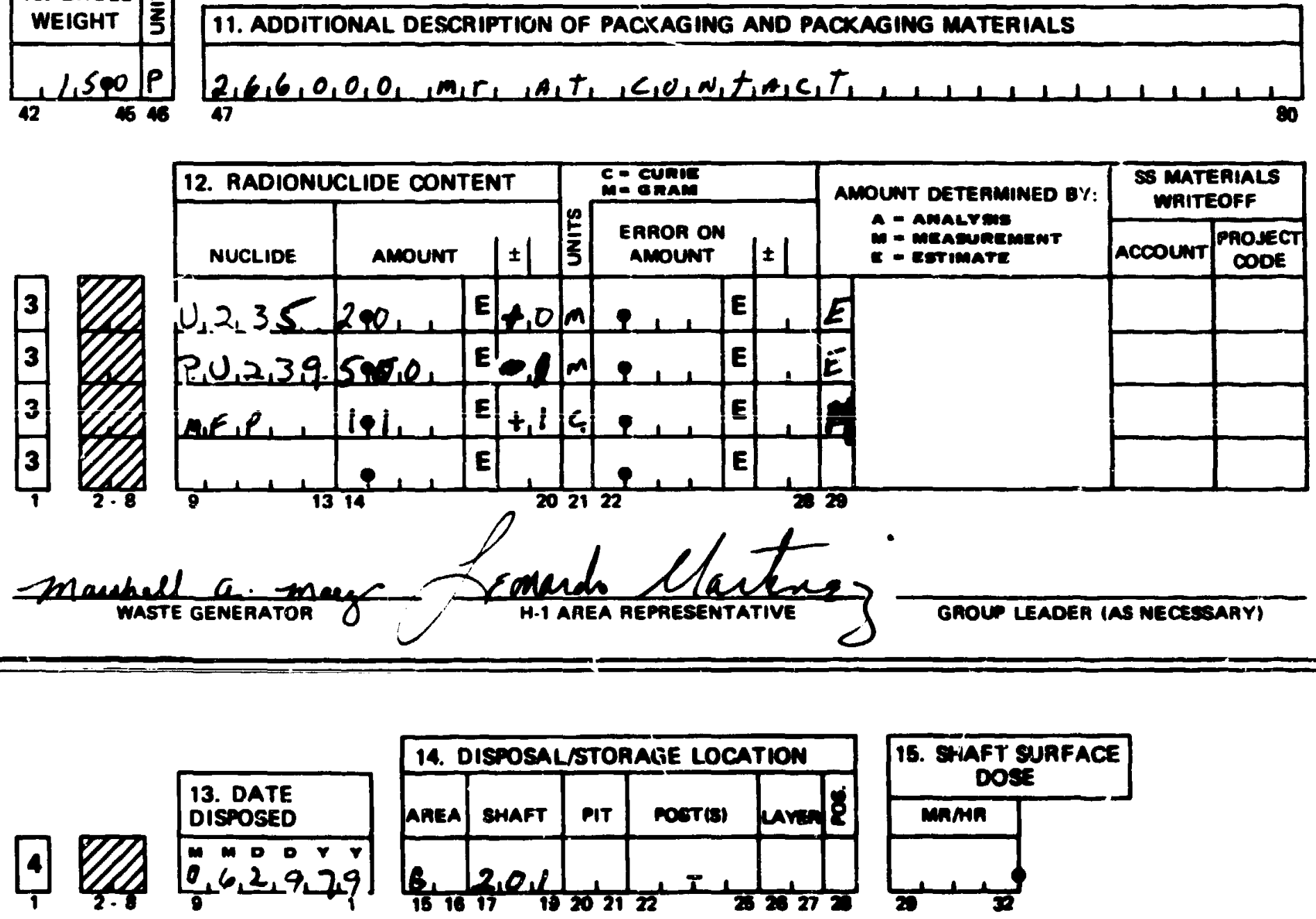

10

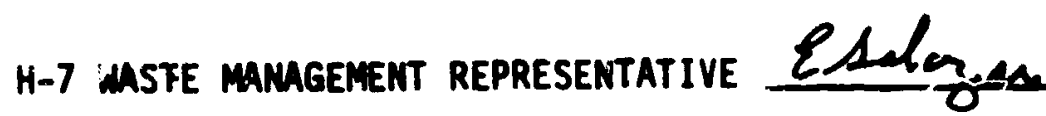



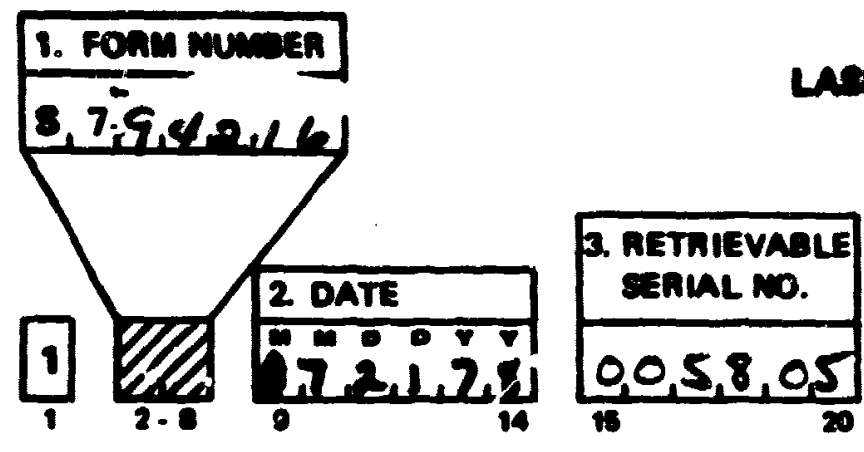

LAA RADIOAGTVE CLW WASTH-7 Waste Manageman

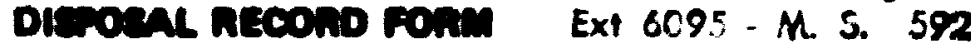
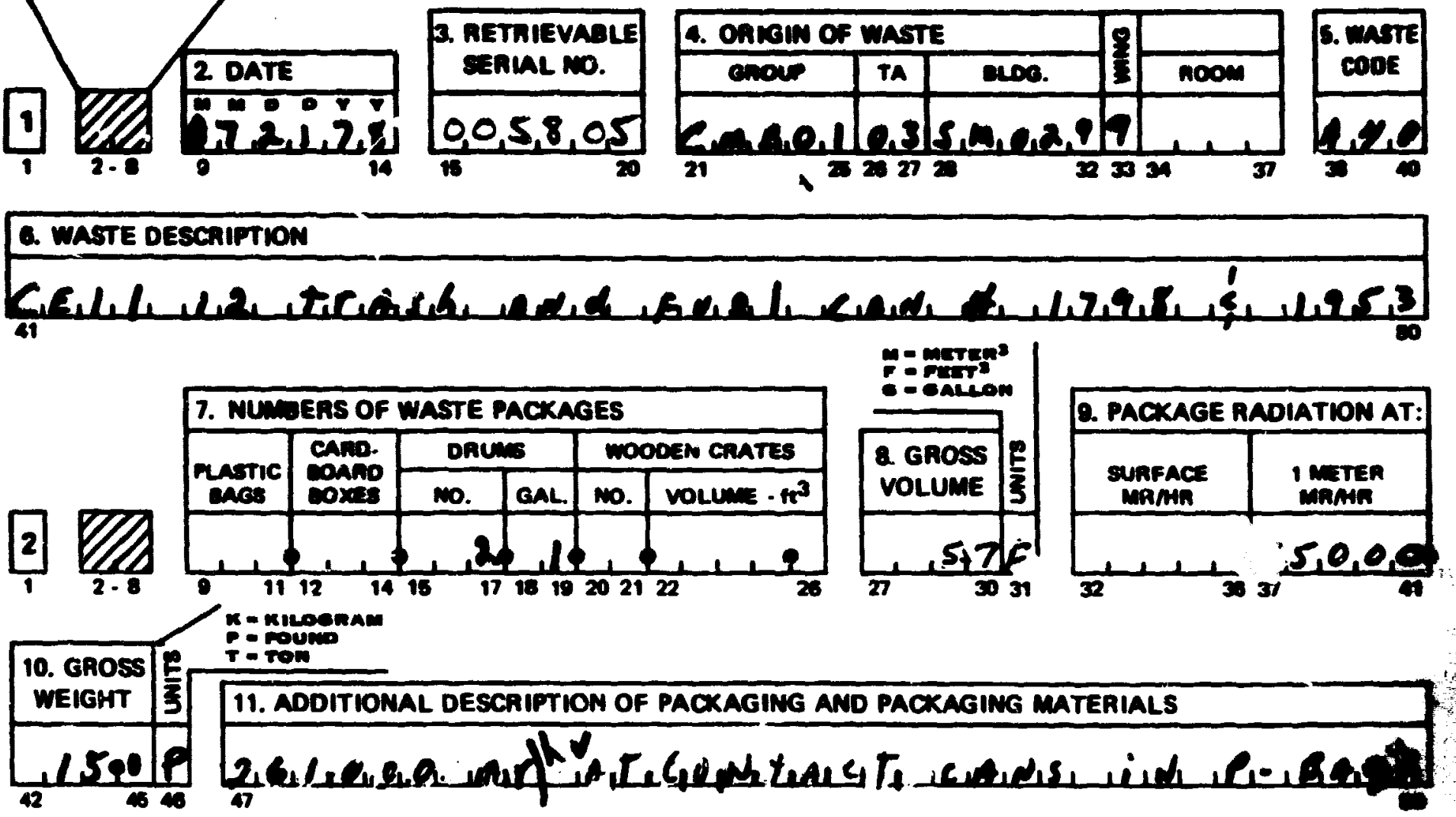

6. WASTE DESCRIPTION

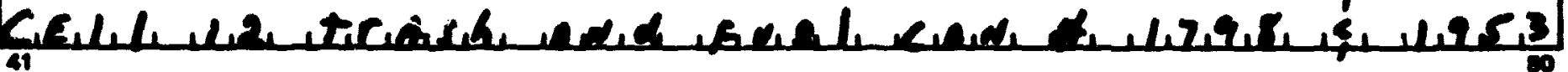

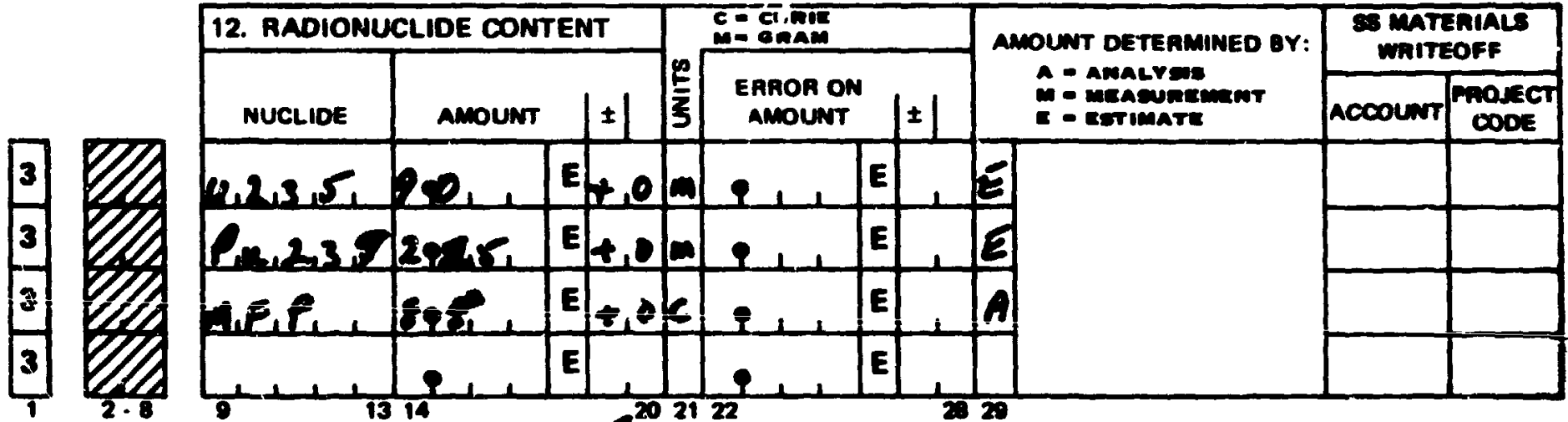

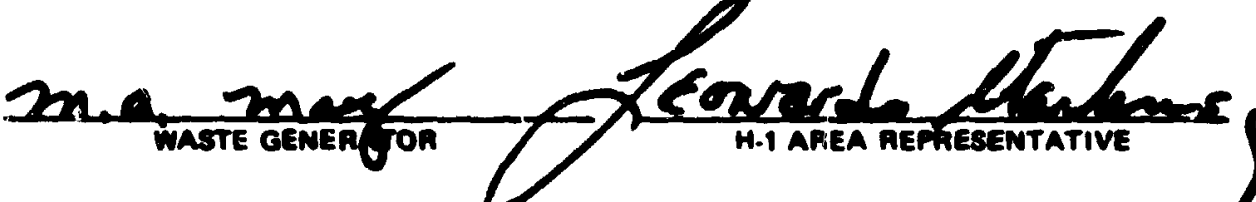

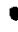

\section{GROUP LEADEA (AS HECEMANY)}

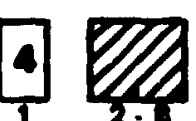

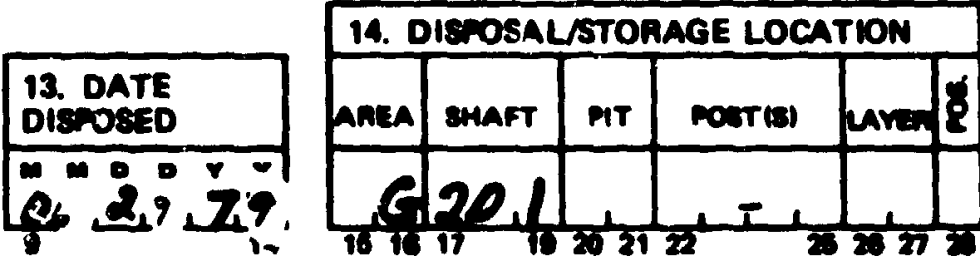

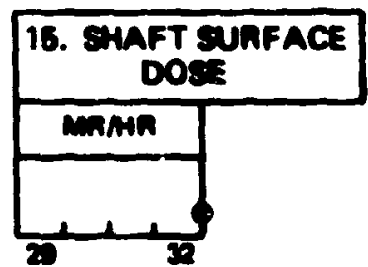

H-7 MASTE MMUGEMENT REPRESENTATIVE 


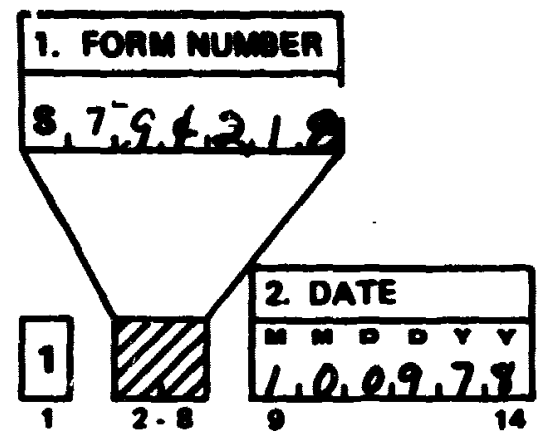

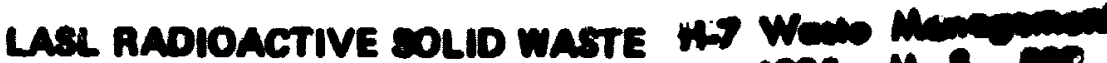 DIENOSAL RECORD FOAM
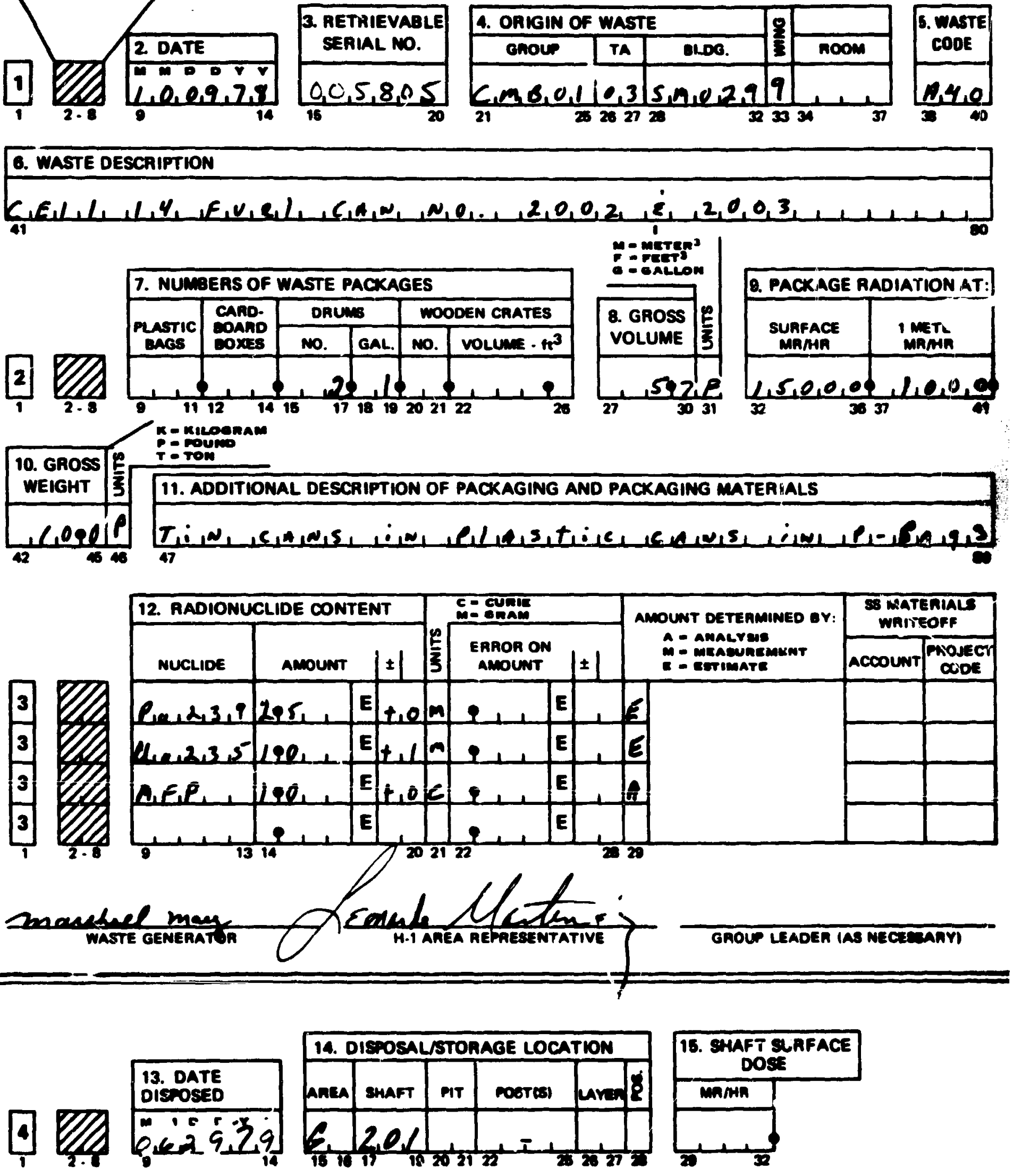

H-7 MASTE MAMGEMENT REPRESENTATIVE

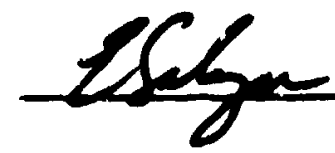




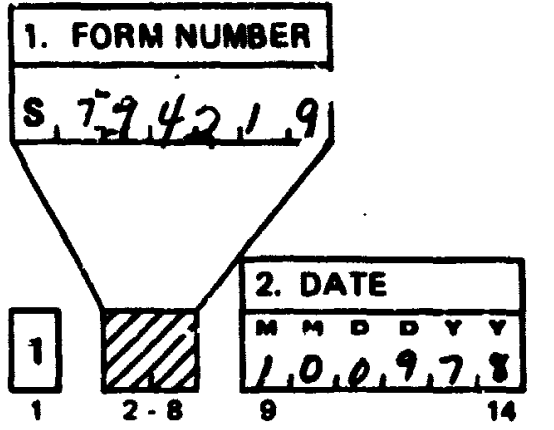

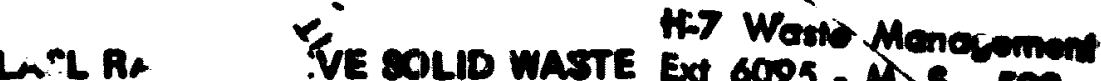 DIEvUEmL RECOAC FORM}
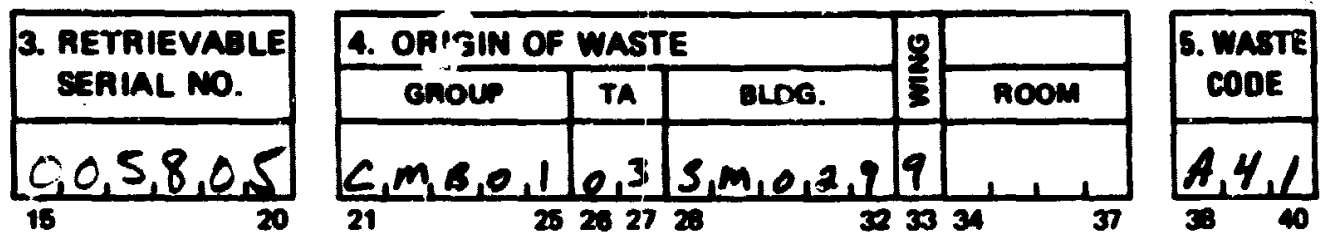

\section{WASTE DESCRIPTION}

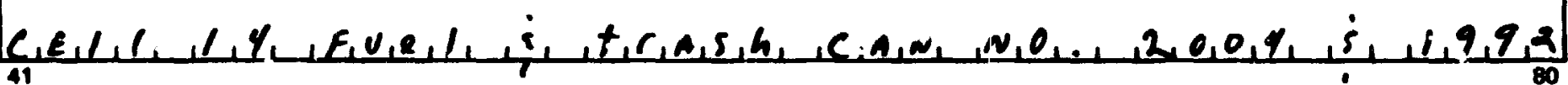
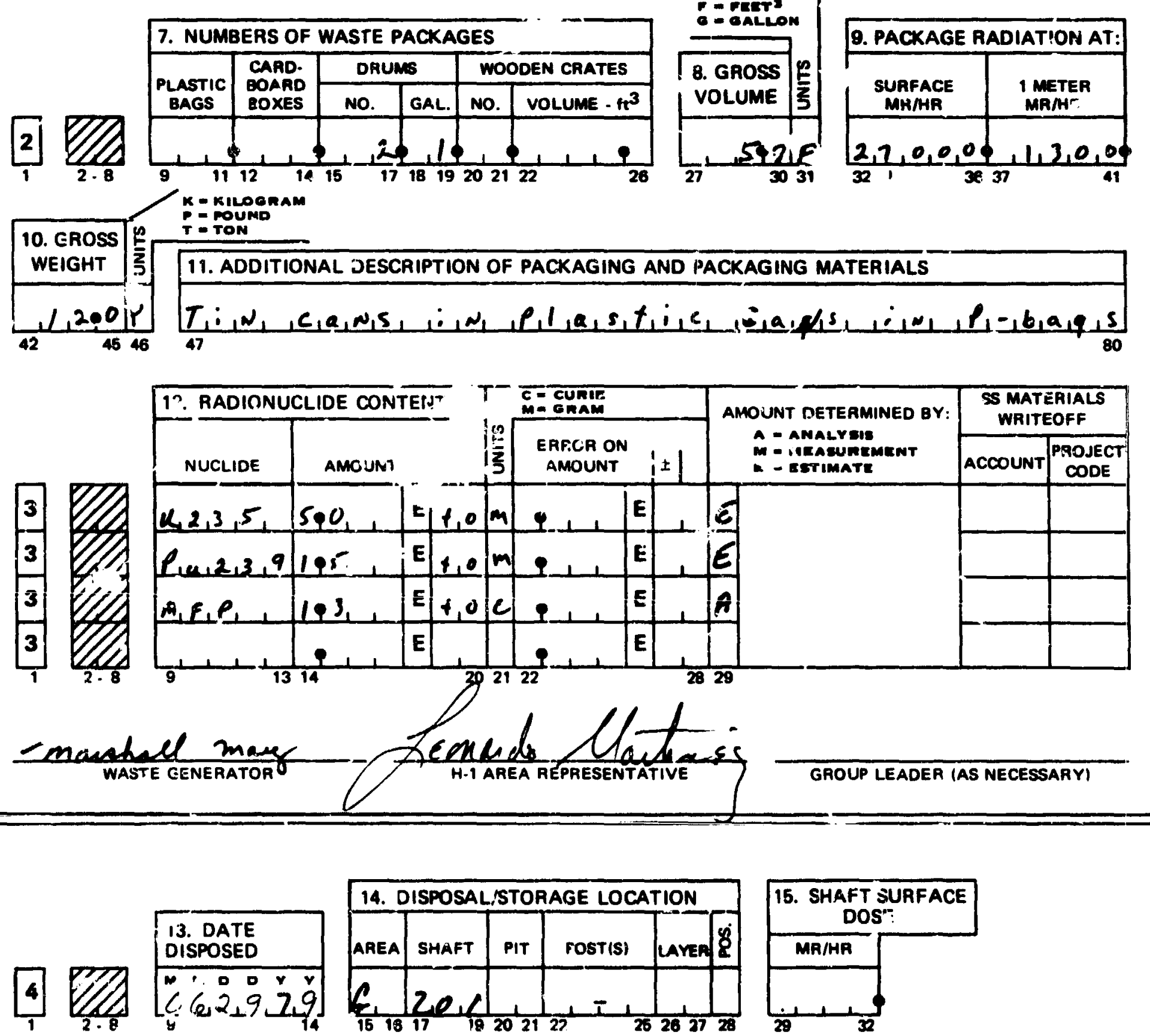

H-7 WASFe managiment refresentative 


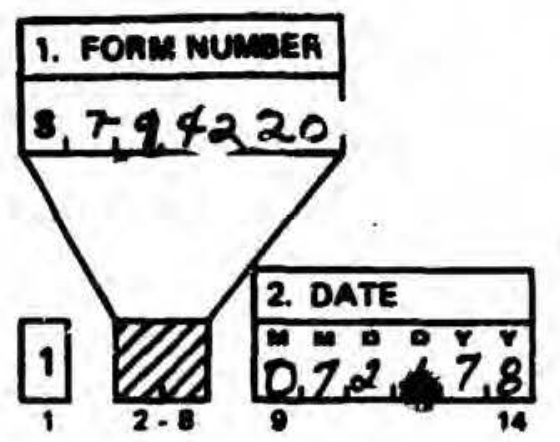

LASE.

OLID WASTE H-7 Waste Management DiscueAl RELOAD FOAM

Ext 6095 - M. S. 592
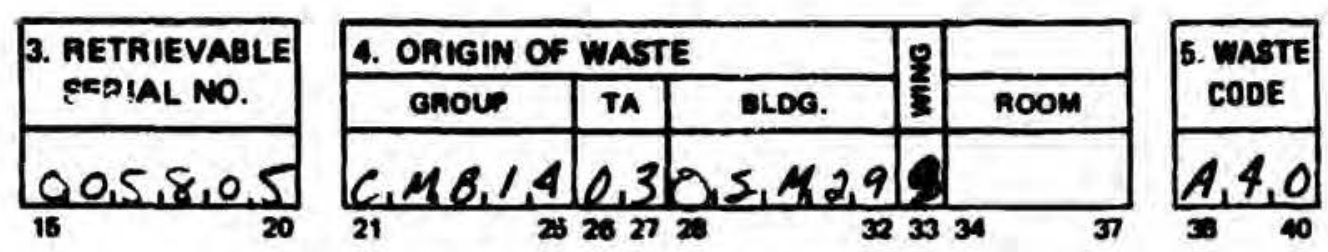

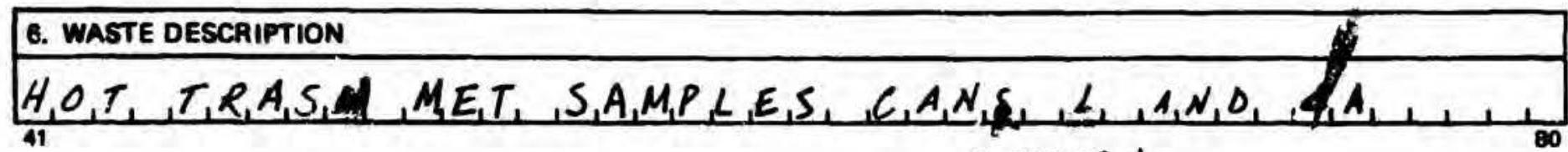
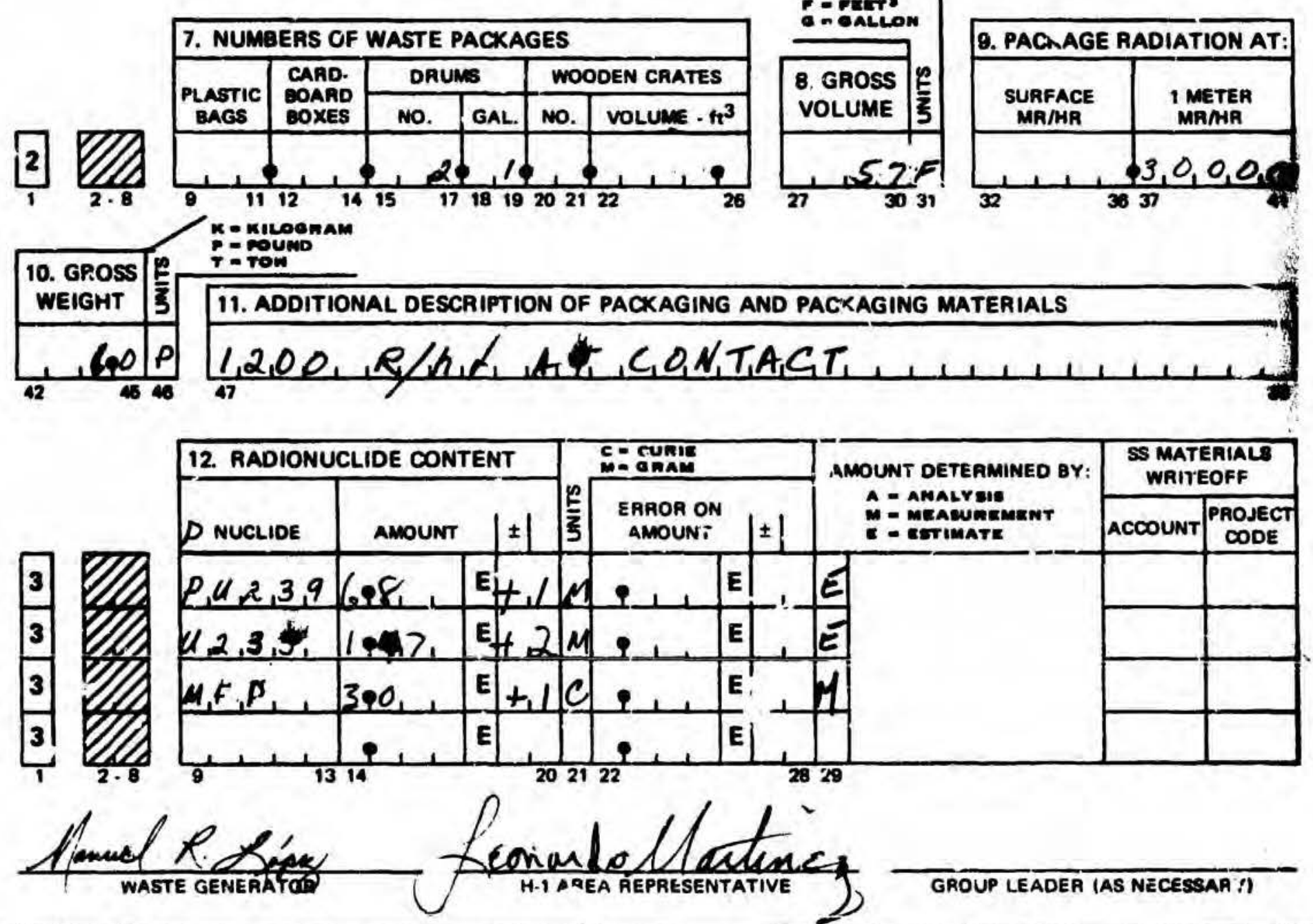

GROUP LEADER (AS NECESSAP ?)

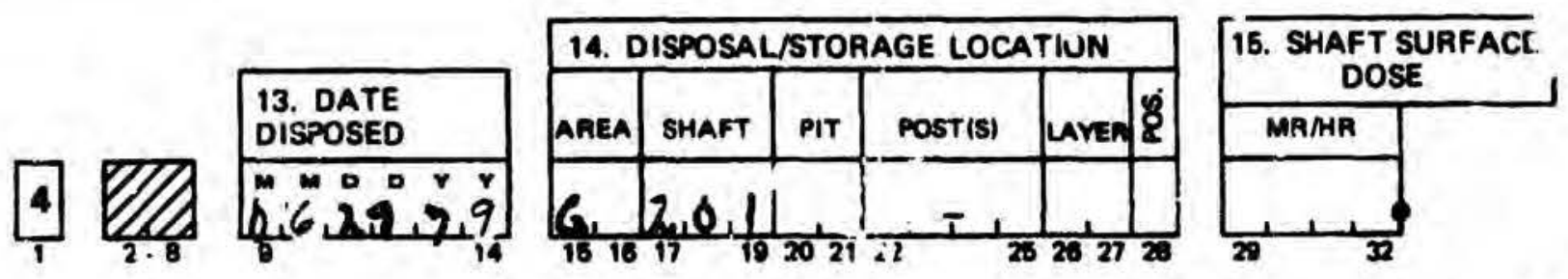

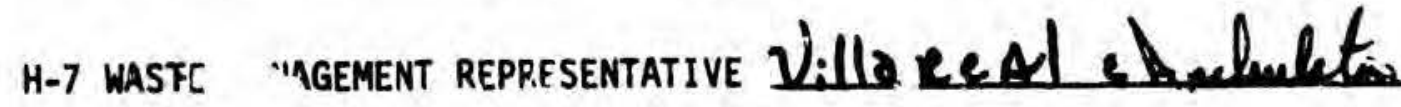




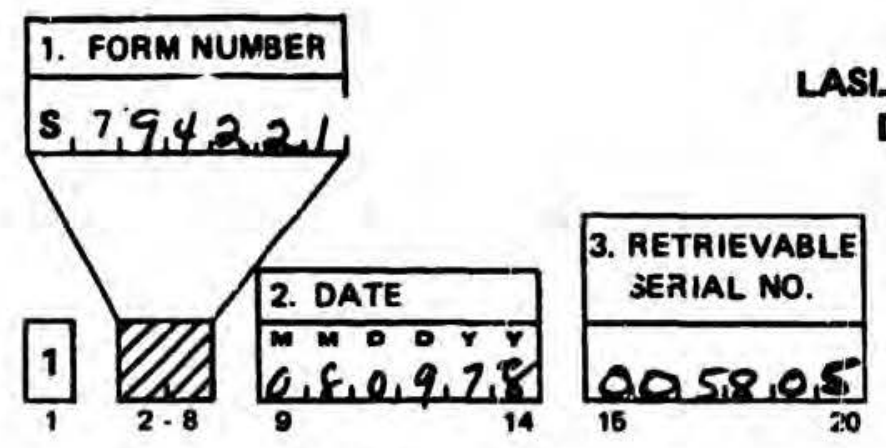

LASI. RADIOACTIVE SOLID WASTEH-7 Waste Management DIsPOSAL RECORD FORM Ext 6095 - M. S. 592
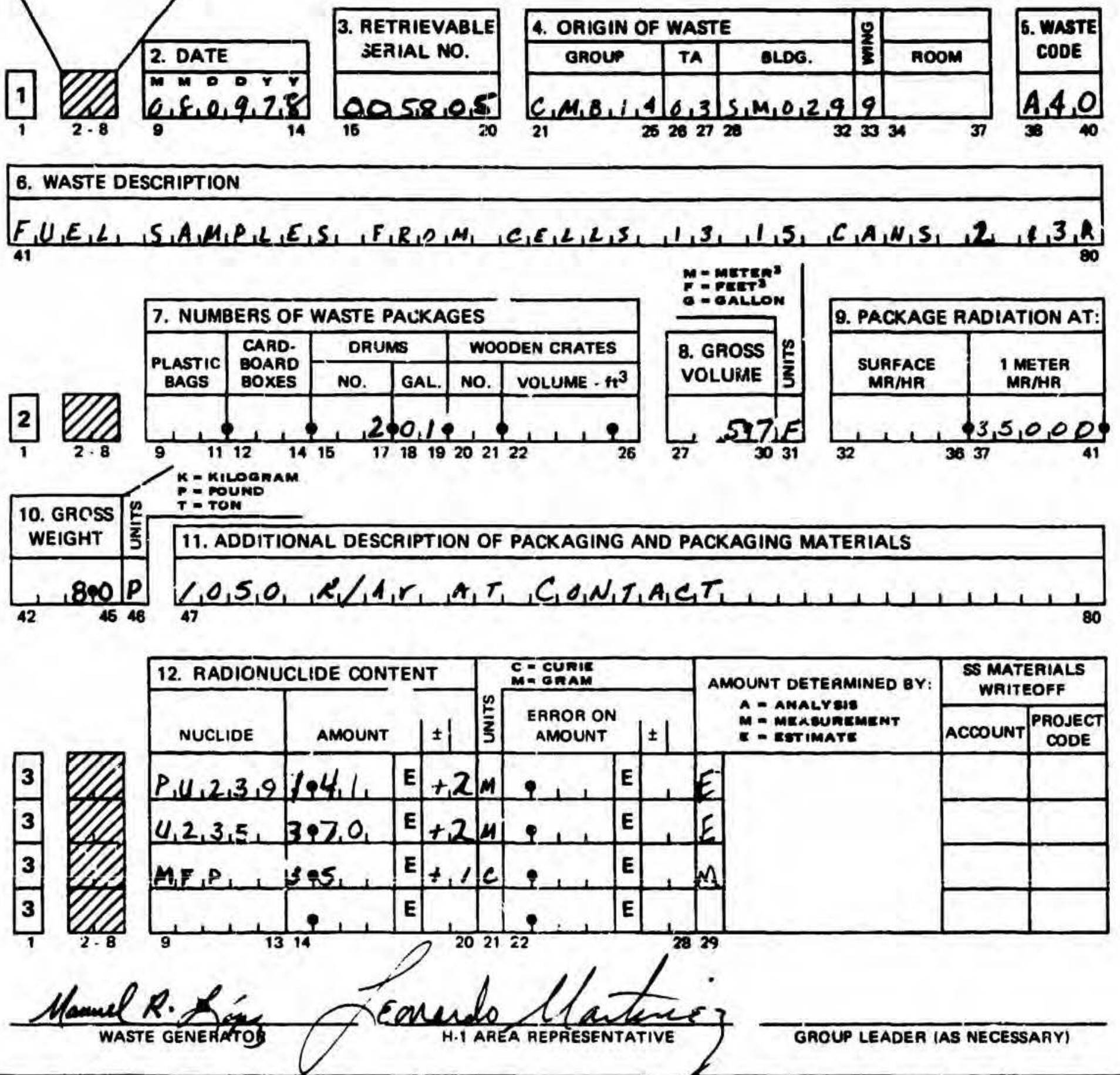

GAOUP LEADER (AS NECESSAAY)

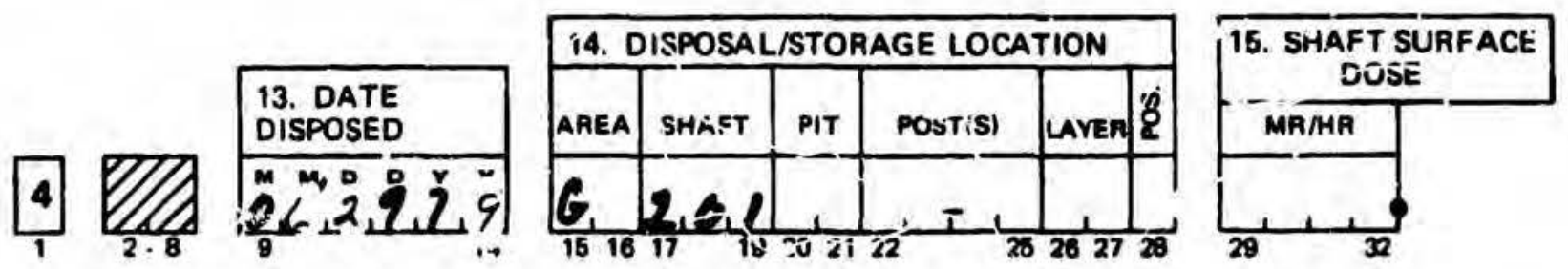

H-7 WASFE MANAGEMENT REPRESENTATIVE 
RADIOACTIVE SOLID WASTE DISPOSAL RECORD FORM

FOR

SHAFT 202

MATERIAL DISPOSAL AREA G 


\section{FoNm MUMmen}

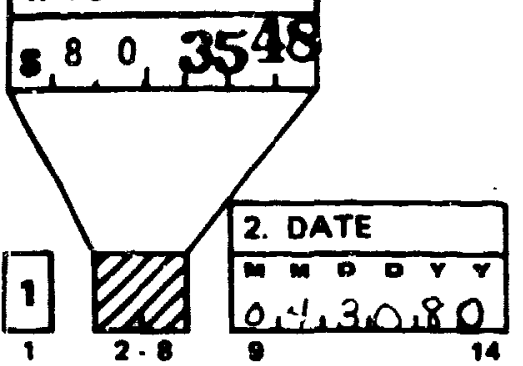

\section{LASL RADIOACTIVE SOLID WASTE DIgOSAL RECOAD FORM}
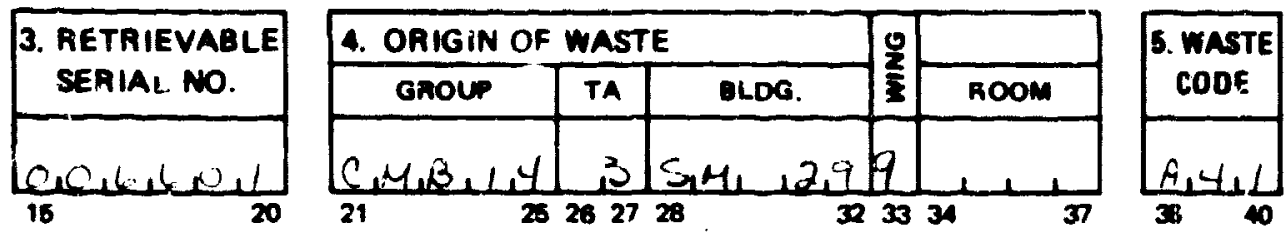

\section{WASTE DESCRIPTION}

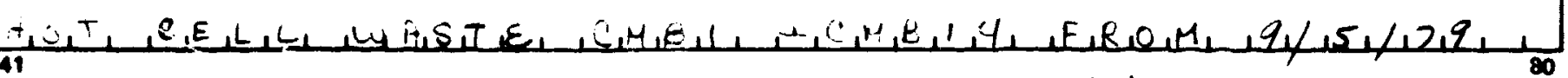
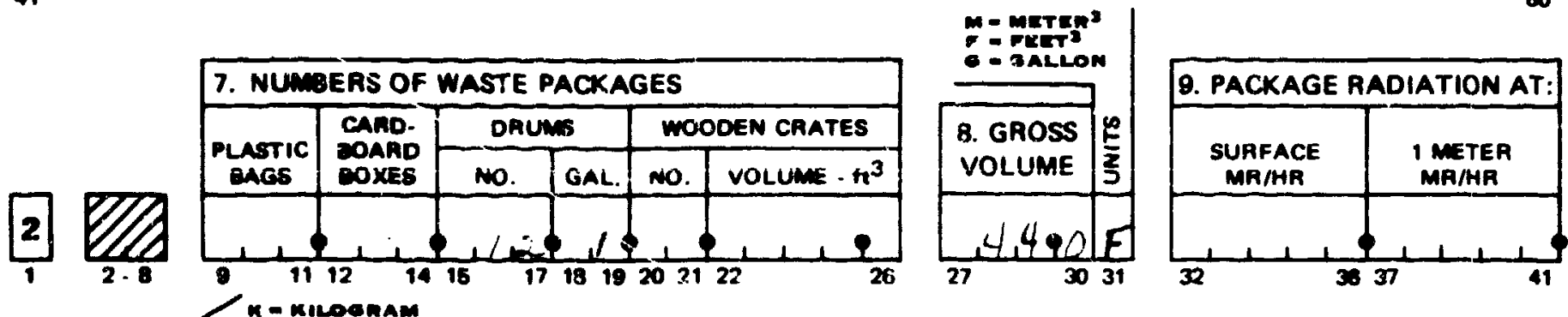

\section{n- kilogran}

\begin{tabular}{|l|l}
\hline $\begin{array}{c}\text { 10. GAOSS } \\
\text { WEIGHT }\end{array}$ & $\frac{2}{5}$ \\
\hline 12 & 293 \\
\hline 4
\end{tabular}

Toun

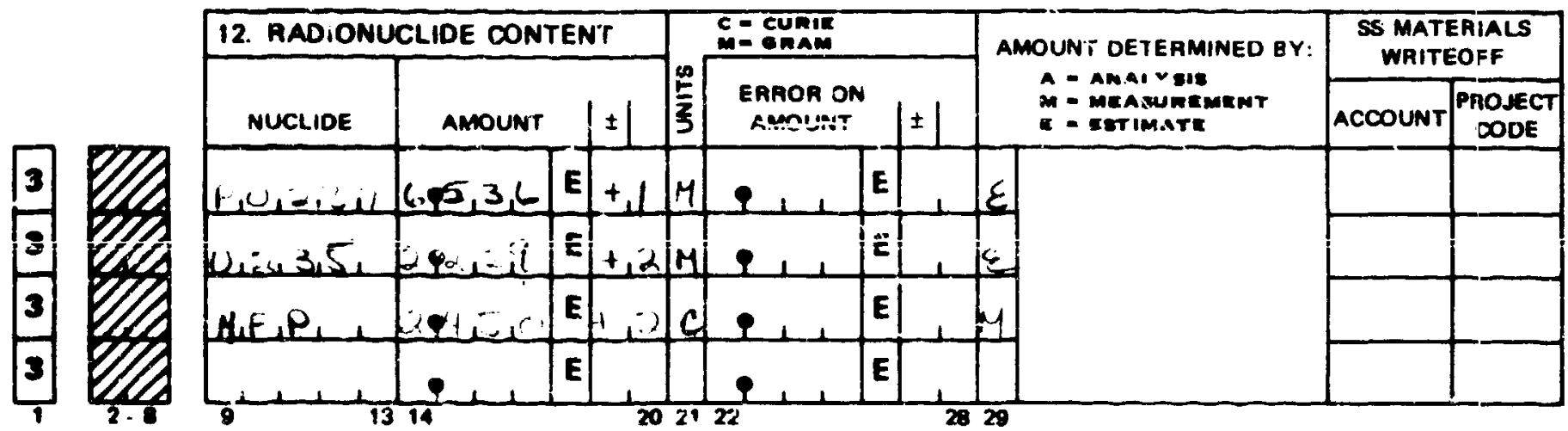

WATE GENEAATOR

jignewre certifies tint ws te is in accoraance its all epolicable disposel requilements.

\section{ADOITIONAL DESCRIPTION OF PACKAGING AND PACKAGING MATERIALS}

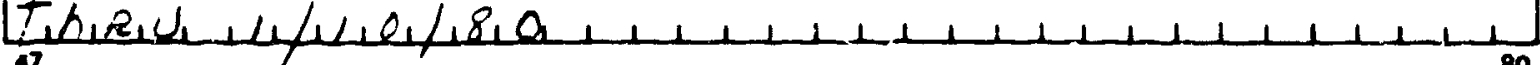


RADIOACTIVE SOLID WASTE DISPOSAL RECORD FORM

FOR

SHAFT 203

MATERIAL DISPOSAL AREA G 


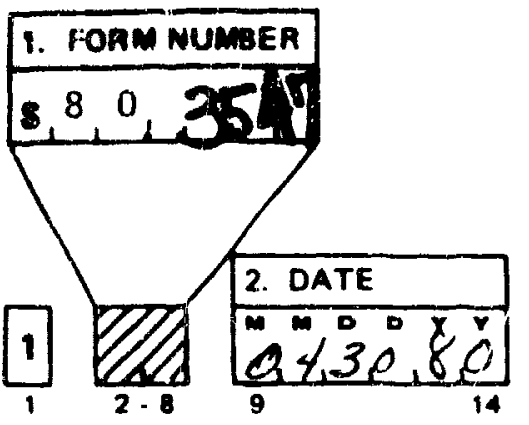

\section{LASL RADIOACTIVE SOLID WASTE DISPOSAL RECORD FORM}
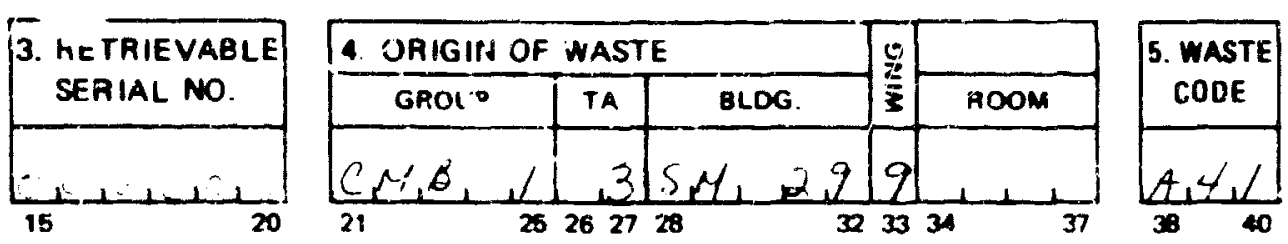

\section{WASTE DESCRIPTION}

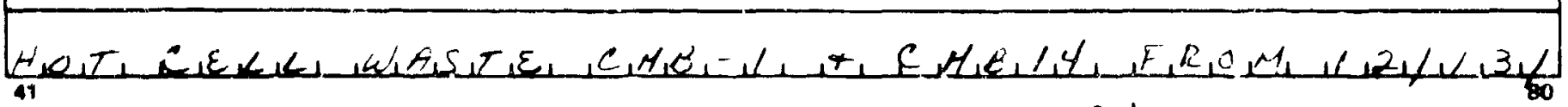
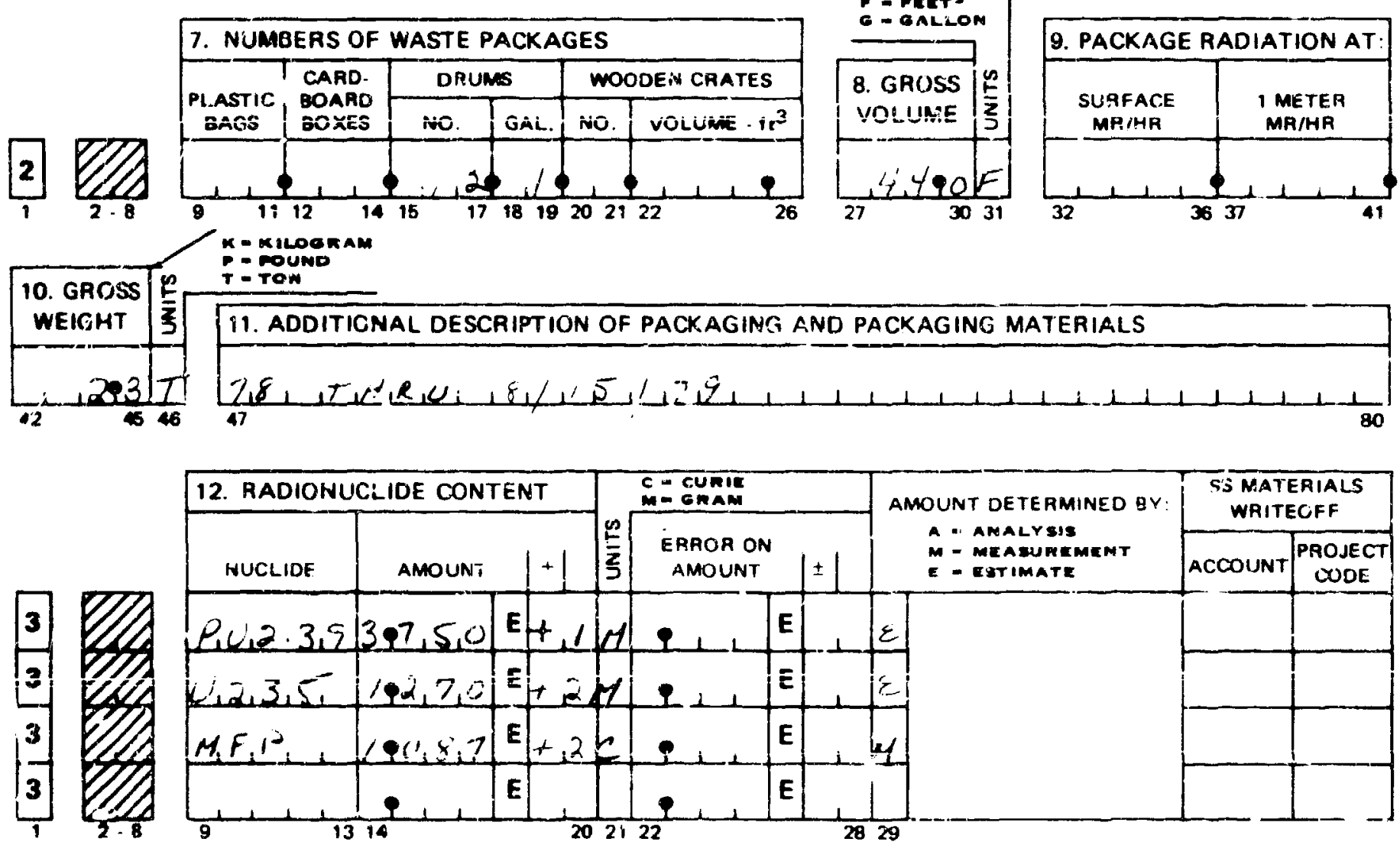

WASTE GENERATOR

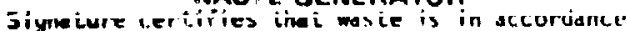
ulth oll apelicable disposal requirements.
H.1 A REA REPRESENTATIVE

jignecure cerciries that wa's te package or shipanent. is safe to handie ar.d transpert.
GROUP LEADER (AS NECESSARY)

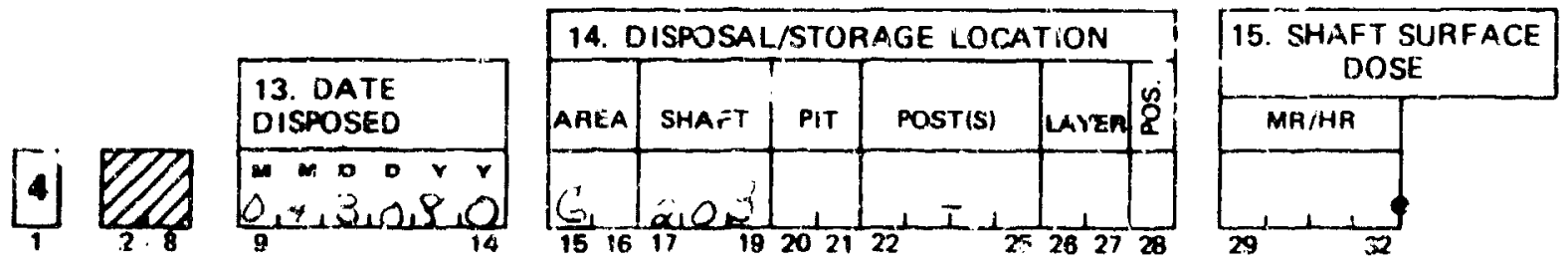


RADIOACTIVE SOLID WASTE DISPOSAL RECORD FORMS

FOR

SHAFT 204

MATERIAL DISPOSAL AREA G 


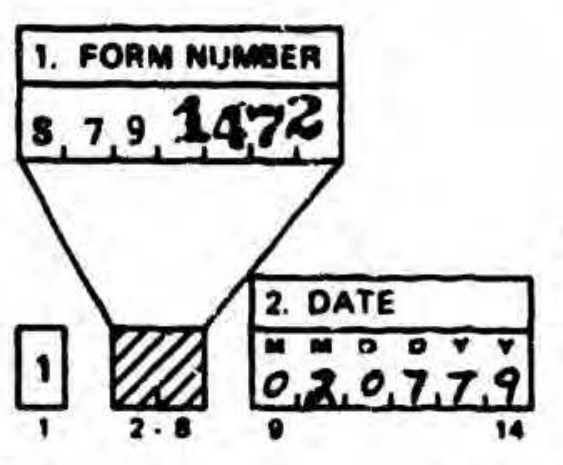
PLEASE READ INSTRUCTIONS ON BACK CAREFULLY LAY RADIOACTIVE COLID WASTE DIEOSAL RECORD NOAM
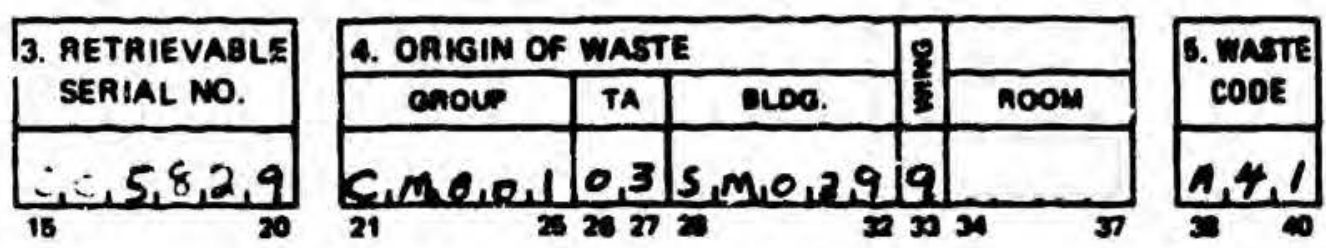

6. WASTE DESCRIPTION

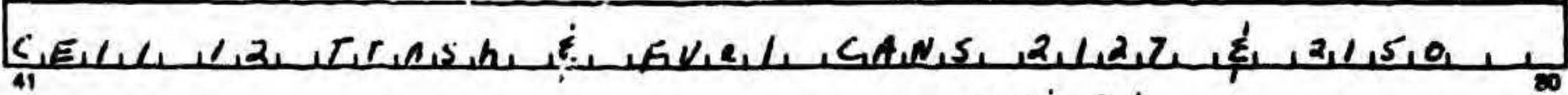
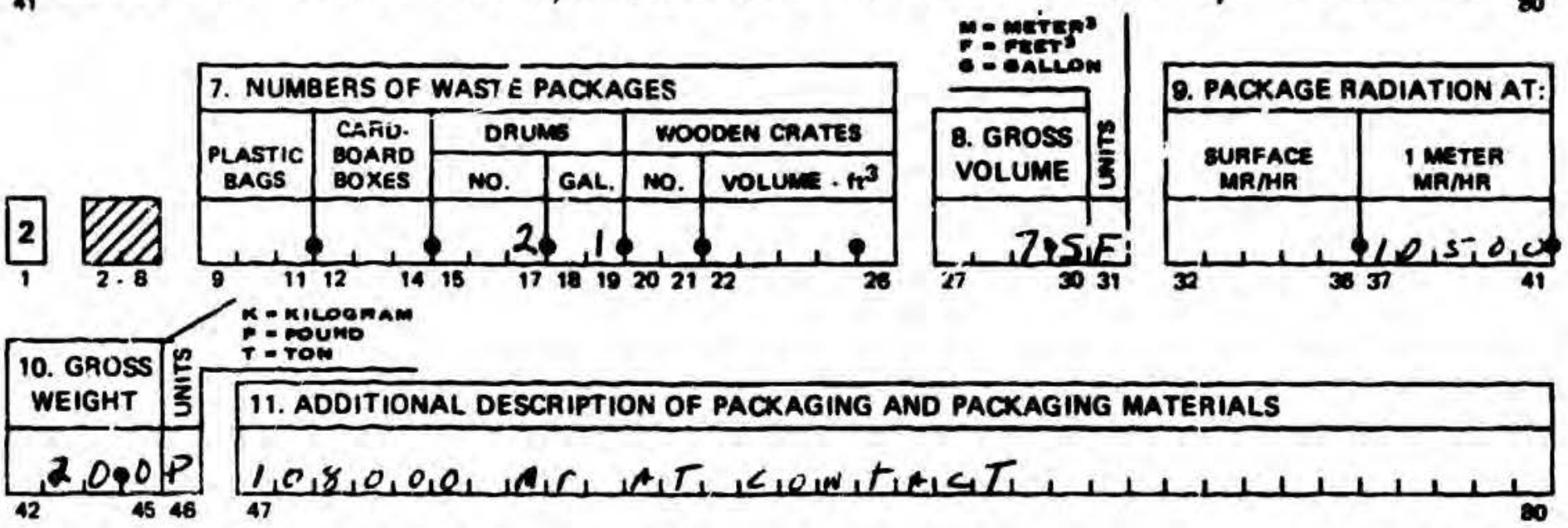

$$
\text { Toumo }
$$
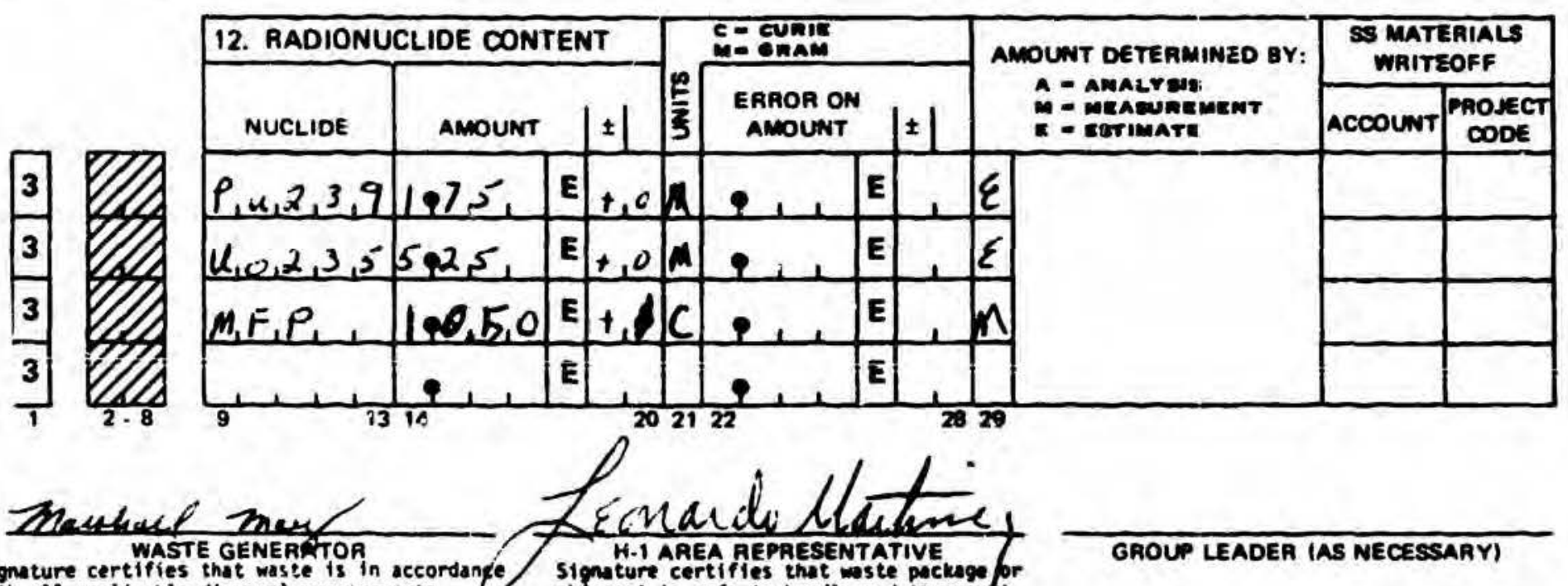

\section{ADDITIONAL DESCRIPTION OF PACKAGING AND PACKAGING MATERIALS}

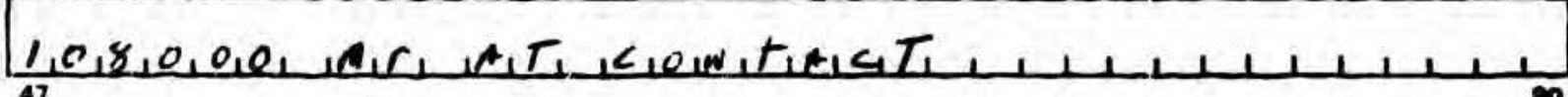

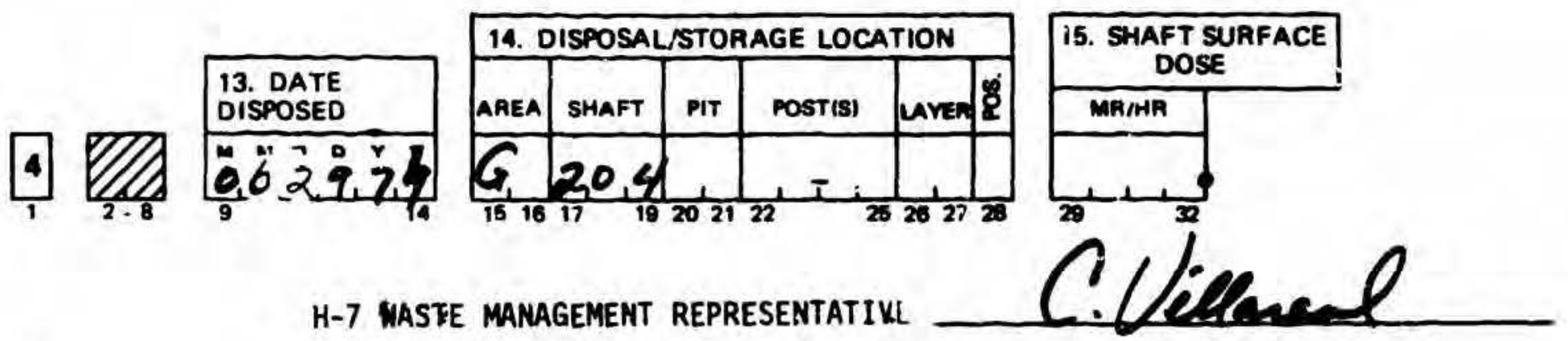

11) - 7R 

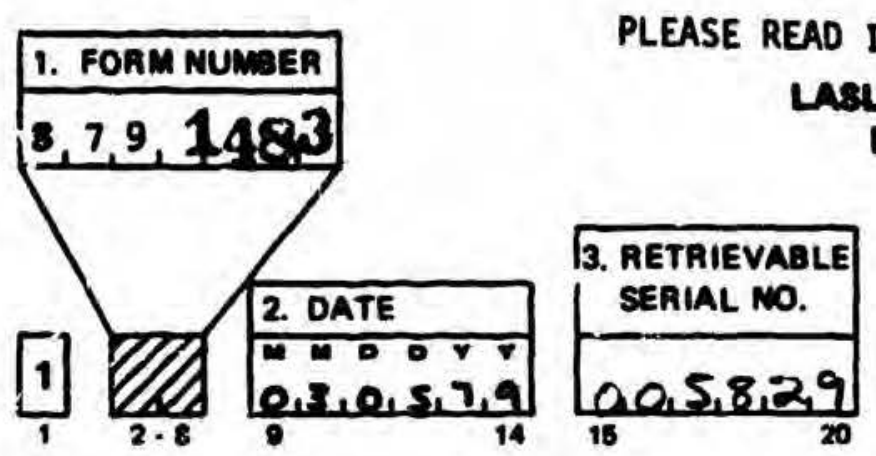

H-7 Maste hintis

Ext 6095 MS-592

LASL RADIOACTIVE EOLID WASTE DIEPOALAL RECORD FORM
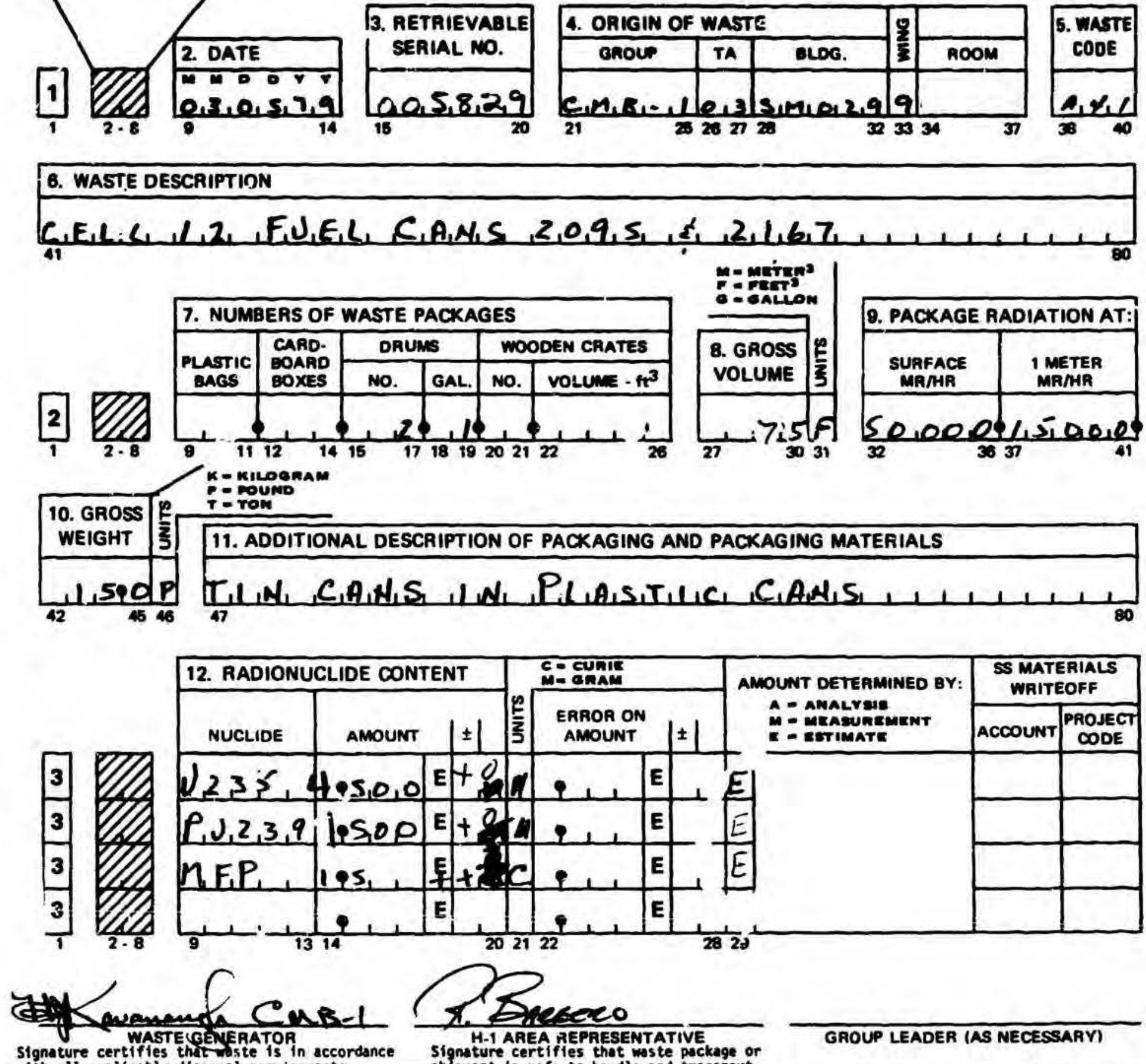

GAOUP LEADER (AS NECESSARV) shipent is safe to handie and transport.

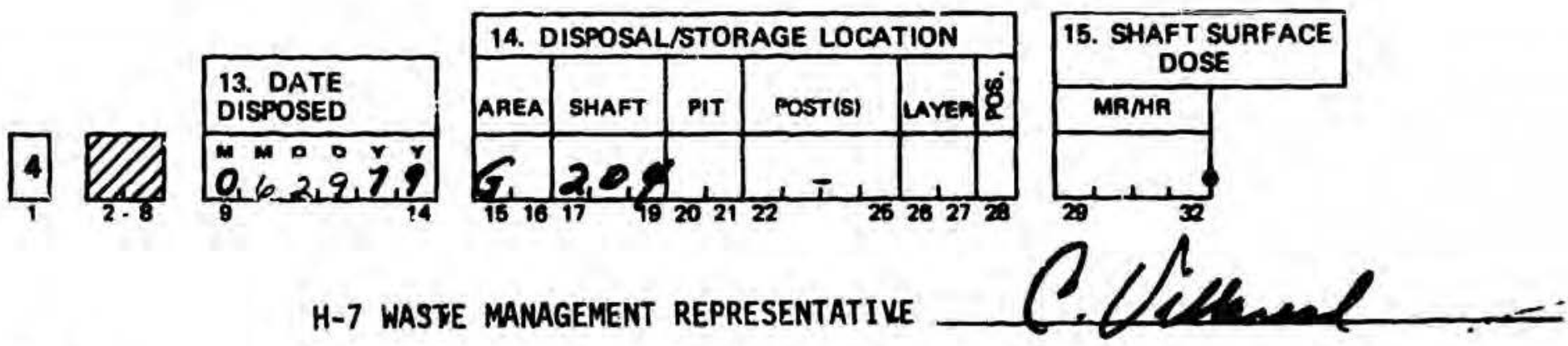



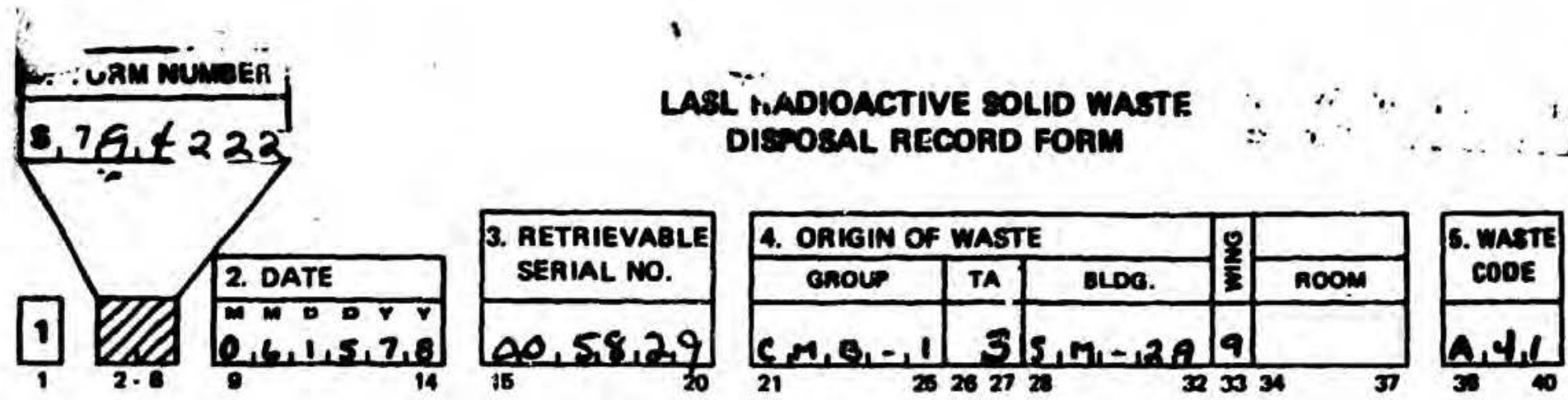

\section{WASTE DESCRIPTION}

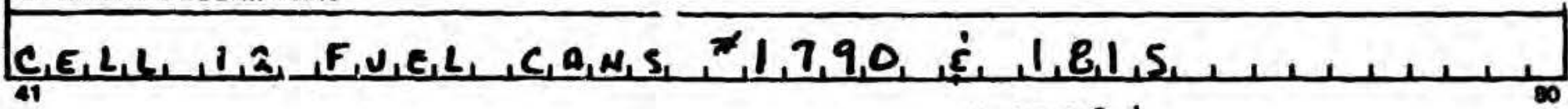
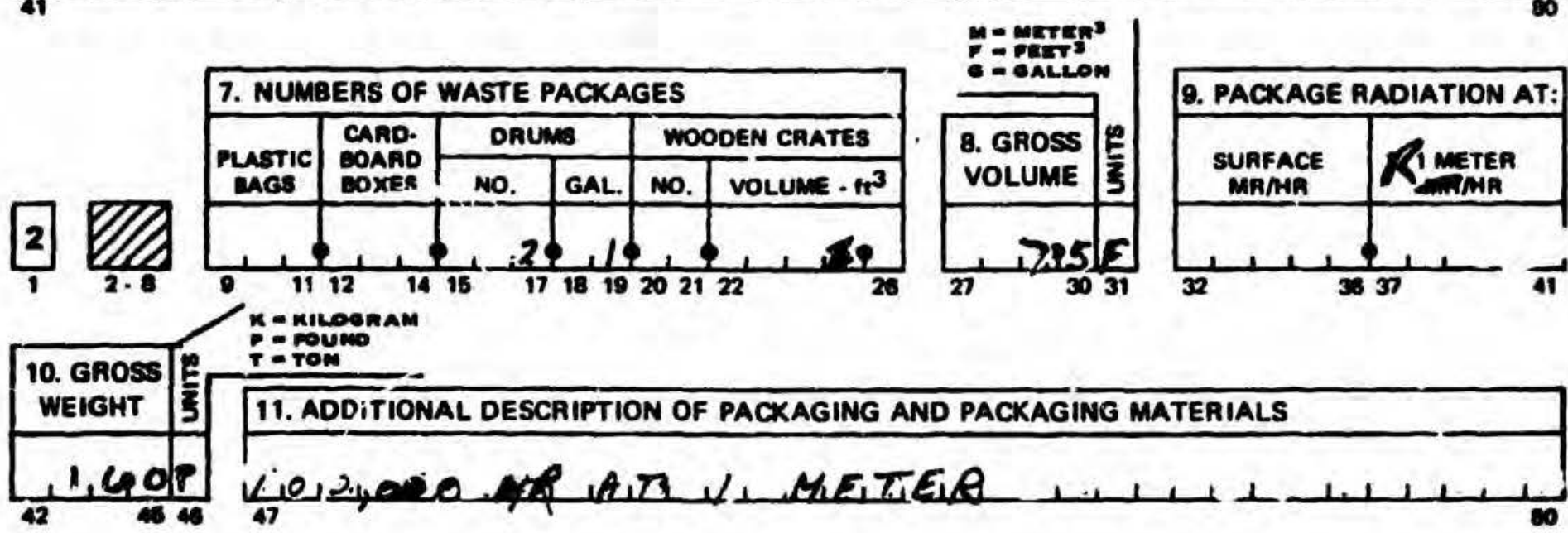

K= Kiloenam

$\mathbf{T}$ - Tow
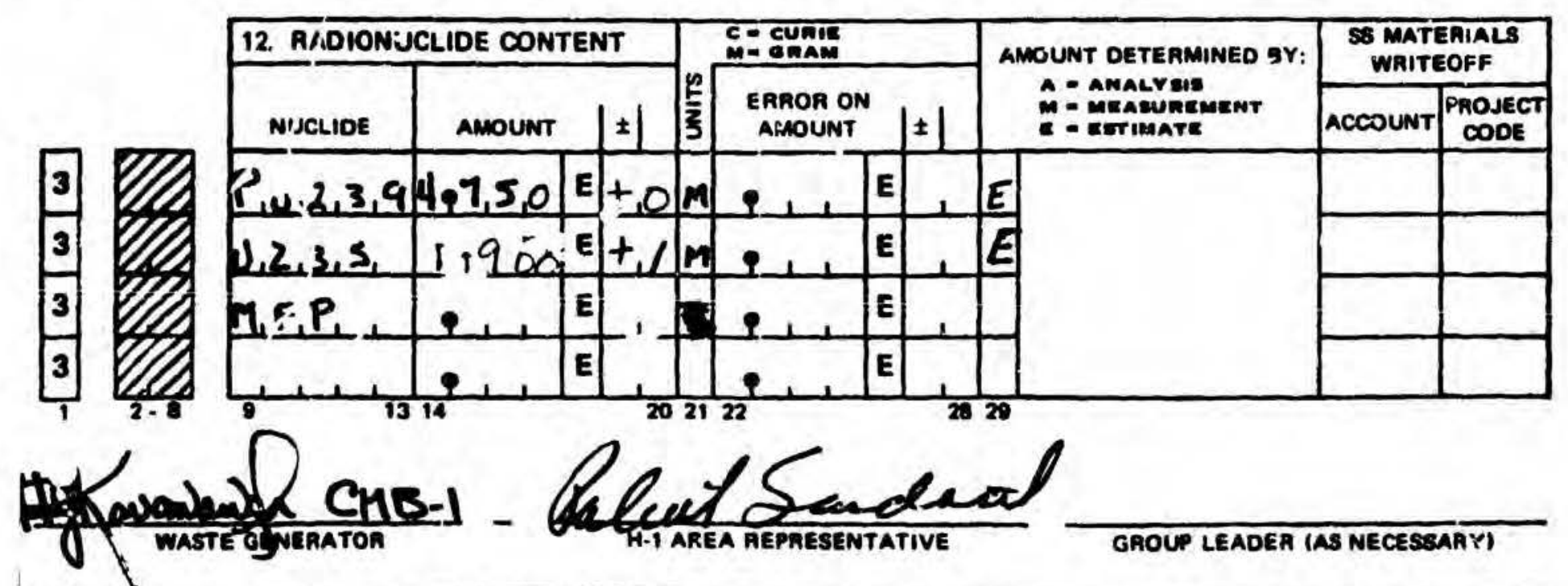

betion

202

MADIOACTIVE gOLID WASTE DISPOSAL RECORD FOAM

11. ADDITIONA

11. ADDITIONAL DESCAIPTION OF PACKAGING AND PACKAGING MATERIALS

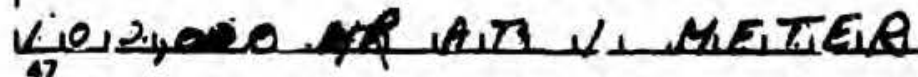

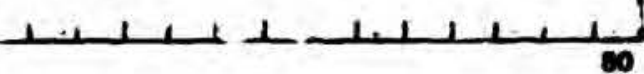

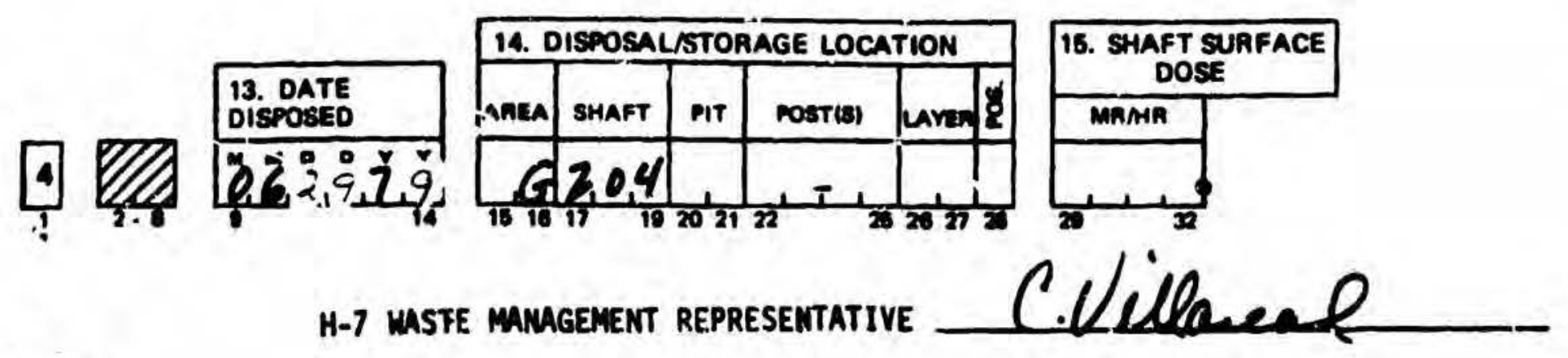

$10-72$ 


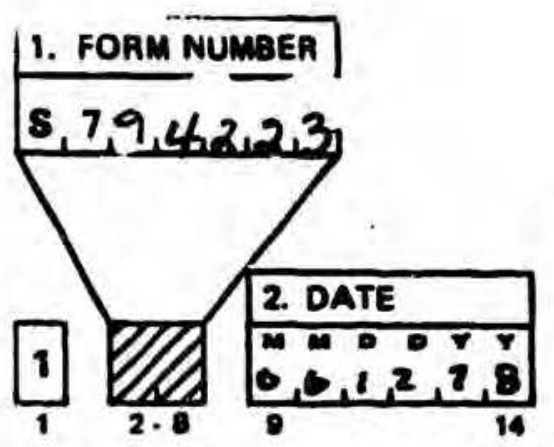

\section{LASL RADIOACTIVE SCI D WANTE DIEOSAL RECORD FORM}

H-7 Waste Management

Ext 6095 - M \& 592
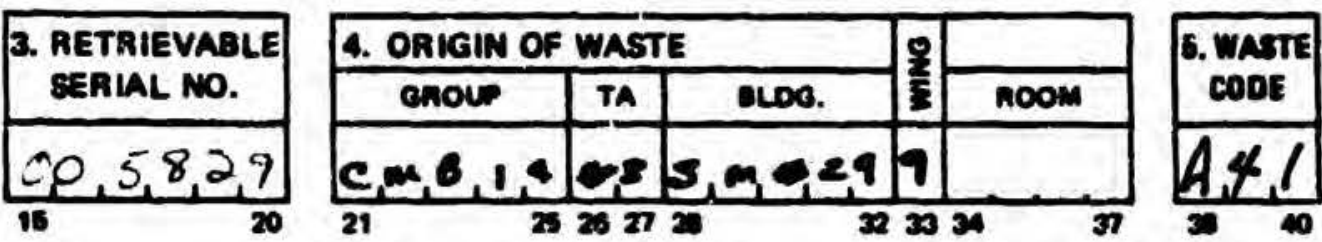

\section{WASTE DESCRIPTION}

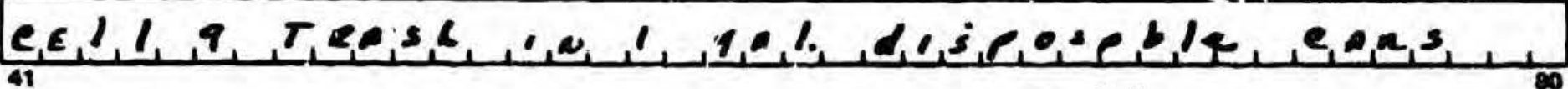

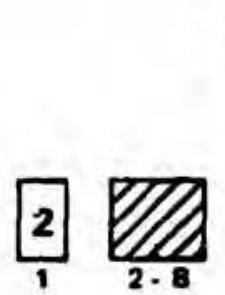

\begin{tabular}{|c|c|c|c|c|c|}
\hline \multicolumn{6}{|c|}{ 7. NUMBERS OF WASTE PACKAGES } \\
\hline \multirow{2}{*}{$\begin{array}{l}\text { PLASTIC } \\
\text { BAGS }\end{array}$} & \multirow{2}{*}{$\begin{array}{l}\text { CAAD. } \\
\text { BOAND } \\
\text { BOXES }\end{array}$} & \multicolumn{2}{|c|}{ DAUME } & \multicolumn{2}{|c|}{ WOODEN CAATES } \\
\hline & & No. & GAL. & no. & VOLUAm $-\mathrm{fr}^{3}$ \\
\hline & & & & & \\
\hline
\end{tabular}
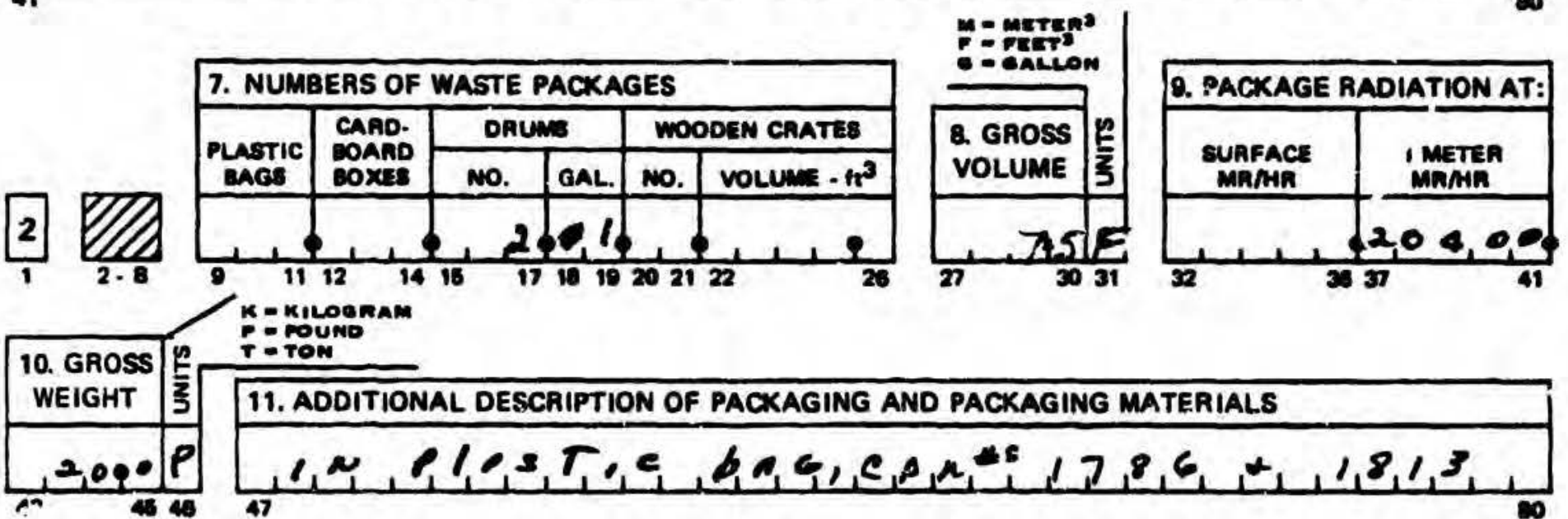

K = KiLoenak

T= TON
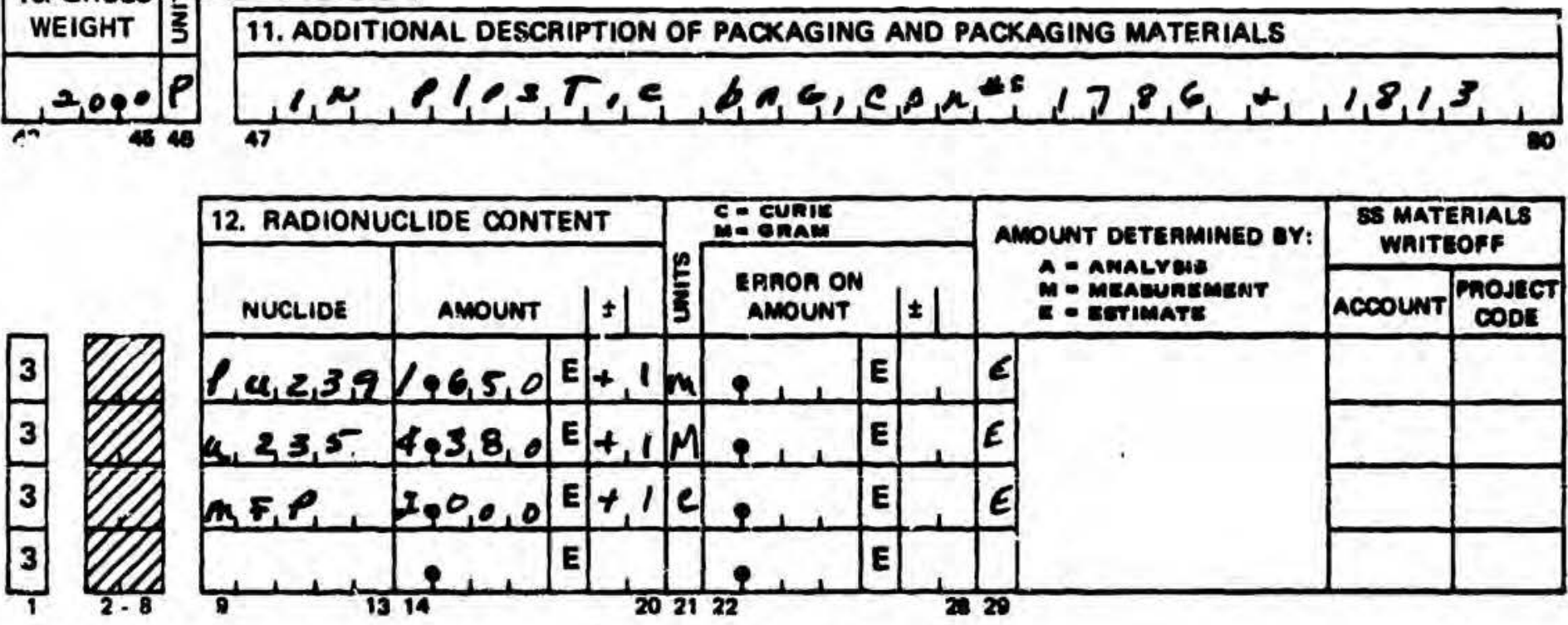

$D$ Waste Leta
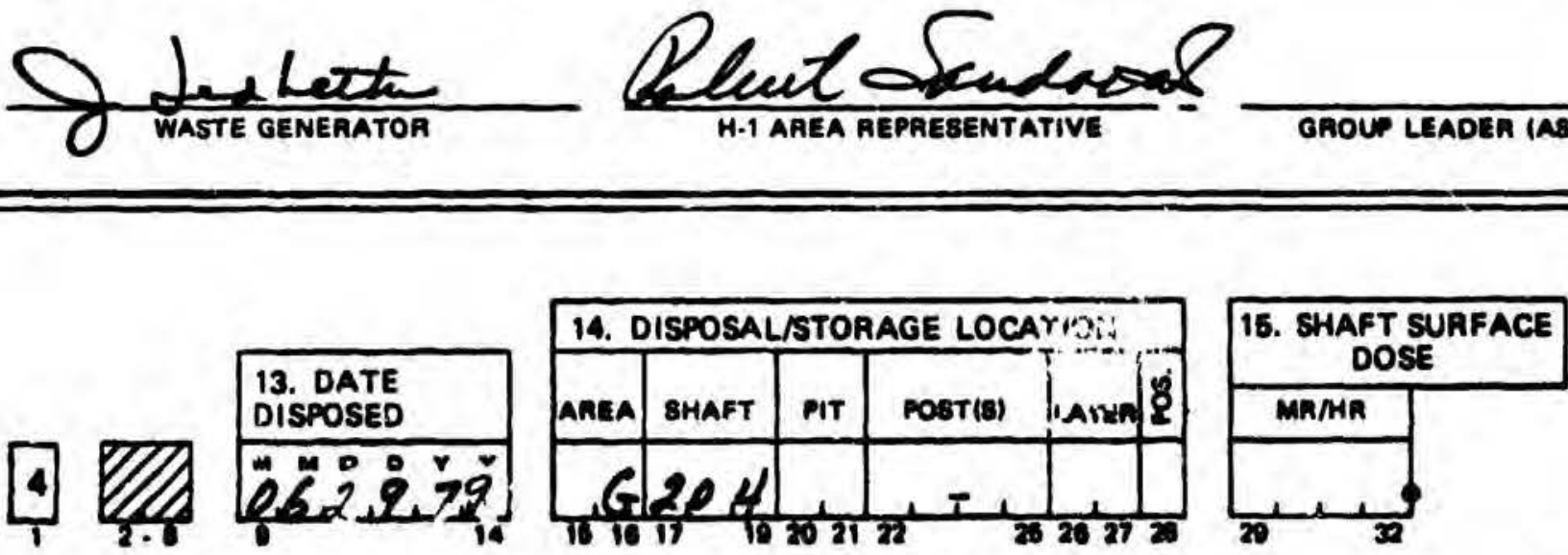

H-7 WASTE MANGGEMENT REPRESENTATIVE

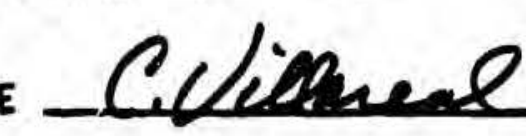


RADIOACTIVE SOLID WASTE DISPOSAL RECORD FORMS

FOR

SHAFT 205

MATERIAL DISPOSAL AREA G 

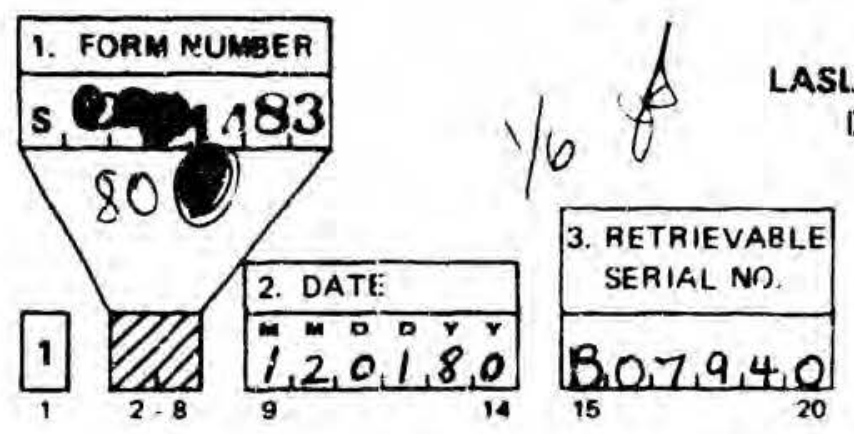

\section{LASL. RADIOACTIVE SOLID WASTE DISPOSAL RECORD FORM}

\begin{tabular}{|c|c|c|c|c|c|}
\hline \multicolumn{3}{|c|}{ 4. ORIGIN OF WASTE } & \multirow{2}{*}{$\begin{array}{l}0 \\
\frac{2}{3} \\
\end{array}$} & \multirow[b]{2}{*}{ 9OOM } & 5. WASTE \\
\hline GROUP & TA & BLDG. & & & CDOE \\
\hline$C_{1} M_{1} B_{1} L_{4}$ & 0,3 & $5, M-2.9$ & 9 & & $(A, 4$, \\
\hline
\end{tabular}

\section{WASTE DESCRIPTION}

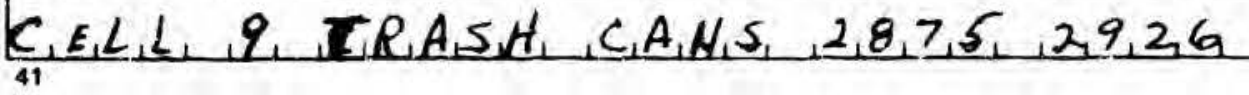

$M=\operatorname{metrm} 3$

G - GALLON

7. NUMBERS OF WASTE PACKAGES

[2] $2 \cdot 8$

\begin{tabular}{|c|c|c|c|c|c|}
\hline \multirow{2}{*}{$\begin{array}{c}\text { PLASTIC } \\
\text { BAGS }\end{array}$} & $\begin{array}{l}\text { CARD } \\
\text { BOARD } \\
\text { BOXES }\end{array}$ & \multicolumn{2}{|c|}{ DRUMS } & \multicolumn{3}{c|}{ WOODEN CRATES } \\
\cline { 3 - 6 } & & MO. & GAL. & NO. & VOLUME $\cdot \mathrm{At}^{3}$ \\
\hline
\end{tabular}

\section{K-KHognam}

10. GROSS 2 re roiv

$$
\begin{aligned}
& \text { 11. ADDITIONAL- DESCRIPTION OF PACKAGING AND PACKAGING MATERIALS }
\end{aligned}
$$

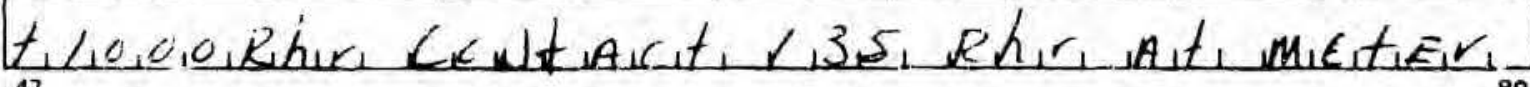
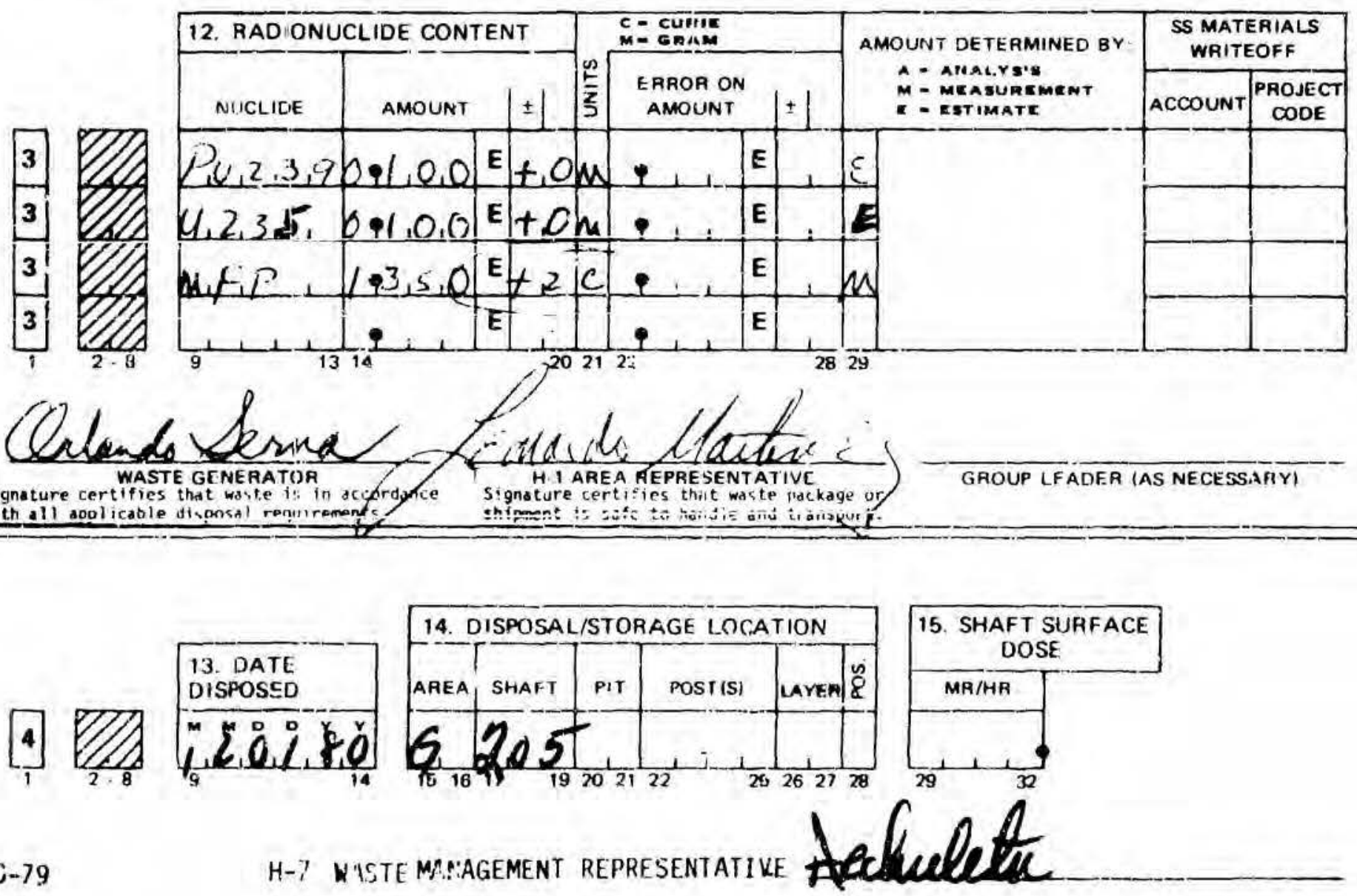
(2)

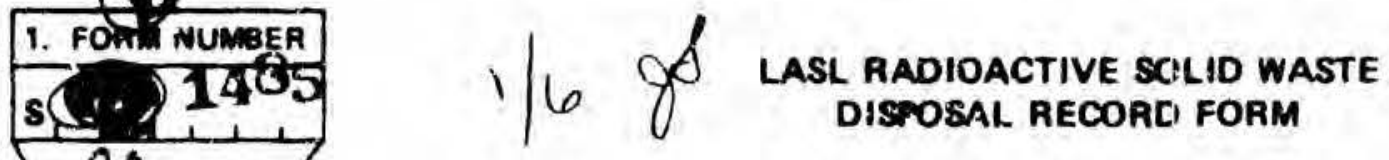

80

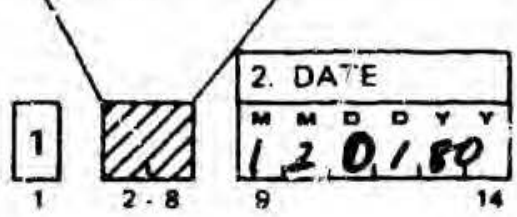

PLEASE READ INSTRUCTIONS ON BACK CAREFULLY 1690

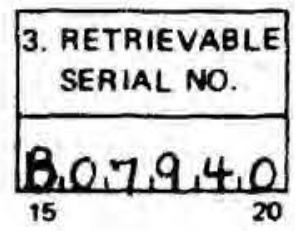

$\mathrm{H}-7$ Waste Management Ext 6095 MS-592

\section{WASTE DESCRIPTION}

$C_{11} \in L_{1} L_{1}, q_{2}, T, R_{1} A_{1} S_{1} N_{1}, A_{A} M_{1}, 2,9,20$

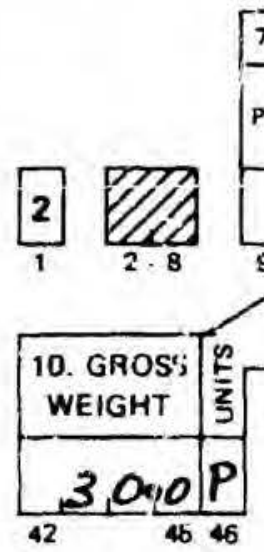

K KILOGNAM
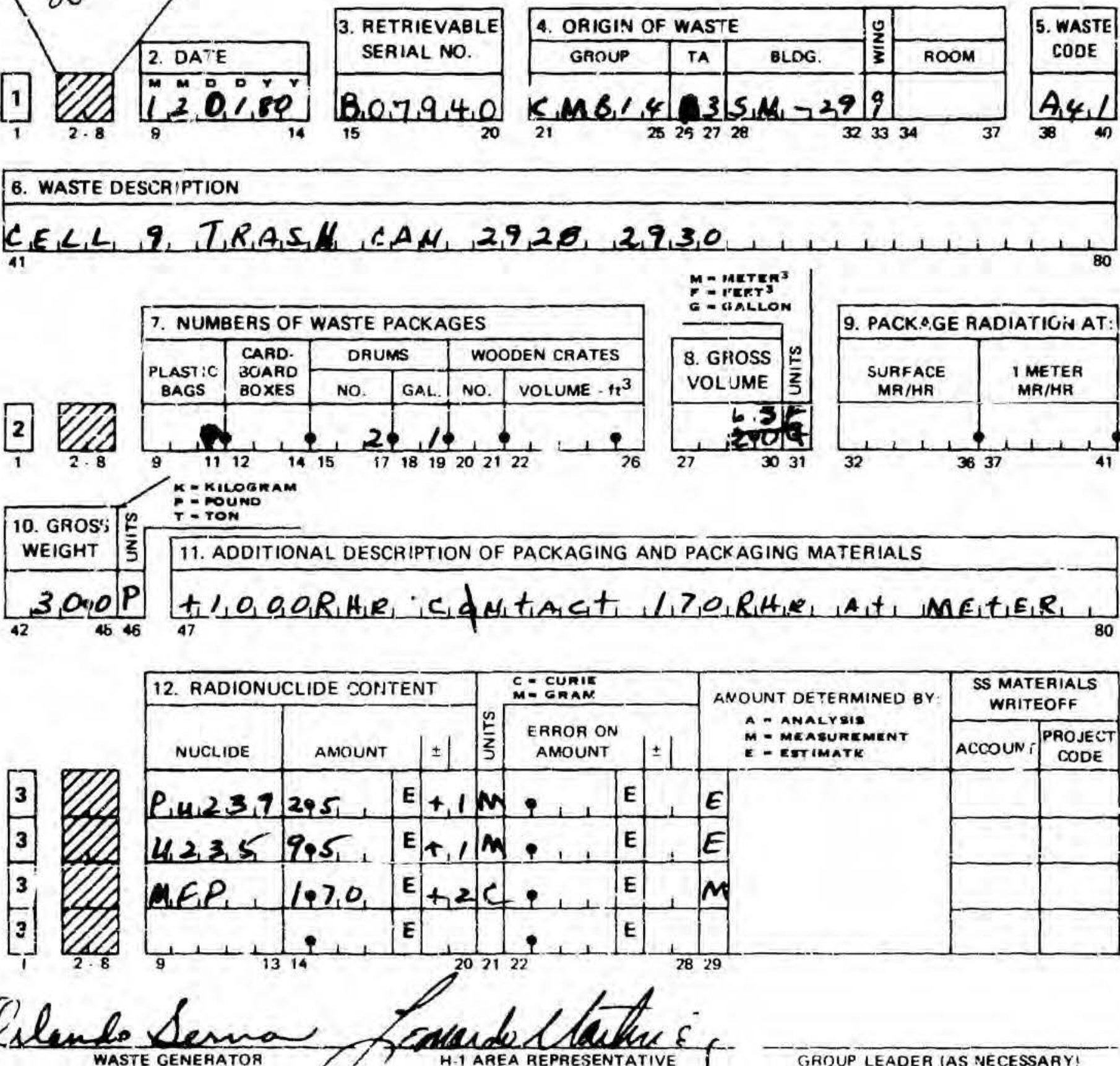

(C) 1 Laste Generator

11. ADDITIONAL DESCRIPTION OF PACKAGING AND PACKAGING MATERIALS

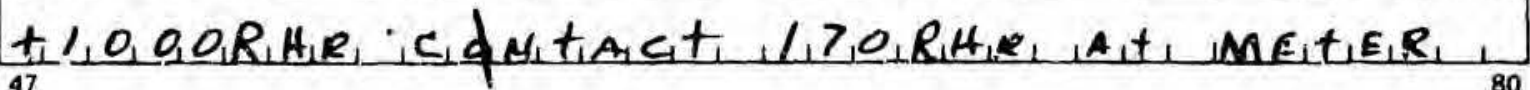
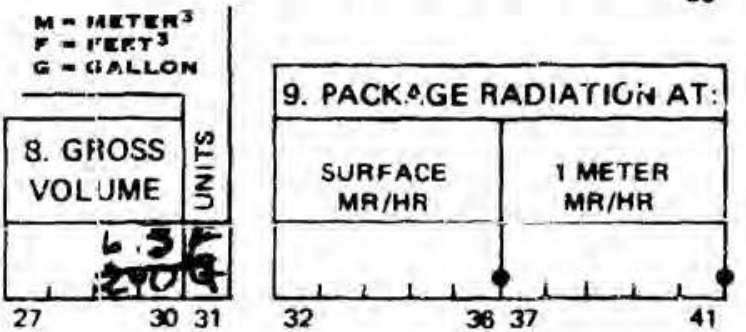

3031

32

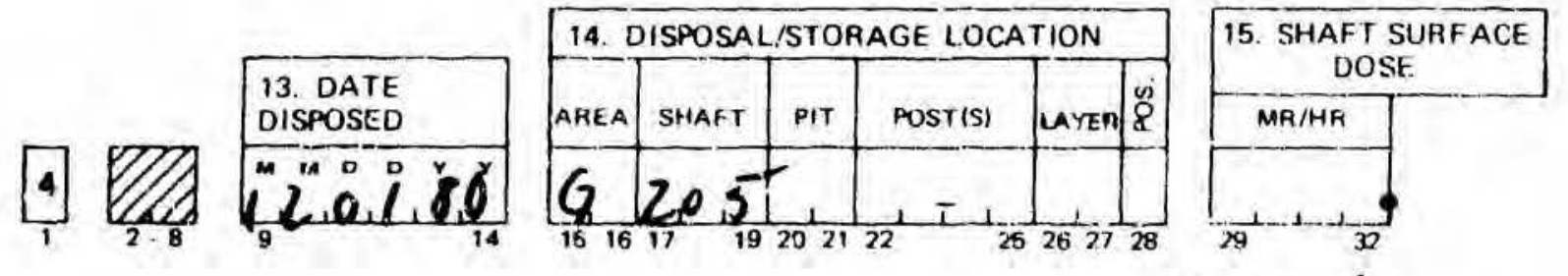



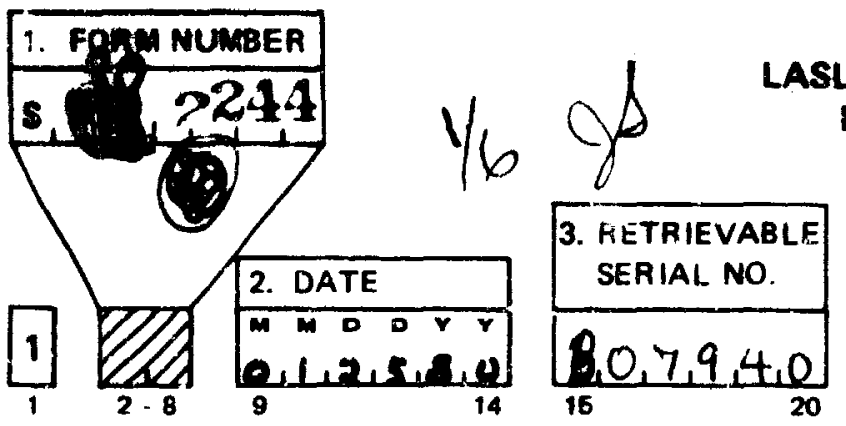

\section{LASL RADIOACTIVE SOLID WASTE DISNOSAL RECORD FORM}

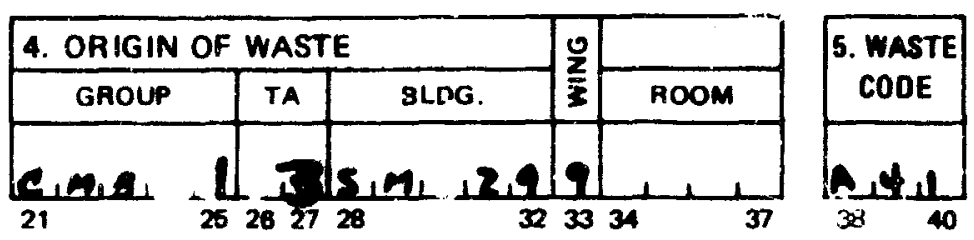

\section{WASTE DESCAIPTION}

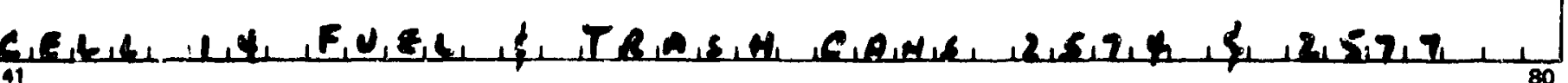

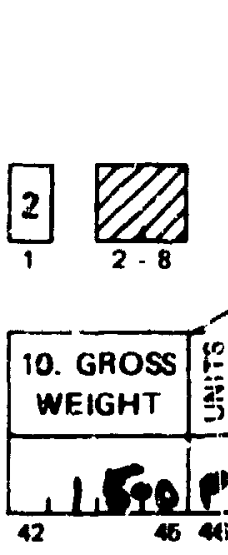

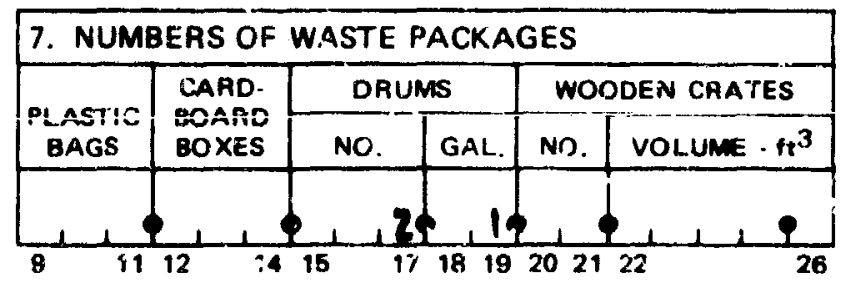
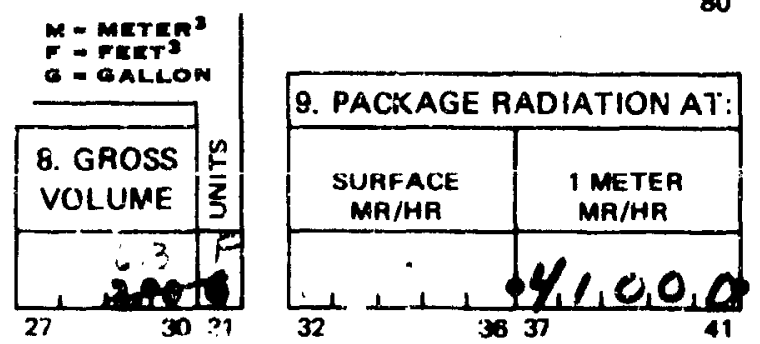

\section{K- Kiloenam}

$T=$ TOW

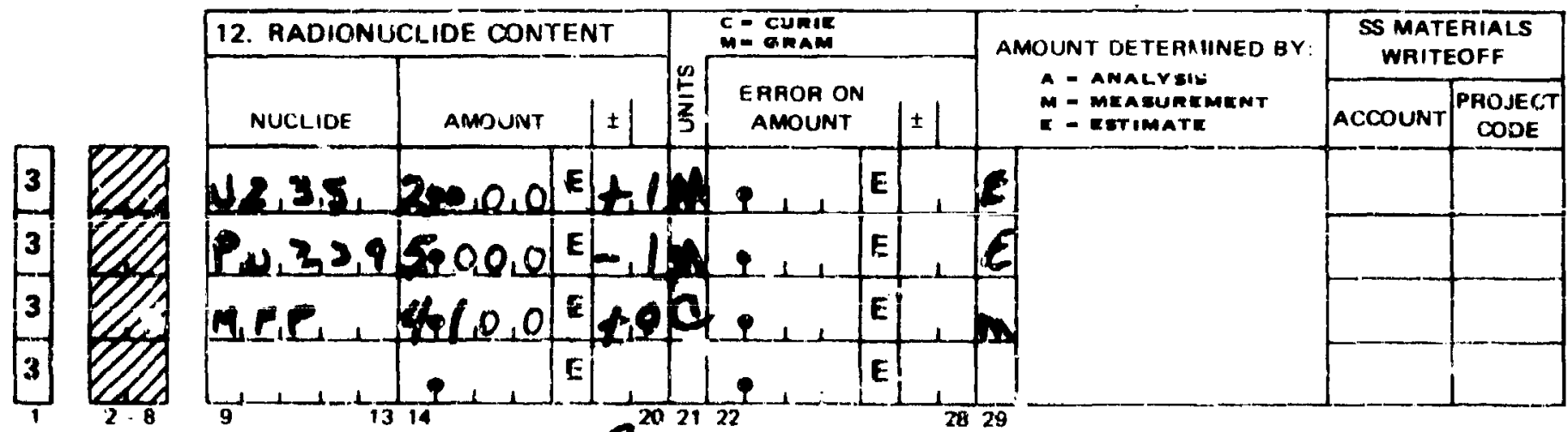

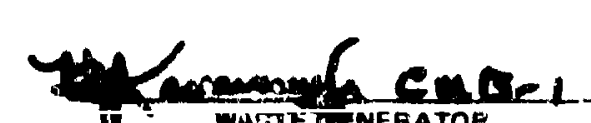

WHETE stgnature certifies that waste is 11 accordy. Wth all yplicable dtspoisal requ rements.
11. ADDITIUNAL DESCRIPTION OF PACKAGING AND PACKAGING MATERIALS

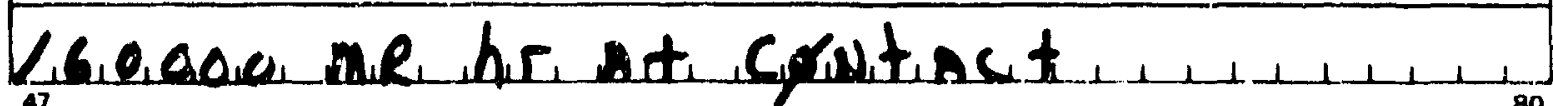



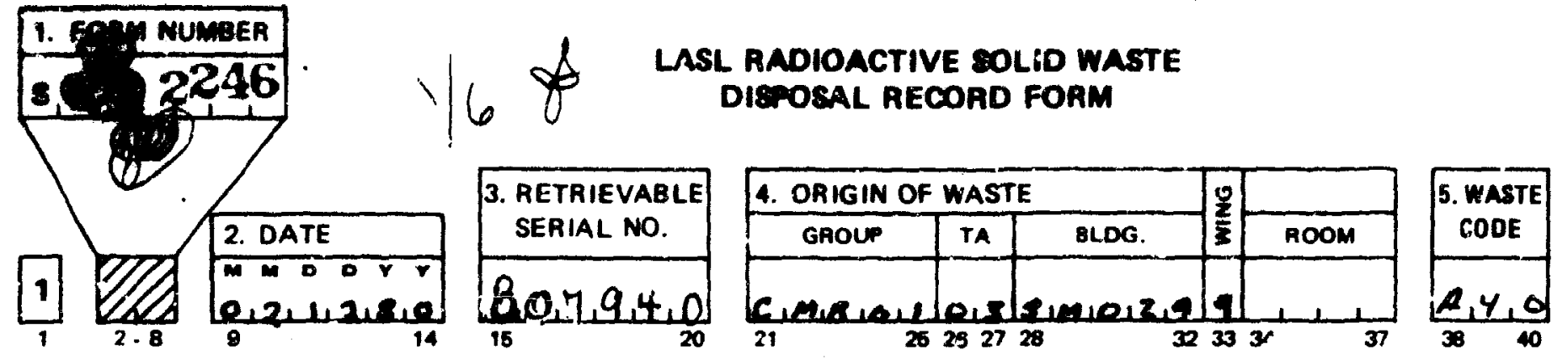

6. WASTE DESCRIPTION

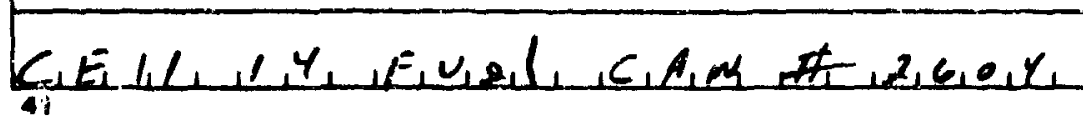
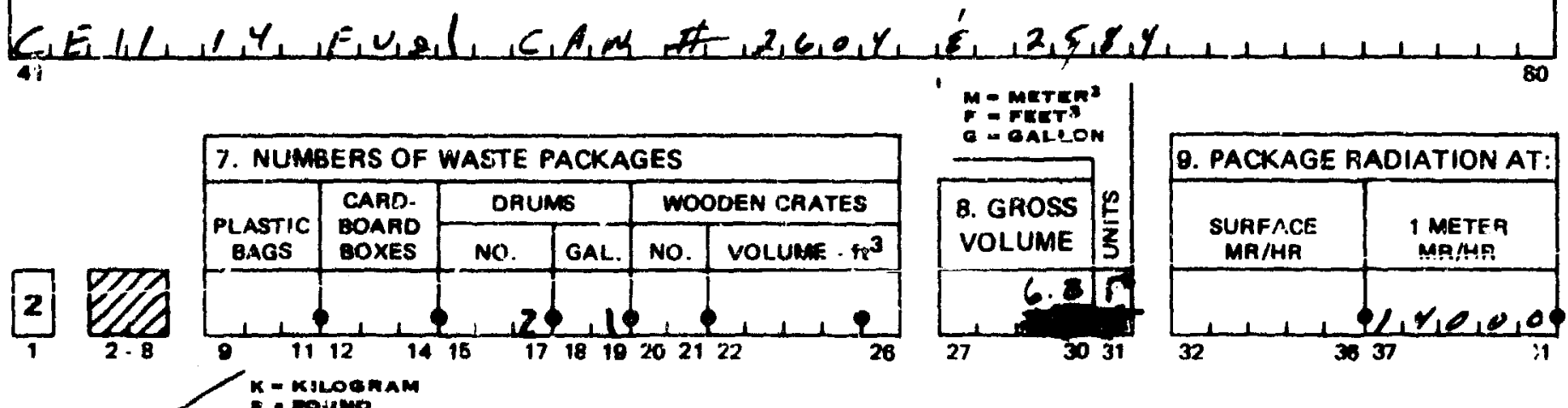

K- KILOegnam

\begin{tabular}{l|l} 
10. GROSS \\
WEIGHT
\end{tabular}$\frac{T=\text { TEM }}{\frac{1}{5}}$

WEIGHT $\frac{\bar{z}}{3}$ 11. ADDITIONAL DESCAIPTION OF PACKAGIING AND PACKAGING MATERIALS

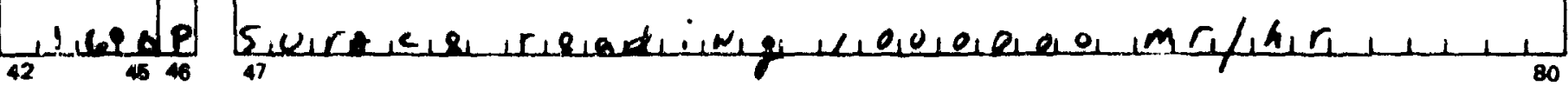
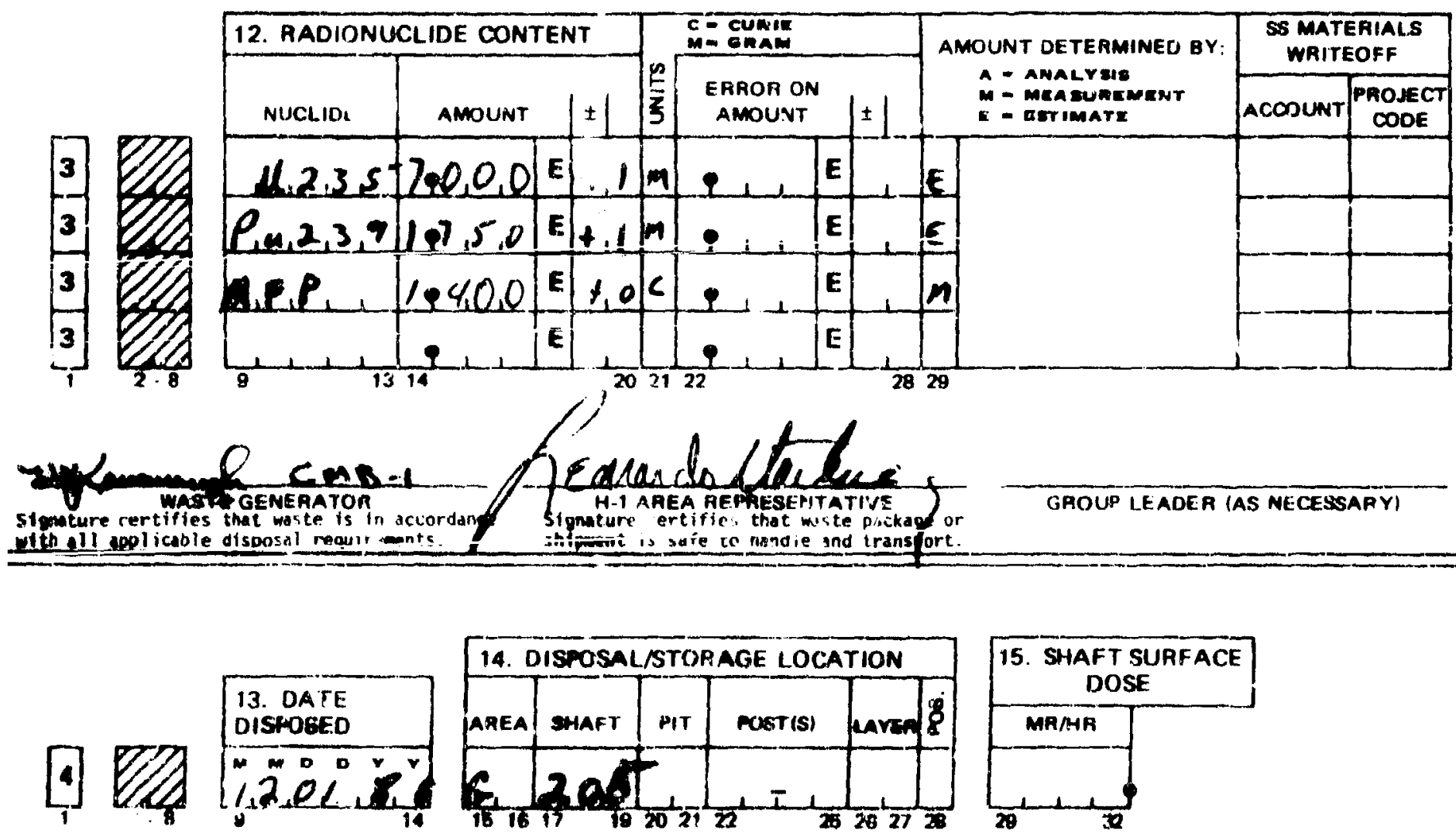

$10-79$ 

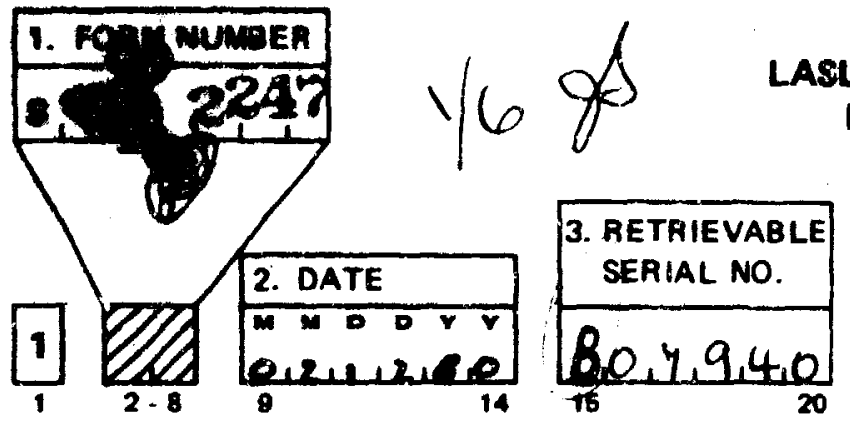

\section{LASL RADIOACTIVE SOLID WASTE DISTOSAL RECORD FORM}

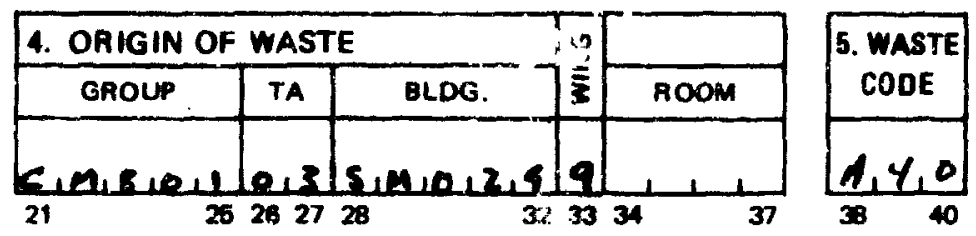

8. WASTE DESCRIPTION

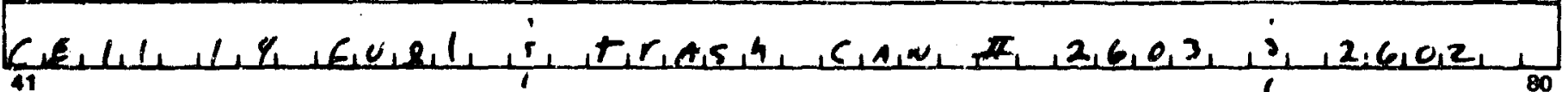
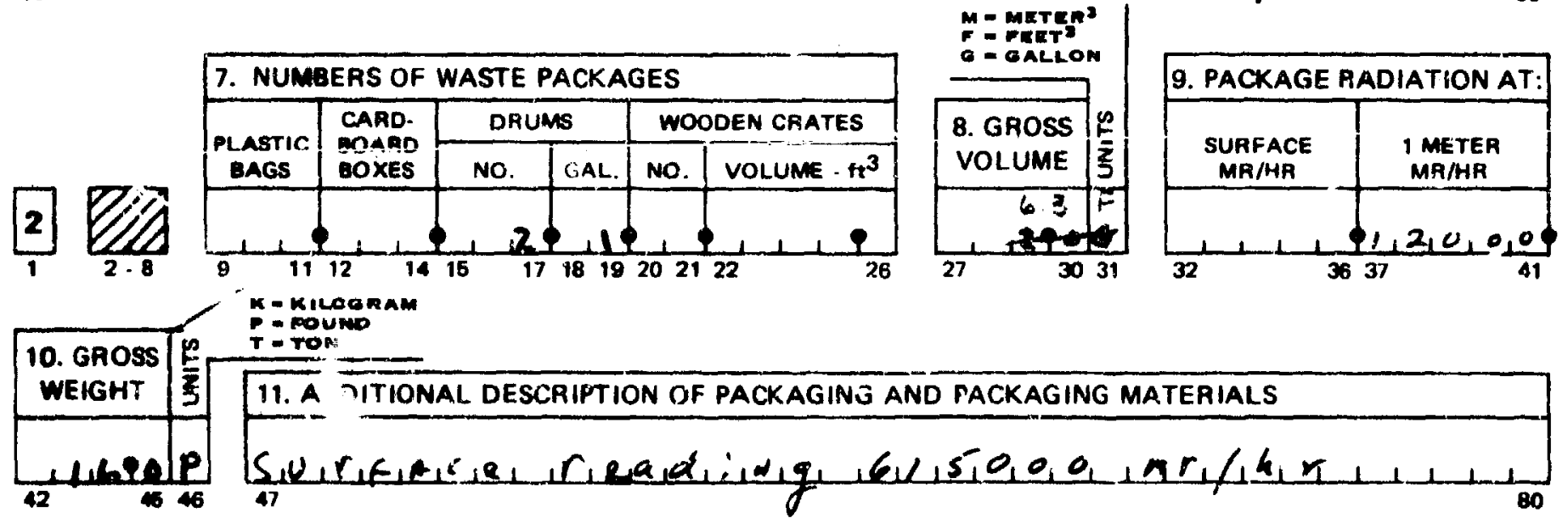

Kilogram

11. A TITIONAL DESCRIPTION OF PACKAGING AND FACKAGING MATERIALS
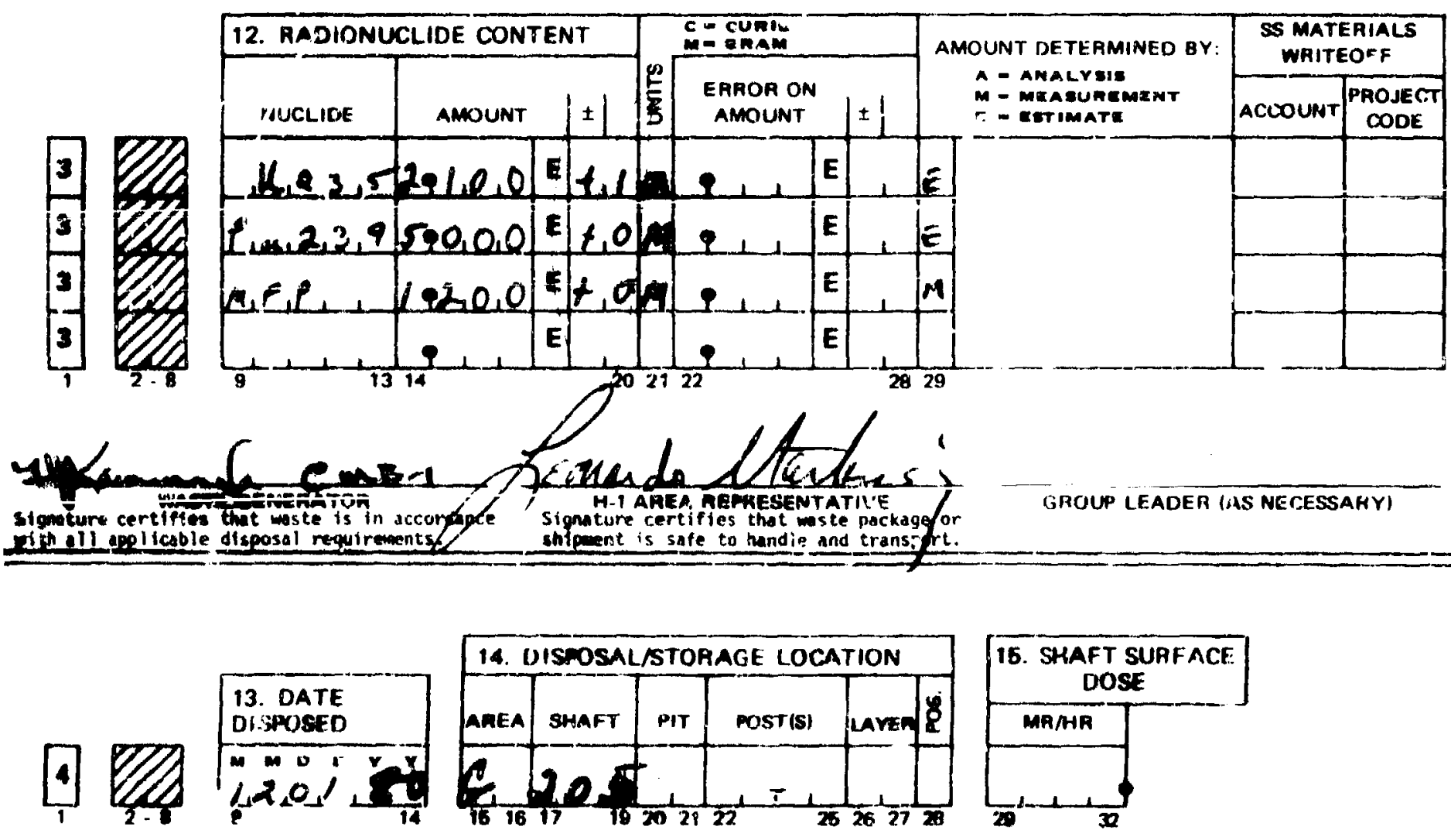

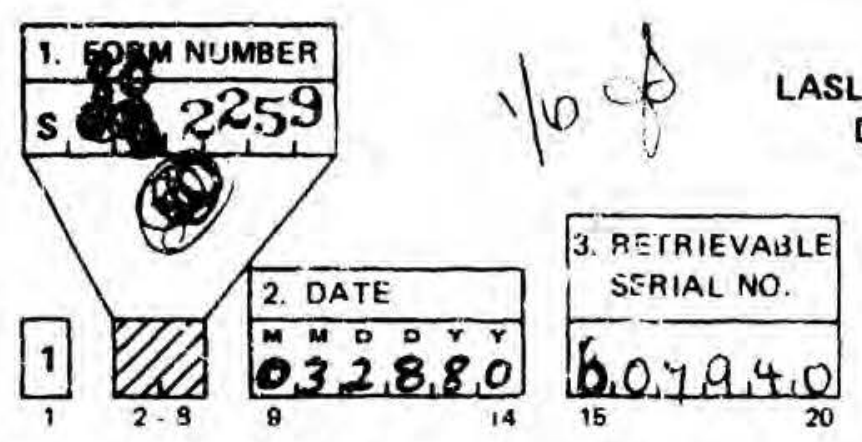
LASL RADIOACTIVE SOLID WASTE
DISPOSAL RECORD FORM

6. WASTE DESCRIPTION

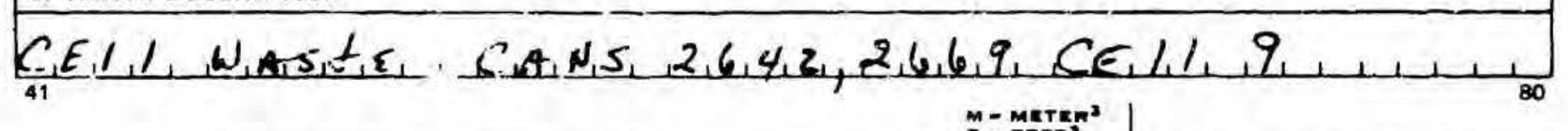
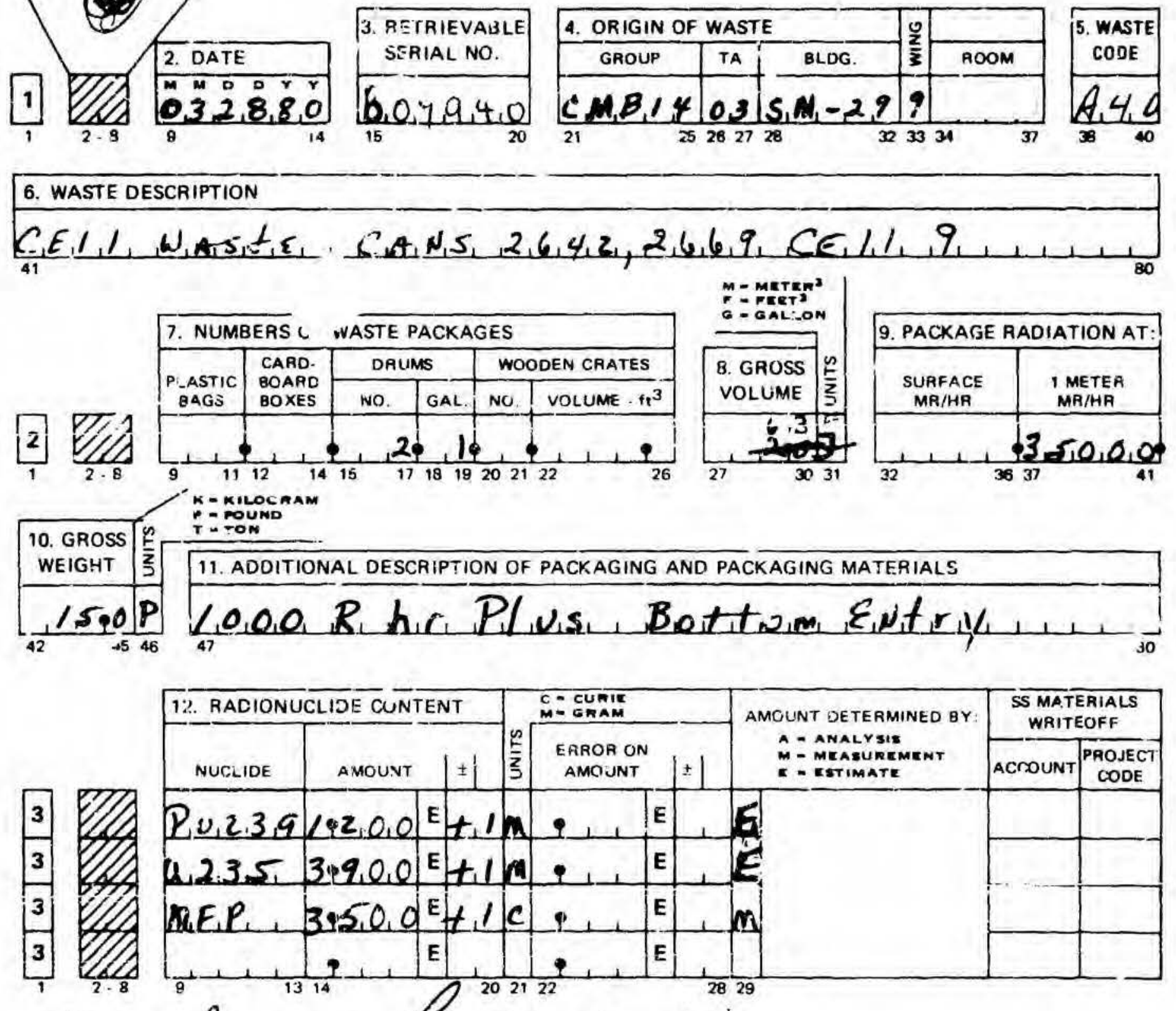

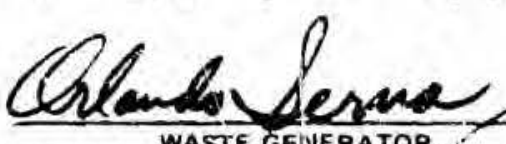

WASTE GEIVERATOR

Signoture certifics that waite is 10 accofdance with all applicable dispoial recutemepls.

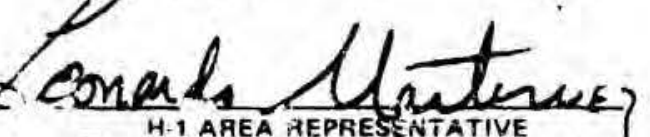

H-1 AREA MEPRESENTATIVE Signatb." cert tes that waste portige or
shipment. fe 20 handie and transpgra
GROUP LEADER (AS NECESSAAY!

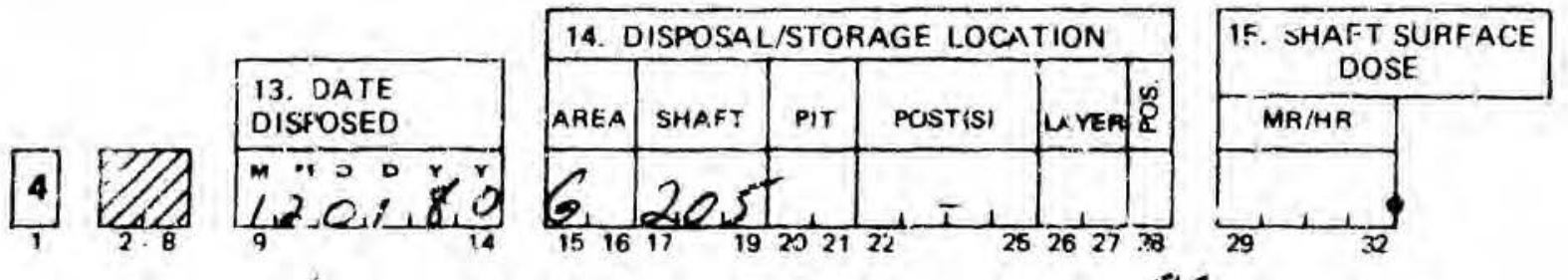




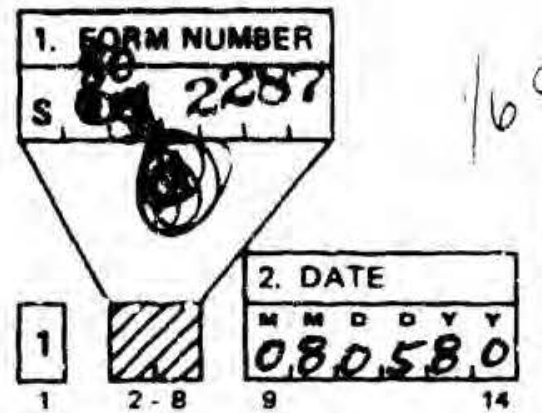

LASL RADIOACTIVE SOLID WASTE DISPOSAL RECORD FORM

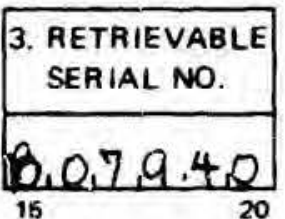

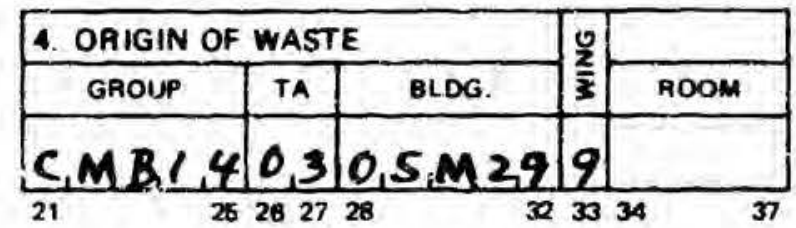

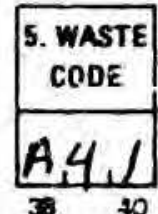

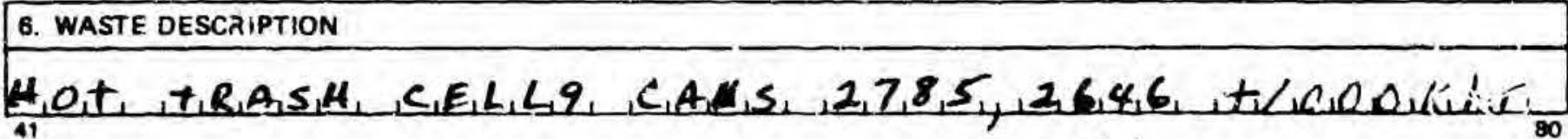
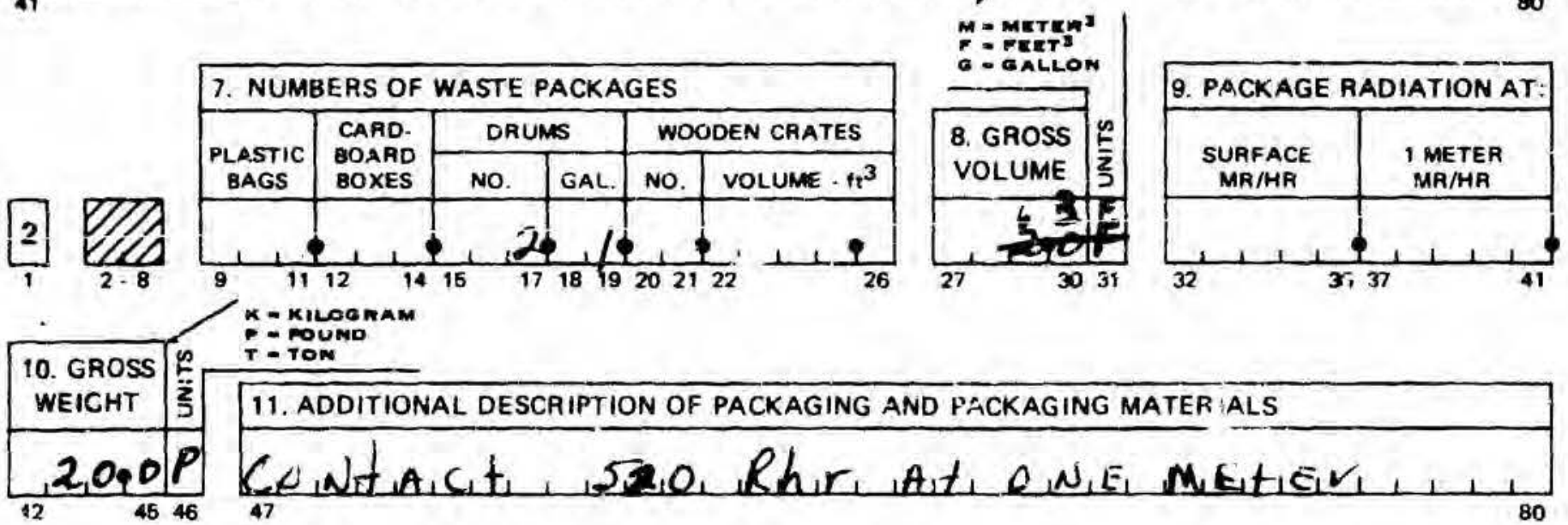

K- KiLOenam

T noumo
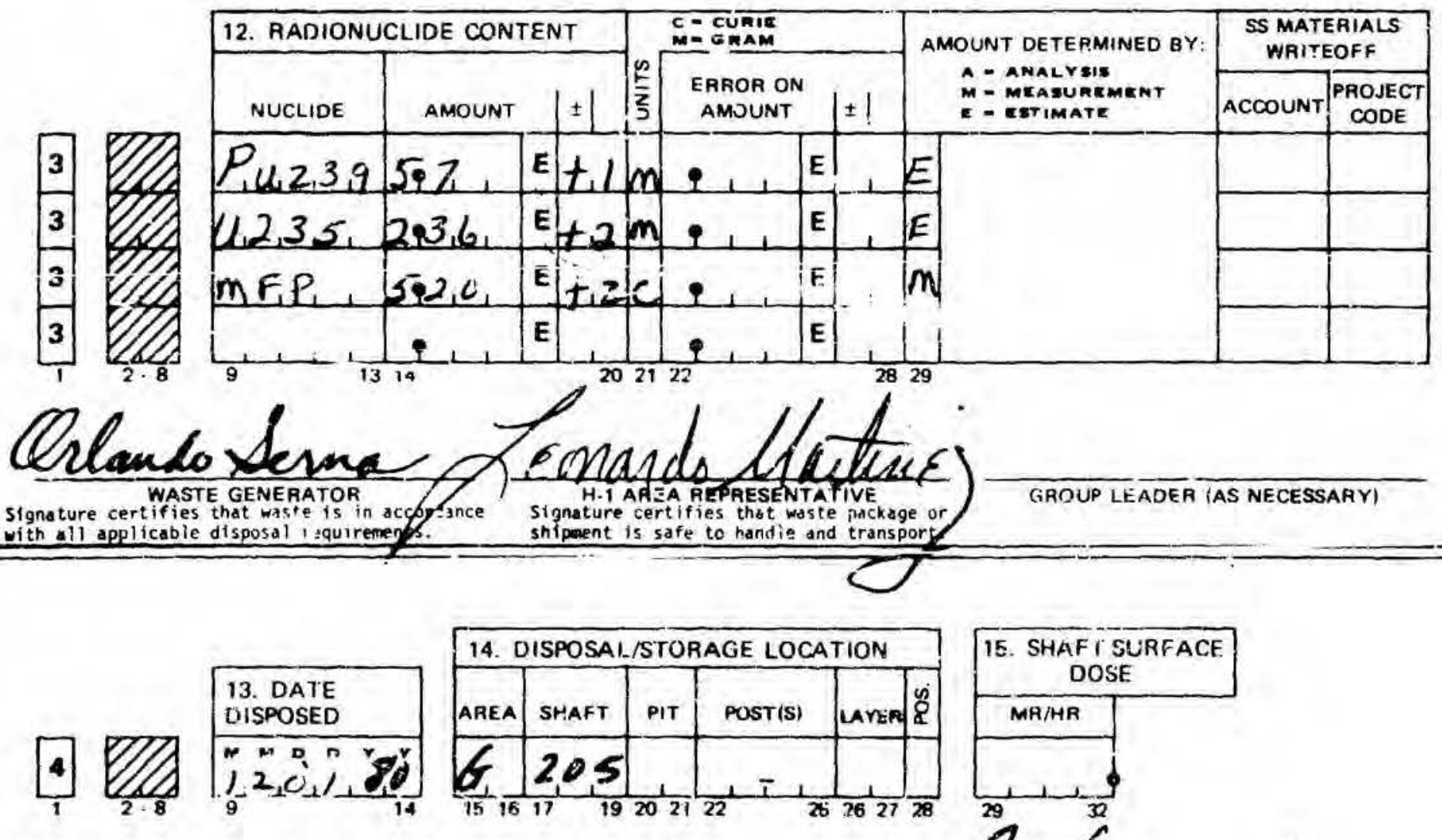
RADIOACTIVE SOLID WASTE DISPOSAL RECORD FORMS

FOR

SHAFT 206

MATERIAL DISPOSAL AREA G 

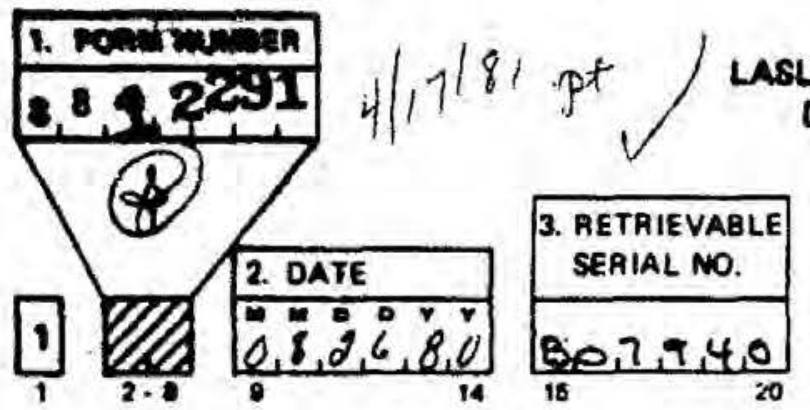

\section{RADIOACTIVE SOLID WASTE DISPOSAL AECORD FORM}

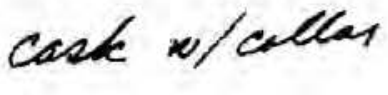

\section{Q. WASTE DESCRIPTION}

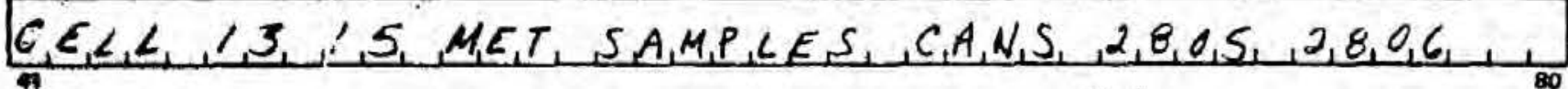

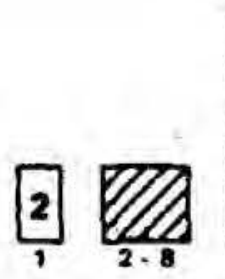

\section{NUMBEAS OF WASTE PACKAGES}

\begin{tabular}{|c|c|c|c|c|c|}
\hline \multicolumn{3}{|c|}{ 4. ORIGIN OF WASTE } & \multirow{2}{*}{$\mid$} & \multirow{2}{*}{ คOOM } & \multirow{2}{*}{$\begin{array}{l}\text { 5. WASTE } \\
\text { CODE }\end{array}$} \\
\hline GROUP & TA & BLDG. & & & \\
\hline$C, M B, A$ & & $S, M$ & & & $4,4,0$ \\
\hline
\end{tabular}
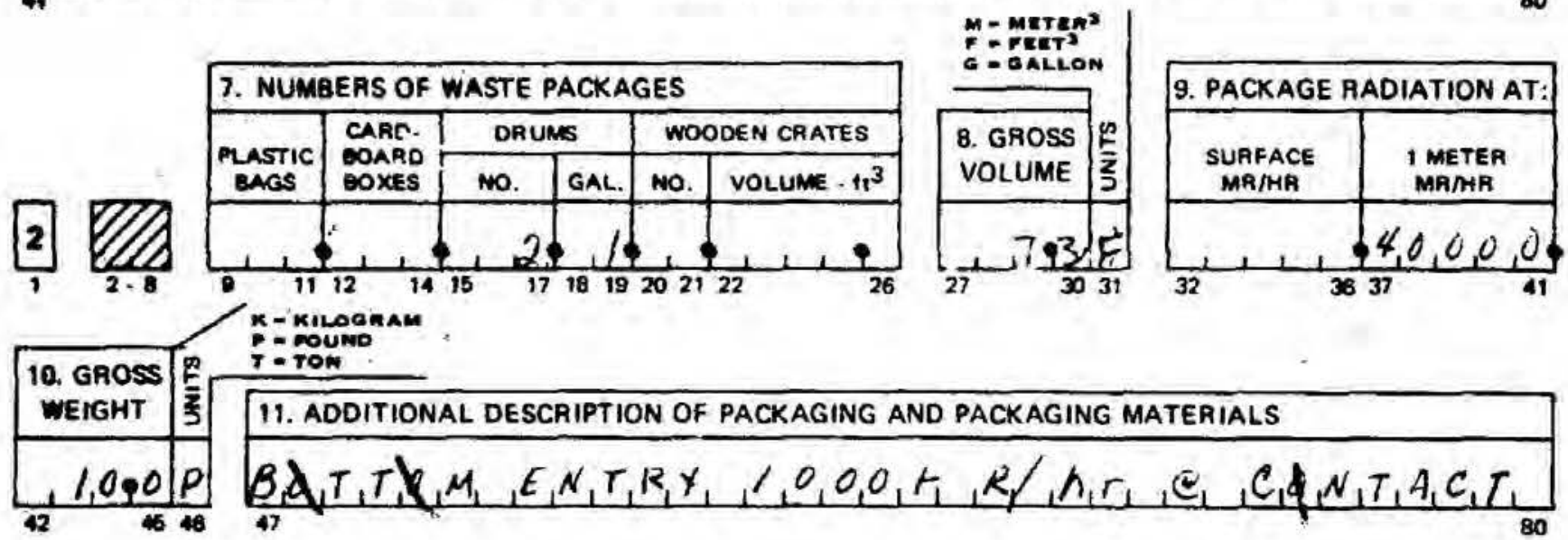

\section{K-KiLoginam}

- nOUND

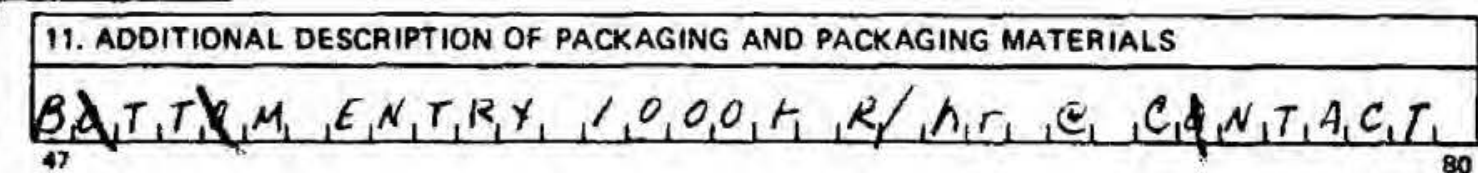

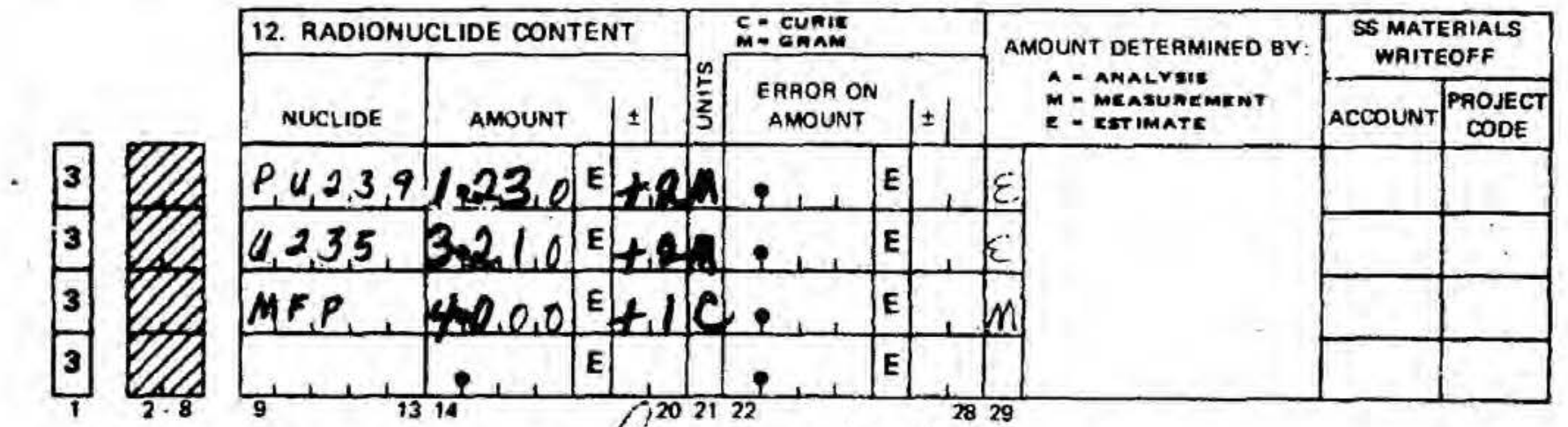

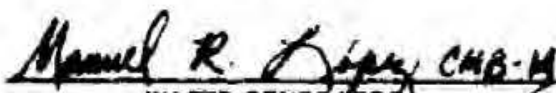

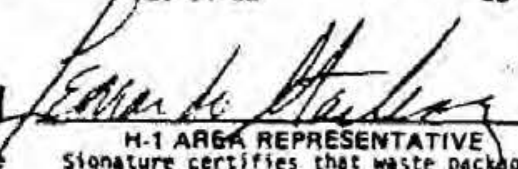
H.1 AREA REPAESENTATIVE
Signature certiffies that waste paCkage or GROUP LEADER (AS NECESSAAY)

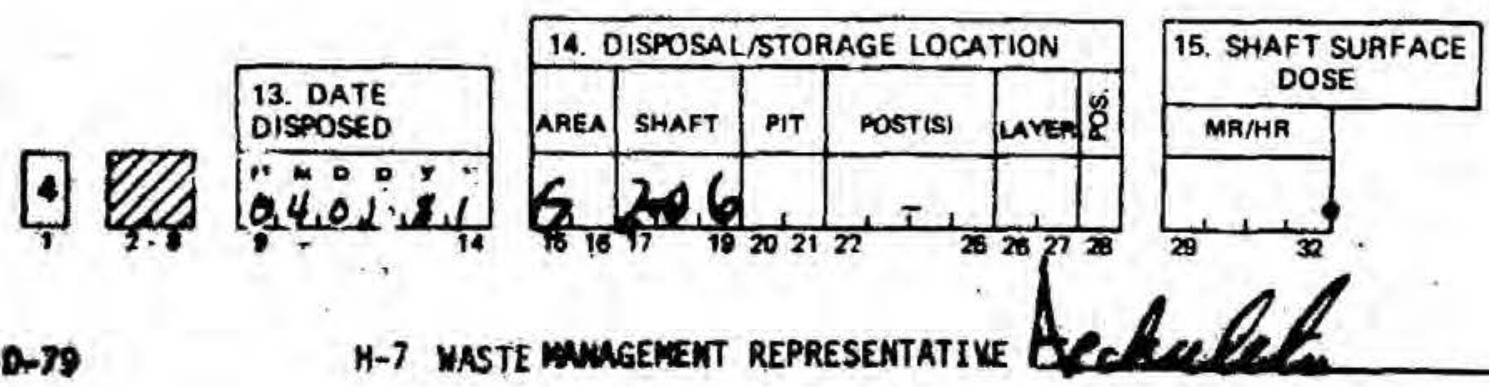




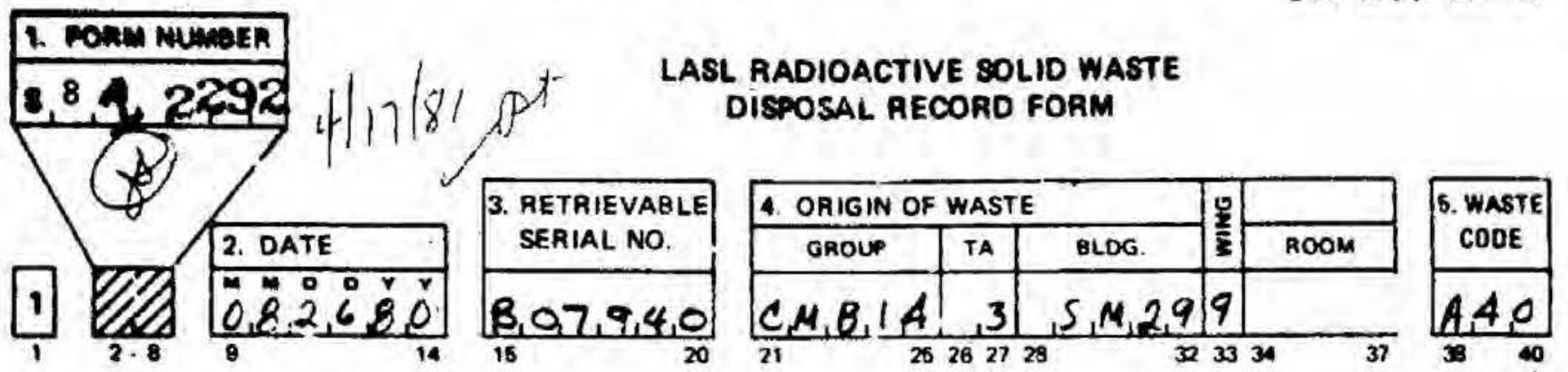

Ex: $6095 \mathrm{x}-4$, i?
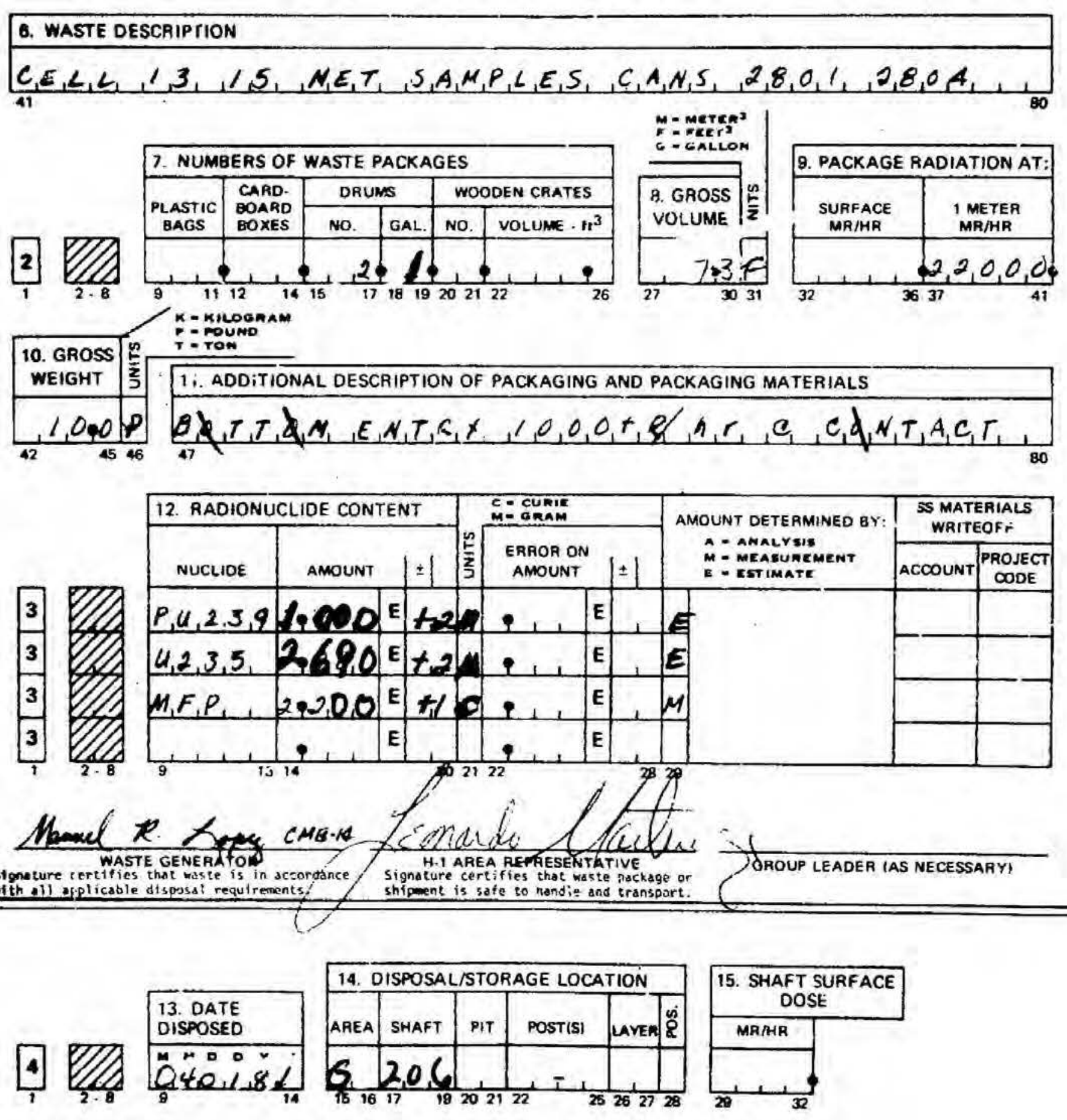


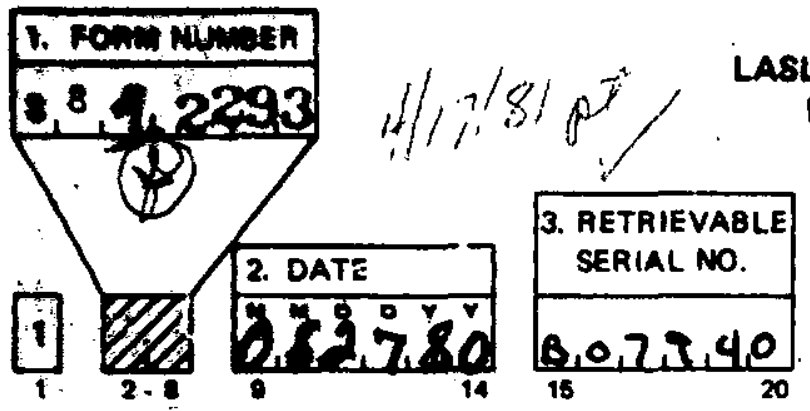

\section{ASL RADIOACTIVE 8OLID WASTE DIEPOSAL RECORD FORM}

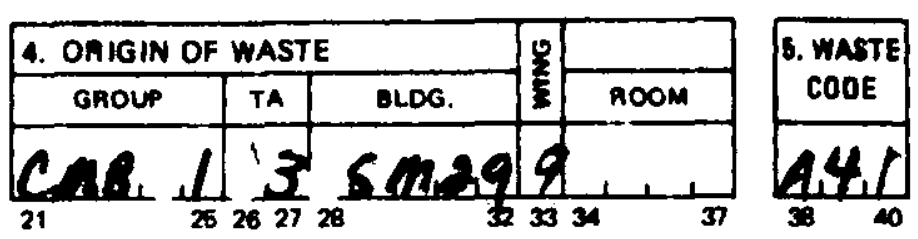

\section{MASTE DESCAIPTION}

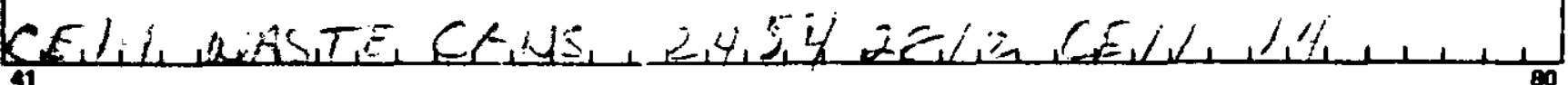
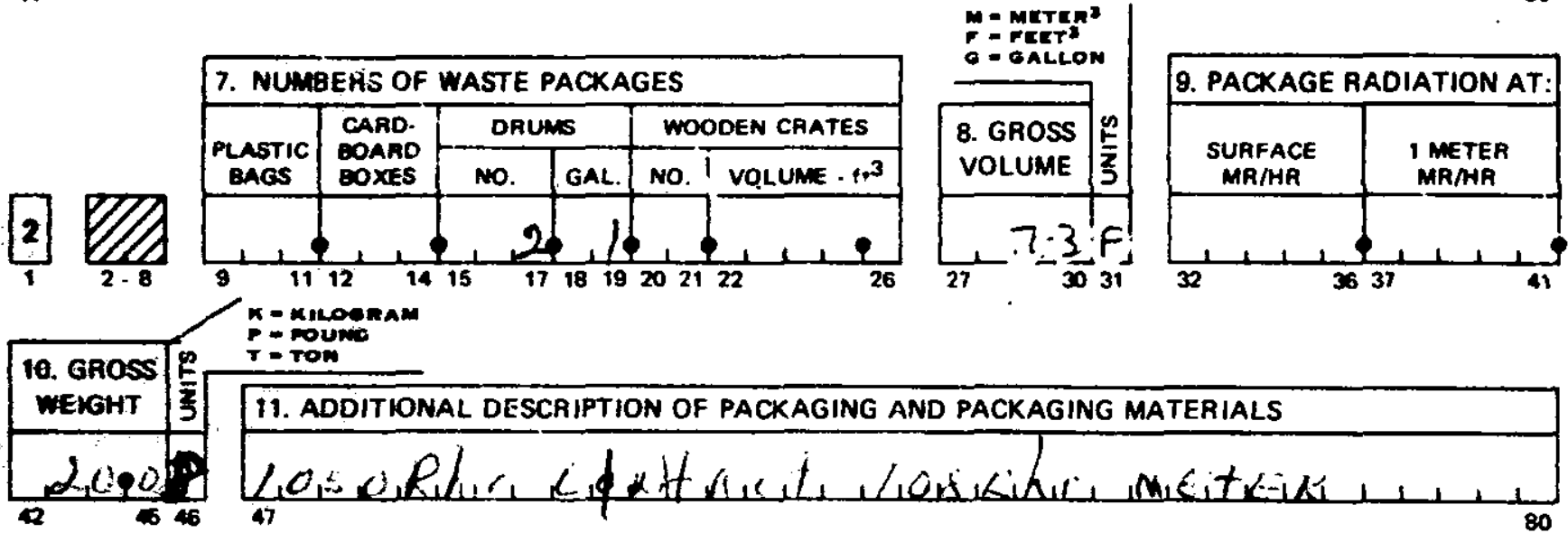

$$
\text { rounio }
$$

19. ADOITIONA

11. ADDITIONAL DESCRIPTION OF PACKAGING AND PACKAGING MATERIALS

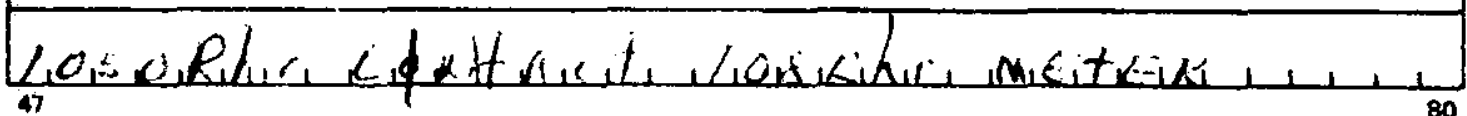
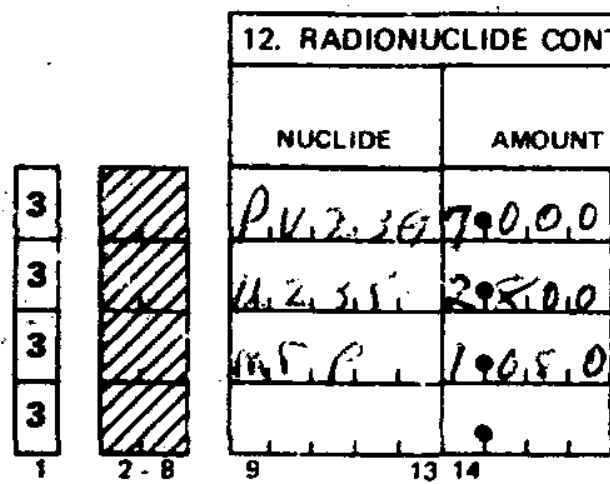

\section{Titert}

$+1$

1

\section{c- cunir me enam} ERAOR ON AMOUNT

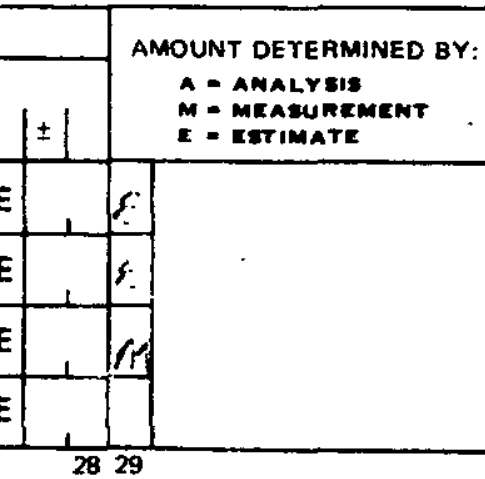

\begin{tabular}{|c|c|}
\hline \multicolumn{2}{|c|}{$\begin{array}{l}\text { SS MATERIALLS } \\
\text { WRITEOFF }\end{array}$} \\
\hline ACCOUNT & PROJECT \\
\hline & \\
\hline & \\
\hline & \\
\hline & \\
\hline
\end{tabular}

\section{$-24 a$ mares} WASTE GENERATO ignature certifies that wastebis in accordange ifth all applicable disposa! requirements.

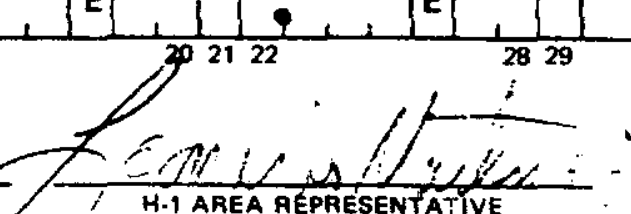
Signature certifies that waste packsge or shipment is safe to handit and transport.
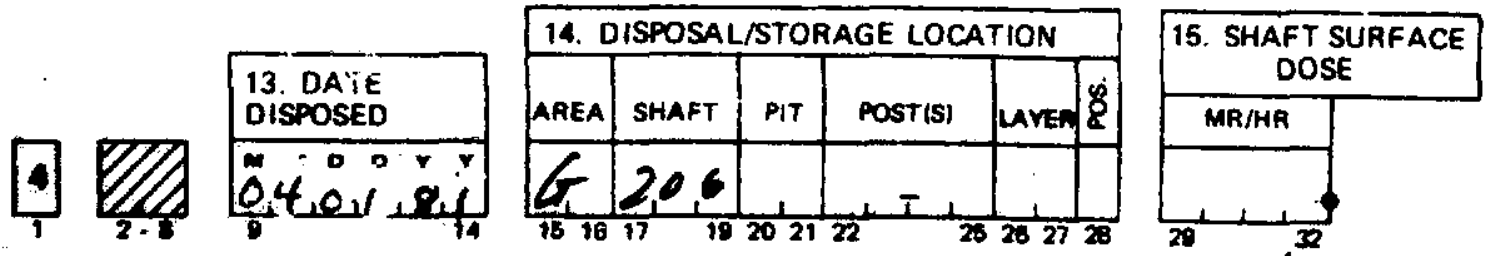

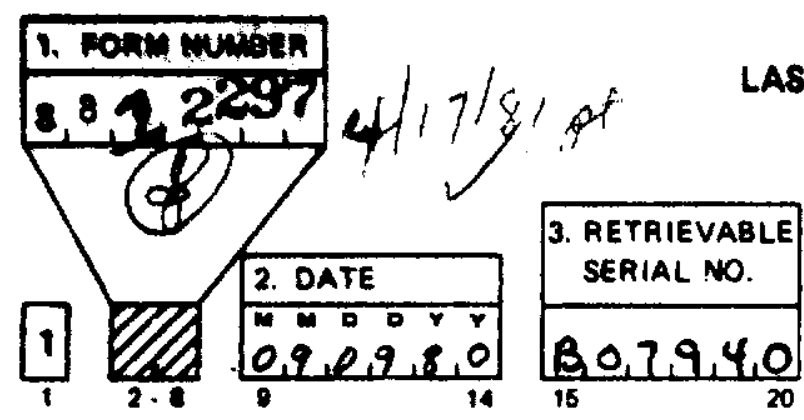

\section{LASL RADIOACTIVE BOLID WASTE DIEOSAL RECORD FORM}
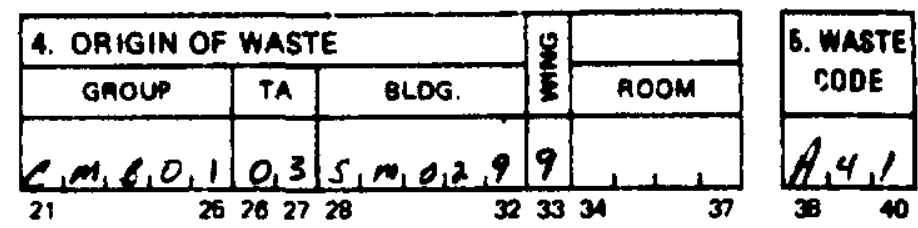

\section{WASTE DESCRIPTION}

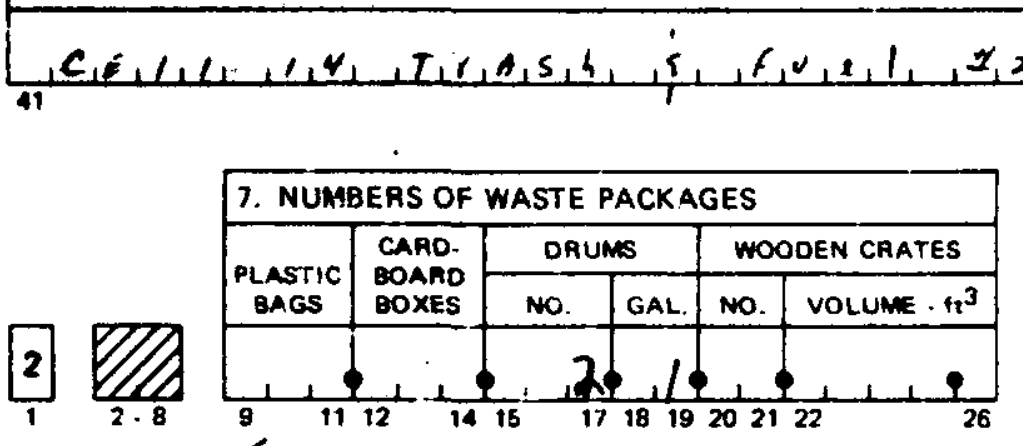

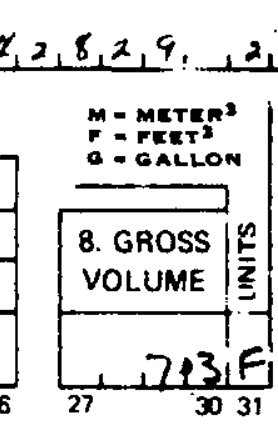

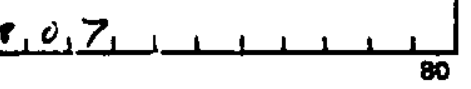
$x-$ xhoomam

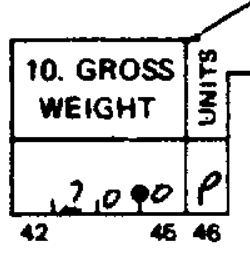
$T=$ Toun

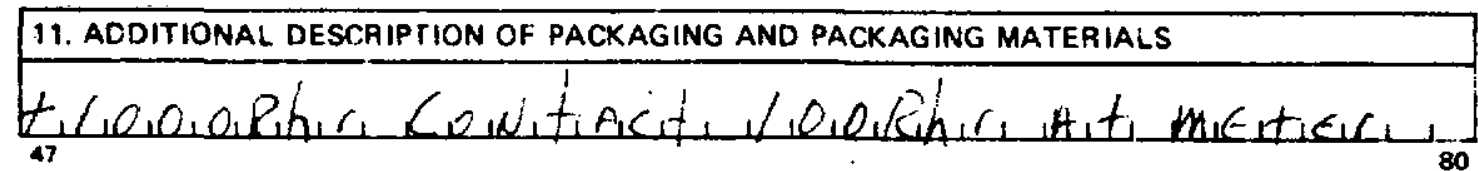

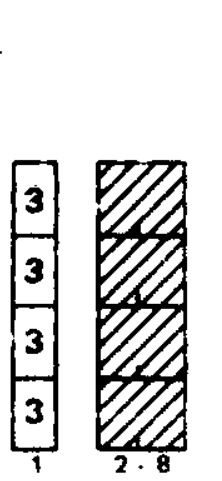

\begin{tabular}{|c|c|c|c|c|c|c|c|c|c|c|c|}
\hline \multicolumn{4}{|c|}{ 12. RADIONUCLIDE CONTENT } & \multicolumn{4}{|c|}{ 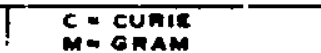 } & \multirow{2}{*}{\multicolumn{2}{|c|}{ 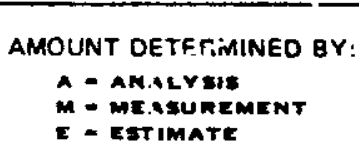 }} & \multicolumn{2}{|c|}{$\begin{array}{l}\text { SS MATERIALS } \\
\text { WRITEOFFF }\end{array}$} \\
\hline NUC: $10 E$ & AMOUN1 & & \pm & $\frac{5}{5}$ & $\begin{array}{l}\text { EAROR O } \\
\text { AMOUNT }\end{array}$ & & \pm & & & ACCOUNT & $\begin{array}{l}\text { PROJECT } \\
\text { CODE }\end{array}$ \\
\hline $1,2,3,5$ & $2,6,0,0$ & E & +1 & $m$ & 1 & E & & $\varepsilon$ & & & \\
\hline $\operatorname{lin} 2,3,9$ & $2,2,0,0$ & $\mathbf{E}$ & +1 & $M$ & & $\mathbf{E}$ & & $\varepsilon$ & & & \\
\hline$m_{1} t_{1} \rho_{1}$ & $\angle 0,0,0$ & $\mathbf{E}$ & \pm 2 & c & 9 & E & & $M$ & & & \\
\hline & & $\mathbf{E}$ & & & 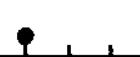 & E & & & & & \\
\hline
\end{tabular}

20.9. mare WASTE GS TERATOR Signature cereffies that waste is in accordance with all apolicable disposal requirements.

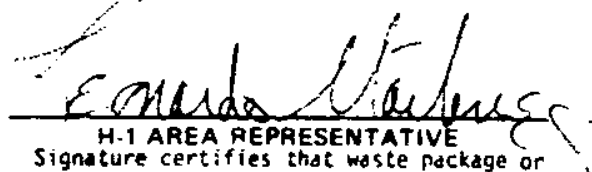
shipant is safe to handie and transport.
GROUP LEADER (AS NECESSARY)

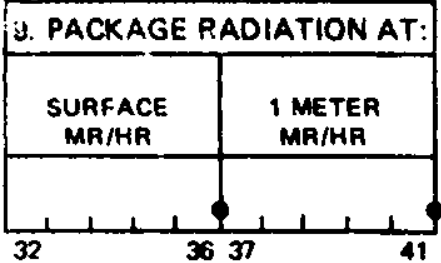

30

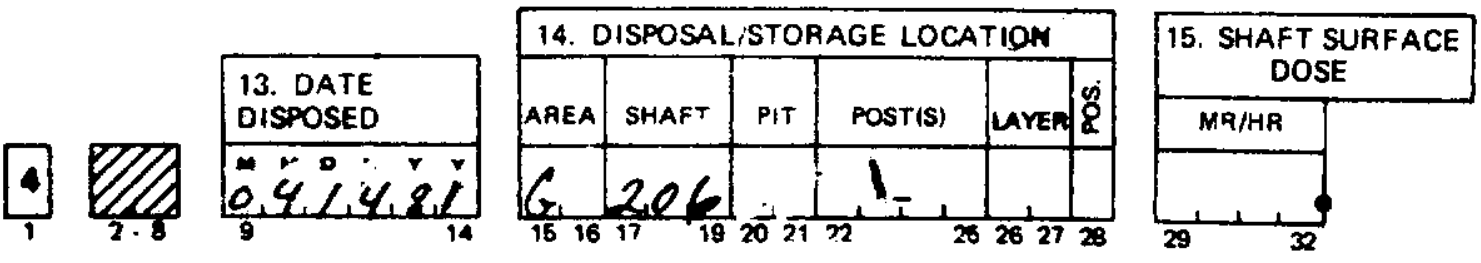



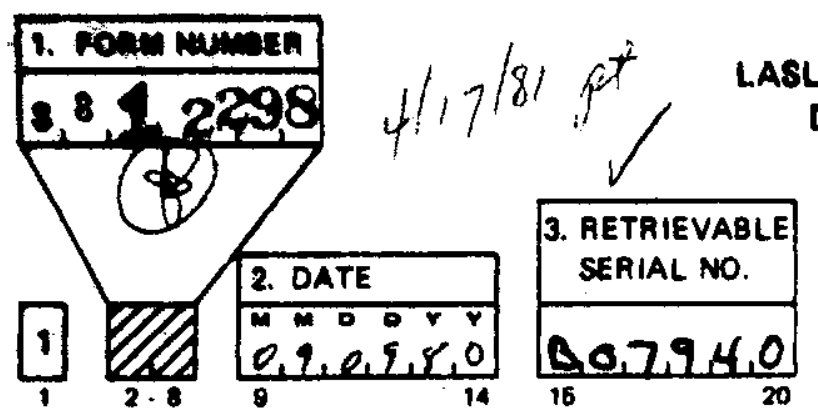

\section{LASL RADIOACTIVE SOLID WASTE DISPOEAL RECORD FORM}

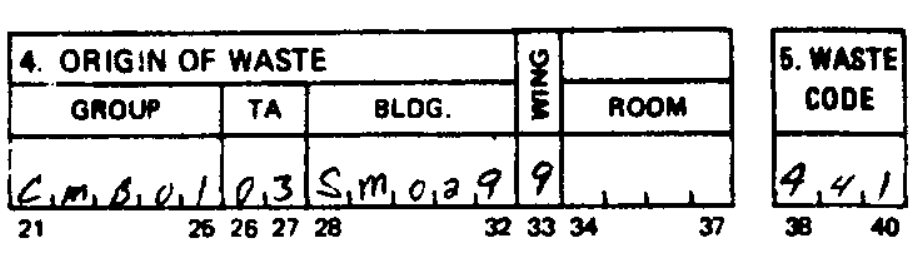

\section{MASTE DESCRIPTION}

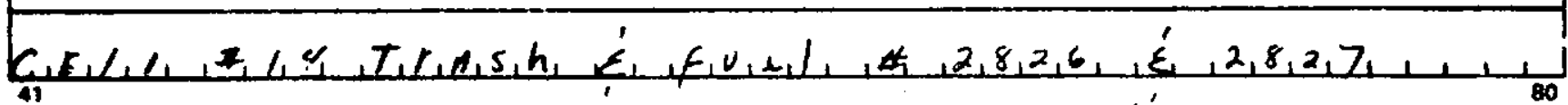
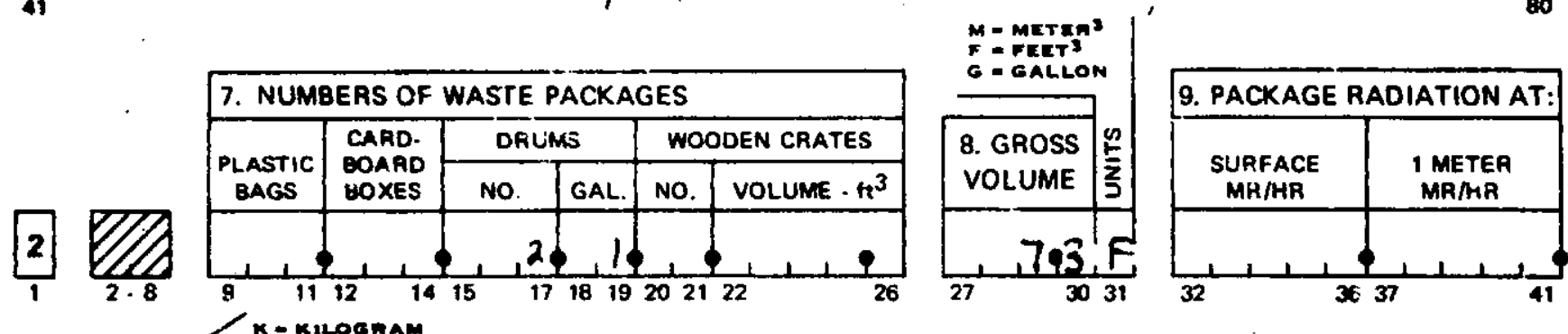

\section{K- Kirogmam}

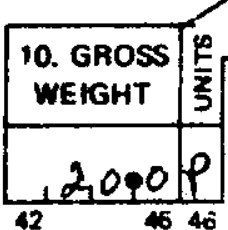

$T-$ TON

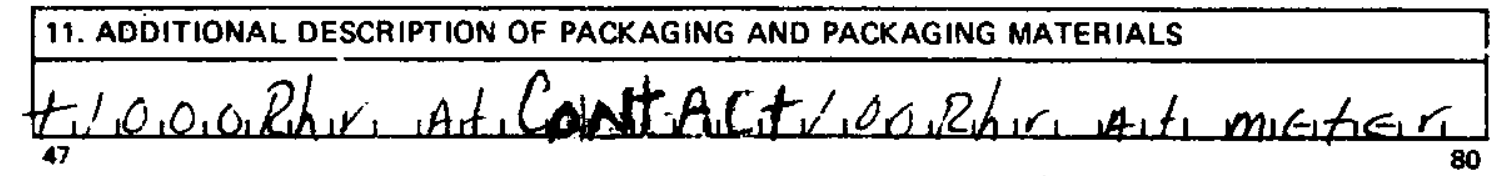
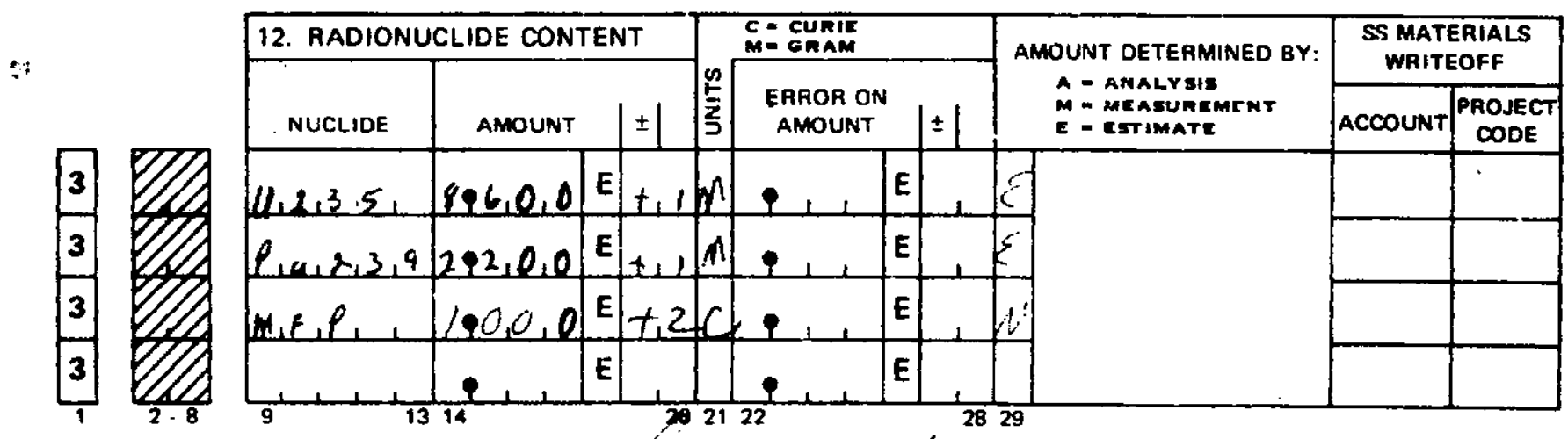

\section{M. a. 2n, nen.}

stcreture certifies that waste is in accordance with all apel icable disposal reoui rements.

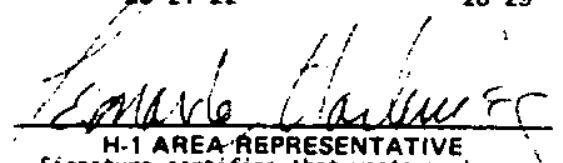
H-1 AREA AEPRESENTATIVE
Signature certifies that waste pockage or shipment is safe to handie and transport.
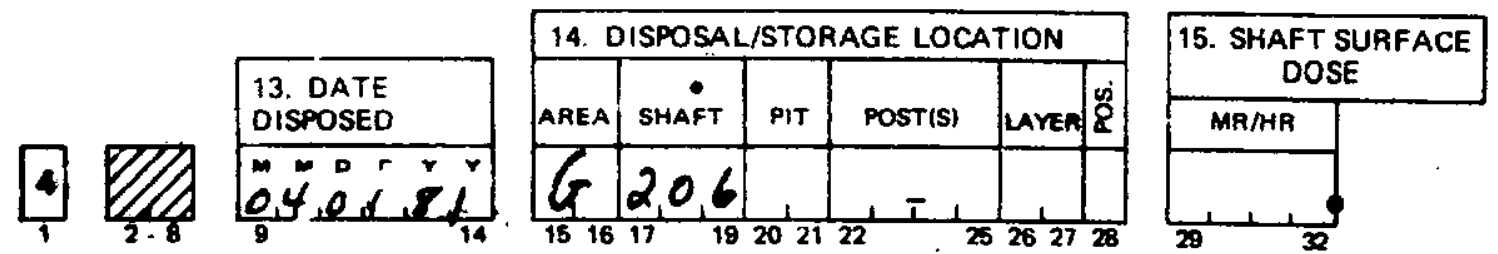

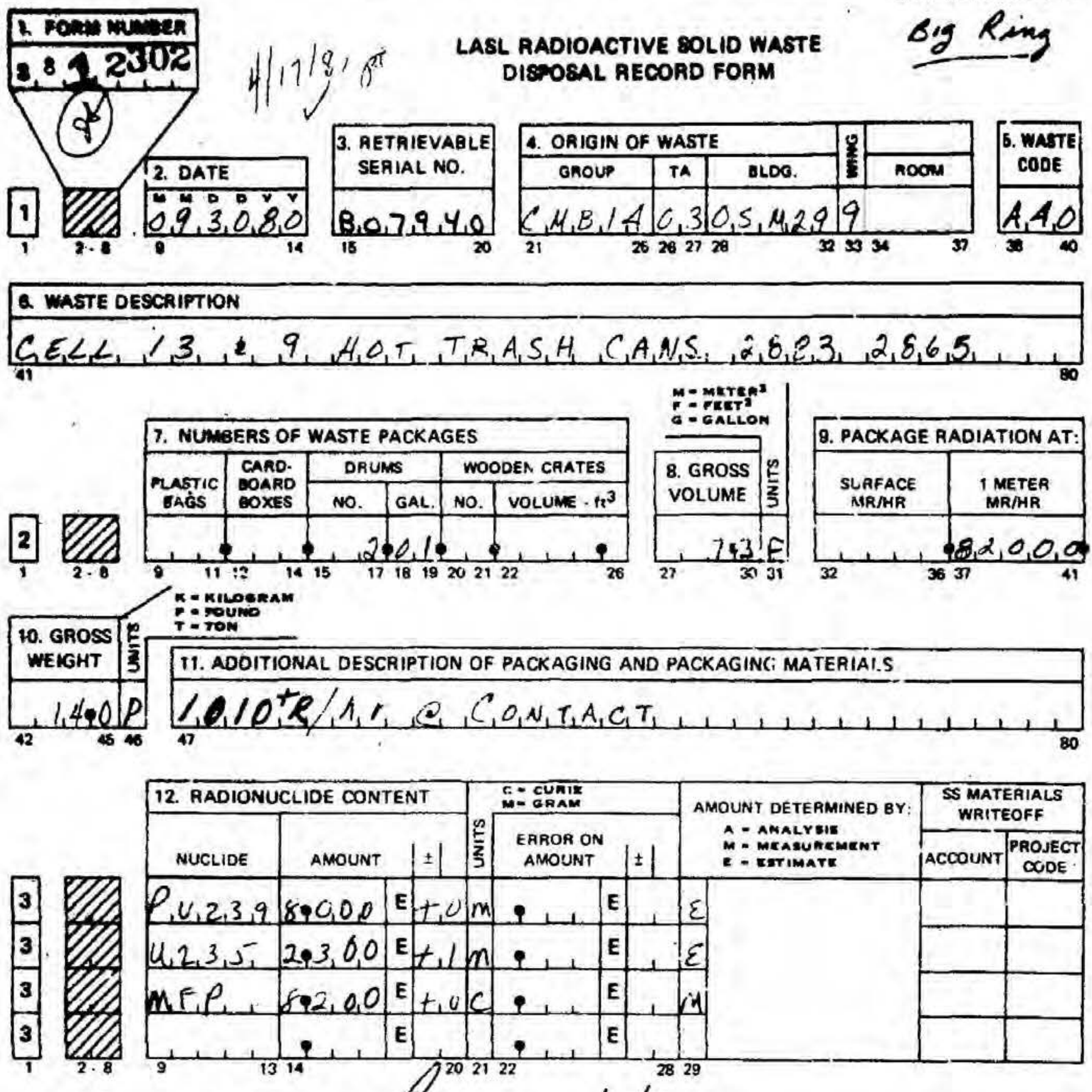

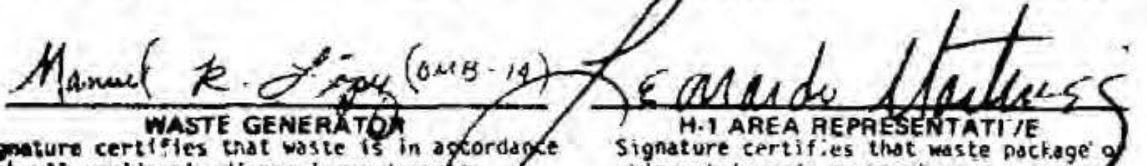

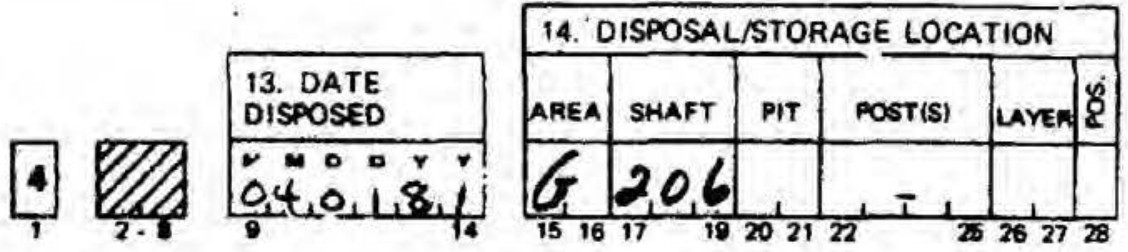




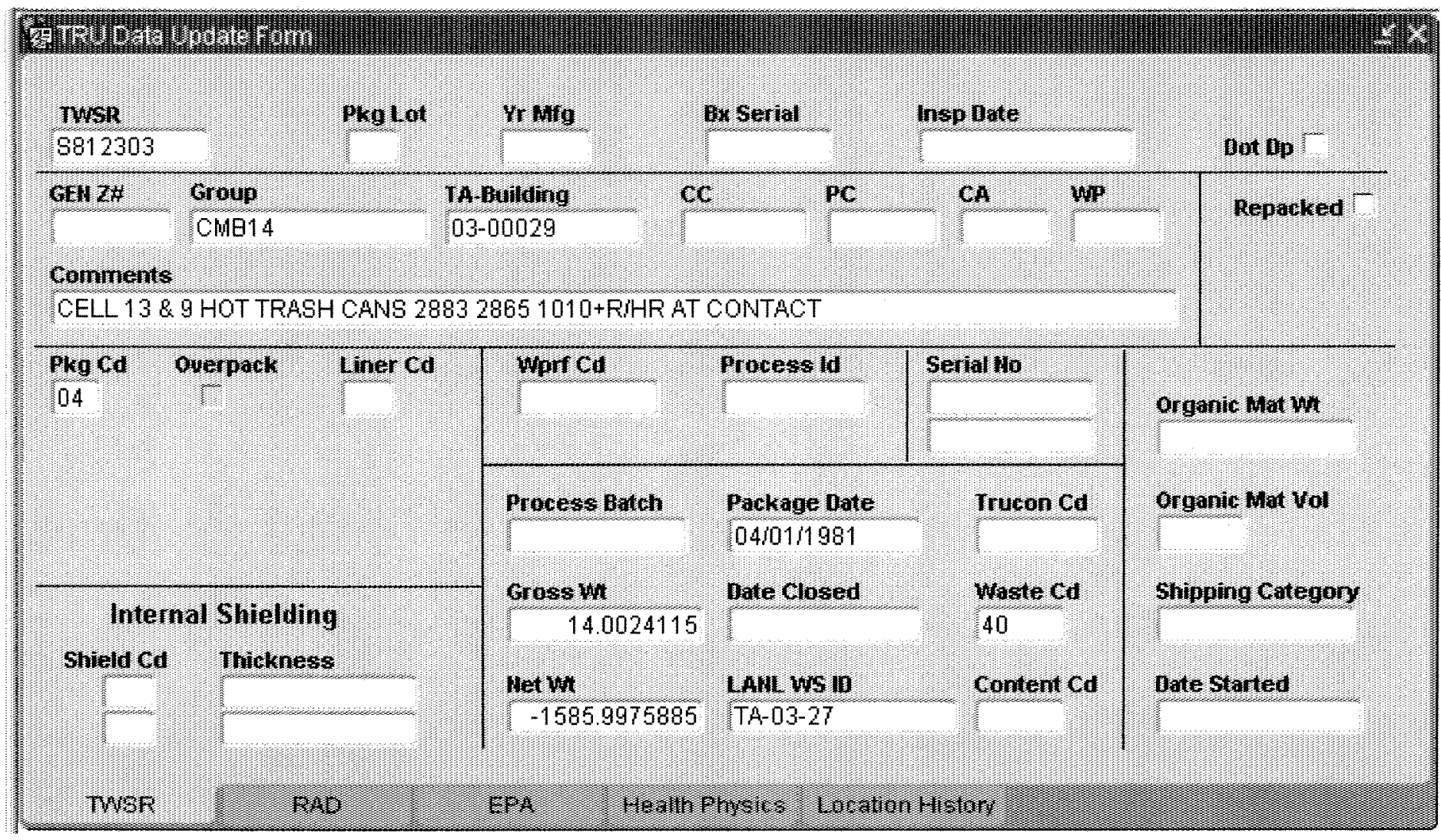




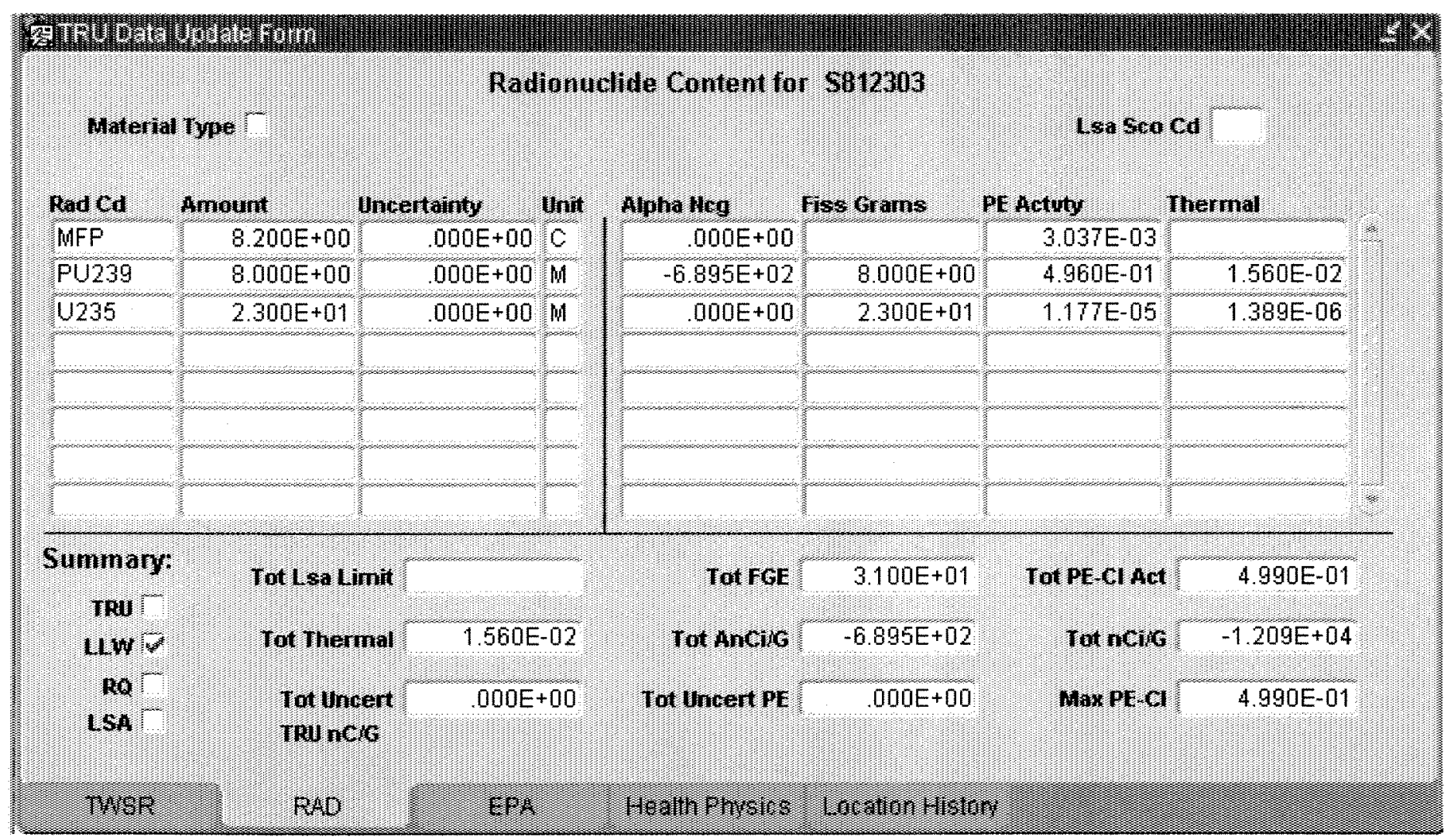




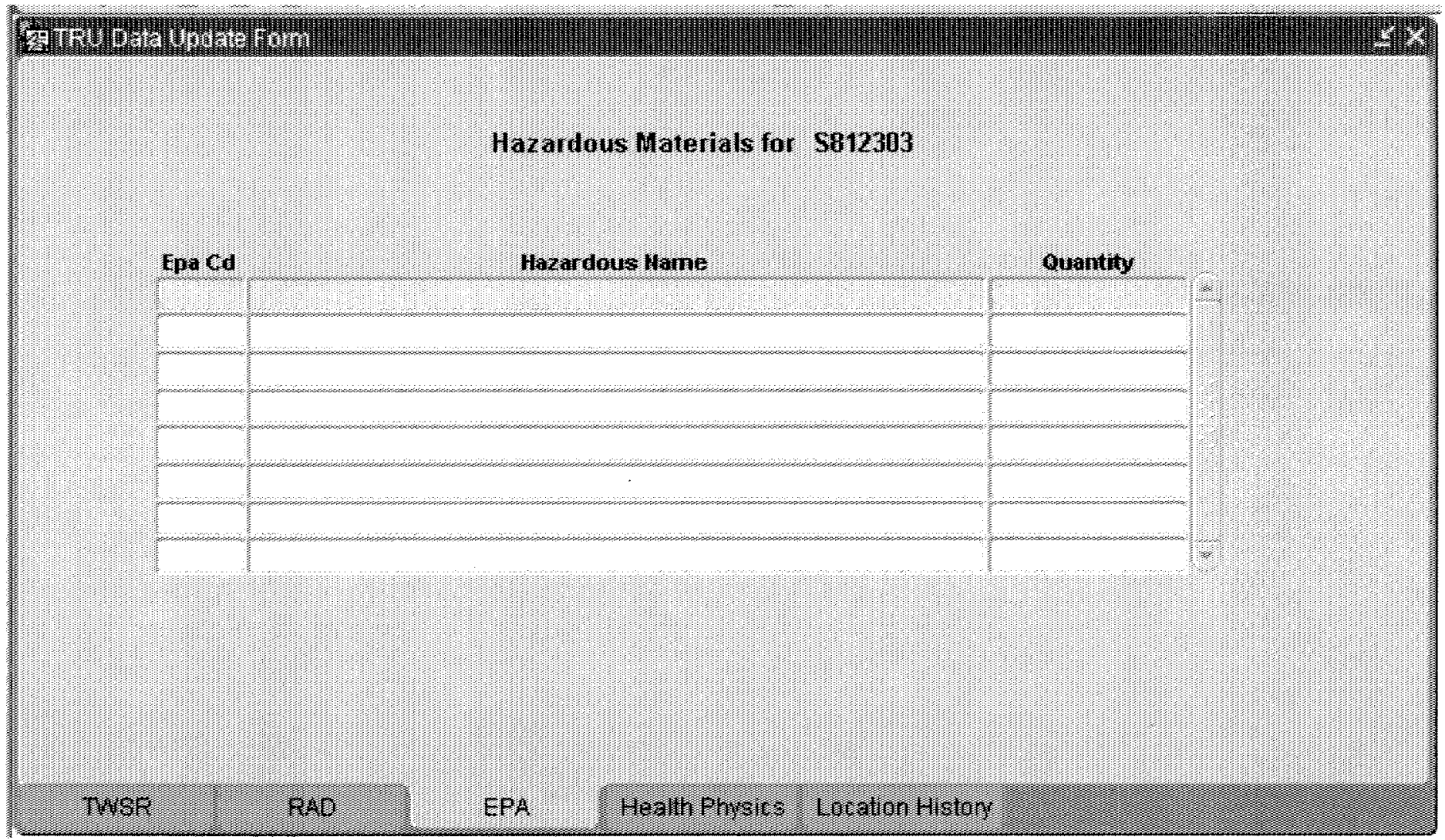




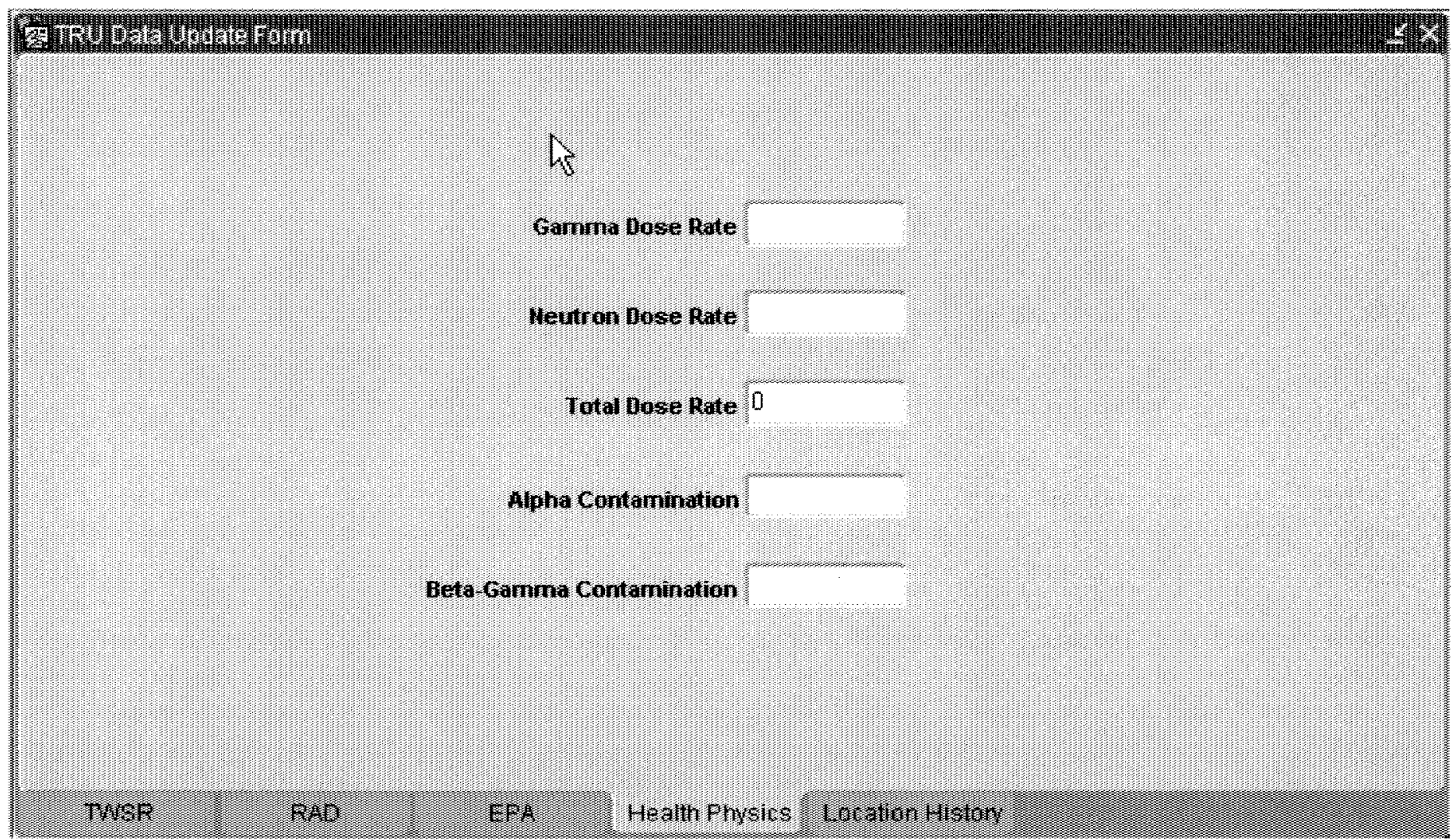




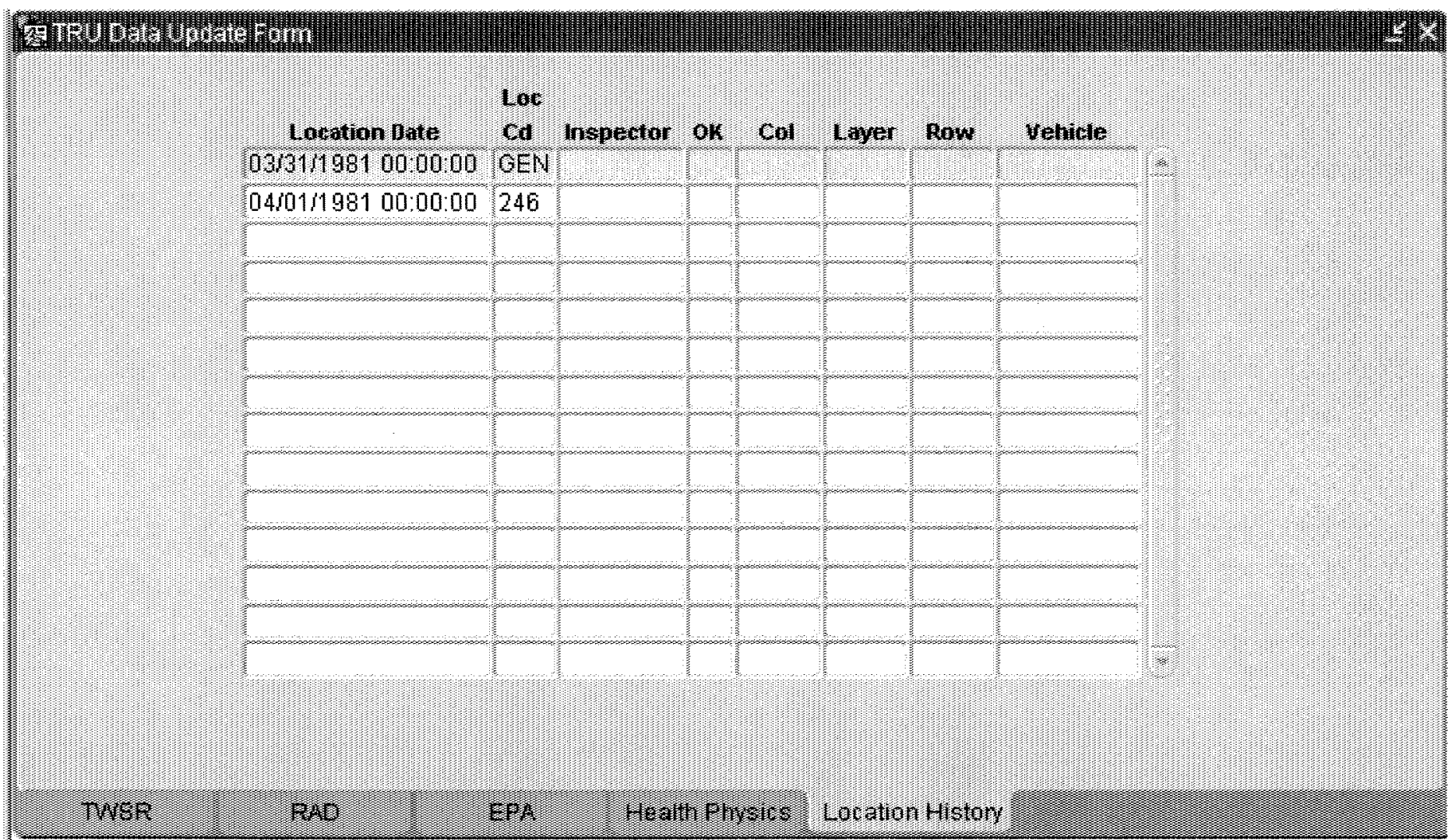


RADIOACTIVE SOLID WASTE DISPOSAL RECORD FORMS

FOR

SHAFT 207

MATERIAL DISPOSAL AREA G 


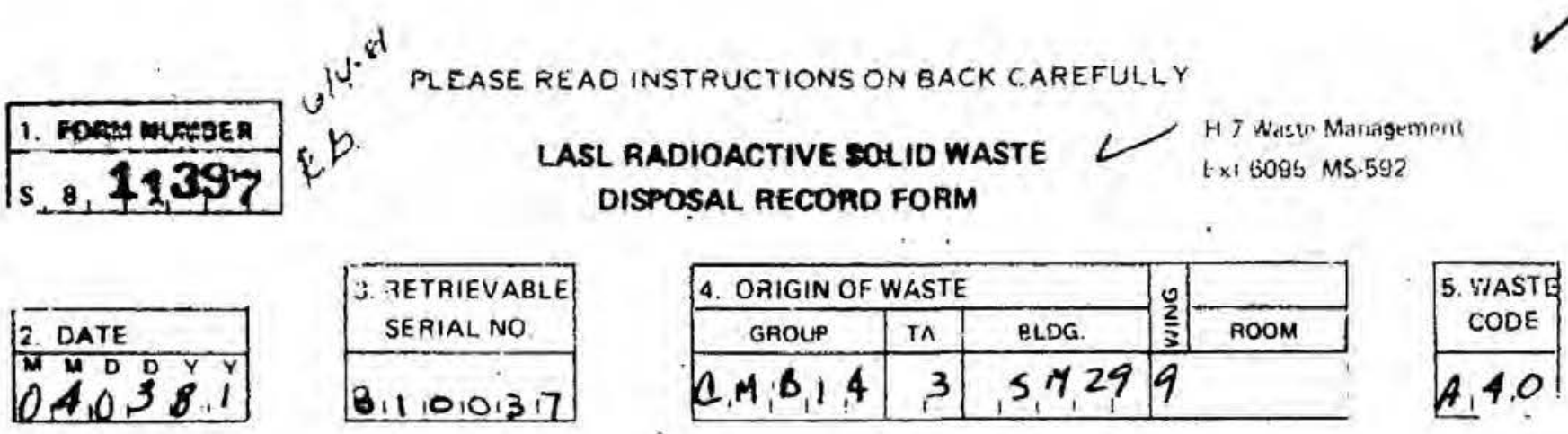

\section{WASTE DESCRIPTION}

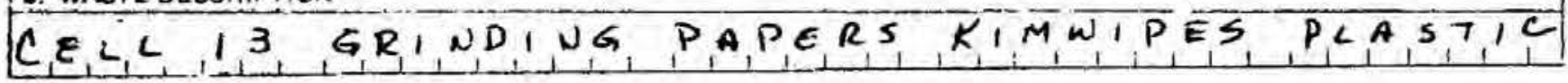
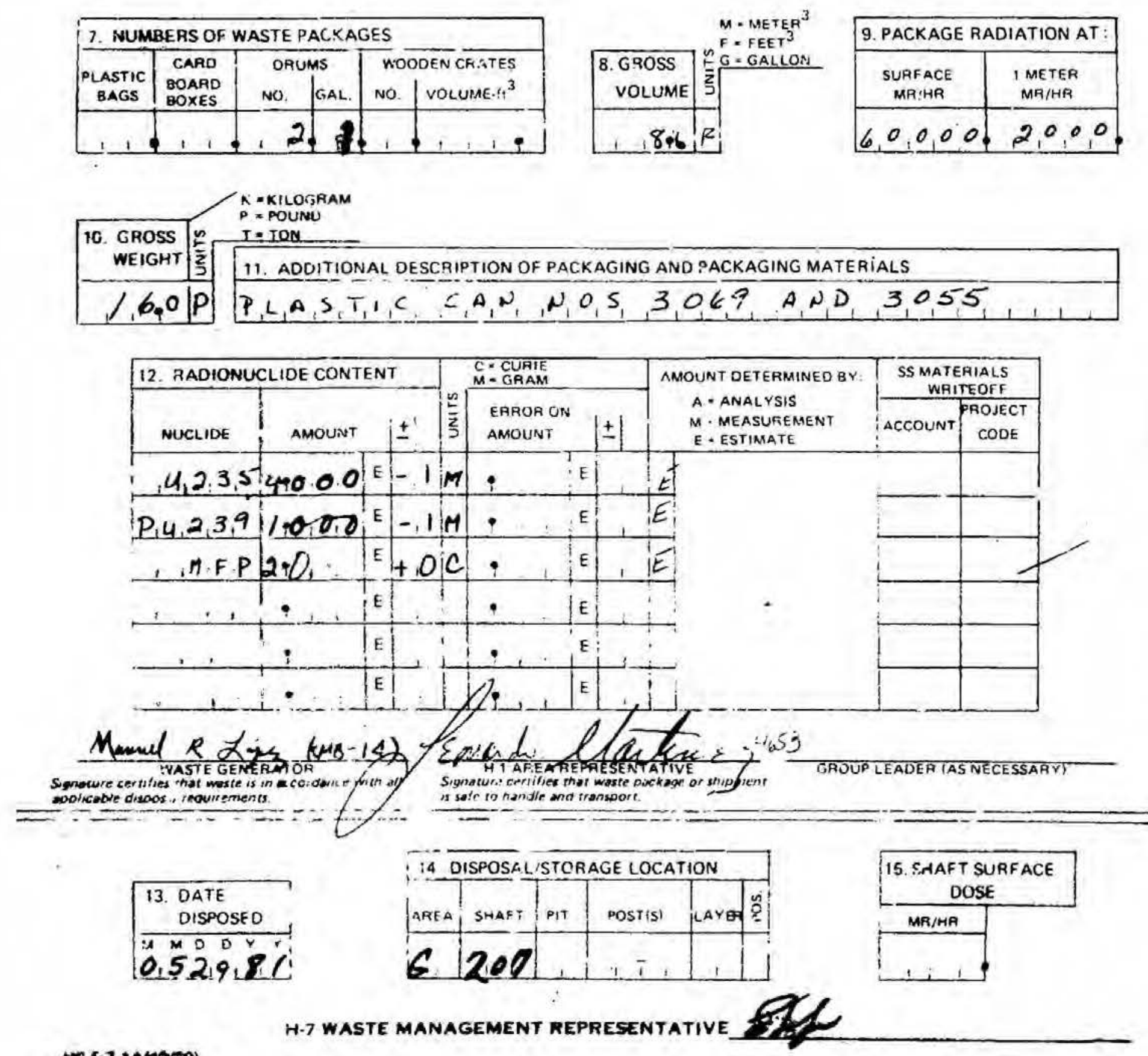
PLEASE READ WNSTRUCTIONS ON BACK CAREFULLY

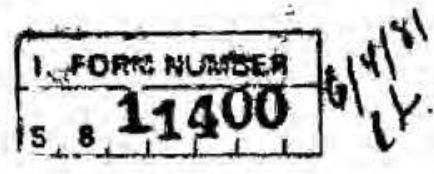

\section{LASL RADIOACTHE SOLIO WASTE DISPOSAL RECORD FORM}

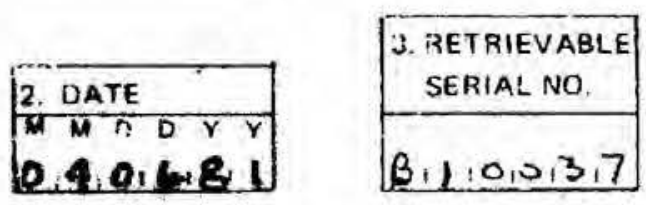

\begin{tabular}{|c|c|c|c|c|}
\hline \multicolumn{3}{|c|}{ 4. ORIGIN OF WASTE } & \multirow{2}{*}{$\begin{array}{l}0 \\
\vdots \\
\vdots \\
3\end{array}$} & \multirow[b]{2}{*}{ मOOM } \\
\hline GROUP & TA & ELDG. & & \\
\hline
\end{tabular}

\section{WASTE description}

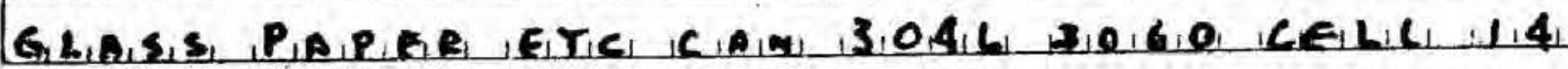

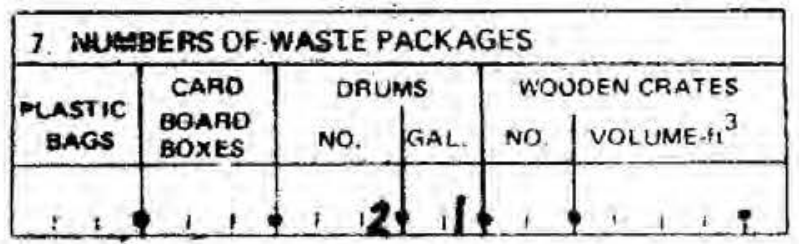
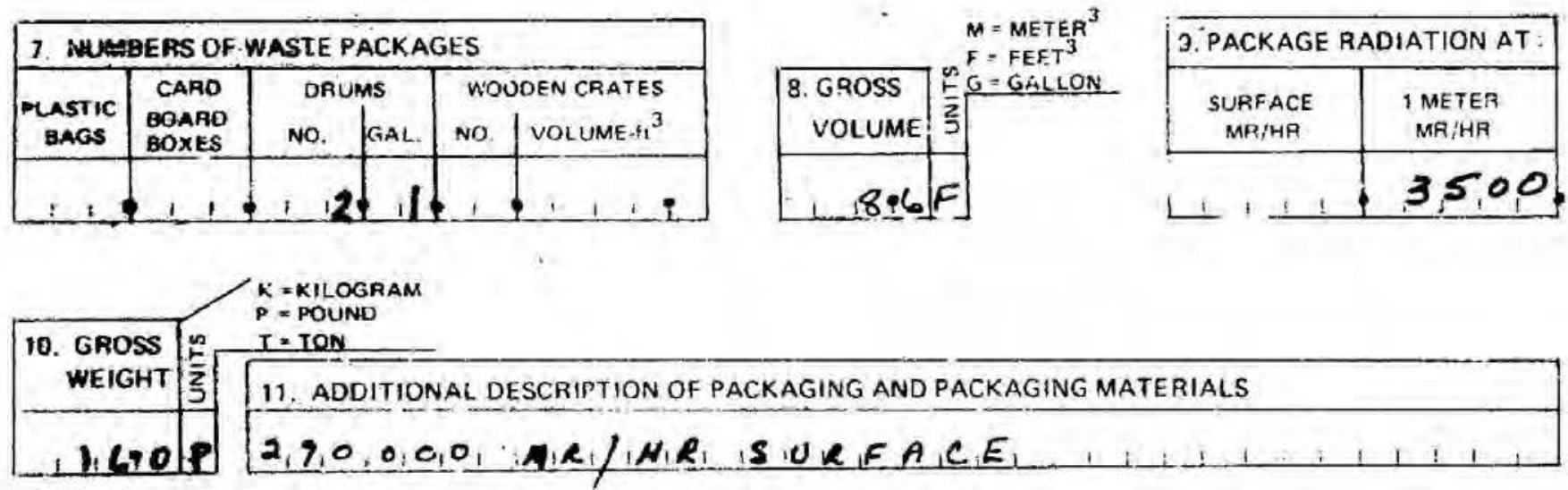

\begin{tabular}{|c|c|c|c|c|c|c|c|c|c|c|}
\hline \multicolumn{4}{|c|}{ 12. RADIONUCLIDE CONTENT } & \multicolumn{3}{|l|}{$\begin{array}{l}C=\text { CURIE } \\
M=\text { GRAM }\end{array}$} & \multirow{2}{*}{\multicolumn{2}{|c|}{$\begin{array}{l}\text { AMOUNT DETERMINED BY } \\
\text { A = ANALYSIS } \\
M \text { - MEASUREMENT } \\
E=\text { ESTIMATE }\end{array}$}} & \multicolumn{2}{|c|}{$\begin{array}{c}\text { SS MATERIALS } \\
\text { WRITEOFF }\end{array}$} \\
\hline NUCLLOE & AMOUNT & & \pm & $\begin{array}{l}\text { ERROR ON } \\
\text { AMOUNT }\end{array}$ & & \pm & & & Account & $\begin{array}{c}\text { PROJECT } \\
\text { CODE }\end{array}$ \\
\hline PIUREA & $0=10,0$ & E & & 1, & E & & E & & i & \\
\hline $1,2,3,51$ & $0,4,0,0$ & E & & 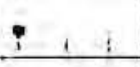 & E & & $E$ & & & \\
\hline AF $\mathbf{P}$ & $3,50,0$ & E &,+ 0 & & E & & $H$ & & & \\
\hline$\therefore 111$ & $\stackrel{\square}{1}$ & E & & & E & & & & & \\
\hline 1.1 & 1 & E & & i. 1 & E & & & & & \\
\hline $1 \div 1$. & $P, r$ & E & & - i i & E & & & & & \\
\hline
\end{tabular}

\section{पृतix}
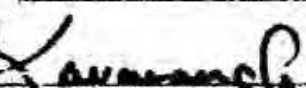

P Car-1 VASTE GENERT WR

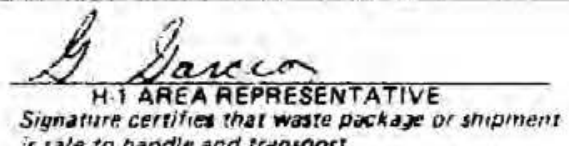

\section{GROUP LEAOEA TAS TECESSARYI} is sale to handle and transport.

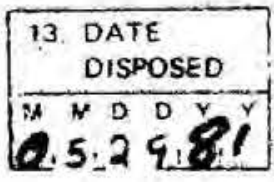
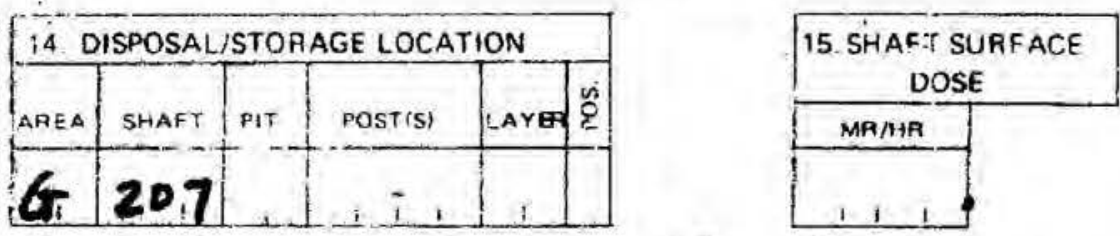


\section{Retrivalle}

i.

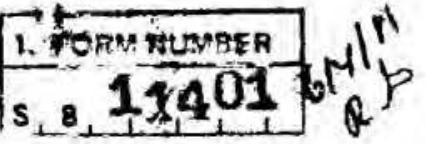

PLEASF RF, AO INSTRUCTIONS ON BACK CAREFULLY

\section{LASL RADIOACTIVE SOLID WASTE DISPOSAL RECORD FORM}
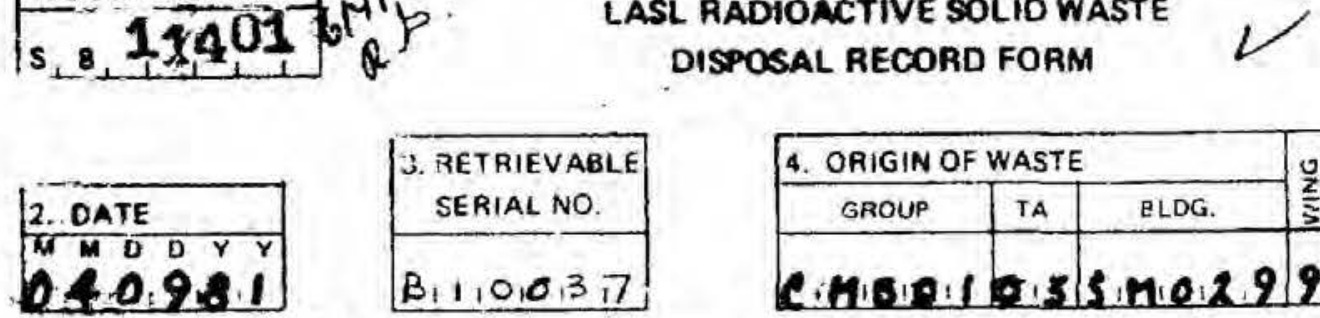

\begin{tabular}{|c|c|c|c|c|}
\hline \multicolumn{3}{|c|}{ 4. ORIGIN OF WASTE } & \multirow{2}{*}{$\frac{0}{z}$} & \multirow[b]{2}{*}{ ROON } \\
\hline GROUP & TA & ELDG. & & \\
\hline
\end{tabular}

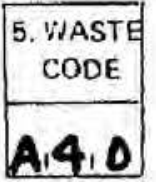

(2)

6. WASTE DESCRIPTION

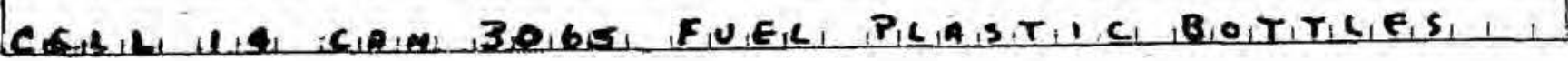

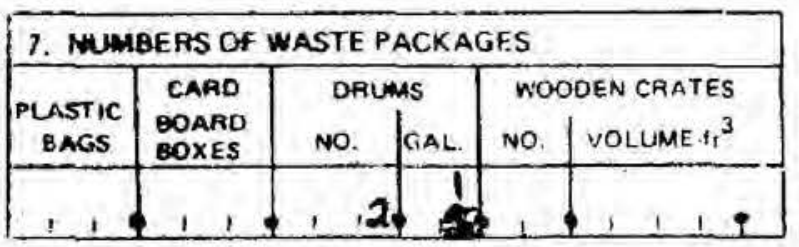
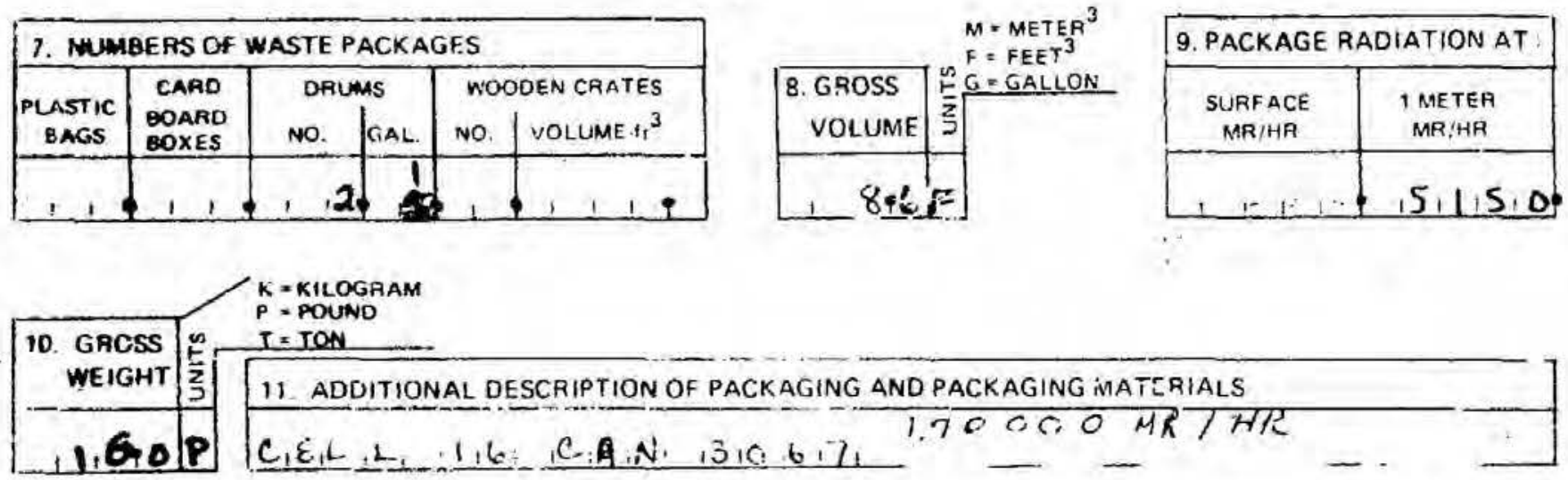

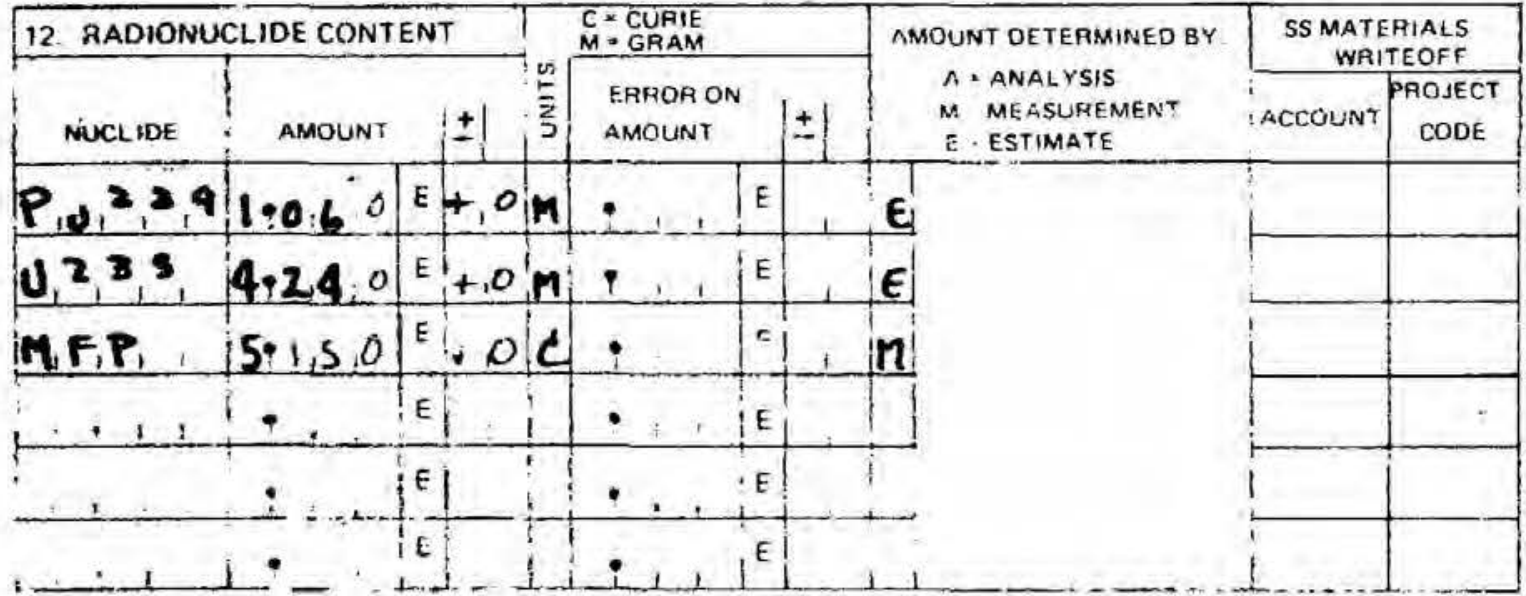

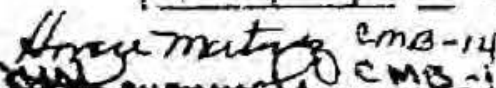
IVASTENERATOR

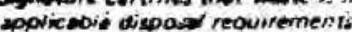

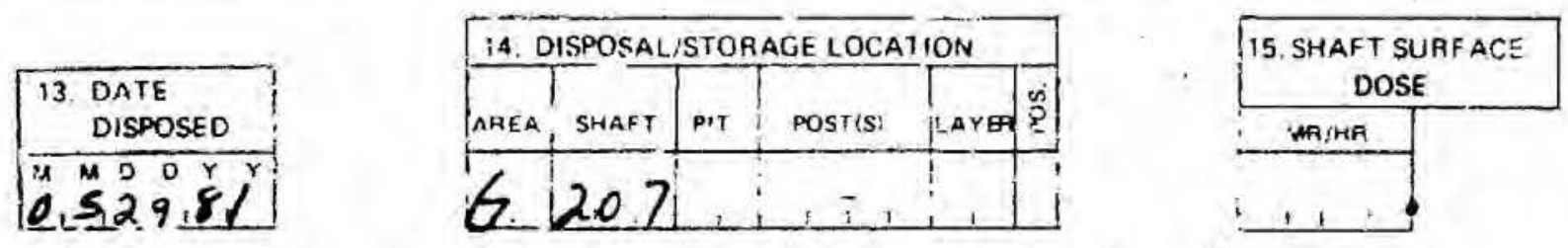

h.7 Waste management representat.ve Aed bulfota 
Cack w/o collen

PLEASF REAQ INSTRUUTIONS ON BACK CAREFULIYY 


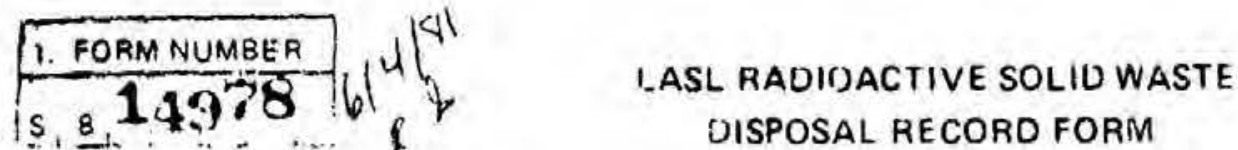

$$
\begin{aligned}
& \text { UISPOSAL RECORO FORM }
\end{aligned}
$$

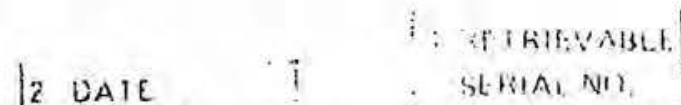

$$
\begin{aligned}
& \begin{array}{l}
\text { 10 } \\
\text { C.MBI4 3SM29 }
\end{array}
\end{aligned}
$$

76. WASTE Discriprion

CELG IS WIPES,POLISHING CLOTHS PLASTIC :

INUMBERS CE DASTE RACKAGES

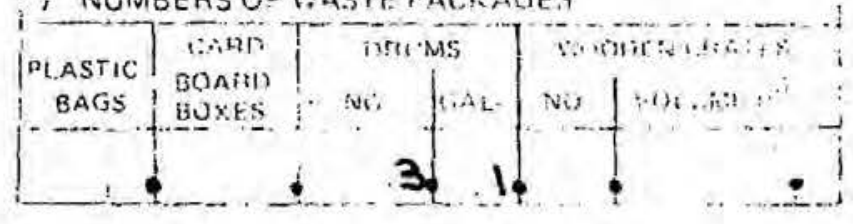

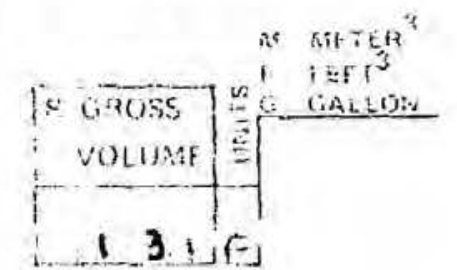
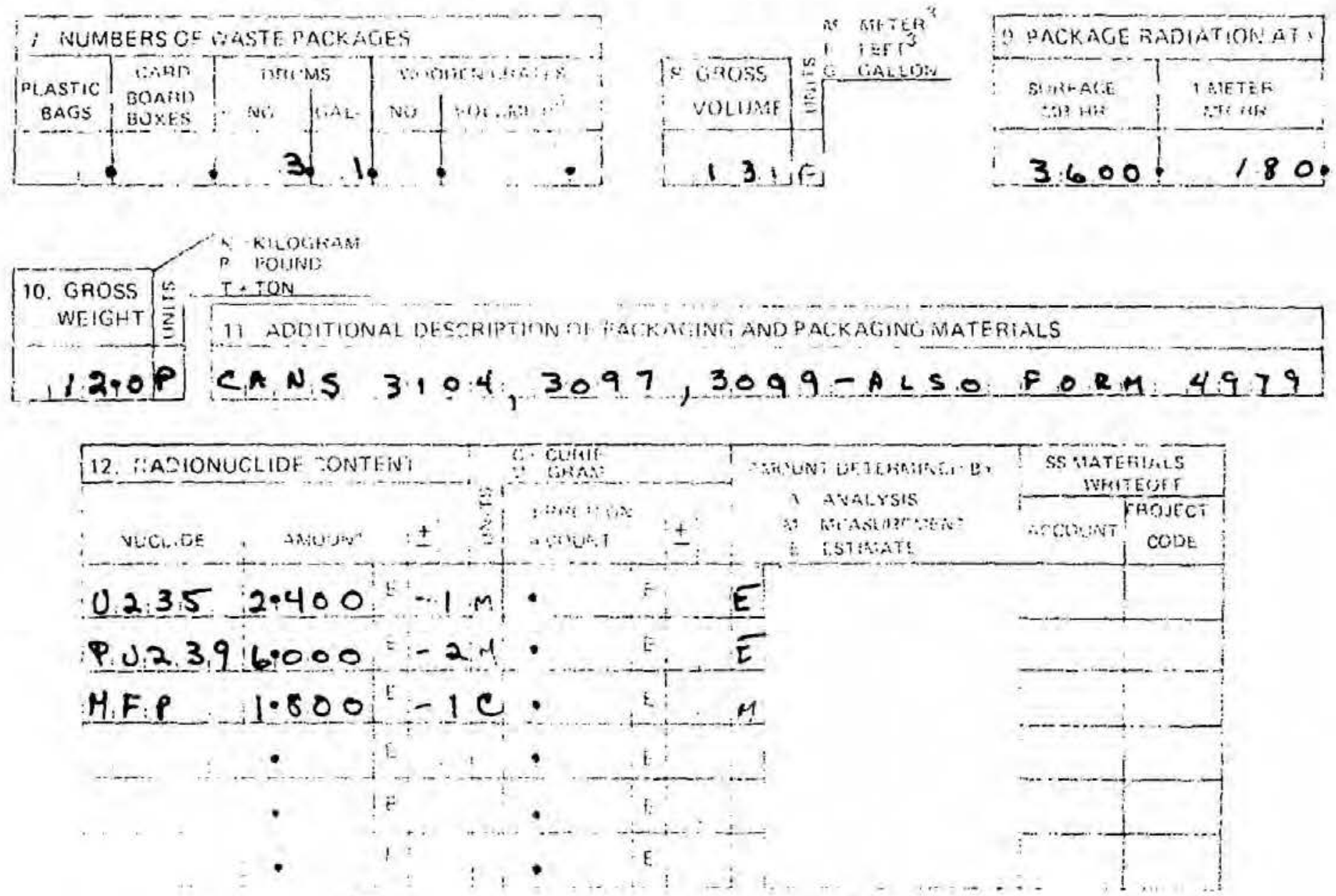

Manuel R.2.apez

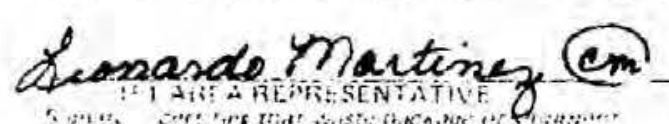

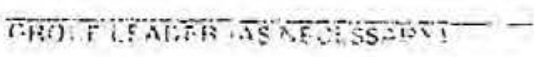

(ant $=$

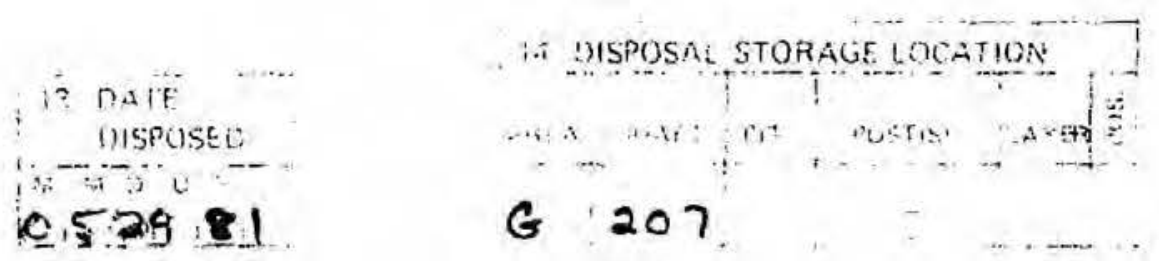

i5. SHAF I SUIRF ACE UUSE

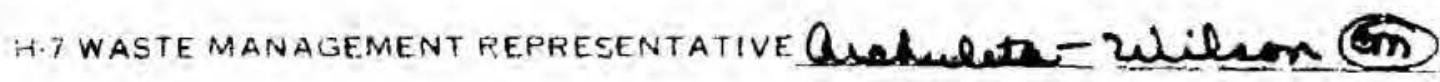


RADIOACTIVE SOLID WASTE DISPOSAL RECORD FORMS

FOR

SHAFT 208

MATERIAL DISPOSAL AREA G 


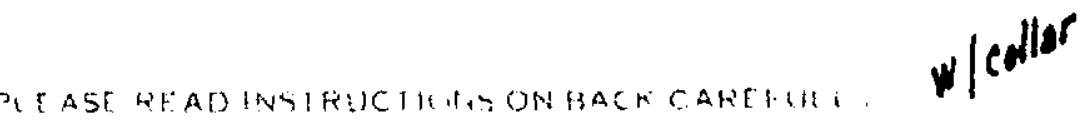

1. FöMA MUMBER

s., 10794

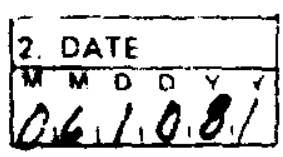

$\|^{2} e^{8}$

LASL RADIOACTIVE SOLIO WASTE

DISPOSAL RECORD FORM

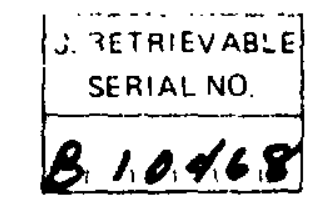

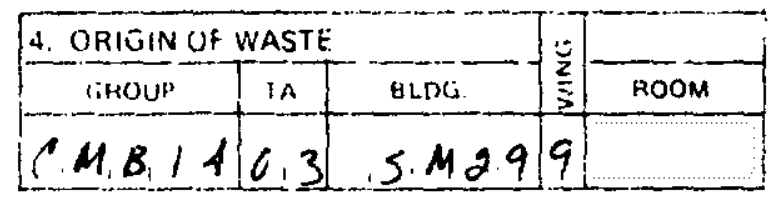

5. $\because$ ASTE

CODE

A.4.0

- WASTE DESCRIPTION

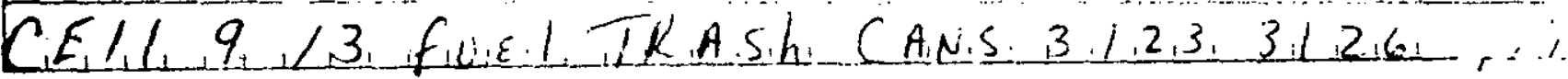
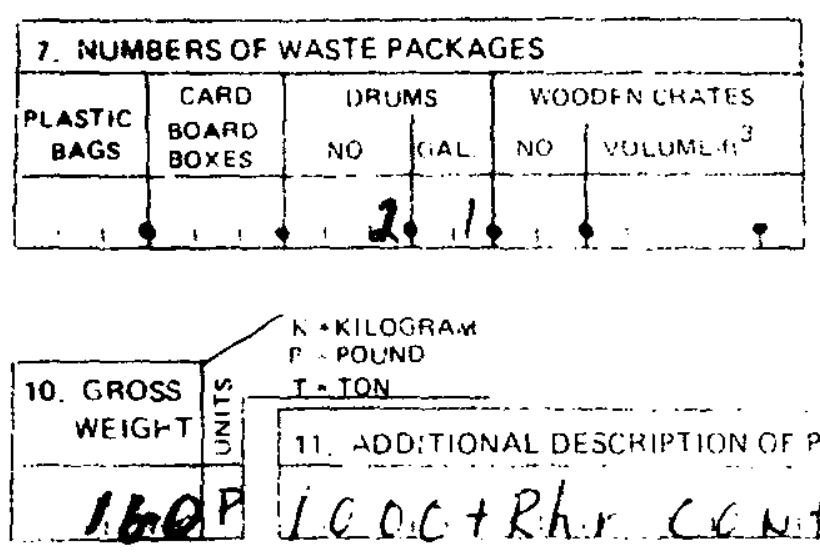

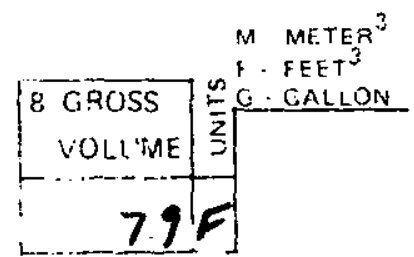

\begin{tabular}{|l|l|}
\hline 9. PACKAGE RADIATIONN AT: \\
\hline $\begin{array}{c}\text { SURFACE } \\
\text { MHR HIR }\end{array}$ & $\begin{array}{c}\text { TMETER } \\
\text { MAR HHR }\end{array}$ \\
\hline
\end{tabular}

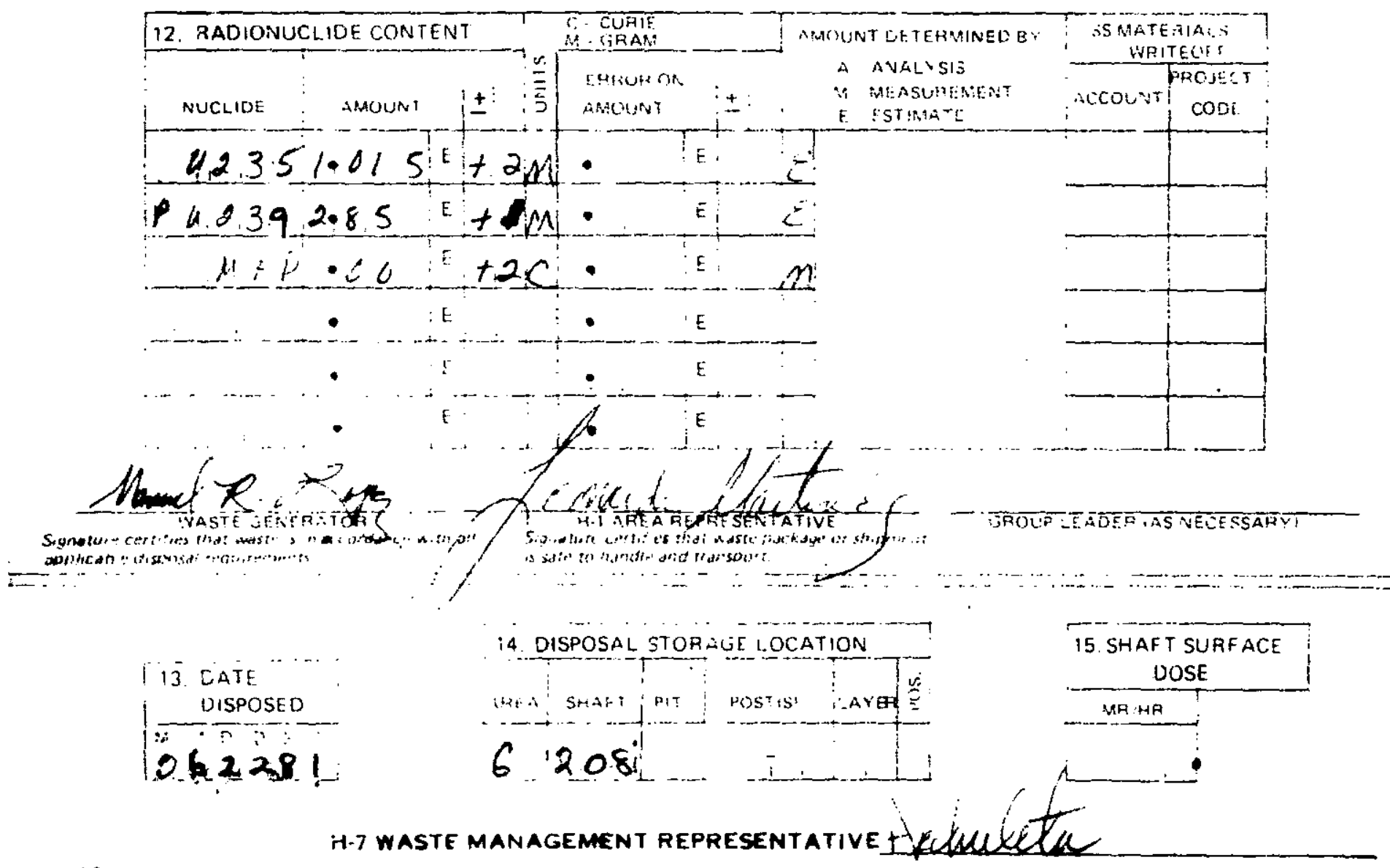


PLEASE READ INSTRUCTIONS ON BACK CAREFULII
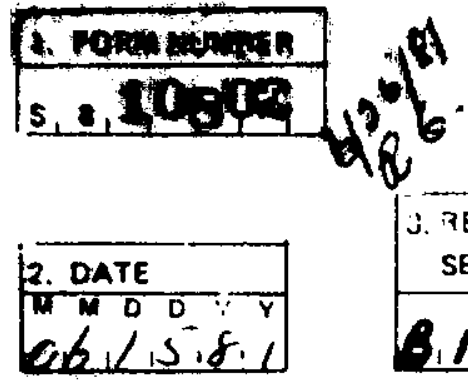

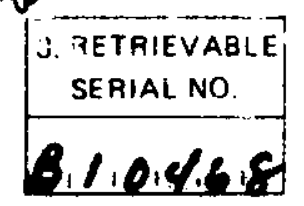

LASL AADIOACTIVE \&OLID WASTE DISPOSAL RECORD FORM

\begin{tabular}{|c|c|c|c|c|}
\hline \multicolumn{3}{|c|}{ 4. URIGIN OF WASTE } & \multirow{2}{*}{$\frac{0}{3}$} & \multirow[b]{2}{*}{ HOOM } \\
\hline GROUP & $T A$ & BLDG. & & \\
\hline$m, B_{1}$ & 0,3 & $15 m_{12}, 9$ & 9 & $: \quad: \quad 1$ \\
\hline
\end{tabular}

\begin{tabular}{|c|}
\hline 5. VIASTA \\
CODE \\
\hline$A_{1} \mathrm{H}_{1} \mathrm{C}$ \\
\hline
\end{tabular}

\section{. WASTE DESCRIPTION}

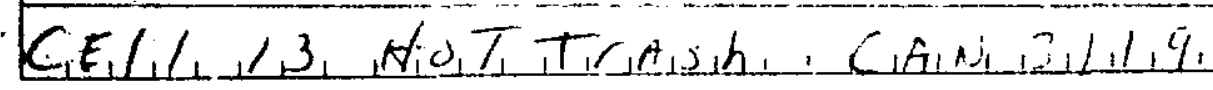

\begin{tabular}{|c|c|c|c|c|c|}
\hline \multicolumn{6}{|c|}{ 3. AurmoERS OF WASTE PACKAGES } \\
\hline \multirow[b]{2}{*}{$\begin{array}{l}\text { PLASTIC } \\
\text { EAGS }\end{array}$} & \multirow{2}{*}{$\begin{array}{l}\text { CARD } \\
\text { GOAAD } \\
\text { GOXES }\end{array}$} & \multicolumn{2}{|c|}{ DRUMS } & \multicolumn{2}{|c|}{ MOODEN CRATES } \\
\hline & & No. & GiAL. & No. & VOLUME $\cdot t^{3}$ \\
\hline & & & & & 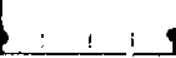 \\
\hline
\end{tabular}
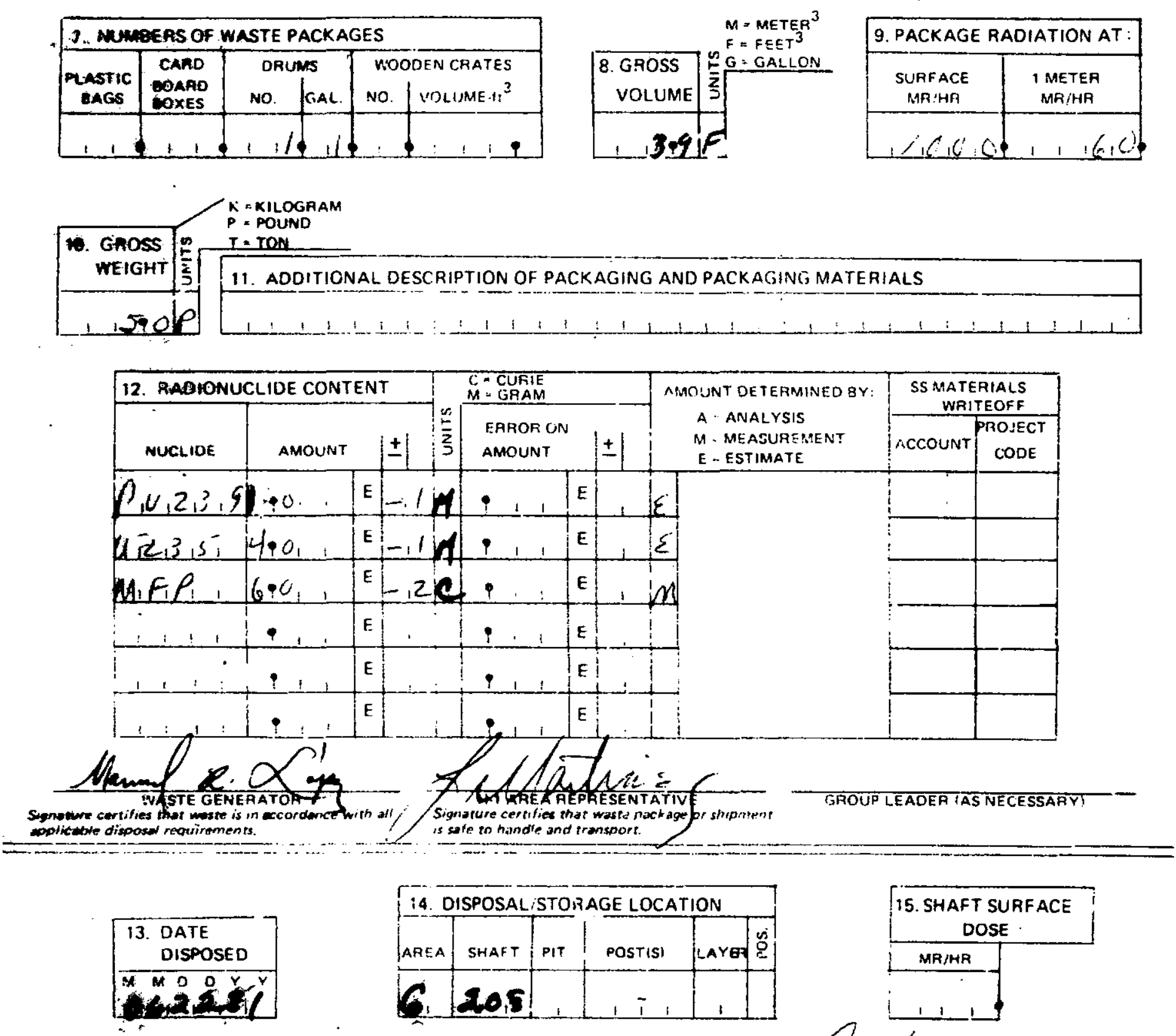

H-7 WASTE MANAGEMENT REPRESENTATIVE

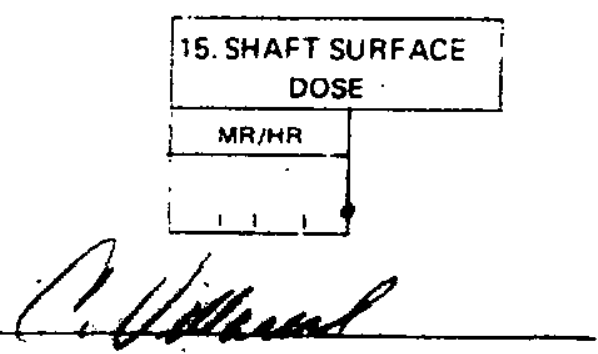




\section{Cacte $w /$ colliar}

PI.EASE READ INSTRUCTIONS ON B.ACK CAREFULLY

\section{$\left.\left.\frac{1 \text {. FOAM NUMBER }}{5,8,11.495} 6\right|^{2}\right|^{8}$}

\section{LASL RADIOACTIVE SOLID WASTE DISPOSAL RECORD FORM}

r. Wrast. Manatje:ments

Exi Go95 Ais.59?
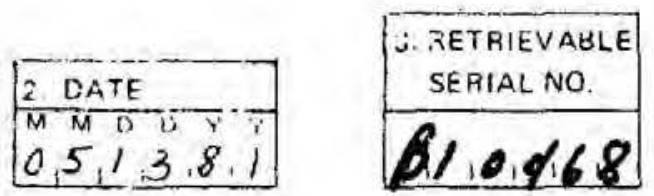

\begin{tabular}{|c|c|c|c|c|}
\hline 4. ORIGIN OF WASTE & & \\
\hline GROUP & TA & PLDG & 5 & ROOM \\
\hline$C, M, B, 1,4$ & 0,3 & $13, M, 0,9$ & 9 & \\
\hline
\end{tabular}

\begin{tabular}{|l} 
5. VIASTE \\
CODE \\
\hline $4,4,0$ \\
\hline
\end{tabular}

6. WASTE NESCRIPTION

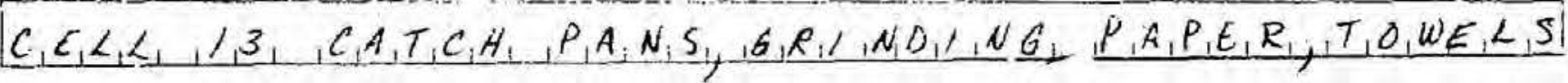
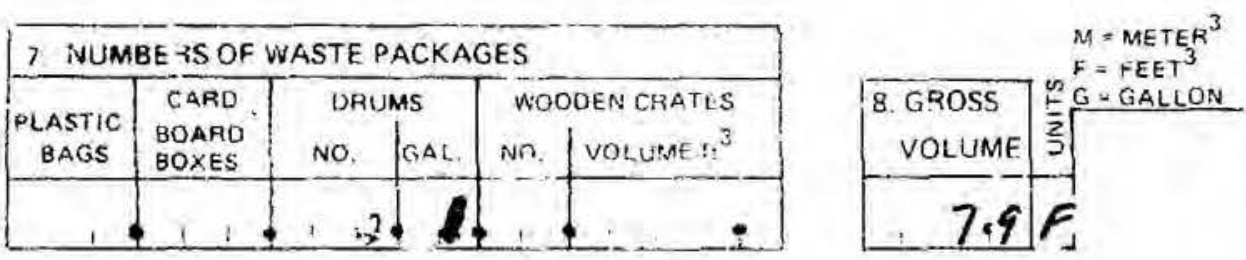

\begin{tabular}{|c|c|}
\hline 9. PACKAGE RADIATION AT \\
\hline $\begin{array}{c}\text { SURF ACE } \\
\text { MAR }\end{array}$ & $\begin{array}{c}\text { METER } \\
\text { METHA }\end{array}$ \\
\hline E. $0,0,0.0$ & $2,0.0,0$ \\
\hline
\end{tabular}
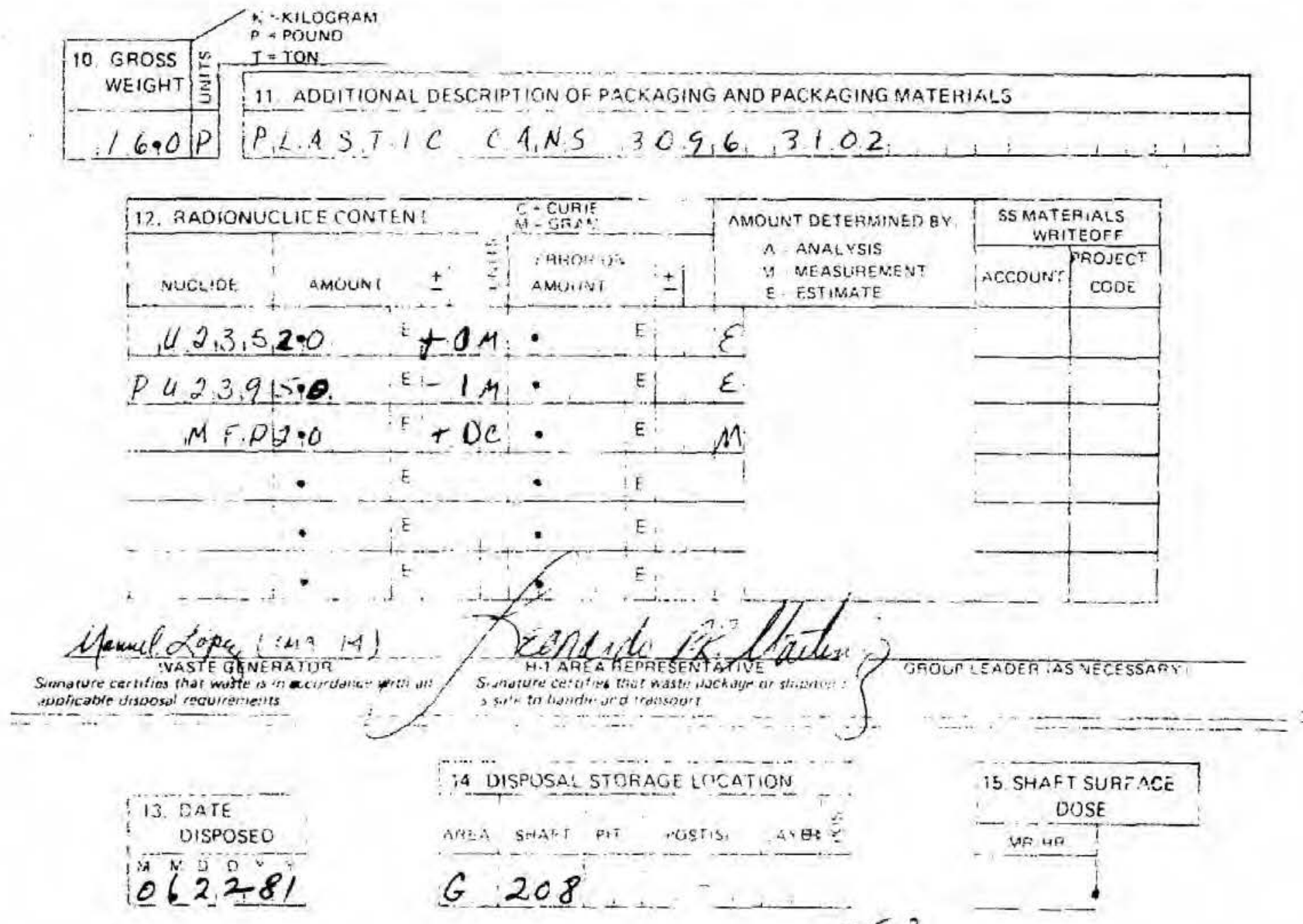

H.7 WASTE MANAGEMENT REPRESENTATIVE 6 ? 


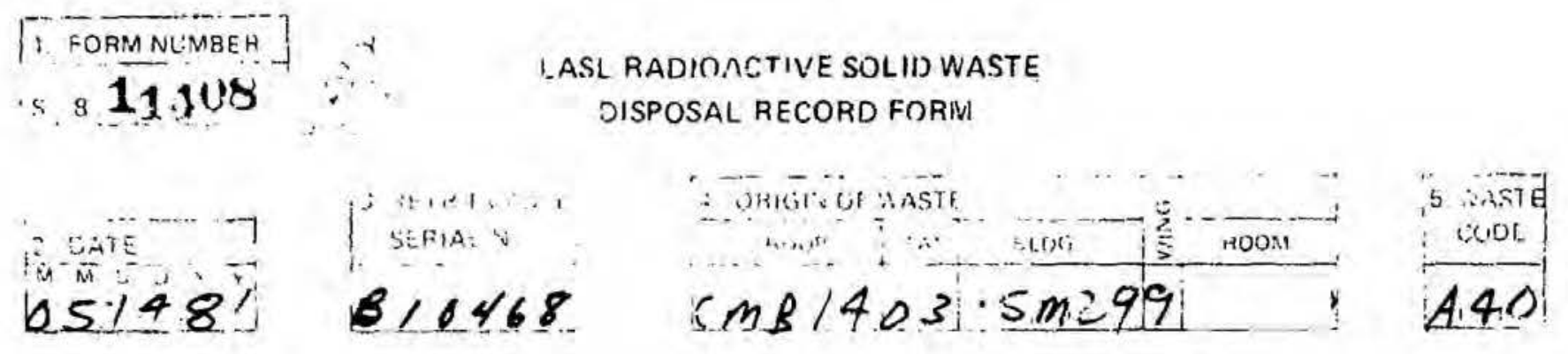

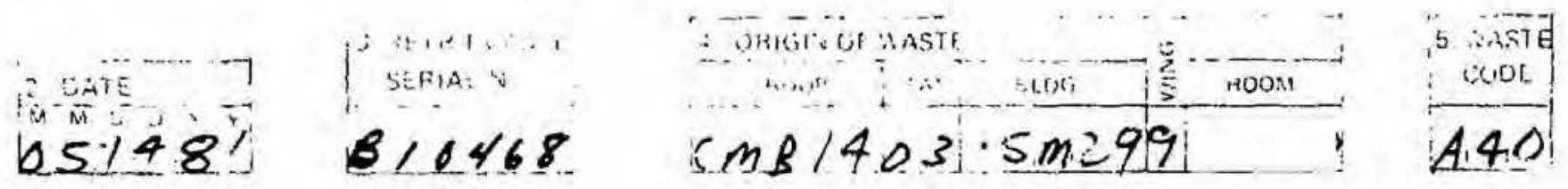

6. NASTE '2ESCRIPTION

COLL IS WIPES POLI SLANG GIOTLS F.LASTICS

7 IULMBERS OF VASTI PACKACFS

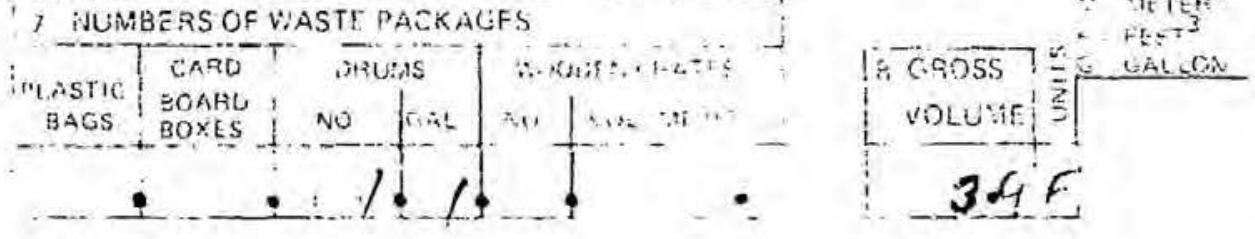

9. PACKAGE RADIATICNAT

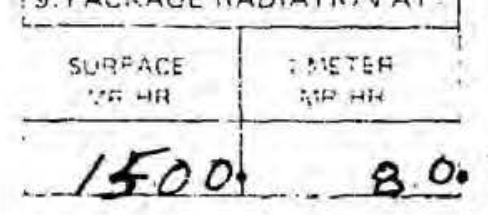

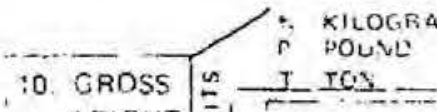

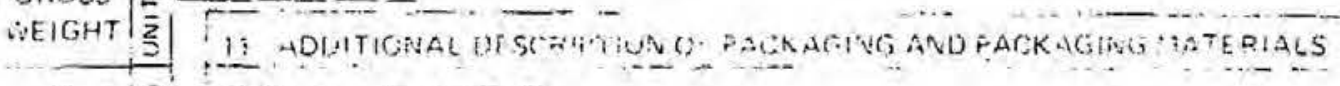

brde CAN 3093

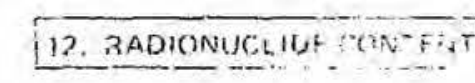

$$
423.5=4:
$$$$
\text { P.42391. }
$$$$
M F P-B .6
$$$$
-1 y
$$$$
\text { Ains: }
$$

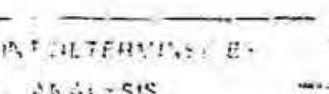

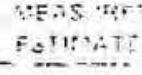

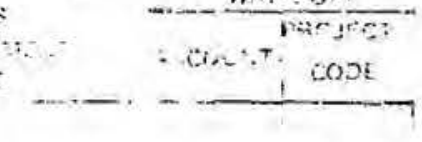

$-14$.

$$
\begin{aligned}
& -\frac{1}{2}= \\
& +14: \therefore-\frac{\varepsilon}{E} \\
& -14 \cdot \frac{E}{\varepsilon}-\frac{E}{E}
\end{aligned}
$$
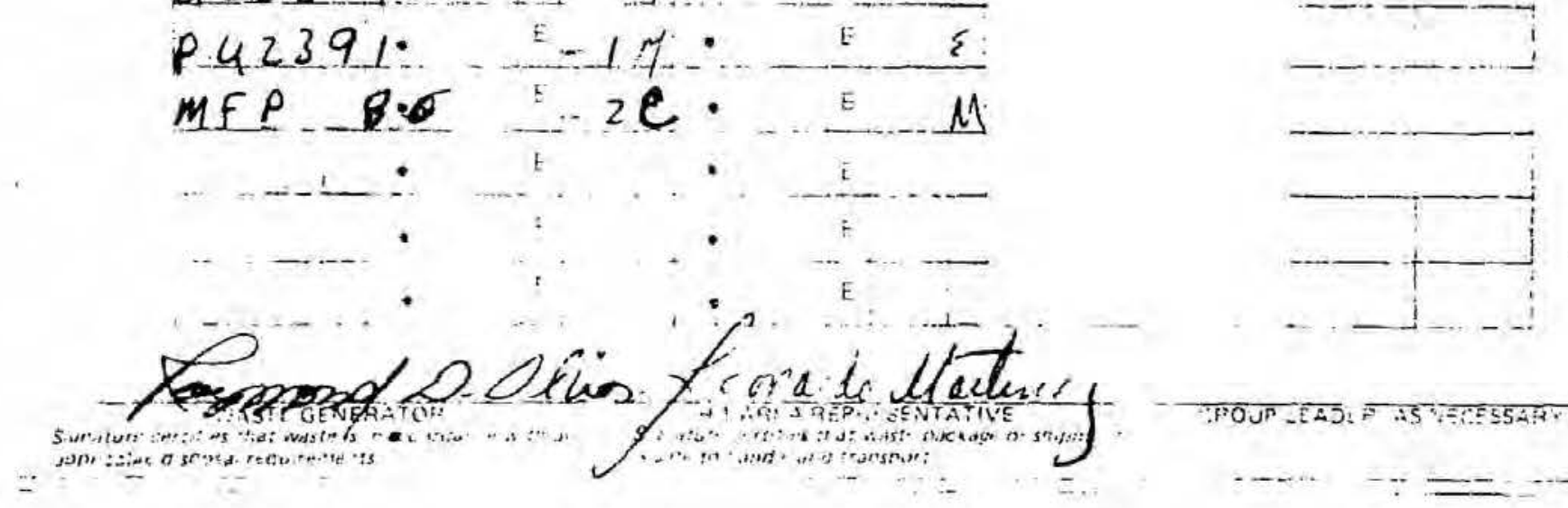

$$
\begin{aligned}
& 10 \text { DAI } \\
& \text { nSPUSED } \\
& 062281
\end{aligned}
$$

i4 OISPISAL STORAGE IOEATION 6208

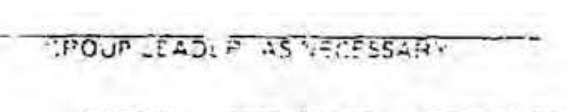

D. FHAT SLRTALE DUSE

HS.E 7.1A(10/80)

H-7 WASTE MANAGEMENT REPRESENTATIVE 
PL.EASE READ INSTRUCTIONS ON GACK CAREFULLV

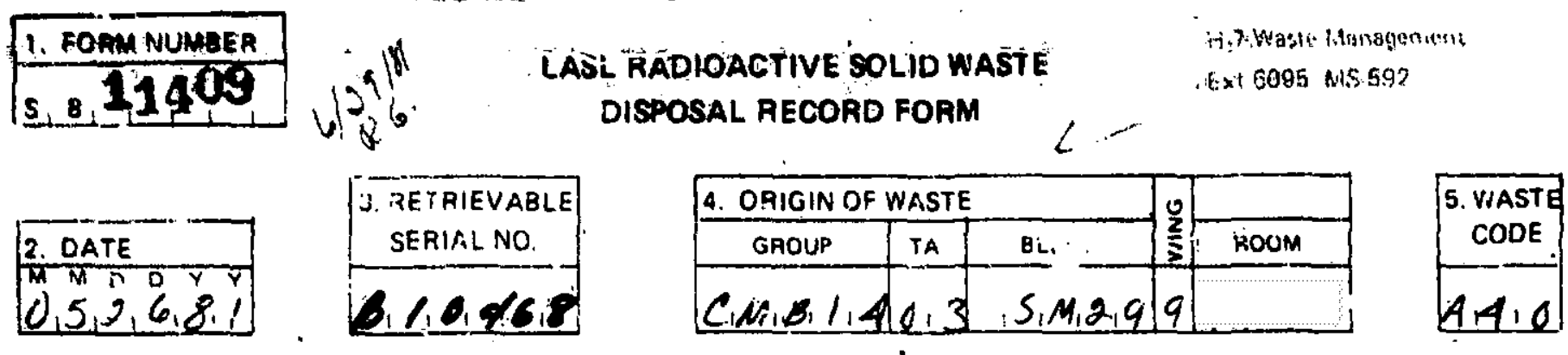

6. WASTE DESCRIPTION

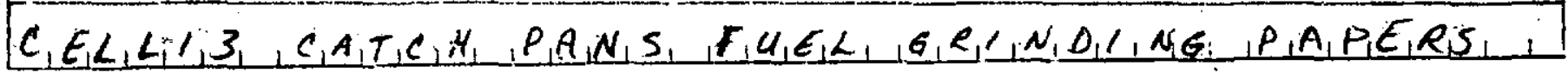
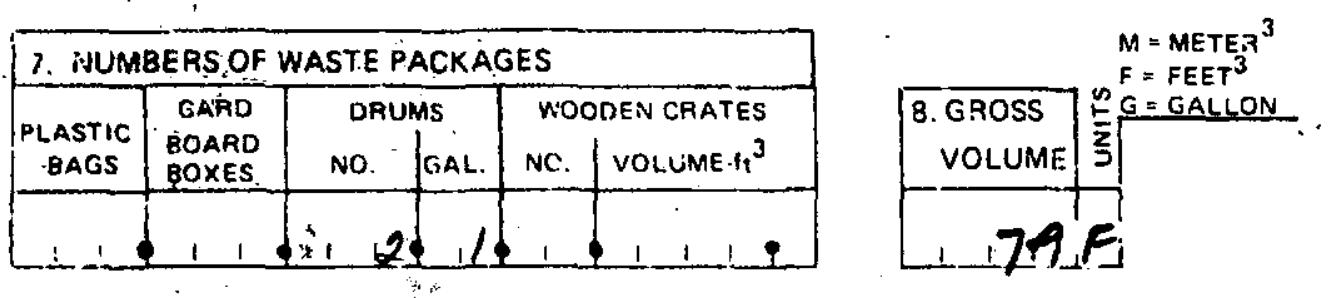
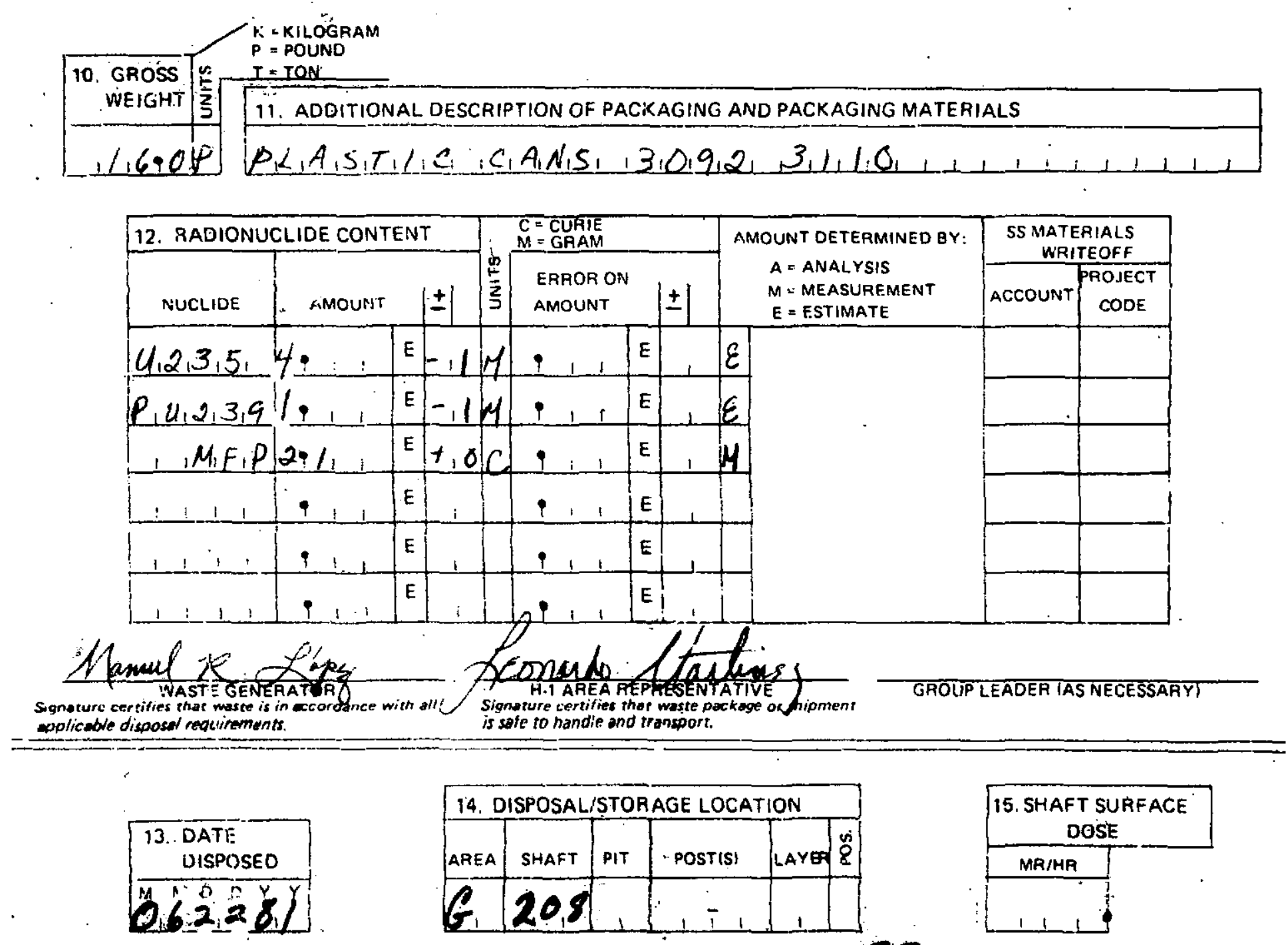
PLEASE READ INSTRLCTIONS OA GAE - WR' + N

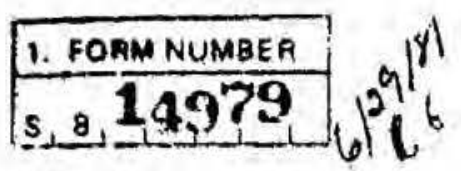

\section{LASL RADIOACTIVE SOLII) WASTE DISPOSAL RECORD FOR:A}
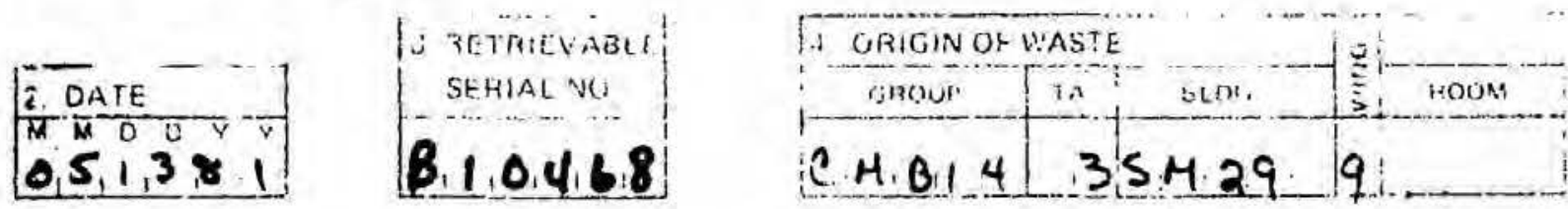

$\mid$\begin{tabular}{l}
5 asi 1 \\
- cont \\
\hline 40
\end{tabular}

6. WASTE DESCRIPTION

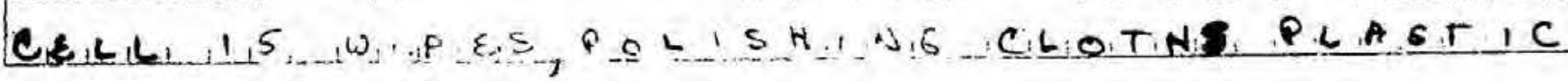

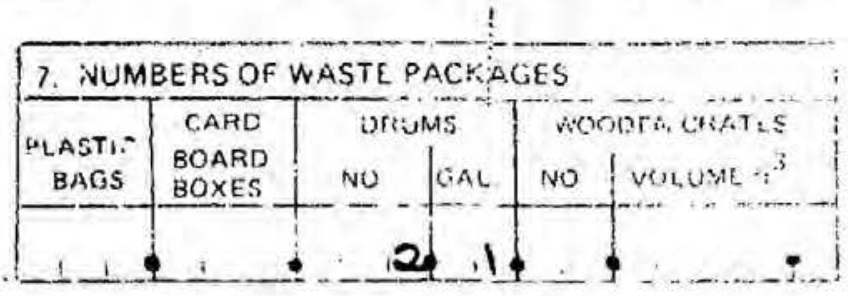
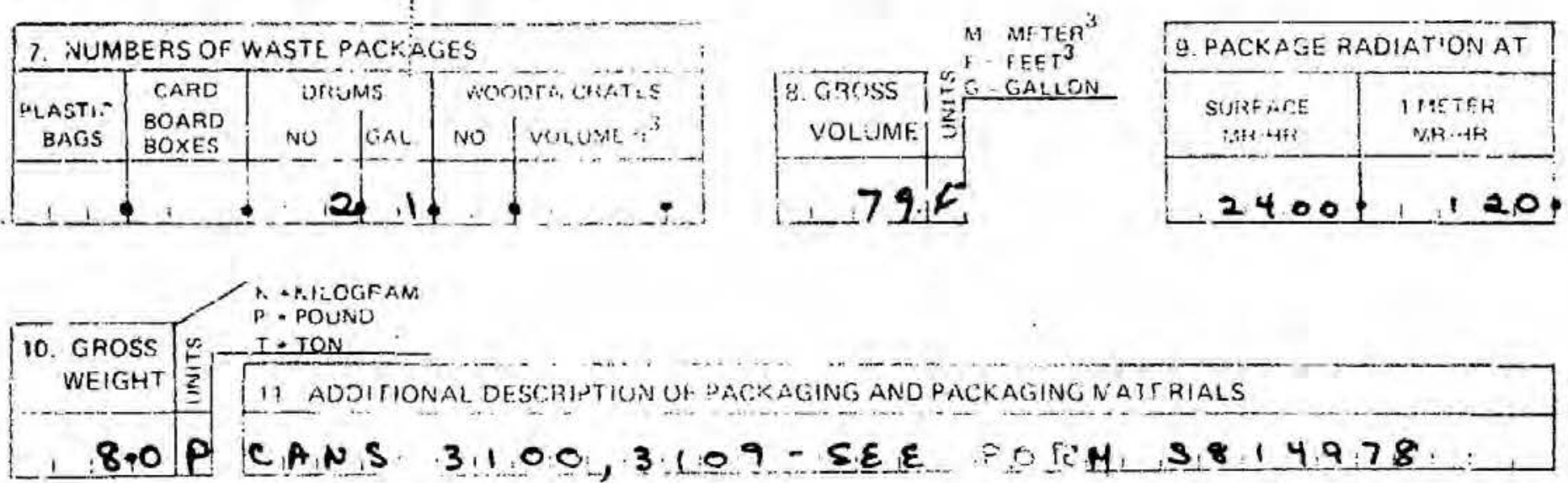

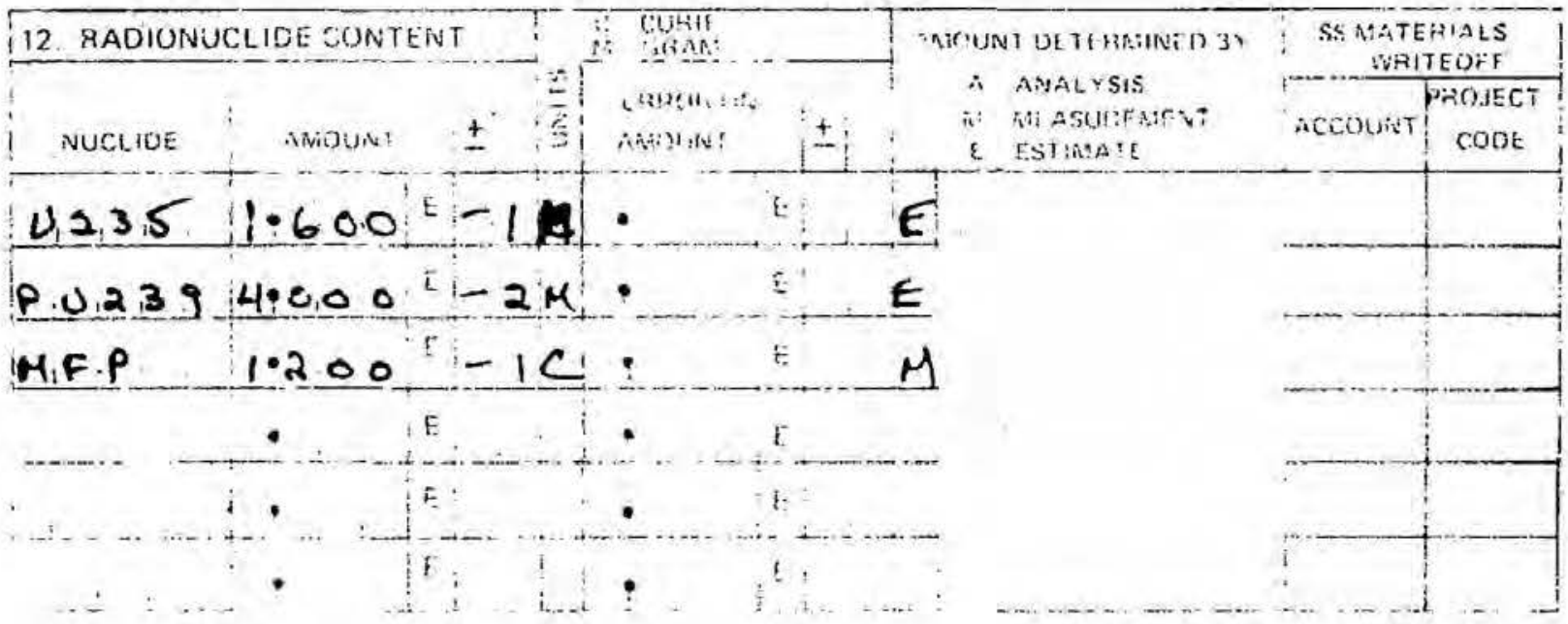

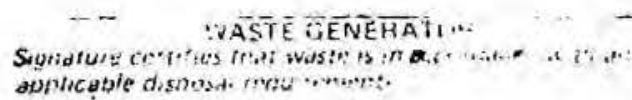

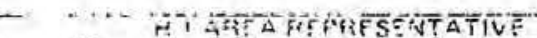

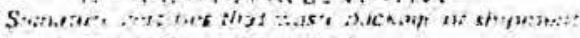

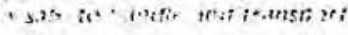

4. OISPOSRE STORAGE LOCATION

13 DATE

D:SPOSE (3)

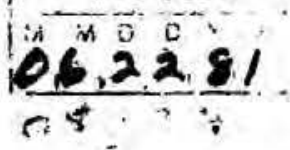

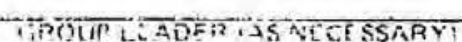


RADIOACTIVE SOLID WASTE DISPOSAL RECORD FORMS

FOR

SHAFT 209

MATERIAL DISPOSAL AREA G 


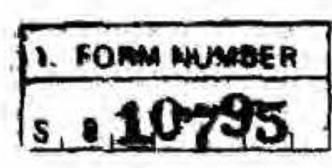

PI.EASE F.E AD INSTRUIT TIONS UN BACK CAREFULL.Y

$10 \int^{3} \int_{6}^{1 / 2}$

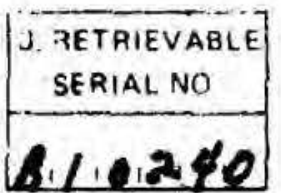

LASL RADIOACTIVE SOLID WASTE DISFOSAL RECORD FORM

\begin{tabular}{|c|c|c|c|c|}
\hline 4. URIGIN OF WASTE & & & \\
\hline GROUP & 1 & BL UG & s. & ROOM \\
\hline C.M.8.1.1 & 0.3 & $5 . M 2.9$ & 9 \\
\hline
\end{tabular}

5. VIASTE CODE

$A, 4,0$

\section{WUSTEE BESCRIPTION}

$C, E, L, L, L, 3, T, R, A, S, H, P, L, A, T, C, C, P, A, L, N, T, V, E_{1}, M_{1}, C, U_{1}, L, L, T, E_{1}$

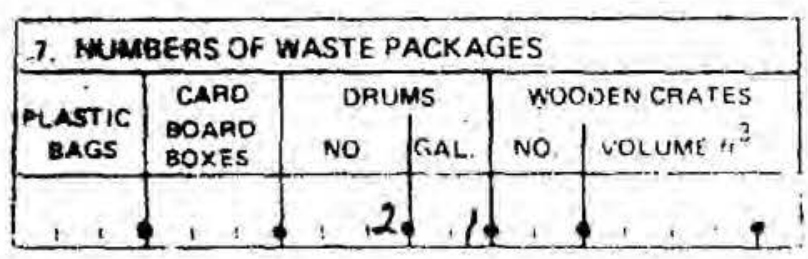

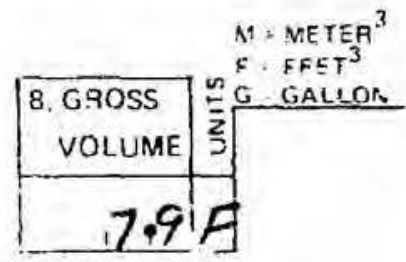

\begin{tabular}{|l|c|}
\hline 9. PACKAGE RADIATION AT: \\
\hline $\begin{array}{c}\text { SURFACE } \\
\text { MR HR }\end{array}$ & $\begin{array}{c}\text { 1METER } \\
\text { MRIHR }\end{array}$ \\
\hline 5,0 C C & $1 / .0 .00$ \\
\hline
\end{tabular}
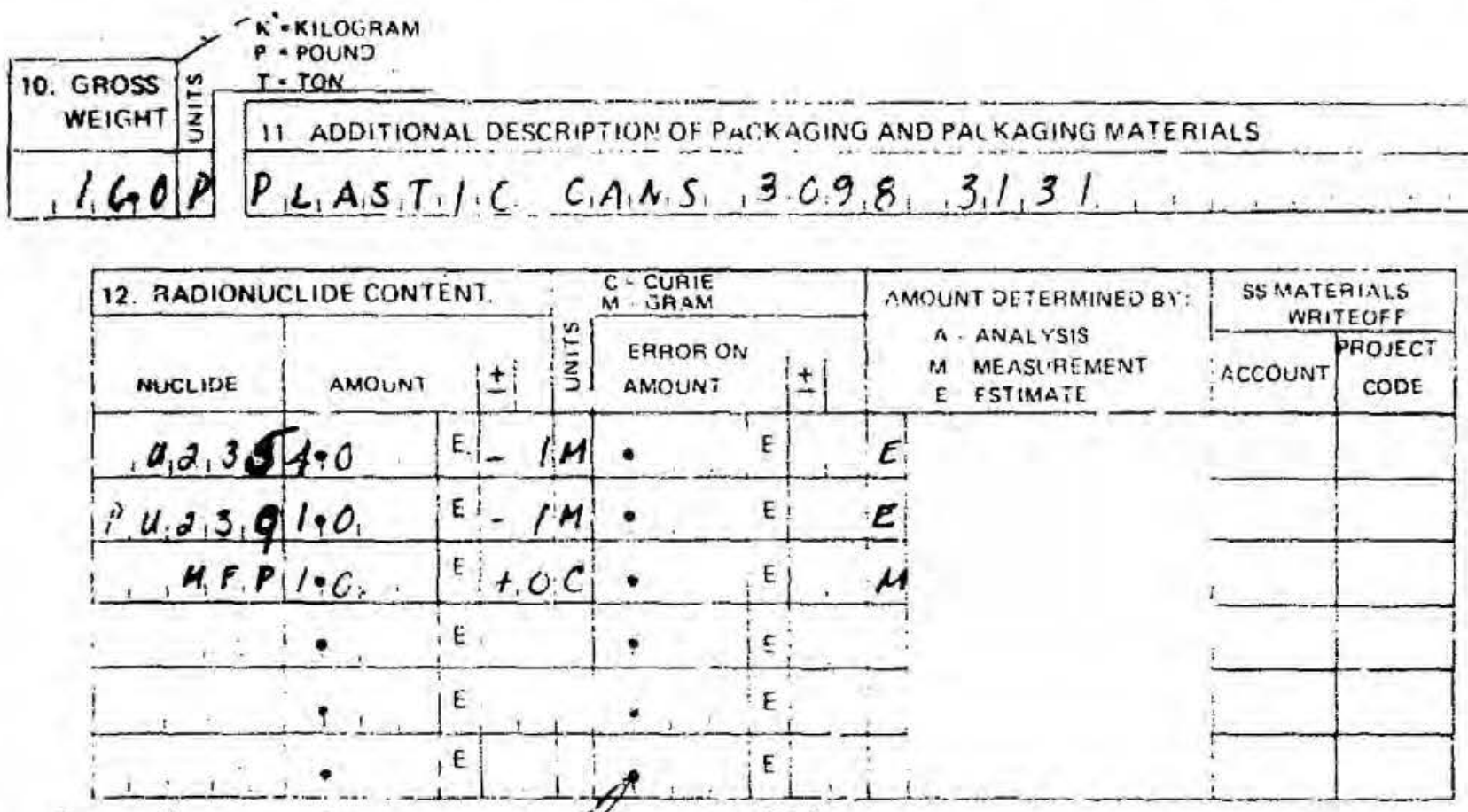

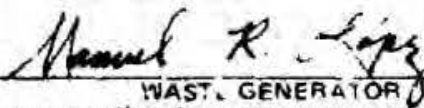

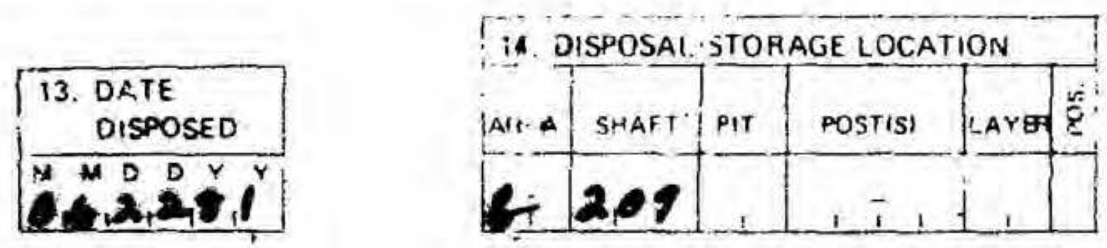

15. SHAFT SURFACE DOSE

MR/HR

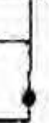




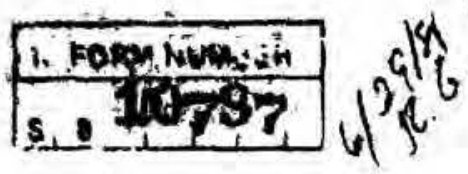

PLEASE READ INSTRUCTIONS ON BACK CAPEFULI Y
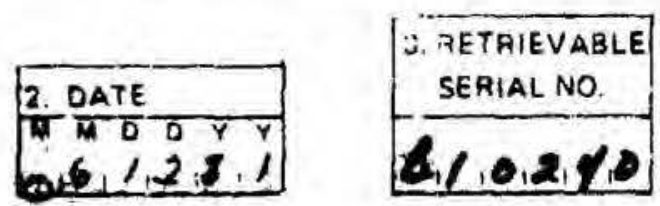

\begin{tabular}{|c|c|c|c|c|}
\hline 4. ORIGIN OF WASTE & & & \\
\hline GROUP & TA & BLDG & 5 & ROOM \\
\hline$C, M, B, 1$ & 0,3 & $5 M_{1}, 2,9$ & 9 & \\
\hline
\end{tabular}

$\begin{array}{r}\hline \text { W. WASTE } \\ \text { CODE } \\ \hline A_{1}, 0 \\ \hline\end{array}$

\section{WASTE DESCRIPTION}

$C_{1} E_{1} L_{1} L_{1}, S_{1}, T, P_{1} A_{1} S_{1} H_{1}, W_{1}, P_{1} E_{1} S_{1}, C_{1} H_{1}, P_{1} S_{1}, P_{1} L_{1} A_{1} S_{1} T, C_{1}$

\begin{tabular}{|c|c|c|c|c|c|}
\hline \multirow[b]{2}{*}{$\begin{array}{c}\text { PLASTIC } \\
\text { BAGS }\end{array}$} & \multirow{2}{*}{$\begin{array}{l}\text { CARD } \\
\text { BOARD } \\
\text { BOXES }\end{array}$} & \multicolumn{2}{|c|}{ DRUMS } & \multicolumn{2}{|c|}{ HDODEN CKATES } \\
\hline & & & fiAL & & VOLUME $\cdot \mathrm{ft}^{3}$ \\
\hline
\end{tabular}

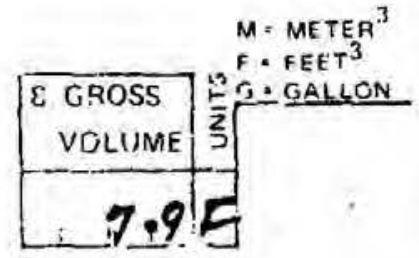

\begin{tabular}{|c|c|}
\hline $\begin{array}{c}\text { 9.PACKAGE RADIATION AT: } \\
\text { SUAFACE } \\
\text { MAIHR }\end{array}$ & $\begin{array}{c}\text { IMETER } \\
\text { MR }\end{array}$ \\
\hline $2,8,00 \%$ & $1.0,0$ \\
\hline
\end{tabular}

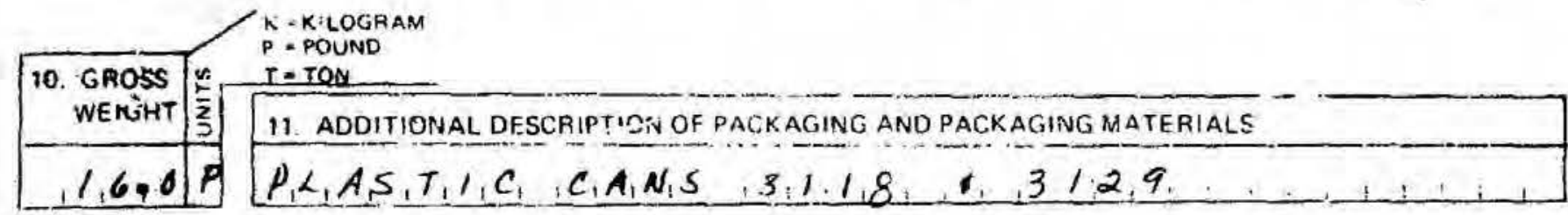

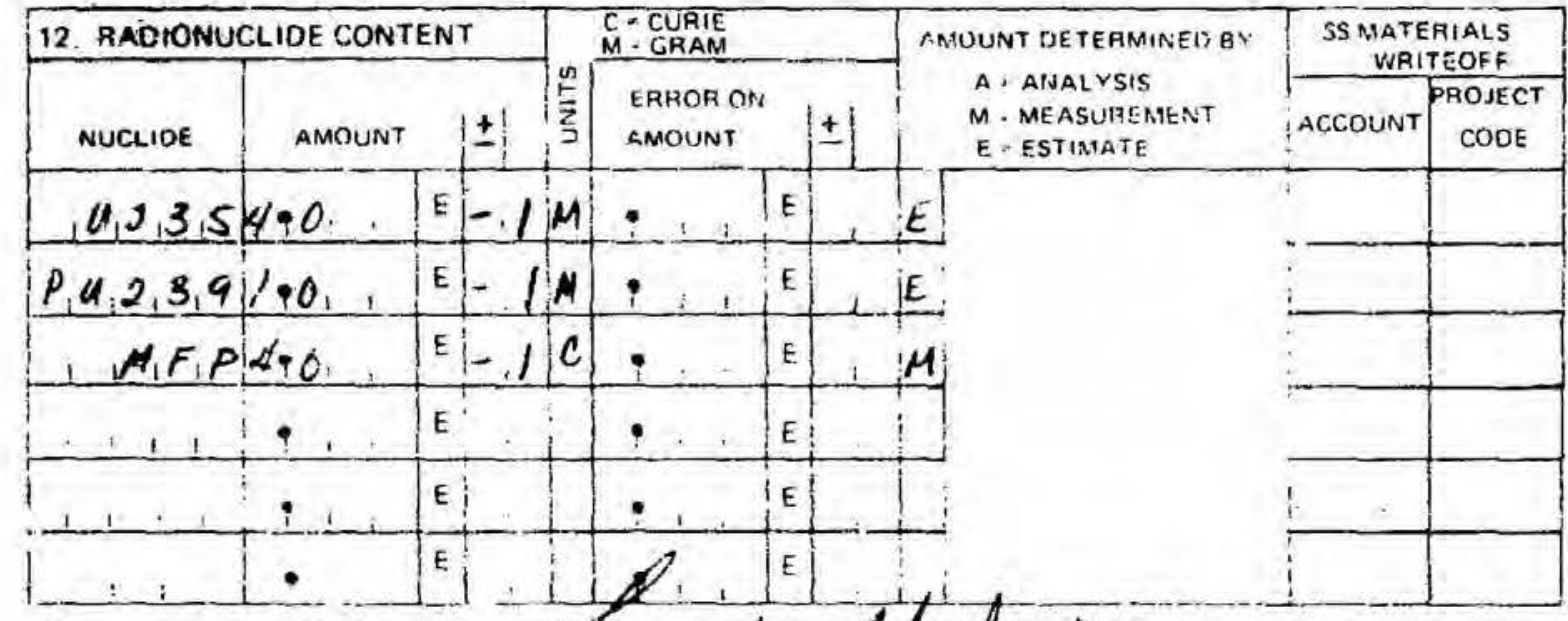

Memal R. Kof Signorure cartifies that weste ifn eccordance wich all apiticable disposal requirements.

\section{Concendo}

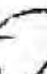
T.TAREAREMTESTNATIVE Signatuite cer tifies thist woste pockage or shipun oft is sale to handle and transoont.

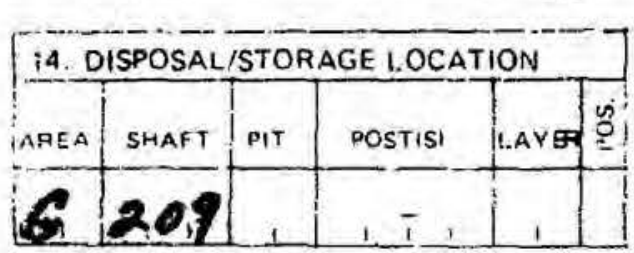

GROUP LEADER IAS NECESSARY,

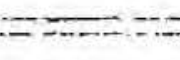

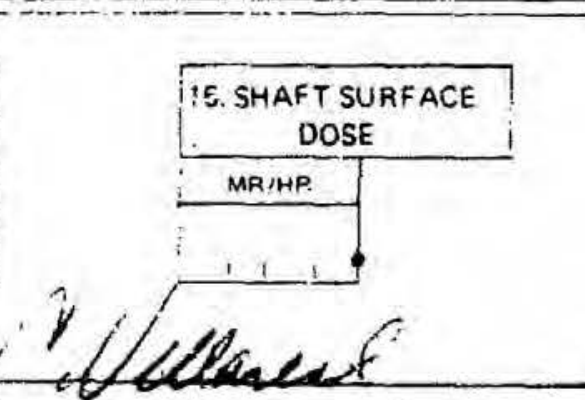


PLEASE READ INSTRULTTIONS ON BACK CAREFULLY

1. renin gumption

LAST. RADIOACTIVE SOLID WASTE

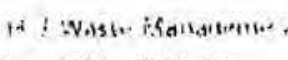

DISPOSAL RECORD FORM

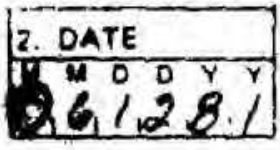

\begin{tabular}{l}
$\begin{array}{l}\text { 3. TETRIEVABLE } \\
\text { SERIAL NO }\end{array}$ \\
\hline B.102014.0
\end{tabular}

\begin{tabular}{|l|l|l|l|l|}
\hline 4. ORIGIN OF WASTE & & & \\
\hline GROUP & TA & BLDG & 5 & ROM \\
\hline$C M B_{1} 14$ & 3 & $9 M 29$ & 9 & \\
\hline
\end{tabular}

\begin{tabular}{l} 
5. WASTE \\
CODE \\
\hline$A A D$ \\
\hline
\end{tabular}

6. WASTE DESCRIPTION

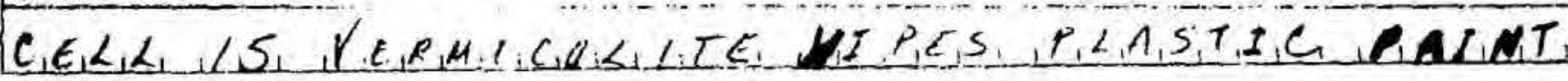
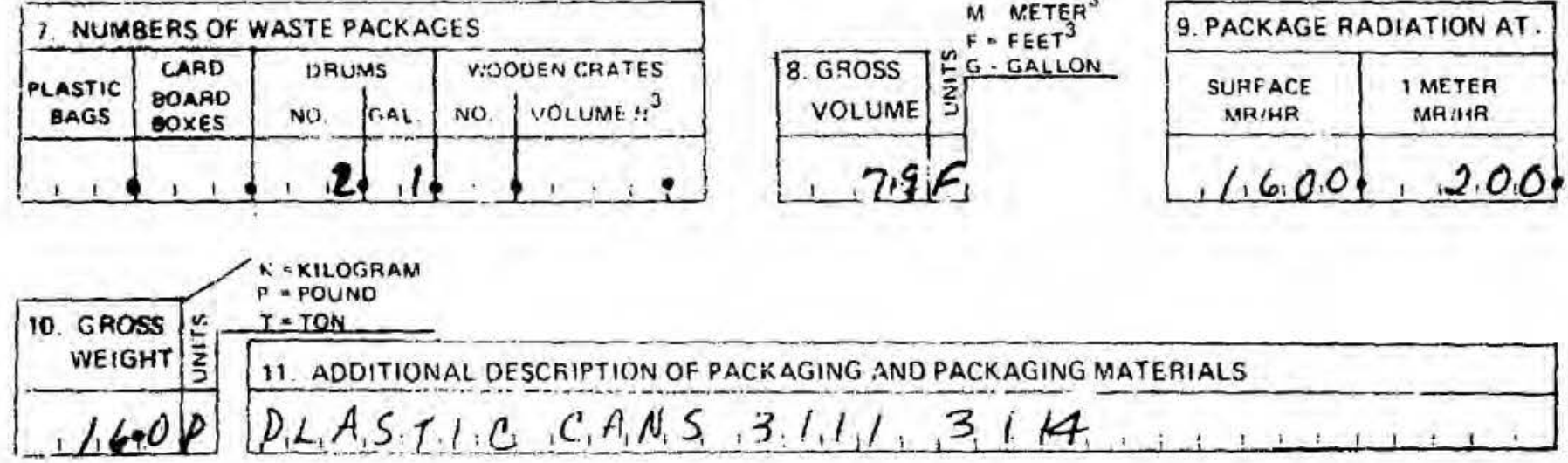

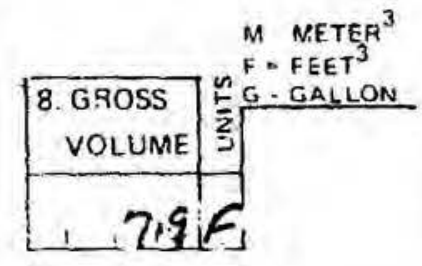

12. RADIONUCLIDE CONTENT

NUCLIDE

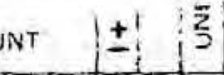

$112,3,5,40$

P. 0.2.3.9).

MF .PQ.1:

$-\square-\ldots, \ldots E$

$-$

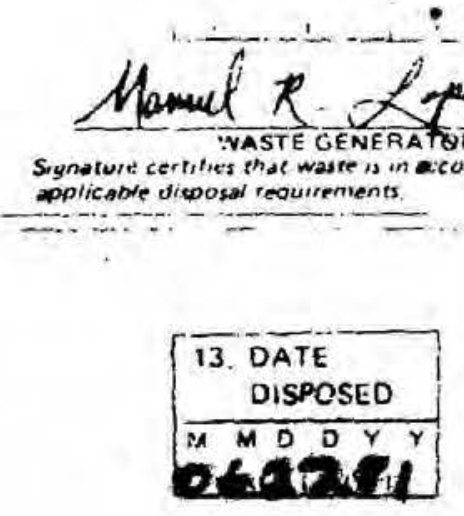


PI.S.ASE READ INSTRUCTIONS ON BACK CAREFIULI.?

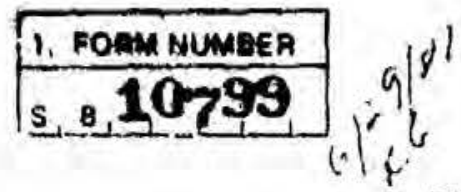

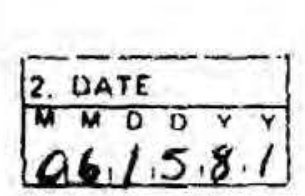

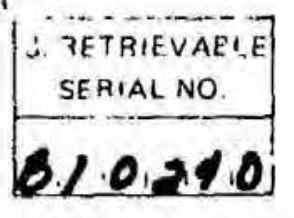

\section{LASL RADIOACTIVE SOLID WASTE} DISPOSAL RECORD FORM

\begin{tabular}{|c|c|c|c|c|}
\hline \multicolumn{3}{|c|}{ 4. ORIGIN OF WASTE } & \multirow{2}{*}{$\begin{array}{l}0 \\
\frac{2}{3}\end{array}$} & \multirow[b]{2}{*}{ ROOM } \\
\hline GROUP & IA & BLOC. & & \\
\hline$\therefore A B \mid A$ & 3 & $5, A, 2: 9$ & & \\
\hline
\end{tabular}

\begin{tabular}{l} 
5. WASTE \\
CODE \\
\hline$A, 4,0$ \\
\hline
\end{tabular}

\section{WASTE DESCRIPTION}

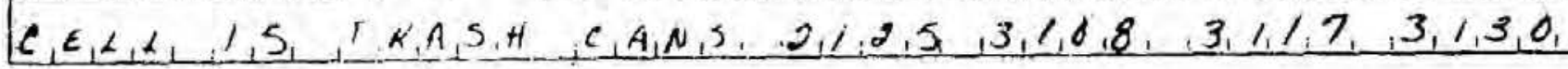

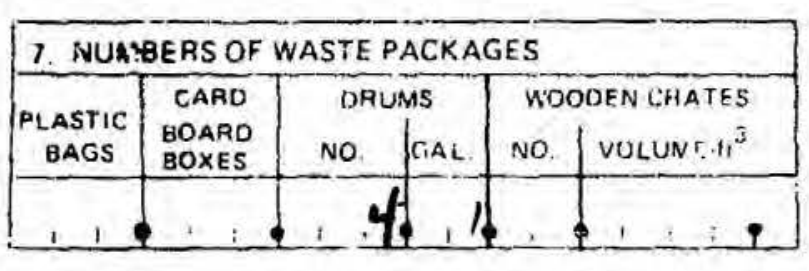

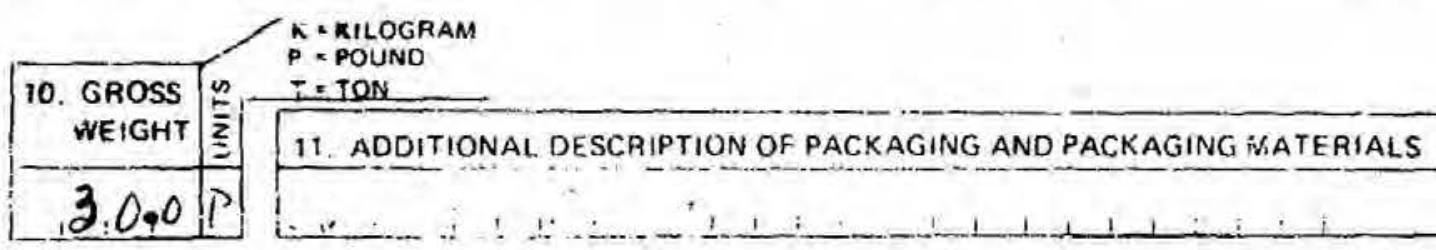

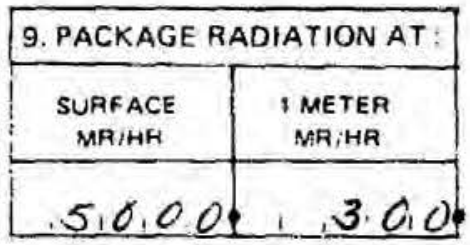
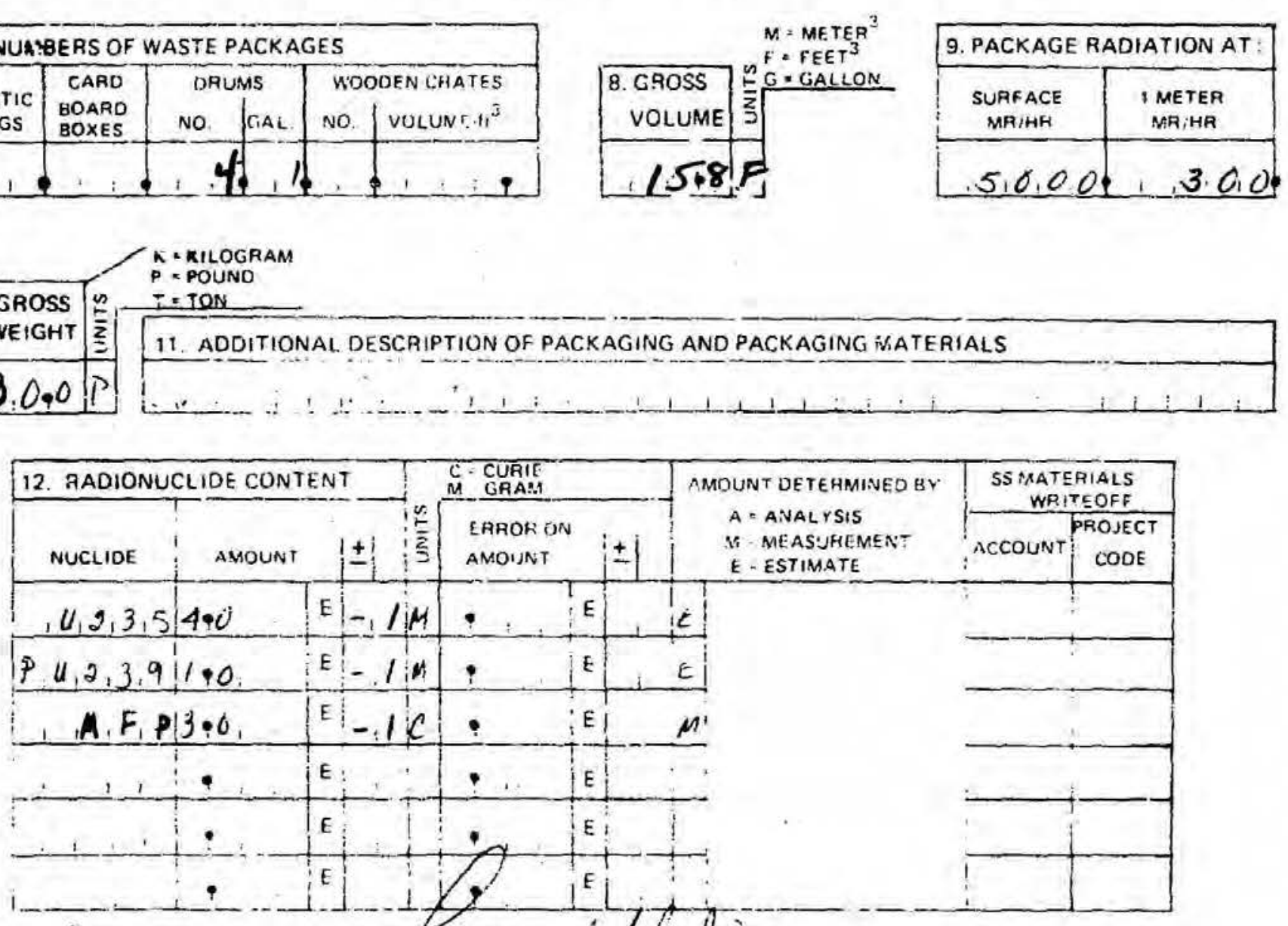

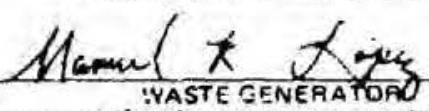

Sionsture certilies that waste is in acio
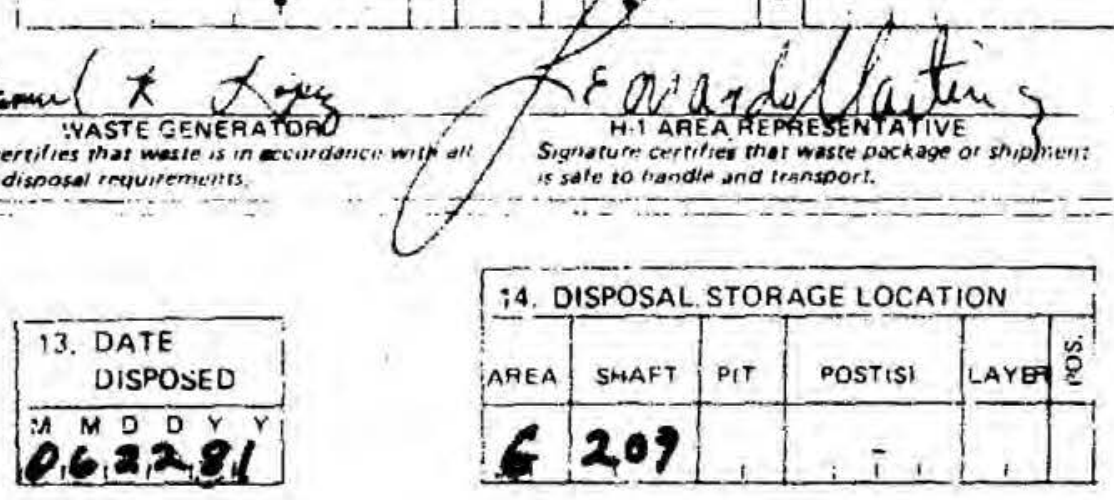

\begin{tabular}{|l|l|l|l|l|l|}
\hline i4. DISPOSAL STORAGE LOCATION \\
\hline AREA & SHAFT & PIT & POSTISI & LAYE & PA \\
\hline & 203 & & & & \\
\hline
\end{tabular}
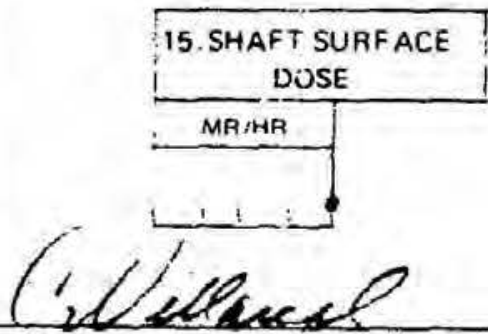


\section{WASTEEESCRIPTION}

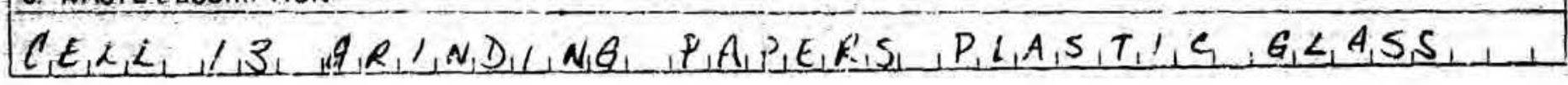
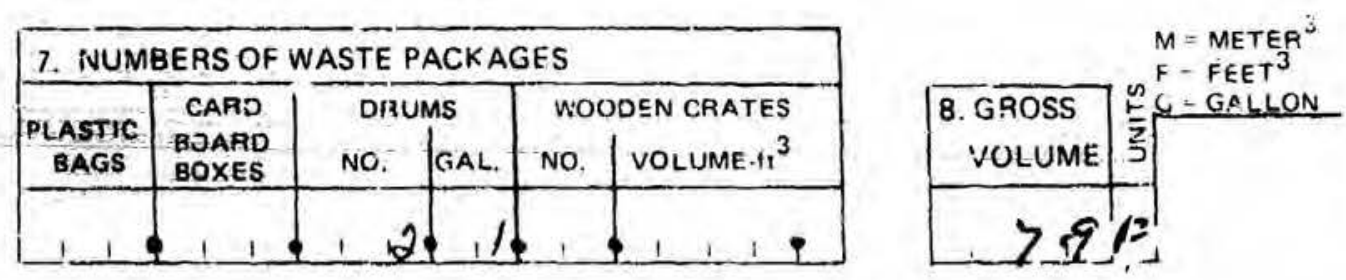

\begin{tabular}{|c|c|c|c|c|}
\hline \multicolumn{3}{|c|}{ 4. ORIGIN OF WASTE } & \multirow{2}{*}{$\begin{array}{l}0 \\
2 \\
3\end{array}$} & \multirow{2}{*}{$C_{\text {ROOM }}$} \\
\hline GROUP & TA & B:DG. & & \\
\hline$(, M: B, 1$ & 0,5 & $8, \mathrm{Mul}_{10}$ & 9 & \\
\hline
\end{tabular}

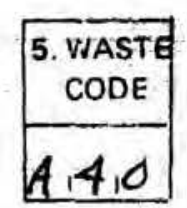

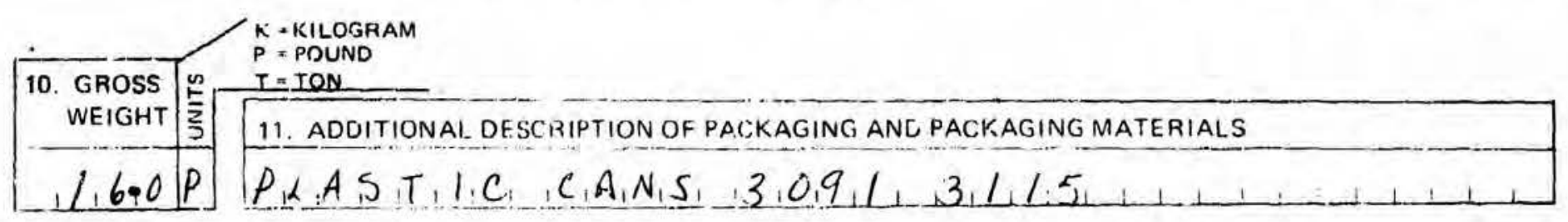

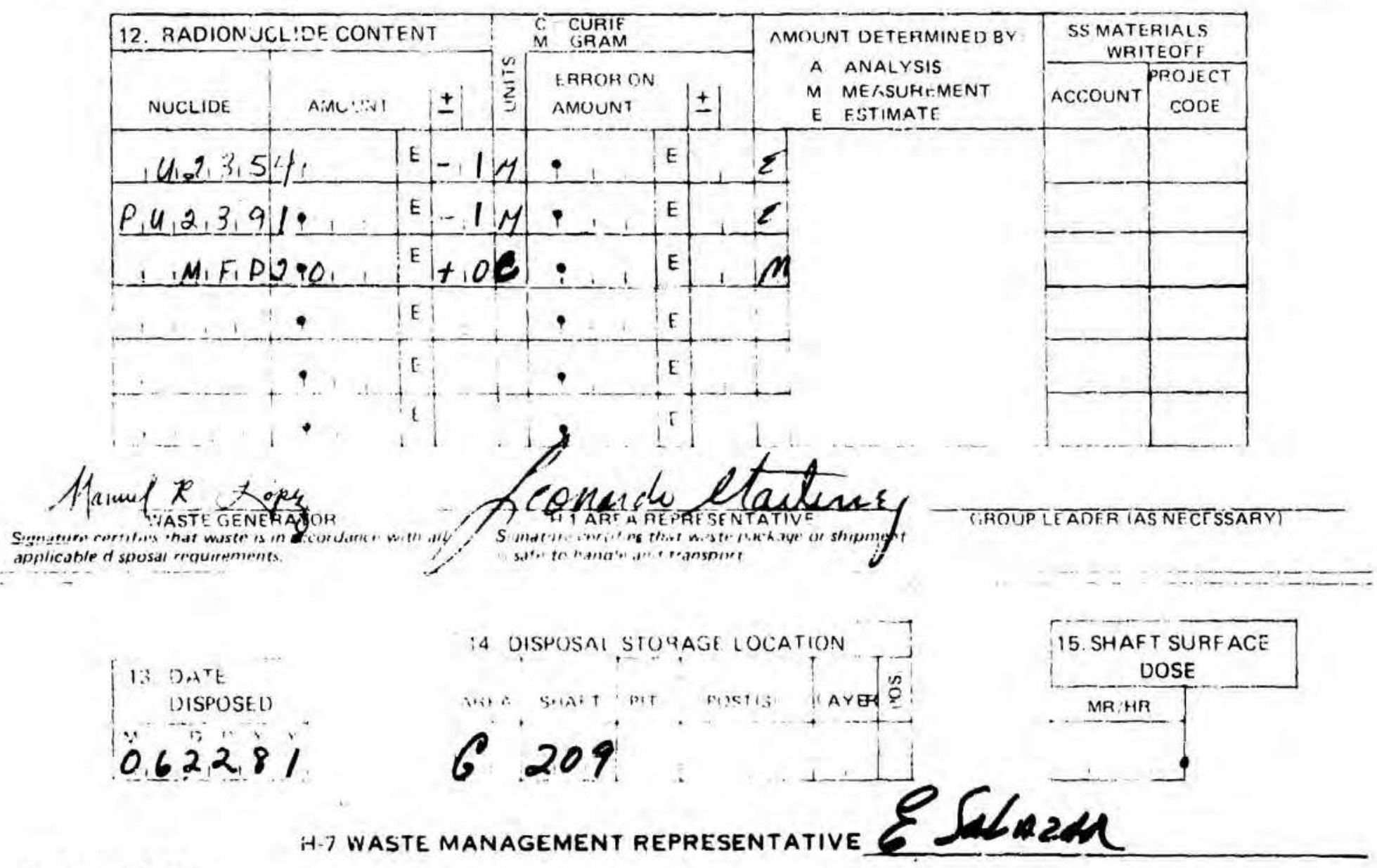


RADIOACTIVE SOLID WASTE DISPOSAL RECORD FORMS

FOR

SHAFT 210

MATERIAL DISPOSAL AREA G 
1. CORM NUMBER

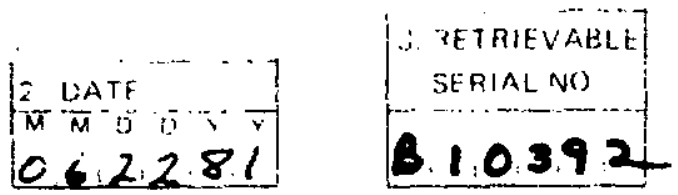

LASL RADIOACTIVE SOLIU WASTE DISPOSAL RECORD FORM
6. WASTE DESCRIPTION

$C E<L, 13,15,40 I E$ IRASA CANS $3: 45,3,4 Z$

7. IVUMBEKS OF WASTE PACKAGES
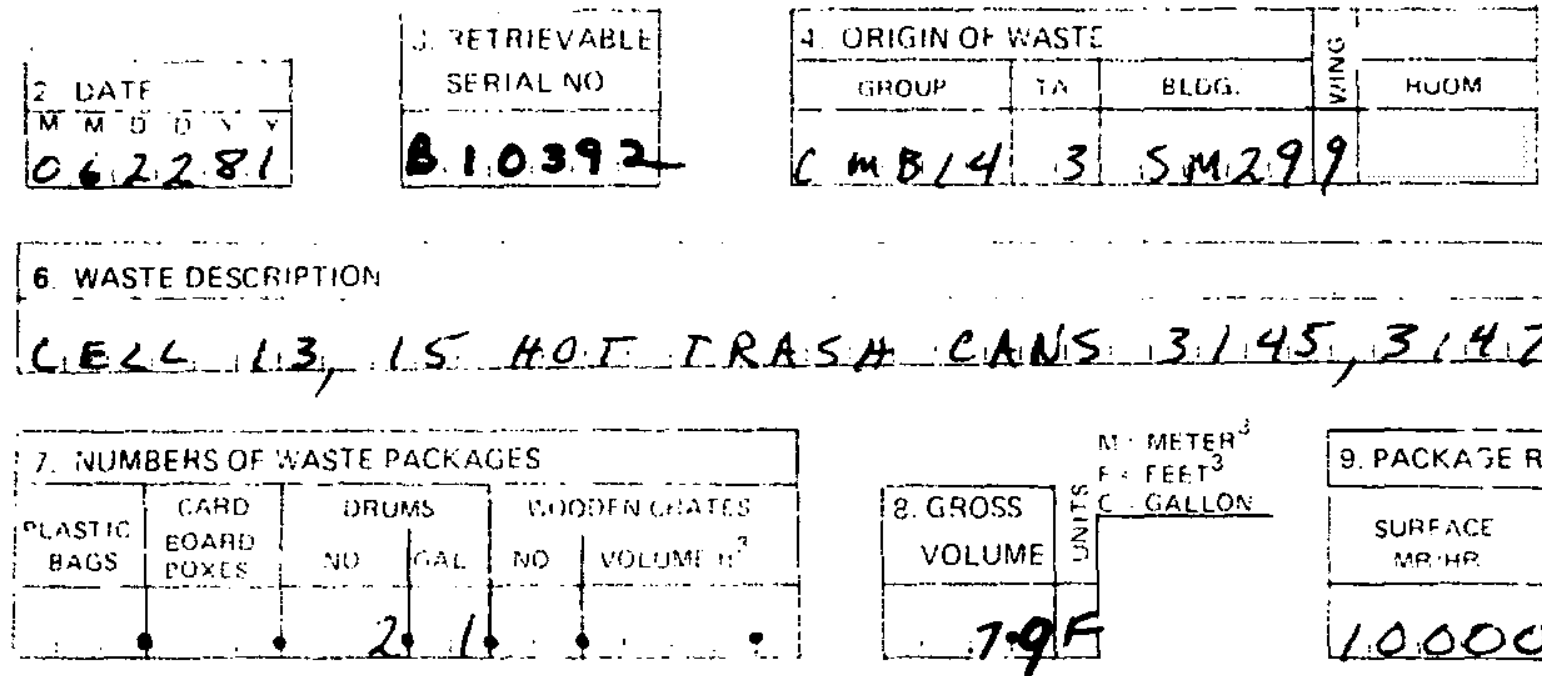

5. WASTE CODE

A.40
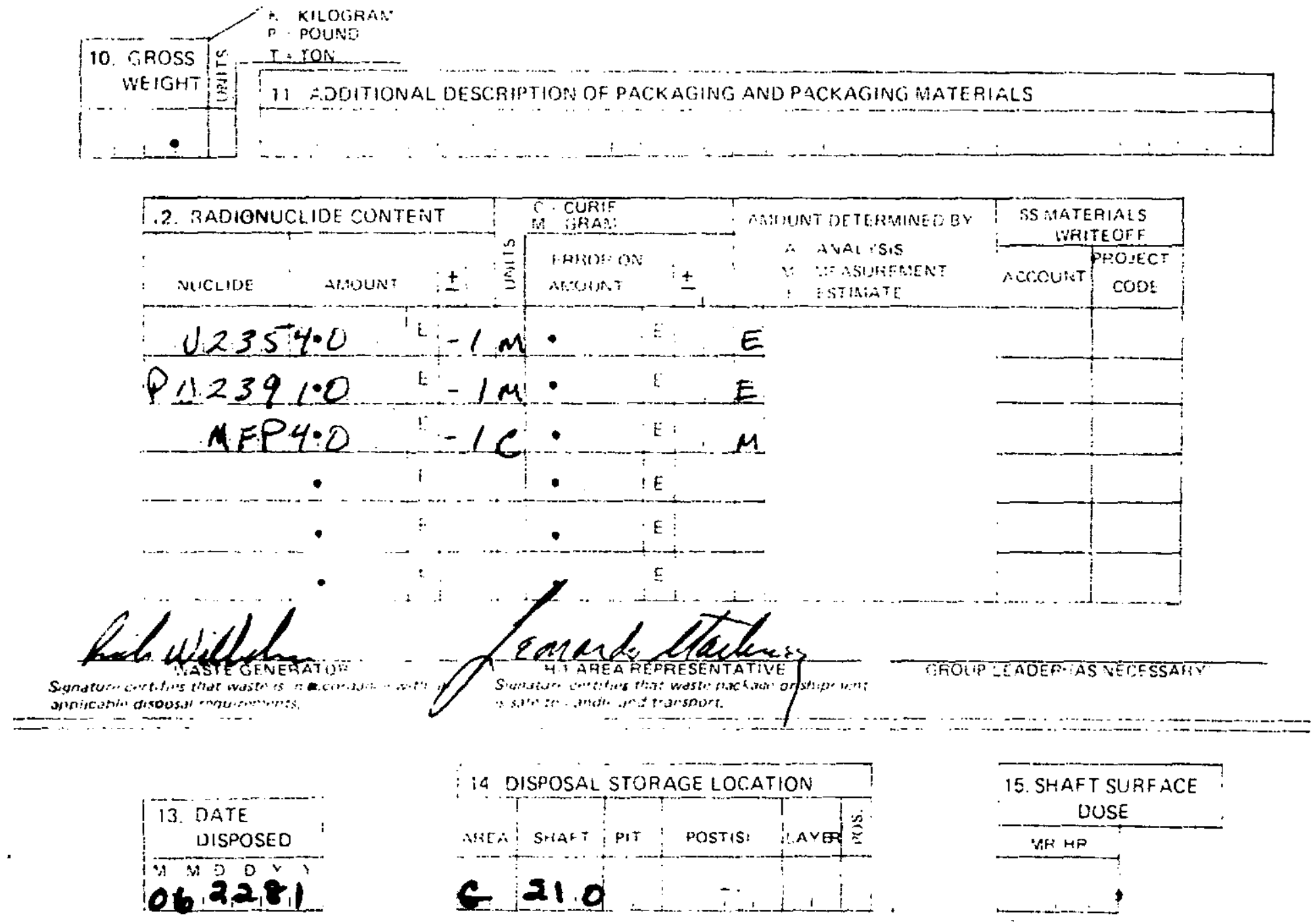

H.7 WASTE MANAGEMENT REPRESENTATIVE 


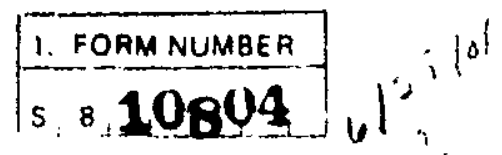

LASL RADIOACTIVE SOLID WASTE DISPOSAL RECORD FORM

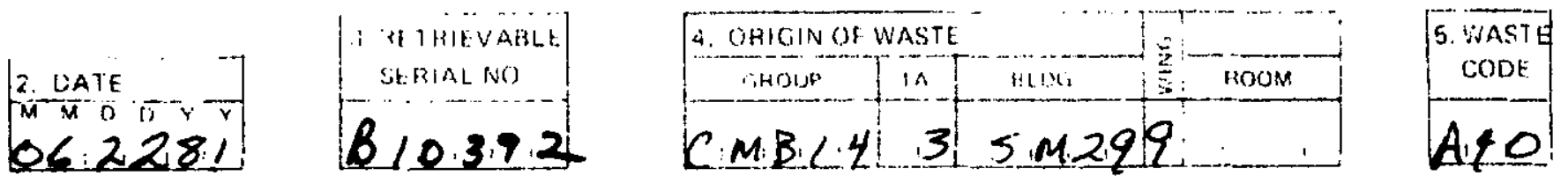

6. WASTE DESCRIPTION

CELL L L, L HOT TRASH CANS $3139,3 / 3,3,3135$
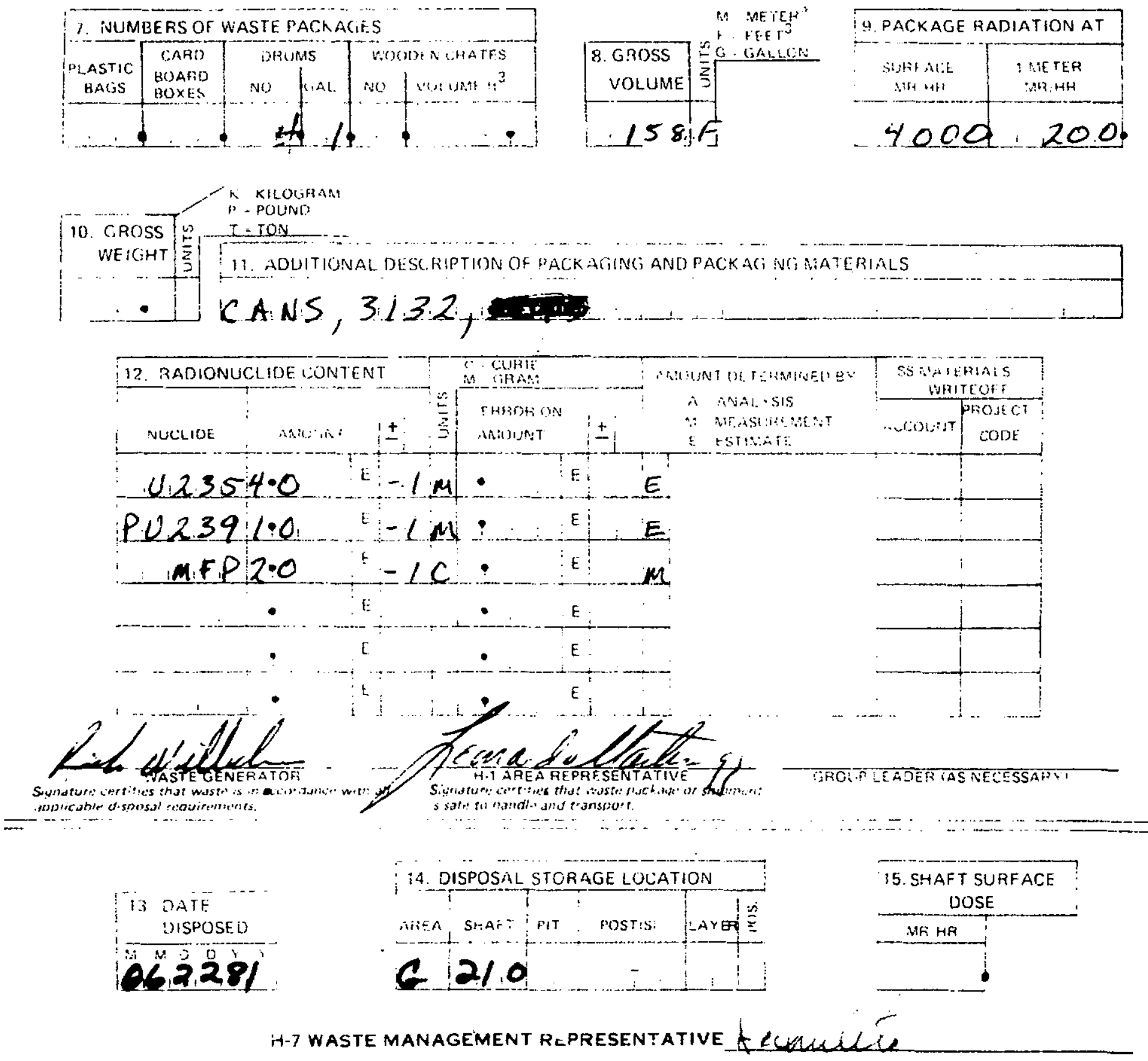
PI ASE REAC INSTIR:ICIIONSON UACR CAREFULI:

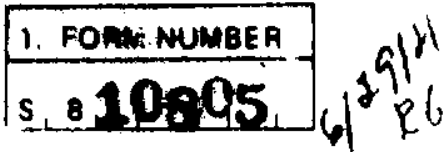

LASL RADIOACTIVE SOLIU WASTE

DISPOSAL RECORD FORM L

\begin{tabular}{|c|c|c|c|c|c|c|c|}
\hline \multirow{3}{*}{ 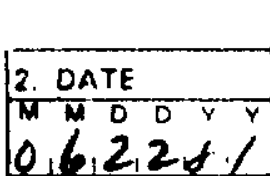 } & U. TETRIEVABLE & \multicolumn{3}{|c|}{ 4. ORIGIN OF WASTE } & \multirow{2}{*}{\multicolumn{2}{|c|}{ ROOM }} & \multirow{2}{*}{$\begin{array}{l}\text { 5. WASTE } \\
\text { CODE }\end{array}$} \\
\hline & SERIAL NO & GROuP & TA & $B L D C_{1}$. & & & \\
\hline & $B / 0,9,2$ & $C m_{1} B_{1} \prime$ & & $2 \sin 29$ & $\xi$ & & $A, 4,0$ \\
\hline
\end{tabular}

6. WASTE DESCRIPTION

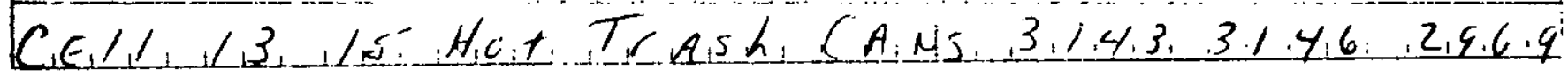

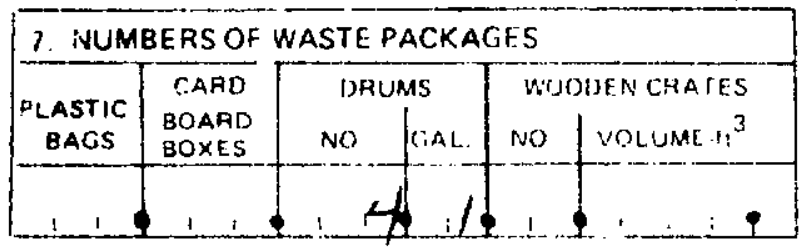

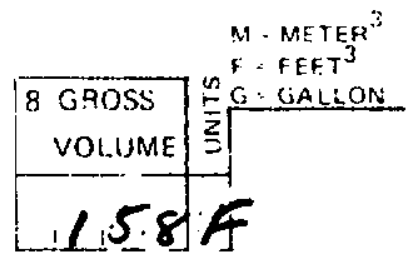

\begin{tabular}{|c|c|}
\hline \multicolumn{2}{|c|}{ 9. PACKAGE RADIATIONAT: } \\
\hline $\begin{array}{c}\text { SUPFACE } \\
\text { MF: +HFi }\end{array}$ & $\begin{array}{l}\text { 1 METER } \\
\text { MFPHHR }\end{array}$ \\
\hline 5.0. & $3 \cdot c \cdot 0$ \\
\hline
\end{tabular}

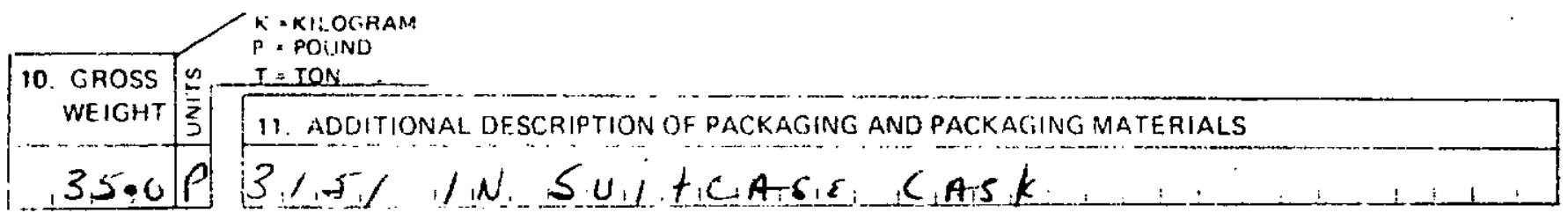
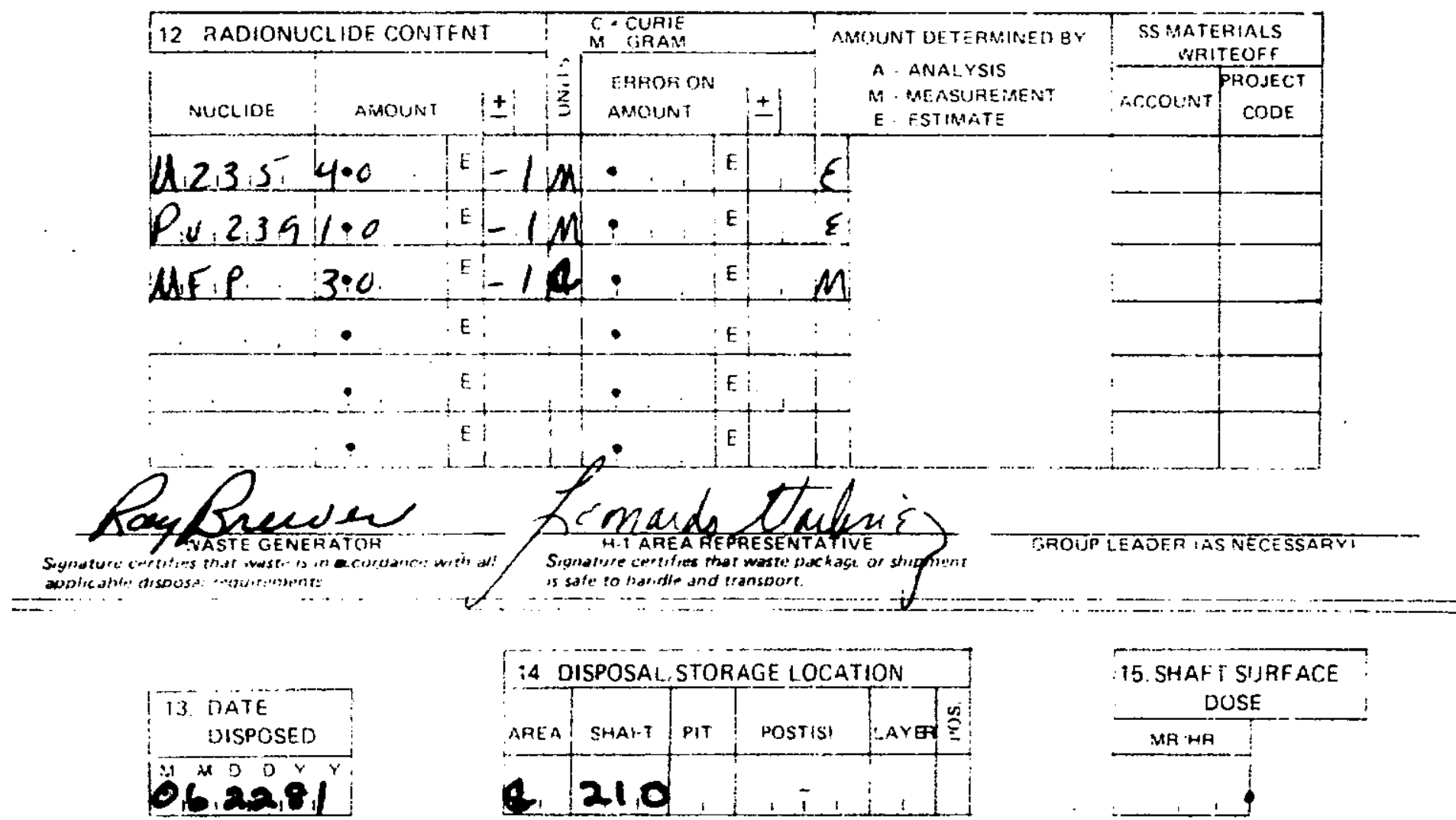

H.7 waste management RePresentative frécuchli: 


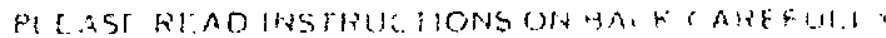

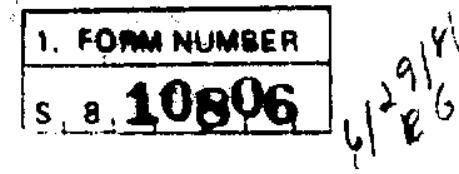

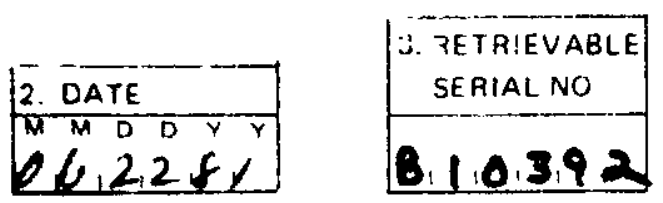

\section{LASL RADIOACYIVE SOLID WASTE DISPOSAL RECORD FORM}

\begin{tabular}{c}
5. .VAST: \\
COUE \\
\hline $4,4,0$
\end{tabular}

\section{WASTE DESCRIPTION}

CEIIII3, /S HOT IR AS.K CANS 3,150, 3./S3:

\begin{tabular}{|c|c|c|c|c|}
\hline \multicolumn{5}{|c|}{ 7. NUMBERS OF WASTE PACKAGES } \\
\hline & CARD & DRUMS & & DENCHATES \\
\hline $\begin{array}{l}\text { PLASTIC } \\
\text { BAGS }\end{array}$ & $\begin{array}{l}\text { BOARD } \\
\text { BOXES }\end{array}$ & no. Gial & NO & voludum..$f^{3}$ \\
\hline & & 7 & & \\
\hline
\end{tabular}
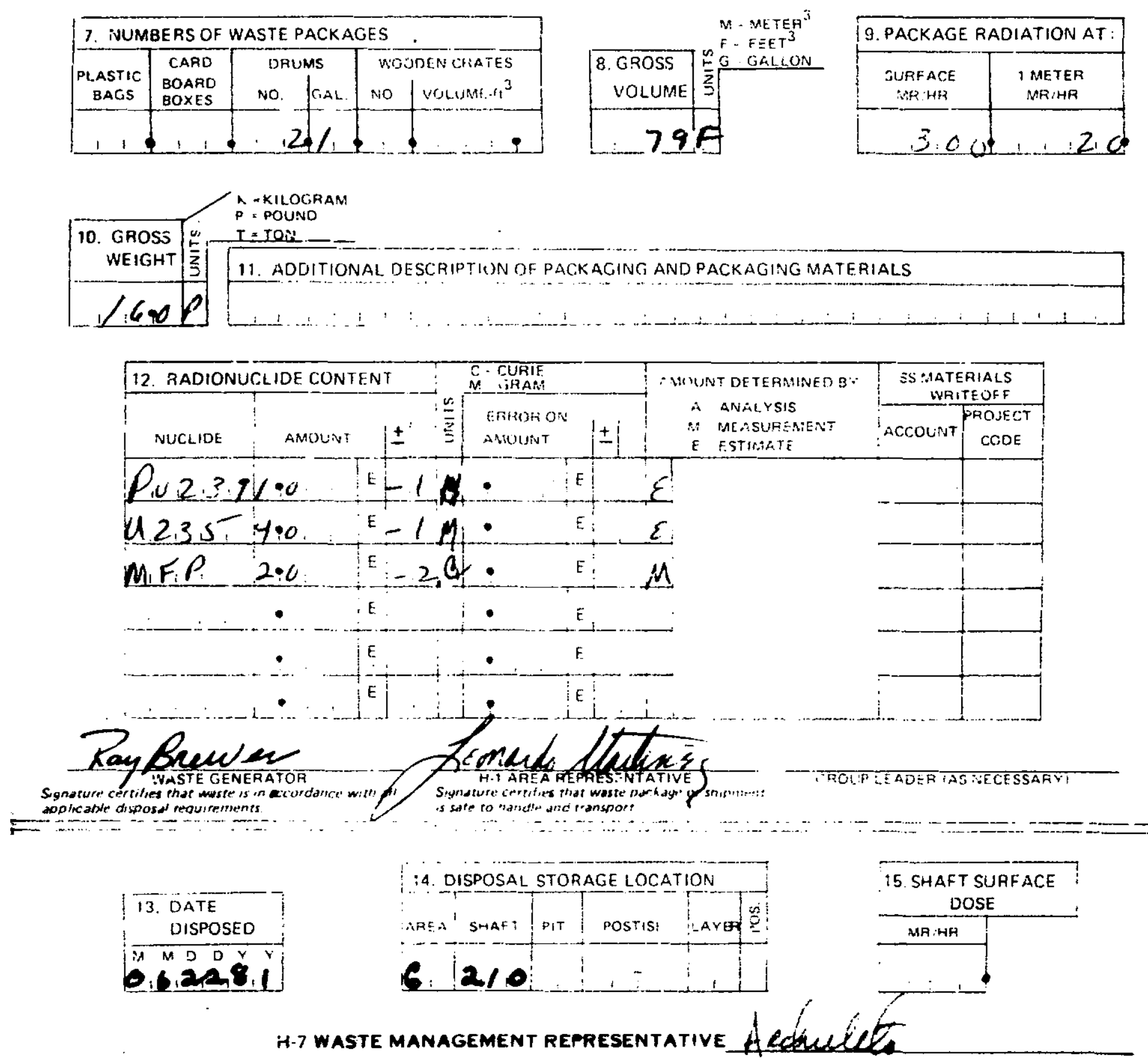
RADIOACTIVE SOLID WASTE DISPOSAL RECORD FORMS

FOR

SHAFT 211

MATERIAL DISPOSAL AREA G 

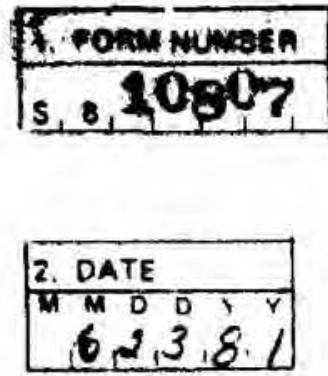

PLEASE READ INSTRUT FIONS ON INACK CAREFIJLI

LASL RADIOACTIVE SOLID WASTE DISPOSAL RECORD FORM

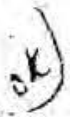

\begin{tabular}{|c|c|c|c|c|c|}
\hline \multicolumn{3}{|c|}{ 4. ORIGIN UF WASTE } & \multirow{2}{*}{$\dot{z}$} & & \multirow{2}{*}{$\begin{array}{l}5 \text { VIASTE } \\
\text { CODE }\end{array}$} \\
\hline GROUP & TA & BLDG. & & ROOM & \\
\hline$i, M, b_{1} /, 4$ & 0,3 & $S M_{10}$ & 9 & & $A, 40$ \\
\hline
\end{tabular}

\section{IVASTE DESCRIPTION}

$C_{1} E_{1} L_{1}, 1,3, \cdots, 1,5,1 / 0, T_{1}, T, R, A S H_{1}$

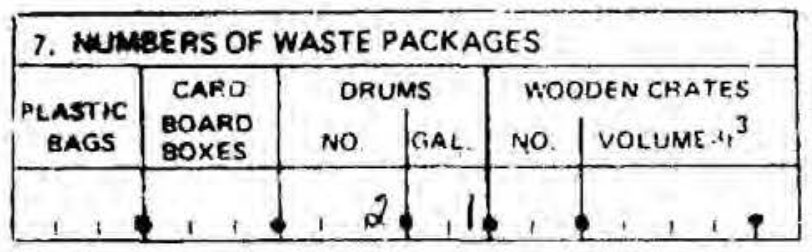

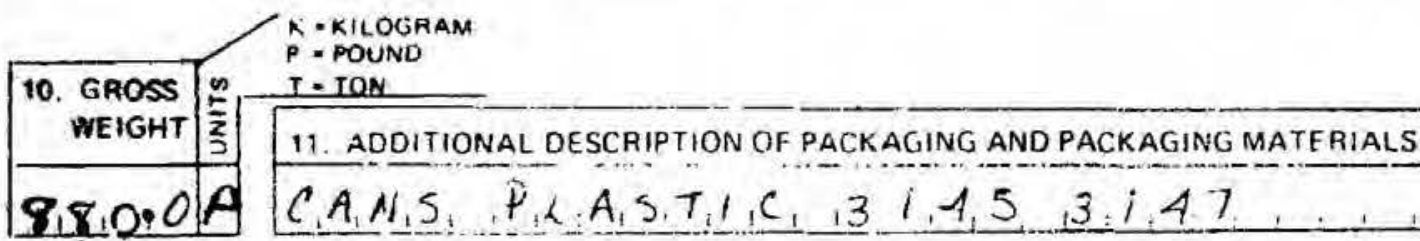

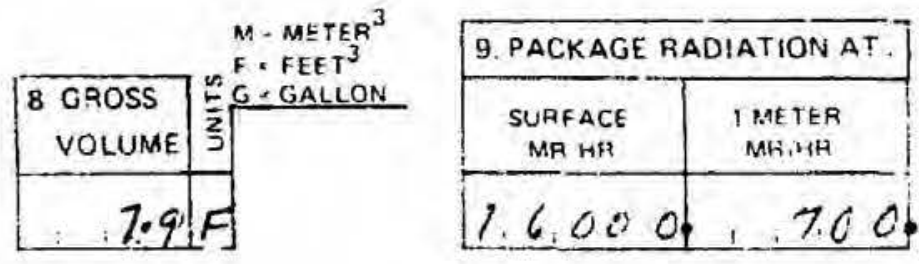

- FEET ${ }^{3}$ $7: 9 ! F$

1.6 .00 of 1.700

j. TETRIEVABLE SERIAL NO

$0,1,6,2,8$

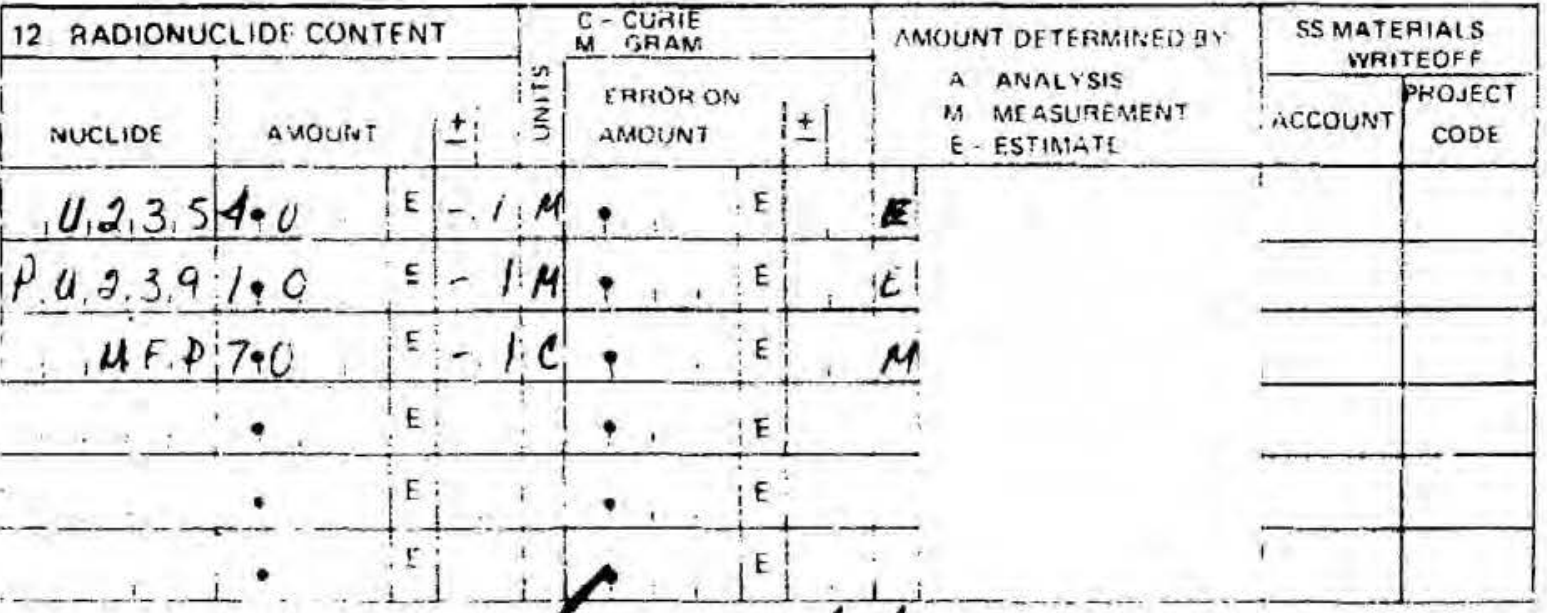

\section{Mamul 7 से कer}
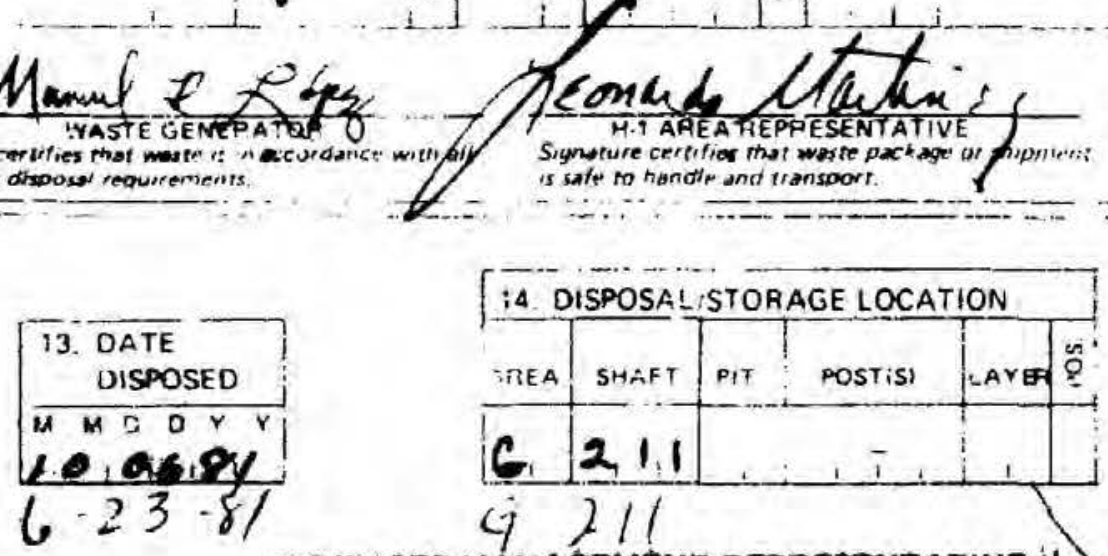
1. FORM NUMBER

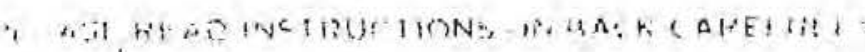

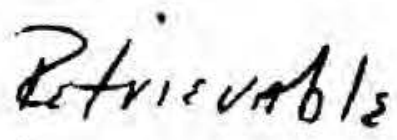

LASL RADIOACTIVE SOLIU WASTE DISPOSAL RECORD FORM

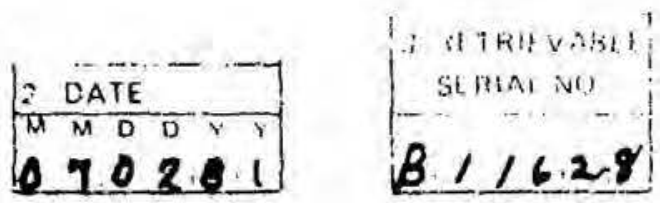

4 ORIGINO: Wr.ste

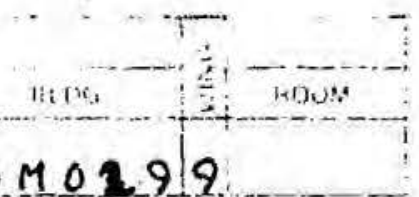

$5 \therefore$ Ast CODE.

MB.D. $1.315 M 01.919$

A.4. 0

6. WASTE DESCRIPTION

CELL L4 CANS 3158 I 59 HOL TRESA GLASS -
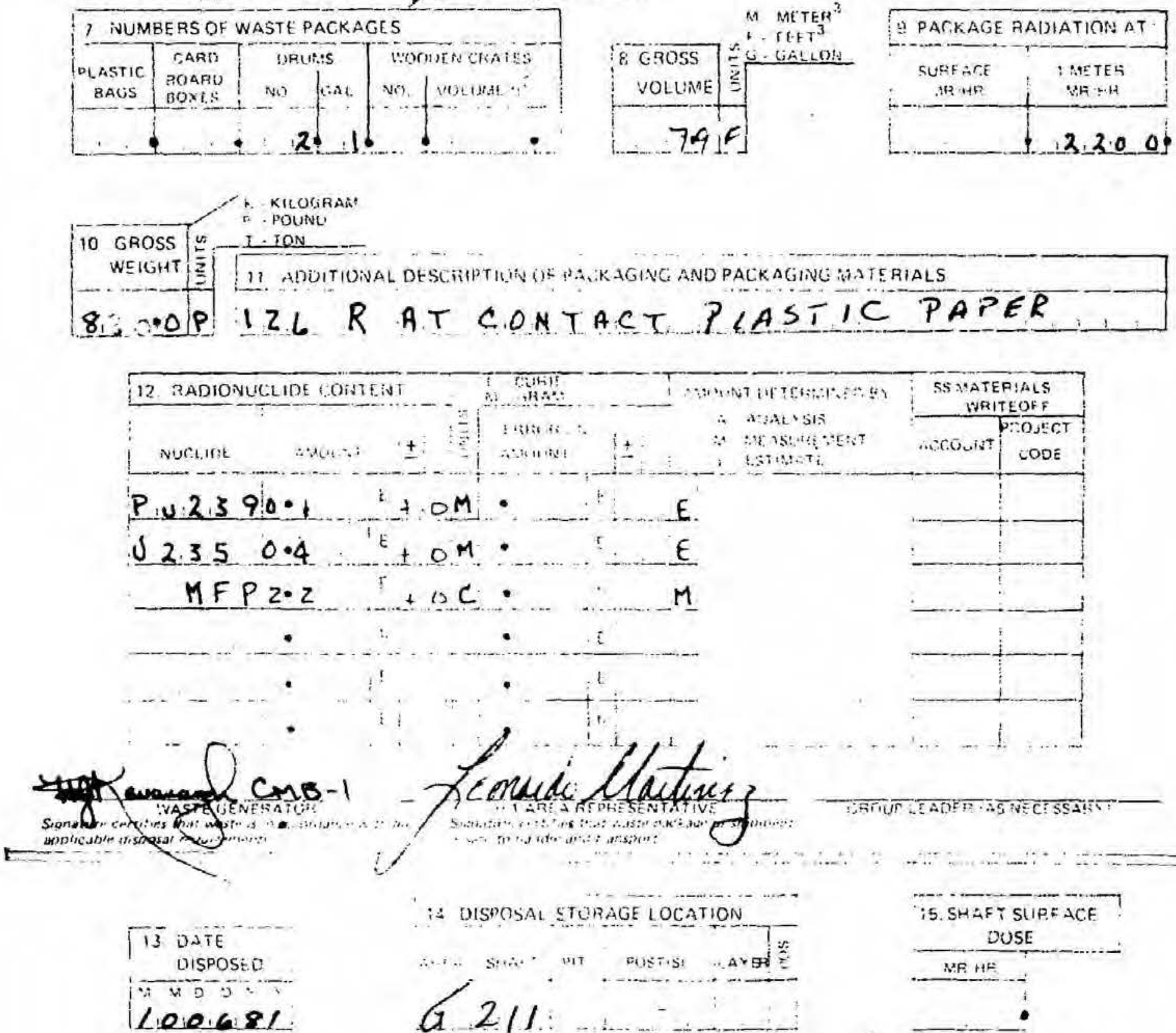

i־ UISPOSAL STURAGE LOCATION
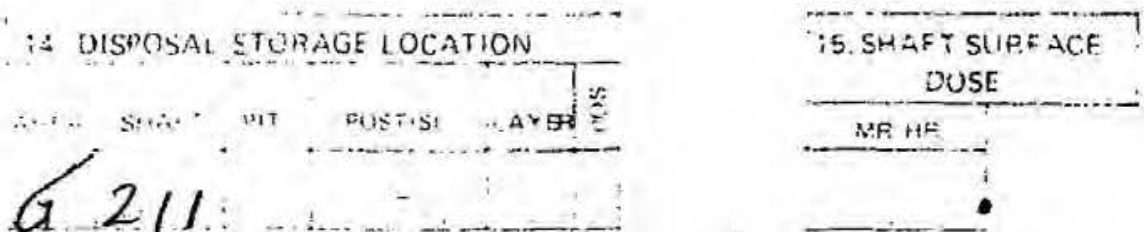


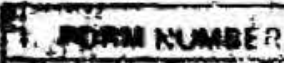

5.10009

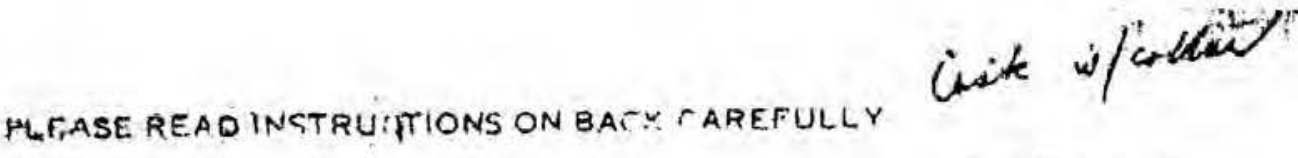

LASL RADIOACTIVE SOLIO WASTE DISPOSAL RECORO FORM

"Vaste Mahagrinem"

2. DATE

की

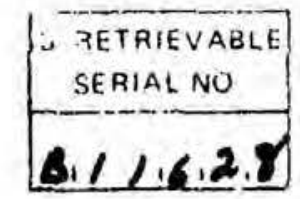

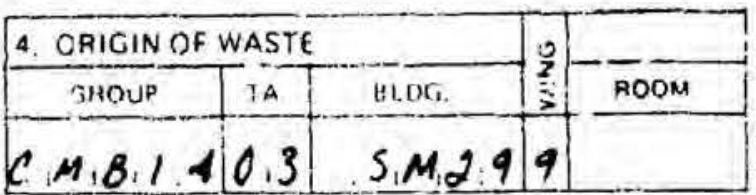

\begin{tabular}{|l|}
\hline CODE \\
\hline
\end{tabular}

6. WASTE QESCRIPTION

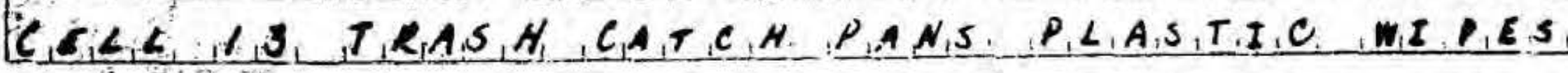

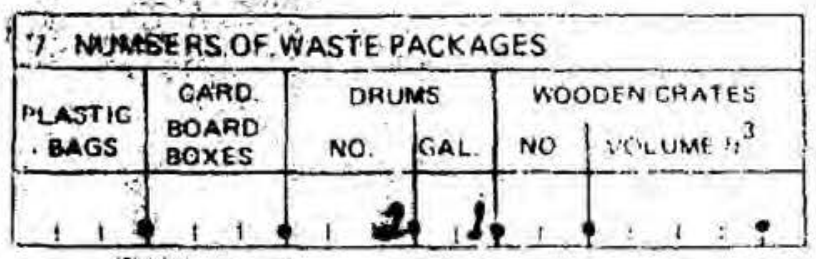

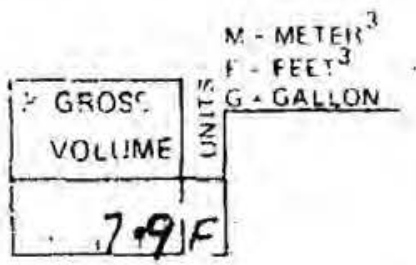

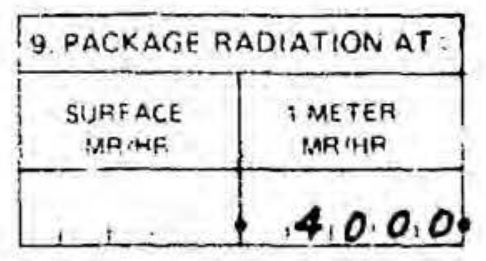
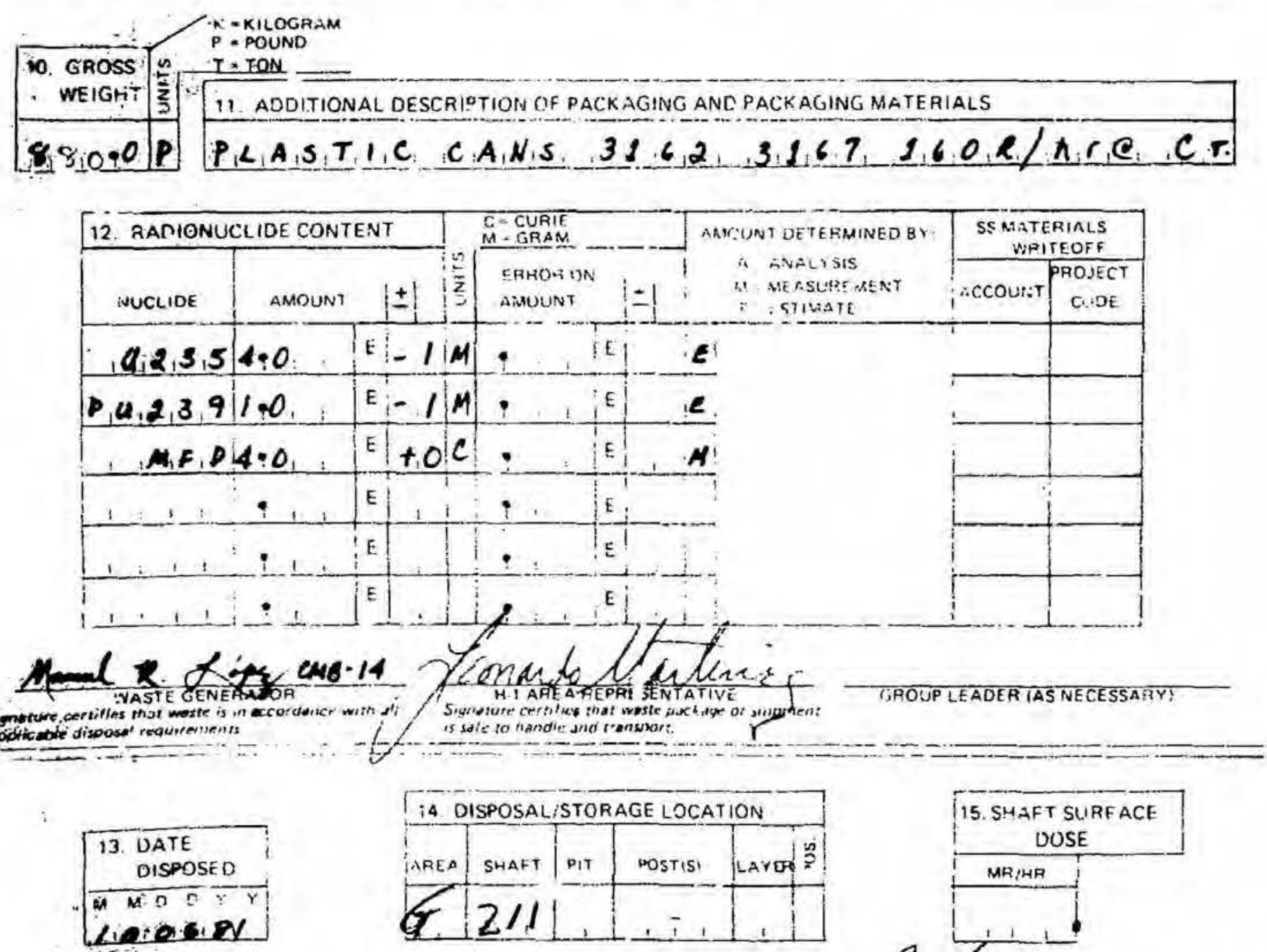

15. SHAFT SUIRFACE UOSE

H.7 WASTE MANAGEMENTT RËPRESENTATIVE 
1. FORM NUMBER

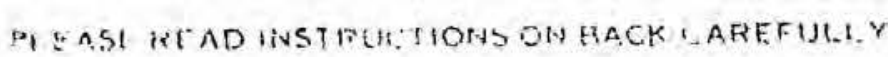

s; 10810

LASL RADIOACTIVE SOLID WASTE

DISPOSAL RECORD FORM

(t)
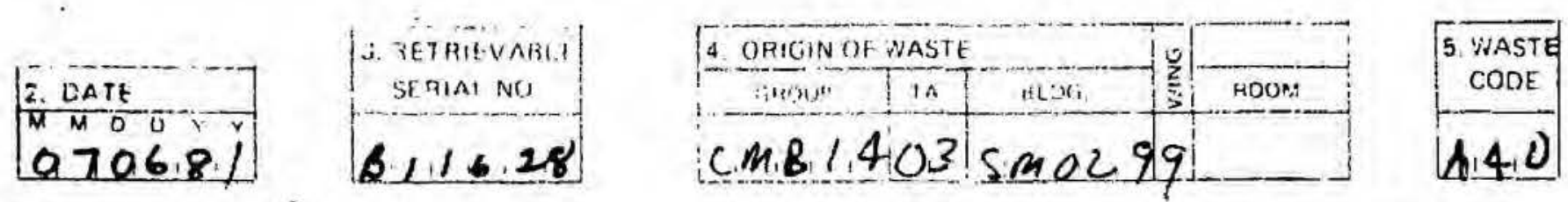

6 WASTE DESCRIPTION

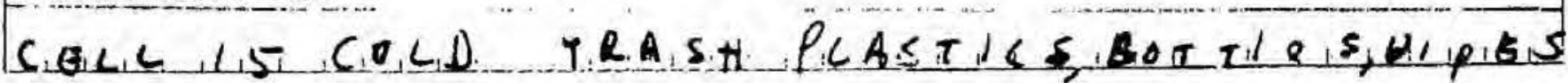
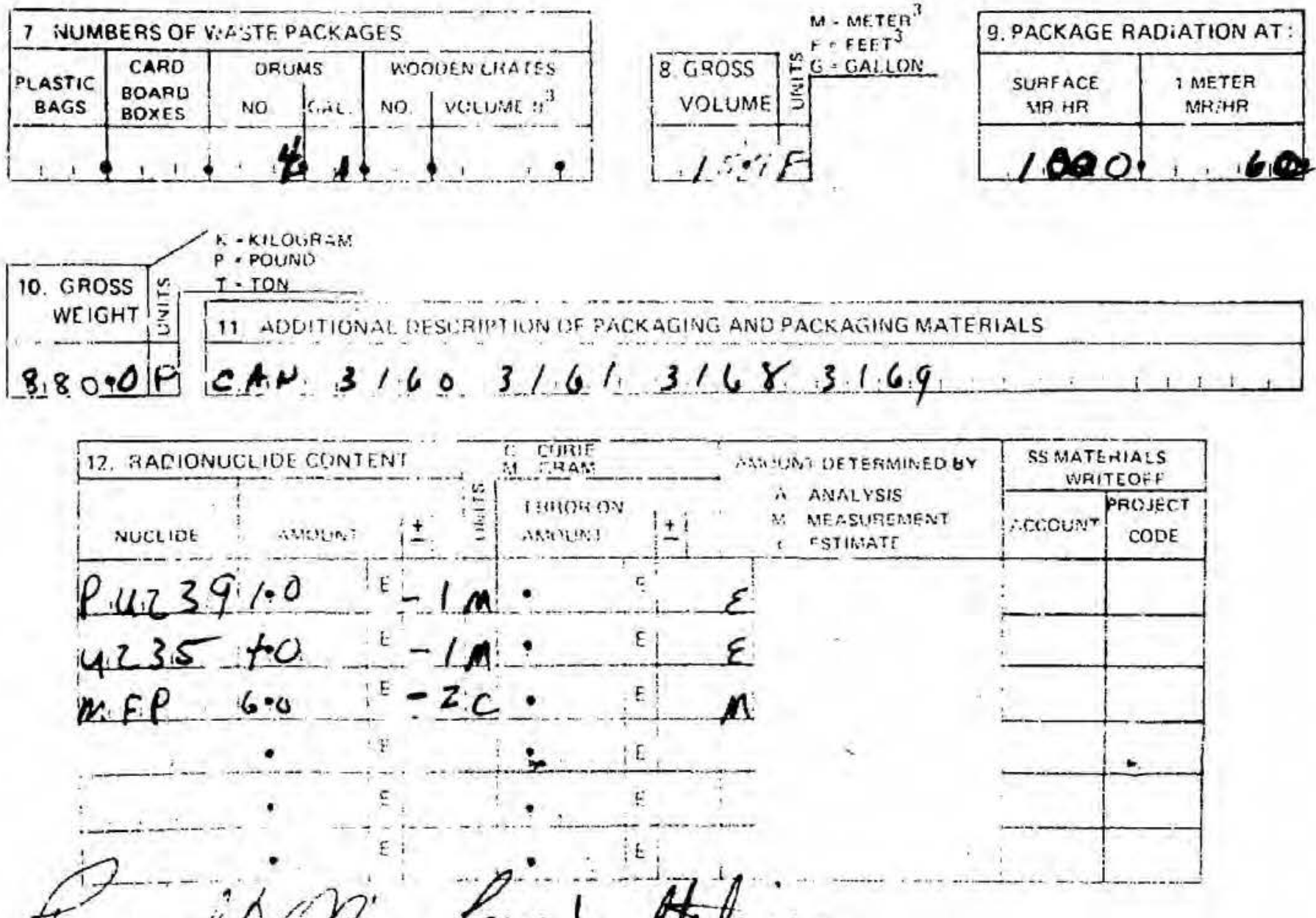

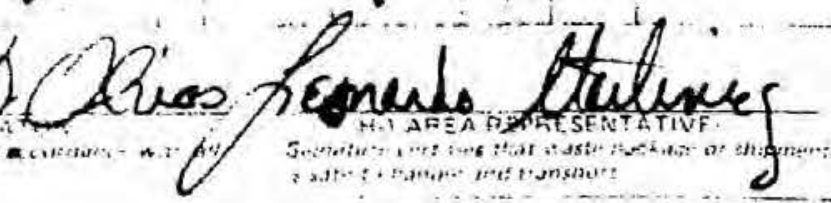
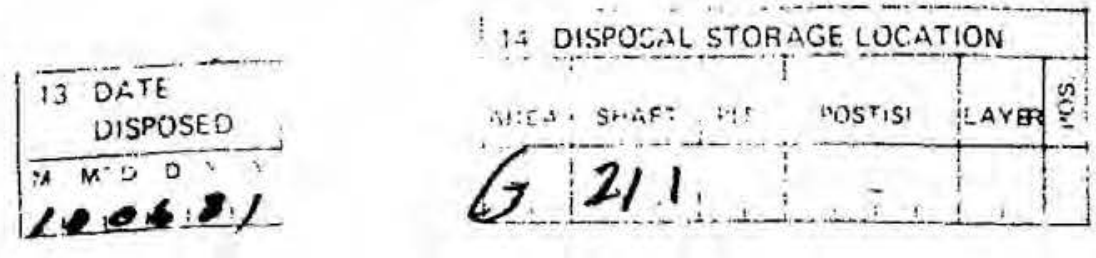

15. SHAFT SURFACE

DUSE

MR $N A$

H.T WASTE MANAGEMENT REPRESENTATIVE 
PLO ALE RF AC INSTRUCTIONS ON HACK : AW. I, .

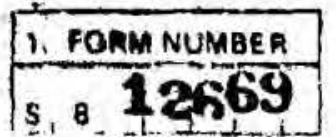

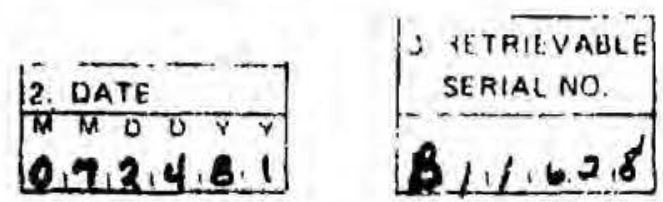

LAST RADIOACTIVE SULU WASTE DISPOSAL RECORD FOAM (

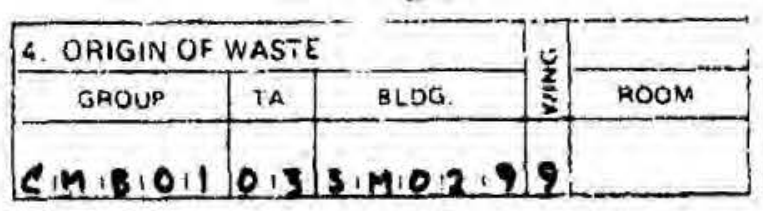

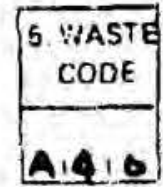

6. WASTE DESCRIPTION

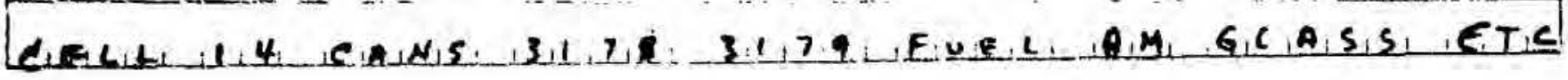
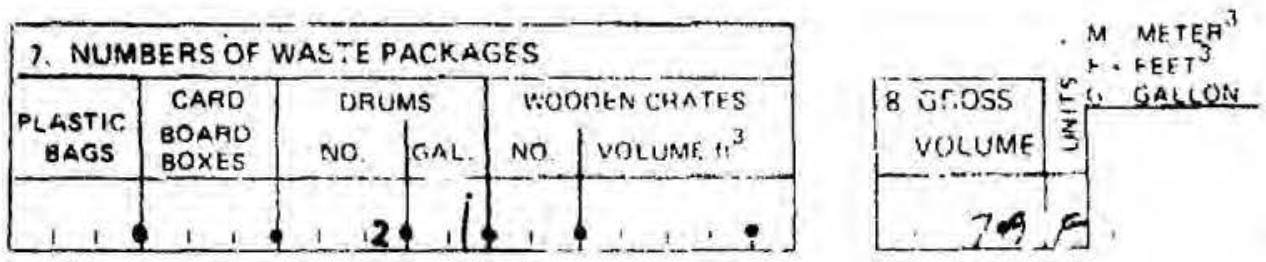

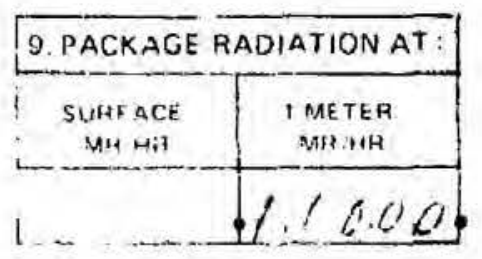

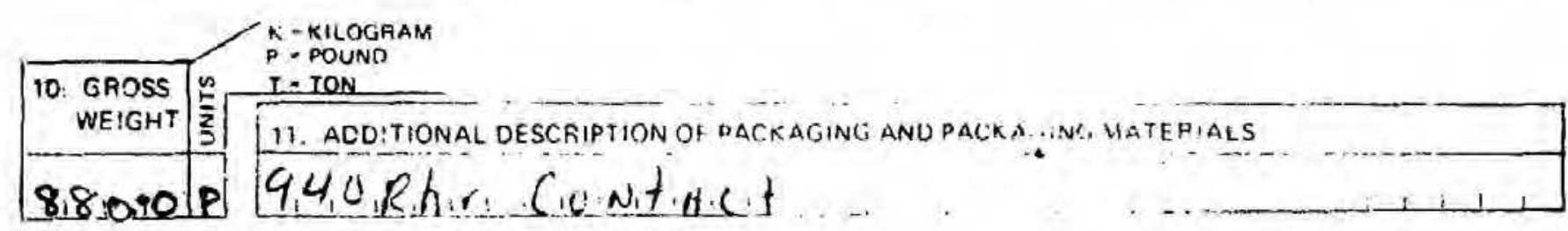

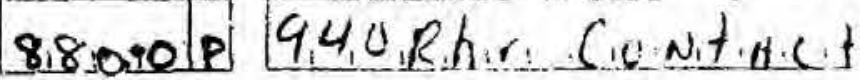

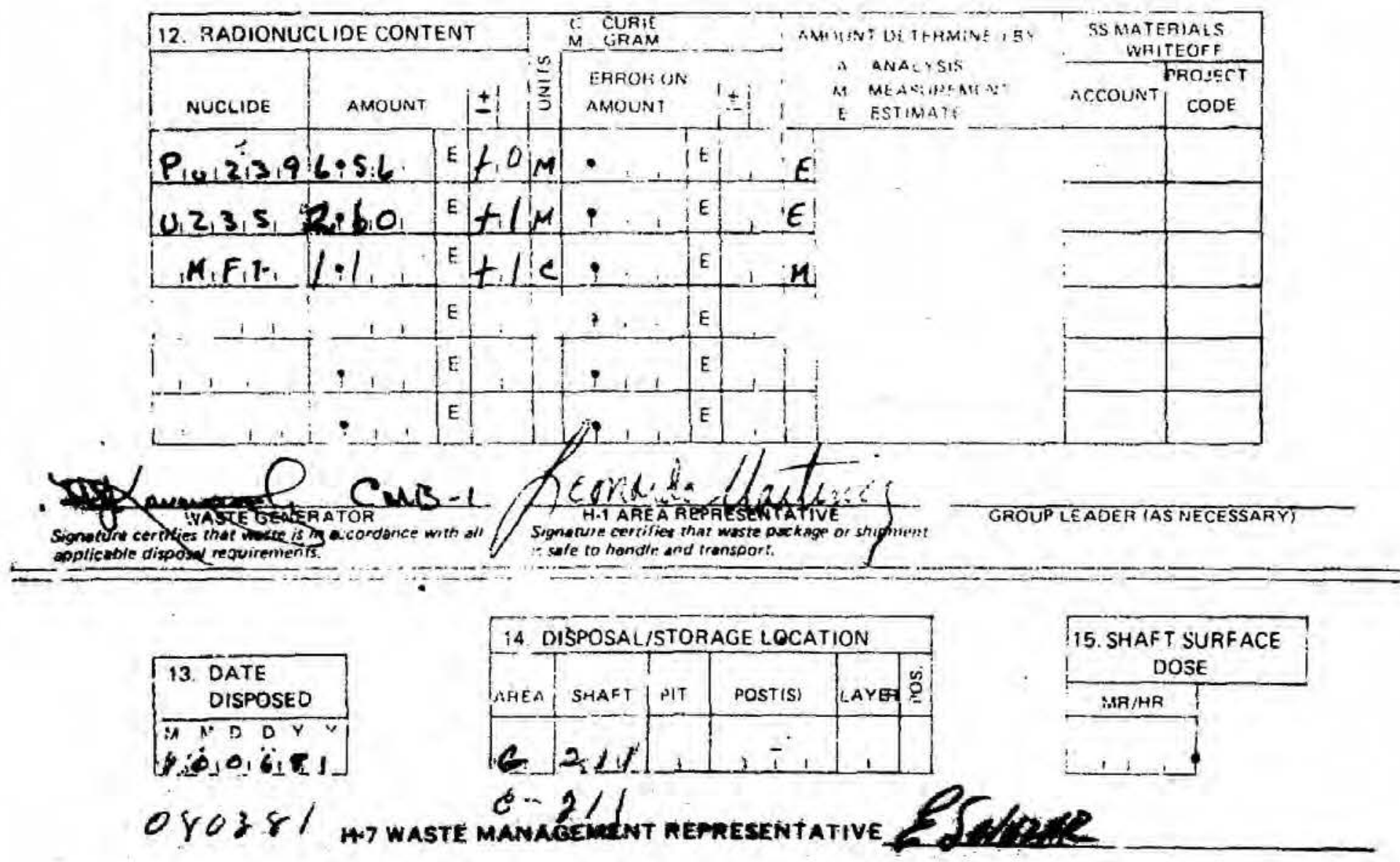


RADIOACTIVE SOLID WASTE DISPOSAL RECORD FORM

FOR

SHAFT 212

MATERIAL DISPOSAL AREA G 


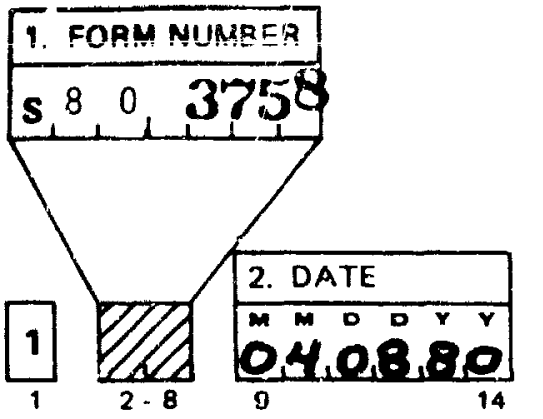

\section{LASL RADIOACTIVE SOLID WASTE DISPOSAL RECORD FORM}
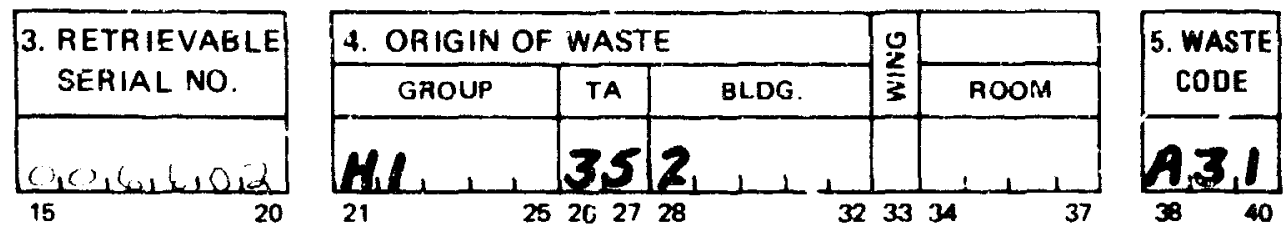

6. WASTE DESCRIPTION

LAMPRE REQCTQRR VESSEL SEALED IN CASKL L
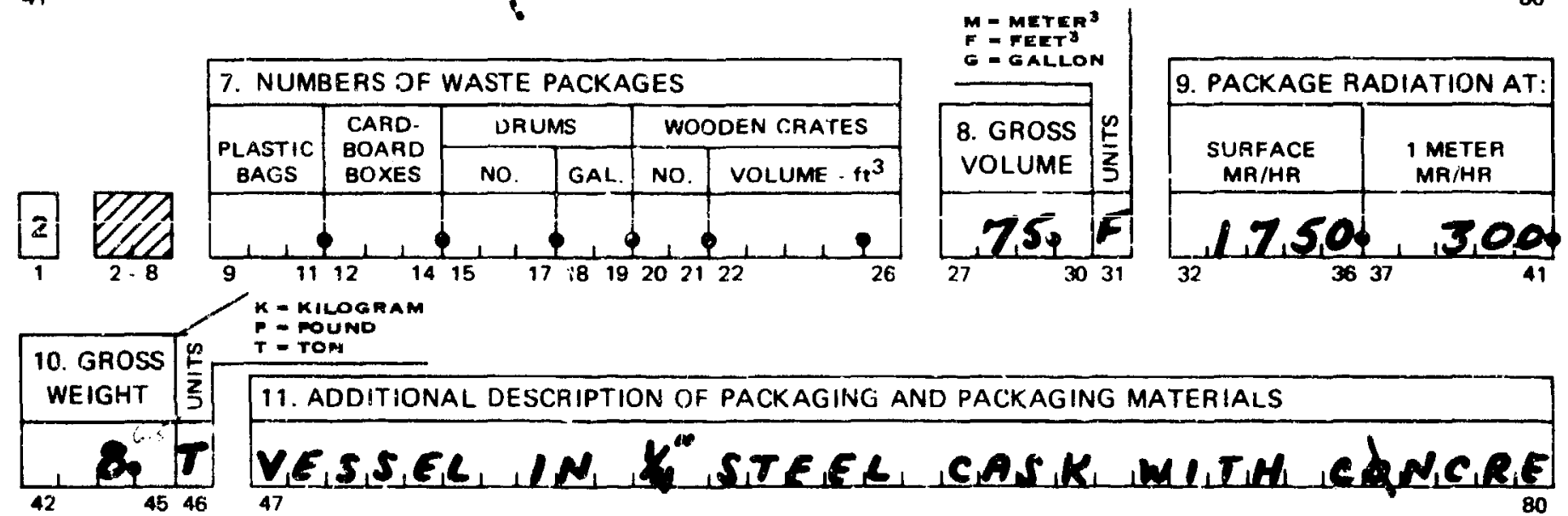

r Kilogana

T $=$ TOM
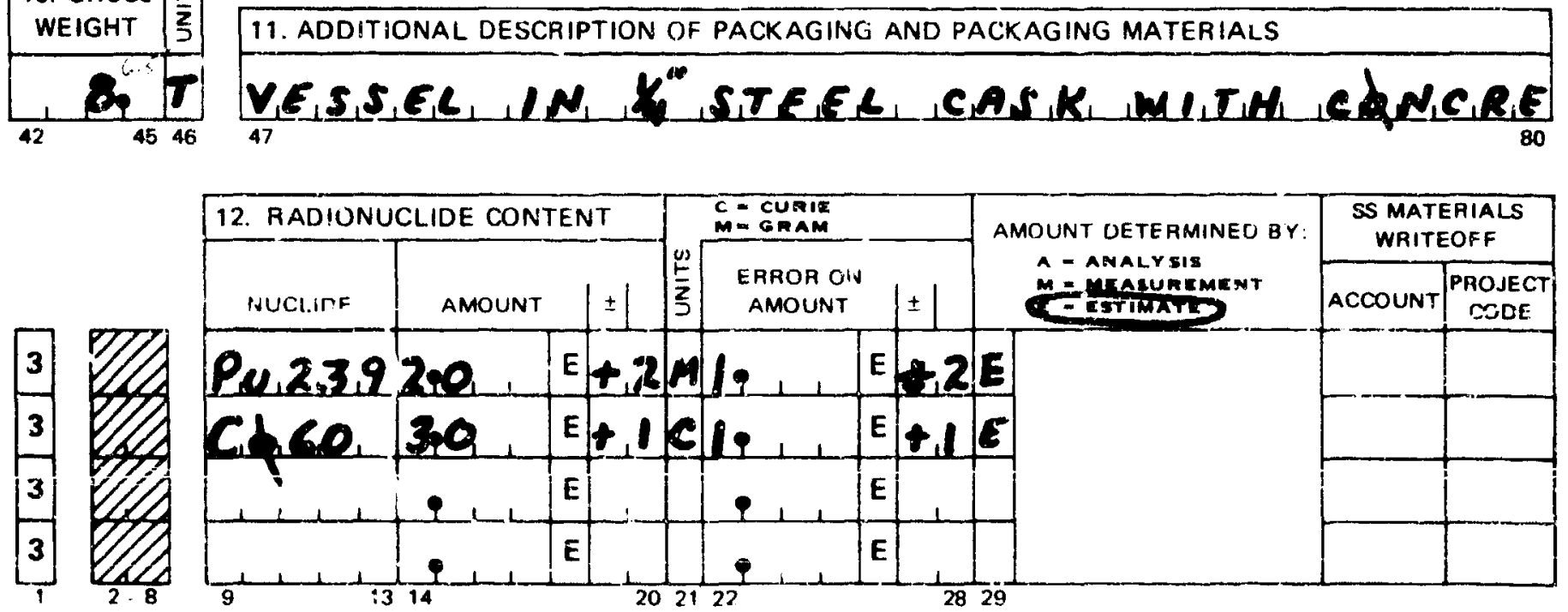

\section{E. Derr}

WASTE GENERATOR

signature cartifies that waste is in accordance with all applicable disposal requirements.

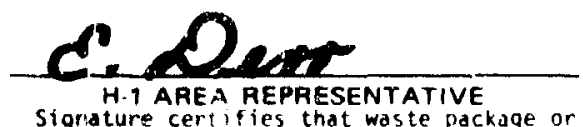
Signature certifies that waste package or shipmert is sofe to handie and transport.
GROUP LEADEP. (AS NECESSARY)

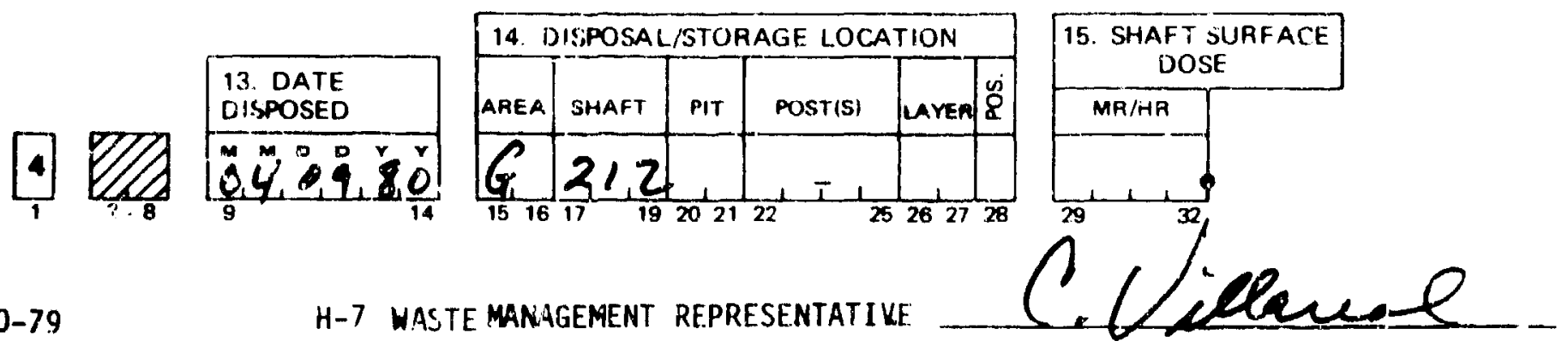


RADIOACTIVE SOLID WASTE DISPOSAL RECORD FORMS

FOR

SHAFT 213

MATERIAL DISPOSAL AREA G 


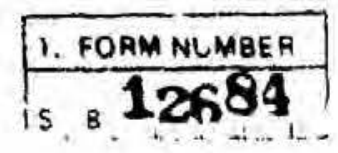

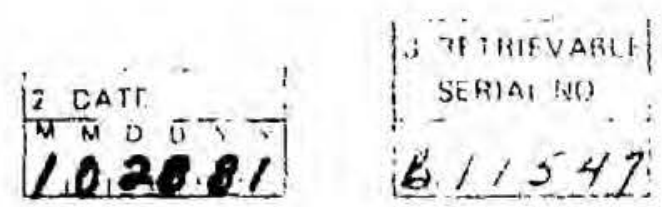

LASL RADIOACTIVE SOLIO WASTE DISPOSAL RECORD FORM

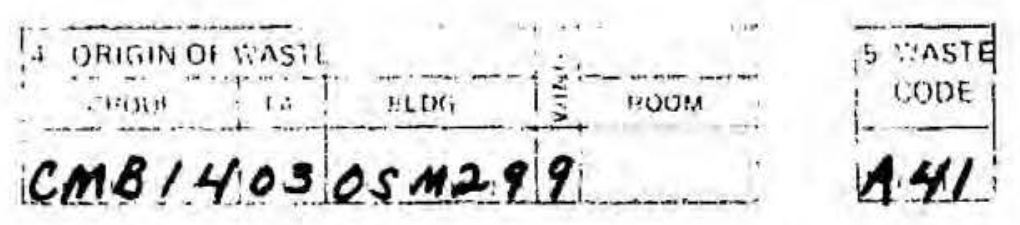

6. WASTE DESCRIPTION

CELLI 9 CELL WASTE\&FUELTCELL I6 WASTE

7. IUUMBERS OF WASTE PACKAGIES

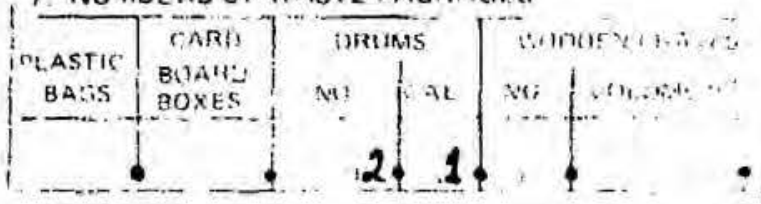

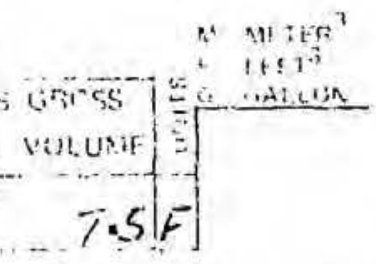

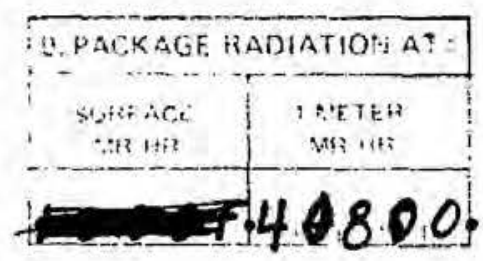

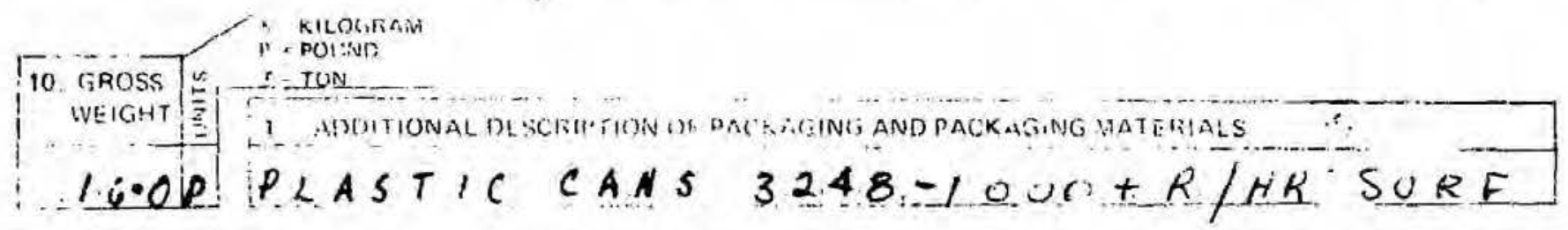

12 TADIONURLIE COATIENT

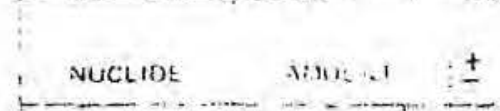

U.235: $11.380+24$

P. $23.93 \cdot 2.58+1 M$

MFP $4 \cdot 28$

$+1 C \cdot \quad M$

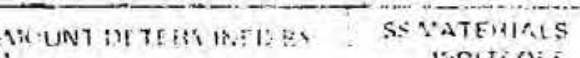
IURITiOi DSRAEC:

An:-YSIS

isos

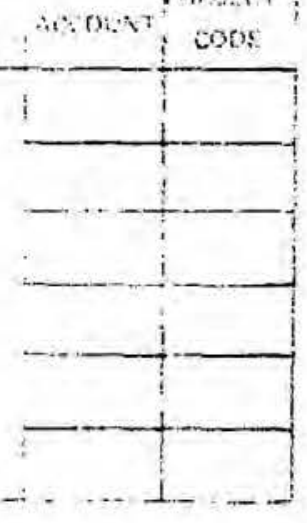

Calendaserma

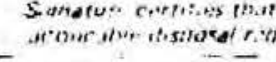

i) $3 . \mathrm{A} \div \mathrm{F}$ 1)ISPOSE:

110381

ia mISYOSAE STORAGE LOCATION

i5. SHAFT SUAFACE UOSE

:? $+x \cdot$

6213

H-7 WASTE MANAGEMEN T REPRESENTATIVE

HSE 7.1A(1000) 
PLEAS: WINSTRUGTIONS ON BACKCARIHI, I

1. FOMM NUMBER

\section{LASL RADIOACTIVE SOLID WASTE DISPOSAL RECORD FOAM}

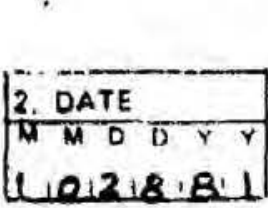

SETRIEVABLE
SERIAL NO
$6,1 / 5,4,7$

\begin{tabular}{|c|c|c|c|c|}
\hline \multicolumn{3}{|c|}{ 4. ORIGIN OF WASTE } & \multirow{2}{*}{$\frac{0}{2}$} & \\
\hline GROUP & IA & BLDG & & ноОМ \\
\hline
\end{tabular}

\begin{tabular}{l} 
5. WASTE \\
CUDE \\
\hline A.4,
\end{tabular}

\section{WASTE DESCRIPTION}

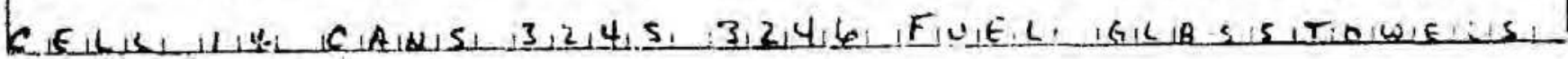

\begin{tabular}{|c|c|c|c|}
\hline \multicolumn{4}{|c|}{ 1. NUMBERS OF WASTE PACKAGES } \\
\hline & CARD & DRUMS & WOODEN CHATES \\
\hline 'BAGS & $\begin{array}{l}\text { BOARO } \\
\text { BOXES }\end{array}$ & GAL & No. $\mid$ vOLUME $*{ }^{3}$ \\
\hline
\end{tabular}
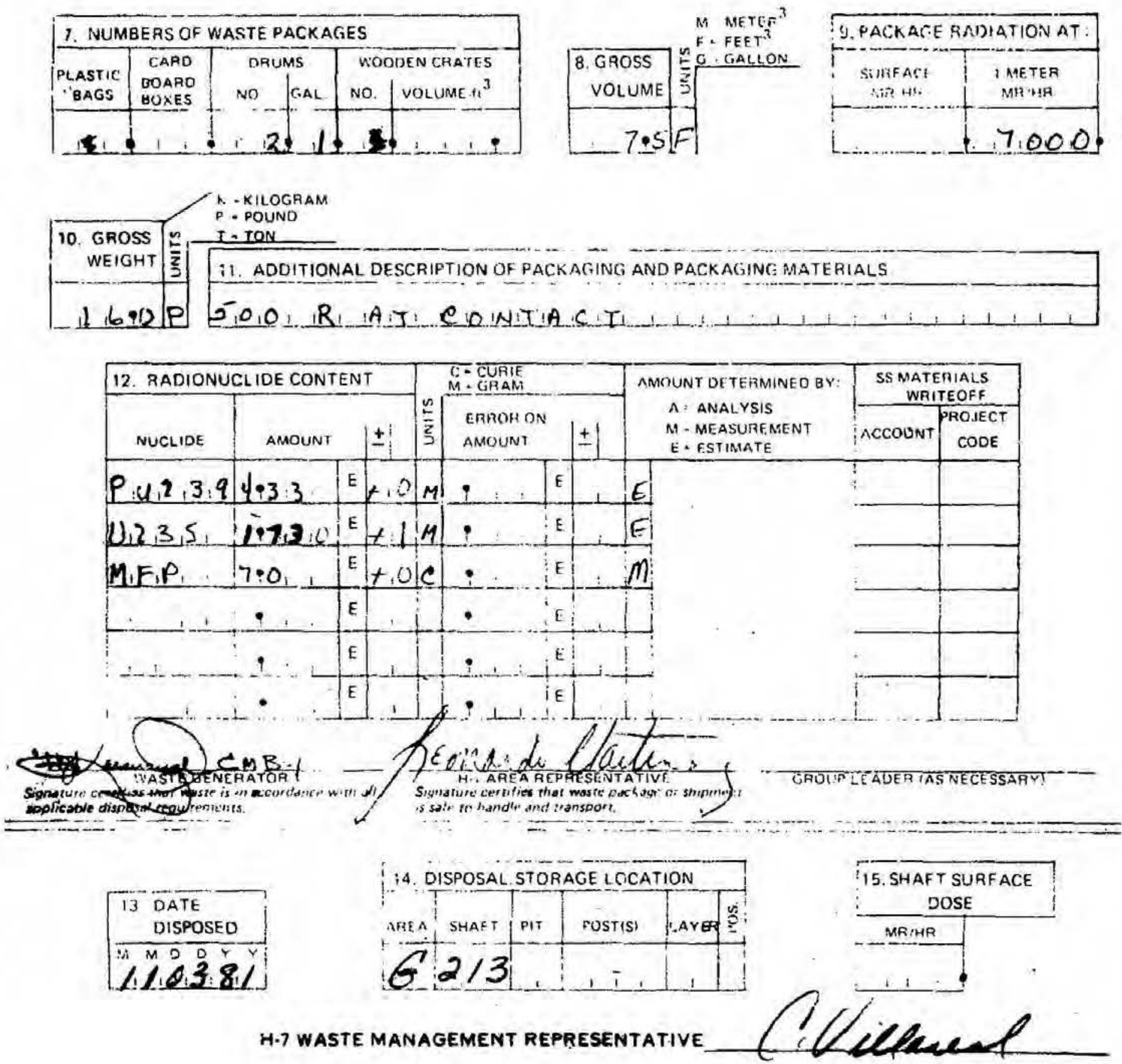
$\left[\begin{array}{c}\text { 1. FORM NUMBER } \\ \text { s. B }\end{array}\right.$

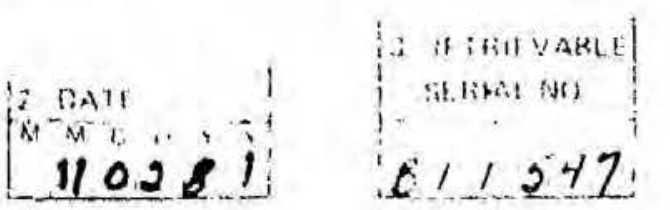

\section{I.ASL RAUIOACTIVE SOLIO WASTE DISPOSAL RECORD FORM}

6. WASTE MESCRIPIION

CELL A II FUEL I HOT TRASH

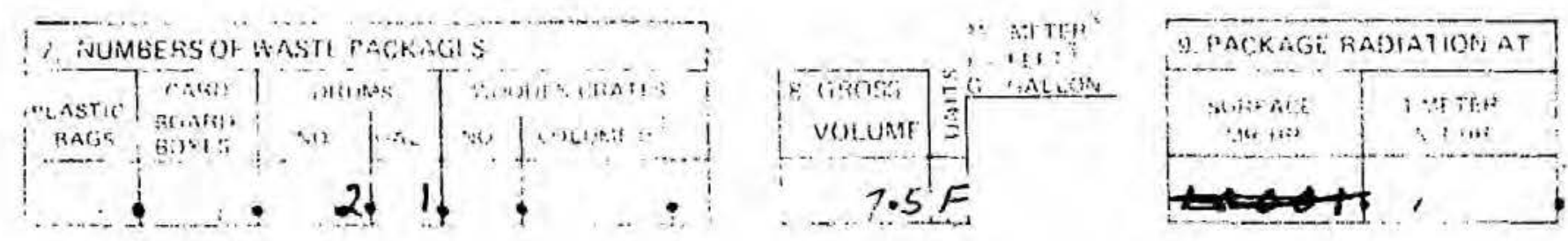

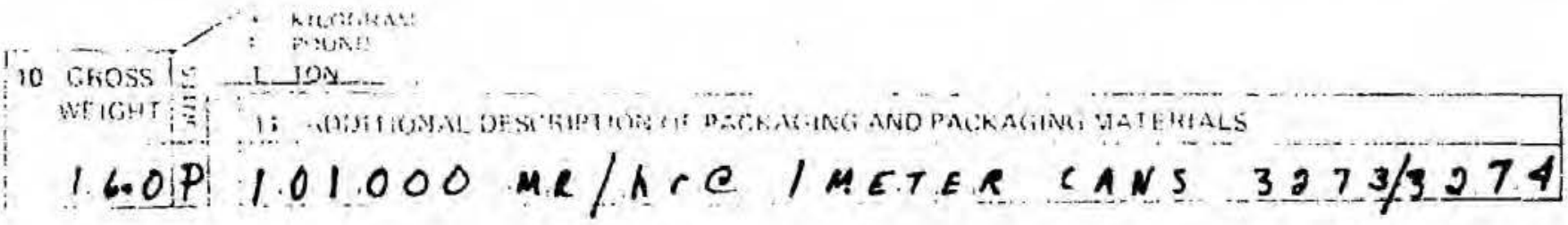

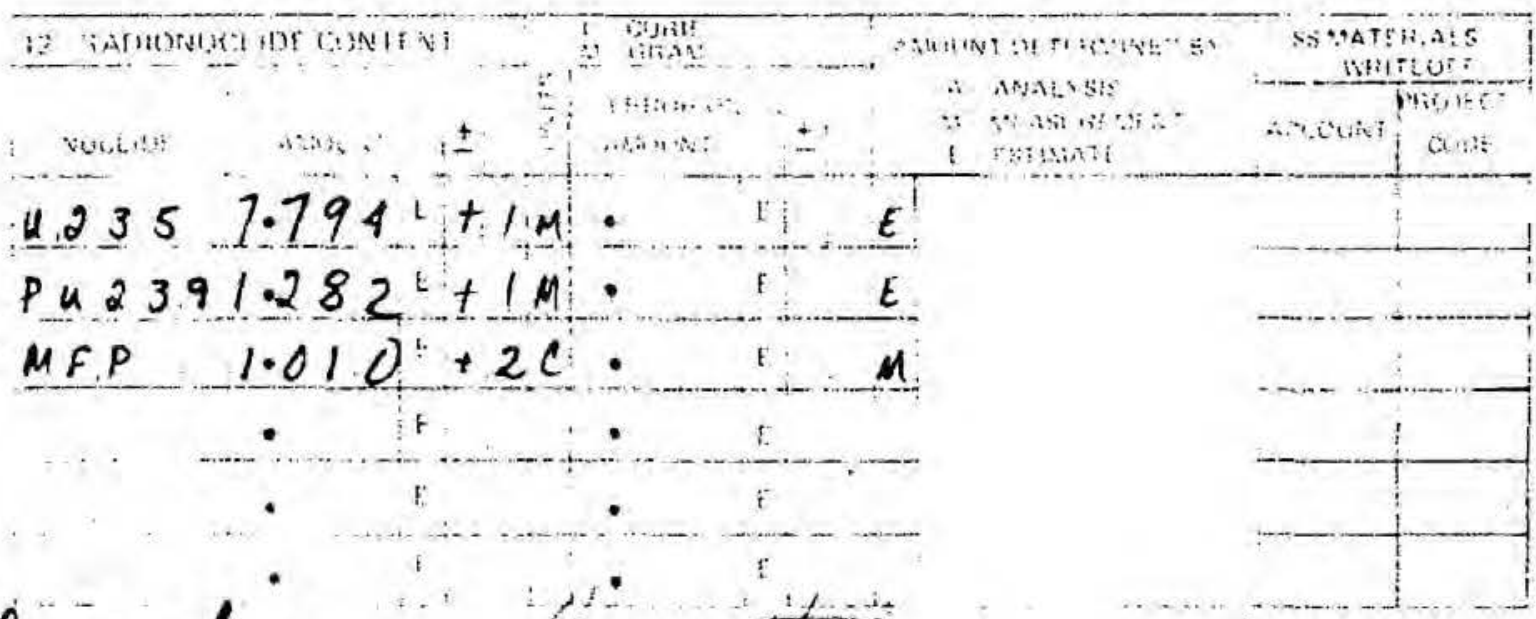

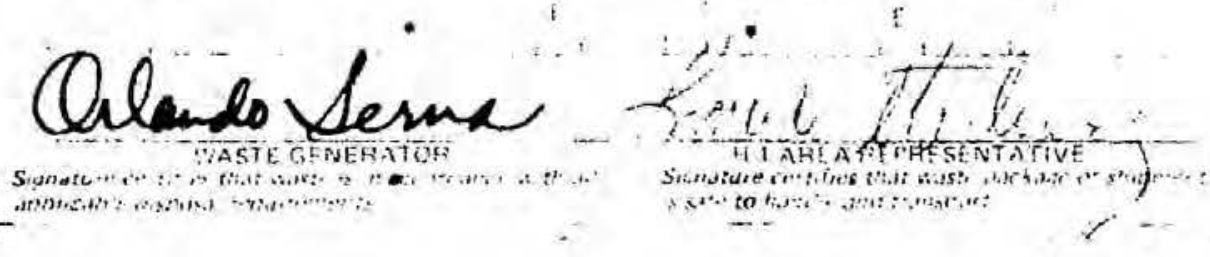

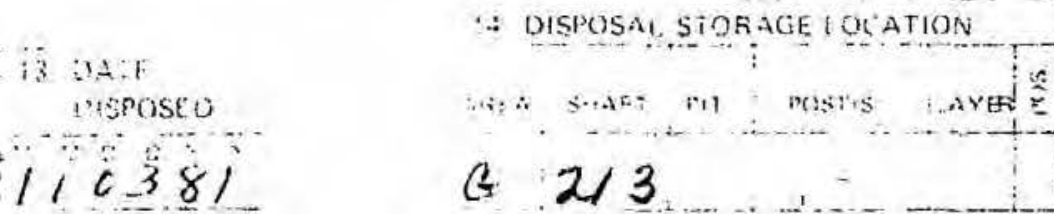

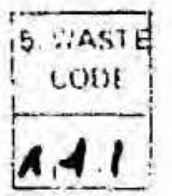

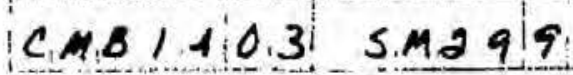

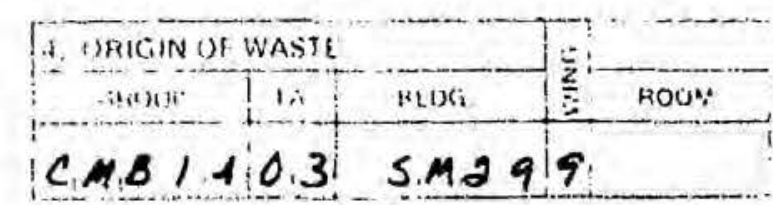

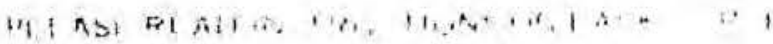


PLEASE READ INSTRUCTIONS ON RACK CAME

1. FORM NUMBER

s. 8,12689

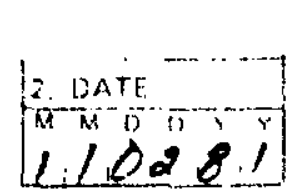

L.SL RADIOACTIVE SOLID WASTE DISPOSAL RECORD FORM

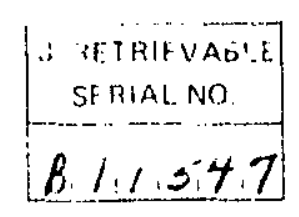

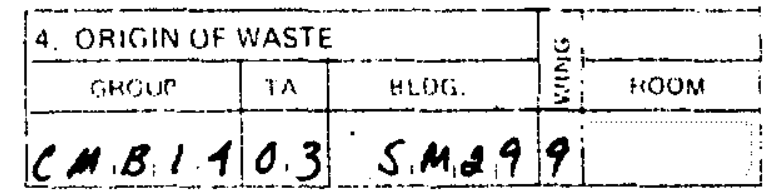

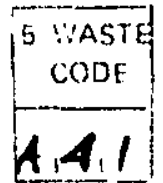

6. WASTE DESCRIPTION

CELL I 14 CELL WASTE CANS 3.26, 3,2,2
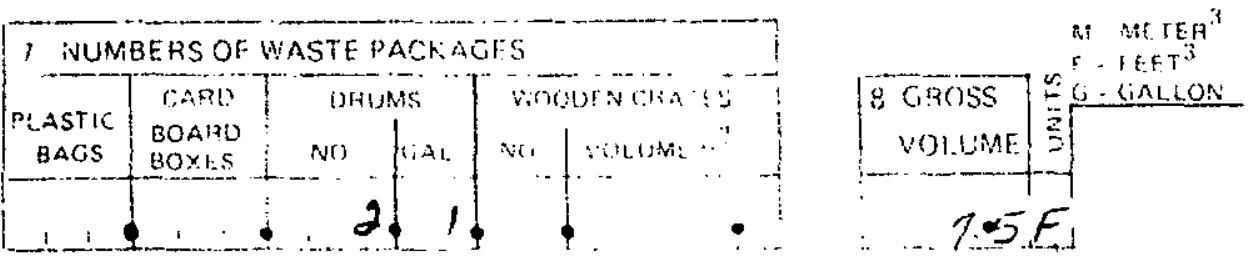

\begin{tabular}{|l|l|}
\hline 9. PACKAGE RADIATION AT: \\
\hline SURA ACE & $\begin{array}{c}\text { M METER } \\
\text { MAT HA }\end{array}$ \\
\hline & 28,00 \\
\hline
\end{tabular}

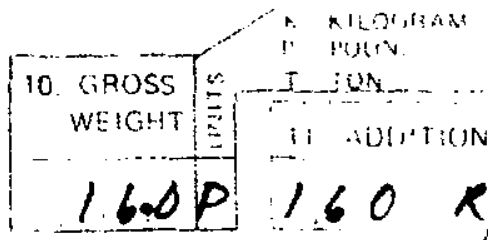

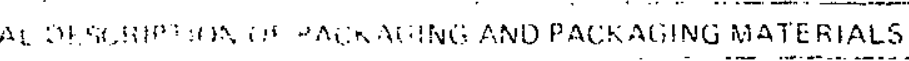

12. RADIONUCLID CUN IE:

e CONTACT

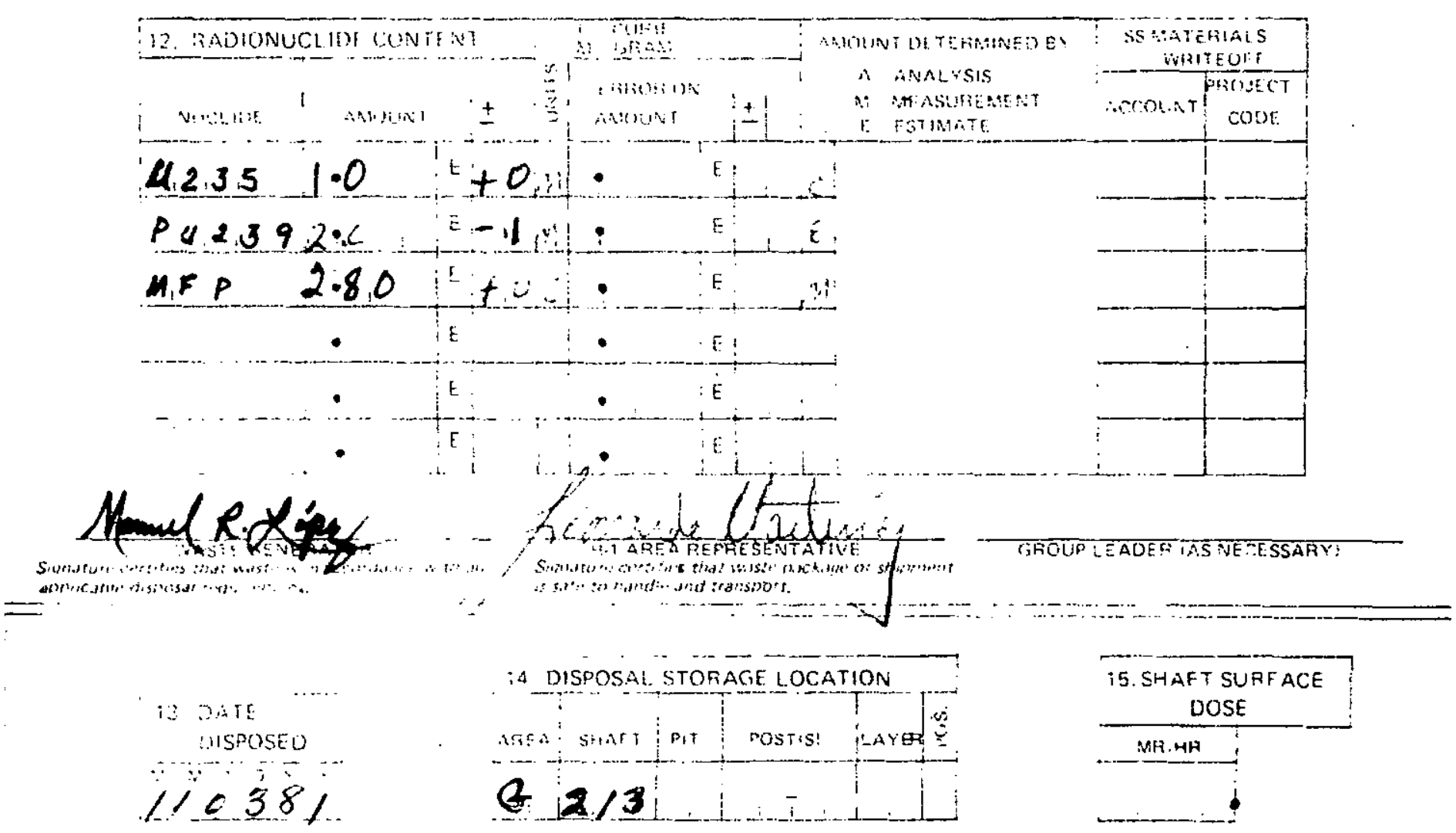

H.7 WASTE MANAGEMENT REPRESENTATIVE

ween-

(ES EX-1A(100O), 
RADIOACTIVE SOLID WASTE DISPOSAL RECORD FORMS

FOR

SHAFT 214

MATERIAL DISPOSAL AREA G 
PLEASF READ INSTRUCTIONS ON BACK CAREFULLY

1. FORM NUMBER

S. $, 2,00,5 ?$
LOE ALAMOS RANIOACTIVE SOLID WASTE DISPOSAL RECORD FORM
H.7 Waste Management

Ex16095 MS.592

\begin{tabular}{|l|}
\hline $\begin{array}{c}\text { 3. RETRIEVABLF } \\
\text { SERIAL NO. }\end{array}$ \\
\hline BIC 1711911 \\
\hline
\end{tabular}

\begin{tabular}{|c|c|c|}
\hline \multicolumn{3}{|c|}{ 4. ORIGIN OF WASTE } \\
\hline GROUP & TA & BLDG. \\
\hline$\left.C+x_{1} B_{1}\right)+4$ & $\mathrm{CH}_{3}$ & 051924 \\
\hline
\end{tabular}

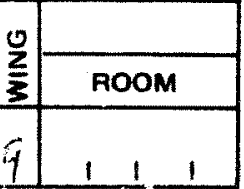

\begin{tabular}{l} 
CODE WASTE \\
\hline 4,41 \\
\hline
\end{tabular}

\section{WASTE DESCRIPTION}

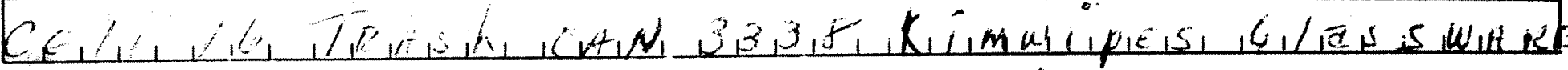

\section{NUMBERS OF WASTE PACKAGES}

\begin{tabular}{|c|c|c|c|c|c|}
\hline & CARD & DRI & & wo & DEN CRATES \\
\hline $\begin{array}{c}\text { PLASTIC } \\
\text { BAGS }\end{array}$ & $\begin{array}{l}\text { BOARD } \\
\text { BOXES }\end{array}$ & No. & GaL. & No. & VOLUME $-\mathrm{ft}^{3}$ \\
\hline
\end{tabular}

K $=$ KILOGRAM

10. GROSS $\sim T$ T $T$ TON

11. ADDITIONAL DESCRIPTION OF PACKAGING AND PACKAGING MATERIALS

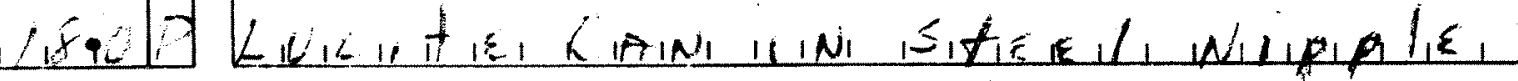

\begin{tabular}{|c|c|c|c|c|c|c|c|c|c|c|c|}
\hline \multicolumn{4}{|c|}{ 12. RADIONUCLIDE CONTENT } & \multicolumn{4}{|c|}{$\begin{array}{l}C=\text { CURAIE } \\
M=\text { GRAM }\end{array}$} & \multirow{2}{*}{\multicolumn{2}{|c|}{ 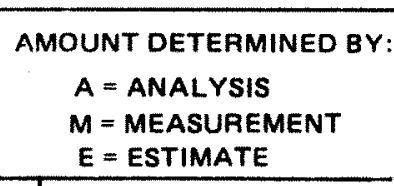 }} & \multicolumn{2}{|c|}{$\begin{array}{c}\text { SS MATEAIALS } \\
\text { WAITEOFF }\end{array}$} \\
\hline NUCLIDE & AMOUNT & & \pm & $\frac{5}{3}$ & $\begin{array}{l}\text { ERROR ON } \\
\text { AMOUNT }\end{array}$ & & \pm & & & ACCOUNT & $\begin{array}{c}\text { PROJECT } \\
\text { CODE }\end{array}$ \\
\hline$P_{14} Z 0$ & $19 ! 1$ & $E$ & $-1 \mid$ & $m$ & 911 & $E$ & & 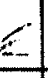 & & & \\
\hline $41231 \div$ & 4911 & $E$ & -11 & m & 111 & $E$ & $\perp$ & $\mathscr{2}$ & & & \\
\hline$Y_{1}=F_{1}$ & $390_{1}$, & $E$ & -1 & C & 911 & $\mathbf{E}$ & 1 & 4 & & $\cdots$ & \\
\hline 1111 & 911 & $E$ & 1 & & 111 & E & & & & & \\
\hline $111_{1}$ & 911 & $E$ & 1 & & $9 \quad 1 \quad 1$ & $\mathbf{E}$ & . & & & & \\
\hline 1111 & 911 & $E$ & 1 & & 911 & E & 1 & & & & \\
\hline
\end{tabular}

ivaste Generator

Sign life certifies that weste is in accurdance with all oplicoble disposal requirements.

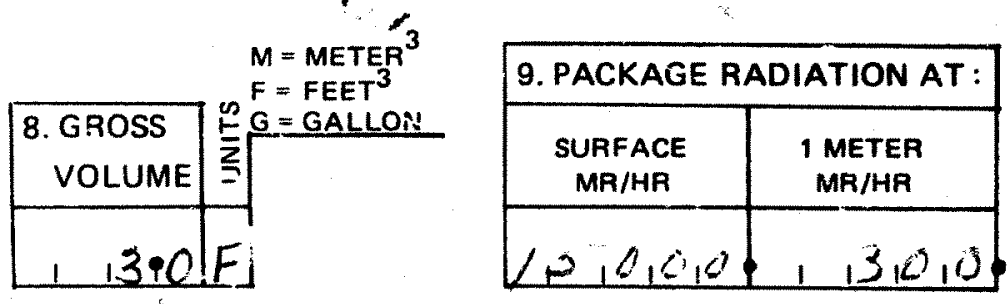

零

\begin{tabular}{|l|} 
13. DATE \\
DISPOSED \\
\hline $14 M, D$ D Y Y \\
$0,4,2,0,8,2$ \\
\hline
\end{tabular}

\begin{tabular}{|c|c|c|c|c|c|}
\hline \multicolumn{6}{|c|}{ 14. DISPOSAL/STORAGE LOCATION } \\
\hline AREA & SHAFT & PIT & POSTIS) & LAYT & 80 \\
\hline & 2,14 & & $1 \tau$ & 1 & \\
\hline
\end{tabular}

15. SHAFT SURFACE DOSE

MR/HR

\begin{tabular}{|c|}
\hline MR/MR \\
\hline 111 \\
\hline 11
\end{tabular}


FLEASE READ INSTRUCTIONS ON BACK CAREFULL

\begin{tabular}{|l|l|}
\hline 1. ForM NUMBEA \\
\hline $5,8,2,0058$ \\
\hline
\end{tabular}

\section{LOS ALAMOS RADIOACTIVE SOLID WASTE DISPOSAL RECORD FORM}

\begin{tabular}{|c|c|c|c|c|c|c|c|}
\hline \multirow{3}{*}{ 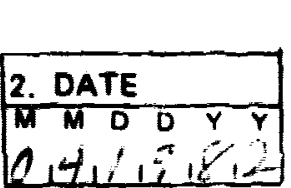 } & 3. RETRIEVABLE & \multicolumn{3}{|c|}{ 4. ORIGIN OF WASTE } & \multirow{2}{*}{$\frac{0}{5}$} & \multirow[b]{2}{*}{ ROOM } & 6. WASTA \\
\hline & SERIAL NO. & GROUP & $T A$ & BLDG. & & & CODE \\
\hline & $(3,0,7,1,9,1$ & $C M+B$ & 0,3 & 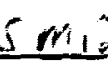 & 1.1 & 1 & \\
\hline
\end{tabular}

\section{WASTE DESCRIPTION}

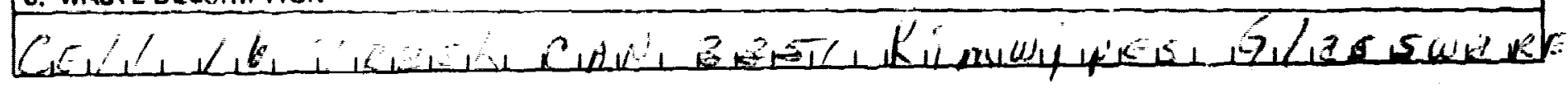

\begin{tabular}{|c|c|c|c|c|c|}
\hline \multicolumn{6}{|c|}{ 7. NUMBERS OF WASTE PACKAGES } \\
\hline \multirow[b]{2}{*}{$\begin{array}{l}\text { PLASTIC } \\
\text { BAGS }\end{array}$} & \multirow{2}{*}{$\begin{array}{l}\text { CARD } \\
\text { BOARD } \\
\text { BOXES }\end{array}$} & \multicolumn{2}{|c|}{ DRUMS } & \multicolumn{2}{|c|}{ WOODEN CRATES } \\
\hline & & NO. & GAL. & No. & VOLUME $\cdot \mathrm{Ht}^{3}$ \\
\hline
\end{tabular}
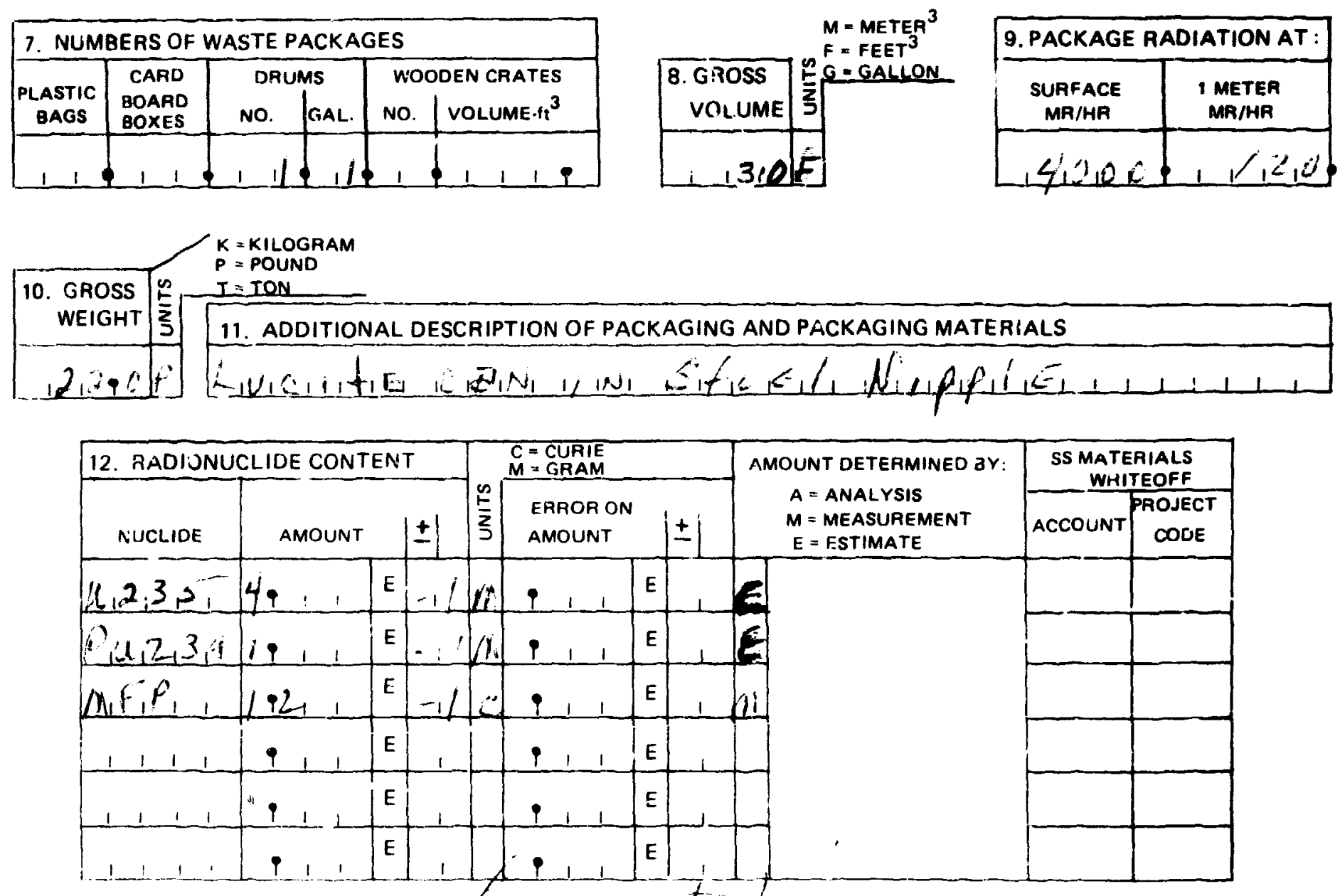

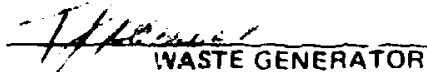

Signa the certifies thist waste is in eccordance with all. applicable disposal requirements.
Xitis

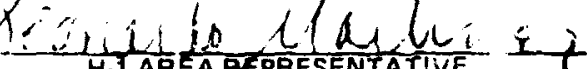
H.T AREA AEPAESENTATIVE
Signature certivites that waste pock age or shipm or is safe to handle and transport.

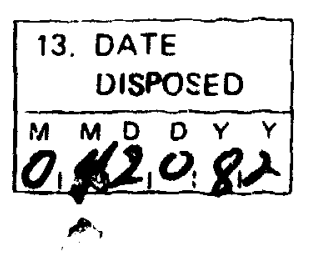

H-7 WASTE MANAGEMENT REPRESENTATIVE

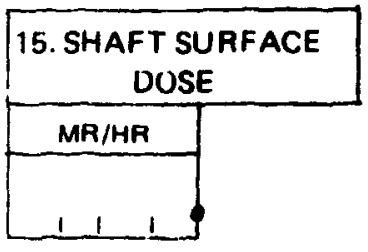

HS-E 7-1A $(10 / 81)$

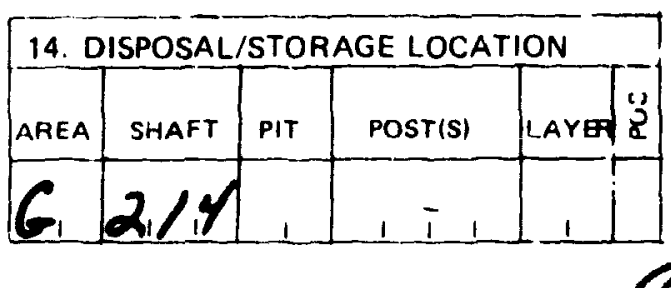

$\varepsilon$ 


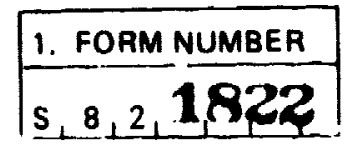

2. DATE

M M D $\bar{C}$ Y Y

$4,2, i, 8,2$

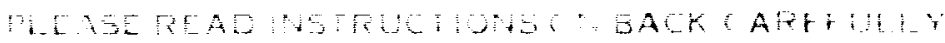

\section{LOS ALAMOS RADIOACTIVE SOLID WASTE OISPOSAL RECORD FORM}

\begin{tabular}{c} 
3. RETRIEVABLE \\
SERIAL NO. \\
\hline$B I C 1711 \% 11$
\end{tabular}

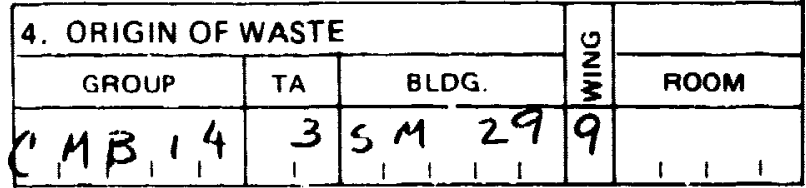

\begin{tabular}{l} 
5. WAS \\
CODE \\
\hline $4,4,1$ \\
\hline
\end{tabular}

6. WASTE DESCRIPTION

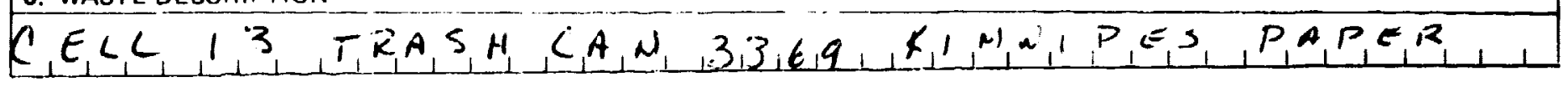

\begin{tabular}{|c|c|c|c|c|c|}
\hline \multicolumn{6}{|c|}{ 7. NUMBERS OF W'ASTE PACKAGES } \\
\hline & CARD & & & wo & DEN CRATES \\
\hline $\begin{array}{l}\text { PLASTIC } \\
\text { BAGS }\end{array}$ & $\begin{array}{l}\text { BOARD } \\
\text { BOXES }\end{array}$ & NO. & GAL. & NO. & VOLUME $-\mathrm{ft}^{3}$ \\
\hline
\end{tabular}
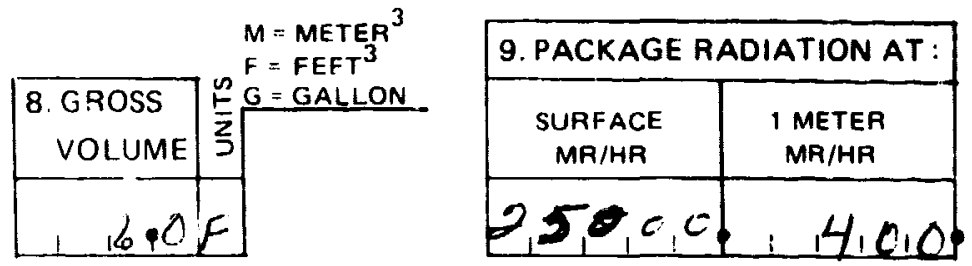

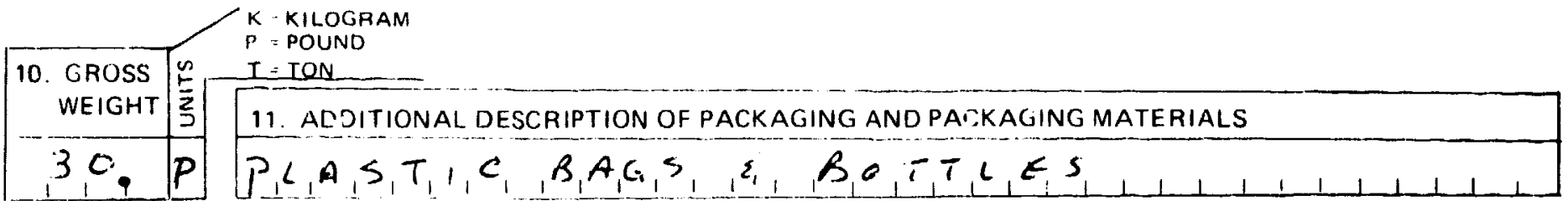

\begin{tabular}{|c|c|c|c|c|c|c|c|c|c|c|c|}
\hline \multicolumn{4}{|c|}{ 12. RADIONUCLIOE CONTENT } & \multicolumn{4}{|c|}{$\begin{array}{r}\text { C: CURIE } \\
M \text {-GRAM }\end{array}$} & \multirow{2}{*}{\multicolumn{2}{|c|}{$\begin{array}{c}\text { AMOUNT DETERMINED BY } \\
\text { A }=\text { ANALYSIS } \\
M=\text { MEASUREMENT } \\
\text { E - ESTIMATE }\end{array}$}} & \multicolumn{2}{|c|}{$\begin{array}{c}\text { SS MATERIALS } \\
\text { WRITEOFF } \\
\end{array}$} \\
\hline NUCLIDE & AMOUNT & & \pm & $\left|\begin{array}{l}0 \\
\frac{1}{2} \\
=\end{array}\right|$ & $\begin{array}{l}\text { ERROR ON } \\
\text { AMOUNT }\end{array}$ & & \pm & & & Account & $\begin{array}{c}\text { PROJECT } \\
\text { CODE }\end{array}$ \\
\hline $4,23,5$ & 49 & $E$ & -1 & M. & $1 \quad 1 \quad 1$ & E & & $E$ & & & \\
\hline$P_{1} U_{1}, 2,3,9$ & $19 \quad 1$ & $E$ & -.1 & $M$ & $P \quad 1$ & E & & $\epsilon$ & & & \\
\hline$M_{1} P_{1} P_{1}$ & 40 & E & -1 & $C$ & $i 1$ & E & & H & & & \\
\hline $1 \quad 1 \quad 1 \quad 1$ & 911 & E & 1 & & $1 \quad 1$ & $E$ & & & & & \\
\hline 1.1 & $i_{i} \quad i$ & $E$ & 1 & & $1: 1$ & E & & & & & \\
\hline 1,1 & $P \quad 1$ & $E$ & 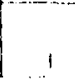 & & 9.1 & $\mathrm{E}$ & & & & & \\
\hline
\end{tabular}

Áay LuLCL

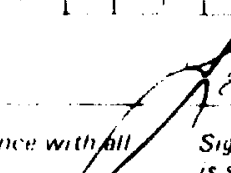

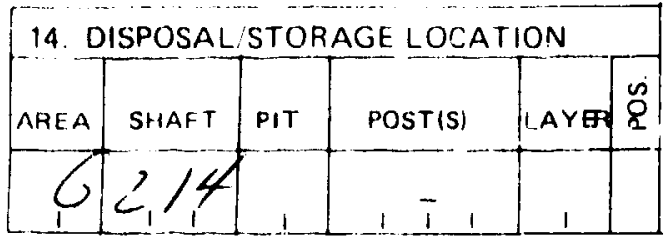



DISPOSAL RECORC FORM

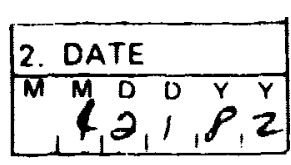

\begin{tabular}{l} 
3. RETRIEVABLE \\
SERIAL NO. \\
\hline BIS 17,19111 \\
\hline
\end{tabular}

\begin{tabular}{|c|c|c|c|c|}
\hline \multicolumn{3}{|c|}{ 4. ORIGIN OF WASTE } & \multirow{2}{*}{$\frac{20}{3}$} & \multirow[b]{2}{*}{ ROOM } \\
\hline GROUP & TA & BLDG. & & \\
\hline$C, M, B, 1,4$ & 3 & $d$ & 9 & 1 \\
\hline
\end{tabular}

\begin{tabular}{|r|}
\hline 5. WASTE \\
CODE \\
\hline$A_{1} 4,1$ \\
\hline
\end{tabular}

6. WASTE DESCRIPTION

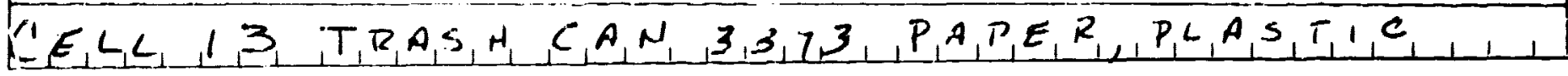
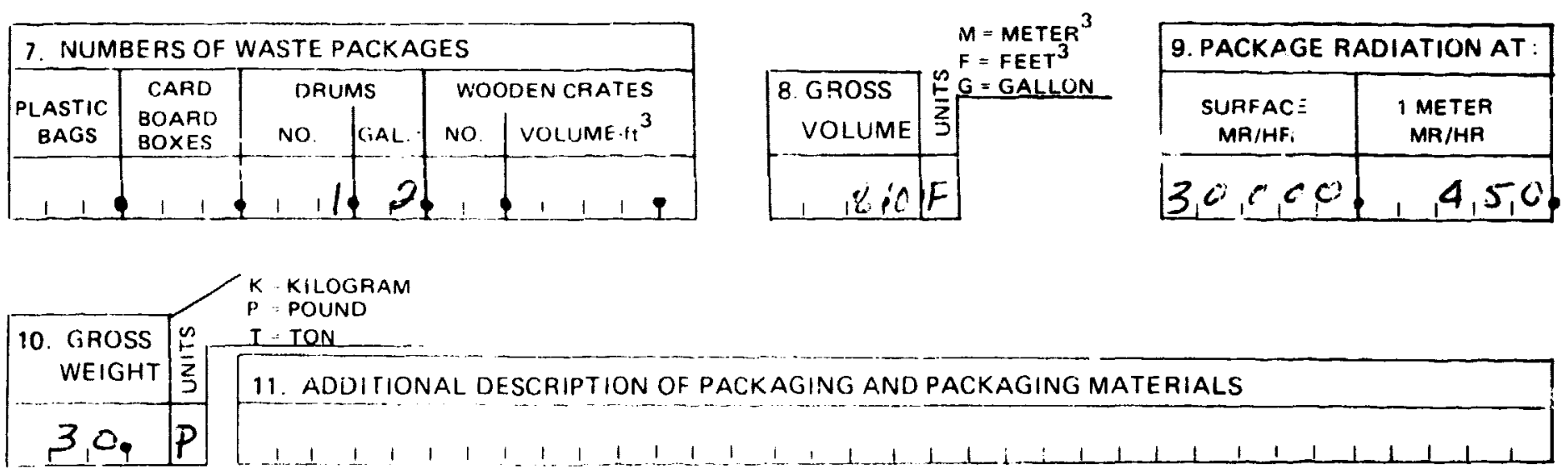

\begin{tabular}{|c|c|c|c|c|c|c|c|c|c|c|}
\hline \multicolumn{4}{|c|}{ 12. ITACIONUCLIUE CONTENT } & \multicolumn{4}{|c|}{$\begin{array}{l}\text { C-CURIE } \\
M \text { GRAM } \\
\end{array}$} & \multirow{2}{*}{$\begin{array}{c}\text { AMOUNT DETERMINED BY: } \\
\text { A }=\text { ANALYSIS } \\
\text { M MEASUREMENT } \\
\text { E - ES TIMATE }\end{array}$} & \multicolumn{2}{|c|}{$\begin{array}{c}\text { SS MATEAIALS } \\
\text { WRITEOFF } \\
\end{array}$} \\
\hline NUCLIDE & AMOUNT & & \pm & $\stackrel{n}{\stackrel{n}{z}}$ & $\begin{array}{l}\text { TRROR ON } \\
\text { AMOUNT }\end{array}$ & & \pm & & ACCOUNT & $\begin{array}{c}\text { PROJECT } \\
\text { CODE }\end{array}$ \\
\hline $4,2,35$ & 9 & & E1 & 16 & $1 \quad 1$ & $E$ & & $z$ & & \\
\hline$P_{1} 61,2,3,9$ & 11 & E & -1 & & 11 & $E$ & & $E$ & & \\
\hline$M_{1} F P$ & A.S & $E$ & -1 & $c$ & 9 & $E$ & & $M$ & & \\
\hline 1111 & $9 \quad 1$ & $E$ & & & 111 & $E$ & & & & \\
\hline 1 & $9 \quad 1 \quad 1$ & E & & & $1 \quad 1$ & $E$ & & & & \\
\hline $1 \quad 1 \quad 1 \quad 1$ & +11 & $E$ & 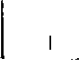 & & 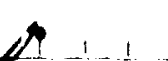 & $E$ & & & & \\
\hline
\end{tabular}

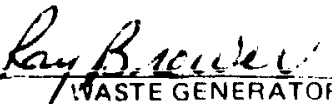
applicanle diswosal requirements. apolicable disposal requirements.

$$
\text { , }
$$

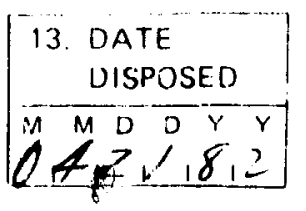

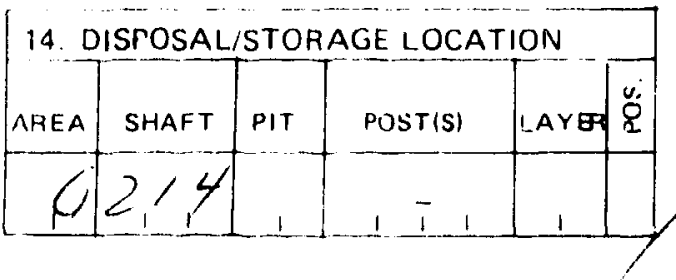

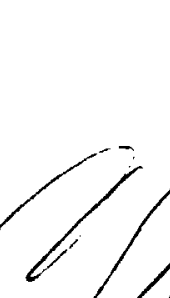

15. SHAFT SUIIFACE DUSE

HS.E $7 \cdot 1$ A $(10 / 81)$

H.7 WASTE MANAGEMENT REPRESENTATIVE Sigmature certifié that waste package or shifment
is safe :o handle and transport.

\section{GROUP LEADER IAS NECESSARY)}


1. FORM NUMBER

S. $3,2,1,82 \mathrm{G}$

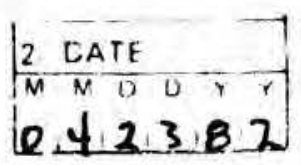

LOS ALAMOS RADIOACTIVE SOLID WASTE DISPOSAL RECORD FORM

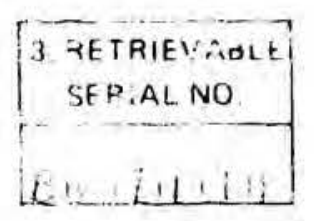

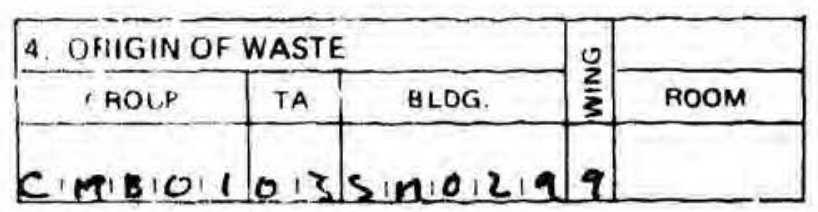

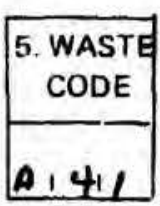

6. WASTE DESCHIPTION

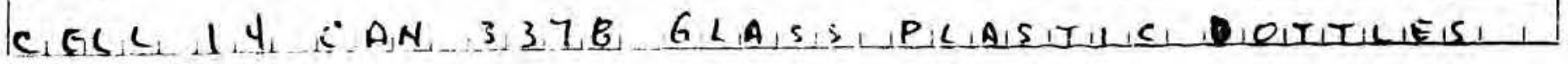

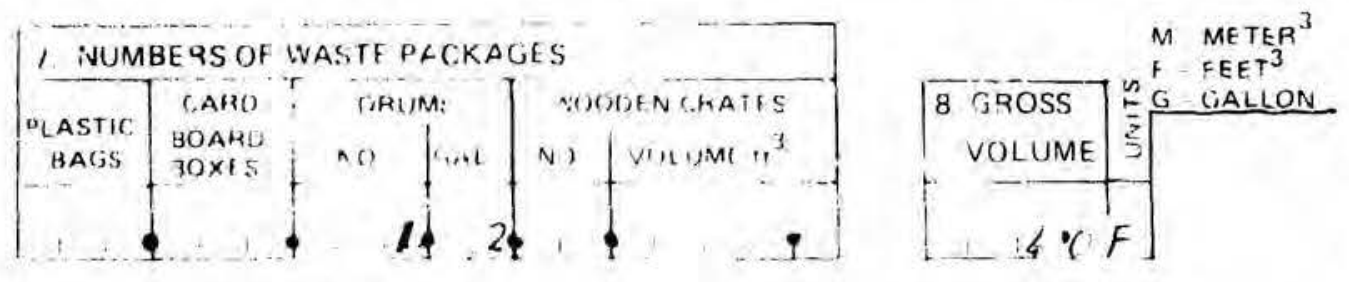

\begin{tabular}{|c|c|}
\hline 9. PACKAGE RADIATION AT \\
\cline { 2 - 3 } $\begin{array}{c}\text { SURFACE } \\
\text { MRIAR }\end{array}$ & $\begin{array}{c}\text { IMETER } \\
\text { MR/MF }\end{array}$ \\
\hline 201000 & 40,0 \\
\hline
\end{tabular}
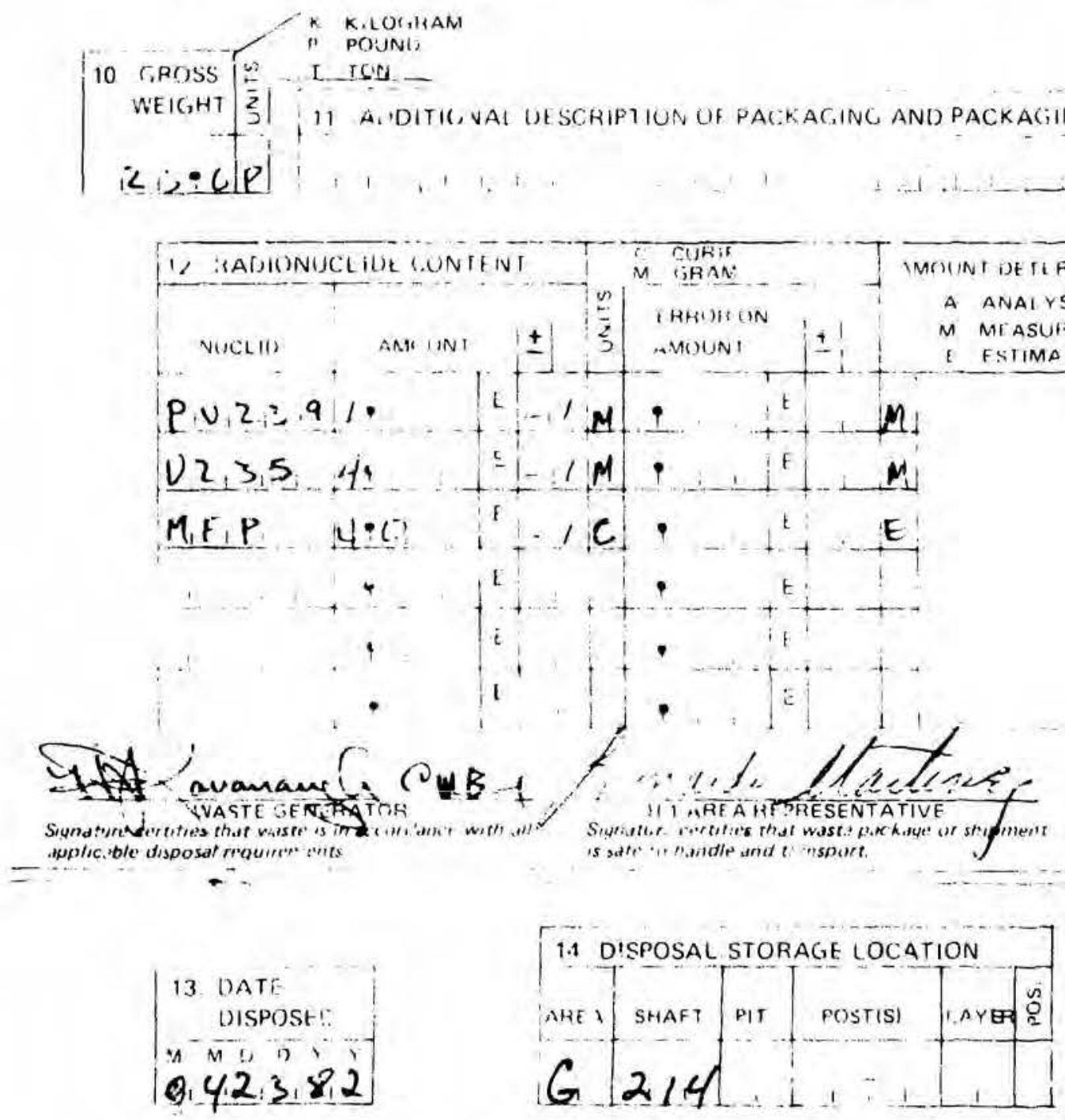

GROUPLFA. TER IAS NECESSAR T-

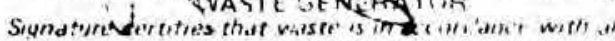
ipplic. ble disposat requirre toits
SS MATERIALS WRITEOFF

PROJECT

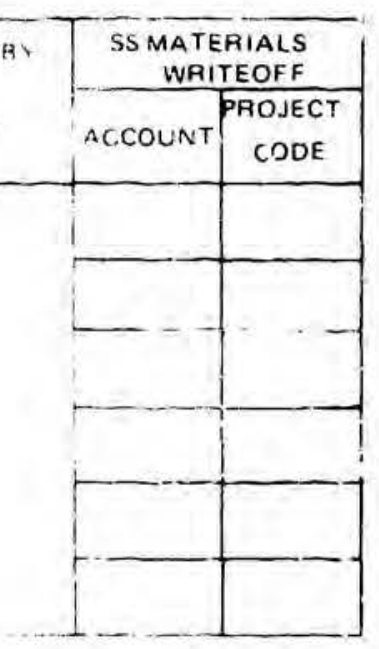

(20)

15. SHAFT QURFACE DUSE

MR/h.7

11.

h.7 UASTE MANAGEMENT RePresentative_G Sulazar

HS-E 7.1A (10/8?) 
PLEASE READ INSTRUCTIONS ON BACK CAREFULLY

\begin{tabular}{|l|}
\hline 1. FORM NUMBER \\
\hline $5,8,23,410$ \\
\hline
\end{tabular}

case w lo collar

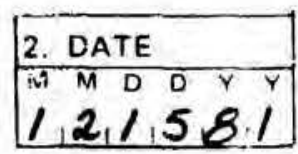

LAS RADIOACTIVE SOLID WASTE DISPOSAL RECORD FORM
H.7 Waste Management

Ext 6095 MS -592

\begin{tabular}{l} 
3. PETRIEVABLE \\
SERIAL NO. \\
\hline B, $0,7,1,9,1$ \\
\hline
\end{tabular}

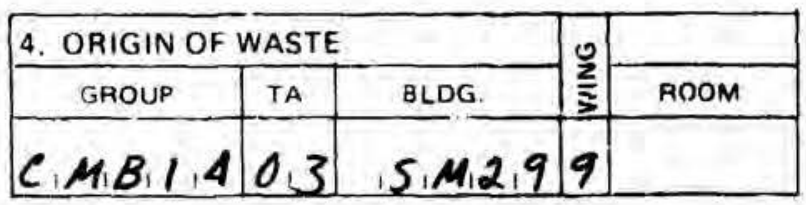

\begin{tabular}{|l|} 
5. WASTE \\
CODE \\
\hline$A, A, I$ \\
\hline
\end{tabular}

6. WASTE DESCRIPTION

$C_{1} E_{1} L_{1}, 3,3, C_{1} E_{1} \leq, 14, H, T, T, A_{1}, H_{1}, C_{1} A_{1} N_{1} S_{1}, 3,3,0,7$

7. INUMBERS OF WASTE PACKAGES

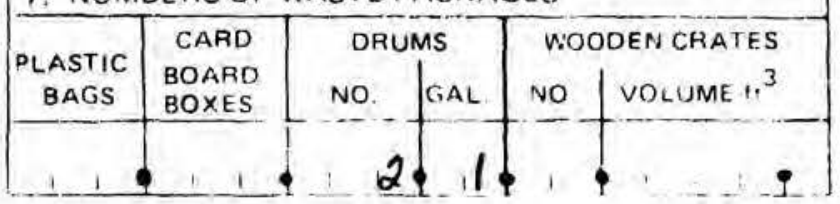

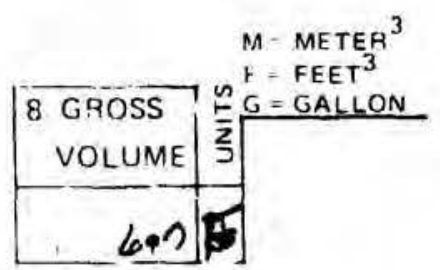

\begin{tabular}{|c|c|}
\hline 9. PACKAGE RADIATION AT \\
\hline $\begin{array}{c}\text { SURFACE } \\
\text { MRIHP. }\end{array}$ & $\begin{array}{c}\text { I METER } \\
\text { MAIA }\end{array}$ \\
\hline & $1,3,0,0$ \\
\hline
\end{tabular}
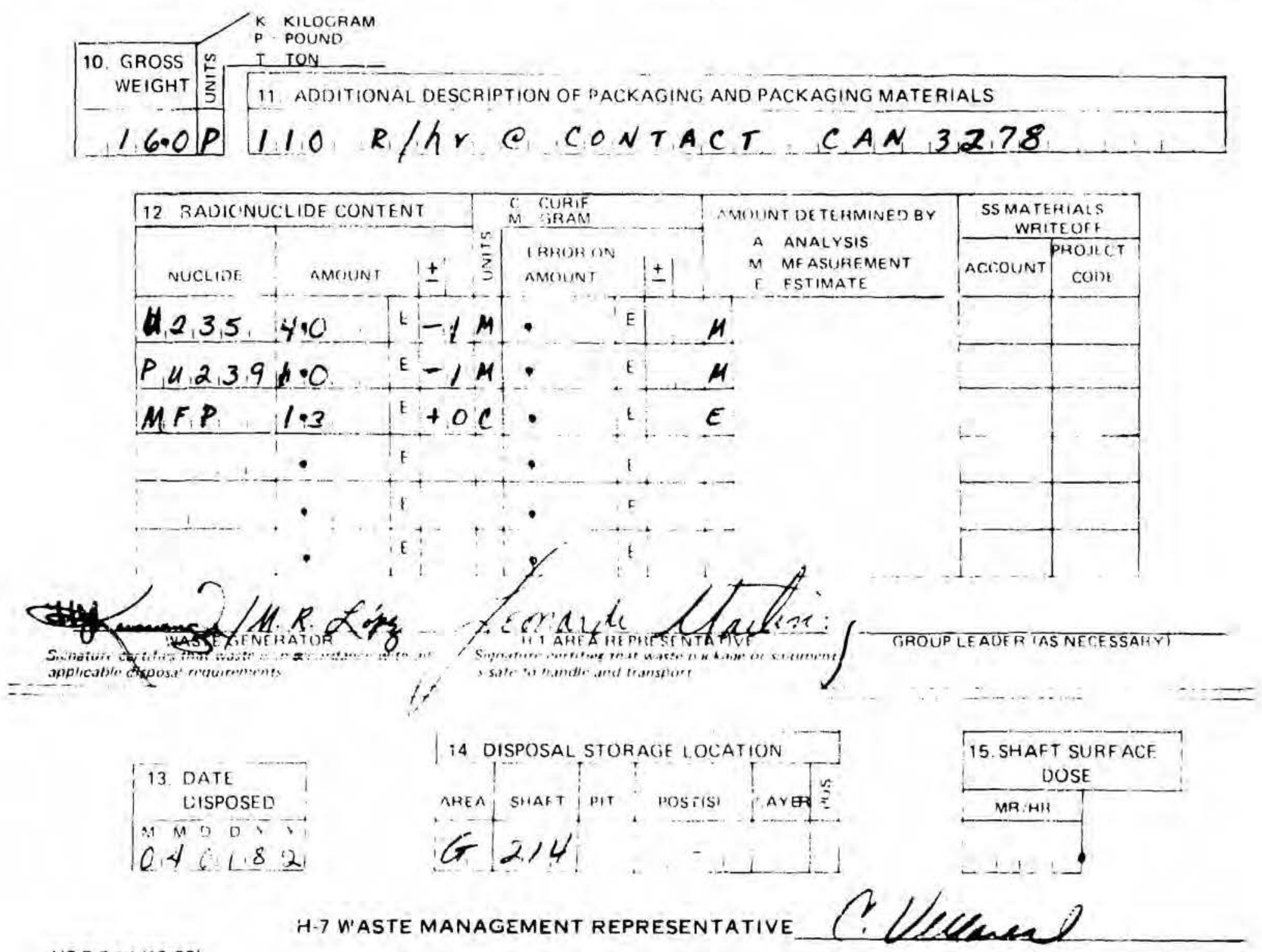

HS.E 7.1A(10/80) 
RADIOACTIVE SOLID WASTE DISPOSAL RECORD FORMS

FOR

SHAFT 215

MATERIAL DISPOSAL AREA G 
\begin{tabular}{c} 
cell \\
1. FORM NUMBER \\
\hline$s, 8,2,0041$ \\
\hline
\end{tabular}

PLEASE FAD INSTRUCTIONS ON BACK CA FULLY

LOS ALAMO RADIOACTIVE SOLID WASTE DISPOSAL RECORD FOAM

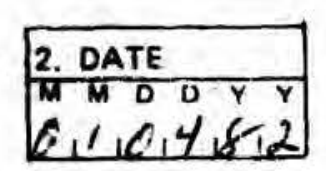

\begin{tabular}{|l|}
\hline $\begin{array}{c}\text { 3. RETRIEVABLE } \\
\text { SERIAL NO. }\end{array}$ \\
\hline BIO 191914,7 \\
\hline
\end{tabular}

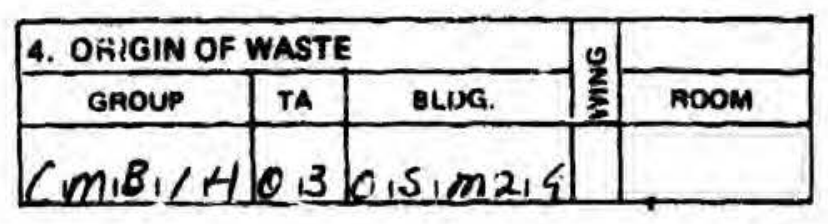

\begin{tabular}{|c|}
\hline 5. WASTE \\
CODE \\
\hline 2,412 \\
\hline
\end{tabular}

6. VIASTE DESCRIPTION

$C_{1} E_{1} L_{1}, g_{1}$ if $U_{k}, 1, C A_{1} N_{1}, 3,3,12$
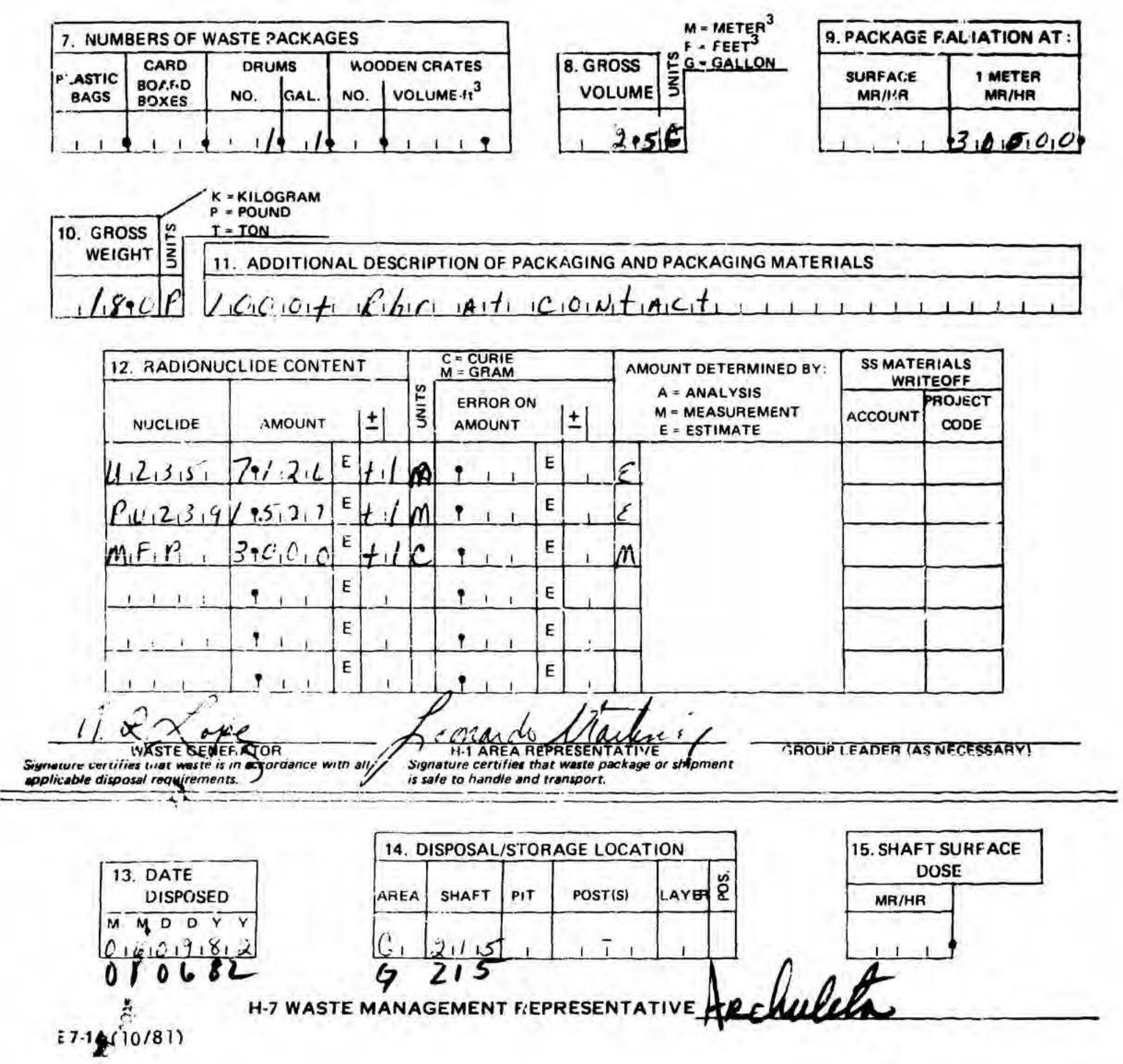
PLEATE READ INSTRUCTIONS ON BACK GAREFULLY

\section{FoRM NUMBEP \\ s, $8,2,0092$}

\section{LOS AL AWHS RADIOACTIVE SOLID WASTE DISPOSAL RECORD FORM}

H.f Wiste Marartumer:

E. 6095 MS.5:12

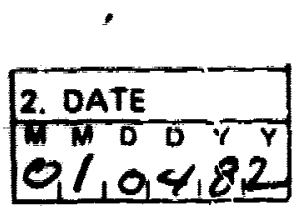

\begin{tabular}{c} 
3. AETRIEVABI.E \\
SERIAL NO. \\
\hline B, $0,9,9,4,7$ \\
\hline
\end{tabular}

\begin{tabular}{|c|c|c|c|c|}
\hline \multicolumn{3}{|c|}{ 4. OAIGIN OF WASTE } & \multirow{2}{*}{ 氕 } & \multirow[b]{2}{*}{ FOOM } \\
\hline GAOUP & TA & BLDG. & & \\
\hline & & & & \\
\hline
\end{tabular}

\section{WASTE DESCRIPTION}

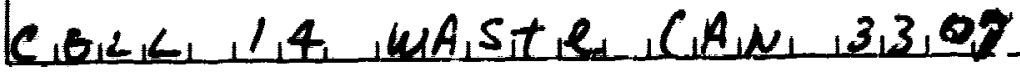

\begin{tabular}{|c|c|c|c|c|c|}
\hline \multicolumn{6}{|c|}{ 7. NUMBERS OF WASTE PACKAGES } \\
\hline & CARD & & & & DEN CRATES \\
\hline $\begin{array}{l}\text { PLASTIC } \\
\text { BAGS }\end{array}$ & $\begin{array}{l}\text { BOARD } \\
\text { BOXES }\end{array}$ & No. & GAL. & No & VOLUME-ft ${ }^{3}$ \\
\hline
\end{tabular}
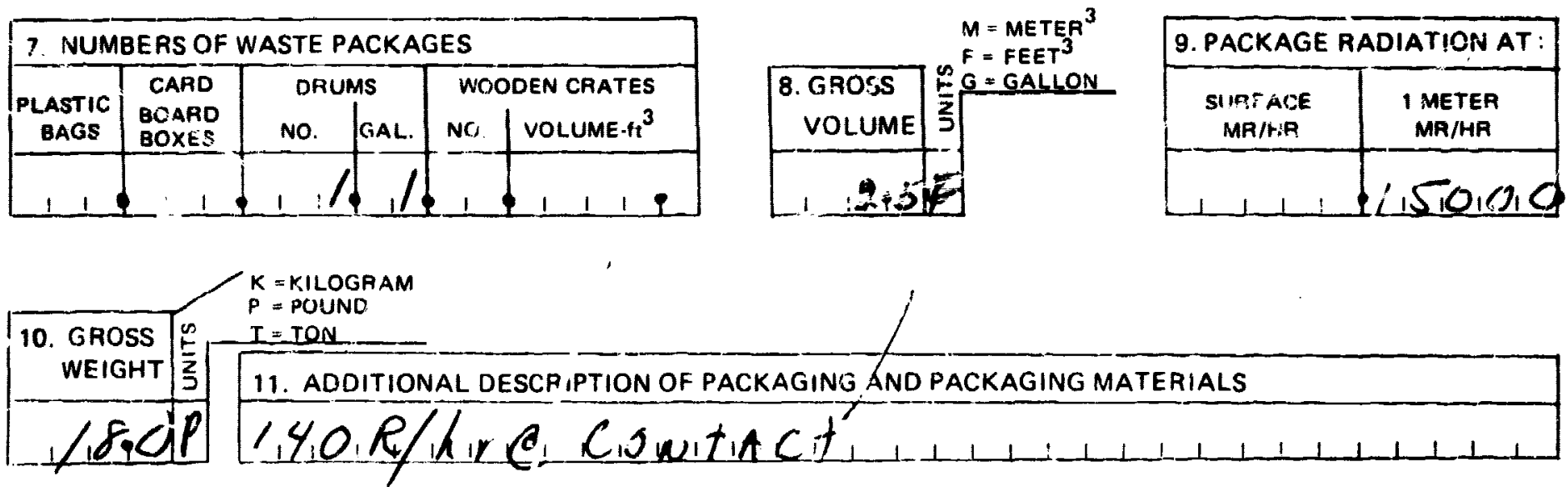

$K=K I L O G R A M$

$P=P O U N D$

$I \equiv$ TON

11. ADDITIONAL DESCRIPTION OF PACKAGING AND PACKAGING MATERIALS

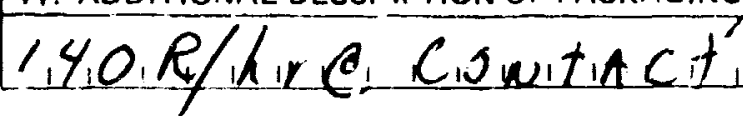

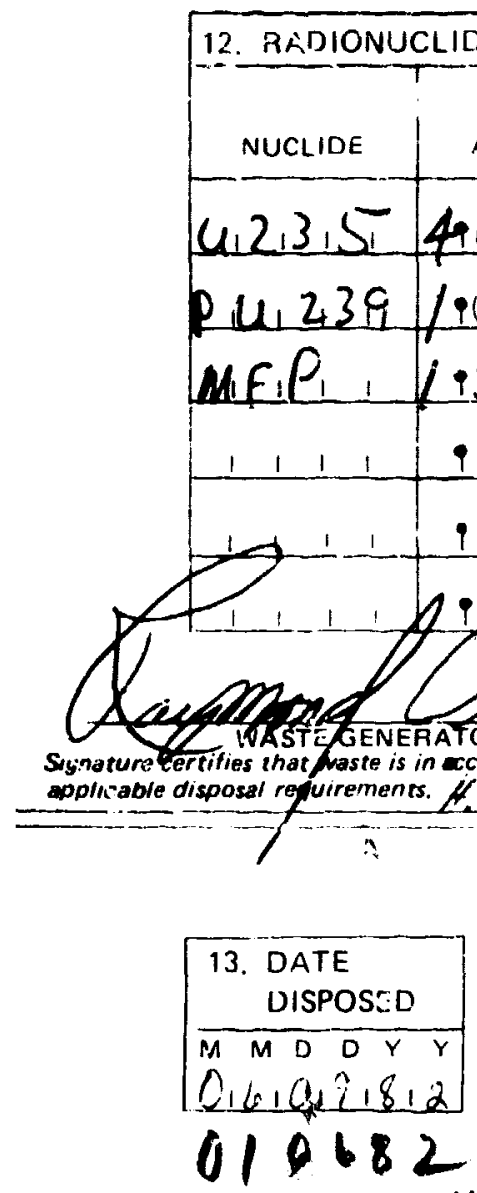

HS-E 7-1A $(10$ \& 1$)$
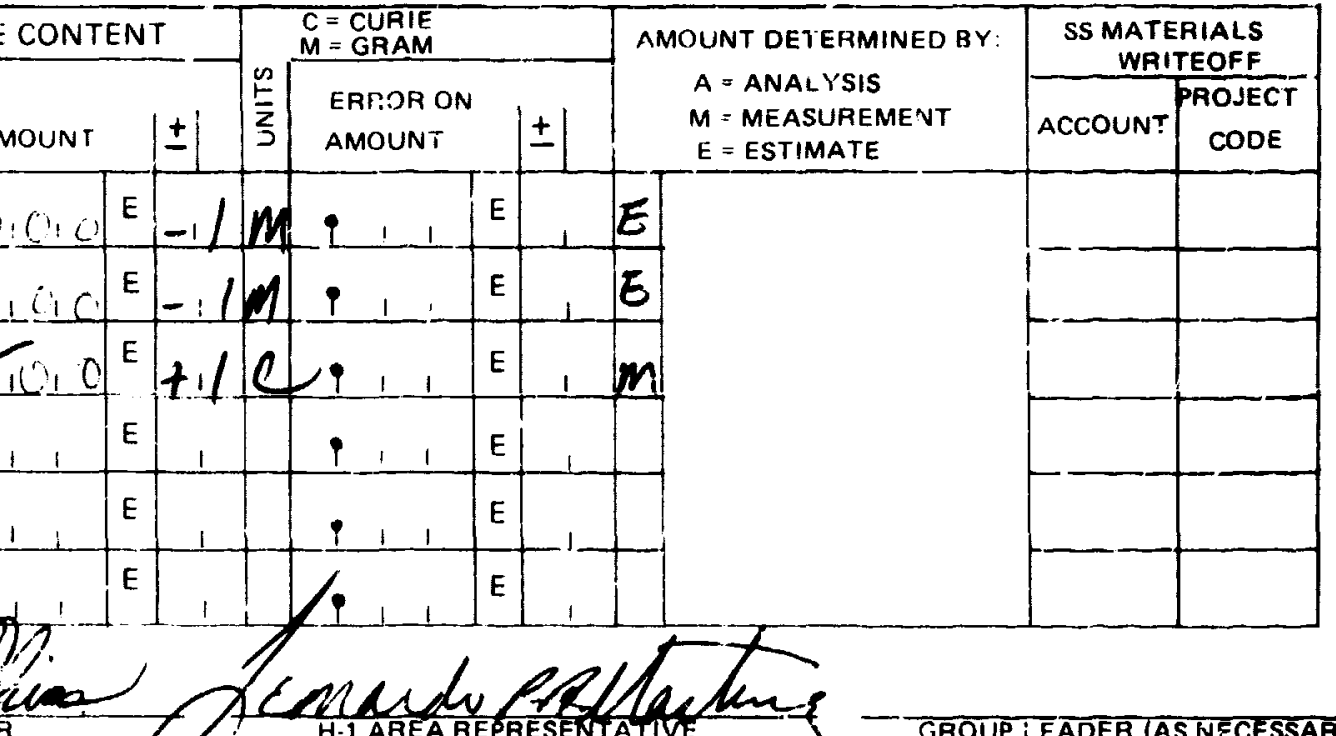
Sisnaturetertifies that waste is in eccordance
applnable disposal refuirements. If 5 . 2 I.

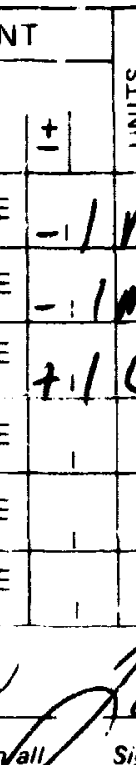
H-1 AREA REPRESENTATIVE (that waste package or shipmen is safe to handle and transport.

\begin{tabular}{|c|c|c|c|c|c|}
\hline AREA & SHAFT & PIT & POST(S) & LAYE & $\mathscr{l}_{1}^{\infty}$ \\
\hline & $2,1,5$ & 1 & 1 & 1 & \\
\hline
\end{tabular}

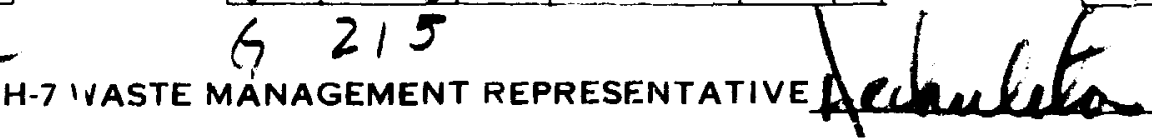

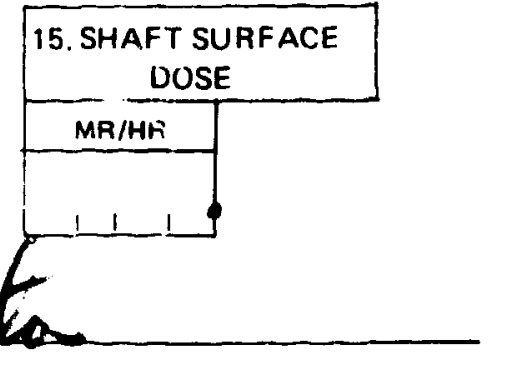


PLEASE READ INSTRUCTIONS ON BACK CAREFULLY
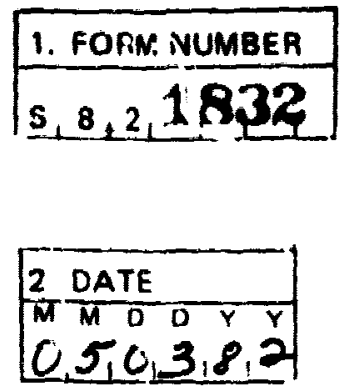

LOS ALAMO RADIOACTIVE SOLID WASTE DISPOSAL RECORD FORM
H 7 Waste Matarembet

F. 6095 M..59\%

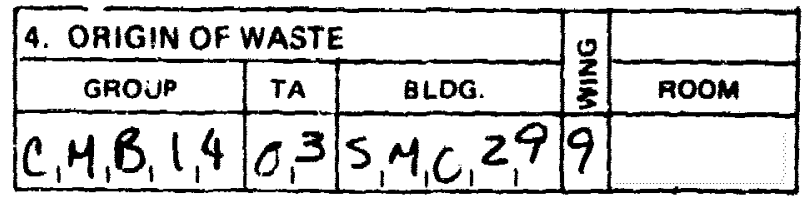

6. WASTE DESCRIPTION

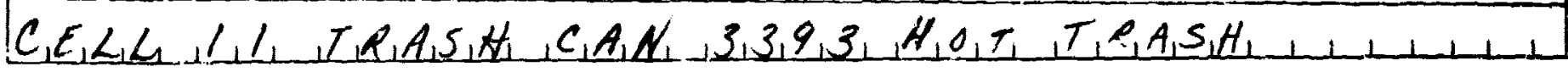

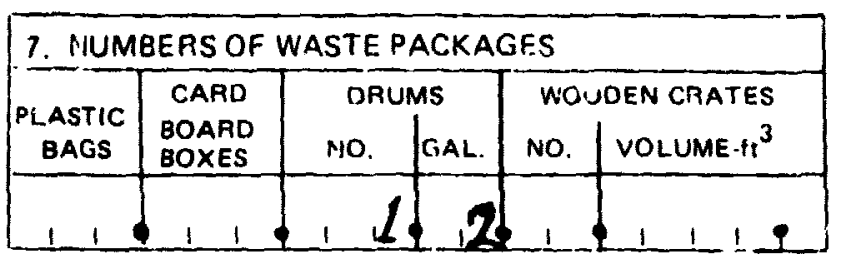

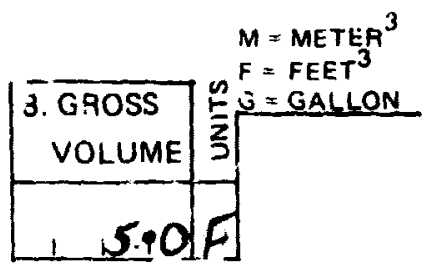

\begin{tabular}{|c|c|}
\hline \begin{tabular}{c} 
9. PACKAGE RADIATINN AT: \\
\hline $\begin{array}{c}\text { SURFACE } \\
\text { MR/HR }\end{array}$
\end{tabular} & $\begin{array}{c}\text { I METER } \\
\text { MAIA }\end{array}$ \\
\hline $3,5,0,0,0$ & $2,0,0,0$ \\
\hline
\end{tabular}
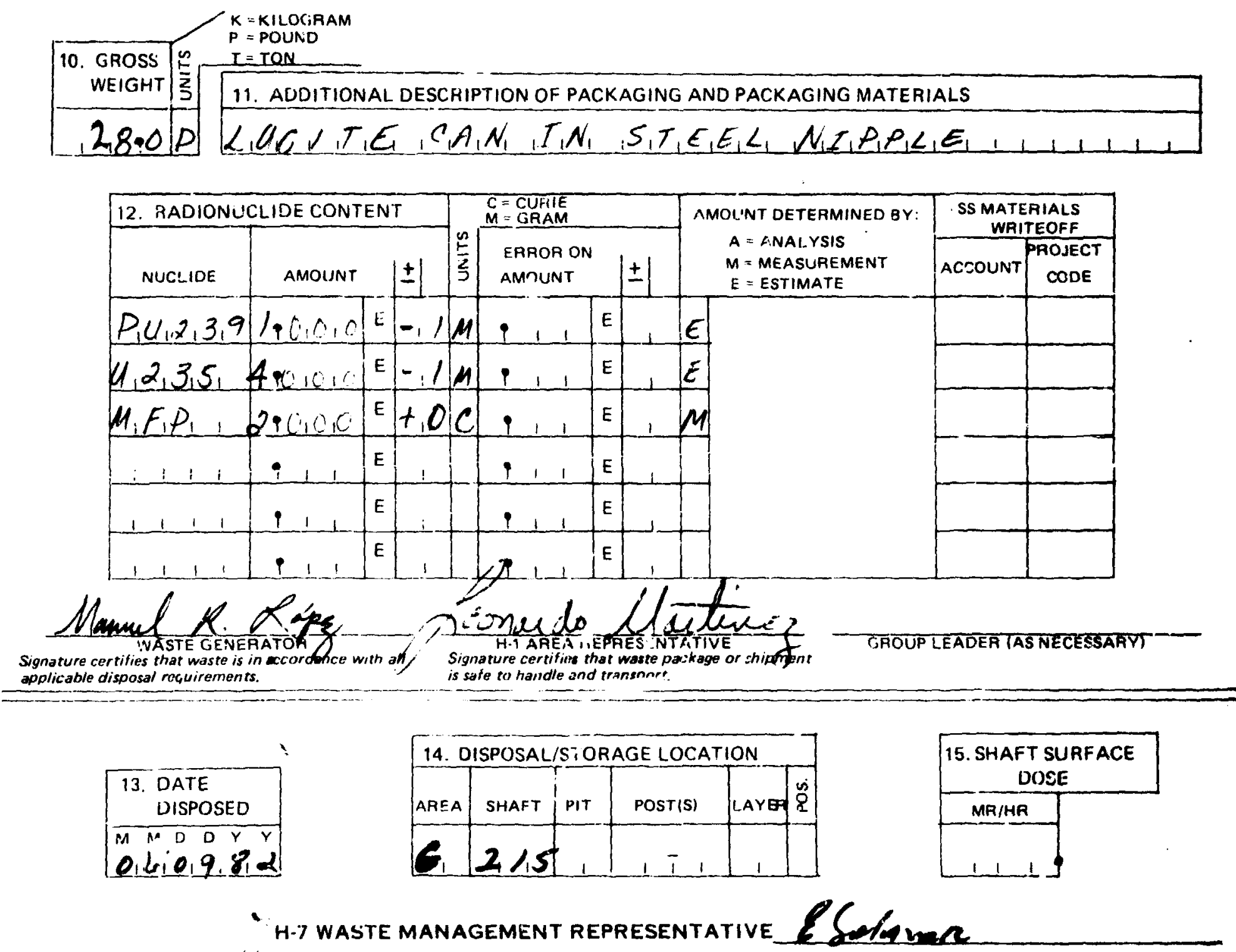

HST 7-1A ( $10 / 81)$ 
PLEASE RE AD INSTRUCTIONS ON BACK CAREFULLY
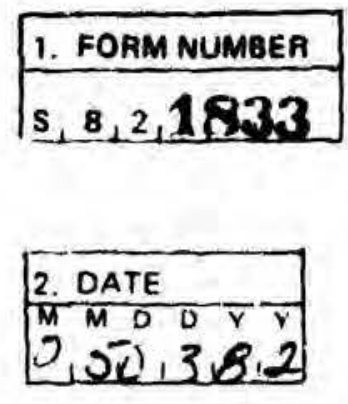

LOS ALAMOS RADIOACTIVE SOLID WASTE DISPOSAL RECORD FORM

\begin{tabular}{l} 
3. RETRIEVABLE \\
SERIAL NO \\
\hline$B, 0,9,9,4,7$
\end{tabular}

\begin{tabular}{|c|c|c|c|c|}
\hline \multicolumn{2}{|l|}{ O. ORIGIN OF WASTE } & 0 & \\
\hline GROUP & TA & BLOG. & : & ROOM \\
\hline$C, M Q / 14$ & $0,30,5, \mu, 2,9$ & 0 \\
\hline
\end{tabular}

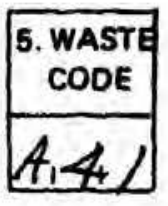

6. WASTE DESCRIPTION

$C_{1} \epsilon_{1}<L_{1}$ i file $H_{1} O_{1} I_{1}, T_{1}, A_{1} S_{1} H_{1}, C_{1} A_{1} N, 3,30, O$

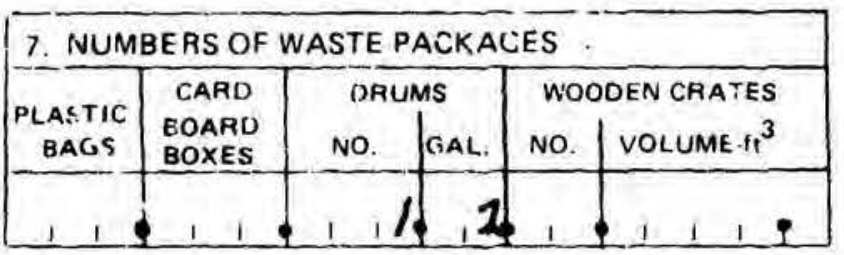

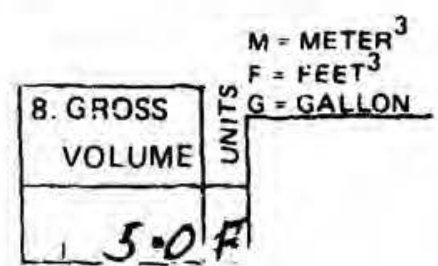

\begin{tabular}{|c|c|}
\hline 9. PACKAGE RADIATION AT: \\
\hline $\begin{array}{c}\text { SURFACE } \\
\text { MR! HR }\end{array}$ & $\begin{array}{c}1 \text { METER } \\
\text { MR/HR }\end{array}$ \\
\hline $1,130,0$, \\
\hline
\end{tabular}
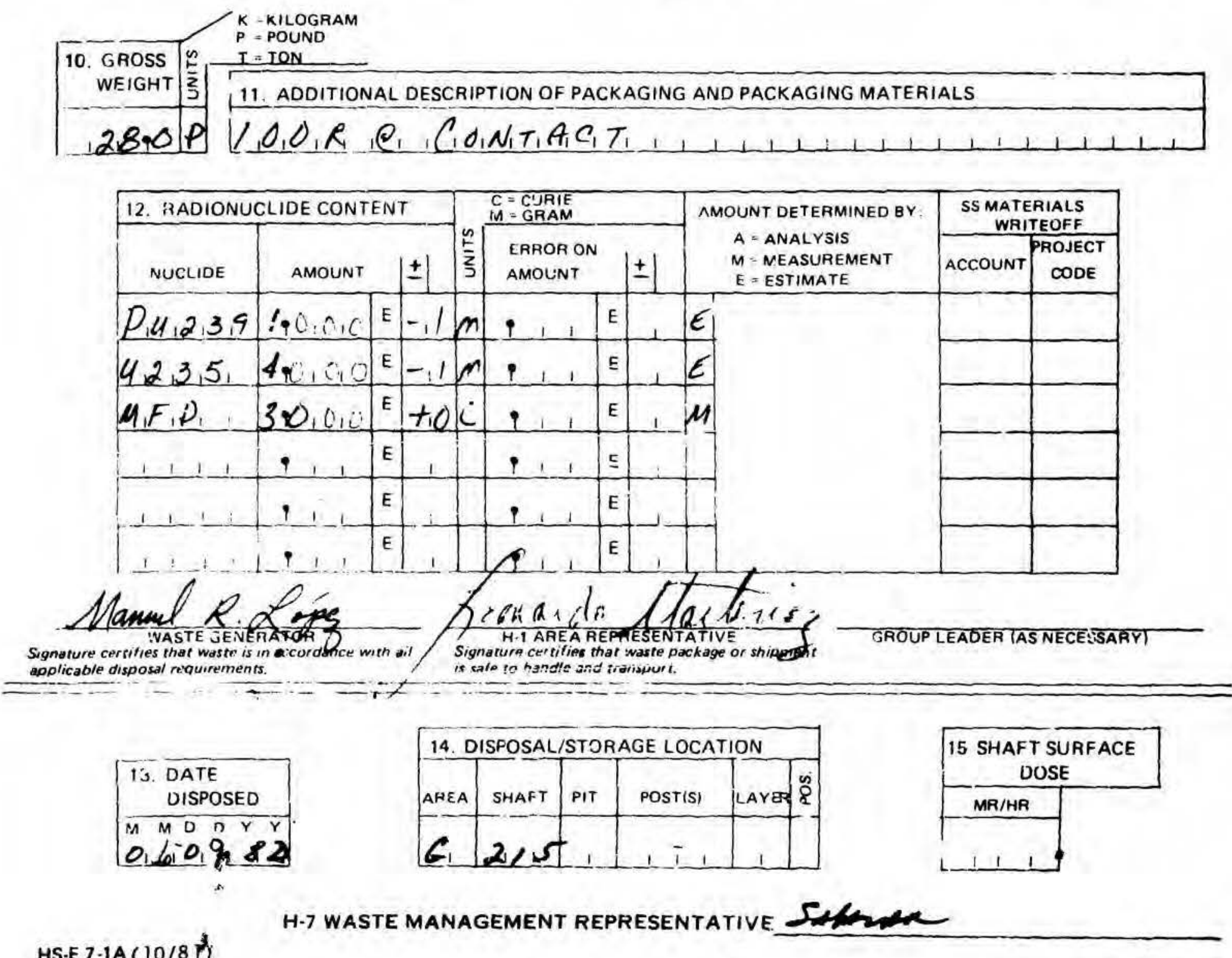

HST 7-1A $10 / 8$ H 
PLEASE READ INSTRUCTIONS ON BACK CAREFULLY

\section{FORM NUMBER \\ s, $8,2,18,39$}

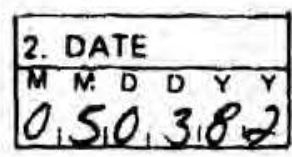

\section{LOS ALAMOS RADIOACTIVE SOL'D WASTE} DISPOSAL RECORD FORM

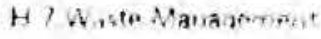

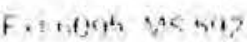

\begin{tabular}{|l|}
\hline $\begin{array}{l}\text { 3. RETRIEVABLE } \\
\text { SERIAL NO. }\end{array}$ \\
\hline BIC, $9,914,7$ \\
\hline
\end{tabular}

\begin{tabular}{|c|c|c|c|c|}
\hline \multicolumn{3}{|c|}{ 4. ORIGIN OF WASTE } & \multirow{2}{*}{$\begin{array}{l}0 \\
\frac{2}{3} \\
\end{array}$} & \multirow[b]{2}{*}{ ROOM } \\
\hline GAOUP & $T A$ & BLDG. & & \\
\hline$\left.C_{i} \mu_{1} B_{1}\right)$ & 1 & $5, \mu_{10}: 9$ & 9 & \\
\hline
\end{tabular}

\begin{tabular}{|l|}
\hline 5. WASTE \\
CODE \\
\hline $4,4,0$ \\
\hline
\end{tabular}

6. WASTE DESCRIPTION

$C_{1} E_{1}<L_{1}, / 3, H_{1} \theta_{1} T, T, R, A S, H, G A N, 32,92$
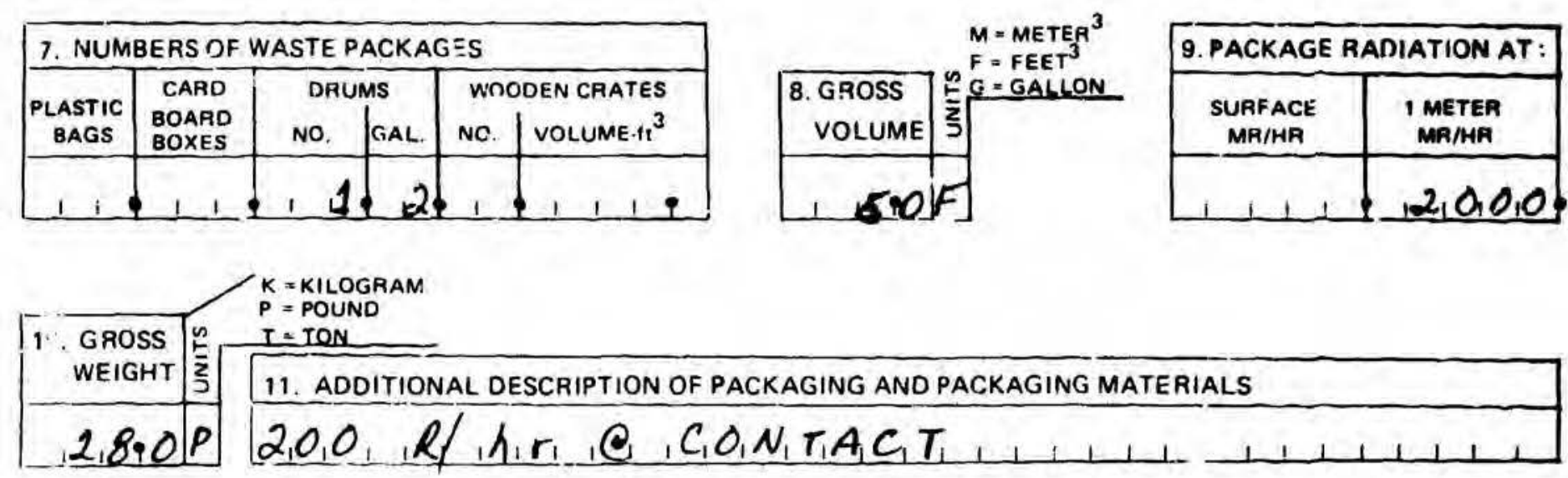
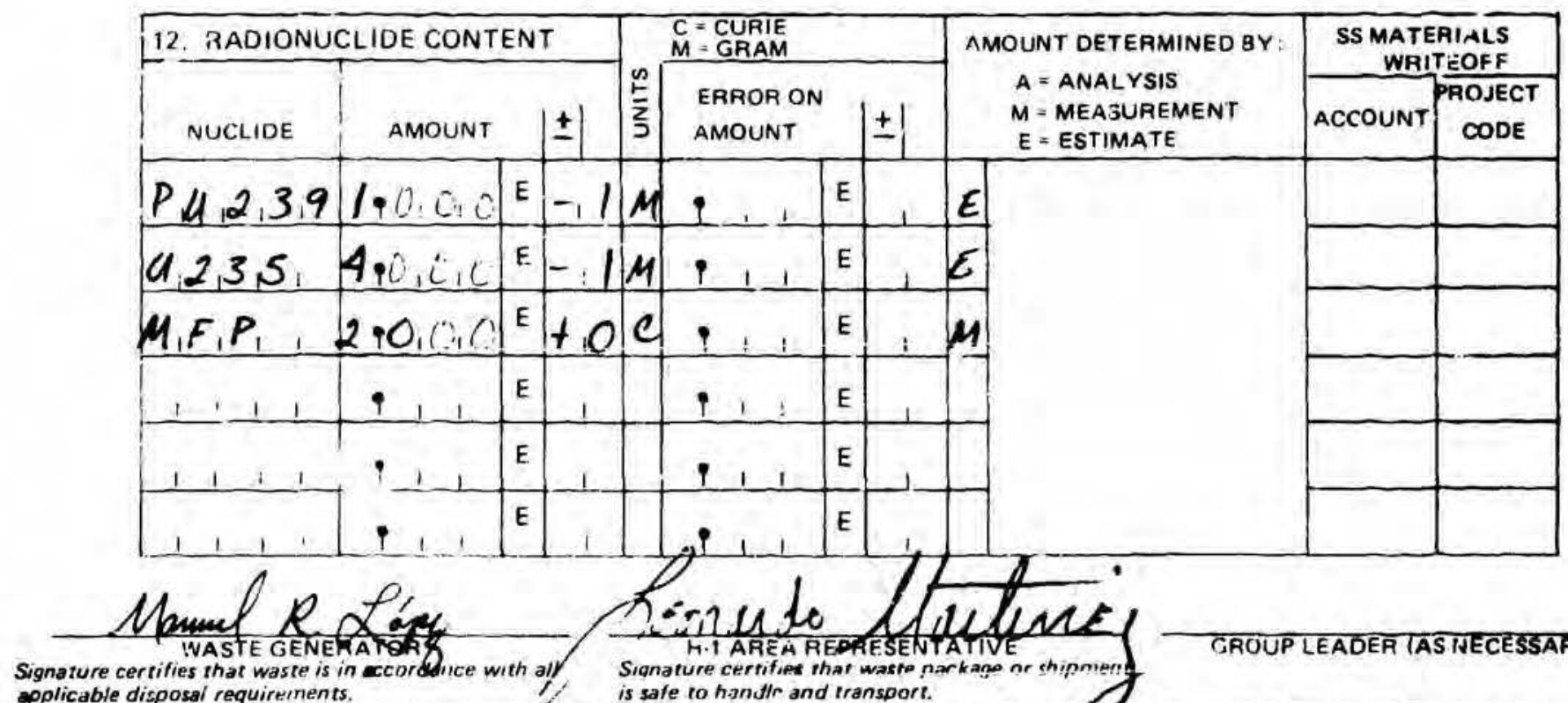
is safe to handlr and transport.

\begin{tabular}{l} 
13. DATE \\
DISFOSEU \\
\hline 19 M D D Y Y Y \\
$0,0_{1}, 9,8,2$
\end{tabular}

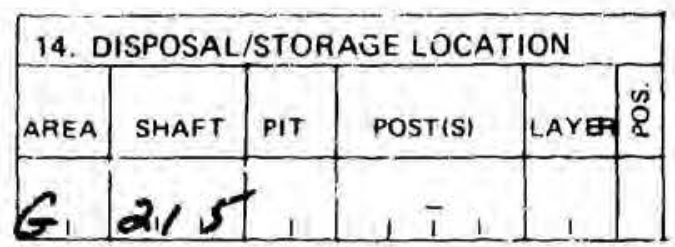

\begin{tabular}{|c|}
\hline \begin{tabular}{|} 
15. SHAFT SURFACE \\
DOSE
\end{tabular} \\
\hline MR/HR \\
\hline 11 \\
\hline
\end{tabular}


\begin{tabular}{|l|}
\hline 1. FOAM NUMBER \\
\hline$S_{1} 8,2,1,8,3,5$ \\
\hline
\end{tabular}

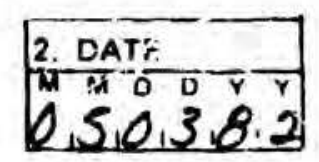

PLEASE READ INSTRECTIUINS ON BACK CAREFUL

LOS ALAMO RADIOACTIVE SOLID WASTE DISPOSAL RECORD FORM

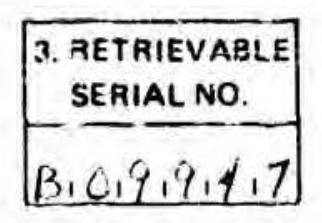

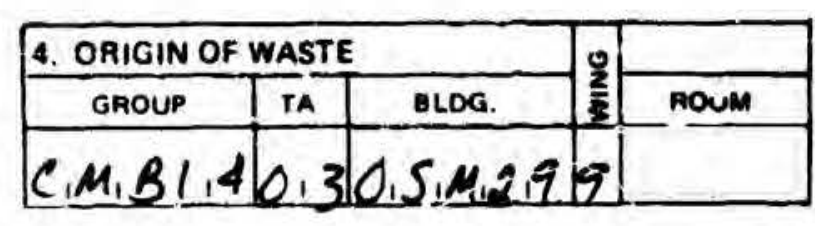

6. WASTE DESCRIPTION

$C_{1} E_{2}<L_{1} / B_{1}, H_{1} O_{1} T_{1}, T, K_{1} A_{1} S_{1} H_{1}, C_{1} A_{1} N_{1}, 3,3, \theta_{1} Z_{1}$

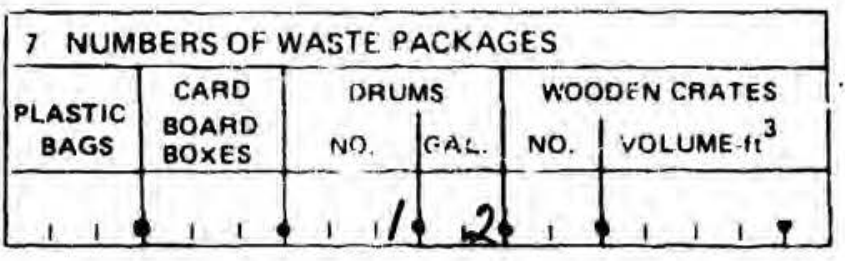

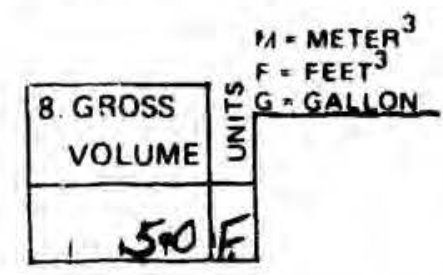

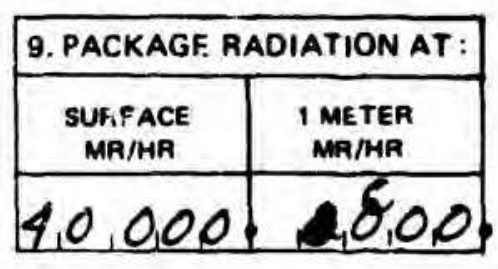
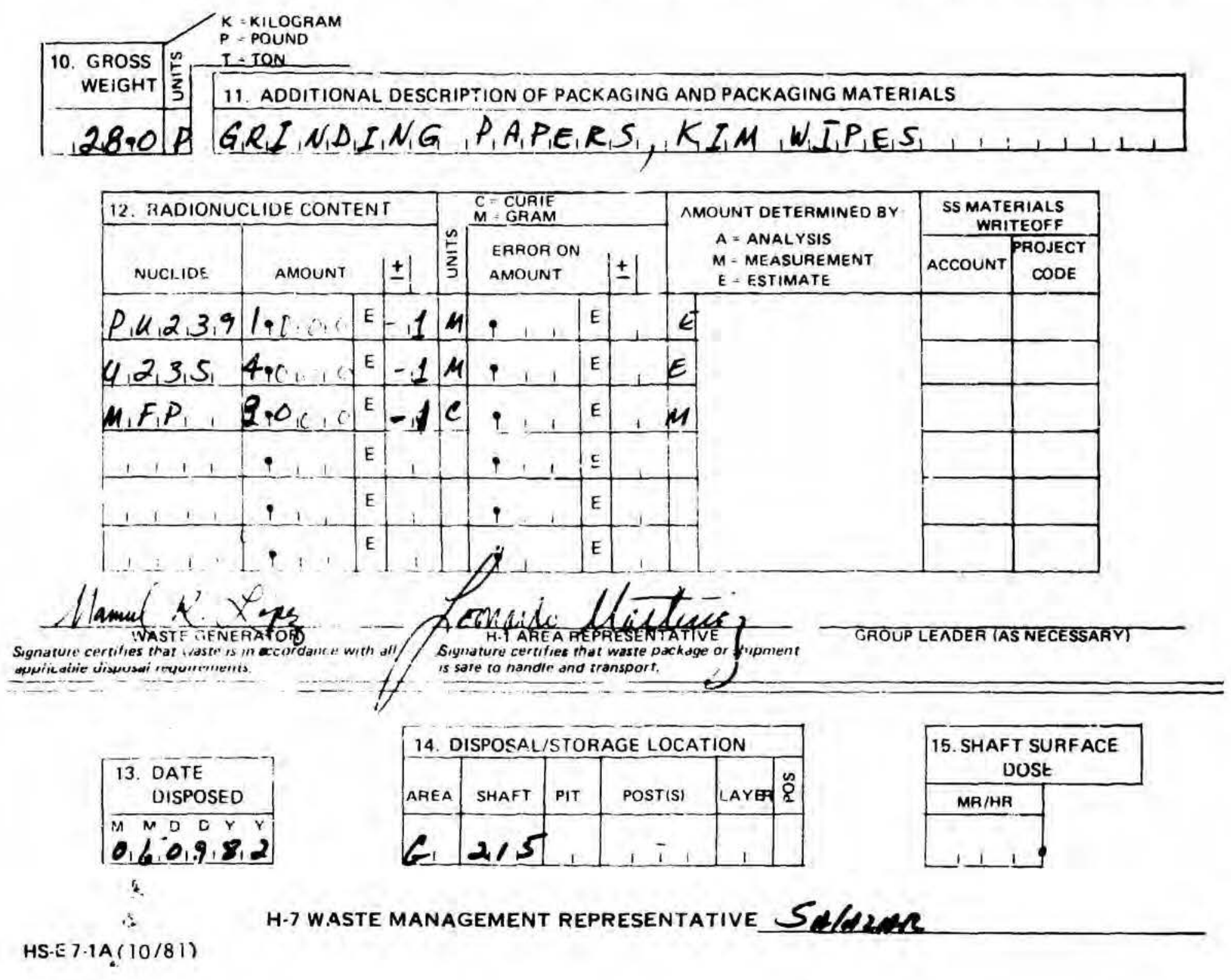
PLEASE READ INSTRUCTIONS ON BACK CAREFULLY

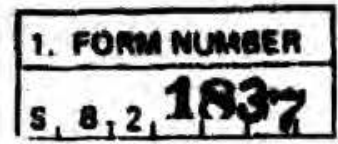

\section{LOS ALAMOS RADIOACTIVE SOLID WASTE DISPOSAL RECORD FORM}

I' 7 Warte Manaqurnem

$t \times 16095$ MS59:

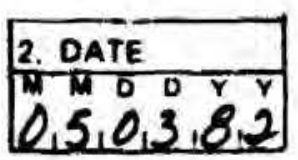

\begin{tabular}{l} 
3. AETRIEVABLE \\
SERIAL. NO. \\
\hline B. $0,919,4,7$ \\
\hline
\end{tabular}

\begin{tabular}{|c|c|c|c|c|}
\hline 4. ORIGIN OF WASTE & \multirow{2}{*}{} & \\
\hline GROUP & TA & OLDG. & & ROOM \\
\hline$C_{1 M 16,1 / 4}$ & 0,3 & $0,5, M_{1}, 9$ & 9 & \\
\hline
\end{tabular}

$\begin{array}{r}\text { 5. WASTE } \\ \text { CODE } \\ \hline 4,40 \\ \hline\end{array}$

6. WASTE OESChIPTIOIN

$C_{1} \varepsilon_{1} L_{1} L_{1}, 1,3, H_{1}, T_{1}, T_{1}, R_{1}, S, H_{1}, G A_{1} N_{1}, 3,4,1,5$

\section{NUMBERS OF WASTE PACKAGES}

\begin{tabular}{|c|c|c|c|c|c|}
\hline & CARD & DR & MS & wo & DEN CAATES \\
\hline $\begin{array}{c}\text { PLASTIC } \\
\text { BAGS }\end{array}$ & $\begin{array}{l}\text { BOARD } \\
\text { BOXES }\end{array}$ & NO. & GAL. & No. & VOLUME $-1 t^{3}$ \\
\hline
\end{tabular}

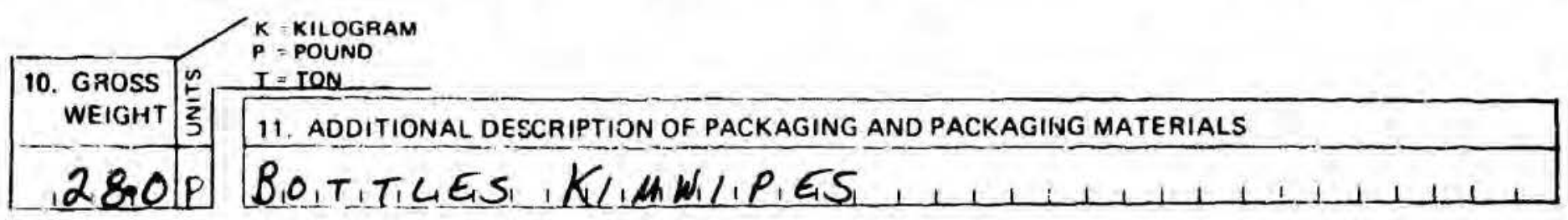

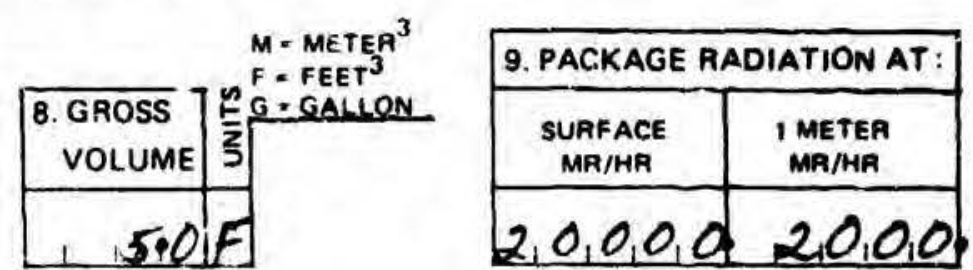

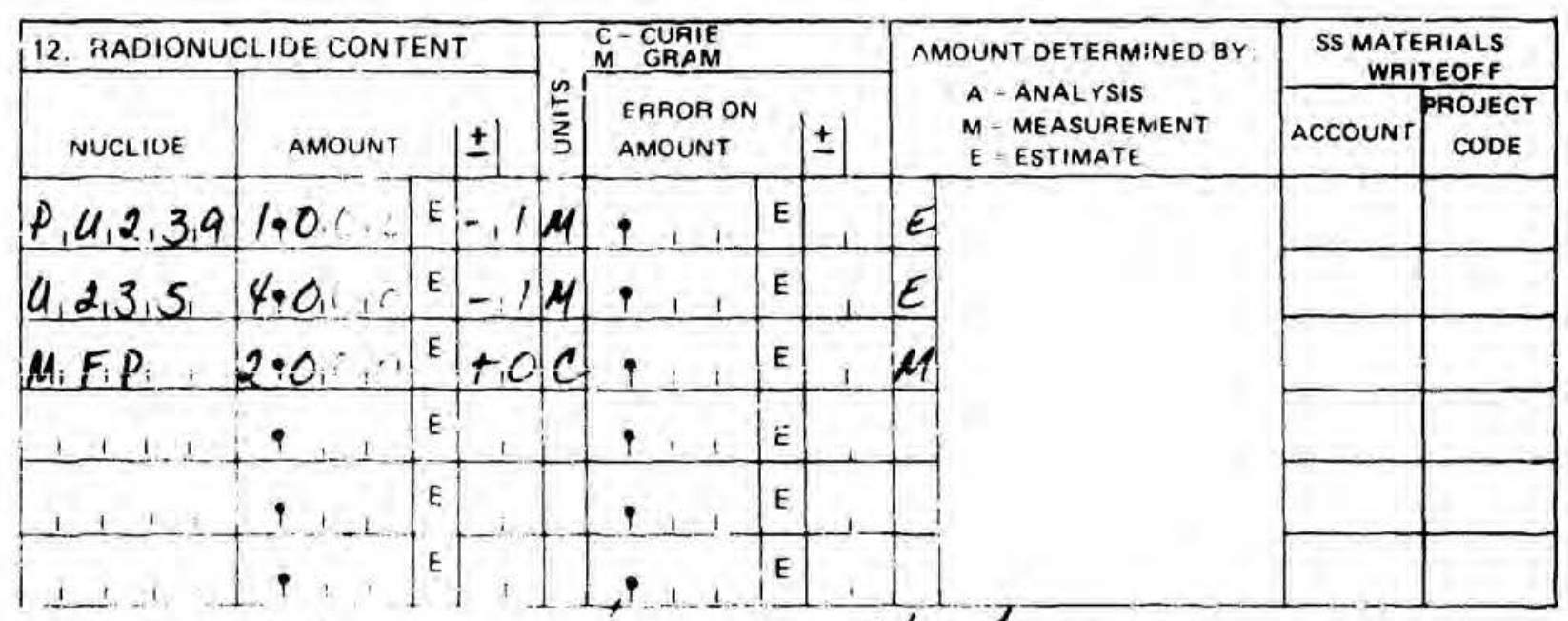

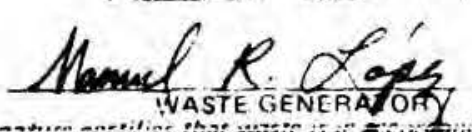

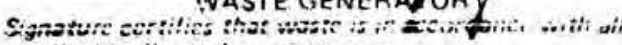
applicable disposal requirements.

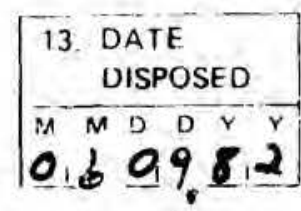

a.

\section{xomade} H.1 AREA REPRESENTATIVE Siytrature certifies ihat waste $p$
is safe to handle an.i transport. MATERIALS

GROUP LEADER (AS NECESSARY)
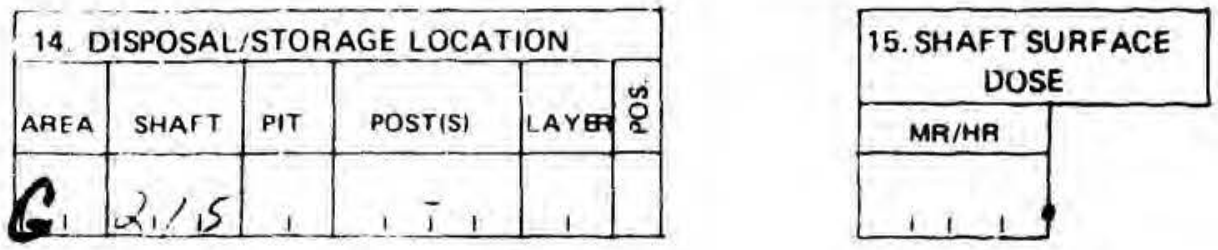

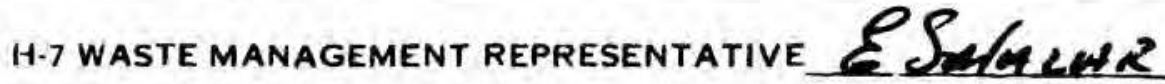

HS-E 7.1A $(10 / 8$ H) 
RADIOACTIVE SOLID WASTE DISPOSAL RECORD FORMS

FOR

SHAFT 216

MATERIAL DISPOSAL AREA G 


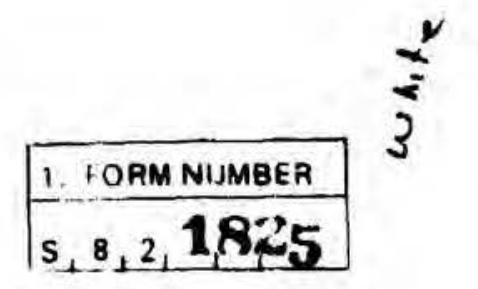

\section{LOS ALAMOS RADIOACTIVE SOLID WASTE DISPOSAL RECORD FORM}

\begin{tabular}{|c|c|}
\hline & 3. नETRIEVABLE \\
\hline 2. DATE & SERIAL NO \\
\hline 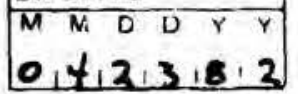 & $B, 0, \vec{i} ;, 1,1$ \\
\hline
\end{tabular}

\begin{tabular}{|c|c|c|c|c|}
\hline \multicolumn{3}{|l|}{ 4. ORIGIN OF WASTE } & 0 & \\
\hline GROUP & TA & BLOG & $\frac{2}{3}$ & ROOM \\
\hline CIMIBIO,1 & 0,3 & SIMIO12,9 & \\
\hline
\end{tabular}

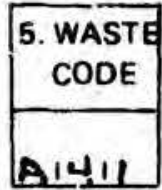

6. WASTE DESCRIPTIOIN

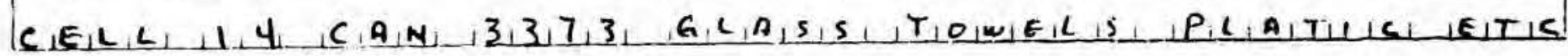
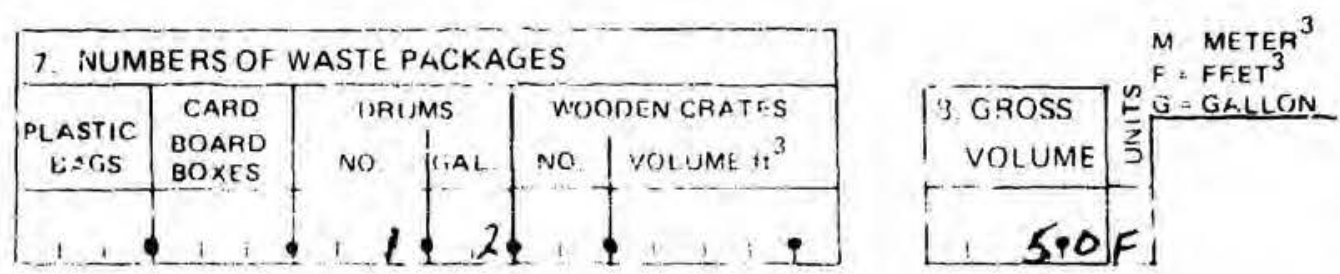

5. PACKAGE RADIATION AT:

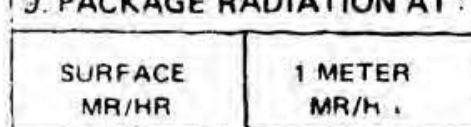

$4101010,01.181010$
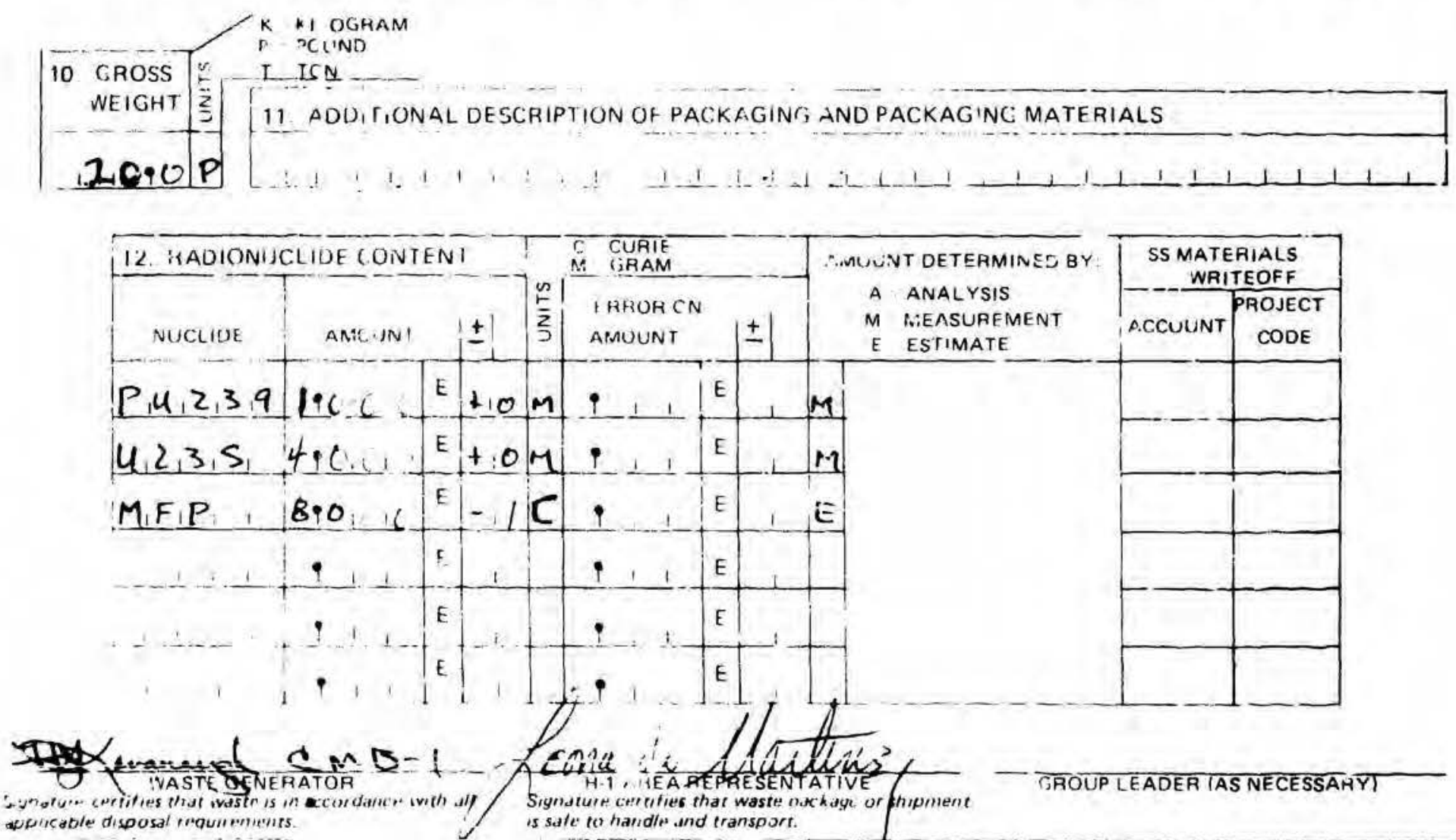
is sale to halidie and transport.

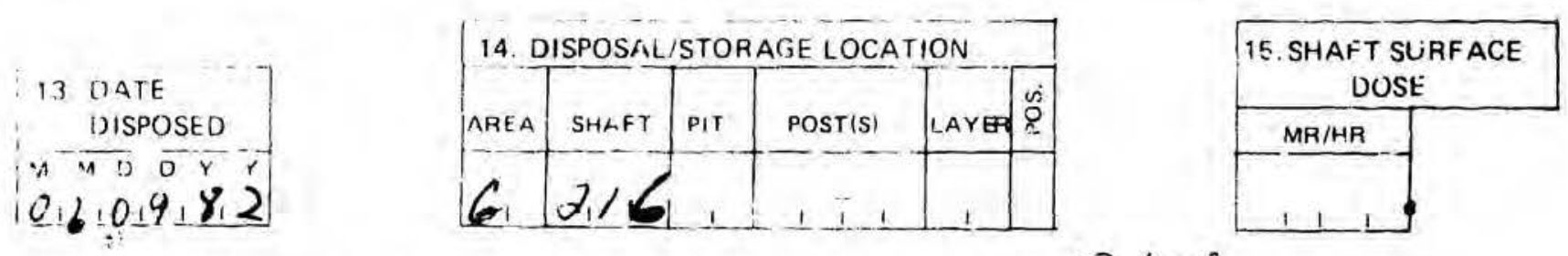




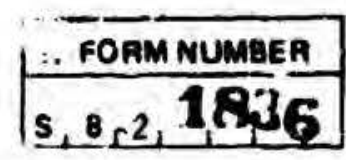

PLEASE READ INSTRUCTIONS GN BACK CAFIFIMI I

\section{LOS ALAMOS RADIOACTIVE SOLID WASTE DISPOSAL RECORD FORM}

Th1 MS 59 ?

\begin{tabular}{l} 
3. HETRIEVABLE \\
SERIAL NO. \\
\hline B: $0,7,2: 41$, \\
\hline
\end{tabular}

\begin{tabular}{|c|c|c|c|c|}
\hline \multicolumn{3}{|c|}{ 4. ORIGIN OF WASTE } & \multirow{2}{*}{ 产 } & \multirow{2}{*}{ A0OM } \\
\hline GROUP & TA & 81.06. & & \\
\hline$\theta$ & & & 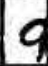 & \\
\hline
\end{tabular}

\section{WASTE DESCRIPTION}

$C_{1}, \varepsilon_{1} L_{1}, !, 3_{1}, H, O_{1}, T, T, R_{1}, S_{1}, H_{1}, C_{1} A_{1}, N_{1}, 3,4,1,6$

\begin{tabular}{|c|c|c|c|c|c|}
\hline \multicolumn{6}{|c|}{ 7. NUMBERS OF WASTE PACKAGES } \\
\hline \multirow{2}{*}{$\begin{array}{l}\text { PLASTIC } \\
\text { BAGS }\end{array}$} & \multirow{2}{*}{$\begin{array}{l}\text { CARD } \\
\text { BOARD } \\
\text { BOXES }\end{array}$} & \multicolumn{2}{|c|}{ DFiUMS } & \multicolumn{2}{|c|}{ WOODEN CRATES } \\
\hline & & NO. & GAL. & No. & VOLUM $\mathrm{h}^{3}$ \\
\hline 11 & 1 & 1 & & i & 1 \\
\hline
\end{tabular}

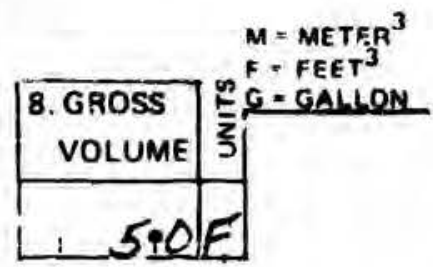

\begin{tabular}{|c|c|}
\hline \begin{tabular}{c} 
9. PACKAGE RADIATION AT: \\
\hline $\begin{array}{c}\text { SURFACE } \\
\text { PARIHR }\end{array}$
\end{tabular} & $\begin{array}{c}\text { I METER } \\
\text { MAMRR }\end{array}$ \\
\hline $2,0,0,0,2$ & $2,0,0,0$ \\
\hline
\end{tabular}

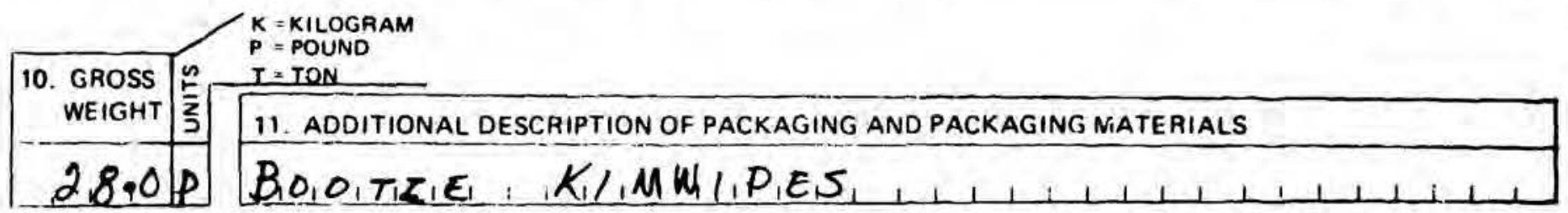

\begin{tabular}{|c|c|c|c|c|c|c|c|c|c|c|c|}
\hline \multicolumn{4}{|c|}{ 12. RADIONUCLIDE CONTENT } & \multicolumn{4}{|c|}{$\begin{array}{l}C \text { CUPIE } \\
M \text { GRAM } \\
\end{array}$} & \multirow{2}{*}{\multicolumn{2}{|c|}{$\begin{array}{c}\text { AMOUNT DETERMINED BY } \\
\text { A - ANALYSIS } \\
\text { M }=\text { ME ASUREMENT } \\
\text { E- ESTIMATE }\end{array}$}} & \multicolumn{2}{|c|}{$\begin{array}{c}\text { SS MATERIALS } \\
\text { WRITEOFF } \\
\end{array}$} \\
\hline NUCLIDE & AMOUNT & & \pm & $\mid \begin{array}{l}\frac{\omega}{2} \\
\frac{2}{2}\end{array}$ & $\begin{array}{l}\text { EAROR ON } \\
\text { AMOUNT }\end{array}$ & & \pm 1 & & & ACCOUNT & $\begin{array}{l}\text { PROJECT } \\
\text { CODE }\end{array}$ \\
\hline$P, 4,2,3,9$ & I $90 \cdot 0.0$ & E & $|-1|$ & $M$ & $1 \perp 1$ & E & & $E$ & & & \\
\hline $4,2,3,5$ & $4 \%, 0_{1}$ & E & -1 & M & $1 \quad 1$ & E & & $E$ & & & \\
\hline$\mu_{i} F_{i} P_{i}$ & 290,0 & E & $\pm C$ & $d c$ & & E & & A & & & \\
\hline 1,11 & $1-1$ & E & 1 & & $1 \quad 1$ & E & & & & & \\
\hline 111 & $1 \pm 1$ & E & 1 & & $i \quad 1$ & E & & & & & \\
\hline 11 & P , , & E & & & : i i & E & & & & & \\
\hline
\end{tabular}

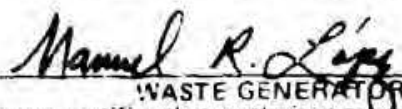

Sigavtere certific: that wate is in a applicable disposal requirements.

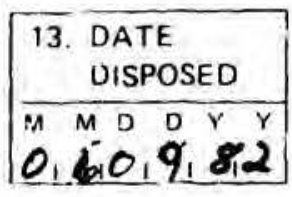
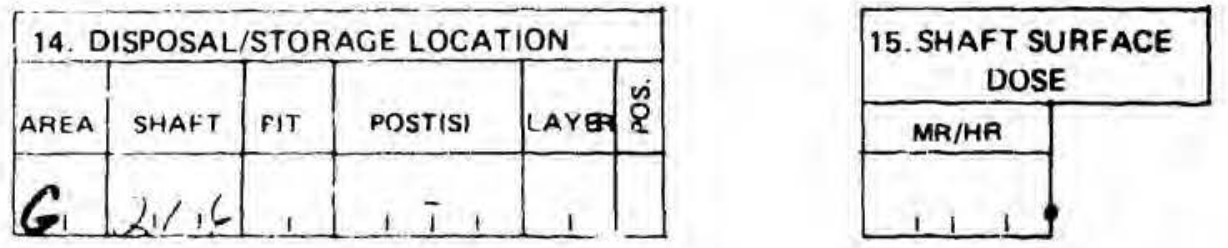

H-7 WASTE MANAGEMENT REPRESENTATIVE 
FLEASE READ INSTRUCTIONS ON BACK CAREFULLY

\section{LOS ALAMOS RADIOACTIVE SOLIS YASTE H 7 Wasie Manaifene! DISPOSAL RECORO FORM

\begin{tabular}{|c|}
\hline $\begin{array}{c}\text { 3. RETAIEVABLE } \\
\text { SERIAL NO. }\end{array}$ \\
\hline BIOI72,611 \\
\hline
\end{tabular}

\begin{tabular}{|c|c|c|c|c|}
\hline 4. ORIGIN OF WASTE & & \\
\hline GAOUP & IA & BLDG & ROOM & ROOM \\
\hline$C_{1} M, 0,1,4$ & 0,3 & $0,5, M, 2,99$ & \\
\hline
\end{tabular}

\section{WASTE DESCRIPTION}

$C_{1} E_{1} L_{1}, 1,1,3, H_{1}, T_{1}, T_{1} R_{1} A_{1} S_{1} H_{1}, C_{1} A_{1} N_{1} *, 3,3,9,5, G, R_{1}, N_{1} D_{1}, N_{1} G_{1}, E_{1}, T_{1}$

\section{NUMBERS OF WASTE PACKAGES}

\begin{tabular}{|c|c|c|c|c|c|}
\hline \multirow[b]{2}{*}{$\begin{array}{c}\text { PLASTIC } \\
\text { BAGS }\end{array}$} & \multirow{2}{*}{$\begin{array}{l}\text { CARO } \\
\text { BOAQD } \\
\text { BOXES } \\
\end{array}$} & \multicolumn{2}{|c|}{ DRUMS } & \multicolumn{2}{|c|}{ WOODEN CRATES } \\
\hline & & NO. & GALL. & No. & VOLUME $\cdot 1 t^{3}$ \\
\hline 11 & 1 & 1 & & 1 & 1119 \\
\hline
\end{tabular}

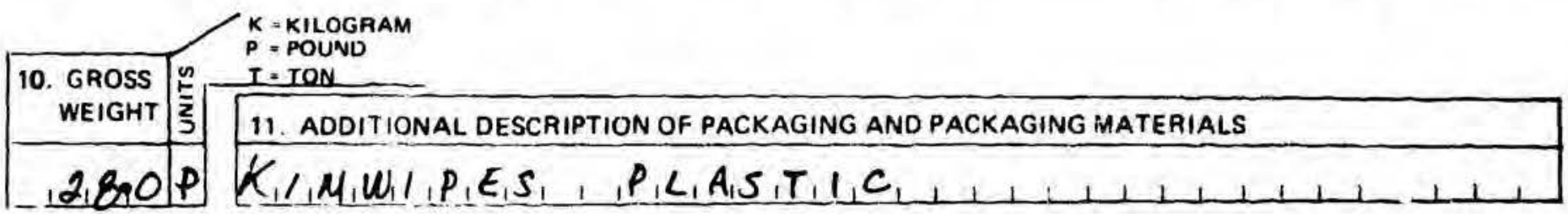

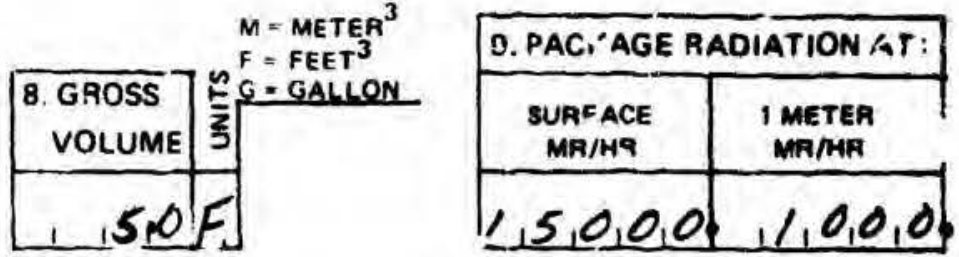

\begin{tabular}{|c|c|c|c|c|c|c|c|c|c|c|}
\hline \multicolumn{4}{|c|}{ 12. RADIONUCLIDE CONTENT } & \multicolumn{4}{|c|}{$\begin{aligned} C & =\text { CURIE } \\
M & =\text { GRAM }\end{aligned}$} & \multirow{2}{*}{ 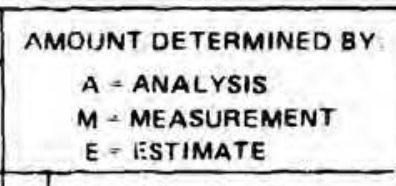 } & \multicolumn{2}{|c|}{$\begin{array}{c}\text { SS MATERIALS } \\
\text { WRITEOFF } \\
\end{array}$} \\
\hline NUCLIDE & AMOUNT & & \pm & $\frac{n}{\Sigma}$ & $\begin{array}{l}\text { ERRDR ON } \\
\text { AMOUNT }\end{array}$ & & \pm & & ACCOUNT & $\begin{array}{c}\text { PAOJECT } \\
\text { CODE }\end{array}$ \\
\hline$P, u, 2,3,9$ & $1.0 .5:$ & E & -11 & $M$ & 11 & $\Xi$ & & $E$ & & \\
\hline $4,2,3,5$ & $4 \cdot O_{1} C_{1}$ & E & -11 & $M$ & 1,1 & E & & $E$ & & \\
\hline$M_{1} F_{1} P_{1}$ & 190,010 & E & +0 & C & 111 & $E$ & & $M$ & & \\
\hline 1111 & 11 & E & & & 11 & $t$ & & & & \\
\hline 1111 & $1-1$ & E & & & 1,1 & E & & & & \\
\hline $1 \quad 1-1$ & 11, & E & 1 & & 911 & E & & & & \\
\hline
\end{tabular}

\section{Mamuel R. Xope}

Signature certifies that waste is in tordance with all applicable disposal requirements.

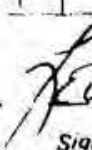
Signaturs cerviee that wasto pac'sage or shipment
is sale to handle and trinsport.
GRO JPLEADER IAS NECESSARY

\begin{tabular}{|c|}
\hline $\begin{array}{l}\text { 13. DATE } \\
\text { JISPOSED }\end{array}$ \\
\hline $\begin{array}{lllll}1 & 0 & 0 & & \\
0,6 & 01 & 9 & 812\end{array}$ \\
\hline
\end{tabular}
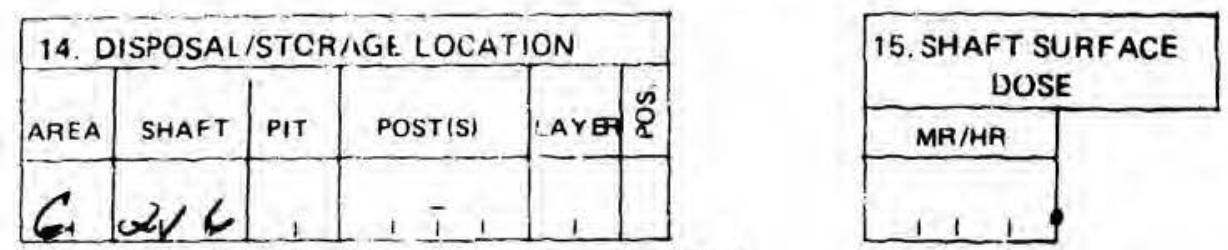

H-7 WASTE MANAGEMENT REPRESENTATIVE

HS-E 7-1A (10/81) 
PLLASE FEAD INGIRUETIONS ON BQCK, AREFLLL ,

\begin{tabular}{|l|}
\hline 1. FORM NUMBE. \\
\hline$S, 8,2,1839$
\end{tabular}

\section{LOS ALAMOS RADIOAC'TIVE SOLID WASTE DISPOSAL REI;ORD FORM}

\begin{tabular}{|c|}
\hline $\begin{array}{l}\text { 3. RETRIEVABLE } \\
\text { SERIAL NO. }\end{array}$ \\
\hline $6,(7,7.21 .91$ \\
\hline
\end{tabular}

\begin{tabular}{|c|c|c|c|c|}
\hline 4. ORI IIN OF WASTE & \multirow{2}{*}{ TA } & \\
\hline GR JUP & BLDG & $\frac{2}{3}$ & ROOM \\
\hline$C_{1} M \boldsymbol{g}_{1} 1,4$ & 0,3 & $U_{1} S, M, 2,9$ & 9 & \\
\hline
\end{tabular}

\begin{tabular}{|c|}
\hline $\begin{array}{l}\text { 5. WASTE } \\
\text { CODE }\end{array}$ \\
\hline$A, 4, C$ \\
\hline
\end{tabular}

6. WASTE DESCRIPTION

$C_{1}, E_{1} L, L, 1,3, H, O, T, T, R, A, S, 1+, C_{1} A_{1}, N_{1}, 3,4,0,5$
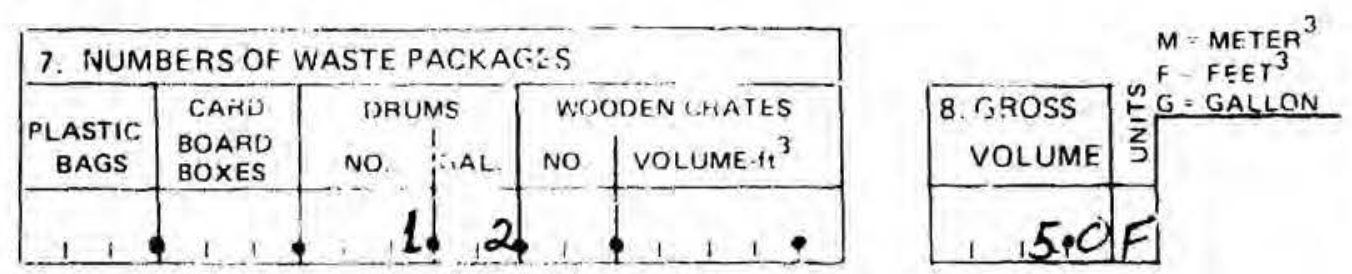

\begin{tabular}{|c|c|}
\hline 9. PACKAGE RADIATION AT: \\
\hline $\begin{array}{c}\text { SURFACE } \\
\text { MRIHR }\end{array}$ & $\begin{array}{c}\text { 1 METER } \\
\text { MR/HR }\end{array}$ \\
\hline $8,0,0,0$ & $1,2,0,0$ \\
\hline
\end{tabular}
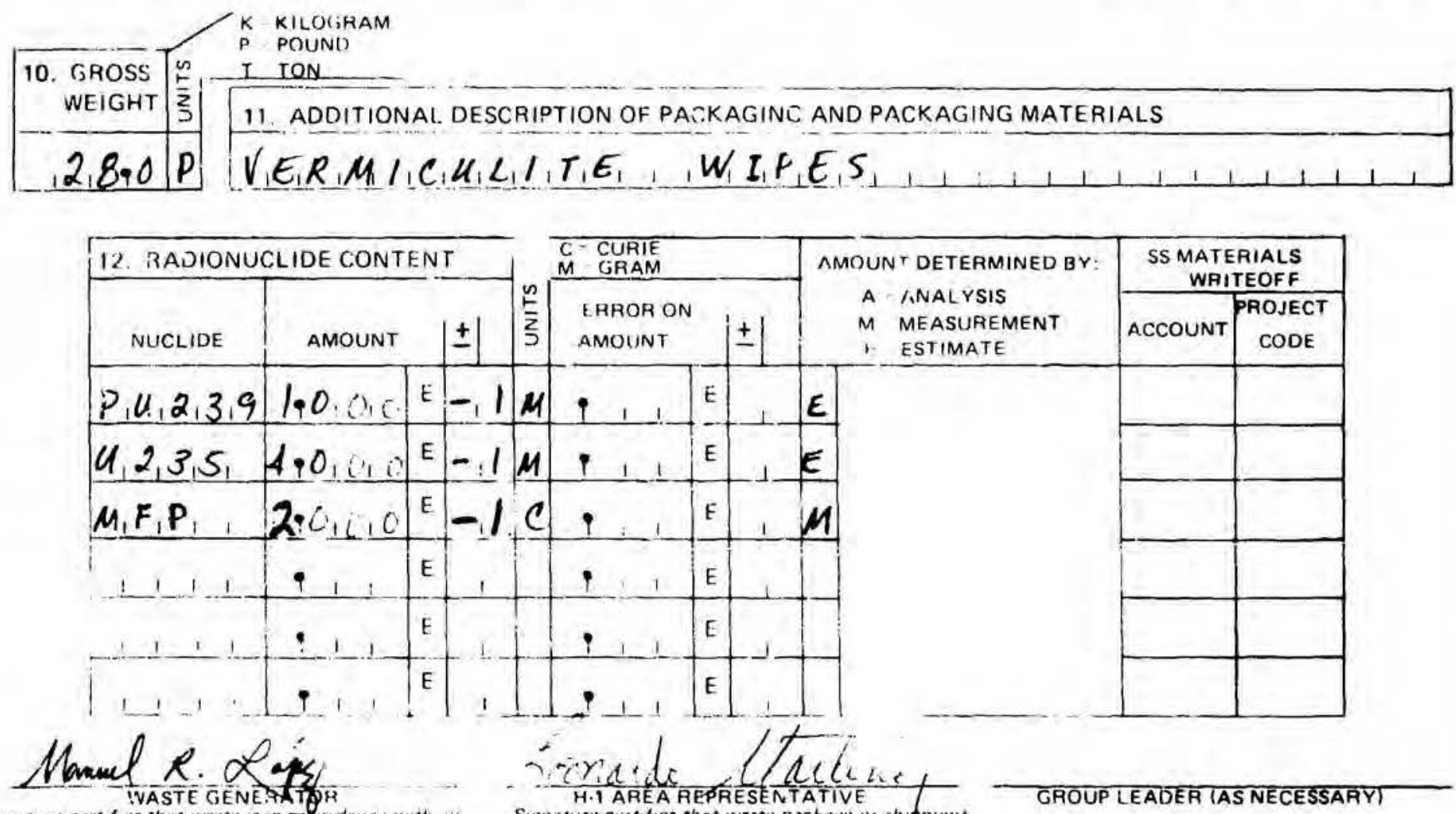

Signature certifies that waste is in ace ordance with applicable disposal requirments
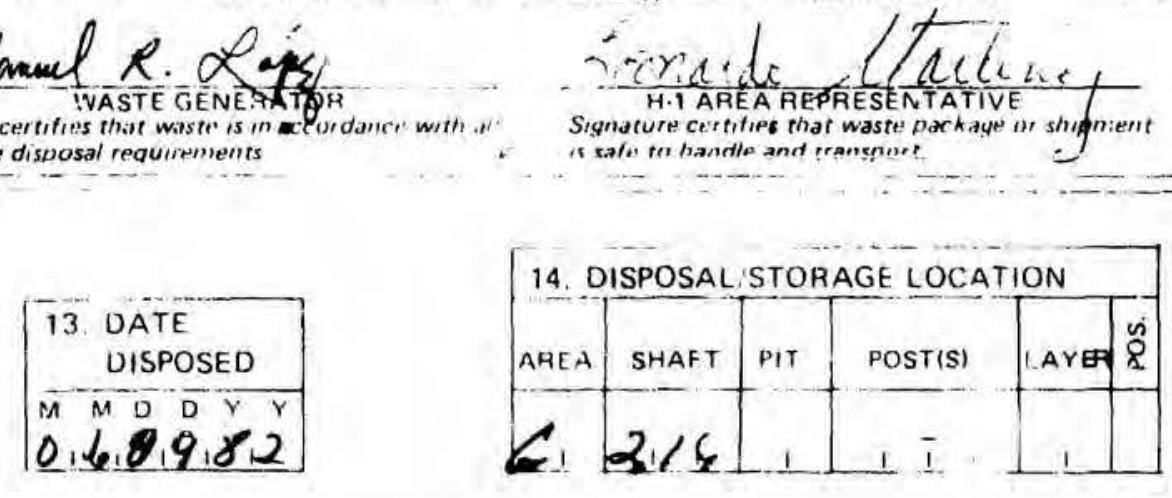

H-7 WASTE MANAGEMENT REPRESENTATIVE 
1. FORM NUMBER

$\mathrm{S}_{+}, 8,2,1840$
LOS ALAMOS RADIOACTIVE SOLID WASTE DISPOSAL RECORD FORM

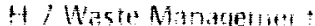

$\times 10095 \quad 115592$

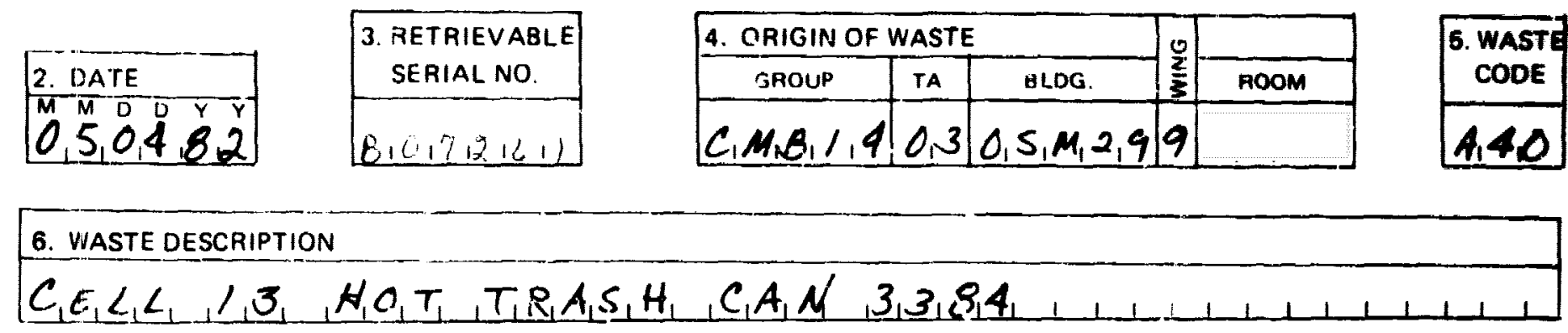

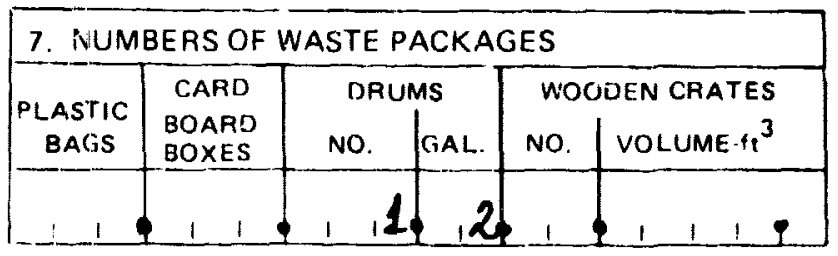

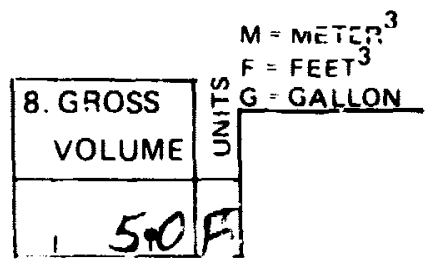

\begin{tabular}{|c|c|}
\hline $\begin{array}{c}\text { 9. PACKAGE RADIATION AT: } \\
\text { SURACE } \\
\text { MR/HR }\end{array}$ & $\begin{array}{c}\text { IMETER } \\
\text { MR/HR }\end{array}$ \\
\hline 1,1, & $, 4,0,0,0$ \\
\hline
\end{tabular}

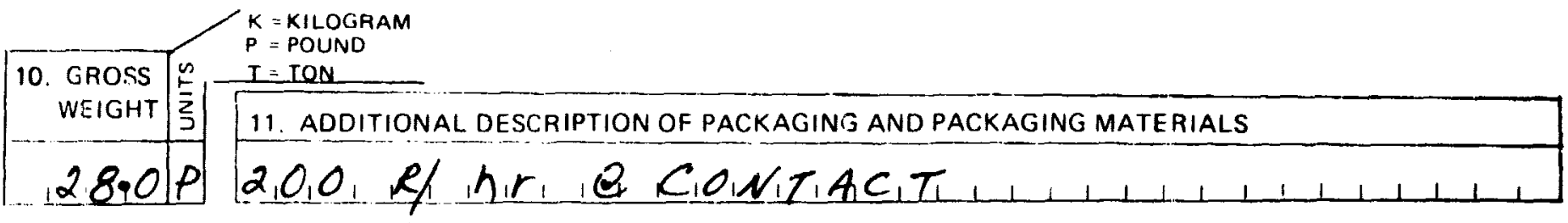

\begin{tabular}{|c|c|c|c|c|c|c|c|c|c|c|c|}
\hline \multicolumn{4}{|c|}{ 12. R IDIONUCLIIDE CONTENT } & \multicolumn{4}{|c|}{$\begin{array}{l}C=\text { CURIE } \\
M=\text { GAAM }\end{array}$} & \multirow{2}{*}{\multicolumn{2}{|c|}{$\begin{aligned} & \text { AMOUNT DETERMINED BY } \\
& \text { A }=\text { ANALYSIS } \\
& M=\text { MEASUREMENT } \\
& E=\text { ESTIMATE }\end{aligned}$}} & \multicolumn{2}{|c|}{$\begin{array}{c}\text { SS MATERIALS } \\
\text { WRITEOFF }\end{array}$} \\
\hline NUCLIDE & AMOUNT & & \pm & $\frac{\mathfrak{c}}{\mathfrak{s}}$ & $\begin{array}{l}\text { ERROR ON } \\
\text { AMOUNT }\end{array}$ & & \pm 1 & & & ACCOUNT & $\begin{array}{c}\text { POUACT } \\
\text { CODE }\end{array}$ \\
\hline$P, 4,2,3,9$ & 1.0 & E & -11 & $m$ & $1 \quad 1$ & E & & $E$ & & & \\
\hline$\mu, 2,3,5$ & $4,0,1$ & $E$ & -1 & $m$ & $1 \quad 1$ & E & & $\epsilon$ & & & \\
\hline$M_{1} F P_{1}$ & $4.0 !$ & $E$ & +.0 & $c$ & $1: i$ & $E$ & & $M$ & & & \\
\hline 1111 & 911 & $E$ & 1 & & $9 \quad 1$ & E & & & & & \\
\hline 111 & $i_{1} \quad 1$ & $E$ & & & $1 \quad 1$ & E & & & & & \\
\hline & 911 & E & & & - 11 & E & & & & & \\
\hline
\end{tabular}

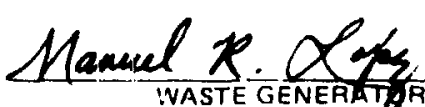

Signatuie cortitios that waste is in ece applicable disposal requirements.

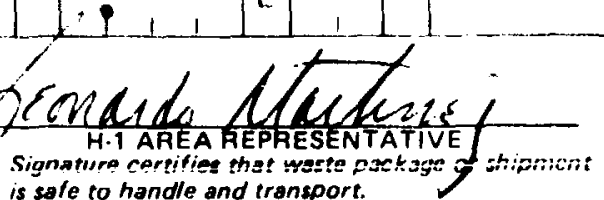

Signoture cortities that watto pact
is sale to handle and transport.
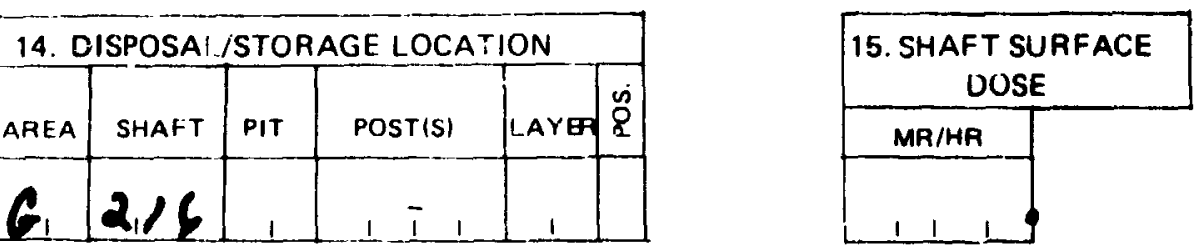


\section{LOS ALAMOS RADIOACTIVE SOLID WASTE DISPOSAL RECORD FORM}

\begin{tabular}{|c|}
\hline \multirow[t]{2}{*}{$\begin{array}{l}\text { 3. RETRIEVABLE } \\
\text { SERIAL NO }\end{array}$} \\
\hline \\
\hline$\left.B_{1} 1,17, \cdots, 1\right]$ \\
\hline
\end{tabular}

\begin{tabular}{|c|c|c|c|c|}
\hline 4. ORIGIN OF WASTE & 0 & \\
\hline GROUP & TA & BLOG. & $\frac{2}{3}$ & ROOM \\
\hline$C_{1} M, Q_{1}, 1,4$ & 0,3 & $0,5, M_{1}, 2,9$ & 9 & \\
\hline
\end{tabular}

\section{WASTE DESCRIPYION}

$C_{1} E_{1} L_{1} L_{1}, /, 3, H_{1} O_{1} T_{1}, T_{1} R, A_{1} S_{1} H_{1}, C_{1} A_{1} N_{1}, 3,3,8,5, K_{1}, M W /, R, E_{1} S_{1}, \perp_{1}$

\begin{tabular}{|c|c|c|c|c|c|}
\hline \multicolumn{6}{|c|}{ 7. NUMBERS OF WASTE PACKAGES } \\
\hline \multirow{2}{*}{$\begin{array}{c}\text { PLASTIC } \\
\text { BAGS }\end{array}$} & \multirow{2}{*}{$\begin{array}{l}\text { CARD } \\
\text { BCARD } \\
\text { BOXES }\end{array}$} & \multicolumn{2}{|c|}{ DRUMS } & \multicolumn{2}{|c|}{ WOODEN CRATES } \\
\hline & & NO. & GAL. & NO. & VOLUME $\cdot \mathrm{ft}^{3}$ \\
\hline 1 & & I & & & 11 \\
\hline
\end{tabular}

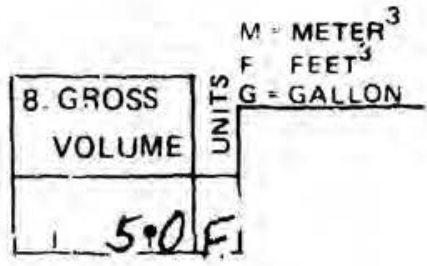

\begin{tabular}{|c|c|}
\hline $\begin{array}{c}\text { 9. PACKAGE RADIATION AT: } \\
\text { SURFACE } \\
\text { MR/HR }\end{array}$ & $\begin{array}{c}\text { I METER } \\
\text { MR/HR }\end{array}$ \\
\hline $3,0,0,0,0$ & $2,0,0 O$ \\
\hline
\end{tabular}
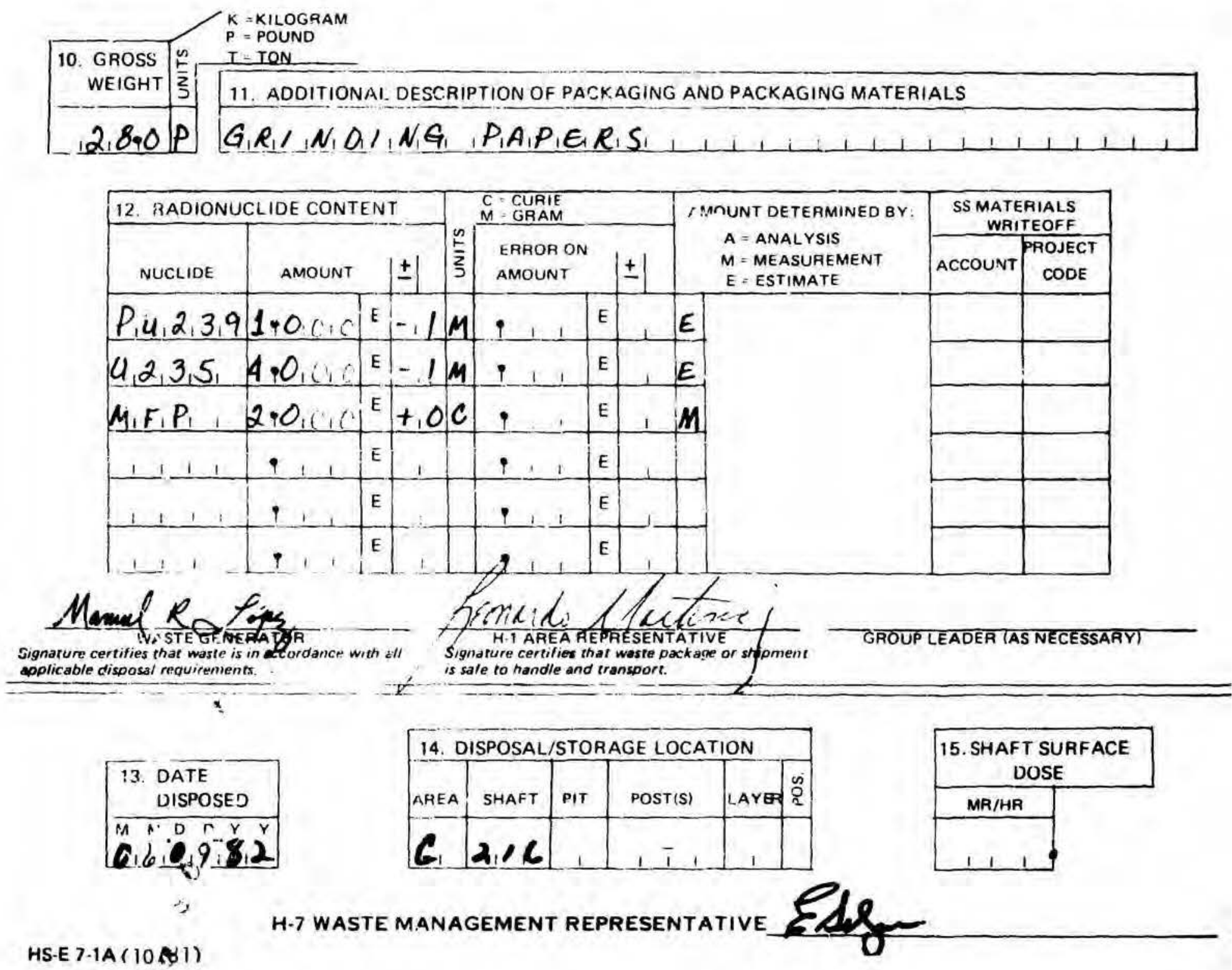
RADIOACTIVE SOLID WASTE DISPOSAL RECORD FORMS

FOR

SHAFT 217

MATERIAL DISPOSAL AREA G 


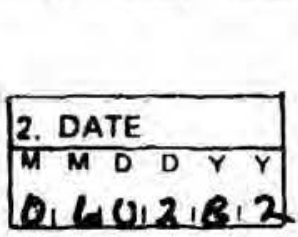

\section{LOS ALAMOS RADIOACTIVE SOLID WASTE OISPOSAL RECORD FORM}

H 7 W ste Management

Ext 6095 M 592

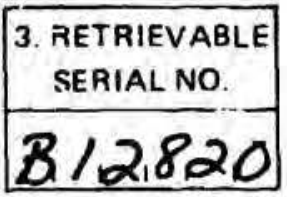

\begin{tabular}{|c|c|c|c|c|}
\hline 4. ORIGIN OF WASTE & & \\
\hline GROUP & TA & BLDG. & $\frac{2}{3}$ & ROOM \\
\hline CIMIBIOII & 0,3 & SIM1O,2,9 & \\
\hline
\end{tabular}

5. WASTE CODE

1411

\section{WASTE DESCR:PTION}

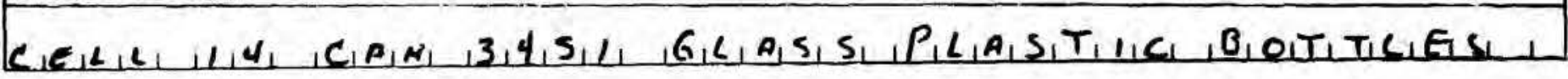

\begin{tabular}{|c|c|c|c|c|c|}
\hline \multicolumn{6}{|c|}{ 7. NUMBERS OF WASTE PACKAGES } \\
\hline & CARD & & & wo & DEN CRATES \\
\hline BAGS & $\begin{array}{l}\text { BOARD } \\
\text { BOXES }\end{array}$ & No. & GALL. & No. & VOLUME $\cdot \mathrm{ft}^{3}$ \\
\hline
\end{tabular}

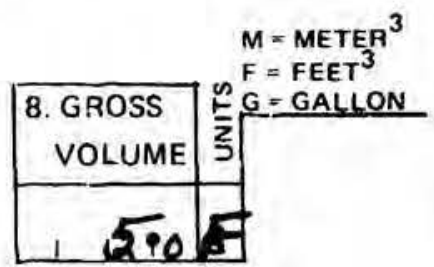

\begin{tabular}{|c|c|}
\hline \begin{tabular}{c} 
9. PACKAGE RADIATION AT: \\
\hline $\begin{array}{c}\text { SURFACE } \\
\text { MR/HR }\end{array}$
\end{tabular} & $\begin{array}{c}\text { I METER } \\
\text { MR/HA }\end{array}$ \\
\hline IISIOIOIOS & 1, ISIO,O \\
\hline
\end{tabular}

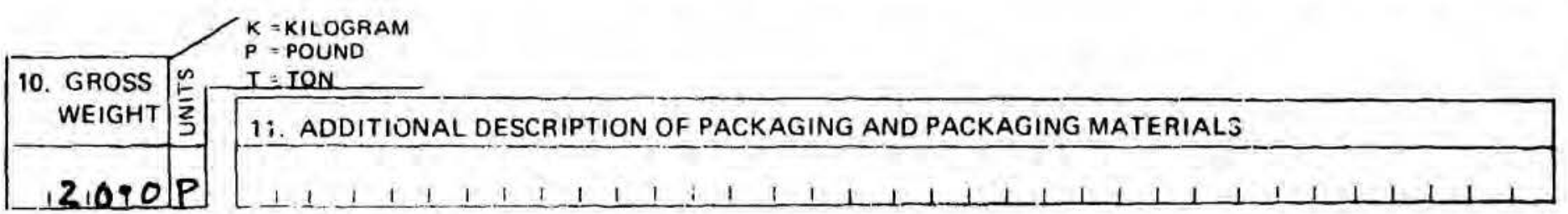

\begin{tabular}{|c|c|c|c|c|c|c|c|c|c|c|c|}
\hline \multicolumn{4}{|c|}{ 12. RADIONUCLIDE CONTENT } & \multicolumn{4}{|c|}{$\begin{array}{l}C=\text { CUAIE } \\
M=\text { GRAM }\end{array}$} & \multirow{2}{*}{\multicolumn{2}{|c|}{$\begin{aligned} \text { AMOUNT DEY ERMINED BY } & \text { B } \\
A & =\text { ANALYSIS } \\
\mathrm{N} 1 & =\text { ME/SUREMENT } \\
E & =\text { ES }\end{aligned}$}} & \multicolumn{2}{|c|}{$\begin{array}{c}\text { SS MATERIALS } \\
\text { WRITEOFF } \\
\end{array}$} \\
\hline NUCLIDE & AMOUNT & & \pm & $\frac{5}{z}$ & $\begin{array}{l}\text { ERROR ON } \\
\text { AMOUNT }\end{array}$ & & \pm & & & ACCOUNT & $\begin{array}{l}\text { PROJECT } \\
\text { CODE }\end{array}$ \\
\hline$P, 0,2,3,9$ & $19: 1$ & E & -11 & $\mu$ & $1 \quad 1 \quad 1$ & E & & $M$ & & & \\
\hline $02,3, s_{1}$ & 4111 & $\mathrm{E}$ & -1 & $M$ & $9: 1$ & $E$ & & $\mu$ & & & \\
\hline$H_{1} F_{1} P_{1}$, & 198 & $\underline{E}$ & -11 & c. & i 11 & E & -1 & $E$ & & & \\
\hline 1111 & 211 & $\mathrm{E}$ & 1 & & $1 \quad 1$ & E & & & & & \\
\hline 11 & 1.1_. & E & -1 & & i 11 & $E$ & & & & & \\
\hline $111 \therefore$ & $1 \quad 1$ & $E$ & 1 & & 1,1 & E & & & & & \\
\hline
\end{tabular}

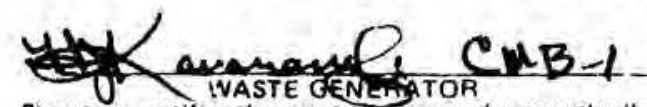
Signarure certilies that waste is in eccordance with till applicable disposal reyuirements.

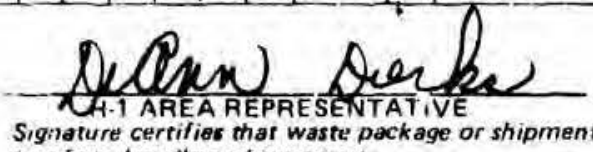

Signature certifies that waste package or shipment is safe to handle and trarisport.

\section{GROUP IEADER (ASNECESSARY)}

H-7 WASTE MANAGEMENT REPRESENTATIVE

HS-E 7-1A (10, 81$)$

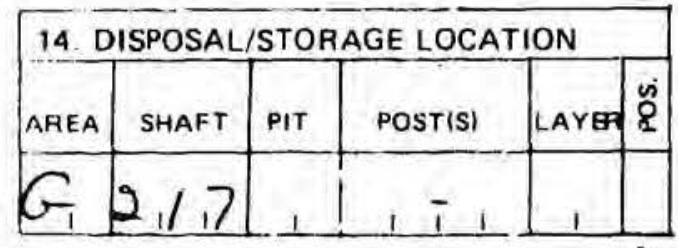

1 
PLEASE READ INSTRUCTIONS ON BACK CAREFULLY

1. FORM NUMBER

s, $8,2,18,1$

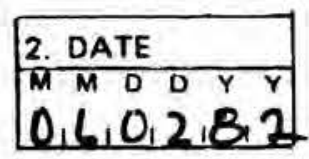

LOS ALAMOS RADIOACTIVE SOLID WASTE DISPOSAL RECORD FORM
$\mathrm{H} ;$ Waste Maraquenent

Fit 6 G95 MS -59?

\begin{tabular}{l} 
3. RETRIEVABLE \\
SERIAL No. \\
\hline $8 / 2,8,20$ \\
\hline
\end{tabular}

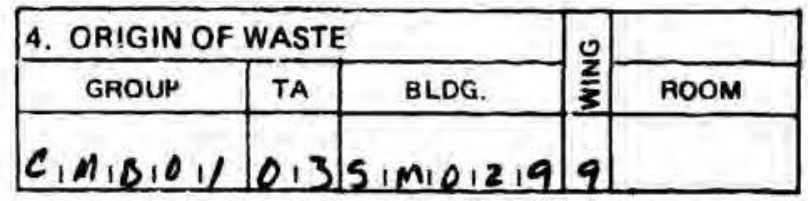

\begin{tabular}{|l|}
\hline $\begin{array}{r}\text { 5. WASTE } \\
\text { CODE }\end{array}$ \\
\hline A. 40 \\
\hline
\end{tabular}

6. WASTE DESCRIPTION

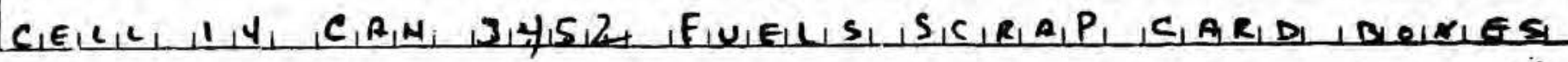

7. NUMBERS OF WASTE PACKAGES

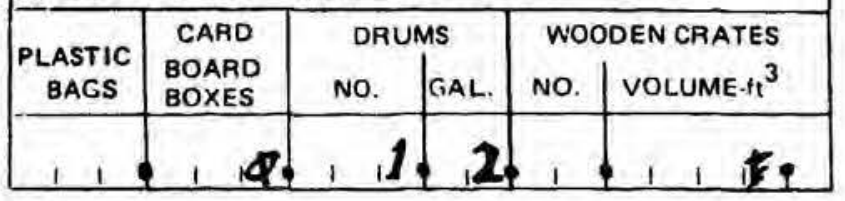

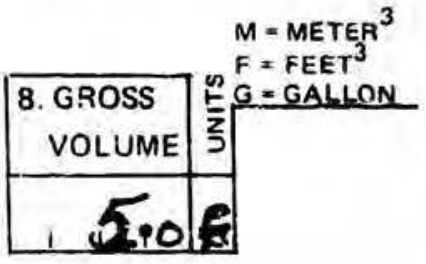

\begin{tabular}{|c|c|}
\hline \multicolumn{2}{|c|}{ 9. PACKAGE RADIATION AT : } \\
\hline $\begin{array}{c}\text { SURFACE } \\
\text { MR/HR }\end{array}$ & $\begin{array}{c}1 \text { METER } \\
\text { MR/HR }\end{array}$ \\
\hline 111 & $14,50,0$ \\
\hline
\end{tabular}
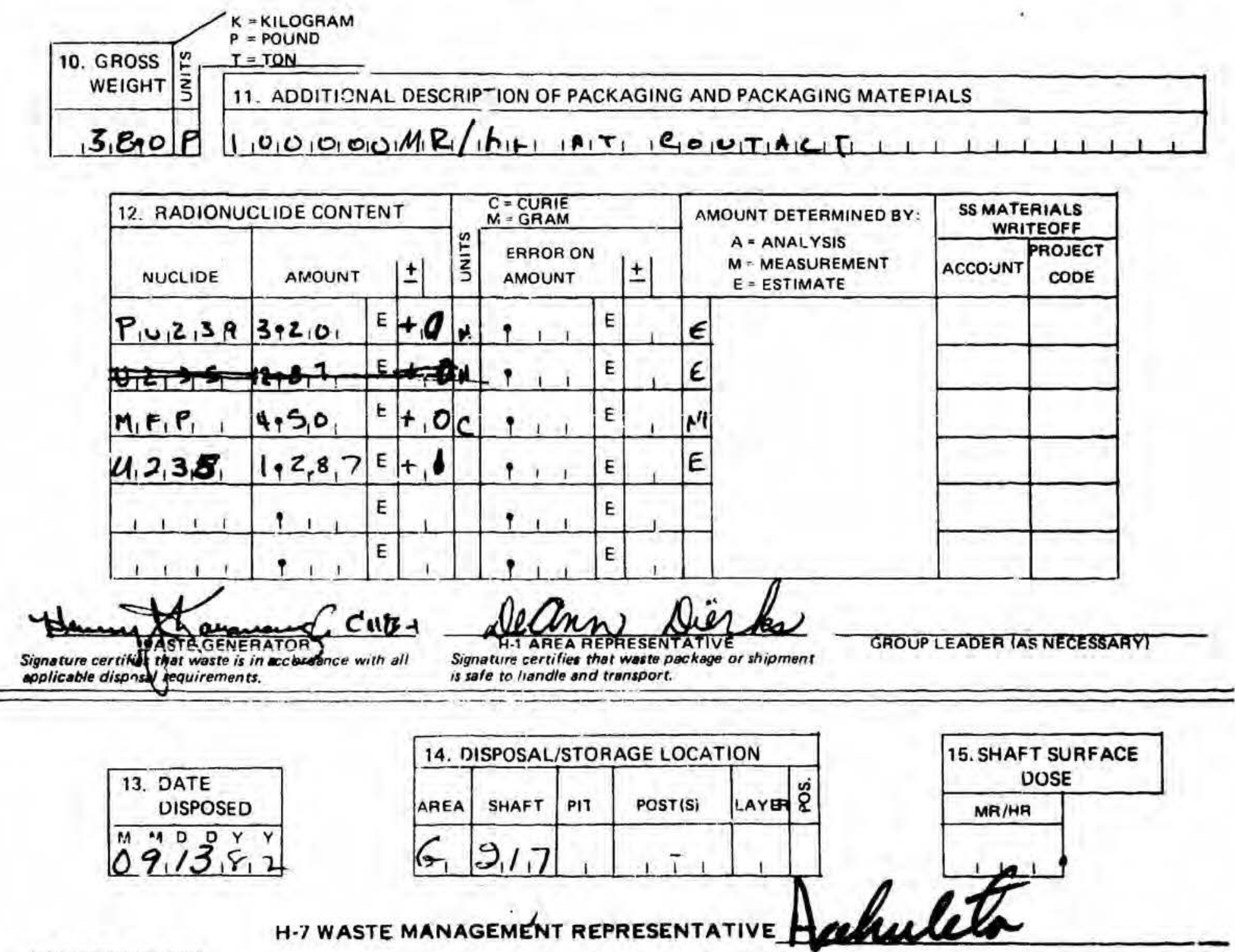

HS-E 7-1A $(10 / 81)$

h-7 Waste management representative 


\section{FORM NUMBER \\ $5,8,2,1674$}

2. DATE

M M D D Y Y

$0,6,0,4,8,2$

\section{LOS ALAMOS RADIOACTIVE SOLID WASTE} DISPOSAL RESORD FORM

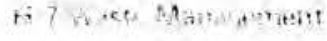

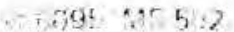

\begin{tabular}{|l|}
\hline $\begin{array}{c}\text { 3. RETRIEVABLE } \\
\text { SERIAL NO }\end{array}$ \\
\hline B/2,8,20 \\
\hline
\end{tabular}

\begin{tabular}{|c|c|c|c|c|}
\hline 4. ORIGIN OF WASTE & \multirow{2}{*}{ BLDG. } & \\
\hline GROUP & TA & BLOM & ROOM \\
\hline$C_{1} M, B_{1} / 4$ & 0,3 & $, S, M, 2,9$ & 9 & \\
\hline
\end{tabular}

6. WASTE DESCRIPTION

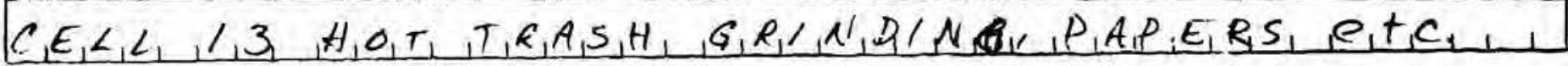

\begin{tabular}{|c|c|c|c|c|c|}
\hline \multicolumn{6}{|c|}{ 7. NUMBERS OF WASTE PA.CKAGES } \\
\hline & CARD & & & wo & DEN CHATES \\
\hline $\begin{array}{l}\text { BAGS } \\
\text { BAGS }\end{array}$ & $\begin{array}{l}\text { BOARD } \\
\text { BOXES }\end{array}$ & NO. & $E \ldots L$. & & VOLUME $+\mathrm{tr}^{3}$ \\
\hline
\end{tabular}

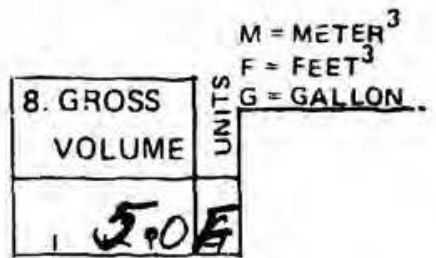

\begin{tabular}{|c|c|}
\hline \multicolumn{2}{|c|}{ 9. PACKAGE RADIATION AT: } \\
\hline $\begin{array}{c}\text { SURFACE } \\
\text { MFI/HR }\end{array}$ & $\begin{array}{c}1 \text { METER } \\
\text { MR/HR }\end{array}$ \\
\hline
\end{tabular}

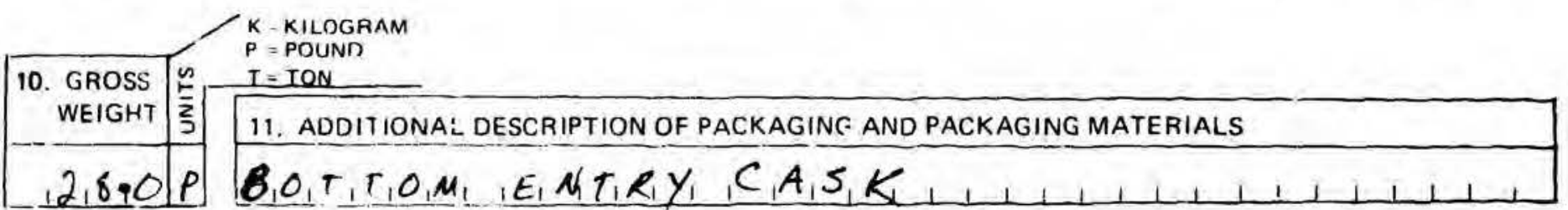

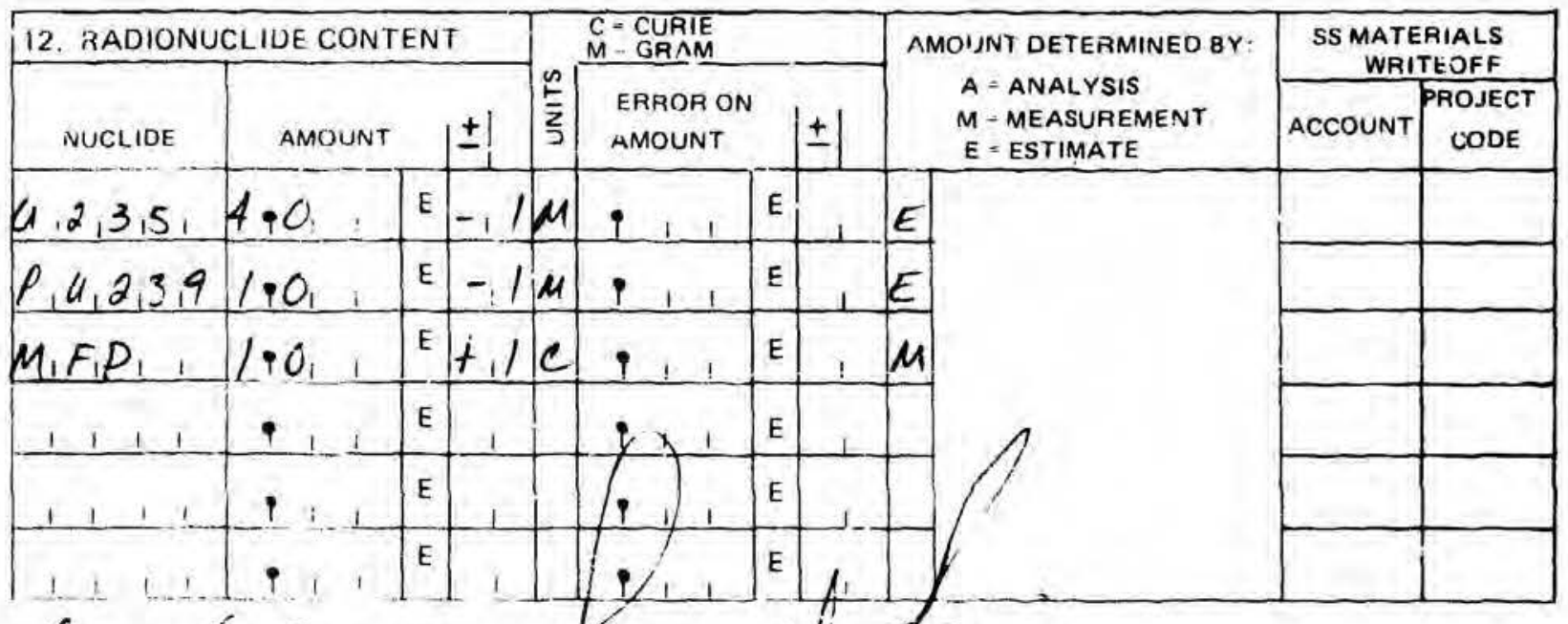

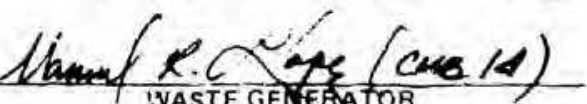

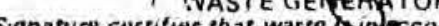
aypiriabie disposai requirements.

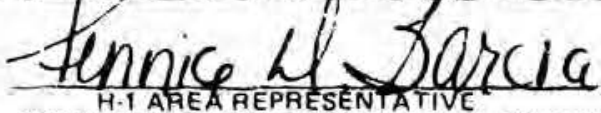

SIgI H.I AREA REPRESENTATIVE is safe to handle and transport.

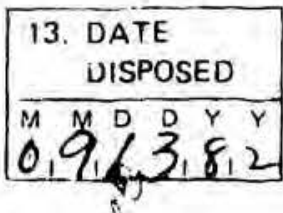

ta.

HS.E 7.1A $(10281)$

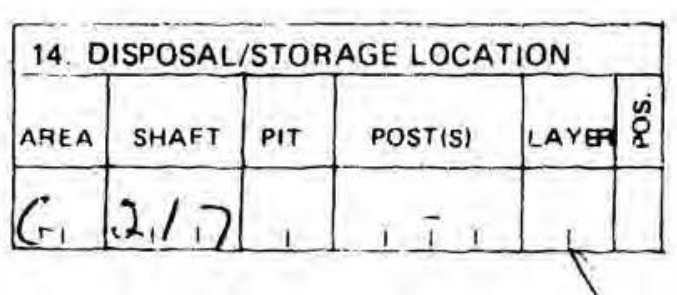

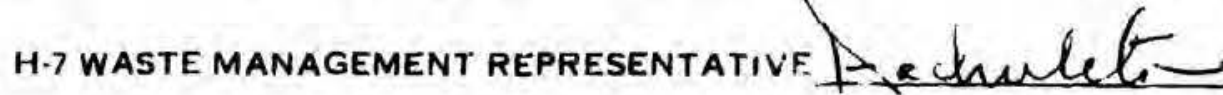

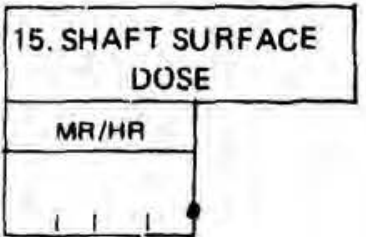


PLEASE READ INSTRIJCTIONS ON BACK CAREFULLY

$$
\begin{array}{|l|}
\hline \text { 1. FORM NUMBER } \\
\hline \leq, 8,2,18 R 2 \\
\hline
\end{array}
$$

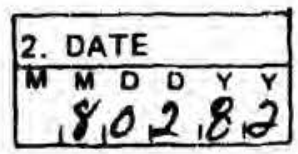

LOS ALAMO RADIOACTIVE SOLID WASTE DISPOSAL RECORD FORM it i Waste Maridejement

(.). 9095 MIS.592

\begin{tabular}{l}
$\begin{array}{c}\text { 3. TETRIEVABLE } \\
\text { SERIAL NO. }\end{array}$ \\
\hline , $/ 2,8$, \\
\hline
\end{tabular}

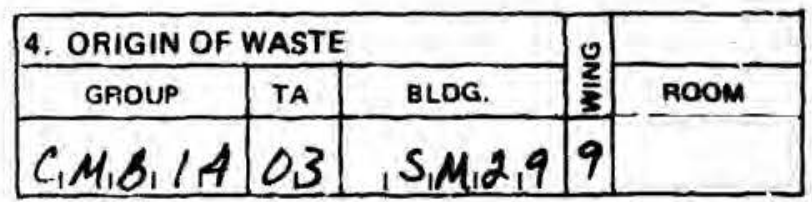

\begin{tabular}{|l|}
\hline . WASTE \\
CODE \\
\hline$A 4,1$ \\
\hline
\end{tabular}

6. WASTE DESCRIPTION

$C_{1} E_{1} \leq, / \beta_{1}, T_{1} R_{1}, S_{1}, H_{1}, C_{1} A_{1} N_{1}, N_{1}, 3,4,7,8,1,1,1,1,1,1,1,1$

7. NUMBERS OF WASTE PACKAGES

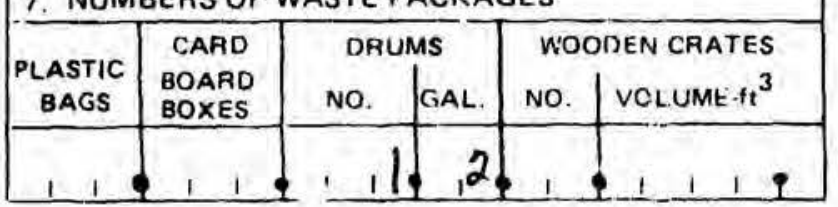

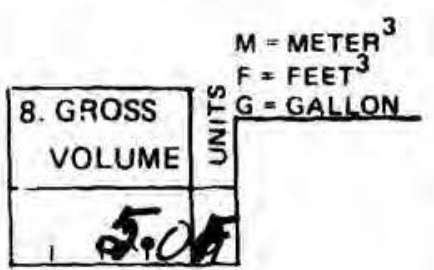

\begin{tabular}{|c|c|}
\hline \multicolumn{2}{|c|}{ 9. PACKAGE RADIATION AT: } \\
\hline $\begin{array}{c}\text { SURFACE } \\
\text { MR/HR }\end{array}$ & $\begin{array}{c}\text { 1 METER } \\
\text { MR/HR }\end{array}$ \\
\hline $16,0,0,0$ & $1,00,0$ \\
\hline
\end{tabular}
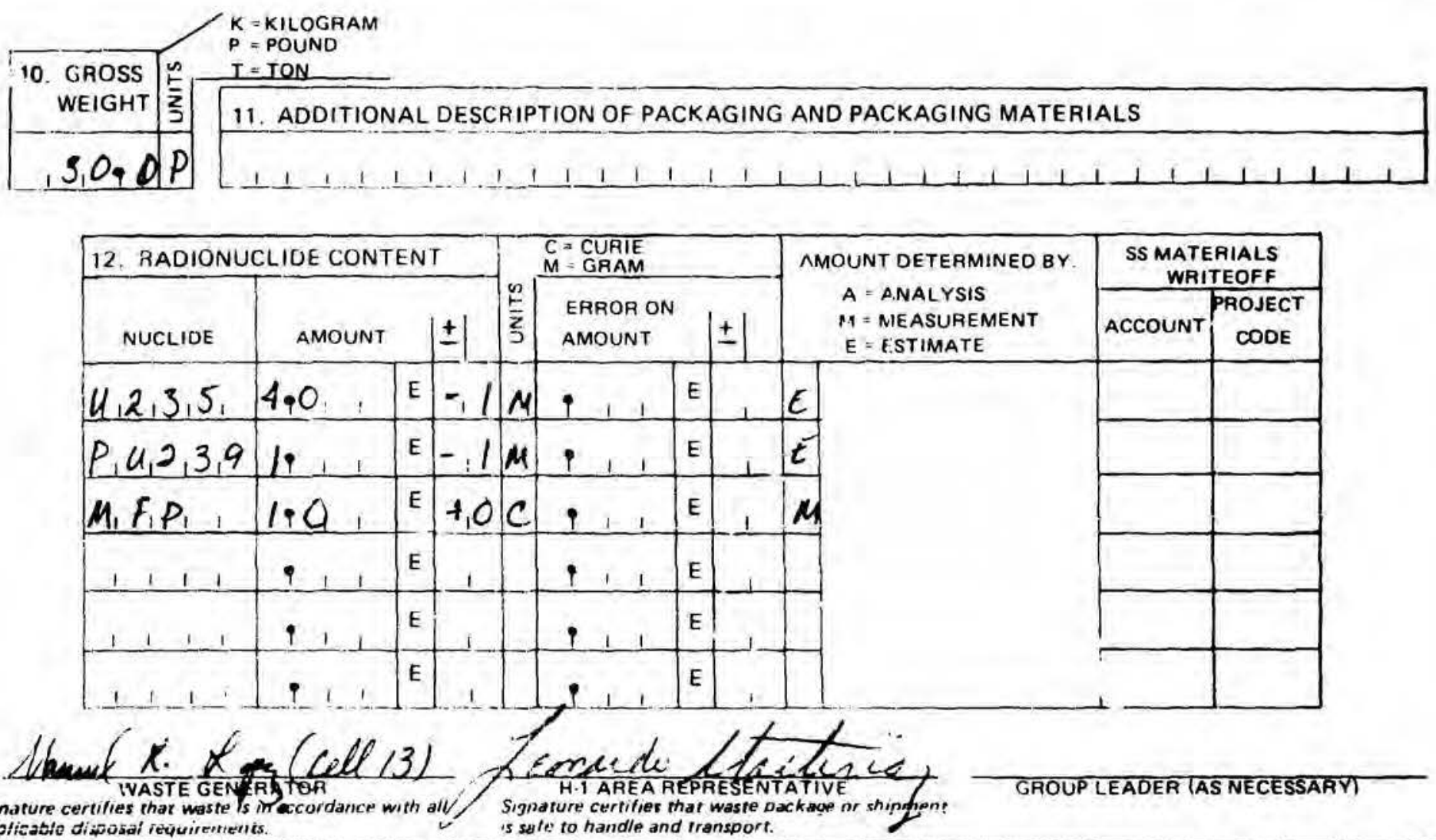
applicative disposal requirentenis.
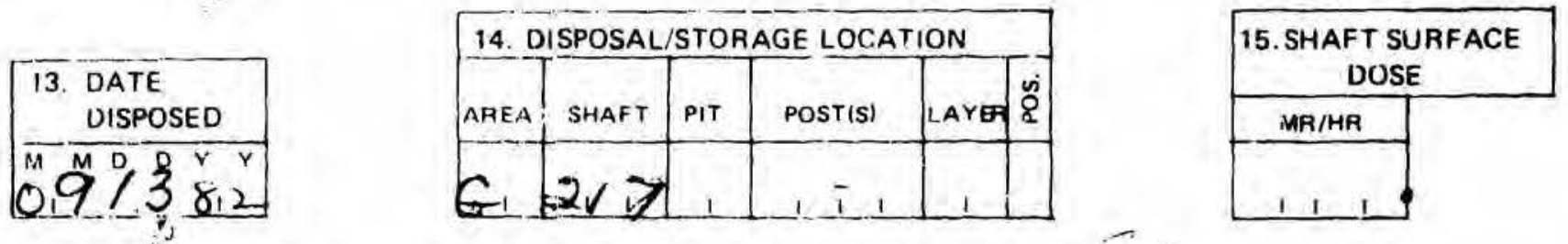

H.7 WASTE MANAGEMENT REPRESENTATIVE $C$

HS-E 7.1A $(10 / 8+)$ 
PLEASE READ INSTRUCTIONS ON BACK CAREFULLY

\begin{tabular}{|l|}
\hline 1. FORM NUMBER \\
\hline $5,8,2,1915$ \\
\hline
\end{tabular}

\section{LOS ALAMOS RADIOACTIVE SOLID WASTE DISPOSAL RECORD FORM}

H 7 Waste Manzgement

E 16095 MS.E92

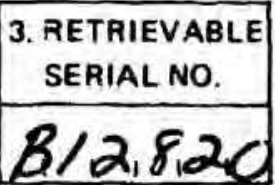

\begin{tabular}{|c|c|c|c|c|}
\hline 4. ORIGIN OF VIASTE & 0 & \\
\hline GROUP & TA & BLDG. & $\frac{2}{3}$ & ROOM \\
\hline$C_{1} M, B, 1,4$ & 0,3 & $S_{1} M, 0,2,9$ & 9 & \\
\hline
\end{tabular}

6. WASTE DESCRIPTION

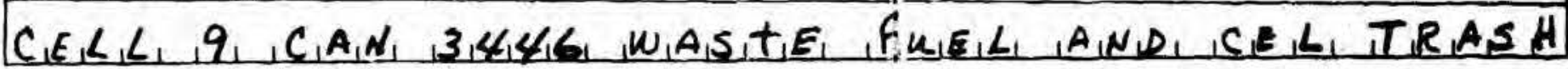

\begin{tabular}{|c|c|c|c|c|c|}
\hline \multicolumn{6}{|c|}{ 7. NUMBERS OF WASTE PACKAGES } \\
\hline & CARD & & & & DEN CRATES \\
\hline BAGS & $\begin{array}{l}\text { BOARD } \\
\text { BOXES }\end{array}$ & NO. & GAL. & No. & VOLUME $\cdot f t^{3}$ \\
\hline 11 & 1 & & & 1 & 1 \\
\hline
\end{tabular}
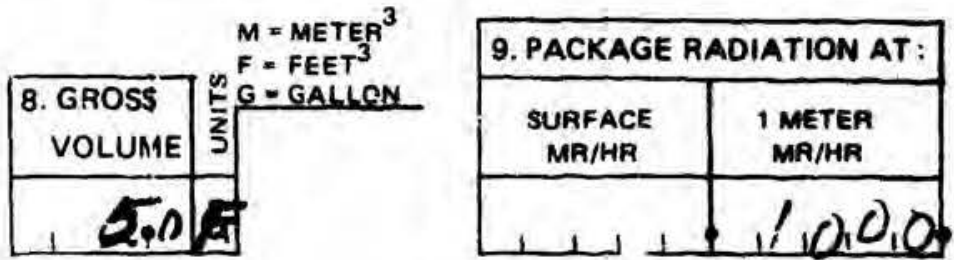

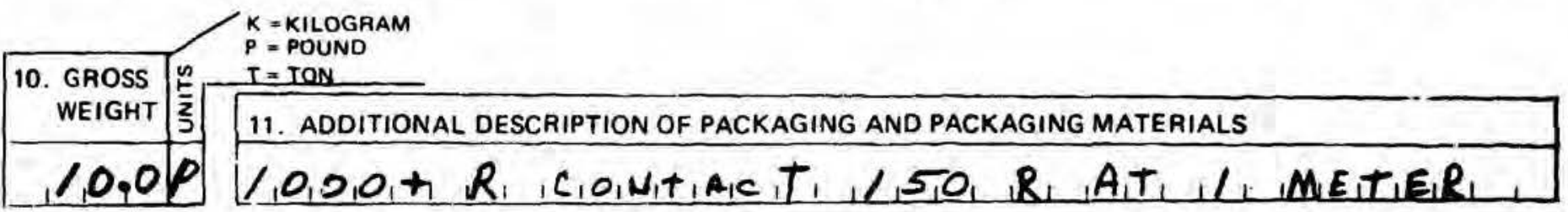

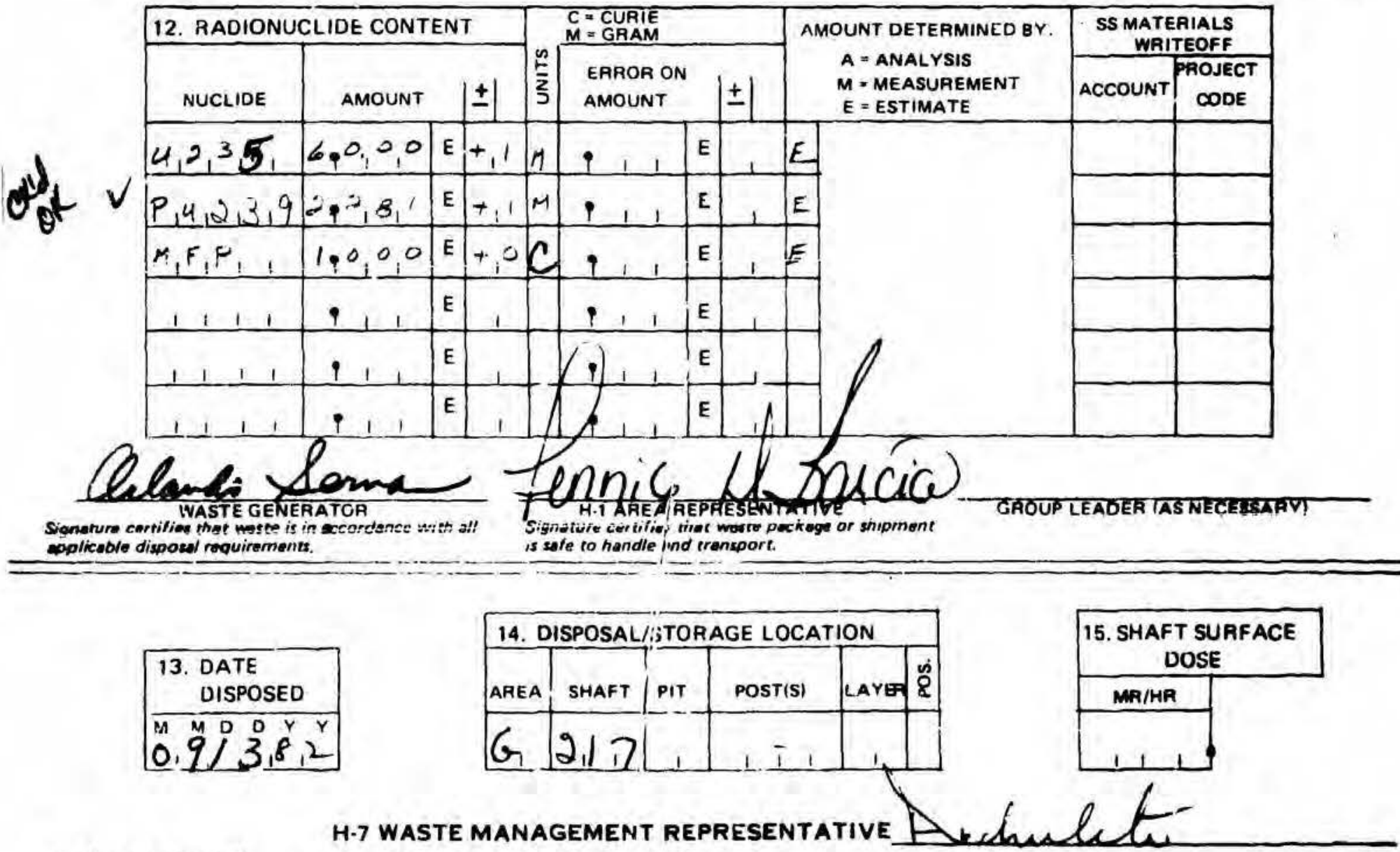

HS-E 7.1A $(10 / 81)$ 
PLEASE READ INSTRUCTIONS ON BACK CAREFULLY

\begin{tabular}{|l|}
\hline 1. FORM NUMBER \\
\hline$S, 6,2,1,918$ \\
\hline
\end{tabular}

\section{LOS ALAMOS RADIOACTIVE SOLID WASTE DISPOSAL RECORD FORM \\ H 7 Saste: Nowatneril
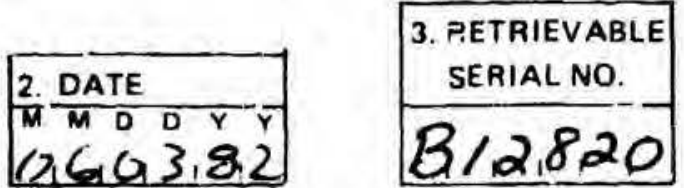

\begin{tabular}{|c|c|c|c|c|}
\hline \multicolumn{3}{|c|}{ 4. ORIGIN OF WASTE } & \multirow{2}{*}{$\frac{0}{\frac{2}{3}}$} & \\
\hline GROUP & TA & BLDG. & & ROOM \\
\hline$C_{1} M_{1} B_{1} O_{1}$ & & & 9 & \\
\hline
\end{tabular}

$\begin{array}{r}\text { 5. WASTE } \\ \text { CODE } \\ \hline, 4, O\end{array}$

\section{WASTE DESCRIPTION}

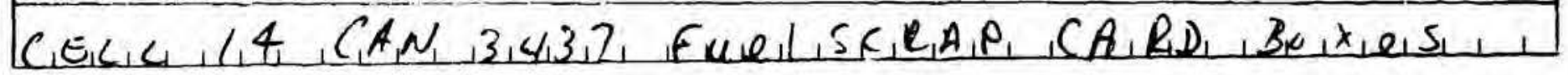

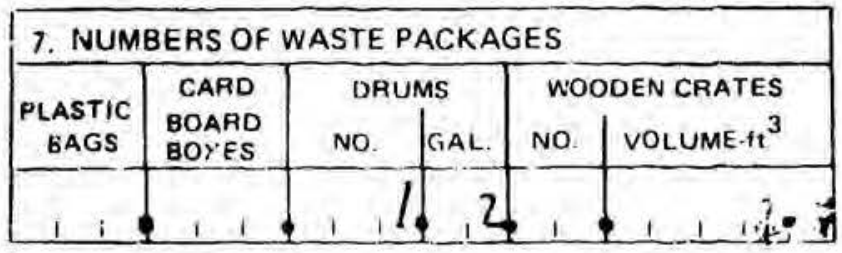

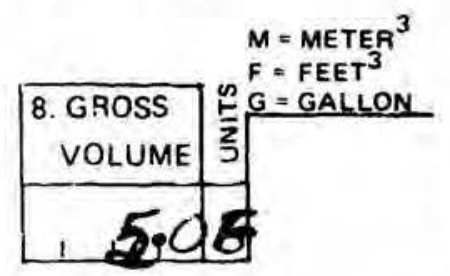

\begin{tabular}{|c|c|}
\hline \multicolumn{2}{|c|}{ 9. PACKAGE RADIATION AT: } \\
\hline $\begin{array}{c}\text { SURFACE } \\
\text { MR/HA }\end{array}$ & $\begin{array}{c}\text { 1 METER } \\
\text { MR/HR }\end{array}$ \\
\hline 111,1 & 10,0010 \\
\hline
\end{tabular}

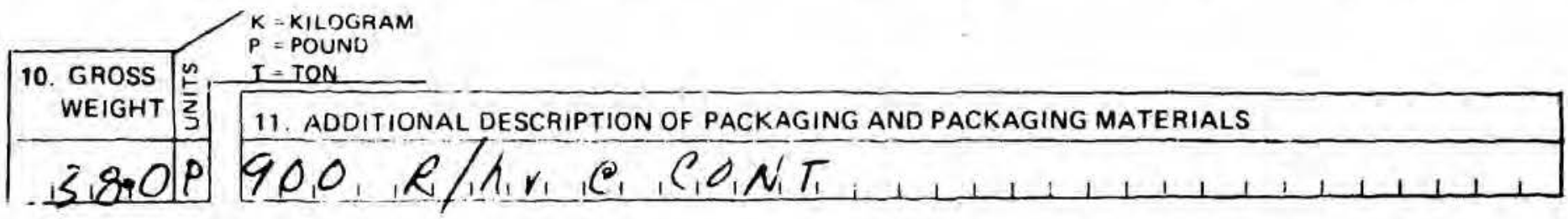

\begin{tabular}{|c|c|c|c|c|c|c|c|c|c|c|c|}
\hline \multicolumn{4}{|c|}{ 12. RADIONUCLIDE CONTENT } & \multicolumn{4}{|c|}{$\begin{array}{l}C=\text { CURIE } \\
M=\text { GRAM }\end{array}$} & \multirow{2}{*}{\multicolumn{2}{|c|}{ 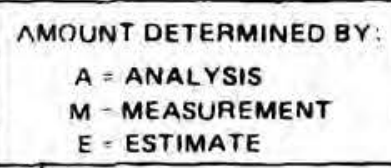 }} & \multicolumn{2}{|c|}{$\begin{array}{c}\text { SS MATERIALS } \\
\text { WRITEOFFF }\end{array}$} \\
\hline NUCLIDE & AMOUNT & & \pm & $\underline{z}$ & $\begin{array}{l}\text { ERROR OI } \\
\text { AMOUNT }\end{array}$ & & \pm & & & ACCOUNT & $\begin{array}{c}\text { PROJECT } \\
\text { CODE }\end{array}$ \\
\hline$P, u_{1} 2_{1} 3$ & 3,2 & E & +1 & & 11 & E & & $E$ & & & \\
\hline$M f_{1} P_{1}$ & D.O & E & $+:$ & $\mathcal{C}$ & 111 & E & & $E$ & & & \\
\hline$(4,2,3 i)$ & $1 \cdot 2,8,7$ & E & +1 & in & $9 \div 1$ & E & 1 & $m$ & & & \\
\hline 1111 & 1 11 & $E$ & 1 & & i 1 & E & & & & & \\
\hline 111 & 111 & $E$ & & & 111 & E & & & & & \\
\hline $1: 1$ & 11 & E & & & $91:$ & E & & & & & \\
\hline
\end{tabular}

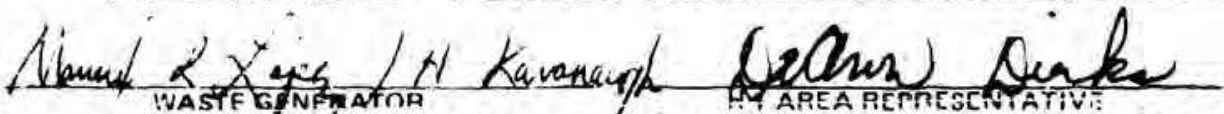

Signature certifies that waste if in cciordance with all I Signature certifies that waste package or shipment

GROUF LEAUER (AS NECESSARY)

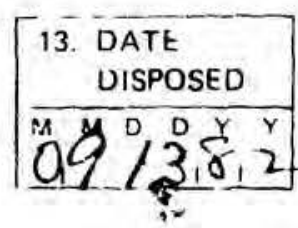

*,

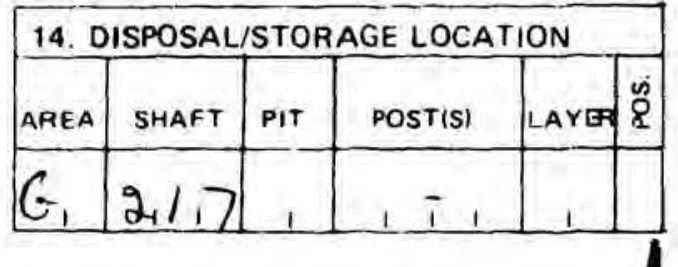

H.7 WASTE MANAGEMENT REPRESEINTATIVE

HS-E 7.1A (10/) 
RADIOACTIVE SOLID WASTE DISPOSAL RECORD FORMS

FOR

SHAFT 218

MATERIAL DISPOSAL AREA G 
218

PLEASE READ INSTRUCTIONS ON BACK CAREFULLY

\begin{tabular}{|l|}
\hline . FORM NUMBER \\
\hline$\varepsilon_{1}, 8_{1}, 187,5$ \\
\hline
\end{tabular}

LOS ALAMOS RADIOACTIVE SOLID WASTE

H 7 Wa th Management DISPOSAL RECORD FORM

Ext 6095 ME 592

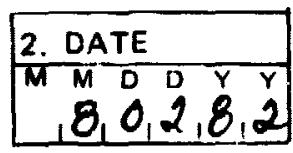

\begin{tabular}{l} 
3. RETRIEVABLE \\
SERIAL NO. \\
\hline R PRISE SIS
\end{tabular}

\begin{tabular}{|c|c|c|c|c|}
\hline 4. ORIGIN OF WASTE & \multirow{2}{*}{} & \\
\hline GROUP & TA & BLDG. & ROOM & ROO \\
\hline$C_{1} \mu_{1} \& / 1$, & $\sigma_{1} 3$ & $, S, M, 2,9$ & 9 & \\
\hline
\end{tabular}

\begin{tabular}{l} 
5. WASTE \\
CODE \\
\hline $4,4, /$ \\
\hline
\end{tabular}

6. WASTE DESCRIPTION

$C_{1} \epsilon_{1} \alpha_{1} L_{1}, 9, T_{1} N_{1} A_{1} S_{1} H_{1}, C_{1} A_{1} N_{1}, H_{1}, 3,4,9,9,1,1,1,1,1,1,1,1,1,1,1$,

7. NUMBERS OF WASTE PACKAGES

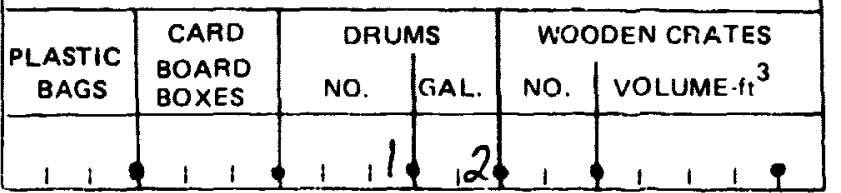

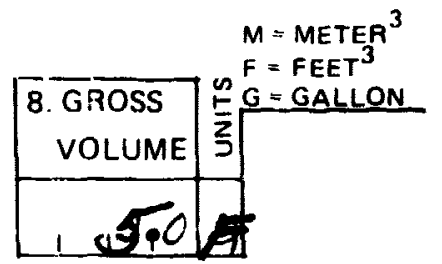

\begin{tabular}{|c|c|}
\hline $9 . P:-$ RAGE RADIATION AT: \\
\hline $\begin{array}{c}\text { SURFACE } \\
\text { MR/HR }\end{array}$ & $\begin{array}{c}\text { 1 METER } \\
\text { MR/HR }\end{array}$ \\
\hline $1,1,1$ & $2,0,0,0,0$ \\
\hline
\end{tabular}

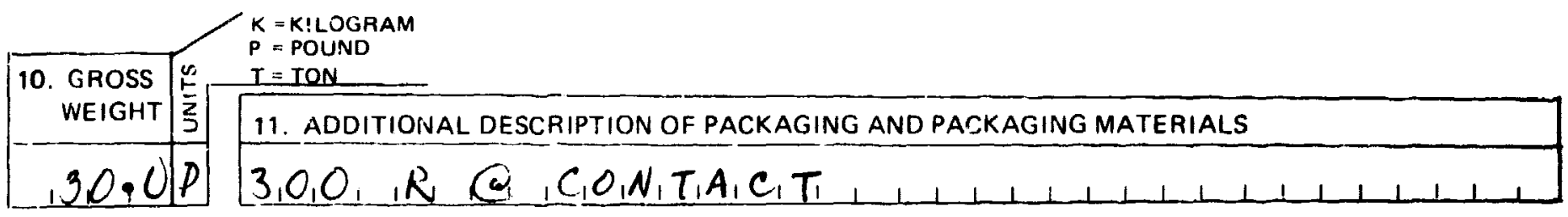

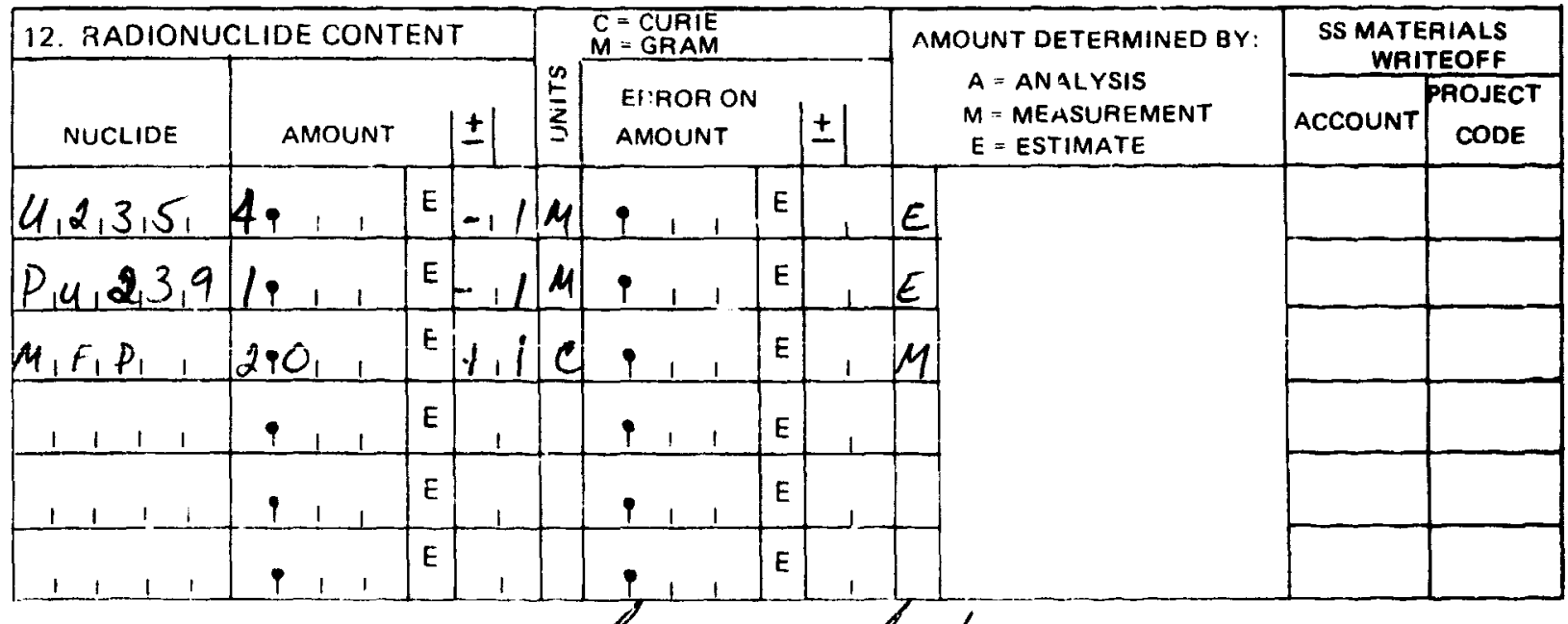

Whenas R. ofóeg (culpa)

IVASTE GENERATOr
signature certifies that waste is in accordance with ali, Signature certifies that waste package or shipment
applicable disposal requirements

CROUP LEADERIASTHECESGAFTI

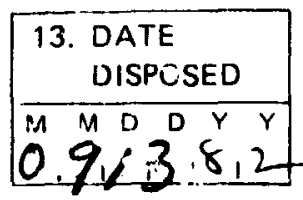

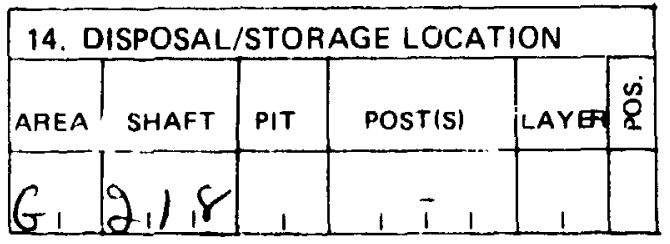

\begin{tabular}{|c|}
\hline $\begin{array}{c}\text { 15. SHAFT SURFACE } \\
\text { DOSE }\end{array}$ \\
\hline MR/HR \\
\hline 1 \\
\hline 1 \\
\hline
\end{tabular}

H-7 WASTE MANAGEMENT REPRESENTATIVE

HS-E 7.1A $(10 / 81)$ 
1. FORM NUMBER

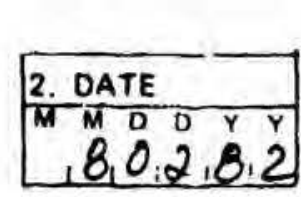

PI A AS TEAD INSTRUCTIOT,S ON RACK CAREFULLY

\section{LOS ALAMOS RADIOACTIVE SOLID WASTE DISPOSAL RECORD FORM

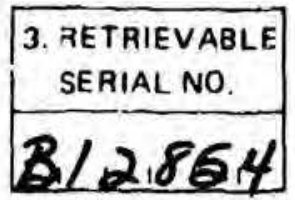

\begin{tabular}{|c|c|c|c|c|}
\hline \multicolumn{3}{|c|}{ 4. ORIGIN OF WASTE } & \multirow{2}{*}{$\frac{0}{\frac{2}{3}}$} & \multirow[b]{2}{*}{ ROOM } \\
\hline GROUP & TA & BLDG. & & \\
\hline & 0. & $S_{1} M_{1}$ & 9 & \\
\hline
\end{tabular}

\begin{tabular}{r|}
\hline 5. WASTE \\
COOE \\
\hline $1,4,1$ \\
\hline
\end{tabular}

B. WASTE DESCRIPTION

$C_{1} \varepsilon_{1} L_{1},{ }_{1},{ }_{1}, T_{1} R_{1} A_{1} s_{1} \mu_{1}, C_{1} A_{1} T_{1} C_{1} n_{1}, P_{1} A_{1} N_{1}, C_{1} A_{1} N_{1}{ }_{1}, 3,4, Z_{1} Z_{1}, \ldots, 1, \ldots$

\begin{tabular}{|c|c|c|c|c|c|}
\hline \multicolumn{6}{|c|}{ 7. NUMBERS OF WASTE PACKAGES } \\
\hline \multirow[b]{2}{*}{$\begin{array}{l}\text { PLASTIC } \\
\text { BAGS }\end{array}$} & \multirow{2}{*}{$\begin{array}{l}\text { CARD } \\
\text { BOARD } \\
\text { BOXES }\end{array}$} & \multicolumn{2}{|c|}{ DHUMS } & \multicolumn{2}{|c|}{ WOODEN CRATES } \\
\hline & & NO. & GAAL. & No. & VOLUME. $\mathrm{ft}^{3}$ \\
\hline
\end{tabular}

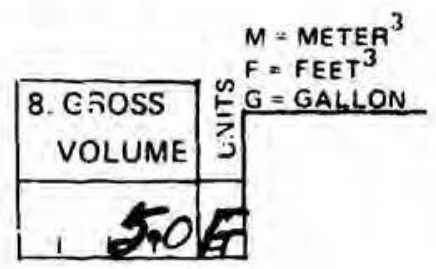

\begin{tabular}{|c|c|}
\hline $\begin{array}{c}\text { 9. PACKAGE RADIATION AT: } \\
\text { SURFACE: } \\
\text { MR/HR }\end{array}$ & $\begin{array}{c}\text { 1 METER } \\
\text { MA/HR }\end{array}$ \\
\hline $1,1,3,0,0,0,0$ \\
\hline
\end{tabular}

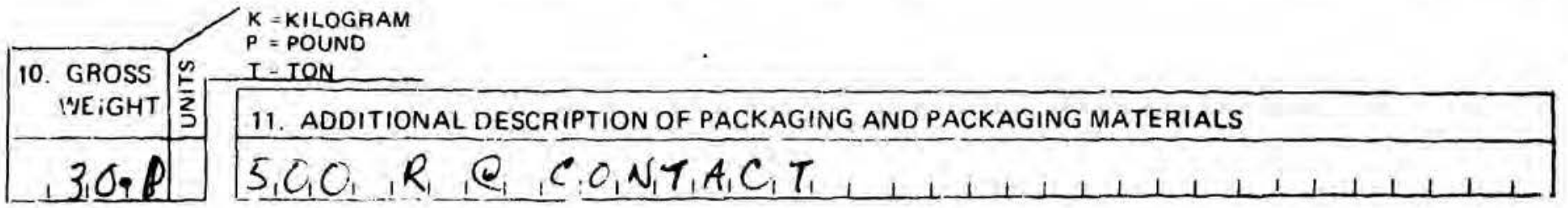

\begin{tabular}{|c|c|c|c|c|c|c|c|c|c|c|c|}
\hline \multicolumn{4}{|c|}{ 12. RADIONUCLIDE CONTENT } & \multicolumn{4}{|c|}{$\begin{array}{c}C=\text { CURIE } \\
M \text { GRAM }\end{array}$} & \multirow{2}{*}{\multicolumn{2}{|c|}{$\begin{aligned} \text { AMOUNT DETERMINED BY } \\
A=\text { ANALYSIS } \\
M=\text { MEASUREMENT } \\
E=\text { ESTIMATE }\end{aligned}$}} & \multicolumn{2}{|c|}{$\begin{array}{c}\text { SS MATERIALS } \\
\text { WRITEOFF } \\
\end{array}$} \\
\hline NUCLIOE & AMOUNT & & \pm & $\mid \frac{n}{\frac{\omega}{z}}$ & $\begin{array}{l}\text { FRRDR ON } \\
\text { AMOUNT }\end{array}$ & & \pm & & & ACCOUNT & $\begin{array}{l}\text { PROJECT } \\
\text { CODE }\end{array}$ \\
\hline $4,2,3,5$, & $9 \cdot 0,1$ & E & the & M & $1 \quad 1$ & F & & $E$ & & & \\
\hline$P, u, 2,3$, & $\mathrm{Ag} \mathrm{C}_{1}$ & E & +0 & $M$ & $1 \quad 1$ & E & & $E$ & & & \\
\hline$M F_{1} P_{1}$, & $3 \% 0,1$ & E & +1 & C. & 1,1 & E & 1 & $M$ & & & \\
\hline $\begin{array}{llll}1 & 1 & 1 \\
\end{array}$ & 911 & $E$ & 1 & & 1 11 & E & 1 & & & & \\
\hline 1111 & 111 & E & & & 111 & E & & & & & \\
\hline $11 f^{\prime}$ & 111 & E & & & $i 11$ & E & & & & & \\
\hline
\end{tabular}

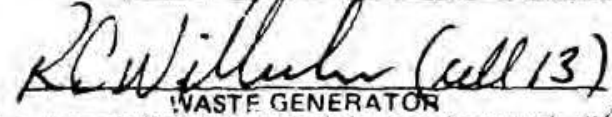
Signature certifies that waste is in ccordance with all applicable disposal requiruments.

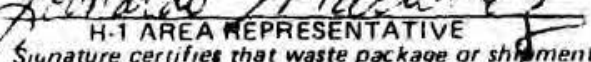
Siynature certifies that waste package or shiment is safe to handle and transpurt.
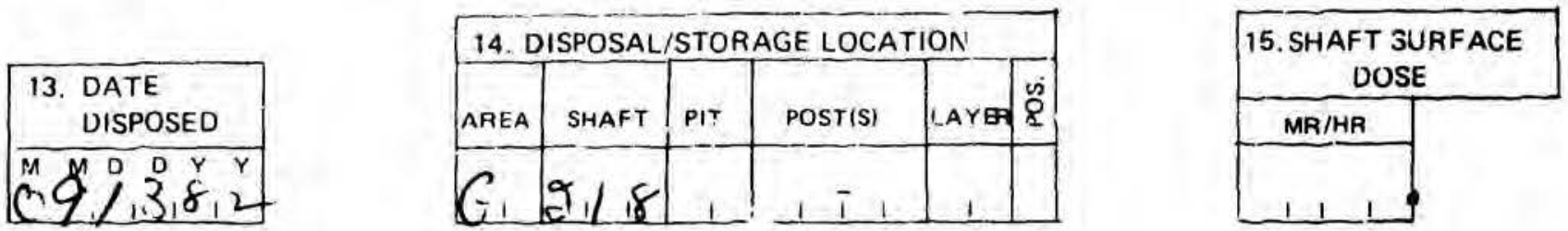

H-7 WASTE MANAGEMENT REPRESENTATIVE

HS-E 7-1A $(10 / 81)$ 
FLEASE READ INSTFIUCTIONS ON BACK CAREFULLY

\section{LOS ALAMOS RADIOACTIVE SOLID WASTE H. Wasti Management DISPOSAL RECORD FORM

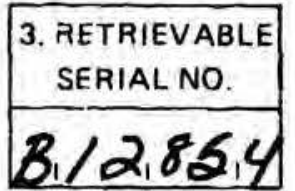

\begin{tabular}{|c|c|c|c|c|}
\hline 4. ORIGIN OF WASTE & & \multirow{2}{*|}{} & \\
\hline GROUP & TA & BLDG. & 妾 & ROOM \\
\hline$C_{1} M_{1} b_{1} 1,4$ & 0,3 & $S_{1} M_{12}, 9$ & 9 & \\
\hline
\end{tabular}

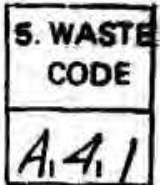

6. WASTE DESCRIPTION

$C_{1}, E_{1}, 2,1,3, T, R, A_{1}, H_{1}, C_{1} A_{1} N_{1}, \ldots, 3,4,6,8$

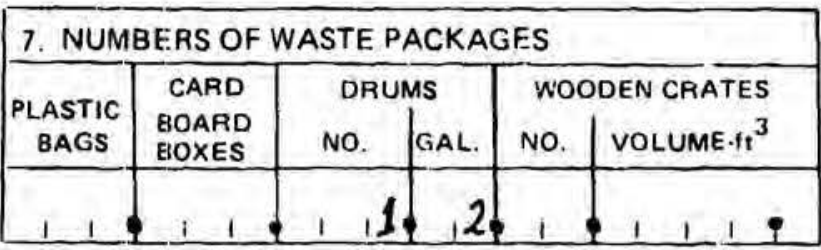

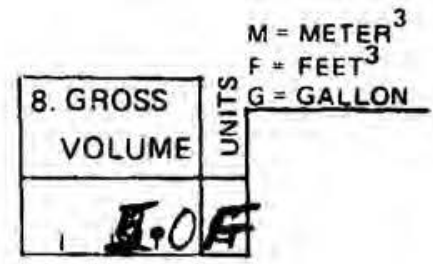

\begin{tabular}{|c|c|}
\hline \begin{tabular}{c} 
9. PACKAGE RADIATION AT: \\
\hline $\begin{array}{c}\text { SURFACE } \\
\text { MR/HR }\end{array}$
\end{tabular} & $\begin{array}{c}\text { 1 METER } \\
\text { MR/HR }\end{array}$ \\
\hline 1111 & $4,0,0,0,0$ \\
\hline
\end{tabular}

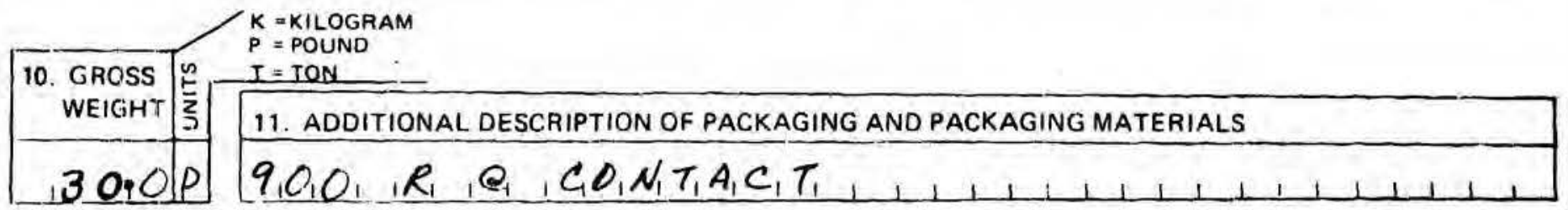

\begin{tabular}{|c|c|c|c|c|c|c|c|c|c|c|c|}
\hline \multicolumn{4}{|c|}{ 12. RADIONUCLIDE CONTENT } & \multicolumn{4}{|c|}{$\begin{array}{l}C=\text { CURIE } \\
M=\text { GRAM }\end{array}$} & \multirow{2}{*}{\multicolumn{2}{|c|}{$\begin{aligned} \text { AMOUNT DETERMINEO BY: } & \\
A & =\text { ANALYSIS } \\
M & =\text { MEASUREMENT } \\
E & =\text { ESTIMATE }\end{aligned}$}} & \multicolumn{2}{|c|}{$\begin{array}{l}\text { SS MATERIALS } \\
\text { WRITEOFF }\end{array}$} \\
\hline NUCLIDE & AMOUNT & & \pm & $\mid \frac{s}{z}$ & $\begin{array}{l}\text { ERROR ON } \\
\text { AMOUNT }\end{array}$ & & \pm & & & ACCOUNT & $\begin{array}{l}\text { POOJECT } \\
\text { CODE }\end{array}$ \\
\hline $4,2,3,5$, & $9 \cdot 0,1$ & $E$ & +10 & & $1 \quad 1$ & $\mathrm{E}$ & & $E$ & & & \\
\hline$P_{1}, 1,2,3,9$ & $2,0,1$ & $E$ & 10 & $M$ & $1 \quad 11$ & E & & $E$ & & & \\
\hline$M_{1} F_{1} P_{1}$, & $4 \cdot 0,1$ & $E$ & +1 & C & 1 11 & E & 1 & $M$ & & & \\
\hline 11.1 & 911 & $E$ & -1 & & 111 & E & & & & & \\
\hline 1111 & 911 & $E$ & & & $1 \quad 1$ & E & & & & & \\
\hline 11,1 & 111 & $E$ & 1 & & 1,1 & E & & & & & \\
\hline
\end{tabular}

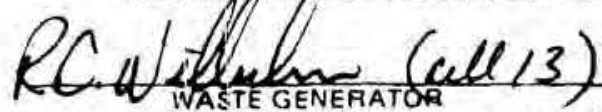
Signature certities that waste is in ecurdance with all applicable disposal rêuiraments.
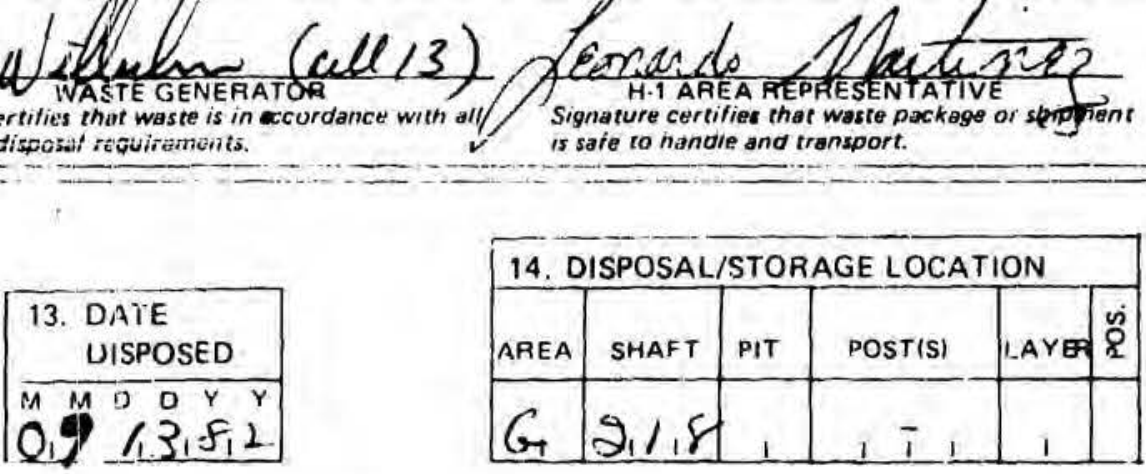

\begin{tabular}{|c|c|c|c|c|c|}
\hline AREA & SHAFT & PIT & POST(S) & LAYEA & $\stackrel{\text { ஜ }}{2}$ \\
\hline $\mathrm{G}$ & $Q_{1} / 1$ & 1 & $\overline{1}$ & 1 & \\
\hline
\end{tabular}

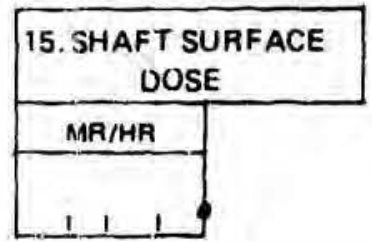

H-7 WASTE MANAGEMENT REPRESENTATIVE

HS.E 7.1A $(10 / 81)$ 
1. FORM NUMBER

$5,8,2,1803$

PLEASE READ INSTRUCTIONS ON BACK CAREFULLY

LOS ALAMOS RADIOACTIVE SOLID WASTE OISPOSAL RECORD FORM
Hi Wast: Ma ageinent

Ext 5095 :15.592

2. DATE

WM D D Y Y

$6,8,0,2,8,2$

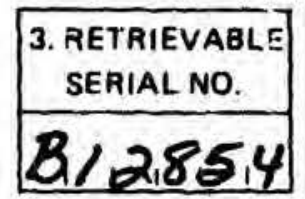

\begin{tabular}{|c|c|c|c|c|}
\hline \multicolumn{3}{|c|}{ 4. ORIGIN OF WASTE } & \multirow[b]{2}{*}{3} & \\
\hline GROUP & TA & BLDG. & & ROOM \\
\hline$C_{1} M_{1} B_{1} l_{1}$ & 0,3 & $S_{1} \mu_{1} 2$ & 9 & \\
\hline
\end{tabular}

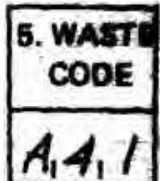

6. WASTE DESCRIPTION

$C_{1} E_{1} L_{1} L_{1}, /, Z_{1}, T, R_{1} A_{1}, H_{1}, C_{1}, A_{1} N_{1}, A_{1}, 3,4,6 q_{1}$

7. NUMBERS OF WASTE PACKAGES

\begin{tabular}{|c|c|c|c|c|c|}
\hline \multirow[b]{2}{*}{$\begin{array}{c}\text { PLASTIC } \\
\text { BAGS }\end{array}$} & \multirow{2}{*}{$\begin{array}{l}\text { CARD } \\
\text { BOARD } \\
\text { BOXES }\end{array}$} & \multicolumn{2}{|c|}{ DRUMS } & \multicolumn{2}{|c|}{ WOODEN CRATES } \\
\hline & & NO. & GAL. & No. & VOLUME-ft ${ }^{3}$ \\
\hline 1 & I & 1 & 12 & । & 1 \\
\hline
\end{tabular}

10. GROSS
WEIGHT

\section{$K=K I L O G R A M$}

$P=$ POUND

$I=$ rON

11. ADDITIONAL DESCRIPTION OF PACKAGING AND PACKAGING MATERIALS

$2, O, O, R, R_{1} Q_{1}, C_{1}, O_{1} N_{1} T_{1} A_{1} C_{1} T_{1}$

\begin{tabular}{|c|c|c|}
\hline NUCLIDE & AMOUNT & \\
\hline $0,2,3,5$, & $4 \cdot 1$, & E \\
\hline$, 2,3,9$ & $1,1,1$ & E \\
\hline$\mu_{1} F_{1} P_{1}$, & $670_{1}$ & E \\
\hline 1111 & 9,1 & $\mathrm{E}$ \\
\hline 1111 & 111 & $E$ \\
\hline & $P \quad 1 \quad 1$ & E \\
\hline
\end{tabular}

E GENERTOR

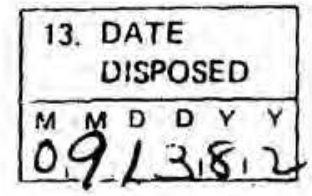

\begin{tabular}{|c|c|c|c|c|c|}
\hline AREA & SHAFT & PIT & $\operatorname{POST}$ (S) & LAYEA & gi \\
\hline & & & $1 T$ & 1 & \\
\hline
\end{tabular}

\begin{tabular}{|c|}
\hline $\begin{array}{c}\text { 15. SHAFT SURFACE } \\
\text { DOSE }\end{array}$ \\
\hline MR/HR \\
\hline 1 \\
\hline 1 \\
\hline
\end{tabular}

H.7 WASTE MANAGEMENT REPRESENTATIVE

HS-E 7-1A $(10 / 81)$ 
PLEASE READ INSTRUCTIONS ON BACK CAREFULLY

\begin{tabular}{|l|}
\hline 1. FORM NUMBER \\
\hline$\underline{s_{1}}{ }_{-1}, 191,6$, \\
\hline
\end{tabular}

2. DATE

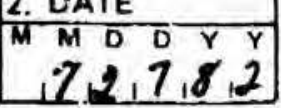

LOS ALAMO RADIOACTIVE SOLID WASTE DISPOSAL RECORD FORM
H 7 Waste Manacjectipnt

0.16095 MS 59?

\begin{tabular}{|l|}
\hline $\begin{array}{c}\text { 3. REFTIEVABLE } \\
\text { SERIAL NO. }\end{array}$ \\
\hline$B / 2,854$ \\
\hline
\end{tabular}

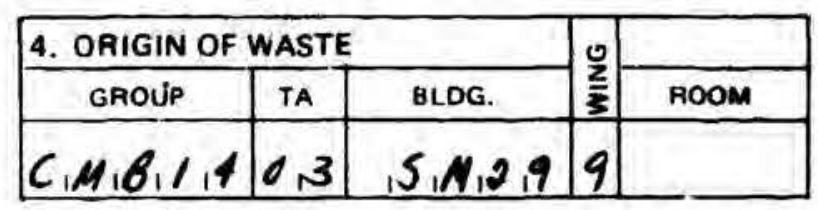

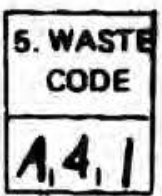

6. WASTE DESCRIPTION

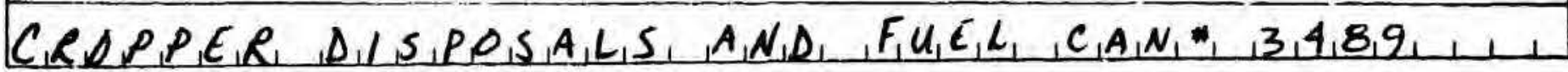

7. NUMBERS OF WASTE PACKAGES

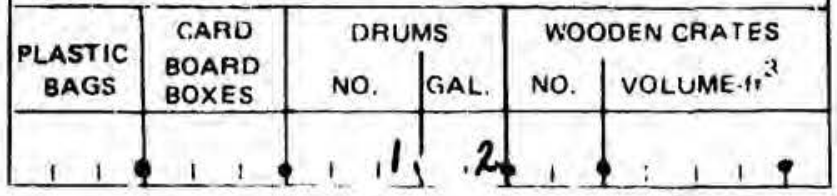

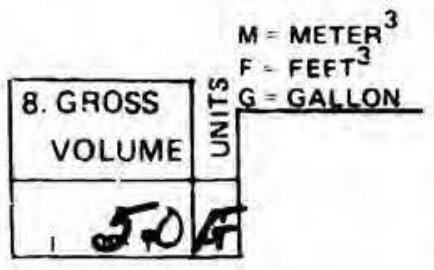

\begin{tabular}{|c|c|}
\hline \begin{tabular}{c} 
9. PACKAGE RADIATION AT: \\
\hline $\begin{array}{c}\text { SURFACE } \\
\text { MR/HR }\end{array}$
\end{tabular} & $\begin{array}{c}\text { I METER } \\
\text { MR/HR }\end{array}$ \\
\hline 1,1, & $3,0,0,0,0$ \\
\hline
\end{tabular}
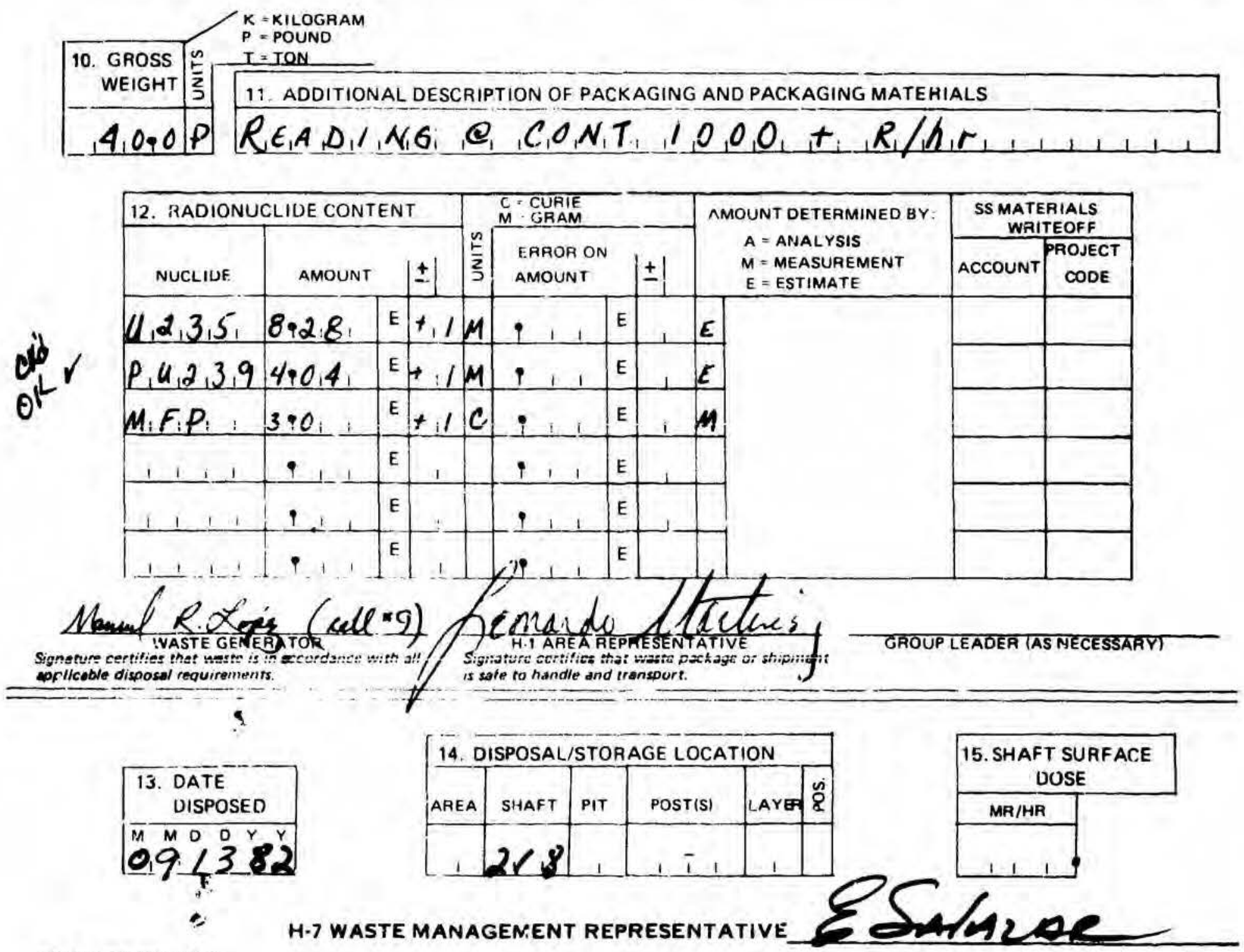

HS -E 7.1A $(10$ 1) 
PLEASE READ INSTRUCTIONS ON BACK CAREFULLY

\begin{tabular}{|l|}
\hline 1. FORM NUMBER \\
\hline$\leq, 8,2,1917 ?$ \\
\hline
\end{tabular}

2. DATE

$\begin{array}{lllll}M & D & D & Y & Y \\ 7 & 0 & 8 & B_{1}\end{array}$
LOS ALAMOS RADIOACTIVE SOL ID WASTE DISPOSAL RECORD FORM
H 7 Waste Management

Li 60195 MS 592

\begin{tabular}{l} 
3. RETRIEVABLE \\
SERIAL NO. \\
\hline BLDG EA
\end{tabular}

\begin{tabular}{|c|c|c|c|c|}
\hline 4. ORIGIN OF WASTE & \multirow{2}{*}{} & \\
\hline GROUP & TA & BLDG. & 3. & ROOM \\
\hline$C_{1} M_{1} \sigma_{1} /, 4$ & 0,3 & $, 5, M_{1} 2,9$ & 9 & \\
\hline
\end{tabular}

\begin{tabular}{|r|}
\hline 5. WASTR \\
CODE \\
\hline $1,4,1$ \\
\hline
\end{tabular}

6. WASTE DESCRIPTION

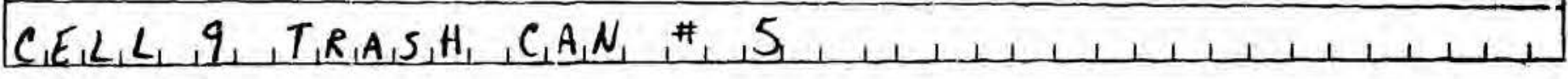

\begin{tabular}{|c|c|c|c|c|c|c|}
\hline 7. NUMBERS OF WASTE PACKAGES \\
\hline $\begin{array}{c}\text { PLASTIC } \\
\text { BAGS }\end{array}$ & $\begin{array}{c}\text { CARD } \\
\text { BOARD } \\
\text { BOXES }\end{array}$ & $\begin{array}{c}\text { DO RUMS } \\
\text { NO. }\end{array}$ & GAL. & WO & WOODEN CRATES \\
\hline 1 & 1 & 1 & 1 & 1 & VOLUME. $\mathrm{ft}^{3}$ \\
\hline
\end{tabular}

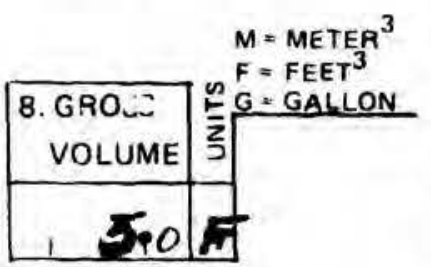

\begin{tabular}{|c|c|}
\hline \begin{tabular}{c} 
9. PACK AGE RADIATION AT: \\
\hline $\begin{array}{c}\text { SURFACE } \\
\text { MR/HR }\end{array}$
\end{tabular} & $\begin{array}{c}1 \text { METER } \\
\text { MARTHA }\end{array}$ \\
\hline $1,1,16,0,0,0$ \\
\hline
\end{tabular}
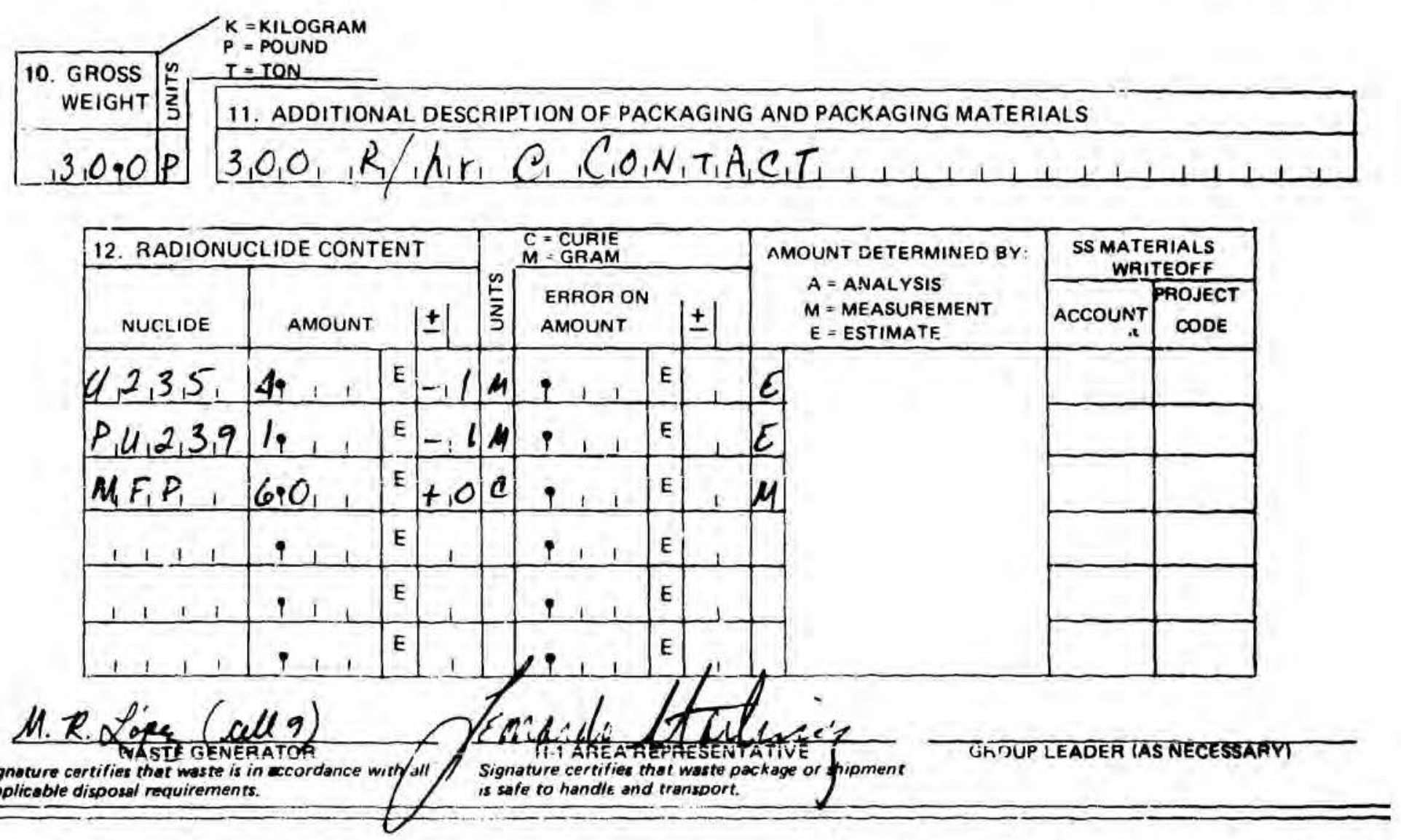

applicable disposal requirements.
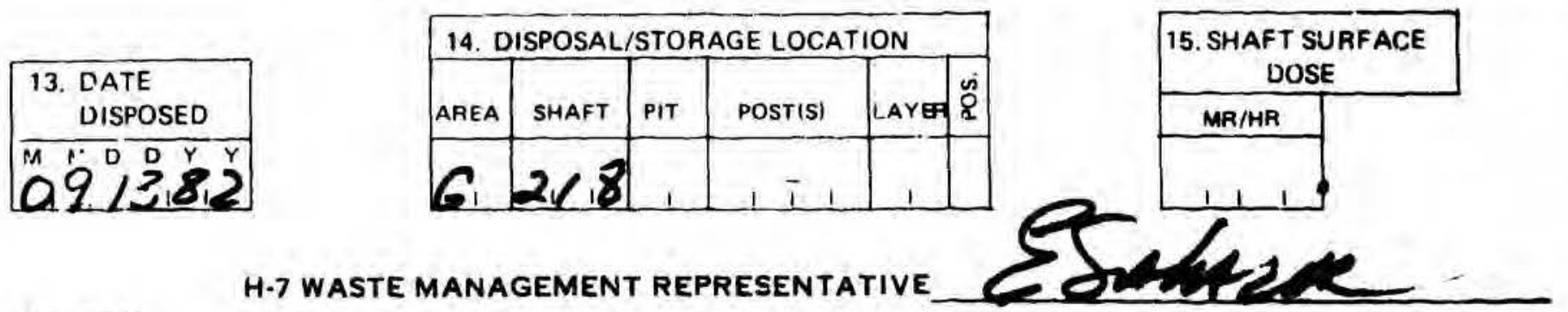

USE 7.1A $(10 / 81)$ 
RADIOACTIVE SOLID WASTE DISPOSAL RECORD FORMS

FOR

SHAFT 219

MATERIAL DISPOSAL AREA G 
PLEASE READ INSTRUCTIONS ON BACK CAREFULLY

1. FOAM NUMBEA

LOS ALAMO RADIOACTIVE SOLID WASTE

DISPOSAL RECORD FOAM

4.7 What e Minogemont

Ext 6095 MS 5592

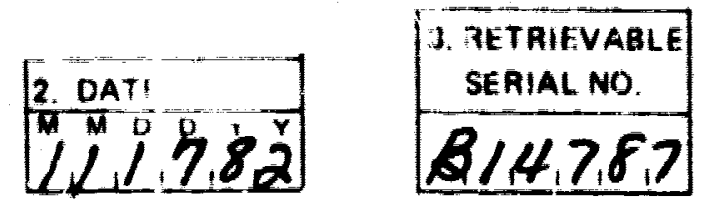

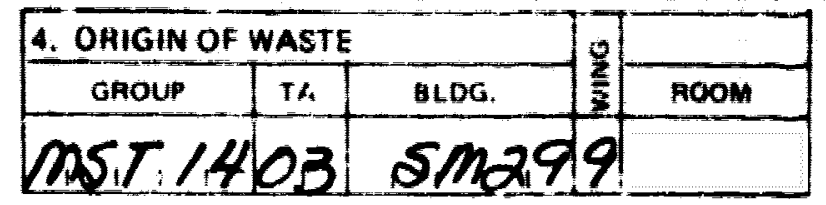

5. WASTE

6. WASTE DESCRIPTION

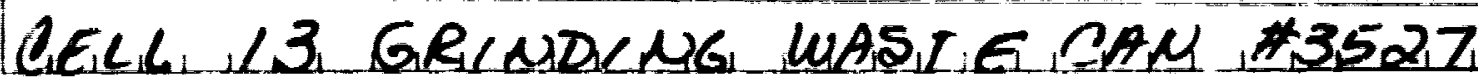
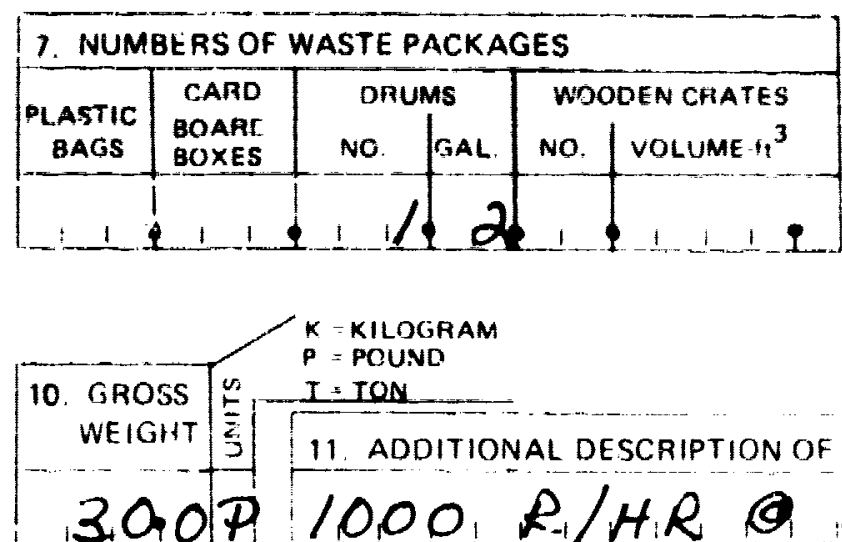
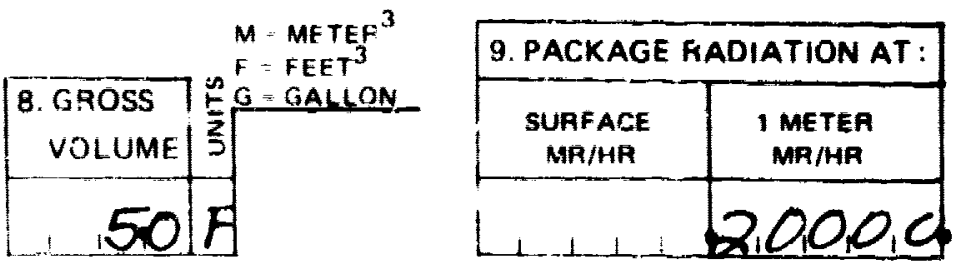

$30.0 P 1000, R / H R$ Q CONTACT

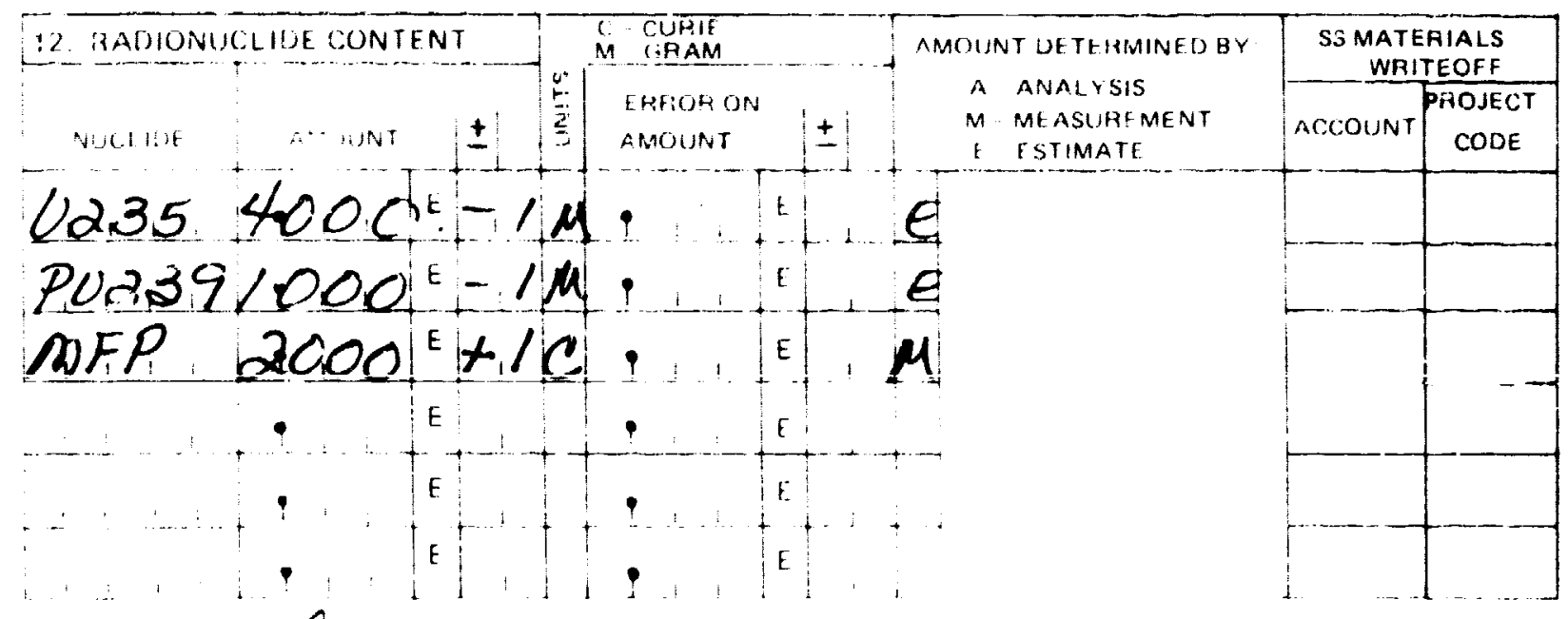

Manuel R Lopez

H. 1 AREAREFPE TENTATIVE

CROUP LEADER IASNECESSARY

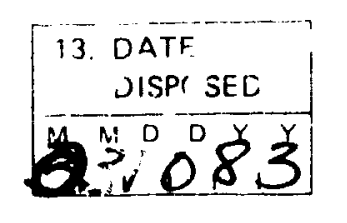
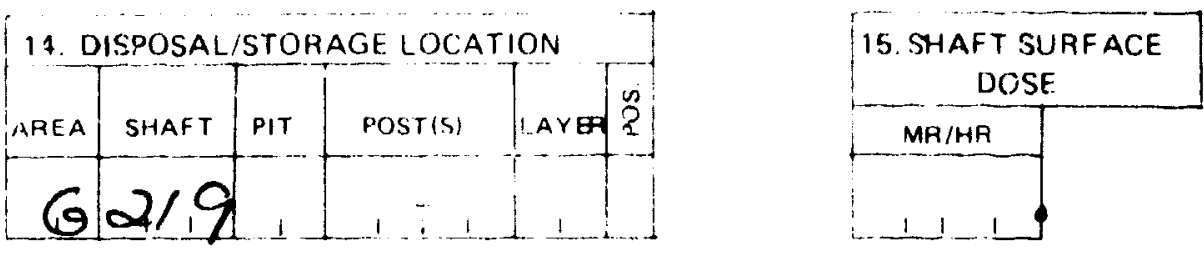

HST 7.1A $(10 / 81)$

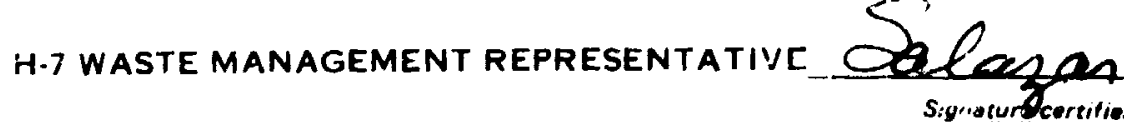

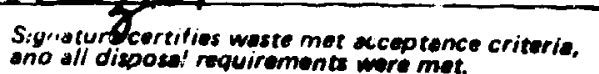


PLEASE READ INSTRUCTIONS ON BACK CAREFUL Y

1. FORN: NUMBER

LOS ALAMOS RADIOACTIVE SOLID WASTE

DISPOSAL RECORD FORM

H. 7 Waste Management

Ext 6095 MS J592

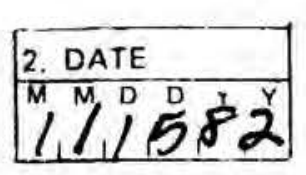

\begin{tabular}{|l|}
\hline $\begin{array}{l}\text { 3. RETRIEVABLE } \\
\text { SERIAL No. }\end{array}$ \\
\hline $3 / 4,7,8,7$ \\
\hline
\end{tabular}

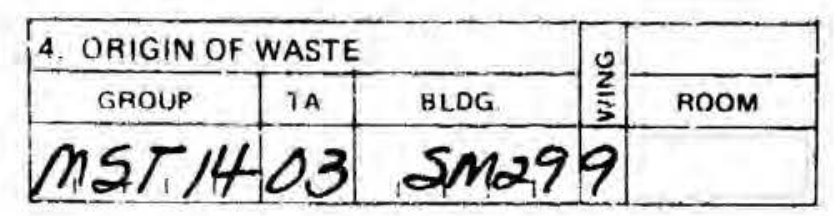

\begin{tabular}{r|}
\hline . WASTE \\
CODE \\
\hline$A 14 D$ \\
\hline
\end{tabular}

6. WASTE DESCRIPTION

CELC 9 FUEL \& HARDWARE CAM 3,724
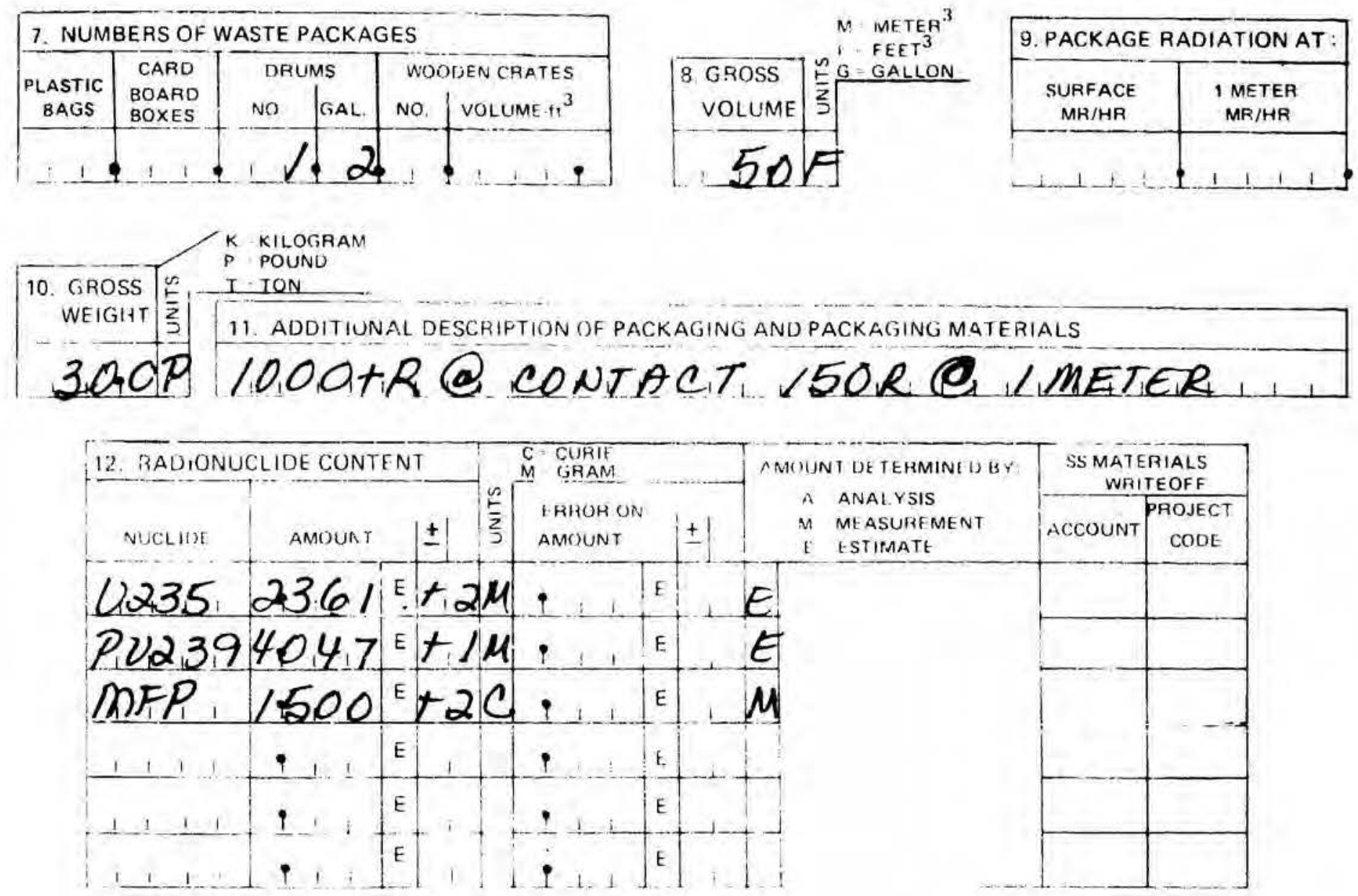

:WASTE GENEAATTOF

H.1 AREA REPRESENTATIV

GROUP LA AUER (AS NECESSARY)

13. DATE
DISPOSE O
$0,3 / 0,8,3$
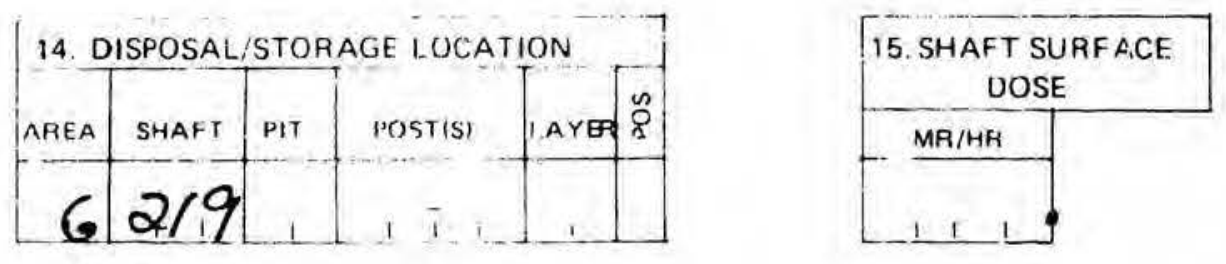

H-7 WASTE MANAGEMENT REPRESENTATIVE

HS-E 7-1A $(i 0 / 81)$

Signature certifies. waste met acceptance criteria,
ind all disposal roque foments were mot. 
LOS ALAMOS PADIOACTIVE SOLID WASTE DISPOSAL RECORD FORM
H. 7 Viaste Maragement Ex: 6035 MS $J 592$

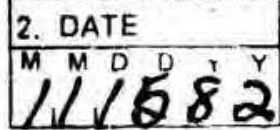

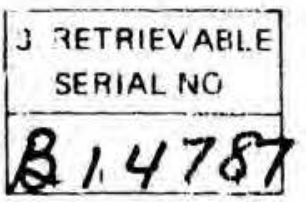

\begin{tabular}{|c|c|c|c|c|}
\hline \multicolumn{3}{|c|}{ 4. ORIGIN OF WASTE } & \multirow{2}{*}{$\frac{0}{3}$} & \\
\hline GROUP & TA & BLDG. & & ROOM \\
\hline msill & 0,3 & $5 m$ & 9 & \\
\hline
\end{tabular}

6. WASTE DESCRIPTION

\section{CELL9 WASTE CAN 3725}
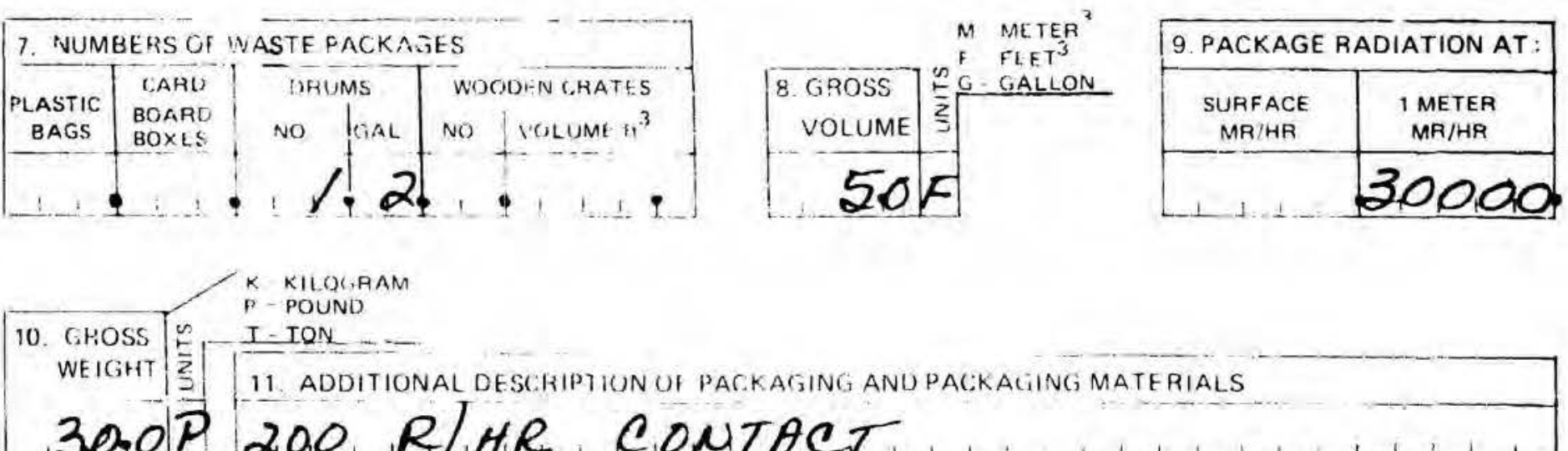

R. R. HR.

CONTACT

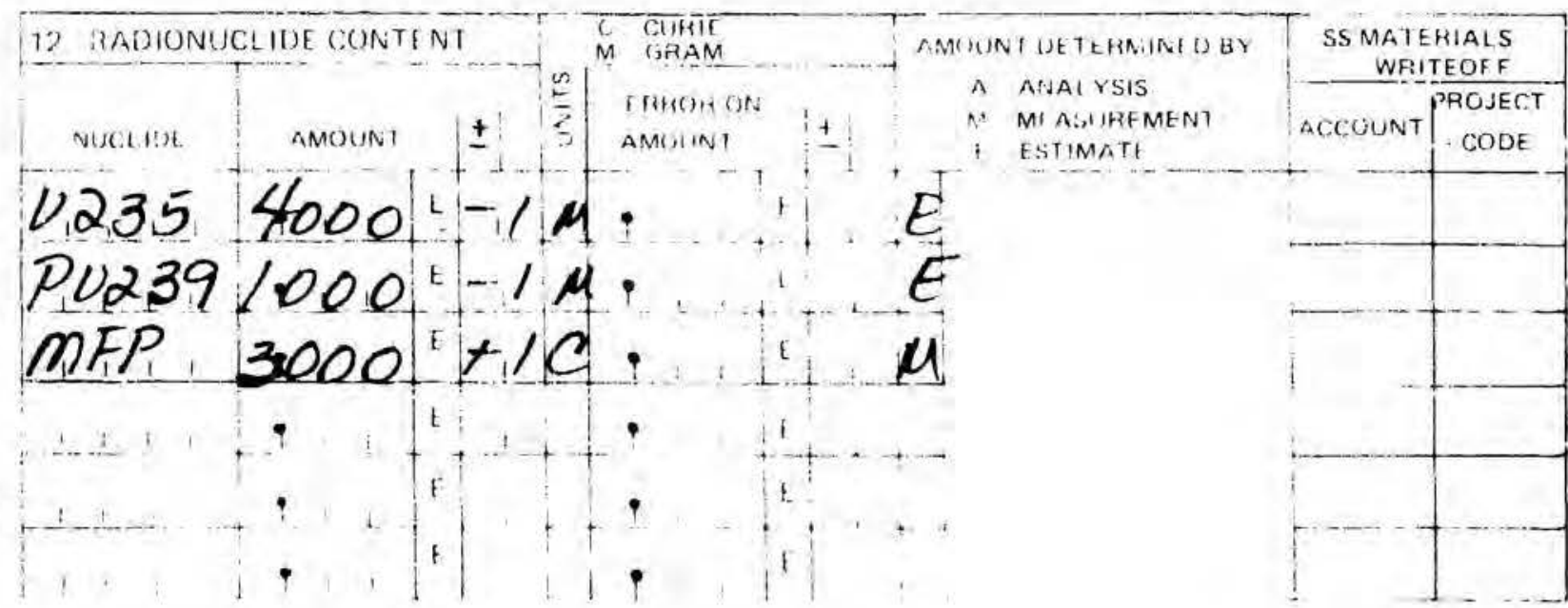

IVASTE GENERATOH

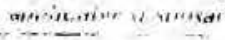

HI AHFA RE MHE SE NTAT VE

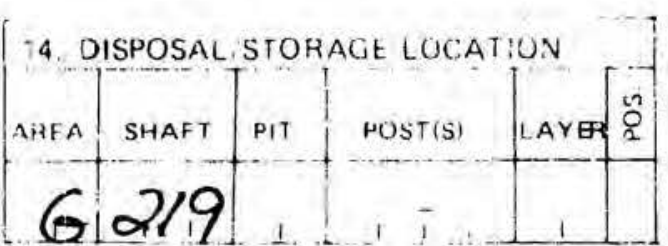

TROUF LEADER IAS NECESSARVI

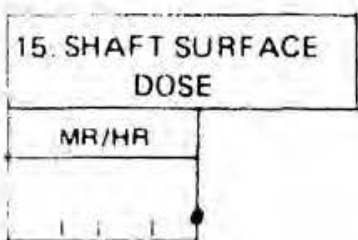


PLEASE READ INSTRUCTIONS ON BACK CAREFULLY Y

$$
\begin{array}{|l|}
\hline \text { 1. FORM NUMBER } \\
\hline \mathrm{s}, 8,3,28,34 \\
\hline
\end{array}
$$

LOS ALAMO RADIOACTIVE SOLID WASTE DISPOSAL RECORD FORM

H.7 Waste Management

LAt 6095 MS J592

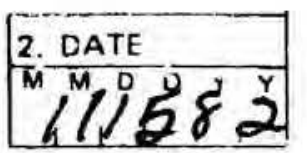

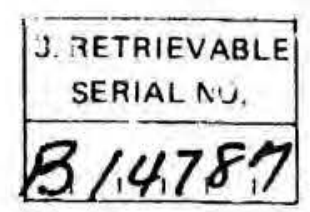

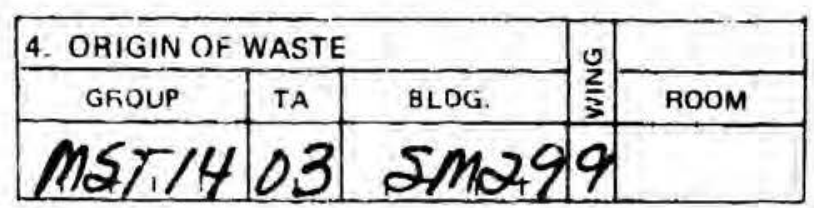

\begin{tabular}{l}
\hline . WASTE \\
CODE \\
\hline A $1 / 1$ \\
\hline
\end{tabular}

6. WASTE DESCRIPTION

CE LA 9 HOT TRASH CAN 3524
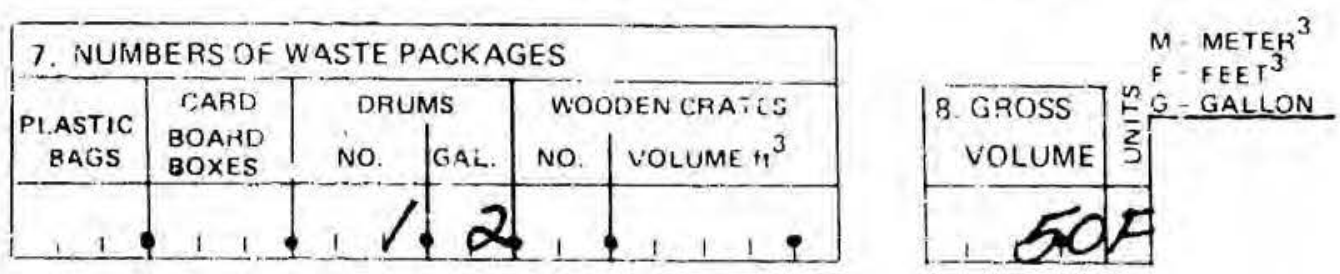

\begin{tabular}{|c|c|}
\hline 9. PACKAGE RADIATION AT \\
\hline $\begin{array}{c}\text { SURFACE } \\
\text { MR/HR }\end{array}$ & $\begin{array}{c}1 \text { METER } \\
\text { MR/HR }\end{array}$ \\
\hline & \\
\hline & \\
\hline
\end{tabular}
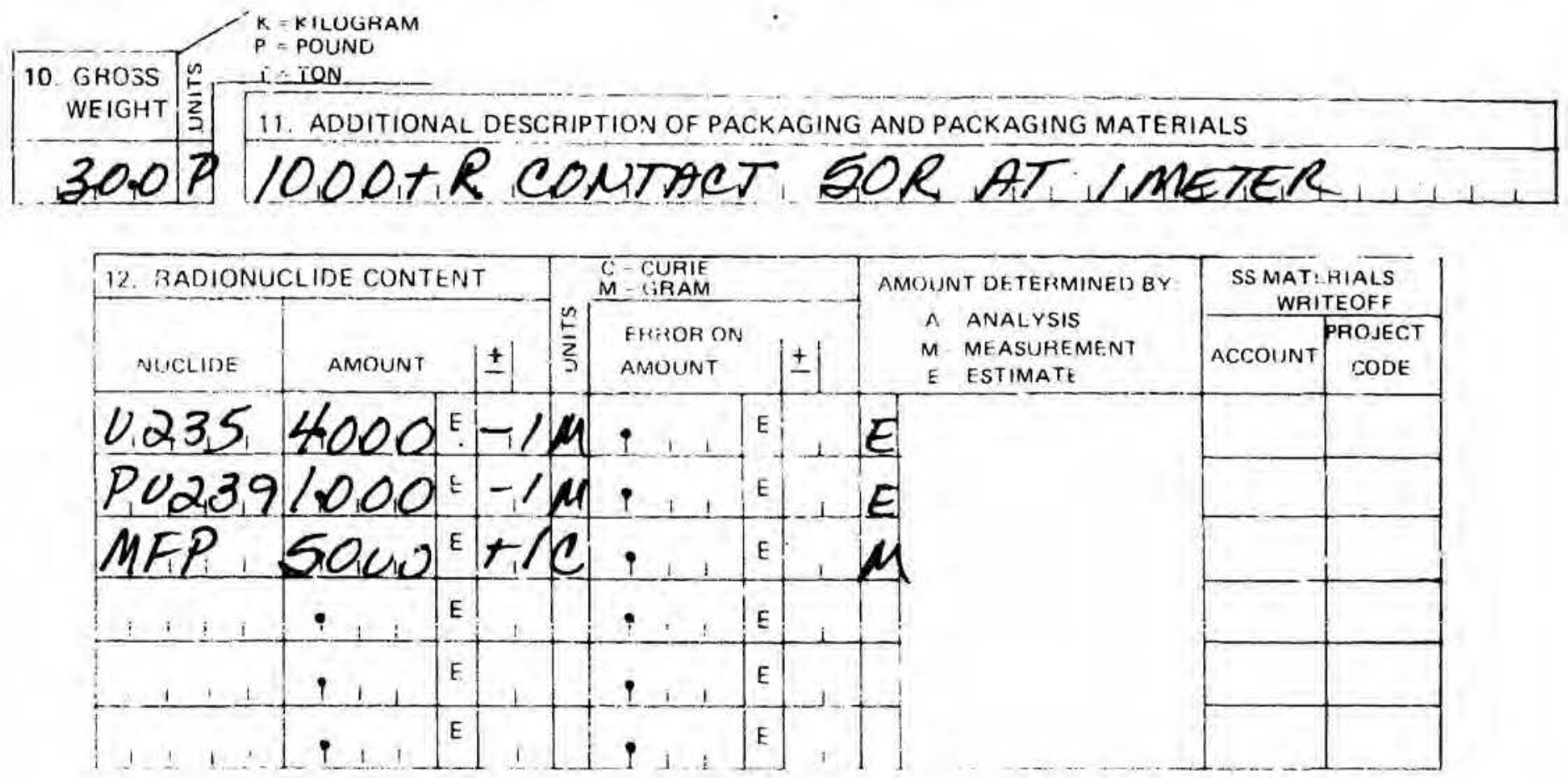

WASTE GENERATOR

H.1 AREA REPRESENTATIVE

STOUP LEADER (AS NECESSARY) -

Sondicists

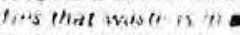

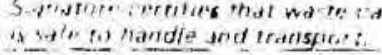
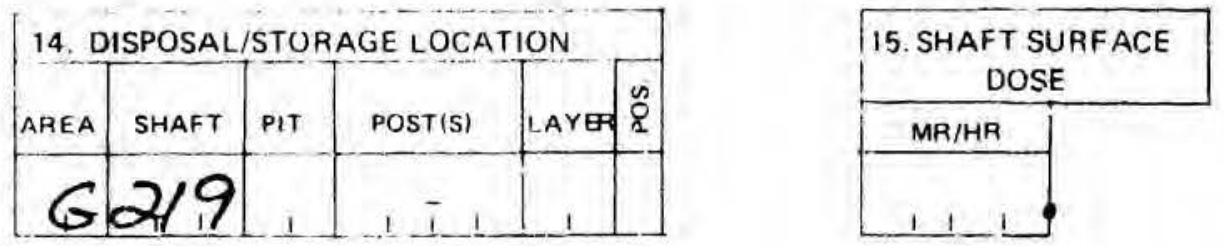

H-7 WASTE MANAGEMENT REPRESENTATIVE

HS-E 7.1A $(10 / 81)$ Sig.7ature certifies waste met acceptance criteria,
and all disposal requirements were mat. 
1. FORM NUMBER

s, 8,3,28,35
LOS ALAMOS RADIOACTIVE SOLID WASTE DISPOSAL RECORD FORM
H.7 Waste Management Ext 6095 MS J592
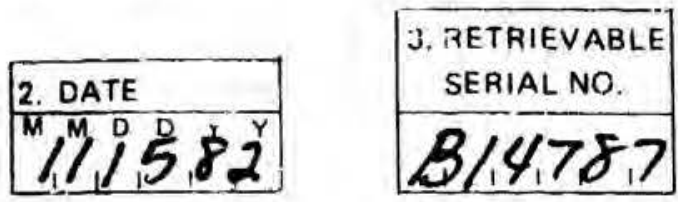

\begin{tabular}{|c|c|c|c|c|}
\hline 4. ORIGIN OF WASTE & 0 & \\
\hline GROUP & TA & BLOG & $\frac{2}{3}$ & ROOM \\
\hline MSTI/4 D3 & $5 M 299$ & \\
\hline
\end{tabular}

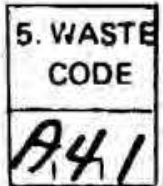

6. WASTS DESCRIPTION

CELL 9 HOT TRASH CAM 3495

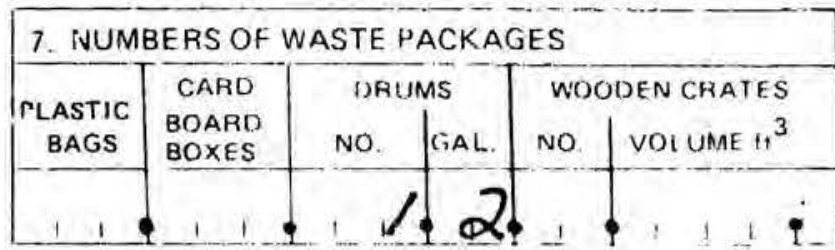

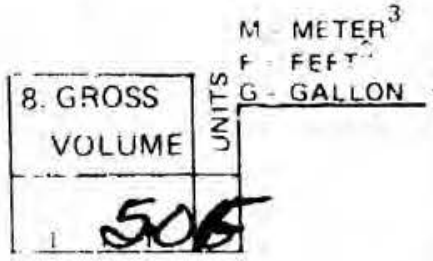

\begin{tabular}{|c|c|}
\hline \multicolumn{2}{|c|}{ 9. PACKAGE RADIATION AT } \\
\hline $\begin{array}{l}\text { SURFACE } \\
\text { MR/KH }\end{array}$ & $\begin{array}{l}\text { I METER } \\
\text { MR/HR }\end{array}$ \\
\hline
\end{tabular}
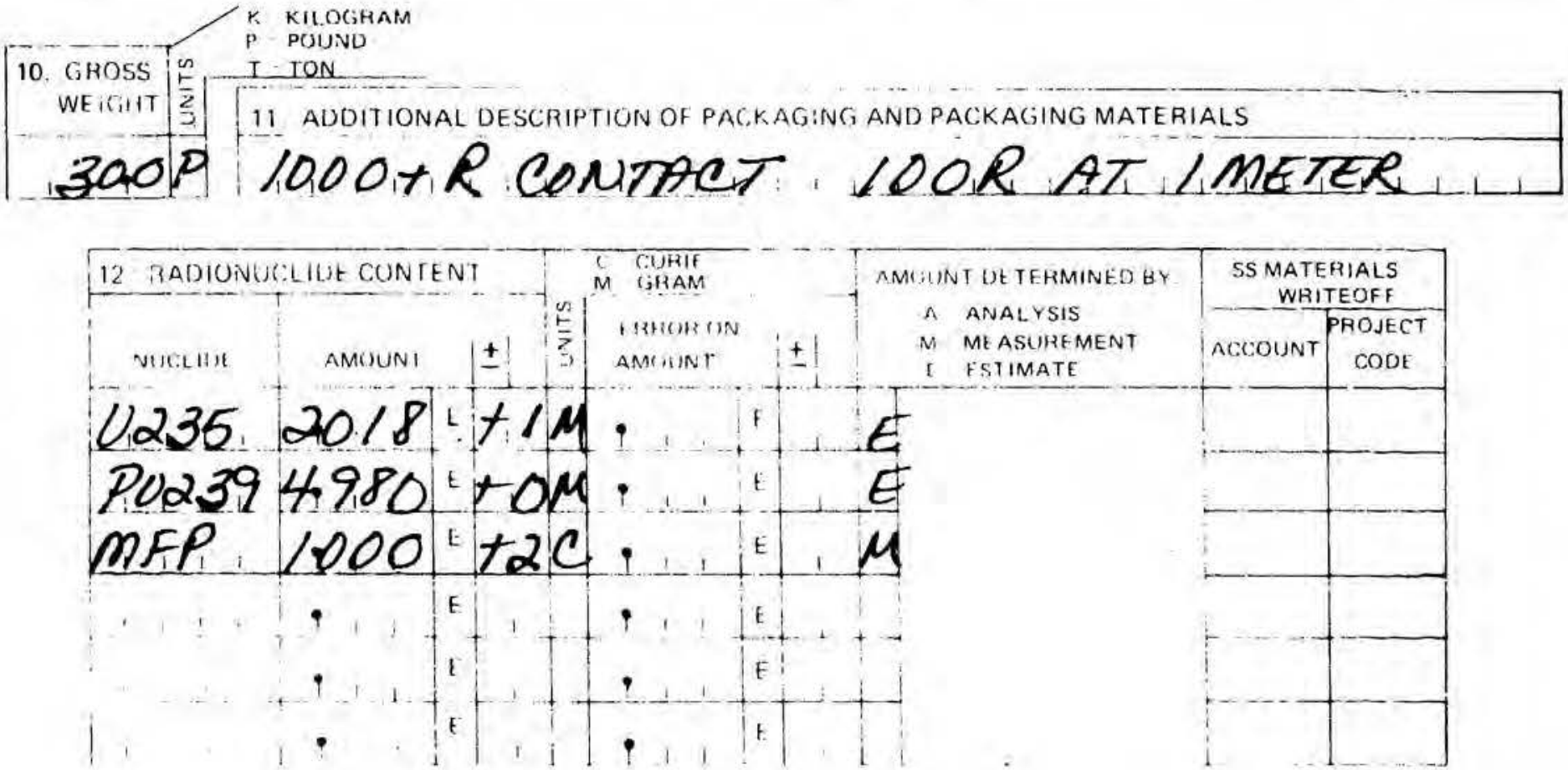

IVASTE GENEHATOH

STY

ant
TI AHE A RE PRESENTATIIVE

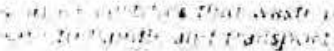

\section{SRUUP LEAUER IAS NECESSARY)}

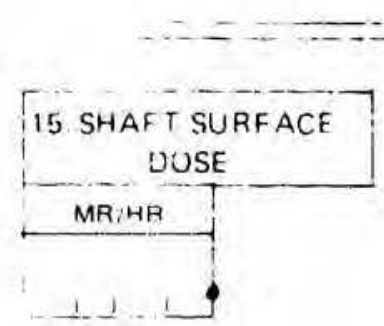

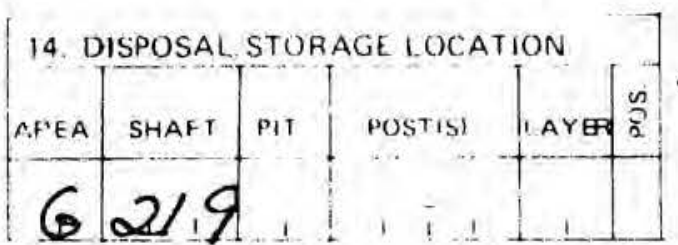


RADIOACTIVE SOLID WASTE DISPOSAL RECORD FORMS

FOR

SHAFT 220

MATERIAL DISPOSAL AREA G 
PLEASE READ INSTRUCTIONS ON BACK CAREFUL Y

c

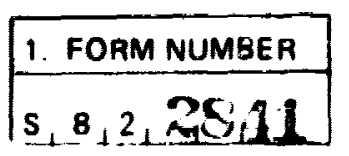

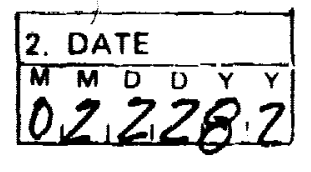

LOS ALAMO RADIOACTIVE SOLID WASTE DISPOSAL RECORD FORM

6. WASTE DESCRIPTION

Qombusitibie

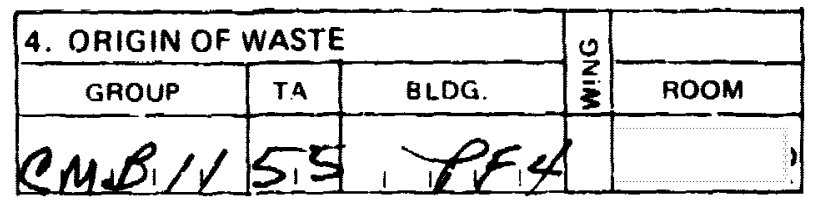

$\begin{array}{r}\text { 5. WAST } \\ \text { CODE } \\ \hline \text { A } 1,4 \\ \hline\end{array}$

7. NUMBERS OF WASTE PACKAGES

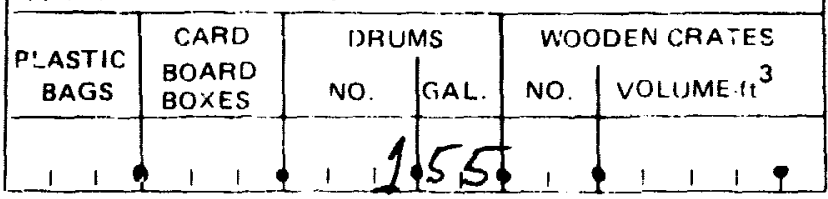

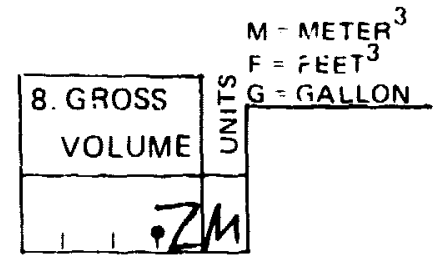

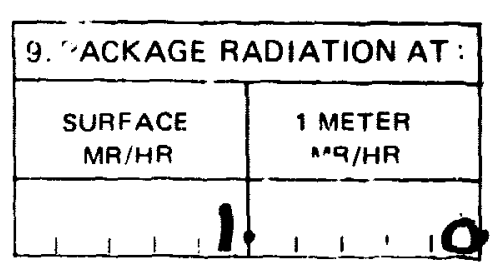

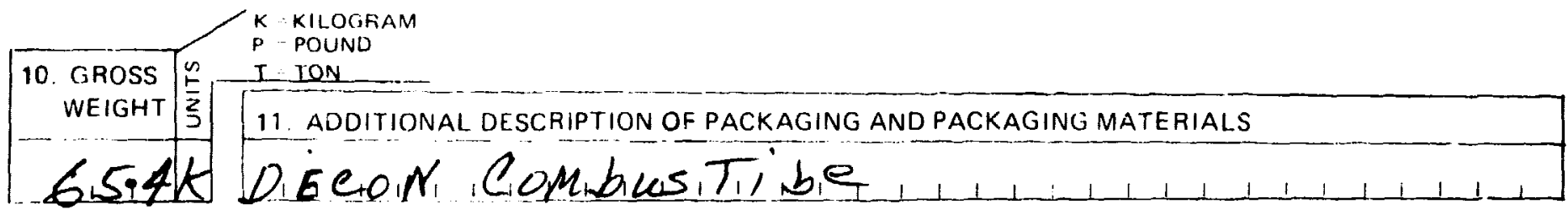

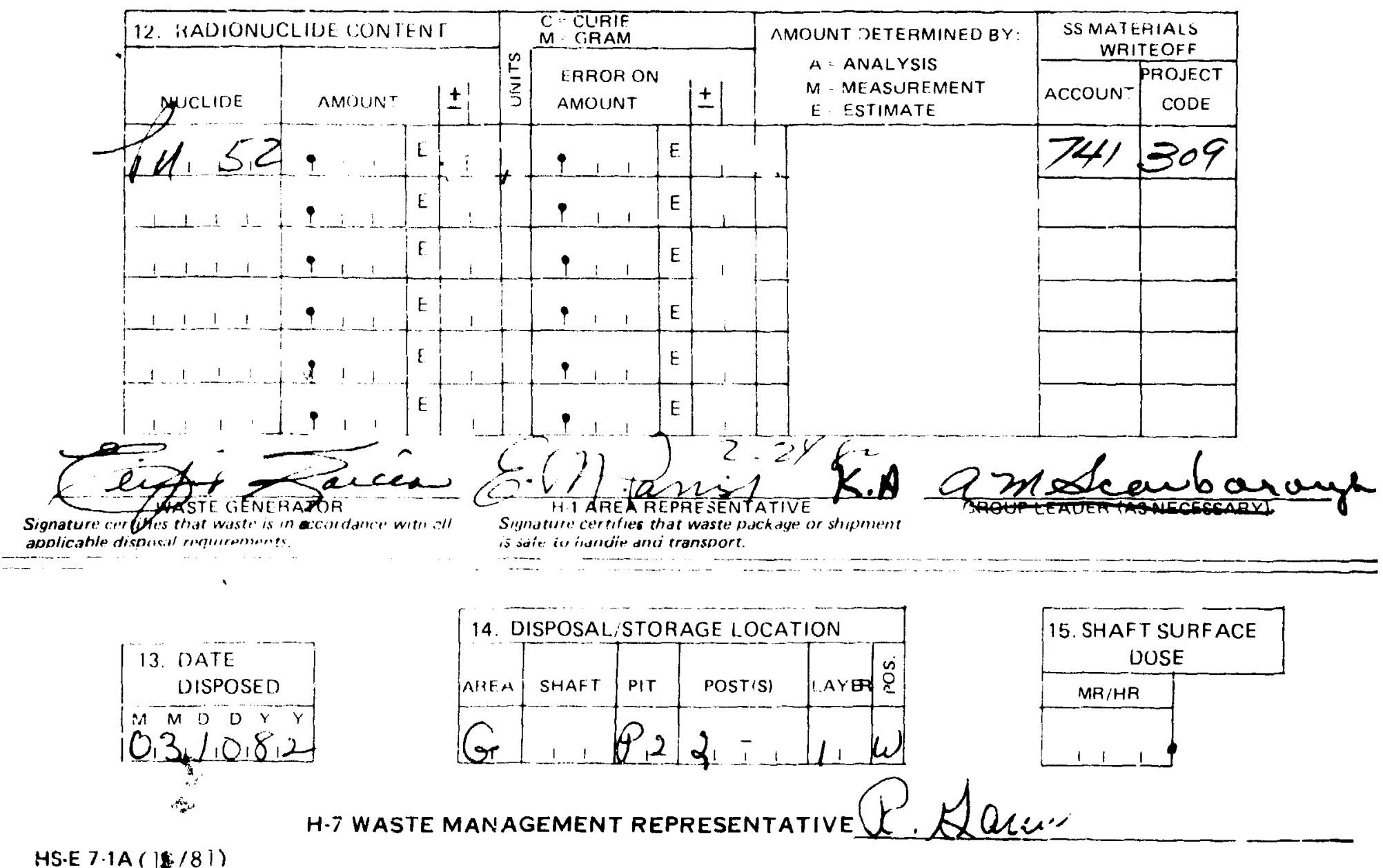

USE 7.1A ( I / / I) 
PLEASE READ INSTRUCTIONS ON BACK CAREFULLY

1. FORM NUMBER

$s, 8,3,2836$

LOS ALAMO RADIOACTIVE SOLID WASTE

DISPOSAL RECORD FORM

$H>$ Waste Management

Ext 6095 MS $J 592$

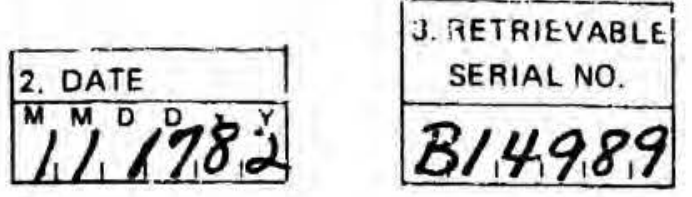

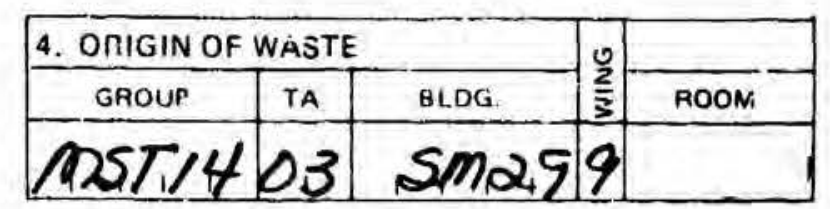

\begin{tabular}{l}
\hline 5. WASTE \\
CODE \\
\hline$Q \angle 4 \angle$ \\
\hline
\end{tabular}

6. WASTE DESCRIPTIOIN

$\angle C_{1} L$, I WASTE ETC CAN 37278
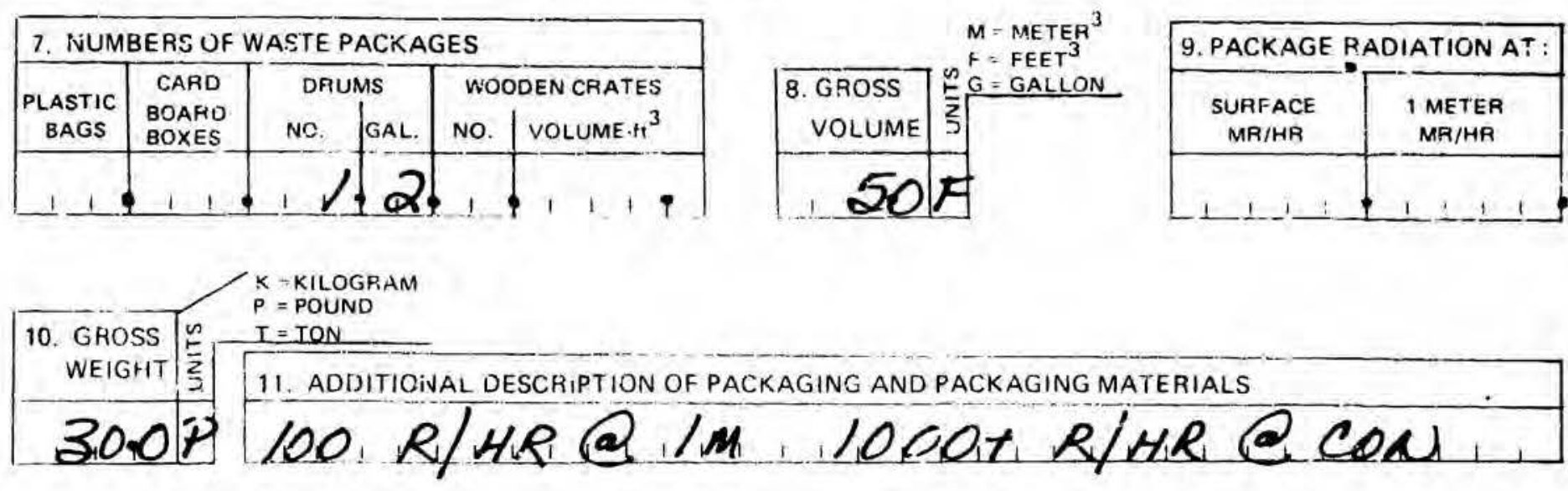

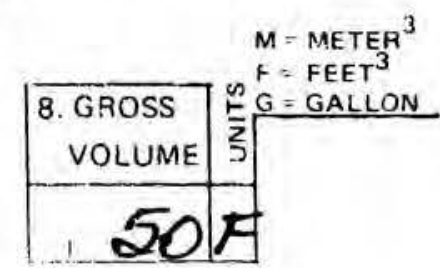

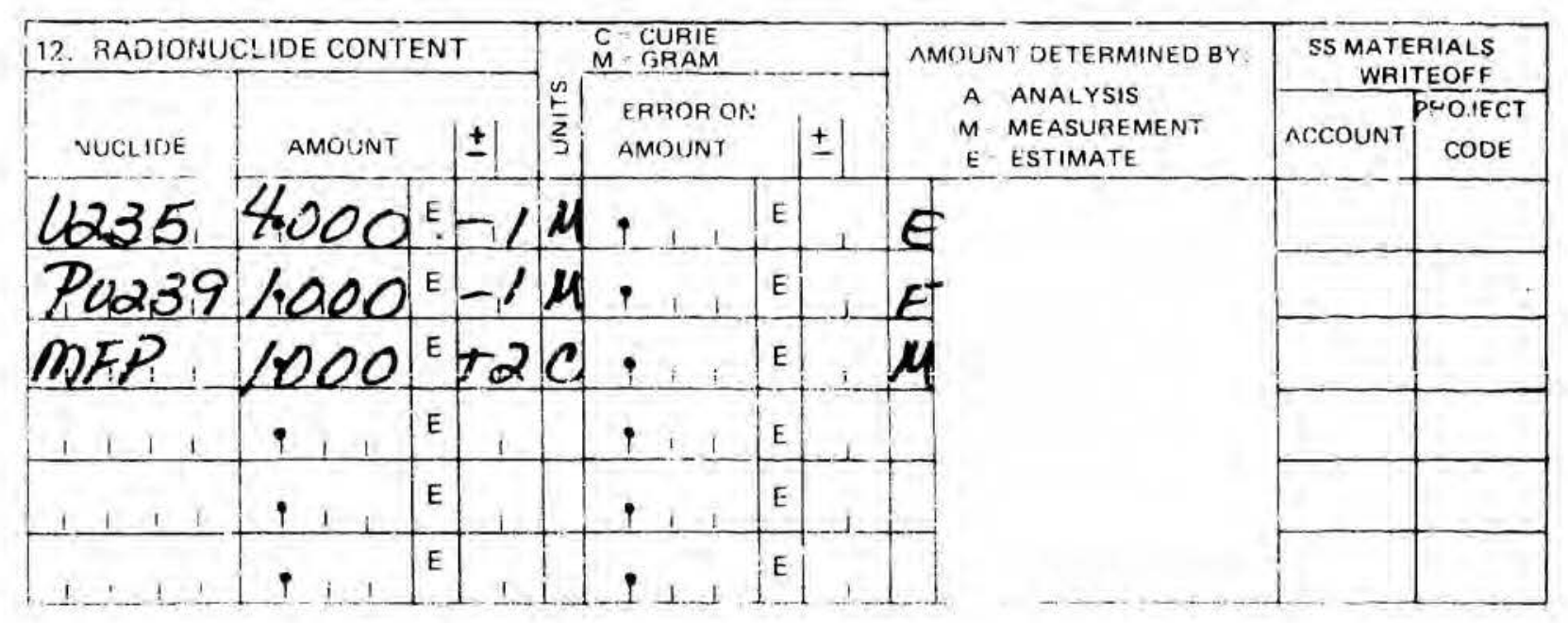

IVASTE GENERATOR

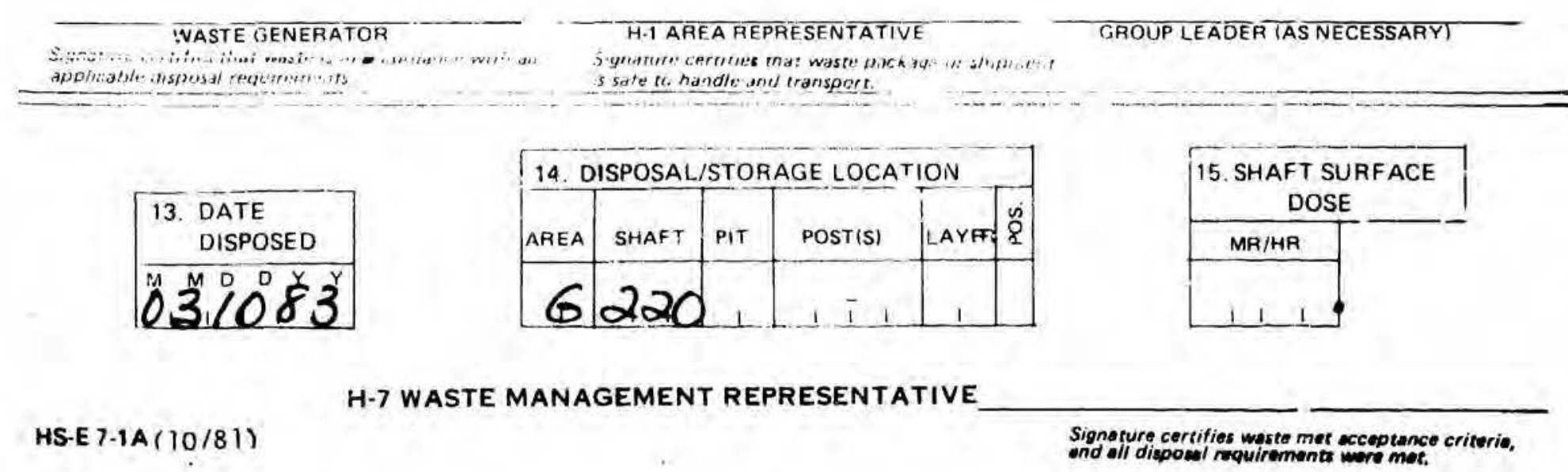


PLEASE PEAD INSTRUCTIONS ON GACK CAREFULLY

1. FORM NUMBER

s, 8, 3, 25.3\%
LOS ALAMOS RADIOACTIVE SOLID WASTE

DISPOSAL RECORD FORM
$\mathrm{H}>7$ Waste Managernent t. 6095 MS $\mathrm{j} 592$
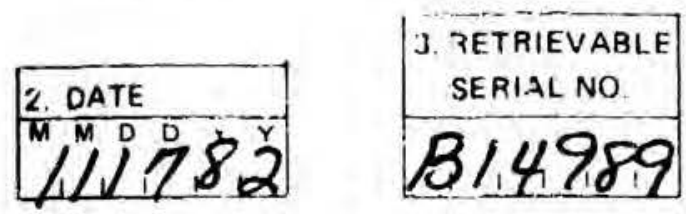

\begin{tabular}{|c|c|c|c|}
\hline 4 ORIGIN OF WASTE & & \\
\hline GROUP & TA & BLDG & ROOM \\
\hline MST/14 & OB & SMO29 & \\
\hline
\end{tabular}

\begin{tabular}{l} 
5. VIASTA \\
CODE \\
\hline$A 4 / 2$ \\
\hline
\end{tabular}

6. WASTE DESCRIPTION

\section{CELL Q WASTE CAN 3491}

7. NUMBERS OF WASTE FACKAGES
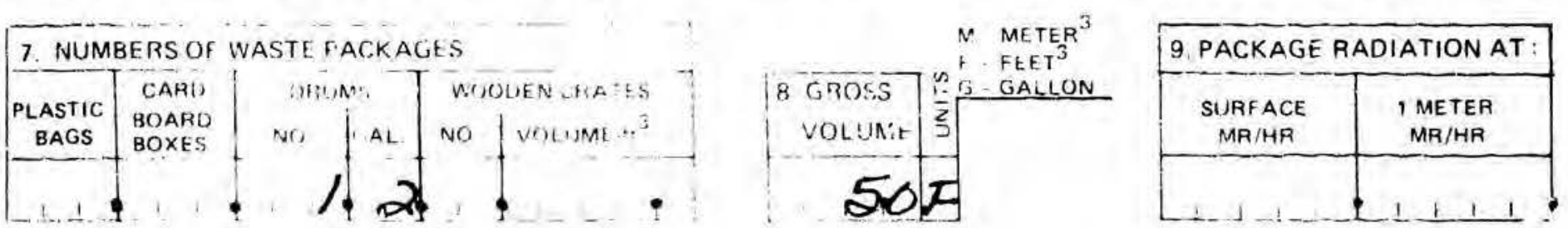

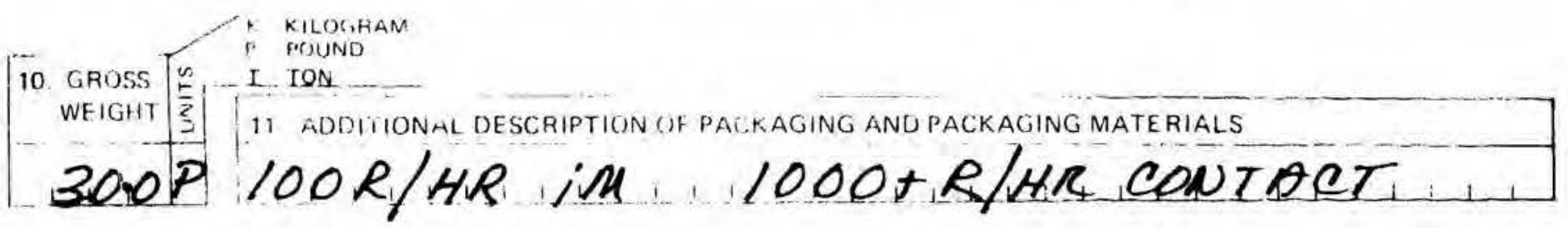

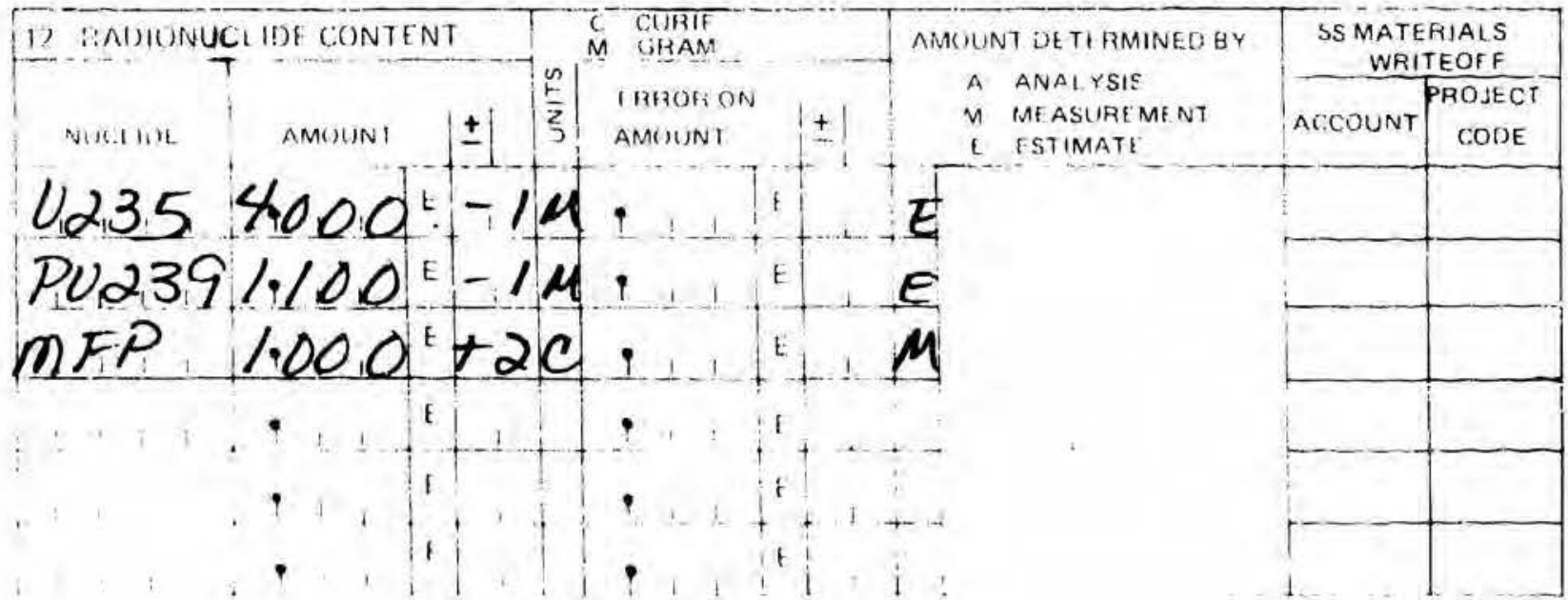

:VASTI GENFHATIK

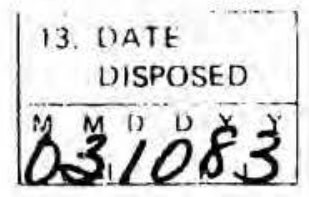

14 A ARE A REPHESENTATIVE

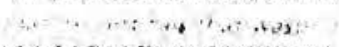

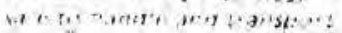

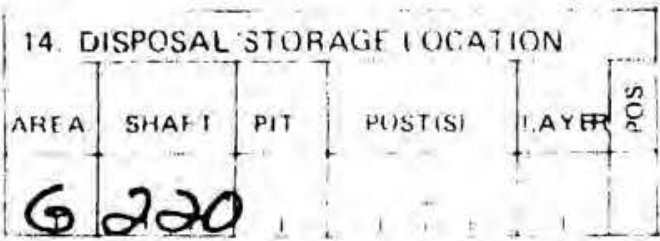

CRCUP LEADE ? (AS NECESSARY)

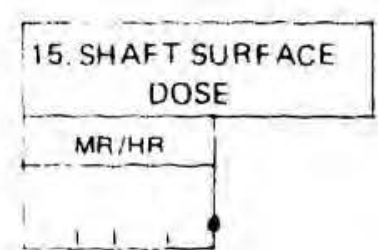


1. FORM NUMBER

$5,8,3,28,39$
PLEASE READ INSTRUCTIONS ON BACK CAREFULLY

LOS ALAMOS RADIOACTIVE SOLID WASTE

DISPOSAL RECORD FORTY
H 7 Waste Management

Ext 6095 MSS 1592

\begin{tabular}{|l|l|}
\hline 2. DATE & 3. REtrievable \\
\hline$M, M$ & SERIAL No. \\
\hline & $3 / 14989$ \\
\hline
\end{tabular}

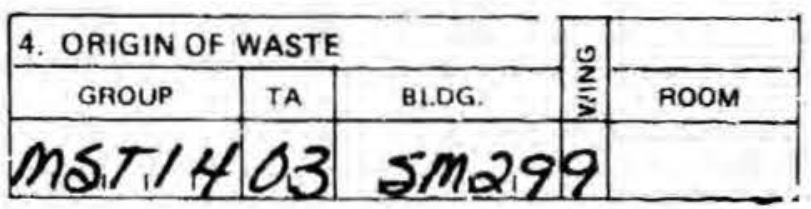

\begin{tabular}{|c|}
\hline $\begin{array}{c}\text { 5. WASTR } \\
\text { CODE }\end{array}$ \\
\hline$A 4.2$ \\
\hline
\end{tabular}

6. WASTE DESCRIPTION

CELL, LI TRASH CAM 3706

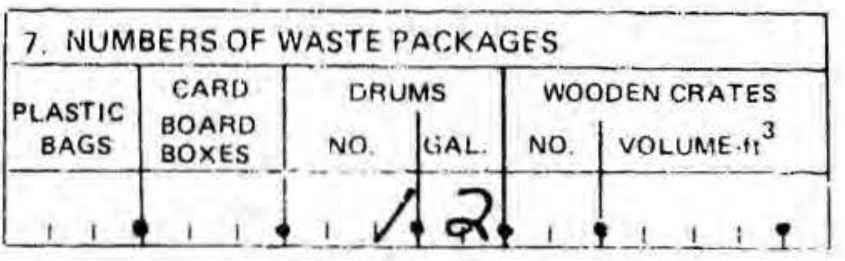

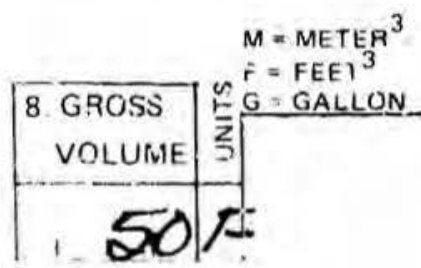

\begin{tabular}{|c|c|}
\hline \multicolumn{2}{|c|}{ 9. PACKAGE RADIATION AT: } \\
\hline $\begin{array}{c}\text { SURFACE } \\
\text { MRIHR }\end{array}$ & $\begin{array}{c}\text { METER } \\
\text { MR/HR }\end{array}$ \\
\hline $1,1 \ldots$ & 2QQOC \\
\hline
\end{tabular}
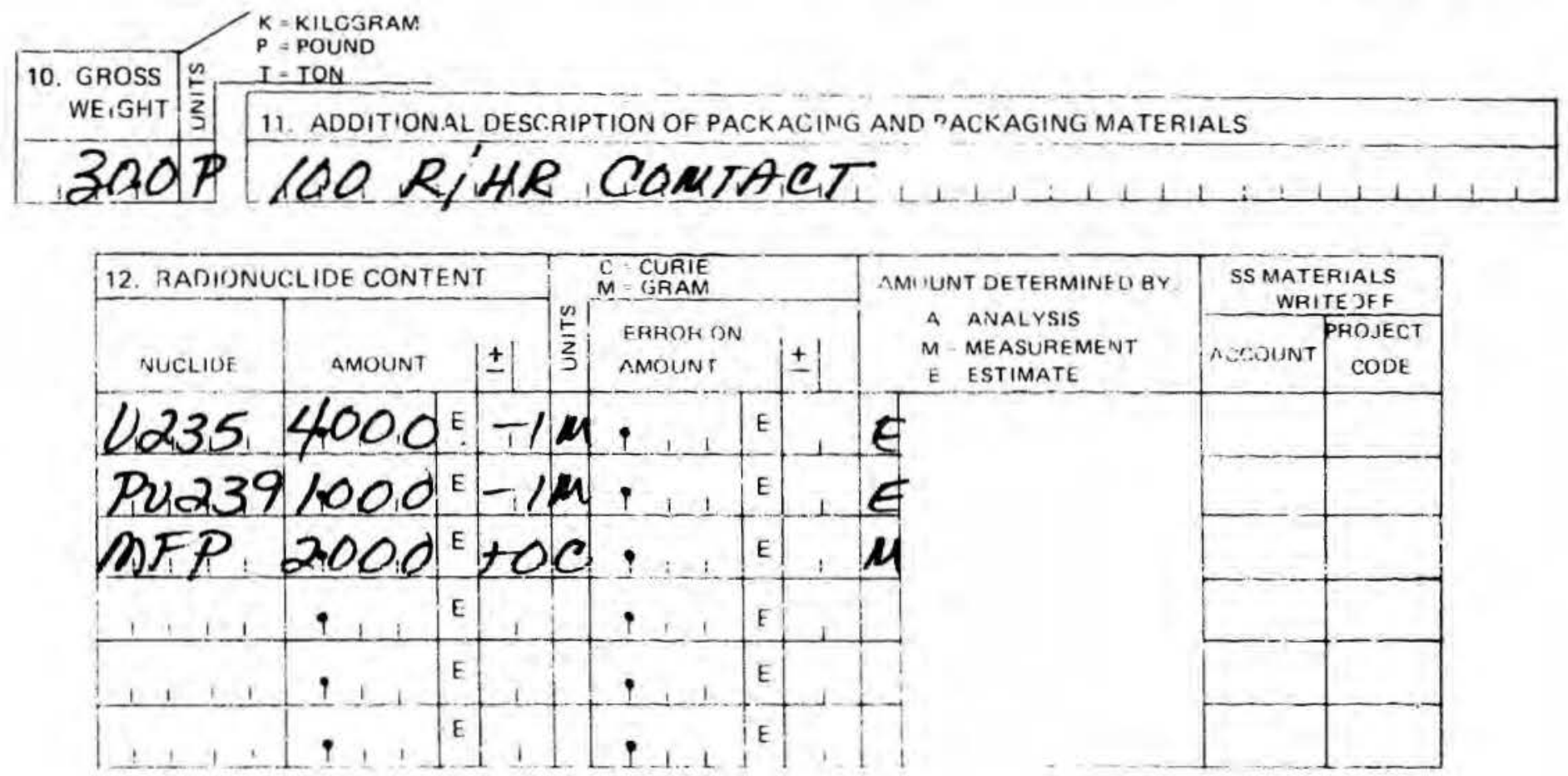

WASTE GENERATOR

GROUP LEADER (AS NECESSARY)

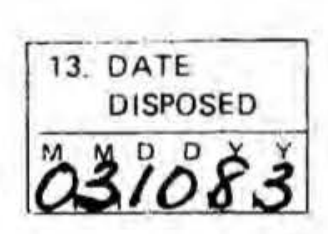

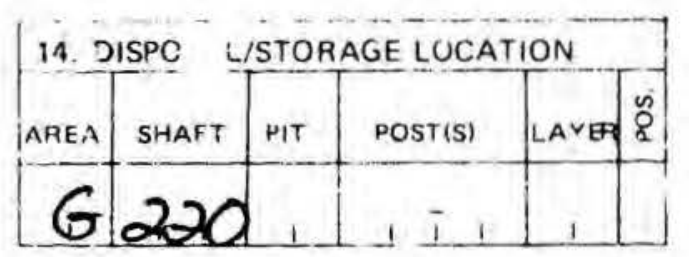

15. SHAFT SURF F.CE

DOSE

MR/HR

HS .E 7.1A $(10 / 81)$

H-7 WASTE MANAGEMENT REPRESENTATIVE

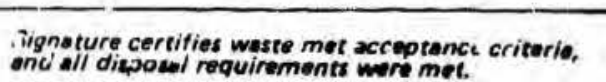


PLEASE READ INSTRUCTIONS ON BACK CAREFULLY

1. FORM NUMBER

\section{LOS ALAMOS RADIOACTIVE SOLID WASTE DISPOSAL RECORD FORM:}

H 7 Waste Management

Ex 6095 MS $J 592$
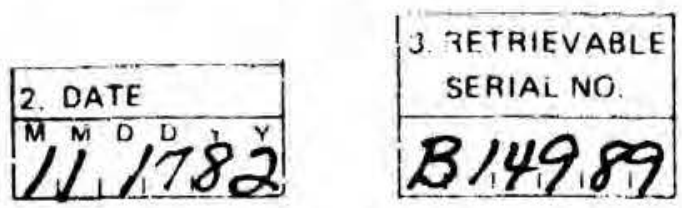

\begin{tabular}{|c|c|c|c|c|}
\hline 4. ORIGIN OF WASTE & & \\
\hline GROUP & TA & BLDG & S & ROOM \\
\hline MST $/ 4$ & OS & SMR29 & \\
\hline
\end{tabular}

\begin{tabular}{|l|}
\hline 5. WASTR \\
CODE \\
\hline$A 4 / 2$
\end{tabular}

6. WASTE DESCRIPTION

CELL 13 GRINDING CAN 3528
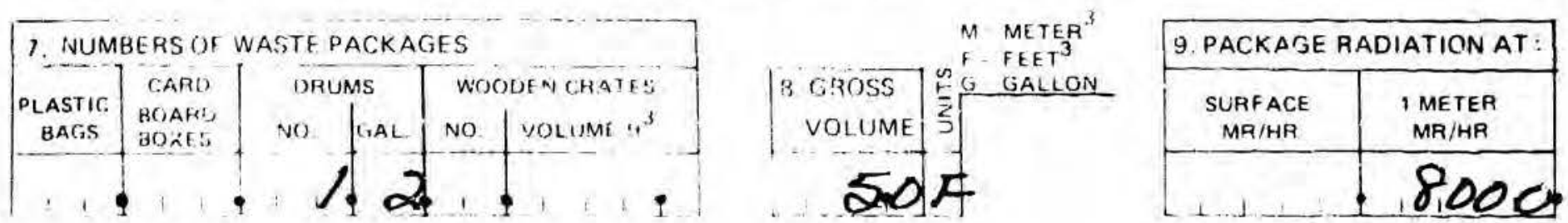

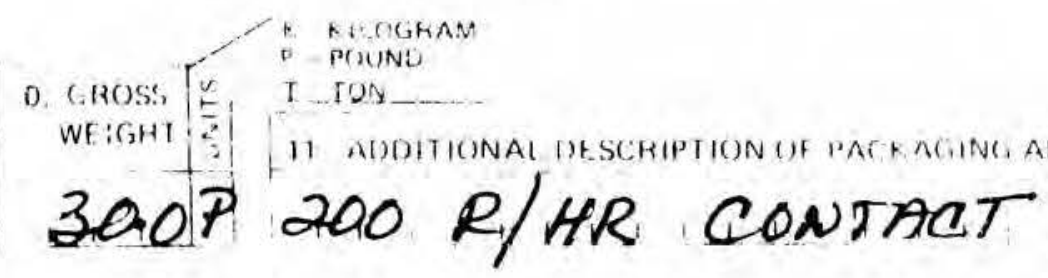

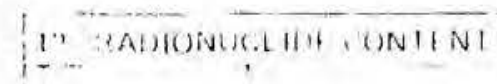

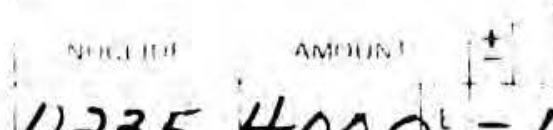

$02354.000^{-1 \mu}$

P023910000-14.

MAP $8000^{\circ}$

+oa

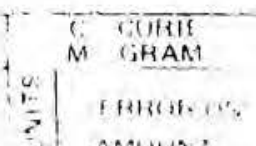
AMulin:
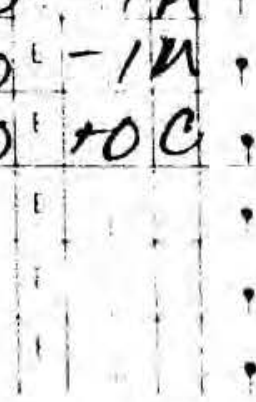

:VASTI GINTRATUK

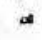

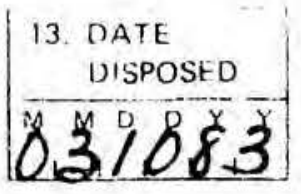

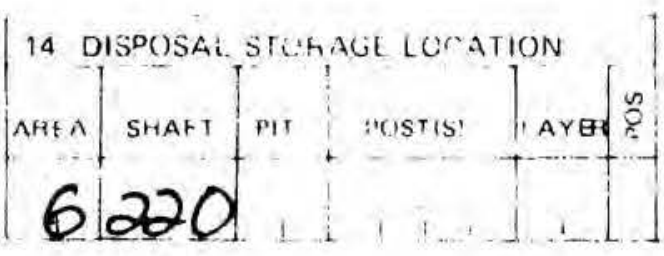

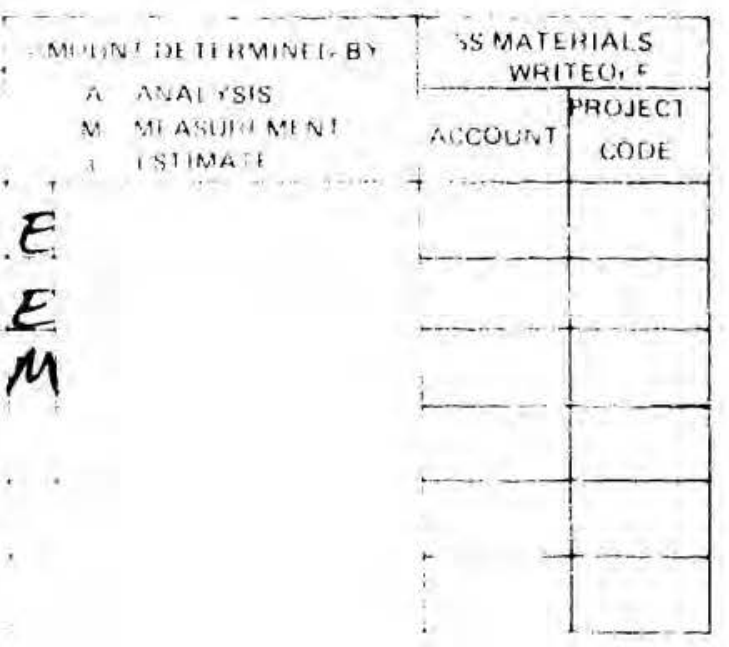

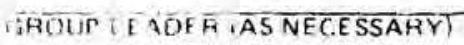

TERIALS 
PLEASE READ INSTRUCTIONS ON BACK CAREFULLY

1. FORM NUMBER

$5,8,3,28,30$

LOS ALAMO RADIOACTIVE SOLID WASTE

DISPOSAL. RECORD FO : IT

H 7 Waste Management

F xt 6095 MS J592
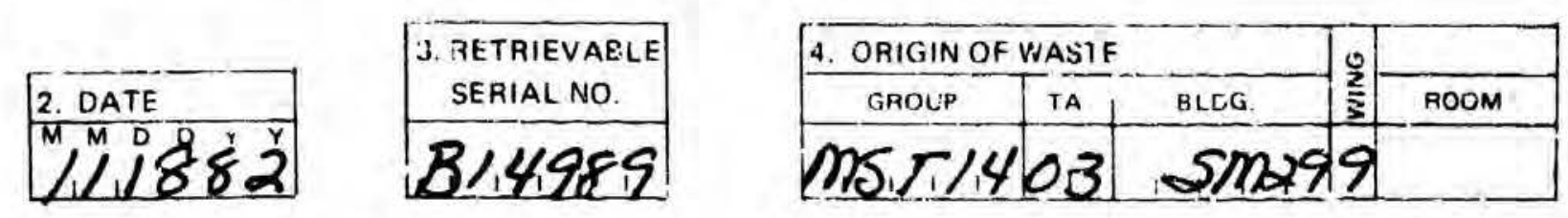

\begin{tabular}{|l|}
\hline $\begin{array}{l}\text { 5. WAST } \\
\text { CODE }\end{array}$ \\
\hline AU \\
\hline
\end{tabular}

6. WASTE DESCRIPTION

CELL /3 GRINDING CAM 35न2
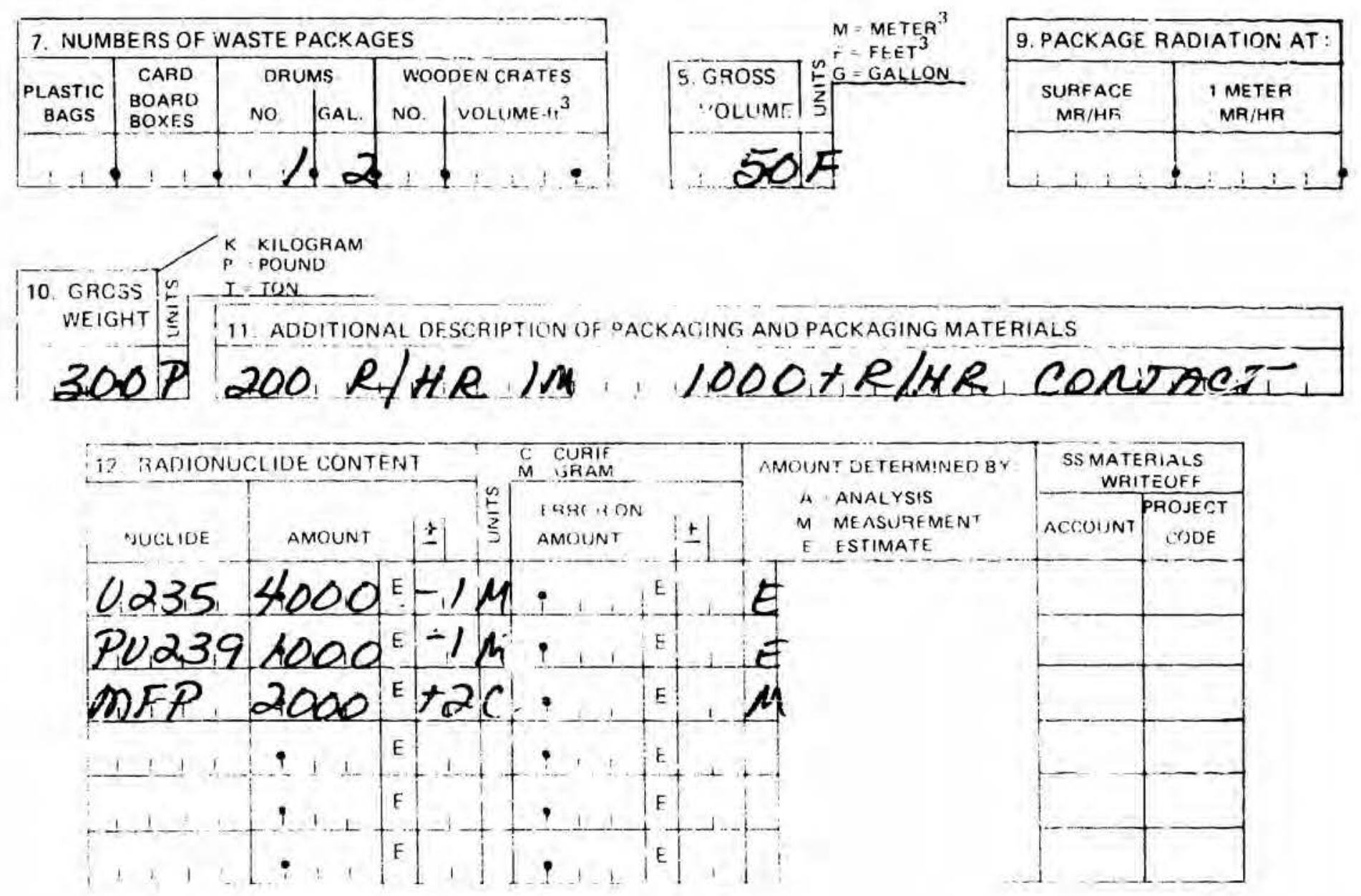

WASTE GENERATOR

GRE UP LEADER. (ADS NECESSARY)
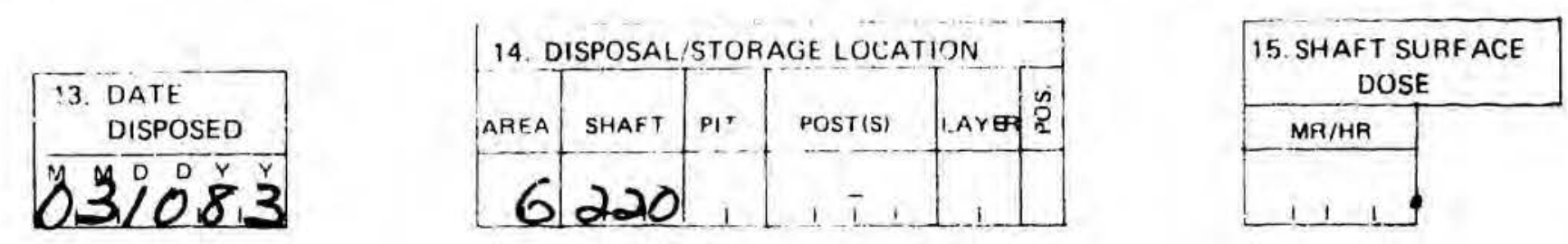

H-7 WASTE MANAGEMENT REPRESENTATIVE

HS-E 7-1A $(10 / 81)$

Signature certifies waste met acceptance criteria.
and all disposed noquinoments wore mac. 
RADIOACTIVE SOLID WASTE DISPOSAL RECORD FORMS

FOR

SHAFT 221

MATERIAL DISPOSAL AREA G 


\section{PLEASE READ INSTRUCTIONS ON BACK CAREFULLY}

1. FORM NUMBER

$s_{1}, 3$, तो

$\frac{2 . \text { DATE }}{M{ }^{M} \mathrm{D}}$
LOS ALAMOS RADIOACTIVE SOLID WASTE DISPOSAL RECORD FORM
H.7 Waste Management

F $\times 16095$ MS $J 592$

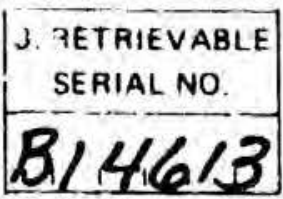

\begin{tabular}{|c|c|c|c|c|}
\hline \multicolumn{3}{|c|}{ 4. ORIGIN OF WASTE } & \multirow{2}{*}{$\mid \begin{array}{l}0 \\
\frac{2}{y}\end{array}$} & \\
\hline GHOUP & TA & BLDG. & & Ac COM \\
\hline$M \lesssim T_{1}$ & & $m$. & & \\
\hline
\end{tabular}

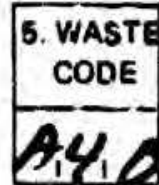

6. WASTE DESCRIPTION

CELL L WIRE WRARS 3554

\begin{tabular}{|c|c|c|c|c|c|}
\hline 7. NUMBERS OF WASTE PACKAGES \\
\hline $\begin{array}{c}\text { PLASTIC } \\
\text { BAGS }\end{array}$ & $\begin{array}{c}\text { CARO } \\
\text { BOARO } \\
\text { BOXES }\end{array}$ & \multicolumn{2}{|c|}{ DRUMS } & \multicolumn{2}{|c|}{ WOODEN CHATES } \\
\hline & & GAL. & NO & vOLUME $1^{3}$ \\
\hline
\end{tabular}

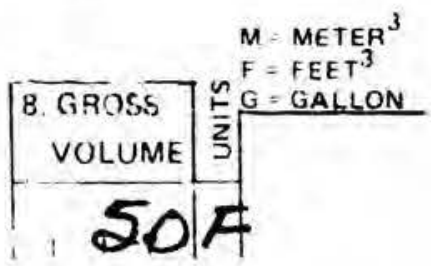

\begin{tabular}{|c|c|}
\hline \multicolumn{2}{|c|}{ 9. PACKAGE RADIATION AT } \\
\hline $\begin{array}{l}\text { SURFACE } \\
\text { MR/MR }\end{array}$ & $\begin{array}{c}\text { I METEA } \\
\text { MF/HA }\end{array}$ \\
\hline & 50 \\
\hline
\end{tabular}

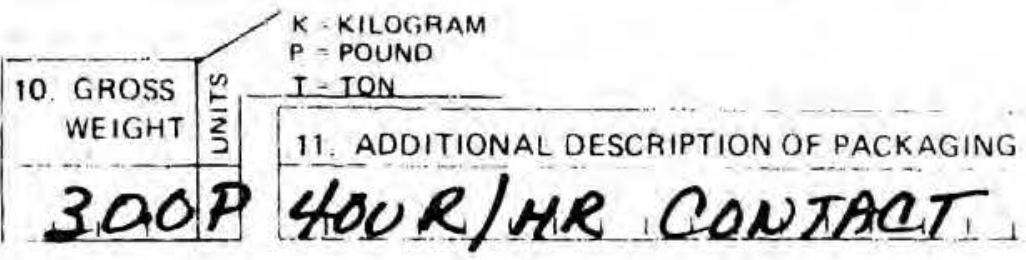

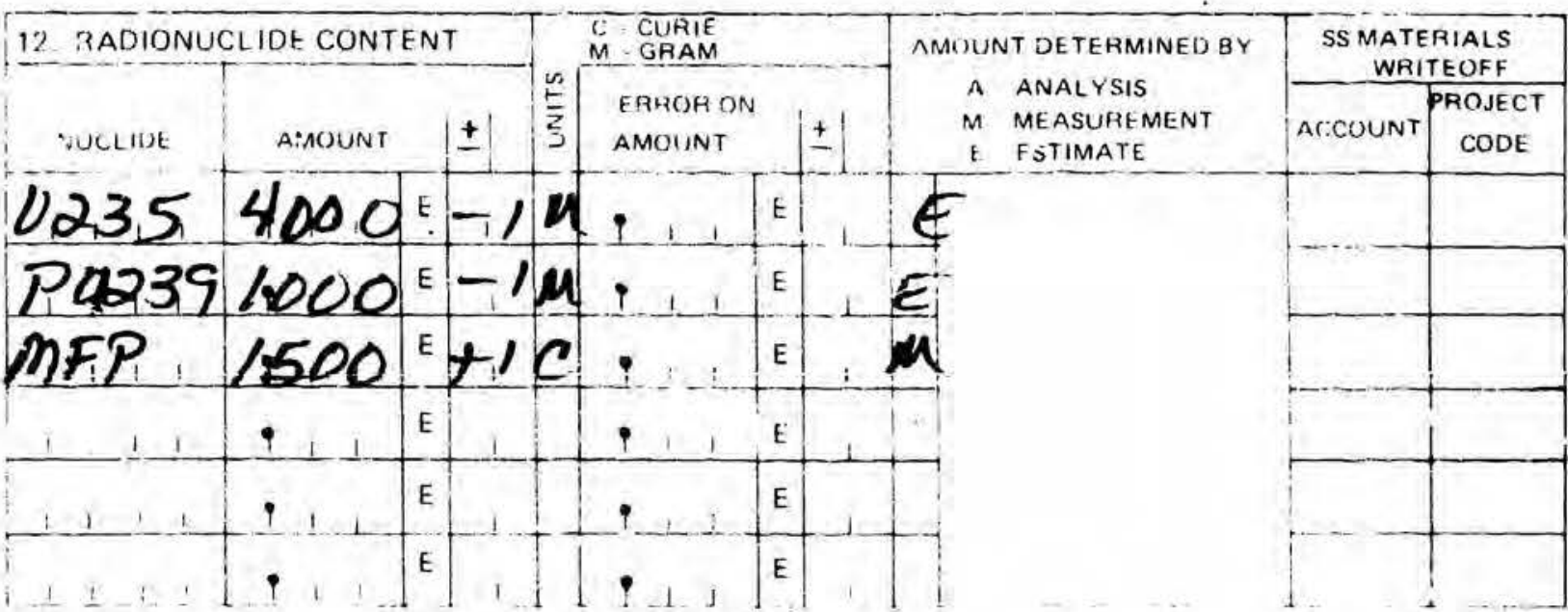

IVASTE GENERATOR

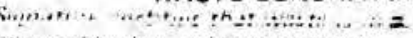

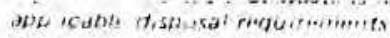

HI AREA REPRESENTATIVE

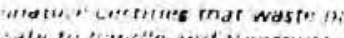

CKAGING MATERIALS 


\section{LOS ALAMOS RADIOACTIVE SOLID WASTE} DISPOSAL RECORD FORM
$H$ ) Waste Management

fxi 6095 Ni, J592

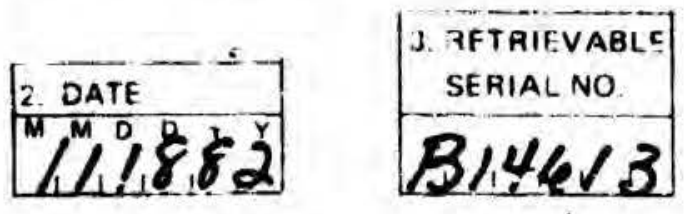

\begin{tabular}{|c|c|c|c|c|}
\hline \multicolumn{3}{|c|}{ 4. ORIGIN OF WASTE: } & \multirow{2}{*}{$\frac{0}{3}$} & \\
\hline GROUP & TA & BLDG & & ROOM \\
\hline & & $\log$ & c & \\
\hline
\end{tabular}

\begin{tabular}{l} 
5. WASTE \\
CODE \\
\hline A4C \\
\hline
\end{tabular}

6. WASTE DESCRIPTION

CELL L WIRE WRAPS 3507.

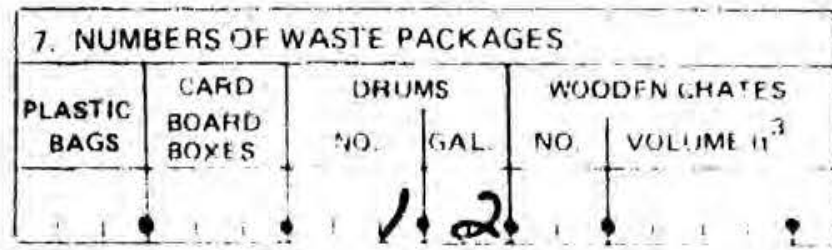

WEIGHT 10 GROS

KIIOCRAM

POUND

11 ADDITIONAL DFSCRIPTIUN OF PACKAGINE, ANUP, CKKAGING MATERIALS

1000AR/HR CONTACT

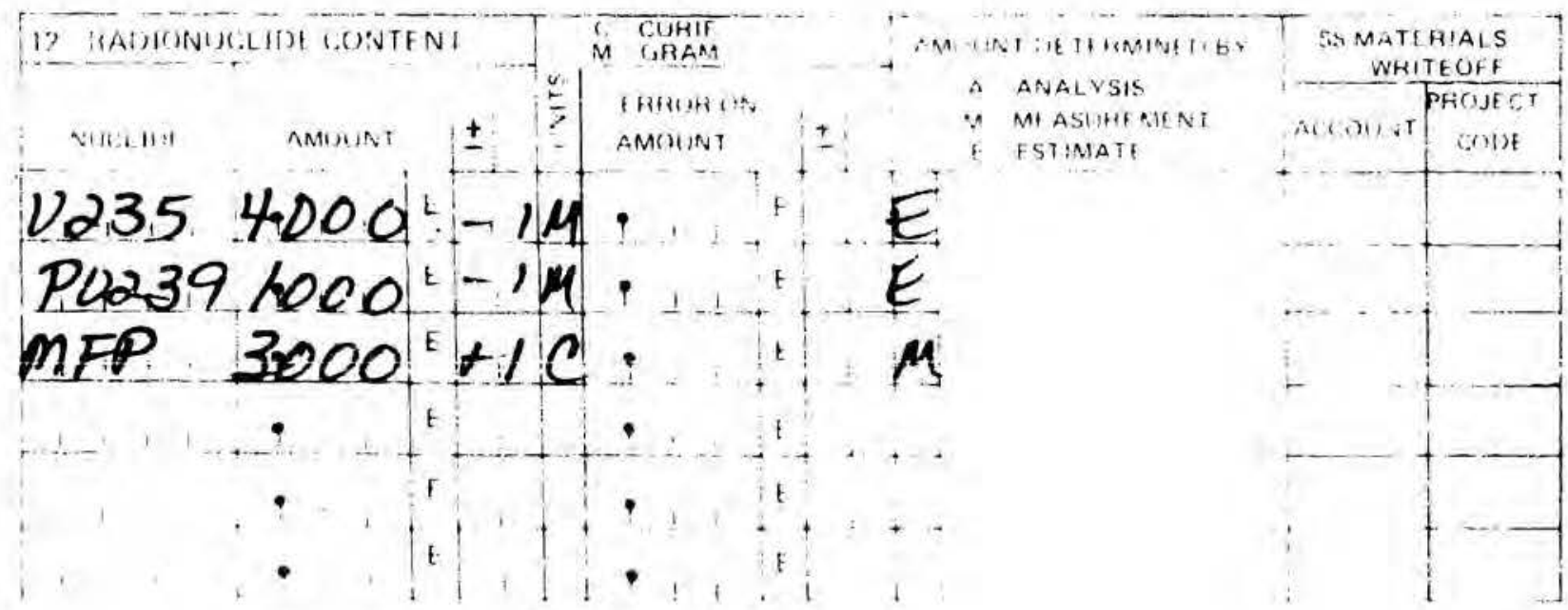

:VASTI (IFNERATUB

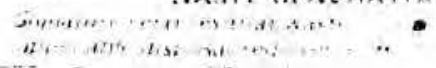

III AREA RERHE SENTATIVI

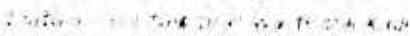

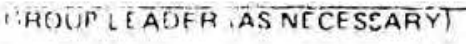

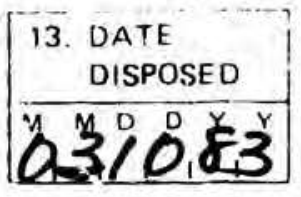

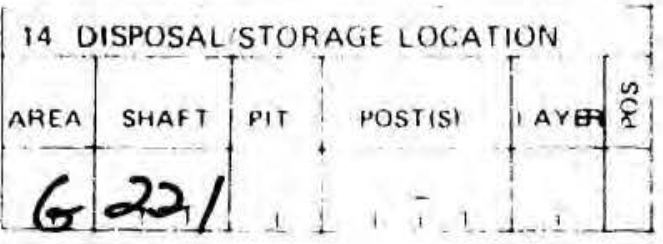

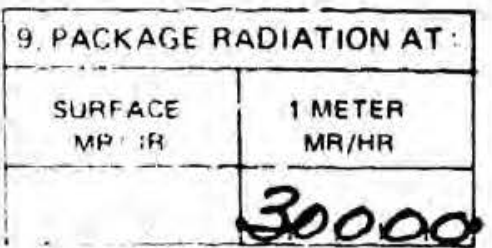


PLEASE READ INST - UCTIONS ON BACK CAREFULLY

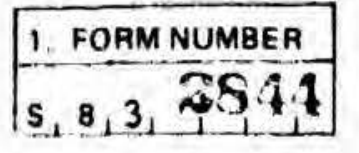

LOS ALAMOS RADIOACTIVE SOLID WASTE DISPCSAL RECORD FORM

H.7 Waste Management

Ex/ 6095 MS 5592
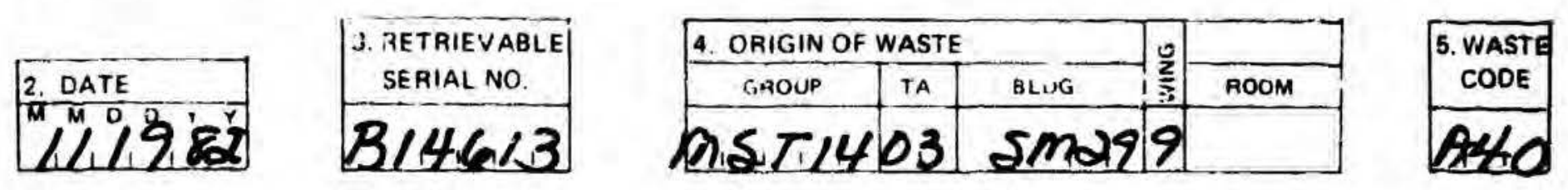

6. WASTE DESCRIPTION

GE LL IN HOT TRASH 3569

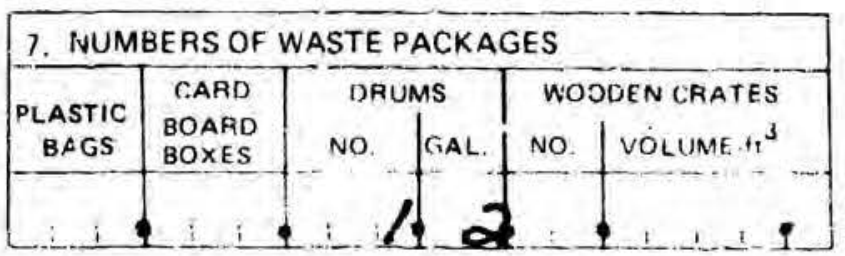
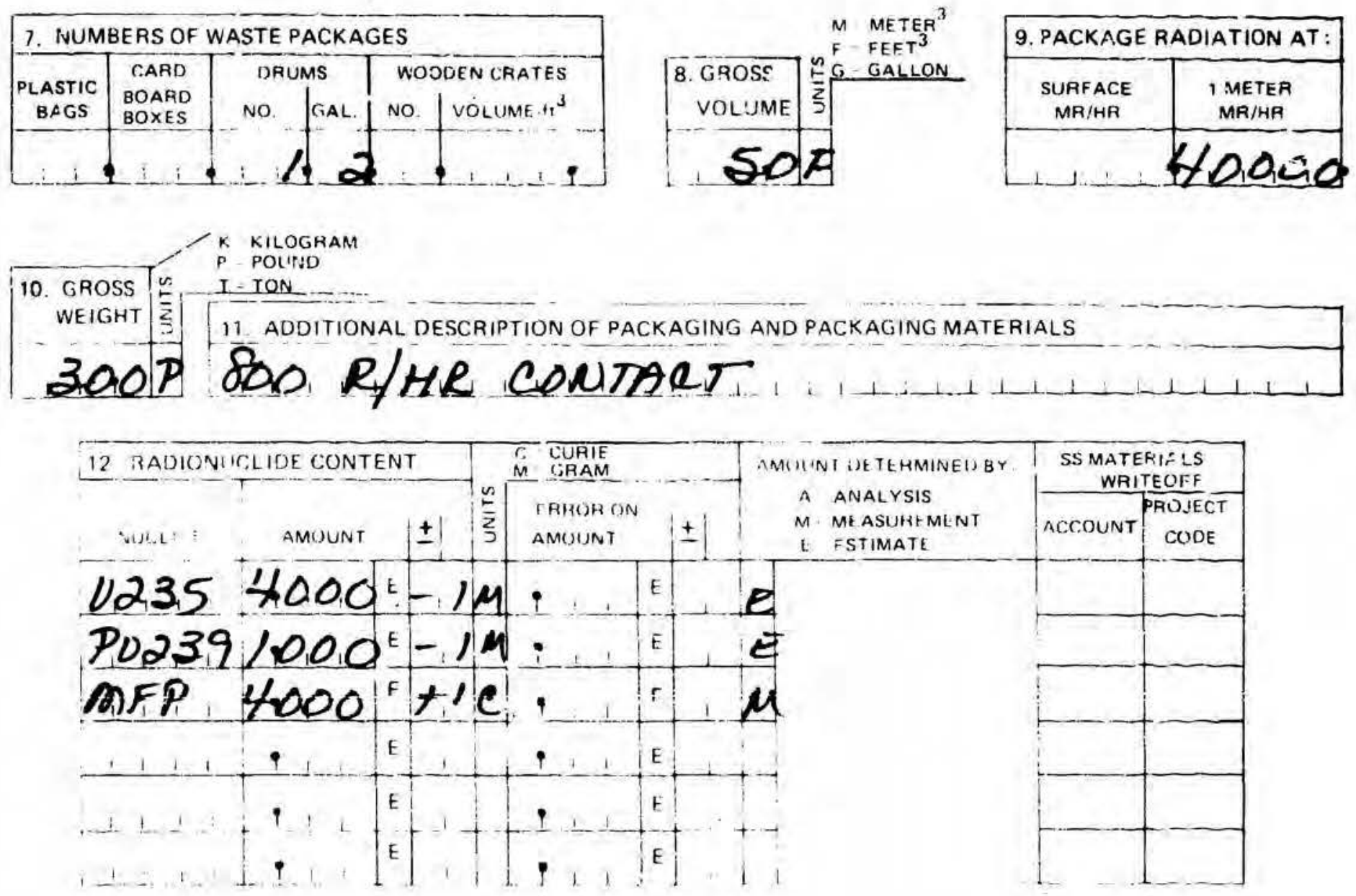

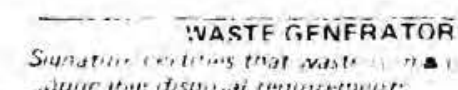

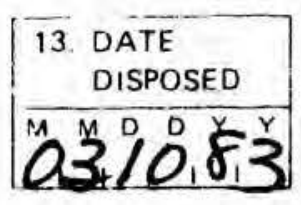
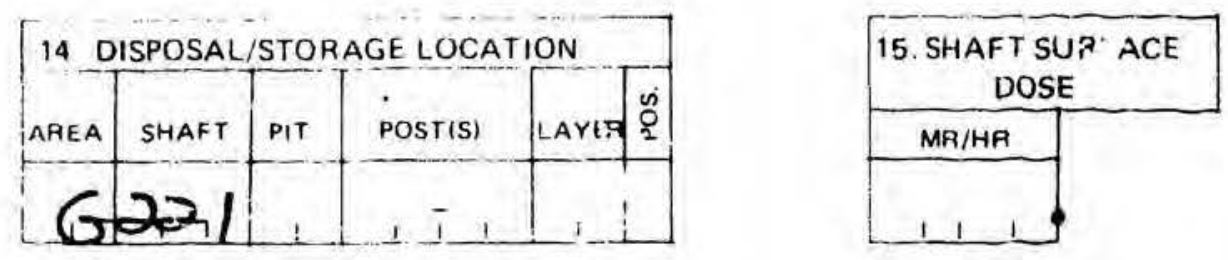

HS-E 7-1A $(10 / 81)$

H-7 WASTE MANAGEMENT REPRESENTATIVE_-

Signature certifies waste mot acceptance criteria,
and oil disocsel requirements were met 
PLEASE READ INSTRUCTIONS ON BACK CAREFULLY

1. FORM NUMBER

$5,8,3,78,45$

$$
\text { [1, DATE }
$$

LOS ALAMO RADIOACTIVE SOLID WASTE

DISPOSAL RECORD FORM
H.7 Waste Management

Ext 6095 MS $J 592$ \begin{tabular}{|l|}
\hline 3 . RETRIEVABLE \\
\hline SERIAL NO \\
\hline$B / 46 / 3$ \\
\hline
\end{tabular}

6. WASTE DESCRIPTION

CELL 14 HOT TRASH CAN 3722
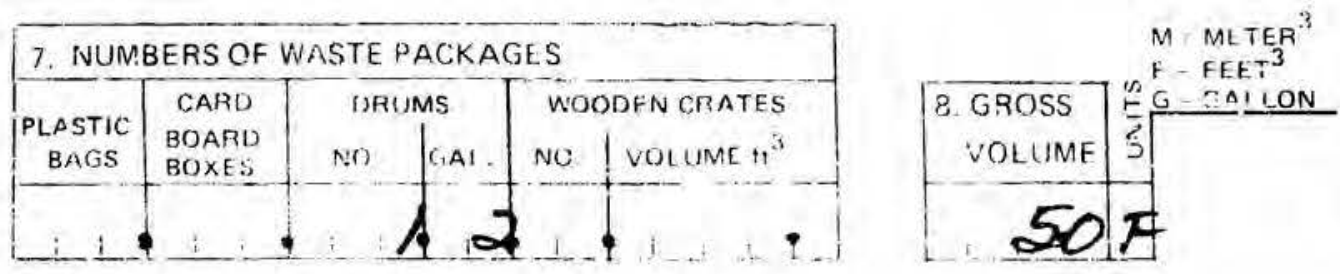

\begin{tabular}{|c|c|}
\hline 9. PACKAGE RADIATION AT: \\
\hline $\begin{array}{c}\text { SURFACE } \\
\text { MR/HR }\end{array}$ & $\begin{array}{c}1 \text { METER } \\
\text { MR/HIR }\end{array}$ \\
\hline 60000 & 1500 \\
\hline
\end{tabular}
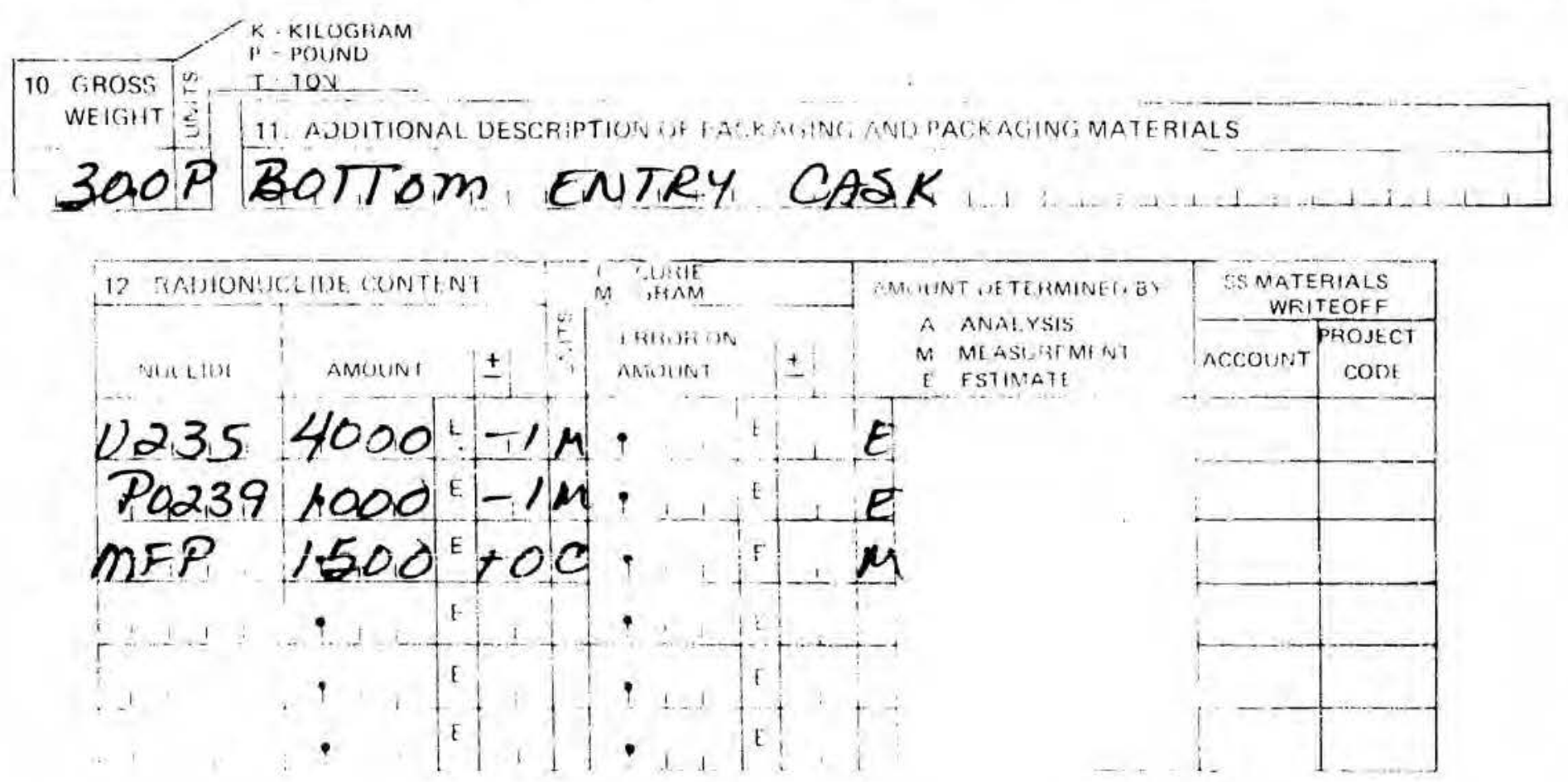

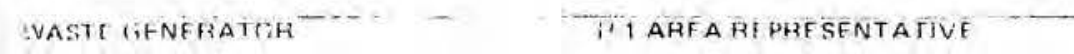

SIAOTITTTANFR LASNFCFSSATAVI

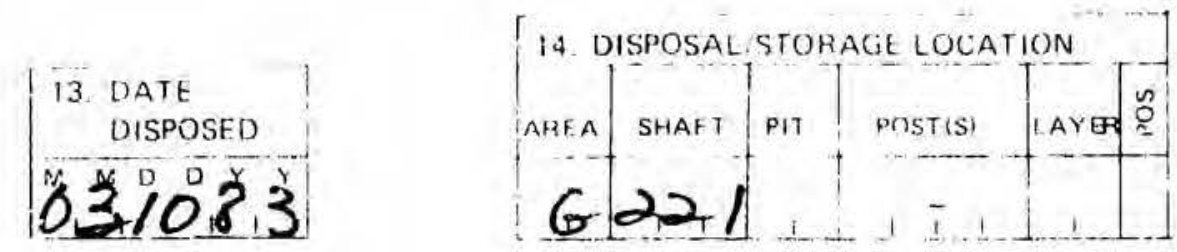

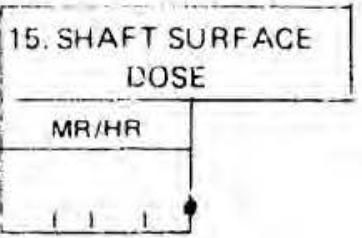

H-7 WASTE MANAGEMENT REPRESENTATIVE

HS.E 7.1A $(10 / 81)$

Signature certifies waste met acceptance criteria.
and all disposal requirements were mot. 
LOS ALAMOS RADIOACTIVE SOLID WASTE DISPOSAL RECORD FORM
H.7 Waste Management Ext 6095 MS J592

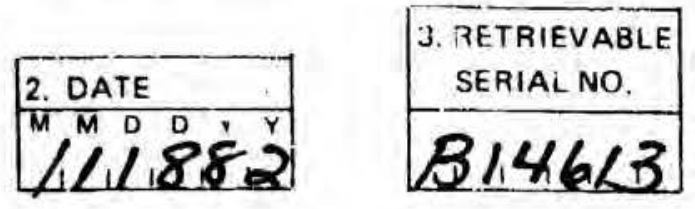

\begin{tabular}{|c|c|c|c|c|}
\hline \multicolumn{3}{|l|}{ 4. ORIGIN OF WASTE } & 0 & \\
\hline GROUP & TA & BLDG. & $\frac{2}{3}$ & ROOM \\
\hline MSTI/4 & OS & SMN29 & \\
\hline
\end{tabular}

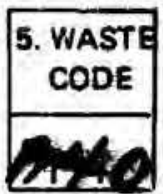

6. WASTE DESCRIPTION

\section{CELL IH WASTE CAN 3720}

\begin{tabular}{|c|c|c|c|c|c|}
\hline \multirow[b]{2}{*}{$\begin{array}{c}\text { PLASTIC } \\
\text { BAGS }\end{array}$} & \multirow{2}{*}{$\begin{array}{l}\text { CARD } \\
\text { BOARD } \\
\text { BOXES }\end{array}$} & \multicolumn{2}{|c|}{ DRUIMS } & \multicolumn{2}{|c|}{ WDODEN CRATES } \\
\hline & & & GAL. & & VOLUME $\mathrm{n}^{3}$ \\
\hline
\end{tabular}
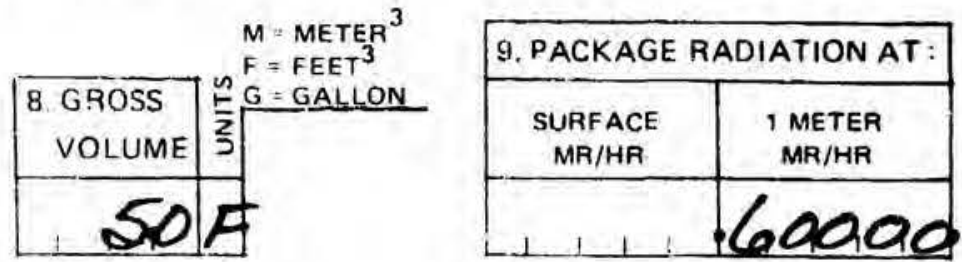

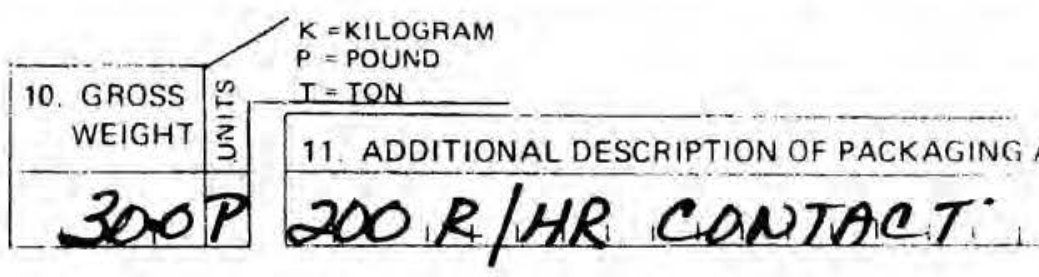

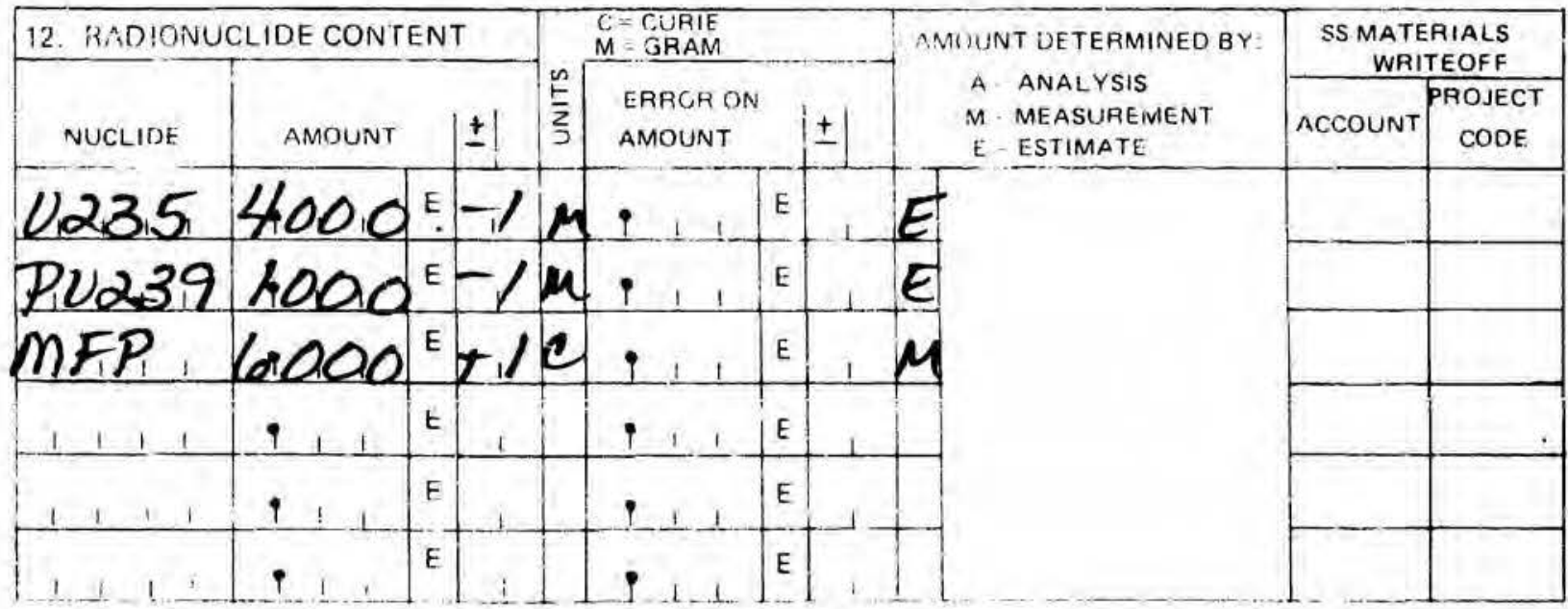

IVASTE GENËRATTOR

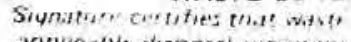

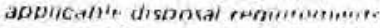

HT AREA REPRESENT ATIVE

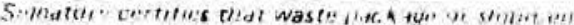

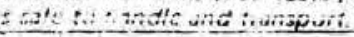

GROUP LEADER (AS NECESSAFY)

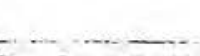

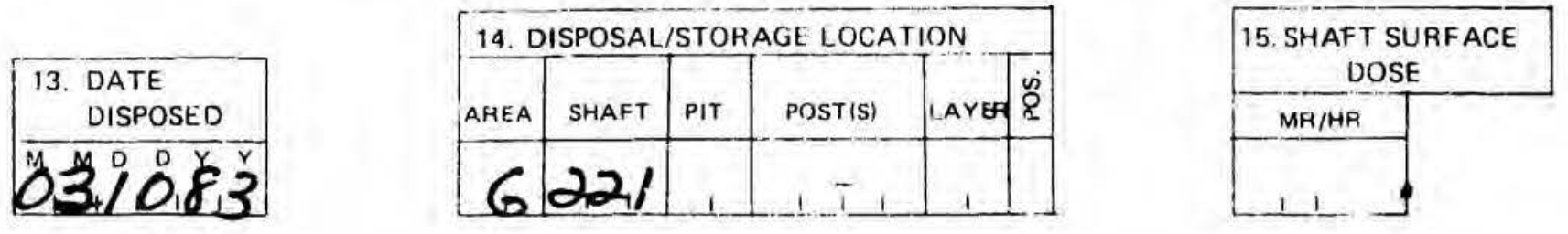


PLEASE READ INSTRUCTIONS ON BACK CAREFULLY

1. FORM NUMBER

$5,8,3,28,79$
LOS ALAMOS RADIOACTIVE SOLID WASTE DISPOSAL RECORD FORM
$H>7$ Waste Management

Fix: 6095 MS $J 592$

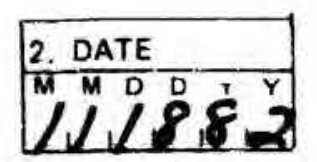

\begin{tabular}{l}
\hline $\begin{array}{c}\text { 3. RETRIEVABLE } \\
\text { SERIAL NO. }\end{array}$ \\
\hline 8/446/B
\end{tabular}

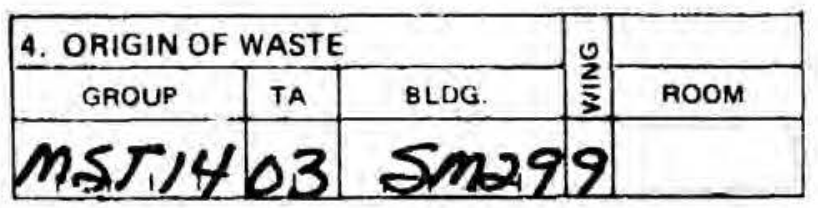

\begin{tabular}{|l|}
\hline 5. WASTE \\
CODE \\
\hline APC \\
\hline
\end{tabular}

6. WASTE DESCRIPTION

CELL LI WI ATE CAN \#3721

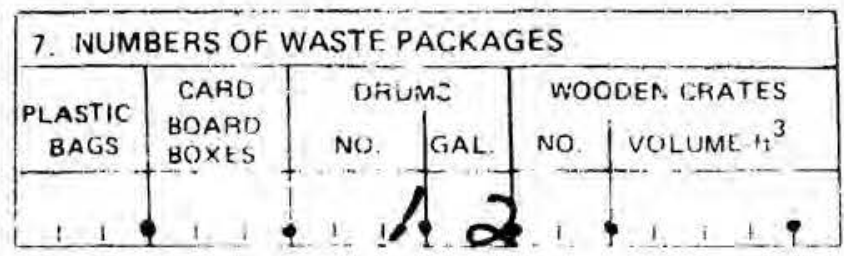
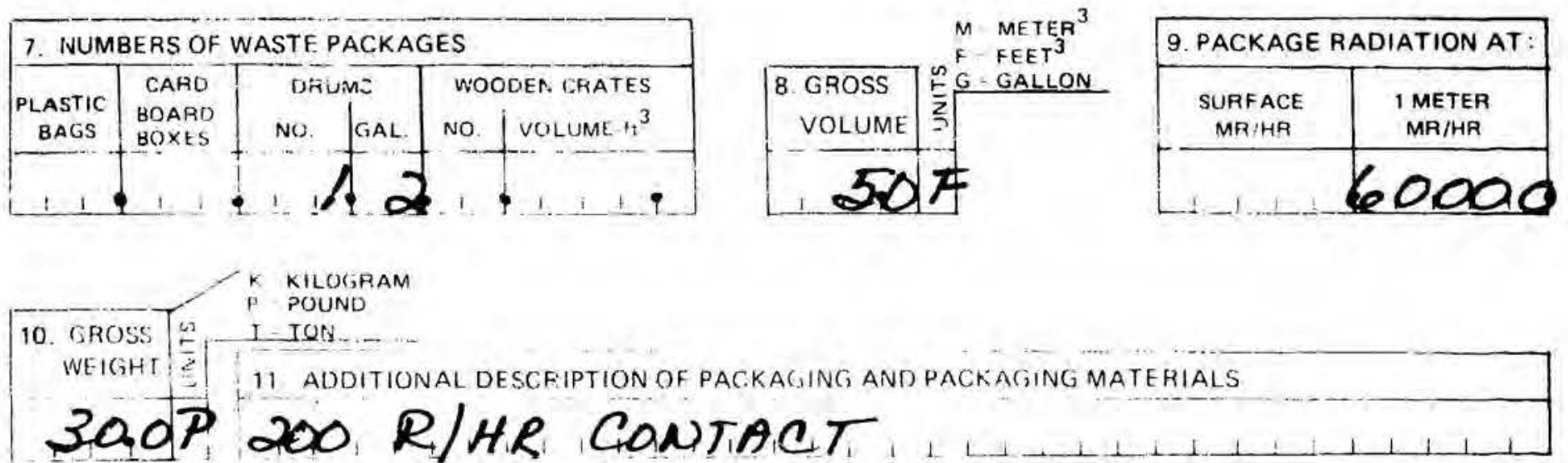

$30.0 P$ 200 R/HR GONTIACT

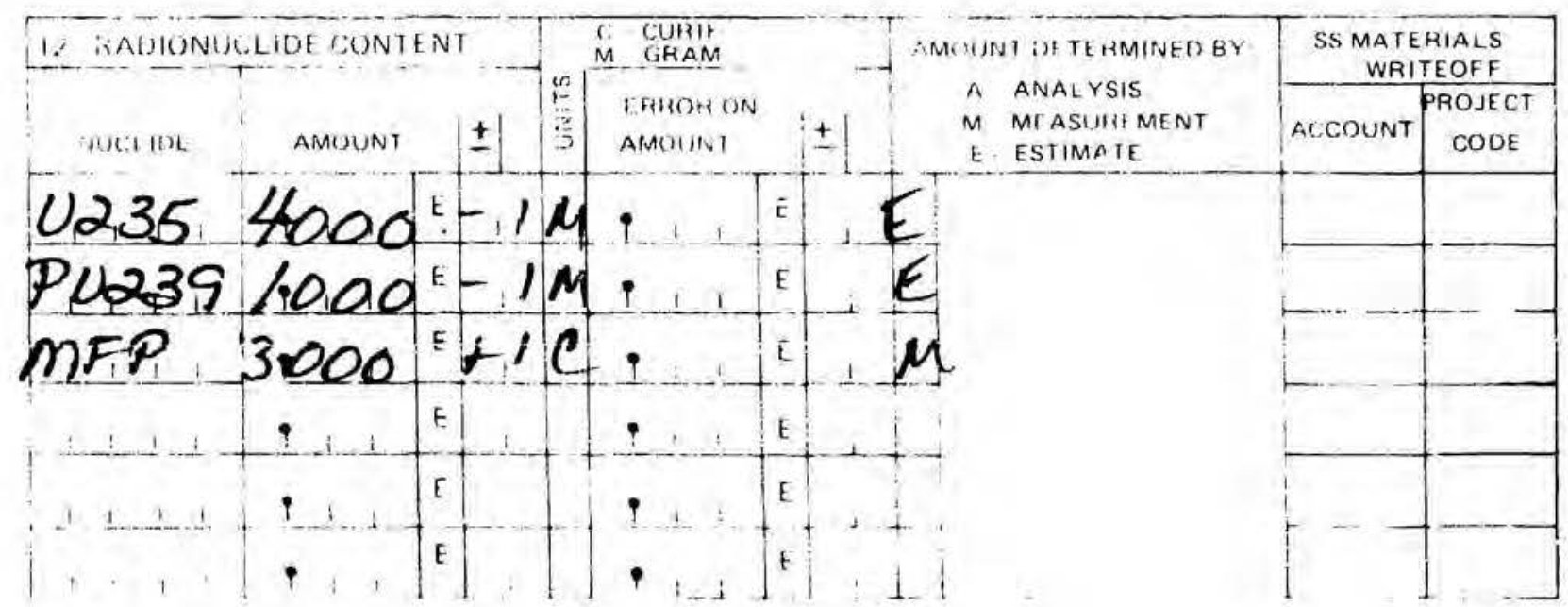

WASTE CENETATOP

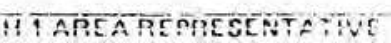

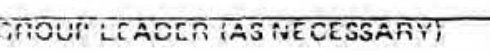
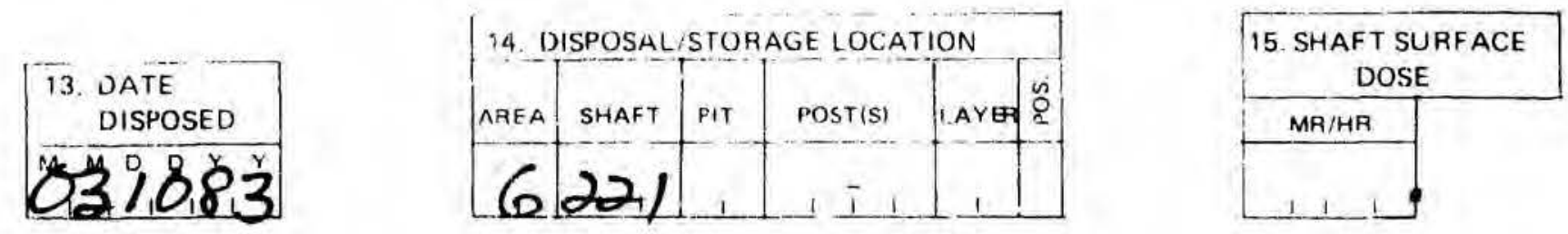

HS-E 7-1A $(10 / 81)$

H-7 WASTE MANAGEMENT REPRESENTATIVE

Signature certifies waste met acceptance criterion.
and ill disposal requirements more mot. 
RADIOACTIVE SOLID WASTE DISPOSAL RECORD FORMS

FOR

SHAFT 222

MATERIAL DISPOSAL AREA G 
1. FORM NUMBER

s, $8,3,1,2,6$

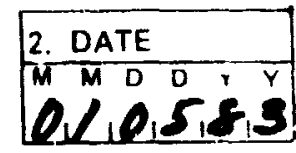

PLEASE READ INSTRUCTIONS ON BACK CAREFULLY

LOS ALAMOS RADIOACTIVE SOLID WASTE

DISPOSAL RECORD FORM
H.7 Waste Management

Ext 6095 MS J592

3. RETRIEVABLE
SERIAL NO.

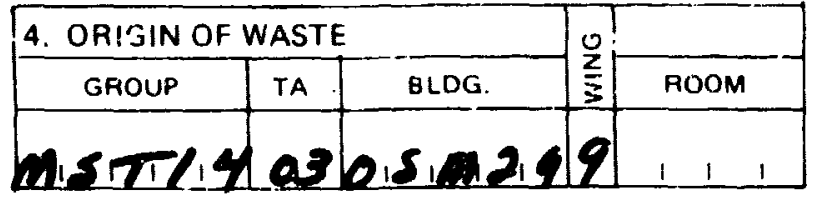

5. VIASTE

CODE

6. WASTE DESCRIPTION

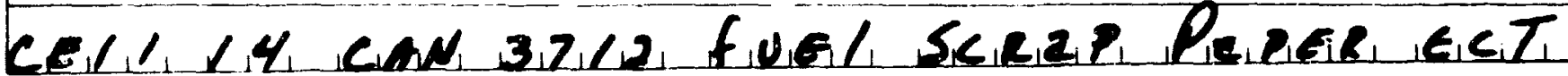
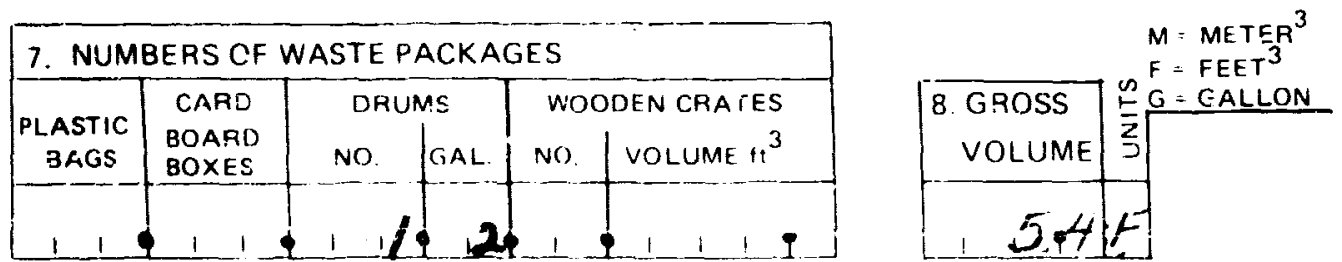

\begin{tabular}{|c|c|}
\hline 9. PACKAGE RADIATION AT: \\
\hline $\begin{array}{c}\text { SURFACE } \\
\text { MR/HR }\end{array}$ & $\begin{array}{c}\text { I METER } \\
\text { MR/HR }\end{array}$ \\
\hline 1, & $20,0,0,0$ \\
\hline
\end{tabular}

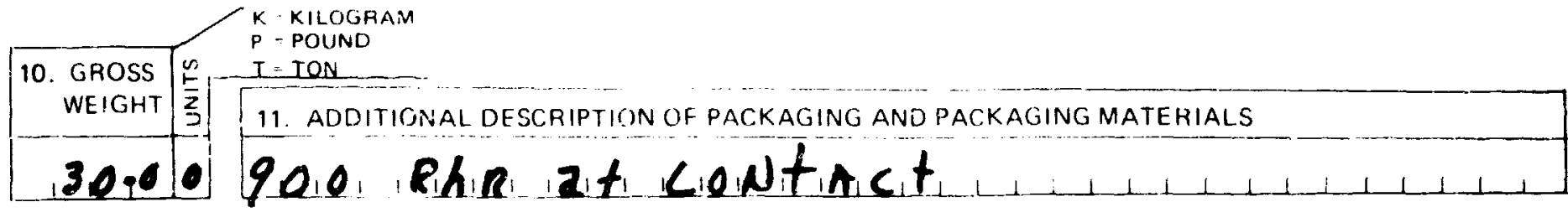

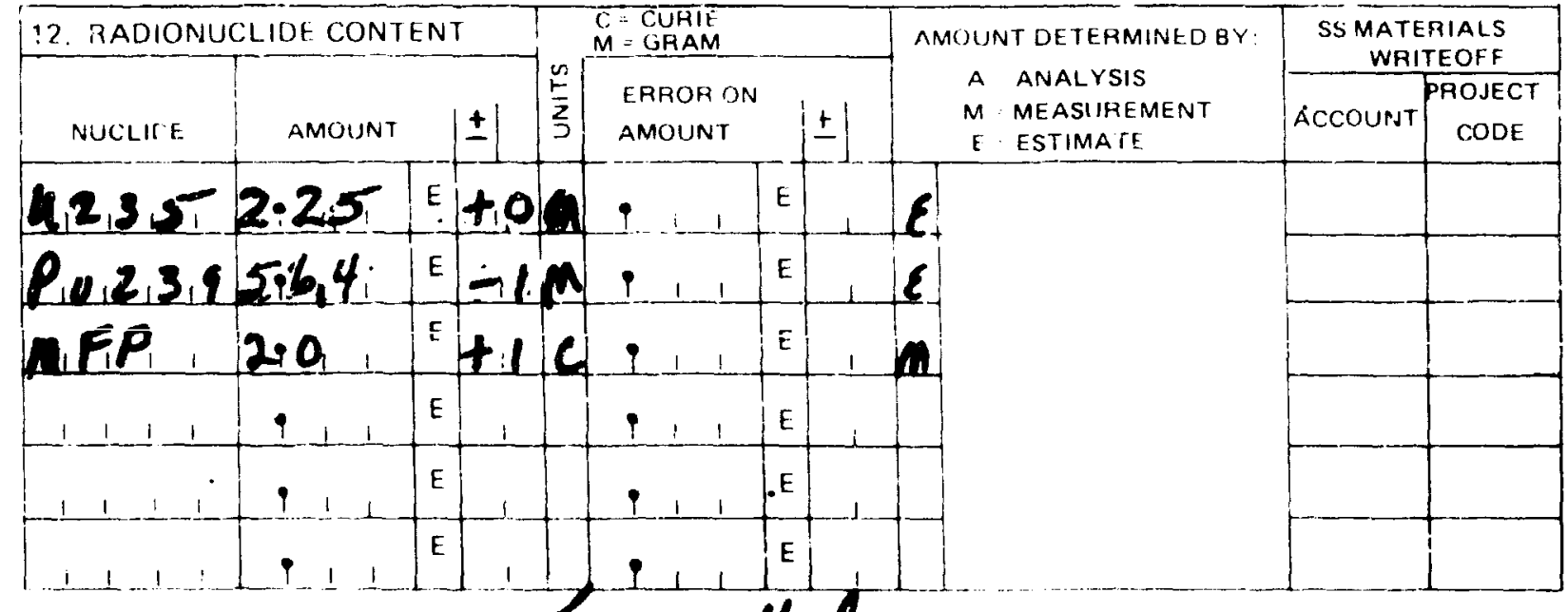

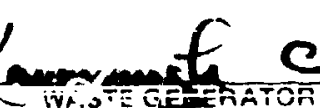

Signature certified that waste

(ROUP LEADER (AS NECESSARY)

\begin{tabular}{|c|c|c|c|c|c|}
\hline 14. OISPOSAI./STORAGE LOCATION \\
\hline AREA & SHAFT & PIT & POSTISI & L.AYE & 8 \\
\hline$G$ & $2,2 p$ & 1 & 1 & & \\
\hline
\end{tabular}

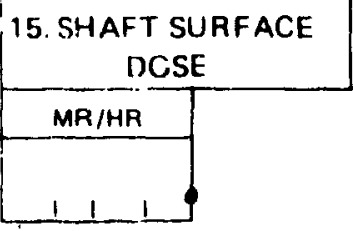

He E $7-1 A(10 / 81)$

H.7 WASTE MANAGEMENT REPRESENTATIVE 
PLEASE READ INST RUCTIONS ON BACK CAREFULLY

1. FORM NUMBER

$5,8,3$, Pin
LOS ALAMOS RADIOACTIVE SOLID WASTE DISPOSAL RECORD FORM
H.7 Waste Management

Ext 6095 MS J592

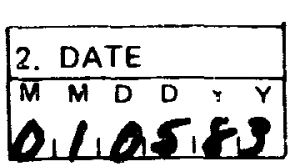

\begin{tabular}{l} 
3. RETRIEVABLE \\
SERIAL NO. \\
\hline $3 / 5,9,4,9$ \\
\hline
\end{tabular}

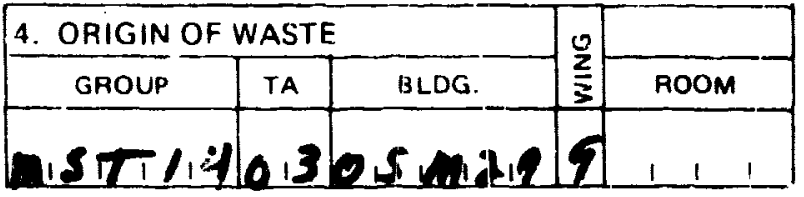

\begin{tabular}{l}
\hline 5. WASTE \\
CODE \\
\hline $4,4,19$ \\
\hline
\end{tabular}

6. WASTE DESCRIPTION

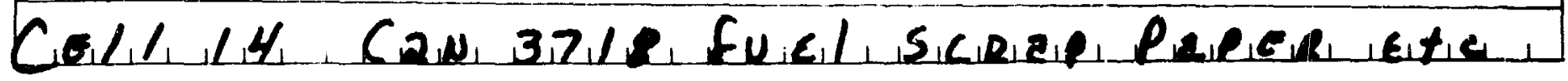
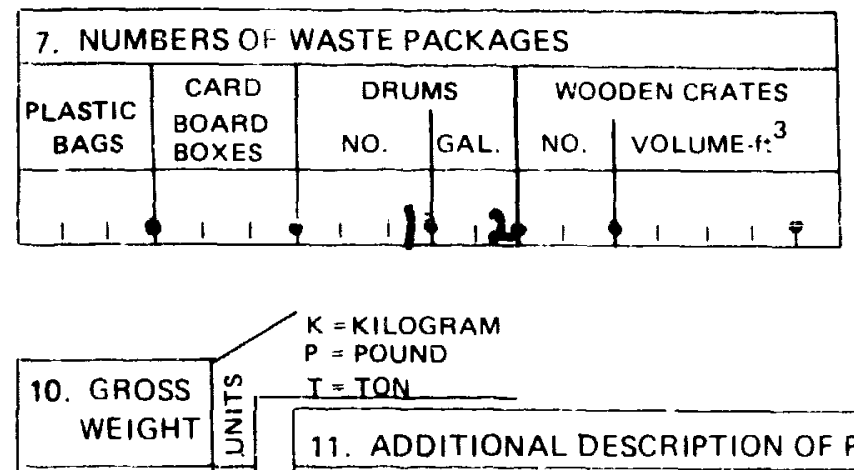
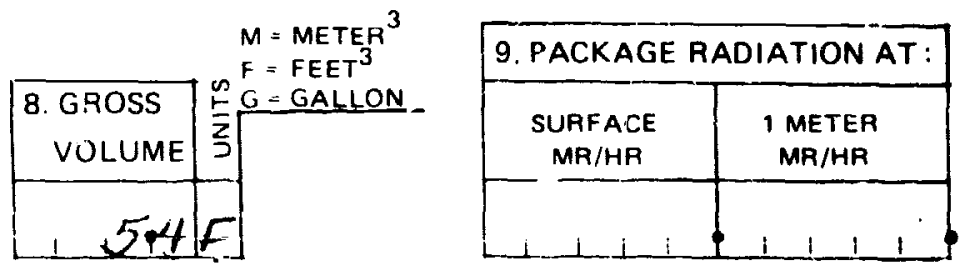

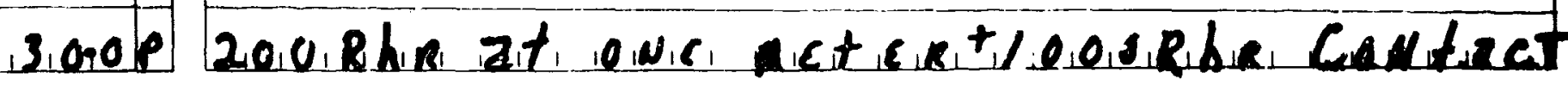

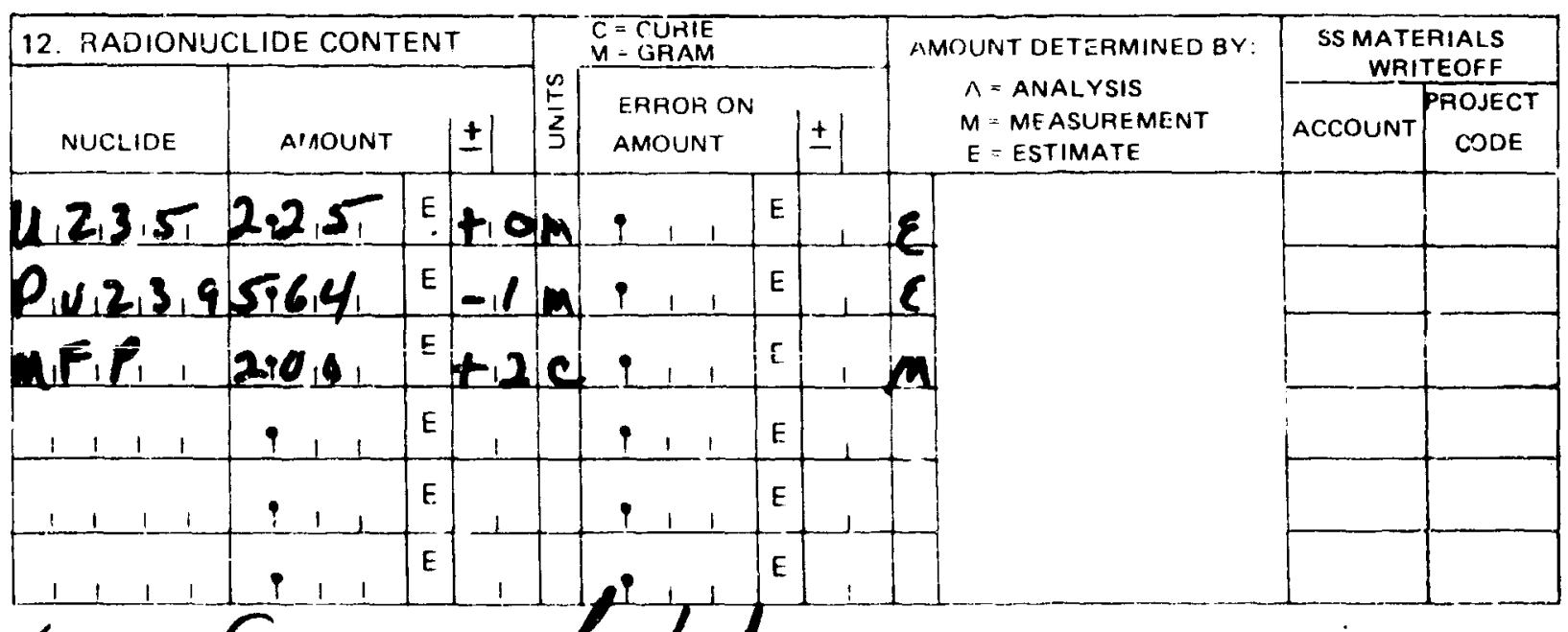

Signdurt certifies that waste in in accordance with

13. DATE m, $2,4,8\}$

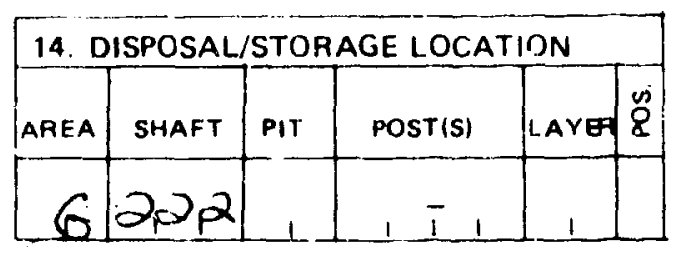

15. SHAFT SURFACE

DOSE

ME 7-1A $(10 / 81)$

H-7 WASTE MANAGEMENT REPRESENTATIVE 
PLEASE READ INSTRUCTIONS ON BACK CAREFULLY

1. FORM NUMBER

s, $8,3,9,81$

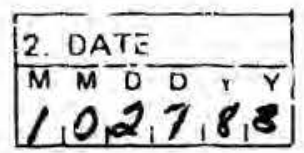

LOS ALAMO RADIOACTIVE SOLID WASTE DISPOSAL RECORD FORM
7 Waste Management-

Ext 6095 MS J592

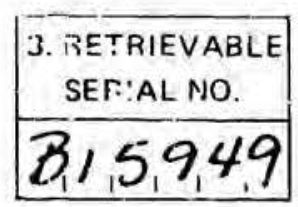

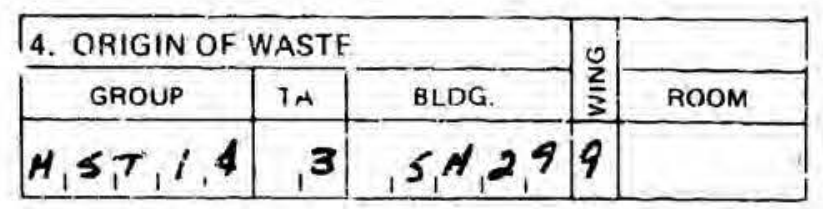

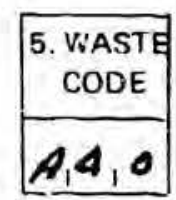

€. WASTE RESCRIPTION

$C_{1} L, L, 4, T R R_{1}, N_{1}, 1, C_{1} A_{N} N$

7. NUMBERS OF WASTE PACKAGES

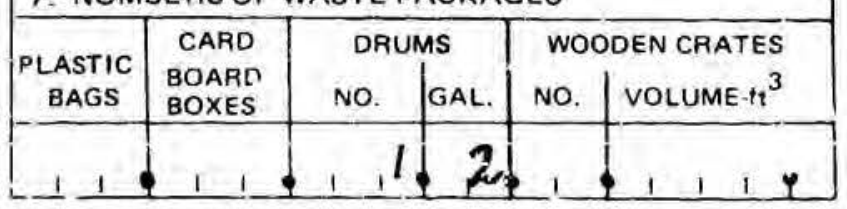

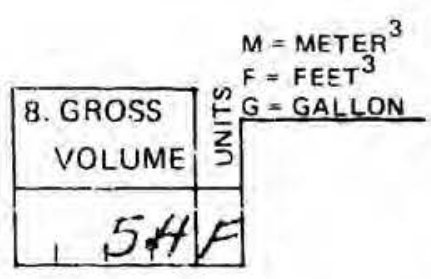

\begin{tabular}{|c|c|}
\hline 9. PACKAGE RADIATION AT: \\
\hline $\begin{array}{c}\text { SURFACE } \\
\text { MR/HR }\end{array}$ & $\begin{array}{c}1 \text { METER } \\
\text { MR/HR }\end{array}$ \\
\hline $2,0,0,0,0$ & $1,0,0,0$ \\
\hline
\end{tabular}
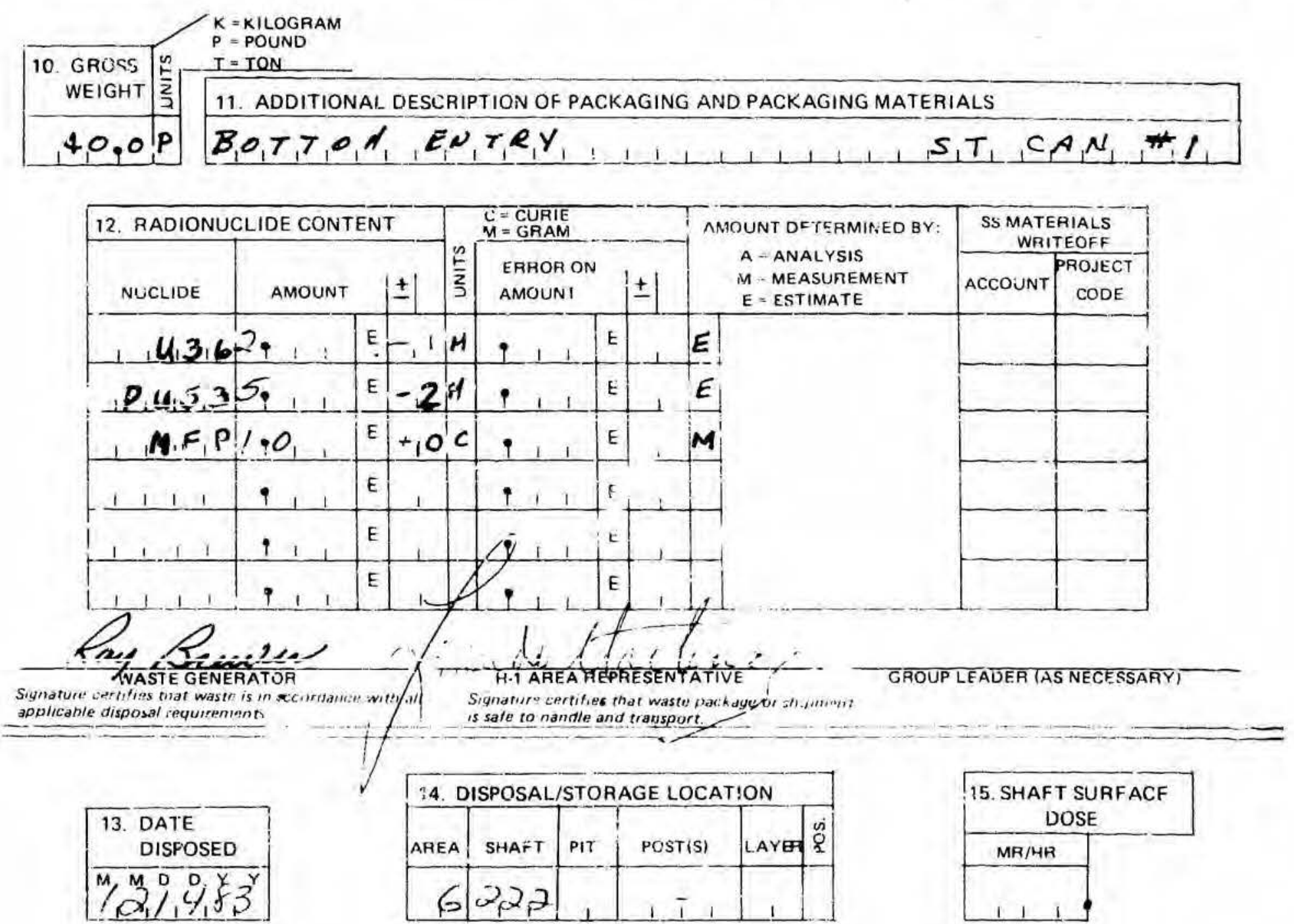

H.7 WASTE MANAGFMENT REPRESENTATIVE Ae thereto

HS-E 7.1/ $(10 / 81)$

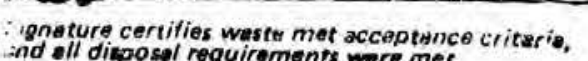


PLEASE READ INSTRUCTIONS ON BACK CAREFULLY

1. FORM NUMBEP

LOS ALAMUS RADIOACTIVE SOLID WASTE DISPOSA! RECORD FORM
H.\% Waste Mai iagement

Ext 6095 MS j592
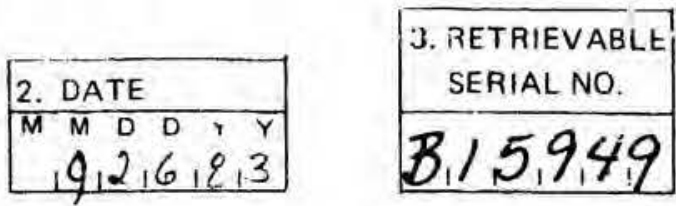

\begin{tabular}{|c|c|c|c|c|}
\hline 4. ORIGIN OF WASTE & \multirow{2}{*}{} & \\
\hline GROUP & TA & BLDG. & $\frac{2}{3}$ & ROOM \\
\hline$M_{1} S_{1} T_{1} /, A$ &, 3 & $15, M, 29$ & 9 & \\
\hline
\end{tabular}

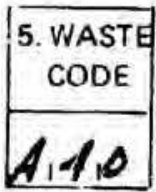

6. WASTE DESCRIPTION

$C, E, L, L, 9, T, R, A, S, H, I, C, A, N$

\begin{tabular}{|c|c|c|c|c|c|}
\hline \multicolumn{6}{|c|}{ 7. NUMBERS OF WASTE PACKAGES } \\
\hline & CARD & DF & uS & Wo & DEN CAATES \\
\hline BACS & $\begin{array}{l}\text { BOARD } \\
\text { BOXES }\end{array}$ & NO. & GAL. & No. & VOLUME- $\mathrm{ft}^{3}$ \\
\hline
\end{tabular}
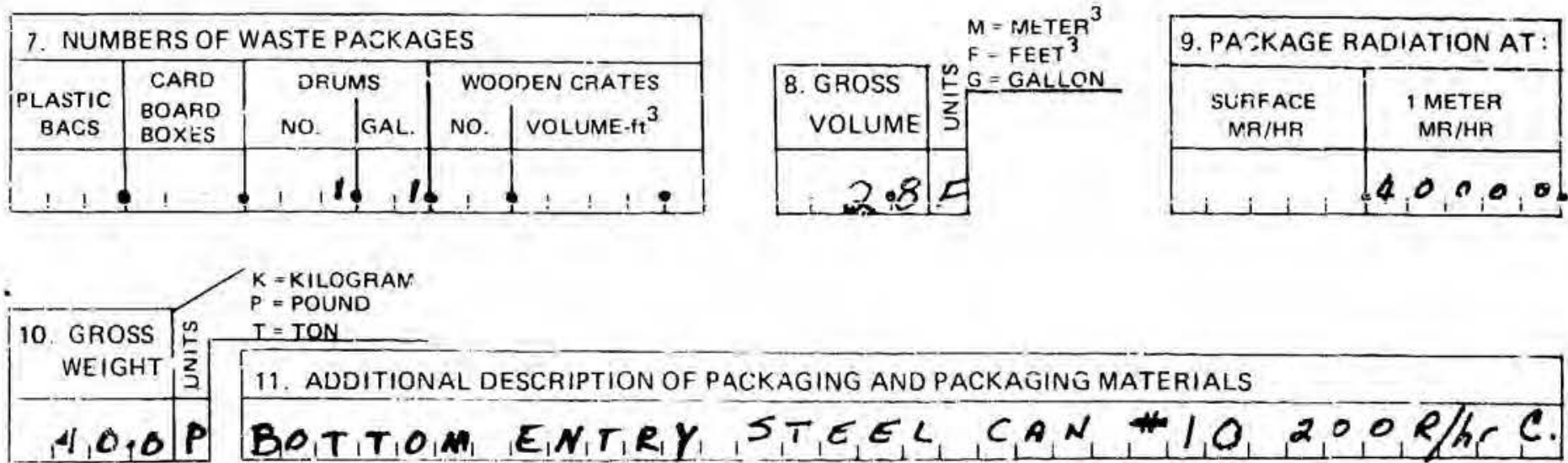

$K=$ KILOGRAN

$P=P O U N D$

$I=$ TON

11. ADDITIONAL DESCRIPTION OF PACKAGING AND PACKAGING MATERIALS

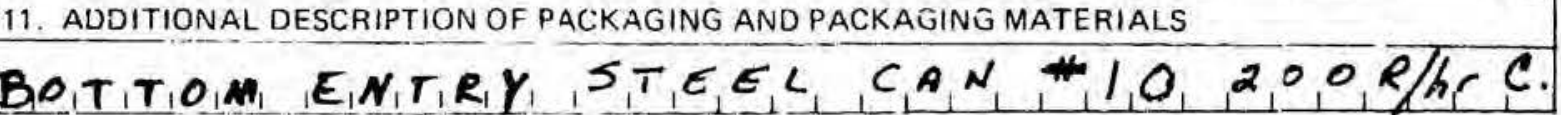

\begin{tabular}{|c|c|c|c|c|c|c|c|c|c|c|c|}
\hline \multicolumn{4}{|c|}{$\therefore$ RADIONIJCLIDE CONTENT } & \multicolumn{4}{|c|}{$\begin{array}{l}C \text { - CUAIE } \\
\text { IM GAAM }\end{array}$} & \multirow{2}{*}{\multicolumn{2}{|c|}{$\begin{array}{c}\text { AMOUNT UETERMINED BY: } \\
\text { A - ANALYSIS } \\
\text { M- MEASUHEMENT } \\
\text { E - ESTIMATE }\end{array}$}} & \multicolumn{2}{|c|}{$\begin{array}{c}\text { SS MATERIALS } \\
\text { WR:TEOFFF }\end{array}$} \\
\hline NGCLIDE & AMOUNT & & \pm & $\frac{n}{z}$ & $\begin{array}{l}\text { ERAOR ON } \\
\text { AMOUNT }\end{array}$ & & \pm & & & $\frac{\text { WA! }}{\text { ACCOUNT }}$ & $\begin{array}{c}\text { TEOFF } \\
\text { CODECT } \\
\text { CODE }\end{array}$ \\
\hline 14,36 & $5, \ldots$ & $\mathrm{E}$. & -1 & $M$ & $\{1,1$ & $\mathrm{t}$ & & $\boldsymbol{E}$ & & & \\
\hline$P_{1} 0,53_{2}$ & 1.2 & $E$ & -1 & $M$ & $1 \quad 1$ & $\mathrm{E}$ & 1 & $\boldsymbol{E}$ & & & \\
\hline${ }_{1} \mu_{i} F_{i}$ & $4=0_{i}$ & E & +1 & 2 & 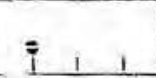 & E & & קה & & & \\
\hline 1,11 & 911 & E & & & $9 \quad 1$ & E & $\perp$ & & & & \\
\hline$-\ldots 1 \quad 1$ & 111 & E & 1 & & $1 \quad 1$ & E & & & & & \\
\hline 1111 & $! 11$ & E & I & & i. 1 & $\mathrm{~F}$ & & & & & \\
\hline
\end{tabular}

IVASTE GENERATOR

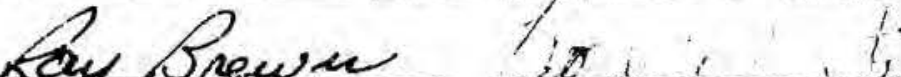

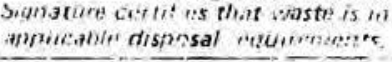

H.1 AREA REPAESENTATIVE )

signature certiles that waste packayotor shymmow

GROUP LEADER (AS NECESSARY) Ale.tn haldile and transport
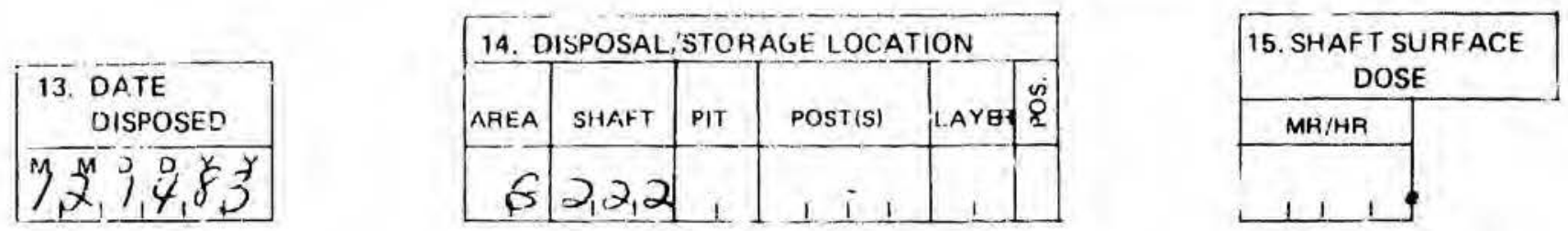
PLEASE READ INSTRUCTIONS ON BACK CAREFULLY

1. FORM NUMBER

$5,8,3,4,88$
LOS ALAMOS RADIOACTIVE SOLID WASTE DISPOSAL RECORD FORM
$\mathrm{H}$, Waste Manazement Ext 6095 IMS J592

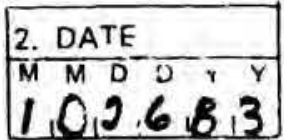

\begin{tabular}{l} 
3. RETRIEVABLE \\
SERIAL NO \\
\hline B, $/ 5,9,49$
\end{tabular}

\begin{tabular}{|c|c|c|c|c|}
\hline \multicolumn{3}{|c|}{ 4. ORIGIN OT WASTE } & \multirow{2}{*}{$\frac{0}{3}$} & \multirow[b]{2}{*}{ HOOM } \\
\hline GROUP & TA & BLDG. & & \\
\hline$M, S, T, I$ & 12 & $\mathbf{S} M$ & 9 & \\
\hline
\end{tabular}

\begin{tabular}{|l|} 
5. VIASTE \\
CODE \\
\hline $1,4,0$ \\
\hline
\end{tabular}

6. WASTE DESCRIPTION

$C_{1} E_{1} L_{1} L_{1}, 1,4, T R A_{1}, H_{1}, L_{1}, G_{1} A_{1} N_{1}$

\section{NUMBERS OF WASTE PACK.AGES}

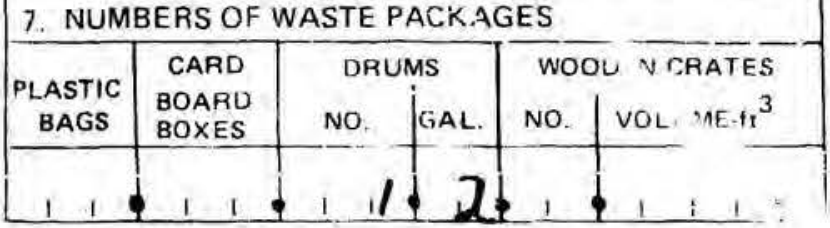

$K=K I L O G R A M$
$P=P O U N D$

10. GROSS in

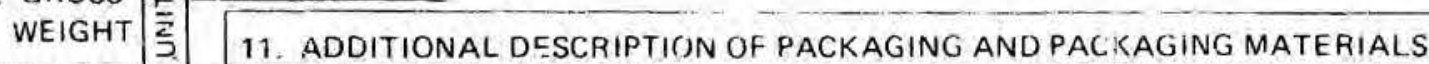

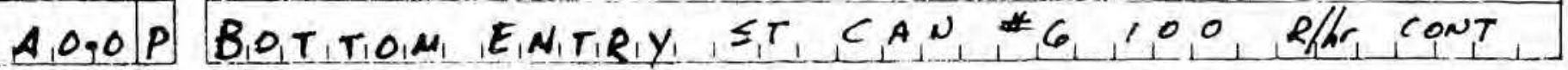

\begin{tabular}{|c|c|c|c|c|c|c|c|c|c|c|}
\hline 12. RADIONUC & LIDE CON & ENT & & & $\begin{array}{l}C \text { CUARE } \\
M=\text { GRAM }\end{array}$ & & & F.MOUNT OC TERMINED BY. & $\begin{array}{l}\text { SS MATE } \\
\text { WRIT }\end{array}$ & $\begin{array}{l}\text { ERIALS } \\
\text { TEOFF }\end{array}$ \\
\hline NUCLIDE & AMOUNT & & \pm & $\frac{w}{2}$ & $\begin{array}{l}\text { ERROR ON } \\
\text { AMOIUNT }\end{array}$ & & \pm & $\begin{array}{l}\text { A ANALYSIS } \\
M \text { MEASUREMENT } \\
\text { E - ESTIMATE }\end{array}$ & ACCOUNT & $\begin{array}{l}\text { PROJECT } \\
\text { COLE }\end{array}$ \\
\hline $1,4 \div 6$ & 5. 1.1 & $\mathrm{E}$ & -11 & $M$ & $1 \quad 1$ & E & & $\Sigma$ & & \\
\hline$P_{\perp}\left\langle J_{1} 5\right.$ & $18 \alpha_{1}$ & E & -11 & $M$ & $\therefore 11$ & E & & $E$ & & \\
\hline$\perp M_{1} F P$ & $4 ., 1$ & E & $+1 !$ & $c$ & $1 \perp 1$ & $\varepsilon$ & 1 & $\mu$ & & \\
\hline $1 \quad 111$ & 91.1 & $E$ & 1 & & 111 & E & & & & \\
\hline 1111 & $91 \ldots$ & $E$ & -1 & & 111 & E & & & & \\
\hline 1 & 1,1 & E & 1 & & i 1 & E & & & & \\
\hline
\end{tabular}

Lan $/$ Sonsin

WKSTE GENER, TOR

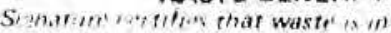

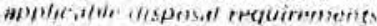
H.1 ATEA REPRESENTATIVE $1 T_{1}$

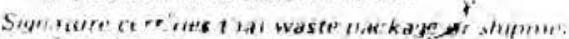

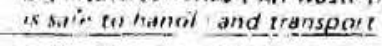

i. METER 8. GROSS $\frac{G}{z} G=$ GALLON $5.41 F$

\begin{tabular}{|c|c|}
\hline \begin{tabular}{c} 
9. PACKAGE RADIATION AT: \\
\hline $\begin{array}{c}\text { SURFACE } \\
\text { MR/HR }\end{array}$
\end{tabular} & $\begin{array}{c}1 \text { METER } \\
\text { MR/HR }\end{array}$ \\
\hline & $111,0,0,0,0$ \\
\hline
\end{tabular}

\section{GROUJP LEADER IAS NECESSARY)}

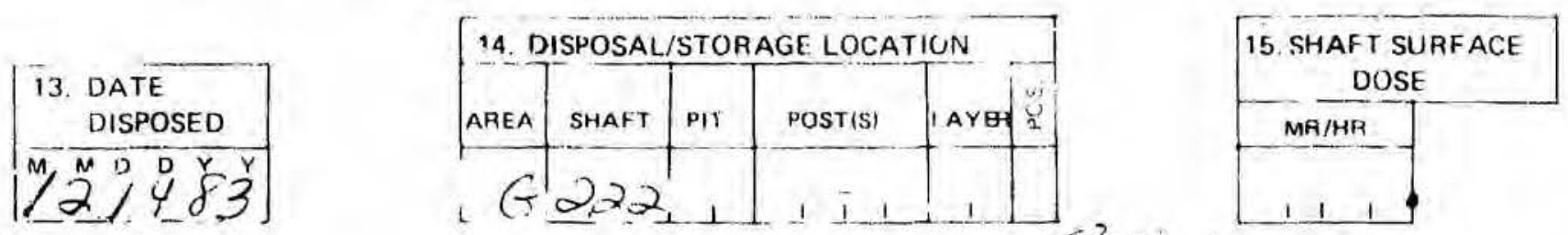

H.7 WASTE MANAGEMENT REPRESENTATI:'E 
PLEASE READ INSTR.jETIONS ON BACK CAREFULLY

1. FORM NUMBER

$\mathrm{s}, 8,3,0 \% 89$
LOS ALAMOS RADIOACTIVE SOLID WASTE DISPOSAL. RECORD FORM
H.7 Waste Management

Ext 6095 MS J592

\begin{tabular}{|c|}
\hline 3. RETRIEVABLE \\
SERIAL No. \\
\hline Bi l $1,59,49$ \\
\hline
\end{tabular}

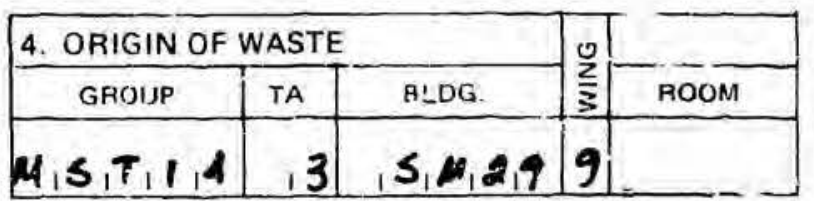

\begin{tabular}{|r|}
\hline 5. WA.STE \\
CODE \\
\hline 1.0 \\
\hline
\end{tabular}

6. WASTE DESCRIPTION

$C_{1} E_{1} L_{1} L_{1}, / A_{1}, T, R_{1} A_{1} S_{1} H_{1}, C_{1}, C_{1} N_{1}$

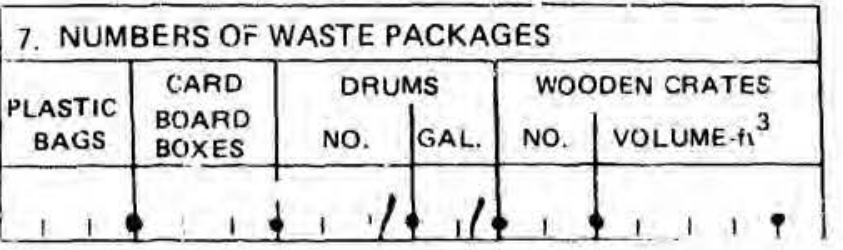

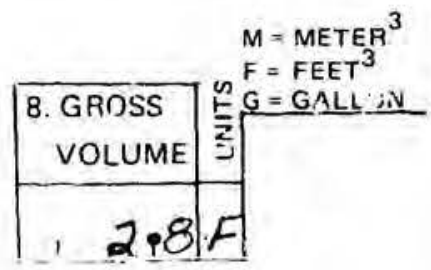

\begin{tabular}{|l|c|}
\hline 9. PACKAGE RADIATION .T: \\
\hline $\begin{array}{c}\text { SURFACE } \\
\text { MR/HR }\end{array}$ & $\begin{array}{c}\text { 1 METER } \\
\text { MR, HR }\end{array}$ \\
\hline $1,0,0,0,0$ & $, 12,0,0$ \\
\hline
\end{tabular}
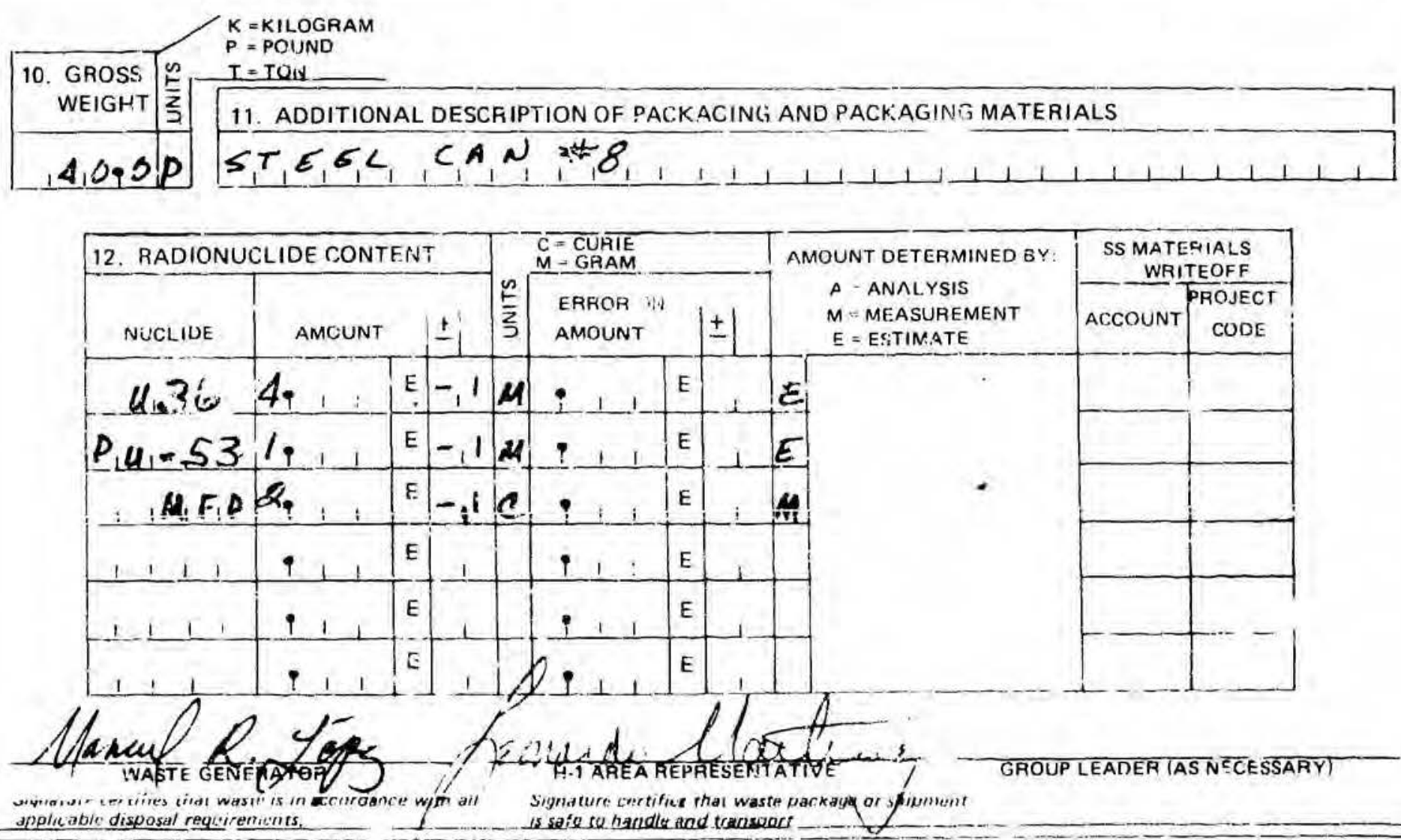

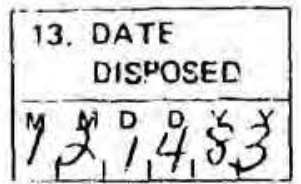

\begin{tabular}{|c|c|c|c|c|c|}
\hline 14. DISPOSAL/STORAGE LOCATION \\
\hline AREA & SHAFT & PIT & POSTS & LAVE & ES \\
\hline 6 & $2,2,2$ & & 1 & & \\
\hline
\end{tabular}

GROUP LEADER (AS N pESSARY)

applicable disposal reguirenich

15. SHAFT SUFFACE DOSE

MR/HB

HOE T-1A $(10 / 81)$

H-7 WASTE MANAGEMENT RTUFESENTATIVE

signature certifies waste met acceptance criteria.
ind all disposal requirements snore mot. 
1. FORM NUMBER

s, 8, 3, Gr, 90
LOS ALAMOS RADIOACTIVE SOLID VIASTE DISPOSAL RECORD FORM
H.7 Waste Mani gement

Ext 6 C65 MS J59?

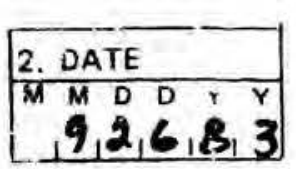

\begin{tabular}{l} 
3. RETRIEVABLE \\
SERIAL NO \\
\hline$B, 5,9,4,9$ \\
\hline
\end{tabular}
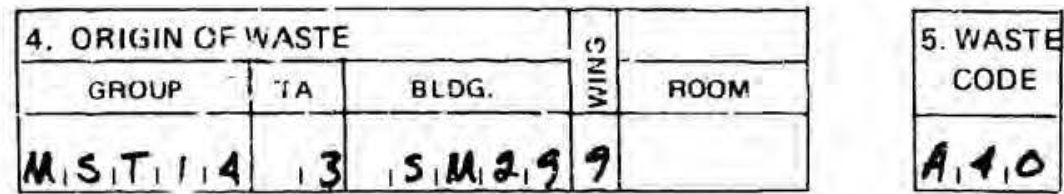

6. WASTE DESCRIPTIGN

$C_{1} E_{1}<_{1} L_{1}, 1_{1} 4_{1}, T, R_{1} A_{1} S_{1} N_{1}, 1, C_{1} A_{1} N_{1}$

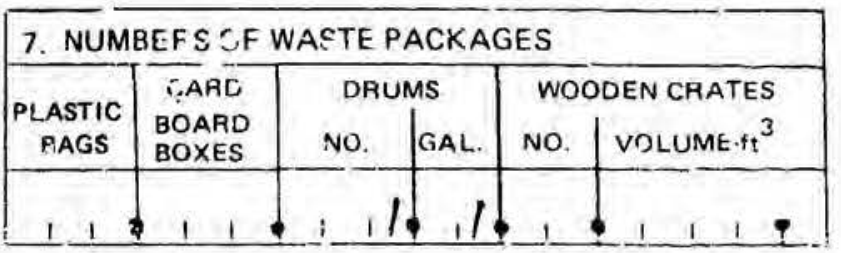

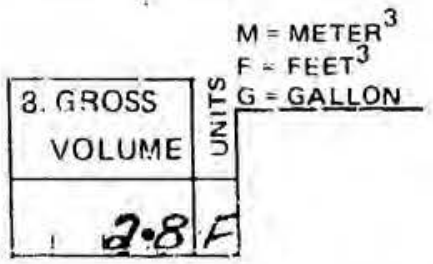

\begin{tabular}{|c|c|}
\hline \multicolumn{2}{|c|}{ 9. PACKAGE RADIATION AT: } \\
\hline $\begin{array}{c}\text { SUPFACE } \\
\text { MR'HR }\end{array}$ & $\begin{array}{c}1 \text { METEF } \\
\text { MR/HR }\end{array}$ \\
\hline & $4,0,0,0,0$ \\
\hline
\end{tabular}

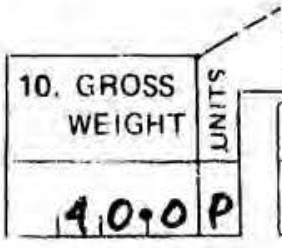

$K=$ KILOGRAM

$P=$ POUND

$I=I Q N$

\section{ADDITIONAL DESCRIPTION OF PACKAGING AND PACKAGING MATERIALS}

$S_{1} E_{1} E_{1} \epsilon_{1} L_{1}, C_{1} A_{1} N_{1}: q_{1}, 2,0, R_{1} C_{1} N_{1} T_{1} C_{1} T_{1}$

\begin{tabular}{|c|c|c|c|c|c|c|c|c|c|c|}
\hline \multicolumn{4}{|c|}{ 12. RADIONUCLIDF CONTENT } & \multicolumn{4}{|c|}{$\begin{array}{r}C=\text { CURIE } \\
\text { M. GRAM? }\end{array}$} & \multirow{2}{*}{ 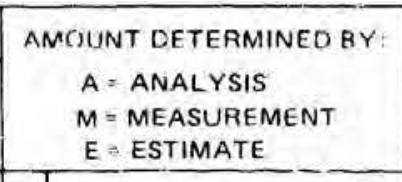 } & \multicolumn{2}{|c|}{$\begin{array}{l}\text { SS MATERIALLS } \\
\text { WFIITEO'.F }\end{array}$} \\
\hline NUCLIDE & A.MOUNT & & \pm 1 & $\begin{array}{l}\frac{s}{z} \\
\frac{z}{J}\end{array}$ & $\begin{array}{l}\text { ERROR ON } \\
\text { AMOUNT }\end{array}$ & & \pm & & ACCOUNT & $\begin{array}{l}\text { CODE } \\
\text { COAECT }\end{array}$ \\
\hline 436 & $1,1,6,4$ & $\mathrm{E}$ & +1 & $M$ & 111 & E & & $E$ & & \\
\hline$P \times 5=$ & $2.9,1$ & E & +10 & $M$ & $1 \quad 1$ & E & & $E$ & & \\
\hline$M F$ & 4.0 & $\mathrm{E}$ & +1 & ?ִ? & i i i & E & 1 & ât & & \\
\hline 1111 & 911 & E & 1 & & $1 \quad 1$ & E & 1 & & & \\
\hline $11: 1$ & $1 \quad 1.1$. & E & \lrcorner & & i 11 & E & 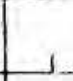 & & & \\
\hline $1+b 1$ & 1,1 & E & 1 & & 2 & E & & & & \\
\hline
\end{tabular}

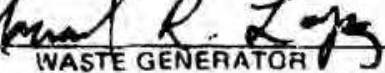$$
\text { - V. }
$$

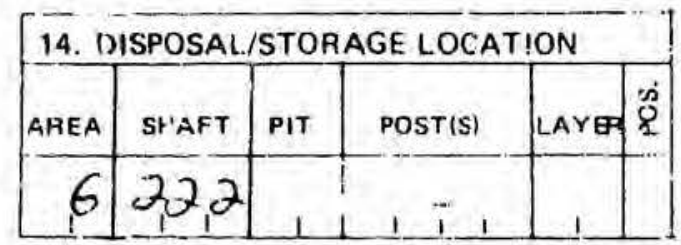

\section{GROUP LEADER (AS NE CE SSARY)}

Sighature certifier that waste pik kage or ship? is sate. tre handire and transpori.
H-7 WASTE MANAGEMENT REPRESENTATIVE

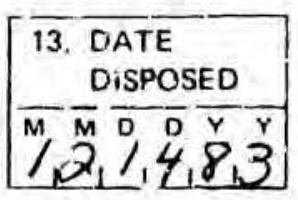

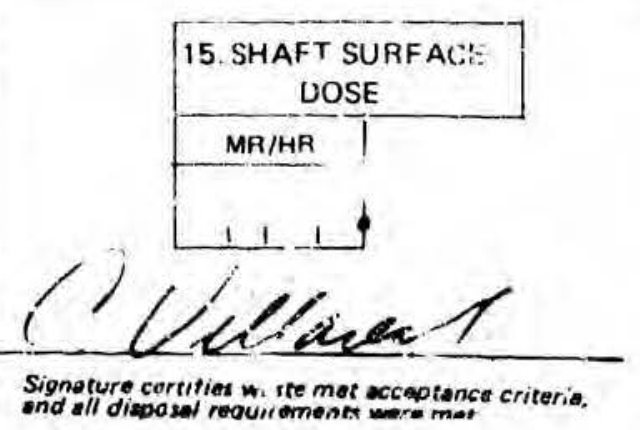

HS-E 7-1A $(10 / 81)$ 
RADIOACTIVE SOLID WASTE DISPOSAL RECORD FORMS

FOR

SHAFT 223

MATERIAL DISPOSAL AREA G 
PLEASE READ INSTRUCTIONS ON BACK CAREFULL

\begin{tabular}{|l|l|}
\hline 1. FORM NUMBER \\
\hline $5,8,3$, & OYPOB: \\
\hline
\end{tabular}

LOS ALAMOS RAD OOACTIVE SOLID WASTE DISPOSAL RE?ORD FORM
17 Waste Managemon!

$[\times \uparrow 6095$ MS .15y2

\begin{tabular}{|c|c|}
\hline & 3. RETRIEVAELE \\
\hline 2. DATE & SERIAL NO. \\
\hline 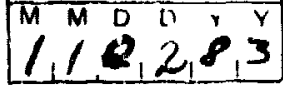 & $3 / 50 / 6$ \\
\hline
\end{tabular}

\begin{tabular}{|c|c|c|c|c|}
\hline 4. ORIGIN OF WASTE & & 0 & \\
\hline GROUP & TA & BLDG & $\frac{2}{3}$ & ROOM \\
\hline$M, S, T, 1,4$ & 3 & $5, M, Z 9$ & 9 & \\
\hline
\end{tabular}

\begin{tabular}{|}
5 WASTE \\
COJE \\
\hline$A, 4,0$
\end{tabular}

6. WASTE UESCARIFTION

CELLCILIIIRASN I C A N

\begin{tabular}{|c|c|c|c|c|c|}
\hline \multicolumn{6}{|c|}{ 7. NUMBERS UF WASTE PACKAGES } \\
\hline & CAF'D & & & wo & DEN CRATES \\
\hline $\begin{array}{l}\text { PLASIIC } \\
\text { BAGS }\end{array}$ & $\begin{array}{l}\text { BOAFO } \\
\text { BOXE:: }\end{array}$ & NO & GAL. & NC. & VOLUME- $+t^{3}$ \\
\hline
\end{tabular}
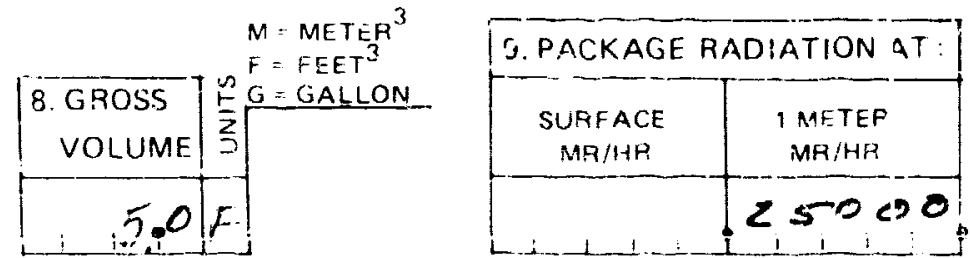

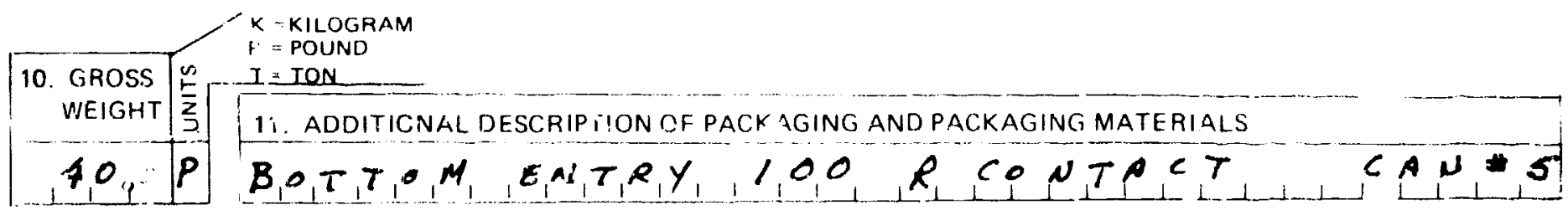

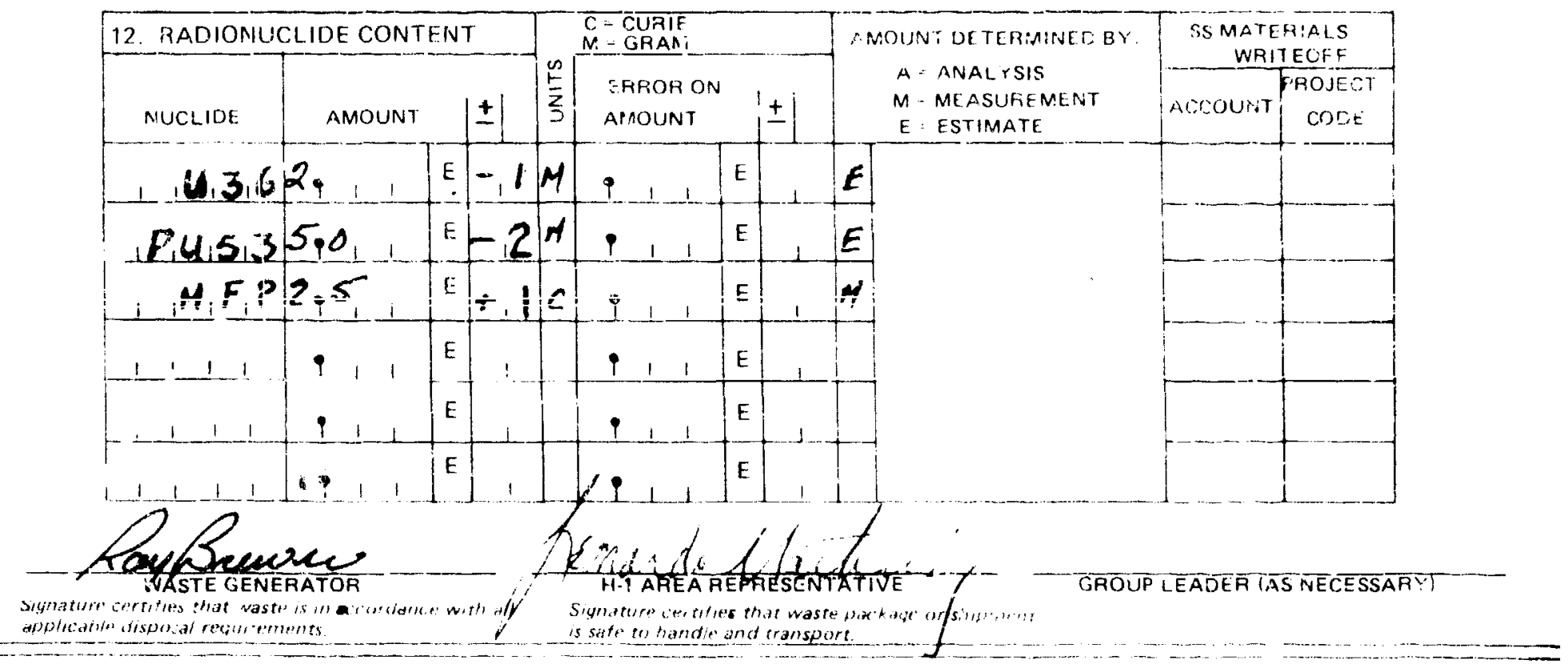

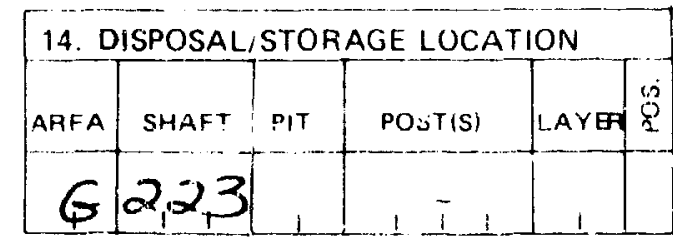

H-7 WASTE MANAGEMENT REPRESENTATI':E

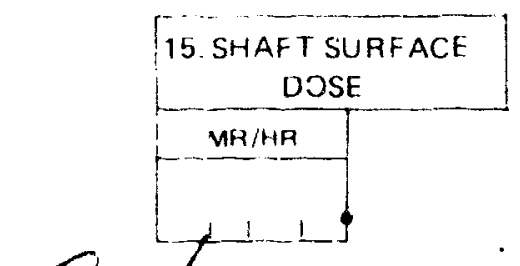




$$
\begin{array}{|l|}
\hline \text { 1. FORM NUMEER } \\
\hline 5,8,3,6,7,8,3 \\
\hline
\end{array}
$$

PLEASE READ INSTRUCT I INS ON BALK APEFIILLY LOS ALAMOS RADIOACTIVE SOLID WASTE. DISPOSAL RECORD FORM

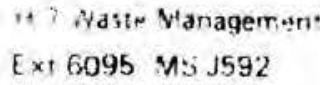
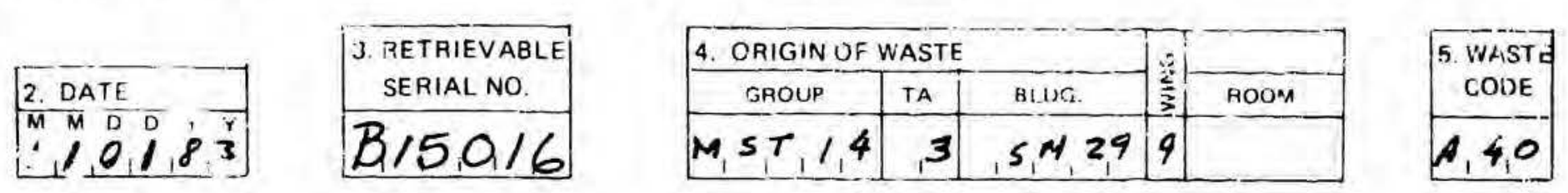

6. WASTE DESCRIPTION

$$
C_{1} E_{1} L_{1} / 4, T_{1} R A_{1} H_{\perp} /, C_{\perp} A_{1}
$$
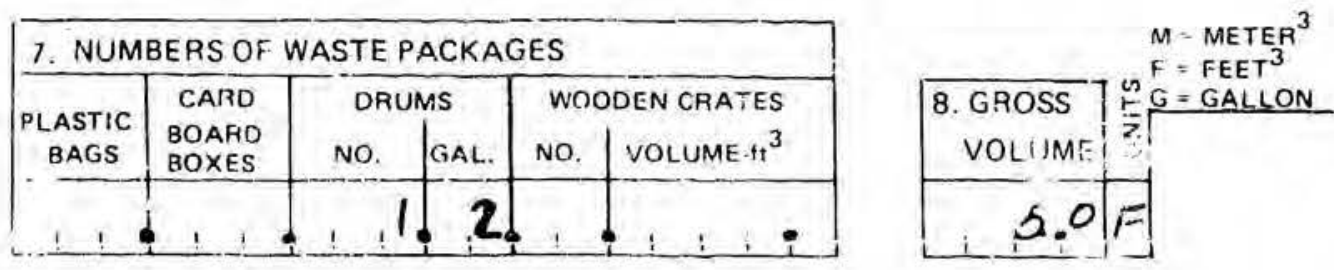

\begin{tabular}{|c|c|}
\hline 9. PACKAGE RADIATION AT: \\
\hline $\begin{array}{c}\text { SURFACE } \\
\text { MR } / \text { HR }\end{array}$ & $\begin{array}{c}1 \text { METER } \\
\text { MR/HR }\end{array}$ \\
\hline 250,00 & $3,0,00$ \\
\hline
\end{tabular}
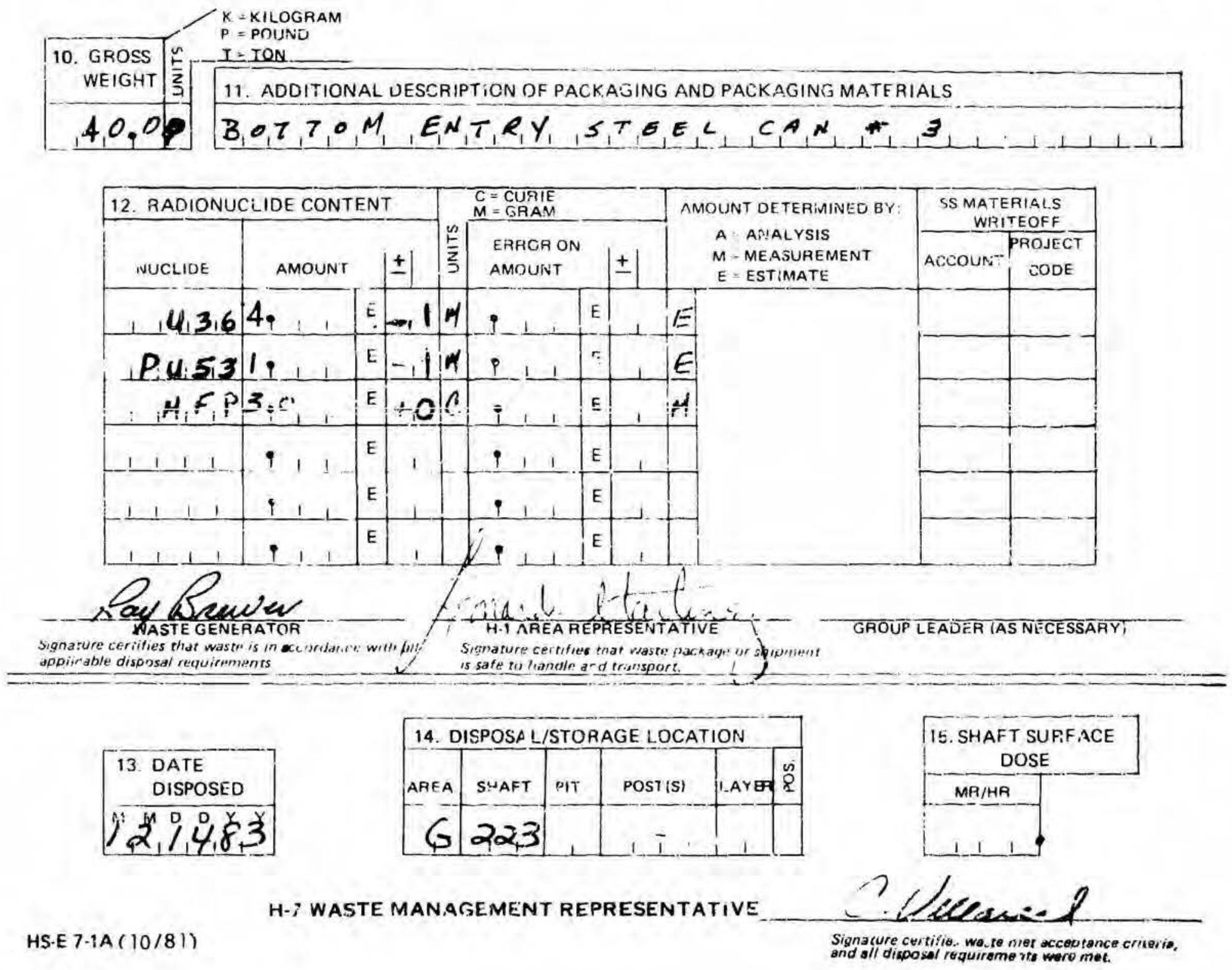


$$
\begin{array}{|l|l|}
\hline \text { 1. FORM NUMBER } \\
\hline \underline{S}, 8,3, & 9,2, B_{i} \\
\hline
\end{array}
$$

LOS ALAMOS RADIOACTIVE SOLID WASTE DISPOSAL RECORD FORM

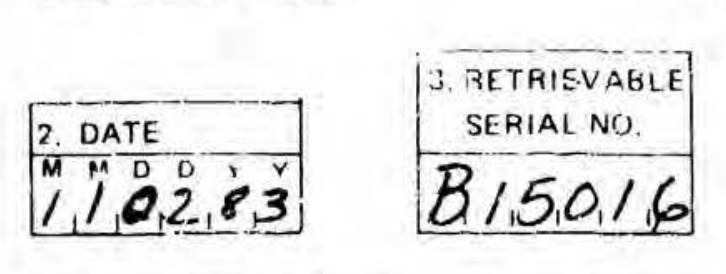

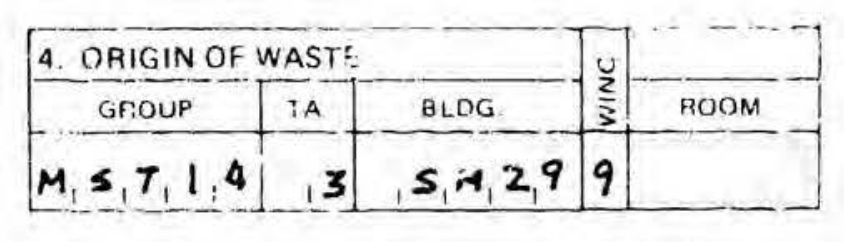

\begin{tabular}{|l|}
5. WASTE \\
\hline $1,4,0$ \\
\hline
\end{tabular}

6. WASTE DESCPIPTION

$C_{1} E L_{1} L_{1}, T, A_{\perp} \leq N, C_{A} N$
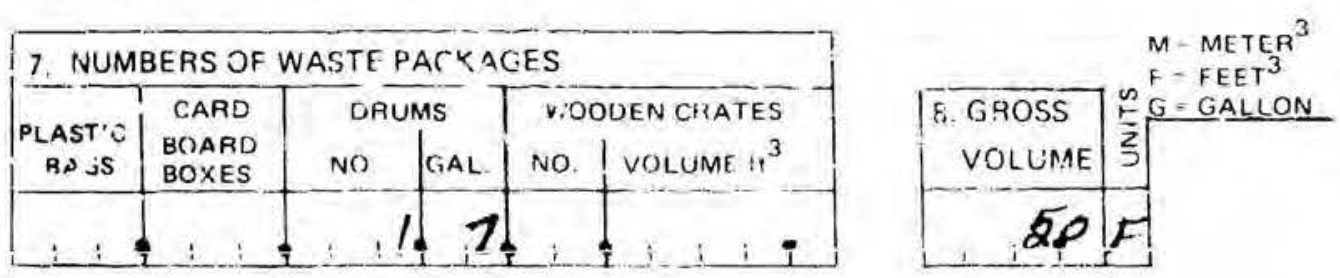

\begin{tabular}{|c|c|}
\hline 9. PACKAGE RAUIATION AT: \\
\hline $\begin{array}{c}\text { SURFACE } \\
\text { MR/HR }\end{array}$ & $\begin{array}{c}1 \text { METER } \\
\text { NIHIHR }\end{array}$ \\
\hline 30,000 & $0,0,000$ \\
\hline
\end{tabular}
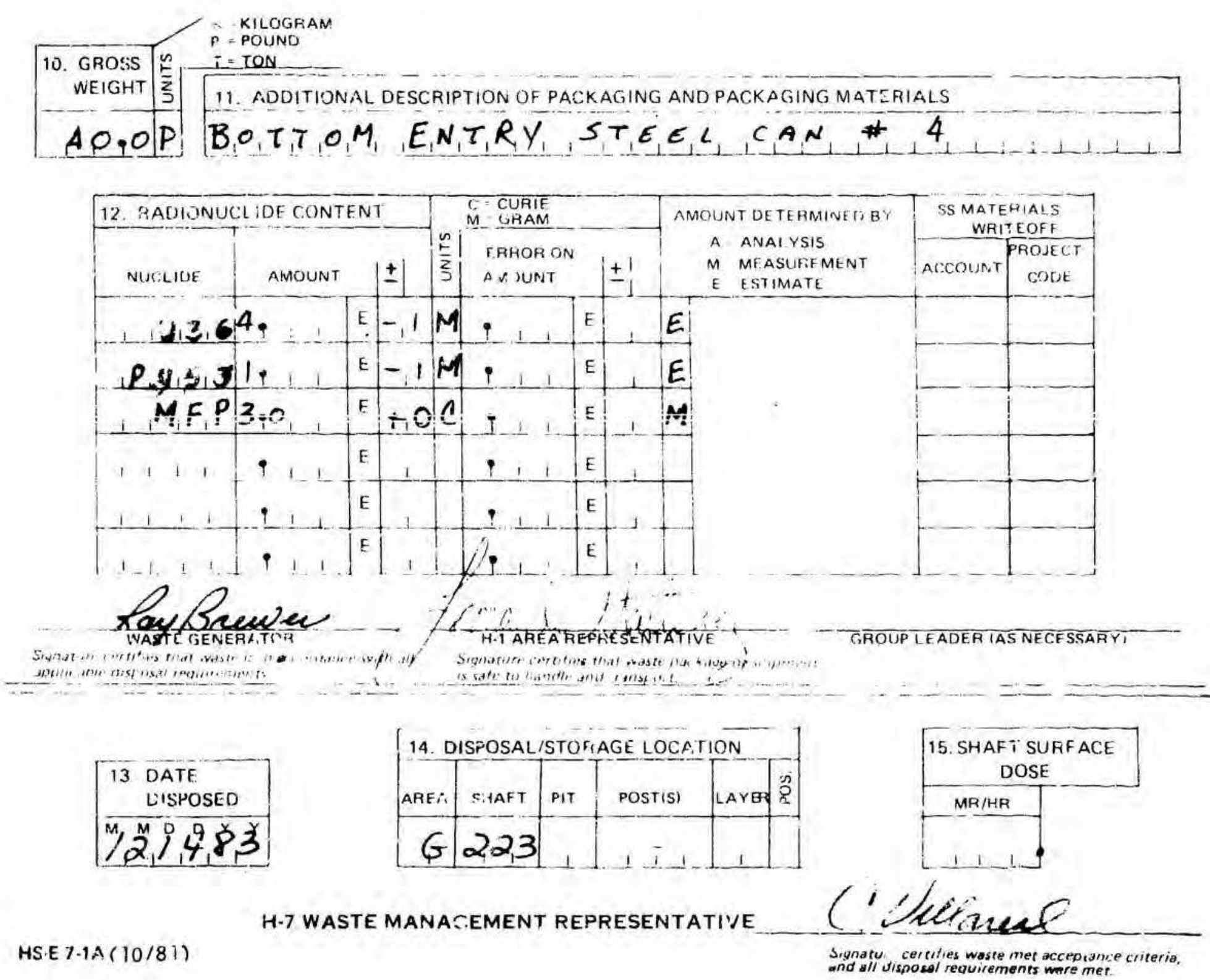

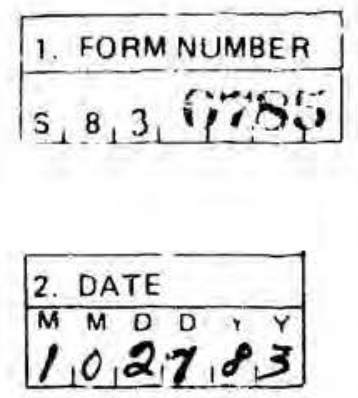

DLEASE FE AD NSTRUC FIONS ONA BACK CAREFULLI

LOS AL.AMOS RADIOACTIVE SOLID WASTE DISPOSAL RECORD FORM
- Naste Aiaragen ery

1. : 295 MS $j 59$ ?

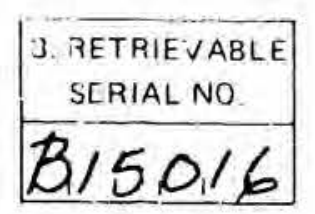

$\left[\begin{array}{c|c|c|c|c|}\hline \text { O. ORIG!N OF WASTE } & 0 & \\ \hline \text { GROL? } & \text { TA } & \text { ELOG } & \frac{2}{3} & \text { ROOM } \\ \hline M, s, T, 1,4 & , 3 & s_{1} M, 2,9 & 9\end{array}\right]$

$\begin{array}{r}\text { 5. WASTH } \\ \text { CODE } \\ \hline, 4,0 \\ \hline\end{array}$

6. WASTE DESCRIPTION

$$
\text { C,ELL I } 4 \text { TRASH I CA A }
$$
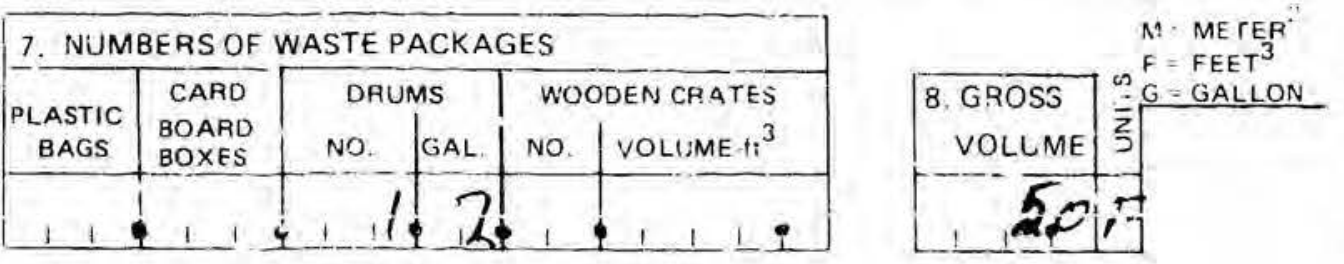

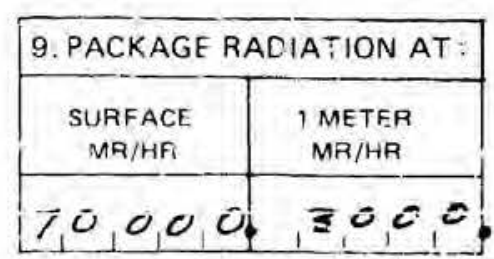
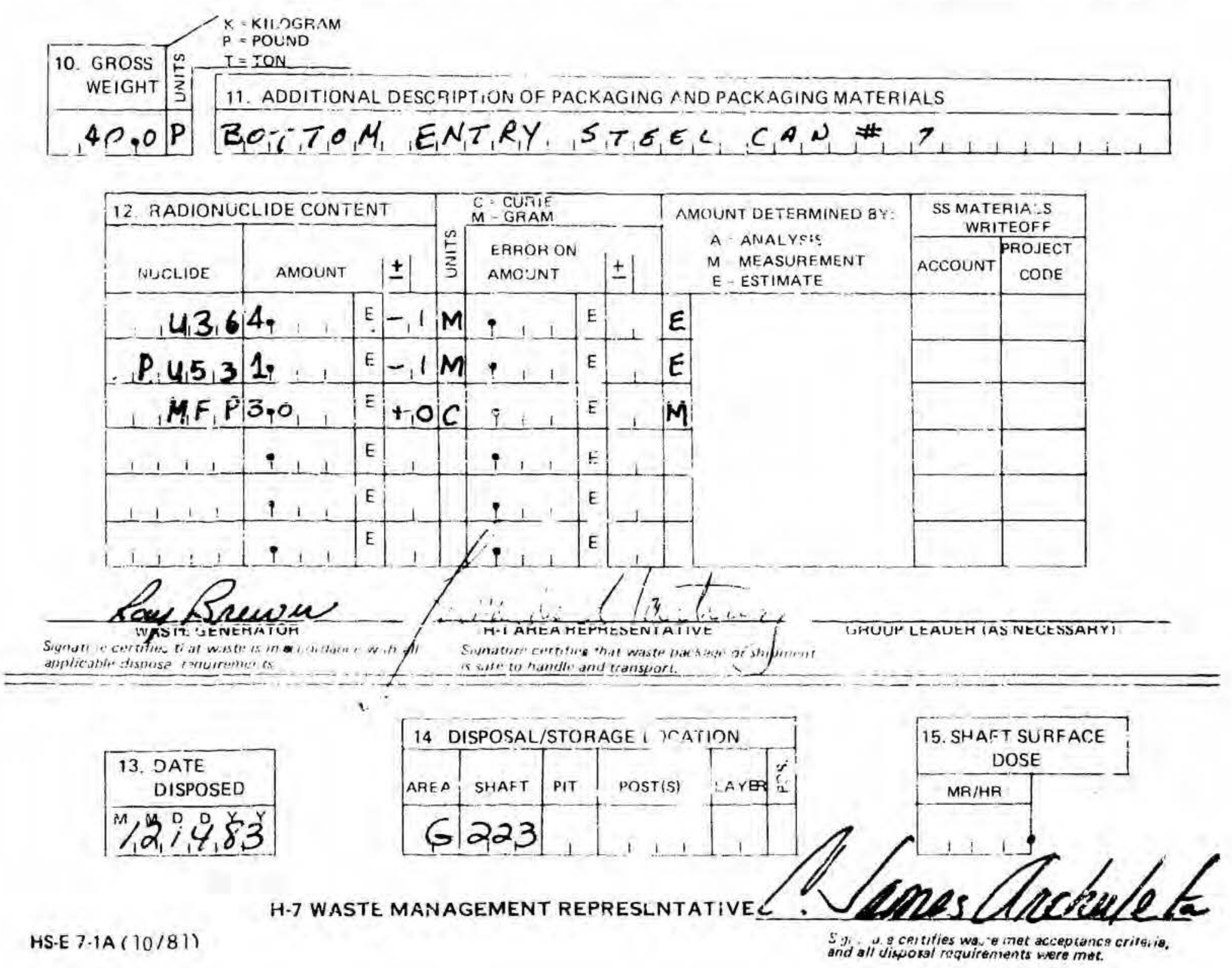
PLEASE READ INSTRUCTIONS ON BACK CAREFULLY

1. FORM NUMBER

$S, 8,3$, G,186

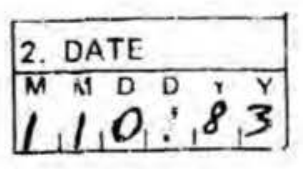

LOS ALAMO RADIOACTIVE SOLID WASTE DISPOSAL RECORD FORM
47 Waste Management

xt 6095 MS j592

\begin{tabular}{|c|c|c|c|c|}
\hline 4. ORIGIN OF WASTE & & \multirow{2}{*|}{} & \\
\hline GROUP & $T A$ & BLDG & $\frac{2}{5}$ & ROOM \\
\hline$M, 5, T, 1,4$ & 3 & $5, M, 2,9$ & 9 & \\
\hline
\end{tabular}

\begin{tabular}{l} 
5. WASTE \\
CODE \\
$4,4,0$ \\
\hline
\end{tabular}

6. WASTE DESCRIPTION

C. $G_{1} L_{1}{ }_{1}, 1,4, T_{1} R_{1} A_{1} S_{1} h_{1} I_{\perp} C_{1} A_{1} N$

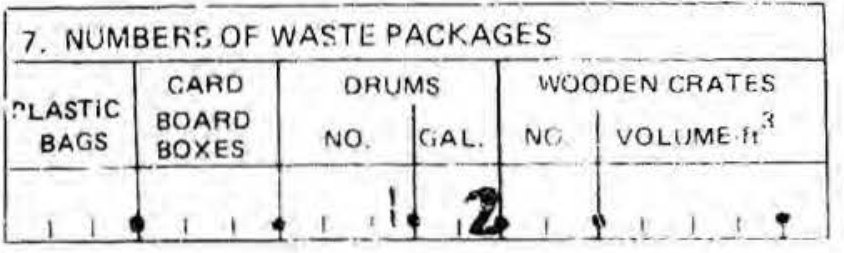

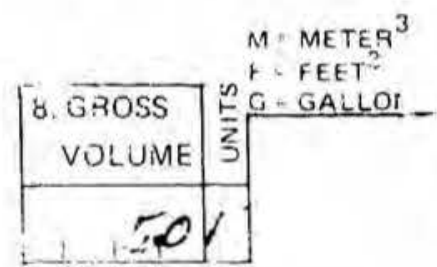

\begin{tabular}{|c|c|}
\hline 9. PACKAGE RADIATION AT: \\
\hline $\begin{array}{c}\text { SURFACE } \\
\text { MR/HR }\end{array}$ & $\begin{array}{c}1 \text { METER } \\
\text { MR/HR }\end{array}$ \\
\hline $2,0,0,00$ & $115,0,0$ \\
\hline
\end{tabular}
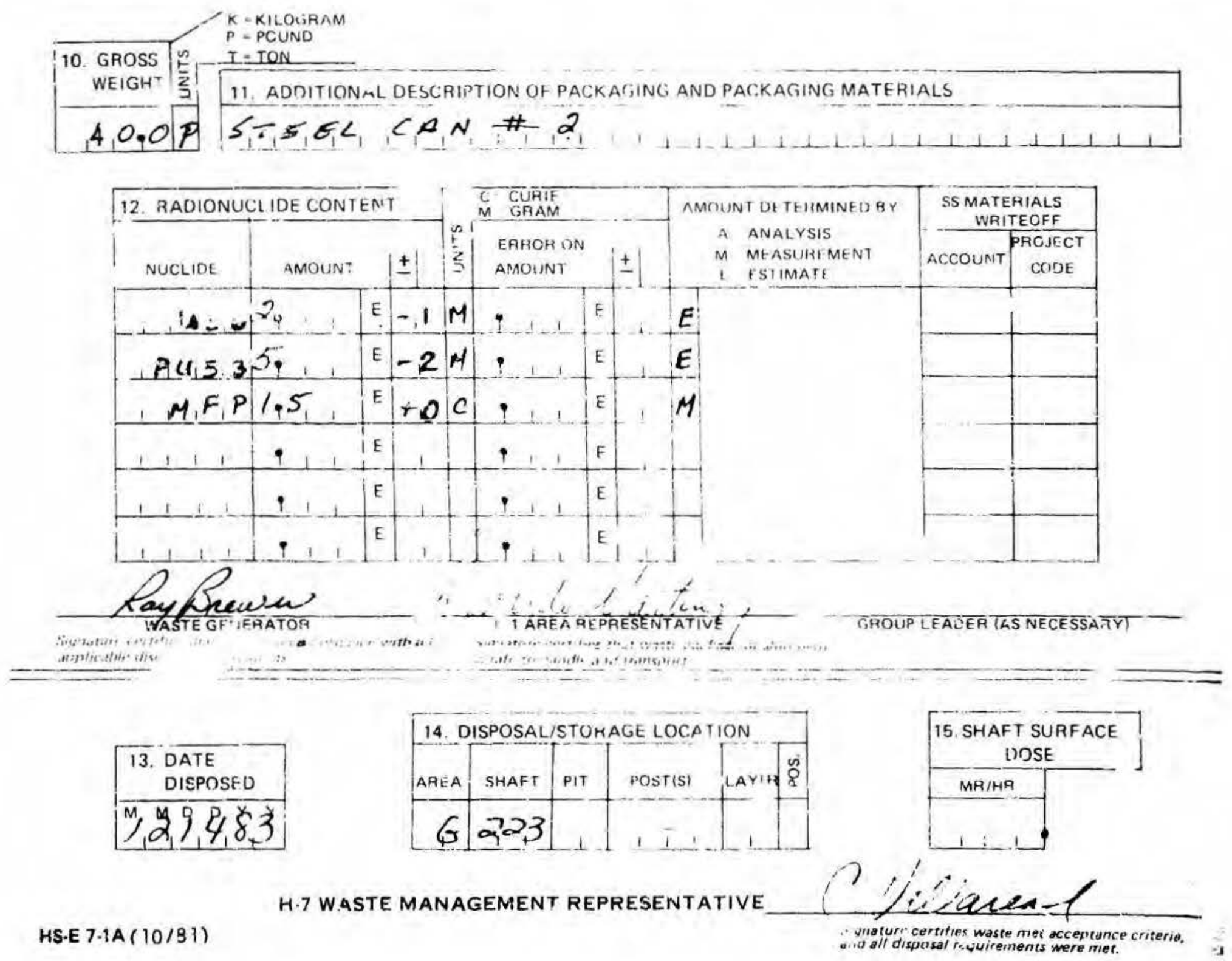
PLEASE READ INSTRUCTIONS ON BACK CAREFULLY

1. FORM NUMBER

$\mathrm{s}, 8,3,0 \% 91$

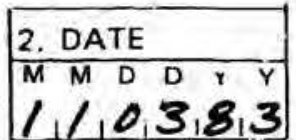

LOS ALAMO RADIOACTIVE SOLID WASTE DISPOSAL RECORD FORM
H-7 Waste Management

Ext 6095 MS J592

\begin{tabular}{l}
$\begin{array}{l}\text { 3. RETRIEVABLE } \\
\text { SERIAL NO. }\end{array}$ \\
\hline B/50,6/6 \\
\hline
\end{tabular}

\begin{tabular}{|c|c|c|c|c|}
\hline \multicolumn{2}{|l|}{ ORIGIN OF WASTE } & \multirow{2}{*}{} & \\
\hline GROUP & TA & BLDG. & $\frac{2}{3}$ & ROOM \\
\hline$M_{1} S_{1} T_{1} / 14$ & L:3 & S $1 M 12,9$ & 9 & \\
\hline
\end{tabular}

\begin{tabular}{|r|}
\hline . WASTE \\
CODE \\
\hline $4,4,0$ \\
\hline
\end{tabular}

6. WASTE DESCRIPTION

$C_{1} E_{1} L_{1} L_{1}, C_{1}, 6, T_{1} R_{1} A_{1} S_{1} H_{1}, I_{1}, C_{1} A_{1} N_{1}$

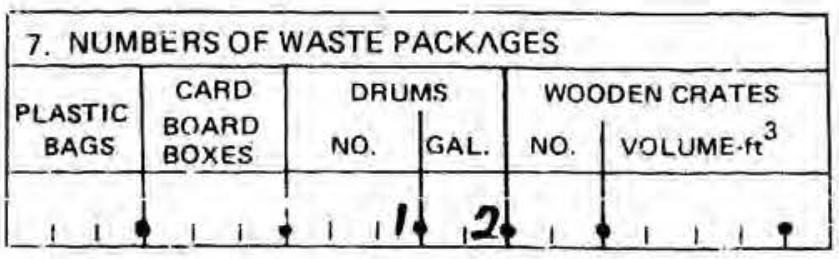
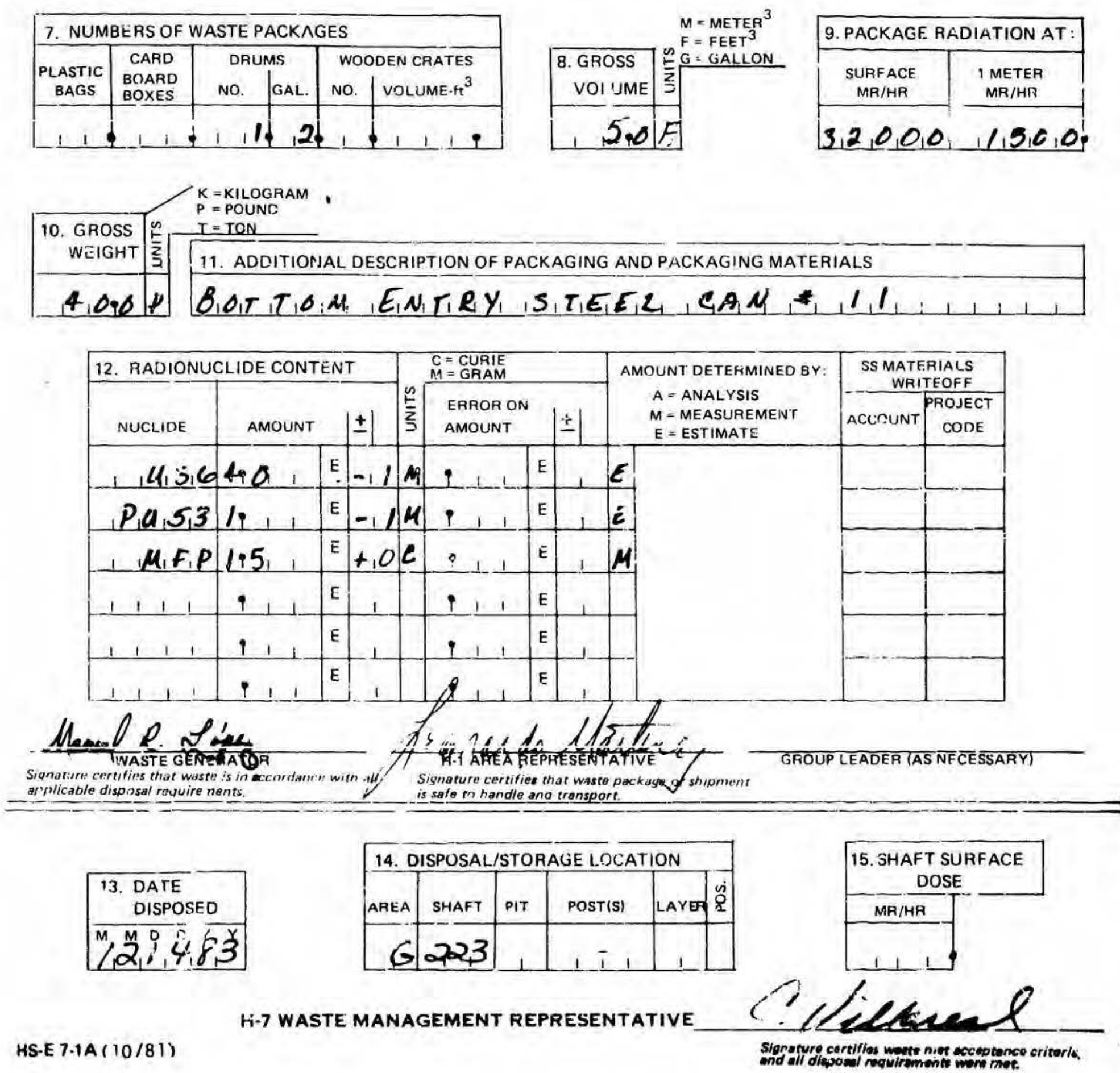
RADIOACTIVE SOLID WASTE DISPOSAL RECORD FORMS

FOR

SHAFT 224

MATERIAL DISPOSAL AREA G 


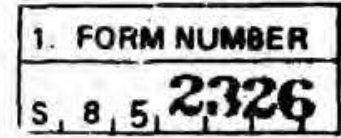

\begin{tabular}{|l|}
\hline 1. FORM NUMAER \\
\hline $5,8,5,2,396$ \\
\hline
\end{tabular}
PLEASE READ INSTRUCTIONS ON BACK CAREFULL

LOS ALAMOS RADIOACTIVE SOLID WASTE DISPOSAL RECORD
HSE 7 Waste Management

Exi 6095 MS $J 592$
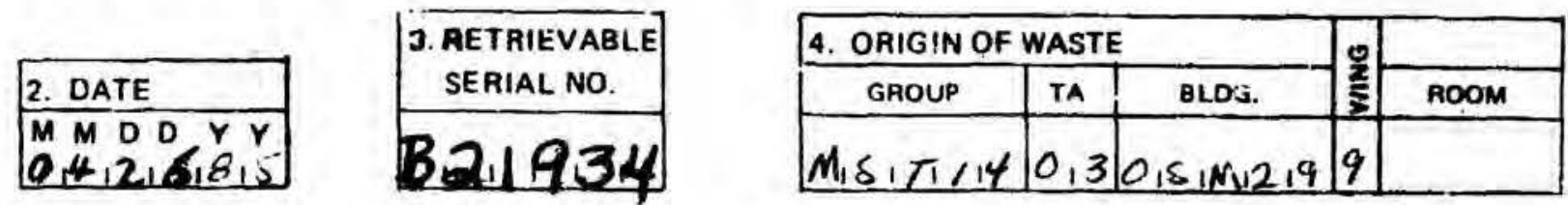

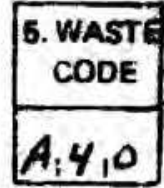

\section{WASTE DESCRIPTION}

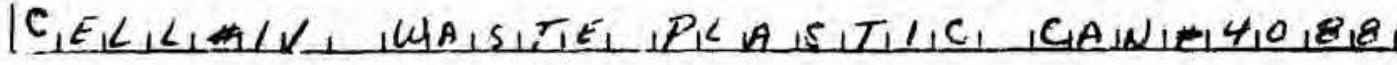

\begin{tabular}{|c|c|c|c|c|c|}
\hline \multicolumn{6}{|c|}{ 7. NUMBERS OF WASTE PACKAGES } \\
\hline P A & CARD- & & & wo & DEN CRATES \\
\hline BAGS & $\begin{array}{l}\text { BOARD } \\
\text { BOXES }\end{array}$ & NO. & GAL. & No. & VOLUME $\cdot t^{3}$ \\
\hline
\end{tabular}
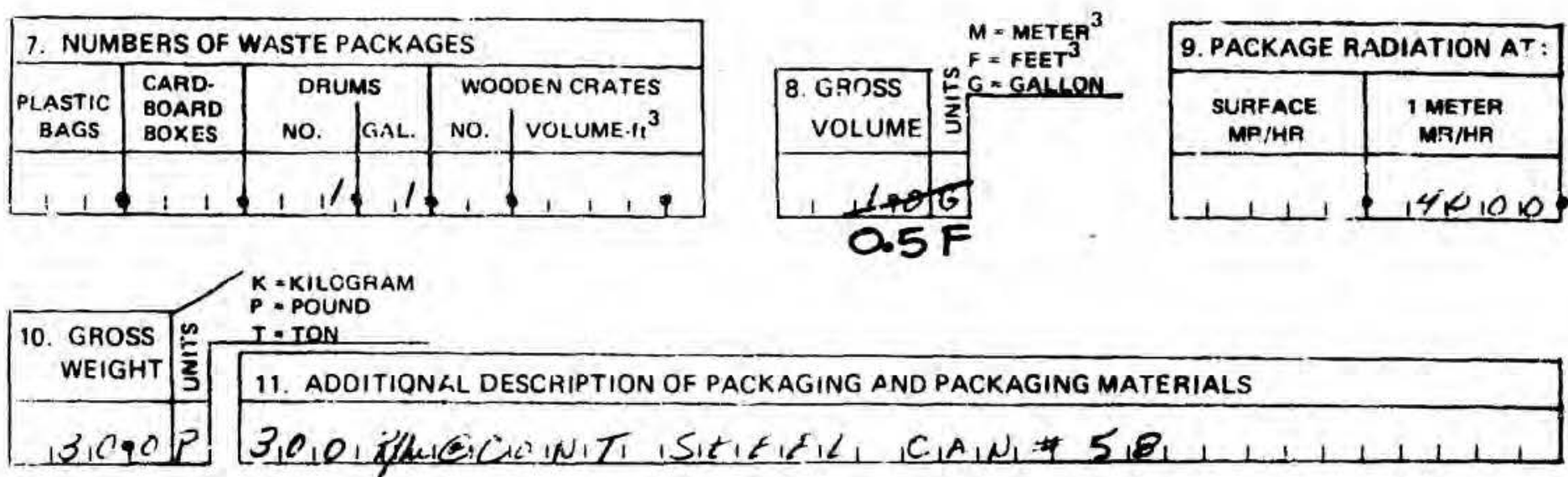

$K=$ KILOGRAM P. POUND

$0.5 \mathrm{~F}$

$I=$ ION

11. ADOITIONGL DESCRIPTION OF PACKAGING AND PACKAGING MATERIALS

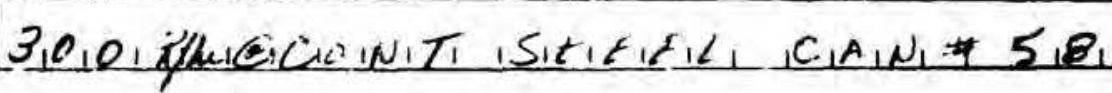

\begin{tabular}{|c|c|c|c|c|c|c|c|c|c|c|c|}
\hline \multicolumn{4}{|c|}{ 12. RADIONUCLIDE CONTEINT } & \multicolumn{4}{|c|}{$\begin{array}{r}C=\text { CUAIE } \\
M=G R A M \\
\end{array}$} & \multirow{2}{*}{\multicolumn{2}{|c|}{$\begin{aligned} & \text { AMOUINT DETERMINED BY } \\
& \text { A }=\text { ANALYSIS } \\
& M=\text { MEASUREMENT } \\
& E=\text { ESTIMATE }\end{aligned}$}} & \multicolumn{2}{|c|}{$\begin{array}{c}\text { SS MATERIALS } \\
\text { WRITEOFFF } \\
\end{array}$} \\
\hline NUCLIOE & AMOUNT & & \pm & $\frac{n}{2}$ & $\begin{array}{l}\text { ERPOQ ON } \\
\text { AMOUNT }\end{array}$ & & \pm 1 & & & ACCOUNT & $\begin{array}{l}\text { PROJECT } \\
\text { CODE }\end{array}$ \\
\hline $11,2,3,5$, & $4,0,0,0$ & $\mathrm{E}$ & -11 & M & 111 & E & & $E$ & & & \\
\hline$P_{1} 11,2,3,3$ & $1,0,0,0$ & E & -11 & M & $1 \quad 1$ & $E$ & & $E$ & & & \\
\hline$H_{1} F_{1} \bar{P}_{1}$ & $\ddot{40,0,0}$ & $\mathbf{E}$ & $+\left(c^{\prime}\right.$ & $\bar{c}$ & 11 & $\Xi$ & & $M i$ & & & \\
\hline 1111 & 911 & E & 1 & & 111 & $E$ & & & & & \\
\hline 1111 & 1,1 & E & & & 1,1 & E & & & & & \\
\hline & 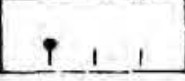 & $E$ & 1 & & 111 & E & (i) & & & & \\
\hline
\end{tabular}

\section{RAsolecen}

WASTE GENEAATOR

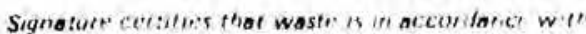

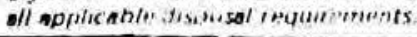

HSE-1 AREA REPAESENTATIVE

GROUP LEADER (AS NECESSARY)

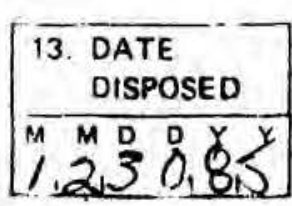

\begin{tabular}{|l|c|c|c|c|c|}
\hline 14. DISPOSAL/STORAGE LOCATION \\
\hline AREA & SHA :T & PIT & POSTISI & LAVE: & \& \\
\hline$G_{1}$ & $2,2,4$ & 1 & 1 & & \\
\hline
\end{tabular}

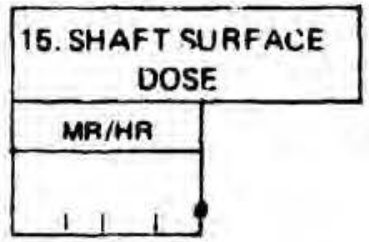



DISPOSAL RECORD

\begin{tabular}{|c|}
\hline 2. DATE \\
\hline 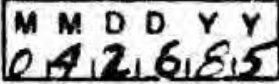 \\
\hline
\end{tabular}

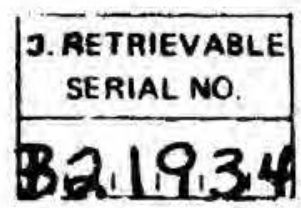

\begin{tabular}{|c|c|c|c|c|}
\hline 4. ORIGIN OF WASTE & \multirow{2}{*|}{} & \\
\hline GROUP & TA & BLDG. & 20 & ROOM \\
\hline$M, S, \pi / 19$ & 0,3 & $0,5, M, 2,9$ & 9 & \\
\hline
\end{tabular}

\begin{tabular}{|r|}
\hline 5. WASTR \\
COCE \\
\hline$A, 4,0$ \\
\hline
\end{tabular}

\section{WASTE DESCRIPTION}

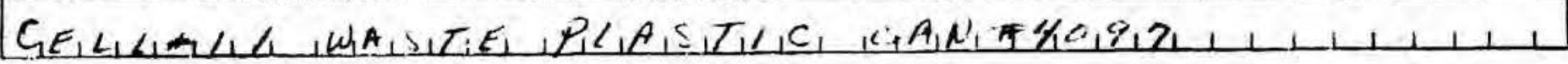

\begin{tabular}{|c|c|c|c|c|c|}
\hline \multicolumn{6}{|c|}{ 7. NIJMBERS OF WASTE PACKAGES } \\
\hline $\begin{array}{c}\text { PLASTIC } \\
\text { BAGS }\end{array}$ & $\begin{array}{l}\text { C RD. } \\
\text { BOARD } \\
\text { BOXES }\end{array}$ & & MS & $\begin{array}{l}\text { no } \\
\text { No. }\end{array}$ & $\begin{array}{l}\text { WEN CRATES } \\
\text { VOLUME } \mathrm{ft}^{3}\end{array}$ \\
\hline & 1 & 1 & & & 11 \\
\hline
\end{tabular}

\begin{tabular}{|l|l|l|l|}
\hline 10. GROSS \\
\hline WEIGHT \\
\hline
\end{tabular}

$$
\text { K-KILOGRAM }
$$

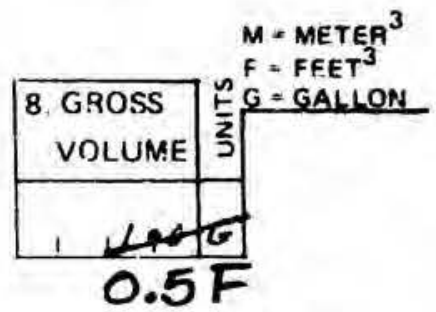

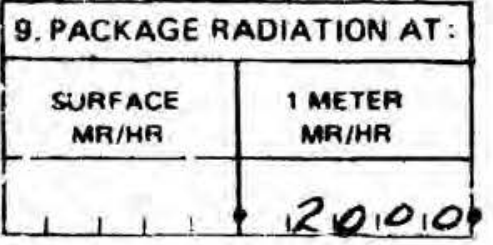

11. ADDITIONAL DESCRIPTION OF PACKAGING AND PACKAGING MATERIALS

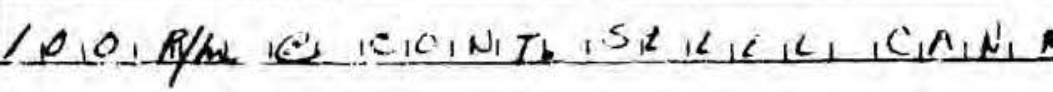

$$
\text { Lél, }
$$

\begin{tabular}{|c|c|c|c|c|c|c|c|c|c|c|}
\hline 12. RADIONL & CLIDE CONTE & NT & & & $\begin{array}{l}\text { CUARIE } \\
\text { M. GAAM }\end{array}$ & & & AMOUNT DETERMINED BY: & $\begin{array}{l}\text { SS MATE } \\
\text { WRII }\end{array}$ & $\begin{array}{l}\text { RIALS } \\
\text { TEOFF }\end{array}$ \\
\hline NUCLIDE & AMOUNT & & & $\frac{n}{z}$ & $\begin{array}{l}\text { ERAOR O } \\
\text { AMOUNT }\end{array}$ & & \pm & $\begin{array}{l}\text { A }=\text { ANALYSIS } \\
M-\text { MEASURENIENT } \\
E=\text { ESTIMATE }\end{array}$ & ACCOUNT & $\begin{array}{l}\text { PROJECT } \\
\text { CODE }\end{array}$ \\
\hline$U_{1}\langle 1 ; 1 s$ & $\because 90.0 .0$ & E & $\because 1$ & $\mu$ & $: 11$ & E & & $E$ & & \\
\hline$P_{1} u_{1} 2: 3,9$ & $\angle 9000$ & $E$ & -11 & $M$ & 111 & $E$ & & $k$ & & \\
\hline$A, F, P$ : & $2 \times 0,0$ & $E$ & $\pm n$ & $c$ & $1: i$ & E & & $M$ & & \\
\hline 1111 & $i \perp 1$ & E & 1 & & $i \perp 1$ & $E$ & & & & \\
\hline 1111 & 11.1 & r: & & & \pm 11 & $E$ & & & & \\
\hline & $p \quad 1$ & $E$ & & & & E & & & & \\
\hline
\end{tabular}

R.A S. Luen WASTE GENERATOR
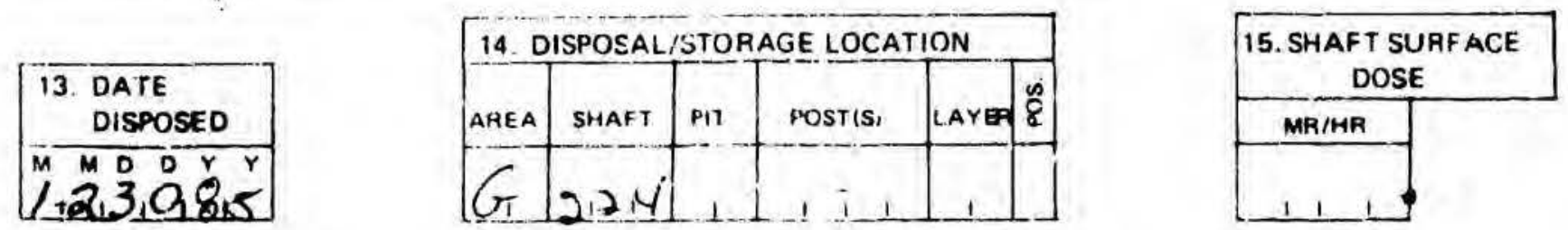
PLEASE READ INSTRUCTIONS ON BACK CAREFULL

LOS ALAMOS RADIOACTIVE SOLIO WABTE DIEPDSAL RECORD
HSE 7 Waste Manapoment Ext 6095 MS $\mathrm{J502}$
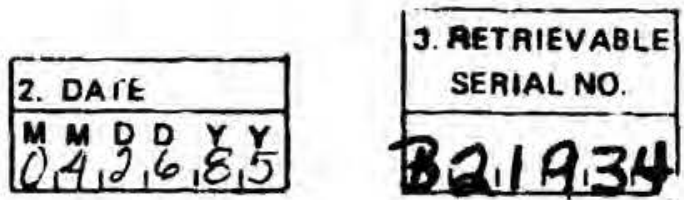

\begin{tabular}{|c|c|c|c|c|}
\hline 4. ORIGIN OF WASTE & U & \\
\hline GROUP & TA & BLOG. & 5 & ROOM \\
\hline$M, S, T, / 14$ & $0,30,5, M, 2,9$ & 4 & \\
\hline
\end{tabular}

\begin{tabular}{l} 
5. WASTE \\
CODE \\
\hline $4,4,0$ \\
\hline
\end{tabular}

6. WASTE DESCRIPTION

$C_{1} E_{1} L_{1} L_{1}, B_{1}, W_{1} A_{1} S_{1} T_{1} E_{1}, P_{1} L_{1} A_{1} S_{1} T_{1} L_{1} C_{1}, C_{1} A_{1} N_{1}, 4,0, T_{1}, \ldots, 1,1,1$,

\begin{tabular}{|c|c|c|c|c|c|}
\hline \multirow{2}{*}{$\begin{array}{c}\text { PLASTIC } \\
\text { BAGS }\end{array}$} & \multirow{2}{*}{$\begin{array}{l}\text { CARD- } \\
\text { BOARD } \\
\text { BOXES }\end{array}$} & \multicolumn{2}{|c|}{ DRUMS } & \multicolumn{2}{|c|}{ WOODEN CRATES } \\
\hline & & & GAL. & & VOLLIME $\cdot t^{3}$ \\
\hline 11 & 1 & 1 & & & , \\
\hline
\end{tabular}

\begin{tabular}{|l|l|}
\hline $\begin{array}{l}\text { 10. GROSS } \\
\text { WEIGHT }\end{array}$ & $\frac{2}{2}$ \\
\hline 13,090 & $P$ \\
\hline
\end{tabular}

$K=$ KILOGRAM

$P=$ POUND

$I=$ ION
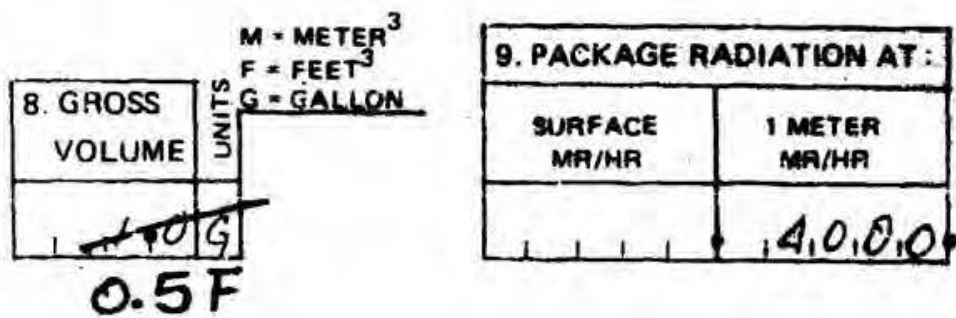

\section{$0.5 \mathrm{~F}$}

11. ADDITIONAL DESCRIPTION OF PACKAGING AND PACKAGING MATERIALS

$3,0, O_{1}, R / R_{1} V_{1}, Q, C_{1}, O_{1} N_{1} T_{1}, S_{1} T_{1} E_{1}, E_{1}, C_{1} A_{1} N_{1}$

3,2

\begin{tabular}{|c|c|c|c|c|c|c|c|c|c|c|}
\hline \multicolumn{4}{|c|}{ 12. RADIONUCLIDE CONTENT } & \multicolumn{4}{|c|}{$\begin{array}{l}C=\text { CUAIE } \\
M=\text { GHAM }\end{array}$} & \multirow{2}{*}{$\begin{array}{c}\text { AMOUNT DETERMINED BY: } \\
\text { A - ANALYSIS } \\
\text { PEASUREMENT } \\
\text { ESTIMATE }\end{array}$} & \multicolumn{2}{|c|}{$\begin{array}{c}\text { SS MATERIALS } \\
\text { WRITEOFF }\end{array}$} \\
\hline NUCLIDE & AMOUNT & & \pm & $\frac{n}{\frac{n}{2}}$ & $\begin{array}{l}\text { EAHOR CI } \\
\text { AMOUNT }\end{array}$ & & \pm & & ACCOUNT & $\begin{array}{l}\text { PAOJECT } \\
\text { CODE }\end{array}$ \\
\hline $4,2,3,5$ & $4,0,0,0$ & $E$ & -11 & A & 11 & E & & E) & & \\
\hline$P, a, 2,3,9$ & $1,0,0,0$ & E & -11 & $M$ & 111 & E & & $E$ & 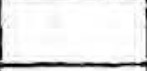 & \\
\hline$\mu_{1} F_{1} P, 1$ & $4,0,0,0$ & E &,+ 0 & c & 111 & E & & $\mu$ & & \\
\hline 11 & 911 & E & 1 & & 11 & t. & & & & \\
\hline 111 & 1,1 & $E$ & & & $1 i$ & E & & & & \\
\hline 11,1 & 11.1 & E & 1 & & 21. & E & & $L$ & & \\
\hline
\end{tabular}

M. R O P.

WASTE GENERATOR

Signefure cert ties that waste is in m acir

\begin{tabular}{|c|c|c|c|c|c|c|}
\hline \multirow[b]{2}{*}{$\begin{array}{l}\text { 13. DATE } \\
\text { UISPOSED }\end{array}$} & \multicolumn{6}{|c|}{ 14. DISPOSAL/STORAGE LOCATION } \\
\hline & AREA & SHAFT & PIT & POSTIS) & LAYG & ? \\
\hline $1,23,0,8,5$ & $G_{1}$ & $2,2,4$ & & & & \\
\hline
\end{tabular}

HSE.7 WASTE MANAGEMENT REPRESENTATIVE

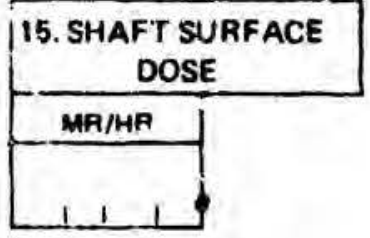


PLEASE READ INSTRUCTIONS ON BACK CAREF'JLLY

\begin{tabular}{l} 
1. FOAM MUMUER \\
$5,8,5,2804$ \\
\hline
\end{tabular}

\section{LOS ALAMOS RADIOACTIVE SOLID WASTF DISPOSAL RECORD}

HSE 7 Waste Manageinent

Ex: 6095 MS $J 592$

\section{DATE \\ $M M D D Y T$ \\ $12,9,8,5$}

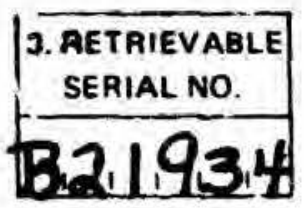

\begin{tabular}{|c|c|c|c|c|}
\hline \multicolumn{3}{|c|}{ 4. ORIGIN OF WASTE } & \multirow{2}{*}{ 该 } & \multirow[b]{2}{*}{ ROOM } \\
\hline GROUP & TA & OLOG. & & \\
\hline MisiTiLi4 & 0,3 & $D_{1} \leq 1 M_{1} 2,9$ & 19 & \\
\hline
\end{tabular}

\begin{tabular}{l} 
5. VIASTE \\
CODE \\
\hline$A_{1} \perp O$ \\
\hline
\end{tabular}

\section{W.ASTE DESCRIPTION}

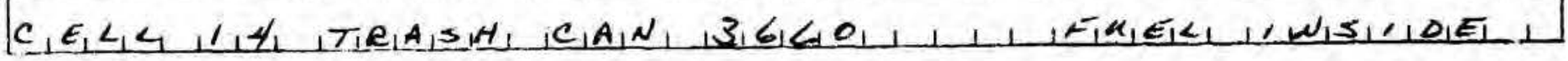

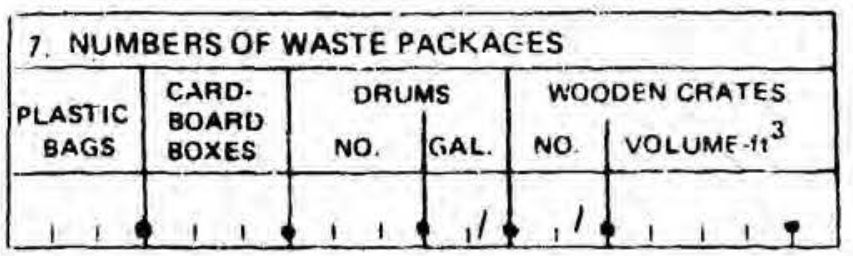

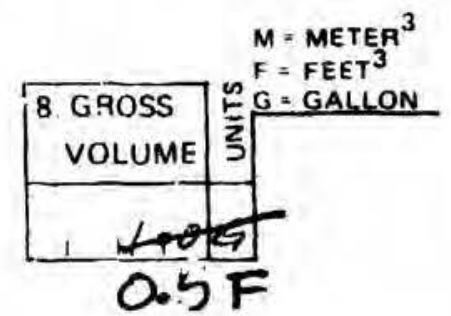

\begin{tabular}{|c|c|}
\hline \begin{tabular}{c} 
9. PACKAGE RADIATION AT: \\
\hline $\begin{array}{c}\text { SURFACE } \\
\text { MR/HR }\end{array}$
\end{tabular} & $\begin{array}{c}\text { I METER } \\
\text { MR/HR }\end{array}$ \\
\hline 1111 & $12,8,0,0$ \\
\hline
\end{tabular}

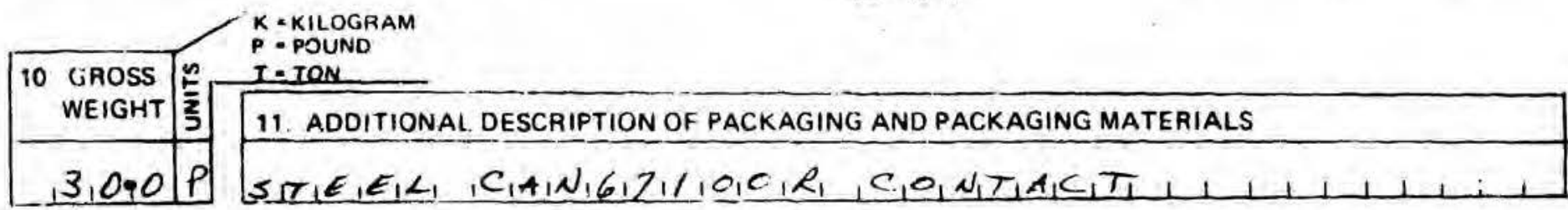
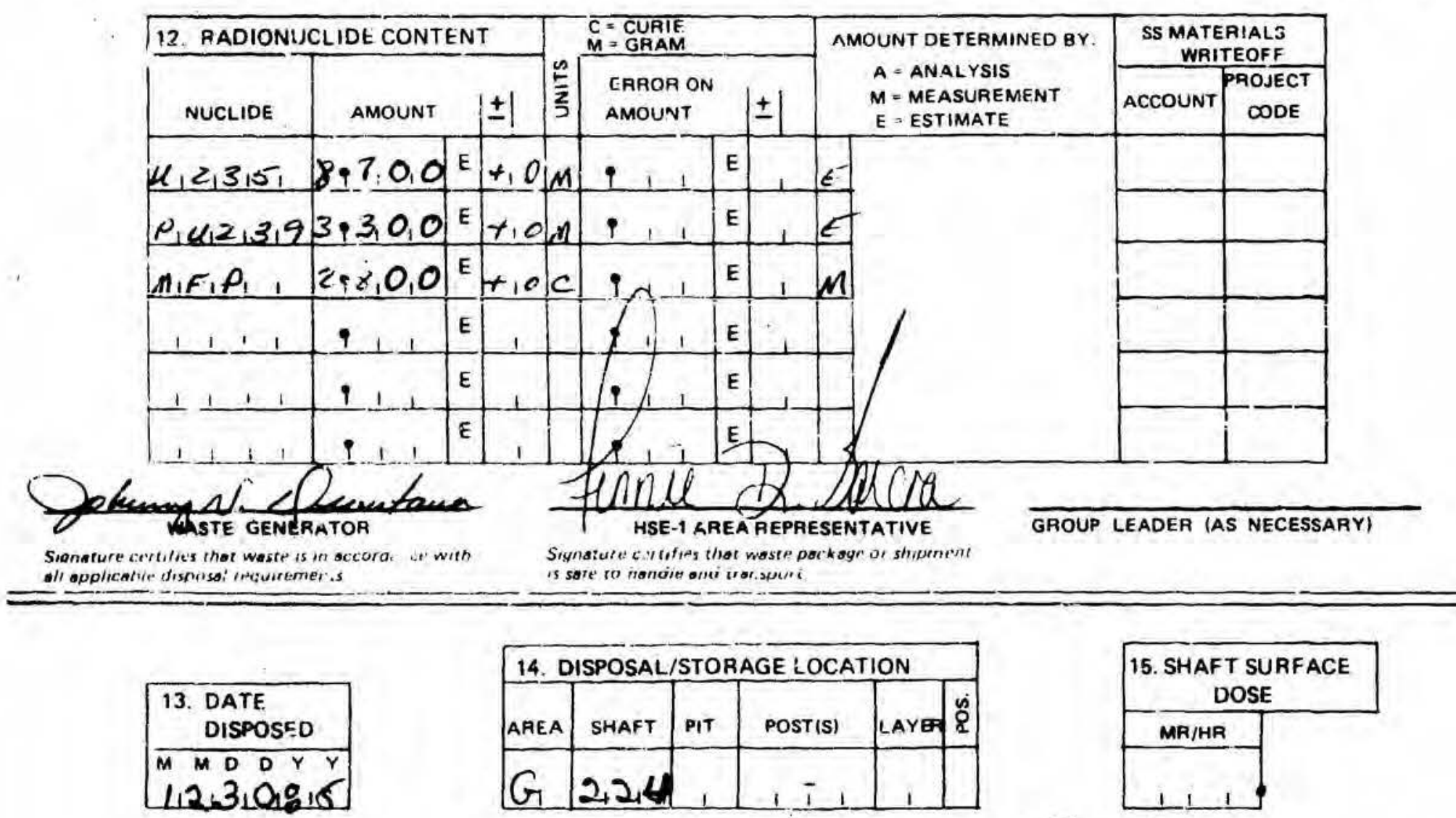

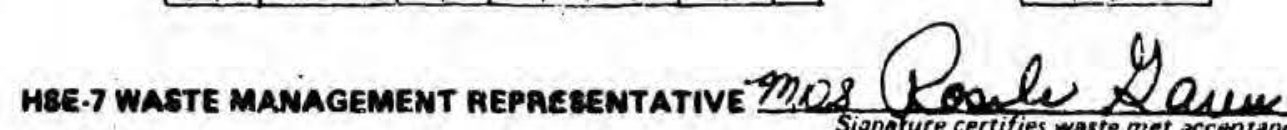
HB Forn Number $10.2 A$ (12/4s) 
eal $C A N=14-21$

satertol - FuEL.

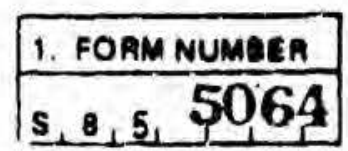

PLEASE RE.AD INSTRUCTIONS ON BACK CAREFULLY

LOS ALAMCS RADIOACTIVE SOLID WASTE HSE; WasiE Maragemen! DISPOSAL RECORD

F +6095 MS J59?

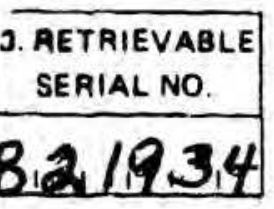

\begin{tabular}{|c|c|c|c|c|}
\hline 4. ORIGIN OF WASTE & & \\
\hline GROUP & TA & BLOG & 5 & ROOM \\
\hline MISI TI14 & OI3 & OLSIMI2M & 9 & \\
\hline
\end{tabular}

\begin{tabular}{l}
\hline . WASTE \\
CODE \\
\hline$A_{1}+1,2$ \\
\hline
\end{tabular}

6. WASTE OESCAIPTION

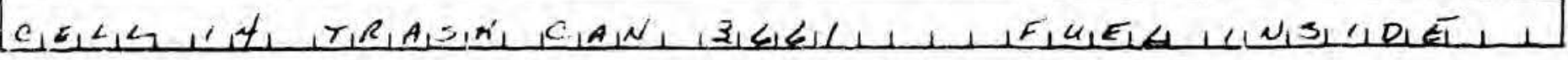

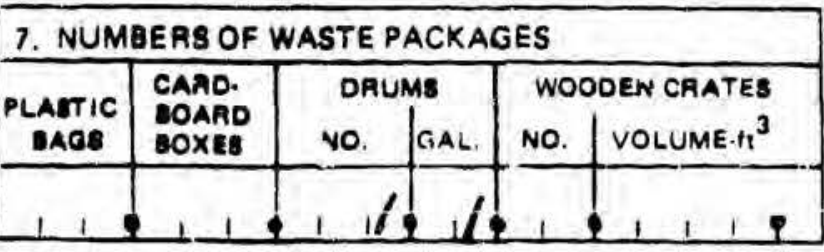

K- KILOGAAM P. MOUND

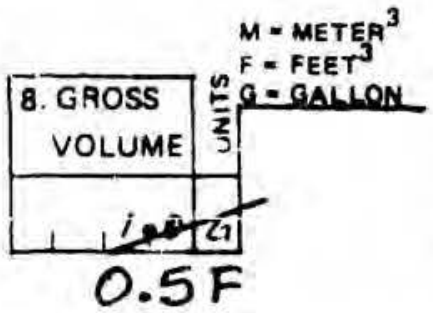

10. GROSS WEIGHT

I.TON

11. ADDITIONAL DESCRIPTION OF PACKAGING AND PACKA.GING MATERIALS

3,09018

$S_{1} I E_{1} E_{1} L_{1}, C_{1} A \mid N_{1} C_{1} B_{1} / 0_{10}, R_{1} / H_{1} R_{1}$

c. 0

NIIAC, T, , , 1, 1,

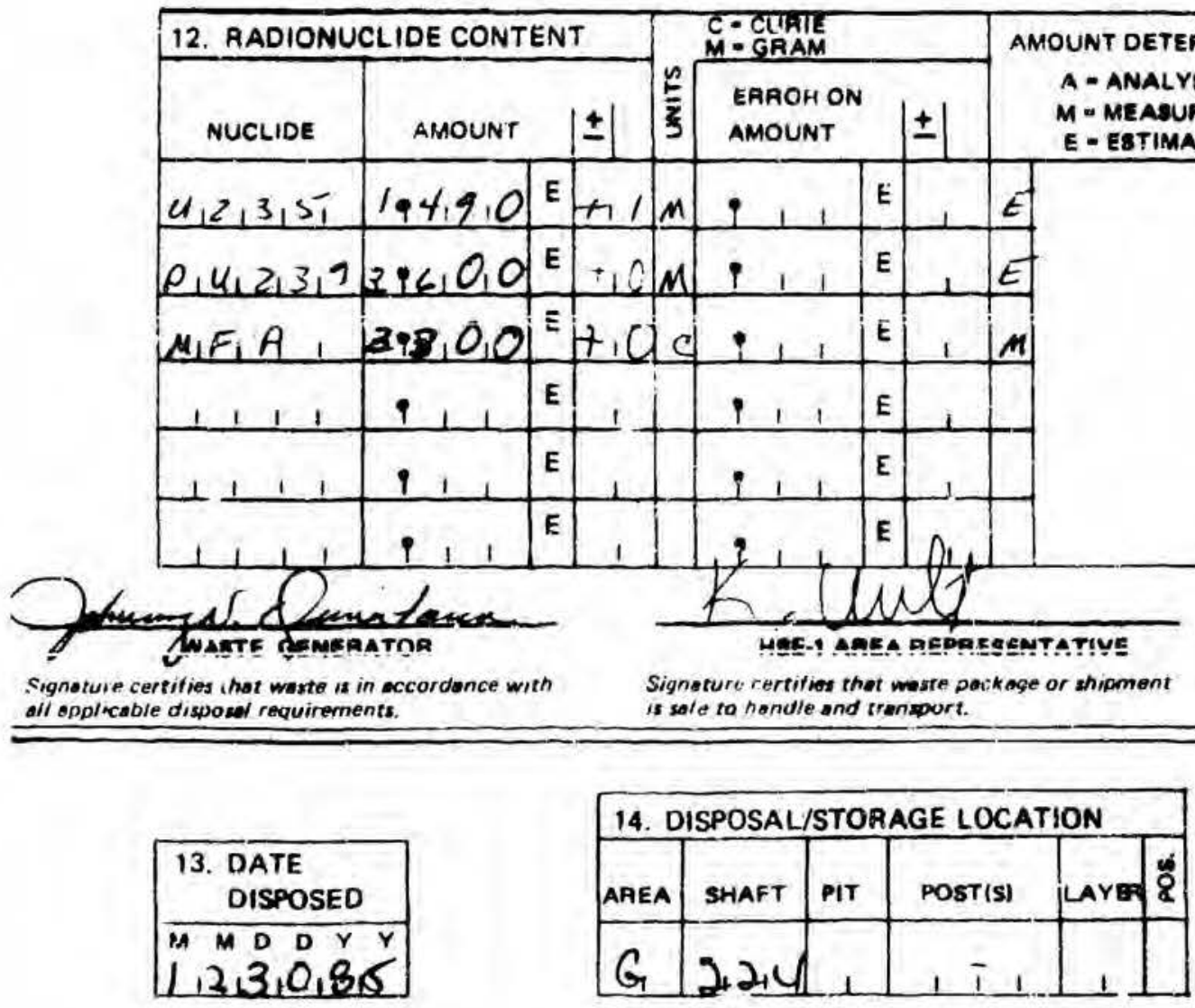

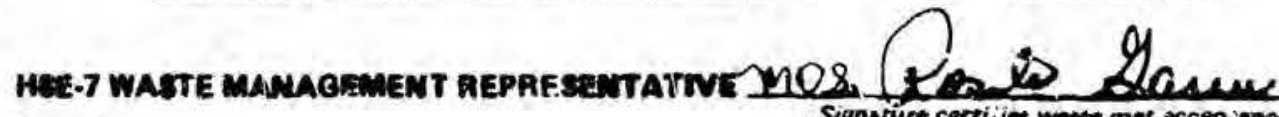
HS Ferm Number $10 \cdot 2 A$ (12/63)
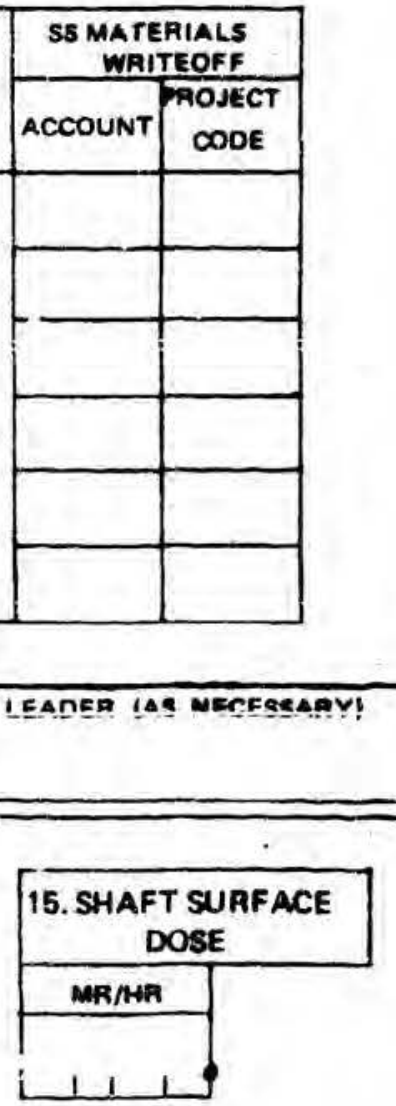

GRMU IEADER !AS NECFGSATY!

\begin{tabular}{|c|c|}
\hline 8. PACKAGE RADIATION AT: \\
\hline $\begin{array}{c}\text { SURFACE } \\
\text { MR/MR }\end{array}$ & $\begin{array}{c}\text { I METER } \\
\text { MAIHR }\end{array}$ \\
\hline 1,1 & $13,3,0,0$ \\
\hline
\end{tabular}


CEZL CAN $14-31$

TRASH

\begin{tabular}{|l|}
\hline 1. FOAM NUMBER \\
\hline$s, 8,5,506,6$
\end{tabular}

3663

PLEASE READ INSTK TIONS ON BAKK CAREFULI Y

\section{LOS ALAMOS RADIOACTIVE SOLID WASTE DISPOSAL RECORD}

\begin{tabular}{|c|c|c|c|}
\hline \multicolumn{4}{|l|}{ 2. DATE } \\
\hline & & & 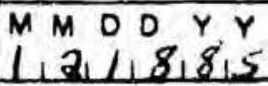 \\
\hline
\end{tabular}

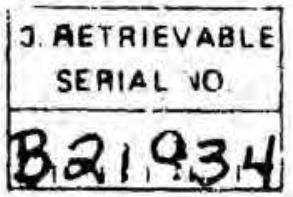

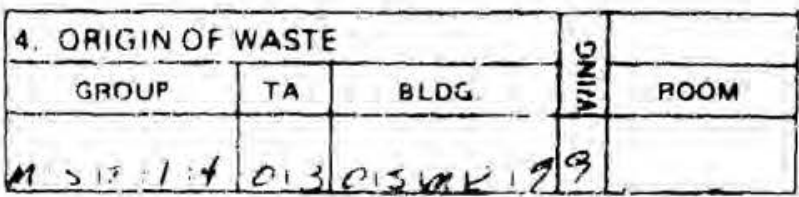

\section{B. WASTE DESCRIPTION}

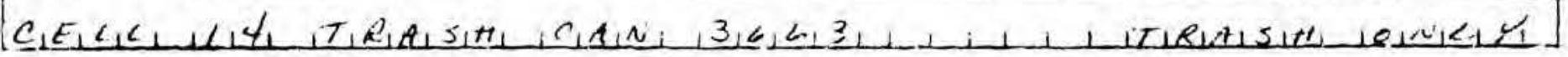

\begin{tabular}{|c|c|c|c|c|c|}
\hline \multicolumn{6}{|c|}{ 7. NUMBERS OF WASTE PACKACES } \\
\hline & CAAD. & & & wo & DEN CAATES \\
\hline LAOS & DOXES & NO & GALL. & NO. & VOLUME $: \mathrm{ft}^{3}$ \\
\hline
\end{tabular}

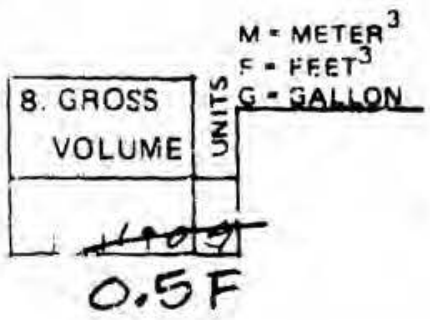

\begin{tabular}{|c|c|}
\hline 9. PACKAGE RADIATION AT \\
\hline $\begin{array}{c}\text { SURFACE } \\
\text { MR/HA }\end{array}$ & $\begin{array}{c}\text { 1 METER } \\
\text { MA/HR }\end{array}$ \\
\hline $1,0,0,0,2)$ & $\perp(5,0,2)$ \\
\hline
\end{tabular}

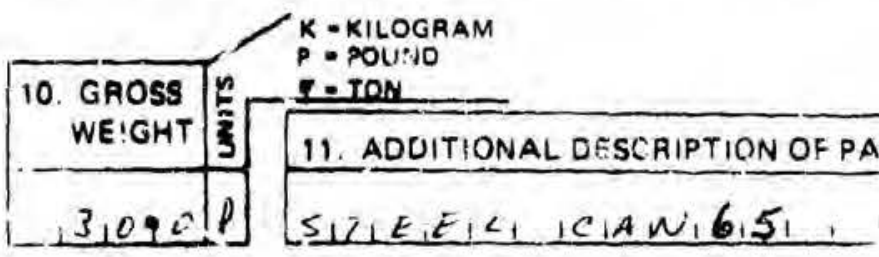

\begin{tabular}{|c|c|c|c|c|c|c|c|c|c|c|}
\hline \multicolumn{4}{|c|}{ 12. FADIONUI:LIDE CONTENI } & \multicolumn{4}{|c|}{$\begin{array}{l}\text { C.CUARE } \\
M \text { - GRAM }\end{array}$} & \multirow{2}{*}{$\begin{array}{l}\text { AMUUNT DETEFMINED BY } \\
\text { A - ANALYSIS } \\
\text { M }=\text { MEASUREMENT } \\
\text { E-ESTIMATE }\end{array}$} & \multicolumn{2}{|c|}{$\begin{array}{c}\text { SS MATERIALS } \\
\text { WRITEOFF }\end{array}$} \\
\hline NUCLIDE & AMOUNT & & \pm & $\frac{5}{3}$ & $\begin{array}{l}\text { EAROR ON } \\
\text { AMOUNT }\end{array}$ & & \pm & & ACCOUNT & $\begin{array}{l}\text { PROJECT } \\
\text { CODE }\end{array}$ \\
\hline$u_{1}<_{1} 31_{1} 5 i$ & $4,0,0,0$ & E & -11 & $m$ & i i : & $E$ & & $E$ & & \\
\hline$P_{1} u_{12}, \Sigma_{2}$ & $1,0,0,0$ & E & -11 & $M$ & i $\quad 1 \quad 1$ & $E$ & & $E$ & & \\
\hline 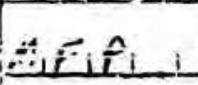 & $1: 500$ & E & 40 & $c$ & $1: \quad:$ & E & 1 & $M$ & & \\
\hline 1111 & $1 \quad 1$ & E & 1 & & 111 & E & it & & & \\
\hline $1 \perp 11$ & 1,1 & $E$ & & & 1,1 & E & ـــ & & & \\
\hline 1,1 & 1,1 & E & 1 & & 21 & E & & 0 & & \\
\hline
\end{tabular}

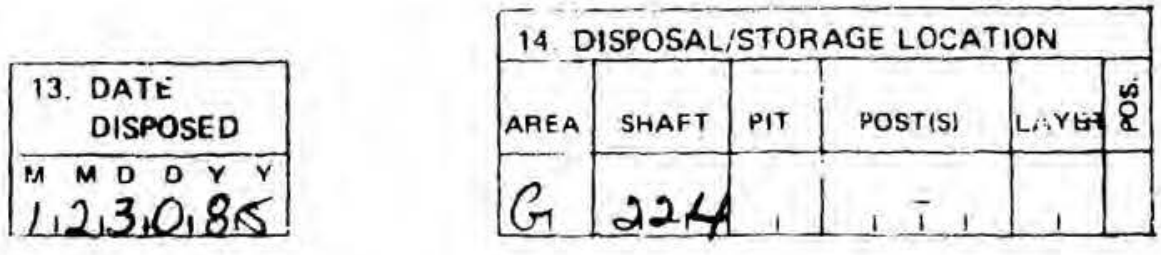

HSE.7 WAETE MANAGEMENT REPRESEHTATIVE

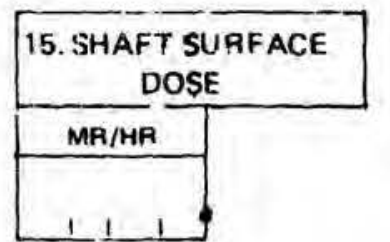


CACL CAN \#14-32 3664

SOUTION - PUEL - TRASH

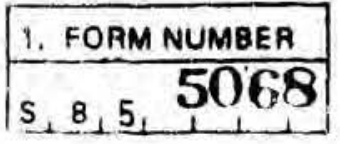

PLEASE READ INSTRUCTIONS ON BACK CAREFULLY

S, 8, 5, 5068

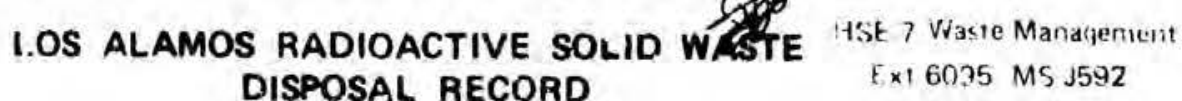

\begin{tabular}{|c|c|c|c|c|c|c|c|}
\hline \multirow[b]{2}{*}{ 2. DATE } & \multirow{2}{*}{$\begin{array}{l}\text { 3. RETRIEVABLE } \\
\text { SERIAL NO. }\end{array}$} & \multicolumn{3}{|c|}{ 4. ORIGIN OF WASTE } & \multirow{2}{*}{$\frac{0}{\frac{2}{5}}$} & \multirow[b]{2}{*}{ ROOM } & \multirow{2}{*}{$\begin{array}{l}\text { 5. WASTE } \\
\text { CODE }\end{array}$} \\
\hline & & GROUP & TA & BLDG. & & & \\
\hline $1,2,1,8,8,5$ & $132,19=$ & $M_{1} s_{1} T_{1}$ & & $\sin _{12}$ & $q$ & & 4140 \\
\hline
\end{tabular}

B. WASTE DESCRIPTION

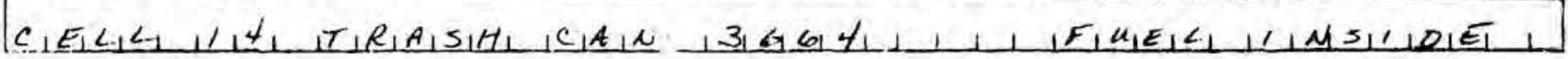

\begin{tabular}{|c|c|c|c|c|c|}
\hline \multicolumn{6}{|c|}{ 7. NUMBERS OF WASTE PACKAGES } \\
\hline PLASTIC & CARD- & & & wo & DEN CRATES \\
\hline BAGS & $\begin{array}{l}\text { BOAAD } \\
\text { BOXES }\end{array}$ & No. & GAL. & no. & VOLUME $\cdot \mathrm{tt}^{3}$ \\
\hline
\end{tabular}

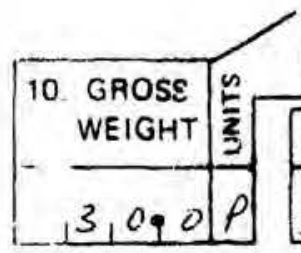

-KILOGRAM

$P=$ POUND

$I=\mathrm{TON}$

$\leq \perp \pi E_{1} E_{1} C_{1}, C_{1} A_{1} N_{1}, 6_{1} 4_{1}$

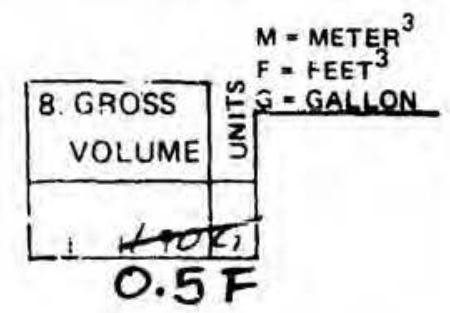

\begin{tabular}{|c|c|}
\hline \begin{tabular}{c} 
9. PACKAGE RADIATION AT: \\
\hline $\begin{array}{c}\text { SURFACE } \\
\text { MR/HA }\end{array}$
\end{tabular} & $\begin{array}{c}\text { 1 METER } \\
\text { MR/HR }\end{array}$ \\
\hline $2,0,0,0,0$ & 15,90 \\
\hline
\end{tabular}

11. ADDITIONAL DESCAIPTION OF PACKAGING AND PACKAGING MATERIALS

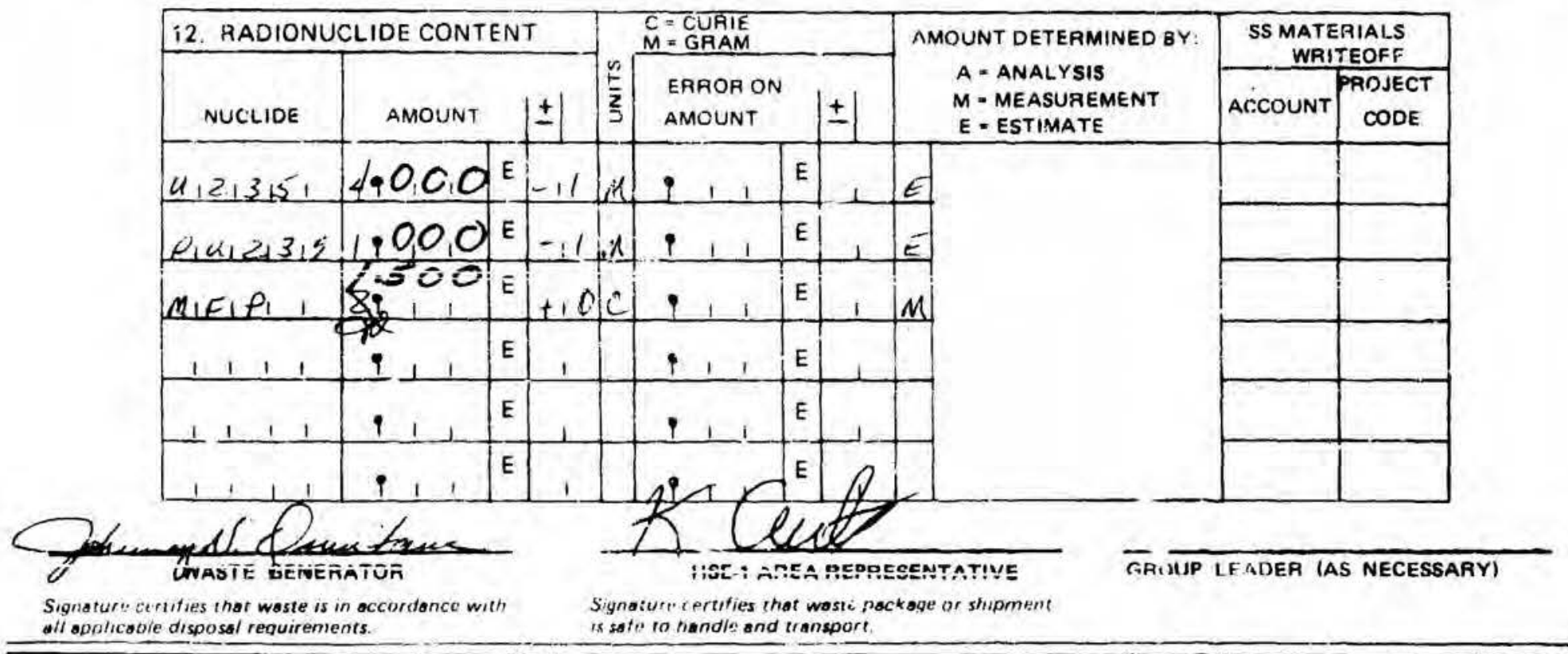

\begin{tabular}{l} 
13. DATE \\
DISPOSED \\
\hline $1,2,3 O_{1} 9,5$ \\
\hline 190,5 \\
\hline
\end{tabular}

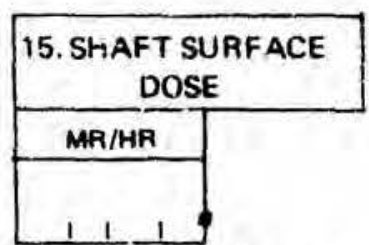


RADIOACTIVE SOLID WASTE DISPOSAL RECORD FORMS

FOR

SHAFT 225

MATERIAL DISPOSAL AREA G 
PLEASE READ INSTRUCTIONS ON BACK CAREFULLY

1. FOAM NUMBER

s, 8, TR,

\section{LUS ALAMOS RADIOACTIVE SOLID WASTE DISPOSAL RECORD FORM}

H.;E-7 Waste Management

Ext 6035 MS $\mathbf{1 5 9 2}$

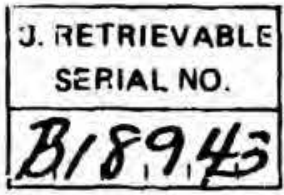

\begin{tabular}{|c|c|c|c|c|}
\hline 4. ORIGIN OF WASTE & & \\
\hline GROUP & TA & BLDG & & ROOM \\
\hline NIS ITI $/ 4$ & 0,3 & $5, M_{1} 0,2,4$ & 9 & \\
\hline
\end{tabular}

\begin{tabular}{|r|}
\hline 5. WIASTE \\
COOE \\
\hline$A, 4,0$ \\
\hline
\end{tabular}

6. WASTE DESCRIPTION

$C_{1} E_{1} L_{1} L_{1}, 3_{1}, U_{1} A_{1} S I T, E, P_{1} L, A, S, T_{1}, C_{1}, C_{1}, A_{1} N, 4,0,2,6$

\begin{tabular}{|c|c|c|c|c|c|}
\hline \multicolumn{6}{|c|}{ 7. NUMBERS OF WASTE PACKAGES } \\
\hline \multirow{2}{*}{$\begin{array}{c}\text { PLASTIC } \\
\text { BAGS }\end{array}$} & \multirow{2}{*}{$\begin{array}{l}\text { CARD } \\
\text { BOARD } \\
\text { BOXES }\end{array}$} & \multicolumn{2}{|c|}{ DRUMS } & \multicolumn{2}{|c|}{ WOODEN CRATES } \\
\hline & & NO. & GAL. & NO. & VOLUME- $f:^{3}$ \\
\hline 11 & 1 & 1 & & 1 & 111 \\
\hline
\end{tabular}

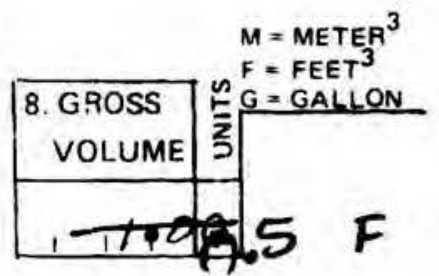

\begin{tabular}{|c|c|}
\hline \multicolumn{2}{|c|}{ 9. PACKAGE RADIATION AT: } \\
\hline $\begin{array}{c}\text { SURFACE } \\
\text { MR/HR }\end{array}$ & $\begin{array}{c}\text { I METER } \\
\text { MR/HR }\end{array}$ \\
\hline $4,0,0,0,0$ & $14,0,0$ \\
\hline
\end{tabular}
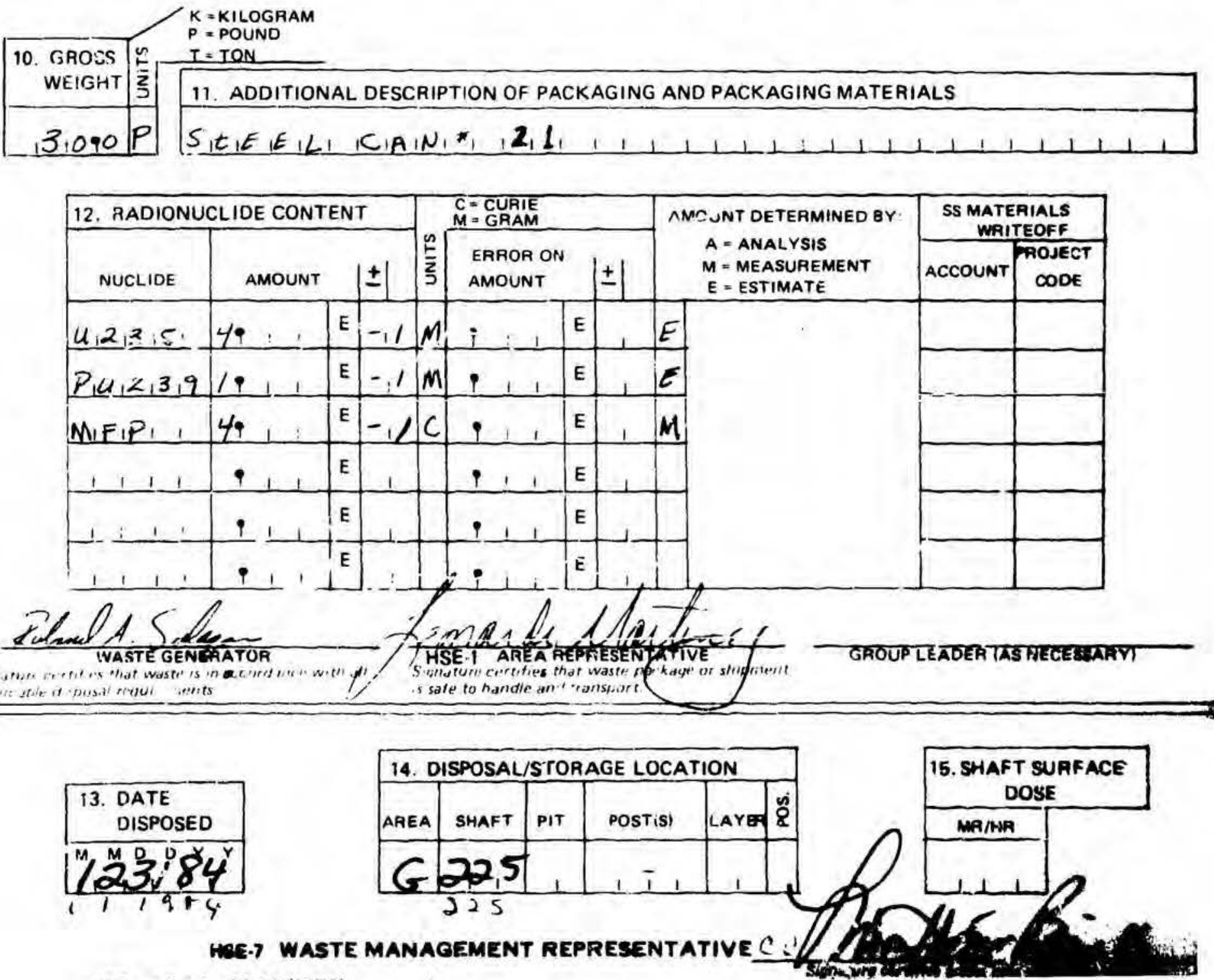

HE. 7 WASTE MANAGEMENT REPRESENTATIVEC: 
PLEASE READ INETRUCTIONS ON BACK CAREFULLY

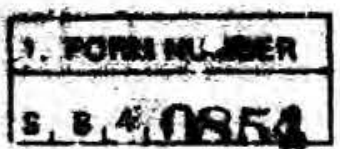

\section{LOS ALAMS RADIOACTIVE SOLID WASTE OIENOSAL NECORD FORM}

HSE-7 Wastc: Management

Ext 6095 MS J592

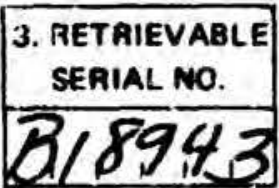

\begin{tabular}{|c|c|c|c|c|}
\hline \multicolumn{3}{|c|}{ 4. ORIGIN OF WASTE } & \multirow{2}{*}{$\frac{0}{3}$} & \multirow[b]{2}{*}{ ROOM } \\
\hline GROUP & TA & BLDG. & & \\
\hline$M, 5, T_{1},{ }_{1}$ & 0,3 & $0,5,4,2,9$ & 9 & \\
\hline
\end{tabular}

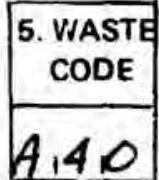

6. WASTE DESCRIPTION

$C_{1}, E_{1}, L_{1}, 1, Z_{1}, W_{1} A_{1} S, T, E_{1}, P_{1} L_{1} A_{1}, S_{1}, T_{1}, C_{1}, C_{1} A_{1} N_{1}, A, 0,3,3$

\section{NUMBERS OF WASTE PACKAGES}

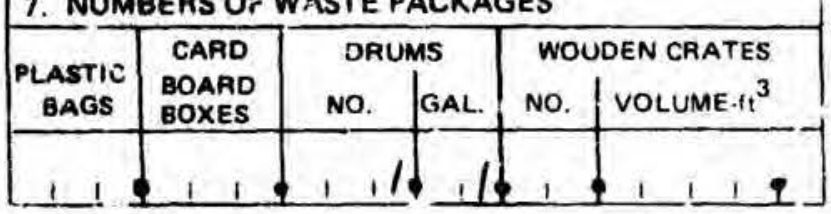

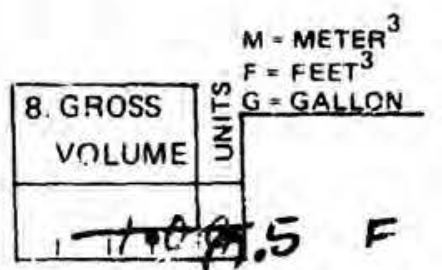

\begin{tabular}{|c|c|}
\hline 3. PACKAGE RADIATION AT: \\
\hline $\begin{array}{c}\text { SURFACE } \\
\text { MR/HR }\end{array}$ & $\begin{array}{c}\text { I METER } \\
\text { MiR/HR }\end{array}$ \\
\hline $5,0,0,0,0$ & $1 / 5,0,0$ \\
\hline
\end{tabular}

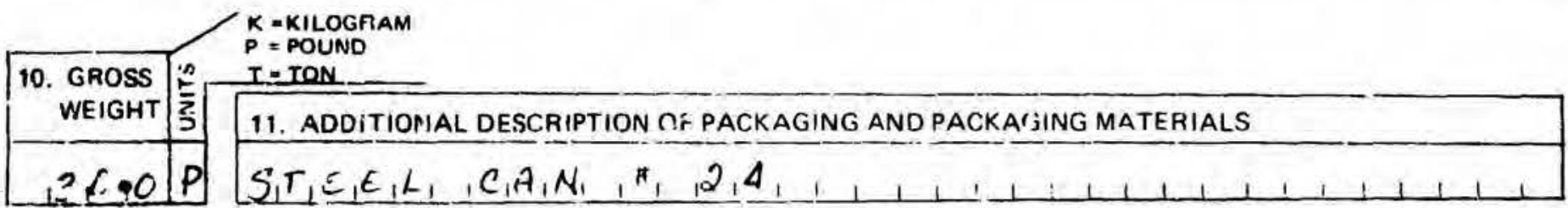

\begin{tabular}{|c|c|c|c|c|c|c|c|c|c|c|}
\hline \multicolumn{4}{|c|}{ 12. RADIONUCL IDE CO, ENT } & \multicolumn{4}{|c|}{$\begin{aligned} C & =\text { CURIE } \\
M & =\text { GRAII }\end{aligned}$} & \multirow{2}{*}{$\begin{aligned} \text { AMOUNT DETERMINED BY: } & \text { B } \\
A & =\text { ANALYSIS } \\
M & =\text { MEASURFMENT } \\
E & =\text { ESTIMATE }\end{aligned}$} & \multicolumn{2}{|c|}{$\begin{array}{c}\text { SS MATEFIALE } \\
\text { WRITEOOFF }\end{array}$} \\
\hline NUCLIDE & AYOUNT & & \pm & $\begin{array}{l}0 \\
\frac{2}{2} \\
2 \\
2\end{array}$ & $\begin{array}{l}\text { ERROR ON } \\
\text { AMOUT : }\end{array}$ & & \pm & & ACCOUNT & $\begin{array}{c}\text { ROJECT } \\
\text { CODE }\end{array}$ \\
\hline$(1,2,3,5$, & 4.: & $E$ & -11 & $M$ & i $\quad 1 \quad 1$ & E & & E & & \\
\hline$F, n, 1,3,9$ & 1211 & E & -1 & 4 & $i 1$ & E & & $\varepsilon$ & & \\
\hline$M_{1} F, P_{1}$ & $1+51$. & E & +0 & C & 211 & E & 1 & $N$ & & \\
\hline 1111 & 1,1 & E & 1 & & 11 & E & & & & \\
\hline 111 & 111. & E & $-\perp$ & & 1.1 & E & & & & \\
\hline 1111 & $9+1$ & $E$ & & & $20+1$ & E & & & & \\
\hline
\end{tabular}

$=2$ \& 15 a

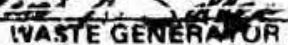

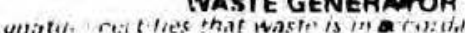

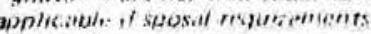

\section{ma di}

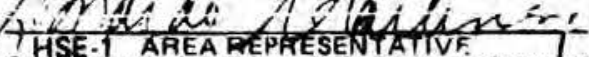

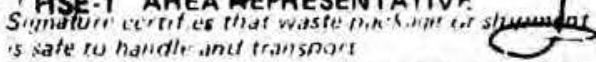

\section{GROUP LEADER (AS NTECESSARY)}

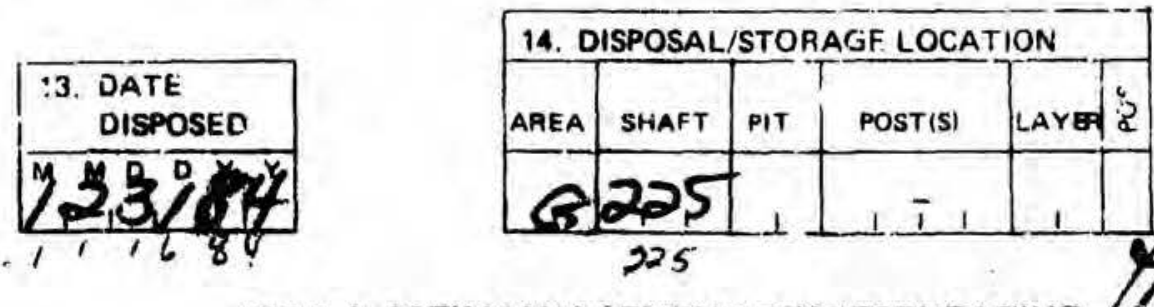

Wh-7 WASTE MANALEMENT REPRESENTATIVE 
WHAE WEAO WHTHCTIONS ON BACK CAREFULLY

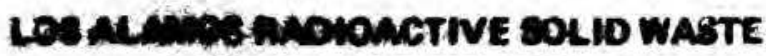
Ditrosal RECOND FORM
HSE.j Waste Management

Ext 6095 MS J5i?

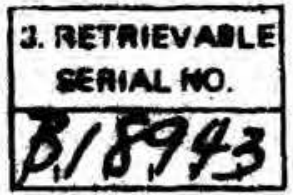

\begin{tabular}{|c|c|c|c|c|}
\hline \multicolumn{3}{|c|}{ 4. ORIGIN OF WASTE } & \multirow{2}{*}{$\mid \begin{array}{l}0 \\
\frac{2}{3}\end{array}$} & \multirow[b]{2}{*}{ ROOM } \\
\hline GAOUP & $T A$ & BLDG. & & \\
\hline$\mu, s, T_{1} \mid, 4$ & 0,3 & $0,3, M, 2,9$ & 9 & \\
\hline
\end{tabular}

\section{VATTE DESCRIPTION}

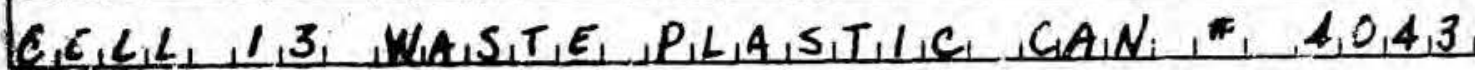

\begin{tabular}{|c|c|c|c|c|c|}
\hline \multirow[b]{2}{*}{$\begin{array}{l}\text { PLAETIC } \\
\text { EAGS }\end{array}$} & \multirow[b]{2}{*}{$\begin{array}{l}\text { CARD } \\
\text { BOARD } \\
\text { EOXES }\end{array}$} & \multirow{2}{*}{\multicolumn{2}{|c|}{ DFUMAS }} & \multicolumn{2}{|c|}{ WOODEN CRATES } \\
\hline & & & GS & $\begin{array}{l}\text { Wo } \\
\text { No. }\end{array}$ & $\begin{array}{l}\text { DDEN CRATES } \\
\text { VOLUME.f: } \\
\text { | }\end{array}$ \\
\hline
\end{tabular}

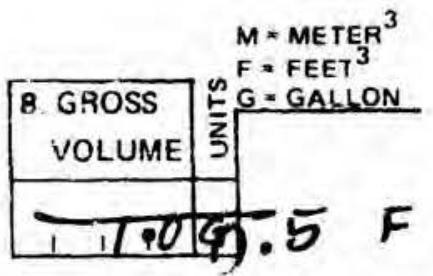

\begin{tabular}{|c|c|}
\hline 9. PACKAGE RAD:ATION AT \\
\hline $\begin{array}{c}\text { SURFACE } \\
\text { MR/HR }\end{array}$ & $\begin{array}{c}\text { 1 METER } \\
\text { MR/HR }\end{array}$ \\
\hline $9,0,0,0,0$ & $1,5,0,0$ \\
\hline
\end{tabular}

10. GROSS

\section{$K$ - KILOGAAM}

$P$ \& POUND

WEIGHT

$3,0.00]\left[S_{1} T_{1} E_{1} E_{1} L_{1}, C_{1} A_{1} N_{1}, *, 3,1\right.$

11. ADDITIONAL DESCRIPTION OF PACKAGING AND PACKAGING MATERIALS

\begin{tabular}{|c|c|c|c|c|c|c|c|c|c|c|}
\hline \multicolumn{4}{|c|}{ 12. RADIONUCLIDE CONTENT } & \multicolumn{4}{|c|}{$\begin{array}{l}\text { C-CUAIE } \\
M \text { - GAAM }\end{array}$} & \multirow{2}{*}{$\begin{aligned} \text { AMOUNT DETERMINED BY: } & \text { B } \\
\text { A } & =\text { ANALYSIS } \\
M & =\text { MEASUAEMENT } \\
\text { E } & =\text { ESTIMATE }\end{aligned}$} & \multicolumn{2}{|c|}{$\begin{array}{c}\text { SS MATERIALS } \\
\text { WAITEOFF }\end{array}$} \\
\hline NUCLIDE & AMOUNT & & \pm & $\frac{\pi}{\xi}$ & $\begin{array}{l}\text { ERROR ON } \\
\text { AMOUNT }\end{array}$ & & \pm & & ACCOUNT & $\begin{array}{c}\text { PROJECT } \\
\text { CODE }\end{array}$ \\
\hline $2,8,5$, & 11 & $\mathbf{E}$ & -11 & $\mu$ & 11 & $\mathbf{E}$ & & $\varepsilon$ & & \\
\hline$\hat{x}, \hat{y}$ & 1.11 & $\mathbf{E}$ & $-i 1$ & in & 111 & $\mathbf{E}$ & & $E$ & & \\
\hline$M F_{1}$ & 15,1 & $\mathbf{E}$ & +0 & c & 911 & $\mathbf{E}$ & & $M$ & & \\
\hline 11 & 4 & E & 1 & & $1 ; 1$ & $\mathbf{E}$ & & & & \\
\hline 1111 & $1+1$ & E & 1 & & 911 & E & & & & \\
\hline $1: 11$ & 111 & E & 1 & & 911 & E & & $A$ & & \\
\hline
\end{tabular}

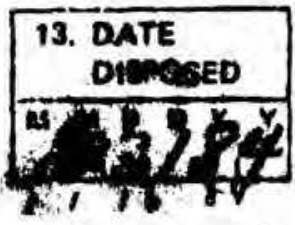

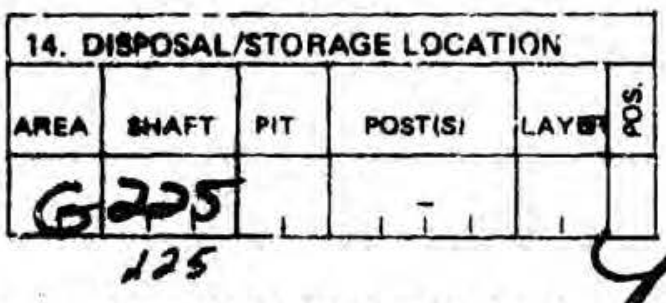

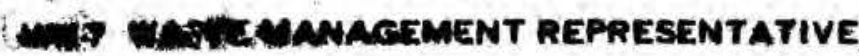


PLEASE READ INSTRUCTIONS ON BACK CAPEFULLY

1. FORM NUMBER

s, 8,4, MR.5\%

\section{LOS AL.AMOS RADIOACTIVE SOLID WASTE DISPOSAL RECORD FORM}

HSE-7 Waste Management

Ext 6095 MS $\mathbf{5 6 9 2}$

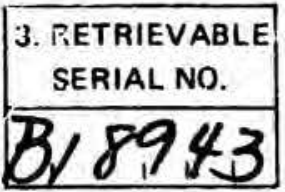

\begin{tabular}{|c|c|c|c|c|}
\hline 4. OFIGIN OF WASTE & \multirow{2}{*}{} & \\
\hline GROUP & TA & BLOG. & $\frac{2}{3}$ & RLOM \\
\hline$M_{1} S_{1} T_{1} / 14$ & 0,3 & $0,5, M_{12}, 9$ & 9 & \\
\hline
\end{tabular}

6. WASTE CESCRIPTION

$C_{1} E_{1} L_{1} L_{1}, Z_{1}, N_{1} A_{1} S_{1} T_{1} E_{1}, P_{1}, A, S, T_{1}, C, C_{1} A_{1}, *, A, 0,3,5$

\begin{tabular}{|c|c|c|c|c|c|}
\hline \multirow[b]{2}{*}{$\begin{array}{l}\text { PLASTIC } \\
\text { SAGS }\end{array}$} & \multirow{2}{*}{$\begin{array}{l}\text { CARD } \\
\text { BOARD } \\
\text { SOXES }\end{array}$} & \multicolumn{2}{|c|}{ DRUMS } & \multicolumn{2}{|c|}{ WOODEN CAATES } \\
\hline & & NO. & cal. & No. & VOLUME. $\cdot \mathrm{ft}^{3}$ \\
\hline
\end{tabular}

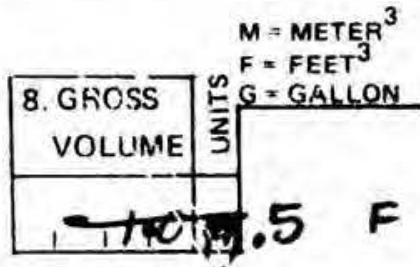

\begin{tabular}{|c|c|}
\hline 9. PACKAGE RADIATION AT: \\
\hline $\begin{array}{c}\text { SURFACE } \\
\text { MR/HR }\end{array}$ & $\begin{array}{c}\text { 1 METER } \\
\text { MR/HR }\end{array}$ \\
\hline 1,1, & $, 3,0,0,0$ \\
\hline
\end{tabular}

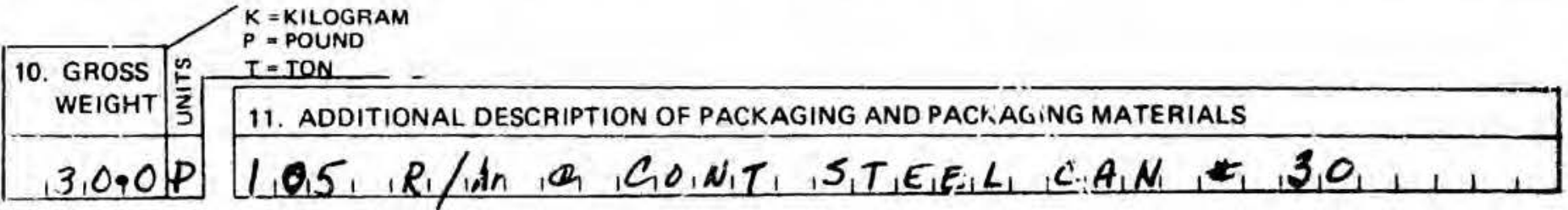
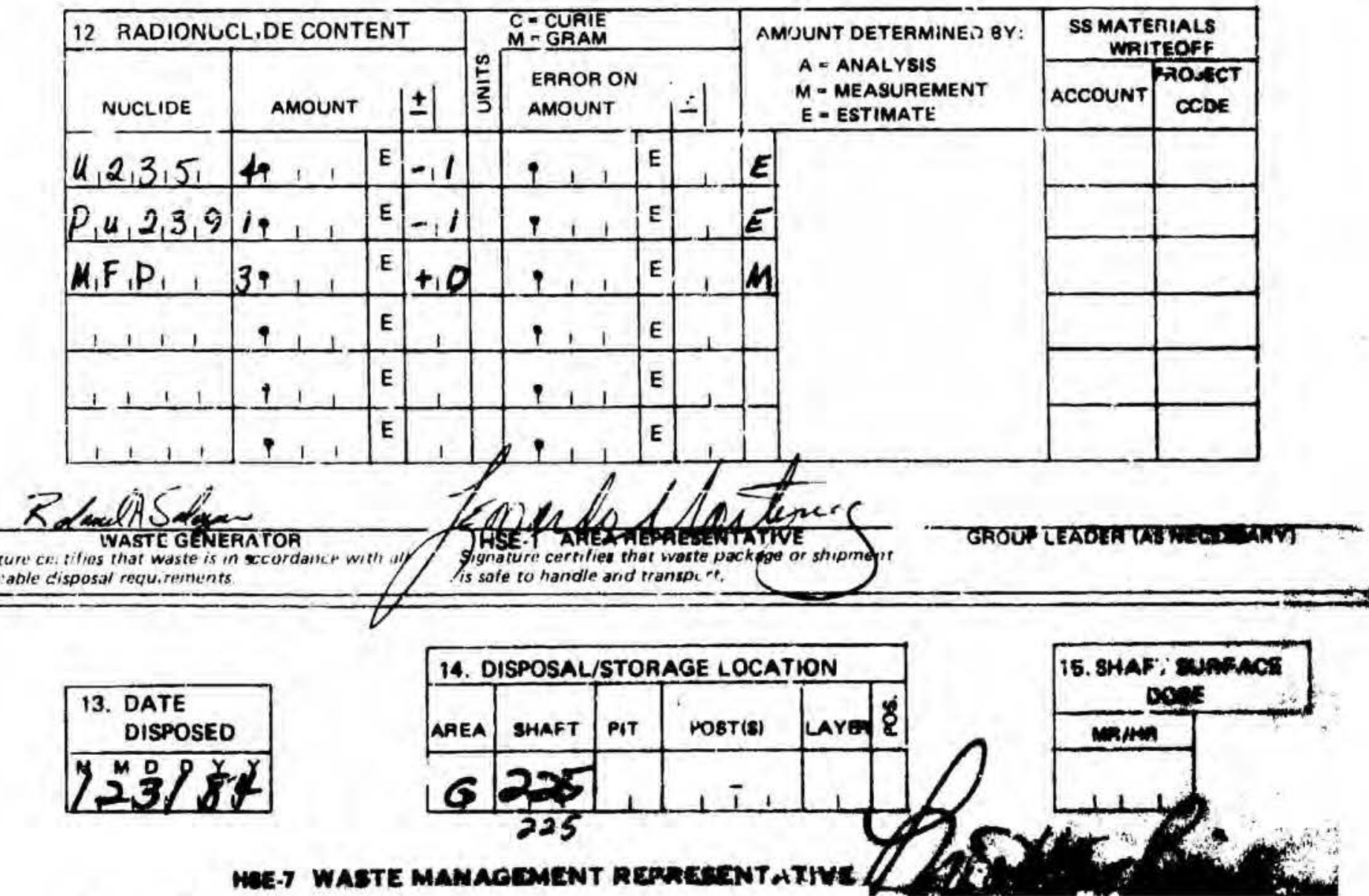
PLEASE RE.AD INSTRUCTIONS OH BACK CAREFULLY

\begin{tabular}{|l|}
\hline 1. FORM NUMEER \\
\hline$S_{1},{ }_{1}$, NRF 3 \\
\hline
\end{tabular}

\section{LOS ALAMOS RADIOACTIVE SOLID mASTE HSE.7 Waste Manager om DISPOSAL RECORD FOAM

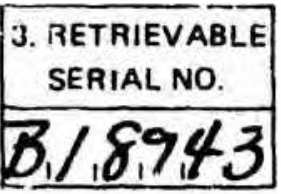

\begin{tabular}{|c|c|c|c|c|}
\hline \multicolumn{3}{|c|}{ 4. ORIGIN OF WLSTE } & \multirow{2}{*}{$\frac{0}{5}$} & \multirow[b]{2}{*}{ ROOM } \\
\hline GROUP & TA & BLDG. & & \\
\hline$M \mid S, T, 1$ & 0,3 & $5 m, 219$ & 9 & \\
\hline
\end{tabular}

6. NASTE DESCRIPTION

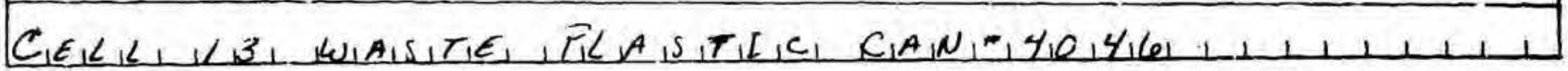

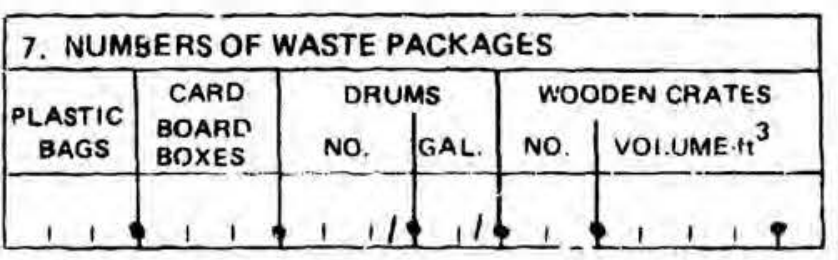
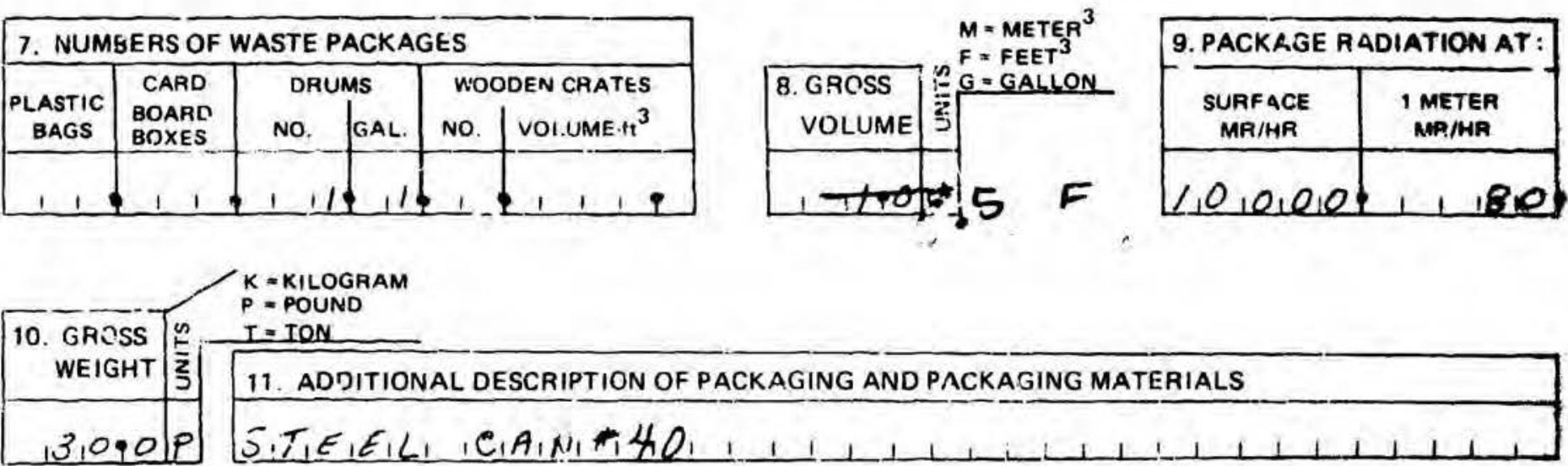

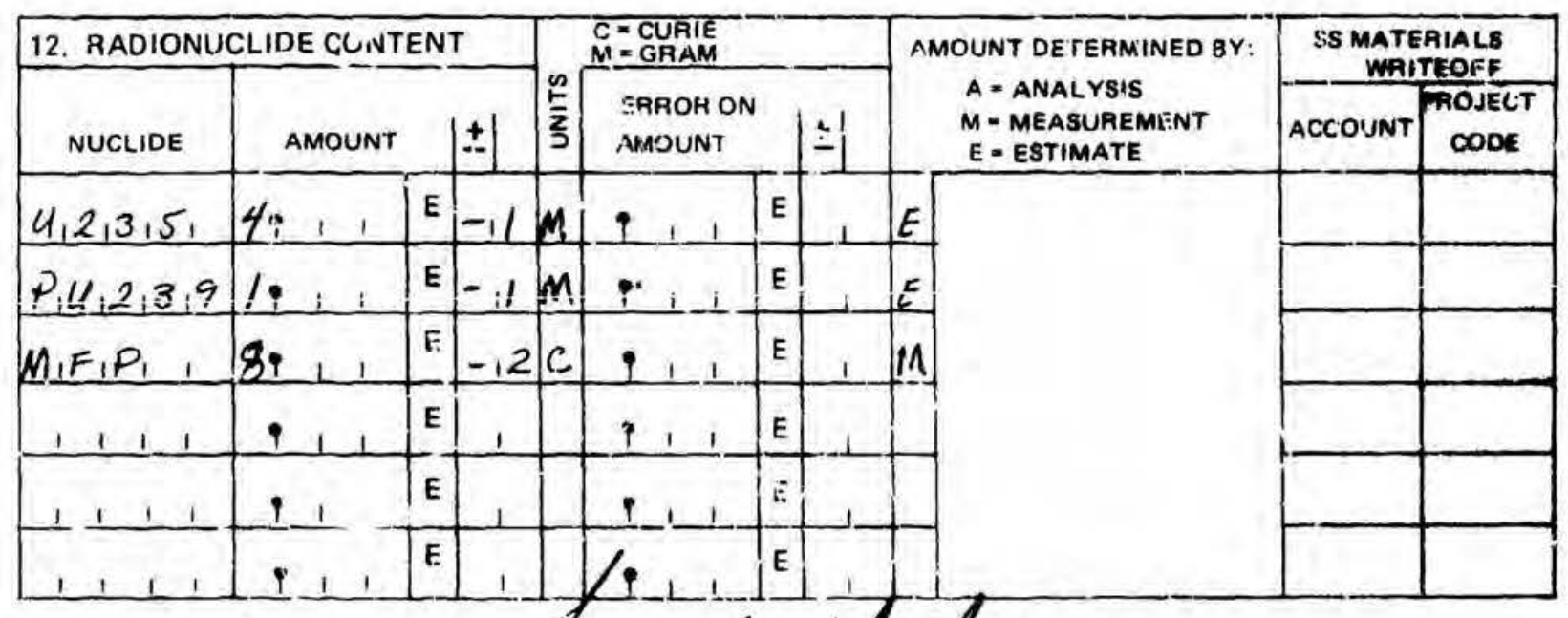

Solanel A. Salaion IVASTE GENECAMTOR
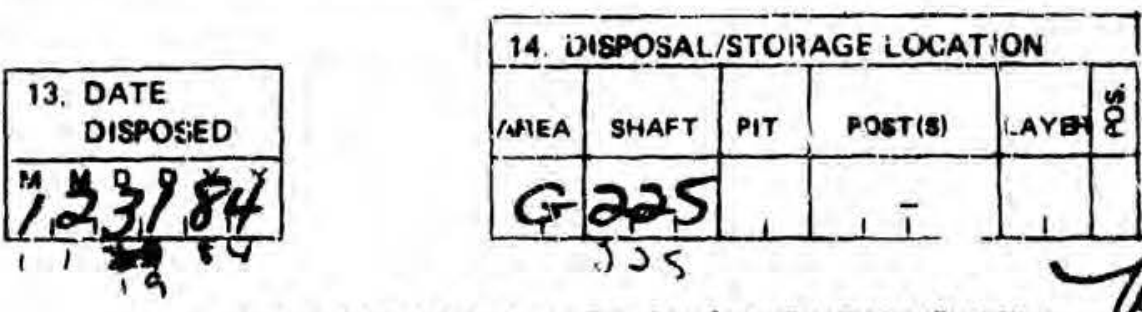

MET-? WASTE MANAGGMENT REPRIESENTATIVE 
MEATE READ INSTRUCTIONS ON BACK CAREFULLY

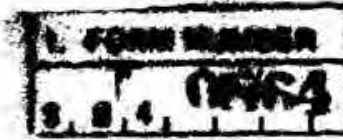

\section{LC ALAMOB RADIOACTIVE SOLID WASTE DISPOSAL RECORD TORM}

HSE 7 Wes? Niariagement

Exi 6095 MS J592

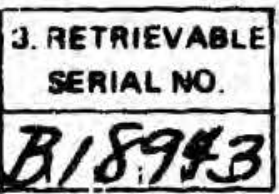

\begin{tabular}{|c|c|c|c|c|}
\hline 4. ORIGIN OF WASTE & \multirow{3}{*}{} & \\
\hline GAOUP & TA & BLOG. & \multirow{3}{*}{} & HOOM \\
\hline MIS IT, 1,4 & 0,3 & $0,5, M, 2,9$ & 9 & \\
\hline
\end{tabular}

\begin{tabular}{r|}
\hline T. VIASTE \\
CODE \\
\hline$A, 4,0$ \\
\hline
\end{tabular}

6. WASTE DESCRIPTION

\begin{tabular}{|c|c|c|c|c|c|}
\hline \multirow[b]{2}{*}{$\begin{array}{l}\text { PLASTIC } \\
\text { BAGS }\end{array}$} & \multirow{2}{*}{$\begin{array}{l}\text { CARD } \\
\text { BOARD } \\
\text { GOXES }\end{array}$} & \multicolumn{2}{|c|}{ DRUMS } & \multicolumn{2}{|c|}{ WOODEN CI:ATES } \\
\hline & & NO. & GAL. & NO. & VOLUME $-f t^{3}$ \\
\hline
\end{tabular}

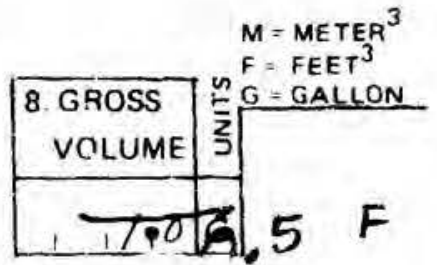

\begin{tabular}{|c|c|}
\hline 9. PACKAGE RADIATION AT \\
\hline $\begin{array}{c}\text { SURFACE } \\
\text { MRIHR }\end{array}$ & $\begin{array}{c}\text { 1 METER } \\
\text { MR/HR }\end{array}$ \\
\hline $25,0,0$ & $1,30,0$ \\
\hline 2,5
\end{tabular}

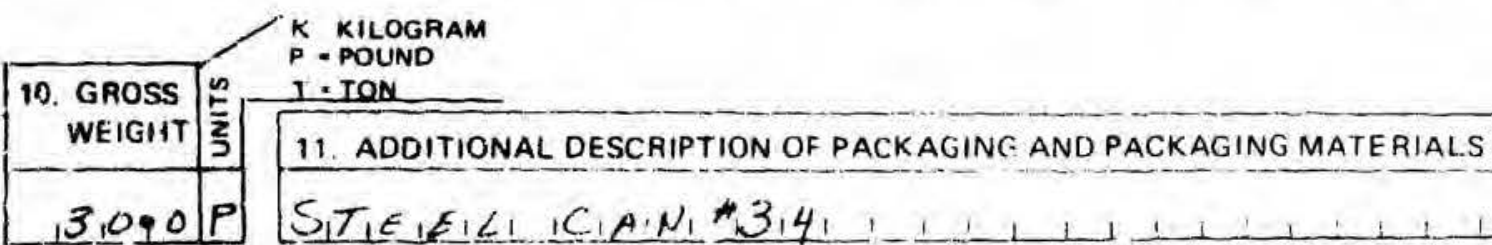

\begin{tabular}{|c|c|c|c|c|c|c|c|c|c|c|c|}
\hline \multicolumn{4}{|c|}{ 12. RADIONUCLIDE CONTENT } & \multicolumn{4}{|c|}{$\begin{array}{l}\text { C. CURIE } \\
M-G \text { GAM }\end{array}$} & \multirow{2}{*}{\multicolumn{2}{|c|}{$\begin{array}{l}\text { AMOUNT DETERMINEO BY } \\
\text { A ANAL SIS } \\
\text { M MEASUREMENT } \\
\text { E-ESTIMATE }\end{array}$}} & \multicolumn{2}{|c|}{$\begin{array}{l}\text { SS MATEITIIS } \\
\text { WRITEL FF }\end{array}$} \\
\hline NUCLIDE & AMOUNT & & \pm & $\frac{n}{2}$ & $\begin{array}{l}\text { EAROR ON } \\
\text { AMOUNT }\end{array}$ & & \pm & & & ACCOUN: & $\begin{array}{l}\text { PRU:ECT } \\
\text {.ODE }\end{array}$ \\
\hline $4,2,3,5$, & $\therefore$ & E & $|-1|$ & $M$ & $1 \quad 1$ & E & & $t$ & & & \\
\hline$P, u_{12,3,9}$ & $1 \cdot$ & E & -1 & $M$ & $1 \quad 1$ & $E$ & & E & & & \\
\hline$M E_{1} P_{1}$ & 39,1 & E & -1 & C & +1 & E & 1 & $M$ & & & \\
\hline 1111 & $9+1$ & E & 1 & & & E & & & & & \\
\hline 11.11 & i 1.1. & E & & & $1 \quad 1$ & E & & & & & \\
\hline 111 & 11 & E & & & 11,1 & E & & & & & \\
\hline
\end{tabular}

\section{Felarel A Sahar} IVASTE GENERATOA

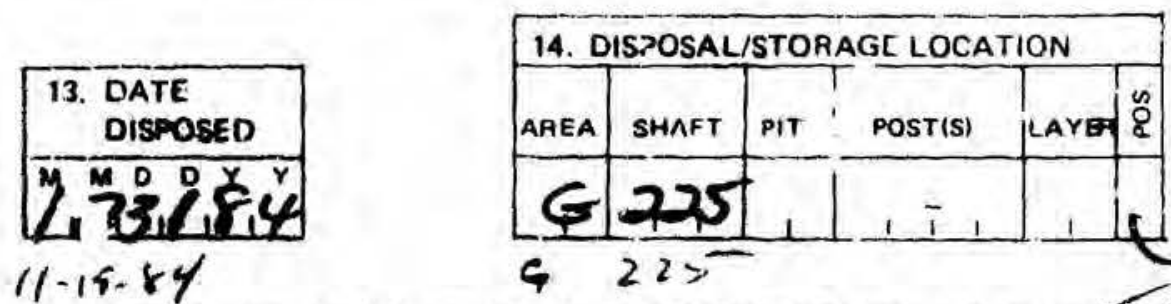

WE-7 WASTE MANAREMENT REPRESENTATIVE T

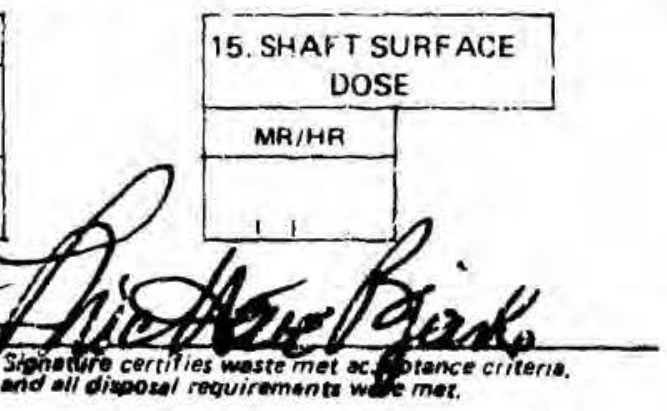


RLEASE AEAD IASTRUCTIKNS ON BACK CAREFULLY

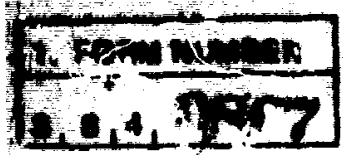

\section{' HSE.7 Waste Management \\ Fxt 60: MS J59? =:SOMA RECORD FORM}

\begin{tabular}{c} 
3. RETRIEVABLE \\
GERIAL NO. \\
\hline $2 / 3013$
\end{tabular}

\begin{tabular}{|c|c|c|c|c|}
\hline \multicolumn{3}{|c|}{ 4. OFIGIN OF WASTE } & \multirow{2}{*}{$\stackrel{0}{\underline{z}}$} & \multirow[b]{2}{*}{ ROOM } \\
\hline GROUP & TA & BLDG. & & \\
\hline$M I S, T$ & 0,3 & $O_{1} s m_{1}$ & 9 & \\
\hline
\end{tabular}

\begin{tabular}{l}
$\begin{array}{r}\text { 5. VASTE } \\
\text { COJE }\end{array}$ \\
\hline$A, 4, O$ \\
\hline
\end{tabular}

6. MASTE DEST:FIPTION

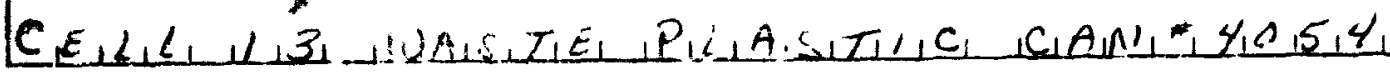

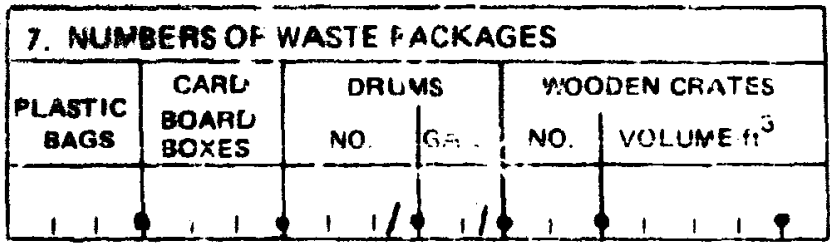

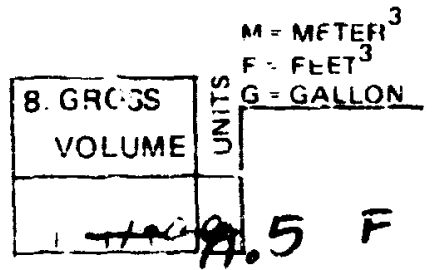

\begin{tabular}{|c|c|}
\hline $\begin{array}{c}\text { 9. PACKAGE RADIATION AT: } \\
\text { SURFACE } \\
\text { MF/HR }\end{array}$ & $\begin{array}{c}\text { IMETER } \\
\text { MH/HR }\end{array}$ \\
\hline $3,0,0,00$ & $14,0,0$ \\
\hline
\end{tabular}

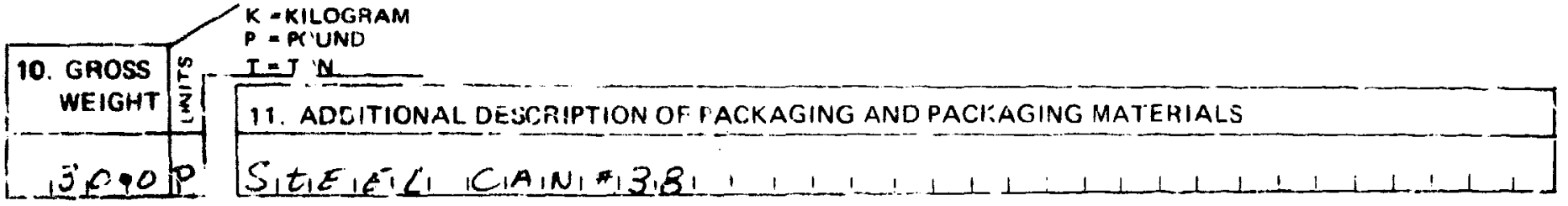

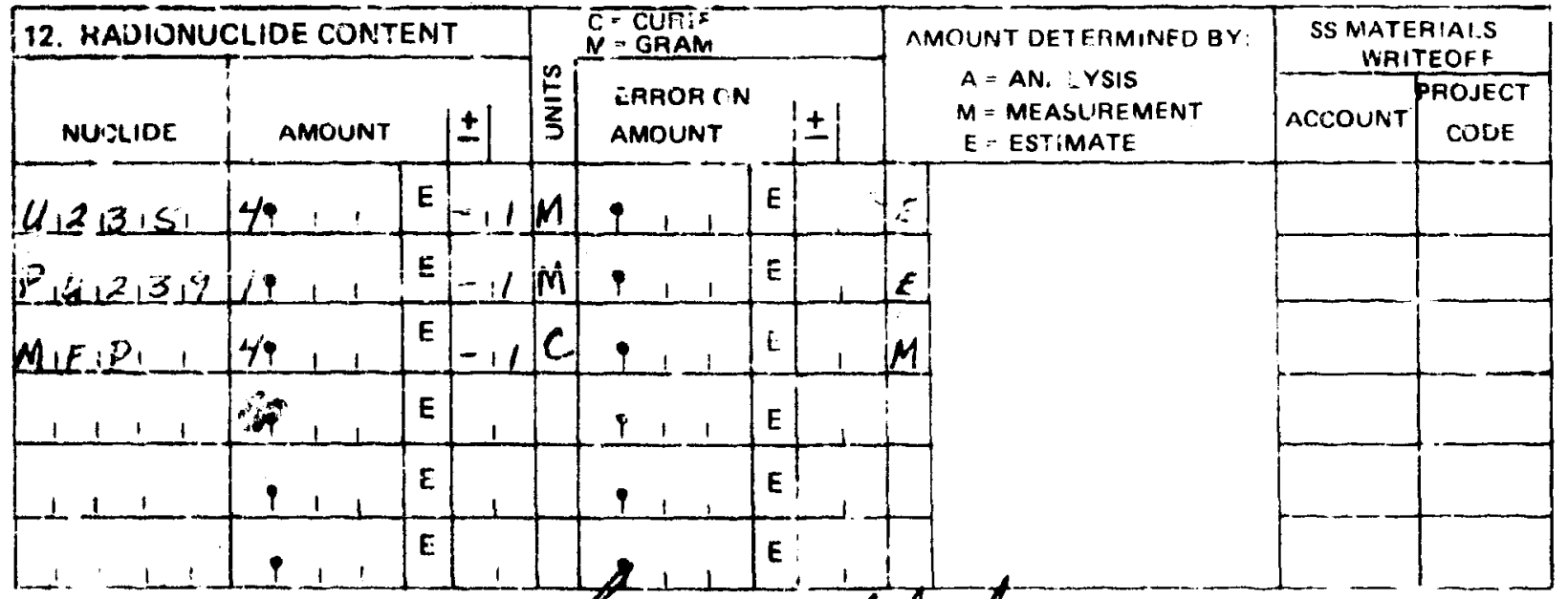

\section{Balam A. Ś.}

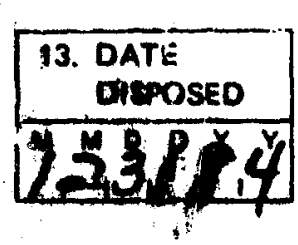

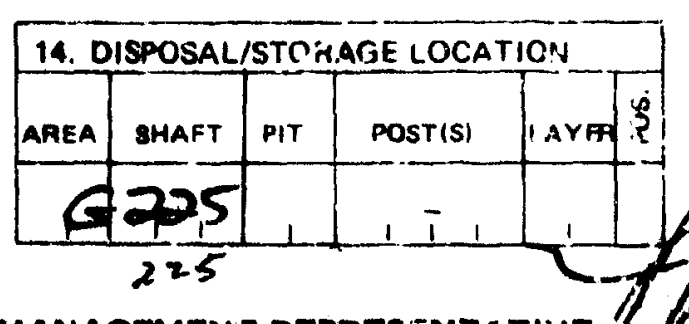


RADIOACTIVE SOLID WASTE DISPOSAL RECORD FORMS

FOR

SHAFT 226

MATERIAL DISPOSAL AREA G 
PLEASE READ INSTRUCTIONS ON GACK CAREFULLY

1. FORM NUMBER

$5,8,4,9892$

\section{LOS ALAMOS RADIOACTIVE SOLID WASTE} DISFOSAL RECOAD FORM
HSE.7 Waste Management

Ext 6095 MS 2592

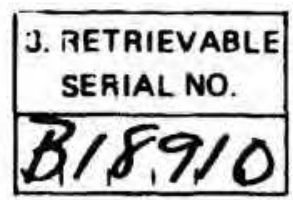

\begin{tabular}{|c|c|c|c|c|}
\hline \multicolumn{3}{|c|}{ 4. ORIGIN OF WASTE } & \multirow{2}{*}{$\frac{0}{2}$} & \multirow[b]{2}{*}{ คоOм } \\
\hline GROUP & TA & BLDG. & & \\
\hline$M_{1} S_{1}, T_{1}, 4$ & 13 & $s_{1} m_{1}$ & 9 & \\
\hline
\end{tabular}

\begin{tabular}{|c|}
\hline . WAST \\
CODE \\
\hline$A, 4,0$ \\
\hline
\end{tabular}

6. WASTE DESCRIPTION

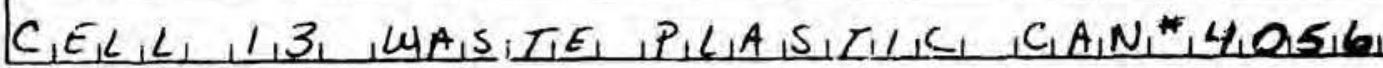

\begin{tabular}{|c|c|c|c|c|c|}
\hline \multirow[b]{2}{*}{$\begin{array}{c}\text { PLASTIC } \\
\text { BAGS }\end{array}$} & \multirow[b]{2}{*}{$\begin{array}{l}\text { CARD } \\
\text { BOARD } \\
\text { BOXES }\end{array}$} & \multicolumn{2}{|c|}{ DRUMS } & \multicolumn{2}{|c|}{ WOODEN CAATES } \\
\hline & & NO. & GAL. & No. & VOLUME. $4 t^{3}$ \\
\hline
\end{tabular}
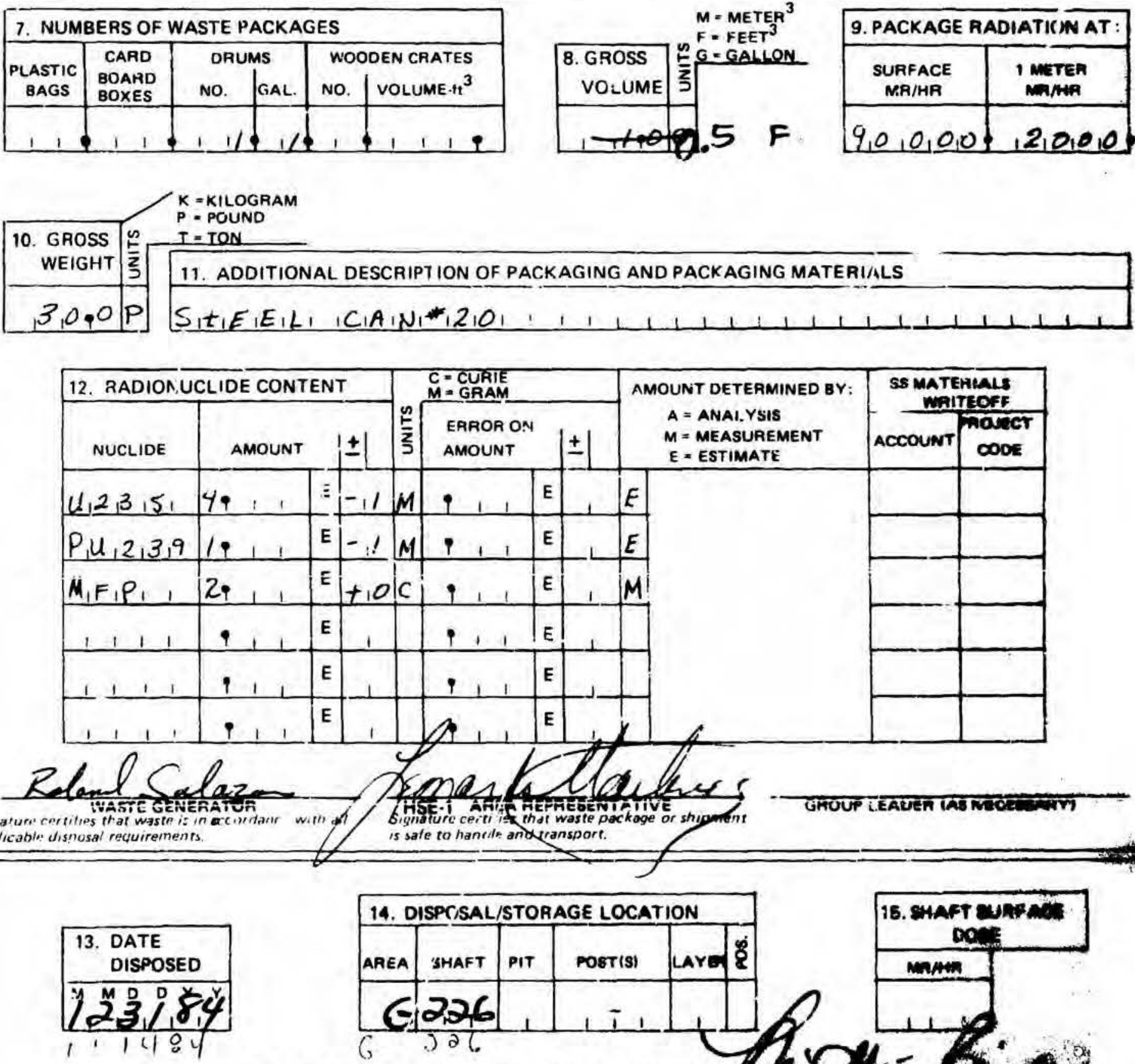

\begin{tabular}{|l|l|l|l|l|l|}
\hline \multicolumn{5}{|c|}{ 14. DISPCISAL/STORAGE LOCATION } \\
\hline AREA & SHAFT & PIT & POSTISI & LAYE & 8 \\
\hline & & & & & \\
\hline
\end{tabular}

ME.7 WASTE MANAGEMENT REPRE 


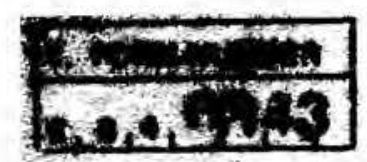

TLEASE READ WSTHUCTIONS ON BACK CAREFULLY

\section{LOS AMU 3 RNDLACTNE COLD WASTE Buroul Recond rones}

HSE.7 Waste Management

Ext 6095 MS $j 592$

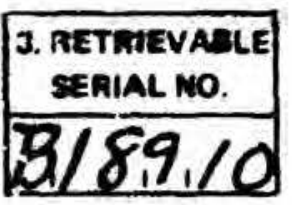

\begin{tabular}{|c|c|c|c|c|}
\hline \multicolumn{3}{|c|}{ 4. ORIGIN OF WASTE } & \multirow{2}{*}{$\frac{0}{=}$} & \multirow[b]{2}{*}{ ROUM } \\
\hline GAOUP & TA & BLDG. & & \\
\hline$M, S, T / 14$ & 3 & $S_{1} m_{1}$, & 9 & \\
\hline
\end{tabular}

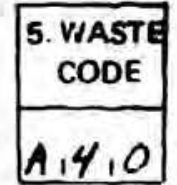

\section{WASTE DESCRIPTION}

$C_{1} E_{1}, L_{1}, /, S, U A_{1} S, T, E_{1}, P_{1} L_{1} A_{1}, T_{1}, C_{1}, C_{1} A_{1} N_{1}, 4,0,4,5$

\section{MUMEERS OF WASTE PACKAGES}

\begin{tabular}{|c|c|c|c|c|c|}
\hline \multirow{2}{*}{$\begin{array}{l}\text { PLASTIC } \\
\text { BAGS }\end{array}$} & \multirow{2}{*}{$\begin{array}{l}\text { CARD } \\
\text { DOARD } \\
\text { DOXES }\end{array}$} & \multicolumn{2}{|c|}{ DRUMA } & \multicolumn{2}{|c|}{ WOOOEN CRATES } \\
\hline & & No. & GAL. & No. & VOLUME $-\mathrm{ft}^{3}$ \\
\hline
\end{tabular}

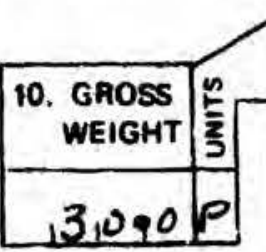

\section{$K$ - KILOGAAM}

$P$ - POUND

$I=T O N$

$S, L_{1} E_{1} E_{1} L_{1}, C_{1} A_{1} N_{1} N_{1} Z_{1} C_{1}$

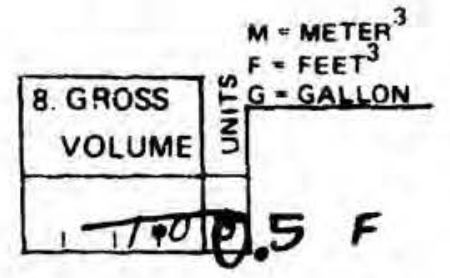

\begin{tabular}{|c|c|}
\hline 9. PACKAGE RADIATION AT: \\
\hline $\begin{array}{c}\text { SURFACE } \\
\text { MR/HR }\end{array}$ & $\begin{array}{c}\text { 1 METER } \\
\text { MR/HR }\end{array}$ \\
\hline $8,0,0,0,0$ & $2,0,0,0$ \\
\hline
\end{tabular}

11. ADDITIONAL DESCRIPTION OF PACKAGING AND PACKAGING MATERIALS

\begin{tabular}{|c|c|c|c|c|c|c|c|c|c|c|}
\hline \multicolumn{4}{|c|}{ 12. RADIONUCLIDE CONTENT } & \multicolumn{4}{|c|}{$\begin{array}{c}\text { C. CURIE } \\
M=\text { GRAM } \\
\end{array}$} & \multirow{2}{*}{ 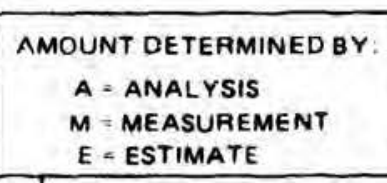 } & \multicolumn{2}{|c|}{$\begin{array}{c}\text { SS MATERIALS } \\
\text { WRITEOFF } \\
\end{array}$} \\
\hline NUCLIOE & AMOUNT & & \pm & $\frac{n}{\xi}$ & $\begin{array}{l}\text { EAROR ON } \\
\text { AMOUNT }\end{array}$ & & \pm 1 & & ACCOUNT & $\begin{array}{l}\text { PROJECT } \\
\text { CODE }\end{array}$ \\
\hline $4,2,3,5$, & $49: 1$ & E & -11 & $M$ & $1 \quad 1$ & E & & $E$ & & \\
\hline$P, 4,2,3,9$ & $1 / 21.1$ & E & -1 & $M$ & 1,1 & E & & $E$ & & \\
\hline$M_{1} E \cdot P_{1}$, & 29,1 & E & +.0 & C & $1: 1$ & $E$ & 1 & M & & \\
\hline 1111 & $\neq 1,1$ & E & 1 & & 1,1 & E & & & & \\
\hline 1111 & 11, & E & $\perp$ & & 111 & E & & & & \\
\hline $111:$ & 111 & E & 1 & & 1,1 & E & & A & & \\
\hline
\end{tabular}

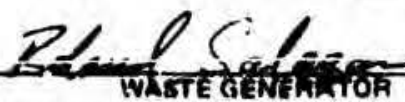

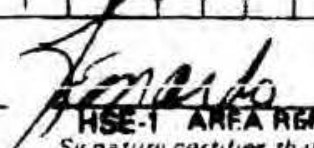

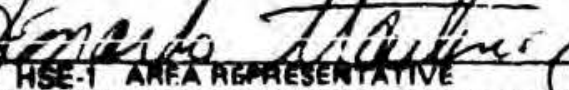
shnature certifier that waste nackay" or shipm is sate to handle ent transpert.

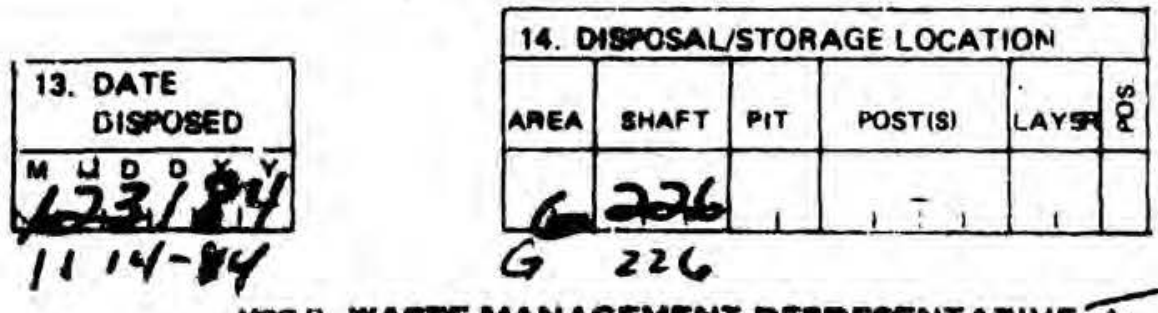

10

\section{GROUPLEADEA IAS NECESSARYI}

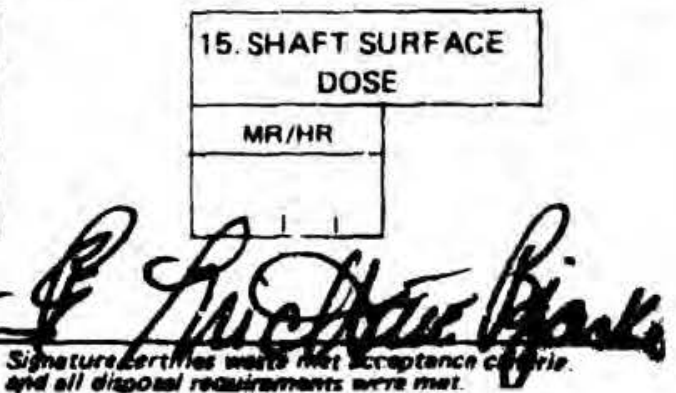


PLEASE READ INSTRUCTIONS ON BACK CAREFULLY

\begin{tabular}{|l|}
\hline 1. FORM NUMBER \\
\hline S, 8,4,88,2.4 \\
\hline
\end{tabular}

\section{LOS ALAMOS RADIOACTIVE SOLID WASTE HSE.7 Waste Management DISPOSAL RECORD FORM

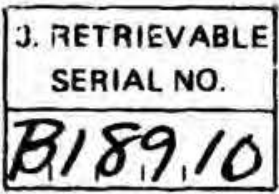

\begin{tabular}{|c|c|c|c|c|}
\hline \multicolumn{3}{|c|}{ 4. ORIGIN OF WASTE } & \multirow{2}{*}{$\begin{array}{l}0 \\
\frac{2}{3}\end{array}$} & \multirow[b]{2}{*}{ ROOM } \\
\hline GROUP & TA & BLDG. & & \\
\hline$M_{1} S_{1} T_{1} / 4$ &, 3 & $S, M_{1}, 2,9$ & & \\
\hline
\end{tabular}

\begin{tabular}{r|}
\hline S. WASTE \\
COOE \\
\hline $4,4,0$ \\
\hline
\end{tabular}

6. WASTE DESCRIPTION

$C_{1} E_{1} L_{1} L_{1}, I_{1} 3_{1}, W A_{1} S_{1} T_{1} E_{1}, P_{1} L 4_{1} S_{1} T_{1}, C_{1}, C_{1} A_{1} N_{1} H_{10} 2_{1} 3_{1}$

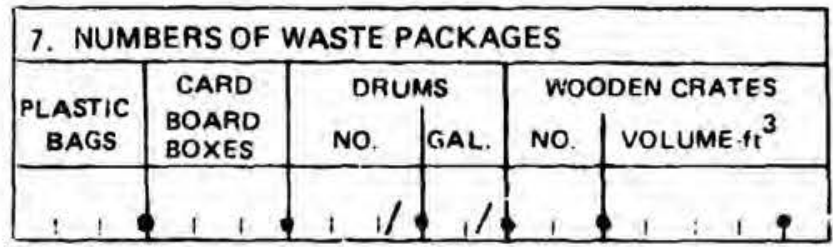

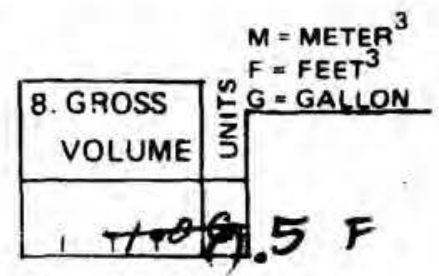

\begin{tabular}{|c|c|}
\hline 9. PACKAGE RADIATION AT: \\
\hline $\begin{array}{c}\text { SURFACE } \\
\text { MR/HR }\end{array}$ & $\begin{array}{c}\text { I METER } \\
\text { MEANR }\end{array}$ \\
\hline $7,0,0,010$ & $115,0,0$ \\
\hline
\end{tabular}

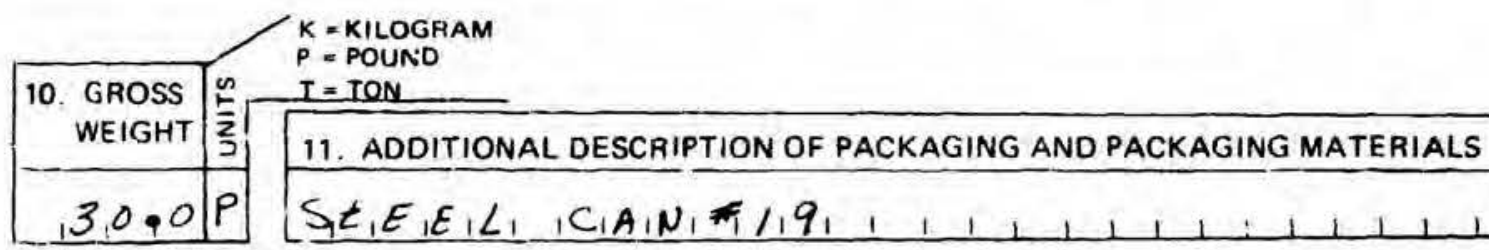

\begin{tabular}{|c|c|c|c|c|c|c|c|c|c|c|}
\hline \multicolumn{4}{|c|}{ 12. RADIONUCLIDE CONTENT } & \multicolumn{4}{|c|}{$\begin{aligned} C & =\text { CURIE } \\
M & =\text { GRAM }\end{aligned}$} & \multirow{2}{*}{$\begin{aligned} \text { AMOUNT DETERMINED BY: } & \text { } \\
\text { A } & =\text { ANALYSIS } \\
M & =\text { MEASUREMENT } \\
E & =\text { ESTIMATE }\end{aligned}$} & \multicolumn{2}{|c|}{$\begin{array}{c}\text { SS MATERIALS } \\
\text { WRITEOFF }\end{array}$} \\
\hline NUCLIDE & AMOUNT & & \pm & $\stackrel{n}{\Sigma}$ & $\begin{array}{l}\text { ERROR ON } \\
\text { ANOUNT }\end{array}$ & & \pm 1 & & ACCOUNT & $\begin{array}{l}\text { PONeCt } \\
\text { code }\end{array}$ \\
\hline$u_{1}, 2,3,5$, & $4 \cdot: 1$ & $E$ & -11 & $m$ & 111 & E & & $E$ & & \\
\hline$P, 4,2,3,9$ & 1,11 & E & $-i 1$ & $m$ & 11 & E & & E & & \\
\hline$M_{1} F_{1} F_{1}$ & 195,1 & E & +10 & C & 911 & $\varepsilon$ & 1 & Mi & & \\
\hline 1111 & 9.11 & E & 1 & & 111 & E & & & & \\
\hline-1111 & 111 & $\varepsilon$ & 1 & & +1 & E & & & & \\
\hline 111, & 111 & E & 1 & & 11 & E & & A & & \\
\hline
\end{tabular}
Reland Salaran

Sundure rertifies that waste is in acuedance with at? aopicican'e Iisposal requirements.

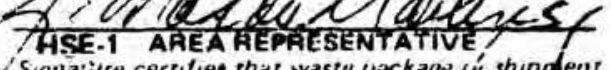

Signative cerrifies that wast" package 'í shipolent

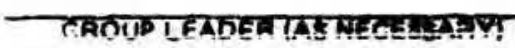

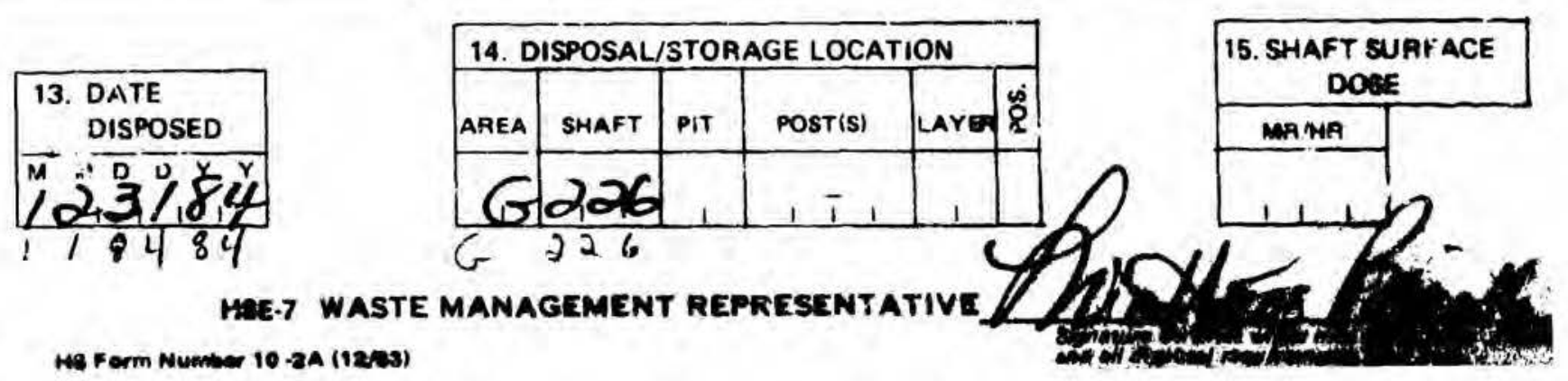


PLEAE WEAB WETWUCTICNS ON BACK CAREFULLY

\section{LOS ALAMS RADUNATTE EOLO WASTE Dienal nECOAD FORM}

HSE.7 Wast: Management

Ext 6095 MS J592

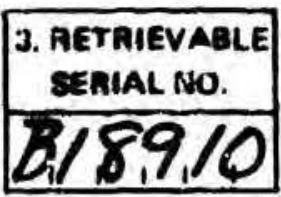

\begin{tabular}{|c|c|c|c|c|}
\hline 4. ORIGIN OF WASTE & 0 & \\
\hline GAOUP & TA & BLDG. & ROOM & ROOM \\
\hline$M, \delta, T, 1,4$ & 13 & $S_{1} M_{1}, 2,9$ & 9 & \\
\hline
\end{tabular}

\begin{tabular}{|c|}
\hline $\begin{array}{c}\text { 5. VIAST: } \\
\text { CODE }\end{array}$ \\
\hline$A, 4,0$ \\
\hline
\end{tabular}

\section{WASTE DESCAIPTION}

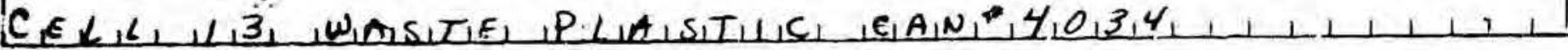

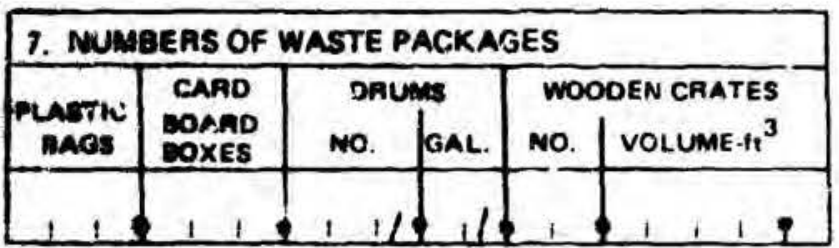

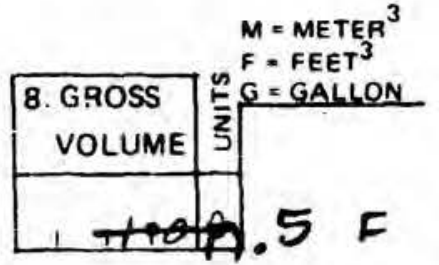

\begin{tabular}{|c|c|}
\hline 8. PACKAGE RADIATION AT: \\
\hline $\begin{array}{c}\text { SURFACE } \\
\text { MR/HR }\end{array}$ & $\begin{array}{c}\text { 1MTTER } \\
\text { MR/HA }\end{array}$ \\
\hline $2,1,0,0,0$ & $13,0,0$ \\
\hline
\end{tabular}
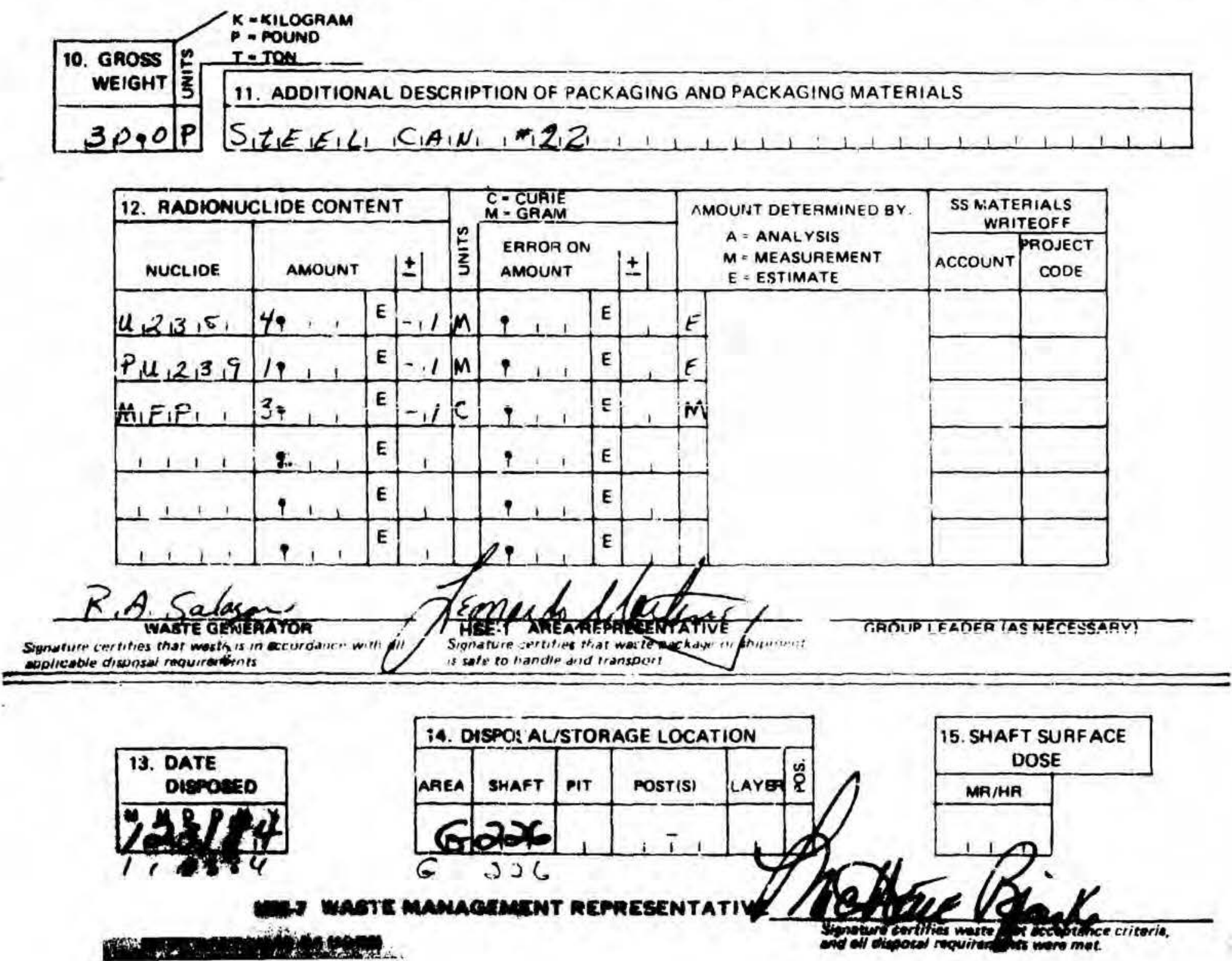
PLEASE READ INSTRUCTIONS ON BACK CAREFUI.LY

\begin{tabular}{|l|}
\hline 1. FOAM NUMBER \\
\hline$S, 8,4,0$ OSA6 \\
\hline
\end{tabular}

\section{LOS ALAMOS RADIOACTIVE SOLID WASTE DISPOSAL RECORD FORM}

HSE-7 Waste Marggernent Ext 6095 MS J592
2. DATE

$M$ M D D Y Y

L, $0,8,8,4$

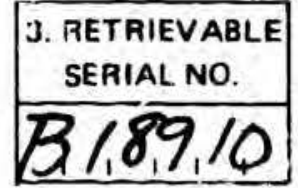

6. WASTE DESCRIPTION

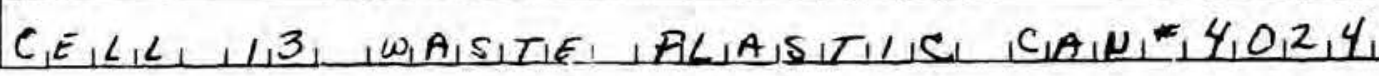
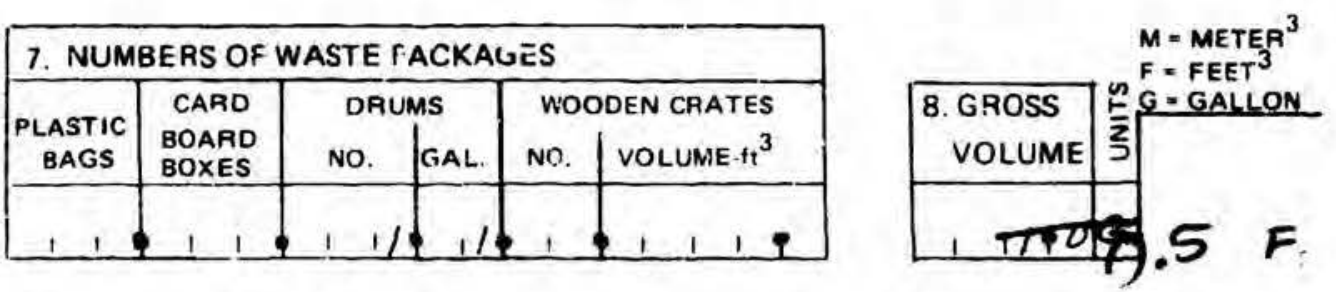

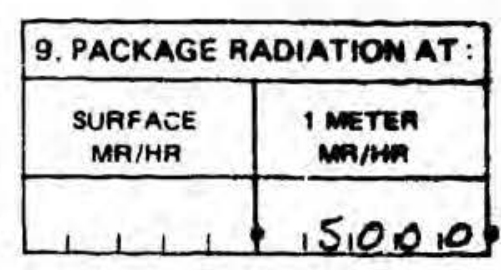

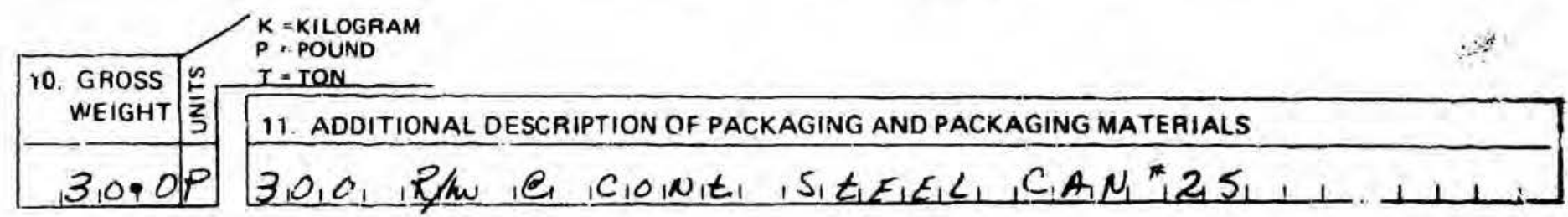

\begin{tabular}{|c|c|c|c|c|c|c|c|c|c|c|c|}
\hline \multicolumn{4}{|c|}{ 12. IADIONUCLIDE CONTENT } & \multicolumn{4}{|c|}{$\begin{array}{l}C=\text { CUATE } \\
M=\text { GRAM }\end{array}$} & \multirow{2}{*}{\multicolumn{2}{|c|}{ 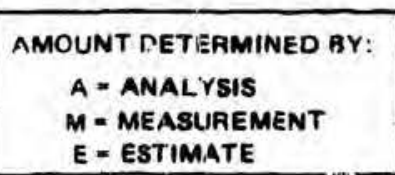 }} & \multicolumn{2}{|c|}{$\begin{array}{l}\text { SS MATERIALS } \\
\text { MeITEOFE }\end{array}$} \\
\hline NUCLIDE & AMOUNT & & \pm & $\frac{m}{\frac{2}{j}}$ & $\begin{array}{l}\text { EHROR ON } \\
\text { AMOUNT }\end{array}$ & & \pm & & & Account & $\begin{array}{l}\text { CODE } \\
\text { CUECT }\end{array}$ \\
\hline$u: 2,3,5$, & $4 \cdot 1$, & $E$ & $-1 /$ & $M$ & P 11 & $\varepsilon$ & & E & & & \\
\hline ? $\mu_{i}^{2}, 3,9$ & $1: i i$ & E & $-i 1$ & $M$ & $1 \quad i \quad$ i & E & & $E$ & & & \\
\hline$M_{1} F_{1} P_{1}$, & $59+1$ & $\mathrm{E}$ & +10 & C & 1,1 & E & 1 & M & & & \\
\hline $1 \quad 11$ & 911 & E & 1 & & $? \quad 1$ & E & & & & & \\
\hline 1111 & 111 & E & 1 & & 1,1 & E & & & & & \\
\hline 111 & P $1 \quad 1$ & E & 1 & & A, & E & & & & & \\
\hline
\end{tabular}

सM Salaza. IVASTE GENEFATOA ignatur. wi cifies that wasto is in
policabin disposal reaurem ants. eridanew with all

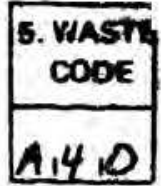

A14 10

\begin{tabular}{|c|c|c|c|c|}
\hline \multicolumn{3}{|c|}{ 4. ORIGIN OF WA,TE } & \multirow{2}{*}{ 证 } & \multirow[b]{2}{*}{ ROOM } \\
\hline GROUP & TA & BLDG. & & \\
\hline$M_{1} \leq, T, 1,4$ & 13 & 12,9 & 9 & \\
\hline
\end{tabular}




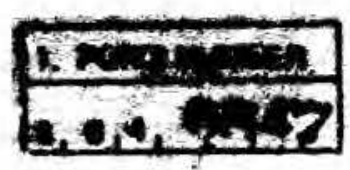

PEACE titho instructions ON BACK CAREFULLY

LCS AL ANDS MADIOACTIVE CLID WASTE DUNOAL RECORO FONM
HSE-7 Waste Mariagement

Ext 6095 MS J592

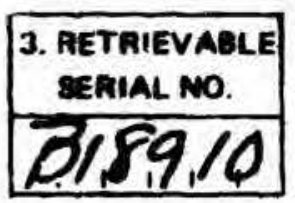

\begin{tabular}{|c|c|c|c|c|}
\hline \multicolumn{3}{|c|}{ 4. OAIGIN OF WASTE } & \multirow{2}{*}{$\sum_{=}^{0}$} & \multirow[b]{2}{*}{ ROOM } \\
\hline GROUP & TA & BLDG. & & \\
\hline$M, S, T, 14$ & 13 & $m_{1}{ }_{12}$ & 9 & \\
\hline
\end{tabular}

\begin{tabular}{|c|}
\hline 5. VIASTE \\
CODE \\
\hline$A, 4,0$ \\
\hline
\end{tabular}

\section{WASTE DESCRIPTION}

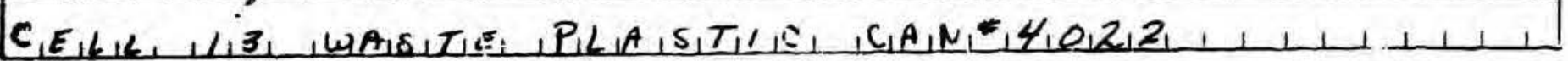

\begin{tabular}{|c|c|c|c|c|c|}
\hline \multicolumn{6}{|c|}{ 7. MUMBERS OF WASTE PACKAGES } \\
\hline \multirow{2}{*}{$\begin{array}{l}\text { Anstic } \\
\text { moses }\end{array}$} & \multirow{2}{*}{$\begin{array}{l}\text { CAND } \\
\text { BOARD } \\
\text { COXES }\end{array}$} & \multicolumn{2}{|c|}{ DaUnis } & \multicolumn{2}{|c|}{ WOODEN CRATES } \\
\hline & & NO. & GAL. & NO. & VOLUME. $\cdot \mathrm{tt}^{2}$ \\
\hline 1 & 1 & 1 & & $!$ & 1 \\
\hline
\end{tabular}
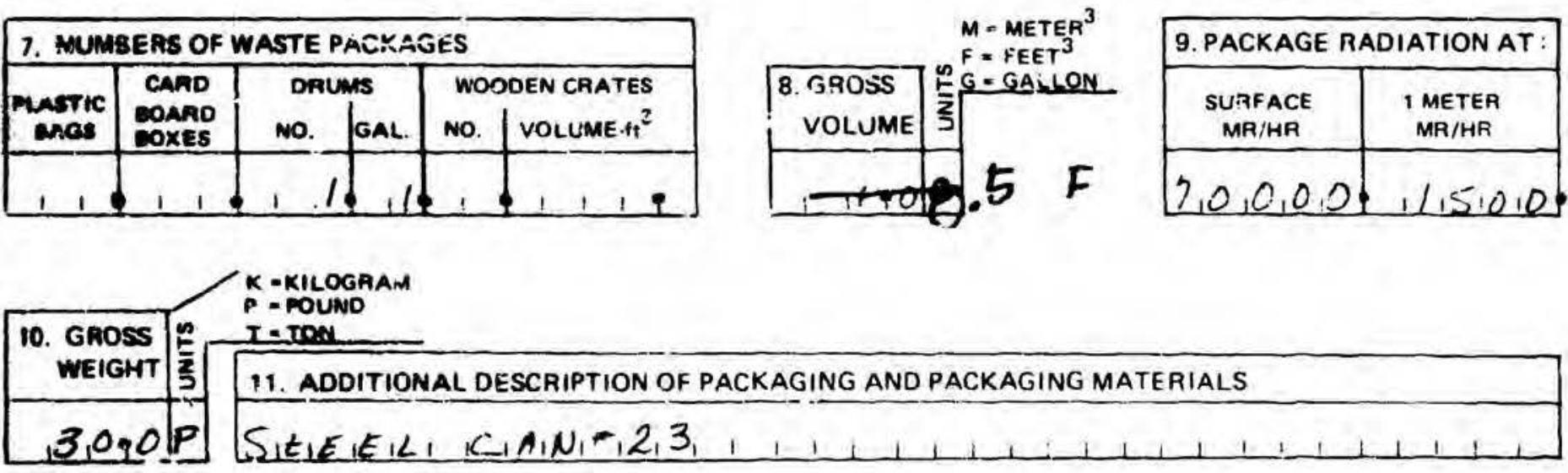

\begin{tabular}{|c|c|c|c|c|c|c|c|c|c|c|c|}
\hline \multicolumn{4}{|c|}{ 1?. RADIONUCLIDE CONTENT } & \multicolumn{4}{|c|}{$\begin{array}{l}C=\text { CUAIE } \\
M=\text { GAAM }\end{array}$} & \multirow{2}{*}{\multicolumn{2}{|c|}{ 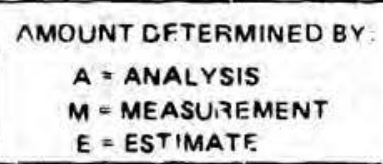 }} & \multicolumn{2}{|c|}{$\begin{array}{l}\text { SS MATERIALS } \\
\text { WRITEOFF }\end{array}$} \\
\hline NUCLIDE & AMOUNT & & \pm & $\frac{m_{2}^{2}}{3}$ & $\begin{array}{l}\text { ERPOR ON } \\
\text { AMOUNT }\end{array}$ & & \pm 1 & & & ACCOUNT & $\begin{array}{l}\text { PROJECT } \\
\text { CODE }\end{array}$ \\
\hline $42^{2}, 3,51$ & $49: 1$ & E & -11 & $M$ & 111 & $E$ & & $E$ & & & \\
\hline$P, 4,2,39$ & 19,1 & $\mathbf{E}$ & $-! I$ & $M$ & $P \quad 1 \quad 1$ & $E$ & & $E$ & & & \\
\hline$M_{H} E P_{i}$ & 151 & $\mathbf{E}$ & \pm 10 & C & i: i : & $F$ & & is: & & & \\
\hline 1111 & $1+1$ & $E$ & 1 & & & E & & & & & \\
\hline-111 & 111 & E & & & 1,1 & $\mathbf{E}$ & & & & & \\
\hline 111,1 & $1 \quad 1$ & $\mathbf{E}$ & & & 1,1 & E & & & & & \\
\hline
\end{tabular}

irisaner wi

(1)

$=-\frac{1}{2}$
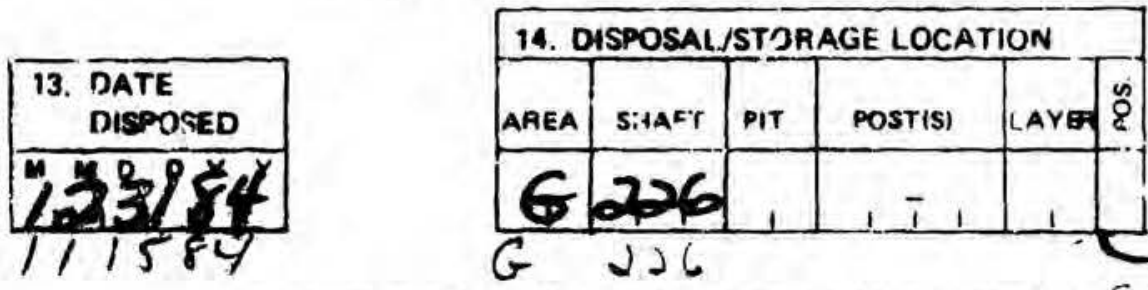

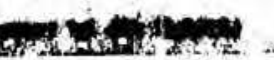

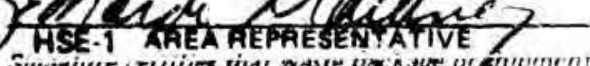

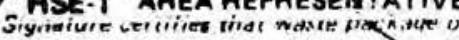
is saip to handle and transourt.

\section{GROUP LEADER (AS NECESSAFY)}


PLF.ASE READ INSTRUCTIONS ON BACK CAREFULLY

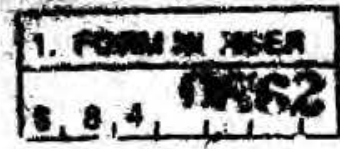

\section{HSE.7 Waste Managerr.ent \\ Ext 6095 MS J592 OLEPSAL RECORD FORM}

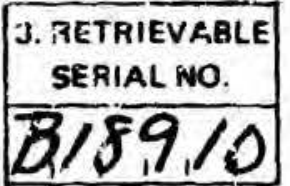

\begin{tabular}{|c|c|c|c|c|}
\hline 4. ORIGIN OF WASTE & & \\
\hline GROUP & TA & BLOG & ROOM \\
\hline$M S, T, L, 4$ & 0,3 & $0,5, M, 2,9$ & \\
\hline
\end{tabular}

\begin{tabular}{l} 
5. WASTE \\
CONE \\
\hline $1,4,0$
\end{tabular}

\section{IVASTE DESCRIFTION}

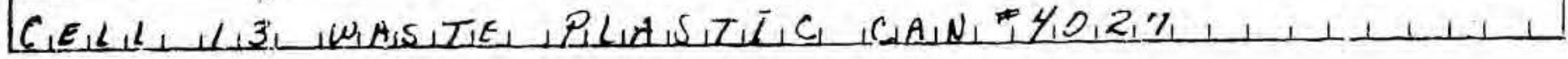

\begin{tabular}{|c|c|c|c|c|}
\hline \multicolumn{5}{|c|}{ 7. NUMBERS OF WASTE PACKAGES } \\
\hline & CARD & DRUMS & wo & IDEN CRATES \\
\hline BAGS & $\begin{array}{l}\text { BOARD } \\
\text { BOXES }\end{array}$ & NO. GAL. & no. & VOLIMEE-ft ${ }^{3}$ \\
\hline & & & & 1 \\
\hline
\end{tabular}

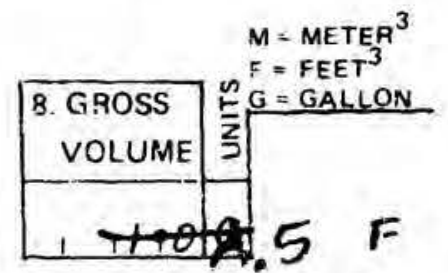

\begin{tabular}{|c|c|}
\hline \begin{tabular}{c} 
9. PACKAGE RADIATION AT: \\
\hline $\begin{array}{c}\text { SURFACE } \\
\text { MR/HR }\end{array}$
\end{tabular} & $\begin{array}{c}\text { IMETER } \\
\text { MR/HR }\end{array}$ \\
\hline $1,5,0 R, 0$ & $1,2,0,0$ \\
\hline
\end{tabular}

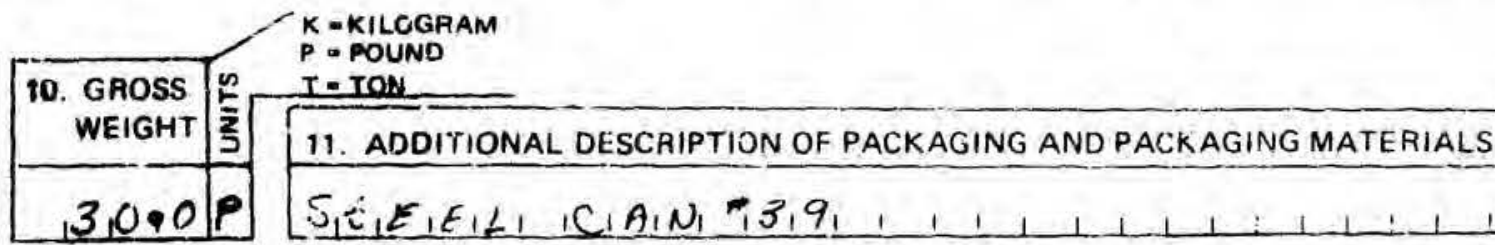

\begin{tabular}{|c|c|c|c|c|c|c|c|c|c|c|c|}
\hline \multicolumn{4}{|c|}{ 12. RADIONUCLIDE CONTENT } & \multicolumn{4}{|c|}{$\begin{array}{l}C=\text { CURIE } \\
M=\text { GAAM }\end{array}$} & \multirow{2}{*}{\multicolumn{2}{|c|}{$\begin{aligned} & \text { AMOUNT DETERMINED OY } \\
& \text { A }=\text { ANALYSIS } \\
& M=\text { MEASUREMENT } \\
& E=\text { ESTIMATE }\end{aligned}$}} & \multicolumn{2}{|c|}{$\begin{array}{c}\text { SS MATERIALS } \\
\text { WRITSOFF }\end{array}$} \\
\hline NUCLIDE & ANIOUNT & & \pm & $\frac{c}{z}$ & $\begin{array}{l}\text { ERROR ON } \\
\text { AMOUNT }\end{array}$ & & \pm & & & AC_OUNT & $\begin{array}{l}\text { PROJECT } \\
\text { CODE }\end{array}$ \\
\hline $4,2,3,51$ & $4 \%, 1$ & E & -11 & $M$ & 111 & $\mathrm{E}$ & & E & & & \\
\hline$P, u, 2,3,9$ & $19 \quad 1 \quad 1$ & E & $-: 1$ & $M$ & $p+1$ & E & & E & & & \\
\hline$N_{1} E_{1} P_{1}$, & 11 & E & -11 & C & 111 & E & & $M$ & & & \\
\hline-111 & $\psi_{1}$ & E & 1 & & 11 & E & & & & & \\
\hline 1111 & 111 & E & 1 & & $1 \quad 1$ & $E$ & & & & & \\
\hline 1111 & 111 & E & 1 & & 1,1 & $E$ & & & & & \\
\hline
\end{tabular}

Rolamela Salaza

$=$ $=7$
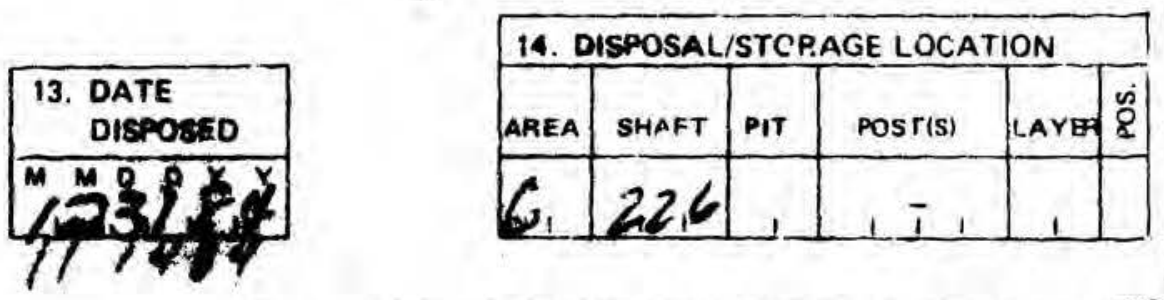

Wha ¿VAGTE MANAOEMENT REPRESENTATIVE SS 
PL E ASE RE AD INSTRUCTICNS ON BACK CAREFULLY

\begin{tabular}{|l|} 
1. FORM NUMBER \\
\hline $5,8,4,0,868$
\end{tabular}

\section{LUS ALA MOS RADIOACTIVE SOLID WASTE HSE 7 Waste Management DISPOSAL RECORD FORM \\ Ext 6105 MS 1532}

2. DATE

$M$ I D D Y Y

i. $1,4,8,4$

\begin{tabular}{l} 
S. RETRIEVABLE \\
SERIAL NO \\
\hline $3 \%$ Y ?
\end{tabular}

\begin{tabular}{|c|c|c|c|c|}
\hline 4. ORIGIN OF WASTE & \multirow{2}{*|}{} & \\
\hline GROUP & TA & BLOG & ह & ROON \\
\hline$M I S, T_{1}, 4$ & 0,3 & $0,5, M, 2,2$ & 9 & \\
\hline
\end{tabular}

CODE

6. WASTE DESCRIPTION

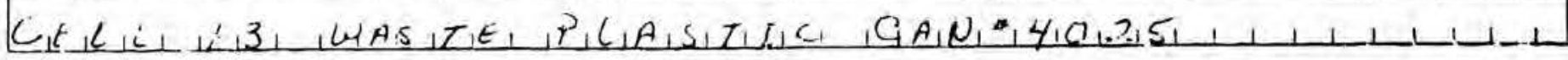

7. NUMESRS OF WASTE PACKAGES

\begin{tabular}{|c|c|c|c|c|c|}
\hline \multirow[b]{2}{*}{$\begin{array}{c}\text { PLASTIC } \\
\text { BAGS }\end{array}$} & \multirow{2}{*}{$\begin{array}{l}\text { CARE, } \\
\text { BOARO } \\
\text { ROYES }\end{array}$} & \multicolumn{2}{|c|}{ DRUMS } & \multicolumn{2}{|c|}{ WOODEN CRATES } \\
\hline & & NO. & fGAL. & No. & VOLUME $\cdot t^{3}$ \\
\hline
\end{tabular}

$\left\{\begin{array}{l}k=K I L O G H A M \\ P=-P O C I N D\end{array}\right.$

10. GFOSS

WEIGHT כू| 11. ADDITIONAL DESCRIPTION OF PACKAGING AND PACKAGING MATERIALS

$J_{1}, 0(0) P\left[S_{1} E_{1} E_{1} E_{1} L_{1}, C_{1}, \Delta_{1} \mu_{1} * 1,3,5\right.$

12. FADIONLICLIDE CONITENT

\begin{tabular}{|c|c|c|c|c|c|c|}
\hline 12. $A \mathrm{ADIO}$ & DE CON!? & & & $=$ CURIE & & AN JUNT DCTERMINED GY \\
\hline$\wedge$ UCLIDE & AMICUNT & \pm & $\stackrel{n}{\frac{n}{z}}$ & $\begin{array}{l}\text { ERROR ON } \\
\text { AMOUNT }\end{array}$ & \pm & $\begin{array}{l}\text { A }=\text { AN.ALYSIS } \\
M=\text { NEASUREMENT } \\
F=\text { ESTIMATE }\end{array}$ \\
\hline
\end{tabular}

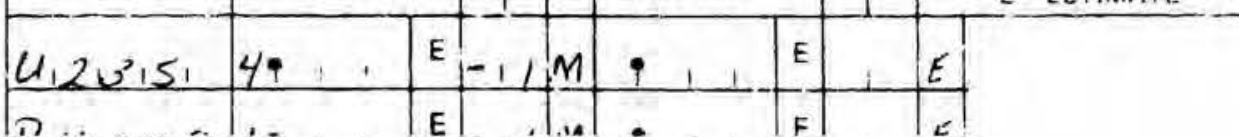

P

\begin{tabular}{|c|c|c|}
\hline $14,2,3,7$ & $i \overline{1}$ & \\
\hline काष्टार & 391 & \\
\hline
\end{tabular}

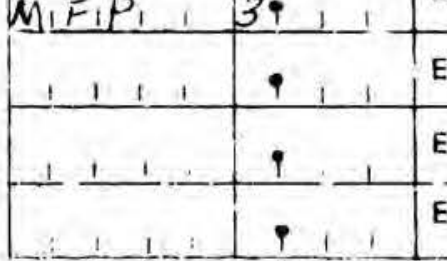

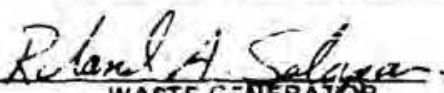
TASTE GENEATATOK

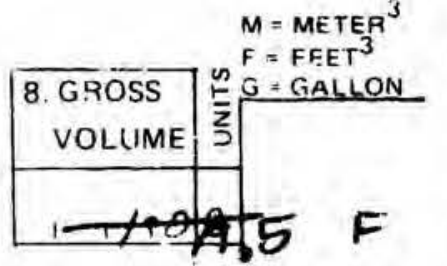

\begin{tabular}{|c|c|}
\hline 9. PACKAGE ADIATION AT: \\
\hline $\begin{array}{c}\text { SIJFFAGE } \\
\text { MR/HR }\end{array}$ & $\begin{array}{c}\text { 1 METER } \\
\text { :ARIHR }\end{array}$ \\
\hline $3,5,0,0,0$ & $1,3,0,0$ \\
\hline
\end{tabular}
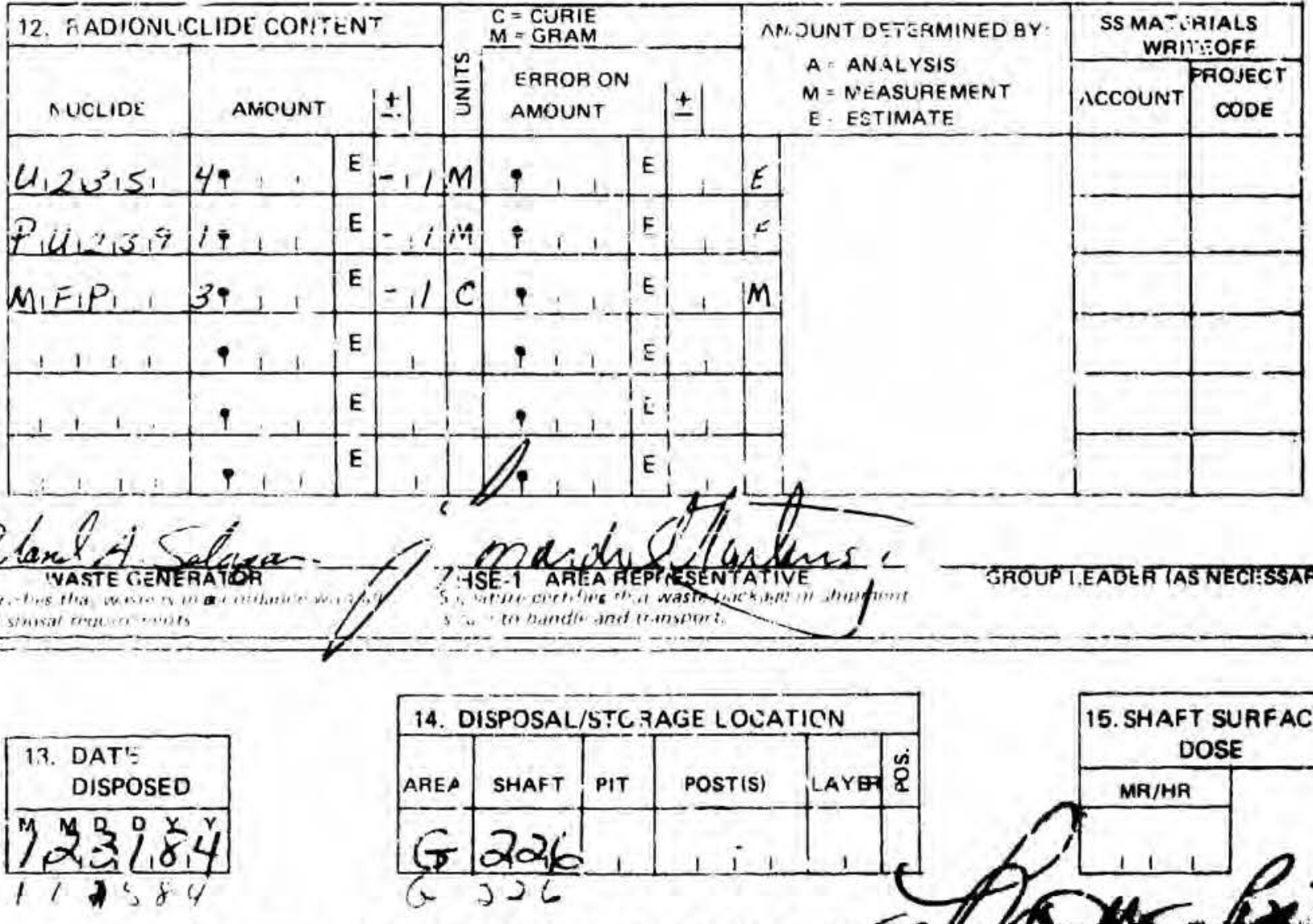
RADIOACTIVE SOLID WASTE DISPOSAL RECORD FORMS

FOR

SHAFT 227

MATERIAL DISPOSAL AREA G 
1. Femingen

1., s, pipr
PLEAES NEAD INBTRUCTIONS ON BACK CAREFULLY

\section{LOS ALAMES RABIOACTNE 8OLID WASTE DIENOSAL RECORD FORM}

HSE.7 Waste Management

LA 6095 MS J592
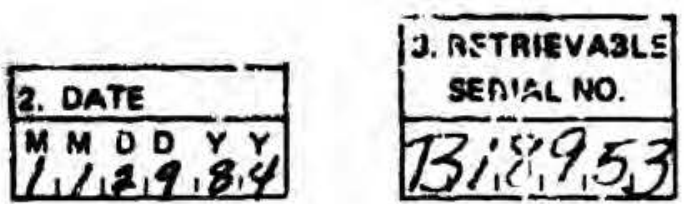

\begin{tabular}{|c|c|c|c|c|}
\hline \multicolumn{3}{|l|}{ 4. ORIGIN OF WASTE } & OL \\
\hline GROUP & TA & BLOG. & है & ROOM \\
\hline$M_{1} S_{1} T_{1} 1,4$ & 0,3 & $C_{1} S_{1} M_{12} 2,9$ & 9 & \\
\hline
\end{tabular}

\section{WASTE DESCRIPTION}

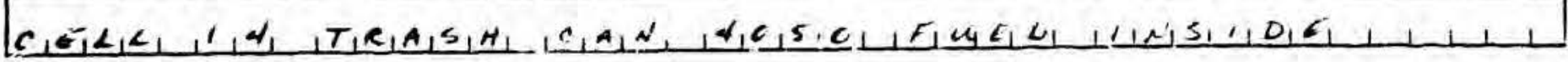

\begin{tabular}{|c|c|c|c|c|}
\hline \multicolumn{5}{|c|}{ 7. NUMBERS OF WASTE PACKAGES } \\
\hline & & DRUA98 & no & DEN CRATES \\
\hline $\begin{array}{l}\text { PLASTIC } \\
\text { eAGS }\end{array}$ & $\begin{array}{l}\text { BOAAD } \\
\text { BOXES }\end{array}$ & no. jGaL. & No. & VOLIJME $\cdot f_{t}^{3}$ \\
\hline
\end{tabular}
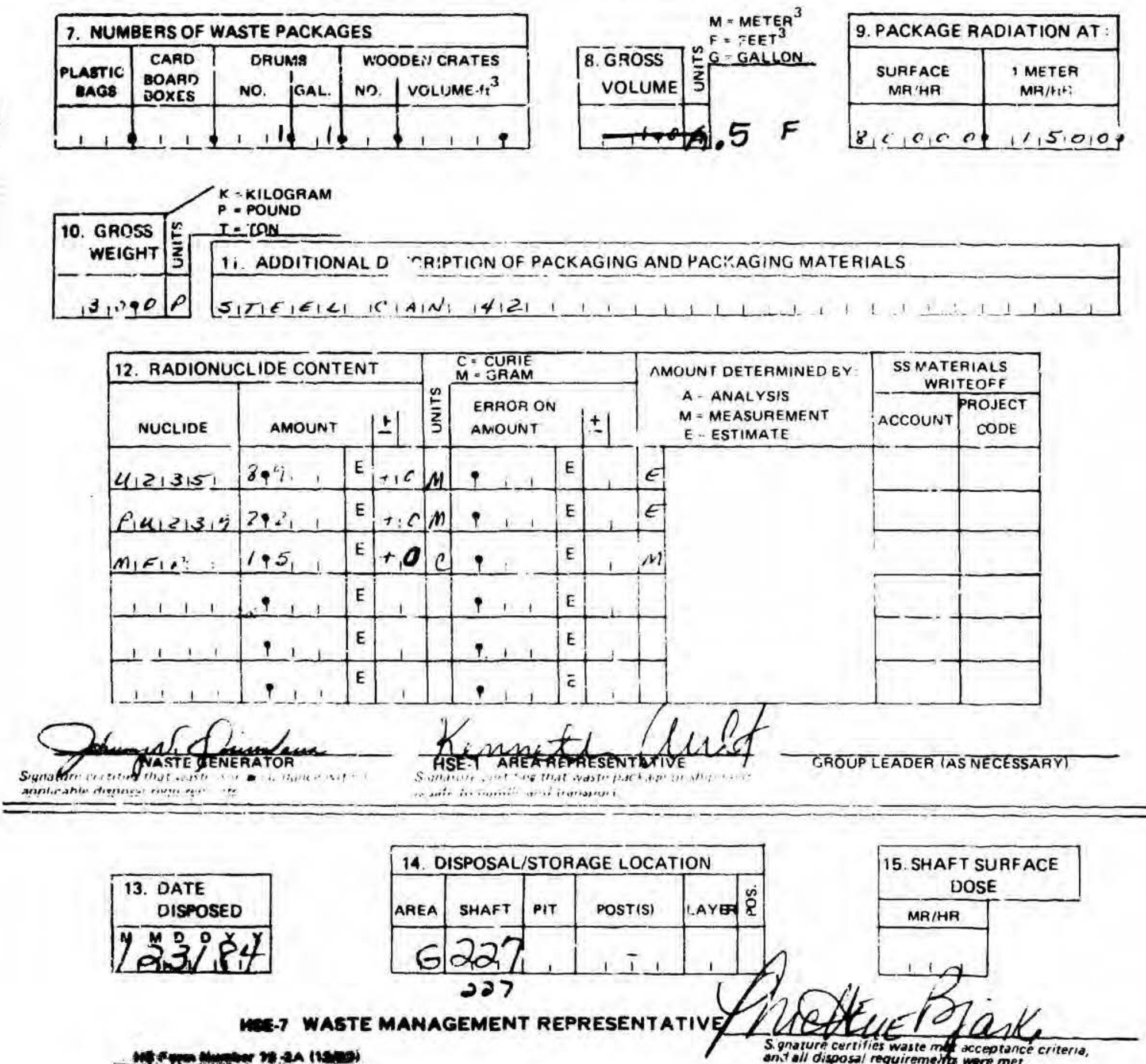

WE-7 WASTE MANAGEMENT REPRESENT ATIV 
PLEASE REAL INSTRUCTIONS ON BACK CAFEFULLY

\begin{tabular}{|l|}
\hline 1. FORM NUMBER \\
\hline$S, 8,4$, OPN, \\
\hline
\end{tabular}

\section{LOS ALAMJS RADIOACTIVE SOLID WASTE DISPOSAL RECORD FORM \\ I. 1 if 94. MS JE32}

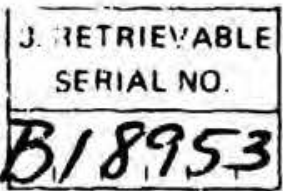

\begin{tabular}{|c|c|c|c|c|}
\hline \multicolumn{3}{|c|}{ 4. ORIGIN OF WASTE } & \multirow{2}{*}{$\frac{0}{3}$} & \multirow[b]{2}{*}{ ROOM } \\
\hline GROUP & TA & BLDG. & & \\
\hline
\end{tabular}

6. WASTE DESC.RIPTION

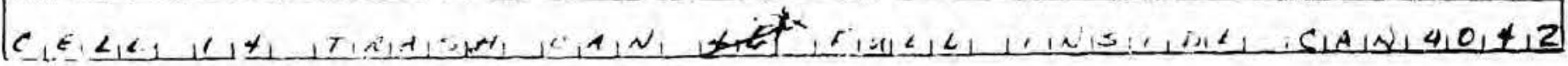

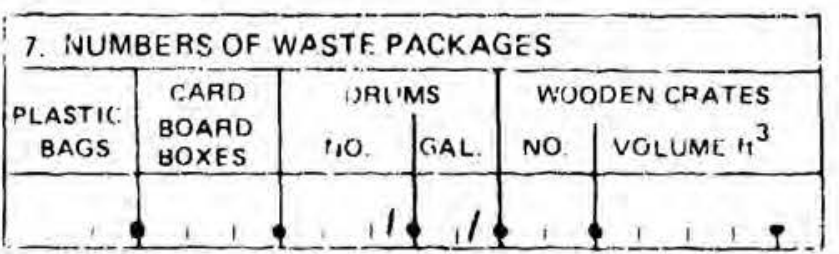

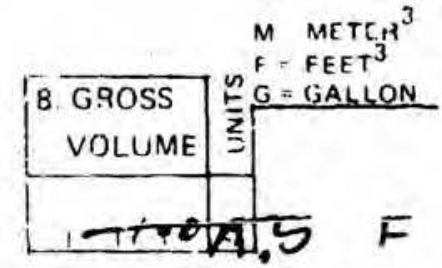

\begin{tabular}{|l|c|}
\hline 9. PACKAGE RADIATION AT: \\
\hline $\begin{array}{c}\text { SURFACE } \\
\text { MR/HA }\end{array}$ & $\begin{array}{c}\text { 1 METER } \\
\text { MR/HR }\end{array}$ \\
\hline & $12,5,0,0$ \\
\hline
\end{tabular}

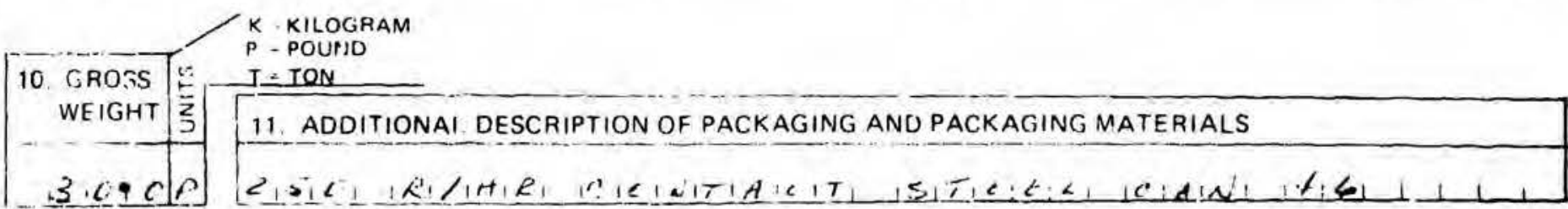

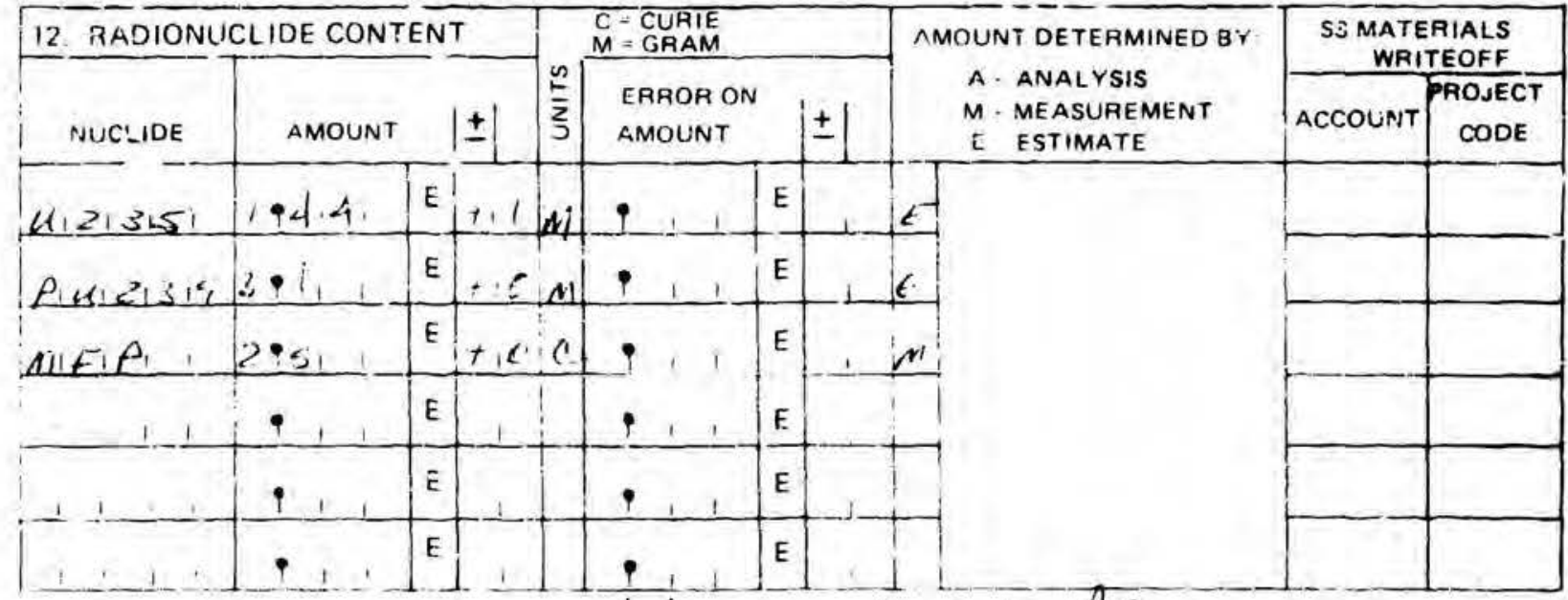

13. DATE DISPOSER

$2 / 230 \%$
HBE.7 WASTE MANAGEMENT REPRESENTATI HS Form Number $10-2 \mathrm{~A}$ (12/83)

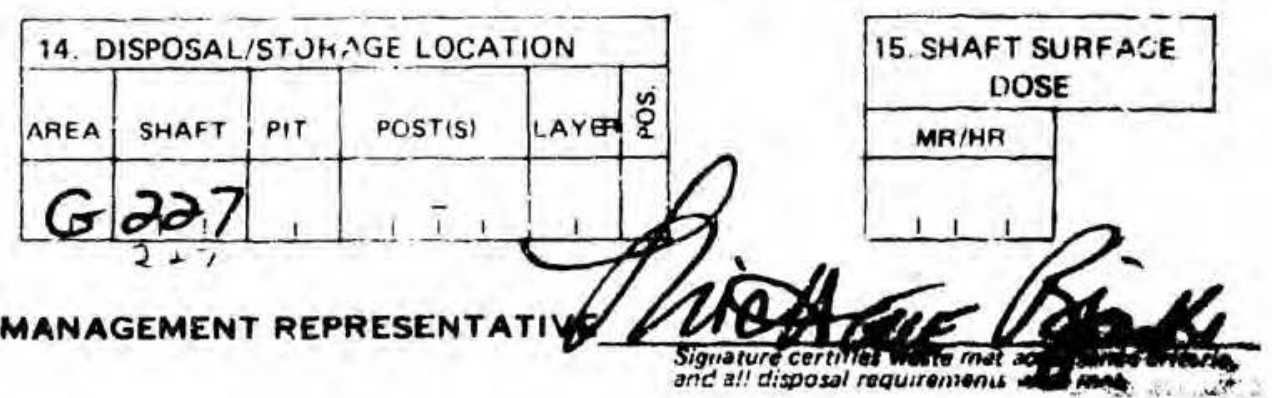




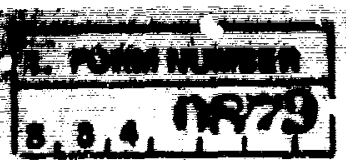

ALET REAO WOTKUGTIONS ON BACK CAREFULLV

\section{LOS ALAOA RABNACTIVE COLIO WASTE Disroanl AEcono FonM}

HSE 7 Woste Managemert

E. 6095 MS J592

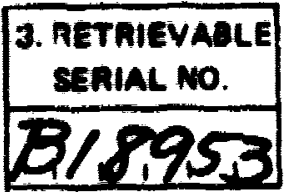

\begin{tabular}{|c|c|c|c|c|}
\hline \multicolumn{3}{|c|}{ 4. OAIGIN OF WASTE } & \multirow{2}{*}{$\frac{9}{2}$} & \multirow[b]{2}{*}{ मOOM } \\
\hline onOuP & TA & OLOG & & \\
\hline$M_{1} \leq T_{1}||$, & 013 & $0_{1} s_{1, n 1}$ & 5 & \\
\hline
\end{tabular}

$\begin{array}{r}\text { 6. WASTE } \\ \text { CODE } \\ \hline A_{1} \perp 10 \\ \hline\end{array}$

\section{WASTE DESCRIPTION}

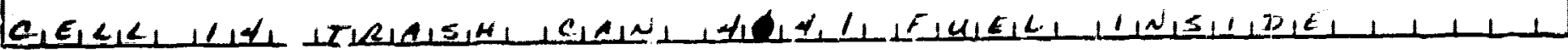

\begin{tabular}{|c|c|c|c|c|c|}
\hline \multicolumn{6}{|c|}{ 1. NUMBERS OF WASTE PACKAGES } \\
\hline & CARD & & & wor & DEN CRATES \\
\hline $\begin{array}{l}\text { Lastic } \\
\text { GAGS }\end{array}$ & $\begin{array}{l}\text { 3OAAD } \\
\text { I10XES }\end{array}$ & No. & GaL. & No. & VOLUME $\cdot \mathrm{tt}^{3}$ \\
\hline & & & & & \\
\hline
\end{tabular}
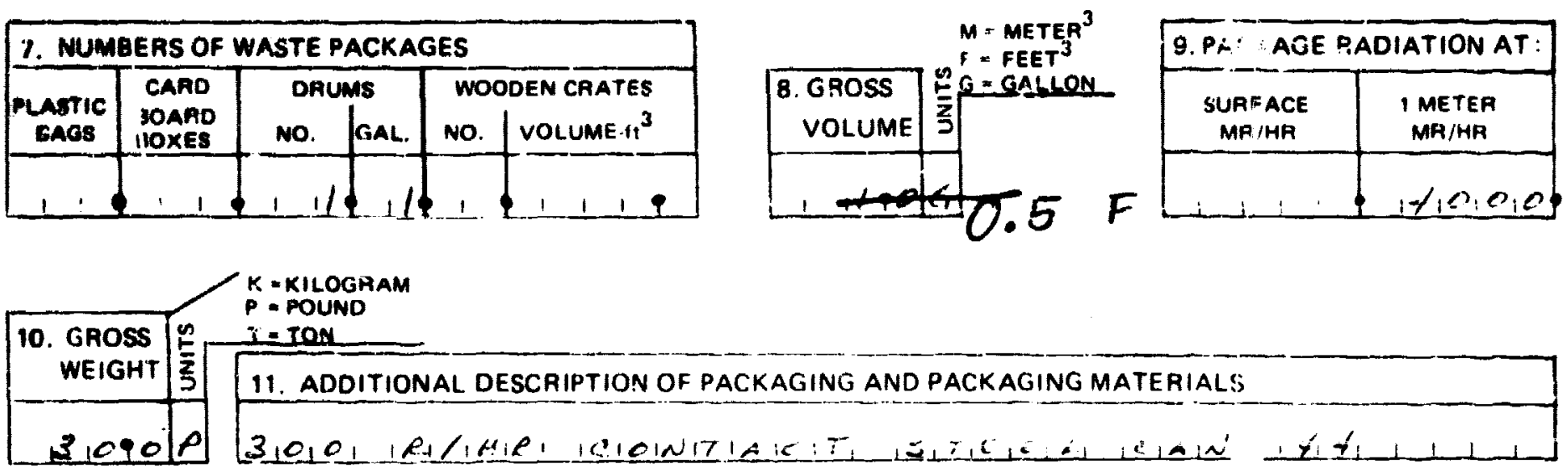

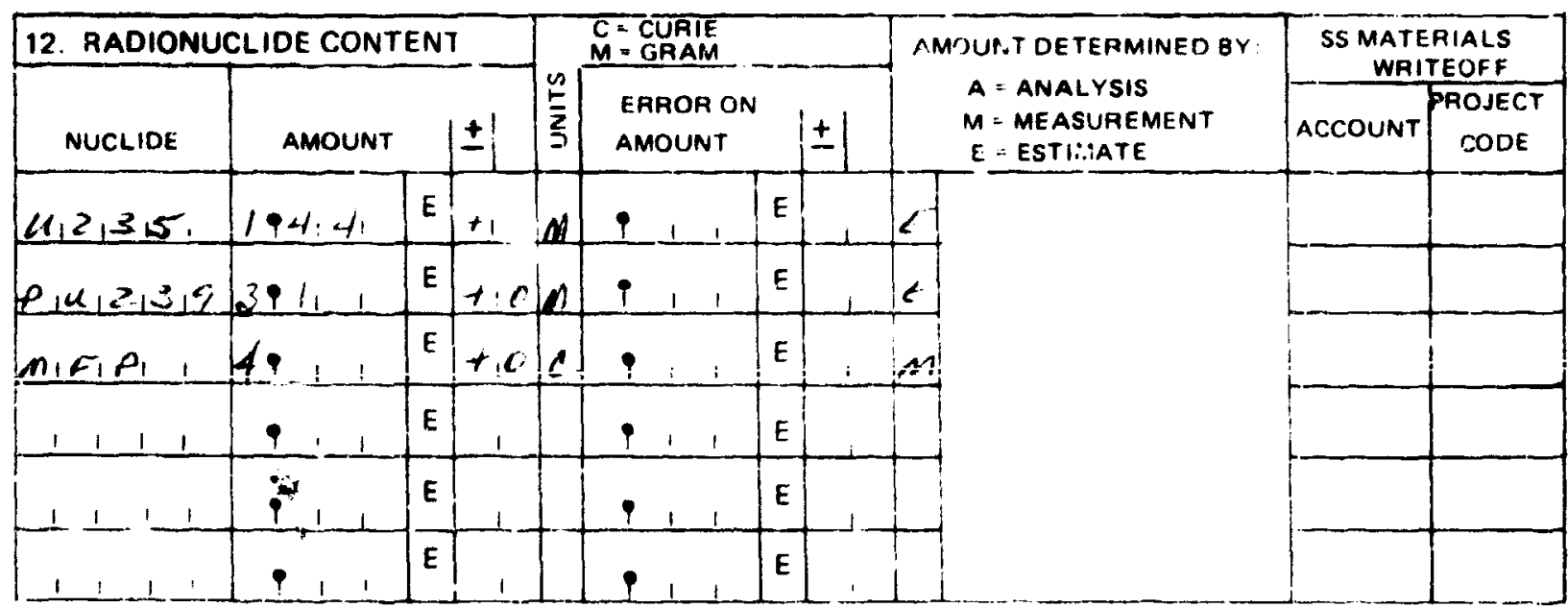

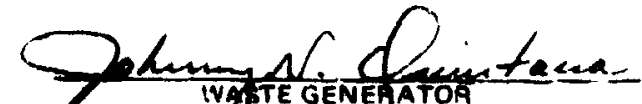

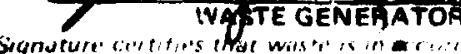
Kengapte He.1. A. E.....

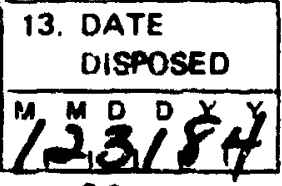

$1+-28-8 v$
W.7 WASTE MANAGEMENT REPRESENTATIVE

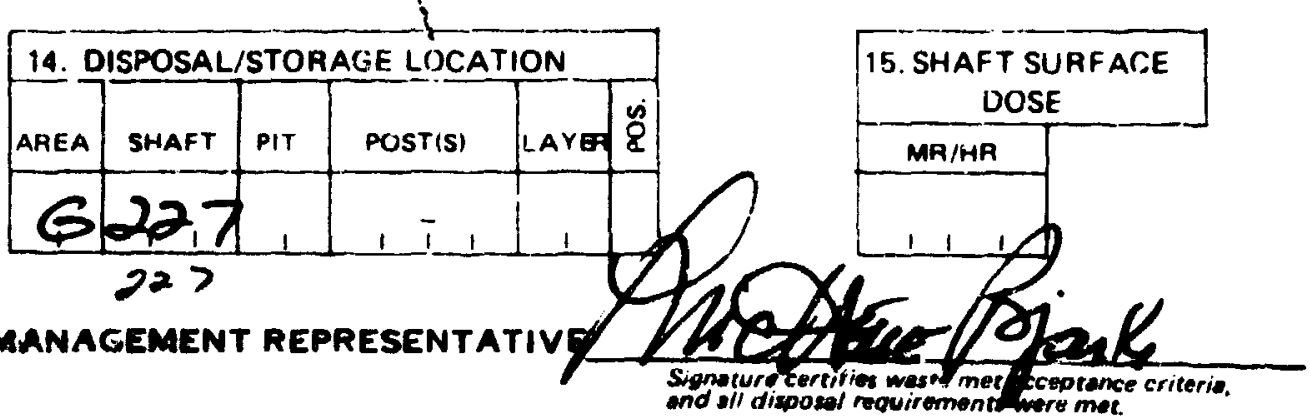


PLEASE READ INSTRUCTIONS ON GACK CAREFULLY

1. FJAM PJUMEER

s. $, 4,1), 890$
LO8 ALAMOS RADIOACTIVE SOLLID WASTE DISPOSAL RECORD FORM
HSE 7 Waste Managomant

Ext 6095 MS J692
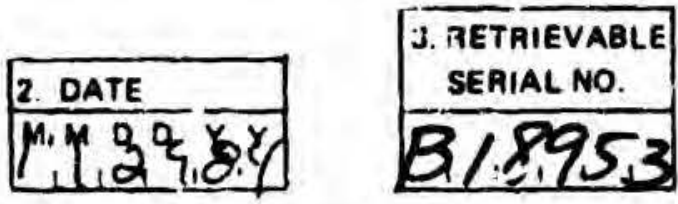

\begin{tabular}{|c|c|c|c|c|}
\hline \multicolumn{3}{|c|}{ 4. ORIGIN OF WASTE } & \multirow{2}{*}{ 谤 } & \multirow[b]{2}{*}{ ROOM } \\
\hline GAOUP & TA & BLDG. & & \\
\hline$n s, r, 1$ & 0,3 & $S_{1} t_{12}$ & & \\
\hline
\end{tabular}

\section{WASTE DESCRIPTION}

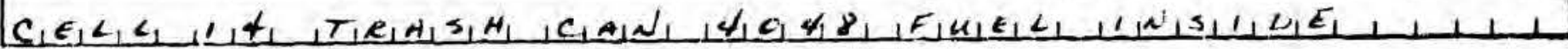

\begin{tabular}{|c|c|c|c|c|c|}
\hline \multicolumn{6}{|c|}{ 7. NUMBERS OF WASTE P CKAGES } \\
\hline & CARO & DR & & & DEN CHATES \\
\hline BAGS & $\begin{array}{l}\text { ROARD } \\
\text { BOXES }\end{array}$ & No. & GAL. & No & VOLUME $\cdot \mathrm{At}^{3}$ \\
\hline & & & & & 1 \\
\hline
\end{tabular}
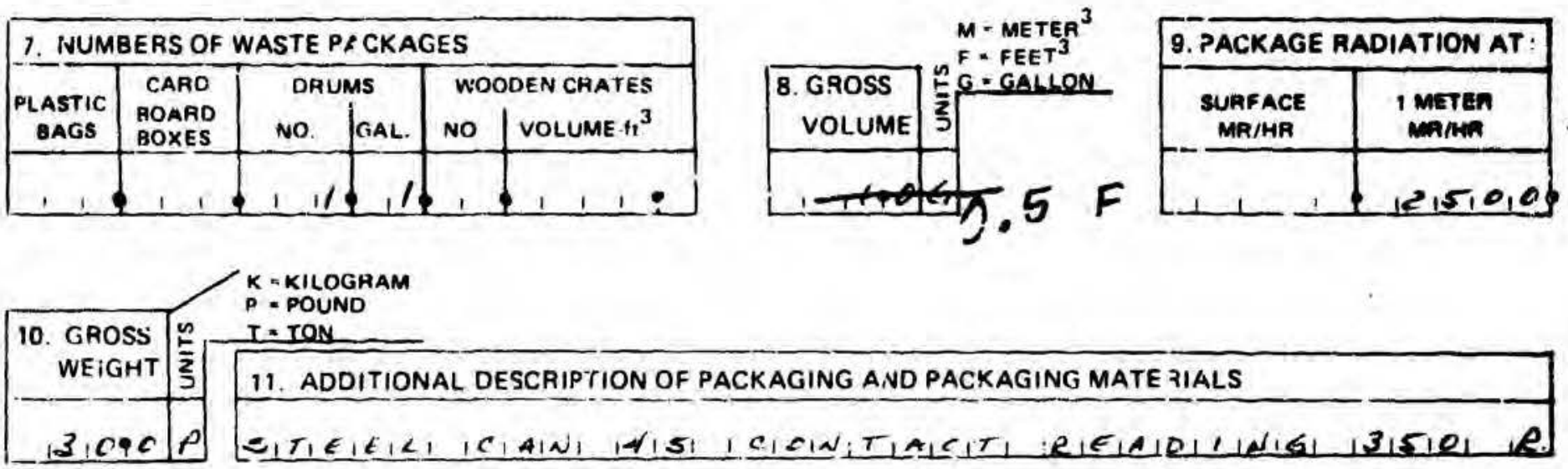

\begin{tabular}{|c|c|c|c|c|c|c|c|c|c|c|c|}
\hline \multicolumn{4}{|c|}{ 12. RADIONUCLIDE CONTEINT } & \multicolumn{4}{|c|}{$\begin{array}{l}C=\text { CUAIE } \\
M=\text { RAM }\end{array}$} & \multirow{2}{*}{\multicolumn{2}{|c|}{$\begin{aligned} & \text { AMOUNT DETERMINED B } \\
& \text { A }=\text { ANALYSIS } \\
& M=\text { MEASUREAIENT } \\
& E \text { ESTIMATE }\end{aligned}$}} & \multicolumn{2}{|c|}{$\begin{array}{c}\text { SS MATERIALS } \\
\text { WRITEOFF } \\
\end{array}$} \\
\hline NUCLIDE & AMOUNT & & \pm & $\mid \begin{array}{c}n \\
\frac{2}{2}\end{array}$ & $\begin{array}{l}\text { EFROR ON } \\
\text { ANIOUNT }\end{array}$ & & \pm & & & ACCOUNT & CODE \\
\hline$u_{1} 2_{1}, S_{1}$ & $11 \cdot 4: 4$ & E & +1 & $M$ & 911 & E & & $E$ & & & \\
\hline$P_{1} u_{1} \geq_{1} z_{1}$ & $3: 1,1$ & E & +0 & $M$ & $1 \quad 1$ & E & & $E$ & & & \\
\hline$M_{1} F_{1} A_{1}$ & $2951 \quad 1$ & E &,+ 0 & ac & $9: 1$ & $\mathrm{E}$ & & $M$ & & & \\
\hline 1,11 & 1 1 & E & 1 & & 9,1 & E & & & & & \\
\hline 11,1 & 9,1 & E & 1 & & 1. 1 & E & & & & & \\
\hline 1.1 & i 1 & E & + & & 1,1 & $E$ & & & & & \\
\hline
\end{tabular}
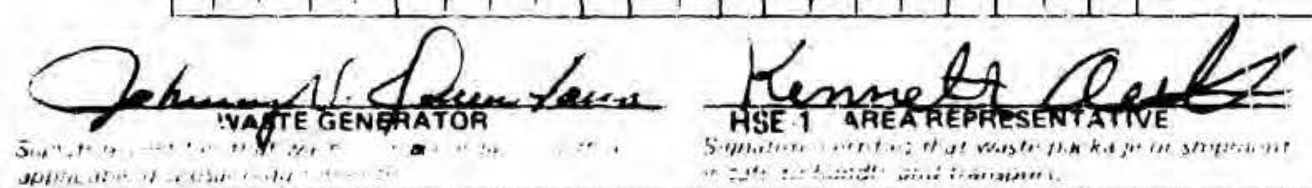

GROUP LEADEATASTECESSARY
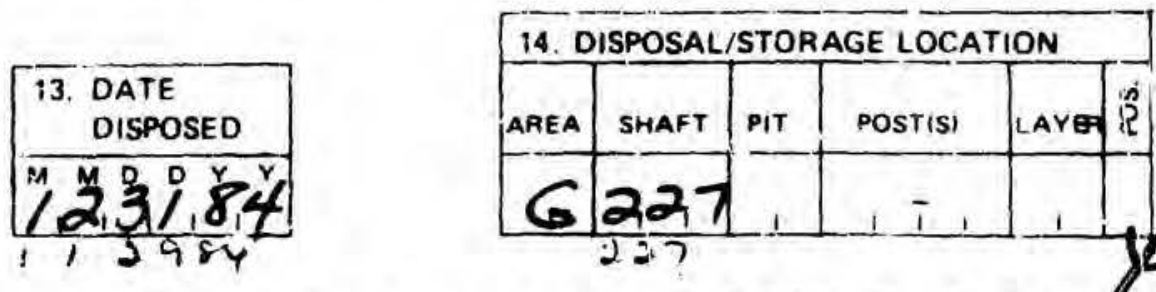

HEE-7 WASTE MANAGEMENT REPRESENTATIVE 


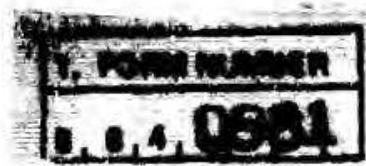

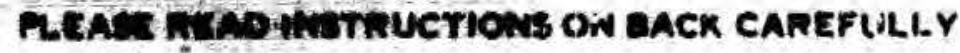
LOS AMANS RADHONCTNE EOLID WASTE
CUEOSAL RECOAO FOAM

HSE 7 Waste Mandgemen

Ext 6095 MS $J 592$

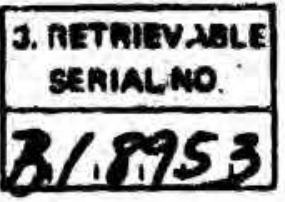

\begin{tabular}{|c|c|c|c|c|}
\hline \multicolumn{3}{|c|}{ 4. ORIGIN OF WASTE } & \multirow{2}{*}{$\frac{2}{5}$} & \multirow[b]{2}{*}{ POOM } \\
\hline Gnoup & TA & BLDG. & & \\
\hline$A_{1} \leq 1 T, 1,4$ & 0,3 & & 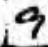 & \\
\hline
\end{tabular}

$\begin{array}{r}\text { D. VASTE } \\ \text { CODE } \\ \hline \text { A' } \\ \hline\end{array}$

\section{WASTE DESCAIPTION}

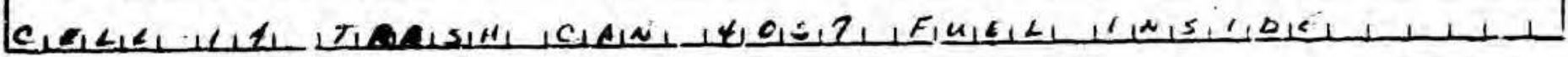

\begin{tabular}{|c|c|c|c|c|c|}
\hline \multicolumn{6}{|c|}{ 7. NUMBERS OF WASTE PACKACES } \\
\hline $\begin{array}{c}\text { RLAST'C } \\
\text { BAOS }\end{array}$ & $\begin{array}{l}\text { CAAD } \\
\text { SOAAD } \\
\text { BOXES }\end{array}$ & & mis & & $\begin{array}{l}\text { DDEN CAATES } \\
\text { | VOLUME. }{ }^{3}\end{array}$ \\
\hline & & & & & $1 \quad 1 \quad 1$ \\
\hline
\end{tabular}

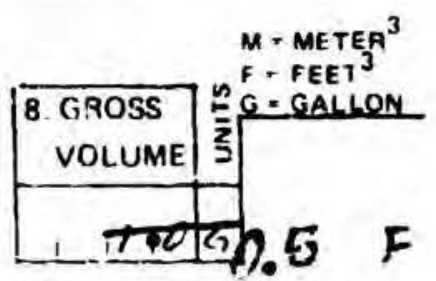

\begin{tabular}{|c|c|}
\hline 9. PACKAGE RADIATION AT \\
\hline $\begin{array}{c}\text { SURFACE } \\
\text { MRIHR }\end{array}$ & $\begin{array}{c}\text { 1 METEF } \\
\text { MRIHR }\end{array}$ \\
\hline & $3: 0$ \\
\hline
\end{tabular}

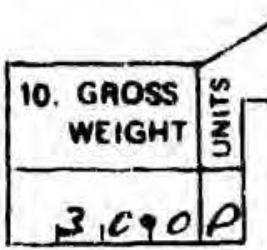

$K$ - KILOGRAM

$P \rightarrow$ POUNU

\section{$I=$ TON}

11. ADDITIONAL DESCRIPTION OF PACKAGING AND PACKAGING MATERIALS

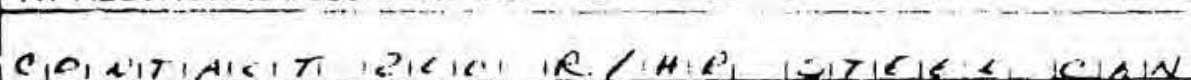

\begin{tabular}{|c|c|c|c|c|c|c|c|c|c|c|c|}
\hline \multicolumn{4}{|c|}{ 12. RAOIONUCLILE CONTENT } & \multicolumn{4}{|c|}{$\begin{array}{l}\text { C. CUAIE } \\
M \text { GAAM } \\
\end{array}$} & \multirow{2}{*}{\multicolumn{2}{|c|}{$\begin{array}{l}\text { AMOUNT UETERMINED BY } \\
\text { A ANALYSIS } \\
M \text { MEASUREMENT } \\
E \text { - ESTIMATE }\end{array}$}} & \multicolumn{2}{|c|}{$\begin{array}{c}\text { SS MATERIALS } \\
\text { WRITEOFF }\end{array}$} \\
\hline NUCLIDE & AMOUNT & & \pm & $\frac{n}{3}$ & $\begin{array}{l}\text { ERROR ON } \\
\text { AMOUNT }\end{array}$ & & \pm & & & Accourst & $\begin{array}{l}\text { PAOJECT } \\
\text { CODE }\end{array}$ \\
\hline$u_{1} \geq_{1} \dot{B}_{10}$ & 1.4 .4$. & E & +11 & $M$ & 11,1 & E & & $\epsilon$ & & & \\
\hline$\rho_{14} \geq 3,3$ & 3911 & E & +10 & al & 1 & E & & 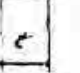 & & & \\
\hline$m: E ! P$ & $3:+1$ & $\mathrm{E}$ & $\pm: 0$ & $c$ & $\therefore=$ & E & : & 2 & & & \\
\hline $1+1.1$ & $1+1$ & E & & & 1,1 & E & & & & & \\
\hline $11+1$ & 11 & E & $\perp$ & & P. 1 & E & & & & & \\
\hline $1 \ldots 1$. & 11. & $E$ & 1 & & 1,1 & E & & & & & \\
\hline
\end{tabular}

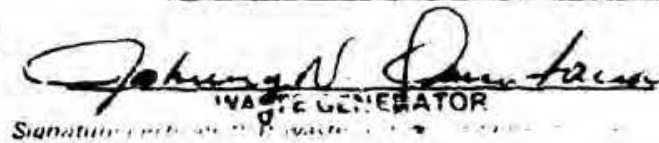

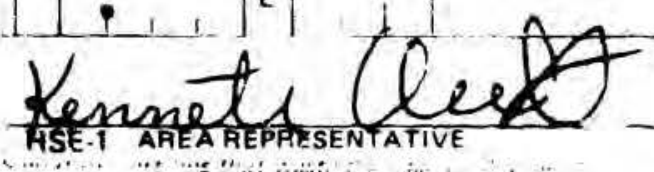

GROUP LEADER IAS NECESSARYI
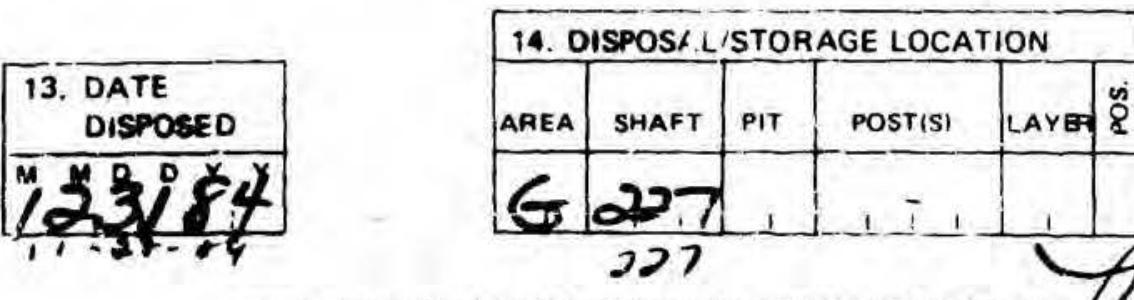

\%AETE MANAGEMENT REPRESENTATIVE

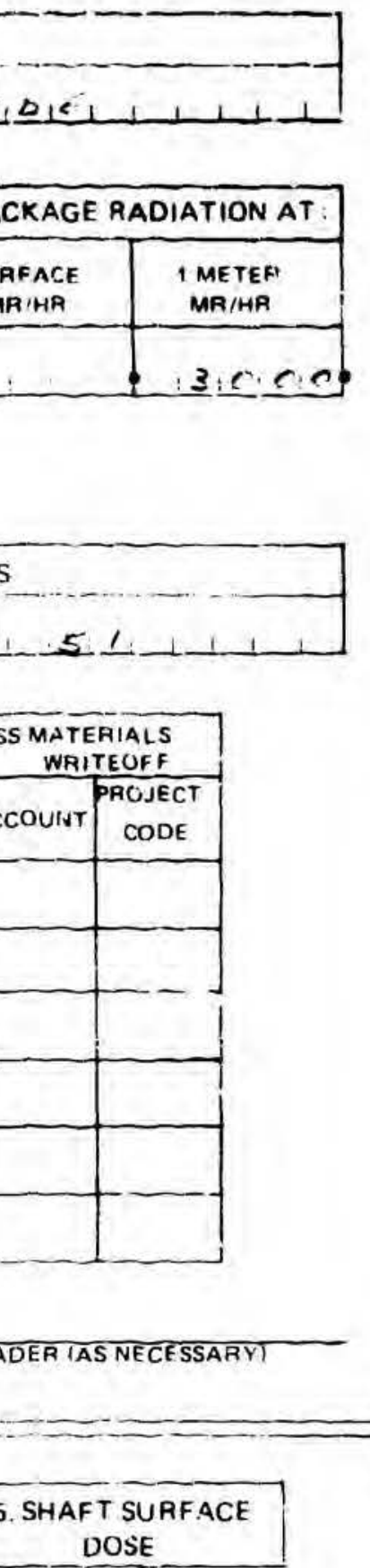


i. Fown ruving in

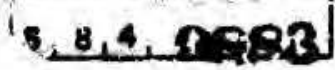

\section{LOS ALAMDS RADIOACTIVE COAID WASTE DISPOSAL AECOAD FOAM}

HSE 7 Waste Manaqement

Ex: 6095 MS $J 592$

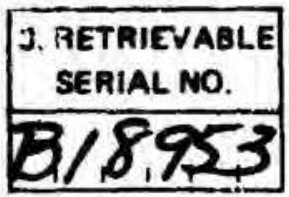

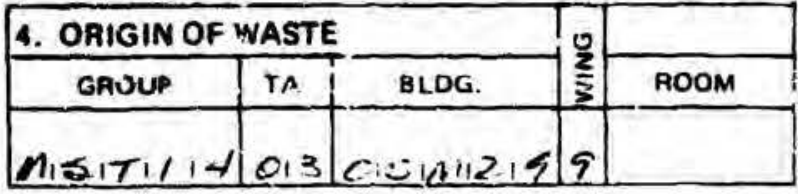

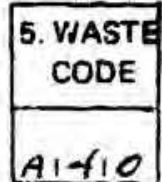

6. WASTE DESCRIPTION

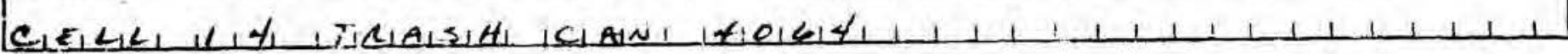

\begin{tabular}{|c|c|c|c|c|c|}
\hline \multicolumn{4}{|c|}{ 7. NUMBERS OF WASTE PACKAGES } & wo & DEN CRATES \\
\hline $\begin{array}{l}\text { PLASTIC } \\
\text { BAGS }\end{array}$ & $\begin{array}{l}\text { BOARD } \\
\text { BOXES }\end{array}$ & NO. & GAL. & NO. & VOLUNIE. $\cdot t^{3}$ \\
\hline
\end{tabular}

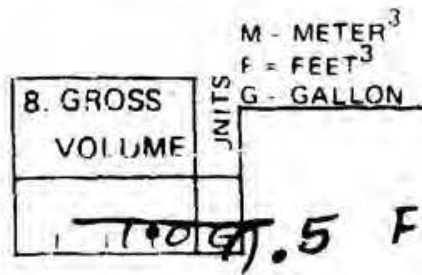

\begin{tabular}{|c|c|}
\hline \multicolumn{2}{|c|}{ 9. PACKAGE RADIATION AT: } \\
\hline $\begin{array}{c}\text { SURFACE } \\
\text { MR/HR }\end{array}$ & $\begin{array}{c}\text { IMETER } \\
\text { MR/HR }\end{array}$ \\
\hline 1 & IZIOIOIOS \\
\hline
\end{tabular}

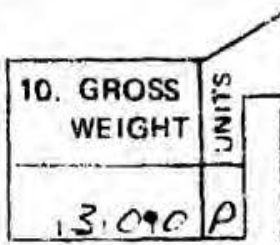

$K=K I L O G A M M$

$P=$ POUND

$I=$ TON

11. ADDITIONAL DESCRIPTION OF PACKAGING AND PACKAGING MATERIALS

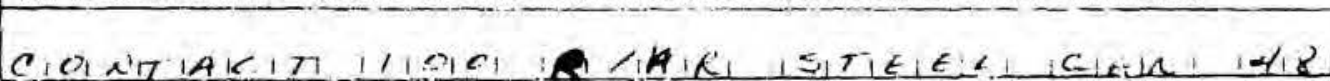

\begin{tabular}{|c|c|c|c|c|c|c|c|c|c|c|c|}
\hline \multicolumn{4}{|c|}{ 12. RADIONUCLIDE CGNTENT } & \multicolumn{4}{|c|}{$\begin{aligned} C & =\text { CURIE } \\
M & =G R A M\end{aligned}$} & \multirow{2}{*}{\multicolumn{2}{|c|}{$\begin{array}{l}\text { AMOUNT DETERMINED BY } \\
\text { A ANALYYSIS } \\
M \text { - MEASUREMENT } \\
\text { E : ESTIMATE }\end{array}$}} & \multicolumn{2}{|c|}{$\begin{array}{l}\text { MATERIALS } \\
\text { WRITEOFF }\end{array}$} \\
\hline NUCLIDE & AMOUNT & & \pm & $\frac{n}{z}$ & $\begin{array}{l}\text { ERROR ON } \\
\text { AMOUNT }\end{array}$ & & \pm & & & ACCOUNT & $\begin{array}{c}\text { PROJECT } \\
\text { CODE }\end{array}$ \\
\hline $4,2,3,51$ & $4 \cdot:$ & E & 011 & m. & $i \quad i \quad i$ & $\mathrm{~F}$ & & $\epsilon$ & & & \\
\hline$\rho_{1 \times 121313}$ & $1 \cdot 1,1$ & E & $=1$ & ti. & 1 11 & $E$ & & E & & & \\
\hline A)FIA, & $2 \cdot:$ & $E$ & $+c^{2}$ & ic & $1: 1$ & E & & 11 & & & \\
\hline 1111 & $9 \quad 1$ & [ & & & $\cdot 1$ & E- & & & & & \\
\hline 1111 & 1.1 & E & -1 & & 1,1 & E & & & & & \\
\hline $1 \div 1$ & P. 1 & E & & & - 1 & E & & & & & \\
\hline
\end{tabular}
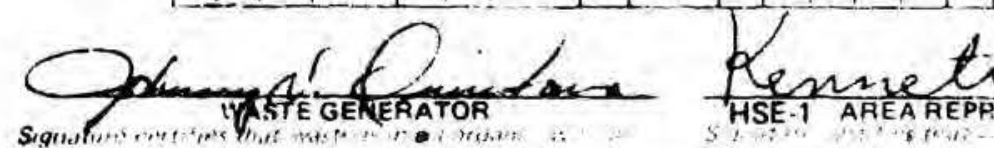

ti
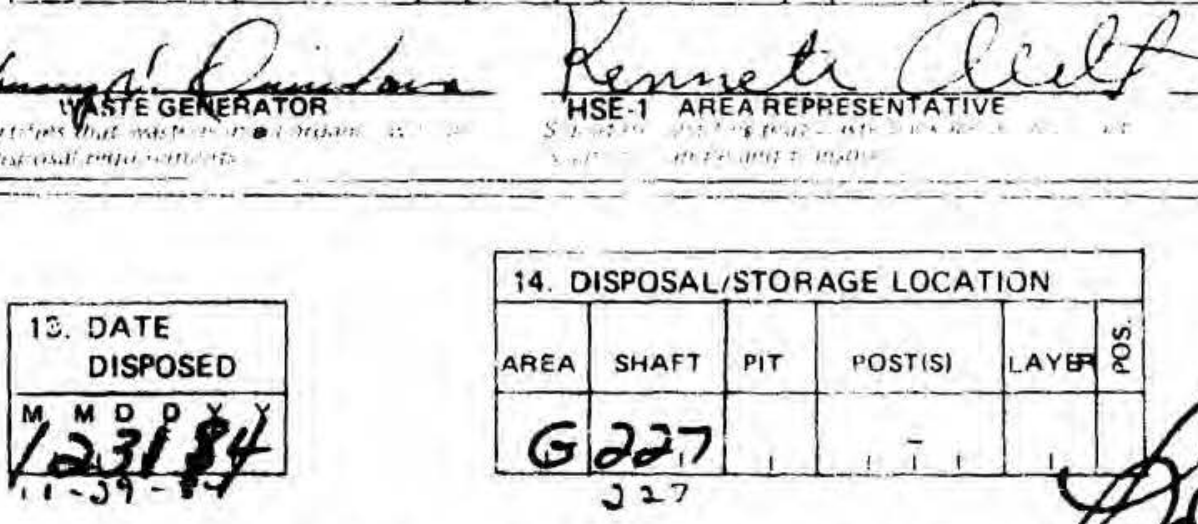

HEE-7 WASTE MANAGEMENT REPRESENTATIV 
PLIASE READ INSTRUCTIONSC J BACK CAREFULLY

1. FORM NUMBER

s, 8, 4, 199
LOS ALAMOS RADIOACTIVE SOLID WASTE DISPOSAL RECORD FORM
HSE.7 Waste Manageinent

Ext 6095 MS $J 592$

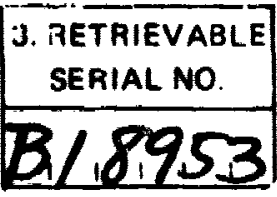

\begin{tabular}{|c|c|c|c|c|}
\hline \multicolumn{3}{|c|}{ 1.. ORIGIN OF WASTE } & \multirow{2}{*}{$\frac{0}{\frac{0}{3}}$} & \multirow[b]{2}{*}{ foom } \\
\hline GROUP & TA & BLDG. & & \\
\hline$M S_{171}$ & $C_{1}$ & $\leqslant m_{1}$ & 19 & \\
\hline
\end{tabular}

$\begin{array}{r}\text { 5. WAYT } \\ \text { Cove } \\ \hline 1+10 \\ \hline\end{array}$

\section{WASTE DESCRIPTION}

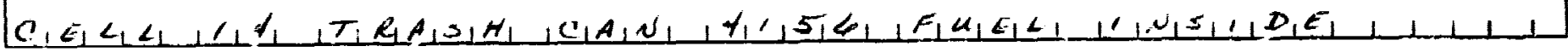

\begin{tabular}{|c|c|c|c|c|c|}
\hline \multicolumn{6}{|c|}{ 7. NUMBERS OF WASTE $r$ ACKAGES } \\
\hline & CARD & & & WO & DEN CSATES \\
\hline $\begin{array}{l}\text { PLASTIC } \\
\text { BAGS }\end{array}$ & $\begin{array}{l}\text { BOARD } \\
\text { BOXES }\end{array}$ & No. & GAL. & No. & VOLUME $\cdot \mathrm{ft}^{3}$ \\
\hline 1 & & 1 & 11 & 1 & 1 \\
\hline
\end{tabular}

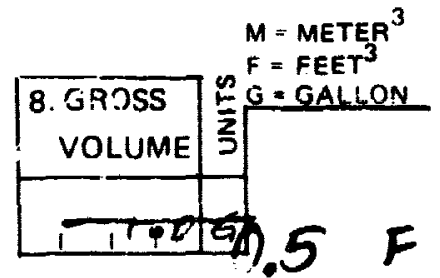

\begin{tabular}{|c|c|}
\hline \multicolumn{2}{|c|}{ 9. PACKAGE RADIATION AT: } \\
\hline $\begin{array}{c}\text { SURFACE } \\
\text { MA/HR }\end{array}$ & $\begin{array}{c}1 \text { METER } \\
\text { MA/MP }\end{array}$ \\
\hline & $16,0,0,0$ \\
\hline
\end{tabular}

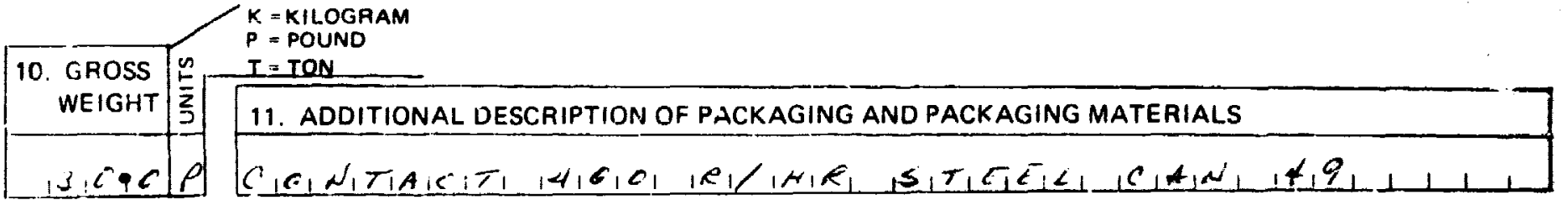

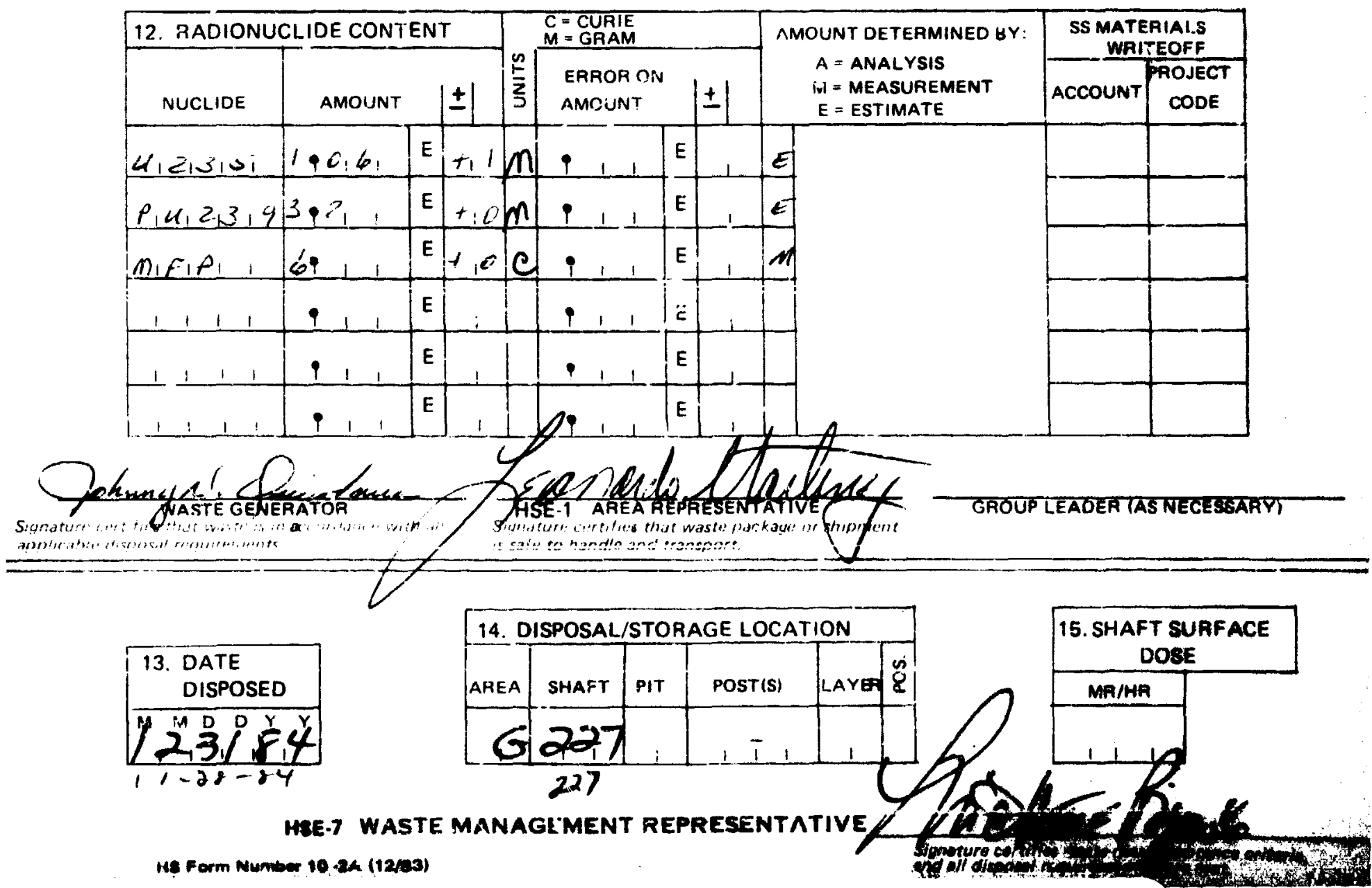


PLEASE READ INSTRUCTIONS ON BACK CAREFULLY

1. FONM NUMBER
$5,8,4,0896$

\section{LOS ALAMOS RADIOACTIVE SOLID WASTE DISPOSAL RECOPD FORM}

HC. 7 Vusin Management

$F .+5095$ MS J592

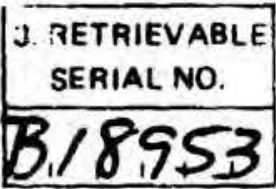

\begin{tabular}{|c|c|c|c|c|}
\hline \multicolumn{3}{|c|}{ 4. ORIGIN OF WASTE } & \multirow{2}{*}{$\frac{0}{2}$} & \multirow[b]{2}{*}{ ROOM } \\
\hline GAOUP & TA & BLDG. & & \\
\hline$m_{1} \leq, 7,1,4$ & 2,3 & $2, s_{1} n_{1} 2,43$ & $\because$ & \\
\hline
\end{tabular}

\begin{tabular}{|c|}
\hline $\begin{array}{l}\text { 5. VJASTE } \\
\text { CODE }\end{array}$ \\
\hline$A, \pm 1 C$ \\
\hline
\end{tabular}

\section{WASTE DESCRIPTION}

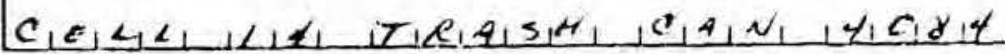

\begin{tabular}{|c|c|c|c|c|c|}
\hline \multicolumn{6}{|c|}{ 7. NUMBERS OF WASTE PACKAGES } \\
\hline & CARO & & & wo & DEN CRATES \\
\hline PLAGS & $\begin{array}{l}\text { BOARD } \\
\text { BOXES }\end{array}$ & NO. & GAL. & NO. & VOLUME $+t^{3}$ \\
\hline
\end{tabular}
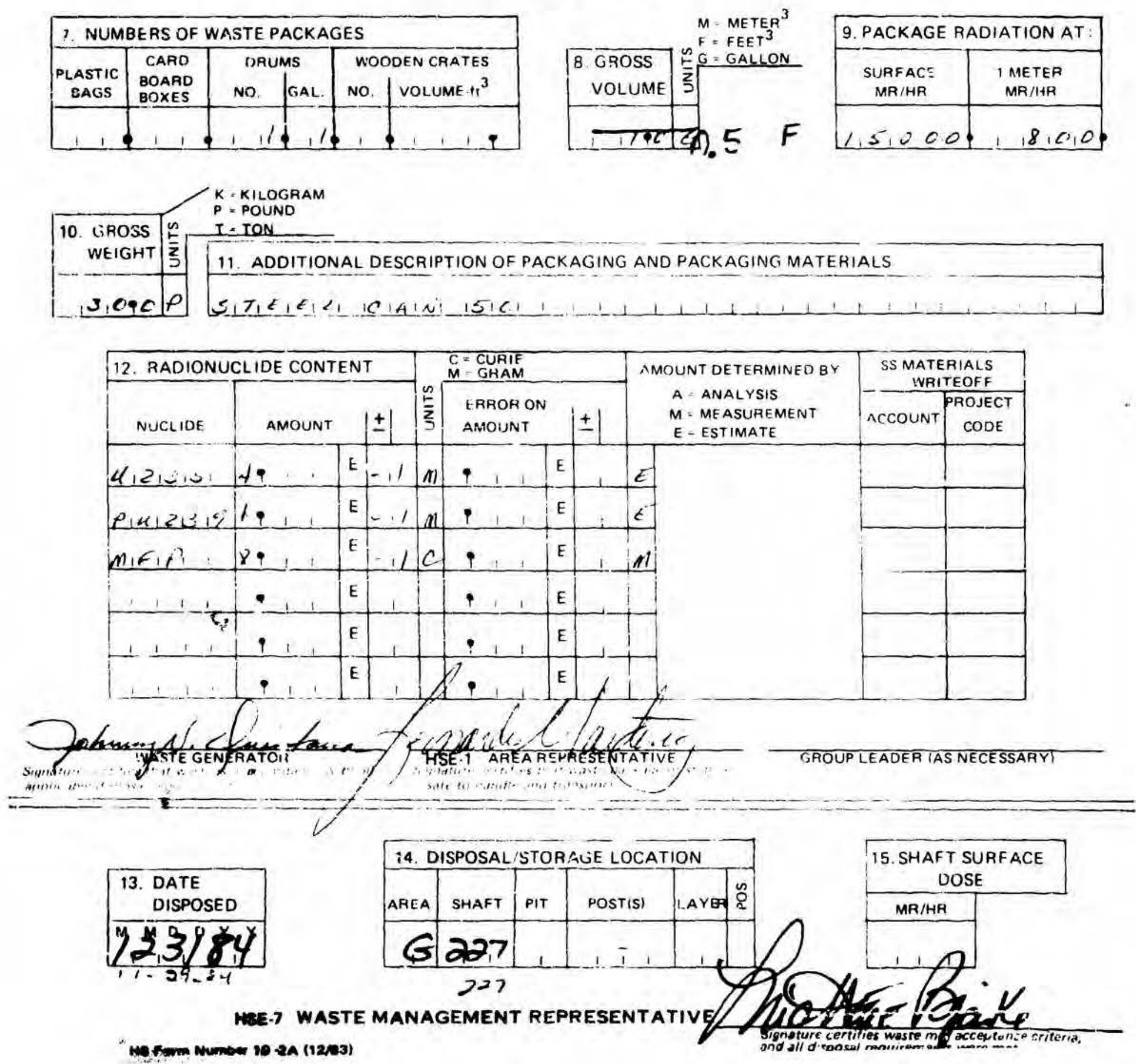
RADIOACTIVE SOLID WASTE DISPOSAL RECORD FORMS

FOR

SHAFT 228

MATERIAL DISPOSAL AREA G 


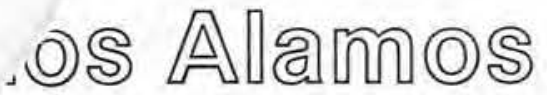

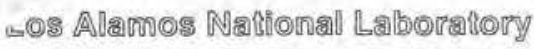

Los Al:mos, New Mexilco 87545

RADIOACTIVE SOLID WASTE DISPOSAL RECORD

1. Form Number

$\mathrm{S}|8| 7 \mid \quad 4123$

NOTE: Read instructions on back carefully before completing this torm

HSE-7 Waste Management Exi. 6095. MS 1592

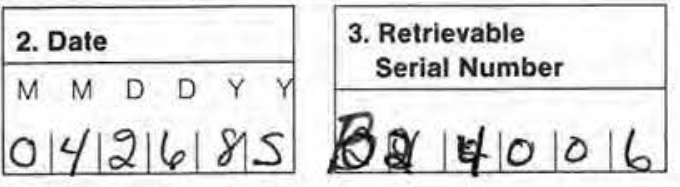

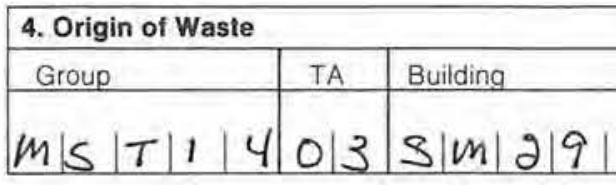

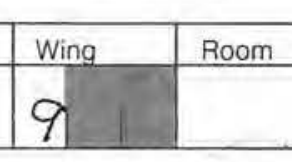

\begin{tabular}{|l|}
\hline $\begin{array}{l}\text { 5. Waste } \\
\text { Code }\end{array}$ \\
\hline 71410 \\
\hline
\end{tabular}

\section{Waste Description}

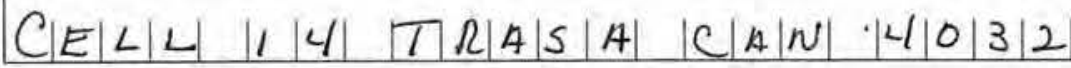

\begin{tabular}{|l|l|l|l|l|l|l|l|}
\hline \multicolumn{7}{|l|}{ 7. Numbers of Waste Packages } \\
\hline $\begin{array}{l}\text { Plastic } \\
\text { Bags }\end{array}$ & $\begin{array}{l}\text { Card- } \\
\text { Board } \\
\text { Boxes }\end{array}$ & No. & Gal. & No. & Volume- $\mathrm{fl}^{3}$ \\
\hline & & & & & & \\
\hline
\end{tabular}
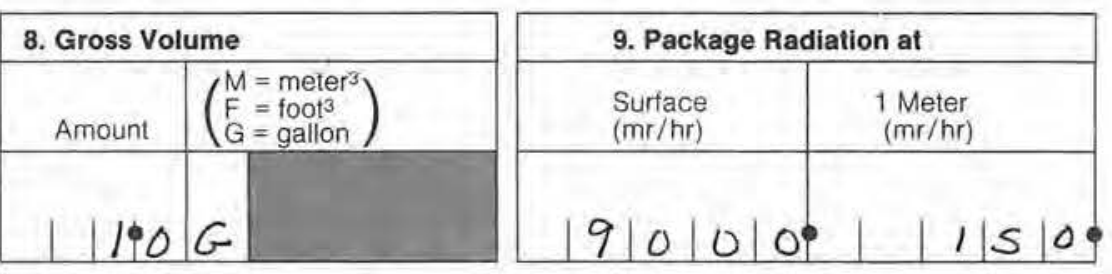

\begin{tabular}{|l|l|}
\hline 10. Gross Weight \\
\hline Amount & $\left.\begin{array}{l}K=\text { kilogram } \\
P=\text { pound } \\
T=\text { ton }\end{array}\right)$ \\
\hline & \\
131000 & $P$ \\
\hline
\end{tabular}

11. Additional Description of Packaging and Packaging Materials

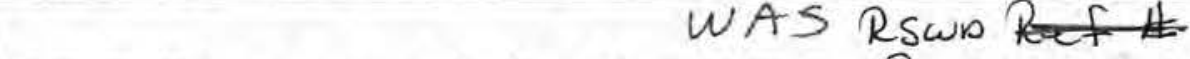

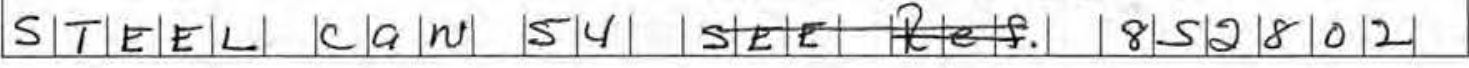

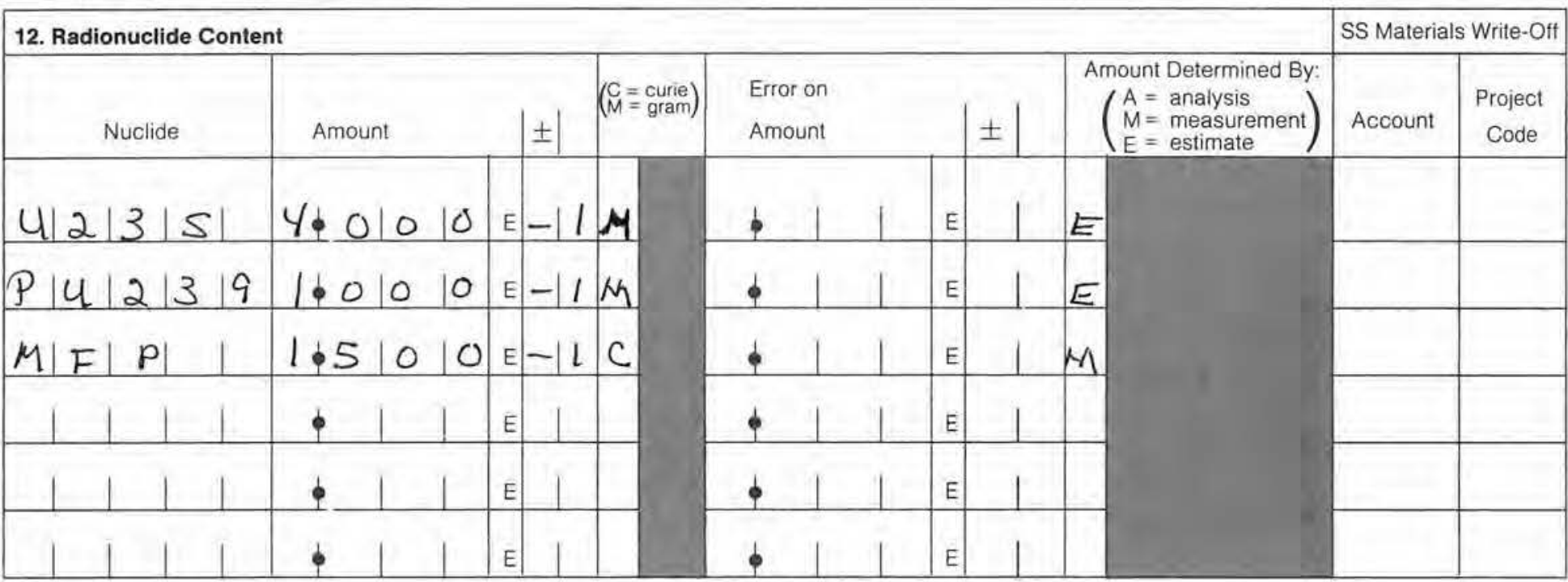

\section{APPROVALS}

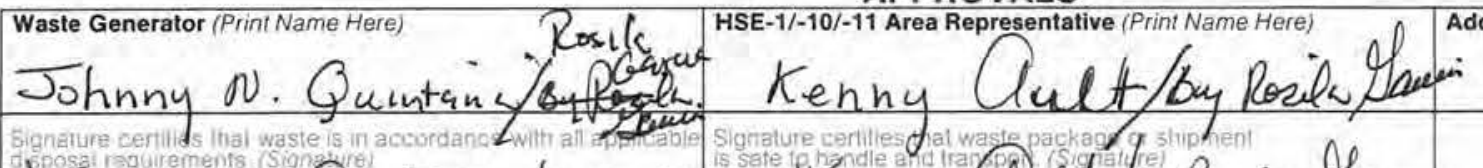

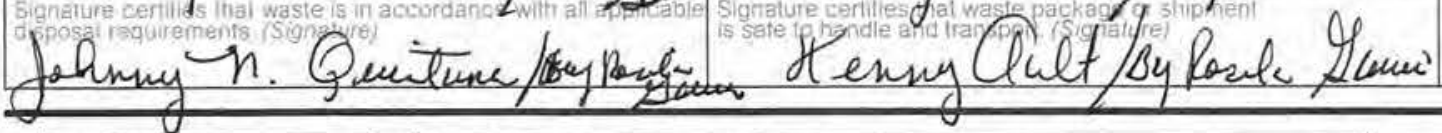

\begin{tabular}{|c|c|c|c|c|c|c|}
\hline \multirow{2}{*}{$\begin{array}{l}\text { 13. Date } \\
\text { Disposed }\end{array}$} & \multicolumn{6}{|c|}{ 14. Disposal/Storage Location } \\
\hline & Area & Shaft & Pit & Post(s) & Layer & Pos. \\
\hline 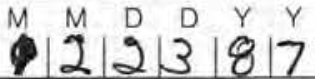 & $G$ & 12 & & & & \\
\hline
\end{tabular}

HSE-7 Waste Management Representative (Print Name Here)

ROSIIA F. GARCLA

Signature Zeriles that wate accegence theria and all disposal requirements were met:

(Signature) Loselu h.Daw

\begin{tabular}{|l|l|l|l|}
\hline Received & Logbook & Computer & Verified \\
\hline Date & Date & Date & Daye $1 / 7$ \\
\hline
\end{tabular}


药的 Alamos

Los A.lamos Nathonal Laboratory

LOS ANmos, Nem MEx?CO 97545

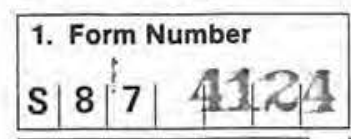

RADIOACTIVE SOLID WASTE DISPOSAL RECORD

NOTE: Read instructions on back carelully tefore completing inis form.

HSE-7 Waste Management

Ex1. 6095. MS J592

\begin{tabular}{|c|c|c|c|c|c|c|c|}
\hline 2. Date & 3. Retrievable & 4. Origin of Waste & & & & & 5. Waste \\
\hline$M M D D \quad Y \quad Y$ & Serial Number & Group & TA & Building & Wing & Room & Code \\
\hline 0.412141815 & 81214101016 & $M|S| T|1| 4$ & 013 & $5|\pi| 219$ & ? & & $A|4| O$ \\
\hline
\end{tabular}

\section{Waste Description}

C|E $44413 \mid$

\begin{tabular}{|c|c|c|c|c|c|c|}
\hline \multicolumn{2}{|l|}{ 7. Numbers of Waste Packages } \\
\hline $\begin{array}{l}\text { Plastic } \\
\text { Bags }\end{array}$ & $\begin{array}{l}\text { Card- } \\
\text { Board } \\
\text { Boxes }\end{array}$ & No. & Gal. & No. & Volume- $\mathrm{ft}^{3}$ \\
\hline & & & & & & \\
\hline \\
\hline
\end{tabular}

8. Gross Volume

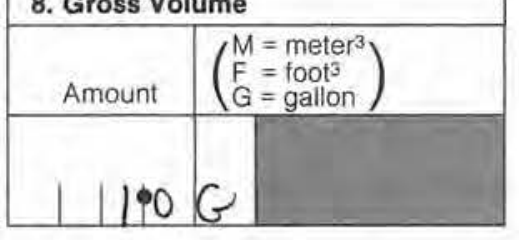

9. Package Radiation at

\begin{tabular}{|c|c|}
\hline $\begin{array}{l}\text { Surface } \\
(\mathrm{mr} / \mathrm{hr})\end{array}$ & $\begin{array}{l}1 \text { Meter } \\
(\mathrm{mr} / \mathrm{hr})\end{array}$ \\
\hline & \\
\hline
\end{tabular}

\section{Gross Weight}

\begin{tabular}{|l|l|l|}
\hline Amount & $\left(\begin{array}{l}K=\text { kilogram } \\
P=\text { pound } \\
T=\text { ton }\end{array}\right)$ \\
\hline $2 \mid$ S $O$ & $P$ & \\
\hline
\end{tabular}

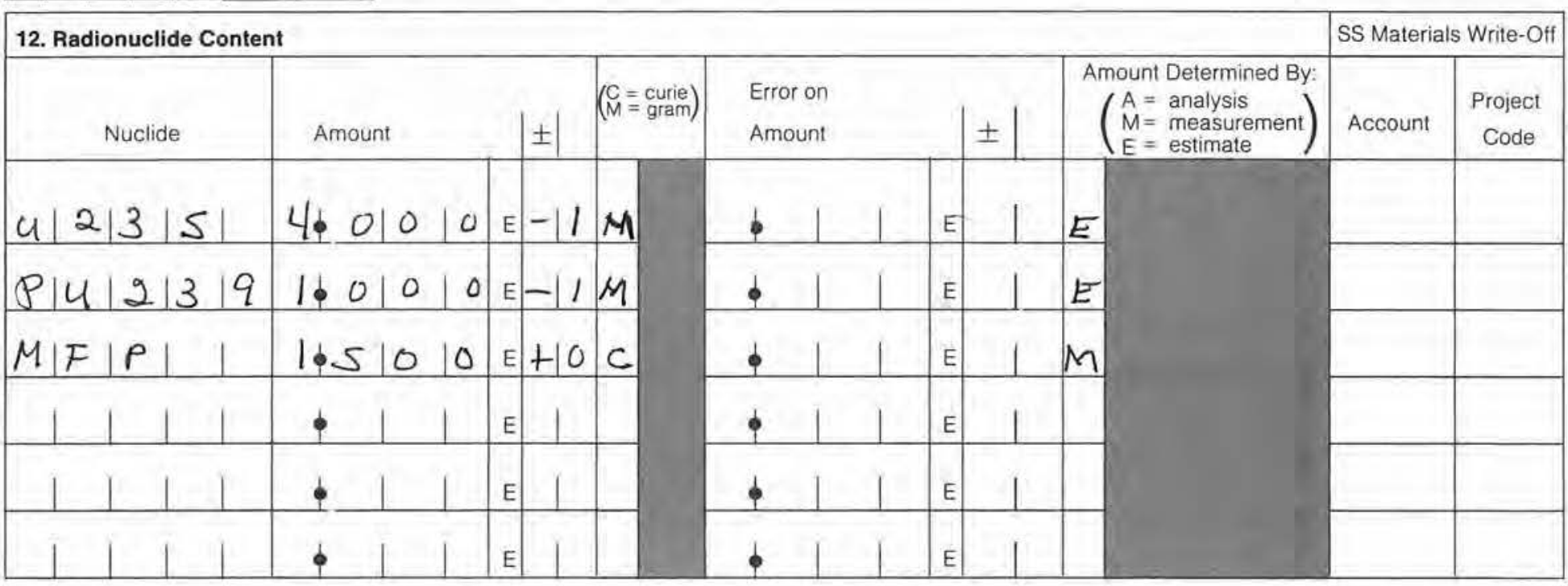

\section{APPROVALS}

Waste Generator (Print Name Here) Ros lla GarculHSE-1/-10/-11 Area Representative (Print Naprofere) 11. Additional Description of Packaging and Packaging Materials WAS RSWD

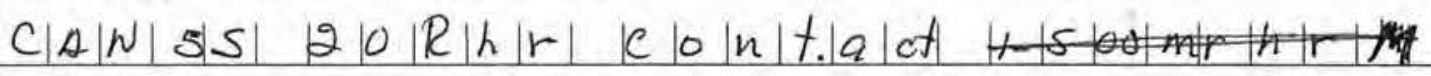

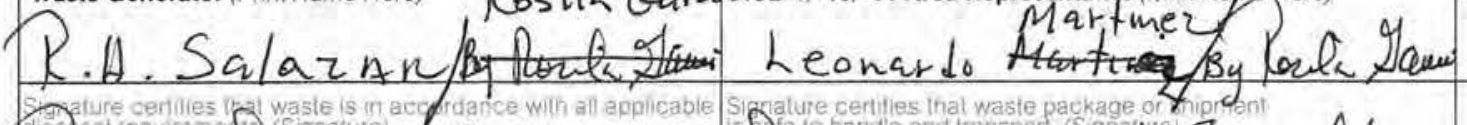

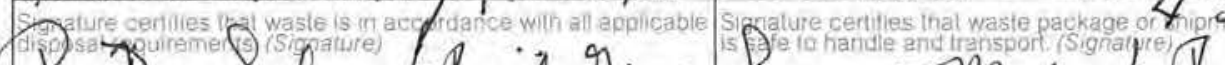

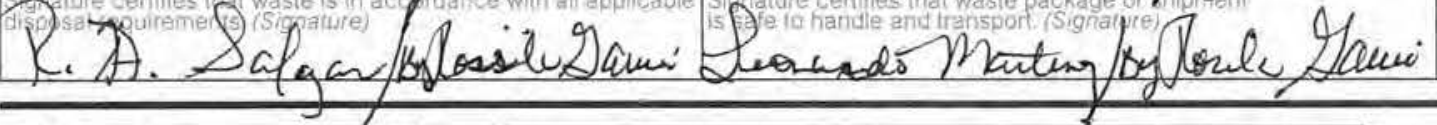

\begin{tabular}{|l|l|l|l|}
\hline $\begin{array}{l}\text { 13. Date } \\
\text { Disposed }\end{array}$ \\
\hline 1 & 2 & 2 & 3 \\
\hline
\end{tabular}

\begin{tabular}{|c|c|c|c|c|c|}
\hline \multicolumn{6}{|c|}{ 14. Disposal/Storage Location } \\
\hline Area & Shaft & Pit & Post(s) & Layer & Pos. \\
\hline$G$ & 12 & & & & \\
\hline
\end{tabular}

HSE-7 Waste Management Representative (Print Name Here) ROSIIA E. GARCLA

\begin{tabular}{|l|l|l|c|}
\hline Received & Logbook & Computer & Verified \\
\hline Date & Date & Date & Date \\
& & & $17 / 81$ \\
\hline
\end{tabular}


L(OS AlañS

LOS Alamos Natonal Labratory

RADIOACTIVE SOLID WASTE DISPOSAL RECORD

LOS Almmos, New Mexico 87545

NOTE: Fead instructions on back carelully before completing this form.

\section{Form Number

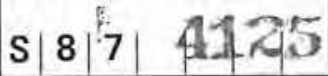

\begin{tabular}{|l|lllll|}
\hline 2. Date & & & \\
\hline$M$ & $M$ & $D$ & $D$ & $Y$ & $Y$ \\
$O$ & 4 & 1 & 4 & 8 & $S$ \\
\hline
\end{tabular}

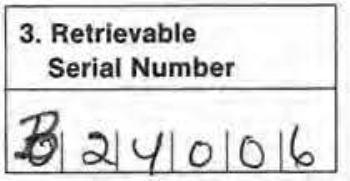

\begin{tabular}{|c|c|c|}
\hline \multicolumn{3}{|l|}{ 4. Origin of Waste } \\
\hline Group & TA & Building \\
\hline MIS $1 T 114$ & 0.3 & $5|m| 219$ \\
\hline
\end{tabular}

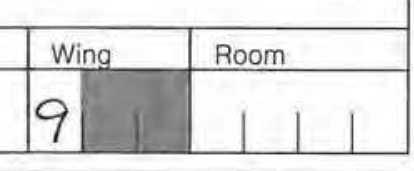

Ext 6095 MS 1592

\section{Waste Description}

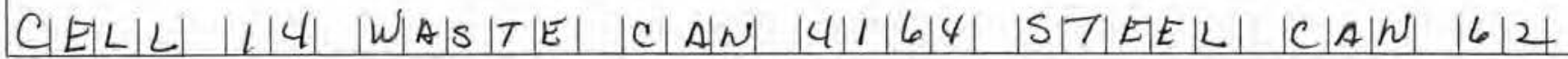

\begin{tabular}{|c|c|c|c|c|}
\hline \multicolumn{5}{|c|}{ 7. Numbers of Waste Packages } \\
\hline $\begin{array}{l}\text { Plastic } \\
\text { Bags }\end{array}$ & $\begin{array}{l}\text { Car } \\
\text { Boa } \\
\text { Box }\end{array}$ & & No. & ns \\
\hline & & & & \\
\hline \multicolumn{5}{|c|}{ 10. Gross Weight } \\
\hline \multicolumn{2}{|l|}{ Amount } & \multicolumn{3}{|c|}{$\left(\begin{array}{l}K=\text { kilogram } \\
P=\text { pound } \\
T=\text { ton }\end{array}\right)$} \\
\hline 3 & & $A$ & & \\
\hline
\end{tabular}

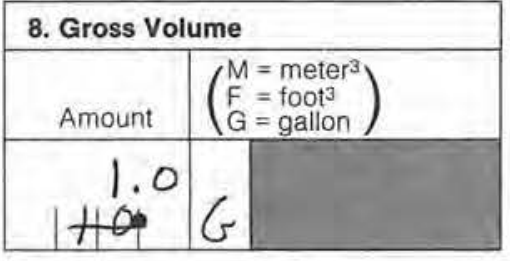

\begin{tabular}{|c|c|}
\hline \multicolumn{2}{|c|}{ 9. Package Radiation at } \\
\hline $\begin{array}{l}\text { Surface } \\
\text { (mr/hr) }\end{array}$ & $\begin{array}{l}1 \text { Meter } \\
(\mathrm{mr} / \mathrm{hr})\end{array}$ \\
\hline & \\
\hline
\end{tabular}

12. Radionuclide Content

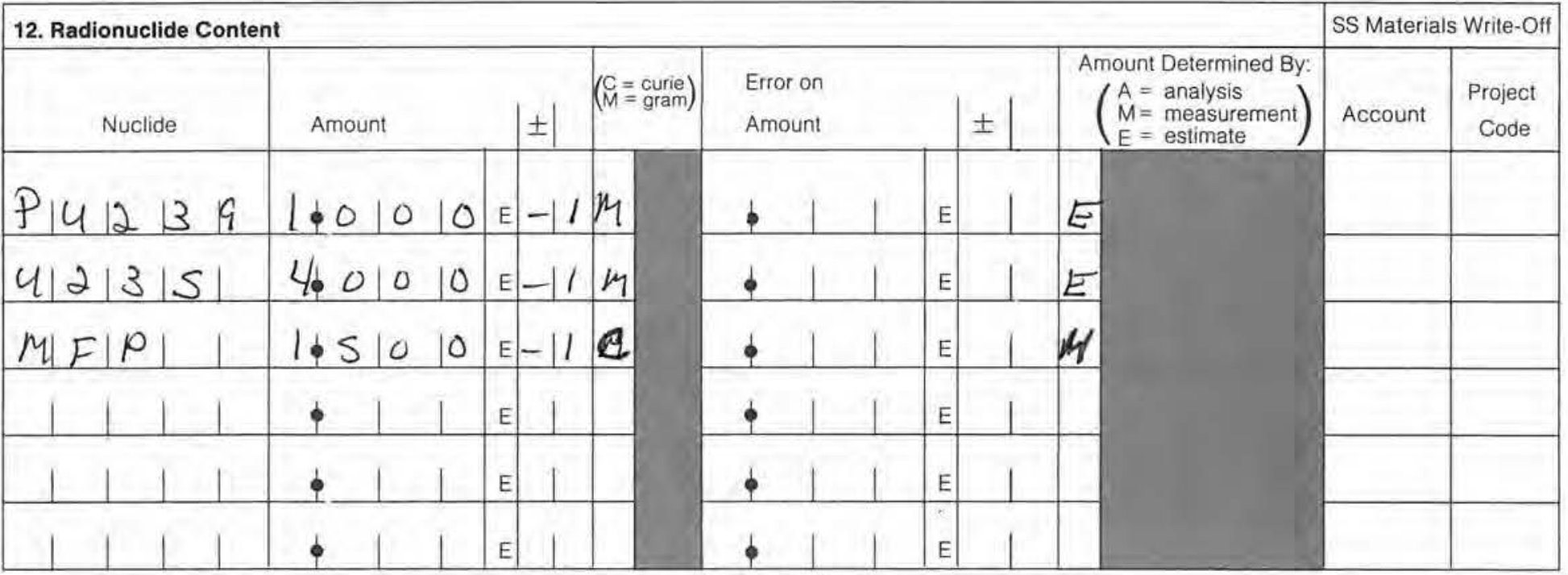

\section{APPROVALS}

Waste Generator (Print Name Here) ${ }^{D}$ G Garucise-1/-10/-11 Area Representative (Print Name Here)

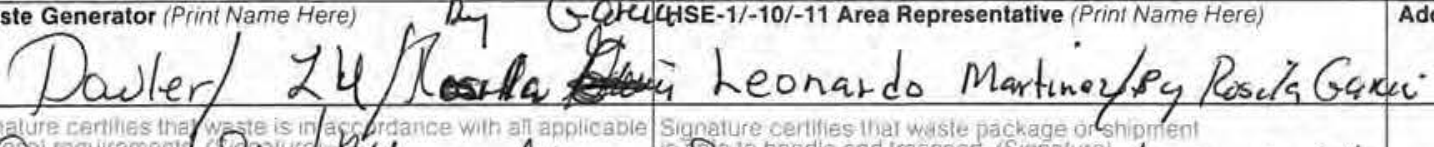

Dowbor
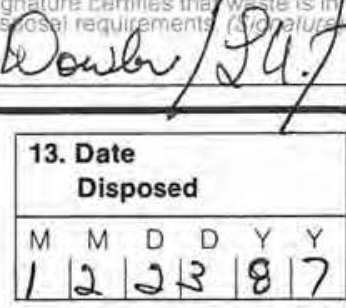

\begin{tabular}{|c|c|c|}
\hline \multicolumn{3}{|c|}{ 14. Disposal/Storage Location } \\
\hline Area & Shaft & Pit \\
\hline$C$ & 2 & \\
\hline
\end{tabular}

Yhateng Myloula Itaun

\begin{tabular}{|c|c|c|c|c|}
\hline $\begin{array}{l}\text { HSE-7 Waste Management Representative (Print Name Here) } \\
\text { BROSIIA 5. GARCIA. }\end{array}$ & Received & Logbook. & Computer, & Verifigg \\
\hline $\begin{array}{l}\text { Signature perit es) hat wasyacceptonfe griteria and all disposal requirements were met } \\
\text { (Signature) }\end{array}$ & Date & Date & Date & Date 198 \\
\hline
\end{tabular}




\section{INSTRUCTIONS FOR WASTE GENERATOR}

Filling Out the Form. The waste generator must complete this form to document all waste buried or retrievably stored at the Laboratory's TA-54, Area G, site. Be sure to complete each section before proceeding to the next section. The waste generator must follow these instructions:

1. Don't use more than the allotted spaces on the form (one letter or number per space).

2. Ensure that all data recorded on this form are legibly printed and clearly readable.

3. Note that the decimal point positions are already indicated in the sections where decimals would be needed (for example, see Section 7 on the front of this form). Enter information accurately in relation to these decimal points. Do not alter decimal point positions.

4. Use the number zero $(0)$ on the form $O N L Y$ on entries requiring that numerical designation. Do not use the number zero to fill blank spaces.

5. Where the amount of information available does not allow recording all data on one form, use additional forms for different portions of the waste.

When the Form is Completed. The waste generator must ensure that the properly completed form accompanies each waste shipment and each package of retrievable transuranic (TRU) waste delivered to the disposal/storage site. Waste generators may keep a copy of the completed form for their files.

\section{PERTINENT INSTRUCTIONS FOR SPECIFIC SECTIONS OF THIS FORM}

Section 5, Waste Code. Identify all waste by a 3-digit description code, as given in Attachment I, "Valid Waste Codes." Choose the code that best describes the waste material.

Section 6, Waste Description. Allow one space for each letter and one space after each word. Use this section to provide any additional information about the waste.

Section 9, Package Radiation. Do not use symbols for "greater than $(>)$," for "less than $(<)$," for "greater than or equal to $(\geq)$," or for "less than or equal to $(\leq)$." Round off fractions to the nearest whole number. If radiation levels exceed that which can be listed, leave this section blank and record the data in Section 11.

Section 11, Additional Description of Packaging and Packaging Materials. Use this space to provide property number, related form numbers, data that cannot be entered in Sections 6 or 9 (see above), etc.

Section 12, Radionuclide Content. List radionuclides using either the normally accepted notations (for example, U235, Pu239, Co60, and H3) or, for accountable materials, the element identification plus the SS Material Type Code (for example, Pu52 for plutonium code 52, U38 for uranium code 38). Acceptable codes include MFP for mixed fission products and MAP for mixed activation products.

For nonradioactive chemical or hazardous waste, enter the correct chemical identification, such as CHEM, $\mathrm{PCB}$, or ASBES. If more than one contaminant is identifiable, each contaminant should be listed (with all appropriate data) on a separate line in Section 12. If there are more than six (6) radionuclides identified, or if there are any questions regarding the completion of this form, contact HSE-7 at 7-5397.

Questions regarding the handling or packaging of radioactive or hazardous wastes should be referred to Disposal Site Operations (7-6095).

\section{APPROVAL SIGNATURES}

Waste Generator. The waste generator must sign the form in the space allotted to indicate compliance with applicable waste packaging and disposal requirements. This signature is required for all waste, whether radioactive or nonradioactive. Note that both the generator's printed name and written signature are required.

HSE-1/-10/-11 Area Representative. An area representative from either the HSE-1, -10 , or - 11 group must sign the form if the wastes are radioactively contaminated. This signature indicates that the package or shipment is safe to handle and transport. Note that both the area representative's printed name and written signature are required.

Additional Signatures. An area representative from HSE-3 or HSE-5 may be required to sign this form before certain hazardous materials are transported. This signature space also may be used for the group leader's signature, if required by the generator's group/division. 
LOS AIañอS

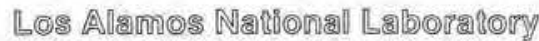

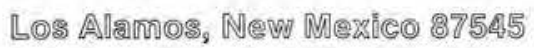

\section{Form Number \\ S|8|7| 4126}

\section{RADIOACTIVE SOLID WASTE DISPOSAL RECORD}

NOTE: Read instructions on back carefully before completing this fom.

HSE-7 Waste Management Exl. 6095, MS J592

\begin{tabular}{|l|l|l|l|l|}
\hline 4. Origin of Waste \\
\hline Group & $T A$ & Building & Wing & Room \\
\hline$M \mid S T / / \mathrm{K}$ & $O B$ & $\mathrm{~S} \mathrm{M} / 2 / 9$ & 9 & \\
\hline
\end{tabular}

\section{Waste Description}

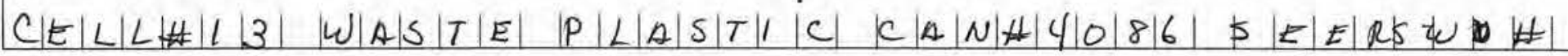

\section{Numbers of Waste Packages}

\begin{tabular}{|c|c|c|c|c|c|}
\hline \multirow{2}{*}{$\begin{array}{l}\text { Plastic } \\
\text { Bags }\end{array}$} & \multirow{2}{*}{$\begin{array}{l}\text { Card- } \\
\text { Board } \\
\text { Boxes }\end{array}$} & \multicolumn{2}{|c|}{ Drums } & \multicolumn{2}{|c|}{ Wooden Crates } \\
\hline & & No. & Gal. & No. & Volume- $\mathrm{ft}^{3}$ \\
\hline & & & & & i \\
\hline
\end{tabular}

\section{Gross Volume}

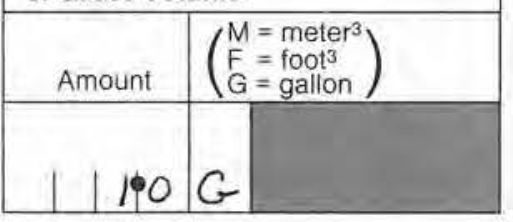

\section{Package Radiation at}

\begin{tabular}{|c|c|}
\hline $\begin{array}{l}\text { Surface } \\
(\mathrm{mr} / \mathrm{hr})\end{array}$ & $\begin{array}{c}1 \text { Meter } \\
(\mathrm{mr} / \mathrm{hr})\end{array}$ \\
\hline & $2 \mathrm{ks}$ \\
\hline
\end{tabular}

10. Gross Weight

\begin{tabular}{|l|l|}
\hline Amount & $\left.\begin{array}{l}K=\text { kilogram } \\
P=\text { pound } \\
T=\text { ton }\end{array}\right)$ \\
\hline & \\
\hline $3 \mid 0 \phi 0$ & $P$
\end{tabular}

11. Additional Description of Packaging and Packaging Materials

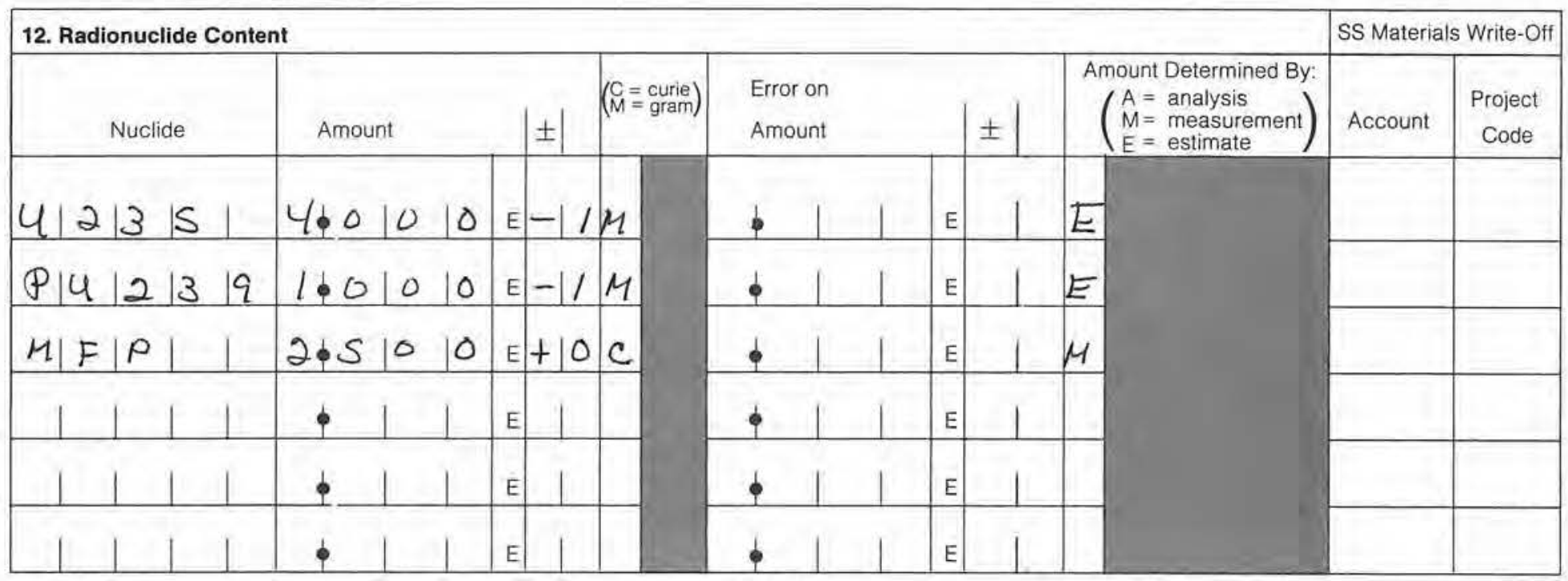

\section{APPROVALS}

Waste Generator (Print Name Here)

HSE-1/-10/-11 Area Representative (Print Name Here)

Additional Signatures (Optional)

R.A. Salazon By Rosila Garewi: heonardo Martiner/sy Rositw Garcur

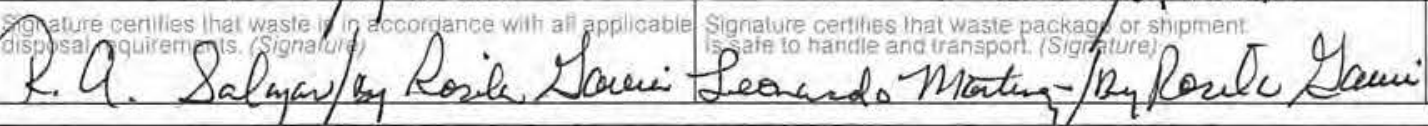

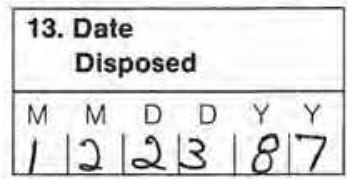

\begin{tabular}{|c|c|c|c|c|c|}
\hline \multicolumn{6}{|c|}{ 14. Disposal/Storage Location } \\
\hline Area & Shaft & Pit & Post(s) & Layer & Pos. \\
\hline$G$ & & & & & \\
\hline
\end{tabular}

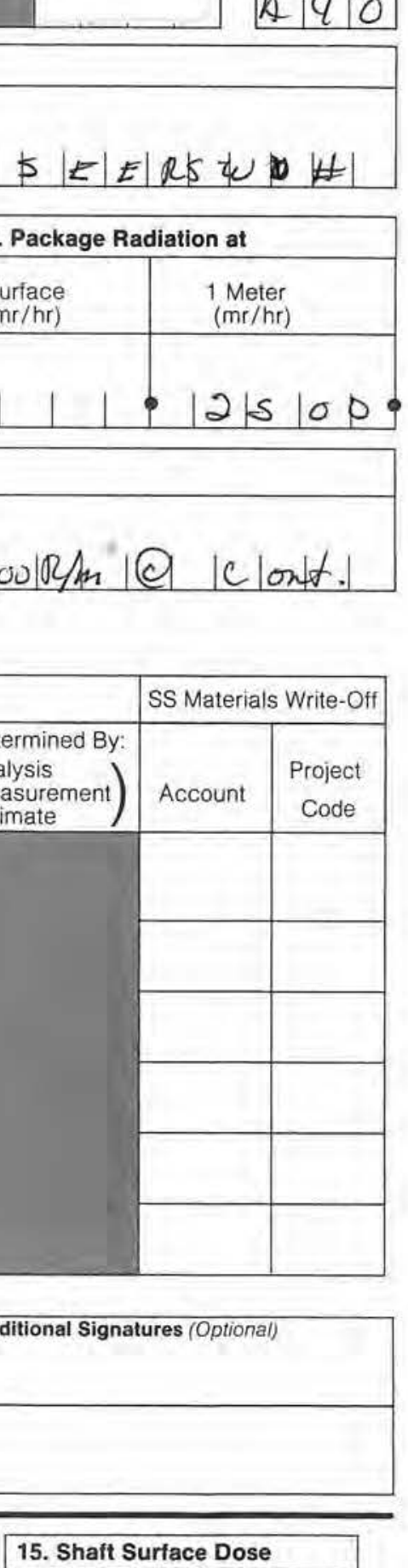

HSE-7 Waste Management Representative (Print Name Here)

ROSIIA, F, GARCLA

\begin{tabular}{|l|l|l|c|}
\hline Received & Logbook & Computer & $\begin{array}{c}\text { Veritied } \\
\text { J }\end{array}$ \\
\hline Date & Date & Date & $\begin{array}{c}\text { Date } \\
1\end{array}$ \\
\hline
\end{tabular}




\section{INSTRUCTIONS FOR WASTE GENERATOR}

Filling Out the Form. The waste generator must complete this form to document all waste buried or retrievably stored at the Laboratory's TA-54, Area G, site. Be sure to complete each section before proceeding to the next section. The waste generator must follow these instructions:

1. Don't use more than the allotted spaces on the form (one letter or number per space).

2. Ensure that all data recorded on this form are legibly printed and clearly readable.

3. Note that the decimal point positions are already indicated in the sections where decimals would be needed (for example, see Section 7 on the front of this form). Enter information accurately in relation to these decimal points. Do not alter decimal point positions.

4. Use the number zero ( 0$)$ on the form $O N L Y$ on entries requiring that numerical designation. Do not use the number zero to fill blank spaces.

5. Where the amount of information available does not allow recording all data on one form, use additional forms for different portions of the waste.

When the Form is Completed. The waste generator must ensure that the properly completed form accompanies each waste shipment and each package of retrievable transuranic (TRU) waste delivered to the disposal/storage site. Waste generators may keep a copy of the completed form for their files.

\section{PERTINENT INSTRUCTIONS FOR SPECIFIC SECTIONS OF THIS FORM}

Section 5, Waste Code. Identify all waste by a 3-digit description code, as given in Attachment I, "Valid Waste Codes." Choose the code that best describes the waste material.

Section 6, Waste Description. Allow one space for each letter and one space after each word. Use this section to provide any additional information about the waste.

Section 9, Package Radiation. Do not use symbols for "greater than $(>)$," for "less than $(<)$," for "greater than or equal to $(\geq)$," or for "less than or equal to $(\leq)$." Round off fractions to the nearest whole number. If radiation levels exceed that which can be listed, leave this section blank and record the data in Section 11.

Section 11, Additional Description of Packaging and Packaging Materials. Use this space to provide property number, related form numbers, data that cannot be entered in Sections 6 or 9 (see above), etc.

Section 12, Radionuclide Content. List radionuclides using either the normally accepted notations (for example, U235, Pu239, Co60, and H3) or, for accountable materials, the element identification plus the SS Material Type Code (for example, Pu 52 for plutonium code 52, U38 for uranium code 38). Acceptable codes include MFP for mixed fission products and MAP for mixed activation products.

For nonradioactive chemical or hazardous waste, enter the correct chemical identification, such as CHEM, $\mathrm{PCB}$, or ASBES. If more than one contaminant is identifiable, each contaminant should be listed (with all appropriate data) on a separate line in Section 12. If there are more than six (6) radionuclides identified, or if there are any questions regarding the completion of this form, contact HSE-7 at 7-5397.

Questions regarding the handling or packaging of radioactive or hazardous wastes should be referred to Disposal Site Operations (7-6095).

\section{APPROVAL SIGNATURES}

Waste Generator. The waste generator must sign the form in the space allotted to indicate compliance with applicable waste packaging and disposal requirements. This signature is required for all waste, whether radioactive or nonradioactive. Note that both the generator's printed name and written signature are required.

HSE-1/-10/-11 Area Representative. An area representative from either the HSE-1, -10, or -11 group must sign the form if the wastes are radioactively contaminated. This signature indicates that the package or shipment is safe to handle and transport. Note that both the area representative's printed name and written signature are required.

Additional Signatures. An area representative from HSE-3 or HSE-5 may be required to sign this form before certain hazardous materials are transported. This signature space also may be used for the group leader's signature, if required by the generator's group/division. 
ட03 Alamos

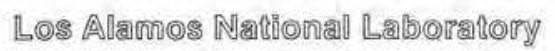

Los Alamos; $\mathbb{N e w}$ Mexice 87545

\begin{tabular}{l|l|l|}
\hline 1. Form Number \\
$\mathrm{S}|8|$ & 7 & Al \\
\hline
\end{tabular}
RADIOACTIVE SOLID WASTE DISPOSAL RECORD

NOTE: Read instructions on tack carelully belore completing this form.
HSE-7 Waste Management Ext 6095 MS 1.592

\begin{tabular}{|c|c|c|c|c|c|c|c|}
\hline 2. Date & 3. Retrievable & 4. Origin of Waste & & & & & 5. Waste \\
\hline 2. Date & Serial Number & Group & TA & Building & Wing & Room & Code \\
\hline 0.4121418 .5 & 18214101016 & $M|S| T|1| 4$ & 013 & $S|m| 219$ & 9 & & A. \\
\hline
\end{tabular}

\section{Waste Description}

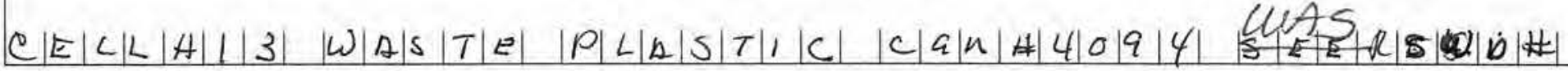

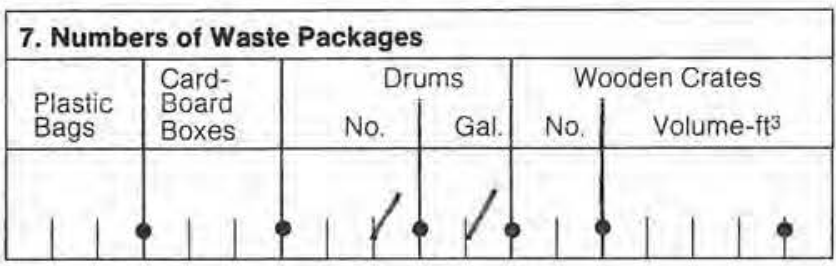

\section{Gross Volume}

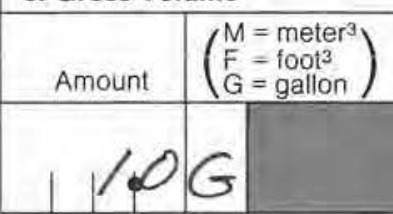

\begin{tabular}{|l|l|}
\hline \multicolumn{2}{|l|}{ 10. Gross Weight } \\
\hline Amount & $\left.\begin{array}{l}K=\text { kilogram } \\
P=\text { pound } \\
T=\text { ton }\end{array}\right)$ \\
\hline 1310 \% & $p$ \\
\hline
\end{tabular}

11. Additional Description of Packaging and Packaging Materials

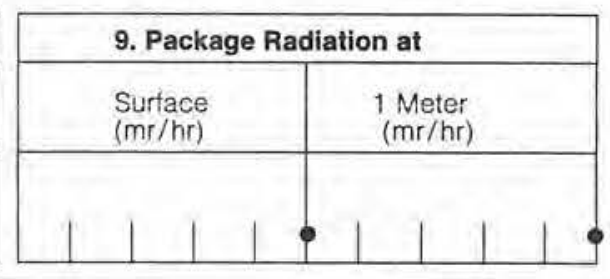

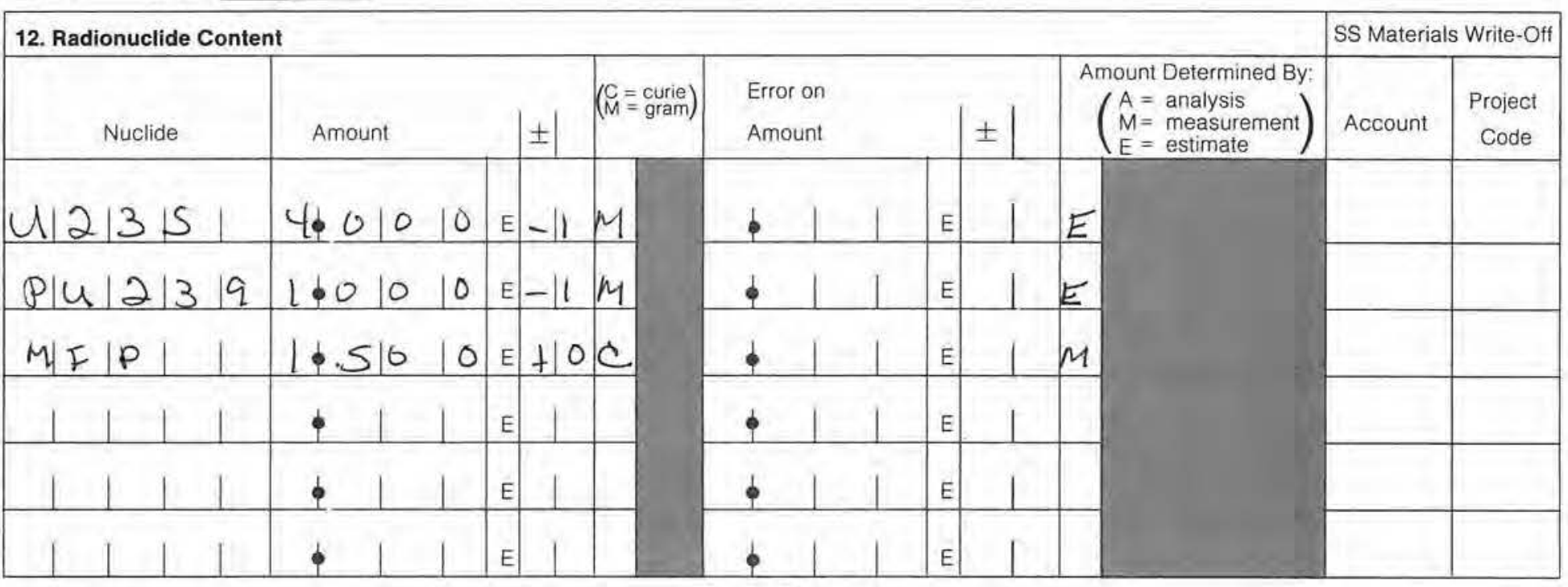

\section{APPROVALS}

\begin{tabular}{|l|l}
\hline Waste Generator (Print Name Here) & HSE-1/-10/-11 Area Representative (Print Name Here)
\end{tabular}

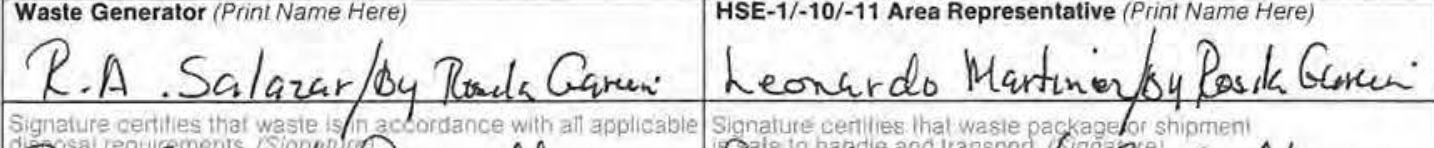

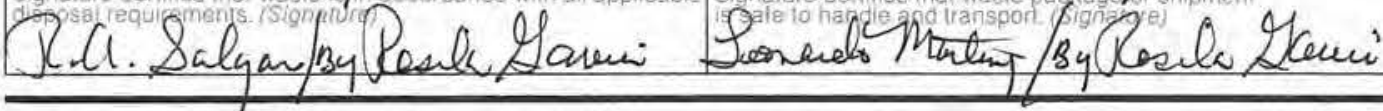

\begin{tabular}{|l|l|l|l|}
\hline $\begin{array}{l}\text { 13. Date } \\
\text { Disposed }\end{array}$ \\
\hline \begin{tabular}{l|l|l|l|l|l|}
\hline & $M$ & $D$ & $D$ & $Y$ & $Y$ \\
1 & 2 & 2 & 3 & 8 & 7 \\
\hline
\end{tabular} \\
\hline
\end{tabular}

\begin{tabular}{|c|c|c|c|c|c|}
\hline \multicolumn{6}{|c|}{ 14. Disposal/Storage Location } \\
\hline Area & Shaft & Pit & Post(s) & Layer & Pos. \\
\hline 6 & 12 & & & & \\
\hline
\end{tabular}

\begin{tabular}{|c|c|c|c|c|}
\hline $\begin{array}{l}\text { HSE-7 Waste Management Representative (Print Name Here) } \\
\text { ROSIIA E. GAY }\end{array}$ & Received & Logbook & Computer. & Verified \\
\hline 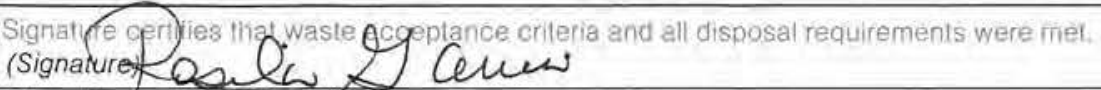 & Date & Date & Date & 117188 \\
\hline
\end{tabular}




\section{INSTRUCTIONS FOR WASTE GENERATOR}

Filling Out the Form. The waste generator must complete this form to document all waste buried or retrievably stored at the Laboratory's TA-54, Area G, site. Be sure to complete each section before proceeding to the next section. The waste generator must follow these instructions:

1. Don't use more than the allotted spaces on the form (one letter or number per space).

2. Ensure that all data recorded on this form are legibly printed and clearly readable.

3. Note that the decimal point positions are already indicated in the sections where decimals would be needed (for example, see Section 7 on the front of this form). Enter information accurately in relation to these decimal points. Do not alter decimal point positions.

4. Use the number zero $(0)$ on the form $O N L Y$ on entries requiring that numerical designation. Do not use the number zero to fill blank spaces.

5. Where the amount of information available does not allow recording all data on one form, use additional forms for different portions of the waste.

When the Form is Completed. The waste generator must ensure that the properly completed form accompanies each waste shipment and each package of retrievable transuranic (TRU) waste delivered to the disposal/storage site. Waste generators may keep a copy of the completed form for their files.

\section{PERTINENT INSTRUCTIONS FOR SPECIFIC SECTIONS OF THIS FORM}

Section 5, Waste Code. Identify all waste by a 3-digit description code, as given in Attachment I, "Valid Waste Codes." Choose the code that best describes the waste material.

Section 6, Waste Description. Allow one space for each letter and one space after each word. Use this section to provide any additional information about the waste.

Section 9, Package Radiation. Do not use symbols for "greater than $(>)$," for "less than $(<)$," for "greater than or equal to $(\geq)$," or for "less than or equal to $(\leq)$." Round off fractions to the nearest whole number. If radiation levels exceed that which can be listed, leave this section blank and record the data in Section 11 .

Section 11, Additional Description of Packaging and Packaging Materials. Use this space to provide property number, related form numbers, data that cannot be entered in Sections 6 or 9 (see above), etc.

Section 12, Radionuclide Content. List radionuclides using either the normally accepted notations (for example, U235, Pu239, Co60, and $\mathrm{H} 3$ ) or, for accountable materials, the element identification plus the SS Material Type Code (for example, Pu 52 for plutonium code $52, \mathrm{U} 38$ for uranium code 38 ). Acceptable codes include MFP for mixed fission products and MAP for mixed activation products.

For nonradioactive chemical or hazardous waste, enter the correct chemical identification, such as CHEM, $\mathrm{PCB}$, or ASBES. If more than one contaminant is identifiable, each contaminant should be listed (with all appropriate data) on a separate line in Section 12. If there are more than six (6) radionuclides identified, or if there are any questions regarding the completion of this form, contact HSE-7 at 7-5397.

Questions regarding the handling or packaging of radioactive or hazardous wastes should be referred to Disposal Site Operations (7-6095).

\section{APPROVAL SIGNATURES}

Waste Generator. The waste generator must sign the form in the space allotted to indicate compliance with applicable waste packaging and disposal requirements. This signature is required for all waste, whether radioactive or nonradioactive. Note that both the generator's printed name and written signature are required.

HSE-1/-10/-11 Area Representative. An area representative from either the HSE-1, -10, or -11 group must sign the form if the wastes are radioactively contaminated. This signature indicates that the package or shipment is safe to handle and transport. Note that both the area representative's printed name and written signature are required.

Additional Signatures. An area representative from HSE-3 or HSE-5 may be required to sign this form before certain hazardous materials are transported. This signature space also may be used for the group leader's signature, if required by the generator's group/division. 


\section{ட0S ADamos}

LOS Alamos Natfonall Lsboratory

LOS Alamos, Nev Mexlco 87545

\section{RADIOACTIVE SOLID WASTE DISPOSAL RECORD}

\section{Form Number}

S $18 \sqrt{7} \quad 4128$

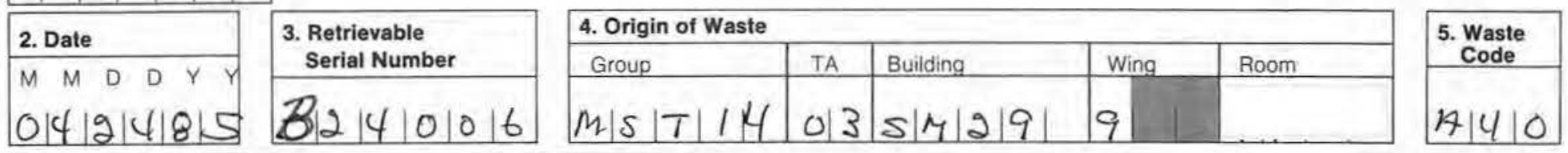

6. Waste Description

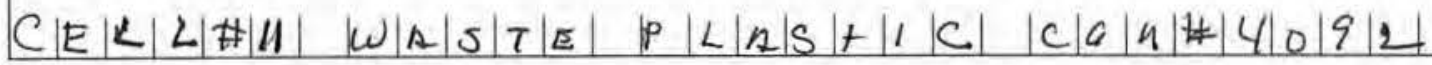

\section{Numbers of Waste Packages}

\begin{tabular}{|l|l|l|l|l|l|l|l|l|}
\hline $\begin{array}{l}\text { Plastic } \\
\text { Bags }\end{array}$ & $\begin{array}{l}\text { Card- } \\
\text { Board } \\
\text { Boxes }\end{array}$ & No. & Gal. & No. & \multicolumn{2}{|c|}{ Volume- $\mathrm{ft}^{3}$} \\
\hline & & & & & & & & \\
\hline
\end{tabular}

\section{Gross Volume}

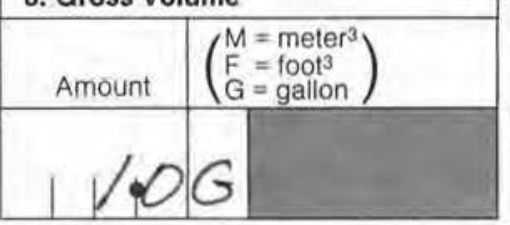

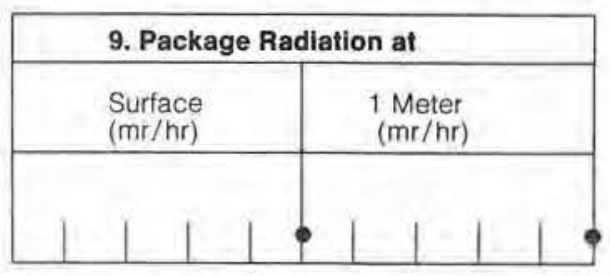

10. Gross Weight

\begin{tabular}{|c|c|}
\hline Amount & $\left(\begin{array}{l}K=\text { kilogram } \\
P=\text { pound } \\
T=\text { fon }\end{array}\right)$ \\
\hline $310=0$ & $p$ \\
\hline
\end{tabular}

11. Additional Description of Packaging and Packaging Materials

$S T|E| E|L| \quad|C| a|n| \#|6| 0|\quad| S|E| E \mid$ R $S|\omega| D|\#| r|S| 2|3| 3 \mid 0$

\section{Radionuclide Content}

\begin{tabular}{|c|c|c|c|c|c|c|c|c|c|}
\hline \multicolumn{8}{|c|}{ 12. Radionuclide Content } & \multicolumn{2}{|c|}{ SS Materials Write-Off } \\
\hline Nuclide & Amount & \pm & $\left(\begin{array}{l}C=\text { curie } \\
M=\text { gram }\end{array}\right)$ & $\begin{array}{l}\text { Error on } \\
\text { Amount }\end{array}$ & & \pm & $\begin{array}{l}\text { Amount Determined By: } \\
\left.\qquad \begin{array}{l}A=\text { analysis } \\
M=\text { measurement } \\
E=\text { estimate }\end{array}\right)\end{array}$ & Account & $\begin{array}{c}\text { Project } \\
\text { Code }\end{array}$ \\
\hline 412131. & \begin{tabular}{ll|l|l|}
40 & 0 & 0 & 0 \\
\end{tabular} & $E-1 /$ & $M$ & $\phi$ & $\mathrm{E}$ & & E & & \\
\hline 01412 & $1 \% 0|0| 0$ & $E-11$ & $M$ & ф옹 & E & & $E$ & & \\
\hline$M \mid F$ & $1 \% 5|0| 0$ & $E+O$ & C. & $\phi$ & E & & 4 & 4 & \\
\hline & $\phi$ & $E$ & & $\phi$ & $E$ & & & & \\
\hline & q. & E & & $\phi$ & E & & & & \\
\hline & $\varphi$ & E) & & $\phi$ & $E$ & & & & \\
\hline
\end{tabular}

\section{APPROVALS}

\begin{tabular}{|l|l|l|l|l|}
\hline Waste Generator (Print Name Here) & HSE-1/-10/-11 Area Representative (Prin/Name Here) & Additional Signatures (Optional)
\end{tabular}

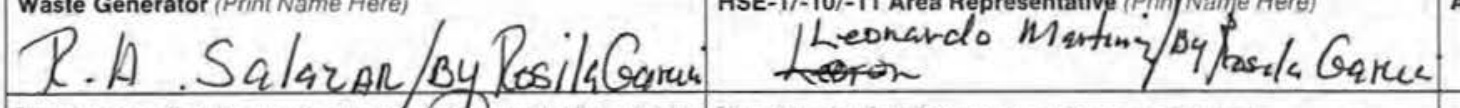

13. Date

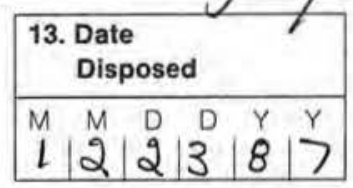

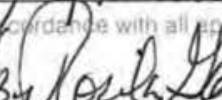

3.

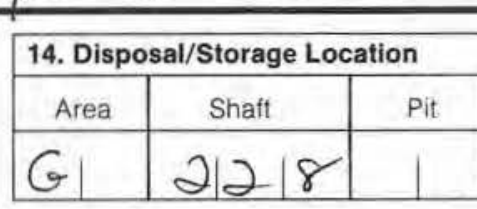

dontatam
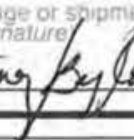
fonde fowi: 


\section{INSTRUCTIONS FOR WASTE GENERATOR}

Filling Out the Form. The waste generator must complete this form to document all waste buried or retrievably stored at the Laboratory's TA-54, Area G, site. Be sure to complete each section before proceeding to the next section. The waste generator must follow these instructions:

1. Don't use more than the allotted spaces on the form (one letter or number per space).

2. Ensure that all data recorded on this form are legibly printed and clearly readable.

3. Note that the decimal point positions are already indicated in the sections where decimals would be needed (for example, see Section 7 on the front of this form). Enter information accurately in relation to these decimal points. Do not alter decimal point positions.

4. Use the number zero $(0)$ on the form $O N L Y$ on entries requiring that numerical designation. Do not use the number zero to fill blank spaces.

5. Where the amount of information available does not allow recording all data on one form, use additional forms for different portions of the waste.

When the Form is Completed. The waste generator must ensure that the properly completed form accompanies each waste shipment and each package of retrievable transuranic (TRU) waste delivered to the disposal/storage site. Waste generators may keep a copy of the completed form for their files.

\section{PERTINENT INSTRUCTIONS FOR SPECIFIC SECTIONS OF THIS FORM}

Section 5, Waste Code. Identify all waste by a 3-digit description code, as given in Attachment I, "Valid Waste Codes." Choose the code that best describes the waste material.

Section 6, Waste Description. Allow one space for each letter and one space after each word. Use this section to provide any additional information about the waste.

Section 9, Package Radiation. Do not use symbols for "greater than $(>)$," for "less than $(<)$," for "greater than or equal to $(\geq)$," or for "less than or equal to $(\leq)$." Round off fractions to the nearest whole number. If radiation levels exceed that which can be listed, leave this section blank and record the data in Section 11.

Section 11, Additional Description of Packaging and Packaging Materials. Use this space to provide property number, related form numbers, data that cannot be entered in Sections 6 or 9 (see above), etc.

Section 12, Radionuclide Content. List radionuclides using either the normally accepted notations (for example, U235, Pu239, Co60, and $\mathrm{H} 3$ ) or, for accountable materials, the element identification plus the SS Material Type Code (for example, Pu 52 for plutonium code 52 , U 38 for uranium code 38 ). Acceptable codes include MFP for mixed fission products and MAP for mixed activation products.

For nonradioactive chemical or hazardous waste, enter the correct chemical identification, such as CHEM, $\mathrm{PCB}$, or ASBES. If more than one contaminant is identifiable, each contaminant should be listed (with all appropriate data) on a separate line in Section 12. If there are more than six (6) radionuclides identified, or if there are any questions regarding the completion of this form, contact HSE-7 at 7-5397.

Questions regarding the handling or packaging of radioactive or hazardous wastes should be referred to Disposal Site Operations (7-6095).

\section{APPROVAL SIGNATURES}

Waste Generator. The waste generator must sign the form in the space allotted to indicate compliance with applicable waste packaging and disposal requirements. This signature is required for all waste, whether radioactive or nonradioactive. Note that both the generator's printed name and written signature are required.

HSE-1/-10/-11 Area Representative. An area representative from either the HSE-1, -10 , or -11 group must sign the form if the wastes are radioactively contaminated. This signature indicates that the package or shipment is safe to handle and transport. Note that both the area representative's printed name and written signature are required.

Additional Signatures. An area representative from HSE- 3 or HSE-5 may be required to sign this form before certain hazardous materials are transported. This signature space also may be used for the group leader's signature, if required by the generator's group/division. 
ᄂ(5) Alamo

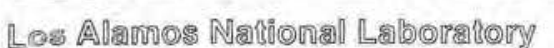

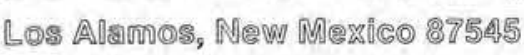

1. Form Number

$s|8| \frac{5}{3} \mid 41.23$

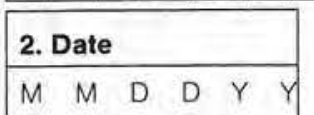

01412141815

6. Waste Description
RADIOACTIVE SOLID WASTE DISPOSAL RECORD

NOTE: Read instructions on back carefully before completing this form.

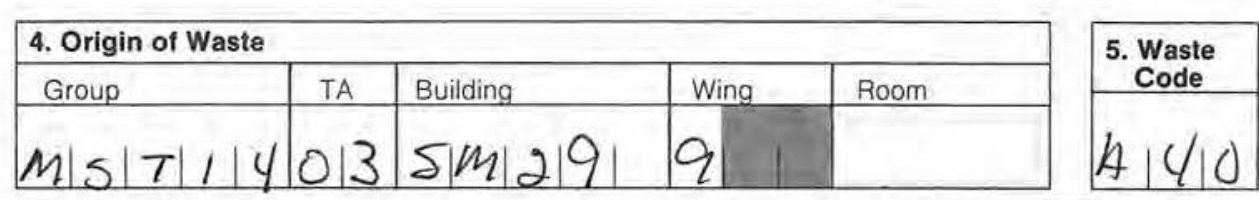

CEEILILIEHUIII WAISITIE PILIASITIIIC ICIAW|\#40185T

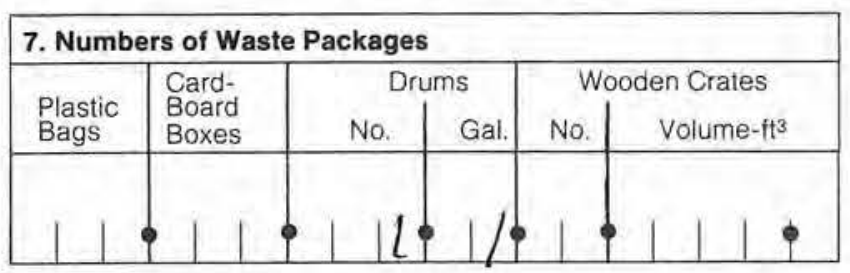
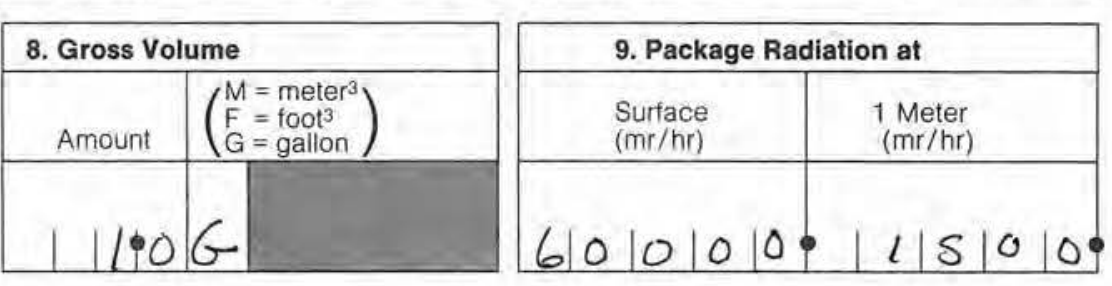

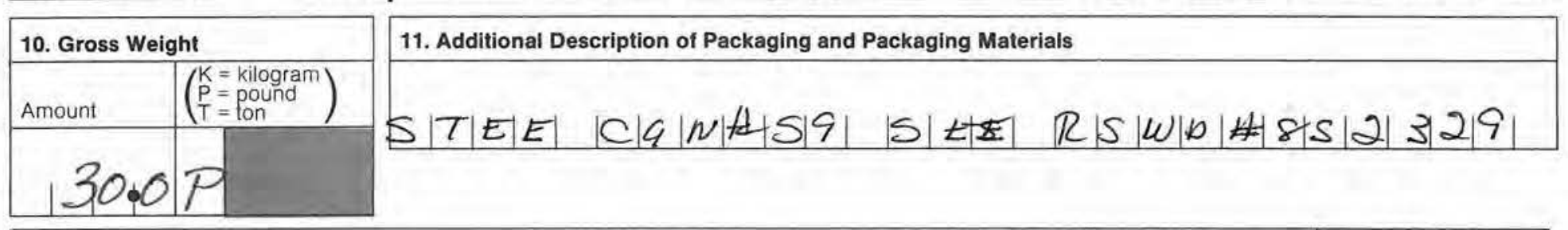

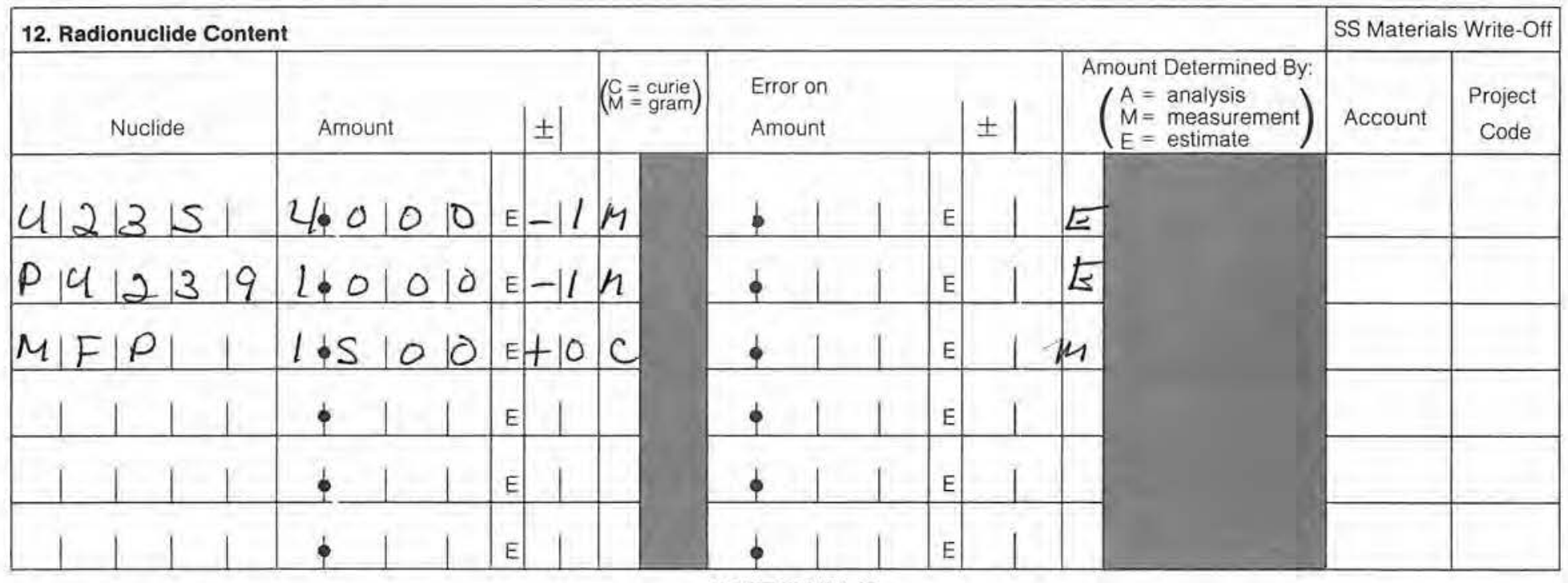

APPROVALS

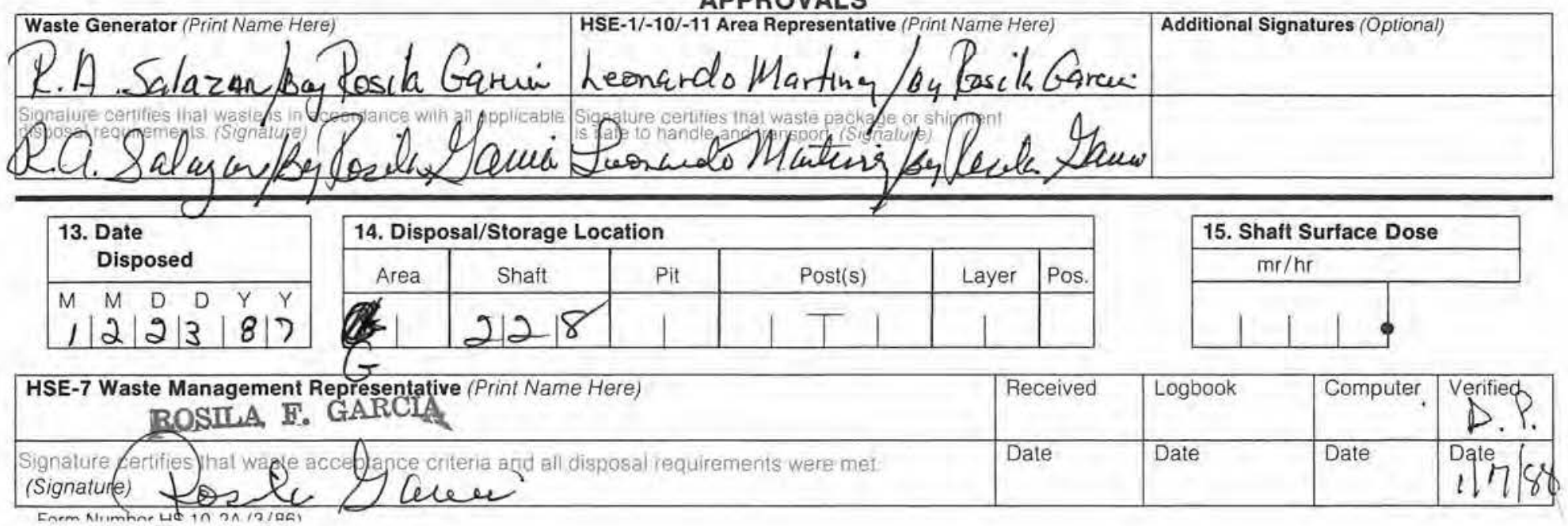




\section{INSTRUCTIONS FOR WASTE GENERATOR}

Filling Out the Form. The waste generator must complete this form to document all waste buried or retrievably stored at the Laboratory's TA-54, Area G, site. Be sure to complete each section before proceeding to the next section. The waste generator must follow these instructions:

1. Don't use more than the allotted spaces on the form (one letter or number per space).

2. Ensure that all data recorded on this form are legibly printed and clearly readable.

3. Note that the decimal point positions are already indicated in the sections where decimals would be needed (for example, see Section 7 on the front of this form). Enter information accurately in relation to these decimal points. Do not alter decimal point positions.

4. Use the number zero $(0)$ on the form $O N L Y$ on entries requiring that numerical designation. Do not use the number zero to fill blank spaces.

5. Where the amount of information available does not allow recording all data on one form, use additional forms for different portions of the waste.

When the Form is Completed. The waste generator must ensure that the properly completed form accompanies each waste shipment and each package of retrievable transuranic (TRU) waste delivered to the disposal/storage site. Waste generators may keep a copy of the completed form for their files.

\section{PERTINENT INSTRUCTIONS FOR SPECIFIC SECTIONS OF THIS FORM}

Section 5, Waste Code. Identify all waste by a 3-digit description code, as given in Attachment I, "Valid Waste Codes." Choose the code that best describes the waste material.

Section 6, Waste Description. Allow one space for each letter and one space after each word. Use this section to provide any additional information about the waste.

Section 9, Package Radiation. Do not use symbols for "greater than $(>)$," for "less than $(<)$," for "greater than or equal to $(\geq)$," or for "less than or equal to $(\leq)$." Round off fractions to the nearest whole number. If radiation levels exceed that which can be listed, leave this section blank and record the data in Section 11.

Section 11, Additional Description of Packaging and Packaging Materials. Use this space to provide property number, related form numbers, data that cannot be entered in Sections 6 or 9 (see above), etc.

Section 12, Radionuclide Content. List radionuclides using either the normally accepted notations (for example, U235, Pu239, Co60, and H3) or, for accountable materials, the element identification plus the SS Material Type Code (for example, Pu 52 for plutonium code 52, U38 for uranium code 38). Acceptable codes include MFP for mixed fission products and MAP for mixed activation products.

For nonradioactive chemical or hazardous waste, enter the correct chemical identification, such as CHEM, $\mathrm{PCB}$, or ASBES. If more than one contaminant is identifiable, each contaminant should be listed (with all appropriate data) on a separate line in Section 12. If there are more than six (6) radionuclides identified, or if there are any questions regarding the completion of this form, contact HSE-7 at 7-5397.

Questions regarding the handling or packaging of radioactive or hazardous wastes should be referred to Disposal Site Operations (7-6095).

\section{APPROVAL SIGNATURES}

Waste Generator. The waste generator must sign the form in the space allotted to indicate compliance with applicable waste packaging and disposal requirements. This signature is required for all waste, whether radioactive or nonradioactive. Note that both the generator's printed name and written signature are required.

HSE-1/-10/-11 Area Representative. An area representative from either the HSE-1, -10, or -11 group must sign the form if the wastes are radioactively contaminated. This signature indicates that the package or shipment is safe to handle and transport. Note that both the area representative's printed name and written signature are required.

Additional Signatures. An area representative from HSE-3 or HSE- 5 may be required to sign this form before certain hazardous materials are transported. This signature space also may be used for the group leader's signature, if required by the generator's group/division. 


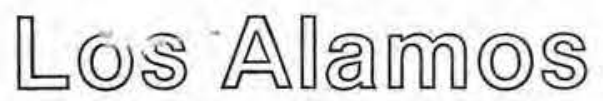

LOS Amos Nat tom Lab

LO8 Alamo, New Mexico 87545

1. Form Number

$s|8| 7 \mid \$ 130$

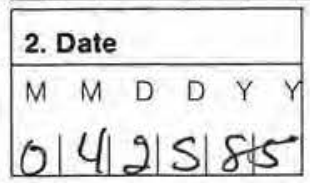

\begin{tabular}{|l|}
\hline 3. Retrievable \\
serial Number \\
\hline$B 214101016$ \\
\hline
\end{tabular}
RADIOACTIVE SOLID WASTE DISPOSAL RECORD

NOTE: Read instructions on back carefully before completing this form. \begin{tabular}{c}
\hline HSE-7 Waste Management \\
Ext. 6095. MS J592
\end{tabular}

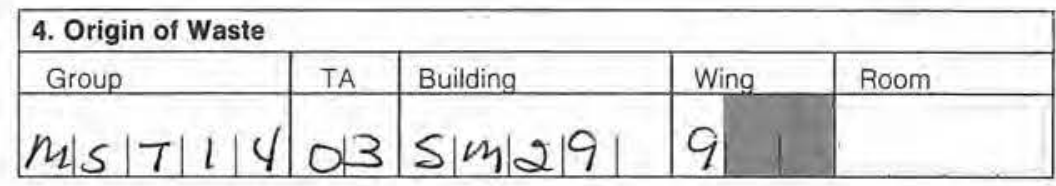

6. Waste Description

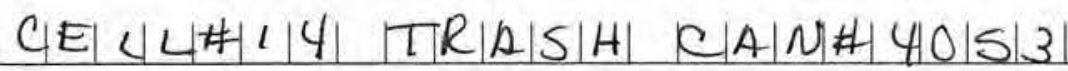

\begin{tabular}{|l|l|l|l|l|l|l|l|l|}
\hline \multicolumn{2}{|c|}{ 7. Numbers of Waste Packages } \\
\hline $\begin{array}{l}\text { Plastic } \\
\text { Bags }\end{array}$ & $\begin{array}{l}\text { Card- } \\
\text { Board } \\
\text { Boxes }\end{array}$ & No. & Gal. & No. & Volume- $\mathrm{ft}^{3}$ \\
\hline & & & & & & & \\
\hline
\end{tabular}

\begin{tabular}{|c|l|}
\hline \multicolumn{2}{|l|}{ 8. Gross Volume } \\
\hline Amount & $\left(\begin{array}{l}M=\text { meter }^{3} \\
F=\text { foot }^{3} \\
G=\text { gallon }^{2}\end{array}\right)$ \\
\hline & \multicolumn{1}{|l}{$\mid$} \\
\hline $1 / 0$ & $G$ \\
\hline
\end{tabular}

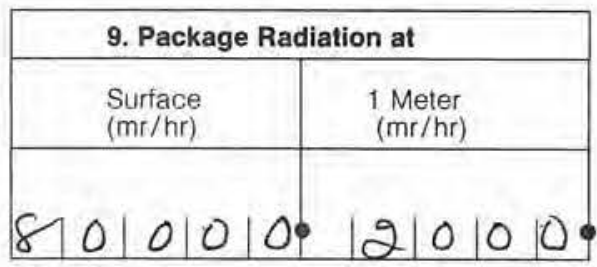

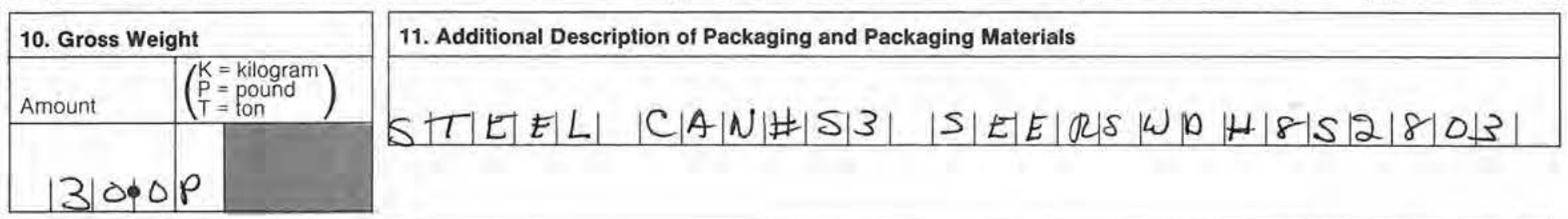

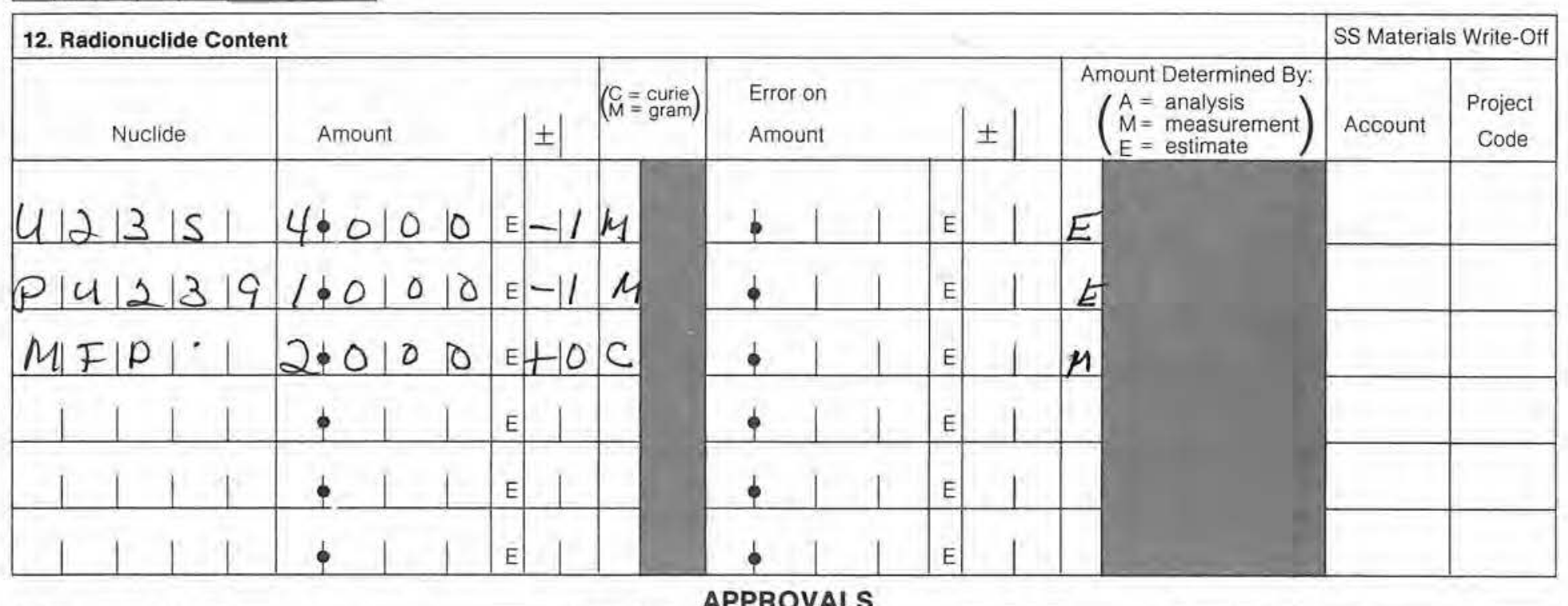

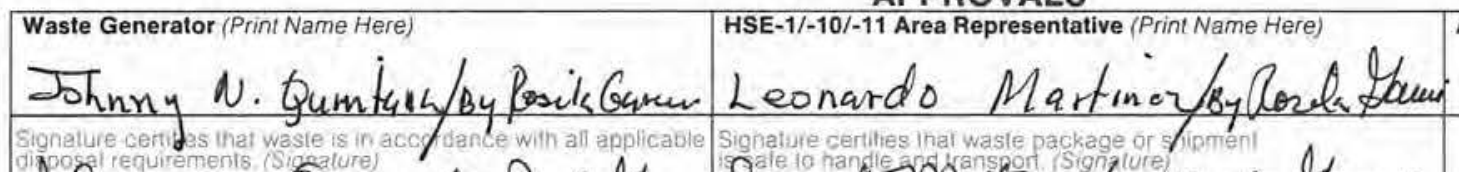

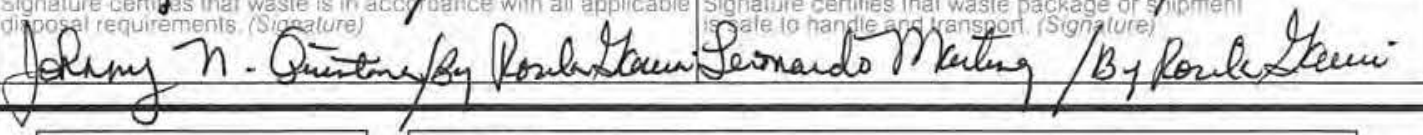

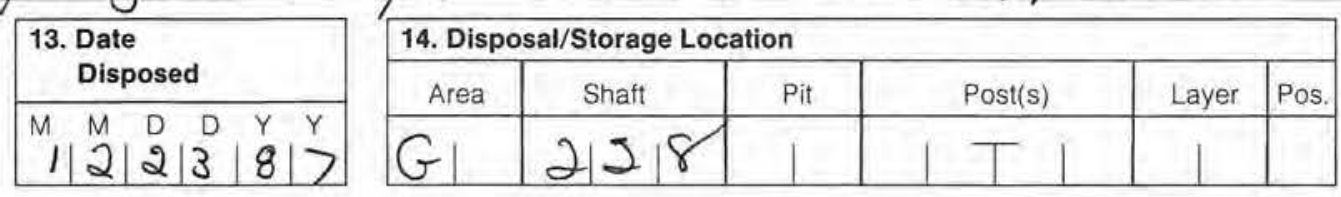

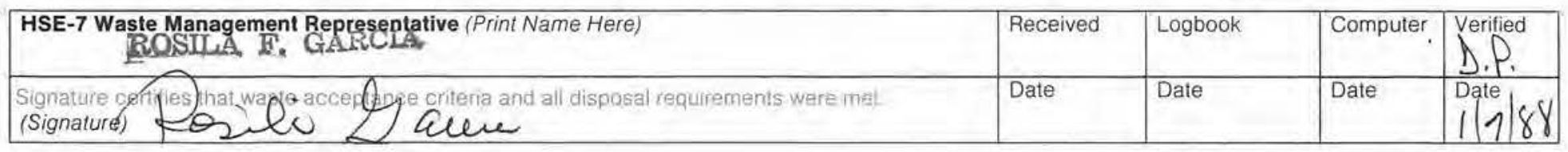




\section{INSTRUCTIONS FOR WASTE GENERATOR}

Filling Out the Form. The waste generator must complete this form to document all waste buried or retrievably stored at the Laboratory's TA-54, Area G, site. Be sure to complete each section before proceeding to the next section. The waste generator must follow these instructions:

1. Don't use more than the allotted spaces on the form (one letter or number per space).

2. Ensure that all data recorded on this form are legibly printed and clearly readable.

3. Note that the decimal point positions are already indicated in the sections where decimals would be needed (for example, see Section 7 on the front of this form). Enter information accurately in relation to these decimal points. Do not alter decimal point positions.

4. Use the number zero $(0)$ on the form $O N L Y$ on entries requiring that numerical designation. Do not use the number zero to fill blank spaces.

5. Where the amount of information available does not allow recording all data on one form, use additional forms for different portions of the waste.

When the Form is Completed. The waste generator must ensure that the properly completed form accompanies each waste shipment and each package of retrievable transuranic (TRU) waste delivered to the disposal/storage site. Waste generators may keep a copy of the completed form for their files.

\section{PERTINENT INSTRUCTIONS FOR SPECIFIC SECTIONS OF THIS FORM}

Section 5, Waste Code. Identify all waste by a 3-digit description code, as given in Attachment I, "Valid Waste Codes." Choose the code that best describes the waste material.

Section 6, Waste Description. Allow one space for each letter and one space after each word. Use this section to provide any additional information about the waste.

Section 9, Package Radiation. Do not use symbols for "greater than $(>)$," for "less than $(<)$," for "greater than or equal to $(\geq)$," or for "less than or equal to $(\leq)$." Round off fractions to the nearest whole number, If radiation levels exceed that which can be listed, leave this section blank and record the data in Section 11.

Section 11, Additional Description of Packaging and Packaging Materials. Use this space to provide property number, related form numbers, data that cannot be entered in Sections 6 or 9 (see above), etc.

Section 12, Radionuclide Content. List radionuclides using either the normally accepted notations (for example, U235, Pu239, Co60, and $\mathrm{H} 3$ ) or, for accountable materials, the element identification plus the SS Material Type Code (for example, Pu 52 for plutonium code 52 , U38 for uranium code 38 ). Acceptable codes include MFP for mixed fission products and MAP for mixed activation products.

For nonradioactive chemical or hazardous waste, enter the correct chemical identification, such as CHEM, $\mathrm{PCB}$, or ASBES. If more than one contaminant is identifiable, each contaminant should be listed (with all appropriate data) on a separate line in Section 12. If there are more than six (6) radionuclides identified, or if there are any questions regarding the completion of this form, contact HSE-7 at 7-5397.

Questions regarding the handling or packaging of radioactive or hazardous wastes should be referred to Disposal Site Operations (7-6095).

\section{APPROVAL SIGNATURES}

Waste Generator. The waste generator must sign the form in the space allotted to indicate compliance with applicable waste packaging and disposal requirements. This signature is required for all waste, whether radioactive or nonradioactive. Note that both the generator's printed name and written signature are required.

HSE-1/-10/-11 Area Representative. An area representative from either the HSE-1, -10 , or -11 group must sign the form if the wastes are radioactively contaminated. This signature indicates that the package or shipment is safe to handle and transport. Note that both the area representative's printed name and written signature are required.

Additional Signatures. An area representative from HSE- 3 or HSE-5 may be required to sign this form before certain hazardous materials are transported. This signature space also may be used for the group leader's signature, if required by the generator's group/division. 
RADIOACTIVE SOLID WASTE DISPOSAL RECORD FORMS

FOR

SHAFT 229

MATERIAL DISPOSAL AREA G 


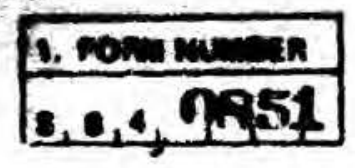

MEASE NEAD IRSTRUCTIONS ON BACK AREFULLY

\section{LOS AR NEOS RADOACTIVE SOLID WATTE HSE.7 Waste Managemen DIEMOEAL AECORD FORM

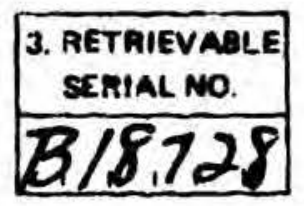

\begin{tabular}{|c|c|c|c|c|}
\hline \multicolumn{3}{|c|}{ 4. ORIGIN SF WASTE } & \multirow{2}{*}{$\frac{2}{3}$} & \multirow[b]{2}{*}{ ROOM } \\
\hline GROLF & TA & BLDG. & & \\
\hline$M, S, T_{1}$ & 0,3 & $s, m, 0,2,9$ & 9 & \\
\hline
\end{tabular}

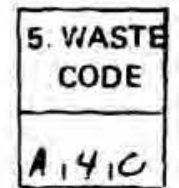

\section{WASTE DESCRIPTIINN}

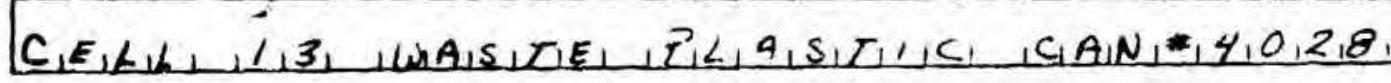

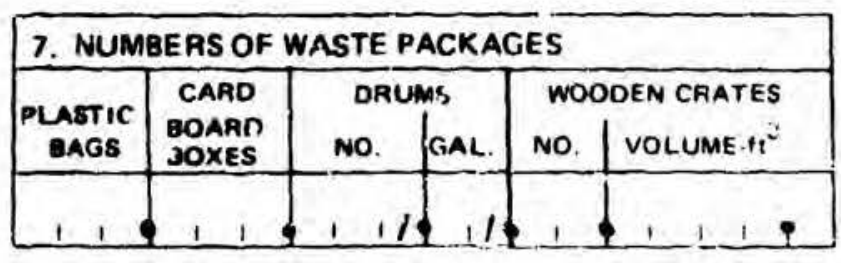
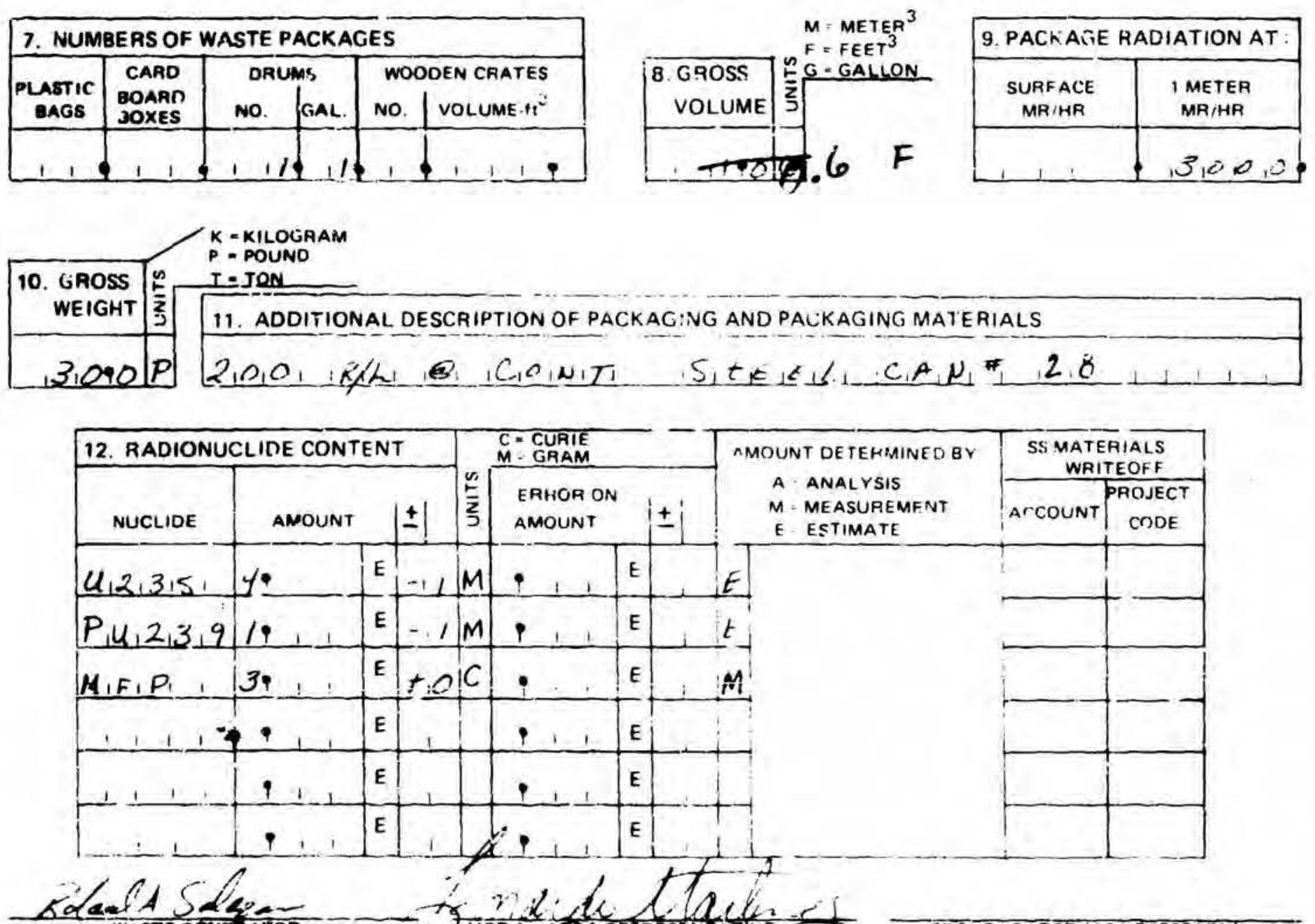

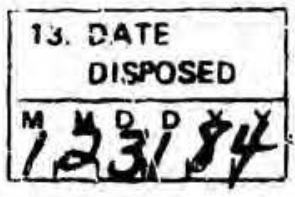

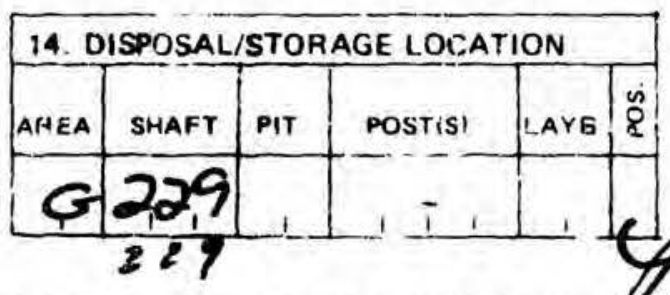


PLEASE READ INSTRUCTIONS OIN BACK CAREFULLY

\begin{tabular}{|l|}
\hline 1. FOAM NUMBER \\
\hline $5,8,4$, NR, 5 \\
\hline
\end{tabular}

\section{LOS ALAMOS RADIOACTIVE SOLID WASTE} DISPOSAL RECORD FORM

HSE.7 Waste Management

Ext 6095 MS J592

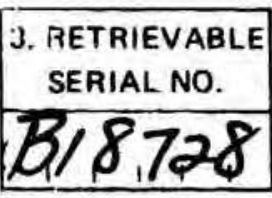

\begin{tabular}{|c|c|c|c|c|}
\hline \multicolumn{3}{|c|}{ 4. ORIGIN OF WASTE } & \multirow{2}{*}{$\sum_{z}^{0}$} & \multirow{2}{*}{$-\overline{\text { ROOM }}$} \\
\hline GROUP & TA & BLDG. & & \\
\hline$M_{1} S_{1} T_{1} I_{1}$ & $O_{1}$ & $0, S, M$ & 9 & \\
\hline
\end{tabular}

6. WASTE DESCRIPTION

$C_{1} E_{1} L, L_{1}, Z_{1}, W_{1} A_{1} S_{1} T, E_{1}, P_{1} L_{1} A_{1} S_{1} T_{1}, C_{1}, C_{1} A_{1} N_{1}, 4,1,4,5, \ldots, \ldots, \ldots, \ldots$

\begin{tabular}{|c|c|c|c|c|c|}
\hline \multicolumn{6}{|c|}{ 7. NUMBERS OF WASTE PACKAGES } \\
\hline \multirow{2}{*}{$\begin{array}{c}\text { PLASTIC } \\
\text { BAGS }\end{array}$} & \multirow{2}{*}{$\begin{array}{l}\text { CARD } \\
\text { BOARD } \\
\text { BOXES }\end{array}$} & \multicolumn{2}{|c|}{ DRUMS } & \multicolumn{2}{|c|}{ WOODEN CRATES } \\
\hline & & NO. & GAL. & NO. & VOLUME- $\cdot \mathrm{ft}^{3}$ \\
\hline 1 & 1 & & if & 1 & 11 \\
\hline
\end{tabular}

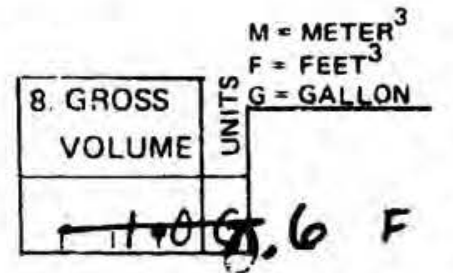

\begin{tabular}{|c|c|}
\hline 9. PACKAGE RADIATICN AT: \\
\hline $\begin{array}{c}\text { SURFACE } \\
\text { MR/HR }\end{array}$ & $\begin{array}{c}\text { 1 METEA } \\
\text { MRRITA }\end{array}$ \\
\hline $4,0,0,0,0$ & $1,0,0,0$ \\
\hline
\end{tabular}

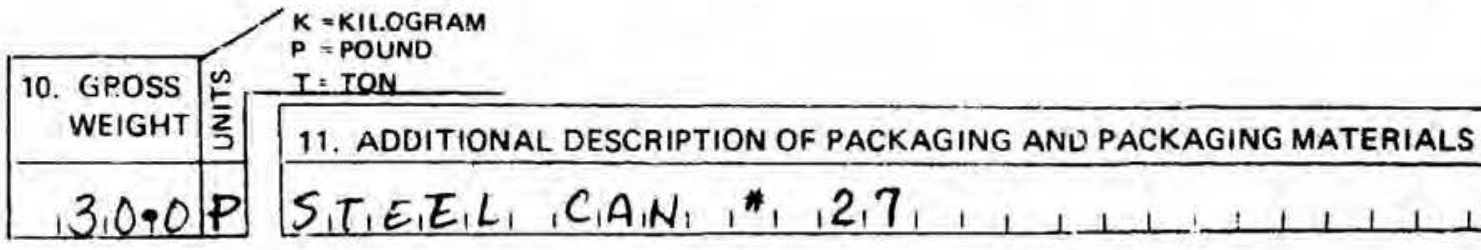

\begin{tabular}{|c|c|c|c|c|c|c|c|c|c|c|c|}
\hline \multicolumn{4}{|c|}{ 12. RADIONUCLIDE CONTENT } & \multicolumn{4}{|c|}{$\begin{array}{r}\text { C= CUAIE } \\
\text { IA }=\text { GRAMM } \\
\end{array}$} & \multirow{2}{*}{\multicolumn{2}{|c|}{$\begin{array}{c}\text { AMOUNT DETERMINED BY: } \\
\text { A }=\text { ANALYSIS } \\
\text { M MEASUAEMENT } \\
E=\text { STIMATE }\end{array}$}} & \multicolumn{2}{|c|}{$\begin{array}{c}\text { SS MATERIALS } \\
\text { WRITHOFF }\end{array}$} \\
\hline NUCLIDE & AMOUNT & & $| \pm|$ & $\frac{n}{2}$ & $\begin{array}{l}\text { ERROR O } \\
\text { AMOUNT }\end{array}$ & & \pm & & & ACCOUNT & $\begin{array}{l}\text { ROAECT } \\
\text { CODE }\end{array}$ \\
\hline $4,2,3,5$, & 4911 & E & $-1 \mid$ & $M$ & 1,1 & $E$ & & $E$ & & & \\
\hline$D, u, 2,3,9$ & $1 \%:$ & E & $-1 !$ & $M$ & $? \quad 1 \quad 1$ & E & & E & & & . \\
\hline$H_{1} F_{1} P_{1}$ & 1911 & E & +10 & C & $9+1$ & E & 1 & $M$ & & & \\
\hline 1111 & 91 & E & 1 & & 111 & E & & & & & \\
\hline 1111 & 91, & E & $\perp$ & & 111 & E & & & & & \\
\hline 11,1 & 9,1 & E & 1 & & 1,1 & E & & & & & \\
\hline
\end{tabular}

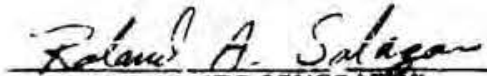

IVASTE GENERATOR

apulicatie ispessal requirements.

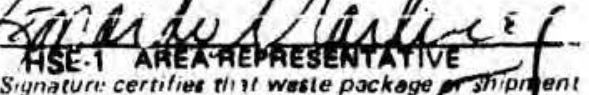
Signaturt: certifies thl " wasle poch
is safe to handle and transport.

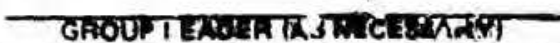

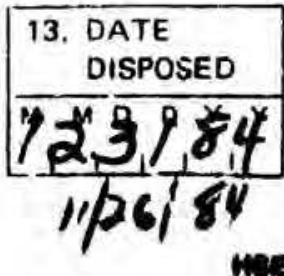

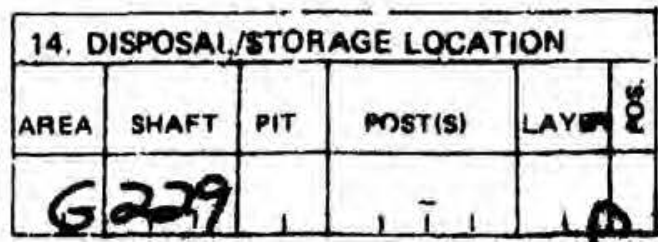

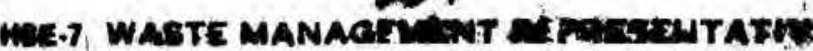

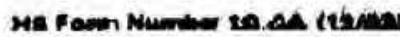




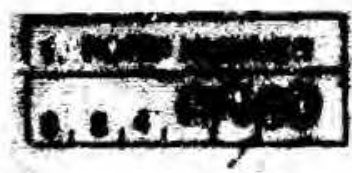

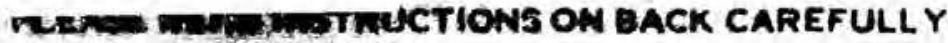

LCS ALAT MADOACTNE COLID WASTE ov vesel nicOAD FOAM
HSE.7 Waste Maragement Ext 6095 MS J592

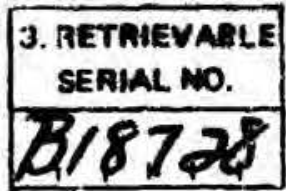

\begin{tabular}{|c|c|c|c|c|}
\hline 4. ORIGIN OF WASTE & \multirow{2}{*|}{} & \\
\hline GROUP & TA & OLDG & $\frac{2}{3}$ & ROOM \\
\hline MIS, $T 1 / 14$ & 13 & $S_{1 M} M_{12,9}$ & 9 & \\
\hline
\end{tabular}

\begin{tabular}{|l|} 
5. VIASTE \\
CODE \\
\hline$A, 4,0$ \\
\hline
\end{tabular}

\section{WASTE DESCR:OTION}

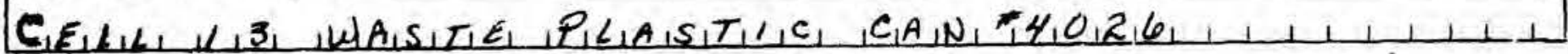

\begin{tabular}{|c|c|c|c|c|}
\hline \multicolumn{5}{|c|}{ 7. MUMEERS OF WASTE PACKAGES } \\
\hline & CARD & DRUMS & wor & DEN CRATES \\
\hline $\begin{array}{l}\text { LASTIC } \\
\text { EaGS }\end{array}$ & $\begin{array}{l}\text { EOARD } \\
\text { DOXES }\end{array}$ & no. GGL. & No. & VOLUME- $-\mathrm{t}^{3}$ \\
\hline & & 1/4 & & 1,19 \\
\hline
\end{tabular}

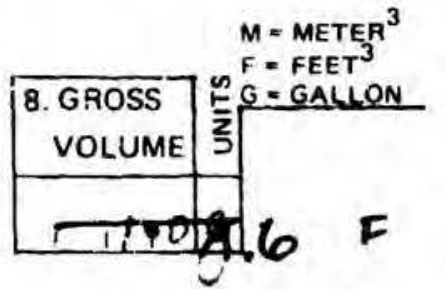

\begin{tabular}{|c|c|}
\hline \begin{tabular}{c} 
9. PACKAGE RADIATION AT: \\
\hline $\begin{array}{c}\text { SURFACE } \\
\text { MR/HR }\end{array}$
\end{tabular} & $\begin{array}{c}\text { IMETER } \\
\text { MR/HR }\end{array}$ \\
\hline & $12,0,0,0$ \\
\hline
\end{tabular}

10. GROSS T-TOY $K=$ KILOGF. $+M$

WEIGHT $\bar{\Sigma}$ 11. ADDITIONAL DESCRIPTION UF PACKAGING AND PACKAGING MATERIALS

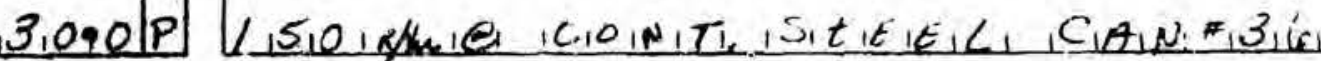

\begin{tabular}{|c|c|c|c|c|c|c|c|c|c|c|c|}
\hline \multicolumn{4}{|c|}{ 12. RADIONUCLIDE CONTENT } & \multicolumn{4}{|c|}{$\begin{array}{r}\text { C. CUAIE } \\
M=\text { GRAM }\end{array}$} & \multirow{2}{*}{\multicolumn{2}{|c|}{ 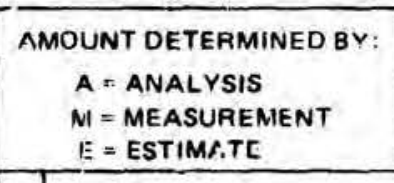 }} & \multicolumn{2}{|c|}{$\begin{array}{c}\text { SS NiATERIALS } \\
\text { WRITEOFF }\end{array}$} \\
\hline NUCLIDE & AMOUNT & & \pm & $\frac{2}{5}$ & $\begin{array}{l}\text { ERROR ON } \\
\text { AMOUNT }\end{array}$ & & \pm & & & ACCOUNT & $\begin{array}{c}\text { PROJECT } \\
\text { CODE }\end{array}$ \\
\hline$k_{1} 2_{1} \geq s_{1}$ & $4 \cdot 1$. & E & -11 & M. & 111 & E & & $E$ & & & \\
\hline$P, v_{1}, 3,3,9$ & 1911 & E & -1 & $M$ & $1 \quad 1$ & E & & $E$ & & & \\
\hline$M_{1} F_{1} P_{1}$, & 2,1 & $E$ & +10 & c & 1,1 & E & & $M$ & & & \\
\hline 1111 & ix. & is. & 1 & & $1 \quad 1$ & E & & & & & \\
\hline $1.1 \cdot 1$ & 1,1 & E & & & -111 & $\mathbf{E}$ & & & & & \\
\hline 1111 & $\uparrow, 1$ & E & & & $2, \ldots$ & E & & & & & \\
\hline
\end{tabular}

\section{Relanl A. Soloser}

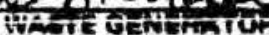
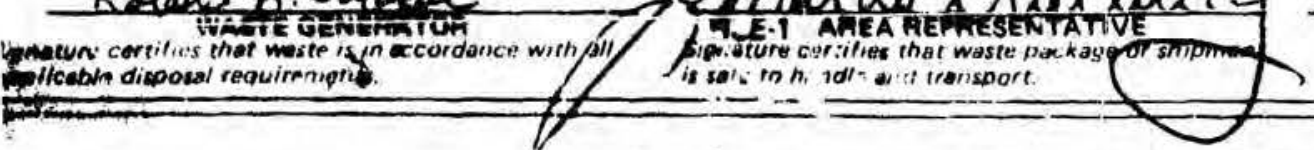

GAOUP LEADER TAS NECEESARYI

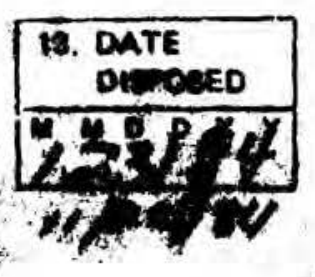

\begin{tabular}{|c|c|c|c|c|c|}
\hline 14. DIE OSAL/STORAGE LOCATION \\
\hline AMEA & EHAFT & PIT & POSTISI & IA: & है \\
\hline & 229 & & & & \\
\hline
\end{tabular}

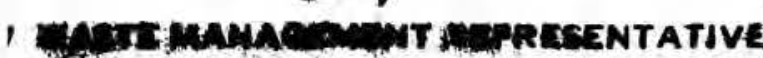


PLEASE READ INSTRUCTIONS ON BACK CAREFULLY

\begin{tabular}{|l|}
\hline 1. FORM NLMBER \\
\hline $5,8,4,0,65$ \\
\hline
\end{tabular}

\section{LOS ALAMUS RADIOACTIVE SOLID WASTE DISPOSAL RECORD FORM}

HSE. 7 Waste Menagement

Ex1 6095 MS J592

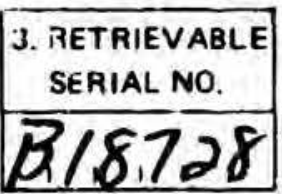

\begin{tabular}{|c|c|c|c|c|}
\hline \multicolumn{3}{|c|}{ 4. OAIGIN OF WASTE } & \multirow{2}{*}{$\frac{2}{\frac{2}{3}}$} & \multirow[b]{2}{*}{ RUOM } \\
\hline GROUP & TA & BLDG. & & \\
\hline$M, S, T, 1,4$ & 0,3 & $c_{1} s, m, 2,9$ & 9 & \\
\hline
\end{tabular}

\begin{tabular}{l}
\hline 5. VASTR \\
SODE \\
\hline $4,4,0$ \\
\hline
\end{tabular}

\section{WASTE DESCRIPTION}

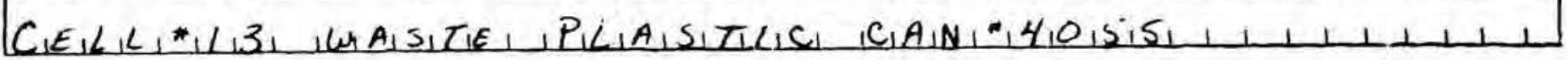

\begin{tabular}{|c|c|c|c|c|c|}
\hline \multicolumn{6}{|c|}{ 7. NUMBERS OF WASTE PACKAGES } \\
\hline \multirow{2}{*}{$\begin{array}{c}\text { PLASTIC } \\
\text { BAGS }\end{array}$} & \multirow{2}{*}{$\begin{array}{l}\text { CARD } \\
\text { BOARD } \\
\text { BOXES } \\
\end{array}$} & \multicolumn{2}{|c|}{ DRUMS } & \multicolumn{2}{|c|}{ WOODEN CRATES } \\
\hline & & NO. & GAL. & NO. & VOLUME $-\mathrm{ft} \mathrm{t}^{3}$ \\
\hline 11 & 11 & 1 & & 1 & 1 \\
\hline
\end{tabular}
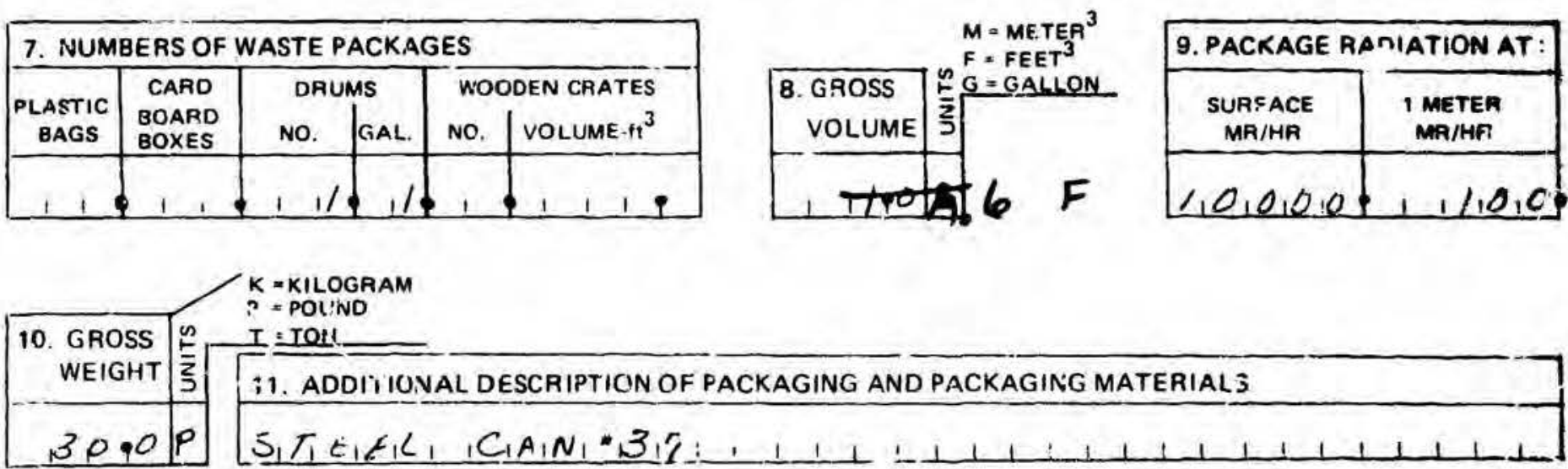

\begin{tabular}{|c|c|c|c|c|c|c|c|c|c|c|}
\hline \multicolumn{4}{|c|}{ 12. RADIONUCLIDE CIONTENT } & \multicolumn{4}{|c|}{$\begin{array}{l}C=\text { C JRIE } \\
M=\text { SRAMM }\end{array}$} & \multirow{2}{*}{ 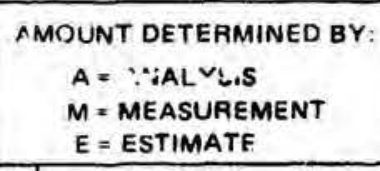 } & \multicolumn{2}{|c|}{$\begin{array}{l}\text { SS NATERIALS } \\
\text { WRITEOFF } \\
\end{array}$} \\
\hline NUCLIDE & AMOUNT & & \pm & $\frac{\omega}{b}$ & $\begin{array}{l}\text { ERROR ON } \\
\text { AMOUNT }\end{array}$ & & \pm & & ACCOUNT & $\begin{array}{c}\text { QOJECT } \\
\text { CODE }\end{array}$ \\
\hline $4,2,3,5$, & $49 \div 1$ & E & -1 & $M$ & 91 & $\mathrm{E}$ & & $E$ & & \\
\hline$P u_{1} 2_{1}$, & 191 & E & $-\div 1$ & $M$ & $P \quad 1$ & E & & $\underline{E}$ & & \\
\hline$M F_{1} P_{1}$ & $19 \quad 1$ & $E$ & -11 & c & $1 \quad 1 \quad 1$ & E & 1 & $M$ & & \\
\hline 1111 & 11 & $E$ & 1 & & $i 11$ & $E$ & & & & \\
\hline 1111 & 111 & E & 1 & & i 1 & E & & & & \\
\hline 111 & $1 \quad 1$ & E & & & 9 & E & & & & \\
\hline
\end{tabular}

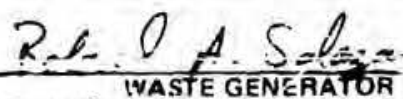

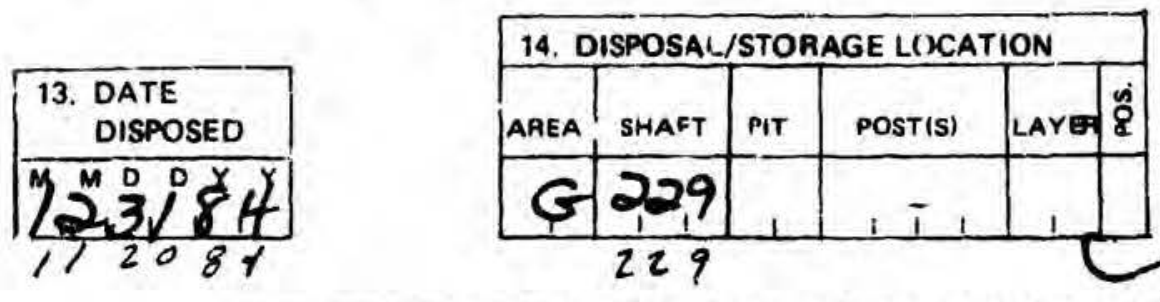

MEE.7 WASTE MANAGENEST REPRESENTATIV 


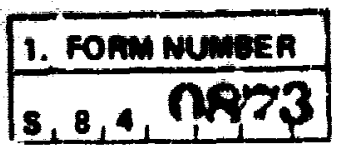

PLEASE READ INSTRUCTIONS ON BACK CAREFULLY

LOS ALAmos RADUOACTIVE OLID WASTE HSE./ Waste Management DIEROSAL RECORD FORM

Fxt 6095 MS $J 592$

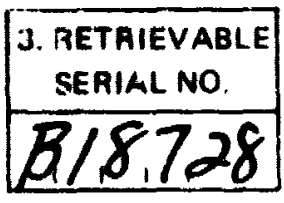

\begin{tabular}{|c|c|c|c|c|}
\hline \multicolumn{3}{|c|}{ 4. ORIGIN OF WASTE } & \multirow{2}{*}{$\stackrel{0}{\stackrel{0}{3}}$} & \multirow[b]{2}{*}{ ROOM } \\
\hline GAOUP & TA & BLDG. & & \\
\hline$T 1$ & 0,3 & & 9 & : \\
\hline
\end{tabular}

$\left[\begin{array}{c}\text { 5. VASTE } \\ \text { rODE } \\ \hline A+U\end{array}\right.$

6. WASTE DESCRIPTION

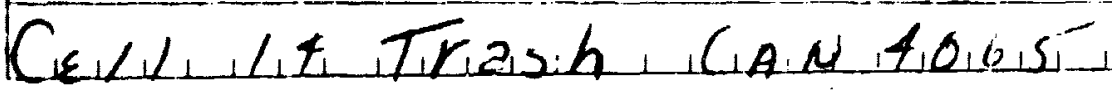

\begin{tabular}{|c|c|c|c|c|c|}
\hline \multicolumn{6}{|c|}{ 7. NUMBERS OF WASTE PACY:AGES } \\
\hline & CARO & & & wod & DEN CAATES \\
\hline BAGS & $\begin{array}{l}\text { BOAAD } \\
\text { BOXEE }\end{array}$ & No. & GAAL. & No. & VOLUME $-f t^{3}$ \\
\hline
\end{tabular}

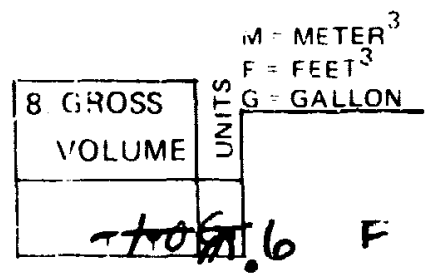

\begin{tabular}{|c|c|}
\hline 9. PACKAGE RADIATION AT: \\
\hline $\begin{array}{c}\text { SURFACE } \\
\text { MR:AH }\end{array}$ & $\begin{array}{c}\text { M METER } \\
\text { MRIHR }\end{array}$ \\
\hline 1 & 21000 \\
\hline
\end{tabular}

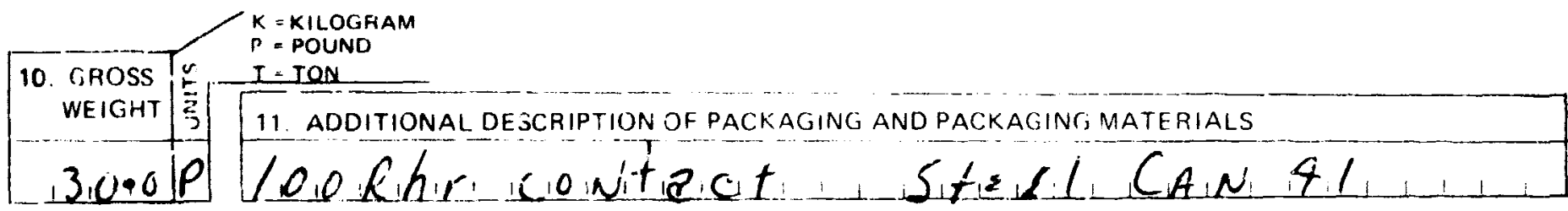

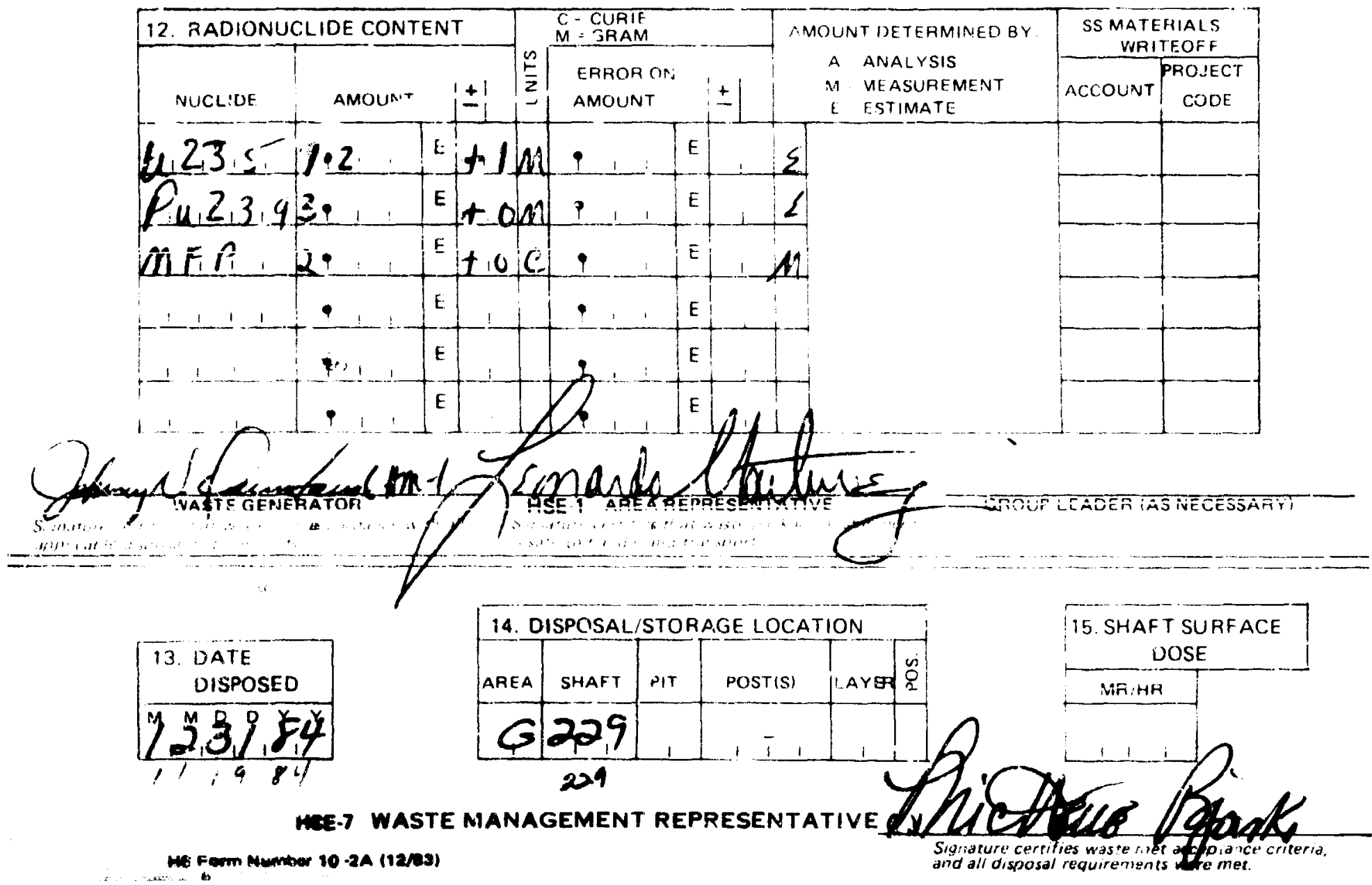


PLEASE KEAD IÂTTRUCTIONS ON BAGK CAREFULLY

1. rona unuese

$8,8,4,092$
LOS ALAMOS RADIOACTME WOLID WASTE DIRouAL AECOND FORM
Het 7 Woste Manowinnt

Ext 6004 MS JEa?
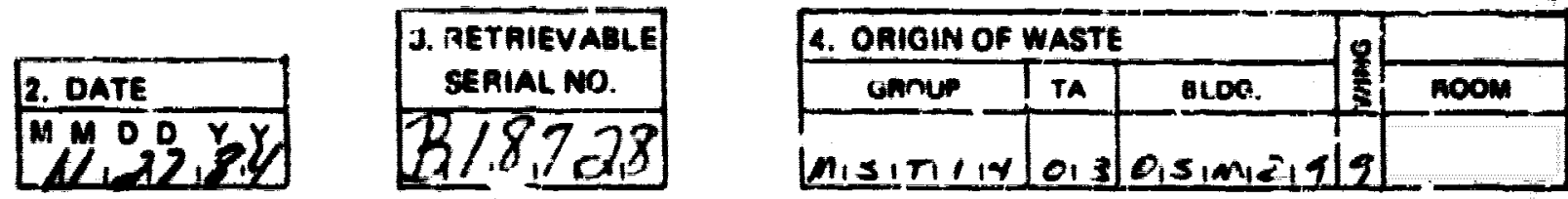

\section{WASTE DESCAIPTION}

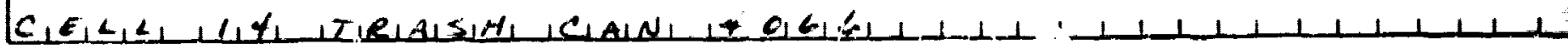

\begin{tabular}{|c|c|c|c|c|c|}
\hline \multicolumn{6}{|c|}{ 1. NUMBERS OF WASTE PACKAGES } \\
\hline & CAAD & & & nor & DEN CRATES \\
\hline GAGS & $\begin{array}{l}\text { BOARC } \\
\text { BOXES }\end{array}$ & NO. & GAL. & No. & VOLUME- $-t^{3}$ \\
\hline
\end{tabular}

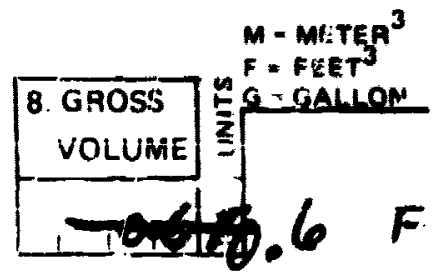

\begin{tabular}{|c|c|}
\hline \multicolumn{2}{|c|}{ 9. PACKAGE RADIATION AT } \\
\hline $\begin{array}{l}\text { 'UAFACE: } \\
\text { MFAHAF }\end{array}$ & 1 meten \\
\hline 810 & \\
\hline
\end{tabular}

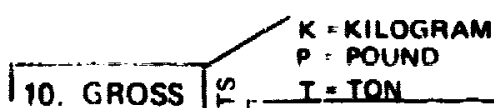

WEIGHT [1. ADDITIONAL DESCQ:PTION OF PACKAGING AND PACKAGING MATERIALS

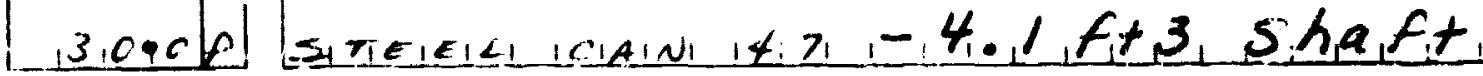

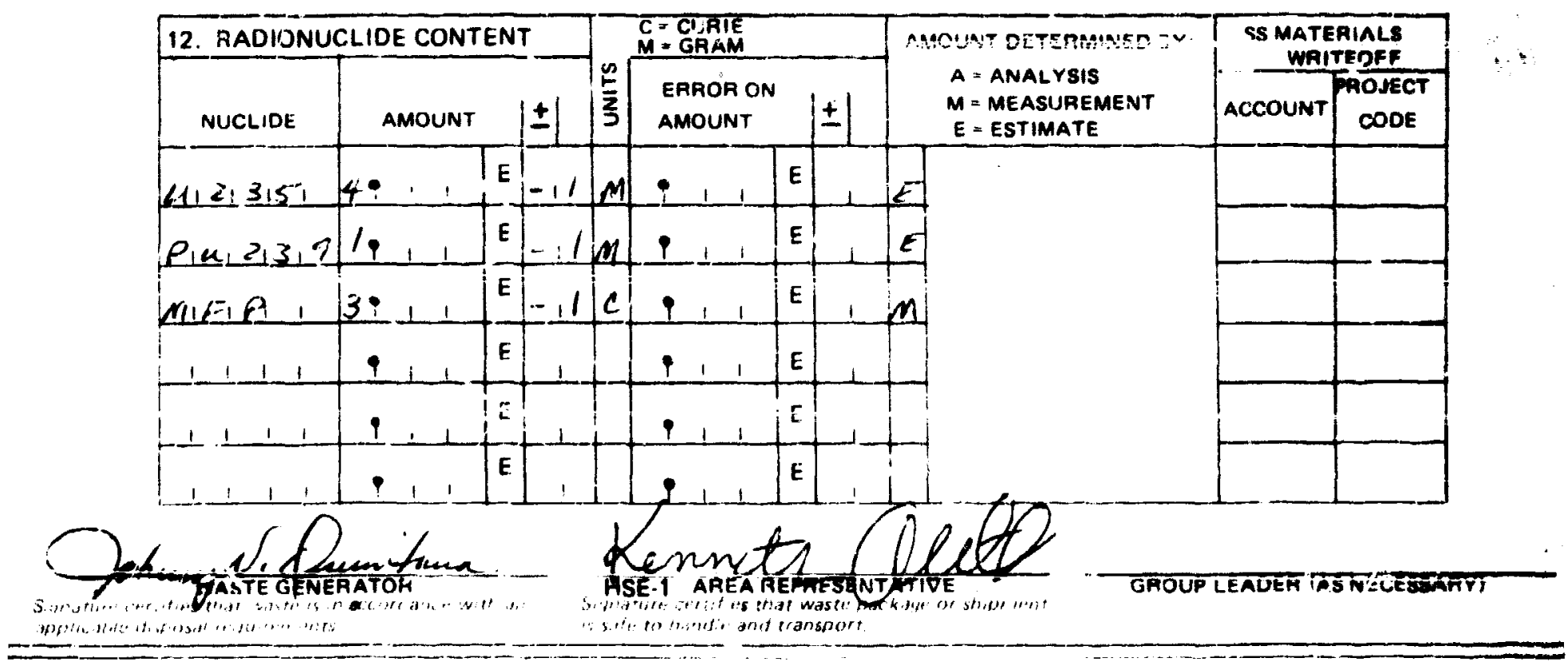

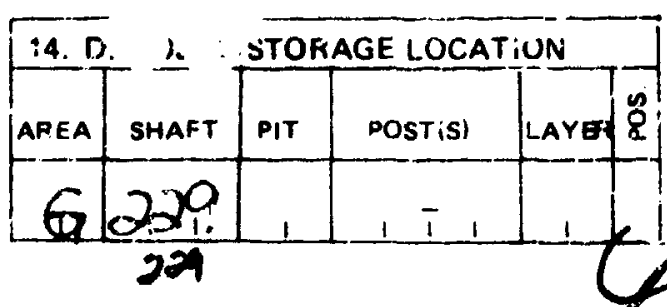

ME.7 WASTE: MANAGEMENT REPRESFN I ATIVE

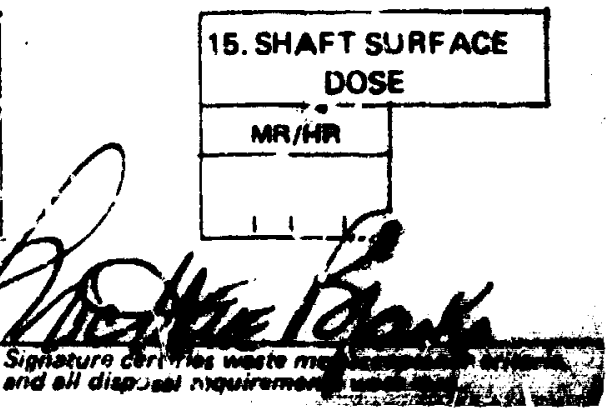


PLEASE READ INSTRUCTIONS ON BACK CAREFULLY

\begin{tabular}{|l|}
\hline 1. FOFM NUMBER \\
\hline $58,4 \times 898$ \\
\hline
\end{tabular}

2. DATE

rrio

\section{LOS ALAMOS RADIOACTIVE SOLID WASTE DISPOSAL RECORD FORM}

HSF 7 Waste: Managerrent

Ext 6095 MS J592

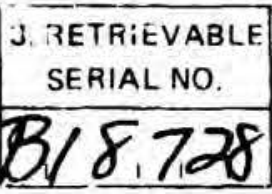

\begin{tabular}{|c|c|c|c|c|}
\hline \multicolumn{3}{|c|}{ 4. ORIGIN OF WASTE } & \multirow{2}{*}{$\frac{0}{z}$} & \multirow[b]{2}{*}{ ROOM } \\
\hline GROUP & TA & BLDG. & & \\
\hline$M_{1} \leq|T|, 1 \%$ & 0,3 & $0,5, n_{12}, 4$ & c) & \\
\hline
\end{tabular}

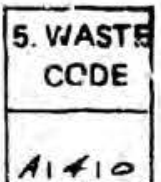

6. WASTE DESCRIPTION

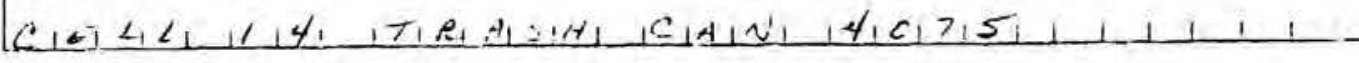

\begin{tabular}{|c|c|c|c|c|c|}
\hline \multicolumn{6}{|c|}{ 7. NUMBERS OF WASTE PACKAGES } \\
\hline & CARD & & & wo & DEN CRATES \\
\hline BAGS & $\begin{array}{l}\text { BOARD } \\
\text { BOXES }\end{array}$ & NO. & GAL. & No. & VOLUME $\cdot \mathrm{ft}^{3}$ \\
\hline
\end{tabular}
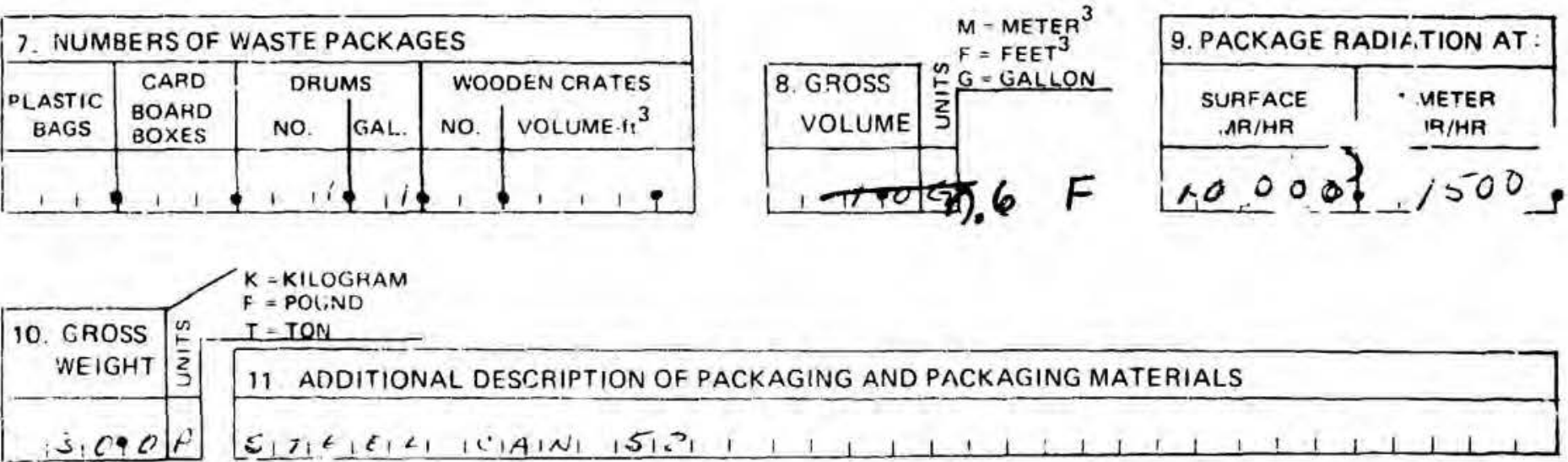

\begin{tabular}{|c|c|c|c|c|c|c|c|c|c|c|c|}
\hline \multicolumn{4}{|c|}{ 12. 3 ADIONUCLIDE CONTENT } & \multicolumn{4}{|c|}{$\begin{array}{l}C=\text { CURIE } \\
M=G R A M\end{array}$} & \multirow{2}{*}{\multicolumn{2}{|c|}{$\begin{aligned} \text { AMOUNT DETERMINED BY: } & \\
A & =\text { ANALYSIS } \\
M & =\text { MEASUHEMENT } \\
E & =\text { ESTIMATE }\end{aligned}$}} & \multicolumn{2}{|c|}{$\begin{array}{c}\text { SS MATERIALS } \\
\text { VIRITEOFF } \\
\end{array}$} \\
\hline NUCLIDE & AMOUNT & & \pm & $\frac{5}{3}$ & $\begin{array}{l}\text { ERROR ON } \\
\text { AMOUNT }\end{array}$ & & \pm & & & ACCOUNT & $\begin{array}{l}\text { ROJECT } \\
\text { CODE }\end{array}$ \\
\hline 4121,2151 & $\therefore$ & E & $-1 \mid$ & Wi & 1 11 & $E$ & & $\epsilon$ & & & \\
\hline$P, 4,2,3,9$ & 1411 & $E$ & -1 & $M$ & $p \quad 1$ & E & & $\epsilon$ & & & \\
\hline$m_{1} F_{1} p_{1}$ & 195,1 & E & -11 & ce & 1 1 & E & & $M$ & & & \\
\hline 1111 & 1,1 & E & 1 & & i 1 & E & & & & & \\
\hline 1111 & $1 \quad 1$ & E & 1 & & $1 \quad 1 \quad 1$ & E & & & & & \\
\hline$\therefore \quad 11$ & P 1 & E & 1 & & p i b & E & & & & & \\
\hline
\end{tabular}

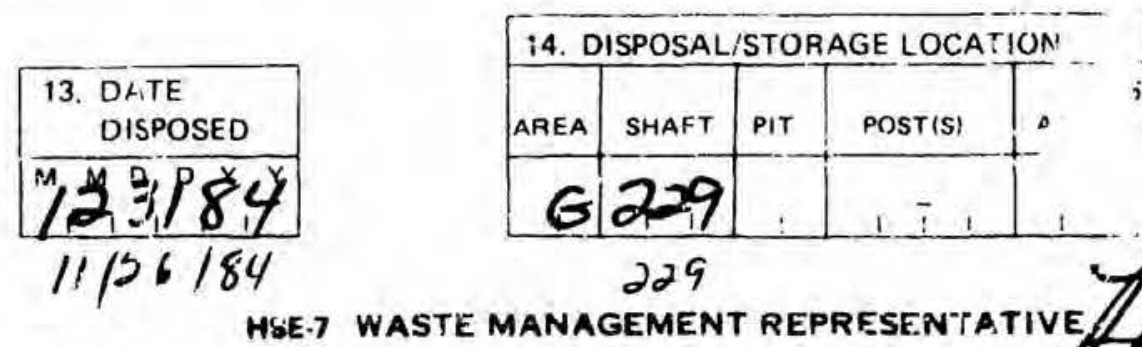

HSE.7 WAS

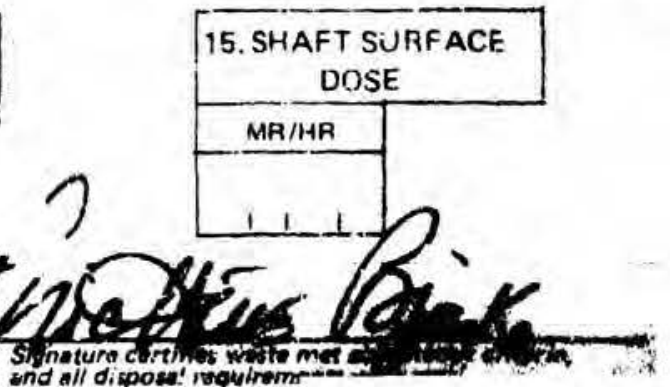


RADIOACTIVE SOLID WASTE DISPOSAL RECORD FORMS

FOR

SHAFT 230

MATERIAL DISPOSAL AREA G 


\section{PLEA F OADWWTACTIONS ON BACK CAREFULLY}

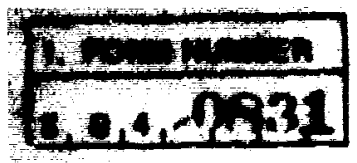

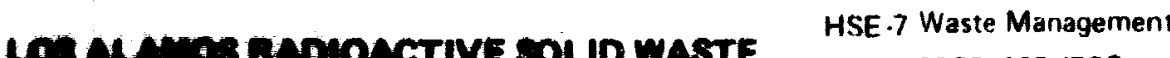
OISTOSAL RECORD FORM

\begin{tabular}{|c|c|c|c|c|c|c|c|}
\hline \multirow[b]{2}{*}{ 2. 0} & \multirow{2}{*}{$\begin{array}{l}\text { 3. RETAIEVAOLE } \\
\text { SERIAL NO. }\end{array}$} & \multicolumn{3}{|c|}{ 4. ORIGIN OF WASTE } & \multirow{2}{*}{$\sum_{0}^{0}$} & \multirow[b]{2}{*}{ ROOM } & \multirow{2}{*}{$\begin{array}{l}\text { 5. VIASTE } \\
\text { CODE }\end{array}$} \\
\hline & & GROUP & TA & BLDG. & & & \\
\hline & B/,8,703 & MSTIII & & & & & $A, 4,1$ \\
\hline
\end{tabular}

6. WASTE DESCBIPTION

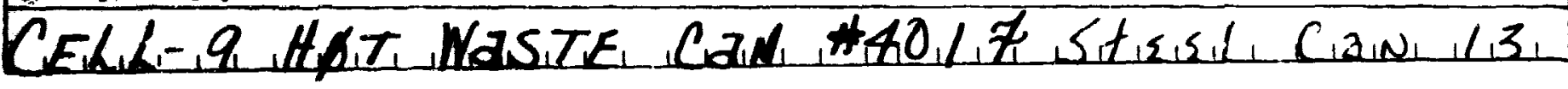

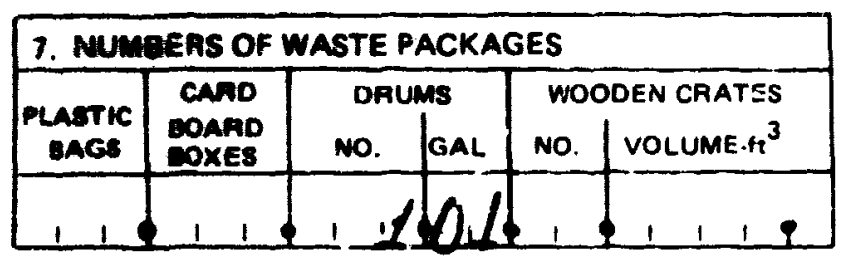
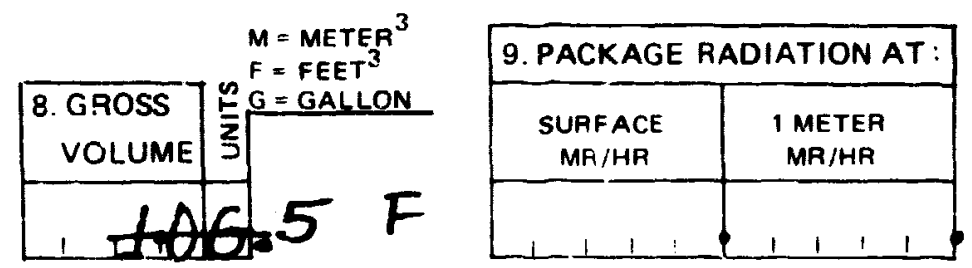

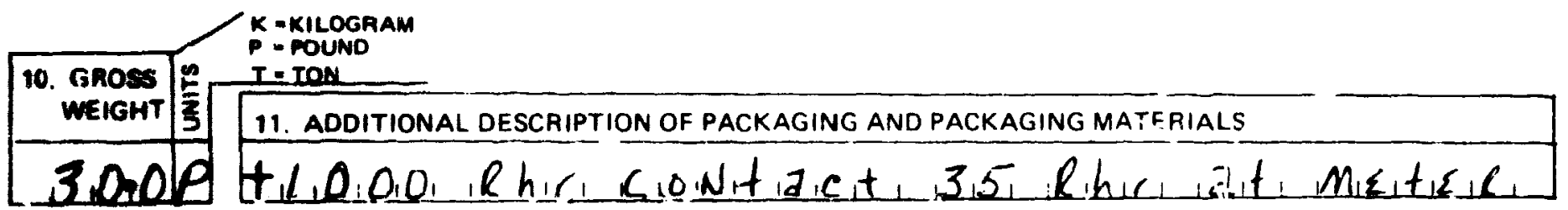
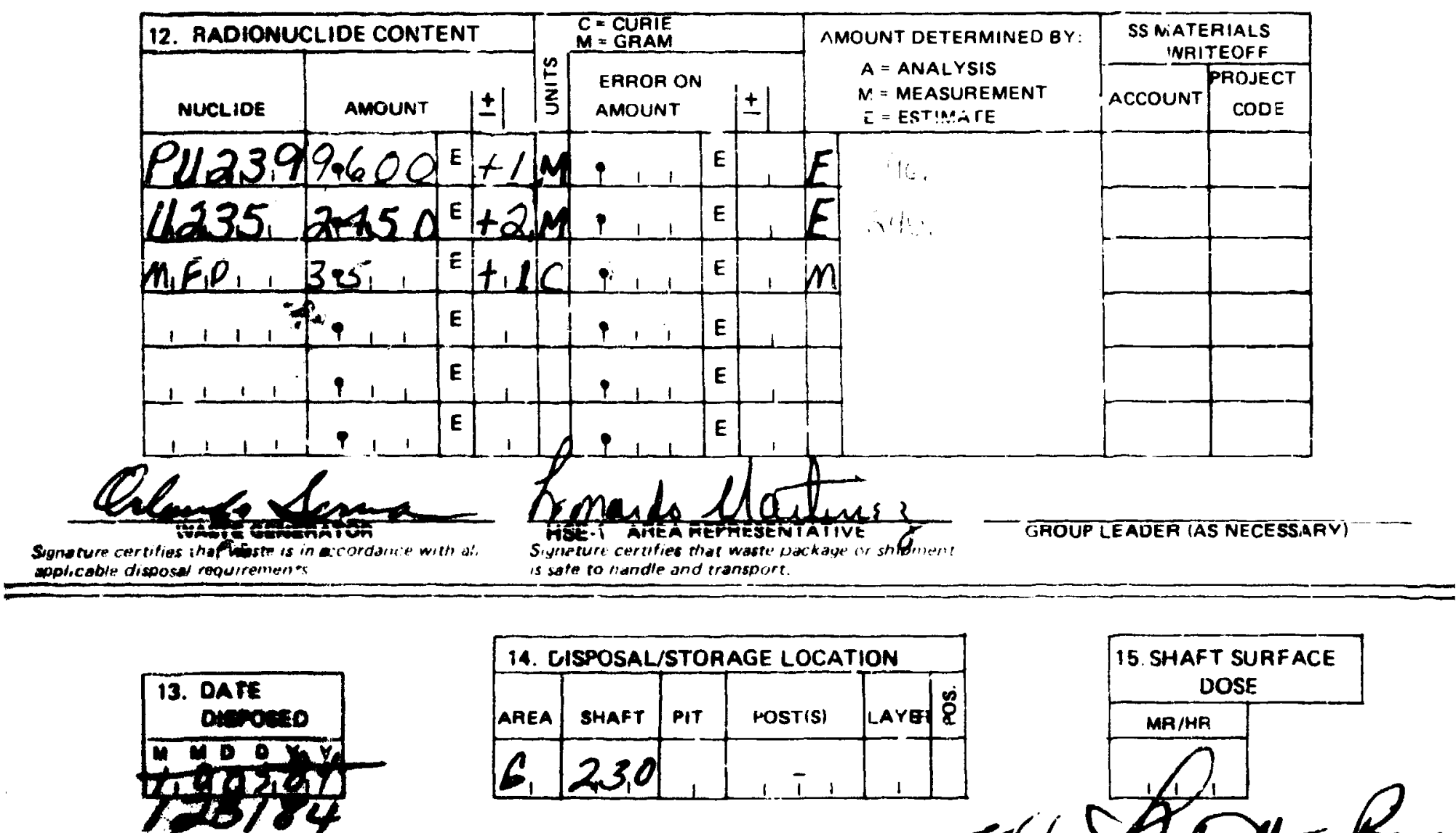

WMTE MANACEMENT REPREgENTATIVE

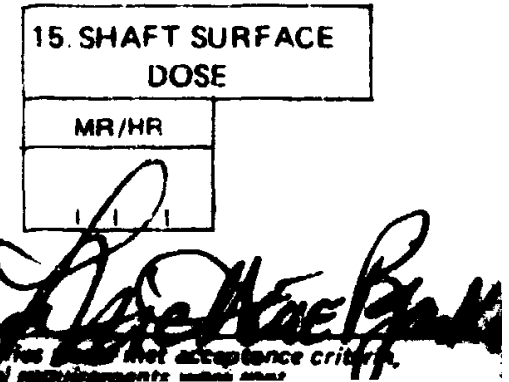


PLEAE READ WOTRUCTIONS ON BACK CAREFULLY

LA. ALAOS RMDNACTIVE SOLID WASTE DIEOSAL RECORD FORM

\begin{tabular}{|c|}
\hline \\
\hline $\begin{array}{l}M \text { D D Y } \\
\angle / Q_{1}, \beta, 8, q\end{array}$ \\
\hline
\end{tabular}

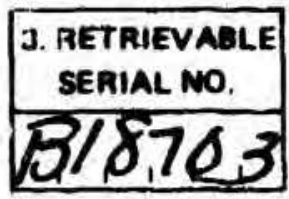

\begin{tabular}{|c|c|c|c|c|}
\hline \multicolumn{3}{|c|}{ 4. ORIGIN OF WASTE } & \multirow{2}{*}{$\begin{array}{l}0 \\
2 \\
\frac{2}{3}\end{array}$} & \multirow[b]{2}{*}{ ROOM } \\
\hline GROUP & TA & BLDG. & & \\
\hline$M=1, \pi / 14$ & 0,3 & $S_{1} M_{1}$ & 9 & \\
\hline
\end{tabular}

\begin{tabular}{|l|}
\hline 5. VIASTE \\
CODE \\
\hline$A_{1}, 1,0$ \\
\hline
\end{tabular}

\section{WASTE DESCRIPTION}

$C_{1} E_{1} K_{1}, K_{1} B_{1}, W A_{1} S_{1} T_{1}, P_{1} L_{1} A_{1} S_{1} T_{1} I_{1} C_{1} C_{1} A_{1} N_{1}, H_{1} / S_{1} 3_{1}, \ldots, 1,1,1,1$

\begin{tabular}{|c|c|c|c|c|c|}
\hline \multicolumn{6}{|c|}{ 7. MUMBE AS OF WASTE PACKAGES } \\
\hline & CAAD & & & & DEN CRATES \\
\hline aAGs & $\begin{array}{l}\text { OAARD } \\
\text { BOXES }\end{array}$ & No. & GAL. & No. & VOLUME $-\mathrm{ft}^{3}$ \\
\hline
\end{tabular}

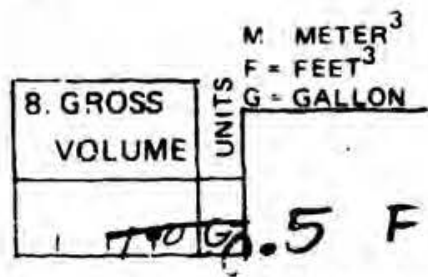

\begin{tabular}{|c|c|}
\hline 9. PACKAGE RADIATION AT: \\
\hline $\begin{array}{c}\text { SURFACE } \\
\text { MR/HR }\end{array}$ & $\begin{array}{c}\text { 1 METER } \\
\text { MR/HR }\end{array}$ \\
\hline 1 & $1 / 10,0,0$ \\
\hline
\end{tabular}

\begin{tabular}{|c|}
\hline $\begin{array}{l}\text { 10. GROSS } \\
\text { WEIGHT }\end{array}$ \\
\hline 3,090 \\
\hline
\end{tabular}

$K$-KILOGRAM

$P=$ POUND

11. ADDITIONAL DESCRIPTION OF PACKAGING AND PACKAGING MATEKIALS

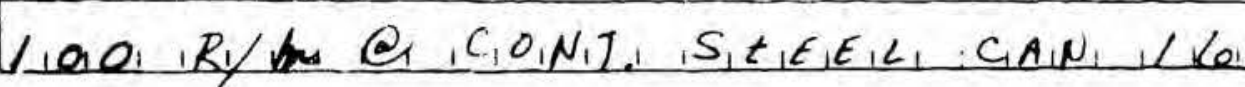
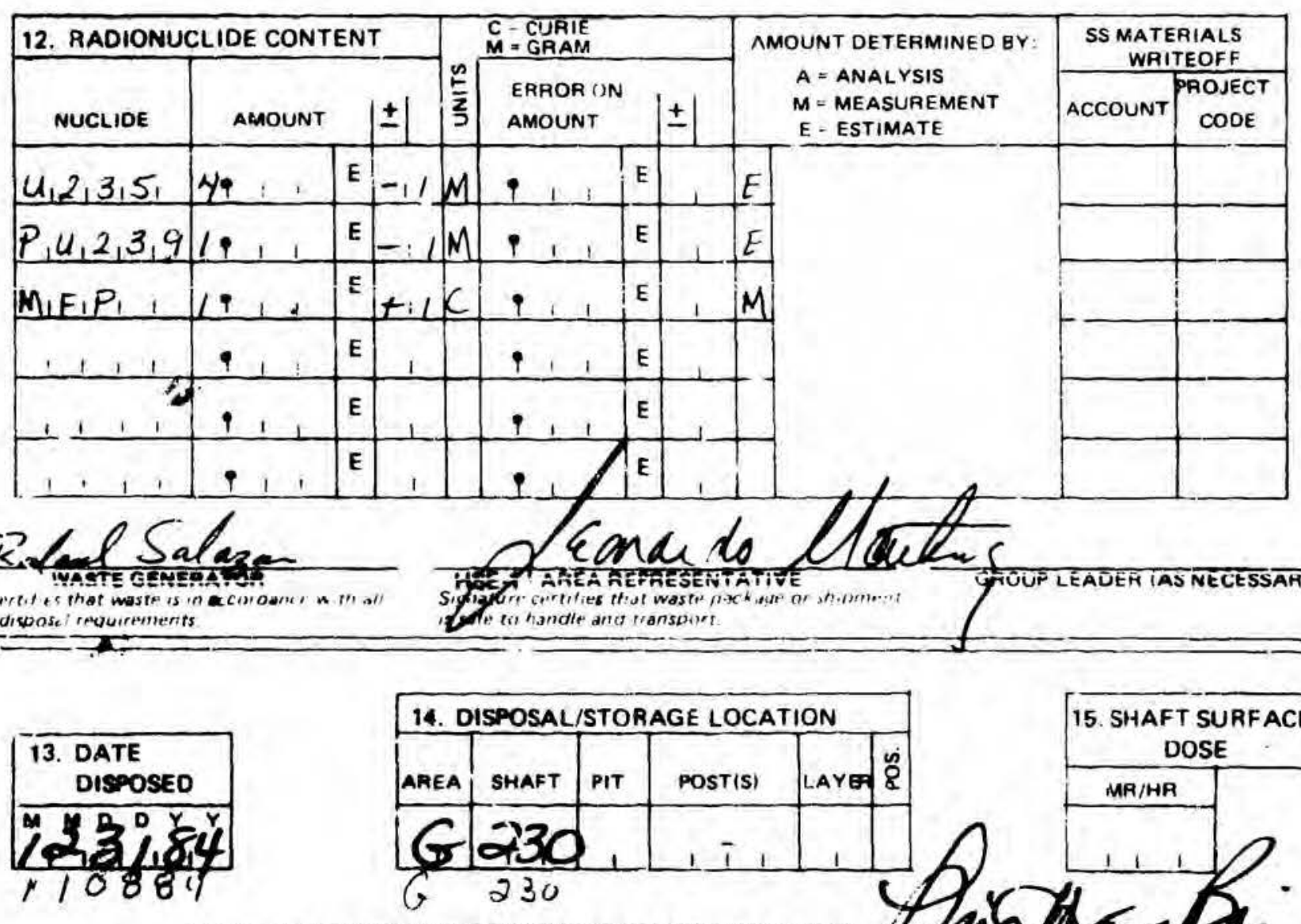

WIT WATE MANACEMENT REPRESENTATIVE 
PLEASE READ INSTRUCTIONS ON BACK CAREFULLY

\begin{tabular}{|l|}
\hline 1. FORM NUMBER \\
\hline $\mathrm{S}, 8,4,02,86$ \\
\hline
\end{tabular}

\section{LOS ALAMOS RADIOACTIVE SOLID WASTE DISPOSAL RECORD FORM}

HSE.7 Waste Management

Ext 6095 MS j592
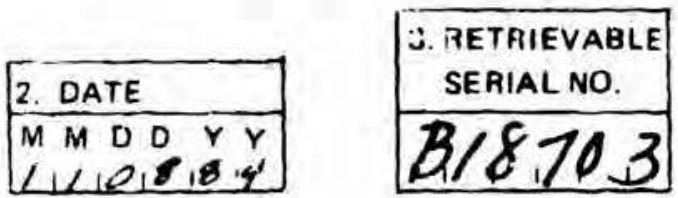

\begin{tabular}{|c|c|c|c|c|}
\hline \multicolumn{3}{|c|}{ 4. OR!GIN OF WASTE } & \multirow{2}{*}{$\frac{0}{3}$} & \\
\hline GROUP & TA & BLDG. & & ROOM \\
\hline Mis & 0,3 & $M_{1}$ & 9 & \\
\hline
\end{tabular}

\begin{tabular}{|c|}
\hline 5. VIASTE \\
CODE \\
\hline$A, 4,0$ \\
\hline
\end{tabular}

6. WASTE DESCRIPTION

$\left.C_{1} E_{1}, L, 1,3, \quad W_{1} A_{1} S_{1} T_{1} E_{1}, F_{1}, A_{1}, T_{1}, C_{1}, A_{1} N_{1}, 3,9,2,4,1,1,1,1,1\right]$

\begin{tabular}{|c|c|c|c|c|c|}
\hline \multicolumn{6}{|c|}{ 7. NUMBERS OF WASTE PACKAGES } \\
\hline & CARD & & & & DEN CRATES \\
\hline BAGS & $\begin{array}{l}\text { BOARD } \\
\text { BOXES }\end{array}$ & NO. & GAL. & NO. & VOLUME $\cdot \mathrm{tt}^{3}$ \\
\hline$:$ & 1 & 1 & & 1 & 1 \\
\hline
\end{tabular}

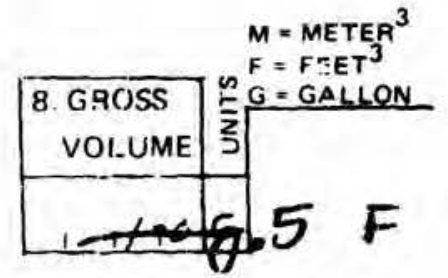

\begin{tabular}{|l|c|}
\hline 9. PACKAGE RADIATION AT: \\
\hline $\begin{array}{c}\text { SURFACE } \\
\text { MR/HR }\end{array}$ & $\begin{array}{c}\text { 1 METER } \\
\text { MA/HA }\end{array}$ \\
\hline $3,0,0,0,0$ & $1,4,0,0$ \\
\hline
\end{tabular}
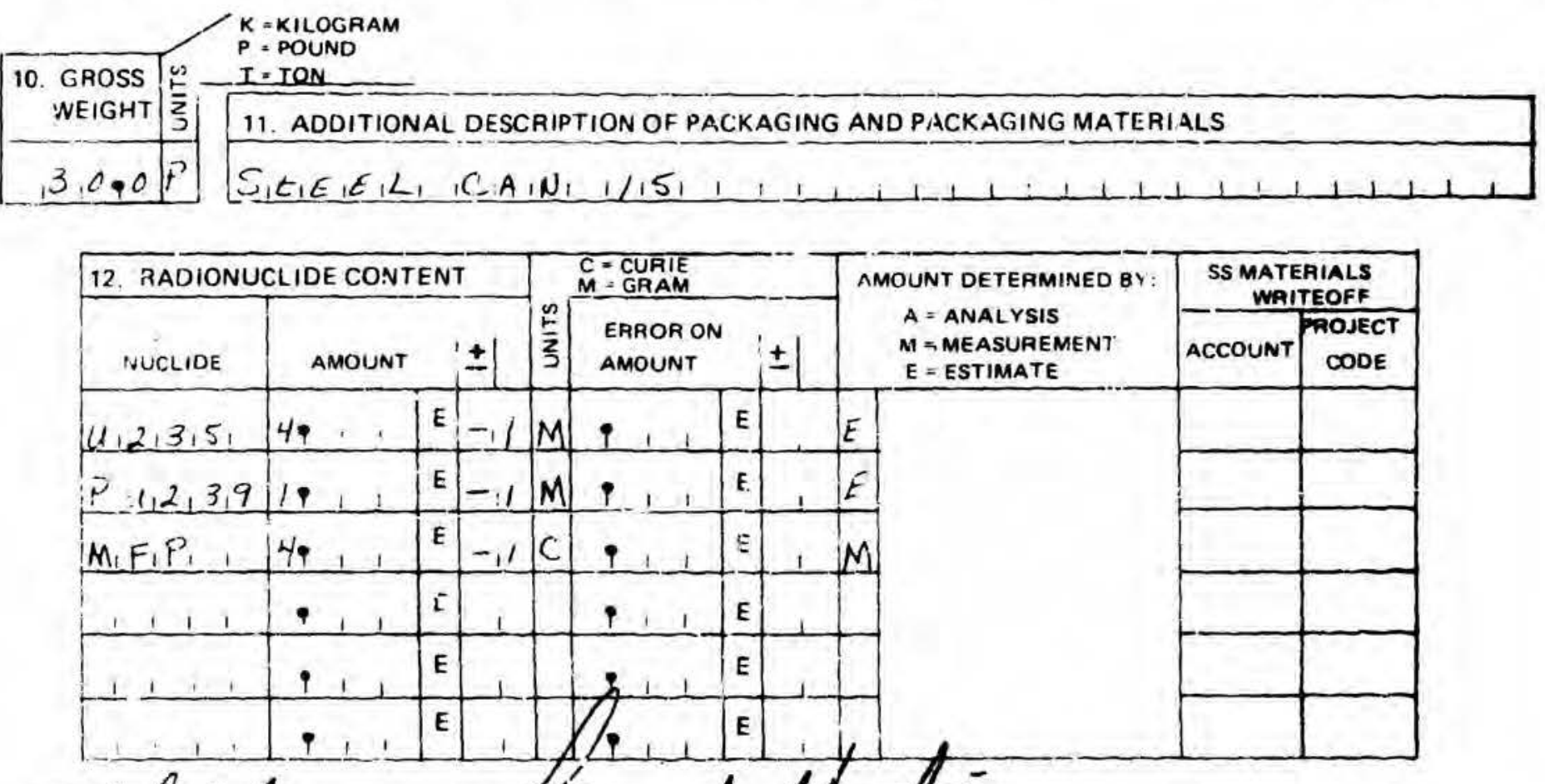

Patanul Salazan IVASTE GENEFATOA

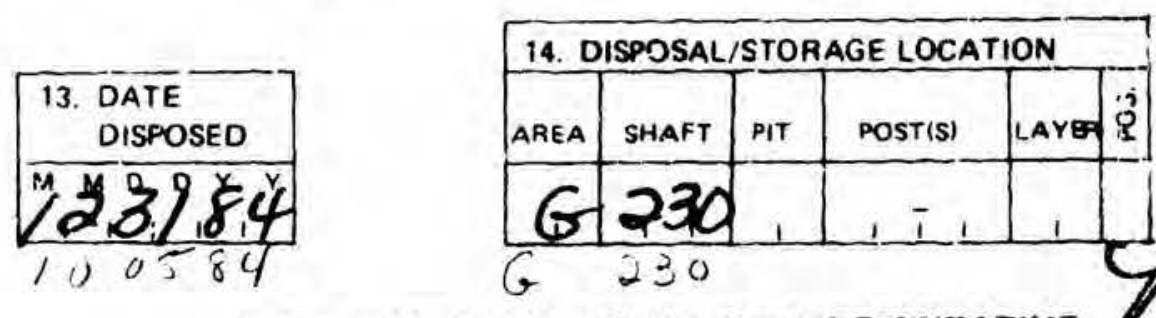

HEE-7 WASTE MANAGEMENT REPRESENTATIVE He Form Number 10 -2A (12/e3) is sidte to tand'e and tratisport

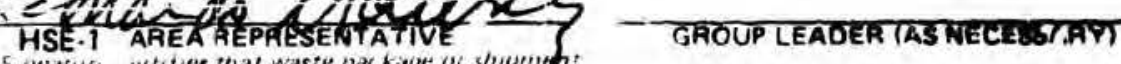

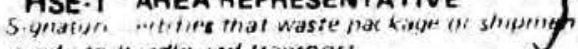


PLEASE READ INSTRUCTIONS ON BACK CAREFULLY

\begin{tabular}{|l|}
\hline 1. FORM NUMBER \\
\hline$S_{1} 8,4,98.28$ \\
\hline
\end{tabular}

\section{LOS ALAMOS RADIOACTIVE SOLID WASTE DISPOSAL RECORD FORM: \\ HSE-7 Wasie Management \\ EX广 6095 MS J592}

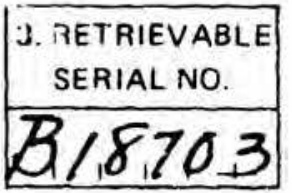

\begin{tabular}{|c|c|c|c|c|}
\hline \multicolumn{3}{|c|}{ 4. ORIGIN OF WASTE } & \multirow{2}{*}{$\stackrel{u}{\stackrel{2}{z}}$} & \multirow[b]{2}{*}{ ROOM } \\
\hline GROUP & TA & BLDG. & & \\
\hline$M S, T, *, 4$ &, 3 & Sisi, 2,9 & 9 & \\
\hline
\end{tabular}

\begin{tabular}{|r|}
\hline $\begin{array}{r}\text { 5. WIASTB } \\
\text { CODE }\end{array}$ \\
\hline$A, 4,0$ \\
\hline
\end{tabular}

6. WASTE DESCRIPTION

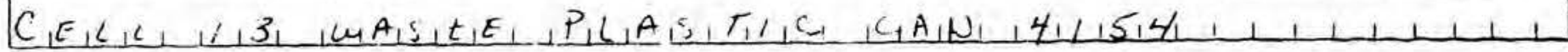

\begin{tabular}{|c|c|c|c|c|c|}
\hline \multicolumn{6}{|c|}{ 7. NUMBERS OF WASTE PACKAGES } \\
\hline & CARU & & & wo & DEN CRATES \\
\hline $\begin{array}{l}\text { PLASTIC } \\
\text { BAGS }\end{array}$ & $\begin{array}{l}\text { BOARD } \\
\text { BOXES }\end{array}$ & NO. & GAL. & & VOLUME $+t^{3}$ \\
\hline
\end{tabular}
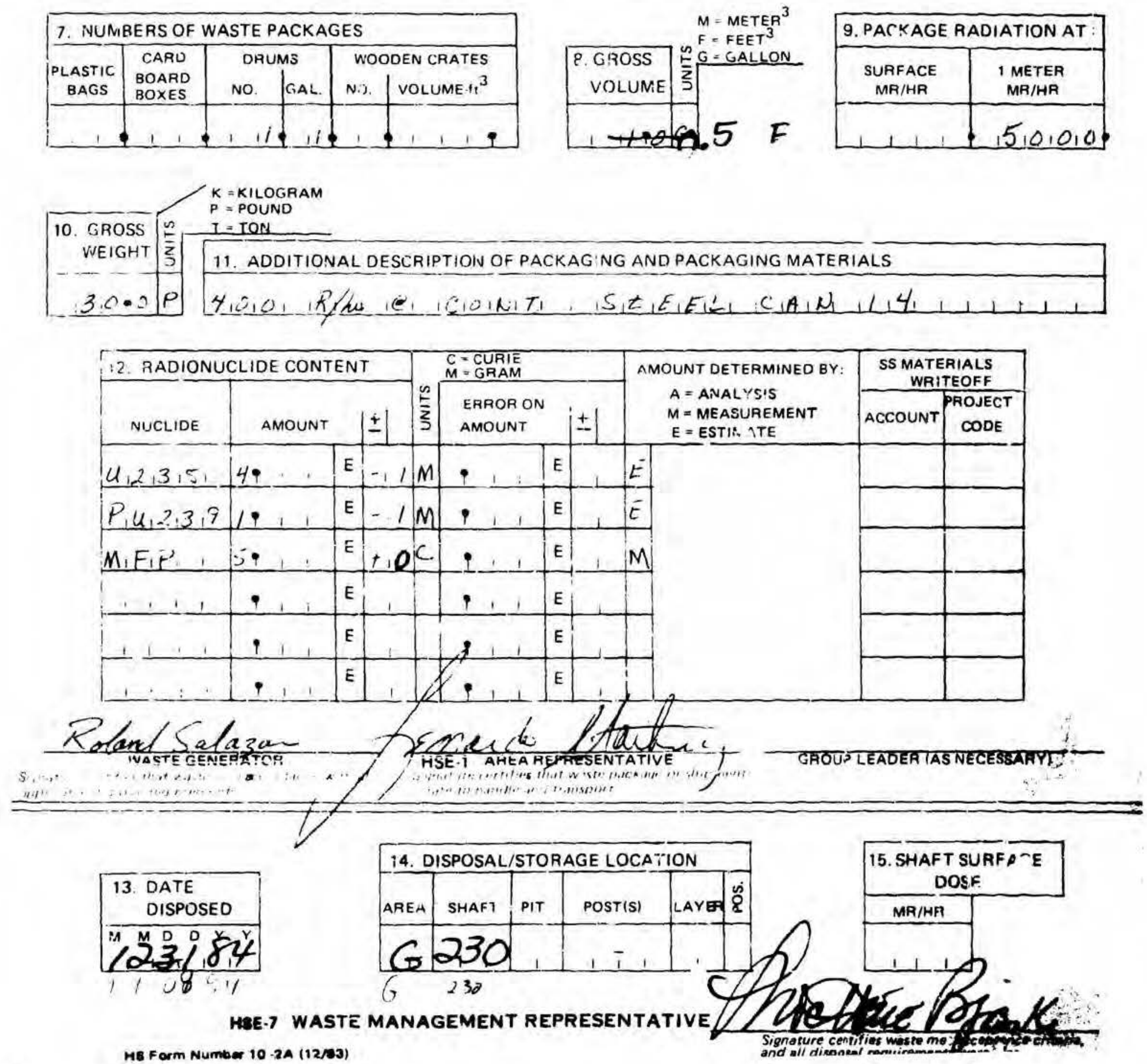


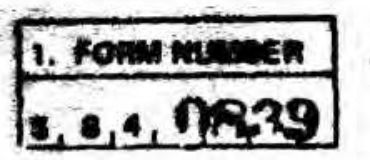

M.ease read instructions on back carefully

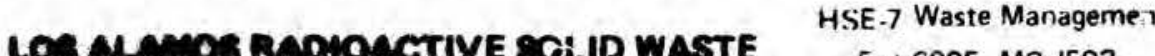 DIENOSAL RECORD FORM \\ Ext 6095 IMS J592}

2. DATE

$M M D D Y Y$

$1,1,0,8,8,4$

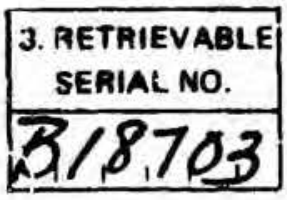

\begin{tabular}{|c|c|c|c|c|}
\hline \multicolumn{3}{|c|}{ 4. ORIGIN OF WASTE } & \multirow{2}{*}{$\frac{0}{3}$} & \multirow[b]{2}{*}{ ROOM } \\
\hline GROUP & TA & BLDG. & & \\
\hline$M, \delta, T_{1}: 4$ & 13 & $S_{1} m_{1} \quad 2,9$ & 9 & \\
\hline
\end{tabular}

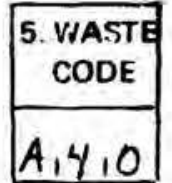

B. WASTE DESCRIPTIO:

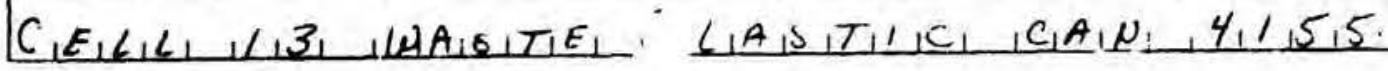

\begin{tabular}{|c|c|c|c|c|c|}
\hline \multicolumn{6}{|c|}{ 1. NUMBERS OF WASTE PACKAGES } \\
\hline & CARD & OR & & wo & DEN CGATES \\
\hline BAGS & $\begin{array}{l}\text { BOARD } \\
\text { BOXES }\end{array}$ & No. & GAL. & no. & VOLUME. $\cdot \mathrm{ti}^{3}$ \\
\hline
\end{tabular}

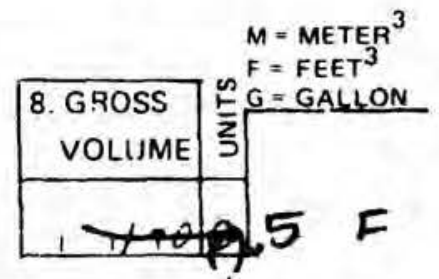

\begin{tabular}{|c|c|}
\hline 9. PACKAGE RADIATION AT : \\
\hline $\begin{array}{c}\text { SURFACE } \\
\text { MR/HR }\end{array}$ & $\begin{array}{c}\text { 1 METER } \\
\text { MR/HR }\end{array}$ \\
\hline $9,0,0,0,0$ & $115,0,0$ \\
\hline
\end{tabular}

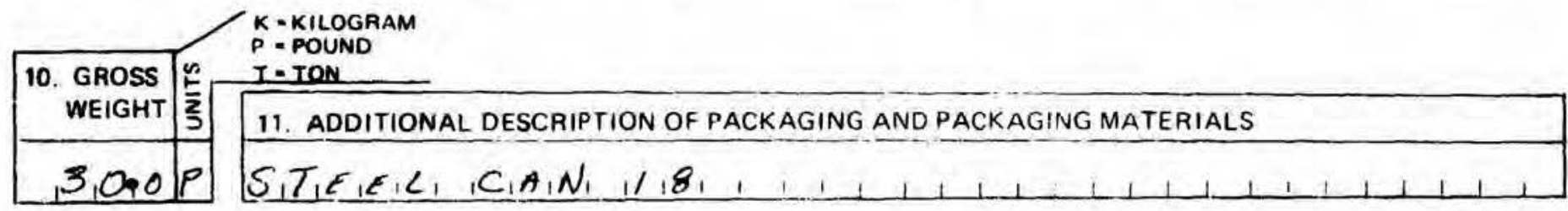
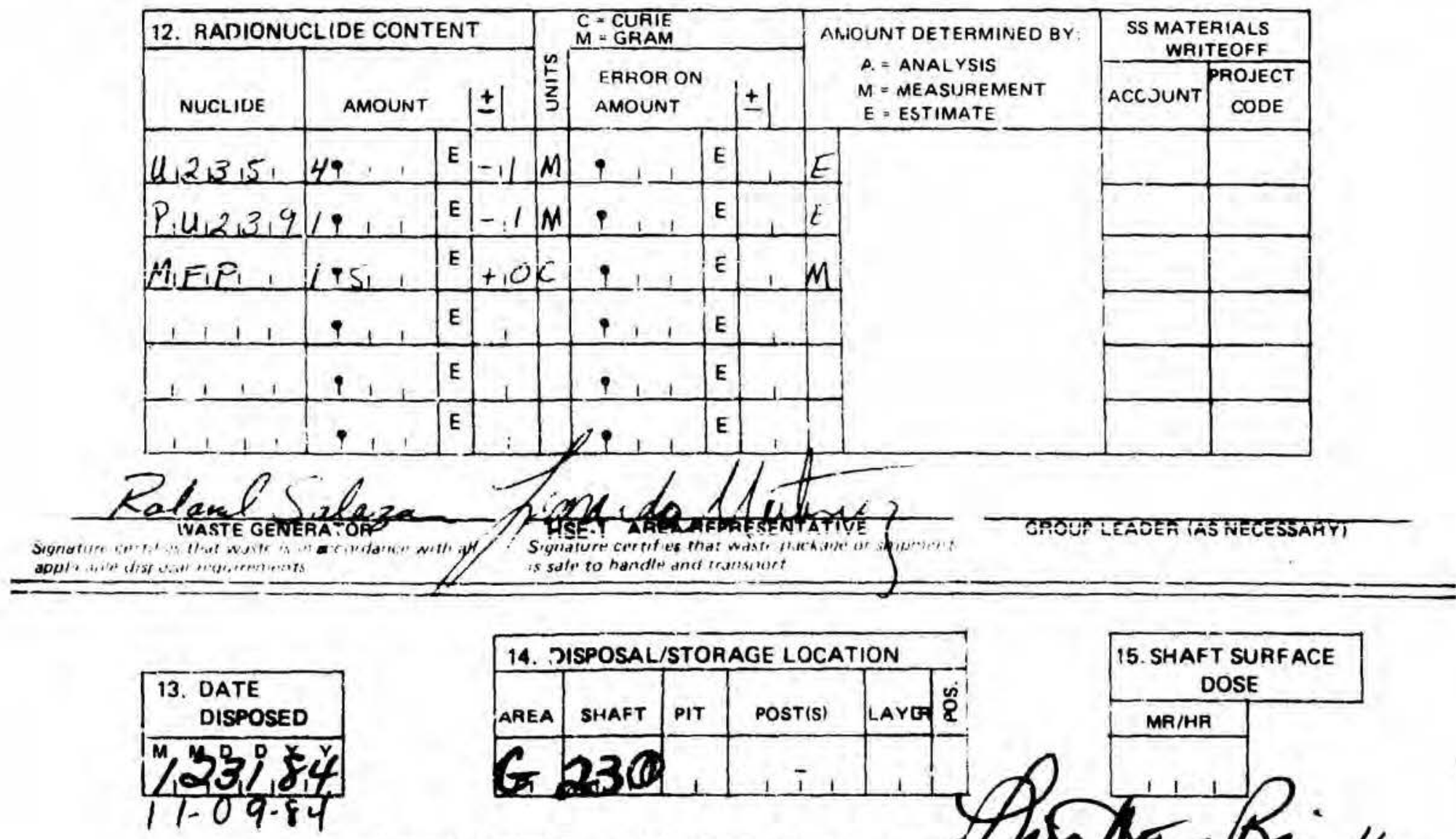
PLEASE READ INSTRUCTIONS ON BACK CAREFULLY

1. FORM NUMBER

s, 8,4, D, 90

\section{LOS ALAMOS RADIOACTIVE SOLID WASTE DISPOSAL RECORD FORM}

HSE-7 Waste Menagement

Ext 6095 MS $\mathbf{1 5 9 2}$

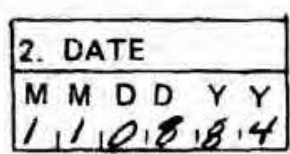

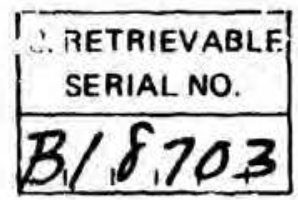

\begin{tabular}{|c|c|c|c|c|}
\hline \multicolumn{3}{|c|}{ 4. ORIGIN OF WASTE } & \multirow{2}{*}{$\frac{0}{2}$} & \multirow[b]{2}{*}{ ROOM } \\
\hline GROUP & TA & BLDG. & & \\
\hline$M \cdot S, T, 1,4$ & 13 & 12,9 & 9 & \\
\hline
\end{tabular}

\section{WASTE DESCRIPTION}

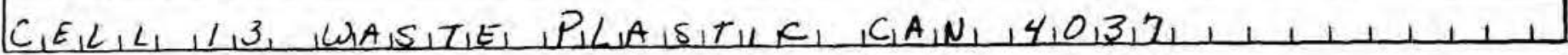

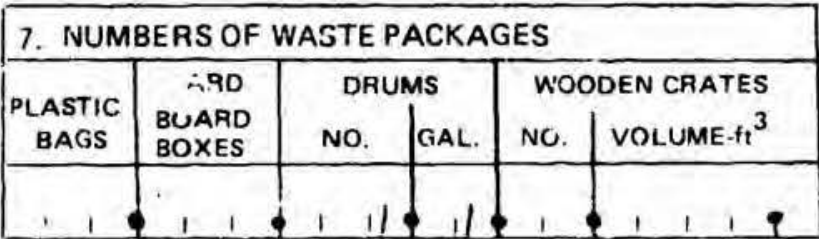

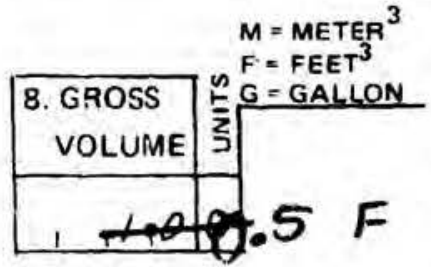

\begin{tabular}{|c|c|}
\hline \multicolumn{2}{|c|}{ 9. PACKAGE RADIATION AT: } \\
\hline $\begin{array}{c}\text { SURFACE } \\
\text { MR/HR }\end{array}$ & $\begin{array}{c}\text { 1 METER } \\
\text { MA/HA }\end{array}$ \\
\hline $9,0,0,0,0$ & $1,1,0,0,0$ \\
\hline
\end{tabular}

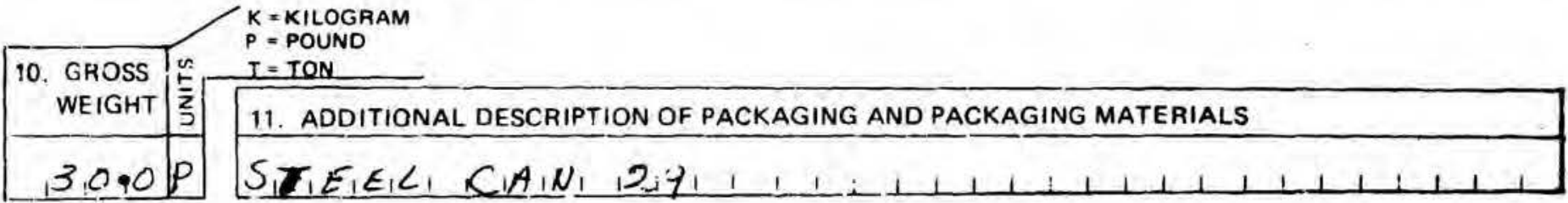

\begin{tabular}{|c|c|c|c|c|c|c|c|c|c|c|c|}
\hline \multicolumn{4}{|c|}{ 12. RADIONUCLIDE CONTENT } & \multicolumn{4}{|c|}{$\begin{aligned} C & =\text { CUAIE } \\
M & =\text { GRAM }\end{aligned}$} & \multirow{2}{*}{\multicolumn{2}{|c|}{$\begin{array}{c}\text { AMOUNT DETERMINED BY: } \\
\text { A }=\text { ANALYSIS } \\
M=\text { MEASUREMENT } \\
\text { E }=\text { ESTIMATE }\end{array}$}} & \multicolumn{2}{|c|}{$\begin{array}{r}\text { SS MATERIALS } \\
\text { MAITEOFF } \\
\end{array}$} \\
\hline NUCLIDE & AMOUNT & & \pm & $\frac{n}{\frac{n}{z}}$ & $\begin{array}{l}\text { ERAOR ON } \\
\text { AMOUNT }\end{array}$ & & \pm & & & ACCOUNT & $\begin{array}{l}\text { CODECT } \\
\text { CODE }\end{array}$ \\
\hline $4,2,3,5$, & $49: 1$ & E & -11 & $M$ & 111 & E & & $E$ & & & \\
\hline$P_{1} u_{1}, 2,3,9$ & 1911 & E & $-: 1$ & $M$ & 111 & $\mathbf{E}$ & & $E$ & & $=$ & \\
\hline$M, F, P_{1}$ & 1911 & E & +10 & C & 111 & E & 1 & $M$ & & & \\
\hline 1111 & 911 & E & & & 111 & E & & & & & \\
\hline 1111 & 111 & $\mathbf{E}$ & & & 111 & $\mathbf{E}$ & & & & & \\
\hline 1111 & 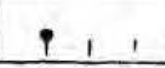 & E & 1 & & 911 & $\mathbf{E}$ & & & & & \\
\hline
\end{tabular}

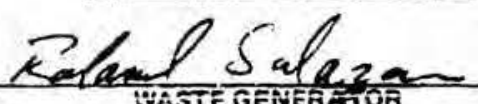
Siqnatur nertities that wast is in apolicalble elisposal if alumeneints

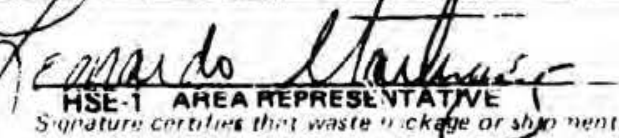
HSE-1 AREA FEPRESENTATNE I is sate to hadidle ind trinspi-t.

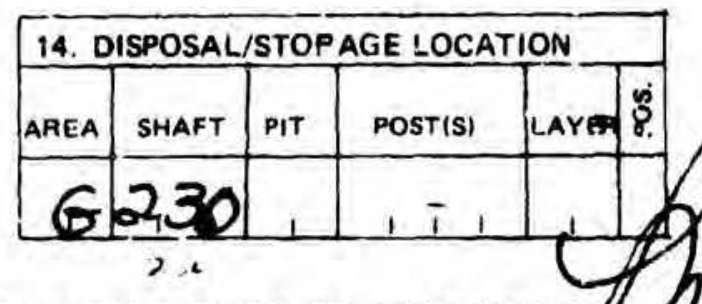

WE.I WASTE MANAGEMENT REPRESENTATIVE
15 SHAFT SUAFACE DOSE

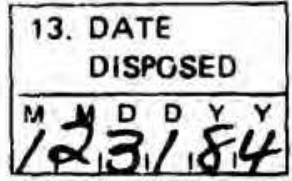

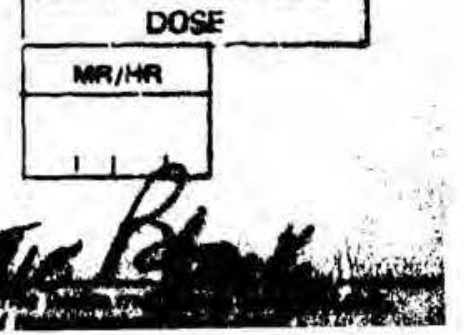




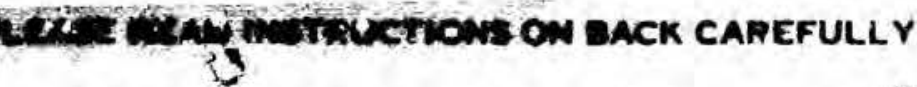

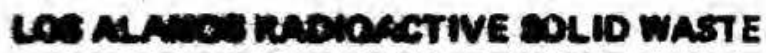
Dimesal necono fonm

HSE.7 Waste Management Ex
3. RETRIEVABLE

ectank Ro.

B/8.7.0.3 $\begin{array}{r}\text { 5. VIASTE } \\ \text { CODE } \\ \hline A, 4, O \\ \hline\end{array}$

\section{WASTE DESCRIPTION}

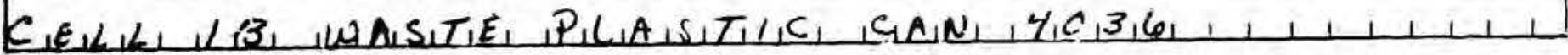

\section{MUMAERS OF WASTE PACKAGES}

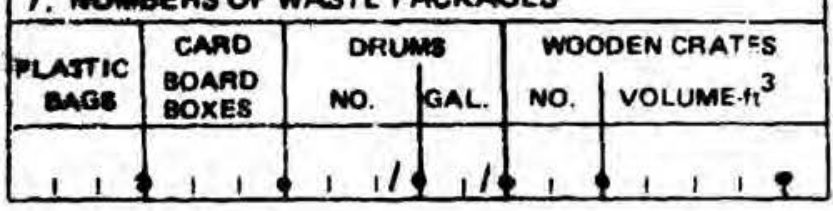

\begin{tabular}{|c|c|c|c|c|c|}
\hline \multicolumn{4}{|c|}{ 4. ORYGWN OF WASTE } & \multirow{2}{*}{$\frac{0}{\frac{2}{5}}$} & \multirow[b]{2}{*}{ ROOM } \\
\hline EnOU & Th & B:DG & & & \\
\hline$M, S, T, 1,4$ & 13 & $\delta, M$, & 2,9 & 9 & \\
\hline
\end{tabular}

\begin{tabular}{|c|c|}
\hline $\begin{array}{c}\text { 9. PACKAGE RADIATION AT: } \\
\text { MURACE } \\
\text { MR/HR }\end{array}$ & $\begin{array}{c}\text { I METER } \\
\text { MR/HR }\end{array}$ \\
\hline $6,0,0,0,0$ & $, 17,0,0$ \\
\hline
\end{tabular}

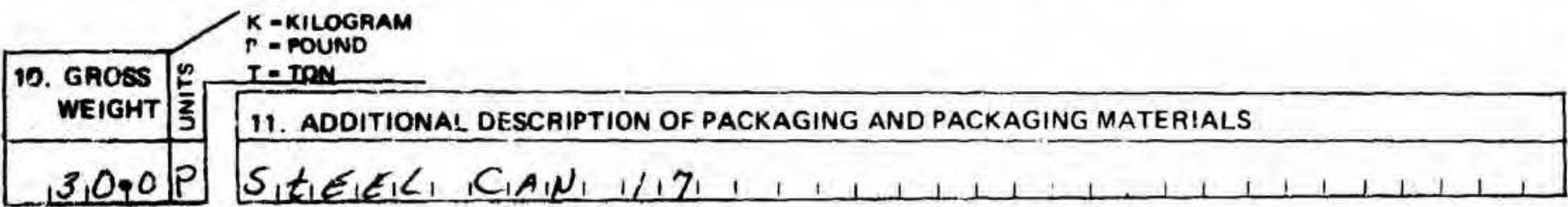

\begin{tabular}{|c|c|c|c|c|c|c|c|c|c|c|c|}
\hline \multicolumn{4}{|c|}{ 12. RADIONUCLIDE CONTENT } & \multicolumn{4}{|c|}{$\begin{array}{l}\text { CE-CUAIE } \\
\text { M= GRAM }\end{array}$} & \multirow{2}{*}{\multicolumn{2}{|c|}{ 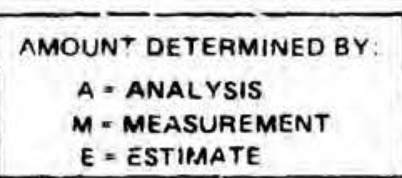 }} & \multicolumn{2}{|c|}{$\begin{array}{l}\text { SS MATERIALS } \\
\text { WRITEOFF }\end{array}$} \\
\hline NUSCLIDE & AMOUNT & & \pm & $\frac{n}{z}$ & $\begin{array}{l}\text { ERROR ON } \\
\text { AMOUNT }\end{array}$ & & \pm 1 & & & ACCOUNT & $\begin{array}{l}\text { PROJECT } \\
\text { CODE }\end{array}$ \\
\hline $1,2,3,5$, & $49: 1$ & E & -11 & M & 1,1 & E & & E & & & \\
\hline$P, u, 2,3,9$ & 19,1 & E & -11 & M & 1,1 & E & & $E$ & & & \\
\hline$M_{1} F_{1} P_{1}$, & 74,1 & E & -11 & c & 1,1 & E & & $M$ & & & \\
\hline 111 & 111 & $\mathbf{E}$ & 1 & & 911 & E & & & & & \\
\hline 1111 & 911 & E & & & 9,1 & E & & & & & \\
\hline 1111 & 111 & E & 1 & & 1,1 & E & & & & & \\
\hline
\end{tabular}

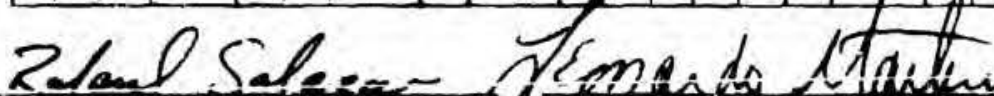

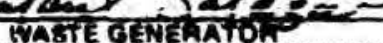
Syoniture cer ifies that moste is in acurdance with aly

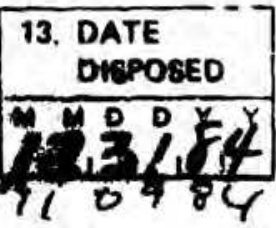

\begin{tabular}{|c|c|c|c|c|c|}
\hline AREA & SHAFT & PIT & POST(S) & LAYEA & ஜ̆ \\
\hline & & & 11 & 1 & \\
\hline
\end{tabular}


PLEASE READ INSTRUCTIONS ON BACK CAREFULLY

1. FORM NUMBER

s, $8,4,08.59$

\section{LOS ALAMOS RADIOACTIYE SOLID WASTE DISPOSAL RECOAD FORM}

HSE.7 Waste Menagement

Ext 6095 MS $J 592$

\begin{tabular}{|c|c|c|c|c|}
\hline 4. ORIGIN OF WASTE & \multirow{2}{*|}{} & \\
\hline GROUP & TA & BLDG & \multirow{3}{*}{} & ROOM \\
\hline H., $, 1,1 / 4$ & 0,3 & $\operatorname{SiM}, 0,2,9$ & 9 & \\
\hline
\end{tabular}

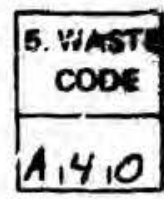

\begin{tabular}{|l|}
\hline 2. DATE \\
\hline$M$ M D O Y Y Y \\
$1,1,0,9,8,4$ \\
\hline
\end{tabular}

\begin{tabular}{|c|}
\hline $\begin{array}{c}\text { 3. RetRIEVABLE } \\
\text { Serial No. }\end{array}$ \\
\hline$B, 1,8,7,0,3$ \\
\hline
\end{tabular}

6. WASTE DESCRIPTION

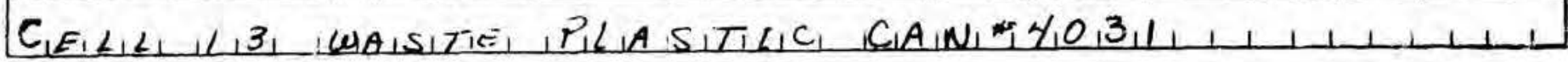

\begin{tabular}{|c|c|c|c|c|c|}
\hline \multicolumn{6}{|c|}{ 7. NUMBERS OF WASTE PACKAGES } \\
\hline & CARD & & & wo & DEN CRATES \\
\hline BAGS & $\begin{array}{l}\text { BOARD } \\
\text { BOXES }\end{array}$ & NO. & GAL. & No. & VOLUME- $-\mathrm{ft}^{3}$ \\
\hline 11 & 1 & 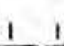 & & & 1 \\
\hline
\end{tabular}

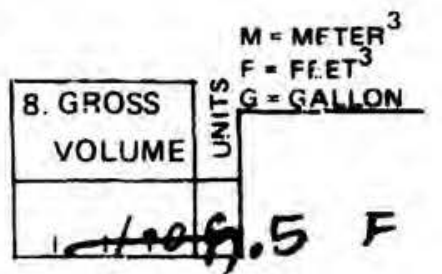

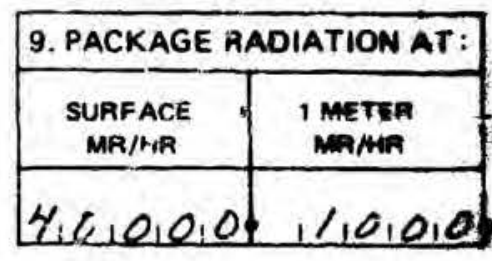

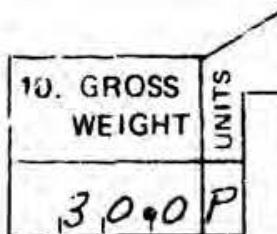

$K=$ KILOGRAM

$P=$ POUND

$I=$ TON

11. ADDITIONAL DESCRIPTION OF PACKAGING AND PACKAGING MATERIALS

$3,0,0 P\left[S_{1} T_{1} E_{1} E_{1} L_{1}, C_{1} A_{1} N_{1}, \ldots, 3,3,1, \ldots\right.$

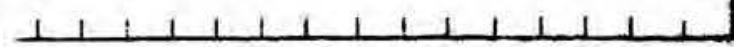

\begin{tabular}{|c|c|c|c|c|c|c|c|c|c|c|c|}
\hline \multicolumn{4}{|c|}{ 12. RADIONUCLIDE CONTENT } & \multicolumn{4}{|c|}{$\begin{array}{l}C=\text { CUEIE } \\
M=\text { GRAM }\end{array}$} & \multirow{2}{*}{\multicolumn{2}{|c|}{$\begin{array}{c}\text { AMOUNT DETERMINED BY: } \\
\text { A }=\text { ANALYSIS } \\
M=\text { MEASUREMENT } \\
E=\text { ESTIMAYE }\end{array}$}} & \multicolumn{2}{|c|}{ 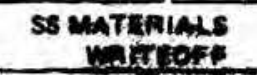 } \\
\hline NUCLIOE & AMOUNT & & \pm & $\frac{E}{3}$ & $\begin{array}{l}\text { EAROR ON } \\
\text { AMOUNT }\end{array}$ & & \pm & & & Account & $\cos$ \\
\hline$U_{12}, 3,5$, & $4 \%, 1$ & E & $-1 i$ & m & 111 & E & & $E$ & & & \\
\hline$P, u, 2,3,9$ & 1911 & E & -1 & $M$ & $1 \quad 1$ & E & & $E$ & & & \\
\hline$M_{1} F_{1} P_{1}, 1$ & 1911 & E & +10 & c & 111 & $E$ & 1 & $M$ & & & \\
\hline 1111 & $9 \perp 1$ & E & 1 & & 11 & E & & & & & \\
\hline 1111 & 111 & E & 1 & & 1,1 & E & & & & & \\
\hline 1111 & 111 & E & 1 & & 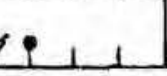 & E & & & & & \\
\hline
\end{tabular}
Remelfi. Slum Signature certifu's that waste is in a spplicable disposal requirements

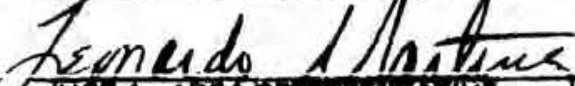

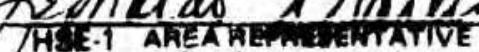

signature certifies that woste package or in ing tren. is safe to handle and transport.
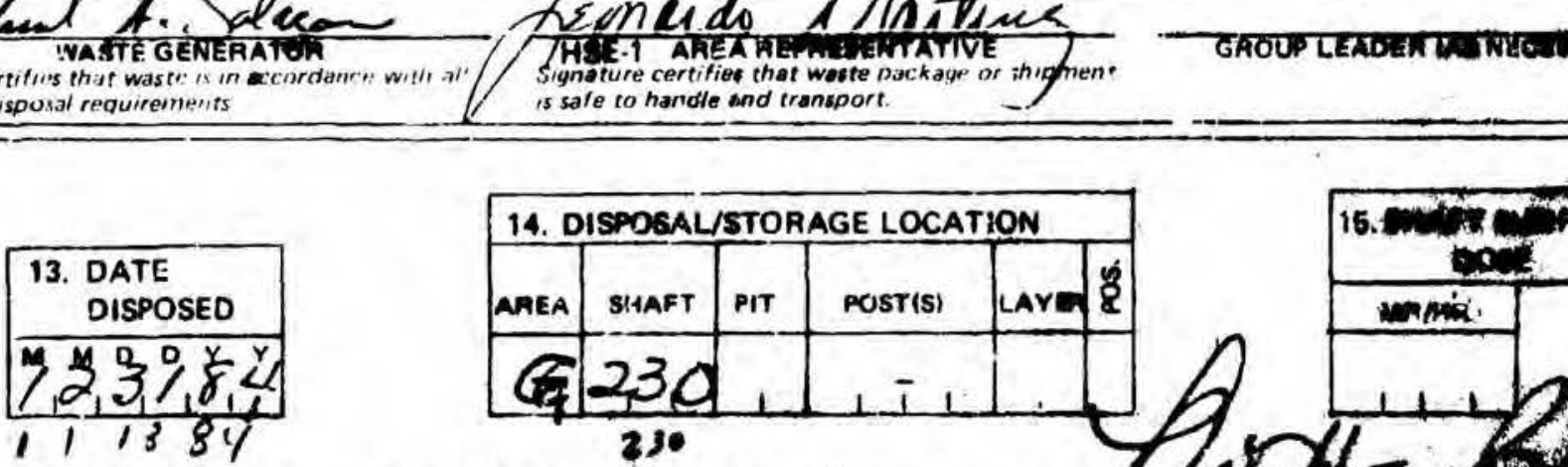

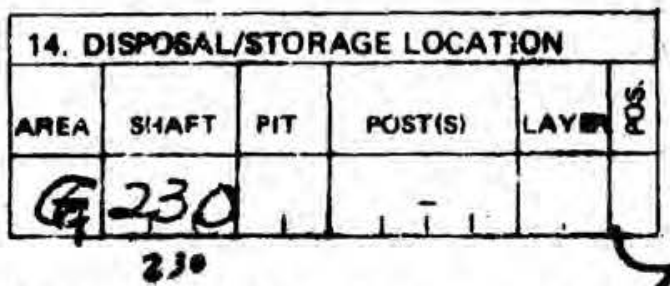

Met.7 MASTE MAMAN.

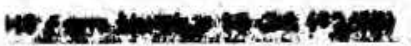

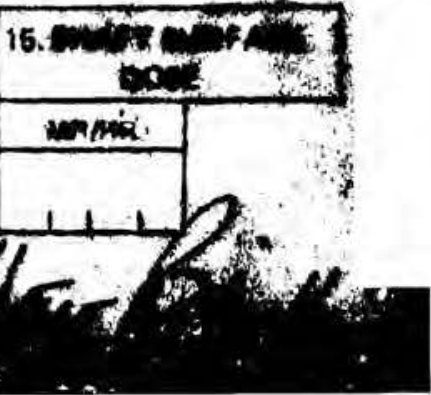


RADIOACTIVE SOLID WASTE DISPOSAL RECORD FORMS

FOR

SHAFT 231

MATERIAL DISPOSAL AREA G 


$$
\begin{array}{|l|}
\text { 1. FORM NUATSER } \\
\hline S, 8,5,5096
\end{array}
$$

PLEASE READ INSTRUCTIONS ON BACK CAREFULLY Y

LOS ALAMOS RADIOACTIVE SOLID WASTE DISPOSAL RF.CORD

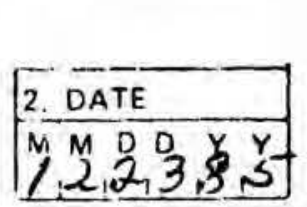

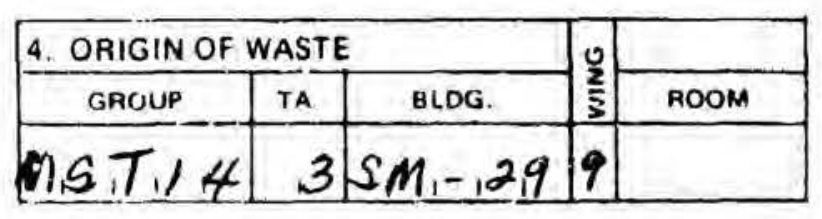

6. WASTE DESCRIPTION

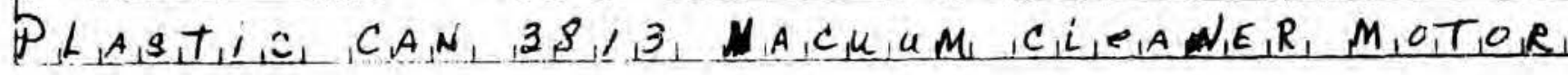
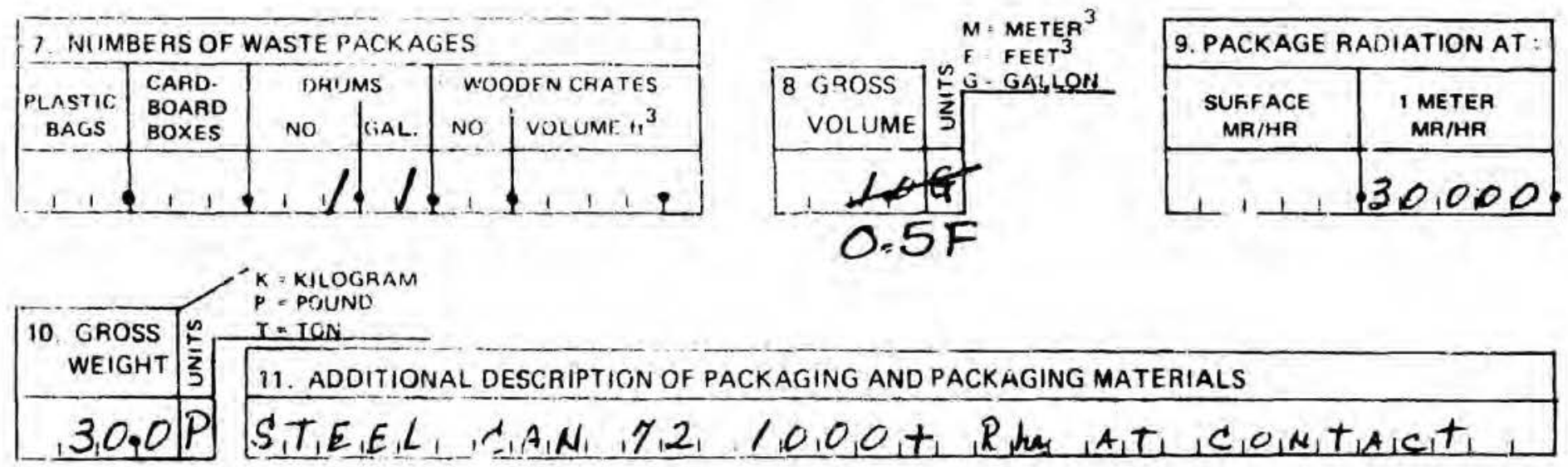

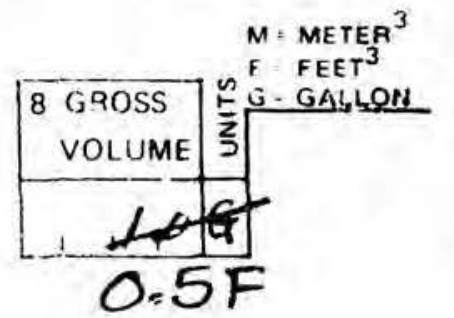

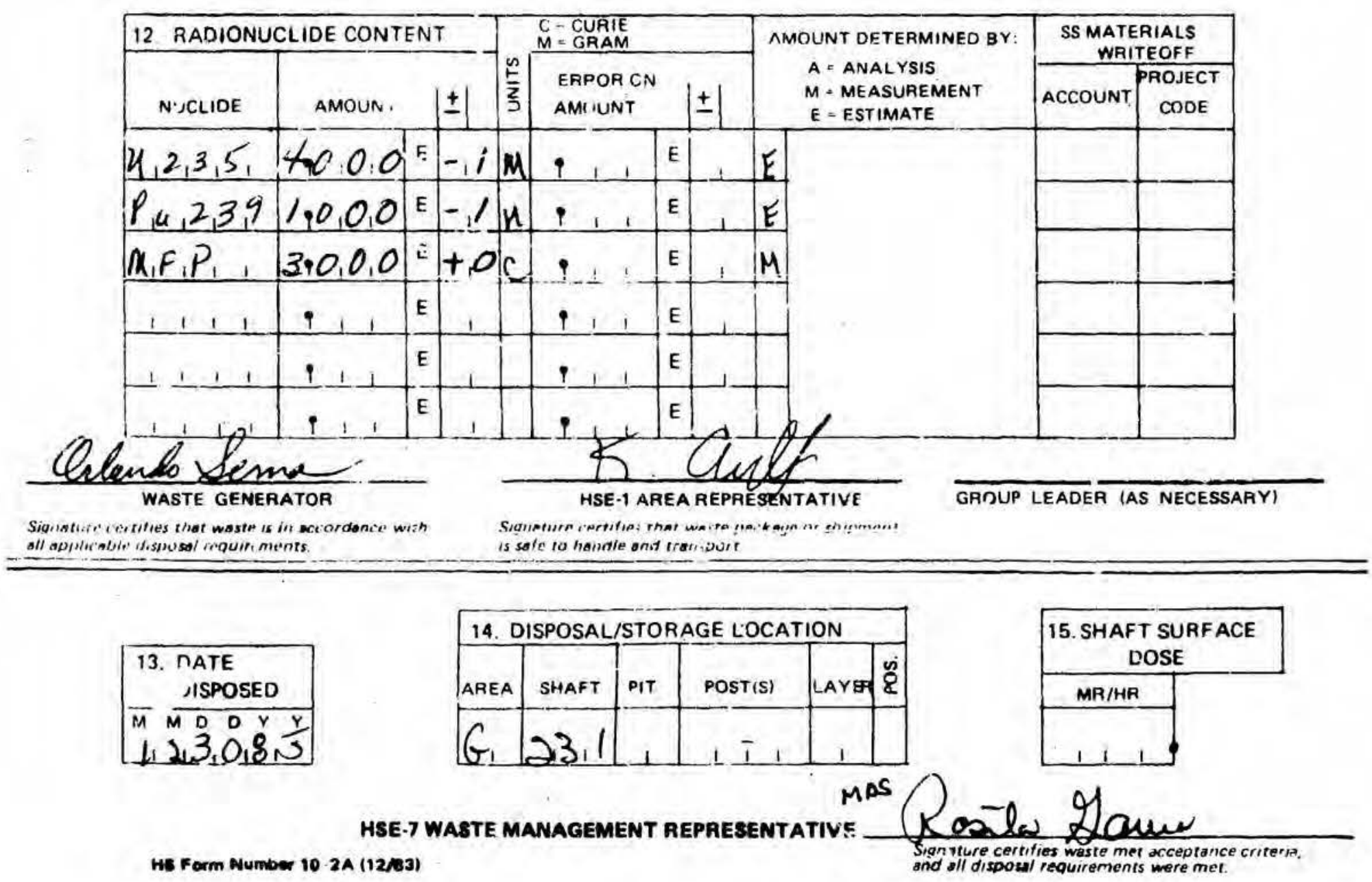


PLEASE READ INSTRUCTIONS ON BACK CAREFULLY

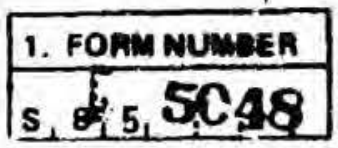

LOS ALAMOS RADIOACTIVE SOLID WASTE HSE.7 Waste Management DISPOSAL RECORD

Ext 6095 MS J592
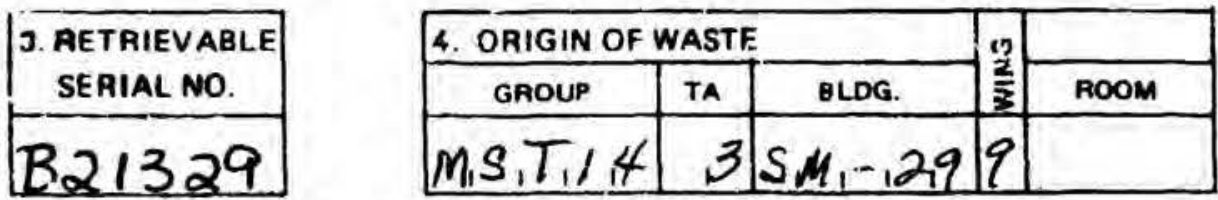

\begin{tabular}{|c|}
\hline $\begin{array}{c}\text { 5. WASTR } \\
\text { CODE }\end{array}$ \\
\hline $4,4,0$ \\
\hline
\end{tabular}

B. WASTE DESCRIPTION

$C_{1} E_{1} L_{1} L_{1}, O_{1}, T_{1} R_{1} A_{1} S_{1} t_{1}, P_{1} L_{1} A_{1} S_{1} T_{1}, C_{1}, C_{1} A_{1} N_{1}, 3,8,5,9,1,1,1,1,1$,

\begin{tabular}{|c|c|c|c|c|c|}
\hline \multicolumn{6}{|c|}{ 7. NUMBERS OF WASTE PACKAGES } \\
\hline \multirow{2}{*}{$\begin{array}{l}\text { PLASTIC } \\
\text { BAGS }\end{array}$} & \multirow{2}{*}{$\begin{array}{l}\text { CARD } \\
\text { BOARD } \\
\text { BOXES }\end{array}$} & \multicolumn{2}{|c|}{ DRUMS } & \multicolumn{2}{|c|}{ WOODEN CRATES } \\
\hline & & NO. & GAL. & No. & VOLUME- $+t^{3}$ \\
\hline 11 & $i$ & 1 & & 1 & 11 \\
\hline
\end{tabular}

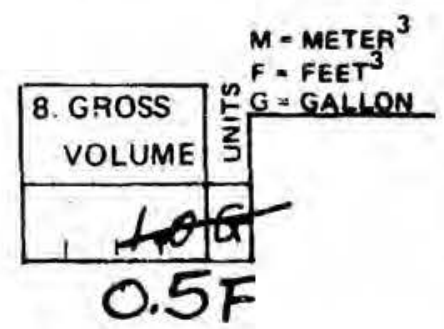

\begin{tabular}{|c|c|}
\hline 9. PACKAGE RADIA.TION AT: \\
\hline $\begin{array}{c}\text { SURFACE } \\
\text { MR/HR }\end{array}$ & $\begin{array}{c}\text { 1 METER } \\
\text { MR/HR }\end{array}$ \\
\hline $111,19,0,0$ \\
\hline
\end{tabular}

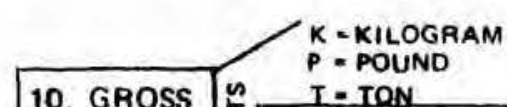

\begin{tabular}{l|l} 
10. GROSS \\
WEIGHT
\end{tabular}

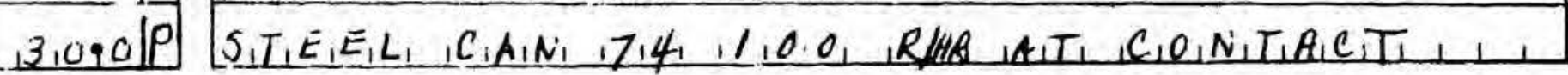

\begin{tabular}{|c|c|c|c|c|c|c|c|c|c|c|c|}
\hline \multicolumn{4}{|c|}{ 12. RADIONUCLIDE CONTENT } & \multicolumn{4}{|c|}{$\begin{array}{l}\text { C. CUAIE } \\
M=\text { GAAM }\end{array}$} & \multirow{2}{*}{\multicolumn{2}{|c|}{$\begin{aligned} & \text { AMOUNT DETERMINED } 8 Y: \\
& \text { A }=\text { ANALYYIS } \\
& M=\text { VEASUAEMENT } \\
& E=\text { ES I IMATE }\end{aligned}$}} & \multicolumn{2}{|c|}{$\begin{array}{l}\text { SS MATERIALS } \\
\text { WRITEOFF }\end{array}$} \\
\hline NUCLIDE & AMOUNT & & \pm & $\frac{n}{2}$ & $\begin{array}{l}\text { ERPOR ON } \\
\text { AMOUNT }\end{array}$ & & \pm & & & ACCOUNT & $\begin{array}{l}\text { PROJECT } \\
\text { CODE }\end{array}$ \\
\hline$u_{1}{ }^{2} r^{3} r_{1}$ & $\angle 45,00$ & $E$ & +1 & $M$ & 111 & E & & $E$ & & & \\
\hline$A F P$ & 9000 & $E$ & -1 & c & 711 & E & & E & & & \\
\hline 1111 & 111 & $\mathbf{E}$ & 1 & & 1,1 & E & 1 & & & & \\
\hline 1111 & $9+1$ & E & -1 & & 111 & E & & & & & \\
\hline 1111 & $1 ! 1$ & E & $\perp$ & & 111 & E & & & & & \\
\hline$\angle, 1,1$ & in 1 & E. & 1 & & & E & & $\hat{i}$ & & & \\
\hline
\end{tabular}

WASTE GENETATOR

Signeture certities that waste is in accordance wish all applicable disposal requirements.

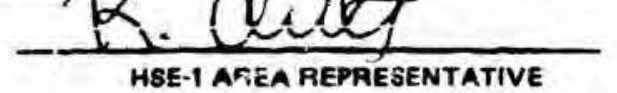

Signoture certifies thot maste package or shipment is bete to handle and trensport.
GROUP LEADER (AS NECESSAPY)

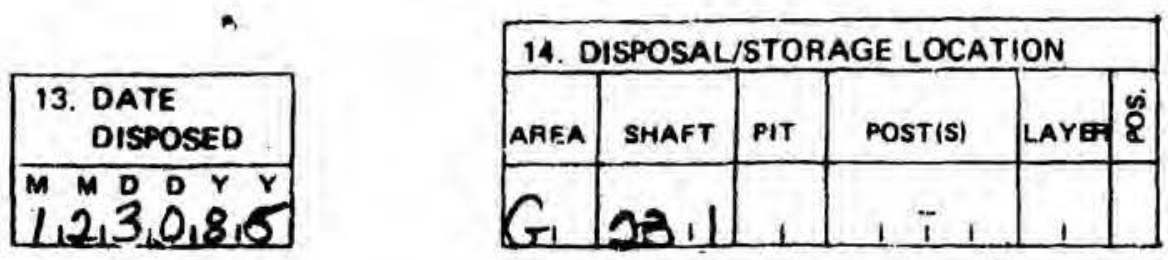

ME-7 WATTE MAMAGENENT REPREECNTATIVE

mas
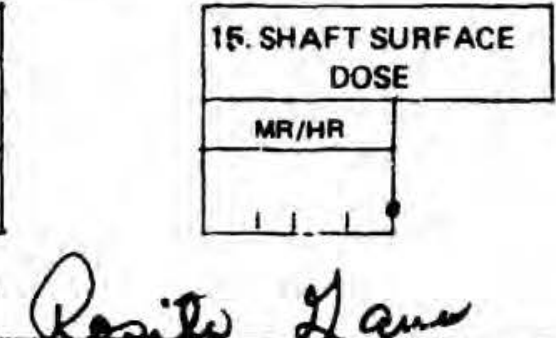
\begin{tabular}{|l|}
\hline 1. FORM NUMAER \\
\hline $5,8,5,5099$ \\
\hline
\end{tabular}

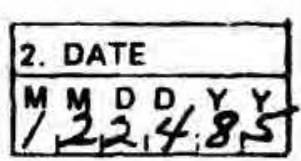

PLEASE READ INSTRUCTIONS ON BACK CAREFULL

\section{LOS ALAMOS RADIOACTIVE SOL.ID WASTE DISPOSAL RECOHD}

HSE-7 Waste Managonent

Ext $6095 M^{\prime}<02$

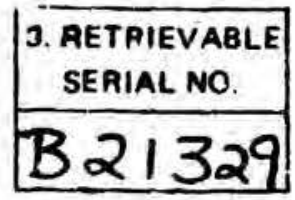

\begin{tabular}{|c|c|c|c|c|}
\hline ORIGIN OF WASTE & \multicolumn{1}{|c|}{} & \\
\hline GHCUP & TA & GLOG. & nOOM \\
\hline$M G_{1} T_{1} / 4$ & 3 & $S_{1} M_{1}-2,9$ & 9 & \\
\hline
\end{tabular}

\begin{tabular}{l} 
5. WASTE \\
CODE \\
\hline$A, 4,0$ \\
\hline
\end{tabular}

6. WASTE DESCRIPTION

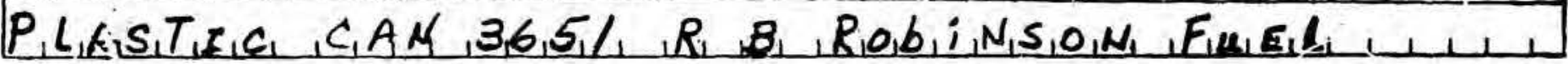

\begin{tabular}{|c|c|c|c|c|c|}
\hline \multicolumn{6}{|c|}{ 7. NUMBERS OF WASTE PACKAL $S$} \\
\hline \multirow{2}{*}{$\begin{array}{l}\text { PLASTIC } \\
\text { BAGS }\end{array}$} & \multirow{2}{*}{$\begin{array}{l}\text { CARD- } \\
\text { BOARD } \\
\text { BOXES }\end{array}$} & \multicolumn{2}{|c|}{ DRUMS } & \multicolumn{2}{|c|}{ WOODEN CRATES } \\
\hline & & No. & GAL. & NO. & VOLUME. $\mathrm{ft}^{3}$ \\
\hline
\end{tabular}

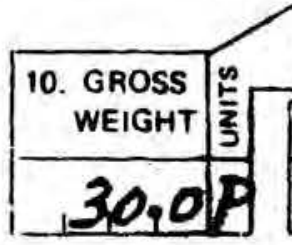

\section{$K=$ KILOGPAM}

$P$ = POUND
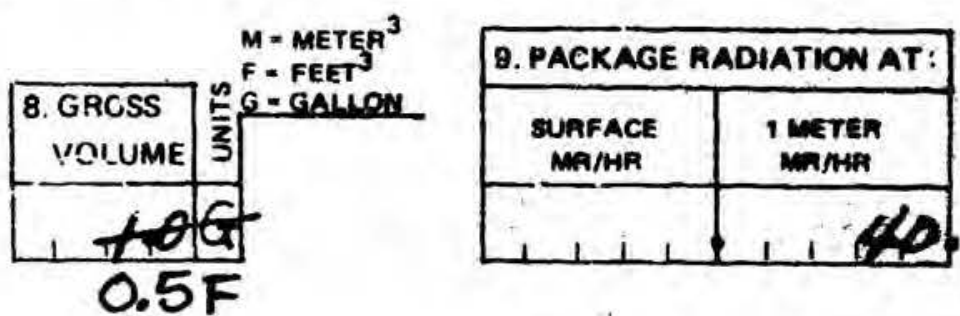

$0.5 \mathrm{~F}$

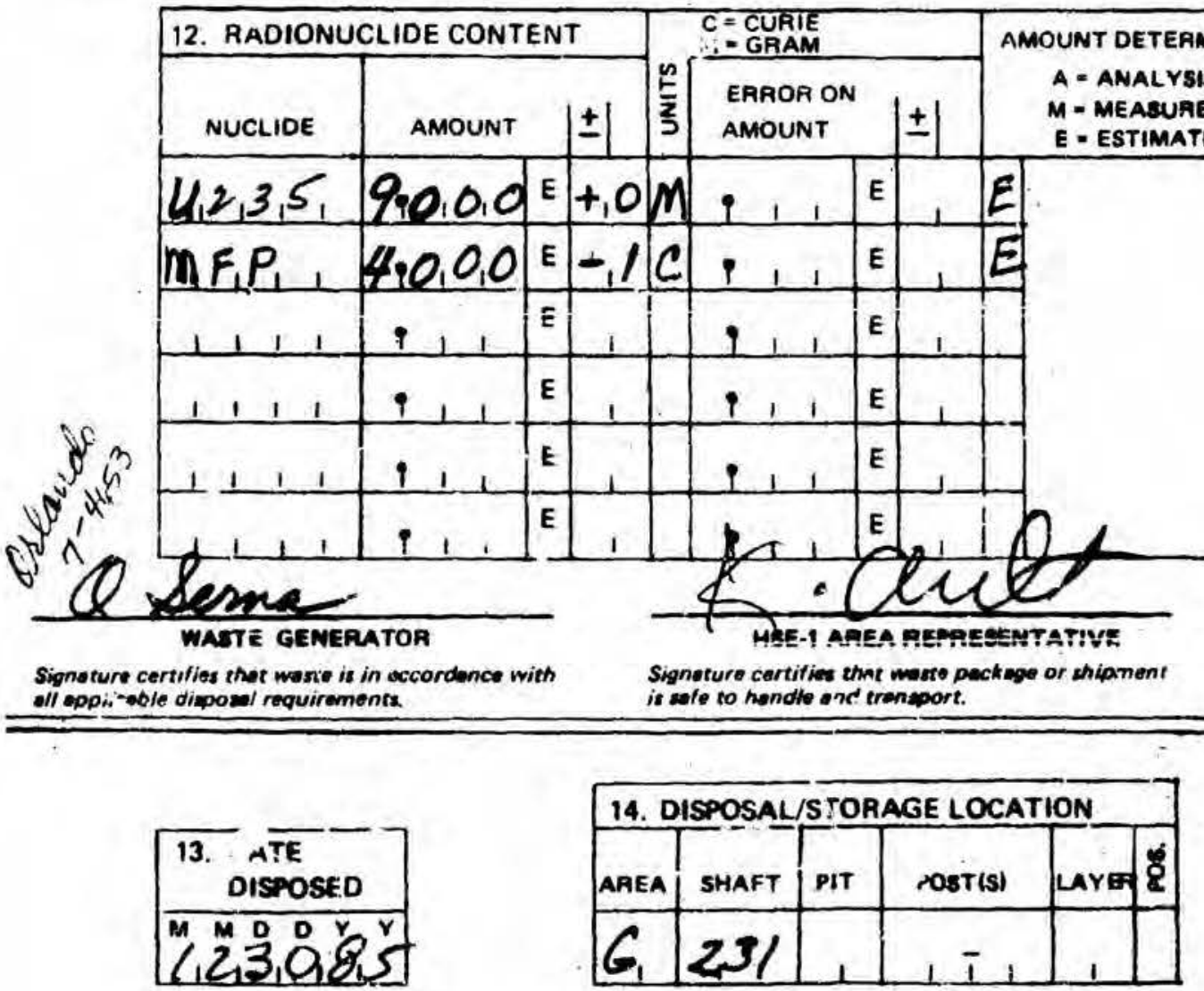

11. ADDITIONAL DESCRIPTION OF PACKAGING AND PACKAGING MATERIALS

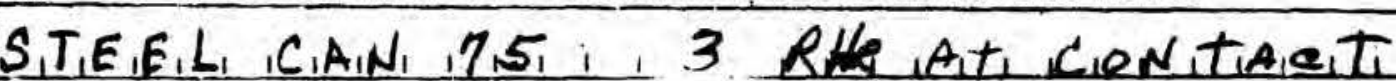




\section{FOAM NUYGEER \\ s. $6,5,9215$}

PLEASE READ INSTRUCTIONS ON BACK CAREFUI.LY

LOS ALAMOS RADIOACTIVE SOLID WASTE HSE / Waste Monagempr, DIEPDSAL RECORD

\section{DATE}
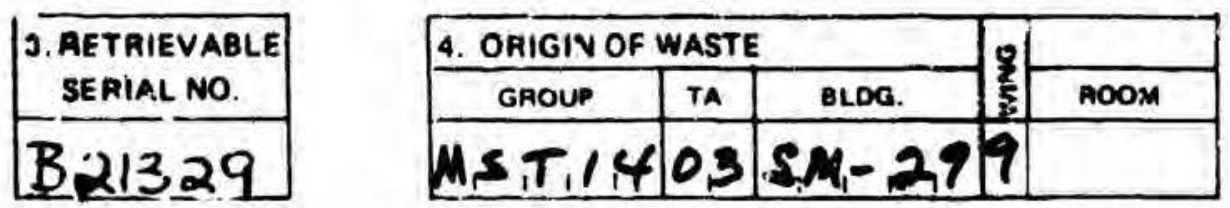

\begin{tabular}{l} 
15. WAST \\
CODE \\
\hline A.YO
\end{tabular}

\section{WASTE DESCRIPTION}

\section{P.LABStic CA,N 3649}

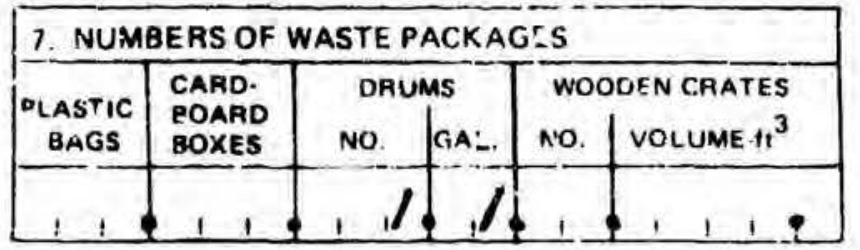

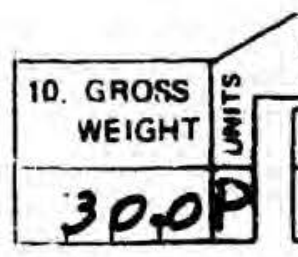

\section{$K$ - KILOGAAM}

$$
\text { P. POUND }
$$
- Ton

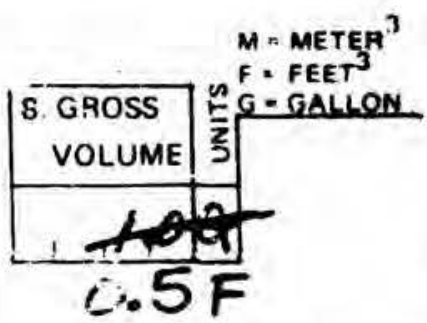

\begin{tabular}{|c|c|}
\hline \multicolumn{2}{|c|}{ 9. PACKAGE RADIATION AT } \\
\hline $\begin{array}{l}\text { SUREACE } \\
\text { MR/HR }\end{array}$ & $\begin{array}{l}\text { 1 MEETER } \\
\text { NR/HR }\end{array}$ \\
\hline & $22^{2} 000$ \\
\hline
\end{tabular}
11. ADDITIONAL DESI:RIPTION OF PACKAGING AND PACKAGING MATERIAI.S

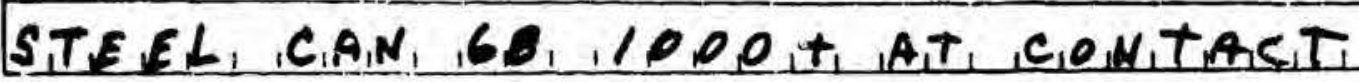

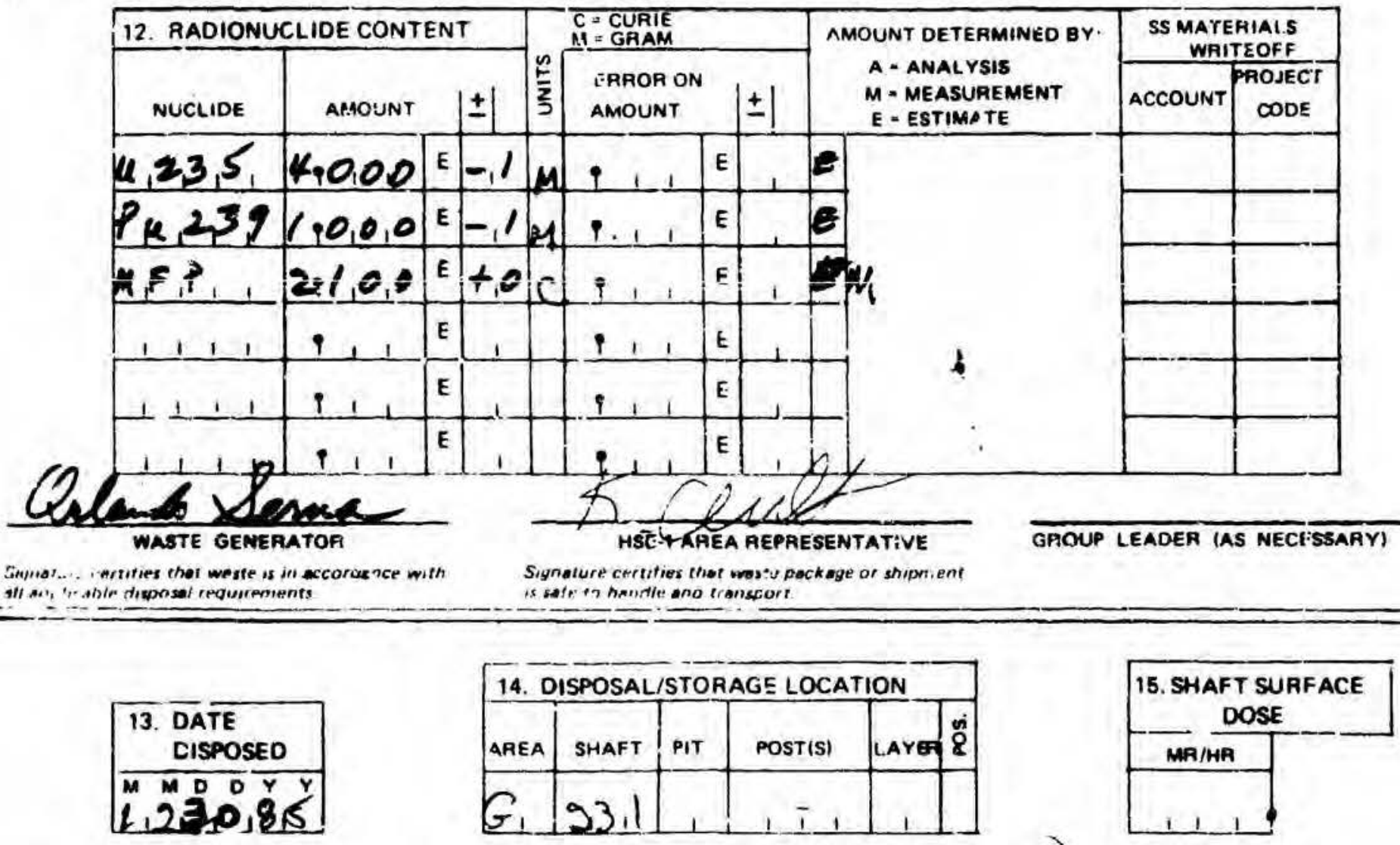


PLEASE READ INSTRUCTIONS ON BACK CAREFULLY

LOS ALAMOS RADIOACTIVIE SOLID WASTE DISOBAL RECCHD
HSE.7 Waste Manadement

Ext 6095 MS J592

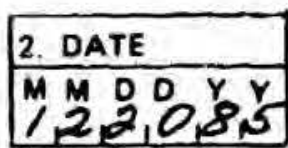

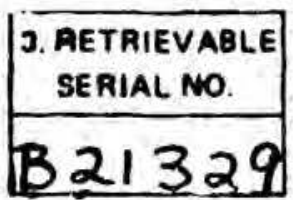

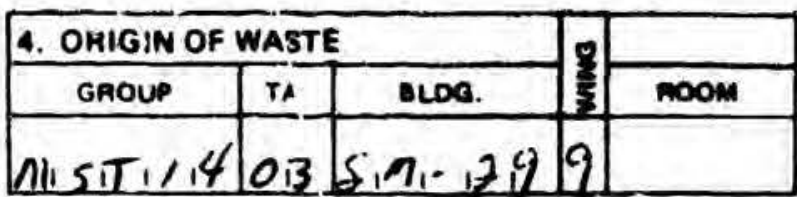

\section{WASTE DESCRIPTION}

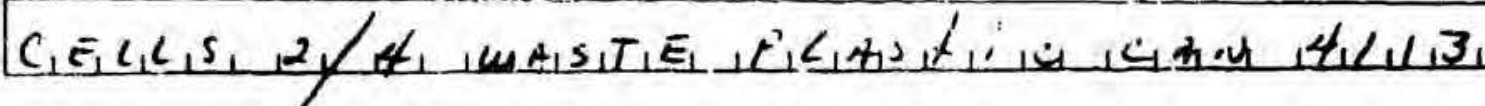

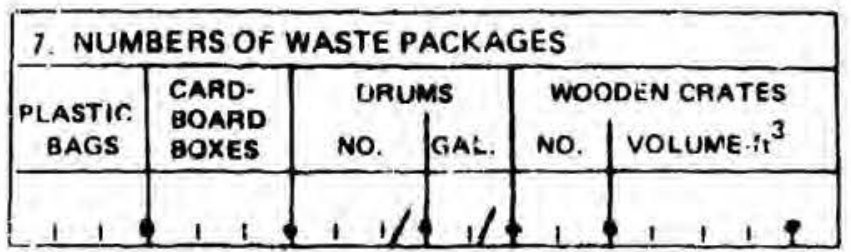
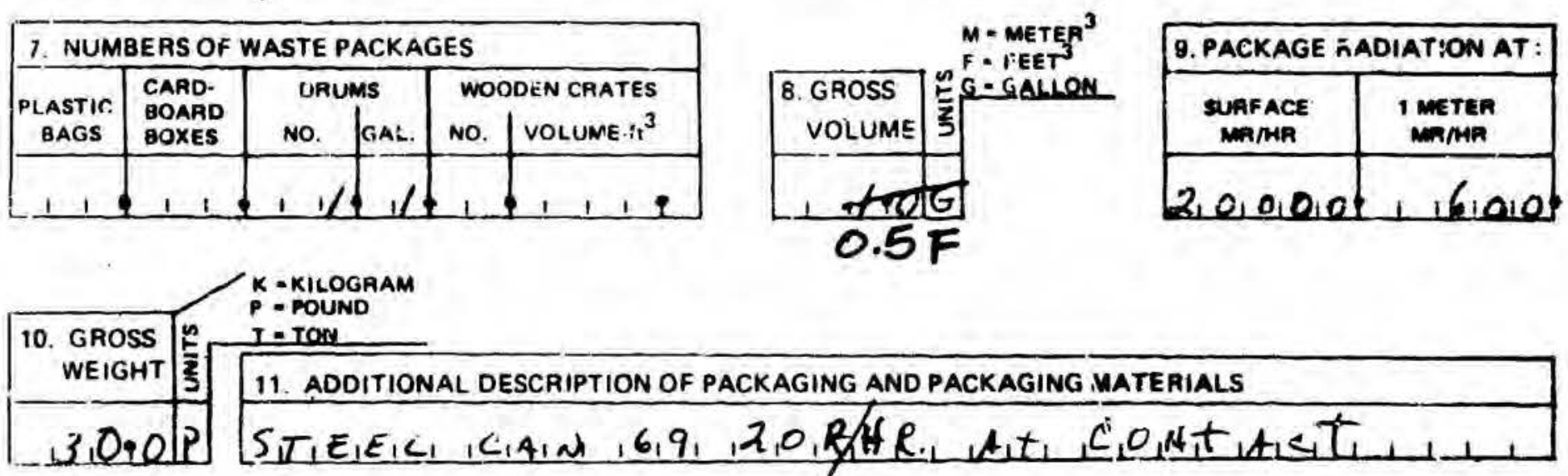

$K$ - KILOGAAM

$$
P=\text { POUND }
$$

- Ton

11. ADDITIONAL DESCRIPTION OF PACKAGING AND PACKAGING MATERIALS

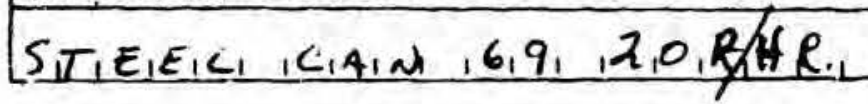

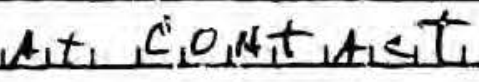

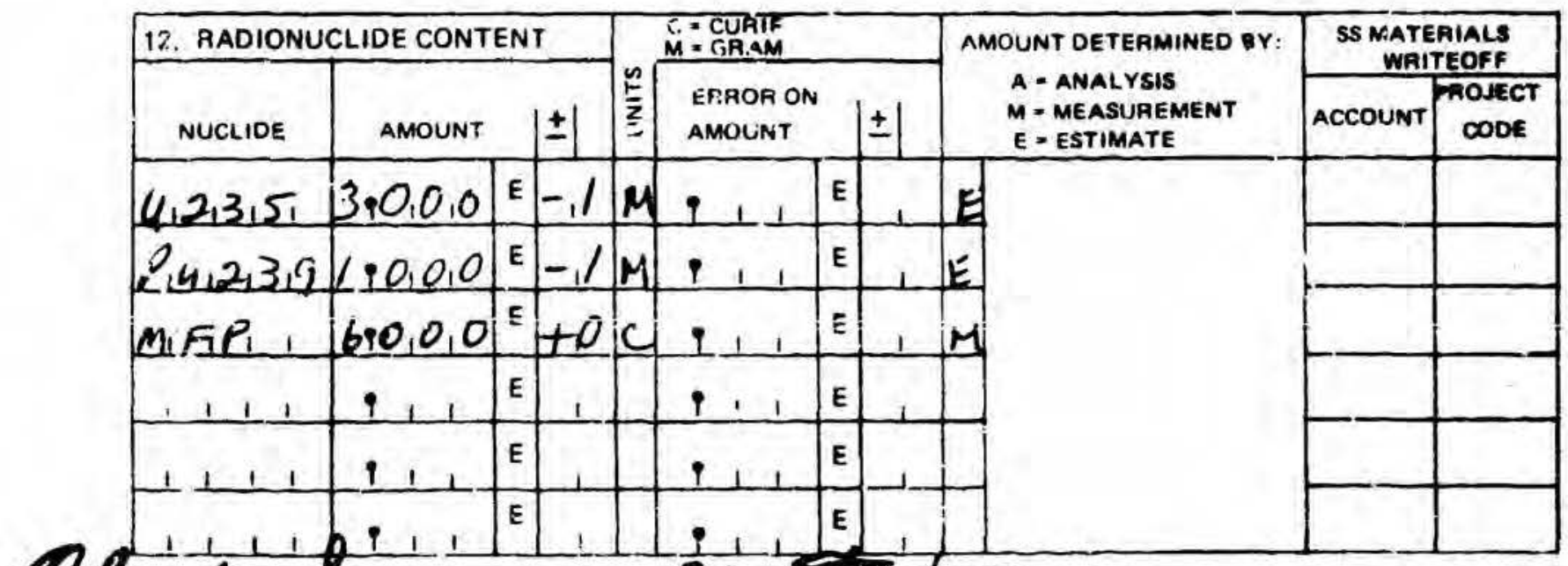

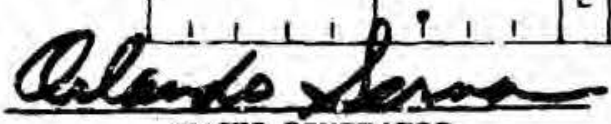

WATTE GENERATOR

Sangiue cerifies that waste is in accordance with alf ophicable disposel requirements.

\section{$\lim \sin s \min$}

HRE-1 AAEA REPRESENA ATIVE

Siynature certifies that inste pack age or shipmen is sare to hanule and transport.

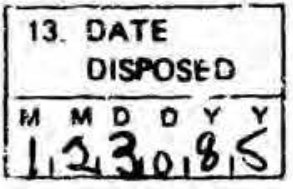

H. Ferki Number $10.2 A$ (12)

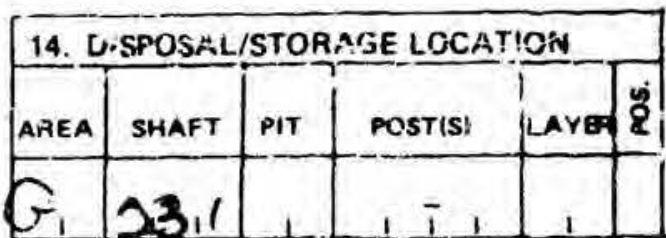

11

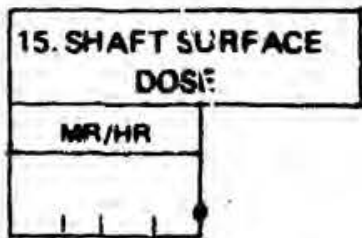

Q. Dole you

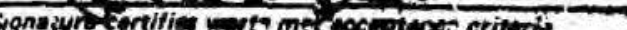

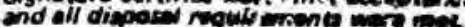


PLEAEE RLAD INSTRUCTIONS ON BACK CARFFULLY

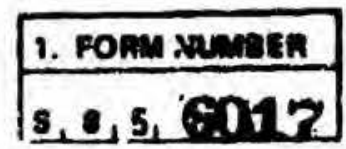

LCS aLAMOS RADIOACTIVE SOLID WASTE H'SF ? Waste Monagmment DISPOSAL RECORD

2. DATE

M D

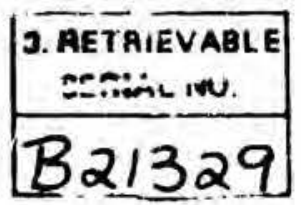

\begin{tabular}{|c|c|c|c|c|}
\hline \multicolumn{3}{|c|}{ 4. ORIGIN OF WASTE } & \multirow{2}{*}{\multicolumn{2}{|c|}{ noom }} \\
\hline GROUP & ra & BLOS. & & \\
\hline$M, s, T_{1}, \mathcal{L}$ & 3 & $M_{1}$ & 9 & \\
\hline
\end{tabular}

\begin{tabular}{l} 
6. WASTE \\
COOE \\
\hline$A, Y O$ \\
\hline
\end{tabular}

6. WASTE DESCRIPTION

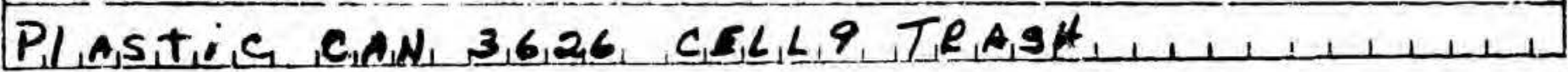

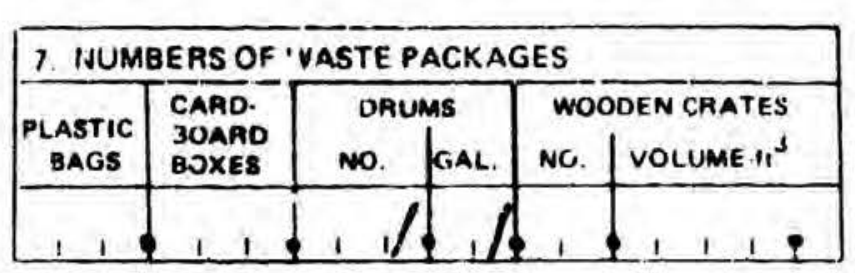

10. GROSS IM L=TOMND

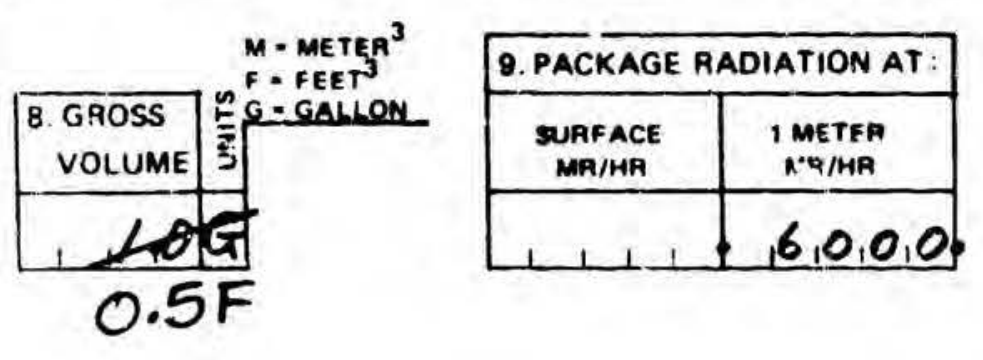

WEIGITT 5 11. ADDITIONAL DESCRIPTION OF PACKAGING AND PACKAGING MATERIALS

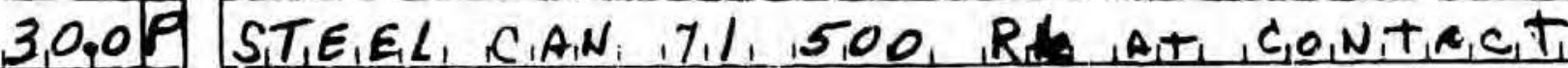
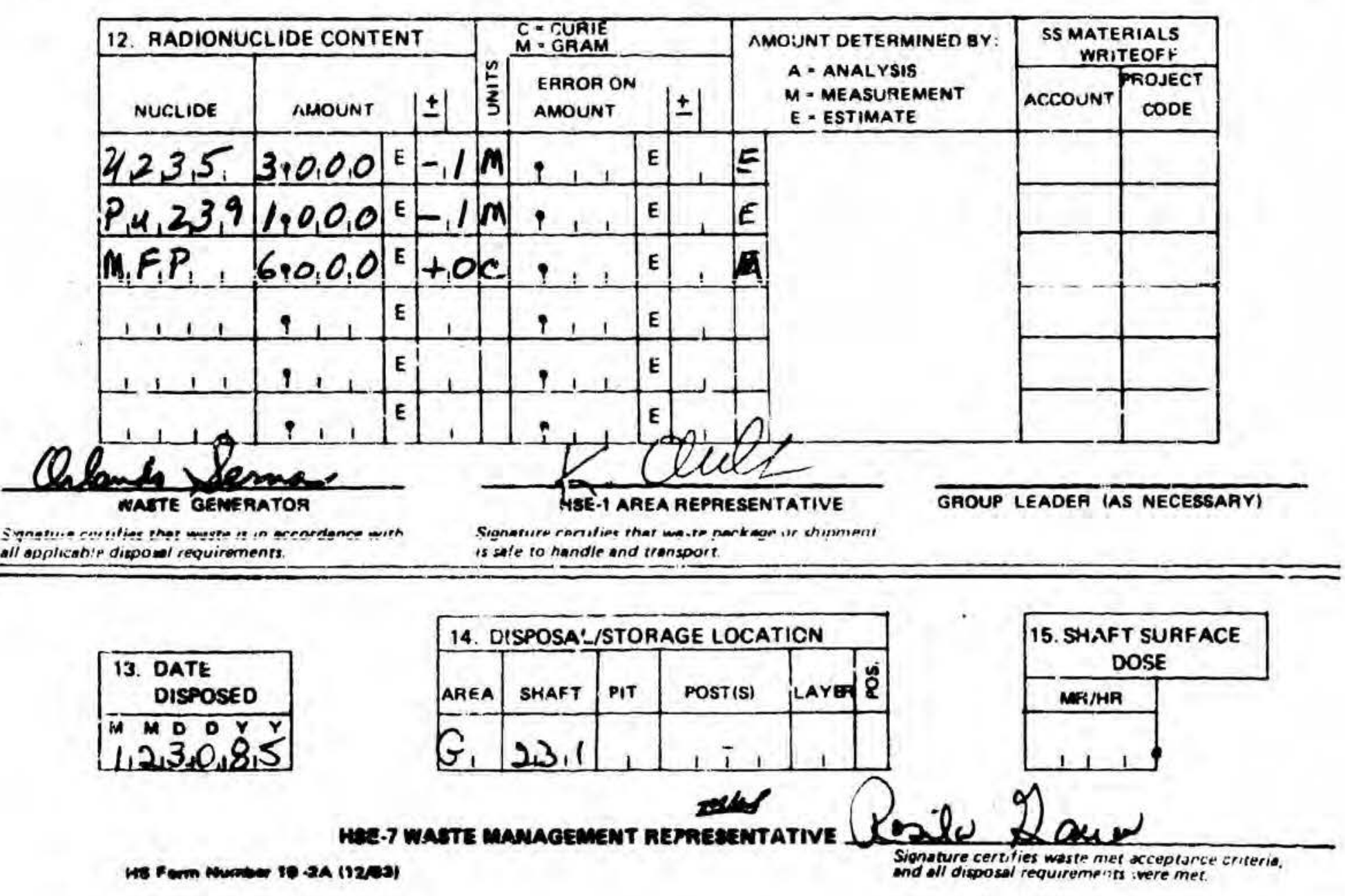
PLEASE: READ ! NSTKUCTIONS ON BATK CAREFULLY

1. FORM NUMAER

LOS ALAMOS RADIOACTIVE YOLID WATTE Disposal Recore

Hsxil Wate Manag ment

Ext 6095 A'S 3592

\begin{tabular}{|c|c|}
\hline 2. DATE & SERIAL NO. \\
\hline$M M D D$ & \\
\hline
\end{tabular}

\begin{tabular}{|c|c|c|c|c|}
\hline 4. ORIGIN OF WASTE & & \\
\hline GAOUP & TA & WLOO. & & nOOM \\
\hline$M_{1} S_{1} T_{1}, 4$ & 3 & $S_{1} M_{1}-2,29$ & 4 & \\
\hline
\end{tabular}

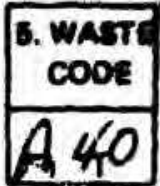

6. WASTE DESCHIPTION

$P_{1} A_{1} S_{1} T_{1} i_{1} C_{1} \#, 3,6,25_{1}, C_{1} E_{1} I_{1}, q_{1}, T_{1} R_{1} A_{2} S_{1} H_{1}$

\begin{tabular}{|c|c|c|c|c|c|}
\hline \multicolumn{6}{|c|}{ 7. NUMBERS OF WASTE PACKAGES } \\
\hline \multirow{2}{*}{$\begin{array}{c}\text { PLASTIC } \\
\text { BAGS }\end{array}$} & \multirow{2}{*}{$\begin{array}{l}\text { CAAD. } \\
\text { BOAR } \\
\text { GOXES }\end{array}$} & \multicolumn{2}{|c|}{ DRUMS } & \multicolumn{2}{|c|}{ WOODEN CAATES } \\
\hline & & No. & C.AL. & NO. & VOLUME H $^{3}$ \\
\hline $1 \quad 1$ & 1 & 1 & & & $11 ; 1$ \\
\hline
\end{tabular}

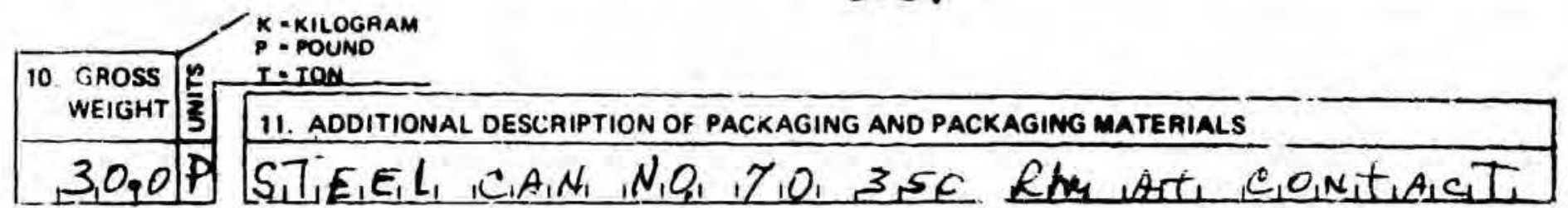
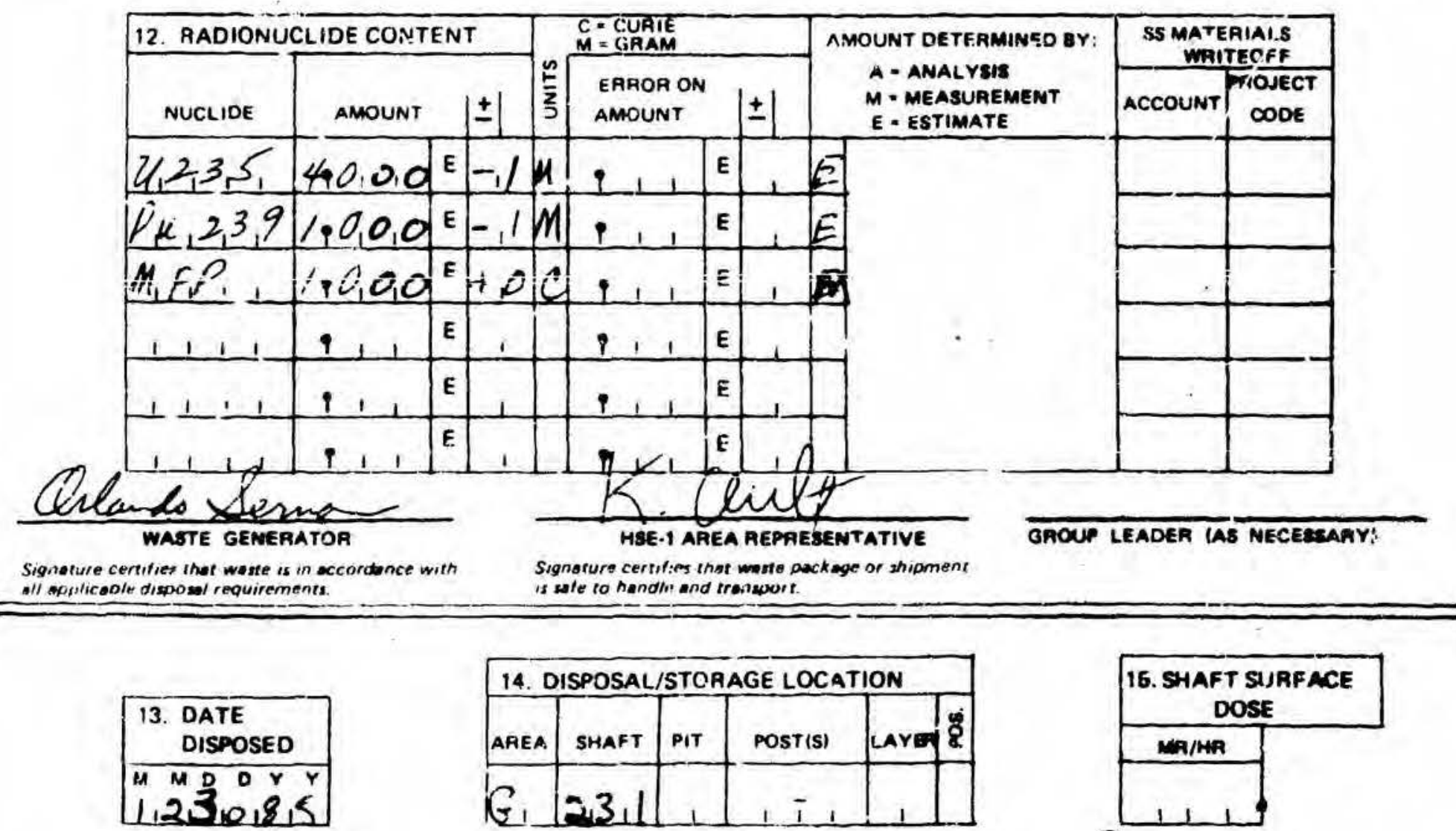

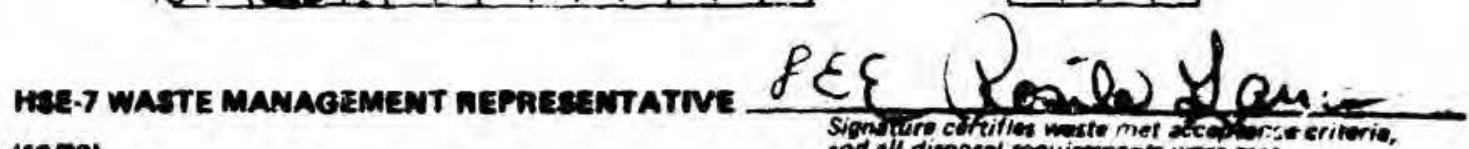
Hes Ferm Number $10-24$ (19) 
RADIOACTIVE SOLID WASTE DISPOSAL RECORD FORMS

FOR

SHAFT 232

MATERIAL DISPOSAL AREA G 
Los Alamos

Los Alamos National Laboratory

Los Alamos, New Mexico 87545

1. Form Number

38741,32

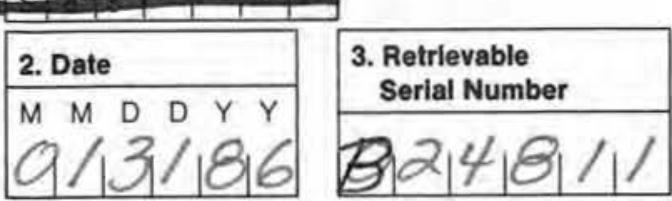

RADIOACTIVE SOLID WASTE DISPOSAL RECORD

NOTE: Read instructions on back carefully before completing this form.

\section{Waste Description}

\begin{tabular}{|c|c|c|c|c|}
\hline \multicolumn{4}{|c|}{ 4. Origin of Waste } & Room \\
\hline Group & TA & Building & Wing & Program code \\
\hline$M_{1} S_{1}$ & & $S_{1}$ & & \\
\hline
\end{tabular}

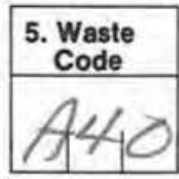

\section{$3 M / K|K| /|S K| A M P \mid$}

MAASTIEI CANM
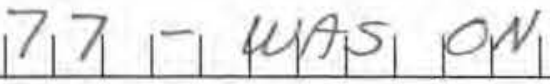

\section{Numbers of Waste Packages}

\begin{tabular}{|c|c|c|c|c|c|}
\hline \multirow{2}{*}{$\begin{array}{l}\text { Plastic } \\
\text { Bags }\end{array}$} & \multirow{2}{*}{$\begin{array}{l}\text { Card- } \\
\text { Board } \\
\text { Boxes }\end{array}$} & \multicolumn{2}{|c|}{ Drums } & \multicolumn{2}{|c|}{ Wooden Crates } \\
\hline & & No. & Gal. & No. & Volume- $\mathrm{ft}^{3}$ \\
\hline
\end{tabular}

\section{Gross Volume}

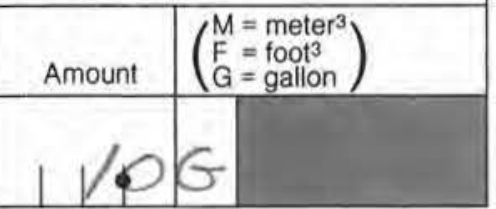

9. Package Radiation at

\begin{tabular}{|c|c|}
\hline $\begin{array}{l}\text { Surface } \\
(\mathrm{mr} / \mathrm{hr})\end{array}$ & $\begin{array}{l}1 \text { Meter } \\
(\mathrm{mr} / \mathrm{hr})\end{array}$ \\
\hline & \\
\hline
\end{tabular}

\section{Gross Weight}

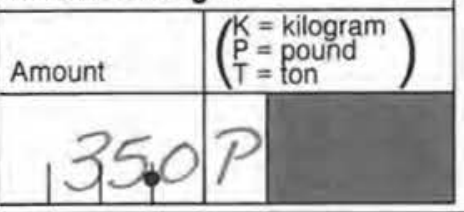

\section{Radionuclide Content}

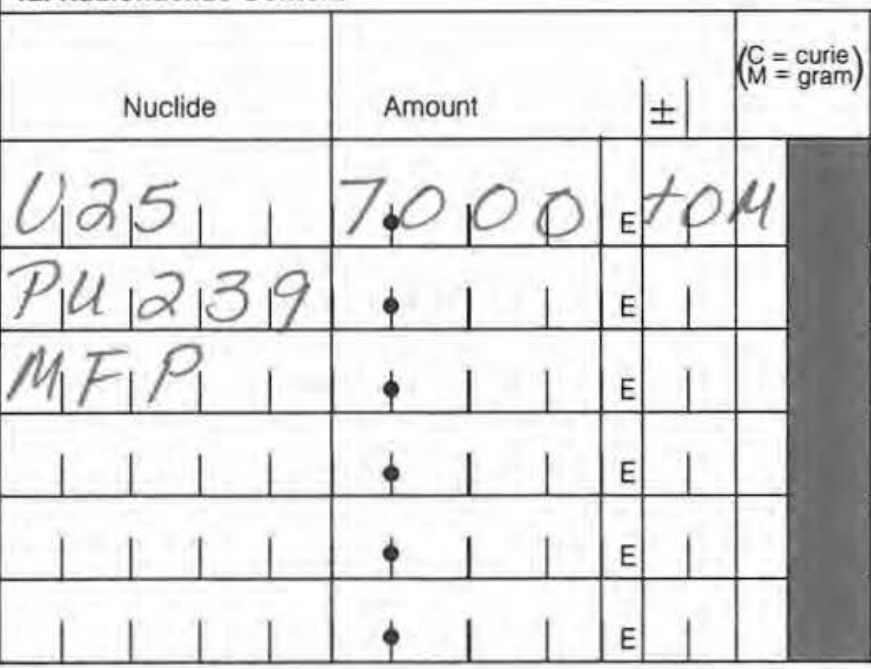

\section{Additional Description of Packaging and Packaging Materials}

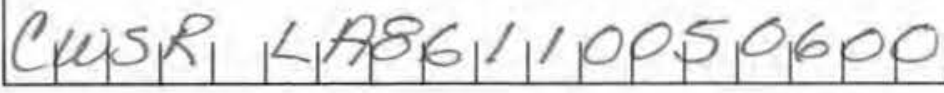

Waste Generator (Print Name Here)

\section{APPROVALS} -1/-10/-11 Area Representative (Print Name Here)
dle and transport. (Signature)

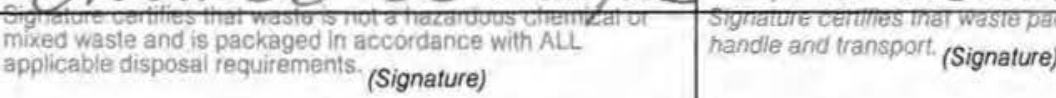

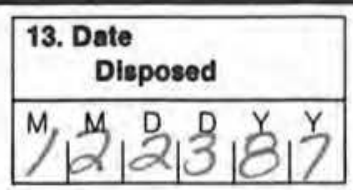

\section{Disposal/Storage Location}

\begin{tabular}{|c|c|c|c|}
\hline Area & Shaft & Pit & Post(s) \\
\hline & & & \\
\hline
\end{tabular}

15. Shaft Surface Dose \begin{tabular}{|l|l|}
\hline Layer & Pos. \\
\hline
\end{tabular}

\begin{tabular}{|c|c|c|c|}
\hline Received & Logbook & Computer & Verified \\
\hline Date & Date & Date & Date $1 / 7 / 88$ \\
\hline
\end{tabular}




\section{INSTRUCTIONS FOR WASTE GENERATOR}

Filling Out the Form. The waste generator must complete this form to document all waste buried or retrievably stored at the Laboratory's TA-54, Area G, site. Be sure to complete each section before proceeding to the next section. The waste generator must follow these instructions:

1. Don't use more than the allotted spaces on the form (one letter or number per space).

2. Ensure that all data recorded on this form are legibly printed and clearly readable.

3. Note that the decimal point positions are already indicated in the sections where decimals would be needed (for example, see Section 7 on the front of this form). Enter information accurately in relation to these decimal points. Do not alter decimal point positions.

4. Use the number zero $(0)$ on the form $O N L Y$ on entries requiring that numerical designation, Do not use the number zero to fill blank spaces.

5. Where the amount of information available does not allow recording all data on one form, use additional forms for different portions of the waste.

When the Form is Completed. The waste generator must ensure that the properly completed form accompanies each waste shipment and each package of retrievable transuranic (TRU) waste delivered to the disposal/storage site. Waste generators may keep a copy of the completed form for their files.

\section{PERTINENT INSTRUCTIONS FOR SPECIFIC SECTIONS OF THIS FORM}

Section 5, Waste Code. Identify all waste by a 3-digit description code, as given in Attachment I, "Valid Waste Codes." Choose the code that best describes the waste material.

Section 6, Waste Description. Allow one space for each letter and one space after each word. Use this section to provide any additional information about the waste.

Section 9, Package Radiation. Do not use symbols for "greater than $(>)$," for "less than $(<)$," for "greater than or equal to $(\geq)$," or for "less than or equal to $(\leq)$. " Round off fractions to the nearest whole number. If radiation levels exceed that which can be listed, leave this section blank and record the data in Section 11.

Section 11, Additional Description of Packaging and Packaging Materials. Use this space to provide property number, related form numbers, data that cannot be entered in Sections 6 or 9 (see above), etc.

Section 12, Radionuclide Content. List radionuclides using either the normally accepted notations (for example, U235, Pu239, Co60, and H3) or, for accountable materials, the element identification plus the SS Material Type Code (for example, Pu 52 for plutonium code 52, U38 for uranium code 38). Acceptable codes include MFP for mixed fission products and MAP for mixed activation products.

For nonradioactive chemical or hazardous waste, enter the correct chemical identification, such as CHEM, $\mathrm{PCB}$, or ASBES. If more than one contaminant is identifiable, each contaminant should be listed (with all appropriate data) on a separate line in Section 12. If there are more than six (6) radionuclides identified, or if there are any questions regarding the completion of this form, contact HSE-7 at 7-5397.

Questions regarding the handling or packaging of radioactive or hazardous wastes should be referred to Disposal Site Operations (7-6095).

\section{APPROVAL SIGNATURES}

Waste Generator. The waste generator must sign the form in the space allotted to indicate compliance with applicable waste packaging and disposal requirements. This signature is required for all waste, whether radioactive or nonradioactive. Note that both the generator's printed name and written signature are required.

HSE-1/-10/-11 Area Representative. An area representative from either the HSE-1, -10, or -11 group must sign the form if the wastes are radioactively contaminated. This signature indicates that the package or shipment is safe to handle and transport. Note that both the area representative's printed name and written signature are required.

Additional Signatures. An area representative from HSE-3 or HSE- 5 may be required to sign this form before certain hazardous materials are transported. This signature space also may be used for the group leader's signature, if required by the generator's group/division. 


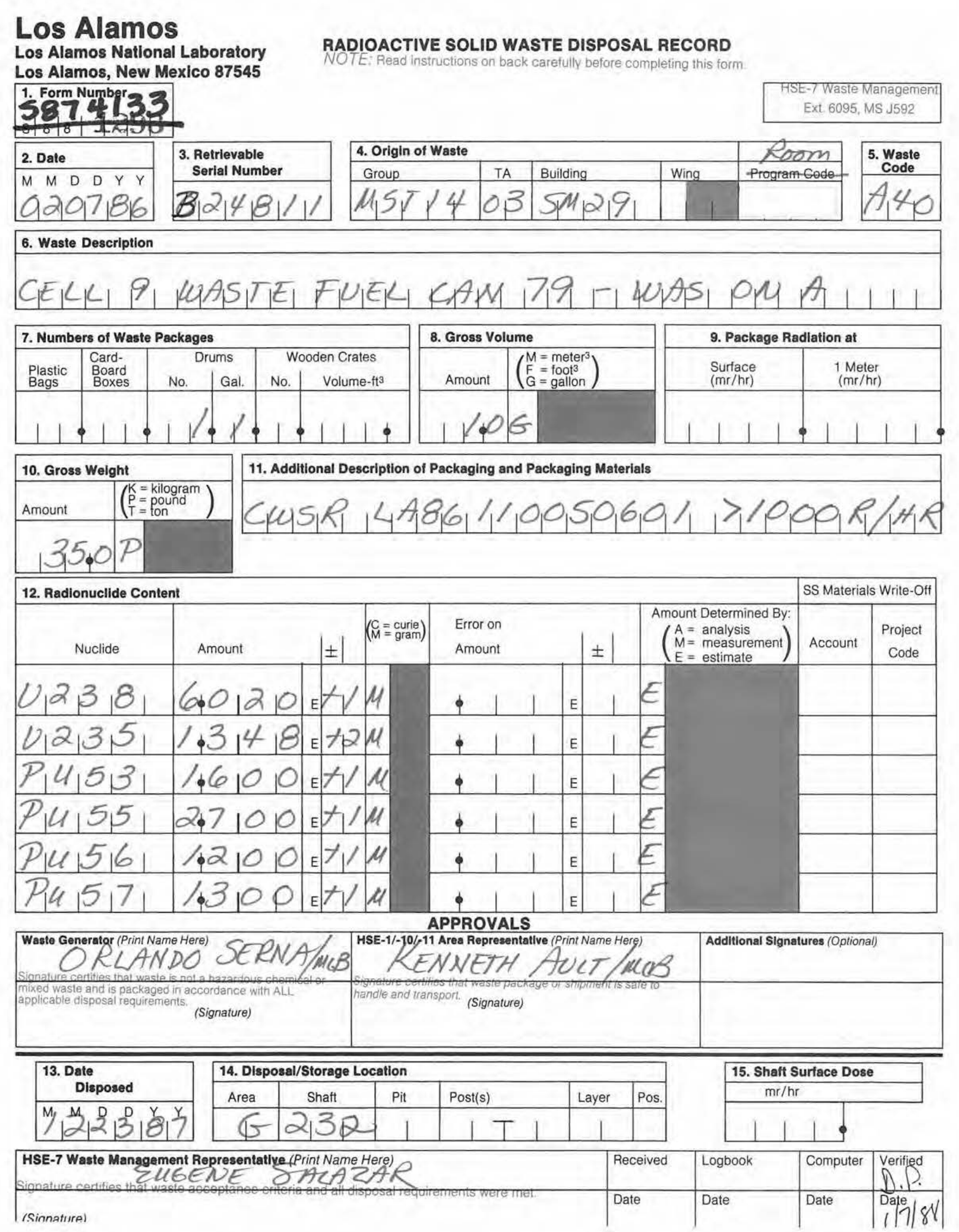




\section{INSTRUCTIONS FOR WASTE GENERATOR}

Filling Out the Form. The waste generator must complete this form to document all waste buried or retrievably stored at the Laboratory's TA-54, Area G, site. Be sure to complete each section before proceeding to the next section. The waste generator must follow these instructions:

1. Don't use more than the allotted spaces on the form (one letter or number per space).

2. Ensure that all data recorded on this form are legibly printed and clearly readable.

3. Note that the decimal point positions are already indicated in the sections where decimals would be needed (for example, see Section 7 on the front of this form). Enter information accurately in relation to these decimal points. Do not alter decimal point positions.

4. Use the number zero $(0)$ on the form $O N L Y$ on entries requiring that numerical designation. Do not use the number zero to fill blank spaces.

5. Where the amount of information available does not allow recording all data on one form, use additional forms for different portions of the waste.

When the Form is Completed. The waste generator must ensure that the properly completed form accompanies each waste shipment and each package of retrievable transuranic (TRU) waste delivered to the disposal/storage site. Waste generators may keep a copy of the completed form for their files.

\section{PERTINENT INSTRUCTIONS FOR SPECIFIC SECTIONS OF THIS FORM}

Section 5, Waste Code. Identify all waste by a 3-digit description code, as given in Attachment I, "Valid Waste Codes." Choose the code that best describes the waste material.

Section 6, Waste Description. Allow one space for each letter and one space after each word. Use this section to provide any additional information about the waste.

Section 9, Package Radiation. Do not use symbols for "greater than $(>)$," for "less than $(<)$," for "greater than or equal to $(\geq)$," or for "less than or equal to $(\leq)$." Round off fractions to the nearest whole number. If radiation levels exceed that which can be listed, leave this section blank and record the data in Section I1.

Section 11, Additional Description of Packaging and Packaging Materials. Use this space to provide property number, related form numbers, data that cannot be entered in Sections 6 or 9 (see above), etc.

Section 12, Radionuclide Content. List radionuclides using either the normally accepted notations (for example, U235, Pu239, Co60, and H3) or, for accountable materials, the element identification plus the SS Material Type Code (for example, Pu 52 for plutonium code 52, U38 for uranium code 38 ). Acceptable codes include MFP for mixed fission products and MAP for mixed activation products.

For nonradioactive chemical or hazardous waste, enter the correct chemical identification, such as CHEM, $\mathrm{PCB}$, or ASBES. If more than one contaminant is identifiable, each contaminant should be listed (with all appropriate data) on a separate line in Section 12. If there are more than six (6) radionuclides identified, or if there are any questions regarding the completion of this form, contact HSE-7 at 7-5397.

Questions regarding the handling or packaging of radioactive or hazardous wastes should be referred to Disposal Site Operations (7-6095).

\section{APPROVAL SIGNATURES}

Waste Generator. The waste generator must sign the form in the space allotted to indicate compliance with applicable waste packaging and disposal requirements. This signature is required for all waste, whether radioactive or nonradioactive. Note that both the generator's printed name and written signature are required.

HSE-1/-10/-11 Area Representative. An area representative from either the HSE-1, -10, or -11 group must sign the form if the wastes are radioactively contaminated. This signature indicates that the package or shipment is safe to handle and transport. Note that both the area representative's printed name and written signature are required.

Additional Signatures. An area representative from HSE-3 or HSE-5 may be required to sign this form before certain hazardous materials are transported. This signature space also may be used for the group leader's signature, if required by the generator's group/division. 
Los Alamos

Los Alamos National Laboratory

Los Alamos, New Mexico 87545

1. Form Number 21
RADIOACTIVE SOLID WASTE DISPOSAL RECORD

NOTE: Read instructions on back carefully before completing this iorm.

\begin{tabular}{|c|c|}
\hline 2. Date & 3. Retrievable \\
\hline $\begin{array}{llllll}M & M & D & D & Y & Y\end{array}$ & $2 / 10$ \\
\hline
\end{tabular}

\begin{tabular}{|c|c|c|c|c|}
\hline 4. Origin of Waste & & & & Room \\
\hline Group & TA & Building & Wing & Program Gede \\
\hline 14 & & $S M_{1}$ & & \\
\hline
\end{tabular}

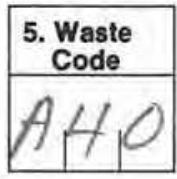

6. Waste Description

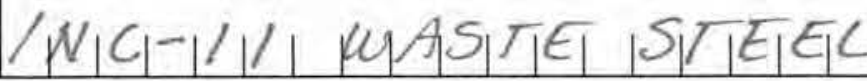

\section{Numbers of Waste Packages}

\begin{tabular}{|c|c|c|c|c|c|}
\hline \multirow{2}{*}{$\begin{array}{l}\text { Plastic } \\
\text { Bags }\end{array}$} & \multirow{2}{*}{$\begin{array}{l}\text { Card- } \\
\text { Board } \\
\text { Boxes }\end{array}$} & \multicolumn{2}{|c|}{ Drums } & \multicolumn{2}{|c|}{ Wooden Crates } \\
\hline & & No, & $\mathrm{Gal}_{\text {. }}$ & No. & Volume- $\mathrm{ft}^{3}$ \\
\hline & & & & & \\
\hline
\end{tabular}

\section{Gross Volume}

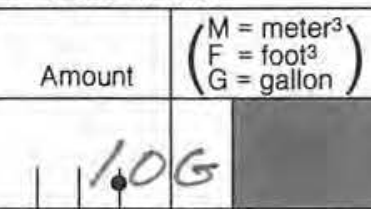

HSE-7 Waste Management Ext. 6095, MS J592

\section{Gross Weight}

\begin{tabular}{|l|l|}
\hline Amount & $\left.\begin{array}{l}K=\text { kilogram } \\
P=\text { pound } \\
T=\text { fon }\end{array}\right)$ \\
\hline 350 & $P$ \\
\hline
\end{tabular}

11. Additional Description of Packaging and Packaging Materials

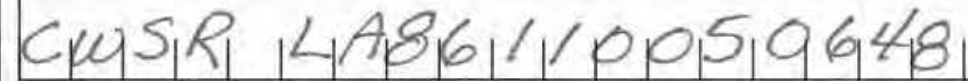

12. Radionuclide Content

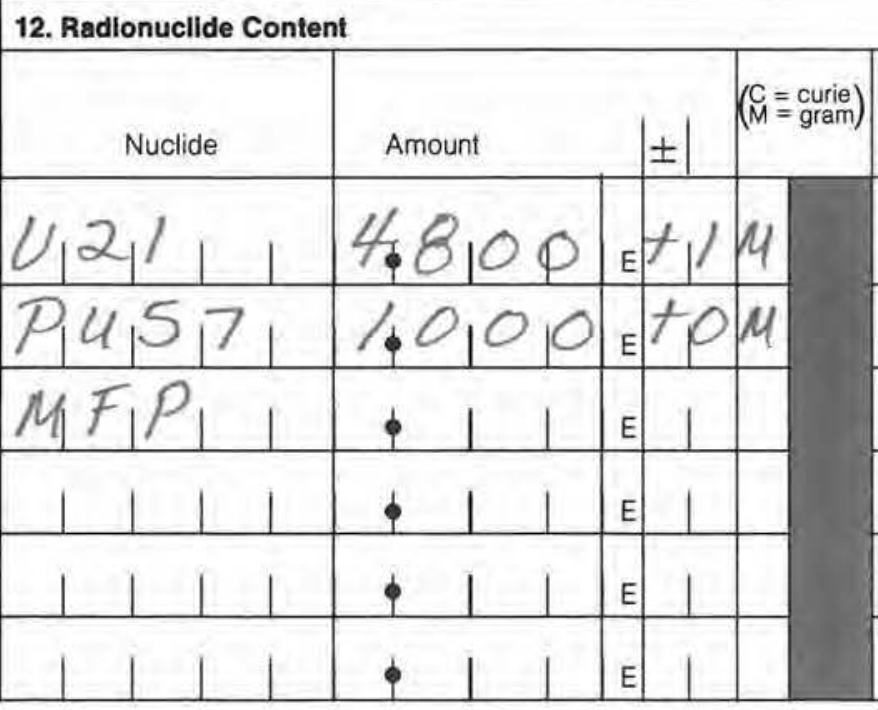

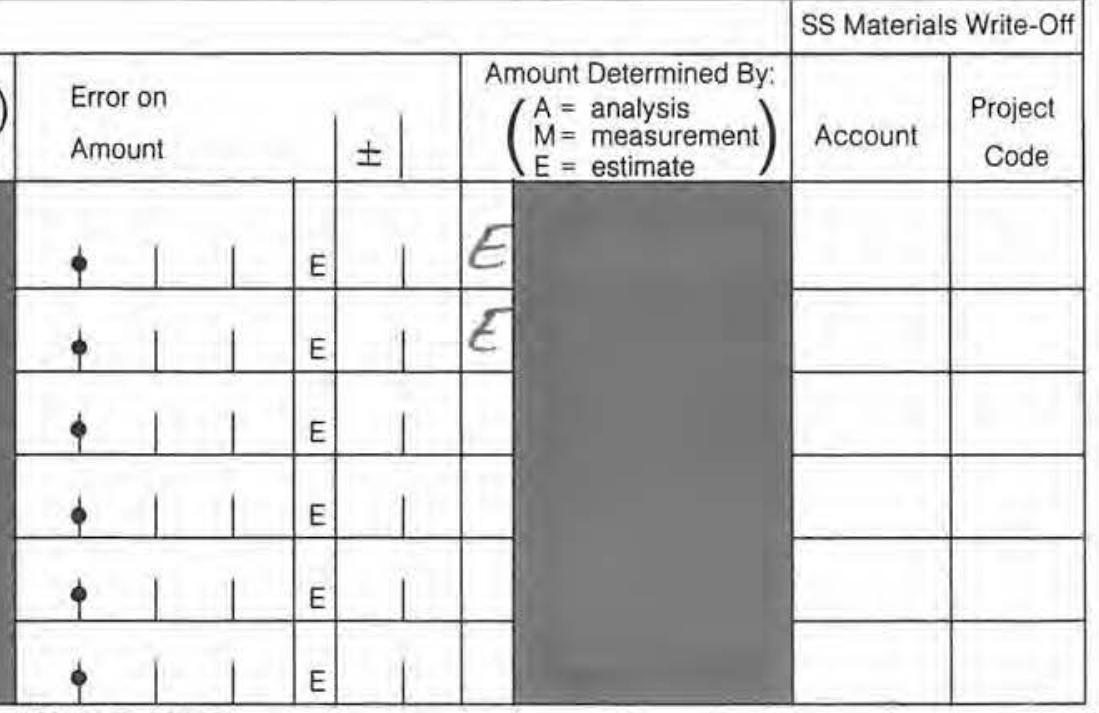

\section{APPROVALS}

Waste Generator (Print Name Here)

\begin{tabular}{l|l} 
Signature cerlifies that waste is not a hazardous chenical or & Signalure certilies that waste pach \\
mixed waste and is packaged in accordance witf ALL & hahdle and transpor(Signature)
\end{tabular} applicable disposat requirements(Signature)

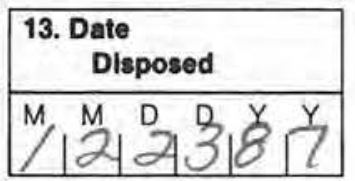

\begin{tabular}{|c|c|c|c|c|c|}
\hline \multicolumn{6}{|c|}{ 14. Disposal/Storage Location } \\
\hline Area & Shaft & Pit & Post(s) & Layer & Pos. \\
\hline
\end{tabular}

\begin{tabular}{|l|l|l|l|}
\hline Received & Logbook & Computer & Verified \\
\hline Date & Date & Date & Date \\
\hline ru $\mid$ \&
\end{tabular}




\section{INSTRUCTIONS FOR WASTE GENERATOR}

Filling Out the Form. The waste generator must complete this form to document all waste buried or retrievably stored at the Laboratory's TA- 54 , Area G, site. Be sure to complete each section before proceeding to the next section. The waste generator must follow these instructions:

1. Don't use more than the allotted spaces on the form (one letter or number per space).

2. Ensure that all data recorded on this form are legibly printed and clearly readable,

3. Note that the decimal point positions are already indicated in the sections where decimals would be needed (for example, see Section 7 on the front of this form). Enter information accurately in relation to these decimal points. Do not alter decimal point positions.

4. Use the number zero $(0)$ on the form $O N L Y$ on entries requiring that numerical designation. Do not use the number zero to fill blank spaces.

5. Where the amount of information available does not allow recording all data on one form, use additional forms for different portions of the waste.

When the Form is Completed. The waste generator must ensure that the properly completed form accompanies each waste shipment and each package of retrievable transuranic (TRU) waste delivered to the disposal/storage site. Waste generators may keep a copy of the completed form for their files.

\section{PERTINENT INSTRUCTIONS FOR SPECIFIC SECTIONS OF THIS FORM}

Section 5, Waste Code. Identify all waste by a 3-digit description code, as given in Attachment I, "Valid Waste Codes." Choose the code that best describes the waste material.

Section 6, Waste Description. Allow one space for each letter and one space after each word. Use this section to provide any additional information about the waste.

Section 9, Package Radiation. Do not use symbols for "greater than $(>)$," for "less than $(<)$," for "greater than or equal to $(\geq)$," or for "less than or equal to $(\leq)$." Round off fractions to the nearest whole number. If radiation levels exceed that which can be listed, leave this section blank and record the data in Section 11.

Section 11, Additional Description of Packaging and Packaging Materials. Use this space to provide property number, related form numbers, data that cannot be entered in Sections 6 or 9 (see above), etc.

Section 12, Radionuclide Content. List radionuclides using either the normally accepted notations (for example, U235, Pu239, Co60, and H3) or, for accountable materials, the element identification plus the SS Material Type Code (for example, Pu 52 for plutonium code 52, U38 for uranium code 38). Acceptable codes include MFP for mixed fission products and MAP for mixed activation products.

For nonradioactive chemical or hazardous waste, enter the correct chemical identification, such as CHEM, $\mathrm{PCB}$, or ASBES. If more than one contaminant is identifiable, each contaminant should be listed (with all appropriate data) on a separate line in Section 12. If there are more than six (6) radionuclides identified, or if there are any questions regarding the completion of this form, contact HSE-7 at 7-5397.

Questions regarding the handling or packaging of radioactive or hazardous wastes should be referred to Disposal Site Operations (7-6095).

\section{APPROVAL SIGNATURES}

Waste Generator. The waste generator must sign the form in the space allotted to indicate compliance with applicable waste packaging and disposal requirements. This signature is required for all waste, whether radioactive or nonradioactive. Note that both the generator's printed name and written signature are required.

HSE-1/-10/-11 Area Representative. An area representative from either the HSE-1, -10 , or -11 group must sign the form if the wastes are radioactively contaminated. This signature indicates that the package or shipment is safe to handle and transport. Note that both the area representative's printed name and written signature are required.

Additional Signatures. An area representative from HSE-3 or HSE-5 may be required to sign this form before certain hazardous materials are transported. This signature space also may be used for the group leader's signature, if required by the generator's group/division. 



\section{Appendix D}

\section{Portions of Weston Report \\ Relevant to 33 Shafts}

\section{"Historical Emplacement Data Review for}

Remote-Handled and Contact-Handled Transuranic Waste at Los Alamos National Laboratory"

Weston Solutions, Inc.

December 2005 
This page intentionally left blank.

Page D-2 


\section{Historical Emplacement Data Review for Remote- Handled and Contact-Handled Transuranic Waste at Los Alamos National Laboratory}

Prepared for Los Alamos National Laboratory Nuclear Waste and Infrastructure Services TRU Programs

Prepared by

Weston Solutions, Inc.

December 22, 2005 


\section{TABLE OF CONTENTS}

SECTION

Page

1.0 INTRODUCTION 1

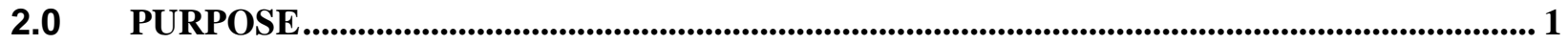

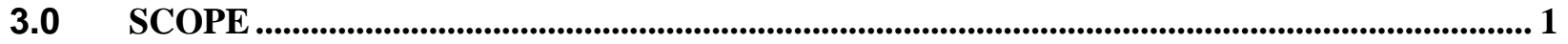

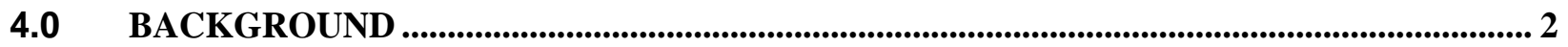

$4.1 \quad$ LINED SHAFTS (200 THROUGH 232) ................................................................... 2

4.2 HOT CELL LINER SHAFTS (302 THROUGH 306)ERROR! BOOKMARK NOT DEFINED.

4.3 CANISTER SHAFTS (236 THROUGH 243, AND 246 THROUGH 253)ERROR! BOOKMARK NOT

4.4 UNLINED SHAFTS (33, 72 THROUGH 76)ERROR! BOOKMARK NOT DEFINED.

4.5 TRITIUM TORPEDO SHAFTS (262 THROUGH 266)ERROR! BOOKMARK NOT DEFINED.

5.0 SOURCES OF INFORMATION REVIEWED ................................................................. 2

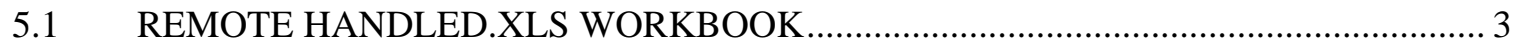

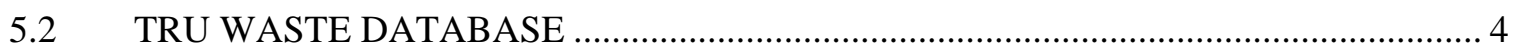

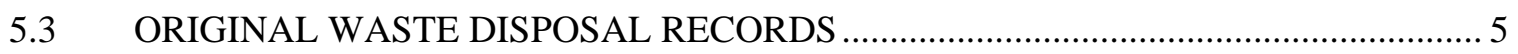

5.3.1 Radioactive Solid Waste Disposal (RSWD) Forms ........................................ 5

5.3.2 TRU Waste Storage Record (TWSR) Forms ....Error! Bookmark not defined.

5.4 MATERIAL TYPES AND CALCULATIONS ............................................................. 5

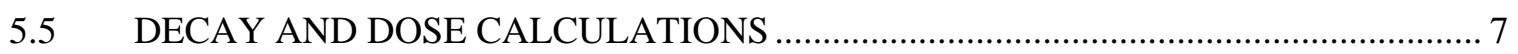

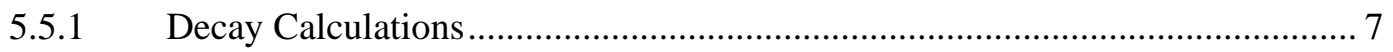

5.6 JUSTIFICATION FOR SELECTING THE FINAL DATA TO BE USED....................... 7

5.6.1 Remote handled.xls Workbook ........................................................................ 7

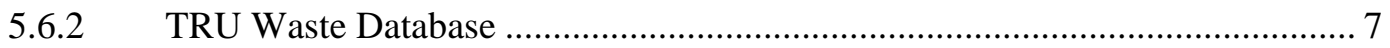

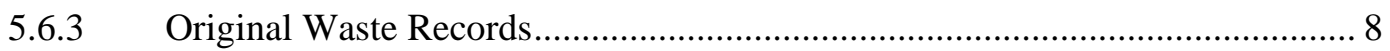

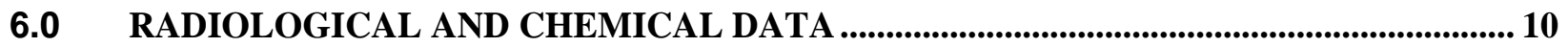

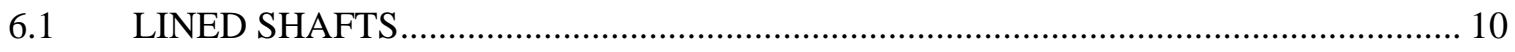

6.2 HOT CELL LINER SHAFTS........................ ERROR! BOOKMARK NOT DEFINED.

6.3 CANISTER SHAFTS ……........................... ERROR! BOOKMARK NOT DEFINED.

6.4 UNLINED SHAFTS .................................... ERROR! BOOKMARK NOT DEFINED.

6.5 TRITIUM TORPEDO SHAFTS................... ERROR! BOOKMARK NOT DEFINED.

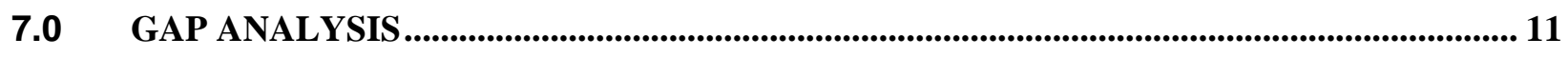

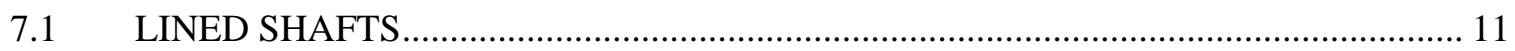

7.2 HOT CELL LINER SHAFTS........................ ERROR! BOOKMARK NOT DEFINED.

7.3 CANISTER SHAFTS ................................... ERROR! BOOKMARK NOT DEFINED.

7.4 UNLINED SHAFTS ……............................ ERROR! BOOKMARK NOT DEFINED.

7.5 TRITIUM TORPEDO SHAFTS..................... ERROR! BOOKMARK NOT DEFINED.

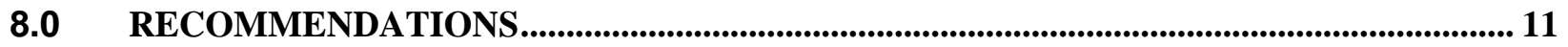

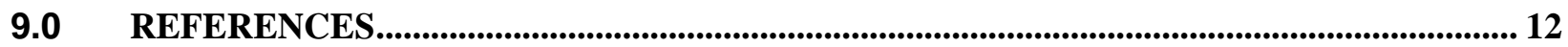




\section{TABLES}

Tables

Page

Table 1. $\quad$ Remote handled.xls Workbook Data Fields ......................................................................... 3

Table 2. $\quad$ TRU Waste Database Data Fields …................................................................................... 4

Table 3. Radioactive Solid Waste Disposal Form Data Fields.......................................................... 5

Table 4. TRU Waste Storage Record Forms Data Fields ....................... Error! Bookmark not defined.

Table 5. Isotopic Content of Plutonium and Uranium Material Types ............................................. 6

Table 6. Isotopic Activity Fractions for $1 \mathrm{Ci}$ of Reported MFPs .................................................... 6

Table 7. Final Data Selection and Justification for Lined Shafts, Hot Cell Liners, and

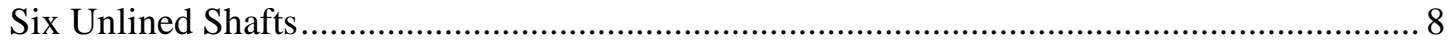

Table 8. Final Data Selection and Justification for Canisters and Tritium Torpedoes.......................... 9

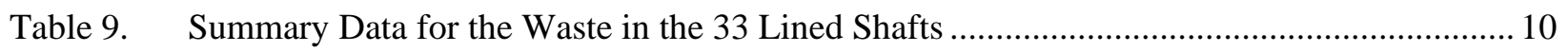

Table 10. Summary Data for the Hot Cell Liners.................................... Error! Bookmark not defined.

Table 11. Summary Data for the 16 Canisters....................................... Error! Bookmark not defined.

Table 12. Summary Data for the Unlined Shafts..................................... Error! Bookmark not defined.

Table 13. Summary Data for the Tritium Torpedoes .............................. Error! Bookmark not defined.

\section{LIST OF APPENDICES}

Appendix A—Lined Shafts

Appendix B-Hot Cell Liner Shafts

Appendix C-Canister Shafts

Appendix D-Unlined Shafts

Appendix E-Tritium Torpedo Shafts

Appendix F-Software Quality Assurance Documentation

Appendix G—Data Reviewed But Not in Appendices 


\section{LIST OF ACRONYMS}

Ac

AK

Am

$\mathrm{Ba}$

$\mathrm{Bi}$

CBFO

$\mathrm{CH}$

CMB

Cs

CMR

$\mathrm{Ci}$

DOE

EPA

$\mathrm{Eu}$

$\mathrm{Fr}$

g

hr

ID

IDCs

LANL

MDA

MFP

mrem

MST

MST-5

MT

NMT-7

NWIS-TP

ORNL

$\mathrm{Pa}$

$\mathrm{Pb}$

PF

Pm actinium

acceptable knowledge

americium

barium

bismuth

Carlsbad Field Office

contact-handled

Chemistry Metallurgy Baker (Division)

cesium

Chemistry and Metallurgy Research (Building)

curies

Department of Energy

Environmental Protection Agency

Europium

francium

gram

hour

identification

item description codes

Los Alamos National Laboratory

Material Disposal Area

Mixed Fission Products

millirem

Material Science and Technology (Division)

Materials Research and Processing Science Group

material type

Nuclear Materials Technology Group

Nuclear Waste and Infrastructure Services, TRU Programs

Oak Ridge National Laboratory

protactinium

lead

Plutonium Facility

promethium 


\begin{tabular}{|c|c|}
\hline Po & polonium \\
\hline $\mathrm{Pu}$ & plutonium \\
\hline QA & quality assurance \\
\hline QAOs & quality assurance objectives \\
\hline $\mathrm{Ra}$ & radium \\
\hline $\mathrm{Rh}$ & Rhodium \\
\hline RH & remote-handled \\
\hline $\mathrm{Rn}$ & radon \\
\hline RSICC & Radiation Safety Information Computation Center \\
\hline RSWD & Radioactive Solid Waste Disposal (Form) \\
\hline $\mathrm{Ru}$ & ruthenium \\
\hline $\mathrm{Sb}$ & antimony \\
\hline Sm & samarium \\
\hline $\mathrm{Sr}$ & strontium \\
\hline SRL & Special Recovery Line \\
\hline TA & technical area \\
\hline $\mathrm{Te}$ & technecium \\
\hline Th & thorium \\
\hline $\mathrm{Tl}$ & thallium \\
\hline TRU & transuranic \\
\hline TWDB & TRU Waste Database \\
\hline TWSR & TRU Waste Storage Record (Form) \\
\hline $\mathrm{U}$ & uranium \\
\hline VOCs & volatile organic compounds \\
\hline WCPIP & RH-TRU Waste Characterization Program Implementation Plan \\
\hline WIPP & Waste Isolation Pilot Plant \\
\hline WPF & Waste Stream Profile (form) \\
\hline $\mathrm{Y}$ & yttrium \\
\hline
\end{tabular}




\section{HISTORICAL EMPLACEMENT DATA REVIEW FOR REMOTE-HANDLED AND CONTACT-HANDLED TRANSURANIC WASTE AT LOS ALAMOS NATIONAL LABORATORY}

\subsection{INTRODUCTION}

Los Alamos National Laboratory (LANL), established in the 1940s to support the Manhattan Project, is located in northern New Mexico, approximately 30 miles from Santa Fe, and encompasses 43 square miles, 47 separate technical areas (TAs), and more than 2,100 individual facilities [1]. The Department of Energy (DOE) contracts with the University of California to operate LANL. The mission of LANL is critical to DOE defense programs, such as non-proliferation and nuclear safeguards; counter-proliferation; stockpile surveillance; nuclear materials technologies; basic chemistry; environmental stewardship; and waste treatment, minimization and management.

LANL generates transuranic (TRU) waste as a result of various projects and activities. Programs generating TRU waste have included plutonium research and processing, analytical chemistry and metallurgy research, waste minimization and management research, and postmortem studies of irradiated fuels for breeder reactors. TRU waste is either contact-handled $(\mathrm{CH})$ or remote-handled $(\mathrm{RH})$ depending upon the surface dose rate of the waste container. Three facilities have generated the majority of the TRU waste stored at LANL, the Plutonium Facility (PF) located at TA-55, the former plutonium facility at TA21, and the Chemistry and Metallurgy Research (CMR) facility located in TA-3. Scientific focus areas for the PF are plutonium metallurgy, actinide ceramics, and actinide chemistry [2]. The CMR facility focuses on analytical chemistry and metallurgical studies on small samples of plutonium and other special nuclear materials [3]. Other facilities have generated smaller amounts of TRU waste, and many of these activities were in support of the plutonium research at TA-55.

The RH-TRU waste at LANL has been generated primarily from the hot cells of Wing 9 of the CMR facility at TA-3, with minor amounts being generated at TA-21. LANL began storing RH-TRU waste in shafts at TA-54, Material Disposal Area G (MDA-G) in the 1970s. Shaft storage of RH-TRU wastes at Area $G$ continues today. Area $G$ is located in the east-southeast portion of LANL and is bordered on the north and east by the San Ildefonso Indian Reservation and to the south and west by TA-18, -36, -46, and -51 . The TRU wastes addressed in this report are stored in lined shafts of different dimensions and in different waste configurations [4].

\subsection{PURPOSE}

The purpose of this report is to present the results of a review and compilation of the historical, physical, chemical, and radiological data in support of retrieval and safe interim storage efforts for $\mathrm{RH}$ - and $\mathrm{CH}-$ TRU waste currently stored in shafts at Area G. This report (1) includes the results of the review of historical data, (2) documents the evaluation of the physical, radiological, and chemical constituents of the wastes and the storage shafts, (3) documents the results of decay calculations for each container, (4) identifies gaps in the historical data required for safe retrieval and subsequent interim storage, and (5) provides recommendations for additional data needs. This report also discusses the justifications for selecting the best data to use for the decay calculations and gap analysis.

\subsection{SCOPE}

This report includes historical data for four RH-TRU shaft configurations (A, B, C, and D) and one CHTRU shaft configuration (E). The RH-TRU shaft configurations consist of the following: 
- 33 lined shafts, each containing numerous 1- and 2-gallon cans of waste, or larger waste items

- 5 lined shafts, each containing a glovebox hot cell liner within a steel box

- 16 lined shafts, each containing one canister, with each canister containing three drums of waste

- 6 unlined shafts, each containing numerous 1-gallon cans of waste

The CH-TRU shaft configuration is a set of five lined shafts, each containing a CH-TRU waste container commonly referred to as a 'torpedo'. Each torpedo contains either three 55-gallon drums of tritium contaminated TRU waste or equipment contaminated with tritium.

\subsection{BACKGROUND}

This section summarizes physical information about the four configurations of shafts and the waste they contain.

\subsection{LINED SHAFTS (200 THROUGH 232)}

The 33 lined shafts, numbered 200 through 232, were constructed in Shaft Field B. Waste was emplaced in these shafts from 1979 through 1987. The shafts were augered into the volcanic tuff approximately 3 feet in diameter and 18 feet deep. A 13-ft. long by 8.5 inch diameter $1 / 4$-inch thick carbon steel pipe liner was placed into the shaft. The steel pipe liner had a steel plate welded to the bottom and a steel cap attached to the top. Crushed tuff, cobbles, and sand were backfilled into the void between the pipe liner and the initial boring. A concrete cap was then placed over the top [4]. Figure 1-5 in Project Management Objectives for Remote-Handled TRU Wastes Stored in Below-Grade Shafts, TA-54, MDA-G illustrates the shaft and emplaced waste configuration.

This waste, generated from 1979 through 1987 by the LANL Chemistry Metallurgy Baker (CMB) Division, and later by the Material Science and Technology (MST) Division, is general hot cell debris waste consisting of metals, inorganics, and combustible solids. The majority of the waste was placed into 1-gallon packages, which included an inner galvanized-steel can, a middle plastic liner, and an outer carbon-steel container with a welded steel lid [4]. The average weight of these packages is estimated to be approximately 20 to 30 pounds. Historical data indicates that Shafts 202, 203, 211, and 212 each contain much larger items, weighing 2.3 tons, 880 pounds, or 8 tons, respectively. Shaft 211 lists five items, each weighing 880 pounds [5 and 6]. The waste generator descriptions do not always correlate with the weights reported. For example, the waste description may state "Hot cell waste from CMB1 - CMB14", with no indication of the physical form of the waste that contributes to a weight of 2.3 tons.

This waste may be considered mixed waste due to the historical use of solvents and the presence of lead in the hot cells [4]. The specific physical, chemical, and radiological characteristics of the waste packages in each lined shaft are listed in Appendix A of this report.

\subsection{SOURCES OF INFORMATION REVIEWED}

The sources of information reviewed included the following:

- An Excel workbook entitled "Remote handled.xls” created by Jene Vance, Vance \& Associates [10]

- LANL TRU Waste Management Database (TWDB) [5] 
- Original waste records (i.e., Radioactive Solid Waste Disposal [RSWD] forms, TRU Waste Storage Record [TWSR] forms) [6 and 8].

The initial set of data reviewed was the Remote handled.xls workbook. This workbook did not include data for the tritium torpedoes, and the source of the information was undocumented. Mixed fission product (MFP) activities were calculated, but the equations were not included in the spreadsheet. Section 5.1 describes the data included in this workbook.

A request was initiated to query the TWDB to obtain the information required to support the retrieval and interim safe storage effort. The data fields queried are listed in Section 5.2. The review of the queried results revealed some fields had missing data, especially for the older waste items. The TWDB had been updated several times, and new fields added, but the new fields were not always updated from the original forms. In addition, it was determined that while the information had been entered into the TWDB from the original records, the accuracy had not been verified for entries made before the early 1990s. Therefore, the original waste generator records were required for review to ensure the most complete and accurate information was used.

The original disposal forms were requested and were available with few exceptions. The original RSWD forms were thought to have been archived off-site, and only a microfiche copy of the first page was available on-site. However, upon further investigation, there was no record of any of the RSWDs being sent to a storage facility. The original TWSRs were still stored on-site at LANL and included the supporting documentation. Section 5.3 discusses the data reviewed from the original disposal forms.

Data obtained from original disposal forms (RSWDs, TWSRs) were entered into spreadsheets and independently verified to ensure transcription was accurate. Data from the Remote handled.xls workbook and exported information from the TWDB were used directly.

Initial calculations were performed to: (1) convert MT to individual isotopes, (2) convert grams to curies, and/or (3) calculate MFP activities, if applicable. After apportioning the MT mass into individual isotopic masses, the isotopic masses were converted to curies using the isotopic specific activity in curies per gram (Ci/g) values from Table A-1 of 10 CFR Part 71, Appendix A [11]. The total reported activity of MFP was distributed as activities of individual isotopes (Ba-137m, Cs-137, Eu-155, Pm-147, Rh-106, Ru-106, Sb-125, Sr-90, Te-125m, Y-90) for each package, as needed. These calculations were independently verified to document accuracy. The following sections discuss in detail the type of information obtained from each source and list the specific shafts the data represent. References used for calculating MTs and MFPs are also discussed.

\subsection{REMOTE HANDLED.XLS WORKBOOK}

The original information obtained was included in an Excel workbook developed by Jene Vance [10]. Table 1 lists the data fields reviewed.

Table 1. Remote handled.xls Workbook Data Fields

\begin{tabular}{|l|l|l|}
\hline \multicolumn{1}{|c|}{ Shaft Number } & \multicolumn{1}{c|}{ Package Number } & \multicolumn{1}{c|}{ Grams of Pu-239 } \\
\hline Curies of Pu-239 & Curies Calculated from Dose Rate & Mixed Fission Products (Curies) \\
\hline Measured Dose Rate & Calculated Dose Rate at 1 Meter & Curies of MFP at t=0 \\
\hline Curies of MFP at t=2004 & Power from MFP (watts) & Power from Pu (watts) \\
\hline $\begin{array}{l}\text { 55-Gallon Drum Dose Rate at } \\
\text { Surface (Unshielded) }\end{array}$ & $\begin{array}{l}\text { 55-Gallon Drum Dose Rate at 3 } \\
\text { feet (Unshielded) }\end{array}$ & $\begin{array}{l}\text { 55-Gallon Drum Dose Rate at 10 feet } \\
\text { (Unshielded) }\end{array}$ \\
\hline 55 Gallon Drum Dose Rate at 20 & 55-Gallon Drum Dose Rate at 1 & 55-Gallon Drum Dose Rate at 1 foot \\
\hline
\end{tabular}




\begin{tabular}{|l|l|l|}
\hline feet (Unshielded) & foot (3 inches Shielding) & (4 inches Shielding) \\
\hline $\begin{array}{l}\text { 55-Gallon Drum Dose Rate at } 1 \text { foot } \\
\text { (4 inches Shielding) }\end{array}$ & $\begin{array}{l}\text { 55-Gallon Drum Dose Rate at } 1 \\
\text { feet (inches Shielding) }\end{array}$ & $\begin{array}{l}\text { 55-Gallon Drum Dose Rate at } 1 \text { feet } \\
\text { (6 inches Shielding) }\end{array}$ \\
\hline Canister Dose Rate at 15 feet & Transfer Cask Contact Dose Rate & 72-B Cask Contact Dose Rate \\
\hline
\end{tabular}

Much of this radiological information is needed for safe retrieval and interim storage, however, as mentioned previously, the source of the data could not be verified, and the equations used to determine the calculated numbers were not included in the source documents. This Remote handled.xls data source did not include an evaluation of the tritium torpedoes, therefore, Appendices A-1, B-1, C-1, and D-1 are the only spreadsheets containing the data from Remote handled.xls for the wastes in the 33 lined shafts containing waste cans, the 5 lined shafts containing cell liners, the 16 lined shafts containing canisters, and the 6 unlined shafts, respectively.

\subsection{TRU WASTE DATABASE}

Table 2 lists the data fields queried, exported, and reviewed from the TWDB. They were obtained from the TWDB [5] based on the queries for each shaft number and package ID.

Table 2. TRU Waste Database Data Fields

\begin{tabular}{|l|l|}
\hline \multicolumn{1}{|c|}{ Data Field } & \multicolumn{1}{c|}{ Description } \\
\hline LOC DESC & Description of location where stored \\
\hline PKG_ID & $\begin{array}{l}\text { Uniquely identifies each package of TRU waste. It is a 5 digit barcode label assigned by the } \\
\text { waste generator and provided by the TRU Waste Certification Official. }\end{array}$ \\
\hline BLDG_CD & $\begin{array}{l}\text { Building designation. Will include the technical area and building. May pertain to any or all } \\
\text { of the buildings where the package came from, where it is being held, or where it is stored. } \\
\text { Value will conform to format in Engineering "Structure TA-NUM". A leading (zero) will be } \\
\text { put in front of TA component if TA is single digit. }\end{array}$ \\
\hline GRP & Designation of the LANL group that generated the waste \\
\hline PKG_DATE & Date packaged \\
\hline REC_DATE & Date recorded \\
\hline RCV_DATE & Date received at Area G \\
\hline STORAGE_DATE & Date stored \\
\hline GROSS_WT & Weight of container and waste \\
\hline NET_WT & Weight of waste \\
\hline VOLUME (m $\left.{ }^{3}\right)$ & Package volume for standard packages $\left(\mathrm{m}^{3}\right)$ \\
\hline EPA_CD & Hazardous waste code \\
\hline WASTE DESC & Description of the waste code \\
\hline COMMENTS & General comments to denote special concerns \\
\hline RAD_CD & Isotope or material type \\
\hline GRAMS & Amount of radionuclide in grams \\
\hline PKG_PE-ACT & Total Pu-equivalent curies \\
\hline TOTAL DOSE & Total surface dose rate, mrem/hr \\
\hline
\end{tabular}

Appendices A-2, B-2, C-2, D-2, and E-1 are spreadsheets developed from the data obtained from the TWDB for the 33 lined shafts containing waste cans, the 5 lined shafts containing hot cell liners, the 16 
lined shafts containing canisters, the 6 unlined shafts containing waste cans, and the 5 lined shafts containing tritium torpedoes, respectively.

\subsection{ORIGINAL WASTE DISPOSAL RECORDS}

Facilities that generated TRU waste were required to complete either an RSWD form or a TWSR form. The original waste records were obtained for packages in all shafts, with the exception of one package, S812303, in Shaft 206.

\subsubsection{Radioactive Solid Waste Disposal (RSWD) Forms}

RSWDs [6] were available for the wastes in the 33 lined shafts, the 5 hot cell liner shafts, and the 6 unlined shafts. The use of RSWD forms was initiated in 1971 and discontinued in 1992. The original RSWD and any associated supporting documentation were unavailable However, the first page of the RSWD was on microfiche and copies of the microfiche were obtained and used as original data. No supporting documentation was available for review for this report. Table 3 lists the data fields reviewed and evaluated from the first page of the RSWD.

Table 3. Radioactive Solid Waste Disposal Form Data Fields

\begin{tabular}{|l|l|l|}
\hline \multicolumn{1}{|c|}{ Shaft Number } & Form Number (RSWD Number) & \multicolumn{1}{c|}{ Date (Form Date) } \\
\hline Date Disposed & Group & Technical Area \\
\hline Building and Room & Wing (if applicable) & Gross Weight (units) \\
\hline Net Weight (units) & Waste Description & Additional Comments \\
\hline Hazardous Waste Code & Nuclide & Amount (curies or grams) \\
\hline Method of Measurement & Dose at Contact & Dose at 1 meter \\
\hline
\end{tabular}

Appendices A-3, B-3, and D-3 are spreadsheets documenting the data fields obtained from the original RSWDs for wastes in the 33 lined shafts containing waste cans, the 5 lined shafts containing hot cell liners, and the 6 unlined shafts containing waste cans, respectively.

\subsection{MATERIAL TYPES AND CALCULATIONS}

To compare the isotopic contents reported in the data sources, the masses of isotopes from the original waste records (e.g., RSWDs and TWSRs) were converted into curies. In addition, the masses of different MTs were reported in the original waste documents. Thus, the masses of the MTs were apportioned into masses of individual isotopes based on the definition (i.e., weight percentage) of the MTs. The isotopic weight percentages in Table 5 [12] were used to define the average isotopic content (in weight percentage) of plutonium and uranium material types and enrichments for each MT. The ratios in these tables were calculated under the assumption that no chemical fractionation occurred and, hence, were intended to be used to identify fractionation when it is present by comparing these upper bounds to actual radioassay data [12]. Weapons grade plutonium is typically MT-52. Plutonium from the hot cell debris waste is typically MT-55. MTs listed in the original waste records were assumed to be as follows:

- $\mathrm{U}-21$ was assumed to be a typographical error and should be MT12

- U-25 was assumed to be a typographical error and should be MT35

- U-36 was MT36

- Pu-53 was MT53

- Pu-55 was MT55 
- Pu-56 was MT56

- Pu-57 was MT57.

Table 5. Isotopic Content of Plutonium and Uranium Material Types

\begin{tabular}{|l|l|l|l|l|l|l|l|l|l|l|l|}
\hline $\begin{array}{c}\text { Material } \\
\text { Type } \\
(\mathbf{M T})\end{array}$ & $\mathbf{P u - 2 3 8}$ & $\mathbf{P u}-239$ & $\mathbf{P u}-240$ & $\mathbf{P u}-241$ & $\mathbf{P u}-242$ & $\mathbf{U}-234$ & $\mathbf{U}-235$ & $\mathbf{U}-236$ & U-238 & Am-241 & Cs-137 \\
\hline 51 & 0.006 & 96.77 & 3.13 & 0.076 & 0.018 & 0.001 & 0.1 & 0 & 0 & 0.06 & $4.00 \mathrm{E}-07$ \\
\hline 52 & 0.01 & 93.78 & 6 & 0.2 & 0.02 & 0.002 & 0.1 & 0 & 0 & 0.2 & $4.00 \mathrm{E}-07$ \\
\hline 53 & 0.03 & 91.08 & 8.45 & 0.366 & 0.071 & 0.007 & 0.09 & 0 & 0 & 0.3 & $4.00 \mathrm{E}-07$ \\
\hline 54 & 0.046 & 87.42 & 11.5 & 0.81 & 0.22 & 0.01 & 0.09 & 0 & 0 & 0.7 & $4.00 \mathrm{E}-07$ \\
\hline 55 & 0.06 & 83.88 & 14.73 & 1.03 & 0.304 & 0.02 & 0.09 & 0 & 0 & 0.9 & $4.00 \mathrm{E}-07$ \\
\hline 56 & 0.061 & 81.9 & 16.51 & 1.18 & 0.355 & 0.02 & 0.09 & 0 & 0 & 1 & $4.00 \mathrm{E}-07$ \\
\hline 57 & 0.433 & 74.63 & 20.7 & 2.55 & 1.69 & 0.1 & 0.08 & 0 & 0 & 2 & $4.00 \mathrm{E}-07$ \\
\hline 42 & 0.73 & 1.06 & 6.4 & 1.97 & 89.83 & 0.3 & 0.0009 & 0 & 0 & 3 & $4.00 \mathrm{E}-07$ \\
\hline 83 & 81.2 & 16.3 & 2.3 & 0.12 & 0.13 & 18.2 & 0.012 & 0 & 0 & 0.3 & $4.00 \mathrm{E}-09$ \\
\hline 12 & 0 & 0 & 0 & 0 & 0 & 0.0015 & 0.23 & 0.008 & 99.77 & 0 & 0 \\
\hline 35 & 0 & 0 & 0 & 0 & 0 & 0.36 & 37.6 & 0.14 & 61.9 & 0 & 0 \\
\hline 36 & 0 & 0 & 0 & 0 & 0 & 0.63 & 62.44 & 0.18 & 36.75 & 0 & 0 \\
\hline 38 & 0 & 0 & 0 & 0 & 0 & 1.03 & 93.04 & 0.41 & 5.53 & 0 & 0 \\
\hline 39 & 0 & 0 & 0 & 0 & 0 & 1.32 & 97.52 & 0.17 & 0.99 & 0 & 0 \\
\hline
\end{tabular}

In general, uranium and its isotopes are expected to be present only in trace amounts, if at all, if the feed material did not purposely contain uranium.

The MFP activity distribution was obtained by averaging each isotope's percentage across all the WIPP RH canisters as provided by isotopic information in the TWSRs. Table 6 lists the calculated isotopic fractions.

Table 6. Isotopic Activity Fractions for $1 \mathrm{Ci}$ of Reported MFPs

\begin{tabular}{|c|c|c|}
\hline Isotope & Fraction & Units \\
\hline Ba-137m & 0.2396 & $\mathrm{Ci}$ \\
\hline Cs-137 & 0.2555 & $\mathrm{Ci}$ \\
\hline Eu-155 & 0.0048 & $\mathrm{Ci}$ \\
\hline Pm-147 & 0.0146 & $\mathrm{Ci}$ \\
\hline Rh-106 & 0.0019 & $\mathrm{Ci}$ \\
\hline Ru-106 & 0.0019 & $\mathrm{Ci}$ \\
\hline Sb-125 & 0.0104 & $\mathrm{Ci}$ \\
\hline Sr-90 & 0.2335 & $\mathrm{Ci}$ \\
\hline Te-125m & 0.0043 & $\mathrm{Ci}$ \\
\hline Y-90 & 0.2335 & $\mathrm{Ci}$ \\
\hline
\end{tabular}




\subsection{DECAY AND DOSE CALCULATIONS}

\subsubsection{Decay Calculations}

The final, verified spreadsheet data for wastes in the 33 lined shafts, 5 hot cell liner shafts, 16 canister shafts, 6 unlined shafts, and 5 tritium torpedo shafts were used to perform decay calculations. The initial date used for all calculations was the latest date identified on the original waste forms or the TWDB. The final date used in the decay calculations was 2009.

TransOrigin.xls, Version 1.0, A Pre-Post Processor for the ORIGEN2, Version 2.2 Software [13] was used to perform these calculations. This Microsoft Excel spreadsheet application provides a standard interface to process radionuclide data using the Oak Ridge National Laboratory (ORNL) computer code, ORIGEN2, Version 2.2. This isotope generation and depletion code uses the matrix exponential solution method and was developed and distributed by the Radiation Safety Information Computation Center (RSICC) at ORNL. This software calculated and reported the inventory of radionuclides on a given shaft/package basis decayed to a common base year.

The input data were the verified data from the original waste records or the TWDB if the original waste records were insufficient. The input files contained activities for all plutonium and uranium isotopes listed or partitioned isotopes from the listed MTs. The input files also included the partitioned MFP activities. Output files included all daughter products from decay of the input radionuclides. The software was verified by an independent qualified software developer. Appendix F contains the software quality assurance (QA) documentation [14].

Appendices A-4, B-4, C-4, D-4, and E-3 are spreadsheets listing all of the input and output data for the wastes in the 33 lined shafts, 5 hot cell liner shafts, 16 canister shafts, 6 unlined shafts, and 5 tritium torpedo shafts, respectively.

\subsection{JUSTIFICATION FOR SELECTING THE FINAL DATA TO BE USED}

After the source documents were received and reviewed, the information was entered into spreadsheets and independently verified to assure that no transcription errors occurred. For each shaft configuration, the data from each source document were compared. A determination was made regarding the completeness of the data, the source of the information, and the quality of the data.

\subsubsection{Remote handled.xls Workbook}

The data from the Remote handled.xls workbook included the wastes in the 33 lined shafts, 5 hot cell liner shafts, the 16 canister shafts, and 6 unlined shafts [10]. While the information was nearly complete for the four configurations, calculated values could not be verified as there was no accompanying information documenting the equations used to construct the spreadsheet. Also, there were some packages missing from the 6 unlined shafts. In addition, the shaft numbers for the canisters were not the same as those documented in the TWDB or on the TWSRs (See Appendix C-1). Consequently, it was determined that this data were not used for the final calculations.

\subsubsection{TRU Waste Database}

The information in the TWDB was more complete and correlated, in most cases, with other data sources [5]. This database was a work in progress, and, according to LANL staff, data fields were continuously being added over a period of time. In some cases, the new fields were updated with data from the original records, but in many other cases these new fields were left blank if the original data had been entered previously. Before the early 1990s, the database entries were not verified against the original waste 
records. After the early 1990s, data entry personnel used the double entry verification system for quality control purposes. The TWDB did not always include individual complete radiological information, e.g., the database did not include activity for the MFPs in many cases. Based on this information and evaluation, it was decided that the data in the TWDB would be used as a secondary information source if the information were also available on the original waste records. The TWDB would be used as the primary source if data was missing or illegible on the original records.

\subsubsection{Original Waste Records}

The original waste records included RSWDs for the wastes in the 33 lined shafts, 5 hot cell liner shafts, and the 6 unlined shafts, and TWSRs for the wastes in the 16 canister shafts and the 5 tritium torpedo shafts [6 and 8]. As discussed previously, the RSWD included the first page of the RSWD, but no supplemental backup data. The RSWD listed the estimated mass of U-235 or Pu-239, or both, and, in most cases, the measured activity of the MFPs. The dose rates at the surface and at one meter were also noted in most cases. However, for some RSWDs, certain information is illegible or blank. When the original RSWD data was not available, the TWDB data was used. Table 7 provides the data fields of interest and primary and secondary sources of information used.

Table 7. Final Data Selection and Justification for Lined Shafts, Hot Cell Liners, and Six Unlined Shafts

\begin{tabular}{|c|c|c|c|}
\hline $\begin{array}{c}\text { Information } \\
\text { Field }\end{array}$ & $\begin{array}{c}\text { Primary } \\
\text { Source }\end{array}$ & $\begin{array}{c}\text { Secondary } \\
\text { Source }\end{array}$ & Comments \\
\hline $\begin{array}{l}\text { Shaft number } \\
\text { - and - } \\
\text { Package ID }\end{array}$ & TWDB & RSWD & $\begin{array}{l}\text { TWDB appears to have the most complete list of shafts and correlations to } \\
\text { Package ID number. } \\
\text { Some RSWDs have illegible form numbers and shaft numbers. However, } \\
\text { because portions of these numbers are legible, it is possible to correlate the } \\
\text { RSWD numbers to Package ID numbers from the TWDB. } \\
\text { Assumption: the Package ID numbers in the TWDB are correct. }\end{array}$ \\
\hline $\begin{array}{l}\text { Waste } \\
\text { Generation } \\
\text { Location } \\
\text { (Building, Wing, } \\
\text { and Room) }\end{array}$ & RSWD & TWDB & $\begin{array}{l}\text { RSWD data are most complete. When available, RSWDs provide the } \\
\text { building, and often also provide the wing and room of generation. } \\
\text { TWDB provides some data for the building of waste generation for missing } \\
\text { RSWD. } \\
\text { Assumption: the same building (TA-3, Building SM-29) when no data are } \\
\text { available. }\end{array}$ \\
\hline Group & RSWD & TWDB & $\begin{array}{l}\text { RSWDs and TWDB are combined to provide the most complete data due to } \\
\text { missing or illegible RSWDs. } \\
\text { RSWDs provide data when field is blank in TWDB. }\end{array}$ \\
\hline Date & RSWD & TWDB & $\begin{array}{l}\text { RSWDs provide data for most of the packages. } \\
\text { TWDB provides data when missing in the RSWDs. } \\
\text { Used latest date listed from both sources for decay calculations. } \\
\text { RSWDs include "Date Disposed”, which generally matches TWDB. An } \\
\text { earlier date is also included and is assumed to be the date of RSWD } \\
\text { preparation and waste packaging. } \\
\text { Some RSWDs also include another date written in lower margin. It is } \\
\text { unclear to what this additional date refers to; so, it was not considered. }\end{array}$ \\
\hline Gross weight & RSWD & TWDB & $\begin{array}{l}\text { RSWDs provide the most complete data, including units. } \\
\text { TWDB provides data if RSWD data are missing or illegible. } \\
\text { TWDB does not indicate units: therefore it is assumed the data are given in } \\
\text { pounds. This assumption is based on the correlation between data in an } \\
\text { RSWD and TWDB when provided by both. }\end{array}$ \\
\hline Gross volume & RSWD & TWDB & $\begin{array}{l}\text { RSWDs provide the most complete data, including units. } \\
\text { TWDB provides data if RSWD data are missing or illegible. }\end{array}$ \\
\hline $\begin{array}{l}\text { Number and } \\
\text { Type of Waste } \\
\text { Containers }\end{array}$ & RSWD & NA & $\begin{array}{l}\text { RSWDs provide the most complete data. } \\
\text { TWDB does not provide data. }\end{array}$ \\
\hline
\end{tabular}




\begin{tabular}{|l|l|l|l|}
\hline $\begin{array}{l}\text { Information } \\
\text { Field }\end{array}$ & $\begin{array}{c}\text { Primary } \\
\text { Source }\end{array}$ & $\begin{array}{l}\text { Secondary } \\
\text { Source }\end{array}$ & \multicolumn{1}{c|}{ Comments } \\
\hline $\begin{array}{l}\text { Waste } \\
\text { Description }\end{array}$ & $\begin{array}{l}\text { RSWD } \\
\text { TWDB }\end{array}$ & NA & $\begin{array}{l}\text { Used all data from RSWDs and TWDB, which included waste descriptions, } \\
\text { comments, and waste codes. Waste codes are LANL-specific and are } \\
\text { different from hazardous waste numbers. } \\
\text { A field for EPA hazardous waste numbers was provided in the TWDB, but } \\
\text { was blank for all Package IDs, except one. Therefore, it was not used. }\end{array}$ \\
\hline $\begin{array}{l}\text { Radiological } \\
\text { Information } \\
\text { curie, method of } \\
\text { measurement) }\end{array}$ & RSWD & TWDB & $\begin{array}{l}\text { RSWD provides the most complete data, which includes estimated Pu-239 } \\
\text { and U-235 mass in grams and measured activity of MFPs in Ci. } \\
\text { TWDB provides data if RSWD data are missing or illegible. } \\
\text { TWDB does not provide data for MFP. } \\
\text { Some RSWDs list MT instead of isotopes. This information was used to } \\
\text { calculate isotopic distribution and curies for MT. }\end{array}$ \\
\hline $\begin{array}{l}\text { Dose Rate } \\
\text { contact and 1- } \\
\text { meter) }\end{array}$ & RSWD & TWDB & $\begin{array}{l}\text { RSWDs provide the most complete data, which includes a contact and 1- } \\
\text { meter dose rate reading for nearly all waste items. Dose rate information is } \\
\text { often included in the 'Comments' field. } \\
\text { TWDB provides data if RSWD data are missing or illegible. }\end{array}$ \\
\hline
\end{tabular}

The TWSRs had the most complete data of all data sources. TWSRs were available for the 16 canisters and the 5 tritium torpedoes. The TWSR data were entered into the TWDB and verified by a second data entry staff member, which was documented on the TWSR form. Supplemental backup information was attached to the TWSR form, and provided additional descriptions regarding contents of the canisters or the torpedoes. Specific radioisotope activities, including individual MFP isotopes, were listed. Table 8 provides the data fields of interest and the primary and secondary sources of information used.

Table 8. Final Data Selection and Justification for Canisters and Tritium Torpedoes

\begin{tabular}{|c|c|c|c|}
\hline $\begin{array}{l}\text { Information } \\
\text { Field }\end{array}$ & $\begin{array}{l}\text { Primary } \\
\text { Source }\end{array}$ & $\begin{array}{l}\text { Secondary } \\
\text { Source }\end{array}$ & Comments \\
\hline $\begin{array}{l}\text { Shaft number } \\
\text { - and - } \\
\text { Waste Package } \\
\text { Serial Number }\end{array}$ & TWSR & TWDB & $\begin{array}{l}\text { TWSR and the TWDB appear to have equally complete list of shafts and } \\
\text { correlations to Package ID number. TWSR did not include shaft number, } \\
\text { but did have package number, which was correlated with the data in the } \\
\text { TWDB. } \\
\text { TWSR and TWDB information agreed. }\end{array}$ \\
\hline $\begin{array}{l}\text { Generating } \\
\text { location } \\
\text { (Building, } \\
\text { Wing, and } \\
\text { Room) }\end{array}$ & TWSR & TWDB & $\begin{array}{l}\text { TWSR data are most complete and provide the building, and often also } \\
\text { provide the wing and room of generation. } \\
\text { TWDB provides some data for building. }\end{array}$ \\
\hline Group & TWSR & TWDB & TWSR provides the most complete data. \\
\hline Date & TWSR & TWDB & $\begin{array}{l}\text { TWSR provides most complete data. } \\
\text { Used latest date listed from both sources, which provides conservative } \\
\text { approach for decay calculations. }\end{array}$ \\
\hline Gross weight & TWSR & TWDB & $\begin{array}{l}\text { TWSR provides the most complete data, including units. } \\
\text { Used TWDB if TWSR data are missing or illegible. } \\
\text { TWDB does not indicate units. } \\
\text { Assumption: the data are given in pounds. This assumption is based on } \\
\text { the correlation between data in the TWSR and TWDB when provided by } \\
\text { both. }\end{array}$ \\
\hline Gross volume & TWSR & TWDB & $\begin{array}{l}\text { TWSR provides the most complete data, including units. } \\
\text { TWDB provides data if TWSR data are missing or illegible. }\end{array}$ \\
\hline $\begin{array}{l}\text { Number and } \\
\text { Type of Waste } \\
\text { Containers }\end{array}$ & TWSR & NA & $\begin{array}{l}\text { TWSR provides the most complete data. } \\
\text { TWDB does not provide data. }\end{array}$ \\
\hline
\end{tabular}




\begin{tabular}{|l|l|l|l|}
\hline \multicolumn{1}{|c|}{$\begin{array}{c}\text { Information } \\
\text { Field }\end{array}$} & \multicolumn{1}{|c|}{$\begin{array}{c}\text { Primary } \\
\text { Source }\end{array}$} & $\begin{array}{c}\text { Secondary } \\
\text { Source }\end{array}$ & \multicolumn{1}{c|}{ Comments } \\
\hline $\begin{array}{l}\text { Waste } \\
\text { Description }\end{array}$ & TWSR & TWDB & $\begin{array}{l}\text { Used all data from TWSR and TWDB, which included waste } \\
\text { descriptions, comments, and non-radioactive hazardous materials. } \\
\text { A field for EPA hazardous waste numbers was provided in the TWDB, } \\
\text { but was blank for all Package IDs. Therefore, it was not used. }\end{array}$ \\
\hline $\begin{array}{l}\text { Radiological } \\
\text { Information } \\
\text { (nuclide, mass, } \\
\text { curie, method of } \\
\text { measurement) }\end{array}$ & TWSR & TWDB & $\begin{array}{l}\text { TWSR provides the most complete data. This includes Pu-239, U-235, } \\
\text { and a listing of MFPs in Ci. } \\
\text { TWDB does not provide data for MFP. }\end{array}$ \\
\hline $\begin{array}{l}\text { Dose Rate } \\
\text { contact and 1- } \\
\text { meter) }\end{array}$ & TWSR & TWDB & $\begin{array}{l}\text { TWSR provides the most complete data, which includes total dose rate } \\
\text { and gamma and neutron dose rates. Contamination information is also } \\
\text { included. } \\
\text { TWDB provides data if TWSR data are missing or illegible. }\end{array}$ \\
\hline
\end{tabular}

\subsection{RADIOLOGICAL AND CHEMICAL DATA}

As discussed in Section 5.6, the data in the original waste records (RSWDs for the 33 lined shafts, 5 hot cell liners, and 6 unlined shafts, and TWSRs for the 16 canisters and the 5 tritium torpedoes) were the most complete and were used to calculate the MFPs and the MT activities and to perform the decay calculations. In the absence of data or if the original waste record data were illegible, the data from the TWDB were used. In all cases, these two sources of information provided sufficient radiological data to perform the calculations. LANL began using Item Description Codes (IDCs) and Waste Profile Forms (WPF) in 1990. In 1992, IDCs were discontinued. The following sections discuss each shaft storage configuration and the radiological and chemical data results.

\subsection{LINED SHAFTS}

Radiological and chemical information was reviewed for each waste package in each of the 33 lined shafts. Appendix A contains four sets of spreadsheets: A-1 is the data from the Remote handled.xls workbook, A-2 is the data from the TWDB, A-3 is the data from the RSWDs, and A-4 is the final activity and dose rate used and the results of the decay calculations. Table 9 lists the minimum and maximum $\mathrm{Pu}-$ 239, Pu-241, and U-235 activity and initial and decayed surface dose rates in all of the 33 lined shafts and tentatively identified hazardous waste codes. The hazardous waste codes were tentatively identified based on reviewed source documents [4].

Table 9. Summary Data for the Waste in the 33 Lined Shafts

\begin{tabular}{|l|l|l|l|}
\hline \multicolumn{1}{|c|}{ Item } & \multicolumn{1}{|c|}{ Units } & \multicolumn{1}{c|}{ Minimum } & \multicolumn{1}{c|}{ Maximum } \\
\hline Pu-239 & Curies & $2.48 \mathrm{E}-03$ & $1.24 \mathrm{E}+01$ \\
\hline U-235 & Curies & $2.0 \mathrm{E}-07$ & $8.14 \mathrm{E}-04$ \\
\hline Pu-241 & Curies & $1.83 \mathrm{E}-02$ & $8.10 \mathrm{E}+01$ \\
\hline Dose rate (surface) initial & $\mathrm{mrem} / \mathrm{hr}$ & 10 & $1,200,000$ \\
\hline Dose rate (surface) decayed & $\mathrm{mrem} / \mathrm{hr}$ & 10 & $1,029,000$ \\
\hline \multirow{2}{*}{ Chemical codes } & \multicolumn{2}{|c|}{ Hazardous Waste Codes } & Constituents \\
\cline { 2 - 4 } & D008 & Lead \\
\cline { 2 - 4 } & $\begin{array}{l}\text { F001, F002, F003, F004, F005 } \\
\text { (possible pending AK investigation) }\end{array}$ & $\begin{array}{l}\text { Organic } \\
\text { solvents }\end{array}$ \\
\hline
\end{tabular}


The tables in the appendices reflect the data considered to be the most critical for the decay calculations and safe retrieval and interim storage. Many other data points were reviewed but were not included in this report. Appendix G-1 lists the data fields that were included in the original source documents, but not included in the appendices for the 33 lined shafts.

\subsection{GAP ANALYSIS}

The RH-TRU WCPIP [21] is a programmatic document that specifies how RH-TRU waste characterization will be implemented at sites that generate and/or store RH-TRU wastes and provides quality assurance objectives (QAOs) for certification purposes.

All sites are required to collect, review, and document AK information for their TRU waste characterization program. The result of the AK process is an auditable record and an AK summary report.

The information required for safe retrieval and interim storage operations includes physical, radiological, and chemical data for the shafts and the waste contained in the shafts. However, it does not require that the WIPP RH-TRU waste characterization QAOs be met. The information gathered, reviewed, and documented in this report can be used as supplemental AK source documentation and is not intended to meet the requirements of the WCPIP [21]. However, this report and the reference documents will be placed in the Nuclear Waste and Infrastructure Services, TRU Programs (NWIS-TP) records center. The following sections discuss the data gaps for each of the five waste storage configurations.

\subsection{LINED SHAFTS}

The lined shaft configuration is one of two configurations that pose the most challenges for safe retrieval and interim storage. This storage configuration and the unlined shafts have the least reliable data reviewed at this time.

The RSWDs for the wastes in the lined shafts are incomplete and sometimes illegible. Only the first page of the RSWD form was available from microfiche. The data used in this report were usually a combination of the TWDB and the RSWD information. There was no RSWD for item number S812303. Questions regarding the dose rates remain, as the dose rate was sometimes written in the waste description box and the units not always clearly identified. Most references described the lined shafts as containing one- or two-gallon cans; however, data from the TWDB and the RSWDs state that there are larger items weighing 880 pounds, 2.3 tons, or 8 tons, which is inconsistent with the waste descriptions. A reactor vessel inside a cask, weighing approximately 8 tons was emplaced in shaft 212. That shaft has a larger diameter in order to fit the reactor vessel in it, and is most likely, not TRU waste. Discussions with CMR personnel also indicated that the large weights listed on the RSWDs do not reflect the actual weight of the items placed in the shafts.

Due to the configuration of the shafts and the waste emplaced in them, it is expected that the integrity of at least some of the cans is breached and there may be potential contamination either from breached cans or from surrounding shafts. Additional concerns are the potential for flammable gases inside the shafts, the integrity of the shafts, and surface contamination of the cans.

\subsection{RECOMMENDATIONS}

Based on the discussion throughout this report, the following recommendations are suggested:

- Originally, it was thought that retrieval the original RSWDs and supporting documentation for the 33 lined shafts and 6 unlined shafts from off-site storage for further evaluation was possible. It 
was later learned that there is no record of the RSWDs being sent to storage. Therefore, the forms used for this report are all that is available at this time and no further recommendation is made.

- Conduct interviews with personnel knowledgeable about the physical form of the waste, chemical constituents, packaging, radiological data, and dose rates, for the 33 lined shafts, 6 unlined shafts, and the hot cell liner shafts.

- Calculate estimated gas generation rates based on the waste form and the radionuclides known to be present

- Prepare a field characterization plan for the 33 lined shafts, 5 hot cell liner shafts, and 6 unlined shafts. Include surface dose rate determinations, swipes for surface contamination, flammable gas determinations, and physical status using visual examination of the shafts and containers inside the shafts

- Prepare a field characterization plan for the 16 canisters. Include surface dose rate determinations, swipes for surface contamination, flammable gas determinations, and physical status of the shafts and the canisters inside the shafts

- Assess historical engineering documentation for the tritium torpedo packaging configuration

- Calculate radiolysis calculations to estimate maximum pressure due to tritium radiolysis of any entrained water

- Assess molecular sieve design criteria and calculate the capacity

- Conduct interviews with cognizant personnel to determine if getters were placed in the waste containers

- Prepare a field characterization plan for the tritium torpedo shafts. Include surface contamination, flammable gas determinations, and physical status of the shafts and containers inside the shafts

\subsection{REFERENCES}

1. “Laboratory Organization,” Los Alamos National Laboratory, http://www.lanl.gov/organization/

2. “The Los Alamos Plutonium Facility: A World Class Model,” Dateline: Los Alamos, NovemberDecember, 1996.

3. "Chemistry and Metallurgy Research Building," Los Alamos National Laboratory Public Affairs Office, April 2004.

4. Draft Feasibility Study for the Retrieval of Remote-Handled Transuranic Waste at Los Alamos National Laboratory, prepared for Los Alamos National Laboratory by IT Corporation, Boissiere Engineering and Applied Robotics, Inc., and Roy F. Weston, Inc., September 1997.

5. TRU Waste Management Database. Los Alamos National Laboratory.

6. Radioactive Solid Waste Disposal (RSWDs), Form HS 10-2A (12/89) (33 lined shafts and hot cell liners).

7. CCP Acceptable Knowledge Summary Report for RH TRU Debris Waste Packaged from January 31, 1986 to June 5, 1991, Revision 0, Draft A, Los Alamos National Laboratory, Los Alamos, NM, 2003. 
8. TRU Waste Storage Records, Form 1562 (tritium torpedoes and canisters).

9. R.E. Wieneke (NMT-2, LANL) Memorandum to D.P. Taggert (EM-7, LANL), "Packaging Agreement for Tritium Contaminated Transuranic Waste from TA-55,” August 23, 1993.

10. Jene Vance, Vance and Associates, Excel spreadsheet.

11. 10 CFR 71, Packaging and Transportation of Radioactive Material, Appendix A, Table A-1, "A1 and A2 Values for Radionuclides.”

12. Central Characterization Project, Los Alamos National Laboratory Pu-239 Contaminated Mixed Heterogeneous Debris, CCP-AK-LANL-006, Revision 2, Carlsbad, NM.

13. TransOrigen.xls, Version 1.0, a Pre-Post-Processor for the ORIGEN2, Version 2.2 Software, An Excel Spreadsheet Application, prepared by Weston Solutions, Inc. for Los Alamos National Laboratory.

14. Weston Solutions, Inc., Calculation Report, TransOrigen.xls, Version 1.0, a Pre-Post-Processor for the ORIGEN2, Version 2.2 Software, An Excel Spreadsheet Application, Version 1.00, prepared for Los Alamos National Laboratory, September 30, 2005.

15. VECTRA Technologies, Inc. Safety Analysis Report for the RH-TRU 72-B Waste Shipping Package, San Jose, California, 1999.

16. R. Villarreal, L. Field, L. Bustos, W. Sandoval, K. Hollis (LANL), and S. Djordjevic (DJINDECO Consulting), Headspace Gas Sampling of Remote-Handled Transuranic Waste Containers at Los Alamos National Laboratory Fiscal Year 2000 Year-End Status Report, Los Alamos National Laboratory, September 2000.

17. CCP Remote-Handled TRU Waste Certification Plan, CCP-PO-020, Revision 0, Draft B, September xx, 2003.

18. CCP Qualification of Acceptable Knowledge for RH TRU Waste through a Quality Assurance Equivalency Demonstration, CCP-QP-036, Revision 0, Draft A, xx/xx/2003.

19. CCP Los Alamos National Laboratory Quality Assurance Equivalency Summary Report and QAPD Matrix for Remote-Handled TRU Debris Waste, CCP-AK-LANL-003, Revision 0, October xx, 2003.

20. Radiological Characterization of LANL RH TRU Waste Packaged in 16 WIPP Canisters, CCP-AKLANL-002, Revision 0, xx/xx/03.

21. DOE, Remote-Handled TRU Waste Characterization Program Implementation Plan, DOE/WIPP-023214, Revision 0D (Subject to Approval), Carlsbad Field Office, October 30, 2003. 


\section{Appendix A-1 - Information from "RemoteHandled.xls” Workbook for Lined Shafts}

\begin{tabular}{|c|c|c|c|c|c|c|c|c|c|c|c|}
\hline $\begin{array}{c}\text { Shaft } \\
\text { Number }\end{array}$ & $\begin{array}{l}\text { RSWD } \\
\text { Number }\end{array}$ & $\begin{array}{c}\text { Date } \\
\text { Placed }\end{array}$ & Waste Description & $\begin{array}{c}\text { Grams } \\
\text { of } \\
\text { Pu-239 }\end{array}$ & $\begin{array}{c}\text { Grams } \\
\text { of } \\
\text { U-235 }\end{array}$ & $\begin{array}{l}\text { MFP } \\
\text { (Ci)* }\end{array}$ & $\begin{array}{c}\text { Decayed } \\
\text { MFP } \\
\text { (Ci)* }\end{array}$ & $\begin{array}{c}\text { Curies } \\
\text { of } \\
\text { Pu-239 }\end{array}$ & $\begin{array}{c}\text { Curies } \\
\text { of } \\
\text { U-235 } \\
\end{array}$ & $\begin{array}{c}\text { Contact } \\
\text { Dose } \\
\text { Rate } \\
\text { (R/hr) } \\
\end{array}$ & $\begin{array}{c}1 \\
\text { Meter } \\
\text { Dose } \\
\text { Rate } \\
(\mathrm{R} / \mathrm{hr})\end{array}$ \\
\hline 200 & 811387 & $4 / 14 / 1981$ & Fuel cans \#3021 \& 3008 & 20.2 & 8.1 & 2.5 & 1.5 & 1.24 & $1.73 \mathrm{E}-05$ & 140 & 2.5 \\
\hline 200 & 811390 & 4/14/1981 & Fuel cans \#3010 \& 3016 & 10 & 38.0 & 6 & 3.5 & 0.615 & 8.14E-05 & 800 & 6 \\
\hline 200 & 811396 & 4/14/1981 & $\begin{array}{l}\text { Plastic cans \#3061 \& 3053, Grinding papers, } \\
\text { Kimwipes, plastic }\end{array}$ & 0.1 & 0.4 & 0.6 & 0.3 & 0.00614 & 8.56E-07 & 60 & 0.6 \\
\hline 200 & 811398 & $4 / 14 / 1981$ & Cans \#3051 \& 3052, Catch \& drain pans, Kimwipes & 4 & 16.0 & 0.6 & 0.3 & 0.246 & $3.42 \mathrm{E}-05$ & 120 & 0.6 \\
\hline 200 & 811471 & $4 / 14 / 1981$ & Trash cans \#2864 \& 2846 & 12.5 & 21.5 & 2.7 & 1.6 & 0.768 & 4.60E-05 & 700 & 9 \\
\hline 200 & 811473 & $4 / 14 / 1981$ & Trash fuel cans \#2877 \& 2863 & 5 & 49.0 & 20 & 11.6 & 0.307 & 1.05E-04 & 1150 & 20 \\
\hline 201 & 791484 & 6/29/1979 & One fuel can \#2171, Tin can in plastic container & 3 & 1.0 & 4 & 2.2 & 0.184 & $2.16 \mathrm{E}-06$ & 17.5 & 4 \\
\hline 201 & 794215 & $6 / 29 / 1979$ & Trash and Fuel cans \#1854 \& 1851 & 0.5 & 2.0 & 11 & 6.1 & 0.0307 & 4.28E-06 & 266 & 11 \\
\hline 201 & 794216 & $6 / 29 / 1979$ & Fuel and trash cans \#1798 \& 1953, cans in plastic bags & 2.25 & 9.0 & 8.5 & 4.7 & 0.138 & 1.93E-05 & 261 & 85 \\
\hline 201 & 794218 & $6 / 29 / 1979$ & $\begin{array}{l}\text { Fuel cans \#2002 \& 2003, tin cans in plastic cans in } \\
\text { plastic bags }\end{array}$ & 2.5 & 10.0 & 1 & 0.6 & 0.154 & 2.15E-05 & 15 & 1 \\
\hline 201 & 794219 & $6 / 29 / 1979$ & $\begin{array}{l}\text { Cans \#2004 \& 1992, Fuel \& trash can, tin cans in } \\
\text { plastic cans in plastic bags }\end{array}$ & 1.5 & 5.0 & 1.3 & 0.7 & 0.0921 & 1.07E-04 & 27 & 1.3 \\
\hline 201 & 794220 & $6 / 29 / 1979$ & Cans $1 \& 4 \mathrm{~A}$, hot trash Met samples & 68 & 147.0 & 30 & 16.7 & 4.18 & 3.15E-04 & 1200 & 30 \\
\hline 201 & 794221 & $6 / 29 / 1979$ & Fuel samples, cans $2 \& 3 \mathrm{~A}$ & 141 & 370.0 & 35 & 19.5 & 8.66 & 7.92E-04 & 1050 & 35 \\
\hline 202 & 803548 & & Hot cell waste CMB1 \& CMB14 & 65.4 & 223.0 & 245 & 21.2 & 4.01 & 4.77E-04 & & \\
\hline 203 & 803547 & & Hot cell waste CMB1 \& CMB14 & 37.5 & 127.0 & 109 & 9.5 & 2.3 & 2.72E-04 & & \\
\hline 204 & 791472 & 6/29/1979 & Trash and Fuel cans \#2127 \& 2150 & 1.75 & 5.3 & 10.5 & 5.9 & 0.108 & $1.12 \mathrm{E}-05$ & 108 & 10.5 \\
\hline 204 & 791478 & 6/29/1979 & Hot trash cans \#2015 \& 2117 & 35 & 121.0 & 0 & 0.0 & 2.15 & 2.59E-04 & 1000 & 140 \\
\hline 204 & 791483 & $6 / 29 / 1979$ & Fuel cans \#2095 \& 2167, tin cans in plastic cans & 1.5 & 4.5 & 15 & 8.4 & 0.0921 & 9.63E-06 & 50 & 15 \\
\hline 204 & 794222 & $6 / 29 / 1979$ & Fuel cans \#1790 \& 1815 & 4.75 & 19.0 & 0 & 0.0 & 0.292 & 4.07E-05 & & 100 \\
\hline 204 & 794223 & $6 / 29 / 1979$ & Trash in 1-gal cans \#1786,1813 in plastic bag & 16.5 & 43.8 & 20 & 11.2 & 1.01 & 9.73E-05 & & 20.4 \\
\hline 205 & 801483 & $12 / 1 / 1980$ & Trash cans \#2875 \& 2926 & 0.1 & 0.1 & 135 & 77.9 & 0.0614 & 2.14E-06 & 1000 & 135 \\
\hline 205 & 801485 & $12 / 1 / 1980$ & Trash cans \#2928 \& 2930 & 25 & 95.0 & 170 & 98.0 & 1.54 & 2.03E-04 & 1000 & 170 \\
\hline 205 & 802244 & $12 / 1 / 1980$ & Fuel trash cans \#2574 \& 2577 & 0.5 & 20.0 & 4.1 & 2.4 & 0.0307 & $4.28 \mathrm{E}-05$ & 160 & 41 \\
\hline 205 & 802246 & $12 / 1 / 1980$ & Fuel trash cans \#2604 \& 2584 & 17.5 & 70.0 & 14 & 8.1 & 1.08 & $1.50 \mathrm{E}-04$ & 1000 & 14 \\
\hline 205 & 802247 & $12 / 1 / 1980$ & Fuel trash cans \#2603 \& 2602 & 5 & 21.0 & 12 & 6.9 & 0.307 & 4.49E-05 & 615 & 12 \\
\hline 205 & 802259 & $12 / 1 / 1980$ & Cans \#2642, 2669, Cell waste & 12 & 39.0 & 35 & 20.2 & 0.737 & 8.35E-05 & 1000 & 35 \\
\hline 205 & 802287 & $12 / 1 / 1980$ & Cans \#2785 \& 2646, Hot trash & 57 & 236.0 & 520 & 299.9 & 3.5 & 5.05E-05 & 1000 & 520 \\
\hline 206 & 812291 & $4 / 1 / 1981$ & Cans \#2805 \& 2806, 15 Met samples & 123 & 321.0 & 40 & 23.2 & 7.55 & $6.87 \mathrm{E}-04$ & 1000 & 40 \\
\hline
\end{tabular}


Appendix A-1 - Information from "RemoteHandled.xls” Workbook for Lined Shafts

\begin{tabular}{|c|c|c|c|c|c|c|c|c|c|c|c|}
\hline $\begin{array}{l}\text { Shaft } \\
\text { Number }\end{array}$ & $\begin{array}{l}\text { RSWD } \\
\text { Number }\end{array}$ & $\begin{array}{c}\text { Date } \\
\text { Placed }\end{array}$ & Waste Description & $\begin{array}{c}\text { Grams } \\
\text { of } \\
\text { Pu-239 } \\
\end{array}$ & $\begin{array}{c}\text { Grams } \\
\text { of } \\
\mathrm{U}-235 \\
\end{array}$ & $\begin{array}{l}\text { MFP } \\
(\mathbf{C i})^{*}\end{array}$ & $\begin{array}{c}\text { Decayed } \\
\text { MFP } \\
(\mathrm{Ci})^{*} \\
\end{array}$ & $\begin{array}{c}\text { Curies } \\
\text { of } \\
\text { Pu-239 } \\
\end{array}$ & $\begin{array}{c}\text { Curies } \\
\text { of } \\
\mathrm{U}-235 \\
\end{array}$ & $\begin{array}{c}\text { Contact } \\
\text { Dose } \\
\text { Rate } \\
\text { (R/hr) } \\
\end{array}$ & $\begin{array}{c}1 \\
\text { Meter } \\
\text { Dose } \\
\text { Rate } \\
\text { (R/hr) } \\
\end{array}$ \\
\hline 206 & 812292 & $4 / 1 / 1981$ & Cans \#2801 \& 2804, 15 Met samples & 100 & 269.0 & 22 & 12.8 & 6.14 & $5.76 \mathrm{E}-04$ & 1000 & 22 \\
\hline 206 & 812293 & $4 / 1 / 1981$ & Waste cans \#2454 \& 2812 & 7 & 28.0 & 108 & 62.8 & 0.431 & $6.00 \mathrm{E}-05$ & 1050 & 108 \\
\hline 206 & 812297 & $4 / 1 / 1981$ & Cans \# 2829 \& 2807, Trash \& fuel & 22 & 86.0 & 100 & 58.1 & 1.35 & $1.84 \mathrm{E}-04$ & 1000 & 100 \\
\hline 206 & 812298 & $4 / 1 / 1981$ & Cans \#2826 \& 2827,Trash and Fuel & 22 & 86.0 & 100 & 58.1 & 1.35 & $1.84 \mathrm{E}-04$ & 1000 & 100 \\
\hline 206 & 812302 & $4 / 1 / 1981$ & Hot trash cans \#2883 \& 2865 & 8 & 23.0 & 8.2 & 4.8 & 0.491 & 4.92E-05 & 1010 & 82 \\
\hline 206 & 812303 & $4 / 1 / 1981$ & & & & 8.2 & 4.8 & 0.491 & 4.92E-05 & & \\
\hline 207 & 811397 & $5 / 29 / 1981$ & $\begin{array}{l}\text { Plastic cans \#3069 \& 3055, Grinding papers, } \\
\text { Kimwipes, plastic }\end{array}$ & 0.1 & 0.4 & 2 & 1.2 & 0.00614 & 8.56E-07 & 60 & 2 \\
\hline 207 & 811400 & $5 / 29 / 1981$ & Cans \#3046 \& 3060, Glass, Paper, etc & 0.1 & 0.4 & 3.5 & 2.0 & 0.00614 & 8.56E-07 & 290 & 3.5 \\
\hline 207 & 811401 & $5 / 29 / 1981$ & Cans \#3065 \& 3067, Fuel, plastic bottles & 1.06 & 4.2 & 5.15 & 3.0 & 0.0651 & 9.07E-06 & 170 & 5.15 \\
\hline 207 & 811406 & $5 / 29 / 1981$ & $\begin{array}{l}\text { Plastic cans \#3103 \& 3101, Grinding papers, } \\
\text { Kimwipes, plastic }\end{array}$ & 0.1 & 0.4 & 2.5 & 1.5 & 0.00614 & 8.56E-07 & 150 & 2.5 \\
\hline 207 & 814978 & $5 / 29 / 1981$ & Wipes, polishing cloth, plastic, cans\#3104,3097 & 0.06 & 0.2 & 0.18 & 0.1 & 0.00368 & 5.14E-07 & 3.6 & 0.18 \\
\hline 208 & 810794 & $6 / 22 / 1981$ & Fuel trash cans \#3123, 3126 & 28.5 & 101.0 & 100 & 58.4 & 1.75 & 2.17E-04 & 1000 & 100 \\
\hline 208 & 810802 & $6 / 22 / 1981$ & Can \#3119, Hot trash & 0.1 & 0.4 & 0.06 & 0.0 & 0.00614 & 8.56E-07 & 1 & 0.06 \\
\hline 208 & 811405 & $6 / 22 / 1981$ & $\begin{array}{l}\text { Plastic cans \#3096 \& 3102, Catch pans, grinding paper, } \\
\text { towels }\end{array}$ & 0.5 & 2.0 & 2 & 1.2 & 0.0307 & 4.28E-06 & 80 & 2 \\
\hline 208 & 811408 & $6 / 22 / 1981$ & Can \#3093, Wipes, polishing cloth, plastics & 0.1 & 0.4 & 0.08 & 0.0 & 0.00614 & 8.56E-07 & 1.5 & 0.08 \\
\hline 208 & 811409 & $6 / 22 / 1981$ & $\begin{array}{l}\text { Plastic cans \#3092 \& 3110, Catch pans, fuel, grinding } \\
\text { papers }\end{array}$ & 0.1 & 0.4 & 2.1 & 1.2 & 0.00614 & 8.56E-07 & 32 & 2.1 \\
\hline 208 & 811411 & $6 / 22 / 1981$ & $\begin{array}{l}\text { Plastic cans \#3094 \& 3116, Grinding papers, plastic, } \\
\text { towels }\end{array}$ & 0.1 & 0.4 & 1 & 0.6 & 0.00614 & 8.56E-07 & 29 & 1 \\
\hline 208 & 814979 & $6 / 22 / 1981$ & Wipes, polishing cloth, plastic, cans\#3100,3109 & 0.04 & 0.2 & 0.12 & 0.1 & 0.00246 & 3.42E-07 & 2.4 & 0.12 \\
\hline 209 & 810795 & $6 / 22 / 1981$ & $\begin{array}{l}\text { Plastic cans \#3098, 3131, Trash, Plastic, paint, } \\
\text { vermiculite }\end{array}$ & 0.1 & 0.4 & 1 & 0.6 & 0.00614 & 8.56E-07 & 15 & 1 \\
\hline 209 & 810797 & $6 / 22 / 1981$ & Plastic cans \#3118, 3129, Trash, wipes, chips, plastic & 0.1 & 0.4 & 0.4 & 0.2 & 0.00614 & 8.56E-07 & 2.8 & 0.4 \\
\hline 209 & 810798 & $6 / 22 / 1981$ & $\begin{array}{l}\text { Plastic cans \#3111, 3114, Vermiculite, wipes, plastic, } \\
\text { paint }\end{array}$ & 0.1 & 0.4 & 0.2 & 0.1 & 0.00613 & 8.56E-07 & 1.6 & 0.2 \\
\hline 209 & 810799 & $6 / 22 / 1981$ & Trash cans \#2125, 3108, 3117, 3130 & 0.1 & 0.4 & 0.3 & 0.2 & 0.00614 & 8.56E-07 & 5 & 0.3 \\
\hline 209 & 811412 & $6 / 22 / 1981$ & $\begin{array}{l}\text { Plastic cans \#3091 \& 3115, Grinding paper, plastic, } \\
\text { glass }\end{array}$ & 0.1 & 0.4 & 2 & 1.2 & 0.00614 & 8.56E-07 & 90 & 2 \\
\hline 210 & 810800 & $6 / 22 / 1981$ & Cans \#3145, 3147, Hot trash & 0.1 & 0.4 & 0.4 & 0.2 & 0.00614 & $8.56 \mathrm{E}-07$ & 10 & 0.4 \\
\hline 210 & 810804 & $6 / 22 / 1981$ & Cans \#3139, 3133, 3135, 3132, Hot trash & 0.1 & 0.4 & 0.2 & 0.1 & 0.00614 & 8.56E-07 & 4 & 0.2 \\
\hline
\end{tabular}


Appendix A-1 - Information from "RemoteHandled.xls" Workbook for Lined Shafts

\begin{tabular}{|c|c|c|c|c|c|c|c|c|c|c|c|}
\hline $\begin{array}{c}\text { Shaft } \\
\text { Number }\end{array}$ & $\begin{array}{l}\text { RSWD } \\
\text { Number } \\
\end{array}$ & $\begin{array}{c}\text { Date } \\
\text { Placed } \\
\end{array}$ & Waste Description & $\begin{array}{c}\text { Grams } \\
\text { of } \\
\text { Pu-239 } \\
\end{array}$ & $\begin{array}{c}\text { Grams } \\
\text { of } \\
\text { U-235 } \\
\end{array}$ & $\begin{array}{l}\text { MFP } \\
(\mathbf{C i})^{*}\end{array}$ & $\begin{array}{c}\text { Decayed } \\
\text { MFP } \\
\text { (Ci)* } \\
\end{array}$ & $\begin{array}{c}\text { Curies } \\
\text { of } \\
\text { Pu-239 } \\
\end{array}$ & 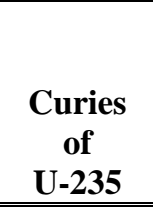 & $\begin{array}{c}\text { Contact } \\
\text { Dose } \\
\text { Rate } \\
\text { (R/hr) } \\
\end{array}$ & $\begin{array}{c}1 \\
\text { Meter } \\
\text { Dose } \\
\text { Rate } \\
\text { (R/hr) } \\
\end{array}$ \\
\hline 210 & 810805 & $6 / 22 / 1981$ & Cans \#3143, 3146, 2969, 3151, hot trash & 0.1 & 0.4 & 0.3 & 0.2 & 0.00614 & 8.56E-07 & 5 & 0.3 \\
\hline 210 & 810806 & $6 / 22 / 1981$ & Cans \#3150 \& 3153, hot trash cans & 0.1 & 0.4 & 0.02 & 0.0 & 0.00614 & $8.56 \mathrm{E}-07$ & 0.3 & 0.02 \\
\hline 211 & 810807 & $10 / 6 / 1981$ & Plastic cans \#3145 \& 3147, Hot trash & 0.1 & 0.4 & 0.7 & 0.4 & 0.00614 & $8.56 \mathrm{E}-07$ & 16 & 0.7 \\
\hline 211 & 810808 & $10 / 6 / 1981$ & Cans \#3158 \& 3159, Hot trash, glass, plastic, paper & 0.1 & 0.4 & 2.2 & 1.3 & 0.00614 & $8.56 \mathrm{E}-07$ & 126 & 2.2 \\
\hline 211 & 810809 & $10 / 6 / 1981$ & $\begin{array}{l}\text { Plastic cans \#3162 \&3167, Trash catch pans, plastic, } \\
\text { wipes }\end{array}$ & 0.1 & 0.4 & 4 & 2.4 & 0.00614 & 8.56E-07 & 160 & 4 \\
\hline 211 & 810810 & $10 / 6 / 1981$ & $\begin{array}{l}\text { Cans \#3160,3161,3168,3169, Cold trash, Plastic, } \\
\text { bottles, wipes }\end{array}$ & 0.1 & 0.4 & 0.06 & 0.0 & 0.00614 & 8.56E-07 & 1 & 0.06 \\
\hline 211 & 812669 & $10 / 6 / 1981$ & Cans \#3178 \& 3179, Fuel, glass, etc. & 6.56 & 26.0 & 11 & 6.5 & 0.403 & $5.56 \mathrm{E}-05$ & 940 & 11 \\
\hline 212 & 803758 & 4/9/1980 & $\begin{array}{l}\text { LAMPRE reactor vessel sealed in } 1 / 4 \text { " steel cask with } \\
\text { concrete }\end{array}$ & 200 & 0.0 & & 0.0 & 12.4 & & 1.8 & 0.3 \\
\hline 213 & 812684 & $11 / 3 / 1981$ & Cell waste \& Fuel cell 16 waste, plastic can \#3248 & 32.6 & 138.0 & 40.8 & 24.0 & 2 & 2.95E-04 & 1000 & 40.8 \\
\hline 213 & 812686 & $11 / 3 / 1981$ & Cans \#3245 \&3246, Fuel, glass, towels & 4.33 & 17.3 & 7 & 4.1 & 0.266 & 3.70E-05 & 500 & 7 \\
\hline 213 & 812688 & $11 / 3 / 1981$ & Fuel and Hot trash in cans \#3273 \& 3274 & 12.8 & 77.9 & 101 & 59.5 & 0.787 & 1.67E-04 & 1000 & 101 \\
\hline 213 & 812689 & $11 / 3 / 1981$ & Cell waste cans \#3266 \& 3272 & 0.2 & 1.0 & 2.8 & 1.7 & 0.0124 & $2.14 \mathrm{E}-06$ & 160 & 2.8 \\
\hline 214 & 820057 & $4 / 20 / 1982$ & $\begin{array}{l}\text { Trash can \#3338, Kimwipes, glassware, Lucite can in } \\
\text { Steel nipple }\end{array}$ & 0.1 & 0.4 & 0.3 & 0.2 & 0.00614 & $8.56 \mathrm{E}-07$ & 15 & 0.3 \\
\hline 214 & 820058 & 4/20/1982 & $\begin{array}{l}\text { Trash can \#3351, Kimwipes, glassware, Lucite can in } \\
\text { steel nipple }\end{array}$ & 0.1 & 0.4 & 0.12 & 0.1 & 0.00614 & 8.56E-07 & 4 & 0.12 \\
\hline 214 & 821822 & $4 / 20 / 1982$ & Trash can \#3369, Kimwipes, paper & 0.1 & 0.4 & 0.4 & 0.2 & 0.00614 & $8.56 \mathrm{E}-07$ & 25 & 0.4 \\
\hline 214 & 821823 & $4 / 20 / 1982$ & Trash can \#3373, Paper, plastic & 0.1 & 0.4 & 0.45 & 0.3 & 0.00614 & 8.56E-07 & 30 & 0.45 \\
\hline 214 & 821826 & $4 / 20 / 1982$ & Waste can \#3378, Glass \& plastic bottles & 0.1 & 0.4 & 0.4 & 0.2 & 0.00614 & 8.56E-07 & 20 & 0.4 \\
\hline 214 & 823410 & $4 / 20 / 1982$ & Hot trash cans \#3307 \& \#3278 & 0.1 & 0.4 & 1.3 & 0.8 & 0.00614 & 8.56E-07 & 110 & 1.3 \\
\hline 215 & 820041 & 6/9/1982 & Fuel can \#3312 & 15.27 & 71.26 & 30 & 17.9 & 0.938 & $1.53 \mathrm{E}-04$ & 1000 & 30 \\
\hline 215 & 820042 & 6/9/1982 & Waste can \#3307 & 0.1 & 0.4 & 15 & 9.0 & 0.00614 & 8.56E-07 & 140 & 15 \\
\hline 215 & 821832 & 6/9/1982 & Trash can \#3393, Hot trash Lucite can in Steel Nipple & 0.1 & 0.4 & 2 & 1.2 & 0.00614 & 8.56E-07 & 35 & 2 \\
\hline 215 & 821833 & 6/9/1982 & Hot trash can \#3300 & 0.1 & 0.4 & 3 & 1.8 & 0.00614 & 8.56E-07 & 100 & 3 \\
\hline 215 & 821834 & 6/9/1982 & Hot trash can \#3397 & 0.1 & 0.4 & 2 & 1.2 & 0.00614 & 8.56E-07 & 200 & 2 \\
\hline 215 & 821835 & $6 / 9 / 1982$ & Hot trash can \#3383, Grinding papers, Kimwipes & 0.1 & 0.4 & 0.3 & 0.2 & 0.00614 & $8.56 \mathrm{E}-07$ & 40 & 0.8 \\
\hline 215 & 821837 & 6/9/1982 & Hot trash can \#3415, Bottles, Kimwipes & 0.1 & 0.4 & 2 & 1.2 & 0.00614 & 8.56E-07 & 20 & 2 \\
\hline 216 & 821825 & 6/9/1982 & Can \#3373, Glass, towels, plastic etc. & 0.1 & 0.4 & 0.8 & 0.5 & 0.00614 & 8.56E-06 & 40 & 0.8 \\
\hline 216 & 821836 & 6/9/1982 & Hot trash can \#3416, bootie, Kimwipes & 0.1 & 0.4 & 2 & 1.2 & 0.00614 & 8.56E-07 & 20 & 2 \\
\hline 216 & 821838 & 6/9/1982 & Hot trash can \#3395, Grinding, Kimwipes, plastic & 0.1 & 0.4 & 1 & 0.6 & 0.00614 & $8.56 \mathrm{E}-07$ & 15 & 1 \\
\hline
\end{tabular}


Appendix A-1 - Information from “RemoteHandled.xls” Workbook for Lined Shafts

\begin{tabular}{|c|c|c|c|c|c|c|c|c|c|c|c|}
\hline $\begin{array}{c}\text { Shaft } \\
\text { Number }\end{array}$ & $\begin{array}{c}\text { RSWD } \\
\text { Number }\end{array}$ & $\begin{array}{c}\text { Date } \\
\text { Placed }\end{array}$ & Waste Description & $\begin{array}{c}\text { Grams } \\
\text { of } \\
\text { Pu-239 } \\
\end{array}$ & $\begin{array}{c}\text { Grams } \\
\text { of } \\
\mathrm{U}-235 \\
\end{array}$ & $\begin{array}{l}\text { MFP } \\
(\mathrm{Ci})^{*}\end{array}$ & $\begin{array}{c}\text { Decayed } \\
\text { MFP } \\
(\mathrm{Ci})^{*} \\
\end{array}$ & $\begin{array}{c}\text { Curies } \\
\text { of } \\
\text { Pu-239 } \\
\end{array}$ & $\begin{array}{c}\text { Curies } \\
\text { of } \\
\text { U-235 } \\
\end{array}$ & $\begin{array}{c}\text { Contact } \\
\text { Dose } \\
\text { Rate } \\
\text { (R/hr) } \\
\end{array}$ & $\begin{array}{c}1 \\
\text { Meter } \\
\text { Dose } \\
\text { Rate } \\
\text { (R/hr) }\end{array}$ \\
\hline 216 & 821839 & 6/9/1982 & Hot trash can \#3405, Vermiculite, wipes & 0.1 & 0.4 & 0.2 & 0.1 & 0.00614 & 8.56E-07 & 8 & 0.2 \\
\hline 216 & 821840 & 6/9/1982 & Hot trash can \#3384 & 0.1 & 0.4 & 4 & 2.4 & 0.00614 & 8.56E-07 & 200 & 4 \\
\hline 216 & 821841 & 6/9/1982 & Hot trash can \#3385, Kimwipes, grinding papers & 0.1 & 0.4 & 2 & 1.2 & 0.00614 & $8.56 \mathrm{E}-07$ & 30 & 2 \\
\hline 217 & 821870 & 9/13/1982 & Can \#3451, Glass \& plastic bottles & 0.1 & 0.4 & 1.5 & 0.9 & 0.00614 & $8.56 \mathrm{E}-07$ & 15 & 1.5 \\
\hline 217 & 821871 & 9/13/1982 & Can \#3452, Fuel, scrap card boxes & 3.2 & 12.9 & 4.5 & 2.7 & 0.197 & $2.75 \mathrm{E}-05$ & 100 & 4.5 \\
\hline 217 & 821874 & $9 / 13 / 1982$ & Hot trash, grinding paper, etc., bottom entry cask & 0.1 & 0.4 & 10 & 6.0 & 0.00614 & $8.56 \mathrm{E}-07$ & 80 & 1 \\
\hline 217 & 821882 & 9/13/1982 & Trash can \#3478 & 0.1 & 0.4 & 1 & 0.6 & 0.00614 & 8.56E-07 & 6 & 1 \\
\hline 217 & 821915 & 9/13/1982 & Can \#3446, Waste Fuel and Cell trash & 22.8 & 60.0 & 1 & 0.6 & 1.4 & $1.28 \mathrm{E}-04$ & 1000 & 150 \\
\hline 217 & 821918 & 9/13/1982 & Can \#3437, Fuel, scrap card boxes & 3.2 & 12.9 & 1 & 0.6 & 0.197 & $2.75 \mathrm{E}-05$ & 900 & 10 \\
\hline 218 & 821875 & $9 / 13 / 1982$ & Trash can \#3499 & 0.1 & 0.4 & 20 & 12.0 & 0.00614 & $8.56 \mathrm{E}-07$ & 300 & 20 \\
\hline 218 & 821879 & 9/13/1982 & Trash catch pan can \#3477 & 2 & 9.0 & 30 & 18.0 & 0.123 & $1.92 \mathrm{E}-05$ & 500 & 30 \\
\hline 218 & 821881 & 9/13/1982 & Trash can \#3468 & 2 & 9.0 & 40 & 24.1 & 0.123 & 1.93E-05 & 900 & 40 \\
\hline 218 & 821883 & 9/13/1982 & Trash can \#3469 & 0.1 & 0.4 & 6 & 3.6 & 0.00614 & 8.56E-07 & 200 & 6 \\
\hline 218 & 821916 & 9/13/1982 & Cropper disposal and Fuel can \#3489 & 40.4 & 82.8 & 30 & 18.0 & 2.48 & 1.77E-04 & 1000 & 30 \\
\hline 218 & 821917 & 9/13/1982 & Trash can \#5 & 0.1 & 0.4 & 6 & 3.6 & 0.00614 & 8.56E-07 & 300 & 6 \\
\hline 219 & 832830 & 3/10/1983 & Grinding waste can \#3527 & 0.1 & 0.4 & 20 & 12.2 & 0.00614 & 8.56E-07 & 1000 & 20 \\
\hline 219 & 832831 & $3 / 10 / 1983$ & Trash can \#3727 & 0.1 & 0.4 & 0.8 & 0.5 & 0.00614 & 8.56E-07 & 30 & 0.8 \\
\hline 219 & 832832 & $3 / 10 / 1983$ & Fuel \& hardware can \#3724 & 40.47 & 236.0 & 150 & 91.2 & 2.49 & $5.05 \mathrm{E}-04$ & 1000 & 150 \\
\hline 219 & 832833 & 3/10/1983 & Hot waste can \#3725 & 0.1 & 0.4 & 30 & 18.2 & 0.00614 & 8.56E-07 & 200 & 30 \\
\hline 219 & 832834 & 3/10/1983 & Hot trash can \#3524 & 0.1 & 0.4 & 50 & 30.4 & 0.00614 & $8.56 \mathrm{E}-07$ & 1000 & 50 \\
\hline 219 & 832835 & $3 / 10 / 1983$ & Hot Cell Trash, can \#3495 & 4.98 & 20.2 & 100 & 60.8 & 0.306 & 4.32E-05 & 1000 & 100 \\
\hline 220 & 832836 & $3 / 10 / 1983$ & Waste can \#3728 & 0.1 & 0.4 & 100 & 60.8 & 0.00614 & $8.56 \mathrm{E}-07$ & 1000 & 100 \\
\hline 220 & 832837 & 3/10/1983 & Waste can \#3491 & 0.11 & 0.4 & 100 & 60.8 & 0.00675 & 8.56E-07 & 1000 & 100 \\
\hline 220 & 832838 & 3/10/1983 & Hot cell trash \#3706 & 0.1 & 0.4 & 2 & 1.2 & 0.00614 & 8.56E-07 & 100 & 2 \\
\hline 220 & 832839 & 3/10/1983 & Grinding can \#3528 & 0.1 & 0.4 & 8 & 4.9 & 0.00614 & 8.56E-07 & 200 & 8 \\
\hline 220 & 832840 & 3/10/1983 & Grinding can \#3522 & 0.1 & 0.4 & 200 & 121.6 & 0.00614 & $8.56 \mathrm{E}-07$ & 1000 & 200 \\
\hline 220 & 832841 & $3 / 10 / 1983$ & Wire wrap \#3726 & 0.1 & 0.4 & 50 & 30.4 & 0.00614 & $8.56 \mathrm{E}-07$ & 1000 & 50 \\
\hline 221 & 832842 & $3 / 10 / 1983$ & Wire wraps \#3554 & 0.1 & 0.4 & 15 & 9.1 & 0.00614 & $8.56 \mathrm{E}-07$ & 400 & 15 \\
\hline 221 & 832843 & $3 / 10 / 1983$ & Wire wraps \#3507 & 0.1 & 0.4 & 30 & 18.2 & 0.00614 & $8.56 \mathrm{E}-07$ & 1000 & 30 \\
\hline 221 & 832844 & 3/10/1983 & Hot trash can \#3569 & 0.1 & 0.4 & 40 & 24.3 & 0.00614 & $8.56 \mathrm{E}-07$ & 800 & 40 \\
\hline 221 & 832845 & $3 / 10 / 1983$ & Hot trash can \#3722 & 0.1 & 0.4 & 1.5 & 0.9 & 0.00614 & $8.56 \mathrm{E}-07$ & 60 & 1.5 \\
\hline
\end{tabular}

4 of 7 
Appendix A-1 - Information from “RemoteHandled.xls” Workbook for Lined Shafts

\begin{tabular}{|c|c|c|c|c|c|c|c|c|c|c|c|}
\hline $\begin{array}{c}\text { Shaft } \\
\text { Number }\end{array}$ & $\begin{array}{c}\text { RSWD } \\
\text { Number }\end{array}$ & $\begin{array}{c}\text { Date } \\
\text { Placed }\end{array}$ & Waste Description & $\begin{array}{c}\text { Grams } \\
\text { of } \\
\text { Pu-239 } \\
\end{array}$ & $\begin{array}{c}\text { Grams } \\
\text { of } \\
\text { U-235 } \\
\end{array}$ & $\begin{array}{l}\text { MFP } \\
(\mathbf{C i})^{*}\end{array}$ & $\begin{array}{c}\text { Decayed } \\
\text { MFP } \\
(\mathrm{Ci}) * \\
\end{array}$ & $\begin{array}{c}\text { Curies } \\
\text { of } \\
\text { Pu-239 } \\
\end{array}$ & $\begin{array}{c}\text { Curies } \\
\text { of } \\
\text { U-235 } \\
\end{array}$ & $\begin{array}{c}\text { Contact } \\
\text { Dose } \\
\text { Rate } \\
\text { (R/hr) } \\
\end{array}$ & $\begin{array}{c}1 \\
\text { Meter } \\
\text { Dose } \\
\text { Rate } \\
\text { (R/hr) }\end{array}$ \\
\hline 221 & 832846 & $3 / 10 / 1983$ & Hot trash can \#3720 & 0.1 & 0.4 & 60 & 36.5 & 0.00614 & 8.56E-07 & 200 & 60 \\
\hline 221 & 832847 & $3 / 10 / 1983$ & Waste can \#3721 & 0.1 & 0.4 & 30 & 18.2 & 0.006124 & 8.56E-07 & 200 & 60 \\
\hline 222 & 830716 & $12 / 14 / 1983$ & Can\#3712, Fuel scrap paper, etc & 0.564 & 2.3 & 20 & 12.4 & 0.0342 & $4.82 \mathrm{E}-06$ & 900 & 20 \\
\hline 222 & 830717 & $12 / 14 / 1983$ & Can\#3718, Fuel scrap paper, etc & 0.564 & 2.3 & 200 & 123.8 & 0.0346 & $4.82 \mathrm{E}-06$ & 1000 & 200 \\
\hline 222 & 830781 & $12 / 14 / 1983$ & Trash 1 can, bottom entry steel can \#1 & 0.05 & 0.2 & 1 & 0.6 & 0.00377 & $4.26 \mathrm{E}-07$ & 20 & 1 \\
\hline 222 & 830787 & $12 / 14 / 1983$ & Trash 1 can, bottom entry steel can \#10 & 0.12 & 0.5 & 40 & 24.8 & 0.00905 & $1.07 \mathrm{E}-06$ & 200 & 40 \\
\hline 222 & 830788 & $12 / 14 / 1983$ & Trash 1 can, bottom entry steel can \#6 & 0.12 & 0.5 & 40 & 24.8 & 0.00905 & 1.07E-06 & 100 & 40 \\
\hline 222 & 830789 & $12 / 14 / 1983$ & Trash 1 can, Steel can \#8 & 0.1 & 0.4 & 0.2 & 0.1 & 0.00754 & 8.53E-07 & 10 & 0.2 \\
\hline 222 & 830790 & $12 / 14 / 1983$ & Trash 1 can, Steel can \#9 & 2.91 & 11.64 & 40 & 24.8 & 0.219 & $2.48 \mathrm{E}-05$ & 200 & 40 \\
\hline 223 & 830782 & $12 / 14 / 1983$ & Trash 1 can, bottom entry steel can \#5 & 0.05 & 0.2 & 25 & 15.5 & 0.00377 & 4.26E-07 & 100 & 25 \\
\hline 223 & 830783 & $12 / 14 / 1983$ & Trash 1 can, bottom entry steel can \#3 & 0.1 & 0.4 & 3 & 1.9 & 0.00754 & 8.53E-07 & 25 & 3 \\
\hline 223 & 830784 & $12 / 14 / 1983$ & Trash 1 can, bottom entry steel can \#4 & 0.1 & 0.4 & 3 & 1.9 & 0.00754 & 8.53E-07 & 30 & 3 \\
\hline 223 & 830785 & $12 / 14 / 1983$ & Trash 1 can, bottom entry steel can \#7 & 0.1 & 0.4 & 3 & 1.9 & 0.00754 & 8.53E-07 & 70 & 3 \\
\hline 223 & 830786 & $12 / 14 / 1983$ & Trash 1 can, Steel can \#2 & 0.05 & 0.2 & 1.5 & 0.9 & 0.00377 & $4.26 \mathrm{E}-07$ & 20 & 1.5 \\
\hline 223 & 830791 & $12 / 14 / 1983$ & Trash 1 can, bottom entry steel can \#11 & 0.1 & 0.4 & 1.5 & 0.9 & 0.00754 & 8.53E-07 & 32 & 1.5 \\
\hline 224 & 852326 & $12 / 30 / 1985$ & Waste, plastic can \#4088, steel can \#58 & 0.1 & 0.4 & 4 & 2.6 & 0.00614 & $8.56 \mathrm{E}-07$ & 300 & 4 \\
\hline 224 & 852328 & $12 / 30 / 1985$ & Waste plastic can \#4097, Steel can \#61 & 0.1 & 0.4 & 2 & 1.3 & 0.00614 & 8.56E-07 & 100 & 2 \\
\hline 224 & 852332 & $12 / 30 / 1985$ & Waste plastic can \#4072, Steel can \#32 & 0.1 & 0.4 & 4 & 2.6 & 0.00614 & 8.56E-07 & 300 & 4 \\
\hline 224 & 852804 & 12/30/1985 & Trash can \#3660, Fuel inside Steel can \#67 & 3.3 & 8.7 & 2.8 & 1.8 & 0.203 & $1.86 \mathrm{E}-05$ & 100 & 2.8 \\
\hline 224 & 855064 & 12/30/1985 & Trash can \#3661, Fuel inside Steel can \#63 & 3.6 & 14.9 & 3.3 & 2.1 & 0.221 & 3.19E-05 & 100 & 3.3 \\
\hline 224 & 855065 & $12 / 30 / 1985$ & Trash can \#3662, Fuel inside Steel can \#66 & 3.6 & 14.9 & 4.2 & 2.7 & 0.221 & 3.19E-05 & 300 & 4.2 \\
\hline 224 & 855066 & $12 / 30 / 1985$ & Trash can \#3663, trash only, Steel can \#65 & 0.1 & 0.4 & 1.5 & 1.0 & 0.00614 & $8.56 \mathrm{E}-07$ & 70 & 1.5 \\
\hline 224 & 855068 & 12/30/1985 & Trash can \#3664, Fuel inside Steel can \#64 & 0.1 & 0.4 & 1.5 & 1.0 & 0.00614 & $8.56 \mathrm{E}-07$ & 20 & 0.5 \\
\hline 225 & 840848 & $12 / 31 / 1984$ & Waste plastic can \#4076, Steel can \#21 & 0.1 & 0.4 & 0.4 & 0.3 & 0.00614 & 8.56E-07 & 40 & 0.4 \\
\hline 225 & 840854 & 12/31/1984 & Waste plastic can \#4033, Steel can \#24 & 0.1 & 0.4 & 1.5 & 1.0 & 0.00614 & 8.56E-07 & 50 & 1.5 \\
\hline 225 & 840856 & 12/31/1984 & Waste plastic can \#4043, Steel can \#31 & 0.1 & 0.4 & 1.5 & 1.0 & 0.00614 & 8.56E-07 & 90 & 1.5 \\
\hline 225 & 840857 & $12 / 31 / 1984$ & Waste plastic can \#4035, Steel can \#30 & 0.1 & 0.4 & 3 & 1.9 & 0.00614 & 8.56E-07 & 105 & 3 \\
\hline 225 & 840863 & $12 / 31 / 1984$ & Waste plastic can \#4046, Steel can \#40 & 0.1 & 0.4 & 0.08 & 0.1 & 0.00614 & $8.56 \mathrm{E}-07$ & 10 & 0.08 \\
\hline 225 & 840864 & $12 / 31 / 1984$ & Waste plastic can \#4044, Steel can \#34 & 0.1 & 0.4 & 0.3 & 0.2 & 0.00614 & $8.56 \mathrm{E}-07$ & 25 & 0.3 \\
\hline 225 & 840867 & $12 / 31 / 1984$ & Waste plastic can \#4054, Steel can \#38 & 0.1 & 0.4 & 0.4 & 0.3 & 0.00614 & 8.56E-07 & 30 & 0.4 \\
\hline 225 & 840874 & 12/31/1984 & Trash can \#4051, Steel can \#43 & 0.1 & 0.4 & 0.2 & 0.1 & 0.00614 & 8.56E-07 & 15 & 0.2 \\
\hline
\end{tabular}


Appendix A-1 - Information from "RemoteHandled.xls" Workbook for Lined Shafts

\begin{tabular}{|c|c|c|c|c|c|c|c|c|c|c|c|}
\hline $\begin{array}{c}\text { Shaft } \\
\text { Number }\end{array}$ & $\begin{array}{c}\text { RSWD } \\
\text { Number }\end{array}$ & $\begin{array}{c}\text { Date } \\
\text { Placed }\end{array}$ & Waste Description & $\begin{array}{c}\text { Grams } \\
\text { of } \\
\text { Pu-239 } \\
\end{array}$ & $\begin{array}{c}\text { Grams } \\
\text { of } \\
\text { U-235 } \\
\end{array}$ & $\begin{array}{l}\text { MFP } \\
(\mathbf{C i})^{*}\end{array}$ & $\begin{array}{c}\text { Decayed } \\
\text { MFP } \\
(\mathrm{Ci}) * \\
\end{array}$ & $\begin{array}{c}\text { Curies } \\
\text { of } \\
\text { Pu-239 } \\
\end{array}$ & $\begin{array}{c}\text { Curies } \\
\text { of } \\
\mathbf{U}-235 \\
\end{array}$ & $\begin{array}{c}\text { Contact } \\
\text { Dose } \\
\text { Rate } \\
\text { (R/hr) } \\
\end{array}$ & $\begin{array}{c}1 \\
\text { Meter } \\
\text { Dose } \\
\text { Rate } \\
\text { (R/hr) }\end{array}$ \\
\hline 226 & 840842 & $12 / 31 / 1984$ & Waste plastic can \#4056, Steel can \#20 & 0.1 & 0.4 & 2 & 1.3 & 0.00614 & 8.56E-07 & 90 & 2 \\
\hline 226 & 840843 & $12 / 31 / 1984$ & Waste plastic can \#4045, Steel can \#36 & 0.1 & 0.4 & 2 & 1.3 & 0.00614 & 8.56E-07 & 80 & 2 \\
\hline 226 & 840844 & $12 / 31 / 1984$ & Waste plastic can \#4023, Steel can \#19 & 0.1 & 0.4 & 1.5 & 1.0 & 0.00614 & 8.56E-07 & 70 & 1.5 \\
\hline 226 & 840845 & $12 / 31 / 1984$ & Waste plastic can \#4034, Steel can \#22 & 0.1 & 0.4 & 0.3 & 0.2 & 0.00614 & $8.56 \mathrm{E}-07$ & 21 & 0.3 \\
\hline 226 & 840846 & $12 / 31 / 1984$ & Waste plastic can \#4024, Steel can \#25 & 0.1 & 0.4 & 5 & 3.2 & 0.00614 & $8.56 \mathrm{E}-07$ & 300 & 5 \\
\hline 226 & 840847 & $12 / 31 / 1984$ & Waste plastic can \#4022, Steel can \#23 & 0.1 & 0.4 & 1.5 & 1.0 & 0.00614 & $8.56 \mathrm{E}-07$ & 70 & 1.5 \\
\hline 226 & 840862 & $12 / 31 / 1984$ & Waste plastic can \#4027, Steel can \#39 & 0.1 & 0.4 & 0.2 & 0.1 & 0.00614 & $8.56 \mathrm{E}-07$ & 15 & 0.2 \\
\hline 226 & 840868 & $12 / 31 / 1984$ & Waste plastic can \#4025, Steel can \#35 & 0.1 & 0.4 & 0.3 & 0.2 & 0.00614 & 8.56E-07 & 35 & 0.3 \\
\hline 227 & 840877 & $12 / 31 / 1984$ & Trash can \#4050, Fuel inside Steel can \#42 & 2.2 & 8.9 & 1.5 & 1.0 & 0.135 & $1.91 \mathrm{E}-05$ & 80 & 1.5 \\
\hline 227 & 840878 & $12 / 31 / 1984$ & Trash can \#4042, Fuel inside Steel can \#46 & 3.1 & 14.4 & 2.5 & 1.6 & 0.19 & 3.08E-05 & 250 & 2.5 \\
\hline 227 & 840879 & $12 / 31 / 1984$ & Trash can \#4041, Fuel inside Steel can \#44 & 3.1 & 14.4 & 4 & 2.5 & 0.19 & $3.08 \mathrm{E}-05$ & 300 & 4 \\
\hline 227 & 840880 & $12 / 31 / 1984$ & Trash can \#4048, Fuel inside Steel can \#45 & 3.1 & 14.4 & 2.5 & 1.6 & 0.19 & $3.08 \mathrm{E}-05$ & 350 & 2.5 \\
\hline 227 & 840881 & $12 / 31 / 1984$ & Trash can \#4057, Fuel inside Steel can \#51 & 3.1 & 14.4 & 3 & 1.9 & 0.19 & $3.08 \mathrm{E}-05$ & 200 & 3 \\
\hline 227 & 840883 & $12 / 31 / 1984$ & Trash can \#4064, Steel can \#48 & 0.1 & 0.4 & 2 & 1.3 & 0.00614 & $8.56 \mathrm{E}-07$ & 100 & 2 \\
\hline 227 & 840885 & $12 / 31 / 1984$ & Trash can \#4056, Fuel inside Steel can \#49 & 3.2 & 10.6 & 6 & 3.8 & 0.197 & 2.27E-05 & 400 & 6 \\
\hline 227 & 840886 & $12 / 31 / 1984$ & Trash can \#4084, Steel can \#50 & 0.1 & 0.4 & 0.8 & 0.5 & 0.00614 & 8.56E-07 & 15 & 0.8 \\
\hline 228 & 874123 & $12 / 23 / 1987$ & Trash can \#4032, Steel can \#54 & 0.1 & 0.4 & 0.15 & 0.1 & 0.00614 & 8.56E-07 & 9 & 0.15 \\
\hline 228 & 874124 & $12 / 23 / 1987$ & Waste plastic can \#4093, Steel can \#55 & 0.1 & 0.4 & 1.5 & 1.0 & 0.00614 & 8.56E-07 & 20 & 1.5 \\
\hline 228 & 874125 & $12 / 23 / 1987$ & Waste can \#4164, Steel can \#62 & 0.1 & 0.4 & 0.15 & 0.1 & 0.00614 & 8.56E-07 & 10 & 0.12 \\
\hline 228 & 874126 & $12 / 23 / 1987$ & Waste plastic can \#4086, Steel can \#57 & 0.1 & 0.4 & 2.5 & 1.7 & 0.00614 & 8.56E-07 & 200 & 2.5 \\
\hline 228 & 874127 & $12 / 23 / 1987$ & Waste plastic can \#4094, Steel can \#56 & 0.1 & 0.4 & 1.5 & 1.0 & 0.00614 & $8.56 \mathrm{E}-07$ & ? & 1.5 \\
\hline 228 & 874128 & $12 / 23 / 1987$ & Waste plastic can \#4092, Steel can \#60 & 0.1 & 0.4 & 1.5 & 1.0 & 0.00614 & $8.56 \mathrm{E}-07$ & $?$ & 1.5 \\
\hline 228 & 874129 & $12 / 23 / 1987$ & Waste, plastic can \#4085, steel can \#59 & 0.1 & 0.4 & 1.5 & 1.0 & 0.00614 & 8.56E-07 & 60 & 1.5 \\
\hline 228 & 874130 & $12 / 23 / 1987$ & Trash can \#4053, steel can \#53 & 0.1 & 0.4 & 2 & 1.4 & 0.00614 & 8.56E-07 & 80 & 2 \\
\hline 229 & 840851 & 12/31/1984 & Waste plastic can \#4028, Steel can \#28 & 0.1 & 0.4 & 3 & 1.9 & 0.00614 & 8.56E-07 & 200 & 3 \\
\hline 229 & 840855 & 12/31/1984 & Waste plastic can \#4145, Steel can \#27 & 0.1 & 0.4 & 1 & 0.6 & 0.00614 & 8.56E-07 & 40 & 1 \\
\hline 229 & 840860 & $12 / 31 / 1984$ & Waste plastic can \#4026, Steel can \#36 & 0.1 & 0.4 & 2 & 1.3 & 0.00614 & 8.56E-07 & 150 & 2 \\
\hline 229 & 840865 & $12 / 31 / 1984$ & Waste plastic can \#4055, Steel can \#37 & 0.1 & 0.4 & 0.1 & 0.1 & 0.00614 & $8.56 \mathrm{E}-07$ & 10 & 0.1 \\
\hline 229 & 840873 & $12 / 31 / 1984$ & Trash can \#4065, Steel can \#41 & 3 & 12 & 2 & 1.3 & 0.184 & $2.57 \mathrm{E}-05$ & 100 & 2 \\
\hline 229 & 840882 & $12 / 31 / 1984$ & Trash plastic can \#4066, steel can \#47 & 0.1 & 0.4 & 0.3 & 0.2 & 0.00614 & 8.56E-07 & 18 & 0.3 \\
\hline 229 & 840888 & 12/31/1984 & Trash can \#4075, Steel can \#52 & 0.1 & 0.4 & 0.15 & 0.1 & 0.00614 & 8.56E-07 & 10 & 1.5 \\
\hline
\end{tabular}

6 of 7 
Appendix A-1 - Information from "RemoteHandled.xls” Workbook for Lined Shafts

\begin{tabular}{|c|c|c|c|c|c|c|c|c|c|c|c|}
\hline $\begin{array}{c}\text { Shaft } \\
\text { Number }\end{array}$ & $\begin{array}{c}\text { RSWD } \\
\text { Number }\end{array}$ & $\begin{array}{c}\text { Date } \\
\text { Placed }\end{array}$ & Waste Description & $\begin{array}{c}\text { Grams } \\
\text { of } \\
\text { Pu-239 } \\
\end{array}$ & $\begin{array}{c}\text { Grams } \\
\text { of } \\
\text { U-235 } \\
\end{array}$ & $\begin{array}{l}\text { MFP } \\
(\mathrm{Ci})^{*}\end{array}$ & $\begin{array}{c}\text { Decayed } \\
\text { MFP } \\
\text { (Ci)* } \\
\end{array}$ & $\begin{array}{c}\text { Curies } \\
\text { of } \\
\text { Pu-239 } \\
\end{array}$ & $\begin{array}{c}\text { Curies } \\
\text { of } \\
\text { U-235 } \\
\end{array}$ & $\begin{array}{c}\text { Contact } \\
\text { Dose } \\
\text { Rate } \\
\text { (R/hr) } \\
\end{array}$ & $\begin{array}{c}1 \\
\text { Meter } \\
\text { Dose } \\
\text { Rate } \\
\text { (R/hr) }\end{array}$ \\
\hline 230 & 840831 & $12 / 31 / 1984$ & Hot waste can \#4017, Steel can \#13 & 96 & 245 & 35 & 22.2 & 5.89 & $5.24 \mathrm{E}-04$ & 1000 & 35 \\
\hline 230 & 840835 & $12 / 31 / 1984$ & Waste plastic can \#4153, Steel can \#16 & 0.1 & 0.4 & 10 & 6.3 & 0.00614 & 8.56E-07 & 100 & 1 \\
\hline 230 & 840836 & $12 / 31 / 1984$ & Waste plastic can \#3974, Steel can \#15 & 0.1 & 0.4 & 0.4 & 0.3 & 0.00614 & 8.56E-07 & 30 & 0.4 \\
\hline 230 & 840838 & $12 / 31 / 1984$ & Waste, plastic can \#4154, steel can \#14 & 0.1 & 0.4 & 5 & 3.2 & 0.00614 & 8.56E-07 & 400 & 5 \\
\hline 230 & 840839 & $12 / 31 / 1984$ & Waste, plastic can \#4155, steel can \#18 & 0.1 & 0.4 & 1.5 & 1.0 & 0.00614 & 8.56E-07 & 90 & 1.5 \\
\hline 230 & 840840 & $12 / 31 / 1984$ & Waste, plastic can \#4037, steel can \#29 & 0.1 & 0.4 & 1 & 0.6 & 0.00614 & 8.56E-07 & 90 & 1 \\
\hline 230 & 840841 & $12 / 31 / 1984$ & Waste, plastic can \#4036, steel can \#17 & 0.1 & 0.4 & 0.7 & 0.4 & 0.00614 & 8.56E-07 & 60 & 0.7 \\
\hline 230 & 840859 & $12 / 31 / 1984$ & Waste, plastic can \#4031, steel can \#33 & 0.1 & 0.4 & 1 & 0.6 & 0.00614 & 8.56E-07 & 40 & 1 \\
\hline 231 & 855046 & $12 / 30 / 1985$ & $\begin{array}{l}\text { Vacuum cleaner motor, plastic can \#3813, steel can } \\
\text { \#72 }\end{array}$ & 0.1 & 0.4 & 3 & 1.9 & 0.00614 & 8.56E-07 & 1000 & 30 \\
\hline 231 & 855047 & 12/30/1985 & Manipulator boot, plastic can \#4114, steel can \#73 & 0.1 & 0.3 & 3 & 1.9 & 0.00614 & 6.42E-07 & 1000 & 6.5 \\
\hline 231 & 855048 & $12 / 30 / 1985$ & Trash plastic can \#3859, steel can \#74 & 0 & 15 & 0.9 & 0.6 & 0 & 3.21E-05 & 100 & 0.9 \\
\hline 231 & 855049 & $12 / 30 / 1985$ & RB. Robinson Fuel, can \#3651, steel can \#75 & 0 & 9 & 0.4 & 0.3 & 0 & 1.93E-05 & 3 & 0.04 \\
\hline 231 & 856015 & $12 / 30 / 1985$ & Plastic can \#3649, steel can \#68 & 0.1 & 0.4 & 2.1 & 1.4 & 0.00614 & 8.56E-07 & 1000 & 22 \\
\hline 231 & 856016 & 12/30/1985 & Plastic waste can \#4113, steel can \#69 & 0.1 & 0.3 & 6 & 3.9 & 0.00614 & $6.42 \mathrm{E}-07$ & 20 & 0.6 \\
\hline 231 & 856017 & $12 / 30 / 1985$ & Plastic and can trash \#3626, steel can \#71 & 0.1 & 0.3 & 6 & 3.9 & 0.00614 & $6.42 \mathrm{E}-07$ & 500 & 6 \\
\hline 231 & 856018 & $12 / 30 / 1985$ & Plastic and can trash \#3625, steel can \#70 & 0.1 & 0.4 & 1 & 0.6 & 0.00614 & 8.56E-07 & 350 & 7 \\
\hline 232 & 874132 & $12 / 23 / 1987$ & Three Mile Island waste, can \#77 & 0 & 7 & 0 & 0.0 & 0 & 2.61E-06 & 6.5 & 0 \\
\hline 232 & 874133 & $12 / 23 / 1987$ & Waste can \#79 & & 134.8 & 0 & 0.0 & 5.83 & 2.89E-04 & 1000 & \\
\hline 232 & 874134 & $12 / 23 / 1987$ & Waste steel can \#78 & 1 & 48 & 0 & 0.0 & 0.0943 & $1.37 \mathrm{E}-05$ & 29 & \\
\hline
\end{tabular}

* Assume units, original information source does not indicate units. 
Appendix A-2 - Information from the TRU Waste Database for Lined Shafts

\begin{tabular}{|c|c|c|c|c|c|c|c|c|c|}
\hline Location & $\begin{array}{l}\text { Package } \\
\text { ID }\end{array}$ & Date & $\begin{array}{l}\text { Gross } \\
\text { Weight } \\
\text { (lbs) }\end{array}$ & $\begin{array}{l}\text { Volume } \\
\text { (m3) }\end{array}$ & Waste description & Comments & $\begin{array}{l}\text { Radio- } \\
\text { nuclides }\end{array}$ & Grams & $\begin{array}{c}\text { Total } \\
\text { Dose } \\
(\mathrm{mR} / \mathrm{hr})\end{array}$ \\
\hline \multirow[t]{3}{*}{ Shaft 200} & S811387 & 14-Apr-81 & 16.00 & 0.21 & Non-combustible hot-cell waste & $\begin{array}{l}\text { Cell } 14 \text { fuel can } 3021,300 \text { b cell } 13 \\
140 \text { R at contact }\end{array}$ & U-235 & 8.08 & 0 \\
\hline & & & & & & & Pu-239 & 20.20 & \\
\hline & & & & & & & MFP & & \\
\hline \multirow[t]{3}{*}{ Shaft 200} & S811390 & 14-Apr-81 & 16.00 & & & $\begin{array}{l}\text { Cell \#14 fuel cans \#3010 \& } 3016 \\
800 \text { R at contact }\end{array}$ & U-235 & 38.04 & 0 \\
\hline & & & & & & & Pu-239 & 10.01 & \\
\hline & & & & & & & MFP & & \\
\hline \multirow[t]{3}{*}{ Shaft 200} & S811396 & 14-Apr-81 & 16.00 & 0.21 & Combustible hot-cell waste & $\begin{array}{l}\text { Cell } 13 \text { grinding papers kimwipes } \\
\text { plastic cans } 30613053\end{array}$ & U-235 & 0.40 & 60,000 \\
\hline & & & & & & & $\mathrm{Pu}-239$ & 0.10 & \\
\hline & & & & & & & MFP & & \\
\hline \multirow[t]{3}{*}{ Shaft 200} & S811398 & 14-Apr-81 & 20.00 & & & $\begin{array}{l}\text { Cell } 13 \text { catch \& drain pans } \\
\text { kimwipes } 120,000 \mathrm{mR} / \mathrm{hr} \text { surface } \\
\text { cans } 30513052\end{array}$ & U-235 & 16.00 & 0 \\
\hline & & & & & & & $\mathrm{Pu}-239$ & 4.00 & \\
\hline & & & & & & & MFP & & \\
\hline \multirow[t]{3}{*}{ Shaft 200} & S811471 & 14-Apr-81 & 9.00 & 0.21 & Non-combustible hot-cell waste & $\begin{array}{l}\text { Cell } 14 \text { trash cans } 28642846700 \\
\text { R/hr at contact }\end{array}$ & U-235 & 21.50 & 0 \\
\hline & & & & & & & MFP & & \\
\hline & & & & & & & $\mathrm{Pu}-239$ & 12.50 & \\
\hline \multirow[t]{3}{*}{ Shaft 200} & S811473 & 14-Apr-81 & 16.00 & 0.21 & Non-combustible hot-cell waste & $\begin{array}{l}\text { Cell } 14 \text { trash fuel cans \#2877 } 2863 \\
1150 \text { R/hr at contact }\end{array}$ & U-235 & 49.00 & 0 \\
\hline & & & & & & & MFP & & \\
\hline & & & & & & & $\mathrm{Pu}-239$ & 5.00 & \\
\hline \multirow[t]{3}{*}{ Shaft 201} & S791484 & 29-Jun-79 & 0.00 & 0.09 & Non-combustible hot-cell waste & $\begin{array}{l}\text { Cell } 12 \text { one fuel can } 2171 \text { tin can in } \\
\text { plastic container }\end{array}$ & MFP & & 17,500 \\
\hline & & & & & & & Pu-239 & 3.00 & \\
\hline & & & & & & & U-235 & 1.00 & \\
\hline \multirow[t]{3}{*}{ Shaft 201} & S794215 & 29-Jun-79 & 14.99 & 0.16 & Non-combustible hot-cell waste & $\begin{array}{l}\text { Cell } 12 \text { trash + fuel 1854,1851 } \\
266,000 \mathrm{mR} \text { at contact }\end{array}$ & U-235 & 2.00 & 0 \\
\hline & & & & & & & MFP & & \\
\hline & & & & & & & Pu-239 & 0.50 & \\
\hline Shaft 201 & S794216 & 29-Jun-79 & 14.99 & & Combustible hot-cell waste & $\begin{array}{l}\text { Cell } 12 \text { trash and fuel can } 1798+ \\
1953261,000 \text { mR at contact cans in }\end{array}$ & U-235 & 9.00 & 0 \\
\hline
\end{tabular}


Appendix A-2 - Information from the TRU Waste Database for Lined Shafts

\begin{tabular}{|c|c|c|c|c|c|c|c|c|c|}
\hline Location & $\begin{array}{c}\text { Package } \\
\text { ID }\end{array}$ & Date & $\begin{array}{l}\text { Gross } \\
\text { Weight } \\
\text { (lbs) }\end{array}$ & $\begin{array}{c}\text { Volume } \\
(\mathrm{m} 3)\end{array}$ & Waste description & Comments & $\begin{array}{c}\text { Radio- } \\
\text { nuclides }\end{array}$ & Grams & $\begin{array}{c}\text { Total } \\
\text { Dose } \\
(\mathrm{mR} / \mathrm{hr}) \\
\end{array}$ \\
\hline & & & & & & p-bag & & & \\
\hline & & & & & & & MFP & & \\
\hline & & & & & & & $\mathrm{Pu}-239$ & 2.25 & \\
\hline \multirow[t]{3}{*}{ Shaft 201} & S794218 & 29-Jun-79 & 9.92 & & & $\begin{array}{l}\text { Cell } 14 \text { fuel can no. } 2002+2003 \text { tin } \\
\text { cans in plastic cans in p-bags }\end{array}$ & U-235 & 10.00 & 15,000 \\
\hline & & & & & & & Pu-239 & 2.50 & \\
\hline & & & & & & & MFP & & \\
\hline \multirow[t]{3}{*}{ Shaft 201} & S794219 & 29-Jun-79 & 11.91 & & Non-combustible hot-cell waste & $\begin{array}{l}\text { Cell } 14 \text { fuel }+ \text { trash can no. } 2004+ \\
1992 \text { tin cans in plastic cans in p- } \\
\text { bags }\end{array}$ & MFP & & 27,000 \\
\hline & & & & & & & Pu-239 & 1.50 & \\
\hline & & & & & & & U-235 & 5.00 & \\
\hline \multirow[t]{3}{*}{ Shaft 201} & S794220 & 29-Jun-79 & 5.95 & 0.16 & Combustible hot-cell waste & $\begin{array}{l}\text { Hot trash met samples cans } 1 \text { and } 4 a \\
1200 \mathrm{R} / \mathrm{hr} \text { at contact }\end{array}$ & U-235 & 147.00 & 0 \\
\hline & & & & & & & Pu-239 & 68.00 & \\
\hline & & & & & & & MFP & & \\
\hline \multirow[t]{3}{*}{ Shaft 201} & S794221 & 29-Jun-79 & 7.94 & & & $\begin{array}{l}\text { Fuel samples from cells 13,15 cans } \\
2 \text { 13a } 1050 \mathrm{R} / \mathrm{hr} \text { at contact }\end{array}$ & U-235 & 370.00 & 0 \\
\hline & & & & & & & Pu-239 & 141.00 & \\
\hline & & & & & & & MFP & & \\
\hline \multirow[t]{3}{*}{ Shaft 202} & S803548 & 30-Apr-80 & 4600.73 & 1.20 & Non-combustible hot-cell waste & $\begin{array}{l}\text { Hot cell waste cmb1 +cmb14 from } \\
9 / 5 / 79 \text { thru } 1 / 10 / 80\end{array}$ & U-235 & 222.90 & 0 \\
\hline & & & & & & & MFP & & \\
\hline & & & & & & & Pu-239 & 65.36 & \\
\hline \multirow[t]{3}{*}{ Shaft 203} & S803547 & 30-Apr-80 & 4600.73 & 1.20 & Non-combustible hot-cell waste & $\begin{array}{l}\text { Hot cell waste cmb- } 1+\text { cmb14 from } \\
12 / 13 / 78 \text { thru 8/15/79 }\end{array}$ & $\mathrm{U}-235$ & 127.00 & 0 \\
\hline & & & & & & & $\mathrm{Pu}-239$ & 37.50 & \\
\hline & & & & & & & MFP & & \\
\hline \multirow[t]{3}{*}{ Shaft 204} & S791472 & 29-Jun-79 & 20.07 & 0.21 & Non-combustible hot-cell waste & $\begin{array}{l}\text { Cell } 12 \text { trash + fuel cans } 2127+ \\
2150108000 \mathrm{mR} \text { at contact }\end{array}$ & U-235 & 5.25 & 0 \\
\hline & & & & & & & $\mathrm{Pu}-239$ & 1.75 & \\
\hline & & & & & & & MFP & & \\
\hline Shaft 204 & S791478 & 29-Jun-79 & 14.99 & 0.21 & Combustible hot-cell waste & $\begin{array}{l}\text { Cell } 9 \text { hot trash cans } \\
\text { 2015,2117,1000pR/hr at contact }\end{array}$ & MFP & & 0 \\
\hline
\end{tabular}


Appendix A-2 - Information from the TRU Waste Database for Lined Shafts

\begin{tabular}{|c|c|c|c|c|c|c|c|c|c|}
\hline Location & $\begin{array}{c}\text { Package } \\
\text { ID }\end{array}$ & Date & $\begin{array}{l}\text { Gross } \\
\text { Weight } \\
\text { (lbs) }\end{array}$ & $\begin{array}{c}\text { Volume } \\
(\mathrm{m} 3)\end{array}$ & Waste description & Comments & $\begin{array}{c}\text { Radio- } \\
\text { nuclides }\end{array}$ & Grams & $\begin{array}{l}\text { Total } \\
\text { Dose } \\
(\mathrm{mR} / \mathrm{hr})\end{array}$ \\
\hline & & & & & & $140000 \mathrm{mR} / \mathrm{hr}$ at meter & & & \\
\hline & & & & & & & Pu-239 & 35.00 & \\
\hline & & & & & & & U-235 & 121.00 & \\
\hline \multirow[t]{3}{*}{ Shaft 204} & S791483 & 29-Jun-79 & 14.99 & 0.21 & Non-combustible hot-cell waste & $\begin{array}{l}\text { Cell12 fuel cans 2095+2167 tin cans } \\
\text { in plastic bags }\end{array}$ & U-235 & 4.50 & 50,000 \\
\hline & & & & & & & Pu-239 & 1.50 & \\
\hline & & & & & & & MFP & & \\
\hline \multirow[t]{3}{*}{ Shaft 204} & S794222 & 29-Jun-79 & 16.10 & & & $\begin{array}{l}\text { Cell } 12 \text { fuel cans } 1790+1815 \\
100,000 \mathrm{hr} \text { at } 1 \text { meter }\end{array}$ & $\mathrm{Pu}-239$ & 4.75 & 0 \\
\hline & & & & & & & U-235 & 19.00 & \\
\hline & & & & & & & MFP & & \\
\hline \multirow[t]{3}{*}{ Shaft 204} & S794223 & 29-Jun-79 & 20.07 & 0.21 & Non-combustible hot-cell waste & $\begin{array}{l}\text { Cell } 9 \text { trash in } 1 \text { gal. Disposable } \\
\text { cans in plastic bag, cans } 1786+ \\
1813\end{array}$ & $\mathrm{U}-235$ & 43.80 & 0 \\
\hline & & & & & & & MFP & & \\
\hline & & & & & & & Pu-239 & 16.50 & \\
\hline \multirow[t]{3}{*}{ Shaft 205} & S801483 & 1-Dec-80 & 20.00 & 0.18 & Non-combustible hot-cell waste & $\begin{array}{l}\text { Cell } 9 \text { trash cans } 2875,2926+1000 \\
\mathrm{R} / \mathrm{hr} \text { contact } 135 \mathrm{R} / \mathrm{hr} \text { at meter }\end{array}$ & $\mathrm{U}-235$ & 1.00 & 0 \\
\hline & & & & & & & Pu239 & 1.00 & \\
\hline & & & & & & & MFP & & \\
\hline \multirow[t]{3}{*}{ Shaft 205} & S801485 & 1-Dec-80 & 30.01 & & & $\begin{array}{l}\text { Cell } 9 \text { trash can 2928,2930 +1000 } \\
\mathrm{R} / \mathrm{hr} \text { contact } 170 \mathrm{R} / \mathrm{hr} \text { at meter }\end{array}$ & $\mathrm{U}-235$ & 95.00 & 0 \\
\hline & & & & & & & Pu-239 & 25.00 & \\
\hline & & & & & & & MFP & & \\
\hline \multirow[t]{3}{*}{ Shaft 205} & S802244 & 1-Dec-80 & 15.00 & 0.18 & Non-combustible hot-cell waste & $\begin{array}{l}\text { Hotcell } 14 \text { fuel \& trash cans } \\
2574,2577160,000 \mathrm{mR} / \mathrm{hr} \text { at contact }\end{array}$ & U-235 & 20.00 & 0 \\
\hline & & & & & & & $\mathrm{Pu}-239$ & 0.50 & \\
\hline & & & & & & & MFP & & \\
\hline \multirow[t]{3}{*}{ Shaft 205} & S802246 & 1-Dec-80 & 16.00 & & Combustible hot-cell waste & $\begin{array}{l}\text { Cell } 14 \text { fuel can } 2604,2584 \text { surface } \\
\text { reading } 1,000,000 \mathrm{mR} / \mathrm{hr}\end{array}$ & U-235 & 70.00 & 0 \\
\hline & & & & & & & MFP & & \\
\hline & & & & & & & Pu-239 & 17.50 & \\
\hline Shaft 205 & S802247 & 1-Dec-80 & 16.00 & & & $\begin{array}{l}\text { Cell } 14 \text { fuel \& trash cans 2603, } 2602 \\
\text { surface reading 615,000 mR/hr }\end{array}$ & $\mathrm{U}-235$ & 21.00 & 0 \\
\hline
\end{tabular}


Appendix A-2 - Information from the TRU Waste Database for Lined Shafts

\begin{tabular}{|c|c|c|c|c|c|c|c|c|c|}
\hline Location & $\begin{array}{l}\text { Package } \\
\text { ID }\end{array}$ & Date & $\begin{array}{l}\text { Gross } \\
\text { Weight } \\
\text { (lbs) }\end{array}$ & $\begin{array}{l}\text { Volume } \\
\text { (m3) }\end{array}$ & Waste description & Comments & $\begin{array}{l}\text { Radio- } \\
\text { nuclides }\end{array}$ & Grams & $\begin{array}{c}\text { Total } \\
\text { Dose } \\
(\mathrm{mR} / \mathrm{hr})\end{array}$ \\
\hline & & & & & & & Pu-239 & 5.00 & \\
\hline & & & & & & & MFP & & \\
\hline \multirow[t]{3}{*}{ Shaft 205} & S802259 & 1-Dec-80 & 15.00 & 0.18 & Combustible hot-cell waste & $\begin{array}{l}\text { Cell waste cans 2642,2669 cell } 9 \\
1000 \mathrm{R} / \mathrm{hr} \text { plus bottom entry }\end{array}$ & $\mathrm{U}-235$ & 39.00 & 0 \\
\hline & & & & & & & MFP & & \\
\hline & & & & & & & Pu-239 & 12.00 & \\
\hline \multirow[t]{3}{*}{ Shaft 205} & S802287 & 1-Dec-80 & 20.00 & & Non-combustible hot-cell waste & $\begin{array}{l}\text { Hot trash cell } 9 \text { cans } 2785,2646 \\
+1000 \mathrm{R} / \mathrm{hr} \text { contact } 520 \mathrm{R} / \mathrm{hr} \text { at one } \\
\text { meter }\end{array}$ & U-235 & 23.60 & 0 \\
\hline & & & & & & & MFP & & \\
\hline & & & & & & & Pu-239 & 57.00 & \\
\hline \multirow[t]{3}{*}{ Shaft 206} & S812291 & 1-Apr-81 & 10.00 & 0.21 & Combustible hot-cell waste & $\begin{array}{l}\text { Cell } 1315 \text { met samples cans } 2805 \\
2806 \text { bottom entry 1000+R/hr @ } \\
\text { contact }\end{array}$ & $\mathrm{U}-235$ & 321.00 & 0 \\
\hline & & & & & & & MFP & & \\
\hline & & & & & & & Pu-239 & 123.00 & \\
\hline \multirow[t]{3}{*}{ Shaft 206} & S812292 & 1-Apr-81 & 10.00 & & & $\begin{array}{l}\text { Cell 13,15 met samples cans } 2801 \\
2804 \text { bottom entry } 1000+R / h r \text { at } \\
\text { contact }\end{array}$ & U-235 & 269.00 & 0 \\
\hline & & & & & & & Pu-239 & 100.00 & \\
\hline & & & & & & & MFP & & \\
\hline \multirow[t]{3}{*}{ Shaft 206} & S812293 & 1-Apr-81 & 20.00 & 0.21 & Non-combustible hot-cell waste & $\begin{array}{l}\text { Cell waste cans } 24542812 \text { cell } 14 \\
1050 \mathrm{R} / \mathrm{hr} \text { contact } 108 \mathrm{R} / \mathrm{hr} \text { meter }\end{array}$ & $\mathrm{Pu}-239$ & 7.00 & 0 \\
\hline & & & & & & & U-235 & 28.00 & \\
\hline & & & & & & & MFP & & \\
\hline \multirow[t]{3}{*}{ Shaft 206} & S812297 & 14-Apr-81 & 20.00 & 0.21 & Non-combustible hot-cell waste & $\begin{array}{l}\text { Cell } 14 \text { trash \& fuel \#2829 } 2807 \\
+1000 \mathrm{R} / \mathrm{hr} \text { contact } 100 \mathrm{R} / \mathrm{hr} \text { at meter }\end{array}$ & $\mathrm{U}-235$ & 86.00 & 0 \\
\hline & & & & & & & Pu-239 & 22.00 & \\
\hline & & & & & & & MFP & & \\
\hline \multirow[t]{3}{*}{ Shaft 206} & S812298 & 1-Apr-81 & 20.00 & 0.21 & Non-combustible hot-cell waste & $\begin{array}{l}\text { Cell } 14 \text { trash \& fuel \#2826 \& } 2827 \\
1000 \mathrm{R} / \mathrm{hr} \text { at contact } 100 \mathrm{R} / \mathrm{hr} \text { at } \\
\text { meter }\end{array}$ & U-235 & 86.00 & 0 \\
\hline & & & & & & & MFP & & \\
\hline & & & & & & & Pu-239 & 22.00 & \\
\hline
\end{tabular}


Appendix A-2 - Information from the TRU Waste Database for Lined Shafts

\begin{tabular}{|c|c|c|c|c|c|c|c|c|c|}
\hline Location & $\begin{array}{l}\text { Package } \\
\text { ID }\end{array}$ & Date & $\begin{array}{l}\text { Gross } \\
\text { Weight } \\
\text { (lbs) }\end{array}$ & $\begin{array}{c}\text { Volume } \\
\text { (m3) }\end{array}$ & Waste description & Comments & $\begin{array}{c}\text { Radio- } \\
\text { nuclides }\end{array}$ & Grams & $\begin{array}{l}\text { Total } \\
\text { Dose } \\
(\mathrm{mR} / \mathrm{hr})\end{array}$ \\
\hline \multirow[t]{3}{*}{ Shaft 206} & S812302 & 1-Apr-81 & 14.00 & 0.21 & Combustible hot-cell waste & $\begin{array}{l}\text { Cell 13\&9 hot trash cans } 28832865 \\
1010+\mathrm{R} / \mathrm{hr} \text { at contact }\end{array}$ & Pu-239 & 8.00 & 0 \\
\hline & & & & & & & MFP & & \\
\hline & & & & & & & U-235 & 23.00 & \\
\hline \multirow[t]{3}{*}{ Shaft 206} & S812303 & 1-Apr-81 & 14.00 & & & $\begin{array}{l}\text { Cell } 13 \& 9 \text { hot trash cans } 2883 \\
28651010+\mathrm{R} / \mathrm{hr} \text { at contact }\end{array}$ & U-235 & 23.00 & 0 \\
\hline & & & & & & & $\mathrm{Pu}-239$ & 8.00 & \\
\hline & & & & & & & MFP & & \\
\hline \multirow[t]{3}{*}{ Shaft 207} & S811397 & 29-May-81 & 16.00 & 0.24 & Combustible hot-cell waste & $\begin{array}{l}\text { Cell } 13 \text { grinding papers kimwipes } \\
\text { plastic plastic can nos } 3069 \text { and } \\
3055\end{array}$ & U-235 & 0.40 & 60,000 \\
\hline & & & & & & & MFP & & \\
\hline & & & & & & & Pu-239 & 0.10 & \\
\hline \multirow[t]{3}{*}{ Shaft 207} & S811400 & 29-May-81 & 16.00 & 0.24 & Combustible hot-cell waste & $\begin{array}{l}\text { Glass paper etc can 3046,6060 cell } \\
14290,000 \mathrm{mR} / \mathrm{nr} \text { surface }\end{array}$ & U-235 & 0.40 & 0 \\
\hline & & & & & & & Pu-239 & 0.10 & \\
\hline & & & & & & & MFP & & \\
\hline \multirow[t]{3}{*}{ Shaft 207} & S811401 & 29-May-81 & 16.00 & 0.24 & Combustible hot-cell waste & $\begin{array}{l}\text { Cell } 14 \text { can } 3065 \text { fuel plastic bottles } \\
\text { cell } 16 \text { cam 3067,170,000 mR/hr }\end{array}$ & U-235 & 4.24 & 0 \\
\hline & & & & & & & Pu-239 & 1.06 & \\
\hline & & & & & & & MFP & & \\
\hline \multirow[t]{3}{*}{ Shaft 207} & S811406 & 29-May-81 & 16.00 & 0.24 & Combustible hot-cell waste & $\begin{array}{l}\text { Cell } 13 \text { grinding papers kimwipes } \\
\text { plastic cans 3103,3101,150,000 } \\
\text { mR/a }\end{array}$ & U-235 & 0.40 & 0 \\
\hline & & & & & & & Pu239 & 0.10 & \\
\hline & & & & & & & MFP & & \\
\hline \multirow[t]{3}{*}{ Shaft 207} & S814978 & 29-May-81 & 12.00 & 0.37 & Combustible hot-cell waste & $\begin{array}{l}\text { Cell } 15 \text { wipes, polishing cloths } \\
\text { plastic cans 3104,3097,3099-also } \\
\text { fpr, } 4979\end{array}$ & U-235 & 0.24 & 3,600 \\
\hline & & & & & & & Pu-239 & 0.06 & \\
\hline & & & & & & & MFP & & \\
\hline \multirow[t]{3}{*}{ Shaft 208} & S810794 & 22-Jun-81 & 16.00 & 0.22 & Combustible hot-cell waste & $\begin{array}{l}\text { Cell } 913 \text { fuel trash cans } 31233126 \\
1000+\mathrm{R} / \mathrm{hr} \text { contact } 100 \mathrm{R} / \mathrm{hr} \text { meter }\end{array}$ & U-235 & 101.50 & 0 \\
\hline & & & & & & & MFP & & \\
\hline & & & & & & & $\mathrm{Pu}-239$ & 28.50 & \\
\hline
\end{tabular}


Appendix A-2 - Information from the TRU Waste Database for Lined Shafts

\begin{tabular}{|c|c|c|c|c|c|c|c|c|c|}
\hline Location & $\begin{array}{l}\text { Package } \\
\text { ID }\end{array}$ & Date & $\begin{array}{l}\text { Gross } \\
\text { Weight } \\
\text { (lbs) }\end{array}$ & $\begin{array}{c}\text { Volume } \\
(\mathrm{m} 3)\end{array}$ & Waste description & Comments & $\begin{array}{c}\text { Radio- } \\
\text { nuclides }\end{array}$ & Grams & $\begin{array}{c}\text { Total } \\
\text { Dose } \\
\text { (mR/hr) } \\
\end{array}$ \\
\hline \multirow[t]{3}{*}{ Shaft 208} & S810802 & 22-Jun-81 & 5.00 & 0.11 & Combustible hot-cell waste & Cell 13 hot trash can 3119 & U-235 & 0.40 & 1,000 \\
\hline & & & & & & & Pu-239 & 0.10 & \\
\hline & & & & & & & MFP & & \\
\hline \multirow[t]{3}{*}{ Shaft 208} & S811405 & 22-Jun-81 & 16.00 & 0.22 & Combustible hot-cell waste & $\begin{array}{l}\text { Cell } 13 \text { catch pans, grinding } \\
\text { paper,towel plastic cans } 30963102\end{array}$ & U-235 & 2.00 & 80,000 \\
\hline & & & & & & & MFP & & \\
\hline & & & & & & & $\mathrm{Pu}-239$ & 0.50 & \\
\hline \multirow[t]{3}{*}{ Shaft 208} & S811408 & 22-Jun-81 & 8.00 & 0.11 & Combustible hot-cell waste & $\begin{array}{l}\text { Cell } 15 \text { wipbs polishing clothes } \\
\text { plastics can } 3093\end{array}$ & U-235 & 0.40 & 1,500 \\
\hline & & & & & & & MFP & & \\
\hline & & & & & & & Pu-239 & 1.61 & \\
\hline \multirow[t]{3}{*}{ Shaft 208} & S811409 & 22-Jun-81 & 16.00 & 0.22 & Combustible hot-cell waste & $\begin{array}{l}\text { Cells } 13 \text { catch pans fuel grinding } \\
\text { papers plastic cans } 30923110\end{array}$ & $\mathrm{U}-235$ & 0.40 & 32,000 \\
\hline & & & & & & & $\mathrm{Pu}-239$ & 0.10 & \\
\hline & & & & & & & MFP & & \\
\hline \multirow[t]{3}{*}{ Shaft 208} & S811411 & 22-Jun-81 & 16.00 & & & $\begin{array}{l}\text { Cell } 13 \text { grinding paper plastic } \\
\text { towels plastic cans } 30943116\end{array}$ & U-235 & 0.40 & 29,000 \\
\hline & & & & & & & MFP & & \\
\hline & & & & & & & Pu-239 & 0.10 & \\
\hline \multirow[t]{3}{*}{ Shaft 208} & S814979 & 22-Jun-81 & 8.00 & & & $\begin{array}{l}\text { Cell } 15 \text { wipes, polishing cloths } \\
\text { plastic cans 3100,3109 - see form } \\
\text { S814978 }\end{array}$ & $\mathrm{U}-235$ & 0.16 & 2,400 \\
\hline & & & & & & & Pu-239 & 0.04 & \\
\hline & & & & & & & MFP & & \\
\hline \multirow[t]{2}{*}{ Shaft 209} & S810795 & 22-Jun-81 & 16.00 & & & $\begin{array}{l}\text { Cell } 13 \text { trash plastic paint } \\
\text { vermiculite plastic cans paint } \\
\text { vermiculite }\end{array}$ & U-235 & 0.40 & 15,000 \\
\hline & & & & & & & & & \\
\hline \multirow[t]{3}{*}{ Shaft 209} & S810797 & 22-Jun-81 & 16.00 & & & $\begin{array}{l}\text { Cell } 15 \text { trash wipes chips plastic } \\
\text { cans } 3118 \& 3129\end{array}$ & U-235 & 0.40 & 2,800 \\
\hline & & & & & & & Pu-239 & 0.10 & \\
\hline & & & & & & & MFP & & \\
\hline Shaft 209 & S810798 & 22-Jun-81 & 16.00 & & & Cell 15 vermiculite wipes plastic & U-235 & 0.40 & 1,600 \\
\hline
\end{tabular}


Appendix A-2 - Information from the TRU Waste Database for Lined Shafts

\begin{tabular}{|c|c|c|c|c|c|c|c|c|c|}
\hline Location & $\begin{array}{c}\text { Package } \\
\text { ID }\end{array}$ & Date & $\begin{array}{c}\text { Gross } \\
\text { Weight } \\
\text { (lbs) }\end{array}$ & $\begin{array}{c}\text { Volume } \\
\text { (m3) }\end{array}$ & Waste description & Comments & $\begin{array}{c}\text { Radio- } \\
\text { nuclides }\end{array}$ & Grams & $\begin{array}{c}\text { Total } \\
\text { Dose } \\
\text { (mR/hr) }\end{array}$ \\
\hline & & & & & & " paint plastic cans 31113114 & & & \\
\hline & & & & & & & $\mathrm{Pu}-239$ & 0.10 & \\
\hline & & & & & & & MFP & & \\
\hline \multirow[t]{3}{*}{ Shaft 209} & S810799 & 22-Jun-81 & 30.01 & 0.45 & Combustible hot-cell waste & $\begin{array}{l}\text { Cell } 15 \text { trash cans } 212531083117 \\
3130\end{array}$ & U-235 & 0.40 & 5,000 \\
\hline & & & & & & & $\mathrm{Pu}-239$ & 0.10 & \\
\hline & & & & & & & MFP & & \\
\hline \multirow[t]{3}{*}{ Shaft 209} & S811412 & 22-Jun-81 & 16.00 & 0.22 & Combustible hot-cell waste & $\begin{array}{l}\text { Cell } 13 \text { grinding papers plastic glass } \\
\text { plastic cans } 30913115\end{array}$ & U-235 & 0.40 & 90,000 \\
\hline & & & & & & & $\mathrm{Pu}-239$ & 0.10 & \\
\hline & & & & & & & MFP & & \\
\hline \multirow[t]{3}{*}{ Shaft 210} & S810800 & 22-Jun-81 & 0.00 & & & Cell 13,15 hot trash cans 3145,3147 & MFP & & 10,000 \\
\hline & & & & & & & U-235 & 0.40 & \\
\hline & & & & & & & Pu-239 & 0.10 & \\
\hline \multirow[t]{3}{*}{ Shaft 210} & S810804 & 22-Jun-81 & 0.00 & 0.45 & Combustible hot-cell waste & $\begin{array}{l}\text { Cell 13,150hot trash cans } \\
3139,3133,3135 \text { cans, } 3132\end{array}$ & U-235 & 0.40 & 4,000 \\
\hline & & & & & & & $\mathrm{Pu}-239$ & 0.10 & \\
\hline & & & & & & & MFP & & \\
\hline \multirow[t]{3}{*}{ Shaft 210} & S810805 & 22-Jun-81 & 35.01 & & & $\begin{array}{l}\text { Cell } 1315 \text { hot trash cans } 31433146 \\
29693151 \text { in suitcase cask }\end{array}$ & MFP & & 5,000 \\
\hline & & & & & & & Pu-239 & 0.10 & \\
\hline & & & & & & & U-235 & 0.40 & \\
\hline \multirow[t]{3}{*}{ Shaft 210} & S810806 & 22-Jun-81 & 16.00 & 0.22 & Combustible hot-cell waste & Cell 1315 hot trash cans 31503153 & U-235 & 0.40 & 300 \\
\hline & & & & & & & Pu-239 & 0.10 & \\
\hline & & & & & & & MFP & & \\
\hline \multirow[t]{3}{*}{ Shaft 211} & S810807 & 6-Oct-81 & 880.15 & 0.22 & Combustible hot-cell waste & $\begin{array}{l}\text { Cell } 13 \text { \& } 15 \text { hot trash cans plastic } \\
31453147\end{array}$ & U-235 & 0.40 & 16,000 \\
\hline & & & & & & & MFP & & \\
\hline & & & & & & & Pu-239 & 0.10 & \\
\hline \multirow[t]{3}{*}{ Shaft 211} & S810808 & 6-Oct-81 & 880.15 & 0.22 & Combustible hot-cell waste & $\begin{array}{l}\text { Cell } 14 \text { cans } 31583159 \text { hot trash } \\
\text { glass } 126 \text { rat contact plastic paper }\end{array}$ & U-235 & 0.40 & 0 \\
\hline & & & & & & & Pu-239 & 0.10 & \\
\hline & & & & & & & MFP & & \\
\hline Shaft 211 & S810809 & 6-Oct-81 & 880.15 & 0.22 & Combustible hot-cell waste & Cell 13 trash catch pans, plastic & U-235 & 0.40 & 0 \\
\hline
\end{tabular}


Appendix A-2 - Information from the TRU Waste Database for Lined Shafts

\begin{tabular}{|c|c|c|c|c|c|c|c|c|c|}
\hline Location & $\begin{array}{l}\text { Package } \\
\text { ID }\end{array}$ & Date & $\begin{array}{l}\text { Gross } \\
\text { Weight } \\
\text { (lbs) }\end{array}$ & $\begin{array}{c}\text { Volume } \\
\text { (m3) }\end{array}$ & Waste description & Comments & $\begin{array}{c}\text { Radio- } \\
\text { nuclides }\end{array}$ & Grams & $\begin{array}{l}\text { Total } \\
\text { Dose } \\
(\mathrm{mR} / \mathrm{hr})\end{array}$ \\
\hline & & & & & & $\begin{array}{l}\text { wipes plastic cans } 31623167 \\
\text { 160R/hr @ c }\end{array}$ & & & \\
\hline & & & & & & & MFP & & \\
\hline & & & & & & & $\mathrm{Pu}-239$ & 0.10 & \\
\hline \multirow[t]{3}{*}{ Shaft 211} & S810810 & 6-Oct-81 & 880.15 & 0.44 & Combustible hot-cell waste & $\begin{array}{l}\text { Cell } 15 \text { cold trash plastics, bottles } \\
\text { wipes can } 3160316131683169\end{array}$ & $\mathrm{U}-235$ & 0.40 & 1,000 \\
\hline & & & & & & & Pu-239 & 0.10 & \\
\hline & & & & & & & MFP & & \\
\hline \multirow[t]{3}{*}{ Shaft 211} & S812669 & 6-Oct-81 & 880.15 & 0.22 & Combustible hot-cell waste & $\begin{array}{l}\text { Cell } 14 \text { cans } 31783179 \text { fuel am } \\
\text { glass etc } 940 \mathrm{R} / \mathrm{hr} \text { contact }\end{array}$ & $\mathrm{U}-235$ & 26.00 & 0 \\
\hline & & & & & & & Pu-239 & 6.56 & \\
\hline & & & & & & & MFP & & \\
\hline \multirow[t]{2}{*}{ Shaft 212} & S803758 & 9-Apr-80 & 16002.57 & 2.10 & Non-pn equipment & $\begin{array}{l}\text { Lampre reactor vessel sealed in cask } \\
\text { vessel in } 1 / 4 \text { steel cask with conc }\end{array}$ & Co-60 & 0.03 & 1,750 \\
\hline & & & & & & & Pu-239 & 200.00 & \\
\hline \multirow[t]{3}{*}{ Shaft 213} & S812684 & 3-Nov-81 & 16.00 & 0.21 & Non-combustible hot-cell waste & $\begin{array}{l}\text { Cell } 9 \text { and cell } 16 \text { waste and fuel } \\
\text { plastic cans } 32481000+\mathrm{R} / \mathrm{hr} \text { surf }\end{array}$ & $\mathrm{Pu}-239$ & 32.58 & 0 \\
\hline & & & & & & & MFP & & \\
\hline & & & & & & & U-235 & 138.00 & \\
\hline \multirow[t]{3}{*}{ Shaft 213} & S812686 & 3-Nov-81 & 16.00 & 0.21 & Non-combustible hot-cell waste & $\begin{array}{l}\text { Cell } 14 \text { fuel glass towels cans } 3246 \\
3245500 \mathrm{R} \text { at contact }\end{array}$ & U-235 & 17.30 & 0 \\
\hline & & & & & & & $\mathrm{Pu}-239$ & 4.33 & \\
\hline & & & & & & & MFP & & \\
\hline \multirow[t]{3}{*}{ Shaft 213} & S812688 & 3-Nov-81 & 16.00 & 0.21 & Non-combustible hot-cell waste & $\begin{array}{l}\text { Cell } 9 \text { and } 13 \text { fuel and hot trash } \\
101,000 \mathrm{mR} / \mathrm{hr} @ 1 \mathrm{~m} \text { cans } \\
3273 / 3274\end{array}$ & $\mathrm{U}-235$ & 77.94 & 0 \\
\hline & & & & & & & Pu-239 & 12.82 & \\
\hline & & & & & & & MFP & & \\
\hline \multirow[t]{3}{*}{ Shaft 213} & S812689 & 3-Nov-81 & 16.00 & & & $\begin{array}{l}\text { Cell } 13 \text { and } 14 \text { waste cans } 3266 \\
3272 \text { 160R/hr @ contact }\end{array}$ & MFP & & 0 \\
\hline & & & & & & & Pu-239 & 0.20 & \\
\hline & & & & & & & U-235 & 1.00 & \\
\hline \multirow[t]{2}{*}{ Shaft 214} & S820057 & 20-Apr-82 & 18.00 & 0.08 & Non-combustible hot-cell waste & $\begin{array}{l}\text { Cell } 16 \text { trash can } 3338 \text { wipes, } \\
\text { glassware lucite can in steel nipple }\end{array}$ & U-235 & 0.40 & 15,000 \\
\hline & & & & & & & MFP & & \\
\hline
\end{tabular}


Appendix A-2 - Information from the TRU Waste Database for Lined Shafts

\begin{tabular}{|c|c|c|c|c|c|c|c|c|c|}
\hline Location & $\begin{array}{c}\text { Package } \\
\text { ID } \\
\end{array}$ & Date & $\begin{array}{c}\text { Gross } \\
\text { Weight } \\
\text { (lbs) } \\
\end{array}$ & $\begin{array}{c}\text { Volume } \\
\text { (m3) }\end{array}$ & Waste description & Comments & $\begin{array}{c}\text { Radio- } \\
\text { nuclides }\end{array}$ & Grams & $\begin{array}{c}\text { Total } \\
\text { Dose } \\
\text { (mR/hr) } \\
\end{array}$ \\
\hline & & & & & & & $\mathrm{Pu}-239$ & 0.10 & \\
\hline \multirow[t]{3}{*}{ Shaft 214} & S820058 & 20-Apr-82 & 22.00 & & & $\begin{array}{l}\text { Cell } 16 \text { trash can } 3351 \text { lucite can in } \\
\text { steel nipple }\end{array}$ & U-235 & 0.40 & 4,000 \\
\hline & & & & & & & $\mathrm{Pu}-239$ & 0.10 & \\
\hline & & & & & & & MFP & & \\
\hline \multirow[t]{3}{*}{ Shaft 214} & S821822 & 21-Apr-82 & 30.01 & 0.17 & Non-combustible hot-cell waste & $\begin{array}{l}\text { Cell } 13 \text { trash can } 3369 \text { plastic bags } \\
\text { and bottles }\end{array}$ & U-235 & 0.40 & 25,000 \\
\hline & & & & & & & MFP & & \\
\hline & & & & & & & $\mathrm{Pu}-239$ & 0.10 & \\
\hline \multirow[t]{3}{*}{ Shaft 214} & S821823 & 21-Apr-82 & 30.01 & & & Cell 13 trash can 3373 & U-235 & 0.40 & 30,000 \\
\hline & & & & & & & Pu-239 & 0.10 & \\
\hline & & & & & & & MFP & & \\
\hline \multirow[t]{3}{*}{ Shaft 214} & S821826 & 23-Apr-82 & 25.00 & 0.17 & Non-combustible hot-cell waste & Cell 14 can 3378 & U-235 & 0.40 & 20,000 \\
\hline & & & & & & & MFP & & \\
\hline & & & & & & & Pu-239 & 0.10 & \\
\hline \multirow[t]{3}{*}{ Shaft 214} & S823410 & 1-Apr-82 & 16.00 & 0.17 & Non-combustible hot-cell waste & $\begin{array}{l}\text { Cell } 13 \text { and } 14 \text { cans 3307,3278 } 110 \\
\text { R/hr contact }\end{array}$ & U-235 & 0.40 & 0 \\
\hline & & & & & & & MFP & & \\
\hline & & & & & & & Pu-239 & 0.10 & \\
\hline \multirow[t]{3}{*}{ Shaft 215} & S820041 & 9-Jun-82 & 18.00 & 0.07 & Non-combustible hot-cell waste & $\begin{array}{l}\text { Cell } 9 \text { fuel can } 33121000+\mathrm{R} / \mathrm{hr} \\
\text { contact }\end{array}$ & U-235 & 71.26 & 0 \\
\hline & & & & & & & Pu-239 & 15.27 & \\
\hline & & & & & & & MFP & & \\
\hline \multirow[t]{3}{*}{ Shaft 215} & S820042 & 9-Jun-82 & 18.00 & & & $\begin{array}{l}\text { Cell } 14 \text { waste can } 3307 \text { 140R/hr } \\
\text { contact }\end{array}$ & U-235 & 0.40 & 0 \\
\hline & & & & & & & Pu-239 & 0.10 & \\
\hline & & & & & & & MFP & & \\
\hline \multirow[t]{3}{*}{ Shaft 215} & S821832 & 9-Jun-82 & 28.01 & 0.14 & Non-combustible hot-cell waste & Cell 11 trash can 3393 lucite can & Pu-239 & 0.10 & 35,000 \\
\hline & & & & & & & MFP & & \\
\hline & & & & & & & U-235 & 0.40 & \\
\hline \multirow[t]{3}{*}{ Shaft 215} & S821833 & 9-Jun-82 & 28.01 & & & $\begin{array}{l}\text { Cell } 11 \text { hot trash can } 3300100 \text { R/hr } \\
\text { contact }\end{array}$ & U-235 & 0.40 & 0 \\
\hline & & & & & & & MFP & & \\
\hline & & & & & & & Pu-239 & 0.10 & \\
\hline
\end{tabular}


Appendix A-2 - Information from the TRU Waste Database for Lined Shafts

\begin{tabular}{|c|c|c|c|c|c|c|c|c|c|}
\hline Location & $\begin{array}{l}\text { Package } \\
\text { ID }\end{array}$ & Date & $\begin{array}{l}\text { Gross } \\
\text { Weight } \\
\text { (lbs) }\end{array}$ & $\begin{array}{c}\text { Volume } \\
\text { (m3) }\end{array}$ & Waste description & Comments & $\begin{array}{c}\text { Radio- } \\
\text { nuclides }\end{array}$ & Grams & $\begin{array}{c}\text { Total } \\
\text { Dose } \\
\text { (mR/hr) } \\
\end{array}$ \\
\hline \multirow[t]{3}{*}{ Shaft 215} & S821834 & 9-Jun-82 & 28.01 & & Combustible hot-cell waste & $\begin{array}{l}\text { Cell } 13 \text { hot trash can } 3397200 \mathrm{R} / \mathrm{hr} \\
\text { contact }\end{array}$ & U-235 & 0.40 & 0 \\
\hline & & & & & & & MFP & & \\
\hline & & & & & & & Pu-239 & 0.10 & \\
\hline \multirow[t]{3}{*}{ Shaft 215} & S821835 & 9-Jun-82 & 28.01 & & Non-combustible hot-cell waste & Cell 13 hot trash can 3383 & U-235 & 0.40 & 40,000 \\
\hline & & & & & & & MFP & & \\
\hline & & & & & & & $\mathrm{Pu}-239$ & 0.10 & \\
\hline \multirow[t]{3}{*}{ Shaft 215} & S821837 & 9-Jun-82 & 28.01 & & Combustible hot-cell waste & Cell 13 hot trash can 3415 & U-235 & 0.40 & 20,000 \\
\hline & & & & & & & Pu-239 & 0.10 & \\
\hline & & & & & & & MFP & & \\
\hline \multirow[t]{3}{*}{ Shaft 216} & S821825 & 9-Jun-82 & 20.00 & 0.14 & Non-combustible hot-cell waste & Cell 14 can 3373 & U-235 & 4.00 & 40,000 \\
\hline & & & & & & & $\mathrm{Pu}-239$ & 1.00 & \\
\hline & & & & & & & MFP & & \\
\hline \multirow[t]{3}{*}{ Shaft 216} & S821836 & 9-Jun-82 & 28.01 & 0.14 & Combustible hot-cell waste & Cell 13 hot trash can 3416 & U-235 & 0.40 & 20,000 \\
\hline & & & & & & & MFP & & \\
\hline & & & & & & & Pu-239 & 0.10 & \\
\hline \multirow[t]{3}{*}{ Shaft 216} & S821838 & 9-Jun-82 & 28.01 & & & Cell 13 hot trash can 3395 & $\mathrm{U}-235$ & 0.40 & 15,000 \\
\hline & & & & & & & $\mathrm{Pu}-239$ & 0.10 & \\
\hline & & & & & & & MFP & & \\
\hline \multirow[t]{3}{*}{ Shaft 216} & S821839 & 9-Jun-82 & 28.01 & & & Cell 13 hot trash can 3405 & U-235 & 0.40 & 8,000 \\
\hline & & & & & & & Pu-239 & 0.10 & \\
\hline & & & & & & & MFP & & \\
\hline \multirow[t]{3}{*}{ Shaft 216} & S821840 & 9-Jun-82 & 28.01 & & & $\begin{array}{l}\text { Cell } 13 \text { hot trash can } 3384 \text { 200R/hr } \\
\text { contact }\end{array}$ & U-235 & 0.40 & 0 \\
\hline & & & & & & & $\mathrm{Pu}-239$ & 0.10 & \\
\hline & & & & & & & MFP & & \\
\hline \multirow[t]{3}{*}{ Shaft 216} & S821841 & 9-Jun-82 & 28.01 & & & Cell 13 hot trash can 3385 & U-235 & 0.40 & 30,000 \\
\hline & & & & & & & Pu-239 & 0.10 & \\
\hline & & & & & & & MFP & & \\
\hline \multirow[t]{3}{*}{ Shaft 217} & S821870 & 13-Sep-82 & 20.00 & 0.14 & Non-combustible hot-cell waste & $\begin{array}{l}\text { Cell } 14 \text { can } 3451 \text { glass, plastic } \\
\text { bottles }\end{array}$ & U-235 & 0.40 & 15,000 \\
\hline & & & & & & & $\mathrm{Pu}-239$ & 0.10 & \\
\hline & & & & & & & MFP & & \\
\hline
\end{tabular}

10 of 23 
Appendix A-2 - Information from the TRU Waste Database for Lined Shafts

\begin{tabular}{|c|c|c|c|c|c|c|c|c|c|}
\hline Location & $\begin{array}{l}\text { Package } \\
\text { ID }\end{array}$ & Date & $\begin{array}{c}\text { Gross } \\
\text { Weight } \\
\text { (lbs) }\end{array}$ & $\begin{array}{c}\text { Volume } \\
(\mathrm{m} 3)\end{array}$ & Waste description & Comments & $\begin{array}{c}\text { Radio- } \\
\text { nuclides }\end{array}$ & Grams & $\begin{array}{c}\text { Total } \\
\text { Dose } \\
\text { (mR/hr) } \\
\end{array}$ \\
\hline \multirow[t]{3}{*}{ Shaft 217} & S821871 & 13-Sep-82 & 38.01 & & Combustible hot-cell waste & $\begin{array}{l}\text { Cell } 14 \text { can } 3452 \text { fuel scrap } \\
100000 \mathrm{mR} / \mathrm{hr} \text { at contact }\end{array}$ & $\mathrm{U}-235$ & 12.87 & 0 \\
\hline & & & & & & & Pu-239 & 3.20 & \\
\hline & & & & & & & MFP & & \\
\hline \multirow[t]{3}{*}{ Shaft 217} & S821874 & 13-Sep-82 & 28.01 & 0.14 & Combustible hot-cell waste & $\begin{array}{l}\text { Cell } 13 \text { hot trash grinding papers, } \\
\text { etc. Bottom entry cask }\end{array}$ & U-235 & 0.40 & 80,000 \\
\hline & & & & & & & MFP & & \\
\hline & & & & & & & $\mathrm{Pu}-239$ & 0.10 & \\
\hline \multirow[t]{3}{*}{ Shaft 217} & S821882 & 13-Sep-82 & 30.01 & & Non-combustible hot-cell waste & Cell 13 trash can 3478 & $\mathrm{U}-235$ & 0.40 & 6,000 \\
\hline & & & & & & & MFP & & \\
\hline & & & & & & & $\mathrm{Pu}-239$ & 0.10 & \\
\hline \multirow[t]{3}{*}{ Shaft 217} & S821915 & 13-Sep-82 & 10.00 & & Combustible hot-cell waste & $\begin{array}{l}\text { Cell } 9 \text { can } 3446 \text { waste fuel \& cell } \\
\text { trash } 1000+\mathrm{R} / \mathrm{hr} \text { contact }\end{array}$ & $\mathrm{U}-235$ & 60.00 & 0 \\
\hline & & & & & & & MFP & & \\
\hline & & & & & & & $\mathrm{Pu}-239$ & 22.81 & \\
\hline \multirow[t]{3}{*}{ Shaft 217} & S821918 & 13-Sep-82 & 38.01 & 0.14 & Combustible hot-cell waste & $\begin{array}{l}\text { Cell } 14 \text { can } 3437 \text { fuel scrap card } \\
\text { boxes } 900 \mathrm{R} / \mathrm{hr} \text { at contact }\end{array}$ & $\mathrm{U}-235$ & 12.87 & 0 \\
\hline & & & & & & & MFP & & \\
\hline & & & & & & & $\mathrm{Pu}-239$ & 3.20 & \\
\hline \multirow[t]{3}{*}{ Shaft 218} & S821875 & 13-Sep-82 & 30.01 & 0.14 & Non-combustible hot-cell waste & $\begin{array}{l}\text { Cell } 9 \text { trash can } 3499300 \text { R @ } \\
\text { contact }\end{array}$ & $\mathrm{U}-235$ & 0.40 & 0 \\
\hline & & & & & & & MFP & & \\
\hline & & & & & & & Pu-239 & 0.10 & \\
\hline \multirow[t]{3}{*}{ Shaft 218} & S821879 & 13-Sep-82 & 30.01 & & & $\begin{array}{l}\text { Cell } 13 \text { trash can } 3477500 \\
\text { R/contact }\end{array}$ & $\mathrm{U}-235$ & 9.00 & 0 \\
\hline & & & & & & & MFP & & \\
\hline & & & & & & & Pu-239 & 2.00 & \\
\hline \multirow[t]{3}{*}{ Shaft 218} & S821881 & 13-Sep-82 & 30.01 & & & $\begin{array}{l}\text { Cell } 13 \text { trash can } 3468 \text { 900R @ } \\
\text { contact }\end{array}$ & $\mathrm{U}-235$ & 9.00 & 0 \\
\hline & & & & & & & MFP & & \\
\hline & & & & & & & Pu-239 & 2.00 & \\
\hline \multirow[t]{2}{*}{ Shaft 218} & S821883 & 13-Sep-82 & 30.01 & & & $\begin{array}{l}\text { Cell } 13 \text { trash can } 3469 \text { 200R/hr at } \\
\text { contact }\end{array}$ & U-235 & 0.40 & 0 \\
\hline & & & & & & & Pu-239 & 0.10 & \\
\hline
\end{tabular}


Appendix A-2 - Information from the TRU Waste Database for Lined Shafts

\begin{tabular}{|c|c|c|c|c|c|c|c|c|c|}
\hline Location & $\begin{array}{l}\text { Package } \\
\text { ID }\end{array}$ & Date & $\begin{array}{c}\text { Gross } \\
\text { Weight } \\
\text { (lbs) }\end{array}$ & $\begin{array}{c}\text { Volume } \\
(\mathrm{m} 3)\end{array}$ & Waste description & Comments & $\begin{array}{c}\text { Radio- } \\
\text { nuclides }\end{array}$ & Grams & $\begin{array}{c}\text { Total } \\
\text { Dose } \\
(\mathrm{mR} / \mathrm{hr})\end{array}$ \\
\hline & & & & & & & MFP & & \\
\hline \multirow[t]{3}{*}{ Shaft 218} & S821916 & 13-Sep-82 & 40.01 & & & $\begin{array}{l}\text { Cropper disposals and fuel can } 3489 \\
1000 \mathrm{R} / \mathrm{hr} \text { at contact }\end{array}$ & U-235 & 82.80 & 0 \\
\hline & & & & & & & $\mathrm{Pu}-239$ & 40.40 & \\
\hline & & & & & & & MFP & & \\
\hline \multirow[t]{3}{*}{ Shaft 218} & S821917 & 13-Sep-82 & 30.01 & & & Cell 9 trash can 5 300R @ contact & MFP & & 0 \\
\hline & & & & & & & U-235 & 0.40 & \\
\hline & & & & & & & $\mathrm{Pu}-239$ & 0.10 & \\
\hline \multirow[t]{3}{*}{ Shaft 219} & S832830 & 10-Mar-83 & 30.01 & 0.14 & Non-combustible hot-cell waste & $\begin{array}{l}\text { Cell } 13 \text { grinding waste can } 3527 \\
1000 \text { R/hr@ contact }\end{array}$ & U-235 & 0.40 & 0 \\
\hline & & & & & & & MFP & & \\
\hline & & & & & & & Pu-239 & 0.10 & \\
\hline \multirow[t]{3}{*}{ Shaft 219} & S832831 & 10-Mar-83 & 30.01 & & & $\begin{array}{l}\text { Cell } 11 \text { trash can } 3727 \text { bottom entry } \\
\text { cask }\end{array}$ & U-235 & 0.40 & 30,000 \\
\hline & & & & & & & $\mathrm{Pu}-239$ & 0.10 & \\
\hline & & & & & & & MFP & & \\
\hline \multirow[t]{3}{*}{ Shaft 219} & S832832 & 10-Mar-83 & 30.01 & & Combustible hot-cell waste & $\begin{array}{l}\text { Cell } 9 \text { fuel and hardware can } 3724 \\
\text { 1000+R@contact 150R @ } 1 \text { meter }\end{array}$ & U-235 & 236.10 & 0 \\
\hline & & & & & & & MFP & & \\
\hline & & & & & & & $\mathrm{Pu}-239$ & 40.47 & \\
\hline \multirow[t]{3}{*}{ Shaft 219} & S832833 & 10-Mar-83 & 30.01 & & & $\begin{array}{l}\text { Cell } 9 \text { waste can } 3725200 \mathrm{R} / \mathrm{hr} \\
\text { contact }\end{array}$ & U-235 & 0.40 & 0 \\
\hline & & & & & & & Pu-239 & 0.10 & \\
\hline & & & & & & & MFP & & \\
\hline \multirow[t]{3}{*}{ Shaft 219} & S832834 & 10-Mar-83 & 30.01 & & Non-combustible hot-cell waste & $\begin{array}{l}\text { Cell } 9 \text { hot trash can } 35241000+\mathrm{R} \\
\text { contact } 50 \mathrm{R} \text { at } 1 \text { meter }\end{array}$ & U-235 & 0.40 & 0 \\
\hline & & & & & & & Pu-239 & 0.10 & \\
\hline & & & & & & & MFP & & \\
\hline \multirow[t]{3}{*}{ Shaft 219} & S832835 & 10-Mar-83 & 30.01 & & & $\begin{array}{l}\text { Cell } 9 \text { hot trash can } 34951000+\mathrm{R} \\
\text { contact } 100 \mathrm{R} \text { at } 1 \text { meter }\end{array}$ & U-235 & 20.18 & 0 \\
\hline & & & & & & & $\mathrm{Pu}-239$ & 4.98 & \\
\hline & & & & & & & MFP & & \\
\hline Shaft 220 & S832836 & 10-Mar-83 & 30.01 & & & $\begin{array}{l}\text { Cell } 9 \text { waste etc can } 3728 \text { 100R/hr } \\
\text { @ } 1 \mathrm{~m} \quad 1000+\mathrm{R} / \mathrm{hr} @ \text { con }\end{array}$ & U-235 & 0.40 & 0 \\
\hline
\end{tabular}


Appendix A-2 - Information from the TRU Waste Database for Lined Shafts

\begin{tabular}{|c|c|c|c|c|c|c|c|c|c|}
\hline Location & $\begin{array}{l}\text { Package } \\
\text { ID }\end{array}$ & Date & $\begin{array}{c}\text { Gross } \\
\text { Weight } \\
\text { (lbs) }\end{array}$ & $\begin{array}{c}\text { Volume } \\
\text { (m3) }\end{array}$ & Waste description & Comments & $\begin{array}{c}\text { Radio- } \\
\text { nuclides }\end{array}$ & Grams & $\begin{array}{c}\text { Total } \\
\text { Dose } \\
\text { (mR/hr) } \\
\end{array}$ \\
\hline & & & & & & & MFP & & \\
\hline & & & & & & & Pu-239 & 0.10 & \\
\hline \multirow[t]{3}{*}{ Shaft 220} & S832837 & 10-Mar-83 & 30.01 & & & $\begin{array}{l}\text { Cell } 9 \text { waste can } 3491 \text { 100R/hr } 1 \mathrm{~m} \\
1000+\mathrm{R} / \mathrm{hr} \text { contact }\end{array}$ & $\mathrm{U}-235$ & 0.40 & 0 \\
\hline & & & & & & & MFP & & \\
\hline & & & & & & & Pu-239 & 0.11 & \\
\hline \multirow[t]{3}{*}{ Shaft 220} & S832838 & 10-Mar-83 & 30.01 & & & $\begin{array}{l}\text { Cell } 11 \text { trash can } 3706100 \mathrm{R} / \mathrm{hr} \\
\text { contact }\end{array}$ & $\mathrm{U}-235$ & 0.40 & 0 \\
\hline & & & & & & & Pu-239 & 0.10 & \\
\hline & & & & & & & MFP & & \\
\hline \multirow[t]{3}{*}{ Shaft 220} & S832839 & 10-Mar-83 & 30.01 & & & $\begin{array}{l}\text { Cell } 13 \text { grinding can } 3528 \text { 200R/hr } \\
\text { contact }\end{array}$ & U-235 & 0.40 & 0 \\
\hline & & & & & & & MFP & & \\
\hline & & & & & & & Pu-239 & 0.10 & \\
\hline \multirow[t]{3}{*}{ Shaft 220} & S832840 & 10-Mar-83 & 30.01 & & Combustible hot-cell waste & $\begin{array}{l}\text { Cell } 13 \text { grinding can } 3522 \text { 200R/hr } 1 \\
\text { m } 1000+\mathrm{R} / \mathrm{hr} \text { contact }\end{array}$ & U-235 & 0.40 & 0 \\
\hline & & & & & & & Pu-239 & 0.10 & \\
\hline & & & & & & & MFP & & \\
\hline \multirow[t]{3}{*}{ Shaft 220} & S832841 & 10-Mar-83 & 30.01 & & & $\begin{array}{l}\text { Cell } 16 \text { wire wrap can } 372650 \mathrm{R} / \mathrm{hr} \\
1 \mathrm{~m} 1000+\mathrm{R} / \mathrm{hr} \text { contact }\end{array}$ & U-235 & 0.40 & 0 \\
\hline & & & & & & & MFP & & \\
\hline & & & & & & & $\mathrm{Pu}-239$ & 0.10 & \\
\hline \multirow[t]{3}{*}{ Shaft 221} & S832842 & 10-Mar-83 & 30.01 & & & $\begin{array}{l}\text { Cell } 1 \text { wire wraps } 3554400 \mathrm{R} / \mathrm{hr} \\
\text { contact }\end{array}$ & U-235 & 0.40 & 0 \\
\hline & & & & & & & $\mathrm{Pu}-239$ & 0.10 & \\
\hline & & & & & & & MFP & & \\
\hline \multirow[t]{3}{*}{ Shaft 221} & S832843 & 10-Mar-83 & 30.01 & & & $\begin{array}{l}\text { Cell } 1 \text { wire wraps } 3507 \text { 1000+ R/hr } \\
\text { contact }\end{array}$ & U-235 & 0.40 & 0 \\
\hline & & & & & & & MFP & & \\
\hline & & & & & & & Pu-239 & 0.10 & \\
\hline \multirow[t]{3}{*}{ Shaft 221} & S832844 & 10-Mar-83 & 30.01 & & & $\begin{array}{l}\text { Cell } 14 \text { hot trash } 3569800 \mathrm{R} / \mathrm{hr} \\
\text { contact }\end{array}$ & $\mathrm{U}-235$ & 0.40 & 0 \\
\hline & & & & & & & MFP & & \\
\hline & & & & & & & Pu-239 & 0.10 & \\
\hline
\end{tabular}


Appendix A-2 - Information from the TRU Waste Database for Lined Shafts

\begin{tabular}{|c|c|c|c|c|c|c|c|c|c|}
\hline Location & $\begin{array}{l}\text { Package } \\
\text { ID }\end{array}$ & Date & $\begin{array}{l}\text { Gross } \\
\text { Weight } \\
\text { (lbs) }\end{array}$ & $\begin{array}{c}\text { Volume } \\
(\mathrm{m} 3)\end{array}$ & Waste description & \begin{tabular}{|c} 
Comments \\
\end{tabular} & $\begin{array}{c}\text { Radio- } \\
\text { nuclides } \\
\end{array}$ & Grams & $\begin{array}{l}\text { Total } \\
\text { Dose } \\
(\mathrm{mR} / \mathrm{hr})\end{array}$ \\
\hline \multirow[t]{3}{*}{ Shaft 221} & S832845 & 10-Mar-83 & 30.01 & & & $\begin{array}{l}\text { Cell } 14 \text { hot trash can } 3722 \text { bottom } \\
\text { entry cask }\end{array}$ & $\mathrm{U}-235$ & 0.40 & 60,000 \\
\hline & & & & & & & MFP & & \\
\hline & & & & & & & Pu-239 & 0.10 & \\
\hline \multirow[t]{3}{*}{ Shaft 221} & S832846 & 10-Mar-83 & 30.01 & & & $\begin{array}{l}\text { Cell } 14 \text { waste can } 3720200 \mathrm{R} / \mathrm{hr} \\
\text { contact }\end{array}$ & $\mathrm{U}-235$ & 0.40 & 0 \\
\hline & & & & & & & MFP & & \\
\hline & & & & & & & $\mathrm{Pu}-239$ & 0.10 & \\
\hline \multirow[t]{3}{*}{ Shaft 221} & S832847 & 10-Mar-83 & 30.01 & & & $\begin{array}{l}\text { Cell } 14 \text { waste can } 3721 \text { 200R/hr } \\
\text { contact }\end{array}$ & $\mathrm{U}-235$ & 0.40 & 0 \\
\hline & & & & & & & Pu-239 & 0.10 & \\
\hline & & & & & & & MFP & & \\
\hline \multirow[t]{3}{*}{ Shaft 222} & S830716 & 14-Dec-83 & 30.01 & 0.15 & Combustible hot-cell waste & $\begin{array}{l}\text { Cell } 14 \text { can } 3712 \text { fuel scrap paper } \\
\text { etc. } 900 \mathrm{R} / \mathrm{hr} \text { contact }\end{array}$ & U-235 & 2.25 & 0 \\
\hline & & & & & & & MFP & & \\
\hline & & & & & & & $\mathrm{Pu}-239$ & 0.56 & \\
\hline \multirow[t]{3}{*}{ Shaft 222} & S830717 & 14-Dec-83 & 30.01 & & & $\begin{array}{l}\text { Cell } 14 \text { can } 3718 \text { fuel scrap paper } \\
\text { etc. } 200 \mathrm{R} / \mathrm{hr} 1 \text { meter }-1000 \mathrm{R} / \mathrm{hr} \\
\text { contact }\end{array}$ & $\mathrm{U}-235$ & 2.25 & 0 \\
\hline & & & & & & & MFP & & \\
\hline & & & & & & & $\mathrm{Pu}-239$ & 0.56 & \\
\hline \multirow[t]{3}{*}{ Shaft 222} & S830781 & 14-Dec-83 & 40.01 & & & $\begin{array}{l}\text { Cell } 14 \text { trash - } 1 \text { can bottom entry } \\
\text { can \#1 }\end{array}$ & U-36 & 0.20 & 20,000 \\
\hline & & & & & & & MFP & & \\
\hline & & & & & & & Pu-53 & 0.05 & \\
\hline \multirow[t]{3}{*}{ Shaft 222} & S830787 & 14-Dec-83 & 40.01 & 0.08 & Combustible hot-cell waste & $\begin{array}{l}\text { Cell } 9 \text { trash - } 1 \text { can bottom entry } \\
\text { steel can \#10 200R/hr }\end{array}$ & $\mathrm{U}-36$ & 0.50 & 0 \\
\hline & & & & & & & Pu-53 & 0.12 & \\
\hline & & & & & & & MFP & & \\
\hline \multirow[t]{3}{*}{ Shaft 222} & S830788 & 14-Dec-83 & 40.01 & 0.15 & Combustible hot-cell waste & $\begin{array}{l}\text { Cell } 14 \text { trash - } 1 \text { can bottom entry } \\
\text { can \#6 100R/hr contact }\end{array}$ & U-36 & 0.50 & 0 \\
\hline & & & & & & & Pu-53 & 0.12 & \\
\hline & & & & & & & MFP & & \\
\hline Shaft 222 & S830789 & 14-Dec-83 & 40.01 & 0.08 & Combustible hot-cell waste & Cell 14 trash - 1 can steel can \#8 & U-36 & 0.40 & 10,000 \\
\hline
\end{tabular}


Appendix A-2 - Information from the TRU Waste Database for Lined Shafts

\begin{tabular}{|c|c|c|c|c|c|c|c|c|c|}
\hline Location & $\begin{array}{l}\text { Package } \\
\text { ID }\end{array}$ & Date & $\begin{array}{c}\text { Gross } \\
\text { Weight } \\
\text { (lbs) }\end{array}$ & $\begin{array}{c}\text { Volume } \\
(\mathrm{m} 3)\end{array}$ & Waste description & Comments & $\begin{array}{c}\text { Radio- } \\
\text { nuclides }\end{array}$ & Grams & $\begin{array}{c}\text { Total } \\
\text { Dose } \\
\text { (mR/hr) } \\
\end{array}$ \\
\hline & & & & & & & MFP & & \\
\hline & & & & & & & $\mathrm{Pu}-53$ & 0.10 & \\
\hline \multirow[t]{3}{*}{ Shaft 222} & S830790 & 14-Dec-83 & 40.01 & & & $\begin{array}{l}\text { Cell } 14 \text { trash - } 1 \text { can steel can \#9 } \\
200 \text { R contact }\end{array}$ & U-36 & 11.64 & 0 \\
\hline & & & & & & & Pu-53 & 2.91 & \\
\hline & & & & & & & MFP & & \\
\hline \multirow[t]{3}{*}{ Shaft 223} & S830782 & 14-Dec-83 & 40.01 & 0.14 & Combustible hot-cell waste & $\begin{array}{l}\text { Cell } 14 \text { trash - } 1 \text { can bottom entry } \\
\text { can \#5 } 100 \text { R contact }\end{array}$ & U-36 & 0.20 & 0 \\
\hline & & & & & & & Pu-53 & 0.05 & \\
\hline & & & & & & & MFP & & \\
\hline \multirow[t]{3}{*}{ Shaft 223} & S830783 & 14-Dec-83 & 40.01 & & & $\begin{array}{l}\text { Cell } 14 \text { trash - } 1 \text { can bottom entry } \\
\text { steel can \#3 }\end{array}$ & U-36 & 0.40 & 25,000 \\
\hline & & & & & & & Pu-53 & 0.10 & \\
\hline & & & & & & & MFP & & \\
\hline \multirow[t]{3}{*}{ Shaft 223} & S830784 & 14-Dec-83 & 40.01 & & & $\begin{array}{l}\text { Cell } 14 \text { trash - } 1 \text { can bottom entry } \\
\text { steel can \#4 }\end{array}$ & U-36 & 0.40 & 30,000 \\
\hline & & & & & & & MFP & & \\
\hline & & & & & & & Pu-53 & 0.10 & \\
\hline \multirow[t]{3}{*}{ Shaft 223} & S830785 & 14-Dec-83 & 40.01 & & & $\begin{array}{l}\text { Cell } 14 \text { trash can - } 1 \text { can bottom } \\
\text { entry steel can \#7 }\end{array}$ & U-36 & 0.40 & 70,000 \\
\hline & & & & & & & Pu-53 & 0.10 & \\
\hline & & & & & & & MFP & & \\
\hline \multirow[t]{3}{*}{ Shaft 223} & S830786 & 14-Dec-83 & 40.01 & & & Cell 14 trash - 1 can steel can \#2 & U-36 & 0.20 & 20,000 \\
\hline & & & & & & & MFP & & \\
\hline & & & & & & & Pu-53 & 0.05 & \\
\hline \multirow[t]{3}{*}{ Shaft 223} & S830791 & 14-Dec-83 & 40.01 & & & $\begin{array}{l}\text { Cell } 16 \text { trash - } 1 \text { can bottom entry } \\
\text { steel can \#11 }\end{array}$ & U-36 & 0.40 & 32,000 \\
\hline & & & & & & & Pu-53 & 0.10 & \\
\hline & & & & & & & MFP & & \\
\hline \multirow[t]{3}{*}{ Shaft 224} & S852326 & 30-Dec-85 & 30.01 & 0.01 & Combustible hot-cell waste & $\begin{array}{l}\text { Cell } 11 \text { waste - plastic can } 4088300 \\
\text { R/hr contact - steel can } 58\end{array}$ & U-235 & 0.40 & 0 \\
\hline & & & & & & & MFP & & \\
\hline & & & & & & & Pu-239 & 0.10 & \\
\hline Shaft 224 & S852328 & 30-Dec-85 & 30.01 & & & Cell 11 waste - plastic can 4097100 & U-235 & 0.40 & 0 \\
\hline
\end{tabular}


Appendix A-2 - Information from the TRU Waste Database for Lined Shafts

\begin{tabular}{|c|c|c|c|c|c|c|c|c|c|}
\hline Location & $\begin{array}{l}\text { Package } \\
\text { ID }\end{array}$ & Date & $\begin{array}{c}\text { Gross } \\
\text { Weight } \\
\text { (lbs) }\end{array}$ & $\begin{array}{c}\text { Volume } \\
(\mathrm{m} 3)\end{array}$ & Waste description & Comments & $\begin{array}{c}\text { Radio- } \\
\text { nuclides }\end{array}$ & Grams & $\begin{array}{c}\text { Total } \\
\text { Dose } \\
\text { (mR/hr) } \\
\end{array}$ \\
\hline & & & & & & R/hr contact - steel can 61 & & & \\
\hline & & & & & & & MFP & & \\
\hline & & & & & & & Pu-239 & 0.10 & \\
\hline \multirow[t]{3}{*}{ Shaft 224} & S852332 & 30-Dec-85 & 30.01 & & & $\begin{array}{l}\text { Cell } 13 \text { waste, plastic can } 4072300 \\
\text { R/hr contact - steel can } 32\end{array}$ & $\mathrm{Pu}-239$ & 0.10 & 0 \\
\hline & & & & & & & MFP & & \\
\hline & & & & & & & U-235 & 0.40 & \\
\hline \multirow[t]{3}{*}{ Shaft 224} & S852804 & 30-Dec-85 & 30.01 & & & $\begin{array}{l}\text { Cell } 14 \text { trash can } 3660 \text { - fuel inside } \\
\text { steel can } 67 \text { - } 100 \mathrm{R} / \mathrm{hr} \text { contact }\end{array}$ & $\mathrm{U}-235$ & 8.70 & 0 \\
\hline & & & & & & & Pu-239 & 3.30 & \\
\hline & & & & & & & MFP & & \\
\hline \multirow[t]{3}{*}{ Shaft 224} & S855064 & 30-Dec-85 & 30.01 & & & $\begin{array}{l}\text { Cell } 14 \text { trash can } 3661 \text { - fuel inside } \\
\text { steel can } 63 \text { - } 100 \mathrm{R} / \mathrm{hr} \text { contact }\end{array}$ & $\mathrm{Pu}-239$ & 3.60 & 0 \\
\hline & & & & & & & MFP & & \\
\hline & & & & & & & U-235 & 14.90 & \\
\hline \multirow[t]{3}{*}{ Shaft 224} & S855065 & 30-Dec-85 & 30.01 & & & $\begin{array}{l}\text { Cell } 14 \text { trash, plastic can } 3662 \text {, fuel } \\
\text { steel can } 66 \text { - } 300 \mathrm{R} / \mathrm{hr} \text { contact }\end{array}$ & $\mathrm{U}-235$ & 14.90 & 0 \\
\hline & & & & & & & MFP & & \\
\hline & & & & & & & Pu-239 & 3.60 & \\
\hline \multirow[t]{3}{*}{ Shaft 224} & S855066 & 30-Dec-85 & 30.01 & & & $\begin{array}{l}\text { Cell } 14 \text { trash can } 3663 \text { - trash only } \\
\text { steel can } 65\end{array}$ & $\mathrm{U}-235$ & 0.40 & 70,000 \\
\hline & & & & & & & MFP & & \\
\hline & & & & & & & Pu-239 & 0.10 & \\
\hline \multirow[t]{3}{*}{ Shaft 224} & S855068 & 30-Dec-85 & 30.01 & & & $\begin{array}{l}\text { Cell } 14 \text { trash can } 3664 \text { - fuel inside } \\
\text { steel can } 64\end{array}$ & $\mathrm{U}-235$ & 0.40 & 20,000 \\
\hline & & & & & & & MFP & & \\
\hline & & & & & & & Pu-239 & 0.10 & \\
\hline \multirow[t]{3}{*}{ Shaft 225} & S840848 & 31-Dec-84 & 30.01 & 0.01 & Combustible hot-cell waste & $\begin{array}{l}\text { Cell } 13 \text { waste - plastic can } 4076 \\
\text { steel can } 21\end{array}$ & U-235 & 0.40 & 40,000 \\
\hline & & & & & & & $\mathrm{Pu}-239$ & 0.10 & \\
\hline & & & & & & & MFP & & \\
\hline \multirow[t]{2}{*}{ Shaft 225} & S840854 & 31-Dec-84 & 30.01 & & & $\begin{array}{l}\text { Cell } 13 \text { waste - plastic can } 4033 \\
\text { steel can } 24\end{array}$ & $\mathrm{U}-235$ & 0.40 & 50,000 \\
\hline & & & & & & & MFP & & \\
\hline
\end{tabular}


Appendix A-2 - Information from the TRU Waste Database for Lined Shafts

\begin{tabular}{|c|c|c|c|c|c|c|c|c|c|}
\hline Location & $\begin{array}{l}\text { Package } \\
\text { ID }\end{array}$ & Date & $\begin{array}{c}\text { Gross } \\
\text { Weight } \\
\text { (lbs) }\end{array}$ & $\begin{array}{l}\text { Volume } \\
\text { (m3) }\end{array}$ & Waste description & Comments & $\begin{array}{c}\text { Radio- } \\
\text { nuclides }\end{array}$ & Grams & $\begin{array}{c}\text { Total } \\
\text { Dose } \\
(\mathrm{mR} / \mathrm{hr})\end{array}$ \\
\hline & & & & & & & Pu-239 & 0.10 & \\
\hline \multirow[t]{3}{*}{ Shaft 225} & S840856 & 31-Dec-84 & 30.01 & & & $\begin{array}{l}\text { Cell } 13 \text { waste - plastic can } 4043 \\
\text { steel can } 31\end{array}$ & U-235 & 0.40 & 90,000 \\
\hline & & & & & & & Pu-239 & 0.10 & \\
\hline & & & & & & & MFP & & \\
\hline \multirow[t]{3}{*}{ Shaft 225} & S840857 & 31-Dec-84 & 30.01 & & & $\begin{array}{l}\text { Cell } 13 \text { waste - plastic can } 4035105 \\
\text { R/hr contact - steel can } 30\end{array}$ & U-235 & 0.40 & 0 \\
\hline & & & & & & & Pu-239 & 0.10 & \\
\hline & & & & & & & MFP & & \\
\hline \multirow[t]{3}{*}{ Shaft 225} & S840863 & 31-Dec-84 & 30.01 & & & $\begin{array}{l}\text { Cell } 13 \text { waste - plastic can } 4046 \\
\text { steel can } 40\end{array}$ & U-235 & 0.40 & 10,000 \\
\hline & & & & & & & Pu-239 & 0.10 & \\
\hline & & & & & & & MFP & & \\
\hline \multirow[t]{3}{*}{ Shaft 225} & S840864 & 31-Dec-84 & 30.01 & & & $\begin{array}{l}\text { Cell } 13 \text { waste - plastic can } 4044 \\
\text { steel can } 34\end{array}$ & U-235 & 0.40 & 25,000 \\
\hline & & & & & & & Pu-239 & 0.10 & \\
\hline & & & & & & & MFP & & \\
\hline \multirow[t]{3}{*}{ Shaft 225} & S840867 & 31-Dec-84 & 30.01 & & & $\begin{array}{l}\text { Cell } 13 \text { waste - plastic can } 4054 \\
\text { steel can } 38\end{array}$ & U-235 & 0.40 & 30,000 \\
\hline & & & & & & & Pu-239 & 0.10 & \\
\hline & & & & & & & MFP & & \\
\hline \multirow[t]{3}{*}{ Shaft 225} & S840874 & 31-Dec-84 & 30.01 & & & Cell 14 trash can 4051 steel can 43 & $\mathrm{U}-235$ & 0.40 & 15,000 \\
\hline & & & & & & & Pu-239 & 0.10 & \\
\hline & & & & & & & MFP & & \\
\hline \multirow[t]{3}{*}{ Shaft 226} & S840842 & 31-Dec-84 & 30.01 & & & $\begin{array}{l}\text { Cell } 13 \text { waste - plastic can } 4056 \\
\text { steel can } 20\end{array}$ & U-235 & 0.40 & 90,000 \\
\hline & & & & & & & $\mathrm{Pu}-239$ & 0.10 & \\
\hline & & & & & & & MFP & & \\
\hline \multirow[t]{3}{*}{ Shaft 226} & S840843 & 31-Dec-84 & 30.01 & & & $\begin{array}{l}\text { Cell } 13 \text { waste - plastic can } 4045 \\
\text { steel can } 26\end{array}$ & U-235 & 0.40 & 80,000 \\
\hline & & & & & & & $\mathrm{Pu}-239$ & 0.10 & \\
\hline & & & & & & & MFP & & \\
\hline Shaft 226 & S840844 & 31-Dec-84 & 30.01 & & & $\begin{array}{l}\text { Cell } 13 \text { waste - plastic can } 4023 \\
\text { steel can } 19\end{array}$ & U-235 & 0.40 & 70,000 \\
\hline
\end{tabular}


Appendix A-2 - Information from the TRU Waste Database for Lined Shafts

\begin{tabular}{|c|c|c|c|c|c|c|c|c|c|}
\hline Location & $\begin{array}{l}\text { Package } \\
\text { ID }\end{array}$ & Date & $\begin{array}{c}\text { Gross } \\
\text { Weight } \\
\text { (lbs) }\end{array}$ & $\begin{array}{c}\text { Volume } \\
\text { (m3) }\end{array}$ & Waste description & Comments & $\begin{array}{c}\text { Radio- } \\
\text { nuclides }\end{array}$ & Grams & $\begin{array}{c}\text { Total } \\
\text { Dose } \\
\text { (mR/hr) } \\
\end{array}$ \\
\hline & & & & & & & Pu-239 & 0.10 & \\
\hline & & & & & & & MFP & & \\
\hline \multirow[t]{3}{*}{ Shaft 226} & S840845 & 31-Dec-84 & 30.01 & & & $\begin{array}{l}\text { Cell } 13 \text { waste - plastic can } 4034 \\
\text { steel can } 22\end{array}$ & U-235 & 0.40 & 21,000 \\
\hline & & & & & & & Pu-239 & 0.10 & \\
\hline & & & & & & & MFP & & \\
\hline \multirow[t]{3}{*}{ Shaft 226} & S840846 & 31-Dec-84 & 30.01 & & & $\begin{array}{l}\text { Cell } 13 \text { waste - plastic can } 4024300 \\
\text { R/hr contact - steel can } 25\end{array}$ & MFP & & 0 \\
\hline & & & & & & & Pu-239 & 0.10 & \\
\hline & & & & & & & U-235 & 0.40 & \\
\hline \multirow[t]{3}{*}{ Shaft 226} & S840847 & 31-Dec-84 & 30.00 & & & $\begin{array}{l}\text { Cell } 13 \text { waste - plastic can } 4022 \\
\text { steel can } 23\end{array}$ & U-235 & 0.40 & 70,000 \\
\hline & & & & & & & MFP & & \\
\hline & & & & & & & Pu-239 & 0.10 & \\
\hline \multirow[t]{3}{*}{ Shaft 226} & S840862 & 31-Dec-84 & 30.01 & & & $\begin{array}{l}\text { Cell } 13 \text { waste - plastic can } 4027 \\
\text { steel can } 39\end{array}$ & U-235 & 0.40 & 15,000 \\
\hline & & & & & & & Pu-239 & 0.10 & \\
\hline & & & & & & & MFP & & \\
\hline \multirow[t]{3}{*}{ Shaft 226} & S840868 & 31-Dec-84 & 30.01 & & & $\begin{array}{l}\text { Cell } 13 \text { waste - plastic can } 4025 \\
\text { steel can } 35\end{array}$ & U-235 & 0.40 & 35,000 \\
\hline & & & & & & & Pu-239 & 0.10 & \\
\hline & & & & & & & MFP & & \\
\hline \multirow[t]{3}{*}{ Shaft 227} & S840877 & 31-Dec-84 & 30.01 & & & $\begin{array}{l}\text { Cell } 14 \text { trash can } 4050 \text { - fuel inside } \\
\text { steel can } 42\end{array}$ & U-235 & 8.90 & 80,000 \\
\hline & & & & & & & $\mathrm{Pu}-239$ & 2.20 & \\
\hline & & & & & & & MFP & & \\
\hline \multirow[t]{3}{*}{ Shaft 227} & S840878 & 31-Dec-84 & 30.01 & & & $\begin{array}{l}\text { Cell } 14 \text { trash can } 4042 \text { - fuel inside } \\
250 \mathrm{R} / \mathrm{hr} \text { contact - steel can } 46\end{array}$ & U-235 & 14.40 & 0 \\
\hline & & & & & & & MFP & & \\
\hline & & & & & & & Pu-239 & 3.10 & \\
\hline \multirow[t]{3}{*}{ Shaft 227} & S840879 & 31-Dec-84 & 30.01 & & & $\begin{array}{l}\text { Cell } 14 \text { trash can } 4041 \text { - fuel inside } \\
300 \mathrm{R} / \mathrm{hr} \text { contact - steel can } 44\end{array}$ & U-235 & 14.40 & 0 \\
\hline & & & & & & & MFP & & \\
\hline & & & & & & & Pu-239 & 3.10 & \\
\hline
\end{tabular}


Appendix A-2 - Information from the TRU Waste Database for Lined Shafts

\begin{tabular}{|c|c|c|c|c|c|c|c|c|c|}
\hline Location & $\begin{array}{l}\text { Package } \\
\text { ID }\end{array}$ & Date & $\begin{array}{c}\text { Gross } \\
\text { Weight } \\
\text { (lbs) }\end{array}$ & $\begin{array}{c}\text { Volume } \\
\text { (m3) }\end{array}$ & Waste description & $\begin{array}{c}\text { Comments } \\
\end{array}$ & $\begin{array}{c}\text { Radio- } \\
\text { nuclides }\end{array}$ & Grams & $\begin{array}{c}\text { Total } \\
\text { Dose } \\
(\mathbf{m R} / \mathbf{h r}) \\
\end{array}$ \\
\hline \multirow[t]{3}{*}{ Shaft 227} & S840880 & 31-Dec-84 & 30.01 & & & $\begin{array}{l}\text { Cell } 14 \text { trash can } 4048 \text { - fuel inside } \\
\text { steel can } 45 \text { - } 350 \mathrm{R} / \mathrm{hr} \text { contact }\end{array}$ & U-235 & 14.40 & 0 \\
\hline & & & & & & & MFP & & \\
\hline & & & & & & & Pu-239 & 3.10 & \\
\hline \multirow[t]{3}{*}{ Shaft 227} & S840881 & 31-Dec-84 & 30.01 & & & $\begin{array}{l}\text { Cell } 14 \text { trash can } 4057 \text { - fuel inside } \\
200 \mathrm{R} / \mathrm{hr} \text { contact - steel can } 51\end{array}$ & U-235 & 14.40 & 0 \\
\hline & & & & & & & MFP & & \\
\hline & & & & & & & Pu-239 & 3.10 & \\
\hline \multirow[t]{3}{*}{ Shaft 227} & S840883 & 31-Dec-84 & 30.01 & & & $\begin{array}{l}\text { Cell } 14 \text { trash can } 4064100 \mathrm{R} / \mathrm{hr} \\
\text { contact - steel can } 48\end{array}$ & U-235 & 0.40 & 0 \\
\hline & & & & & & & Pu-239 & 0.10 & \\
\hline & & & & & & & MFP & & \\
\hline \multirow[t]{3}{*}{ Shaft 227} & S840885 & 31-Dec-84 & 30.01 & & & $\begin{array}{l}\text { Cell } 14 \text { trash can } 4156 \text { - fuel inside } \\
\text { contact } 400 \mathrm{R} / \mathrm{hr} \text { - steel can } 49\end{array}$ & U-235 & 10.60 & 0 \\
\hline & & & & & & & $\mathrm{Pu}-239$ & 3.20 & \\
\hline & & & & & & & MFP & & \\
\hline \multirow[t]{3}{*}{ Shaft 227} & S840886 & 31-Dec-84 & 30.01 & & & Cell 14 trash can 4084 steel can 50 & U-235 & 0.40 & 15,000 \\
\hline & & & & & & & Pu-239 & 0.10 & \\
\hline & & & & & & & MFP & & \\
\hline \multirow[t]{3}{*}{ Shaft 228} & S874123 & 23-Dec-87 & 30.01 & 0.00 & Combustible hot-cell waste & $\begin{array}{l}\text { Cell } 14 \text { trash can } 4032 \text { steel can } 54 \text { - } \\
\text { was RSWD S852802 }\end{array}$ & U-235 & 0.40 & 9,000 \\
\hline & & & & & & & Pu-239 & 0.10 & \\
\hline & & & & & & & MFP & & \\
\hline \multirow[t]{3}{*}{ Shaft 228} & S874124 & 23-Dec-87 & 25.00 & & & $\begin{array}{l}\text { Cell } 13 \text { waste plastic can } 4093 \text { - } \\
\text { steel can } 35 \text { - } 20 \mathrm{R} / \mathrm{hr} \text { - was RSWD } \\
\text { S852325 }\end{array}$ & U-235 & 0.40 & 0 \\
\hline & & & & & & & Pu-239 & 0.10 & \\
\hline & & & & & & & MFP & & \\
\hline \multirow[t]{3}{*}{ Shaft 228} & S874125 & 23-Dec-87 & 30.01 & & & $\begin{array}{l}\text { Cell } 14 \text { waste can } 4164 \text { steel can } 62 \\
10 \mathrm{R} / \mathrm{hr} \text { cont - was RSWD S852811 }\end{array}$ & U-235 & 0.40 & 0 \\
\hline & & & & & & & Pu-239 & 0.10 & \\
\hline & & & & & & & MFP & & \\
\hline Shaft 228 & S874126 & 23-Dec-87 & 30.01 & & & $\begin{array}{l}\text { Cell } 13 \text { waste plastic can } 4086 \text { steel } \\
\text { can } 57 \text { - } 200 \mathrm{R} / \mathrm{hr} \text { - was RSWD }\end{array}$ & U-235 & 0.40 & 0 \\
\hline
\end{tabular}


Appendix A-2 - Information from the TRU Waste Database for Lined Shafts

\begin{tabular}{|c|c|c|c|c|c|c|c|c|c|}
\hline Location & $\begin{array}{l}\text { Package } \\
\text { ID }\end{array}$ & Date & $\begin{array}{c}\text { Gross } \\
\text { Weight } \\
\text { (lbs) }\end{array}$ & $\begin{array}{l}\text { Volume } \\
\text { (m3) }\end{array}$ & Waste description & Comments & $\begin{array}{c}\text { Radio- } \\
\text { nuclides }\end{array}$ & Grams & $\begin{array}{c}\text { Total } \\
\text { Dose } \\
(\mathrm{mR} / \mathrm{hr})\end{array}$ \\
\hline & & & & & & S852323 & & & \\
\hline & & & & & & & Pu-239 & 0.10 & \\
\hline & & & & & & & MFP & & \\
\hline \multirow[t]{3}{*}{ Shaft 228} & S874127 & 23-Dec-87 & 30.01 & & & $\begin{array}{l}\text { Cell } 13 \text { waste plastic can } 4094 \text { steel } \\
\text { can } 56 \text { - was RSWD S852324 }\end{array}$ & $\mathrm{U}-235$ & 0.40 & 0 \\
\hline & & & & & & & Pu-239 & 0.10 & \\
\hline & & & & & & & MFP & & \\
\hline \multirow[t]{3}{*}{ Shaft 228} & S874128 & 23-Dec-87 & 30.01 & & & $\begin{array}{l}\text { Cell } 11 \text { waste plastic can } 4092 \text { steel } \\
\text { can } 60 \text { - was RSWD S852330 }\end{array}$ & U-235 & 0.40 & 0 \\
\hline & & & & & & & MFP & & \\
\hline & & & & & & & Pu-239 & 0.10 & \\
\hline \multirow[t]{3}{*}{ Shaft 228} & S874129 & 23-Dec-87 & 30.01 & & & $\begin{array}{l}\text { Cell } 11 \text { waste plastic can } 4085 \text { steel } \\
\text { can } 59 \text { - was RSWD S852329 }\end{array}$ & MFP & & 60,000 \\
\hline & & & & & & & Pu-239 & 0.10 & \\
\hline & & & & & & & U-235 & 0.40 & \\
\hline \multirow[t]{3}{*}{ Shaft 228} & S874130 & 23-Dec-87 & 30.01 & & & $\begin{array}{l}\text { Cell } 14 \text { trash can } 4053 \text { - steel can } 53 \\
\text { was RSWD S852803 }\end{array}$ & $\mathrm{U}-235$ & 0.40 & 80,000 \\
\hline & & & & & & & Pu-239 & 0.10 & \\
\hline & & & & & & & MFP & & \\
\hline \multirow[t]{3}{*}{ Shaft 229} & S840851 & 31-Dec-84 & 30.01 & 0.02 & Combustible hot-cell waste & $\begin{array}{l}\text { Cell } 13 \text { waste - plastic can } 4028 \\
\text { 200R/hr contact - steel can } 28\end{array}$ & U-235 & 0.40 & 0 \\
\hline & & & & & & & MFP & & \\
\hline & & & & & & & Pu-239 & 0.10 & \\
\hline \multirow[t]{3}{*}{ Shaft 229} & S840855 & 31-Dec-84 & 30.01 & & & $\begin{array}{l}\text { Cell } 13 \text { waste - plastic can } 4145 \\
\text { steel can } 27\end{array}$ & $\mathrm{U}-235$ & 0.40 & 40,000 \\
\hline & & & & & & & MFP & & \\
\hline & & & & & & & Pu-239 & 0.10 & \\
\hline \multirow[t]{3}{*}{ Shaft 229} & S840860 & 31-Dec-84 & 30.01 & & & $\begin{array}{l}\text { Cell } 13 \text { waste - plastic can } 4026150 \\
\text { R/hr contact - steel can } 36\end{array}$ & U-235 & 0.40 & 0 \\
\hline & & & & & & & Pu-239 & 0.10 & \\
\hline & & & & & & & MFP & & \\
\hline \multirow[t]{2}{*}{ Shaft 229} & S840865 & 31-Dec-84 & 30.01 & & & $\begin{array}{l}\text { Cell } 13 \text { waste - plastic can } 4055 \\
\text { steel can } 37\end{array}$ & $\mathrm{U}-235$ & 0.40 & 10,000 \\
\hline & & & & & & & MFP & & \\
\hline
\end{tabular}


Appendix A-2 - Information from the TRU Waste Database for Lined Shafts

\begin{tabular}{|c|c|c|c|c|c|c|c|c|c|}
\hline Location & $\begin{array}{c}\text { Package } \\
\text { ID }\end{array}$ & Date & $\begin{array}{c}\text { Gross } \\
\text { Weight } \\
\text { (lbs) } \\
\end{array}$ & $\begin{array}{c}\text { Volume } \\
\text { (m3) }\end{array}$ & Waste description & Comments & $\begin{array}{c}\text { Radio- } \\
\text { nuclides }\end{array}$ & Grams & $\begin{array}{c}\text { Total } \\
\text { Dose } \\
\text { (mR/hr) } \\
\end{array}$ \\
\hline & & & & & & & Pu-239 & 0.10 & \\
\hline \multirow[t]{3}{*}{ Shaft 229} & S840873 & 31-Dec-84 & 30.01 & & & $\begin{array}{l}\text { Cell } 14 \text { trash can } 4065100 \text { R/hr } \\
\text { contact - steel can } 41\end{array}$ & U-235 & 12.00 & 0 \\
\hline & & & & & & & MFP & & \\
\hline & & & & & & & Pu-239 & 3.00 & \\
\hline \multirow[t]{3}{*}{ Shaft 229} & S840882 & 31-Dec-84 & 30.01 & & & $\begin{array}{l}\text { Cell } 14 \text { trash can } 4066 \text { steel can } 47 \text { - } \\
4.1 \mathrm{ft} 3 \text { shaft }\end{array}$ & U-235 & 0.40 & 18,000 \\
\hline & & & & & & & MFP & & \\
\hline & & & & & & & $\mathrm{Pu}-239$ & 0.10 & \\
\hline \multirow[t]{3}{*}{ Shaft 229} & S840888 & 31-Dec-84 & 30.01 & & & Cell 14 trash can 4075 steel can 52 & U-235 & 0.40 & 10,000 \\
\hline & & & & & & & Pu-239 & 0.10 & \\
\hline & & & & & & & MFP & & \\
\hline \multirow[t]{3}{*}{ Shaft 230} & S840831 & 31-Dec-84 & 30.01 & 0.01 & Non-combustible hot-cell waste & $\begin{array}{l}\text { Cell } 9 \text { hot waste can } 4017 \text { - steel can } \\
131000+\mathrm{R} / \mathrm{hr} \text { contact/35 R/hr } 1 \\
\text { meter }\end{array}$ & U-235 & 245.00 & 0 \\
\hline & & & & & & & Pu-239 & 96.00 & \\
\hline & & & & & & & MFP & & \\
\hline \multirow[t]{3}{*}{ Shaft 230} & S840835 & 31-Dec-84 & 30.01 & & Combustible hot-cell waste & $\begin{array}{l}\text { Cell } 13 \text { waste - plastic can } 4153100 \\
\text { R/hr contact - steel can } 16\end{array}$ & U-235 & 0.40 & 0 \\
\hline & & & & & & & MFP & & \\
\hline & & & & & & & $\mathrm{Pu}-239$ & 0.10 & \\
\hline \multirow[t]{3}{*}{ Shaft 230} & S840836 & 31-Dec-84 & 30.01 & & & $\begin{array}{l}\text { Cell } 13 \text { waste - plastic can } 3974 \\
\text { steel can } 15\end{array}$ & U-235 & 0.40 & 30,000 \\
\hline & & & & & & & MFP & & \\
\hline & & & & & & & $\mathrm{Pu}-239$ & 0.10 & \\
\hline \multirow[t]{3}{*}{ Shaft 230} & S840838 & 31-Dec-84 & 30.01 & & & $\begin{array}{l}\text { Cell } 13 \text { waste - plastic can } 4154400 \\
\text { R/hr contact - steel can } 14\end{array}$ & U-235 & 0.40 & 0 \\
\hline & & & & & & & Pu-239 & 0.10 & \\
\hline & & & & & & & MFP & & \\
\hline \multirow[t]{3}{*}{ Shaft 230} & S840839 & 31-Dec-84 & 30.01 & & & $\begin{array}{l}\text { Cell } 13 \text { waste - plastic can } 4155 \\
\text { steel can } 18\end{array}$ & U-235 & 0.40 & 90,000 \\
\hline & & & & & & & MFP & & \\
\hline & & & & & & & Pu-239 & 0.10 & \\
\hline Shaft 230 & S840840 & 31-Dec-84 & 30.01 & & & Cell 13 waste - plastic can 4037 & U-235 & 0.40 & 90,000 \\
\hline
\end{tabular}


Appendix A-2 - Information from the TRU Waste Database for Lined Shafts

\begin{tabular}{|c|c|c|c|c|c|c|c|c|c|}
\hline Location & $\begin{array}{l}\text { Package } \\
\text { ID }\end{array}$ & Date & $\begin{array}{l}\text { Gross } \\
\text { Weight } \\
\text { (lbs) }\end{array}$ & $\begin{array}{l}\text { Volume } \\
\text { (m3) }\end{array}$ & Waste description & Comments & $\begin{array}{c}\text { Radio- } \\
\text { nuclides }\end{array}$ & Grams & $\begin{array}{l}\text { Total } \\
\text { Dose } \\
(\mathrm{mR} / \mathrm{hr})\end{array}$ \\
\hline & & & & & & steel can 29 & & & \\
\hline & & & & & & & Pu-239 & 0.10 & \\
\hline & & & & & & & MFP & & \\
\hline \multirow[t]{3}{*}{ Shaft 230} & S840841 & 31-Dec-84 & 30.01 & & & $\begin{array}{l}\text { cell } 13 \text { waste - plastic can } 4036 \text { steel } \\
\text { can } 17\end{array}$ & $\mathrm{U}-235$ & 0.40 & 60,000 \\
\hline & & & & & & & Pu-239 & 0.10 & \\
\hline & & & & & & & MFP & & \\
\hline \multirow[t]{3}{*}{ Shaft 230} & S840859 & 31-Dec-84 & 30.01 & & & $\begin{array}{l}\text { cell } 13 \text { waste - plastic can } 4031 \text { steel } \\
\text { can } 33\end{array}$ & U-235 & 0.40 & 40,000 \\
\hline & & & & & & & MFP & & \\
\hline & & & & & & & Pu-239 & 0.10 & \\
\hline \multirow[t]{3}{*}{ Shaft 231} & S855046 & 30-Dec-85 & 30.01 & 0.01 & Combustible hot-cell waste & $\begin{array}{l}\text { Plastic can } 3813 \text { - vacuum cleaner } \\
\text { motor steel can } 72-1000+\mathrm{R} / \mathrm{hr} \\
\text { contact }\end{array}$ & U-235 & 0.40 & 0 \\
\hline & & & & & & & MFP & & \\
\hline & & & & & & & $\mathrm{Pu}-239$ & 0.10 & \\
\hline \multirow[t]{3}{*}{ Shaft 231} & S855047 & 30-Dec-85 & 25.00 & & & $\begin{array}{l}\text { plastic can } 4114-\text { manipulator boot } \\
\text { steel can } 73-1000+\mathrm{R} / \mathrm{hr} \text { contact }\end{array}$ & U-235 & 0.30 & 0 \\
\hline & & & & & & & MFP & & \\
\hline & & & & & & & Pu-239 & 0.10 & \\
\hline \multirow[t]{2}{*}{ Shaft 231} & S855048 & 30-Dec-85 & 30.01 & & & $\begin{array}{l}\text { Cell } 10 \text { trash - plastic can } 3859 \text { steel } \\
\text { can } 74-100 \mathrm{R} / \mathrm{hr} \text { contact }\end{array}$ & $\mathrm{U}-235$ & 15.00 & 0 \\
\hline & & & & & & & MFP & & \\
\hline \multirow[t]{2}{*}{ Shaft 231} & S855049 & 30-Dec-85 & 30.01 & & & $\begin{array}{l}\text { Plastic can } 3651 \text { - rb robinson fuel } \\
\text { steel can } 75 \text { - } 3 \mathrm{R} / \mathrm{hr} \text { contact }\end{array}$ & U-235 & 9.00 & 0 \\
\hline & & & & & & & MFP & & \\
\hline \multirow[t]{3}{*}{ Shaft 231} & S856015 & 30-Dec-85 & 30.01 & & & $\begin{array}{l}\text { Plastic can } 3649 \text { steel can } 68 \text { - } \\
1000+\text { R/hr contact }\end{array}$ & U-235 & 0.40 & 0 \\
\hline & & & & & & & Pu-239 & 0.10 & \\
\hline & & & & & & & MFP & & \\
\hline \multirow[t]{3}{*}{ Shaft 231} & S856016 & 30-Dec-85 & 30.01 & & & $\begin{array}{l}\text { Cells 2/4 waste, plastic can } 4113 \\
\text { steel can } 69-20 \mathrm{R} / \mathrm{hr} \text { contact }\end{array}$ & U-235 & 0.30 & 20,000 \\
\hline & & & & & & & MFP & & \\
\hline & & & & & & & $\mathrm{Pu}-239$ & 0.10 & \\
\hline
\end{tabular}


Appendix A-2 - Information from the TRU Waste Database for Lined Shafts

\begin{tabular}{|c|c|c|c|c|c|c|c|c|c|}
\hline Location & $\begin{array}{l}\text { Package } \\
\text { ID }\end{array}$ & Date & $\begin{array}{c}\text { Gross } \\
\text { Weight } \\
\text { (lbs) }\end{array}$ & $\begin{array}{c}\text { Volume } \\
(\mathrm{m} 3)\end{array}$ & Waste description & Comments & $\begin{array}{c}\text { Radio- } \\
\text { nuclides }\end{array}$ & Grams & $\begin{array}{c}\text { Total } \\
\text { Dose } \\
\text { (mR/hr) }\end{array}$ \\
\hline \multirow[t]{3}{*}{ Shaft 231} & S856017 & 30-Dec-85 & 30.01 & & & $\begin{array}{l}\text { Plastic can } 3626 \text { cell } 9 \text { trash steel } \\
\text { can } 71 \text { - } 500 \mathrm{R} / \mathrm{hr} \text { contact }\end{array}$ & U-235 & 0.30 & 0 \\
\hline & & & & & & & MFP & & \\
\hline & & & & & & & $\mathrm{Pu}-239$ & 0.10 & \\
\hline \multirow[t]{3}{*}{ Shaft 231} & S856018 & 30-Dec-85 & 30.01 & & & $\begin{array}{l}\text { Plastic \#3625 cell } 9 \text { trash steel can } \\
\text { \#70 - } 350 \mathrm{R} / \mathrm{hr} \text { contact }\end{array}$ & $\mathrm{U}-235$ & 0.40 & 0 \\
\hline & & & & & & & $\mathrm{Pu}-239$ & 0.10 & \\
\hline & & & & & & & MFP & & \\
\hline \multirow[t]{3}{*}{ Shaft 232} & S874132 & 23-Dec-87 & 35.01 & 0.00 & Combustible hot-cell waste & $\begin{array}{l}3 \text { mile island waste can } 77 \text { - was on } \\
\text { a cwsr la86110050600 }\end{array}$ & $\mathrm{U}-25$ & 7.00 & 6,500 \\
\hline & & & & & & & MFP & & \\
\hline & & & & & & & Pu-239 & 0.00 & \\
\hline \multirow[t]{6}{*}{ Shaft 232} & S874133 & 23-Dec-87 & 35.01 & & & $\begin{array}{l}\text { Cell } 9 \text { waste fuel can } 79 \text { - was on a } \\
\text { cwsr la86110050601 >1000 R/hr }\end{array}$ & $\mathrm{U}-238$ & 60.20 & 0 \\
\hline & & & & & & & $\mathrm{Pu}-56$ & 12.00 & \\
\hline & & & & & & & Pu-53 & 16.00 & \\
\hline & & & & & & & $\mathrm{Pu}-55$ & 27.00 & \\
\hline & & & & & & & $\mathrm{Pu}-57$ & 13.00 & \\
\hline & & & & & & & U-235 & 134.80 & \\
\hline \multirow[t]{3}{*}{ Shaft 232} & S874134 & 23-Dec-87 & 35.01 & & & $\begin{array}{l}\text { Inc11 waste steel can } 78 \text { - was on a } \\
\text { cwsr la86110050648 }\end{array}$ & MFP & & 29,000 \\
\hline & & & & & & & U-21 & 48.00 & \\
\hline & & & & & & & $\mathrm{Pu}-57$ & 1.00 & \\
\hline
\end{tabular}


Appendix A-3 - Information from Radioactive Solid Waste Disposal Forms for Lined Shafts

\begin{tabular}{|c|c|c|c|c|c|c|c|c|c|c|c|c|c|}
\hline Shaft & $\begin{array}{l}\text { RSWD } \\
\text { Number }\end{array}$ & $\begin{array}{c}\text { Date } \\
\text { Disposed }\end{array}$ & $\begin{array}{c}\text { Gross } \\
\text { Weight }\end{array}$ & Units & $\begin{array}{c}\text { Gross } \\
\text { Volume }\end{array}$ & Units & Waste Description & $\begin{array}{c}\text { Additional Description } \\
\text { of Packaging and } \\
\text { Packaging Materials }\end{array}$ & Nuclide & Amount & Units & $\begin{array}{c}\text { Package } \\
\text { Radiation } \\
\text { at } \\
\text { Surface } \\
(\mathrm{mR} / \mathrm{hr})\end{array}$ & $\begin{array}{c}\text { Package } \\
\text { Radiation } \\
\text { at } 1 \\
\text { meter } \\
(\mathrm{mR} / \mathrm{hr}) \\
\end{array}$ \\
\hline \multirow[t]{3}{*}{200} & S811387 & $4 / 14 / 81$ & 16 & $\mathrm{lb}$ & 7.3 & $\mathrm{ft}^{3}$ & $\begin{array}{l}\text { Cell } 14 \text { fuel can \#3021 } \\
\# 3008 \text { Cell } 13\end{array}$ & $140 \mathrm{R}$ at contact & Pu-239 & $2.02 \mathrm{E}+01$ & $\mathrm{~g}$ & & 2,500 \\
\hline & & & & & & & & & U-235 & $8.08 \mathrm{E}+00$ & $g$ & & \\
\hline & & & & & & & & & MFP & $2.50 \mathrm{E}+00$ & $\mathrm{Ci}$ & & \\
\hline \multirow[t]{3}{*}{200} & S811390 & $4 / 14 / 81$ & 16 & $\mathrm{lb}$ & 7.3 & $\mathrm{ft}^{3}$ & $\begin{array}{l}\text { Cell \#14 fuel cans } \\
\# 3010 \text { \& } 3016\end{array}$ & $800 \mathrm{R}$ at contact & $\mathrm{Pu}-239$ & $1.00 \mathrm{E}+01$ & $\mathrm{~g}$ & & 6,000 \\
\hline & & & & & & & & & $\mathrm{U}-235$ & $3.80 \mathrm{E}+01$ & $\mathrm{~g}$ & & \\
\hline & & & & & & & & & MFP & $6.00 \mathrm{E}+00$ & $\mathrm{Ci}$ & & \\
\hline \multirow[t]{3}{*}{200} & S811396 & $4 / 14 / 81$ & 16 & $\mathrm{lb}$ & 7.3 & $\mathrm{ft}^{3}$ & $\begin{array}{l}\text { Cell } 13 \text { grinding papers, } \\
\text { kimwipes, plastic }\end{array}$ & Plastic cans 3061,3053 & Pu-239 & $1.00 \mathrm{E}-01$ & $\mathrm{~g}$ & 60,000 & 600 \\
\hline & & & & & & & & & $\mathrm{U}-235$ & $4.00 \mathrm{E}-01$ & $\mathrm{~g}$ & & \\
\hline & & & & & & & & & MFP & $6.00 \mathrm{E}-01$ & $\mathrm{Ci}$ & & \\
\hline \multirow[t]{3}{*}{200} & S811398 & $4 / 14 / 81$ & 20 & $\mathrm{lb}$ & 7.3 & $\mathrm{ft}^{3}$ & $\begin{array}{l}\text { Cell } 13 \text { catch \& drain } \\
\text { pans, kimwipes }\end{array}$ & $\begin{array}{l}120,000 \mathrm{mR} / \mathrm{hr} \text { surface, } \\
\text { cans } 3051 \& 3052\end{array}$ & Pu-239 & $4.00 \mathrm{E}+00$ & $\mathrm{~g}$ & 120,000 & 600 \\
\hline & & & & & & & & & U-235 & $1.60 \mathrm{E}+01$ & $\mathrm{~g}$ & & \\
\hline & & & & & & & & & MFP & $6.00 \mathrm{E}-01$ & $\mathrm{Ci}$ & & \\
\hline \multirow[t]{3}{*}{200} & S811471 & $4 / 14 / 81$ & 9 & $\mathrm{lb}$ & 7.3 & $\mathrm{ft}^{3}$ & $\begin{array}{l}\text { Cell } 14 \text { trash cans } 2864, \\
2846\end{array}$ & $700 \mathrm{R} / \mathrm{hr}$ at contact & $\mathrm{Pu}-239$ & $1.25 \mathrm{E}+01$ & $\mathrm{~g}$ & & 9,000 \\
\hline & & & & & & & & & U-235 & $2.15 \mathrm{E}+01$ & $\mathrm{~g}$ & & \\
\hline & & & & & & & & & MFP & $2.70 \mathrm{E}+00$ & $\mathrm{Ci}$ & & \\
\hline \multirow[t]{3}{*}{200} & $\mathrm{~S} 811473$ & $4 / 14 / 81$ & 16 & $\mathrm{lb}$ & 7.3 & $\mathrm{ft}^{3}$ & $\begin{array}{l}\text { Cell } 14 \text { trash - fuel cans } \\
\# 2877 \text { - } 2863\end{array}$ & $1150 \mathrm{R} / \mathrm{hr}$ at contact & $\mathrm{Pu}-239$ & $5.00 \mathrm{E}+00$ & $\mathrm{~g}$ & & 20,000 \\
\hline & & & & & & & & & $\mathrm{U}-235$ & $4.90 \mathrm{E}+01$ & $\mathrm{~g}$ & & \\
\hline & & & & & & & & & MFP & $2.00 \mathrm{E}+01$ & $\mathrm{Ci}$ & & \\
\hline \multirow[t]{3}{*}{201} & S791484 & $6 / 29 / 79$ & & & 3.2 & $\mathrm{ft}^{3}$ & $\begin{array}{l}\text { Cell \#12 one fuel can } \\
\# 2171\end{array}$ & $\begin{array}{l}\text { Tin can in plastic } \\
\text { container }\end{array}$ & $\mathrm{Pu}-239$ & $3.00 \mathrm{E}+00$ & g & 17,500 & 4,000 \\
\hline & & & & & & & & & $\mathrm{U}-235$ & $1.00 \mathrm{E}+00$ & $\mathrm{~g}$ & & \\
\hline & & & & & & & 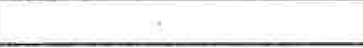 & & MFP & $4.00 \mathrm{E}+00$ & $\mathrm{Ci}$ & & \\
\hline \multirow[t]{3}{*}{201} & S794215 & $6 / 29 / 79$ & 15 & $\mathrm{lb}$ & 5.7 & $\mathrm{ft}^{3}$ & $\begin{array}{l}\text { Cell } 12 \text { trash \& fuel } \\
\# 1854,1851\end{array}$ & $266000 \mathrm{mr}$ at contact & Pu-239 & $5.50 \mathrm{E}-01$ & $\mathrm{~g}$ & 266,000 & 11,000 \\
\hline & & & & & & & & & $\mathrm{U}-235$ & $2.00 \mathrm{E}+00$ & $\mathrm{~g}$ & & \\
\hline & & & & & & & & & MFP & $1.10 \mathrm{E}+01$ & $\mathrm{Ci}$ & & \\
\hline
\end{tabular}




\section{Appendix A-3 - Information from Radioactive Solid Waste Disposal Forms for Lined Shafts}

\begin{tabular}{|c|c|c|c|c|c|c|c|c|c|c|c|c|c|}
\hline Shaft & $\begin{array}{c}\text { RSWD } \\
\text { Number } \\
\end{array}$ & $\begin{array}{c}\text { Date } \\
\text { Disposed } \\
\end{array}$ & $\begin{array}{c}\text { Gross } \\
\text { Weight } \\
\end{array}$ & Units & $\begin{array}{c}\text { Gross } \\
\text { Volume } \\
\end{array}$ & Units & Waste Description & $\begin{array}{c}\text { Additional Description } \\
\text { of Packaging and } \\
\text { Packaging Materials }\end{array}$ & Nuclide & Amount & Units & $\begin{array}{c}\text { Package } \\
\text { Radiation } \\
\text { at } \\
\text { Surface } \\
(\mathrm{mR} / \mathrm{hr}) \\
\end{array}$ & $\begin{array}{c}\text { Package } \\
\text { Radiation } \\
\text { at } 1 \\
\text { meter } \\
(\mathrm{mR} / \mathrm{hr}) \\
\end{array}$ \\
\hline \multirow[t]{3}{*}{201} & $\mathrm{~S} 794216$ & $6 / 29 / 79$ & 15 & $\mathrm{lb}$ & 5.7 & $\mathrm{ft}^{3}$ & $\begin{array}{l}\text { Cell } 12 \text { trash and fuel } \\
\text { can } \# 1798 \& 1953\end{array}$ & $\begin{array}{l}261000 \mathrm{mr} / \mathrm{hr} \text { at contact, } \\
\text { cans in p-bags }\end{array}$ & Pu-239 & $2.25 \mathrm{E}+00$ & $\mathrm{~g}$ & 261,000 & 85,000 \\
\hline & & & & & & & & & $\mathrm{U}-235$ & $9.00 \mathrm{E}+00$ & $\mathrm{~g}$ & & \\
\hline & & & & & & & & & MFP & $8.00 \mathrm{E}+00$ & $\mathrm{Ci}$ & & \\
\hline \multirow[t]{3}{*}{201} & S794218 & $6 / 29 / 79$ & 10 & $\mathrm{lb}$ & 5.7 & $\mathrm{ft}^{3}$ & $\begin{array}{l}\text { Cell } 14 \text { fuel can no. } \\
2002 \& 2003\end{array}$ & $\begin{array}{l}\text { tin cans in plastic cans } \\
\text { in p-bags }\end{array}$ & $\mathrm{Pu}-239$ & $2.50 \mathrm{E}+00$ & $\mathrm{~g}$ & 15,000 & 1,000 \\
\hline & & & & & & & & & $\mathrm{U}-235$ & $1.00 \mathrm{E}+01$ & $\mathrm{~g}$ & & \\
\hline & & & & & & & & & MFP & $1.00 \mathrm{E}+00$ & $\mathrm{Ci}$ & & \\
\hline \multirow[t]{3}{*}{201} & S794219 & $6 / 29 / 79$ & 12 & $\mathrm{lb}$ & 5.7 & $\mathrm{ft}^{3}$ & $\begin{array}{l}\text { Cell } 14 \text { fuel } \& \text { trash can } \\
\text { no. } 2004 \& 1992\end{array}$ & $\begin{array}{l}\text { Tin cans in plastic cans } \\
\text { in p-bags }\end{array}$ & $\mathrm{Pu}-239$ & $1.50 \mathrm{E}+00$ & $\mathrm{~g}$ & 27,000 & 1,300 \\
\hline & & & & & & & & & $\mathrm{U}-235$ & $5.00 \mathrm{E}+00$ & $\mathrm{~g}$ & & \\
\hline & & & & & & & & & MFP & $1.30 \mathrm{E}+00$ & $\mathrm{Ci}$ & & \\
\hline \multirow[t]{3}{*}{201} & $\mathrm{~S} 794220$ & $6 / 29 / 79$ & 6 & $\mathrm{lb}$ & 5.7 & $\mathrm{ft}^{3}$ & $\begin{array}{l}\text { Hot trash met samples } \\
\text { cans land } 4 \mathrm{~A}\end{array}$ & $1200 \mathrm{R} / \mathrm{hr}$ at contact & $\mathrm{Pu}-239$ & $6.80 \mathrm{E}+01$ & $\mathrm{~g}$ & & 30,000 \\
\hline & & & & & & & & & U-235 & $1.47 \mathrm{E}+02$ & $\mathrm{~g}$ & & \\
\hline & & & & & & & & & MFP & $3.00 \mathrm{E}+01$ & $\mathrm{Ci}$ & & \\
\hline \multirow[t]{3}{*}{201} & S794221 & $6 / 29 / 79$ & 8 & $\mathrm{lb}$ & 5.7 & $\mathrm{ft}^{3}$ & $\begin{array}{l}\text { Fuel samples from cells } \\
13,15 \text {, cans } 2 \text { \& } 3 \mathrm{~A}\end{array}$ & $1050 \mathrm{R} / \mathrm{hr}$ at contact & Pu-239 & $1.40 \mathrm{E}+02$ & $\mathrm{~g}$ & & 35,000 \\
\hline & & & & & & & & & $\mathrm{U}-235$ & $3.70 \mathrm{E}+02$ & $\mathrm{~g}$ & & \\
\hline & & & & & & & & & MFP & $3.50 \mathrm{E}+01$ & $\mathrm{Ci}$ & & \\
\hline \multirow[t]{3}{*}{202} & S803548 & $4 / 30 / 80$ & 2.3 & ton & 44 & $\mathrm{ft}^{3}$ & $\begin{array}{l}\text { Hot cell waste CMB1 - } \\
\text { CMB14 from } 9 / 15 / 79\end{array}$ & thru $1 / 10 / 80$ & $\mathrm{Pu}-239$ & $6.54 \mathrm{E}+01$ & g & & \\
\hline & & & & & & & & & $\mathrm{U}-235$ & $2.23 \mathrm{E}+02$ & $\mathrm{~g}$ & & \\
\hline & & & & & & & & & MFP & $2.15 \mathrm{E}+02$ & $\mathrm{Ci}$ & & \\
\hline \multirow[t]{3}{*}{203} & S803547 & $4 / 30 / 80$ & 2.3 & ton & 44 & $\mathrm{ft}^{3}$ & $\begin{array}{l}\text { Hot cell waste CMB1 - } \\
\text { CMB14 from } 12 / 13 /\end{array}$ & 78 thru $8 / 15 / 79$ & $\mathrm{Pu}-239$ & $3.75 \mathrm{E}+01$ & $\mathrm{~g}$ & & \\
\hline & & & & & & & & & $\mathrm{U}-235$ & $1.27 \mathrm{E}+02$ & $\mathrm{~g}$ & & \\
\hline & & & & & & & & & MFP & $1.09 \mathrm{E}+02$ & $\mathrm{Ci}$ & & \\
\hline \multirow[t]{3}{*}{204} & S791472 & $6 / 29 / 79$ & 20 & $\mathrm{lb}$ & 7.5 & $\mathrm{ft}^{3}$ & $\begin{array}{l}\text { Cell } 12 \text { trash \& fuel cans } \\
2127 \& 2150\end{array}$ & $108000 \mathrm{Mr}$ at contact & Pu-239 & $1.75 \mathrm{E}+00$ & g & 108,000 & 10,500 \\
\hline & & & & & & & & & U-235 & $5.25 \mathrm{E}+00$ & $\mathrm{~g}$ & & \\
\hline & & & & & & & & & MFP & $1.05 \mathrm{E}+01$ & $\mathrm{Ci}$ & & \\
\hline
\end{tabular}


Appendix A-3 - Information from Radioactive Solid Waste Disposal Forms for Lined Shafts

\begin{tabular}{|c|c|c|c|c|c|c|c|c|c|c|c|c|c|}
\hline Shaft & $\begin{array}{c}\text { RSWD } \\
\text { Number } \\
\end{array}$ & $\begin{array}{c}\text { Date } \\
\text { Disposed } \\
\end{array}$ & $\begin{array}{l}\text { Gross } \\
\text { Weight } \\
\end{array}$ & Units & $\begin{array}{c}\text { Gross } \\
\text { Volume } \\
\end{array}$ & Units & Waste Description & $\begin{array}{c}\text { Additional Description } \\
\text { of Packaging and } \\
\text { Packaging Materials }\end{array}$ & Nuclide & Amount & Units & $\begin{array}{c}\text { Package } \\
\text { Radiation } \\
\text { at } \\
\text { Surface } \\
\text { (mR/hr) } \\
\end{array}$ & $\begin{array}{c}\text { Package } \\
\text { Radiation } \\
\text { at } 1 \\
\text { meter } \\
(\mathrm{mR} / \mathrm{hr}) \\
\end{array}$ \\
\hline \multirow[t]{3}{*}{204} & S791478 & $6 / 29 / 79$ & 15 & $\mathrm{lb}$ & 7.5 & $\mathrm{ft}^{3}$ & $\begin{array}{l}\text { Cell } 9 \text { hot trash cans } \\
2015,2117,1000+\mathrm{Rhr}\end{array}$ & $\begin{array}{l}\text { at contact } 140000 \\
\mathrm{mR} / \mathrm{hr} \text { at meter }\end{array}$ & Pu-239 & $3.50 \mathrm{E}+01$ & $\mathrm{~g}$ & & \\
\hline & & & & & & & & & $\mathrm{U}-235$ & $1.21 \mathrm{E}+02$ & $\mathrm{~g}$ & & \\
\hline & & & & & & & & & MFP & & & & \\
\hline \multirow[t]{3}{*}{204} & S791483 & $6 / 29 / 79$ & 15 & $\mathrm{lb}$ & 7.5 & $\mathrm{ft}^{3}$ & $\begin{array}{l}\text { Cell } 12 \text { fuel cans } 2095 \\
\& 2167\end{array}$ & tin cans in plastic cans & $\mathrm{Pu}-239$ & $1.50 \mathrm{E}+00$ & $\mathrm{~g}$ & 50,000 & 15,000 \\
\hline & & & & & & & & & $\mathrm{U}-235$ & $4.50 \mathrm{E}+00$ & $\mathrm{~g}$ & & \\
\hline & & & & & & & & & MFP & $1.5 \mathrm{E}+? ? ?$ & $\mathrm{Ci}$ & & \\
\hline \multirow[t]{3}{*}{204} & S794222 & $6 / 29 / 79$ & 16 & $\mathrm{lb}$ & 7.5 & $\mathrm{ft}^{3}$ & $\begin{array}{l}\text { Cell } 12 \text { fuel cans \#1790 } \\
\& 1815\end{array}$ & $100000 \mathrm{R}$ at 1 meter & $\mathrm{Pu}-239$ & $4.75 \mathrm{E}+00$ & $\mathrm{~g}$ & & \\
\hline & & & & & & & & & U-235 & $1.90 \mathrm{E}+01$ & $\mathrm{~g}$ & & \\
\hline & & & & & & & & & MFP & & & & \\
\hline \multirow[t]{3}{*}{204} & $\mathrm{~S} 794223$ & $6 / 29 / 79$ & 20 & $\mathrm{lb}$ & 7.5 & $\mathrm{ft}^{3}$ & $\begin{array}{l}\text { Cell } 9 \text { trash in } 1 \text { gal. } \\
\text { disposable cans }\end{array}$ & $\begin{array}{l}\text { in plastic bag, can \#s } \\
1786 \& 1813\end{array}$ & $\mathrm{Pu}-239$ & $1.65 \mathrm{E}+01$ & $\mathrm{~g}$ & & 20,400 \\
\hline & & & & & & & & & U-235 & $4.38 \mathrm{E}+01$ & $\mathrm{~g}$ & & \\
\hline & & & & & & & & & MFP & $2.00 \mathrm{E}+01$ & $\mathrm{Ci}$ & & \\
\hline \multirow[t]{3}{*}{205} & $\mathrm{~S} 801483$ & $12 / 1 / 80$ & 20 & $\mathrm{lb}$ & 6.3 & $\mathrm{ft}^{3}$ & $\begin{array}{l}\text { Cell } 9 \text { trash cans } 2875 \text {, } \\
2926\end{array}$ & $\begin{array}{l}+1000 \mathrm{R} / \mathrm{hr} \text { contact } 135 \\
\mathrm{R} / \mathrm{hr} \text { at meter }\end{array}$ & Pu-239 & $1.00 \mathrm{E}-01$ & $g$ & & \\
\hline & & & & & & & & & U-235 & $1.00 \mathrm{E}-01$ & $\mathrm{~g}$ & & \\
\hline & & & & & & & & & MFP & $1.35 \mathrm{E}+02$ & $\mathrm{Ci}$ & & \\
\hline \multirow[t]{3}{*}{205} & S801485 & $12 / 1 / 80$ & 30 & $\mathrm{lb}$ & 6.3 & $\mathrm{ft}^{3}$ & $\begin{array}{l}\text { Cell } 9 \text { trash can 2928, } \\
2930\end{array}$ & $\begin{array}{l}+1000 \mathrm{R} / \mathrm{hr} \text { contact } 170 \\
\mathrm{R} / \mathrm{hr} \text { at meter }\end{array}$ & Pu-239 & $2.50 \mathrm{E}+01$ & $\mathrm{~g}$ & & \\
\hline & & & & & & & & & U-235 & $9.50 \mathrm{E}+01$ & $\mathrm{~g}$ & & \\
\hline & & & & & & & & & MFP & $1.70 \mathrm{E}+02$ & $\mathrm{Ci}$ & & \\
\hline \multirow[t]{3}{*}{205} & S802244 & $12 / 1 / 80$ & 15 & $\mathrm{lb}$ & 6.3 & $\mathrm{ft}^{3}$ & $\begin{array}{l}\text { Cell } 14 \text { fuel \& trash cans } \\
2574 \& 2577\end{array}$ & $\begin{array}{l}160000 \mathrm{mR} / \mathrm{hr} \text { at } \\
\text { contact }\end{array}$ & Pu-239 & $5.00 \mathrm{E}-01$ & $\mathrm{~g}$ & 160,000 & 41,000 \\
\hline & & & & & & & & & U-235 & $2.00 \mathrm{E}+01$ & $\mathrm{~g}$ & & \\
\hline & & & & & & & & & MFP & $4.10 \mathrm{E}+00$ & $\mathrm{Ci}$ & & \\
\hline \multirow[t]{3}{*}{205} & S??2246 & $12 / 1 / 80$ & 16 & $\mathrm{lb}$ & 6.3 & $\mathrm{ft}^{3}$ & $\begin{array}{l}\text { Cell } 14 \text { fuel can \# } 2604 \\
\& 2584\end{array}$ & $\begin{array}{l}\text { surface reading } \\
1,000,000 \mathrm{mR} / \mathrm{hr}\end{array}$ & Pu-239 & $1.75 \mathrm{E}+01$ & $\mathrm{~g}$ & $1,000,000$ & 14,000 \\
\hline & & & & & & & & & U-235 & $7.00 \mathrm{E}+01$ & $\mathrm{~g}$ & & \\
\hline & & & & & & & & & MFP & $1.40 \mathrm{E}+00$ & $\mathrm{Ci}$ & & \\
\hline
\end{tabular}




\section{Appendix A-3 - Information from Radioactive Solid Waste Disposal Forms for Lined Shafts}

\begin{tabular}{|c|c|c|c|c|c|c|c|c|c|c|c|c|c|}
\hline Shaft & $\begin{array}{c}\text { RSWD } \\
\text { Number }\end{array}$ & $\begin{array}{c}\text { Date } \\
\text { Disposed }\end{array}$ & $\begin{array}{l}\text { Gross } \\
\text { Weight }\end{array}$ & Units & $\begin{array}{c}\text { Cross } \\
\text { Volume }\end{array}$ & Units & Waste Description & $\begin{array}{c}\text { Additional Description } \\
\text { of Packaging and } \\
\text { Packaging Materials }\end{array}$ & Nuclide & Amount & Units & $\begin{array}{c}\text { Package } \\
\text { Radiation } \\
\text { at } \\
\text { Surface } \\
(\mathrm{mR} / \mathrm{hr})\end{array}$ & $\begin{array}{c}\text { Package } \\
\text { Radiation } \\
\text { at } 1 \\
\text { meter } \\
(\mathrm{mR} / \mathrm{hr})\end{array}$ \\
\hline \multirow[t]{3}{*}{205} & S??2247 & $12 / 1 / 80$ & 16 & $\mathrm{lb}$ & 6.3 & $\mathrm{ft}^{3}$ & $\begin{array}{l}\text { Cell } 14 \text { fuel \& trash can } \\
\# 2603 \text { \& } 2602\end{array}$ & $\begin{array}{l}\text { surface reading } 615000 \\
\mathrm{mR} / \mathrm{hr}\end{array}$ & Pu-239 & $5.00 \mathrm{E}+00$ & $\mathrm{~g}$ & 615,000 & 12,000 \\
\hline & & & & & & & & & $\mathrm{U}-235$ & $2.10 \mathrm{E}+01$ & $\mathrm{~g}$ & & \\
\hline & & & & & & & & & MFP & $1.20 \mathrm{E}+00$ & $\mathrm{~g}$ & & \\
\hline \multirow[t]{3}{*}{205} & S802259 & $12 / 1 / 80$ & 15 & $\mathrm{lb}$ & 6.3 & $?$ & $\begin{array}{l}\text { Cell waste cans } 2642, \\
2669, \text { Cell } 9\end{array}$ & $\begin{array}{l}1000 \mathrm{R} \text { hr plus bottom } \\
\text { entry }\end{array}$ & Pu-239 & $1.20 \mathrm{E}+01$ & $\mathrm{~g}$ & & 35,000 \\
\hline & & & & & & & & & U-235 & $3.90 \mathrm{E}+01$ & $\mathrm{~g}$ & & \\
\hline & & & & & & & & & MFP & $3.50 \mathrm{E}+01$ & $\mathrm{Ci}$ & & \\
\hline \multirow[t]{3}{*}{205} & S802287 & $12 / 1 / 80$ & 20 & $\mathrm{lb}$ & 6.3 & $\mathrm{ft}^{3}$ & $\begin{array}{l}\text { Hot trash cell } 9 \text { cans } \\
2785,2646+1000 \mathrm{Rhr}\end{array}$ & $\begin{array}{l}\text { contact } 520 \mathrm{Rhr} \text { at one } \\
\text { meter }\end{array}$ & Pu-239 & $5.70 \mathrm{E}+01$ & $\mathrm{~g}$ & & \\
\hline & & & & & & & & & U-235 & $2.36 \mathrm{E}+02$ & $\mathrm{~g}$ & & \\
\hline & & & & & & & & & MFP & $5.20 \mathrm{E}+02$ & $\mathrm{Ci}$ & & \\
\hline \multirow[t]{3}{*}{206} & S812291 & $4 / 1 / 81$ & 10 & $\mathrm{lb}$ & 7.3 & $\mathrm{ft}^{3}$ & $\begin{array}{l}\text { Cell } 13,15 \text { met samples, } \\
\text { cans } 2805,2806\end{array}$ & $\begin{array}{l}\text { Bottom entry } 1000+ \\
\text { R/hr@, contact }\end{array}$ & Pu-239 & $1.23 \mathrm{E}+02$ & g & & 40,000 \\
\hline & & & & & & & & & $\mathrm{U}-235$ & $3.21 \mathrm{E}+02$ & $\mathrm{~g}$ & & \\
\hline & & & & & & & & & MFP & $4.00 \mathrm{E}+01$ & $\mathrm{Ci}$ & & \\
\hline \multirow[t]{3}{*}{206} & S812292 & $4 / 1 / 81$ & 10 & $\mathrm{lb}$ & 7.3 & $\mathrm{ft}^{3}$ & $\begin{array}{l}\text { Cell } 13,15 \text { met samples } \\
\text { cans } 2801,2804\end{array}$ & $\begin{array}{l}\text { Bottom entry 1000+ } \\
\text { R/hr@ contact }\end{array}$ & $\mathrm{Pu}-239$ & $1.00 \mathrm{E}+02$ & $\mathrm{~g}$ & & 22,000 \\
\hline & & & & & & & & & $\mathrm{U}-235$ & $2.69 \mathrm{E}+02$ & $\mathrm{~g}$ & & \\
\hline & & & & & & & & & MFP & $2.20 \mathrm{E}+01$ & $\mathrm{Ci}$ & & \\
\hline \multirow[t]{3}{*}{206} & S812293 & $4 / 1 / 81$ & 20 & $\mathrm{lb}$ & 7.3 & $\mathrm{ft}^{3}$ & $\begin{array}{l}\text { Cell waste cans } 2454, \\
2812 \text {, cell } 14\end{array}$ & $\begin{array}{l}1000 \text { Rhr contact, } 108 \\
\text { Rhr meter }\end{array}$ & $\mathrm{Pu}-239$ & $7.00 \mathrm{E}+00$ & $\mathrm{~g}$ & & \\
\hline & & & & & & & & & U-235 & $2.80 \mathrm{E}+01$ & $\mathrm{~g}$ & & \\
\hline & & & & & & & & & MFP & $1.00 \mathrm{E}+02$ & $\mathrm{Ci}$ & & \\
\hline \multirow[t]{3}{*}{206} & S812297 & 4/14/81 & 20 & $\mathrm{lb}$ & 7.3 & $\mathrm{ft}^{3}$ & $\begin{array}{l}\text { Cell 14 trash \& fuel } \\
\# 2829,2807\end{array}$ & $\begin{array}{l}+1000 \text { Rhr contact } 100 \\
\text { Rhr at meter }\end{array}$ & $\mathrm{Pu}-239$ & $2.20 \mathrm{E}+01$ & $\mathrm{~g}$ & & \\
\hline & & & & & & & & & U-235 & $? .6 \mathrm{E}+01$ & $\mathrm{~g}$ & & \\
\hline & & & & & & & & & MFP & $1.00 \mathrm{E}+02$ & $\mathrm{Ci}$ & & \\
\hline \multirow[t]{3}{*}{206} & S812298 & $4 / 1 / 81$ & 20 & $\mathrm{lb}$ & 7.3 & $\mathrm{ft}^{3}$ & $\begin{array}{l}\text { Cell \#14 trash \& fuel } \\
\# 2826 \& 2827\end{array}$ & $\begin{array}{l}+1000 \mathrm{Rhr} \text { at contact } \\
100 \mathrm{Rhr} \text { at meter }\end{array}$ & $\mathrm{Pu}-239$ & $2.20 \mathrm{E}+01$ & $\mathrm{~g}$ & & \\
\hline & & & & & & & & & U-235 & $8.60 \mathrm{E}+01$ & $\mathrm{~g}$ & & \\
\hline & & & & & & & & & MFP & $1.00 \mathrm{E}+02$ & $\mathrm{Ci}$ & & \\
\hline
\end{tabular}




\section{Appendix A-3 - Information from Radioactive Solid Waste Disposal Forms for Lined Shafts}

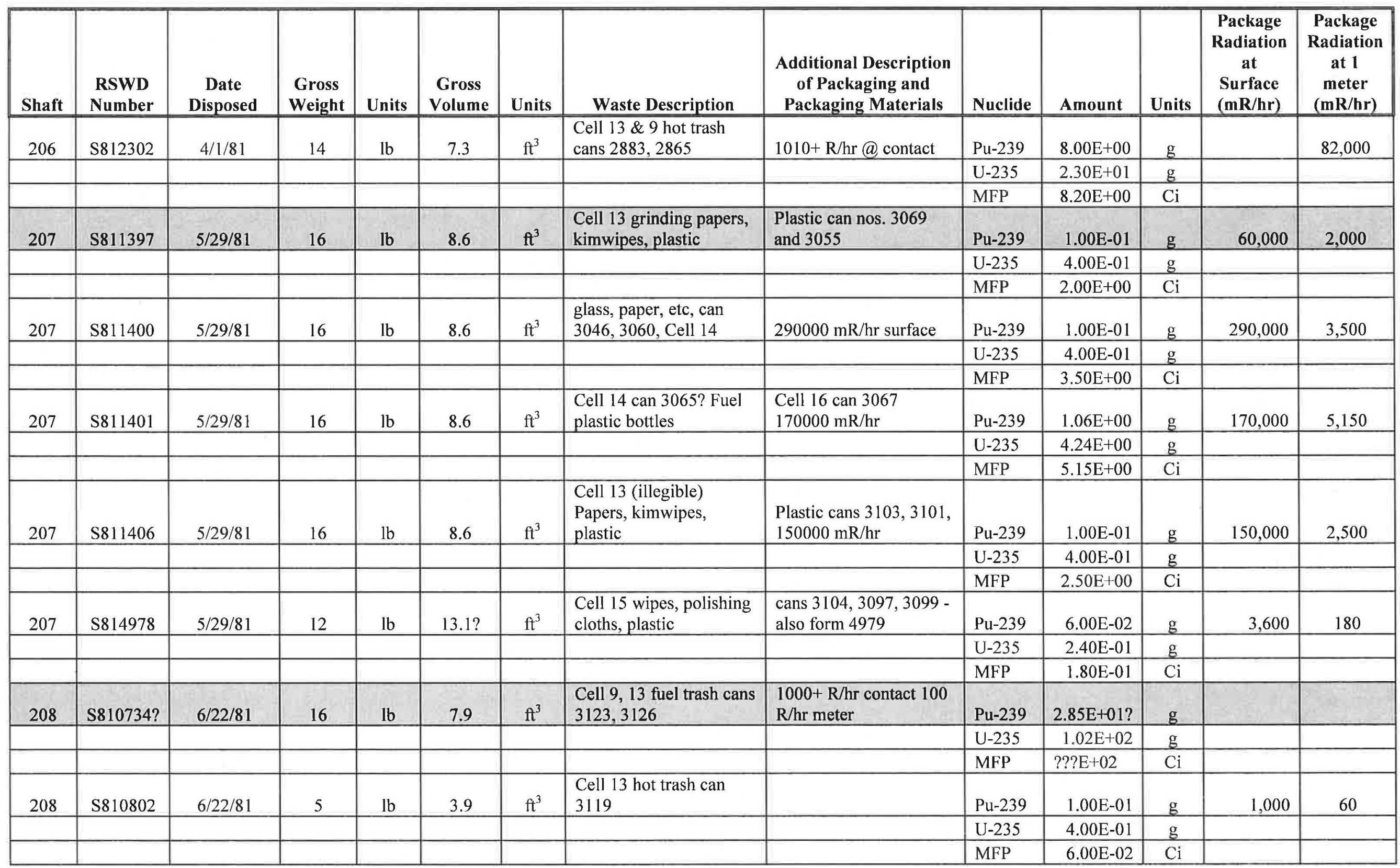




\section{Appendix A-3 - Information from Radioactive Solid Waste Disposal Forms for Lined Shafts}

\begin{tabular}{|c|c|c|c|c|c|c|c|c|c|c|c|c|c|}
\hline Shaft & $\begin{array}{l}\text { RSWD } \\
\text { Number }\end{array}$ & $\begin{array}{c}\text { Date } \\
\text { Disposed }\end{array}$ & $\begin{array}{c}\text { Gross } \\
\text { Weight }\end{array}$ & Units & $\begin{array}{c}\text { Gross } \\
\text { Volume } \\
\end{array}$ & Units & Waste Description & $\begin{array}{c}\text { Additional Description } \\
\text { of Packaging and } \\
\text { Packaging Materials } \\
\end{array}$ & Nuclide & Amount & Units & $\begin{array}{c}\text { Package } \\
\text { Radiation } \\
\text { at } \\
\text { Surface } \\
(\mathrm{mR} / \mathrm{hr}) \\
\end{array}$ & $\begin{array}{c}\text { Package } \\
\text { Radiation } \\
\text { at } 1 \\
\text { meter } \\
(\mathrm{mR} / \mathrm{hr}) \\
\end{array}$ \\
\hline \multirow[t]{3}{*}{208} & S811405 & $6 / 22 / 81$ & 16 & $\mathrm{lb}$ & 7.9 & $\mathrm{ft}^{3}$ & $\begin{array}{l}\text { Cell } 13 \text { catch pans, } \\
\text { grinding papers, towels }\end{array}$ & plastic cans 3096,3102 & $\mathrm{Pu}-239$ & $5.00 \mathrm{E}-01$ & $\mathrm{~g}$ & 80,000 & 2,000 \\
\hline & & & & & & & & & U-235 & $2.00 \mathrm{E}+00$ & $\mathrm{~g}$ & & \\
\hline & & & & & & & & & MFP & $2.00 \mathrm{E}+00$ & $\mathrm{Ci}$ & & \\
\hline \multirow[t]{3}{*}{208} & S811408 & $6 / 22 / 81$ & $8 ?$ & $\mathrm{lb}$ & 3.9 & $\mathrm{ft}^{3}$ & $\begin{array}{l}\text { Cell } 15 \text { wipes, polishing } \\
\text { cloths, plastics }\end{array}$ & Can 3093 & $\mathrm{Pu}-239$ & $1.00 \mathrm{E}-01$ & $\mathrm{~g}$ & 1,500 & 80 \\
\hline & & & & & & & & & U-235 & $4.00 \mathrm{E}-01$ & $\mathrm{~g}$ & & \\
\hline & & & & & & & & & MFP & $9.0 ? \mathrm{E}-02$ & $\mathrm{Ci}$ & & \\
\hline \multirow[t]{3}{*}{208} & S811409 & $6 / 22 / 81$ & 16 & lb & 7.9 & $\mathrm{ft}^{3}$ & $\begin{array}{l}\text { Cell } 13 \text { catch pans, fuel, } \\
\text { grinding papers }\end{array}$ & plastic cans 3092,3110 & Pu-239 & $1.00 \mathrm{E}-01$ & $\mathrm{~g}$ & 32,000 & 2,100 \\
\hline & & & & & & & & & $\mathrm{U}-235$ & $4.00 \mathrm{E}-01$ & $\mathrm{~g}$ & & \\
\hline & & & & & & & & & MFP & $2.10 \mathrm{E}+00$ & $\mathrm{Ci}$ & & \\
\hline \multirow[t]{3}{*}{208} & S811411 & $6 / 22 / 81$ & 16 & lb & 7.9 & $\mathrm{ft}^{3}$ & $\begin{array}{l}\text { Cell } 13 \text { grinding papers, } \\
\text { plastic, towels }\end{array}$ & Plastic cans 3094,3116 & Pu-239 & $1.00 \mathrm{E}-01$ & $\mathrm{~g}$ & 29,000 & 1,000 \\
\hline & & & & & & & & & U-235 & $4.00 \mathrm{E}-01$ & $\mathrm{~g}$ & & \\
\hline & & & & & & & & & MFP & $1.00 \mathrm{E}+00$ & $\mathrm{Ci}$ & & \\
\hline \multirow[t]{3}{*}{208} & S814979 & $6 / 22 / 81$ & 8 & $\mathrm{lb}$ & 7.9 & $\mathrm{ft}^{3}$ & $\begin{array}{l}\text { Cell } 15 \text { wipes, polishing } \\
\text { cloths, plastic }\end{array}$ & $\begin{array}{l}\text { Cans } 3100,3109-\text { see } \\
\text { form } S 814978\end{array}$ & Pu-239 & $4.00 \mathrm{E}-02$ & $\mathrm{~g}$ & 2,400 & 120 \\
\hline & & & & & & & & & $\mathrm{U}-235$ & $1.60 \mathrm{E}-01$ & $\mathrm{~g}$ & & \\
\hline & & & & & & & & & MFP & $1.20 \mathrm{E}-01$ & $\mathrm{Ci}$ & & \\
\hline \multirow[t]{3}{*}{209} & S810795 & $6 / 22 / 81$ & 16 & lb & 7.9 & $\mathrm{ft}^{3}$ & $\begin{array}{l}\text { Cell } 13 \text { trash, plastic, } \\
\text { paint, vermiculite }\end{array}$ & Plastic cans 3098,3131 & Pu-239 & $1.00 \mathrm{E}-01$ & $\mathrm{~g}$ & 15,000 & 1,000 \\
\hline & & & & & & & & & U-235 & $4.00 \mathrm{E}-01$ & $\mathrm{~g}$ & & \\
\hline & & & & & & & & & MFP & $1.00 \mathrm{E}+00$ & $\mathrm{Ci}$ & & \\
\hline \multirow[t]{3}{*}{209} & S810787? & $6 / 22 / 81$ & 16 & $\mathrm{lb}$ & 7.9 & $\mathrm{ft}^{3}$ & $\begin{array}{l}\text { Cell } 15 \text { trash, wipes, } \\
\text { chips, plastic }\end{array}$ & $\begin{array}{l}\text { Plastic cans } 3118 \& \\
3129\end{array}$ & $\mathrm{Pu}-239$ & $1.00 \mathrm{E}-01$ & $\mathrm{~g}$ & 2,800 & 400 \\
\hline & & & & & & & & & U-235 & $4.00 \mathrm{E}-01$ & $\mathrm{~g}$ & & \\
\hline & & & & & & & & & MFP & $4.00 \mathrm{E}-01$ & $\mathrm{Ci}$ & & \\
\hline \multirow[t]{3}{*}{209} & S810798 & $6 / 22 / 81$ & 16 & $\mathrm{lb}$ & 7.9 & $\mathrm{ft}^{3}$ & $\begin{array}{l}\text { Cell } 15 \text { vermiculite, } \\
\text { wipes, plastic, paint }\end{array}$ & Plastic cans 3111,3114 & $\mathrm{Pu}-239$ & $1.00 \mathrm{E}-01$ & $\mathrm{~g}$ & 1,600 & 200 \\
\hline & & & & & & & & & $\mathrm{U}-235$ & $4.00 \mathrm{E}-01$ & $\mathrm{~g}$ & & \\
\hline & & & & & & & & & MFP & $2.00 \mathrm{E}-01$ & $\mathrm{Ci}$ & & \\
\hline
\end{tabular}




\section{Appendix A-3 - Information from Radioactive Solid Waste Disposal Forms for Lined Shafts}

\begin{tabular}{|c|c|c|c|c|c|c|c|c|c|c|c|c|c|}
\hline Shaft & $\begin{array}{l}\text { RSWD } \\
\text { Number }\end{array}$ & $\begin{array}{c}\text { Date } \\
\text { Disposed }\end{array}$ & $\begin{array}{c}\text { Gross } \\
\text { Weight }\end{array}$ & Units & $\begin{array}{c}\text { Gross } \\
\text { Volume }\end{array}$ & Units & Waste Description & $\begin{array}{c}\text { Additional Description } \\
\text { of Packaging and } \\
\text { Packaging Materials }\end{array}$ & Nuclide & Amount & Units & $\begin{array}{c}\text { Package } \\
\text { Radiation } \\
\text { at } \\
\text { Surface } \\
(\mathrm{mR} / \mathrm{hr})\end{array}$ & $\begin{array}{c}\text { Package } \\
\text { Radiation } \\
\text { at } 1 \\
\text { meter } \\
(\mathrm{mR} / \mathrm{hr}) \\
\end{array}$ \\
\hline 209 & S810799 & $6 / 22 / 81$ & 30 & $\mathrm{lb}$ & 15.8 & $\mathrm{ft}^{3}$ & \multicolumn{2}{|c|}{ Cell 15 trash cans $2125,3108,3117,3130$} & $\mathrm{Pu}-239$ & $1.00 \mathrm{E}-01$ & $\mathrm{~g}$ & 5,000 & 300 \\
\hline & & & & & & & & & $\mathrm{U}-235$ & $4.00 \mathrm{E}-01$ & $\mathrm{~g}$ & & \\
\hline & & & & & & & & & MFP & $3.00 \mathrm{E}-01$ & $\mathrm{Ci}$ & & \\
\hline 209 & S811412 & $6 / 22 / 81$ & 16 & $\mathrm{lb}$ & 7.9 & $\mathrm{ft}^{3}$ & $\begin{array}{l}\text { Cell } 13 \text { grinding papers, } \\
\text { plastic, glass }\end{array}$ & Plastic cans 3091,3115 & Pu-239 & $1.00 \mathrm{E}-01$ & $\mathrm{~g}$ & 90,000 & 2,000 \\
\hline & & & & & & & & & U-235 & $4.00 \mathrm{E}-01$ & $\mathrm{~g}$ & & \\
\hline & & & & & & & & & MFP & $2.00 \mathrm{E}+00$ & $\mathrm{Ci}$ & & \\
\hline 210 & S810800 & $6 / 22 / 81$ & & & 7.9 & $\mathrm{ft}^{3}$ & \multicolumn{2}{|c|}{ Cell 13,15 hot trash cans 3145,3147} & Pu-239 & $1.00 \mathrm{E}-01$ & $g$ & 10,000 & 400 \\
\hline & 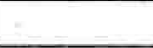 & & & & & & & & $\mathrm{U}-235$ & $4.00 \mathrm{E}-01$ & $\mathrm{~g}$ & & \\
\hline & & & & & & & & & MFP & $4.00 \mathrm{E}-01$ & $\mathrm{Ci}$ & & \\
\hline \multirow[t]{3}{*}{210} & S810804 & $6 / 22 / 81$ & & & $15.8 ?$ & $\mathrm{ft}^{3}$ & $\begin{array}{l}\text { Cell } 13,15 \text { hot trash } \\
\text { cans } 3139,3133,3135\end{array}$ & Cans, 3132 & Pu-239 & $1.00 \mathrm{E}-01$ & g & 4,000 & 200 \\
\hline & & & & & & & & & $\mathrm{U}-235$ & $4.00 \mathrm{E}-01$ & $\mathrm{~g}$ & & \\
\hline & & & & & & & & & MFP & $2.00 \mathrm{E}-01$ & $\mathrm{Ci}$ & & \\
\hline \multirow[t]{3}{*}{210} & S810805 & $6 / 22 / 81$ & 35 & $\mathrm{lb}$ & 15.8 & $\mathrm{ft}^{3}$ & $\begin{array}{l}\text { Cell } 13,15 \text { hot trash } \\
\text { cans } 3143,3146,2969\end{array}$ & 3151 in suitcase cask & Pu-239 & $1.00 \mathrm{E}-01$ & $\mathrm{~g}$ & 5,000 & 300 \\
\hline & & & & & & & & & $\mathrm{U}-235$ & $4.00 \mathrm{E}-01$ & $\mathrm{~g}$ & & \\
\hline & & & & & & & & & MFP & $3.00 \mathrm{E}-01$ & $\mathrm{Ci}$ & & \\
\hline \multirow[t]{3}{*}{210} & S810806 & $6 / 22 / 81$ & 16 & $\mathrm{lb}$ & 7.9 & $\mathrm{ft}^{3}$ & \multicolumn{2}{|c|}{ Cell 13,15 hot trash cans 3150,3153} & Pu-239 & $1.00 \mathrm{E}-01$ & $\mathrm{~g}$ & 300 & 20 \\
\hline & & & & & & & & & $\mathrm{U}-235$ & $4.00 \mathrm{E}-01$ & $\mathrm{~g}$ & & \\
\hline & & & & & & & & & MFP & $2.00 \mathrm{E}-02$ & $\mathrm{Ci}$ & & \\
\hline \multirow[t]{3}{*}{211} & $\$ 810807$ & $6 / 23 / 81$ & 880 & $\mathrm{lb}$ & 7.9 & $\mathrm{ft}^{3}$ & Cell $13 \& 15$ hot trash & cans plastic 3145,3147 & $\mathrm{Pu}-239$ & $1.00 \mathrm{E}-01$ & $\mathrm{~g}$ & 16,000 & 700 \\
\hline & 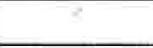 & $10 / 6 / 81$ & & & & & & & $\mathrm{U}-235$ & $4.00 \mathrm{E}-01$ & $\mathrm{~g}$ & & \\
\hline & & & & & & & & & MFP & $7.00 \mathrm{E}-01$ & $\mathrm{Ci}$ & & \\
\hline \multirow[t]{3}{*}{$211 ?$} & $\mathrm{~S} 810808$ & $10 / 6 / 81$ & 880 & $\mathrm{lb}$ & 7.9 & $\mathrm{ft}^{3}$ & $\begin{array}{l}\text { Cell } 14 \text { cans } 3158,3159 \text {, } \\
\text { hot trash, glass }\end{array}$ & $\begin{array}{l}126 \mathrm{R} \text { at contact, } \\
\text { plastic, paper }\end{array}$ & Pu-239 & $1.00 \mathrm{E}-01$ & $\mathrm{~g}$ & & 2,200 \\
\hline & & & & & & & & & U-235 & $4.00 \mathrm{E}-01$ & $\mathrm{~g}$ & & \\
\hline & & & & & & & & & MFP & $2.20 \mathrm{E}+00$ & $\mathrm{Ci}$ & & \\
\hline \multirow[t]{3}{*}{$211 ?$} & S810809 & $10 / 6 / 81$ & 880 & $\mathrm{lb}$ & 7.9 & $\mathrm{ft}^{3}$ & $\begin{array}{l}\text { Cell } 13 \text { trash catch pans, } \\
\text { plastic wipes }\end{array}$ & $\begin{array}{l}\text { Plastic cans } 3162,3167, \\
160 \mathrm{R} / \mathrm{hr} @ \mathrm{ct} .\end{array}$ & Pu-239 & $1.00 \mathrm{E}-01$ & $\mathrm{~g}$ & & 4,000 \\
\hline & & & & & & & & & U-235 & $4.00 \mathrm{E}-01$ & $\mathrm{~g}$ & & \\
\hline & & & & & & & & & MFP & $4.00 \mathrm{E}+00$ & $\mathrm{Ci}$ & & \\
\hline
\end{tabular}




\section{Appendix A-3 - Information from Radioactive Solid Waste Disposal Forms for Lined Shafts}

\begin{tabular}{|c|c|c|c|c|c|c|c|c|c|c|c|c|c|}
\hline Shaft & $\begin{array}{c}\text { RSWD } \\
\text { Number }\end{array}$ & $\begin{array}{c}\text { Date } \\
\text { Disposed } \\
\end{array}$ & $\begin{array}{c}\text { Gross } \\
\text { Weight }\end{array}$ & Units & $\begin{array}{c}\text { Gross } \\
\text { Volume } \\
\end{array}$ & Units & Waste Description & $\begin{array}{c}\text { Additional Description } \\
\text { of Packaging and } \\
\text { Packaging Materials }\end{array}$ & Nuclide & Amount & Units & $\begin{array}{c}\text { Package } \\
\text { Radiation } \\
\text { at } \\
\text { Surface } \\
(\mathrm{mR} / \mathrm{hr})\end{array}$ & $\begin{array}{c}\text { Package } \\
\text { Radiation } \\
\text { at } 1 \\
\text { meter } \\
(\mathrm{mR} / \mathrm{hr})\end{array}$ \\
\hline \multirow[t]{3}{*}{$211 ?$} & S810810 & $10 / 6 / 81$ & 880 & $\mathrm{lb}$ & 15.7 & $\mathrm{ft}^{3}$ & $\begin{array}{l}\text { Cell } 15 \text { cold trash, } \\
\text { plastics, bottles, wipes }\end{array}$ & $\begin{array}{l}\text { Can } 3160,3161,3168, \\
3169\end{array}$ & $\mathrm{Pu}-239$ & $1.00 \mathrm{E}-01$ & $\mathrm{~g}$ & 1,000 & 60 \\
\hline & & & & & & & & & U-235 & $4.00 \mathrm{E}-01$ & $\mathrm{~g}$ & & \\
\hline & & & & & & & & & MFP & $6.00 \mathrm{E}-02$ & $\mathrm{Ci}$ & & \\
\hline \multirow[t]{3}{*}{211} & S812669 & $10 / 6 / 81$ & 880 & $\mathrm{lb}$ & 7.9 & $\mathrm{ft}^{3}$ & $\begin{array}{l}\text { Cell } 14 \text { cans } 3171 ? \text {, } \\
3179, \text { fuel, OM?, glass, } \\
\text { etc }\end{array}$ & $940 \mathrm{Rhr}$ contact & $\mathrm{Pu}-239$ & $6.56 \mathrm{E}+00$ & $\mathrm{~g}$ & & 11,000 \\
\hline & & $8 / 3 / 81$ & & & & & & & U-235 & $2.60 \mathrm{E}+01$ & $\mathrm{~g}$ & & \\
\hline & & & & & & & & & MFP & $1.10 \mathrm{E}+01$ & $\mathrm{Ci}$ & & \\
\hline \multirow[t]{2}{*}{212} & S803758 & $4 / 9 / 80$ & 8 & ton & 75 & $\mathrm{ft}^{3}$ & $\begin{array}{l}\text { LAMPRE reactor vessel } \\
\text { sealed in cask }\end{array}$ & $\begin{array}{l}\text { Vessel in } 1 / 4^{\prime \prime} \text { steel cask } \\
\text { with concre }\end{array}$ & Pu-239 & $2.00 \mathrm{E}+02$ & g & 1,750 & 300 \\
\hline & & & & & & & & & Co-60 & $3.00 \mathrm{E}+01$ & $\mathrm{Ci}$ & & \\
\hline \multirow[t]{3}{*}{213} & S812684 & $11 / 3 / 81$ & 16 & $\mathrm{lb}$ & 7.5 & $\mathrm{ft}^{3}$ & $\begin{array}{l}\text { Cell } 9 \text { cell waste } \& \text { fuel } \\
\& \text { cell } 16 \text { waste }\end{array}$ & $\begin{array}{l}\text { Plastic cans } 3248 \text { - } \\
1000+R / h r \text { surf. }\end{array}$ & Pu-239 & $3.26 \mathrm{E}+01$ & $\mathrm{~g}$ & & 40,800 \\
\hline & & & & & & & & & $\mathrm{U}-235$ & $1.38 \mathrm{E}+02$ & $\mathrm{~g}$ & & \\
\hline & & & & & & & & & MFP & $4.08 \mathrm{E}+01$ & $\mathrm{Ci}$ & & \\
\hline \multirow[t]{3}{*}{213} & S812686 & $11 / 3 / 81$ & 16 & $\mathrm{lb}$ & 7.5 & $\mathrm{ft}^{3}$ & $\begin{array}{l}\text { Cell } 14 \text { cans } 3245,3246, \\
\text { fuel, glass, towels }\end{array}$ & $500 \mathrm{R}$ at contact & $\mathrm{Pu}-239$ & $4.33 \mathrm{E}+00$ & $\mathrm{~g}$ & & 7,000 \\
\hline & & & & & & & & & $\mathrm{U}-235$ & $1.73 \mathrm{E}+01$ & $\mathrm{~g}$ & & \\
\hline & & & & & & & & & MFP & $7.00 \mathrm{E}+00$ & $\mathrm{Ci}$ & & \\
\hline \multirow[t]{3}{*}{213} & S812688 & $11 / 3 / 81$ & 16 & $\mathrm{lb}$ & 7.5 & $\mathrm{ft}^{3}$ & $\begin{array}{l}\text { Cell } 9 \& 13 \text { fuel \& hot } \\
\text { trash }\end{array}$ & $\begin{array}{l}101000 \text { mR/hr@1 } \\
\text { meter, Cans 3273/3274 }\end{array}$ & $\mathrm{Pu}-239$ & $1.28 \mathrm{E}+01$ & $\mathrm{~g}$ & & 101,000 \\
\hline & & & & & & & & & U-235 & $7.79 \mathrm{E}+01$ & $\mathrm{~g}$ & & \\
\hline & & & & & & & & & MFP & $1.01 \mathrm{E}+02$ & $\mathrm{Ci}$ & & \\
\hline \multirow[t]{3}{*}{213} & S812689 & $11 / 3 / 81$ & 16 & $\mathrm{lb}$ & 7.5 & $\mathrm{ft}^{3}$ & $\begin{array}{l}\text { Cell } 1314 \text { cell waste } \\
\text { cans } 3266,3272\end{array}$ & 160R/hr@contact & Pu-239 & $2.00 \mathrm{E}-01$ & $\mathrm{~g}$ & & 2,800 \\
\hline & & & & & & & & & U-235 & $1.00 \mathrm{E}+01$ & $\mathrm{~g}$ & & \\
\hline & & & & & & & & & MFP & $2.80 \mathrm{E}+00$ & $\mathrm{Ci}$ & & \\
\hline \multirow[t]{3}{*}{214} & S820057 & $4 / 20 / 82$ & 18 & $\mathrm{lb}$ & 3 & $\mathrm{ft}^{3}$ & $\begin{array}{l}\text { Cell } 16 \text { trash can } 3338 \text {, } \\
\text { kimwipes, glassware }\end{array}$ & $\begin{array}{l}\text { Lucite can in steel } \\
\text { nipple }\end{array}$ & $\mathrm{Pu}-239$ & $1.00 \mathrm{E}-01$ & $\mathrm{~g}$ & 15,000 & 300 \\
\hline & & & & & & & & & U-235 & $4.00 \mathrm{E}-01$ & $\mathrm{~g}$ & & \\
\hline & & & & & & & & & MFP & $3.00 \mathrm{E}-01$ & $\mathrm{Ci}$ & & \\
\hline 214 & S820058 & $4 / 20 / 82$ & 22 & $\mathrm{lb}$ & 3 & $\mathrm{ft}^{3}$ & Cell 16 trash can 3351 , & Lucite can in steel & $\mathrm{Pu}-239$ & $1.00 \mathrm{E}-01$ & $\mathrm{~g}$ & 4,000 & 120 \\
\hline
\end{tabular}

$$
8 \text { of } 24
$$




\section{Appendix A-3 - Information from Radioactive Solid Waste Disposal Forms for Lined Shafts}

\begin{tabular}{|c|c|c|c|c|c|c|c|c|c|c|c|c|c|}
\hline Shaft & $\begin{array}{c}\text { RSWD } \\
\text { Number }\end{array}$ & $\begin{array}{c}\text { Date } \\
\text { Disposed }\end{array}$ & $\begin{array}{c}\text { Gross } \\
\text { Weight }\end{array}$ & Units & $\begin{array}{c}\text { Gross } \\
\text { Volume } \\
\end{array}$ & Units & Waste Description & $\begin{array}{c}\text { Additional Description } \\
\text { of Packaging and } \\
\text { Packaging Materials } \\
\end{array}$ & Nuclide & Amount & Units & $\begin{array}{c}\text { Package } \\
\text { Radiation } \\
\text { at } \\
\text { Surface } \\
\text { (mR/hr) } \\
\end{array}$ & $\begin{array}{c}\text { Package } \\
\text { Radiation } \\
\text { at } 1 \\
\text { meter } \\
(\mathrm{mR} / \mathrm{hr}) \\
\end{array}$ \\
\hline & & & & & & & & & U-235 & $4.00 \mathrm{E}-01$ & $\mathrm{~g}$ & & \\
\hline & & & & & & & & & MFP & $1.20 \mathrm{E}-01$ & $\mathrm{Ci}$ & & \\
\hline 214 & S821822 & $4 / 21 / 82$ & 30 & $\mathrm{lb}$ & 6 & $\mathrm{ft}^{3}$ & $\begin{array}{l}\text { Cell } 13 \text { trash can } 3369, \\
\text { kimwipes, paper }\end{array}$ & Plastic bags \& bottles & Pu-239 & $1.00 \mathrm{E}-01$ & $\mathrm{~g}$ & 25,000 & 400 \\
\hline & & & & & & & & & MFP & $4.00 \mathrm{E}-01$ & $\mathrm{Ci}$ & & \\
\hline 214 & S821823 & $4 / 21 / 82$ & 30 & $\mathrm{lb}$ & 8 & $\mathrm{ft}^{3}$ & \multicolumn{2}{|c|}{ Cell 13 trash can 3373 , paper, plastic } & $\mathrm{Pu}-239$ & $1.00 \mathrm{E}-01$ & $\mathrm{~g}$ & 30,000 & 450 \\
\hline & & & & & & & & & $\mathrm{U}-235$ & $4.00 \mathrm{E}-01$ & $\mathrm{~g}$ & & \\
\hline & & & & & & & & & MFP & $4.50 \mathrm{E}-01$ & $\mathrm{Ci}$ & & \\
\hline 214 & $\mathrm{~S} 821826$ & $4 / 23 / 82$ & $20 ?$ & $\mathrm{lb}$ & $6.0 ?$ & $\mathrm{ft}^{3}$ & \multicolumn{2}{|c|}{ Cell 14 can 3378 , glass, plastic bottles } & Pu-239 & $1.00 \mathrm{E}-01$ & $\mathrm{~g}$ & 20,000 & 400 \\
\hline & & & & & & & & & $\mathrm{U}-235$ & $4.00 \mathrm{E}-01$ & $\mathrm{~g}$ & & \\
\hline & & & & & & & & & MFP & $4.00 \mathrm{E}-01$ & $\mathrm{Ci}$ & & \\
\hline 214 & S823410 & $4 / 1 / 82$ & 16 & $\mathrm{lb}$ & 6 & $\mathrm{ft}^{3}$ & $\begin{array}{l}\text { Cell } 13 \& \text { Cell } 14 \text { hot } \\
\text { trash cans } 3307 \& \text { \& }\end{array}$ & $\begin{array}{l}110 \mathrm{R} / \mathrm{hr} @ \text { contact, can } \\
3278\end{array}$ & $\mathrm{Pu}-239$ & $1.00 \mathrm{E}-01$ & $\mathrm{~g}$ & & 1,300 \\
\hline & & & & & & & & & MFP & $1.30 \mathrm{E}+00$ & $\mathrm{Ci}$ & & \\
\hline 215 & S820041 & $6 / 9 / 82$ & 18 & $\mathrm{lb}$ & 2.5 & Gal. & Cell 9 fuel can 3312 & $1000+\mathrm{Rhr}$ at contact & Pu-239 & $1.50 \mathrm{E}+01$ & $\mathrm{~g}$ & & 30,000 \\
\hline & & $1 / 6 / 82$ & & & & & & & U-235 & $7.12 \mathrm{E}+01$ & $\mathrm{~g}$ & & \\
\hline & & & & & & & & & MFP & $3.00 \mathrm{E}+01$ & $\mathrm{Ci}$ & & \\
\hline 215 & S820042 & $6 / 9 / 82$ & 18 & $\mathrm{lb}$ & 2.5 & $\mathrm{ft}^{3}$ & Cell 14 waste can 3307 & 140 R/hr@ contact & Pu-239 & $1.00 \mathrm{E}-01$ & $\mathrm{~g}$ & & 15,000 \\
\hline & & $1 / 6 / 82$ & & & & & & & $\mathrm{U}-235$ & $4.00 \mathrm{E}-01$ & $\mathrm{~g}$ & & \\
\hline & & & & & & & & & MFP & $1.50 \mathrm{E}+01$ & $\mathrm{Ci}$ & & \\
\hline 215 & S821832 & $6 / 9 / 82$ & 28 & $\mathrm{lb}$ & 5 & $\mathrm{ft}^{3}$ & $\begin{array}{l}\text { Cell } 11 \text { trash can } 3393 \\
\text { hot trash }\end{array}$ & $\begin{array}{l}\text { Lucite can in steel } \\
\text { nipple }\end{array}$ & Pu-239 & $1.00 \mathrm{E}-01$ & $\mathrm{~g}$ & 35,000 & 2,000 \\
\hline & & & & & & & & & $\mathrm{U}-235$ & $4.00 \mathrm{E}-01$ & $\mathrm{~g}$ & & \\
\hline & & & & & & & & & MFP & $2.00 \mathrm{E}+00$ & $\mathrm{Ci}$ & & \\
\hline 215 & S821833 & $6 / 9 / 82$ & 28 & $\mathrm{lb}$ & 5 & $\mathrm{ft}^{3}$ & $\begin{array}{l}\text { Cell } 11 \text { hot trash can } \\
3300\end{array}$ & 100R@,contact & Pu-239 & $1.00 \mathrm{E}-01$ & $\mathrm{~g}$ & & 3,000 \\
\hline & & & & & & & & & U-235 & $4.00 \mathrm{E}-01$ & $\mathrm{~g}$ & & \\
\hline & & & & & & & & & MFP & $3.00 \mathrm{E}+00$ & $\mathrm{Ci}$ & & \\
\hline 215 & S821834 & $6 / 9 / 82$ & 28 & $\mathrm{lb}$ & 5 & $\mathrm{ft}^{3}$ & Cell 13 hot trash can & 200R/hr@ contact & $\mathrm{Pu}-239$ & $1.00 \mathrm{E}-01$ & $\mathrm{~g}$ & & 2,000 \\
\hline
\end{tabular}




\section{Appendix A-3 - Information from Radioactive Solid Waste Disposal Forms for Lined Shafts}

\begin{tabular}{|c|c|c|c|c|c|c|c|c|c|c|c|c|c|}
\hline Shaft & $\begin{array}{c}\text { RSWD } \\
\text { Number }\end{array}$ & $\begin{array}{c}\text { Date } \\
\text { Disposed } \\
\end{array}$ & $\begin{array}{c}\text { Gross } \\
\text { Weight }\end{array}$ & Units & $\begin{array}{l}\text { Gross } \\
\text { Volume } \\
\end{array}$ & Units & Waste Description & $\begin{array}{c}\text { Additional Description } \\
\text { of Packaging and } \\
\text { Packaging Materials }\end{array}$ & Nuclide & Amount & Units & $\begin{array}{c}\text { Package } \\
\text { Radiation } \\
\text { at } \\
\text { Surface } \\
\text { (mR/hr) }\end{array}$ & $\begin{array}{c}\text { Package } \\
\text { Radiation } \\
\text { at } 1 \\
\text { meter } \\
(\mathrm{mR} / \mathrm{hr}) \\
\end{array}$ \\
\hline & & & & & & & $3387 ?$ & & & & & & \\
\hline & & & & & & & & & $\mathrm{U}-235$ & $4.00 \mathrm{E}-01$ & $\mathrm{~g}$ & & \\
\hline & & & & & & & & & MFP & $2.00 \mathrm{E}+00$ & $\mathrm{Ci}$ & & \\
\hline \multirow[t]{3}{*}{215} & S821835 & $6 / 9 / 82$ & 28 & $\mathrm{lb}$ & 5 & $\mathrm{ft}^{3}$ & $\begin{array}{l}\text { Cell } 13 \text { hot trash can } \\
3383\end{array}$ & $\begin{array}{l}\text { Grinding papers, kim } \\
\text { wipes }\end{array}$ & Pu-239 & $1.00 \mathrm{E}-01$ & $\mathrm{~g}$ & 40,000 & 800 \\
\hline & & & & & & & & & $\mathrm{U}-235$ & $4.00 \mathrm{E}-01$ & $\mathrm{~g}$ & & \\
\hline & & & & & & & & & MFP & $3.00 \mathrm{E}-01$ & $\mathrm{Ci}$ & & \\
\hline \multirow[t]{3}{*}{215} & S821837 & $6 / 9 / 82$ & 28 & $\mathrm{lb}$ & 5 & $\mathrm{ft}^{3}$ & $\begin{array}{l}\text { Cell } 13 \text { hot trash can } \\
3415\end{array}$ & Bottles, kimwipes & $\mathrm{Pu}-239$ & $1.00 \mathrm{E}-01$ & $\mathrm{~g}$ & 20,000 & 2,000 \\
\hline & & & & & & & & & $\mathrm{U}-235$ & $4.00 \mathrm{E}-01$ & $\mathrm{~g}$ & & \\
\hline & & & & & & & & & MFP & $2.00 \mathrm{E}+00$ & $\mathrm{Ci}$ & & \\
\hline \multirow[t]{3}{*}{216} & S821825 & $6 / 9 / 82$ & 20 & $\mathrm{lb}$ & 5 & $\mathrm{ft}^{3}$ & \multicolumn{2}{|c|}{ Cell 14 can 3373 , glass, towels, plstic, etc } & Pu-239 & $1.00 \mathrm{E}+00$ & $g$ & 40,000 & 800 \\
\hline & & & & & & & & & U-235 & $4.00 \mathrm{E}+00$ & $\mathrm{~g}$ & & \\
\hline & & & & & & & & & MFP & $8.00 \mathrm{E}-01$ & $\mathrm{Ci}$ & & \\
\hline \multirow[t]{3}{*}{216} & S821836 & $6 / 9 / 82$ & 28 & $\mathrm{lb}$ & 5 & $\mathrm{ft}^{3}$ & $\begin{array}{l}\text { Cell } 13 \text { hot trash can } \\
3416\end{array}$ & Bottles, kimwipes & Pu-239 & $1.00 \mathrm{E}-01$ & $\mathrm{~g}$ & 20,000 & 2,000 \\
\hline & & & & & & & & & $\mathrm{U}-235$ & $4.00 \mathrm{E}-01$ & $\mathrm{~g}$ & & \\
\hline & & & & & & & & & MFP & $2.00 \mathrm{E}+00$ & $\mathrm{Ci}$ & & \\
\hline \multirow[t]{3}{*}{216} & S821838 & $6 / 9 / 82$ & 28 & $\mathrm{lb}$ & 5 & $\mathrm{ft}^{3}$ & $\begin{array}{l}\text { Cell } 13 \text { hot trash can\# } \\
3395 \text {, grinding, etc }\end{array}$ & Kimwipes, plastic & Pu-239 & $1.00 \mathrm{E}-01$ & $\mathrm{~g}$ & 15,000 & 1,000 \\
\hline & & & & & & & & & $\mathrm{U}-235$ & $4.00 \mathrm{E}-01$ & $\mathrm{~g}$ & & \\
\hline & & & & & & & & & MFP & $1.00 \mathrm{E}+00$ & $\mathrm{Ci}$ & & \\
\hline \multirow[t]{3}{*}{216} & S821839 & $6 / 9 / 82$ & 28 & $\mathrm{lb}$ & 5 & $\mathrm{ft}^{3}$ & $\begin{array}{l}\text { Cell } 13 \text { hot trash can } \\
3405\end{array}$ & Vermiculite wipes & Pu-239 & $1.00 \mathrm{E}-01$ & $\mathrm{~g}$ & 8,000 & 200 \\
\hline & & & & & & & & & $\mathrm{U}-235$ & $4.00 \mathrm{E}-01$ & $\mathrm{~g}$ & & \\
\hline & & & & & & & & & MFP & $2.00 \mathrm{E}-01$ & $\mathrm{Ci}$ & & \\
\hline \multirow[t]{3}{*}{216} & $\mathrm{~S} 821840$ & $6 / 9 / 82$ & 28 & $\mathrm{lb}$ & 5 & $\mathrm{ft}^{3}$ & $\begin{array}{l}\text { Cell } 13 \text { hot trash can } \\
3384\end{array}$ & 200R/hr@ contact & Pu-239 & $1.00 \mathrm{E}-01$ & $\mathrm{~g}$ & & 4,000 \\
\hline & 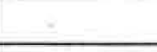 & & & & & & & & U-235 & $4.00 \mathrm{E}-01$ & $\mathrm{~g}$ & & \\
\hline & & & & & & & & & MFP & $4.00 \mathrm{E}+00$ & $\mathrm{Ci}$ & & \\
\hline 216 & S821841 & $6 / 9 / 82$ & 28 & $\mathrm{lb}$ & 5 & $\mathrm{ft}^{3}$ & $\begin{array}{l}\text { Cell } 13 \text { hot trash can } \\
3385 \text {, kimwipes }\end{array}$ & Grinding papers & Pu-239 & $1.00 \mathrm{E}-01$ & $\mathrm{~g}$ & 30,000 & 2,000 \\
\hline
\end{tabular}




\section{Appendix A-3 - Information from Radioactive Solid Waste Disposal Forms for Lined Shafts}

\begin{tabular}{|c|c|c|c|c|c|c|c|c|c|c|c|c|c|}
\hline Shaft & $\begin{array}{l}\text { RSWD } \\
\text { Number }\end{array}$ & $\begin{array}{c}\text { Date } \\
\text { Disposed }\end{array}$ & $\begin{array}{c}\text { Gross } \\
\text { Weight }\end{array}$ & Units & $\begin{array}{c}\text { Gross } \\
\text { Volume }\end{array}$ & Units & Waste Description & $\begin{array}{c}\text { Additional Description } \\
\text { of Packaging and } \\
\text { Packaging Materials }\end{array}$ & Nuclide & Amount & Units & $\begin{array}{c}\text { Package } \\
\text { Radiation } \\
\text { at } \\
\text { Surface } \\
(\mathrm{mR} / \mathrm{hr}) \\
\end{array}$ & $\begin{array}{c}\text { Package } \\
\text { Radiation } \\
\text { at } 1 \\
\text { meter } \\
(\mathrm{mR} / \mathrm{hr}) \\
\end{array}$ \\
\hline & & & & & & & & & $\mathrm{U}-235$ & $4.00 \mathrm{E}-01$ & $\mathrm{~g}$ & & \\
\hline & & & & & & & & & MFP & $2.00 \mathrm{E}+00$ & $\mathrm{Ci}$ & & \\
\hline \multirow[t]{3}{*}{217} & $S 821870$ & $9 / 13 / 82$ & 20 & $\mathrm{lb}$ & 5 & $\mathrm{ft}^{3}$ & \multicolumn{2}{|c|}{ Cell 14 can 3451 , glass, plastic bottles } & Pu-239 & $1.00 \mathrm{E}-01$ & $g$ & 15,000 & 1,500 \\
\hline & & & & & & & & & $\mathrm{U}-235$ & $4.00 \mathrm{E}-01$ & $\mathrm{~g}$ & & \\
\hline & & & & & & & & & MFP & $1.80 \mathrm{E}-01$ & $\mathrm{Ci}$ & & \\
\hline \multirow[t]{3}{*}{217} & S821871 & $9 / 13 / 82$ & 38 & $\mathrm{lb}$ & 5 & $\mathrm{ft}^{3}$ & $\begin{array}{l}\text { Cell } 14 \text { can } 3452 \text {, fuels } \\
\text { scrap, card boxes }\end{array}$ & $\begin{array}{l}100000 \mathrm{mR} / \mathrm{hr} \text { at } \\
\text { contact }\end{array}$ & $\mathrm{Pu}-239$ & $3.20 \mathrm{E}+00$ & $\mathrm{~g}$ & 100,000 & 4,500 \\
\hline & & & & & & & & & U-235 & $1.29 \mathrm{E}+01$ & $\mathrm{~g}$ & & \\
\hline & & & & & & & & & MFP & $4.50 \mathrm{E}+00$ & $\mathrm{Ci}$ & & \\
\hline \multirow[t]{3}{*}{217} & S821874 & $9 / 13 / 82$ & 28 & $\mathrm{lb}$ & 5 & $\mathrm{ft}^{3}$ & $\begin{array}{l}\text { Cell } 13 \text { hot trash, } \\
\text { grinding papers, etc }\end{array}$ & Bottom entry cask & Pu-239 & $1.00 \mathrm{E}-01$ & $\mathrm{~g}$ & 80,000 & 1,000 \\
\hline & & & & & & & & & $\mathrm{U}-235$ & $4.00 \mathrm{E}-01$ & $\mathrm{~g}$ & & \\
\hline & & & & & & & & & MFP & $1.00 \mathrm{E}+01$ & $\mathrm{Ci}$ & & \\
\hline \multirow[t]{3}{*}{217} & S821882 & $9 / 13 / 82$ & 30 & $\mathrm{lb}$ & 5 & $\mathrm{ft}^{3}$ & Cell 13 trash can \# 3478 & & $\mathrm{Pu}-239$ & $1.00 \mathrm{E}-01$ & $\mathrm{~g}$ & 6,000 & 1,000 \\
\hline & & & & & & & & & $\mathrm{U}-235$ & $4.00 \mathrm{E}-01$ & $\mathrm{~g}$ & & \\
\hline & & & & & & & & & MFP & $1.00 \mathrm{E}+00$ & $\mathrm{Ci}$ & & \\
\hline \multirow[t]{3}{*}{217} & S821915 & $9 / 13 / 82$ & 10 & $\mathrm{lb}$ & 5 & $\mathrm{ft}^{3}$ & $\begin{array}{l}\text { Cell } 9 \text { can } 3446, \text { waste } \\
\text { fuel and cel trash }\end{array}$ & $\begin{array}{l}1000+\mathrm{R} \text { contact } 150 \mathrm{R} \\
\text { at } 1 \text { meter }\end{array}$ & $\mathrm{Pu}-239$ & $2.28 \mathrm{E}+01$ & $\mathrm{~g}$ & & 1,000 \\
\hline & & & & & & & & & U-235 & $6.00 \mathrm{E}+01$ & $\mathrm{~g}$ & & \\
\hline & & & & & & & & & MFP & $1.00 \mathrm{E}+00$ & $\mathrm{Ci}$ & & \\
\hline \multirow[t]{3}{*}{217} & S821918 & $9 / 13 / 82$ & 38 & $\mathrm{lb}$ & 5 & $\mathrm{ft}^{3}$ & $\begin{array}{l}\text { Cell } 14 \text { can } 3437 \text { fuel } \\
\text { scrap card boxes }\end{array}$ & 900R/hr@cont & $\mathrm{Pu}-239$ & $3.20 \mathrm{E}+00$ & $\mathrm{~g}$ & & 10,000 \\
\hline & & & & & & & & & $\mathrm{U}-235$ & $1.29 \mathrm{E}+01$ & $\mathrm{~g}$ & & \\
\hline & & & & & & & & & MFP & $1.00 \mathrm{E}+00$ & $\mathrm{Ci}$ & & \\
\hline \multirow[t]{3}{*}{218} & S821875 & $9 / 13 / 82$ & 30 & lb & 5 & $\mathrm{ft}^{3}$ & Cell 9 trash can \# 3499 & 300R@ contact & Pu-239 & $1.00 \mathrm{E}-01$ & $\mathrm{~g}$ & & 20,000 \\
\hline & & & & & & & & & $\mathrm{U}-235$ & $4.00 \mathrm{E}-01$ & $\mathrm{~g}$ & & \\
\hline & & & & & & & & & MFP & $2.00 \mathrm{E}+01$ & $\mathrm{Ci}$ & & \\
\hline \multirow[t]{3}{*}{218} & S821879 & $9 / 13 / 82$ & 30 & $\mathrm{lb}$ & 5 & $\mathrm{ft}^{3}$ & $\begin{array}{l}\text { Cell } 13 \text { trash catch pan } \\
\text { can\# } 3477\end{array}$ & 500R@ contact & Pu-239 & $2.00 \mathrm{E}+00$ & $\mathrm{~g}$ & & 30,000 \\
\hline & & & & & & & & & U-235 & $9.00 \mathrm{E}+00$ & $\mathrm{~g}$ & & \\
\hline & & & & & & & & & MFP & $3.00 \mathrm{E}+01$ & $\mathrm{Ci}$ & & \\
\hline 218 & S821881 & $9 / 13 / 82$ & 30 & lbs & 1 & $\mathrm{ft}^{3}$ & Cell 13 trash can $\# 3468$ & 900R@contact & Pu-239 & $2.00 \mathrm{E}+00$ & $\mathrm{~g}$ & & 40,000 \\
\hline
\end{tabular}

$$
11 \text { of } 24
$$




\section{Appendix A-3 - Information from Radioactive Solid Waste Disposal Forms for Lined Shafts}

\begin{tabular}{|c|c|c|c|c|c|c|c|c|c|c|c|c|c|}
\hline Shaft & $\begin{array}{c}\text { RSWD } \\
\text { Number }\end{array}$ & $\begin{array}{c}\text { Date } \\
\text { Disposed }\end{array}$ & $\begin{array}{l}\text { Gross } \\
\text { Weight }\end{array}$ & Units & $\begin{array}{c}\text { Gross } \\
\text { Volume } \\
\end{array}$ & Units & Waste Description & $\begin{array}{c}\text { Additional Description } \\
\text { of Packaging and } \\
\text { Packaging Materials }\end{array}$ & Nuclide & Amount & Units & $\begin{array}{c}\text { Package } \\
\text { Radiation } \\
\text { at } \\
\text { Surface } \\
\text { (mR/hr) } \\
\end{array}$ & $\begin{array}{c}\text { Package } \\
\text { Radiation } \\
\text { at } 1 \\
\text { meter } \\
(\mathrm{mR} / \mathrm{hr}) \\
\end{array}$ \\
\hline & & & & & & & & & U-235 & $9.00 \mathrm{E}+00$ & $\mathrm{~g}$ & & \\
\hline & & & & & & & & & MFP & $4.00 \mathrm{E}+01$ & $\mathrm{Ci}$ & & \\
\hline \multirow[t]{3}{*}{218} & S821883 & $9 / 13 / 82$ & 30 & $\mathrm{lb}$ & 5 & $\mathrm{ft}^{3}$ & Cell 13 trash can \# 3469 & 200Rhr@, contact & $\mathrm{Pu}-239$ & $1.00 \mathrm{E}-01$ & & & 6,000 \\
\hline & & & & & & & & & U-235 & $4.00 \mathrm{E}-01$ & & & \\
\hline & & & & & & & & & MFP & $6.00 \mathrm{E}+00$ & & & \\
\hline \multirow[t]{3}{*}{218} & S821916 & $9 / 13 / 82$ & 40 & $\mathrm{lb}$ & 5 & $\mathrm{ft}^{3}$ & $\begin{array}{l}\text { Cropper disposals and } \\
\text { fuel can\# } 3489\end{array}$ & $\begin{array}{l}\text { Reading @ cont 1000+ } \\
\text { R/hr }\end{array}$ & Pu-239 & $4.04 \mathrm{E}+01$ & $\mathrm{~g}$ & & 30,000 \\
\hline & & & & & & & & & U-235 & $8.28 \mathrm{E}+01$ & $\mathrm{~g}$ & & \\
\hline & & & & & & & & & MFP & $3.00 \mathrm{E}+01$ & $\mathrm{Ci}$ & & \\
\hline \multirow[t]{3}{*}{218} & S821917 & $9 / 13 / 82$ & 30 & $\mathrm{lb}$ & 5 & $\mathrm{ft}^{3}$ & Cell 9 trash can \# 5 & 300R/hr@ contact & $\mathrm{Pu}-239$ & $1.00 \mathrm{E}-01$ & $\mathrm{~g}$ & & 6,000 \\
\hline & & & & & & & & & U-235 & $4.00 \mathrm{E}-01$ & $\mathrm{~g}$ & & \\
\hline & & & & & & & & & MFP & $6.00 \mathrm{E}+00$ & $\mathrm{Ci}$ & & \\
\hline \multirow[t]{3}{*}{219} & S832830 & $3 / 10 / 83$ & 30 & lb & 5 & $\mathrm{ft}^{3}$ & $\begin{array}{l}\text { Cell } 13 \text { grinding waste } \\
\text { can } \# 3527\end{array}$ & $1000 \mathrm{R} / \mathrm{hr} @$ contact & $\mathrm{Pu}-239$ & $1.00 \mathrm{E}-01$ & $\mathrm{~g}$ & & 20,000 \\
\hline & & & & & & & & & $\mathrm{U}-235$ & $4.00 \mathrm{E}-01$ & $\mathrm{~g}$ & & \\
\hline & & & & & & & & & MFP & $2.00 \mathrm{E}+01$ & $\mathrm{Ci}$ & & \\
\hline \multirow[t]{3}{*}{219} & S832831 & $3 / 10 / 83$ & 30 & $\mathrm{lb}$ & 5 & $\mathrm{ft}^{3}$ & Cell 11 trash can 3727 & Bottom entry cask & $\mathrm{Pu}-239$ & $1.00 \mathrm{E}-01$ & $\mathrm{~g}$ & 30,000 & 800 \\
\hline & & & & & & & & & U-235 & $4.00 \mathrm{E}-01$ & $\mathrm{~g}$ & & \\
\hline & & & & & & & & & MFP & $8.00 \mathrm{E}-01$ & $\mathrm{Ci}$ & & \\
\hline \multirow[t]{3}{*}{219} & S832832 & $3 / 10 / 83$ & 30 & $\mathrm{lb}$ & 5 & $\mathrm{ft}^{3}$ & $\begin{array}{l}\text { Cell } 9 \text { fuel \& hardware } \\
\text { can } 3724\end{array}$ & $\begin{array}{l}\text { 1000+R @ contact } \\
150 \mathrm{R} @ 1 \text { meter }\end{array}$ & Pu-239 & $4.05 \mathrm{E}+01$ & $\mathrm{~g}$ & & \\
\hline & & & & & & & & & U-235 & $2.36 \mathrm{E}+02$ & $\mathrm{~g}$ & & \\
\hline & & & & & & & & & MFP & $1.50 \mathrm{E}+02$ & $\mathrm{Ci}$ & & \\
\hline \multirow[t]{3}{*}{219} & S832833 & $3 / 10 / 83$ & 30 & $\mathrm{lb}$ & 5 & $\mathrm{ft}^{3}$ & Cell 9 waste can 3725 & $200 \mathrm{R} / \mathrm{hr}$ contact & $\mathrm{Pu}-239$ & $1.00 \mathrm{E}-01$ & $\mathrm{~g}$ & & 30,000 \\
\hline & & & & & & & & & U-235 & $4.00 \mathrm{E}-01$ & $\mathrm{~g}$ & & \\
\hline & & & & & & & & & MFP & $3.00 \mathrm{E}+01$ & $\mathrm{Ci}$ & & \\
\hline \multirow[t]{3}{*}{219} & S832834 & $3 / 10 / 83$ & 30 & $\mathrm{lb}$ & 5 & $\mathrm{ft}^{3}$ & $\begin{array}{l}\text { Cell } 9 \text { hot trash can } \\
3524\end{array}$ & $\begin{array}{l}1000+\mathrm{R} \text { contact } 50 \mathrm{R} \text { at } \\
1 \text { meter }\end{array}$ & $\mathrm{Pu}-239$ & $1.00 \mathrm{E}-01$ & $\mathrm{~g}$ & & \\
\hline & & & & & & & & & U-235 & $4.00 \mathrm{E}-01$ & $\mathrm{~g}$ & & \\
\hline & & & & & & & & & MFP & $5.00 \mathrm{E}+01$ & $\mathrm{Ci}$ & & \\
\hline 219 & S832835 & $3 / 10 / 83$ & 30 & $\mathrm{lb}$ & 5 & $\mathrm{ft}^{3}$ & $\begin{array}{l}\text { Cell } 9 \text { hot trash can } \\
3495\end{array}$ & $\begin{array}{l}1000+R \text { contact } 100 R \text { at } \\
1 \text { meter }\end{array}$ & Pu-239 & $4.98 \mathrm{E}+00$ & $\mathrm{~g}$ & & \\
\hline
\end{tabular}

12 of 24 


\section{Appendix A-3 - Information from Radioactive Solid Waste Disposal Forms for Lined Shafts}

\begin{tabular}{|c|c|c|c|c|c|c|c|c|c|c|c|c|c|}
\hline Shaft & $\begin{array}{c}\text { RSWD } \\
\text { Number } \\
\end{array}$ & $\begin{array}{c}\text { Date } \\
\text { Disposed } \\
\end{array}$ & $\begin{array}{c}\text { Gross } \\
\text { Weight } \\
\end{array}$ & Units & $\begin{array}{c}\text { Gross } \\
\text { Volume } \\
\end{array}$ & Units & Waste Description & $\begin{array}{c}\text { Additional Description } \\
\text { of Packaging and } \\
\text { Packaging Materials }\end{array}$ & Nuclide & Amount & Units & $\begin{array}{c}\text { Package } \\
\text { Radiation } \\
\text { at } \\
\text { Surface } \\
(\mathrm{mR} / \mathrm{hr}) \\
\end{array}$ & $\begin{array}{c}\text { Package } \\
\text { Radiation } \\
\text { at } 1 \\
\text { meter } \\
(\mathrm{mR} / \mathrm{hr}) \\
\end{array}$ \\
\hline & & & & & & & & & U-235 & $2.02 \mathrm{E}+01$ & $\mathrm{~g}$ & & \\
\hline & & & & & & & & & MFP & $1.00 \mathrm{E}+02$ & $\mathrm{Ci}$ & & \\
\hline \multirow[t]{3}{*}{220} & S832836 & $3 / 10 / 83$ & 30 & $\mathrm{lb}$ & 5 & $\mathrm{ft}^{3}$ & $\begin{array}{l}\text { Cell } 9 \text { waste etc can } \\
3728\end{array}$ & $\begin{array}{l}\text { 100R/hr@1m 1000+ } \\
\text { R/hr@con }\end{array}$ & Pu-239 & $1.00 \mathrm{E}-01$ & g & & \\
\hline & & & & & & & & & $\mathrm{U}-235$ & $4.00 \mathrm{E}-01$ & $\mathrm{~g}$ & & \\
\hline & & & & & & & & & MFP & $1.00 \mathrm{E}+02$ & $\mathrm{Ci}$ & & \\
\hline \multirow[t]{3}{*}{220} & S832837 & $3 / 10 / 83$ & 30 & $\mathrm{lb}$ & 5 & $\mathrm{ft}^{3}$ & Cell 9 waste can 3491 & $\begin{array}{l}100 \mathrm{R} / \mathrm{hr} 1 \mathrm{~m} 1000+ \\
\mathrm{R} / \mathrm{hr} \text { contact }\end{array}$ & $\mathrm{Pu}-239$ & $1.10 \mathrm{E}-01$ & $\mathrm{~g}$ & & \\
\hline & & +2 & & & & & & & $\mathrm{U}-235$ & $4.00 \mathrm{E}-01$ & $\mathrm{~g}$ & & \\
\hline & & & & & & & & & MFP & $1.00 \mathrm{E}+02$ & $\mathrm{Ci}$ & & \\
\hline \multirow[t]{3}{*}{220} & S832838 & $3 / 10 / 83$ & 30 & $\mathrm{lb}$ & 5 & $\mathrm{ft}^{3}$ & Cell 11 trash can 3706 & $100 \mathrm{R} / \mathrm{hr}$ contact & $\mathrm{Pu}-239$ & $1.00 \mathrm{E}-01$ & $g$ & & 2,000 \\
\hline & & & & & & & & & $\mathrm{U}-235$ & $4.00 \mathrm{E}-01$ & $\mathrm{~g}$ & & \\
\hline & & & & & & & & & MFP & $2.00 \mathrm{E}+00$ & $\mathrm{Ci}$ & & \\
\hline \multirow[t]{3}{*}{220} & S832839 & $3 / 10 / 83$ & 30 & $\mathrm{lb}$ & 5 & $\mathrm{ft}^{3}$ & $\begin{array}{l}\text { Cell } 13 \text { grinding can } \\
3528\end{array}$ & $200 \mathrm{R} / \mathrm{hr}$ contact & Pu-239 & $1.00 \mathrm{E}-01$ & $\mathrm{~g}$ & & 8,000 \\
\hline & & & & & & & & & $\mathrm{U}-235$ & $4.00 \mathrm{E}-01$ & $\mathrm{~g}$ & & \\
\hline & & & & & & & & & MFP & $8.00 \mathrm{E}+00$ & $\mathrm{Ci}$ & & \\
\hline \multirow[t]{3}{*}{220} & S832840 & $3 / 10 / 83$ & 30 & $\mathrm{lb}$ & 5 & $\mathrm{ft}^{3}$ & $\begin{array}{l}\text { Cell } 13 \text { grinding can } \\
3522\end{array}$ & $\begin{array}{l}200 \mathrm{R} / \mathrm{hr} \operatorname{lm} 1000+ \\
\mathrm{R} / \mathrm{hr} \text { contact }\end{array}$ & Pu-239 & $1.00 \mathrm{E}-01$ & $\mathrm{~g}$ & & \\
\hline & & & & & & & & & $\mathrm{U}-235$ & $4.00 \mathrm{E}-01$ & $\mathrm{~g}$ & & \\
\hline & & & & & & & & & MFP & $2.00 \mathrm{E}+02$ & $\mathrm{Ci}$ & & \\
\hline \multirow[t]{3}{*}{220} & S832841 & $3 / 10 / 83$ & 30 & $\mathrm{lb}$ & 5 & $\mathrm{ft}^{3}$ & $\begin{array}{l}\text { Cell } 16 \text { wire wrap can } \\
3726\end{array}$ & $\begin{array}{l}50 \mathrm{R} / \mathrm{hr} 1 \mathrm{~m} 1000+ \\
\mathrm{R} / \mathrm{hr} \text { contact }\end{array}$ & Pu-239 & $1.00 \mathrm{E}-01$ & $\mathrm{~g}$ & & 50,000 \\
\hline & & & & & & & & & U-235 & $4.00 \mathrm{E}-01$ & $\mathrm{~g}$ & & \\
\hline & & & & & & & & & MFP & $5.00 \mathrm{E}+01$ & $\mathrm{Ci}$ & & \\
\hline \multirow[t]{3}{*}{221} & S832842 & $3 / 10 / 83$ & 30 & $\mathrm{lb}$ & 5 & $\mathrm{ft}^{3}$ & Cell 1 wire wraps 3554 & $400 \mathrm{R} / \mathrm{hr}$ contact & $\mathrm{Pu}-239$ & $1.00 \mathrm{E}-01$ & $\mathrm{~g}$ & & 15,000 \\
\hline & & & & & & & & & $\mathrm{U}-235$ & $4.00 \mathrm{E}-01$ & $\mathrm{~g}$ & & \\
\hline & & & & & & & & & MFP & $1.50 \mathrm{E}+01$ & $\mathrm{Ci}$ & & \\
\hline \multirow[t]{3}{*}{221} & $\mathrm{~S} 832843$ & $3 / 10 / 83$ & 30 & $\mathrm{lb}$ & 5 & $\mathrm{ft}^{3}$ & Cell 1 wire wraps 3507 & $1000+\mathrm{R} / \mathrm{hr}$ contact & $\mathrm{Pu}-239$ & $1.00 \mathrm{E}-01$ & $\mathrm{~g}$ & & 30,000 \\
\hline & & & & & & & & & $\mathrm{U}-235$ & $4.00 \mathrm{E}-01$ & $\mathrm{~g}$ & & \\
\hline & & & & & & & & & MFP & $3.00 \mathrm{E}+01$ & $\mathrm{Ci}$ & & \\
\hline 221 & S832844 & $3 / 10 / 83$ & 30 & $\mathrm{lb}$ & 5 & $\mathrm{ft}^{3}$ & Cell 14 hot trash 3569 & $800 \mathrm{R} / \mathrm{hr}$ contact & $\mathrm{Pu}-239$ & $1.00 \mathrm{E}-01$ & $\mathrm{~g}$ & & 40,000 \\
\hline
\end{tabular}

$$
13 \text { of } 24
$$




\section{Appendix A-3 - Information from Radioactive Solid Waste Disposal Forms for Lined Shafts}

\begin{tabular}{|c|c|c|c|c|c|c|c|c|c|c|c|c|c|}
\hline Shaft & $\begin{array}{l}\text { RSWD } \\
\text { Number }\end{array}$ & $\begin{array}{c}\text { Date } \\
\text { Disposed } \\
\end{array}$ & $\begin{array}{c}\text { Gross } \\
\text { Weight } \\
\end{array}$ & Units & $\begin{array}{c}\text { Gross } \\
\text { Volume } \\
\end{array}$ & Units & Waste Description & $\begin{array}{c}\text { Additional Description } \\
\text { of Packaging and } \\
\text { Packaging Materials } \\
\end{array}$ & Nuclide & Amount & Units & $\begin{array}{c}\text { Package } \\
\text { Radiation } \\
\text { at } \\
\text { Surface } \\
(\mathrm{mR} / \mathrm{hr}) \\
\end{array}$ & $\begin{array}{c}\text { Package } \\
\text { Radiation } \\
\text { at } 1 \\
\text { meter } \\
(\mathrm{mR} / \mathrm{hr}) \\
\end{array}$ \\
\hline & & & & & & & & & $\mathrm{U}-235$ & $4.00 \mathrm{E}-01$ & $\mathrm{~g}$ & & \\
\hline & & & & & & & & & MFP & $4.00 \mathrm{E}+01$ & $\mathrm{Ci}$ & & \\
\hline \multirow[t]{3}{*}{221} & $\mathrm{~S} 832845$ & $3 / 10 / 83$ & 30 & $\mathrm{lb}$ & 5 & $\mathrm{ft}^{3}$ & $\begin{array}{l}\text { Cell } 14 \text { hot trash can } \\
3722\end{array}$ & Bottom entry cask & Pu-239 & $1.00 \mathrm{E}-01$ & $\mathrm{~g}$ & 60,000 & 1,500 \\
\hline & & & & & & & & & U-235 & $4.00 \mathrm{E}-01$ & $\mathrm{~g}$ & & \\
\hline & & & & & & & & & MFP & $1.50 \mathrm{E}+00$ & $\mathrm{Ci}$ & & \\
\hline \multirow[t]{3}{*}{221} & S832846 & $3 / 10 / 83$ & 30 & $\mathrm{Ib}$ & 5 & $\mathrm{ft}^{3}$ & Cell 14 waste can 3720 & $200 \mathrm{R} / \mathrm{hr}$ contact & $\mathrm{Pu}-239$ & $1.00 \mathrm{E}-01$ & $\mathrm{~g}$ & & 60,000 \\
\hline & & & & & & & & & $\mathrm{U}-235$ & $4.00 \mathrm{E}-01$ & $\mathrm{~g}$ & & \\
\hline & & & & & & & & & MFP & $6.00 \mathrm{E}+01$ & $\mathrm{Ci}$ & & \\
\hline \multirow[t]{3}{*}{221} & S832847 & $3 / 10 / 83$ & 30 & $\mathrm{lb}$ & 5 & $\mathrm{ft}^{3}$ & Cell 14 waste can $\# 3721$ & $200 \mathrm{R} / \mathrm{hr}$ contact & Pu-239 & $1.00 \mathrm{E}-01$ & $\mathrm{~g}$ & & 60,000 \\
\hline & & & & & & & & & $\mathrm{U}-235$ & $4.00 \mathrm{E}-01$ & $\mathrm{~g}$ & & \\
\hline & & & & & & & & & MFP & $3.00 \mathrm{E}+01$ & $\mathrm{Ci}$ & & \\
\hline \multirow[t]{3}{*}{222} & S830716? & $12 / 14 / 83$ & 30 & $\mathrm{lb}$ & 5.4 & $\mathrm{ft}^{3}$ & $\begin{array}{l}\text { Cell } 14 \text { can } 3712 \text { fuel } \\
\text { scrap, paper, etc }\end{array}$ & $900 \mathrm{Rhr}$ at contact & Pu-239 & 5.64E-01 & g & & 20,000 \\
\hline & & & & & & & & & U-235 & $2.25 \mathrm{E}+00$ & $\mathrm{~g}$ & & \\
\hline & & & & & & & & & MFP & $2.00 \mathrm{E}+01$ & $\mathrm{Ci}$ & & \\
\hline \multirow[t]{3}{*}{222} & S830717 & $12 / 14 / 83$ & 30 & $\mathrm{lb}$ & 5.4 & $\mathrm{ft}^{3}$ & $\begin{array}{l}\text { Cell } 14 \text { can } 3718 \text { fuel } \\
\text { scrap, paper, etc }\end{array}$ & $\begin{array}{l}200 \mathrm{Rhr} \text { at one } \\
\text { meter+1000 Rhr contact }\end{array}$ & $\mathrm{Pu}-239$ & $5.64 \mathrm{E}-01$ & $\mathrm{~g}$ & & \\
\hline & & & & & & & & & $\mathrm{U}-235$ & $2.25 \mathrm{E}+00$ & $\mathrm{~g}$ & & \\
\hline & & & & & & & & & MFP & $2.00 \mathrm{E}+02$ & $\mathrm{Ci}$ & & \\
\hline \multirow[t]{3}{*}{222} & $\mathrm{~S} 830781$ & $12 / 14 / 83$ & 40 & $\mathrm{lb}$ & 5.4 & $\mathrm{ft}^{3}$ & Cell 14 trash 1 can & Bottom entry, ST can \#1 & Pu-53 & $5.00 \mathrm{E}-02$ & $\mathrm{~g}$ & 20,000 & 1,000 \\
\hline & & & & & & & & & $\mathrm{U}-36$ & $2.00 \mathrm{E}-01$ & $\mathrm{~g}$ & & \\
\hline & & & & & & & 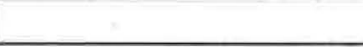 & & MFP & $1.00 \mathrm{E}+00$ & $\mathrm{Ci}$ & & \\
\hline \multirow[t]{3}{*}{222} & $\mathrm{~S} 830787$ & $12 / 14 / 83$ & 40 & $\mathrm{lb}$ & 2.8 & $\mathrm{ft}^{3}$ & Cell 9 trash 1 can & $\begin{array}{l}\text { Bottom entry steel can } \\
\# 10200 \mathrm{R} / \mathrm{hr} \text { C. }\end{array}$ & Pu-53 & $1.20 \mathrm{E}-01$ & $\mathrm{~g}$ & & 40,000 \\
\hline & & & & & & & & & U-36 & $5.00 \mathrm{E}-01$ & $\mathrm{~g}$ & & \\
\hline & & & & & & & & & MFP & $4.00 \mathrm{E}+01$ & $\mathrm{Ci}$ & & \\
\hline \multirow[t]{3}{*}{222} & S830788 & $12 / 14 / 83$ & 40 & $\mathrm{lb}$ & 5.4 & $\mathrm{ft}^{3}$ & Cell 14 trash 1 can & $\begin{array}{l}\text { Bottom entry steel can } \\
\text { \#6 } 100 \mathrm{R} / \mathrm{hr} \text { cont. }\end{array}$ & $\mathrm{Pu}-53$ & $1.20 \mathrm{E}-01$ & $\mathrm{~g}$ & & 40,000 \\
\hline & & & & & & & & & U-36 & $5.00 \mathrm{E}-01$ & $\mathrm{~g}$ & & \\
\hline & & & & & & & & & MFP & $4.00 \mathrm{E}+01$ & $\mathrm{Ci}$ & & \\
\hline 222 & S830789 & $12 / 14 / 83$ & 40 & $\mathrm{lb}$ & 2.8 & $\mathrm{ft}^{3}$ & Cell 14 trash 1 can & Steel can $\# 8$ & $\mathrm{Pu}-53$ & $1.00 \mathrm{E}-01$ & $\mathrm{~g}$ & 10,000 & 200 \\
\hline
\end{tabular}




\section{Appendix A-3 - Information from Radioactive Solid Waste Disposal Forms for Lined Shafts}

\begin{tabular}{|c|c|c|c|c|c|c|c|c|c|c|c|c|c|}
\hline Shaft & $\begin{array}{c}\text { RSWD } \\
\text { Number }\end{array}$ & $\begin{array}{c}\text { Date } \\
\text { Disposed } \\
\end{array}$ & $\begin{array}{c}\text { Gross } \\
\text { Weight } \\
\end{array}$ & Units & $\begin{array}{l}\text { Gross } \\
\text { Volume } \\
\end{array}$ & Units & Waste Description & $\begin{array}{c}\text { Additional Description } \\
\text { of Packaging and } \\
\text { Packaging Materials }\end{array}$ & Nuclide & Amount & Units & $\begin{array}{c}\text { Package } \\
\text { Radiation } \\
\text { at } \\
\text { Surface } \\
\text { (mR/hr) } \\
\end{array}$ & $\begin{array}{c}\text { Package } \\
\text { Radiation } \\
\text { at } 1 \\
\text { meter } \\
(\mathrm{mR} / \mathrm{hr}) \\
\end{array}$ \\
\hline & & & & & & & & & U-36 & $4.00 \mathrm{E}-01$ & $\mathrm{~g}$ & & \\
\hline & & & & & & & & & MFP & $2.00 \mathrm{E}-01$ & $\mathrm{Ci}$ & & \\
\hline \multirow[t]{3}{*}{222} & S830790 & $12 / 14 / 83$ & 40 & $\mathrm{lb}$ & 2.8 & $\mathrm{ft}^{3}$ & Cell 14 trash 1 can & $\begin{array}{l}\text { Steel can \#9200 R } \\
\text { contact }\end{array}$ & $\mathrm{Pu}-53$ & $2.91 \mathrm{E}+00$ & $\mathrm{~g}$ & & 40,000 \\
\hline & & & & & & & & & U-36 & $1.16 \mathrm{E}+01$ & $\mathrm{~g}$ & & \\
\hline & & & & & & & & & MFP & $4.00 \mathrm{E}+01$ & $\mathrm{Ci}$ & & \\
\hline \multirow[t]{3}{*}{223} & S830782 & $12 / 14 / 83$ & 40 & $\mathrm{lb}$ & 5 & $\mathrm{ft}^{3}$ & Cell 14 trash 1 can & $\begin{array}{l}\text { Bottom entry } 100 \mathrm{R} \\
\text { contact can \#5 }\end{array}$ & $\mathrm{Pu}-53$ & $5.00 \mathrm{E}-02$ & $\mathrm{~g}$ & & 25,000 \\
\hline & & & & & & & & & U-36 & $2.00 \mathrm{E}-01$ & $\mathrm{~g}$ & & \\
\hline & & & & & & & & & MFP & $2.50 \mathrm{E}+01$ & $\mathrm{Ci}$ & & \\
\hline \multirow[t]{3}{*}{223} & S830783 & $12 / 14 / 83$ & 40 & $\mathrm{lb}$ & 5 & $\mathrm{ft}^{3}$ & Cell 14 trash 1 can & $\begin{array}{l}\text { Bottom entry steel can } \\
\# 3\end{array}$ & $\mathrm{Pu}-53$ & $1.00 \mathrm{E}-01$ & $\mathrm{~g}$ & 25,000 & 3,000 \\
\hline & & & & & & & & & U-36 & $4.00 \mathrm{E}-01$ & $\mathrm{~g}$ & & \\
\hline & & & & & & & & & MFP & $3.00 \mathrm{E}+00$ & $\mathrm{Ci}$ & & \\
\hline \multirow[t]{3}{*}{223} & S830784 & $12 / 14 / 83$ & 40 & $\mathrm{lb}$ & 5 & $\mathrm{ft}^{3}$ & Cell 14 trash 1 can & $\begin{array}{l}\text { Bottom entry steel can } \\
\# 4\end{array}$ & $\mathrm{Pu}-53$ & $1.00 \mathrm{E}-01$ & $\mathrm{~g}$ & 30,000 & 3,000 \\
\hline & & & & & & & & & U-36 & $4.00 \mathrm{E}-01$ & $\mathrm{~g}$ & & \\
\hline & & & & & & & & & MFP & $3.00 \mathrm{E}+00$ & $\mathrm{Ci}$ & & \\
\hline \multirow[t]{3}{*}{223} & S830785 & $12 / 14 / 83$ & 40 & $\mathrm{lb}$ & 5 & $\mathrm{ft}^{3}$ & Cell 14 trash 1 can & $\begin{array}{l}\text { Bottom entry steel can } \\
\# 7\end{array}$ & $\mathrm{Pu}-53$ & $1.00 \mathrm{E}-01$ & $\mathrm{~g}$ & 70,000 & 3,000 \\
\hline & & & & & & & & & U-36 & $4.00 \mathrm{E}-01$ & $\mathrm{~g}$ & & \\
\hline & & & & & & & & & MFP & $3.00 \mathrm{E}+00$ & $\mathrm{Ci}$ & & \\
\hline \multirow[t]{3}{*}{223} & $\mathrm{~S} 830786$ & $12 / 14 / 83$ & 40 & $\mathrm{lb}$ & 5 & $\mathrm{ft}^{3}$ & Cell 14 trash 1 can & Steel can \#2 & $\mathrm{Pu}-53$ & $5.00 \mathrm{E}-02$ & $\mathrm{~g}$ & 20,000 & 1,500 \\
\hline & & & & & & & & & U-36 & $2.00 \mathrm{E}-01$ & $\mathrm{~g}$ & & \\
\hline & & & & & & & & & MFP & $1.50 \mathrm{E}+00$ & $\mathrm{Ci}$ & & \\
\hline \multirow[t]{3}{*}{223} & S830791 & $12 / 14 / 83$ & 40 & $\mathrm{lb}$ & 5 & $\mathrm{ft}^{3}$ & Cell 16 trash 1 can & $\begin{array}{l}\text { Bottom entry steel can } \\
\# 11\end{array}$ & $\mathrm{Pu}-53$ & $1.00 \mathrm{E}-01$ & $\mathrm{~g}$ & 32,000 & 1,500 \\
\hline & & & & & & & & & U-36 & $4.00 \mathrm{E}-01$ & $\mathrm{~g}$ & & \\
\hline & & & & & & & & & MFP & $1.50 \mathrm{E}+00$ & $\mathrm{Ci}$ & & \\
\hline \multirow[t]{2}{*}{224} & S852326 & $12 / 30 / 85$ & 30 & $\mathrm{lb}$ & 0.5 & $\mathrm{ft}^{3}$ & $\begin{array}{l}\text { Cell \#11 waste plastic } \\
\text { can } \# 4088\end{array}$ & $\begin{array}{l}300 \mathrm{R} / \mathrm{hr} @ \text { cont steel } \\
\text { can \#58 }\end{array}$ & $\mathrm{Pu}-239$ & $1.00 \mathrm{E}-01$ & $\mathrm{~g}$ & & 4,000 \\
\hline & & & & & & & & & U-235 & $4.00 \mathrm{E}-01$ & $\mathrm{~g}$ & & \\
\hline
\end{tabular}

15 of 24 


\section{Appendix A-3 - Information from Radioactive Solid Waste Disposal Forms for Lined Shafts}

\begin{tabular}{|c|c|c|c|c|c|c|c|c|c|c|c|c|c|}
\hline Shaft & $\begin{array}{l}\text { RSWD } \\
\text { Number }\end{array}$ & $\begin{array}{c}\text { Date } \\
\text { Disposed }\end{array}$ & $\begin{array}{c}\text { Gross } \\
\text { Weight } \\
\end{array}$ & Units & $\begin{array}{c}\text { Gross } \\
\text { Volume }\end{array}$ & Units & Waste Description & $\begin{array}{c}\text { Additional Description } \\
\text { of Packaging and } \\
\text { Packaging Materials }\end{array}$ & Nuclide & Amount & Units & $\begin{array}{c}\text { Package } \\
\text { Radiation } \\
\text { at } \\
\text { Surface } \\
(\mathrm{mR} / \mathrm{hr}) \\
\end{array}$ & $\begin{array}{c}\text { Package } \\
\text { Radiation } \\
\text { at } 1 \\
\text { meter } \\
(\mathrm{mR} / \mathrm{hr}) \\
\end{array}$ \\
\hline & & & & & & & & & MFP & $4.00 \mathrm{E}+00$ & $\mathrm{Ci}$ & & \\
\hline \multirow[t]{3}{*}{224} & $\mathrm{~S} 852328$ & $12 / 30 / 85$ & 30 & $\mathrm{lb}$ & 0.5 & $\mathrm{ft}^{3}$ & $\begin{array}{l}\text { Cell \#11 waste plastic } \\
\text { can } \# 4097\end{array}$ & $\begin{array}{l}\text { 100R/hr@ cont steel } \\
\text { can\#61 }\end{array}$ & $\mathrm{Pu}-239$ & $1.00 \mathrm{E}-01$ & $\mathrm{~g}$ & & 2,000 \\
\hline & & & & & & & & & U-235 & $4.00 \mathrm{E}-01$ & $\mathrm{~g}$ & & \\
\hline & & & & & & & & & MFP & $2.00 \mathrm{E}+00$ & $\mathrm{Ci}$ & & \\
\hline \multirow[t]{3}{*}{224} & S852332 & $12 / 30 / 85$ & 30 & lb & 0.5 & $\mathrm{ft}^{3}$ & $\begin{array}{l}\text { Cell \#13 waste plastic } \\
\text { can } \# 4072\end{array}$ & $\begin{array}{l}\text { 300 R/hr@ cont steel } \\
\text { can\#32 }\end{array}$ & $\mathrm{Pu}-239$ & $1.00 \mathrm{E}-01$ & $\mathrm{~g}$ & & 4,000 \\
\hline & & & & & & & & & U-235 & $4.00 \mathrm{E}-01$ & $\mathrm{~g}$ & & \\
\hline & & & & & & & & & MFP & $4.00 \mathrm{E}+00$ & $\mathrm{Ci}$ & & \\
\hline \multirow[t]{3}{*}{224} & S852804 & $12 / 30 / 85$ & 30 & lb & 0.5 & $\mathrm{ft}^{3}$ & $\begin{array}{l}\text { Cell } 14 \text { trash can } 3660 \\
\text { fuel inside }\end{array}$ & $\begin{array}{l}\text { Steel can } 67100 \mathrm{R} \\
\text { contact }\end{array}$ & $\mathrm{Pu}-239$ & $3.30 \mathrm{E}+00$ & $\mathrm{~g}$ & & 2,800 \\
\hline & & & & & & & & & U-235 & $8.70 \mathrm{E}+00$ & $\mathrm{~g}$ & & \\
\hline & & & & & & & & & MFP & $2.80 \mathrm{E}+00$ & $\mathrm{Ci}$ & & \\
\hline \multirow[t]{3}{*}{224} & S855064 & $12 / 30 / 85$ & 30 & $\mathrm{lb}$ & 0.5 & $\mathrm{ft}^{3}$ & $\begin{array}{l}\text { Cell } 14 \text { trash can } 3661 \\
\text { fuel inside }\end{array}$ & $\begin{array}{l}\text { Steel can } 63100 \mathrm{R} / \mathrm{hr} \\
\text { contact }\end{array}$ & Pu-239 & $3.60 \mathrm{E}+00$ & g & & 3,300 \\
\hline & & & & & & & & & $\mathrm{U}-235$ & $1.49 \mathrm{E}+01$ & $\mathrm{~g}$ & & \\
\hline & & & & & & & & & MFP & $3.80 \mathrm{E}+00$ & $\mathrm{Ci}$ & & \\
\hline \multirow[t]{3}{*}{224} & S855065 & $12 / 30 / 85$ & 30 & $\mathrm{lb}$ & 0.5 & $\mathrm{ft}^{3}$ & $\begin{array}{l}\text { Cell } 14 \text { trash can } 3662 \\
\text { fuel inside }\end{array}$ & $\begin{array}{l}\text { Steel can } 66300 \mathrm{R} / \mathrm{hr} \\
\text { contact }\end{array}$ & $\mathrm{Pu}-239$ & $3.60 \mathrm{E}+00$ & g & & 4,200 \\
\hline & & & & & & & & & U-235 & $1.49 \mathrm{E}+01$ & $\mathrm{~g}$ & & \\
\hline & & & & & & & & & MFP & $4.20 \mathrm{E}+00$ & $\mathrm{Ci}$ & & \\
\hline \multirow[t]{3}{*}{224} & S855066 & $12 / 30 / 85$ & 30 & $\mathrm{lb}$ & 0.5 & $\mathrm{ft}^{3}$ & $\begin{array}{l}\text { Cell } 14 \text { trash can } 3663 \\
\text { trash only }\end{array}$ & Steel can 65 & $\mathrm{Pu}-239$ & $1.00 \mathrm{E}-01$ & $\mathrm{~g}$ & 70,000 & 1,500 \\
\hline & & & & & & & & & U-235 & $4.00 \mathrm{E}-01$ & $\mathrm{~g}$ & & \\
\hline & & & & & & & & & MFP & $1.50 \mathrm{E}+00$ & $\mathrm{Ci}$ & & \\
\hline \multirow[t]{3}{*}{224} & S855068 & $12 / 30 / 85$ & 30 & $\mathrm{lb}$ & 0.5 & $\mathrm{ft}^{3}$ & $\begin{array}{l}\text { Cell } 14 \text { trash can } 3664 \\
\text { fuel inside }\end{array}$ & Steel can 64 & $\mathrm{Pu}-239$ & $1.00 \mathrm{E}-01$ & $\mathrm{~g}$ & 20,000 & 500 \\
\hline & & & & & & & & & U-235 & $4.00 \mathrm{E}-01$ & $\mathrm{~g}$ & & \\
\hline & & & & & & & & & MFP & $1.50 \mathrm{E}+00$ & $\mathrm{Ci}$ & & \\
\hline \multirow[t]{2}{*}{225} & S840848 & $12 / 31 / 84$ & 30 & $\mathrm{lb}$ & 0.5 & $\mathrm{ft}^{3}$ & $\begin{array}{l}\text { Cell } 13 \text { waste plastic can } \\
\# 4076\end{array}$ & Steel can \#21 & $\mathrm{Pu}-239$ & $1.00 \mathrm{E}-01$ & $\mathrm{~g}$ & 40,000 & 400 \\
\hline & & $11 / 19 / 84$ & & & & & & & U-235 & $4.00 \mathrm{E}-01$ & $\mathrm{~g}$ & & \\
\hline
\end{tabular}

16 of 24 


\section{Appendix A-3 - Information from Radioactive Solid Waste Disposal Forms for Lined Shafts}

\begin{tabular}{|c|c|c|c|c|c|c|c|c|c|c|c|c|c|}
\hline Shaft & $\begin{array}{l}\text { RSWD } \\
\text { Number }\end{array}$ & $\begin{array}{c}\text { Date } \\
\text { Disposed }\end{array}$ & $\begin{array}{c}\text { Gross } \\
\text { Weight }\end{array}$ & Units & $\begin{array}{l}\text { Gross } \\
\text { Volume }\end{array}$ & Units & Waste Description & $\begin{array}{l}\text { Additional Description } \\
\text { of Packaging and } \\
\text { Packaging Materials }\end{array}$ & Nuclide & Amount & Units & $\begin{array}{c}\text { Package } \\
\text { Radiation } \\
\text { at } \\
\text { Surface } \\
\text { (mR/hr) }\end{array}$ & $\begin{array}{c}\text { Package } \\
\text { Radiation } \\
\text { at } 1 \\
\text { meter } \\
(\mathrm{mR} / \mathrm{hr})\end{array}$ \\
\hline \multirow[t]{3}{*}{225} & S840854 & $12 / 31 / 84$ & $30 ?$ & $\mathrm{lb}$ & 0.5 & $\mathrm{ft}^{3}$ & $\begin{array}{l}\text { Cell } 13 \text { waste plastic can } \\
\# 4033\end{array}$ & Steel can \#24 & Pu-239 & $1.00 \mathrm{E}-01$ & $\mathrm{~g}$ & 50,000 & 1,500 \\
\hline & & $11 / 16 / 84$ & & & & & & & U-235 & $4.00 \mathrm{E}-01$ & $\mathrm{~g}$ & & \\
\hline & & & & & & & & & MFP & $1.50 \mathrm{E}+00$ & $\mathrm{Ci}$ & & \\
\hline \multirow{2}{*}{225} & & \multicolumn{2}{|c|}{$11 / 16 / 1984 ?$} & & & & & & U-235 & $4.00 \mathrm{E}-01$ & $\mathrm{~g}$ & & \\
\hline & & & & & & & & & MFP & $1.50 \mathrm{E}+00$ & $\mathrm{Ci}$ & & \\
\hline \multirow[t]{3}{*}{225} & S840857 & $12 / 31 / 84$ & 30 & $\mathrm{lb}$ & 0.5 & $\mathrm{ft}^{3}$ & $\begin{array}{l}\text { Cell } 13 \text { waste plastic can } \\
\# 4035\end{array}$ & $\begin{array}{l}105 \mathrm{R} / \mathrm{hr} @ \text { cont steel } \\
\text { can } \# 30\end{array}$ & $\mathrm{Pu}-239$ & $1.00 \mathrm{E}-01$ & & & 3,000 \\
\hline & & & & & & & & & U-235 & $4.00 \mathrm{E}-01$ & & & \\
\hline & & & & & & & & & MFP & $3.00 \mathrm{E}+00$ & & & \\
\hline 225 & S840863 & $12 / 31 / 84$ & 30 & $\mathrm{lb}$ & 0.5 & $\mathrm{ft}^{3}$ & $\begin{array}{l}\text { Cell } 13 \text { waste plastic can } \\
\# 4046\end{array}$ & Steel can $\# 40$ & $\mathrm{Pu}-239$ & $1.00 \mathrm{E}-01$ & $\mathrm{~g}$ & 10,000 & 80 \\
\hline \multirow[t]{3}{*}{225} & S840864? & $12 / 31 / 84$ & 30 & $\mathrm{lb}$ & 0.5 & $\mathrm{ft}^{3}$ & $\begin{array}{l}\text { Cell } 13 \text { waste plastic can } \\
\# 4044\end{array}$ & Steel can \#34 & $\mathrm{Pu}-239$ & $1.00 \mathrm{E}-01$ & $\mathrm{~g}$ & 25,000 & 300 \\
\hline & & $11 / 19 / 84$ & & & & & & & U-235 & $4.00 \mathrm{E}-01$ & $\mathrm{~g}$ & & \\
\hline & & & & & & & & & MFP & $3.00 \mathrm{E}-01$ & $\mathrm{Ci}$ & & \\
\hline \multirow[t]{3}{*}{225} & S840807? & $12 / 31 / 84$ & 30 & $\mathrm{lb}$ & 0.5 & $\mathrm{ft}^{3}$ & $\begin{array}{l}\text { Cell } 13 \text { waste plastic can } \\
\# 4054\end{array}$ & Steel can \#38 & Pu-239 & $1.00 \mathrm{E}-01$ & $\mathrm{~g}$ & 30,000 & 400 \\
\hline & & & & & & & & & U-235 & $4.00 \mathrm{E}-01$ & $\mathrm{~g}$ & & \\
\hline & & & & & & & & & MFP & $4.00 \mathrm{E}-01$ & $\mathrm{Ci}$ & & \\
\hline \multirow[t]{3}{*}{225} & S840874 & $12 / 31 / 84$ & 30 & $\mathrm{lb}$ & 0.5 & $\mathrm{ft}^{3}$ & Cell 14 trash can 4051 & Steel can $\# 43$ & $\mathrm{Pu}-239$ & $1.00 \mathrm{E}-01$ & $\mathrm{~g}$ & 15,000 & 200 \\
\hline & & $11 / 20 / 84$ & & & & & & & U-235 & $4.00 \mathrm{E}-01$ & $\mathrm{~g}$ & & \\
\hline & & & & & & & & & MFP & $2.00 \mathrm{E}-01$ & $\mathrm{Ci}$ & & \\
\hline \multirow[t]{3}{*}{226} & S840842 & $12 / 31 / 84$ & 30 & $\mathrm{lb}$ & 0.5 & $\mathrm{ft}^{3}$ & $\begin{array}{l}\text { Cell } 13 \text { waste plastic can } \\
\# 4056\end{array}$ & Steel can \#20 & Pu-239 & $1.00 \mathrm{E}-01$ & g & 90,000 & 2,000 \\
\hline & & $11 / 14 / 84$ & & & & & & & U-235 & $4.00 \mathrm{E}-01$ & $\mathrm{~g}$ & & \\
\hline & & & & & & & & & MFP & $2.00 \mathrm{E}+00$ & $\mathrm{Ci}$ & & \\
\hline
\end{tabular}

17 of 24 


\section{Appendix A-3 - Information from Radioactive Solid Waste Disposal Forms for Lined Shafts}

\begin{tabular}{|c|c|c|c|c|c|c|c|c|c|c|c|c|c|}
\hline Shaft & $\begin{array}{c}\text { RSWD } \\
\text { Number }\end{array}$ & $\begin{array}{c}\text { Date } \\
\text { Disposed }\end{array}$ & $\begin{array}{l}\text { Gross } \\
\text { Weight }\end{array}$ & Units & $\begin{array}{l}\text { Gross } \\
\text { Volume }\end{array}$ & Units & Waste Description & $\begin{array}{l}\text { Additional Description } \\
\text { of Packaging and } \\
\text { Packaging Materials }\end{array}$ & Nuclide & Amount & Units & $\begin{array}{c}\text { Package } \\
\text { Radiation } \\
\text { at } \\
\text { Surface } \\
\text { (mR/hr) }\end{array}$ & $\begin{array}{c}\text { Package } \\
\text { Radiation } \\
\text { at } 1 \\
\text { meter } \\
(\mathrm{mR} / \mathrm{hr})\end{array}$ \\
\hline 226 & S84????3? & $12 / 31 / 84$ & 30 & $\mathrm{lb}$ & 0.5 & $\mathrm{ft}^{3}$ & $\begin{array}{l}\text { Cell } 13 \text { waste plastic can } \\
\# 4045\end{array}$ & Steel can \#26 & Pu-239 & $1.00 \mathrm{E}-01$ & $\mathrm{~g}$ & 80,000 & 2,000 \\
\hline & & $11 / 14 / 84$ & & & & & & & U-235 & $4.00 \mathrm{E}-01$ & $\mathrm{~g}$ & & \\
\hline & & & & & & & & & MFP & $2.00 \mathrm{E}+00$ & $\mathrm{Ci}$ & & \\
\hline 226 & S840844 & $12 / 31 / 84$ & 30 & $\mathrm{lb}$ & 0.5 & $\mathrm{ft}^{3}$ & $\begin{array}{l}\text { Cell } 13 \text { waste plastic can } \\
\# 4023\end{array}$ & Steel can \#19 & Pu-239 & $1.00 \mathrm{E}-01$ & $\mathrm{~g}$ & 70,000 & 1,500 \\
\hline & & \multicolumn{2}{|c|}{ 11/14/1984? } & & & & & & U-235 & $4.00 \mathrm{E}-01$ & $\mathrm{~g}$ & & \\
\hline & & & & & & & & & MFP & $1.50 \mathrm{E}+00$ & $\mathrm{Ci}$ & & \\
\hline \multirow[t]{3}{*}{226} & S840845? & $12 / 31 / 1984 ?$ & 30 & $\mathrm{lb}$ & 0.5 & $\mathrm{ft}^{3}$ & $\begin{array}{l}\text { Cell } 13 \text { waste plastic can } \\
\# 4034\end{array}$ & Steel can $\# 22$ & $\mathrm{Pu}-239$ & $1.00 \mathrm{E}-01$ & $\mathrm{~g}$ & 21,000 & 300 \\
\hline & & \multicolumn{2}{|c|}{$11 / 14 / 1984 ?$} & & & & & & U-235 & $4.00 \mathrm{E}-01$ & $\mathrm{~g}$ & & \\
\hline & & & & & & & & & MFP & $3.00 \mathrm{E}-01$ & $\mathrm{Ci}$ & & \\
\hline \multirow[t]{3}{*}{226} & S840846 & $12 / 31 / 84$ & 30 & $\mathrm{lb}$ & 0.5 & $\mathrm{ft}^{3}$ & $\begin{array}{l}\text { Cell } 13 \text { waste plastic can } \\
\# 4024\end{array}$ & $\begin{array}{l}300 \mathrm{R} / \mathrm{hr} @ \text { cont Steel } \\
\text { can \#25 }\end{array}$ & Pu-239 & $1.00 \mathrm{E}-01$ & $\mathrm{~g}$ & & 5,000 \\
\hline & & $11 / 15 / 84$ & & & & & & & $\mathrm{U}-235$ & $4.00 \mathrm{E}-01$ & $\mathrm{~g}$ & & \\
\hline & & & & & & & & & MFP & $5.00 \mathrm{E}+00$ & $\mathrm{Ci}$ & & \\
\hline \multirow[t]{3}{*}{226} & S84??47 & $12 / 31 / 84$ & 30 & $\mathrm{lb}$ & 0.5 & $\mathrm{ft}^{3}$ & $\begin{array}{l}\text { Cell } 13 \text { waste plastic can } \\
\# 4022\end{array}$ & Steel can $\# 23$ & $\mathrm{Pu}-239$ & $1.00 \mathrm{E}-01$ & $\mathrm{~g}$ & 70,000 & 1,500 \\
\hline & & $11 / 15 / 84$ & & & & & & & U-235 & $4.00 \mathrm{E}-01$ & $\mathrm{~g}$ & & \\
\hline & & & & & & & & & MFP & $1.50 \mathrm{E}+00$ & $\mathrm{Ci}$ & & \\
\hline \multirow[t]{3}{*}{226} & S840862 & $12 / 31 / 84$ & 30 & $\mathrm{lb}$ & 0.5 & $\mathrm{ft}^{3}$ & $\begin{array}{l}\text { Cell } 13 \text { waste plastic can } \\
\# 4027\end{array}$ & Steel can \#39 & $\mathrm{Pu}-239$ & $1.00 \mathrm{E}-01$ & $\mathrm{~g}$ & 15,000 & 200 \\
\hline & & $11 / 14 / 84$ & & & & & & & U-235 & $4.00 \mathrm{E}-01$ & $\mathrm{~g}$ & 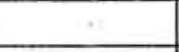 & \\
\hline & & & & & & & & & MFP & $2.00 \mathrm{E}-01$ & $\mathrm{Ci}$ & & \\
\hline \multirow[t]{3}{*}{226} & S840868 & $12 / 31 / 84$ & 30 & $\mathrm{lb}$ & 0.5 & $\mathrm{ft}^{3}$ & $\begin{array}{l}\text { Cell } 13 \text { waste plastic can } \\
\# 4025\end{array}$ & Steel can \#35 & $\mathrm{Pu}-239$ & $1.00 \mathrm{E}-01$ & $\mathrm{~g}$ & 35,000 & 300 \\
\hline & & $11 / 15 / 84$ & & & & & & & U-235 & $4.00 \mathrm{E}-01$ & $\mathrm{~g}$ & & \\
\hline & & & & & & & & & MFP & $3.00 \mathrm{E}-01$ & $\mathrm{Ci}$ & & \\
\hline \multirow[t]{3}{*}{227} & S840877? & $12 / 31 / 84$ & 30 & $\mathrm{lb}$ & 0.5 & $\mathrm{ft}^{3}$ & $\begin{array}{l}\text { Cell } 14 \text { trash can } 4050 \text {, } \\
\text { fuel inside }\end{array}$ & Steel can 42 & Pu-239 & $2.20 \mathrm{E}+00$ & $\mathrm{~g}$ & 80,000 & 1,500 \\
\hline & & & & & & & & & U-235 & $8.90 \mathrm{E}+00$ & $\mathrm{~g}$ & & \\
\hline & & & & & & & & & MFP & $1.50 \mathrm{E}+00$ & $\mathrm{Ci}$ & & \\
\hline
\end{tabular}

18 of 24 


\section{Appendix A-3 - Information from Radioactive Solid Waste Disposal Forms for Lined Shafts}

\begin{tabular}{|c|c|c|c|c|c|c|c|c|c|c|c|c|c|}
\hline Shaft & $\begin{array}{l}\text { RSWD } \\
\text { Number }\end{array}$ & $\begin{array}{c}\text { Date } \\
\text { Disposed }\end{array}$ & $\begin{array}{c}\text { Gross } \\
\text { Weight }\end{array}$ & Units & $\begin{array}{l}\text { Gross } \\
\text { Volume }\end{array}$ & Units & Waste Description & $\begin{array}{c}\text { Additional Description } \\
\text { of Packaging and } \\
\text { Packaging Materials }\end{array}$ & Nuclide & Amount & Units & $\begin{array}{c}\text { Package } \\
\text { Radiation } \\
\text { at } \\
\text { Surface } \\
\text { (mR/hr) } \\
\end{array}$ & $\begin{array}{c}\text { Package } \\
\text { Radiation } \\
\text { at } 1 \\
\text { meter } \\
(\mathrm{mR} / \mathrm{hr}) \\
\end{array}$ \\
\hline \multirow[t]{3}{*}{227} & S840878? & $12 / 31 / 84$ & 30 & $\mathrm{lb}$ & 0.5 & $\mathrm{ft}^{3}$ & $\begin{array}{l}\text { Cell } 14 \text { trash can, fuel } \\
\text { inside, can } 4042\end{array}$ & $\begin{array}{l}250 \text { R/hr@contact, } \\
\text { Steel can } 46\end{array}$ & $\mathrm{Pu}-239$ & $3.10 \mathrm{E}+00$ & $\mathrm{~g}$ & & 2,500 \\
\hline & & & & & & & & & $\mathrm{U}-235$ & $1.44 \mathrm{E}+01$ & $\mathrm{~g}$ & & \\
\hline & & & & & & & & & MFP & $2.50 \mathrm{E}+00$ & $\mathrm{Ci}$ & & \\
\hline \multirow[t]{3}{*}{227} & S840879 & $12 / 31 / 84$ & 30 & $\mathrm{lb}$ & 0.5 & $\mathrm{ft}^{3}$ & $\begin{array}{l}\text { Cell } 14 \text { trash can } 4041 \text {, } \\
\text { fuel inside }\end{array}$ & $\begin{array}{l}300 \mathrm{R} / \mathrm{hr} \text { contact, Steel } \\
\text { can } 44\end{array}$ & $\mathrm{Pu}-239$ & $3.10 \mathrm{E}+00$ & $\mathrm{~g}$ & & 4,000 \\
\hline & & $11 / 28 / 84$ & & & & & & & U-235 & $1.44 \mathrm{E}+01$ & $\mathrm{~g}$ & & \\
\hline & & & & & & & & & MFP & $4.00 \mathrm{E}+00$ & $\mathrm{Ci}$ & & \\
\hline \multirow[t]{3}{*}{227} & $\mathrm{~S} 840880$ & $12 / 31 / 84$ & 30 & $\mathrm{lb}$ & 0.5 & $\mathrm{ft}^{3}$ & $\begin{array}{l}\text { Cell } 14 \text { trash can } 4048, \\
\text { fuel inside }\end{array}$ & $\begin{array}{l}\text { Steel can } 45 \text {, contact } \\
\text { reading } 350 \mathrm{R}\end{array}$ & Pu-239 & $3.10 \mathrm{E}+00$ & $\mathrm{~g}$ & & 2,500 \\
\hline & & $11 / 29 / 84$ & & & & & & & U-235 & $1.44 \mathrm{E}+01$ & $\mathrm{~g}$ & & \\
\hline & & & & & & & & & MFP & $2.50 \mathrm{E}+00$ & $\mathrm{Ci}$ & & \\
\hline \multirow[t]{3}{*}{227} & S840881? & $12 / 31 / 84$ & 30 & $\mathrm{lb}$ & 0.5 & $\mathrm{ft}^{3}$ & $\begin{array}{l}\text { Cell } 14 \text { trash can } 4057 \text {, } \\
\text { fuel inside }\end{array}$ & $\begin{array}{l}\text { Contact } 200 \mathrm{R} / \mathrm{hr} \text {, Steel } \\
\text { can } 51\end{array}$ & $\mathrm{Pu}-239$ & $3.10 \mathrm{E}+00$ & $\mathrm{~g}$ & & 3,000 \\
\hline & & $11 / 28 / 84$ & & & & & & & $\mathrm{U}-235$ & $1.44 \mathrm{E}+01$ & $\mathrm{~g}$ & & \\
\hline & & & & & & & & & MFP & $3.00 \mathrm{E}+00$ & $\mathrm{Ci}$ & & \\
\hline \multirow[t]{3}{*}{227} & S840883? & $12 / 31 / 84$ & 30 & $\mathrm{lb}$ & 0.5 & $\mathrm{ft}^{3}$ & Cell 14 trash can 4064 & $\begin{array}{l}\text { Contact } 100 \mathrm{R} / \mathrm{hr} \text {, Steel } \\
\text { can } 48\end{array}$ & Pu-239 & $1.00 \mathrm{E}-01$ & $\mathrm{~g}$ & & 2,000 \\
\hline & & $11 / 29 / 84$ & & & & & & & U-235 & $4.00 \mathrm{E}-01$ & $\mathrm{~g}$ & & \\
\hline & & & & & & & & & MFP & $2.00 \mathrm{E}+00$ & $\mathrm{Ci}$ & & \\
\hline \multirow[t]{3}{*}{227} & S840885 & $12 / 31 / 84$ & 30 & $\mathrm{lb}$ & 0.5 & $\mathrm{ft}^{3}$ & $\begin{array}{l}\text { Cell } 14 \text { trash can } 4156 \text {, } \\
\text { fuel inside }\end{array}$ & $\begin{array}{l}\text { Contact } 400 \mathrm{R} / \mathrm{hr} \text {, Steel } \\
\text { can } 49\end{array}$ & $\mathrm{Pu}-239$ & $3.20 \mathrm{E}+00$ & $\mathrm{~g}$ & & 6,000 \\
\hline & & $11 / 28 / 84$ & . & & & & & & $\mathrm{U}-235$ & $1.06 \mathrm{E}+01$ & $\mathrm{~g}$ & & \\
\hline & & & & & & & & & MFP & $6.00 \mathrm{E}+00$ & $\mathrm{Ci}$ & & \\
\hline \multirow[t]{3}{*}{227} & S840886 & $12 / 31 / 84$ & 30 & $\mathrm{lb}$ & 0.5 & $\mathrm{ft}^{3}$ & Cell 14 trash can 4084 & Steel can 50 & Pu-239 & $1.00 \mathrm{E}-01$ & $\mathrm{~g}$ & 15,000 & 800 \\
\hline & & $11 / 29 / 84$ & & & & & & & U-235 & $4.00 \mathrm{E}-01$ & $\mathrm{~g}$ & & \\
\hline & & & & & & & & & MFP & $8.00 \mathrm{E}-01$ & $\mathrm{Ci}$ & & \\
\hline \multirow[t]{3}{*}{228} & S874123 & $12 / 23 / 87$ & 30 & lbs & 1 & gal & Cell 14 trash can 4032 & $\begin{array}{l}\text { Steel can 54, was } \\
\text { RSWD } 852802\end{array}$ & Pu-239 & $1.00 \mathrm{E}-01$ & $\mathrm{~g}$ & 9,000 & 150 \\
\hline & & & & & & & & & U-235 & $4.00 \mathrm{E}-01$ & $\mathrm{~g}$ & & \\
\hline & & & & & & & & & MFP & $1.50 \mathrm{E}-01$ & $\mathrm{Ci}$ & & \\
\hline 228 & $\mathbf{S 8 7 4 1 2 4}$ & $12 / 23 / 87$ & 25 & lbs & 1 & gal & Cell 13 waste plastic can & can $55,20 \mathrm{R} / \mathrm{hr}$ contact, & Pu-239 & $1.00 \mathrm{E}-01$ & $\mathrm{~g}$ & & \\
\hline
\end{tabular}

19 of 24 


\section{Appendix A-3 - Information from Radioactive Solid Waste Disposal Forms for Lined Shafts}

\begin{tabular}{|c|c|c|c|c|c|c|c|c|c|c|c|c|c|}
\hline Shaft & $\begin{array}{c}\text { RSWD } \\
\text { Number }\end{array}$ & $\begin{array}{c}\text { Date } \\
\text { Disposed }\end{array}$ & $\begin{array}{c}\text { Gross } \\
\text { Weight }\end{array}$ & Units & $\begin{array}{c}\text { Gross } \\
\text { Volume }\end{array}$ & Units & Waste Description & $\begin{array}{c}\text { Additional Description } \\
\text { of Packaging and } \\
\text { Packaging Materials } \\
\end{array}$ & Nuclide & Amount & Units & $\begin{array}{c}\text { Package } \\
\text { Radiation } \\
\text { at } \\
\text { Surface } \\
\text { (mR/hr) }\end{array}$ & $\begin{array}{c}\text { Package } \\
\text { Radiation } \\
\text { at } 1 \\
\text { meter } \\
(\mathrm{mR} / \mathrm{hr})\end{array}$ \\
\hline & & & & & & & \#4093 steel & was RSWD \#852325 & & & & & \\
\hline & & & & & & & & & $\mathrm{U}-235$ & $4.00 \mathrm{E}-01$ & $\mathrm{~g}$ & & \\
\hline & & & & & & & & & MFP & $1.50 \mathrm{E}+00$ & $\mathrm{Ci}$ & & \\
\hline \multirow[t]{3}{*}{228} & $\mathrm{~S} 874125$ & $12 / 23 / 87$ & 30 & lbs & 1 & gal & $\begin{array}{l}\text { Cell } 14 \text { waste can } 4164, \\
\text { Steel can } 62\end{array}$ & $\begin{array}{l}10 \mathrm{R} / \mathrm{hr} \text { contact, was } \\
\mathrm{RSWD} \# 852811\end{array}$ & $\mathrm{Pu}-239$ & $1.00 \mathrm{E}-01$ & $\mathrm{~g}$ & & 120 \\
\hline & & & & & & & & & $\mathrm{U}-235$ & $4.00 \mathrm{E}-01$ & $\mathrm{~g}$ & & \\
\hline & & & & & & & & & MFP & $1.50 \mathrm{E}-01$ & $\mathrm{Ci}$ & & \\
\hline \multirow[t]{3}{*}{228} & $\mathrm{~S} 874126$ & $12 / 23 / 87$ & 30 & lbs & 1 & gal & $\begin{array}{l}\text { Cell \#13 waste plastic } \\
\text { can \#4086, see RSWD \# }\end{array}$ & $\begin{array}{l}\text { 852323, Steel Can \#57, } \\
200 \text { R/hr @ cont. }\end{array}$ & Pu-239 & $1.00 \mathrm{E}-01$ & g & & 2,500 \\
\hline & & & & & & & & & $\mathrm{U}-235$ & $4.00 \mathrm{E}-01$ & $\mathrm{~g}$ & & \\
\hline & & & & & & & & & MFP & $2.50 \mathrm{E}+00$ & $\mathrm{Ci}$ & & \\
\hline \multirow[t]{3}{*}{228} & S874127 & $12 / 23 / 87$ & 30 & lbs & 1 & gal & $\begin{array}{l}\text { Cell \#13 waste plastic } \\
\text { can \#4094, Was } \\
\text { RSWD\# }\end{array}$ & 852324, Steel Can 56 & $\mathrm{Pu}-239$ & $1.00 \mathrm{E}-01$ & g & & \\
\hline & & & & & & & & & U-235 & $4.00 \mathrm{E}-01$ & $\mathrm{~g}$ & & \\
\hline & & & & & & & & & MFP & $1.50 \mathrm{E}+00$ & $\mathrm{Ci}$ & & \\
\hline \multirow[t]{3}{*}{228} & $\mathrm{~S} 874128$ & $12 / 23 / 87$ & 30 & lbs & 1 & gal & $\begin{array}{l}\text { Cell \#11 waste plastic } \\
\text { can \#4092. }\end{array}$ & $\begin{array}{l}\text { Steel can \#60 See } \\
\text { RSWD \#852330 }\end{array}$ & Pu-239 & $1.00 \mathrm{E}-01$ & $\mathrm{~g}$ & & \\
\hline & & & & & & & & & U-235 & $4.00 \mathrm{E}-01$ & $\mathrm{~g}$ & & \\
\hline & & & & & & & & & MFP & $1.50 \mathrm{E}+00$ & $\mathrm{Ci}$ & & \\
\hline \multirow[t]{3}{*}{228} & S874129 & $12 / 23 / 87$ & 30 & lbs & 1 & gal & $\begin{array}{l}\text { Cell \#11 waste plastic } \\
\text { can \#4085 }\end{array}$ & $\begin{array}{l}\text { Steel can \#59, see } \\
\text { RSWD \#852329 }\end{array}$ & Pu-239 & $1.00 \mathrm{E}-01$ & $\mathrm{~g}$ & 60,000 & 1,500 \\
\hline & & + & & & & & & & $\mathrm{U}-235$ & $4.00 \mathrm{E}-01$ & $\mathrm{~g}$ & & \\
\hline & & & & & & & & & MFP & $1.50 \mathrm{E}+00$ & $\mathrm{Ci}$ & & \\
\hline \multirow[t]{3}{*}{228} & $\mathrm{~S} 874130$ & $12 / 23 / 87$ & 30 & lbs & 1 & gal & $\begin{array}{l}\text { Cell \#14 trash can } \\
\# 4053\end{array}$ & $\begin{array}{l}\text { Steel can \#53, see } \\
\text { RSWD \#852803 }\end{array}$ & $\mathrm{Pu}-239$ & $1.00 \mathrm{E}-01$ & g & 80,000 & 2,000 \\
\hline & & & & & & & & & $\mathrm{U}-235$ & $4.00 \mathrm{E}-01$ & $\mathrm{~g}$ & & \\
\hline & & & & & & & & & MFP & $2.00 \mathrm{E}+00$ & $\mathrm{Ci}$ & & \\
\hline \multirow[t]{3}{*}{229} & S840851 & $12 / 31 / 84$ & 30 & lb & 0.6 & $\mathrm{ft}^{3}$ & $\begin{array}{l}\text { Cell } 13 \text { waste plastic can } \\
\# 4028\end{array}$ & $\begin{array}{l}200 \text { R/hr@ cont, Steel } \\
\text { can \#28 }\end{array}$ & Pu-239 & $1.00 \mathrm{E}-01$ & g & & 3,000 \\
\hline & & & & & & & & & $\mathrm{U}-235$ & $4.00 \mathrm{E}-01$ & $\mathrm{~g}$ & & \\
\hline & & & & & & & & & MFP & $3.00 \mathrm{E}+00$ & $\mathrm{Ci}$ & & \\
\hline
\end{tabular}




\section{Appendix A-3 - Information from Radioactive Solid Waste Disposal Forms for Lined Shafts}

\begin{tabular}{|c|c|c|c|c|c|c|c|c|c|c|c|c|c|}
\hline Shaft & $\begin{array}{l}\text { RSWD } \\
\text { Number }\end{array}$ & $\begin{array}{c}\text { Date } \\
\text { Disposed }\end{array}$ & $\begin{array}{l}\text { Gross } \\
\text { Weight }\end{array}$ & Units & $\begin{array}{l}\text { Gross } \\
\text { Volume }\end{array}$ & Units & Waste Description & $\begin{array}{c}\text { Additional Description } \\
\text { of Packaging and } \\
\text { Packaging Materials }\end{array}$ & Nuclide & Amount & Units & $\begin{array}{c}\text { Package } \\
\text { Radiation } \\
\text { at } \\
\text { Surface } \\
\text { (mR/hr) }\end{array}$ & $\begin{array}{c}\text { Package } \\
\text { Radiation } \\
\text { at 1 } \\
\text { meter } \\
(\mathrm{mR} / \mathrm{hr})\end{array}$ \\
\hline \multirow{2}{*}{229} & & $11 / 29 / 84$ & & & & & & & U-235 & $4.00 \mathrm{E}-01$ & $\mathrm{~g}$ & & \\
\hline & & & & & & & & & MFP & $1.00 \mathrm{E}+00$ & $\mathrm{Ci}$ & & \\
\hline \multirow[t]{3}{*}{229} & S84???? & $12 / 31 / 84$ & 30 & $\mathrm{lb}$ & 0.6 & $\mathrm{ft}^{3}$ & $\begin{array}{l}\text { Cell } 13 \text { waste plastic can } \\
\# 4026\end{array}$ & $\begin{array}{l}150 \mathrm{R} / \mathrm{hr} @ \text {, cont, Steel } \\
\text { can \#36 }\end{array}$ & Pu-239 & $1.00 \mathrm{E}-01$ & $\mathrm{~g}$ & & 2,000 \\
\hline & & $11 / 29 / 84$ & & & & & & & U-235 & $4.00 \mathrm{E}-01$ & $\mathrm{~g}$ & & \\
\hline & & & & & & & & & MFP & $2.00 \mathrm{E}+00$ & $\mathrm{Ci}$ & & \\
\hline \multirow[t]{3}{*}{229} & S840865 & $12 / 31 / 84$ & 30 & $\mathrm{lb}$ & 0.6 & $\mathrm{ft}^{3}$ & $\begin{array}{l}\text { Cell \#13 waste plastic } \\
\text { can \#4055 }\end{array}$ & Steel can \#37 & $\mathrm{Pu}-239$ & $1.00 \mathrm{E}-01$ & $\mathrm{~g}$ & 10,000 & 100 \\
\hline & & $11 / 20 / 84$ & & & & & & & U-235 & $4.00 \mathrm{E}-01$ & $\mathrm{~g}$ & & \\
\hline & & & & & & & & & MFP & $1.00 \mathrm{E}-01$ & $\mathrm{Ci}$ & & \\
\hline \multirow[t]{2}{*}{229} & $\mathrm{~S} 840873$ & $12 / 31 / 84$ & 30 & $\mathrm{lb}$ & 0.6 & $\mathrm{ft}^{3}$ & Cell 14 trash can 4065 & $\begin{array}{l}100 \mathrm{Rhr} \text { contact, Steel } \\
\text { can } 41\end{array}$ & $\mathrm{Pu}-239$ & $3.00 \mathrm{E}+00$ & $\mathrm{~g}$ & & 2,000 \\
\hline & & $11 / 19 / 84$ & & & & & & & U-235 & $1.20 \mathrm{E}+01$ & $\mathrm{~g}$ & & \\
\hline \multirow{2}{*}{229} & & $11 / 27 / 84$ & & & & & & & U-235 & $4.00 \mathrm{E}-01$ & $\mathrm{~g}$ & & \\
\hline & & & & & & & & & MFP & $3.00 \mathrm{E}-01$ & $\mathrm{Ci}$ & & \\
\hline \multirow[t]{3}{*}{229} & S840888 & $12 / 31 / 84$ & 30 & $\mathrm{lb}$ & 0.6 & $\mathrm{ft}^{3}$ & Cell 14 trash can 4075 & Steel can 52 & $\mathrm{Pu}-239$ & $1.00 \mathrm{E}-01$ & $\mathrm{~g}$ & 10,000 & 1,500 \\
\hline & & $11 / 26 / 84$ & & & & & & & $\mathrm{U}-235$ & $4.00 \mathrm{E}-01$ & $\mathrm{~g}$ & & \\
\hline & & & & & & & & & MFP & $1.50 \mathrm{E}-01$ & $\mathrm{Ci}$ & & \\
\hline \multirow[t]{3}{*}{230} & S840831 & $10 / 2 / 1984 ?$ & 30 & $\mathrm{lb}$ & 0.5 & $\mathrm{ft}^{3}$ & $\begin{array}{l}\text { Cell } 9 \text { hot waste can } \\
\# 4017 \text {, Steel can } 13\end{array}$ & $\begin{array}{l}+1000 \mathrm{Rhr} \text { contact, } 35 \\
\mathrm{Rhr} \text { at meter }\end{array}$ & $\mathrm{Pu}-239$ & $9.60 \mathrm{E}+01$ & $\mathrm{~g}$ & & \\
\hline & & $12 / 8 / 84 ?$ & & & & & & & U-235 & $2.45 \mathrm{E}+02$ & $\mathrm{~g}$ & & \\
\hline & & & & & & & & & MFP & $3.50 \mathrm{E}+01$ & $\mathrm{Ci}$ & & \\
\hline \multirow[t]{3}{*}{230} & S840835 & $12 / 31 / 84$ & 30 & $\mathrm{lb}$ & 0.5 & $\mathrm{ft}^{3}$ & $\begin{array}{l}\text { Cell } 13 \text { waste plastic can } \\
4153\end{array}$ & $\begin{array}{l}100 \mathrm{R} / \mathrm{hr} @ \text { cont, Steel } \\
\text { can } 16\end{array}$ & Pu-239 & $1.00 \mathrm{E}-01$ & $\mathrm{~g}$ & & 1,000 \\
\hline & & $11 / 8 / 84$ & & & & & & & $\mathrm{U}-235$ & $4.00 \mathrm{E}-01$ & $\mathrm{~g}$ & & \\
\hline & & & & & & & & & MFP & $1.00 \mathrm{E}+01$ & $\mathrm{Ci}$ & & \\
\hline 230 & S840836 & $12 / 31 / 84$ & 30 & $\mathrm{Ib}$ & 0.5 & $\mathrm{ft}^{3}$ & Cell 13 waste plastic can & Steel can 15 & $\mathrm{Pu}-239$ & $1.00 \mathrm{E}-01$ & $\mathrm{~g}$ & 30,000 & 400 \\
\hline
\end{tabular}

21 of 24 


\section{Appendix A-3 - Information from Radioactive Solid Waste Disposal Forms for Lined Shafts}

\begin{tabular}{|c|c|c|c|c|c|c|c|c|c|c|c|c|c|}
\hline Shaft & $\begin{array}{l}\text { RSWD } \\
\text { Number }\end{array}$ & $\begin{array}{c}\text { Date } \\
\text { Disposed }\end{array}$ & $\begin{array}{c}\text { Gross } \\
\text { Weight } \\
\end{array}$ & Units & $\begin{array}{l}\text { Gross } \\
\text { Volume } \\
\end{array}$ & Units & Waste Description & $\begin{array}{c}\text { Additional Description } \\
\text { of Packaging and } \\
\text { Packaging Materials }\end{array}$ & Nuclide & Amount & Units & $\begin{array}{c}\text { Package } \\
\text { Radiation } \\
\text { at } \\
\text { Surface } \\
(\mathrm{mR} / \mathrm{hr}) \\
\end{array}$ & $\begin{array}{c}\text { Package } \\
\text { Radiation } \\
\text { at } 1 \\
\text { meter } \\
(\mathrm{mR} / \mathrm{hr}) \\
\end{array}$ \\
\hline & & & & & & & 3974 & & & & & & \\
\hline & & $10 / 5 / 84$ & & & & & & & $\mathrm{U}-235$ & $4.00 \mathrm{E}-01$ & $\mathrm{~g}$ & & \\
\hline & & & & & & & & & MFP & $4.00 \mathrm{E}-01$ & $\mathrm{Ci}$ & & \\
\hline \multirow[t]{3}{*}{230} & S840838 & $12 / 31 / 84$ & 30 & $\mathrm{lb}$ & 0.5 & $\mathrm{ft}^{3}$ & $\begin{array}{l}\text { Cell } 13 \text { waste plastic can } \\
4154\end{array}$ & $\begin{array}{l}400 \mathrm{R} / \mathrm{hr} @ \text { cont, Steel } \\
\text { can } 14\end{array}$ & Pu-239 & $1.00 \mathrm{E}-01$ & $\mathrm{~g}$ & & 5,000 \\
\hline & & $11 / 8 / 84$ & & & & & & & U-235 & $4.00 \mathrm{E}-01$ & $\mathrm{~g}$ & & \\
\hline & & & & & & & & & MFP & $5.00 \mathrm{E}+00$ & $\mathrm{Ci}$ & & \\
\hline \multirow[t]{3}{*}{230} & S840839 & $12 / 31 / 84$ & 30 & $\mathrm{lb}$ & 0.5 & $\mathrm{ft}^{3}$ & $\begin{array}{l}\text { Cell } 13 \text { waste [p]lastic } \\
\text { can } 4155\end{array}$ & Steel can 18 & $\mathrm{Pu}-239$ & $1.00 \mathrm{E}-01$ & $\mathrm{~g}$ & 90,000 & 1,500 \\
\hline & & $11 / 9 / 84$ & & & & & & & U-235 & $4.00 \mathrm{E}-01$ & $\mathrm{~g}$ & & \\
\hline & & & & & & & & & MFP & $1.50 \mathrm{E}+00$ & $\mathrm{Ci}$ & & \\
\hline \multirow[t]{3}{*}{230} & S840840 & $12 / 31 / 84$ & 30 & $\mathrm{lb}$ & 0.5 & $\mathrm{ft}^{3}$ & $\begin{array}{l}\text { Cell } 13 \text { waste plastic can } \\
4037\end{array}$ & Steel can 29 & $\mathrm{Pu}-239$ & $1.00 \mathrm{E}-01$ & $\mathrm{~g}$ & 90,000 & 1,000 \\
\hline & & & & & & & & & U-235 & $4.00 \mathrm{E}-01$ & $\mathrm{~g}$ & & \\
\hline & & & & & & & & & MFP & $1.00 \mathrm{E}+00$ & $\mathrm{Ci}$ & & \\
\hline \multirow[t]{3}{*}{230} & S840841? & $12 / 31 / 84$ & 30 & $\mathrm{lb}$ & 0.5 & $\mathrm{ft}^{3}$ & $\begin{array}{l}\text { Cell } 13 \text { waste plastic can } \\
4036\end{array}$ & Steel can 17 & $\mathrm{Pu}-239$ & $1.00 \mathrm{E}-01$ & $\mathrm{~g}$ & 60,000 & 700 \\
\hline & & $11 / 9 / 84$ & & & & & & & U-235 & $4.00 \mathrm{E}-01$ & $\mathrm{~g}$ & & \\
\hline & & & & & & & & & MFP & $7.00 \mathrm{E}-01$ & $\mathrm{Ci}$ & & \\
\hline \multirow[t]{5}{*}{230} & S840859 & $12 / 31 / 84$ & 30 & $\mathrm{lbs}$ & 0.5 & $\mathrm{ft}^{3}$ & $\begin{array}{l}\text { Cell } 13 \text { Waste Plastic } \\
\text { Can \#4031 }\end{array}$ & Steel can \#33 & $\mathrm{Pu}-239$ & $1.00 \mathrm{E}-01$ & $\mathrm{~g}$ & 40,000 & 1,000 \\
\hline & & $11 / 18 / 84$ & & & & & & & U-235 & $4.00 \mathrm{E}-01$ & $\mathrm{~g}$ & & \\
\hline & & & & & & & & & MFP & $1.00 \mathrm{E}+00$ & $\mathrm{Ci}$ & & \\
\hline & S855059 & $11 / 4 / 85$ & & & 116 & $\mathrm{ft}^{3}$ & $\begin{array}{l}\mathrm{HOH} \text { ? Compactible hot } \\
\text { cell waste }\end{array}$ & & $\mathrm{Pu}-239$ & & & 50 & 3 \\
\hline & & & & & & & & & MFP & & & & \\
\hline \multirow[t]{3}{*}{231} & S855046 & $12 / 30 / 85$ & 30 & lb & 0.5 & $\mathrm{ft}^{3}$ & $\begin{array}{l}\text { Plastic can } 3813 \text {, } \\
\text { vacuum cleaner motor }\end{array}$ & $\begin{array}{l}\text { Steel can } 72,1000+ \\
\mathrm{R} / \mathrm{hr} \text { at contact }\end{array}$ & $\mathrm{Pu}-239$ & $1.00 \mathrm{E}-01$ & $\mathrm{~g}$ & & 30,000 \\
\hline & & & & & & & & & U-235 & $4.00 \mathrm{E}-01$ & $\mathrm{~g}$ & & \\
\hline & & & & & & & & & MFP & $3.00 \mathrm{E}+00$ & $\mathrm{Ci}$ & & \\
\hline 231 & S855047 & $12 / 30 / 85$ & 25 & $\mathrm{lb}$ & 0.5 & $\mathrm{ft}^{3}$ & $\begin{array}{l}\text { Plastic can } 4114 \text {, } \\
\text { manipulator boot }\end{array}$ & $\begin{array}{l}\text { Steel can } 73,1000+ \\
\mathrm{R} / \mathrm{hr} \text { at contact }\end{array}$ & Pu-239 & $1.00 \mathrm{E}-01$ & $\mathrm{~g}$ & & 6,500 \\
\hline
\end{tabular}




\section{Appendix A-3 - Information from Radioactive Solid Waste Disposal Forms for Lined Shafts}

\begin{tabular}{|c|c|c|c|c|c|c|c|c|c|c|c|c|c|}
\hline Shaft & $\begin{array}{l}\text { RSWD } \\
\text { Number } \\
\end{array}$ & $\begin{array}{c}\text { Date } \\
\text { Disposed } \\
\end{array}$ & $\begin{array}{c}\text { Gross } \\
\text { Weight } \\
\end{array}$ & Units & $\begin{array}{c}\text { Gross } \\
\text { Volume } \\
\end{array}$ & Units & Waste Description & $\begin{array}{c}\text { Additional Description } \\
\text { of Packaging and } \\
\text { Packaging Materials }\end{array}$ & Nuclide & Amount & Units & $\begin{array}{c}\text { Package } \\
\text { Radiation } \\
\text { at } \\
\text { Surface } \\
(\mathrm{mR} / \mathrm{hr}) \\
\end{array}$ & $\begin{array}{c}\text { Package } \\
\text { Radiation } \\
\text { at } 1 \\
\text { meter } \\
(\mathrm{mR} / \mathrm{hr}) \\
\end{array}$ \\
\hline & & & & & & & & & MFP & $3.00 \mathrm{E}+00$ & $\mathrm{Ci}$ & & \\
\hline \multirow[t]{2}{*}{231} & S855048 & $12 / 30 / 85$ & 30 & $\mathrm{lb}$ & 0.5 & $\mathrm{ft}^{3}$ & $\begin{array}{l}\text { Cell } 10 \text { trash, plastic can } \\
3859\end{array}$ & $\begin{array}{l}\text { Steel can } 74,100 \mathrm{R} / \mathrm{hr} \\
\text { at contact }\end{array}$ & U-235 & $1.50 \mathrm{E}+01$ & $\mathrm{~g}$ & & 900 \\
\hline & & & & & & & & & MFP & $9.00 \mathrm{E}-01$ & $\mathrm{Ci}$ & & \\
\hline 231 & & & & & & & & & MFP & $4.00 \mathrm{E}-01$ & $\mathrm{Ci}$ & & \\
\hline \multirow[t]{3}{*}{231} & S856015 & $12 / 30 / 85$ & 30 & $\mathrm{lb}$ & 0.5 & $\mathrm{ft}^{3}$ & Plastic can 3649 & $\begin{array}{l}\text { Steel can } 68,1000+\text { at } \\
\text { contact }\end{array}$ & Pu-239 & $1.00 \mathrm{E}-01$ & $\mathrm{~g}$ & & 22,000 \\
\hline & & & & & & & & & U-235 & $4.00 \mathrm{E}-01$ & $\mathrm{~g}$ & & \\
\hline & & & & & & & & & MFP & $2.10 \mathrm{E}+00$ & $\mathrm{Ci}$ & & \\
\hline \multirow[t]{3}{*}{231} & $\mathrm{~S} 856016$ & $12 / 30 / 85$ & 30 & $\mathrm{lb}$ & 0.5 & $\mathrm{ft}^{3}$ & $\begin{array}{l}\text { Cells } 2 / 4 \text { waste plastic } \\
\text { can } 4113\end{array}$ & $\begin{array}{l}\text { Steel can } 69,20 \mathrm{R} / \mathrm{hr} \text { at } \\
\text { contact }\end{array}$ & Pu-239 & $1.00 \mathrm{E}-01$ & $\mathrm{~g}$ & 20,000 & 600 \\
\hline & & & & & & & & & U-235 & $3.00 \mathrm{E}-01$ & $\mathrm{~g}$ & & \\
\hline & & & & & & & & & MFP & $6.00 \mathrm{E}+00$ & $\mathrm{Ci}$ & & \\
\hline \multirow{2}{*}{231} & & & & & & & & & U-235 & $3.00 \mathrm{E}-01$ & $\mathrm{~g}$ & & \\
\hline & & & & & & & & & MFP & $6.00 \mathrm{E}+00$ & $\mathrm{Ci}$ & & \\
\hline \multirow[t]{3}{*}{231} & S856018 & $12 / 30 / 85$ & 30 & $\mathrm{lb}$ & 0.5 & $\mathrm{ft}^{3}$ & $\begin{array}{l}\text { Plastic \# 3625, Cell } 9 \\
\text { trash }\end{array}$ & $\begin{array}{l}\text { Steel can No } 70,350 \\
\text { Rhr at contact }\end{array}$ & Pu-239 & $1.00 \mathrm{E}-01$ & $\mathrm{~g}$ & & 7,000 \\
\hline & & & & & & & & & $\mathrm{U}-235$ & $4.00 \mathrm{E}-01$ & $\mathrm{~g}$ & & \\
\hline & & & & & & & & & MFP & $1.00 \mathrm{E}+00$ & $\mathrm{Ci}$ & & \\
\hline \multirow[t]{3}{*}{232} & S874132 & $12 / 23 / 87$ & 35 & lbs & 1 & gal & $\begin{array}{l}\text { 3Mile Island waste can } \\
77 \text { - was on a }\end{array}$ & $\begin{array}{l}\text { CWSR } \\
\text { LA86110050600 } \\
\end{array}$ & Pu-239 & & & 6,500 & \\
\hline & & & & & & & & & U-25 & $7.00 \mathrm{E}+00$ & $\mathrm{~g}$ & & \\
\hline & & & & & & & & & MFP & & & & \\
\hline \multirow[t]{3}{*}{232} & S874133 & $12 / 23 / 87$ & 35 & $\mathrm{lbs}$ & 1 & gal & $\begin{array}{l}\text { Cell } 9 \text { waste fuel can } 79 \\
\text { - was on a }\end{array}$ & $\begin{array}{l}\text { CWSR } \\
\text { LA86110050601, } \\
>1000 \mathrm{R} / \mathrm{hr}\end{array}$ & $\mathrm{Pu}-53$ & $1.60 \mathrm{E}+01$ & $\mathrm{~g}$ & & \\
\hline & & & & & & & & & $\mathrm{Pu}-55$ & $2.70 \mathrm{E}+01$ & $\mathrm{~g}$ & & \\
\hline & & & & & & & & & $\mathrm{Pu}-56$ & $1.20 \mathrm{E}+01$ & $\mathrm{~g}$ & & \\
\hline
\end{tabular}




\section{Appendix A-3 - Information from Radioactive Solid Waste Disposal Forms for Lined Shafts}

\begin{tabular}{|c|c|c|c|c|c|c|c|c|c|c|c|c|c|}
\hline Shaft & $\begin{array}{c}\text { RSWD } \\
\text { Number } \\
\end{array}$ & $\begin{array}{c}\text { Date } \\
\text { Disposed }\end{array}$ & $\begin{array}{c}\text { Gross } \\
\text { Weight } \\
\end{array}$ & Units & $\begin{array}{c}\text { Gross } \\
\text { Volume } \\
\end{array}$ & Units & Waste Description & $\begin{array}{c}\text { Additional Description } \\
\text { of Packaging and } \\
\text { Packaging Materials }\end{array}$ & Nuclide & Amount & Units & $\begin{array}{c}\text { Package } \\
\text { Radiation } \\
\text { at } \\
\text { Surface } \\
(\mathrm{mR} / \mathrm{hr}) \\
\end{array}$ & $\begin{array}{c}\text { Package } \\
\text { Radiation } \\
\text { at } 1 \\
\text { meter } \\
(\mathrm{mR} / \mathrm{hr}) \\
\end{array}$ \\
\hline & & & & & & & & & $\mathrm{Pu}-57$ & $1.30 \mathrm{E}+01$ & $\mathrm{~g}$ & & \\
\hline & & & & & & & & & U-235 & $1.35 \mathrm{E}+02$ & $\mathrm{~g}$ & & \\
\hline & & & & & & & & & U-238 & $6.02 \mathrm{E}+01$ & $\mathrm{~g}$ & & \\
\hline 232 & S874134 & $12 / 23 / 87$ & 35 & lbs & 1 & gal & $\begin{array}{l}\text { INC-11 Waste steel can } \\
78 \text { - was on a }\end{array}$ & $\begin{array}{l}\text { CWSR } \\
\text { LA86110050648 }\end{array}$ & Pu-57 & $1.00 \mathrm{E}+00$ & $\mathrm{~g}$ & 29,000 & \\
\hline & & & & & & & & & U-21 & $4.80 \mathrm{E}+01$ & $\mathrm{~g}$ & & \\
\hline & & & & & & & & & MFP & & & & \\
\hline
\end{tabular}


Appendix A-4 - Initial and Decayed Radionuclide and Dose Data for Lined Shafts

\begin{tabular}{|c|c|c|c|c|c|c|c|c|c|}
\hline \multirow[b]{2}{*}{ Shaft Number } & \multirow[b]{2}{*}{ Package ID } & \multirow[b]{2}{*}{ Base Year } & \multicolumn{2}{|c|}{ Initial Isotopic Distribution } & \multirow[b]{2}{*}{ Target Year } & \multicolumn{2}{|c|}{ Decayed Isotopic Distribution } & \multirow{2}{*}{$\begin{array}{c}\text { Initial Contact } \\
\text { Dose Rate } \\
(\mathrm{mR} / \mathrm{hr})\end{array}$} & \multirow{2}{*}{$\begin{array}{c}\text { Decayed } \\
\text { Contact Dose } \\
\text { Rate }(\mathrm{mR} / \mathrm{hr})^{1}\end{array}$} \\
\hline & & & Isotope & Activity $(\mathrm{Ci})$ & & Isotope & Activity (Ci) & & \\
\hline \multirow[t]{25}{*}{200} & S811387 & 1981 & & & 2009 & Ac-227 & $3.56 \mathrm{E}-09$ & 140,000 & 69,000 \\
\hline & & & Ba-137m & $5.99 \mathrm{E}-01$ & & Ba-137m & $3.13 \mathrm{E}-01$ & & \\
\hline & & & & & & Bi-211 & $3.51 \mathrm{E}-09$ & & \\
\hline & & & Cs-137 & $6.38 \mathrm{E}-01$ & & Cs-137 & $3.34 \mathrm{E}-01$ & & \\
\hline & & & $\mathrm{Eu}-155$ & $1.19 \mathrm{E}-02$ & & Eu-155 & $2.39 \mathrm{E}-04$ & & \\
\hline & & & & & & Fr-223 & $4.86 \mathrm{E}-11$ & & \\
\hline & & & & & & $\mathrm{Pa}-231$ & $1.05 \mathrm{E}-08$ & & \\
\hline & & & & & & $\mathrm{Pb}-211$ & $3.52 \mathrm{E}-09$ & & \\
\hline & & & Pm-147 & $3.65 \mathrm{E}-02$ & & Pm-147 & $2.23 \mathrm{E}-05$ & & \\
\hline & & & & & & Po-211 & $1.07 \mathrm{E}-11$ & & \\
\hline & & & & & & Po-215 & $3.52 \mathrm{E}-09$ & & \\
\hline & & & $\mathrm{Pu}-239$ & $1.25 \mathrm{E}+00$ & & $\mathrm{Pu}-239$ & $1.25 \mathrm{E}+00$ & & \\
\hline & & & & & & Ra-223 & $3.56 \mathrm{E}-09$ & & \\
\hline & & & Rh-106 & $4.68 \mathrm{E}-03$ & & Rh-106 & $2.01 \mathrm{E}-11$ & & \\
\hline & & & & & & $\mathrm{Rn}-219$ & $3.51 \mathrm{E}-09$ & & \\
\hline & & & $\mathrm{Ru}-106$ & $4.68 \mathrm{E}-03$ & & $\mathrm{Ru}-106$ & $2.03 \mathrm{E}-11$ & & \\
\hline & & & Sb-125 & $2.60 \mathrm{E}-02$ & & Sb-125 & $2.35 \mathrm{E}-05$ & & \\
\hline & & & & & & Sm-147 & $8.94 \mathrm{E}-13$ & & \\
\hline & & & Sr-90 & $5.84 \mathrm{E}-01$ & & Sr-90 & $3.00 \mathrm{E}-01$ & & \\
\hline & & & $\mathrm{Te}-125 \mathrm{~m}$ & $1.08 \mathrm{E}-02$ & & Te- $125 \mathrm{~m}$ & $5.70 \mathrm{E}-06$ & & \\
\hline & & & & & & Th-227 & $3.46 \mathrm{E}-09$ & & \\
\hline & & & & & & Th-231 & $1.76 \mathrm{E}-05$ & & \\
\hline & & & & & & T1-207 & $3.50 \mathrm{E}-09$ & & \\
\hline & & & U-235 & $1.78 \mathrm{E}-05$ & & U-235 & $1.78 \mathrm{E}-05$ & & \\
\hline & & & Y-90 & $5.83 \mathrm{E}-01$ & & $\mathrm{Y}-90$ & $2.96 \mathrm{E}-01$ & & \\
\hline \multirow[t]{6}{*}{200} & S811390 & 1981 & & & 2009 & Ac- 227 & $1.67 \mathrm{E}-08$ & 800,000 & 396,000 \\
\hline & & & $\mathrm{Ba}-137 \mathrm{~m}$ & $1.44 \mathrm{E}+00$ & & $\mathrm{Ba}-137 \mathrm{~m}$ & $7.50 \mathrm{E}-01$ & & \\
\hline & & & & & & Bi-211 & $1.65 \mathrm{E}-08$ & & \\
\hline & & & Cs-137 & $1.53 \mathrm{E}+00$ & & Cs-137 & $8.02 \mathrm{E}-01$ & & \\
\hline & & & Eu-155 & $2.87 \mathrm{E}-02$ & & Eu-155 & $5.72 \mathrm{E}-04$ & & \\
\hline & & & & & & Fr-223 & $2.28 \mathrm{E}-10$ & & \\
\hline
\end{tabular}

${ }^{1}$ Calculated decayed contact dose rate. Rounded to nearest $10 \mathrm{mR} / \mathrm{hr}$ for values to 1000 ; rounded to nearest $100 \mathrm{mR} / \mathrm{hr}$ for values $>1000$ to 10,000 ; rounded to nearest $1000 \mathrm{mR} / \mathrm{hr}$ for values $>10,000$. * Initial contact dose rate assumed to be $1,000,000 \mathrm{mR} / \mathrm{hr}$; **Initial contact dose rate assumed to be $1,010,000 \mathrm{mR} / \mathrm{hr}$.

$$
1 \text { of } 168
$$


Appendix A-4 - Initial and Decayed Radionuclide and Dose Data for Lined Shafts

\begin{tabular}{|c|c|c|c|c|c|c|c|c|c|}
\hline \multirow[b]{2}{*}{ Shaft Number } & \multirow[b]{2}{*}{ Package ID } & \multirow[b]{2}{*}{ Base Year } & \multicolumn{2}{|c|}{ Initial Isotopic Distribution } & \multirow[b]{2}{*}{ Target Year } & \multicolumn{2}{|c|}{ Decayed Isotopic Distribution } & \multirow{2}{*}{$\begin{array}{c}\text { Initial Contact } \\
\text { Dose Rate } \\
(\mathrm{mR} / \mathrm{hr})\end{array}$} & \multirow{2}{*}{$\begin{array}{c}\text { Decayed } \\
\text { Contact Dose } \\
\text { Rate }(\mathrm{mR} / \mathrm{hr})^{1} \\
\end{array}$} \\
\hline & & & Isotope & Activity (Ci) & & Isotope & Activity (Ci) & & \\
\hline & & & & & & $\mathrm{Pa}-231$ & $4.95 \mathrm{E}-08$ & & \\
\hline & & & & & & $\mathrm{Pb}-211$ & $1.66 \mathrm{E}-08$ & & \\
\hline & & & Pm-147 & $8.75 \mathrm{E}-02$ & & Pm-147 & $5.36 \mathrm{E}-05$ & & \\
\hline & & & & & & Po-211 & $5.05 \mathrm{E}-11$ & & \\
\hline & & & & & & Po-215 & $1.66 \mathrm{E}-08$ & & \\
\hline & & & $\mathrm{Pu}-239$ & $6.21 \mathrm{E}-01$ & & $\mathrm{Pu}-239$ & $6.20 \mathrm{E}-01$ & & \\
\hline & & & & & & Ra-223 & $1.67 \mathrm{E}-08$ & & \\
\hline & & & $\mathrm{Rh}-106$ & $1.12 \mathrm{E}-02$ & & Rh-106 & $4.83 \mathrm{E}-11$ & & \\
\hline & & & & & & Rn-219 & $1.65 \mathrm{E}-08$ & & \\
\hline & & & $\mathrm{Ru}-106$ & $1.12 \mathrm{E}-02$ & & $\mathrm{Ru}-106$ & $4.88 \mathrm{E}-11$ & & \\
\hline & & & Sb-125 & $6.24 \mathrm{E}-02$ & & Sb-125 & $5.65 \mathrm{E}-05$ & & \\
\hline & & & & & & Sm-147 & $2.14 \mathrm{E}-12$ & & \\
\hline & & & Sr-90 & $1.40 \mathrm{E}+00$ & & Sr-90 & 7.19E-01 & & \\
\hline & & & $\mathrm{Te}-125 \mathrm{~m}$ & $2.59 \mathrm{E}-02$ & & $\mathrm{Te}-125 \mathrm{~m}$ & $1.37 \mathrm{E}-05$ & & \\
\hline & & & & & & Th-227 & $1.63 \mathrm{E}-08$ & & \\
\hline & & & & & & Th-231 & $8.27 \mathrm{E}-05$ & & \\
\hline & & & & & & Tl-207 & $1.65 \mathrm{E}-08$ & & \\
\hline & & & $\mathrm{U}-235$ & $8.37 \mathrm{E}-05$ & & $\mathrm{U}-235$ & $8.37 \mathrm{E}-05$ & & \\
\hline & & & Y-90 & $1.40 \mathrm{E}+00$ & & Y-90 & $7.11 \mathrm{E}-01$ & & \\
\hline \multirow[t]{13}{*}{200} & S811396 & 1981 & & & 2009 & Ac-227 & $1.76 \mathrm{E}-10$ & 60,000 & 30,000 \\
\hline & & & Ba-137m & $1.44 \mathrm{E}-01$ & & Ba-137m & $7.50 \mathrm{E}-02$ & & \\
\hline & & & & & & $\mathrm{Bi}-211$ & $1.74 \mathrm{E}-10$ & & \\
\hline & & & Cs-137 & $1.53 \mathrm{E}-01$ & & Cs-137 & $8.02 \mathrm{E}-02$ & & \\
\hline & & & Eu-155 & $2.87 \mathrm{E}-03$ & & Eu-155 & $5.72 \mathrm{E}-05$ & & \\
\hline & & & & & & Fr-223 & $2.40 \mathrm{E}-12$ & & \\
\hline & & & & & & $\mathrm{Pa}-231$ & $5.21 \mathrm{E}-10$ & & \\
\hline & & & & & & $\mathrm{Pb}-211$ & $1.74 \mathrm{E}-10$ & & \\
\hline & & & Pm-147 & $8.75 \mathrm{E}-03$ & & Pm-147 & $5.36 \mathrm{E}-06$ & & \\
\hline & & & & & & Po-211 & $5.31 \mathrm{E}-13$ & & \\
\hline & & & & & & Po-215 & $1.74 \mathrm{E}-10$ & & \\
\hline & & & Pu-239 & $6.20 \mathrm{E}-03$ & & $\mathrm{Pu}-239$ & $6.20 \mathrm{E}-03$ & & \\
\hline & & & & & & Ra-223 & $1.76 \mathrm{E}-10$ & & \\
\hline
\end{tabular}

${ }^{1}$ Calculated decayed contact dose rate. Rounded to nearest $10 \mathrm{mR} / \mathrm{hr}$ for values to 1000 ; rounded to nearest $100 \mathrm{mR} / \mathrm{hr}$ for values $>1000$ to 10,000 ; rounded to nearest $1000 \mathrm{mR} / \mathrm{hr}$ for values $>10,000$. * Initial contact dose rate assumed to be $1,000,000 \mathrm{mR} / \mathrm{hr}$; **Initial contact dose rate assumed to be $1,010,000 \mathrm{mR} / \mathrm{hr}$.

$$
2 \text { of } 168
$$


Appendix A-4 - Initial and Decayed Radionuclide and Dose Data for Lined Shafts

\begin{tabular}{|c|c|c|c|c|c|c|c|c|c|}
\hline \multirow[b]{2}{*}{ Shaft Number } & \multirow[b]{2}{*}{ Package ID } & \multirow[b]{2}{*}{ Base Year } & \multicolumn{2}{|c|}{ Initial Isotopic Distribution } & \multirow[b]{2}{*}{ Target Year } & \multicolumn{2}{|c|}{ Decayed Isotopic Distribution } & \multirow{2}{*}{$\begin{array}{c}\text { Initial Contact } \\
\text { Dose Rate } \\
(\mathrm{mR} / \mathrm{hr})\end{array}$} & \multirow{2}{*}{$\begin{array}{c}\text { Decayed } \\
\text { Contact Dose } \\
\text { Rate }(\mathrm{mR} / \mathrm{hr})^{1} \\
\end{array}$} \\
\hline & & & Isotope & Activity (Ci) & & Isotope & Activity (Ci) & & \\
\hline & & & Rh-106 & $1.12 \mathrm{E}-03$ & & Rh-106 & $4.83 \mathrm{E}-12$ & & \\
\hline & & & & & & $\mathrm{Rn}-219$ & $1.74 \mathrm{E}-10$ & & \\
\hline & & & $\mathrm{Ru}-106$ & $1.12 \mathrm{E}-03$ & & Ru-106 & $4.88 \mathrm{E}-12$ & & \\
\hline & & & $\mathrm{Sb}-125$ & $6.24 \mathrm{E}-03$ & & $\mathrm{Sb}-125$ & $5.65 \mathrm{E}-06$ & & \\
\hline & & & & & & Sm-147 & $2.14 \mathrm{E}-13$ & & \\
\hline & & & Sr-90 & $1.40 \mathrm{E}-01$ & & Sr-90 & $7.19 \mathrm{E}-02$ & & \\
\hline & & & $\mathrm{Te}-125 \mathrm{~m}$ & $2.59 \mathrm{E}-03$ & & $\mathrm{Te}-125 \mathrm{~m}$ & $1.37 \mathrm{E}-06$ & & \\
\hline & & & & & & Th-227 & $1.71 \mathrm{E}-10$ & & \\
\hline & & & & & & Th-231 & $8.69 \mathrm{E}-07$ & & \\
\hline & & & & & & Tl-207 & $1.73 \mathrm{E}-10$ & & \\
\hline & & & $\mathrm{U}-235$ & $8.80 \mathrm{E}-07$ & & $\mathrm{U}-235$ & $8.80 \mathrm{E}-07$ & & \\
\hline & & & $\mathrm{Y}-90$ & $1.40 \mathrm{E}-01$ & & Y-90 & $7.11 \mathrm{E}-02$ & & \\
\hline \multirow[t]{20}{*}{200} & S811398 & 1981 & & & 2009 & Ac-227 & $7.04 \mathrm{E}-09$ & 120,000 & 59,000 \\
\hline & & & $\mathrm{Ba}-137 \mathrm{~m}$ & $1.44 \mathrm{E}-01$ & & $\mathrm{Ba}-137 \mathrm{~m}$ & $7.50 \mathrm{E}-02$ & & \\
\hline & & & & & & Bi-211 & $6.95 \mathrm{E}-09$ & & \\
\hline & & & Cs-137 & $1.53 \mathrm{E}-01$ & & Cs-137 & $8.02 \mathrm{E}-02$ & & \\
\hline & & & Eu-155 & $2.87 \mathrm{E}-03$ & & Eu-155 & $5.72 \mathrm{E}-05$ & & \\
\hline & & & & & & Fr-223 & $9.61 \mathrm{E}-11$ & & \\
\hline & & & & & & $\mathrm{Pa}-231$ & $2.08 \mathrm{E}-08$ & & \\
\hline & & & & & & $\mathrm{Pb}-211$ & $6.96 \mathrm{E}-09$ & & \\
\hline & & & Pm-147 & $8.75 \mathrm{E}-03$ & & Pm-147 & $5.36 \mathrm{E}-06$ & & \\
\hline & & & & & & Po-211 & $2.12 \mathrm{E}-11$ & & \\
\hline & & & & & & Po-215 & $6.96 \mathrm{E}-09$ & & \\
\hline & & & $\mathrm{Pu}-239$ & $2.48 \mathrm{E}-01$ & & $\mathrm{Pu}-239$ & $2.48 \mathrm{E}-01$ & & \\
\hline & & & & & & $\mathrm{Ra}-223$ & 7.04E-09 & & \\
\hline & & & Rh-106 & $1.12 \mathrm{E}-03$ & & Rh-106 & $4.83 \mathrm{E}-12$ & & \\
\hline & & & & & & Rn-219 & $6.95 \mathrm{E}-09$ & & \\
\hline & & & $\mathrm{Ru}-106$ & $1.12 \mathrm{E}-03$ & & $\mathrm{Ru}-106$ & $4.88 \mathrm{E}-12$ & & \\
\hline & & & Sb-125 & $6.24 \mathrm{E}-03$ & & Sb-125 & $5.65 \mathrm{E}-06$ & & \\
\hline & & & & & & Sm-147 & $2.14 \mathrm{E}-13$ & & \\
\hline & & & Sr-90 & $1.40 \mathrm{E}-01$ & & Sr-90 & 7.19E-02 & & \\
\hline & & & $\mathrm{Te}-125 \mathrm{~m}$ & $2.59 \mathrm{E}-03$ & & $\mathrm{Te}-125 \mathrm{~m}$ & $1.37 \mathrm{E}-06$ & & \\
\hline
\end{tabular}

${ }^{1}$ Calculated decayed contact dose rate. Rounded to nearest $10 \mathrm{mR} / \mathrm{hr}$ for values to 1000 ; rounded to nearest $100 \mathrm{mR} / \mathrm{hr}$ for values $>1000$ to 10,000 ; rounded to nearest $1000 \mathrm{mR} / \mathrm{hr}$ for values $>10,000$. * Initial contact dose rate assumed to be $1,000,000 \mathrm{mR} / \mathrm{hr}$; **Initial contact dose rate assumed to be $1,010,000 \mathrm{mR} / \mathrm{hr}$.

$$
3 \text { of } 168
$$


Appendix A-4 - Initial and Decayed Radionuclide and Dose Data for Lined Shafts

\begin{tabular}{|c|c|c|c|c|c|c|c|c|c|}
\hline \multirow[b]{2}{*}{ Shaft Number } & \multirow[b]{2}{*}{ Package ID } & \multirow[b]{2}{*}{ Base Year } & \multicolumn{2}{|c|}{ Initial Isotopic Distribution } & \multirow[b]{2}{*}{ Target Year } & \multicolumn{2}{|c|}{ Decayed Isotopic Distribution } & \multirow{2}{*}{$\begin{array}{c}\text { Initial Contact } \\
\text { Dose Rate } \\
(\mathrm{mR} / \mathrm{hr})\end{array}$} & \multirow{2}{*}{$\begin{array}{c}\text { Decayed } \\
\text { Contact Dose } \\
\text { Rate }(\mathrm{mR} / \mathrm{hr})^{1} \\
\end{array}$} \\
\hline & & & Isotope & Activity (Ci) & & Isotope & Activity (Ci) & & \\
\hline & & & & & & Th-227 & $6.86 \mathrm{E}-09$ & & \\
\hline & & & & & & Th-231 & $3.48 \mathrm{E}-05$ & & \\
\hline & & & & & & Tl-207 & $6.92 \mathrm{E}-09$ & & \\
\hline & & & $\mathrm{U}-235$ & $3.52 \mathrm{E}-05$ & & U-235 & $3.52 \mathrm{E}-05$ & & \\
\hline & & & $\mathrm{Y}-90$ & $1.40 \mathrm{E}-01$ & & $\mathrm{Y}-90$ & $7.11 \mathrm{E}-02$ & & \\
\hline \multirow[t]{25}{*}{200} & S811471 & 1981 & & & 2009 & Ac-227 & $9.46 \mathrm{E}-09$ & 700,000 & 346,000 \\
\hline & & & Ba-137m & $6.47 \mathrm{E}-01$ & & $\mathrm{Ba}-137 \mathrm{~m}$ & $3.38 \mathrm{E}-01$ & & \\
\hline & & & & & & Bi-211 & $9.34 \mathrm{E}-09$ & & \\
\hline & & & Cs-137 & $6.89 \mathrm{E}-01$ & & Cs-137 & $3.61 \mathrm{E}-01$ & & \\
\hline & & & Eu-155 & $1.29 \mathrm{E}-02$ & & Eu-155 & $2.58 \mathrm{E}-04$ & & \\
\hline & & & & & & Fr-223 & $1.29 \mathrm{E}-10$ & & \\
\hline & & & & & & $\mathrm{Pa}-231$ & $2.80 \mathrm{E}-08$ & & \\
\hline & & & & & & $\mathrm{Pb}-211$ & $9.36 \mathrm{E}-09$ & & \\
\hline & & & Pm-147 & $3.94 \mathrm{E}-02$ & & Pm-147 & $2.41 \mathrm{E}-05$ & & \\
\hline & & & & & & Po-211 & $2.85 \mathrm{E}-11$ & & \\
\hline & & & & & & Po-215 & $9.36 \mathrm{E}-09$ & & \\
\hline & & & $\mathrm{Pu}-239$ & $7.75 \mathrm{E}-01$ & & $\mathrm{Pu}-239$ & 7.74E-01 & & \\
\hline & & & & & & Ra-223 & $9.46 \mathrm{E}-09$ & & \\
\hline & & & Rh-106 & $5.06 \mathrm{E}-03$ & & Rh-106 & $2.17 \mathrm{E}-11$ & & \\
\hline & & & & & & Rn-219 & $9.35 \mathrm{E}-09$ & & \\
\hline & & & Ru-106 & $5.06 \mathrm{E}-03$ & & Ru-106 & $2.20 \mathrm{E}-11$ & & \\
\hline & & & Sb-125 & $2.81 \mathrm{E}-02$ & & Sb-125 & $2.54 \mathrm{E}-05$ & & \\
\hline & & & & & & Sm-147 & $9.65 \mathrm{E}-13$ & & \\
\hline & & & Sr-90 & $6.30 \mathrm{E}-01$ & & Sr-90 & $3.24 \mathrm{E}-01$ & & \\
\hline & & & $\mathrm{Te}-125 \mathrm{~m}$ & $1.17 \mathrm{E}-02$ & & $\mathrm{Te}-125 \mathrm{~m}$ & $6.15 \mathrm{E}-06$ & & \\
\hline & & & & & & Th-227 & $9.21 \mathrm{E}-09$ & & \\
\hline & & & & & & Th-231 & 4.67E-05 & & \\
\hline & & & & & & Tl-207 & $9.30 \mathrm{E}-09$ & & \\
\hline & & & U-235 & 4.73E-05 & & U-235 & 4.73E-05 & & \\
\hline & & & Y-90 & $6.29 \mathrm{E}-01$ & & Y-90 & $3.20 \mathrm{E}-01$ & & \\
\hline \multirow[t]{2}{*}{200} & S811473 & 1981 & & & 2009 & Ac-227 & $2.16 \mathrm{E}-08$ & $1,150,000$ & 569,000 \\
\hline & & & $\mathrm{Ba}-137 \mathrm{~m}$ & $4.79 \mathrm{E}+00$ & & Ba-137m & $2.50 \mathrm{E}+00$ & & \\
\hline
\end{tabular}

${ }^{1}$ Calculated decayed contact dose rate. Rounded to nearest $10 \mathrm{mR} / \mathrm{hr}$ for values to 1000 ; rounded to nearest $100 \mathrm{mR} / \mathrm{hr}$ for values $>1000$ to 10,000 ; rounded to nearest $1000 \mathrm{mR} / \mathrm{hr}$ for values $>10,000$. * Initial contact dose rate assumed to be $1,000,000 \mathrm{mR} / \mathrm{hr}$; **Initial contact dose rate assumed to be $1,010,000 \mathrm{mR} / \mathrm{hr}$.

$$
4 \text { of } 168
$$


Appendix A-4 - Initial and Decayed Radionuclide and Dose Data for Lined Shafts

\begin{tabular}{|c|c|c|c|c|c|c|c|c|c|}
\hline \multirow[b]{2}{*}{ Shaft Number } & \multirow[b]{2}{*}{ Package ID } & \multirow[b]{2}{*}{ Base Year } & \multicolumn{2}{|c|}{ Initial Isotopic Distribution } & \multirow[b]{2}{*}{ Target Year } & \multicolumn{2}{|c|}{ Decayed Isotopic Distribution } & \multirow{2}{*}{$\begin{array}{c}\text { Initial Contact } \\
\text { Dose Rate } \\
(\mathrm{mR} / \mathrm{hr})\end{array}$} & \multirow{2}{*}{$\begin{array}{c}\text { Decayed } \\
\text { Contact Dose } \\
\text { Rate }(\mathrm{mR} / \mathrm{hr})^{1}\end{array}$} \\
\hline & & & Isotope & Activity (Ci) & & Isotope & Activity (Ci) & & \\
\hline & & & & & & $\mathrm{Bi}-211$ & $2.13 \mathrm{E}-08$ & & \\
\hline & & & Cs-137 & $5.11 \mathrm{E}+00$ & & Cs-137 & $2.67 \mathrm{E}+00$ & & \\
\hline & & & Eu-155 & $9.55 \mathrm{E}-02$ & & $\mathrm{Eu}-155$ & $1.91 \mathrm{E}-03$ & & \\
\hline & & & & & & Fr-223 & $2.94 \mathrm{E}-10$ & & \\
\hline & & & & & & $\mathrm{Pa}-231$ & $6.38 \mathrm{E}-08$ & & \\
\hline & & & & & & $\mathrm{Pb}-211$ & $2.13 \mathrm{E}-08$ & & \\
\hline & & & Pm-147 & 2.92E-01 & & Pm-147 & $1.79 \mathrm{E}-04$ & & \\
\hline & & & & & & Po-211 & $6.50 \mathrm{E}-11$ & & \\
\hline & & & & & & Po-215 & $2.13 \mathrm{E}-08$ & & \\
\hline & & & $\mathrm{Pu}-239$ & $3.10 \mathrm{E}-01$ & & $\mathrm{Pu}-239$ & $3.10 \mathrm{E}-01$ & & \\
\hline & & & & & & $\mathrm{Ra}-223$ & $2.16 \mathrm{E}-08$ & & \\
\hline & & & Rh-106 & $3.74 \mathrm{E}-02$ & & Rh-106 & $1.61 \mathrm{E}-10$ & & \\
\hline & & & & & & Rn-219 & $2.13 \mathrm{E}-08$ & & \\
\hline & & & Ru-106 & $3.74 \mathrm{E}-02$ & & $\mathrm{Ru}-106$ & $1.63 \mathrm{E}-10$ & & \\
\hline & & & Sb-125 & $2.08 \mathrm{E}-01$ & & $\mathrm{Sb}-125$ & $1.88 \mathrm{E}-04$ & & \\
\hline & & & & & & Sm-147 & $7.15 \mathrm{E}-12$ & & \\
\hline & & & Sr-90 & $4.67 \mathrm{E}+00$ & & Sr-90 & $2.40 \mathrm{E}+00$ & & \\
\hline & & & $\mathrm{Te}-125 \mathrm{~m}$ & $8.63 \mathrm{E}-02$ & & $\mathrm{Te}-125 \mathrm{~m}$ & $4.56 \mathrm{E}-05$ & & \\
\hline & & & & & & Th-227 & $2.10 \mathrm{E}-08$ & & \\
\hline & & & & & & Th-231 & $1.07 \mathrm{E}-04$ & & \\
\hline & & & & & & Tl-207 & 2.12E-08 & & \\
\hline & & & U-235 & $1.08 \mathrm{E}-04$ & & U-235 & $1.08 \mathrm{E}-04$ & & \\
\hline & & & $\mathrm{Y}-90$ & $4.66 \mathrm{E}+00$ & & Y-90 & $2.37 \mathrm{E}+00$ & & \\
\hline \multirow[t]{9}{*}{201} & S791484 & 1979 & & & 2009 & Ac- 227 & $4.97 \mathrm{E}-10$ & 17,500 & 8,300 \\
\hline & & & Ba-137m & $9.59 \mathrm{E}-01$ & & Ba-137m & $4.78 \mathrm{E}-01$ & & \\
\hline & & & & & & $\mathrm{Bi}-211$ & $4.90 \mathrm{E}-10$ & & \\
\hline & & & Cs-137 & $1.02 \mathrm{E}+00$ & & Cs-137 & $5.11 \mathrm{E}-01$ & & \\
\hline & & & Eu-155 & $1.91 \mathrm{E}-02$ & & Eu-155 & 2.89E-04 & & \\
\hline & & & & & & Fr-223 & $6.78 \mathrm{E}-12$ & & \\
\hline & & & & & & $\mathrm{Pa}-231$ & $1.40 \mathrm{E}-09$ & & \\
\hline & & & & & & $\mathrm{Pb}-211$ & $4.91 \mathrm{E}-10$ & & \\
\hline & & & Pm-147 & $5.83 \mathrm{E}-02$ & & Pm-147 & $2.11 \mathrm{E}-05$ & & \\
\hline
\end{tabular}

${ }^{1}$ Calculated decayed contact dose rate. Rounded to nearest $10 \mathrm{mR} / \mathrm{hr}$ for values to 1000 ; rounded to nearest $100 \mathrm{mR} / \mathrm{hr}$ for values $>1000$ to 10,000 ; rounded to nearest $1000 \mathrm{mR} / \mathrm{hr}$ for values $>10,000$. * Initial contact dose rate assumed to be $1,000,000 \mathrm{mR} / \mathrm{hr}$; **Initial contact dose rate assumed to be $1,010,000 \mathrm{mR} / \mathrm{hr}$.

5 of 168 
Appendix A-4 - Initial and Decayed Radionuclide and Dose Data for Lined Shafts

\begin{tabular}{|c|c|c|c|c|c|c|c|c|c|}
\hline \multirow[b]{2}{*}{ Shaft Number } & \multirow[b]{2}{*}{ Package ID } & \multirow[b]{2}{*}{ Base Year } & \multicolumn{2}{|c|}{ Initial Isotopic Distribution } & \multirow[b]{2}{*}{ Target Year } & \multicolumn{2}{|c|}{ Decayed Isotopic Distribution } & \multirow{2}{*}{$\begin{array}{c}\text { Initial Contact } \\
\text { Dose Rate } \\
(\mathrm{mR} / \mathrm{hr})\end{array}$} & \multirow{2}{*}{$\begin{array}{c}\text { Decayed } \\
\text { Contact Dose } \\
\text { Rate }(\mathrm{mR} / \mathrm{hr})^{1} \\
\end{array}$} \\
\hline & & & Isotope & Activity (Ci) & & Isotope & Activity (Ci) & & \\
\hline & & & & & & Po-211 & $1.50 \mathrm{E}-12$ & & \\
\hline & & & & & & Po-215 & $4.91 \mathrm{E}-10$ & & \\
\hline & & & $\mathrm{Pu}-239$ & $1.86 \mathrm{E}-01$ & & $\mathrm{Pu}-239$ & $1.86 \mathrm{E}-01$ & & \\
\hline & & & & & & Ra-223 & $4.96 \mathrm{E}-10$ & & \\
\hline & & & Rh-106 & 7.49E-03 & & Rh-106 & $8.15 \mathrm{E}-12$ & & \\
\hline & & & & & & $\mathrm{Rn}-219$ & $4.90 \mathrm{E}-10$ & & \\
\hline & & & $\mathrm{Ru}-106$ & 7.49E-03 & & $\mathrm{Ru}-106$ & $8.23 \mathrm{E}-12$ & & \\
\hline & & & $\mathrm{Sb}-125$ & $4.16 \mathrm{E}-02$ & & $\mathrm{Sb}-125$ & $2.28 \mathrm{E}-05$ & & \\
\hline & & & & & & Sm-147 & $1.43 \mathrm{E}-12$ & & \\
\hline & & & Sr-90 & 9.34E-01 & & Sr-90 & 4.57E-01 & & \\
\hline & & & Te-125m & $1.73 \mathrm{E}-02$ & & Te-125m & $5.53 \mathrm{E}-06$ & & \\
\hline & & & & & & Th-227 & 4.84E-10 & & \\
\hline & & & & & & Th-231 & $2.18 \mathrm{E}-06$ & & \\
\hline & & & & & & Tl-207 & $4.88 \mathrm{E}-10$ & & \\
\hline & & & $\mathrm{U}-235$ & $2.20 \mathrm{E}-06$ & & $\mathrm{U}-235$ & $2.21 \mathrm{E}-06$ & & \\
\hline & & & Y-90 & 9.33E-01 & & Y-90 & $4.52 \mathrm{E}-01$ & & \\
\hline \multirow[t]{16}{*}{201} & S794215 & 1979 & & & 2009 & Ac- 227 & $9.93 \mathrm{E}-10$ & 266,000 & 126,000 \\
\hline & & & Ba-137m & $2.64 \mathrm{E}+00$ & & Ba-137m & $1.31 \mathrm{E}+00$ & & \\
\hline & & & & & & Bi-211 & $9.80 \mathrm{E}-10$ & & \\
\hline & & & Cs-137 & $2.81 \mathrm{E}+00$ & & Cs-137 & $1.40 \mathrm{E}+00$ & & \\
\hline & & & Eu-155 & $5.26 \mathrm{E}-02$ & & Eu-155 & 7.93E-04 & & \\
\hline & & & & & & Fr-223 & $1.35 \mathrm{E}-11$ & & \\
\hline & & & & & & $\mathrm{Pa}-231$ & 2.79E-09 & & \\
\hline & & & & & & $\mathrm{Pb}-211$ & $9.81 \mathrm{E}-10$ & & \\
\hline & & & Pm-147 & $1.60 \mathrm{E}-01$ & & Pm-147 & 5.79E-05 & & \\
\hline & & & & & & Po-211 & $2.99 \mathrm{E}-12$ & & \\
\hline & & & & & & Po-215 & $9.81 \mathrm{E}-10$ & & \\
\hline & & & $\mathrm{Pu}-239$ & $3.41 \mathrm{E}-02$ & & $\mathrm{Pu}-239$ & $3.41 \mathrm{E}-02$ & & \\
\hline & & & & & & $\mathrm{Ra}-223$ & $9.92 \mathrm{E}-10$ & & \\
\hline & & & Rh-106 & $2.06 \mathrm{E}-02$ & & Rh-106 & $2.24 \mathrm{E}-11$ & & \\
\hline & & & & & & Rn-219 & $9.80 \mathrm{E}-10$ & & \\
\hline & & & Ru-106 & $2.06 \mathrm{E}-02$ & & $\mathrm{Ru}-106$ & $2.26 \mathrm{E}-11$ & & \\
\hline
\end{tabular}

${ }^{1}$ Calculated decayed contact dose rate. Rounded to nearest $10 \mathrm{mR} / \mathrm{hr}$ for values to 1000 ; rounded to nearest $100 \mathrm{mR} / \mathrm{hr}$ for values $>1000$ to 10,000 ; rounded to nearest $1000 \mathrm{mR} / \mathrm{hr}$ for values $>10,000$. * Initial contact dose rate assumed to be $1,000,000 \mathrm{mR} / \mathrm{hr}$; **Initial contact dose rate assumed to be $1,010,000 \mathrm{mR} / \mathrm{hr}$.

6 of 168 
Appendix A-4 - Initial and Decayed Radionuclide and Dose Data for Lined Shafts

\begin{tabular}{|c|c|c|c|c|c|c|c|c|c|}
\hline \multirow[b]{2}{*}{ Shaft Number } & \multirow[b]{2}{*}{ Package ID } & \multirow[b]{2}{*}{ Base Year } & \multicolumn{2}{|c|}{ Initial Isotopic Distribution } & \multirow[b]{2}{*}{ Target Year } & \multicolumn{2}{|c|}{ Decayed Isotopic Distribution } & \multirow{2}{*}{$\begin{array}{c}\text { Initial Contact } \\
\text { Dose Rate } \\
(\mathrm{mR} / \mathrm{hr})\end{array}$} & \multirow{2}{*}{$\begin{array}{c}\text { Decayed } \\
\text { Contact Dose } \\
\text { Rate }(\mathrm{mR} / \mathrm{hr})^{1} \\
\end{array}$} \\
\hline & & & Isotope & Activity (Ci) & & Isotope & Activity (Ci) & & \\
\hline & & & Sb-125 & $1.14 \mathrm{E}-01$ & & $\mathrm{Sb}-125$ & $6.28 \mathrm{E}-05$ & & \\
\hline & & & & & & Sm-147 & $3.93 \mathrm{E}-12$ & & \\
\hline & & & Sr-90 & $2.57 \mathrm{E}+00$ & & Sr-90 & $1.26 \mathrm{E}+00$ & & \\
\hline & & & $\mathrm{Te}-125 \mathrm{~m}$ & $4.75 \mathrm{E}-02$ & & $\mathrm{Te}-125 \mathrm{~m}$ & $1.52 \mathrm{E}-05$ & & \\
\hline & & & & & & Th-227 & $9.66 \mathrm{E}-10$ & & \\
\hline & & & & & & Th-231 & $4.35 \mathrm{E}-06$ & & \\
\hline & & & & & & T1-207 & $9.76 \mathrm{E}-10$ & & \\
\hline & & & $\mathrm{U}-235$ & $4.40 \mathrm{E}-06$ & & $\mathrm{U}-235$ & $4.40 \mathrm{E}-06$ & & \\
\hline & & & $\mathrm{Y}-90$ & $2.56 \mathrm{E}+00$ & & $\mathrm{Y}-90$ & $1.24 \mathrm{E}+00$ & & \\
\hline \multirow[t]{23}{*}{201} & S794216 & 1979 & & & 2009 & Ac-227 & 4.47E-09 & 261,000 & 123,000 \\
\hline & & & $\mathrm{Ba}-137 \mathrm{~m}$ & $1.92 \mathrm{E}+00$ & & $\mathrm{Ba}-137 \mathrm{~m}$ & $9.55 \mathrm{E}-01$ & & \\
\hline & & & & & & $\mathrm{Bi}-211$ & $4.41 \mathrm{E}-09$ & & \\
\hline & & & Cs-137 & $2.04 \mathrm{E}+00$ & & Cs-137 & $1.02 \mathrm{E}+00$ & & \\
\hline & & & Eu-155 & $3.82 \mathrm{E}-02$ & & Eu-155 & $5.77 \mathrm{E}-04$ & & \\
\hline & & & & & & Fr-223 & $6.09 \mathrm{E}-11$ & & \\
\hline & & & & & & $\mathrm{Pa}-231$ & $1.25 \mathrm{E}-08$ & & \\
\hline & & & & & & $\mathrm{Pb}-211$ & 4.42E-09 & & \\
\hline & & & Pm-147 & $1.17 \mathrm{E}-01$ & & Pm-147 & $4.21 \mathrm{E}-05$ & & \\
\hline & & & & & & Рo-211 & $1.35 \mathrm{E}-11$ & & \\
\hline & & & & & & Po-215 & $4.42 \mathrm{E}-09$ & & \\
\hline & & & $\mathrm{Pu}-239$ & $1.40 \mathrm{E}-01$ & & Pu-239 & $1.39 \mathrm{E}-01$ & & \\
\hline & & & & & & Ra-223 & $4.46 \mathrm{E}-09$ & & \\
\hline & & & Rh-106 & $1.50 \mathrm{E}-02$ & & Rh-106 & $1.63 \mathrm{E}-11$ & & \\
\hline & & & & & & Rn-219 & $4.41 \mathrm{E}-09$ & & \\
\hline & & & $\mathrm{Ru}-106$ & $1.50 \mathrm{E}-02$ & & Ru-106 & $1.65 \mathrm{E}-11$ & & \\
\hline & & & Sb-125 & 8.32E-02 & & Sb-125 & $4.57 \mathrm{E}-05$ & & \\
\hline & & & & & & Sm-147 & $2.86 \mathrm{E}-12$ & & \\
\hline & & & Sr-90 & $1.87 \mathrm{E}+00$ & & Sr-90 & $9.14 \mathrm{E}-01$ & & \\
\hline & & & $\mathrm{Te}-125 \mathrm{~m}$ & $3.45 \mathrm{E}-02$ & & $\mathrm{Te}-125 \mathrm{~m}$ & $1.11 \mathrm{E}-05$ & & \\
\hline & & & & & & Th-227 & 4.35E-09 & & \\
\hline & & & & & & Th-231 & $1.96 \mathrm{E}-05$ & & \\
\hline & & & & & & T1-207 & 4.39E-09 & & \\
\hline
\end{tabular}

${ }^{1}$ Calculated decayed contact dose rate. Rounded to nearest $10 \mathrm{mR} / \mathrm{hr}$ for values to 1000 ; rounded to nearest $100 \mathrm{mR} / \mathrm{hr}$ for values $>1000$ to 10,000 ; rounded to nearest $1000 \mathrm{mR} / \mathrm{hr}$ for values $>10,000$. * Initial contact dose rate assumed to be $1,000,000 \mathrm{mR} / \mathrm{hr}$; **Initial contact dose rate assumed to be $1,010,000 \mathrm{mR} / \mathrm{hr}$.

$$
7 \text { of } 168
$$


Appendix A-4 - Initial and Decayed Radionuclide and Dose Data for Lined Shafts

\begin{tabular}{|c|c|c|c|c|c|c|c|c|c|}
\hline \multirow[b]{2}{*}{ Shaft Number } & \multirow[b]{2}{*}{ Package ID } & \multirow[b]{2}{*}{ Base Year } & \multicolumn{2}{|c|}{ Initial Isotopic Distribution } & \multirow[b]{2}{*}{ Target Year } & \multicolumn{2}{|c|}{ Decayed Isotopic Distribution } & \multirow{2}{*}{$\begin{array}{c}\text { Initial Contact } \\
\text { Dose Rate } \\
(\mathrm{mR} / \mathrm{hr})\end{array}$} & \multirow{2}{*}{$\begin{array}{c}\text { Decayed } \\
\text { Contact Dose } \\
\text { Rate }(\mathrm{mR} / \mathrm{hr})^{1} \\
\end{array}$} \\
\hline & & & Isotope & Activity (Ci) & & Isotope & Activity (Ci) & & \\
\hline & & & U-235 & $1.98 \mathrm{E}-05$ & & U-235 & $1.98 \mathrm{E}-05$ & & \\
\hline & & & $\mathrm{Y}-90$ & $1.87 \mathrm{E}+00$ & & Y-90 & $9.04 \mathrm{E}-01$ & & \\
\hline \multirow[t]{25}{*}{201} & S794218 & 1979 & & & 2009 & Ac-227 & $4.96 \mathrm{E}-09$ & 15,000 & 7,100 \\
\hline & & & Ba-137m & $2.40 \mathrm{E}-01$ & & $\mathrm{Ba}-137 \mathrm{~m}$ & $1.19 \mathrm{E}-01$ & & \\
\hline & & & & & & Bi-211 & $4.90 \mathrm{E}-09$ & & \\
\hline & & & Cs-137 & $2.55 \mathrm{E}-01$ & & Cs-137 & $1.28 \mathrm{E}-01$ & & \\
\hline & & & Eu-155 & $4.78 \mathrm{E}-03$ & & Eu-155 & $7.21 \mathrm{E}-05$ & & \\
\hline & & & & & & Fr-223 & $6.77 \mathrm{E}-11$ & & \\
\hline & & & & & & $\mathrm{Pa}-231$ & $1.39 \mathrm{E}-08$ & & \\
\hline & & & & & & $\mathrm{Pb}-211$ & 4.91E-09 & & \\
\hline & & & Pm-147 & $1.46 \mathrm{E}-02$ & & Pm-147 & $5.27 \mathrm{E}-06$ & & \\
\hline & & & & & & Po-211 & $1.50 \mathrm{E}-11$ & & \\
\hline & & & & & & Po-215 & 4.91E-09 & & \\
\hline & & & $\mathrm{Pu}-239$ & $1.55 \mathrm{E}-01$ & & $\mathrm{Pu}-239$ & $1.55 \mathrm{E}-01$ & & \\
\hline & & & & & & Ra-223 & $4.96 \mathrm{E}-09$ & & \\
\hline & & & $\mathrm{Rh}-106$ & $1.87 \mathrm{E}-03$ & & Rh-106 & $2.04 \mathrm{E}-12$ & & \\
\hline & & & & & & Rn-219 & $4.90 \mathrm{E}-09$ & & \\
\hline & & & $\mathrm{Ru}-106$ & $1.87 \mathrm{E}-03$ & & Ru-106 & $2.06 \mathrm{E}-12$ & & \\
\hline & & & Sb-125 & $1.04 \mathrm{E}-02$ & & Sb-125 & $5.71 \mathrm{E}-06$ & & \\
\hline & & & & & & Sm-147 & $3.57 \mathrm{E}-13$ & & \\
\hline & & & Sr-90 & $2.33 \mathrm{E}-01$ & & Sr-90 & $1.14 \mathrm{E}-01$ & & \\
\hline & & & $\mathrm{Te}-125 \mathrm{~m}$ & 4.32E-03 & & Te-125m & $1.38 \mathrm{E}-06$ & & \\
\hline & & & & & & Th-227 & $4.83 \mathrm{E}-09$ & & \\
\hline & & & & & & Th-231 & $2.17 \mathrm{E}-05$ & & \\
\hline & & & & & & Tl-207 & $4.88 \mathrm{E}-09$ & & \\
\hline & & & U-235 & $2.20 \mathrm{E}-05$ & & U-235 & $2.20 \mathrm{E}-05$ & & \\
\hline & & & Y-90 & $2.33 \mathrm{E}-01$ & & $\mathrm{Y}-90$ & $1.13 \mathrm{E}-01$ & & \\
\hline \multirow[t]{5}{*}{201} & S794219 & 1979 & & & 2009 & Ac- 227 & $2.48 \mathrm{E}-09$ & 27,000 & 13,000 \\
\hline & & & $\mathrm{Ba}-137 \mathrm{~m}$ & $3.12 \mathrm{E}-01$ & & $\mathrm{Ba}-137 \mathrm{~m}$ & $1.55 \mathrm{E}-01$ & & \\
\hline & & & & & & Bi-211 & $2.45 \mathrm{E}-09$ & & \\
\hline & & & Cs-137 & $3.32 \mathrm{E}-01$ & & Cs-137 & $1.66 \mathrm{E}-01$ & & \\
\hline & & & Eu-155 & $6.21 \mathrm{E}-03$ & & Eu-155 & $9.38 \mathrm{E}-05$ & & \\
\hline
\end{tabular}

${ }^{1}$ Calculated decayed contact dose rate. Rounded to nearest $10 \mathrm{mR} / \mathrm{hr}$ for values to 1000 ; rounded to nearest $100 \mathrm{mR} / \mathrm{hr}$ for values $>1000$ to 10,000 ; rounded to nearest $1000 \mathrm{mR} / \mathrm{hr}$ for values $>10,000$. * Initial contact dose rate assumed to be $1,000,000 \mathrm{mR} / \mathrm{hr}$; **Initial contact dose rate assumed to be $1,010,000 \mathrm{mR} / \mathrm{hr}$.

$$
8 \text { of } 168
$$


Appendix A-4 - Initial and Decayed Radionuclide and Dose Data for Lined Shafts

\begin{tabular}{|c|c|c|c|c|c|c|c|c|c|}
\hline \multirow[b]{2}{*}{ Shaft Number } & \multirow[b]{2}{*}{ Package ID } & \multirow[b]{2}{*}{ Base Year } & \multicolumn{2}{|c|}{ Initial Isotopic Distribution } & \multirow[b]{2}{*}{ Target Year } & \multicolumn{2}{|c|}{ Decayed Isotopic Distribution } & \multirow{2}{*}{$\begin{array}{c}\text { Initial Contact } \\
\text { Dose Rate } \\
(\mathrm{mR} / \mathrm{hr})\end{array}$} & \multirow{2}{*}{$\begin{array}{c}\text { Decayed } \\
\text { Contact Dose } \\
\text { Rate }(\mathrm{mR} / \mathrm{hr})^{1} \\
\end{array}$} \\
\hline & & & Isotope & Activity (Ci) & & Isotope & Activity (Ci) & & \\
\hline & & & & & & Fr-223 & $3.39 \mathrm{E}-11$ & & \\
\hline & & & & & & $\mathrm{Pa}-231$ & $6.97 \mathrm{E}-09$ & & \\
\hline & & & & & & $\mathrm{Pb}-211$ & $2.45 \mathrm{E}-09$ & & \\
\hline & & & Pm-147 & $1.90 \mathrm{E}-02$ & & Pm-147 & $6.85 \mathrm{E}-06$ & & \\
\hline & & & & & & Po-211 & $7.48 \mathrm{E}-12$ & & \\
\hline & & & & & & Po-215 & $2.45 \mathrm{E}-09$ & & \\
\hline & & & $\mathrm{Pu}-239$ & $9.30 \mathrm{E}-02$ & & $\mathrm{Pu}-239$ & $9.29 \mathrm{E}-02$ & & \\
\hline & & & & & & Ra-223 & $2.48 \mathrm{E}-09$ & & \\
\hline & & & Rh-106 & $2.43 \mathrm{E}-03$ & & Rh-106 & $2.65 \mathrm{E}-12$ & & \\
\hline & & & & & & $\mathrm{Rn}-219$ & $2.45 \mathrm{E}-09$ & & \\
\hline & & & $\mathrm{Ru}-106$ & $2.43 \mathrm{E}-03$ & & Ru-106 & $2.67 \mathrm{E}-12$ & & \\
\hline & & & $\mathrm{Sb}-125$ & $1.35 \mathrm{E}-02$ & & $\mathrm{Sb}-125$ & $7.42 \mathrm{E}-06$ & & \\
\hline & & & & & & Sm-147 & $4.65 \mathrm{E}-13$ & & \\
\hline & & & Sr-90 & $3.03 \mathrm{E}-01$ & & Sr-90 & $1.49 \mathrm{E}-01$ & & \\
\hline & & & $\mathrm{Te}-125 \mathrm{~m}$ & $5.61 \mathrm{E}-03$ & & $\mathrm{Te}-125 \mathrm{~m}$ & $1.80 \mathrm{E}-06$ & & \\
\hline & & & & & & Th-227 & $2.41 \mathrm{E}-09$ & & \\
\hline & & & & & & Th-231 & $1.09 \mathrm{E}-05$ & & \\
\hline & & & & & & Tl-207 & $2.44 \mathrm{E}-09$ & & \\
\hline & & & $\mathrm{U}-235$ & $1.10 \mathrm{E}-05$ & & U-235 & $1.10 \mathrm{E}-05$ & & \\
\hline & & & Y-90 & $3.03 \mathrm{E}-01$ & & $\mathrm{Y}-90$ & $1.47 \mathrm{E}-01$ & & \\
\hline \multirow[t]{12}{*}{201} & S794220 & 1979 & & & 2009 & Ac- 227 & 7.29E-08 & $1,200,000$ & 567,000 \\
\hline & & & $\mathrm{Ba}-137 \mathrm{~m}$ & $7.19 \mathrm{E}+00$ & & $\mathrm{Ba}-137 \mathrm{~m}$ & $3.58 \mathrm{E}+00$ & & \\
\hline & & & & & & Bi-211 & $7.20 \mathrm{E}-08$ & & \\
\hline & & & Cs-137 & $7.66 \mathrm{E}+00$ & & Cs-137 & $3.83 \mathrm{E}+00$ & & \\
\hline & & & Eu-155 & $1.43 \mathrm{E}-01$ & & Eu-155 & $2.16 \mathrm{E}-03$ & & \\
\hline & & & & & & Fr-223 & $9.95 \mathrm{E}-10$ & & \\
\hline & & & & & & $\mathrm{Pa}-231$ & $2.05 \mathrm{E}-07$ & & \\
\hline & & & & & & $\mathrm{Pb}-211$ & $7.21 \mathrm{E}-08$ & & \\
\hline & & & Pm-147 & $4.38 \mathrm{E}-01$ & & Pm-147 & $1.58 \mathrm{E}-04$ & & \\
\hline & & & & & & Po-211 & $2.20 \mathrm{E}-10$ & & \\
\hline & & & & & & Po-215 & $7.21 \mathrm{E}-08$ & & \\
\hline & & & $\mathrm{Pu}-239$ & $4.22 \mathrm{E}+00$ & & $\mathrm{Pu}-239$ & $4.21 \mathrm{E}+00$ & & \\
\hline
\end{tabular}

${ }^{1}$ Calculated decayed contact dose rate. Rounded to nearest $10 \mathrm{mR} / \mathrm{hr}$ for values to 1000 ; rounded to nearest $100 \mathrm{mR} / \mathrm{hr}$ for values $>1000$ to 10,000 ; rounded to nearest $1000 \mathrm{mR} / \mathrm{hr}$ for values $>10,000$. * Initial contact dose rate assumed to be $1,000,000 \mathrm{mR} / \mathrm{hr}$; **Initial contact dose rate assumed to be $1,010,000 \mathrm{mR} / \mathrm{hr}$.

$$
9 \text { of } 168
$$


Appendix A-4 - Initial and Decayed Radionuclide and Dose Data for Lined Shafts

\begin{tabular}{|c|c|c|c|c|c|c|c|c|c|}
\hline \multirow[b]{2}{*}{ Shaft Number } & \multirow[b]{2}{*}{ Package ID } & \multirow[b]{2}{*}{ Base Year } & \multicolumn{2}{|c|}{ Initial Isotopic Distribution } & \multirow[b]{2}{*}{ Target Year } & \multicolumn{2}{|c|}{ Decayed Isotopic Distribution } & \multirow{2}{*}{$\begin{array}{c}\text { Initial Contact } \\
\text { Dose Rate } \\
(\mathrm{mR} / \mathrm{hr})\end{array}$} & \multirow{2}{*}{$\begin{array}{c}\text { Decayed } \\
\text { Contact Dose } \\
\text { Rate }(\mathrm{mR} / \mathrm{hr})^{1} \\
\end{array}$} \\
\hline & & & Isotope & Activity (Ci) & & Isotope & Activity (Ci) & & \\
\hline & & & & & & Ra-223 & $7.29 \mathrm{E}-08$ & & \\
\hline & & & Rh-106 & $5.62 \mathrm{E}-02$ & & Rh-106 & $6.11 \mathrm{E}-11$ & & \\
\hline & & & & & & $\mathrm{Rn}-219$ & $7.20 \mathrm{E}-08$ & & \\
\hline & & & $\mathrm{Ru}-106$ & $5.62 \mathrm{E}-02$ & & $\mathrm{Ru}-106$ & $6.17 \mathrm{E}-11$ & & \\
\hline & & & Sb-125 & $3.12 \mathrm{E}-01$ & & $\mathrm{Sb}-125$ & $1.71 \mathrm{E}-04$ & & \\
\hline & & & & & & Sm-147 & $1.07 \mathrm{E}-11$ & & \\
\hline & & & Sr-90 & $7.00 \mathrm{E}+00$ & & Sr-90 & $3.43 \mathrm{E}+00$ & & \\
\hline & & & $\mathrm{Te}-125 \mathrm{~m}$ & $1.30 \mathrm{E}-01$ & & $\mathrm{Te}-125 \mathrm{~m}$ & $4.15 \mathrm{E}-05$ & & \\
\hline & & & & & & Th-227 & $7.10 \mathrm{E}-08$ & & \\
\hline & & & & & & Th-231 & $3.20 \mathrm{E}-04$ & & \\
\hline & & & & & & Tl-207 & 7.17E-08 & & \\
\hline & & & $\mathrm{U}-235$ & $3.23 \mathrm{E}-04$ & & $\mathrm{U}-235$ & $3.23 \mathrm{E}-04$ & & \\
\hline & & & Y-90 & $6.99 \mathrm{E}+00$ & & $\mathrm{Y}-90$ & $3.39 \mathrm{E}+00$ & & \\
\hline \multirow[t]{19}{*}{201} & S794221 & 1979 & & & 2009 & Ac- 227 & $1.84 \mathrm{E}-07$ & $1,050,000$ & 496,000 \\
\hline & & & Ba-137m & $8.39 \mathrm{E}+00$ & & $\mathrm{Ba}-137 \mathrm{~m}$ & $4.18 \mathrm{E}+00$ & & \\
\hline & & & & & & Bi-211 & $1.81 \mathrm{E}-07$ & & \\
\hline & & & Cs-137 & $8.94 \mathrm{E}+00$ & & Cs-137 & $4.47 \mathrm{E}+00$ & & \\
\hline & & & Eu-155 & $1.67 \mathrm{E}-01$ & & Eu-155 & $2.52 \mathrm{E}-03$ & & \\
\hline & & & & & & Fr-223 & $2.51 \mathrm{E}-09$ & & \\
\hline & & & & & & $\mathrm{Pa}-231$ & $5.16 \mathrm{E}-07$ & & \\
\hline & & & & & & $\mathrm{Pb}-211$ & $1.82 \mathrm{E}-07$ & & \\
\hline & & & Pm-147 & $5.10 \mathrm{E}-01$ & & Pm-147 & $1.84 \mathrm{E}-04$ & & \\
\hline & & & & & & Po-211 & $5.53 \mathrm{E}-10$ & & \\
\hline & & & & & & Po-215 & $1.82 \mathrm{E}-07$ & & \\
\hline & & & $\mathrm{Pu}-239$ & $8.68 \mathrm{E}+00$ & & $\mathrm{Pu}-239$ & $8.67 \mathrm{E}+00$ & & \\
\hline & & & & & & Ra-223 & $1.84 \mathrm{E}-07$ & & \\
\hline & & & Rh-106 & $6.55 \mathrm{E}-02$ & & Rh-106 & $7.13 \mathrm{E}-11$ & & \\
\hline & & & & & & Rn-219 & $1.81 \mathrm{E}-07$ & & \\
\hline & & & $\mathrm{Ru}-106$ & $6.55 \mathrm{E}-02$ & & $\mathrm{Ru}-106$ & $7.20 \mathrm{E}-11$ & & \\
\hline & & & Sb-125 & $3.64 \mathrm{E}-01$ & & Sb-125 & $2.00 \mathrm{E}-04$ & & \\
\hline & & & & & & Sm-147 & $1.25 \mathrm{E}-11$ & & \\
\hline & & & Sr-90 & $8.17 \mathrm{E}+00$ & & Sr-90 & $4.00 \mathrm{E}+00$ & & \\
\hline
\end{tabular}

${ }^{1}$ Calculated decayed contact dose rate. Rounded to nearest $10 \mathrm{mR} / \mathrm{hr}$ for values to 1000 ; rounded to nearest $100 \mathrm{mR} / \mathrm{hr}$ for values $>1000$ to 10,000 ; rounded to nearest $1000 \mathrm{mR} / \mathrm{hr}$ for values $>10,000$. * Initial contact dose rate assumed to be $1,000,000 \mathrm{mR} / \mathrm{hr}$; **Initial contact dose rate assumed to be $1,010,000 \mathrm{mR} / \mathrm{hr}$.

$$
10 \text { of } 168
$$


Appendix A-4 - Initial and Decayed Radionuclide and Dose Data for Lined Shafts

\begin{tabular}{|c|c|c|c|c|c|c|c|c|c|}
\hline \multirow[b]{2}{*}{ Shaft Number } & \multirow[b]{2}{*}{ Package ID } & \multirow[b]{2}{*}{ Base Year } & \multicolumn{2}{|c|}{ Initial Isotopic Distribution } & \multirow[b]{2}{*}{ Target Year } & \multicolumn{2}{|c|}{ Decayed Isotopic Distribution } & \multirow{2}{*}{$\begin{array}{c}\text { Initial Contact } \\
\text { Dose Rate } \\
(\mathrm{mR} / \mathrm{hr})\end{array}$} & \multirow{2}{*}{$\begin{array}{c}\text { Decayed } \\
\text { Contact Dose } \\
\text { Rate }(\mathrm{mR} / \mathrm{hr})^{1}\end{array}$} \\
\hline & & & Isotope & Activity (Ci) & & Isotope & Activity (Ci) & & \\
\hline & & & $\mathrm{Te}-125 \mathrm{~m}$ & $1.51 \mathrm{E}-01$ & & $\mathrm{Te}-125 \mathrm{~m}$ & $4.84 \mathrm{E}-05$ & & \\
\hline & & & & & & Th-227 & $1.79 \mathrm{E}-07$ & & \\
\hline & & & & & & Th-231 & $8.04 \mathrm{E}-04$ & & \\
\hline & & & & & & Tl-207 & $1.81 \mathrm{E}-07$ & & \\
\hline & & & $\mathrm{U}-235$ & $8.14 \mathrm{E}-04$ & & $\mathrm{U}-235$ & $8.14 \mathrm{E}-04$ & & \\
\hline & & & Y-90 & $8.16 \mathrm{E}+00$ & & Y-90 & $3.95 \mathrm{E}+00$ & & \\
\hline \multirow[t]{25}{*}{202} & S803548 & 1979 & & & 2009 & Ac-227 & $1.11 \mathrm{E}-07$ & & 0 \\
\hline & & & Ba-137m & $5.15 \mathrm{E}+01$ & & Ba-137m & $2.57 \mathrm{E}+01$ & & \\
\hline & & & & & & Bi-211 & $1.09 \mathrm{E}-07$ & & \\
\hline & & & Cs-137 & $5.49 \mathrm{E}+01$ & & Cs-137 & $2.74 \mathrm{E}+01$ & & \\
\hline & & & Eu-155 & $1.03 \mathrm{E}+00$ & & Eu-155 & $1.55 \mathrm{E}-02$ & & \\
\hline & & & & & & Fr-223 & $1.51 \mathrm{E}-09$ & & \\
\hline & & & & & & $\mathrm{Pa}-231$ & $3.11 \mathrm{E}-07$ & & \\
\hline & & & & & & $\mathrm{Pb}-211$ & $1.09 \mathrm{E}-07$ & & \\
\hline & & & Pm-147 & $3.14 \mathrm{E}+00$ & & Pm-147 & $1.13 \mathrm{E}-03$ & & \\
\hline & & & & & & Po-211 & $3.33 \mathrm{E}-10$ & & \\
\hline & & & & & & Po-215 & $1.09 \mathrm{E}-07$ & & \\
\hline & & & $\mathrm{Pu}-239$ & $4.05 \mathrm{E}+00$ & & Pu-239 & $4.05 \mathrm{E}+00$ & & \\
\hline & & & & & & Ra-223 & $1.11 \mathrm{E}-07$ & & \\
\hline & & & Rh-106 & $4.03 \mathrm{E}-01$ & & Rh-106 & $4.38 \mathrm{E}-10$ & & \\
\hline & & & & & & Rn-219 & $1.09 \mathrm{E}-07$ & & \\
\hline & & & Ru-106 & $4.03 \mathrm{E}-01$ & & $\mathrm{Ru}-106$ & $4.42 \mathrm{E}-10$ & & \\
\hline & & & Sb-125 & $2.24 \mathrm{E}+00$ & & Sb-125 & $1.23 \mathrm{E}-03$ & & \\
\hline & & & & & & Sm-147 & 7.69E-11 & & \\
\hline & & & Sr-90 & $5.02 \mathrm{E}+01$ & & Sr-90 & $2.46 \mathrm{E}+01$ & & \\
\hline & & & Te-125m & $9.28 \mathrm{E}-01$ & & $\mathrm{Te}-125 \mathrm{~m}$ & $2.97 \mathrm{E}-04$ & & \\
\hline & & & & & & Th-227 & $1.08 \mathrm{E}-07$ & & \\
\hline & & & & & & Th-231 & $4.84 \mathrm{E}-04$ & & \\
\hline & & & & & & Tl-207 & $1.09 \mathrm{E}-07$ & & \\
\hline & & & U-235 & $4.90 \mathrm{E}-04$ & & U-235 & 4.91E-04 & & \\
\hline & & & Y-90 & $5.01 \mathrm{E}+01$ & & Y-90 & $2.43 \mathrm{E}+01$ & & \\
\hline 203 & S803547 & 1979 & & & 2009 & Ac-227 & $6.30 \mathrm{E}-08$ & & 0 \\
\hline
\end{tabular}

${ }^{1}$ Calculated decayed contact dose rate. Rounded to nearest $10 \mathrm{mR} / \mathrm{hr}$ for values to 1000 ; rounded to nearest $100 \mathrm{mR} / \mathrm{hr}$ for values $>1000$ to 10,000 ; rounded to nearest $1000 \mathrm{mR} / \mathrm{hr}$ for values $>10,000$. * Initial contact dose rate assumed to be $1,000,000 \mathrm{mR} / \mathrm{hr}$; **Initial contact dose rate assumed to be $1,010,000 \mathrm{mR} / \mathrm{hr}$.

$$
11 \text { of } 168
$$


Appendix A-4 - Initial and Decayed Radionuclide and Dose Data for Lined Shafts

\begin{tabular}{|c|c|c|c|c|c|c|c|c|c|}
\hline \multirow[b]{2}{*}{ Shaft Number } & \multirow[b]{2}{*}{ Package ID } & \multirow[b]{2}{*}{ Base Year } & \multicolumn{2}{|c|}{ Initial Isotopic Distribution } & \multirow[b]{2}{*}{ Target Year } & \multicolumn{2}{|c|}{ Decayed Isotopic Distribution } & \multirow{2}{*}{$\begin{array}{c}\text { Initial Contact } \\
\text { Dose Rate } \\
(\mathrm{mR} / \mathrm{hr})\end{array}$} & \multirow{2}{*}{$\begin{array}{c}\text { Decayed } \\
\text { Contact Dose } \\
\text { Rate }(\mathrm{mR} / \mathrm{hr})^{1} \\
\end{array}$} \\
\hline & & & Isotope & Activity (Ci) & & Isotope & Activity (Ci) & & \\
\hline & & & Ba-137m & $2.61 \mathrm{E}+01$ & & Ba-137m & $1.30 \mathrm{E}+01$ & & \\
\hline & & & & & & Bi-211 & $6.22 \mathrm{E}-08$ & & \\
\hline & & & Cs-137 & $2.78 \mathrm{E}+01$ & & Cs-137 & $1.39 \mathrm{E}+01$ & & \\
\hline & & & $\mathrm{Eu}-155$ & $5.19 \mathrm{E}-01$ & & $\mathrm{Eu}-155$ & $7.84 \mathrm{E}-03$ & & \\
\hline & & & & & & Fr-223 & $8.60 \mathrm{E}-10$ & & \\
\hline & & & & & & $\mathrm{Pa}-231$ & $1.77 \mathrm{E}-07$ & & \\
\hline & & & & & & $\mathrm{Pb}-211$ & $6.23 \mathrm{E}-08$ & & \\
\hline & & & Pm-147 & $1.59 \mathrm{E}+00$ & & Pm-147 & $5.72 \mathrm{E}-04$ & & \\
\hline & & & & & & Po-211 & $1.90 \mathrm{E}-10$ & & \\
\hline & & & & & & Po-215 & $6.23 \mathrm{E}-08$ & & \\
\hline & & & $\mathrm{Pu}-239$ & $2.33 \mathrm{E}+00$ & & $\mathrm{Pu}-239$ & $2.32 \mathrm{E}+00$ & & \\
\hline & & & & & & $\mathrm{Ra}-223$ & $6.30 \mathrm{E}-08$ & & \\
\hline & & & Rh-106 & $2.04 \mathrm{E}-01$ & & Rh-106 & $2.21 \mathrm{E}-10$ & & \\
\hline & & & & & & $\mathrm{Rn}-219$ & $6.22 \mathrm{E}-08$ & & \\
\hline & & & $\mathrm{Ru}-106$ & $2.04 \mathrm{E}-01$ & & $\mathrm{Ru}-106$ & $2.24 \mathrm{E}-10$ & & \\
\hline & & & $\mathrm{Sb}-125$ & $1.13 \mathrm{E}+00$ & & $\mathrm{Sb}-125$ & $6.21 \mathrm{E}-04$ & & \\
\hline & & & & & & Sm-147 & $3.89 \mathrm{E}-11$ & & \\
\hline & & & Sr-90 & $2.54 \mathrm{E}+01$ & & Sr-90 & $1.24 \mathrm{E}+01$ & & \\
\hline & & & Te-125m & $4.69 \mathrm{E}-01$ & & $\mathrm{Te}-125 \mathrm{~m}$ & $1.50 \mathrm{E}-04$ & & \\
\hline & & & & & & Th-227 & $6.13 \mathrm{E}-08$ & & \\
\hline & & & & & & Th-231 & $2.76 \mathrm{E}-04$ & & \\
\hline & & & & & & Tl-207 & $6.20 \mathrm{E}-08$ & & \\
\hline & & & U-235 & $2.79 \mathrm{E}-04$ & & U-235 & $2.79 \mathrm{E}-04$ & & \\
\hline & & & Y-90 & $2.53 \mathrm{E}+01$ & & Y-90 & $1.23 \mathrm{E}+01$ & & \\
\hline \multirow[t]{8}{*}{204} & S791472 & 1979 & & & 2009 & Ac- 227 & 2.61E-09 & 108,000 & 51,000 \\
\hline & & & Ba-137m & $2.52 \mathrm{E}+00$ & & $\mathrm{Ba}-137 \mathrm{~m}$ & $1.25 \mathrm{E}+00$ & & \\
\hline & & & & & & Bi-211 & $2.57 \mathrm{E}-09$ & & \\
\hline & & & Cs-137 & $2.68 \mathrm{E}+00$ & & Cs-137 & $1.34 \mathrm{E}+00$ & & \\
\hline & & & $\mathrm{Eu}-155$ & $5.02 \mathrm{E}-02$ & & $\mathrm{Eu}-155$ & $7.58 \mathrm{E}-04$ & & \\
\hline & & & & & & Fr-223 & $3.55 \mathrm{E}-11$ & & \\
\hline & & & & & & $\mathrm{Pa}-231$ & 7.32E-09 & & \\
\hline & & & & & & $\mathrm{Pb}-211$ & $2.58 \mathrm{E}-09$ & & \\
\hline
\end{tabular}

${ }^{1}$ Calculated decayed contact dose rate. Rounded to nearest $10 \mathrm{mR} / \mathrm{hr}$ for values to 1000 ; rounded to nearest $100 \mathrm{mR} / \mathrm{hr}$ for values $>1000$ to 10,000 ; rounded to nearest $1000 \mathrm{mR} / \mathrm{hr}$ for values $>10,000$. * Initial contact dose rate assumed to be $1,000,000 \mathrm{mR} / \mathrm{hr}$; **Initial contact dose rate assumed to be $1,010,000 \mathrm{mR} / \mathrm{hr}$.

$$
12 \text { of } 168
$$


Appendix A-4 - Initial and Decayed Radionuclide and Dose Data for Lined Shafts

\begin{tabular}{|c|c|c|c|c|c|c|c|c|c|}
\hline \multirow[b]{2}{*}{ Shaft Number } & \multirow[b]{2}{*}{ Package ID } & \multirow[b]{2}{*}{ Base Year } & \multicolumn{2}{|c|}{ Initial Isotopic Distribution } & \multirow[b]{2}{*}{ Target Year } & \multicolumn{2}{|c|}{ Decayed Isotopic Distribution } & \multirow{2}{*}{$\begin{array}{c}\text { Initial Contact } \\
\text { Dose Rate } \\
(\mathrm{mR} / \mathrm{hr})\end{array}$} & \multirow{2}{*}{$\begin{array}{c}\text { Decayed } \\
\text { Contact Dose } \\
\text { Rate }(\mathrm{mR} / \mathrm{hr})^{1} \\
\end{array}$} \\
\hline & & & Isotope & Activity (Ci) & & Isotope & Activity (Ci) & & \\
\hline & & & Pm-147 & $1.53 \mathrm{E}-01$ & & Pm-147 & $5.53 \mathrm{E}-05$ & & \\
\hline & & & & & & Po-211 & $7.85 \mathrm{E}-12$ & & \\
\hline & & & & & & Po-215 & $2.58 \mathrm{E}-09$ & & \\
\hline & & & $\mathrm{Pu}-239$ & $1.09 \mathrm{E}-01$ & & $\mathrm{Pu}-239$ & $1.08 \mathrm{E}-01$ & & \\
\hline & & & & & & Ra-223 & $2.60 \mathrm{E}-09$ & & \\
\hline & & & $\mathrm{Rh}-106$ & $1.97 \mathrm{E}-02$ & & Rh-106 & $2.14 \mathrm{E}-11$ & & \\
\hline & & & & & & Rn-219 & $2.57 \mathrm{E}-09$ & & \\
\hline & & & $\mathrm{Ru}-106$ & $1.97 \mathrm{E}-02$ & & $\mathrm{Ru}-106$ & $2.16 \mathrm{E}-11$ & & \\
\hline & & & Sb-125 & $1.09 \mathrm{E}-01$ & & Sb-125 & $5.99 \mathrm{E}-05$ & & \\
\hline & & & & & & Sm-147 & $3.75 \mathrm{E}-12$ & & \\
\hline & & & Sr-90 & $2.45 \mathrm{E}+00$ & & Sr-90 & $1.20 \mathrm{E}+00$ & & \\
\hline & & & $\mathrm{Te}-125 \mathrm{~m}$ & $4.53 \mathrm{E}-02$ & & $\mathrm{Te}-125 \mathrm{~m}$ & $1.45 \mathrm{E}-05$ & & \\
\hline & & & & & & Th-227 & $2.54 \mathrm{E}-09$ & & \\
\hline & & & & & & Th-231 & $1.14 \mathrm{E}-05$ & & \\
\hline & & & & & & Tl-207 & $2.56 \mathrm{E}-09$ & & \\
\hline & & & $\mathrm{U}-235$ & $1.16 \mathrm{E}-05$ & & $\mathrm{U}-235$ & $1.16 \mathrm{E}-05$ & & \\
\hline & & & Y-90 & $2.45 \mathrm{E}+00$ & & $\mathrm{Y}-90$ & $1.19 \mathrm{E}+00$ & & \\
\hline \multirow[t]{14}{*}{204} & S791478 & 1979 & & & 2009 & Ac-227 & $6.00 \mathrm{E}-08$ & $1000000+$ & $1,029,000 *$ \\
\hline & & & & & & Bi-211 & $5.93 \mathrm{E}-08$ & & \\
\hline & & & & & & Fr-223 & $8.19 \mathrm{E}-10$ & & \\
\hline & & & & & & $\mathrm{Pa}-231$ & $1.69 \mathrm{E}-07$ & & \\
\hline & & & & & & $\mathrm{Pb}-211$ & $5.94 \mathrm{E}-08$ & & \\
\hline & & & & & & Po-211 & $1.81 \mathrm{E}-10$ & & \\
\hline & & & & & & Po-215 & $5.94 \mathrm{E}-08$ & & \\
\hline & & & $\mathrm{Pu}-239$ & $2.17 \mathrm{E}+00$ & & $\mathrm{Pu}-239$ & $2.17 \mathrm{E}+00$ & & \\
\hline & & & & & & Ra-223 & $6.00 \mathrm{E}-08$ & & \\
\hline & & & & & & $\mathrm{Rn}-219$ & $5.93 \mathrm{E}-08$ & & \\
\hline & & & & & & Th-227 & $5.85 \mathrm{E}-08$ & & \\
\hline & & & & & & Th-231 & $2.63 \mathrm{E}-04$ & & \\
\hline & & & & & & Tl-207 & $5.90 \mathrm{E}-08$ & & \\
\hline & & & $\mathrm{U}-235$ & $2.66 \mathrm{E}-04$ & & U-235 & $2.66 \mathrm{E}-04$ & & \\
\hline 204 & S791483 & 1979 & & & 2009 & Ac-227 & $2.23 \mathrm{E}-09$ & 50,000 & 24,000 \\
\hline
\end{tabular}

${ }^{1}$ Calculated decayed contact dose rate. Rounded to nearest $10 \mathrm{mR} / \mathrm{hr}$ for values to 1000 ; rounded to nearest $100 \mathrm{mR} / \mathrm{hr}$ for values $>1000$ to 10,000 ; rounded to nearest $1000 \mathrm{mR} / \mathrm{hr}$ for values $>10,000$. * Initial contact dose rate assumed to be $1,000,000 \mathrm{mR} / \mathrm{hr}$; **Initial contact dose rate assumed to be $1,010,000 \mathrm{mR} / \mathrm{hr}$.

$$
13 \text { of } 168
$$


Appendix A-4 - Initial and Decayed Radionuclide and Dose Data for Lined Shafts

\begin{tabular}{|c|c|c|c|c|c|c|c|c|c|}
\hline \multirow[b]{2}{*}{ Shaft Number } & \multirow[b]{2}{*}{ Package ID } & \multirow[b]{2}{*}{ Base Year } & \multicolumn{2}{|c|}{ Initial Isotopic Distribution } & \multirow[b]{2}{*}{ Target Year } & \multicolumn{2}{|c|}{ Decayed Isotopic Distribution } & \multirow{2}{*}{$\begin{array}{c}\text { Initial Contact } \\
\text { Dose Rate } \\
(\mathrm{mR} / \mathrm{hr})\end{array}$} & \multirow{2}{*}{$\begin{array}{c}\text { Decayed } \\
\text { Contact Dose } \\
\text { Rate }(\mathrm{mR} / \mathrm{hr})^{1} \\
\end{array}$} \\
\hline & & & Isotope & Activity (Ci) & & Isotope & Activity (Ci) & & \\
\hline & & & Ba-137m & $3.59 \mathrm{E}-01$ & & Ba-137m & $1.79 \mathrm{E}-01$ & & \\
\hline & & & & & & Bi-211 & $2.20 \mathrm{E}-09$ & & \\
\hline & & & Cs-137 & $3.83 \mathrm{E}-01$ & & Cs-137 & $1.91 \mathrm{E}-01$ & & \\
\hline & & & Eu-155 & 7.17E-03 & & Eu-155 & $1.08 \mathrm{E}-04$ & & \\
\hline & & & & & & Fr-223 & $3.05 \mathrm{E}-11$ & & \\
\hline & & & & & & $\mathrm{Pa}-231$ & $6.28 \mathrm{E}-09$ & & \\
\hline & & & & & & $\mathrm{Pb}-211$ & $2.21 \mathrm{E}-09$ & & \\
\hline & & & Pm-147 & 2.19E-02 & & Pm-147 & $7.90 \mathrm{E}-06$ & & \\
\hline & & & & & & Po-211 & $6.73 \mathrm{E}-12$ & & \\
\hline & & & & & & Po-215 & $2.21 \mathrm{E}-09$ & & \\
\hline & & & Pu-239 & $9.30 \mathrm{E}-02$ & & $\mathrm{Pu}-239$ & $9.29 \mathrm{E}-02$ & & \\
\hline & & & & & & Ra-223 & $2.23 \mathrm{E}-09$ & & \\
\hline & & & Rh-106 & $2.81 \mathrm{E}-03$ & & Rh-106 & $3.05 \mathrm{E}-12$ & & \\
\hline & & & & & & Rn-219 & $2.20 \mathrm{E}-09$ & & \\
\hline & & & $\mathrm{Ru}-106$ & $2.81 \mathrm{E}-03$ & & Ru-106 & $3.08 \mathrm{E}-12$ & & \\
\hline & & & Sb-125 & $1.56 \mathrm{E}-02$ & & $\mathrm{Sb}-125$ & $8.56 \mathrm{E}-06$ & & \\
\hline & & & & & & Sm-147 & $5.36 \mathrm{E}-13$ & & \\
\hline & & & Sr-90 & $3.50 \mathrm{E}-01$ & & Sr-90 & $1.71 \mathrm{E}-01$ & & \\
\hline & & & $\mathrm{Te}-125 \mathrm{~m}$ & $6.48 \mathrm{E}-03$ & & $\mathrm{Te}-125 \mathrm{~m}$ & $2.07 \mathrm{E}-06$ & & \\
\hline & & & & & & Th-227 & $2.17 \mathrm{E}-09$ & & \\
\hline & & & & & & Th-231 & $9.78 \mathrm{E}-06$ & & \\
\hline & & & & & & Tl-207 & 2.19E-09 & & \\
\hline & & & U-235 & $9.90 \mathrm{E}-06$ & & U-235 & $9.90 \mathrm{E}-06$ & & \\
\hline & & & Y-90 & $3.50 \mathrm{E}-01$ & & Y-90 & $1.70 \mathrm{E}-01$ & & \\
\hline \multirow[t]{8}{*}{204} & S794222 & 1979 & & & 2009 & Ac- 227 & $9.43 \mathrm{E}-09$ & & 0 \\
\hline & & & & & & Bi-211 & $9.31 \mathrm{E}-09$ & & \\
\hline & & & & & & Fr-223 & $1.29 \mathrm{E}-10$ & & \\
\hline & & & & & & $\mathrm{Pa}-231$ & $2.65 \mathrm{E}-08$ & & \\
\hline & & & & & & $\mathrm{Pb}-211$ & $9.32 \mathrm{E}-09$ & & \\
\hline & & & & & & Po-211 & $2.84 \mathrm{E}-11$ & & \\
\hline & & & & & & Po-215 & $9.32 \mathrm{E}-09$ & & \\
\hline & & & $\mathrm{Pu}-239$ & $2.95 \mathrm{E}-01$ & & $\mathrm{Pu}-239$ & 2.94E-01 & & \\
\hline
\end{tabular}

${ }^{1}$ Calculated decayed contact dose rate. Rounded to nearest $10 \mathrm{mR} / \mathrm{hr}$ for values to 1000 ; rounded to nearest $100 \mathrm{mR} / \mathrm{hr}$ for values $>1000$ to 10,000 ; rounded to nearest $1000 \mathrm{mR} / \mathrm{hr}$ for values $>10,000$. * Initial contact dose rate assumed to be $1,000,000 \mathrm{mR} / \mathrm{hr}$; **Initial contact dose rate assumed to be $1,010,000 \mathrm{mR} / \mathrm{hr}$.

$$
14 \text { of } 168
$$


Appendix A-4 - Initial and Decayed Radionuclide and Dose Data for Lined Shafts

\begin{tabular}{|c|c|c|c|c|c|c|c|c|c|}
\hline \multirow[b]{2}{*}{ Shaft Number } & \multirow[b]{2}{*}{ Package ID } & \multirow[b]{2}{*}{ Base Year } & \multicolumn{2}{|c|}{ Initial Isotopic Distribution } & \multirow[b]{2}{*}{ Target Year } & \multicolumn{2}{|c|}{ Decayed Isotopic Distribution } & \multirow{2}{*}{$\begin{array}{c}\text { Initial Contact } \\
\text { Dose Rate } \\
(\mathrm{mR} / \mathrm{hr})\end{array}$} & \multirow{2}{*}{$\begin{array}{c}\text { Decayed } \\
\text { Contact Dose } \\
\text { Rate }(\mathrm{mR} / \mathrm{hr})^{1} \\
\end{array}$} \\
\hline & & & Isotope & Activity (Ci) & & Isotope & Activity (Ci) & & \\
\hline & & & & & & Ra-223 & $9.42 \mathrm{E}-09$ & & \\
\hline & & & & & & $\mathrm{Rn}-219$ & $9.31 \mathrm{E}-09$ & & \\
\hline & & & & & & Th-227 & $9.18 \mathrm{E}-09$ & & \\
\hline & & & & & & Th-231 & $4.13 \mathrm{E}-05$ & & \\
\hline & & & & & & T1-207 & $9.27 \mathrm{E}-09$ & & \\
\hline & & & $\mathrm{U}-235$ & 4.18E-05 & & $\mathrm{U}-235$ & $4.18 \mathrm{E}-05$ & & \\
\hline \multirow[t]{25}{*}{204} & S794223 & 1979 & & & 2009 & Ac-227 & $2.17 \mathrm{E}-08$ & & 0 \\
\hline & & & Ba-137m & $4.79 \mathrm{E}+00$ & & Ba-137m & $2.39 \mathrm{E}+00$ & & \\
\hline & & & & & & $\mathrm{Bi}-211$ & $2.15 \mathrm{E}-08$ & & \\
\hline & & & Cs-137 & $5.11 \mathrm{E}+00$ & & Cs-137 & $2.55 \mathrm{E}+00$ & & \\
\hline & & & $\mathrm{Eu}-155$ & $9.55 \mathrm{E}-02$ & & Eu-155 & $1.44 \mathrm{E}-03$ & & \\
\hline & & & & & & Fr-223 & $2.97 \mathrm{E}-10$ & & \\
\hline & & & & & & $\mathrm{Pa}-231$ & $6.11 \mathrm{E}-08$ & & \\
\hline & & & & & & $\mathrm{Pb}-211$ & $2.15 \mathrm{E}-08$ & & \\
\hline & & & Pm-147 & $2.92 \mathrm{E}-01$ & & Pm-147 & $1.05 \mathrm{E}-04$ & & \\
\hline & & & & & & Po-211 & $6.55 \mathrm{E}-11$ & & \\
\hline & & & & & & Po-215 & $2.15 \mathrm{E}-08$ & & \\
\hline & & & $\mathrm{Pu}-239$ & $1.02 \mathrm{E}+00$ & & $\mathrm{Pu}-239$ & $1.02 \mathrm{E}+00$ & & \\
\hline & & & & & & Ra-223 & $2.17 \mathrm{E}-08$ & & \\
\hline & & & Rh-106 & $3.74 \mathrm{E}-02$ & & Rh-106 & $4.07 \mathrm{E}-11$ & & \\
\hline & & & & & & Rn-219 & $2.15 \mathrm{E}-08$ & & \\
\hline & & & $\mathrm{Ru}-106$ & $3.74 \mathrm{E}-02$ & & $\mathrm{Ru}-106$ & $4.11 \mathrm{E}-11$ & & \\
\hline & & & Sb-125 & $2.08 \mathrm{E}-01$ & & Sb-125 & $1.14 \mathrm{E}-04$ & & \\
\hline & & & & & & Sm-147 & $7.15 \mathrm{E}-12$ & & \\
\hline & & & Sr-90 & $4.67 \mathrm{E}+00$ & & Sr-90 & $2.29 \mathrm{E}+00$ & & \\
\hline & & & $\mathrm{Te}-125 \mathrm{~m}$ & 8.63E-02 & & $\mathrm{Te}-125 \mathrm{~m}$ & $2.76 \mathrm{E}-05$ & & \\
\hline & & & & & & Th-227 & $2.12 \mathrm{E}-08$ & & \\
\hline & & & & & & Th-231 & $9.52 \mathrm{E}-05$ & & \\
\hline & & & & & & T1-207 & $2.14 \mathrm{E}-08$ & & \\
\hline & & & U-235 & $9.64 \mathrm{E}-05$ & & U-235 & $9.64 \mathrm{E}-05$ & & \\
\hline & & & Y-90 & $4.66 \mathrm{E}+00$ & & Y-90 & $2.26 \mathrm{E}+00$ & & \\
\hline 205 & S801483 & 1980 & & & 2009 & Ac- 227 & $4.68 \mathrm{E}-11$ & $1000000+$ & $483,000 *$ \\
\hline
\end{tabular}

${ }^{1}$ Calculated decayed contact dose rate. Rounded to nearest $10 \mathrm{mR} / \mathrm{hr}$ for values to 1000 ; rounded to nearest $100 \mathrm{mR} / \mathrm{hr}$ for values $>1000$ to 10,000 ; rounded to nearest $1000 \mathrm{mR} / \mathrm{hr}$ for values $>10,000$. * Initial contact dose rate assumed to be $1,000,000 \mathrm{mR} / \mathrm{hr}$; **Initial contact dose rate assumed to be $1,010,000 \mathrm{mR} / \mathrm{hr}$.

$$
15 \text { of } 168
$$


Appendix A-4 - Initial and Decayed Radionuclide and Dose Data for Lined Shafts

\begin{tabular}{|c|c|c|c|c|c|c|c|c|c|}
\hline \multirow[b]{2}{*}{ Shaft Number } & \multirow[b]{2}{*}{ Package ID } & \multirow[b]{2}{*}{ Base Year } & \multicolumn{2}{|c|}{ Initial Isotopic Distribution } & \multirow[b]{2}{*}{ Target Year } & \multicolumn{2}{|c|}{ Decayed Isotopic Distribution } & \multirow{2}{*}{$\begin{array}{c}\text { Initial Contact } \\
\text { Dose Rate } \\
(\mathrm{mR} / \mathrm{hr})\end{array}$} & \multirow{2}{*}{$\begin{array}{c}\text { Decayed } \\
\text { Contact Dose } \\
\text { Rate }(\mathrm{mR} / \mathrm{hr})^{1} \\
\end{array}$} \\
\hline & & & Isotope & Activity (Ci) & & Isotope & Activity (Ci) & & \\
\hline & & & Ba-137m & $3.24 \mathrm{E}+01$ & & Ba-137m & $1.65 \mathrm{E}+01$ & & \\
\hline & & & & & & Bi-211 & $4.62 \mathrm{E}-11$ & & \\
\hline & & & Cs-137 & $3.45 \mathrm{E}+01$ & & Cs-137 & $1.76 \mathrm{E}+01$ & & \\
\hline & & & Eu-155 & $6.45 \mathrm{E}-01$ & & Eu-155 & $1.12 \mathrm{E}-02$ & & \\
\hline & & & & & & Fr-223 & $6.39 \mathrm{E}-13$ & & \\
\hline & & & & & & $\mathrm{Pa}-231$ & $1.35 \mathrm{E}-10$ & & \\
\hline & & & & & & $\mathrm{Pb}-211$ & $4.63 \mathrm{E}-11$ & & \\
\hline & & & Pm-147 & $1.97 \mathrm{E}+00$ & & Pm-147 & $9.26 \mathrm{E}-04$ & & \\
\hline & & & & & & Po-211 & $1.41 \mathrm{E}-13$ & & \\
\hline & & & & & & Po-215 & $4.63 \mathrm{E}-11$ & & \\
\hline & & & Pu-239 & $6.20 \mathrm{E}-03$ & & $\mathrm{Pu}-239$ & $6.20 \mathrm{E}-03$ & & \\
\hline & & & & & & Ra-223 & $4.68 \mathrm{E}-11$ & & \\
\hline & & & Rh-106 & $2.53 \mathrm{E}-01$ & & Rh-106 & $5.47 \mathrm{E}-10$ & & \\
\hline & & & & & & Rn-219 & $4.62 \mathrm{E}-11$ & & \\
\hline & & & $\mathrm{Ru}-106$ & $2.53 \mathrm{E}-01$ & & Ru-106 & $5.52 \mathrm{E}-10$ & & \\
\hline & & & Sb-125 & $1.40 \mathrm{E}+00$ & & $\mathrm{Sb}-125$ & $9.90 \mathrm{E}-04$ & & \\
\hline & & & & & & Sm-147 & $4.83 \mathrm{E}-11$ & & \\
\hline & & & Sr-90 & $3.15 \mathrm{E}+01$ & & Sr-90 & $1.58 \mathrm{E}+01$ & & \\
\hline & & & $\mathrm{Te}-125 \mathrm{~m}$ & $5.83 \mathrm{E}-01$ & & $\mathrm{Te}-125 \mathrm{~m}$ & $2.40 \mathrm{E}-04$ & & \\
\hline & & & & & & Th-227 & $4.56 \mathrm{E}-11$ & & \\
\hline & & & & & & Th-231 & $2.17 \mathrm{E}-07$ & & \\
\hline & & & & & & Tl-207 & $4.60 \mathrm{E}-11$ & & \\
\hline & & & U-235 & $2.20 \mathrm{E}-07$ & & U-235 & $2.20 \mathrm{E}-07$ & & \\
\hline & & & Y-90 & $3.15 \mathrm{E}+01$ & & $\mathrm{Y}-90$ & $1.56 \mathrm{E}+01$ & & \\
\hline \multirow[t]{8}{*}{205} & S801485 & 1980 & & & 2009 & Ac-227 & $3.37 \mathrm{E}-12$ & $1000000+$ & $483,000 *$ \\
\hline & & & Ba-137m & $4.07 \mathrm{E}+01$ & & Ba-137m & $2.08 \mathrm{E}+01$ & & \\
\hline & & & & & & Bi-211 & $3.32 \mathrm{E}-12$ & & \\
\hline & & & Cs-137 & $4.34 \mathrm{E}+01$ & & Cs-137 & $2.22 \mathrm{E}+01$ & & \\
\hline & & & Eu-155 & $8.12 \mathrm{E}-01$ & & Eu-155 & $1.41 \mathrm{E}-02$ & & \\
\hline & & & & & & Fr-223 & $4.59 \mathrm{E}-14$ & & \\
\hline & & & & & & $\mathrm{Pa}-231$ & $1.36 \mathrm{E}-11$ & & \\
\hline & & & & & & $\mathrm{Pb}-211$ & $3.33 \mathrm{E}-12$ & & \\
\hline
\end{tabular}

${ }^{1}$ Calculated decayed contact dose rate. Rounded to nearest $10 \mathrm{mR} / \mathrm{hr}$ for values to 1000 ; rounded to nearest $100 \mathrm{mR} / \mathrm{hr}$ for values $>1000$ to 10,000 ; rounded to nearest $1000 \mathrm{mR} / \mathrm{hr}$ for values $>10,000$. * Initial contact dose rate assumed to be $1,000,000 \mathrm{mR} / \mathrm{hr}$; **Initial contact dose rate assumed to be $1,010,000 \mathrm{mR} / \mathrm{hr}$.

$$
16 \text { of } 168
$$


Appendix A-4 - Initial and Decayed Radionuclide and Dose Data for Lined Shafts

\begin{tabular}{|c|c|c|c|c|c|c|c|c|c|}
\hline \multirow[b]{2}{*}{ Shaft Number } & \multirow[b]{2}{*}{ Package ID } & \multirow[b]{2}{*}{ Base Year } & \multicolumn{2}{|c|}{ Initial Isotopic Distribution } & \multirow[b]{2}{*}{ Target Year } & \multicolumn{2}{|c|}{ Decayed Isotopic Distribution } & \multirow{2}{*}{$\begin{array}{c}\text { Initial Contact } \\
\text { Dose Rate } \\
(\mathrm{mR} / \mathrm{hr})\end{array}$} & \multirow{2}{*}{$\begin{array}{c}\text { Decayed } \\
\text { Contact Dose } \\
\text { Rate }(\mathrm{mR} / \mathrm{hr})^{1} \\
\end{array}$} \\
\hline & & & Isotope & Activity (Ci) & & Isotope & Activity (Ci) & & \\
\hline & & & Pm-147 & $2.48 \mathrm{E}+00$ & & Pm-147 & $1.17 \mathrm{E}-03$ & & \\
\hline & & & & & & Po-211 & $1.01 \mathrm{E}-14$ & & \\
\hline & & & & & & Po-215 & $3.33 \mathrm{E}-12$ & & \\
\hline & & & $\mathrm{Pu}-239$ & $1.55 \mathrm{E}+00$ & & $\mathrm{Pu}-239$ & $1.55 \mathrm{E}+00$ & & \\
\hline & & & & & & $\mathrm{Ra}-223$ & $3.37 \mathrm{E}-12$ & & \\
\hline & & & Rh-106 & $3.18 \mathrm{E}-01$ & & Rh-106 & $6.89 \mathrm{E}-10$ & & \\
\hline & & & & & & $\mathrm{Rn}-219$ & $3.33 \mathrm{E}-12$ & & \\
\hline & & & $\mathrm{Ru}-106$ & $3.18 \mathrm{E}-01$ & & $\mathrm{Ru}-106$ & $6.95 \mathrm{E}-10$ & & \\
\hline & & & Sb-125 & $1.77 \mathrm{E}+00$ & & $\mathrm{Sb}-125$ & $1.25 \mathrm{E}-03$ & & \\
\hline & & & & & & Sm-147 & $6.08 \mathrm{E}-11$ & & \\
\hline & & & Sr-90 & $3.97 \mathrm{E}+01$ & & Sr-90 & $1.99 \mathrm{E}+01$ & & \\
\hline & & & $\mathrm{Te}-125 \mathrm{~m}$ & 7.34E-01 & & Te-125m & $3.02 \mathrm{E}-04$ & & \\
\hline & & & & & & Th-227 & $3.28 \mathrm{E}-12$ & & \\
\hline & & & & & & Th-231 & 4.38E-08 & & \\
\hline & & & & & & Tl-207 & $3.31 \mathrm{E}-12$ & & \\
\hline & & & U-235 & 2.09E-04 & & $\mathrm{U}-235$ & $4.43 \mathrm{E}-08$ & & \\
\hline & & & $\mathrm{Y}-90$ & $3.96 \mathrm{E}+01$ & & Y-90 & $1.97 \mathrm{E}+01$ & & \\
\hline \multirow[t]{15}{*}{205} & S802244 & 1980 & & & 2009 & Ac- 227 & $9.35 \mathrm{E}-09$ & 160,000 & 77,000 \\
\hline & & & Ba-137m & $9.83 \mathrm{E}-01$ & & Ba-137m & $5.01 \mathrm{E}-01$ & & \\
\hline & & & & & & Bi-211 & 9.24E-09 & & \\
\hline & & & Cs-137 & $1.05 \mathrm{E}+00$ & & Cs-137 & $5.36 \mathrm{E}-01$ & & \\
\hline & & & Eu-155 & $1.96 \mathrm{E}-02$ & & Eu-155 & $3.40 \mathrm{E}-04$ & & \\
\hline & & & & & & Fr-223 & $1.28 \mathrm{E}-10$ & & \\
\hline & & & & & & $\mathrm{Pa}-231$ & $2.70 \mathrm{E}-08$ & & \\
\hline & & & & & & $\mathrm{Pb}-211$ & 9.25E-09 & & \\
\hline & & & Pm-147 & $5.98 \mathrm{E}-02$ & & Pm-147 & $2.81 \mathrm{E}-05$ & & \\
\hline & & & & & & Po-211 & $2.82 \mathrm{E}-11$ & & \\
\hline & & & & & & Po-215 & $9.25 \mathrm{E}-09$ & & \\
\hline & & & $\mathrm{Pu}-239$ & $3.10 \mathrm{E}-02$ & & $\mathrm{Pu}-239$ & $3.10 \mathrm{E}-02$ & & \\
\hline & & & & & & Ra-223 & $9.35 \mathrm{E}-09$ & & \\
\hline & & & Rh-106 & $7.68 \mathrm{E}-03$ & & Rh-106 & $1.66 \mathrm{E}-11$ & & \\
\hline & & & & & & Rn-219 & 9.24E-09 & & \\
\hline
\end{tabular}

${ }^{1}$ Calculated decayed contact dose rate. Rounded to nearest $10 \mathrm{mR} / \mathrm{hr}$ for values to 1000 ; rounded to nearest $100 \mathrm{mR} / \mathrm{hr}$ for values $>1000$ to 10,000 ; rounded to nearest $1000 \mathrm{mR} / \mathrm{hr}$ for values $>10,000$. * Initial contact dose rate assumed to be $1,000,000 \mathrm{mR} / \mathrm{hr}$; **Initial contact dose rate assumed to be $1,010,000 \mathrm{mR} / \mathrm{hr}$.

$$
17 \text { of } 168
$$


Appendix A-4 - Initial and Decayed Radionuclide and Dose Data for Lined Shafts

\begin{tabular}{|c|c|c|c|c|c|c|c|c|c|}
\hline \multirow[b]{2}{*}{ Shaft Number } & \multirow[b]{2}{*}{ Package ID } & \multirow[b]{2}{*}{ Base Year } & \multicolumn{2}{|c|}{ Initial Isotopic Distribution } & \multirow[b]{2}{*}{ Target Year } & \multicolumn{2}{|c|}{ Decayed Isotopic Distribution } & \multirow{2}{*}{$\begin{array}{c}\text { Initial Contact } \\
\text { Dose Rate } \\
(\mathrm{mR} / \mathrm{hr})\end{array}$} & \multirow{2}{*}{$\begin{array}{c}\text { Decayed } \\
\text { Contact Dose } \\
\text { Rate }(\mathrm{mR} / \mathrm{hr})^{1} \\
\end{array}$} \\
\hline & & & Isotope & Activity (Ci) & & Isotope & Activity (Ci) & & \\
\hline & & & $\mathrm{Ru}-106$ & $7.68 \mathrm{E}-03$ & & $\mathrm{Ru}-106$ & $1.68 \mathrm{E}-11$ & & \\
\hline & & & $\mathrm{Sb}-125$ & $4.26 \mathrm{E}-02$ & & $\mathrm{Sb}-125$ & $3.01 \mathrm{E}-05$ & & \\
\hline & & & & & & Sm-147 & $1.47 \mathrm{E}-12$ & & \\
\hline & & & Sr-90 & $9.57 \mathrm{E}-01$ & & Sr-90 & $4.80 \mathrm{E}-01$ & & \\
\hline & & & $\mathrm{Te}-125 \mathrm{~m}$ & $1.77 \mathrm{E}-02$ & & Te-125m & $7.28 \mathrm{E}-06$ & & \\
\hline & & & & & & Th-227 & $9.11 \mathrm{E}-09$ & & \\
\hline & & & & & & Th-231 & $4.35 \mathrm{E}-05$ & & \\
\hline & & & & & & Tl-207 & $9.20 \mathrm{E}-09$ & & \\
\hline & & & U-235 & $4.40 \mathrm{E}-05$ & & U-235 & $4.40 \mathrm{E}-05$ & & \\
\hline & & & $\mathrm{Y}-90$ & $9.56 \mathrm{E}-01$ & & $\mathrm{Y}-90$ & 4.74E-01 & & \\
\hline \multirow[t]{22}{*}{205} & S802246 & 1980 & & & 2009 & Ac-227 & $3.27 \mathrm{E}-08$ & $1,000,000$ & 483,000 \\
\hline & & & $\mathrm{Ba}-137 \mathrm{~m}$ & $3.36 \mathrm{E}-01$ & & $\mathrm{Ba}-137 \mathrm{~m}$ & $1.71 \mathrm{E}-01$ & & \\
\hline & & & & & & Bi-211 & $3.23 \mathrm{E}-08$ & & \\
\hline & & & Cs-137 & $3.57 \mathrm{E}-01$ & & Cs-137 & $1.83 \mathrm{E}-01$ & & \\
\hline & & & $\mathrm{Eu}-155$ & $6.69 \mathrm{E}-03$ & & $\mathrm{Eu}-155$ & $1.16 \mathrm{E}-04$ & & \\
\hline & & & & & & Fr-223 & $4.47 \mathrm{E}-10$ & & \\
\hline & & & & & & $\mathrm{Pa}-231$ & $9.44 \mathrm{E}-08$ & & \\
\hline & & & & & & $\mathrm{Pb}-211$ & $3.24 \mathrm{E}-08$ & & \\
\hline & & & Pm-147 & $2.04 \mathrm{E}-02$ & & Pm-147 & $9.61 \mathrm{E}-06$ & & \\
\hline & & & & & & Po-211 & $9.87 \mathrm{E}-11$ & & \\
\hline & & & & & & Po-215 & $3.24 \mathrm{E}-08$ & & \\
\hline & & & $\mathrm{Pu}-239$ & $1.09 \mathrm{E}+00$ & & Pu-239 & $1.08 \mathrm{E}+00$ & & \\
\hline & & & & & & Ra-223 & $3.27 \mathrm{E}-08$ & & \\
\hline & & & Rh-106 & $2.62 \mathrm{E}-03$ & & Rh-106 & $5.67 \mathrm{E}-12$ & & \\
\hline & & & & & & Rn-219 & $3.23 \mathrm{E}-08$ & & \\
\hline & & & $\mathrm{Ru}-106$ & $2.62 \mathrm{E}-03$ & & $\mathrm{Ru}-106$ & $5.73 \mathrm{E}-12$ & & \\
\hline & & & Sb-125 & $1.46 \mathrm{E}-02$ & & $\mathrm{Sb}-125$ & $1.03 \mathrm{E}-05$ & & \\
\hline & & & & & & Sm-147 & $5.00 \mathrm{E}-13$ & & \\
\hline & & & Sr-90 & $3.27 \mathrm{E}-01$ & & Sr-90 & $1.64 \mathrm{E}-01$ & & \\
\hline & & & Te-125m & $6.04 \mathrm{E}-03$ & & $\mathrm{Te}-125 \mathrm{~m}$ & $2.48 \mathrm{E}-06$ & & \\
\hline & & & & & & Th-227 & $3.19 \mathrm{E}-08$ & & \\
\hline & & & & & & Th-231 & $1.52 \mathrm{E}-04$ & & \\
\hline
\end{tabular}

${ }^{1}$ Calculated decayed contact dose rate. Rounded to nearest $10 \mathrm{mR} / \mathrm{hr}$ for values to 1000 ; rounded to nearest $100 \mathrm{mR} / \mathrm{hr}$ for values $>1000$ to 10,000 ; rounded to nearest $1000 \mathrm{mR} / \mathrm{hr}$ for values $>10,000$. * Initial contact dose rate assumed to be $1,000,000 \mathrm{mR} / \mathrm{hr}$; **Initial contact dose rate assumed to be $1,010,000 \mathrm{mR} / \mathrm{hr}$.

$$
18 \text { of } 168
$$


Appendix A-4 - Initial and Decayed Radionuclide and Dose Data for Lined Shafts

\begin{tabular}{|c|c|c|c|c|c|c|c|c|c|}
\hline \multirow[b]{2}{*}{ Shaft Number } & \multirow[b]{2}{*}{ Package ID } & \multirow[b]{2}{*}{ Base Year } & \multicolumn{2}{|c|}{ Initial Isotopic Distribution } & \multirow[b]{2}{*}{ Target Year } & \multicolumn{2}{|c|}{ Decayed Isotopic Distribution } & \multirow{2}{*}{$\begin{array}{c}\text { Initial Contact } \\
\text { Dose Rate } \\
(\mathrm{mR} / \mathrm{hr})\end{array}$} & \multirow{2}{*}{$\begin{array}{c}\text { Decayed } \\
\text { Contact Dose } \\
\text { Rate }(\mathrm{mR} / \mathrm{hr})^{1} \\
\end{array}$} \\
\hline & & & Isotope & Activity (Ci) & & Isotope & Activity (Ci) & & \\
\hline & & & & & & Tl-207 & $3.22 \mathrm{E}-08$ & & \\
\hline & & & $\mathrm{U}-235$ & $1.54 \mathrm{E}-04$ & & $\mathrm{U}-235$ & $1.54 \mathrm{E}-04$ & & \\
\hline & & & $\mathrm{Y}-90$ & $3.26 \mathrm{E}-01$ & & Y-90 & $1.62 \mathrm{E}-01$ & & \\
\hline \multirow[t]{25}{*}{205} & $\mathrm{~S} 802247$ & 1980 & & & 2009 & Ac-227 & $9.82 \mathrm{E}-09$ & 615,000 & 297,000 \\
\hline & & & Ba-137m & $2.88 \mathrm{E}-01$ & & $\mathrm{Ba}-137 \mathrm{~m}$ & $1.47 \mathrm{E}-01$ & & \\
\hline & & & & & & Bi-211 & $9.70 \mathrm{E}-09$ & & \\
\hline & & & Cs-137 & $3.06 \mathrm{E}-01$ & & Cs-137 & $1.57 \mathrm{E}-01$ & & \\
\hline & & & Eu-155 & $5.73 \mathrm{E}-03$ & & Eu-155 & $9.95 \mathrm{E}-05$ & & \\
\hline & & & & & & Fr-223 & $1.34 \mathrm{E}-10$ & & \\
\hline & & & & & & $\mathrm{Pa}-231$ & $2.83 \mathrm{E}-08$ & & \\
\hline & & & & & & $\mathrm{Pb}-211$ & $9.71 \mathrm{E}-09$ & & \\
\hline & & & Pm-147 & $1.75 \mathrm{E}-02$ & & Pm-147 & $8.23 \mathrm{E}-06$ & & \\
\hline & & & & & & Po-211 & $2.96 \mathrm{E}-11$ & & \\
\hline & & & & & & Po-215 & $9.71 \mathrm{E}-09$ & & \\
\hline & & & $\mathrm{Pu}-239$ & $3.10 \mathrm{E}-01$ & & $\mathrm{Pu}-239$ & $3.10 \mathrm{E}-01$ & & \\
\hline & & & & & & Ra-223 & $9.82 \mathrm{E}-09$ & & \\
\hline & & & Rh-106 & $2.25 \mathrm{E}-03$ & & Rh-106 & $4.86 \mathrm{E}-12$ & & \\
\hline & & & & & & Rn-219 & $9.70 \mathrm{E}-09$ & & \\
\hline & & & Ru-106 & $2.25 \mathrm{E}-03$ & & Ru-106 & $4.91 \mathrm{E}-12$ & & \\
\hline & & & Sb-125 & $1.25 \mathrm{E}-02$ & & Sb-125 & $8.80 \mathrm{E}-06$ & & \\
\hline & & & & & & Sm-147 & $4.29 \mathrm{E}-13$ & & \\
\hline & & & Sr-90 & $2.80 \mathrm{E}-01$ & & Sr-90 & $1.40 \mathrm{E}-01$ & & \\
\hline & & & $\mathrm{Te}-125 \mathrm{~m}$ & $5.18 \mathrm{E}-03$ & & $\mathrm{Te}-125 \mathrm{~m}$ & $2.13 \mathrm{E}-06$ & & \\
\hline & & & & & & Th-227 & $9.56 \mathrm{E}-09$ & & \\
\hline & & & & & & Th-231 & $4.56 \mathrm{E}-05$ & & \\
\hline & & & & & & Tl-207 & $9.66 \mathrm{E}-09$ & & \\
\hline & & & U-235 & $4.62 \mathrm{E}-05$ & & U-235 & $4.62 \mathrm{E}-05$ & & \\
\hline & & & Y-90 & $2.80 \mathrm{E}-01$ & & $\mathrm{Y}-90$ & $1.39 \mathrm{E}-01$ & & \\
\hline \multirow[t]{4}{*}{205} & S802259 & 1980 & & & 2009 & Ac- 227 & $1.82 \mathrm{E}-08$ & $1000000+$ & $483,000^{*}$ \\
\hline & & & $\mathrm{Ba}-137 \mathrm{~m}$ & $8.39 \mathrm{E}+00$ & & Ba-137m & $4.28 \mathrm{E}+00$ & & \\
\hline & & & & & & $\mathrm{Bi}-211$ & $1.80 \mathrm{E}-08$ & & \\
\hline & & & Cs-137 & $8.94 \mathrm{E}+00$ & & Cs-137 & $4.57 \mathrm{E}+00$ & & \\
\hline
\end{tabular}

${ }^{1}$ Calculated decayed contact dose rate. Rounded to nearest $10 \mathrm{mR} / \mathrm{hr}$ for values to 1000 ; rounded to nearest $100 \mathrm{mR} / \mathrm{hr}$ for values $>1000$ to 10,000 ; rounded to nearest $1000 \mathrm{mR} / \mathrm{hr}$ for values $>10,000$. * Initial contact dose rate assumed to be $1,000,000 \mathrm{mR} / \mathrm{hr}$; **Initial contact dose rate assumed to be $1,010,000 \mathrm{mR} / \mathrm{hr}$.

$$
19 \text { of } 168
$$


Appendix A-4 - Initial and Decayed Radionuclide and Dose Data for Lined Shafts

\begin{tabular}{|c|c|c|c|c|c|c|c|c|c|}
\hline \multirow[b]{2}{*}{ Shaft Number } & \multirow[b]{2}{*}{ Package ID } & \multirow[b]{2}{*}{ Base Year } & \multicolumn{2}{|c|}{ Initial Isotopic Distribution } & \multirow[b]{2}{*}{ Target Year } & \multicolumn{2}{|c|}{ Decayed Isotopic Distribution } & \multirow{2}{*}{$\begin{array}{c}\text { Initial Contact } \\
\text { Dose Rate } \\
(\mathrm{mR} / \mathrm{hr})\end{array}$} & \multirow{2}{*}{$\begin{array}{c}\text { Decayed } \\
\text { Contact Dose } \\
\text { Rate }(\mathrm{mR} / \mathrm{hr})^{1} \\
\end{array}$} \\
\hline & & & Isotope & Activity (Ci) & & Isotope & Activity (Ci) & & \\
\hline & & & Eu-155 & $1.67 \mathrm{E}-01$ & & Eu-155 & $2.90 \mathrm{E}-03$ & & \\
\hline & & & & & & Fr-223 & $2.49 \mathrm{E}-10$ & & \\
\hline & & & & & & $\mathrm{Pa}-231$ & $5.26 \mathrm{E}-08$ & & \\
\hline & & & & & & $\mathrm{Pb}-211$ & $1.80 \mathrm{E}-08$ & & \\
\hline & & & Pm-147 & $5.10 \mathrm{E}-01$ & & Pm-147 & $2.40 \mathrm{E}-04$ & & \\
\hline & & & & & & Po-211 & $5.50 \mathrm{E}-11$ & & \\
\hline & & & & & & Po-215 & $1.80 \mathrm{E}-08$ & & \\
\hline & & & $\mathrm{Pu}-239$ & 7.44E-01 & & $\mathrm{Pu}-239$ & $7.43 \mathrm{E}-01$ & & \\
\hline & & & & & & Ra-223 & $1.82 \mathrm{E}-08$ & & \\
\hline & & & Rh-106 & $6.55 \mathrm{E}-02$ & & Rh-106 & $1.42 \mathrm{E}-10$ & & \\
\hline & & & & & & Rn-219 & $1.80 \mathrm{E}-08$ & & \\
\hline & & & $\mathrm{Ru}-106$ & $6.55 \mathrm{E}-02$ & & $\mathrm{Ru}-106$ & $1.43 \mathrm{E}-10$ & & \\
\hline & & & Sb-125 & $3.64 \mathrm{E}-01$ & & $\mathrm{Sb}-125$ & $2.57 \mathrm{E}-04$ & & \\
\hline & & & & & & Sm-147 & $1.25 \mathrm{E}-11$ & & \\
\hline & & & Sr-90 & $8.17 \mathrm{E}+00$ & & Sr-90 & $4.10 \mathrm{E}+00$ & & \\
\hline & & & $\mathrm{Te}-125 \mathrm{~m}$ & $1.51 \mathrm{E}-01$ & & $\mathrm{Te}-125 \mathrm{~m}$ & $6.21 \mathrm{E}-05$ & & \\
\hline & & & & & & Th-227 & $1.78 \mathrm{E}-08$ & & \\
\hline & & & & & & Th-231 & $8.47 \mathrm{E}-05$ & & \\
\hline & & & & & & T1-207 & $1.79 \mathrm{E}-08$ & & \\
\hline & & & U-235 & $8.58 \mathrm{E}-05$ & & U-235 & $8.58 \mathrm{E}-05$ & & \\
\hline & & & Y-90 & $8.16 \mathrm{E}+00$ & & $\mathrm{Y}-90$ & $4.05 \mathrm{E}+00$ & & \\
\hline \multirow[t]{11}{*}{205} & S802287 & 1980 & & & 2009 & Ac-227 & $1.10 \mathrm{E}-07$ & $1000000+$ & $483,000 *$ \\
\hline & & & Ba-137m & $1.25 \mathrm{E}+02$ & & Ba-137m & $6.35 \mathrm{E}+01$ & & \\
\hline & & & & & & Bi-211 & $1.09 \mathrm{E}-07$ & & \\
\hline & & & Cs-137 & $1.33 \mathrm{E}+02$ & & Cs-137 & $6.79 \mathrm{E}+01$ & & \\
\hline & & & Eu-155 & $2.48 \mathrm{E}+00$ & & Eu-155 & $4.31 \mathrm{E}-02$ & & \\
\hline & & & & & & Fr-223 & $1.51 \mathrm{E}-09$ & & \\
\hline & & & & & & $\mathrm{Pa}-231$ & $3.18 \mathrm{E}-07$ & & \\
\hline & & & & & & $\mathrm{Pb}-211$ & $1.09 \mathrm{E}-07$ & & \\
\hline & & & Pm-147 & $7.58 \mathrm{E}+00$ & & Pm-147 & $3.57 \mathrm{E}-03$ & & \\
\hline & & & & & & Po-211 & $3.33 \mathrm{E}-10$ & & \\
\hline & & & & & & Po-215 & $1.09 \mathrm{E}-07$ & & \\
\hline
\end{tabular}

${ }^{1}$ Calculated decayed contact dose rate. Rounded to nearest $10 \mathrm{mR} / \mathrm{hr}$ for values to 1000 ; rounded to nearest $100 \mathrm{mR} / \mathrm{hr}$ for values $>1000$ to 10,000 ; rounded to nearest $1000 \mathrm{mR} / \mathrm{hr}$ for values $>10,000$. * Initial contact dose rate assumed to be $1,000,000 \mathrm{mR} / \mathrm{hr}$; **Initial contact dose rate assumed to be $1,010,000 \mathrm{mR} / \mathrm{hr}$.

$$
20 \text { of } 168
$$


Appendix A-4 - Initial and Decayed Radionuclide and Dose Data for Lined Shafts

\begin{tabular}{|c|c|c|c|c|c|c|c|c|c|}
\hline \multirow[b]{2}{*}{ Shaft Number } & \multirow[b]{2}{*}{ Package ID } & \multirow[b]{2}{*}{ Base Year } & \multicolumn{2}{|c|}{ Initial Isotopic Distribution } & \multirow[b]{2}{*}{ Target Year } & \multicolumn{2}{|c|}{ Decayed Isotopic Distribution } & \multirow{2}{*}{$\begin{array}{c}\text { Initial Contact } \\
\text { Dose Rate } \\
(\mathrm{mR} / \mathrm{hr})\end{array}$} & \multirow{2}{*}{$\begin{array}{c}\text { Decayed } \\
\text { Contact Dose } \\
\text { Rate }(\mathrm{mR} / \mathrm{hr})^{1} \\
\end{array}$} \\
\hline & & & Isotope & Activity (Ci) & & Isotope & Activity (Ci) & & \\
\hline & & & $\mathrm{Pu}-239$ & $3.53 \mathrm{E}+00$ & & $\mathrm{Pu}-239$ & $3.53 \mathrm{E}+00$ & & \\
\hline & & & & & & Ra-223 & $1.10 \mathrm{E}-07$ & & \\
\hline & & & Rh-106 & $9.74 \mathrm{E}-01$ & & Rh-106 & $2.11 \mathrm{E}-09$ & & \\
\hline & & & & & & $\mathrm{Rn}-219$ & $1.09 \mathrm{E}-07$ & & \\
\hline & & & $\mathrm{Ru}-106$ & $9.74 \mathrm{E}-01$ & & $\mathrm{Ru}-106$ & $2.13 \mathrm{E}-09$ & & \\
\hline & & & $\mathrm{Sb}-125$ & $5.41 \mathrm{E}+00$ & & Sb-125 & $3.81 \mathrm{E}-03$ & & \\
\hline & & & & & & Sm-147 & $1.86 \mathrm{E}-10$ & & \\
\hline & & & Sr-90 & $1.21 \mathrm{E}+02$ & & Sr-90 & $6.09 \mathrm{E}+01$ & & \\
\hline & & & $\mathrm{Te}-125 \mathrm{~m}$ & $2.25 \mathrm{E}+00$ & & $\mathrm{Te}-125 \mathrm{~m}$ & $9.23 \mathrm{E}-04$ & & \\
\hline & & & & & & Th-227 & $1.07 \mathrm{E}-07$ & & \\
\hline & & & & & & Th-231 & $5.13 \mathrm{E}-04$ & & \\
\hline & & & & & & T1-207 & $1.09 \mathrm{E}-07$ & & \\
\hline & & & $\mathrm{U}-235$ & $5.19 \mathrm{E}-04$ & & $\mathrm{U}-235$ & $5.19 \mathrm{E}-04$ & & \\
\hline & & & $\mathrm{Y}-90$ & $1.21 \mathrm{E}+02$ & & $\mathrm{Y}-90$ & $6.02 \mathrm{E}+01$ & & \\
\hline \multirow[t]{18}{*}{206} & S812291 & 1981 & & & 2009 & Ac- 227 & $1.41 \mathrm{E}-07$ & $1000000+$ & $495,000 *$ \\
\hline & & & Ba-137m & $9.59 \mathrm{E}+00$ & & Ba-137m & $5.00 \mathrm{E}+00$ & & \\
\hline & & & & & & Bi-211 & $1.39 \mathrm{E}-07$ & & \\
\hline & & & Cs-137 & $1.02 \mathrm{E}+01$ & & Cs-137 & $5.35 \mathrm{E}+00$ & & \\
\hline & & & Eu-155 & $1.91 \mathrm{E}-01$ & & Eu-155 & $3.82 \mathrm{E}-03$ & & \\
\hline & & & & & & Fr-223 & $1.93 \mathrm{E}-09$ & & \\
\hline & & & & & & $\mathrm{Pa}-231$ & $4.18 \mathrm{E}-07$ & & \\
\hline & & & & & & $\mathrm{Pb}-211$ & $1.40 \mathrm{E}-07$ & & \\
\hline & & & Pm-147 & $5.83 \mathrm{E}-01$ & & Pm-147 & $3.57 \mathrm{E}-04$ & & \\
\hline & & & & & & Po-211 & $4.26 \mathrm{E}-10$ & & \\
\hline & & & & & & Po-215 & $1.40 \mathrm{E}-07$ & & \\
\hline & & & $\mathrm{Pu}-239$ & $7.63 \mathrm{E}+00$ & & Pu-239 & $7.62 \mathrm{E}+00$ & & \\
\hline & & & & & & Ra-223 & $1.41 \mathrm{E}-07$ & & \\
\hline & & & Rh-106 & 7.49E-02 & & Rh-106 & $3.22 \mathrm{E}-10$ & & \\
\hline & & & & & & Rn-219 & $1.39 \mathrm{E}-07$ & & \\
\hline & & & Ru-106 & 7.49E-02 & & Ru-106 & $3.25 \mathrm{E}-10$ & & \\
\hline & & & Sb-125 & 4.16E-01 & & Sb-125 & $3.77 \mathrm{E}-04$ & & \\
\hline & & & & & & Sm-147 & $1.43 \mathrm{E}-11$ & & \\
\hline
\end{tabular}

${ }^{1}$ Calculated decayed contact dose rate. Rounded to nearest $10 \mathrm{mR} / \mathrm{hr}$ for values to 1000 ; rounded to nearest $100 \mathrm{mR} / \mathrm{hr}$ for values $>1000$ to 10,000 ; rounded to nearest $1000 \mathrm{mR} / \mathrm{hr}$ for values $>10,000$. * Initial contact dose rate assumed to be $1,000,000 \mathrm{mR} / \mathrm{hr}$; **Initial contact dose rate assumed to be $1,010,000 \mathrm{mR} / \mathrm{hr}$.

$$
21 \text { of } 168
$$


Appendix A-4 - Initial and Decayed Radionuclide and Dose Data for Lined Shafts

\begin{tabular}{|c|c|c|c|c|c|c|c|c|c|}
\hline \multirow[b]{2}{*}{ Shaft Number } & \multirow[b]{2}{*}{ Package ID } & \multirow[b]{2}{*}{ Base Year } & \multicolumn{2}{|c|}{ Initial Isotopic Distribution } & \multirow[b]{2}{*}{ Target Year } & \multicolumn{2}{|c|}{ Decayed Isotopic Distribution } & \multirow{2}{*}{$\begin{array}{c}\text { Initial Contact } \\
\text { Dose Rate } \\
(\mathrm{mR} / \mathrm{hr})\end{array}$} & \multirow{2}{*}{$\begin{array}{c}\text { Decayed } \\
\text { Contact Dose } \\
\text { Rate }(\mathrm{mR} / \mathrm{hr})^{1} \\
\end{array}$} \\
\hline & & & Isotope & Activity (Ci) & & Isotope & Activity (Ci) & & \\
\hline & & & Sr-90 & $9.34 \mathrm{E}+00$ & & Sr-90 & $4.80 \mathrm{E}+00$ & & \\
\hline & & & $\mathrm{Te}-125 \mathrm{~m}$ & $1.73 \mathrm{E}-01$ & & $\mathrm{Te}-125 \mathrm{~m}$ & $9.12 \mathrm{E}-05$ & & \\
\hline & & & & & & Th-227 & $1.38 \mathrm{E}-07$ & & \\
\hline & & & & & & Th-231 & $6.98 \mathrm{E}-04$ & & \\
\hline & & & & & & Tl-207 & $1.39 \mathrm{E}-07$ & & \\
\hline & & & U-235 & $7.06 \mathrm{E}-04$ & & U-235 & $7.06 \mathrm{E}-04$ & & \\
\hline & & & Y-90 & $9.33 \mathrm{E}+00$ & & Y-90 & $4.74 \mathrm{E}+00$ & & \\
\hline \multirow[t]{25}{*}{206} & S812292 & 1981 & & & 2009 & Ac- 227 & $1.18 \mathrm{E}-07$ & $1000000+$ & $495,000 *$ \\
\hline & & & Ba-137m & $5.27 \mathrm{E}+00$ & & $\mathrm{Ba}-137 \mathrm{~m}$ & $2.75 \mathrm{E}+00$ & & \\
\hline & & & & & & Bi-211 & $1.17 \mathrm{E}-07$ & & \\
\hline & & & Cs-137 & $5.62 \mathrm{E}+00$ & & Cs-137 & $2.94 \mathrm{E}+00$ & & \\
\hline & & & $\mathrm{Eu}-155$ & $1.05 \mathrm{E}-01$ & & $\mathrm{Eu}-155$ & $2.10 \mathrm{E}-03$ & & \\
\hline & & & & & & Fr-223 & $1.62 \mathrm{E}-09$ & & \\
\hline & & & & & & $\mathrm{Pa}-231$ & $3.50 \mathrm{E}-07$ & & \\
\hline & & & & & & $\mathrm{Pb}-211$ & $1.17 \mathrm{E}-07$ & & \\
\hline & & & Pm-147 & $3.21 \mathrm{E}-01$ & & Pm-147 & $1.97 \mathrm{E}-04$ & & \\
\hline & & & & & & Po-211 & $3.57 \mathrm{E}-10$ & & \\
\hline & & & & & & Po-215 & $1.17 \mathrm{E}-07$ & & \\
\hline & & & $\mathrm{Pu}-239$ & $6.20 \mathrm{E}+00$ & & $\mathrm{Pu}-239$ & $6.20 \mathrm{E}+00$ & & \\
\hline & & & & & & Ra-223 & $1.18 \mathrm{E}-07$ & & \\
\hline & & & Rh-106 & 4.12E-02 & & Rh-106 & $1.77 \mathrm{E}-10$ & & \\
\hline & & & & & & Rn-219 & $1.17 \mathrm{E}-07$ & & \\
\hline & & & $\mathrm{Ru}-106$ & $4.12 \mathrm{E}-02$ & & $\mathrm{Ru}-106$ & $1.79 \mathrm{E}-10$ & & \\
\hline & & & $\mathrm{Sb}-125$ & $2.29 \mathrm{E}-01$ & & $\mathrm{Sb}-125$ & $2.07 \mathrm{E}-04$ & & \\
\hline & & & & & & Sm-147 & $7.86 \mathrm{E}-12$ & & \\
\hline & & & Sr-90 & $5.14 \mathrm{E}+00$ & & Sr-90 & $2.64 \mathrm{E}+00$ & & \\
\hline & & & Te-125m & $9.50 \mathrm{E}-02$ & & $\mathrm{Te}-125 \mathrm{~m}$ & $5.01 \mathrm{E}-05$ & & \\
\hline & & & & & & Th-227 & $1.15 \mathrm{E}-07$ & & \\
\hline & & & & & & Th-231 & $5.85 \mathrm{E}-04$ & & \\
\hline & & & & & & Tl-207 & $1.16 \mathrm{E}-07$ & & \\
\hline & & & U-235 & $5.92 \mathrm{E}-04$ & & U-235 & $5.92 \mathrm{E}-04$ & & \\
\hline & & & Y-90 & $5.13 \mathrm{E}+00$ & & $\mathrm{Y}-90$ & $2.61 \mathrm{E}+00$ & & \\
\hline
\end{tabular}

${ }^{1}$ Calculated decayed contact dose rate. Rounded to nearest $10 \mathrm{mR} / \mathrm{hr}$ for values to 1000 ; rounded to nearest $100 \mathrm{mR} / \mathrm{hr}$ for values $>1000$ to 10,000 ; rounded to nearest $1000 \mathrm{mR} / \mathrm{hr}$ for values $>10,000$. * Initial contact dose rate assumed to be $1,000,000 \mathrm{mR} / \mathrm{hr}$; **Initial contact dose rate assumed to be $1,010,000 \mathrm{mR} / \mathrm{hr}$.

$$
22 \text { of } 168
$$


Appendix A-4 - Initial and Decayed Radionuclide and Dose Data for Lined Shafts

\begin{tabular}{|c|c|c|c|c|c|c|c|c|c|}
\hline \multirow[b]{2}{*}{ Shaft Number } & \multirow[b]{2}{*}{ Package ID } & \multirow[b]{2}{*}{ Base Year } & \multicolumn{2}{|c|}{ Initial Isotopic Distribution } & \multirow[b]{2}{*}{ Target Year } & \multicolumn{2}{|c|}{ Decayed Isotopic Distribution } & \multirow{2}{*}{$\begin{array}{c}\text { Initial Contact } \\
\text { Dose Rate } \\
(\mathrm{mR} / \mathrm{hr})\end{array}$} & \multirow{2}{*}{$\begin{array}{c}\text { Decayed } \\
\text { Contact Dose } \\
\text { Rate }(\mathrm{mR} / \mathrm{hr})^{1} \\
\end{array}$} \\
\hline & & & Isotope & Activity (Ci) & & Isotope & Activity (Ci) & & \\
\hline \multirow[t]{25}{*}{206} & S812293 & 1981 & & & 2009 & Ac-227 & $1.23 \mathrm{E}-08$ & $1,000,000$ & 495,000 \\
\hline & & & $\mathrm{Ba}-137 \mathrm{~m}$ & $2.40 \mathrm{E}+01$ & & $\mathrm{Ba}-137 \mathrm{~m}$ & $1.25 \mathrm{E}+01$ & & \\
\hline & & & & & & $\mathrm{Bi}-211$ & $1.22 \mathrm{E}-08$ & & \\
\hline & & & Cs-137 & $2.55 \mathrm{E}+01$ & & Cs-137 & $1.34 \mathrm{E}+01$ & & \\
\hline & & & Eu-155 & $4.78 \mathrm{E}-01$ & & Eu-155 & $9.54 \mathrm{E}-03$ & & \\
\hline & & & & & & Fr-223 & $1.68 \mathrm{E}-10$ & & \\
\hline & & & & & & $\mathrm{Pa}-231$ & $3.64 \mathrm{E}-08$ & & \\
\hline & & & & & & $\mathrm{Pb}-211$ & $1.22 \mathrm{E}-08$ & & \\
\hline & & & Pm-147 & $1.46 \mathrm{E}+00$ & & Pm-147 & $8.93 \mathrm{E}-04$ & & \\
\hline & & & & & & Po-211 & $3.71 \mathrm{E}-11$ & & \\
\hline & & & & & & Po-215 & $1.22 \mathrm{E}-08$ & & \\
\hline & & & $\mathrm{Pu}-239$ & 4.34E-01 & & $\mathrm{Pu}-239$ & $4.34 \mathrm{E}-01$ & & \\
\hline & & & & & & Ra-223 & $1.23 \mathrm{E}-08$ & & \\
\hline & & & Rh-106 & $1.87 \mathrm{E}-01$ & & Rh-106 & $8.06 \mathrm{E}-10$ & & \\
\hline & & & & & & Rn-219 & $1.22 \mathrm{E}-08$ & & \\
\hline & & & $\mathrm{Ru}-106$ & $1.87 \mathrm{E}-01$ & & $\mathrm{Ru}-106$ & $8.14 \mathrm{E}-10$ & & \\
\hline & & & Sb-125 & $1.04 \mathrm{E}+00$ & & Sb-125 & $9.42 \mathrm{E}-04$ & & \\
\hline & & & & & & Sm-147 & $3.57 \mathrm{E}-11$ & & \\
\hline & & & Sr-90 & $2.33 \mathrm{E}+01$ & & Sr-90 & $1.20 \mathrm{E}+01$ & & \\
\hline & & & $\mathrm{Te}-125 \mathrm{~m}$ & $4.32 \mathrm{E}-01$ & & $\mathrm{Te}-125 \mathrm{~m}$ & $2.28 \mathrm{E}-04$ & & \\
\hline & & & & & & Th-227 & $1.20 \mathrm{E}-08$ & & \\
\hline & & & & & & Th-231 & $6.09 \mathrm{E}-05$ & & \\
\hline & & & & & & Tl-207 & $1.21 \mathrm{E}-08$ & & \\
\hline & & & U-235 & $6.16 \mathrm{E}-05$ & & U-235 & $6.16 \mathrm{E}-05$ & & \\
\hline & & & Y-90 & $2.33 \mathrm{E}+01$ & & Y-90 & $1.19 \mathrm{E}+01$ & & \\
\hline \multirow[t]{7}{*}{206} & S812297 & 1981 & & & 2009 & Ac-227 & $3.68 \mathrm{E}-08$ & $1000000+$ & $495,000 *$ \\
\hline & & & Ba-137m & $2.40 \mathrm{E}+01$ & & Ba-137m & $1.25 \mathrm{E}+01$ & & \\
\hline & & & & & & Bi-211 & $3.63 \mathrm{E}-08$ & & \\
\hline & & & Cs-137 & $2.55 \mathrm{E}+01$ & & Cs-137 & $1.34 \mathrm{E}+01$ & & \\
\hline & & & Eu-155 & $4.78 \mathrm{E}-01$ & & Eu-155 & $9.54 \mathrm{E}-03$ & & \\
\hline & & & & & & Fr-223 & $5.02 \mathrm{E}-10$ & & \\
\hline & & & & & & $\mathrm{Pa}-231$ & $1.09 \mathrm{E}-07$ & & \\
\hline
\end{tabular}

${ }^{1}$ Calculated decayed contact dose rate. Rounded to nearest $10 \mathrm{mR} / \mathrm{hr}$ for values to 1000 ; rounded to nearest $100 \mathrm{mR} / \mathrm{hr}$ for values $>1000$ to 10,000 ; rounded to nearest $1000 \mathrm{mR} / \mathrm{hr}$ for values $>10,000$. * Initial contact dose rate assumed to be $1,000,000 \mathrm{mR} / \mathrm{hr}$; **Initial contact dose rate assumed to be $1,010,000 \mathrm{mR} / \mathrm{hr}$.

$$
23 \text { of } 168
$$


Appendix A-4 - Initial and Decayed Radionuclide and Dose Data for Lined Shafts

\begin{tabular}{|c|c|c|c|c|c|c|c|c|c|}
\hline \multirow[b]{2}{*}{ Shaft Number } & \multirow[b]{2}{*}{ Package ID } & \multirow[b]{2}{*}{ Base Year } & \multicolumn{2}{|c|}{ Initial Isotopic Distribution } & \multirow[b]{2}{*}{ Target Year } & \multicolumn{2}{|c|}{ Decayed Isotopic Distribution } & \multirow{2}{*}{$\begin{array}{c}\text { Initial Contact } \\
\text { Dose Rate } \\
(\mathrm{mR} / \mathrm{hr})\end{array}$} & \multirow{2}{*}{$\begin{array}{c}\text { Decayed } \\
\text { Contact Dose } \\
\text { Rate }(\mathrm{mR} / \mathrm{hr})^{1} \\
\end{array}$} \\
\hline & & & Isotope & Activity (Ci) & & Isotope & Activity (Ci) & & \\
\hline & & & & & & $\mathrm{Pb}-211$ & $3.64 \mathrm{E}-08$ & & \\
\hline & & & Pm-147 & $1.46 \mathrm{E}+00$ & & Pm-147 & $8.93 \mathrm{E}-04$ & & \\
\hline & & & & & & Po-211 & $1.11 \mathrm{E}-10$ & & \\
\hline & & & & & & Po-215 & $3.64 \mathrm{E}-08$ & & \\
\hline & & & $\mathrm{Pu}-239$ & $1.36 \mathrm{E}+00$ & & $\mathrm{Pu}-239$ & $1.36 \mathrm{E}+00$ & & \\
\hline & & & & & & Ra-223 & $3.68 \mathrm{E}-08$ & & \\
\hline & & & Rh-106 & $1.87 \mathrm{E}-01$ & & Rh-106 & $8.06 \mathrm{E}-10$ & & \\
\hline & & & & & & $\mathrm{Rn}-219$ & $3.63 \mathrm{E}-08$ & & \\
\hline & & & $\mathrm{Ru}-106$ & $1.87 \mathrm{E}-01$ & & $\mathrm{Ru}-106$ & $8.14 \mathrm{E}-10$ & & \\
\hline & & & $\mathrm{Sb}-125$ & $1.04 \mathrm{E}+00$ & & $\mathrm{Sb}-125$ & $9.42 \mathrm{E}-04$ & & \\
\hline & & & & & & Sm-147 & $3.57 \mathrm{E}-11$ & & \\
\hline & & & Sr-90 & $2.33 \mathrm{E}+01$ & & Sr-90 & $1.20 \mathrm{E}+01$ & & \\
\hline & & & $\mathrm{Te}-125 \mathrm{~m}$ & $4.32 \mathrm{E}-01$ & & $\mathrm{Te}-125 \mathrm{~m}$ & $2.28 \mathrm{E}-04$ & & \\
\hline & & & & & & Th-227 & $3.58 \mathrm{E}-08$ & & \\
\hline & & & & & & Th-231 & $1.82 \mathrm{E}-04$ & & \\
\hline & & & & & & Tl-207 & $3.62 \mathrm{E}-08$ & & \\
\hline & & & $\mathrm{U}-235$ & $1.84 \mathrm{E}-04$ & & $\mathrm{U}-235$ & $1.84 \mathrm{E}-04$ & & \\
\hline & & & Y-90 & $2.33 \mathrm{E}+01$ & & $\mathrm{Y}-90$ & $1.19 \mathrm{E}+01$ & & \\
\hline \multirow[t]{14}{*}{206} & S812298 & 1981 & & & 2009 & Ac- 227 & $3.79 \mathrm{E}-08$ & $1000000+$ & $495,000 *$ \\
\hline & & & $\mathrm{Ba}-137 \mathrm{~m}$ & $2.40 \mathrm{E}+01$ & & Ba-137m & $1.25 \mathrm{E}+01$ & & \\
\hline & & & & & & Bi-211 & $3.74 \mathrm{E}-08$ & & \\
\hline & & & Cs-137 & $2.55 \mathrm{E}+01$ & & Cs-137 & $1.34 \mathrm{E}+01$ & & \\
\hline & & & Eu-155 & 4.78E-01 & & Eu-155 & $9.54 \mathrm{E}-03$ & & \\
\hline & & & & & & Fr-223 & $5.17 \mathrm{E}-10$ & & \\
\hline & & & & & & $\mathrm{Pa}-231$ & $1.12 \mathrm{E}-07$ & & \\
\hline & & & & & & $\mathrm{Pb}-211$ & $3.74 \mathrm{E}-08$ & & \\
\hline & & & Pm-147 & $1.46 \mathrm{E}+00$ & & Pm-147 & 8.93E-04 & & \\
\hline & & & & & & Po-211 & $1.14 \mathrm{E}-10$ & & \\
\hline & & & & & & Po-215 & $3.74 \mathrm{E}-08$ & & \\
\hline & & & $\mathrm{Pu}-239$ & $1.36 \mathrm{E}+00$ & & $\mathrm{Pu}-239$ & $1.36 \mathrm{E}+00$ & & \\
\hline & & & & & & $\mathrm{Ra}-223$ & $3.78 \mathrm{E}-08$ & & \\
\hline & & & Rh-106 & $1.87 \mathrm{E}-01$ & & Rh-106 & $8.06 \mathrm{E}-10$ & & \\
\hline
\end{tabular}

${ }^{1}$ Calculated decayed contact dose rate. Rounded to nearest $10 \mathrm{mR} / \mathrm{hr}$ for values to 1000 ; rounded to nearest $100 \mathrm{mR} / \mathrm{hr}$ for values $>1000$ to 10,000 ; rounded to nearest $1000 \mathrm{mR} / \mathrm{hr}$ for values $>10,000$. * Initial contact dose rate assumed to be $1,000,000 \mathrm{mR} / \mathrm{hr}$; **Initial contact dose rate assumed to be $1,010,000 \mathrm{mR} / \mathrm{hr}$.

$$
24 \text { of } 168
$$


Appendix A-4 - Initial and Decayed Radionuclide and Dose Data for Lined Shafts

\begin{tabular}{|c|c|c|c|c|c|c|c|c|c|}
\hline \multirow[b]{2}{*}{ Shaft Number } & \multirow[b]{2}{*}{ Package ID } & \multirow[b]{2}{*}{ Base Year } & \multicolumn{2}{|c|}{ Initial Isotopic Distribution } & \multirow[b]{2}{*}{ Target Year } & \multicolumn{2}{|c|}{ Decayed Isotopic Distribution } & \multirow{2}{*}{$\begin{array}{c}\text { Initial Contact } \\
\text { Dose Rate } \\
(\mathrm{mR} / \mathrm{hr})\end{array}$} & \multirow{2}{*}{$\begin{array}{c}\text { Decayed } \\
\text { Contact Dose } \\
\text { Rate }(\mathrm{mR} / \mathrm{hr})^{1} \\
\end{array}$} \\
\hline & & & Isotope & Activity (Ci) & & Isotope & Activity (Ci) & & \\
\hline & & & & & & $\mathrm{Rn}-219$ & 3.74E-08 & & \\
\hline & & & $\mathrm{Ru}-106$ & $1.87 \mathrm{E}-01$ & & $\mathrm{Ru}-106$ & $8.14 \mathrm{E}-10$ & & \\
\hline & & & $\mathrm{Sb}-125$ & $1.04 \mathrm{E}+00$ & & $\mathrm{Sb}-125$ & $9.42 \mathrm{E}-04$ & & \\
\hline & & & & & & Sm-147 & $3.57 \mathrm{E}-11$ & & \\
\hline & & & Sr-90 & $2.33 \mathrm{E}+01$ & & Sr-90 & $1.20 \mathrm{E}+01$ & & \\
\hline & & & $\mathrm{Te}-125 \mathrm{~m}$ & $4.32 \mathrm{E}-01$ & & $\mathrm{Te}-125 \mathrm{~m}$ & $2.28 \mathrm{E}-04$ & & \\
\hline & & & & & & Th-227 & $3.68 \mathrm{E}-08$ & & \\
\hline & & & & & & Th-231 & $1.87 \mathrm{E}-04$ & & \\
\hline & & & & & & Tl-207 & $3.72 \mathrm{E}-08$ & & \\
\hline & & & $\mathrm{U}-235$ & $1.89 \mathrm{E}-04$ & & $\mathrm{U}-235$ & $1.89 \mathrm{E}-04$ & & \\
\hline & & & Y-90 & $2.33 \mathrm{E}+01$ & & $\mathrm{Y}-90$ & $1.19 \mathrm{E}+01$ & & \\
\hline \multirow[t]{21}{*}{206} & S812302 & 1981 & & & 2009 & Ac-227 & $1.01 \mathrm{E}-08$ & $1010000+$ & $500,000 * *$ \\
\hline & & & Ba-137m & $1.97 \mathrm{E}+00$ & & Ba-137m & $1.03 \mathrm{E}+00$ & & \\
\hline & & & & & & Bi-211 & 9.99E-09 & & \\
\hline & & & Cs-137 & $2.09 \mathrm{E}+00$ & & Cs-137 & $1.10 \mathrm{E}+00$ & & \\
\hline & & & Eu-155 & $3.92 \mathrm{E}-02$ & & Eu-155 & 7.82E-04 & & \\
\hline & & & & & & Fr-223 & $1.38 \mathrm{E}-10$ & & \\
\hline & & & & & & $\mathrm{Pa}-231$ & $2.99 \mathrm{E}-08$ & & \\
\hline & & & & & & $\mathrm{Pb}-211$ & $1.00 \mathrm{E}-08$ & & \\
\hline & & & Pm-147 & $1.20 \mathrm{E}-01$ & & Pm-147 & 7.33E-05 & & \\
\hline & & & & & & Po-211 & $3.05 \mathrm{E}-11$ & & \\
\hline & & & & & & Po-215 & $1.00 \mathrm{E}-08$ & & \\
\hline & & & $\mathrm{Pu}-239$ & 4.96E-01 & & $\mathrm{Pu}-239$ & $4.96 \mathrm{E}-01$ & & \\
\hline & & & & & & $\mathrm{Ra}-223$ & $1.01 \mathrm{E}-08$ & & \\
\hline & & & Rh-106 & $1.54 \mathrm{E}-02$ & & Rh-106 & $6.60 \mathrm{E}-11$ & & \\
\hline & & & & & & Rn-219 & $1.00 \mathrm{E}-08$ & & \\
\hline & & & $\mathrm{Ru}-106$ & $1.54 \mathrm{E}-02$ & & Ru-106 & $6.67 \mathrm{E}-11$ & & \\
\hline & & & Sb-125 & $8.53 \mathrm{E}-02$ & & Sb-125 & 7.72E-05 & & \\
\hline & & & & & & Sm-147 & $2.93 \mathrm{E}-12$ & & \\
\hline & & & Sr-90 & $1.91 \mathrm{E}+00$ & & Sr-90 & $9.83 \mathrm{E}-01$ & & \\
\hline & & & $\mathrm{Te}-125 \mathrm{~m}$ & $3.54 \mathrm{E}-02$ & & $\mathrm{Te}-125 \mathrm{~m}$ & $1.87 \mathrm{E}-05$ & & \\
\hline & & & & & & Th-227 & 9.85E-09 & & \\
\hline
\end{tabular}

${ }^{1}$ Calculated decayed contact dose rate. Rounded to nearest $10 \mathrm{mR} / \mathrm{hr}$ for values to 1000 ; rounded to nearest $100 \mathrm{mR} / \mathrm{hr}$ for values $>1000$ to 10,000 ; rounded to nearest $1000 \mathrm{mR} / \mathrm{hr}$ for values $>10,000$. * Initial contact dose rate assumed to be $1,000,000 \mathrm{mR} / \mathrm{hr}$; **Initial contact dose rate assumed to be $1,010,000 \mathrm{mR} / \mathrm{hr}$.

$$
25 \text { of } 168
$$


Appendix A-4 - Initial and Decayed Radionuclide and Dose Data for Lined Shafts

\begin{tabular}{|c|c|c|c|c|c|c|c|c|c|}
\hline \multirow[b]{2}{*}{ Shaft Number } & \multirow[b]{2}{*}{ Package ID } & \multirow[b]{2}{*}{ Base Year } & \multicolumn{2}{|c|}{ Initial Isotopic Distribution } & \multirow[b]{2}{*}{ Target Year } & \multicolumn{2}{|c|}{ Decayed Isotopic Distribution } & \multirow{2}{*}{$\begin{array}{c}\text { Initial Contact } \\
\text { Dose Rate } \\
(\mathrm{mR} / \mathrm{hr})\end{array}$} & \multirow{2}{*}{$\begin{array}{c}\text { Decayed } \\
\text { Contact Dose } \\
\text { Rate }(\mathrm{mR} / \mathrm{hr})\end{array}$} \\
\hline & & & Isotope & Activity (Ci) & & Isotope & Activity $(\mathrm{Ci})$ & & \\
\hline & & & & & & Th-231 & $5.00 \mathrm{E}-05$ & & \\
\hline & & & & & & Tl-207 & $9.95 \mathrm{E}-09$ & & \\
\hline & & & $\mathrm{U}-235$ & $5.06 \mathrm{E}-05$ & & $\mathrm{U}-235$ & $5.06 \mathrm{E}-05$ & & \\
\hline & & & $\mathrm{Y}-90$ & $1.91 \mathrm{E}+00$ & & Y-90 & $9.72 \mathrm{E}-01$ & & \\
\hline \multirow[t]{14}{*}{206} & S812303 & 1981 & & & 2009 & Ac- 227 & $1.01 \mathrm{E}-08$ & & 0 \\
\hline & & & & & & Bi-211 & $9.96 \mathrm{E}-09$ & & \\
\hline & & & & & & Fr-223 & $1.38 \mathrm{E}-10$ & & \\
\hline & & & & & & $\mathrm{Pa}-231$ & $2.98 \mathrm{E}-08$ & & \\
\hline & & & & & & $\mathrm{Pb}-211$ & 9.97E-09 & & \\
\hline & & & & & & Po-211 & $3.04 \mathrm{E}-11$ & & \\
\hline & & & & & & Po-215 & 9.97E-09 & & \\
\hline & & & Pu-239 & $5.03 \mathrm{E}-01$ & & $\mathrm{Pu}-239$ & $5.03 \mathrm{E}-01$ & & \\
\hline & & & & & & Ra-223 & $1.01 \mathrm{E}-08$ & & \\
\hline & & & & & & $\mathrm{Rn}-219$ & $9.96 \mathrm{E}-09$ & & \\
\hline & & & & & & Th-227 & $9.81 \mathrm{E}-09$ & & \\
\hline & & & & & & Th-231 & $4.98 \mathrm{E}-05$ & & \\
\hline & & & & & & Tl-207 & 9.91E-09 & & \\
\hline & & & $\mathrm{U}-235$ & $5.04 \mathrm{E}-05$ & & $\mathrm{U}-235$ & $5.04 \mathrm{E}-05$ & & \\
\hline \multirow[t]{14}{*}{207} & S811397 & 1981 & & & 2009 & Ac- 227 & $1.76 \mathrm{E}-10$ & 60,000 & 30,000 \\
\hline & & & $\mathrm{Ba}-137 \mathrm{~m}$ & 4.79E-01 & & Ba-137m & $2.50 \mathrm{E}-01$ & & \\
\hline & & & & & & Bi-211 & $1.74 \mathrm{E}-10$ & & \\
\hline & & & Cs-137 & $5.11 \mathrm{E}-01$ & & Cs-137 & $2.67 \mathrm{E}-01$ & & \\
\hline & & & Eu-155 & $9.55 \mathrm{E}-03$ & & Eu-155 & $1.91 \mathrm{E}-04$ & & \\
\hline & & & & & & Fr-223 & $2.40 \mathrm{E}-12$ & & \\
\hline & & & & & & $\mathrm{Pa}-231$ & $5.21 \mathrm{E}-10$ & & \\
\hline & & & & & & $\mathrm{Pb}-211$ & $1.74 \mathrm{E}-10$ & & \\
\hline & & & Pm-147 & $2.92 \mathrm{E}-02$ & & Pm-147 & $1.79 \mathrm{E}-05$ & & \\
\hline & & & & & & Po-211 & $5.31 \mathrm{E}-13$ & & \\
\hline & & & & & & Po-215 & $1.74 \mathrm{E}-10$ & & \\
\hline & & & $\mathrm{Pu}-239$ & $6.20 \mathrm{E}-03$ & & $\mathrm{Pu}-239$ & $6.20 \mathrm{E}-03$ & & \\
\hline & & & & & & Ra-223 & $1.76 \mathrm{E}-10$ & & \\
\hline & & & Rh-106 & $3.74 \mathrm{E}-03$ & & Rh-106 & $1.61 \mathrm{E}-11$ & & \\
\hline
\end{tabular}

${ }^{1}$ Calculated decayed contact dose rate. Rounded to nearest $10 \mathrm{mR} / \mathrm{hr}$ for values to 1000 ; rounded to nearest $100 \mathrm{mR} / \mathrm{hr}$ for values $>1000$ to 10,000 ; rounded to nearest $1000 \mathrm{mR} / \mathrm{hr}$ for values $>10,000$. * Initial contact dose rate assumed to be $1,000,000 \mathrm{mR} / \mathrm{hr}$; **Initial contact dose rate assumed to be $1,010,000 \mathrm{mR} / \mathrm{hr}$.

$$
26 \text { of } 168
$$


Appendix A-4 - Initial and Decayed Radionuclide and Dose Data for Lined Shafts

\begin{tabular}{|c|c|c|c|c|c|c|c|c|c|}
\hline \multirow[b]{2}{*}{ Shaft Number } & \multirow[b]{2}{*}{ Package ID } & \multirow[b]{2}{*}{ Base Year } & \multicolumn{2}{|c|}{ Initial Isotopic Distribution } & \multirow[b]{2}{*}{ Target Year } & \multicolumn{2}{|c|}{ Decayed Isotopic Distribution } & \multirow{2}{*}{$\begin{array}{c}\text { Initial Contact } \\
\text { Dose Rate } \\
(\mathrm{mR} / \mathrm{hr})\end{array}$} & \multirow{2}{*}{$\begin{array}{c}\text { Decayed } \\
\text { Contact Dose } \\
\text { Rate }(\mathrm{mR} / \mathrm{hr})^{1} \\
\end{array}$} \\
\hline & & & Isotope & Activity (Ci) & & Isotope & Activity (Ci) & & \\
\hline & & & & & & Rn-219 & $1.74 \mathrm{E}-10$ & & \\
\hline & & & $\mathrm{Ru}-106$ & $3.74 \mathrm{E}-03$ & & $\mathrm{Ru}-106$ & $1.63 \mathrm{E}-11$ & & \\
\hline & & & $\mathrm{Sb}-125$ & $2.08 \mathrm{E}-02$ & & $\mathrm{Sb}-125$ & $1.88 \mathrm{E}-05$ & & \\
\hline & & & & & & Sm-147 & $7.15 \mathrm{E}-13$ & & \\
\hline & & & Sr-90 & $4.67 \mathrm{E}-01$ & & Sr-90 & $2.40 \mathrm{E}-01$ & & \\
\hline & & & Te- $125 \mathrm{~m}$ & $8.63 \mathrm{E}-03$ & & $\mathrm{Te}-125 \mathrm{~m}$ & $4.56 \mathrm{E}-06$ & & \\
\hline & & & & & & Th-227 & $1.71 \mathrm{E}-10$ & & \\
\hline & & & & & & Th-231 & $8.69 \mathrm{E}-07$ & & \\
\hline & & & & & & Tl-207 & $1.73 \mathrm{E}-10$ & & \\
\hline & & & U-235 & $8.80 \mathrm{E}-07$ & & $\mathrm{U}-235$ & $8.80 \mathrm{E}-07$ & & \\
\hline & & & Y-90 & $4.66 \mathrm{E}-01$ & & Y-90 & $2.37 \mathrm{E}-01$ & & \\
\hline \multirow[t]{21}{*}{207} & S811400 & 1981 & & & 2009 & Ac-227 & $1.76 \mathrm{E}-10$ & 290,000 & 143,000 \\
\hline & & & Ba-137m & 8.39E-01 & & $\mathrm{Ba}-137 \mathrm{~m}$ & $4.38 \mathrm{E}-01$ & & \\
\hline & & & & & & Bi-211 & $1.74 \mathrm{E}-10$ & & \\
\hline & & & Cs-137 & 8.94E-01 & & Cs-137 & $4.68 \mathrm{E}-01$ & & \\
\hline & & & $\mathrm{Eu}-155$ & $1.67 \mathrm{E}-02$ & & $\mathrm{Eu}-155$ & $3.34 \mathrm{E}-04$ & & \\
\hline & & & & & & Fr-223 & $2.40 \mathrm{E}-12$ & & \\
\hline & & & & & & $\mathrm{Pa}-231$ & $5.21 \mathrm{E}-10$ & & \\
\hline & & & & & & $\mathrm{Pb}-211$ & $1.74 \mathrm{E}-10$ & & \\
\hline & & & Pm-147 & $5.10 \mathrm{E}-02$ & & Pm-147 & $3.13 \mathrm{E}-05$ & & \\
\hline & & & & & & Po-211 & $5.31 \mathrm{E}-13$ & & \\
\hline & & & & & & Po-215 & $1.74 \mathrm{E}-10$ & & \\
\hline & & & $\mathrm{Pu}-239$ & $6.20 \mathrm{E}-03$ & & $\mathrm{Pu}-239$ & $6.20 \mathrm{E}-03$ & & \\
\hline & & & & & & Ra-223 & $1.76 \mathrm{E}-10$ & & \\
\hline & & & Rh-106 & $6.55 \mathrm{E}-03$ & & Rh-106 & $2.82 \mathrm{E}-11$ & & \\
\hline & & & & & & Rn-219 & $1.74 \mathrm{E}-10$ & & \\
\hline & & & $\mathrm{Ru}-106$ & $6.55 \mathrm{E}-03$ & & $\mathrm{Ru}-106$ & $2.85 \mathrm{E}-11$ & & \\
\hline & & & Sb-125 & $3.64 \mathrm{E}-02$ & & $\mathrm{Sb}-125$ & $3.30 \mathrm{E}-05$ & & \\
\hline & & & & & & Sm-147 & $1.25 \mathrm{E}-12$ & & \\
\hline & & & Sr-90 & 8.17E-01 & & Sr-90 & $4.20 \mathrm{E}-01$ & & \\
\hline & & & $\mathrm{Te}-125 \mathrm{~m}$ & $1.51 \mathrm{E}-02$ & & Te- $125 \mathrm{~m}$ & $7.98 \mathrm{E}-06$ & & \\
\hline & & & & & & Th-227 & $1.71 \mathrm{E}-10$ & & \\
\hline
\end{tabular}

${ }^{1}$ Calculated decayed contact dose rate. Rounded to nearest $10 \mathrm{mR} / \mathrm{hr}$ for values to 1000 ; rounded to nearest $100 \mathrm{mR} / \mathrm{hr}$ for values $>1000$ to 10,000 ; rounded to nearest $1000 \mathrm{mR} / \mathrm{hr}$ for values $>10,000$. * Initial contact dose rate assumed to be $1,000,000 \mathrm{mR} / \mathrm{hr}$; **Initial contact dose rate assumed to be $1,010,000 \mathrm{mR} / \mathrm{hr}$.

$$
27 \text { of } 168
$$


Appendix A-4 - Initial and Decayed Radionuclide and Dose Data for Lined Shafts

\begin{tabular}{|c|c|c|c|c|c|c|c|c|c|}
\hline \multirow[b]{2}{*}{ Shaft Number } & \multirow[b]{2}{*}{ Package ID } & \multirow[b]{2}{*}{ Base Year } & \multicolumn{2}{|c|}{ Initial Isotopic Distribution } & \multirow[b]{2}{*}{ Target Year } & \multicolumn{2}{|c|}{ Decayed Isotopic Distribution } & \multirow{2}{*}{$\begin{array}{c}\text { Initial Contact } \\
\text { Dose Rate } \\
(\mathrm{mR} / \mathrm{hr}) \\
\end{array}$} & \multirow{2}{*}{$\begin{array}{c}\text { Decayed } \\
\text { Contact Dose } \\
\text { Rate }(\mathrm{mR} / \mathrm{hr})^{1} \\
\end{array}$} \\
\hline & & & Isotope & Activity (Ci) & & Isotope & Activity (Ci) & & \\
\hline & & & & & & Th-231 & 8.69E-07 & & \\
\hline & & & & & & Tl-207 & $1.73 \mathrm{E}-10$ & & \\
\hline & & & $\mathrm{U}-235$ & $8.80 \mathrm{E}-07$ & & $\mathrm{U}-235$ & $8.80 \mathrm{E}-07$ & & \\
\hline & & & Y-90 & $8.16 \mathrm{E}-01$ & & Y-90 & 4.15E-01 & & \\
\hline \multirow[t]{25}{*}{207} & S811401 & 1981 & & & 2009 & Ac- 227 & $1.87 \mathrm{E}-09$ & 170,000 & 84,000 \\
\hline & & & Ba-137m & $1.23 \mathrm{E}+00$ & & Ba-137m & $6.44 \mathrm{E}-01$ & & \\
\hline & & & & & & Bi-211 & $1.84 \mathrm{E}-09$ & & \\
\hline & & & Cs-137 & $1.31 \mathrm{E}+00$ & & Cs-137 & $6.89 \mathrm{E}-01$ & & \\
\hline & & & Eu-155 & $2.46 \mathrm{E}-02$ & & Eu-155 & 4.91E-04 & & \\
\hline & & & & & & Fr-223 & $2.55 \mathrm{E}-11$ & & \\
\hline & & & & & & $\mathrm{Pa}-231$ & $5.52 \mathrm{E}-09$ & & \\
\hline & & & & & & $\mathrm{Pb}-211$ & $1.85 \mathrm{E}-09$ & & \\
\hline & & & Pm-147 & 7.51E-02 & & Pm-147 & 4.60E-05 & & \\
\hline & & & & & & Po-211 & $5.62 \mathrm{E}-12$ & & \\
\hline & & & & & & Po-215 & $1.85 \mathrm{E}-09$ & & \\
\hline & & & $\mathrm{Pu}-239$ & $6.57 \mathrm{E}-02$ & & $\mathrm{Pu}-239$ & $6.57 \mathrm{E}-02$ & & \\
\hline & & & & & & Ra-223 & $1.87 \mathrm{E}-09$ & & \\
\hline & & & Rh-106 & $9.64 \mathrm{E}-03$ & & Rh-106 & $4.15 \mathrm{E}-11$ & & \\
\hline & & & & & & Rn-219 & $1.84 \mathrm{E}-09$ & & \\
\hline & & & Ru-106 & $9.64 \mathrm{E}-03$ & & Ru-106 & 4.19E-11 & & \\
\hline & & & Sb-125 & $5.35 \mathrm{E}-02$ & & Sb-125 & $4.85 \mathrm{E}-05$ & & \\
\hline & & & & & & Sm-147 & $1.84 \mathrm{E}-12$ & & \\
\hline & & & Sr-90 & $1.20 \mathrm{E}+00$ & & Sr-90 & $6.17 \mathrm{E}-01$ & & \\
\hline & & & $\mathrm{Te}-125 \mathrm{~m}$ & $2.22 \mathrm{E}-02$ & & Te-125m & $1.17 \mathrm{E}-05$ & & \\
\hline & & & & & & Th-227 & $1.82 \mathrm{E}-09$ & & \\
\hline & & & & & & Th-231 & $9.21 \mathrm{E}-06$ & & \\
\hline & & & & & & Tl-207 & $1.83 \mathrm{E}-09$ & & \\
\hline & & & U-235 & $9.33 \mathrm{E}-06$ & & U-235 & 9.33E-06 & & \\
\hline & & & Y-90 & $1.20 \mathrm{E}+00$ & & Y-90 & $6.10 \mathrm{E}-01$ & & \\
\hline \multirow[t]{3}{*}{207} & S811406 & 1981 & & & 2009 & Ac-227 & $1.76 \mathrm{E}-10$ & 150,000 & 74,000 \\
\hline & & & Ba-137m & $5.99 \mathrm{E}-01$ & & Ba-137m & $3.13 \mathrm{E}-01$ & & \\
\hline & & & & & & Bi-211 & $1.74 \mathrm{E}-10$ & & \\
\hline
\end{tabular}

${ }^{1}$ Calculated decayed contact dose rate. Rounded to nearest $10 \mathrm{mR} / \mathrm{hr}$ for values to 1000 ; rounded to nearest $100 \mathrm{mR} / \mathrm{hr}$ for values $>1000$ to 10,000 ; rounded to nearest $1000 \mathrm{mR} / \mathrm{hr}$ for values $>10,000$. * Initial contact dose rate assumed to be $1,000,000 \mathrm{mR} / \mathrm{hr}$; **Initial contact dose rate assumed to be $1,010,000 \mathrm{mR} / \mathrm{hr}$.

$$
28 \text { of } 168
$$


Appendix A-4 - Initial and Decayed Radionuclide and Dose Data for Lined Shafts

\begin{tabular}{|c|c|c|c|c|c|c|c|c|c|}
\hline \multirow[b]{2}{*}{ Shaft Number } & \multirow[b]{2}{*}{ Package ID } & \multirow[b]{2}{*}{ Base Year } & \multicolumn{2}{|c|}{ Initial Isotopic Distribution } & \multirow[b]{2}{*}{ Target Year } & \multicolumn{2}{|c|}{ Decayed Isotopic Distribution } & \multirow{2}{*}{$\begin{array}{c}\text { Initial Contact } \\
\text { Dose Rate } \\
(\mathrm{mR} / \mathrm{hr})\end{array}$} & \multirow{2}{*}{$\begin{array}{c}\text { Decayed } \\
\text { Contact Dose } \\
\text { Rate }(\mathrm{mR} / \mathrm{hr})^{1} \\
\end{array}$} \\
\hline & & & Isotope & Activity (Ci) & & Isotope & Activity (Ci) & & \\
\hline & & & Cs-137 & $6.38 \mathrm{E}-01$ & & Cs-137 & 3.34E-01 & & \\
\hline & & & Eu-155 & $1.19 \mathrm{E}-02$ & & Eu-155 & $2.39 \mathrm{E}-04$ & & \\
\hline & & & & & & Fr-223 & $2.40 \mathrm{E}-12$ & & \\
\hline & & & & & & $\mathrm{Pa}-231$ & $5.21 \mathrm{E}-10$ & & \\
\hline & & & & & & $\mathrm{Pb}-211$ & $1.74 \mathrm{E}-10$ & & \\
\hline & & & Pm-147 & $3.65 \mathrm{E}-02$ & & Pm-147 & $2.23 \mathrm{E}-05$ & & \\
\hline & & & & & & Po-211 & $5.31 \mathrm{E}-13$ & & \\
\hline & & & & & & Po-215 & $1.74 \mathrm{E}-10$ & & \\
\hline & & & $\mathrm{Pu}-239$ & $6.20 \mathrm{E}-03$ & & $\mathrm{Pu}-239$ & $6.20 \mathrm{E}-03$ & & \\
\hline & & & & & & Ra-223 & $1.76 \mathrm{E}-10$ & & \\
\hline & & & Rh-106 & $4.68 \mathrm{E}-03$ & & Rh-106 & $2.01 \mathrm{E}-11$ & & \\
\hline & & & & & & Rn-219 & $1.74 \mathrm{E}-10$ & & \\
\hline & & & $\mathrm{Ru}-106$ & $4.68 \mathrm{E}-03$ & & $\mathrm{Ru}-106$ & $2.03 \mathrm{E}-11$ & & \\
\hline & & & Sb-125 & $2.60 \mathrm{E}-02$ & & $\mathrm{Sb}-125$ & $2.35 \mathrm{E}-05$ & & \\
\hline & & & & & & Sm-147 & 8.94E-13 & & \\
\hline & & & Sr-90 & $5.84 \mathrm{E}-01$ & & Sr-90 & $3.00 \mathrm{E}-01$ & & \\
\hline & & & $\mathrm{Te}-125 \mathrm{~m}$ & $1.08 \mathrm{E}-02$ & & $\mathrm{Te}-125 \mathrm{~m}$ & $5.70 \mathrm{E}-06$ & & \\
\hline & & & & & & Th-227 & $1.71 \mathrm{E}-10$ & & \\
\hline & & & & & & Th-231 & 8.69E-07 & & \\
\hline & & & & & & Tl-207 & $1.73 \mathrm{E}-10$ & & \\
\hline & & & U-235 & $8.80 \mathrm{E}-07$ & & U-235 & $8.80 \mathrm{E}-07$ & & \\
\hline & & & Y-90 & $5.83 \mathrm{E}-01$ & & Y-90 & $2.96 \mathrm{E}-01$ & & \\
\hline \multirow[t]{10}{*}{207} & S814978 & 1981 & & & 2009 & Ac-227 & $1.06 \mathrm{E}-10$ & 3,600 & 1,800 \\
\hline & & & $\mathrm{Ba}-137 \mathrm{~m}$ & 4.31E-02 & & Ba-137m & $2.25 \mathrm{E}-02$ & & \\
\hline & & & & & & Bi-211 & $1.04 \mathrm{E}-10$ & & \\
\hline & & & Cs-137 & $4.60 \mathrm{E}-02$ & & Cs-137 & $2.41 \mathrm{E}-02$ & & \\
\hline & & & Eu-155 & $8.60 \mathrm{E}-04$ & & Eu-155 & $1.72 \mathrm{E}-05$ & & \\
\hline & & & & & & Fr-223 & $1.44 \mathrm{E}-12$ & & \\
\hline & & & & & & $\mathrm{Pa}-231$ & $3.12 \mathrm{E}-10$ & & \\
\hline & & & & & & $\mathrm{Pb}-211$ & $1.04 \mathrm{E}-10$ & & \\
\hline & & & Pm-147 & $2.63 \mathrm{E}-03$ & & Pm-147 & $1.61 \mathrm{E}-06$ & & \\
\hline & & & & & & Ро-211 & $3.18 \mathrm{E}-13$ & & \\
\hline
\end{tabular}

${ }^{1}$ Calculated decayed contact dose rate. Rounded to nearest $10 \mathrm{mR} / \mathrm{hr}$ for values to 1000 ; rounded to nearest $100 \mathrm{mR} / \mathrm{hr}$ for values $>1000$ to 10,000 ; rounded to nearest $1000 \mathrm{mR} / \mathrm{hr}$ for values $>10,000$. * Initial contact dose rate assumed to be $1,000,000 \mathrm{mR} / \mathrm{hr}$; **Initial contact dose rate assumed to be $1,010,000 \mathrm{mR} / \mathrm{hr}$.

$$
29 \text { of } 168
$$


Appendix A-4 - Initial and Decayed Radionuclide and Dose Data for Lined Shafts

\begin{tabular}{|c|c|c|c|c|c|c|c|c|c|}
\hline \multirow[b]{2}{*}{ Shaft Number } & \multirow[b]{2}{*}{ Package ID } & \multirow[b]{2}{*}{ Base Year } & \multicolumn{2}{|c|}{ Initial Isotopic Distribution } & \multirow[b]{2}{*}{ Target Year } & \multicolumn{2}{|c|}{ Decayed Isotopic Distribution } & \multirow{2}{*}{$\begin{array}{c}\text { Initial Contact } \\
\text { Dose Rate } \\
(\mathrm{mR} / \mathrm{hr})\end{array}$} & \multirow{2}{*}{$\begin{array}{c}\text { Decayed } \\
\text { Contact Dose } \\
\text { Rate }(\mathrm{mR} / \mathrm{hr})^{1}\end{array}$} \\
\hline & & & Isotope & Activity (Ci) & & Isotope & Activity (Ci) & & \\
\hline & & & & & & Po-215 & $1.04 \mathrm{E}-10$ & & \\
\hline & & & $\mathrm{Pu}-239$ & $3.72 \mathrm{E}-03$ & & $\mathrm{Pu}-239$ & $3.72 \mathrm{E}-03$ & & \\
\hline & & & & & & $\mathrm{Ra}-223$ & $1.06 \mathrm{E}-10$ & & \\
\hline & & & $\mathrm{Rh}-106$ & $3.37 \mathrm{E}-04$ & & Rh-106 & $1.45 \mathrm{E}-12$ & & \\
\hline & & & & & & Rn-219 & $1.04 \mathrm{E}-10$ & & \\
\hline & & & $\mathrm{Ru}-106$ & 3.37E-04 & & $\mathrm{Ru}-106$ & $1.46 \mathrm{E}-12$ & & \\
\hline & & & $\mathrm{Sb}-125$ & $1.87 \mathrm{E}-03$ & & $\mathrm{Sb}-125$ & $1.70 \mathrm{E}-06$ & & \\
\hline & & & & & & Sm-147 & $6.43 \mathrm{E}-14$ & & \\
\hline & & & Sr-90 & $4.20 \mathrm{E}-02$ & & Sr-90 & $2.16 \mathrm{E}-02$ & & \\
\hline & & & $\mathrm{Te}-125 \mathrm{~m}$ & 7.77E-04 & & $\mathrm{Te}-125 \mathrm{~m}$ & 4.10E-07 & & \\
\hline & & & & & & Th-227 & $1.03 \mathrm{E}-10$ & & \\
\hline & & & & & & Th-231 & $5.22 \mathrm{E}-07$ & & \\
\hline & & & & & & Tl-207 & $1.04 \mathrm{E}-10$ & & \\
\hline & & & $\mathrm{U}-235$ & $5.28 \mathrm{E}-07$ & & $\mathrm{U}-235$ & $5.28 \mathrm{E}-07$ & & \\
\hline & & & Y-90 & 4.20E-02 & & Y-90 & $2.13 \mathrm{E}-02$ & & \\
\hline \multirow[t]{17}{*}{208} & S810794 & 1981 & & & 2009 & Ac- 227 & 4.47E-08 & $1000000+$ & $495,000 *$ \\
\hline & & & Ba-137m & $2.40 \mathrm{E}+01$ & & Ba-137m & $1.25 \mathrm{E}+01$ & & \\
\hline & & & & & & Bi-211 & 4.41E-08 & & \\
\hline & & & Cs-137 & $2.55 \mathrm{E}+01$ & & Cs-137 & $1.34 \mathrm{E}+01$ & & \\
\hline & & & Eu-155 & $4.78 \mathrm{E}-01$ & & Eu-155 & $9.54 \mathrm{E}-03$ & & \\
\hline & & & & & & Fr-223 & $6.10 \mathrm{E}-10$ & & \\
\hline & & & & & & $\mathrm{Pa}-231$ & $1.32 \mathrm{E}-07$ & & \\
\hline & & & & & & $\mathrm{Pb}-211$ & $4.42 \mathrm{E}-08$ & & \\
\hline & & & Pm-147 & $1.46 \mathrm{E}+00$ & & Pm-147 & 8.93E-04 & & \\
\hline & & & & & & Po-211 & $1.35 \mathrm{E}-10$ & & \\
\hline & & & & & & Po-215 & 4.42E-08 & & \\
\hline & & & $\mathrm{Pu}-239$ & $1.75 \mathrm{E}+00$ & & $\mathrm{Pu}-239$ & $1.75 \mathrm{E}+00$ & & \\
\hline & & & & & & Ra-223 & $4.47 \mathrm{E}-08$ & & \\
\hline & & & Rh-106 & $1.87 \mathrm{E}-01$ & & Rh-106 & $8.06 \mathrm{E}-10$ & & \\
\hline & & & & & & Rn-219 & $4.41 \mathrm{E}-08$ & & \\
\hline & & & Ru-106 & $1.87 \mathrm{E}-01$ & & Ru-106 & $8.14 \mathrm{E}-10$ & & \\
\hline & & & Sb-125 & $1.04 \mathrm{E}+00$ & & Sb-125 & $9.42 \mathrm{E}-04$ & & \\
\hline
\end{tabular}

${ }^{1}$ Calculated decayed contact dose rate. Rounded to nearest $10 \mathrm{mR} / \mathrm{hr}$ for values to 1000 ; rounded to nearest $100 \mathrm{mR} / \mathrm{hr}$ for values $>1000$ to 10,000 ; rounded to nearest $1000 \mathrm{mR} / \mathrm{hr}$ for values $>10,000$. * Initial contact dose rate assumed to be $1,000,000 \mathrm{mR} / \mathrm{hr}$; **Initial contact dose rate assumed to be $1,010,000 \mathrm{mR} / \mathrm{hr}$.

$$
30 \text { of } 168
$$


Appendix A-4 - Initial and Decayed Radionuclide and Dose Data for Lined Shafts

\begin{tabular}{|c|c|c|c|c|c|c|c|c|c|}
\hline \multirow[b]{2}{*}{ Shaft Number } & \multirow[b]{2}{*}{ Package ID } & \multirow[b]{2}{*}{ Base Year } & \multicolumn{2}{|c|}{ Initial Isotopic Distribution } & \multirow[b]{2}{*}{ Target Year } & \multicolumn{2}{|c|}{ Decayed Isotopic Distribution } & \multirow{2}{*}{$\begin{array}{c}\text { Initial Contact } \\
\text { Dose Rate } \\
(\mathrm{mR} / \mathrm{hr})\end{array}$} & \multirow{2}{*}{$\begin{array}{c}\text { Decayed } \\
\text { Contact Dose } \\
\text { Rate }(\mathrm{mR} / \mathrm{hr})^{1}\end{array}$} \\
\hline & & & Isotope & Activity (Ci) & & Isotope & Activity (Ci) & & \\
\hline & & & & & & Sm-147 & $3.57 \mathrm{E}-11$ & & \\
\hline & & & Sr-90 & $2.33 \mathrm{E}+01$ & & Sr-90 & $1.20 \mathrm{E}+01$ & & \\
\hline & & & $\mathrm{Te}-125 \mathrm{~m}$ & $4.32 \mathrm{E}-01$ & & Te-125m & $2.28 \mathrm{E}-04$ & & \\
\hline & & & & & & Th-227 & $4.35 \mathrm{E}-08$ & & \\
\hline & & & & & & Th-231 & $2.21 \mathrm{E}-04$ & & \\
\hline & & & & & & Tl-207 & 4.39E-08 & & \\
\hline & & & $\mathrm{U}-235$ & $2.23 \mathrm{E}-04$ & & $\mathrm{U}-235$ & $2.23 \mathrm{E}-04$ & & \\
\hline & & & Y-90 & $2.33 \mathrm{E}+01$ & & Y-90 & $1.19 \mathrm{E}+01$ & & \\
\hline \multirow[t]{24}{*}{208} & S810802 & 1981 & & & 2009 & Ac-227 & $1.76 \mathrm{E}-10$ & 1,000 & 490 \\
\hline & & & Ba-137m & $1.44 \mathrm{E}-02$ & & $\mathrm{Ba}-137 \mathrm{~m}$ & $7.50 \mathrm{E}-03$ & & \\
\hline & & & & & & Bi-211 & $1.74 \mathrm{E}-10$ & & \\
\hline & & & Cs-137 & $1.53 \mathrm{E}-02$ & & Cs-137 & $8.02 \mathrm{E}-03$ & & \\
\hline & & & Eu-155 & $2.87 \mathrm{E}-04$ & & Eu-155 & $5.72 \mathrm{E}-06$ & & \\
\hline & & & & & & Fr-223 & $2.40 \mathrm{E}-12$ & & \\
\hline & & & & & & $\mathrm{Pa}-231$ & $5.21 \mathrm{E}-10$ & & \\
\hline & & & & & & $\mathrm{Pb}-211$ & $1.74 \mathrm{E}-10$ & & \\
\hline & & & Pm-147 & $8.75 \mathrm{E}-04$ & & Pm-147 & $5.36 \mathrm{E}-07$ & & \\
\hline & & & & & & Po-211 & $5.31 \mathrm{E}-13$ & & \\
\hline & & & & & & Po-215 & $1.74 \mathrm{E}-10$ & & \\
\hline & & & Pu-239 & $6.20 \mathrm{E}-03$ & & $\mathrm{Pu}-239$ & $6.20 \mathrm{E}-03$ & & \\
\hline & & & & & & Ra-223 & $1.76 \mathrm{E}-10$ & & \\
\hline & & & Rh-106 & $1.12 \mathrm{E}-04$ & & Rh-106 & $4.83 \mathrm{E}-13$ & & \\
\hline & & & & & & Rn-219 & $1.74 \mathrm{E}-10$ & & \\
\hline & & & $\mathrm{Ru}-106$ & $1.12 \mathrm{E}-04$ & & Ru-106 & $4.88 \mathrm{E}-13$ & & \\
\hline & & & Sb-125 & $6.24 \mathrm{E}-04$ & & Sb-125 & $5.65 \mathrm{E}-07$ & & \\
\hline & & & & & & Sm-147 & $2.14 \mathrm{E}-14$ & & \\
\hline & & & Sr-90 & $1.40 \mathrm{E}-02$ & & Sr-90 & 7.19E-03 & & \\
\hline & & & $\mathrm{Te}-125 \mathrm{~m}$ & $2.59 \mathrm{E}-04$ & & $\mathrm{Te}-125 \mathrm{~m}$ & $1.37 \mathrm{E}-07$ & & \\
\hline & & & & & & Th-227 & $1.71 \mathrm{E}-10$ & & \\
\hline & & & & & & Th-231 & 8.69E-07 & & \\
\hline & & & & & & T1-207 & $1.73 \mathrm{E}-10$ & & \\
\hline & & & U-235 & $8.80 \mathrm{E}-07$ & & U-235 & $8.80 \mathrm{E}-07$ & & \\
\hline
\end{tabular}

${ }^{1}$ Calculated decayed contact dose rate. Rounded to nearest $10 \mathrm{mR} / \mathrm{hr}$ for values to 1000 ; rounded to nearest $100 \mathrm{mR} / \mathrm{hr}$ for values $>1000$ to 10,000 ; rounded to nearest $1000 \mathrm{mR} / \mathrm{hr}$ for values $>10,000$. * Initial contact dose rate assumed to be $1,000,000 \mathrm{mR} / \mathrm{hr}$; **Initial contact dose rate assumed to be $1,010,000 \mathrm{mR} / \mathrm{hr}$.

$$
31 \text { of } 168
$$


Appendix A-4 - Initial and Decayed Radionuclide and Dose Data for Lined Shafts

\begin{tabular}{|c|c|c|c|c|c|c|c|c|c|}
\hline \multirow[b]{2}{*}{ Shaft Number } & \multirow[b]{2}{*}{ Package ID } & \multirow[b]{2}{*}{ Base Year } & \multicolumn{2}{|c|}{ Initial Isotopic Distribution } & \multirow[b]{2}{*}{ Target Year } & \multicolumn{2}{|c|}{ Decayed Isotopic Distribution } & \multirow{2}{*}{$\begin{array}{c}\text { Initial Contact } \\
\text { Dose Rate } \\
(\mathrm{mR} / \mathrm{hr})\end{array}$} & \multirow{2}{*}{$\begin{array}{c}\text { Decayed } \\
\text { Contact Dose } \\
\text { Rate }(\mathrm{mR} / \mathrm{hr})\end{array}$} \\
\hline & & & Isotope & Activity (Ci) & & Isotope & Activity (Ci) & & \\
\hline & & & $\mathrm{Y}-90$ & $1.40 \mathrm{E}-02$ & & $\mathrm{Y}-90$ & $7.11 \mathrm{E}-03$ & & \\
\hline \multirow[t]{25}{*}{208} & S811405 & 1981 & & & 2009 & Ac-227 & $8.81 \mathrm{E}-10$ & 80,000 & 40,000 \\
\hline & & & Ba-137m & 4.79E-01 & & $\mathrm{Ba}-137 \mathrm{~m}$ & $2.50 \mathrm{E}-01$ & & \\
\hline & & & & & & Bi-211 & $8.69 \mathrm{E}-10$ & & \\
\hline & & & Cs-137 & $5.11 \mathrm{E}-01$ & & Cs-137 & $2.67 \mathrm{E}-01$ & & \\
\hline & & & Eu-155 & $9.55 \mathrm{E}-03$ & & Eu-155 & $1.91 \mathrm{E}-04$ & & \\
\hline & & & & & & Fr-223 & $1.20 \mathrm{E}-11$ & & \\
\hline & & & & & & $\mathrm{Pa}-231$ & $2.60 \mathrm{E}-09$ & & \\
\hline & & & & & & $\mathrm{Pb}-211$ & $8.70 \mathrm{E}-10$ & & \\
\hline & & & Pm-147 & $2.92 \mathrm{E}-02$ & & Pm-147 & $1.79 \mathrm{E}-05$ & & \\
\hline & & & & & & Po-211 & $2.65 \mathrm{E}-12$ & & \\
\hline & & & & & & Po-215 & $8.71 \mathrm{E}-10$ & & \\
\hline & & & $\mathrm{Pu}-239$ & $3.10 \mathrm{E}-02$ & & $\mathrm{Pu}-239$ & $3.10 \mathrm{E}-02$ & & \\
\hline & & & & & & Ra-223 & $8.80 \mathrm{E}-10$ & & \\
\hline & & & Rh-106 & $3.74 \mathrm{E}-03$ & & Rh-106 & $1.61 \mathrm{E}-11$ & & \\
\hline & & & & & & $\mathrm{Rn}-219$ & $8.69 \mathrm{E}-10$ & & \\
\hline & & & Ru-106 & $3.74 \mathrm{E}-03$ & & $\mathrm{Ru}-106$ & $1.63 \mathrm{E}-11$ & & \\
\hline & & & Sb-125 & $2.08 \mathrm{E}-02$ & & Sb-125 & $1.88 \mathrm{E}-05$ & & \\
\hline & & & & & & Sm-147 & $7.15 \mathrm{E}-13$ & & \\
\hline & & & Sr-90 & $4.67 \mathrm{E}-01$ & & Sr-90 & $2.40 \mathrm{E}-01$ & & \\
\hline & & & $\mathrm{Te}-125 \mathrm{~m}$ & $8.63 \mathrm{E}-03$ & & $\mathrm{Te}-125 \mathrm{~m}$ & $4.56 \mathrm{E}-06$ & & \\
\hline & & & & & & Th-227 & $8.57 \mathrm{E}-10$ & & \\
\hline & & & & & & Th-231 & $4.35 \mathrm{E}-06$ & & \\
\hline & & & & & & T1-207 & $8.65 \mathrm{E}-10$ & & \\
\hline & & & U-235 & $4.40 \mathrm{E}-06$ & & U-235 & $4.40 \mathrm{E}-06$ & & \\
\hline & & & $\mathrm{Y}-90$ & $4.66 \mathrm{E}-01$ & & $\mathrm{Y}-90$ & $2.37 \mathrm{E}-01$ & & \\
\hline \multirow[t]{6}{*}{208} & S811408 & 1981 & & & 2009 & Ac- 227 & $1.76 \mathrm{E}-10$ & 1,500 & 740 \\
\hline & & & $\mathrm{Ba}-137 \mathrm{~m}$ & $1.92 \mathrm{E}-02$ & & $\mathrm{Ba}-137 \mathrm{~m}$ & $1.00 \mathrm{E}-02$ & & \\
\hline & & & & & & Bi-211 & $1.74 \mathrm{E}-10$ & & \\
\hline & & & Cs-137 & $2.04 \mathrm{E}-02$ & & Cs-137 & $1.07 \mathrm{E}-02$ & & \\
\hline & & & Eu-155 & $3.82 \mathrm{E}-04$ & & Eu-155 & $7.63 \mathrm{E}-06$ & & \\
\hline & & & & & & Fr-223 & $2.40 \mathrm{E}-12$ & & \\
\hline
\end{tabular}

${ }^{1}$ Calculated decayed contact dose rate. Rounded to nearest $10 \mathrm{mR} / \mathrm{hr}$ for values to 1000 ; rounded to nearest $100 \mathrm{mR} / \mathrm{hr}$ for values $>1000$ to 10,000 ; rounded to nearest $1000 \mathrm{mR} / \mathrm{hr}$ for values $>10,000$. * Initial contact dose rate assumed to be $1,000,000 \mathrm{mR} / \mathrm{hr}$; **Initial contact dose rate assumed to be $1,010,000 \mathrm{mR} / \mathrm{hr}$.

$$
32 \text { of } 168
$$


Appendix A-4 - Initial and Decayed Radionuclide and Dose Data for Lined Shafts

\begin{tabular}{|c|c|c|c|c|c|c|c|c|c|}
\hline \multirow[b]{2}{*}{ Shaft Number } & \multirow[b]{2}{*}{ Package ID } & \multirow[b]{2}{*}{ Base Year } & \multicolumn{2}{|c|}{ Initial Isotopic Distribution } & \multirow[b]{2}{*}{ Target Year } & \multicolumn{2}{|c|}{ Decayed Isotopic Distribution } & \multirow{2}{*}{$\begin{array}{c}\text { Initial Contact } \\
\text { Dose Rate } \\
(\mathrm{mR} / \mathrm{hr})\end{array}$} & \multirow{2}{*}{$\begin{array}{c}\text { Decayed } \\
\text { Contact Dose } \\
\text { Rate }(\mathrm{mR} / \mathrm{hr})^{1} \\
\end{array}$} \\
\hline & & & Isotope & Activity (Ci) & & Isotope & Activity (Ci) & & \\
\hline & & & & & & $\mathrm{Pa}-231$ & $5.21 \mathrm{E}-10$ & & \\
\hline & & & & & & $\mathrm{Pb}-211$ & $1.74 \mathrm{E}-10$ & & \\
\hline & & & Pm-147 & $1.17 \mathrm{E}-03$ & & Pm-147 & $7.15 \mathrm{E}-07$ & & \\
\hline & & & & & & Po-211 & $5.31 \mathrm{E}-13$ & & \\
\hline & & & & & & Po-215 & $1.74 \mathrm{E}-10$ & & \\
\hline & & & $\mathrm{Pu}-239$ & $6.20 \mathrm{E}-03$ & & $\mathrm{Pu}-239$ & $6.20 \mathrm{E}-03$ & & \\
\hline & & & & & & Ra-223 & $1.76 \mathrm{E}-10$ & & \\
\hline & & & $\mathrm{Rh}-106$ & $1.50 \mathrm{E}-04$ & & Rh-106 & $6.44 \mathrm{E}-13$ & & \\
\hline & & & & & & Rn-219 & $1.74 \mathrm{E}-10$ & & \\
\hline & & & $\mathrm{Ru}-106$ & $1.50 \mathrm{E}-04$ & & $\mathrm{Ru}-106$ & $6.51 \mathrm{E}-13$ & & \\
\hline & & & Sb-125 & $8.32 \mathrm{E}-04$ & & Sb-125 & $7.53 \mathrm{E}-07$ & & \\
\hline & & & & & & Sm-147 & $2.86 \mathrm{E}-14$ & & \\
\hline & & & Sr-90 & $1.87 \mathrm{E}-02$ & & Sr-90 & $9.59 \mathrm{E}-03$ & & \\
\hline & & & $\mathrm{Te}-125 \mathrm{~m}$ & $3.45 \mathrm{E}-04$ & & $\mathrm{Te}-125 \mathrm{~m}$ & $1.82 \mathrm{E}-07$ & & \\
\hline & & & & & & Th-227 & $1.71 \mathrm{E}-10$ & & \\
\hline & & & & & & Th-231 & $8.69 \mathrm{E}-07$ & & \\
\hline & & & & & & Tl-207 & $1.73 \mathrm{E}-10$ & & \\
\hline & & & $\mathrm{U}-235$ & $8.80 \mathrm{E}-07$ & & $\mathrm{U}-235$ & $8.80 \mathrm{E}-07$ & & \\
\hline & & & Y-90 & $1.87 \mathrm{E}-02$ & & Y-90 & $9.48 \mathrm{E}-03$ & & \\
\hline \multirow[t]{13}{*}{208} & S811409 & 1981 & & & 2009 & Ac-227 & $1.76 \mathrm{E}-10$ & 32,000 & 16,000 \\
\hline & & & Ba-137m & $5.03 \mathrm{E}-01$ & & Ba-137m & $2.63 \mathrm{E}-01$ & & \\
\hline & & & & & & $\mathrm{Bi}-211$ & $1.74 \mathrm{E}-10$ & & \\
\hline & & & Cs-137 & $5.36 \mathrm{E}-01$ & & Cs-137 & $2.81 \mathrm{E}-01$ & & \\
\hline & & & Eu-155 & $1.00 \mathrm{E}-02$ & & Eu-155 & $2.00 \mathrm{E}-04$ & & \\
\hline & & & & & & Fr-223 & $2.40 \mathrm{E}-12$ & & \\
\hline & & & & & & $\mathrm{Pa}-231$ & $5.21 \mathrm{E}-10$ & & \\
\hline & & & & & & $\mathrm{Pb}-211$ & $1.74 \mathrm{E}-10$ & & \\
\hline & & & Pm-147 & $3.06 \mathrm{E}-02$ & & Pm-147 & $1.88 \mathrm{E}-05$ & & \\
\hline & & & & & & Po-211 & $5.31 \mathrm{E}-13$ & & \\
\hline & & & & & & Po-215 & $1.74 \mathrm{E}-10$ & & \\
\hline & & & Pu-239 & $6.20 \mathrm{E}-03$ & & $\mathrm{Pu}-239$ & $6.20 \mathrm{E}-03$ & & \\
\hline & & & & & & Ra-223 & $1.76 \mathrm{E}-10$ & & \\
\hline
\end{tabular}

${ }^{1}$ Calculated decayed contact dose rate. Rounded to nearest $10 \mathrm{mR} / \mathrm{hr}$ for values to 1000 ; rounded to nearest $100 \mathrm{mR} / \mathrm{hr}$ for values $>1000$ to 10,000 ; rounded to nearest $1000 \mathrm{mR} / \mathrm{hr}$ for values $>10,000$. * Initial contact dose rate assumed to be $1,000,000 \mathrm{mR} / \mathrm{hr}$; **Initial contact dose rate assumed to be $1,010,000 \mathrm{mR} / \mathrm{hr}$.

$$
33 \text { of } 168
$$


Appendix A-4 - Initial and Decayed Radionuclide and Dose Data for Lined Shafts

\begin{tabular}{|c|c|c|c|c|c|c|c|c|c|}
\hline \multirow[b]{2}{*}{ Shaft Number } & \multirow[b]{2}{*}{ Package ID } & \multirow[b]{2}{*}{ Base Year } & \multicolumn{2}{|c|}{ Initial Isotopic Distribution } & \multirow[b]{2}{*}{ Target Year } & \multicolumn{2}{|c|}{ Decayed Isotopic Distribution } & \multirow{2}{*}{$\begin{array}{c}\text { Initial Contact } \\
\text { Dose Rate } \\
(\mathrm{mR} / \mathrm{hr})\end{array}$} & \multirow{2}{*}{$\begin{array}{c}\text { Decayed } \\
\text { Contact Dose } \\
\text { Rate }(\mathrm{mR} / \mathrm{hr})^{1}\end{array}$} \\
\hline & & & Isotope & Activity (Ci) & & Isotope & Activity (Ci) & & \\
\hline & & & Rh-106 & $3.93 \mathrm{E}-03$ & & Rh-106 & $1.69 \mathrm{E}-11$ & & \\
\hline & & & & & & $\mathrm{Rn}-219$ & $1.74 \mathrm{E}-10$ & & \\
\hline & & & $\mathrm{Ru}-106$ & 3.93E-03 & & $\mathrm{Ru}-106$ & $1.71 \mathrm{E}-11$ & & \\
\hline & & & Sb-125 & $2.18 \mathrm{E}-02$ & & Sb-125 & $1.98 \mathrm{E}-05$ & & \\
\hline & & & & & & Sm-147 & $7.50 \mathrm{E}-13$ & & \\
\hline & & & Sr-90 & 4.90E-01 & & Sr-90 & $2.52 \mathrm{E}-01$ & & \\
\hline & & & $\mathrm{Te}-125 \mathrm{~m}$ & $9.07 \mathrm{E}-03$ & & $\mathrm{Te}-125 \mathrm{~m}$ & 4.79E-06 & & \\
\hline & & & & & & Th-227 & $1.71 \mathrm{E}-10$ & & \\
\hline & & & & & & Th-231 & 8.69E-07 & & \\
\hline & & & & & & T1-207 & $1.73 \mathrm{E}-10$ & & \\
\hline & & & $\mathrm{U}-235$ & $8.80 \mathrm{E}-07$ & & $\mathrm{U}-235$ & $8.80 \mathrm{E}-07$ & & \\
\hline & & & $\mathrm{Y}-90$ & 4.90E-01 & & $\mathrm{Y}-90$ & $2.49 \mathrm{E}-01$ & & \\
\hline \multirow[t]{20}{*}{208} & S811411 & 1981 & & & 2009 & Ac-227 & $1.76 \mathrm{E}-10$ & 29,000 & 14,000 \\
\hline & & & $\mathrm{Ba}-137 \mathrm{~m}$ & $2.40 \mathrm{E}-01$ & & Ba-137m & $1.25 \mathrm{E}-01$ & & \\
\hline & & & & & & $\mathrm{Bi}-211$ & $1.74 \mathrm{E}-10$ & & \\
\hline & & & Cs-137 & $2.55 \mathrm{E}-01$ & & Cs-137 & $1.34 \mathrm{E}-01$ & & \\
\hline & & & Eu-155 & $4.78 \mathrm{E}-03$ & & Eu-155 & $9.54 \mathrm{E}-05$ & & \\
\hline & & & & & & Fr-223 & $2.40 \mathrm{E}-12$ & & \\
\hline & & & & & & $\mathrm{Pa}-231$ & $5.21 \mathrm{E}-10$ & & \\
\hline & & & & & & $\mathrm{Pb}-211$ & $1.74 \mathrm{E}-10$ & & \\
\hline & & & Pm-147 & $1.46 \mathrm{E}-02$ & & Pm-147 & 8.93E-06 & & \\
\hline & & & & & & Po-211 & $5.31 \mathrm{E}-13$ & & \\
\hline & & & & & & Po-215 & $1.74 \mathrm{E}-10$ & & \\
\hline & & & $\mathrm{Pu}-239$ & $6.20 \mathrm{E}-03$ & & $\mathrm{Pu}-239$ & $6.20 \mathrm{E}-03$ & & \\
\hline & & & & & & Ra-223 & $1.76 \mathrm{E}-10$ & & \\
\hline & & & Rh-106 & $1.87 \mathrm{E}-03$ & & Rh-106 & $8.06 \mathrm{E}-12$ & & \\
\hline & & & & & & Rn-219 & $1.74 \mathrm{E}-10$ & & \\
\hline & & & $\mathrm{Ru}-106$ & $1.87 \mathrm{E}-03$ & & Ru-106 & $8.14 \mathrm{E}-12$ & & \\
\hline & & & Sb-125 & $1.04 \mathrm{E}-02$ & & Sb-125 & $9.42 \mathrm{E}-06$ & & \\
\hline & & & & & & Sm-147 & $3.57 \mathrm{E}-13$ & & \\
\hline & & & Sr-90 & 2.33E-01 & & Sr-90 & $1.20 \mathrm{E}-01$ & & \\
\hline & & & $\mathrm{Te}-125 \mathrm{~m}$ & 4.32E-03 & & $\mathrm{Te}-125 \mathrm{~m}$ & $2.28 \mathrm{E}-06$ & & \\
\hline
\end{tabular}

${ }^{1}$ Calculated decayed contact dose rate. Rounded to nearest $10 \mathrm{mR} / \mathrm{hr}$ for values to 1000 ; rounded to nearest $100 \mathrm{mR} / \mathrm{hr}$ for values $>1000$ to 10,000 ; rounded to nearest $1000 \mathrm{mR} / \mathrm{hr}$ for values $>10,000$. * Initial contact dose rate assumed to be $1,000,000 \mathrm{mR} / \mathrm{hr}$; **Initial contact dose rate assumed to be $1,010,000 \mathrm{mR} / \mathrm{hr}$.

$$
34 \text { of } 168
$$


Appendix A-4 - Initial and Decayed Radionuclide and Dose Data for Lined Shafts

\begin{tabular}{|c|c|c|c|c|c|c|c|c|c|}
\hline \multirow[b]{2}{*}{ Shaft Number } & \multirow[b]{2}{*}{ Package ID } & \multirow[b]{2}{*}{ Base Year } & \multicolumn{2}{|c|}{ Initial Isotopic Distribution } & \multirow[b]{2}{*}{ Target Year } & \multicolumn{2}{|c|}{ Decayed Isotopic Distribution } & \multirow{2}{*}{$\begin{array}{c}\text { Initial Contact } \\
\text { Dose Rate } \\
(\mathrm{mR} / \mathrm{hr})\end{array}$} & \multirow{2}{*}{$\begin{array}{c}\text { Decayed } \\
\text { Contact Dose } \\
\text { Rate }(\mathrm{mR} / \mathrm{hr})^{1} \\
\end{array}$} \\
\hline & & & Isotope & Activity (Ci) & & Isotope & Activity (Ci) & & \\
\hline & & & & & & Th-227 & $1.71 \mathrm{E}-10$ & & \\
\hline & & & & & & Th-231 & $8.69 \mathrm{E}-07$ & & \\
\hline & & & & & & Tl-207 & $1.73 \mathrm{E}-10$ & & \\
\hline & & & $\mathrm{U}-235$ & $8.80 \mathrm{E}-07$ & & $\mathrm{U}-235$ & $8.80 \mathrm{E}-07$ & & \\
\hline & & & Y-90 & $2.33 \mathrm{E}-01$ & & $\mathrm{Y}-90$ & $1.19 \mathrm{E}-01$ & & \\
\hline \multirow[t]{25}{*}{208} & S814979 & 1981 & & & 2009 & Ac-227 & $7.04 \mathrm{E}-11$ & 2,400 & 1,200 \\
\hline & & & Ba-137m & $2.88 \mathrm{E}-02$ & & $\mathrm{Ba}-137 \mathrm{~m}$ & $1.50 \mathrm{E}-02$ & & \\
\hline & & & & & & Bi-211 & $6.95 \mathrm{E}-11$ & & \\
\hline & & & Cs-137 & $3.06 \mathrm{E}-02$ & & Cs-137 & $1.60 \mathrm{E}-02$ & & \\
\hline & & & Eu-155 & $5.73 \mathrm{E}-04$ & & Eu-155 & $1.14 \mathrm{E}-05$ & & \\
\hline & & & & & & Fr-223 & $9.61 \mathrm{E}-13$ & & \\
\hline & & & & & & $\mathrm{Pa}-231$ & $2.08 \mathrm{E}-10$ & & \\
\hline & & & & & & $\mathrm{Pb}-211$ & $6.96 \mathrm{E}-11$ & & \\
\hline & & & Pm-147 & $1.75 \mathrm{E}-03$ & & Pm-147 & $1.07 \mathrm{E}-06$ & & \\
\hline & & & & & & Po-211 & $2.12 \mathrm{E}-13$ & & \\
\hline & & & & & & Po-215 & $6.96 \mathrm{E}-11$ & & \\
\hline & & & $\mathrm{Pu}-239$ & $2.48 \mathrm{E}-03$ & & $\mathrm{Pu}-239$ & $2.48 \mathrm{E}-03$ & & \\
\hline & & & & & & Ra-223 & $7.04 \mathrm{E}-11$ & & \\
\hline & & & Rh-106 & $2.25 \mathrm{E}-04$ & & Rh-106 & $9.67 \mathrm{E}-13$ & & \\
\hline & & & & & & Rn-219 & $6.95 \mathrm{E}-11$ & & \\
\hline & & & Ru-106 & $2.25 \mathrm{E}-04$ & & Ru-106 & $9.76 \mathrm{E}-13$ & & \\
\hline & & & Sb-125 & $1.25 \mathrm{E}-03$ & & Sb-125 & $1.13 \mathrm{E}-06$ & & \\
\hline & & & & & & Sm-147 & 4.29E-14 & & \\
\hline & & & Sr-90 & $2.80 \mathrm{E}-02$ & & Sr-90 & $1.44 \mathrm{E}-02$ & & \\
\hline & & & $\mathrm{Te}-125 \mathrm{~m}$ & $5.18 \mathrm{E}-04$ & & $\mathrm{Te}-125 \mathrm{~m}$ & $2.74 \mathrm{E}-07$ & & \\
\hline & & & & & & Th-227 & $6.86 \mathrm{E}-11$ & & \\
\hline & & & & & & Th-231 & $3.48 \mathrm{E}-07$ & & \\
\hline & & & & & & Tl-207 & $6.92 \mathrm{E}-11$ & & \\
\hline & & & U-235 & $3.52 \mathrm{E}-07$ & & U-235 & $3.52 \mathrm{E}-07$ & & \\
\hline & & & Y-90 & $2.80 \mathrm{E}-02$ & & Y-90 & $1.42 \mathrm{E}-02$ & & \\
\hline \multirow[t]{2}{*}{209} & S810787 & 1981 & & & 2009 & Ac-227 & $1.76 \mathrm{E}-10$ & 15,000 & 7,400 \\
\hline & & & Ba-137m & $9.59 \mathrm{E}-02$ & & Ba-137m & $5.00 \mathrm{E}-02$ & & \\
\hline
\end{tabular}

${ }^{1}$ Calculated decayed contact dose rate. Rounded to nearest $10 \mathrm{mR} / \mathrm{hr}$ for values to 1000 ; rounded to nearest $100 \mathrm{mR} / \mathrm{hr}$ for values $>1000$ to 10,000 ; rounded to nearest $1000 \mathrm{mR} / \mathrm{hr}$ for values $>10,000$. * Initial contact dose rate assumed to be $1,000,000 \mathrm{mR} / \mathrm{hr}$; **Initial contact dose rate assumed to be $1,010,000 \mathrm{mR} / \mathrm{hr}$.

$$
35 \text { of } 168
$$


Appendix A-4 - Initial and Decayed Radionuclide and Dose Data for Lined Shafts

\begin{tabular}{|c|c|c|c|c|c|c|c|c|c|}
\hline \multirow[b]{2}{*}{ Shaft Number } & \multirow[b]{2}{*}{ Package ID } & \multirow[b]{2}{*}{ Base Year } & \multicolumn{2}{|c|}{ Initial Isotopic Distribution } & \multirow[b]{2}{*}{ Target Year } & \multicolumn{2}{|c|}{ Decayed Isotopic Distribution } & \multirow{2}{*}{$\begin{array}{c}\text { Initial Contact } \\
\text { Dose Rate } \\
(\mathrm{mR} / \mathrm{hr})\end{array}$} & \multirow{2}{*}{$\begin{array}{c}\text { Decayed } \\
\text { Contact Dose } \\
\text { Rate }(\mathrm{mR} / \mathrm{hr})^{1}\end{array}$} \\
\hline & & & Isotope & Activity (Ci) & & Isotope & Activity (Ci) & & \\
\hline & & & & & & $\mathrm{Bi}-211$ & $1.74 \mathrm{E}-10$ & & \\
\hline & & & Cs-137 & $1.02 \mathrm{E}-01$ & & Cs-137 & $5.35 \mathrm{E}-02$ & & \\
\hline & & & Eu-155 & $1.91 \mathrm{E}-03$ & & $\mathrm{Eu}-155$ & $3.82 \mathrm{E}-05$ & & \\
\hline & & & & & & Fr-223 & $2.40 \mathrm{E}-12$ & & \\
\hline & & & & & & $\mathrm{Pa}-231$ & $5.21 \mathrm{E}-10$ & & \\
\hline & & & & & & $\mathrm{Pb}-211$ & $1.74 \mathrm{E}-10$ & & \\
\hline & & & Pm-147 & $5.83 \mathrm{E}-03$ & & Pm-147 & $3.57 \mathrm{E}-06$ & & \\
\hline & & & & & & Po-211 & $5.31 \mathrm{E}-13$ & & \\
\hline & & & & & & Po-215 & $1.74 \mathrm{E}-10$ & & \\
\hline & & & $\mathrm{Pu}-239$ & $6.20 \mathrm{E}-03$ & & $\mathrm{Pu}-239$ & $6.20 \mathrm{E}-03$ & & \\
\hline & & & & & & $\mathrm{Ra}-223$ & $1.76 \mathrm{E}-10$ & & \\
\hline & & & Rh-106 & 7.49E-04 & & Rh-106 & $3.22 \mathrm{E}-12$ & & \\
\hline & & & & & & Rn-219 & $1.74 \mathrm{E}-10$ & & \\
\hline & & & Ru-106 & 7.49E-04 & & $\mathrm{Ru}-106$ & $3.25 \mathrm{E}-12$ & & \\
\hline & & & Sb-125 & 4.16E-03 & & Sb-125 & 3.77E-06 & & \\
\hline & & & & & & Sm-147 & $1.43 \mathrm{E}-13$ & & \\
\hline & & & Sr-90 & 9.34E-02 & & Sr-90 & 4.80E-02 & & \\
\hline & & & $\mathrm{Te}-125 \mathrm{~m}$ & $1.73 \mathrm{E}-03$ & & $\mathrm{Te}-125 \mathrm{~m}$ & $9.12 \mathrm{E}-07$ & & \\
\hline & & & & & & Th-227 & $1.71 \mathrm{E}-10$ & & \\
\hline & & & & & & Th-231 & 8.69E-07 & & \\
\hline & & & & & & Tl-207 & $1.73 \mathrm{E}-10$ & & \\
\hline & & & U-235 & $8.80 \mathrm{E}-07$ & & U-235 & $8.80 \mathrm{E}-07$ & & \\
\hline & & & $\mathrm{Y}-90$ & 9.33E-02 & & Y-90 & 4.74E-02 & & \\
\hline \multirow[t]{9}{*}{209} & S810795 & 1981 & & & 2009 & Ac- 227 & $1.76 \mathrm{E}-10$ & 2,800 & 1,400 \\
\hline & & & Ba-137m & $2.40 \mathrm{E}-01$ & & Ba-137m & $1.25 \mathrm{E}-01$ & & \\
\hline & & & & & & $\mathrm{Bi}-211$ & $1.74 \mathrm{E}-10$ & & \\
\hline & & & Cs-137 & $2.55 \mathrm{E}-01$ & & Cs-137 & $1.34 \mathrm{E}-01$ & & \\
\hline & & & Eu-155 & $4.78 \mathrm{E}-03$ & & Eu-155 & $9.54 \mathrm{E}-05$ & & \\
\hline & & & & & & Fr-223 & $2.40 \mathrm{E}-12$ & & \\
\hline & & & & & & $\mathrm{Pa}-231$ & $5.21 \mathrm{E}-10$ & & \\
\hline & & & & & & $\mathrm{Pb}-211$ & $1.74 \mathrm{E}-10$ & & \\
\hline & & & Pm-147 & $1.46 \mathrm{E}-02$ & & Pm-147 & 8.93E-06 & & \\
\hline
\end{tabular}

${ }^{1}$ Calculated decayed contact dose rate. Rounded to nearest $10 \mathrm{mR} / \mathrm{hr}$ for values to 1000 ; rounded to nearest $100 \mathrm{mR} / \mathrm{hr}$ for values $>1000$ to 10,000 ; rounded to nearest $1000 \mathrm{mR} / \mathrm{hr}$ for values $>10,000$. * Initial contact dose rate assumed to be $1,000,000 \mathrm{mR} / \mathrm{hr}$; **Initial contact dose rate assumed to be $1,010,000 \mathrm{mR} / \mathrm{hr}$.

$$
36 \text { of } 168
$$


Appendix A-4 - Initial and Decayed Radionuclide and Dose Data for Lined Shafts

\begin{tabular}{|c|c|c|c|c|c|c|c|c|c|}
\hline \multirow[b]{2}{*}{ Shaft Number } & \multirow[b]{2}{*}{ Package ID } & \multirow[b]{2}{*}{ Base Year } & \multicolumn{2}{|c|}{ Initial Isotopic Distribution } & \multirow[b]{2}{*}{ Target Year } & \multicolumn{2}{|c|}{ Decayed Isotopic Distribution } & \multirow{2}{*}{$\begin{array}{c}\text { Initial Contact } \\
\text { Dose Rate } \\
(\mathrm{mR} / \mathrm{hr})\end{array}$} & \multirow{2}{*}{$\begin{array}{c}\text { Decayed } \\
\text { Contact Dose } \\
\text { Rate }(\mathrm{mR} / \mathrm{hr})^{1}\end{array}$} \\
\hline & & & Isotope & Activity (Ci) & & Isotope & Activity (Ci) & & \\
\hline & & & & & & Po-211 & $5.31 \mathrm{E}-13$ & & \\
\hline & & & & & & Po-215 & $1.74 \mathrm{E}-10$ & & \\
\hline & & & $\mathrm{Pu}-239$ & $6.20 \mathrm{E}-03$ & & $\mathrm{Pu}-239$ & $6.20 \mathrm{E}-03$ & & \\
\hline & & & & & & $\mathrm{Ra}-223$ & $1.76 \mathrm{E}-10$ & & \\
\hline & & & Rh-106 & $1.87 \mathrm{E}-03$ & & Rh-106 & $8.06 \mathrm{E}-12$ & & \\
\hline & & & & & & Rn-219 & $1.74 \mathrm{E}-10$ & & \\
\hline & & & $\mathrm{Ru}-106$ & $1.87 \mathrm{E}-03$ & & $\mathrm{Ru}-106$ & $8.14 \mathrm{E}-12$ & & \\
\hline & & & Sb-125 & $1.04 \mathrm{E}-02$ & & Sb-125 & 9.42E-06 & & \\
\hline & & & & & & Sm-147 & $3.57 \mathrm{E}-13$ & & \\
\hline & & & Sr-90 & 2.33E-01 & & Sr-90 & $1.20 \mathrm{E}-01$ & & \\
\hline & & & $\mathrm{Te}-125 \mathrm{~m}$ & 4.32E-03 & & $\mathrm{Te}-125 \mathrm{~m}$ & $2.28 \mathrm{E}-06$ & & \\
\hline & & & & & & Th-227 & $1.71 \mathrm{E}-10$ & & \\
\hline & & & & & & Th-231 & 8.69E-07 & & \\
\hline & & & & & & Tl-207 & $1.73 \mathrm{E}-10$ & & \\
\hline & & & $\mathrm{U}-235$ & $8.80 \mathrm{E}-07$ & & $\mathrm{U}-235$ & $8.80 \mathrm{E}-07$ & & \\
\hline & & & $\mathrm{Y}-90$ & $2.33 \mathrm{E}-01$ & & Y-90 & $1.19 \mathrm{E}-01$ & & \\
\hline \multirow[t]{16}{*}{209} & S810798 & 1981 & & & 2009 & Ac- 227 & $1.76 \mathrm{E}-10$ & 1,600 & 790 \\
\hline & & & Ba-137m & 4.79E-02 & & $\mathrm{Ba}-137 \mathrm{~m}$ & $2.50 \mathrm{E}-02$ & & \\
\hline & & & & & & $\mathrm{Bi}-211$ & $1.74 \mathrm{E}-10$ & & \\
\hline & & & Cs-137 & $5.11 \mathrm{E}-02$ & & Cs-137 & $2.67 \mathrm{E}-02$ & & \\
\hline & & & Eu-155 & $9.55 \mathrm{E}-04$ & & Eu-155 & $1.91 \mathrm{E}-05$ & & \\
\hline & & & & & & Fr-223 & $2.40 \mathrm{E}-12$ & & \\
\hline & & & & & & $\mathrm{Pa}-231$ & $5.21 \mathrm{E}-10$ & & \\
\hline & & & & & & $\mathrm{Pb}-211$ & $1.74 \mathrm{E}-10$ & & \\
\hline & & & Pm-147 & $2.92 \mathrm{E}-03$ & & Pm-147 & $1.79 \mathrm{E}-06$ & & \\
\hline & & & & & & Po-211 & $5.31 \mathrm{E}-13$ & & \\
\hline & & & & & & Po-215 & $1.74 \mathrm{E}-10$ & & \\
\hline & & & $\mathrm{Pu}-239$ & $6.20 \mathrm{E}-03$ & & Pu-239 & $6.20 \mathrm{E}-03$ & & \\
\hline & & & & & & Ra-223 & $1.76 \mathrm{E}-10$ & & \\
\hline & & & Rh-106 & $3.74 \mathrm{E}-04$ & & Rh-106 & $1.61 \mathrm{E}-12$ & & \\
\hline & & & & & & Rn-219 & $1.74 \mathrm{E}-10$ & & \\
\hline & & & Ru-106 & $3.74 \mathrm{E}-04$ & & $\mathrm{Ru}-106$ & $1.63 \mathrm{E}-12$ & & \\
\hline
\end{tabular}

${ }^{1}$ Calculated decayed contact dose rate. Rounded to nearest $10 \mathrm{mR} / \mathrm{hr}$ for values to 1000 ; rounded to nearest $100 \mathrm{mR} / \mathrm{hr}$ for values $>1000$ to 10,000 ; rounded to nearest $1000 \mathrm{mR} / \mathrm{hr}$ for values $>10,000$. * Initial contact dose rate assumed to be $1,000,000 \mathrm{mR} / \mathrm{hr}$; **Initial contact dose rate assumed to be $1,010,000 \mathrm{mR} / \mathrm{hr}$.

$$
37 \text { of } 168
$$


Appendix A-4 - Initial and Decayed Radionuclide and Dose Data for Lined Shafts

\begin{tabular}{|c|c|c|c|c|c|c|c|c|c|}
\hline \multirow[b]{2}{*}{ Shaft Number } & \multirow[b]{2}{*}{ Package ID } & \multirow[b]{2}{*}{ Base Year } & \multicolumn{2}{|c|}{ Initial Isotopic Distribution } & \multirow[b]{2}{*}{ Target Year } & \multicolumn{2}{|c|}{ Decayed Isotopic Distribution } & \multirow{2}{*}{$\begin{array}{c}\text { Initial Contact } \\
\text { Dose Rate } \\
(\mathrm{mR} / \mathrm{hr})\end{array}$} & \multirow{2}{*}{$\begin{array}{c}\text { Decayed } \\
\text { Contact Dose } \\
\text { Rate }(\mathrm{mR} / \mathrm{hr})^{1} \\
\end{array}$} \\
\hline & & & Isotope & Activity (Ci) & & Isotope & Activity (Ci) & & \\
\hline & & & Sb-125 & $2.08 \mathrm{E}-03$ & & $\mathrm{Sb}-125$ & $1.88 \mathrm{E}-06$ & & \\
\hline & & & & & & Sm-147 & $7.15 \mathrm{E}-14$ & & \\
\hline & & & Sr-90 & 4.67E-02 & & Sr-90 & $2.40 \mathrm{E}-02$ & & \\
\hline & & & $\mathrm{Te}-125 \mathrm{~m}$ & $8.63 \mathrm{E}-04$ & & $\mathrm{Te}-125 \mathrm{~m}$ & $4.56 \mathrm{E}-07$ & & \\
\hline & & & & & & Th-227 & $1.71 \mathrm{E}-10$ & & \\
\hline & & & & & & Th-231 & $8.69 \mathrm{E}-07$ & & \\
\hline & & & & & & T1-207 & $1.73 \mathrm{E}-10$ & & \\
\hline & & & $\mathrm{U}-235$ & $8.80 \mathrm{E}-07$ & & $\mathrm{U}-235$ & $8.80 \mathrm{E}-07$ & & \\
\hline & & & $\mathrm{Y}-90$ & $4.66 \mathrm{E}-02$ & & $\mathrm{Y}-90$ & $2.37 \mathrm{E}-02$ & & \\
\hline \multirow[t]{23}{*}{209} & S810799 & 1981 & & & 2009 & Ac-227 & $1.76 \mathrm{E}-10$ & 5,000 & 2,500 \\
\hline & & & $\mathrm{Ba}-137 \mathrm{~m}$ & 7.19E-02 & & $\mathrm{Ba}-137 \mathrm{~m}$ & $3.75 \mathrm{E}-02$ & & \\
\hline & & & & & & $\mathrm{Bi}-211$ & $1.74 \mathrm{E}-10$ & & \\
\hline & & & Cs-137 & $7.66 \mathrm{E}-02$ & & Cs-137 & $4.01 \mathrm{E}-02$ & & \\
\hline & & & Eu-155 & $1.43 \mathrm{E}-03$ & & Eu-155 & $2.86 \mathrm{E}-05$ & & \\
\hline & & & & & & Fr-223 & $2.40 \mathrm{E}-12$ & & \\
\hline & & & & & & $\mathrm{Pa}-231$ & $5.21 \mathrm{E}-10$ & & \\
\hline & & & & & & $\mathrm{Pb}-211$ & $1.74 \mathrm{E}-10$ & & \\
\hline & & & Pm-147 & 4.38E-03 & & Pm-147 & $2.68 \mathrm{E}-06$ & & \\
\hline & & & & & & Рo-211 & $5.31 \mathrm{E}-13$ & & \\
\hline & & & & & & Po-215 & $1.74 \mathrm{E}-10$ & & \\
\hline & & & $\mathrm{Pu}-239$ & $6.20 \mathrm{E}-03$ & & Pu-239 & $6.20 \mathrm{E}-03$ & & \\
\hline & & & & & & Ra-223 & $1.76 \mathrm{E}-10$ & & \\
\hline & & & Rh-106 & $5.62 \mathrm{E}-04$ & & Rh-106 & $2.42 \mathrm{E}-12$ & & \\
\hline & & & & & & Rn-219 & $1.74 \mathrm{E}-10$ & & \\
\hline & & & $\mathrm{Ru}-106$ & $5.62 \mathrm{E}-04$ & & Ru-106 & $2.44 \mathrm{E}-12$ & & \\
\hline & & & Sb-125 & $3.12 \mathrm{E}-03$ & & Sb-125 & $2.82 \mathrm{E}-06$ & & \\
\hline & & & & & & Sm-147 & $1.07 \mathrm{E}-13$ & & \\
\hline & & & Sr-90 & 7.00E-02 & & Sr-90 & $3.60 \mathrm{E}-02$ & & \\
\hline & & & $\mathrm{Te}-125 \mathrm{~m}$ & $1.30 \mathrm{E}-03$ & & $\mathrm{Te}-125 \mathrm{~m}$ & $6.84 \mathrm{E}-07$ & & \\
\hline & & & & & & Th-227 & $1.71 \mathrm{E}-10$ & & \\
\hline & & & & & & Th-231 & 8.69E-07 & & \\
\hline & & & & & & Tl-207 & $1.73 \mathrm{E}-10$ & & \\
\hline
\end{tabular}

${ }^{1}$ Calculated decayed contact dose rate. Rounded to nearest $10 \mathrm{mR} / \mathrm{hr}$ for values to 1000 ; rounded to nearest $100 \mathrm{mR} / \mathrm{hr}$ for values $>1000$ to 10,000 ; rounded to nearest $1000 \mathrm{mR} / \mathrm{hr}$ for values $>10,000$. * Initial contact dose rate assumed to be $1,000,000 \mathrm{mR} / \mathrm{hr}$; **Initial contact dose rate assumed to be $1,010,000 \mathrm{mR} / \mathrm{hr}$.

$$
38 \text { of } 168
$$


Appendix A-4 - Initial and Decayed Radionuclide and Dose Data for Lined Shafts

\begin{tabular}{|c|c|c|c|c|c|c|c|c|c|}
\hline \multirow[b]{2}{*}{ Shaft Number } & \multirow[b]{2}{*}{ Package ID } & \multirow[b]{2}{*}{ Base Year } & \multicolumn{2}{|c|}{ Initial Isotopic Distribution } & \multirow[b]{2}{*}{ Target Year } & \multicolumn{2}{|c|}{ Decayed Isotopic Distribution } & \multirow{2}{*}{$\begin{array}{c}\text { Initial Contact } \\
\text { Dose Rate } \\
(\mathrm{mR} / \mathrm{hr})\end{array}$} & \multirow{2}{*}{$\begin{array}{c}\text { Decayed } \\
\text { Contact Dose } \\
\text { Rate }(\mathrm{mR} / \mathrm{hr})^{1} \\
\end{array}$} \\
\hline & & & Isotope & Activity (Ci) & & Isotope & Activity (Ci) & & \\
\hline & & & U-235 & $8.80 \mathrm{E}-07$ & & U-235 & $8.80 \mathrm{E}-07$ & & \\
\hline & & & $\mathrm{Y}-90$ & $6.99 \mathrm{E}-02$ & & Y-90 & $3.56 \mathrm{E}-02$ & & \\
\hline \multirow[t]{25}{*}{209} & S811412 & 1981 & & & 2009 & Ac-227 & $1.76 \mathrm{E}-10$ & 90,000 & 45,000 \\
\hline & & & Ba-137m & 4.79E-01 & & $\mathrm{Ba}-137 \mathrm{~m}$ & $2.50 \mathrm{E}-01$ & & \\
\hline & & & & & & $\mathrm{Bi}-211$ & $1.74 \mathrm{E}-10$ & & \\
\hline & & & Cs-137 & $5.11 \mathrm{E}-01$ & & Cs-137 & $2.67 \mathrm{E}-01$ & & \\
\hline & & & Eu-155 & $9.55 \mathrm{E}-03$ & & Eu-155 & $1.91 \mathrm{E}-04$ & & \\
\hline & & & & & & Fr-223 & $2.40 \mathrm{E}-12$ & & \\
\hline & & & & & & $\mathrm{Pa}-231$ & $5.21 \mathrm{E}-10$ & & \\
\hline & & & & & & $\mathrm{Pb}-211$ & $1.74 \mathrm{E}-10$ & & \\
\hline & & & Pm-147 & $2.92 \mathrm{E}-02$ & & Pm-147 & $1.79 \mathrm{E}-05$ & & \\
\hline & & & & & & Po-211 & $5.31 \mathrm{E}-13$ & & \\
\hline & & & & & & Po-215 & $1.74 \mathrm{E}-10$ & & \\
\hline & & & $\mathrm{Pu}-239$ & $6.20 \mathrm{E}-03$ & & $\mathrm{Pu}-239$ & $6.20 \mathrm{E}-03$ & & \\
\hline & & & & & & Ra-223 & $1.76 \mathrm{E}-10$ & & \\
\hline & & & $\mathrm{Rh}-106$ & $3.74 \mathrm{E}-03$ & & Rh-106 & $1.61 \mathrm{E}-11$ & & \\
\hline & & & & & & Rn-219 & $1.74 \mathrm{E}-10$ & & \\
\hline & & & Ru-106 & $3.74 \mathrm{E}-03$ & & Ru-106 & $1.63 \mathrm{E}-11$ & & \\
\hline & & & Sb-125 & $2.08 \mathrm{E}-02$ & & Sb-125 & $1.88 \mathrm{E}-05$ & & \\
\hline & & & & & & Sm-147 & $7.15 \mathrm{E}-13$ & & \\
\hline & & & Sr-90 & 4.67E-01 & & Sr-90 & $2.40 \mathrm{E}-01$ & & \\
\hline & & & $\mathrm{Te}-125 \mathrm{~m}$ & 8.63E-03 & & $\mathrm{Te}-125 \mathrm{~m}$ & $4.56 \mathrm{E}-06$ & & \\
\hline & & & & & & Th-227 & $1.71 \mathrm{E}-10$ & & \\
\hline & & & & & & Th-231 & 8.69E-07 & & \\
\hline & & & & & & Tl-207 & $1.73 \mathrm{E}-10$ & & \\
\hline & & & U-235 & $8.80 \mathrm{E}-07$ & & U-235 & $8.80 \mathrm{E}-07$ & & \\
\hline & & & Y-90 & $4.66 \mathrm{E}-01$ & & $\mathrm{Y}-90$ & $2.37 \mathrm{E}-01$ & & \\
\hline \multirow[t]{5}{*}{210} & S810800 & 1981 & & & 2009 & Ac- 227 & $1.76 \mathrm{E}-10$ & 10,000 & 4,900 \\
\hline & & & $\mathrm{Ba}-137 \mathrm{~m}$ & $9.59 \mathrm{E}-02$ & & Ba-137m & $5.00 \mathrm{E}-02$ & & \\
\hline & & & & & & Bi-211 & $1.74 \mathrm{E}-10$ & & \\
\hline & & & Cs-137 & $1.02 \mathrm{E}-01$ & & Cs-137 & $5.35 \mathrm{E}-02$ & & \\
\hline & & & Eu-155 & $1.91 \mathrm{E}-03$ & & Eu-155 & $3.82 \mathrm{E}-05$ & & \\
\hline
\end{tabular}

${ }^{1}$ Calculated decayed contact dose rate. Rounded to nearest $10 \mathrm{mR} / \mathrm{hr}$ for values to 1000 ; rounded to nearest $100 \mathrm{mR} / \mathrm{hr}$ for values $>1000$ to 10,000 ; rounded to nearest $1000 \mathrm{mR} / \mathrm{hr}$ for values $>10,000$. * Initial contact dose rate assumed to be $1,000,000 \mathrm{mR} / \mathrm{hr}$; **Initial contact dose rate assumed to be $1,010,000 \mathrm{mR} / \mathrm{hr}$.

$$
39 \text { of } 168
$$


Appendix A-4 - Initial and Decayed Radionuclide and Dose Data for Lined Shafts

\begin{tabular}{|c|c|c|c|c|c|c|c|c|c|}
\hline \multirow[b]{2}{*}{ Shaft Number } & \multirow[b]{2}{*}{ Package ID } & \multirow[b]{2}{*}{ Base Year } & \multicolumn{2}{|c|}{ Initial Isotopic Distribution } & \multirow[b]{2}{*}{ Target Year } & \multicolumn{2}{|c|}{ Decayed Isotopic Distribution } & \multirow{2}{*}{$\begin{array}{c}\text { Initial Contact } \\
\text { Dose Rate } \\
(\mathrm{mR} / \mathrm{hr})\end{array}$} & \multirow{2}{*}{$\begin{array}{c}\text { Decayed } \\
\text { Contact Dose } \\
\text { Rate }(\mathrm{mR} / \mathrm{hr})^{1}\end{array}$} \\
\hline & & & Isotope & Activity (Ci) & & Isotope & Activity (Ci) & & \\
\hline & & & & & & Fr-223 & $2.40 \mathrm{E}-12$ & & \\
\hline & & & & & & $\mathrm{Pa}-231$ & $5.21 \mathrm{E}-10$ & & \\
\hline & & & & & & $\mathrm{Pb}-211$ & $1.74 \mathrm{E}-10$ & & \\
\hline & & & Pm-147 & $5.83 \mathrm{E}-03$ & & Pm-147 & $3.57 \mathrm{E}-06$ & & \\
\hline & & & & & & Po-211 & $5.31 \mathrm{E}-13$ & & \\
\hline & & & & & & Po-215 & $1.74 \mathrm{E}-10$ & & \\
\hline & & & $\mathrm{Pu}-239$ & $6.20 \mathrm{E}-03$ & & $\mathrm{Pu}-239$ & $6.20 \mathrm{E}-03$ & & \\
\hline & & & & & & Ra-223 & $1.76 \mathrm{E}-10$ & & \\
\hline & & & Rh-106 & 7.49E-04 & & Rh-106 & $3.22 \mathrm{E}-12$ & & \\
\hline & & & & & & $\mathrm{Rn}-219$ & $1.74 \mathrm{E}-10$ & & \\
\hline & & & $\mathrm{Ru}-106$ & 7.49E-04 & & Ru-106 & $3.25 \mathrm{E}-12$ & & \\
\hline & & & $\mathrm{Sb}-125$ & $4.16 \mathrm{E}-03$ & & $\mathrm{Sb}-125$ & $3.77 \mathrm{E}-06$ & & \\
\hline & & & & & & Sm-147 & $1.43 \mathrm{E}-13$ & & \\
\hline & & & Sr-90 & 9.34E-02 & & Sr-90 & $4.80 \mathrm{E}-02$ & & \\
\hline & & & $\mathrm{Te}-125 \mathrm{~m}$ & $1.73 \mathrm{E}-03$ & & $\mathrm{Te}-125 \mathrm{~m}$ & $9.12 \mathrm{E}-07$ & & \\
\hline & & & & & & Th-227 & $1.71 \mathrm{E}-10$ & & \\
\hline & & & & & & Th-231 & $8.69 \mathrm{E}-07$ & & \\
\hline & & & & & & Tl-207 & $1.73 \mathrm{E}-10$ & & \\
\hline & & & $\mathrm{U}-235$ & $8.80 \mathrm{E}-07$ & & U-235 & $8.80 \mathrm{E}-07$ & & \\
\hline & & & Y-90 & 9.33E-02 & & $\mathrm{Y}-90$ & $4.74 \mathrm{E}-02$ & & \\
\hline \multirow[t]{12}{*}{210} & S810804 & 1981 & & & 2009 & Ac- 227 & $1.76 \mathrm{E}-10$ & 4,000 & 2,000 \\
\hline & & & $\mathrm{Ba}-137 \mathrm{~m}$ & 4.79E-02 & & $\mathrm{Ba}-137 \mathrm{~m}$ & $2.50 \mathrm{E}-02$ & & \\
\hline & & & & & & Bi-211 & $1.74 \mathrm{E}-10$ & & \\
\hline & & & Cs-137 & $5.11 \mathrm{E}-02$ & & Cs-137 & $2.67 \mathrm{E}-02$ & & \\
\hline & & & Eu-155 & $9.55 \mathrm{E}-04$ & & Eu-155 & $1.91 \mathrm{E}-05$ & & \\
\hline & & & & & & Fr-223 & $2.40 \mathrm{E}-12$ & & \\
\hline & & & & & & $\mathrm{Pa}-231$ & $5.21 \mathrm{E}-10$ & & \\
\hline & & & & & & $\mathrm{Pb}-211$ & $1.74 \mathrm{E}-10$ & & \\
\hline & & & Pm-147 & $2.92 \mathrm{E}-03$ & & Pm-147 & $1.79 \mathrm{E}-06$ & & \\
\hline & & & & & & Po-211 & $5.31 \mathrm{E}-13$ & & \\
\hline & & & & & & Po-215 & $1.74 \mathrm{E}-10$ & & \\
\hline & & & $\mathrm{Pu}-239$ & $6.20 \mathrm{E}-03$ & & $\mathrm{Pu}-239$ & $6.20 \mathrm{E}-03$ & & \\
\hline
\end{tabular}

${ }^{1}$ Calculated decayed contact dose rate. Rounded to nearest $10 \mathrm{mR} / \mathrm{hr}$ for values to 1000 ; rounded to nearest $100 \mathrm{mR} / \mathrm{hr}$ for values $>1000$ to 10,000 ; rounded to nearest $1000 \mathrm{mR} / \mathrm{hr}$ for values $>10,000$. * Initial contact dose rate assumed to be $1,000,000 \mathrm{mR} / \mathrm{hr}$; **Initial contact dose rate assumed to be $1,010,000 \mathrm{mR} / \mathrm{hr}$.

$$
40 \text { of } 168
$$


Appendix A-4 - Initial and Decayed Radionuclide and Dose Data for Lined Shafts

\begin{tabular}{|c|c|c|c|c|c|c|c|c|c|}
\hline \multirow[b]{2}{*}{ Shaft Number } & \multirow[b]{2}{*}{ Package ID } & \multirow[b]{2}{*}{ Base Year } & \multicolumn{2}{|c|}{ Initial Isotopic Distribution } & \multirow[b]{2}{*}{ Target Year } & \multicolumn{2}{|c|}{ Decayed Isotopic Distribution } & \multirow{2}{*}{$\begin{array}{c}\text { Initial Contact } \\
\text { Dose Rate } \\
(\mathrm{mR} / \mathrm{hr})\end{array}$} & \multirow{2}{*}{$\begin{array}{c}\text { Decayed } \\
\text { Contact Dose } \\
\text { Rate }(\mathrm{mR} / \mathrm{hr})^{1}\end{array}$} \\
\hline & & & Isotope & Activity $(\mathrm{Ci})$ & & Isotope & Activity (Ci) & & \\
\hline & & & & & & Ra-223 & $1.76 \mathrm{E}-10$ & & \\
\hline & & & Rh-106 & $3.74 \mathrm{E}-04$ & & Rh-106 & $1.61 \mathrm{E}-12$ & & \\
\hline & & & & & & Rn-219 & $1.74 \mathrm{E}-10$ & & \\
\hline & & & $\mathrm{Ru}-106$ & $3.74 \mathrm{E}-04$ & & Ru-106 & $1.63 \mathrm{E}-12$ & & \\
\hline & & & Sb-125 & $2.08 \mathrm{E}-03$ & & $\mathrm{Sb}-125$ & $1.88 \mathrm{E}-06$ & & \\
\hline & & & & & & Sm-147 & $7.15 \mathrm{E}-14$ & & \\
\hline & & & Sr-90 & 4.67E-02 & & Sr-90 & $2.40 \mathrm{E}-02$ & & \\
\hline & & & $\mathrm{Te}-125 \mathrm{~m}$ & $8.63 \mathrm{E}-04$ & & $\mathrm{Te}-125 \mathrm{~m}$ & $4.56 \mathrm{E}-07$ & & \\
\hline & & & & & & Th-227 & $1.71 \mathrm{E}-10$ & & \\
\hline & & & & & & Th-231 & $8.69 \mathrm{E}-07$ & & \\
\hline & & & & & & T1-207 & $1.73 \mathrm{E}-10$ & & \\
\hline & & & $\mathrm{U}-235$ & $8.80 \mathrm{E}-07$ & & $\mathrm{U}-235$ & $8.80 \mathrm{E}-07$ & & \\
\hline & & & Y-90 & $4.66 \mathrm{E}-02$ & & $\mathrm{Y}-90$ & $2.37 \mathrm{E}-02$ & & \\
\hline \multirow[t]{19}{*}{210} & S810805 & 1981 & & & 2009 & Ac-227 & $1.76 \mathrm{E}-10$ & 5,000 & 2,500 \\
\hline & & & Ba-137m & 7.19E-02 & & $\mathrm{Ba}-137 \mathrm{~m}$ & $3.75 \mathrm{E}-02$ & & \\
\hline & & & & & & Bi-211 & $1.74 \mathrm{E}-10$ & & \\
\hline & & & Cs-137 & $7.66 \mathrm{E}-02$ & & Cs-137 & $4.01 \mathrm{E}-02$ & & \\
\hline & & & Eu-155 & $1.43 \mathrm{E}-03$ & & Eu-155 & $2.86 \mathrm{E}-05$ & & \\
\hline & & & & & & Fr-223 & $2.40 \mathrm{E}-12$ & & \\
\hline & & & & & & $\mathrm{Pa}-231$ & $5.21 \mathrm{E}-10$ & & \\
\hline & & & & & & $\mathrm{Pb}-211$ & $1.74 \mathrm{E}-10$ & & \\
\hline & & & Pm-147 & $4.38 \mathrm{E}-03$ & & Pm-147 & $2.68 \mathrm{E}-06$ & & \\
\hline & & & & & & Po-211 & $5.31 \mathrm{E}-13$ & & \\
\hline & & & & & & Po-215 & $1.74 \mathrm{E}-10$ & & \\
\hline & & & $\mathrm{Pu}-239$ & $6.20 \mathrm{E}-03$ & & $\mathrm{Pu}-239$ & $6.20 \mathrm{E}-03$ & & \\
\hline & & & & & & Ra-223 & $1.76 \mathrm{E}-10$ & & \\
\hline & & & Rh-106 & $5.62 \mathrm{E}-04$ & & Rh-106 & $2.42 \mathrm{E}-12$ & & \\
\hline & & & & & & Rn-219 & $1.74 \mathrm{E}-10$ & & \\
\hline & & & $\mathrm{Ru}-106$ & $5.62 \mathrm{E}-04$ & & $\mathrm{Ru}-106$ & $2.44 \mathrm{E}-12$ & & \\
\hline & & & Sb-125 & $3.12 \mathrm{E}-03$ & & Sb-125 & $2.82 \mathrm{E}-06$ & & \\
\hline & & & & & & Sm-147 & $1.07 \mathrm{E}-13$ & & \\
\hline & & & Sr-90 & $7.00 \mathrm{E}-02$ & & Sr-90 & $3.60 \mathrm{E}-02$ & & \\
\hline
\end{tabular}

${ }^{1}$ Calculated decayed contact dose rate. Rounded to nearest $10 \mathrm{mR} / \mathrm{hr}$ for values to 1000 ; rounded to nearest $100 \mathrm{mR} / \mathrm{hr}$ for values $>1000$ to 10,000 ; rounded to nearest $1000 \mathrm{mR} / \mathrm{hr}$ for values $>10,000$. * Initial contact dose rate assumed to be $1,000,000 \mathrm{mR} / \mathrm{hr}$; **Initial contact dose rate assumed to be $1,010,000 \mathrm{mR} / \mathrm{hr}$.

$$
41 \text { of } 168
$$


Appendix A-4 - Initial and Decayed Radionuclide and Dose Data for Lined Shafts

\begin{tabular}{|c|c|c|c|c|c|c|c|c|c|}
\hline \multirow[b]{2}{*}{ Shaft Number } & \multirow[b]{2}{*}{ Package ID } & \multirow[b]{2}{*}{ Base Year } & \multicolumn{2}{|c|}{ Initial Isotopic Distribution } & \multirow[b]{2}{*}{ Target Year } & \multicolumn{2}{|c|}{ Decayed Isotopic Distribution } & \multirow{2}{*}{$\begin{array}{c}\text { Initial Contact } \\
\text { Dose Rate } \\
(\mathrm{mR} / \mathrm{hr}) \\
\end{array}$} & \multirow{2}{*}{$\begin{array}{c}\text { Decayed } \\
\text { Contact Dose } \\
\text { Rate }(\mathrm{mR} / \mathrm{hr})^{1} \\
\end{array}$} \\
\hline & & & Isotope & Activity $(\mathrm{Ci})$ & & Isotope & Activity (Ci) & & \\
\hline & & & Te-125m & $1.30 \mathrm{E}-03$ & & Te-125m & 6.84E-07 & & \\
\hline & & & & & & Th-227 & $1.71 \mathrm{E}-10$ & & \\
\hline & & & & & & Th-231 & 8.69E-07 & & \\
\hline & & & & & & Tl-207 & $1.73 \mathrm{E}-10$ & & \\
\hline & & & $\mathrm{U}-235$ & $8.80 \mathrm{E}-07$ & & $\mathrm{U}-235$ & $8.80 \mathrm{E}-07$ & & \\
\hline & & & Y-90 & 6.99E-02 & & Y-90 & $3.56 \mathrm{E}-02$ & & \\
\hline \multirow[t]{25}{*}{210} & S810806 & 1981 & & & 2009 & Ac-227 & $1.76 \mathrm{E}-10$ & 300 & 150 \\
\hline & & & $\mathrm{Ba}-137 \mathrm{~m}$ & 4.79E-03 & & Ba-137m & $2.50 \mathrm{E}-03$ & & \\
\hline & & & & & & Bi-211 & $1.74 \mathrm{E}-10$ & & \\
\hline & & & Cs-137 & $5.11 \mathrm{E}-03$ & & Cs-137 & $2.67 \mathrm{E}-03$ & & \\
\hline & & & Eu-155 & $9.55 \mathrm{E}-05$ & & Eu-155 & $1.91 \mathrm{E}-06$ & & \\
\hline & & & & & & Fr-223 & $2.40 \mathrm{E}-12$ & & \\
\hline & & & & & & $\mathrm{Pa}-231$ & $5.21 \mathrm{E}-10$ & & \\
\hline & & & & & & $\mathrm{Pb}-211$ & $1.74 \mathrm{E}-10$ & & \\
\hline & & & Pm-147 & $2.92 \mathrm{E}-04$ & & Pm-147 & $1.79 \mathrm{E}-07$ & & \\
\hline & & & & & & Po-211 & $5.31 \mathrm{E}-13$ & & \\
\hline & & & & & & Po-215 & $1.74 \mathrm{E}-10$ & & \\
\hline & & & $\mathrm{Pu}-239$ & $6.20 \mathrm{E}-03$ & & Pu-239 & $6.20 \mathrm{E}-03$ & & \\
\hline & & & & & & Ra-223 & $1.76 \mathrm{E}-10$ & & \\
\hline & & & Rh-106 & $3.74 \mathrm{E}-05$ & & Rh-106 & $1.61 \mathrm{E}-13$ & & \\
\hline & & & & & & Rn-219 & $1.74 \mathrm{E}-10$ & & \\
\hline & & & Ru-106 & $3.74 \mathrm{E}-05$ & & $\mathrm{Ru}-106$ & $1.63 \mathrm{E}-13$ & & \\
\hline & & & Sb-125 & $2.08 \mathrm{E}-04$ & & Sb-125 & $1.88 \mathrm{E}-07$ & & \\
\hline & & & & & & Sm-147 & $7.15 \mathrm{E}-15$ & & \\
\hline & & & Sr-90 & $4.67 \mathrm{E}-03$ & & Sr-90 & $2.40 \mathrm{E}-03$ & & \\
\hline & & & $\mathrm{Te}-125 \mathrm{~m}$ & 8.63E-05 & & $\mathrm{Te}-125 \mathrm{~m}$ & $4.56 \mathrm{E}-08$ & & \\
\hline & & & & & & Th-227 & $1.71 \mathrm{E}-10$ & & \\
\hline & & & & & & Th-231 & 8.69E-07 & & \\
\hline & & & & & & T1-207 & $1.73 \mathrm{E}-10$ & & \\
\hline & & & U-235 & $8.80 \mathrm{E}-07$ & & U-235 & $8.80 \mathrm{E}-07$ & & \\
\hline & & & Y-90 & $4.66 \mathrm{E}-03$ & & Y-90 & $2.37 \mathrm{E}-03$ & & \\
\hline 211 & S810807 & 1981 & & & 2009 & Ac-227 & $1.76 \mathrm{E}-10$ & 16,000 & 7,900 \\
\hline
\end{tabular}

${ }^{1}$ Calculated decayed contact dose rate. Rounded to nearest $10 \mathrm{mR} / \mathrm{hr}$ for values to 1000 ; rounded to nearest $100 \mathrm{mR} / \mathrm{hr}$ for values $>1000$ to 10,000 ; rounded to nearest $1000 \mathrm{mR} / \mathrm{hr}$ for values $>10,000$. * Initial contact dose rate assumed to be $1,000,000 \mathrm{mR} / \mathrm{hr}$; **Initial contact dose rate assumed to be $1,010,000 \mathrm{mR} / \mathrm{hr}$.

$$
42 \text { of } 168
$$


Appendix A-4 - Initial and Decayed Radionuclide and Dose Data for Lined Shafts

\begin{tabular}{|c|c|c|c|c|c|c|c|c|c|}
\hline \multirow[b]{2}{*}{ Shaft Number } & \multirow[b]{2}{*}{ Package ID } & \multirow[b]{2}{*}{ Base Year } & \multicolumn{2}{|c|}{ Initial Isotopic Distribution } & \multirow[b]{2}{*}{ Target Year } & \multicolumn{2}{|c|}{ Decayed Isotopic Distribution } & \multirow{2}{*}{$\begin{array}{c}\text { Initial Contact } \\
\text { Dose Rate } \\
(\mathrm{mR} / \mathrm{hr})\end{array}$} & \multirow{2}{*}{$\begin{array}{c}\text { Decayed } \\
\text { Contact Dose } \\
\text { Rate }(\mathrm{mR} / \mathrm{hr})^{1} \\
\end{array}$} \\
\hline & & & Isotope & Activity (Ci) & & Isotope & Activity (Ci) & & \\
\hline & & & Ba-137m & $1.68 \mathrm{E}-01$ & & Ba-137m & $8.75 \mathrm{E}-02$ & & \\
\hline & & & & & & Bi-211 & $1.74 \mathrm{E}-10$ & & \\
\hline & & & Cs-137 & $1.79 \mathrm{E}-01$ & & Cs-137 & $9.35 \mathrm{E}-02$ & & \\
\hline & & & Eu-155 & $3.34 \mathrm{E}-03$ & & Eu-155 & $6.68 \mathrm{E}-05$ & & \\
\hline & & & & & & Fr-223 & $2.40 \mathrm{E}-12$ & & \\
\hline & & & & & & $\mathrm{Pa}-231$ & $5.21 \mathrm{E}-10$ & & \\
\hline & & & & & & $\mathrm{Pb}-211$ & $1.74 \mathrm{E}-10$ & & \\
\hline & & & Pm-147 & $1.02 \mathrm{E}-02$ & & Pm-147 & $6.25 \mathrm{E}-06$ & & \\
\hline & & & & & & Po-211 & $5.31 \mathrm{E}-13$ & & \\
\hline & & & & & & Po-215 & $1.74 \mathrm{E}-10$ & & \\
\hline & & & Pu-239 & $6.20 \mathrm{E}-03$ & & $\mathrm{Pu}-239$ & $6.20 \mathrm{E}-03$ & & \\
\hline & & & & & & Ra-223 & $1.76 \mathrm{E}-10$ & & \\
\hline & & & Rh-106 & $1.31 \mathrm{E}-03$ & & Rh-106 & $5.64 \mathrm{E}-12$ & & \\
\hline & & & & & & Rn-219 & $1.74 \mathrm{E}-10$ & & \\
\hline & & & $\mathrm{Ru}-106$ & $1.31 \mathrm{E}-03$ & & Ru-106 & $5.70 \mathrm{E}-12$ & & \\
\hline & & & Sb-125 & 7.28E-03 & & $\mathrm{Sb}-125$ & $6.59 \mathrm{E}-06$ & & \\
\hline & & & & & & Sm-147 & $2.50 \mathrm{E}-13$ & & \\
\hline & & & Sr-90 & $1.63 \mathrm{E}-01$ & & Sr-90 & 8.39E-02 & & \\
\hline & & & $\mathrm{Te}-125 \mathrm{~m}$ & $3.02 \mathrm{E}-03$ & & $\mathrm{Te}-125 \mathrm{~m}$ & $1.60 \mathrm{E}-06$ & & \\
\hline & & & & & & Th-227 & $1.71 \mathrm{E}-10$ & & \\
\hline & & & & & & Th-231 & 8.69E-07 & & \\
\hline & & & & & & Tl-207 & $1.73 \mathrm{E}-10$ & & \\
\hline & & & U-235 & $8.80 \mathrm{E}-07$ & & U-235 & $8.80 \mathrm{E}-07$ & & \\
\hline & & & Y-90 & $1.63 \mathrm{E}-01$ & & $\mathrm{Y}-90$ & $8.30 \mathrm{E}-02$ & & \\
\hline \multirow[t]{8}{*}{211} & S810808 & 1981 & & & 2009 & Ac-227 & $1.76 \mathrm{E}-10$ & 126,000 & 62,000 \\
\hline & & & Ba-137m & $5.27 \mathrm{E}-01$ & & $\mathrm{Ba}-137 \mathrm{~m}$ & $2.75 \mathrm{E}-01$ & & \\
\hline & & & & & & Bi-211 & $1.74 \mathrm{E}-10$ & & \\
\hline & & & Cs-137 & $5.62 \mathrm{E}-01$ & & Cs-137 & $2.94 \mathrm{E}-01$ & & \\
\hline & & & Eu-155 & $1.05 \mathrm{E}-02$ & & Eu-155 & $2.10 \mathrm{E}-04$ & & \\
\hline & & & & & & Fr-223 & $2.40 \mathrm{E}-12$ & & \\
\hline & & & & & & $\mathrm{Pa}-231$ & $5.21 \mathrm{E}-10$ & & \\
\hline & & & & & & $\mathrm{Pb}-211$ & $1.74 \mathrm{E}-10$ & & \\
\hline
\end{tabular}

${ }^{1}$ Calculated decayed contact dose rate. Rounded to nearest $10 \mathrm{mR} / \mathrm{hr}$ for values to 1000 ; rounded to nearest $100 \mathrm{mR} / \mathrm{hr}$ for values $>1000$ to 10,000 ; rounded to nearest $1000 \mathrm{mR} / \mathrm{hr}$ for values $>10,000$. * Initial contact dose rate assumed to be $1,000,000 \mathrm{mR} / \mathrm{hr}$; **Initial contact dose rate assumed to be $1,010,000 \mathrm{mR} / \mathrm{hr}$.

$$
43 \text { of } 168
$$


Appendix A-4 - Initial and Decayed Radionuclide and Dose Data for Lined Shafts

\begin{tabular}{|c|c|c|c|c|c|c|c|c|c|}
\hline \multirow[b]{2}{*}{ Shaft Number } & \multirow[b]{2}{*}{ Package ID } & \multirow[b]{2}{*}{ Base Year } & \multicolumn{2}{|c|}{ Initial Isotopic Distribution } & \multirow[b]{2}{*}{ Target Year } & \multicolumn{2}{|c|}{ Decayed Isotopic Distribution } & \multirow{2}{*}{$\begin{array}{c}\text { Initial Contact } \\
\text { Dose Rate } \\
(\mathrm{mR} / \mathrm{hr})\end{array}$} & \multirow{2}{*}{$\begin{array}{c}\text { Decayed } \\
\text { Contact Dose } \\
\text { Rate }(\mathrm{mR} / \mathrm{hr})^{1} \\
\end{array}$} \\
\hline & & & Isotope & Activity (Ci) & & Isotope & Activity (Ci) & & \\
\hline & & & Pm-147 & $3.21 \mathrm{E}-02$ & & Pm-147 & $1.97 \mathrm{E}-05$ & & \\
\hline & & & & & & Po-211 & $5.31 \mathrm{E}-13$ & & \\
\hline & & & & & & Po-215 & $1.74 \mathrm{E}-10$ & & \\
\hline & & & $\mathrm{Pu}-239$ & $6.20 \mathrm{E}-03$ & & $\mathrm{Pu}-239$ & $6.20 \mathrm{E}-03$ & & \\
\hline & & & & & & $\mathrm{Ra}-223$ & $1.76 \mathrm{E}-10$ & & \\
\hline & & & Rh-106 & 4.12E-03 & & Rh-106 & $1.77 \mathrm{E}-11$ & & \\
\hline & & & & & & $\mathrm{Rn}-219$ & $1.74 \mathrm{E}-10$ & & \\
\hline & & & $\mathrm{Ru}-106$ & $4.12 \mathrm{E}-03$ & & $\mathrm{Ru}-106$ & $1.79 \mathrm{E}-11$ & & \\
\hline & & & $\mathrm{Sb}-125$ & $2.29 \mathrm{E}-02$ & & $\mathrm{Sb}-125$ & $2.07 \mathrm{E}-05$ & & \\
\hline & & & & & & Sm-147 & $7.86 \mathrm{E}-13$ & & \\
\hline & & & Sr-90 & $5.14 \mathrm{E}-01$ & & Sr-90 & $2.64 \mathrm{E}-01$ & & \\
\hline & & & $\mathrm{Te}-125 \mathrm{~m}$ & $9.50 \mathrm{E}-03$ & & $\mathrm{Te}-125 \mathrm{~m}$ & $5.01 \mathrm{E}-06$ & & \\
\hline & & & & & & Th-227 & $1.71 \mathrm{E}-10$ & & \\
\hline & & & & & & Th-231 & 8.69E-07 & & \\
\hline & & & & & & Tl-207 & $1.73 \mathrm{E}-10$ & & \\
\hline & & & U-235 & $8.80 \mathrm{E}-07$ & & U-235 & $8.80 \mathrm{E}-07$ & & \\
\hline & & & Y-90 & $5.13 \mathrm{E}-01$ & & Y-90 & $2.61 \mathrm{E}-01$ & & \\
\hline \multirow[t]{15}{*}{211} & S810809 & 1981 & & & 2009 & Ac-227 & $1.76 \mathrm{E}-10$ & 160,000 & 79,000 \\
\hline & & & $\mathrm{Ba}-137 \mathrm{~m}$ & $9.59 \mathrm{E}-01$ & & $\mathrm{Ba}-137 \mathrm{~m}$ & $5.00 \mathrm{E}-01$ & & \\
\hline & & & & & & Bi-211 & $1.74 \mathrm{E}-10$ & & \\
\hline & & & Cs-137 & $1.02 \mathrm{E}+00$ & & Cs-137 & $5.35 \mathrm{E}-01$ & & \\
\hline & & & Eu-155 & $1.91 \mathrm{E}-02$ & & Eu-155 & $3.82 \mathrm{E}-04$ & & \\
\hline & & & & & & Fr-223 & $2.40 \mathrm{E}-12$ & & \\
\hline & & & & & & $\mathrm{Pa}-231$ & $5.21 \mathrm{E}-10$ & & \\
\hline & & & & & & $\mathrm{Pb}-211$ & $1.74 \mathrm{E}-10$ & & \\
\hline & & & Pm-147 & $5.83 \mathrm{E}-02$ & & Pm-147 & $3.57 \mathrm{E}-05$ & & \\
\hline & & & & & & Po-211 & $5.31 \mathrm{E}-13$ & & \\
\hline & & & & & & Po-215 & $1.74 \mathrm{E}-10$ & & \\
\hline & & & Pu-239 & $6.20 \mathrm{E}-03$ & & $\mathrm{Pu}-239$ & $6.20 \mathrm{E}-03$ & & \\
\hline & & & & & & $\mathrm{Ra}-223$ & $1.76 \mathrm{E}-10$ & & \\
\hline & & & Rh-106 & 7.49E-03 & & Rh-106 & $3.22 \mathrm{E}-11$ & & \\
\hline & & & & & & $\mathrm{Rn}-219$ & $1.74 \mathrm{E}-10$ & & \\
\hline
\end{tabular}

${ }^{1}$ Calculated decayed contact dose rate. Rounded to nearest $10 \mathrm{mR} / \mathrm{hr}$ for values to 1000 ; rounded to nearest $100 \mathrm{mR} / \mathrm{hr}$ for values $>1000$ to 10,000 ; rounded to nearest $1000 \mathrm{mR} / \mathrm{hr}$ for values $>10,000$. * Initial contact dose rate assumed to be $1,000,000 \mathrm{mR} / \mathrm{hr}$; **Initial contact dose rate assumed to be $1,010,000 \mathrm{mR} / \mathrm{hr}$.

$$
44 \text { of } 168
$$


Appendix A-4 - Initial and Decayed Radionuclide and Dose Data for Lined Shafts

\begin{tabular}{|c|c|c|c|c|c|c|c|c|c|}
\hline \multirow[b]{2}{*}{ Shaft Number } & \multirow[b]{2}{*}{ Package ID } & \multirow[b]{2}{*}{ Base Year } & \multicolumn{2}{|c|}{ Initial Isotopic Distribution } & \multirow[b]{2}{*}{ Target Year } & \multicolumn{2}{|c|}{ Decayed Isotopic Distribution } & \multirow{2}{*}{$\begin{array}{c}\text { Initial Contact } \\
\text { Dose Rate } \\
(\mathrm{mR} / \mathrm{hr})\end{array}$} & \multirow{2}{*}{$\begin{array}{c}\text { Decayed } \\
\text { Contact Dose } \\
\text { Rate }(\mathrm{mR} / \mathrm{hr})^{1} \\
\end{array}$} \\
\hline & & & Isotope & Activity (Ci) & & Isotope & Activity (Ci) & & \\
\hline & & & $\mathrm{Ru}-106$ & $7.49 \mathrm{E}-03$ & & $\mathrm{Ru}-106$ & $3.25 \mathrm{E}-11$ & & \\
\hline & & & $\mathrm{Sb}-125$ & $4.16 \mathrm{E}-02$ & & $\mathrm{Sb}-125$ & $3.77 \mathrm{E}-05$ & & \\
\hline & & & & & & Sm-147 & $1.43 \mathrm{E}-12$ & & \\
\hline & & & Sr-90 & 9.34E-01 & & Sr-90 & $4.80 \mathrm{E}-01$ & & \\
\hline & & & $\mathrm{Te}-125 \mathrm{~m}$ & $1.73 \mathrm{E}-02$ & & Te-125m & $9.12 \mathrm{E}-06$ & & \\
\hline & & & & & & Th-227 & $1.71 \mathrm{E}-10$ & & \\
\hline & & & & & & Th-231 & $8.69 \mathrm{E}-07$ & & \\
\hline & & & & & & Tl-207 & $1.73 \mathrm{E}-10$ & & \\
\hline & & & U-235 & $8.80 \mathrm{E}-07$ & & U-235 & $8.80 \mathrm{E}-07$ & & \\
\hline & & & $\mathrm{Y}-90$ & 9.33E-01 & & $\mathrm{Y}-90$ & 4.74E-01 & & \\
\hline \multirow[t]{22}{*}{211} & S810810 & 1981 & & & 2009 & Ac-227 & $1.76 \mathrm{E}-10$ & 1,000 & 490 \\
\hline & & & $\mathrm{Ba}-137 \mathrm{~m}$ & $1.44 \mathrm{E}-02$ & & $\mathrm{Ba}-137 \mathrm{~m}$ & $7.50 \mathrm{E}-03$ & & \\
\hline & & & & & & Bi-211 & $1.74 \mathrm{E}-10$ & & \\
\hline & & & Cs-137 & $1.53 \mathrm{E}-02$ & & Cs-137 & $8.02 \mathrm{E}-03$ & & \\
\hline & & & $\mathrm{Eu}-155$ & $2.87 \mathrm{E}-04$ & & $\mathrm{Eu}-155$ & $5.72 \mathrm{E}-06$ & & \\
\hline & & & & & & Fr-223 & $2.40 \mathrm{E}-12$ & & \\
\hline & & & & & & $\mathrm{Pa}-231$ & $5.21 \mathrm{E}-10$ & & \\
\hline & & & & & & $\mathrm{Pb}-211$ & $1.74 \mathrm{E}-10$ & & \\
\hline & & & Pm-147 & $8.75 \mathrm{E}-04$ & & Pm-147 & $5.36 \mathrm{E}-07$ & & \\
\hline & & & & & & Po-211 & $5.31 \mathrm{E}-13$ & & \\
\hline & & & & & & Po-215 & $1.74 \mathrm{E}-10$ & & \\
\hline & & & $\mathrm{Pu}-239$ & $6.20 \mathrm{E}-03$ & & Pu-239 & $6.20 \mathrm{E}-03$ & & \\
\hline & & & & & & $\mathrm{Ra}-223$ & $1.76 \mathrm{E}-10$ & & \\
\hline & & & Rh-106 & $1.12 \mathrm{E}-04$ & & Rh-106 & $4.83 \mathrm{E}-13$ & & \\
\hline & & & & & & Rn-219 & $1.74 \mathrm{E}-10$ & & \\
\hline & & & $\mathrm{Ru}-106$ & $1.12 \mathrm{E}-04$ & & $\mathrm{Ru}-106$ & $4.88 \mathrm{E}-13$ & & \\
\hline & & & Sb-125 & $6.24 \mathrm{E}-04$ & & $\mathrm{Sb}-125$ & $5.65 \mathrm{E}-07$ & & \\
\hline & & & & & & Sm-147 & $2.14 \mathrm{E}-14$ & & \\
\hline & & & Sr-90 & $1.40 \mathrm{E}-02$ & & Sr-90 & 7.19E-03 & & \\
\hline & & & Te-125m & $2.59 \mathrm{E}-04$ & & $\mathrm{Te}-125 \mathrm{~m}$ & $1.37 \mathrm{E}-07$ & & \\
\hline & & & & & & Th-227 & $1.71 \mathrm{E}-10$ & & \\
\hline & & & & & & Th-231 & 8.69E-07 & & \\
\hline
\end{tabular}

${ }^{1}$ Calculated decayed contact dose rate. Rounded to nearest $10 \mathrm{mR} / \mathrm{hr}$ for values to 1000 ; rounded to nearest $100 \mathrm{mR} / \mathrm{hr}$ for values $>1000$ to 10,000 ; rounded to nearest $1000 \mathrm{mR} / \mathrm{hr}$ for values $>10,000$. * Initial contact dose rate assumed to be $1,000,000 \mathrm{mR} / \mathrm{hr}$; **Initial contact dose rate assumed to be $1,010,000 \mathrm{mR} / \mathrm{hr}$.

$$
45 \text { of } 168
$$


Appendix A-4 - Initial and Decayed Radionuclide and Dose Data for Lined Shafts

\begin{tabular}{|c|c|c|c|c|c|c|c|c|c|}
\hline \multirow[b]{2}{*}{ Shaft Number } & \multirow[b]{2}{*}{ Package ID } & \multirow[b]{2}{*}{ Base Year } & \multicolumn{2}{|c|}{ Initial Isotopic Distribution } & \multirow[b]{2}{*}{ Target Year } & \multicolumn{2}{|c|}{ Decayed Isotopic Distribution } & \multirow{2}{*}{$\begin{array}{c}\text { Initial Contact } \\
\text { Dose Rate } \\
(\mathrm{mR} / \mathrm{hr})\end{array}$} & \multirow{2}{*}{$\begin{array}{c}\text { Decayed } \\
\text { Contact Dose } \\
\text { Rate }(\mathrm{mR} / \mathrm{hr}) \\
\end{array}$} \\
\hline & & & Isotope & Activity (Ci) & & Isotope & Activity (Ci) & & \\
\hline & & & & & & Tl-207 & $1.73 \mathrm{E}-10$ & & \\
\hline & & & U-235 & $8.80 \mathrm{E}-07$ & & $\mathrm{U}-235$ & $8.80 \mathrm{E}-07$ & & \\
\hline & & & $\mathrm{Y}-90$ & $1.40 \mathrm{E}-02$ & & $\mathrm{Y}-90$ & $7.11 \mathrm{E}-03$ & & \\
\hline \multirow[t]{25}{*}{211} & S812669 & 1981 & & & 2009 & Ac-227 & $1.14 \mathrm{E}-08$ & 940,000 & 465,000 \\
\hline & & & Ba-137m & $2.64 \mathrm{E}+00$ & & Ba-137m & $1.38 \mathrm{E}+00$ & & \\
\hline & & & & & & Bi-211 & $1.13 \mathrm{E}-08$ & & \\
\hline & & & Cs-137 & $2.81 \mathrm{E}+00$ & & Cs-137 & $1.47 \mathrm{E}+00$ & & \\
\hline & & & Eu-155 & $5.26 \mathrm{E}-02$ & & Eu-155 & $1.05 \mathrm{E}-03$ & & \\
\hline & & & & & & Fr-223 & $1.56 \mathrm{E}-10$ & & \\
\hline & & & & & & $\mathrm{Pa}-231$ & 3.38E-08 & & \\
\hline & & & & & & $\mathrm{Pb}-211$ & $1.13 \mathrm{E}-08$ & & \\
\hline & & & Pm-147 & $1.60 \mathrm{E}-01$ & & Pm-147 & $9.83 \mathrm{E}-05$ & & \\
\hline & & & & & & Po-211 & $3.45 \mathrm{E}-11$ & & \\
\hline & & & & & & Po-215 & $1.13 \mathrm{E}-08$ & & \\
\hline & & & $\mathrm{Pu}-239$ & 4.07E-01 & & $\mathrm{Pu}-239$ & 4.06E-01 & & \\
\hline & & & & & & $\mathrm{Ra}-223$ & $1.14 \mathrm{E}-08$ & & \\
\hline & & & Rh-106 & $2.06 \mathrm{E}-02$ & & Rh-106 & $8.86 \mathrm{E}-11$ & & \\
\hline & & & & & & Rn-219 & $1.13 \mathrm{E}-08$ & & \\
\hline & & & $\mathrm{Ru}-106$ & $2.06 \mathrm{E}-02$ & & $\mathrm{Ru}-106$ & $8.95 \mathrm{E}-11$ & & \\
\hline & & & Sb-125 & $1.14 \mathrm{E}-01$ & & Sb-125 & $1.04 \mathrm{E}-04$ & & \\
\hline & & & & & & Sm-147 & $3.93 \mathrm{E}-12$ & & \\
\hline & & & Sr-90 & $2.57 \mathrm{E}+00$ & & Sr-90 & $1.32 \mathrm{E}+00$ & & \\
\hline & & & $\mathrm{Te}-125 \mathrm{~m}$ & $4.75 \mathrm{E}-02$ & & $\mathrm{Te}-125 \mathrm{~m}$ & $2.51 \mathrm{E}-05$ & & \\
\hline & & & & & & Th-227 & $1.11 \mathrm{E}-08$ & & \\
\hline & & & & & & Th-231 & $5.65 \mathrm{E}-05$ & & \\
\hline & & & & & & Tl-207 & $1.13 \mathrm{E}-08$ & & \\
\hline & & & U-235 & $5.72 \mathrm{E}-05$ & & U-235 & $5.72 \mathrm{E}-05$ & & \\
\hline & & & Y-90 & $2.56 \mathrm{E}+00$ & & Y-90 & $1.30 \mathrm{E}+00$ & & \\
\hline \multirow[t]{4}{*}{212} & S803758 & 1980 & & & 2009 & Ac-227 & $2.69 \mathrm{E}-11$ & 1,750 & 40 \\
\hline & & & & & & Bi-211 & $2.66 \mathrm{E}-11$ & & \\
\hline & & & Co-60 & $3.00 \mathrm{E}+01$ & & Co-60 & $6.61 \mathrm{E}-01$ & & \\
\hline & & & & & & Fr-223 & $3.68 \mathrm{E}-13$ & & \\
\hline
\end{tabular}

${ }^{1}$ Calculated decayed contact dose rate. Rounded to nearest $10 \mathrm{mR} / \mathrm{hr}$ for values to 1000 ; rounded to nearest $100 \mathrm{mR} / \mathrm{hr}$ for values $>1000$ to 10,000 ; rounded to nearest $1000 \mathrm{mR} / \mathrm{hr}$ for values $>10,000$. * Initial contact dose rate assumed to be $1,000,000 \mathrm{mR} / \mathrm{hr}$; **Initial contact dose rate assumed to be $1,010,000 \mathrm{mR} / \mathrm{hr}$. 
Appendix A-4 - Initial and Decayed Radionuclide and Dose Data for Lined Shafts

\begin{tabular}{|c|c|c|c|c|c|c|c|c|c|}
\hline \multirow[b]{2}{*}{ Shaft Number } & \multirow[b]{2}{*}{ Package ID } & \multirow[b]{2}{*}{ Base Year } & \multicolumn{2}{|c|}{ Initial Isotopic Distribution } & \multirow[b]{2}{*}{ Target Year } & \multicolumn{2}{|c|}{ Decayed Isotopic Distribution } & \multirow{2}{*}{$\begin{array}{c}\text { Initial Contact } \\
\text { Dose Rate } \\
(\mathrm{mR} / \mathrm{hr})\end{array}$} & \multirow{2}{*}{$\begin{array}{c}\text { Decayed } \\
\text { Contact Dose } \\
\text { Rate }(\mathrm{mR} / \mathrm{hr})^{1} \\
\end{array}$} \\
\hline & & & Isotope & Activity (Ci) & & Isotope & Activity (Ci) & & \\
\hline & & & & & & $\mathrm{Pa}-231$ & $1.09 \mathrm{E}-10$ & & \\
\hline & & & & & & $\mathrm{Pb}-211$ & $2.66 \mathrm{E}-11$ & & \\
\hline & & & & & & Po-211 & $8.12 \mathrm{E}-14$ & & \\
\hline & & & & & & Po-215 & $2.66 \mathrm{E}-11$ & & \\
\hline & & & $\mathrm{Pu}-239$ & $1.24 \mathrm{E}+01$ & & $\mathrm{Pu}-239$ & $1.24 \mathrm{E}+01$ & & \\
\hline & & & & & & Ra-223 & $2.69 \mathrm{E}-11$ & & \\
\hline & & & & & & $\mathrm{Rn}-219$ & $2.66 \mathrm{E}-11$ & & \\
\hline & & & & & & Th-227 & $2.62 \mathrm{E}-11$ & & \\
\hline & & & & & & Th-231 & $3.50 \mathrm{E}-07$ & & \\
\hline & & & & & & Tl-207 & $2.65 \mathrm{E}-11$ & & \\
\hline & & & & & & $\mathrm{U}-235$ & $3.55 \mathrm{E}-07$ & & \\
\hline \multirow[t]{21}{*}{213} & S812684 & 1981 & & & 2009 & Ac-227 & $6.07 \mathrm{E}-08$ & $1000000+$ & $495,000 *$ \\
\hline & & & Ba-137m & $9.78 \mathrm{E}+00$ & & $\mathrm{Ba}-137 \mathrm{~m}$ & $5.10 \mathrm{E}+00$ & & \\
\hline & & & & & & Bi-211 & $6.00 \mathrm{E}-08$ & & \\
\hline & & & Cs-137 & $1.04 \mathrm{E}+01$ & & Cs-137 & $5.45 \mathrm{E}+00$ & & \\
\hline & & & Eu-155 & $1.95 \mathrm{E}-01$ & & Eu-155 & $3.89 \mathrm{E}-03$ & & \\
\hline & & & & & & Fr-223 & $8.29 \mathrm{E}-10$ & & \\
\hline & & & & & & $\mathrm{Pa}-231$ & $1.80 \mathrm{E}-07$ & & \\
\hline & & & & & & $\mathrm{Pb}-211$ & $6.00 \mathrm{E}-08$ & & \\
\hline & & & Pm-147 & $5.95 \mathrm{E}-01$ & & Pm-147 & $3.65 \mathrm{E}-04$ & & \\
\hline & & & & & & Po-211 & $1.83 \mathrm{E}-10$ & & \\
\hline & & & & & & Po-215 & $6.01 \mathrm{E}-08$ & & \\
\hline & & & Pu-239 & $2.02 \mathrm{E}+00$ & & $\mathrm{Pu}-239$ & $2.02 \mathrm{E}+00$ & & \\
\hline & & & & & & Ra-223 & $6.07 \mathrm{E}-08$ & & \\
\hline & & & Rh-106 & 7.64E-02 & & Rh-106 & $3.29 \mathrm{E}-10$ & & \\
\hline & & & & & & Rn-219 & $6.00 \mathrm{E}-08$ & & \\
\hline & & & $\mathrm{Ru}-106$ & 7.64E-02 & & $\mathrm{Ru}-106$ & $3.32 \mathrm{E}-10$ & & \\
\hline & & & Sb-125 & 4.24E-01 & & Sb-125 & $3.84 \mathrm{E}-04$ & & \\
\hline & & & & & & Sm-147 & $1.46 \mathrm{E}-11$ & & \\
\hline & & & Sr-90 & $9.52 \mathrm{E}+00$ & & Sr-90 & $4.89 \mathrm{E}+00$ & & \\
\hline & & & $\mathrm{Te}-125 \mathrm{~m}$ & $1.76 \mathrm{E}-01$ & & $\mathrm{Te}-125 \mathrm{~m}$ & $9.30 \mathrm{E}-05$ & & \\
\hline & & & & & & Th-227 & $5.91 \mathrm{E}-08$ & & \\
\hline
\end{tabular}

${ }^{1}$ Calculated decayed contact dose rate. Rounded to nearest $10 \mathrm{mR} / \mathrm{hr}$ for values to 1000 ; rounded to nearest $100 \mathrm{mR} / \mathrm{hr}$ for values $>1000$ to 10,000 ; rounded to nearest $1000 \mathrm{mR} / \mathrm{hr}$ for values $>10,000$. * Initial contact dose rate assumed to be $1,000,000 \mathrm{mR} / \mathrm{hr}$; **Initial contact dose rate assumed to be $1,010,000 \mathrm{mR} / \mathrm{hr}$.

$$
47 \text { of } 168
$$


Appendix A-4 - Initial and Decayed Radionuclide and Dose Data for Lined Shafts

\begin{tabular}{|c|c|c|c|c|c|c|c|c|c|}
\hline \multirow[b]{2}{*}{ Shaft Number } & \multirow[b]{2}{*}{ Package ID } & \multirow[b]{2}{*}{ Base Year } & \multicolumn{2}{|c|}{ Initial Isotopic Distribution } & \multirow[b]{2}{*}{ Target Year } & \multicolumn{2}{|c|}{ Decayed Isotopic Distribution } & \multirow{2}{*}{$\begin{array}{c}\text { Initial Contact } \\
\text { Dose Rate } \\
(\mathrm{mR} / \mathrm{hr})\end{array}$} & \multirow{2}{*}{$\begin{array}{c}\text { Decayed } \\
\text { Contact Dose } \\
\text { Rate }(\mathrm{mR} / \mathrm{hr})^{1}\end{array}$} \\
\hline & & & Isotope & Activity (Ci) & & Isotope & Activity (Ci) & & \\
\hline & & & & & & Th-231 & $3.00 \mathrm{E}-04$ & & \\
\hline & & & & & & Tl-207 & $5.97 \mathrm{E}-08$ & & \\
\hline & & & $\mathrm{U}-235$ & $3.04 \mathrm{E}-04$ & & U-235 & $3.04 \mathrm{E}-04$ & & \\
\hline & & & $\mathrm{Y}-90$ & $9.51 \mathrm{E}+00$ & & $\mathrm{Y}-90$ & $4.84 \mathrm{E}+00$ & & \\
\hline \multirow[t]{25}{*}{213} & S812686 & 1981 & & & 2009 & Ac- 227 & 7.61E-09 & 500,000 & 247,000 \\
\hline & & & Ba-137m & $1.68 \mathrm{E}+00$ & & Ba-137m & $8.75 \mathrm{E}-01$ & & \\
\hline & & & & & & $\mathrm{Bi}-211$ & 7.52E-09 & & \\
\hline & & & Cs-137 & $1.79 \mathrm{E}+00$ & & Cs-137 & 9.35E-01 & & \\
\hline & & & Eu-155 & 3.34E-02 & & Eu-155 & $6.68 \mathrm{E}-04$ & & \\
\hline & & & & & & Fr-223 & $1.04 \mathrm{E}-10$ & & \\
\hline & & & & & & $\mathrm{Pa}-231$ & $2.25 \mathrm{E}-08$ & & \\
\hline & & & & & & $\mathrm{Pb}-211$ & 7.53E-09 & & \\
\hline & & & Pm-147 & $1.02 \mathrm{E}-01$ & & Pm-147 & $6.25 \mathrm{E}-05$ & & \\
\hline & & & & & & Po-211 & $2.30 \mathrm{E}-11$ & & \\
\hline & & & & & & Po-215 & 7.53E-09 & & \\
\hline & & & $\mathrm{Pu}-239$ & $2.68 \mathrm{E}-01$ & & $\mathrm{Pu}-239$ & $2.68 \mathrm{E}-01$ & & \\
\hline & & & & & & Ra-223 & 7.61E-09 & & \\
\hline & & & Rh-106 & $1.31 \mathrm{E}-02$ & & Rh-106 & $5.64 \mathrm{E}-11$ & & \\
\hline & & & & & & Rn-219 & $7.52 \mathrm{E}-09$ & & \\
\hline & & & $\mathrm{Ru}-106$ & $1.31 \mathrm{E}-02$ & & Ru-106 & $5.70 \mathrm{E}-11$ & & \\
\hline & & & Sb-125 & 7.28E-02 & & Sb-125 & $6.59 \mathrm{E}-05$ & & \\
\hline & & & & & & Sm-147 & $2.50 \mathrm{E}-12$ & & \\
\hline & & & Sr-90 & $1.63 \mathrm{E}+00$ & & Sr-90 & 8.39E-01 & & \\
\hline & & & $\mathrm{Te}-125 \mathrm{~m}$ & $3.02 \mathrm{E}-02$ & & Te-125m & $1.60 \mathrm{E}-05$ & & \\
\hline & & & & & & Th-227 & 7.41E-09 & & \\
\hline & & & & & & Th-231 & $3.76 \mathrm{E}-05$ & & \\
\hline & & & & & & Tl-207 & 7.49E-09 & & \\
\hline & & & U-235 & $3.81 \mathrm{E}-05$ & & U-235 & $3.81 \mathrm{E}-05$ & & \\
\hline & & & Y-90 & $1.63 \mathrm{E}+00$ & & Y-90 & 8.30E-01 & & \\
\hline \multirow[t]{3}{*}{213} & S812688 & 1981 & & & 2009 & Ac-227 & $3.43 \mathrm{E}-08$ & & 0 \\
\hline & & & Ba-137m & $2.42 \mathrm{E}+01$ & & Ba-137m & $1.26 \mathrm{E}+01$ & & \\
\hline & & & & & & Bi-211 & 3.39E-08 & & \\
\hline
\end{tabular}

${ }^{1}$ Calculated decayed contact dose rate. Rounded to nearest $10 \mathrm{mR} / \mathrm{hr}$ for values to 1000 ; rounded to nearest $100 \mathrm{mR} / \mathrm{hr}$ for values $>1000$ to 10,000 ; rounded to nearest $1000 \mathrm{mR} / \mathrm{hr}$ for values $>10,000$. * Initial contact dose rate assumed to be $1,000,000 \mathrm{mR} / \mathrm{hr}$; **Initial contact dose rate assumed to be $1,010,000 \mathrm{mR} / \mathrm{hr}$. 
Appendix A-4 - Initial and Decayed Radionuclide and Dose Data for Lined Shafts

\begin{tabular}{|c|c|c|c|c|c|c|c|c|c|}
\hline \multirow[b]{2}{*}{ Shaft Number } & \multirow[b]{2}{*}{ Package ID } & \multirow[b]{2}{*}{ Base Year } & \multicolumn{2}{|c|}{ Initial Isotopic Distribution } & \multirow[b]{2}{*}{ Target Year } & \multicolumn{2}{|c|}{ Decayed Isotopic Distribution } & \multirow{2}{*}{$\begin{array}{c}\text { Initial Contact } \\
\text { Dose Rate } \\
(\mathrm{mR} / \mathrm{hr})\end{array}$} & \multirow{2}{*}{$\begin{array}{c}\text { Decayed } \\
\text { Contact Dose } \\
\text { Rate }(\mathrm{mR} / \mathrm{hr})^{1} \\
\end{array}$} \\
\hline & & & Isotope & Activity (Ci) & & Isotope & Activity (Ci) & & \\
\hline & & & Cs-137 & $2.58 \mathrm{E}+01$ & & Cs-137 & $1.35 \mathrm{E}+01$ & & \\
\hline & & & Eu-155 & $4.83 \mathrm{E}-01$ & & Eu-155 & $9.64 \mathrm{E}-03$ & & \\
\hline & & & & & & Fr-223 & $4.68 \mathrm{E}-10$ & & \\
\hline & & & & & & $\mathrm{Pa}-231$ & $1.01 \mathrm{E}-07$ & & \\
\hline & & & & & & $\mathrm{Pb}-211$ & $3.39 \mathrm{E}-08$ & & \\
\hline & & & Pm-147 & $1.47 \mathrm{E}+00$ & & Pm-147 & $9.02 \mathrm{E}-04$ & & \\
\hline & & & & & & Po-211 & $1.03 \mathrm{E}-10$ & & \\
\hline & & & & & & Po-215 & $3.39 \mathrm{E}-08$ & & \\
\hline & & & $\mathrm{Pu}-239$ & $7.95 \mathrm{E}-01$ & & $\mathrm{Pu}-239$ & $7.94 \mathrm{E}-01$ & & \\
\hline & & & & & & $\mathrm{Ra}-223$ & $3.43 \mathrm{E}-08$ & & \\
\hline & & & Rh-106 & $1.89 \mathrm{E}-01$ & & Rh-106 & $8.13 \mathrm{E}-10$ & & \\
\hline & & & & & & $\mathrm{Rn}-219$ & $3.39 \mathrm{E}-08$ & & \\
\hline & & & $\mathrm{Ru}-106$ & $1.89 \mathrm{E}-01$ & & $\mathrm{Ru}-106$ & $8.22 \mathrm{E}-10$ & & \\
\hline & & & $\mathrm{Sb}-125$ & $1.05 \mathrm{E}+00$ & & $\mathrm{Sb}-125$ & $9.51 \mathrm{E}-04$ & & \\
\hline & & & & & & Sm-147 & $3.61 \mathrm{E}-11$ & & \\
\hline & & & Sr-90 & $2.36 \mathrm{E}+01$ & & Sr-90 & $1.21 \mathrm{E}+01$ & & \\
\hline & & & $\mathrm{Te}-125 \mathrm{~m}$ & $4.36 \mathrm{E}-01$ & & Te- $125 \mathrm{~m}$ & $2.30 \mathrm{E}-04$ & & \\
\hline & & & & & & Th-227 & $3.34 \mathrm{E}-08$ & & \\
\hline & & & & & & Th-231 & $1.69 \mathrm{E}-04$ & & \\
\hline & & & & & & Tl-207 & $3.37 \mathrm{E}-08$ & & \\
\hline & & & $\mathrm{U}-235$ & $1.71 \mathrm{E}-04$ & & U-235 & $1.71 \mathrm{E}-04$ & & \\
\hline & & & Y-90 & $2.35 \mathrm{E}+01$ & & Y-90 & $1.20 \mathrm{E}+01$ & & \\
\hline \multirow[t]{10}{*}{213} & S812689 & 1981 & & & 2009 & Ac- 227 & 4.40E-09 & 160,000 & 79,000 \\
\hline & & & Ba-137m & $6.71 \mathrm{E}-01$ & & Ba-137m & $3.50 \mathrm{E}-01$ & & \\
\hline & & & & & & Bi-211 & $4.35 \mathrm{E}-09$ & & \\
\hline & & & Cs-137 & $7.15 \mathrm{E}-01$ & & Cs-137 & $3.74 \mathrm{E}-01$ & & \\
\hline & & & Eu-155 & $1.34 \mathrm{E}-02$ & & Eu-155 & $2.67 \mathrm{E}-04$ & & \\
\hline & & & & & & Fr-223 & $6.01 \mathrm{E}-11$ & & \\
\hline & & & & & & $\mathrm{Pa}-231$ & $1.30 \mathrm{E}-08$ & & \\
\hline & & & & & & $\mathrm{Pb}-211$ & 4.35E-09 & & \\
\hline & & & Pm-147 & 4.08E-02 & & Pm-147 & $2.50 \mathrm{E}-05$ & & \\
\hline & & & & & & Po-211 & $1.33 \mathrm{E}-11$ & & \\
\hline
\end{tabular}

${ }^{1}$ Calculated decayed contact dose rate. Rounded to nearest $10 \mathrm{mR} / \mathrm{hr}$ for values to 1000 ; rounded to nearest $100 \mathrm{mR} / \mathrm{hr}$ for values $>1000$ to 10,000 ; rounded to nearest $1000 \mathrm{mR} / \mathrm{hr}$ for values $>10,000$. * Initial contact dose rate assumed to be $1,000,000 \mathrm{mR} / \mathrm{hr}$; **Initial contact dose rate assumed to be $1,010,000 \mathrm{mR} / \mathrm{hr}$. 
Appendix A-4 - Initial and Decayed Radionuclide and Dose Data for Lined Shafts

\begin{tabular}{|c|c|c|c|c|c|c|c|c|c|}
\hline \multirow[b]{2}{*}{ Shaft Number } & \multirow[b]{2}{*}{ Package ID } & \multirow[b]{2}{*}{ Base Year } & \multicolumn{2}{|c|}{ Initial Isotopic Distribution } & \multirow[b]{2}{*}{ Target Year } & \multicolumn{2}{|c|}{ Decayed Isotopic Distribution } & \multirow{2}{*}{$\begin{array}{c}\text { Initial Contact } \\
\text { Dose Rate } \\
(\mathrm{mR} / \mathrm{hr})\end{array}$} & \multirow{2}{*}{$\begin{array}{c}\text { Decayed } \\
\text { Contact Dose } \\
\text { Rate }(\mathrm{mR} / \mathrm{hr})^{1}\end{array}$} \\
\hline & & & Isotope & Activity (Ci) & & Isotope & Activity (Ci) & & \\
\hline & & & & & & Po-215 & $4.35 \mathrm{E}-09$ & & \\
\hline & & & $\mathrm{Pu}-239$ & $1.24 \mathrm{E}-02$ & & $\mathrm{Pu}-239$ & $1.24 \mathrm{E}-02$ & & \\
\hline & & & & & & $\mathrm{Ra}-223$ & $4.40 \mathrm{E}-09$ & & \\
\hline & & & $\mathrm{Rh}-106$ & $5.24 \mathrm{E}-03$ & & Rh-106 & $2.26 \mathrm{E}-11$ & & \\
\hline & & & & & & Rn-219 & 4.35E-09 & & \\
\hline & & & $\mathrm{Ru}-106$ & $5.24 \mathrm{E}-03$ & & $\mathrm{Ru}-106$ & $2.28 \mathrm{E}-11$ & & \\
\hline & & & $\mathrm{Sb}-125$ & $2.91 \mathrm{E}-02$ & & $\mathrm{Sb}-125$ & $2.64 \mathrm{E}-05$ & & \\
\hline & & & & & & Sm-147 & $1.00 \mathrm{E}-12$ & & \\
\hline & & & Sr-90 & $6.54 \mathrm{E}-01$ & & Sr-90 & $3.36 \mathrm{E}-01$ & & \\
\hline & & & $\mathrm{Te}-125 \mathrm{~m}$ & $1.21 \mathrm{E}-02$ & & $\mathrm{Te}-125 \mathrm{~m}$ & $6.38 \mathrm{E}-06$ & & \\
\hline & & & & & & Th-227 & 4.29E-09 & & \\
\hline & & & & & & Th-231 & $2.17 \mathrm{E}-05$ & & \\
\hline & & & & & & Tl-207 & 4.33E-09 & & \\
\hline & & & $\mathrm{U}-235$ & $2.20 \mathrm{E}-05$ & & $\mathrm{U}-235$ & $2.20 \mathrm{E}-05$ & & \\
\hline & & & Y-90 & $6.53 \mathrm{E}-01$ & & Y-90 & 3.32E-01 & & \\
\hline \multirow[t]{17}{*}{214} & S820057 & 1982 & & & 2009 & Ac-227 & $1.65 \mathrm{E}-10$ & 15,000 & 7,600 \\
\hline & & & Ba-137m & 7.19E-02 & & Ba-137m & $3.84 \mathrm{E}-02$ & & \\
\hline & & & & & & Bi-211 & $1.63 \mathrm{E}-10$ & & \\
\hline & & & Cs-137 & 7.66E-02 & & Cs-137 & 4.10E-02 & & \\
\hline & & & Eu-155 & $1.43 \mathrm{E}-03$ & & Eu-155 & $3.29 \mathrm{E}-05$ & & \\
\hline & & & & & & Fr-223 & $2.25 \mathrm{E}-12$ & & \\
\hline & & & & & & $\mathrm{Pa}-231$ & $5.02 \mathrm{E}-10$ & & \\
\hline & & & & & & $\mathrm{Pb}-211$ & $1.63 \mathrm{E}-10$ & & \\
\hline & & & Pm-147 & $4.38 \mathrm{E}-03$ & & Pm-147 & $3.49 \mathrm{E}-06$ & & \\
\hline & & & & & & Po-211 & $4.98 \mathrm{E}-13$ & & \\
\hline & & & & & & Po-215 & $1.63 \mathrm{E}-10$ & & \\
\hline & & & $\mathrm{Pu}-239$ & $6.20 \mathrm{E}-03$ & & $\mathrm{Pu}-239$ & $6.20 \mathrm{E}-03$ & & \\
\hline & & & & & & Ra-223 & $1.65 \mathrm{E}-10$ & & \\
\hline & & & Rh-106 & $5.62 \mathrm{E}-04$ & & Rh-106 & $4.81 \mathrm{E}-12$ & & \\
\hline & & & & & & Rn-219 & $1.63 \mathrm{E}-10$ & & \\
\hline & & & Ru-106 & $5.62 \mathrm{E}-04$ & & Ru-106 & $4.85 \mathrm{E}-12$ & & \\
\hline & & & Sb-125 & $3.12 \mathrm{E}-03$ & & Sb-125 & $3.63 \mathrm{E}-06$ & & \\
\hline
\end{tabular}

${ }^{1}$ Calculated decayed contact dose rate. Rounded to nearest $10 \mathrm{mR} / \mathrm{hr}$ for values to 1000 ; rounded to nearest $100 \mathrm{mR} / \mathrm{hr}$ for values $>1000$ to 10,000 ; rounded to nearest $1000 \mathrm{mR} / \mathrm{hr}$ for values $>10,000$. * Initial contact dose rate assumed to be $1,000,000 \mathrm{mR} / \mathrm{hr}$; **Initial contact dose rate assumed to be $1,010,000 \mathrm{mR} / \mathrm{hr}$.

$$
50 \text { of } 168
$$


Appendix A-4 - Initial and Decayed Radionuclide and Dose Data for Lined Shafts

\begin{tabular}{|c|c|c|c|c|c|c|c|c|c|}
\hline \multirow[b]{2}{*}{ Shaft Number } & \multirow[b]{2}{*}{ Package ID } & \multirow[b]{2}{*}{ Base Year } & \multicolumn{2}{|c|}{ Initial Isotopic Distribution } & \multirow[b]{2}{*}{ Target Year } & \multicolumn{2}{|c|}{ Decayed Isotopic Distribution } & \multirow{2}{*}{$\begin{array}{c}\text { Initial Contact } \\
\text { Dose Rate } \\
(\mathrm{mR} / \mathrm{hr})\end{array}$} & \multirow{2}{*}{$\begin{array}{c}\text { Decayed } \\
\text { Contact Dose } \\
\text { Rate }(\mathrm{mR} / \mathrm{hr})^{1} \\
\end{array}$} \\
\hline & & & Isotope & Activity (Ci) & & Isotope & Activity (Ci) & & \\
\hline & & & & & & Sm-147 & $1.07 \mathrm{E}-13$ & & \\
\hline & & & Sr-90 & $7.00 \mathrm{E}-02$ & & Sr-90 & $3.68 \mathrm{E}-02$ & & \\
\hline & & & $\mathrm{Te}-125 \mathrm{~m}$ & $1.30 \mathrm{E}-03$ & & $\mathrm{Te}-125 \mathrm{~m}$ & 8.79E-07 & & \\
\hline & & & & & & Th-227 & $1.61 \mathrm{E}-10$ & & \\
\hline & & & & & & Th-231 & 8.69E-07 & & \\
\hline & & & & & & T1-207 & $1.62 \mathrm{E}-10$ & & \\
\hline & & & U-235 & 8.80E-07 & & U-235 & $8.80 \mathrm{E}-07$ & & \\
\hline & & & Y-90 & $6.99 \mathrm{E}-02$ & & Y-90 & $3.64 \mathrm{E}-02$ & & \\
\hline \multirow[t]{24}{*}{214} & S820058 & 1982 & & & 2009 & Ac- 227 & $1.65 \mathrm{E}-10$ & 4,000 & 2,000 \\
\hline & & & Ba-137m & $2.88 \mathrm{E}-02$ & & $\mathrm{Ba}-137 \mathrm{~m}$ & $1.54 \mathrm{E}-02$ & & \\
\hline & & & & & & Bi-211 & $1.63 \mathrm{E}-10$ & & \\
\hline & & & Cs-137 & $3.06 \mathrm{E}-02$ & & Cs-137 & $1.64 \mathrm{E}-02$ & & \\
\hline & & & $\mathrm{Eu}-155$ & $5.73 \mathrm{E}-04$ & & $\mathrm{Eu}-155$ & $1.32 \mathrm{E}-05$ & & \\
\hline & & & & & & Fr-223 & $2.25 \mathrm{E}-12$ & & \\
\hline & & & & & & $\mathrm{Pa}-231$ & $5.02 \mathrm{E}-10$ & & \\
\hline & & & & & & $\mathrm{Pb}-211$ & $1.63 \mathrm{E}-10$ & & \\
\hline & & & Pm-147 & $1.75 \mathrm{E}-03$ & & Pm-147 & $1.40 \mathrm{E}-06$ & & \\
\hline & & & & & & Po-211 & $4.98 \mathrm{E}-13$ & & \\
\hline & & & & & & Po-215 & $1.63 \mathrm{E}-10$ & & \\
\hline & & & Pu-239 & $6.20 \mathrm{E}-03$ & & $\mathrm{Pu}-239$ & $6.20 \mathrm{E}-03$ & & \\
\hline & & & & & & $\mathrm{Ra}-223$ & $1.65 \mathrm{E}-10$ & & \\
\hline & & & Rh-106 & $2.25 \mathrm{E}-04$ & & Rh-106 & $1.92 \mathrm{E}-12$ & & \\
\hline & & & & & & Rn-219 & $1.63 \mathrm{E}-10$ & & \\
\hline & & & $\mathrm{Ru}-106$ & $2.25 \mathrm{E}-04$ & & $\mathrm{Ru}-106$ & $1.94 \mathrm{E}-12$ & & \\
\hline & & & $\mathrm{Sb}-125$ & $1.25 \mathrm{E}-03$ & & $\mathrm{Sb}-125$ & $1.45 \mathrm{E}-06$ & & \\
\hline & & & & & & Sm-147 & 4.29E-14 & & \\
\hline & & & Sr-90 & $2.80 \mathrm{E}-02$ & & Sr-90 & $1.47 \mathrm{E}-02$ & & \\
\hline & & & $\mathrm{Te}-125 \mathrm{~m}$ & $5.18 \mathrm{E}-04$ & & Te- $125 \mathrm{~m}$ & $3.52 \mathrm{E}-07$ & & \\
\hline & & & & & & Th-227 & $1.61 \mathrm{E}-10$ & & \\
\hline & & & & & & Th-231 & 8.69E-07 & & \\
\hline & & & & & & T1-207 & $1.62 \mathrm{E}-10$ & & \\
\hline & & & U-235 & 8.80E-07 & & U-235 & $8.80 \mathrm{E}-07$ & & \\
\hline
\end{tabular}

${ }^{1}$ Calculated decayed contact dose rate. Rounded to nearest $10 \mathrm{mR} / \mathrm{hr}$ for values to 1000 ; rounded to nearest $100 \mathrm{mR} / \mathrm{hr}$ for values $>1000$ to 10,000 ; rounded to nearest $1000 \mathrm{mR} / \mathrm{hr}$ for values $>10,000$. * Initial contact dose rate assumed to be $1,000,000 \mathrm{mR} / \mathrm{hr}$; **Initial contact dose rate assumed to be $1,010,000 \mathrm{mR} / \mathrm{hr}$.

$$
51 \text { of } 168
$$


Appendix A-4 - Initial and Decayed Radionuclide and Dose Data for Lined Shafts

\begin{tabular}{|c|c|c|c|c|c|c|c|c|c|}
\hline \multirow[b]{2}{*}{ Shaft Number } & \multirow[b]{2}{*}{ Package ID } & \multirow[b]{2}{*}{ Base Year } & \multicolumn{2}{|c|}{ Initial Isotopic Distribution } & \multirow[b]{2}{*}{ Target Year } & \multicolumn{2}{|c|}{ Decayed Isotopic Distribution } & \multirow{2}{*}{$\begin{array}{c}\text { Initial Contact } \\
\text { Dose Rate } \\
(\mathrm{mR} / \mathrm{hr})\end{array}$} & \multirow{2}{*}{$\begin{array}{c}\text { Decayed } \\
\text { Contact Dose } \\
\text { Rate }(\mathrm{mR} / \mathrm{hr})\end{array}$} \\
\hline & & & Isotope & Activity (Ci) & & Isotope & Activity $(\mathrm{Ci})$ & & \\
\hline & & & $\mathrm{Y}-90$ & $2.80 \mathrm{E}-02$ & & $\mathrm{Y}-90$ & $1.46 \mathrm{E}-02$ & & \\
\hline \multirow[t]{25}{*}{214} & S821822 & 1982 & & & 2009 & Ac-227 & $1.65 \mathrm{E}-10$ & 25,000 & 13,000 \\
\hline & & & Ba-137m & $9.59 \mathrm{E}-02$ & & $\mathrm{Ba}-137 \mathrm{~m}$ & $5.12 \mathrm{E}-02$ & & \\
\hline & & & & & & Bi-211 & $1.63 \mathrm{E}-10$ & & \\
\hline & & & Cs-137 & $1.02 \mathrm{E}-01$ & & Cs-137 & $5.47 \mathrm{E}-02$ & & \\
\hline & & & Eu-155 & $1.91 \mathrm{E}-03$ & & Eu-155 & 4.39E-05 & & \\
\hline & & & & & & Fr-223 & $2.25 \mathrm{E}-12$ & & \\
\hline & & & & & & $\mathrm{Pa}-231$ & $5.02 \mathrm{E}-10$ & & \\
\hline & & & & & & $\mathrm{Pb}-211$ & $1.63 \mathrm{E}-10$ & & \\
\hline & & & Pm-147 & $5.83 \mathrm{E}-03$ & & Pm-147 & $4.65 \mathrm{E}-06$ & & \\
\hline & & & & & & Po-211 & $4.98 \mathrm{E}-13$ & & \\
\hline & & & & & & Po-215 & $1.63 \mathrm{E}-10$ & & \\
\hline & & & $\mathrm{Pu}-239$ & $6.20 \mathrm{E}-03$ & & $\mathrm{Pu}-239$ & $6.20 \mathrm{E}-03$ & & \\
\hline & & & & & & Ra-223 & $1.65 \mathrm{E}-10$ & & \\
\hline & & & Rh-106 & 7.49E-04 & & Rh-106 & $6.41 \mathrm{E}-12$ & & \\
\hline & & & & & & $\mathrm{Rn}-219$ & $1.63 \mathrm{E}-10$ & & \\
\hline & & & Ru-106 & 7.49E-04 & & $\mathrm{Ru}-106$ & $6.47 \mathrm{E}-12$ & & \\
\hline & & & Sb-125 & $4.16 \mathrm{E}-03$ & & Sb-125 & $4.85 \mathrm{E}-06$ & & \\
\hline & & & & & & Sm-147 & $1.43 \mathrm{E}-13$ & & \\
\hline & & & Sr-90 & $9.34 \mathrm{E}-02$ & & Sr-90 & $4.91 \mathrm{E}-02$ & & \\
\hline & & & $\mathrm{Te}-125 \mathrm{~m}$ & $1.73 \mathrm{E}-03$ & & $\mathrm{Te}-125 \mathrm{~m}$ & $1.18 \mathrm{E}-06$ & & \\
\hline & & & & & & Th-227 & $1.61 \mathrm{E}-10$ & & \\
\hline & & & & & & Th-231 & 8.69E-07 & & \\
\hline & & & & & & T1-207 & $1.62 \mathrm{E}-10$ & & \\
\hline & & & U-235 & $8.80 \mathrm{E}-07$ & & U-235 & $8.80 \mathrm{E}-07$ & & \\
\hline & & & Y-90 & $9.33 \mathrm{E}-02$ & & $\mathrm{Y}-90$ & $4.85 \mathrm{E}-02$ & & \\
\hline \multirow[t]{6}{*}{214} & S821823 & 1982 & & & 2009 & Ac- 227 & $1.65 \mathrm{E}-10$ & 30,000 & 15,000 \\
\hline & & & $\mathrm{Ba}-137 \mathrm{~m}$ & $1.08 \mathrm{E}-01$ & & $\mathrm{Ba}-137 \mathrm{~m}$ & $5.76 \mathrm{E}-02$ & & \\
\hline & & & & & & Bi-211 & $1.63 \mathrm{E}-10$ & & \\
\hline & & & Cs-137 & $1.15 \mathrm{E}-01$ & & Cs-137 & $6.16 \mathrm{E}-02$ & & \\
\hline & & & Eu-155 & $2.15 \mathrm{E}-03$ & & Eu-155 & $4.94 \mathrm{E}-05$ & & \\
\hline & & & & & & Fr-223 & $2.25 \mathrm{E}-12$ & & \\
\hline
\end{tabular}

${ }^{1}$ Calculated decayed contact dose rate. Rounded to nearest $10 \mathrm{mR} / \mathrm{hr}$ for values to 1000 ; rounded to nearest $100 \mathrm{mR} / \mathrm{hr}$ for values $>1000$ to 10,000 ; rounded to nearest $1000 \mathrm{mR} / \mathrm{hr}$ for values $>10,000$. * Initial contact dose rate assumed to be $1,000,000 \mathrm{mR} / \mathrm{hr}$; **Initial contact dose rate assumed to be $1,010,000 \mathrm{mR} / \mathrm{hr}$.

$$
52 \text { of } 168
$$


Appendix A-4 - Initial and Decayed Radionuclide and Dose Data for Lined Shafts

\begin{tabular}{|c|c|c|c|c|c|c|c|c|c|}
\hline \multirow[b]{2}{*}{ Shaft Number } & \multirow[b]{2}{*}{ Package ID } & \multirow[b]{2}{*}{ Base Year } & \multicolumn{2}{|c|}{ Initial Isotopic Distribution } & \multirow[b]{2}{*}{ Target Year } & \multicolumn{2}{|c|}{ Decayed Isotopic Distribution } & \multirow{2}{*}{$\begin{array}{c}\text { Initial Contact } \\
\text { Dose Rate } \\
(\mathrm{mR} / \mathrm{hr})\end{array}$} & \multirow{2}{*}{$\begin{array}{c}\text { Decayed } \\
\text { Contact Dose } \\
\text { Rate }(\mathrm{mR} / \mathrm{hr})^{1} \\
\end{array}$} \\
\hline & & & Isotope & Activity (Ci) & & Isotope & Activity (Ci) & & \\
\hline & & & & & & $\mathrm{Pa}-231$ & $5.02 \mathrm{E}-10$ & & \\
\hline & & & & & & $\mathrm{Pb}-211$ & $1.63 \mathrm{E}-10$ & & \\
\hline & & & Pm-147 & $6.56 \mathrm{E}-03$ & & Pm-147 & $5.24 \mathrm{E}-06$ & & \\
\hline & & & & & & Po-211 & $4.98 \mathrm{E}-13$ & & \\
\hline & & & & & & Po-215 & $1.63 \mathrm{E}-10$ & & \\
\hline & & & $\mathrm{Pu}-239$ & $6.20 \mathrm{E}-03$ & & $\mathrm{Pu}-239$ & $6.20 \mathrm{E}-03$ & & \\
\hline & & & & & & Ra-223 & $1.65 \mathrm{E}-10$ & & \\
\hline & & & $\mathrm{Rh}-106$ & $8.43 \mathrm{E}-04$ & & Rh-106 & $7.21 \mathrm{E}-12$ & & \\
\hline & & & & & & Rn-219 & $1.63 \mathrm{E}-10$ & & \\
\hline & & & $\mathrm{Ru}-106$ & $8.43 \mathrm{E}-04$ & & $\mathrm{Ru}-106$ & $7.28 \mathrm{E}-12$ & & \\
\hline & & & Sb-125 & $4.68 \mathrm{E}-03$ & & Sb-125 & $5.44 \mathrm{E}-06$ & & \\
\hline & & & & & & Sm-147 & $1.61 \mathrm{E}-13$ & & \\
\hline & & & Sr-90 & $1.05 \mathrm{E}-01$ & & Sr-90 & $5.52 \mathrm{E}-02$ & & \\
\hline & & & $\mathrm{Te}-125 \mathrm{~m}$ & $1.94 \mathrm{E}-03$ & & $\mathrm{Te}-125 \mathrm{~m}$ & $1.32 \mathrm{E}-06$ & & \\
\hline & & & & & & Th-227 & $1.61 \mathrm{E}-10$ & & \\
\hline & & & & & & Th-231 & $8.69 \mathrm{E}-07$ & & \\
\hline & & & & & & Tl-207 & $1.62 \mathrm{E}-10$ & & \\
\hline & & & $\mathrm{U}-235$ & $8.80 \mathrm{E}-07$ & & $\mathrm{U}-235$ & $8.80 \mathrm{E}-07$ & & \\
\hline & & & Y-90 & $1.05 \mathrm{E}-01$ & & Y-90 & $5.46 \mathrm{E}-02$ & & \\
\hline \multirow[t]{13}{*}{214} & S821826 & 1982 & & & 2009 & Ac-227 & $1.65 \mathrm{E}-10$ & 20,000 & 10,000 \\
\hline & & & Ba-137m & $9.59 \mathrm{E}-02$ & & Ba-137m & $5.12 \mathrm{E}-02$ & & \\
\hline & & & & & & $\mathrm{Bi}-211$ & $1.63 \mathrm{E}-10$ & & \\
\hline & & & Cs-137 & $1.02 \mathrm{E}-01$ & & Cs-137 & $5.47 \mathrm{E}-02$ & & \\
\hline & & & Eu-155 & $1.91 \mathrm{E}-03$ & & Eu-155 & 4.39E-05 & & \\
\hline & & & & & & Fr-223 & $2.25 \mathrm{E}-12$ & & \\
\hline & & & & & & $\mathrm{Pa}-231$ & $5.02 \mathrm{E}-10$ & & \\
\hline & & & & & & $\mathrm{Pb}-211$ & $1.63 \mathrm{E}-10$ & & \\
\hline & & & Pm-147 & $5.83 \mathrm{E}-03$ & & Pm-147 & $4.65 \mathrm{E}-06$ & & \\
\hline & & & & & & Po-211 & $4.98 \mathrm{E}-13$ & & \\
\hline & & & & & & Po-215 & $1.63 \mathrm{E}-10$ & & \\
\hline & & & Pu-239 & $6.20 \mathrm{E}-03$ & & Pu-239 & $6.20 \mathrm{E}-03$ & & \\
\hline & & & & & & Ra-223 & $1.65 \mathrm{E}-10$ & & \\
\hline
\end{tabular}

${ }^{1}$ Calculated decayed contact dose rate. Rounded to nearest $10 \mathrm{mR} / \mathrm{hr}$ for values to 1000 ; rounded to nearest $100 \mathrm{mR} / \mathrm{hr}$ for values $>1000$ to 10,000 ; rounded to nearest $1000 \mathrm{mR} / \mathrm{hr}$ for values $>10,000$. * Initial contact dose rate assumed to be $1,000,000 \mathrm{mR} / \mathrm{hr}$; **Initial contact dose rate assumed to be $1,010,000 \mathrm{mR} / \mathrm{hr}$.

$$
53 \text { of } 168
$$


Appendix A-4 - Initial and Decayed Radionuclide and Dose Data for Lined Shafts

\begin{tabular}{|c|c|c|c|c|c|c|c|c|c|}
\hline \multirow[b]{2}{*}{ Shaft Number } & \multirow[b]{2}{*}{ Package ID } & \multirow[b]{2}{*}{ Base Year } & \multicolumn{2}{|c|}{ Initial Isotopic Distribution } & \multirow[b]{2}{*}{ Target Year } & \multicolumn{2}{|c|}{ Decayed Isotopic Distribution } & \multirow{2}{*}{$\begin{array}{c}\text { Initial Contact } \\
\text { Dose Rate } \\
(\mathrm{mR} / \mathrm{hr})\end{array}$} & \multirow{2}{*}{$\begin{array}{c}\text { Decayed } \\
\text { Contact Dose } \\
\text { Rate }(\mathrm{mR} / \mathrm{hr})^{1} \\
\end{array}$} \\
\hline & & & Isotope & Activity (Ci) & & Isotope & Activity (Ci) & & \\
\hline & & & Rh-106 & $7.49 \mathrm{E}-04$ & & Rh-106 & $6.41 \mathrm{E}-12$ & & \\
\hline & & & & & & $\mathrm{Rn}-219$ & $1.63 \mathrm{E}-10$ & & \\
\hline & & & $\mathrm{Ru}-106$ & 7.49E-04 & & Ru-106 & $6.47 \mathrm{E}-12$ & & \\
\hline & & & $\mathrm{Sb}-125$ & $4.16 \mathrm{E}-03$ & & $\mathrm{Sb}-125$ & $4.85 \mathrm{E}-06$ & & \\
\hline & & & & & & Sm-147 & $1.43 \mathrm{E}-13$ & & \\
\hline & & & Sr-90 & $9.34 \mathrm{E}-02$ & & Sr-90 & $4.91 \mathrm{E}-02$ & & \\
\hline & & & $\mathrm{Te}-125 \mathrm{~m}$ & $1.73 \mathrm{E}-03$ & & $\mathrm{Te}-125 \mathrm{~m}$ & $1.18 \mathrm{E}-06$ & & \\
\hline & & & & & & Th-227 & $1.61 \mathrm{E}-10$ & & \\
\hline & & & & & & Th-231 & $8.69 \mathrm{E}-07$ & & \\
\hline & & & & & & Tl-207 & $1.62 \mathrm{E}-10$ & & \\
\hline & & & $\mathrm{U}-235$ & $8.80 \mathrm{E}-07$ & & $\mathrm{U}-235$ & $8.80 \mathrm{E}-07$ & & \\
\hline & & & $\mathrm{Y}-90$ & $9.33 \mathrm{E}-02$ & & Y-90 & $4.85 \mathrm{E}-02$ & & \\
\hline \multirow[t]{20}{*}{214} & $\mathrm{~S} 823410$ & 1982 & & & 2009 & Ac-227 & $1.65 \mathrm{E}-10$ & 110,000 & 56,000 \\
\hline & & & $\mathrm{Ba}-137 \mathrm{~m}$ & $3.12 \mathrm{E}-01$ & & $\mathrm{Ba}-137 \mathrm{~m}$ & $1.66 \mathrm{E}-01$ & & \\
\hline & & & & & & Bi-211 & $1.63 \mathrm{E}-10$ & & \\
\hline & & & Cs-137 & $3.32 \mathrm{E}-01$ & & Cs-137 & $1.78 \mathrm{E}-01$ & & \\
\hline & & & Eu-155 & $6.21 \mathrm{E}-03$ & & Eu-155 & $1.43 \mathrm{E}-04$ & & \\
\hline & & & & & & Fr-223 & $2.25 \mathrm{E}-12$ & & \\
\hline & & & & & & $\mathrm{Pa}-231$ & $5.02 \mathrm{E}-10$ & & \\
\hline & & & & & & $\mathrm{Pb}-211$ & $1.63 \mathrm{E}-10$ & & \\
\hline & & & Pm-147 & $1.90 \mathrm{E}-02$ & & Pm-147 & $1.51 \mathrm{E}-05$ & & \\
\hline & & & & & & Po-211 & $4.98 \mathrm{E}-13$ & & \\
\hline & & & & & & Po-215 & $1.63 \mathrm{E}-10$ & & \\
\hline & & & $\mathrm{Pu}-239$ & $6.20 \mathrm{E}-03$ & & $\mathrm{Pu}-239$ & $6.20 \mathrm{E}-03$ & & \\
\hline & & & & & & $\mathrm{Ra}-223$ & $1.65 \mathrm{E}-10$ & & \\
\hline & & & Rh-106 & $2.43 \mathrm{E}-03$ & & Rh-106 & $2.08 \mathrm{E}-11$ & & \\
\hline & & & & & & Rn-219 & $1.63 \mathrm{E}-10$ & & \\
\hline & & & $\mathrm{Ru}-106$ & $2.43 \mathrm{E}-03$ & & $\mathrm{Ru}-106$ & $2.10 \mathrm{E}-11$ & & \\
\hline & & & Sb-125 & $1.35 \mathrm{E}-02$ & & Sb-125 & $1.57 \mathrm{E}-05$ & & \\
\hline & & & & & & Sm-147 & $4.65 \mathrm{E}-13$ & & \\
\hline & & & Sr-90 & $3.03 \mathrm{E}-01$ & & Sr-90 & $1.60 \mathrm{E}-01$ & & \\
\hline & & & $\mathrm{Te}-125 \mathrm{~m}$ & $5.61 \mathrm{E}-03$ & & $\mathrm{Te}-125 \mathrm{~m}$ & $3.81 \mathrm{E}-06$ & & \\
\hline
\end{tabular}

${ }^{1}$ Calculated decayed contact dose rate. Rounded to nearest $10 \mathrm{mR} / \mathrm{hr}$ for values to 1000 ; rounded to nearest $100 \mathrm{mR} / \mathrm{hr}$ for values $>1000$ to 10,000 ; rounded to nearest $1000 \mathrm{mR} / \mathrm{hr}$ for values $>10,000$. * Initial contact dose rate assumed to be $1,000,000 \mathrm{mR} / \mathrm{hr}$; **Initial contact dose rate assumed to be $1,010,000 \mathrm{mR} / \mathrm{hr}$.

$$
54 \text { of } 168
$$


Appendix A-4 - Initial and Decayed Radionuclide and Dose Data for Lined Shafts

\begin{tabular}{|c|c|c|c|c|c|c|c|c|c|}
\hline \multirow[b]{2}{*}{ Shaft Number } & \multirow[b]{2}{*}{ Package ID } & \multirow[b]{2}{*}{ Base Year } & \multicolumn{2}{|c|}{ Initial Isotopic Distribution } & \multirow[b]{2}{*}{ Target Year } & \multicolumn{2}{|c|}{ Decayed Isotopic Distribution } & \multirow{2}{*}{$\begin{array}{c}\text { Initial Contact } \\
\text { Dose Rate } \\
(\mathrm{mR} / \mathrm{hr})\end{array}$} & \multirow{2}{*}{$\begin{array}{c}\text { Decayed } \\
\text { Contact Dose } \\
\text { Rate }(\mathrm{mR} / \mathrm{hr})^{1} \\
\end{array}$} \\
\hline & & & Isotope & Activity (Ci) & & Isotope & Activity (Ci) & & \\
\hline & & & & & & Th-227 & $1.61 \mathrm{E}-10$ & & \\
\hline & & & & & & Th-231 & $8.69 \mathrm{E}-07$ & & \\
\hline & & & & & & Tl-207 & $1.62 \mathrm{E}-10$ & & \\
\hline & & & $\mathrm{U}-235$ & $8.80 \mathrm{E}-07$ & & $\mathrm{U}-235$ & $8.80 \mathrm{E}-07$ & & \\
\hline & & & Y-90 & $3.03 \mathrm{E}-01$ & & $\mathrm{Y}-90$ & $1.58 \mathrm{E}-01$ & & \\
\hline \multirow[t]{25}{*}{215} & S820041 & 1982 & & & 2009 & Ac-227 & $2.94 \mathrm{E}-08$ & $1000000+$ & $506,000 *$ \\
\hline & & & Ba-137m & $7.19 \mathrm{E}+00$ & & $\mathrm{Ba}-137 \mathrm{~m}$ & $3.84 \mathrm{E}+00$ & & \\
\hline & & & & & & Bi-211 & $2.90 \mathrm{E}-08$ & & \\
\hline & & & Cs-137 & $7.66 \mathrm{E}+00$ & & Cs-137 & $4.10 \mathrm{E}+00$ & & \\
\hline & & & Eu-155 & $1.43 \mathrm{E}-01$ & & Eu-155 & $3.29 \mathrm{E}-03$ & & \\
\hline & & & & & & Fr-223 & $4.01 \mathrm{E}-10$ & & \\
\hline & & & & & & $\mathrm{Pa}-231$ & 8.93E-08 & & \\
\hline & & & & & & $\mathrm{Pb}-211$ & $2.91 \mathrm{E}-08$ & & \\
\hline & & & Pm-147 & 4.38E-01 & & Pm-147 & $3.49 \mathrm{E}-04$ & & \\
\hline & & & & & & Po-211 & $8.86 \mathrm{E}-11$ & & \\
\hline & & & & & & Po-215 & $2.91 \mathrm{E}-08$ & & \\
\hline & & & $\mathrm{Pu}-239$ & $9.30 \mathrm{E}-01$ & & $\mathrm{Pu}-239$ & $9.29 \mathrm{E}-01$ & & \\
\hline & & & & & & Ra-223 & $2.94 \mathrm{E}-08$ & & \\
\hline & & & Rh-106 & $5.62 \mathrm{E}-02$ & & Rh-106 & $4.81 \mathrm{E}-10$ & & \\
\hline & & & & & & Rn-219 & $2.90 \mathrm{E}-08$ & & \\
\hline & & & Ru-106 & $5.62 \mathrm{E}-02$ & & Ru-106 & $4.85 \mathrm{E}-10$ & & \\
\hline & & & Sb-125 & $3.12 \mathrm{E}-01$ & & Sb-125 & $3.60 \mathrm{E}-04$ & & \\
\hline & & & & & & Sm-147 & $1.07 \mathrm{E}-11$ & & \\
\hline & & & Sr-90 & $7.00 \mathrm{E}+00$ & & Sr-90 & $3.68 \mathrm{E}+00$ & & \\
\hline & & & $\mathrm{Te}-125 \mathrm{~m}$ & $1.30 \mathrm{E}-01$ & & $\mathrm{Te}-125 \mathrm{~m}$ & $8.78 \mathrm{E}-05$ & & \\
\hline & & & & & & Th-227 & $2.86 \mathrm{E}-08$ & & \\
\hline & & & & & & Th-231 & $1.55 \mathrm{E}-04$ & & \\
\hline & & & & & & Tl-207 & $2.89 \mathrm{E}-08$ & & \\
\hline & & & U-235 & $1.57 \mathrm{E}-04$ & & U-235 & $1.57 \mathrm{E}-04$ & & \\
\hline & & & Y-90 & $6.99 \mathrm{E}+00$ & & Y-90 & $3.64 \mathrm{E}+00$ & & \\
\hline \multirow[t]{2}{*}{215} & S820042 & 1982 & & & 2009 & Ac-227 & $1.65 \mathrm{E}-10$ & 140,000 & 71,000 \\
\hline & & & $\mathrm{Ba}-137 \mathrm{~m}$ & $3.59 \mathrm{E}+00$ & & Ba-137m & $1.92 \mathrm{E}+00$ & & \\
\hline
\end{tabular}

${ }^{1}$ Calculated decayed contact dose rate. Rounded to nearest $10 \mathrm{mR} / \mathrm{hr}$ for values to 1000 ; rounded to nearest $100 \mathrm{mR} / \mathrm{hr}$ for values $>1000$ to 10,000 ; rounded to nearest $1000 \mathrm{mR} / \mathrm{hr}$ for values $>10,000$. * Initial contact dose rate assumed to be $1,000,000 \mathrm{mR} / \mathrm{hr}$; **Initial contact dose rate assumed to be $1,010,000 \mathrm{mR} / \mathrm{hr}$.

$$
55 \text { of } 168
$$


Appendix A-4 - Initial and Decayed Radionuclide and Dose Data for Lined Shafts

\begin{tabular}{|c|c|c|c|c|c|c|c|c|c|}
\hline \multirow[b]{2}{*}{ Shaft Number } & \multirow[b]{2}{*}{ Package ID } & \multirow[b]{2}{*}{ Base Year } & \multicolumn{2}{|c|}{ Initial Isotopic Distribution } & \multirow[b]{2}{*}{ Target Year } & \multicolumn{2}{|c|}{ Decayed Isotopic Distribution } & \multirow{2}{*}{$\begin{array}{c}\text { Initial Contact } \\
\text { Dose Rate } \\
(\mathrm{mR} / \mathrm{hr})\end{array}$} & \multirow{2}{*}{$\begin{array}{c}\text { Decayed } \\
\text { Contact Dose } \\
\text { Rate }(\mathrm{mR} / \mathrm{hr})^{1}\end{array}$} \\
\hline & & & Isotope & Activity (Ci) & & Isotope & Activity (Ci) & & \\
\hline & & & & & & $\mathrm{Bi}-211$ & $1.63 \mathrm{E}-10$ & & \\
\hline & & & Cs-137 & $3.83 \mathrm{E}+00$ & & Cs-137 & $2.05 \mathrm{E}+00$ & & \\
\hline & & & Eu-155 & 7.17E-02 & & $\mathrm{Eu}-155$ & $1.65 \mathrm{E}-03$ & & \\
\hline & & & & & & Fr-223 & $2.25 \mathrm{E}-12$ & & \\
\hline & & & & & & $\mathrm{Pa}-231$ & $5.02 \mathrm{E}-10$ & & \\
\hline & & & & & & $\mathrm{Pb}-211$ & $1.63 \mathrm{E}-10$ & & \\
\hline & & & Pm-147 & 2.19E-01 & & Pm-147 & $1.75 \mathrm{E}-04$ & & \\
\hline & & & & & & Po-211 & $4.98 \mathrm{E}-13$ & & \\
\hline & & & & & & Po-215 & $1.63 \mathrm{E}-10$ & & \\
\hline & & & $\mathrm{Pu}-239$ & $6.20 \mathrm{E}-03$ & & $\mathrm{Pu}-239$ & $6.20 \mathrm{E}-03$ & & \\
\hline & & & & & & $\mathrm{Ra}-223$ & $1.65 \mathrm{E}-10$ & & \\
\hline & & & Rh-106 & $2.81 \mathrm{E}-02$ & & Rh-106 & $2.40 \mathrm{E}-10$ & & \\
\hline & & & & & & Rn-219 & $1.63 \mathrm{E}-10$ & & \\
\hline & & & Ru-106 & $2.81 \mathrm{E}-02$ & & $\mathrm{Ru}-106$ & $2.43 \mathrm{E}-10$ & & \\
\hline & & & Sb-125 & $1.56 \mathrm{E}-01$ & & Sb-125 & $1.80 \mathrm{E}-04$ & & \\
\hline & & & & & & Sm-147 & $5.36 \mathrm{E}-12$ & & \\
\hline & & & Sr-90 & $3.50 \mathrm{E}+00$ & & Sr-90 & $1.84 \mathrm{E}+00$ & & \\
\hline & & & $\mathrm{Te}-125 \mathrm{~m}$ & $6.48 \mathrm{E}-02$ & & $\mathrm{Te}-125 \mathrm{~m}$ & 4.39E-05 & & \\
\hline & & & & & & Th-227 & $1.61 \mathrm{E}-10$ & & \\
\hline & & & & & & Th-231 & 8.69E-07 & & \\
\hline & & & & & & Tl-207 & $1.62 \mathrm{E}-10$ & & \\
\hline & & & U-235 & $8.80 \mathrm{E}-07$ & & U-235 & $8.80 \mathrm{E}-07$ & & \\
\hline & & & $\mathrm{Y}-90$ & $3.50 \mathrm{E}+00$ & & Y-90 & $1.82 \mathrm{E}+00$ & & \\
\hline \multirow[t]{9}{*}{215} & S821832 & 1982 & & & 2009 & Ac- 227 & $1.65 \mathrm{E}-10$ & 35,000 & 18,000 \\
\hline & & & Ba-137m & 4.79E-01 & & Ba-137m & $2.56 \mathrm{E}-01$ & & \\
\hline & & & & & & $\mathrm{Bi}-211$ & $1.63 \mathrm{E}-10$ & & \\
\hline & & & Cs-137 & $5.11 \mathrm{E}-01$ & & Cs-137 & $2.74 \mathrm{E}-01$ & & \\
\hline & & & Eu-155 & $9.55 \mathrm{E}-03$ & & Eu-155 & 2.19E-04 & & \\
\hline & & & & & & Fr-223 & $2.25 \mathrm{E}-12$ & & \\
\hline & & & & & & $\mathrm{Pa}-231$ & $5.02 \mathrm{E}-10$ & & \\
\hline & & & & & & $\mathrm{Pb}-211$ & $1.63 \mathrm{E}-10$ & & \\
\hline & & & Pm-147 & 2.92E-02 & & Pm-147 & 2.33E-05 & & \\
\hline
\end{tabular}

${ }^{1}$ Calculated decayed contact dose rate. Rounded to nearest $10 \mathrm{mR} / \mathrm{hr}$ for values to 1000 ; rounded to nearest $100 \mathrm{mR} / \mathrm{hr}$ for values $>1000$ to 10,000 ; rounded to nearest $1000 \mathrm{mR} / \mathrm{hr}$ for values $>10,000$. * Initial contact dose rate assumed to be $1,000,000 \mathrm{mR} / \mathrm{hr}$; **Initial contact dose rate assumed to be $1,010,000 \mathrm{mR} / \mathrm{hr}$.

$$
56 \text { of } 168
$$


Appendix A-4 - Initial and Decayed Radionuclide and Dose Data for Lined Shafts

\begin{tabular}{|c|c|c|c|c|c|c|c|c|c|}
\hline \multirow[b]{2}{*}{ Shaft Number } & \multirow[b]{2}{*}{ Package ID } & \multirow[b]{2}{*}{ Base Year } & \multicolumn{2}{|c|}{ Initial Isotopic Distribution } & \multirow[b]{2}{*}{ Target Year } & \multicolumn{2}{|c|}{ Decayed Isotopic Distribution } & \multirow{2}{*}{$\begin{array}{c}\text { Initial Contact } \\
\text { Dose Rate } \\
(\mathrm{mR} / \mathrm{hr})\end{array}$} & \multirow{2}{*}{$\begin{array}{c}\text { Decayed } \\
\text { Contact Dose } \\
\text { Rate }(\mathrm{mR} / \mathrm{hr})^{1}\end{array}$} \\
\hline & & & Isotope & Activity (Ci) & & Isotope & Activity (Ci) & & \\
\hline & & & & & & Po-211 & $4.98 \mathrm{E}-13$ & & \\
\hline & & & & & & Po-215 & $1.63 \mathrm{E}-10$ & & \\
\hline & & & $\mathrm{Pu}-239$ & $6.20 \mathrm{E}-03$ & & $\mathrm{Pu}-239$ & $6.20 \mathrm{E}-03$ & & \\
\hline & & & & & & $\mathrm{Ra}-223$ & $1.65 \mathrm{E}-10$ & & \\
\hline & & & Rh-106 & $3.74 \mathrm{E}-03$ & & Rh-106 & $3.20 \mathrm{E}-11$ & & \\
\hline & & & & & & Rn-219 & $1.63 \mathrm{E}-10$ & & \\
\hline & & & $\mathrm{Ru}-106$ & $3.74 \mathrm{E}-03$ & & $\mathrm{Ru}-106$ & $3.24 \mathrm{E}-11$ & & \\
\hline & & & Sb-125 & $2.08 \mathrm{E}-02$ & & Sb-125 & $2.41 \mathrm{E}-05$ & & \\
\hline & & & & & & Sm-147 & $7.15 \mathrm{E}-13$ & & \\
\hline & & & Sr-90 & 4.67E-01 & & Sr-90 & $2.46 \mathrm{E}-01$ & & \\
\hline & & & $\mathrm{Te}-125 \mathrm{~m}$ & $8.63 \mathrm{E}-03$ & & $\mathrm{Te}-125 \mathrm{~m}$ & $5.86 \mathrm{E}-06$ & & \\
\hline & & & & & & Th-227 & $1.61 \mathrm{E}-10$ & & \\
\hline & & & & & & Th-231 & 8.69E-07 & & \\
\hline & & & & & & Tl-207 & $1.62 \mathrm{E}-10$ & & \\
\hline & & & $\mathrm{U}-235$ & $8.80 \mathrm{E}-07$ & & $\mathrm{U}-235$ & $8.80 \mathrm{E}-07$ & & \\
\hline & & & $\mathrm{Y}-90$ & $4.66 \mathrm{E}-01$ & & $\mathrm{Y}-90$ & $2.43 \mathrm{E}-01$ & & \\
\hline \multirow[t]{16}{*}{215} & S821833 & 1982 & & & 2009 & Ac- 227 & $1.65 \mathrm{E}-10$ & 100,000 & 51,000 \\
\hline & & & Ba-137m & 7.19E-01 & & $\mathrm{Ba}-137 \mathrm{~m}$ & $3.84 \mathrm{E}-01$ & & \\
\hline & & & & & & $\mathrm{Bi}-211$ & $1.63 \mathrm{E}-10$ & & \\
\hline & & & Cs-137 & 7.66E-01 & & Cs-137 & 4.10E-01 & & \\
\hline & & & Eu-155 & $1.43 \mathrm{E}-02$ & & Eu-155 & $3.29 \mathrm{E}-04$ & & \\
\hline & & & & & & Fr-223 & $2.25 \mathrm{E}-12$ & & \\
\hline & & & & & & $\mathrm{Pa}-231$ & $5.02 \mathrm{E}-10$ & & \\
\hline & & & & & & $\mathrm{Pb}-211$ & $1.63 \mathrm{E}-10$ & & \\
\hline & & & Pm-147 & 4.38E-02 & & Pm-147 & $3.49 \mathrm{E}-05$ & & \\
\hline & & & & & & Po-211 & $4.98 \mathrm{E}-13$ & & \\
\hline & & & & & & Po-215 & $1.63 \mathrm{E}-10$ & & \\
\hline & & & $\mathrm{Pu}-239$ & $6.20 \mathrm{E}-03$ & & Pu-239 & $6.20 \mathrm{E}-03$ & & \\
\hline & & & & & & Ra-223 & $1.65 \mathrm{E}-10$ & & \\
\hline & & & Rh-106 & $5.62 \mathrm{E}-03$ & & Rh-106 & $4.81 \mathrm{E}-11$ & & \\
\hline & & & & & & Rn-219 & $1.63 \mathrm{E}-10$ & & \\
\hline & & & Ru-106 & $5.62 \mathrm{E}-03$ & & $\mathrm{Ru}-106$ & $4.85 \mathrm{E}-11$ & & \\
\hline
\end{tabular}

${ }^{1}$ Calculated decayed contact dose rate. Rounded to nearest $10 \mathrm{mR} / \mathrm{hr}$ for values to 1000 ; rounded to nearest $100 \mathrm{mR} / \mathrm{hr}$ for values $>1000$ to 10,000 ; rounded to nearest $1000 \mathrm{mR} / \mathrm{hr}$ for values $>10,000$. * Initial contact dose rate assumed to be $1,000,000 \mathrm{mR} / \mathrm{hr}$; **Initial contact dose rate assumed to be $1,010,000 \mathrm{mR} / \mathrm{hr}$.

$$
57 \text { of } 168
$$


Appendix A-4 - Initial and Decayed Radionuclide and Dose Data for Lined Shafts

\begin{tabular}{|c|c|c|c|c|c|c|c|c|c|}
\hline \multirow[b]{2}{*}{ Shaft Number } & \multirow[b]{2}{*}{ Package ID } & \multirow[b]{2}{*}{ Base Year } & \multicolumn{2}{|c|}{ Initial Isotopic Distribution } & \multirow[b]{2}{*}{ Target Year } & \multicolumn{2}{|c|}{ Decayed Isotopic Distribution } & \multirow{2}{*}{$\begin{array}{c}\text { Initial Contact } \\
\text { Dose Rate } \\
(\mathrm{mR} / \mathrm{hr})\end{array}$} & \multirow{2}{*}{$\begin{array}{c}\text { Decayed } \\
\text { Contact Dose } \\
\text { Rate }(\mathrm{mR} / \mathrm{hr})^{1} \\
\end{array}$} \\
\hline & & & Isotope & Activity (Ci) & & Isotope & Activity (Ci) & & \\
\hline & & & Sb-125 & $3.12 \mathrm{E}-02$ & & $\mathrm{Sb}-125$ & $3.65 \mathrm{E}-05$ & & \\
\hline & & & & & & Sm-147 & $1.07 \mathrm{E}-12$ & & \\
\hline & & & Sr-90 & $7.00 \mathrm{E}-01$ & & Sr-90 & $3.68 \mathrm{E}-01$ & & \\
\hline & & & $\mathrm{Te}-125 \mathrm{~m}$ & $1.30 \mathrm{E}-02$ & & $\mathrm{Te}-125 \mathrm{~m}$ & $8.83 \mathrm{E}-06$ & & \\
\hline & & & & & & Th-227 & $1.61 \mathrm{E}-10$ & & \\
\hline & & & & & & Th-231 & $8.69 \mathrm{E}-07$ & & \\
\hline & & & & & & T1-207 & $1.62 \mathrm{E}-10$ & & \\
\hline & & & $\mathrm{U}-235$ & $8.80 \mathrm{E}-07$ & & $\mathrm{U}-235$ & $8.80 \mathrm{E}-07$ & & \\
\hline & & & $\mathrm{Y}-90$ & $6.99 \mathrm{E}-01$ & & $\mathrm{Y}-90$ & $3.64 \mathrm{E}-01$ & & \\
\hline \multirow[t]{23}{*}{215} & S821834 & 1982 & & & 2009 & Ac-227 & $1.65 \mathrm{E}-10$ & 200,000 & 101,000 \\
\hline & & & $\mathrm{Ba}-137 \mathrm{~m}$ & 4.79E-01 & & $\mathrm{Ba}-137 \mathrm{~m}$ & $2.56 \mathrm{E}-01$ & & \\
\hline & & & & & & $\mathrm{Bi}-211$ & $1.63 \mathrm{E}-10$ & & \\
\hline & & & Cs-137 & $5.11 \mathrm{E}-01$ & & Cs-137 & $2.74 \mathrm{E}-01$ & & \\
\hline & & & Eu-155 & $9.55 \mathrm{E}-03$ & & Eu-155 & $2.19 \mathrm{E}-04$ & & \\
\hline & & & & & & Fr-223 & $2.25 \mathrm{E}-12$ & & \\
\hline & & & & & & $\mathrm{Pa}-231$ & $5.02 \mathrm{E}-10$ & & \\
\hline & & & & & & $\mathrm{Pb}-211$ & $1.63 \mathrm{E}-10$ & & \\
\hline & & & Pm-147 & 2.92E-02 & & Pm-147 & $2.33 \mathrm{E}-05$ & & \\
\hline & & & & & & Po-211 & $4.98 \mathrm{E}-13$ & & \\
\hline & & & & & & Po-215 & $1.63 \mathrm{E}-10$ & & \\
\hline & & & $\mathrm{Pu}-239$ & $6.20 \mathrm{E}-03$ & & Pu-239 & $6.20 \mathrm{E}-03$ & & \\
\hline & & & & & & Ra-223 & $1.65 \mathrm{E}-10$ & & \\
\hline & & & Rh-106 & $3.74 \mathrm{E}-03$ & & Rh-106 & $3.20 \mathrm{E}-11$ & & \\
\hline & & & & & & Rn-219 & $1.63 \mathrm{E}-10$ & & \\
\hline & & & $\mathrm{Ru}-106$ & $3.74 \mathrm{E}-03$ & & Ru-106 & $3.24 \mathrm{E}-11$ & & \\
\hline & & & Sb-125 & $2.08 \mathrm{E}-02$ & & Sb-125 & $2.41 \mathrm{E}-05$ & & \\
\hline & & & & & & Sm-147 & $7.15 \mathrm{E}-13$ & & \\
\hline & & & Sr-90 & 4.67E-01 & & Sr-90 & $2.46 \mathrm{E}-01$ & & \\
\hline & & & $\mathrm{Te}-125 \mathrm{~m}$ & 8.63E-03 & & $\mathrm{Te}-125 \mathrm{~m}$ & $5.86 \mathrm{E}-06$ & & \\
\hline & & & & & & Th-227 & $1.61 \mathrm{E}-10$ & & \\
\hline & & & & & & Th-231 & 8.69E-07 & & \\
\hline & & & & & & Tl-207 & $1.62 \mathrm{E}-10$ & & \\
\hline
\end{tabular}

${ }^{1}$ Calculated decayed contact dose rate. Rounded to nearest $10 \mathrm{mR} / \mathrm{hr}$ for values to 1000 ; rounded to nearest $100 \mathrm{mR} / \mathrm{hr}$ for values $>1000$ to 10,000 ; rounded to nearest $1000 \mathrm{mR} / \mathrm{hr}$ for values $>10,000$. * Initial contact dose rate assumed to be $1,000,000 \mathrm{mR} / \mathrm{hr}$; **Initial contact dose rate assumed to be $1,010,000 \mathrm{mR} / \mathrm{hr}$.

$$
58 \text { of } 168
$$


Appendix A-4 - Initial and Decayed Radionuclide and Dose Data for Lined Shafts

\begin{tabular}{|c|c|c|c|c|c|c|c|c|c|}
\hline \multirow[b]{2}{*}{ Shaft Number } & \multirow[b]{2}{*}{ Package ID } & \multirow[b]{2}{*}{ Base Year } & \multicolumn{2}{|c|}{ Initial Isotopic Distribution } & \multirow[b]{2}{*}{ Target Year } & \multicolumn{2}{|c|}{ Decayed Isotopic Distribution } & \multirow{2}{*}{$\begin{array}{c}\text { Initial Contact } \\
\text { Dose Rate } \\
(\mathrm{mR} / \mathrm{hr})\end{array}$} & \multirow{2}{*}{$\begin{array}{c}\text { Decayed } \\
\text { Contact Dose } \\
\text { Rate }(\mathrm{mR} / \mathrm{hr})^{1}\end{array}$} \\
\hline & & & Isotope & Activity (Ci) & & Isotope & Activity (Ci) & & \\
\hline & & & $\mathrm{U}-235$ & $8.80 \mathrm{E}-07$ & & $\mathrm{U}-235$ & $8.80 \mathrm{E}-07$ & & \\
\hline & & & $\mathrm{Y}-90$ & $4.66 \mathrm{E}-01$ & & $\mathrm{Y}-90$ & $2.43 \mathrm{E}-01$ & & \\
\hline \multirow[t]{25}{*}{215} & S821835 & 1982 & & & 2009 & Ac-227 & $1.65 \mathrm{E}-10$ & 40,000 & 20,000 \\
\hline & & & Ba-137m & 7.19E-02 & & Ba-137m & $3.84 \mathrm{E}-02$ & & \\
\hline & & & & & & $\mathrm{Bi}-211$ & $1.63 \mathrm{E}-10$ & & \\
\hline & & & Cs-137 & 7.66E-02 & & Cs-137 & 4.10E-02 & & \\
\hline & & & Eu-155 & $1.43 \mathrm{E}-03$ & & $\mathrm{Eu}-155$ & $3.29 \mathrm{E}-05$ & & \\
\hline & & & & & & Fr-223 & $2.25 \mathrm{E}-12$ & & \\
\hline & & & & & & $\mathrm{Pa}-231$ & $5.02 \mathrm{E}-10$ & & \\
\hline & & & & & & $\mathrm{Pb}-211$ & $1.63 \mathrm{E}-10$ & & \\
\hline & & & Pm-147 & 4.38E-03 & & Pm-147 & $3.49 \mathrm{E}-06$ & & \\
\hline & & & & & & Po-211 & $4.98 \mathrm{E}-13$ & & \\
\hline & & & & & & Po-215 & $1.63 \mathrm{E}-10$ & & \\
\hline & & & $\mathrm{Pu}-239$ & $6.20 \mathrm{E}-03$ & & $\mathrm{Pu}-239$ & $6.20 \mathrm{E}-03$ & & \\
\hline & & & & & & $\mathrm{Ra}-223$ & $1.65 \mathrm{E}-10$ & & \\
\hline & & & Rh-106 & $5.62 \mathrm{E}-04$ & & Rh-106 & $4.81 \mathrm{E}-12$ & & \\
\hline & & & & & & Rn-219 & $1.63 \mathrm{E}-10$ & & \\
\hline & & & Ru-106 & $5.62 \mathrm{E}-04$ & & Ru-106 & $4.85 \mathrm{E}-12$ & & \\
\hline & & & Sb-125 & $3.12 \mathrm{E}-03$ & & Sb-125 & $3.63 \mathrm{E}-06$ & & \\
\hline & & & & & & $\mathrm{Sm}-147$ & $1.07 \mathrm{E}-13$ & & \\
\hline & & & Sr-90 & 7.00E-02 & & Sr-90 & $3.68 \mathrm{E}-02$ & & \\
\hline & & & $\mathrm{Te}-125 \mathrm{~m}$ & $1.30 \mathrm{E}-03$ & & $\mathrm{Te}-125 \mathrm{~m}$ & 8.79E-07 & & \\
\hline & & & & & & Th-227 & $1.61 \mathrm{E}-10$ & & \\
\hline & & & & & & Th-231 & 8.69E-07 & & \\
\hline & & & & & & T1-207 & $1.62 \mathrm{E}-10$ & & \\
\hline & & & U-235 & $8.80 \mathrm{E}-07$ & & U-235 & $8.80 \mathrm{E}-07$ & & \\
\hline & & & $\mathrm{Y}-90$ & $6.99 \mathrm{E}-02$ & & Y-90 & $3.64 \mathrm{E}-02$ & & \\
\hline \multirow[t]{5}{*}{215} & S821837 & 1982 & & & 2009 & Ac- 227 & $1.65 \mathrm{E}-10$ & 20,000 & 10,000 \\
\hline & & & Ba-137m & 4.79E-01 & & Ba-137m & $2.56 \mathrm{E}-01$ & & \\
\hline & & & & & & Bi-211 & $1.63 \mathrm{E}-10$ & & \\
\hline & & & Cs-137 & $5.11 \mathrm{E}-01$ & & Cs-137 & $2.74 \mathrm{E}-01$ & & \\
\hline & & & Eu-155 & $9.55 \mathrm{E}-03$ & & Eu-155 & 2.19E-04 & & \\
\hline
\end{tabular}

${ }^{1}$ Calculated decayed contact dose rate. Rounded to nearest $10 \mathrm{mR} / \mathrm{hr}$ for values to 1000 ; rounded to nearest $100 \mathrm{mR} / \mathrm{hr}$ for values $>1000$ to 10,000 ; rounded to nearest $1000 \mathrm{mR} / \mathrm{hr}$ for values $>10,000$. * Initial contact dose rate assumed to be $1,000,000 \mathrm{mR} / \mathrm{hr}$; **Initial contact dose rate assumed to be $1,010,000 \mathrm{mR} / \mathrm{hr}$.

$$
59 \text { of } 168
$$


Appendix A-4 - Initial and Decayed Radionuclide and Dose Data for Lined Shafts

\begin{tabular}{|c|c|c|c|c|c|c|c|c|c|}
\hline \multirow[b]{2}{*}{ Shaft Number } & \multirow[b]{2}{*}{ Package ID } & \multirow[b]{2}{*}{ Base Year } & \multicolumn{2}{|c|}{ Initial Isotopic Distribution } & \multirow[b]{2}{*}{ Target Year } & \multicolumn{2}{|c|}{ Decayed Isotopic Distribution } & \multirow{2}{*}{$\begin{array}{c}\text { Initial Contact } \\
\text { Dose Rate } \\
(\mathrm{mR} / \mathrm{hr})\end{array}$} & \multirow{2}{*}{$\begin{array}{c}\text { Decayed } \\
\text { Contact Dose } \\
\text { Rate }(\mathrm{mR} / \mathrm{hr})^{1}\end{array}$} \\
\hline & & & Isotope & Activity (Ci) & & Isotope & Activity (Ci) & & \\
\hline & & & & & & Fr-223 & $2.25 \mathrm{E}-12$ & & \\
\hline & & & & & & $\mathrm{Pa}-231$ & $5.02 \mathrm{E}-10$ & & \\
\hline & & & & & & $\mathrm{Pb}-211$ & $1.63 \mathrm{E}-10$ & & \\
\hline & & & Pm-147 & $2.92 \mathrm{E}-02$ & & Pm-147 & $2.33 \mathrm{E}-05$ & & \\
\hline & & & & & & Po-211 & $4.98 \mathrm{E}-13$ & & \\
\hline & & & & & & Po-215 & $1.63 \mathrm{E}-10$ & & \\
\hline & & & $\mathrm{Pu}-239$ & $6.20 \mathrm{E}-03$ & & $\mathrm{Pu}-239$ & $6.20 \mathrm{E}-03$ & & \\
\hline & & & & & & Ra-223 & $1.65 \mathrm{E}-10$ & & \\
\hline & & & Rh-106 & $3.74 \mathrm{E}-03$ & & Rh-106 & $3.20 \mathrm{E}-11$ & & \\
\hline & & & & & & $\mathrm{Rn}-219$ & $1.63 \mathrm{E}-10$ & & \\
\hline & & & $\mathrm{Ru}-106$ & $3.74 \mathrm{E}-03$ & & Ru-106 & $3.24 \mathrm{E}-11$ & & \\
\hline & & & $\mathrm{Sb}-125$ & $2.08 \mathrm{E}-02$ & & $\mathrm{Sb}-125$ & $2.41 \mathrm{E}-05$ & & \\
\hline & & & & & & Sm-147 & $7.15 \mathrm{E}-13$ & & \\
\hline & & & Sr-90 & $4.67 \mathrm{E}-01$ & & Sr-90 & $2.46 \mathrm{E}-01$ & & \\
\hline & & & $\mathrm{Te}-125 \mathrm{~m}$ & $8.63 \mathrm{E}-03$ & & $\mathrm{Te}-125 \mathrm{~m}$ & $5.86 \mathrm{E}-06$ & & \\
\hline & & & & & & Th-227 & $1.61 \mathrm{E}-10$ & & \\
\hline & & & & & & Th-231 & $8.69 \mathrm{E}-07$ & & \\
\hline & & & & & & Tl-207 & $1.62 \mathrm{E}-10$ & & \\
\hline & & & $\mathrm{U}-235$ & $8.80 \mathrm{E}-07$ & & U-235 & $8.80 \mathrm{E}-07$ & & \\
\hline & & & Y-90 & $4.66 \mathrm{E}-01$ & & $\mathrm{Y}-90$ & $2.43 \mathrm{E}-01$ & & \\
\hline \multirow[t]{12}{*}{216} & S821825 & 1982 & & & 2009 & Ac- 227 & $1.65 \mathrm{E}-09$ & 40,000 & 20,000 \\
\hline & & & $\mathrm{Ba}-137 \mathrm{~m}$ & $1.92 \mathrm{E}-01$ & & $\mathrm{Ba}-137 \mathrm{~m}$ & $1.02 \mathrm{E}-01$ & & \\
\hline & & & & & & Bi-211 & $1.63 \mathrm{E}-09$ & & \\
\hline & & & Cs-137 & $2.04 \mathrm{E}-01$ & & Cs-137 & $1.09 \mathrm{E}-01$ & & \\
\hline & & & Eu-155 & $3.82 \mathrm{E}-03$ & & Eu-155 & $8.77 \mathrm{E}-05$ & & \\
\hline & & & & & & Fr-223 & $2.25 \mathrm{E}-11$ & & \\
\hline & & & & & & $\mathrm{Pa}-231$ & $5.02 \mathrm{E}-09$ & & \\
\hline & & & & & & $\mathrm{Pb}-211$ & $1.63 \mathrm{E}-09$ & & \\
\hline & & & Pm-147 & $1.17 \mathrm{E}-02$ & & Pm-147 & $9.31 \mathrm{E}-06$ & & \\
\hline & & & & & & Po-211 & $4.98 \mathrm{E}-12$ & & \\
\hline & & & & & & Po-215 & $1.63 \mathrm{E}-09$ & & \\
\hline & & & $\mathrm{Pu}-239$ & $6.20 \mathrm{E}-02$ & & $\mathrm{Pu}-239$ & $6.20 \mathrm{E}-02$ & & \\
\hline
\end{tabular}

${ }^{1}$ Calculated decayed contact dose rate. Rounded to nearest $10 \mathrm{mR} / \mathrm{hr}$ for values to 1000 ; rounded to nearest $100 \mathrm{mR} / \mathrm{hr}$ for values $>1000$ to 10,000 ; rounded to nearest $1000 \mathrm{mR} / \mathrm{hr}$ for values $>10,000$. * Initial contact dose rate assumed to be $1,000,000 \mathrm{mR} / \mathrm{hr}$; **Initial contact dose rate assumed to be $1,010,000 \mathrm{mR} / \mathrm{hr}$.

$$
60 \text { of } 168
$$


Appendix A-4 - Initial and Decayed Radionuclide and Dose Data for Lined Shafts

\begin{tabular}{|c|c|c|c|c|c|c|c|c|c|}
\hline \multirow[b]{2}{*}{ Shaft Number } & \multirow[b]{2}{*}{ Package ID } & \multirow[b]{2}{*}{ Base Year } & \multicolumn{2}{|c|}{ Initial Isotopic Distribution } & \multirow[b]{2}{*}{ Target Year } & \multicolumn{2}{|c|}{ Decayed Isotopic Distribution } & \multirow{2}{*}{$\begin{array}{c}\text { Initial Contact } \\
\text { Dose Rate } \\
(\mathrm{mR} / \mathrm{hr})\end{array}$} & \multirow{2}{*}{$\begin{array}{c}\text { Decayed } \\
\text { Contact Dose } \\
\text { Rate }(\mathrm{mR} / \mathrm{hr})^{1}\end{array}$} \\
\hline & & & Isotope & Activity (Ci) & & Isotope & Activity (Ci) & & \\
\hline & & & & & & $\mathrm{Ra}-223$ & $1.65 \mathrm{E}-09$ & & \\
\hline & & & $\mathrm{Rh}-106$ & $1.50 \mathrm{E}-03$ & & Rh-106 & $1.28 \mathrm{E}-11$ & & \\
\hline & & & & & & Rn-219 & $1.63 \mathrm{E}-09$ & & \\
\hline & & & $\mathrm{Ru}-106$ & $1.50 \mathrm{E}-03$ & & $\mathrm{Ru}-106$ & $1.29 \mathrm{E}-11$ & & \\
\hline & & & $\mathrm{Sb}-125$ & $8.32 \mathrm{E}-03$ & & $\mathrm{Sb}-125$ & $9.71 \mathrm{E}-06$ & & \\
\hline & & & & & & Sm-147 & $2.86 \mathrm{E}-13$ & & \\
\hline & & & Sr-90 & $1.87 \mathrm{E}-01$ & & Sr-90 & $9.82 \mathrm{E}-02$ & & \\
\hline & & & Te-125m & $3.45 \mathrm{E}-03$ & & Te- $125 \mathrm{~m}$ & $2.35 \mathrm{E}-06$ & & \\
\hline & & & & & & Th-227 & $1.61 \mathrm{E}-09$ & & \\
\hline & & & & & & Th-231 & $8.69 \mathrm{E}-06$ & & \\
\hline & & & & & & Tl-207 & $1.62 \mathrm{E}-09$ & & \\
\hline & & & $\mathrm{U}-235$ & $8.80 \mathrm{E}-06$ & & $\mathrm{U}-235$ & $8.80 \mathrm{E}-06$ & & \\
\hline & & & Y-90 & $1.87 \mathrm{E}-01$ & & $Y-90$ & $9.71 \mathrm{E}-02$ & & \\
\hline \multirow[t]{19}{*}{216} & S821836 & 1982 & & & 2009 & Ac- 227 & $1.65 \mathrm{E}-10$ & 20,000 & 10,000 \\
\hline & & & Ba-137m & 4.79E-01 & & $\mathrm{Ba}-137 \mathrm{~m}$ & $2.56 \mathrm{E}-01$ & & \\
\hline & & & & & & Bi-211 & $1.63 \mathrm{E}-10$ & & \\
\hline & & & Cs-137 & $5.11 \mathrm{E}-01$ & & Cs-137 & $2.74 \mathrm{E}-01$ & & \\
\hline & & & Eu-155 & $9.55 \mathrm{E}-03$ & & Eu-155 & 2.19E-04 & & \\
\hline & & & & & & Fr-223 & $2.25 \mathrm{E}-12$ & & \\
\hline & & & & & & $\mathrm{Pa}-231$ & $5.02 \mathrm{E}-10$ & & \\
\hline & & & & & & $\mathrm{Pb}-211$ & $1.63 \mathrm{E}-10$ & & \\
\hline & & & Pm-147 & $2.92 \mathrm{E}-02$ & & Pm-147 & $2.33 \mathrm{E}-05$ & & \\
\hline & & & & & & Po-211 & $4.98 \mathrm{E}-13$ & & \\
\hline & & & & & & Po-215 & $1.63 \mathrm{E}-10$ & & \\
\hline & & & $\mathrm{Pu}-239$ & $6.20 \mathrm{E}-03$ & & $\mathrm{Pu}-239$ & $6.20 \mathrm{E}-03$ & & \\
\hline & & & & & & $\mathrm{Ra}-223$ & $1.65 \mathrm{E}-10$ & & \\
\hline & & & Rh-106 & $3.74 \mathrm{E}-03$ & & Rh-106 & $3.20 \mathrm{E}-11$ & & \\
\hline & & & & & & Rn-219 & $1.63 \mathrm{E}-10$ & & \\
\hline & & & $\mathrm{Ru}-106$ & $3.74 \mathrm{E}-03$ & & Ru-106 & $3.24 \mathrm{E}-11$ & & \\
\hline & & & Sb-125 & $2.08 \mathrm{E}-02$ & & Sb-125 & $2.41 \mathrm{E}-05$ & & \\
\hline & & & & & & Sm-147 & $7.15 \mathrm{E}-13$ & & \\
\hline & & & Sr-90 & $4.67 \mathrm{E}-01$ & & Sr-90 & $2.46 \mathrm{E}-01$ & & \\
\hline
\end{tabular}

${ }^{1}$ Calculated decayed contact dose rate. Rounded to nearest $10 \mathrm{mR} / \mathrm{hr}$ for values to 1000 ; rounded to nearest $100 \mathrm{mR} / \mathrm{hr}$ for values $>1000$ to 10,000 ; rounded to nearest $1000 \mathrm{mR} / \mathrm{hr}$ for values $>10,000$. * Initial contact dose rate assumed to be $1,000,000 \mathrm{mR} / \mathrm{hr}$; **Initial contact dose rate assumed to be $1,010,000 \mathrm{mR} / \mathrm{hr}$.

$$
61 \text { of } 168
$$


Appendix A-4 - Initial and Decayed Radionuclide and Dose Data for Lined Shafts

\begin{tabular}{|c|c|c|c|c|c|c|c|c|c|}
\hline \multirow[b]{2}{*}{ Shaft Number } & \multirow[b]{2}{*}{ Package ID } & \multirow[b]{2}{*}{ Base Year } & \multicolumn{2}{|c|}{ Initial Isotopic Distribution } & \multirow[b]{2}{*}{ Target Year } & \multicolumn{2}{|c|}{ Decayed Isotopic Distribution } & \multirow{2}{*}{$\begin{array}{c}\text { Initial Contact } \\
\text { Dose Rate } \\
(\mathrm{mR} / \mathrm{hr})\end{array}$} & \multirow{2}{*}{$\begin{array}{c}\text { Decayed } \\
\text { Contact Dose } \\
\text { Rate }(\mathrm{mR} / \mathrm{hr})^{1} \\
\end{array}$} \\
\hline & & & Isotope & Activity (Ci) & & Isotope & Activity (Ci) & & \\
\hline & & & $\mathrm{Te}-125 \mathrm{~m}$ & $8.63 \mathrm{E}-03$ & & Te-125m & $5.86 \mathrm{E}-06$ & & \\
\hline & & & & & & Th-227 & $1.61 \mathrm{E}-10$ & & \\
\hline & & & & & & Th-231 & $8.69 \mathrm{E}-07$ & & \\
\hline & & & & & & T1-207 & $1.62 \mathrm{E}-10$ & & \\
\hline & & & $\mathrm{U}-235$ & $8.80 \mathrm{E}-07$ & & $\mathrm{U}-235$ & $8.80 \mathrm{E}-07$ & & \\
\hline & & & $\mathrm{Y}-90$ & $4.66 \mathrm{E}-01$ & & $\mathrm{Y}-90$ & $2.43 \mathrm{E}-01$ & & \\
\hline \multirow[t]{25}{*}{216} & S821838 & 1982 & & & 2009 & Ac-227 & $1.65 \mathrm{E}-10$ & 15,000 & 7,600 \\
\hline & & & $\mathrm{Ba}-137 \mathrm{~m}$ & $2.40 \mathrm{E}-01$ & & $\mathrm{Ba}-137 \mathrm{~m}$ & $1.28 \mathrm{E}-01$ & & \\
\hline & & & & & & $\mathrm{Bi}-211$ & $1.63 \mathrm{E}-10$ & & \\
\hline & & & Cs-137 & $2.55 \mathrm{E}-01$ & & Cs-137 & $1.37 \mathrm{E}-01$ & & \\
\hline & & & $\mathrm{Eu}-155$ & $4.78 \mathrm{E}-03$ & & Eu-155 & $1.10 \mathrm{E}-04$ & & \\
\hline & & & & & & Fr-223 & $2.25 \mathrm{E}-12$ & & \\
\hline & & & & & & $\mathrm{Pa}-231$ & $5.02 \mathrm{E}-10$ & & \\
\hline & & & & & & $\mathrm{Pb}-211$ & $1.63 \mathrm{E}-10$ & & \\
\hline & & & Pm-147 & $1.46 \mathrm{E}-02$ & & Pm-147 & $1.16 \mathrm{E}-05$ & & \\
\hline & & & & & & Po-211 & $4.98 \mathrm{E}-13$ & & \\
\hline & & & & & & Po-215 & $1.63 \mathrm{E}-10$ & & \\
\hline & & & $\mathrm{Pu}-239$ & $6.20 \mathrm{E}-03$ & & $\mathrm{Pu}-239$ & $6.20 \mathrm{E}-03$ & & \\
\hline & & & & & & Ra-223 & $1.65 \mathrm{E}-10$ & & \\
\hline & & & Rh-106 & $1.87 \mathrm{E}-03$ & & Rh-106 & $1.60 \mathrm{E}-11$ & & \\
\hline & & & & & & Rn-219 & $1.63 \mathrm{E}-10$ & & \\
\hline & & & Ru-106 & $1.87 \mathrm{E}-03$ & & $\mathrm{Ru}-106$ & $1.62 \mathrm{E}-11$ & & \\
\hline & & & Sb-125 & $1.04 \mathrm{E}-02$ & & Sb-125 & $1.21 \mathrm{E}-05$ & & \\
\hline & & & & & & Sm-147 & $3.57 \mathrm{E}-13$ & & \\
\hline & & & Sr-90 & $2.33 \mathrm{E}-01$ & & Sr-90 & $1.23 \mathrm{E}-01$ & & \\
\hline & & & $\mathrm{Te}-125 \mathrm{~m}$ & $4.32 \mathrm{E}-03$ & & $\mathrm{Te}-125 \mathrm{~m}$ & $2.93 \mathrm{E}-06$ & & \\
\hline & & & & & & Th-227 & $1.61 \mathrm{E}-10$ & & \\
\hline & & & & & & Th-231 & $8.69 \mathrm{E}-07$ & & \\
\hline & & & & & & T1-207 & $1.62 \mathrm{E}-10$ & & \\
\hline & & & U-235 & $8.80 \mathrm{E}-07$ & & U-235 & $8.80 \mathrm{E}-07$ & & \\
\hline & & & $\mathrm{Y}-90$ & $2.33 \mathrm{E}-01$ & & Y-90 & $1.21 \mathrm{E}-01$ & & \\
\hline 216 & S821839 & 1982 & & & 2009 & Ac- 227 & $1.65 \mathrm{E}-10$ & 8,000 & 4,000 \\
\hline
\end{tabular}

${ }^{1}$ Calculated decayed contact dose rate. Rounded to nearest $10 \mathrm{mR} / \mathrm{hr}$ for values to 1000 ; rounded to nearest $100 \mathrm{mR} / \mathrm{hr}$ for values $>1000$ to 10,000 ; rounded to nearest $1000 \mathrm{mR} / \mathrm{hr}$ for values $>10,000$. * Initial contact dose rate assumed to be $1,000,000 \mathrm{mR} / \mathrm{hr}$; **Initial contact dose rate assumed to be $1,010,000 \mathrm{mR} / \mathrm{hr}$.

$$
62 \text { of } 168
$$


Appendix A-4 - Initial and Decayed Radionuclide and Dose Data for Lined Shafts

\begin{tabular}{|c|c|c|c|c|c|c|c|c|c|}
\hline \multirow[b]{2}{*}{ Shaft Number } & \multirow[b]{2}{*}{ Package ID } & \multirow[b]{2}{*}{ Base Year } & \multicolumn{2}{|c|}{ Initial Isotopic Distribution } & \multirow[b]{2}{*}{ Target Year } & \multicolumn{2}{|c|}{ Decayed Isotopic Distribution } & \multirow{2}{*}{$\begin{array}{c}\text { Initial Contact } \\
\text { Dose Rate } \\
(\mathrm{mR} / \mathrm{hr}) \\
\end{array}$} & \multirow{2}{*}{$\begin{array}{c}\text { Decayed } \\
\text { Contact Dose } \\
\text { Rate }(\mathrm{mR} / \mathrm{hr})^{1} \\
\end{array}$} \\
\hline & & & Isotope & Activity (Ci) & & Isotope & Activity (Ci) & & \\
\hline & & & Ba-137m & $4.79 \mathrm{E}-02$ & & $\mathrm{Ba}-137 \mathrm{~m}$ & $2.56 \mathrm{E}-02$ & & \\
\hline & & & & & & Bi-211 & $1.63 \mathrm{E}-10$ & & \\
\hline & & & Cs-137 & $5.11 \mathrm{E}-02$ & & Cs-137 & $2.74 \mathrm{E}-02$ & & \\
\hline & & & $\mathrm{Eu}-155$ & $9.55 \mathrm{E}-04$ & & $\mathrm{Eu}-155$ & $2.19 \mathrm{E}-05$ & & \\
\hline & & & & & & Fr-223 & $2.25 \mathrm{E}-12$ & & \\
\hline & & & & & & $\mathrm{Pa}-231$ & $5.02 \mathrm{E}-10$ & & \\
\hline & & & & & & $\mathrm{Pb}-211$ & $1.63 \mathrm{E}-10$ & & \\
\hline & & & Pm-147 & $2.92 \mathrm{E}-03$ & & Pm-147 & $2.33 \mathrm{E}-06$ & & \\
\hline & & & & & & Po-211 & $4.98 \mathrm{E}-13$ & & \\
\hline & & & & & & Po-215 & $1.63 \mathrm{E}-10$ & & \\
\hline & & & $\mathrm{Pu}-239$ & $6.20 \mathrm{E}-03$ & & $\mathrm{Pu}-239$ & $6.20 \mathrm{E}-03$ & & \\
\hline & & & & & & $\mathrm{Ra}-223$ & $1.65 \mathrm{E}-10$ & & \\
\hline & & & Rh-106 & $3.74 \mathrm{E}-04$ & & Rh-106 & $3.20 \mathrm{E}-12$ & & \\
\hline & & & & & & $\mathrm{Rn}-219$ & $1.63 \mathrm{E}-10$ & & \\
\hline & & & $\mathrm{Ru}-106$ & $3.74 \mathrm{E}-04$ & & $\mathrm{Ru}-106$ & $3.24 \mathrm{E}-12$ & & \\
\hline & & & $\mathrm{Sb}-125$ & $2.08 \mathrm{E}-03$ & & $\mathrm{Sb}-125$ & $2.43 \mathrm{E}-06$ & & \\
\hline & & & & & & Sm-147 & $7.15 \mathrm{E}-14$ & & \\
\hline & & & Sr-90 & $4.67 \mathrm{E}-02$ & & Sr-90 & $2.46 \mathrm{E}-02$ & & \\
\hline & & & $\mathrm{Te}-125 \mathrm{~m}$ & 8.63E-04 & & $\mathrm{Te}-125 \mathrm{~m}$ & $5.88 \mathrm{E}-07$ & & \\
\hline & & & & & & Th-227 & $1.61 \mathrm{E}-10$ & & \\
\hline & & & & & & Th-231 & 8.69E-07 & & \\
\hline & & & & & & Tl-207 & $1.62 \mathrm{E}-10$ & & \\
\hline & & & U-235 & $8.80 \mathrm{E}-07$ & & U-235 & $8.80 \mathrm{E}-07$ & & \\
\hline & & & Y-90 & $4.66 \mathrm{E}-02$ & & Y-90 & $2.43 \mathrm{E}-02$ & & \\
\hline 216 & S821840 & 1982 & & & 2009 & Ac- 227 & $1.65 \mathrm{E}-10$ & 200,000 & 101,000 \\
\hline & & & Ba-137m & $9.59 \mathrm{E}-01$ & & $\mathrm{Ba}-137 \mathrm{~m}$ & $5.12 \mathrm{E}-01$ & & \\
\hline & & & & & & Bi-211 & $1.63 \mathrm{E}-10$ & & \\
\hline & & & Cs-137 & $1.02 \mathrm{E}+00$ & & Cs-137 & $5.47 \mathrm{E}-01$ & & \\
\hline & & & Eu-155 & $1.91 \mathrm{E}-02$ & & Eu-155 & 4.39E-04 & & \\
\hline & & & & & & Fr-223 & $2.25 \mathrm{E}-12$ & & \\
\hline & & & & & & $\mathrm{Pa}-231$ & $5.02 \mathrm{E}-10$ & & \\
\hline & & & & & & $\mathrm{Pb}-211$ & $1.63 \mathrm{E}-10$ & & \\
\hline
\end{tabular}

${ }^{1}$ Calculated decayed contact dose rate. Rounded to nearest $10 \mathrm{mR} / \mathrm{hr}$ for values to 1000 ; rounded to nearest $100 \mathrm{mR} / \mathrm{hr}$ for values $>1000$ to 10,000 ; rounded to nearest $1000 \mathrm{mR} / \mathrm{hr}$ for values $>10,000$. * Initial contact dose rate assumed to be $1,000,000 \mathrm{mR} / \mathrm{hr}$; **Initial contact dose rate assumed to be $1,010,000 \mathrm{mR} / \mathrm{hr}$.

$$
63 \text { of } 168
$$


Appendix A-4 - Initial and Decayed Radionuclide and Dose Data for Lined Shafts

\begin{tabular}{|c|c|c|c|c|c|c|c|c|c|}
\hline \multirow[b]{2}{*}{ Shaft Number } & \multirow[b]{2}{*}{ Package ID } & \multirow[b]{2}{*}{ Base Year } & \multicolumn{2}{|c|}{ Initial Isotopic Distribution } & \multirow[b]{2}{*}{ Target Year } & \multicolumn{2}{|c|}{ Decayed Isotopic Distribution } & \multirow{2}{*}{$\begin{array}{c}\text { Initial Contact } \\
\text { Dose Rate } \\
(\mathrm{mR} / \mathrm{hr})\end{array}$} & \multirow{2}{*}{$\begin{array}{c}\text { Decayed } \\
\text { Contact Dose } \\
\text { Rate }(\mathrm{mR} / \mathrm{hr})^{1} \\
\end{array}$} \\
\hline & & & Isotope & Activity (Ci) & & Isotope & Activity (Ci) & & \\
\hline & & & Pm-147 & 5.83E-02 & & Pm-147 & $4.65 \mathrm{E}-05$ & & \\
\hline & & & & & & Po-211 & $4.98 \mathrm{E}-13$ & & \\
\hline & & & & & & Po-215 & $1.63 \mathrm{E}-10$ & & \\
\hline & & & $\mathrm{Pu}-239$ & $6.20 \mathrm{E}-03$ & & $\mathrm{Pu}-239$ & $6.20 \mathrm{E}-03$ & & \\
\hline & & & & & & Ra-223 & $1.65 \mathrm{E}-10$ & & \\
\hline & & & Rh-106 & 7.49E-03 & & Rh-106 & $6.41 \mathrm{E}-11$ & & \\
\hline & & & & & & $\mathrm{Rn}-219$ & $1.63 \mathrm{E}-10$ & & \\
\hline & & & $\mathrm{Ru}-106$ & 7.49E-03 & & $\mathrm{Ru}-106$ & $6.47 \mathrm{E}-11$ & & \\
\hline & & & Sb-125 & 4.16E-02 & & $\mathrm{Sb}-125$ & $4.83 \mathrm{E}-05$ & & \\
\hline & & & & & & Sm-147 & $1.43 \mathrm{E}-12$ & & \\
\hline & & & Sr-90 & $9.34 \mathrm{E}-01$ & & Sr-90 & 4.91E-01 & & \\
\hline & & & $\mathrm{Te}-125 \mathrm{~m}$ & $1.73 \mathrm{E}-02$ & & $\mathrm{Te}-125 \mathrm{~m}$ & $1.17 \mathrm{E}-05$ & & \\
\hline & & & & & & Th-227 & $1.61 \mathrm{E}-10$ & & \\
\hline & & & & & & Th-231 & $8.69 \mathrm{E}-07$ & & \\
\hline & & & & & & T1-207 & $1.62 \mathrm{E}-10$ & & \\
\hline & & & $\mathrm{U}-235$ & $8.80 \mathrm{E}-07$ & & $\mathrm{U}-235$ & $8.80 \mathrm{E}-07$ & & \\
\hline & & & $\mathrm{Y}-90$ & $9.33 \mathrm{E}-01$ & & Y-90 & $4.85 \mathrm{E}-01$ & & \\
\hline \multirow[t]{15}{*}{216} & S821841 & 1982 & & & 2009 & Ac-227 & $1.65 \mathrm{E}-10$ & 30,000 & 15,000 \\
\hline & & & Ba-137m & 4.79E-01 & & $\mathrm{Ba}-137 \mathrm{~m}$ & $2.56 \mathrm{E}-01$ & & \\
\hline & & & & & & Bi-211 & $1.63 \mathrm{E}-10$ & & \\
\hline & & & Cs-137 & $5.11 \mathrm{E}-01$ & & Cs-137 & $2.74 \mathrm{E}-01$ & & \\
\hline & & & Eu-155 & $9.55 \mathrm{E}-03$ & & Eu-155 & $2.19 \mathrm{E}-04$ & & \\
\hline & & & & & & Fr-223 & $2.25 \mathrm{E}-12$ & & \\
\hline & & & & & & $\mathrm{Pa}-231$ & $5.02 \mathrm{E}-10$ & & \\
\hline & & & & & & $\mathrm{Pb}-211$ & $1.63 \mathrm{E}-10$ & & \\
\hline & & & Pm-147 & $2.92 \mathrm{E}-02$ & & Pm-147 & $2.33 \mathrm{E}-05$ & & \\
\hline & & & & & & Po-211 & $4.98 \mathrm{E}-13$ & & \\
\hline & & & & & & Po-215 & $1.63 \mathrm{E}-10$ & & \\
\hline & & & $\mathrm{Pu}-239$ & $6.20 \mathrm{E}-03$ & & Pu-239 & $6.20 \mathrm{E}-03$ & & \\
\hline & & & & & & Ra-223 & $1.65 \mathrm{E}-10$ & & \\
\hline & & & Rh-106 & $3.74 \mathrm{E}-03$ & & Rh-106 & $3.20 \mathrm{E}-11$ & & \\
\hline & & & & & & Rn-219 & $1.63 \mathrm{E}-10$ & & \\
\hline
\end{tabular}

${ }^{1}$ Calculated decayed contact dose rate. Rounded to nearest $10 \mathrm{mR} / \mathrm{hr}$ for values to 1000 ; rounded to nearest $100 \mathrm{mR} / \mathrm{hr}$ for values $>1000$ to 10,000 ; rounded to nearest $1000 \mathrm{mR} / \mathrm{hr}$ for values $>10,000$. * Initial contact dose rate assumed to be $1,000,000 \mathrm{mR} / \mathrm{hr}$; **Initial contact dose rate assumed to be $1,010,000 \mathrm{mR} / \mathrm{hr}$.

$$
64 \text { of } 168
$$


Appendix A-4 - Initial and Decayed Radionuclide and Dose Data for Lined Shafts

\begin{tabular}{|c|c|c|c|c|c|c|c|c|c|}
\hline \multirow[b]{2}{*}{ Shaft Number } & \multirow[b]{2}{*}{ Package ID } & \multirow[b]{2}{*}{ Base Year } & \multicolumn{2}{|c|}{ Initial Isotopic Distribution } & \multirow[b]{2}{*}{ Target Year } & \multicolumn{2}{|c|}{ Decayed Isotopic Distribution } & \multirow{2}{*}{$\begin{array}{c}\text { Initial Contact } \\
\text { Dose Rate } \\
(\mathrm{mR} / \mathrm{hr})\end{array}$} & \multirow{2}{*}{$\begin{array}{c}\text { Decayed } \\
\text { Contact Dose } \\
\text { Rate }(\mathrm{mR} / \mathrm{hr})^{1} \\
\end{array}$} \\
\hline & & & Isotope & Activity (Ci) & & Isotope & Activity (Ci) & & \\
\hline & & & $\mathrm{Ru}-106$ & $3.74 \mathrm{E}-03$ & & $\mathrm{Ru}-106$ & $3.24 \mathrm{E}-11$ & & \\
\hline & & & $\mathrm{Sb}-125$ & $2.08 \mathrm{E}-02$ & & $\mathrm{Sb}-125$ & $2.41 \mathrm{E}-05$ & & \\
\hline & & & & & & Sm-147 & $7.15 \mathrm{E}-13$ & & \\
\hline & & & Sr-90 & 4.67E-01 & & Sr-90 & $2.46 \mathrm{E}-01$ & & \\
\hline & & & $\mathrm{Te}-125 \mathrm{~m}$ & 8.63E-03 & & Te-125m & $5.86 \mathrm{E}-06$ & & \\
\hline & & & & & & Th-227 & $1.61 \mathrm{E}-10$ & & \\
\hline & & & & & & Th-231 & $8.69 \mathrm{E}-07$ & & \\
\hline & & & & & & Tl-207 & $1.62 \mathrm{E}-10$ & & \\
\hline & & & U-235 & $8.80 \mathrm{E}-07$ & & U-235 & $8.80 \mathrm{E}-07$ & & \\
\hline & & & $\mathrm{Y}-90$ & $4.66 \mathrm{E}-01$ & & $\mathrm{Y}-90$ & $2.43 \mathrm{E}-01$ & & \\
\hline \multirow[t]{22}{*}{217} & S821870 & 1982 & & & 2009 & Ac-227 & $1.65 \mathrm{E}-10$ & 15,000 & 7,600 \\
\hline & & & $\mathrm{Ba}-137 \mathrm{~m}$ & 4.31E-02 & & $\mathrm{Ba}-137 \mathrm{~m}$ & $2.30 \mathrm{E}-02$ & & \\
\hline & & & & & & Bi-211 & $1.63 \mathrm{E}-10$ & & \\
\hline & & & Cs-137 & $4.60 \mathrm{E}-02$ & & Cs-137 & $2.46 \mathrm{E}-02$ & & \\
\hline & & & $\mathrm{Eu}-155$ & $8.60 \mathrm{E}-04$ & & $\mathrm{Eu}-155$ & $1.97 \mathrm{E}-05$ & & \\
\hline & & & & & & Fr-223 & $2.25 \mathrm{E}-12$ & & \\
\hline & & & & & & $\mathrm{Pa}-231$ & $5.02 \mathrm{E}-10$ & & \\
\hline & & & & & & $\mathrm{Pb}-211$ & $1.63 \mathrm{E}-10$ & & \\
\hline & & & Pm-147 & $2.63 \mathrm{E}-03$ & & Pm-147 & $2.09 \mathrm{E}-06$ & & \\
\hline & & & & & & Po-211 & $4.98 \mathrm{E}-13$ & & \\
\hline & & & & & & Po-215 & $1.63 \mathrm{E}-10$ & & \\
\hline & & & $\mathrm{Pu}-239$ & $6.20 \mathrm{E}-03$ & & Pu-239 & $6.20 \mathrm{E}-03$ & & \\
\hline & & & & & & $\mathrm{Ra}-223$ & $1.65 \mathrm{E}-10$ & & \\
\hline & & & Rh-106 & $3.37 \mathrm{E}-04$ & & Rh-106 & $2.88 \mathrm{E}-12$ & & \\
\hline & & & & & & Rn-219 & $1.63 \mathrm{E}-10$ & & \\
\hline & & & $\mathrm{Ru}-106$ & $3.37 \mathrm{E}-04$ & & $\mathrm{Ru}-106$ & $2.91 \mathrm{E}-12$ & & \\
\hline & & & Sb-125 & $1.87 \mathrm{E}-03$ & & $\mathrm{Sb}-125$ & $2.18 \mathrm{E}-06$ & & \\
\hline & & & & & & Sm-147 & $6.43 \mathrm{E}-14$ & & \\
\hline & & & Sr-90 & $4.20 \mathrm{E}-02$ & & Sr-90 & $2.21 \mathrm{E}-02$ & & \\
\hline & & & Te-125m & 7.77E-04 & & $\mathrm{Te}-125 \mathrm{~m}$ & $5.28 \mathrm{E}-07$ & & \\
\hline & & & & & & Th-227 & $1.61 \mathrm{E}-10$ & & \\
\hline & & & & & & Th-231 & 8.69E-07 & & \\
\hline
\end{tabular}

${ }^{1}$ Calculated decayed contact dose rate. Rounded to nearest $10 \mathrm{mR} / \mathrm{hr}$ for values to 1000 ; rounded to nearest $100 \mathrm{mR} / \mathrm{hr}$ for values $>1000$ to 10,000 ; rounded to nearest $1000 \mathrm{mR} / \mathrm{hr}$ for values $>10,000$. * Initial contact dose rate assumed to be $1,000,000 \mathrm{mR} / \mathrm{hr}$; **Initial contact dose rate assumed to be $1,010,000 \mathrm{mR} / \mathrm{hr}$.

$$
65 \text { of } 168
$$


Appendix A-4 - Initial and Decayed Radionuclide and Dose Data for Lined Shafts

\begin{tabular}{|c|c|c|c|c|c|c|c|c|c|}
\hline \multirow[b]{2}{*}{ Shaft Number } & \multirow[b]{2}{*}{ Package ID } & \multirow[b]{2}{*}{ Base Year } & \multicolumn{2}{|c|}{ Initial Isotopic Distribution } & \multirow[b]{2}{*}{ Target Year } & \multicolumn{2}{|c|}{ Decayed Isotopic Distribution } & \multirow{2}{*}{$\begin{array}{c}\text { Initial Contact } \\
\text { Dose Rate } \\
(\mathrm{mR} / \mathrm{hr})\end{array}$} & \multirow{2}{*}{$\begin{array}{c}\text { Decayed } \\
\text { Contact Dose } \\
\text { Rate }(\mathrm{mR} / \mathrm{hr})^{1} \\
\end{array}$} \\
\hline & & & Isotope & Activity (Ci) & & Isotope & Activity (Ci) & & \\
\hline & & & & & & Tl-207 & $1.62 \mathrm{E}-10$ & & \\
\hline & & & $\mathrm{U}-235$ & $8.80 \mathrm{E}-07$ & & $\mathrm{U}-235$ & $8.80 \mathrm{E}-07$ & & \\
\hline & & & Y-90 & $4.20 \mathrm{E}-02$ & & Y-90 & $2.18 \mathrm{E}-02$ & & \\
\hline \multirow[t]{25}{*}{217} & S821871 & 1982 & & & 2009 & Ac-227 & $5.32 \mathrm{E}-09$ & 100,000 & 51,000 \\
\hline & & & Ba-137m & $1.08 \mathrm{E}+00$ & & $\mathrm{Ba}-137 \mathrm{~m}$ & $5.76 \mathrm{E}-01$ & & \\
\hline & & & & & & Bi-211 & $5.25 \mathrm{E}-09$ & & \\
\hline & & & Cs-137 & $1.15 \mathrm{E}+00$ & & Cs-137 & $6.16 \mathrm{E}-01$ & & \\
\hline & & & Eu-155 & $2.15 \mathrm{E}-02$ & & Eu-155 & 4.94E-04 & & \\
\hline & & & & & & Fr-223 & $7.25 \mathrm{E}-11$ & & \\
\hline & & & & & & $\mathrm{Pa}-231$ & $1.62 \mathrm{E}-08$ & & \\
\hline & & & & & & $\mathrm{Pb}-211$ & $5.26 \mathrm{E}-09$ & & \\
\hline & & & Pm-147 & $6.56 \mathrm{E}-02$ & & Pm-147 & $5.24 \mathrm{E}-05$ & & \\
\hline & & & & & & Po-211 & $1.60 \mathrm{E}-11$ & & \\
\hline & & & & & & Po-215 & $5.26 \mathrm{E}-09$ & & \\
\hline & & & $\mathrm{Pu}-239$ & $1.98 \mathrm{E}-01$ & & $\mathrm{Pu}-239$ & $1.98 \mathrm{E}-01$ & & \\
\hline & & & & & & Ra-223 & $5.31 \mathrm{E}-09$ & & \\
\hline & & & Rh-106 & $8.43 \mathrm{E}-03$ & & Rh-106 & $7.21 \mathrm{E}-11$ & & \\
\hline & & & & & & Rn-219 & $5.25 \mathrm{E}-09$ & & \\
\hline & & & Ru-106 & $8.43 \mathrm{E}-03$ & & Ru-106 & $7.28 \mathrm{E}-11$ & & \\
\hline & & & Sb-125 & $4.68 \mathrm{E}-02$ & & Sb-125 & $5.46 \mathrm{E}-05$ & & \\
\hline & & & & & & Sm-147 & $1.61 \mathrm{E}-12$ & & \\
\hline & & & Sr-90 & $1.05 \mathrm{E}+00$ & & Sr-90 & $5.52 \mathrm{E}-01$ & & \\
\hline & & & $\mathrm{Te}-125 \mathrm{~m}$ & $1.94 \mathrm{E}-02$ & & $\mathrm{Te}-125 \mathrm{~m}$ & $1.32 \mathrm{E}-05$ & & \\
\hline & & & & & & Th-227 & $5.18 \mathrm{E}-09$ & & \\
\hline & & & & & & Th-231 & $2.80 \mathrm{E}-05$ & & \\
\hline & & & & & & Tl-207 & $5.23 \mathrm{E}-09$ & & \\
\hline & & & U-235 & $2.83 \mathrm{E}-05$ & & U-235 & $2.83 \mathrm{E}-05$ & & \\
\hline & & & Y-90 & $1.05 \mathrm{E}+00$ & & $\mathrm{Y}-90$ & $5.46 \mathrm{E}-01$ & & \\
\hline \multirow[t]{4}{*}{217} & S821874 & 1982 & & & 2009 & Ac- 227 & $1.65 \mathrm{E}-10$ & 80,000 & 40,000 \\
\hline & & & $\mathrm{Ba}-137 \mathrm{~m}$ & $2.40 \mathrm{E}+00$ & & Ba-137m & $1.28 \mathrm{E}+00$ & & \\
\hline & & & & & & $\mathrm{Bi}-211$ & $1.63 \mathrm{E}-10$ & & \\
\hline & & & Cs-137 & $2.55 \mathrm{E}+00$ & & Cs-137 & $1.37 \mathrm{E}+00$ & & \\
\hline
\end{tabular}

${ }^{1}$ Calculated decayed contact dose rate. Rounded to nearest $10 \mathrm{mR} / \mathrm{hr}$ for values to 1000 ; rounded to nearest $100 \mathrm{mR} / \mathrm{hr}$ for values $>1000$ to 10,000 ; rounded to nearest $1000 \mathrm{mR} / \mathrm{hr}$ for values $>10,000$. * Initial contact dose rate assumed to be $1,000,000 \mathrm{mR} / \mathrm{hr}$; **Initial contact dose rate assumed to be $1,010,000 \mathrm{mR} / \mathrm{hr}$. 
Appendix A-4 - Initial and Decayed Radionuclide and Dose Data for Lined Shafts

\begin{tabular}{|c|c|c|c|c|c|c|c|c|c|}
\hline \multirow[b]{2}{*}{ Shaft Number } & \multirow[b]{2}{*}{ Package ID } & \multirow[b]{2}{*}{ Base Year } & \multicolumn{2}{|c|}{ Initial Isotopic Distribution } & \multirow[b]{2}{*}{ Target Year } & \multicolumn{2}{|c|}{ Decayed Isotopic Distribution } & \multirow{2}{*}{$\begin{array}{c}\text { Initial Contact } \\
\text { Dose Rate } \\
(\mathrm{mR} / \mathrm{hr})\end{array}$} & \multirow{2}{*}{$\begin{array}{c}\text { Decayed } \\
\text { Contact Dose } \\
\text { Rate }(\mathrm{mR} / \mathrm{hr})^{1} \\
\end{array}$} \\
\hline & & & Isotope & Activity (Ci) & & Isotope & Activity (Ci) & & \\
\hline & & & Eu-155 & $4.78 \mathrm{E}-02$ & & Eu-155 & $1.10 \mathrm{E}-03$ & & \\
\hline & & & & & & Fr-223 & $2.25 \mathrm{E}-12$ & & \\
\hline & & & & & & $\mathrm{Pa}-231$ & $5.02 \mathrm{E}-10$ & & \\
\hline & & & & & & $\mathrm{Pb}-211$ & $1.63 \mathrm{E}-10$ & & \\
\hline & & & Pm-147 & $1.46 \mathrm{E}-01$ & & Pm-147 & $1.16 \mathrm{E}-04$ & & \\
\hline & & & & & & Po-211 & $4.98 \mathrm{E}-13$ & & \\
\hline & & & & & & Po-215 & $1.63 \mathrm{E}-10$ & & \\
\hline & & & $\mathrm{Pu}-239$ & $6.20 \mathrm{E}-03$ & & $\mathrm{Pu}-239$ & $6.20 \mathrm{E}-03$ & & \\
\hline & & & & & & Ra-223 & $1.65 \mathrm{E}-10$ & & \\
\hline & & & Rh-106 & $1.87 \mathrm{E}-02$ & & Rh-106 & $1.60 \mathrm{E}-10$ & & \\
\hline & & & & & & Rn-219 & $1.63 \mathrm{E}-10$ & & \\
\hline & & & $\mathrm{Ru}-106$ & $1.87 \mathrm{E}-02$ & & $\mathrm{Ru}-106$ & $1.62 \mathrm{E}-10$ & & \\
\hline & & & Sb-125 & $1.04 \mathrm{E}-01$ & & $\mathrm{Sb}-125$ & $1.20 \mathrm{E}-04$ & & \\
\hline & & & & & & Sm-147 & $3.57 \mathrm{E}-12$ & & \\
\hline & & & Sr-90 & $2.33 \mathrm{E}+00$ & & Sr-90 & $1.23 \mathrm{E}+00$ & & \\
\hline & & & $\mathrm{Te}-125 \mathrm{~m}$ & $4.32 \mathrm{E}-02$ & & $\mathrm{Te}-125 \mathrm{~m}$ & $2.93 \mathrm{E}-05$ & & \\
\hline & & & & & & Th-227 & $1.61 \mathrm{E}-10$ & & \\
\hline & & & & & & Th-231 & 8.69E-07 & & \\
\hline & & & & & & T1-207 & $1.62 \mathrm{E}-10$ & & \\
\hline & & & U-235 & $8.80 \mathrm{E}-07$ & & U-235 & $8.80 \mathrm{E}-07$ & & \\
\hline & & & Y-90 & $2.33 \mathrm{E}+00$ & & $\mathrm{Y}-90$ & $1.21 \mathrm{E}+00$ & & \\
\hline \multirow[t]{11}{*}{217} & S821882 & 1982 & & & 2009 & Ac-227 & $1.65 \mathrm{E}-10$ & 6,000 & 3,000 \\
\hline & & & Ba-137m & $2.40 \mathrm{E}-01$ & & Ba-137m & $1.28 \mathrm{E}-01$ & & \\
\hline & & & & & & Bi-211 & $1.63 \mathrm{E}-10$ & & \\
\hline & & & Cs-137 & $2.55 \mathrm{E}-01$ & & Cs-137 & $1.37 \mathrm{E}-01$ & & \\
\hline & & & Eu-155 & $4.78 \mathrm{E}-03$ & & Eu-155 & $1.10 \mathrm{E}-04$ & & \\
\hline & & & & & & Fr-223 & $2.25 \mathrm{E}-12$ & & \\
\hline & & & & & & $\mathrm{Pa}-231$ & $5.02 \mathrm{E}-10$ & & \\
\hline & & & & & & $\mathrm{Pb}-211$ & $1.63 \mathrm{E}-10$ & & \\
\hline & & & Pm-147 & $1.46 \mathrm{E}-02$ & & Pm-147 & $1.16 \mathrm{E}-05$ & & \\
\hline & & & & & & Po-211 & $4.98 \mathrm{E}-13$ & & \\
\hline & & & & & & Рo-215 & $1.63 \mathrm{E}-10$ & & \\
\hline
\end{tabular}

${ }^{1}$ Calculated decayed contact dose rate. Rounded to nearest $10 \mathrm{mR} / \mathrm{hr}$ for values to 1000 ; rounded to nearest $100 \mathrm{mR} / \mathrm{hr}$ for values $>1000$ to 10,000 ; rounded to nearest $1000 \mathrm{mR} / \mathrm{hr}$ for values $>10,000$. * Initial contact dose rate assumed to be $1,000,000 \mathrm{mR} / \mathrm{hr}$; **Initial contact dose rate assumed to be $1,010,000 \mathrm{mR} / \mathrm{hr}$.

$$
67 \text { of } 168
$$


Appendix A-4 - Initial and Decayed Radionuclide and Dose Data for Lined Shafts

\begin{tabular}{|c|c|c|c|c|c|c|c|c|c|}
\hline \multirow[b]{2}{*}{ Shaft Number } & \multirow[b]{2}{*}{ Package ID } & \multirow[b]{2}{*}{ Base Year } & \multicolumn{2}{|c|}{ Initial Isotopic Distribution } & \multirow[b]{2}{*}{ Target Year } & \multicolumn{2}{|c|}{ Decayed Isotopic Distribution } & \multirow{2}{*}{$\begin{array}{c}\text { Initial Contact } \\
\text { Dose Rate } \\
(\mathrm{mR} / \mathrm{hr})\end{array}$} & \multirow{2}{*}{$\begin{array}{c}\text { Decayed } \\
\text { Contact Dose } \\
\text { Rate }(\mathrm{mR} / \mathrm{hr})^{1} \\
\end{array}$} \\
\hline & & & Isotope & Activity (Ci) & & Isotope & Activity (Ci) & & \\
\hline & & & $\mathrm{Pu}-239$ & $6.20 \mathrm{E}-03$ & & $\mathrm{Pu}-239$ & $6.20 \mathrm{E}-03$ & & \\
\hline & & & & & & Ra-223 & $1.65 \mathrm{E}-10$ & & \\
\hline & & & Rh-106 & $1.87 \mathrm{E}-03$ & & Rh-106 & $1.60 \mathrm{E}-11$ & & \\
\hline & & & & & & $\mathrm{Rn}-219$ & $1.63 \mathrm{E}-10$ & & \\
\hline & & & $\mathrm{Ru}-106$ & $1.87 \mathrm{E}-03$ & & $\mathrm{Ru}-106$ & $1.62 \mathrm{E}-11$ & & \\
\hline & & & $\mathrm{Sb}-125$ & $1.04 \mathrm{E}-02$ & & Sb-125 & $1.21 \mathrm{E}-05$ & & \\
\hline & & & & & & Sm-147 & $3.57 \mathrm{E}-13$ & & \\
\hline & & & Sr-90 & $2.33 \mathrm{E}-01$ & & Sr-90 & $1.23 \mathrm{E}-01$ & & \\
\hline & & & $\mathrm{Te}-125 \mathrm{~m}$ & 4.32E-03 & & $\mathrm{Te}-125 \mathrm{~m}$ & $2.93 \mathrm{E}-06$ & & \\
\hline & & & & & & Th-227 & $1.61 \mathrm{E}-10$ & & \\
\hline & & & & & & Th-231 & $8.69 \mathrm{E}-07$ & & \\
\hline & & & & & & T1-207 & $1.62 \mathrm{E}-10$ & & \\
\hline & & & $\mathrm{U}-235$ & $8.80 \mathrm{E}-07$ & & $\mathrm{U}-235$ & $8.80 \mathrm{E}-07$ & & \\
\hline & & & $\mathrm{Y}-90$ & $2.33 \mathrm{E}-01$ & & $\mathrm{Y}-90$ & $1.21 \mathrm{E}-01$ & & \\
\hline \multirow[t]{18}{*}{217} & S821915 & 1982 & & & 2009 & Ac-227 & $2.48 \mathrm{E}-08$ & $1000000+$ & $507,000 *$ \\
\hline & & & Ba-137m & $2.40 \mathrm{E}-01$ & & Ba-137m & $1.28 \mathrm{E}-01$ & & \\
\hline & & & & & & Bi-211 & $2.45 \mathrm{E}-08$ & & \\
\hline & & & Cs-137 & $2.55 \mathrm{E}-01$ & & Cs-137 & $1.37 \mathrm{E}-01$ & & \\
\hline & & & Eu-155 & $4.78 \mathrm{E}-03$ & & Eu-155 & $1.10 \mathrm{E}-04$ & & \\
\hline & & & & & & Fr-223 & $3.38 \mathrm{E}-10$ & & \\
\hline & & & & & & $\mathrm{Pa}-231$ & 7.53E-08 & & \\
\hline & & & & & & $\mathrm{Pb}-211$ & $2.45 \mathrm{E}-08$ & & \\
\hline & & & Pm-147 & $1.46 \mathrm{E}-02$ & & Pm-147 & $1.16 \mathrm{E}-05$ & & \\
\hline & & & & & & Po-211 & $7.47 \mathrm{E}-11$ & & \\
\hline & & & & & & Po-215 & $2.45 \mathrm{E}-08$ & & \\
\hline & & & $\mathrm{Pu}-239$ & $1.41 \mathrm{E}+00$ & & Pu-239 & $1.41 \mathrm{E}+00$ & & \\
\hline & & & & & & $\mathrm{Ra}-223$ & $2.48 \mathrm{E}-08$ & & \\
\hline & & & Rh-106 & $1.87 \mathrm{E}-03$ & & Rh-106 & $1.60 \mathrm{E}-11$ & & \\
\hline & & & & & & Rn-219 & $2.45 \mathrm{E}-08$ & & \\
\hline & & & Ru-106 & $1.87 \mathrm{E}-03$ & & Ru-106 & $1.62 \mathrm{E}-11$ & & \\
\hline & & & Sb-125 & $1.04 \mathrm{E}-02$ & & Sb-125 & $1.21 \mathrm{E}-05$ & & \\
\hline & & & & & & Sm-147 & $3.57 \mathrm{E}-13$ & & \\
\hline
\end{tabular}

${ }^{1}$ Calculated decayed contact dose rate. Rounded to nearest $10 \mathrm{mR} / \mathrm{hr}$ for values to 1000 ; rounded to nearest $100 \mathrm{mR} / \mathrm{hr}$ for values $>1000$ to 10,000 ; rounded to nearest $1000 \mathrm{mR} / \mathrm{hr}$ for values $>10,000$. * Initial contact dose rate assumed to be $1,000,000 \mathrm{mR} / \mathrm{hr}$; **Initial contact dose rate assumed to be $1,010,000 \mathrm{mR} / \mathrm{hr}$.

$$
68 \text { of } 168
$$


Appendix A-4 - Initial and Decayed Radionuclide and Dose Data for Lined Shafts

\begin{tabular}{|c|c|c|c|c|c|c|c|c|c|}
\hline \multirow[b]{2}{*}{ Shaft Number } & \multirow[b]{2}{*}{ Package ID } & \multirow[b]{2}{*}{ Base Year } & \multicolumn{2}{|c|}{ Initial Isotopic Distribution } & \multirow[b]{2}{*}{ Target Year } & \multicolumn{2}{|c|}{ Decayed Isotopic Distribution } & \multirow{2}{*}{$\begin{array}{c}\text { Initial Contact } \\
\text { Dose Rate } \\
(\mathrm{mR} / \mathrm{hr})\end{array}$} & \multirow{2}{*}{$\begin{array}{c}\text { Decayed } \\
\text { Contact Dose } \\
\text { Rate }(\mathrm{mR} / \mathrm{hr})^{1} \\
\end{array}$} \\
\hline & & & Isotope & Activity (Ci) & & Isotope & Activity (Ci) & & \\
\hline & & & Sr-90 & $2.33 \mathrm{E}-01$ & & Sr-90 & $1.23 \mathrm{E}-01$ & & \\
\hline & & & $\mathrm{Te}-125 \mathrm{~m}$ & $4.32 \mathrm{E}-03$ & & $\mathrm{Te}-125 \mathrm{~m}$ & $2.93 \mathrm{E}-06$ & & \\
\hline & & & & & & Th-227 & $2.41 \mathrm{E}-08$ & & \\
\hline & & & & & & Th-231 & $1.30 \mathrm{E}-04$ & & \\
\hline & & & & & & Tl-207 & $2.44 \mathrm{E}-08$ & & \\
\hline & & & U-235 & $1.32 \mathrm{E}-04$ & & U-235 & $1.32 \mathrm{E}-04$ & & \\
\hline & & & Y-90 & $2.33 \mathrm{E}-01$ & & Y-90 & $1.21 \mathrm{E}-01$ & & \\
\hline \multirow[t]{25}{*}{217} & S821918 & 1982 & & & 2009 & Ac- 227 & $5.32 \mathrm{E}-09$ & 900,000 & 456,000 \\
\hline & & & Ba-137m & $2.40 \mathrm{E}-01$ & & $\mathrm{Ba}-137 \mathrm{~m}$ & $1.28 \mathrm{E}-01$ & & \\
\hline & & & & & & Bi-211 & $5.25 \mathrm{E}-09$ & & \\
\hline & & & Cs-137 & $2.55 \mathrm{E}-01$ & & Cs-137 & $1.37 \mathrm{E}-01$ & & \\
\hline & & & $\mathrm{Eu}-155$ & $4.78 \mathrm{E}-03$ & & $\mathrm{Eu}-155$ & $1.10 \mathrm{E}-04$ & & \\
\hline & & & & & & Fr-223 & $7.25 \mathrm{E}-11$ & & \\
\hline & & & & & & $\mathrm{Pa}-231$ & $1.62 \mathrm{E}-08$ & & \\
\hline & & & & & & $\mathrm{Pb}-211$ & $5.26 \mathrm{E}-09$ & & \\
\hline & & & Pm-147 & $1.46 \mathrm{E}-02$ & & Pm-147 & $1.16 \mathrm{E}-05$ & & \\
\hline & & & & & & Po-211 & $1.60 \mathrm{E}-11$ & & \\
\hline & & & & & & Po-215 & $5.26 \mathrm{E}-09$ & & \\
\hline & & & $\mathrm{Pu}-239$ & $1.98 \mathrm{E}-01$ & & $\mathrm{Pu}-239$ & $1.98 \mathrm{E}-01$ & & \\
\hline & & & & & & Ra-223 & 5.31E-09 & & \\
\hline & & & Rh-106 & $1.87 \mathrm{E}-03$ & & Rh-106 & $1.60 \mathrm{E}-11$ & & \\
\hline & & & & & & Rn-219 & $5.25 \mathrm{E}-09$ & & \\
\hline & & & $\mathrm{Ru}-106$ & $1.87 \mathrm{E}-03$ & & $\mathrm{Ru}-106$ & $1.62 \mathrm{E}-11$ & & \\
\hline & & & $\mathrm{Sb}-125$ & $1.04 \mathrm{E}-02$ & & $\mathrm{Sb}-125$ & $1.21 \mathrm{E}-05$ & & \\
\hline & & & & & & Sm-147 & $3.57 \mathrm{E}-13$ & & \\
\hline & & & Sr-90 & 2.33E-01 & & Sr-90 & $1.23 \mathrm{E}-01$ & & \\
\hline & & & Te-125m & $4.32 \mathrm{E}-03$ & & $\mathrm{Te}-125 \mathrm{~m}$ & $2.93 \mathrm{E}-06$ & & \\
\hline & & & & & & Th-227 & $5.18 \mathrm{E}-09$ & & \\
\hline & & & & & & Th-231 & $2.80 \mathrm{E}-05$ & & \\
\hline & & & & & & Tl-207 & $5.23 \mathrm{E}-09$ & & \\
\hline & & & U-235 & $2.83 \mathrm{E}-05$ & & U-235 & $2.83 \mathrm{E}-05$ & & \\
\hline & & & Y-90 & $2.33 \mathrm{E}-01$ & & Y-90 & $1.21 \mathrm{E}-01$ & & \\
\hline
\end{tabular}

${ }^{1}$ Calculated decayed contact dose rate. Rounded to nearest $10 \mathrm{mR} / \mathrm{hr}$ for values to 1000 ; rounded to nearest $100 \mathrm{mR} / \mathrm{hr}$ for values $>1000$ to 10,000 ; rounded to nearest $1000 \mathrm{mR} / \mathrm{hr}$ for values $>10,000$. * Initial contact dose rate assumed to be $1,000,000 \mathrm{mR} / \mathrm{hr}$; **Initial contact dose rate assumed to be $1,010,000 \mathrm{mR} / \mathrm{hr}$.

$$
69 \text { of } 168
$$


Appendix A-4 - Initial and Decayed Radionuclide and Dose Data for Lined Shafts

\begin{tabular}{|c|c|c|c|c|c|c|c|c|c|}
\hline \multirow[b]{2}{*}{ Shaft Number } & \multirow[b]{2}{*}{ Package ID } & \multirow[b]{2}{*}{ Base Year } & \multicolumn{2}{|c|}{ Initial Isotopic Distribution } & \multirow[b]{2}{*}{ Target Year } & \multicolumn{2}{|c|}{ Decayed Isotopic Distribution } & \multirow{2}{*}{$\begin{array}{c}\text { Initial Contact } \\
\text { Dose Rate } \\
(\mathrm{mR} / \mathrm{hr})\end{array}$} & \multirow{2}{*}{$\begin{array}{c}\text { Decayed } \\
\text { Contact Dose } \\
\text { Rate }(\mathrm{mR} / \mathrm{hr})^{1}\end{array}$} \\
\hline & & & Isotope & Activity (Ci) & & Isotope & Activity (Ci) & & \\
\hline \multirow[t]{25}{*}{218} & $\mathrm{~S} 821875$ & 1982 & & & 2009 & Ac-227 & $1.65 \mathrm{E}-10$ & 300,000 & 152,000 \\
\hline & & & Ba-137m & $4.79 \mathrm{E}+00$ & & $\mathrm{Ba}-137 \mathrm{~m}$ & $2.56 \mathrm{E}+00$ & & \\
\hline & & & & & & $\mathrm{Bi}-211$ & $1.63 \mathrm{E}-10$ & & \\
\hline & & & Cs-137 & $5.11 \mathrm{E}+00$ & & Cs-137 & $2.74 \mathrm{E}+00$ & & \\
\hline & & & Eu-155 & $9.55 \mathrm{E}-02$ & & Eu-155 & $2.19 \mathrm{E}-03$ & & \\
\hline & & & & & & Fr-223 & $2.25 \mathrm{E}-12$ & & \\
\hline & & & & & & $\mathrm{Pa}-231$ & $5.02 \mathrm{E}-10$ & & \\
\hline & & & & & & $\mathrm{Pb}-211$ & $1.63 \mathrm{E}-10$ & & \\
\hline & & & Pm-147 & $2.92 \mathrm{E}-01$ & & Pm-147 & 2.33E-04 & & \\
\hline & & & & & & Po-211 & $4.98 \mathrm{E}-13$ & & \\
\hline & & & & & & Po-215 & $1.63 \mathrm{E}-10$ & & \\
\hline & & & $\mathrm{Pu}-239$ & $6.20 \mathrm{E}-03$ & & $\mathrm{Pu}-239$ & $6.20 \mathrm{E}-03$ & & \\
\hline & & & & & & Ra-223 & $1.65 \mathrm{E}-10$ & & \\
\hline & & & $\mathrm{Rh}-106$ & $3.74 \mathrm{E}-02$ & & Rh-106 & $3.20 \mathrm{E}-10$ & & \\
\hline & & & & & & Rn-219 & $1.63 \mathrm{E}-10$ & & \\
\hline & & & $\mathrm{Ru}-106$ & $3.74 \mathrm{E}-02$ & & $\mathrm{Ru}-106$ & $3.24 \mathrm{E}-10$ & & \\
\hline & & & Sb-125 & $2.08 \mathrm{E}-01$ & & Sb-125 & $2.43 \mathrm{E}-04$ & & \\
\hline & & & & & & Sm-147 & $7.15 \mathrm{E}-12$ & & \\
\hline & & & Sr-90 & $4.67 \mathrm{E}+00$ & & Sr-90 & $2.46 \mathrm{E}+00$ & & \\
\hline & & & $\mathrm{Te}-125 \mathrm{~m}$ & $8.63 \mathrm{E}-02$ & & $\mathrm{Te}-125 \mathrm{~m}$ & $5.88 \mathrm{E}-05$ & & \\
\hline & & & & & & Th-227 & $1.61 \mathrm{E}-10$ & & \\
\hline & & & & & & Th-231 & 8.69E-07 & & \\
\hline & & & & & & Tl-207 & $1.62 \mathrm{E}-10$ & & \\
\hline & & & U-235 & $8.80 \mathrm{E}-07$ & & U-235 & $8.80 \mathrm{E}-07$ & & \\
\hline & & & $\mathrm{Y}-90$ & $4.66 \mathrm{E}+00$ & & $Y-90$ & $2.43 \mathrm{E}+00$ & & \\
\hline \multirow[t]{7}{*}{218} & S821879 & 1982 & & & 2009 & Ac-227 & $3.72 \mathrm{E}-09$ & 500,000 & 253,000 \\
\hline & & & Ba-137m & $7.19 \mathrm{E}+00$ & & Ba-137m & $3.84 \mathrm{E}+00$ & & \\
\hline & & & & & & Bi-211 & $3.67 \mathrm{E}-09$ & & \\
\hline & & & Cs-137 & $7.66 \mathrm{E}+00$ & & Cs-137 & $4.10 \mathrm{E}+00$ & & \\
\hline & & & Eu-155 & $1.43 \mathrm{E}-01$ & & $\mathrm{Eu}-155$ & $3.29 \mathrm{E}-03$ & & \\
\hline & & & & & & Fr-223 & $5.07 \mathrm{E}-11$ & & \\
\hline & & & & & & $\mathrm{Pa}-231$ & $1.13 \mathrm{E}-08$ & & \\
\hline
\end{tabular}

${ }^{1}$ Calculated decayed contact dose rate. Rounded to nearest $10 \mathrm{mR} / \mathrm{hr}$ for values to 1000 ; rounded to nearest $100 \mathrm{mR} / \mathrm{hr}$ for values $>1000$ to 10,000 ; rounded to nearest $1000 \mathrm{mR} / \mathrm{hr}$ for values $>10,000$. * Initial contact dose rate assumed to be $1,000,000 \mathrm{mR} / \mathrm{hr}$; **Initial contact dose rate assumed to be $1,010,000 \mathrm{mR} / \mathrm{hr}$.

$$
70 \text { of } 168
$$


Appendix A-4 - Initial and Decayed Radionuclide and Dose Data for Lined Shafts

\begin{tabular}{|c|c|c|c|c|c|c|c|c|c|}
\hline \multirow[b]{2}{*}{ Shaft Number } & \multirow[b]{2}{*}{ Package ID } & \multirow[b]{2}{*}{ Base Year } & \multicolumn{2}{|c|}{ Initial Isotopic Distribution } & \multirow[b]{2}{*}{ Target Year } & \multicolumn{2}{|c|}{ Decayed Isotopic Distribution } & \multirow{2}{*}{$\begin{array}{c}\text { Initial Contact } \\
\text { Dose Rate } \\
(\mathrm{mR} / \mathrm{hr})\end{array}$} & \multirow{2}{*}{$\begin{array}{c}\text { Decayed } \\
\text { Contact Dose } \\
\text { Rate }(\mathrm{mR} / \mathrm{hr})^{1}\end{array}$} \\
\hline & & & Isotope & Activity (Ci) & & Isotope & Activity (Ci) & & \\
\hline & & & & & & $\mathrm{Pb}-211$ & $3.68 \mathrm{E}-09$ & & \\
\hline & & & Pm-147 & 4.38E-01 & & Pm-147 & $3.49 \mathrm{E}-04$ & & \\
\hline & & & & & & Po-211 & $1.12 \mathrm{E}-11$ & & \\
\hline & & & & & & Po-215 & $3.68 \mathrm{E}-09$ & & \\
\hline & & & $\mathrm{Pu}-239$ & $1.24 \mathrm{E}-01$ & & $\mathrm{Pu}-239$ & $1.24 \mathrm{E}-01$ & & \\
\hline & & & & & & $\mathrm{Ra}-223$ & $3.72 \mathrm{E}-09$ & & \\
\hline & & & Rh-106 & $5.62 \mathrm{E}-02$ & & Rh-106 & $4.81 \mathrm{E}-10$ & & \\
\hline & & & & & & Rn-219 & $3.67 \mathrm{E}-09$ & & \\
\hline & & & $\mathrm{Ru}-106$ & $5.62 \mathrm{E}-02$ & & $\mathrm{Ru}-106$ & $4.85 \mathrm{E}-10$ & & \\
\hline & & & Sb-125 & $3.12 \mathrm{E}-01$ & & Sb-125 & $3.60 \mathrm{E}-04$ & & \\
\hline & & & & & & Sm-147 & $1.07 \mathrm{E}-11$ & & \\
\hline & & & Sr-90 & $7.00 \mathrm{E}+00$ & & Sr-90 & $3.68 \mathrm{E}+00$ & & \\
\hline & & & Te-125m & $1.30 \mathrm{E}-01$ & & Te-125m & $8.78 \mathrm{E}-05$ & & \\
\hline & & & & & & Th-227 & $3.62 \mathrm{E}-09$ & & \\
\hline & & & & & & Th-231 & $1.96 \mathrm{E}-05$ & & \\
\hline & & & & & & Tl-207 & $3.66 \mathrm{E}-09$ & & \\
\hline & & & $\mathrm{U}-235$ & $1.98 \mathrm{E}-05$ & & $\mathrm{U}-235$ & $1.98 \mathrm{E}-05$ & & \\
\hline & & & $\mathrm{Y}-90$ & $6.99 \mathrm{E}+00$ & & $\mathrm{Y}-90$ & $3.64 \mathrm{E}+00$ & & \\
\hline \multirow[t]{14}{*}{218} & S821881 & 1982 & & & 2009 & Ac- 227 & $3.72 \mathrm{E}-09$ & 900,000 & 456,000 \\
\hline & & & Ba-137m & $9.59 \mathrm{E}+00$ & & Ba-137m & $5.12 \mathrm{E}+00$ & & \\
\hline & & & & & & Bi-211 & $3.67 \mathrm{E}-09$ & & \\
\hline & & & Cs-137 & $1.02 \mathrm{E}+01$ & & Cs-137 & $5.47 \mathrm{E}+00$ & & \\
\hline & & & Eu-155 & $1.91 \mathrm{E}-01$ & & Eu-155 & 4.39E-03 & & \\
\hline & & & & & & Fr-223 & $5.07 \mathrm{E}-11$ & & \\
\hline & & & & & & $\mathrm{Pa}-231$ & $1.13 \mathrm{E}-08$ & & \\
\hline & & & & & & $\mathrm{Pb}-211$ & $3.68 \mathrm{E}-09$ & & \\
\hline & & & Pm-147 & $5.83 \mathrm{E}-01$ & & Pm-147 & 4.65E-04 & & \\
\hline & & & & & & Po-211 & $1.12 \mathrm{E}-11$ & & \\
\hline & & & & & & Po-215 & $3.68 \mathrm{E}-09$ & & \\
\hline & & & $\mathrm{Pu}-239$ & $1.24 \mathrm{E}-01$ & & $\mathrm{Pu}-239$ & $1.24 \mathrm{E}-01$ & & \\
\hline & & & & & & Ra-223 & $3.72 \mathrm{E}-09$ & & \\
\hline & & & Rh-106 & 7.49E-02 & & Rh-106 & $6.41 \mathrm{E}-10$ & & \\
\hline
\end{tabular}

${ }^{1}$ Calculated decayed contact dose rate. Rounded to nearest $10 \mathrm{mR} / \mathrm{hr}$ for values to 1000 ; rounded to nearest $100 \mathrm{mR} / \mathrm{hr}$ for values $>1000$ to 10,000 ; rounded to nearest $1000 \mathrm{mR} / \mathrm{hr}$ for values $>10,000$. * Initial contact dose rate assumed to be $1,000,000 \mathrm{mR} / \mathrm{hr}$; **Initial contact dose rate assumed to be $1,010,000 \mathrm{mR} / \mathrm{hr}$.

$$
71 \text { of } 168
$$


Appendix A-4 - Initial and Decayed Radionuclide and Dose Data for Lined Shafts

\begin{tabular}{|c|c|c|c|c|c|c|c|c|c|}
\hline \multirow[b]{2}{*}{ Shaft Number } & \multirow[b]{2}{*}{ Package ID } & \multirow[b]{2}{*}{ Base Year } & \multicolumn{2}{|c|}{ Initial Isotopic Distribution } & \multirow[b]{2}{*}{ Target Year } & \multicolumn{2}{|c|}{ Decayed Isotopic Distribution } & \multirow{2}{*}{$\begin{array}{c}\text { Initial Contact } \\
\text { Dose Rate } \\
(\mathrm{mR} / \mathrm{hr})\end{array}$} & \multirow{2}{*}{$\begin{array}{c}\text { Decayed } \\
\text { Contact Dose } \\
\text { Rate }(\mathrm{mR} / \mathrm{hr})^{1} \\
\end{array}$} \\
\hline & & & Isotope & Activity (Ci) & & Isotope & Activity (Ci) & & \\
\hline & & & & & & Rn-219 & $3.67 \mathrm{E}-09$ & & \\
\hline & & & $\mathrm{Ru}-106$ & $7.49 \mathrm{E}-02$ & & $\mathrm{Ru}-106$ & $6.47 \mathrm{E}-10$ & & \\
\hline & & & $\mathrm{Sb}-125$ & $4.16 \mathrm{E}-01$ & & $\mathrm{Sb}-125$ & $4.86 \mathrm{E}-04$ & & \\
\hline & & & & & & Sm-147 & $1.43 \mathrm{E}-11$ & & \\
\hline & & & Sr-90 & $9.34 \mathrm{E}+00$ & & Sr-90 & $4.91 \mathrm{E}+00$ & & \\
\hline & & & Te- $125 \mathrm{~m}$ & $1.73 \mathrm{E}-01$ & & $\mathrm{Te}-125 \mathrm{~m}$ & $1.18 \mathrm{E}-04$ & & \\
\hline & & & & & & Th-227 & $3.62 \mathrm{E}-09$ & & \\
\hline & & & & & & Th-231 & $1.96 \mathrm{E}-05$ & & \\
\hline & & & & & & Tl-207 & $3.66 \mathrm{E}-09$ & & \\
\hline & & & U-235 & $1.98 \mathrm{E}-05$ & & $\mathrm{U}-235$ & $1.98 \mathrm{E}-05$ & & \\
\hline & & & $\mathrm{Y}-90$ & $9.33 \mathrm{E}+00$ & & Y-90 & $4.85 \mathrm{E}+00$ & & \\
\hline \multirow[t]{21}{*}{218} & S821883 & 1982 & & & 2009 & Ac-227 & $1.65 \mathrm{E}-10$ & 200,000 & 101,000 \\
\hline & & & Ba-137m & $1.44 \mathrm{E}+00$ & & $\mathrm{Ba}-137 \mathrm{~m}$ & $7.68 \mathrm{E}-01$ & & \\
\hline & & & & & & Bi-211 & $1.63 \mathrm{E}-10$ & & \\
\hline & & & Cs-137 & $1.53 \mathrm{E}+00$ & & Cs-137 & $8.21 \mathrm{E}-01$ & & \\
\hline & & & $\mathrm{Eu}-155$ & $2.87 \mathrm{E}-02$ & & $\mathrm{Eu}-155$ & $6.58 \mathrm{E}-04$ & & \\
\hline & & & & & & Fr-223 & $2.25 \mathrm{E}-12$ & & \\
\hline & & & & & & $\mathrm{Pa}-231$ & $5.02 \mathrm{E}-10$ & & \\
\hline & & & & & & $\mathrm{Pb}-211$ & $1.63 \mathrm{E}-10$ & & \\
\hline & & & Pm-147 & $8.75 \mathrm{E}-02$ & & Pm-147 & $6.98 \mathrm{E}-05$ & & \\
\hline & & & & & & Po-211 & $4.98 \mathrm{E}-13$ & & \\
\hline & & & & & & Po-215 & $1.63 \mathrm{E}-10$ & & \\
\hline & & & $\mathrm{Pu}-239$ & $6.20 \mathrm{E}-03$ & & $\mathrm{Pu}-239$ & $6.20 \mathrm{E}-03$ & & \\
\hline & & & & & & Ra-223 & $1.65 \mathrm{E}-10$ & & \\
\hline & & & Rh-106 & $1.12 \mathrm{E}-02$ & & Rh-106 & $9.61 \mathrm{E}-11$ & & \\
\hline & & & & & & Rn-219 & $1.63 \mathrm{E}-10$ & & \\
\hline & & & $\mathrm{Ru}-106$ & $1.12 \mathrm{E}-02$ & & $\mathrm{Ru}-106$ & $9.71 \mathrm{E}-11$ & & \\
\hline & & & Sb-125 & $6.24 \mathrm{E}-02$ & & $\mathrm{Sb}-125$ & 7.29E-05 & & \\
\hline & & & & & & Sm-147 & $2.14 \mathrm{E}-12$ & & \\
\hline & & & Sr-90 & $1.40 \mathrm{E}+00$ & & Sr-90 & 7.37E-01 & & \\
\hline & & & $\mathrm{Te}-125 \mathrm{~m}$ & $2.59 \mathrm{E}-02$ & & Te- $125 \mathrm{~m}$ & $1.77 \mathrm{E}-05$ & & \\
\hline & & & & & & Th-227 & $1.61 \mathrm{E}-10$ & & \\
\hline
\end{tabular}

${ }^{1}$ Calculated decayed contact dose rate. Rounded to nearest $10 \mathrm{mR} / \mathrm{hr}$ for values to 1000 ; rounded to nearest $100 \mathrm{mR} / \mathrm{hr}$ for values $>1000$ to 10,000 ; rounded to nearest $1000 \mathrm{mR} / \mathrm{hr}$ for values $>10,000$. * Initial contact dose rate assumed to be $1,000,000 \mathrm{mR} / \mathrm{hr}$; **Initial contact dose rate assumed to be $1,010,000 \mathrm{mR} / \mathrm{hr}$.

$$
72 \text { of } 168
$$


Appendix A-4 - Initial and Decayed Radionuclide and Dose Data for Lined Shafts

\begin{tabular}{|c|c|c|c|c|c|c|c|c|c|}
\hline \multirow[b]{2}{*}{ Shaft Number } & \multirow[b]{2}{*}{ Package ID } & \multirow[b]{2}{*}{ Base Year } & \multicolumn{2}{|c|}{ Initial Isotopic Distribution } & \multirow[b]{2}{*}{ Target Year } & \multicolumn{2}{|c|}{ Decayed Isotopic Distribution } & \multirow{2}{*}{$\begin{array}{c}\text { Initial Contact } \\
\text { Dose Rate } \\
(\mathrm{mR} / \mathrm{hr})\end{array}$} & \multirow{2}{*}{$\begin{array}{c}\text { Decayed } \\
\text { Contact Dose } \\
\text { Rate }(\mathrm{mR} / \mathrm{hr})^{1} \\
\end{array}$} \\
\hline & & & Isotope & Activity (Ci) & & Isotope & Activity (Ci) & & \\
\hline & & & & & & Th-231 & $8.69 \mathrm{E}-07$ & & \\
\hline & & & & & & Tl-207 & $1.62 \mathrm{E}-10$ & & \\
\hline & & & $\mathrm{U}-235$ & $8.80 \mathrm{E}-07$ & & $\mathrm{U}-235$ & $8.80 \mathrm{E}-07$ & & \\
\hline & & & $\mathrm{Y}-90$ & $1.40 \mathrm{E}+00$ & & Y-90 & $7.28 \mathrm{E}-01$ & & \\
\hline \multirow[t]{25}{*}{218} & S821916 & 1982 & & & 2009 & Ac-227 & $3.42 \mathrm{E}-08$ & $1000000+$ & $506,000 *$ \\
\hline & & & $\mathrm{Ba}-137 \mathrm{~m}$ & $7.19 \mathrm{E}+00$ & & Ba-137m & $3.84 \mathrm{E}+00$ & & \\
\hline & & & & & & $\mathrm{Bi}-211$ & $3.38 \mathrm{E}-08$ & & \\
\hline & & & Cs-137 & $7.66 \mathrm{E}+00$ & & Cs-137 & $4.10 \mathrm{E}+00$ & & \\
\hline & & & Eu-155 & $1.43 \mathrm{E}-01$ & & Eu-155 & $3.29 \mathrm{E}-03$ & & \\
\hline & & & & & & Fr-223 & $4.67 \mathrm{E}-10$ & & \\
\hline & & & & & & $\mathrm{Pa}-231$ & $1.04 \mathrm{E}-07$ & & \\
\hline & & & & & & $\mathrm{Pb}-211$ & $3.38 \mathrm{E}-08$ & & \\
\hline & & & Pm-147 & 4.38E-01 & & Pm-147 & $3.49 \mathrm{E}-04$ & & \\
\hline & & & & & & Po-211 & $1.03 \mathrm{E}-10$ & & \\
\hline & & & & & & Po-215 & $3.38 \mathrm{E}-08$ & & \\
\hline & & & $\mathrm{Pu}-239$ & $2.50 \mathrm{E}+00$ & & $\mathrm{Pu}-239$ & $2.50 \mathrm{E}+00$ & & \\
\hline & & & & & & Ra-223 & $3.42 \mathrm{E}-08$ & & \\
\hline & & & Rh-106 & $5.62 \mathrm{E}-02$ & & Rh-106 & $4.81 \mathrm{E}-10$ & & \\
\hline & & & & & & Rn-219 & $3.38 \mathrm{E}-08$ & & \\
\hline & & & $\mathrm{Ru}-106$ & $5.62 \mathrm{E}-02$ & & Ru-106 & $4.85 \mathrm{E}-10$ & & \\
\hline & & & Sb-125 & $3.12 \mathrm{E}-01$ & & Sb-125 & $3.60 \mathrm{E}-04$ & & \\
\hline & & & & & & Sm-147 & $1.07 \mathrm{E}-11$ & & \\
\hline & & & Sr-90 & $7.00 \mathrm{E}+00$ & & Sr-90 & $3.68 \mathrm{E}+00$ & & \\
\hline & & & Te-125m & $1.30 \mathrm{E}-01$ & & $\mathrm{Te}-125 \mathrm{~m}$ & $8.78 \mathrm{E}-05$ & & \\
\hline & & & & & & Th-227 & $3.33 \mathrm{E}-08$ & & \\
\hline & & & & & & Th-231 & $1.80 \mathrm{E}-04$ & & \\
\hline & & & & & & T1-207 & $3.36 \mathrm{E}-08$ & & \\
\hline & & & U-235 & $1.82 \mathrm{E}-04$ & & U-235 & $1.82 \mathrm{E}-04$ & & \\
\hline & & & Y-90 & $6.99 \mathrm{E}+00$ & & Y-90 & $3.64 \mathrm{E}+00$ & & \\
\hline \multirow[t]{3}{*}{218} & S821917 & 1982 & & & 2009 & Ac- 227 & $1.65 \mathrm{E}-10$ & 300,000 & 152,000 \\
\hline & & & Ba-137m & $1.44 \mathrm{E}+00$ & & Ba-137m & $7.68 \mathrm{E}-01$ & & \\
\hline & & & & & & Bi-211 & $1.63 \mathrm{E}-10$ & & \\
\hline
\end{tabular}

${ }^{1}$ Calculated decayed contact dose rate. Rounded to nearest $10 \mathrm{mR} / \mathrm{hr}$ for values to 1000 ; rounded to nearest $100 \mathrm{mR} / \mathrm{hr}$ for values $>1000$ to 10,000 ; rounded to nearest $1000 \mathrm{mR} / \mathrm{hr}$ for values $>10,000$. * Initial contact dose rate assumed to be $1,000,000 \mathrm{mR} / \mathrm{hr}$; **Initial contact dose rate assumed to be $1,010,000 \mathrm{mR} / \mathrm{hr}$.

$$
73 \text { of } 168
$$


Appendix A-4 - Initial and Decayed Radionuclide and Dose Data for Lined Shafts

\begin{tabular}{|c|c|c|c|c|c|c|c|c|c|}
\hline \multirow[b]{2}{*}{ Shaft Number } & \multirow[b]{2}{*}{ Package ID } & \multirow[b]{2}{*}{ Base Year } & \multicolumn{2}{|c|}{ Initial Isotopic Distribution } & \multirow[b]{2}{*}{ Target Year } & \multicolumn{2}{|c|}{ Decayed Isotopic Distribution } & \multirow{2}{*}{$\begin{array}{c}\text { Initial Contact } \\
\text { Dose Rate } \\
(\mathrm{mR} / \mathrm{hr}) \\
\end{array}$} & \multirow{2}{*}{$\begin{array}{c}\text { Decayed } \\
\text { Contact Dose } \\
\text { Rate }(\mathrm{mR} / \mathrm{hr})^{1} \\
\end{array}$} \\
\hline & & & Isotope & Activity (Ci) & & Isotope & Activity (Ci) & & \\
\hline & & & Cs-137 & $1.53 \mathrm{E}+00$ & & Cs-137 & $8.21 \mathrm{E}-01$ & & \\
\hline & & & Eu-155 & $2.87 \mathrm{E}-02$ & & Eu-155 & $6.58 \mathrm{E}-04$ & & \\
\hline & & & & & & Fr-223 & $2.25 \mathrm{E}-12$ & & \\
\hline & & & & & & $\mathrm{Pa}-231$ & $5.02 \mathrm{E}-10$ & & \\
\hline & & & & & & $\mathrm{Pb}-211$ & $1.63 \mathrm{E}-10$ & & \\
\hline & & & Pm-147 & $8.75 \mathrm{E}-02$ & & Pm-147 & $6.98 \mathrm{E}-05$ & & \\
\hline & & & & & & Po-211 & $4.98 \mathrm{E}-13$ & & \\
\hline & & & & & & Po-215 & $1.63 \mathrm{E}-10$ & & \\
\hline & & & $\mathrm{Pu}-239$ & $6.20 \mathrm{E}-03$ & & $\mathrm{Pu}-239$ & $6.20 \mathrm{E}-03$ & & \\
\hline & & & & & & Ra-223 & $1.65 \mathrm{E}-10$ & & \\
\hline & & & Rh-106 & $1.12 \mathrm{E}-02$ & & Rh-106 & $9.61 \mathrm{E}-11$ & & \\
\hline & & & & & & $\mathrm{Rn}-219$ & $1.63 \mathrm{E}-10$ & & \\
\hline & & & $\mathrm{Ru}-106$ & $1.12 \mathrm{E}-02$ & & $\mathrm{Ru}-106$ & $9.71 \mathrm{E}-11$ & & \\
\hline & & & $\mathrm{Sb}-125$ & $6.24 \mathrm{E}-02$ & & $\mathrm{Sb}-125$ & 7.29E-05 & & \\
\hline & & & & & & Sm-147 & $2.14 \mathrm{E}-12$ & & \\
\hline & & & Sr-90 & $1.40 \mathrm{E}+00$ & & Sr-90 & 7.37E-01 & & \\
\hline & & & $\mathrm{Te}-125 \mathrm{~m}$ & $2.59 \mathrm{E}-02$ & & Te- $125 \mathrm{~m}$ & $1.77 \mathrm{E}-05$ & & \\
\hline & & & & & & Th-227 & $1.61 \mathrm{E}-10$ & & \\
\hline & & & & & & Th-231 & 8.69E-07 & & \\
\hline & & & & & & Tl-207 & $1.62 \mathrm{E}-10$ & & \\
\hline & & & U-235 & 8.80E-07 & & U-235 & $8.80 \mathrm{E}-07$ & & \\
\hline & & & Y-90 & $1.40 \mathrm{E}+00$ & & Y-90 & $7.28 \mathrm{E}-01$ & & \\
\hline \multirow[t]{10}{*}{219} & S832830 & 1983 & & & 2009 & Ac- 227 & $1.55 \mathrm{E}-10$ & $1,000,000$ & 518,000 \\
\hline & & & Ba-137m & $4.79 \mathrm{E}+00$ & & Ba-137m & $2.62 \mathrm{E}+00$ & & \\
\hline & & & & & & Bi-211 & $1.53 \mathrm{E}-10$ & & \\
\hline & & & Cs-137 & $5.11 \mathrm{E}+00$ & & Cs-137 & $2.80 \mathrm{E}+00$ & & \\
\hline & & & Eu-155 & $9.55 \mathrm{E}-02$ & & Eu-155 & $2.52 \mathrm{E}-03$ & & \\
\hline & & & & & & Fr-223 & $2.11 \mathrm{E}-12$ & & \\
\hline & & & & & & $\mathrm{Pa}-231$ & $4.83 \mathrm{E}-10$ & & \\
\hline & & & & & & $\mathrm{Pb}-211$ & $1.53 \mathrm{E}-10$ & & \\
\hline & & & Pm-147 & $2.92 \mathrm{E}-01$ & & Pm-147 & $3.06 \mathrm{E}-04$ & & \\
\hline & & & & & & Po-211 & $4.66 \mathrm{E}-13$ & & \\
\hline
\end{tabular}

${ }^{1}$ Calculated decayed contact dose rate. Rounded to nearest $10 \mathrm{mR} / \mathrm{hr}$ for values to 1000 ; rounded to nearest $100 \mathrm{mR} / \mathrm{hr}$ for values $>1000$ to 10,000 ; rounded to nearest $1000 \mathrm{mR} / \mathrm{hr}$ for values $>10,000$. * Initial contact dose rate assumed to be $1,000,000 \mathrm{mR} / \mathrm{hr}$; **Initial contact dose rate assumed to be $1,010,000 \mathrm{mR} / \mathrm{hr}$.

$$
74 \text { of } 168
$$


Appendix A-4 - Initial and Decayed Radionuclide and Dose Data for Lined Shafts

\begin{tabular}{|c|c|c|c|c|c|c|c|c|c|}
\hline \multirow[b]{2}{*}{ Shaft Number } & \multirow[b]{2}{*}{ Package ID } & \multirow[b]{2}{*}{ Base Year } & \multicolumn{2}{|c|}{ Initial Isotopic Distribution } & \multirow[b]{2}{*}{ Target Year } & \multicolumn{2}{|c|}{ Decayed Isotopic Distribution } & \multirow{2}{*}{$\begin{array}{c}\text { Initial Contact } \\
\text { Dose Rate } \\
(\mathrm{mR} / \mathrm{hr})\end{array}$} & \multirow{2}{*}{$\begin{array}{c}\text { Decayed } \\
\text { Contact Dose } \\
\text { Rate }(\mathrm{mR} / \mathrm{hr})^{1}\end{array}$} \\
\hline & & & Isotope & Activity (Ci) & & Isotope & Activity (Ci) & & \\
\hline & & & & & & Po-215 & $1.53 \mathrm{E}-10$ & & \\
\hline & & & $\mathrm{Pu}-239$ & $6.20 \mathrm{E}-03$ & & $\mathrm{Pu}-239$ & $6.20 \mathrm{E}-03$ & & \\
\hline & & & & & & $\mathrm{Ra}-223$ & $1.55 \mathrm{E}-10$ & & \\
\hline & & & $\mathrm{Rh}-106$ & $3.74 \mathrm{E}-02$ & & Rh-106 & $6.37 \mathrm{E}-10$ & & \\
\hline & & & & & & Rn-219 & $1.53 \mathrm{E}-10$ & & \\
\hline & & & $\mathrm{Ru}-106$ & 3.74E-02 & & $\mathrm{Ru}-106$ & $6.44 \mathrm{E}-10$ & & \\
\hline & & & $\mathrm{Sb}-125$ & $2.08 \mathrm{E}-01$ & & $\mathrm{Sb}-125$ & $3.10 \mathrm{E}-04$ & & \\
\hline & & & & & & Sm-147 & $7.15 \mathrm{E}-12$ & & \\
\hline & & & Sr-90 & $4.67 \mathrm{E}+00$ & & Sr-90 & $2.51 \mathrm{E}+00$ & & \\
\hline & & & $\mathrm{Te}-125 \mathrm{~m}$ & $8.63 \mathrm{E}-02$ & & $\mathrm{Te}-125 \mathrm{~m}$ & $7.52 \mathrm{E}-05$ & & \\
\hline & & & & & & Th-227 & $1.51 \mathrm{E}-10$ & & \\
\hline & & & & & & Th-231 & 8.69E-07 & & \\
\hline & & & & & & Tl-207 & $1.52 \mathrm{E}-10$ & & \\
\hline & & & $\mathrm{U}-235$ & $8.80 \mathrm{E}-07$ & & $\mathrm{U}-235$ & $8.80 \mathrm{E}-07$ & & \\
\hline & & & Y-90 & $4.66 \mathrm{E}+00$ & & Y-90 & $2.49 \mathrm{E}+00$ & & \\
\hline \multirow[t]{17}{*}{219} & S832831 & 1983 & & & 2009 & Ac-227 & $1.55 \mathrm{E}-10$ & 30,000 & 16,000 \\
\hline & & & Ba-137m & $1.92 \mathrm{E}-01$ & & Ba-137m & $1.05 \mathrm{E}-01$ & & \\
\hline & & & & & & Bi-211 & $1.53 \mathrm{E}-10$ & & \\
\hline & & & Cs-137 & $2.04 \mathrm{E}-01$ & & Cs-137 & $1.12 \mathrm{E}-01$ & & \\
\hline & & & Eu-155 & $3.82 \mathrm{E}-03$ & & Eu-155 & $1.01 \mathrm{E}-04$ & & \\
\hline & & & & & & Fr-223 & $2.11 \mathrm{E}-12$ & & \\
\hline & & & & & & $\mathrm{Pa}-231$ & $4.83 \mathrm{E}-10$ & & \\
\hline & & & & & & $\mathrm{Pb}-211$ & $1.53 \mathrm{E}-10$ & & \\
\hline & & & Pm-147 & $1.17 \mathrm{E}-02$ & & Pm-147 & $1.22 \mathrm{E}-05$ & & \\
\hline & & & & & & Po-211 & $4.66 \mathrm{E}-13$ & & \\
\hline & & & & & & Po-215 & $1.53 \mathrm{E}-10$ & & \\
\hline & & & $\mathrm{Pu}-239$ & $6.20 \mathrm{E}-03$ & & $\mathrm{Pu}-239$ & $6.20 \mathrm{E}-03$ & & \\
\hline & & & & & & Ra-223 & $1.55 \mathrm{E}-10$ & & \\
\hline & & & Rh-106 & $1.50 \mathrm{E}-03$ & & Rh-106 & $2.55 \mathrm{E}-11$ & & \\
\hline & & & & & & Rn-219 & $1.53 \mathrm{E}-10$ & & \\
\hline & & & Ru-106 & $1.50 \mathrm{E}-03$ & & Ru-106 & $2.58 \mathrm{E}-11$ & & \\
\hline & & & Sb-125 & $8.32 \mathrm{E}-03$ & & Sb-125 & $1.24 \mathrm{E}-05$ & & \\
\hline
\end{tabular}

${ }^{1}$ Calculated decayed contact dose rate. Rounded to nearest $10 \mathrm{mR} / \mathrm{hr}$ for values to 1000 ; rounded to nearest $100 \mathrm{mR} / \mathrm{hr}$ for values $>1000$ to 10,000 ; rounded to nearest $1000 \mathrm{mR} / \mathrm{hr}$ for values $>10,000$. * Initial contact dose rate assumed to be $1,000,000 \mathrm{mR} / \mathrm{hr}$; **Initial contact dose rate assumed to be $1,010,000 \mathrm{mR} / \mathrm{hr}$.

$$
75 \text { of } 168
$$


Appendix A-4 - Initial and Decayed Radionuclide and Dose Data for Lined Shafts

\begin{tabular}{|c|c|c|c|c|c|c|c|c|c|}
\hline \multirow[b]{2}{*}{ Shaft Number } & \multirow[b]{2}{*}{ Package ID } & \multirow[b]{2}{*}{ Base Year } & \multicolumn{2}{|c|}{ Initial Isotopic Distribution } & \multirow[b]{2}{*}{ Target Year } & \multicolumn{2}{|c|}{ Decayed Isotopic Distribution } & \multirow{2}{*}{$\begin{array}{c}\text { Initial Contact } \\
\text { Dose Rate } \\
(\mathrm{mR} / \mathrm{hr})\end{array}$} & \multirow{2}{*}{$\begin{array}{c}\text { Decayed } \\
\text { Contact Dose } \\
\text { Rate }(\mathrm{mR} / \mathrm{hr})^{1} \\
\end{array}$} \\
\hline & & & Isotope & Activity (Ci) & & Isotope & Activity (Ci) & & \\
\hline & & & & & & Sm-147 & $2.86 \mathrm{E}-13$ & & \\
\hline & & & Sr-90 & $1.87 \mathrm{E}-01$ & & Sr-90 & $1.01 \mathrm{E}-01$ & & \\
\hline & & & $\mathrm{Te}-125 \mathrm{~m}$ & $3.45 \mathrm{E}-03$ & & $\mathrm{Te}-125 \mathrm{~m}$ & $3.01 \mathrm{E}-06$ & & \\
\hline & & & & & & Th-227 & $1.51 \mathrm{E}-10$ & & \\
\hline & & & & & & Th-231 & $8.69 \mathrm{E}-07$ & & \\
\hline & & & & & & Tl-207 & $1.52 \mathrm{E}-10$ & & \\
\hline & & & $\mathrm{U}-235$ & $8.80 \mathrm{E}-07$ & & $\mathrm{U}-235$ & $8.80 \mathrm{E}-07$ & & \\
\hline & & & Y-90 & $1.87 \mathrm{E}-01$ & & $\mathrm{Y}-90$ & $9.94 \mathrm{E}-02$ & & \\
\hline \multirow[t]{24}{*}{219} & S832832 & 1983 & & & 2009 & Ac-227 & $9.13 \mathrm{E}-08$ & $1000000+$ & $518,000 *$ \\
\hline & & & $\mathrm{Ba}-137 \mathrm{~m}$ & $3.59 \mathrm{E}+01$ & & $\mathrm{Ba}-137 \mathrm{~m}$ & $1.96 \mathrm{E}+01$ & & \\
\hline & & & & & & $\mathrm{Bi}-211$ & $9.01 \mathrm{E}-08$ & & \\
\hline & & & Cs-137 & $3.83 \mathrm{E}+01$ & & Cs-137 & $2.10 \mathrm{E}+01$ & & \\
\hline & & & Eu-155 & $7.17 \mathrm{E}-01$ & & Eu-155 & $1.89 \mathrm{E}-02$ & & \\
\hline & & & & & & Fr-223 & $1.25 \mathrm{E}-09$ & & \\
\hline & & & & & & $\mathrm{Pa}-231$ & $2.85 \mathrm{E}-07$ & & \\
\hline & & & & & & $\mathrm{Pb}-211$ & $9.02 \mathrm{E}-08$ & & \\
\hline & & & Pm-147 & $2.19 \mathrm{E}+00$ & & Pm-147 & $2.27 \mathrm{E}-03$ & & \\
\hline & & & & & & Po-211 & $2.75 \mathrm{E}-10$ & & \\
\hline & & & & & & Po-215 & $9.02 \mathrm{E}-08$ & & \\
\hline & & & $\mathrm{Pu}-239$ & $2.51 \mathrm{E}+00$ & & $\mathrm{Pu}-239$ & $2.51 \mathrm{E}+00$ & & \\
\hline & & & & & & Ra-223 & 9.12E-08 & & \\
\hline & & & Rh-106 & $2.81 \mathrm{E}-01$ & & Rh-106 & 4.78E-09 & & \\
\hline & & & & & & Rn-219 & $9.01 \mathrm{E}-08$ & & \\
\hline & & & $\mathrm{Ru}-106$ & $2.81 \mathrm{E}-01$ & & Ru-106 & 4.83E-09 & & \\
\hline & & & Sb-125 & $1.56 \mathrm{E}+00$ & & Sb-125 & $2.33 \mathrm{E}-03$ & & \\
\hline & & & & & & Sm-147 & $5.36 \mathrm{E}-11$ & & \\
\hline & & & Sr-90 & $3.50 \mathrm{E}+01$ & & Sr-90 & $1.89 \mathrm{E}+01$ & & \\
\hline & & & $\mathrm{Te}-125 \mathrm{~m}$ & $6.48 \mathrm{E}-01$ & & $\mathrm{Te}-125 \mathrm{~m}$ & $5.64 \mathrm{E}-04$ & & \\
\hline & & & & & & Th-227 & 8.88E-08 & & \\
\hline & & & & & & Th-231 & $5.13 \mathrm{E}-04$ & & \\
\hline & & & & & & T1-207 & 8.97E-08 & & \\
\hline & & & U-235 & $5.19 \mathrm{E}-04$ & & U-235 & 5.19E-04 & & \\
\hline
\end{tabular}

${ }^{1}$ Calculated decayed contact dose rate. Rounded to nearest $10 \mathrm{mR} / \mathrm{hr}$ for values to 1000 ; rounded to nearest $100 \mathrm{mR} / \mathrm{hr}$ for values $>1000$ to 10,000 ; rounded to nearest $1000 \mathrm{mR} / \mathrm{hr}$ for values $>10,000$. * Initial contact dose rate assumed to be $1,000,000 \mathrm{mR} / \mathrm{hr}$; **Initial contact dose rate assumed to be $1,010,000 \mathrm{mR} / \mathrm{hr}$.

$$
76 \text { of } 168
$$


Appendix A-4 - Initial and Decayed Radionuclide and Dose Data for Lined Shafts

\begin{tabular}{|c|c|c|c|c|c|c|c|c|c|}
\hline \multirow[b]{2}{*}{ Shaft Number } & \multirow[b]{2}{*}{ Package ID } & \multirow[b]{2}{*}{ Base Year } & \multicolumn{2}{|c|}{ Initial Isotopic Distribution } & \multirow[b]{2}{*}{ Target Year } & \multicolumn{2}{|c|}{ Decayed Isotopic Distribution } & \multirow{2}{*}{$\begin{array}{c}\text { Initial Contact } \\
\text { Dose Rate } \\
(\mathrm{mR} / \mathrm{hr})\end{array}$} & \multirow{2}{*}{$\begin{array}{c}\text { Decayed } \\
\text { Contact Dose } \\
\text { Rate }(\mathrm{mR} / \mathrm{hr}) \\
\end{array}$} \\
\hline & & & Isotope & Activity (Ci) & & Isotope & Activity (Ci) & & \\
\hline & & & $\mathrm{Y}-90$ & $3.50 \mathrm{E}+01$ & & $\mathrm{Y}-90$ & $1.86 \mathrm{E}+01$ & & \\
\hline \multirow[t]{25}{*}{219} & S832833 & 1983 & & & 2009 & Ac- 227 & $1.55 \mathrm{E}-10$ & 200,000 & 104,000 \\
\hline & & & Ba-137m & $7.19 \mathrm{E}+00$ & & $\mathrm{Ba}-137 \mathrm{~m}$ & $3.93 \mathrm{E}+00$ & & \\
\hline & & & & & & Bi-211 & $1.53 \mathrm{E}-10$ & & \\
\hline & & & Cs-137 & $7.66 \mathrm{E}+00$ & & Cs-137 & $4.20 \mathrm{E}+00$ & & \\
\hline & & & $\mathrm{Eu}-155$ & $1.43 \mathrm{E}-01$ & & Eu-155 & $3.78 \mathrm{E}-03$ & & \\
\hline & & & & & & Fr-223 & $2.11 \mathrm{E}-12$ & & \\
\hline & & & & & & $\mathrm{Pa}-231$ & $4.83 \mathrm{E}-10$ & & \\
\hline & & & & & & $\mathrm{Pb}-211$ & $1.53 \mathrm{E}-10$ & & \\
\hline & & & Pm-147 & 4.38E-01 & & Pm-147 & $4.55 \mathrm{E}-04$ & & \\
\hline & & & & & & Po-211 & $4.66 \mathrm{E}-13$ & & \\
\hline & & & & & & Po-215 & $1.53 \mathrm{E}-10$ & & \\
\hline & & & $\mathrm{Pu}-239$ & $6.20 \mathrm{E}-03$ & & $\mathrm{Pu}-239$ & $6.20 \mathrm{E}-03$ & & \\
\hline & & & & & & $\mathrm{Ra}-223$ & $1.55 \mathrm{E}-10$ & & \\
\hline & & & Rh-106 & $5.62 \mathrm{E}-02$ & & Rh-106 & $9.56 \mathrm{E}-10$ & & \\
\hline & & & & & & $\mathrm{Rn}-219$ & $1.53 \mathrm{E}-10$ & & \\
\hline & & & $\mathrm{Ru}-106$ & $5.62 \mathrm{E}-02$ & & $\mathrm{Ru}-106$ & $9.66 \mathrm{E}-10$ & & \\
\hline & & & $\mathrm{Sb}-125$ & $3.12 \mathrm{E}-01$ & & $\mathrm{Sb}-125$ & $4.66 \mathrm{E}-04$ & & \\
\hline & & & & & & Sm-147 & $1.07 \mathrm{E}-11$ & & \\
\hline & & & Sr-90 & $7.00 \mathrm{E}+00$ & & Sr-90 & $3.77 \mathrm{E}+00$ & & \\
\hline & & & $\mathrm{Te}-125 \mathrm{~m}$ & $1.30 \mathrm{E}-01$ & & $\mathrm{Te}-125 \mathrm{~m}$ & $1.13 \mathrm{E}-04$ & & \\
\hline & & & & & & Th-227 & $1.51 \mathrm{E}-10$ & & \\
\hline & & & & & & Th-231 & 8.69E-07 & & \\
\hline & & & & & & T1-207 & $1.52 \mathrm{E}-10$ & & \\
\hline & & & U-235 & $8.80 \mathrm{E}-07$ & & U-235 & $8.80 \mathrm{E}-07$ & & \\
\hline & & & Y-90 & $6.99 \mathrm{E}+00$ & & Y-90 & $3.73 \mathrm{E}+00$ & & \\
\hline \multirow[t]{6}{*}{219} & S832834 & 1983 & & & 2009 & Ac- 227 & $1.55 \mathrm{E}-10$ & $1000000+$ & $518,000 *$ \\
\hline & & & Ba-137m & $1.20 \mathrm{E}+01$ & & Ba-137m & $6.55 \mathrm{E}+00$ & & \\
\hline & & & & & & $\mathrm{Bi}-211$ & $1.53 \mathrm{E}-10$ & & \\
\hline & & & Cs-137 & $1.28 \mathrm{E}+01$ & & Cs-137 & $7.00 \mathrm{E}+00$ & & \\
\hline & & & Eu-155 & 2.39E-01 & & $\mathrm{Eu}-155$ & $6.31 \mathrm{E}-03$ & & \\
\hline & & & & & & Fr-223 & $2.11 \mathrm{E}-12$ & & \\
\hline
\end{tabular}

${ }^{1}$ Calculated decayed contact dose rate. Rounded to nearest $10 \mathrm{mR} / \mathrm{hr}$ for values to 1000 ; rounded to nearest $100 \mathrm{mR} / \mathrm{hr}$ for values $>1000$ to 10,000 ; rounded to nearest $1000 \mathrm{mR} / \mathrm{hr}$ for values $>10,000$. * Initial contact dose rate assumed to be $1,000,000 \mathrm{mR} / \mathrm{hr}$; **Initial contact dose rate assumed to be $1,010,000 \mathrm{mR} / \mathrm{hr}$.

$$
77 \text { of } 168
$$


Appendix A-4 - Initial and Decayed Radionuclide and Dose Data for Lined Shafts

\begin{tabular}{|c|c|c|c|c|c|c|c|c|c|}
\hline \multirow[b]{2}{*}{ Shaft Number } & \multirow[b]{2}{*}{ Package ID } & \multirow[b]{2}{*}{ Base Year } & \multicolumn{2}{|c|}{ Initial Isotopic Distribution } & \multirow[b]{2}{*}{ Target Year } & \multicolumn{2}{|c|}{ Decayed Isotopic Distribution } & \multirow{2}{*}{$\begin{array}{c}\text { Initial Contact } \\
\text { Dose Rate } \\
(\mathrm{mR} / \mathrm{hr})\end{array}$} & \multirow{2}{*}{$\begin{array}{c}\text { Decayed } \\
\text { Contact Dose } \\
\text { Rate }(\mathrm{mR} / \mathrm{hr})^{1} \\
\end{array}$} \\
\hline & & & Isotope & Activity (Ci) & & Isotope & Activity (Ci) & & \\
\hline & & & & & & $\mathrm{Pa}-231$ & $4.83 \mathrm{E}-10$ & & \\
\hline & & & & & & $\mathrm{Pb}-211$ & $1.53 \mathrm{E}-10$ & & \\
\hline & & & Pm-147 & 7.29E-01 & & Pm-147 & $7.53 \mathrm{E}-04$ & & \\
\hline & & & & & & Po-211 & $4.66 \mathrm{E}-13$ & & \\
\hline & & & & & & Po-215 & $1.53 \mathrm{E}-10$ & & \\
\hline & & & $\mathrm{Pu}-239$ & $6.20 \mathrm{E}-03$ & & $\mathrm{Pu}-239$ & $6.20 \mathrm{E}-03$ & & \\
\hline & & & & & & Ra-223 & $1.55 \mathrm{E}-10$ & & \\
\hline & & & $\mathrm{Rh}-106$ & $9.36 \mathrm{E}-02$ & & Rh-106 & $1.59 \mathrm{E}-09$ & & \\
\hline & & & & & & Rn-219 & $1.53 \mathrm{E}-10$ & & \\
\hline & & & $\mathrm{Ru}-106$ & $9.36 \mathrm{E}-02$ & & $\mathrm{Ru}-106$ & $1.61 \mathrm{E}-09$ & & \\
\hline & & & Sb-125 & $5.20 \mathrm{E}-01$ & & Sb-125 & $7.76 \mathrm{E}-04$ & & \\
\hline & & & & & & Sm-147 & $1.79 \mathrm{E}-11$ & & \\
\hline & & & Sr-90 & $1.17 \mathrm{E}+01$ & & Sr-90 & $6.29 \mathrm{E}+00$ & & \\
\hline & & & $\mathrm{Te}-125 \mathrm{~m}$ & $2.16 \mathrm{E}-01$ & & $\mathrm{Te}-125 \mathrm{~m}$ & $1.88 \mathrm{E}-04$ & & \\
\hline & & & & & & Th-227 & $1.51 \mathrm{E}-10$ & & \\
\hline & & & & & & Th-231 & $8.69 \mathrm{E}-07$ & & \\
\hline & & & & & & Tl-207 & $1.52 \mathrm{E}-10$ & & \\
\hline & & & $\mathrm{U}-235$ & $8.80 \mathrm{E}-07$ & & U-235 & $8.80 \mathrm{E}-07$ & & \\
\hline & & & Y-90 & $1.17 \mathrm{E}+01$ & & Y-90 & $6.21 \mathrm{E}+00$ & & \\
\hline \multirow[t]{13}{*}{219} & S832835 & 1983 & & & 2009 & Ac-227 & $7.80 \mathrm{E}-09$ & $1000000+$ & $518,000 *$ \\
\hline & & & Ba-137m & $2.40 \mathrm{E}+01$ & & Ba-137m & $1.31 \mathrm{E}+01$ & & \\
\hline & & & & & & Bi-211 & 7.70E-09 & & \\
\hline & & & Cs-137 & $2.55 \mathrm{E}+01$ & & Cs-137 & $1.40 \mathrm{E}+01$ & & \\
\hline & & & Eu-155 & $4.78 \mathrm{E}-01$ & & Eu-155 & $1.26 \mathrm{E}-02$ & & \\
\hline & & & & & & Fr-223 & $1.06 \mathrm{E}-10$ & & \\
\hline & & & & & & $\mathrm{Pa}-231$ & $2.44 \mathrm{E}-08$ & & \\
\hline & & & & & & $\mathrm{Pb}-211$ & 7.71E-09 & & \\
\hline & & & Pm-147 & $1.46 \mathrm{E}+00$ & & Pm-147 & $1.52 \mathrm{E}-03$ & & \\
\hline & & & & & & Po-211 & $2.35 \mathrm{E}-11$ & & \\
\hline & & & & & & Po-215 & 7.71E-09 & & \\
\hline & & & $\mathrm{Pu}-239$ & $3.09 \mathrm{E}-01$ & & $\mathrm{Pu}-239$ & $3.09 \mathrm{E}-01$ & & \\
\hline & & & & & & $\mathrm{Ra}-223$ & 7.80E-09 & & \\
\hline
\end{tabular}

${ }^{1}$ Calculated decayed contact dose rate. Rounded to nearest $10 \mathrm{mR} / \mathrm{hr}$ for values to 1000 ; rounded to nearest $100 \mathrm{mR} / \mathrm{hr}$ for values $>1000$ to 10,000 ; rounded to nearest $1000 \mathrm{mR} / \mathrm{hr}$ for values $>10,000$. * Initial contact dose rate assumed to be $1,000,000 \mathrm{mR} / \mathrm{hr}$; **Initial contact dose rate assumed to be $1,010,000 \mathrm{mR} / \mathrm{hr}$.

$$
78 \text { of } 168
$$


Appendix A-4 - Initial and Decayed Radionuclide and Dose Data for Lined Shafts

\begin{tabular}{|c|c|c|c|c|c|c|c|c|c|}
\hline \multirow[b]{2}{*}{ Shaft Number } & \multirow[b]{2}{*}{ Package ID } & \multirow[b]{2}{*}{ Base Year } & \multicolumn{2}{|c|}{ Initial Isotopic Distribution } & \multirow[b]{2}{*}{ Target Year } & \multicolumn{2}{|c|}{ Decayed Isotopic Distribution } & \multirow{2}{*}{$\begin{array}{c}\text { Initial Contact } \\
\text { Dose Rate } \\
(\mathrm{mR} / \mathrm{hr})\end{array}$} & \multirow{2}{*}{$\begin{array}{c}\text { Decayed } \\
\text { Contact Dose } \\
\text { Rate }(\mathrm{mR} / \mathrm{hr})^{1} \\
\end{array}$} \\
\hline & & & Isotope & Activity (Ci) & & Isotope & Activity (Ci) & & \\
\hline & & & $\mathrm{Rh}-106$ & $1.87 \mathrm{E}-01$ & & Rh-106 & 3.19E-09 & & \\
\hline & & & & & & $\mathrm{Rn}-219$ & $7.70 \mathrm{E}-09$ & & \\
\hline & & & $\mathrm{Ru}-106$ & $1.87 \mathrm{E}-01$ & & Ru-106 & $3.22 \mathrm{E}-09$ & & \\
\hline & & & Sb-125 & $1.04 \mathrm{E}+00$ & & Sb-125 & $1.55 \mathrm{E}-03$ & & \\
\hline & & & & & & Sm-147 & $3.57 \mathrm{E}-11$ & & \\
\hline & & & Sr-90 & $2.33 \mathrm{E}+01$ & & Sr-90 & $1.26 \mathrm{E}+01$ & & \\
\hline & & & $\mathrm{Te}-125 \mathrm{~m}$ & 4.32E-01 & & $\mathrm{Te}-125 \mathrm{~m}$ & $3.76 \mathrm{E}-04$ & & \\
\hline & & & & & & Th-227 & 7.59E-09 & & \\
\hline & & & & & & Th-231 & 4.39E-05 & & \\
\hline & & & & & & Tl-207 & 7.67E-09 & & \\
\hline & & & $\mathrm{U}-235$ & 4.44E-05 & & $\mathrm{U}-235$ & 4.44E-05 & & \\
\hline & & & Y-90 & $2.33 \mathrm{E}+01$ & & Y-90 & $1.24 \mathrm{E}+01$ & & \\
\hline \multirow[t]{20}{*}{220} & S832836 & 1983 & & & 2009 & Ac-227 & $1.55 \mathrm{E}-10$ & $1000000+$ & $518,000 *$ \\
\hline & & & Ba-137m & $2.40 \mathrm{E}+01$ & & $\mathrm{Ba}-137 \mathrm{~m}$ & $1.31 \mathrm{E}+01$ & & \\
\hline & & & & & & Bi-211 & $1.53 \mathrm{E}-10$ & & \\
\hline & & & Cs-137 & $2.55 \mathrm{E}+01$ & & Cs-137 & $1.40 \mathrm{E}+01$ & & \\
\hline & & & Eu-155 & $4.78 \mathrm{E}-01$ & & Eu-155 & $1.26 \mathrm{E}-02$ & & \\
\hline & & & & & & Fr-223 & $2.11 \mathrm{E}-12$ & & \\
\hline & & & & & & $\mathrm{Pa}-231$ & $4.83 \mathrm{E}-10$ & & \\
\hline & & & & & & $\mathrm{Pb}-211$ & $1.53 \mathrm{E}-10$ & & \\
\hline & & & Pm-147 & $1.46 \mathrm{E}+00$ & & Pm-147 & $1.52 \mathrm{E}-03$ & & \\
\hline & & & & & & Po-211 & $4.66 \mathrm{E}-13$ & & \\
\hline & & & & & & Po-215 & $1.53 \mathrm{E}-10$ & & \\
\hline & & & $\mathrm{Pu}-239$ & $6.20 \mathrm{E}-03$ & & $\mathrm{Pu}-239$ & $6.20 \mathrm{E}-03$ & & \\
\hline & & & & & & Ra-223 & $1.55 \mathrm{E}-10$ & & \\
\hline & & & Rh-106 & $1.87 \mathrm{E}-01$ & & Rh-106 & $3.19 \mathrm{E}-09$ & & \\
\hline & & & & & & Rn-219 & $1.53 \mathrm{E}-10$ & & \\
\hline & & & Ru-106 & $1.87 \mathrm{E}-01$ & & Ru-106 & $3.22 \mathrm{E}-09$ & & \\
\hline & & & Sb-125 & $1.04 \mathrm{E}+00$ & & Sb-125 & $1.55 \mathrm{E}-03$ & & \\
\hline & & & & & & Sm-147 & $3.57 \mathrm{E}-11$ & & \\
\hline & & & Sr-90 & $2.33 \mathrm{E}+01$ & & Sr-90 & $1.26 \mathrm{E}+01$ & & \\
\hline & & & $\mathrm{Te}-125 \mathrm{~m}$ & 4.32E-01 & & $\mathrm{Te}-125 \mathrm{~m}$ & $3.76 \mathrm{E}-04$ & & \\
\hline
\end{tabular}

${ }^{1}$ Calculated decayed contact dose rate. Rounded to nearest $10 \mathrm{mR} / \mathrm{hr}$ for values to 1000 ; rounded to nearest $100 \mathrm{mR} / \mathrm{hr}$ for values $>1000$ to 10,000 ; rounded to nearest $1000 \mathrm{mR} / \mathrm{hr}$ for values $>10,000$. * Initial contact dose rate assumed to be $1,000,000 \mathrm{mR} / \mathrm{hr}$; **Initial contact dose rate assumed to be $1,010,000 \mathrm{mR} / \mathrm{hr}$.

$$
79 \text { of } 168
$$


Appendix A-4 - Initial and Decayed Radionuclide and Dose Data for Lined Shafts

\begin{tabular}{|c|c|c|c|c|c|c|c|c|c|}
\hline \multirow[b]{2}{*}{ Shaft Number } & \multirow[b]{2}{*}{ Package ID } & \multirow[b]{2}{*}{ Base Year } & \multicolumn{2}{|c|}{ Initial Isotopic Distribution } & \multirow[b]{2}{*}{ Target Year } & \multicolumn{2}{|c|}{ Decayed Isotopic Distribution } & \multirow{2}{*}{$\begin{array}{c}\text { Initial Contact } \\
\text { Dose Rate } \\
(\mathrm{mR} / \mathrm{hr})\end{array}$} & \multirow{2}{*}{$\begin{array}{c}\text { Decayed } \\
\text { Contact Dose } \\
\text { Rate }(\mathrm{mR} / \mathrm{hr})^{1} \\
\end{array}$} \\
\hline & & & Isotope & Activity (Ci) & & Isotope & Activity (Ci) & & \\
\hline & & & & & & Th-227 & $1.51 \mathrm{E}-10$ & & \\
\hline & & & & & & Th-231 & $8.69 \mathrm{E}-07$ & & \\
\hline & & & & & & Tl-207 & $1.52 \mathrm{E}-10$ & & \\
\hline & & & $\mathrm{U}-235$ & $8.80 \mathrm{E}-07$ & & $\mathrm{U}-235$ & $8.80 \mathrm{E}-07$ & & \\
\hline & & & $\mathrm{Y}-90$ & $2.33 \mathrm{E}+01$ & & $\mathrm{Y}-90$ & $1.24 \mathrm{E}+01$ & & \\
\hline \multirow[t]{25}{*}{220} & S832837 & 1983 & & & 2009 & Ac-227 & $1.55 \mathrm{E}-10$ & $1000000+$ & $518,000 *$ \\
\hline & & & Ba-137m & $2.40 \mathrm{E}+01$ & & $\mathrm{Ba}-137 \mathrm{~m}$ & $1.31 \mathrm{E}+01$ & & \\
\hline & & & & & & Bi-211 & $1.53 \mathrm{E}-10$ & & \\
\hline & & & Cs-137 & $2.55 \mathrm{E}+01$ & & Cs-137 & $1.40 \mathrm{E}+01$ & & \\
\hline & & & Eu-155 & $4.78 \mathrm{E}-01$ & & Eu-155 & $1.26 \mathrm{E}-02$ & & \\
\hline & & & & & & Fr-223 & $2.11 \mathrm{E}-12$ & & \\
\hline & & & & & & $\mathrm{Pa}-231$ & 4.83E-10 & & \\
\hline & & & & & & $\mathrm{Pb}-211$ & $1.53 \mathrm{E}-10$ & & \\
\hline & & & Pm-147 & $1.46 \mathrm{E}+00$ & & Pm-147 & $1.52 \mathrm{E}-03$ & & \\
\hline & & & & & & Po-211 & $4.66 \mathrm{E}-13$ & & \\
\hline & & & & & & Po-215 & $1.53 \mathrm{E}-10$ & & \\
\hline & & & $\mathrm{Pu}-239$ & $6.82 \mathrm{E}-03$ & & $\mathrm{Pu}-239$ & $6.81 \mathrm{E}-03$ & & \\
\hline & & & & & & Ra-223 & $1.55 \mathrm{E}-10$ & & \\
\hline & & & Rh-106 & $1.87 \mathrm{E}-01$ & & Rh-106 & $3.19 \mathrm{E}-09$ & & \\
\hline & & & & & & Rn-219 & $1.53 \mathrm{E}-10$ & & \\
\hline & & & Ru-106 & $1.87 \mathrm{E}-01$ & & Ru-106 & $3.22 \mathrm{E}-09$ & & \\
\hline & & & Sb-125 & $1.04 \mathrm{E}+00$ & & Sb-125 & $1.55 \mathrm{E}-03$ & & \\
\hline & & & & & & Sm-147 & $3.57 \mathrm{E}-11$ & & \\
\hline & & & Sr-90 & $2.33 \mathrm{E}+01$ & & Sr-90 & $1.26 \mathrm{E}+01$ & & \\
\hline & & & $\mathrm{Te}-125 \mathrm{~m}$ & $4.32 \mathrm{E}-01$ & & $\mathrm{Te}-125 \mathrm{~m}$ & $3.76 \mathrm{E}-04$ & & \\
\hline & & & & & & Th-227 & $1.51 \mathrm{E}-10$ & & \\
\hline & & & & & & Th-231 & 8.69E-07 & & \\
\hline & & & & & & Tl-207 & $1.52 \mathrm{E}-10$ & & \\
\hline & & & U-235 & $8.80 \mathrm{E}-07$ & & U-235 & 8.80E-07 & & \\
\hline & & & Y-90 & $2.33 \mathrm{E}+01$ & & Y-90 & $1.24 \mathrm{E}+01$ & & \\
\hline \multirow[t]{2}{*}{220} & S832838 & 1983 & & & 2009 & Ac-227 & $1.55 \mathrm{E}-10$ & 100,000 & 52,000 \\
\hline & & & $\mathrm{Ba}-137 \mathrm{~m}$ & 4.79E-01 & & Ba-137m & $2.62 \mathrm{E}-01$ & & \\
\hline
\end{tabular}

${ }^{1}$ Calculated decayed contact dose rate. Rounded to nearest $10 \mathrm{mR} / \mathrm{hr}$ for values to 1000 ; rounded to nearest $100 \mathrm{mR} / \mathrm{hr}$ for values $>1000$ to 10,000 ; rounded to nearest $1000 \mathrm{mR} / \mathrm{hr}$ for values $>10,000$. * Initial contact dose rate assumed to be $1,000,000 \mathrm{mR} / \mathrm{hr}$; **Initial contact dose rate assumed to be $1,010,000 \mathrm{mR} / \mathrm{hr}$.

$$
80 \text { of } 168
$$


Appendix A-4 - Initial and Decayed Radionuclide and Dose Data for Lined Shafts

\begin{tabular}{|c|c|c|c|c|c|c|c|c|c|}
\hline \multirow[b]{2}{*}{ Shaft Number } & \multirow[b]{2}{*}{ Package ID } & \multirow[b]{2}{*}{ Base Year } & \multicolumn{2}{|c|}{ Initial Isotopic Distribution } & \multirow[b]{2}{*}{ Target Year } & \multicolumn{2}{|c|}{ Decayed Isotopic Distribution } & \multirow{2}{*}{$\begin{array}{c}\text { Initial Contact } \\
\text { Dose Rate } \\
(\mathrm{mR} / \mathrm{hr})\end{array}$} & \multirow{2}{*}{$\begin{array}{c}\text { Decayed } \\
\text { Contact Dose } \\
\text { Rate }(\mathrm{mR} / \mathrm{hr})^{1}\end{array}$} \\
\hline & & & Isotope & Activity (Ci) & & Isotope & Activity (Ci) & & \\
\hline & & & & & & $\mathrm{Bi}-211$ & $1.53 \mathrm{E}-10$ & & \\
\hline & & & Cs-137 & $5.11 \mathrm{E}-01$ & & Cs-137 & $2.80 \mathrm{E}-01$ & & \\
\hline & & & Eu-155 & $9.55 \mathrm{E}-03$ & & $\mathrm{Eu}-155$ & $2.52 \mathrm{E}-04$ & & \\
\hline & & & & & & Fr-223 & $2.11 \mathrm{E}-12$ & & \\
\hline & & & & & & $\mathrm{Pa}-231$ & $4.83 \mathrm{E}-10$ & & \\
\hline & & & & & & $\mathrm{Pb}-211$ & $1.53 \mathrm{E}-10$ & & \\
\hline & & & Pm-147 & $2.92 \mathrm{E}-02$ & & Pm-147 & $3.02 \mathrm{E}-05$ & & \\
\hline & & & & & & Po-211 & $4.66 \mathrm{E}-13$ & & \\
\hline & & & & & & Po-215 & $1.53 \mathrm{E}-10$ & & \\
\hline & & & $\mathrm{Pu}-239$ & $6.20 \mathrm{E}-03$ & & $\mathrm{Pu}-239$ & $6.20 \mathrm{E}-03$ & & \\
\hline & & & & & & $\mathrm{Ra}-223$ & $1.55 \mathrm{E}-10$ & & \\
\hline & & & Rh-106 & $3.74 \mathrm{E}-03$ & & Rh-106 & $6.37 \mathrm{E}-11$ & & \\
\hline & & & & & & Rn-219 & $1.53 \mathrm{E}-10$ & & \\
\hline & & & Ru-106 & $3.74 \mathrm{E}-03$ & & $\mathrm{Ru}-106$ & $6.44 \mathrm{E}-11$ & & \\
\hline & & & Sb-125 & $2.08 \mathrm{E}-02$ & & Sb-125 & $3.12 \mathrm{E}-05$ & & \\
\hline & & & & & & Sm-147 & $7.15 \mathrm{E}-13$ & & \\
\hline & & & Sr-90 & 4.67E-01 & & Sr-90 & $2.51 \mathrm{E}-01$ & & \\
\hline & & & $\mathrm{Te}-125 \mathrm{~m}$ & $8.63 \mathrm{E}-03$ & & $\mathrm{Te}-125 \mathrm{~m}$ & 7.55E-06 & & \\
\hline & & & & & & Th-227 & $1.51 \mathrm{E}-10$ & & \\
\hline & & & & & & Th-231 & 8.69E-07 & & \\
\hline & & & & & & Tl-207 & $1.52 \mathrm{E}-10$ & & \\
\hline & & & U-235 & $8.80 \mathrm{E}-07$ & & U-235 & $8.80 \mathrm{E}-07$ & & \\
\hline & & & $\mathrm{Y}-90$ & $4.66 \mathrm{E}-01$ & & Y-90 & $2.49 \mathrm{E}-01$ & & \\
\hline \multirow[t]{9}{*}{220} & S832839 & 1983 & & & 2009 & Ac- 227 & $1.55 \mathrm{E}-10$ & 200,000 & 104,000 \\
\hline & & & Ba-137m & $1.92 \mathrm{E}+00$ & & Ba-137m & $1.05 \mathrm{E}+00$ & & \\
\hline & & & & & & $\mathrm{Bi}-211$ & $1.53 \mathrm{E}-10$ & & \\
\hline & & & Cs-137 & $2.04 \mathrm{E}+00$ & & Cs-137 & $1.12 \mathrm{E}+00$ & & \\
\hline & & & Eu-155 & $3.82 \mathrm{E}-02$ & & Eu-155 & $1.01 \mathrm{E}-03$ & & \\
\hline & & & & & & Fr-223 & $2.11 \mathrm{E}-12$ & & \\
\hline & & & & & & $\mathrm{Pa}-231$ & $4.83 \mathrm{E}-10$ & & \\
\hline & & & & & & $\mathrm{Pb}-211$ & $1.53 \mathrm{E}-10$ & & \\
\hline & & & Pm-147 & $1.17 \mathrm{E}-01$ & & Pm-147 & $1.21 \mathrm{E}-04$ & & \\
\hline
\end{tabular}

${ }^{1}$ Calculated decayed contact dose rate. Rounded to nearest $10 \mathrm{mR} / \mathrm{hr}$ for values to 1000 ; rounded to nearest $100 \mathrm{mR} / \mathrm{hr}$ for values $>1000$ to 10,000 ; rounded to nearest $1000 \mathrm{mR} / \mathrm{hr}$ for values $>10,000$. * Initial contact dose rate assumed to be $1,000,000 \mathrm{mR} / \mathrm{hr}$; **Initial contact dose rate assumed to be $1,010,000 \mathrm{mR} / \mathrm{hr}$.

$$
81 \text { of } 168
$$


Appendix A-4 - Initial and Decayed Radionuclide and Dose Data for Lined Shafts

\begin{tabular}{|c|c|c|c|c|c|c|c|c|c|}
\hline \multirow[b]{2}{*}{ Shaft Number } & \multirow[b]{2}{*}{ Package ID } & \multirow[b]{2}{*}{ Base Year } & \multicolumn{2}{|c|}{ Initial Isotopic Distribution } & \multirow[b]{2}{*}{ Target Year } & \multicolumn{2}{|c|}{ Decayed Isotopic Distribution } & \multirow{2}{*}{$\begin{array}{c}\text { Initial Contact } \\
\text { Dose Rate } \\
(\mathrm{mR} / \mathrm{hr})\end{array}$} & \multirow{2}{*}{$\begin{array}{c}\text { Decayed } \\
\text { Contact Dose } \\
\text { Rate }(\mathrm{mR} / \mathrm{hr})^{1}\end{array}$} \\
\hline & & & Isotope & Activity (Ci) & & Isotope & Activity (Ci) & & \\
\hline & & & & & & Po-211 & $4.66 \mathrm{E}-13$ & & \\
\hline & & & & & & Po-215 & $1.53 \mathrm{E}-10$ & & \\
\hline & & & $\mathrm{Pu}-239$ & $6.20 \mathrm{E}-03$ & & $\mathrm{Pu}-239$ & $6.20 \mathrm{E}-03$ & & \\
\hline & & & & & & $\mathrm{Ra}-223$ & $1.55 \mathrm{E}-10$ & & \\
\hline & & & Rh-106 & $1.50 \mathrm{E}-02$ & & Rh-106 & $2.55 \mathrm{E}-10$ & & \\
\hline & & & & & & Rn-219 & $1.53 \mathrm{E}-10$ & & \\
\hline & & & $\mathrm{Ru}-106$ & $1.50 \mathrm{E}-02$ & & $\mathrm{Ru}-106$ & $2.58 \mathrm{E}-10$ & & \\
\hline & & & Sb-125 & 8.32E-02 & & Sb-125 & $1.25 \mathrm{E}-04$ & & \\
\hline & & & & & & Sm-147 & $2.86 \mathrm{E}-12$ & & \\
\hline & & & Sr-90 & $1.87 \mathrm{E}+00$ & & Sr-90 & $1.01 \mathrm{E}+00$ & & \\
\hline & & & $\mathrm{Te}-125 \mathrm{~m}$ & $3.45 \mathrm{E}-02$ & & $\mathrm{Te}-125 \mathrm{~m}$ & $3.02 \mathrm{E}-05$ & & \\
\hline & & & & & & Th-227 & $1.51 \mathrm{E}-10$ & & \\
\hline & & & & & & Th-231 & 8.69E-07 & & \\
\hline & & & & & & Tl-207 & $1.52 \mathrm{E}-10$ & & \\
\hline & & & $\mathrm{U}-235$ & $8.80 \mathrm{E}-07$ & & $\mathrm{U}-235$ & $8.80 \mathrm{E}-07$ & & \\
\hline & & & Y-90 & $1.87 \mathrm{E}+00$ & & Y-90 & 9.94E-01 & & \\
\hline \multirow[t]{16}{*}{220} & S832840 & 1983 & & & 2009 & Ac- 227 & $1.55 \mathrm{E}-10$ & $1000000+$ & $518,000 *$ \\
\hline & & & Ba-137m & $4.79 \mathrm{E}+01$ & & $\mathrm{Ba}-137 \mathrm{~m}$ & $2.62 \mathrm{E}+01$ & & \\
\hline & & & & & & $\mathrm{Bi}-211$ & $1.53 \mathrm{E}-10$ & & \\
\hline & & & Cs-137 & $5.11 \mathrm{E}+01$ & & Cs-137 & $2.80 \mathrm{E}+01$ & & \\
\hline & & & Eu-155 & $9.55 \mathrm{E}-01$ & & Eu-155 & $2.52 \mathrm{E}-02$ & & \\
\hline & & & & & & Fr-223 & $2.11 \mathrm{E}-12$ & & \\
\hline & & & & & & $\mathrm{Pa}-231$ & $4.83 \mathrm{E}-10$ & & \\
\hline & & & & & & $\mathrm{Pb}-211$ & $1.53 \mathrm{E}-10$ & & \\
\hline & & & Pm-147 & $2.92 \mathrm{E}+00$ & & Pm-147 & $3.01 \mathrm{E}-03$ & & \\
\hline & & & & & & Po-211 & $4.66 \mathrm{E}-13$ & & \\
\hline & & & & & & Po-215 & $1.53 \mathrm{E}-10$ & & \\
\hline & & & $\mathrm{Pu}-239$ & $6.20 \mathrm{E}-03$ & & Pu-239 & $6.20 \mathrm{E}-03$ & & \\
\hline & & & & & & Ra-223 & $1.55 \mathrm{E}-10$ & & \\
\hline & & & Rh-106 & $3.74 \mathrm{E}-01$ & & Rh-106 & 6.37E-09 & & \\
\hline & & & & & & Rn-219 & $1.53 \mathrm{E}-10$ & & \\
\hline & & & $\mathrm{Ru}-106$ & $3.74 \mathrm{E}-01$ & & $\mathrm{Ru}-106$ & $6.44 \mathrm{E}-09$ & & \\
\hline
\end{tabular}

${ }^{1}$ Calculated decayed contact dose rate. Rounded to nearest $10 \mathrm{mR} / \mathrm{hr}$ for values to 1000 ; rounded to nearest $100 \mathrm{mR} / \mathrm{hr}$ for values $>1000$ to 10,000 ; rounded to nearest $1000 \mathrm{mR} / \mathrm{hr}$ for values $>10,000$. * Initial contact dose rate assumed to be $1,000,000 \mathrm{mR} / \mathrm{hr}$; **Initial contact dose rate assumed to be $1,010,000 \mathrm{mR} / \mathrm{hr}$.

$$
82 \text { of } 168
$$


Appendix A-4 - Initial and Decayed Radionuclide and Dose Data for Lined Shafts

\begin{tabular}{|c|c|c|c|c|c|c|c|c|c|}
\hline \multirow[b]{2}{*}{ Shaft Number } & \multirow[b]{2}{*}{ Package ID } & \multirow[b]{2}{*}{ Base Year } & \multicolumn{2}{|c|}{ Initial Isotopic Distribution } & \multirow[b]{2}{*}{ Target Year } & \multicolumn{2}{|c|}{ Decayed Isotopic Distribution } & \multirow{2}{*}{$\begin{array}{c}\text { Initial Contact } \\
\text { Dose Rate } \\
(\mathrm{mR} / \mathrm{hr})\end{array}$} & \multirow{2}{*}{$\begin{array}{c}\text { Decayed } \\
\text { Contact Dose } \\
\text { Rate }(\mathrm{mR} / \mathrm{hr})^{1} \\
\end{array}$} \\
\hline & & & Isotope & Activity (Ci) & & Isotope & Activity (Ci) & & \\
\hline & & & Sb-125 & $2.08 \mathrm{E}+00$ & & $\mathrm{Sb}-125$ & $3.10 \mathrm{E}-03$ & & \\
\hline & & & & & & Sm-147 & $7.15 \mathrm{E}-11$ & & \\
\hline & & & Sr-90 & 4.67E+01 & & Sr-90 & $2.51 \mathrm{E}+01$ & & \\
\hline & & & $\mathrm{Te}-125 \mathrm{~m}$ & $8.63 \mathrm{E}-01$ & & $\mathrm{Te}-125 \mathrm{~m}$ & $7.52 \mathrm{E}-04$ & & \\
\hline & & & & & & Th-227 & $1.51 \mathrm{E}-10$ & & \\
\hline & & & & & & Th-231 & $8.69 \mathrm{E}-07$ & & \\
\hline & & & & & & T1-207 & $1.52 \mathrm{E}-10$ & & \\
\hline & & & $\mathrm{U}-235$ & $8.80 \mathrm{E}-07$ & & $\mathrm{U}-235$ & $8.80 \mathrm{E}-07$ & & \\
\hline & & & $\mathrm{Y}-90$ & $4.66 \mathrm{E}+01$ & & $\mathrm{Y}-90$ & $2.49 \mathrm{E}+01$ & & \\
\hline \multirow[t]{23}{*}{220} & S832841 & 1983 & & & 2009 & Ac-227 & $1.55 \mathrm{E}-10$ & $1000000+$ & $518,000 *$ \\
\hline & & & $\mathrm{Ba}-137 \mathrm{~m}$ & $1.20 \mathrm{E}+01$ & & $\mathrm{Ba}-137 \mathrm{~m}$ & $6.55 \mathrm{E}+00$ & & \\
\hline & & & & & & $\mathrm{Bi}-211$ & $1.53 \mathrm{E}-10$ & & \\
\hline & & & Cs-137 & $1.28 \mathrm{E}+01$ & & Cs-137 & $7.00 \mathrm{E}+00$ & & \\
\hline & & & Eu-155 & $2.39 \mathrm{E}-01$ & & Eu-155 & $6.31 \mathrm{E}-03$ & & \\
\hline & & & & & & Fr-223 & $2.11 \mathrm{E}-12$ & & \\
\hline & & & & & & $\mathrm{Pa}-231$ & $4.83 \mathrm{E}-10$ & & \\
\hline & & & & & & $\mathrm{Pb}-211$ & $1.53 \mathrm{E}-10$ & & \\
\hline & & & Pm-147 & 7.29E-01 & & Pm-147 & $7.53 \mathrm{E}-04$ & & \\
\hline & & & & & & Po-211 & $4.66 \mathrm{E}-13$ & & \\
\hline & & & & & & Po-215 & $1.53 \mathrm{E}-10$ & & \\
\hline & & & $\mathrm{Pu}-239$ & $6.20 \mathrm{E}-03$ & & Pu-239 & $6.20 \mathrm{E}-03$ & & \\
\hline & & & & & & Ra-223 & $1.55 \mathrm{E}-10$ & & \\
\hline & & & Rh-106 & $9.36 \mathrm{E}-02$ & & Rh-106 & $1.59 \mathrm{E}-09$ & & \\
\hline & & & & & & Rn-219 & $1.53 \mathrm{E}-10$ & & \\
\hline & & & $\mathrm{Ru}-106$ & $9.36 \mathrm{E}-02$ & & Ru-106 & $1.61 \mathrm{E}-09$ & & \\
\hline & & & Sb-125 & $5.20 \mathrm{E}-01$ & & Sb-125 & $7.76 \mathrm{E}-04$ & & \\
\hline & & & & & & Sm-147 & $1.79 \mathrm{E}-11$ & & \\
\hline & & & Sr-90 & $1.17 \mathrm{E}+01$ & & Sr-90 & $6.29 \mathrm{E}+00$ & & \\
\hline & & & $\mathrm{Te}-125 \mathrm{~m}$ & $2.16 \mathrm{E}-01$ & & $\mathrm{Te}-125 \mathrm{~m}$ & $1.88 \mathrm{E}-04$ & & \\
\hline & & & & & & Th-227 & $1.51 \mathrm{E}-10$ & & \\
\hline & & & & & & Th-231 & 8.69E-07 & & \\
\hline & & & & & & Tl-207 & $1.52 \mathrm{E}-10$ & & \\
\hline
\end{tabular}

${ }^{1}$ Calculated decayed contact dose rate. Rounded to nearest $10 \mathrm{mR} / \mathrm{hr}$ for values to 1000 ; rounded to nearest $100 \mathrm{mR} / \mathrm{hr}$ for values $>1000$ to 10,000 ; rounded to nearest $1000 \mathrm{mR} / \mathrm{hr}$ for values $>10,000$. * Initial contact dose rate assumed to be $1,000,000 \mathrm{mR} / \mathrm{hr}$; **Initial contact dose rate assumed to be $1,010,000 \mathrm{mR} / \mathrm{hr}$.

$$
83 \text { of } 168
$$


Appendix A-4 - Initial and Decayed Radionuclide and Dose Data for Lined Shafts

\begin{tabular}{|c|c|c|c|c|c|c|c|c|c|}
\hline \multirow[b]{2}{*}{ Shaft Number } & \multirow[b]{2}{*}{ Package ID } & \multirow[b]{2}{*}{ Base Year } & \multicolumn{2}{|c|}{ Initial Isotopic Distribution } & \multirow[b]{2}{*}{ Target Year } & \multicolumn{2}{|c|}{ Decayed Isotopic Distribution } & \multirow{2}{*}{$\begin{array}{c}\text { Initial Contact } \\
\text { Dose Rate } \\
(\mathrm{mR} / \mathrm{hr})\end{array}$} & \multirow{2}{*}{$\begin{array}{c}\text { Decayed } \\
\text { Contact Dose } \\
\text { Rate }(\mathrm{mR} / \mathrm{hr})^{1} \\
\end{array}$} \\
\hline & & & Isotope & Activity (Ci) & & Isotope & Activity (Ci) & & \\
\hline & & & U-235 & $8.80 \mathrm{E}-07$ & & U-235 & $8.80 \mathrm{E}-07$ & & \\
\hline & & & $\mathrm{Y}-90$ & $1.17 \mathrm{E}+01$ & & Y-90 & $6.21 \mathrm{E}+00$ & & \\
\hline \multirow[t]{25}{*}{221} & S832842 & 1983 & & & 2009 & Ac-227 & $1.55 \mathrm{E}-10$ & 400,000 & 207,000 \\
\hline & & & Ba-137m & $3.59 \mathrm{E}+00$ & & $\mathrm{Ba}-137 \mathrm{~m}$ & $1.96 \mathrm{E}+00$ & & \\
\hline & & & & & & $\mathrm{Bi}-211$ & $1.53 \mathrm{E}-10$ & & \\
\hline & & & Cs-137 & $3.83 \mathrm{E}+00$ & & Cs-137 & $2.10 \mathrm{E}+00$ & & \\
\hline & & & Eu-155 & $7.17 \mathrm{E}-02$ & & Eu-155 & $1.89 \mathrm{E}-03$ & & \\
\hline & & & & & & Fr-223 & $2.11 \mathrm{E}-12$ & & \\
\hline & & & & & & $\mathrm{Pa}-231$ & $4.83 \mathrm{E}-10$ & & \\
\hline & & & & & & $\mathrm{Pb}-211$ & $1.53 \mathrm{E}-10$ & & \\
\hline & & & Pm-147 & $2.19 \mathrm{E}-01$ & & Pm-147 & $2.27 \mathrm{E}-04$ & & \\
\hline & & & & & & Po-211 & $4.66 \mathrm{E}-13$ & & \\
\hline & & & & & & Po-215 & $1.53 \mathrm{E}-10$ & & \\
\hline & & & $\mathrm{Pu}-239$ & $6.20 \mathrm{E}-03$ & & $\mathrm{Pu}-239$ & $6.20 \mathrm{E}-03$ & & \\
\hline & & & & & & Ra-223 & $1.55 \mathrm{E}-10$ & & \\
\hline & & & $\mathrm{Rh}-106$ & $2.81 \mathrm{E}-02$ & & Rh-106 & $4.78 \mathrm{E}-10$ & & \\
\hline & & & & & & Rn-219 & $1.53 \mathrm{E}-10$ & & \\
\hline & & & Ru-106 & $2.81 \mathrm{E}-02$ & & Ru-106 & $4.83 \mathrm{E}-10$ & & \\
\hline & & & Sb-125 & $1.56 \mathrm{E}-01$ & & Sb-125 & $2.33 \mathrm{E}-04$ & & \\
\hline & & & & & & Sm-147 & $5.36 \mathrm{E}-12$ & & \\
\hline & & & Sr-90 & $3.50 \mathrm{E}+00$ & & Sr-90 & $1.89 \mathrm{E}+00$ & & \\
\hline & & & $\mathrm{Te}-125 \mathrm{~m}$ & $6.48 \mathrm{E}-02$ & & $\mathrm{Te}-125 \mathrm{~m}$ & $5.65 \mathrm{E}-05$ & & \\
\hline & & & & & & Th-227 & $1.51 \mathrm{E}-10$ & & \\
\hline & & & & & & Th-231 & 8.69E-07 & & \\
\hline & & & & & & Tl-207 & $1.52 \mathrm{E}-10$ & & \\
\hline & & & U-235 & $8.80 \mathrm{E}-07$ & & U-235 & $8.80 \mathrm{E}-07$ & & \\
\hline & & & Y-90 & $3.50 \mathrm{E}+00$ & & $\mathrm{Y}-90$ & $1.86 \mathrm{E}+00$ & & \\
\hline \multirow[t]{5}{*}{221} & S832843 & 1983 & & & 2009 & Ac- 227 & $1.55 \mathrm{E}-10$ & $1000000+$ & $518,000 *$ \\
\hline & & & $\mathrm{Ba}-137 \mathrm{~m}$ & $7.19 \mathrm{E}+00$ & & Ba-137m & $3.93 \mathrm{E}+00$ & & \\
\hline & & & & & & Bi-211 & $1.53 \mathrm{E}-10$ & & \\
\hline & & & Cs-137 & $7.66 \mathrm{E}+00$ & & Cs-137 & $4.20 \mathrm{E}+00$ & & \\
\hline & & & Eu-155 & $1.43 \mathrm{E}-01$ & & Eu-155 & $3.78 \mathrm{E}-03$ & & \\
\hline
\end{tabular}

${ }^{1}$ Calculated decayed contact dose rate. Rounded to nearest $10 \mathrm{mR} / \mathrm{hr}$ for values to 1000 ; rounded to nearest $100 \mathrm{mR} / \mathrm{hr}$ for values $>1000$ to 10,000 ; rounded to nearest $1000 \mathrm{mR} / \mathrm{hr}$ for values $>10,000$. * Initial contact dose rate assumed to be $1,000,000 \mathrm{mR} / \mathrm{hr}$; **Initial contact dose rate assumed to be $1,010,000 \mathrm{mR} / \mathrm{hr}$.

$$
84 \text { of } 168
$$


Appendix A-4 - Initial and Decayed Radionuclide and Dose Data for Lined Shafts

\begin{tabular}{|c|c|c|c|c|c|c|c|c|c|}
\hline \multirow[b]{2}{*}{ Shaft Number } & \multirow[b]{2}{*}{ Package ID } & \multirow[b]{2}{*}{ Base Year } & \multicolumn{2}{|c|}{ Initial Isotopic Distribution } & \multirow[b]{2}{*}{ Target Year } & \multicolumn{2}{|c|}{ Decayed Isotopic Distribution } & \multirow{2}{*}{$\begin{array}{c}\text { Initial Contact } \\
\text { Dose Rate } \\
(\mathrm{mR} / \mathrm{hr})\end{array}$} & \multirow{2}{*}{$\begin{array}{c}\text { Decayed } \\
\text { Contact Dose } \\
\text { Rate }(\mathrm{mR} / \mathrm{hr})^{1}\end{array}$} \\
\hline & & & Isotope & Activity (Ci) & & Isotope & Activity (Ci) & & \\
\hline & & & & & & Fr-223 & $2.11 \mathrm{E}-12$ & & \\
\hline & & & & & & $\mathrm{Pa}-231$ & $4.83 \mathrm{E}-10$ & & \\
\hline & & & & & & $\mathrm{Pb}-211$ & $1.53 \mathrm{E}-10$ & & \\
\hline & & & Pm-147 & 4.38E-01 & & Pm-147 & $4.55 \mathrm{E}-04$ & & \\
\hline & & & & & & Po-211 & $4.66 \mathrm{E}-13$ & & \\
\hline & & & & & & Po-215 & $1.53 \mathrm{E}-10$ & & \\
\hline & & & $\mathrm{Pu}-239$ & $6.20 \mathrm{E}-03$ & & $\mathrm{Pu}-239$ & $6.20 \mathrm{E}-03$ & & \\
\hline & & & & & & Ra-223 & $1.55 \mathrm{E}-10$ & & \\
\hline & & & Rh-106 & $5.62 \mathrm{E}-02$ & & Rh-106 & $9.56 \mathrm{E}-10$ & & \\
\hline & & & & & & $\mathrm{Rn}-219$ & $1.53 \mathrm{E}-10$ & & \\
\hline & & & $\mathrm{Ru}-106$ & $5.62 \mathrm{E}-02$ & & Ru-106 & $9.66 \mathrm{E}-10$ & & \\
\hline & & & $\mathrm{Sb}-125$ & $3.12 \mathrm{E}-01$ & & $\mathrm{Sb}-125$ & $4.66 \mathrm{E}-04$ & & \\
\hline & & & & & & Sm-147 & $1.07 \mathrm{E}-11$ & & \\
\hline & & & Sr-90 & $7.00 \mathrm{E}+00$ & & Sr-90 & $3.77 \mathrm{E}+00$ & & \\
\hline & & & $\mathrm{Te}-125 \mathrm{~m}$ & $1.30 \mathrm{E}-01$ & & $\mathrm{Te}-125 \mathrm{~m}$ & $1.13 \mathrm{E}-04$ & & \\
\hline & & & & & & Th-227 & $1.51 \mathrm{E}-10$ & & \\
\hline & & & & & & Th-231 & $8.69 \mathrm{E}-07$ & & \\
\hline & & & & & & Tl-207 & $1.52 \mathrm{E}-10$ & & \\
\hline & & & $\mathrm{U}-235$ & $8.80 \mathrm{E}-07$ & & U-235 & $8.80 \mathrm{E}-07$ & & \\
\hline & & & Y-90 & $6.99 \mathrm{E}+00$ & & $\mathrm{Y}-90$ & $3.73 \mathrm{E}+00$ & & \\
\hline \multirow[t]{12}{*}{221} & S832844 & 1983 & & & 2009 & Ac- 227 & $1.55 \mathrm{E}-10$ & 800,000 & 414,000 \\
\hline & & & $\mathrm{Ba}-137 \mathrm{~m}$ & $9.59 \mathrm{E}+00$ & & $\mathrm{Ba}-137 \mathrm{~m}$ & $5.24 \mathrm{E}+00$ & & \\
\hline & & & & & & Bi-211 & $1.53 \mathrm{E}-10$ & & \\
\hline & & & Cs-137 & $1.02 \mathrm{E}+01$ & & Cs-137 & $5.60 \mathrm{E}+00$ & & \\
\hline & & & Eu-155 & $1.91 \mathrm{E}-01$ & & Eu-155 & $5.05 \mathrm{E}-03$ & & \\
\hline & & & & & & Fr-223 & $2.11 \mathrm{E}-12$ & & \\
\hline & & & & & & $\mathrm{Pa}-231$ & $4.83 \mathrm{E}-10$ & & \\
\hline & & & & & & $\mathrm{Pb}-211$ & $1.53 \mathrm{E}-10$ & & \\
\hline & & & Pm-147 & $5.83 \mathrm{E}-01$ & & Pm-147 & $6.11 \mathrm{E}-04$ & & \\
\hline & & & & & & Po-211 & $4.66 \mathrm{E}-13$ & & \\
\hline & & & & & & Po-215 & $1.53 \mathrm{E}-10$ & & \\
\hline & & & $\mathrm{Pu}-239$ & $6.20 \mathrm{E}-03$ & & $\mathrm{Pu}-239$ & $6.20 \mathrm{E}-03$ & & \\
\hline
\end{tabular}

${ }^{1}$ Calculated decayed contact dose rate. Rounded to nearest $10 \mathrm{mR} / \mathrm{hr}$ for values to 1000 ; rounded to nearest $100 \mathrm{mR} / \mathrm{hr}$ for values $>1000$ to 10,000 ; rounded to nearest $1000 \mathrm{mR} / \mathrm{hr}$ for values $>10,000$. * Initial contact dose rate assumed to be $1,000,000 \mathrm{mR} / \mathrm{hr}$; **Initial contact dose rate assumed to be $1,010,000 \mathrm{mR} / \mathrm{hr}$.

$$
85 \text { of } 168
$$


Appendix A-4 - Initial and Decayed Radionuclide and Dose Data for Lined Shafts

\begin{tabular}{|c|c|c|c|c|c|c|c|c|c|}
\hline \multirow[b]{2}{*}{ Shaft Number } & \multirow[b]{2}{*}{ Package ID } & \multirow[b]{2}{*}{ Base Year } & \multicolumn{2}{|c|}{ Initial Isotopic Distribution } & \multirow[b]{2}{*}{ Target Year } & \multicolumn{2}{|c|}{ Decayed Isotopic Distribution } & \multirow{2}{*}{$\begin{array}{c}\text { Initial Contact } \\
\text { Dose Rate } \\
(\mathrm{mR} / \mathrm{hr})\end{array}$} & \multirow{2}{*}{$\begin{array}{c}\text { Decayed } \\
\text { Contact Dose } \\
\text { Rate }(\mathrm{mR} / \mathrm{hr})^{1}\end{array}$} \\
\hline & & & Isotope & Activity (Ci) & & Isotope & Activity (Ci) & & \\
\hline & & & & & & $\mathrm{Ra}-223$ & $1.55 \mathrm{E}-10$ & & \\
\hline & & & $\mathrm{Rh}-106$ & 7.49E-02 & & Rh-106 & $1.27 \mathrm{E}-09$ & & \\
\hline & & & & & & Rn-219 & $1.53 \mathrm{E}-10$ & & \\
\hline & & & $\mathrm{Ru}-106$ & 7.49E-02 & & $\mathrm{Ru}-106$ & $1.29 \mathrm{E}-09$ & & \\
\hline & & & Sb-125 & 4.16E-01 & & Sb-125 & $6.21 \mathrm{E}-04$ & & \\
\hline & & & & & & Sm-147 & $1.43 \mathrm{E}-11$ & & \\
\hline & & & Sr-90 & $9.34 \mathrm{E}+00$ & & Sr-90 & $5.03 \mathrm{E}+00$ & & \\
\hline & & & Te-125m & $1.73 \mathrm{E}-01$ & & Te- $125 \mathrm{~m}$ & $1.50 \mathrm{E}-04$ & & \\
\hline & & & & & & Th-227 & $1.51 \mathrm{E}-10$ & & \\
\hline & & & & & & Th-231 & 8.69E-07 & & \\
\hline & & & & & & Tl-207 & $1.52 \mathrm{E}-10$ & & \\
\hline & & & $\mathrm{U}-235$ & $8.80 \mathrm{E}-07$ & & $\mathrm{U}-235$ & $8.80 \mathrm{E}-07$ & & \\
\hline & & & Y-90 & $9.33 \mathrm{E}+00$ & & $Y-90$ & $4.97 \mathrm{E}+00$ & & \\
\hline \multirow[t]{19}{*}{221} & S832845 & 1983 & & & 2009 & Ac- 227 & $1.55 \mathrm{E}-10$ & 60,000 & 31,000 \\
\hline & & & Ba-137m & $3.59 \mathrm{E}-01$ & & Ba-137m & $1.96 \mathrm{E}-01$ & & \\
\hline & & & & & & Bi-211 & $1.53 \mathrm{E}-10$ & & \\
\hline & & & Cs-137 & 3.83E-01 & & Cs-137 & $2.10 \mathrm{E}-01$ & & \\
\hline & & & Eu-155 & 7.17E-03 & & Eu-155 & $1.89 \mathrm{E}-04$ & & \\
\hline & & & & & & Fr-223 & $2.11 \mathrm{E}-12$ & & \\
\hline & & & & & & $\mathrm{Pa}-231$ & $4.83 \mathrm{E}-10$ & & \\
\hline & & & & & & $\mathrm{Pb}-211$ & $1.53 \mathrm{E}-10$ & & \\
\hline & & & Pm-147 & 2.19E-02 & & Pm-147 & $2.27 \mathrm{E}-05$ & & \\
\hline & & & & & & Po-211 & $4.66 \mathrm{E}-13$ & & \\
\hline & & & & & & Po-215 & $1.53 \mathrm{E}-10$ & & \\
\hline & & & $\mathrm{Pu}-239$ & $6.20 \mathrm{E}-03$ & & $\mathrm{Pu}-239$ & $6.20 \mathrm{E}-03$ & & \\
\hline & & & & & & $\mathrm{Ra}-223$ & $1.55 \mathrm{E}-10$ & & \\
\hline & & & Rh-106 & $2.81 \mathrm{E}-03$ & & Rh-106 & $4.78 \mathrm{E}-11$ & & \\
\hline & & & & & & Rn-219 & $1.53 \mathrm{E}-10$ & & \\
\hline & & & $\mathrm{Ru}-106$ & $2.81 \mathrm{E}-03$ & & Ru-106 & $4.83 \mathrm{E}-11$ & & \\
\hline & & & Sb-125 & $1.56 \mathrm{E}-02$ & & Sb-125 & 2.34E-05 & & \\
\hline & & & & & & Sm-147 & $5.36 \mathrm{E}-13$ & & \\
\hline & & & Sr-90 & $3.50 \mathrm{E}-01$ & & Sr-90 & $1.89 \mathrm{E}-01$ & & \\
\hline
\end{tabular}

${ }^{1}$ Calculated decayed contact dose rate. Rounded to nearest $10 \mathrm{mR} / \mathrm{hr}$ for values to 1000 ; rounded to nearest $100 \mathrm{mR} / \mathrm{hr}$ for values $>1000$ to 10,000 ; rounded to nearest $1000 \mathrm{mR} / \mathrm{hr}$ for values $>10,000$. * Initial contact dose rate assumed to be $1,000,000 \mathrm{mR} / \mathrm{hr}$; **Initial contact dose rate assumed to be $1,010,000 \mathrm{mR} / \mathrm{hr}$. 
Appendix A-4 - Initial and Decayed Radionuclide and Dose Data for Lined Shafts

\begin{tabular}{|c|c|c|c|c|c|c|c|c|c|}
\hline \multirow[b]{2}{*}{ Shaft Number } & \multirow[b]{2}{*}{ Package ID } & \multirow[b]{2}{*}{ Base Year } & \multicolumn{2}{|c|}{ Initial Isotopic Distribution } & \multirow[b]{2}{*}{ Target Year } & \multicolumn{2}{|c|}{ Decayed Isotopic Distribution } & \multirow{2}{*}{$\begin{array}{c}\text { Initial Contact } \\
\text { Dose Rate } \\
(\mathrm{mR} / \mathrm{hr})\end{array}$} & \multirow{2}{*}{$\begin{array}{c}\text { Decayed } \\
\text { Contact Dose } \\
\text { Rate }(\mathrm{mR} / \mathrm{hr})^{1} \\
\end{array}$} \\
\hline & & & Isotope & Activity (Ci) & & Isotope & Activity (Ci) & & \\
\hline & & & $\mathrm{Te}-125 \mathrm{~m}$ & $6.48 \mathrm{E}-03$ & & Te-125m & $5.66 \mathrm{E}-06$ & & \\
\hline & & & & & & Th-227 & $1.51 \mathrm{E}-10$ & & \\
\hline & & & & & & Th-231 & $8.69 \mathrm{E}-07$ & & \\
\hline & & & & & & T1-207 & $1.52 \mathrm{E}-10$ & & \\
\hline & & & $\mathrm{U}-235$ & $8.80 \mathrm{E}-07$ & & $\mathrm{U}-235$ & $8.80 \mathrm{E}-07$ & & \\
\hline & & & $\mathrm{Y}-90$ & $3.50 \mathrm{E}-01$ & & $\mathrm{Y}-90$ & $1.86 \mathrm{E}-01$ & & \\
\hline \multirow[t]{25}{*}{221} & S832846 & 1983 & & & 2009 & Ac-227 & $1.55 \mathrm{E}-10$ & 200,000 & 104,000 \\
\hline & & & $\mathrm{Ba}-137 \mathrm{~m}$ & $1.44 \mathrm{E}+01$ & & Ba-137m & $7.85 \mathrm{E}+00$ & & \\
\hline & & & & & & $\mathrm{Bi}-211$ & $1.53 \mathrm{E}-10$ & & \\
\hline & & & Cs-137 & $1.53 \mathrm{E}+01$ & & Cs-137 & $8.40 \mathrm{E}+00$ & & \\
\hline & & & Eu-155 & $2.87 \mathrm{E}-01$ & & Eu-155 & $7.57 \mathrm{E}-03$ & & \\
\hline & & & & & & Fr-223 & $2.11 \mathrm{E}-12$ & & \\
\hline & & & & & & $\mathrm{Pa}-231$ & $4.83 \mathrm{E}-10$ & & \\
\hline & & & & & & $\mathrm{Pb}-211$ & $1.53 \mathrm{E}-10$ & & \\
\hline & & & Pm-147 & $8.75 \mathrm{E}-01$ & & Pm-147 & $9.15 \mathrm{E}-04$ & & \\
\hline & & & & & & Po-211 & $4.66 \mathrm{E}-13$ & & \\
\hline & & & & & & Po-215 & $1.53 \mathrm{E}-10$ & & \\
\hline & & & $\mathrm{Pu}-239$ & $6.20 \mathrm{E}-03$ & & $\mathrm{Pu}-239$ & $6.20 \mathrm{E}-03$ & & \\
\hline & & & & & & Ra-223 & $1.55 \mathrm{E}-10$ & & \\
\hline & & & Rh-106 & $1.12 \mathrm{E}-01$ & & Rh-106 & $1.91 \mathrm{E}-09$ & & \\
\hline & & & & & & Rn-219 & $1.53 \mathrm{E}-10$ & & \\
\hline & & & Ru-106 & $1.12 \mathrm{E}-01$ & & $\mathrm{Ru}-106$ & $1.93 \mathrm{E}-09$ & & \\
\hline & & & Sb-125 & $6.24 \mathrm{E}-01$ & & Sb-125 & 9.33E-04 & & \\
\hline & & & & & & Sm-147 & $2.14 \mathrm{E}-11$ & & \\
\hline & & & Sr-90 & $1.40 \mathrm{E}+01$ & & Sr-90 & $7.54 \mathrm{E}+00$ & & \\
\hline & & & Te-125m & $2.59 \mathrm{E}-01$ & & $\mathrm{Te}-125 \mathrm{~m}$ & $2.26 \mathrm{E}-04$ & & \\
\hline & & & & & & Th-227 & $1.51 \mathrm{E}-10$ & & \\
\hline & & & & & & Th-231 & $8.69 \mathrm{E}-07$ & & \\
\hline & & & & & & T1-207 & $1.52 \mathrm{E}-10$ & & \\
\hline & & & U-235 & $8.80 \mathrm{E}-07$ & & U-235 & $8.80 \mathrm{E}-07$ & & \\
\hline & & & $\mathrm{Y}-90$ & $1.40 \mathrm{E}+01$ & & Y-90 & $7.46 \mathrm{E}+00$ & & \\
\hline 221 & S832847 & 1983 & & & 2009 & Ac- 227 & $1.55 \mathrm{E}-10$ & 200,000 & 104,000 \\
\hline
\end{tabular}

${ }^{1}$ Calculated decayed contact dose rate. Rounded to nearest $10 \mathrm{mR} / \mathrm{hr}$ for values to 1000 ; rounded to nearest $100 \mathrm{mR} / \mathrm{hr}$ for values $>1000$ to 10,000 ; rounded to nearest $1000 \mathrm{mR} / \mathrm{hr}$ for values $>10,000$. * Initial contact dose rate assumed to be $1,000,000 \mathrm{mR} / \mathrm{hr}$; **Initial contact dose rate assumed to be $1,010,000 \mathrm{mR} / \mathrm{hr}$.

$$
87 \text { of } 168
$$


Appendix A-4 - Initial and Decayed Radionuclide and Dose Data for Lined Shafts

\begin{tabular}{|c|c|c|c|c|c|c|c|c|c|}
\hline \multirow[b]{2}{*}{ Shaft Number } & \multirow[b]{2}{*}{ Package ID } & \multirow[b]{2}{*}{ Base Year } & \multicolumn{2}{|c|}{ Initial Isotopic Distribution } & \multirow[b]{2}{*}{ Target Year } & \multicolumn{2}{|c|}{ Decayed Isotopic Distribution } & \multirow{2}{*}{$\begin{array}{c}\text { Initial Contact } \\
\text { Dose Rate } \\
(\mathrm{mR} / \mathrm{hr})\end{array}$} & \multirow{2}{*}{$\begin{array}{c}\text { Decayed } \\
\text { Contact Dose } \\
\text { Rate }(\mathrm{mR} / \mathrm{hr})^{1} \\
\end{array}$} \\
\hline & & & Isotope & Activity (Ci) & & Isotope & Activity (Ci) & & \\
\hline & & & Ba-137m & $7.19 \mathrm{E}+00$ & & Ba-137m & $3.93 \mathrm{E}+00$ & & \\
\hline & & & & & & Bi-211 & $1.53 \mathrm{E}-10$ & & \\
\hline & & & Cs-137 & $7.66 \mathrm{E}+00$ & & Cs-137 & $4.20 \mathrm{E}+00$ & & \\
\hline & & & $\mathrm{Eu}-155$ & $1.43 \mathrm{E}-01$ & & $\mathrm{Eu}-155$ & $3.78 \mathrm{E}-03$ & & \\
\hline & & & & & & Fr-223 & $2.11 \mathrm{E}-12$ & & \\
\hline & & & & & & $\mathrm{Pa}-231$ & $4.83 \mathrm{E}-10$ & & \\
\hline & & & & & & $\mathrm{Pb}-211$ & $1.53 \mathrm{E}-10$ & & \\
\hline & & & Pm-147 & 4.38E-01 & & Pm-147 & $4.55 \mathrm{E}-04$ & & \\
\hline & & & & & & Po-211 & $4.66 \mathrm{E}-13$ & & \\
\hline & & & & & & Po-215 & $1.53 \mathrm{E}-10$ & & \\
\hline & & & $\mathrm{Pu}-239$ & $6.20 \mathrm{E}-03$ & & $\mathrm{Pu}-239$ & $6.20 \mathrm{E}-03$ & & \\
\hline & & & & & & $\mathrm{Ra}-223$ & $1.55 \mathrm{E}-10$ & & \\
\hline & & & Rh-106 & $5.62 \mathrm{E}-02$ & & Rh-106 & $9.56 \mathrm{E}-10$ & & \\
\hline & & & & & & $\mathrm{Rn}-219$ & $1.53 \mathrm{E}-10$ & & \\
\hline & & & $\mathrm{Ru}-106$ & $5.62 \mathrm{E}-02$ & & $\mathrm{Ru}-106$ & $9.66 \mathrm{E}-10$ & & \\
\hline & & & $\mathrm{Sb}-125$ & $3.12 \mathrm{E}-01$ & & $\mathrm{Sb}-125$ & $4.66 \mathrm{E}-04$ & & \\
\hline & & & & & & Sm-147 & $1.07 \mathrm{E}-11$ & & \\
\hline & & & Sr-90 & $7.00 \mathrm{E}+00$ & & Sr-90 & $3.77 \mathrm{E}+00$ & & \\
\hline & & & $\mathrm{Te}-125 \mathrm{~m}$ & $1.30 \mathrm{E}-01$ & & $\mathrm{Te}-125 \mathrm{~m}$ & $1.13 \mathrm{E}-04$ & & \\
\hline & & & & & & Th-227 & $1.51 \mathrm{E}-10$ & & \\
\hline & & & & & & Th-231 & 8.69E-07 & & \\
\hline & & & & & & Tl-207 & $1.52 \mathrm{E}-10$ & & \\
\hline & & & U-235 & $8.80 \mathrm{E}-07$ & & U-235 & $8.80 \mathrm{E}-07$ & & \\
\hline & & & Y-90 & $6.99 \mathrm{E}+00$ & & Y-90 & $3.73 \mathrm{E}+00$ & & \\
\hline \multirow[t]{8}{*}{222} & S830716 & 1983 & & & 2009 & Ac- 227 & $8.70 \mathrm{E}-10$ & 900,000 & 466,000 \\
\hline & & & Ba-137m & $4.79 \mathrm{E}+00$ & & $\mathrm{Ba}-137 \mathrm{~m}$ & $2.62 \mathrm{E}+00$ & & \\
\hline & & & & & & Bi-211 & $8.59 \mathrm{E}-10$ & & \\
\hline & & & Cs-137 & $5.11 \mathrm{E}+00$ & & Cs-137 & $2.80 \mathrm{E}+00$ & & \\
\hline & & & Eu-155 & $9.55 \mathrm{E}-02$ & & Eu-155 & $2.52 \mathrm{E}-03$ & & \\
\hline & & & & & & Fr-223 & $1.19 \mathrm{E}-11$ & & \\
\hline & & & & & & $\mathrm{Pa}-231$ & $2.72 \mathrm{E}-09$ & & \\
\hline & & & & & & $\mathrm{Pb}-211$ & $8.60 \mathrm{E}-10$ & & \\
\hline
\end{tabular}

${ }^{1}$ Calculated decayed contact dose rate. Rounded to nearest $10 \mathrm{mR} / \mathrm{hr}$ for values to 1000 ; rounded to nearest $100 \mathrm{mR} / \mathrm{hr}$ for values $>1000$ to 10,000 ; rounded to nearest $1000 \mathrm{mR} / \mathrm{hr}$ for values $>10,000$. * Initial contact dose rate assumed to be $1,000,000 \mathrm{mR} / \mathrm{hr}$; **Initial contact dose rate assumed to be $1,010,000 \mathrm{mR} / \mathrm{hr}$. 
Appendix A-4 - Initial and Decayed Radionuclide and Dose Data for Lined Shafts

\begin{tabular}{|c|c|c|c|c|c|c|c|c|c|}
\hline \multirow[b]{2}{*}{ Shaft Number } & \multirow[b]{2}{*}{ Package ID } & \multirow[b]{2}{*}{ Base Year } & \multicolumn{2}{|c|}{ Initial Isotopic Distribution } & \multirow[b]{2}{*}{ Target Year } & \multicolumn{2}{|c|}{ Decayed Isotopic Distribution } & \multirow{2}{*}{$\begin{array}{c}\text { Initial Contact } \\
\text { Dose Rate } \\
(\mathrm{mR} / \mathrm{hr})\end{array}$} & \multirow{2}{*}{$\begin{array}{c}\text { Decayed } \\
\text { Contact Dose } \\
\text { Rate }(\mathrm{mR} / \mathrm{hr})^{1} \\
\end{array}$} \\
\hline & & & Isotope & Activity (Ci) & & Isotope & Activity (Ci) & & \\
\hline & & & Pm-147 & $2.92 \mathrm{E}-01$ & & Pm-147 & $3.06 \mathrm{E}-04$ & & \\
\hline & & & & & & Po-211 & $2.62 \mathrm{E}-12$ & & \\
\hline & & & & & & Po-215 & $8.60 \mathrm{E}-10$ & & \\
\hline & & & $\mathrm{Pu}-239$ & $3.50 \mathrm{E}-02$ & & $\mathrm{Pu}-239$ & $3.49 \mathrm{E}-02$ & & \\
\hline & & & & & & $\mathrm{Ra}-223$ & $8.69 \mathrm{E}-10$ & & \\
\hline & & & Rh-106 & $3.74 \mathrm{E}-02$ & & Rh-106 & $6.37 \mathrm{E}-10$ & & \\
\hline & & & & & & $\mathrm{Rn}-219$ & $8.59 \mathrm{E}-10$ & & \\
\hline & & & $\mathrm{Ru}-106$ & $3.74 \mathrm{E}-02$ & & $\mathrm{Ru}-106$ & $6.44 \mathrm{E}-10$ & & \\
\hline & & & $\mathrm{Sb}-125$ & $2.08 \mathrm{E}-01$ & & $\mathrm{Sb}-125$ & $3.10 \mathrm{E}-04$ & & \\
\hline & & & & & & Sm-147 & $7.15 \mathrm{E}-12$ & & \\
\hline & & & Sr-90 & 4.67E+00 & & Sr-90 & $2.51 \mathrm{E}+00$ & & \\
\hline & & & $\mathrm{Te}-125 \mathrm{~m}$ & $8.63 \mathrm{E}-02$ & & $\mathrm{Te}-125 \mathrm{~m}$ & $7.52 \mathrm{E}-05$ & & \\
\hline & & & & & & Th-227 & $8.47 \mathrm{E}-10$ & & \\
\hline & & & & & & Th-231 & 4.89E-06 & & \\
\hline & & & & & & Tl-207 & $8.55 \mathrm{E}-10$ & & \\
\hline & & & U-235 & $4.95 \mathrm{E}-06$ & & U-235 & $4.95 \mathrm{E}-06$ & & \\
\hline & & & Y-90 & $4.66 \mathrm{E}+00$ & & Y-90 & $2.49 \mathrm{E}+00$ & & \\
\hline \multirow[t]{15}{*}{222} & S830717 & 1983 & & & 2009 & Ac-227 & $8.70 \mathrm{E}-10$ & $1000000+$ & $518,000 *$ \\
\hline & & & $\mathrm{Ba}-137 \mathrm{~m}$ & $4.79 \mathrm{E}+01$ & & $\mathrm{Ba}-137 \mathrm{~m}$ & $2.62 \mathrm{E}+01$ & & \\
\hline & & & & & & Bi-211 & $8.59 \mathrm{E}-10$ & & \\
\hline & & & Cs-137 & $5.11 \mathrm{E}+01$ & & Cs-137 & $2.80 \mathrm{E}+01$ & & \\
\hline & & & Eu-155 & $9.55 \mathrm{E}-01$ & & Eu-155 & $2.52 \mathrm{E}-02$ & & \\
\hline & & & & & & Fr-223 & $1.19 \mathrm{E}-11$ & & \\
\hline & & & & & & $\mathrm{Pa}-231$ & $2.72 \mathrm{E}-09$ & & \\
\hline & & & & & & $\mathrm{Pb}-211$ & $8.60 \mathrm{E}-10$ & & \\
\hline & & & Pm-147 & $2.92 \mathrm{E}+00$ & & Pm-147 & $3.01 \mathrm{E}-03$ & & \\
\hline & & & & & & Po-211 & $2.62 \mathrm{E}-12$ & & \\
\hline & & & & & & Po-215 & $8.60 \mathrm{E}-10$ & & \\
\hline & & & Pu-239 & $3.50 \mathrm{E}-02$ & & $\mathrm{Pu}-239$ & $3.49 \mathrm{E}-02$ & & \\
\hline & & & & & & $\mathrm{Ra}-223$ & 8.69E-10 & & \\
\hline & & & Rh-106 & $3.74 \mathrm{E}-01$ & & Rh-106 & 6.37E-09 & & \\
\hline & & & & & & $\mathrm{Rn}-219$ & $8.59 \mathrm{E}-10$ & & \\
\hline
\end{tabular}

${ }^{1}$ Calculated decayed contact dose rate. Rounded to nearest $10 \mathrm{mR} / \mathrm{hr}$ for values to 1000 ; rounded to nearest $100 \mathrm{mR} / \mathrm{hr}$ for values $>1000$ to 10,000 ; rounded to nearest $1000 \mathrm{mR} / \mathrm{hr}$ for values $>10,000$. * Initial contact dose rate assumed to be $1,000,000 \mathrm{mR} / \mathrm{hr}$; **Initial contact dose rate assumed to be $1,010,000 \mathrm{mR} / \mathrm{hr}$. 
Appendix A-4 - Initial and Decayed Radionuclide and Dose Data for Lined Shafts

\begin{tabular}{|c|c|c|c|c|c|c|c|c|c|}
\hline \multirow[b]{2}{*}{ Shaft Number } & \multirow[b]{2}{*}{ Package ID } & \multirow[b]{2}{*}{ Base Year } & \multicolumn{2}{|c|}{ Initial Isotopic Distribution } & \multirow[b]{2}{*}{ Target Year } & \multicolumn{2}{|c|}{ Decayed Isotopic Distribution } & \multirow{2}{*}{$\begin{array}{c}\text { Initial Contact } \\
\text { Dose Rate } \\
(\mathrm{mR} / \mathrm{hr})\end{array}$} & \multirow{2}{*}{$\begin{array}{c}\text { Decayed } \\
\text { Contact Dose } \\
\text { Rate }(\mathrm{mR} / \mathrm{hr})^{1} \\
\end{array}$} \\
\hline & & & Isotope & Activity (Ci) & & Isotope & Activity (Ci) & & \\
\hline & & & $\mathrm{Ru}-106$ & $3.74 \mathrm{E}-01$ & & $\mathrm{Ru}-106$ & $6.44 \mathrm{E}-09$ & & \\
\hline & & & $\mathrm{Sb}-125$ & $2.08 \mathrm{E}+00$ & & $\mathrm{Sb}-125$ & $3.10 \mathrm{E}-03$ & & \\
\hline & & & & & & Sm-147 & $7.15 \mathrm{E}-11$ & & \\
\hline & & & Sr-90 & $4.67 \mathrm{E}+01$ & & Sr-90 & $2.51 \mathrm{E}+01$ & & \\
\hline & & & $\mathrm{Te}-125 \mathrm{~m}$ & $8.63 \mathrm{E}-01$ & & $\mathrm{Te}-125 \mathrm{~m}$ & $7.52 \mathrm{E}-04$ & & \\
\hline & & & & & & Th-227 & $8.47 \mathrm{E}-10$ & & \\
\hline & & & & & & Th-231 & $4.89 \mathrm{E}-06$ & & \\
\hline & & & & & & Tl-207 & $8.55 \mathrm{E}-10$ & & \\
\hline & & & U-235 & $4.95 \mathrm{E}-06$ & & U-235 & $4.95 \mathrm{E}-06$ & & \\
\hline & & & $\mathrm{Y}-90$ & $4.66 \mathrm{E}+01$ & & Y-90 & $2.49 \mathrm{E}+01$ & & \\
\hline \multirow[t]{22}{*}{222} & S830781 & 1983 & & & 2009 & Ac- 225 & $5.81 \mathrm{E}-17$ & 20,000 & 10,000 \\
\hline & & & & & & Ac- 227 & $4.83 \mathrm{E}-11$ & & \\
\hline & & & & & & Ac-228 & $1.96 \mathrm{E}-17$ & & \\
\hline & & & & & & Am-241 & $4.25 \mathrm{E}-04$ & & \\
\hline & & & & & & At-217 & $5.82 \mathrm{E}-17$ & & \\
\hline & & & $\mathrm{Ba}-137 \mathrm{~m}$ & $2.40 \mathrm{E}-01$ & & $\mathrm{Ba}-137 \mathrm{~m}$ & $1.31 \mathrm{E}-01$ & & \\
\hline & & & & & & Bi-210 & $2.26 \mathrm{E}-12$ & & \\
\hline & & & & & & Bi-211 & $4.77 \mathrm{E}-11$ & & \\
\hline & & & & & & Bi-212 & $1.97 \mathrm{E}-17$ & & \\
\hline & & & & & & Bi-213 & $5.80 \mathrm{E}-17$ & & \\
\hline & & & & & & Bi-214 & $1.01 \mathrm{E}-11$ & & \\
\hline & & & Cs-137 & $2.55 \mathrm{E}-01$ & & Cs-137 & $1.40 \mathrm{E}-01$ & & \\
\hline & & & Eu-155 & $4.78 \mathrm{E}-03$ & & Eu-155 & $1.26 \mathrm{E}-04$ & & \\
\hline & & & & & & Fr-221 & $5.81 \mathrm{E}-17$ & & \\
\hline & & & & & & Fr-223 & $6.59 \mathrm{E}-13$ & & \\
\hline & & & & & & $\mathrm{Np}-237$ & $2.18 \mathrm{E}-09$ & & \\
\hline & & & & & & $\mathrm{Pa}-231$ & $1.51 \mathrm{E}-10$ & & \\
\hline & & & & & & $\mathrm{Pa}-233$ & $2.16 \mathrm{E}-09$ & & \\
\hline & & & & & & $\mathrm{Pa}-234$ & $3.21 \mathrm{E}-11$ & & \\
\hline & & & & & & $\mathrm{Pa}-234 \mathrm{~m}$ & $2.47 \mathrm{E}-08$ & & \\
\hline & & & & & & Pb-209 & $5.81 \mathrm{E}-17$ & & \\
\hline & & & & & & $\mathrm{Pb}-210$ & $2.29 \mathrm{E}-12$ & & \\
\hline
\end{tabular}

${ }^{1}$ Calculated decayed contact dose rate. Rounded to nearest $10 \mathrm{mR} / \mathrm{hr}$ for values to 1000 ; rounded to nearest $100 \mathrm{mR} / \mathrm{hr}$ for values $>1000$ to 10,000 ; rounded to nearest $1000 \mathrm{mR} / \mathrm{hr}$ for values $>10,000$. * Initial contact dose rate assumed to be $1,000,000 \mathrm{mR} / \mathrm{hr}$; **Initial contact dose rate assumed to be $1,010,000 \mathrm{mR} / \mathrm{hr}$.

$$
90 \text { of } 168
$$


Appendix A-4 - Initial and Decayed Radionuclide and Dose Data for Lined Shafts

\begin{tabular}{|c|c|c|c|c|c|c|c|c|c|}
\hline \multirow[b]{2}{*}{ Shaft Number } & \multirow[b]{2}{*}{ Package ID } & \multirow[b]{2}{*}{ Base Year } & \multicolumn{2}{|c|}{ Initial Isotopic Distribution } & \multirow[b]{2}{*}{ Target Year } & \multicolumn{2}{|c|}{ Decayed Isotopic Distribution } & \multirow{2}{*}{$\begin{array}{c}\text { Initial Contact } \\
\text { Dose Rate } \\
(\mathrm{mR} / \mathrm{hr})\end{array}$} & \multirow{2}{*}{$\begin{array}{c}\text { Decayed } \\
\text { Contact Dose } \\
\text { Rate }(\mathrm{mR} / \mathrm{hr})^{1} \\
\end{array}$} \\
\hline & & & Isotope & Activity (Ci) & & Isotope & Activity (Ci) & & \\
\hline & & & & & & $\mathrm{Pb}-211$ & 4.77E-11 & & \\
\hline & & & & & & $\mathrm{Pb}-212$ & $1.97 \mathrm{E}-17$ & & \\
\hline & & & & & & $\mathrm{Pb}-214$ & $1.02 \mathrm{E}-11$ & & \\
\hline & & & Pm-147 & $1.46 \mathrm{E}-02$ & & Pm-147 & $1.51 \mathrm{E}-05$ & & \\
\hline & & & & & & Po-210 & $2.28 \mathrm{E}-12$ & & \\
\hline & & & & & & Po-211 & $1.45 \mathrm{E}-13$ & & \\
\hline & & & & & & Po-212 & $1.26 \mathrm{E}-17$ & & \\
\hline & & & & & & Po-213 & $5.68 \mathrm{E}-17$ & & \\
\hline & & & & & & Po-214 & $1.02 \mathrm{E}-11$ & & \\
\hline & & & & & & Po-215 & 4.77E-11 & & \\
\hline & & & & & & Po-216 & $1.96 \mathrm{E}-17$ & & \\
\hline & & & & & & Po-218 & $9.98 \mathrm{E}-12$ & & \\
\hline & & & $\mathrm{Pu}-238$ & $2.55 \mathrm{E}-04$ & & $\mathrm{Pu}-238$ & $2.08 \mathrm{E}-04$ & & \\
\hline & & & $\mathrm{Pu}-239$ & $2.82 \mathrm{E}-03$ & & $\mathrm{Pu}-239$ & $2.82 \mathrm{E}-03$ & & \\
\hline & & & $\mathrm{Pu}-240$ & 9.72E-04 & & $\mathrm{Pu}-240$ & 9.69E-04 & & \\
\hline & & & $\mathrm{Pu}-241$ & $1.83 \mathrm{E}-02$ & & $\mathrm{Pu}-241$ & $5.23 \mathrm{E}-03$ & & \\
\hline & & & $\mathrm{Pu}-242$ & $1.38 \mathrm{E}-07$ & & $\mathrm{Pu}-242$ & $1.38 \mathrm{E}-07$ & & \\
\hline & & & & & & Ra-223 & $4.83 \mathrm{E}-11$ & & \\
\hline & & & & & & Ra-224 & $1.96 \mathrm{E}-17$ & & \\
\hline & & & & & & $\mathrm{Ra}-225$ & $5.81 \mathrm{E}-17$ & & \\
\hline & & & & & & Ra-226 & $1.03 \mathrm{E}-11$ & & \\
\hline & & & & & & Ra-228 & $2.32 \mathrm{E}-17$ & & \\
\hline & & & Rh-106 & $1.87 \mathrm{E}-03$ & & Rh-106 & $3.19 \mathrm{E}-11$ & & \\
\hline & & & & & & Rn-219 & $4.77 \mathrm{E}-11$ & & \\
\hline & & & & & & Rn-220 & $1.96 \mathrm{E}-17$ & & \\
\hline & & & & & & Rn-222 & $1.02 \mathrm{E}-11$ & & \\
\hline & & & Ru-106 & $1.87 \mathrm{E}-03$ & & Ru-106 & $3.22 \mathrm{E}-11$ & & \\
\hline & & & Sb-125 & $1.04 \mathrm{E}-02$ & & Sb-125 & $1.54 \mathrm{E}-05$ & & \\
\hline & & & & & & Sm-147 & $3.57 \mathrm{E}-13$ & & \\
\hline & & & Sr-90 & $2.33 \mathrm{E}-01$ & & Sr-90 & $1.26 \mathrm{E}-01$ & & \\
\hline & & & $\mathrm{Te}-125 \mathrm{~m}$ & 4.32E-03 & & $\mathrm{Te}-125 \mathrm{~m}$ & $3.76 \mathrm{E}-06$ & & \\
\hline & & & & & & Th-227 & $4.70 \mathrm{E}-11$ & & \\
\hline
\end{tabular}

${ }^{1}$ Calculated decayed contact dose rate. Rounded to nearest $10 \mathrm{mR} / \mathrm{hr}$ for values to 1000 ; rounded to nearest $100 \mathrm{mR} / \mathrm{hr}$ for values $>1000$ to 10,000 ; rounded to nearest $1000 \mathrm{mR} / \mathrm{hr}$ for values $>10,000$. * Initial contact dose rate assumed to be $1,000,000 \mathrm{mR} / \mathrm{hr}$; **Initial contact dose rate assumed to be $1,010,000 \mathrm{mR} / \mathrm{hr}$.

$$
91 \text { of } 168
$$


Appendix A-4 - Initial and Decayed Radionuclide and Dose Data for Lined Shafts

\begin{tabular}{|c|c|c|c|c|c|c|c|c|c|}
\hline \multirow[b]{2}{*}{ Shaft Number } & \multirow[b]{2}{*}{ Package ID } & \multirow[b]{2}{*}{ Base Year } & \multicolumn{2}{|c|}{ Initial Isotopic Distribution } & \multirow[b]{2}{*}{ Target Year } & \multicolumn{2}{|c|}{ Decayed Isotopic Distribution } & \multirow{2}{*}{$\begin{array}{c}\text { Initial Contact } \\
\text { Dose Rate } \\
(\mathrm{mR} / \mathrm{hr})\end{array}$} & \multirow{2}{*}{$\begin{array}{c}\text { Decayed } \\
\text { Contact Dose } \\
\text { Rate }(\mathrm{mR} / \mathrm{hr})^{1} \\
\end{array}$} \\
\hline & & & Isotope & Activity (Ci) & & Isotope & Activity (Ci) & & \\
\hline & & & & & & Th-228 & $1.99 \mathrm{E}-17$ & & \\
\hline & & & & & & Th-229 & $5.82 \mathrm{E}-17$ & & \\
\hline & & & & & & Th-230 & $1.83 \mathrm{E}-09$ & & \\
\hline & & & & & & Th-231 & $2.71 \mathrm{E}-07$ & & \\
\hline & & & & & & Th-232 & $3.05 \mathrm{E}-17$ & & \\
\hline & & & & & & Th-234 & $2.48 \mathrm{E}-08$ & & \\
\hline & & & & & & Tl-207 & $4.75 \mathrm{E}-11$ & & \\
\hline & & & & & & T1-208 & $7.07 \mathrm{E}-18$ & & \\
\hline & & & & & & Tl-209 & $1.28 \mathrm{E}-18$ & & \\
\hline & & & & & & U-233 & $9.02 \mathrm{E}-14$ & & \\
\hline & & & U-234 & 7.81E-06 & & U-234 & $7.83 \mathrm{E}-06$ & & \\
\hline & & & $\mathrm{U}-235$ & $2.75 \mathrm{E}-07$ & & U-235 & $2.75 \mathrm{E}-07$ & & \\
\hline & & & $\mathrm{U}-236$ & $2.34 \mathrm{E}-08$ & & $\mathrm{U}-236$ & $2.41 \mathrm{E}-08$ & & \\
\hline & & & & & & U-237 & $1.29 \mathrm{E}-07$ & & \\
\hline & & & $\mathrm{U}-238$ & $2.50 \mathrm{E}-08$ & & U-238 & $2.50 \mathrm{E}-08$ & & \\
\hline & & & Y-90 & $2.33 \mathrm{E}-01$ & & Y-90 & $1.24 \mathrm{E}-01$ & & \\
\hline \multirow[t]{16}{*}{222} & S830787 & 1983 & & & 2009 & Ac- 225 & $1.39 \mathrm{E}-16$ & 200,000 & 104,000 \\
\hline & & & & & & Ac-227 & $1.21 \mathrm{E}-10$ & & \\
\hline & & & & & & Ac- 228 & $4.91 \mathrm{E}-17$ & & \\
\hline & & & & & & Am-241 & $1.02 \mathrm{E}-03$ & & \\
\hline & & & & & & At-217 & $1.40 \mathrm{E}-16$ & & \\
\hline & & & Ba-137m & $9.59 \mathrm{E}+00$ & & $\mathrm{Ba}-137 \mathrm{~m}$ & $5.24 \mathrm{E}+00$ & & \\
\hline & & & & & & Bi-210 & $5.65 \mathrm{E}-12$ & & \\
\hline & & & & & & Bi-211 & $1.19 \mathrm{E}-10$ & & \\
\hline & & & & & & Bi-212 & $4.93 \mathrm{E}-17$ & & \\
\hline & & & & & & Bi-213 & $1.39 \mathrm{E}-16$ & & \\
\hline & & & & & & Bi-214 & $2.53 \mathrm{E}-11$ & & \\
\hline & & & Cs-137 & $1.02 \mathrm{E}+01$ & & Cs-137 & $5.60 \mathrm{E}+00$ & & \\
\hline & & & Eu-155 & $1.91 \mathrm{E}-01$ & & Eu-155 & $5.05 \mathrm{E}-03$ & & \\
\hline & & & & & & Fr-221 & $1.39 \mathrm{E}-16$ & & \\
\hline & & & & & & Fr-223 & $1.65 \mathrm{E}-12$ & & \\
\hline & & & & & & $\mathrm{Np}-237$ & $5.23 \mathrm{E}-09$ & & \\
\hline
\end{tabular}

${ }^{1}$ Calculated decayed contact dose rate. Rounded to nearest $10 \mathrm{mR} / \mathrm{hr}$ for values to 1000 ; rounded to nearest $100 \mathrm{mR} / \mathrm{hr}$ for values $>1000$ to 10,000 ; rounded to nearest $1000 \mathrm{mR} / \mathrm{hr}$ for values $>10,000$. * Initial contact dose rate assumed to be $1,000,000 \mathrm{mR} / \mathrm{hr}$; **Initial contact dose rate assumed to be $1,010,000 \mathrm{mR} / \mathrm{hr}$.

$$
92 \text { of } 168
$$


Appendix A-4 - Initial and Decayed Radionuclide and Dose Data for Lined Shafts

\begin{tabular}{|c|c|c|c|c|c|c|c|c|c|}
\hline \multirow[b]{2}{*}{ Shaft Number } & \multirow[b]{2}{*}{ Package ID } & \multirow[b]{2}{*}{ Base Year } & \multicolumn{2}{|c|}{ Initial Isotopic Distribution } & \multirow[b]{2}{*}{ Target Year } & \multicolumn{2}{|c|}{ Decayed Isotopic Distribution } & \multirow{2}{*}{$\begin{array}{c}\text { Initial Contact } \\
\text { Dose Rate } \\
(\mathrm{mR} / \mathrm{hr})\end{array}$} & \multirow{2}{*}{$\begin{array}{c}\text { Decayed } \\
\text { Contact Dose } \\
\text { Rate }(\mathrm{mR} / \mathrm{hr})^{1} \\
\end{array}$} \\
\hline & & & Isotope & Activity (Ci) & & Isotope & Activity (Ci) & & \\
\hline & & & & & & $\mathrm{Pa}-231$ & $3.77 \mathrm{E}-10$ & & \\
\hline & & & & & & $\mathrm{Pa}-233$ & $5.18 \mathrm{E}-09$ & & \\
\hline & & & & & & $\mathrm{Pa}-234$ & $8.04 \mathrm{E}-11$ & & \\
\hline & & & & & & $\mathrm{Pa}-234 \mathrm{~m}$ & $6.18 \mathrm{E}-08$ & & \\
\hline & & & & & & $\mathrm{Pb}-209$ & $1.39 \mathrm{E}-16$ & & \\
\hline & & & & & & $\mathrm{Pb}-210$ & $5.71 \mathrm{E}-12$ & & \\
\hline & & & & & & $\mathrm{Pb}-211$ & $1.19 \mathrm{E}-10$ & & \\
\hline & & & & & & $\mathrm{Pb}-212$ & $4.91 \mathrm{E}-17$ & & \\
\hline & & & & & & $\mathrm{Pb}-214$ & $2.54 \mathrm{E}-11$ & & \\
\hline & & & Pm-147 & $5.83 \mathrm{E}-01$ & & Pm-147 & $6.11 \mathrm{E}-04$ & & \\
\hline & & & & & & Po-210 & $5.71 \mathrm{E}-12$ & & \\
\hline & & & & & & Po-211 & $3.64 \mathrm{E}-13$ & & \\
\hline & & & & & & Po-212 & $3.14 \mathrm{E}-17$ & & \\
\hline & & & & & & Po-213 & $1.36 \mathrm{E}-16$ & & \\
\hline & & & & & & Po-214 & $2.54 \mathrm{E}-11$ & & \\
\hline & & & & & & Po-215 & $1.19 \mathrm{E}-10$ & & \\
\hline & & & & & & Po-216 & $4.91 \mathrm{E}-17$ & & \\
\hline & & & & & & Po-218 & $2.49 \mathrm{E}-11$ & & \\
\hline & & & $\mathrm{Pu}-238$ & $6.12 \mathrm{E}-04$ & & $\mathrm{Pu}-238$ & 4.98E-04 & & \\
\hline & & & $\mathrm{Pu}-239$ & $6.78 \mathrm{E}-03$ & & $\mathrm{Pu}-239$ & $6.77 \mathrm{E}-03$ & & \\
\hline & & & $\mathrm{Pu}-240$ & $2.33 \mathrm{E}-03$ & & $\mathrm{Pu}-240$ & $2.33 \mathrm{E}-03$ & & \\
\hline & & & $\mathrm{Pu}-241$ & 4.39E-02 & & $\mathrm{Pu}-241$ & $1.26 \mathrm{E}-02$ & & \\
\hline & & & $\mathrm{Pu}-242$ & $3.32 \mathrm{E}-07$ & & $\mathrm{Pu}-242$ & $3.32 \mathrm{E}-07$ & & \\
\hline & & & & & & $\mathrm{Ra}-223$ & $1.21 \mathrm{E}-10$ & & \\
\hline & & & & & & Ra-224 & $4.90 \mathrm{E}-17$ & & \\
\hline & & & & & & Ra-225 & $1.40 \mathrm{E}-16$ & & \\
\hline & & & & & & Ra-226 & $2.57 \mathrm{E}-11$ & & \\
\hline & & & & & & Ra-228 & $5.79 \mathrm{E}-17$ & & \\
\hline & & & Rh-106 & 7.49E-02 & & Rh-106 & $1.27 \mathrm{E}-09$ & & \\
\hline & & & & & & Rn-219 & $1.19 \mathrm{E}-10$ & & \\
\hline & & & & & & Rn-220 & $4.91 \mathrm{E}-17$ & & \\
\hline & & & & & & Rn-222 & $2.54 \mathrm{E}-11$ & & \\
\hline
\end{tabular}

${ }^{1}$ Calculated decayed contact dose rate. Rounded to nearest $10 \mathrm{mR} / \mathrm{hr}$ for values to 1000 ; rounded to nearest $100 \mathrm{mR} / \mathrm{hr}$ for values $>1000$ to 10,000 ; rounded to nearest $1000 \mathrm{mR} / \mathrm{hr}$ for values $>10,000$. * Initial contact dose rate assumed to be $1,000,000 \mathrm{mR} / \mathrm{hr}$; **Initial contact dose rate assumed to be $1,010,000 \mathrm{mR} / \mathrm{hr}$.

$$
93 \text { of } 168
$$


Appendix A-4 - Initial and Decayed Radionuclide and Dose Data for Lined Shafts

\begin{tabular}{|c|c|c|c|c|c|c|c|c|c|}
\hline \multirow[b]{2}{*}{ Shaft Number } & \multirow[b]{2}{*}{ Package ID } & \multirow[b]{2}{*}{ Base Year } & \multicolumn{2}{|c|}{ Initial Isotopic Distribution } & \multirow[b]{2}{*}{ Target Year } & \multicolumn{2}{|c|}{ Decayed Isotopic Distribution } & \multirow{2}{*}{$\begin{array}{c}\text { Initial Contact } \\
\text { Dose Rate } \\
(\mathrm{mR} / \mathrm{hr})\end{array}$} & \multirow{2}{*}{$\begin{array}{c}\text { Decayed } \\
\text { Contact Dose } \\
\text { Rate }(\mathrm{mR} / \mathrm{hr})^{1} \\
\end{array}$} \\
\hline & & & Isotope & Activity (Ci) & & Isotope & Activity (Ci) & & \\
\hline & & & $\mathrm{Ru}-106$ & 7.49E-02 & & $\mathrm{Ru}-106$ & $1.29 \mathrm{E}-09$ & & \\
\hline & & & $\mathrm{Sb}-125$ & $4.16 \mathrm{E}-01$ & & $\mathrm{Sb}-125$ & $6.21 \mathrm{E}-04$ & & \\
\hline & & & & & & Sm-147 & $1.43 \mathrm{E}-11$ & & \\
\hline & & & Sr-90 & $9.34 \mathrm{E}+00$ & & Sr-90 & $5.03 \mathrm{E}+00$ & & \\
\hline & & & $\mathrm{Te}-125 \mathrm{~m}$ & $1.73 \mathrm{E}-01$ & & $\mathrm{Te}-125 \mathrm{~m}$ & $1.50 \mathrm{E}-04$ & & \\
\hline & & & & & & Th-227 & $1.17 \mathrm{E}-10$ & & \\
\hline & & & & & & Th-228 & $4.97 \mathrm{E}-17$ & & \\
\hline & & & & & & Th-229 & $1.40 \mathrm{E}-16$ & & \\
\hline & & & & & & Th-230 & $4.57 \mathrm{E}-09$ & & \\
\hline & & & & & & Th-231 & $6.79 \mathrm{E}-07$ & & \\
\hline & & & & & & Th-232 & 7.63E-17 & & \\
\hline & & & & & & Th-234 & $6.19 \mathrm{E}-08$ & & \\
\hline & & & & & & Tl-207 & $1.19 \mathrm{E}-10$ & & \\
\hline & & & & & & Tl-208 & $1.77 \mathrm{E}-17$ & & \\
\hline & & & & & & Tl-209 & $3.07 \mathrm{E}-18$ & & \\
\hline & & & & & & $\mathrm{U}-233$ & $2.16 \mathrm{E}-13$ & & \\
\hline & & & U-234 & $1.95 \mathrm{E}-05$ & & $\mathrm{U}-234$ & $1.96 \mathrm{E}-05$ & & \\
\hline & & & $\mathrm{U}-235$ & $6.87 \mathrm{E}-07$ & & $\mathrm{U}-235$ & $6.87 \mathrm{E}-07$ & & \\
\hline & & & $\mathrm{U}-236$ & $5.85 \mathrm{E}-08$ & & $\mathrm{U}-236$ & $6.03 \mathrm{E}-08$ & & \\
\hline & & & & & & $\mathrm{U}-237$ & $3.09 \mathrm{E}-07$ & & \\
\hline & & & U-238 & $6.25 \mathrm{E}-08$ & & $\mathrm{U}-238$ & $6.25 \mathrm{E}-08$ & & \\
\hline & & & Y-90 & $9.33 \mathrm{E}+00$ & & Y-90 & $4.97 \mathrm{E}+00$ & & \\
\hline \multirow[t]{10}{*}{222} & S830788 & 1983 & & & 2009 & Ac- 225 & $1.39 \mathrm{E}-16$ & 100,000 & 52,000 \\
\hline & & & & & & Ac-227 & $1.21 \mathrm{E}-10$ & & \\
\hline & & & & & & Ac- 228 & $4.91 \mathrm{E}-17$ & & \\
\hline & & & & & & Am-241 & $1.02 \mathrm{E}-03$ & & \\
\hline & & & & & & At-217 & $1.40 \mathrm{E}-16$ & & \\
\hline & & & Ba-137m & $9.59 \mathrm{E}+00$ & & Ba-137m & $5.24 \mathrm{E}+00$ & & \\
\hline & & & & & & $\mathrm{Bi}-210$ & $5.65 \mathrm{E}-12$ & & \\
\hline & & & & & & Bi-211 & $1.19 \mathrm{E}-10$ & & \\
\hline & & & & & & Bi-212 & $4.93 \mathrm{E}-17$ & & \\
\hline & & & & & & Bi-213 & $1.39 \mathrm{E}-16$ & & \\
\hline
\end{tabular}

${ }^{1}$ Calculated decayed contact dose rate. Rounded to nearest $10 \mathrm{mR} / \mathrm{hr}$ for values to 1000 ; rounded to nearest $100 \mathrm{mR} / \mathrm{hr}$ for values $>1000$ to 10,000 ; rounded to nearest $1000 \mathrm{mR} / \mathrm{hr}$ for values $>10,000$. * Initial contact dose rate assumed to be $1,000,000 \mathrm{mR} / \mathrm{hr}$; **Initial contact dose rate assumed to be $1,010,000 \mathrm{mR} / \mathrm{hr}$.

$$
94 \text { of } 168
$$


Appendix A-4 - Initial and Decayed Radionuclide and Dose Data for Lined Shafts

\begin{tabular}{|c|c|c|c|c|c|c|c|c|c|}
\hline \multirow[b]{2}{*}{ Shaft Number } & \multirow[b]{2}{*}{ Package ID } & \multirow[b]{2}{*}{ Base Year } & \multicolumn{2}{|c|}{ Initial Isotopic Distribution } & \multirow[b]{2}{*}{ Target Year } & \multicolumn{2}{|c|}{ Decayed Isotopic Distribution } & \multirow{2}{*}{$\begin{array}{c}\text { Initial Contact } \\
\text { Dose Rate } \\
(\mathrm{mR} / \mathrm{hr})\end{array}$} & \multirow{2}{*}{$\begin{array}{c}\text { Decayed } \\
\text { Contact Dose } \\
\text { Rate }(\mathrm{mR} / \mathrm{hr})^{1} \\
\end{array}$} \\
\hline & & & Isotope & Activity (Ci) & & Isotope & Activity (Ci) & & \\
\hline & & & & & & Bi-214 & $2.53 \mathrm{E}-11$ & & \\
\hline & & & Cs-137 & $1.02 \mathrm{E}+01$ & & Cs-137 & $5.60 \mathrm{E}+00$ & & \\
\hline & & & Eu-155 & $1.91 \mathrm{E}-01$ & & $\mathrm{Eu}-155$ & $5.05 \mathrm{E}-03$ & & \\
\hline & & & & & & Fr-221 & $1.39 \mathrm{E}-16$ & & \\
\hline & & & & & & Fr-223 & $1.65 \mathrm{E}-12$ & & \\
\hline & & & & & & $\mathrm{Np}-237$ & 5.23E-09 & & \\
\hline & & & & & & $\mathrm{Pa}-231$ & $3.77 \mathrm{E}-10$ & & \\
\hline & & & & & & $\mathrm{Pa}-233$ & $5.18 \mathrm{E}-09$ & & \\
\hline & & & & & & $\mathrm{Pa}-234$ & $8.04 \mathrm{E}-11$ & & \\
\hline & & & & & & $\mathrm{Pa}-234 \mathrm{~m}$ & $6.18 \mathrm{E}-08$ & & \\
\hline & & & & & & $\mathrm{Pb}-209$ & $1.39 \mathrm{E}-16$ & & \\
\hline & & & & & & $\mathrm{Pb}-210$ & $5.71 \mathrm{E}-12$ & & \\
\hline & & & & & & $\mathrm{Pb}-211$ & $1.19 \mathrm{E}-10$ & & \\
\hline & & & & & & $\mathrm{Pb}-212$ & $4.91 \mathrm{E}-17$ & & \\
\hline & & & & & & $\mathrm{Pb}-214$ & $2.54 \mathrm{E}-11$ & & \\
\hline & & & Pm-147 & $5.83 \mathrm{E}-01$ & & Pm-147 & $6.11 \mathrm{E}-04$ & & \\
\hline & & & & & & Po-210 & $5.71 \mathrm{E}-12$ & & \\
\hline & & & & & & Po-211 & $3.64 \mathrm{E}-13$ & & \\
\hline & & & & & & Po-212 & $3.14 \mathrm{E}-17$ & & \\
\hline & & & & & & Po-213 & $1.36 \mathrm{E}-16$ & & \\
\hline & & & & & & Po-214 & $2.54 \mathrm{E}-11$ & & \\
\hline & & & & & & Po-215 & $1.19 \mathrm{E}-10$ & & \\
\hline & & & & & & Po-216 & $4.91 \mathrm{E}-17$ & & \\
\hline & & & & & & Po-218 & $2.49 \mathrm{E}-11$ & & \\
\hline & & & $\mathrm{Pu}-238$ & $6.12 \mathrm{E}-04$ & & $\mathrm{Pu}-238$ & 4.98E-04 & & \\
\hline & & & $\mathrm{Pu}-239$ & $6.78 \mathrm{E}-03$ & & $\mathrm{Pu}-239$ & $6.77 \mathrm{E}-03$ & & \\
\hline & & & $\mathrm{Pu}-240$ & 2.33E-03 & & $\mathrm{Pu}-240$ & $2.33 \mathrm{E}-03$ & & \\
\hline & & & $\mathrm{Pu}-241$ & 4.39E-02 & & $\mathrm{Pu}-241$ & $1.26 \mathrm{E}-02$ & & \\
\hline & & & $\mathrm{Pu}-242$ & $3.32 \mathrm{E}-07$ & & $\mathrm{Pu}-242$ & $3.32 \mathrm{E}-07$ & & \\
\hline & & & & & & Ra-223 & $1.21 \mathrm{E}-10$ & & \\
\hline & & & & & & Ra-224 & $4.90 \mathrm{E}-17$ & & \\
\hline & & & & & & Ra-225 & $1.40 \mathrm{E}-16$ & & \\
\hline
\end{tabular}

${ }^{1}$ Calculated decayed contact dose rate. Rounded to nearest $10 \mathrm{mR} / \mathrm{hr}$ for values to 1000 ; rounded to nearest $100 \mathrm{mR} / \mathrm{hr}$ for values $>1000$ to 10,000 ; rounded to nearest $1000 \mathrm{mR} / \mathrm{hr}$ for values $>10,000$. * Initial contact dose rate assumed to be $1,000,000 \mathrm{mR} / \mathrm{hr}$; **Initial contact dose rate assumed to be $1,010,000 \mathrm{mR} / \mathrm{hr}$.

$$
95 \text { of } 168
$$


Appendix A-4 - Initial and Decayed Radionuclide and Dose Data for Lined Shafts

\begin{tabular}{|c|c|c|c|c|c|c|c|c|c|}
\hline \multirow[b]{2}{*}{ Shaft Number } & \multirow[b]{2}{*}{ Package ID } & \multirow[b]{2}{*}{ Base Year } & \multicolumn{2}{|c|}{ Initial Isotopic Distribution } & \multirow[b]{2}{*}{ Target Year } & \multicolumn{2}{|c|}{ Decayed Isotopic Distribution } & \multirow{2}{*}{$\begin{array}{c}\text { Initial Contact } \\
\text { Dose Rate } \\
(\mathrm{mR} / \mathrm{hr})\end{array}$} & \multirow{2}{*}{$\begin{array}{c}\text { Decayed } \\
\text { Contact Dose } \\
\text { Rate }(\mathrm{mR} / \mathrm{hr})^{1} \\
\end{array}$} \\
\hline & & & Isotope & Activity (Ci) & & Isotope & Activity (Ci) & & \\
\hline & & & & & & $\mathrm{Ra}-226$ & $2.57 \mathrm{E}-11$ & & \\
\hline & & & & & & $\mathrm{Ra}-228$ & $5.79 \mathrm{E}-17$ & & \\
\hline & & & Rh-106 & 7.49E-02 & & Rh-106 & $1.27 \mathrm{E}-09$ & & \\
\hline & & & & & & Rn-219 & $1.19 \mathrm{E}-10$ & & \\
\hline & & & & & & Rn-220 & $4.91 \mathrm{E}-17$ & & \\
\hline & & & & & & $\mathrm{Rn}-222$ & $2.54 \mathrm{E}-11$ & & \\
\hline & & & $\mathrm{Ru}-106$ & 7.49E-02 & & $\mathrm{Ru}-106$ & $1.29 \mathrm{E}-09$ & & \\
\hline & & & $\mathrm{Sb}-125$ & 4.16E-01 & & Sb-125 & $6.21 \mathrm{E}-04$ & & \\
\hline & & & & & & Sm-147 & $1.43 \mathrm{E}-11$ & & \\
\hline & & & Sr-90 & $9.34 \mathrm{E}+00$ & & Sr-90 & $5.03 \mathrm{E}+00$ & & \\
\hline & & & Te-125m & $1.73 \mathrm{E}-01$ & & $\mathrm{Te}-125 \mathrm{~m}$ & $1.50 \mathrm{E}-04$ & & \\
\hline & & & & & & Th-227 & $1.17 \mathrm{E}-10$ & & \\
\hline & & & & & & Th-228 & $4.97 \mathrm{E}-17$ & & \\
\hline & & & & & & Th-229 & $1.40 \mathrm{E}-16$ & & \\
\hline & & & & & & Th-230 & 4.57E-09 & & \\
\hline & & & & & & Th-231 & $6.79 \mathrm{E}-07$ & & \\
\hline & & & & & & Th-232 & 7.63E-17 & & \\
\hline & & & & & & Th-234 & 6.19E-08 & & \\
\hline & & & & & & Tl-207 & $1.19 \mathrm{E}-10$ & & \\
\hline & & & & & & Tl-208 & $1.77 \mathrm{E}-17$ & & \\
\hline & & & & & & Tl-209 & $3.07 \mathrm{E}-18$ & & \\
\hline & & & & & & U-233 & $2.16 \mathrm{E}-13$ & & \\
\hline & & & U-234 & $1.95 \mathrm{E}-05$ & & U-234 & $1.96 \mathrm{E}-05$ & & \\
\hline & & & U-235 & $6.87 \mathrm{E}-07$ & & U-235 & $6.87 \mathrm{E}-07$ & & \\
\hline & & & U-236 & $5.85 \mathrm{E}-08$ & & U-236 & $6.03 \mathrm{E}-08$ & & \\
\hline & & & & & & U-237 & $3.09 \mathrm{E}-07$ & & \\
\hline & & & U-238 & $6.25 \mathrm{E}-08$ & & U-238 & $6.25 \mathrm{E}-08$ & & \\
\hline & & & Y-90 & $9.33 \mathrm{E}+00$ & & Y-90 & $4.97 \mathrm{E}+00$ & & \\
\hline \multirow[t]{4}{*}{222} & S830789 & 1983 & & & 2009 & Ac- 225 & $1.16 \mathrm{E}-16$ & 10,000 & 5,200 \\
\hline & & & & & & Ac-227 & $9.66 \mathrm{E}-11$ & & \\
\hline & & & & & & Ac- 228 & $3.93 \mathrm{E}-17$ & & \\
\hline & & & & & & Am-241 & 8.50E-04 & & \\
\hline
\end{tabular}

${ }^{1}$ Calculated decayed contact dose rate. Rounded to nearest $10 \mathrm{mR} / \mathrm{hr}$ for values to 1000 ; rounded to nearest $100 \mathrm{mR} / \mathrm{hr}$ for values $>1000$ to 10,000 ; rounded to nearest $1000 \mathrm{mR} / \mathrm{hr}$ for values $>10,000$. * Initial contact dose rate assumed to be $1,000,000 \mathrm{mR} / \mathrm{hr}$; **Initial contact dose rate assumed to be $1,010,000 \mathrm{mR} / \mathrm{hr}$. 
Appendix A-4 - Initial and Decayed Radionuclide and Dose Data for Lined Shafts

\begin{tabular}{|c|c|c|c|c|c|c|c|c|c|}
\hline \multirow[b]{2}{*}{ Shaft Number } & \multirow[b]{2}{*}{ Package ID } & \multirow[b]{2}{*}{ Base Year } & \multicolumn{2}{|c|}{ Initial Isotopic Distribution } & \multirow[b]{2}{*}{ Target Year } & \multicolumn{2}{|c|}{ Decayed Isotopic Distribution } & \multirow{2}{*}{$\begin{array}{c}\text { Initial Contact } \\
\text { Dose Rate } \\
(\mathrm{mR} / \mathrm{hr})\end{array}$} & \multirow{2}{*}{$\begin{array}{c}\text { Decayed } \\
\text { Contact Dose } \\
\text { Rate }(\mathrm{mR} / \mathrm{hr})^{1} \\
\end{array}$} \\
\hline & & & Isotope & Activity (Ci) & & Isotope & Activity (Ci) & & \\
\hline & & & & & & At-217 & $1.16 \mathrm{E}-16$ & & \\
\hline & & & $\mathrm{Ba}-137 \mathrm{~m}$ & 4.79E-02 & & Ba-137m & $2.62 \mathrm{E}-02$ & & \\
\hline & & & & & & $\mathrm{Bi}-210$ & $4.52 \mathrm{E}-12$ & & \\
\hline & & & & & & Bi-211 & $9.53 \mathrm{E}-11$ & & \\
\hline & & & & & & $\mathrm{Bi}-212$ & $3.94 \mathrm{E}-17$ & & \\
\hline & & & & & & Bi-213 & $1.16 \mathrm{E}-16$ & & \\
\hline & & & & & & $\mathrm{Bi}-214$ & $2.03 \mathrm{E}-11$ & & \\
\hline & & & Cs-137 & $5.11 \mathrm{E}-02$ & & Cs-137 & $2.80 \mathrm{E}-02$ & & \\
\hline & & & Eu-155 & $9.55 \mathrm{E}-04$ & & Eu-155 & $2.52 \mathrm{E}-05$ & & \\
\hline & & & & & & Fr-221 & $1.16 \mathrm{E}-16$ & & \\
\hline & & & & & & Fr-223 & $1.32 \mathrm{E}-12$ & & \\
\hline & & & & & & $\mathrm{Np}-237$ & 4.36E-09 & & \\
\hline & & & & & & $\mathrm{Pa}-231$ & $3.02 \mathrm{E}-10$ & & \\
\hline & & & & & & $\mathrm{Pa}-233$ & 4.32E-09 & & \\
\hline & & & & & & $\mathrm{Pa}-234$ & $6.43 \mathrm{E}-11$ & & \\
\hline & & & & & & $\mathrm{Pa}-234 \mathrm{~m}$ & 4.94E-08 & & \\
\hline & & & & & & $\mathrm{Pb}-209$ & $1.16 \mathrm{E}-16$ & & \\
\hline & & & & & & $\mathrm{Pb}-210$ & $4.57 \mathrm{E}-12$ & & \\
\hline & & & & & & $\mathrm{Pb}-211$ & $9.55 \mathrm{E}-11$ & & \\
\hline & & & & & & $\mathrm{Pb}-212$ & $3.93 \mathrm{E}-17$ & & \\
\hline & & & & & & $\mathrm{Pb}-214$ & $2.03 \mathrm{E}-11$ & & \\
\hline & & & Pm-147 & $2.92 \mathrm{E}-03$ & & Pm-147 & $3.05 \mathrm{E}-06$ & & \\
\hline & & & & & & Po-210 & $4.57 \mathrm{E}-12$ & & \\
\hline & & & & & & Po-211 & $2.91 \mathrm{E}-13$ & & \\
\hline & & & & & & Po-212 & $2.51 \mathrm{E}-17$ & & \\
\hline & & & & & & Po-213 & $1.14 \mathrm{E}-16$ & & \\
\hline & & & & & & Po-214 & $2.03 \mathrm{E}-11$ & & \\
\hline & & & & & & Po-215 & $9.55 \mathrm{E}-11$ & & \\
\hline & & & & & & Po-216 & $3.93 \mathrm{E}-17$ & & \\
\hline & & & & & & Рo-218 & $2.00 \mathrm{E}-11$ & & \\
\hline & & & $\mathrm{Pu}-238$ & $5.10 \mathrm{E}-04$ & & $\mathrm{Pu}-238$ & $4.15 \mathrm{E}-04$ & & \\
\hline & & & $\mathrm{Pu}-239$ & $5.65 \mathrm{E}-03$ & & $\mathrm{Pu}-239$ & $5.64 \mathrm{E}-03$ & & \\
\hline
\end{tabular}

${ }^{1}$ Calculated decayed contact dose rate. Rounded to nearest $10 \mathrm{mR} / \mathrm{hr}$ for values to 1000 ; rounded to nearest $100 \mathrm{mR} / \mathrm{hr}$ for values $>1000$ to 10,000 ; rounded to nearest $1000 \mathrm{mR} / \mathrm{hr}$ for values $>10,000$. * Initial contact dose rate assumed to be $1,000,000 \mathrm{mR} / \mathrm{hr}$; **Initial contact dose rate assumed to be $1,010,000 \mathrm{mR} / \mathrm{hr}$.

$$
97 \text { of } 168
$$


Appendix A-4 - Initial and Decayed Radionuclide and Dose Data for Lined Shafts

\begin{tabular}{|c|c|c|c|c|c|c|c|c|c|}
\hline \multirow[b]{2}{*}{ Shaft Number } & \multirow[b]{2}{*}{ Package ID } & \multirow[b]{2}{*}{ Base Year } & \multicolumn{2}{|c|}{ Initial Isotopic Distribution } & \multirow[b]{2}{*}{ Target Year } & \multicolumn{2}{|c|}{ Decayed Isotopic Distribution } & \multirow{2}{*}{$\begin{array}{c}\text { Initial Contact } \\
\text { Dose Rate } \\
(\mathrm{mR} / \mathrm{hr}) \\
\end{array}$} & \multirow{2}{*}{$\begin{array}{c}\text { Decayed } \\
\text { Contact Dose } \\
\text { Rate }(\mathrm{mR} / \mathrm{hr})^{1} \\
\end{array}$} \\
\hline & & & Isotope & Activity (Ci) & & Isotope & Activity (Ci) & & \\
\hline & & & $\mathrm{Pu}-240$ & $1.94 \mathrm{E}-03$ & & $\mathrm{Pu}-240$ & $1.94 \mathrm{E}-03$ & & \\
\hline & & & $\mathrm{Pu}-241$ & $3.66 \mathrm{E}-02$ & & $\mathrm{Pu}-241$ & $1.05 \mathrm{E}-02$ & & \\
\hline & & & $\mathrm{Pu}-242$ & $2.77 \mathrm{E}-07$ & & $\mathrm{Pu}-242$ & $2.77 \mathrm{E}-07$ & & \\
\hline & & & & & & Ra-223 & $9.65 \mathrm{E}-11$ & & \\
\hline & & & & & & $\mathrm{Ra}-224$ & $3.92 \mathrm{E}-17$ & & \\
\hline & & & & & & Ra-225 & $1.16 \mathrm{E}-16$ & & \\
\hline & & & & & & Ra-226 & $2.05 \mathrm{E}-11$ & & \\
\hline & & & & & & $\mathrm{Ra}-228$ & $4.63 \mathrm{E}-17$ & & \\
\hline & & & Rh-106 & $3.74 \mathrm{E}-04$ & & Rh-106 & $6.37 \mathrm{E}-12$ & & \\
\hline & & & & & & $\mathrm{Rn}-219$ & $9.53 \mathrm{E}-11$ & & \\
\hline & & & & & & $\mathrm{Rn}-220$ & $3.93 \mathrm{E}-17$ & & \\
\hline & & & & & & $\mathrm{Rn}-222$ & $2.03 \mathrm{E}-11$ & & \\
\hline & & & $\mathrm{Ru}-106$ & $3.74 \mathrm{E}-04$ & & $\mathrm{Ru}-106$ & $6.44 \mathrm{E}-12$ & & \\
\hline & & & $\mathrm{Sb}-125$ & $2.08 \mathrm{E}-03$ & & $\mathrm{Sb}-125$ & $3.11 \mathrm{E}-06$ & & \\
\hline & & & & & & Sm-147 & $7.15 \mathrm{E}-14$ & & \\
\hline & & & Sr-90 & 4.67E-02 & & Sr-90 & $2.51 \mathrm{E}-02$ & & \\
\hline & & & $\mathrm{Te}-125 \mathrm{~m}$ & 8.63E-04 & & Te- $125 \mathrm{~m}$ & $7.52 \mathrm{E}-07$ & & \\
\hline & & & & & & Th-227 & $9.40 \mathrm{E}-11$ & & \\
\hline & & & & & & Th-228 & $3.97 \mathrm{E}-17$ & & \\
\hline & & & & & & Th-229 & $1.16 \mathrm{E}-16$ & & \\
\hline & & & & & & Th-230 & $3.66 \mathrm{E}-09$ & & \\
\hline & & & & & & Th-231 & $5.43 \mathrm{E}-07$ & & \\
\hline & & & & & & Th-232 & $6.11 \mathrm{E}-17$ & & \\
\hline & & & & & & Th-234 & $4.95 \mathrm{E}-08$ & & \\
\hline & & & & & & Tl-207 & $9.49 \mathrm{E}-11$ & & \\
\hline & & & & & & Tl-208 & $1.41 \mathrm{E}-17$ & & \\
\hline & & & & & & Tl-209 & $2.56 \mathrm{E}-18$ & & \\
\hline & & & & & & U-233 & $1.80 \mathrm{E}-13$ & & \\
\hline & & & U-234 & $1.56 \mathrm{E}-05$ & & U-234 & $1.57 \mathrm{E}-05$ & & \\
\hline & & & U-235 & $5.49 \mathrm{E}-07$ & & U-235 & $5.50 \mathrm{E}-07$ & & \\
\hline & & & U-236 & $4.68 \mathrm{E}-08$ & & U-236 & 4.83E-08 & & \\
\hline & & & & & & U-237 & $2.57 \mathrm{E}-07$ & & \\
\hline
\end{tabular}

${ }^{1}$ Calculated decayed contact dose rate. Rounded to nearest $10 \mathrm{mR} / \mathrm{hr}$ for values to 1000 ; rounded to nearest $100 \mathrm{mR} / \mathrm{hr}$ for values $>1000$ to 10,000 ; rounded to nearest $1000 \mathrm{mR} / \mathrm{hr}$ for values $>10,000$. * Initial contact dose rate assumed to be $1,000,000 \mathrm{mR} / \mathrm{hr}$; **Initial contact dose rate assumed to be $1,010,000 \mathrm{mR} / \mathrm{hr}$.

$$
98 \text { of } 168
$$


Appendix A-4 - Initial and Decayed Radionuclide and Dose Data for Lined Shafts

\begin{tabular}{|c|c|c|c|c|c|c|c|c|c|}
\hline \multirow[b]{2}{*}{ Shaft Number } & \multirow[b]{2}{*}{ Package ID } & \multirow[b]{2}{*}{ Base Year } & \multicolumn{2}{|c|}{ Initial Isotopic Distribution } & \multirow[b]{2}{*}{ Target Year } & \multicolumn{2}{|c|}{ Decayed Isotopic Distribution } & \multirow{2}{*}{$\begin{array}{c}\text { Initial Contact } \\
\text { Dose Rate } \\
(\mathrm{mR} / \mathrm{hr})\end{array}$} & \multirow{2}{*}{$\begin{array}{c}\text { Decayed } \\
\text { Contact Dose } \\
\text { Rate }(\mathrm{mR} / \mathrm{hr})^{1} \\
\end{array}$} \\
\hline & & & Isotope & Activity (Ci) & & Isotope & Activity (Ci) & & \\
\hline & & & U-238 & $5.00 \mathrm{E}-08$ & & $\mathrm{U}-238$ & $5.00 \mathrm{E}-08$ & & \\
\hline & & & $\mathrm{Y}-90$ & $4.66 \mathrm{E}-02$ & & Y-90 & $2.49 \mathrm{E}-02$ & & \\
\hline \multirow[t]{30}{*}{222} & S830790 & 1983 & & & 2009 & Ac- 225 & $3.38 \mathrm{E}-15$ & 200,000 & 104,000 \\
\hline & & & & & & Ac-227 & $2.81 \mathrm{E}-09$ & & \\
\hline & & & & & & Ac-228 & $1.14 \mathrm{E}-15$ & & \\
\hline & & & & & & Am-241 & $2.47 \mathrm{E}-02$ & & \\
\hline & & & & & & At-217 & $3.38 \mathrm{E}-15$ & & \\
\hline & & & Ba-137m & $9.59 \mathrm{E}+00$ & & $\mathrm{Ba}-137 \mathrm{~m}$ & $5.24 \mathrm{E}+00$ & & \\
\hline & & & & & & Bi-210 & $1.31 \mathrm{E}-10$ & & \\
\hline & & & & & & Bi-211 & $2.77 \mathrm{E}-09$ & & \\
\hline & & & & & & $\mathrm{Bi}-212$ & $1.15 \mathrm{E}-15$ & & \\
\hline & & & & & & $\mathrm{Bi}-213$ & $3.38 \mathrm{E}-15$ & & \\
\hline & & & & & & $\mathrm{Bi}-214$ & $5.90 \mathrm{E}-10$ & & \\
\hline & & & Cs-137 & $1.02 \mathrm{E}+01$ & & Cs-137 & $5.60 \mathrm{E}+00$ & & \\
\hline & & & Eu-155 & $1.91 \mathrm{E}-01$ & & Eu-155 & $5.05 \mathrm{E}-03$ & & \\
\hline & & & & & & Fr-221 & $3.38 \mathrm{E}-15$ & & \\
\hline & & & & & & Fr-223 & $3.83 \mathrm{E}-11$ & & \\
\hline & & & & & & $\mathrm{Np}-237$ & $1.27 \mathrm{E}-07$ & & \\
\hline & & & & & & $\mathrm{Pa}-231$ & 8.79E-09 & & \\
\hline & & & & & & $\mathrm{Pa}-233$ & $1.26 \mathrm{E}-07$ & & \\
\hline & & & & & & $\mathrm{Pa}-234$ & $1.87 \mathrm{E}-09$ & & \\
\hline & & & & & & $\mathrm{Pa}-234 \mathrm{~m}$ & $1.44 \mathrm{E}-06$ & & \\
\hline & & & & & & $\mathrm{Pb}-209$ & $3.38 \mathrm{E}-15$ & & \\
\hline & & & & & & $\mathrm{Pb}-210$ & $1.33 \mathrm{E}-10$ & & \\
\hline & & & & & & $\mathrm{Pb}-211$ & $2.78 \mathrm{E}-09$ & & \\
\hline & & & & & & $\mathrm{Pb}-212$ & $1.14 \mathrm{E}-15$ & & \\
\hline & & & & & & $\mathrm{Pb}-214$ & $5.91 \mathrm{E}-10$ & & \\
\hline & & & Pm-147 & $5.83 \mathrm{E}-01$ & & Pm-147 & $6.11 \mathrm{E}-04$ & & \\
\hline & & & & & & Po-210 & $1.33 \mathrm{E}-10$ & & \\
\hline & & & & & & Po-211 & $8.47 \mathrm{E}-12$ & & \\
\hline & & & & & & Po-212 & $7.31 \mathrm{E}-16$ & & \\
\hline & & & & & & Рo-213 & $3.31 \mathrm{E}-15$ & & \\
\hline
\end{tabular}

${ }^{1}$ Calculated decayed contact dose rate. Rounded to nearest $10 \mathrm{mR} / \mathrm{hr}$ for values to 1000 ; rounded to nearest $100 \mathrm{mR} / \mathrm{hr}$ for values $>1000$ to 10,000 ; rounded to nearest $1000 \mathrm{mR} / \mathrm{hr}$ for values $>10,000$. * Initial contact dose rate assumed to be $1,000,000 \mathrm{mR} / \mathrm{hr}$; **Initial contact dose rate assumed to be $1,010,000 \mathrm{mR} / \mathrm{hr}$.

$$
99 \text { of } 168
$$


Appendix A-4 - Initial and Decayed Radionuclide and Dose Data for Lined Shafts

\begin{tabular}{|c|c|c|c|c|c|c|c|c|c|}
\hline \multirow[b]{2}{*}{ Shaft Number } & \multirow[b]{2}{*}{ Package ID } & \multirow[b]{2}{*}{ Base Year } & \multicolumn{2}{|c|}{ Initial Isotopic Distribution } & \multirow[b]{2}{*}{ Target Year } & \multicolumn{2}{|c|}{ Decayed Isotopic Distribution } & \multirow{2}{*}{$\begin{array}{c}\text { Initial Contact } \\
\text { Dose Rate } \\
(\mathrm{mR} / \mathrm{hr})\end{array}$} & \multirow{2}{*}{$\begin{array}{c}\text { Decayed } \\
\text { Contact Dose } \\
\text { Rate }(\mathrm{mR} / \mathrm{hr})^{1} \\
\end{array}$} \\
\hline & & & Isotope & Activity (Ci) & & Isotope & Activity (Ci) & & \\
\hline & & & & & & Po-214 & $5.91 \mathrm{E}-10$ & & \\
\hline & & & & & & Po-215 & $2.78 \mathrm{E}-09$ & & \\
\hline & & & & & & Po-216 & $1.14 \mathrm{E}-15$ & & \\
\hline & & & & & & Po-218 & $5.81 \mathrm{E}-10$ & & \\
\hline & & & $\mathrm{Pu}-238$ & $1.48 \mathrm{E}-02$ & & $\mathrm{Pu}-238$ & $1.21 \mathrm{E}-02$ & & \\
\hline & & & $\mathrm{Pu}-239$ & $1.64 \mathrm{E}-01$ & & $\mathrm{Pu}-239$ & $1.64 \mathrm{E}-01$ & & \\
\hline & & & $\mathrm{Pu}-240$ & $5.66 \mathrm{E}-02$ & & $\mathrm{Pu}-240$ & $5.64 \mathrm{E}-02$ & & \\
\hline & & & $\mathrm{Pu}-241$ & $1.07 \mathrm{E}+00$ & & $\mathrm{Pu}-241$ & $3.05 \mathrm{E}-01$ & & \\
\hline & & & $\mathrm{Pu}-242$ & $8.06 \mathrm{E}-06$ & & $\mathrm{Pu}-242$ & $8.06 \mathrm{E}-06$ & & \\
\hline & & & & & & Ra-223 & 2.81E-09 & & \\
\hline & & & & & & Ra-224 & $1.14 \mathrm{E}-15$ & & \\
\hline & & & & & & $\mathrm{Ra}-225$ & $3.38 \mathrm{E}-15$ & & \\
\hline & & & & & & $\mathrm{Ra}-226$ & $5.97 \mathrm{E}-10$ & & \\
\hline & & & & & & Ra-228 & $1.35 \mathrm{E}-15$ & & \\
\hline & & & Rh-106 & 7.49E-02 & & Rh-106 & $1.27 \mathrm{E}-09$ & & \\
\hline & & & & & & Rn-219 & 2.77E-09 & & \\
\hline & & & & & & $\mathrm{Rn}-220$ & $1.14 \mathrm{E}-15$ & & \\
\hline & & & & & & Rn-222 & $5.91 \mathrm{E}-10$ & & \\
\hline & & & Ru-106 & 7.49E-02 & & $\mathrm{Ru}-106$ & $1.29 \mathrm{E}-09$ & & \\
\hline & & & Sb-125 & $4.16 \mathrm{E}-01$ & & Sb-125 & $6.21 \mathrm{E}-04$ & & \\
\hline & & & & & & Sm-147 & $1.43 \mathrm{E}-11$ & & \\
\hline & & & Sr-90 & $9.34 \mathrm{E}+00$ & & Sr-90 & $5.03 \mathrm{E}+00$ & & \\
\hline & & & $\mathrm{Te}-125 \mathrm{~m}$ & $1.73 \mathrm{E}-01$ & & $\mathrm{Te}-125 \mathrm{~m}$ & $1.50 \mathrm{E}-04$ & & \\
\hline & & & & & & Th-227 & $2.73 \mathrm{E}-09$ & & \\
\hline & & & & & & Th-228 & $1.16 \mathrm{E}-15$ & & \\
\hline & & & & & & Th-229 & $3.39 \mathrm{E}-15$ & & \\
\hline & & & & & & Th-230 & $1.06 \mathrm{E}-07$ & & \\
\hline & & & & & & Th-231 & $1.58 \mathrm{E}-05$ & & \\
\hline & & & & & & Th-232 & $1.78 \mathrm{E}-15$ & & \\
\hline & & & & & & Th-234 & $1.44 \mathrm{E}-06$ & & \\
\hline & & & & & & Tl-207 & $2.76 \mathrm{E}-09$ & & \\
\hline & & & & & & Tl-208 & $4.12 \mathrm{E}-16$ & & \\
\hline
\end{tabular}

${ }^{1}$ Calculated decayed contact dose rate. Rounded to nearest $10 \mathrm{mR} / \mathrm{hr}$ for values to 1000 ; rounded to nearest $100 \mathrm{mR} / \mathrm{hr}$ for values $>1000$ to 10,000 ; rounded to nearest $1000 \mathrm{mR} / \mathrm{hr}$ for values $>10,000$. * Initial contact dose rate assumed to be $1,000,000 \mathrm{mR} / \mathrm{hr}$; **Initial contact dose rate assumed to be $1,010,000 \mathrm{mR} / \mathrm{hr}$.

100 of 168 
Appendix A-4 - Initial and Decayed Radionuclide and Dose Data for Lined Shafts

\begin{tabular}{|c|c|c|c|c|c|c|c|c|c|}
\hline \multirow[b]{2}{*}{ Shaft Number } & \multirow[b]{2}{*}{ Package ID } & \multirow[b]{2}{*}{ Base Year } & \multicolumn{2}{|c|}{ Initial Isotopic Distribution } & \multirow[b]{2}{*}{ Target Year } & \multicolumn{2}{|c|}{ Decayed Isotopic Distribution } & \multirow{2}{*}{$\begin{array}{c}\text { Initial Contact } \\
\text { Dose Rate } \\
(\mathrm{mR} / \mathrm{hr})\end{array}$} & \multirow{2}{*}{$\begin{array}{c}\text { Decayed } \\
\text { Contact Dose } \\
\text { Rate }(\mathrm{mR} / \mathrm{hr})^{1} \\
\end{array}$} \\
\hline & & & Isotope & Activity (Ci) & & Isotope & Activity (Ci) & & \\
\hline & & & & & & Tl-209 & $7.43 \mathrm{E}-17$ & & \\
\hline & & & & & & U-233 & $5.25 \mathrm{E}-12$ & & \\
\hline & & & U-234 & $4.55 \mathrm{E}-04$ & & $\mathrm{U}-234$ & $4.56 \mathrm{E}-04$ & & \\
\hline & & & U-235 & $1.60 \mathrm{E}-05$ & & U-235 & $1.60 \mathrm{E}-05$ & & \\
\hline & & & $\mathrm{U}-236$ & $1.36 \mathrm{E}-06$ & & $\mathrm{U}-236$ & $1.41 \mathrm{E}-06$ & & \\
\hline & & & & & & U-237 & $7.48 \mathrm{E}-06$ & & \\
\hline & & & $\mathrm{U}-238$ & $1.45 \mathrm{E}-06$ & & $\mathrm{U}-238$ & $1.45 \mathrm{E}-06$ & & \\
\hline & & & Y-90 & $9.33 \mathrm{E}+00$ & & Y-90 & $4.97 \mathrm{E}+00$ & & \\
\hline \multirow[t]{24}{*}{223} & S830782 & 1983 & & & 2009 & Ac- 225 & $5.81 \mathrm{E}-17$ & 100,000 & 52,000 \\
\hline & & & & & & Ac- 227 & $4.83 \mathrm{E}-11$ & & \\
\hline & & & & & & Ac- 228 & $1.96 \mathrm{E}-17$ & & \\
\hline & & & & & & Am-241 & $4.25 \mathrm{E}-04$ & & \\
\hline & & & & & & At-217 & $5.82 \mathrm{E}-17$ & & \\
\hline & & & $\mathrm{Ba}-137 \mathrm{~m}$ & $5.99 \mathrm{E}+00$ & & $\mathrm{Ba}-137 \mathrm{~m}$ & $3.27 \mathrm{E}+00$ & & \\
\hline & & & & & & Bi-210 & $2.26 \mathrm{E}-12$ & & \\
\hline & & & & & & Bi-211 & $4.77 \mathrm{E}-11$ & & \\
\hline & & & & & & Bi-212 & $1.97 \mathrm{E}-17$ & & \\
\hline & & & & & & Bi-213 & $5.80 \mathrm{E}-17$ & & \\
\hline & & & & & & $\mathrm{Bi}-214$ & $1.01 \mathrm{E}-11$ & & \\
\hline & & & Cs-137 & $6.38 \mathrm{E}+00$ & & Cs-137 & $3.50 \mathrm{E}+00$ & & \\
\hline & & & Eu-155 & $1.19 \mathrm{E}-01$ & & $\mathrm{Eu}-155$ & $3.15 \mathrm{E}-03$ & & \\
\hline & & & & & & Fr-221 & $5.81 \mathrm{E}-17$ & & \\
\hline & & & & & & Fr-223 & $6.59 \mathrm{E}-13$ & & \\
\hline & & & & & & $\mathrm{Np}-237$ & $2.18 \mathrm{E}-09$ & & \\
\hline & & & & & & $\mathrm{Pa}-231$ & $1.51 \mathrm{E}-10$ & & \\
\hline & & & & & & $\mathrm{Pa}-233$ & $2.16 \mathrm{E}-09$ & & \\
\hline & & & & & & $\mathrm{Pa}-234$ & $3.21 \mathrm{E}-11$ & & \\
\hline & & & & & & $\mathrm{Pa}-234 \mathrm{~m}$ & $2.47 \mathrm{E}-08$ & & \\
\hline & & & & & & $\mathrm{Pb}-209$ & $5.81 \mathrm{E}-17$ & & \\
\hline & & & & & & $\mathrm{Pb}-210$ & $2.29 \mathrm{E}-12$ & & \\
\hline & & & & & & $\mathrm{Pb}-211$ & $4.77 \mathrm{E}-11$ & & \\
\hline & & & & & & $\mathrm{Pb}-212$ & $1.97 \mathrm{E}-17$ & & \\
\hline
\end{tabular}

${ }^{1}$ Calculated decayed contact dose rate. Rounded to nearest $10 \mathrm{mR} / \mathrm{hr}$ for values to 1000 ; rounded to nearest $100 \mathrm{mR} / \mathrm{hr}$ for values $>1000$ to 10,000 ; rounded to nearest $1000 \mathrm{mR} / \mathrm{hr}$ for values $>10,000$. * Initial contact dose rate assumed to be $1,000,000 \mathrm{mR} / \mathrm{hr}$; **Initial contact dose rate assumed to be $1,010,000 \mathrm{mR} / \mathrm{hr}$.

$$
101 \text { of } 168
$$


Appendix A-4 - Initial and Decayed Radionuclide and Dose Data for Lined Shafts

\begin{tabular}{|c|c|c|c|c|c|c|c|c|c|}
\hline \multirow[b]{2}{*}{ Shaft Number } & \multirow[b]{2}{*}{ Package ID } & \multirow[b]{2}{*}{ Base Year } & \multicolumn{2}{|c|}{ Initial Isotopic Distribution } & \multirow[b]{2}{*}{ Target Year } & \multicolumn{2}{|c|}{ Decayed Isotopic Distribution } & \multirow{2}{*}{$\begin{array}{c}\text { Initial Contact } \\
\text { Dose Rate } \\
(\mathrm{mR} / \mathrm{hr}) \\
\end{array}$} & \multirow{2}{*}{$\begin{array}{c}\text { Decayed } \\
\text { Contact Dose } \\
\text { Rate }(\mathrm{mR} / \mathrm{hr})^{1} \\
\end{array}$} \\
\hline & & & Isotope & Activity (Ci) & & Isotope & Activity (Ci) & & \\
\hline & & & & & & $\mathrm{Pb}-214$ & $1.02 \mathrm{E}-11$ & & \\
\hline & & & Pm-147 & $3.65 \mathrm{E}-01$ & & Pm-147 & $3.77 \mathrm{E}-04$ & & \\
\hline & & & & & & Po-210 & $2.28 \mathrm{E}-12$ & & \\
\hline & & & & & & Po-211 & $1.45 \mathrm{E}-13$ & & \\
\hline & & & & & & Po-212 & $1.26 \mathrm{E}-17$ & & \\
\hline & & & & & & Po-213 & $5.68 \mathrm{E}-17$ & & \\
\hline & & & & & & Po-214 & $1.02 \mathrm{E}-11$ & & \\
\hline & & & & & & Po-215 & $4.77 \mathrm{E}-11$ & & \\
\hline & & & & & & Po-216 & $1.96 \mathrm{E}-17$ & & \\
\hline & & & & & & Po-218 & $9.98 \mathrm{E}-12$ & & \\
\hline & & & $\mathrm{Pu}-238$ & $2.55 \mathrm{E}-04$ & & $\mathrm{Pu}-238$ & $2.08 \mathrm{E}-04$ & & \\
\hline & & & $\mathrm{Pu}-239$ & $2.82 \mathrm{E}-03$ & & $\mathrm{Pu}-239$ & $2.82 \mathrm{E}-03$ & & \\
\hline & & & $\mathrm{Pu}-240$ & $9.72 \mathrm{E}-04$ & & $\mathrm{Pu}-240$ & $9.69 \mathrm{E}-04$ & & \\
\hline & & & $\mathrm{Pu}-241$ & $1.83 \mathrm{E}-02$ & & $\mathrm{Pu}-241$ & $5.23 \mathrm{E}-03$ & & \\
\hline & & & $\mathrm{Pu}-242$ & $1.38 \mathrm{E}-07$ & & $\mathrm{Pu}-242$ & $1.38 \mathrm{E}-07$ & & \\
\hline & & & & & & Ra-223 & $4.83 \mathrm{E}-11$ & & \\
\hline & & & & & & $\mathrm{Ra}-224$ & $1.96 \mathrm{E}-17$ & & \\
\hline & & & & & & Ra-225 & $5.81 \mathrm{E}-17$ & & \\
\hline & & & & & & $\mathrm{Ra}-226$ & $1.03 \mathrm{E}-11$ & & \\
\hline & & & & & & $\mathrm{Ra}-228$ & $2.32 \mathrm{E}-17$ & & \\
\hline & & & Rh-106 & $4.68 \mathrm{E}-02$ & & Rh-106 & $7.97 \mathrm{E}-10$ & & \\
\hline & & & & & & Rn-219 & $4.77 \mathrm{E}-11$ & & \\
\hline & & & & & & Rn-220 & $1.96 \mathrm{E}-17$ & & \\
\hline & & & & & & Rn-222 & $1.02 \mathrm{E}-11$ & & \\
\hline & & & $\mathrm{Ru}-106$ & $4.68 \mathrm{E}-02$ & & $\mathrm{Ru}-106$ & $8.05 \mathrm{E}-10$ & & \\
\hline & & & $\mathrm{Sb}-125$ & $2.60 \mathrm{E}-01$ & & $\mathrm{Sb}-125$ & $3.88 \mathrm{E}-04$ & & \\
\hline & & & & & & Sm-147 & $8.93 \mathrm{E}-12$ & & \\
\hline & & & Sr-90 & $5.84 \mathrm{E}+00$ & & Sr-90 & $3.14 \mathrm{E}+00$ & & \\
\hline & & & Te-125m & $1.08 \mathrm{E}-01$ & & Te-125m & $9.40 \mathrm{E}-05$ & & \\
\hline & & & & & & Th-227 & $4.70 \mathrm{E}-11$ & & \\
\hline & & & & & & Th-228 & $1.99 \mathrm{E}-17$ & & \\
\hline & & & & & & Th-229 & $5.82 \mathrm{E}-17$ & & \\
\hline
\end{tabular}

${ }^{1}$ Calculated decayed contact dose rate. Rounded to nearest $10 \mathrm{mR} / \mathrm{hr}$ for values to 1000 ; rounded to nearest $100 \mathrm{mR} / \mathrm{hr}$ for values $>1000$ to 10,000 ; rounded to nearest $1000 \mathrm{mR} / \mathrm{hr}$ for values $>10,000$. * Initial contact dose rate assumed to be $1,000,000 \mathrm{mR} / \mathrm{hr}$; **Initial contact dose rate assumed to be $1,010,000 \mathrm{mR} / \mathrm{hr}$.

$$
102 \text { of } 168
$$


Appendix A-4 - Initial and Decayed Radionuclide and Dose Data for Lined Shafts

\begin{tabular}{|c|c|c|c|c|c|c|c|c|c|}
\hline \multirow[b]{2}{*}{ Shaft Number } & \multirow[b]{2}{*}{ Package ID } & \multirow[b]{2}{*}{ Base Year } & \multicolumn{2}{|c|}{ Initial Isotopic Distribution } & \multirow[b]{2}{*}{ Target Year } & \multicolumn{2}{|c|}{ Decayed Isotopic Distribution } & \multirow{2}{*}{$\begin{array}{c}\text { Initial Contact } \\
\text { Dose Rate } \\
(\mathrm{mR} / \mathrm{hr})\end{array}$} & \multirow{2}{*}{$\begin{array}{c}\text { Decayed } \\
\text { Contact Dose } \\
\text { Rate }(\mathrm{mR} / \mathrm{hr})^{1} \\
\end{array}$} \\
\hline & & & Isotope & Activity (Ci) & & Isotope & Activity (Ci) & & \\
\hline & & & & & & Th-230 & $1.83 \mathrm{E}-09$ & & \\
\hline & & & & & & Th-231 & $2.71 \mathrm{E}-07$ & & \\
\hline & & & & & & Th-232 & $3.05 \mathrm{E}-17$ & & \\
\hline & & & & & & Th-234 & $2.48 \mathrm{E}-08$ & & \\
\hline & & & & & & Tl-207 & $4.75 \mathrm{E}-11$ & & \\
\hline & & & & & & Tl-208 & $7.07 \mathrm{E}-18$ & & \\
\hline & & & & & & T1-209 & $1.28 \mathrm{E}-18$ & & \\
\hline & & & & & & $\mathrm{U}-233$ & $9.02 \mathrm{E}-14$ & & \\
\hline & & & U-234 & 7.81E-06 & & U-234 & $7.83 \mathrm{E}-06$ & & \\
\hline & & & $\mathrm{U}-235$ & $2.75 \mathrm{E}-07$ & & $\mathrm{U}-235$ & $2.75 \mathrm{E}-07$ & & \\
\hline & & & $\mathrm{U}-236$ & $2.34 \mathrm{E}-08$ & & $\mathrm{U}-236$ & $2.41 \mathrm{E}-08$ & & \\
\hline & & & & & & U-237 & $1.29 \mathrm{E}-07$ & & \\
\hline & & & $\mathrm{U}-238$ & $2.50 \mathrm{E}-08$ & & $\mathrm{U}-238$ & $2.50 \mathrm{E}-08$ & & \\
\hline & & & Y-90 & $5.83 \mathrm{E}+00$ & & Y-90 & $3.11 \mathrm{E}+00$ & & \\
\hline \multirow[t]{18}{*}{223} & S830783 & 1983 & & & 2009 & Ac-225 & $1.16 \mathrm{E}-16$ & 25,000 & 13,000 \\
\hline & & & & & & Ac-227 & $9.66 \mathrm{E}-11$ & & \\
\hline & & & & & & Ac-228 & $3.93 \mathrm{E}-17$ & & \\
\hline & & & & & & Am-241 & $8.50 \mathrm{E}-04$ & & \\
\hline & & & & & & At-217 & $1.16 \mathrm{E}-16$ & & \\
\hline & & & Ba-137m & 7.19E-01 & & Ba-137m & $3.93 \mathrm{E}-01$ & & \\
\hline & & & & & & Bi-210 & $4.52 \mathrm{E}-12$ & & \\
\hline & & & & & & Bi-211 & $9.53 \mathrm{E}-11$ & & \\
\hline & & & & & & Bi-212 & $3.94 \mathrm{E}-17$ & & \\
\hline & & & & & & Bi-213 & $1.16 \mathrm{E}-16$ & & \\
\hline & & & & & & Bi-214 & $2.03 \mathrm{E}-11$ & & \\
\hline & & & Cs-137 & 7.66E-01 & & Cs-137 & 4.20E-01 & & \\
\hline & & & Eu-155 & $1.43 \mathrm{E}-02$ & & Eu-155 & $3.78 \mathrm{E}-04$ & & \\
\hline & & & & & & Fr-221 & $1.16 \mathrm{E}-16$ & & \\
\hline & & & & & & Fr-223 & $1.32 \mathrm{E}-12$ & & \\
\hline & & & & & & $\mathrm{Np}-237$ & $4.36 \mathrm{E}-09$ & & \\
\hline & & & & & & $\mathrm{Pa}-231$ & $3.02 \mathrm{E}-10$ & & \\
\hline & & & & & & $\mathrm{Pa}-233$ & 4.32E-09 & & \\
\hline
\end{tabular}

${ }^{1}$ Calculated decayed contact dose rate. Rounded to nearest $10 \mathrm{mR} / \mathrm{hr}$ for values to 1000 ; rounded to nearest $100 \mathrm{mR} / \mathrm{hr}$ for values $>1000$ to 10,000 ; rounded to nearest $1000 \mathrm{mR} / \mathrm{hr}$ for values $>10,000$. * Initial contact dose rate assumed to be $1,000,000 \mathrm{mR} / \mathrm{hr}$; **Initial contact dose rate assumed to be $1,010,000 \mathrm{mR} / \mathrm{hr}$.

$$
103 \text { of } 168
$$


Appendix A-4 - Initial and Decayed Radionuclide and Dose Data for Lined Shafts

\begin{tabular}{|c|c|c|c|c|c|c|c|c|c|}
\hline \multirow[b]{2}{*}{ Shaft Number } & \multirow[b]{2}{*}{ Package ID } & \multirow[b]{2}{*}{ Base Year } & \multicolumn{2}{|c|}{ Initial Isotopic Distribution } & \multirow[b]{2}{*}{ Target Year } & \multicolumn{2}{|c|}{ Decayed Isotopic Distribution } & \multirow{2}{*}{$\begin{array}{c}\text { Initial Contact } \\
\text { Dose Rate } \\
(\mathrm{mR} / \mathrm{hr})\end{array}$} & \multirow{2}{*}{$\begin{array}{c}\text { Decayed } \\
\text { Contact Dose } \\
\text { Rate }(\mathrm{mR} / \mathrm{hr})^{1}\end{array}$} \\
\hline & & & Isotope & Activity (Ci) & & Isotope & Activity (Ci) & & \\
\hline & & & & & & $\mathrm{Pa}-234$ & $6.43 \mathrm{E}-11$ & & \\
\hline & & & & & & $\mathrm{Pa}-234 \mathrm{~m}$ & $4.94 \mathrm{E}-08$ & & \\
\hline & & & & & & $\mathrm{Pb}-209$ & $1.16 \mathrm{E}-16$ & & \\
\hline & & & & & & $\mathrm{Pb}-210$ & $4.57 \mathrm{E}-12$ & & \\
\hline & & & & & & $\mathrm{Pb}-211$ & $9.55 \mathrm{E}-11$ & & \\
\hline & & & & & & $\mathrm{Pb}-212$ & $3.93 \mathrm{E}-17$ & & \\
\hline & & & & & & $\mathrm{Pb}-214$ & $2.03 \mathrm{E}-11$ & & \\
\hline & & & Pm-147 & 4.38E-02 & & Pm-147 & $4.54 \mathrm{E}-05$ & & \\
\hline & & & & & & Po-210 & $4.57 \mathrm{E}-12$ & & \\
\hline & & & & & & Po-211 & $2.91 \mathrm{E}-13$ & & \\
\hline & & & & & & Po-212 & $2.51 \mathrm{E}-17$ & & \\
\hline & & & & & & Po-213 & $1.14 \mathrm{E}-16$ & & \\
\hline & & & & & & Po-214 & $2.03 \mathrm{E}-11$ & & \\
\hline & & & & & & Po-215 & $9.55 \mathrm{E}-11$ & & \\
\hline & & & & & & Po-216 & $3.93 \mathrm{E}-17$ & & \\
\hline & & & & & & Po-218 & $2.00 \mathrm{E}-11$ & & \\
\hline & & & $\mathrm{Pu}-238$ & $5.10 \mathrm{E}-04$ & & $\mathrm{Pu}-238$ & 4.15E-04 & & \\
\hline & & & $\mathrm{Pu}-239$ & $5.65 \mathrm{E}-03$ & & $\mathrm{Pu}-239$ & $5.64 \mathrm{E}-03$ & & \\
\hline & & & $\mathrm{Pu}-240$ & $1.94 \mathrm{E}-03$ & & $\mathrm{Pu}-240$ & $1.94 \mathrm{E}-03$ & & \\
\hline & & & $\mathrm{Pu}-241$ & $3.66 \mathrm{E}-02$ & & $\mathrm{Pu}-241$ & $1.05 \mathrm{E}-02$ & & \\
\hline & & & $\mathrm{Pu}-242$ & 2.77E-07 & & $\mathrm{Pu}-242$ & $2.77 \mathrm{E}-07$ & & \\
\hline & & & & & & Ra-223 & $9.65 \mathrm{E}-11$ & & \\
\hline & & & & & & Ra-224 & $3.92 \mathrm{E}-17$ & & \\
\hline & & & & & & Ra-225 & $1.16 \mathrm{E}-16$ & & \\
\hline & & & & & & $\mathrm{Ra}-226$ & $2.05 \mathrm{E}-11$ & & \\
\hline & & & & & & $\mathrm{Ra}-228$ & $4.63 \mathrm{E}-17$ & & \\
\hline & & & Rh-106 & $5.62 \mathrm{E}-03$ & & Rh-106 & $9.56 \mathrm{E}-11$ & & \\
\hline & & & & & & Rn-219 & $9.53 \mathrm{E}-11$ & & \\
\hline & & & & & & Rn-220 & $3.93 \mathrm{E}-17$ & & \\
\hline & & & & & & Rn-222 & $2.03 \mathrm{E}-11$ & & \\
\hline & & & Ru-106 & $5.62 \mathrm{E}-03$ & & $\mathrm{Ru}-106$ & $9.66 \mathrm{E}-11$ & & \\
\hline & & & $\mathrm{Sb}-125$ & $3.12 \mathrm{E}-02$ & & $\mathrm{Sb}-125$ & 4.67E-05 & & \\
\hline
\end{tabular}

${ }^{1}$ Calculated decayed contact dose rate. Rounded to nearest $10 \mathrm{mR} / \mathrm{hr}$ for values to 1000 ; rounded to nearest $100 \mathrm{mR} / \mathrm{hr}$ for values $>1000$ to 10,000 ; rounded to nearest $1000 \mathrm{mR} / \mathrm{hr}$ for values $>10,000$. * Initial contact dose rate assumed to be $1,000,000 \mathrm{mR} / \mathrm{hr}$; **Initial contact dose rate assumed to be $1,010,000 \mathrm{mR} / \mathrm{hr}$.

$$
104 \text { of } 168
$$


Appendix A-4 - Initial and Decayed Radionuclide and Dose Data for Lined Shafts

\begin{tabular}{|c|c|c|c|c|c|c|c|c|c|}
\hline \multirow[b]{2}{*}{ Shaft Number } & \multirow[b]{2}{*}{ Package ID } & \multirow[b]{2}{*}{ Base Year } & \multicolumn{2}{|c|}{ Initial Isotopic Distribution } & \multirow[b]{2}{*}{ Target Year } & \multicolumn{2}{|c|}{ Decayed Isotopic Distribution } & \multirow{2}{*}{$\begin{array}{c}\text { Initial Contact } \\
\text { Dose Rate } \\
(\mathrm{mR} / \mathrm{hr})\end{array}$} & \multirow{2}{*}{$\begin{array}{c}\text { Decayed } \\
\text { Contact Dose } \\
\text { Rate }(\mathrm{mR} / \mathrm{hr})^{1} \\
\end{array}$} \\
\hline & & & Isotope & Activity (Ci) & & Isotope & Activity (Ci) & & \\
\hline & & & & & & Sm-147 & $1.07 \mathrm{E}-12$ & & \\
\hline & & & Sr-90 & $7.00 \mathrm{E}-01$ & & Sr-90 & $3.77 \mathrm{E}-01$ & & \\
\hline & & & $\mathrm{Te}-125 \mathrm{~m}$ & $1.30 \mathrm{E}-02$ & & $\mathrm{Te}-125 \mathrm{~m}$ & $1.13 \mathrm{E}-05$ & & \\
\hline & & & & & & Th-227 & $9.40 \mathrm{E}-11$ & & \\
\hline & & & & & & Th-228 & $3.97 \mathrm{E}-17$ & & \\
\hline & & & & & & Th-229 & $1.16 \mathrm{E}-16$ & & \\
\hline & & & & & & Th-230 & $3.66 \mathrm{E}-09$ & & \\
\hline & & & & & & Th-231 & $5.43 \mathrm{E}-07$ & & \\
\hline & & & & & & Th-232 & $6.11 \mathrm{E}-17$ & & \\
\hline & & & & & & Th-234 & 4.95E-08 & & \\
\hline & & & & & & Tl-207 & $9.49 \mathrm{E}-11$ & & \\
\hline & & & & & & T1-208 & $1.41 \mathrm{E}-17$ & & \\
\hline & & & & & & Tl-209 & $2.56 \mathrm{E}-18$ & & \\
\hline & & & & & & U-233 & $1.80 \mathrm{E}-13$ & & \\
\hline & & & $\mathrm{U}-234$ & $1.56 \mathrm{E}-05$ & & U-234 & $1.57 \mathrm{E}-05$ & & \\
\hline & & & $\mathrm{U}-235$ & $5.49 \mathrm{E}-07$ & & $\mathrm{U}-235$ & $5.50 \mathrm{E}-07$ & & \\
\hline & & & $\mathrm{U}-236$ & 4.68E-08 & & $\mathrm{U}-236$ & $4.83 \mathrm{E}-08$ & & \\
\hline & & & & & & $\mathrm{U}-237$ & $2.57 \mathrm{E}-07$ & & \\
\hline & & & $\mathrm{U}-238$ & $5.00 \mathrm{E}-08$ & & $\mathrm{U}-238$ & $5.00 \mathrm{E}-08$ & & \\
\hline & & & $\mathrm{Y}-90$ & $6.99 \mathrm{E}-01$ & & $\mathrm{Y}-90$ & $3.73 \mathrm{E}-01$ & & \\
\hline \multirow[t]{12}{*}{223} & S830784 & 1983 & & & 2009 & Ac- 225 & $1.16 \mathrm{E}-16$ & 30,000 & 16,000 \\
\hline & & & & & & Ac- 227 & $9.66 \mathrm{E}-11$ & & \\
\hline & & & & & & Ac-228 & $3.93 \mathrm{E}-17$ & & \\
\hline & & & & & & Am-241 & $8.50 \mathrm{E}-04$ & & \\
\hline & & & & & & At-217 & $1.16 \mathrm{E}-16$ & & \\
\hline & & & Ba-137m & 7.19E-01 & & Ba-137m & $3.93 \mathrm{E}-01$ & & \\
\hline & & & & & & Bi-210 & $4.52 \mathrm{E}-12$ & & \\
\hline & & & & & & $\mathrm{Bi}-211$ & $9.53 \mathrm{E}-11$ & & \\
\hline & & & & & & $\mathrm{Bi}-212$ & $3.94 \mathrm{E}-17$ & & \\
\hline & & & & & & Bi-213 & $1.16 \mathrm{E}-16$ & & \\
\hline & & & & & & Bi-214 & $2.03 \mathrm{E}-11$ & & \\
\hline & & & Cs-137 & $7.66 \mathrm{E}-01$ & & Cs-137 & $4.20 \mathrm{E}-01$ & & \\
\hline
\end{tabular}

${ }^{1}$ Calculated decayed contact dose rate. Rounded to nearest $10 \mathrm{mR} / \mathrm{hr}$ for values to 1000 ; rounded to nearest $100 \mathrm{mR} / \mathrm{hr}$ for values $>1000$ to 10,000 ; rounded to nearest $1000 \mathrm{mR} / \mathrm{hr}$ for values $>10,000$. * Initial contact dose rate assumed to be $1,000,000 \mathrm{mR} / \mathrm{hr}$; **Initial contact dose rate assumed to be $1,010,000 \mathrm{mR} / \mathrm{hr}$.

105 of 168 
Appendix A-4 - Initial and Decayed Radionuclide and Dose Data for Lined Shafts

\begin{tabular}{|c|c|c|c|c|c|c|c|c|c|}
\hline \multirow[b]{2}{*}{ Shaft Number } & \multirow[b]{2}{*}{ Package ID } & \multirow[b]{2}{*}{ Base Year } & \multicolumn{2}{|c|}{ Initial Isotopic Distribution } & \multirow[b]{2}{*}{ Target Year } & \multicolumn{2}{|c|}{ Decayed Isotopic Distribution } & \multirow{2}{*}{$\begin{array}{c}\text { Initial Contact } \\
\text { Dose Rate } \\
(\mathrm{mR} / \mathrm{hr})\end{array}$} & \multirow{2}{*}{$\begin{array}{c}\text { Decayed } \\
\text { Contact Dose } \\
\text { Rate }(\mathrm{mR} / \mathrm{hr})^{1}\end{array}$} \\
\hline & & & Isotope & Activity (Ci) & & Isotope & Activity (Ci) & & \\
\hline & & & Eu-155 & $1.43 \mathrm{E}-02$ & & Eu-155 & $3.78 \mathrm{E}-04$ & & \\
\hline & & & & & & Fr-221 & $1.16 \mathrm{E}-16$ & & \\
\hline & & & & & & Fr-223 & $1.32 \mathrm{E}-12$ & & \\
\hline & & & & & & $\mathrm{Np}-237$ & $4.36 \mathrm{E}-09$ & & \\
\hline & & & & & & $\mathrm{Pa}-231$ & $3.02 \mathrm{E}-10$ & & \\
\hline & & & & & & $\mathrm{Pa}-233$ & $4.32 \mathrm{E}-09$ & & \\
\hline & & & & & & $\mathrm{Pa}-234$ & $6.43 \mathrm{E}-11$ & & \\
\hline & & & & & & $\mathrm{Pa}-234 \mathrm{~m}$ & $4.94 \mathrm{E}-08$ & & \\
\hline & & & & & & $\mathrm{Pb}-209$ & $1.16 \mathrm{E}-16$ & & \\
\hline & & & & & & $\mathrm{Pb}-210$ & $4.57 \mathrm{E}-12$ & & \\
\hline & & & & & & $\mathrm{Pb}-211$ & $9.55 \mathrm{E}-11$ & & \\
\hline & & & & & & $\mathrm{Pb}-212$ & $3.93 \mathrm{E}-17$ & & \\
\hline & & & & & & $\mathrm{Pb}-214$ & $2.03 \mathrm{E}-11$ & & \\
\hline & & & Pm-147 & 4.38E-02 & & Pm-147 & $4.54 \mathrm{E}-05$ & & \\
\hline & & & & & & Po-210 & $4.57 \mathrm{E}-12$ & & \\
\hline & & & & & & Po-211 & $2.91 \mathrm{E}-13$ & & \\
\hline & & & & & & Po-212 & $2.51 \mathrm{E}-17$ & & \\
\hline & & & & & & Po-213 & $1.14 \mathrm{E}-16$ & & \\
\hline & & & & & & Po-214 & $2.03 \mathrm{E}-11$ & & \\
\hline & & & & & & Po-215 & $9.55 \mathrm{E}-11$ & & \\
\hline & & & & & & Po-216 & $3.93 \mathrm{E}-17$ & & \\
\hline & & & & & & Po-218 & $2.00 \mathrm{E}-11$ & & \\
\hline & & & $\mathrm{Pu}-238$ & $5.10 \mathrm{E}-04$ & & $\mathrm{Pu}-238$ & $4.15 \mathrm{E}-04$ & & \\
\hline & & & $\mathrm{Pu}-239$ & $5.65 \mathrm{E}-03$ & & $\mathrm{Pu}-239$ & $5.64 \mathrm{E}-03$ & & \\
\hline & & & $\mathrm{Pu}-240$ & $1.94 \mathrm{E}-03$ & & $\mathrm{Pu}-240$ & $1.94 \mathrm{E}-03$ & & \\
\hline & & & $\mathrm{Pu}-241$ & $3.66 \mathrm{E}-02$ & & $\mathrm{Pu}-241$ & $1.05 \mathrm{E}-02$ & & \\
\hline & & & $\mathrm{Pu}-242$ & $2.77 \mathrm{E}-07$ & & $\mathrm{Pu}-242$ & $2.77 \mathrm{E}-07$ & & \\
\hline & & & & & & Ra-223 & $9.65 \mathrm{E}-11$ & & \\
\hline & & & & & & Ra-224 & $3.92 \mathrm{E}-17$ & & \\
\hline & & & & & & $\mathrm{Ra}-225$ & $1.16 \mathrm{E}-16$ & & \\
\hline & & & & & & Ra-226 & $2.05 \mathrm{E}-11$ & & \\
\hline & & & & & & Ra-228 & $4.63 \mathrm{E}-17$ & & \\
\hline
\end{tabular}

${ }^{1}$ Calculated decayed contact dose rate. Rounded to nearest $10 \mathrm{mR} / \mathrm{hr}$ for values to 1000 ; rounded to nearest $100 \mathrm{mR} / \mathrm{hr}$ for values $>1000$ to 10,000 ; rounded to nearest $1000 \mathrm{mR} / \mathrm{hr}$ for values $>10,000$. * Initial contact dose rate assumed to be $1,000,000 \mathrm{mR} / \mathrm{hr}$; **Initial contact dose rate assumed to be $1,010,000 \mathrm{mR} / \mathrm{hr}$. 
Appendix A-4 - Initial and Decayed Radionuclide and Dose Data for Lined Shafts

\begin{tabular}{|c|c|c|c|c|c|c|c|c|c|}
\hline \multirow[b]{2}{*}{ Shaft Number } & \multirow[b]{2}{*}{ Package ID } & \multirow[b]{2}{*}{ Base Year } & \multicolumn{2}{|c|}{ Initial Isotopic Distribution } & \multirow[b]{2}{*}{ Target Year } & \multicolumn{2}{|c|}{ Decayed Isotopic Distribution } & \multirow{2}{*}{$\begin{array}{c}\text { Initial Contact } \\
\text { Dose Rate } \\
(\mathrm{mR} / \mathrm{hr})\end{array}$} & \multirow{2}{*}{$\begin{array}{c}\text { Decayed } \\
\text { Contact Dose } \\
\text { Rate }(\mathrm{mR} / \mathrm{hr})^{1} \\
\end{array}$} \\
\hline & & & Isotope & Activity (Ci) & & Isotope & Activity (Ci) & & \\
\hline & & & Rh-106 & $5.62 \mathrm{E}-03$ & & Rh-106 & $9.56 \mathrm{E}-11$ & & \\
\hline & & & & & & $\mathrm{Rn}-219$ & $9.53 \mathrm{E}-11$ & & \\
\hline & & & & & & $\mathrm{Rn}-220$ & $3.93 \mathrm{E}-17$ & & \\
\hline & & & & & & $\mathrm{Rn}-222$ & $2.03 \mathrm{E}-11$ & & \\
\hline & & & $\mathrm{Ru}-106$ & $5.62 \mathrm{E}-03$ & & $\mathrm{Ru}-106$ & $9.66 \mathrm{E}-11$ & & \\
\hline & & & $\mathrm{Sb}-125$ & $3.12 \mathrm{E}-02$ & & Sb-125 & $4.67 \mathrm{E}-05$ & & \\
\hline & & & & & & Sm-147 & $1.07 \mathrm{E}-12$ & & \\
\hline & & & Sr-90 & $7.00 \mathrm{E}-01$ & & Sr-90 & $3.77 \mathrm{E}-01$ & & \\
\hline & & & $\mathrm{Te}-125 \mathrm{~m}$ & $1.30 \mathrm{E}-02$ & & $\mathrm{Te}-125 \mathrm{~m}$ & $1.13 \mathrm{E}-05$ & & \\
\hline & & & & & & Th-227 & $9.40 \mathrm{E}-11$ & & \\
\hline & & & & & & Th-228 & $3.97 \mathrm{E}-17$ & & \\
\hline & & & & & & Th-229 & $1.16 \mathrm{E}-16$ & & \\
\hline & & & & & & Th-230 & $3.66 \mathrm{E}-09$ & & \\
\hline & & & & & & Th-231 & $5.43 \mathrm{E}-07$ & & \\
\hline & & & & & & Th-232 & $6.11 \mathrm{E}-17$ & & \\
\hline & & & & & & Th-234 & $4.95 \mathrm{E}-08$ & & \\
\hline & & & & & & Tl-207 & $9.49 \mathrm{E}-11$ & & \\
\hline & & & & & & Tl-208 & $1.41 \mathrm{E}-17$ & & \\
\hline & & & & & & Tl-209 & $2.56 \mathrm{E}-18$ & & \\
\hline & & & & & & U-233 & $1.80 \mathrm{E}-13$ & & \\
\hline & & & $\mathrm{U}-234$ & $1.56 \mathrm{E}-05$ & & U-234 & $1.57 \mathrm{E}-05$ & & \\
\hline & & & $\mathrm{U}-235$ & $5.49 \mathrm{E}-07$ & & U-235 & $5.50 \mathrm{E}-07$ & & \\
\hline & & & $\mathrm{U}-236$ & $4.68 \mathrm{E}-08$ & & U-236 & 4.83E-08 & & \\
\hline & & & & & & U-237 & $2.57 \mathrm{E}-07$ & & \\
\hline & & & U-238 & $5.00 \mathrm{E}-08$ & & U-238 & $5.00 \mathrm{E}-08$ & & \\
\hline & & & Y-90 & $6.99 \mathrm{E}-01$ & & Y-90 & $3.73 \mathrm{E}-01$ & & \\
\hline \multirow[t]{6}{*}{223} & S830785 & 1983 & & & 2009 & Ac- 225 & $1.16 \mathrm{E}-16$ & 70,000 & 36,000 \\
\hline & & & & & & Ac- 227 & $9.66 \mathrm{E}-11$ & & \\
\hline & & & & & & Ac- 228 & $3.93 \mathrm{E}-17$ & & \\
\hline & & & & & & Am-241 & $8.50 \mathrm{E}-04$ & & \\
\hline & & & & & & At-217 & $1.16 \mathrm{E}-16$ & & \\
\hline & & & $\mathrm{Ba}-137 \mathrm{~m}$ & 7.19E-01 & & Ba-137m & $3.93 \mathrm{E}-01$ & & \\
\hline
\end{tabular}

${ }^{1}$ Calculated decayed contact dose rate. Rounded to nearest $10 \mathrm{mR} / \mathrm{hr}$ for values to 1000 ; rounded to nearest $100 \mathrm{mR} / \mathrm{hr}$ for values $>1000$ to 10,000 ; rounded to nearest $1000 \mathrm{mR} / \mathrm{hr}$ for values $>10,000$. * Initial contact dose rate assumed to be $1,000,000 \mathrm{mR} / \mathrm{hr}$; **Initial contact dose rate assumed to be $1,010,000 \mathrm{mR} / \mathrm{hr}$.

$$
107 \text { of } 168
$$


Appendix A-4 - Initial and Decayed Radionuclide and Dose Data for Lined Shafts

\begin{tabular}{|c|c|c|c|c|c|c|c|c|c|}
\hline \multirow[b]{2}{*}{ Shaft Number } & \multirow[b]{2}{*}{ Package ID } & \multirow[b]{2}{*}{ Base Year } & \multicolumn{2}{|c|}{ Initial Isotopic Distribution } & \multirow[b]{2}{*}{ Target Year } & \multicolumn{2}{|c|}{ Decayed Isotopic Distribution } & \multirow{2}{*}{$\begin{array}{c}\text { Initial Contact } \\
\text { Dose Rate } \\
(\mathrm{mR} / \mathrm{hr})\end{array}$} & \multirow{2}{*}{$\begin{array}{c}\text { Decayed } \\
\text { Contact Dose } \\
\text { Rate }(\mathrm{mR} / \mathrm{hr})^{1}\end{array}$} \\
\hline & & & Isotope & Activity (Ci) & & Isotope & Activity (Ci) & & \\
\hline & & & & & & Bi-210 & $4.52 \mathrm{E}-12$ & & \\
\hline & & & & & & Bi-211 & $9.53 \mathrm{E}-11$ & & \\
\hline & & & & & & Bi-212 & $3.94 \mathrm{E}-17$ & & \\
\hline & & & & & & Bi-213 & $1.16 \mathrm{E}-16$ & & \\
\hline & & & & & & $\mathrm{Bi}-214$ & $2.03 \mathrm{E}-11$ & & \\
\hline & & & Cs-137 & $7.66 \mathrm{E}-01$ & & Cs-137 & $4.20 \mathrm{E}-01$ & & \\
\hline & & & $\mathrm{Eu}-155$ & $1.43 \mathrm{E}-02$ & & $\mathrm{Eu}-155$ & $3.78 \mathrm{E}-04$ & & \\
\hline & & & & & & Fr-221 & $1.16 \mathrm{E}-16$ & & \\
\hline & & & & & & Fr-223 & $1.32 \mathrm{E}-12$ & & \\
\hline & & & & & & $\mathrm{Np}-237$ & $4.36 \mathrm{E}-09$ & & \\
\hline & & & & & & $\mathrm{Pa}-231$ & $3.02 \mathrm{E}-10$ & & \\
\hline & & & & & & $\mathrm{Pa}-233$ & 4.32E-09 & & \\
\hline & & & & & & $\mathrm{Pa}-234$ & $6.43 \mathrm{E}-11$ & & \\
\hline & & & & & & $\mathrm{Pa}-234 \mathrm{~m}$ & 4.94E-08 & & \\
\hline & & & & & & $\mathrm{Pb}-209$ & $1.16 \mathrm{E}-16$ & & \\
\hline & & & & & & $\mathrm{Pb}-210$ & $4.57 \mathrm{E}-12$ & & \\
\hline & & & & & & $\mathrm{Pb}-211$ & $9.55 \mathrm{E}-11$ & & \\
\hline & & & & & & $\mathrm{Pb}-212$ & $3.93 \mathrm{E}-17$ & & \\
\hline & & & & & & $\mathrm{Pb}-214$ & $2.03 \mathrm{E}-11$ & & \\
\hline & & & Pm-147 & 4.38E-02 & & Pm-147 & $4.54 \mathrm{E}-05$ & & \\
\hline & & & & & & Po-210 & $4.57 \mathrm{E}-12$ & & \\
\hline & & & & & & Po-211 & $2.91 \mathrm{E}-13$ & & \\
\hline & & & & & & Po-212 & $2.51 \mathrm{E}-17$ & & \\
\hline & & & & & & Po-213 & $1.14 \mathrm{E}-16$ & & \\
\hline & & & & & & Po-214 & $2.03 \mathrm{E}-11$ & & \\
\hline & & & & & & Po-215 & $9.55 \mathrm{E}-11$ & & \\
\hline & & & & & & Po-216 & $3.93 \mathrm{E}-17$ & & \\
\hline & & & & & & Po-218 & $2.00 \mathrm{E}-11$ & & \\
\hline & & & $\mathrm{Pu}-238$ & $5.10 \mathrm{E}-04$ & & $\mathrm{Pu}-238$ & $4.15 \mathrm{E}-04$ & & \\
\hline & & & $\mathrm{Pu}-239$ & $5.65 \mathrm{E}-03$ & & Pu-239 & $5.64 \mathrm{E}-03$ & & \\
\hline & & & $\mathrm{Pu}-240$ & $1.94 \mathrm{E}-03$ & & $\mathrm{Pu}-240$ & $1.94 \mathrm{E}-03$ & & \\
\hline & & & $\mathrm{Pu}-241$ & $3.66 \mathrm{E}-02$ & & $\mathrm{Pu}-241$ & $1.05 \mathrm{E}-02$ & & \\
\hline
\end{tabular}

${ }^{1}$ Calculated decayed contact dose rate. Rounded to nearest $10 \mathrm{mR} / \mathrm{hr}$ for values to 1000 ; rounded to nearest $100 \mathrm{mR} / \mathrm{hr}$ for values $>1000$ to 10,000 ; rounded to nearest $1000 \mathrm{mR} / \mathrm{hr}$ for values $>10,000$. * Initial contact dose rate assumed to be $1,000,000 \mathrm{mR} / \mathrm{hr}$; **Initial contact dose rate assumed to be $1,010,000 \mathrm{mR} / \mathrm{hr}$.

$$
108 \text { of } 168
$$


Appendix A-4 - Initial and Decayed Radionuclide and Dose Data for Lined Shafts

\begin{tabular}{|c|c|c|c|c|c|c|c|c|c|}
\hline \multirow[b]{2}{*}{ Shaft Number } & \multirow[b]{2}{*}{ Package ID } & \multirow[b]{2}{*}{ Base Year } & \multicolumn{2}{|c|}{ Initial Isotopic Distribution } & \multirow[b]{2}{*}{ Target Year } & \multicolumn{2}{|c|}{ Decayed Isotopic Distribution } & \multirow{2}{*}{$\begin{array}{c}\text { Initial Contact } \\
\text { Dose Rate } \\
(\mathrm{mR} / \mathrm{hr})\end{array}$} & \multirow{2}{*}{$\begin{array}{c}\text { Decayed } \\
\text { Contact Dose } \\
\text { Rate }(\mathrm{mR} / \mathrm{hr})^{1} \\
\end{array}$} \\
\hline & & & Isotope & Activity (Ci) & & Isotope & Activity (Ci) & & \\
\hline & & & $\mathrm{Pu}-242$ & 2.77E-07 & & $\mathrm{Pu}-242$ & $2.77 \mathrm{E}-07$ & & \\
\hline & & & & & & $\mathrm{Ra}-223$ & $9.65 \mathrm{E}-11$ & & \\
\hline & & & & & & $\mathrm{Ra}-224$ & $3.92 \mathrm{E}-17$ & & \\
\hline & & & & & & $\mathrm{Ra}-225$ & $1.16 \mathrm{E}-16$ & & \\
\hline & & & & & & $\mathrm{Ra}-226$ & $2.05 \mathrm{E}-11$ & & \\
\hline & & & & & & $\mathrm{Ra}-228$ & $4.63 \mathrm{E}-17$ & & \\
\hline & & & $\mathrm{Rh}-106$ & $5.62 \mathrm{E}-03$ & & Rh-106 & $9.56 \mathrm{E}-11$ & & \\
\hline & & & & & & Rn-219 & $9.53 \mathrm{E}-11$ & & \\
\hline & & & & & & $\mathrm{Rn}-220$ & $3.93 \mathrm{E}-17$ & & \\
\hline & & & & & & Rn-222 & $2.03 \mathrm{E}-11$ & & \\
\hline & & & Ru-106 & $5.62 \mathrm{E}-03$ & & $\mathrm{Ru}-106$ & $9.66 \mathrm{E}-11$ & & \\
\hline & & & Sb-125 & $3.12 \mathrm{E}-02$ & & $\mathrm{Sb}-125$ & 4.67E-05 & & \\
\hline & & & & & & Sm-147 & $1.07 \mathrm{E}-12$ & & \\
\hline & & & Sr-90 & 7.00E-01 & & Sr-90 & $3.77 \mathrm{E}-01$ & & \\
\hline & & & Te-125m & $1.30 \mathrm{E}-02$ & & Te-125m & $1.13 \mathrm{E}-05$ & & \\
\hline & & & & & & Th-227 & $9.40 \mathrm{E}-11$ & & \\
\hline & & & & & & Th-228 & $3.97 \mathrm{E}-17$ & & \\
\hline & & & & & & Th-229 & $1.16 \mathrm{E}-16$ & & \\
\hline & & & & & & Th-230 & $3.66 \mathrm{E}-09$ & & \\
\hline & & & & & & Th-231 & $5.43 \mathrm{E}-07$ & & \\
\hline & & & & & & Th-232 & $6.11 \mathrm{E}-17$ & & \\
\hline & & & & & & Th-234 & $4.95 \mathrm{E}-08$ & & \\
\hline & & & & & & Tl-207 & $9.49 \mathrm{E}-11$ & & \\
\hline & & & & & & Tl-208 & $1.41 \mathrm{E}-17$ & & \\
\hline & & & & & & T1-209 & $2.56 \mathrm{E}-18$ & & \\
\hline & & & & & & U-233 & $1.80 \mathrm{E}-13$ & & \\
\hline & & & U-234 & $1.56 \mathrm{E}-05$ & & U-234 & $1.57 \mathrm{E}-05$ & & \\
\hline & & & U-235 & $5.49 \mathrm{E}-07$ & & U-235 & $5.50 \mathrm{E}-07$ & & \\
\hline & & & U-236 & $4.68 \mathrm{E}-08$ & & U-236 & $4.83 \mathrm{E}-08$ & & \\
\hline & & & & & & U-237 & $2.57 \mathrm{E}-07$ & & \\
\hline & & & U-238 & $5.00 \mathrm{E}-08$ & & U-238 & $5.00 \mathrm{E}-08$ & & \\
\hline & & & Y-90 & 6.99E-01 & & Y-90 & $3.73 \mathrm{E}-01$ & & \\
\hline
\end{tabular}

${ }^{1}$ Calculated decayed contact dose rate. Rounded to nearest $10 \mathrm{mR} / \mathrm{hr}$ for values to 1000 ; rounded to nearest $100 \mathrm{mR} / \mathrm{hr}$ for values $>1000$ to 10,000 ; rounded to nearest $1000 \mathrm{mR} / \mathrm{hr}$ for values $>10,000$. * Initial contact dose rate assumed to be $1,000,000 \mathrm{mR} / \mathrm{hr}$; **Initial contact dose rate assumed to be $1,010,000 \mathrm{mR} / \mathrm{hr}$.

$$
109 \text { of } 168
$$


Appendix A-4 - Initial and Decayed Radionuclide and Dose Data for Lined Shafts

\begin{tabular}{|c|c|c|c|c|c|c|c|c|c|}
\hline \multirow[b]{2}{*}{ Shaft Number } & \multirow[b]{2}{*}{ Package ID } & \multirow[b]{2}{*}{ Base Year } & \multicolumn{2}{|c|}{ Initial Isotopic Distribution } & \multirow[b]{2}{*}{ Target Year } & \multicolumn{2}{|c|}{ Decayed Isotopic Distribution } & \multirow{2}{*}{$\begin{array}{c}\text { Initial Contact } \\
\text { Dose Rate } \\
(\mathrm{mR} / \mathrm{hr})\end{array}$} & \multirow{2}{*}{$\begin{array}{c}\text { Decayed } \\
\text { Contact Dose } \\
\text { Rate }(\mathrm{mR} / \mathrm{hr})^{1} \\
\end{array}$} \\
\hline & & & Isotope & Activity (Ci) & & Isotope & Activity (Ci) & & \\
\hline \multirow[t]{32}{*}{223} & S830786 & 1983 & & & 2009 & Ac-225 & $5.81 \mathrm{E}-17$ & 20,000 & 10,000 \\
\hline & & & & & & Ac-227 & $4.83 \mathrm{E}-11$ & & \\
\hline & & & & & & Ac-228 & $1.96 \mathrm{E}-17$ & & \\
\hline & & & & & & Am-241 & $4.25 \mathrm{E}-04$ & & \\
\hline & & & & & & At-217 & $5.82 \mathrm{E}-17$ & & \\
\hline & & & $\mathrm{Ba}-137 \mathrm{~m}$ & $3.59 \mathrm{E}-01$ & & Ba-137m & $1.96 \mathrm{E}-01$ & & \\
\hline & & & & & & $\mathrm{Bi}-210$ & $2.26 \mathrm{E}-12$ & & \\
\hline & & & & & & Bi-211 & $4.77 \mathrm{E}-11$ & & \\
\hline & & & & & & Bi-212 & $1.97 \mathrm{E}-17$ & & \\
\hline & & & & & & Bi-213 & $5.80 \mathrm{E}-17$ & & \\
\hline & & & & & & $\mathrm{Bi}-214$ & $1.01 \mathrm{E}-11$ & & \\
\hline & & & Cs-137 & $3.83 \mathrm{E}-01$ & & Cs-137 & $2.10 \mathrm{E}-01$ & & \\
\hline & & & Eu-155 & 7.17E-03 & & Eu-155 & $1.89 \mathrm{E}-04$ & & \\
\hline & & & & & & Fr-221 & $5.81 \mathrm{E}-17$ & & \\
\hline & & & & & & Fr-223 & $6.59 \mathrm{E}-13$ & & \\
\hline & & & & & & $\mathrm{Np}-237$ & $2.18 \mathrm{E}-09$ & & \\
\hline & & & & & & $\mathrm{Pa}-231$ & $1.51 \mathrm{E}-10$ & & \\
\hline & & & & & & $\mathrm{Pa}-233$ & $2.16 \mathrm{E}-09$ & & \\
\hline & & & & & & $\mathrm{Pa}-234$ & $3.21 \mathrm{E}-11$ & & \\
\hline & & & & & & $\mathrm{Pa}-234 \mathrm{~m}$ & $2.47 \mathrm{E}-08$ & & \\
\hline & & & & & & Pb-209 & $5.81 \mathrm{E}-17$ & & \\
\hline & & & & & & $\mathrm{Pb}-210$ & $2.29 \mathrm{E}-12$ & & \\
\hline & & & & & & $\mathrm{Pb}-211$ & $4.77 \mathrm{E}-11$ & & \\
\hline & & & & & & $\mathrm{Pb}-212$ & $1.97 \mathrm{E}-17$ & & \\
\hline & & & & & & $\mathrm{Pb}-214$ & $1.02 \mathrm{E}-11$ & & \\
\hline & & & Pm-147 & 2.19E-02 & & Pm-147 & $2.27 \mathrm{E}-05$ & & \\
\hline & & & & & & Po-210 & $2.28 \mathrm{E}-12$ & & \\
\hline & & & & & & Po-211 & $1.45 \mathrm{E}-13$ & & \\
\hline & & & & & & Po-212 & $1.26 \mathrm{E}-17$ & & \\
\hline & & & & & & Po-213 & $5.68 \mathrm{E}-17$ & & \\
\hline & & & & & & Po-214 & $1.02 \mathrm{E}-11$ & & \\
\hline & & & & & & Po-215 & $4.77 \mathrm{E}-11$ & & \\
\hline
\end{tabular}

${ }^{1}$ Calculated decayed contact dose rate. Rounded to nearest $10 \mathrm{mR} / \mathrm{hr}$ for values to 1000 ; rounded to nearest $100 \mathrm{mR} / \mathrm{hr}$ for values $>1000$ to 10,000 ; rounded to nearest $1000 \mathrm{mR} / \mathrm{hr}$ for values $>10,000$. * Initial contact dose rate assumed to be $1,000,000 \mathrm{mR} / \mathrm{hr}$; **Initial contact dose rate assumed to be $1,010,000 \mathrm{mR} / \mathrm{hr}$.

$$
110 \text { of } 168
$$


Appendix A-4 - Initial and Decayed Radionuclide and Dose Data for Lined Shafts

\begin{tabular}{|c|c|c|c|c|c|c|c|c|c|}
\hline \multirow[b]{2}{*}{ Shaft Number } & \multirow[b]{2}{*}{ Package ID } & \multirow[b]{2}{*}{ Base Year } & \multicolumn{2}{|c|}{ Initial Isotopic Distribution } & \multirow[b]{2}{*}{ Target Year } & \multicolumn{2}{|c|}{ Decayed Isotopic Distribution } & \multirow{2}{*}{$\begin{array}{c}\text { Initial Contact } \\
\text { Dose Rate } \\
(\mathrm{mR} / \mathrm{hr}) \\
\end{array}$} & \multirow{2}{*}{$\begin{array}{c}\text { Decayed } \\
\text { Contact Dose } \\
\text { Rate }(\mathrm{mR} / \mathrm{hr})^{1} \\
\end{array}$} \\
\hline & & & Isotope & Activity (Ci) & & Isotope & Activity (Ci) & & \\
\hline & & & & & & Po-216 & $1.96 \mathrm{E}-17$ & & \\
\hline & & & & & & Po-218 & $9.98 \mathrm{E}-12$ & & \\
\hline & & & $\mathrm{Pu}-238$ & $2.55 \mathrm{E}-04$ & & $\mathrm{Pu}-238$ & $2.08 \mathrm{E}-04$ & & \\
\hline & & & $\mathrm{Pu}-239$ & $2.82 \mathrm{E}-03$ & & $\mathrm{Pu}-239$ & $2.82 \mathrm{E}-03$ & & \\
\hline & & & $\mathrm{Pu}-240$ & 9.72E-04 & & $\mathrm{Pu}-240$ & $9.69 \mathrm{E}-04$ & & \\
\hline & & & $\mathrm{Pu}-241$ & $1.83 \mathrm{E}-02$ & & $\mathrm{Pu}-241$ & $5.23 \mathrm{E}-03$ & & \\
\hline & & & $\mathrm{Pu}-242$ & $1.38 \mathrm{E}-07$ & & $\mathrm{Pu}-242$ & $1.38 \mathrm{E}-07$ & & \\
\hline & & & & & & Ra-223 & $4.83 \mathrm{E}-11$ & & \\
\hline & & & & & & $\mathrm{Ra}-224$ & $1.96 \mathrm{E}-17$ & & \\
\hline & & & & & & Ra-225 & $5.81 \mathrm{E}-17$ & & \\
\hline & & & & & & $\mathrm{Ra}-226$ & $1.03 \mathrm{E}-11$ & & \\
\hline & & & & & & $\mathrm{Ra}-228$ & $2.32 \mathrm{E}-17$ & & \\
\hline & & & Rh-106 & $2.81 \mathrm{E}-03$ & & Rh-106 & $4.78 \mathrm{E}-11$ & & \\
\hline & & & & & & $\mathrm{Rn}-219$ & $4.77 \mathrm{E}-11$ & & \\
\hline & & & & & & $\mathrm{Rn}-220$ & $1.96 \mathrm{E}-17$ & & \\
\hline & & & & & & $\mathrm{Rn}-222$ & $1.02 \mathrm{E}-11$ & & \\
\hline & & & $\mathrm{Ru}-106$ & $2.81 \mathrm{E}-03$ & & $\mathrm{Ru}-106$ & $4.83 \mathrm{E}-11$ & & \\
\hline & & & $\mathrm{Sb}-125$ & $1.56 \mathrm{E}-02$ & & $\mathrm{Sb}-125$ & $2.34 \mathrm{E}-05$ & & \\
\hline & & & & & & Sm-147 & $5.36 \mathrm{E}-13$ & & \\
\hline & & & Sr-90 & $3.50 \mathrm{E}-01$ & & Sr-90 & $1.89 \mathrm{E}-01$ & & \\
\hline & & & $\mathrm{Te}-125 \mathrm{~m}$ & $6.48 \mathrm{E}-03$ & & Te-125m & $5.66 \mathrm{E}-06$ & & \\
\hline & & & & & & Th-227 & $4.70 \mathrm{E}-11$ & & \\
\hline & & & & & & Th-228 & $1.99 \mathrm{E}-17$ & & \\
\hline & & & & & & Th-229 & $5.82 \mathrm{E}-17$ & & \\
\hline & & & & & & Th-230 & $1.83 \mathrm{E}-09$ & & \\
\hline & & & & & & Th-231 & $2.71 \mathrm{E}-07$ & & \\
\hline & & & & & & Th-232 & $3.05 \mathrm{E}-17$ & & \\
\hline & & & & & & Th-234 & $2.48 \mathrm{E}-08$ & & \\
\hline & & & & & & T1-207 & $4.75 \mathrm{E}-11$ & & \\
\hline & & & & & & Tl-208 & 7.07E-18 & & \\
\hline & & & & & & T1-209 & $1.28 \mathrm{E}-18$ & & \\
\hline & & & & & & U-233 & $9.02 \mathrm{E}-14$ & & \\
\hline
\end{tabular}

${ }^{1}$ Calculated decayed contact dose rate. Rounded to nearest $10 \mathrm{mR} / \mathrm{hr}$ for values to 1000 ; rounded to nearest $100 \mathrm{mR} / \mathrm{hr}$ for values $>1000$ to 10,000 ; rounded to nearest $1000 \mathrm{mR} / \mathrm{hr}$ for values $>10,000$. * Initial contact dose rate assumed to be $1,000,000 \mathrm{mR} / \mathrm{hr}$; **Initial contact dose rate assumed to be $1,010,000 \mathrm{mR} / \mathrm{hr}$.

$$
111 \text { of } 168
$$


Appendix A-4 - Initial and Decayed Radionuclide and Dose Data for Lined Shafts

\begin{tabular}{|c|c|c|c|c|c|c|c|c|c|}
\hline \multirow[b]{2}{*}{ Shaft Number } & \multirow[b]{2}{*}{ Package ID } & \multirow[b]{2}{*}{ Base Year } & \multicolumn{2}{|c|}{ Initial Isotopic Distribution } & \multirow[b]{2}{*}{ Target Year } & \multicolumn{2}{|c|}{ Decayed Isotopic Distribution } & \multirow{2}{*}{$\begin{array}{c}\text { Initial Contact } \\
\text { Dose Rate } \\
(\mathrm{mR} / \mathrm{hr})\end{array}$} & \multirow{2}{*}{$\begin{array}{c}\text { Decayed } \\
\text { Contact Dose } \\
\text { Rate }(\mathrm{mR} / \mathrm{hr})^{1} \\
\end{array}$} \\
\hline & & & Isotope & Activity (Ci) & & Isotope & Activity (Ci) & & \\
\hline & & & $\mathrm{U}-234$ & $7.81 \mathrm{E}-06$ & & U-234 & $7.83 \mathrm{E}-06$ & & \\
\hline & & & $\mathrm{U}-235$ & $2.75 \mathrm{E}-07$ & & $\mathrm{U}-235$ & $2.75 \mathrm{E}-07$ & & \\
\hline & & & $\mathrm{U}-236$ & $2.34 \mathrm{E}-08$ & & $\mathrm{U}-236$ & $2.41 \mathrm{E}-08$ & & \\
\hline & & & & & & U-237 & $1.29 \mathrm{E}-07$ & & \\
\hline & & & $\mathrm{U}-238$ & $2.50 \mathrm{E}-08$ & & U-238 & $2.50 \mathrm{E}-08$ & & \\
\hline & & & $\mathrm{Y}-90$ & $3.50 \mathrm{E}-01$ & & Y-90 & $1.86 \mathrm{E}-01$ & & \\
\hline \multirow[t]{26}{*}{223} & S830791 & 1983 & & & 2009 & Ac-225 & $1.16 \mathrm{E}-16$ & 32,000 & 17,000 \\
\hline & & & & & & Ac-227 & $9.66 \mathrm{E}-11$ & & \\
\hline & & & & & & Ac-228 & $3.93 \mathrm{E}-17$ & & \\
\hline & & & & & & Am-241 & $8.50 \mathrm{E}-04$ & & \\
\hline & & & & & & At-217 & $1.16 \mathrm{E}-16$ & & \\
\hline & & & Ba-137m & $3.59 \mathrm{E}-01$ & & $\mathrm{Ba}-137 \mathrm{~m}$ & $1.96 \mathrm{E}-01$ & & \\
\hline & & & & & & $\mathrm{Bi}-210$ & $4.52 \mathrm{E}-12$ & & \\
\hline & & & & & & Bi-211 & $9.53 \mathrm{E}-11$ & & \\
\hline & & & & & & Bi-212 & $3.94 \mathrm{E}-17$ & & \\
\hline & & & & & & Bi-213 & $1.16 \mathrm{E}-16$ & & \\
\hline & & & & & & $\mathrm{Bi}-214$ & $2.03 \mathrm{E}-11$ & & \\
\hline & & & Cs-137 & $3.83 \mathrm{E}-01$ & & Cs-137 & $2.10 \mathrm{E}-01$ & & \\
\hline & & & Eu-155 & 7.17E-03 & & Eu-155 & $1.89 \mathrm{E}-04$ & & \\
\hline & & & & & & Fr-221 & $1.16 \mathrm{E}-16$ & & \\
\hline & & & & & & Fr-223 & $1.32 \mathrm{E}-12$ & & \\
\hline & & & & & & $\mathrm{Np}-237$ & 4.36E-09 & & \\
\hline & & & & & & $\mathrm{Pa}-231$ & $3.02 \mathrm{E}-10$ & & \\
\hline & & & & & & $\mathrm{Pa}-233$ & $4.32 \mathrm{E}-09$ & & \\
\hline & & & & & & $\mathrm{Pa}-234$ & $6.43 \mathrm{E}-11$ & & \\
\hline & & & & & & $\mathrm{Pa}-234 \mathrm{~m}$ & 4.94E-08 & & \\
\hline & & & & & & $\mathrm{Pb}-209$ & $1.16 \mathrm{E}-16$ & & \\
\hline & & & & & & $\mathrm{Pb}-210$ & $4.57 \mathrm{E}-12$ & & \\
\hline & & & & & & $\mathrm{Pb}-211$ & $9.55 \mathrm{E}-11$ & & \\
\hline & & & & & & $\mathrm{Pb}-212$ & $3.93 \mathrm{E}-17$ & & \\
\hline & & & & & & $\mathrm{Pb}-214$ & $2.03 \mathrm{E}-11$ & & \\
\hline & & & Pm-147 & $2.19 \mathrm{E}-02$ & & Pm-147 & $2.27 \mathrm{E}-05$ & & \\
\hline
\end{tabular}

${ }^{1}$ Calculated decayed contact dose rate. Rounded to nearest $10 \mathrm{mR} / \mathrm{hr}$ for values to 1000 ; rounded to nearest $100 \mathrm{mR} / \mathrm{hr}$ for values $>1000$ to 10,000 ; rounded to nearest $1000 \mathrm{mR} / \mathrm{hr}$ for values $>10,000$. * Initial contact dose rate assumed to be $1,000,000 \mathrm{mR} / \mathrm{hr}$; **Initial contact dose rate assumed to be $1,010,000 \mathrm{mR} / \mathrm{hr}$.

$$
112 \text { of } 168
$$


Appendix A-4 - Initial and Decayed Radionuclide and Dose Data for Lined Shafts

\begin{tabular}{|c|c|c|c|c|c|c|c|c|c|}
\hline \multirow[b]{2}{*}{ Shaft Number } & \multirow[b]{2}{*}{ Package ID } & \multirow[b]{2}{*}{ Base Year } & \multicolumn{2}{|c|}{ Initial Isotopic Distribution } & \multirow[b]{2}{*}{ Target Year } & \multicolumn{2}{|c|}{ Decayed Isotopic Distribution } & \multirow{2}{*}{$\begin{array}{c}\text { Initial Contact } \\
\text { Dose Rate } \\
(\mathrm{mR} / \mathrm{hr})\end{array}$} & \multirow{2}{*}{$\begin{array}{c}\text { Decayed } \\
\text { Contact Dose } \\
\text { Rate }(\mathrm{mR} / \mathrm{hr})^{1} \\
\end{array}$} \\
\hline & & & Isotope & Activity (Ci) & & Isotope & Activity (Ci) & & \\
\hline & & & & & & Po-210 & $4.57 \mathrm{E}-12$ & & \\
\hline & & & & & & Po-211 & $2.91 \mathrm{E}-13$ & & \\
\hline & & & & & & Po-212 & $2.51 \mathrm{E}-17$ & & \\
\hline & & & & & & Po-213 & $1.14 \mathrm{E}-16$ & & \\
\hline & & & & & & Po-214 & $2.03 \mathrm{E}-11$ & & \\
\hline & & & & & & Po-215 & $9.55 \mathrm{E}-11$ & & \\
\hline & & & & & & Po-216 & $3.93 \mathrm{E}-17$ & & \\
\hline & & & & & & Po-218 & $2.00 \mathrm{E}-11$ & & \\
\hline & & & $\mathrm{Pu}-238$ & $5.10 \mathrm{E}-04$ & & $\mathrm{Pu}-238$ & $4.15 \mathrm{E}-04$ & & \\
\hline & & & $\mathrm{Pu}-239$ & $5.65 \mathrm{E}-03$ & & $\mathrm{Pu}-239$ & $5.64 \mathrm{E}-03$ & & \\
\hline & & & $\mathrm{Pu}-240$ & $1.94 \mathrm{E}-03$ & & $\mathrm{Pu}-240$ & $1.94 \mathrm{E}-03$ & & \\
\hline & & & $\mathrm{Pu}-241$ & $3.66 \mathrm{E}-02$ & & $\mathrm{Pu}-241$ & $1.05 \mathrm{E}-02$ & & \\
\hline & & & $\mathrm{Pu}-242$ & $2.77 \mathrm{E}-07$ & & $\mathrm{Pu}-242$ & $2.77 \mathrm{E}-07$ & & \\
\hline & & & & & & Ra-223 & $9.65 \mathrm{E}-11$ & & \\
\hline & & & & & & $\mathrm{Ra}-224$ & $3.92 \mathrm{E}-17$ & & \\
\hline & & & & & & Ra-225 & $1.16 \mathrm{E}-16$ & & \\
\hline & & & & & & Ra-226 & $2.05 \mathrm{E}-11$ & & \\
\hline & & & & & & Ra-228 & 4.63E-17 & & \\
\hline & & & Rh-106 & $2.81 \mathrm{E}-03$ & & Rh-106 & $4.78 \mathrm{E}-11$ & & \\
\hline & & & & & & Rn-219 & $9.53 \mathrm{E}-11$ & & \\
\hline & & & & & & $\mathrm{Rn}-220$ & $3.93 \mathrm{E}-17$ & & \\
\hline & & & & & & Rn-222 & $2.03 \mathrm{E}-11$ & & \\
\hline & & & $\mathrm{Ru}-106$ & $2.81 \mathrm{E}-03$ & & $\mathrm{Ru}-106$ & $4.83 \mathrm{E}-11$ & & \\
\hline & & & Sb-125 & $1.56 \mathrm{E}-02$ & & Sb-125 & $2.34 \mathrm{E}-05$ & & \\
\hline & & & & & & Sm-147 & $5.36 \mathrm{E}-13$ & & \\
\hline & & & Sr-90 & $3.50 \mathrm{E}-01$ & & Sr-90 & $1.89 \mathrm{E}-01$ & & \\
\hline & & & Te-125m & $6.48 \mathrm{E}-03$ & & $\mathrm{Te}-125 \mathrm{~m}$ & $5.66 \mathrm{E}-06$ & & \\
\hline & & & & & & Th-227 & $9.40 \mathrm{E}-11$ & & \\
\hline & & & & & & Th-228 & $3.97 \mathrm{E}-17$ & & \\
\hline & & & & & & Th-229 & $1.16 \mathrm{E}-16$ & & \\
\hline & & & & & & Th-230 & $3.66 \mathrm{E}-09$ & & \\
\hline & & & & & & Th-231 & $5.43 \mathrm{E}-07$ & & \\
\hline
\end{tabular}

${ }^{1}$ Calculated decayed contact dose rate. Rounded to nearest $10 \mathrm{mR} / \mathrm{hr}$ for values to 1000 ; rounded to nearest $100 \mathrm{mR} / \mathrm{hr}$ for values $>1000$ to 10,000 ; rounded to nearest $1000 \mathrm{mR} / \mathrm{hr}$ for values $>10,000$. * Initial contact dose rate assumed to be $1,000,000 \mathrm{mR} / \mathrm{hr}$; **Initial contact dose rate assumed to be $1,010,000 \mathrm{mR} / \mathrm{hr}$.

$$
113 \text { of } 168
$$


Appendix A-4 - Initial and Decayed Radionuclide and Dose Data for Lined Shafts

\begin{tabular}{|c|c|c|c|c|c|c|c|c|c|}
\hline \multirow[b]{2}{*}{ Shaft Number } & \multirow[b]{2}{*}{ Package ID } & \multirow[b]{2}{*}{ Base Year } & \multicolumn{2}{|c|}{ Initial Isotopic Distribution } & \multirow[b]{2}{*}{ Target Year } & \multicolumn{2}{|c|}{ Decayed Isotopic Distribution } & \multirow{2}{*}{$\begin{array}{c}\text { Initial Contact } \\
\text { Dose Rate } \\
(\mathrm{mR} / \mathrm{hr})\end{array}$} & \multirow{2}{*}{$\begin{array}{c}\text { Decayed } \\
\text { Contact Dose } \\
\text { Rate }(\mathrm{mR} / \mathrm{hr})^{1} \\
\end{array}$} \\
\hline & & & Isotope & Activity (Ci) & & Isotope & Activity (Ci) & & \\
\hline & & & & & & Th-232 & $6.11 \mathrm{E}-17$ & & \\
\hline & & & & & & Th-234 & $4.95 \mathrm{E}-08$ & & \\
\hline & & & & & & $\mathrm{Tl}-207$ & $9.49 \mathrm{E}-11$ & & \\
\hline & & & & & & T1-208 & $1.41 \mathrm{E}-17$ & & \\
\hline & & & & & & T1-209 & $2.56 \mathrm{E}-18$ & & \\
\hline & & & & & & U-233 & $1.80 \mathrm{E}-13$ & & \\
\hline & & & $\mathrm{U}-234$ & $1.56 \mathrm{E}-05$ & & $\mathrm{U}-234$ & $1.57 \mathrm{E}-05$ & & \\
\hline & & & $\mathrm{U}-235$ & $5.49 \mathrm{E}-07$ & & $\mathrm{U}-235$ & $5.50 \mathrm{E}-07$ & & \\
\hline & & & U-236 & $4.68 \mathrm{E}-08$ & & U-236 & $4.83 \mathrm{E}-08$ & & \\
\hline & & & & & & U-237 & $2.57 \mathrm{E}-07$ & & \\
\hline & & & $\mathrm{U}-238$ & $5.00 \mathrm{E}-08$ & & $\mathrm{U}-238$ & $5.00 \mathrm{E}-08$ & & \\
\hline & & & $\mathrm{Y}-90$ & $3.50 \mathrm{E}-01$ & & Y-90 & $1.86 \mathrm{E}-01$ & & \\
\hline \multirow[t]{20}{*}{224} & S852326 & 1985 & & & 2009 & Ac-227 & $1.34 \mathrm{E}-10$ & 300,000 & 163,000 \\
\hline & & & Ba-137m & $9.59 \mathrm{E}-01$ & & $\mathrm{Ba}-137 \mathrm{~m}$ & $5.49 \mathrm{E}-01$ & & \\
\hline & & & & & & Bi-211 & $1.33 \mathrm{E}-10$ & & \\
\hline & & & Cs-137 & $1.02 \mathrm{E}+00$ & & Cs-137 & $5.87 \mathrm{E}-01$ & & \\
\hline & & & Eu-155 & $1.91 \mathrm{E}-02$ & & Eu-155 & $6.67 \mathrm{E}-04$ & & \\
\hline & & & & & & Fr-223 & $1.83 \mathrm{E}-12$ & & \\
\hline & & & & & & $\mathrm{Pa}-231$ & $4.46 \mathrm{E}-10$ & & \\
\hline & & & & & & $\mathrm{Pb}-211$ & $1.33 \mathrm{E}-10$ & & \\
\hline & & & Pm-147 & $5.83 \mathrm{E}-02$ & & Pm-147 & $1.03 \mathrm{E}-04$ & & \\
\hline & & & & & & Po-211 & $4.05 \mathrm{E}-13$ & & \\
\hline & & & & & & Po-215 & $1.33 \mathrm{E}-10$ & & \\
\hline & & & $\mathrm{Pu}-239$ & $6.20 \mathrm{E}-03$ & & $\mathrm{Pu}-239$ & $6.20 \mathrm{E}-03$ & & \\
\hline & & & & & & Ra-223 & $1.34 \mathrm{E}-10$ & & \\
\hline & & & Rh-106 & 7.49E-03 & & Rh-106 & $5.04 \mathrm{E}-10$ & & \\
\hline & & & & & & $\mathrm{Rn}-219$ & $1.33 \mathrm{E}-10$ & & \\
\hline & & & Ru-106 & 7.49E-03 & & Ru-106 & $5.09 \mathrm{E}-10$ & & \\
\hline & & & Sb-125 & $4.16 \mathrm{E}-02$ & & Sb-125 & $1.02 \mathrm{E}-04$ & & \\
\hline & & & & & & Sm-147 & $1.43 \mathrm{E}-12$ & & \\
\hline & & & Sr-90 & $9.34 \mathrm{E}-01$ & & Sr-90 & $5.27 \mathrm{E}-01$ & & \\
\hline & & & $\mathrm{Te}-125 \mathrm{~m}$ & $1.73 \mathrm{E}-02$ & & $\mathrm{Te}-125 \mathrm{~m}$ & $2.48 \mathrm{E}-05$ & & \\
\hline
\end{tabular}

${ }^{1}$ Calculated decayed contact dose rate. Rounded to nearest $10 \mathrm{mR} / \mathrm{hr}$ for values to 1000 ; rounded to nearest $100 \mathrm{mR} / \mathrm{hr}$ for values $>1000$ to 10,000 ; rounded to nearest $1000 \mathrm{mR} / \mathrm{hr}$ for values $>10,000$. * Initial contact dose rate assumed to be $1,000,000 \mathrm{mR} / \mathrm{hr}$; **Initial contact dose rate assumed to be $1,010,000 \mathrm{mR} / \mathrm{hr}$.

$$
114 \text { of } 168
$$


Appendix A-4 - Initial and Decayed Radionuclide and Dose Data for Lined Shafts

\begin{tabular}{|c|c|c|c|c|c|c|c|c|c|}
\hline \multirow[b]{2}{*}{ Shaft Number } & \multirow[b]{2}{*}{ Package ID } & \multirow[b]{2}{*}{ Base Year } & \multicolumn{2}{|c|}{ Initial Isotopic Distribution } & \multirow[b]{2}{*}{ Target Year } & \multicolumn{2}{|c|}{ Decayed Isotopic Distribution } & \multirow{2}{*}{$\begin{array}{c}\text { Initial Contact } \\
\text { Dose Rate } \\
(\mathrm{mR} / \mathrm{hr})\end{array}$} & \multirow{2}{*}{$\begin{array}{c}\text { Decayed } \\
\text { Contact Dose } \\
\text { Rate }(\mathrm{mR} / \mathrm{hr})^{1} \\
\end{array}$} \\
\hline & & & Isotope & Activity (Ci) & & Isotope & Activity (Ci) & & \\
\hline & & & & & & Th-227 & $1.31 \mathrm{E}-10$ & & \\
\hline & & & & & & Th-231 & $8.69 \mathrm{E}-07$ & & \\
\hline & & & & & & Tl-207 & $1.32 \mathrm{E}-10$ & & \\
\hline & & & $\mathrm{U}-235$ & $8.80 \mathrm{E}-07$ & & $\mathrm{U}-235$ & $8.80 \mathrm{E}-07$ & & \\
\hline & & & Y-90 & $9.33 \mathrm{E}-01$ & & $\mathrm{Y}-90$ & $5.21 \mathrm{E}-01$ & & \\
\hline \multirow[t]{25}{*}{224} & S852328 & 1985 & & & 2009 & Ac-227 & $1.34 \mathrm{E}-10$ & 100,000 & 54,000 \\
\hline & & & Ba-137m & 4.79E-01 & & $\mathrm{Ba}-137 \mathrm{~m}$ & $2.74 \mathrm{E}-01$ & & \\
\hline & & & & & & Bi-211 & $1.33 \mathrm{E}-10$ & & \\
\hline & & & Cs-137 & $5.11 \mathrm{E}-01$ & & Cs-137 & $2.93 \mathrm{E}-01$ & & \\
\hline & & & Eu-155 & $9.55 \mathrm{E}-03$ & & Eu-155 & $3.34 \mathrm{E}-04$ & & \\
\hline & & & & & & Fr-223 & $1.83 \mathrm{E}-12$ & & \\
\hline & & & & & & $\mathrm{Pa}-231$ & $4.46 \mathrm{E}-10$ & & \\
\hline & & & & & & $\mathrm{Pb}-211$ & $1.33 \mathrm{E}-10$ & & \\
\hline & & & Pm-147 & $2.92 \mathrm{E}-02$ & & Pm-147 & $5.14 \mathrm{E}-05$ & & \\
\hline & & & & & & Po-211 & $4.05 \mathrm{E}-13$ & & \\
\hline & & & & & & Po-215 & $1.33 \mathrm{E}-10$ & & \\
\hline & & & $\mathrm{Pu}-239$ & $6.20 \mathrm{E}-03$ & & $\mathrm{Pu}-239$ & $6.20 \mathrm{E}-03$ & & \\
\hline & & & & & & Ra-223 & $1.34 \mathrm{E}-10$ & & \\
\hline & & & Rh-106 & $3.74 \mathrm{E}-03$ & & Rh-106 & $2.52 \mathrm{E}-10$ & & \\
\hline & & & & & & Rn-219 & $1.33 \mathrm{E}-10$ & & \\
\hline & & & Ru-106 & $3.74 \mathrm{E}-03$ & & Ru-106 & $2.55 \mathrm{E}-10$ & & \\
\hline & & & Sb-125 & $2.08 \mathrm{E}-02$ & & Sb-125 & $5.12 \mathrm{E}-05$ & & \\
\hline & & & & & & Sm-147 & $7.14 \mathrm{E}-13$ & & \\
\hline & & & Sr-90 & 4.67E-01 & & Sr-90 & $2.64 \mathrm{E}-01$ & & \\
\hline & & & $\mathrm{Te}-125 \mathrm{~m}$ & 8.63E-03 & & $\mathrm{Te}-125 \mathrm{~m}$ & $1.24 \mathrm{E}-05$ & & \\
\hline & & & & & & Th-227 & $1.31 \mathrm{E}-10$ & & \\
\hline & & & & & & Th-231 & 8.69E-07 & & \\
\hline & & & & & & Tl-207 & $1.32 \mathrm{E}-10$ & & \\
\hline & & & U-235 & $8.80 \mathrm{E}-07$ & & U-235 & 8.80E-07 & & \\
\hline & & & Y-90 & 4.66E-01 & & Y-90 & $2.61 \mathrm{E}-01$ & & \\
\hline \multirow[t]{2}{*}{224} & S852332 & 1985 & & & 2009 & Ac-227 & $1.34 \mathrm{E}-10$ & 300,000 & 163,000 \\
\hline & & & Ba-137m & $9.59 \mathrm{E}-01$ & & Ba-137m & $5.49 \mathrm{E}-01$ & & \\
\hline
\end{tabular}

${ }^{1}$ Calculated decayed contact dose rate. Rounded to nearest $10 \mathrm{mR} / \mathrm{hr}$ for values to 1000 ; rounded to nearest $100 \mathrm{mR} / \mathrm{hr}$ for values $>1000$ to 10,000 ; rounded to nearest $1000 \mathrm{mR} / \mathrm{hr}$ for values $>10,000$. * Initial contact dose rate assumed to be $1,000,000 \mathrm{mR} / \mathrm{hr}$; **Initial contact dose rate assumed to be $1,010,000 \mathrm{mR} / \mathrm{hr}$.

$$
115 \text { of } 168
$$


Appendix A-4 - Initial and Decayed Radionuclide and Dose Data for Lined Shafts

\begin{tabular}{|c|c|c|c|c|c|c|c|c|c|}
\hline \multirow[b]{2}{*}{ Shaft Number } & \multirow[b]{2}{*}{ Package ID } & \multirow[b]{2}{*}{ Base Year } & \multicolumn{2}{|c|}{ Initial Isotopic Distribution } & \multirow[b]{2}{*}{ Target Year } & \multicolumn{2}{|c|}{ Decayed Isotopic Distribution } & \multirow{2}{*}{$\begin{array}{c}\text { Initial Contact } \\
\text { Dose Rate } \\
(\mathrm{mR} / \mathrm{hr})\end{array}$} & \multirow{2}{*}{$\begin{array}{c}\text { Decayed } \\
\text { Contact Dose } \\
\text { Rate }(\mathrm{mR} / \mathrm{hr})^{1}\end{array}$} \\
\hline & & & Isotope & Activity (Ci) & & Isotope & Activity (Ci) & & \\
\hline & & & & & & $\mathrm{Bi}-211$ & $1.33 \mathrm{E}-10$ & & \\
\hline & & & Cs-137 & $1.02 \mathrm{E}+00$ & & Cs-137 & $5.87 \mathrm{E}-01$ & & \\
\hline & & & Eu-155 & $1.91 \mathrm{E}-02$ & & $\mathrm{Eu}-155$ & $6.67 \mathrm{E}-04$ & & \\
\hline & & & & & & Fr-223 & $1.83 \mathrm{E}-12$ & & \\
\hline & & & & & & $\mathrm{Pa}-231$ & $4.46 \mathrm{E}-10$ & & \\
\hline & & & & & & $\mathrm{Pb}-211$ & $1.33 \mathrm{E}-10$ & & \\
\hline & & & Pm-147 & $5.83 \mathrm{E}-02$ & & Pm-147 & $1.03 \mathrm{E}-04$ & & \\
\hline & & & & & & Po-211 & $4.05 \mathrm{E}-13$ & & \\
\hline & & & & & & Po-215 & $1.33 \mathrm{E}-10$ & & \\
\hline & & & $\mathrm{Pu}-239$ & $6.20 \mathrm{E}-03$ & & $\mathrm{Pu}-239$ & $6.20 \mathrm{E}-03$ & & \\
\hline & & & & & & $\mathrm{Ra}-223$ & $1.34 \mathrm{E}-10$ & & \\
\hline & & & Rh-106 & 7.49E-03 & & Rh-106 & $5.04 \mathrm{E}-10$ & & \\
\hline & & & & & & Rn-219 & $1.33 \mathrm{E}-10$ & & \\
\hline & & & Ru-106 & 7.49E-03 & & $\mathrm{Ru}-106$ & $5.09 \mathrm{E}-10$ & & \\
\hline & & & Sb-125 & 4.16E-02 & & Sb-125 & $1.02 \mathrm{E}-04$ & & \\
\hline & & & & & & Sm-147 & $1.43 \mathrm{E}-12$ & & \\
\hline & & & Sr-90 & 9.34E-01 & & Sr-90 & $5.27 \mathrm{E}-01$ & & \\
\hline & & & $\mathrm{Te}-125 \mathrm{~m}$ & $1.73 \mathrm{E}-02$ & & $\mathrm{Te}-125 \mathrm{~m}$ & $2.48 \mathrm{E}-05$ & & \\
\hline & & & & & & Th-227 & $1.31 \mathrm{E}-10$ & & \\
\hline & & & & & & Th-231 & 8.69E-07 & & \\
\hline & & & & & & Tl-207 & $1.32 \mathrm{E}-10$ & & \\
\hline & & & U-235 & $8.80 \mathrm{E}-07$ & & U-235 & $8.80 \mathrm{E}-07$ & & \\
\hline & & & $\mathrm{Y}-90$ & 9.33E-01 & & Y-90 & $5.21 \mathrm{E}-01$ & & \\
\hline \multirow[t]{9}{*}{224} & S852804 & 1985 & & & 2009 & Ac- 227 & 2.92E-09 & 100,000 & 54,000 \\
\hline & & & Ba-137m & $6.71 \mathrm{E}-01$ & & Ba-137m & $3.84 \mathrm{E}-01$ & & \\
\hline & & & & & & $\mathrm{Bi}-211$ & $2.88 \mathrm{E}-09$ & & \\
\hline & & & Cs-137 & 7.15E-01 & & Cs-137 & 4.11E-01 & & \\
\hline & & & Eu-155 & $1.34 \mathrm{E}-02$ & & Eu-155 & 4.67E-04 & & \\
\hline & & & & & & Fr-223 & $3.98 \mathrm{E}-11$ & & \\
\hline & & & & & & $\mathrm{Pa}-231$ & $9.70 \mathrm{E}-09$ & & \\
\hline & & & & & & $\mathrm{Pb}-211$ & 2.89E-09 & & \\
\hline & & & Pm-147 & $4.08 \mathrm{E}-02$ & & Pm-147 & 7.20E-05 & & \\
\hline
\end{tabular}

${ }^{1}$ Calculated decayed contact dose rate. Rounded to nearest $10 \mathrm{mR} / \mathrm{hr}$ for values to 1000 ; rounded to nearest $100 \mathrm{mR} / \mathrm{hr}$ for values $>1000$ to 10,000 ; rounded to nearest $1000 \mathrm{mR} / \mathrm{hr}$ for values $>10,000$. * Initial contact dose rate assumed to be $1,000,000 \mathrm{mR} / \mathrm{hr}$; **Initial contact dose rate assumed to be $1,010,000 \mathrm{mR} / \mathrm{hr}$.

116 of 168 
Appendix A-4 - Initial and Decayed Radionuclide and Dose Data for Lined Shafts

\begin{tabular}{|c|c|c|c|c|c|c|c|c|c|}
\hline \multirow[b]{2}{*}{ Shaft Number } & \multirow[b]{2}{*}{ Package ID } & \multirow[b]{2}{*}{ Base Year } & \multicolumn{2}{|c|}{ Initial Isotopic Distribution } & \multirow[b]{2}{*}{ Target Year } & \multicolumn{2}{|c|}{ Decayed Isotopic Distribution } & \multirow{2}{*}{$\begin{array}{c}\text { Initial Contact } \\
\text { Dose Rate } \\
(\mathrm{mR} / \mathrm{hr})\end{array}$} & \multirow{2}{*}{$\begin{array}{c}\text { Decayed } \\
\text { Contact Dose } \\
\text { Rate }(\mathrm{mR} / \mathrm{hr})^{1}\end{array}$} \\
\hline & & & Isotope & Activity (Ci) & & Isotope & Activity (Ci) & & \\
\hline & & & & & & Po-211 & $8.80 \mathrm{E}-12$ & & \\
\hline & & & & & & Po-215 & $2.89 \mathrm{E}-09$ & & \\
\hline & & & $\mathrm{Pu}-239$ & $2.05 \mathrm{E}-01$ & & $\mathrm{Pu}-239$ & $2.04 \mathrm{E}-01$ & & \\
\hline & & & & & & $\mathrm{Ra}-223$ & $2.92 \mathrm{E}-09$ & & \\
\hline & & & $\mathrm{Rh}-106$ & $5.24 \mathrm{E}-03$ & & Rh-106 & $3.53 \mathrm{E}-10$ & & \\
\hline & & & & & & $\mathrm{Rn}-219$ & 2.88E-09 & & \\
\hline & & & $\mathrm{Ru}-106$ & $5.24 \mathrm{E}-03$ & & $\mathrm{Ru}-106$ & $3.57 \mathrm{E}-10$ & & \\
\hline & & & $\mathrm{Sb}-125$ & 2.91E-02 & & $\mathrm{Sb}-125$ & 7.18E-05 & & \\
\hline & & & & & & Sm-147 & $1.00 \mathrm{E}-12$ & & \\
\hline & & & Sr-90 & $6.54 \mathrm{E}-01$ & & Sr-90 & 3.69E-01 & & \\
\hline & & & Te-125m & $1.21 \mathrm{E}-02$ & & Te-125m & $1.74 \mathrm{E}-05$ & & \\
\hline & & & & & & Th-227 & 2.84E-09 & & \\
\hline & & & & & & Th-231 & $1.89 \mathrm{E}-05$ & & \\
\hline & & & & & & Tl-207 & 2.87E-09 & & \\
\hline & & & $\mathrm{U}-235$ & $1.91 \mathrm{E}-05$ & & $\mathrm{U}-235$ & $1.91 \mathrm{E}-05$ & & \\
\hline & & & $\mathrm{Y}-90$ & $6.53 \mathrm{E}-01$ & & $\mathrm{Y}-90$ & $3.65 \mathrm{E}-01$ & & \\
\hline \multirow[t]{16}{*}{224} & S855064 & 1985 & & & 2009 & Ac- 227 & $5.00 \mathrm{E}-09$ & 100,000 & 54,000 \\
\hline & & & Ba-137m & $9.11 \mathrm{E}-01$ & & $\mathrm{Ba}-137 \mathrm{~m}$ & $5.21 \mathrm{E}-01$ & & \\
\hline & & & & & & $\mathrm{Bi}-211$ & 4.94E-09 & & \\
\hline & & & Cs-137 & $9.70 \mathrm{E}-01$ & & Cs-137 & $5.57 \mathrm{E}-01$ & & \\
\hline & & & Eu-155 & $1.82 \mathrm{E}-02$ & & Eu-155 & $6.34 \mathrm{E}-04$ & & \\
\hline & & & & & & Fr-223 & $6.82 \mathrm{E}-11$ & & \\
\hline & & & & & & $\mathrm{Pa}-231$ & $1.66 \mathrm{E}-08$ & & \\
\hline & & & & & & $\mathrm{Pb}-211$ & 4.94E-09 & & \\
\hline & & & Pm-147 & $5.54 \mathrm{E}-02$ & & Pm-147 & $9.76 \mathrm{E}-05$ & & \\
\hline & & & & & & Рo-211 & $1.51 \mathrm{E}-11$ & & \\
\hline & & & & & & Рo-215 & 4.94E-09 & & \\
\hline & & & $\mathrm{Pu}-239$ & $2.23 \mathrm{E}-01$ & & $\mathrm{Pu}-239$ & $2.23 \mathrm{E}-01$ & & \\
\hline & & & & & & Ra-223 & $5.00 \mathrm{E}-09$ & & \\
\hline & & & $\mathrm{Rh}-106$ & 7.12E-03 & & Rh-106 & 4.79E-10 & & \\
\hline & & & & & & Rn-219 & 4.94E-09 & & \\
\hline & & & $\mathrm{Ru}-106$ & 7.12E-03 & & $\mathrm{Ru}-106$ & $4.84 \mathrm{E}-10$ & & \\
\hline
\end{tabular}

${ }^{1}$ Calculated decayed contact dose rate. Rounded to nearest $10 \mathrm{mR} / \mathrm{hr}$ for values to 1000 ; rounded to nearest $100 \mathrm{mR} / \mathrm{hr}$ for values $>1000$ to 10,000 ; rounded to nearest $1000 \mathrm{mR} / \mathrm{hr}$ for values $>10,000$. * Initial contact dose rate assumed to be $1,000,000 \mathrm{mR} / \mathrm{hr}$; **Initial contact dose rate assumed to be $1,010,000 \mathrm{mR} / \mathrm{hr}$.

$$
117 \text { of } 168
$$


Appendix A-4 - Initial and Decayed Radionuclide and Dose Data for Lined Shafts

\begin{tabular}{|c|c|c|c|c|c|c|c|c|c|}
\hline \multirow[b]{2}{*}{ Shaft Number } & \multirow[b]{2}{*}{ Package ID } & \multirow[b]{2}{*}{ Base Year } & \multicolumn{2}{|c|}{ Initial Isotopic Distribution } & \multirow[b]{2}{*}{ Target Year } & \multicolumn{2}{|c|}{ Decayed Isotopic Distribution } & \multirow{2}{*}{$\begin{array}{c}\text { Initial Contact } \\
\text { Dose Rate } \\
(\mathrm{mR} / \mathrm{hr})\end{array}$} & \multirow{2}{*}{$\begin{array}{c}\text { Decayed } \\
\text { Contact Dose } \\
\text { Rate }(\mathrm{mR} / \mathrm{hr})^{1} \\
\end{array}$} \\
\hline & & & Isotope & Activity (Ci) & & Isotope & Activity (Ci) & & \\
\hline & & & $\mathrm{Sb}-125$ & $3.95 \mathrm{E}-02$ & & $\mathrm{Sb}-125$ & $9.74 \mathrm{E}-05$ & & \\
\hline & & & & & & Sm-147 & $1.36 \mathrm{E}-12$ & & \\
\hline & & & Sr-90 & 8.87E-01 & & Sr-90 & $5.01 \mathrm{E}-01$ & & \\
\hline & & & $\mathrm{Te}-125 \mathrm{~m}$ & $1.64 \mathrm{E}-02$ & & $\mathrm{Te}-125 \mathrm{~m}$ & $2.36 \mathrm{E}-05$ & & \\
\hline & & & & & & Th-227 & $4.87 \mathrm{E}-09$ & & \\
\hline & & & & & & Th-231 & $3.24 \mathrm{E}-05$ & & \\
\hline & & & & & & Tl-207 & $4.92 \mathrm{E}-09$ & & \\
\hline & & & U-235 & $3.28 \mathrm{E}-05$ & & U-235 & $3.28 \mathrm{E}-05$ & & \\
\hline & & & Y-90 & $8.86 \mathrm{E}-01$ & & Y-90 & $4.95 \mathrm{E}-01$ & & \\
\hline \multirow[t]{23}{*}{224} & S855065 & 1985 & & & 2009 & Ac-227 & $5.00 \mathrm{E}-09$ & 300,000 & 163,000 \\
\hline & & & $\mathrm{Ba}-137 \mathrm{~m}$ & $1.01 \mathrm{E}+00$ & & $\mathrm{Ba}-137 \mathrm{~m}$ & $5.76 \mathrm{E}-01$ & & \\
\hline & & & & & & Bi-211 & 4.94E-09 & & \\
\hline & & & Cs-137 & $1.07 \mathrm{E}+00$ & & Cs-137 & $6.16 \mathrm{E}-01$ & & \\
\hline & & & Eu-155 & $2.01 \mathrm{E}-02$ & & Eu-155 & 7.01E-04 & & \\
\hline & & & & & & Fr-223 & $6.82 \mathrm{E}-11$ & & \\
\hline & & & & & & $\mathrm{Pa}-231$ & $1.66 \mathrm{E}-08$ & & \\
\hline & & & & & & $\mathrm{Pb}-211$ & 4.94E-09 & & \\
\hline & & & Pm-147 & $6.13 \mathrm{E}-02$ & & Pm-147 & $1.08 \mathrm{E}-04$ & & \\
\hline & & & & & & Po-211 & $1.51 \mathrm{E}-11$ & & \\
\hline & & & & & & Po-215 & $4.94 \mathrm{E}-09$ & & \\
\hline & & & $\mathrm{Pu}-239$ & $2.23 \mathrm{E}-01$ & & Pu-239 & $2.23 \mathrm{E}-01$ & & \\
\hline & & & & & & $\mathrm{Ra}-223$ & $5.00 \mathrm{E}-09$ & & \\
\hline & & & Rh-106 & $7.86 \mathrm{E}-03$ & & Rh-106 & $5.29 \mathrm{E}-10$ & & \\
\hline & & & & & & Rn-219 & 4.94E-09 & & \\
\hline & & & $\mathrm{Ru}-106$ & $7.86 \mathrm{E}-03$ & & $\mathrm{Ru}-106$ & $5.35 \mathrm{E}-10$ & & \\
\hline & & & $\mathrm{Sb}-125$ & 4.37E-02 & & $\mathrm{Sb}-125$ & $1.07 \mathrm{E}-04$ & & \\
\hline & & & & & & Sm-147 & $1.50 \mathrm{E}-12$ & & \\
\hline & & & Sr-90 & $9.80 \mathrm{E}-01$ & & Sr-90 & $5.54 \mathrm{E}-01$ & & \\
\hline & & & Te-125m & $1.81 \mathrm{E}-02$ & & Te-125m & $2.60 \mathrm{E}-05$ & & \\
\hline & & & & & & Th-227 & 4.87E-09 & & \\
\hline & & & & & & Th-231 & $3.24 \mathrm{E}-05$ & & \\
\hline & & & & & & Tl-207 & $4.92 \mathrm{E}-09$ & & \\
\hline
\end{tabular}

${ }^{1}$ Calculated decayed contact dose rate. Rounded to nearest $10 \mathrm{mR} / \mathrm{hr}$ for values to 1000 ; rounded to nearest $100 \mathrm{mR} / \mathrm{hr}$ for values $>1000$ to 10,000 ; rounded to nearest $1000 \mathrm{mR} / \mathrm{hr}$ for values $>10,000$. * Initial contact dose rate assumed to be $1,000,000 \mathrm{mR} / \mathrm{hr}$; **Initial contact dose rate assumed to be $1,010,000 \mathrm{mR} / \mathrm{hr}$.

$$
118 \text { of } 168
$$


Appendix A-4 - Initial and Decayed Radionuclide and Dose Data for Lined Shafts

\begin{tabular}{|c|c|c|c|c|c|c|c|c|c|}
\hline \multirow[b]{2}{*}{ Shaft Number } & \multirow[b]{2}{*}{ Package ID } & \multirow[b]{2}{*}{ Base Year } & \multicolumn{2}{|c|}{ Initial Isotopic Distribution } & \multirow[b]{2}{*}{ Target Year } & \multicolumn{2}{|c|}{ Decayed Isotopic Distribution } & \multirow{2}{*}{$\begin{array}{c}\text { Initial Contact } \\
\text { Dose Rate } \\
(\mathrm{mR} / \mathrm{hr})\end{array}$} & \multirow{2}{*}{$\begin{array}{c}\text { Decayed } \\
\text { Contact Dose } \\
\text { Rate }(\mathrm{mR} / \mathrm{hr})^{1} \\
\end{array}$} \\
\hline & & & Isotope & Activity (Ci) & & Isotope & Activity (Ci) & & \\
\hline & & & U-235 & $3.28 \mathrm{E}-05$ & & U-235 & $3.28 \mathrm{E}-05$ & & \\
\hline & & & $\mathrm{Y}-90$ & $9.79 \mathrm{E}-01$ & & Y-90 & $5.47 \mathrm{E}-01$ & & \\
\hline \multirow[t]{25}{*}{224} & S855066 & 1985 & & & 2009 & Ac- 227 & $1.34 \mathrm{E}-10$ & 70,000 & 38,000 \\
\hline & & & Ba-137m & $3.59 \mathrm{E}-01$ & & $\mathrm{Ba}-137 \mathrm{~m}$ & $2.06 \mathrm{E}-01$ & & \\
\hline & & & & & & $\mathrm{Bi}-211$ & $1.33 \mathrm{E}-10$ & & \\
\hline & & & Cs-137 & $3.83 \mathrm{E}-01$ & & Cs-137 & $2.20 \mathrm{E}-01$ & & \\
\hline & & & Eu-155 & 7.17E-03 & & Eu-155 & $2.50 \mathrm{E}-04$ & & \\
\hline & & & & & & Fr-223 & $1.83 \mathrm{E}-12$ & & \\
\hline & & & & & & $\mathrm{Pa}-231$ & $4.46 \mathrm{E}-10$ & & \\
\hline & & & & & & $\mathrm{Pb}-211$ & $1.33 \mathrm{E}-10$ & & \\
\hline & & & Pm-147 & 2.19E-02 & & Pm-147 & $3.86 \mathrm{E}-05$ & & \\
\hline & & & & & & Po-211 & $4.05 \mathrm{E}-13$ & & \\
\hline & & & & & & Po-215 & $1.33 \mathrm{E}-10$ & & \\
\hline & & & $\mathrm{Pu}-239$ & $6.20 \mathrm{E}-03$ & & $\mathrm{Pu}-239$ & $6.20 \mathrm{E}-03$ & & \\
\hline & & & & & & Ra-223 & $1.34 \mathrm{E}-10$ & & \\
\hline & & & $\mathrm{Rh}-106$ & $2.81 \mathrm{E}-03$ & & Rh-106 & $1.89 \mathrm{E}-10$ & & \\
\hline & & & & & & Rn-219 & $1.33 \mathrm{E}-10$ & & \\
\hline & & & Ru-106 & $2.81 \mathrm{E}-03$ & & Ru-106 & $1.91 \mathrm{E}-10$ & & \\
\hline & & & Sb-125 & $1.56 \mathrm{E}-02$ & & Sb-125 & $3.84 \mathrm{E}-05$ & & \\
\hline & & & & & & Sm-147 & $5.35 \mathrm{E}-13$ & & \\
\hline & & & Sr-90 & $3.50 \mathrm{E}-01$ & & Sr-90 & $1.98 \mathrm{E}-01$ & & \\
\hline & & & $\mathrm{Te}-125 \mathrm{~m}$ & $6.48 \mathrm{E}-03$ & & $\mathrm{Te}-125 \mathrm{~m}$ & $9.30 \mathrm{E}-06$ & & \\
\hline & & & & & & Th-227 & $1.31 \mathrm{E}-10$ & & \\
\hline & & & & & & Th-231 & 8.69E-07 & & \\
\hline & & & & & & Tl-207 & $1.32 \mathrm{E}-10$ & & \\
\hline & & & U-235 & $8.80 \mathrm{E}-07$ & & U-235 & $8.80 \mathrm{E}-07$ & & \\
\hline & & & Y-90 & $3.50 \mathrm{E}-01$ & & $\mathrm{Y}-90$ & $1.96 \mathrm{E}-01$ & & \\
\hline \multirow[t]{5}{*}{224} & S855068 & 1985 & & & 2009 & Ac- 227 & $1.34 \mathrm{E}-10$ & 20,000 & 11,000 \\
\hline & & & $\mathrm{Ba}-137 \mathrm{~m}$ & $3.59 \mathrm{E}-01$ & & Ba-137m & $2.06 \mathrm{E}-01$ & & \\
\hline & & & & & & Bi-211 & $1.33 \mathrm{E}-10$ & & \\
\hline & & & Cs-137 & $3.83 \mathrm{E}-01$ & & Cs-137 & $2.20 \mathrm{E}-01$ & & \\
\hline & & & Eu-155 & $7.17 \mathrm{E}-03$ & & Eu-155 & $2.50 \mathrm{E}-04$ & & \\
\hline
\end{tabular}

${ }^{1}$ Calculated decayed contact dose rate. Rounded to nearest $10 \mathrm{mR} / \mathrm{hr}$ for values to 1000 ; rounded to nearest $100 \mathrm{mR} / \mathrm{hr}$ for values $>1000$ to 10,000 ; rounded to nearest $1000 \mathrm{mR} / \mathrm{hr}$ for values $>10,000$. * Initial contact dose rate assumed to be $1,000,000 \mathrm{mR} / \mathrm{hr}$; **Initial contact dose rate assumed to be $1,010,000 \mathrm{mR} / \mathrm{hr}$.

$$
119 \text { of } 168
$$


Appendix A-4 - Initial and Decayed Radionuclide and Dose Data for Lined Shafts

\begin{tabular}{|c|c|c|c|c|c|c|c|c|c|}
\hline \multirow[b]{2}{*}{ Shaft Number } & \multirow[b]{2}{*}{ Package ID } & \multirow[b]{2}{*}{ Base Year } & \multicolumn{2}{|c|}{ Initial Isotopic Distribution } & \multirow[b]{2}{*}{ Target Year } & \multicolumn{2}{|c|}{ Decayed Isotopic Distribution } & \multirow{2}{*}{$\begin{array}{c}\text { Initial Contact } \\
\text { Dose Rate } \\
(\mathrm{mR} / \mathrm{hr})\end{array}$} & \multirow{2}{*}{$\begin{array}{c}\text { Decayed } \\
\text { Contact Dose } \\
\text { Rate }(\mathrm{mR} / \mathrm{hr})^{1}\end{array}$} \\
\hline & & & Isotope & Activity (Ci) & & Isotope & Activity (Ci) & & \\
\hline & & & & & & Fr-223 & $1.83 \mathrm{E}-12$ & & \\
\hline & & & & & & $\mathrm{Pa}-231$ & $4.46 \mathrm{E}-10$ & & \\
\hline & & & & & & $\mathrm{Pb}-211$ & $1.33 \mathrm{E}-10$ & & \\
\hline & & & Pm-147 & $2.19 \mathrm{E}-02$ & & Pm-147 & $3.86 \mathrm{E}-05$ & & \\
\hline & & & & & & Po-211 & $4.05 \mathrm{E}-13$ & & \\
\hline & & & & & & Po-215 & $1.33 \mathrm{E}-10$ & & \\
\hline & & & $\mathrm{Pu}-239$ & $6.20 \mathrm{E}-03$ & & $\mathrm{Pu}-239$ & $6.20 \mathrm{E}-03$ & & \\
\hline & & & & & & Ra-223 & $1.34 \mathrm{E}-10$ & & \\
\hline & & & Rh-106 & $2.81 \mathrm{E}-03$ & & Rh-106 & $1.89 \mathrm{E}-10$ & & \\
\hline & & & & & & $\mathrm{Rn}-219$ & $1.33 \mathrm{E}-10$ & & \\
\hline & & & $\mathrm{Ru}-106$ & $2.81 \mathrm{E}-03$ & & Ru-106 & $1.91 \mathrm{E}-10$ & & \\
\hline & & & $\mathrm{Sb}-125$ & $1.56 \mathrm{E}-02$ & & $\mathrm{Sb}-125$ & $3.84 \mathrm{E}-05$ & & \\
\hline & & & & & & Sm-147 & $5.35 \mathrm{E}-13$ & & \\
\hline & & & Sr-90 & $3.50 \mathrm{E}-01$ & & Sr-90 & $1.98 \mathrm{E}-01$ & & \\
\hline & & & $\mathrm{Te}-125 \mathrm{~m}$ & $6.48 \mathrm{E}-03$ & & $\mathrm{Te}-125 \mathrm{~m}$ & $9.30 \mathrm{E}-06$ & & \\
\hline & & & & & & Th-227 & $1.31 \mathrm{E}-10$ & & \\
\hline & & & & & & Th-231 & $8.69 \mathrm{E}-07$ & & \\
\hline & & & & & & Tl-207 & $1.32 \mathrm{E}-10$ & & \\
\hline & & & $\mathrm{U}-235$ & $8.80 \mathrm{E}-07$ & & U-235 & $8.80 \mathrm{E}-07$ & & \\
\hline & & & Y-90 & $3.50 \mathrm{E}-01$ & & $\mathrm{Y}-90$ & $1.96 \mathrm{E}-01$ & & \\
\hline \multirow[t]{12}{*}{225} & S840848 & 1984 & & & 2009 & Ac- 227 & $1.44 \mathrm{E}-10$ & 40,000 & 21,000 \\
\hline & & & $\mathrm{Ba}-137 \mathrm{~m}$ & $9.59 \mathrm{E}-02$ & & $\mathrm{Ba}-137 \mathrm{~m}$ & $5.36 \mathrm{E}-02$ & & \\
\hline & & & & & & Bi-211 & $1.42 \mathrm{E}-10$ & & \\
\hline & & & Cs-137 & $1.02 \mathrm{E}-01$ & & Cs-137 & $5.73 \mathrm{E}-02$ & & \\
\hline & & & Eu-155 & $1.91 \mathrm{E}-03$ & & Eu-155 & $5.80 \mathrm{E}-05$ & & \\
\hline & & & & & & Fr-223 & $1.97 \mathrm{E}-12$ & & \\
\hline & & & & & & $\mathrm{Pa}-231$ & $4.65 \mathrm{E}-10$ & & \\
\hline & & & & & & $\mathrm{Pb}-211$ & $1.43 \mathrm{E}-10$ & & \\
\hline & & & Pm-147 & $5.83 \mathrm{E}-03$ & & Pm-147 & $7.88 \mathrm{E}-06$ & & \\
\hline & & & & & & Po-211 & $4.35 \mathrm{E}-13$ & & \\
\hline & & & & & & Po-215 & $1.43 \mathrm{E}-10$ & & \\
\hline & & & $\mathrm{Pu}-239$ & $6.20 \mathrm{E}-03$ & & $\mathrm{Pu}-239$ & $6.20 \mathrm{E}-03$ & & \\
\hline
\end{tabular}

${ }^{1}$ Calculated decayed contact dose rate. Rounded to nearest $10 \mathrm{mR} / \mathrm{hr}$ for values to 1000 ; rounded to nearest $100 \mathrm{mR} / \mathrm{hr}$ for values $>1000$ to 10,000 ; rounded to nearest $1000 \mathrm{mR} / \mathrm{hr}$ for values $>10,000$. * Initial contact dose rate assumed to be $1,000,000 \mathrm{mR} / \mathrm{hr}$; **Initial contact dose rate assumed to be $1,010,000 \mathrm{mR} / \mathrm{hr}$.

$$
120 \text { of } 168
$$


Appendix A-4 - Initial and Decayed Radionuclide and Dose Data for Lined Shafts

\begin{tabular}{|c|c|c|c|c|c|c|c|c|c|}
\hline \multirow[b]{2}{*}{ Shaft Number } & \multirow[b]{2}{*}{ Package ID } & \multirow[b]{2}{*}{ Base Year } & \multicolumn{2}{|c|}{ Initial Isotopic Distribution } & \multirow[b]{2}{*}{ Target Year } & \multicolumn{2}{|c|}{ Decayed Isotopic Distribution } & \multirow{2}{*}{$\begin{array}{c}\text { Initial Contact } \\
\text { Dose Rate } \\
(\mathrm{mR} / \mathrm{hr})\end{array}$} & \multirow{2}{*}{$\begin{array}{c}\text { Decayed } \\
\text { Contact Dose } \\
\text { Rate }(\mathrm{mR} / \mathrm{hr})^{1}\end{array}$} \\
\hline & & & Isotope & Activity $(\mathrm{Ci})$ & & Isotope & Activity (Ci) & & \\
\hline & & & & & & Ra-223 & $1.44 \mathrm{E}-10$ & & \\
\hline & & & Rh-106 & 7.49E-04 & & Rh-106 & $2.54 \mathrm{E}-11$ & & \\
\hline & & & & & & Rn-219 & $1.42 \mathrm{E}-10$ & & \\
\hline & & & $\mathrm{Ru}-106$ & 7.49E-04 & & Ru-106 & $2.56 \mathrm{E}-11$ & & \\
\hline & & & Sb-125 & $4.16 \mathrm{E}-03$ & & $\mathrm{Sb}-125$ & $7.97 \mathrm{E}-06$ & & \\
\hline & & & & & & Sm-147 & $1.43 \mathrm{E}-13$ & & \\
\hline & & & Sr-90 & $9.34 \mathrm{E}-02$ & & Sr-90 & $5.15 \mathrm{E}-02$ & & \\
\hline & & & $\mathrm{Te}-125 \mathrm{~m}$ & $1.73 \mathrm{E}-03$ & & $\mathrm{Te}-125 \mathrm{~m}$ & $1.93 \mathrm{E}-06$ & & \\
\hline & & & & & & Th-227 & $1.40 \mathrm{E}-10$ & & \\
\hline & & & & & & Th-231 & $8.69 \mathrm{E}-07$ & & \\
\hline & & & & & & T1-207 & $1.42 \mathrm{E}-10$ & & \\
\hline & & & $\mathrm{U}-235$ & $8.80 \mathrm{E}-07$ & & $\mathrm{U}-235$ & $8.80 \mathrm{E}-07$ & & \\
\hline & & & Y-90 & 9.33E-02 & & $\mathrm{Y}-90$ & $5.09 \mathrm{E}-02$ & & \\
\hline \multirow[t]{19}{*}{225} & S840854 & 1984 & & & 2009 & Ac-227 & $1.44 \mathrm{E}-10$ & 50,000 & 27,000 \\
\hline & & & Ba-137m & $3.59 \mathrm{E}-01$ & & $\mathrm{Ba}-137 \mathrm{~m}$ & $2.01 \mathrm{E}-01$ & & \\
\hline & & & & & & Bi-211 & $1.42 \mathrm{E}-10$ & & \\
\hline & & & Cs-137 & $3.83 \mathrm{E}-01$ & & Cs-137 & $2.15 \mathrm{E}-01$ & & \\
\hline & & & Eu-155 & 7.17E-03 & & Eu-155 & $2.18 \mathrm{E}-04$ & & \\
\hline & & & & & & Fr-223 & $1.97 \mathrm{E}-12$ & & \\
\hline & & & & & & $\mathrm{Pa}-231$ & $4.65 \mathrm{E}-10$ & & \\
\hline & & & & & & $\mathrm{Pb}-211$ & $1.43 \mathrm{E}-10$ & & \\
\hline & & & Pm-147 & $2.19 \mathrm{E}-02$ & & Pm-147 & $2.95 \mathrm{E}-05$ & & \\
\hline & & & & & & Po-211 & $4.35 \mathrm{E}-13$ & & \\
\hline & & & & & & Po-215 & $1.43 \mathrm{E}-10$ & & \\
\hline & & & $\mathrm{Pu}-239$ & $6.20 \mathrm{E}-03$ & & $\mathrm{Pu}-239$ & $6.20 \mathrm{E}-03$ & & \\
\hline & & & & & & Ra-223 & $1.44 \mathrm{E}-10$ & & \\
\hline & & & Rh-106 & $2.81 \mathrm{E}-03$ & & Rh-106 & $9.51 \mathrm{E}-11$ & & \\
\hline & & & & & & Rn-219 & $1.42 \mathrm{E}-10$ & & \\
\hline & & & $\mathrm{Ru}-106$ & $2.81 \mathrm{E}-03$ & & $\mathrm{Ru}-106$ & $9.60 \mathrm{E}-11$ & & \\
\hline & & & Sb-125 & $1.56 \mathrm{E}-02$ & & Sb-125 & $2.99 \mathrm{E}-05$ & & \\
\hline & & & & & & Sm-147 & $5.36 \mathrm{E}-13$ & & \\
\hline & & & Sr-90 & $3.50 \mathrm{E}-01$ & & Sr-90 & $1.93 \mathrm{E}-01$ & & \\
\hline
\end{tabular}

${ }^{1}$ Calculated decayed contact dose rate. Rounded to nearest $10 \mathrm{mR} / \mathrm{hr}$ for values to 1000 ; rounded to nearest $100 \mathrm{mR} / \mathrm{hr}$ for values $>1000$ to 10,000 ; rounded to nearest $1000 \mathrm{mR} / \mathrm{hr}$ for values $>10,000$. * Initial contact dose rate assumed to be $1,000,000 \mathrm{mR} / \mathrm{hr}$; **Initial contact dose rate assumed to be $1,010,000 \mathrm{mR} / \mathrm{hr}$.

$$
121 \text { of } 168
$$


Appendix A-4 - Initial and Decayed Radionuclide and Dose Data for Lined Shafts

\begin{tabular}{|c|c|c|c|c|c|c|c|c|c|}
\hline \multirow[b]{2}{*}{ Shaft Number } & \multirow[b]{2}{*}{ Package ID } & \multirow[b]{2}{*}{ Base Year } & \multicolumn{2}{|c|}{ Initial Isotopic Distribution } & \multirow[b]{2}{*}{ Target Year } & \multicolumn{2}{|c|}{ Decayed Isotopic Distribution } & \multirow{2}{*}{$\begin{array}{c}\text { Initial Contact } \\
\text { Dose Rate } \\
(\mathrm{mR} / \mathrm{hr})\end{array}$} & \multirow{2}{*}{$\begin{array}{c}\text { Decayed } \\
\text { Contact Dose } \\
\text { Rate }(\mathrm{mR} / \mathrm{hr})^{1} \\
\end{array}$} \\
\hline & & & Isotope & Activity (Ci) & & Isotope & Activity (Ci) & & \\
\hline & & & $\mathrm{Te}-125 \mathrm{~m}$ & $6.48 \mathrm{E}-03$ & & Te-125m & $7.25 \mathrm{E}-06$ & & \\
\hline & & & & & & Th-227 & $1.40 \mathrm{E}-10$ & & \\
\hline & & & & & & Th-231 & $8.69 \mathrm{E}-07$ & & \\
\hline & & & & & & T1-207 & $1.42 \mathrm{E}-10$ & & \\
\hline & & & $\mathrm{U}-235$ & $8.80 \mathrm{E}-07$ & & $\mathrm{U}-235$ & $8.80 \mathrm{E}-07$ & & \\
\hline & & & $\mathrm{Y}-90$ & $3.50 \mathrm{E}-01$ & & $\mathrm{Y}-90$ & $1.91 \mathrm{E}-01$ & & \\
\hline \multirow[t]{25}{*}{225} & S840856 & 1984 & & & 2009 & Ac-227 & $1.44 \mathrm{E}-10$ & 90,000 & 48,000 \\
\hline & & & $\mathrm{Ba}-137 \mathrm{~m}$ & $3.59 \mathrm{E}-01$ & & $\mathrm{Ba}-137 \mathrm{~m}$ & $2.01 \mathrm{E}-01$ & & \\
\hline & & & & & & $\mathrm{Bi}-211$ & $1.42 \mathrm{E}-10$ & & \\
\hline & & & Cs-137 & $3.83 \mathrm{E}-01$ & & Cs-137 & $2.15 \mathrm{E}-01$ & & \\
\hline & & & $\mathrm{Eu}-155$ & $7.17 \mathrm{E}-03$ & & Eu-155 & $2.18 \mathrm{E}-04$ & & \\
\hline & & & & & & Fr-223 & $1.97 \mathrm{E}-12$ & & \\
\hline & & & & & & $\mathrm{Pa}-231$ & $4.65 \mathrm{E}-10$ & & \\
\hline & & & & & & $\mathrm{Pb}-211$ & $1.43 \mathrm{E}-10$ & & \\
\hline & & & Pm-147 & 2.19E-02 & & Pm-147 & $2.95 \mathrm{E}-05$ & & \\
\hline & & & & & & Po-211 & $4.35 \mathrm{E}-13$ & & \\
\hline & & & & & & Po-215 & $1.43 \mathrm{E}-10$ & & \\
\hline & & & $\mathrm{Pu}-239$ & $6.20 \mathrm{E}-03$ & & $\mathrm{Pu}-239$ & $6.20 \mathrm{E}-03$ & & \\
\hline & & & & & & Ra-223 & $1.44 \mathrm{E}-10$ & & \\
\hline & & & Rh-106 & $2.81 \mathrm{E}-03$ & & Rh-106 & $9.51 \mathrm{E}-11$ & & \\
\hline & & & & & & Rn-219 & $1.42 \mathrm{E}-10$ & & \\
\hline & & & Ru-106 & $2.81 \mathrm{E}-03$ & & $\mathrm{Ru}-106$ & $9.60 \mathrm{E}-11$ & & \\
\hline & & & Sb-125 & $1.56 \mathrm{E}-02$ & & Sb-125 & $2.99 \mathrm{E}-05$ & & \\
\hline & & & & & & Sm-147 & $5.36 \mathrm{E}-13$ & & \\
\hline & & & Sr-90 & $3.50 \mathrm{E}-01$ & & Sr-90 & $1.93 \mathrm{E}-01$ & & \\
\hline & & & $\mathrm{Te}-125 \mathrm{~m}$ & $6.48 \mathrm{E}-03$ & & $\mathrm{Te}-125 \mathrm{~m}$ & $7.25 \mathrm{E}-06$ & & \\
\hline & & & & & & Th-227 & $1.40 \mathrm{E}-10$ & & \\
\hline & & & & & & Th-231 & $8.69 \mathrm{E}-07$ & & \\
\hline & & & & & & T1-207 & $1.42 \mathrm{E}-10$ & & \\
\hline & & & U-235 & $8.80 \mathrm{E}-07$ & & U-235 & $8.80 \mathrm{E}-07$ & & \\
\hline & & & $\mathrm{Y}-90$ & $3.50 \mathrm{E}-01$ & & Y-90 & $1.91 \mathrm{E}-01$ & & \\
\hline 225 & S840857 & 1984 & & & 2009 & Ac- 227 & $1.44 \mathrm{E}-10$ & 105,000 & 56,000 \\
\hline
\end{tabular}

${ }^{1}$ Calculated decayed contact dose rate. Rounded to nearest $10 \mathrm{mR} / \mathrm{hr}$ for values to 1000 ; rounded to nearest $100 \mathrm{mR} / \mathrm{hr}$ for values $>1000$ to 10,000 ; rounded to nearest $1000 \mathrm{mR} / \mathrm{hr}$ for values $>10,000$. * Initial contact dose rate assumed to be $1,000,000 \mathrm{mR} / \mathrm{hr}$; **Initial contact dose rate assumed to be $1,010,000 \mathrm{mR} / \mathrm{hr}$.

$$
122 \text { of } 168
$$


Appendix A-4 - Initial and Decayed Radionuclide and Dose Data for Lined Shafts

\begin{tabular}{|c|c|c|c|c|c|c|c|c|c|}
\hline \multirow[b]{2}{*}{ Shaft Number } & \multirow[b]{2}{*}{ Package ID } & \multirow[b]{2}{*}{ Base Year } & \multicolumn{2}{|c|}{ Initial Isotopic Distribution } & \multirow[b]{2}{*}{ Target Year } & \multicolumn{2}{|c|}{ Decayed Isotopic Distribution } & \multirow{2}{*}{$\begin{array}{c}\text { Initial Contact } \\
\text { Dose Rate } \\
(\mathrm{mR} / \mathrm{hr})\end{array}$} & \multirow{2}{*}{$\begin{array}{c}\text { Decayed } \\
\text { Contact Dose } \\
\text { Rate }(\mathrm{mR} / \mathrm{hr})^{1} \\
\end{array}$} \\
\hline & & & Isotope & Activity (Ci) & & Isotope & Activity (Ci) & & \\
\hline & & & Ba-137m & $7.19 \mathrm{E}-01$ & & Ba-137m & $4.02 \mathrm{E}-01$ & & \\
\hline & & & & & & Bi-211 & $1.42 \mathrm{E}-10$ & & \\
\hline & & & Cs-137 & $7.66 \mathrm{E}-01$ & & Cs-137 & $4.30 \mathrm{E}-01$ & & \\
\hline & & & $\mathrm{Eu}-155$ & $1.43 \mathrm{E}-02$ & & $\mathrm{Eu}-155$ & $4.35 \mathrm{E}-04$ & & \\
\hline & & & & & & Fr-223 & $1.97 \mathrm{E}-12$ & & \\
\hline & & & & & & $\mathrm{Pa}-231$ & $4.65 \mathrm{E}-10$ & & \\
\hline & & & & & & $\mathrm{Pb}-211$ & $1.43 \mathrm{E}-10$ & & \\
\hline & & & Pm-147 & 4.38E-02 & & Pm-147 & $5.90 \mathrm{E}-05$ & & \\
\hline & & & & & & Po-211 & $4.35 \mathrm{E}-13$ & & \\
\hline & & & & & & Po-215 & $1.43 \mathrm{E}-10$ & & \\
\hline & & & $\mathrm{Pu}-239$ & $6.20 \mathrm{E}-03$ & & $\mathrm{Pu}-239$ & $6.20 \mathrm{E}-03$ & & \\
\hline & & & & & & $\mathrm{Ra}-223$ & $1.44 \mathrm{E}-10$ & & \\
\hline & & & Rh-106 & $5.62 \mathrm{E}-03$ & & Rh-106 & $1.90 \mathrm{E}-10$ & & \\
\hline & & & & & & $\mathrm{Rn}-219$ & $1.42 \mathrm{E}-10$ & & \\
\hline & & & $\mathrm{Ru}-106$ & $5.62 \mathrm{E}-03$ & & $\mathrm{Ru}-106$ & $1.92 \mathrm{E}-10$ & & \\
\hline & & & $\mathrm{Sb}-125$ & $3.12 \mathrm{E}-02$ & & $\mathrm{Sb}-125$ & $5.98 \mathrm{E}-05$ & & \\
\hline & & & & & & Sm-147 & $1.07 \mathrm{E}-12$ & & \\
\hline & & & Sr-90 & $7.00 \mathrm{E}-01$ & & Sr-90 & $3.86 \mathrm{E}-01$ & & \\
\hline & & & Te-125m & $1.30 \mathrm{E}-02$ & & $\mathrm{Te}-125 \mathrm{~m}$ & $1.45 \mathrm{E}-05$ & & \\
\hline & & & & & & Th-227 & $1.40 \mathrm{E}-10$ & & \\
\hline & & & & & & Th-231 & 8.69E-07 & & \\
\hline & & & & & & Tl-207 & $1.42 \mathrm{E}-10$ & & \\
\hline & & & U-235 & $8.80 \mathrm{E}-07$ & & U-235 & $8.80 \mathrm{E}-07$ & & \\
\hline & & & Y-90 & $6.99 \mathrm{E}-01$ & & Y-90 & $3.82 \mathrm{E}-01$ & & \\
\hline \multirow[t]{8}{*}{225} & S840863 & 1984 & & & 2009 & Ac- 227 & $1.44 \mathrm{E}-10$ & 10,000 & 5,300 \\
\hline & & & Ba-137m & $1.92 \mathrm{E}-02$ & & $\mathrm{Ba}-137 \mathrm{~m}$ & $1.07 \mathrm{E}-02$ & & \\
\hline & & & & & & Bi-211 & $1.42 \mathrm{E}-10$ & & \\
\hline & & & Cs-137 & $2.04 \mathrm{E}-02$ & & Cs-137 & $1.15 \mathrm{E}-02$ & & \\
\hline & & & Eu-155 & $3.82 \mathrm{E}-04$ & & Eu-155 & $1.16 \mathrm{E}-05$ & & \\
\hline & & & & & & Fr-223 & $1.97 \mathrm{E}-12$ & & \\
\hline & & & & & & $\mathrm{Pa}-231$ & $4.65 \mathrm{E}-10$ & & \\
\hline & & & & & & $\mathrm{Pb}-211$ & $1.43 \mathrm{E}-10$ & & \\
\hline
\end{tabular}

${ }^{1}$ Calculated decayed contact dose rate. Rounded to nearest $10 \mathrm{mR} / \mathrm{hr}$ for values to 1000 ; rounded to nearest $100 \mathrm{mR} / \mathrm{hr}$ for values $>1000$ to 10,000 ; rounded to nearest $1000 \mathrm{mR} / \mathrm{hr}$ for values $>10,000$. * Initial contact dose rate assumed to be $1,000,000 \mathrm{mR} / \mathrm{hr}$; **Initial contact dose rate assumed to be $1,010,000 \mathrm{mR} / \mathrm{hr}$.

$$
123 \text { of } 168
$$


Appendix A-4 - Initial and Decayed Radionuclide and Dose Data for Lined Shafts

\begin{tabular}{|c|c|c|c|c|c|c|c|c|c|}
\hline \multirow[b]{2}{*}{ Shaft Number } & \multirow[b]{2}{*}{ Package ID } & \multirow[b]{2}{*}{ Base Year } & \multicolumn{2}{|c|}{ Initial Isotopic Distribution } & \multirow[b]{2}{*}{ Target Year } & \multicolumn{2}{|c|}{ Decayed Isotopic Distribution } & \multirow{2}{*}{$\begin{array}{c}\text { Initial Contact } \\
\text { Dose Rate } \\
(\mathrm{mR} / \mathrm{hr})\end{array}$} & \multirow{2}{*}{$\begin{array}{c}\text { Decayed } \\
\text { Contact Dose } \\
\text { Rate }(\mathrm{mR} / \mathrm{hr})^{1} \\
\end{array}$} \\
\hline & & & Isotope & Activity (Ci) & & Isotope & Activity (Ci) & & \\
\hline & & & Pm-147 & $1.17 \mathrm{E}-03$ & & Pm-147 & $1.57 \mathrm{E}-06$ & & \\
\hline & & & & & & Po-211 & $4.35 \mathrm{E}-13$ & & \\
\hline & & & & & & Po-215 & $1.43 \mathrm{E}-10$ & & \\
\hline & & & $\mathrm{Pu}-239$ & $6.20 \mathrm{E}-03$ & & $\mathrm{Pu}-239$ & $6.20 \mathrm{E}-03$ & & \\
\hline & & & & & & Ra-223 & $1.44 \mathrm{E}-10$ & & \\
\hline & & & Rh-106 & $1.50 \mathrm{E}-04$ & & Rh-106 & $5.07 \mathrm{E}-12$ & & \\
\hline & & & & & & $\mathrm{Rn}-219$ & $1.42 \mathrm{E}-10$ & & \\
\hline & & & $\mathrm{Ru}-106$ & $1.50 \mathrm{E}-04$ & & $\mathrm{Ru}-106$ & $5.12 \mathrm{E}-12$ & & \\
\hline & & & Sb-125 & 8.32E-04 & & $\mathrm{Sb}-125$ & $1.60 \mathrm{E}-06$ & & \\
\hline & & & & & & Sm-147 & $2.86 \mathrm{E}-14$ & & \\
\hline & & & Sr-90 & $1.87 \mathrm{E}-02$ & & Sr-90 & $1.03 \mathrm{E}-02$ & & \\
\hline & & & $\mathrm{Te}-125 \mathrm{~m}$ & $3.45 \mathrm{E}-04$ & & $\mathrm{Te}-125 \mathrm{~m}$ & $3.87 \mathrm{E}-07$ & & \\
\hline & & & & & & Th-227 & $1.40 \mathrm{E}-10$ & & \\
\hline & & & & & & Th-231 & $8.69 \mathrm{E}-07$ & & \\
\hline & & & & & & T1-207 & $1.42 \mathrm{E}-10$ & & \\
\hline & & & $\mathrm{U}-235$ & $8.80 \mathrm{E}-07$ & & $\mathrm{U}-235$ & $8.80 \mathrm{E}-07$ & & \\
\hline & & & Y-90 & $1.87 \mathrm{E}-02$ & & $\mathrm{Y}-90$ & $1.02 \mathrm{E}-02$ & & \\
\hline \multirow[t]{15}{*}{225} & S840864 & 1984 & & & 2009 & Ac- 227 & $1.44 \mathrm{E}-10$ & 25,000 & 13,000 \\
\hline & & & Ba-137m & 7.19E-02 & & $\mathrm{Ba}-137 \mathrm{~m}$ & $4.02 \mathrm{E}-02$ & & \\
\hline & & & & & & Bi-211 & $1.42 \mathrm{E}-10$ & & \\
\hline & & & Cs-137 & 7.66E-02 & & Cs-137 & $4.30 \mathrm{E}-02$ & & \\
\hline & & & Eu-155 & $1.43 \mathrm{E}-03$ & & Eu-155 & 4.35E-05 & & \\
\hline & & & & & & Fr-223 & $1.97 \mathrm{E}-12$ & & \\
\hline & & & & & & $\mathrm{Pa}-231$ & $4.65 \mathrm{E}-10$ & & \\
\hline & & & & & & $\mathrm{Pb}-211$ & $1.43 \mathrm{E}-10$ & & \\
\hline & & & Pm-147 & 4.38E-03 & & Pm-147 & $5.92 \mathrm{E}-06$ & & \\
\hline & & & & & & Po-211 & $4.35 \mathrm{E}-13$ & & \\
\hline & & & & & & Po-215 & $1.43 \mathrm{E}-10$ & & \\
\hline & & & $\mathrm{Pu}-239$ & $6.20 \mathrm{E}-03$ & & Pu-239 & $6.20 \mathrm{E}-03$ & & \\
\hline & & & & & & Ra-223 & $1.44 \mathrm{E}-10$ & & \\
\hline & & & Rh-106 & $5.62 \mathrm{E}-04$ & & Rh-106 & $1.90 \mathrm{E}-11$ & & \\
\hline & & & & & & Rn-219 & $1.42 \mathrm{E}-10$ & & \\
\hline
\end{tabular}

${ }^{1}$ Calculated decayed contact dose rate. Rounded to nearest $10 \mathrm{mR} / \mathrm{hr}$ for values to 1000 ; rounded to nearest $100 \mathrm{mR} / \mathrm{hr}$ for values $>1000$ to 10,000 ; rounded to nearest $1000 \mathrm{mR} / \mathrm{hr}$ for values $>10,000$. * Initial contact dose rate assumed to be $1,000,000 \mathrm{mR} / \mathrm{hr}$; **Initial contact dose rate assumed to be $1,010,000 \mathrm{mR} / \mathrm{hr}$.

$$
124 \text { of } 168
$$


Appendix A-4 - Initial and Decayed Radionuclide and Dose Data for Lined Shafts

\begin{tabular}{|c|c|c|c|c|c|c|c|c|c|}
\hline \multirow[b]{2}{*}{ Shaft Number } & \multirow[b]{2}{*}{ Package ID } & \multirow[b]{2}{*}{ Base Year } & \multicolumn{2}{|c|}{ Initial Isotopic Distribution } & \multirow[b]{2}{*}{ Target Year } & \multicolumn{2}{|c|}{ Decayed Isotopic Distribution } & \multirow{2}{*}{$\begin{array}{c}\text { Initial Contact } \\
\text { Dose Rate } \\
(\mathrm{mR} / \mathrm{hr})\end{array}$} & \multirow{2}{*}{$\begin{array}{c}\text { Decayed } \\
\text { Contact Dose } \\
\text { Rate }(\mathrm{mR} / \mathrm{hr})^{1} \\
\end{array}$} \\
\hline & & & Isotope & Activity (Ci) & & Isotope & Activity (Ci) & & \\
\hline & & & $\mathrm{Ru}-106$ & $5.62 \mathrm{E}-04$ & & $\mathrm{Ru}-106$ & $1.92 \mathrm{E}-11$ & & \\
\hline & & & $\mathrm{Sb}-125$ & $3.12 \mathrm{E}-03$ & & $\mathrm{Sb}-125$ & $5.99 \mathrm{E}-06$ & & \\
\hline & & & & & & Sm-147 & $1.07 \mathrm{E}-13$ & & \\
\hline & & & Sr-90 & 7.00E-02 & & Sr-90 & $3.86 \mathrm{E}-02$ & & \\
\hline & & & $\mathrm{Te}-125 \mathrm{~m}$ & $1.30 \mathrm{E}-03$ & & $\mathrm{Te}-125 \mathrm{~m}$ & $1.45 \mathrm{E}-06$ & & \\
\hline & & & & & & Th-227 & $1.40 \mathrm{E}-10$ & & \\
\hline & & & & & & Th-231 & $8.69 \mathrm{E}-07$ & & \\
\hline & & & & & & T1-207 & $1.42 \mathrm{E}-10$ & & \\
\hline & & & $\mathrm{U}-235$ & $8.80 \mathrm{E}-07$ & & $\mathrm{U}-235$ & $8.80 \mathrm{E}-07$ & & \\
\hline & & & $\mathrm{Y}-90$ & $6.99 \mathrm{E}-02$ & & $\mathrm{Y}-90$ & $3.82 \mathrm{E}-02$ & & \\
\hline \multirow[t]{22}{*}{225} & S840867 & 1984 & & & 2009 & Ac-227 & $1.44 \mathrm{E}-10$ & 30,000 & 16,000 \\
\hline & & & Ba-137m & $9.59 \mathrm{E}-02$ & & $\mathrm{Ba}-137 \mathrm{~m}$ & $5.36 \mathrm{E}-02$ & & \\
\hline & & & & & & Bi-211 & $1.42 \mathrm{E}-10$ & & \\
\hline & & & Cs-137 & $1.02 \mathrm{E}-01$ & & Cs-137 & $5.73 \mathrm{E}-02$ & & \\
\hline & & & Eu-155 & $1.91 \mathrm{E}-03$ & & Eu-155 & $5.80 \mathrm{E}-05$ & & \\
\hline & & & & & & Fr-223 & $1.97 \mathrm{E}-12$ & & \\
\hline & & & & & & $\mathrm{Pa}-231$ & $4.65 \mathrm{E}-10$ & & \\
\hline & & & & & & $\mathrm{Pb}-211$ & $1.43 \mathrm{E}-10$ & & \\
\hline & & & Pm-147 & $5.83 \mathrm{E}-03$ & & Pm-147 & $7.88 \mathrm{E}-06$ & & \\
\hline & & & & & & Po-211 & $4.35 \mathrm{E}-13$ & & \\
\hline & & & & & & Po-215 & $1.43 \mathrm{E}-10$ & & \\
\hline & & & Pu-239 & $6.20 \mathrm{E}-03$ & & Pu-239 & $6.20 \mathrm{E}-03$ & & \\
\hline & & & & & & $\mathrm{Ra}-223$ & $1.44 \mathrm{E}-10$ & & \\
\hline & & & Rh-106 & 7.49E-04 & & Rh-106 & $2.54 \mathrm{E}-11$ & & \\
\hline & & & & & & Rn-219 & $1.42 \mathrm{E}-10$ & & \\
\hline & & & $\mathrm{Ru}-106$ & 7.49E-04 & & $\mathrm{Ru}-106$ & $2.56 \mathrm{E}-11$ & & \\
\hline & & & Sb-125 & 4.16E-03 & & Sb-125 & 7.97E-06 & & \\
\hline & & & & & & Sm-147 & $1.43 \mathrm{E}-13$ & & \\
\hline & & & Sr-90 & $9.34 \mathrm{E}-02$ & & Sr-90 & $5.15 \mathrm{E}-02$ & & \\
\hline & & & $\mathrm{Te}-125 \mathrm{~m}$ & $1.73 \mathrm{E}-03$ & & $\mathrm{Te}-125 \mathrm{~m}$ & $1.93 \mathrm{E}-06$ & & \\
\hline & & & & & & Th-227 & $1.40 \mathrm{E}-10$ & & \\
\hline & & & & & & Th-231 & 8.69E-07 & & \\
\hline
\end{tabular}

${ }^{1}$ Calculated decayed contact dose rate. Rounded to nearest $10 \mathrm{mR} / \mathrm{hr}$ for values to 1000 ; rounded to nearest $100 \mathrm{mR} / \mathrm{hr}$ for values $>1000$ to 10,000 ; rounded to nearest $1000 \mathrm{mR} / \mathrm{hr}$ for values $>10,000$. * Initial contact dose rate assumed to be $1,000,000 \mathrm{mR} / \mathrm{hr}$; **Initial contact dose rate assumed to be $1,010,000 \mathrm{mR} / \mathrm{hr}$.

$$
125 \text { of } 168
$$


Appendix A-4 - Initial and Decayed Radionuclide and Dose Data for Lined Shafts

\begin{tabular}{|c|c|c|c|c|c|c|c|c|c|}
\hline \multirow[b]{2}{*}{ Shaft Number } & \multirow[b]{2}{*}{ Package ID } & \multirow[b]{2}{*}{ Base Year } & \multicolumn{2}{|c|}{ Initial Isotopic Distribution } & \multirow[b]{2}{*}{ Target Year } & \multicolumn{2}{|c|}{ Decayed Isotopic Distribution } & \multirow{2}{*}{$\begin{array}{c}\text { Initial Contact } \\
\text { Dose Rate } \\
(\mathrm{mR} / \mathrm{hr})\end{array}$} & \multirow{2}{*}{$\begin{array}{c}\text { Decayed } \\
\text { Contact Dose } \\
\text { Rate }(\mathrm{mR} / \mathrm{hr}) \\
\end{array}$} \\
\hline & & & Isotope & Activity (Ci) & & Isotope & Activity (Ci) & & \\
\hline & & & & & & Tl-207 & $1.42 \mathrm{E}-10$ & & \\
\hline & & & U-235 & $8.80 \mathrm{E}-07$ & & $\mathrm{U}-235$ & $8.80 \mathrm{E}-07$ & & \\
\hline & & & $\mathrm{Y}-90$ & 9.33E-02 & & $\mathrm{Y}-90$ & $5.09 \mathrm{E}-02$ & & \\
\hline \multirow[t]{25}{*}{225} & S840874 & 1984 & & & 2009 & Ac-227 & $1.44 \mathrm{E}-10$ & 15,000 & 8,000 \\
\hline & & & Ba-137m & 4.79E-02 & & Ba-137m & $2.68 \mathrm{E}-02$ & & \\
\hline & & & & & & $\mathrm{Bi}-211$ & $1.42 \mathrm{E}-10$ & & \\
\hline & & & Cs-137 & $5.11 \mathrm{E}-02$ & & Cs-137 & $2.87 \mathrm{E}-02$ & & \\
\hline & & & Eu-155 & $9.55 \mathrm{E}-04$ & & Eu-155 & $2.90 \mathrm{E}-05$ & & \\
\hline & & & & & & Fr-223 & $1.97 \mathrm{E}-12$ & & \\
\hline & & & & & & $\mathrm{Pa}-231$ & $4.65 \mathrm{E}-10$ & & \\
\hline & & & & & & $\mathrm{Pb}-211$ & $1.43 \mathrm{E}-10$ & & \\
\hline & & & Pm-147 & $2.92 \mathrm{E}-03$ & & Pm-147 & $3.94 \mathrm{E}-06$ & & \\
\hline & & & & & & Po-211 & $4.35 \mathrm{E}-13$ & & \\
\hline & & & & & & Po-215 & $1.43 \mathrm{E}-10$ & & \\
\hline & & & $\mathrm{Pu}-239$ & $6.20 \mathrm{E}-03$ & & $\mathrm{Pu}-239$ & $6.20 \mathrm{E}-03$ & & \\
\hline & & & & & & $\mathrm{Ra}-223$ & $1.44 \mathrm{E}-10$ & & \\
\hline & & & Rh-106 & $3.74 \mathrm{E}-04$ & & Rh-106 & $1.27 \mathrm{E}-11$ & & \\
\hline & & & & & & Rn-219 & $1.42 \mathrm{E}-10$ & & \\
\hline & & & $\mathrm{Ru}-106$ & $3.74 \mathrm{E}-04$ & & $\mathrm{Ru}-106$ & $1.28 \mathrm{E}-11$ & & \\
\hline & & & Sb-125 & $2.08 \mathrm{E}-03$ & & Sb-125 & 3.99E-06 & & \\
\hline & & & & & & Sm-147 & 7.14E-14 & & \\
\hline & & & Sr-90 & 4.67E-02 & & Sr-90 & $2.58 \mathrm{E}-02$ & & \\
\hline & & & Te-125m & 8.63E-04 & & $\mathrm{Te}-125 \mathrm{~m}$ & $9.66 \mathrm{E}-07$ & & \\
\hline & & & & & & Th-227 & $1.40 \mathrm{E}-10$ & & \\
\hline & & & & & & Th-231 & 8.69E-07 & & \\
\hline & & & & & & Tl-207 & $1.42 \mathrm{E}-10$ & & \\
\hline & & & U-235 & 8.80E-07 & & U-235 & $8.80 \mathrm{E}-07$ & & \\
\hline & & & Y-90 & 4.66E-02 & & Y-90 & $2.55 \mathrm{E}-02$ & & \\
\hline \multirow[t]{4}{*}{226} & S840842 & 1984 & & & 2009 & Ac-227 & $1.44 \mathrm{E}-10$ & 90,000 & 48,000 \\
\hline & & & Ba-137m & 4.79E-01 & & Ba-137m & $2.68 \mathrm{E}-01$ & & \\
\hline & & & & & & Bi-211 & $1.42 \mathrm{E}-10$ & & \\
\hline & & & Cs-137 & $5.11 \mathrm{E}-01$ & & Cs-137 & $2.87 \mathrm{E}-01$ & & \\
\hline
\end{tabular}

${ }^{1}$ Calculated decayed contact dose rate. Rounded to nearest $10 \mathrm{mR} / \mathrm{hr}$ for values to 1000 ; rounded to nearest $100 \mathrm{mR} / \mathrm{hr}$ for values $>1000$ to 10,000 ; rounded to nearest $1000 \mathrm{mR} / \mathrm{hr}$ for values $>10,000$. * Initial contact dose rate assumed to be $1,000,000 \mathrm{mR} / \mathrm{hr}$; **Initial contact dose rate assumed to be $1,010,000 \mathrm{mR} / \mathrm{hr}$.

$$
126 \text { of } 168
$$


Appendix A-4 - Initial and Decayed Radionuclide and Dose Data for Lined Shafts

\begin{tabular}{|c|c|c|c|c|c|c|c|c|c|}
\hline \multirow[b]{2}{*}{ Shaft Number } & \multirow[b]{2}{*}{ Package ID } & \multirow[b]{2}{*}{ Base Year } & \multicolumn{2}{|c|}{ Initial Isotopic Distribution } & \multirow[b]{2}{*}{ Target Year } & \multicolumn{2}{|c|}{ Decayed Isotopic Distribution } & \multirow{2}{*}{$\begin{array}{c}\text { Initial Contact } \\
\text { Dose Rate } \\
(\mathrm{mR} / \mathrm{hr})\end{array}$} & \multirow{2}{*}{$\begin{array}{c}\text { Decayed } \\
\text { Contact Dose } \\
\text { Rate }(\mathrm{mR} / \mathrm{hr})^{1} \\
\end{array}$} \\
\hline & & & Isotope & Activity (Ci) & & Isotope & Activity (Ci) & & \\
\hline & & & Eu-155 & $9.55 \mathrm{E}-03$ & & Eu-155 & $2.90 \mathrm{E}-04$ & & \\
\hline & & & & & & Fr-223 & $1.97 \mathrm{E}-12$ & & \\
\hline & & & & & & $\mathrm{Pa}-231$ & $4.65 \mathrm{E}-10$ & & \\
\hline & & & & & & $\mathrm{Pb}-211$ & $1.43 \mathrm{E}-10$ & & \\
\hline & & & Pm-147 & $2.92 \mathrm{E}-02$ & & Pm-147 & $3.93 \mathrm{E}-05$ & & \\
\hline & & & & & & Po-211 & $4.35 \mathrm{E}-13$ & & \\
\hline & & & & & & Po-215 & $1.43 \mathrm{E}-10$ & & \\
\hline & & & $\mathrm{Pu}-239$ & $6.20 \mathrm{E}-03$ & & $\mathrm{Pu}-239$ & $6.20 \mathrm{E}-03$ & & \\
\hline & & & & & & Ra-223 & $1.44 \mathrm{E}-10$ & & \\
\hline & & & Rh-106 & $3.74 \mathrm{E}-03$ & & Rh-106 & $1.27 \mathrm{E}-10$ & & \\
\hline & & & & & & Rn-219 & $1.42 \mathrm{E}-10$ & & \\
\hline & & & $\mathrm{Ru}-106$ & $3.74 \mathrm{E}-03$ & & $\mathrm{Ru}-106$ & $1.28 \mathrm{E}-10$ & & \\
\hline & & & Sb-125 & $2.08 \mathrm{E}-02$ & & $\mathrm{Sb}-125$ & $4.00 \mathrm{E}-05$ & & \\
\hline & & & & & & Sm-147 & $7.14 \mathrm{E}-13$ & & \\
\hline & & & Sr-90 & 4.67E-01 & & Sr-90 & $2.58 \mathrm{E}-01$ & & \\
\hline & & & $\mathrm{Te}-125 \mathrm{~m}$ & 8.63E-03 & & $\mathrm{Te}-125 \mathrm{~m}$ & $9.67 \mathrm{E}-06$ & & \\
\hline & & & & & & Th-227 & $1.40 \mathrm{E}-10$ & & \\
\hline & & & & & & Th-231 & 8.69E-07 & & \\
\hline & & & & & & T1-207 & $1.42 \mathrm{E}-10$ & & \\
\hline & & & U-235 & $8.80 \mathrm{E}-07$ & & U-235 & $8.80 \mathrm{E}-07$ & & \\
\hline & & & Y-90 & $4.66 \mathrm{E}-01$ & & $\mathrm{Y}-90$ & $2.55 \mathrm{E}-01$ & & \\
\hline \multirow[t]{11}{*}{226} & S840843 & 1984 & & & 2009 & Ac-227 & $1.44 \mathrm{E}-10$ & 80,000 & 42,000 \\
\hline & & & Ba-137m & 4.79E-01 & & Ba-137m & $2.68 \mathrm{E}-01$ & & \\
\hline & & & & & & Bi-211 & $1.42 \mathrm{E}-10$ & & \\
\hline & & & Cs-137 & $5.11 \mathrm{E}-01$ & & Cs-137 & $2.87 \mathrm{E}-01$ & & \\
\hline & & & Eu-155 & $9.55 \mathrm{E}-03$ & & Eu-155 & $2.90 \mathrm{E}-04$ & & \\
\hline & & & & & & Fr-223 & $1.97 \mathrm{E}-12$ & & \\
\hline & & & & & & $\mathrm{Pa}-231$ & $4.65 \mathrm{E}-10$ & & \\
\hline & & & & & & $\mathrm{Pb}-211$ & $1.43 \mathrm{E}-10$ & & \\
\hline & & & Pm-147 & $2.92 \mathrm{E}-02$ & & Pm-147 & $3.93 \mathrm{E}-05$ & & \\
\hline & & & & & & Рo-211 & $4.35 \mathrm{E}-13$ & & \\
\hline & & & & & & Po-215 & $1.43 \mathrm{E}-10$ & & \\
\hline
\end{tabular}

${ }^{1}$ Calculated decayed contact dose rate. Rounded to nearest $10 \mathrm{mR} / \mathrm{hr}$ for values to 1000 ; rounded to nearest $100 \mathrm{mR} / \mathrm{hr}$ for values $>1000$ to 10,000 ; rounded to nearest $1000 \mathrm{mR} / \mathrm{hr}$ for values $>10,000$. * Initial contact dose rate assumed to be $1,000,000 \mathrm{mR} / \mathrm{hr}$; **Initial contact dose rate assumed to be $1,010,000 \mathrm{mR} / \mathrm{hr}$.

$$
127 \text { of } 168
$$


Appendix A-4 - Initial and Decayed Radionuclide and Dose Data for Lined Shafts

\begin{tabular}{|c|c|c|c|c|c|c|c|c|c|}
\hline \multirow[b]{2}{*}{ Shaft Number } & \multirow[b]{2}{*}{ Package ID } & \multirow[b]{2}{*}{ Base Year } & \multicolumn{2}{|c|}{ Initial Isotopic Distribution } & \multirow[b]{2}{*}{ Target Year } & \multicolumn{2}{|c|}{ Decayed Isotopic Distribution } & \multirow{2}{*}{$\begin{array}{c}\text { Initial Contact } \\
\text { Dose Rate } \\
(\mathrm{mR} / \mathrm{hr})\end{array}$} & \multirow{2}{*}{$\begin{array}{c}\text { Decayed } \\
\text { Contact Dose } \\
\text { Rate }(\mathrm{mR} / \mathrm{hr})^{1} \\
\end{array}$} \\
\hline & & & Isotope & Activity (Ci) & & Isotope & Activity (Ci) & & \\
\hline & & & $\mathrm{Pu}-239$ & $6.20 \mathrm{E}-03$ & & $\mathrm{Pu}-239$ & $6.20 \mathrm{E}-03$ & & \\
\hline & & & & & & Ra-223 & $1.44 \mathrm{E}-10$ & & \\
\hline & & & Rh-106 & $3.74 \mathrm{E}-03$ & & Rh-106 & $1.27 \mathrm{E}-10$ & & \\
\hline & & & & & & $\mathrm{Rn}-219$ & $1.42 \mathrm{E}-10$ & & \\
\hline & & & $\mathrm{Ru}-106$ & $3.74 \mathrm{E}-03$ & & $\mathrm{Ru}-106$ & $1.28 \mathrm{E}-10$ & & \\
\hline & & & $\mathrm{Sb}-125$ & $2.08 \mathrm{E}-02$ & & Sb-125 & $4.00 \mathrm{E}-05$ & & \\
\hline & & & & & & Sm-147 & $7.14 \mathrm{E}-13$ & & \\
\hline & & & Sr-90 & 4.67E-01 & & Sr-90 & $2.58 \mathrm{E}-01$ & & \\
\hline & & & $\mathrm{Te}-125 \mathrm{~m}$ & 8.63E-03 & & $\mathrm{Te}-125 \mathrm{~m}$ & $9.67 \mathrm{E}-06$ & & \\
\hline & & & & & & Th-227 & $1.40 \mathrm{E}-10$ & & \\
\hline & & & & & & Th-231 & $8.69 \mathrm{E}-07$ & & \\
\hline & & & & & & T1-207 & $1.42 \mathrm{E}-10$ & & \\
\hline & & & $\mathrm{U}-235$ & $8.80 \mathrm{E}-07$ & & $\mathrm{U}-235$ & $8.80 \mathrm{E}-07$ & & \\
\hline & & & $\mathrm{Y}-90$ & $4.66 \mathrm{E}-01$ & & $\mathrm{Y}-90$ & $2.55 \mathrm{E}-01$ & & \\
\hline \multirow[t]{18}{*}{226} & S840844 & 1984 & & & 2009 & Ac-227 & $1.44 \mathrm{E}-10$ & 70,000 & 37,000 \\
\hline & & & Ba-137m & $3.59 \mathrm{E}-01$ & & Ba-137m & $2.01 \mathrm{E}-01$ & & \\
\hline & & & & & & Bi-211 & $1.42 \mathrm{E}-10$ & & \\
\hline & & & Cs-137 & $3.83 \mathrm{E}-01$ & & Cs-137 & $2.15 \mathrm{E}-01$ & & \\
\hline & & & Eu-155 & 7.17E-03 & & Eu-155 & $2.18 \mathrm{E}-04$ & & \\
\hline & & & & & & Fr-223 & $1.97 \mathrm{E}-12$ & & \\
\hline & & & & & & $\mathrm{Pa}-231$ & $4.65 \mathrm{E}-10$ & & \\
\hline & & & & & & $\mathrm{Pb}-211$ & $1.43 \mathrm{E}-10$ & & \\
\hline & & & Pm-147 & 2.19E-02 & & Pm-147 & $2.95 \mathrm{E}-05$ & & \\
\hline & & & & & & Po-211 & $4.35 \mathrm{E}-13$ & & \\
\hline & & & & & & Po-215 & $1.43 \mathrm{E}-10$ & & \\
\hline & & & $\mathrm{Pu}-239$ & $6.20 \mathrm{E}-03$ & & $\mathrm{Pu}-239$ & $6.20 \mathrm{E}-03$ & & \\
\hline & & & & & & Ra-223 & $1.44 \mathrm{E}-10$ & & \\
\hline & & & Rh-106 & $2.81 \mathrm{E}-03$ & & Rh-106 & $9.51 \mathrm{E}-11$ & & \\
\hline & & & & & & Rn-219 & $1.42 \mathrm{E}-10$ & & \\
\hline & & & Ru-106 & $2.81 \mathrm{E}-03$ & & Ru-106 & $9.60 \mathrm{E}-11$ & & \\
\hline & & & Sb-125 & $1.56 \mathrm{E}-02$ & & Sb-125 & $2.99 \mathrm{E}-05$ & & \\
\hline & & & & & & Sm-147 & $5.36 \mathrm{E}-13$ & & \\
\hline
\end{tabular}

${ }^{1}$ Calculated decayed contact dose rate. Rounded to nearest $10 \mathrm{mR} / \mathrm{hr}$ for values to 1000 ; rounded to nearest $100 \mathrm{mR} / \mathrm{hr}$ for values $>1000$ to 10,000 ; rounded to nearest $1000 \mathrm{mR} / \mathrm{hr}$ for values $>10,000$. * Initial contact dose rate assumed to be $1,000,000 \mathrm{mR} / \mathrm{hr}$; **Initial contact dose rate assumed to be $1,010,000 \mathrm{mR} / \mathrm{hr}$.

$$
128 \text { of } 168
$$


Appendix A-4 - Initial and Decayed Radionuclide and Dose Data for Lined Shafts

\begin{tabular}{|c|c|c|c|c|c|c|c|c|c|}
\hline \multirow[b]{2}{*}{ Shaft Number } & \multirow[b]{2}{*}{ Package ID } & \multirow[b]{2}{*}{ Base Year } & \multicolumn{2}{|c|}{ Initial Isotopic Distribution } & \multirow[b]{2}{*}{ Target Year } & \multicolumn{2}{|c|}{ Decayed Isotopic Distribution } & \multirow{2}{*}{$\begin{array}{c}\text { Initial Contact } \\
\text { Dose Rate } \\
(\mathrm{mR} / \mathrm{hr})\end{array}$} & \multirow{2}{*}{$\begin{array}{c}\text { Decayed } \\
\text { Contact Dose } \\
\text { Rate }(\mathrm{mR} / \mathrm{hr})^{1} \\
\end{array}$} \\
\hline & & & Isotope & Activity (Ci) & & Isotope & Activity (Ci) & & \\
\hline & & & Sr-90 & $3.50 \mathrm{E}-01$ & & Sr-90 & $1.93 \mathrm{E}-01$ & & \\
\hline & & & $\mathrm{Te}-125 \mathrm{~m}$ & $6.48 \mathrm{E}-03$ & & $\mathrm{Te}-125 \mathrm{~m}$ & $7.25 \mathrm{E}-06$ & & \\
\hline & & & & & & Th-227 & $1.40 \mathrm{E}-10$ & & \\
\hline & & & & & & Th-231 & $8.69 \mathrm{E}-07$ & & \\
\hline & & & & & & Tl-207 & $1.42 \mathrm{E}-10$ & & \\
\hline & & & $\mathrm{U}-235$ & $8.80 \mathrm{E}-07$ & & U-235 & $8.80 \mathrm{E}-07$ & & \\
\hline & & & $\mathrm{Y}-90$ & $3.50 \mathrm{E}-01$ & & Y-90 & $1.91 \mathrm{E}-01$ & & \\
\hline \multirow[t]{25}{*}{226} & S840845 & 1984 & & & 2009 & Ac-227 & $1.44 \mathrm{E}-10$ & 21,000 & 11,000 \\
\hline & & & Ba-137m & 7.19E-02 & & Ba-137m & $4.02 \mathrm{E}-02$ & & \\
\hline & & & & & & Bi-211 & $1.42 \mathrm{E}-10$ & & \\
\hline & & & Cs-137 & $7.66 \mathrm{E}-02$ & & Cs-137 & 4.30E-02 & & \\
\hline & & & Eu-155 & $1.43 \mathrm{E}-03$ & & Eu-155 & $4.35 \mathrm{E}-05$ & & \\
\hline & & & & & & Fr-223 & $1.97 \mathrm{E}-12$ & & \\
\hline & & & & & & $\mathrm{Pa}-231$ & $4.65 \mathrm{E}-10$ & & \\
\hline & & & & & & $\mathrm{Pb}-211$ & $1.43 \mathrm{E}-10$ & & \\
\hline & & & Pm-147 & 4.38E-03 & & Pm-147 & $5.92 \mathrm{E}-06$ & & \\
\hline & & & & & & Po-211 & $4.35 \mathrm{E}-13$ & & \\
\hline & & & & & & Рo-215 & $1.43 \mathrm{E}-10$ & & \\
\hline & & & $\mathrm{Pu}-239$ & $6.20 \mathrm{E}-03$ & & $\mathrm{Pu}-239$ & $6.20 \mathrm{E}-03$ & & \\
\hline & & & & & & Ra-223 & $1.44 \mathrm{E}-10$ & & \\
\hline & & & Rh-106 & $5.62 \mathrm{E}-04$ & & Rh-106 & $1.90 \mathrm{E}-11$ & & \\
\hline & & & & & & Rn-219 & $1.42 \mathrm{E}-10$ & & \\
\hline & & & Ru-106 & $5.62 \mathrm{E}-04$ & & Ru-106 & $1.92 \mathrm{E}-11$ & & \\
\hline & & & Sb-125 & $3.12 \mathrm{E}-03$ & & Sb-125 & $5.99 \mathrm{E}-06$ & & \\
\hline & & & & & & Sm-147 & $1.07 \mathrm{E}-13$ & & \\
\hline & & & Sr-90 & 7.00E-02 & & Sr-90 & $3.86 \mathrm{E}-02$ & & \\
\hline & & & $\mathrm{Te}-125 \mathrm{~m}$ & $1.30 \mathrm{E}-03$ & & $\mathrm{Te}-125 \mathrm{~m}$ & $1.45 \mathrm{E}-06$ & & \\
\hline & & & & & & Th-227 & $1.40 \mathrm{E}-10$ & & \\
\hline & & & & & & Th-231 & 8.69E-07 & & \\
\hline & & & & & & Tl-207 & $1.42 \mathrm{E}-10$ & & \\
\hline & & & U-235 & $8.80 \mathrm{E}-07$ & & U-235 & $8.80 \mathrm{E}-07$ & & \\
\hline & & & Y-90 & $6.99 \mathrm{E}-02$ & & Y-90 & $3.82 \mathrm{E}-02$ & & \\
\hline
\end{tabular}

${ }^{1}$ Calculated decayed contact dose rate. Rounded to nearest $10 \mathrm{mR} / \mathrm{hr}$ for values to 1000 ; rounded to nearest $100 \mathrm{mR} / \mathrm{hr}$ for values $>1000$ to 10,000 ; rounded to nearest $1000 \mathrm{mR} / \mathrm{hr}$ for values $>10,000$. * Initial contact dose rate assumed to be $1,000,000 \mathrm{mR} / \mathrm{hr}$; **Initial contact dose rate assumed to be $1,010,000 \mathrm{mR} / \mathrm{hr}$.

$$
129 \text { of } 168
$$


Appendix A-4 - Initial and Decayed Radionuclide and Dose Data for Lined Shafts

\begin{tabular}{|c|c|c|c|c|c|c|c|c|c|}
\hline \multirow[b]{2}{*}{ Shaft Number } & \multirow[b]{2}{*}{ Package ID } & \multirow[b]{2}{*}{ Base Year } & \multicolumn{2}{|c|}{ Initial Isotopic Distribution } & \multirow[b]{2}{*}{ Target Year } & \multicolumn{2}{|c|}{ Decayed Isotopic Distribution } & \multirow{2}{*}{$\begin{array}{c}\text { Initial Contact } \\
\text { Dose Rate } \\
(\mathrm{mR} / \mathrm{hr})\end{array}$} & \multirow{2}{*}{$\begin{array}{c}\text { Decayed } \\
\text { Contact Dose } \\
\text { Rate }(\mathrm{mR} / \mathrm{hr})^{1} \\
\end{array}$} \\
\hline & & & Isotope & Activity (Ci) & & Isotope & Activity (Ci) & & \\
\hline \multirow[t]{25}{*}{226} & S840846 & 1984 & & & 2009 & Ac-227 & $1.44 \mathrm{E}-10$ & 300,000 & 159,000 \\
\hline & & & Ba-137m & $1.20 \mathrm{E}+00$ & & $\mathrm{Ba}-137 \mathrm{~m}$ & $6.70 \mathrm{E}-01$ & & \\
\hline & & & & & & $\mathrm{Bi}-211$ & $1.42 \mathrm{E}-10$ & & \\
\hline & & & Cs-137 & $1.28 \mathrm{E}+00$ & & Cs-137 & $7.16 \mathrm{E}-01$ & & \\
\hline & & & Eu-155 & $2.39 \mathrm{E}-02$ & & Eu-155 & $7.26 \mathrm{E}-04$ & & \\
\hline & & & & & & Fr-223 & $1.97 \mathrm{E}-12$ & & \\
\hline & & & & & & $\mathrm{Pa}-231$ & $4.65 \mathrm{E}-10$ & & \\
\hline & & & & & & $\mathrm{Pb}-211$ & $1.43 \mathrm{E}-10$ & & \\
\hline & & & Pm-147 & 7.29E-02 & & Pm-147 & $9.84 \mathrm{E}-05$ & & \\
\hline & & & & & & Po-211 & $4.35 \mathrm{E}-13$ & & \\
\hline & & & & & & Po-215 & $1.43 \mathrm{E}-10$ & & \\
\hline & & & $\mathrm{Pu}-239$ & $6.20 \mathrm{E}-03$ & & $\mathrm{Pu}-239$ & $6.20 \mathrm{E}-03$ & & \\
\hline & & & & & & Ra-223 & $1.44 \mathrm{E}-10$ & & \\
\hline & & & Rh-106 & $9.36 \mathrm{E}-03$ & & Rh-106 & $3.17 \mathrm{E}-10$ & & \\
\hline & & & & & & Rn-219 & $1.42 \mathrm{E}-10$ & & \\
\hline & & & $\mathrm{Ru}-106$ & $9.36 \mathrm{E}-03$ & & $\mathrm{Ru}-106$ & $3.20 \mathrm{E}-10$ & & \\
\hline & & & Sb-125 & $5.20 \mathrm{E}-02$ & & Sb-125 & $9.98 \mathrm{E}-05$ & & \\
\hline & & & & & & Sm-147 & $1.79 \mathrm{E}-12$ & & \\
\hline & & & Sr-90 & $1.17 \mathrm{E}+00$ & & Sr-90 & $6.44 \mathrm{E}-01$ & & \\
\hline & & & $\mathrm{Te}-125 \mathrm{~m}$ & $2.16 \mathrm{E}-02$ & & $\mathrm{Te}-125 \mathrm{~m}$ & $2.42 \mathrm{E}-05$ & & \\
\hline & & & & & & Th-227 & $1.40 \mathrm{E}-10$ & & \\
\hline & & & & & & Th-231 & 8.69E-07 & & \\
\hline & & & & & & Tl-207 & $1.42 \mathrm{E}-10$ & & \\
\hline & & & U-235 & $8.80 \mathrm{E}-07$ & & U-235 & $8.80 \mathrm{E}-07$ & & \\
\hline & & & Y-90 & $1.17 \mathrm{E}+00$ & & Y-90 & $6.36 \mathrm{E}-01$ & & \\
\hline \multirow[t]{7}{*}{226} & S840847 & 1984 & & & 2009 & Ac-227 & $1.44 \mathrm{E}-10$ & 70,000 & 37,000 \\
\hline & & & Ba-137m & $3.59 \mathrm{E}-01$ & & Ba-137m & $2.01 \mathrm{E}-01$ & & \\
\hline & & & & & & Bi-211 & $1.42 \mathrm{E}-10$ & & \\
\hline & & & Cs-137 & $3.83 \mathrm{E}-01$ & & Cs-137 & $2.15 \mathrm{E}-01$ & & \\
\hline & & & Eu-155 & 7.17E-03 & & Eu-155 & $2.18 \mathrm{E}-04$ & & \\
\hline & & & & & & Fr-223 & $1.97 \mathrm{E}-12$ & & \\
\hline & & & & & & $\mathrm{Pa}-231$ & $4.65 \mathrm{E}-10$ & & \\
\hline
\end{tabular}

${ }^{1}$ Calculated decayed contact dose rate. Rounded to nearest $10 \mathrm{mR} / \mathrm{hr}$ for values to 1000 ; rounded to nearest $100 \mathrm{mR} / \mathrm{hr}$ for values $>1000$ to 10,000 ; rounded to nearest $1000 \mathrm{mR} / \mathrm{hr}$ for values $>10,000$. * Initial contact dose rate assumed to be $1,000,000 \mathrm{mR} / \mathrm{hr}$; **Initial contact dose rate assumed to be $1,010,000 \mathrm{mR} / \mathrm{hr}$.

$$
130 \text { of } 168
$$


Appendix A-4 - Initial and Decayed Radionuclide and Dose Data for Lined Shafts

\begin{tabular}{|c|c|c|c|c|c|c|c|c|c|}
\hline \multirow[b]{2}{*}{ Shaft Number } & \multirow[b]{2}{*}{ Package ID } & \multirow[b]{2}{*}{ Base Year } & \multicolumn{2}{|c|}{ Initial Isotopic Distribution } & \multirow[b]{2}{*}{ Target Year } & \multicolumn{2}{|c|}{ Decayed Isotopic Distribution } & \multirow{2}{*}{$\begin{array}{c}\text { Initial Contact } \\
\text { Dose Rate } \\
(\mathrm{mR} / \mathrm{hr})\end{array}$} & \multirow{2}{*}{$\begin{array}{c}\text { Decayed } \\
\text { Contact Dose } \\
\text { Rate }(\mathrm{mR} / \mathrm{hr})^{1}\end{array}$} \\
\hline & & & Isotope & Activity (Ci) & & Isotope & Activity (Ci) & & \\
\hline & & & & & & $\mathrm{Pb}-211$ & $1.43 \mathrm{E}-10$ & & \\
\hline & & & Pm-147 & $2.19 \mathrm{E}-02$ & & Pm-147 & $2.95 \mathrm{E}-05$ & & \\
\hline & & & & & & Po-211 & $4.35 \mathrm{E}-13$ & & \\
\hline & & & & & & Po-215 & $1.43 \mathrm{E}-10$ & & \\
\hline & & & $\mathrm{Pu}-239$ & $6.20 \mathrm{E}-03$ & & $\mathrm{Pu}-239$ & $6.20 \mathrm{E}-03$ & & \\
\hline & & & & & & Ra-223 & $1.44 \mathrm{E}-10$ & & \\
\hline & & & Rh-106 & $2.81 \mathrm{E}-03$ & & Rh-106 & $9.51 \mathrm{E}-11$ & & \\
\hline & & & & & & Rn-219 & $1.42 \mathrm{E}-10$ & & \\
\hline & & & $\mathrm{Ru}-106$ & $2.81 \mathrm{E}-03$ & & $\mathrm{Ru}-106$ & $9.60 \mathrm{E}-11$ & & \\
\hline & & & Sb-125 & $1.56 \mathrm{E}-02$ & & $\mathrm{Sb}-125$ & $2.99 \mathrm{E}-05$ & & \\
\hline & & & & & & Sm-147 & $5.36 \mathrm{E}-13$ & & \\
\hline & & & Sr-90 & $3.50 \mathrm{E}-01$ & & Sr-90 & $1.93 \mathrm{E}-01$ & & \\
\hline & & & $\mathrm{Te}-125 \mathrm{~m}$ & $6.48 \mathrm{E}-03$ & & $\mathrm{Te}-125 \mathrm{~m}$ & $7.25 \mathrm{E}-06$ & & \\
\hline & & & & & & Th-227 & $1.40 \mathrm{E}-10$ & & \\
\hline & & & & & & Th-231 & 8.69E-07 & & \\
\hline & & & & & & Tl-207 & $1.42 \mathrm{E}-10$ & & \\
\hline & & & $\mathrm{U}-235$ & $8.80 \mathrm{E}-07$ & & $\mathrm{U}-235$ & $8.80 \mathrm{E}-07$ & & \\
\hline & & & Y-90 & $3.50 \mathrm{E}-01$ & & Y-90 & $1.91 \mathrm{E}-01$ & & \\
\hline \multirow[t]{14}{*}{226} & S840862 & 1984 & & & 2009 & Ac- 227 & $1.44 \mathrm{E}-10$ & 15,000 & 8,000 \\
\hline & & & Ba-137m & 4.79E-02 & & Ba-137m & $2.68 \mathrm{E}-02$ & & \\
\hline & & & & & & Bi-211 & $1.42 \mathrm{E}-10$ & & \\
\hline & & & Cs-137 & $5.11 \mathrm{E}-02$ & & Cs-137 & $2.87 \mathrm{E}-02$ & & \\
\hline & & & Eu-155 & $9.55 \mathrm{E}-04$ & & Eu-155 & $2.90 \mathrm{E}-05$ & & \\
\hline & & & & & & Fr-223 & $1.97 \mathrm{E}-12$ & & \\
\hline & & & & & & $\mathrm{Pa}-231$ & $4.65 \mathrm{E}-10$ & & \\
\hline & & & & & & $\mathrm{Pb}-211$ & $1.43 \mathrm{E}-10$ & & \\
\hline & & & Pm-147 & $2.92 \mathrm{E}-03$ & & Pm-147 & $3.94 \mathrm{E}-06$ & & \\
\hline & & & & & & Po-211 & $4.35 \mathrm{E}-13$ & & \\
\hline & & & & & & Po-215 & $1.43 \mathrm{E}-10$ & & \\
\hline & & & Pu-239 & $6.20 \mathrm{E}-03$ & & Pu-239 & $6.20 \mathrm{E}-03$ & & \\
\hline & & & & & & Ra-223 & $1.44 \mathrm{E}-10$ & & \\
\hline & & & Rh-106 & $3.74 \mathrm{E}-04$ & & Rh-106 & $1.27 \mathrm{E}-11$ & & \\
\hline
\end{tabular}

${ }^{1}$ Calculated decayed contact dose rate. Rounded to nearest $10 \mathrm{mR} / \mathrm{hr}$ for values to 1000 ; rounded to nearest $100 \mathrm{mR} / \mathrm{hr}$ for values $>1000$ to 10,000 ; rounded to nearest $1000 \mathrm{mR} / \mathrm{hr}$ for values $>10,000$. * Initial contact dose rate assumed to be $1,000,000 \mathrm{mR} / \mathrm{hr}$; **Initial contact dose rate assumed to be $1,010,000 \mathrm{mR} / \mathrm{hr}$.

$$
131 \text { of } 168
$$


Appendix A-4 - Initial and Decayed Radionuclide and Dose Data for Lined Shafts

\begin{tabular}{|c|c|c|c|c|c|c|c|c|c|}
\hline \multirow[b]{2}{*}{ Shaft Number } & \multirow[b]{2}{*}{ Package ID } & \multirow[b]{2}{*}{ Base Year } & \multicolumn{2}{|c|}{ Initial Isotopic Distribution } & \multirow[b]{2}{*}{ Target Year } & \multicolumn{2}{|c|}{ Decayed Isotopic Distribution } & \multirow{2}{*}{$\begin{array}{c}\text { Initial Contact } \\
\text { Dose Rate } \\
(\mathrm{mR} / \mathrm{hr})\end{array}$} & \multirow{2}{*}{$\begin{array}{c}\text { Decayed } \\
\text { Contact Dose } \\
\text { Rate }(\mathrm{mR} / \mathrm{hr})^{1} \\
\end{array}$} \\
\hline & & & Isotope & Activity (Ci) & & Isotope & Activity (Ci) & & \\
\hline & & & & & & $\mathrm{Rn}-219$ & $1.42 \mathrm{E}-10$ & & \\
\hline & & & $\mathrm{Ru}-106$ & $3.74 \mathrm{E}-04$ & & $\mathrm{Ru}-106$ & $1.28 \mathrm{E}-11$ & & \\
\hline & & & $\mathrm{Sb}-125$ & $2.08 \mathrm{E}-03$ & & $\mathrm{Sb}-125$ & $3.99 \mathrm{E}-06$ & & \\
\hline & & & & & & Sm-147 & $7.14 \mathrm{E}-14$ & & \\
\hline & & & Sr-90 & 4.67E-02 & & Sr-90 & $2.58 \mathrm{E}-02$ & & \\
\hline & & & Te- $125 \mathrm{~m}$ & $8.63 \mathrm{E}-04$ & & $\mathrm{Te}-125 \mathrm{~m}$ & $9.66 \mathrm{E}-07$ & & \\
\hline & & & & & & Th-227 & $1.40 \mathrm{E}-10$ & & \\
\hline & & & & & & Th-231 & $8.69 \mathrm{E}-07$ & & \\
\hline & & & & & & Tl-207 & $1.42 \mathrm{E}-10$ & & \\
\hline & & & $\mathrm{U}-235$ & $8.80 \mathrm{E}-07$ & & $\mathrm{U}-235$ & $8.80 \mathrm{E}-07$ & & \\
\hline & & & $\mathrm{Y}-90$ & $4.66 \mathrm{E}-02$ & & Y-90 & $2.55 \mathrm{E}-02$ & & \\
\hline \multirow[t]{21}{*}{226} & S840868 & 1984 & & & 2009 & Ac-227 & $1.44 \mathrm{E}-10$ & 35,000 & 19,000 \\
\hline & & & Ba-137m & 7.19E-02 & & $\mathrm{Ba}-137 \mathrm{~m}$ & $4.02 \mathrm{E}-02$ & & \\
\hline & & & & & & Bi-211 & $1.42 \mathrm{E}-10$ & & \\
\hline & & & Cs-137 & $7.66 \mathrm{E}-02$ & & Cs-137 & $4.30 \mathrm{E}-02$ & & \\
\hline & & & Eu-155 & $1.43 \mathrm{E}-03$ & & Eu-155 & $4.35 \mathrm{E}-05$ & & \\
\hline & & & & & & Fr-223 & $1.97 \mathrm{E}-12$ & & \\
\hline & & & & & & $\mathrm{Pa}-231$ & $4.65 \mathrm{E}-10$ & & \\
\hline & & & & & & $\mathrm{Pb}-211$ & $1.43 \mathrm{E}-10$ & & \\
\hline & & & Pm-147 & $4.38 \mathrm{E}-03$ & & Pm-147 & $5.92 \mathrm{E}-06$ & & \\
\hline & & & & & & Po-211 & $4.35 \mathrm{E}-13$ & & \\
\hline & & & & & & Po-215 & $1.43 \mathrm{E}-10$ & & \\
\hline & & & Pu-239 & $6.20 \mathrm{E}-03$ & & Pu-239 & $6.20 \mathrm{E}-03$ & & \\
\hline & & & & & & Ra-223 & $1.44 \mathrm{E}-10$ & & \\
\hline & & & Rh-106 & $5.62 \mathrm{E}-04$ & & Rh-106 & $1.90 \mathrm{E}-11$ & & \\
\hline & & & & & & Rn-219 & $1.42 \mathrm{E}-10$ & & \\
\hline & & & $\mathrm{Ru}-106$ & $5.62 \mathrm{E}-04$ & & Ru-106 & $1.92 \mathrm{E}-11$ & & \\
\hline & & & Sb-125 & $3.12 \mathrm{E}-03$ & & Sb-125 & $5.99 \mathrm{E}-06$ & & \\
\hline & & & & & & Sm-147 & $1.07 \mathrm{E}-13$ & & \\
\hline & & & Sr-90 & 7.00E-02 & & Sr-90 & $3.86 \mathrm{E}-02$ & & \\
\hline & & & $\mathrm{Te}-125 \mathrm{~m}$ & $1.30 \mathrm{E}-03$ & & $\mathrm{Te}-125 \mathrm{~m}$ & $1.45 \mathrm{E}-06$ & & \\
\hline & & & & & & Th-227 & $1.40 \mathrm{E}-10$ & & \\
\hline
\end{tabular}

${ }^{1}$ Calculated decayed contact dose rate. Rounded to nearest $10 \mathrm{mR} / \mathrm{hr}$ for values to 1000 ; rounded to nearest $100 \mathrm{mR} / \mathrm{hr}$ for values $>1000$ to 10,000 ; rounded to nearest $1000 \mathrm{mR} / \mathrm{hr}$ for values $>10,000$. * Initial contact dose rate assumed to be $1,000,000 \mathrm{mR} / \mathrm{hr}$; **Initial contact dose rate assumed to be $1,010,000 \mathrm{mR} / \mathrm{hr}$.

$$
132 \text { of } 168
$$


Appendix A-4 - Initial and Decayed Radionuclide and Dose Data for Lined Shafts

\begin{tabular}{|c|c|c|c|c|c|c|c|c|c|}
\hline \multirow[b]{2}{*}{ Shaft Number } & \multirow[b]{2}{*}{ Package ID } & \multirow[b]{2}{*}{ Base Year } & \multicolumn{2}{|c|}{ Initial Isotopic Distribution } & \multirow[b]{2}{*}{ Target Year } & \multicolumn{2}{|c|}{ Decayed Isotopic Distribution } & \multirow{2}{*}{$\begin{array}{c}\text { Initial Contact } \\
\text { Dose Rate } \\
(\mathrm{mR} / \mathrm{hr})\end{array}$} & \multirow{2}{*}{$\begin{array}{c}\text { Decayed } \\
\text { Contact Dose } \\
\text { Rate }(\mathrm{mR} / \mathrm{hr})^{1}\end{array}$} \\
\hline & & & Isotope & Activity (Ci) & & Isotope & Activity (Ci) & & \\
\hline & & & & & & Th-231 & 8.69E-07 & & \\
\hline & & & & & & Tl-207 & $1.42 \mathrm{E}-10$ & & \\
\hline & & & $\mathrm{U}-235$ & $8.80 \mathrm{E}-07$ & & $\mathrm{U}-235$ & $8.80 \mathrm{E}-07$ & & \\
\hline & & & $\mathrm{Y}-90$ & $6.99 \mathrm{E}-02$ & & $\mathrm{Y}-90$ & $3.82 \mathrm{E}-02$ & & \\
\hline \multirow[t]{25}{*}{227} & S840877 & 1984 & & & 2009 & Ac-227 & $3.21 \mathrm{E}-09$ & 80,000 & 42,000 \\
\hline & & & Ba-137m & $3.59 \mathrm{E}-01$ & & Ba-137m & $2.01 \mathrm{E}-01$ & & \\
\hline & & & & & & $\mathrm{Bi}-211$ & $3.17 \mathrm{E}-09$ & & \\
\hline & & & Cs-137 & 3.83E-01 & & Cs-137 & $2.15 \mathrm{E}-01$ & & \\
\hline & & & Eu-155 & 7.17E-03 & & Eu-155 & $2.18 \mathrm{E}-04$ & & \\
\hline & & & & & & Fr-223 & $4.38 \mathrm{E}-11$ & & \\
\hline & & & & & & $\mathrm{Pa}-231$ & $1.03 \mathrm{E}-08$ & & \\
\hline & & & & & & $\mathrm{Pb}-211$ & 3.17E-09 & & \\
\hline & & & Pm-147 & 2.19E-02 & & Pm-147 & 2.95E-05 & & \\
\hline & & & & & & Po-211 & $9.68 \mathrm{E}-12$ & & \\
\hline & & & & & & Po-215 & 3.17E-09 & & \\
\hline & & & $\mathrm{Pu}-239$ & $1.36 \mathrm{E}-01$ & & $\mathrm{Pu}-239$ & $1.36 \mathrm{E}-01$ & & \\
\hline & & & & & & Ra-223 & $3.21 \mathrm{E}-09$ & & \\
\hline & & & Rh-106 & $2.81 \mathrm{E}-03$ & & Rh-106 & $9.51 \mathrm{E}-11$ & & \\
\hline & & & & & & Rn-219 & $3.17 \mathrm{E}-09$ & & \\
\hline & & & $\mathrm{Ru}-106$ & $2.81 \mathrm{E}-03$ & & $\mathrm{Ru}-106$ & $9.60 \mathrm{E}-11$ & & \\
\hline & & & Sb-125 & $1.56 \mathrm{E}-02$ & & Sb-125 & $2.99 \mathrm{E}-05$ & & \\
\hline & & & & & & Sm-147 & $5.36 \mathrm{E}-13$ & & \\
\hline & & & Sr-90 & $3.50 \mathrm{E}-01$ & & Sr-90 & $1.93 \mathrm{E}-01$ & & \\
\hline & & & $\mathrm{Te}-125 \mathrm{~m}$ & $6.48 \mathrm{E}-03$ & & Te-125m & 7.25E-06 & & \\
\hline & & & & & & Th-227 & $3.13 \mathrm{E}-09$ & & \\
\hline & & & & & & Th-231 & $1.93 \mathrm{E}-05$ & & \\
\hline & & & & & & Tl-207 & $3.16 \mathrm{E}-09$ & & \\
\hline & & & U-235 & $1.96 \mathrm{E}-05$ & & U-235 & $1.96 \mathrm{E}-05$ & & \\
\hline & & & Y-90 & $3.50 \mathrm{E}-01$ & & Y-90 & $1.91 \mathrm{E}-01$ & & \\
\hline \multirow[t]{3}{*}{227} & S840878 & 1984 & & & 2009 & Ac-227 & $5.19 \mathrm{E}-09$ & 250,000 & 133,000 \\
\hline & & & Ba-137m & 5.99E-01 & & Ba-137m & $3.35 \mathrm{E}-01$ & & \\
\hline & & & & & & Bi-211 & $5.13 \mathrm{E}-09$ & & \\
\hline
\end{tabular}

${ }^{1}$ Calculated decayed contact dose rate. Rounded to nearest $10 \mathrm{mR} / \mathrm{hr}$ for values to 1000 ; rounded to nearest $100 \mathrm{mR} / \mathrm{hr}$ for values $>1000$ to 10,000 ; rounded to nearest $1000 \mathrm{mR} / \mathrm{hr}$ for values $>10,000$. * Initial contact dose rate assumed to be $1,000,000 \mathrm{mR} / \mathrm{hr}$; **Initial contact dose rate assumed to be $1,010,000 \mathrm{mR} / \mathrm{hr}$.

$$
133 \text { of } 168
$$


Appendix A-4 - Initial and Decayed Radionuclide and Dose Data for Lined Shafts

\begin{tabular}{|c|c|c|c|c|c|c|c|c|c|}
\hline \multirow[b]{2}{*}{ Shaft Number } & \multirow[b]{2}{*}{ Package ID } & \multirow[b]{2}{*}{ Base Year } & \multicolumn{2}{|c|}{ Initial Isotopic Distribution } & \multirow[b]{2}{*}{ Target Year } & \multicolumn{2}{|c|}{ Decayed Isotopic Distribution } & \multirow{2}{*}{$\begin{array}{c}\text { Initial Contact } \\
\text { Dose Rate } \\
(\mathrm{mR} / \mathrm{hr})\end{array}$} & \multirow{2}{*}{$\begin{array}{c}\text { Decayed } \\
\text { Contact Dose } \\
\text { Rate }(\mathrm{mR} / \mathrm{hr})^{1} \\
\end{array}$} \\
\hline & & & Isotope & Activity (Ci) & & Isotope & Activity (Ci) & & \\
\hline & & & Cs-137 & $6.38 \mathrm{E}-01$ & & Cs-137 & $3.58 \mathrm{E}-01$ & & \\
\hline & & & Eu-155 & $1.19 \mathrm{E}-02$ & & Eu-155 & $3.63 \mathrm{E}-04$ & & \\
\hline & & & & & & Fr-223 & $7.09 \mathrm{E}-11$ & & \\
\hline & & & & & & $\mathrm{Pa}-231$ & $1.67 \mathrm{E}-08$ & & \\
\hline & & & & & & $\mathrm{Pb}-211$ & $5.14 \mathrm{E}-09$ & & \\
\hline & & & Pm-147 & $3.65 \mathrm{E}-02$ & & Pm-147 & $4.94 \mathrm{E}-05$ & & \\
\hline & & & & & & Po-211 & $1.57 \mathrm{E}-11$ & & \\
\hline & & & & & & Po-215 & $5.14 \mathrm{E}-09$ & & \\
\hline & & & $\mathrm{Pu}-239$ & $1.92 \mathrm{E}-01$ & & $\mathrm{Pu}-239$ & $1.92 \mathrm{E}-01$ & & \\
\hline & & & & & & $\mathrm{Ra}-223$ & 5.19E-09 & & \\
\hline & & & Rh-106 & $4.68 \mathrm{E}-03$ & & Rh-106 & $1.58 \mathrm{E}-10$ & & \\
\hline & & & & & & $\mathrm{Rn}-219$ & $5.13 \mathrm{E}-09$ & & \\
\hline & & & $\mathrm{Ru}-106$ & 4.68E-03 & & $\mathrm{Ru}-106$ & $1.60 \mathrm{E}-10$ & & \\
\hline & & & $\mathrm{Sb}-125$ & $2.60 \mathrm{E}-02$ & & $\mathrm{Sb}-125$ & $4.99 \mathrm{E}-05$ & & \\
\hline & & & & & & Sm-147 & $8.93 \mathrm{E}-13$ & & \\
\hline & & & Sr-90 & $5.84 \mathrm{E}-01$ & & Sr-90 & $3.22 \mathrm{E}-01$ & & \\
\hline & & & $\mathrm{Te}-125 \mathrm{~m}$ & $1.08 \mathrm{E}-02$ & & Te- $125 \mathrm{~m}$ & $1.21 \mathrm{E}-05$ & & \\
\hline & & & & & & Th-227 & $5.06 \mathrm{E}-09$ & & \\
\hline & & & & & & Th-231 & $3.13 \mathrm{E}-05$ & & \\
\hline & & & & & & Tl-207 & $5.11 \mathrm{E}-09$ & & \\
\hline & & & $\mathrm{U}-235$ & $3.17 \mathrm{E}-05$ & & U-235 & $3.17 \mathrm{E}-05$ & & \\
\hline & & & Y-90 & $5.83 \mathrm{E}-01$ & & Y-90 & $3.18 \mathrm{E}-01$ & & \\
\hline \multirow[t]{10}{*}{227} & S840879 & 1984 & & & 2009 & Ac- 227 & $5.19 \mathrm{E}-09$ & 300,000 & 159,000 \\
\hline & & & Ba-137m & $9.59 \mathrm{E}-01$ & & Ba-137m & $5.36 \mathrm{E}-01$ & & \\
\hline & & & & & & Bi-211 & $5.13 \mathrm{E}-09$ & & \\
\hline & & & Cs-137 & $1.02 \mathrm{E}+00$ & & Cs-137 & $5.73 \mathrm{E}-01$ & & \\
\hline & & & Eu-155 & $1.91 \mathrm{E}-02$ & & Eu-155 & $5.80 \mathrm{E}-04$ & & \\
\hline & & & & & & Fr-223 & $7.09 \mathrm{E}-11$ & & \\
\hline & & & & & & $\mathrm{Pa}-231$ & $1.67 \mathrm{E}-08$ & & \\
\hline & & & & & & $\mathrm{Pb}-211$ & 5.14E-09 & & \\
\hline & & & Pm-147 & 5.83E-02 & & Pm-147 & $7.87 \mathrm{E}-05$ & & \\
\hline & & & & & & Po-211 & $1.57 \mathrm{E}-11$ & & \\
\hline
\end{tabular}

${ }^{1}$ Calculated decayed contact dose rate. Rounded to nearest $10 \mathrm{mR} / \mathrm{hr}$ for values to 1000 ; rounded to nearest $100 \mathrm{mR} / \mathrm{hr}$ for values $>1000$ to 10,000 ; rounded to nearest $1000 \mathrm{mR} / \mathrm{hr}$ for values $>10,000$. * Initial contact dose rate assumed to be $1,000,000 \mathrm{mR} / \mathrm{hr}$; **Initial contact dose rate assumed to be $1,010,000 \mathrm{mR} / \mathrm{hr}$.

$$
134 \text { of } 168
$$


Appendix A-4 - Initial and Decayed Radionuclide and Dose Data for Lined Shafts

\begin{tabular}{|c|c|c|c|c|c|c|c|c|c|}
\hline \multirow[b]{2}{*}{ Shaft Number } & \multirow[b]{2}{*}{ Package ID } & \multirow[b]{2}{*}{ Base Year } & \multicolumn{2}{|c|}{ Initial Isotopic Distribution } & \multirow[b]{2}{*}{ Target Year } & \multicolumn{2}{|c|}{ Decayed Isotopic Distribution } & \multirow{2}{*}{$\begin{array}{c}\text { Initial Contact } \\
\text { Dose Rate } \\
(\mathrm{mR} / \mathrm{hr})\end{array}$} & \multirow{2}{*}{$\begin{array}{c}\text { Decayed } \\
\text { Contact Dose } \\
\text { Rate }(\mathrm{mR} / \mathrm{hr})^{1}\end{array}$} \\
\hline & & & Isotope & Activity (Ci) & & Isotope & Activity (Ci) & & \\
\hline & & & & & & Po-215 & 5.14E-09 & & \\
\hline & & & $\mathrm{Pu}-239$ & $1.92 \mathrm{E}-01$ & & $\mathrm{Pu}-239$ & $1.92 \mathrm{E}-01$ & & \\
\hline & & & & & & $\mathrm{Ra}-223$ & $5.19 \mathrm{E}-09$ & & \\
\hline & & & $\mathrm{Rh}-106$ & 7.49E-03 & & Rh-106 & $2.54 \mathrm{E}-10$ & & \\
\hline & & & & & & Rn-219 & $5.13 \mathrm{E}-09$ & & \\
\hline & & & $\mathrm{Ru}-106$ & 7.49E-03 & & $\mathrm{Ru}-106$ & $2.56 \mathrm{E}-10$ & & \\
\hline & & & $\mathrm{Sb}-125$ & $4.16 \mathrm{E}-02$ & & $\mathrm{Sb}-125$ & 7.99E-05 & & \\
\hline & & & & & & Sm-147 & $1.43 \mathrm{E}-12$ & & \\
\hline & & & Sr-90 & 9.34E-01 & & Sr-90 & $5.15 \mathrm{E}-01$ & & \\
\hline & & & $\mathrm{Te}-125 \mathrm{~m}$ & $1.73 \mathrm{E}-02$ & & $\mathrm{Te}-125 \mathrm{~m}$ & $1.94 \mathrm{E}-05$ & & \\
\hline & & & & & & Th-227 & $5.06 \mathrm{E}-09$ & & \\
\hline & & & & & & Th-231 & $3.13 \mathrm{E}-05$ & & \\
\hline & & & & & & Tl-207 & $5.11 \mathrm{E}-09$ & & \\
\hline & & & $\mathrm{U}-235$ & $3.17 \mathrm{E}-05$ & & $\mathrm{U}-235$ & $3.17 \mathrm{E}-05$ & & \\
\hline & & & Y-90 & 9.33E-01 & & Y-90 & $5.09 \mathrm{E}-01$ & & \\
\hline \multirow[t]{17}{*}{227} & S840880 & 1984 & & & 2009 & Ac-227 & $5.19 \mathrm{E}-09$ & 350,000 & 186,000 \\
\hline & & & Ba-137m & $5.99 \mathrm{E}-01$ & & Ba-137m & $3.35 \mathrm{E}-01$ & & \\
\hline & & & & & & Bi-211 & 5.13E-09 & & \\
\hline & & & Cs-137 & $6.38 \mathrm{E}-01$ & & Cs-137 & $3.58 \mathrm{E}-01$ & & \\
\hline & & & Eu-155 & $1.19 \mathrm{E}-02$ & & Eu-155 & $3.63 \mathrm{E}-04$ & & \\
\hline & & & & & & Fr-223 & 7.09E-11 & & \\
\hline & & & & & & $\mathrm{Pa}-231$ & $1.67 \mathrm{E}-08$ & & \\
\hline & & & & & & $\mathrm{Pb}-211$ & $5.14 \mathrm{E}-09$ & & \\
\hline & & & Pm-147 & $3.65 \mathrm{E}-02$ & & Pm-147 & 4.94E-05 & & \\
\hline & & & & & & Po-211 & $1.57 \mathrm{E}-11$ & & \\
\hline & & & & & & Po-215 & $5.14 \mathrm{E}-09$ & & \\
\hline & & & $\mathrm{Pu}-239$ & $1.92 \mathrm{E}-01$ & & $\mathrm{Pu}-239$ & $1.92 \mathrm{E}-01$ & & \\
\hline & & & & & & Ra-223 & 5.19E-09 & & \\
\hline & & & Rh-106 & $4.68 \mathrm{E}-03$ & & Rh-106 & $1.58 \mathrm{E}-10$ & & \\
\hline & & & & & & Rn-219 & $5.13 \mathrm{E}-09$ & & \\
\hline & & & Ru-106 & $4.68 \mathrm{E}-03$ & & Ru-106 & $1.60 \mathrm{E}-10$ & & \\
\hline & & & Sb-125 & $2.60 \mathrm{E}-02$ & & Sb-125 & 4.99E-05 & & \\
\hline
\end{tabular}

${ }^{1}$ Calculated decayed contact dose rate. Rounded to nearest $10 \mathrm{mR} / \mathrm{hr}$ for values to 1000 ; rounded to nearest $100 \mathrm{mR} / \mathrm{hr}$ for values $>1000$ to 10,000 ; rounded to nearest $1000 \mathrm{mR} / \mathrm{hr}$ for values $>10,000$. * Initial contact dose rate assumed to be $1,000,000 \mathrm{mR} / \mathrm{hr}$; **Initial contact dose rate assumed to be $1,010,000 \mathrm{mR} / \mathrm{hr}$.

$$
135 \text { of } 168
$$


Appendix A-4 - Initial and Decayed Radionuclide and Dose Data for Lined Shafts

\begin{tabular}{|c|c|c|c|c|c|c|c|c|c|}
\hline \multirow[b]{2}{*}{ Shaft Number } & \multirow[b]{2}{*}{ Package ID } & \multirow[b]{2}{*}{ Base Year } & \multicolumn{2}{|c|}{ Initial Isotopic Distribution } & \multirow[b]{2}{*}{ Target Year } & \multicolumn{2}{|c|}{ Decayed Isotopic Distribution } & \multirow{2}{*}{$\begin{array}{c}\text { Initial Contact } \\
\text { Dose Rate } \\
(\mathrm{mR} / \mathrm{hr})\end{array}$} & \multirow{2}{*}{$\begin{array}{c}\text { Decayed } \\
\text { Contact Dose } \\
\text { Rate }(\mathrm{mR} / \mathrm{hr})^{1} \\
\end{array}$} \\
\hline & & & Isotope & Activity (Ci) & & Isotope & Activity (Ci) & & \\
\hline & & & & & & Sm-147 & $8.93 \mathrm{E}-13$ & & \\
\hline & & & Sr-90 & $5.84 \mathrm{E}-01$ & & Sr-90 & $3.22 \mathrm{E}-01$ & & \\
\hline & & & $\mathrm{Te}-125 \mathrm{~m}$ & $1.08 \mathrm{E}-02$ & & $\mathrm{Te}-125 \mathrm{~m}$ & $1.21 \mathrm{E}-05$ & & \\
\hline & & & & & & Th-227 & $5.06 \mathrm{E}-09$ & & \\
\hline & & & & & & Th-231 & $3.13 \mathrm{E}-05$ & & \\
\hline & & & & & & Tl-207 & $5.11 \mathrm{E}-09$ & & \\
\hline & & & $\mathrm{U}-235$ & $3.17 \mathrm{E}-05$ & & $\mathrm{U}-235$ & $3.17 \mathrm{E}-05$ & & \\
\hline & & & Y-90 & $5.83 \mathrm{E}-01$ & & Y-90 & $3.18 \mathrm{E}-01$ & & \\
\hline \multirow[t]{24}{*}{227} & S840881 & 1984 & & & 2009 & Ac-227 & $5.19 \mathrm{E}-09$ & 200,000 & 106,000 \\
\hline & & & Ba-137m & 7.19E-01 & & $\mathrm{Ba}-137 \mathrm{~m}$ & $4.02 \mathrm{E}-01$ & & \\
\hline & & & & & & Bi-211 & $5.13 \mathrm{E}-09$ & & \\
\hline & & & Cs-137 & $7.66 \mathrm{E}-01$ & & Cs-137 & $4.30 \mathrm{E}-01$ & & \\
\hline & & & Eu-155 & $1.43 \mathrm{E}-02$ & & Eu-155 & $4.35 \mathrm{E}-04$ & & \\
\hline & & & & & & Fr-223 & $7.09 \mathrm{E}-11$ & & \\
\hline & & & & & & $\mathrm{Pa}-231$ & $1.67 \mathrm{E}-08$ & & \\
\hline & & & & & & $\mathrm{Pb}-211$ & $5.14 \mathrm{E}-09$ & & \\
\hline & & & Pm-147 & 4.38E-02 & & Pm-147 & $5.90 \mathrm{E}-05$ & & \\
\hline & & & & & & Po-211 & $1.57 \mathrm{E}-11$ & & \\
\hline & & & & & & Po-215 & $5.14 \mathrm{E}-09$ & & \\
\hline & & & Pu-239 & $1.92 \mathrm{E}-01$ & & $\mathrm{Pu}-239$ & $1.92 \mathrm{E}-01$ & & \\
\hline & & & & & & Ra-223 & 5.19E-09 & & \\
\hline & & & Rh-106 & $5.62 \mathrm{E}-03$ & & Rh-106 & $1.90 \mathrm{E}-10$ & & \\
\hline & & & & & & Rn-219 & $5.13 \mathrm{E}-09$ & & \\
\hline & & & Ru-106 & $5.62 \mathrm{E}-03$ & & Ru-106 & $1.92 \mathrm{E}-10$ & & \\
\hline & & & Sb-125 & $3.12 \mathrm{E}-02$ & & Sb-125 & $5.98 \mathrm{E}-05$ & & \\
\hline & & & & & & Sm-147 & $1.07 \mathrm{E}-12$ & & \\
\hline & & & Sr-90 & 7.00E-01 & & Sr-90 & $3.86 \mathrm{E}-01$ & & \\
\hline & & & $\mathrm{Te}-125 \mathrm{~m}$ & $1.30 \mathrm{E}-02$ & & $\mathrm{Te}-125 \mathrm{~m}$ & $1.45 \mathrm{E}-05$ & & \\
\hline & & & & & & Th-227 & $5.06 \mathrm{E}-09$ & & \\
\hline & & & & & & Th-231 & $3.13 \mathrm{E}-05$ & & \\
\hline & & & & & & T1-207 & $5.11 \mathrm{E}-09$ & & \\
\hline & & & U-235 & $3.17 \mathrm{E}-05$ & & $\mathrm{U}-235$ & $3.17 \mathrm{E}-05$ & & \\
\hline
\end{tabular}

${ }^{1}$ Calculated decayed contact dose rate. Rounded to nearest $10 \mathrm{mR} / \mathrm{hr}$ for values to 1000 ; rounded to nearest $100 \mathrm{mR} / \mathrm{hr}$ for values $>1000$ to 10,000 ; rounded to nearest $1000 \mathrm{mR} / \mathrm{hr}$ for values $>10,000$. * Initial contact dose rate assumed to be $1,000,000 \mathrm{mR} / \mathrm{hr}$; **Initial contact dose rate assumed to be $1,010,000 \mathrm{mR} / \mathrm{hr}$.

136 of 168 
Appendix A-4 - Initial and Decayed Radionuclide and Dose Data for Lined Shafts

\begin{tabular}{|c|c|c|c|c|c|c|c|c|c|}
\hline \multirow[b]{2}{*}{ Shaft Number } & \multirow[b]{2}{*}{ Package ID } & \multirow[b]{2}{*}{ Base Year } & \multicolumn{2}{|c|}{ Initial Isotopic Distribution } & \multirow[b]{2}{*}{ Target Year } & \multicolumn{2}{|c|}{ Decayed Isotopic Distribution } & \multirow{2}{*}{$\begin{array}{c}\text { Initial Contact } \\
\text { Dose Rate } \\
(\mathrm{mR} / \mathrm{hr})\end{array}$} & \multirow{2}{*}{$\begin{array}{c}\text { Decayed } \\
\text { Contact Dose } \\
\text { Rate }(\mathrm{mR} / \mathrm{hr})^{1} \\
\end{array}$} \\
\hline & & & Isotope & Activity (Ci) & & Isotope & Activity (Ci) & & \\
\hline & & & Y-90 & $6.99 \mathrm{E}-01$ & & $\mathrm{Y}-90$ & $3.82 \mathrm{E}-01$ & & \\
\hline \multirow[t]{25}{*}{227} & S840883 & 1984 & & & 2009 & Ac-227 & $1.44 \mathrm{E}-10$ & 100,000 & 53,000 \\
\hline & & & $\mathrm{Ba}-137 \mathrm{~m}$ & 4.79E-01 & & $\mathrm{Ba}-137 \mathrm{~m}$ & $2.68 \mathrm{E}-01$ & & \\
\hline & & & & & & $\mathrm{Bi}-211$ & $1.42 \mathrm{E}-10$ & & \\
\hline & & & Cs-137 & $5.11 \mathrm{E}-01$ & & Cs-137 & $2.87 \mathrm{E}-01$ & & \\
\hline & & & Eu-155 & $9.55 \mathrm{E}-03$ & & Eu-155 & $2.90 \mathrm{E}-04$ & & \\
\hline & & & & & & Fr-223 & $1.97 \mathrm{E}-12$ & & \\
\hline & & & & & & $\mathrm{Pa}-231$ & $4.65 \mathrm{E}-10$ & & \\
\hline & & & & & & $\mathrm{Pb}-211$ & $1.43 \mathrm{E}-10$ & & \\
\hline & & & Pm-147 & $2.92 \mathrm{E}-02$ & & Pm-147 & $3.93 \mathrm{E}-05$ & & \\
\hline & & & & & & Po-211 & 4.35E-13 & & \\
\hline & & & & & & Po-215 & $1.43 \mathrm{E}-10$ & & \\
\hline & & & $\mathrm{Pu}-239$ & $6.20 \mathrm{E}-03$ & & $\mathrm{Pu}-239$ & $6.20 \mathrm{E}-03$ & & \\
\hline & & & & & & Ra-223 & $1.44 \mathrm{E}-10$ & & \\
\hline & & & $\mathrm{Rh}-106$ & $3.74 \mathrm{E}-03$ & & Rh-106 & $1.27 \mathrm{E}-10$ & & \\
\hline & & & & & & Rn-219 & $1.42 \mathrm{E}-10$ & & \\
\hline & & & $\mathrm{Ru}-106$ & $3.74 \mathrm{E}-03$ & & $\mathrm{Ru}-106$ & $1.28 \mathrm{E}-10$ & & \\
\hline & & & Sb-125 & $2.08 \mathrm{E}-02$ & & Sb-125 & $4.00 \mathrm{E}-05$ & & \\
\hline & & & & & & Sm-147 & $7.14 \mathrm{E}-13$ & & \\
\hline & & & Sr-90 & 4.67E-01 & & Sr-90 & $2.58 \mathrm{E}-01$ & & \\
\hline & & & $\mathrm{Te}-125 \mathrm{~m}$ & 8.63E-03 & & $\mathrm{Te}-125 \mathrm{~m}$ & $9.67 \mathrm{E}-06$ & & \\
\hline & & & & & & Th-227 & $1.40 \mathrm{E}-10$ & & \\
\hline & & & & & & Th-231 & 8.69E-07 & & \\
\hline & & & & & & Tl-207 & $1.42 \mathrm{E}-10$ & & \\
\hline & & & U-235 & $8.80 \mathrm{E}-07$ & & U-235 & $8.80 \mathrm{E}-07$ & & \\
\hline & & & Y-90 & $4.66 \mathrm{E}-01$ & & Y-90 & $2.55 \mathrm{E}-01$ & & \\
\hline \multirow[t]{6}{*}{227} & S840885 & 1984 & & & 2009 & Ac- 227 & $3.82 \mathrm{E}-09$ & 400,000 & 212,000 \\
\hline & & & Ba-137m & $1.44 \mathrm{E}+00$ & & Ba-137m & 8.04E-01 & & \\
\hline & & & & & & Bi-211 & 3.77E-09 & & \\
\hline & & & Cs-137 & $1.53 \mathrm{E}+00$ & & Cs-137 & $8.60 \mathrm{E}-01$ & & \\
\hline & & & $\mathrm{Eu}-155$ & $2.87 \mathrm{E}-02$ & & Eu-155 & $8.70 \mathrm{E}-04$ & & \\
\hline & & & & & & Fr-223 & $5.22 \mathrm{E}-11$ & & \\
\hline
\end{tabular}

${ }^{1}$ Calculated decayed contact dose rate. Rounded to nearest $10 \mathrm{mR} / \mathrm{hr}$ for values to 1000 ; rounded to nearest $100 \mathrm{mR} / \mathrm{hr}$ for values $>1000$ to 10,000 ; rounded to nearest $1000 \mathrm{mR} / \mathrm{hr}$ for values $>10,000$. * Initial contact dose rate assumed to be $1,000,000 \mathrm{mR} / \mathrm{hr}$; **Initial contact dose rate assumed to be $1,010,000 \mathrm{mR} / \mathrm{hr}$.

$$
137 \text { of } 168
$$


Appendix A-4 - Initial and Decayed Radionuclide and Dose Data for Lined Shafts

\begin{tabular}{|c|c|c|c|c|c|c|c|c|c|}
\hline \multirow[b]{2}{*}{ Shaft Number } & \multirow[b]{2}{*}{ Package ID } & \multirow[b]{2}{*}{ Base Year } & \multicolumn{2}{|c|}{ Initial Isotopic Distribution } & \multirow[b]{2}{*}{ Target Year } & \multicolumn{2}{|c|}{ Decayed Isotopic Distribution } & \multirow{2}{*}{$\begin{array}{c}\text { Initial Contact } \\
\text { Dose Rate } \\
(\mathrm{mR} / \mathrm{hr})\end{array}$} & \multirow{2}{*}{$\begin{array}{c}\text { Decayed } \\
\text { Contact Dose } \\
\text { Rate }(\mathrm{mR} / \mathrm{hr})^{1} \\
\end{array}$} \\
\hline & & & Isotope & Activity (Ci) & & Isotope & Activity (Ci) & & \\
\hline & & & & & & $\mathrm{Pa}-231$ & $1.23 \mathrm{E}-08$ & & \\
\hline & & & & & & $\mathrm{Pb}-211$ & $3.78 \mathrm{E}-09$ & & \\
\hline & & & Pm-147 & $8.75 \mathrm{E}-02$ & & Pm-147 & $1.18 \mathrm{E}-04$ & & \\
\hline & & & & & & Po-211 & $1.15 \mathrm{E}-11$ & & \\
\hline & & & & & & Po-215 & $3.78 \mathrm{E}-09$ & & \\
\hline & & & $\mathrm{Pu}-239$ & $1.98 \mathrm{E}-01$ & & $\mathrm{Pu}-239$ & $1.98 \mathrm{E}-01$ & & \\
\hline & & & & & & Ra-223 & $3.82 \mathrm{E}-09$ & & \\
\hline & & & $\mathrm{Rh}-106$ & $1.12 \mathrm{E}-02$ & & Rh-106 & $3.80 \mathrm{E}-10$ & & \\
\hline & & & & & & Rn-219 & $3.78 \mathrm{E}-09$ & & \\
\hline & & & $\mathrm{Ru}-106$ & $1.12 \mathrm{E}-02$ & & $\mathrm{Ru}-106$ & $3.84 \mathrm{E}-10$ & & \\
\hline & & & Sb-125 & $6.24 \mathrm{E}-02$ & & Sb-125 & $1.20 \mathrm{E}-04$ & & \\
\hline & & & & & & Sm-147 & $2.14 \mathrm{E}-12$ & & \\
\hline & & & Sr-90 & $1.40 \mathrm{E}+00$ & & Sr-90 & $7.73 \mathrm{E}-01$ & & \\
\hline & & & $\mathrm{Te}-125 \mathrm{~m}$ & $2.59 \mathrm{E}-02$ & & $\mathrm{Te}-125 \mathrm{~m}$ & $2.90 \mathrm{E}-05$ & & \\
\hline & & & & & & Th-227 & $3.72 \mathrm{E}-09$ & & \\
\hline & & & & & & Th-231 & $2.30 \mathrm{E}-05$ & & \\
\hline & & & & & & Tl-207 & $3.76 \mathrm{E}-09$ & & \\
\hline & & & $\mathrm{U}-235$ & $2.33 \mathrm{E}-05$ & & U-235 & $2.33 \mathrm{E}-05$ & & \\
\hline & & & Y-90 & $1.40 \mathrm{E}+00$ & & Y-90 & $7.64 \mathrm{E}-01$ & & \\
\hline \multirow[t]{13}{*}{227} & S840886 & 1984 & & & 2009 & Ac-227 & $1.44 \mathrm{E}-10$ & 15,000 & 8,000 \\
\hline & & & Ba-137m & $1.92 \mathrm{E}-01$ & & Ba-137m & $1.07 \mathrm{E}-01$ & & \\
\hline & & & & & & $\mathrm{Bi}-211$ & $1.42 \mathrm{E}-10$ & & \\
\hline & & & Cs-137 & $2.04 \mathrm{E}-01$ & & Cs-137 & $1.15 \mathrm{E}-01$ & & \\
\hline & & & Eu-155 & $3.82 \mathrm{E}-03$ & & Eu-155 & $1.16 \mathrm{E}-04$ & & \\
\hline & & & & & & Fr-223 & $1.97 \mathrm{E}-12$ & & \\
\hline & & & & & & $\mathrm{Pa}-231$ & $4.65 \mathrm{E}-10$ & & \\
\hline & & & & & & $\mathrm{Pb}-211$ & $1.43 \mathrm{E}-10$ & & \\
\hline & & & Pm-147 & $1.17 \mathrm{E}-02$ & & Pm-147 & $1.58 \mathrm{E}-05$ & & \\
\hline & & & & & & Po-211 & $4.35 \mathrm{E}-13$ & & \\
\hline & & & & & & Po-215 & $1.43 \mathrm{E}-10$ & & \\
\hline & & & Pu-239 & $6.20 \mathrm{E}-03$ & & $\mathrm{Pu}-239$ & $6.20 \mathrm{E}-03$ & & \\
\hline & & & & & & Ra-223 & $1.44 \mathrm{E}-10$ & & \\
\hline
\end{tabular}

${ }^{1}$ Calculated decayed contact dose rate. Rounded to nearest $10 \mathrm{mR} / \mathrm{hr}$ for values to 1000 ; rounded to nearest $100 \mathrm{mR} / \mathrm{hr}$ for values $>1000$ to 10,000 ; rounded to nearest $1000 \mathrm{mR} / \mathrm{hr}$ for values $>10,000$. * Initial contact dose rate assumed to be $1,000,000 \mathrm{mR} / \mathrm{hr}$; **Initial contact dose rate assumed to be $1,010,000 \mathrm{mR} / \mathrm{hr}$.

$$
138 \text { of } 168
$$


Appendix A-4 - Initial and Decayed Radionuclide and Dose Data for Lined Shafts

\begin{tabular}{|c|c|c|c|c|c|c|c|c|c|}
\hline \multirow[b]{2}{*}{ Shaft Number } & \multirow[b]{2}{*}{ Package ID } & \multirow[b]{2}{*}{ Base Year } & \multicolumn{2}{|c|}{ Initial Isotopic Distribution } & \multirow[b]{2}{*}{ Target Year } & \multicolumn{2}{|c|}{ Decayed Isotopic Distribution } & \multirow{2}{*}{$\begin{array}{c}\text { Initial Contact } \\
\text { Dose Rate } \\
(\mathrm{mR} / \mathrm{hr})\end{array}$} & \multirow{2}{*}{$\begin{array}{c}\text { Decayed } \\
\text { Contact Dose } \\
\text { Rate }(\mathrm{mR} / \mathrm{hr})^{1} \\
\end{array}$} \\
\hline & & & Isotope & Activity (Ci) & & Isotope & Activity (Ci) & & \\
\hline & & & Rh-106 & $1.50 \mathrm{E}-03$ & & Rh-106 & $5.07 \mathrm{E}-11$ & & \\
\hline & & & & & & $\mathrm{Rn}-219$ & $1.42 \mathrm{E}-10$ & & \\
\hline & & & $\mathrm{Ru}-106$ & $1.50 \mathrm{E}-03$ & & Ru-106 & $5.12 \mathrm{E}-11$ & & \\
\hline & & & $\mathrm{Sb}-125$ & $8.32 \mathrm{E}-03$ & & $\mathrm{Sb}-125$ & $1.59 \mathrm{E}-05$ & & \\
\hline & & & & & & Sm-147 & $2.86 \mathrm{E}-13$ & & \\
\hline & & & Sr-90 & $1.87 \mathrm{E}-01$ & & Sr-90 & $1.03 \mathrm{E}-01$ & & \\
\hline & & & $\mathrm{Te}-125 \mathrm{~m}$ & $3.45 \mathrm{E}-03$ & & $\mathrm{Te}-125 \mathrm{~m}$ & $3.86 \mathrm{E}-06$ & & \\
\hline & & & & & & Th-227 & $1.40 \mathrm{E}-10$ & & \\
\hline & & & & & & Th-231 & $8.69 \mathrm{E}-07$ & & \\
\hline & & & & & & Tl-207 & $1.42 \mathrm{E}-10$ & & \\
\hline & & & $\mathrm{U}-235$ & $8.80 \mathrm{E}-07$ & & $\mathrm{U}-235$ & $8.80 \mathrm{E}-07$ & & \\
\hline & & & $\mathrm{Y}-90$ & $1.87 \mathrm{E}-01$ & & Y-90 & $1.02 \mathrm{E}-01$ & & \\
\hline \multirow[t]{20}{*}{228} & S874123 & 1987 & & & 2009 & Ac-227 & $1.15 \mathrm{E}-10$ & 9,000 & 5,100 \\
\hline & & & $\mathrm{Ba}-137 \mathrm{~m}$ & $3.59 \mathrm{E}-02$ & & $\mathrm{Ba}-137 \mathrm{~m}$ & $2.15 \mathrm{E}-02$ & & \\
\hline & & & & & & Bi-211 & $1.13 \mathrm{E}-10$ & & \\
\hline & & & Cs-137 & $3.83 \mathrm{E}-02$ & & Cs-137 & $2.30 \mathrm{E}-02$ & & \\
\hline & & & Eu-155 & 7.17E-04 & & Eu-155 & $3.31 \mathrm{E}-05$ & & \\
\hline & & & & & & Fr-223 & $1.57 \mathrm{E}-12$ & & \\
\hline & & & & & & $\mathrm{Pa}-231$ & $4.09 \mathrm{E}-10$ & & \\
\hline & & & & & & $\mathrm{Pb}-211$ & $1.14 \mathrm{E}-10$ & & \\
\hline & & & Pm-147 & 2.19E-03 & & Pm-147 & $6.54 \mathrm{E}-06$ & & \\
\hline & & & & & & Po-211 & $3.46 \mathrm{E}-13$ & & \\
\hline & & & & & & Po-215 & $1.14 \mathrm{E}-10$ & & \\
\hline & & & $\mathrm{Pu}-239$ & $6.20 \mathrm{E}-03$ & & $\mathrm{Pu}-239$ & $6.20 \mathrm{E}-03$ & & \\
\hline & & & & & & $\mathrm{Ra}-223$ & $1.15 \mathrm{E}-10$ & & \\
\hline & & & Rh-106 & 2.81E-04 & & Rh-106 & $7.48 \mathrm{E}-11$ & & \\
\hline & & & & & & Rn-219 & $1.13 \mathrm{E}-10$ & & \\
\hline & & & $\mathrm{Ru}-106$ & $2.81 \mathrm{E}-04$ & & $\mathrm{Ru}-106$ & $7.56 \mathrm{E}-11$ & & \\
\hline & & & Sb-125 & $1.56 \mathrm{E}-03$ & & Sb-125 & $6.34 \mathrm{E}-06$ & & \\
\hline & & & & & & Sm-147 & $5.35 \mathrm{E}-14$ & & \\
\hline & & & Sr-90 & $3.50 \mathrm{E}-02$ & & Sr-90 & $2.07 \mathrm{E}-02$ & & \\
\hline & & & $\mathrm{Te}-125 \mathrm{~m}$ & $6.48 \mathrm{E}-04$ & & $\mathrm{Te}-125 \mathrm{~m}$ & $1.53 \mathrm{E}-06$ & & \\
\hline
\end{tabular}

${ }^{1}$ Calculated decayed contact dose rate. Rounded to nearest $10 \mathrm{mR} / \mathrm{hr}$ for values to 1000 ; rounded to nearest $100 \mathrm{mR} / \mathrm{hr}$ for values $>1000$ to 10,000 ; rounded to nearest $1000 \mathrm{mR} / \mathrm{hr}$ for values $>10,000$. * Initial contact dose rate assumed to be $1,000,000 \mathrm{mR} / \mathrm{hr}$; **Initial contact dose rate assumed to be $1,010,000 \mathrm{mR} / \mathrm{hr}$.

$$
139 \text { of } 168
$$


Appendix A-4 - Initial and Decayed Radionuclide and Dose Data for Lined Shafts

\begin{tabular}{|c|c|c|c|c|c|c|c|c|c|}
\hline \multirow[b]{2}{*}{ Shaft Number } & \multirow[b]{2}{*}{ Package ID } & \multirow[b]{2}{*}{ Base Year } & \multicolumn{2}{|c|}{ Initial Isotopic Distribution } & \multirow[b]{2}{*}{ Target Year } & \multicolumn{2}{|c|}{ Decayed Isotopic Distribution } & \multirow{2}{*}{$\begin{array}{c}\text { Initial Contact } \\
\text { Dose Rate } \\
(\mathrm{mR} / \mathrm{hr})\end{array}$} & \multirow{2}{*}{$\begin{array}{c}\text { Decayed } \\
\text { Contact Dose } \\
\text { Rate }(\mathrm{mR} / \mathrm{hr})^{1}\end{array}$} \\
\hline & & & Isotope & Activity (Ci) & & Isotope & Activity (Ci) & & \\
\hline & & & & & & Th-227 & $1.12 \mathrm{E}-10$ & & \\
\hline & & & & & & Th-231 & $8.69 \mathrm{E}-07$ & & \\
\hline & & & & & & Tl-207 & $1.13 \mathrm{E}-10$ & & \\
\hline & & & $\mathrm{U}-235$ & $8.80 \mathrm{E}-07$ & & $\mathrm{U}-235$ & $8.80 \mathrm{E}-07$ & & \\
\hline & & & $\mathrm{Y}-90$ & $3.50 \mathrm{E}-02$ & & $\mathrm{Y}-90$ & $2.05 \mathrm{E}-02$ & & \\
\hline \multirow[t]{25}{*}{228} & S874124 & 1987 & & & 2009 & Ac-227 & $1.15 \mathrm{E}-10$ & 20,000 & 11,000 \\
\hline & & & $\mathrm{Ba}-137 \mathrm{~m}$ & $3.59 \mathrm{E}-01$ & & $\mathrm{Ba}-137 \mathrm{~m}$ & $2.15 \mathrm{E}-01$ & & \\
\hline & & & & & & Bi-211 & $1.13 \mathrm{E}-10$ & & \\
\hline & & & Cs-137 & $3.83 \mathrm{E}-01$ & & Cs-137 & $2.30 \mathrm{E}-01$ & & \\
\hline & & & Eu-155 & 7.17E-03 & & Eu-155 & $3.31 \mathrm{E}-04$ & & \\
\hline & & & & & & Fr-223 & $1.57 \mathrm{E}-12$ & & \\
\hline & & & & & & $\mathrm{Pa}-231$ & $4.09 \mathrm{E}-10$ & & \\
\hline & & & & & & $\mathrm{Pb}-211$ & $1.14 \mathrm{E}-10$ & & \\
\hline & & & Pm-147 & $2.19 \mathrm{E}-02$ & & Pm-147 & $6.54 \mathrm{E}-05$ & & \\
\hline & & & & & & Po-211 & $3.46 \mathrm{E}-13$ & & \\
\hline & & & & & & Po-215 & $1.14 \mathrm{E}-10$ & & \\
\hline & & & $\mathrm{Pu}-239$ & $6.20 \mathrm{E}-03$ & & $\mathrm{Pu}-239$ & $6.20 \mathrm{E}-03$ & & \\
\hline & & & & & & Ra-223 & $1.15 \mathrm{E}-10$ & & \\
\hline & & & Rh-106 & $2.81 \mathrm{E}-03$ & & Rh-106 & $7.48 \mathrm{E}-10$ & & \\
\hline & & & & & & Rn-219 & $1.13 \mathrm{E}-10$ & & \\
\hline & & & $\mathrm{Ru}-106$ & $2.81 \mathrm{E}-03$ & & Ru-106 & $7.56 \mathrm{E}-10$ & & \\
\hline & & & Sb-125 & $1.56 \mathrm{E}-02$ & & $\mathrm{Sb}-125$ & $6.34 \mathrm{E}-05$ & & \\
\hline & & & & & & Sm-147 & $5.35 \mathrm{E}-13$ & & \\
\hline & & & Sr-90 & $3.50 \mathrm{E}-01$ & & Sr-90 & $2.07 \mathrm{E}-01$ & & \\
\hline & & & $\mathrm{Te}-125 \mathrm{~m}$ & $6.48 \mathrm{E}-03$ & & $\mathrm{Te}-125 \mathrm{~m}$ & $1.53 \mathrm{E}-05$ & & \\
\hline & & & & & & Th-227 & $1.12 \mathrm{E}-10$ & & \\
\hline & & & & & & Th-231 & 8.69E-07 & & \\
\hline & & & & & & T1-207 & $1.13 \mathrm{E}-10$ & & \\
\hline & & & U-235 & $8.80 \mathrm{E}-07$ & & U-235 & $8.80 \mathrm{E}-07$ & & \\
\hline & & & Y-90 & $3.50 \mathrm{E}-01$ & & Y-90 & $2.05 \mathrm{E}-01$ & & \\
\hline \multirow[t]{2}{*}{228} & S874125 & 1987 & & & 2009 & Ac- 227 & $1.15 \mathrm{E}-10$ & 10,000 & 5,700 \\
\hline & & & Ba-137m & $3.59 \mathrm{E}-02$ & & Ba-137m & $2.15 \mathrm{E}-02$ & & \\
\hline
\end{tabular}

${ }^{1}$ Calculated decayed contact dose rate. Rounded to nearest $10 \mathrm{mR} / \mathrm{hr}$ for values to 1000 ; rounded to nearest $100 \mathrm{mR} / \mathrm{hr}$ for values $>1000$ to 10,000 ; rounded to nearest $1000 \mathrm{mR} / \mathrm{hr}$ for values $>10,000$. * Initial contact dose rate assumed to be $1,000,000 \mathrm{mR} / \mathrm{hr}$; **Initial contact dose rate assumed to be $1,010,000 \mathrm{mR} / \mathrm{hr}$.

$$
140 \text { of } 168
$$


Appendix A-4 - Initial and Decayed Radionuclide and Dose Data for Lined Shafts

\begin{tabular}{|c|c|c|c|c|c|c|c|c|c|}
\hline \multirow[b]{2}{*}{ Shaft Number } & \multirow[b]{2}{*}{ Package ID } & \multirow[b]{2}{*}{ Base Year } & \multicolumn{2}{|c|}{ Initial Isotopic Distribution } & \multirow[b]{2}{*}{ Target Year } & \multicolumn{2}{|c|}{ Decayed Isotopic Distribution } & \multirow{2}{*}{$\begin{array}{c}\text { Initial Contact } \\
\text { Dose Rate } \\
(\mathrm{mR} / \mathrm{hr})\end{array}$} & \multirow{2}{*}{$\begin{array}{c}\text { Decayed } \\
\text { Contact Dose } \\
\text { Rate }(\mathrm{mR} / \mathrm{hr})^{1}\end{array}$} \\
\hline & & & Isotope & Activity (Ci) & & Isotope & Activity (Ci) & & \\
\hline & & & & & & $\mathrm{Bi}-211$ & $1.13 \mathrm{E}-10$ & & \\
\hline & & & Cs-137 & 3.83E-02 & & Cs-137 & $2.30 \mathrm{E}-02$ & & \\
\hline & & & Eu-155 & 7.17E-04 & & $\mathrm{Eu}-155$ & $3.31 \mathrm{E}-05$ & & \\
\hline & & & & & & Fr-223 & $1.57 \mathrm{E}-12$ & & \\
\hline & & & & & & $\mathrm{Pa}-231$ & $4.09 \mathrm{E}-10$ & & \\
\hline & & & & & & $\mathrm{Pb}-211$ & $1.14 \mathrm{E}-10$ & & \\
\hline & & & Pm-147 & $2.19 \mathrm{E}-03$ & & Pm-147 & $6.54 \mathrm{E}-06$ & & \\
\hline & & & & & & Po-211 & $3.46 \mathrm{E}-13$ & & \\
\hline & & & & & & Po-215 & $1.14 \mathrm{E}-10$ & & \\
\hline & & & $\mathrm{Pu}-239$ & $6.20 \mathrm{E}-03$ & & $\mathrm{Pu}-239$ & $6.20 \mathrm{E}-03$ & & \\
\hline & & & & & & $\mathrm{Ra}-223$ & $1.15 \mathrm{E}-10$ & & \\
\hline & & & Rh-106 & $2.81 \mathrm{E}-04$ & & Rh-106 & $7.48 \mathrm{E}-11$ & & \\
\hline & & & & & & Rn-219 & $1.13 \mathrm{E}-10$ & & \\
\hline & & & Ru-106 & $2.81 \mathrm{E}-04$ & & $\mathrm{Ru}-106$ & $7.56 \mathrm{E}-11$ & & \\
\hline & & & Sb-125 & $1.56 \mathrm{E}-03$ & & Sb-125 & $6.34 \mathrm{E}-06$ & & \\
\hline & & & & & & Sm-147 & $5.35 \mathrm{E}-14$ & & \\
\hline & & & Sr-90 & $3.50 \mathrm{E}-02$ & & Sr-90 & $2.07 \mathrm{E}-02$ & & \\
\hline & & & $\mathrm{Te}-125 \mathrm{~m}$ & $6.48 \mathrm{E}-04$ & & $\mathrm{Te}-125 \mathrm{~m}$ & $1.53 \mathrm{E}-06$ & & \\
\hline & & & & & & Th-227 & $1.12 \mathrm{E}-10$ & & \\
\hline & & & & & & Th-231 & 8.69E-07 & & \\
\hline & & & & & & Tl-207 & $1.13 \mathrm{E}-10$ & & \\
\hline & & & U-235 & $8.80 \mathrm{E}-07$ & & U-235 & $8.80 \mathrm{E}-07$ & & \\
\hline & & & $\mathrm{Y}-90$ & $3.50 \mathrm{E}-02$ & & Y-90 & $2.05 \mathrm{E}-02$ & & \\
\hline \multirow[t]{9}{*}{228} & S874126 & 1987 & & & 2009 & Ac- 227 & $1.15 \mathrm{E}-10$ & 200,000 & 114,000 \\
\hline & & & Ba-137m & $5.99 \mathrm{E}-01$ & & Ba-137m & $3.59 \mathrm{E}-01$ & & \\
\hline & & & & & & $\mathrm{Bi}-211$ & $1.13 \mathrm{E}-10$ & & \\
\hline & & & Cs-137 & $6.38 \mathrm{E}-01$ & & Cs-137 & $3.84 \mathrm{E}-01$ & & \\
\hline & & & Eu-155 & 1.19E-02 & & Eu-155 & $5.52 \mathrm{E}-04$ & & \\
\hline & & & & & & Fr-223 & $1.57 \mathrm{E}-12$ & & \\
\hline & & & & & & $\mathrm{Pa}-231$ & $4.09 \mathrm{E}-10$ & & \\
\hline & & & & & & $\mathrm{Pb}-211$ & $1.14 \mathrm{E}-10$ & & \\
\hline & & & Pm-147 & $3.65 \mathrm{E}-02$ & & Pm-147 & $1.09 \mathrm{E}-04$ & & \\
\hline
\end{tabular}

${ }^{1}$ Calculated decayed contact dose rate. Rounded to nearest $10 \mathrm{mR} / \mathrm{hr}$ for values to 1000 ; rounded to nearest $100 \mathrm{mR} / \mathrm{hr}$ for values $>1000$ to 10,000 ; rounded to nearest $1000 \mathrm{mR} / \mathrm{hr}$ for values $>10,000$. * Initial contact dose rate assumed to be $1,000,000 \mathrm{mR} / \mathrm{hr}$; **Initial contact dose rate assumed to be $1,010,000 \mathrm{mR} / \mathrm{hr}$.

$$
141 \text { of } 168
$$


Appendix A-4 - Initial and Decayed Radionuclide and Dose Data for Lined Shafts

\begin{tabular}{|c|c|c|c|c|c|c|c|c|c|}
\hline \multirow[b]{2}{*}{ Shaft Number } & \multirow[b]{2}{*}{ Package ID } & \multirow[b]{2}{*}{ Base Year } & \multicolumn{2}{|c|}{ Initial Isotopic Distribution } & \multirow[b]{2}{*}{ Target Year } & \multicolumn{2}{|c|}{ Decayed Isotopic Distribution } & \multirow{2}{*}{$\begin{array}{c}\text { Initial Contact } \\
\text { Dose Rate } \\
(\mathrm{mR} / \mathrm{hr})\end{array}$} & \multirow{2}{*}{$\begin{array}{c}\text { Decayed } \\
\text { Contact Dose } \\
\text { Rate }(\mathrm{mR} / \mathrm{hr})^{1}\end{array}$} \\
\hline & & & Isotope & Activity (Ci) & & Isotope & Activity (Ci) & & \\
\hline & & & & & & Po-211 & $3.46 \mathrm{E}-13$ & & \\
\hline & & & & & & Po-215 & $1.14 \mathrm{E}-10$ & & \\
\hline & & & $\mathrm{Pu}-239$ & $6.20 \mathrm{E}-03$ & & $\mathrm{Pu}-239$ & $6.20 \mathrm{E}-03$ & & \\
\hline & & & & & & $\mathrm{Ra}-223$ & $1.15 \mathrm{E}-10$ & & \\
\hline & & & Rh-106 & $4.68 \mathrm{E}-03$ & & Rh-106 & $1.25 \mathrm{E}-09$ & & \\
\hline & & & & & & Rn-219 & $1.13 \mathrm{E}-10$ & & \\
\hline & & & $\mathrm{Ru}-106$ & 4.68E-03 & & $\mathrm{Ru}-106$ & $1.26 \mathrm{E}-09$ & & \\
\hline & & & Sb-125 & $2.60 \mathrm{E}-02$ & & Sb-125 & $1.06 \mathrm{E}-04$ & & \\
\hline & & & & & & Sm-147 & 8.91E-13 & & \\
\hline & & & Sr-90 & $5.84 \mathrm{E}-01$ & & Sr-90 & $3.46 \mathrm{E}-01$ & & \\
\hline & & & $\mathrm{Te}-125 \mathrm{~m}$ & $1.08 \mathrm{E}-02$ & & $\mathrm{Te}-125 \mathrm{~m}$ & $2.56 \mathrm{E}-05$ & & \\
\hline & & & & & & Th-227 & $1.12 \mathrm{E}-10$ & & \\
\hline & & & & & & Th-231 & 8.69E-07 & & \\
\hline & & & & & & Tl-207 & $1.13 \mathrm{E}-10$ & & \\
\hline & & & $\mathrm{U}-235$ & $8.80 \mathrm{E}-07$ & & $\mathrm{U}-235$ & $8.80 \mathrm{E}-07$ & & \\
\hline & & & $\mathrm{Y}-90$ & $5.83 \mathrm{E}-01$ & & Y-90 & $3.42 \mathrm{E}-01$ & & \\
\hline \multirow[t]{16}{*}{228} & S874127 & 1987 & & & 2009 & Ac- 227 & $1.15 \mathrm{E}-10$ & & 0 \\
\hline & & & Ba-137m & $3.59 \mathrm{E}-01$ & & $\mathrm{Ba}-137 \mathrm{~m}$ & $2.15 \mathrm{E}-01$ & & \\
\hline & & & & & & $\mathrm{Bi}-211$ & $1.13 \mathrm{E}-10$ & & \\
\hline & & & Cs-137 & 3.83E-01 & & Cs-137 & $2.30 \mathrm{E}-01$ & & \\
\hline & & & Eu-155 & 7.17E-03 & & Eu-155 & $3.31 \mathrm{E}-04$ & & \\
\hline & & & & & & Fr-223 & $1.57 \mathrm{E}-12$ & & \\
\hline & & & & & & $\mathrm{Pa}-231$ & $4.09 \mathrm{E}-10$ & & \\
\hline & & & & & & $\mathrm{Pb}-211$ & $1.14 \mathrm{E}-10$ & & \\
\hline & & & Pm-147 & 2.19E-02 & & Pm-147 & $6.54 \mathrm{E}-05$ & & \\
\hline & & & & & & Po-211 & $3.46 \mathrm{E}-13$ & & \\
\hline & & & & & & Po-215 & $1.14 \mathrm{E}-10$ & & \\
\hline & & & $\mathrm{Pu}-239$ & $6.20 \mathrm{E}-03$ & & Pu-239 & $6.20 \mathrm{E}-03$ & & \\
\hline & & & & & & Ra-223 & $1.15 \mathrm{E}-10$ & & \\
\hline & & & Rh-106 & $2.81 \mathrm{E}-03$ & & Rh-106 & $7.48 \mathrm{E}-10$ & & \\
\hline & & & & & & Rn-219 & $1.13 \mathrm{E}-10$ & & \\
\hline & & & Ru-106 & $2.81 \mathrm{E}-03$ & & $\mathrm{Ru}-106$ & $7.56 \mathrm{E}-10$ & & \\
\hline
\end{tabular}

${ }^{1}$ Calculated decayed contact dose rate. Rounded to nearest $10 \mathrm{mR} / \mathrm{hr}$ for values to 1000 ; rounded to nearest $100 \mathrm{mR} / \mathrm{hr}$ for values $>1000$ to 10,000 ; rounded to nearest $1000 \mathrm{mR} / \mathrm{hr}$ for values $>10,000$. * Initial contact dose rate assumed to be $1,000,000 \mathrm{mR} / \mathrm{hr}$; **Initial contact dose rate assumed to be $1,010,000 \mathrm{mR} / \mathrm{hr}$.

$$
142 \text { of } 168
$$


Appendix A-4 - Initial and Decayed Radionuclide and Dose Data for Lined Shafts

\begin{tabular}{|c|c|c|c|c|c|c|c|c|c|}
\hline \multirow[b]{2}{*}{ Shaft Number } & \multirow[b]{2}{*}{ Package ID } & \multirow[b]{2}{*}{ Base Year } & \multicolumn{2}{|c|}{ Initial Isotopic Distribution } & \multirow[b]{2}{*}{ Target Year } & \multicolumn{2}{|c|}{ Decayed Isotopic Distribution } & \multirow{2}{*}{$\begin{array}{c}\text { Initial Contact } \\
\text { Dose Rate } \\
(\mathrm{mR} / \mathrm{hr})\end{array}$} & \multirow{2}{*}{$\begin{array}{c}\text { Decayed } \\
\text { Contact Dose } \\
\text { Rate }(\mathrm{mR} / \mathrm{hr})^{1} \\
\end{array}$} \\
\hline & & & Isotope & Activity (Ci) & & Isotope & Activity (Ci) & & \\
\hline & & & $\mathrm{Sb}-125$ & $1.56 \mathrm{E}-02$ & & $\mathrm{Sb}-125$ & $6.34 \mathrm{E}-05$ & & \\
\hline & & & & & & Sm-147 & $5.35 \mathrm{E}-13$ & & \\
\hline & & & Sr-90 & $3.50 \mathrm{E}-01$ & & Sr-90 & $2.07 \mathrm{E}-01$ & & \\
\hline & & & $\mathrm{Te}-125 \mathrm{~m}$ & $6.48 \mathrm{E}-03$ & & $\mathrm{Te}-125 \mathrm{~m}$ & $1.53 \mathrm{E}-05$ & & \\
\hline & & & & & & Th-227 & $1.12 \mathrm{E}-10$ & & \\
\hline & & & & & & Th-231 & $8.69 \mathrm{E}-07$ & & \\
\hline & & & & & & Tl-207 & $1.13 \mathrm{E}-10$ & & \\
\hline & & & U-235 & 8.80E-07 & & U-235 & $8.80 \mathrm{E}-07$ & & \\
\hline & & & Y-90 & $3.50 \mathrm{E}-01$ & & Y-90 & $2.05 \mathrm{E}-01$ & & \\
\hline \multirow[t]{23}{*}{228} & S874128 & 1987 & & & 2009 & Ac-227 & $1.15 \mathrm{E}-10$ & & 0 \\
\hline & & & $\mathrm{Ba}-137 \mathrm{~m}$ & $3.59 \mathrm{E}-01$ & & $\mathrm{Ba}-137 \mathrm{~m}$ & $2.15 \mathrm{E}-01$ & & \\
\hline & & & & & & Bi-211 & $1.13 \mathrm{E}-10$ & & \\
\hline & & & Cs-137 & $3.83 \mathrm{E}-01$ & & Cs-137 & $2.30 \mathrm{E}-01$ & & \\
\hline & & & Eu-155 & 7.17E-03 & & Eu-155 & $3.31 \mathrm{E}-04$ & & \\
\hline & & & & & & Fr-223 & $1.57 \mathrm{E}-12$ & & \\
\hline & & & & & & $\mathrm{Pa}-231$ & $4.09 \mathrm{E}-10$ & & \\
\hline & & & & & & $\mathrm{Pb}-211$ & $1.14 \mathrm{E}-10$ & & \\
\hline & & & Pm-147 & $2.19 \mathrm{E}-02$ & & Pm-147 & $6.54 \mathrm{E}-05$ & & \\
\hline & & & & & & Po-211 & $3.46 \mathrm{E}-13$ & & \\
\hline & & & & & & Po-215 & $1.14 \mathrm{E}-10$ & & \\
\hline & & & $\mathrm{Pu}-239$ & $6.20 \mathrm{E}-03$ & & Pu-239 & $6.20 \mathrm{E}-03$ & & \\
\hline & & & & & & $\mathrm{Ra}-223$ & $1.15 \mathrm{E}-10$ & & \\
\hline & & & Rh-106 & $2.81 \mathrm{E}-03$ & & Rh-106 & $7.48 \mathrm{E}-10$ & & \\
\hline & & & & & & Rn-219 & $1.13 \mathrm{E}-10$ & & \\
\hline & & & $\mathrm{Ru}-106$ & $2.81 \mathrm{E}-03$ & & $\mathrm{Ru}-106$ & $7.56 \mathrm{E}-10$ & & \\
\hline & & & $\mathrm{Sb}-125$ & $1.56 \mathrm{E}-02$ & & $\mathrm{Sb}-125$ & $6.34 \mathrm{E}-05$ & & \\
\hline & & & & & & Sm-147 & $5.35 \mathrm{E}-13$ & & \\
\hline & & & Sr-90 & $3.50 \mathrm{E}-01$ & & Sr-90 & $2.07 \mathrm{E}-01$ & & \\
\hline & & & Te-125m & $6.48 \mathrm{E}-03$ & & Te-125m & $1.53 \mathrm{E}-05$ & & \\
\hline & & & & & & Th-227 & $1.12 \mathrm{E}-10$ & & \\
\hline & & & & & & Th-231 & 8.69E-07 & & \\
\hline & & & & & & Tl-207 & $1.13 \mathrm{E}-10$ & & \\
\hline
\end{tabular}

${ }^{1}$ Calculated decayed contact dose rate. Rounded to nearest $10 \mathrm{mR} / \mathrm{hr}$ for values to 1000 ; rounded to nearest $100 \mathrm{mR} / \mathrm{hr}$ for values $>1000$ to 10,000 ; rounded to nearest $1000 \mathrm{mR} / \mathrm{hr}$ for values $>10,000$. * Initial contact dose rate assumed to be $1,000,000 \mathrm{mR} / \mathrm{hr}$; **Initial contact dose rate assumed to be $1,010,000 \mathrm{mR} / \mathrm{hr}$.

$$
143 \text { of } 168
$$


Appendix A-4 - Initial and Decayed Radionuclide and Dose Data for Lined Shafts

\begin{tabular}{|c|c|c|c|c|c|c|c|c|c|}
\hline \multirow[b]{2}{*}{ Shaft Number } & \multirow[b]{2}{*}{ Package ID } & \multirow[b]{2}{*}{ Base Year } & \multicolumn{2}{|c|}{ Initial Isotopic Distribution } & \multirow[b]{2}{*}{ Target Year } & \multicolumn{2}{|c|}{ Decayed Isotopic Distribution } & \multirow{2}{*}{$\begin{array}{c}\text { Initial Contact } \\
\text { Dose Rate } \\
(\mathrm{mR} / \mathrm{hr})\end{array}$} & \multirow{2}{*}{$\begin{array}{c}\text { Decayed } \\
\text { Contact Dose } \\
\text { Rate }(\mathrm{mR} / \mathrm{hr})^{1} \\
\end{array}$} \\
\hline & & & Isotope & Activity (Ci) & & Isotope & Activity (Ci) & & \\
\hline & & & U-235 & $8.80 \mathrm{E}-07$ & & U-235 & $8.80 \mathrm{E}-07$ & & \\
\hline & & & $\mathrm{Y}-90$ & $3.50 \mathrm{E}-01$ & & Y-90 & $2.05 \mathrm{E}-01$ & & \\
\hline \multirow[t]{25}{*}{228} & S874129 & 1987 & & & 2009 & Ac- 227 & $1.15 \mathrm{E}-10$ & 60,000 & 34,000 \\
\hline & & & Ba-137m & $3.59 \mathrm{E}-01$ & & $\mathrm{Ba}-137 \mathrm{~m}$ & $2.15 \mathrm{E}-01$ & & \\
\hline & & & & & & $\mathrm{Bi}-211$ & $1.13 \mathrm{E}-10$ & & \\
\hline & & & Cs-137 & $3.83 \mathrm{E}-01$ & & Cs-137 & $2.30 \mathrm{E}-01$ & & \\
\hline & & & Eu-155 & 7.17E-03 & & Eu-155 & $3.31 \mathrm{E}-04$ & & \\
\hline & & & & & & Fr-223 & $1.57 \mathrm{E}-12$ & & \\
\hline & & & & & & $\mathrm{Pa}-231$ & $4.09 \mathrm{E}-10$ & & \\
\hline & & & & & & $\mathrm{Pb}-211$ & $1.14 \mathrm{E}-10$ & & \\
\hline & & & Pm-147 & 2.19E-02 & & Pm-147 & $6.54 \mathrm{E}-05$ & & \\
\hline & & & & & & Po-211 & $3.46 \mathrm{E}-13$ & & \\
\hline & & & & & & Po-215 & $1.14 \mathrm{E}-10$ & & \\
\hline & & & $\mathrm{Pu}-239$ & $6.20 \mathrm{E}-03$ & & $\mathrm{Pu}-239$ & $6.20 \mathrm{E}-03$ & & \\
\hline & & & & & & Ra-223 & $1.15 \mathrm{E}-10$ & & \\
\hline & & & Rh-106 & $2.81 \mathrm{E}-03$ & & Rh-106 & $7.48 \mathrm{E}-10$ & & \\
\hline & & & & & & Rn-219 & $1.13 \mathrm{E}-10$ & & \\
\hline & & & Ru-106 & $2.81 \mathrm{E}-03$ & & Ru-106 & $7.56 \mathrm{E}-10$ & & \\
\hline & & & Sb-125 & $1.56 \mathrm{E}-02$ & & Sb-125 & $6.34 \mathrm{E}-05$ & & \\
\hline & & & & & & Sm-147 & $5.35 \mathrm{E}-13$ & & \\
\hline & & & Sr-90 & $3.50 \mathrm{E}-01$ & & Sr-90 & $2.07 \mathrm{E}-01$ & & \\
\hline & & & $\mathrm{Te}-125 \mathrm{~m}$ & $6.48 \mathrm{E}-03$ & & $\mathrm{Te}-125 \mathrm{~m}$ & $1.53 \mathrm{E}-05$ & & \\
\hline & & & & & & Th-227 & $1.12 \mathrm{E}-10$ & & \\
\hline & & & & & & Th-231 & 8.69E-07 & & \\
\hline & & & & & & Tl-207 & $1.13 \mathrm{E}-10$ & & \\
\hline & & & U-235 & $8.80 \mathrm{E}-07$ & & U-235 & $8.80 \mathrm{E}-07$ & & \\
\hline & & & Y-90 & $3.50 \mathrm{E}-01$ & & $\mathrm{Y}-90$ & $2.05 \mathrm{E}-01$ & & \\
\hline \multirow[t]{5}{*}{228} & S874130 & 1987 & & & 2009 & Ac- 227 & $1.15 \mathrm{E}-10$ & 80,000 & 45,000 \\
\hline & & & $\mathrm{Ba}-137 \mathrm{~m}$ & 4.79E-01 & & Ba-137m & $2.87 \mathrm{E}-01$ & & \\
\hline & & & & & & Bi-211 & $1.13 \mathrm{E}-10$ & & \\
\hline & & & Cs-137 & $5.11 \mathrm{E}-01$ & & Cs-137 & $3.07 \mathrm{E}-01$ & & \\
\hline & & & Eu-155 & $9.55 \mathrm{E}-03$ & & Eu-155 & $4.41 \mathrm{E}-04$ & & \\
\hline
\end{tabular}

${ }^{1}$ Calculated decayed contact dose rate. Rounded to nearest $10 \mathrm{mR} / \mathrm{hr}$ for values to 1000 ; rounded to nearest $100 \mathrm{mR} / \mathrm{hr}$ for values $>1000$ to 10,000 ; rounded to nearest $1000 \mathrm{mR} / \mathrm{hr}$ for values $>10,000$. * Initial contact dose rate assumed to be $1,000,000 \mathrm{mR} / \mathrm{hr}$; **Initial contact dose rate assumed to be $1,010,000 \mathrm{mR} / \mathrm{hr}$.

$$
144 \text { of } 168
$$


Appendix A-4 - Initial and Decayed Radionuclide and Dose Data for Lined Shafts

\begin{tabular}{|c|c|c|c|c|c|c|c|c|c|}
\hline \multirow[b]{2}{*}{ Shaft Number } & \multirow[b]{2}{*}{ Package ID } & \multirow[b]{2}{*}{ Base Year } & \multicolumn{2}{|c|}{ Initial Isotopic Distribution } & \multirow[b]{2}{*}{ Target Year } & \multicolumn{2}{|c|}{ Decayed Isotopic Distribution } & \multirow{2}{*}{$\begin{array}{c}\text { Initial Contact } \\
\text { Dose Rate } \\
(\mathrm{mR} / \mathrm{hr})\end{array}$} & \multirow{2}{*}{$\begin{array}{c}\text { Decayed } \\
\text { Contact Dose } \\
\text { Rate }(\mathrm{mR} / \mathrm{hr})^{1}\end{array}$} \\
\hline & & & Isotope & Activity (Ci) & & Isotope & Activity (Ci) & & \\
\hline & & & & & & Fr-223 & $1.57 \mathrm{E}-12$ & & \\
\hline & & & & & & $\mathrm{Pa}-231$ & $4.09 \mathrm{E}-10$ & & \\
\hline & & & & & & $\mathrm{Pb}-211$ & $1.14 \mathrm{E}-10$ & & \\
\hline & & & Pm-147 & $2.92 \mathrm{E}-02$ & & Pm-147 & $8.72 \mathrm{E}-05$ & & \\
\hline & & & & & & Po-211 & $3.46 \mathrm{E}-13$ & & \\
\hline & & & & & & Po-215 & $1.14 \mathrm{E}-10$ & & \\
\hline & & & $\mathrm{Pu}-239$ & $6.20 \mathrm{E}-03$ & & $\mathrm{Pu}-239$ & $6.20 \mathrm{E}-03$ & & \\
\hline & & & & & & Ra-223 & $1.15 \mathrm{E}-10$ & & \\
\hline & & & Rh-106 & $3.74 \mathrm{E}-03$ & & Rh-106 & $9.98 \mathrm{E}-10$ & & \\
\hline & & & & & & $\mathrm{Rn}-219$ & $1.13 \mathrm{E}-10$ & & \\
\hline & & & $\mathrm{Ru}-106$ & $3.74 \mathrm{E}-03$ & & Ru-106 & $1.01 \mathrm{E}-09$ & & \\
\hline & & & $\mathrm{Sb}-125$ & $2.08 \mathrm{E}-02$ & & $\mathrm{Sb}-125$ & $8.45 \mathrm{E}-05$ & & \\
\hline & & & & & & Sm-147 & $7.13 \mathrm{E}-13$ & & \\
\hline & & & Sr-90 & $4.67 \mathrm{E}-01$ & & Sr-90 & $2.77 \mathrm{E}-01$ & & \\
\hline & & & $\mathrm{Te}-125 \mathrm{~m}$ & $8.63 \mathrm{E}-03$ & & $\mathrm{Te}-125 \mathrm{~m}$ & $2.05 \mathrm{E}-05$ & & \\
\hline & & & & & & Th-227 & $1.12 \mathrm{E}-10$ & & \\
\hline & & & & & & Th-231 & $8.69 \mathrm{E}-07$ & & \\
\hline & & & & & & Tl-207 & $1.13 \mathrm{E}-10$ & & \\
\hline & & & $\mathrm{U}-235$ & $8.80 \mathrm{E}-07$ & & U-235 & $8.80 \mathrm{E}-07$ & & \\
\hline & & & Y-90 & $4.66 \mathrm{E}-01$ & & $\mathrm{Y}-90$ & $2.73 \mathrm{E}-01$ & & \\
\hline \multirow[t]{12}{*}{229} & S840851 & 1984 & & & 2009 & Ac- 227 & $1.44 \mathrm{E}-10$ & 200,000 & 106,000 \\
\hline & & & $\mathrm{Ba}-137 \mathrm{~m}$ & 7.19E-01 & & $\mathrm{Ba}-137 \mathrm{~m}$ & $4.02 \mathrm{E}-01$ & & \\
\hline & & & & & & Bi-211 & $1.42 \mathrm{E}-10$ & & \\
\hline & & & Cs-137 & $7.66 \mathrm{E}-01$ & & Cs-137 & $4.30 \mathrm{E}-01$ & & \\
\hline & & & Eu-155 & $1.43 \mathrm{E}-02$ & & Eu-155 & $4.35 \mathrm{E}-04$ & & \\
\hline & & & & & & Fr-223 & $1.97 \mathrm{E}-12$ & & \\
\hline & & & & & & $\mathrm{Pa}-231$ & $4.65 \mathrm{E}-10$ & & \\
\hline & & & & & & $\mathrm{Pb}-211$ & $1.43 \mathrm{E}-10$ & & \\
\hline & & & Pm-147 & $4.38 \mathrm{E}-02$ & & Pm-147 & $5.90 \mathrm{E}-05$ & & \\
\hline & & & & & & Po-211 & $4.35 \mathrm{E}-13$ & & \\
\hline & & & & & & Po-215 & $1.43 \mathrm{E}-10$ & & \\
\hline & & & $\mathrm{Pu}-239$ & $6.20 \mathrm{E}-03$ & & $\mathrm{Pu}-239$ & $6.20 \mathrm{E}-03$ & & \\
\hline
\end{tabular}

${ }^{1}$ Calculated decayed contact dose rate. Rounded to nearest $10 \mathrm{mR} / \mathrm{hr}$ for values to 1000 ; rounded to nearest $100 \mathrm{mR} / \mathrm{hr}$ for values $>1000$ to 10,000 ; rounded to nearest $1000 \mathrm{mR} / \mathrm{hr}$ for values $>10,000$. * Initial contact dose rate assumed to be $1,000,000 \mathrm{mR} / \mathrm{hr}$; **Initial contact dose rate assumed to be $1,010,000 \mathrm{mR} / \mathrm{hr}$.

$$
145 \text { of } 168
$$


Appendix A-4 - Initial and Decayed Radionuclide and Dose Data for Lined Shafts

\begin{tabular}{|c|c|c|c|c|c|c|c|c|c|}
\hline \multirow[b]{2}{*}{ Shaft Number } & \multirow[b]{2}{*}{ Package ID } & \multirow[b]{2}{*}{ Base Year } & \multicolumn{2}{|c|}{ Initial Isotopic Distribution } & \multirow[b]{2}{*}{ Target Year } & \multicolumn{2}{|c|}{ Decayed Isotopic Distribution } & \multirow{2}{*}{$\begin{array}{c}\text { Initial Contact } \\
\text { Dose Rate } \\
(\mathrm{mR} / \mathrm{hr})\end{array}$} & \multirow{2}{*}{$\begin{array}{c}\text { Decayed } \\
\text { Contact Dose } \\
\text { Rate }(\mathrm{mR} / \mathrm{hr})^{1}\end{array}$} \\
\hline & & & Isotope & Activity $(\mathrm{Ci})$ & & Isotope & Activity (Ci) & & \\
\hline & & & & & & Ra-223 & $1.44 \mathrm{E}-10$ & & \\
\hline & & & Rh-106 & $5.62 \mathrm{E}-03$ & & Rh-106 & $1.90 \mathrm{E}-10$ & & \\
\hline & & & & & & Rn-219 & $1.42 \mathrm{E}-10$ & & \\
\hline & & & $\mathrm{Ru}-106$ & $5.62 \mathrm{E}-03$ & & Ru-106 & $1.92 \mathrm{E}-10$ & & \\
\hline & & & Sb-125 & $3.12 \mathrm{E}-02$ & & $\mathrm{Sb}-125$ & $5.98 \mathrm{E}-05$ & & \\
\hline & & & & & & Sm-147 & $1.07 \mathrm{E}-12$ & & \\
\hline & & & Sr-90 & $7.00 \mathrm{E}-01$ & & Sr-90 & $3.86 \mathrm{E}-01$ & & \\
\hline & & & $\mathrm{Te}-125 \mathrm{~m}$ & $1.30 \mathrm{E}-02$ & & $\mathrm{Te}-125 \mathrm{~m}$ & $1.45 \mathrm{E}-05$ & & \\
\hline & & & & & & Th-227 & $1.40 \mathrm{E}-10$ & & \\
\hline & & & & & & Th-231 & $8.69 \mathrm{E}-07$ & & \\
\hline & & & & & & T1-207 & $1.42 \mathrm{E}-10$ & & \\
\hline & & & $\mathrm{U}-235$ & $8.80 \mathrm{E}-07$ & & $\mathrm{U}-235$ & $8.80 \mathrm{E}-07$ & & \\
\hline & & & Y-90 & $6.99 \mathrm{E}-01$ & & $\mathrm{Y}-90$ & $3.82 \mathrm{E}-01$ & & \\
\hline \multirow[t]{19}{*}{229} & S840855 & 1984 & & & 2009 & Ac-227 & $1.44 \mathrm{E}-10$ & 40,000 & 21,000 \\
\hline & & & Ba-137m & $2.40 \mathrm{E}-01$ & & $\mathrm{Ba}-137 \mathrm{~m}$ & $1.34 \mathrm{E}-01$ & & \\
\hline & & & & & & $\mathrm{Bi}-211$ & $1.42 \mathrm{E}-10$ & & \\
\hline & & & Cs-137 & $2.55 \mathrm{E}-01$ & & Cs-137 & $1.43 \mathrm{E}-01$ & & \\
\hline & & & Eu-155 & $4.78 \mathrm{E}-03$ & & Eu-155 & $1.45 \mathrm{E}-04$ & & \\
\hline & & & & & & Fr-223 & $1.97 \mathrm{E}-12$ & & \\
\hline & & & & & & $\mathrm{Pa}-231$ & $4.65 \mathrm{E}-10$ & & \\
\hline & & & & & & $\mathrm{Pb}-211$ & $1.43 \mathrm{E}-10$ & & \\
\hline & & & Pm-147 & $1.46 \mathrm{E}-02$ & & Pm-147 & $1.98 \mathrm{E}-05$ & & \\
\hline & & & & & & Po-211 & $4.35 \mathrm{E}-13$ & & \\
\hline & & & & & & Po-215 & $1.43 \mathrm{E}-10$ & & \\
\hline & & & $\mathrm{Pu}-239$ & $6.20 \mathrm{E}-03$ & & $\mathrm{Pu}-239$ & $6.20 \mathrm{E}-03$ & & \\
\hline & & & & & & Ra-223 & $1.44 \mathrm{E}-10$ & & \\
\hline & & & Rh-106 & $1.87 \mathrm{E}-03$ & & Rh-106 & $6.34 \mathrm{E}-11$ & & \\
\hline & & & & & & Rn-219 & $1.42 \mathrm{E}-10$ & & \\
\hline & & & $\mathrm{Ru}-106$ & $1.87 \mathrm{E}-03$ & & Ru-106 & $6.40 \mathrm{E}-11$ & & \\
\hline & & & Sb-125 & $1.04 \mathrm{E}-02$ & & Sb-125 & $2.00 \mathrm{E}-05$ & & \\
\hline & & & & & & Sm-147 & $3.57 \mathrm{E}-13$ & & \\
\hline & & & Sr-90 & $2.33 \mathrm{E}-01$ & & Sr-90 & $1.29 \mathrm{E}-01$ & & \\
\hline
\end{tabular}

${ }^{1}$ Calculated decayed contact dose rate. Rounded to nearest $10 \mathrm{mR} / \mathrm{hr}$ for values to 1000 ; rounded to nearest $100 \mathrm{mR} / \mathrm{hr}$ for values $>1000$ to 10,000 ; rounded to nearest $1000 \mathrm{mR} / \mathrm{hr}$ for values $>10,000$. * Initial contact dose rate assumed to be $1,000,000 \mathrm{mR} / \mathrm{hr}$; **Initial contact dose rate assumed to be $1,010,000 \mathrm{mR} / \mathrm{hr}$.

146 of 168 
Appendix A-4 - Initial and Decayed Radionuclide and Dose Data for Lined Shafts

\begin{tabular}{|c|c|c|c|c|c|c|c|c|c|}
\hline \multirow[b]{2}{*}{ Shaft Number } & \multirow[b]{2}{*}{ Package ID } & \multirow[b]{2}{*}{ Base Year } & \multicolumn{2}{|c|}{ Initial Isotopic Distribution } & \multirow[b]{2}{*}{ Target Year } & \multicolumn{2}{|c|}{ Decayed Isotopic Distribution } & \multirow{2}{*}{$\begin{array}{c}\text { Initial Contact } \\
\text { Dose Rate } \\
(\mathrm{mR} / \mathrm{hr})\end{array}$} & \multirow{2}{*}{$\begin{array}{c}\text { Decayed } \\
\text { Contact Dose } \\
\text { Rate }(\mathrm{mR} / \mathrm{hr})^{1} \\
\end{array}$} \\
\hline & & & Isotope & Activity (Ci) & & Isotope & Activity (Ci) & & \\
\hline & & & $\mathrm{Te}-125 \mathrm{~m}$ & $4.32 \mathrm{E}-03$ & & Te-125m & $4.83 \mathrm{E}-06$ & & \\
\hline & & & & & & Th-227 & $1.40 \mathrm{E}-10$ & & \\
\hline & & & & & & Th-231 & $8.69 \mathrm{E}-07$ & & \\
\hline & & & & & & T1-207 & $1.42 \mathrm{E}-10$ & & \\
\hline & & & $\mathrm{U}-235$ & $8.80 \mathrm{E}-07$ & & $\mathrm{U}-235$ & $8.80 \mathrm{E}-07$ & & \\
\hline & & & $\mathrm{Y}-90$ & $2.33 \mathrm{E}-01$ & & $\mathrm{Y}-90$ & $1.27 \mathrm{E}-01$ & & \\
\hline \multirow[t]{25}{*}{229} & S840860 & 1984 & & & 2009 & Ac-227 & $1.44 \mathrm{E}-10$ & 150,000 & 80,000 \\
\hline & & & $\mathrm{Ba}-137 \mathrm{~m}$ & 4.79E-01 & & $\mathrm{Ba}-137 \mathrm{~m}$ & $2.68 \mathrm{E}-01$ & & \\
\hline & & & & & & $\mathrm{Bi}-211$ & $1.42 \mathrm{E}-10$ & & \\
\hline & & & Cs-137 & $5.11 \mathrm{E}-01$ & & Cs-137 & $2.87 \mathrm{E}-01$ & & \\
\hline & & & $\mathrm{Eu}-155$ & $9.55 \mathrm{E}-03$ & & Eu-155 & $2.90 \mathrm{E}-04$ & & \\
\hline & & & & & & Fr-223 & $1.97 \mathrm{E}-12$ & & \\
\hline & & & & & & $\mathrm{Pa}-231$ & $4.65 \mathrm{E}-10$ & & \\
\hline & & & & & & $\mathrm{Pb}-211$ & $1.43 \mathrm{E}-10$ & & \\
\hline & & & Pm-147 & $2.92 \mathrm{E}-02$ & & Pm-147 & $3.93 \mathrm{E}-05$ & & \\
\hline & & & & & & Po-211 & $4.35 \mathrm{E}-13$ & & \\
\hline & & & & & & Po-215 & $1.43 \mathrm{E}-10$ & & \\
\hline & & & $\mathrm{Pu}-239$ & $6.20 \mathrm{E}-03$ & & $\mathrm{Pu}-239$ & $6.20 \mathrm{E}-03$ & & \\
\hline & & & & & & Ra-223 & $1.44 \mathrm{E}-10$ & & \\
\hline & & & Rh-106 & $3.74 \mathrm{E}-03$ & & Rh-106 & $1.27 \mathrm{E}-10$ & & \\
\hline & & & & & & Rn-219 & $1.42 \mathrm{E}-10$ & & \\
\hline & & & Ru-106 & $3.74 \mathrm{E}-03$ & & $\mathrm{Ru}-106$ & $1.28 \mathrm{E}-10$ & & \\
\hline & & & Sb-125 & $2.08 \mathrm{E}-02$ & & Sb-125 & $4.00 \mathrm{E}-05$ & & \\
\hline & & & & & & Sm-147 & $7.14 \mathrm{E}-13$ & & \\
\hline & & & Sr-90 & $4.67 \mathrm{E}-01$ & & Sr-90 & $2.58 \mathrm{E}-01$ & & \\
\hline & & & $\mathrm{Te}-125 \mathrm{~m}$ & $8.63 \mathrm{E}-03$ & & $\mathrm{Te}-125 \mathrm{~m}$ & $9.67 \mathrm{E}-06$ & & \\
\hline & & & & & & Th-227 & $1.40 \mathrm{E}-10$ & & \\
\hline & & & & & & Th-231 & $8.69 \mathrm{E}-07$ & & \\
\hline & & & & & & T1-207 & $1.42 \mathrm{E}-10$ & & \\
\hline & & & U-235 & $8.80 \mathrm{E}-07$ & & U-235 & $8.80 \mathrm{E}-07$ & & \\
\hline & & & $\mathrm{Y}-90$ & $4.66 \mathrm{E}-01$ & & Y-90 & $2.55 \mathrm{E}-01$ & & \\
\hline 229 & S840865 & 1984 & & & 2009 & Ac- 227 & $1.44 \mathrm{E}-10$ & 10,000 & 5,300 \\
\hline
\end{tabular}

${ }^{1}$ Calculated decayed contact dose rate. Rounded to nearest $10 \mathrm{mR} / \mathrm{hr}$ for values to 1000 ; rounded to nearest $100 \mathrm{mR} / \mathrm{hr}$ for values $>1000$ to 10,000 ; rounded to nearest $1000 \mathrm{mR} / \mathrm{hr}$ for values $>10,000$. * Initial contact dose rate assumed to be $1,000,000 \mathrm{mR} / \mathrm{hr}$; **Initial contact dose rate assumed to be $1,010,000 \mathrm{mR} / \mathrm{hr}$.

$$
147 \text { of } 168
$$


Appendix A-4 - Initial and Decayed Radionuclide and Dose Data for Lined Shafts

\begin{tabular}{|c|c|c|c|c|c|c|c|c|c|}
\hline \multirow[b]{2}{*}{ Shaft Number } & \multirow[b]{2}{*}{ Package ID } & \multirow[b]{2}{*}{ Base Year } & \multicolumn{2}{|c|}{ Initial Isotopic Distribution } & \multirow[b]{2}{*}{ Target Year } & \multicolumn{2}{|c|}{ Decayed Isotopic Distribution } & \multirow{2}{*}{$\begin{array}{c}\text { Initial Contact } \\
\text { Dose Rate } \\
(\mathrm{mR} / \mathrm{hr})\end{array}$} & \multirow{2}{*}{$\begin{array}{c}\text { Decayed } \\
\text { Contact Dose } \\
\text { Rate }(\mathrm{mR} / \mathrm{hr})^{1} \\
\end{array}$} \\
\hline & & & Isotope & Activity (Ci) & & Isotope & Activity (Ci) & & \\
\hline & & & Ba-137m & $2.40 \mathrm{E}-02$ & & Ba-137m & $1.34 \mathrm{E}-02$ & & \\
\hline & & & & & & Bi-211 & $1.42 \mathrm{E}-10$ & & \\
\hline & & & Cs-137 & $2.55 \mathrm{E}-02$ & & Cs-137 & $1.43 \mathrm{E}-02$ & & \\
\hline & & & $\mathrm{Eu}-155$ & 4.78E-04 & & $\mathrm{Eu}-155$ & $1.45 \mathrm{E}-05$ & & \\
\hline & & & & & & Fr-223 & $1.97 \mathrm{E}-12$ & & \\
\hline & & & & & & $\mathrm{Pa}-231$ & $4.65 \mathrm{E}-10$ & & \\
\hline & & & & & & $\mathrm{Pb}-211$ & $1.43 \mathrm{E}-10$ & & \\
\hline & & & Pm-147 & $1.46 \mathrm{E}-03$ & & Pm-147 & $1.97 \mathrm{E}-06$ & & \\
\hline & & & & & & Po-211 & $4.35 \mathrm{E}-13$ & & \\
\hline & & & & & & Po-215 & $1.43 \mathrm{E}-10$ & & \\
\hline & & & $\mathrm{Pu}-239$ & $6.20 \mathrm{E}-03$ & & $\mathrm{Pu}-239$ & $6.20 \mathrm{E}-03$ & & \\
\hline & & & & & & $\mathrm{Ra}-223$ & $1.44 \mathrm{E}-10$ & & \\
\hline & & & Rh-106 & $1.87 \mathrm{E}-04$ & & Rh-106 & $6.34 \mathrm{E}-12$ & & \\
\hline & & & & & & $\mathrm{Rn}-219$ & $1.42 \mathrm{E}-10$ & & \\
\hline & & & $\mathrm{Ru}-106$ & $1.87 \mathrm{E}-04$ & & $\mathrm{Ru}-106$ & $6.40 \mathrm{E}-12$ & & \\
\hline & & & $\mathrm{Sb}-125$ & $1.04 \mathrm{E}-03$ & & $\mathrm{Sb}-125$ & $2.00 \mathrm{E}-06$ & & \\
\hline & & & & & & Sm-147 & $3.57 \mathrm{E}-14$ & & \\
\hline & & & Sr-90 & $2.33 \mathrm{E}-02$ & & Sr-90 & $1.29 \mathrm{E}-02$ & & \\
\hline & & & $\mathrm{Te}-125 \mathrm{~m}$ & $4.32 \mathrm{E}-04$ & & $\mathrm{Te}-125 \mathrm{~m}$ & $4.83 \mathrm{E}-07$ & & \\
\hline & & & & & & Th-227 & $1.40 \mathrm{E}-10$ & & \\
\hline & & & & & & Th-231 & 8.69E-07 & & \\
\hline & & & & & & Tl-207 & $1.42 \mathrm{E}-10$ & & \\
\hline & & & U-235 & $8.80 \mathrm{E}-07$ & & U-235 & $8.80 \mathrm{E}-07$ & & \\
\hline & & & Y-90 & $2.33 \mathrm{E}-02$ & & Y-90 & $1.27 \mathrm{E}-02$ & & \\
\hline \multirow[t]{8}{*}{229} & S840873 & 1984 & & & 2009 & Ac- 227 & 4.33E-09 & 100,000 & 53,000 \\
\hline & & & Ba-137m & 4.79E-01 & & $\mathrm{Ba}-137 \mathrm{~m}$ & $2.68 \mathrm{E}-01$ & & \\
\hline & & & & & & Bi-211 & 4.27E-09 & & \\
\hline & & & Cs-137 & $5.11 \mathrm{E}-01$ & & Cs-137 & $2.87 \mathrm{E}-01$ & & \\
\hline & & & Eu-155 & $9.55 \mathrm{E}-03$ & & Eu-155 & $2.90 \mathrm{E}-04$ & & \\
\hline & & & & & & Fr-223 & $5.91 \mathrm{E}-11$ & & \\
\hline & & & & & & $\mathrm{Pa}-231$ & $1.39 \mathrm{E}-08$ & & \\
\hline & & & & & & $\mathrm{Pb}-211$ & $4.28 \mathrm{E}-09$ & & \\
\hline
\end{tabular}

${ }^{1}$ Calculated decayed contact dose rate. Rounded to nearest $10 \mathrm{mR} / \mathrm{hr}$ for values to 1000 ; rounded to nearest $100 \mathrm{mR} / \mathrm{hr}$ for values $>1000$ to 10,000 ; rounded to nearest $1000 \mathrm{mR} / \mathrm{hr}$ for values $>10,000$. * Initial contact dose rate assumed to be $1,000,000 \mathrm{mR} / \mathrm{hr}$; **Initial contact dose rate assumed to be $1,010,000 \mathrm{mR} / \mathrm{hr}$.

$$
148 \text { of } 168
$$


Appendix A-4 - Initial and Decayed Radionuclide and Dose Data for Lined Shafts

\begin{tabular}{|c|c|c|c|c|c|c|c|c|c|}
\hline \multirow[b]{2}{*}{ Shaft Number } & \multirow[b]{2}{*}{ Package ID } & \multirow[b]{2}{*}{ Base Year } & \multicolumn{2}{|c|}{ Initial Isotopic Distribution } & \multirow[b]{2}{*}{ Target Year } & \multicolumn{2}{|c|}{ Decayed Isotopic Distribution } & \multirow{2}{*}{$\begin{array}{c}\text { Initial Contact } \\
\text { Dose Rate } \\
(\mathrm{mR} / \mathrm{hr}) \\
\end{array}$} & \multirow{2}{*}{$\begin{array}{c}\text { Decayed } \\
\text { Contact Dose } \\
\text { Rate }(\mathrm{mR} / \mathrm{hr})^{1} \\
\end{array}$} \\
\hline & & & Isotope & Activity (Ci) & & Isotope & Activity (Ci) & & \\
\hline & & & Pm-147 & $2.92 \mathrm{E}-02$ & & Pm-147 & $3.93 \mathrm{E}-05$ & & \\
\hline & & & & & & Po-211 & $1.30 \mathrm{E}-11$ & & \\
\hline & & & & & & Po-215 & $4.28 \mathrm{E}-09$ & & \\
\hline & & & $\mathrm{Pu}-239$ & $1.86 \mathrm{E}-01$ & & $\mathrm{Pu}-239$ & $1.86 \mathrm{E}-01$ & & \\
\hline & & & & & & Ra-223 & 4.33E-09 & & \\
\hline & & & Rh-106 & $3.74 \mathrm{E}-03$ & & Rh-106 & $1.27 \mathrm{E}-10$ & & \\
\hline & & & & & & $\mathrm{Rn}-219$ & $4.27 \mathrm{E}-09$ & & \\
\hline & & & $\mathrm{Ru}-106$ & $3.74 \mathrm{E}-03$ & & $\mathrm{Ru}-106$ & $1.28 \mathrm{E}-10$ & & \\
\hline & & & $\mathrm{Sb}-125$ & $2.08 \mathrm{E}-02$ & & $\mathrm{Sb}-125$ & $4.00 \mathrm{E}-05$ & & \\
\hline & & & & & & Sm-147 & $7.14 \mathrm{E}-13$ & & \\
\hline & & & Sr-90 & 4.67E-01 & & Sr-90 & $2.58 \mathrm{E}-01$ & & \\
\hline & & & $\mathrm{Te}-125 \mathrm{~m}$ & $8.63 \mathrm{E}-03$ & & $\mathrm{Te}-125 \mathrm{~m}$ & $9.67 \mathrm{E}-06$ & & \\
\hline & & & & & & Th-227 & 4.21E-09 & & \\
\hline & & & & & & Th-231 & $2.61 \mathrm{E}-05$ & & \\
\hline & & & & & & Tl-207 & $4.26 \mathrm{E}-09$ & & \\
\hline & & & U-235 & $2.64 \mathrm{E}-05$ & & U-235 & $2.64 \mathrm{E}-05$ & & \\
\hline & & & Y-90 & $4.66 \mathrm{E}-01$ & & Y-90 & $2.55 \mathrm{E}-01$ & & \\
\hline \multirow[t]{15}{*}{229} & S840882 & 1984 & & & 2009 & Ac-227 & $1.44 \mathrm{E}-10$ & 18,000 & 9,500 \\
\hline & & & Ba- $137 m$ & 7.19E-02 & & $\mathrm{Ba}-137 \mathrm{~m}$ & $4.02 \mathrm{E}-02$ & & \\
\hline & & & & & & Bi-211 & $1.42 \mathrm{E}-10$ & & \\
\hline & & & Cs-137 & $7.66 \mathrm{E}-02$ & & Cs-137 & $4.30 \mathrm{E}-02$ & & \\
\hline & & & Eu-155 & $1.43 \mathrm{E}-03$ & & Eu-155 & $4.35 \mathrm{E}-05$ & & \\
\hline & & & & & & Fr-223 & $1.97 \mathrm{E}-12$ & & \\
\hline & & & & & & $\mathrm{Pa}-231$ & $4.65 \mathrm{E}-10$ & & \\
\hline & & & & & & $\mathrm{Pb}-211$ & $1.43 \mathrm{E}-10$ & & \\
\hline & & & Pm-147 & 4.38E-03 & & Pm-147 & $5.92 \mathrm{E}-06$ & & \\
\hline & & & & & & Po-211 & $4.35 \mathrm{E}-13$ & & \\
\hline & & & & & & Po-215 & $1.43 \mathrm{E}-10$ & & \\
\hline & & & Pu-239 & $6.20 \mathrm{E}-03$ & & $\mathrm{Pu}-239$ & $6.20 \mathrm{E}-03$ & & \\
\hline & & & & & & $\mathrm{Ra}-223$ & $1.44 \mathrm{E}-10$ & & \\
\hline & & & Rh-106 & $5.62 \mathrm{E}-04$ & & Rh-106 & $1.90 \mathrm{E}-11$ & & \\
\hline & & & & & & Rn-219 & $1.42 \mathrm{E}-10$ & & \\
\hline
\end{tabular}

${ }^{1}$ Calculated decayed contact dose rate. Rounded to nearest $10 \mathrm{mR} / \mathrm{hr}$ for values to 1000 ; rounded to nearest $100 \mathrm{mR} / \mathrm{hr}$ for values $>1000$ to 10,000 ; rounded to nearest $1000 \mathrm{mR} / \mathrm{hr}$ for values $>10,000$. * Initial contact dose rate assumed to be $1,000,000 \mathrm{mR} / \mathrm{hr}$; **Initial contact dose rate assumed to be $1,010,000 \mathrm{mR} / \mathrm{hr}$.

$$
149 \text { of } 168
$$


Appendix A-4 - Initial and Decayed Radionuclide and Dose Data for Lined Shafts

\begin{tabular}{|c|c|c|c|c|c|c|c|c|c|}
\hline \multirow[b]{2}{*}{ Shaft Number } & \multirow[b]{2}{*}{ Package ID } & \multirow[b]{2}{*}{ Base Year } & \multicolumn{2}{|c|}{ Initial Isotopic Distribution } & \multirow[b]{2}{*}{ Target Year } & \multicolumn{2}{|c|}{ Decayed Isotopic Distribution } & \multirow{2}{*}{$\begin{array}{c}\text { Initial Contact } \\
\text { Dose Rate } \\
(\mathrm{mR} / \mathrm{hr})\end{array}$} & \multirow{2}{*}{$\begin{array}{c}\text { Decayed } \\
\text { Contact Dose } \\
\text { Rate }(\mathrm{mR} / \mathrm{hr})^{1} \\
\end{array}$} \\
\hline & & & Isotope & Activity (Ci) & & Isotope & Activity (Ci) & & \\
\hline & & & $\mathrm{Ru}-106$ & $5.62 \mathrm{E}-04$ & & $\mathrm{Ru}-106$ & $1.92 \mathrm{E}-11$ & & \\
\hline & & & $\mathrm{Sb}-125$ & $3.12 \mathrm{E}-03$ & & $\mathrm{Sb}-125$ & $5.99 \mathrm{E}-06$ & & \\
\hline & & & & & & Sm-147 & $1.07 \mathrm{E}-13$ & & \\
\hline & & & Sr-90 & $7.00 \mathrm{E}-02$ & & Sr-90 & $3.86 \mathrm{E}-02$ & & \\
\hline & & & $\mathrm{Te}-125 \mathrm{~m}$ & $1.30 \mathrm{E}-03$ & & Te-125m & $1.45 \mathrm{E}-06$ & & \\
\hline & & & & & & Th-227 & $1.40 \mathrm{E}-10$ & & \\
\hline & & & & & & Th-231 & $8.69 \mathrm{E}-07$ & & \\
\hline & & & & & & Tl-207 & $1.42 \mathrm{E}-10$ & & \\
\hline & & & U-235 & $8.80 \mathrm{E}-07$ & & U-235 & $8.80 \mathrm{E}-07$ & & \\
\hline & & & $\mathrm{Y}-90$ & $6.99 \mathrm{E}-02$ & & $\mathrm{Y}-90$ & $3.82 \mathrm{E}-02$ & & \\
\hline \multirow[t]{22}{*}{229} & S840888 & 1984 & & & 2009 & Ac-227 & $1.44 \mathrm{E}-10$ & 10,000 & 5,300 \\
\hline & & & $\mathrm{Ba}-137 \mathrm{~m}$ & $3.59 \mathrm{E}-02$ & & $\mathrm{Ba}-137 \mathrm{~m}$ & $2.01 \mathrm{E}-02$ & & \\
\hline & & & & & & Bi-211 & $1.42 \mathrm{E}-10$ & & \\
\hline & & & Cs-137 & $3.83 \mathrm{E}-02$ & & Cs-137 & $2.15 \mathrm{E}-02$ & & \\
\hline & & & $\mathrm{Eu}-155$ & 7.17E-04 & & $\mathrm{Eu}-155$ & $2.18 \mathrm{E}-05$ & & \\
\hline & & & & & & Fr-223 & $1.97 \mathrm{E}-12$ & & \\
\hline & & & & & & $\mathrm{Pa}-231$ & $4.65 \mathrm{E}-10$ & & \\
\hline & & & & & & $\mathrm{Pb}-211$ & $1.43 \mathrm{E}-10$ & & \\
\hline & & & Pm-147 & $2.19 \mathrm{E}-03$ & & Pm-147 & $2.96 \mathrm{E}-06$ & & \\
\hline & & & & & & Po-211 & $4.35 \mathrm{E}-13$ & & \\
\hline & & & & & & Po-215 & $1.43 \mathrm{E}-10$ & & \\
\hline & & & $\mathrm{Pu}-239$ & $6.20 \mathrm{E}-03$ & & Pu-239 & $6.20 \mathrm{E}-03$ & & \\
\hline & & & & & & Ra-223 & $1.44 \mathrm{E}-10$ & & \\
\hline & & & Rh-106 & $2.81 \mathrm{E}-04$ & & Rh-106 & $9.51 \mathrm{E}-12$ & & \\
\hline & & & & & & Rn-219 & $1.42 \mathrm{E}-10$ & & \\
\hline & & & $\mathrm{Ru}-106$ & $2.81 \mathrm{E}-04$ & & $\mathrm{Ru}-106$ & $9.60 \mathrm{E}-12$ & & \\
\hline & & & Sb-125 & $1.56 \mathrm{E}-03$ & & $\mathrm{Sb}-125$ & $3.00 \mathrm{E}-06$ & & \\
\hline & & & & & & Sm-147 & $5.36 \mathrm{E}-14$ & & \\
\hline & & & Sr-90 & $3.50 \mathrm{E}-02$ & & Sr-90 & $1.93 \mathrm{E}-02$ & & \\
\hline & & & Te-125m & $6.48 \mathrm{E}-04$ & & $\mathrm{Te}-125 \mathrm{~m}$ & $7.25 \mathrm{E}-07$ & & \\
\hline & & & & & & Th-227 & $1.40 \mathrm{E}-10$ & & \\
\hline & & & & & & Th-231 & 8.69E-07 & & \\
\hline
\end{tabular}

${ }^{1}$ Calculated decayed contact dose rate. Rounded to nearest $10 \mathrm{mR} / \mathrm{hr}$ for values to 1000 ; rounded to nearest $100 \mathrm{mR} / \mathrm{hr}$ for values $>1000$ to 10,000 ; rounded to nearest $1000 \mathrm{mR} / \mathrm{hr}$ for values $>10,000$. * Initial contact dose rate assumed to be $1,000,000 \mathrm{mR} / \mathrm{hr}$; **Initial contact dose rate assumed to be $1,010,000 \mathrm{mR} / \mathrm{hr}$.

$$
150 \text { of } 168
$$


Appendix A-4 - Initial and Decayed Radionuclide and Dose Data for Lined Shafts

\begin{tabular}{|c|c|c|c|c|c|c|c|c|c|}
\hline \multirow[b]{2}{*}{ Shaft Number } & \multirow[b]{2}{*}{ Package ID } & \multirow[b]{2}{*}{ Base Year } & \multicolumn{2}{|c|}{ Initial Isotopic Distribution } & \multirow[b]{2}{*}{ Target Year } & \multicolumn{2}{|c|}{ Decayed Isotopic Distribution } & \multirow{2}{*}{$\begin{array}{c}\text { Initial Contact } \\
\text { Dose Rate } \\
(\mathrm{mR} / \mathrm{hr})\end{array}$} & \multirow{2}{*}{$\begin{array}{c}\text { Decayed } \\
\text { Contact Dose } \\
\text { Rate }(\mathrm{mR} / \mathrm{hr})^{1} \\
\end{array}$} \\
\hline & & & Isotope & Activity (Ci) & & Isotope & Activity (Ci) & & \\
\hline & & & & & & Tl-207 & $1.42 \mathrm{E}-10$ & & \\
\hline & & & $\mathrm{U}-235$ & $8.80 \mathrm{E}-07$ & & $\mathrm{U}-235$ & $8.80 \mathrm{E}-07$ & & \\
\hline & & & $\mathrm{Y}-90$ & $3.50 \mathrm{E}-02$ & & Y-90 & $1.91 \mathrm{E}-02$ & & \\
\hline \multirow[t]{25}{*}{230} & S840831 & 1984 & & & 2009 & Ac-227 & $8.84 \mathrm{E}-08$ & $1000000+$ & $530,000 *$ \\
\hline & & & Ba-137m & $8.39 \mathrm{E}+00$ & & $\mathrm{Ba}-137 \mathrm{~m}$ & $4.69 \mathrm{E}+00$ & & \\
\hline & & & & & & Bi-211 & $8.72 \mathrm{E}-08$ & & \\
\hline & & & Cs-137 & $8.94 \mathrm{E}+00$ & & Cs-137 & $5.02 \mathrm{E}+00$ & & \\
\hline & & & Eu-155 & $1.67 \mathrm{E}-01$ & & Eu-155 & $5.08 \mathrm{E}-03$ & & \\
\hline & & & & & & Fr-223 & $1.21 \mathrm{E}-09$ & & \\
\hline & & & & & & $\mathrm{Pa}-231$ & $2.85 \mathrm{E}-07$ & & \\
\hline & & & & & & $\mathrm{Pb}-211$ & $8.74 \mathrm{E}-08$ & & \\
\hline & & & Pm-147 & $5.10 \mathrm{E}-01$ & & Pm-147 & $6.92 \mathrm{E}-04$ & & \\
\hline & & & & & & Po-211 & $2.66 \mathrm{E}-10$ & & \\
\hline & & & & & & Po-215 & $8.74 \mathrm{E}-08$ & & \\
\hline & & & $\mathrm{Pu}-239$ & $5.95 \mathrm{E}+00$ & & $\mathrm{Pu}-239$ & $5.95 \mathrm{E}+00$ & & \\
\hline & & & & & & Ra-223 & 8.83E-08 & & \\
\hline & & & Rh-106 & $6.55 \mathrm{E}-02$ & & Rh-106 & $2.22 \mathrm{E}-09$ & & \\
\hline & & & & & & Rn-219 & $8.73 \mathrm{E}-08$ & & \\
\hline & & & Ru-106 & $6.55 \mathrm{E}-02$ & & Ru-106 & $2.24 \mathrm{E}-09$ & & \\
\hline & & & Sb-125 & 3.64E-01 & & Sb-125 & $6.99 \mathrm{E}-04$ & & \\
\hline & & & & & & Sm-147 & $1.25 \mathrm{E}-11$ & & \\
\hline & & & Sr-90 & $8.17 \mathrm{E}+00$ & & Sr-90 & $4.51 \mathrm{E}+00$ & & \\
\hline & & & Te- $125 \mathrm{~m}$ & $1.51 \mathrm{E}-01$ & & $\mathrm{Te}-125 \mathrm{~m}$ & $1.69 \mathrm{E}-04$ & & \\
\hline & & & & & & Th-227 & $8.60 \mathrm{E}-08$ & & \\
\hline & & & & & & Th-231 & $5.33 \mathrm{E}-04$ & & \\
\hline & & & & & & Tl-207 & 8.69E-08 & & \\
\hline & & & U-235 & $5.39 \mathrm{E}-04$ & & U-235 & $5.39 \mathrm{E}-04$ & & \\
\hline & & & Y-90 & $8.16 \mathrm{E}+00$ & & $\mathrm{Y}-90$ & $4.45 \mathrm{E}+00$ & & \\
\hline \multirow[t]{4}{*}{230} & S840835 & 1984 & & & 2009 & Ac- 227 & $1.44 \mathrm{E}-10$ & 100,000 & 53,000 \\
\hline & & & $\mathrm{Ba}-137 \mathrm{~m}$ & $2.40 \mathrm{E}+00$ & & Ba-137m & $1.34 \mathrm{E}+00$ & & \\
\hline & & & & & & $\mathrm{Bi}-211$ & $1.42 \mathrm{E}-10$ & & \\
\hline & & & Cs-137 & $2.55 \mathrm{E}+00$ & & Cs-137 & $1.43 \mathrm{E}+00$ & & \\
\hline
\end{tabular}

${ }^{1}$ Calculated decayed contact dose rate. Rounded to nearest $10 \mathrm{mR} / \mathrm{hr}$ for values to 1000 ; rounded to nearest $100 \mathrm{mR} / \mathrm{hr}$ for values $>1000$ to 10,000 ; rounded to nearest $1000 \mathrm{mR} / \mathrm{hr}$ for values $>10,000$. * Initial contact dose rate assumed to be $1,000,000 \mathrm{mR} / \mathrm{hr}$; **Initial contact dose rate assumed to be $1,010,000 \mathrm{mR} / \mathrm{hr}$.

$$
151 \text { of } 168
$$


Appendix A-4 - Initial and Decayed Radionuclide and Dose Data for Lined Shafts

\begin{tabular}{|c|c|c|c|c|c|c|c|c|c|}
\hline \multirow[b]{2}{*}{ Shaft Number } & \multirow[b]{2}{*}{ Package ID } & \multirow[b]{2}{*}{ Base Year } & \multicolumn{2}{|c|}{ Initial Isotopic Distribution } & \multirow[b]{2}{*}{ Target Year } & \multicolumn{2}{|c|}{ Decayed Isotopic Distribution } & \multirow{2}{*}{$\begin{array}{c}\text { Initial Contact } \\
\text { Dose Rate } \\
(\mathrm{mR} / \mathrm{hr})\end{array}$} & \multirow{2}{*}{$\begin{array}{c}\text { Decayed } \\
\text { Contact Dose } \\
\text { Rate }(\mathrm{mR} / \mathrm{hr})^{1} \\
\end{array}$} \\
\hline & & & Isotope & Activity (Ci) & & Isotope & Activity (Ci) & & \\
\hline & & & Eu-155 & $4.78 \mathrm{E}-02$ & & Eu-155 & $1.45 \mathrm{E}-03$ & & \\
\hline & & & & & & Fr-223 & $1.97 \mathrm{E}-12$ & & \\
\hline & & & & & & $\mathrm{Pa}-231$ & $4.65 \mathrm{E}-10$ & & \\
\hline & & & & & & $\mathrm{Pb}-211$ & $1.43 \mathrm{E}-10$ & & \\
\hline & & & Pm-147 & $1.46 \mathrm{E}-01$ & & Pm-147 & $1.98 \mathrm{E}-04$ & & \\
\hline & & & & & & Po-211 & $4.35 \mathrm{E}-13$ & & \\
\hline & & & & & & Po-215 & $1.43 \mathrm{E}-10$ & & \\
\hline & & & $\mathrm{Pu}-239$ & $6.20 \mathrm{E}-03$ & & $\mathrm{Pu}-239$ & $6.20 \mathrm{E}-03$ & & \\
\hline & & & & & & Ra-223 & $1.44 \mathrm{E}-10$ & & \\
\hline & & & Rh-106 & $1.87 \mathrm{E}-02$ & & Rh-106 & $6.34 \mathrm{E}-10$ & & \\
\hline & & & & & & Rn-219 & $1.42 \mathrm{E}-10$ & & \\
\hline & & & $\mathrm{Ru}-106$ & $1.87 \mathrm{E}-02$ & & $\mathrm{Ru}-106$ & $6.40 \mathrm{E}-10$ & & \\
\hline & & & Sb-125 & $1.04 \mathrm{E}-01$ & & $\mathrm{Sb}-125$ & $1.99 \mathrm{E}-04$ & & \\
\hline & & & & & & Sm-147 & $3.57 \mathrm{E}-12$ & & \\
\hline & & & Sr-90 & $2.33 \mathrm{E}+00$ & & Sr-90 & $1.29 \mathrm{E}+00$ & & \\
\hline & & & $\mathrm{Te}-125 \mathrm{~m}$ & $4.32 \mathrm{E}-02$ & & $\mathrm{Te}-125 \mathrm{~m}$ & 4.83E-05 & & \\
\hline & & & & & & Th-227 & $1.40 \mathrm{E}-10$ & & \\
\hline & & & & & & Th-231 & 8.69E-07 & & \\
\hline & & & & & & T1-207 & $1.42 \mathrm{E}-10$ & & \\
\hline & & & U-235 & $8.80 \mathrm{E}-07$ & & U-235 & $8.80 \mathrm{E}-07$ & & \\
\hline & & & Y-90 & $2.33 \mathrm{E}+00$ & & $\mathrm{Y}-90$ & $1.27 \mathrm{E}+00$ & & \\
\hline \multirow[t]{11}{*}{230} & S840836 & 1984 & & & 2009 & Ac-227 & $1.44 \mathrm{E}-10$ & 30,000 & 16,000 \\
\hline & & & Ba-137m & $9.59 \mathrm{E}-02$ & & Ba-137m & $5.36 \mathrm{E}-02$ & & \\
\hline & & & & & & Bi-211 & $1.42 \mathrm{E}-10$ & & \\
\hline & & & Cs-137 & $1.02 \mathrm{E}-01$ & & Cs-137 & $5.73 \mathrm{E}-02$ & & \\
\hline & & & Eu-155 & $1.91 \mathrm{E}-03$ & & Eu-155 & $5.80 \mathrm{E}-05$ & & \\
\hline & & & & & & Fr-223 & $1.97 \mathrm{E}-12$ & & \\
\hline & & & & & & $\mathrm{Pa}-231$ & $4.65 \mathrm{E}-10$ & & \\
\hline & & & & & & $\mathrm{Pb}-211$ & $1.43 \mathrm{E}-10$ & & \\
\hline & & & Pm-147 & $5.83 \mathrm{E}-03$ & & Pm-147 & $7.88 \mathrm{E}-06$ & & \\
\hline & & & & & & Po-211 & $4.35 \mathrm{E}-13$ & & \\
\hline & & & & & & Рo-215 & $1.43 \mathrm{E}-10$ & & \\
\hline
\end{tabular}

${ }^{1}$ Calculated decayed contact dose rate. Rounded to nearest $10 \mathrm{mR} / \mathrm{hr}$ for values to 1000 ; rounded to nearest $100 \mathrm{mR} / \mathrm{hr}$ for values $>1000$ to 10,000 ; rounded to nearest $1000 \mathrm{mR} / \mathrm{hr}$ for values $>10,000$. * Initial contact dose rate assumed to be $1,000,000 \mathrm{mR} / \mathrm{hr}$; **Initial contact dose rate assumed to be $1,010,000 \mathrm{mR} / \mathrm{hr}$.

$$
152 \text { of } 168
$$


Appendix A-4 - Initial and Decayed Radionuclide and Dose Data for Lined Shafts

\begin{tabular}{|c|c|c|c|c|c|c|c|c|c|}
\hline \multirow[b]{2}{*}{ Shaft Number } & \multirow[b]{2}{*}{ Package ID } & \multirow[b]{2}{*}{ Base Year } & \multicolumn{2}{|c|}{ Initial Isotopic Distribution } & \multirow[b]{2}{*}{ Target Year } & \multicolumn{2}{|c|}{ Decayed Isotopic Distribution } & \multirow{2}{*}{$\begin{array}{c}\text { Initial Contact } \\
\text { Dose Rate } \\
(\mathrm{mR} / \mathrm{hr})\end{array}$} & \multirow{2}{*}{$\begin{array}{c}\text { Decayed } \\
\text { Contact Dose } \\
\text { Rate }(\mathrm{mR} / \mathrm{hr})^{1} \\
\end{array}$} \\
\hline & & & Isotope & Activity (Ci) & & Isotope & Activity (Ci) & & \\
\hline & & & $\mathrm{Pu}-239$ & $6.20 \mathrm{E}-03$ & & $\mathrm{Pu}-239$ & $6.20 \mathrm{E}-03$ & & \\
\hline & & & & & & Ra-223 & $1.44 \mathrm{E}-10$ & & \\
\hline & & & Rh-106 & 7.49E-04 & & Rh-106 & $2.54 \mathrm{E}-11$ & & \\
\hline & & & & & & $\mathrm{Rn}-219$ & $1.42 \mathrm{E}-10$ & & \\
\hline & & & $\mathrm{Ru}-106$ & 7.49E-04 & & $\mathrm{Ru}-106$ & $2.56 \mathrm{E}-11$ & & \\
\hline & & & $\mathrm{Sb}-125$ & $4.16 \mathrm{E}-03$ & & Sb-125 & $7.97 \mathrm{E}-06$ & & \\
\hline & & & & & & Sm-147 & $1.43 \mathrm{E}-13$ & & \\
\hline & & & Sr-90 & 9.34E-02 & & Sr-90 & $5.15 \mathrm{E}-02$ & & \\
\hline & & & $\mathrm{Te}-125 \mathrm{~m}$ & $1.73 \mathrm{E}-03$ & & $\mathrm{Te}-125 \mathrm{~m}$ & $1.93 \mathrm{E}-06$ & & \\
\hline & & & & & & Th-227 & $1.40 \mathrm{E}-10$ & & \\
\hline & & & & & & Th-231 & $8.69 \mathrm{E}-07$ & & \\
\hline & & & & & & T1-207 & $1.42 \mathrm{E}-10$ & & \\
\hline & & & $\mathrm{U}-235$ & $8.80 \mathrm{E}-07$ & & $\mathrm{U}-235$ & $8.80 \mathrm{E}-07$ & & \\
\hline & & & $\mathrm{Y}-90$ & $9.33 \mathrm{E}-02$ & & $\mathrm{Y}-90$ & $5.09 \mathrm{E}-02$ & & \\
\hline \multirow[t]{18}{*}{230} & S840838 & 1984 & & & 2009 & Ac-227 & $1.44 \mathrm{E}-10$ & 400,000 & 212,000 \\
\hline & & & Ba-137m & $1.20 \mathrm{E}+00$ & & Ba-137m & $6.70 \mathrm{E}-01$ & & \\
\hline & & & & & & Bi-211 & $1.42 \mathrm{E}-10$ & & \\
\hline & & & Cs-137 & $1.28 \mathrm{E}+00$ & & Cs-137 & $7.16 \mathrm{E}-01$ & & \\
\hline & & & Eu-155 & $2.39 \mathrm{E}-02$ & & Eu-155 & $7.26 \mathrm{E}-04$ & & \\
\hline & & & & & & Fr-223 & $1.97 \mathrm{E}-12$ & & \\
\hline & & & & & & $\mathrm{Pa}-231$ & $4.65 \mathrm{E}-10$ & & \\
\hline & & & & & & $\mathrm{Pb}-211$ & $1.43 \mathrm{E}-10$ & & \\
\hline & & & Pm-147 & 7.29E-02 & & Pm-147 & $9.84 \mathrm{E}-05$ & & \\
\hline & & & & & & Po-211 & $4.35 \mathrm{E}-13$ & & \\
\hline & & & & & & Po-215 & $1.43 \mathrm{E}-10$ & & \\
\hline & & & $\mathrm{Pu}-239$ & $6.20 \mathrm{E}-03$ & & $\mathrm{Pu}-239$ & $6.20 \mathrm{E}-03$ & & \\
\hline & & & & & & Ra-223 & $1.44 \mathrm{E}-10$ & & \\
\hline & & & Rh-106 & $9.36 \mathrm{E}-03$ & & Rh-106 & $3.17 \mathrm{E}-10$ & & \\
\hline & & & & & & Rn-219 & $1.42 \mathrm{E}-10$ & & \\
\hline & & & Ru-106 & $9.36 \mathrm{E}-03$ & & Ru-106 & $3.20 \mathrm{E}-10$ & & \\
\hline & & & Sb-125 & $5.20 \mathrm{E}-02$ & & Sb-125 & $9.98 \mathrm{E}-05$ & & \\
\hline & & & & & & Sm-147 & $1.79 \mathrm{E}-12$ & & \\
\hline
\end{tabular}

${ }^{1}$ Calculated decayed contact dose rate. Rounded to nearest $10 \mathrm{mR} / \mathrm{hr}$ for values to 1000 ; rounded to nearest $100 \mathrm{mR} / \mathrm{hr}$ for values $>1000$ to 10,000 ; rounded to nearest $1000 \mathrm{mR} / \mathrm{hr}$ for values $>10,000$. * Initial contact dose rate assumed to be $1,000,000 \mathrm{mR} / \mathrm{hr}$; **Initial contact dose rate assumed to be $1,010,000 \mathrm{mR} / \mathrm{hr}$.

$$
153 \text { of } 168
$$


Appendix A-4 - Initial and Decayed Radionuclide and Dose Data for Lined Shafts

\begin{tabular}{|c|c|c|c|c|c|c|c|c|c|}
\hline \multirow[b]{2}{*}{ Shaft Number } & \multirow[b]{2}{*}{ Package ID } & \multirow[b]{2}{*}{ Base Year } & \multicolumn{2}{|c|}{ Initial Isotopic Distribution } & \multirow[b]{2}{*}{ Target Year } & \multicolumn{2}{|c|}{ Decayed Isotopic Distribution } & \multirow{2}{*}{$\begin{array}{c}\text { Initial Contact } \\
\text { Dose Rate } \\
(\mathrm{mR} / \mathrm{hr})\end{array}$} & \multirow{2}{*}{$\begin{array}{c}\text { Decayed } \\
\text { Contact Dose } \\
\text { Rate }(\mathrm{mR} / \mathrm{hr})^{1} \\
\end{array}$} \\
\hline & & & Isotope & Activity (Ci) & & Isotope & Activity (Ci) & & \\
\hline & & & Sr-90 & $1.17 \mathrm{E}+00$ & & Sr-90 & $6.44 \mathrm{E}-01$ & & \\
\hline & & & $\mathrm{Te}-125 \mathrm{~m}$ & $2.16 \mathrm{E}-02$ & & $\mathrm{Te}-125 \mathrm{~m}$ & $2.42 \mathrm{E}-05$ & & \\
\hline & & & & & & Th-227 & $1.40 \mathrm{E}-10$ & & \\
\hline & & & & & & Th-231 & $8.69 \mathrm{E}-07$ & & \\
\hline & & & & & & Tl-207 & $1.42 \mathrm{E}-10$ & & \\
\hline & & & $\mathrm{U}-235$ & $8.80 \mathrm{E}-07$ & & U-235 & $8.80 \mathrm{E}-07$ & & \\
\hline & & & $\mathrm{Y}-90$ & $1.17 \mathrm{E}+00$ & & Y-90 & $6.36 \mathrm{E}-01$ & & \\
\hline \multirow[t]{25}{*}{230} & S840839 & 1984 & & & 2009 & Ac-227 & $1.44 \mathrm{E}-10$ & 90,000 & 48,000 \\
\hline & & & Ba-137m & $3.59 \mathrm{E}-01$ & & Ba-137m & $2.01 \mathrm{E}-01$ & & \\
\hline & & & & & & Bi-211 & $1.42 \mathrm{E}-10$ & & \\
\hline & & & Cs-137 & $3.83 \mathrm{E}-01$ & & Cs-137 & $2.15 \mathrm{E}-01$ & & \\
\hline & & & Eu-155 & 7.17E-03 & & Eu-155 & $2.18 \mathrm{E}-04$ & & \\
\hline & & & & & & Fr-223 & $1.97 \mathrm{E}-12$ & & \\
\hline & & & & & & $\mathrm{Pa}-231$ & $4.65 \mathrm{E}-10$ & & \\
\hline & & & & & & $\mathrm{Pb}-211$ & $1.43 \mathrm{E}-10$ & & \\
\hline & & & Pm-147 & 2.19E-02 & & Pm-147 & $2.95 \mathrm{E}-05$ & & \\
\hline & & & & & & Po-211 & $4.35 \mathrm{E}-13$ & & \\
\hline & & & & & & Рo-215 & $1.43 \mathrm{E}-10$ & & \\
\hline & & & $\mathrm{Pu}-239$ & $6.20 \mathrm{E}-03$ & & $\mathrm{Pu}-239$ & $6.20 \mathrm{E}-03$ & & \\
\hline & & & & & & Ra-223 & $1.44 \mathrm{E}-10$ & & \\
\hline & & & Rh-106 & $2.81 \mathrm{E}-03$ & & Rh-106 & $9.51 \mathrm{E}-11$ & & \\
\hline & & & & & & Rn-219 & $1.42 \mathrm{E}-10$ & & \\
\hline & & & Ru-106 & $2.81 \mathrm{E}-03$ & & Ru-106 & $9.60 \mathrm{E}-11$ & & \\
\hline & & & Sb-125 & $1.56 \mathrm{E}-02$ & & Sb-125 & $2.99 \mathrm{E}-05$ & & \\
\hline & & & & & & Sm-147 & $5.36 \mathrm{E}-13$ & & \\
\hline & & & Sr-90 & $3.50 \mathrm{E}-01$ & & Sr-90 & $1.93 \mathrm{E}-01$ & & \\
\hline & & & $\mathrm{Te}-125 \mathrm{~m}$ & $6.48 \mathrm{E}-03$ & & $\mathrm{Te}-125 \mathrm{~m}$ & $7.25 \mathrm{E}-06$ & & \\
\hline & & & & & & Th-227 & $1.40 \mathrm{E}-10$ & & \\
\hline & & & & & & Th-231 & 8.69E-07 & & \\
\hline & & & & & & Tl-207 & $1.42 \mathrm{E}-10$ & & \\
\hline & & & U-235 & $8.80 \mathrm{E}-07$ & & U-235 & $8.80 \mathrm{E}-07$ & & \\
\hline & & & Y-90 & $3.50 \mathrm{E}-01$ & & Y-90 & $1.91 \mathrm{E}-01$ & & \\
\hline
\end{tabular}

${ }^{1}$ Calculated decayed contact dose rate. Rounded to nearest $10 \mathrm{mR} / \mathrm{hr}$ for values to 1000 ; rounded to nearest $100 \mathrm{mR} / \mathrm{hr}$ for values $>1000$ to 10,000 ; rounded to nearest $1000 \mathrm{mR} / \mathrm{hr}$ for values $>10,000$. * Initial contact dose rate assumed to be $1,000,000 \mathrm{mR} / \mathrm{hr}$; **Initial contact dose rate assumed to be $1,010,000 \mathrm{mR} / \mathrm{hr}$.

$$
154 \text { of } 168
$$


Appendix A-4 - Initial and Decayed Radionuclide and Dose Data for Lined Shafts

\begin{tabular}{|c|c|c|c|c|c|c|c|c|c|}
\hline \multirow[b]{2}{*}{ Shaft Number } & \multirow[b]{2}{*}{ Package ID } & \multirow[b]{2}{*}{ Base Year } & \multicolumn{2}{|c|}{ Initial Isotopic Distribution } & \multirow[b]{2}{*}{ Target Year } & \multicolumn{2}{|c|}{ Decayed Isotopic Distribution } & \multirow{2}{*}{$\begin{array}{c}\text { Initial Contact } \\
\text { Dose Rate } \\
(\mathrm{mR} / \mathrm{hr})\end{array}$} & \multirow{2}{*}{$\begin{array}{c}\text { Decayed } \\
\text { Contact Dose } \\
\text { Rate }(\mathrm{mR} / \mathrm{hr})^{1} \\
\end{array}$} \\
\hline & & & Isotope & Activity (Ci) & & Isotope & Activity (Ci) & & \\
\hline \multirow[t]{25}{*}{230} & S840840 & 1984 & & & 2009 & Ac-227 & $1.44 \mathrm{E}-10$ & 90,000 & 48,000 \\
\hline & & & $\mathrm{Ba}-137 \mathrm{~m}$ & $2.40 \mathrm{E}-01$ & & $\mathrm{Ba}-137 \mathrm{~m}$ & $1.34 \mathrm{E}-01$ & & \\
\hline & & & & & & $\mathrm{Bi}-211$ & $1.42 \mathrm{E}-10$ & & \\
\hline & & & Cs-137 & $2.55 \mathrm{E}-01$ & & Cs-137 & $1.43 \mathrm{E}-01$ & & \\
\hline & & & $\mathrm{Eu}-155$ & $4.78 \mathrm{E}-03$ & & Eu-155 & $1.45 \mathrm{E}-04$ & & \\
\hline & & & & & & Fr-223 & $1.97 \mathrm{E}-12$ & & \\
\hline & & & & & & $\mathrm{Pa}-231$ & $4.65 \mathrm{E}-10$ & & \\
\hline & & & & & & $\mathrm{Pb}-211$ & $1.43 \mathrm{E}-10$ & & \\
\hline & & & Pm-147 & $1.46 \mathrm{E}-02$ & & Pm-147 & $1.98 \mathrm{E}-05$ & & \\
\hline & & & & & & Po-211 & $4.35 \mathrm{E}-13$ & & \\
\hline & & & & & & Po-215 & $1.43 \mathrm{E}-10$ & & \\
\hline & & & $\mathrm{Pu}-239$ & $6.20 \mathrm{E}-03$ & & $\mathrm{Pu}-239$ & $6.20 \mathrm{E}-03$ & & \\
\hline & & & & & & Ra-223 & $1.44 \mathrm{E}-10$ & & \\
\hline & & & Rh-106 & $1.87 \mathrm{E}-03$ & & Rh-106 & $6.34 \mathrm{E}-11$ & & \\
\hline & & & & & & Rn-219 & $1.42 \mathrm{E}-10$ & & \\
\hline & & & $\mathrm{Ru}-106$ & $1.87 \mathrm{E}-03$ & & $\mathrm{Ru}-106$ & $6.40 \mathrm{E}-11$ & & \\
\hline & & & Sb-125 & $1.04 \mathrm{E}-02$ & & Sb-125 & $2.00 \mathrm{E}-05$ & & \\
\hline & & & & & & Sm-147 & $3.57 \mathrm{E}-13$ & & \\
\hline & & & Sr-90 & $2.33 \mathrm{E}-01$ & & Sr-90 & $1.29 \mathrm{E}-01$ & & \\
\hline & & & $\mathrm{Te}-125 \mathrm{~m}$ & 4.32E-03 & & $\mathrm{Te}-125 \mathrm{~m}$ & $4.83 \mathrm{E}-06$ & & \\
\hline & & & & & & Th-227 & $1.40 \mathrm{E}-10$ & & \\
\hline & & & & & & Th-231 & 8.69E-07 & & \\
\hline & & & & & & Tl-207 & $1.42 \mathrm{E}-10$ & & \\
\hline & & & U-235 & $8.80 \mathrm{E}-07$ & & U-235 & $8.80 \mathrm{E}-07$ & & \\
\hline & & & Y-90 & $2.33 \mathrm{E}-01$ & & $\mathrm{Y}-90$ & $1.27 \mathrm{E}-01$ & & \\
\hline \multirow[t]{7}{*}{230} & S840841 & 1984 & & & 2009 & Ac-227 & $1.44 \mathrm{E}-10$ & 60,000 & 32,000 \\
\hline & & & Ba-137m & $1.68 \mathrm{E}-01$ & & Ba-137m & $9.38 \mathrm{E}-02$ & & \\
\hline & & & & & & Bi-211 & $1.42 \mathrm{E}-10$ & & \\
\hline & & & Cs-137 & $1.79 \mathrm{E}-01$ & & Cs-137 & $1.00 \mathrm{E}-01$ & & \\
\hline & & & Eu-155 & $3.34 \mathrm{E}-03$ & & Eu-155 & $1.02 \mathrm{E}-04$ & & \\
\hline & & & & & & Fr-223 & $1.97 \mathrm{E}-12$ & & \\
\hline & & & & & & $\mathrm{Pa}-231$ & $4.65 \mathrm{E}-10$ & & \\
\hline
\end{tabular}

${ }^{1}$ Calculated decayed contact dose rate. Rounded to nearest $10 \mathrm{mR} / \mathrm{hr}$ for values to 1000 ; rounded to nearest $100 \mathrm{mR} / \mathrm{hr}$ for values $>1000$ to 10,000 ; rounded to nearest $1000 \mathrm{mR} / \mathrm{hr}$ for values $>10,000$. * Initial contact dose rate assumed to be $1,000,000 \mathrm{mR} / \mathrm{hr}$; **Initial contact dose rate assumed to be $1,010,000 \mathrm{mR} / \mathrm{hr}$.

$$
155 \text { of } 168
$$


Appendix A-4 - Initial and Decayed Radionuclide and Dose Data for Lined Shafts

\begin{tabular}{|c|c|c|c|c|c|c|c|c|c|}
\hline \multirow[b]{2}{*}{ Shaft Number } & \multirow[b]{2}{*}{ Package ID } & \multirow[b]{2}{*}{ Base Year } & \multicolumn{2}{|c|}{ Initial Isotopic Distribution } & \multirow[b]{2}{*}{ Target Year } & \multicolumn{2}{|c|}{ Decayed Isotopic Distribution } & \multirow{2}{*}{$\begin{array}{c}\text { Initial Contact } \\
\text { Dose Rate } \\
(\mathrm{mR} / \mathrm{hr})\end{array}$} & \multirow{2}{*}{$\begin{array}{c}\text { Decayed } \\
\text { Contact Dose } \\
\text { Rate }(\mathrm{mR} / \mathrm{hr})^{1}\end{array}$} \\
\hline & & & Isotope & Activity (Ci) & & Isotope & Activity (Ci) & & \\
\hline & & & & & & $\mathrm{Pb}-211$ & $1.43 \mathrm{E}-10$ & & \\
\hline & & & Pm-147 & $1.02 \mathrm{E}-02$ & & Pm-147 & $1.39 \mathrm{E}-05$ & & \\
\hline & & & & & & Po-211 & $4.35 \mathrm{E}-13$ & & \\
\hline & & & & & & Po-215 & $1.43 \mathrm{E}-10$ & & \\
\hline & & & $\mathrm{Pu}-239$ & $6.20 \mathrm{E}-03$ & & $\mathrm{Pu}-239$ & $6.20 \mathrm{E}-03$ & & \\
\hline & & & & & & $\mathrm{Ra}-223$ & $1.44 \mathrm{E}-10$ & & \\
\hline & & & Rh-106 & $1.31 \mathrm{E}-03$ & & Rh-106 & $4.44 \mathrm{E}-11$ & & \\
\hline & & & & & & Rn-219 & $1.42 \mathrm{E}-10$ & & \\
\hline & & & $\mathrm{Ru}-106$ & $1.31 \mathrm{E}-03$ & & $\mathrm{Ru}-106$ & $4.48 \mathrm{E}-11$ & & \\
\hline & & & Sb-125 & $7.28 \mathrm{E}-03$ & & Sb-125 & $1.39 \mathrm{E}-05$ & & \\
\hline & & & & & & Sm-147 & $2.50 \mathrm{E}-13$ & & \\
\hline & & & Sr-90 & $1.63 \mathrm{E}-01$ & & Sr-90 & $9.01 \mathrm{E}-02$ & & \\
\hline & & & Te-125m & $3.02 \mathrm{E}-03$ & & Te-125m & $3.38 \mathrm{E}-06$ & & \\
\hline & & & & & & Th-227 & $1.40 \mathrm{E}-10$ & & \\
\hline & & & & & & Th-231 & 8.69E-07 & & \\
\hline & & & & & & Tl-207 & $1.42 \mathrm{E}-10$ & & \\
\hline & & & $\mathrm{U}-235$ & $8.80 \mathrm{E}-07$ & & $\mathrm{U}-235$ & $8.80 \mathrm{E}-07$ & & \\
\hline & & & $\mathrm{Y}-90$ & $1.63 \mathrm{E}-01$ & & Y-90 & $8.91 \mathrm{E}-02$ & & \\
\hline \multirow[t]{14}{*}{230} & S840859 & 1984 & & & 2009 & Ac- 227 & $1.44 \mathrm{E}-10$ & 40,000 & 21,000 \\
\hline & & & Ba-137m & $2.40 \mathrm{E}-01$ & & Ba-137m & $1.34 \mathrm{E}-01$ & & \\
\hline & & & & & & Bi-211 & $1.42 \mathrm{E}-10$ & & \\
\hline & & & Cs-137 & $2.55 \mathrm{E}-01$ & & Cs-137 & $1.43 \mathrm{E}-01$ & & \\
\hline & & & Eu-155 & $4.78 \mathrm{E}-03$ & & Eu-155 & $1.45 \mathrm{E}-04$ & & \\
\hline & & & & & & Fr-223 & $1.97 \mathrm{E}-12$ & & \\
\hline & & & & & & $\mathrm{Pa}-231$ & $4.65 \mathrm{E}-10$ & & \\
\hline & & & & & & $\mathrm{Pb}-211$ & $1.43 \mathrm{E}-10$ & & \\
\hline & & & Pm-147 & $1.46 \mathrm{E}-02$ & & Pm-147 & $1.98 \mathrm{E}-05$ & & \\
\hline & & & & & & Po-211 & $4.35 \mathrm{E}-13$ & & \\
\hline & & & & & & Po-215 & $1.43 \mathrm{E}-10$ & & \\
\hline & & & $\mathrm{Pu}-239$ & $6.20 \mathrm{E}-03$ & & $\mathrm{Pu}-239$ & $6.20 \mathrm{E}-03$ & & \\
\hline & & & & & & Ra-223 & $1.44 \mathrm{E}-10$ & & \\
\hline & & & Rh-106 & $1.87 \mathrm{E}-03$ & & Rh-106 & $6.34 \mathrm{E}-11$ & & \\
\hline
\end{tabular}

${ }^{1}$ Calculated decayed contact dose rate. Rounded to nearest $10 \mathrm{mR} / \mathrm{hr}$ for values to 1000 ; rounded to nearest $100 \mathrm{mR} / \mathrm{hr}$ for values $>1000$ to 10,000 ; rounded to nearest $1000 \mathrm{mR} / \mathrm{hr}$ for values $>10,000$. * Initial contact dose rate assumed to be $1,000,000 \mathrm{mR} / \mathrm{hr}$; **Initial contact dose rate assumed to be $1,010,000 \mathrm{mR} / \mathrm{hr}$.

156 of 168 
Appendix A-4 - Initial and Decayed Radionuclide and Dose Data for Lined Shafts

\begin{tabular}{|c|c|c|c|c|c|c|c|c|c|}
\hline \multirow[b]{2}{*}{ Shaft Number } & \multirow[b]{2}{*}{ Package ID } & \multirow[b]{2}{*}{ Base Year } & \multicolumn{2}{|c|}{ Initial Isotopic Distribution } & \multirow[b]{2}{*}{ Target Year } & \multicolumn{2}{|c|}{ Decayed Isotopic Distribution } & \multirow{2}{*}{$\begin{array}{c}\text { Initial Contact } \\
\text { Dose Rate } \\
(\mathrm{mR} / \mathrm{hr})\end{array}$} & \multirow{2}{*}{$\begin{array}{c}\text { Decayed } \\
\text { Contact Dose } \\
\text { Rate }(\mathrm{mR} / \mathrm{hr})^{1} \\
\end{array}$} \\
\hline & & & Isotope & Activity (Ci) & & Isotope & Activity (Ci) & & \\
\hline & & & & & & $\mathrm{Rn}-219$ & $1.42 \mathrm{E}-10$ & & \\
\hline & & & $\mathrm{Ru}-106$ & $1.87 \mathrm{E}-03$ & & $\mathrm{Ru}-106$ & $6.40 \mathrm{E}-11$ & & \\
\hline & & & $\mathrm{Sb}-125$ & $1.04 \mathrm{E}-02$ & & $\mathrm{Sb}-125$ & $2.00 \mathrm{E}-05$ & & \\
\hline & & & & & & Sm-147 & $3.57 \mathrm{E}-13$ & & \\
\hline & & & Sr-90 & $2.33 \mathrm{E}-01$ & & Sr-90 & $1.29 \mathrm{E}-01$ & & \\
\hline & & & Te- $125 \mathrm{~m}$ & $4.32 \mathrm{E}-03$ & & Te-125m & $4.83 \mathrm{E}-06$ & & \\
\hline & & & & & & Th-227 & $1.40 \mathrm{E}-10$ & & \\
\hline & & & & & & Th-231 & $8.69 \mathrm{E}-07$ & & \\
\hline & & & & & & Tl-207 & $1.42 \mathrm{E}-10$ & & \\
\hline & & & $\mathrm{U}-235$ & $8.80 \mathrm{E}-07$ & & $\mathrm{U}-235$ & $8.80 \mathrm{E}-07$ & & \\
\hline & & & $\mathrm{Y}-90$ & $2.33 \mathrm{E}-01$ & & Y-90 & $1.27 \mathrm{E}-01$ & & \\
\hline \multirow[t]{21}{*}{231} & S855046 & 1985 & & & 2009 & Ac-227 & $1.34 \mathrm{E}-10$ & $1000000+$ & $543,000 *$ \\
\hline & & & Ba-137m & 7.19E-01 & & $\mathrm{Ba}-137 \mathrm{~m}$ & 4.11E-01 & & \\
\hline & & & & & & Bi-211 & $1.33 \mathrm{E}-10$ & & \\
\hline & & & Cs-137 & $7.66 \mathrm{E}-01$ & & Cs-137 & $4.40 \mathrm{E}-01$ & & \\
\hline & & & Eu-155 & $1.43 \mathrm{E}-02$ & & Eu-155 & $5.01 \mathrm{E}-04$ & & \\
\hline & & & & & & Fr-223 & $1.83 \mathrm{E}-12$ & & \\
\hline & & & & & & $\mathrm{Pa}-231$ & $4.46 \mathrm{E}-10$ & & \\
\hline & & & & & & $\mathrm{Pb}-211$ & $1.33 \mathrm{E}-10$ & & \\
\hline & & & Pm-147 & 4.38E-02 & & Pm-147 & 7.72E-05 & & \\
\hline & & & & & & Po-211 & $4.05 \mathrm{E}-13$ & & \\
\hline & & & & & & Po-215 & $1.33 \mathrm{E}-10$ & & \\
\hline & & & Pu-239 & $6.20 \mathrm{E}-03$ & & Pu-239 & $6.20 \mathrm{E}-03$ & & \\
\hline & & & & & & Ra-223 & $1.34 \mathrm{E}-10$ & & \\
\hline & & & Rh-106 & $5.62 \mathrm{E}-03$ & & Rh-106 & $3.78 \mathrm{E}-10$ & & \\
\hline & & & & & & Rn-219 & $1.33 \mathrm{E}-10$ & & \\
\hline & & & $\mathrm{Ru}-106$ & $5.62 \mathrm{E}-03$ & & $\mathrm{Ru}-106$ & $3.82 \mathrm{E}-10$ & & \\
\hline & & & Sb-125 & $3.12 \mathrm{E}-02$ & & Sb-125 & 7.67E-05 & & \\
\hline & & & & & & Sm-147 & $1.07 \mathrm{E}-12$ & & \\
\hline & & & Sr-90 & 7.00E-01 & & Sr-90 & $3.96 \mathrm{E}-01$ & & \\
\hline & & & $\mathrm{Te}-125 \mathrm{~m}$ & $1.30 \mathrm{E}-02$ & & $\mathrm{Te}-125 \mathrm{~m}$ & $1.86 \mathrm{E}-05$ & & \\
\hline & & & & & & Th-227 & $1.31 \mathrm{E}-10$ & & \\
\hline
\end{tabular}

${ }^{1}$ Calculated decayed contact dose rate. Rounded to nearest $10 \mathrm{mR} / \mathrm{hr}$ for values to 1000 ; rounded to nearest $100 \mathrm{mR} / \mathrm{hr}$ for values $>1000$ to 10,000 ; rounded to nearest $1000 \mathrm{mR} / \mathrm{hr}$ for values $>10,000$. * Initial contact dose rate assumed to be $1,000,000 \mathrm{mR} / \mathrm{hr}$; **Initial contact dose rate assumed to be $1,010,000 \mathrm{mR} / \mathrm{hr}$.

$$
157 \text { of } 168
$$


Appendix A-4 - Initial and Decayed Radionuclide and Dose Data for Lined Shafts

\begin{tabular}{|c|c|c|c|c|c|c|c|c|c|}
\hline \multirow[b]{2}{*}{ Shaft Number } & \multirow[b]{2}{*}{ Package ID } & \multirow[b]{2}{*}{ Base Year } & \multicolumn{2}{|c|}{ Initial Isotopic Distribution } & \multirow[b]{2}{*}{ Target Year } & \multicolumn{2}{|c|}{ Decayed Isotopic Distribution } & \multirow{2}{*}{$\begin{array}{c}\text { Initial Contact } \\
\text { Dose Rate } \\
(\mathrm{mR} / \mathrm{hr})\end{array}$} & \multirow{2}{*}{$\begin{array}{c}\text { Decayed } \\
\text { Contact Dose } \\
\text { Rate }(\mathrm{mR} / \mathrm{hr})^{1} \\
\end{array}$} \\
\hline & & & Isotope & Activity (Ci) & & Isotope & Activity (Ci) & & \\
\hline & & & & & & Th-231 & 8.69E-07 & & \\
\hline & & & & & & Tl-207 & $1.32 \mathrm{E}-10$ & & \\
\hline & & & $\mathrm{U}-235$ & $8.80 \mathrm{E}-07$ & & $\mathrm{U}-235$ & $8.80 \mathrm{E}-07$ & & \\
\hline & & & $\mathrm{Y}-90$ & $6.99 \mathrm{E}-01$ & & $\mathrm{Y}-90$ & $3.91 \mathrm{E}-01$ & & \\
\hline \multirow[t]{25}{*}{231} & S855047 & 1985 & & & 2009 & Ac-227 & $1.01 \mathrm{E}-10$ & $1000000+$ & 543,000 \\
\hline & & & Ba-137m & 7.19E-01 & & Ba-137m & $4.11 \mathrm{E}-01$ & & \\
\hline & & & & & & $\mathrm{Bi}-211$ & 9.94E-11 & & \\
\hline & & & Cs-137 & 7.66E-01 & & Cs-137 & $4.40 \mathrm{E}-01$ & & \\
\hline & & & Eu-155 & $1.43 \mathrm{E}-02$ & & Eu-155 & $5.01 \mathrm{E}-04$ & & \\
\hline & & & & & & Fr-223 & $1.37 \mathrm{E}-12$ & & \\
\hline & & & & & & $\mathrm{Pa}-231$ & $3.35 \mathrm{E}-10$ & & \\
\hline & & & & & & $\mathrm{Pb}-211$ & $9.95 \mathrm{E}-11$ & & \\
\hline & & & Pm-147 & 4.38E-02 & & Pm-147 & 7.72E-05 & & \\
\hline & & & & & & Po-211 & $3.03 \mathrm{E}-13$ & & \\
\hline & & & & & & Po-215 & $9.95 \mathrm{E}-11$ & & \\
\hline & & & $\mathrm{Pu}-239$ & $6.20 \mathrm{E}-03$ & & $\mathrm{Pu}-239$ & $6.20 \mathrm{E}-03$ & & \\
\hline & & & & & & Ra-223 & $1.01 \mathrm{E}-10$ & & \\
\hline & & & Rh-106 & $5.62 \mathrm{E}-03$ & & Rh-106 & $3.78 \mathrm{E}-10$ & & \\
\hline & & & & & & Rn-219 & $9.94 \mathrm{E}-11$ & & \\
\hline & & & $\mathrm{Ru}-106$ & $5.62 \mathrm{E}-03$ & & $\mathrm{Ru}-106$ & $3.82 \mathrm{E}-10$ & & \\
\hline & & & Sb-125 & $3.12 \mathrm{E}-02$ & & Sb-125 & 7.67E-05 & & \\
\hline & & & & & & Sm-147 & $1.07 \mathrm{E}-12$ & & \\
\hline & & & Sr-90 & 7.00E-01 & & Sr-90 & $3.96 \mathrm{E}-01$ & & \\
\hline & & & $\mathrm{Te}-125 \mathrm{~m}$ & $1.30 \mathrm{E}-02$ & & Te-125m & $1.86 \mathrm{E}-05$ & & \\
\hline & & & & & & Th-227 & $9.80 \mathrm{E}-11$ & & \\
\hline & & & & & & Th-231 & $6.52 \mathrm{E}-07$ & & \\
\hline & & & & & & Tl-207 & $9.90 \mathrm{E}-11$ & & \\
\hline & & & U-235 & $6.60 \mathrm{E}-07$ & & U-235 & $6.60 \mathrm{E}-07$ & & \\
\hline & & & Y-90 & $6.99 \mathrm{E}-01$ & & Y-90 & $3.91 \mathrm{E}-01$ & & \\
\hline \multirow[t]{3}{*}{231} & S855048 & 1985 & & & 2009 & Ac-227 & $5.03 \mathrm{E}-09$ & 100,000 & 54,000 \\
\hline & & & Ba-137m & $2.16 \mathrm{E}-01$ & & Ba-137m & $1.23 \mathrm{E}-01$ & & \\
\hline & & & & & & Bi-211 & 4.97E-09 & & \\
\hline
\end{tabular}

${ }^{1}$ Calculated decayed contact dose rate. Rounded to nearest $10 \mathrm{mR} / \mathrm{hr}$ for values to 1000 ; rounded to nearest $100 \mathrm{mR} / \mathrm{hr}$ for values $>1000$ to 10,000 ; rounded to nearest $1000 \mathrm{mR} / \mathrm{hr}$ for values $>10,000$. * Initial contact dose rate assumed to be $1,000,000 \mathrm{mR} / \mathrm{hr}$; **Initial contact dose rate assumed to be $1,010,000 \mathrm{mR} / \mathrm{hr}$.

$$
158 \text { of } 168
$$


Appendix A-4 - Initial and Decayed Radionuclide and Dose Data for Lined Shafts

\begin{tabular}{|c|c|c|c|c|c|c|c|c|c|}
\hline \multirow[b]{2}{*}{ Shaft Number } & \multirow[b]{2}{*}{ Package ID } & \multirow[b]{2}{*}{ Base Year } & \multicolumn{2}{|c|}{ Initial Isotopic Distribution } & \multirow[b]{2}{*}{ Target Year } & \multicolumn{2}{|c|}{ Decayed Isotopic Distribution } & \multirow{2}{*}{$\begin{array}{c}\text { Initial Contact } \\
\text { Dose Rate } \\
(\mathrm{mR} / \mathrm{hr})\end{array}$} & \multirow{2}{*}{$\begin{array}{c}\text { Decayed } \\
\text { Contact Dose } \\
\text { Rate }(\mathrm{mR} / \mathrm{hr})^{1} \\
\end{array}$} \\
\hline & & & Isotope & Activity (Ci) & & Isotope & Activity (Ci) & & \\
\hline & & & Cs-137 & $2.30 \mathrm{E}-01$ & & Cs-137 & $1.32 \mathrm{E}-01$ & & \\
\hline & & & Eu-155 & $4.30 \mathrm{E}-03$ & & Eu-155 & $1.50 \mathrm{E}-04$ & & \\
\hline & & & & & & Fr-223 & $6.87 \mathrm{E}-11$ & & \\
\hline & & & & & & $\mathrm{Pa}-231$ & $1.67 \mathrm{E}-08$ & & \\
\hline & & & & & & $\mathrm{Pb}-211$ & $4.98 \mathrm{E}-09$ & & \\
\hline & & & Pm-147 & $1.31 \mathrm{E}-02$ & & Pm-147 & $2.32 \mathrm{E}-05$ & & \\
\hline & & & & & & Po-211 & $1.52 \mathrm{E}-11$ & & \\
\hline & & & & & & Po-215 & $4.98 \mathrm{E}-09$ & & \\
\hline & & & & & & Ra-223 & $5.03 \mathrm{E}-09$ & & \\
\hline & & & Rh-106 & $1.69 \mathrm{E}-03$ & & Rh-106 & $1.13 \mathrm{E}-10$ & & \\
\hline & & & & & & Rn-219 & 4.97E-09 & & \\
\hline & & & $\mathrm{Ru}-106$ & $1.69 \mathrm{E}-03$ & & $\mathrm{Ru}-106$ & $1.15 \mathrm{E}-10$ & & \\
\hline & & & Sb-125 & $9.36 \mathrm{E}-03$ & & $\mathrm{Sb}-125$ & $2.30 \mathrm{E}-05$ & & \\
\hline & & & & & & Sm-147 & $3.21 \mathrm{E}-13$ & & \\
\hline & & & Sr-90 & $2.10 \mathrm{E}-01$ & & Sr-90 & $1.19 \mathrm{E}-01$ & & \\
\hline & & & $\mathrm{Te}-125 \mathrm{~m}$ & $3.89 \mathrm{E}-03$ & & $\mathrm{Te}-125 \mathrm{~m}$ & $5.58 \mathrm{E}-06$ & & \\
\hline & & & & & & Th-227 & 4.90E-09 & & \\
\hline & & & & & & Th-231 & $3.26 \mathrm{E}-05$ & & \\
\hline & & & & & & T1-207 & $4.95 \mathrm{E}-09$ & & \\
\hline & & & U-235 & $3.30 \mathrm{E}-05$ & & U-235 & $3.30 \mathrm{E}-05$ & & \\
\hline & & & Y-90 & $2.10 \mathrm{E}-01$ & & $\mathrm{Y}-90$ & $1.17 \mathrm{E}-01$ & & \\
\hline \multirow[t]{11}{*}{231} & S855049 & 1985 & & & 2009 & Ac-227 & $3.02 \mathrm{E}-09$ & 3,000 & 1,600 \\
\hline & & & Ba-137m & $9.59 \mathrm{E}-02$ & & Ba-137m & $5.49 \mathrm{E}-02$ & & \\
\hline & & & & & & Bi-211 & $2.98 \mathrm{E}-09$ & & \\
\hline & & & Cs-137 & $1.02 \mathrm{E}-01$ & & Cs-137 & $5.87 \mathrm{E}-02$ & & \\
\hline & & & Eu-155 & $1.91 \mathrm{E}-03$ & & Eu-155 & $6.67 \mathrm{E}-05$ & & \\
\hline & & & & & & Fr-223 & $4.12 \mathrm{E}-11$ & & \\
\hline & & & & & & $\mathrm{Pa}-231$ & $1.00 \mathrm{E}-08$ & & \\
\hline & & & & & & $\mathrm{Pb}-211$ & 2.99E-09 & & \\
\hline & & & Pm-147 & $5.83 \mathrm{E}-03$ & & Pm-147 & $1.03 \mathrm{E}-05$ & & \\
\hline & & & & & & Po-211 & $9.10 \mathrm{E}-12$ & & \\
\hline & & & & & & Рo-215 & 2.99E-09 & & \\
\hline
\end{tabular}

${ }^{1}$ Calculated decayed contact dose rate. Rounded to nearest $10 \mathrm{mR} / \mathrm{hr}$ for values to 1000 ; rounded to nearest $100 \mathrm{mR} / \mathrm{hr}$ for values $>1000$ to 10,000 ; rounded to nearest $1000 \mathrm{mR} / \mathrm{hr}$ for values $>10,000$. * Initial contact dose rate assumed to be $1,000,000 \mathrm{mR} / \mathrm{hr}$; **Initial contact dose rate assumed to be $1,010,000 \mathrm{mR} / \mathrm{hr}$.

$$
159 \text { of } 168
$$


Appendix A-4 - Initial and Decayed Radionuclide and Dose Data for Lined Shafts

\begin{tabular}{|c|c|c|c|c|c|c|c|c|c|}
\hline \multirow[b]{2}{*}{ Shaft Number } & \multirow[b]{2}{*}{ Package ID } & \multirow[b]{2}{*}{ Base Year } & \multicolumn{2}{|c|}{ Initial Isotopic Distribution } & \multirow[b]{2}{*}{ Target Year } & \multicolumn{2}{|c|}{ Decayed Isotopic Distribution } & \multirow{2}{*}{$\begin{array}{c}\text { Initial Contact } \\
\text { Dose Rate } \\
(\mathrm{mR} / \mathrm{hr})\end{array}$} & \multirow{2}{*}{$\begin{array}{c}\text { Decayed } \\
\text { Contact Dose } \\
\text { Rate }(\mathrm{mR} / \mathrm{hr})^{1} \\
\end{array}$} \\
\hline & & & Isotope & Activity (Ci) & & Isotope & Activity (Ci) & & \\
\hline & & & & & & Ra-223 & $3.02 \mathrm{E}-09$ & & \\
\hline & & & Rh-106 & 7.49E-04 & & Rh-106 & $5.04 \mathrm{E}-11$ & & \\
\hline & & & & & & $\mathrm{Rn}-219$ & $2.98 \mathrm{E}-09$ & & \\
\hline & & & $\mathrm{Ru}-106$ & 7.49E-04 & & Ru-106 & $5.09 \mathrm{E}-11$ & & \\
\hline & & & Sb-125 & $4.16 \mathrm{E}-03$ & & $\mathrm{Sb}-125$ & $1.02 \mathrm{E}-05$ & & \\
\hline & & & & & & Sm-147 & $1.43 \mathrm{E}-13$ & & \\
\hline & & & Sr-90 & $9.34 \mathrm{E}-02$ & & Sr-90 & $5.27 \mathrm{E}-02$ & & \\
\hline & & & $\mathrm{Te}-125 \mathrm{~m}$ & $1.73 \mathrm{E}-03$ & & $\mathrm{Te}-125 \mathrm{~m}$ & $2.48 \mathrm{E}-06$ & & \\
\hline & & & & & & Th-227 & $2.94 \mathrm{E}-09$ & & \\
\hline & & & & & & Th-231 & $1.96 \mathrm{E}-05$ & & \\
\hline & & & & & & T1-207 & $2.97 \mathrm{E}-09$ & & \\
\hline & & & $\mathrm{U}-235$ & $1.98 \mathrm{E}-05$ & & $\mathrm{U}-235$ & $1.98 \mathrm{E}-05$ & & \\
\hline & & & Y-90 & 9.33E-02 & & $\mathrm{Y}-90$ & $5.21 \mathrm{E}-02$ & & \\
\hline \multirow[t]{19}{*}{231} & S856015 & 1985 & & & 2009 & Ac-227 & $1.34 \mathrm{E}-10$ & $1000000+$ & $543,000 *$ \\
\hline & & & $\mathrm{Ba}-137 \mathrm{~m}$ & $5.03 \mathrm{E}-01$ & & $\mathrm{Ba}-137 \mathrm{~m}$ & $2.88 \mathrm{E}-01$ & & \\
\hline & & & & & & $\mathrm{Bi}-211$ & $1.33 \mathrm{E}-10$ & & \\
\hline & & & Cs-137 & $5.36 \mathrm{E}-01$ & & Cs-137 & $3.08 \mathrm{E}-01$ & & \\
\hline & & & Eu-155 & $1.00 \mathrm{E}-02$ & & Eu-155 & $3.50 \mathrm{E}-04$ & & \\
\hline & & & & & & Fr-223 & $1.83 \mathrm{E}-12$ & & \\
\hline & & & & & & $\mathrm{Pa}-231$ & $4.46 \mathrm{E}-10$ & & \\
\hline & & & & & & $\mathrm{Pb}-211$ & $1.33 \mathrm{E}-10$ & & \\
\hline & & & Pm-147 & $3.06 \mathrm{E}-02$ & & Pm-147 & $5.40 \mathrm{E}-05$ & & \\
\hline & & & & & & Po-211 & $4.05 \mathrm{E}-13$ & & \\
\hline & & & & & & Po-215 & $1.33 \mathrm{E}-10$ & & \\
\hline & & & $\mathrm{Pu}-239$ & $6.20 \mathrm{E}-03$ & & $\mathrm{Pu}-239$ & $6.20 \mathrm{E}-03$ & & \\
\hline & & & & & & Ra-223 & $1.34 \mathrm{E}-10$ & & \\
\hline & & & Rh-106 & $3.93 \mathrm{E}-03$ & & Rh-106 & $2.65 \mathrm{E}-10$ & & \\
\hline & & & & & & Rn-219 & $1.33 \mathrm{E}-10$ & & \\
\hline & & & Ru-106 & $3.93 \mathrm{E}-03$ & & $\mathrm{Ru}-106$ & $2.67 \mathrm{E}-10$ & & \\
\hline & & & Sb-125 & $2.18 \mathrm{E}-02$ & & Sb-125 & $5.37 \mathrm{E}-05$ & & \\
\hline & & & & & & Sm-147 & $7.50 \mathrm{E}-13$ & & \\
\hline & & & Sr-90 & $4.90 \mathrm{E}-01$ & & Sr-90 & $2.77 \mathrm{E}-01$ & & \\
\hline
\end{tabular}

${ }^{1}$ Calculated decayed contact dose rate. Rounded to nearest $10 \mathrm{mR} / \mathrm{hr}$ for values to 1000 ; rounded to nearest $100 \mathrm{mR} / \mathrm{hr}$ for values $>1000$ to 10,000 ; rounded to nearest $1000 \mathrm{mR} / \mathrm{hr}$ for values $>10,000$. * Initial contact dose rate assumed to be $1,000,000 \mathrm{mR} / \mathrm{hr}$; **Initial contact dose rate assumed to be $1,010,000 \mathrm{mR} / \mathrm{hr}$.

160 of 168 
Appendix A-4 - Initial and Decayed Radionuclide and Dose Data for Lined Shafts

\begin{tabular}{|c|c|c|c|c|c|c|c|c|c|}
\hline \multirow[b]{2}{*}{ Shaft Number } & \multirow[b]{2}{*}{ Package ID } & \multirow[b]{2}{*}{ Base Year } & \multicolumn{2}{|c|}{ Initial Isotopic Distribution } & \multirow[b]{2}{*}{ Target Year } & \multicolumn{2}{|c|}{ Decayed Isotopic Distribution } & \multirow{2}{*}{$\begin{array}{c}\text { Initial Contact } \\
\text { Dose Rate } \\
(\mathrm{mR} / \mathrm{hr}) \\
\end{array}$} & \multirow{2}{*}{$\begin{array}{c}\text { Decayed } \\
\text { Contact Dose } \\
\text { Rate }(\mathrm{mR} / \mathrm{hr})^{1} \\
\end{array}$} \\
\hline & & & Isotope & Activity $(\mathrm{Ci})$ & & Isotope & Activity (Ci) & & \\
\hline & & & Te-125m & 9.07E-03 & & Te-125m & $1.30 \mathrm{E}-05$ & & \\
\hline & & & & & & Th-227 & $1.31 \mathrm{E}-10$ & & \\
\hline & & & & & & Th-231 & 8.69E-07 & & \\
\hline & & & & & & Tl-207 & $1.32 \mathrm{E}-10$ & & \\
\hline & & & $\mathrm{U}-235$ & $8.80 \mathrm{E}-07$ & & $\mathrm{U}-235$ & $8.80 \mathrm{E}-07$ & & \\
\hline & & & Y-90 & 4.90E-01 & & Y-90 & $2.74 \mathrm{E}-01$ & & \\
\hline \multirow[t]{25}{*}{231} & S856016 & 1985 & & & 2009 & Ac-227 & $1.01 \mathrm{E}-10$ & 20,000 & 11,000 \\
\hline & & & $\mathrm{Ba}-137 \mathrm{~m}$ & $1.44 \mathrm{E}+00$ & & Ba-137m & 8.23E-01 & & \\
\hline & & & & & & Bi-211 & $9.94 \mathrm{E}-11$ & & \\
\hline & & & Cs-137 & $1.53 \mathrm{E}+00$ & & Cs-137 & $8.80 \mathrm{E}-01$ & & \\
\hline & & & Eu-155 & $2.87 \mathrm{E}-02$ & & Eu-155 & $1.00 \mathrm{E}-03$ & & \\
\hline & & & & & & Fr-223 & $1.37 \mathrm{E}-12$ & & \\
\hline & & & & & & $\mathrm{Pa}-231$ & $3.35 \mathrm{E}-10$ & & \\
\hline & & & & & & $\mathrm{Pb}-211$ & $9.95 \mathrm{E}-11$ & & \\
\hline & & & Pm-147 & $8.75 \mathrm{E}-02$ & & Pm-147 & $1.54 \mathrm{E}-04$ & & \\
\hline & & & & & & Po-211 & $3.03 \mathrm{E}-13$ & & \\
\hline & & & & & & Po-215 & $9.95 \mathrm{E}-11$ & & \\
\hline & & & $\mathrm{Pu}-239$ & $6.20 \mathrm{E}-03$ & & Pu-239 & $6.20 \mathrm{E}-03$ & & \\
\hline & & & & & & Ra-223 & $1.01 \mathrm{E}-10$ & & \\
\hline & & & Rh-106 & $1.12 \mathrm{E}-02$ & & Rh-106 & $7.57 \mathrm{E}-10$ & & \\
\hline & & & & & & Rn-219 & $9.94 \mathrm{E}-11$ & & \\
\hline & & & Ru-106 & $1.12 \mathrm{E}-02$ & & $\mathrm{Ru}-106$ & $7.64 \mathrm{E}-10$ & & \\
\hline & & & Sb-125 & $6.24 \mathrm{E}-02$ & & Sb-125 & $1.53 \mathrm{E}-04$ & & \\
\hline & & & & & & Sm-147 & $2.14 \mathrm{E}-12$ & & \\
\hline & & & Sr-90 & $1.40 \mathrm{E}+00$ & & Sr-90 & 7.91E-01 & & \\
\hline & & & $\mathrm{Te}-125 \mathrm{~m}$ & $2.59 \mathrm{E}-02$ & & $\mathrm{Te}-125 \mathrm{~m}$ & $3.72 \mathrm{E}-05$ & & \\
\hline & & & & & & Th-227 & $9.80 \mathrm{E}-11$ & & \\
\hline & & & & & & Th-231 & $6.52 \mathrm{E}-07$ & & \\
\hline & & & & & & T1-207 & $9.90 \mathrm{E}-11$ & & \\
\hline & & & U-235 & $6.60 \mathrm{E}-07$ & & U-235 & $6.60 \mathrm{E}-07$ & & \\
\hline & & & Y-90 & $1.40 \mathrm{E}+00$ & & Y-90 & $7.82 \mathrm{E}-01$ & & \\
\hline 231 & S856017 & 1985 & & & 2009 & Ac- 227 & $1.01 \mathrm{E}-10$ & 500,000 & 271,000 \\
\hline
\end{tabular}

${ }^{1}$ Calculated decayed contact dose rate. Rounded to nearest $10 \mathrm{mR} / \mathrm{hr}$ for values to 1000 ; rounded to nearest $100 \mathrm{mR} / \mathrm{hr}$ for values $>1000$ to 10,000 ; rounded to nearest $1000 \mathrm{mR} / \mathrm{hr}$ for values $>10,000$. * Initial contact dose rate assumed to be $1,000,000 \mathrm{mR} / \mathrm{hr}$; **Initial contact dose rate assumed to be $1,010,000 \mathrm{mR} / \mathrm{hr}$.

$$
161 \text { of } 168
$$


Appendix A-4 - Initial and Decayed Radionuclide and Dose Data for Lined Shafts

\begin{tabular}{|c|c|c|c|c|c|c|c|c|c|}
\hline \multirow[b]{2}{*}{ Shaft Number } & \multirow[b]{2}{*}{ Package ID } & \multirow[b]{2}{*}{ Base Year } & \multicolumn{2}{|c|}{ Initial Isotopic Distribution } & \multirow[b]{2}{*}{ Target Year } & \multicolumn{2}{|c|}{ Decayed Isotopic Distribution } & \multirow{2}{*}{$\begin{array}{c}\text { Initial Contact } \\
\text { Dose Rate } \\
(\mathrm{mR} / \mathrm{hr})\end{array}$} & \multirow{2}{*}{$\begin{array}{c}\text { Decayed } \\
\text { Contact Dose } \\
\text { Rate }(\mathrm{mR} / \mathrm{hr})^{1} \\
\end{array}$} \\
\hline & & & Isotope & Activity (Ci) & & Isotope & Activity (Ci) & & \\
\hline & & & Ba-137m & $1.44 \mathrm{E}+00$ & & Ba-137m & $8.23 \mathrm{E}-01$ & & \\
\hline & & & & & & Bi-211 & $9.94 \mathrm{E}-11$ & & \\
\hline & & & Cs-137 & $1.53 \mathrm{E}+00$ & & Cs-137 & $8.80 \mathrm{E}-01$ & & \\
\hline & & & Eu-155 & $2.87 \mathrm{E}-02$ & & Eu-155 & $1.00 \mathrm{E}-03$ & & \\
\hline & & & & & & Fr-223 & $1.37 \mathrm{E}-12$ & & \\
\hline & & & & & & $\mathrm{Pa}-231$ & $3.35 \mathrm{E}-10$ & & \\
\hline & & & & & & $\mathrm{Pb}-211$ & $9.95 \mathrm{E}-11$ & & \\
\hline & & & Pm-147 & $8.75 \mathrm{E}-02$ & & Pm-147 & $1.54 \mathrm{E}-04$ & & \\
\hline & & & & & & Po-211 & $3.03 \mathrm{E}-13$ & & \\
\hline & & & & & & Po-215 & $9.95 \mathrm{E}-11$ & & \\
\hline & & & Pu-239 & $6.20 \mathrm{E}-03$ & & $\mathrm{Pu}-239$ & $6.20 \mathrm{E}-03$ & & \\
\hline & & & & & & Ra-223 & $1.01 \mathrm{E}-10$ & & \\
\hline & & & Rh-106 & $1.12 \mathrm{E}-02$ & & Rh-106 & $7.57 \mathrm{E}-10$ & & \\
\hline & & & & & & Rn-219 & $9.94 \mathrm{E}-11$ & & \\
\hline & & & $\mathrm{Ru}-106$ & $1.12 \mathrm{E}-02$ & & Ru-106 & $7.64 \mathrm{E}-10$ & & \\
\hline & & & Sb-125 & $6.24 \mathrm{E}-02$ & & $\mathrm{Sb}-125$ & $1.53 \mathrm{E}-04$ & & \\
\hline & & & & & & Sm-147 & $2.14 \mathrm{E}-12$ & & \\
\hline & & & Sr-90 & $1.40 \mathrm{E}+00$ & & Sr-90 & $7.91 \mathrm{E}-01$ & & \\
\hline & & & $\mathrm{Te}-125 \mathrm{~m}$ & $2.59 \mathrm{E}-02$ & & $\mathrm{Te}-125 \mathrm{~m}$ & $3.72 \mathrm{E}-05$ & & \\
\hline & & & & & & Th-227 & $9.80 \mathrm{E}-11$ & & \\
\hline & & & & & & Th-231 & $6.52 \mathrm{E}-07$ & & \\
\hline & & & & & & Tl-207 & $9.90 \mathrm{E}-11$ & & \\
\hline & & & U-235 & $6.60 \mathrm{E}-07$ & & U-235 & $6.60 \mathrm{E}-07$ & & \\
\hline & & & Y-90 & $1.40 \mathrm{E}+00$ & & $\mathrm{Y}-90$ & $7.82 \mathrm{E}-01$ & & \\
\hline \multirow[t]{8}{*}{231} & S856018 & 1985 & & & 2009 & Ac-227 & $1.34 \mathrm{E}-10$ & 350,000 & 190,000 \\
\hline & & & Ba-137m & $2.40 \mathrm{E}-01$ & & $\mathrm{Ba}-137 \mathrm{~m}$ & $1.37 \mathrm{E}-01$ & & \\
\hline & & & & & & Bi-211 & $1.33 \mathrm{E}-10$ & & \\
\hline & & & Cs-137 & $2.55 \mathrm{E}-01$ & & Cs-137 & $1.47 \mathrm{E}-01$ & & \\
\hline & & & Eu-155 & $4.78 \mathrm{E}-03$ & & Eu-155 & $1.67 \mathrm{E}-04$ & & \\
\hline & & & & & & Fr-223 & $1.83 \mathrm{E}-12$ & & \\
\hline & & & & & & $\mathrm{Pa}-231$ & $4.46 \mathrm{E}-10$ & & \\
\hline & & & & & & $\mathrm{Pb}-211$ & $1.33 \mathrm{E}-10$ & & \\
\hline
\end{tabular}

${ }^{1}$ Calculated decayed contact dose rate. Rounded to nearest $10 \mathrm{mR} / \mathrm{hr}$ for values to 1000 ; rounded to nearest $100 \mathrm{mR} / \mathrm{hr}$ for values $>1000$ to 10,000 ; rounded to nearest $1000 \mathrm{mR} / \mathrm{hr}$ for values $>10,000$. * Initial contact dose rate assumed to be $1,000,000 \mathrm{mR} / \mathrm{hr}$; **Initial contact dose rate assumed to be $1,010,000 \mathrm{mR} / \mathrm{hr}$.

$$
162 \text { of } 168
$$


Appendix A-4 - Initial and Decayed Radionuclide and Dose Data for Lined Shafts

\begin{tabular}{|c|c|c|c|c|c|c|c|c|c|}
\hline \multirow[b]{2}{*}{ Shaft Number } & \multirow[b]{2}{*}{ Package ID } & \multirow[b]{2}{*}{ Base Year } & \multicolumn{2}{|c|}{ Initial Isotopic Distribution } & \multirow[b]{2}{*}{ Target Year } & \multicolumn{2}{|c|}{ Decayed Isotopic Distribution } & \multirow{2}{*}{$\begin{array}{c}\text { Initial Contact } \\
\text { Dose Rate } \\
(\mathrm{mR} / \mathrm{hr})\end{array}$} & \multirow{2}{*}{$\begin{array}{c}\text { Decayed } \\
\text { Contact Dose } \\
\text { Rate }(\mathrm{mR} / \mathrm{hr})^{1} \\
\end{array}$} \\
\hline & & & Isotope & Activity (Ci) & & Isotope & Activity (Ci) & & \\
\hline & & & Pm-147 & $1.46 \mathrm{E}-02$ & & Pm-147 & $2.57 \mathrm{E}-05$ & & \\
\hline & & & & & & Po-211 & $4.05 \mathrm{E}-13$ & & \\
\hline & & & & & & Po-215 & $1.33 \mathrm{E}-10$ & & \\
\hline & & & $\mathrm{Pu}-239$ & $6.20 \mathrm{E}-03$ & & $\mathrm{Pu}-239$ & $6.20 \mathrm{E}-03$ & & \\
\hline & & & & & & $\mathrm{Ra}-223$ & $1.34 \mathrm{E}-10$ & & \\
\hline & & & Rh-106 & $1.87 \mathrm{E}-03$ & & Rh-106 & $1.26 \mathrm{E}-10$ & & \\
\hline & & & & & & $\mathrm{Rn}-219$ & $1.33 \mathrm{E}-10$ & & \\
\hline & & & $\mathrm{Ru}-106$ & $1.87 \mathrm{E}-03$ & & Ru-106 & $1.27 \mathrm{E}-10$ & & \\
\hline & & & Sb-125 & $1.04 \mathrm{E}-02$ & & Sb-125 & $2.56 \mathrm{E}-05$ & & \\
\hline & & & & & & Sm-147 & $3.57 \mathrm{E}-13$ & & \\
\hline & & & Sr-90 & 2.33E-01 & & Sr-90 & $1.32 \mathrm{E}-01$ & & \\
\hline & & & Te-125m & 4.32E-03 & & Te-125m & $6.20 \mathrm{E}-06$ & & \\
\hline & & & & & & Th-227 & $1.31 \mathrm{E}-10$ & & \\
\hline & & & & & & Th-231 & 8.69E-07 & & \\
\hline & & & & & & Tl-207 & $1.32 \mathrm{E}-10$ & & \\
\hline & & & U-235 & 8.80E-07 & & $\mathrm{U}-235$ & $8.80 \mathrm{E}-07$ & & \\
\hline & & & $\mathrm{Y}-90$ & 2.33E-01 & & Y-90 & $1.30 \mathrm{E}-01$ & & \\
\hline \multirow[t]{15}{*}{232} & S874132 & 1987 & & & 2009 & Ac- 227 & $7.56 \mathrm{E}-10$ & 6,500 & 7,900 \\
\hline & & & & & & Ac- 228 & 4.14E-16 & & \\
\hline & & & & & & $\mathrm{Bi}-210$ & $2.81 \mathrm{E}-11$ & & \\
\hline & & & & & & Bi-211 & 7.47E-10 & & \\
\hline & & & & & & Bi-212 & $4.16 \mathrm{E}-16$ & & \\
\hline & & & & & & Bi-214 & $1.45 \mathrm{E}-10$ & & \\
\hline & & & & & & Fr-223 & $1.03 \mathrm{E}-11$ & & \\
\hline & & & & & & $\mathrm{Pa}-231$ & 2.69E-09 & & \\
\hline & & & & & & $\mathrm{Pa}-234$ & $1.89 \mathrm{E}-09$ & & \\
\hline & & & & & & $\mathrm{Pa}-234 \mathrm{~m}$ & $1.46 \mathrm{E}-06$ & & \\
\hline & & & & & & $\mathrm{Pb}-210$ & $2.85 \mathrm{E}-11$ & & \\
\hline & & & & & & $\mathrm{Pb}-211$ & $7.48 \mathrm{E}-10$ & & \\
\hline & & & & & & $\mathrm{Pb}-212$ & 4.14E-16 & & \\
\hline & & & & & & $\mathrm{Pb}-214$ & $1.45 \mathrm{E}-10$ & & \\
\hline & & & & & & Рo-210 & $2.84 \mathrm{E}-11$ & & \\
\hline
\end{tabular}

${ }^{1}$ Calculated decayed contact dose rate. Rounded to nearest $10 \mathrm{mR} / \mathrm{hr}$ for values to 1000 ; rounded to nearest $100 \mathrm{mR} / \mathrm{hr}$ for values $>1000$ to 10,000 ; rounded to nearest $1000 \mathrm{mR} / \mathrm{hr}$ for values $>10,000$. * Initial contact dose rate assumed to be $1,000,000 \mathrm{mR} / \mathrm{hr}$; **Initial contact dose rate assumed to be $1,010,000 \mathrm{mR} / \mathrm{hr}$.

$$
163 \text { of } 168
$$


Appendix A-4 - Initial and Decayed Radionuclide and Dose Data for Lined Shafts

\begin{tabular}{|c|c|c|c|c|c|c|c|c|c|}
\hline \multirow[b]{2}{*}{ Shaft Number } & \multirow[b]{2}{*}{ Package ID } & \multirow[b]{2}{*}{ Base Year } & \multicolumn{2}{|c|}{ Initial Isotopic Distribution } & \multirow[b]{2}{*}{ Target Year } & \multicolumn{2}{|c|}{ Decayed Isotopic Distribution } & \multirow{2}{*}{$\begin{array}{c}\text { Initial Contact } \\
\text { Dose Rate } \\
(\mathrm{mR} / \mathrm{hr})\end{array}$} & \multirow{2}{*}{$\begin{array}{c}\text { Decayed } \\
\text { Contact Dose } \\
\text { Rate }(\mathrm{mR} / \mathrm{hr})^{1} \\
\end{array}$} \\
\hline & & & Isotope & Activity (Ci) & & Isotope & Activity (Ci) & & \\
\hline & & & & & & Po-211 & $2.28 \mathrm{E}-12$ & & \\
\hline & & & & & & Po-212 & $2.65 \mathrm{E}-16$ & & \\
\hline & & & & & & Po-214 & $1.45 \mathrm{E}-10$ & & \\
\hline & & & & & & Po-215 & $7.48 \mathrm{E}-10$ & & \\
\hline & & & & & & Po-216 & 4.14E-16 & & \\
\hline & & & & & & Po-218 & $1.43 \mathrm{E}-10$ & & \\
\hline & & & & & & $\mathrm{Ra}-223$ & $7.56 \mathrm{E}-10$ & & \\
\hline & & & & & & $\mathrm{Ra}-224$ & $4.14 \mathrm{E}-16$ & & \\
\hline & & & & & & Ra-226 & $1.47 \mathrm{E}-10$ & & \\
\hline & & & & & & Ra-228 & 4.89E-16 & & \\
\hline & & & & & & Rn-219 & $7.47 \mathrm{E}-10$ & & \\
\hline & & & & & & $\mathrm{Rn}-220$ & 4.14E-16 & & \\
\hline & & & & & & Rn-222 & $1.45 \mathrm{E}-10$ & & \\
\hline & & & & & & Th-227 & 7.36E-10 & & \\
\hline & & & & & & Th-228 & 4.19E-16 & & \\
\hline & & & & & & Th-230 & $3.09 \mathrm{E}-08$ & & \\
\hline & & & & & & Th-231 & $5.72 \mathrm{E}-06$ & & \\
\hline & & & & & & Th-232 & $6.92 \mathrm{E}-16$ & & \\
\hline & & & & & & Th-234 & $1.46 \mathrm{E}-06$ & & \\
\hline & & & & & & Tl-207 & $7.43 \mathrm{E}-10$ & & \\
\hline & & & & & & Tl-208 & $1.49 \mathrm{E}-16$ & & \\
\hline & & & $\mathrm{U}-234$ & $1.56 \mathrm{E}-04$ & & $\mathrm{U}-234$ & $1.56 \mathrm{E}-04$ & & \\
\hline & & & $\mathrm{U}-235$ & 5.79E-06 & & $\mathrm{U}-235$ & $5.79 \mathrm{E}-06$ & & \\
\hline & & & $\mathrm{U}-236$ & $6.37 \mathrm{E}-07$ & & U-236 & $6.37 \mathrm{E}-07$ & & \\
\hline & & & U-238 & $1.47 \mathrm{E}-06$ & & $\mathrm{U}-238$ & $1.47 \mathrm{E}-06$ & & \\
\hline \multirow[t]{7}{*}{232} & S874133 & 1987 & & & 2009 & Ac- 225 & $1.36 \mathrm{E}-13$ & & 0 \\
\hline & & & & & & Ac-227 & $3.87 \mathrm{E}-08$ & & \\
\hline & & & & & & Ac-228 & $3.76 \mathrm{E}-16$ & & \\
\hline & & & & & & Am-241 & $1.73 \mathrm{E}+00$ & & \\
\hline & & & & & & At-217 & $1.37 \mathrm{E}-13$ & & \\
\hline & & & & & & Bi-210 & 4.03E-12 & & \\
\hline & & & & & & $\mathrm{Bi}-211$ & $3.82 \mathrm{E}-08$ & & \\
\hline
\end{tabular}

${ }^{1}$ Calculated decayed contact dose rate. Rounded to nearest $10 \mathrm{mR} / \mathrm{hr}$ for values to 1000 ; rounded to nearest $100 \mathrm{mR} / \mathrm{hr}$ for values $>1000$ to 10,000 ; rounded to nearest $1000 \mathrm{mR} / \mathrm{hr}$ for values $>10,000$. * Initial contact dose rate assumed to be $1,000,000 \mathrm{mR} / \mathrm{hr}$; **Initial contact dose rate assumed to be $1,010,000 \mathrm{mR} / \mathrm{hr}$.

$$
164 \text { of } 168
$$


Appendix A-4 - Initial and Decayed Radionuclide and Dose Data for Lined Shafts

\begin{tabular}{|c|c|c|c|c|c|c|c|c|c|}
\hline \multirow[b]{2}{*}{ Shaft Number } & \multirow[b]{2}{*}{ Package ID } & \multirow[b]{2}{*}{ Base Year } & \multicolumn{2}{|c|}{ Initial Isotopic Distribution } & \multirow[b]{2}{*}{ Target Year } & \multicolumn{2}{|c|}{ Decayed Isotopic Distribution } & \multirow{2}{*}{$\begin{array}{c}\text { Initial Contact } \\
\text { Dose Rate } \\
(\mathrm{mR} / \mathrm{hr})\end{array}$} & \multirow{2}{*}{$\begin{array}{c}\text { Decayed } \\
\text { Contact Dose } \\
\text { Rate }(\mathrm{mR} / \mathrm{hr}) \\
\end{array}$} \\
\hline & & & Isotope & Activity (Ci) & & Isotope & Activity (Ci) & & \\
\hline & & & & & & $\mathrm{Bi}-212$ & $3.78 \mathrm{E}-16$ & & \\
\hline & & & & & & Bi-213 & $1.36 \mathrm{E}-13$ & & \\
\hline & & & & & & $\mathrm{Bi}-214$ & $2.66 \mathrm{E}-11$ & & \\
\hline & & & & & & Fr-221 & $1.36 \mathrm{E}-13$ & & \\
\hline & & & & & & Fr-223 & $5.29 \mathrm{E}-10$ & & \\
\hline & & & & & & $\mathrm{Np}-237$ & 7.29E-06 & & \\
\hline & & & & & & $\mathrm{Pa}-231$ & $1.38 \mathrm{E}-07$ & & \\
\hline & & & & & & $\mathrm{Pa}-233$ & 7.23E-06 & & \\
\hline & & & & & & $\mathrm{Pa}-234$ & $2.63 \mathrm{E}-08$ & & \\
\hline & & & & & & $\mathrm{Pa}-234 \mathrm{~m}$ & $2.02 \mathrm{E}-05$ & & \\
\hline & & & & & & $\mathrm{Pb}-209$ & $1.36 \mathrm{E}-13$ & & \\
\hline & & & & & & $\mathrm{Pb}-210$ & $4.08 \mathrm{E}-12$ & & \\
\hline & & & & & & $\mathrm{Pb}-211$ & $3.83 \mathrm{E}-08$ & & \\
\hline & & & & & & $\mathrm{Pb}-212$ & $3.77 \mathrm{E}-16$ & & \\
\hline & & & & & & $\mathrm{Pb}-214$ & $2.67 \mathrm{E}-11$ & & \\
\hline & & & & & & Po-210 & $4.08 \mathrm{E}-12$ & & \\
\hline & & & & & & Po-211 & $1.17 \mathrm{E}-10$ & & \\
\hline & & & & & & Po-212 & $2.41 \mathrm{E}-16$ & & \\
\hline & & & & & & Po-213 & $1.33 \mathrm{E}-13$ & & \\
\hline & & & & & & Po-214 & $2.67 \mathrm{E}-11$ & & \\
\hline & & & & & & Po-215 & $3.83 \mathrm{E}-08$ & & \\
\hline & & & & & & Po-216 & $3.76 \mathrm{E}-16$ & & \\
\hline & & & & & & Po-218 & $2.62 \mathrm{E}-11$ & & \\
\hline & & & $\mathrm{Pu}-238$ & $1.44 \mathrm{E}+00$ & & $\mathrm{Pu}-238$ & $1.21 \mathrm{E}+00$ & & \\
\hline & & & Pu-239 & $3.52 \mathrm{E}+00$ & & $\mathrm{Pu}-239$ & $3.52 \mathrm{E}+00$ & & \\
\hline & & & $\mathrm{Pu}-240$ & $2.30 \mathrm{E}+00$ & & $\mathrm{Pu}-240$ & $2.29 \mathrm{E}+00$ & & \\
\hline & & & $\mathrm{Pu}-241$ & $8.10 \mathrm{E}+01$ & & $\mathrm{Pu}-241$ & $2.81 \mathrm{E}+01$ & & \\
\hline & & & $\mathrm{Pu}-242$ & $1.39 \mathrm{E}-03$ & & $\mathrm{Pu}-242$ & $1.39 \mathrm{E}-03$ & & \\
\hline & & & & & & Ra-223 & $3.87 \mathrm{E}-08$ & & \\
\hline & & & & & & $\mathrm{Ra}-224$ & $3.76 \mathrm{E}-16$ & & \\
\hline & & & & & & Ra-225 & $1.36 \mathrm{E}-13$ & & \\
\hline & & & & & & Ra-226 & $2.70 \mathrm{E}-11$ & & \\
\hline
\end{tabular}

${ }^{1}$ Calculated decayed contact dose rate. Rounded to nearest $10 \mathrm{mR} / \mathrm{hr}$ for values to 1000 ; rounded to nearest $100 \mathrm{mR} / \mathrm{hr}$ for values $>1000$ to 10,000 ; rounded to nearest $1000 \mathrm{mR} / \mathrm{hr}$ for values $>10,000$. * Initial contact dose rate assumed to be $1,000,000 \mathrm{mR} / \mathrm{hr}$; **Initial contact dose rate assumed to be $1,010,000 \mathrm{mR} / \mathrm{hr}$.

$$
165 \text { of } 168
$$


Appendix A-4 - Initial and Decayed Radionuclide and Dose Data for Lined Shafts

\begin{tabular}{|c|c|c|c|c|c|c|c|c|c|}
\hline \multirow[b]{2}{*}{ Shaft Number } & \multirow[b]{2}{*}{ Package ID } & \multirow[b]{2}{*}{ Base Year } & \multicolumn{2}{|c|}{ Initial Isotopic Distribution } & \multirow[b]{2}{*}{ Target Year } & \multicolumn{2}{|c|}{ Decayed Isotopic Distribution } & \multirow{2}{*}{$\begin{array}{c}\text { Initial Contact } \\
\text { Dose Rate } \\
(\mathrm{mR} / \mathrm{hr})\end{array}$} & \multirow{2}{*}{$\begin{array}{c}\text { Decayed } \\
\text { Contact Dose } \\
\text { Rate }(\mathrm{mR} / \mathrm{hr})^{1} \\
\end{array}$} \\
\hline & & & Isotope & Activity (Ci) & & Isotope & Activity (Ci) & & \\
\hline & & & & & & Ra-228 & $4.44 \mathrm{E}-16$ & & \\
\hline & & & & & & $\mathrm{Rn}-219$ & $3.82 \mathrm{E}-08$ & & \\
\hline & & & & & & $\mathrm{Rn}-220$ & $3.76 \mathrm{E}-16$ & & \\
\hline & & & & & & $\mathrm{Rn}-222$ & $2.67 \mathrm{E}-11$ & & \\
\hline & & & & & & Th-227 & $3.77 \mathrm{E}-08$ & & \\
\hline & & & & & & Th-228 & $3.81 \mathrm{E}-16$ & & \\
\hline & & & & & & Th-229 & $1.37 \mathrm{E}-13$ & & \\
\hline & & & & & & Th-230 & 8.39E-09 & & \\
\hline & & & & & & Th-231 & $2.93 \mathrm{E}-04$ & & \\
\hline & & & & & & Th-232 & $8.15 \mathrm{E}-16$ & & \\
\hline & & & & & & Th-234 & $2.03 \mathrm{E}-05$ & & \\
\hline & & & & & & T1-207 & $3.81 \mathrm{E}-08$ & & \\
\hline & & & & & & Tl-208 & $1.35 \mathrm{E}-16$ & & \\
\hline & & & & & & T1-209 & $3.00 \mathrm{E}-15$ & & \\
\hline & & & & & & U-233 & $2.52 \mathrm{E}-10$ & & \\
\hline & & & & & & U-234 & $8.24 \mathrm{E}-05$ & & \\
\hline & & & $\mathrm{U}-235$ & $2.97 \mathrm{E}-04$ & & $\mathrm{U}-235$ & $2.97 \mathrm{E}-04$ & & \\
\hline & & & & & & U-236 & $1.50 \mathrm{E}-06$ & & \\
\hline & & & & & & U-237 & $6.90 \mathrm{E}-04$ & & \\
\hline & & & $\mathrm{U}-238$ & $2.05 \mathrm{E}-05$ & & $\mathrm{U}-238$ & $2.05 \mathrm{E}-05$ & & \\
\hline \multirow[t]{12}{*}{232} & S874134 & 1987 & & & 2009 & Ac-225 & $4.30 \mathrm{E}-15$ & 29,000 & 14,000 \\
\hline & & & & & & Ac- 227 & $3.18 \mathrm{E}-11$ & & \\
\hline & & & & & & Ac-228 & $1.70 \mathrm{E}-16$ & & \\
\hline & & & & & & Am-241 & $5.44 \mathrm{E}-02$ & & \\
\hline & & & & & & At-217 & $4.30 \mathrm{E}-15$ & & \\
\hline & & & & & & $\mathrm{Bi}-210$ & $1.01 \mathrm{E}-12$ & & \\
\hline & & & & & & Bi-211 & $3.14 \mathrm{E}-11$ & & \\
\hline & & & & & & $\mathrm{Bi}-212$ & $1.71 \mathrm{E}-16$ & & \\
\hline & & & & & & $\mathrm{Bi}-213$ & 4.29E-15 & & \\
\hline & & & & & & Bi-214 & $5.51 \mathrm{E}-12$ & & \\
\hline & & & & & & Fr-221 & 4.29E-15 & & \\
\hline & & & & & & Fr-223 & $4.33 \mathrm{E}-13$ & & \\
\hline
\end{tabular}

${ }^{1}$ Calculated decayed contact dose rate. Rounded to nearest $10 \mathrm{mR} / \mathrm{hr}$ for values to 1000 ; rounded to nearest $100 \mathrm{mR} / \mathrm{hr}$ for values $>1000$ to 10,000 ; rounded to nearest $1000 \mathrm{mR} / \mathrm{hr}$ for values $>10,000$. * Initial contact dose rate assumed to be $1,000,000 \mathrm{mR} / \mathrm{hr}$; **Initial contact dose rate assumed to be $1,010,000 \mathrm{mR} / \mathrm{hr}$. 
Appendix A-4 - Initial and Decayed Radionuclide and Dose Data for Lined Shafts

\begin{tabular}{|c|c|c|c|c|c|c|c|c|c|}
\hline \multirow[b]{2}{*}{ Shaft Number } & \multirow[b]{2}{*}{ Package ID } & \multirow[b]{2}{*}{ Base Year } & \multicolumn{2}{|c|}{ Initial Isotopic Distribution } & \multirow[b]{2}{*}{ Target Year } & \multicolumn{2}{|c|}{ Decayed Isotopic Distribution } & \multirow{2}{*}{$\begin{array}{c}\begin{array}{c}\text { Initial Contact } \\
\text { Dose Rate } \\
(\mathrm{mR} / \mathrm{hr})\end{array} \\
\end{array}$} & \multirow{2}{*}{$\begin{array}{c}\text { Decayed } \\
\text { Contact Dose } \\
\text { Rate }(\mathrm{mR} / \mathrm{hr})^{1} \\
\end{array}$} \\
\hline & & & Isotope & Activity (Ci) & & Isotope & Activity (Ci) & & \\
\hline & & & & & & $\mathrm{Np}-237$ & $2.30 \mathrm{E}-07$ & & \\
\hline & & & & & & $\mathrm{Pa}-231$ & $1.13 \mathrm{E}-10$ & & \\
\hline & & & & & & $\mathrm{Pa}-233$ & $2.28 \mathrm{E}-07$ & & \\
\hline & & & & & & $\mathrm{Pa}-234$ & 2.09E-08 & & \\
\hline & & & & & & $\mathrm{Pa}-234 \mathrm{~m}$ & $1.61 \mathrm{E}-05$ & & \\
\hline & & & & & & $\mathrm{Pb}-209$ & $4.29 \mathrm{E}-15$ & & \\
\hline & & & & & & $\mathrm{Pb}-210$ & $1.02 \mathrm{E}-12$ & & \\
\hline & & & & & & $\mathrm{Pb}-211$ & $3.14 \mathrm{E}-11$ & & \\
\hline & & & & & & $\mathrm{Pb}-212$ & $1.70 \mathrm{E}-16$ & & \\
\hline & & & & & & $\mathrm{Pb}-214$ & $5.52 \mathrm{E}-12$ & & \\
\hline & & & & & & Po-210 & $1.02 \mathrm{E}-12$ & & \\
\hline & & & & & & Po-211 & $9.57 \mathrm{E}-14$ & & \\
\hline & & & & & & Po-212 & $1.09 \mathrm{E}-16$ & & \\
\hline & & & & & & Po-213 & 4.20E-15 & & \\
\hline & & & & & & Po-214 & $5.52 \mathrm{E}-12$ & & \\
\hline & & & & & & Po-215 & $3.14 \mathrm{E}-11$ & & \\
\hline & & & & & & Po-216 & $1.70 \mathrm{E}-16$ & & \\
\hline & & & & & & Po-218 & $5.42 \mathrm{E}-12$ & & \\
\hline & & & $\mathrm{Pu}-238$ & $7.36 \mathrm{E}-02$ & & $\mathrm{Pu}-238$ & $6.19 \mathrm{E}-02$ & & \\
\hline & & & $\mathrm{Pu}-239$ & 4.63E-02 & & $\mathrm{Pu}-239$ & 4.62E-02 & & \\
\hline & & & $\mathrm{Pu}-240$ & 4.76E-02 & & $\mathrm{Pu}-240$ & 4.75E-02 & & \\
\hline & & & $\mathrm{Pu}-241$ & $2.55 \mathrm{E}+00$ & & $\mathrm{Pu}-241$ & 8.84E-01 & & \\
\hline & & & $\mathrm{Pu}-242$ & $6.59 \mathrm{E}-05$ & & $\mathrm{Pu}-242$ & $6.59 \mathrm{E}-05$ & & \\
\hline & & & & & & Ra-223 & $3.17 \mathrm{E}-11$ & & \\
\hline & & & & & & Ra-224 & $1.70 \mathrm{E}-16$ & & \\
\hline & & & & & & $\mathrm{Ra}-225$ & 4.30E-15 & & \\
\hline & & & & & & Ra-226 & $5.58 \mathrm{E}-12$ & & \\
\hline & & & & & & Ra-228 & $2.01 \mathrm{E}-16$ & & \\
\hline & & & & & & Rn-219 & $3.14 \mathrm{E}-11$ & & \\
\hline & & & & & & Rn-220 & $1.70 \mathrm{E}-16$ & & \\
\hline & & & & & & Rn-222 & $5.52 \mathrm{E}-12$ & & \\
\hline & & & & & & Th-227 & $3.09 \mathrm{E}-11$ & & \\
\hline
\end{tabular}

${ }^{1}$ Calculated decayed contact dose rate. Rounded to nearest $10 \mathrm{mR} / \mathrm{hr}$ for values to 1000 ; rounded to nearest $100 \mathrm{mR} / \mathrm{hr}$ for values $>1000$ to 10,000 ; rounded to nearest $1000 \mathrm{mR} / \mathrm{hr}$ for values $>10,000$. * Initial contact dose rate assumed to be $1,000,000 \mathrm{mR} / \mathrm{hr}$; **Initial contact dose rate assumed to be $1,010,000 \mathrm{mR} / \mathrm{hr}$.

$$
167 \text { of } 168
$$


Appendix A-4 - Initial and Decayed Radionuclide and Dose Data for Lined Shafts

\begin{tabular}{|c|c|c|c|c|c|c|c|c|c|}
\hline \multirow[b]{2}{*}{ Shaft Number } & \multirow[b]{2}{*}{ Package ID } & \multirow[b]{2}{*}{ Base Year } & \multicolumn{2}{|c|}{ Initial Isotopic Distribution } & \multirow[b]{2}{*}{ Target Year } & \multicolumn{2}{|c|}{ Decayed Isotopic Distribution } & \multirow{2}{*}{$\begin{array}{c}\text { Initial Contact } \\
\text { Dose Rate } \\
(\mathrm{mR} / \mathrm{hr})\end{array}$} & \multirow{2}{*}{$\begin{array}{c}\text { Decayed } \\
\text { Contact Dose } \\
\text { Rate }(\mathrm{mR} / \mathrm{hr})^{1} \\
\end{array}$} \\
\hline & & & Isotope & Activity (Ci) & & Isotope & Activity (Ci) & & \\
\hline & & & & & & Th-228 & $1.72 \mathrm{E}-16$ & & \\
\hline & & & & & & Th-229 & $4.30 \mathrm{E}-15$ & & \\
\hline & & & & & & Th-230 & $1.31 \mathrm{E}-09$ & & \\
\hline & & & & & & Th-231 & $2.41 \mathrm{E}-07$ & & \\
\hline & & & & & & Th-232 & $2.88 \mathrm{E}-16$ & & \\
\hline & & & & & & Th-234 & $1.61 \mathrm{E}-05$ & & \\
\hline & & & & & & Tl-207 & $3.12 \mathrm{E}-11$ & & \\
\hline & & & & & & Tl-208 & $6.12 \mathrm{E}-17$ & & \\
\hline & & & & & & T1-209 & $9.44 \mathrm{E}-17$ & & \\
\hline & & & & & & $\mathrm{U}-233$ & 7.94E-12 & & \\
\hline & & & $\mathrm{U}-234$ & $4.46 \mathrm{E}-06$ & & U-234 & $8.68 \mathrm{E}-06$ & & \\
\hline & & & $\mathrm{U}-235$ & $2.43 \mathrm{E}-07$ & & $\mathrm{U}-235$ & $2.44 \mathrm{E}-07$ & & \\
\hline & & & $\mathrm{U}-236$ & $2.50 \mathrm{E}-07$ & & $\mathrm{U}-236$ & $2.81 \mathrm{E}-07$ & & \\
\hline & & & & & & U-237 & $2.17 \mathrm{E}-05$ & & \\
\hline & & & $\mathrm{U}-238$ & $1.63 \mathrm{E}-05$ & & $\mathrm{U}-238$ & $1.63 \mathrm{E}-05$ & & \\
\hline
\end{tabular}





\section{Appendix E}

\section{Letter and Questionnaire \\ Regarding \\ Remote-Handled TRU Waste Storage at LANL}

H7-79-176

April 17, 1979

Page E-1 
This page intentionally left blank.

Page E-2 


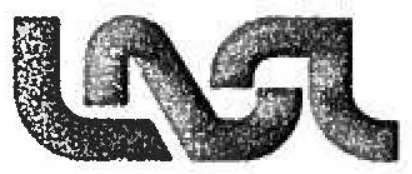

University of California

LOS ALAMOS SCIENTIFIC LABORATORY

Post Office Box 1683 Los Alamos, New Mexico 87545

In repiy refer to: $\quad H 7-79-176$

April 17, 1979

Mai! stop: 517

Ms. R. Monte Greinetz

TWSO

Rockwell International

Rocky Flats Plant

P. 0. Box 464

Golden, Colorado 80401

Dear Ms. Greinetz:

REFRENCE: LETTER, GREINETZ AND BENNETT TO WARREN, 79-RF-0705, REMOTE HANDLED STORED TRU WASTE, DATED APRIL 10, 1979

Enclosed as requested is the "corrected" questionnaire regarding the storage of remote handled TRU-waste at LASL. Also included is a drawing of the LASL storage cask and a copy of a paper describing the packaging of the LASL hot-cell waste. It should be noted that many of the dimensions I have given you are approximate or

"rounded-off" values, and some small variation from the actual

value may occur. We are assuming as of this time that we will

continue use of these casks through the foreseeable future.

Please let me know if there is additional information I can provide you on this matter.

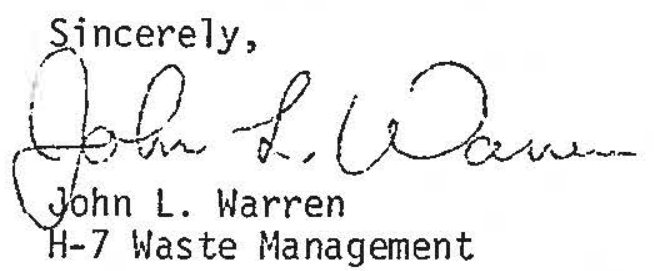

JLW: IW

Enc: $a / s$

XC W/Enc: T. Keenan, H-7, MS -518

H. Jordan, H-DO, MS -400

ISD-5, MS- 150 


\subsection{Types of Containers}

1.1 Long Metal Cylinder, Concrete Lined.

Size: $2 \mathrm{ft}$. diameter $\times 14.5 \mathrm{ft} . \pm .5 \mathrm{ft}$. Tong

Average filled weight: 4,000 lbs. \pm 400 lbs. (mostly concrete)

Volume: $45 \pm 2 \mathrm{ft} .3$

Inside the cylinder is a smaller metal cylinder 0.8 - $1 \mathrm{ft}$. diameter $x 12-13 \mathrm{ft}$. long which is centered inside the large cylinder and surrounded by concrete. Concrete wall thickness is 26 inches on sides and at least $1 \mathrm{ft}$. on bottom and top. The concrete is not removable without breaking it.

Inside the inner cylinder are $12-13$ one gallon packages (paint type cans with pressed lids). Each package is inside a $11 / 8$ inch plastic overpack, having a pressed lid. The plastic overpack is sealed inside two plastic bags.

\subsection{Description of Container Storage and Retrievability}

\subsection{Long Metal Cylinders}

No barrier between cylinder and soil (soft rock tuff) exists. The tuff is soft volcanic rock. Rebars protrude from cylinder and can be hooked to a small crane.

\subsection{Waste Form Characterization}

3.1 Long metal cylinders contain $\beta-\gamma$ TRU waste. The packages inside the cylinders contain hot cell wastes such as rags, rubber gloves, small hand tools, small amounts of liquids absorbed on vermiculite, and irradiated uranium fuel elements.

Number of long cylinders filled as of April 1979 is 2. Just started using them in 1978.

Total weight is about 8,000 lbs., including cask weight. Total volume is about $100 \mathrm{cu}$. ft., including cask volume. Radiation level at surface of cylinder is estimated to be $>100 \mathrm{R} / \mathrm{hr}$ and $<1000 \mathrm{R} / \mathrm{hr}$.

Radiation level is not measured, because inside cylinder is filled at storage site.

Organic and water content of filled cylinder is unknown. (Water content is extremely small; organic < 50 lbs./cask.)

There are currently no plans to assay contents. Other gas producing material is unknown.

Total Pu content is $0.150 \mathrm{~kg}$ Pu per cask for the 2 now filled. Pu content is determined by an accounting technique.

Major Nuclides Besides Pu are: $u^{235}-.37 \mathrm{~kg} /$ cask average for 2 now filled. Nuclide amounts are/were determined by: What type of measurement. Not measured, determined by an accounting technique. 
Analyses of representative samples Data Files yes

Assay Programs are in progress no no yes months to obtain data. yes $X$ no

4.0 Forecast Through Year 2000.

4.1 Long Cylinders, Cement Lined.

At rate of 5 cylinders per year from LASL and 5 cylinders per year from Sandia which will be stored at LASL and which will be the same size and have approximately the same contents.

Total weight will be: 840,000 Tbs. $\pm 50 \%$

Total volume will be: $9,450 \mathrm{cu}$. ft. $\pm 50 \%$

4.2 Contract Handled Stored TRU Waste which will Become Remote Handled By Year 2000. None

Due to americium ingrowth and other decay products, what weight and volume of contact handled waste will require remote handling by the year 2000?

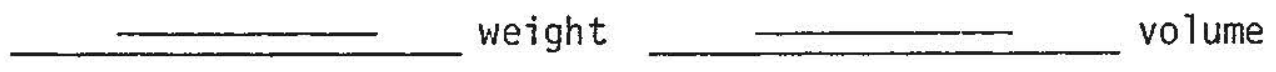

of the above amounts, what weight and volume will contain either organics, water, or gas producers?

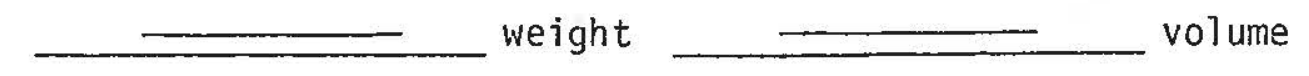

\subsection{Additional Comments}

Please comment on any additional information which might be helpful for determining WIPP waste acceptance criteria or the type of processing necessary before storage in a deep geological repository.

\subsection{Information Sources}

John Warren, Section Leader, Solid Waste Disposal Operations, LASL 


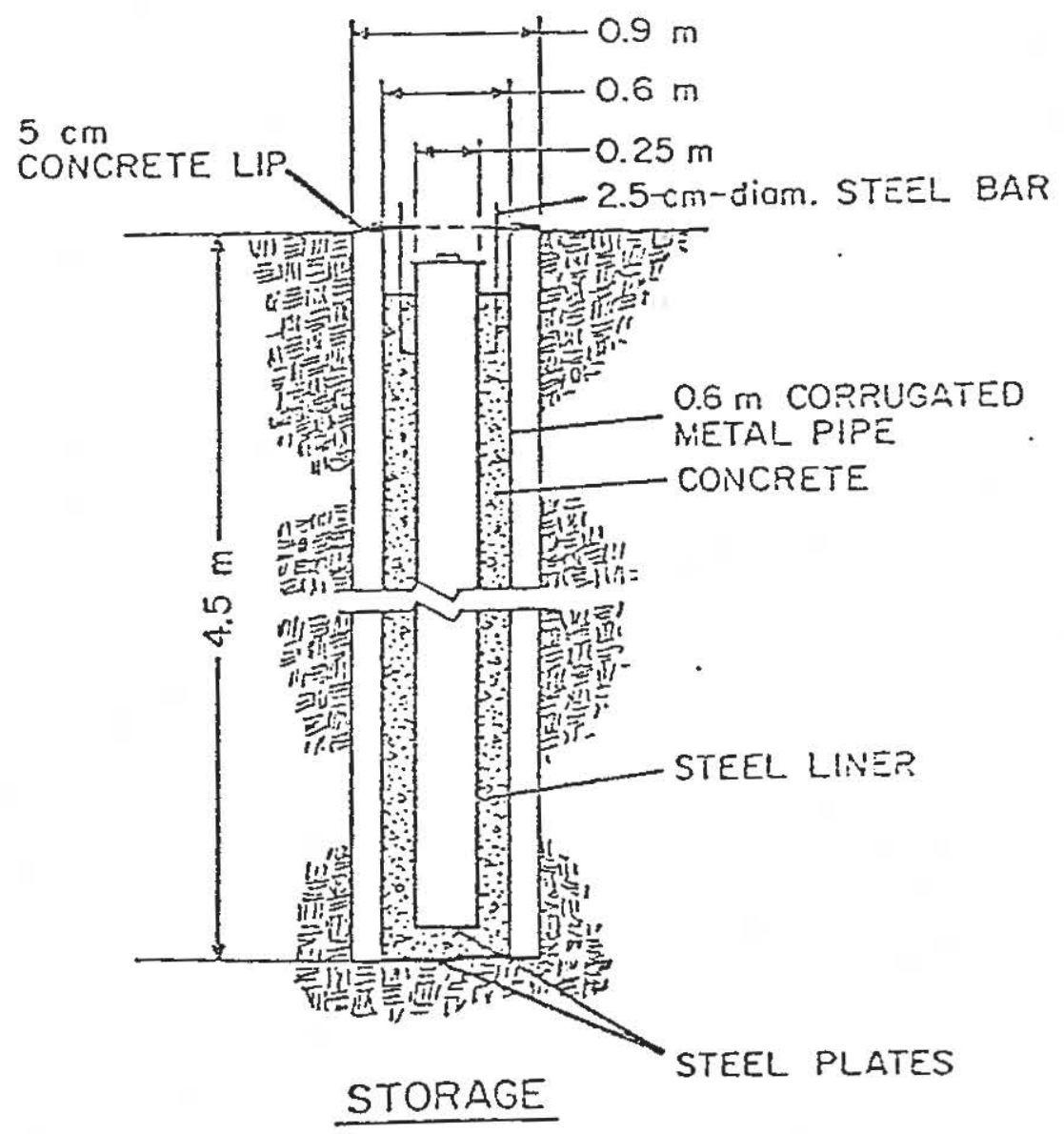

LAS! Storage Cask for Beta-Gamma TRU-Hasta. April, 1979

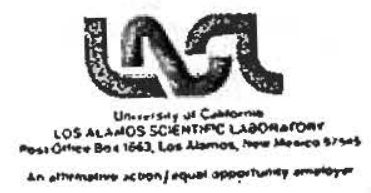




\title{
DISPOSABLE ALPHA-GAMMA TRANSFER CONTAINER
}

M. E. LAZARUS and C. D. MONTGOMERY

Los Alamos Scientific Laboratory

Los Alamos, New Mexico 87544

KEYHORDS: alpha.gamma, transfer

\author{
IECHNICAL NOTE
}

A variety of systems for transferring materials into and out of alpha-gamma cells and containment boxes are in use today. The method developed by Wilson and Thor ${ }^{2}$ for the Wing 9 Hot Cell Facility at the Isos Alamos Scientific Laboratory has been in use for over eight years and is shown in Fig. 1. The stainless-steel cans for the "Seven Inch Transfer System" have given satisfactory performance, but they are too costly to be considered as disposable containers.

Contaminated wastes have been removed from the containment boxes using a modification of this container. ${ }^{2}$ Although the method of waste removal was effective, it was quite time consuming. With the generation of larger quantities of contaminated wastes from metallography operations, it became mandatory that a disposable container be developed.

A plastic container (Fig. 2) was designed to be used interchangeably with the metal cans on the seven-inch-diameter "double cover" system at Los Alamos. The plastic units which have been in service since February 1970 are performing satisfactorily. The container has a "one time" seal (Fig. 3) which is distorted when it is forced against the alpha containment box.

The bucket portion of the can is made of polypropylene and has a holding ridge which mates with a V-shaped groove in the lid. The lid is made of polycarbonate plastic and requires $200 \mathrm{lb}$ of force to remove it from the bucket. The plastics were chosen on the basis of strength, cost, and ease of molding. Radiation resistance was not a consideration since materials are disposed of in the contaminated waste pit immediately after packaging. The metal shell, shown in Fig. 3, is used to provide support and to center the plastic container when effecting the seal to the alpha box.

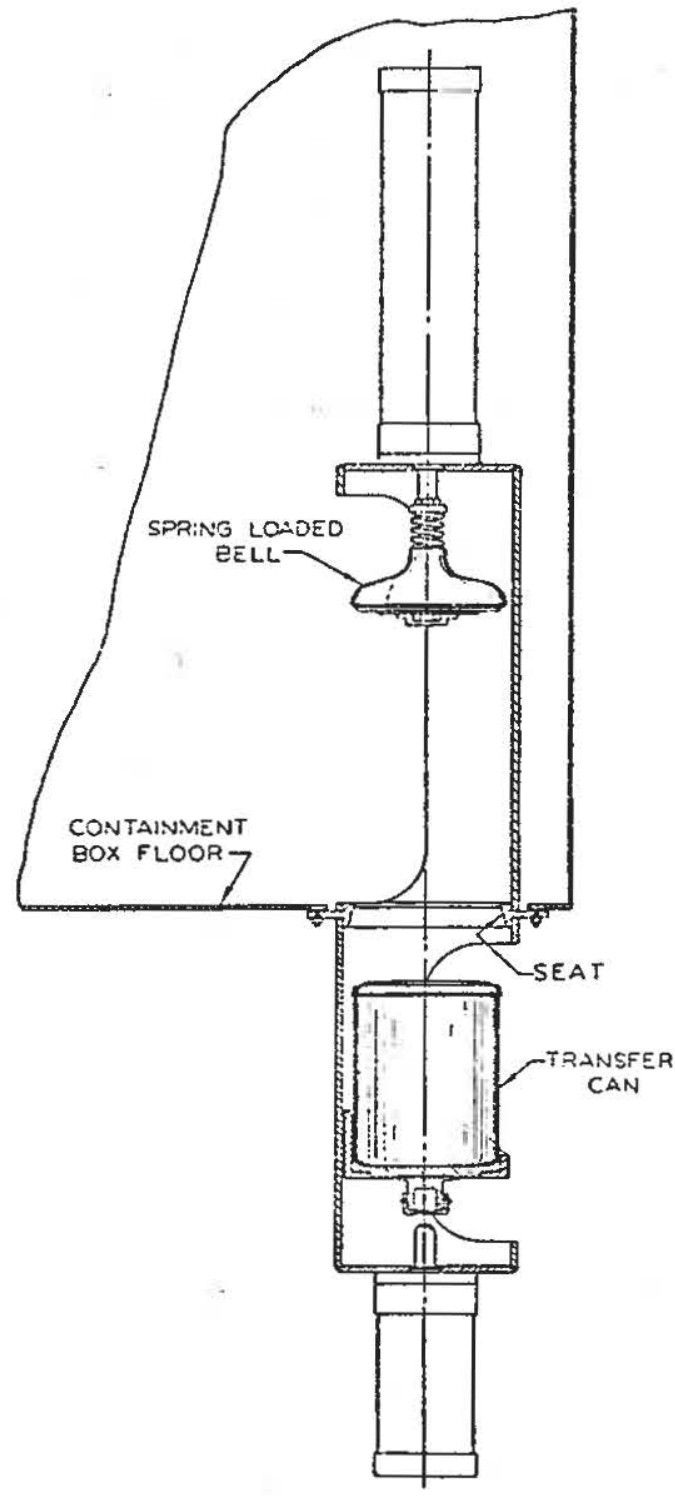

Fig. 1. 7-í. izrefer mechanism. 

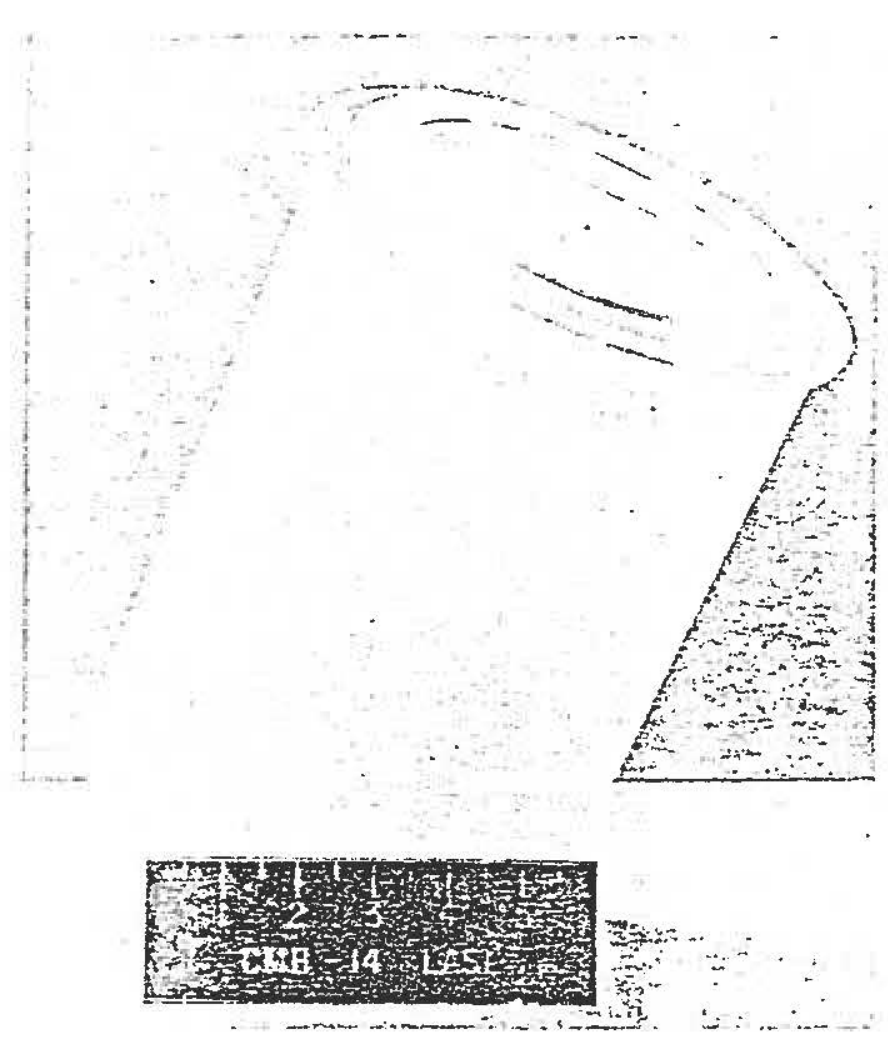

Fig. 2. Plastic transfer container.

\section{ACKNOWLEDGMENTS}

The authors would like to acknowledge the design assistance from $L$. R. Ebaugh, T. Romanik, and P. F. Hartshorne. The help from F. A. Faussone in providing the experimental containers is also appreciated. This work was performed under the auspices of the U.S. Atomic Energy Commission.

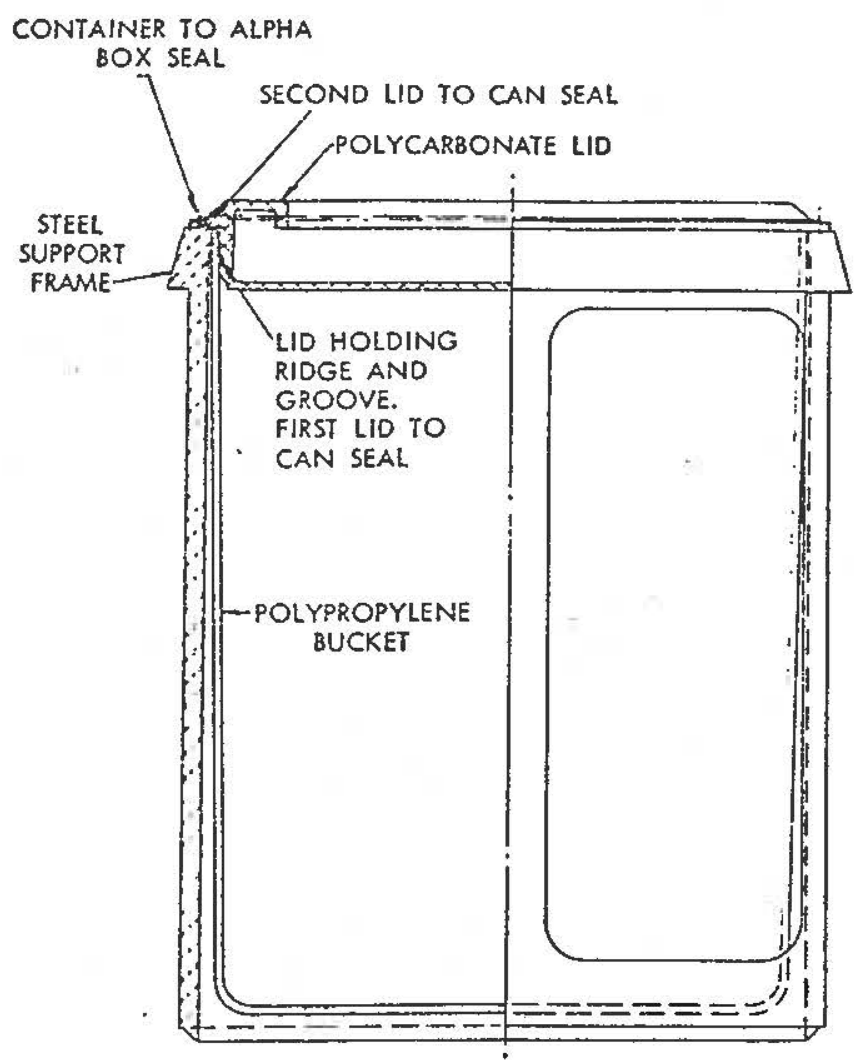

Fig. 3. Cutaway of disposable 7-in. alpha container and support.

\section{REFERENCES}

1. M. T. WLLSON and L. L. THORN, "Alpha Gamma Transfer Systems," Proc. 9th Conf. Hot Lab. Equip., 344 (November 1961).

2. J. W. SCHULTE, "Mathods Used in the United States for Transferring Materials Through Radiation Barriers." Intern. Symp. on Working Methods in High Activity Hot Laboratories, pp. 531, 538, 540, 541, European Nuclear Energy Agency (June 1965). 


\section{BETA-GAMMA TRU SHAFTS \\ 1971 - Sept, 1982}

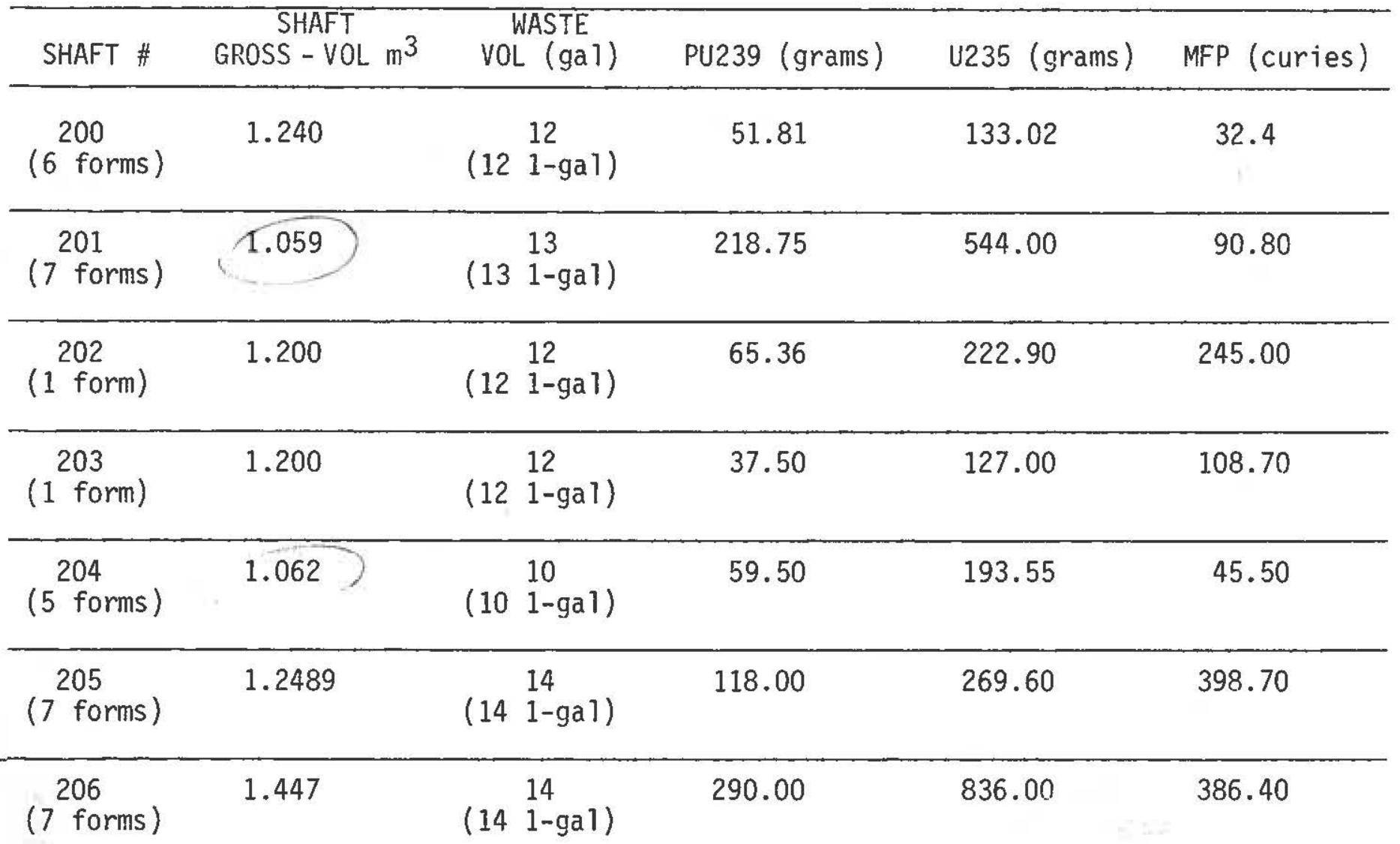

\begin{tabular}{cccccc}
\hline $\begin{array}{c}\text { (5) forms }) \\
\text { (7 forms })\end{array}$ & 1.345 & $(11$ 11-gal $)$ & $\$ 1.42$ & 5.68 & $13.33<$ \\
\hline
\end{tabular}

\begin{tabular}{|c|c|c|c|c|c|}
\hline $\begin{array}{l}\operatorname{leg} \\
\text { (5 forms) }\end{array}$ & 1.342 & (12 $\begin{array}{l}12 \\
1 \text {-gal })\end{array}$ & 0.40 & 2.00 & 2.90 \\
\hline $\begin{array}{l}210 \\
(4,0 \mathrm{~ms})\end{array}$ & 1.342 & (12 $\begin{array}{l}12 \\
1-\text { gal })\end{array}$ & 0.40 & 1.60 & 0.92 \\
\hline $\begin{array}{l}211 \\
\text { (5 forms) }\end{array}$ & 1.3395 & (12 $\begin{array}{l}12 \\
1-g a 1)\end{array}$ & 6.96 & 27.60 & 17.96 \\
\hline
\end{tabular}

* $212 \quad 2.100 \quad 75 \mathrm{ft}^{3} \quad 200.00$.814 006030.00 Curies - no MFP (1 form) Lampre reactor vessel+parts 1081.2

$\begin{array}{cccccc}213 & 0.8496 & 8 & 49.93 & 234.24 & 151.60 \\ (4 \text { forms }) & (81-\text { ga } 1) & & & \end{array}$

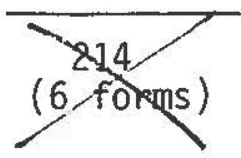

0.8496

10

(4 1-gal/3 2-gal)

2.40


BETA-GAMMA TRU SHAFTS con't.

page 2

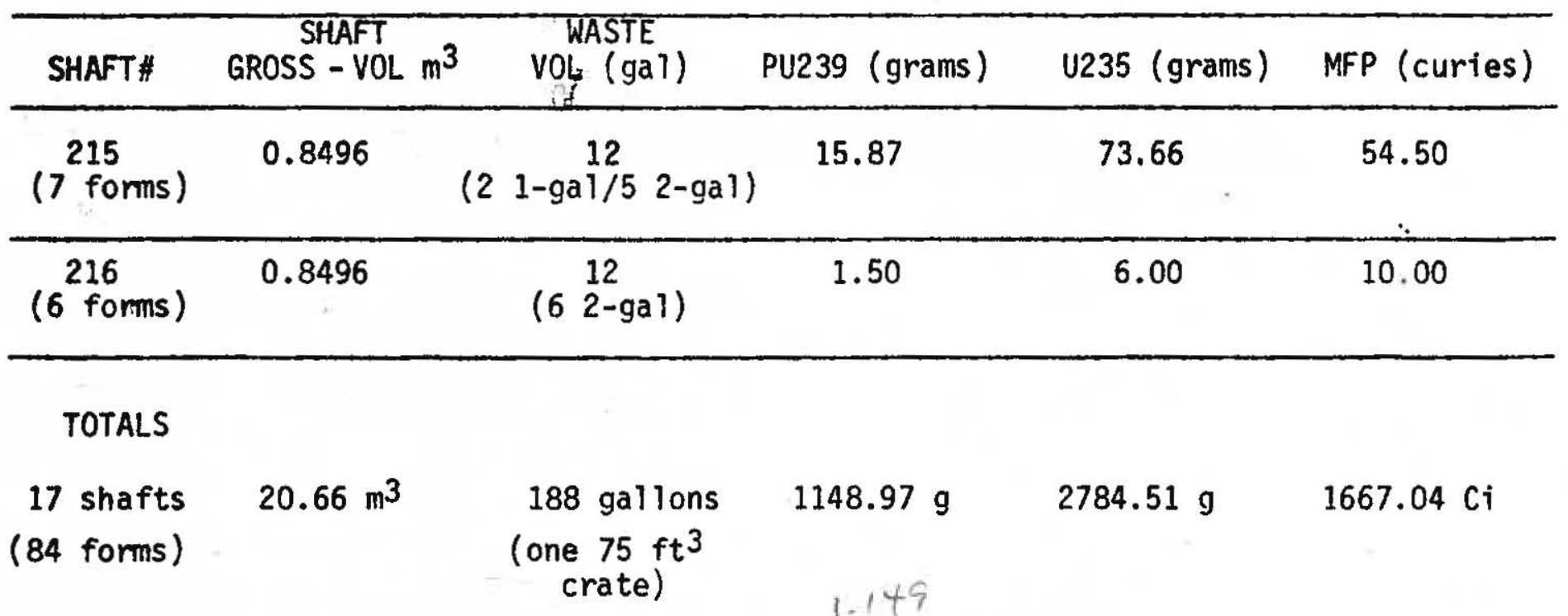

Through 9/30/82:

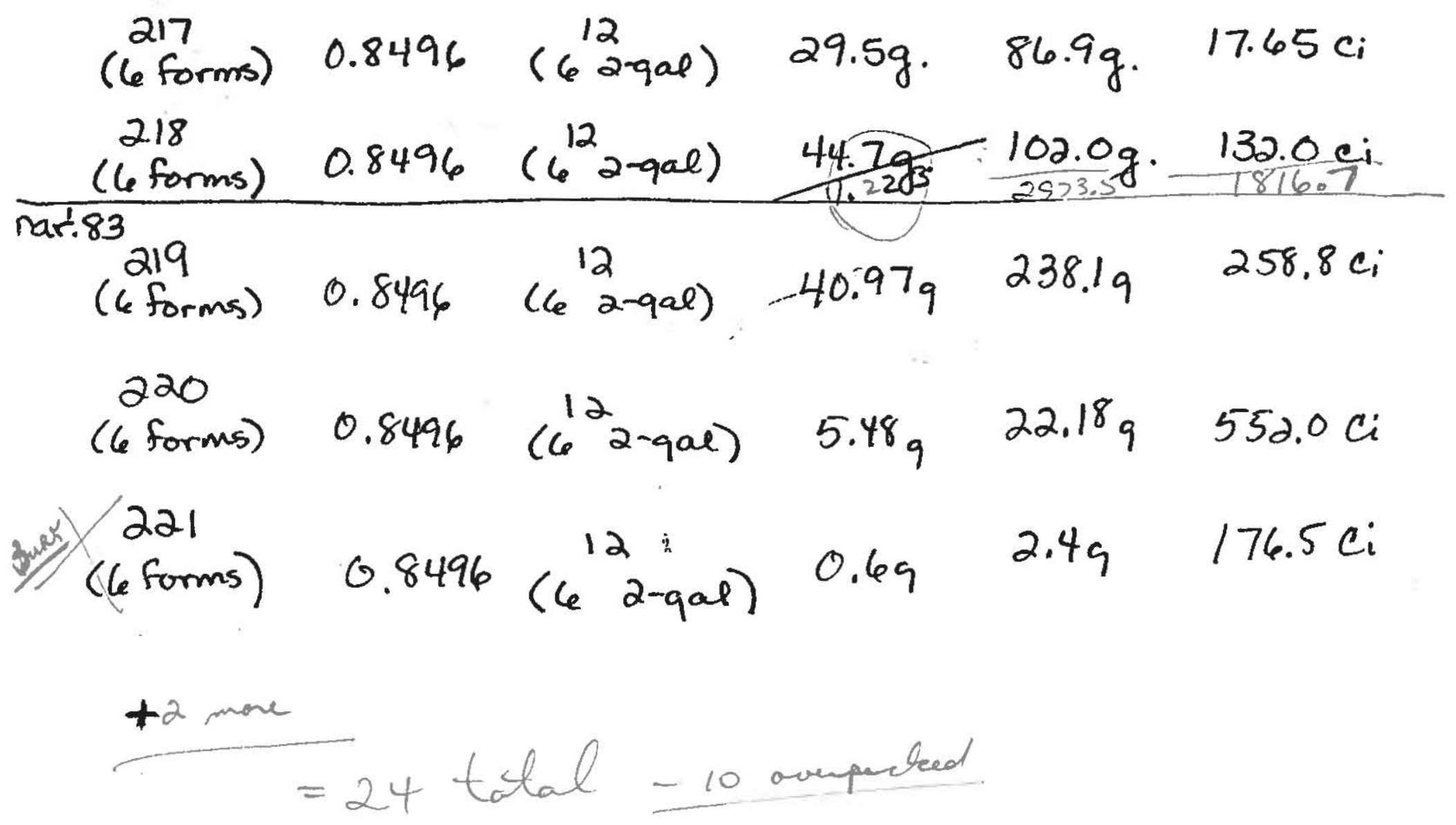





\title{
Appendix F
}

\author{
Disposal Log Book \\ for \\ Shafts 200-232 \\ TA-54 Material Disposal Area G
}

Page F-1 
This page intentionally left blank.

Page F-2 


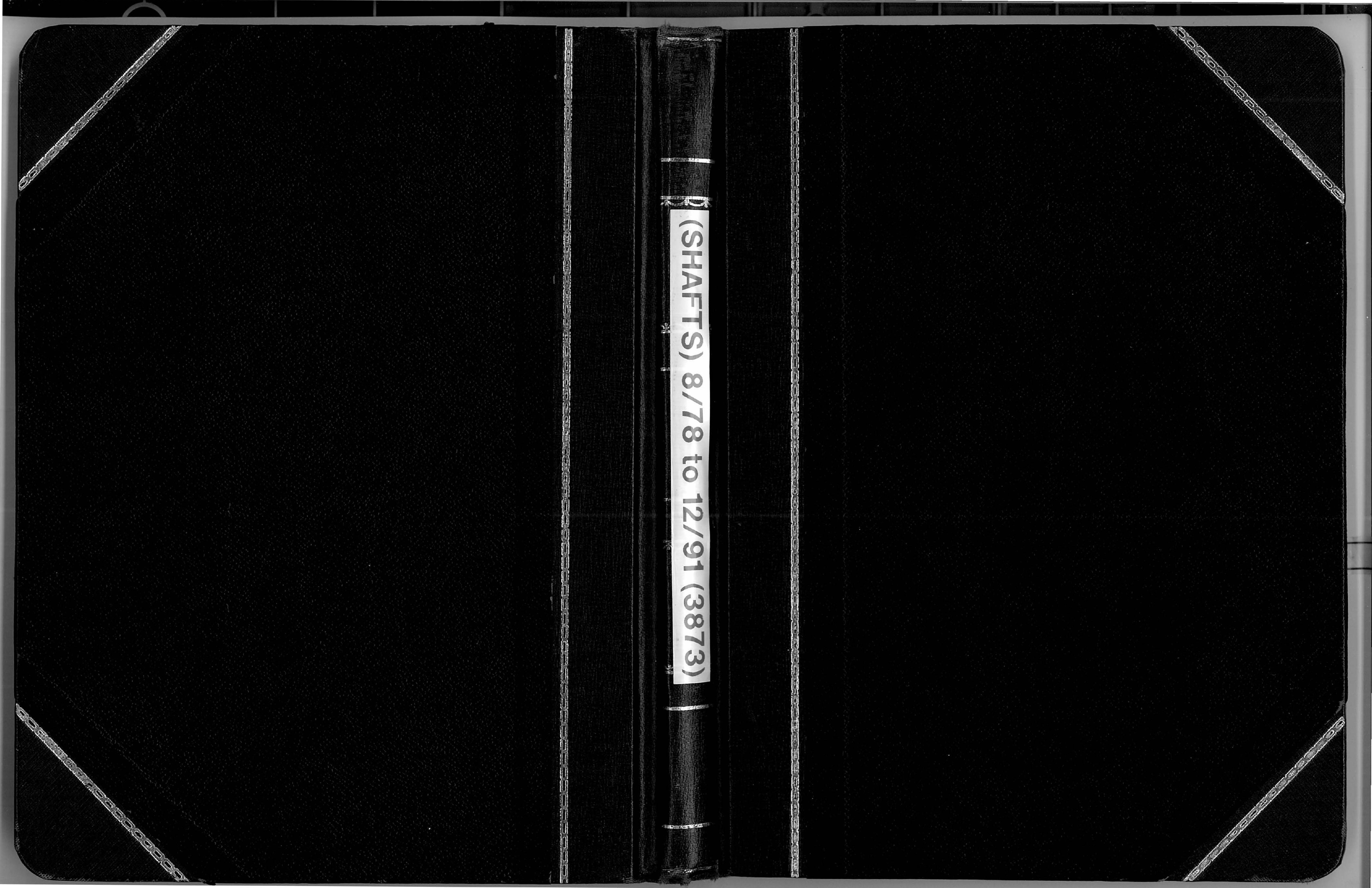




\section{S -3873}

INSTRUCTIONS FOR USING THIS NOTEBOOK

Fill in this information:

THIS NOTEBOOK IS USED BY:

GROUP: STARTING DAT

DATE EACH DAY'S ENTRY SIGN EACH DAY'S ENTRY RECORD ALL EXPERIMENTAL WORK RECORD ALL NEW CONCEPTS

AS SOON AS A CLASSIFIED ENTRY IS MADE IN THIS NOTEBOOK IT MUST BE PROPERLY MARKED AND SAFEGUARDED AS DESCRIBED IN THE "OFFICE PROCEDURES MANUAL".

This book is an official record for which you are responsible. Its purpose is to assist you in keeping accurate
record of technical work, calculations, experiments, ideas, etc., and to provide the United States Government with a means of reviewing our work, both while it is in progress and when it is completed, and, if necessary, to prove in court that work was done

IT IS RECOMMENDED THAT THE PROCEDURE OUTLINED BELOW BE FOLLOWED WHEN USING 1. Record all experimental work, calculations, sketches, and the like DIRECTLY in this book 2. Make successive entries on consecutive pages.
3. Do not start a new page until the previous one is full or has been so marked that no additional entries can be made on it. . the end of each day sign and date the material you have entered in the book on that day.
5.

5. Have the entries in the book witnessed and dated, preferably by someone who has observed and understood the

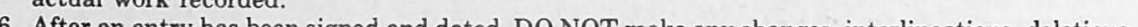
Make a new entry for corrections and refer back to the original entry. . single line through the material to be deleted.
8. Record everything - better too much than too little. 8. Record everything-better too much than
9. Do not remove any pages from this book. It is the responsibility of the one using this book to see that it is marked with the correct classification and
properly safeguarded as soon as a classified entry is made in it.

This notebook is the property of the U. S. Government-if you terminate your employment at LASL you must turn this notebook over to your group office or must send it to the ISD-5 Records Center.

WHEN THIS NOTEBOOK IS COMPLETE, SEND IT TO: LASL RECORDS CENTER ISD-5, MS 322 .

University of California, Los Alamos Scientific Laboratory, Los Alamos, NM 87545 


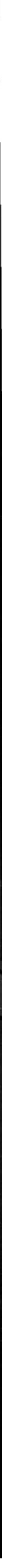




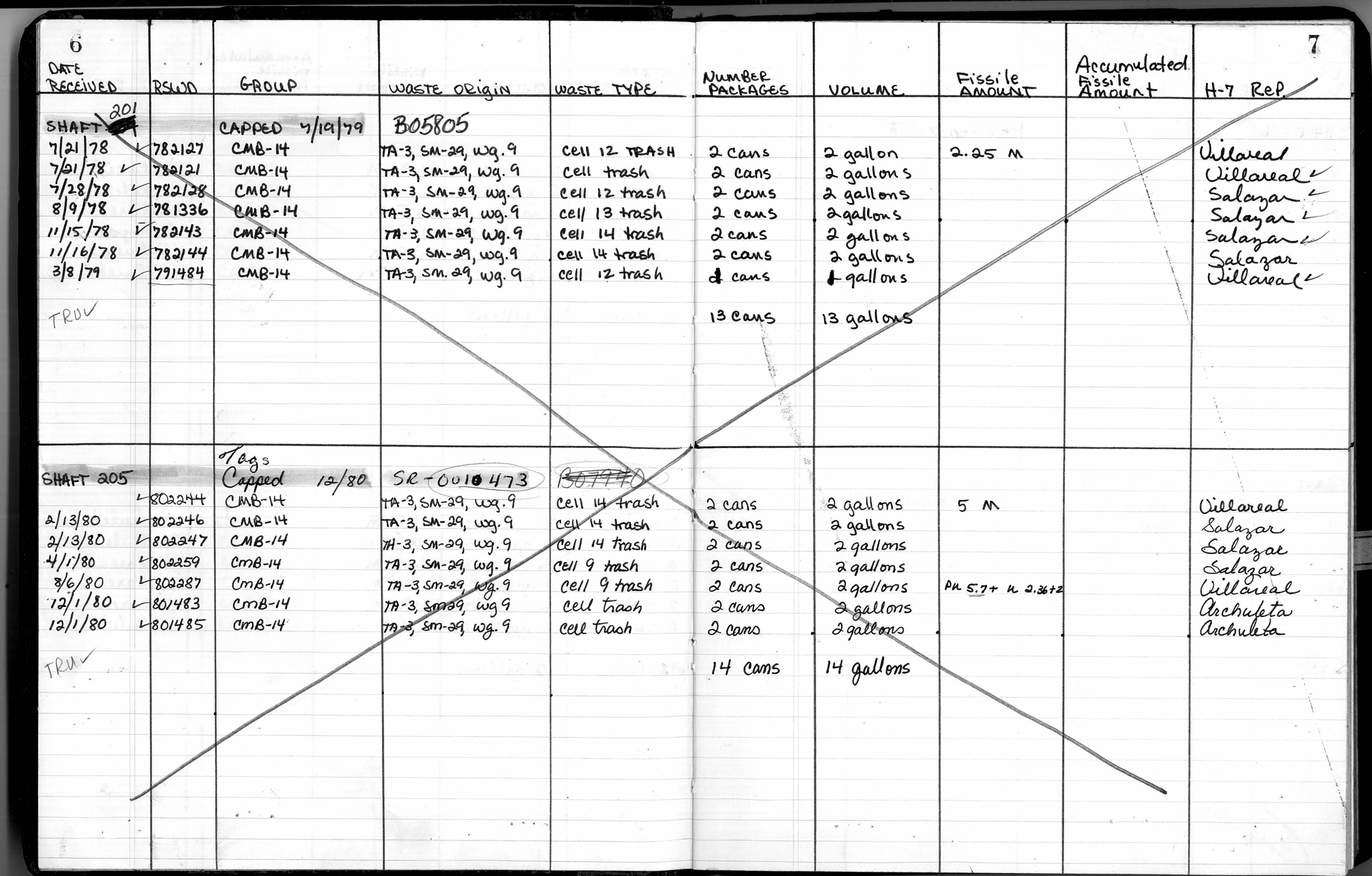




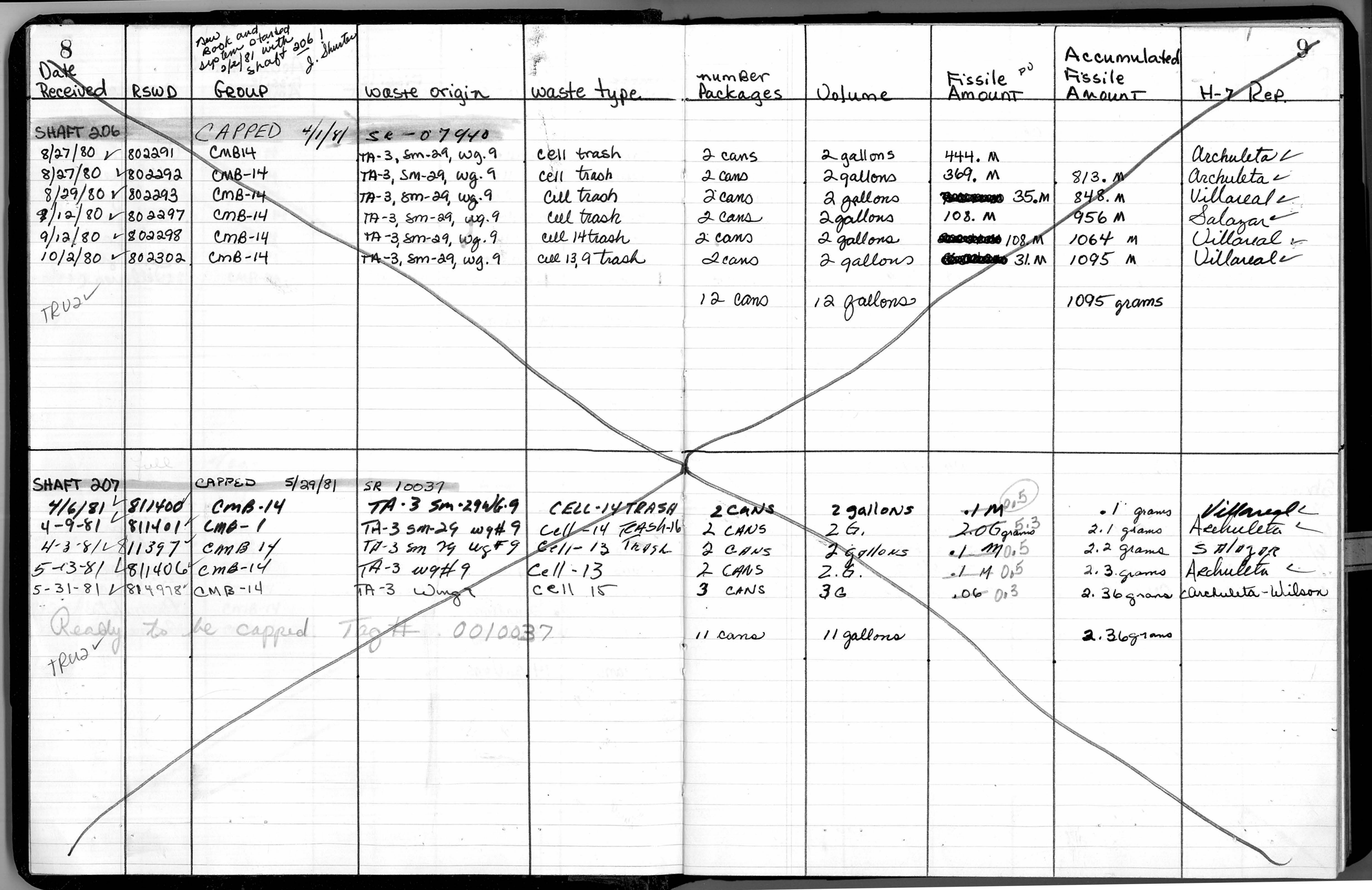




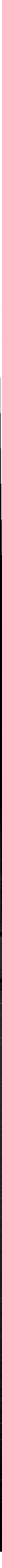




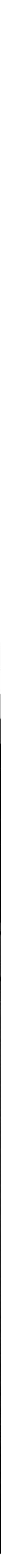




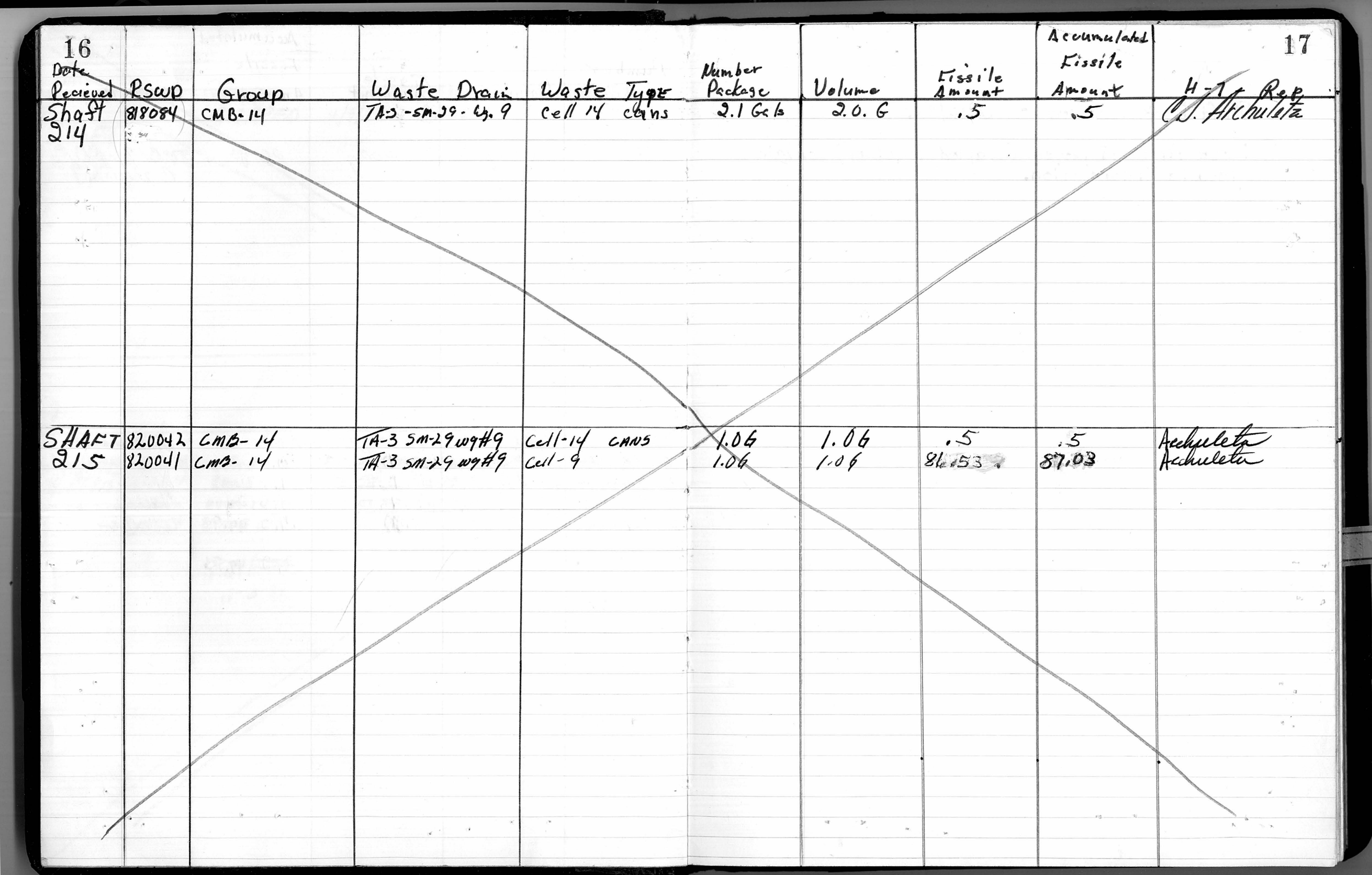


Shaft book recopied on 2/12/82.

These first 18 pages (stapled together) contain

invalid information. 


\begin{tabular}{|c|c|c|c|c|c|c|c|c|c|}
\hline $\begin{array}{c}20 \\
\text { PATE } \\
\text { RECEIVED }\end{array}$ & RSWD & GROUP & WASTE ORIGIN & Waste TyPe & \# OF PACKALES & VoLUme & $\begin{array}{l}\text { FISSILE } \\
\text { AMOUNT }\end{array}$ & $\begin{array}{l}\text { ACCUMULATED } \\
\text { FISSILE T } \\
\text { AMOUNT }\end{array}$ & H-7 REP. \\
\hline \multicolumn{2}{|c|}{ Shaft 200} & capped 4-14-81 & $B 08639$ & & & & & & \\
\hline $2 / 17 / 81$ & 811390 & $\mathrm{CMBl}$ & TA-3, SM29, WING & CELL 14 FUEL CANS & 2 CANS & 2 GALLONS & 48.05 & & Villareal \\
\hline $10 / 3 / 80$ & 811471 & $C M B$ & SAME & CELL 14 TRASH CANS & 2 CANS & 2GALLNS & 34.0 & & Villareal \\
\hline $10 / 3 / 80$ & 811473 & $C M B I$ & SAME & CELL 14 TRASH CANS & 2 CANS & 2 GALLONS & 54.0 & & Villareal \\
\hline $2 / 17 / 81$ & 811387 & $C M B \mid$ & SAME & CELC 14 FUEL CAN & 2 CANS & 2GALCONS & 28.28 & & Villareal \\
\hline $4 / 3 / 81$ & 811396 & $C M B / 4$ & SAME & CELL I 3 WASTE & 2 CANS & 2 GALLONS & 0.5 & & SALAZAR \\
\hline \multirow[t]{6}{*}{$4 / 6 / 81$} & 811398 & $\mathrm{cmB} / 4$ & SAME & CELLI3 WASTE & 2 CANS & 2 GALLONS & 20.0 & 184.83 & Villareal \\
\hline & & & & & 12 CANS & 12 GAUONS & & & \\
\hline & & & & & & & & & \\
\hline & & & & & & & & & \\
\hline & & & & & & & & & \\
\hline & & & & & & & & & \\
\hline \multicolumn{2}{|c|}{ Shaft 201} & capped $7=19-79$ & $B 05805$ & & & & & & \\
\hline $8 / 9 / 78$ & 794221 & $\mathrm{CmB/4}$ & TA-3, 5 M29, WING 9 & CELL 13,15 FUEL & 2 CANS & 2 GALIONS & 511.0 & & SALAZAR. \\
\hline $7 / 21 / 78$ & 794220 & $C M B / 4$ & SAME & CELL TRASH & 2 CANS & 2GALONS & 215.0 & & Villareal \\
\hline $11 / 15 / 78$ & 794219 & $C M B I$ & SAME & CELL 14 TRASH & 2 CANS & 2 EALLONS & 6.5 & & SALAZAR \\
\hline $7 / 28 / 78$ & 794215 & $C M B I$ & SAME & CELC 12 TRASH & 2CANS & 2 GALLONS & 2.5 & & SAIAZAR \\
\hline $3 / 8 / 79$ & 791484 & $\mathrm{CMB}$ & SAME & CELL 12 FUEL CAN & ICAN & IGACLON & 4.0 & & Villareal \\
\hline $11 / 16 / 78$ & 794218 & $\mathrm{cmBl}$ & SAME & CELL 14 FUEL CANS & 2CANS & 2 GALLONS & 12.5 & & SAIAZAR \\
\hline \multirow[t]{10}{*}{$7 / 21 / 78$} & 794216 & $C M B \mid$ & SAME & CELL 12 TRASH & 2CANS & 2 GALLONS & 11.25 & 762.75 & Villareal \\
\hline & & & & & 13 CANS & 13 GALIONS & & & \\
\hline & & & & & & & & & \\
\hline & & & & & & & & & \\
\hline & & & & & & & & & \\
\hline & & , & & & & & & & \\
\hline & & & & & & & & & \\
\hline & & & & 1 & 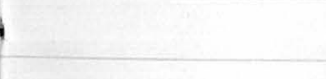 & & & & \\
\hline & & & & & & & & & \\
\hline & & & & & & & & & \\
\hline
\end{tabular}




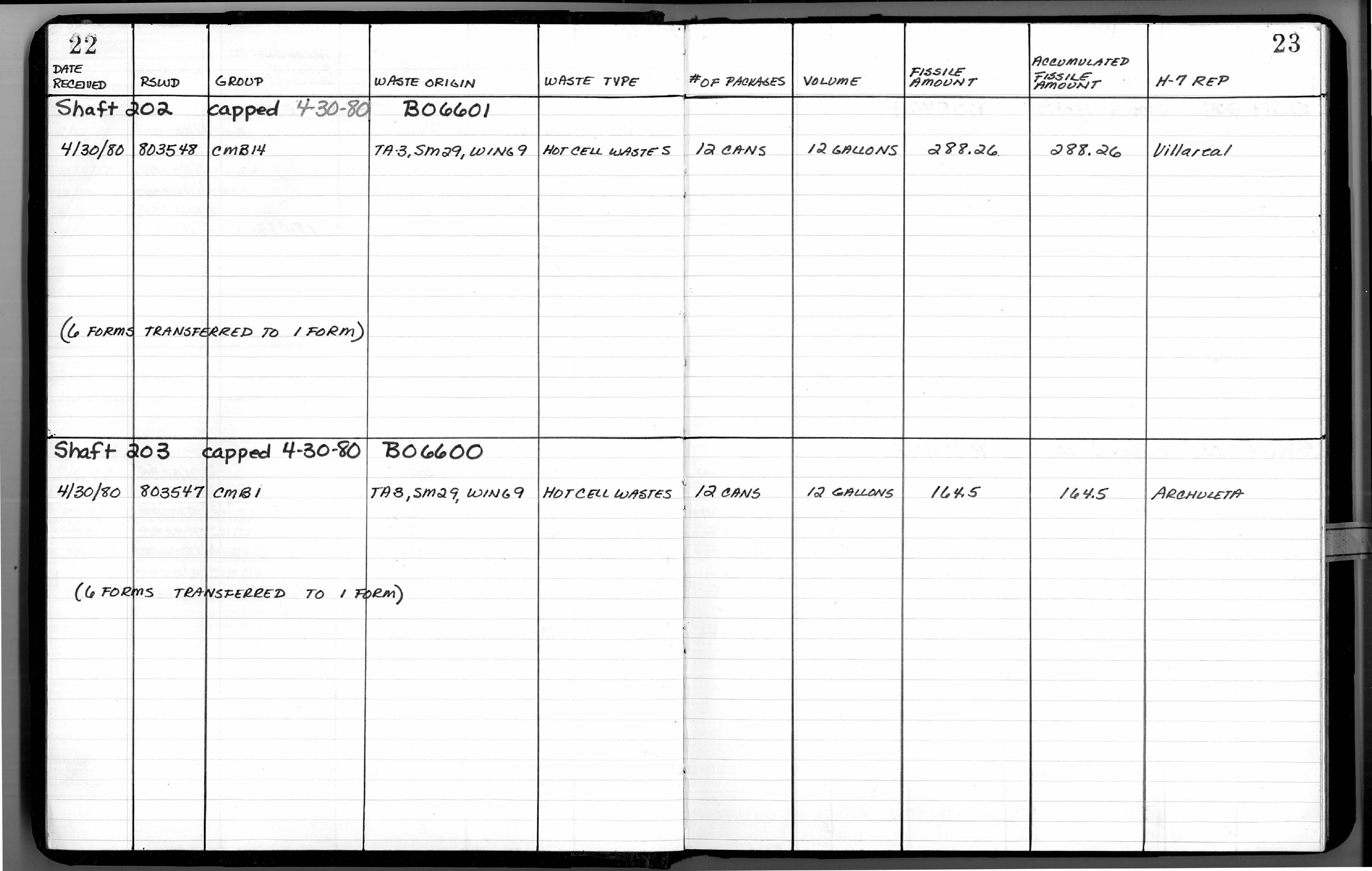




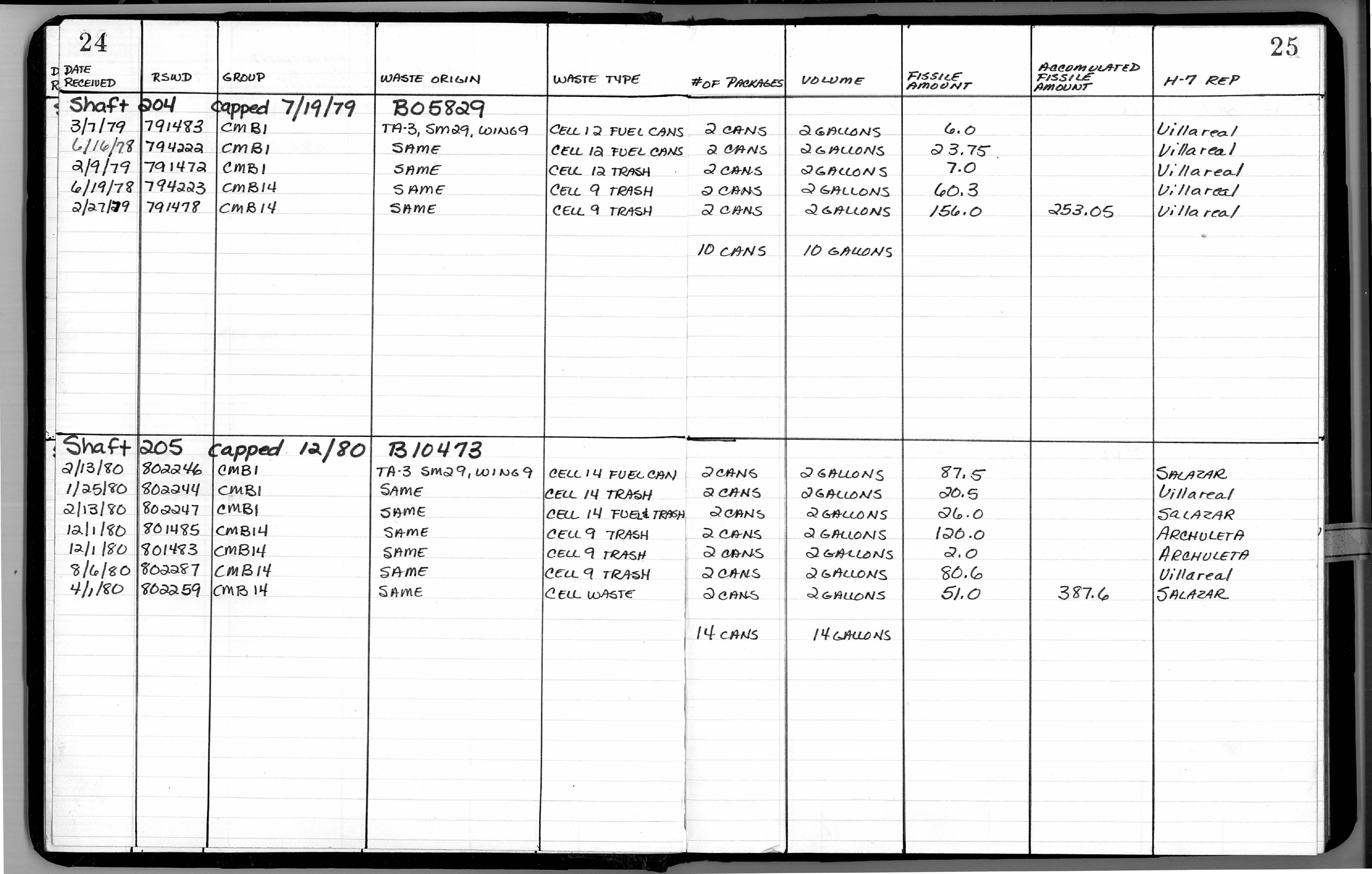




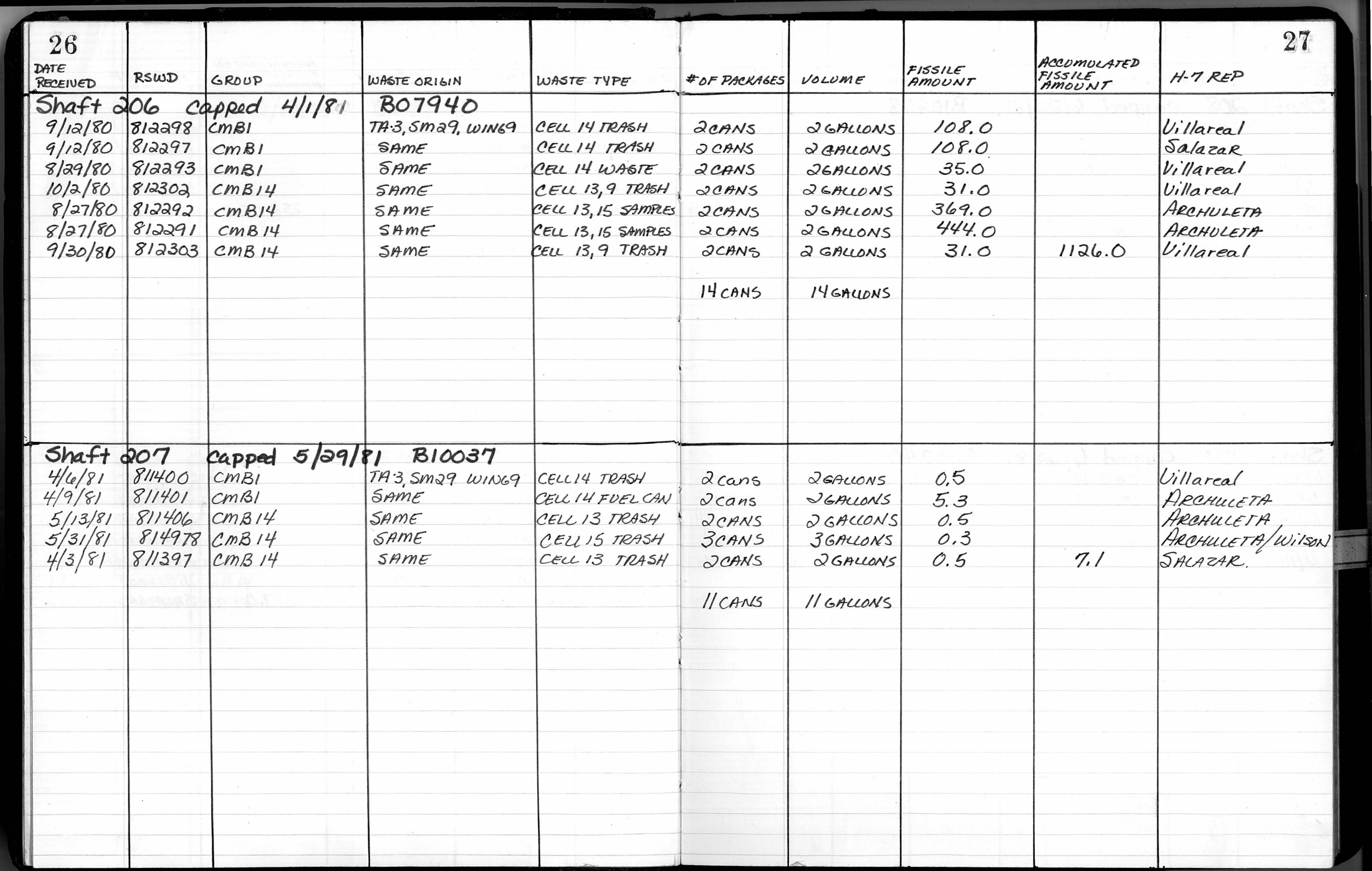




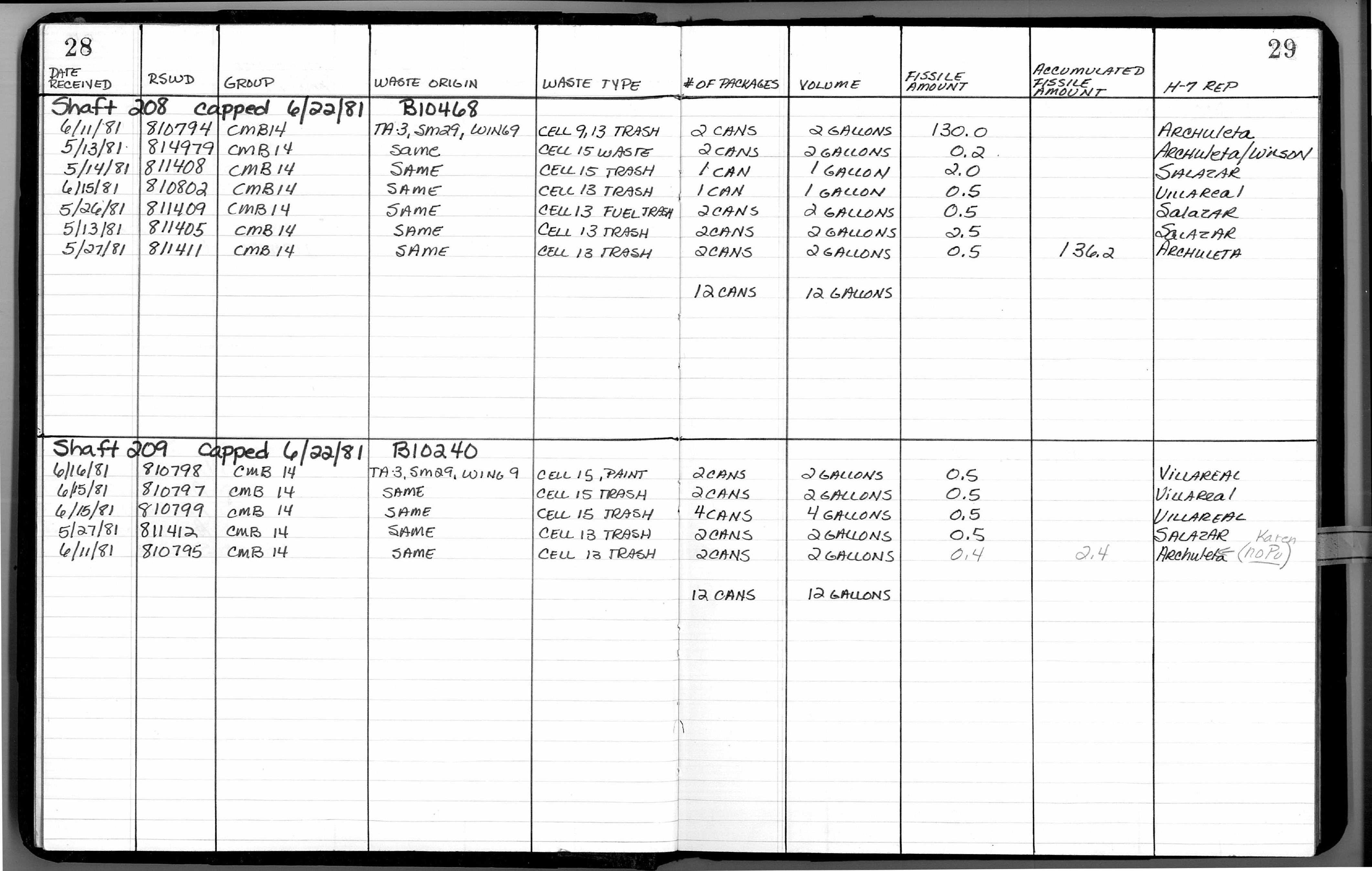




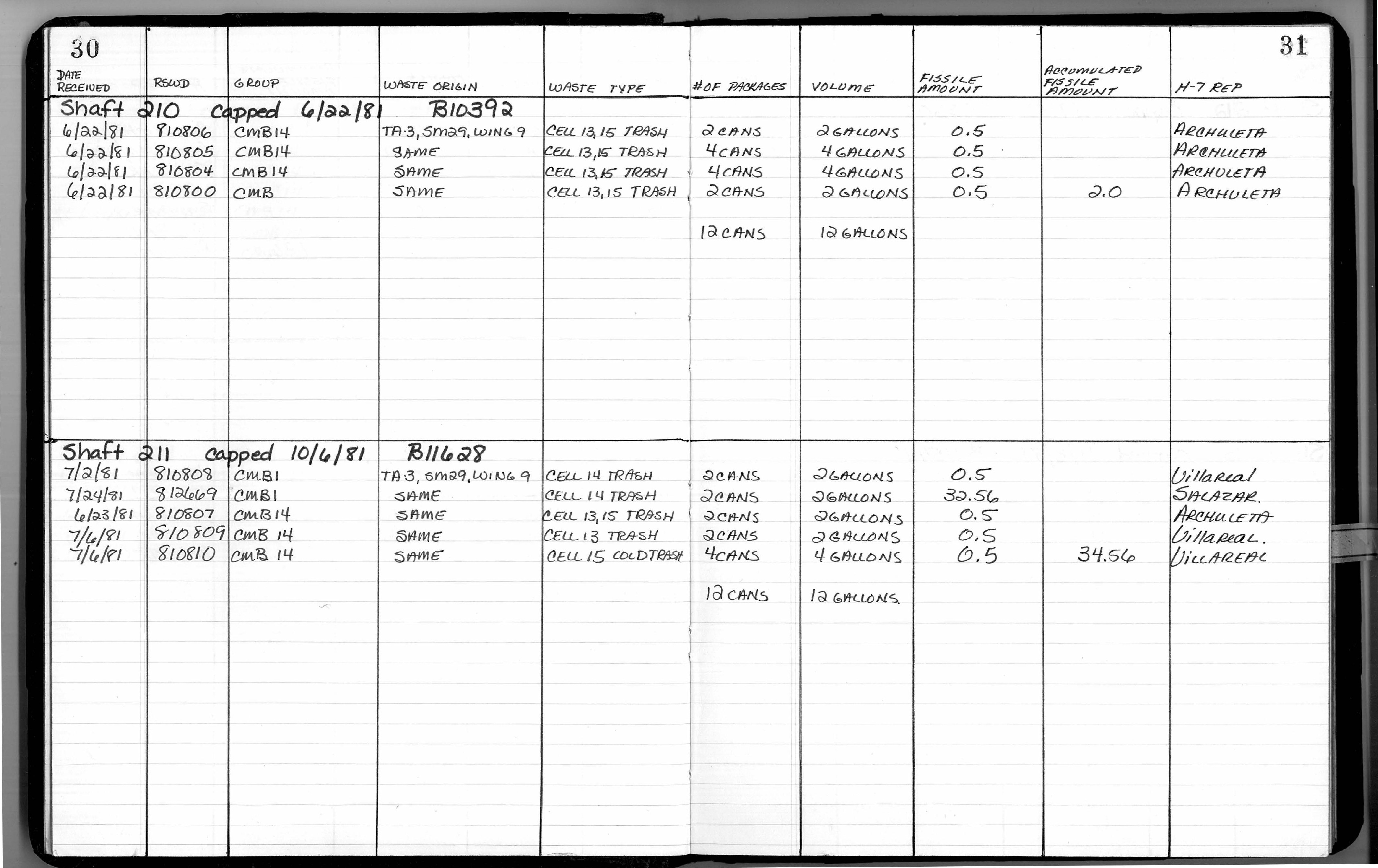




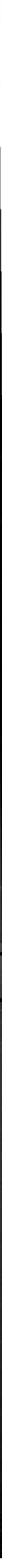




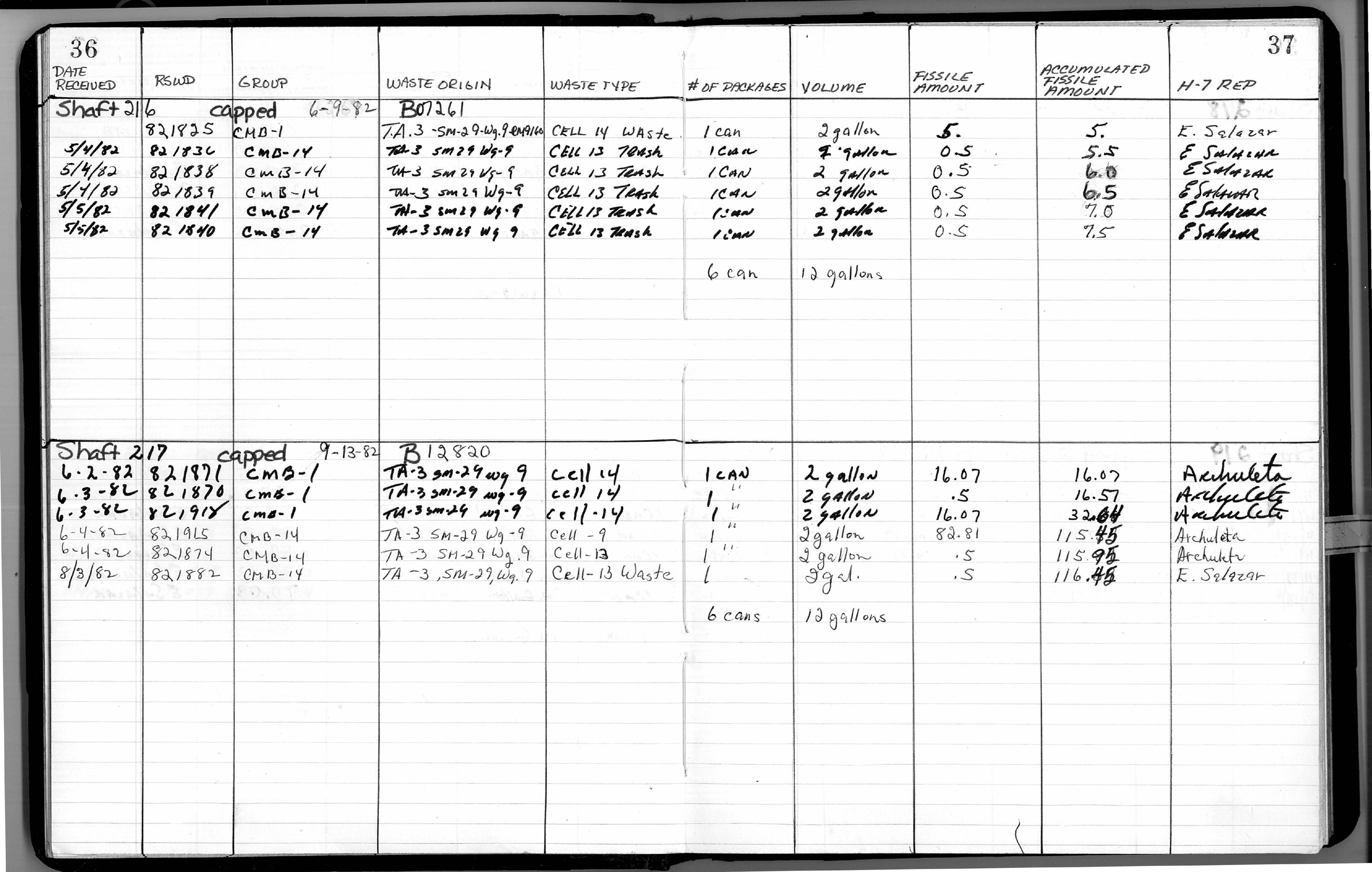




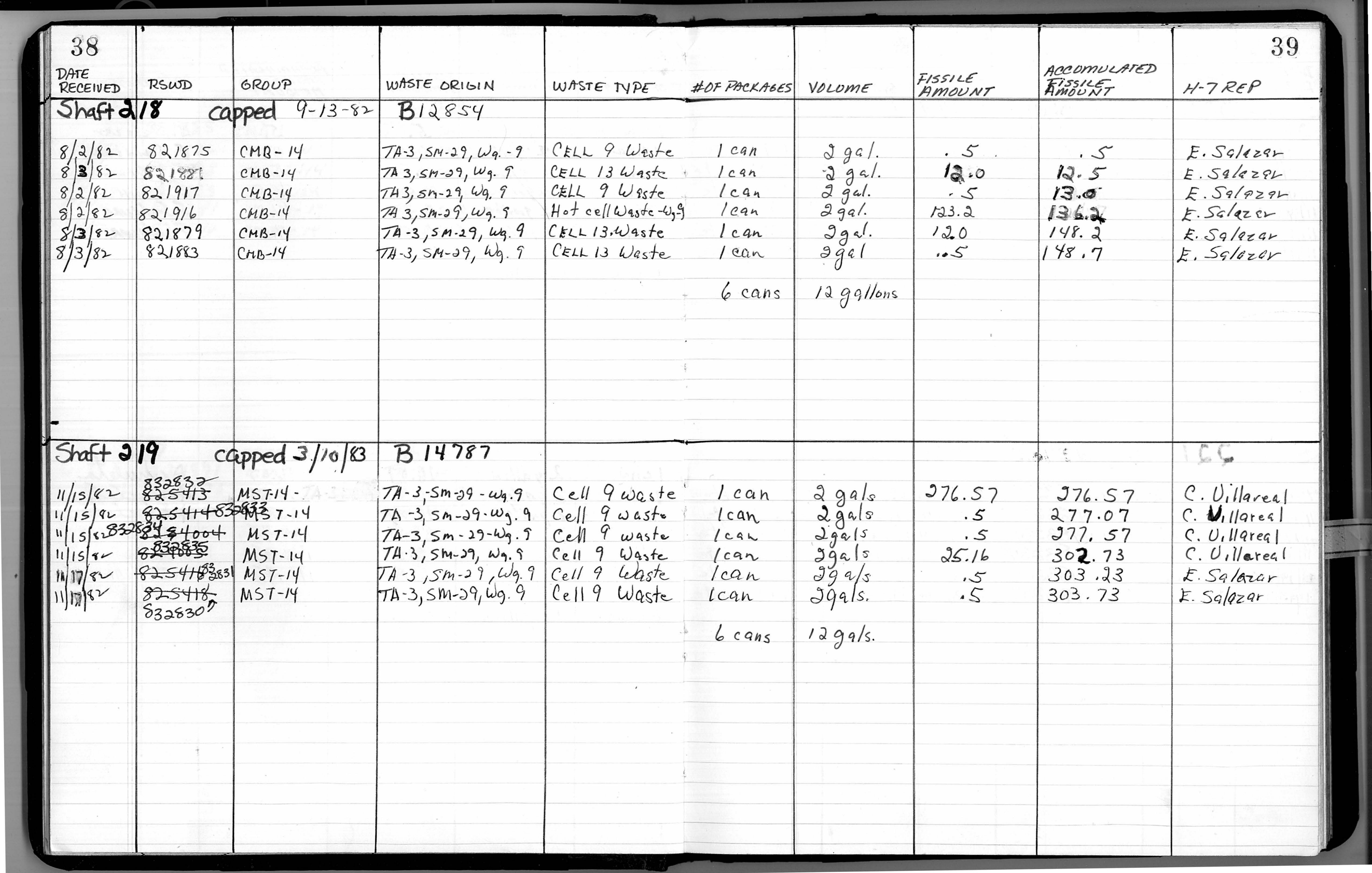




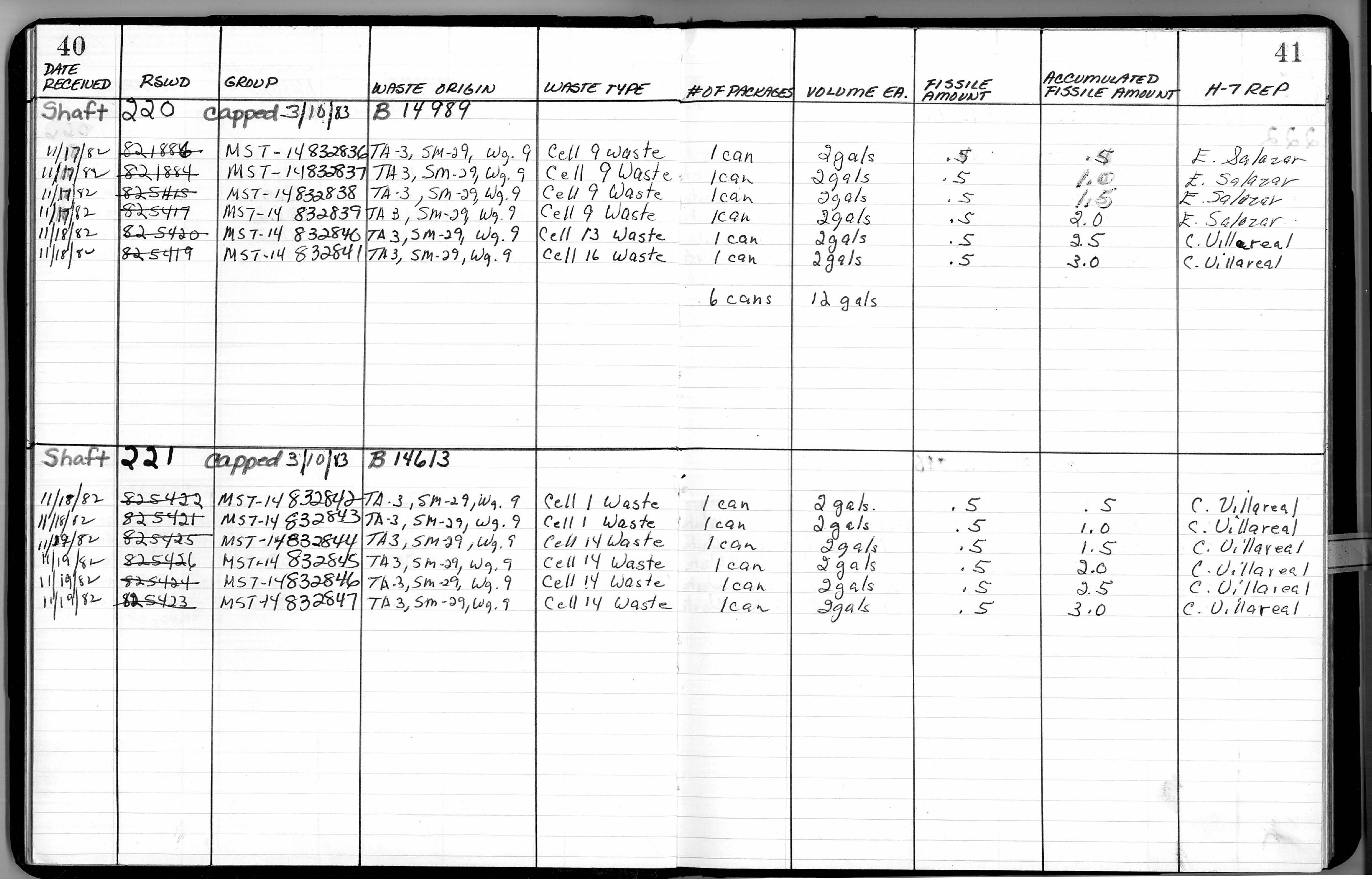




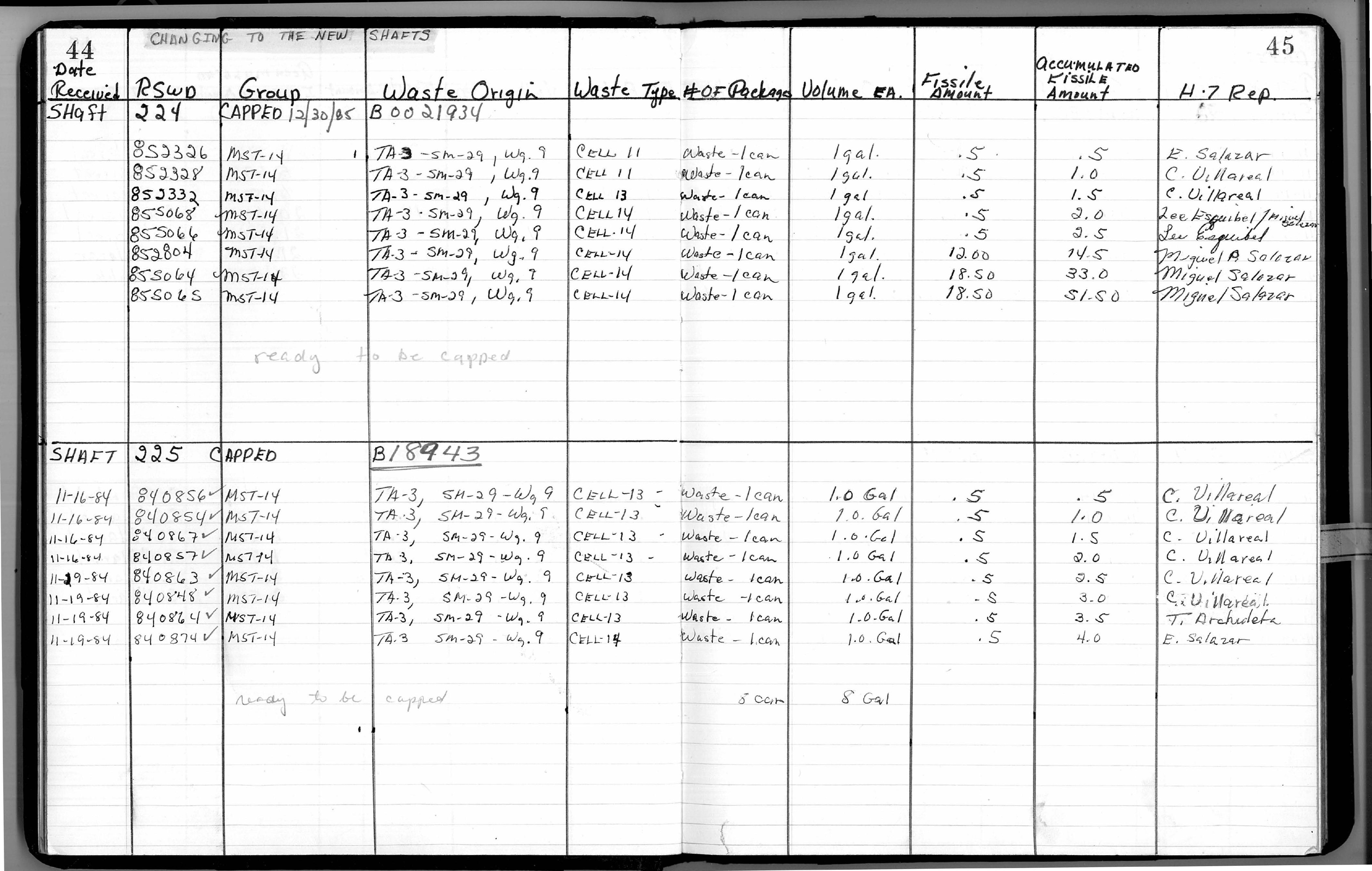




\begin{tabular}{|c|c|c|c|c|c|c|c|c|c|}
\hline $\begin{array}{l}\text { DAFE } \\
\text { RECEIUED }\end{array}$ & RSWD & GROUP & Waste Origin & Waste I & YPE OF PKES & Volume & Fissile & $\begin{array}{l}\text { Acsomulated } \\
\text { Aissile } \\
\text { Amount }\end{array}$ & HSE. 7 REP \\
\hline SHAFT & 226 & CAPPED & $B / 8910$ & & & & & & \\
\hline $11-14-84$ & 840842 & $M S T-14$ & $\pi A-3,54-29-w_{9} .9$ & CELL WaSTE. & $-13-1 \mathrm{can}$ & $1,0 \mathrm{Gal}$ & .5 & .5 & T. ARCAULAT/A \\
\hline $11-14-84$ & $: 408442$ & $M 57-14$ & $\pi / 3,5 m-29-\omega_{9} .9$ & CELL WHSTE & $13-1$ can & $1.0 \mathrm{Gal}$ & .5 & 1.0 & T. ARCHULETH \\
\hline $11-14-84$ & 840862 & MST-M & $T A-3$ SM-29-W9. 9 & CELL WASTE & $13-1$ can & $1.0 \mathrm{Gal}$ & $\cdot 5$ & 1.5 & E. Salazax \\
\hline $11-14-84$ & $: 40843$ & $M \leq T-14$ & $74.3, \quad 54-29-\omega_{9.9}$ & CELL Waste & $13-\operatorname{lcan}$ & $1.0 \mathrm{Gal}$ & .5 & 2.0 & T. ARCHULETA \\
\hline $11-15-84$ & 840846 & MST-14 & TA-3, SM-29- W9. 9 & CELL WASTE & $13-1$ can & 1.0. Gal & $\cdot s$ & 2.5 & C. Villareal \\
\hline $11-15-84$ & 8408452 & MST/4 & TA3, sm-29- Wq. 9 & CELL W OSTE & $=13-1 \operatorname{can}$ & $1.0 . \mathrm{Gal}$ & .5 & 3.0 & c. Villareas \\
\hline $11-15-84$ & $840847^{2}$ & $M S T-14$ & TA3, SM-29-WG.9 & CELl Waste & $13-1 \operatorname{can}$ & $1.0 \mathrm{Gal}$ & .5 & 3.5 & 2. Esquibel \\
\hline $11-15-84$ & $840868 \mathrm{~V}$ & $M S T-14$ & $74-3,54-29-W_{9} .9$ & CELL waste & $13-1 \mathrm{can}$ & $1.0 \mathrm{Gal}$ & .5 & H.O & T. AdeALLETA \\
\hline & & & & & $8 \mathrm{can}$ & & & & \\
\hline & & neody Capped & & & & & & & \\
\hline & & 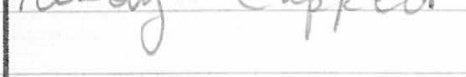 & & & f & & & & \\
\hline & & & & & & & & & \\
\hline & & & & & & & & & \\
\hline SHAFT & 227 & CAPPED & $B / 8953$ & & & & & $x^{2}$ & \\
\hline & & & & & & & & & \\
\hline $11-29-84$ & 840879 & MST-14 & $T A-3,5 m-29-\omega_{g} .9$ & CELL WASTE & $=-14-$ Lcah & $1.0 . \mathrm{Gal}$ & 17.5 & 17.5 & C. Uillareal \\
\hline $11-29-84$ & 840885 & mST-14 & TA-3, Sm-29, Wg. 9 & CELL WASTE & $-14-1 \mathrm{can}$ & $1.0 \mathrm{Gal}$ & 13.8 & $3 / .3$ & C. Oblareal \\
\hline $11-29-84$ & 840881 & MST-14 & $T A-3, \quad S M-29 \Gamma W_{9} .9$ & CELL WASTE & $-14 \cdot 1$ can & $1.0 \mathrm{Gal}$ & 17.8 & 49.1 & $C: U_{i}$ llareal \\
\hline $11-29-84$ & 840886 & MSF-14 & $T h-3,5 m-29-\omega_{g} \cdot 9$ & CELL Waste & $-14-i c a n$ & $1.0 \mathrm{Gal}$ & .5 & 49.6 & T.Archulete \\
\hline $11.29-84$ & 840883 & MSTI4 & $7 A-3, \sin -29-\omega_{9} .9$ & CELL Waste & $-14-1 \mathrm{can}$ & $1.0 \mathrm{Gal}$ & .5 & so.i & T. Archuleta \\
\hline $11-29-84$ & 840878 & HST-14 & $7 A \cdot 3 \cdot 5 A-29-\omega_{9} .9$ & CELL Waste - & $14-1 \mathrm{can}$ & $1.0 \mathrm{Gal}$ & 17.5 & 67.6 & T. Archuleta \\
\hline $11-29-84$ & 840880 & MST-14 & $T_{A} \cdot 3, s_{H}-29-\omega_{9} .9$ & CELL Waste & $-14-1$ can & $1.0 . a_{a l}$ & 17.5 & 85.1 & T. A cichulete \\
\hline $11-2984$ & 840877 & $m s T-14$ & $743,5 M-29-\omega_{9.9}$ & CerLl Waste & $-1 y-1 \mathrm{can}$ & $1.0 \mathrm{Gal}$ & 11.1 & 96.2 & c. Villareal \\
\hline है & & & & & & & & & \\
\hline & & & & + & 8 & r & & & \\
\hline & & & & & & & & & \\
\hline & & & & & & & & & \\
\hline & & & & & & & & & \\
\hline & & & & & & & & & \\
\hline & & & & & & & & & \\
\hline & & & & & & & & & \\
\hline
\end{tabular}




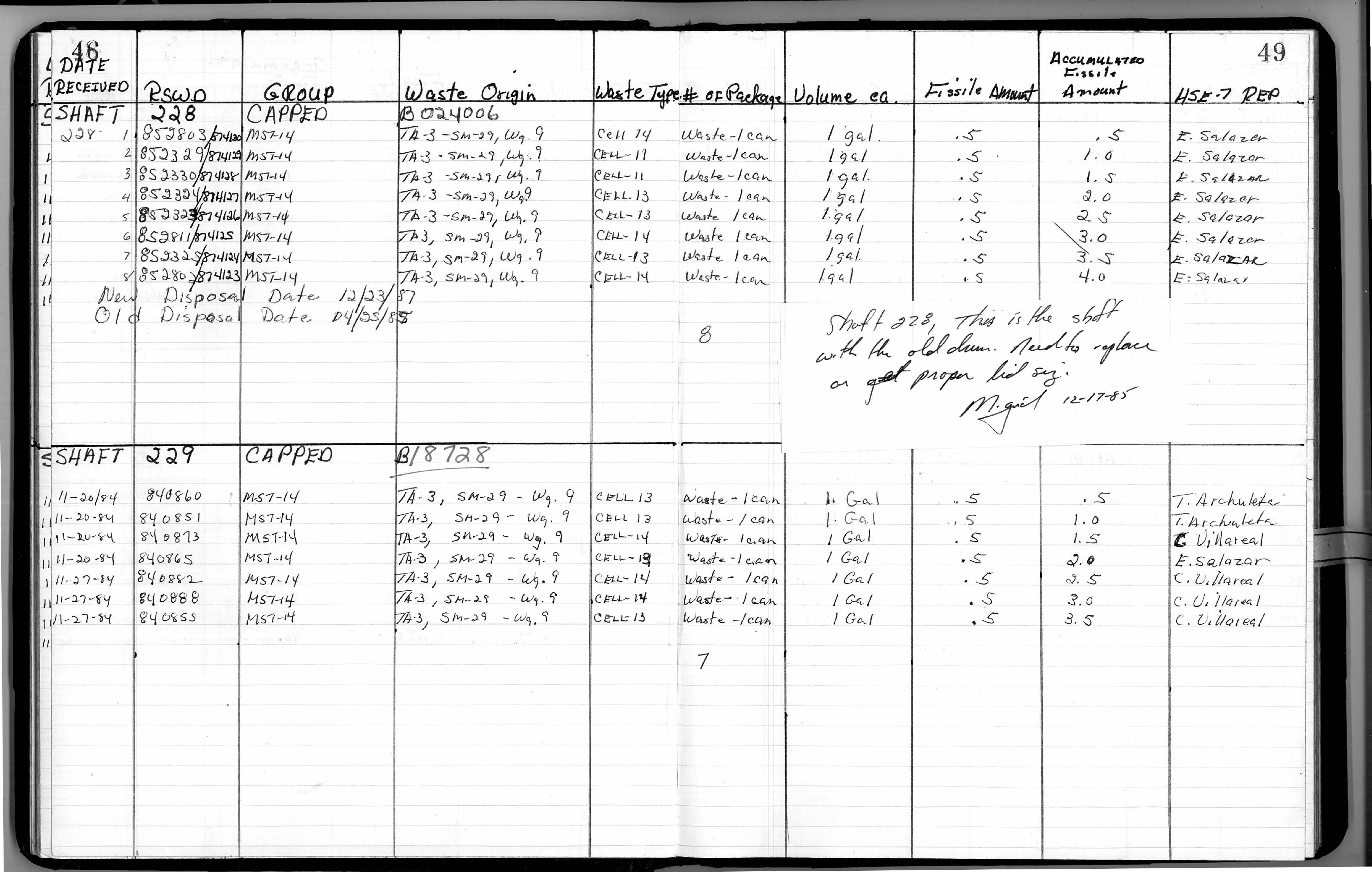




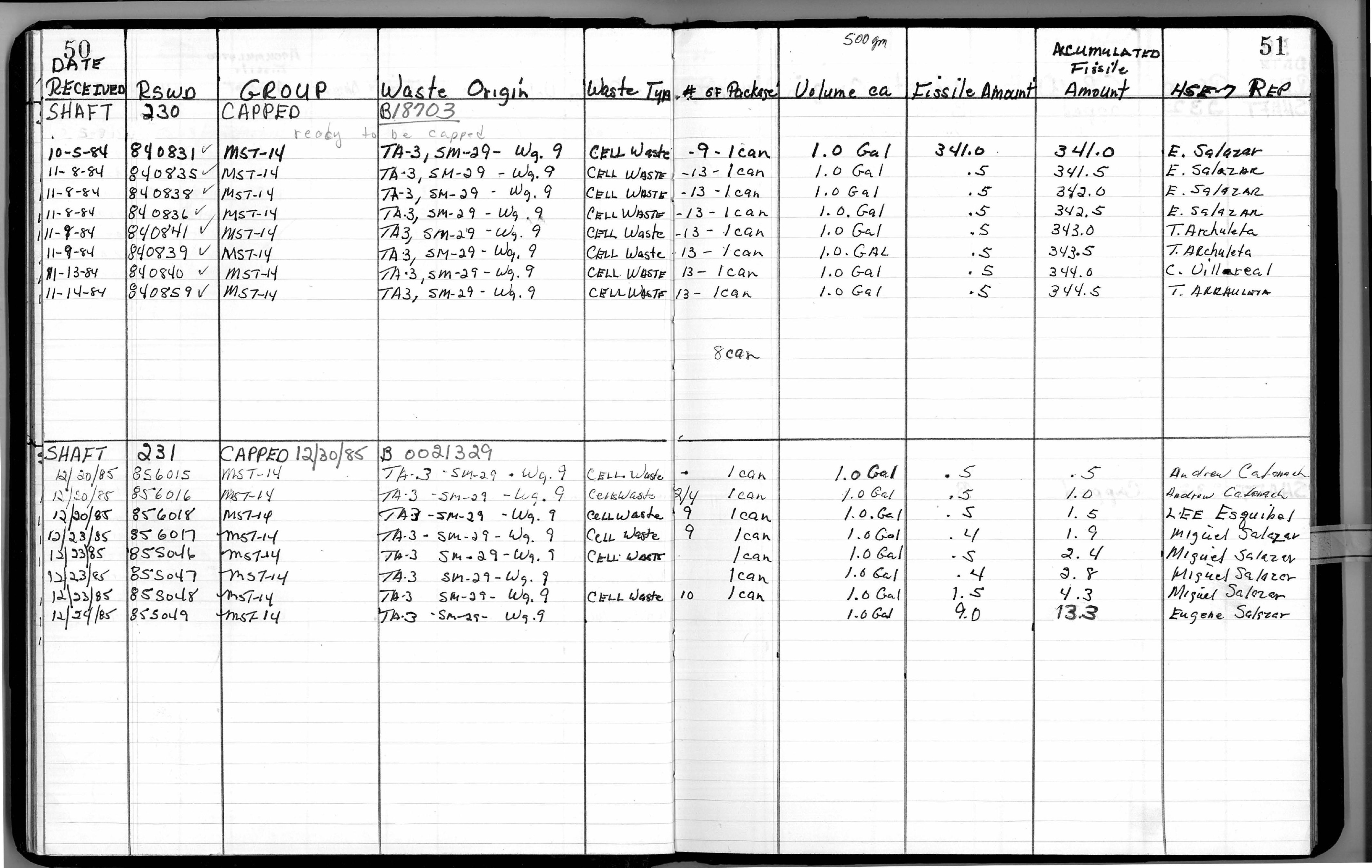




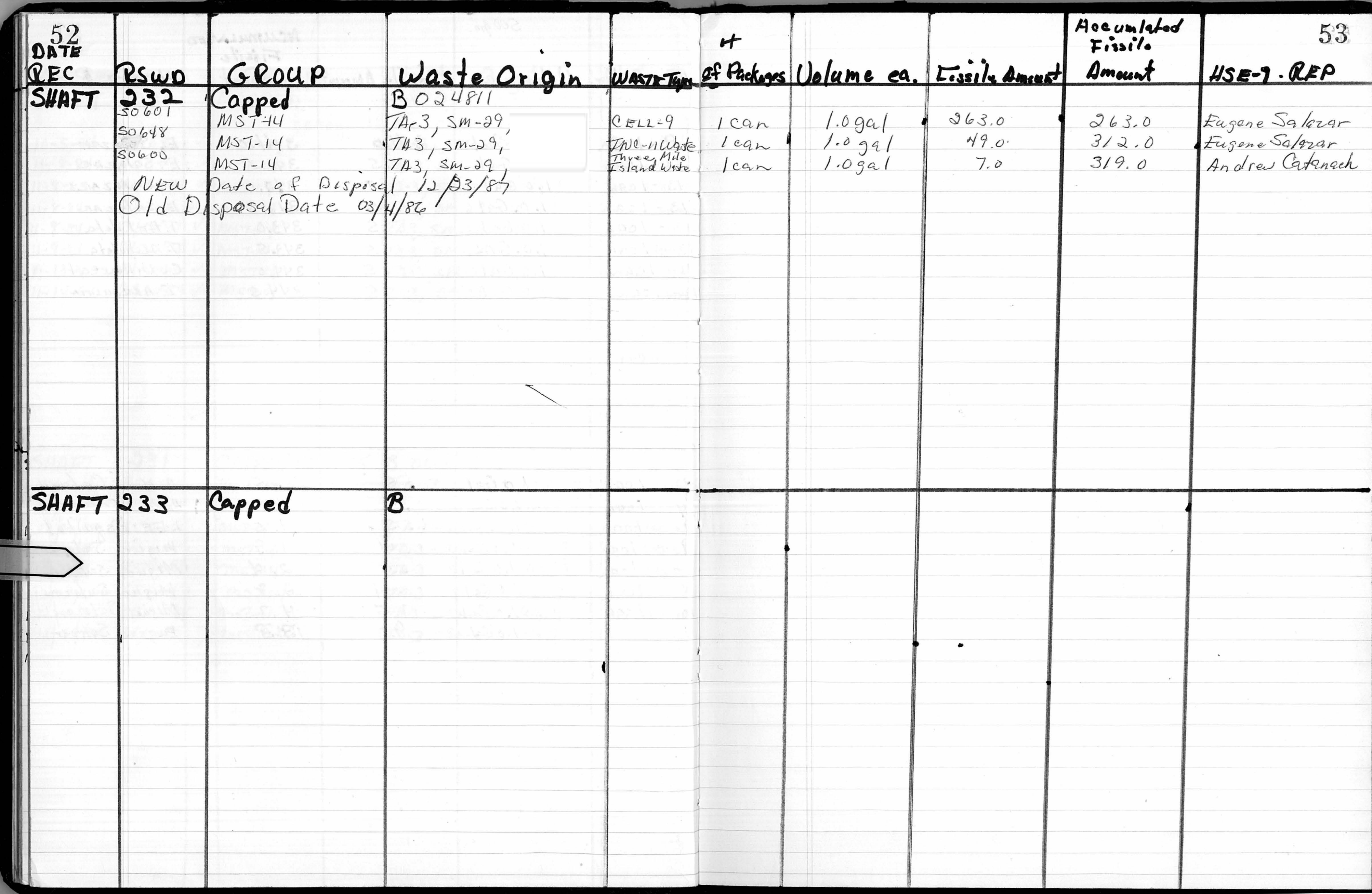


\begin{tabular}{l|l|l|l|l|}
\hline & 0
\end{tabular}

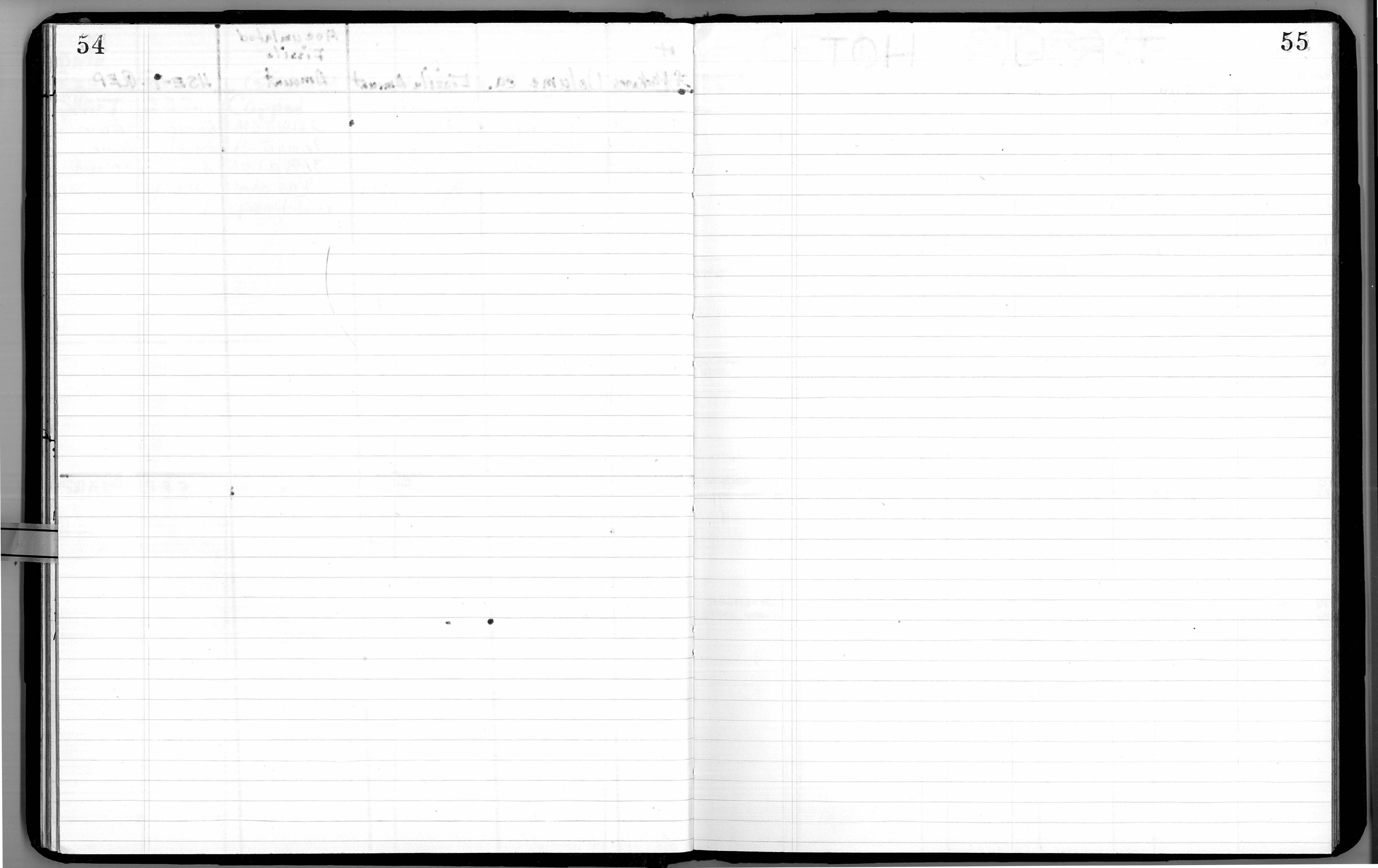




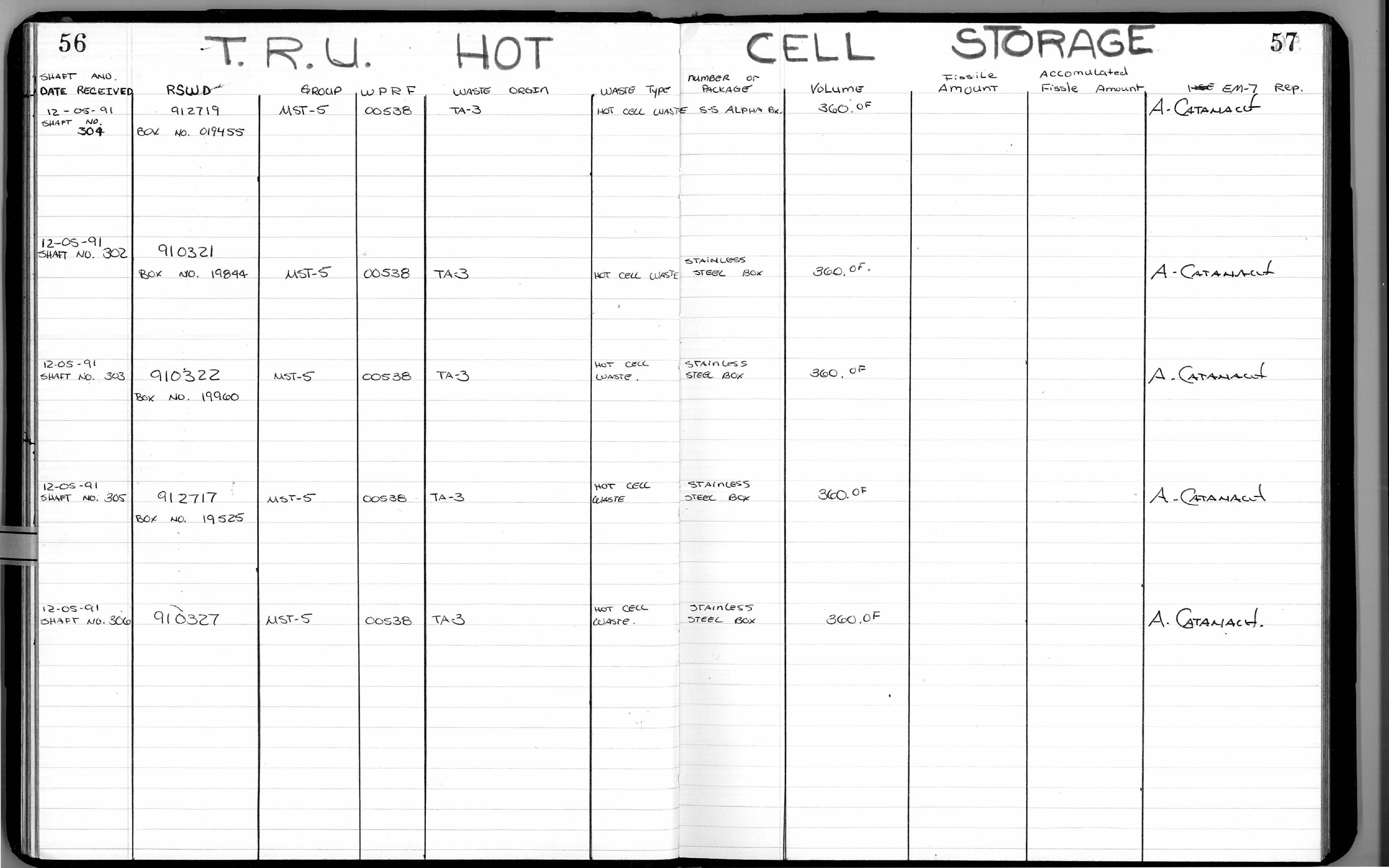




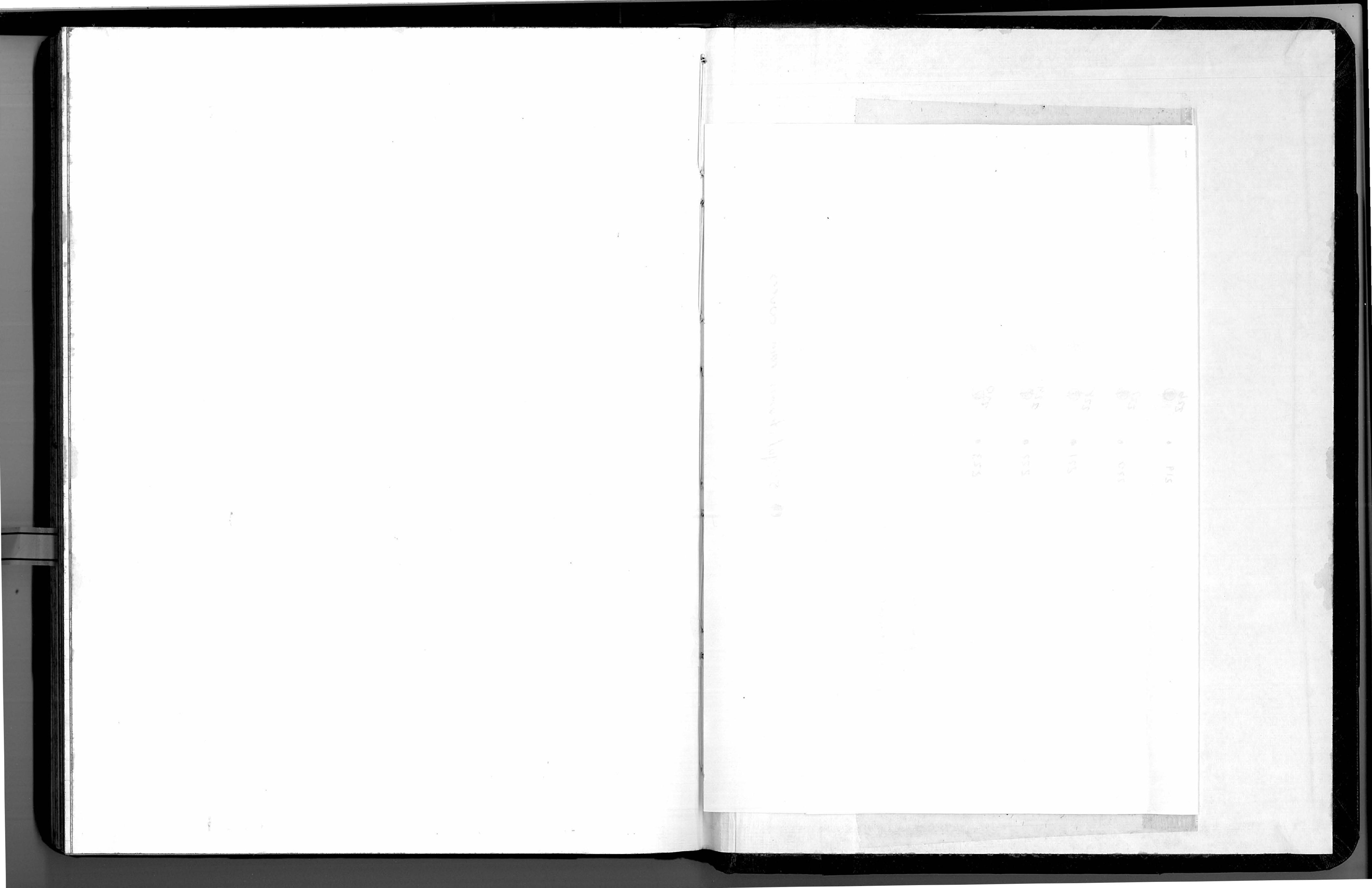


-

$\stackrel{u}{\stackrel{u}{a}}$

ई

s.

$\stackrel{3}{\vdots}$

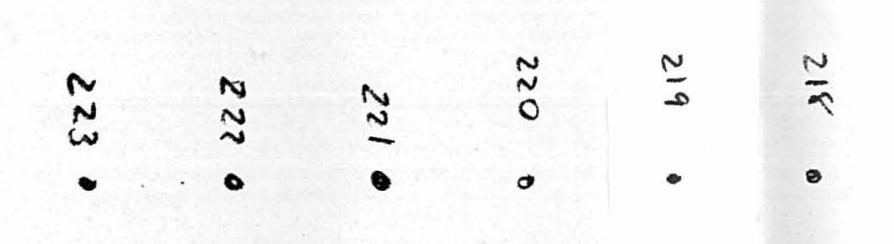

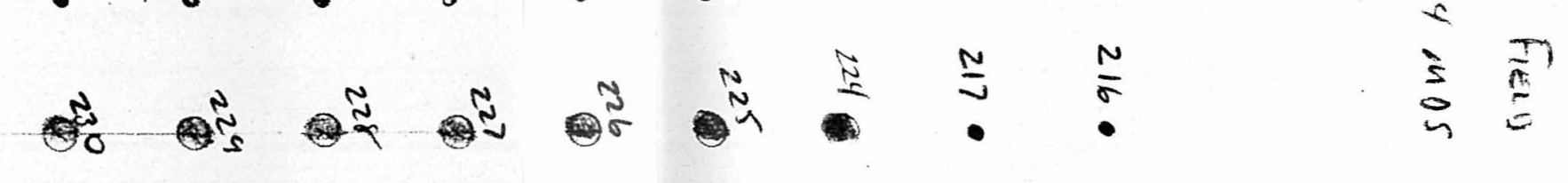

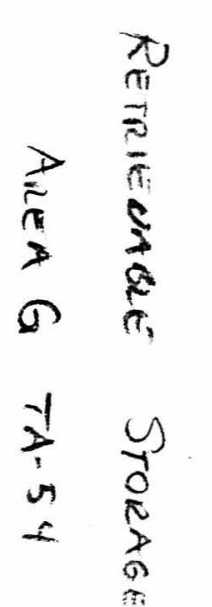

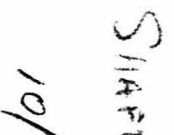




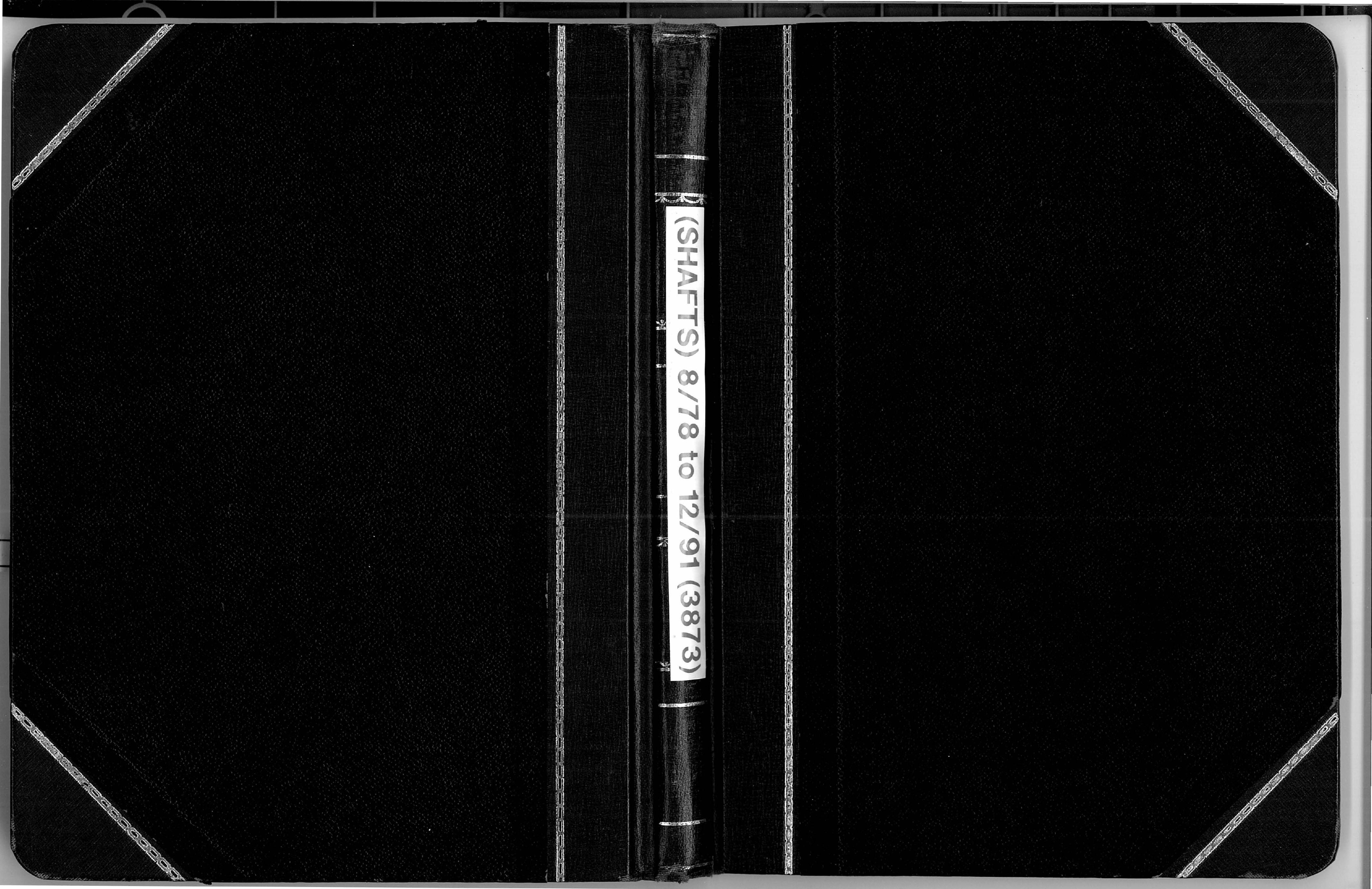





\title{
Appendix G
}

\section{LAMPRE Reactor Decommissioning Report}

\author{
"Decommissioning the Los Alamos Molten \\ Plutonium Reactor Experiment (LAMPRE I)" \\ Johnny R. Harper and Raymond Garde \\ LA-9052-MS \\ November 1981
}


This page intentionally left blank.

Page G-2 


\section{LA-9052-MS}

\section{C.2}

Los Alamos Nattonal Laboratory is operated by the University of Californla for the United States Department of Energy under contract W-74d Se

-ENG-36.

\section{DO NOT CIRCULATE}

PERMANENT RETENTION

REQUIRED BY CONTRACT

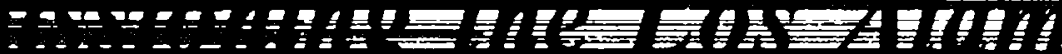

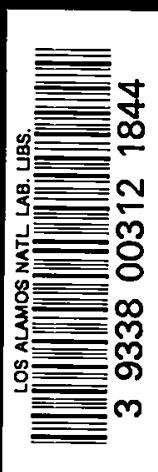

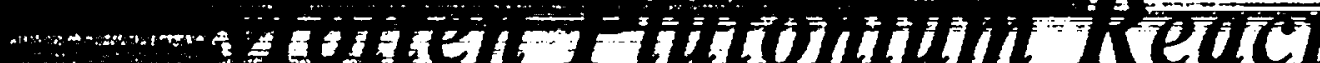

..

(1) .

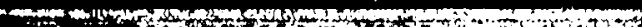

\section{and}


This work was supported by the US Department of Energy, Division of Environmental Control Technology.

This report was prepared as an account of work sponsored by an agency of the United States Covernment. Neither the United States Covernment nor any agency thereof, nor any of their employees, makes any warranty, express or implied, or assumes any legal liability or responsibility for the accuracy, completeness, or usefulness of any information, apparatus, product, or process disclosed, or represents that its use would not infringe privately owned rights. References herein to any specific commercial product, process, or service by trade name, trademark, manufacturer, or otherwise, does not necessarily constitute or imply its endorsement, recommendation, or favoring by the United States Government or any agency thereof. The views and opinions of authors expressed herein do not necessarily state or reflect those of the United Stales Government or any agency thereof. 


\section{Decommissioning the Los Alamos Molten Plutonium Reactor Experiment (LAMPRE I)}

Johnny R. Harper

Raymond Garde

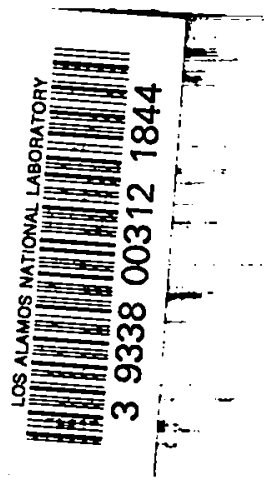

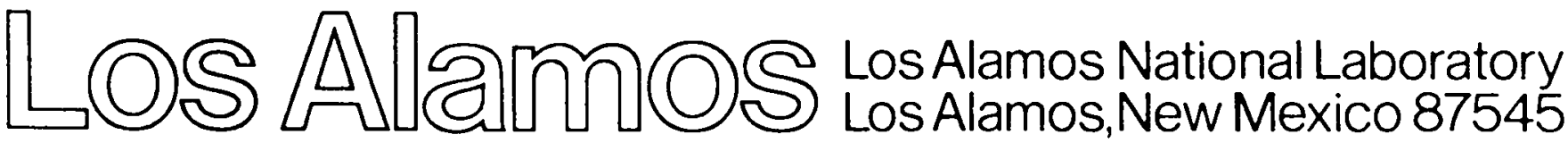




\title{
DECOMMISSIONING THE LOS ALAMOS \\ MOLTEN PLUTONIUM REACTOR EXPERIMENT (LAMPRE I)
}

\author{
by \\ Johnny R. Harper and Raymond Garde
}

\begin{abstract}
The Los Alamos Molten Plutonium Reactor Experiment (LAMPRE I) was decommissioned at the Los Alamos National Laboratory, Los Alamos, New Mexico, in 1980. The LAMPRE I was a sodium-cooled reactor built to develop plutonium fuels for fast breeder applications. It was retired in the mid-1960s.

This report describes the decommissioning procedures, the health physics programs, the waste management, and the costs for the operation.
\end{abstract}

\section{INTRODUCTION}

The Los Alamos Molten Plutonium Reactor Experiment (LAMPRE I) was built in the early 1960s at Technical Area (TA) 35, Los Alamos, New Mexico. The reactor was located in the southeast part of Building 2. It was a sodium-cooled experimental research reactor built to develop plutonium fuels for fast breeder applications. It was retired and defueled during the mid-1960s. The sodium and the sodium-treatment systems such as pumps, dump tank, hot traps, surge tank, and heat exchanger systems were removed at that time (Figs, 1 and 2). Activated metals in the reactor cell and lack of funding prevented further decommissioning.

Complete decommissioning was desirable to make available approximately 140 $\mathrm{m}^{2}$ of floor space for Laboratory personnel and experiments. 
Planning began in late 1979 with the review of relevant design drawings and reports. ${ }^{1-2}$ Individuals who had been involved with the experiment were consulted to gain design information needed for the decommissioning effort.

The decommissioning first focused on the reactor cell, which housed the remaining reactor systems and two sodium-coolant lines (Fig. 3), and the subbasement (Fig. 4) under the reactor cell, which housed the hydraulic control systems for the four control rods and the shim.

Decommissioning began by remotely drilling a hole into each sodium-coolant pipe next to the reactor (Fig. 5) so that expanding polyurethane foam could be introduced into each pipe to $\mathrm{fix}$ any sodium residue and/or internal plutonium contamination that might be encountered. The pipes were cut remotely with a portable band saw (Fig. 6), and the ends were sealed with metal caps (Fig. 7) and roofing tar. Supportive I-beams were removed by remotely unscrewing connecting bolts and nuts. The vessel was lifted vertically and placed into a retrievable cask (Figs. 8 and 9 ). The cask previously had been placed in the nearby heat exchanger pit where ample shielding existed for the ensuing removal and packaging of activated structures. The reactor vessel assembly $(0.3 \mathrm{~m}$ in diameter and $3.8 \mathrm{~m}$ in length) had an average exposure rate at contact of $60 \mathrm{R} / \mathrm{h}$. The cask was filled with standard concrete using vermiculite to provide additional protection of the sodium pipes. The loaded cask was stored retrievably in a shaft (Fig. 10) at the Los Alamos National Laboratory Radioactive Disposal/Storage Site.

Approximately 8000 lead bricks were removed progressively from the reactor cell to allow access into its interior (Fig. 11). All bricks were surveyed for contamination. Although some had to be disposed of, most were recycled for reuse at the Los Alamos National Laboratory. The reactor and its components, such as flue, shim, control rods, and bottom vessel shield, had been surrounded by approximately 900 graphite rods. Each rod was $0.1 \mathrm{~m}$ in diameter and $1.8 \mathrm{~m}$ long. The maximum contact exposure rate on each rod was $50 \mathrm{mR} / \mathrm{h}$ due primarily to ${ }^{60} \mathrm{Co}$. The rods adjacent to the reactor components were remotely removed with a wire-loop tool and pulled up into the bay area above the reactor cell where they were packaged in plastic-lined plywood boxes. A 20-cm thick by 210-cm high semicircular shaped lead shield weighing approximately 6 tons was built and lowered into the resultant space. The shield allowed workers to enter 
the reactor cell without unnecessary exposure from the 70-R/h-activated surfaces of the remaining reactor components (Fig. 12). About 780 graphite rods vere removed, packaged, and stored at Los Alamos National Laboratory for possible reuse. Another 100 rods were broken, removed, packaged, and disposed of as waste.

The flue and the control-rod sleeve spacer (activated to $17 \mathrm{R} / \mathrm{h}$ at contact) were removed remotely (Fig. 13) and placed into a corrugated metal pipe culvert that had been brought into the heat exchanger pit. The culvert was then filled with standard concrete and transported to TA-54 for disposal. The activated shim $(70 \mathrm{R} / \mathrm{h}$ contact) was treated in a similar manner (Fig. 14), except magnetite concrete was used for shielding in the cask.

The hydraulic systems (Fig. 15) in the subbasement were disconnected. The bottom-vessel shield, control rods, and floor-plug assembly were removed (Fig. 16) and placed into another culvert in the heat exchanger pit. The $0.75-m-$

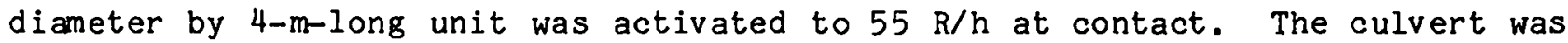
then filled with magnetite concrete.

The remaining activated metal structures (Fig. 17) in the reactor cell were cut with an oxyacetylene torch and removed to provide access to the two sodium-coolant lines and the remaining lead bricks (Fig. 18). The pipe interiors were contaminated with ${ }^{239} \mathrm{Pu}$ levels up to $10^{4} \mathrm{dis} / \mathrm{s} / \mathrm{cm}^{2}$. The pipes were cut by a portable band saw, capped with plastic and cloth-backed tape, and disposed of at $\mathrm{TA}-54$.

The remaining lead bricks were also removed, surveyed, and recycled for use at other Los Alamos National Laboratory facilities. The reactor control room was stripped of electrical systems, surveyed for radioactivity, and rehabilitated. The sodium equipment room, heat exchanger pit, subbasement, and the reactor cell (Fig. 19) were surveyed. All areas except the reactor cell were released for unrestricted use. The reactor cell, with a maximum of $70 \mathrm{mR} / \mathrm{h}$ from the activated cell liner and underlying concrete structures, was considered to be at a level that was as low as reasonably achievable. Plans are for the cell to become a secure vault storage area, freeing more usable floor space elsewhere in the building. 
Personnel assigned to the project were experienced radiation workers. However, some were more familiar with alpha and beta radiation than with gamma radiation. Therefore, all were indoctrinated on working in penetrating radiation areas and on the health physics techniques required. Decommissioning work was not allowed without the presence of at least one health physics surveyor, but almost all of the work was overseen by two.

Workers were provided with ariticontamination clothing such as underwear, coveralls, gloves, hoods, and booties. No personal decontamination beyond normal showering and washing procedures was required.

All workers participated in the Los Alamos National Laboratory's full-face respiratory fitting, testing, and training program. Full-face respirators equipped with high-efficiency particulate filters were used during phases involving a potential for airborne radioactive particulates and for asbestos work. Full-face respirators supplied with breathing air (provided by compressors and hoses) were used during oxyacetylene cutting of activated metals and during the melting of lead bricks. Nose swipes were collected from each worker after each risk period. Analyses of the swipes indicated no inhalation problem had occurred.

Air was sampled from the working areas by passing it through a HV-70 filter paper at a rate of $0.01 \mathrm{~m}^{3} / \mathrm{s}$. The papers were removed at the end of each workday and analyzed for alpha, beta, and gamma activity to provide a record of the workers' potential exposure to airborne radioactivity. The maximum airborne radioactivity detected never approached the DOE concentration guides for cobalt or plutonium.

All workers were provided with thermoluminescent dosimeters to record monthly accumulated radiation exposures. The total exposure received by 12 workers over a 7-month period was 7.26 rems. Individual exposures ranged from 0.26 to 0.95 rems. A calibrated Johnson pocket dosimeter was also worn by each individual. These dosimeters were read and recorded daily.

A variety of instrumentation was required. A Ludlum-129 with a $60-\mathrm{cm}^{2}$ air proportional probe was used to measure surface alpha activity. A Ludlum 14-C with GM-Probe or a Teletector Model 6112 was used to measure beta-gamma activity. Continuous air monitors, an Eberline Alpha-3 and an Eberline AMS-2, were used to provide continuous alpha and beta gamma airborne surveillance. 
IV. WASTE MANAGEMENT

All wastes generated by this operation were buried, or retrievably stored, at the Los Alamos National Laboratory Radioactive Waste Disposal/Storage Site (TA-54) located $8 \mathrm{~km}$ from the decommissioning site. Burial was in pits, which are covered with a meter of uncontaminated soil and revegetated. Approximately $225 \mathrm{~m}^{3}$ of debris were buried. The reactor vessel was placed in a cask, the space between the cask and reactor was filled with concrete, and because of plutonium levels, the cask was stored retrievably in a shaft at the Radioactive Disposal/storage site. The estimated level of ${ }^{239} \mathrm{Pu}$ in the reactor vessel was $12 \mathrm{Ci}$. The ${ }^{239} \mathrm{Pu}$ was released into the sodium during the experiments because of a ruptured fuel pin.

Most wastes were loaded into plywood boxes and transported to the disposal site in tarpaulin-covered, plastic-lined, dump or flatbed trucks with sides and tailgate. Some items, placed in modified corrugated metal pipe culverts that were filled with standard or magnetite concrete, were transported on flatbed trucks. Equipment and tools used during the operation were monitored routinely and decontaminated as necessary.

V. ENVIRONMENTAL SURVEILLANCE

The Laboratory's environmental surveillance group monitored the operation with its routine air sampling network and one additional station outside the reactor cell. Filter papers from the sampling locations were collected and analyzed after a 7- to 10-day decay period. No measurable increase above the Los Alamos National Laboratory norm was detected during the period of decommissioning for gross alpha, beta, or gamma activity.

VI. $\operatorname{cosTS}$

The project required 140 working days. Subcontractor costs for craft inanpower and equipment were $\$ 115000$, and Laboratory health physics and managenent costs were $\$ 30000$ for a total of $\$ 145000$. 


\section{REFERENCES}

1. E. 0. Swickard, "Los Alamos Molten Plutonium Reactor Experiment (LAMPRE) Hazard Report," Los Alamos Scientific Laboratory Report LA-2327 (June 1959).

2. K Division Personnel, "LAMPRE I Final Design Status Report," Los Alamos Scientific Laboratory Report LA-2833 (January 1962). 


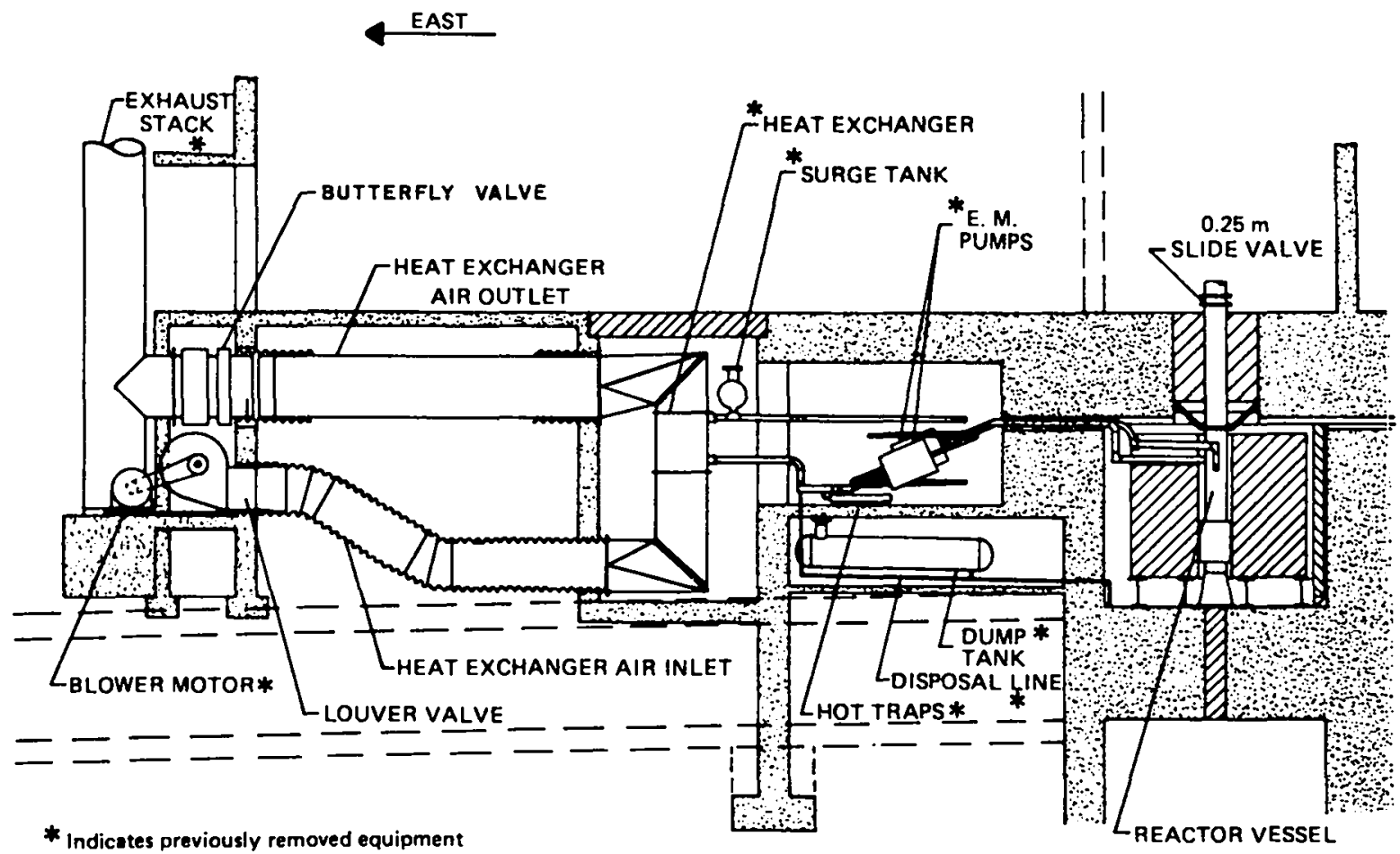

Fig. 1 .

Elevation view of reactor installation.

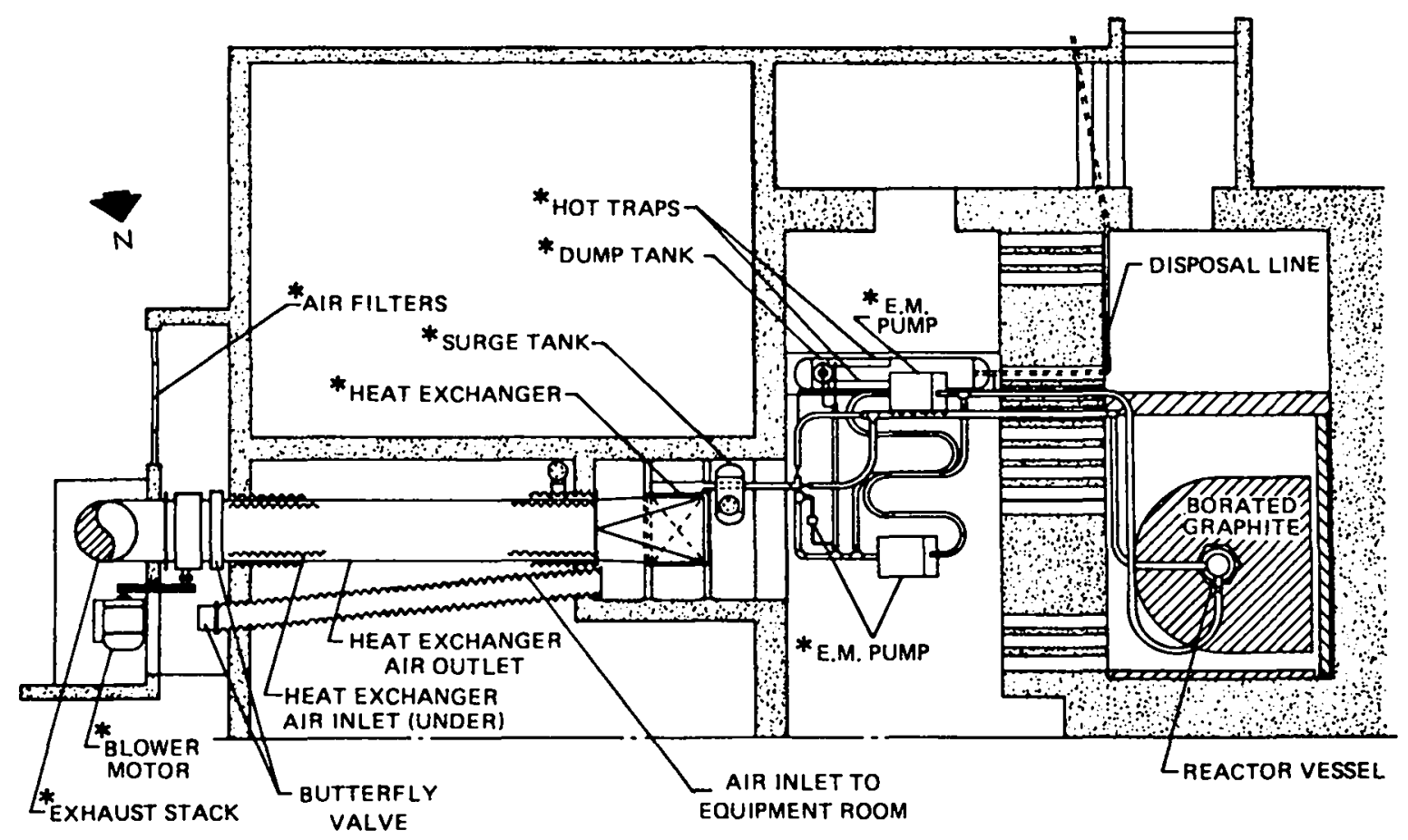

* Indicates previously removed equipment

Fig. 2 .

Plan view of reactor installation. 


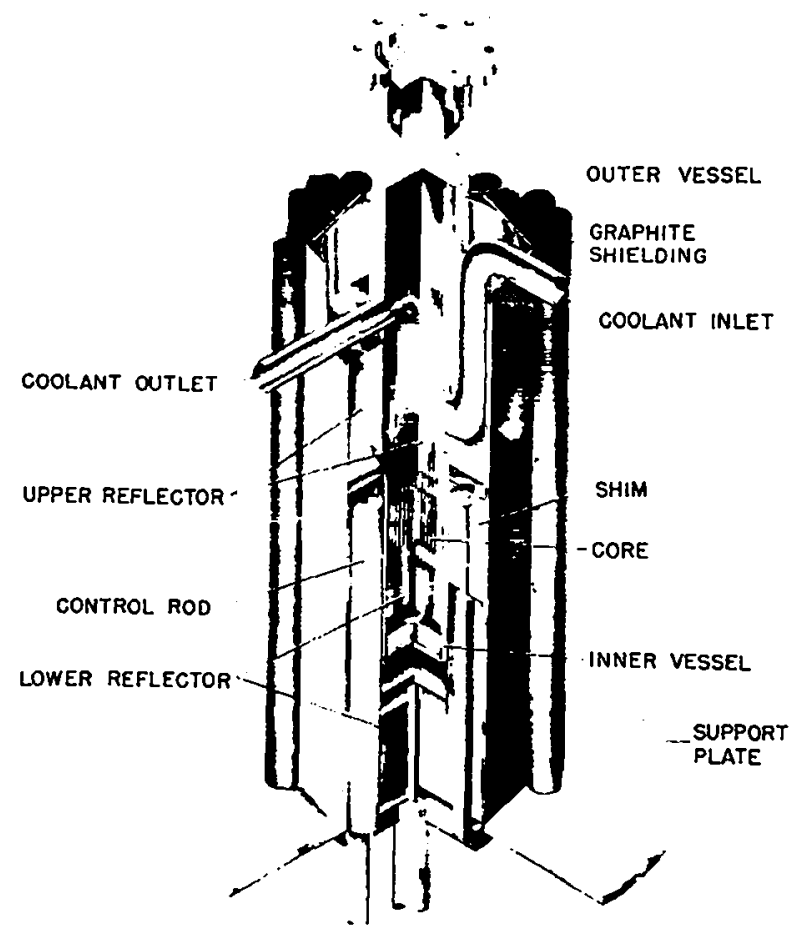

Fig. 3 .

LAMPRE reactor.

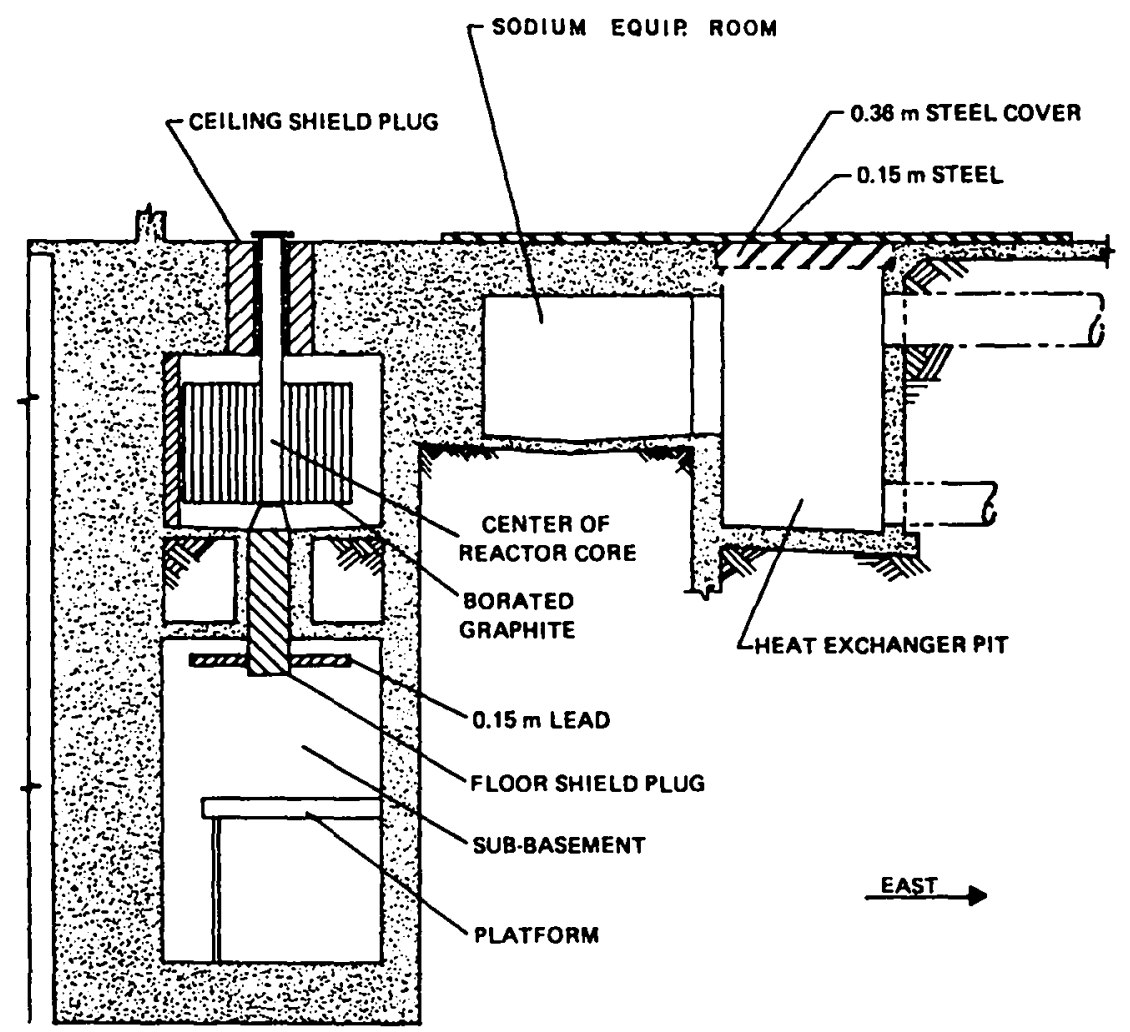

Fig. 4.

Vertical cross section showing core shielding. 


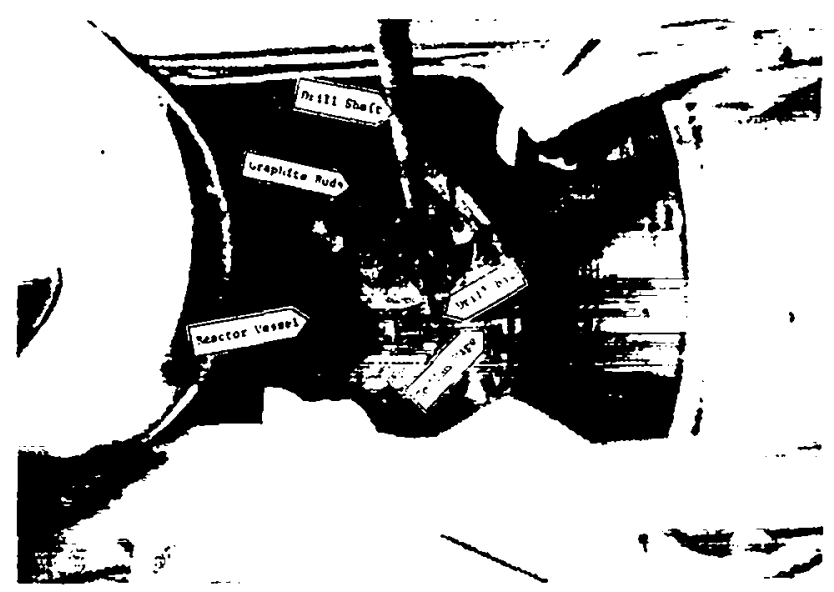

Fig. 5.

Remote drilling into sodium pipe. Drill shaft (center of figure) is $4 \mathrm{~m}$ long.

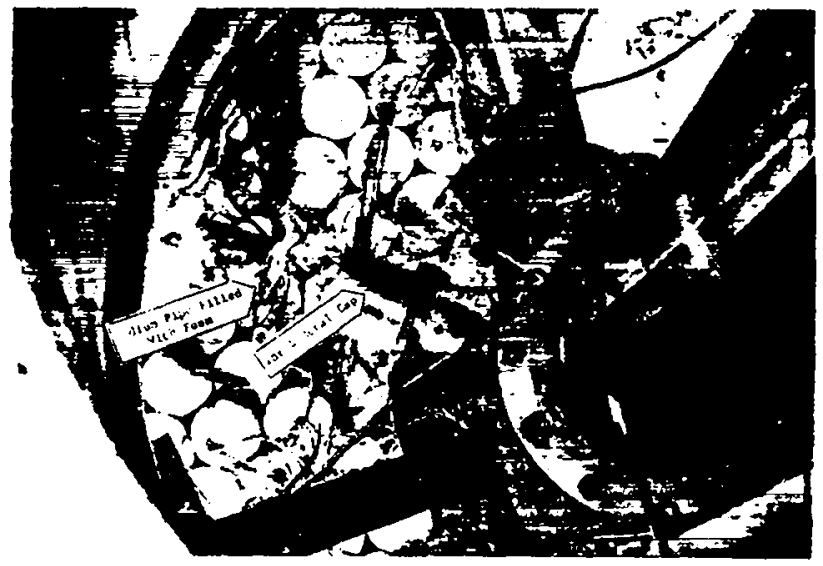

$\mathrm{Fig} \cdot 7$.

Sodium pipe sections showing the foam prior to capping, and the tar and metal cap used to seal ends.

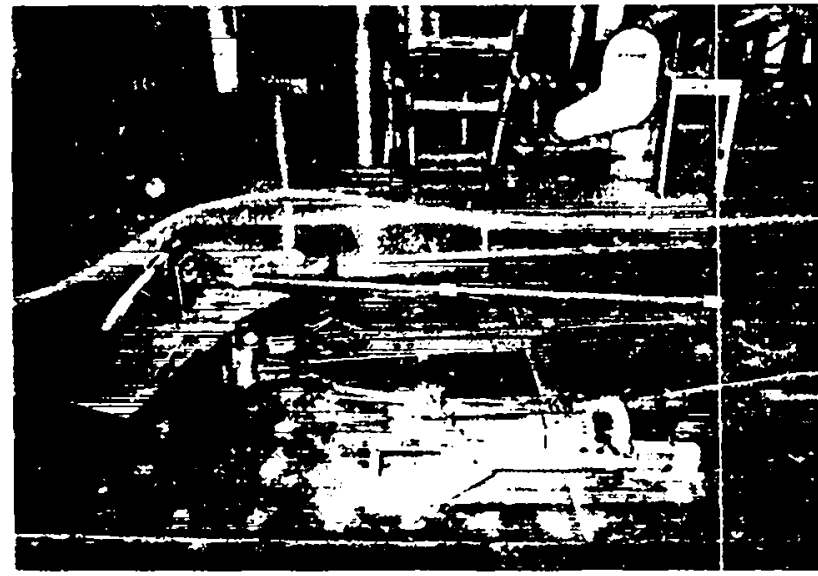

Fig. 6.

Conventional tools with extensions for remote operation.

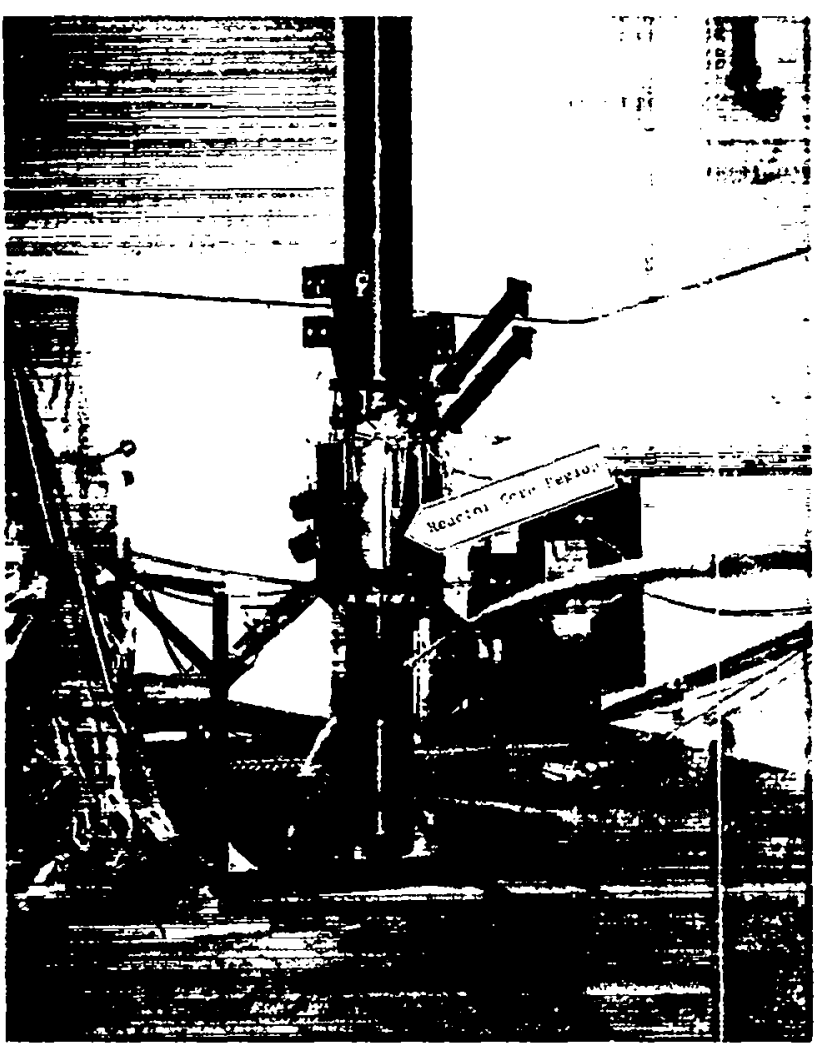

Fig. 8 .

Reactor being lifted from the cell. 


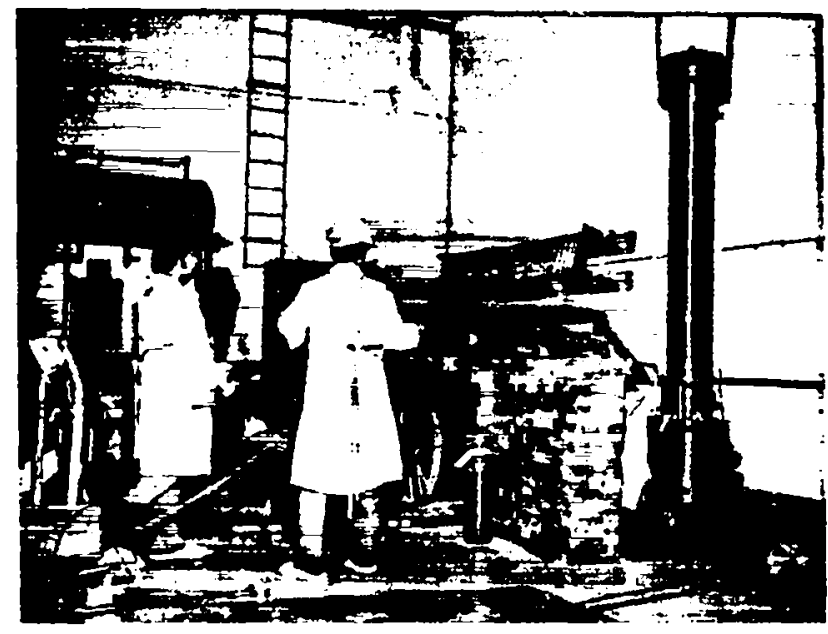

Fig. 9 .

Remote cutting of unnecessary

supports to minimize waste

container size.

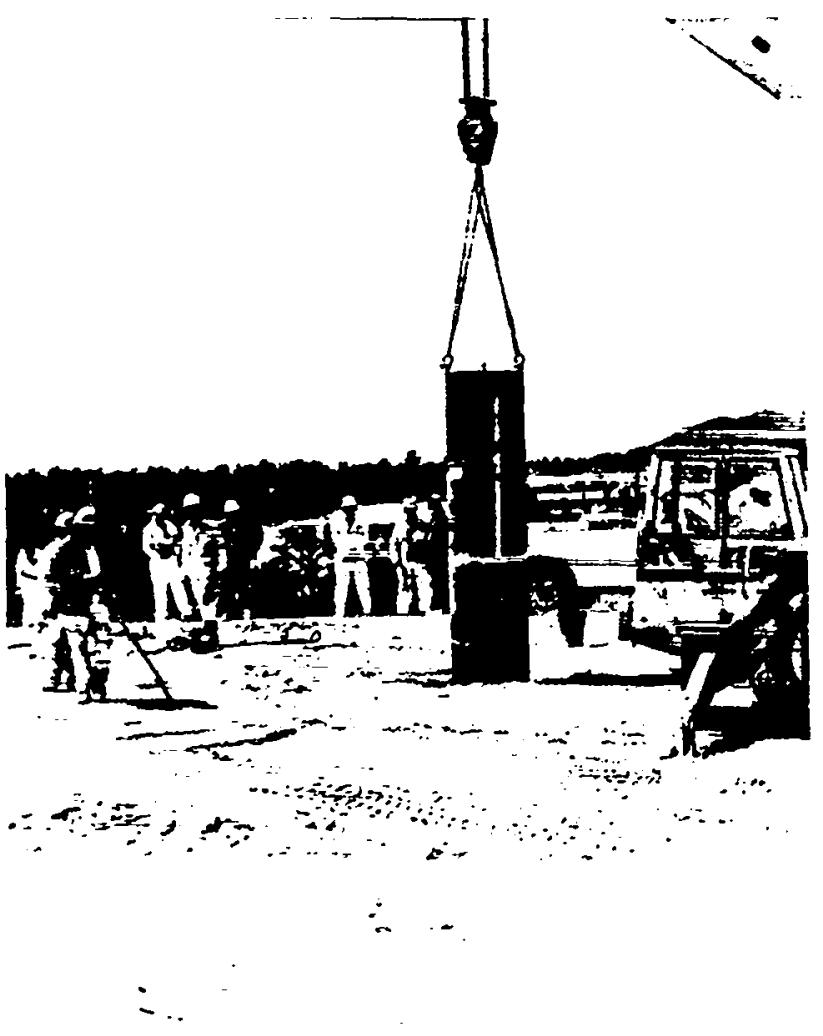

Fig. 10.

Reactor vessel cask being lowered into storage shaft.

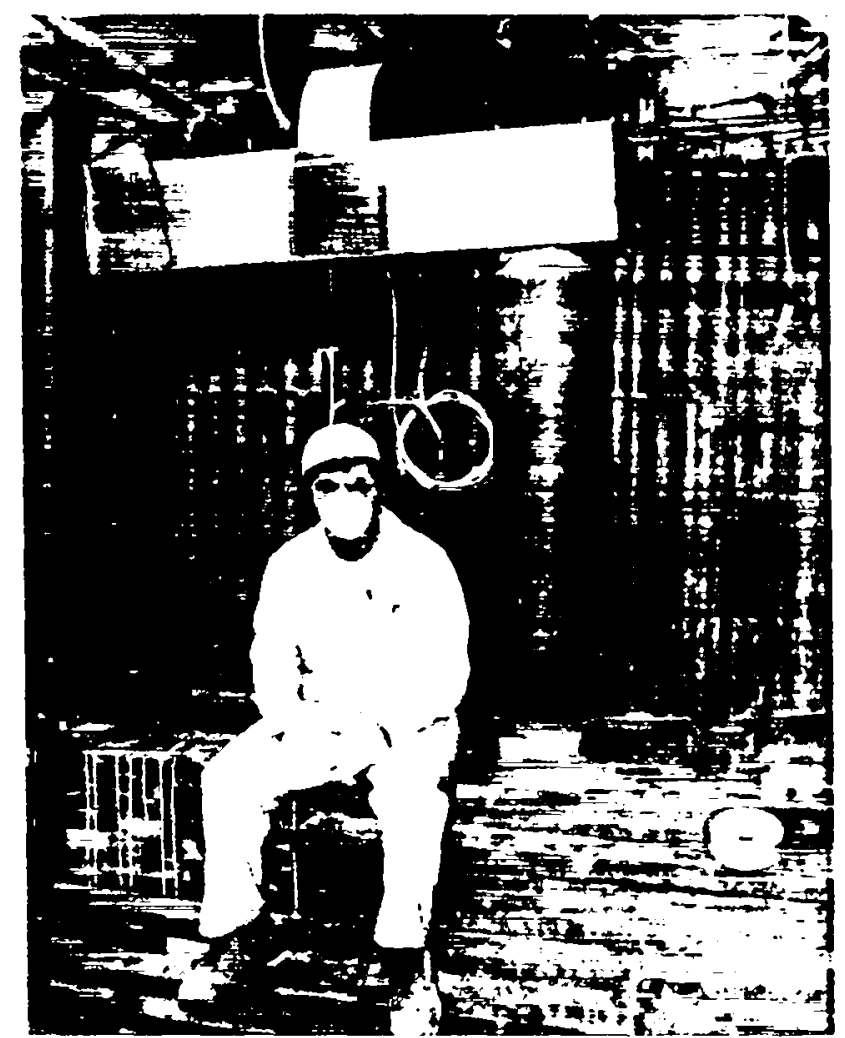

Fig. 11.

View into reactor cell showing lead brick wall and graphite rods used for shielding. 


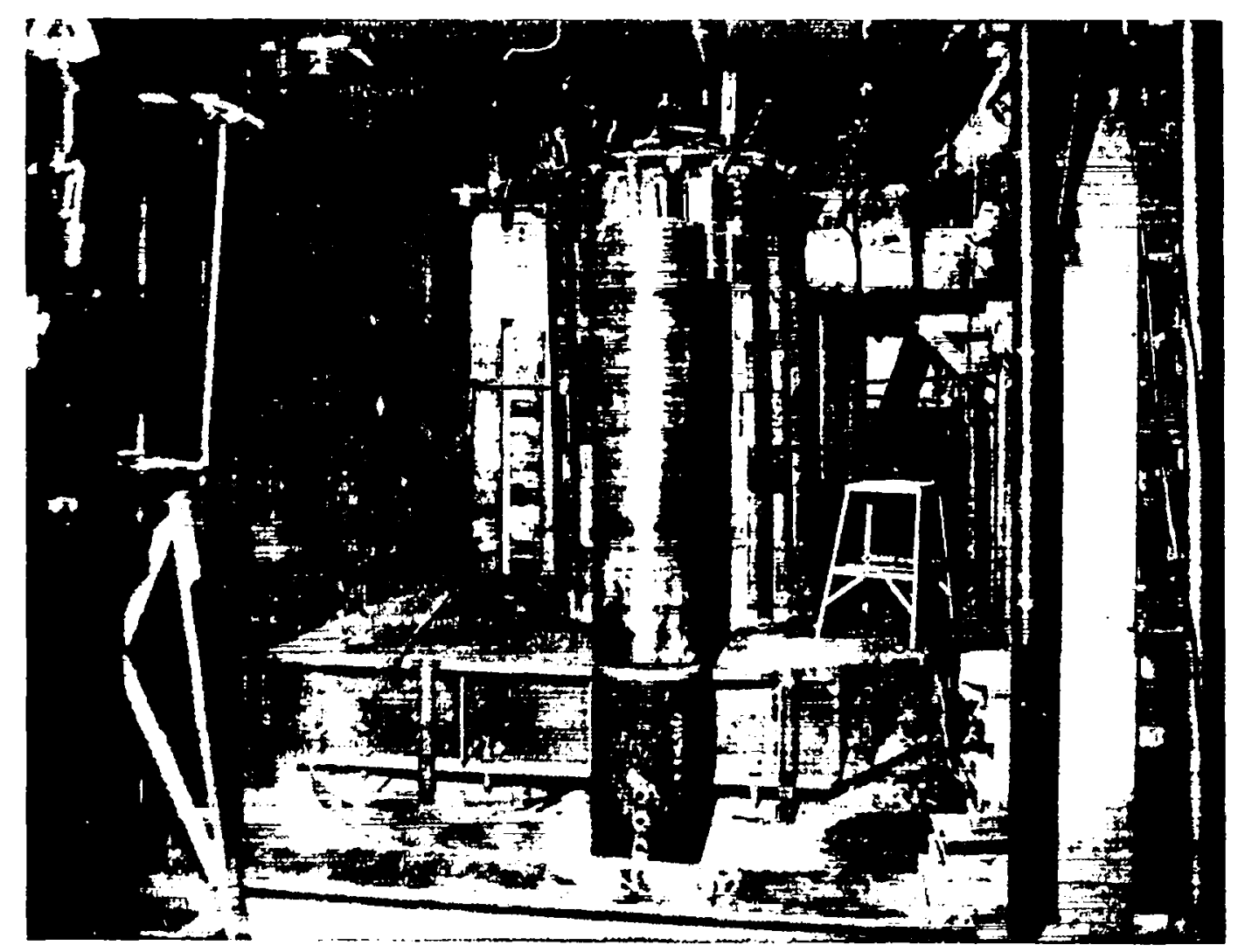

Fig. 12 .

Semicircular shaped lead shield permitted shielding removal with minimal exposure to personnel.

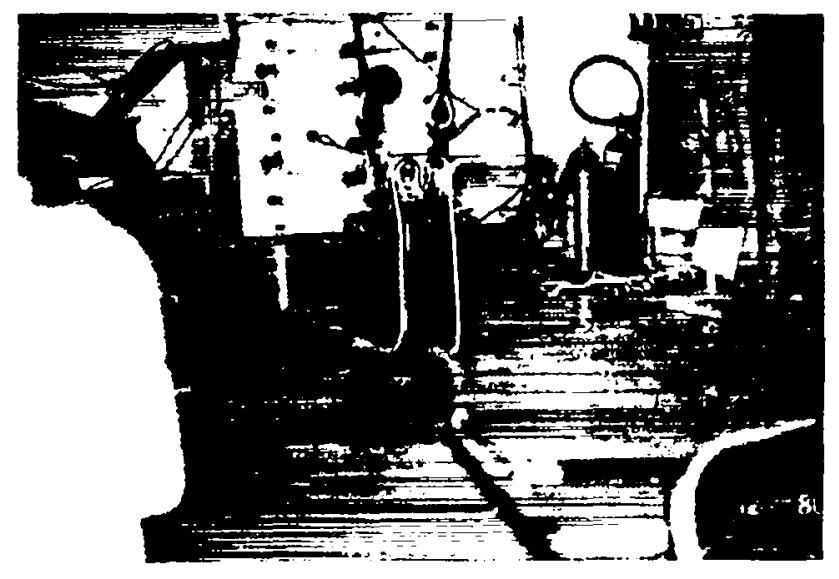

Fig. 13.

Reactor Flue and control rod spacer.

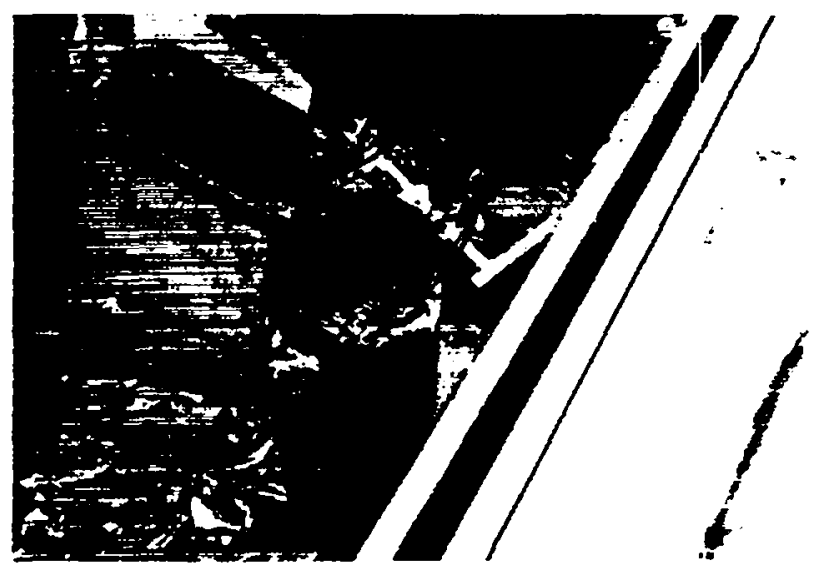

Fig. 14.

The reactor shim. 


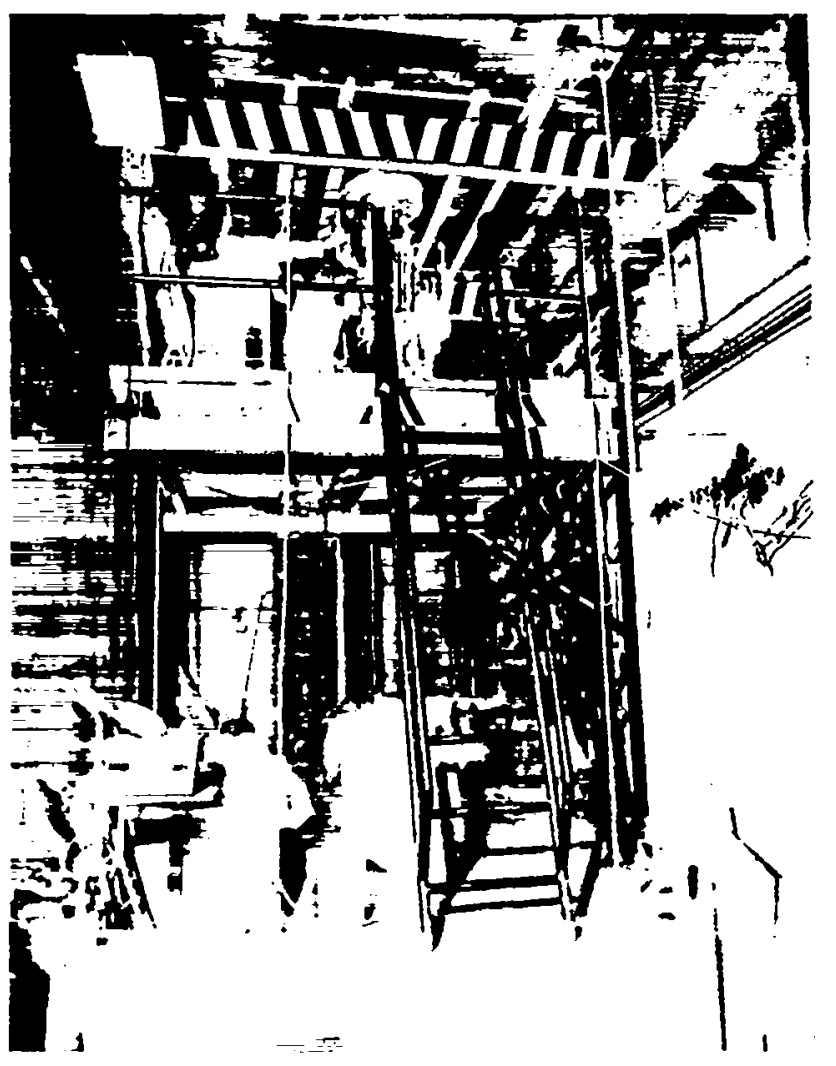

Fig. 15.

The hydraulic systems in the subbasement.

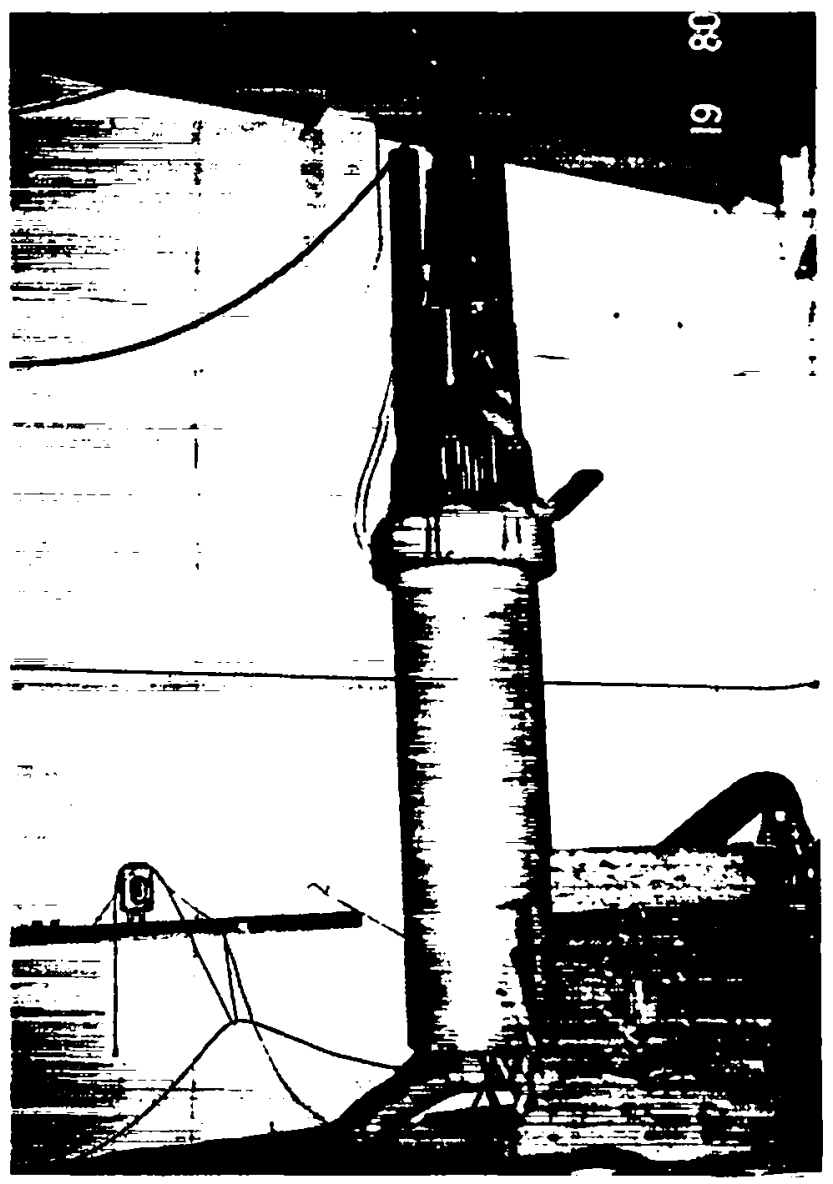

Fig. 16.

The bottom vessel shield, control rods, and floor plug. 

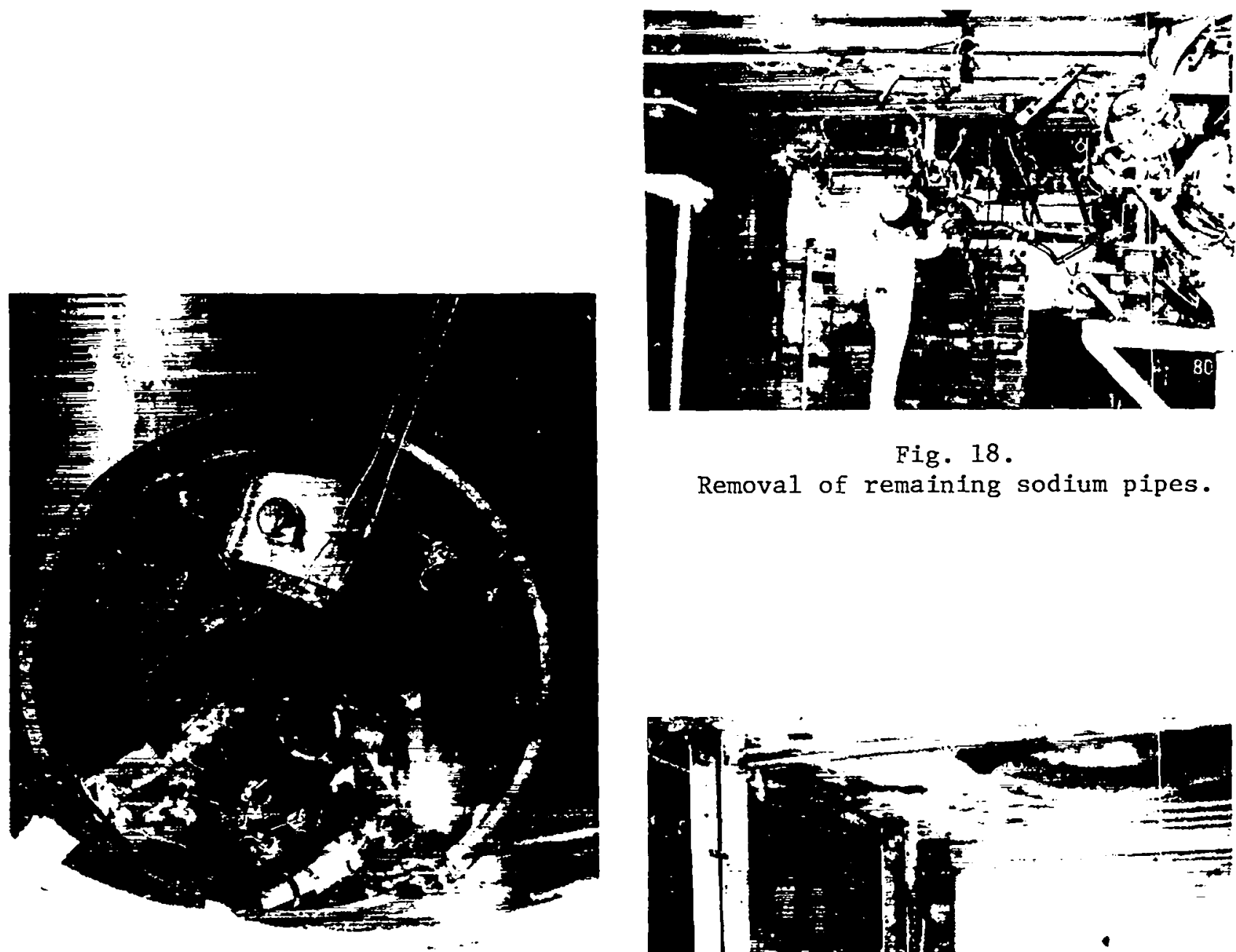

Fig. 18.

Removal of remaining sodium pipes.

Fig. 17.

View into the cell and beyond into the subbasement. Metal structures were cut with an oxyacetylene torch and removed with building crane.

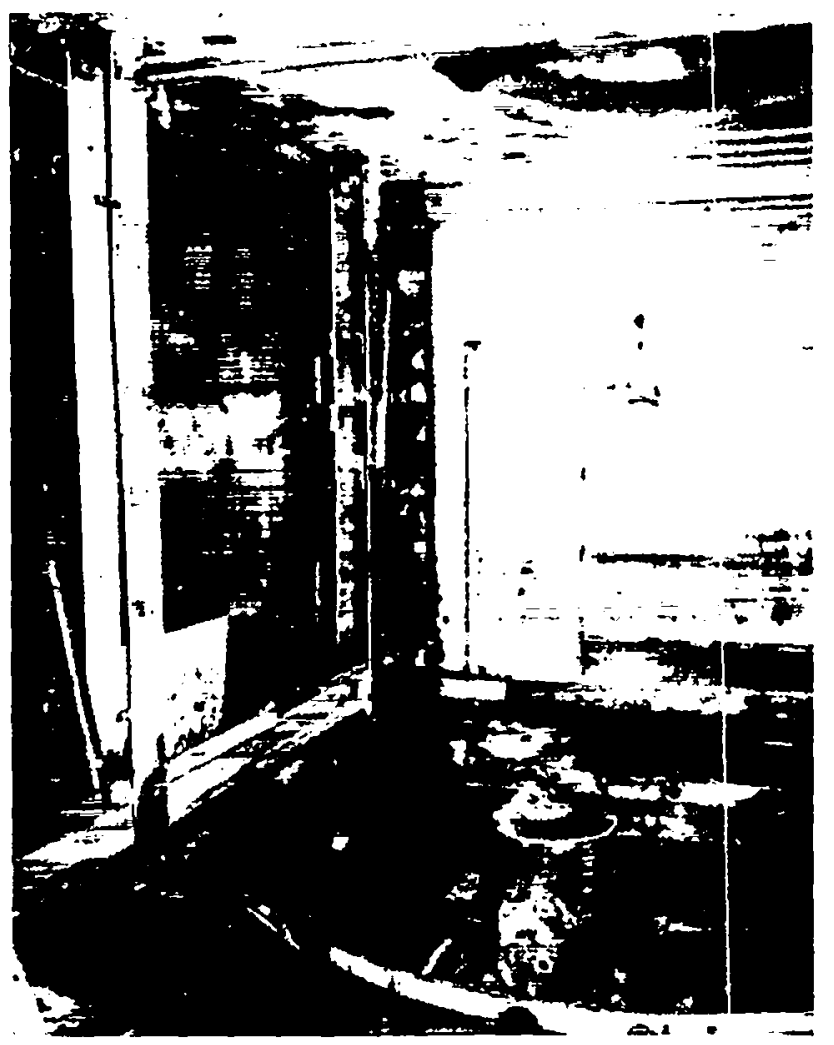

Fig. 19.

Reactor cell after removal of the shielding. 


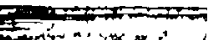

$=$ (i)

Printed in the United States of Americ Available from

Netional Technical information Service

US Department of Commerce

S285 Port Royal Road

Springfield, VA 22161

Microfiche $\$ 3.50$ (AO1)

\begin{tabular}{ccc} 
Paze Range & $\begin{array}{c}\text { Domestic } \\
\text { Price }\end{array}$ & $\begin{array}{c}\text { NTIS } \\
\text { Price Code }\end{array}$ \\
\hline $001-025$ & 35.00 & A02 \\
$026-050$ & 6.00 & A03 \\
051.075 & 7.00 & A04 \\
$076-100$ & 8.00 & A0S \\
101.125 & 9.00 & A06 \\
$126-150$ & 10.00 & A07
\end{tabular}

\begin{tabular}{ccc} 
Page Range & $\begin{array}{c}\text { Domestic } \\
\text { Price }\end{array}$ & $\begin{array}{c}\text { NIIS } \\
\text { Pruee Code }\end{array}$ \\
\hline 151.175 & $\$ 11.00$ & A08 \\
176.200 & 12.00 & A09 \\
201.225 & 13.00 & A10 \\
226.250 & 14.00 & A11 \\
$251-275$ & 15.00 & A 12 \\
276.300 & 16.00 & $A 13$
\end{tabular}

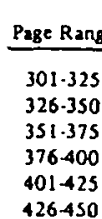

ge

Price Price Code

$517.00 \quad$ A14

18.00
19.00

20.00

21.00

tAdd $\$ 1.00$ for each additjonal 25.page tncrement or portion thereof from 601 pages up

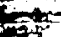

$-2$

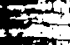

$+\frac{1}{2}$

to

$+4$

-

32

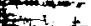

intonto

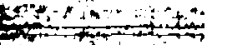

$3+x^{2} \quad 98$

75 mont

tistis

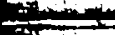

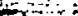

بrim

$=0$ -

50

(x)

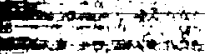

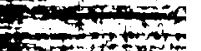

$\therefore$ (B)

$x+1+3 x+20$

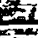

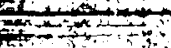

$x+2 \operatorname{sic}$

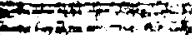

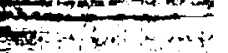

en $-219=2$

Ft+..........

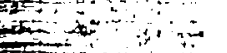

$x=2+4$ EEv

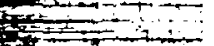

10 thend X
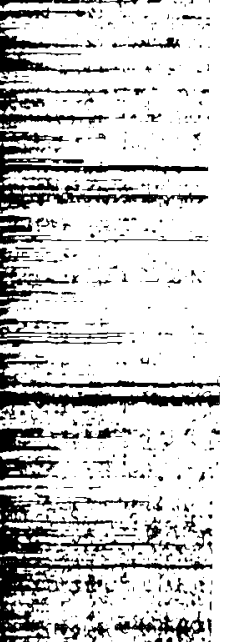


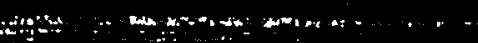

$\therefore=\ldots-. . .-3$

$x+2+\infty-2$

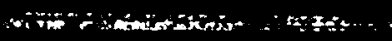

Atat

$\therefore$

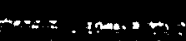

?.

يis.

87

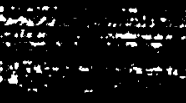

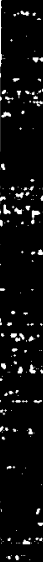





\section{Appendix H}

Portions of

Field/Del Mar Report

Relevant to 33 Shafts

"Survey of RH-TRU Waste

at Los Alamos National Laboratory"

by

Larry R. Field and Peter Del Mar 
This page intentionally left blank.

Page H-2 


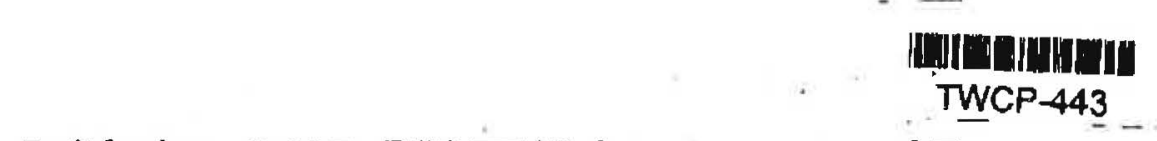

Initiative \# 197: RH-TRU Assessment and Recovery for

National TRU Program Office and WTAC

\title{
Survey of RH-TRU Waste at Los Alamos National Laboratory
}

\author{
Initial Report
}

\author{
from \\ Larry R. Fiold, MST-5 \\ Peter Del ivar, MST-5 \\ Los Alamos National Laboratory
}




\section{Table of Contents}

$\underline{\text { Item }}$

Page

Introduction

Historical Data ....................................................................................................

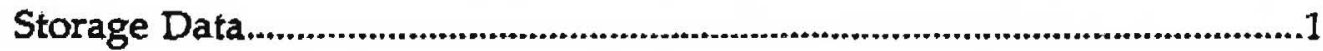

Table 1 RH-TRU (Origin, Date, Amount).....................................................

Table 2 RH-TRU (Isotopes Present)..............................................................10

Table 3 RH-TRU (Waste Activity and Volume) .........................................33

Graphs of Waste Activity and Volume .............................................35A\&B

Table 4 RH-TRU (Shaft Configuration) .......................................................36

Maps 1-4 (Maps of geographical locations of RH-TRU shafts ..................39

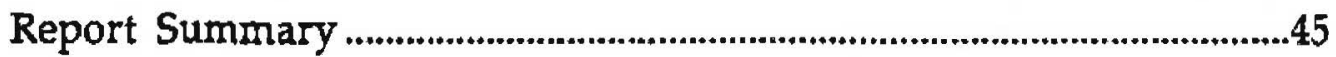

Page i

Field/Del Mar 


\section{Survey of RH-TRU Waste at Los Alamos National Laboratory}

Introduction:

This report is part of the RH-TRU waste assessment and recovery project. The purpose of this project is to provide a plan for the identification, retrieval and re-packaging of RH-TRU waste stored at LANL for subsequent transport and permanent storage at the WIPP site.

A safe and efficient work plan for waste retrieval must be based on detailed and accurate physical and historical data including it's location, volume, and radiological activity, together with a physical description of the shafts used for it's burial. This report attempts to bring all of the required information together in one document. This information is the foundation on which a feasible retrieval plan must be based.

\section{Historical Information:}

LANL began storing RH-TRU waste in shafts in 1970 and this practice has continued to the present day, the most recent burials occurring in 1994. The total volume of RH-TRU waste now stored at TA-54 is approximately $95 \mathrm{~m}^{3}$. The only RH-TRU not presently being stored at TA-54 is $0.33 \mathrm{~m}^{3}$ of RH-TRU located in the CMR building that is being readied for placement at TA-54 sometime later this summer. All of the RH-TRU waste is stored in a series of 60 shafts dug into the local volcanic tuff. Although all of the shafts are found in Area G of TA-54, they are not immediately adjacent to each other but are found in three different shaft fields. In addition, they do not all have the same physical configuration. They vary in depth from 16 to 25 feet and in diameter from 2 to 10 feet. Most of the shafts have metal liners, but some do not, and the method of "capping" the shaft after it is full has varied over the years from steel to concrete or both.

Storage Data:

The information in this report is organized into four discreet tables and a corresponding four maps that describe the site geography. 
Table 1 details each shipment of RH-TRU received at Area G including the package I.D. number, the volume of the package in cubic meters, the shaft it was placed in, the date of it's reception and the total activity of that package in curies. In some cases, the place of origin of the package is also given. As can be seen, there are wide variations in the size and radiological activity of these packages. In size, they range from a volume of a few liters to over 10 cubic meters. In terms of activity, they range from less than a microcurie to over 1400 curies. 
TABLE 1 RH-TRU at TA-54 (Origin, Date, Amount)

\begin{tabular}{|c|c|c|c|c|c|c|}
\hline PKG ID & CROUP & TA/BLDG & PKG VOL (m3) & SHAFT & RECDATE & Total Curies per Pkg \\
\hline$\$ 730482$ & & $03-00029$ & 0.008 & 74 & 17-Apr-73 & 0.61 \\
\hline$S 730487$ & & & 0.008 & 74 & 20-Apr-73 & 6.01 \\
\hline 5730488 & & & 0.008 & 74 & $20-A p r-73$ & 2.61 \\
\hline 5730490 & & & 0.008 & 74 & 23-Apr-73 & 12.01 \\
\hline 5730493 & & & 0.008 & 74 & 30-Apr-73 & 5.61 \\
\hline 5730499 & & & 0.008 & 74 & 8-May-73 & 12.01 \\
\hline 5730502 & & & 0.008 & 74 & 11-May-73 & 8.01 \\
\hline$\$ 730503$ & & & 0.008 & 74 & 30-May-73 & 20.31 \\
\hline$\$ 730504$ & & $03-00000$ & 0.008 & 74 & 30-May-73 & 0.91 \\
\hline$\$ 730508$ & & $21-00029$ & 0.008 & 75 & 20-Jun-73 & 3.61 \\
\hline 5730509 & & 03.00029 & 0.008 & 75 & 20-Jun-73 & 3.51 \\
\hline 5730510 & & & 0.008 & 75 & $21 \cdot$ Jun-73 & 8.04 \\
\hline$\$ 730513$ & CMB14 & $03-00000$ & 0.008 & 75 & $29 \cdot$ Jun- 73 & 14.03 \\
\hline$\$ 730844$ & & & 0.008 & 74 & 3-Apr-73 & 5.51 \\
\hline$\$ 731042$ & & 03.00029 & 0.008 & 75 & 9-Jul-73 & 0.25 \\
\hline$\$ 731045$ & & & 0.008 & 75 & 13-Jul-73 & 0.01 \\
\hline$\$ 731059$ & & & 0.008 & 75 & 22.Aug-73 & 1.01 \\
\hline$\$ 731060$ & & & 0.008 & 75 & 27-Aug-73 & 6.01 \\
\hline$\$ 731063$ & & & 0.008 & 75 & 4-Sep.73 & 1.01 \\
\hline 5731064 & & & 0.008 & 75 & 4-Sep-73 & 3.51 \\
\hline$\$ 731069$ & & & 0.008 & 75 & $21-\operatorname{Sep}-73$ & 1.71 \\
\hline$\$ 731070$ & & 03.00000 & 0.008 & 75 & $21-$ Sep- 73 & 1.51 \\
\hline$\$ 731231$ & & & 0.008 & 75 & 3-Oct-73 & 11.74 \\
\hline 5731232 & & $03-00029$ & 0.004 & 75 & 12-Oct-73 & 2.01 \\
\hline 5731238 & & 03.00043 & 0.008 & 76 & $29-0 \mathrm{ct}-73$ & 0.36 \\
\hline$\$ 731239$ & & 03.00000 & 0.008 & 76 & $25.0 c t-73$ & 0.01 \\
\hline$\$ 731240$ & & 03.00029 & 0.008 & 76 & $31.0 \mathrm{ct}-73$ & 0.02 \\
\hline 5731242 & & & 0.008 & 76 & 2-Nov-73 & 3.00 \\
\hline 5731243 & & & 0.008 & 76 & 2-Nov-73 & 3.00 \\
\hline 5731244 & & & 0.008 & 76 & 2-Nov-73 & 3.00 \\
\hline 5731245 & & & 0.008 & 76 & 2-Nov-73 & 1.01 \\
\hline 5731248 & & & 0.008 & 76 & 15-Noy-73 & 2.01 \\
\hline 5731250 & & 03.00000 & 0.008 & 76 & $30-$ Nov-73 & 3.01 \\
\hline$S 731256$ & & $03-00029$ & 0.004 & 76 & 17-Dec-73 & 13.92 \\
\hline$S 791472$ & CMB & 03.00029 & 0.212 & 204 & 29-Jun-79 & 10.61 \\
\hline$S 791478$ & CMB14 & 03.00029 & 0.212 & 204 & 29-Jun-79 & 2.15 \\
\hline 5791483 & $\mathrm{CMBI}$ & 03.00029 & 0.212 & 204 & 29-Jun-79 & 15.09 \\
\hline 5791484 & & & 0.091 & 201 & 29.Jun-79 & 4.18 \\
\hline 5794215 & & & 0.161 & 201 & 29-Jun-79 & 11.03 \\
\hline$\$ 794216$ & & & 0.161 & 201 & 29-Jun-79 & 8.64 \\
\hline 5794218 & & & 0.161 & 201 & 29.Jun-79 & 1.15 \\
\hline$\$ 794219$ & & & 0.161 & 201 & 29-Jun-79 & 1.39 \\
\hline 5794220 & CMB14 & 03.00029 & 0.161 & 201 & 29-Jun-79 & 34.18 \\
\hline 5794221 & & & 0.161 & 201 & 29-Jun-79 & 43.66 \\
\hline 5794222 & CMBI & $03-00029$ & 0.212 & 204 & 29.Jun-79 & 0.29 \\
\hline
\end{tabular}


TABLE 1 RH-TRU at TA-54 (Origin, Date, Amount)

\begin{tabular}{|c|c|c|c|c|c|c|}
\hline PKG ID & Croup & TA/BLDG & PKG VOL (m3) & SHAFT & AECDATE & Total Curies per Pkg \\
\hline 5794223 & CMB14 & $03-00029$ & 0.212 & 204 & 29-Jun-79 & 21.01 \\
\hline 5801483 & & & 0.178 & 205 & 1-Dec-80 & 135.06 \\
\hline$\$ 801485$ & & & 0.178 & 205 & 1-Dec-80 & 171.54 \\
\hline 5802244 & $C M B$ & $03-00029$ & 0.178 & 205 & 1-Dec-80 & 4.13 \\
\hline$\$ 802246$ & & & 0.178 & 205 & 1-Dec-80 & 2.48 \\
\hline 5802247 & & & 0.178 & 205 & 1-Dec-80 & 1.51 \\
\hline$\$ 802259$ & CMB14 & $03-00029$ & 0.178 & 205 & 1-Dec-80 & 35.74 \\
\hline $\mathrm{S} 802287$ & & & 0.178 & 205 & 1.Dec. 80 & 55.50 \\
\hline$\$ 803547$ & CMBI & 03.00029 & 1.2 & 203 & 30-Apr-80 & 111.30 \\
\hline$\$ 803548$ & CMB14 & 03.00029 & 1.2 & 202 & 30-Apr-80 & 249.01 \\
\hline 5803758 & $\mathrm{HI}$ & 35.00002 & 1.2 & 212 & 9-Apr-80 & 42.30 \\
\hline S810794 & CMB14 & $03-00029$ & 0.224 & 208 & 22-Jun-81 & 101.75 \\
\hline$\$ 810795$ & & & 0.224 & 209 & 22-Jun-81 & 0.00 \\
\hline$\$ 810797$ & & & 0.224 & 209 & 22.Jun-81 & 0.41 \\
\hline 5810798 & & & 0.224 & 209 & 22-Jun-81 & 0.21 \\
\hline 5810799 & & & 0.447 & 209 & $22-J u n-81$ & 0.31 \\
\hline 5810800 & & & 0.224 & 210 & 22-Jun-81 & 0.41 \\
\hline 5810802 & & & 0.11 & 208 & 22-Jun-81 & 0.07 \\
\hline 5810804 & & & 0.447 & 210 & 22-Jun-81 & 0.21 \\
\hline S810805 & & & 0.447 & 210 & 22-Jun-81 & 0.31 \\
\hline 5810806 & & & 0.224 & 210 & 22-Jun-81 & 0.03 \\
\hline S810807 & & & 0.224 & 211 & $6-0 \mathrm{ct}-81$ & 0.71 \\
\hline 5810808 & CMBI & 03.00029 & 0.224 & 211 & $6-0 \mathrm{ct}-81$ & 2.21 \\
\hline 5810809 & CMB14 & $03-00029$ & 0.224 & 211 & 6-Oct-81 & 4.01 \\
\hline 5810810 & CMB14 & 03.00029 & 0.445 & 211 & $6-0 \mathrm{ct}-\mathrm{B1}$ & 0.07 \\
\hline$\$ 811387$ & CMBA & $03-00039$ & 0.207 & 200 & 14-Apr-B1 & 3.74 \\
\hline$S 811390$ & & & 0.207 & 200 & 14-Apr-81 & 6.62 \\
\hline$\$ 811396$ & CMB14 & $03-00029$ & 0.207 & 200 & 14-Apr-81 & 0.61 \\
\hline 5811397 & & & 0.244 & 207 & 29-May-81 & 2.01 \\
\hline$S 811398$ & & & 0.207 & 200 & 14-Apr-B1 & 0.85 \\
\hline$\$ 811400$ & CMB & $03-00039$ & 0.244 & 207 & 29-Мау-81 & 3.51 \\
\hline$S 811401$ & & $03-00029$ & 0.244 & 207 & 29-May-81 & 5.22 \\
\hline 5811405 & CMB14 & $03-00029$ & 0.224 & 208 & 22-Jun-81 & 2.03 \\
\hline 5811406 & & & 0.244 & 207 & 29-May-81 & 2.51 \\
\hline 5811408 & & & 0.11 & 208 & 22-Jun-81 & 0.18 \\
\hline 5811409 & & & 0.224 & 208 & 22-Jun-81 & 2.11 \\
\hline$S 811411$ & & & 0.224 & 208 & 22-Jun-81 & 1.01 \\
\hline$S 811412$ & & & 0.224 & 209 & 22-Jun-81 & 2.01 \\
\hline$S 811471$ & CMB & 03.00029 & 0.207 & 200 & 14-Apr-81 & 3.47 \\
\hline 5811473 & & 03.05429 & 0.207 & 200 & 14-Apr-81 & 20.31 \\
\hline 5812291 & CMB14 & 03.00029 & 0.207 & 206 & 1-Apr-81 & 47.55 \\
\hline 5812292 & & & 0.207 & 206 & 1.Apr-81 & 28.14 \\
\hline 5812293 & CMBI & 03.00029 & 0.207 & 206 & 1-Apr-81 & 108.43 \\
\hline$\$ 812297$ & & & 0.207 & 206 & 14-Apr-81 & 101.35 \\
\hline 5812298 & & & 0.207 & 206 & 1.Apr-81 & 101.35 \\
\hline
\end{tabular}


TABLE 1 RH-TRU at TA-54 (Origin, Date, Amount)

\begin{tabular}{|c|c|c|c|c|c|c|}
\hline PKG ID & Group & TA/BLDG & PKG VOL (m3) & SHAFT & RECDATE & Total Curies per Pkg \\
\hline$\$ 812302$ & CMB14 & $03-00029$ & 0.207 & 206 & 1-Apr-81 & 8.69 \\
\hline 5812303 & & & 0.207 & 206 & $1 \cdot \mathrm{Apr}-81$ & 8.69 \\
\hline$\$ 812669$ & CMBI & 03.00029 & 0.224 & 211 & 6-0ct-81 & 11.40 \\
\hline$\$ 812684$ & CMB14 & 03.00029 & 0.212 & 213 & 3-Nov-81 & 42.80 \\
\hline 5812686 & CMBI & 03.00029 & 0.212 & 213 & 3-Nov-81 & 7.27 \\
\hline$\$ 812688$ & $\mathrm{CMB14}$ & $03-00029$ & 0.212 & 213 & 3-Nov-81 & 101.79 \\
\hline 5812689 & & & 0.212 & 213 & 3-Nov-81 & 2.81 \\
\hline 5814978 & & & 0.371 & 207 & 29-May-81 & 0.18 \\
\hline 5814979 & & & 0.224 & 208 & 22-Jun-81 & 0.12 \\
\hline 5820041 & & & 0.071 & 215 & 9-Jun-82 & 30.94 \\
\hline$\$ 820042$ & & & 0.071 & 215 & 9.Jun-82 & 15.21 \\
\hline 5820057 & & & 0.085 & 214 & 20-Apr-82 & 0.31 \\
\hline 5820058 & & & 0.085 & 214 & 20-Apr-82 & 0.13 \\
\hline S821822 & & & 0.17 & 214 & 21-Apr-82 & 0.41 \\
\hline S821823 & & & 0.17 & 214 & 21-Apr-82 & 0.46 \\
\hline S821825 & $C M B I$ & 03.00029 & 0.142 & 216 & 9-Jun-82 & 0.86 \\
\hline 5821826 & & & 0.17 & 214 & 23-Apr-82 & 0.41 \\
\hline 5821832 & CMB14 & 03.00029 & 0.142 & 215 & 9-Jun-82 & 2.01 \\
\hline 5821833 & & & 0.142 & 215 & 9-Jun-82 & 3.01 \\
\hline 5821834 & & & 0.142 & 215 & 9-Jun-82 & 2.01 \\
\hline$\$ 821835$ & & & 0.142 & 215 & 9-Jun-82 & 0.31 \\
\hline$\$ 821836$ & & & 0.142 & 216 & 9-Jun-82 & 2.01 \\
\hline$\$ 821837$ & & & 0.142 & 215 & 9-Jun-82 & 2.01 \\
\hline 5821838 & & & 0.142 & 216 & 9-Jun-82 & 1.01 \\
\hline$\$ 821839$ & & & 0.142 & 216 & 9-Jun-82 & 0.21 \\
\hline 5821840 & & & 0.142 & 216 & 9-Jun-82 & 4.01 \\
\hline 5821841 & & & 0.142 & 216 & 9.Jun-82 & 2.01 \\
\hline S821870 & CMB & 03.00029 & 0.142 & 217 & 13-Sep-82 & 0.16 \\
\hline$S 821871$ & & & 0.142 & 217 & 13-Sep-82 & 4.70 \\
\hline 5821874 & CMB14 & 03.00029 & 0.142 & 217 & 13-Sep-82 & 10.01 \\
\hline S821875 & & & 0.142 & 218 & 13-Sep-82 & 20.01 \\
\hline 5821879 & & & 0.142 & 218 & 13-Sep-82 & 30.12 \\
\hline S821881 & & & 0.142 & 218 & 13-5ep-82 & 40.12 \\
\hline 5821882 & & & 0.142 & 217 & 13-Sep-82 & 1.01 \\
\hline 5821883 & & & 0.142 & 218 & 13-Sep-82 & 6.01 \\
\hline 5821915 & & & 0.142 & 217 & 13-Sep-82 & 2.40 \\
\hline$S 821916$ & CMB14 & 03.00029 & 0.142 & 218 & 13-Sep-82 & 32.48 \\
\hline 5821917 & & & 0.142 & 218 & 13-Sep-82 & 6.01 \\
\hline$\$ 821918$ & CMBI & $03-00029$ & 0.142 & 217 & 13-Sep-82 & 1.20 \\
\hline$\$ 823410$ & CMB14 & $03-00029$ & 0.17 & 214 & 1-Apr-82 & 1.31 \\
\hline 5830716 & MST14 & $03-00029$ & 0.153 & 222 & 14-DeC-83 & 2.03 \\
\hline$\$ 830717$ & & & 0.153 & 222 & 14.0ec-83 & 200.03 \\
\hline$\$ 830781$ & & & 0.153 & 222 & 14.Dec-83 & 1.00 \\
\hline 5830782 & & & 0.142 & 223 & 14-Dec-83 & 25.00 \\
\hline 5830783 & & & 0.142 & 223 & 14-Dec-83 & 3.01 \\
\hline
\end{tabular}


TABLE 1 RH-TRU at TA-54 (Origin, Date, Amount)

\begin{tabular}{|c|c|c|c|c|c|c|}
\hline PKG ID & GROUP & TA/BLDG & PKG VOL $(\mathrm{m} 3)$ & SHAFT & RECDATE & Total Curies per Pkg \\
\hline 5830784 & & & 0.142 & 223 & 14-Dec-83 & 3.01 \\
\hline$S 830785$ & & & 0.142 & 223 & 14-Dec-83 & 3.01 \\
\hline 5830786 & & & 0.142 & 223 & 14-Dec-83 & 1.50 \\
\hline S830787 & & & 0.079 & 222 & 14-Dec-83 & 40.01 \\
\hline 5830788 & & & 0.153 & 222 & 14-Dec-83 & 40.01 \\
\hline 5830789 & & & 0.079 & 222 & 14-Dec-83 & 0.21 \\
\hline 5830790 & & & 0.079 & 222 & 14-Dec-83 & 40.22 \\
\hline 5830791 & & & 0.142 & 223 & 14-Dec-83 & 1.51 \\
\hline$\$ 832830$ & & & 0.142 & 219 & 10-Mar-83 & 20.01 \\
\hline$S 832831$ & & & 0.142 & 219 & 10-Mar-83 & 0.81 \\
\hline$\$ 832832$ & & & 0.142 & 219 & 10-Mar-83 & 152.49 \\
\hline 5832833 & & & 0.142 & 219 & $10 \cdot$ Mar-83 & 30.01 \\
\hline$\$ 832834$ & & & 0.142 & 219 & 10-Mar-83 & 50.01 \\
\hline$\$ 832835$ & & & 0.142 & 219 & 10-Mar-83 & 100.31 \\
\hline 5832836 & & & 0.142 & 220 & 10-Mar-83 & 100.01 \\
\hline S832837 & & & 0.142 & 220 & 10-Mar-83 & 100.01 \\
\hline S832838 & & & 0.142 & 220 & 10-Mar-83 & 2.01 \\
\hline$\$ 832839$ & & & 0.142 & 220 & 10-Mar-83 & 8.01 \\
\hline 5832840 & & & 0.142 & 220 & 10-Mar-83 & 200.01 \\
\hline S832841 & & & 0.142 & 220 & 10-Mar-83 & 50.01 \\
\hline$\$ 832842$ & & & 0.142 & 221 & 10-Mar-83 & 15.01 \\
\hline 5832843 & & & 0.142 & 221 & 10-Mar-83 & 30.01 \\
\hline 5832844 & & & 0.142 & 221 & 10-Mar-83 & 40.01 \\
\hline 5832845 & & & 0.142 & 221 & 10-Mar-83 & 1.51 \\
\hline 5832846 & & & 0.142 & 221 & 10-Mar-83 & 60.01 \\
\hline$\$ 832847$ & & & 0.142 & 221 & 10-Mar-83 & 30.01 \\
\hline 5840831 & & & 0.014 & 230 & 31-Dec-84 & 40.89 \\
\hline$\$ 840835$ & & & 0.014 & 230 & 31-Dec-84 & 10.01 \\
\hline S840836 & & & 0.014 & 230 & 31-Dec-84 & 0.41 \\
\hline 5840838 & & & 0.014 & 230 & 31-Dec-84 & 5.01 \\
\hline$\$ 840839$ & & & 0.014 & 230 & 31-Dec-84 & 1.51 \\
\hline$S 840840$ & & & 0.014 & 230 & $31-\operatorname{Dec}-84$ & 1.01 \\
\hline S840841 & & & 0.014 & 230 & 31.Dec-84 & 0.71 \\
\hline S840842 & & & 0.014 & 226 & 31-Dec-84 & 2.01 \\
\hline 5840843 & & & 0.014 & 226 & 31.Dec-84 & 2.01 \\
\hline$S 840844$ & & & 0.014 & 226 & $31-\mathrm{Dec}-84$ & 1.51 \\
\hline S840845 & & & 0.014 & 226 & $31-D e c-84$ & 0.31 \\
\hline S840846 & & & 0.014 & 226 & 31.Dec-84 & 5.01 \\
\hline S840847 & & & 0.014 & 226 & 31-Dec-84 & 1.51 \\
\hline 5840848 & & & 0.014 & 225 & 31-Dec-84 & 0.41 \\
\hline 5840851 & & & 0.017 & 229 & $31 \cdot$ Dec-84 & 3.01 \\
\hline 5840854 & & & 0.014 & 225 & 31-Dec-84 & 1.51 \\
\hline 5840855 & & & 0.017 & 229 & 31-Dec-84 & 1.01 \\
\hline 5840856 & & & 0.014 & 225 & 31-Dec-84 & 1.51 \\
\hline 5840857 & & & 0.014 & 225 & 31-Dec-84 & 3.01 \\
\hline
\end{tabular}


TABLE 1 RH-TRU at TA-54 (Origin, Date, Amount)

\begin{tabular}{|c|c|c|c|c|c|c|}
\hline PKG ID & GROUP & TA/BLDG & PKG VOL (m3) & SHAFT & RECDATE & Total Curles per Pkg \\
\hline 5840859 & & & 0.014 & 230 & 31-Dec-84 & 1.01 \\
\hline 5840860 & & & 0.017 & 229 & $31-\operatorname{Dec}-84$ & 2.01 \\
\hline 5840862 & & & 0.014 & 226 & 31. Dec.84 & 0.21 \\
\hline 5840863 & MST14 & $03-00029$ & 0.014 & 225 & 31-Dec-84 & 0.09 \\
\hline 5840864 & & & 0.014 & 225 & 31-Dec-84 & 0.31 \\
\hline S840865 & & & 0.017 & 229 & 31-Dec-84 & 0.11 \\
\hline 5840867 & & & 0.014 & 225 & 31-Dec-84 & 0.41 \\
\hline 5840868 & & & 0.014 & 226 & 31-Dec-84 & 0.31 \\
\hline$\$ 840873$ & & & 0.017 & 229 & 31-Dec-84 & 2.18 \\
\hline 5840874 & & & 0.014 & 225 & 31-Dec-84 & 0.21 \\
\hline S840877 & & & 0.014 & 227 & 31-Dec-84 & 1.64 \\
\hline 5840878 & & & 0.014 & 227 & 31-Dec-84 & 2.69 \\
\hline 5840879 & & & 0.014 & 227 & 31-Dec-84 & 4.19 \\
\hline$\$ 840880$ & & & 0.014 & 227 & $31 \cdot$ Dec-84 & 2.69 \\
\hline 5840881 & & & 0.014 & 227 & 31-Dec-84 & 3.19 \\
\hline 5840882 & & & 0.017 & 229 & $31-D e c-84$ & 0.31 \\
\hline 5840883 & & & 0.014 & 227 & $31-D e C-84$ & 2.01 \\
\hline 5840885 & & & 0.014 & 227 & 31-Dec-84 & 6.20 \\
\hline 5840886 & & & 0.014 & 227 & 31-Dec-84 & 0.81 \\
\hline S840888 & & & 0.017 & 229 & $31-$ Dec-84 & 0.16 \\
\hline 5852326 & & & 0.014 & 224 & $30-D e c-85$ & 4.01 \\
\hline S852328 & & & 0.014 & 224 & 30-Dec-85 & 2.01 \\
\hline $\mathrm{S} 852332$ & & & 0.014 & 224 & 30-Dec-85 & 4.01 \\
\hline$\$ 852804$ & & & 0.014 & 224 & 30-Dec-85 & 3.00 \\
\hline 5855046 & & & 0.014 & 231 & 30-Dec-85 & 3.01 \\
\hline 5855047 & & & 0.014 & 231 & $30-D e c-85$ & 3.01 \\
\hline S855048 & & & 0.014 & 231 & 30-Dec-85 & 0.90 \\
\hline 5855049 & & & 0.014 & 231 & 30-Dec-85 & 0.40 \\
\hline 5855064 & & & 0.014 & 224 & 30-Dec-85 & 3.52 \\
\hline$\$ 855065$ & & & 0.014 & 224 & 30-Dec-85 & 4.42 \\
\hline$\$ 855066$ & & & 0.014 & 224 & $30-\mathrm{Dec}-85$ & 1.51 \\
\hline 5855068 & & & 0.014 & 224 & $30-D e c-85$ & 1.51 \\
\hline$\$ 856015$ & & & 0.014 & 231 & $30 \cdot$ Dec 85 & 2.11 \\
\hline 5856016 & & & 0.014 & 231 & 30-Dec-85 & 6.01 \\
\hline 5856017 & & & 0.014 & 231 & 30-Dec-85 & 6.01 \\
\hline 5856018 & & & 0.014 & 231 & 30-Dec-85 & 1.01 \\
\hline $5874: 23$ & & & 0.004 & 228 & 23-Dec-87 & 0.16 \\
\hline 5874124 & & & 0.004 & 228 & 23-Dec-87 & 1.51 \\
\hline 5874125 & & & 0.004 & 228 & 23-Dec-87 & 0.16 \\
\hline S874126 & & & 0.004 & 228 & 23-Dec-87 & 2.51 \\
\hline 5874127 & & & 0.004 & 228 & 23-Dec-87 & 1.51 \\
\hline 5874128 & & & 0.004 & 228 & 23.Dec-87 & 1.51 \\
\hline 5874129 & 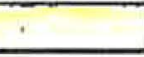 & & 0.004 & 228 & 23-Dec-87 & 1.51 \\
\hline 5874130 & & & 0.004 & 228 & 23-Dec-87 & 2.01 \\
\hline 5874132 & & & 0.004 & 232 & 23-Dec-87 & 0.00 \\
\hline
\end{tabular}


TABLE 1

RH-TRU at TA-54 (Origin, Date, Amount)

\begin{tabular}{|c|c|c|c|c|c|c|}
\hline PKG ID & CROLP & TA/BLDG & PKG VOL (m3) & SHAFT & RECDATE & Total Curies per Pkg \\
\hline S874133 & & & 0.004 & 232 & $23-$ Dec-87 & 5.83 \\
\hline S874134 & & & 0.004 & 232 & $23-$ Dec-87 & 0.09 \\
\hline S910321 & MST-5 & $03-00029$ & 10.195 & 302 & $5-$ Dec-91 & 0.80 \\
\hline S910322 & & & 10.195 & 303 & $5-$ Dec-91 & 2.34 \\
\hline S910327 & & & 10.195 & 306 & $5-$ Dec-91 & 1.75 \\
\hline S912717 & & & 10.195 & 305 & $5-$ Dec-91 & 3.45 \\
\hline S912719 & & & 10.195 & 304 & $5 \cdot$ Dec-91 & 1.57 \\
\hline Totals & & 93.87 & & & 15484.94 \\
\hline
\end{tabular}


Table 2 lists the radionuclides found in each package along with their individual activities in curies. This table shows that a given package may contain as many as $\mathbf{1 2}$ different radionuclides or as few as 3. 


\begin{tabular}{|c|c|c|}
\hline PKG ID & ISOTOPE & T CURIES \\
\hline 5730513 & PU239 & $2.64 E-02$ \\
\hline 5730513 & U235 & $0.00 E+00$ \\
\hline$\$ 730844$ & MP & $5.50 E+00$ \\
\hline 5730844 & PU239 & $6.14 E-03$ \\
\hline$\$ 730844$ & U235 & $0.00 E+00$ \\
\hline$\$ 731042$ & PU239 & $2.46 E-01$ \\
\hline$\$ 731045$ & PU239 & $6.14 E-03$ \\
\hline$\$ 731059$ & MP & $1.00 E+00$ \\
\hline$\$ 731059$ & PU239 & $6.14 E-03$ \\
\hline$\$ 731060$ & MPP & $6.00 E+00$ \\
\hline$\$ 731060$ & PU239 & $6.14 E-03$ \\
\hline$\$ 731063$ & MP & $1.00 E+00$ \\
\hline 5731063 & PU239 & $6.14 \mathrm{E}-03$ \\
\hline$\$ 731064$ & MPP & $3.50 E+00$ \\
\hline$\$ 731064$ & PU239 & $6.14 E-03$ \\
\hline$\$ 731069$ & MFP & $1.70 E+00$ \\
\hline 5731069 & PU239 & $6.14 E-03$ \\
\hline$\$ 731070$ & MP & $1.50 E+00$ \\
\hline$\$ 731070$ & PU239 & $6.14 E-03$ \\
\hline 5731231 & MPP & $1.10 E+01$ \\
\hline$\$ 731231$ & PU239 & 7.37E-01 \\
\hline$\$ 731232$ & MPP & $2.00 E+00$ \\
\hline$\$ 731232$ & PU239 & $1.23 E-02$ \\
\hline$\$ 731238$ & MPP & 1.BOE-01 \\
\hline$\$ 731238$ & PU239 & $1.84 E \cdot 01$ \\
\hline$\$ 731239$ & MP & $6.00 \mathrm{E}=03$ \\
\hline$\$ 731239$ & PU239 & $6.14 E-03$ \\
\hline 5731240 & MP & $1.20 \mathrm{E}-02$ \\
\hline$\$ 731240$ & PU239 & 1.23E-02 \\
\hline$\$ 731242$ & MPP & $0.00 E+00$ \\
\hline$\$ 731242$ & PU239 & $3.00 E+00$ \\
\hline$\$ 731243$ & MP & $0.00 E+00$ \\
\hline$\$ 731243$ & PU239 & $3.00 E+00$ \\
\hline$\$ 731244$ & MP & $0.00 E+00$ \\
\hline 5731244 & PU239 & $3.00 E+00$ \\
\hline$\$ 731245$ & MP & $1.00 E+00$ \\
\hline$\$ 731245$ & PU239 & $6.14 E-03$ \\
\hline$\$ 731248$ & MPP & $2.00 E+00$ \\
\hline 5731248 & PU239 & $1.23 E-02$ \\
\hline$\$ 731250$ & MP & $3.00 E+00$ \\
\hline$S 731250$ & PU239 & $1.23 E-02$ \\
\hline 5731256 & MPP & $1.30 E+01$ \\
\hline$\$ 731256$ & PU239 & $9.21 \mathrm{E}-01$ \\
\hline 5791472 & MFP & $1.05 E+01$ \\
\hline$\$ 791472$ & PU239 & $1.08 E-01$ \\
\hline
\end{tabular}


Table 2

RH-TRU (Isotopes Present)

\begin{tabular}{|c|c|c|}
\hline PKG ID & ISOTOPE & T CURIES \\
\hline 5791472 & U235 & $1.12 E-05$ \\
\hline$\$ 791478$ & MPP & $0.00 E+00$ \\
\hline 5791478 & PU239 & $2.15 E+00$ \\
\hline 5791478 & U235 & $2.59 E .04$ \\
\hline$\$ 791483$ & MPP & $1.50 E+01$ \\
\hline 5791483 & PU239 & 9.21E-02 \\
\hline 5791483 & U235 & $9.63 E .06$ \\
\hline 5791484 & MP & $4.00 E+00$ \\
\hline 5791484 & PU239 & 1.84E-01 \\
\hline 5791484 & U235 & 2.14E-06 \\
\hline 5794215 & MP & $1.10 E+01$ \\
\hline$\$ 794215$ & PU239 & 3.07E-02 \\
\hline$\$ 794215$ & U235 & $4.28 E-06$ \\
\hline 5794216 & NFP & $8.50 E+00$ \\
\hline$\$ 794216$ & PU239 & $1.38 \mathrm{E}-01$ \\
\hline 5794216 & U235 & $1.93 \mathrm{E} .05$ \\
\hline 5794218 & MP & $1.00 E+00$ \\
\hline 5794218 & PU239 & $1.54 \mathrm{E}-01$ \\
\hline 5794218 & $\cup 235$ & $2.14 \mathrm{E}-05$ \\
\hline 5794219 & MP & $1.30 E+00$ \\
\hline 5794219 & PU239 & 9.21E-02 \\
\hline$\$ 794219$ & $\cup 235$ & $1.07 E-05$ \\
\hline$\$ 794220$ & MP & $3.00 E+01$ \\
\hline$\$ 794220$ & PU239 & $4.18 E+00$ \\
\hline$\$ 794220$ & U235 & $3.15 \mathrm{E}-04$ \\
\hline 5794221 & MPP & $3.50 E+01$ \\
\hline$\$ 794221$ & PU239 & $8.66 E+00$ \\
\hline$\$ 794221$ & $\mathrm{U} 235$ & $7.92 \mathrm{E}-04$ \\
\hline$\$ 794222$ & MPP & $0.00 E+00$ \\
\hline$\$ 794222$ & PU239 & 2.92E.01 \\
\hline$\$ 794222$ & U235 & 4.07E-05 \\
\hline 5794223 & MPP & $2.00 E+01$ \\
\hline 5794223 & PU239 & $1.01 E+00$ \\
\hline S794223 & $\cup 235$ & 9.37E-05 \\
\hline$\$ 801483$ & MPP & $1.35 E+02$ \\
\hline 5801483 & PU239 & $6.14 E \cdot 02$ \\
\hline 5801483 & U235 & $2.14 E-06$ \\
\hline 5801485 & MP & $1.70 E+02$ \\
\hline 5801485 & PU239 & $1.54 E+00$ \\
\hline 5801485 & U235 & $2.03 E-04$ \\
\hline 5802244 & $M P$ & $4.10 E+00$ \\
\hline 5802244 & PU239 & 3.07E-02 \\
\hline 5802244 & U235 & $4.28 \mathrm{E}-05$ \\
\hline 5802246 & MP & $1.40 E+00$ \\
\hline 5802246 & PU239 & $1.08 E+00$ \\
\hline
\end{tabular}




\begin{tabular}{|c|c|c|}
\hline PKG ID & SOTOPE & T_CURIES \\
\hline$S 802246$ & U235 & $1.50 E-04$ \\
\hline$\$ 802247$ & MP & $1.20 E+00$ \\
\hline 5802247 & PU239 & 3.07E-01 \\
\hline 5802247 & U235 & $4.49 E-05$ \\
\hline 5802259 & MP & $3.50 E+01$ \\
\hline$\$ 802259$ & PU239 & 7.37E-01 \\
\hline 5802259 & U235 & $8.35 \mathrm{E} .05$ \\
\hline S802267 & MPP & $5.20 E+01$ \\
\hline$\$ 802287$ & PU239 & $3.50 E+00$ \\
\hline 5802287 & U235 & $5.05 E .05$ \\
\hline 5803547 & $M \Phi$ & $1.09 E+02$ \\
\hline 5803547 & PU239 & $2.30 E+00$ \\
\hline S803547 & $\mathrm{U235}$ & $2.72 \mathrm{E} \cdot 04$ \\
\hline 5803548 & MPP & $2.45 E+02$ \\
\hline 5803548 & PU239 & $4.01 E+00$ \\
\hline$S 803548$ & U235 & 4.77E-04 \\
\hline S803758 & $\mathrm{CO} 60$ & $3.00 E+01$ \\
\hline 5803758 & PU239 & $1.23 E+01$ \\
\hline 5810794 & MPP & $1.00 E+02$ \\
\hline S810794 & PU239 & $1.75 E+00$ \\
\hline S810794 & U235 & 2.17E-04 \\
\hline S810795 & U235 & $8.56 E-07$ \\
\hline S810797 & MPP & $4.00 E \cdot 01$ \\
\hline S810797 & PU239 & $6.14 E-03$ \\
\hline 5810797 & U235 & $8.56 E-07$ \\
\hline S810798 & MPP & $2.00 E-01$ \\
\hline S810798 & PU239 & $6.14 E-03$ \\
\hline S810798 & U235 & 8.56E-07 \\
\hline 5810799 & MP & $3.00 E-01$ \\
\hline 5810799 & PU239 & $6.14 E-03$ \\
\hline 5810799 & U235 & $8.56 \mathrm{E}-07$ \\
\hline 5810800 & MPP & $4.00 E-01$ \\
\hline 5810800 & PU239 & $6.14 \mathrm{E}-03$ \\
\hline$\$ 810800$ & บ235 & $8.56 E-07$ \\
\hline S810802 & MPP & $6.00 E-02$ \\
\hline 5810802 & PU239 & $6.14 \mathrm{E}-03$ \\
\hline 5810802 & U235 & $8.56 E-07$ \\
\hline$\$ 810804$ & MFP & $2.00 E-01$ \\
\hline$\$ 810804$ & PU239 & $6.14 E \cdot 03$ \\
\hline 5810804 & U235 & $8.56 \mathrm{E}-07$ \\
\hline S810805 & NFP & $3.00 E \cdot 01$ \\
\hline S810805 & PU239 & $6.14 E-03$ \\
\hline S810805 & U235 & $8.56 E-07$ \\
\hline 5810806 & MP & 2.00 E-02 \\
\hline$\$ 810806$ & PU239 & $6.14 E-03$ \\
\hline
\end{tabular}


Table 2

RH-TRU (Isotopes Present)

\begin{tabular}{|c|c|c|}
\hline PKG ID & SOTOPE & T CURIES \\
\hline$\$ 810806$ & U235 & 8.56E.07 \\
\hline$\$ 810807$ & MPP & 7.00E-01 \\
\hline$\$ 810807$ & PU239 & $6.14 E-03$ \\
\hline$\$ 810807$ & U235 & $8.56 \mathrm{E}-07$ \\
\hline 5810808 & MP & $2.20 E+00$ \\
\hline 5810808 & PU239 & $6.14 E-03$ \\
\hline$\$ 810808$ & U235 & 8.56E-07 \\
\hline$\$ 810809$ & MPP & $4.00 E+00$ \\
\hline 5810809 & PU239 & $6.14 E-03$ \\
\hline 5810809 & U235 & $8.56 \mathrm{E}-07$ \\
\hline 5810810 & MPP & $6.00 E-02$ \\
\hline 5810810 & PU239 & $6.14 E-03$ \\
\hline 5810810 & U235 & 8.56E-07 \\
\hline 5811387 & MPP & $2.50 E+00$ \\
\hline 5811387 & PU239 & $1.24 E+00$ \\
\hline$S 811387$ & U235 & 1.73E-05 \\
\hline 5811390 & MPP & $6.00 E+00$ \\
\hline 5811390 & PU239 & 6.15E-01 \\
\hline$S 811390$ & U235 & $8.14 E-05$ \\
\hline 5811396 & MP & $6.00 \mathrm{E}-01$ \\
\hline 5811396 & PU239 & $6.14 E-03$ \\
\hline 5811396 & U235 & 8.56E-07 \\
\hline S811397 & MFP & $2.00 E+00$ \\
\hline$\$ 811397$ & PU239 & $6.14 \mathrm{E}-03$ \\
\hline S811397 & U235 & $8.56 \mathrm{E}-07$ \\
\hline 5811398 & MPP & $6.00 \mathrm{E}-01$ \\
\hline S811398 & PU239 & $2.46 E-01$ \\
\hline$S 811398$ & U235 & $3.42 \mathrm{E}-0.5$ \\
\hline 5811400 & MPP & $3.50 E+00$ \\
\hline$S 811400$ & PU239 & 6.14E-03 \\
\hline$S 811400$ & U235 & $8.56 \mathrm{E}-07$ \\
\hline$\$ 811401$ & MP & $5.15 \mathrm{E}+00$ \\
\hline 5811401 & PU239 & 6.51E.02 \\
\hline$\$ 811401$ & U235 & 9.07E-06 \\
\hline 5811405 & MPP & $2.00 E+00$ \\
\hline 5811405 & PU239 & 3.07E-02 \\
\hline$S 811405$ & U235 & 4.28E-06 \\
\hline 5811406 & MP & $2.50 E+00$ \\
\hline 5811406 & PU239 & $6.14 E-03$ \\
\hline 5811406 & U235 & $8.56 \mathrm{E} \cdot 07$ \\
\hline$S 811408$ & MFP & $8.00 E \cdot 02$ \\
\hline$S 811408$ & \begin{tabular}{|l|} 
PU239 \\
\end{tabular} & $1.00 E-01$ \\
\hline$S 811408$ & U235 & $8.56 E .07$ \\
\hline 5811409 & MPP & $2.10 E+00$ \\
\hline S811409 & PU239 & $6.14 E \cdot 03$ \\
\hline
\end{tabular}




\begin{tabular}{|c|c|c|}
\hline PKG ID & SOTOPE & T CURIES \\
\hline$\$ 811409$ & U235 & $8.56 \mathrm{E} \cdot 07$ \\
\hline$S 811411$ & MP & $1.00 \mathrm{E}+00$ \\
\hline S811411 & PU239 & $6.14 \mathrm{E}-03$ \\
\hline$S 811411$ & U235 & $8.56 \mathrm{E} .07$ \\
\hline 5811412 & MFP & $2.00 E+00$ \\
\hline 5811412 & PU239 & $6.14 E-03$ \\
\hline$\$ 811412$ & $\cup 235$ & 8.56E-07 \\
\hline 5811471 & MP & $2.70 E+00$ \\
\hline 5811471 & PU239 & $7.68 E-01$ \\
\hline$S 811471$ & U235 & $4.60 \mathrm{E}-05$ \\
\hline$S 811473$ & MP & $2.00 E+01$ \\
\hline 5811473 & PU239 & $3.07 E-01$ \\
\hline 5811473 & U235 & $1.05 E-04$ \\
\hline 5812291 & MPP & $4.00 E+01$ \\
\hline S812291 & PU239 & $7.55 E+00$ \\
\hline S812291 & U235 & 6.87E.04 \\
\hline S812292 & MFP & $2.20 E+01$ \\
\hline 5812292 & PU239 & $6.14 E+00$ \\
\hline 5812292 & U235 & 5.76E.04 \\
\hline 5812293 & MP & $1.08 E+02$ \\
\hline$S 812293$ & PU239 & 4.30E-01 \\
\hline 5812293 & U235 & 5.99E-05 \\
\hline 5812297 & MP & $1.00 E+02$ \\
\hline SB12297 & PU239 & $1.35 E+00$ \\
\hline$S 812297$ & U235 & 1.84E-04 \\
\hline 5812298 & MP & $1.00 E+02$ \\
\hline 5812298 & PU239 & $1.35 E+00$ \\
\hline 5812298 & U235 & $1.84 \mathrm{E}-04$ \\
\hline 5812302 & MPP & $8.20 E+00$ \\
\hline$\$ 812302$ & PU239 & 4.91E-01 \\
\hline 5812302 & U235 & $4.92 E-05$ \\
\hline$\$ 812303$ & MPP & $8.20 E+00$ \\
\hline$\$ 812303$ & PU239 & $4.91 \mathrm{E}-01$ \\
\hline 5812303 & $\mathrm{U} 235$ & $4.92 E-05$ \\
\hline 5812669 & MFP & $1.10 E+01$ \\
\hline 5812669 & PU239 & 4.03E-01 \\
\hline 5812669 & $\cup 235$ & $5.56 E-05$ \\
\hline$\$ 812684$ & MPP & $4.08 E+01$ \\
\hline$\$ 812684$ & PU239 & $2.00 E+00$ \\
\hline 5812684 & U235 & $2.95 E-04$ \\
\hline 5812686 & NPP & $7.00 \mathrm{E}+00$ \\
\hline S812686 & PU239 & $2.66 E-01$ \\
\hline$\$ 812686$ & U235 & $3.70 \mathrm{E}-05$ \\
\hline 5812688 & MPP & $1.01 E+02$ \\
\hline 5812688 & PU239 & 7.87E-01 \\
\hline
\end{tabular}


Table 2

\begin{tabular}{|c|c|c|}
\hline PKG_ID & \begin{tabular}{|l} 
ISOTOPE \\
\end{tabular} & T CURIES \\
\hline$S 812688$ & U235 & $1.67 \mathrm{E} \cdot 04$ \\
\hline$S 812689$ & MPP & $2.80 E+00$ \\
\hline 5812689 & PU239 & 1.23E-02 \\
\hline SB12689 & U235 & $2.14 \mathrm{E}-06$ \\
\hline$S 814978$ & MPP & $1.80 \mathrm{E}-01$ \\
\hline$S 814978$ & PU239 & $3.68 \mathrm{E}-03$ \\
\hline S814978 & U235 & $5.14 \mathrm{E}-07$ \\
\hline 5814979 & MP & $1.20 \mathrm{E}-01$ \\
\hline$S 814979$ & PU239 & $2.46 \mathrm{E} \cdot 03$ \\
\hline$S 814979$ & U235 & $3.42 \mathrm{E} \cdot 07$ \\
\hline 5820041 & MPP & $3.00 E+01$ \\
\hline 5820041 & PU239 & $9.38 \varepsilon \cdot 01$ \\
\hline 5820041 & U235 & $1.53 \mathrm{E}-04$ \\
\hline$S 820042$ & MP & $1.52 \mathrm{E}+01$ \\
\hline $\mathrm{S} 820042$ & PU239 & $6.14 \mathrm{E}-03$ \\
\hline 5820042 & U235 & $8.56 \mathrm{E}-07$ \\
\hline$S 820057$ & MPP & $3.00 E-01$ \\
\hline 5820057 & PU239 & $6.14 \mathrm{E}-03$ \\
\hline SB20057 & U235 & $8.56 E-07$ \\
\hline 5820058 & MPP & $1.20 \mathrm{E}-01$ \\
\hline S820058 & PU239 & $6.14 \mathrm{E}-03$ \\
\hline$S 820058$ & 4235 & $8.56 \mathrm{E}-07$ \\
\hline$S 821822$ & MP & $4.00 E-01$ \\
\hline S821822 & PU239 & $6.14 \mathrm{E}-03$ \\
\hline S821822 & U235 & $8.56 \mathrm{E} \cdot 07$ \\
\hline 5821823 & $\mathrm{MPP}$ & $4.50 E-01$ \\
\hline S821823 & PU239 & $6.14 \mathrm{E}-03$ \\
\hline 5821823 & \begin{tabular}{|l|}
$U 235$ \\
\end{tabular} & $8.56 \mathrm{E}-07$ \\
\hline S821825 & MP & $8.00 \mathrm{E}-01$ \\
\hline$S 821825$ & PU239 & $6.14 \mathrm{E}-02$ \\
\hline S821825 & U235 & $8.56 \mathrm{E}-06$ \\
\hline$S 821826$ & MPP & $4.00 E-01$ \\
\hline 5821826 & PU239 & $6.14 E-03$ \\
\hline S821826 & U235 & $8.56 \mathrm{E}-07$ \\
\hline 5821832 & MP & $2.00 E+00$ \\
\hline$S 821832$ & PU239 & $6.14 \mathrm{E}-03$ \\
\hline 5821832 & \begin{tabular}{|l}
235 \\
\end{tabular} & $8.56 E-07$ \\
\hline 5821833 & MPP & $3.00 E+00$ \\
\hline 5821833 & PU239 & $6.14 E-03$ \\
\hline S821833 & U235 & $8.56 \mathrm{E}-07$ \\
\hline 5821834 & MPP & $2.00 E+00$ \\
\hline 5821834 & PU239 & $6.14 E-03$ \\
\hline 5821834 & U235 & $8.56 E-07$ \\
\hline 5821835 & MPP & $3.00 \mathrm{E}-01$ \\
\hline$S 821835$ & PU239 & $6.14 E-03$ \\
\hline
\end{tabular}


Table 2 RH-TRU (Isotopes Present)

\begin{tabular}{|c|c|c|}
\hline PKG ID & SOTOPE & T CURIES \\
\hline 5821835 & U235 & $8.56 \mathrm{E}-07$ \\
\hline$\$ 821836$ & MP & $2.00 E+00$ \\
\hline 5821836 & PU239 & $6.14 \mathrm{E}-03$ \\
\hline 5821836 & U235 & 8.56E-07 \\
\hline$\$ 821837$ & MP & $2.00 E+00$ \\
\hline$\$ 821837$ & PU239 & $6.14 E-03$ \\
\hline$\$ 821837$ & U235 & 8.56E-07 \\
\hline S821838 & MPP & $1.00 E+00$ \\
\hline 5821838 & PU239 & $6.14 E-03$ \\
\hline 5821838 & U235 & 8.56E-07 \\
\hline S821839 & MP & $2.00 \mathrm{E}-01$ \\
\hline 5821839 & PU239 & $6.14 E-03$ \\
\hline S821839 & U235 & $8.56 \mathrm{E}-07$ \\
\hline 5821840 & MP & $4.00 E+00$ \\
\hline$\$ 821840$ & PU239 & $6.14 E-03$ \\
\hline$S 821840$ & 4235 & 8.56E-07 \\
\hline $582+841$ & MP & $2.00 E+00$ \\
\hline S821841 & PU239 & 6.14E.03 \\
\hline 5821841 & U235 & $8.56 \mathrm{E}-07$ \\
\hline 5821870 & MPP & $1.50 \mathrm{E}-01$ \\
\hline 5821870 & PU239 & $6.14 E-03$ \\
\hline$\$ 821870$ & U235 & 8.56 E-07 \\
\hline 5821871 & MPP & $4.50 E+00$ \\
\hline 5821871 & PU239 & 1.97E-01 \\
\hline 5821871 & U235 & $2.75 E \cdot 05$ \\
\hline$\$ 821874$ & MP & $1.00 E+01$ \\
\hline S821874 & PU239 & $6.14 E-03$ \\
\hline 5821874 & U235 & $8.56 \mathrm{E} \cdot 07$ \\
\hline S821875 & MP & $2.00 E+01$ \\
\hline S821875 & PU239 & $6.14 E-03$ \\
\hline S821875 & U235 & $8.56 E-07$ \\
\hline 5821879 & MPP & $3.00 E+01$ \\
\hline 5821879 & PU239 & $1.23 E-01$ \\
\hline 5821879 & U235 & 1.93E-05 \\
\hline$\$ 821881$ & MPP & $4.00 E+01$ \\
\hline S621881 & PU239 & $1.23 E-01$ \\
\hline S821881 & U235 & $1.93 E-05$ \\
\hline S821882 & MFP & $1.00 E+00$ \\
\hline 5821882 & PU239 & $6.14 E-03$ \\
\hline 5821882 & U235 & 8.56E-07 \\
\hline$\$ 821883$ & MPP & $6.00 E+00$ \\
\hline$\$ 821883$ & PU239 & $6.14 E-03$ \\
\hline$\$ 821883$ & U235 & $8.56 \mathrm{E}-07$ \\
\hline 5821915 & MPP & $1.00 E+00$ \\
\hline S821915 & PU239 & $1.40 E+00$ \\
\hline
\end{tabular}


Table 2

RH-TRU (Isotopes Present)

\begin{tabular}{|c|c|c|}
\hline PKG ID & LSOTOPE & T CURIES \\
\hline S821915 & U235 & $1.28 \mathrm{E} \cdot 04$ \\
\hline 5821916 & MPP & $3.00 E+01$ \\
\hline 5821916 & PU239 & $2.48 E+00$ \\
\hline S821916 & U235 & $1.77 \mathrm{E}-04$ \\
\hline$\$ 821917$ & MPP & $6.00 E+00$ \\
\hline$\$ 821917$ & PU239 & 6.14E-03 \\
\hline S821917 & $\cup 235$ & $8.56 \mathrm{E}-07$ \\
\hline 5821918 & MP & $1.00 E+00$ \\
\hline$\$ 821918$ & PU239 & 1.97E-01 \\
\hline 5821918 & $\cup 235$ & $2.75 E-05$ \\
\hline$\$ 823410$ & MPP & $1.30 E+00$ \\
\hline$\$ 823410$ & PU239 & $6.14 E .03$ \\
\hline$\$ 823410$ & $\mathrm{U} 235$ & 8.56E.07 \\
\hline S830716 & MPP & $2.00 E+00$ \\
\hline$\$ 830716$ & PU239 & $3.46 \mathrm{E} \cdot 02$ \\
\hline 5830716 & $\mathrm{U} 235$ & $4.82 E-06$ \\
\hline$\$ 830717$ & MFP & $2.00 E+02$ \\
\hline$\$ 830717$ & PU239 & $3.46 E-02$ \\
\hline S830717 & U235 & 4.82E.06 \\
\hline 5830781 & MP & $1.00 E+00$ \\
\hline$\$ 830781$ & PU53 & $3.77 \mathrm{E}-03$ \\
\hline$\$ 830781$ & U36 & $2.88 \mathrm{E}-07$ \\
\hline 5830782 & MP & $2.50 E+01$ \\
\hline S830782 & PU53 & $3.77 \mathrm{E} .03$ \\
\hline 5830782 & U36 & 2.88E-07 \\
\hline 5830783 & MPP & $3.00 E+00$ \\
\hline 5830783 & PU53 & $7.54 E-03$ \\
\hline 5830783 & U36 & $5.76 \mathrm{E}-07$ \\
\hline$\$ 830784$ & MP & $3.00 \mathrm{E}+00$ \\
\hline S830784 & PU53 & $7.54 \mathrm{E} \cdot 03$ \\
\hline S830784 & \begin{tabular}{|l|} 
U36 \\
\end{tabular} & $5.76 E .07$ \\
\hline 5830785 & MP & $3.00 E+00$ \\
\hline 5830785 & PU53 & $7.54 E-03$ \\
\hline 5830785 & U36 & $5.76 \mathrm{E} \cdot 07$ \\
\hline 5830786 & MP & $1.50 E+00$ \\
\hline S830786 & PU53 & $3.77 E-03$ \\
\hline 5830786 & U36 & $2.88 \mathrm{E}-07$ \\
\hline$\$ 830787$ & MP & $4.00 E+01$ \\
\hline S830787 & PU53 & $9.05 E-03$ \\
\hline$\$ 830787$ & U36 & 7.20 E- 07 \\
\hline 5830788 & $M P$ & $4.00 E+01$ \\
\hline$\$ 830788$ & PU53 & $9.05 E-03$ \\
\hline $\mathrm{S} 830788$ & U36 & $7.20 \mathrm{E}-07$ \\
\hline 5830789 & $M P$ & $2.00 \mathrm{E} .01$ \\
\hline S830789 & PU53 & $7.54 \mathrm{E} \cdot 03$ \\
\hline
\end{tabular}


Table 2

RH-TRU (Isotopes Present)

\begin{tabular}{|c|c|c|}
\hline PKG ID & SOTOPE & T CURIES \\
\hline 5830789 & U36 & 5.76E- 07 \\
\hline$\$ 830790$ & MP & $4.00 E+01$ \\
\hline 5830790 & PU53 & $2.19 E-01$ \\
\hline$\$ 830790$ & U36 & 1.68E-05 \\
\hline S830791 & MFP & $1.50 E+00$ \\
\hline$\$ 830791$ & PU53 & $7.54 \mathrm{E}-03$ \\
\hline S830791 & U36 & 5.76E-07 \\
\hline 5832830 & MP & $2.00 E+01$ \\
\hline 5832830 & PU239 & 6.14E-03 \\
\hline$\$ 832830$ & U235 & 8.56E-07 \\
\hline 5832831 & MPP & $8.00 E-01$ \\
\hline 5832831 & PU239 & $6.14 E-03$ \\
\hline 5832831 & 0235 & 8.56E-07 \\
\hline$\$ 832832$ & MPP & $1.50 E+02$ \\
\hline$\$ 832832$ & PU239 & $2.49 E+00$ \\
\hline 5832832 & U235 & 5.05E.04 \\
\hline 5832833 & $M \mp$ & $3.00 E+01$ \\
\hline 5832833 & PU239 & $6.14 \mathrm{E} \cdot 03$ \\
\hline S832833 & U235 & $8.56 E-07$ \\
\hline$\$ 832834$ & MP & $5.00 E+01$ \\
\hline 5832834 & PU239 & $6.14 \mathrm{E}-03$ \\
\hline 5832834 & U235 & $8.56 \mathrm{E}-07$ \\
\hline 5832835 & MP & $1.00 E+02$ \\
\hline S832835 & PU239 & $3.06 \mathrm{E}-01$ \\
\hline$\$ 832835$ & U235 & $4.32 E-05$ \\
\hline 5832836 & MP & $1.00 E+02$ \\
\hline 5832836 & PU239 & $6.14 E-03$ \\
\hline 5832836 & U235 & $8.56 \mathrm{E}-07$ \\
\hline 5832837 & MPP & $1.00 E+02$ \\
\hline S832B37 & PU239 & $6.75 \mathrm{E}-03$ \\
\hline S832837 & U235 & 8.56E-07 \\
\hline$\$ 832838$ & MPP & $2.00 E+00$ \\
\hline S832838 & PU239 & $6.14 E-03$ \\
\hline$\$ 832838$ & U235 & 8.56E.07 \\
\hline 5832839 & MP & $8.00 E+00$ \\
\hline 5832839 & PU239 & $6.14 E-03$ \\
\hline S832839 & U235 & $8.56 E \cdot 07$ \\
\hline 5832840 & MP & $2.00 E+02$ \\
\hline 5832840 & PU239 & $6.14 E-03$ \\
\hline 5832840 & U235 & $8.56 \mathrm{E} \cdot 07$ \\
\hline$S 832841$ & MP & $5.00 E+01$ \\
\hline 5832841 & $P \cup 239$ & $6.14 \mathrm{E}-03$ \\
\hline S832841 & บ235 & $8.56 \mathrm{E}-07$ \\
\hline 5832842 & MFP & $1.50 \mathrm{E}+01$ \\
\hline S832842 & PU239 & $6.14 \mathrm{E}-03$ \\
\hline
\end{tabular}


Table 2

RH-TRU (Isotopes Present)

\begin{tabular}{|c|c|c|}
\hline PKG ID & ISOTOPE & T CURIES \\
\hline$S 832842$ & U235 & $8.56 E-07$ \\
\hline 5832843 & MPP & $3.00 E+01$ \\
\hline$\$ 832843$ & PU239 & 6.14E-03 \\
\hline 5832843 & $\mathrm{U} 235$ & 8.56E-07 \\
\hline$\$ 832844$ & MP & $4.00 E+01$ \\
\hline S832844 & PU239 & $6.14 E \cdot 03$ \\
\hline 5832844 & U235 & 8.56E-07 \\
\hline 5832845 & MP & $1.50 E+00$ \\
\hline 5832845 & PU239 & 6.14E-03 \\
\hline S832845 & U235 & 8.56E-07 \\
\hline 5832846 & MP & $6.00 E+01$ \\
\hline$\$ 832846$ & PU239 & $6.14 E-03$ \\
\hline$\$ 832846$ & U235 & $8.56 \mathrm{E}-07$ \\
\hline 5832847 & MFP & $3.00 E+01$ \\
\hline$\$ 832847$ & PU239 & $6.14 E-03$ \\
\hline 5832847 & U235 & B.56E-07 \\
\hline S840831 & MPP & $3.50 E+01$ \\
\hline S840831 & PU239 & $5.89 E+00$ \\
\hline 5840831 & U235 & $5.24 E-04$ \\
\hline$\$ 840835$ & $\mathrm{MP}$ & $1.00 E+01$ \\
\hline S840835 & PU239 & $6.14 E-03$ \\
\hline 5840835 & U235 & 8.56E-07 \\
\hline$\$ 840836$ & MP & $4.00 E-01$ \\
\hline 5840836 & PU239 & $6.14 E-03$ \\
\hline 5840836 & U235 & $8.56 \mathrm{E}-07$ \\
\hline 5840838 & MPP & $5.00 E+00$ \\
\hline 5840838 & PU239 & $6.14 \mathrm{E} .03$ \\
\hline 5840838 & $\mathrm{U} 235$ & 8.56E.07 \\
\hline 5840839 & MPP & $1.50 E+00$ \\
\hline$\$ 840839$ & PU239 & $6.14 \mathrm{E}-03$ \\
\hline 5840839 & U235 & $8.56 \mathrm{E} \cdot 07$ \\
\hline S840840 & MPP & $1.00 E+00$ \\
\hline 5840840 & PU239 & $6.14 \mathrm{E} \cdot 03$ \\
\hline 5840840 & U235 & $8.56 \mathrm{E}-07$ \\
\hline 5840841 & MP & $7.00 E-01$ \\
\hline 5840841 & PU239 & $6.14 E-03$ \\
\hline 5840841 & U235 & 8.56E-07 \\
\hline $\mathrm{S840842}$ & MPP & $2.00 \mathrm{E}+00$ \\
\hline$\$ 840842$ & PU239 & $6.14 \mathrm{E}-03$ \\
\hline 5840842 & U235 & $8.56 \mathrm{E}-07$ \\
\hline 5840843 & $\mathrm{MP}$ & $2.00 E+00$ \\
\hline 5840843 & PU239 & $6.14 \mathrm{E} \cdot 03$ \\
\hline$\$ 840843$ & U235 & $8.56 \mathrm{E} .07$ \\
\hline 5840844 & MP & $1.50 \mathrm{E}+00$ \\
\hline S840844 & PU239 & $6.14 \mathrm{E}-03$ \\
\hline
\end{tabular}

Larry Field

Page 27

Pete Del Mar 
Table 2 RH-TRU (Isotopes Present)

\begin{tabular}{|c|c|c|}
\hline PKG 10 & SOTOPE & T CURIES \\
\hline 5840844 & $\mathrm{U} 235$ & B.56E-07 \\
\hline 5840845 & MP & $3.00 E-01$ \\
\hline 5840845 & PU239 & $6.14 E-03$ \\
\hline 5840845 & U235 & $8.56 E-07$ \\
\hline 5840846 & MP & $5.00 E+00$ \\
\hline 5840846 & PU239 & $6.14 E-03$ \\
\hline 5840846 & U235 & 8.56E.07 \\
\hline 5840847 & MP & $1.50 E+00$ \\
\hline 5840847 & PU239 & $6.14 E \cdot 03$ \\
\hline S840847 & U235 & 8.56E-07 \\
\hline 5840848 & MP & $4.00 \mathrm{E}-01$ \\
\hline 5840848 & PU239 & $6.14 E-03$ \\
\hline 5840848 & U235 & 8.56E.07 \\
\hline 5840851 & MPP & $3.00 E+00$ \\
\hline$\$ 840851$ & PU239 & $6.14 E-03$ \\
\hline$\$ 840851$ & $\cup 235$ & $8.56 E-07$ \\
\hline$\$ 840854$ & $M P$ & $1.50 E+00$ \\
\hline 5840854 & PU239 & $6.14 E-03$ \\
\hline S840854 & U235 & $8.56 E-07$ \\
\hline S840855 & $M P$ & $1.00 E+00$ \\
\hline S840855 & PU239 & $6.14 E-03$ \\
\hline 5840855 & U235 & $8.56 E-07$ \\
\hline 5840856 & MP & $1.50 E+00$ \\
\hline 5840856 & PU239 & $6.14 E-03$ \\
\hline 5840856 & U235 & $8.56 E-07$ \\
\hline S840857 & MPP & $3.00 E+00$ \\
\hline S840857 & PU239 & $6.14 \mathrm{E} \cdot 03$ \\
\hline S840857 & U235 & 8.56E-07 \\
\hline 5840859 & MP & $1.00 E+00$ \\
\hline 5840859 & PU239 & $6.14 E-03$ \\
\hline$\$ 840859$ & U235 & 8.56E-07 \\
\hline 5840860 & MP & $2.00 E+00$ \\
\hline$\$ 840860$ & PU239 & $6.14 E-03$ \\
\hline 5840860 & U235 & $8.56 \mathrm{E}-07$ \\
\hline$\$ 840862$ & MPP & $2.00 E-01$ \\
\hline$\$ 840862$ & PU239 & $6.14 E-03$ \\
\hline$\$ 840862$ & $\mathrm{U} 235$ & 8.56E-07 \\
\hline$\$ 840863$ & $\mathrm{MP}$ & $8.00 E-02$ \\
\hline 5840863 & PU239 & $6.14 \mathrm{E}-03$ \\
\hline 5840863 & $\cup 235$ & 8.56E-07 \\
\hline$\$ 840864$ & MPP & $3.00 E-01$ \\
\hline S840864 & PU239 & $6.14 E \cdot 03$ \\
\hline 5840864 & U235 & $8.56 \mathrm{E}-07$ \\
\hline 5840865 & MP & $1.00 \mathrm{E}-01$ \\
\hline 5840865 & PU239 & $6.14 E-03$ \\
\hline
\end{tabular}


Table 2

RI-TRU (Isotopes Present)

\begin{tabular}{|c|c|c|}
\hline PKG ID & SOTOPE & T CURIES \\
\hline 5840865 & U235 & 8.56E-07 \\
\hline S840867 & $\mathrm{MP}$ & $4.00 E-01$ \\
\hline 5840867 & PU239 & $6.14 E .03$ \\
\hline 5840867 & U235 & 8.56E.07 \\
\hline 5840868 & MPP & $3.00 E-01$ \\
\hline 5840868 & PU239 & $6.14 E-03$ \\
\hline S840868 & U235 & 8.56E-07 \\
\hline S840873 & MPP & $2.00 E+00$ \\
\hline$\$ 840873$ & PU239 & 1.84E-01 \\
\hline 5840873 & $\cup 235$ & 2.57E-05 \\
\hline 5840874 & MP & $2.00 E-01$ \\
\hline 5840874 & PU239 & $6.14 E-03$ \\
\hline 5840874 & U235 & 8.56E-07 \\
\hline S840877 & MP & $1.50 E+00$ \\
\hline S840877 & PU239 & $1.35 \mathrm{E}-01$ \\
\hline 5840877 & U235 & $1.91 \mathrm{E}-05$ \\
\hline 5840878 & MP & $2.50 E+00$ \\
\hline S840878 & PU239 & $1.90 E-01$ \\
\hline S84087B & U235 & 3.08E-05 \\
\hline 5840879 & $\mathrm{MP}$ & $4.00 E+00$ \\
\hline 5840879 & PU239 & $1.90 E-01$ \\
\hline 5840879 & U235 & 3.08E-05 \\
\hline 5840880 & MP & $2.50 E+00$ \\
\hline 5840880 & PU239 & $1.90 \mathrm{E}-01$ \\
\hline 5840880 & U235 & $3.08 E-05$ \\
\hline 5840881 & MPP & $3.00 E+00$ \\
\hline 5840881 & PU239 & $1.90 \mathrm{E}-01$ \\
\hline$S 840881$ & U235 & $3.08 E-05$ \\
\hline 5840882 & MPP & 3.00E-01 \\
\hline S840882 & PU239 & 6.14E-03 \\
\hline S840882 & U235 & $8.56 \mathrm{E}-07$ \\
\hline 5840883 & MPP & $2.00 E+00$ \\
\hline 5840883 & PU239 & $6.14 E .03$ \\
\hline SB40883 & $\mathrm{U} 235$ & $8.56 \mathrm{E}-07$ \\
\hline$\$ 840885$ & MP & $6.00 E+00$ \\
\hline$S 840885$ & PU239 & 1.97E-01 \\
\hline S840885 & $\mathrm{U235}$ & 2.27E-05 \\
\hline 5840886 & $\overline{M P}$ & $8.00 E-01$ \\
\hline 5840886 & PU239 & $6.14 E-03$ \\
\hline$\$ 840886$ & U235 & $8.56 E-07$ \\
\hline S84088B & MP & $1.50 E-01$ \\
\hline 5840888 & PU239 & $6.14 \mathrm{E}-03$ \\
\hline$\$ 840888$ & U235 & $8.56 \mathrm{E}-07$ \\
\hline$\$ 852326$ & MP & $4.00 E+00$ \\
\hline 5852326 & PU239 & $6.14 \mathrm{E} \cdot 03$ \\
\hline
\end{tabular}


Table 2

\section{RH-TRU (Isotopes Present)}

\begin{tabular}{|c|c|c|}
\hline PKG ID & SOTOPE & T CURIES \\
\hline$\$ 852326$ & U235 & 6.56E-07 \\
\hline S852328 & MP & $2.00 E+00$ \\
\hline 5852328 & PU239 & $6.14 E-03$ \\
\hline$\$ 852328$ & $\mathrm{U} 235$ & 8.56E-07 \\
\hline S852332 & MPP & $4.00 E+00$ \\
\hline$\$ 852332$ & PU239 & $6.14 E-03$ \\
\hline$\$ 852332$ & $\mathrm{U} 235$ & 8.56E-07 \\
\hline 5852804 & MP & $2.80 E+00$ \\
\hline 5852804 & PU239 & 2.03E-01 \\
\hline 5852804 & U235 & $1.86 \mathrm{E}-05$ \\
\hline$\$ 855046$ & MP & $3.00 E+00$ \\
\hline 5855046 & PU239 & $6.14 E-03$ \\
\hline$\$ 855046$ & U235 & 8.56E-07 \\
\hline$\$ 855047$ & MPP & $3.00 \mathrm{E}+00$ \\
\hline 5855047 & PU239 & $6.14 E \cdot 03$ \\
\hline 5855047 & U235 & $6.42 E-07$ \\
\hline 5855048 & MPP & $9.00 E-01$ \\
\hline S855048 & U235 & $3.21 E-05$ \\
\hline 5855049 & $M P$ & $4.00 \mathrm{E}-01$ \\
\hline$\$ 855049$ & U235 & $1.93 \mathrm{E}-05$ \\
\hline$\$ 855064$ & MPP & $3.30 E+00$ \\
\hline$\$ 855064$ & PU239 & 2.21E-01 \\
\hline 5855064 & U235 & 3.19E-05 \\
\hline$\$ 855065$ & MPP & $4.20 E+00$ \\
\hline$\$ 855065$ & PU239 & $2.21 E \cdot 01$ \\
\hline 5855065 & $\cup 235$ & $3.19 \mathrm{E} \cdot 05$ \\
\hline 5855066 & MPP & $1.50 E+00$ \\
\hline$\$ 855066$ & PU239 & $6.14 E-03$ \\
\hline 5855066 & $\cup 235$ & $8.56 E-07$ \\
\hline 5855068 & MPP & $1.50 E+00$ \\
\hline 5855068 & PU239 & $6.14 E-03$ \\
\hline S855068 & $\mathrm{U} 235$ & $8.56 \mathrm{E} \cdot 07$ \\
\hline$\$ 856015$ & MPP & $2.10 E+00$ \\
\hline$\$ 856015$ & PU239 & $6.14 \mathrm{E}-03$ \\
\hline$\$ 856015$ & $\cup 235$ & $8.56 \mathrm{E}-07$ \\
\hline$\$ 856016$ & $M P P$ & $6.00 E+00$ \\
\hline$\$ 856016$ & PU239 & $6.14 E-03$ \\
\hline 5856016 & U235 & $6.42 E-07$ \\
\hline S856017 & MPP & $6.00 E+00$ \\
\hline 5856017 & PU239 & $6.14 E-03$ \\
\hline 5856017 & $\cup 235$ & $6.42 E-07$ \\
\hline 5856018 & MP & $1.00 E+00$ \\
\hline 5856018 & PU239 & $6.14 E-03$ \\
\hline 5856018 & $\mathrm{U} 235$ & 8.56E-07 \\
\hline 5874123 & MP & $1.50 E .01$ \\
\hline
\end{tabular}




\begin{tabular}{|c|c|c|}
\hline PKG ID & SOTOPE & T CURIES \\
\hline$\$ 874123$ & PU239 & $6.14 E \cdot 03$ \\
\hline 5874123 & $\cup 235$ & 8.56E-07 \\
\hline 5874124 & MP & $1.50 E+00$ \\
\hline 5874124 & PU239 & $6.14 E-03$ \\
\hline 5874124 & U235 & 8.56 E-07 \\
\hline$\$ 874125$ & MPP & $1.50 E-01$ \\
\hline$\$ 874125$ & PU239 & $6.14 E-03$ \\
\hline$\$ 874125$ & U235 & $8.56 \mathrm{E} \cdot 07$ \\
\hline 5874126 & MP & $2.50 E+00$ \\
\hline S874126 & PU239 & $6.14 E-03$ \\
\hline$\$ 874126$ & $\mathrm{U} 235$ & 8.56E-07 \\
\hline 5874127 & MP & $1.50 E+00$ \\
\hline 5874127 & PU239 & $6.14 E-03$ \\
\hline S874127 & U235 & $8.56 E .07$ \\
\hline S874128 & MPP & $1.50 E+00$ \\
\hline 5874128 & PU239 & $6.14 E-03$ \\
\hline 5874128 & U235 & 8.56E-07 \\
\hline$\$ 874129$ & MP & $1.50 E+00$ \\
\hline 5874129 & PU239 & $6.14 E-03$ \\
\hline 5874129 & U235 & 8.56E-07 \\
\hline$\$ 874130$ & MP & $2.00 E+00$ \\
\hline 5874130 & PU239 & $6.14 E-03$ \\
\hline 5874130 & U235 & $8.56 E-07$ \\
\hline S874132 & MPP & $0.00 E+00$ \\
\hline 5874132 & PU239 & $0.00 E+00$ \\
\hline$\$ 874132$ & U25 & $2.61 E-06$ \\
\hline S874133 & PU53 & $1.21 E+00$ \\
\hline$\$ 874133$ & PU55 & $2.30 E+00$ \\
\hline 5874133 & PU56 & $1.09 E+00$ \\
\hline 5874133 & PU57 & $1.23 E+00$ \\
\hline 5874133 & U235 & $2.89 E-04$ \\
\hline 5874133 & U238 & $2.01 E-05$ \\
\hline 5874134 & MP & $0.00 E+00$ \\
\hline 5874134 & PU57 & $9.43 E-02$ \\
\hline 5874134 & U21 & 1.67E-05 \\
\hline 5910321 & CS137 & 2.70E-01 \\
\hline$\$ 910321$ & PU55 & 2.99E.02 \\
\hline 5910321 & RU106 & $1.98 \mathrm{E} .03$ \\
\hline$\$ 910321$ & SR90 & 2.47E-01 \\
\hline$\$ 910321$ & U38 & $2.76 E-06$ \\
\hline 5910321 & $Y 90$ & 2.47E-01 \\
\hline 5910322 & CS137 & $7.95 E-01$ \\
\hline$\$ 910322$ & PU55 & 8.53E-02 \\
\hline 5910322 & RU106 & $5.83 E-03$ \\
\hline$\$ 910322$ & SR90 & $7.27 \mathrm{E}-01$ \\
\hline
\end{tabular}


Table 3 gives the total volume and total activity of the waste in each shaft. This section also includes two graphs which present this information visually. It is immediately clear that there is a very uneven distribution of activity and volume of waste over the 60 shafts now in use. In terms of activity, an inspection of this table shows that less than $25 \%$ of the 60 shafts contain over $85 \%$ of the total activity. It is also interesting to note that while shafts 302 through 306 contain over $50 \%$ of the total volume of waste, they account for less than $1 \%$ of the total activity. 


\begin{tabular}{|c|c|c|}
\hline Shaft & Total Shaft Activity & Total Shaft Volume \\
\hline Number & (Curies) & $(\mathrm{m} 3)$ \\
\hline 33 & 0.82 & 0.004 \\
\hline 72 & 9.20 & 0.04 \\
\hline 73 & 39.34 & 0.12 \\
\hline 74 & 116.27 & 0.14 \\
\hline 75 & 57.92 & 0.11 \\
\hline 76 & 29.35 & 0.08 \\
\hline 200 & 35.58 & 1.24 \\
\hline 201 & 104.24 & 1.06 \\
\hline 202 & 249.01 & 1.20 \\
\hline 203 & 111.30 & 1.20 \\
\hline 204 & 49.15 & 1.06 \\
\hline 205 & 405.96 & 1.25 \\
\hline 206 & 404.20 & 1.45 \\
\hline 207 & 13.42 & 1.35 \\
\hline 208 & 107.26 & 1.34 \\
\hline 209 & 2.92 & 1.34 \\
\hline 210 & 0.94 & 1.34 \\
\hline 211 & 18.39 & 1.34 \\
\hline 212 & 42.30 & 2.10 \\
\hline 213 & 154.67 & 0.85 \\
\hline 214 & 3.01 & 0.85 \\
\hline 215 & 55.47 & 0.85 \\
\hline 216 & 10.09 & 0.85 \\
\hline 217 & 19.46 & 0.85 \\
\hline 218 & 134.74 & 0.85 \\
\hline 219 & 353.62 & 0.85 \\
\hline 220 & 460.04 & 0.85 \\
\hline 221 & 176.54 & 0.85 \\
\hline 222 & 323.52 & 0.85 \\
\hline 223 & 37.04 & 0.85 \\
\hline 224 & 23.98 & 0.11 \\
\hline 225 & 7.43 & 0.11 \\
\hline 226 & 12.85 & 0.11 \\
\hline 227 & 23.40 & 0.11 \\
\hline 228 & 10.85 & 0.03 \\
\hline 229 & 8.77 & 0.12 \\
\hline 230 & 60.53 & 0.11 \\
\hline 231 & 22.44 & 0.11 \\
\hline 232 & 5.92 & 0.01 \\
\hline 236 & 154.70 & 0.99 \\
\hline 237 & 846.55 & 0.99 \\
\hline 238 & 1264.04 & 0.99 \\
\hline 239 & 1316.61 & 0.99 \\
\hline 240 & 1242.97 & 0.99 \\
\hline
\end{tabular}




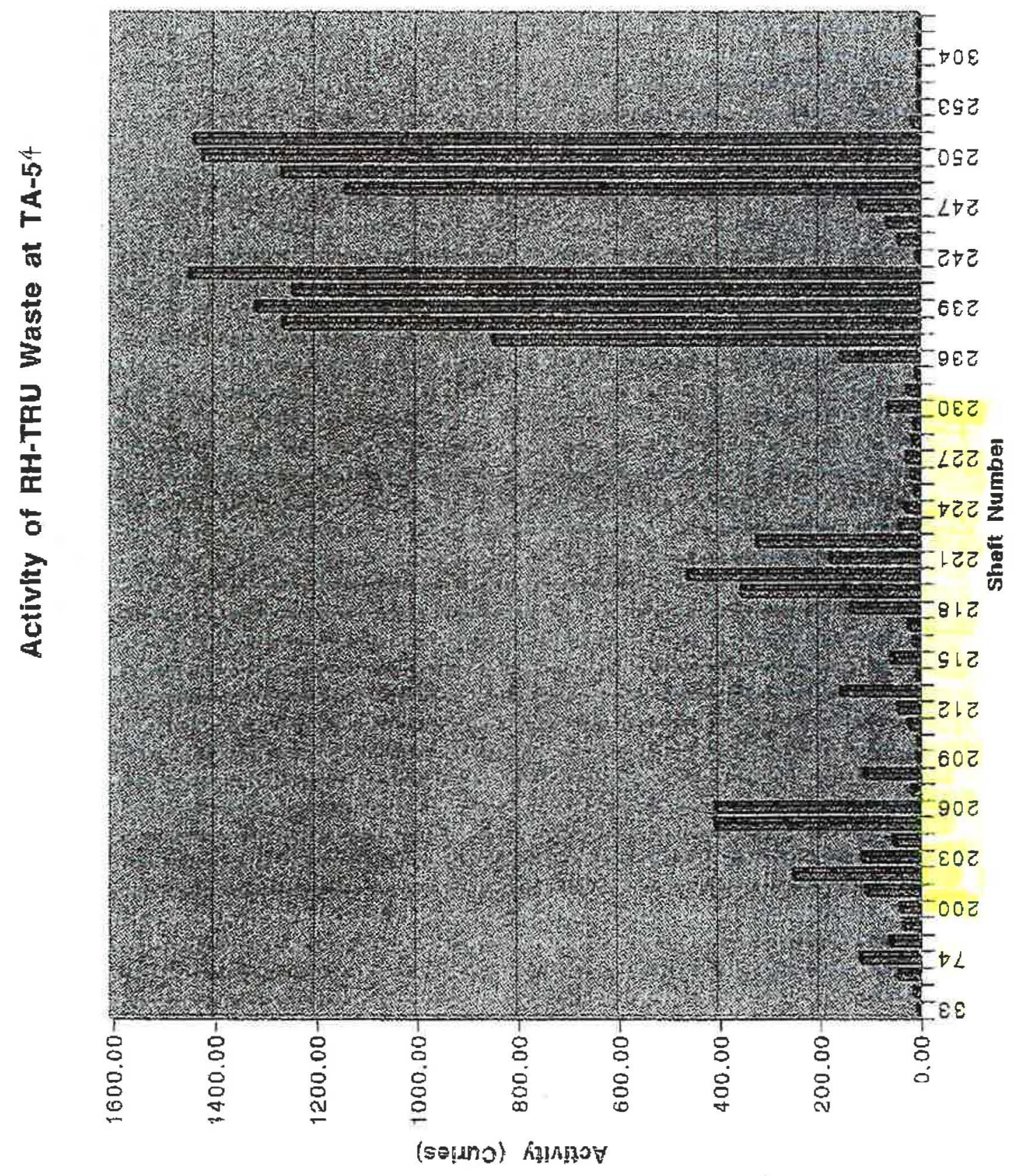




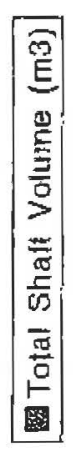

$\frac{\omega}{0}$
$\frac{0}{\Phi}$
0
0
0

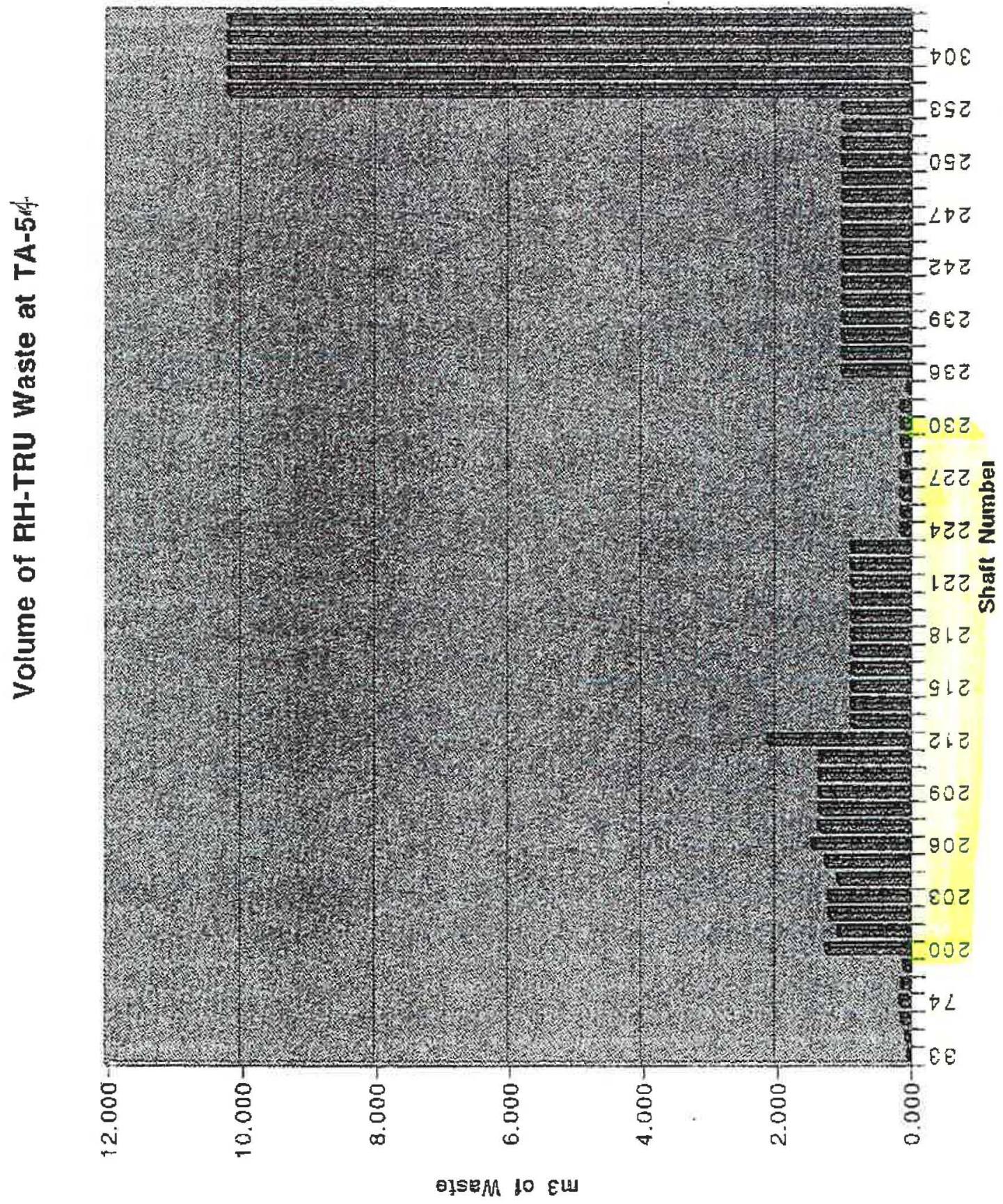


Table 4 presents data on the physical dimensions and configuration of the shafts and the volume of backfill used, if any. The shafts are all similar in depth, varying from 16 to 25 feet. However, the diameters vary more widely. Although 55 of the 60 shafts are from 1 to 3 feet in diameter, the last five are 10 feet in diameter. This much larger size may require modification of any proposed removal techniques. 


\begin{tabular}{|c|c|c|c|c|}
\hline $\begin{array}{c}\text { Shaft } \\
\text { Number }\end{array}$ & $\begin{array}{c}\text { Shaft } \\
\text { Diam.(ft) } \\
\end{array}$ & $\begin{array}{c}\text { Fill } \\
\text { Vol. (FT3) } \\
\end{array}$ & $\begin{array}{c}\text { Oepth } \\
(f t) \\
\end{array}$ & Shaft Type \\
\hline 33 & 2 & 70 & 25 & Tulf, no liners, concrete plugs \\
\hline 72 & 2 & 18 & 25 & Tuft, no liners, concrete plugs \\
\hline 73 & 2 & 67 & 25 & Tuff, no liners, concrete plugs \\
\hline 74 & 2 & 46 & 25 & Tutf, no liners, concrete plugs \\
\hline 75 & 2 & 46 & 25 & Tutf, no liners, concrete plugs \\
\hline 76 & 2 & 50 & 25 & Tuff, no liners, concrete plugs \\
\hline 200 & 2 & 13 & 18 & $1 / 4^{*}$ steel, welded bottom, concrete plug \\
\hline 201 & 2 & 18 & 18 & $1 / 4^{\prime \prime}$ steel, welded bottom, concrete plug \\
\hline 202 & 2 & 14 & 18 & $1 / 4^{\prime \prime}$ steel, welded bottom, concrete plug \\
\hline 203 & 2 & 14 & 18 & $1 / 4^{*}$ steel, welded bottom, concrete plug \\
\hline 204 & 2 & 19 & 18 & $1 / 4^{\prime \prime}$ steel, welded bottom, concrete plug \\
\hline 205 & 2 & 12 & 18 & $1 / 4^{\prime \prime}$ steel, welded bottom, concrete plug \\
\hline 206 & 2 & 5 & 18 & $1 / 4^{*}$ steel, welded bottom, concrete plug \\
\hline 207 & 2 & 9 & 18 & $1 / 4^{\prime \prime}$ steel, welded bottom, concrete plug. \\
\hline 208 & 2 & 9 & 18 & $1 / 4^{\prime \prime}$ steel, welded bottom, concrete plug \\
\hline 209 & 2 & 9 & 18 & $I / 4^{\prime \prime}$ steel, welded bottom, concrete plug \\
\hline 210 & 2 & 9 & 18 & $1 / 4^{\mathrm{E}}$ steel, welded bottom, concrete plug \\
\hline 211 & 2 & 9 & 18 & $1 / 4^{n}$ steel, welded bottom, concrete plug \\
\hline 212 & 2 & 14 & 18 & $1 / 4^{\prime \prime}$ steel, welded bottom, concrele plug \\
\hline 213 & 2 & 26 & 18 & $1 / 4^{*}$ steel, welded bottom, concrete plug \\
\hline 214 & 2 & 26 & 18 & $1 / 4^{\prime \prime}$ steel, welded bottom, concrete plug \\
\hline 215 & 2 & 26 & 18 & $1 / 4^{\prime \prime}$ steel, weided bottom, concrete plug \\
\hline 216 & 2 & 26 & 18 & $1 / 4^{*}$ steel, welded bottom, concrete plug \\
\hline 217 & 2 & 26 & 18 & $1 / 4^{\prime \prime}$ steel, welded botiom, concrele plug \\
\hline 218 & 2 & 26 & 18 & $1 / 4^{\prime \prime}$ steel, welded bottom, concrete plug \\
\hline 219 & 2 & 26 & 18 & $1 / 4^{\prime \prime}$ steel, welded bottom, concrete plug \\
\hline 220 & 2 & 26 & 18 & $1 / 4^{\prime \prime}$ steel, welded bottom, concrete plug \\
\hline 221 & 2 & 26 & 18 & 1/4" steel, welded boltom, concrete plug \\
\hline 222 & 2 & 26 & 18 & $1 / 4^{n}$ steel, welded bottom, concrete plug \\
\hline 223 & 2 & 26 & 18 & $1 / 4^{\prime \prime}$ steel, welded bottom, concrete plug \\
\hline 224 & 2 & 53 & $1 \mathrm{~B}$ & 1/4" steel, welded bottom, concrete plug \\
\hline
\end{tabular}




\begin{tabular}{|c|c|c|c|c|}
\hline $\begin{array}{c}\text { Shaft } \\
\text { Number }\end{array}$ & $\begin{array}{c}\text { Shaft } \\
\text { Diam.(ft) }\end{array}$ & $\begin{array}{c}\text { Fill } \\
\text { Vol. (FT3) }\end{array}$ & $\begin{array}{c}\text { Depth } \\
\text { (ft) }\end{array}$ & Shaft Type \\
\hline 225 & 2 & 53 & 18 & $1 / 4^{\prime \prime}$ steel, welded bollom, concrete plug \\
\hline 226 & 2 & 53 & 18 & $1 / 4^{\prime \prime}$ steel, welded bottom, concrete plug \\
\hline 227 & 2 & 53 & 18 & $1 / 4^{\prime \prime}$ steel, welded bothom, concrete plug \\
\hline 228 & 2 & 55 & 18 & $1 / 4 "$ steel, welded bottom, concrete plug \\
\hline 229 & 2 & 52 & 18 & $1 / 4^{\prime \prime}$ steel, welded bottom, concrete plug \\
\hline 230 & 2 & 53 & 18 & $1 / 4^{\prime \prime}$ steel, welded bottom, concrete plug \\
\hline 231 & 2 & 53 & 18 & $1 / 4^{\prime \prime}$ steel, welded bottom, concrete plug \\
\hline 232 & 2 & 0 & 18 & $1 / 4^{\prime \prime}$ steel, welded bottom, concrete plug \\
\hline 236 & 3 & 0 & 16 & corrugated galv. pipe, gravel bottom, concrete cap \\
\hline 237 & 3 & 0 & 16 & corrugated galv. pipe, gravel bottom, concrete cap \\
\hline 238 & 3 & 0 & 16 & corrugated galv. pipe, gravel bottom, concrete cap \\
\hline 239 & 3 & 0 & 16 & corrugated galv. pipe, gravel bottom, concrete cap \\
\hline 240 & 3 & 0 & 16 & corrugated galv. pipe, gravel bottom, concrete cap \\
\hline 241 & 3 & 0 & 16 & corrugated galv. pipe, gravel bottom, concrete cap \\
\hline 242 & 3 & 0 & 16 & corrugated galv. pipe, gravel bottom, concrete cap \\
\hline 243 & 3 & 0 & 16 & corrugated galv. pipe, gravel bottom, concrete cap \\
\hline 246 & 3 & 0 & 16 & corrugated galv. pipe, gravel bottom, concrete cap \\
\hline 247 & 3 & 0 & 16 & corrugated galv. pipe, gravel bottom, concrete cap \\
\hline 248 & 3 & 0 & 16 & corrugated galv. pipe, gravel bottom, concrete cap \\
\hline 249 & 3 & 0 & 16 & corrugated galv. pipe, gravel bottom, concrete cap \\
\hline 250 & 3 & 0 & 16 & corrugated galv. pipe, gravel bottom, concrete cap \\
\hline 251 & 3 & 0 & 16 & corrugated galv. pipe, gravel bottom, concrete cap \\
\hline 252 & 3 & 0 & 16 & corrugated galv. pipe, gravel bottom, concrete cap \\
\hline 253 & 3 & 0 & 16 & corrugated galv. pipe, gravel bottom, concrete cap \\
\hline 302 & 10 & 0 & 22 & corrugated galv. pipe, gravel bottom, welded steel cap \\
\hline 303 & 10 & 0 & 22 & corrugated galv. pipe, gravel bottom, welded steel cap \\
\hline 304 & 10 & 0 & 22 & corrugated galv. pipe, gravel bottom, welded steel cap \\
\hline 305 & 10 & 0 & 22 & corrugated galv. pipe, gravel bottom, welded steel cap \\
\hline 306 & 10 & 0 & 22 & corrugated galv. pipe, gravel bottom, welded steel cap \\
\hline Grand Tolal & 176 & 1162 & & \\
\hline
\end{tabular}


Maps 1-4 The last section consists of four maps. The first is an overall view of Area G at TA-54 which shows the location of the RHTRU shafts in fields A, B, and C. Three additional maps show each shaft field in detail. 


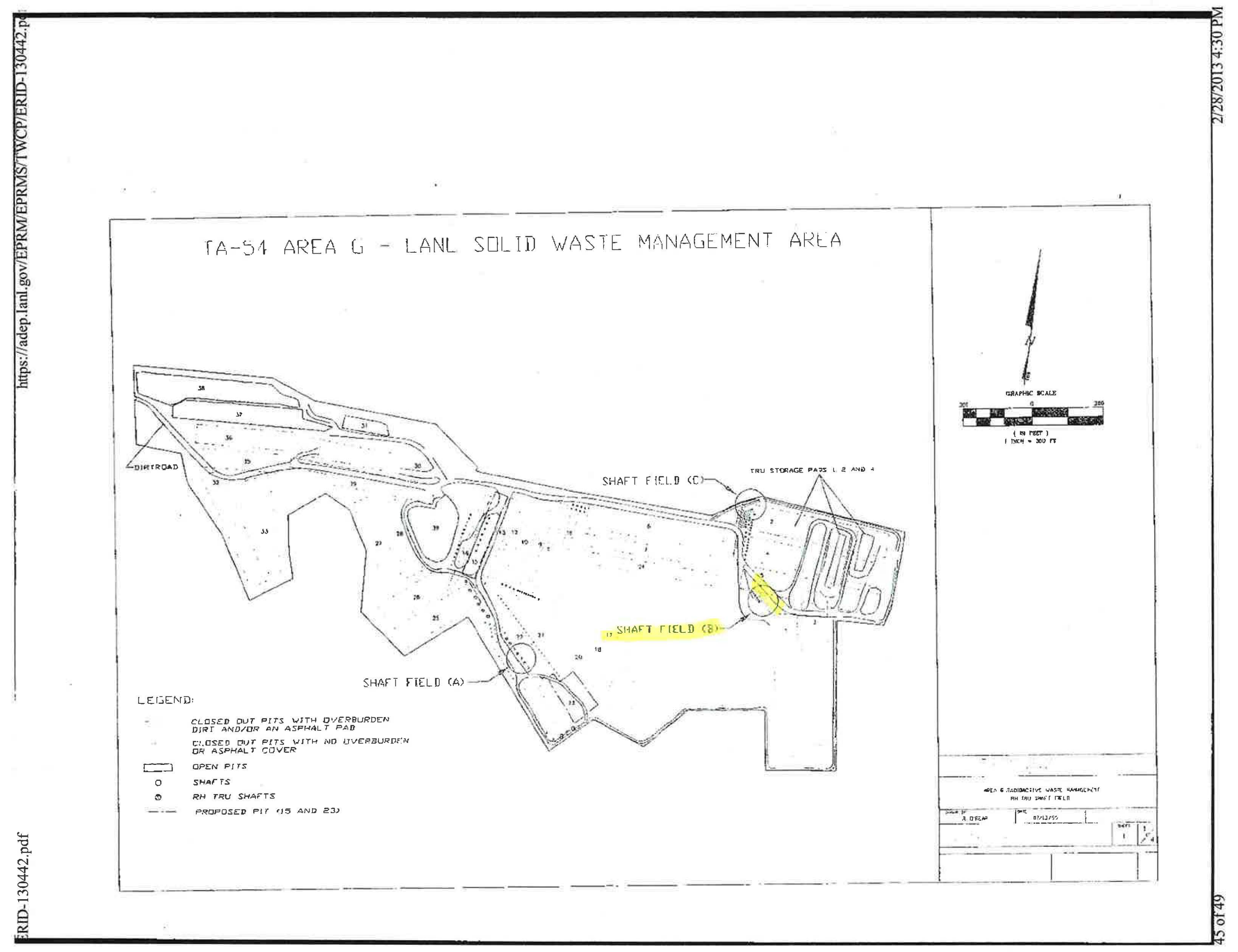




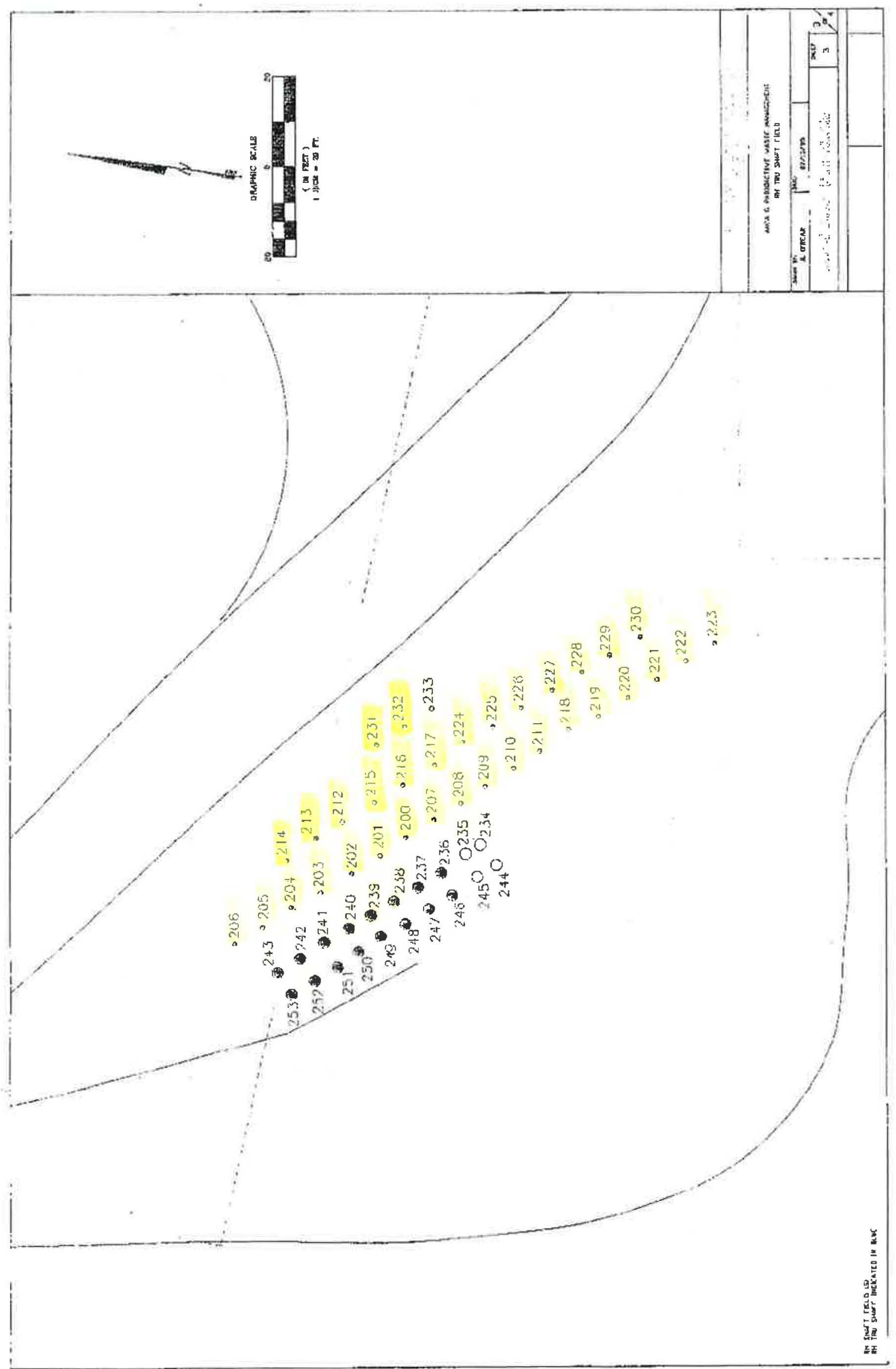




\section{Summary}

This document is the initial report for the RH-TRU Assessment and Recovery Project, (initiative \#197). It is a survey of all RH-TRU waste currently stored at Los Alamos National Laboratory. The purpose of this report is to provide the detailed information necessary to develop a safe and eflicient plan for the retrieval and repackaging of this waste prior to transportation and permanent storage at the WIPP site.

Over the last 25 years, LANL has stored RH-TRU waste in shafts within Area G at TA-54. The 60 shafts now in use contain a total of $95 \mathrm{~m}^{3}$ of RH-TRU with a total radiological activity of over 15,000 curies.

Those totals have been broken down to give the size, activity and isotope content of every package received at TA-54 for storage. The result is that we now have a detailed profile of the waste in each individual shaft including it's volume and activity as well as the volume of fill placed in the shaft.

Finally, information has been presented on the size and method of construction of each shaft including it's diameter, depth, the presence or absence of a liner and the method by which it was capped.

The information collected in this report can now be used to develop a working plan (our final report) for the retrieval, repackaging and transportation of this waste for permanent storage. 



\section{Appendix I}

\section{Portions of \\ Vance/Leonard Report \\ Relevant to 33 Shafts}

"LANL Remote-Handled Transuranic (RH-TRU) Waste Disposition Plan" by

Jene N. Vance and Leroy E. Leonard

November 2002 
This page intentionally left blank.

Page I-2 


\section{DRAFT}

\section{LANL Remote-Handled Transuranic (RH-TRU) Waste Disposition Plan}

Date: November, 2002

\section{Prepared for \\ Los Alamos National Laboratory}

\section{By}

Jene N. Vance

Leroy E. Leonard 


\section{LANL Remote-Handled Transuranic (RH-TRU) Waste Disposition Plan}

\subsection{Introduction}

Remote-handled TRU was generated at LANL from 1970 to 1994. The RH-TRU waste is currently stored in shafts at Area $\mathrm{G}$ and is considered to be legacy waste (waste generated and packaged before October 1998). Because of the storage configurations and the high radiation fields associated with RH-TRU waste, difficulties are anticipated in the retrieval and packaging of the waste for disposal at WIPP. In addition, because WIPP does not currently accept RHTRU waste for disposal, plans for the retrieval and packaging of RH-TRU waste have not been given high priority. Consequently, to this point in time little has been done to develop a disposition plan for RH-TRU waste.

On June 28, 2002 DOE and Westinghouse TRU Solutions submitted a Permit Modification Request to make changes to the Hazardous Waste Facility Permit to allow the management, storage and disposal of remote handled TRU waste at the WIPP facility. WIPP has indicated that they would be prepared to receive RH-TRU waste as early as 2005 . In addition, DOE and LANL have proposed an initiative that accelerates the disposal of all TRU waste by 2010 instead of the baseline date of 2032. These recent developments place the disposition of RH-TRU waste in the 2005-2010 timeframe and consequently have increased the priority for the development of plans to deal with the RH-TRU waste in storage. A draft version of the RH-TRU Waste Acceptance Criteria has also been prepared by $\mathrm{CBFO}$.

The purpose of this document is to describe the broad outlines of plans that will be pursued to ultimately accomplish the disposal of RH-TRU waste. Because the RH-WAP and the RH-WAC are still in draft and have not been approved by the EPA or NMED, these plans are subject to change as the requirements become more defined.

This document is meant to provide an overall view of the status of the plans for the different waste and different storage configurations and to identify areas requiring further development in order to initiate the implementation of the plans. For the purposes of the discussion in this document LANL's RH-TRU waste has been divided into the following waste type categories:

- Debris RH-TRU waste in WTPP Canisters

- Debris RH-TRU waste in Unlined Shafts

- Debris RH-TRU waste in Lined Shafts

- Hot-Cell Liners in Lined Shafts 


\subsection{Remote-Handled TRU Waste Description}

There are two basic types of RH-TRU wastes. The first is hot cell debris consisting of metals, inorganic solids and combustible solids that were packaged into one-gallon containers. The second type is hot cell liners that are essentially gloveboxes that were consolidated by cutting the legs off and packaged in steel boxes. The LANL RH-TRU waste is currently stored in a total of 61 shafts bored into the tuft at Area G.

For the debris waste in the one-gallon containers there are three storage configurations: unlined shafts, lined shafts and WIPP canisters. In the first configuration that was used in the time period from 1971 to 1973 , the one-gallon containers were emplaced into unlined shafts approximately two feet in diameter and 25 feet deep bored into the tuft. The one-gallon containers were not closed with lids. Instead they were bagged, two canisters to a bag, and dropped down the shaft. A total of 114 one-gallon containers are stored in unlined shafts.

In the second storage configuration used from 1979 to 1987 , the containers were emplaced into shafts approximately three feet in diameter and 18 feet deep. An $81 / 2$ " diameter carbon steel pipe liner was place in the bored shaft and backfilled with crushed tuff, cobbles and sand between the pipe and the shaft wall. The one-gallon containers consisted of a galvanized steel paint can without a lid inside of a plastic liner and a $1 / 4$ " thick carbon steel outer canister with a welded lid. The one-gallon containers were dropped into the pipe liner. A total of 290 one-gallon containers are stored in lined shafts.

The final storage configuration was completed in the 1990's in which the welded steel containers were placed into 55-gallon drums and the drums were sealed. Then up to three of the 55-gallon drums were place into stainless steel canisters that had been certified to the WIPP WAC Rev. 3 in 1993. The canisters were designed to fit into the WIPP 72B cask. The canisters are 15 feet long and 30 " in diameter. The canisters were emplaced into bored shafts approximately three feet.in diameter and lined with corrugated steel liners. The shafts are three feet in diameter and 16 feet deep.

In 1991 the hot cell liner boxes were emplaced into bored shafts 10 feet in diameter that had been lined with a $1 / 4$ " carbon steel liner. The liner bottom is open and the top has a $1 / 4$ " steel lid welded to the liner. Table 2-1 shows the number of storage shafts for the different configurations of the LANL RH-TRU waste. 
Table 2-1 Storage Configurations for RH-TRU Waste

\begin{tabular}{|c|c|c|c|c|}
\hline Shaft Design & $\begin{array}{c}\text { Number of } \\
\text { Shafts }\end{array}$ & $\begin{array}{c}\text { Emplaced } \\
\text { Waste }\end{array}$ & Container Type & $\begin{array}{c}\text { Number of } \\
\text { Containers }\end{array}$ \\
\hline Unlined & 6 & Hot Cell Debris & $\begin{array}{c}\text { One-Gallon } \\
\text { Containers }\end{array}$ & 114 \\
\hline Lined & 33 & Hot Cell Debris & $\begin{array}{c}\text { One-Gallon } \\
\text { Containers }\end{array}$ & 290 \\
\hline Lined & 5 & Hot Cell Liner & Metal Boxes & 5 \\
\hline Lined & 17 & Hot Cell Debris & WIPP Canisters & 17 \\
\hline
\end{tabular}

Table 2-2 provides information on the physical characteristics of the storage shafts at Area $G$.

Table 2-2 Physical Characteristics of the RH-TRU Storage Shafts

\begin{tabular}{|c|c|c|c|c|}
\hline Shaft Design & $\begin{array}{c}\text { Container } \\
\text { Type }\end{array}$ & $\begin{array}{c}\text { Shaft Diameter } \\
\text { (feet) }\end{array}$ & $\begin{array}{c}\text { Shaft Depth } \\
\text { (feet) }\end{array}$ & $\begin{array}{c}\text { Liner Diameter } \\
\text { (inches) }\end{array}$ \\
\hline Unlined & $\begin{array}{c}\text { One-Gallon } \\
\text { Containers }\end{array}$ & 2 & 25 & None \\
\hline Lined & $\begin{array}{c}\text { One-Gallon } \\
\text { Containers }\end{array}$ & 3 & 18 & $81 / 2$ \\
\hline Lined & Metal Boxes & 10 & 22 & 112 \\
\hline Lined & $\begin{array}{c}\text { WIPP } \\
\text { Canisters }\end{array}$ & 4 & 16 & 42 \\
\hline
\end{tabular}

Table 2-3 shows the total radiological content of the shafts.

Table 2-3 Total Radiological Contents of the Shafts

\begin{tabular}{|c|c|c|c|c|c|}
\hline Shaft Design & $\begin{array}{l}\text { Container } \\
\text { Type }\end{array}$ & $\begin{array}{l}\text { Curies of } \\
\text { Mixed Fission } \\
\text { Products at } \\
\mathrm{t}=\mathbf{0}\end{array}$ & $\begin{array}{l}\text { Curies of } \\
\text { Mixed Fission } \\
\text { Products at } \\
\mathrm{t}=2004\end{array}$ & $\begin{array}{l}\text { Curies of } \\
\text { Pu-239 }\end{array}$ & $\begin{array}{l}\text { Grams of } \\
\text { Pu-239 }\end{array}$ \\
\hline Unlined & $\begin{array}{c}\text { One-Gallon } \\
\text { Containers }\end{array}$ & 237 & 115 & 15.4 & 249 \\
\hline Lined & $\begin{array}{c}\text { One-Gallon } \\
\text { Containers }\end{array}$ & 3354 & 1996 & 80 & 1286 \\
\hline Lined & $\begin{array}{c}\text { WIPP } \\
\text { Canisters }\end{array}$ & 11,636 & 9041 & 138 & 2220 \\
\hline
\end{tabular}




\begin{tabular}{|c|c|c|c|c|c|}
\hline Lined & $\begin{array}{c}\text { Metal } \\
\text { Boxes }\end{array}$ & 13 & 9.9 & 0.4 & 6 \\
\hline Totals & & $\mathbf{1 5 , 2 4 0}$ & $\mathbf{1 1 , 6 1 9}$ & $\mathbf{2 3 3 . 8}$ & $\mathbf{3 7 6 1}$ \\
\hline
\end{tabular}




\title{
4.0 Disposition Plans
}

The following provides a description of the plans for the disposition of the LANL RH-TRU waste. Because of the differences among the waste packaging and storage configurations, it is expected that the retrieval and disposal activities would be conducted in a phased approach. The retrieval and disposal activities would start with the RH-TRU waste already packaged in WIPP canisters and proceed to the lined and unlined shafts and finally to the hot cell liners. The descriptions are presented for each of the following:

\author{
Debris in WIPP Canisters \\ Debris in Lined Shafts \\ Debris in Unlined Shafts \\ Hot Cell Liners in Lined Shafts
}

\subsection{Debris in WIPP Canisters}

In the first phase, project activities will be aimed at the retrieval, certification and disposal of the RH-TRU waste already packaged in WIPP canisters. The RH-TRU waste packaged into the WIPP canisters should require the least effort to get the waste shipped to WIPP. To ship RHTRU waste to WIPP for disposal, LANL must certify that the waste meets the WIPP waste acceptance criteria (RH-WAC). A draft version of the RH-WAC has been prepared by CBFO that reflects the sampling and analysis protocol requirements contained in the Waste Analysis Plan to be used in determining compliance with the required physical and chemical properties of the waste. The RH-WAC requires that the characterization of the waste be conducted in accordance with the performance requirements of the RH-WAP and implemented in accordance with a site-specific quality assurance project plan.

The objectives for the first phase of the project are to:

(1) Demonstrate that characterization and packaging efforts already completed for the waste canisters satisfy the characterization requirements of the proposed WIPP RH-WAP and draft RH-WAC,

(2) Develop and obtain CBFO approval of an RH-TRU Waste Certification Plan and associated QA Plan,

(3) Demonstrate that the records and documentation supporting the completed characterization efforts satisfy the QA requirements of the RH-WAP and RHWAC

(4) Certify that the WIPP Canisters are acceptable for WIPP.

To complete a gap analysis of the existing CMR hot cell equipment and the equipment requirements associated with the handling, characterization and packaging of the retrieved one-gallon containers. 


\begin{tabular}{|l|c|c|c|c|c|c|}
267 & 117.3 & 92.12 & 32.0 & 0.36 & 4.93 & 0.144 \\
\hline 268 & 152.9 & 120.36 & 41.8 & 0.47 & 6.45 & 0.189 \\
\hline 269 & 61.7 & 48.77 & 16.9 & 0.19 & 2.61 & 0.076 \\
\hline
\end{tabular}

\subsection{Debris in Lined Shafts}

The debris waste in the lined shafts would be addressed in the second phase of the project. The objectives for the second phase are:

(1) Develop an AK report in accordance with the RH-TRU Characterization Plan

(2) Establish an Authorization Basis at Area $G$ for the retrieval operations

(3) Establish an Authorization Basis for the characterization and packaging activities in CMR

(4) Develop the well-head hardware and retrieve the waste containers from the lined shafts

Perform any additional characterization measurements as dictated by the Characterization Plan

Package the waste in WIPP-Approved Containers

Certify that the packaged waste is acceptable for disposal at WIPP

Similar to the first phase, all of the characterization information and data will be retrieved and assembled into an AK report. The AK report will be assessed against the requirements of the RH-TRU Characterization Plan to determine if additional measurements or information is required.

There are 33 lined shafts numbered 200 through 232 in the " $\mathrm{B}$ " shaft field at Area G that contain debris RH-TRU. The exact condition of the liner and containers is unknown, but it is expected that there would not be gross failure of either the liner or the containers that would prevent a relatively simple retrieval technique from the surface over the tops of the shafts. It is expected that the waste materials in the retrieved containers would be fully contained by virtue of the container features and welded closure. The retrieval of the waste containers could be performed either by LANL or a subcontractor with expertise in remote handling operations.

For the retrieval operation it is expected that a shielded enclosure would be set over the shaft opening after the shaft closure device has been removed. The enclosure device would provide shielding to allow the containers to be raised from the shaft and placed into a 55-gallon drum. The enclosure would hous the lifting mechanism and the drumming station for receiving the containers and to provide for a drum closure operation. It may be that the at-surface containment and shielding apparatus could be designed for both the lined and unlined shafts. 


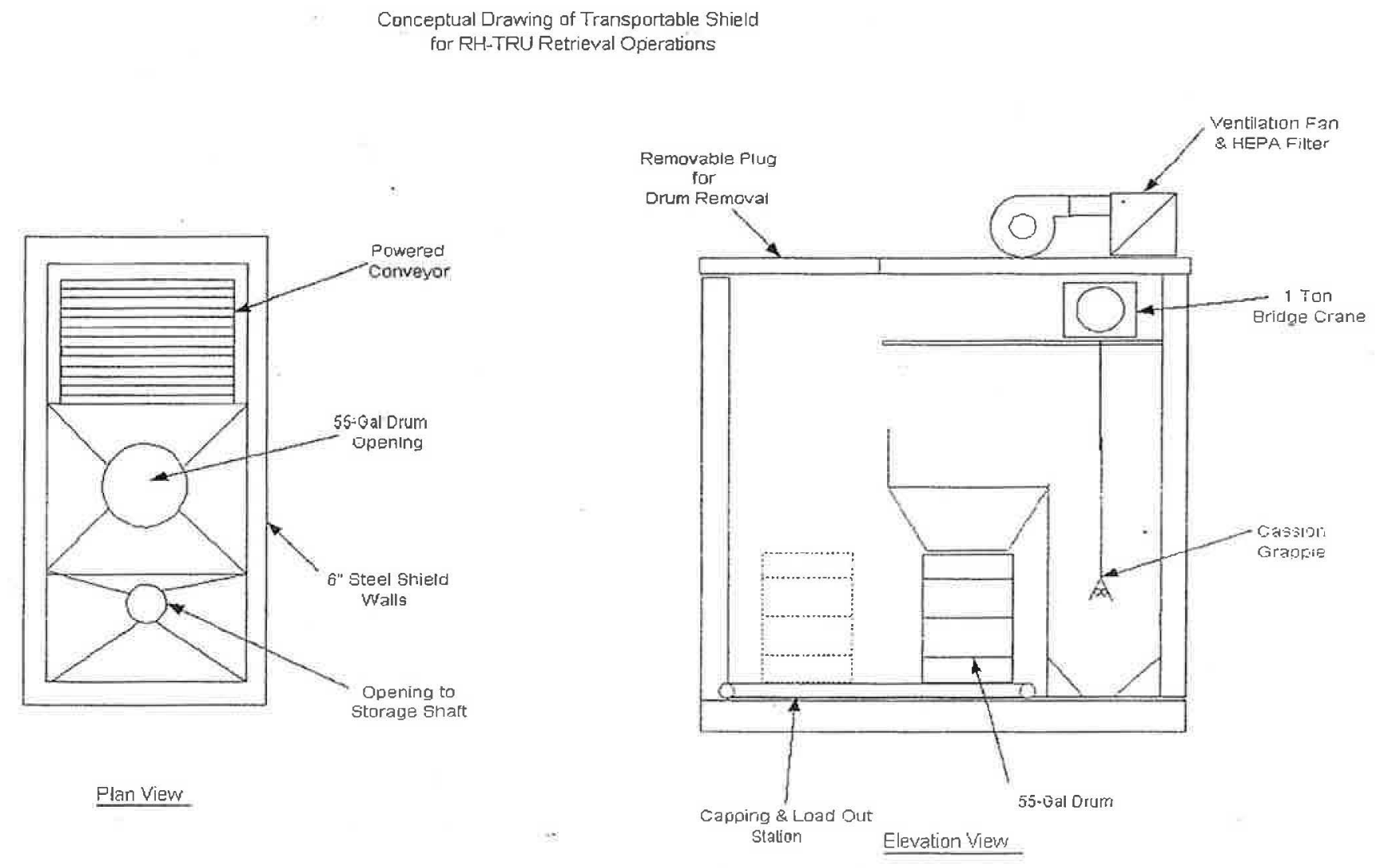


It is expected that the 55-gallon drum would be housed in a shield cask that would allow transport of the closed drum to the CMR facility. Any additional characterization measurements, such as NDA measurements or RTR records, would be performed on the 55-gallon drums in the hot cells at CMR. The packaged 55-gallon drums would be loaded into WIPP canisters and the canister lid affixed in the CMR hot cells, in the same fashion as was done for the 17 canisters discussed in Section 4.1.

An important step in this phase of the project will be to demonstrate that the retrieval of the containers from the lined shafts can be achieved using a simple retrieval mechanism such as a magnetic or mechanical grapple and a lifting device such as a hoist. If either the shaft liner or the containers have corroded to the point where they exhibit gross failure, then a more complicated retrieval technique will be developed.

All of the shafts in field " $\mathrm{B}$ " contain RH-TRU waste, which will eventually be emptied. This means that it is possible to approach the retrieval of the waste by excavating without interfering with shafts that contain other types of waste. Two possible approaches that could be evaluated in the event that the simple retrieval technique discussed above is not feasibility are as followis:

Pull the entire pipe liner intact from the shaft with the waste containers and perform the necessary characterization and repackaging activities in a hot cell at CMR

Excavate down to the pipe liners and lift the liners intact. As in the above option the characterization and repackaging activities would be performed in a CMR hot cell. 
Figure 4-1 shows the configuration of the waste containers in the lined shafts.

1.
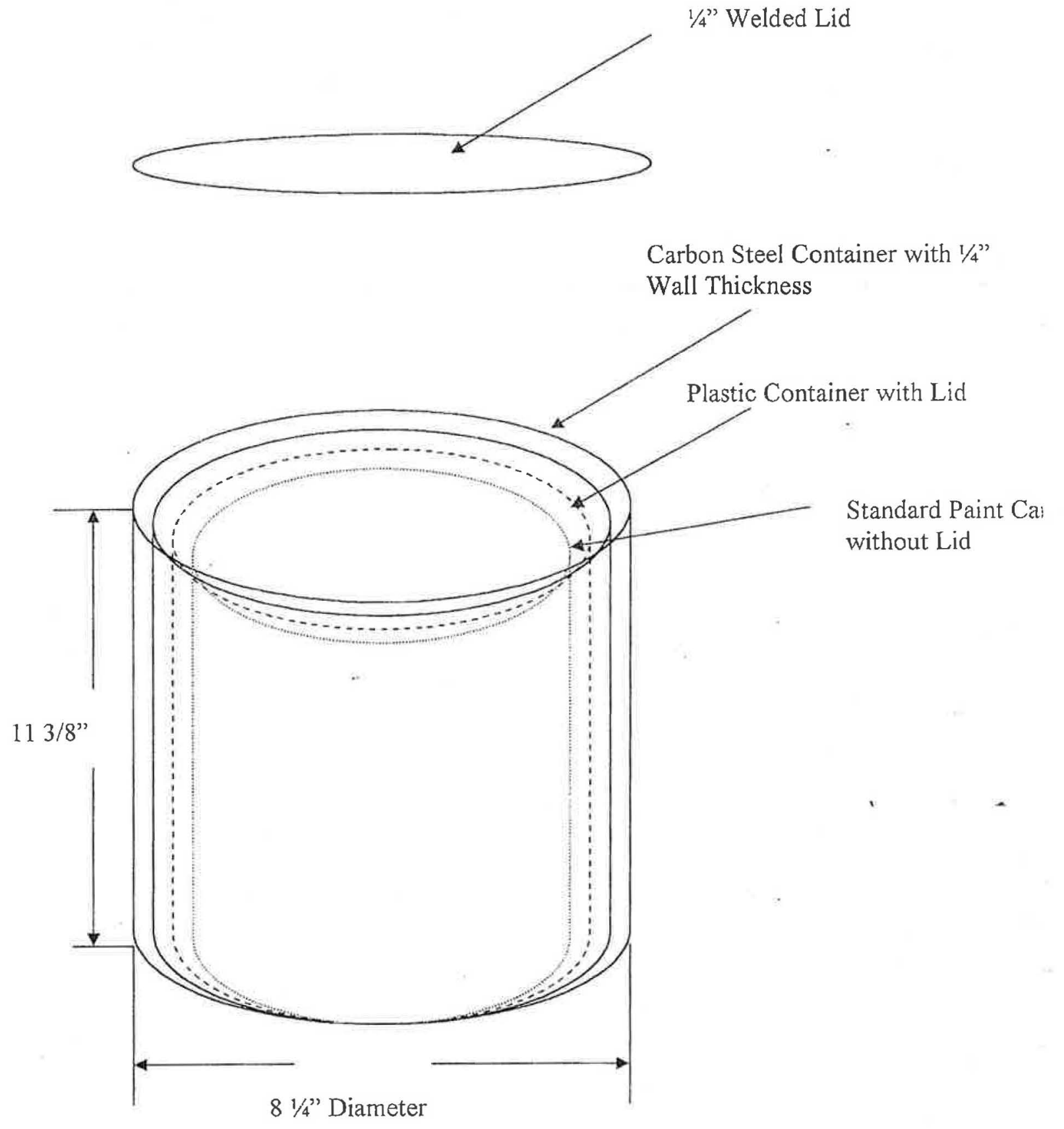

Figure 4-1 
Table 4-4 provides the characteristics of the shafts lined with the $8-1 / 2$ " diameter steel pipes.

\section{Table 4-4 Characteristics of the Individual Lined Shafts Containing One-Gallon Containers}

\begin{tabular}{|c|c|c|c|c|c|c|c|}
\hline Shaft \# & $\begin{array}{c}\text { Shaft } \\
\text { Feature }\end{array}$ & $\begin{array}{c}\text { Shaft } \\
\text { Diameter } \\
\text { (ft) }\end{array}$ & $\begin{array}{c}\text { Shaft Depth } \\
\text { (ft) }\end{array}$ & $\begin{array}{c}\text { Liner } \\
\text { Diameter } \\
\text { (inches) }\end{array}$ & $\begin{array}{c}\text { Date } \\
\text { Emplaced }\end{array}$ & $\begin{array}{c}\text { Number of } \\
\text { 1-gallons } \\
\text { Containers }\end{array}$ & $\begin{array}{c}\text { Number of } \\
\text { Packages }\end{array}$ \\
\hline 200 & Lined & 3 & 18 & 8.5 & $04 / 14 / 81$ & 12 & 6 \\
\hline 201 & Lined & 3 & 18 & 8.5 & $06 / 29 / 79$ & 13 & 7 \\
\hline 202 & Lined & 3 & 18 & 8.5 & $04 / 30 / 80$ & 12 & 6 \\
\hline 203 & Lined & 3 & 18 & 8.5 & $04 / 30 / 80$ & 12 & 6 \\
\hline 204 & Lined & 3 & 18 & 8.5 & $06 / 29 / 79$ & 10 & 5 \\
\hline 205 & Lined & 3 & 18 & 8.5 & $12 / 01 / 80$ & 14 & 7 \\
\hline 206 & Lined & 3 & 18 & 8.5 & $04 / 01 / 81$ & 14 & 7 \\
\hline 207 & Lined & 3 & 18 & 8.5 & $05 / 29 / 81$ & 11 & 5 \\
\hline 208 & Lined & 3 & 18 & 8.5 & $06 / 22 / 81$ & 12 & 6 \\
\hline 209 & Lined & 3 & 18 & 8.5 & $06 / 22 / 81$ & 12 & 5 \\
\hline 210 & Lined & 3 & 18 & 8.5 & $06 / 22 / 81$ & 12 & 4 \\
\hline 211 & Lined & 3 & 18 & 8.5 & $11 / 06 / 81$ & 12 & 5 \\
\hline 212 & Lined & 3 & 18 & 8.5 & & Crate & 75 cu ft \\
\hline 213 & Lined & 3 & 18 & 8.5 & $11 / 03 / 81$ & 8 & 4 \\
\hline 214 & Lined & 3 & 18 & 8.5 & $04 / 20 / 82$ & 6 & 6 \\
\hline 215 & Lined & 3 & 18 & 8.5 & $06 / 09 / 82$ & 7 & 7 \\
\hline 216 & Lined & 3 & 18 & 8.5 & $06 / 09 / 82$ & 6 & 6 \\
\hline 217 & Lined & 3 & 18 & 8.5 & $09 / 13 / 82$ & 6 & 6 \\
\hline 218 & Lined & 3 & 18 & 8.5 & $09 / 13 / 82$ & 6 & 6 \\
\hline 219 & Lined & 3 & 18 & 8.5 & $03 / 10 / 83$ & 6 & 6 \\
\hline 220 & Lined & 3 & 18 & 8.5 & $03 / 10 / 83$ & 6 & 6 \\
\hline 221 & Lined & 3 & 18 & 8.5 & $03 / 10 / 83$ & 6 & 6 \\
\hline 222 & Lined & 3 & 18 & 8.5 & $12 / 14 / 83$ & 7 & 7 \\
\hline 223 & Lined & 3 & 18 & 8.5 & $12 / 14 / 83$ & 6 & 6 \\
\hline 224 & Lined & 3 & 18 & 8.5 & $12 / 30 / 85$ & 8 & 8 \\
\hline 225 & Lined & 3 & 18 & 8.5 & $12 / 31 / 84$ & 8 & 8 \\
\hline 226 & Lined & 3 & 18 & 8.5 & $12 / 31 / 84$ & 8 & 8 \\
\hline 227 & Lined & 3 & 18 & 8.5 & $12 / 31 / 84$ & 8 & 8 \\
\hline 228 & Lined & 3 & 18 & 8.5 & $12 / 23 / 87$ & 8 & 8 \\
\hline 229 & Lined & 3 & 18 & 8.5 & $12 / 31 / 84$ & 7 & 7 \\
\hline 230 & Lined & 3 & 18 & 8.5 & $12 / 31 / 84$ & 8 & 8 \\
\hline 231 & Lined & 3 & 18 & 8.5 & $12 / 30 / 85$ & 7 & 7 \\
\hline 232 & Lined & 3 & 18 & 8.5 & $12 / 23 / 87$ & 3 & 3 \\
\hline & & & & & $70 t a l$ & 290 & \\
\hline & & & & & & & \\
\hline
\end{tabular}

The radiological characteristics of the RH-TRU waste in the lined shafts are shown in Table 4-5. 
Table 4-5 Radiological Characteristics of the RH-TRU Waste in Lined Shafts

\begin{tabular}{|c|c|c|c|c|c|c|}
\hline Shaft \# & $\begin{array}{l}\text { Curies of } \\
\text { Mixed } \\
\text { Fission } \\
\text { Products } \\
\text { at } \mathrm{t}=0\end{array}$ & \begin{tabular}{|l} 
Curies of \\
Mixed \\
Fission \\
Products \\
at $\mathrm{t}=2004$
\end{tabular} & $\begin{array}{l}\text { Curies of } \\
\text { Pu-239 }\end{array}$ & $\begin{array}{l}\text { Grams of } \\
\text { Pu-239 }\end{array}$ & \begin{tabular}{|l|} 
Power \\
from MFP \\
(Watts)
\end{tabular} & $\begin{array}{l}\text { Power } \\
\text { from Pu- } \\
239 \\
\text { (Watts) }\end{array}$ \\
\hline 200 & 32.4 & 18.85 & 3.18 & 51.29 & $1.32 \mathrm{E}-01$ & $9.89 \mathrm{E}-02$ \\
\hline 201 & 90.8 & 50.64 & 13.44 & 216.77 & $3.55 \mathrm{E}-01$ & $4.18 \mathrm{E}-01$ \\
\hline 202 & 245 & 139.36 & 4.01 & 64.68 & $9.75 \mathrm{E}-01$ & 1.25E-01 \\
\hline 203 & 109 & 62.00 & 2.3 & 37.10 & $4.34 \mathrm{E}-01$ & $7.15 E-02$ \\
\hline 204 & 46 & 25.66 & 3.65 & 58.87 & $1.80 \mathrm{E}-01$ & $1.14 \mathrm{E}-01$ \\
\hline 205 & . 422 & 243.37 & 7.26 & 117.10 & $1.70 \mathrm{E}+00$ & $2.26 \mathrm{E}-01$ \\
\hline 206 & 386 & 224.34 & 17.8 & 287.10 & $1.57 E+00$ & $5.54 \mathrm{E}-01$ \\
\hline 207 & 13 & 7.58 & 0.087 & 1.40 & $5.31 \mathrm{E}-02$ & $2.71 \mathrm{E}-03$ \\
\hline 208 & 105 & 61.35 & 1.9 & 30.65 & $4.29 \mathrm{E}-01$ & $5.91 E-02$ \\
\hline 209 & 4 & 2.34 & 0.0245 & 0.40 & $1.64 \mathrm{E}-02$ & $7.62 \mathrm{E}-04$ \\
\hline 210 & 1 & 0.58 & 0.0246 & 0.40 & $4.09 \mathrm{E}-03$ & $7.65 \mathrm{E}-04$ \\
\hline 211 & 0.428 & 0.25 & 0.00006 & 0.00 & 1.77E-03 & $1.87 \mathrm{E}-06$ \\
\hline 213 & 152 & 89.57 & 3.18 & 51.29 & $6.27 \mathrm{E}-01$ & $9.89 \mathrm{E}-02$ \\
\hline 214 & 3 & 1.79 & 0.037 & 0.60 & $1.25 E-02$ & $1.15 E-03$ \\
\hline 215 & 55 & 32.87 & 0.975 & 15.73 & $2.30 \mathrm{E}-01$ & $3.03 E-02$ \\
\hline 216 & 10 & 5.98 & 0.037 & 0.60 & $4.18 \mathrm{E}-02$ & $1.15 \mathrm{E}-03$ \\
\hline 217 & 19 & 11.42 & 1.81 & 29.19 & $8.00 E-02$ & $5.63 E-02$ \\
\hline 218 & 132 & 79.37 & 2.74 & 44.19 & $5.56 \mathrm{E}-01$ & $8.52 \mathrm{E}-02$ \\
\hline 219 & 351 & 213.47 & 2.82 & 45.48 & $1.49 E+00$ & $8.77 \mathrm{E}-02$ \\
\hline 220 & 460 & 279.76 & 0.0375 & 0.60 & $1.96 \mathrm{E}+00$ & 1.17E-03 \\
\hline 221 & 177 & 107.65 & 0.0368 & 0.59 & $7.54 \mathrm{E}-01$ & $1.14 \mathrm{E}-03$ \\
\hline 222 & 341 & 211.13 & 0.317 & 5.11 & $1.48 \mathrm{E}+00$ & $9.86 \mathrm{E}-03$ \\
\hline 223 & 37 & 22.91 & 0.0377 & 0.61 & $1.60 \mathrm{E}-01$ & 1.17E-03 \\
\hline 224 & 23 & 14.94 & 0.676 & 10.90 & $1.05 \mathrm{E}-01$ & $2.10 \mathrm{E}-02$ \\
\hline 225 & 7 & 4.44 & 0.049 & 0.79 & $3.11 \mathrm{E}-02$ & $1.52 \mathrm{E}-03$ \\
\hline 226 & 13 & 8.25 & 0.049 & 0.79 & $5.77 \mathrm{E}-02$ & $1.52 \mathrm{E}-03$ \\
\hline 227 & 22 & 13.96 & 1.1 & 17.74 & $9.77 \mathrm{E}-02$ & $3.42 \mathrm{E}-02$ \\
\hline 228 & 11 & 7.48 & 0.049 & 0.79 & $5.24 \mathrm{E}-02$ & $1.52 \mathrm{E}-03$ \\
\hline 229 & 9 & 5.71 & 0.22 & 3.55 & $4.00 \mathrm{E}-02$ & $6.84 \mathrm{E}-03$ \\
\hline 230 & 55 & 34.90 & 5.93 & 95.64 & $2.44 \mathrm{E}-01$ & $1.84 \mathrm{E}-01$ \\
\hline 231 & 22 & 14.29 & 0.037 & 0.60 & $1.00 \mathrm{E}-01$ & 1.15E-03 \\
\hline 232 & 0 & 0.0 & 5.92 & 95.48 & $0.00 \mathrm{E}+00$ & $1.84 \mathrm{E}-01$ \\
\hline
\end{tabular}

Dose rate calculations were made assuming that the entire contents of a shaft could be loaded into a single 55-gallon drum. Contact dose rates and dose rates at distance of ' ' $10^{\prime}$ and $20^{\prime}$ from an unshielded drum were calculated. The results of these calculations are given in Table 46 
Table 4-6 Dose Rate Results for Unshielded 55-gallon Drums

\begin{tabular}{|c|c|c|c|c|c|c|}
\hline Shaft \# & $\begin{array}{c}\text { Curies of } \\
\text { Mixed } \\
\text { Fission } \\
\text { Products at } \\
t=0\end{array}$ & $\begin{array}{c}\text { Curies of } \\
\text { Mixed } \\
\text { Fission } \\
\text { Products at } \\
t=2004\end{array}$ & $\begin{array}{c}\text { 55-Gal Drum } \\
\text { Dose Rate @ } \\
\text { Surface } \\
\text { Unshielded } \\
\text { (R/hr) }\end{array}$ & $\begin{array}{c}\text { 55-Gal Drum } \\
\text { Dose Rate @ } \\
3 \mathrm{ft} \\
\text { Unshielded } \\
\text { (R/hr) }\end{array}$ & $\begin{array}{c}\text { 55-Gal Drum } \\
\text { Dose Rate @ } \\
10 \mathrm{ft} \\
\text { Unshielded } \\
\text { (R/hr) }\end{array}$ & $\begin{array}{l}\text { 55-Gal Drum } \\
\text { Dose Rate @ } \\
20 \mathrm{ft} \\
\text { Unshielded } \\
\text { (mR/hr) }\end{array}$ \\
\hline 200 & 32.4 & 18.85 & 152 & 10.3 & 1.3 & 350 \\
\hline 201 & 90.8 & 50.64 & 408 & 27.8 & 3.5 & 940 \\
\hline 202 & 245 & 139.36 & 1,122 & 76.4 & 9.6 & 2,586 \\
\hline 203 & 109 & 62.00 & 499 & 34.0 & 4.3 & 1,151 \\
\hline 204 & 46 & 25.66 & 207 & 14.1 & 1.8 & 476 \\
\hline 205 & 422 & 243.37 & 1,960 & 133.4 & 16.9 & 4,517 \\
\hline 206 & 386 & 224.34 & 1,806 & 122.9 & 15.5 & 4,164 \\
\hline 207 & 13 & 7.58 & 61 & 4.2 & 0.5 & 141 \\
\hline 208 & 105 & 61.35 & 494 & 33.6 & 4.2 & 1,139 \\
\hline 209 & 4 & 2.34 & 19 & 1.3 & 0.2 & 43 \\
\hline 210 & 1 & 0.58 & 5 & 0.3 & 0.0 & 11 \\
\hline 211 & 0.428 & 0.25 & 2 & 0.1 & 0.0 & 5 \\
\hline 212 & & & 0 & 0.0 & 0.0 & 0 \\
\hline 213 & 152 & 89.57 & 721 & 49.1 & 6.2 & 1,662 \\
\hline 214 & 3 & 1.79 & 14 & 1.0 & 0.1 & 33 \\
\hline 215 & 55 & 32.87 & 265 & 18.0 & 2.3 & 610 \\
\hline 216 & 10 & 5.98 & 48 & 3.3 & 0.4 & 111 \\
\hline 217 & 19 & 11.42 & 92 & 6.3 & 0.8 & 212 \\
\hline 218 & 132 & 79.37 & 639 & 43.5 & 5.5 & 1,473 \\
\hline 219 & 351 & 213.47 & 1,719 & 117.0 & 14.8 & 3,962 \\
\hline 220 & 460 & 279.76 & 2,253 & 153.3 & 19.4 & 5,192 \\
\hline 221 & 177 & 107.65 & 867 & 59.0 & 7.5 & 1,998 \\
\hline 222 & 341 & 211.13 & 1,700 & 115.7 & 14.6 & 3,919 \\
\hline 223 & 37 & 22.91 & 184 & 12.6 & 1.6 & 425 \\
\hline 224 & 23 & 14.94 & 120 & 8.2 & 1.0 & 277 \\
\hline 225 & 7 & 4.44 & 36 & 2.4 & 0.3 & 82 \\
\hline 226 & 13 & 8.25 & 66 & 4.5 & 0.6 & 153 \\
\hline 227 & 22 & 13.96 & 112 & 7.7 & 1.0 & 259 \\
\hline 228 & 11 & 7.48 & 60 & 4.1 & 0.5 & 139 \\
\hline 229 & 9 & 5.71 & 46 & 3.1 & 0.4 & 106 \\
\hline 230 & 55 & 34.90 & 281 & 19.1 & 2.4 & 648 \\
\hline 231 & 22 & 14.29 & 115 & 7.8 & 1.0 & 265 \\
\hline 232 & 0 & 0.00 & 0 & 0.0 & 0.0 & 0 \\
\hline
\end{tabular}

From an Authorization Basis point of view it seems that the absence of a secondary containment containers makes it unlikely that a mobile crane would remove the containers. If such an operation is feasible, the dose rate calculations also indicate that a boom longer than $20^{\prime}$ would be required for the retrieval and shielding would be required for the drum capping operation. 
Additional dose rate calculations were performed assuming that the 55-gallon drums were loaded with the entire contents of the shaft. The dose rate point for the calculation was one foot from the surface of the shield for different thicknesses of steel shielding for the 55-gallon drums.

Table 4-7 shows the results of these calculations.

Table 4-7 Dose Rate Calculation Results for Shielded 55-gallon Drums

\begin{tabular}{|c|c|c|c|c|c|c|}
\hline Shaft \# & $\begin{array}{l}\text { Curies of } \\
\text { Mixed } \\
\text { Fission } \\
\text { Products at } \\
\mathrm{t}=0\end{array}$ & $\begin{array}{l}\text { Curies of } \\
\text { Mixed } \\
\text { Fission } \\
\text { Products at } \\
t=2004\end{array}$ & $\begin{array}{l}\text { 55-Gal } \\
\text { Drum Dose } \\
\text { Rate @ 1 ft } \\
\text { from 3" } \\
\text { steel shield } \\
(\mathrm{mR} / \mathrm{hr})\end{array}$ & $\begin{array}{l}\text { 55-Gal } \\
\text { Drum Dose } \\
\text { Rate @ } 1 \mathrm{ft} \\
\text { from 4" } \\
\text { steel shield } \\
(\mathrm{mR} / \mathrm{hr})\end{array}$ & $\begin{array}{l}\text { 55-Gal } \\
\text { Drum Dose } \\
\text { Rate @ 1 ft } \\
\text { from 5" } \\
\text { steel shield } \\
(\mathrm{mR} / \mathrm{hr})\end{array}$ & $\begin{array}{l}\text { 55-Gal Dru } \\
\text { Dose Rate } \\
\text { @ } 1 \text { ft from } \\
\text { 6" steel } \\
\text { shield } \\
\text { (mR/hr) }\end{array}$ \\
\hline 200 & 32.4 & 18.85 & 575 & $5 \quad 162.1$ & 43.7 & 11.7 \\
\hline 201 & 90.8 & 50.64 & 1,546 & 435.5 & 117.5 & 31.4 \\
\hline 202 & 245 & 139.36 & 4,253 & 1198.5 & 323.3 & 86.4 \\
\hline 203 & 109 & 62.00 & 1,892 & 533.2 & 143.8 & 38.4 \\
\hline 204 & 46 & 25.66 & 783 & 220.6 & 59.5 & 15.9 \\
\hline 205 & 422 & 243.37 & 7,428 & 2092.9 & 564.6 & 150.9 \\
\hline 206 & 386 & 224.34 & 6,847 & 1929.3 & 520.5 & 139.1 \\
\hline 207 & 13 & 7.58 & 231 & 65.2 & 17.6 & 4.7 \\
\hline 208 & 105 & 61.35 & 1,872 & 527.6 & 142.3 & 38.0 \\
\hline 209 & 4 & 2.34 & 71 & 20.1 & 5.4 & 1.4 \\
\hline 210 & 1 & 0.58 & 18 & 5.0 & 1.4 & 0.4 \\
\hline 211 & 0.428 & 0.25 & 7.7 & 2.2 & 0.6 & 0.2 \\
\hline 212 & & & 0 & 0.0 & 0.0 & 0.0 \\
\hline 213 & 152 & 89.57 & 2,734 & 770.3 & 207.8 & 55.5 \\
\hline 214 & 3 & 1.79 & 55 & 15.4 & 4.1 & 1.1 \\
\hline 215 & 55 & 32.87 & 1,003 & 282.7 & 76.3 & 20.4 \\
\hline 216 & 10 & 5.98 & 182 & 51.4 & 13.9 & 3.7 \\
\hline 217 & 19 & 11.42 & 349 & 98.2 & 26.5 & 7.1 \\
\hline 218 & 132 & 79.37 & 2,422 & 682.6 & 184.1 & 49.2 \\
\hline 219 & 351 & 213.47 & 6,515 & 1835.9 & 495.3 & 132.4 \\
\hline 220 & 460 & 279.76 & 8,538 & 2406.0 & 649.1 & 173.5 \\
\hline 221 & 177 & 107.65 & 3,285 & 925.8 & 249.7 & 66.7 \\
\hline 222 & 341 & 211.13 & 6,444 & 1815.8 & 489.8 & 130.9 \\
\hline 223 & 37 & 22.91 & 699 & 197.0 & 53.1 & 14.2 \\
\hline 224 & 23 & 14.94 & 456 & 128.5 & 34.7 & 9.3 \\
\hline 225 & 7 & 4.44 & 136 & 38.2 & 10.3 & 2.8 \\
\hline 226 & 13 & 8.25 & 252 & 70.9 & 19.1 & 5.1 \\
\hline 227 & 22 & 13.96 & 426 & 120.1 & 32.4 & 8.7 \\
\hline 228 & 11 & 7.48 & 228 & 64.4 & 17.4 & 4.6 \\
\hline 229 & 9 & 5.71 & 174 & 49.1 & 13.2 & 3.5 \\
\hline 230 & 55 & 34.90 & 1,065 & 300.1 & 81.0 & 21.6 \\
\hline 231 & 22 & 14.29 & 436 & 122.9 & 33.2 & 8.9 \\
\hline 232 & 0 & 0.00 & 0 & 0.0 & 0.0 & 0.0 \\
\hline
\end{tabular}




\section{Appendix A Waste Description of Contents of Containers in Lined and Unlined Shafts}

\begin{tabular}{|c|c|c|c|c|c|c|}
\hline \begin{tabular}{|l|} 
Shaft \\
Number
\end{tabular} & $\begin{array}{l}\text { Number } \\
\text { of } \\
\text { Pkgs }\end{array}$ & $\begin{array}{l}\text { Date } \\
\text { Placed }\end{array}$ & RSWD & $\begin{array}{l}\text { Number } \\
\text { of } 1- \\
\text { gallons } \\
\text { Contain } \\
\text { ers }\end{array}$ & Waste Description & \\
\hline 33 & 1 & $1 / 28 / 71$ & 710040 & 1 & Mixture Numec Samples & \\
\hline 72 & 1 & $1 / 5 / 73$ & 730421 & 2 & SS and fuel cuts remains & \\
\hline 72 & 1 & $1 / 5 / 73$ & 730422 & 2 & None & \\
\hline 72 & $\overline{1}$ & $1 / 5 / 73$ & 730423 & 2 & Waste cladding & \\
\hline 72 & 1 & $1 / 5 / 73$ & 730424 & 2 & Grindings & \\
\hline 72 & 1 & $1 / 5 / 73$ & 730441 & 2 & Swipes and grindings & \\
\hline 73 & 1 & $2 / 14 / 73$ & 730428 & 2 & Hot cell trash & $=$ \\
\hline 73 & 1 & $2 / 14 / 73$ & 730431 & 2 & Grindings & \\
\hline 73 & 1 & $2 / 14 / 73$ & 730432 & 2 & Grindings & \\
\hline 73 & 1 & $2 / 14 / 73$ & 730433 & 1 & Swipes & \\
\hline 73 & 1 & $2 / 14 / 73$ & 730444 & 2 & Swipes and grindings & \\
\hline 73 & 1 & $2 / 14 / 73$ & 730445 & 2 & Trash and fuel waste & \\
\hline 73 & 1 & $2 / 14 / 73$ & 730446 & 2 & Trash from 914 Dempster Box & \\
\hline 73 & 1 & $2 / 14 / 73$ & 730448 & 2 & Trash and fuel & \\
\hline 73 & 1 & $2 / 14 / 73$ & 730449 & 2 & Swipes and trash & \\
\hline 73 & 1 & $2 / 14 / 73$ & 730450 & 2 & Swipes and trash & \\
\hline 73 & 1 & $2 / 14 / 73$ & 730455 & 2 & Fuel waste and trash & \\
\hline 73 & 1 & $2 / 14 / 73$ & 730456 & 2 & Hot cell trash & \\
\hline 73 & 1 & $2 / 14 / 73$ & 730458 & 2 & Trash and swipes & \\
\hline 73 & 1 & $2 / 14 / 73$ & 730460 & 2 & Swipes and grindings & \\
\hline 73 & 1 & $2 / 14 / 73$ & 730461 & 2 & Fuel waste and trash & \\
\hline 74 & 1 & $4 / 5 / 73$ & 730463 & 2 & Swipes and trash & \\
\hline 74 & 1 & $4 / 5 / 73$ & 730465 & 2 & Hot cell trash & \\
\hline 74 & 1 & $4 / 5 / 73$ & 730466 & 2 & Hot cell trash & \\
\hline 74 & 1 & $4 / 5 / 73$ & 730471 & 2 & Hot cell trash & \\
\hline 74 & 1 & $4 / 5 / 73$ & 730476 & 2 & Hot cell trash & \\
\hline 74 & 1 & $4 / 5 / 73$ & 730477 & 2 & Hot cell trash & \\
\hline 74 & 1 & $4 / 5 / 73$ & 730478 & 2 & Swipes and grindings & \\
\hline 74 & 1 & $4 / 5 / 73$ & 730480 & 2 & Ultrafilter and trash & \\
\hline 74 & 1 & $4 / 5 / 73$ & 730482 & 2 & Fuel and trash & \\
\hline 74 & 1 & $4 / 5 / 73$ & 730487 & 2 & Hot cell waste and trash & \\
\hline 74 & 1 & $4 / 5 / 73$ & 730488 & 2 & Hot cell waste and trash & \\
\hline 74 & 1 & $4 / 5 / 73$ & 730490 & 2 & Hot cell trash & \\
\hline 74 & 1 & $4 / 5 / 73$ & 730493 & 2 & Hot cell trash & \\
\hline 74 & 1 & $4 / 5 / 73$ & 730499 & 2 & Hot cell trash & \\
\hline
\end{tabular}




\begin{tabular}{|c|c|c|c|c|c|}
\hline 74 & 1 & $4 / 5 / 73$ & 730502 & 2 & Hot cell trash \\
\hline 74 & 1 & $4 / 5 / 73$ & 730503 & 2 & SS Claddings and trash \\
\hline 74 & 1 & $4 / 5 / 73$ & 730504 & 2 & Swipes and grindings \\
\hline 74 & 1 & $4 / 5 / 73$ & 730844 & 2 & Swipes and grindings \\
\hline 75 & 1 & $6 / 20 / 73$ & 730508 & 2 & Fuel and trash \\
\hline 75 & 1 & $6 / 20 / 73$ & 730509 & 2 & Trash \\
\hline 75 & 1 & $6 / 20 / 73$ & 730510 & 2 & Fuel and trash \\
\hline 75 & 1 & $6 / 20 / 73$ & 730513 & 2 & Trash \\
\hline 75 & 1 & $6 / 20 / 73$ & 731042 & 2 & Filter from alpha box in plastic bag \\
\hline 75 & 1 & $6 / 20 / 73$ & 731045 & 2 & Hot cell trash and waste \\
\hline 75 & 1 & $6 / 20 / 73$ & 731059 & 2 & Hot cell trash and waste \\
\hline 75 & 1 & $6 / 20 / 73$ & 731060 & 2 & Trash and waste \\
\hline 75 & 1 & $6 / 20 / 73$ & 731063 & 2 & Hot cell trash \\
\hline 75 & 1 & $6 / 20 / 73$ & 731064 & 2 & Trash \\
\hline 75 & 1 & $6 / 20 / 73$ & 731069 & 2 & Hot cell trash \\
\hline 75 & 1 & $6 / 20 / 73$ & 731070 & 2 & Trash \\
\hline 75 & 1 & $6 / 20 / 73$ & 731231 & 1 & trash and fuel cladding hardware \\
\hline 75 & 1 & $6 / 20 / 73$ & 731232 & 1 & Hot cell waste \\
\hline 76 & 1 & $11 / 2 / 73$ & 731238 & 2 & Hot cell trash and waste \\
\hline 76 & 1 & $11 / 2 / 73$ & 731239 & 2 & Hot cell trash and waste \\
\hline 76 & 1 & $11 / 2 / 73$ & 731240 & 2 & Hot cell trash \\
\hline 76 & 1 & $11 / 2 / 73$ & 731242 & 2 & Induced stainless steel capsule hardware \\
\hline 76 & 1 & $11 / 2 / 73$ & 731243 & 2 & Induced stainless steel capsule hardware \\
\hline 76 & 1 & $11 / 2 / 73$ & 731244 & 2 & Induced stainless steel capsule hardware \\
\hline 76 & 1 & $11 / 2 / 73$ & 731245 & 2 & Hot cell trash and waste \\
\hline 76 & 1 & $11 / 2 / 73$ & 731248 & 2 & Hot cell trash and waste \\
\hline 76 & 1 & $11 / 2 / 73$ & 731250 & 2 & Trash and waste \\
\hline 76 & 1 & $11 / 2 / 73$ & 731256 & 1 & Fuel and trash \\
\hline 200 & & $4 / 14 / 81$ & 811387 & 2 & Fuel cans \#3021 \& 3008 \\
\hline 200 & 6 & $4 / 14 / 81$ & 811390 & 2 & Fuel cans \#3010 \& 3016 \\
\hline 200 & & $4 / 14 / 81$ & 811396 & 2 & $\begin{array}{l}\text { Plastic cans \#3061 \& 3053, Grinding papers, } \\
\text { Kimwipes, plastic }\end{array}$ \\
\hline 200 & & $4 / 14 / 81$ & 811398 & 2 & Cans $\# 3051$ \& 3052, Catch \& drain pans, Kimwipes \\
\hline 200 & & $4 / 14 / 81$ & 811471 & 2 & Trash cans \#2864 \& 2846 \\
\hline 200 & & $4 / 14 / 81$ & 811473 & 2 & Trash fuel cans \#2877 \& 2863 \\
\hline 201 & & $6 / 29 / 79$ & 791484 & 1 & One fuel can \#2171, Tin can in plastic container \\
\hline 201 & & $6 / 29 / 79$ & 794215 & 2 & Trash and Fuel cans \#1854 \& 1851 \\
\hline 201 & & $6 / 29 / 79$ & 794216 & 2 & $\begin{array}{l}\text { Fuel and trash cans \#1798 \& 1953, cans in plastic } \\
\text { bags }\end{array}$ \\
\hline 201 & & $6 / 29 / 79$ & 794218 & 2 & $\begin{array}{l}\text { Fuel cans \#2002 \& 2003, tin cans in plastic cans in } \\
\text { plastic bags }\end{array}$ \\
\hline 201 & & $6 / 29 / 79$ & 794219 & 2 & $\begin{array}{l}\text { Cans \#2004 \& 1992, Fuel \& trash can, tin cans in } \\
\text { plastic cans in plastic bags }\end{array}$ \\
\hline 201 & & $6 / 29 / 79$ & 794220 & 2 & Cans $1 \& 4 \mathrm{~A}$, hot trash Met samples \\
\hline
\end{tabular}




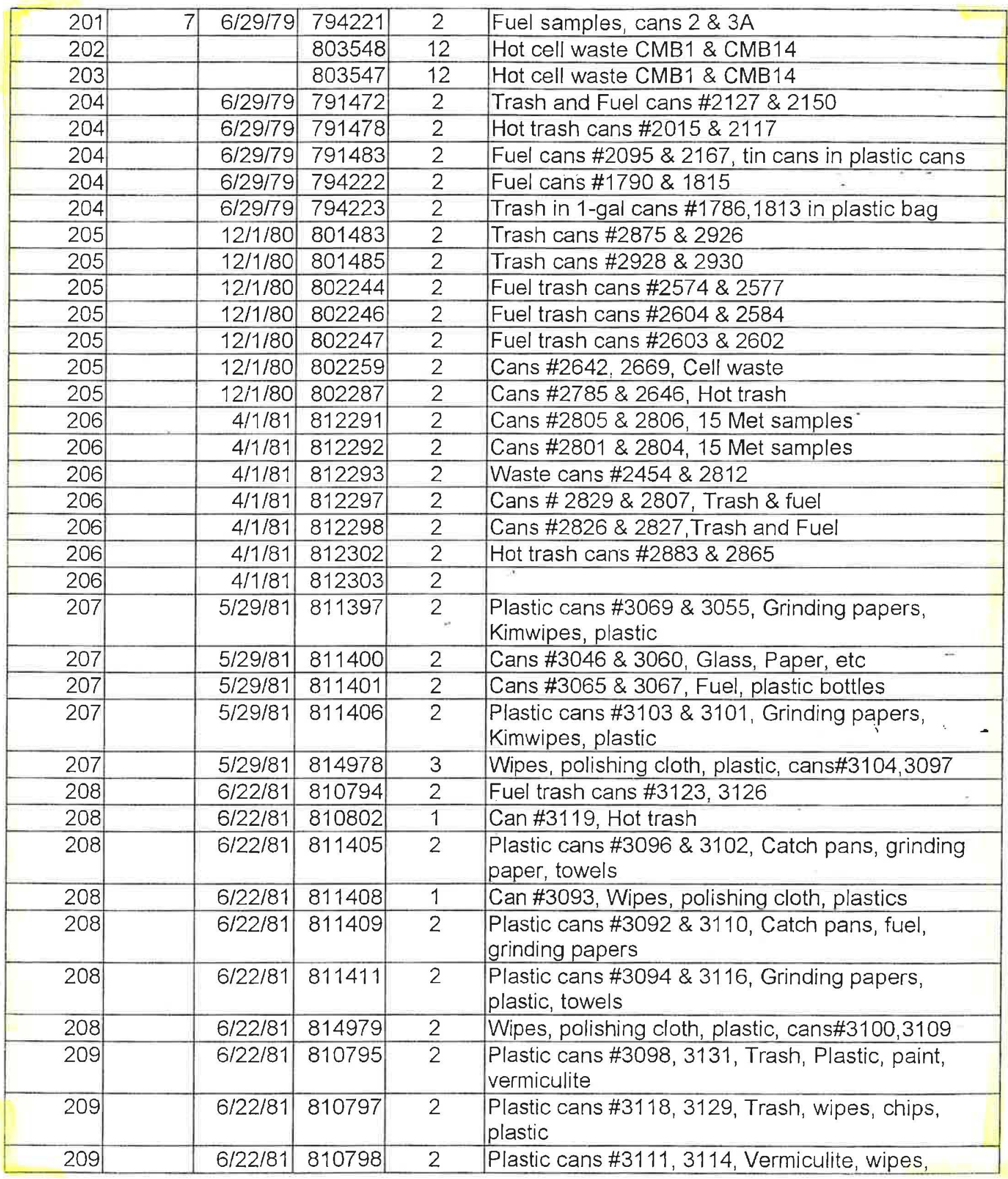




\begin{tabular}{|c|c|c|c|c|}
\hline & & & & plastic, paint \\
\hline 209 & $6 / 22 / 81$ & 810799 & 4 & Trash cans $\# 2125,3108,3117,3130$ \\
\hline 209 & $6 / 22 / 81$ & 811412 & 2 & $\begin{array}{l}\text { Plastic cans \#3091 \& 3115, Grinding paper, plastic, } \\
\text { glass }\end{array}$ \\
\hline 210 & $6 / 22 / 81$ & 810800 & 2 & Cans \#3145, 3147, Hot trash \\
\hline 210 & $6 / 22 / 81$ & 810804 & 4 & Cans \#3139, 3133, 3135, 3132, Hot trash \\
\hline 210 & $6 / 22 / 81$ & 810805 & 4 & Cans \#3143, 3146, 2969, 3151, hot trash \\
\hline 210 & $6 / 22 / 81$ & 810806 & 2 & Cans $\# 3150$ \& 3153, hot trash cans \\
\hline 211 & $10 / 6 / 81$ & 810807 & 2 & Plastic cans \#3145 \& 3147, Hot trash \\
\hline 211 & $10 / 6 / 81$ & 810808 & 2 & Cans \#3158 \& 3159, Hot trash, glass, plastic, paper \\
\hline 211 & $10 / 6 / 81$ & 810809 & 2 & $\begin{array}{l}\text { Plastic cans \#3162 \&3167, Trash catch pans, } \\
\text { plastic, wipes }\end{array}$ \\
\hline 211 & 10/6/81 & 810810 & 4 & $\begin{array}{l}\text { Cans \#3160,3161,3168,3169, Cold trash, Plastic, } \\
\text { bottles, wipes }\end{array}$ \\
\hline 211 & $10 / 6 / 81$ & 812669 & 2 & Cans \#3178 \& 3179 , Fuel, glass, etc. \\
\hline 212 & $4 / 9 / 80$ & 803758 & & $\begin{array}{l}\text { LAMPRE reactor vessel sealed in } 1 / 4^{\prime \prime} \text { steel cask } \\
\text { with concrete }\end{array}$ \\
\hline 213 & $11 / 3 / 81$ & 812684 & 2 & Cell waste \& Fuel cell 16 waste, plastic can $\# 3248$ \\
\hline 213 & $11 / 3 / 81$ & 812686 & 2 & Cans \#3245 \&3246, Fuel, glass, towels \\
\hline 213 & $11 / 3 / 81$ & 812688 & 2 & Fuel and Hot trash in cans \#3273 \& 3274 \\
\hline 213 & $11 / 3 / 81$ & 812689 & 2 & Cell waste cans \#3266 \& 3272 \\
\hline 214 & $4 / 20 / 82$ & 820057 & 1 & $\begin{array}{l}\text { Trash can \#3338, Kimwipes, glassware, Lucite can } \\
\text { in Steel nipple }\end{array}$ \\
\hline 214 & $4 / 20 / 82$ & 820058 & $1^{*}$ & $\begin{array}{l}\text { Trash can \#3351, Kimwipes, glassware, Lucite can } \\
\text { in steel nipple }\end{array}$ \\
\hline 214 & $4 / 20 / 82$ & 821822 & 1 & Trash can \#3369, Kimwipes, paper \\
\hline 214 & $4 / 20 / 82$ & 821823 & 1 & Trash can \#3373, Paper, plastic \\
\hline 214 & $4 / 20 / 82$ & 821826 & 1 & Waste can \#3378, Glass \& plastic bottles \\
\hline 214 & $4 / 20 / 82$ & 823410 & 2 & Hot trash cans \#3307 \& \#3278 \\
\hline 215 & $6 / 9 / 82$ & 820041 & 1 & Fuel can $\# 3312$ \\
\hline 215 & $6 / 9 / 82$ & 820042 & 1 & Waste can \#3307 \\
\hline 215 & $6 / 9 / 82$ & 821832 & 1 & $\begin{array}{l}\text { Trash can \#3393, Hot trash Lucite can in Steel' } \\
\text { Nipple }\end{array}$ \\
\hline 215 & $6 / 9 / 82$ & 821833 & 1 & Hot trash can $\# 3300$ \\
\hline 215 & $6 / 9 / 82$ & 821834 & 1 & Hot trash can \#3397 \\
\hline 215 & $6 / 9 / 82$ & 821835 & 1 & Hot trash can \#3383, Grinding papers, Kimwipes \\
\hline 215 & $6 / 9 / 82$ & 821837 & 1 & Hot trash can \#3415, Bottles, Kimwipes \\
\hline 216 & $6 / 9 / 82$ & 821825 & 1 & Can \#3373, Glass, towels, plastic etc. \\
\hline 216 & $6 / 9 / 82$ & 821836 & 1 & Hot trash can \#3416, bootie, Kimwipes \\
\hline 216 & $6 / 9 / 82$ & 821838 & 1 & Hot trash can \#3395, Grinding, Kimwipes, plastic \\
\hline 216 & $6 / 9 / 82$ & 821839 & 1 & Hot trash can \#3405, Vermiculite, wipes \\
\hline 216 & $6 / 9 / 82$ & 821840 & 1 & Hot trash can \#3384 \\
\hline 216 & $6 / 9 / 82$ & 821841 & 1 & Hot trash can \#3385, Kimwipes, grinding papers \\
\hline 217 & $9 / 13 / 82$ & 821870 & 1 & Can \#3451, Glass \& plastic bottles \\
\hline
\end{tabular}




\begin{tabular}{|c|c|c|c|c|}
\hline 217 & $9 / 13 / 82$ & 821871 & 1 & Can \#3452, Fuel, scrap card boxes \\
\hline 217 & $9 / 13 / 82$ & 821874 & 1 & Hot trash, grinding paper, etc, bottom entry cask \\
\hline 217 & $9 / 13 / 82$ & 821882 & 1 & Trash can $\# 3478$ \\
\hline 217 & $9 / 13 / 82$ & 821915 & 1 & Can \#3446, Waste Fuel and Cell trash \\
\hline 217 & $9 / 13 / 82$ & 821918 & 1 & Can \#3437, Fuel, scrap card boxes \\
\hline 218 & $9 / 13 / 82$ & 821875 & 1 & Trash can \#3499 \\
\hline 218 & $9 / 13 / 82$ & 821879 & 1 & Trash catch pan can $\# 3477$ \\
\hline 218 & $9 / 13 / 82$ & 821881 & 1 & Trash can \#3468 \\
\hline 218 & $9 / 13 / 82$ & 821883 & 1 & Trash can \#3469 \\
\hline 218 & $9 / 13 / 82$ & 821916 & 1 & Cropper disposal and Fuel can \#3489 \\
\hline 218 & $9 / 13 / 82$ & 821917 & 1 & Trash can \#5 \\
\hline 219 & $3 / 10 / 83$ & 832830 & 1 & Grinding waste can \#3527 \\
\hline 219 & $3 / 10 / 83$ & 832831 & 1 & Trash can \#3727 \\
\hline 219 & $3 / 10 / 83$ & 832832 & 1 & Fuel \& hardware can \#3724 \\
\hline 219 & $3 / 10 / 83$ & 832833 & 1 & Hot waste can \#3725 \\
\hline 219 & $3 / 10 / 83$ & 832834 & 1 & Hot trash can \#3524 \\
\hline 219 & $3 / 10 / 83$ & 832835 & 1 & Hot Cell Trash, can \#3495 \\
\hline 220 & $3 / 10 / 83$ & 832836 & 1 & Waste can \#3728 \\
\hline 220 & $3 / 10 / 83$ & 832837 & 1 & Waste can \#3491 \\
\hline 220 & $3 / 10 / 83$ & 832838 & 1 & Hot cell trash \#3706 \\
\hline 220 & $3 / 10 / 83$ & 832839 & 1 & Grinding can \#3528 \\
\hline 220 & $3 / 10 / 83$ & 832840 & 1 & Grinding can \#3522 \\
\hline 220 & $3 / 10 / 83$ & 832841 & 1 & Wire wrap \#3726 \\
\hline 221 & $3 / 10 / 83$ & 832842 & 1 & Wire wraps \#3554 \\
\hline 221 & $3 / 10 / 83$ & 832843 & 1 & Wire wraps \#3507 \\
\hline 221 & $3 / 10 / 83$ & 832844 & 1 & Hot trash can \#3569 \\
\hline 221 & $3 / 10 / 83$ & 832845 & 1 & Hot trash can \#3722 \\
\hline 221 & $3 / 10 / 83$ & 832846 & 1 & Hot trash can \#3720 \\
\hline 221 & $3 / 10 / 83$ & 832847 & 1 & Waste can \#3721 \\
\hline 222 & $12 / 14 / 83$ & 830716 & 1 & Can\#3712, Fuel scrap paper, etc \\
\hline 222 & $12 / 14 / 83$ & 830717 & 1 & Can\#3718, Fuel scrap paper, etc \\
\hline 222 & $12 / 14 / 83$ & 830781 & 1 & Trash 1 can, bottom entry steel can \#1 \\
\hline 222 & $12 / 14 / 83$ & 830787 & 1 & Trash 1 can, bottom entry steel can \#10 \\
\hline 222 & $12 / 14 / 83$ & 830788 & 1 & Trash 1 can, bottom entry steel can \#6 \\
\hline 222 & $12 / 14 / 83$ & 830789 & 1 & Trash 1 can, Steel can \#8 \\
\hline 222 & $12 / 14 / 83$ & 830790 & 1 & Trash 1 can, Steel can \#9 \\
\hline 223 & $12 / 14 / 83$ & 830782 & 1 & Trash 1 can, bottom entry steel can $\# 5$ \\
\hline 223 & $12 / 14 / 83$ & 830783 & 1 & Trash 1 can, bottom entry steel can \#3 \\
\hline 223 & $12 / 14 / 83$ & 830784 & 1 & Trash 1 can, bottom entry steel can \#4 \\
\hline 223 & $12 / 14 / 83$ & 830785 & 1 & Trash 1 can, bottom entry steel can \#7 \\
\hline 223 & $12 / 14 / 83$ & 830786 & 1 & Trash 1 can, Steel can \#2 \\
\hline 223 & $12 / 14 / 83$ & 830791 & 1 & Trash 1 can, bottom entry steel can \#11 \\
\hline 224 & $12 / 30 / 85$ & 852326 & 1 & Waste, plastic can \#4088, steel can \#58 \\
\hline 224 & $12 / 30 / 85$ & 852328 & 1 & Waste plastic can \#4097, Steel can \#61 \\
\hline
\end{tabular}




\begin{tabular}{|c|c|c|c|c|}
\hline 224 & $12 / 30 / 85$ & 852332 & 1 & Waste plastic can \#4072, Steel can \#32 \\
\hline 224 & $12 / 30 / 85$ & 852804 & 1 & Trash can \#3660, Fuel inside Steel can \#67 \\
\hline 224 & $12 / 30 / 85$ & 855064 & 1 & Trash can $\# 3661$, Fuel inside Steel can $\# 63$ \\
\hline 224 & $12 / 30 / 85$ & 855065 & 1 & Trash can \#3662, Fuel inside Steel can \#66 \\
\hline 224 & $12 / 30 / 85$ & 855066 & 1 & Trash can \#3663, trash only, Steel can \#65 \\
\hline 224 & $12 / 30 / 85$ & 855068 & 1 & Trash can \#3664, Fuel inside Steel can \#64 \\
\hline 225 & $12 / 31 / 84$ & 840848 & 1 & Waste plastic ćan \#4076, Steel can \#21 \\
\hline 225 & $12 / 31 / 84$ & 840854 & 1 & Waste plastic can \#4033, Steel can \#24 \\
\hline 225 & $12 / 31 / 84$ & 840856 & 1 & Waste plastic can \#4043, Steel can \#31 \\
\hline 225 & $12 / 31 / 84$ & 840857 & 1 & Waste plastic can \#4035, Steel can \#30 \\
\hline 225 & $12 / 31 / 84$ & 840863 & 1 & Waste plastic can \#4046, Steel can \#40 \\
\hline 225 & $12 / 31 / 84$ & 840864 & 1 & Waste plastic can \#4044, Steel can \#34 \\
\hline 225 & $12 / 31 / 84$ & 840867 & 1 & Waste plastic can \#4054, Steel can \#38 \\
\hline 225 & $12 / 31 / 84$ & 840874 & 1 & Trash can \#4051, Steel can \#43 \\
\hline 226 & $12 / 31 / 84$ & 840842 & 1 & Waste plastic can \#4056, Steel can \#20 \\
\hline 226 & $12 / 31 / 84$ & 840843 & 1 & Waste plastic can \#4045, Steel can \#36 \\
\hline 226 & $12 / 31 / 84$ & 840844 & 1 & Waste plastic can \#4023, Steel can \#19 \\
\hline 226 & $12 / 31 / 84$ & 840845 & 1 & Waste plastic can \#4034, Steel can \#22 \\
\hline 226 & $12 / 31 / 84$ & 840846 & 1 & Waste plastic can \#4024, Steel can \#25 \\
\hline 226 & $12 / 31 / 84$ & 840847 & 1 & Waste plastic can \#4022, Steel can \#23 \\
\hline 226 & $12 / 31 / 84$ & 840862 & 1 & Waste plastic can \#4027, Steel can \#39 \\
\hline 226 & $12 / 31 / 84$ & 840868 & 1 & Waste plastic can \#4025, Steel can \#35 \\
\hline 227 & $12 / 31 / 84$ & 840877 & 1 & Trash can \#4050, Fuel inside Steel can \#42 \\
\hline 227 & $12 / 31 / 84$ & 840878 & 1 & Trash can \#4042, Fuel inside Steel can \#46 \\
\hline 227 & $12 / 31 / 84$ & 840879 & 1 & Trash can \#4041, Fuel inside Steel can \#44 \\
\hline 227 & $12 / 31 / 84$ & 840880 & 1 & Trash can \#4048, Fuel inside Steel can \#45 \\
\hline 227 & $12 / 31 / 84$ & 840881 & 1 & Trash can $\# 4057$, Fuel inside Steel can $\# 51$ \\
\hline 227 & $12 / 31 / 84$ & 840883 & 1 & Trash can \#4064, Steel can \#48 \\
\hline 227 & $12 / 31 / 84$ & 840885 & 1 & Trash can \#4056, Fuel inside Steel can \#49 \\
\hline 227 & $12 / 31 / 84$ & 840886 & 1 & Trash can \#4084, Steel can \#50 \\
\hline 228 & $12 / 23 / 87$ & 874123 & 1 & Trash can $\# 4032$, Steel can $\# 54$ \\
\hline 228 & $12 / 23 / 87$ & 874124 & 1 & Waste plastic can \#4093, Steel can \#55 \\
\hline 228 & $12 / 23 / 87$ & 874125 & 1 & Waste can \#4164, Steel can \#62 \\
\hline 228 & $12 / 23 / 87$ & 874126 & 1 & Waste plastic can \#4086, Steel can \#57 \\
\hline 228 & $12 / 23 / 87$ & 874127 & 1 & Waste plastic can \#4094, Steel can \#56 \\
\hline 228 & $12 / 23 / 87$ & 874128 & 1 & Waste plastic can \#4092, Steel can \#60 \\
\hline 228 & $12 / 23 / 87$ & 874129 & 1 & Waste, plastic can \#4085, steel can \#59 \\
\hline 228 & $12 / 23 / 87$ & 874130 & 1 & Trash can $\# 4053$, steel can $\# 53$ \\
\hline 229 & $12 / 31 / 84$ & 840851 & 1 & Waste plastic can \#4028, Steel can \#28 \\
\hline 229 & $12 / 31 / 84$ & 840855 & 1 & Waste plastic can \#4145, Steel can \#27 \\
\hline 229 & $12 / 31 / 84$ & 840860 & 1 & Waste plastic can \#4026, Steel can \#36 \\
\hline 229 & $12 / 31 / 84$ & 840865 & 1 & Waste plastic can $\# 4055$, Steel can $\# 37$ \\
\hline 229 & $12 / 31 / 84$ & 840873 & 1 & Trash can \#4065, Steel can \#41 \\
\hline 229 & $12 / 31 / 84$ & 840882 & 1 & Trash plastic can \#4066, steel can \#47 \\
\hline
\end{tabular}




\begin{tabular}{|l|l|l|l|l|}
\hline 229 & $12 / 31 / 84$ & 840888 & 1 & Trash can \#4075, Steel can \#52 \\
\hline 230 & $12 / 31 / 84$ & 840831 & 1 & Hot waste can \#4017, Steel can \#13 \\
\hline 230 & $12 / 31 / 84$ & 840835 & 1 & Waste plastic can \#4153, Steel can \#16 \\
\hline 230 & $12 / 31 / 84$ & 840836 & 1 & Waste plastic can \#3974, Steel can \#15 \\
\hline 230 & $12 / 31 / 84$ & 840838 & 1 & Waste, plastic can \#4154, steel can \#14 \\
\hline 230 & $12 / 31 / 84$ & 840839 & 1 & Waste, plastic can \#4155, steel can \#18 \\
\hline 230 & $12 / 31 / 84$ & 840840 & 1 & Waste, plastic can \#4037, steel can \#29 \\
\hline 230 & $12 / 31 / 84$ & 840841 & 1 & Waste, plastic can \#4036, steel can \#17 \\
\hline 230 & $12 / 31 / 84$ & 840859 & 1 & Waste, plastic can \#4031, steel can \#33 \\
\hline 231 & $12 / 30 / 85$ & 855046 & 1 & $\begin{array}{l}\text { Vacuum cleaner motor, plastic can \#3813, steel can } \\
\text { \#72 }\end{array}$ \\
\hline 231 & $12 / 30 / 85$ & 855047 & 1 & Manipulator boot, plastic can \#4114, steel can \#73 \\
\hline 231 & $12 / 30 / 85$ & 855048 & 1 & Trash plastic can \#3859, steel can \#74 \\
\hline 231 & $12 / 30 / 85$ & 855049 & 1 & RB. Robinson Fuel, can \#3651, steel can \#75 \\
\hline 231 & $12 / 30 / 85$ & 856015 & 1 & Plastic can \#3649, steel can \#68 \\
\hline 231 & $12 / 30 / 85$ & 856016 & 1 & Plastic waste can \#4113, steel can \#69 \\
\hline 231 & $12 / 30 / 85$ & 856017 & 1 & Plastic and can trash \#3626, steel can \#71 \\
\hline 231 & $12 / 30 / 85$ & 856018 & 1 & Plastic and can trash \#3625, steel can \#70 \\
\hline 232 & $12 / 23 / 87$ & 874132 & 1 & Three Mile Island waste, can \#77 \\
\hline 232 & $12 / 23 / 87$ & 874133 & 1 & Waste can \#79 \\
\hline 232 & $12 / 23 / 87$ & 874134 & 1 & Waste steel can \#78 \\
\hline & & & & \\
\hline
\end{tabular}




\begin{tabular}{|c|c|c|c|c|c|c|c|c|c|}
\hline 74 & 2 & $4 / 5 / 73$ & 730499 & 12 & 5.8 & 0.00614 & $0.00 \mathrm{E}+00$ & & \\
\hline 74 & 2 & $4 / 5 / 73$ & 730502 & 8 & 3.9 & 0.00614 & $0.00 \mathrm{E}+00$ & & \\
\hline 74 & 2 & $4 / 5 / 73$ & 730503 & 20 & 9.6 & 0.307 & $0.00 \mathrm{E}+00$ & & \\
\hline 74 & 2 & $4 / 5 / 73$ & 730504 & 0.9 & 0.4 & 0.00614 & $0.00 \mathrm{E}+00$ & & \\
\hline 74 & 2 & $4 / 5 / 73$ & 730844 & 5.5 & 2.7 & 0.00614 & $0.00 \mathrm{E}+00$ & & \\
\hline 75 & 2 & $6 / 20 / 73$ & 730508 & 3.5 & 1.7 & 0.111 & $1.24 \mathrm{E}-06$ & & \\
\hline 75 & 2 & $6 / 20 / 73$ & 730509 & 3.5 & 1.7 & 0.00614 & $0.00 \mathrm{E}+00$ & & \\
\hline 75 & 2 & $6 / 20 / 73$ & 730510 & 8 & 3.9 & 0.043 & $6.21 \mathrm{E}-06$ & & \\
\hline 75 & 2 & $6 / 20 / 73$ & 730513 & 14 & 6.8 & 0.0264 & $0.00 \mathrm{E}+00$ & & \\
\hline 75 & 2 & $6 / 20 / 73$ & 731042 & 0 & 0.0 & 0.246 & $0.00 \mathrm{E}+00$ & & \\
\hline 75 & 2 & $6 / 20 / 73$ & 731045 & 0 & 0.0 & 0.00614 & $0.00 \mathrm{E}+00$ & & \\
\hline 75 & 2 & $6 / 20 / 73$ & 731059 & 1 & 0.5 & 0.00614 & $0.00 \mathrm{E}+00$ & & \\
\hline 75 & 2 & $6 / 20 / 73$ & 731060 & 6 & 2.9 & 0.00614 & $0.00 \mathrm{E}+00$ & & \\
\hline 75 & 2 & $6 / 20 / 73$ & 731063 & 1 & 0.5 & 0.00614 & $0.00 E+00$ & & \\
\hline 75 & 2 & $6 / 20 / 73$ & 731064 & 3.5 & 1.7 & 0.00614 & $0.00 E+00$ & & \\
\hline 75 & 2 & $6 / 20 / 73$ & 731069 & 1.7 & 0.8 & 0.00614 & $0.00 E+00$ & & \\
\hline 75 & 2 & $6 / 20 / 73$ & 731070 & 1.5 & 0.7 & 0.00614 & $0.00 E+00$ & & \\
\hline 75 & 2 & $6 / 20 / 73$ & 731231 & 11 & 5.3 & 0.737 & $0.00 \mathrm{E}+00$ & & \\
\hline 75 & 2 & $6 / 20 / 73$ & 731232 & 2 & 1.0 & 0.0123 & $0.00 \mathrm{E}+00$ & & \\
\hline 76 & 2 & $11 / 2 / 73$ & 731238 & 0.18 & 0.1 & 0.184 & $0.00 \mathrm{E}+00$ & & \\
\hline 76 & 2 & $11 / 2 / 73$ & 731239 & 0.006 & 0.0 & 0.00614 & $0.00 \mathrm{E}+00$ & & \\
\hline 76 & 2 & $11 / 2 / 73$ & 731240 & 0.012 & 0.0 & 0.0123 & $0.00 E+00$ & & \\
\hline 76 & 2 & $11 / 2 / 73$ & 731242 & 0 & 0.0 & 0.19 & $0.00 E+00$ & & \\
\hline 76 & 2 & $11 / 2 / 73$ & 731243 & 0 & 0.0 & 0.19 & $0.00 \mathrm{E}+00$ & & \\
\hline 76 & 2 & $11 / 2 / 73$ & 731244 & 0 & 0.0 & 0.19 & $0.00 \mathrm{E}+00$ & & \\
\hline 76 & 2 & $11 / 2 / 73$ & 731245 & 1 & 0.5 & 0.00614 & $0.00 \mathrm{E}+00$ & & \\
\hline 76 & 2 & $11 / 2 / 73$ & 731248 & 2 & 1.0 & 0.0124 & $0.00 \mathrm{E}+00$ & & \\
\hline 76 & 2 & $11 / 2 / 73$ & 731250 & 3 & 1.5 & 0.0124 & $0.00 E+00$ & & \\
\hline 76 & 2 & $11 / 2 / 73$ & 731256 & 13 & 6.4 & 0.92 & $0.00 \mathrm{E}+00$ & & \\
\hline 200 & & $4 / 14 / 81$ & 811387 & 2.5 & 1.5 & 1.24 & $1.73 \mathrm{E}-05$ & 108 & 10.5 \\
\hline 200 & 12 & $4 / 14 / 81$ & 811390 & 6 & 3.5 & 0.615 & $8.14 \mathrm{E}-05$ & 1000 & 140 \\
\hline 200 & & $4 / 14 / 81$ & 811396 & 0.6 & 0.3 & 0.00614 & $8.56 \mathrm{E}-07$ & 50 & 15 \\
\hline 200 & & $4 / 14 / 81$ & 811398 & 0.6 & 0.3 & 0.246 & $3.42 \mathrm{E}-05$ & 17.5 & 4 \\
\hline 200 & & $4 / 14 / 81$ & 811471 & 2.7 & 1.6 & 0.768 & 4.60E-05 & 266 & 11 \\
\hline 200 & & $4 / 14 / 81$ & 811473 & 20 & 11.6 & 0.307 & 1.05E-04 & 261 & 85 \\
\hline 201 & & $6 / 29 / 79$ & 791484 & 4 & 2.2 & 0.184 & $2.16 \mathrm{E}-06$ & 15 & 1 \\
\hline 201 & & $6 / 29 / 79$ & 794215 & 11 & 6.1 & 0.0307 & $4.28 \mathrm{E}-06$ & 27 & 1.3 \\
\hline 201 & & $6 / 29 / 79$ & 794216 & 8.5 & 4.7 & 0.138 & $1.93 \mathrm{E}-05$ & 1200 & 30 \\
\hline 201 & & $6 / 29 / 79$ & 794218 & 1 & 0.6 & 0.154 & $2.15 \mathrm{E}-05$ & 1050 & 35 \\
\hline 201 & & $6 / 29 / 79$ & 794219 & 1.3 & 0.7 & 0.0921 & $1.07 \mathrm{E}-04$ & & 100 \\
\hline 201 & & $6 / 29 / 79$ & 794220 & 30 & 16.7 & 4.18 & $3.15 \mathrm{E}-04$ & & 20.4 \\
\hline 201 & 13 & $6 / 29 / 79$ & 794221 & 35 & 19.5 & 8.66 & $7.92 \mathrm{E}-04$ & 1000 & 135 \\
\hline 202 & 12 & & 803548 & 245 & 21.2 & 4.01 & $4.77 \mathrm{E}-04$ & 1000 & 170 \\
\hline 203 & 12 & & 803547 & 109 & 9.5 & 2.3 & 2.72E-04 & 160 & 41 \\
\hline
\end{tabular}




\begin{tabular}{|c|c|c|c|c|c|c|c|c|c|}
\hline 74 & 2 & $4 / 5 / 73$ & 730499 & 12 & 5.8 & 0.00614 & $0.00 \mathrm{E}+00$ & & \\
\hline 74 & 2 & $4 / 5 / 73$ & 730502 & 8 & 3.9 & 0.00614 & $0.00 E+00$ & & \\
\hline 74 & 2 & $4 / 5 / 73$ & 730503 & 20 & 9.6 & 0.307 & $0.00 E+00$ & & \\
\hline 74 & 2 & $4 / 5 / 73$ & 730504 & 0.9 & 0.4 & 0.00614 & $0.00 \mathrm{E}+00$ & & \\
\hline 74 & 2 & $4 / 5 / 73$ & 730844 & 5.5 & 2.7 & 0.00614 & $0.00 \mathrm{E}+00$ & & \\
\hline 75 & 2 & $6 / 20 / 73$ & 730508 & 3.5 & 1.7 & 0.111 & $1.24 \mathrm{E}-06$ & & \\
\hline 75 & 2 & $6 / 20 / 73$ & 730509 & 3.5 & 1.7 & 0.00614 & $0.00 E+00$ & & \\
\hline 75 & 2 & $6 / 20 / 73$ & 730510 & 8 & 3.9 & 0.043 & $6.21 \mathrm{E}-06$ & & \\
\hline 75 & 2 & $6 / 20 / 73$ & 730513 & 14 & 6.8 & 0.0264 & $0.00 \mathrm{E}+00$ & & \\
\hline 75 & 2 & $6 / 20 / 73$ & 731042 & 0 & 0.0 & 0.246 & $0.00 \mathrm{E}+00$ & & \\
\hline 75 & 2 & $6 / 20 / 73$ & 731045 & 0 & 0.0 & 0.00614 & $0.00 \mathrm{E}+00$ & & \\
\hline 75 & 2 & $6 / 20 / 73$ & 731059 & 1 & 0.5 & 0.00614 & $0.00 \mathrm{E}+00$ & & \\
\hline 75 & 2 & $6 / 20 / 73$ & 731060 & 6 & 2.9 & 0.00614 & $0.00 \mathrm{E}+00$ & & \\
\hline 75 & 2 & $6 / 20 / 73$ & 731063 & 1 & 0.5 & 0.00614 & $0.00 \mathrm{E}+00$ & & \\
\hline 75 & 2 & $6 / 20 / 73$ & 731064 & 3.5 & 1.7 & 0.00614 & $0.00 \mathrm{E}+00$ & & \\
\hline 75 & 2 & $6 / 20 / 73$ & 731069 & 1.7 & 0.8 & 0.00614 & $0.00 \mathrm{E}+00$ & & \\
\hline 75 & 2 & $6 / 20 / 73$ & 731070 & 1.5 & 0.7 & 0.00614 & $0.00 \mathrm{E}+00$ & & \\
\hline 75 & 2 & $6 / 20 / 73$ & 731231 & 11 & 5.3 & 0.737 & $0.00 \mathrm{E}+00$ & & \\
\hline 75 & 2 & $6 / 20 / 73$ & 731232 & 2 & 1.0 & 0.0123 & $0.00 \mathrm{E}+00$ & & \\
\hline 76 & 2 & $11 / 2 / 73$ & 731238 & 0.18 & 0.1 & 0.184 & $0.00 \mathrm{E}+00$ & & \\
\hline 76 & 2 & $11 / 2 / 73$ & 731239 & 0.006 & 0.0 & 0.00614 & $0.00 E+00$ & & \\
\hline 76 & 2 & $11 / 2 / 73$ & 731240 & 0.012 & 0.0 & 0.0123 & $0.00 E+00$ & & \\
\hline 76 & 2 & $11 / 2 / 73$ & 731242 & 0 & 0.0 & 0.19 & $0.00 E+00$ & & \\
\hline 76 & 2 & $11 / 2 / 73$ & 731243 & 0 & 0.0 & 0.19 & $0.00 E+00$ & & \\
\hline 76 & 2 & $11 / 2 / 73$ & 731244 & 0 & 0.0 & 0.19 & $0.00 E+00$ & & \\
\hline 76 & 2 & $11 / 2 / 73$ & 731245 & 1 & 0.5 & 0.00614 & $0.00 \mathrm{E}+00$ & & \\
\hline 76 & 2 & $11 / 2 / 73$ & 731248 & 2 & 1.0 & 0.0124 & $0.00 E+00$ & & \\
\hline 76 & 2 & $11 / 2 / 73$ & 731250 & 3 & 1.5 & 0.0124 & $0.00 E+00$ & & \\
\hline 76 & 2 & $11 / 2 / 73$ & 731256 & 13 & 6.4 & 0.92 & $0.00 E+00$ & & \\
\hline 200 & & $4 / 14 / 81$ & 811387 & 2.5 & 1.5 & 1.24 & $1.73 \mathrm{E}-05$ & 108 & 10.5 \\
\hline 200 & 12 & $4 / 14 / 81$ & 811390 & 6 & 3.5 & 0.615 & $8.14 \mathrm{E}-05$ & 1000 & 140 \\
\hline 200 & & $4 / 14 / 81$ & 811396 & 0.6 & 0.3 & 0.00614 & $8.56 \mathrm{E}-07$ & 50 & 15 \\
\hline 200 & & $4 / 14 / 81$ & 811398 & 0.6 & 0.3 & 0.246 & $3.42 \mathrm{E}-05$ & 17.5 & 4 \\
\hline 200 & & $4 / 14 / 81$ & 811471 & 2.7 & 1.6 & 0.768 & 4.60E-05 & 266 & 11 \\
\hline 200 & & $4 / 14 / 81$ & 811473 & 20 & 11.6 & 0.307 & 1.05E-04 & 261 & 85 \\
\hline 201 & & $6 / 29 / 79$ & 791484 & 4 & 2.2 & 0.184 & $2.16 \mathrm{E}-06$ & 15 & 1 \\
\hline 201 & & $6 / 29 / 79$ & 794215 & 11 & 6.1 & 0.0307 & $4.28 \mathrm{E}-06$ & 27 & 1.3 \\
\hline 201 & & $6 / 29 / 79$ & 794216 & 8.5 & 4.7 & 0.138 & 1.93E-05 & 1200 & 30 \\
\hline 201 & & $6 / 29 / 79$ & 794218 & 1 & 0.6 & 0.154 & $2.15 \mathrm{E}-05$ & 1050 & 35 \\
\hline 201 & & $6 / 29 / 79$ & 794219 & 1.3 & 0.7 & 0.0921 & $1.07 \mathrm{E}-04$ & & 100 \\
\hline 201 & & $6 / 29 / 79$ & 794220 & 30 & 16.7 & 4.18 & $3.15 \mathrm{E}-04$ & & 20.4 \\
\hline 201 & 13 & $6 / 29 / 79$ & 794221 & 35 & 19.5 & 8.66 & $7.92 \mathrm{E}-04$ & 1000 & 135 \\
\hline 202 & 12 & & 803548 & 245 & 21.2 & 4.01 & 4.77E-04 & 1000 & 170 \\
\hline 203 & 12 & & 803547 & 109 & 9.5 & 2.3 & $2.72 \mathrm{E}-04$ & 160 & 41 \\
\hline
\end{tabular}




\begin{tabular}{|c|c|c|c|c|c|c|c|c|c|}
\hline 204 & & $6 / 29 / 79$ & 791472 & 10.5 & 5.9 & 0.108 & $1.12 \mathrm{E}-05$ & 1000 & 14 \\
\hline 204 & & $6 / 29 / 79$ & 791478 & 0 & 0.0 & 2.15 & 2.59E-04 & 615 & 12 \\
\hline 204 & 10 & $6 / 29 / 79$ & 791483 & 15 & 8.4 & 0.0921 & $9.63 \mathrm{E}-06$ & 1000 & 35 \\
\hline 204 & & $6 / 29 / 79$ & 794222 & 0 & 0.0 & 0.292 & $4.07 \mathrm{E}-05$ & 1000 & 520 \\
\hline 204 & & $6 / 29 / 79$ & 794223 & 20 & 11.2 & 1.01 & $9.73 \mathrm{E}-05$ & & \\
\hline 205 & & $12 / 1 / 80$ & 801483 & 135 & 77.9 & 0.0614 & $2.14 \mathrm{E}-06$ & & \\
\hline 205 & & $12 / 1 / 80$ & 801485 & 170 & 98.0 & 1.54 & $2.03 \mathrm{E}-04$ & 1.8 & 0.3 \\
\hline 205 & & $12 / 1 / 80$ & 802244 & 4.1 & 2.4 & 0.0307 & $4.28 \mathrm{E}-05$ & 1000 & 100 \\
\hline 205 & 14 & $12 / 1 / 80$ & 802246 & 14 & 8.1 & 1.08 & $1.50 \mathrm{E}-04$ & 15 & 1 \\
\hline 205 & & $12 / 1 / 80$ & 802247 & 12 & 6.9 & 0.307 & $4.49 \mathrm{E}-05$ & 2.8 & 0.4 \\
\hline 205 & & $12 / 1 / 80$ & 802259 & 35 & 20.2 & 0.737 & 8.35E-05 & 1.6 & 0.2 \\
\hline 205 & & $12 / 1 / 80$ & 802287 & 520 & 299.9 & 3.5 & $5.05 \mathrm{E}-05$ & 5 & 0.3 \\
\hline 206 & & $4 / 1 / 81$ & 812291 & 40 & 23.2 & 7.55 & $6.87 E-04$ & 10 & 0.4 \\
\hline 206 & & $4 / 1 / 81$ & 812292 & 22 & 12.8 & 6.14 & $5.76 \mathrm{E}-04$ & 1 & 0.06 \\
\hline 206 & & $4 / 1 / 81$ & 812293 & 108 & 62.8 & 0.431 & $6.00 E-05$ & 4 & 0.2 \\
\hline 206 & & $4 / 1 / 81$ & 812297 & 100 & 58.1 & 1.35 & 1.84E-04 & 5 & 0.3 \\
\hline 206 & 14 & $4 / 1 / 81$ & 812298 & 100 & 58.1 & 1.35 & 1.84E-04 & 0.3 & 0.02 \\
\hline 206 & & $4 / 1 / 81$ & 812302 & 8.2 & 4.8 & 0.491 & $4.92 E-05$ & 16 & 0.7 \\
\hline 206 & & $4 / 1 / 81$ & 812303 & 8.2 & 4.8 & 0.491 & $4.92 \mathrm{E}-05$ & 126 & 2.2 \\
\hline 207 & & $5 / 29 / 81$ & 811397 & 2 & 1.2 & 0.00614 & $8.56 \mathrm{E}-07$ & 160 & 4 \\
\hline 207 & 11 & $5 / 29 / 81$ & 811400 & 3.5 & 2.0 & 0.00614 & $8.56 \mathrm{E}-07$ & 1 & 0.06 \\
\hline 207 & & $5 / 29 / 81$ & 811401 & 5.15 & 3.0 & \begin{tabular}{|l|}
0.0651 \\
\end{tabular} & $9.07 \mathrm{E}-06$ & 140 & 2.5 \\
\hline 207 & & $5 / 29 / 81$ & 811406 & 2.5 & 1.5 & \begin{tabular}{|l|}
0.00614 \\
\end{tabular} & $8.56 \mathrm{E}-07$ & 800 & 6 \\
\hline 207 & & $5 / 29 / 81$ & 814978 & 0.18 & 0.1 & 0.00368 & $5.14 \mathrm{E}-07$ & 60 & 0.6 \\
\hline 208 & 12 & $6 / 22 / 81$ & 810794 & 100 & 58.4 & 1.75 & $2.17 \mathrm{E}-04$ & 60 & 2 \\
\hline 208 & & $6 / 22 / 81$ & 810802 & 0.06 & 0.0 & 0.00614 & $8.56 \mathrm{E}-07$ & 120 & 0.6 \\
\hline 208 & & $6 / 22 / 81$ & 811405 & 2 & 1.2 & 0.0307 & $4.28 \mathrm{E}-06$ & 290 & 3.5 \\
\hline 208 & & $6 / 22 / 81$ & 811408 & 0.08 & 0.0 & 0.00614 & $8.56 \mathrm{E}-07$ & 170 & 5.15 \\
\hline 208 & & $6 / 22 / 81$ & 811409 & 2.1 & 1.2 & 0.00614 & $8.56 \mathrm{E}-07$ & 80 & 2 \\
\hline 208 & & $6 / 22 / 81$ & 811411 & 1 & 0.6 & 0.00614 & $8.56 \mathrm{E}-07$ & 150 & 2.5 \\
\hline 208 & & $6 / 22 / 81$ & 814979 & 0.12 & 0.1 & 0.00246 & $3.42 \mathrm{E}-07$ & 1.5 & 0.08 \\
\hline 209 & & $6 / 22 / 81$ & 810795 & 1 & 0.6 & 0.00614 & $8.56 \mathrm{E}-07$ & 32 & 2.1 \\
\hline 209 & & $6 / 22 / 81$ & 810797 & 0.4 & 0.2 & 0.00614 & $8.56 \mathrm{E}-07$ & 29 & 1 \\
\hline 209 & 12 & $6 / 22 / 81$ & 810798 & 0.2 & 0.1 & 0.00613 & $8.56 \mathrm{E}-07$ & 90 & 2 \\
\hline 209 & & $6 / 22 / 81$ & 810799 & 0.3 & 0.2 & 0.00614 & $8.56 \mathrm{E}-07$ & 700 & 9 \\
\hline 209 & & $6 / 22 / 81$ & 811412 & 2 & 1.2 & 0.00614 & $8.56 \mathrm{E}-07$ & 1150 & 20 \\
\hline 210 & & $6 / 22 / 81$ & 810800 & 0.4 & 0.2 & 0.00614 & $8.56 \mathrm{E}-07$ & 1000 & 40 \\
\hline 210 & & $6 / 22 / 81$ & 810804 & 0.2 & 0.1 & 0.00614 & 8.56E-07 & 1000 & 22 \\
\hline 210 & & $6 / 22 / 81$ & 810805 & 0.3 & 0.2 & 0.00614 & $8.56 \mathrm{E}-07$ & 1050 & 108 \\
\hline 210 & 12 & $6 / 22 / 81$ & 810806 & 0.02 & 0.0 & 0.00614 & $8.56 \mathrm{E}-07$ & 1000 & 100 \\
\hline 211 & & $10 / 6 / 81$ & 810807 & 0.7 & 0.4 & 0.00614 & $8.56 \mathrm{E}-07$ & 1000 & 100 \\
\hline 211 & 12 & $10 / 6 / 81$ & 810808 & 2.2 & 1.3 & 0.00614 & $8.56 \mathrm{E}-07$ & 1010 & 82 \\
\hline 211 & & $10 / 6 / 81$ & 810809 & 4 & 2.4 & 0.00614 & $8.56 \mathrm{E}-07$ & & \\
\hline 211| & & $10 / 6 / 81$ & 810810 & 0.06 & 0.0 & 0.00614 & $8.56 \mathrm{E}-07$ & 940 & 11 \\
\hline
\end{tabular}




\begin{tabular}{|c|c|c|c|c|c|c|c|c|c|}
\hline 211 & & $10 / 6 / 81$ & 812669 & 11 & 6.5 & 0.403 & $5.56 \mathrm{E}-05$ & 1000 & 40.8 \\
\hline 2120 & crate & $4 / 9 / 80$ & 803758 & & 0.0 & 12.4 & & 500 & \\
\hline 213 & & $11 / 3 / 81$ & 812684 & 40.8 & 24.0 & 2 & $2.95 \mathrm{E}-04$ & 1000 & 101 \\
\hline 213 & 8 & $11 / 3 / 81$ & 812686 & 7 & 4.1 & 0.266 & $3.70 \mathrm{E}-05$ & 160 & 2.8 \\
\hline 213 & & $11 / 3 / 81$ & 812688 & 101 & 59.5 & 0.787 & $1.67 \mathrm{E}-04$ & 3.6 & 0.18 \\
\hline 213 & & $11 / 3 / 81$ & 812689 & 2.8 & 1.7 & 0.0124 & $2.14 \mathrm{E}-06$ & 2.4 & 0.12 \\
\hline 214 & & $4 / 20 / 82$ & 820057 & 0.3 & 0.2 & 0.00614 & $8.56 \mathrm{E}-07$ & 1000 & 30 \\
\hline 214 & & $4 / 20 / 82$ & 820058 & 0.12 & 0.1 & 0.00614 & $8.56 \mathrm{E}-07$ & 140 & 15 \\
\hline 214 & & $4 / 20 / 82$ & 821822 & 0.4 & 0.2 & 0.00614 & $8.56 \mathrm{E}-07$ & 15 & 0.3 \\
\hline 214 & & $4 / 20 / 82$ & 821823 & 0.45 & 0.3 & 0.00614 & $8.56 \mathrm{E}-07$ & 4 & 0.12 \\
\hline 214 & & $4 / 20 / 82$ & 821826 & 0.4 & 0.2 & 0.00614 & $8.56 \mathrm{E}-07$ & 25 & 0.4 \\
\hline 214 & 9 & $4 / 20 / 82$ & 823410 & 1.3 & 0.8 & 0.00614 & 8.56E-07 & 30 & 0.45 \\
\hline 215 & & $6 / 9 / 82$ & 820041 & 30 & 17.9 & 0.938 & $1.53 \mathrm{E}-04$ & 40 & 0.8 \\
\hline 215 & 7 & $6 / 9 / 82$ & 820042 & 15 & 9.0 & 0.00614 & $8.56 \mathrm{E}-07$ & 20 & 0.4 \\
\hline 215 & & $6 / 9 / 82$ & 821832 & 2 & 1.2 & 0.00614 & $8.56 \mathrm{E}-07$ & 35 & 2 \\
\hline 215 & & $6 / 9 / 82$ & 821833 & 3 & 1.8 & 0.00614 & $8.56 \mathrm{E}-07$ & 100 & 3 \\
\hline 215 & & $6 / 9 / 82$ & 821834 & 2 & 1.2 & 0.00614 & $8.56 \mathrm{E}-07$ & 200 & 2 \\
\hline 215 & & $6 / 9 / 82$ & 821835 & 0.3 & 0.2 & 0.00614 & $8.56 \mathrm{E}-07$ & 40 & 0.8 \\
\hline 215 & & $6 / 9 / 82$ & 821837 & 2 & 1.2 & 0.00614 & $8.56 \mathrm{E}-07$ & 20 & 2 \\
\hline 216 & 6 & $6 / 9 / 82$ & 821825 & 0.8 & 0.5 & 0.00614 & $8.56 \mathrm{E}-06$ & 20 & 2 \\
\hline 216 & & $6 / 9 / 82$ & 821836 & 2 & 1.2 & 0.00614 & $8.56 \mathrm{E}-07$ & 15 & 1 \\
\hline 216 & & $6 / 9 / 82$ & 821838 & 1 & 0.6 & 0.00614 & $8.56 \mathrm{E}-07$ & 8 & 0.2 \\
\hline 216 & & $6 / 9 / 82$ & 821839 & 0.2 & 0.1 & \begin{tabular}{|l|}
0.00614 \\
\end{tabular} & $8.56 \mathrm{E}-07$ & 200 & 4 \\
\hline 216 & & $6 / 9 / 82$ & 821840 & 4 & 2.4 & 0.00614 & $8.56 \mathrm{E}-07$ & 30 & 2 \\
\hline 216 & & $6 / 9 / 82$ & 821841 & 2 & 1.2 & 0.00614 & $8.56 \mathrm{E}-07$ & 15 & 1.5 \\
\hline 217 & & $9 / 13 / 82$ & 821870 & 1.5 & 0.9 & 0.00614 & 8.56E-07 & 100 & 4.5 \\
\hline 217 & 6 & $9 / 13 / 82$ & 821871 & 4.5 & 2.7 & 0.197 & $2.75 \mathrm{E}-05$ & 80 & 1 \\
\hline 217 & & $9 / 13 / 82$ & 821874 & 10 & 6.0 & 0.00614 & 8.56E-07 & 300 & 20 \\
\hline 217 & & $9 / 13 / 82$ & 821882 & 1 & 0.6 & 0.00614 & $8.56 \mathrm{E}-07$ & 500 & 30 \\
\hline 217 & & $9 / 13 / 82$ & 821915 & 1 & 0.6 & $\begin{array}{r}1.4 \\
\end{array}$ & $1.28 \mathrm{E}-04$ & 900 & 40 \\
\hline 217 & & $9 / 13 / 82$ & 821918 & 1 & 0.6 & 0.197 & $2.75 \mathrm{E}-05$ & 6 & 11 \\
\hline 218 & 6 & $9 / 13 / 82$ & 821875 & 20 & 12.0 & 0.00614 & 8.56E-07 & 200 & 6 \\
\hline 218 & & $9 / 13 / 82$ & 821879 & 30 & 18.0 & \begin{tabular}{|l|}
0.123 \\
\end{tabular} & $1.92 \mathrm{E}-05$ & 1000 & 150 \\
\hline 218 & & $9 / 13 / 82$ & 821881 & 40 & 24.1 & 0.123 & $1.93 \mathrm{E}-05$ & 1000 & 30 \\
\hline 218 & & $9 / 13 / 82$ & 821883 & 6 & 3.6 & 0.00614 & $8.56 \mathrm{E}-07$ & 300 & 6 \\
\hline 218 & & 9/13/82 & 821916 & 30 & 18.0 & \begin{tabular}{|r|}
2.48 \\
\end{tabular} & 1.77E-04 & 900 & 10 \\
\hline 218 & & $9 / 13 / 82$ & 821917 & 6 & 3.6 & 0.00614 & 8.56E-07 & 110 & 1.3 \\
\hline 219 & & $3 / 10 / 83$ & 832830 & 20 & 12.2 & 0.00614 & $8.56 \mathrm{E}-07$ & 900 & 20 \\
\hline 219 & & $3 / 10 / 83$ & 832831 & 0.8 & 0.5 & \begin{tabular}{|l|}
0.00614 \\
\end{tabular} & $8.56 \mathrm{E}-07$ & 1000 & 200 \\
\hline 219 & 6 & $3 / 10 / 83$ & 832832 & 150 & 91.2 & $\begin{array}{l}2.49 \\
\end{array}$ & $5.05 \mathrm{E}-04$ & 20 & \\
\hline 219 & & $3 / 10 / 83$ & 832833 & 30 & 18.2 & 0.00614 & $8.56 \mathrm{E}-07$ & 100 & 25 \\
\hline 219 & & 3/10/83 & 832834 & 50 & 30.4 & 0.00614 & 8.56E-07 & 25 & 3 \\
\hline 219 & & $3 / 10 / 83$ & 832835 & 100 & 60.8 & 0.306 & $4.32 \mathrm{E}-05$ & 30 & 3 \\
\hline 220 & 6 & $3 / 10 / 83$ & 832836 & 100 & 60.8 & 0.00614 & 8.56E-07 & 70 & 3 \\
\hline
\end{tabular}




\begin{tabular}{|c|c|c|c|c|c|c|c|c|c|}
\hline 220 & & $3 / 10 / 83$ & 832837 & 100 & 60.8 & 0.00675 & $8.56 \mathrm{E}-07$ & 20 & 1.5 \\
\hline 220 & & $3 / 10 / 83$ & 832838 & 2 & 1.2 & 0.00614 & $8.56 \mathrm{E}-07$ & 200 & 40 \\
\hline 220 & & $3 / 10 / 83$ & 832839 & 8 & 4.9 & 0.00614 & $8.56 \mathrm{E}-07$ & 100 & 40 \\
\hline 220 & & $3 / 10 / 83$ & 832840 & 200 & 121.6 & 0.00614 & $8.56 \mathrm{E}-07$ & 10 & 0.2 \\
\hline 220 & & $3 / 10 / 83$ & 832841 & 50 & 30.4 & 0.00614 & $8.56 \mathrm{E}-07$ & 200 & 40 \\
\hline 221 & 6 & $3 / 10 / 83$ & 832842 & 15 & 9.1 & 0.00614 & $8.56 \mathrm{E}-07$ & 32 & 1.5 \\
\hline 221 & & $3 / 10 / 83$ & 832843 & 30 & 18.2 & 0.00614 & $8.56 \mathrm{E}-07$ & 1000 & 20 \\
\hline 221 & & $3 / 10 / 83$ & 832844 & 40 & 24.3 & 0.00614 & $8.56 \mathrm{E}-07$ & 30 & 0.8 \\
\hline 221 & & $3 / 10 / 83$ & 832845 & 1.5 & 0.9 & 0.00614 & $8.56 \mathrm{E}-07$ & 1000 & 150 \\
\hline 221 & & $3 / 10 / 83$ & 832846 & 60 & 36.5 & 0.00614 & $8.56 \mathrm{E}-07$ & 200 & 30 \\
\hline 221 & & $3 / 10 / 83$ & 832847 & 30 & 18.2 & $\begin{array}{r}0.00612 \\
4\end{array}$ & $8.56 \mathrm{E}-07$ & 1000 & 50 \\
\hline 222 & 7 & $12 / 14 / 83$ & 830716 & 20 & 12.4 & 0.0342 & $4.82 \mathrm{E}-06$ & 1000 & 100 \\
\hline 222 & & $12 / 14 / 83$ & 830717 & 200 & 123.8 & 0.0346 & $4.82 \mathrm{E}-06$ & 1000 & 100 \\
\hline 222 & & $12 / 14 / 83$ & 830781 & 1 & 0.6 & 0.00377 & $4.26 \mathrm{E}-07$ & 1000 & 100 \\
\hline 222 & & $12 / 14 / 83$ & 830787 & 40 & 24.8 & 0.00905 & $1.07 \mathrm{E}-06$ & 100 & 2 \\
\hline 222 & & $12 / 14 / 83$ & 830788 & 40 & 24.8 & 0.00905 & $1.07 \mathrm{E}-06$ & 200 & 8 \\
\hline 222 & & $12 / 14 / 83$ & 830789 & 0.2 & 0.1 & 0.00754 & $8.53 \mathrm{E}-07$ & 1000 & 200 \\
\hline 222 & & $12 / 14 / 83$ & 830790 & 40 & 24.8 & 0.219 & $2.48 \mathrm{E}-05$ & 1000 & 50 \\
\hline 223 & & $12 / 14 / 83$ & 830782 & 25 & 15.5 & 0.00377 & $4.26 \mathrm{E}-07$ & 400 & 15 \\
\hline 223 & & $12 / 14 / 83$ & 830783 & 3 & 1.9 & 0.00754 & $8.53 \mathrm{E}-07$ & 1000 & 30 \\
\hline 223 & & $12 / 14 / 83$ & 830784 & 3 & 1.9 & 0.00754 & $8.53 E-07$ & 800 & 40 \\
\hline 223 & 6 & $12 / 14 / 83$ & 830785 & 3 & 1.9 & 0.00754 & $8.53 \mathrm{E}-07$ & 60 & 1.5 \\
\hline 223 & & $12 / 14 / 83$ & 830786 & 1.5 & 0.9 & 0.00377 & $4.26 \mathrm{E}-07$ & 200 & 60 \\
\hline 223 & & $12 / 14 / 83$ & 830791 & 1.5 & 0.9 & 0.00754 & $8.53 \mathrm{E}-07$ & 200 & 60 \\
\hline 224 & 8 & $12 / 30 / 85$ & 852326 & 4 & 2.6 & 0.00614 & $8.56 \mathrm{E}-07$ & 1000 & 35 \\
\hline 224 & & $12 / 30 / 85$ & 852328 & 2 & 1.3 & 0.00614 & $8.56 \mathrm{E}-07$ & 100 & 1 \\
\hline 224 & & $12 / 30 / 85$ & 852332 & 4 & 2.6 & 0.00614 & $8.56 \mathrm{E}-07$ & 30 & 0.4 \\
\hline 224 & & $12 / 30 / 85$ & 852804 & 2.8 & 1.8 & 0.203 & $1.86 \mathrm{E}-05$ & 400 & 5 \\
\hline 224 & & $12 / 30 / 85$ & 855064 & 3.3 & 2.1 & 0.221 & $3.19 \mathrm{E}-05$ & 90 & 1.5 \\
\hline 224 & & $12 / 30 / 85$ & 855065 & 4.2 & 2.7 & 0.221 & $3.19 \mathrm{E}-05$ & 90 & 1 \\
\hline 224 & & $12 / 30 / 85$ & 855066 & 1.5 & 1.0 & 0.00614 & $8.56 \mathrm{E}-07$ & 60 & 0.7 \\
\hline 224 & & $12 / 30 / 85$ & 855068 & 1.5 & 1.0 & 0.00614 & $8.56 \mathrm{E}-07$ & 90 & 2 \\
\hline 225 & & $12 / 31 / 84$ & 840848 & 0.4 & 0.3 & 0.00614 & $8.56 \mathrm{E}-07$ & 80 & 2 \\
\hline 225 & & $12 / 31 / 84$ & 840854 & 1.5 & 1.0 & 0.00614 & 8.56E-07 & 70 & 1.5 \\
\hline 225 & 8 & $12 / 31 / 84$ & 840856 & 1.5 & 1.0 & 0.00614 & $8.56 \mathrm{E}-07$ & 21 & 0.3 \\
\hline 225 & & $12 / 31 / 84$ & 840857 & 3 & 1.9 & 0.00614 & $8.56 \mathrm{E}-07$ & 300 & 5 \\
\hline 225 & & $12 / 31 / 84$ & 840863 & 0.08 & 0.1 & 0.00614 & 8.56E-07 & 70 & 1.5 \\
\hline 225 & & $12 / 31 / 84$ & 840864 & 0.3 & 0.2 & 0.00614 & $8.56 \mathrm{E}-07$ & 40 & 0.4 \\
\hline 225 & & $12 / 31 / 84$ & 840867 & 0.4 & 0.3 & 0.00614 & 8.56E-07 & 200 & 3 \\
\hline 225 & & $12 / 31 / 84$ & 840874 & 0.2 & 0.1 & 0.00614 & 8.56E-07 & 50 & 1.5 \\
\hline 226 & 8 & $12 / 31 / 84$ & 840842 & 2 & 1.3 & 0.00614 & $8.56 \mathrm{E}-07$ & 40 & 1 \\
\hline 226 & & $12 / 31 / 84$ & 840843 & 2 & 1.3 & 0.00614 & $8.56 \mathrm{E}-07$ & 90 & 1.5 \\
\hline 226 & & $12 / 31 / 84$ & 840844 & 1.5 & 1.0 & 0.00614 & $8.56 \mathrm{E}-07$ & 105 & 3 \\
\hline
\end{tabular}




\begin{tabular}{|c|c|c|c|c|c|c|c|c|c|}
\hline 226 & & $12 / 31 / 84$ & 840845 & 0.3 & 0.2 & 0.00614 & $8.56 \mathrm{E}-07$ & 40 & 1 \\
\hline 226 & & $12 / 31 / 84$ & 840846 & 5 & 3.2 & 0.00614 & $8.56 \mathrm{E}-07$ & 150 & 2 \\
\hline 226 & & $12 / 31 / 84$ & 840847 & 1.5 & 1.0 & 0.00614 & $8.56 \mathrm{E}-07$ & 15 & 0.2 \\
\hline 226 & & $12 / 31 / 84$ & 840862 & 0.2 & 0.1 & 0.00614 & $8.56 \mathrm{E}-07$ & 10 & 0.08 \\
\hline 226 & & $12 / 31 / 84$ & 840868 & 0.3 & 0.2 & 0.00614 & $8.56 \mathrm{E}-07$ & 25 & 0.3 \\
\hline 227 & & $12 / 31 / 84$ & 840877 & 1.5 & 1.0 & 0.135 & 1.91E-05 & 10 & 0.1 \\
\hline 227 & & $12 / 31 / 84$ & 840878 & 2.5 & 1.6 & 0.19 & $3.08 \mathrm{E}-05$ & 30 & 0.4 \\
\hline 227 & 8 & $12 / 31 / 84$ & 840879 & 4 & 2.5 & 0.19 & $3.08 \mathrm{E}-05$ & 35 & 0.3 \\
\hline 227 & & $12 / 31 / 84$ & 840880 & 2.5 & 1.6 & 0.19 & $3.08 \mathrm{E}-05$ & 100 & 2 \\
\hline 227 & & $12 / 31 / 84$ & 840881 & 3 & 1.9 & 0.19 & $3.08 \mathrm{E}-05$ & 15 & 0.2 \\
\hline 227 & & $12 / 31 / 84$ & 840883 & 2 & 1.3 & 0.00614 & $8.56 \mathrm{E}-07$ & 80 & 1.5 \\
\hline 227 & & $12 / 31 / 84$ & 840885 & 6 & 3.8 & 0.197 & $2.27 \mathrm{E}-05$ & 250 & 2.5 \\
\hline 227 & & $12 / 31 / 84$ & 840886 & 0.8 & 0.5 & 0.00614 & $8.56 \mathrm{E}-07$ & 300 & 4 \\
\hline 228 & & $12 / 23 / 87$ & 874123 & 0.15 & 0.1 & 0.00614 & $8.56 \mathrm{E}-07$ & 350 & 2.5 \\
\hline 228 & & $12 / 23 / 87$ & 874124 & 1.5 & 1.0 & 0.00614 & $8.56 \mathrm{E}-07$ & 200 & 3 \\
\hline 228 & & $12 / 23 / 87$ & 874125 & 0.15 & 0.1 & 0.00614 & $8.56 \mathrm{E}-07$ & 18 & 0.3 \\
\hline 228 & & $12 / 23 / 87$ & 874126 & 2.5 & 1.7 & 0.00614 & $8.56 \mathrm{E}-07$ & 100 & 2 \\
\hline 228 & & $12 / 23 / 87$ & 874127 & 1.5 & 1.0 & 0.00614 & $8.56 \mathrm{E}-07$ & 400 & 6 \\
\hline 228 & & $12 / 23 / 87$ & 874128 & 1.5 & 1.0 & 0.00614 & $8.56 \mathrm{E}-07$ & 15 & 0.8 \\
\hline 228 & & $12 / 23 / 87$ & 874129 & 1.5 & 1.0 & 0.00614 & $8.56 \mathrm{E}-07$ & 10 & 1.5 \\
\hline 228 & 8 & $12 / 23 / 87$ & 874130 & 2 & 1.4 & 0.00614 & $8.56 \mathrm{E}-07$ & 300 & 4 \\
\hline 229 & & $12 / 31 / 84$ & 840851 & 3 & 1.9 & 0.00614 & $8.56 \mathrm{E}-07$ & 100 & 2 \\
\hline 229 & & $12 / 31 / 84$ & 840855 & 1 & 0.6 & 0.00614 & 8.56E-07 & 300 & 4 \\
\hline 229 & 7 & $12 / 31 / 84$ & 840860 & 2 & 1.3 & 0.00614 & $8.56 \mathrm{E}-07$ & 100 & 2.8 \\
\hline 229 & & $12 / 31 / 84$ & 840865 & 0.1 & 0.1 & 0.00614 & $8.56 \mathrm{E}-07$ & 1000 & 30 \\
\hline 229 & & $12 / 31 / 84$ & 840873 & 2 & 1.3 & 0.184 & $2.57 \mathrm{E}-05$ & 1000 & 6.5 \\
\hline 229 & & $12 / 31 / 84$ & 840882 & 0.3 & 0.2 & 0.00614 & $8.56 \mathrm{E}-07$ & 100 & 0.9 \\
\hline 229 & & $12 / 31 / 84$ & 840888 & 0.15 & 0.1 & 0.00614 & $8.56 \mathrm{E}-07$ & 3 & 0.04 \\
\hline 230 & 8 & $12 / 31 / 84$ & 840831 & 35 & 22.2 & 5.89 & $5.24 \mathrm{E}-04$ & 100 & 3.3 \\
\hline 230 & & $12 / 31 / 84$ & 840835 & 10 & 6.3 & 0.00614 & $8.56 \mathrm{E}-07$ & 300 & 4.2 \\
\hline 230 & & $12 / 31 / 84$ & 840836 & 0.4 & 0.3 & 0.00614 & $8.56 \mathrm{E}-07$ & 70 & 1.5 \\
\hline 230 & & $12 / 31 / 84$ & 840838 & 5 & 3.2 & 0.00614 & $8.56 \mathrm{E}-07$ & 20 & 0.5 \\
\hline 230 & & $12 / 31 / 84$ & 840839 & 1.5 & 1.0 & 0.00614 & 8.56E-07 & 1000 & 22 \\
\hline 230 & & $12 / 31 / 84$ & 840840 & 1 & 0.6 & 0.00614 & $8.56 \mathrm{E}-07$ & 20 & 0.6 \\
\hline 230 & & $12 / 31 / 84$ & 840841 & 0.7 & 0.4 & 0.00614 & $8.56 \mathrm{E}-07$ & 500 & 6 \\
\hline 230 & & $12 / 31 / 84$ & 840859 & 1 & 0.6 & 0.00614 & $8.56 \mathrm{E}-07$ & 350 & 7 \\
\hline 231 & & $12 / 30 / 85$ & 855046 & 3 & 1.9 & 0.00614 & $8.56 \mathrm{E}-07$ & 9 & 0.15 \\
\hline 231 & & $12 / 30 / 85$ & 855047 & 3 & 1.9 & 0.00614 & $6.42 \mathrm{E}-07$ & 20 & 1.5 \\
\hline 231 & & $12 / 30 / 85$ & 855048 & 0.9 & 0.6 & 0 & $3.21 \mathrm{E}-05$ & 10 & 0.12 \\
\hline 231 & & $12 / 30 / 85$ & 855049 & 0.4 & 0.3 & 0 & $1.93 \mathrm{E}-05$ & 200 & 2.5 \\
\hline 231 & 8 & $12 / 30 / 85$ & 856015 & 2.1 & 1.4 & 0.00614 & $8.56 \mathrm{E}-07$ & & 1.5 \\
\hline 231 & & $12 / 30 / 85$ & 856016 & 6 & 3.9 & 0.00614 & $6.42 \mathrm{E}-07$ & & 1.5 \\
\hline 231 & & $12 / 30 / 85$ & 856017 & 6 & 3.9 & 0.00614 & $6.42 \mathrm{E}-07$ & 60 & 1.5 \\
\hline 231 & & $12 / 30 / 85$ & 856018 & 1 & 0.6 & 0.00614 & $8.56 \mathrm{E}-07$ & 80 & 2 \\
\hline
\end{tabular}




\begin{tabular}{|r|r|r|r|r|r|r|r|r|r|}
\hline 232 & 3 & $12 / 23 / 87$ & 874132 & 0 & 0.0 & 0 & $2.61 \mathrm{E}-06$ & 6.5 & 0 \\
\hline 232 & & $12 / 23 / 87$ & 874133 & 0 & 0.0 & 5.83 & $2.89 \mathrm{E}-04$ & 1000 & \\
\hline 232 & & $12 / 23 / 87$ & 874134 & 0 & 0.0 & 0.0943 & $1.37 \mathrm{E}-05$ & 29 & \\
\hline
\end{tabular}





\section{Appendix J}

\section{Oral Interviews}

C. Villareal, May 23, 2012

J. Warren, June 8, 2012

D. Christensen, November 15, 2012 
This page intentionally left blank.

Page J-2 


\section{3-Shafts}

\section{Charles Villareal Interview May 23, 2012}

As part of the planning for disposition of the 33-Shafts located in TA-54 MDA-G shaft field B, persons who may have been involved in the generation, construction and/or operations of the shafts are being interviewed to capture an oral history as part of due diligence.

An interview/conversation was conducted on May 23, 2012 in TA-46-326-125 with Charles Villareal $^{\mathrm{i}}$, who is currently a LANS employee working in ENV-WGS: Waste Generator Services. Charles was involved in the operations of the 33 Shafts. The interview/conversion involved Thomas H. Monk, Project Management for 33-Shafts Planning and Charles Villareal.

The following is a summary of the interview/conversation held with Charles Villareal. This summary was prepared by Thomas Monk and submitted to Charles Villareal for editing and verification. Charles Villareal concurs with the information presented below.

- Charles Villareal worked in LANL waste management organization from about 1976 to 2006.

o His assignments involved work in TA-54 MDA-G and at WCRRF which at the time was referred to as the Size Reduction Facility.

o Charles worked as a disposal technician and as a technical supervisor.

o His name appears in several of the log book entries recording the emplacement of waste in the 33-Shafts (200 through 223).

- Charles reviewed a photo copy a logbook ${ }^{\mathrm{ii}}$ and confirmed that this was the log he remembered using.

o He did not recall voiding of pages 2 through 17.

0 An " $X$ " has been drawn across these pages and an unsigned note entered on page 18 stating "Shaft book recopied on 2/12/82.....these first 18 pages (stapled together) contain invalid information."

o The recopied and possibly changed entries appear on pages 20 through 35 of the same log book.

- Miguel Salazar and Sid Powell, area field engineers, were involved in the development of shaft fields and/or construction of the shafts.

- $\quad$ Physical construction of the shafts was performed by ZIA.

o A hole was excavated into the tuff, and a steel pipe was place in the augured hole, and the space between the pipe and the augured hole filled with sand.

o Charles points to a reference document ${ }^{\mathrm{iii}}$ in support this description.

o Charles does not recall CMPs being placed around the pipe and concrete fill being used to fill the void between the pipe and the CMP. 


\section{3-Shafts}

\section{Charles Villareal Interview May 23, 2012}

- Hot cell waste from Wing 9 of CMR was transported in shielded cask affixed to the bed of a truck to MDA-G shafts for disposal/storage.

o A funnel would be placed in the opening of the pipe in the shaft and the truck positioned so that the cask was directly about the funnel.

o A sliding plate at the bottom of the cask would be pulled out allowing the waste package to drop into the pipe.

o On some occasions, the waste package would lodge. When this occurred, the lid of the cask would be opened and personnel would dislodge the package using long handled tools.

o Depending on the dose of the package and the RCT monitoring the work, the waste disposal technician would be directed to drop bags of lead shot into the pipe to reduce shine from the pipe. Up to 100 pounds was added to some shafts. Charles does not recall any log book entries being made as to which shafts received lead shot.

o The higher dose waste packages were typically placed in the bottom of the pipe while lower dose packages were placed nearer the top of the pipe.

o The waste pages were typically a plastic bag containing two metal or plastic containers. The metal containers were similar to paint cans.

o Charles does not recall seeing any welded steel cans in the bags.

o Each waste package had a Radioactive Solid Waste Disposal form filled out by the generator.

- Once a pipe was filled, a metal lid/cap was placed on the top of the pipe and concrete plug, the diameter of the original augured hole, was poured. The caps were typically 1-1/2 feet thick and contained no steel reinforcing.

- Charles states that he was aware of an Immediate Action Directive to retrievably store TRU waste but points out that what constituted retrievable configurations was not clearly understood by all waste operations personnel.

o Bruce Reich and Bruce Lebrun worked in waste management at the time and frequently provided technical guidance on matters of this nature.

o The plan was to eventually retrieve the entire pipe with its waste packages as an intact assembly which was to be removed from the ground into a shield cask and directly shipped to WIPP.

- The LAMPRE reactor and possibly associated hardware was received in a larger diameter pipe that was already filled with concrete. The concrete filled pipe was placed directly in the augured hole. 


\section{3-Shafts}

\section{Charles Villareal Interview May 23, 2012}

- Charles indentified additional points of contacts for information on the 33-Shafts as follows:

o Miguel D. Salazar, currently a LANL employee.

o Donald B. Lebrun, currently a NNSA employee.

o John Warren, retired former LANL employee living in Denver CO area;

o Johnny Harper retired former LANL employee believed to be living in Los Alamos NM;

o Sid Powell and Bruce Reich listed about are believed to be dead.

- A notebook that contains typed waste management information will be copied and supplied for reference.

\footnotetext{
'This written record of the interview with Charlie Villareal has been reviewed by Charlie and corrections made based on his review comments.

ii Photo copy of Los Alamos National Laboratory Logbook S-3873, end tab titled (Shafts) 8/78 to 12/91 (3873), obtained from K. Hargis.

iii Initiative \# 197: RH-TRU Assessment and Recovery for National TRU Program office and WTAC, Survey of RH-TRU Waste at Los Alamos National Laboratory, Initial Report, prepared by Larry R. Field, MST-5, and Peter Del Mar, MTS-5, Los Alamos National Laboratory (Note that this document does not have a date on it; however, Davis Christenson recalls the document was issued in 1993, the first year he was employed at the laboratory as the TRU Program Manager)
} 


\section{3-Shafts}

\section{John Warren Telephone Interview June 8, 2012}

As part of the planning for disposition of the 33-Shafts located in TA-54 MDA-G shaft field B, persons who may have been involved in the generation, construction and/or operations of the shafts are being interviewed to capture an oral history as part of due diligence.

A telephone interview/conversation was conducted by Thomas (Tom) H. Monk with John L. Warren on June 8, 2012. He is a retired LANL employee who lives in Evergreen, CO. John was responsible for MDA-G operations during the time waste was emplaced in the 33 Shafts.

Following is a summary of the telephone interview/conversation with John. This summary was prepared by Tom Monk and has been submitted to John Warren for editing and verification. John concurs with the information presented below:

- LA-UR-862932 titled “Final TRU Waste Inventory Workoff Plan” December 1986 authored by John L. Warren and A. E. Dross contains factual information on the 33Shafts. It also contains detailed information on the configuration of the shafts in Appendix (B), page 148.

- The shafts were vertically augured in the MDA-G tuff to varying depths. There were three configurations for the pipes placed in the hole to receive the waste packages as follows:

1. A steel pipe with a welded plate on the bottom, centered in a corrugated metal pipe (CMP) with concrete fill material between the pipe and CMP. After the inner pipe was filled to near the top with waste cans, the outer pipe was filled with concrete to its top. In some of these casks lead shot was added on top of the waste cans to reduce surface dose.

2. A steel pipe with a welded plate on the bottom centered in a larger diameter pipe with concrete fill material between the outer and inner pipes. The sealing configuration was the same as above.

3. A steel pipe with a plate welded on the bottom with a latching lid, lifting ring and not sealed.

These configurations and the dimensions are described in LA-UR-862932, Appendix (B), and page 148 .

- There was a special case configuration for the single shaft that received the core of the Molten Plutonium Reactor Experiment. It was received in a thick wall pipe filled with 


\section{3-Shafts}

\section{John Warren Telephone Interview June 8, 2012}

concrete and containing the reactor vessel. The assembly was placed directly into an augured hole.

- Had authors of documents that report configurations for the shafts that are different from the above description checked with John Warren, he would have informed them of the configurations which he accurately reported in LA-UR-862932.

- The first shafts received hot cell waste packaged in paint cans and sealed in a rigid plastic container which had been placed in a plastic bag.

- The last nine shafts received hot cell hot waste packaged in a configuration identical to that of the waste that placed in the 16 RH-TRU canisters. The waste package consisted on an inner paint can sealed in a rigid plastic container, which was weld sealed in HEPA filtered steel can. These packages were lowered from the top of the shielded transportation cask into the pipe in the shaft. This mode of operation was assessed to be retrievable storage specifically for the cans.

- Of the 23 figurations that had concrete fill between the inner and outer pipe, CMP in some cases and smooth pipe in other cases, 12 were considered too long to retrieve and load into a cask for direct shipment to WIPP. The remaining 11 concreted shafts were shorter in length and it was believed that the entire array out and inner pipe with concrete and waste packages could be retrieved directly into a cast for direct shipment to WIPP.

- John is available to consult on the shafts and/or other waste grouping through NFT.

- John suggests that Miguel Salazar be contacted for information of the CMPs from TA-21 that were relocated to MDA-G. 


\section{3-Shafts}

\section{Davis Christenson Interview November 15, 2012}

As part of the planning for disposition of the 33-Shafts located in TA-54 MDA-G shaft field B, persons who may have been involved in the generation, construction and/or operations of the shafts are being interviewed to capture an oral history as part of due diligence.

Davis Christenson was interviewed on November 15, 2012 by Thomas (Tom) H. Monk. He is a full time LANL employee who works in the Los Alamos TRU Program (LTP). Davis is currently Manager for Planning and Technical Services in the LTP.

Following is a summary of the interview/conversation with Davis. This summary was prepared by Tom Monk and has been submitted to Davis Christenson for editing and verification. Davis concurs with the information presented below:

- Davis Christenson was hired as a full time LANL employee in March 1993 in the TRU Waste Program. He worked as TRU Program Manager from 1993 through 2006 responsible for Safe Storage and Maintenance, initially, and expanding over time to also included Characterization and Shipping. From 2006 through the present he has worked in the general functional areas of production control, work off planning and inventory management.

- Davis was not directly involved in the construction or operations of the 33-Shafts. His knowledge about the shafts is based on what he describes as "urban legion".

- He is not aware of the existence of as-built drawings of the 33-Shafts. There are cartoon like illustrations of the shafts in presentations and reports. He recalls that AEC's Immediate Action Directive 0511 (1970) was not fully implemented at LANL until about 1979. Implementation of the directive prior to about 1979 was mainly limited by the lack of funding.

- The 33-Shafts are located in a "low spot" of MDA-G. Following construction of TA-54-412, there was increased water run on over the 33-Shafts field which resulted in significant subsidence around some of the shafts. Tuff and/or concrete were used to back fill holes resulting from subsidence. The elevation of the 33-Shafts field was also increased about 2-feet to reduce water run on over the 33-Sahft field. Markers for each shaft were also placed on top of the fillt.

- The waste in the 33-Shafts has been reported in data calls and reports to be retrievably stored TRU waste. The prevailing vision for retrieving the shafts was based on lifting the entire shaft assembly from the ground with follow on size reduction and sorting being performed in a facility such as CMR. Davis points out that WIPP did not formally baseline the RH-TRU disposition requirements until years after the shafts were filled with waste. 



\section{Appendix K}

Portions of

1986 TRU Waste Inventory Work-Off Plan

Relevant to 33 Shafts

"Final TRU Waste Inventory Work-Off Plan

Los Alamos National Laboratory"

J. L. Warren and A. E. Dross

LA-UR-862932

August 1986

(Revised December 15, 1986) 
This page intentionally left blank.

Page K-2 


\section{FINAL TRU WASTE INVENTORY WORK-OFF PLAN}

LOS ALAMOS NATIONAL LABOFATOAY

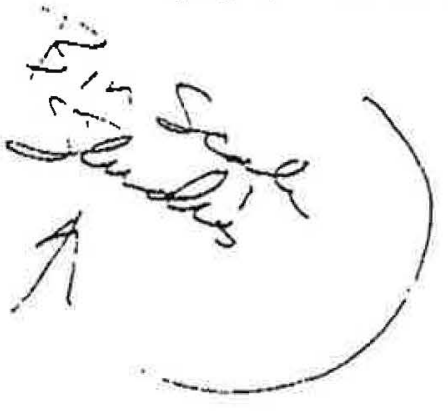

AUGUST 1986

(REVISED: DECEMBER 15, 1986)

BY

J. L. WARREN

A. E. DROSS
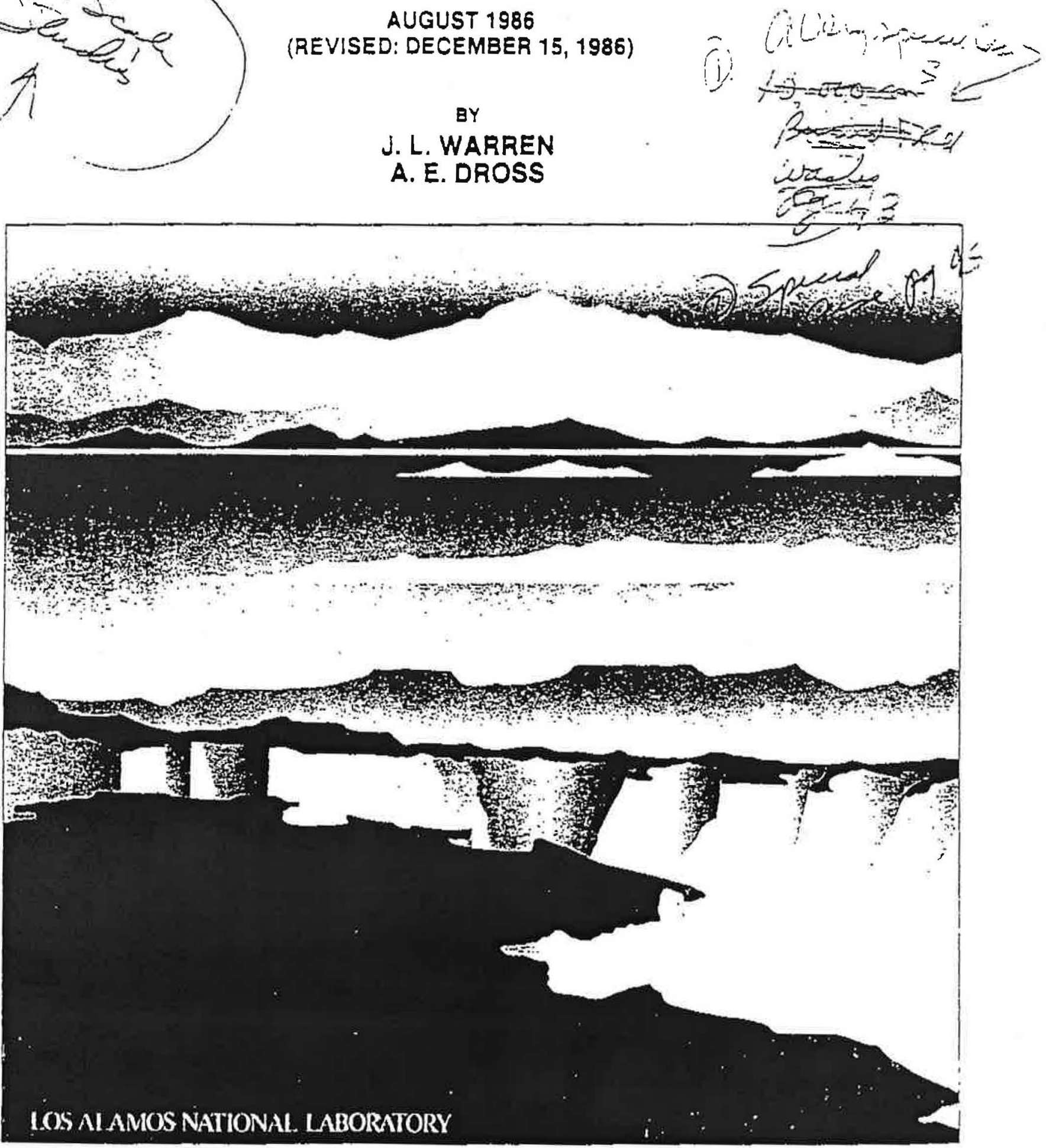
FINAI TRU WASTE INVENTORY WORK-OFF FLAN

LOS ALAMOS NATIONAL IABORATORY

AUGUST 1986

(Revised: December 15, 1986)

BY

J. I. WARREN

A. E. DROSS

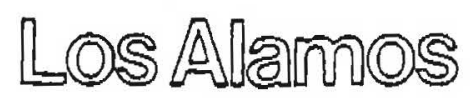

Los Alamos National Laboratory Los Alarnos.New Mexico 87545 
ABSTRACT . . . . . . . . . . . . . . . . . . . . . . . I

1.0 Introduction . . . . . . . . . . . . . . . . . . . . 3

2.0 Waste Characterization . . . . . . . . . . . . . . . . 7

2.1 Existing TRU Waste Records System . . . . . . . . . 7

2.2 Discussion of $\mathrm{CH}$ Data Tables . . . . . . . . . . . 35

2.3 Discussion of RH Data Tables . . . . . . . . . . . 43

3.0 Methods and Facilities Required for

Certification of Wastes. . . . . . . . . . . . . . . 49

3.1 General. . . . . . . . . . . . . . . . . . . 49

3.2 Retrieval. . . . . . . . . . . . . . . . . . 52

3.3 Nondestructive Analysis and

Nondestructive Examination. . . . . . . . . . . . . 53

3.4 Processing Methods for Contact-Handled (CH) Waste. 54

3.5 Remote-Handled Wastes.. . . . . . . . . . . . . 6I

3.6 Facilities. . . . . . . . . . . . . . . . . . . 62

3.7 Detailed operating Schedules and Throughputs. . . . 74

3.8 Facilities and Equipment Reouired for

Continued Retrievable storage . . . . . . . . . 74

4.0 Work-Off Strategy and Schedule... . . . . . . . . . . 78

4.1 Contact-Handled TRU Wastes Strategy for

Facilities and Equipment. . . . . . . . . . . . 78

4.2 Contact-Handled Schedules. . . . . . . . . . . . . 78

4.3 Remote-Handled TRU Waste. . . . . . . . . . . . . . 92

4.4 Special Case TRU Waste . . . . . . . . . . . . . . 95

4.5 Comparison with Planning Documents. . . . . . . . . $\overline{97}$

4.6 Potential Problems that could Impact

Schedules and Strategies. . . . . . . . . . . . . . 97

5.0 Resource Requirements. . . . . . . . . . . . . . . . . . 99

5.1 Facilities Construction. . . . . . . . . . . . . . 99

5.2 Capital Equipment... . . . . . . . . . . . . . . 112

5.3 Facility Operations . . . . . . . . . . . . . . 116

5.4 Cost Summary for CH-IRU Work-Off. . . . . . . . . . 122

5.5 Remote-Handled TRU Wastes............ . . . 123

5.6 Special Case TRU Wastes . . . . . . . . . . . . . . 126

6.0 Public Documentation Requirements. . . . . . . . . . . . 128

6.1 Action Description Memorandum . . . . . . . . . . . 128

6.2 Environmental Assessment . . . . . . . . . . . . . 129

6.3 Supporting Documents. . . . . . . . . . . . 130

Appendix A - Characteristics of Los Alamos Stored TRU waste through CY85 . . . . . . . . . 133

Appendix B - Packaging Characteristics of Los Alamos stored TRU Wastes through CY85. . . . . . . . . 145

Appendix C - Los Alamos TRU Wastes Stored in FRP-Wood Boxes through CY85... . . . . . . . . . . 151 


\section{ABSTRACT}

This document presents an assessment of the current strategy to develop new operations and facilities at the Los Alamos National Laboratory (Los Alamos) to retrieve, process, certify, and transport defense transuranic (TRU) wastes to the Department of Energy's (DOE's) Waste Isolation Pilot Project (WIPP) in southeastern New Mexico. This Final Inventory work-off Plan (IWOP) Will cover all TRU stored and newly-generated (NG) contact-handled ( $\mathrm{CH}$ ), remote-handled ( $\mathrm{RH}$ ), and special-case (SC) wastes expected to be generated, or currently being stored, at Los Alamos through the year 2015. The strategies and actions proposed in this Iwop involve the modification of two existing TRU waste work-off facilities in Techrical Area (TA) 50, and the construction of five new facilities at the present TA-54. The activities leading to certification of wastes to be shipped to the WIPP will be in compliance with the quality assurance requirements of the approved Los Alamos TRU Waste Certification Plan and its waste form specific attachments. Barring unforeseen programatic, funding, and/or political changes, there will be little difficulty in meeting the schedules and strategies with the resources as defined in this IWOP. 


\subsection{Remote-Handled Wastes}

The inventory through 1985 of $\mathrm{kH}$-wastes consisted of 23 steel/concrete casks $0.6 \mathrm{~m}(2 \mathrm{ft})$ in diameter and up to $4.4 \mathrm{~m}$ (14 I/2 ft) Iong, one cask $0.8 \mathrm{~m}(32 \mathrm{in.})$ in diameter by $4 \mathrm{~m}$ (13 ft) long, and 5 pipes $0.3 \mathrm{~m}(9.5 \mathrm{in.})$ in diameter by $2.5 \mathrm{~m}$ (100 in.) long.

The single cask above contains the core of the Los Alamos Molten Plutonium Reactor Experiment. This unit is encased in concrete inside a 6 m ( $1 / 4$ in.) thick steel casing. This cask cannot reasonably be opened, and consequently presents a SC waste. : .

Twelve of the other casks also present SC waste handling problems. "Each consists of small cans of waste sealed in a 13 ma - (1/2 in.) wall, 0.2 m ( 9 in.) diameter steel pipe, surrounded by concrete within a $0.6 \mathrm{~m}$ (24 in.) diameter, $6 \mathrm{~mm}$ ( $1 / 4 \mathrm{in}$ ) wall steel pipe. These casks are too long to be overpacked and fit into the RH waste transport cask. options for disposal of these casks include the following:

- burying the casks on-site permanently,

- making special shipping arrangements for terminal storage at the WIPR, or

- opening the casks and repacking the contents.

The first option would require an environmental impact study before on-site burial could be considered. The second option depends on the final WIPP SC acceptance criteria, and the third 
option would require the construction of a remote handing facility, which, for the few casks involved, would probably be economically infeasible.

The remaining eleven casks are of a size that, we believe, can be over-packed for shipment. Certification of these wastes is thought possible by means of NDA-NDE technology currently being developed at Los Alamos. The proposed schedule for this effort is discussed in sections 4.3 and 4.4 .

\subsection{Facilities}

Containers of wastes removed from the TRU retrievable storage areas will move through a series of inspections and assays, sorting and treatment facilities necessafy for certification, and finally, to the TRO Waste Transportation Facility. This is illustrated in a flow sheet form in Figures 5 and 6 .

\subsubsection{Size-Reduction Facility (SRF)}

The SRF, also designated as TA-50, building Waste Management (WM) -69 , was designed and constructed so that methods could be developed to reduce volume and repackage various types of metallic waste items contaminated with TRU levels greater than $100 \mathrm{nCi} / \mathrm{g}$ of material. The SRF is currently being modified to accept the higher inventories associated with the work-off of TRU wastes.

The materials-handling equipment and plasma-arc cutting torch are parts of a production-oriented prototype process 
LOS ALAMOS MATIONAL LABORATORY STORED TRU-WASTES THROUGH CY8S

$\overrightarrow{5}$

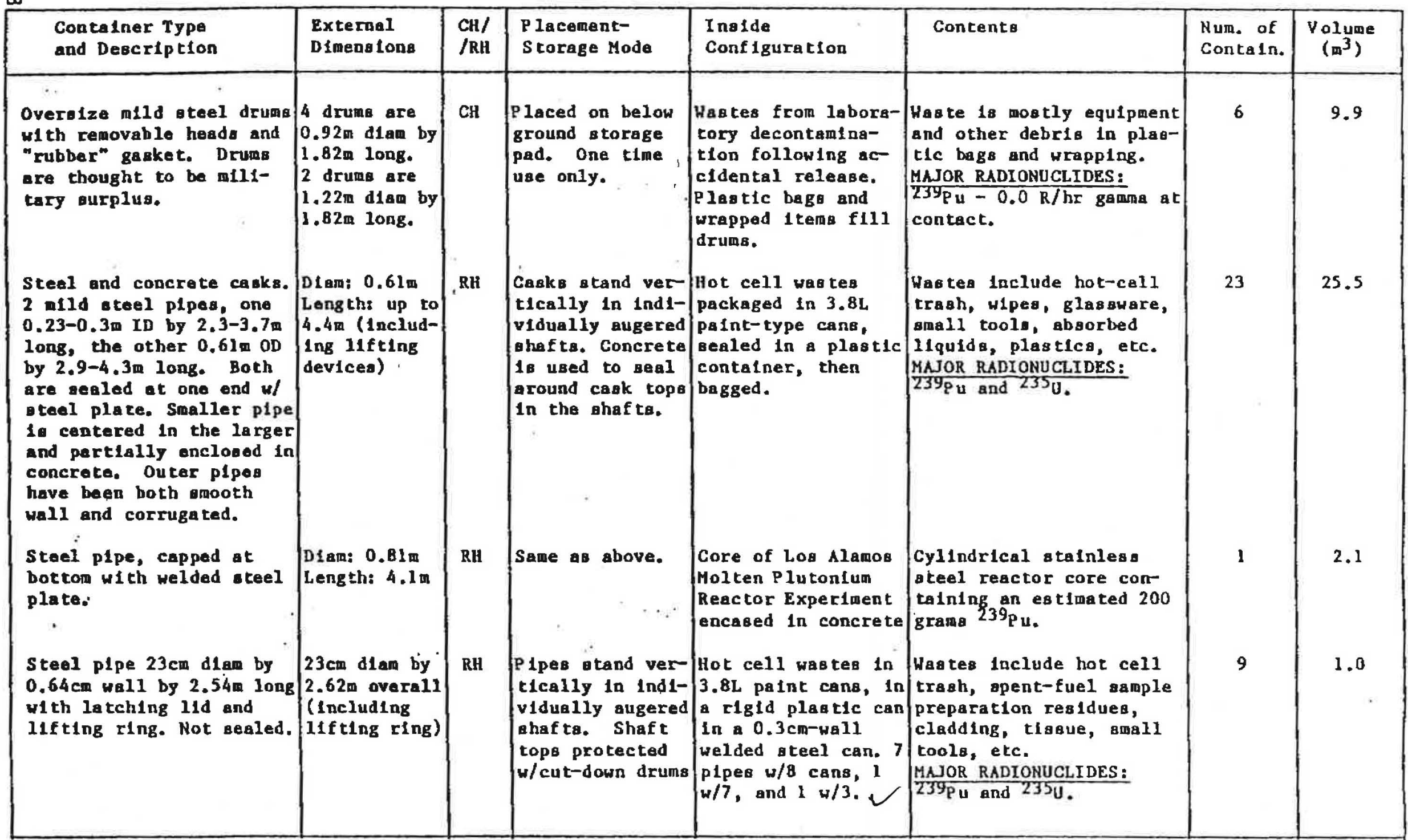


LOS ALAMOS NATIOHAL LABORATORY STORED TRU-WASTES THROUGH CY 85

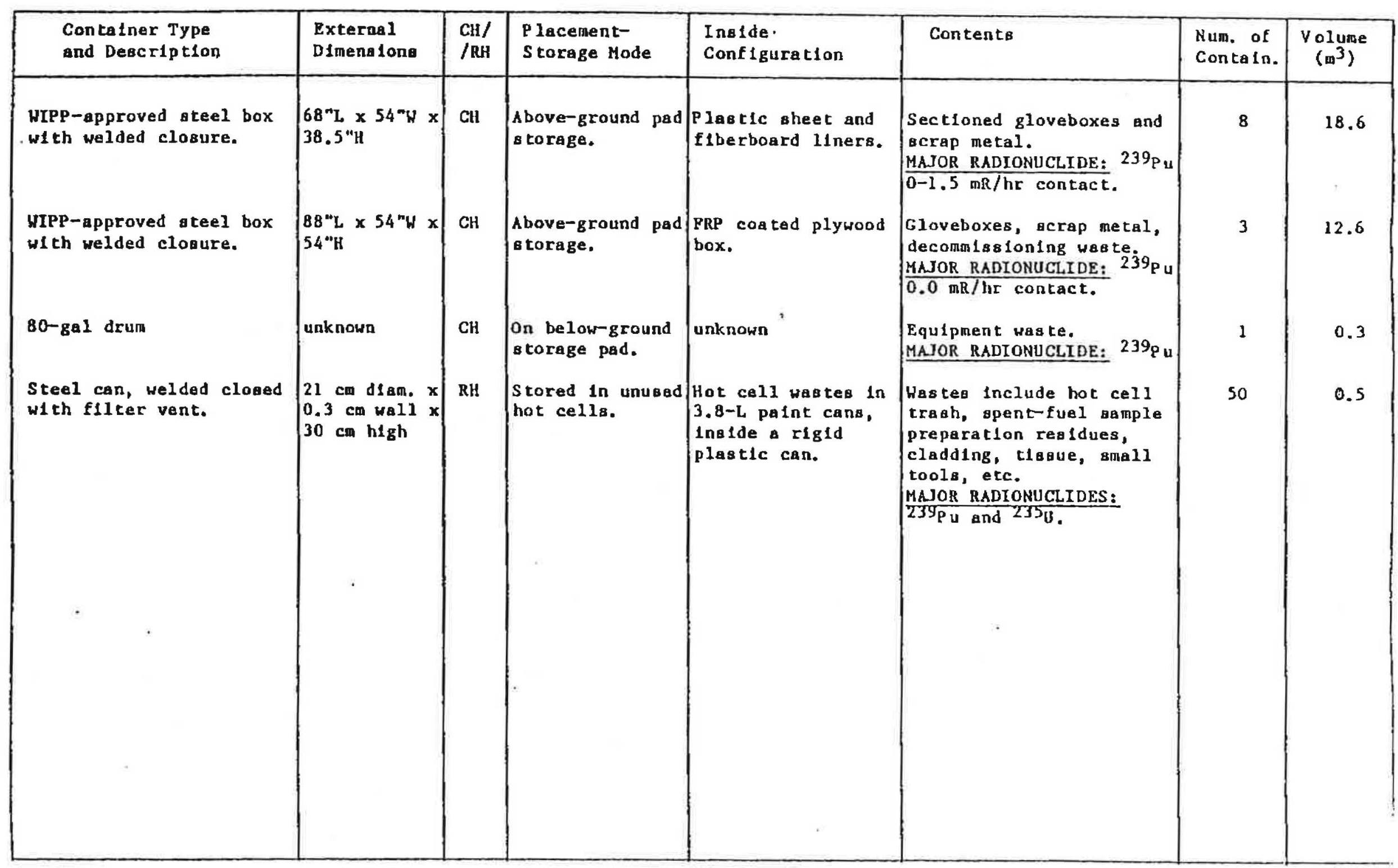





\section{Appendix L}

\section{Portions of \\ CCP AK Report for 16 RH Canisters Relevant to 33 Shafts}

"Central Characterization Project Acceptable Knowledge Summary Report For

16 Canisters of Remote-Handled Transuranic Debris Waste From Los Alamos National Laboratory Chemistry and Metallurgy Research Facility Waste Stream: LA-MHD03.002" CCP-AK-LANL-500

Revision 3, June 5, 2007 
This page intentionally left blank.

Page L-2 
Central Characterization Project Acceptable Knowledge Summary Report

For

16 Canisters of Remote-Handled Transuranic Debris Waste From Los Alamos National Laboratory Chemistry and Metallurgy Research Facility

Waste Stream: LA-MHD03.002

Revision 3

Month xx, 2007

JVME S,2007

Eric D'Amico

Printed Name

APPROVED FOR ÜSE

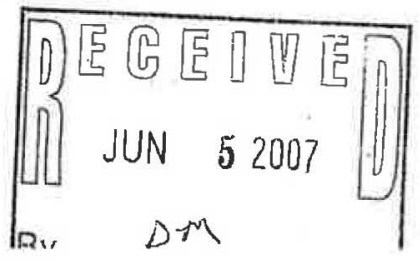




\section{RECORD OF REVISION}

\begin{tabular}{||c|c|l||}
\hline $\begin{array}{c}\text { Revision } \\
\text { Number }\end{array}$ & $\begin{array}{c}\text { Date } \\
\text { Approved }\end{array}$ & Description of Revision \\
\hline 0 & $10 / 13 / 2006$ & Initial issue. \\
\hline 1 & $12 / 04 / 2006$ & $\begin{array}{l}\text { Revised to implement the Waste Isolation Pilot } \\
\text { Plant Hazardous Waste Facility Permit } \\
\text { requirements and associated Section 311/Remote- } \\
\text { Handled (RH) Permit Modification Request (PMR) } \\
\text { changes. }\end{array}$ \\
\hline 2 & $05 / 01 / 2007$ & $\begin{array}{l}\text { Revised to incorporate resolution of comments } \\
\text { resulting from the U.S. Department of Energy } \\
\text { (DOE) review of the Acceptable Knowledge (AK) } \\
\text { Sufficiency Determination Request. }\end{array}$ \\
\hline 3 & $\mathrm{Xx} / \mathrm{xx} / 2007$ & $\begin{array}{l}\text { Revised to address comments provided during the } \\
\text { May 8-10, 2007, EPA Inspection and to clarify that } \\
\text { the 7-inch cans in the direct loaded drums are not } \\
\text { sealed containers. }\end{array}$ \\
\hline
\end{tabular}




\section{TABLE OF CONTENTS}

LIST OF TABLES

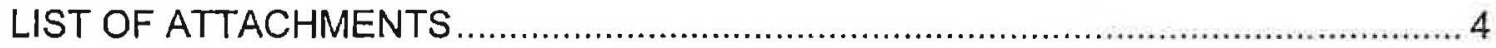

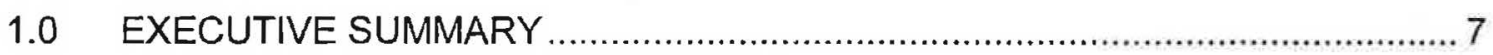

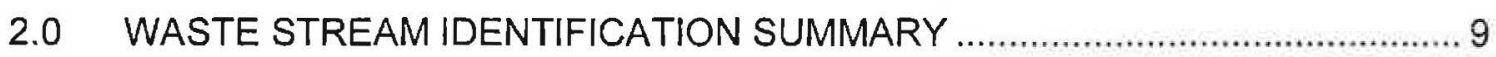

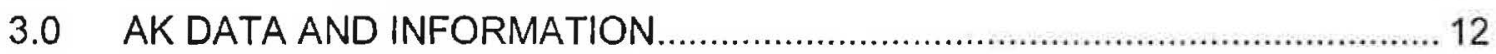

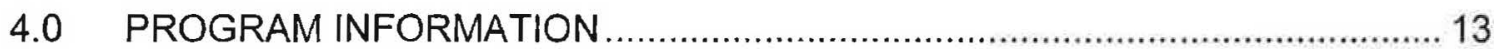

4.1 Facility Location, Description, Mission, and Defense Determination........ 13

4.1.1 Facility Location .................................................................... 13

4.1.2 CMR Description ........................................................................ 13

4.1.3 Wing 9 - Hot Cell Mission .......................................................... 15

4.1.4 Defense Waste Determination ................................................... 15

4.2 RH TRU Waste Management ........................................................... 18

4.2.1 Types and Quantity of TRU Waste Generated.............................. 19

4.2.2 Description of Waste Generating Processes.................................. 20

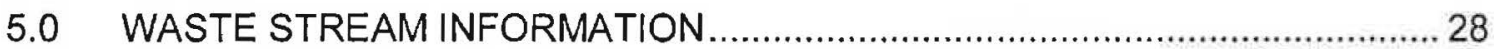

$5.1 \quad$ Area and Building of Generation....................................................... 28

5.2 Waste Stream Volume and Period of Generation ................................... 28

$5.3 \quad$ Waste Generating Activities ............................................................... 28

5.4 Types of Wastes Generated ............................................................... 28

5.4.1 Material Input Related to Physical Form .................................... 29

5.4.1.1 Waste Matrix Code ...................................................... 30

5.4.1.2 Waste Material Parameters ............................................. 30

5.4.2 Chemical Content Identification - Hazardous Constituents ............31

5.4.2.1 F-Listed Solvents .......................................................... 39

5.4.2.2 Toxicity Characteristic Compounds ................................ 39

5.4.2.3 Ignitables, Reactives, and Corrosives............................. 40

5.4.2.4 P- and U-Listed Wastes ................................................. 41

5.4.2.5 K-Listed Waste .............................................................. 41

5.4.3 Radiological Characterization .................................................... 41

5.4.3.1 LANL Reported Radiological Properties ………............... 41

5.4.3.2 CCP Radiological Characterization.................................. 43

5.4.4 Polychlorinated Biphenyls (PCBs) ........................................... 47

5.4.5 Prohibited Items ........................................................................ 47

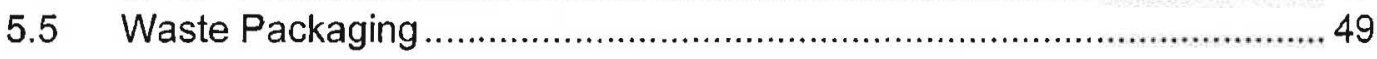

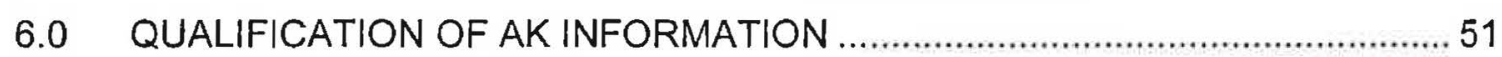

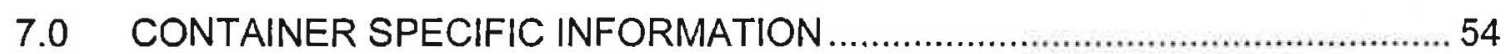

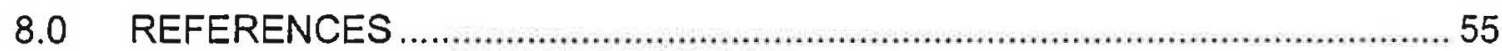

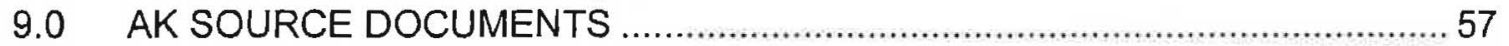




\section{LIST OF TABLES}

Table 1. Wing 9 Hot Cell Operations Timeline 20

Table 2. Waste Stream LA-MHD03.002 Waste Material Parameter Estimates................ 31

Table 3. Waste Stream LA-MHD03.002 Hazardous Waste Characterization Summary ... 31

Table 4. Waste Stream LA-MHD03.002 Material and Chemical Inputs........................... 33

Table 5. LANL Canister Weight, Dose, and Surface Contamination Measurements........ 42

Table 6. LANL Estimated Mixed Fission Products ......................................................... 43

Table 7. Summary of Radiological Characteristics of the 16 Canisters ........................... 45

Table 8. Summary of Activities for WIPP Radionuclides ................................................46

Table 9. Waste Stream LA-MHD03.002 DQO Determination Summary ..........................52

\section{LIST OF ATTACHMENTS}

Attachment 1 - Los Alamos National Laboratory Technical Area 3 .............................. 69

Attachment 2 - Los Alamos National Laboratory Site Map .......................................... 70

Attachment 3 - Location Map for Shafts 236-243 and 246-253 at TA-54, Area G ........... 71

Attachment 4 - Wing 9 RH Canister Inventory ....................................................... 72

Attachment 5 - Wing 9 Post-Irradiation Examination Process Flow Diagram ................... 82

Attachment 6 - Photographs of Internal Packaging Containers ....................................... 83

Attachment 7 - LANL RH 72B Canister Loading Operations ........................................ 85 


\section{LIST OF ACRONYMS AND ABBREVIATIONS}

\begin{tabular}{|c|c|}
\hline ACPR & Annular Core Pulse Reactor \\
\hline AEC & U.S. Atomic Energy Commission \\
\hline AK & Acceptable Knowledge \\
\hline ANL-W & Argonne National Laboratory-West \\
\hline Am & Americium \\
\hline ATR & Advanced Test Reactor \\
\hline CCP & Central Characterization Project \\
\hline CFR & Code of Federal Regulations \\
\hline $\mathrm{CH}$ & Contact-Handled \\
\hline $\mathrm{Ci} / \mathrm{L}$ & Curies per Liter \\
\hline CMR & Chemistry and Metallurgy Research Facility \\
\hline$D \& D$ & Decontamination and Decommissioning \\
\hline DOE & U.S. Department of Energy \\
\hline DOT & U.S. Department of Transportation \\
\hline DQO & Data Quality Objective \\
\hline DTA & Differential Thermal Analysis \\
\hline DTC & Dose-to-Curie \\
\hline EBR-II & Experimental Breeder Reactor-II \\
\hline EPA & U. S. Environmental Protection Agency \\
\hline ERDA & U.S. Energy Research and Development Administration \\
\hline FFTF & Fast Flux Test Facility \\
\hline K & Potassium \\
\hline HWN & Hazardous Waste Number \\
\hline LANL & Los Alamos National Laboratory \\
\hline LLNL & Lawrence Livermore National Laboratory \\
\hline LMFBR & Liquid Metal Fast Breeder Reactor Program \\
\hline LWA & WIPP Land Withdrawal Act (Reference 6) \\
\hline $\mathrm{m}^{3}$ & cubic meters \\
\hline $\mathrm{mm} \mathrm{Hg}$ & millimeters mercury \\
\hline $\mathrm{mR} / \mathrm{hr}$ & millirem per hour \\
\hline MSDS & Material Safety Data Sheet \\
\hline$\mu \mathrm{m}$ & micrometer \\
\hline $\mathrm{Na}$ & Sodium \\
\hline NaK & Sodium-potassium alloy \\
\hline $\mathrm{nCi} / \mathrm{g}$ & Nanocuries per gram \\
\hline $\mathrm{Np}$ & Neptunium \\
\hline NUMEC & Nuclear Materials and Equipment Corporation \\
\hline NWPA & Nuclear Waste Policy Act (Reference 8) \\
\hline ORIGEN & Oakridge Isotope Generation and Depletion \\
\hline OWR & Omega West Reactor \\
\hline PAN & Passive-active Neutron Counter \\
\hline PCB & Polychlorinated Biphenyl \\
\hline psig & pounds per square inch gauge \\
\hline $\mathrm{Pu}$ & Plutonium \\
\hline
\end{tabular}


LIST OF ACRONYMS AND ABBREVIATIONS (Continued)

QA
QAO
QAPD
R\&D
Ra
RCRA
RH
RH-TRUCON
RPM
SDIO
SOP
SRS
TA
TREAT
TRU
U
WCPIP
WIPP
WIPP-WAP
WMP
TWBIR
ZPPR

Quality Assurance

Quality Assurance Objective

CBFO Quality Assurance Program Document (Reference 13)

Research and Development

Radium

Resource Conservation and Recovery Act

Remote-Handled

Remote-Handled Transuranic Waste Content Code

revolutions per minute

Strategic Defense Initiative Organization

Standard Operating Procedure

Savannah River Site

Technical Area

Transient Reactor Test Facility

Transuranic

Uranium

Remote-Handled TRU Waste Characterization Program Implementation Plan (Reference 1)

Waste Isolation Pilot Plant

Waste Isolation Pilot Plant Hazardous Waste Facility Permit, Attachment B, Waste Analysis Plan (Reference 17)

Waste Material Parameters

Transuranic Waste Baseline Inventory Report (Reference 21)

Zero Power Plutonium (Physics) Reactor 


\subsection{EXECUTIVE SUMMARY}

This Acceptable Knowledge (AK) Summary Report (report) has been prepared for the Central Characterization Project (CCP) for 16 canisters of Remote-Handled (RH) Transuranic (TRU) waste generated in the Chemistry and Metallurgy Research (CMR) facility and managed at the Los Alamos National Laboratory (LANL). This report was prepared in accordance with DOEMIPP-02-3214, Remote-Handled TRU Waste Characterization Program Implementation Plan (WCPIP), Attachment A, Acceptable Knowledge Procedure for Remote-Handled Waste, Waste Isolation Pilot Plant Hazardous Waste Facility Permit Waste Analysis Plan (WIPP-WAP), and CCP-TP-005, CCP Acceptable Knowledge Documentation (References 1, 14, and 17).

Based on LANL's generator AK and available analytical data, the facility waste profile certifies the containers in this waste stream as non RCRA regulated waste. These containers have been and will continue to be managed as RCRA non-hazardous waste while at LANL. However, various WIPP documents require a conservative assignment of EPA HWNs to TRU waste streams where analytical evidence is insufficient to demonstrate that these constituents would not exceed regulatory thresholds. In order to meet this requirement, CCP takes a conservative review at operations in the area where the waste was generated and applies all HWNs associated with the processes that occurred there to this waste stream. For this reason, the containers in this waste stream will be assigned additional EPA HWNs prior to shipment to WIPP. As with all wastes generated at LANL if additional information regarding a waste container becomes available, LANL will assign waste codes and waste designations, as appropriate.

The CCP is tasked with certification of TRU waste for transportation to and disposal at the Waste Isolation Pilot Plant (WIPP). The CCP is responsible for reviewing, approving, and maintaining this report and supporting AK source documentation as CCP Quality Assurance (QA) records. The CCP maintains responsibility for all referenced documentation stored at the CCP Records Center, Carlsbad, New Mexico.

In the mid 1980 s to early 1990 s, LANL characterized and packaged approximately half of the existing RH TRU inventory generated at the CMR during the 1970s and 1980s. Waste materials consist predominately of debris (rags, plastic, glassware, tools, and equipment) and solidified radioactive solutions (minor component). The waste stream could contain chemicals and radioisotopes associated with the cutting, grinding, polishing, etching, and dissolution of samples of irradiated reactor fuel materials prepared for remote metallurgical examination and testing. The waste was packaged from January 31,1986 to June 5,1991 to demonstrate compliance with the proposed WIPP requirements that became effective in Revision 4 of the WIPP Waste Acceptance Criteria issued in December 1991. During this time frame, $17 \mathrm{RH}$ TRU waste canisters were packaged for ultimate shipment to WIPP in the 72B cask. This report addresses the waste contained in 16 of the 17 canisters. One canister (LA19) has been excluded from waste stream LA-MHD03.002, due to radiological issues that may result in this container being recharacterized as contact-handled $(\mathrm{CH})$ TRU or low-level waste. 
This document, along with the referenced supporting documentation, provides a conservative, defensible, and auditable record of the AK for an $\mathrm{RH}$ debris waste stream resulting from metallurgical examination operations conducted in the Wing 9 hot cells of the CMR. The references and AK sources used to prepare this report are listed in Sections 8.0 and 9.0 . The AK sources are referenced within this report by an alphanumeric designator (e.g., C001, DR001, M001, P001, and U001), corresponding to a unique CCP Source Document Tracking Number for this waste stream. This report includes information relating to the facility's history, mission, process operations, and waste management practices. Information contained in this report was obtained from numerous sources, including facility safety basis documentation, historical document archives, generator and storage facility waste records and documents, interviews with cognizant personnel, and program/process documents (plans, procedures, etc.).

This report and supporting source documentation provide the mandatory waste program and waste stream-specific information required by Section B4 of the WIPP-WAP (Reference 17). This report also compiles data relevant to the applicable EPA requirements and presents the documentation necessary to satisfy each of the DQO and QAO requirements of the WCPIP for the WIPP requirements for RH TRU waste (Reference 1). 


\subsection{WASTE STREAM IDENTIFICATION SUMMARY}

\section{Site Where TRU Waste Was Generated and Stored:}

Los Alamos National Laboratory

P.O. Box 1663

Los Alamos, New Mexico 87545

\section{Facility Where TRU Waste Was Generated:}

CMR Facility, Wing 9 Hot Cells

\section{Facility Mission:}

The primary mission of LANL has been nuclear weapons research and development (R\&D). LANL's current central mission is to enhance global security by ensuring the safety and reliability of the U.S. nuclear stockpile, developing technologies to reduce threats from weapons of mass destruction, and solving problems related to energy, environment, infrastructure, health, and national security concerns. This mission supports disciplines that enable LANL to contribute to defense, civilian, and industrial needs, including the research, design, development, and analysis of nuclear weapons components; support to research programs in the national interest; energy and environmental research; and environmental management.

The primary mission of the CMR has not changed significantly since it was constructed. These activities include analytical chemistry, physical and inorganic chemistry, and metallurgy operations using U-235 and U-238, Pu-238 and Pu-239, and smaller quantities of neptunium, $U-233$, curium, americium, and other TRU isotopes. With the addition of Wing 9, remote-handling capabilities were used to support post-irradiation examination of irradiated fuels from the Liquid Metal Fast Breeder Reactor (LMFBR) Program, and other advanced-fuel evaluation efforts including development and characterization of nuclear fuels in support of the ROVER Space Propulsion Program.

Waste Stream:

\section{Summary Category Group:}

Waste Matrix Code Group:

Waste Matrix Code:

RH-TRU Waste Content Code (RH-TRUCON):

Transuranic Waste Baseline Inventory Report (TWBIR) Identification Number: (Reference 21)
LA-MHD03.002

S5000 - Debris Waste

Heterogeneous Debris Waste

$S 5400$

LA325

LA-TA-03-27 


\section{Waste Stream Description:}

Waste Stream LA-MHD03.002 consists of 16 canisters of heterogeneous debris materials generated during packaging of waste materials and clean out of the hot cells used for fuel examination activities conducted in the Wing 9 of the CMR building. The waste was packaged from January 31,1986 to June 5,1991 . Waste from this stream was contaminated primarily with fissile materials and mixed fission products. A discussion relating to the radiological characterization of this stream is provided in Section 5.4.3.

This waste stream consists predominantly of organic and inorganic debris and contains the following materials (See Section 5.4.1):

- Cellulosic items including paper, cardboard, cloth rags, cotton, grinding paper, filter media, Kimwipes, paper towels, sand paper, string, swabs, tissues, and wood.

- Plastic items including polyethylene, polypropylene, polystyrene, polyvinyl chloride, alpha cans, bags, bottles, caps, funnels, hoses, lids, Lucite, molds, nylon, pans, pipettes, plastic lined towels, Plexiglas, plugs, resins, Teflon, trays, tubing, vials, and wrap.

- Rubber items including rubber belts, gaskets, gloves, hoses, finger pads, manipulator boots, Neoprene, rings, seals, and tubing.

- Glass items including glass, bottles, broken laboratory glassware, beakers, ceramics, fiberglass filters, insulation, light bulbs, mirrors, plates, powdered glass used during molding, Pyrex, quartz, slides, windows, various glass apparatus (e.g., clamps), and vials.

- Metal (ferrous) items including stainless steel, carbon steel, fuel capsule components such as cladding, alkaline batteries, cans, equipment (e.g., pumps, motors which have had all oil or any other free liquids removed), filters, fuel pin samples, hardware (e.g., nuts, bolts, brackets), manipulator parts, motor tools, plates, pipes, steel sample tubes, trays, tools such as calipers, saws and saw blades, and tubing.

| Metal (nonferrous) items including aluminum, brass, cobalt, copper, gold, graphite. lead, platinum, rhenium, ruthenium, tantalum, terbium, tin, tungsten, yttrium, adapters, brackets, cable, Devarda's alloy (aluminum, copper, and zinc), gauges, fittings, foil, light fixtures, motors, rings, rods, sheeting, tools, tubing, and wire. 
Waste Stream LA-MHD03.002 contains lesser amounts (less than 50 percent in any canister) of homogeneous organic and inorganic materials. Small quantities of floor sweepings, solidified liquids (organic and inorganic matrix), and solidified particulates (solidified inorganic matrix) are packaged with the debris. The liquids and particulates were solidified with Portland cement, Envirostone (Gypsum cement), or vermiculite.

The packaging configuration for Waste Stream LA-MHD03.002 consists of up to three Department of Transportation (DOT) 17C 55-gallon drums packaged into RH TRU canisters with welded lids. In 12 of the 16 canisters, the drums contain waste packaged into 1- to 1.5-gallon inner waste containers as described in Section 5.5, resulting in one layer of confinement (filtered 1.5 gallon steel cans) in these 55 -gallon drums. The remaining four canisters contain 12 direct loaded 55-gallon drums of large debris items and hardware too large to be placed in the waste cans. The canisters will therefore contain no more than two layers of confinement including the vented 55-gallon drums.

This waste stream was conservatively assigned following EPA HWNs: D005, D006, D007, D008, D009, D011, D019, F002, and F005. Refer to Section 5.4.2 for the waste stream chemical content evaluation. In accordance with RCRA requirements, LANL reviews discrete containers and applies generator AK and any other available information to characterize the waste in each container. In order to meet the WIPP requirements; however, CCP takes a conservative overview of operations in the area where the waste was generated and applies all HWNs associated with those processes to the waste stream.

Controls for liquids, compressed gases, explosives, pyrophorics, non-mixed hazardous waste, and incompatible or potentially ignitable, corrosive, and reactive materials precluded prohibited items from CMR RH TRU waste containers during the entire generation period for Waste Stream LA-MHD03.002. Liquids are not present in any waste container in waste stream LA-MHD03.002 due to waste disposal and packaging procedures, which included controls for liquids encountered during waste packaging operations as described in Sections 5.4.2.3 and 5.5.

Waste Stream LA-MHD03.002 meets the WIPP-WAP and the WCPIP waste stream definitions of waste material generated from a single process or from an activity that is similar in material, physical form, hazardous constituents, and radiological constituents. Due to the destructive nature of the examinations performed in the hot cell, in conjunction with the waste management practices associated with the decontamination and decommissioning (D\&D) operations that generated this waste stream, further delineation of this waste stream based on radiological contamination is not possible. 


\subsection{AK DATA AND INFORMATION}

TRU waste destined for disposal at the WIPP must be characterized prior to shipment. Development of knowledge of the waste materials and processes that generate and control the waste supports potential characteristics of each waste stream. The AK characterization documented herein complies with the requirements of the WIPP-WAP (Reference 17) and the WCPIP (Reference 1) and was developed in accordance with CCP-PO-001, CCP TRU Waste Characterization Quality Assurance Project Plan (Reference 7). The WCPIP identifies waste characterization requirements and methods to satisfy requirements in Title 40 Code of Federal Regulations (CFR) Part 191 (Reference 3), 40 CFR Part 194 (Reference 4), EPA Final Certification Decision (Reference 5), and WIPP Land Withdrawal Act (LWA) (Reference 6).

In accordance with RCRA requirements, LANL reviews discrete containers and applies generator AK and any other available information to characterize the waste in each container. In order to meet the WIPP requirements; however, CCP takes a conservative overview of operations in the area where the waste was generated and applies all HWNs associated with those processes to the waste stream.

The primary sources of AK collected from historical files maintained in the CMR included laboratory logbooks, standard operating procedures, program plans, radiological data, waste packaging logs, container forms, and inventory reports. This report presents information obtained from the review of more than 400 sources. Additionally, interviews were conducted with cognizant CMR personnel to augment and clarify the data collected and to resolve discrepancies between sources, when possible. If the inconsistencies could not be resolved, the most conservative information was incorporated into the document. The references and AK sources used to prepare this report are listed in Sections 8.0 and 9.0, respectively. The AK sources referenced within this report by alphanumeric designations (e.g., C001, DR001, M001, P001, and U001) correspond to the Source Document Tracking Number using the following convention:

- C - Correspondence (e.g., memoranda, letters, e-mail, interviews)

- $\quad$ DR - AK Discrepancy Reports

- $\quad M-$ Miscellaneous (e.g., radiological calculations, fuel pin information)

- P-Published Sources (e.g., reports, controlled procedures)

- U - Unpublished Data (e.g., databases, analytical data, draft reports) 


\subsection{PROGRAM INFORMATION}

This section provides a description of the facility and operations associated with the generation and storage of the 16 canisters of LANL RH TRU waste. Included is a description of the location of the CMR. In addition, a description of the facility, summary of the mission, defense determination, and descriptions of the operations associated with the generation of Waste Stream LA-MHD03.002 are provided.

\subsection{Facility Location, Description, Mission, and Defense Determination}

\subsubsection{Facility Location}

The CMR Building 29, is centrally located on the south side of Technical Area 3 (TA-3), as shown in Attachment 1, Los Alamos National Laboratory Technical Area 3. TA-3 is an approximately four square mile area located in the northwest corner of the LANL site; see Attachment 2, Los Alamos National Laboratory Site Map.

LANL's inventory of TRU mixed and non-mixed waste destined for disposal at the WIPP is stored at Material Disposal Area G (Area G), which is located at TA-54. Attachment 2 shows the general location of TA-54. Area G has been in operation since 1957, and is currently managed by the LANL Solid Waste Operations group. TRU waste management at Area $G$ included drum venting, decontamination and volume reduction, and buried waste retrieval operations. Storage Shafts $236-243$ and $246-253$, located at the west end of Area $G$ as shown in Attachment 3, Location Map for Shafts 236-243 and 246-253 at TA-54, Area $G$ were designed to store RH TRU waste canisters pending transportation and disposal at the WIPP. The shaft field consists of 20 shafts in two horizontal rows oriented northwest to southeast. The shafts are approximately 6 feet apart (from center) and are surrounded by a concrete pad. Each shaft is 16 feet deep, has a 3 foot diameter, is lined with a corrugated metal pipe, and is filled with gravel at the bottom to promote drainage. The shafts are sealed with 16 inch thick, 38 inch diameter concrete plugs that are fitted with a lifting ring. In 1993 and 1994, the 16 canisters were placed into the shafts at TA-54 to await certification of the 72-B cask and authorization of WIPP to accept the casks for disposal (References P301 and P302).

\subsubsection{CMR Description}

The CMR was designed and constructed in 1952 to replace the World War II era "D" building and was designed to house analytical chemistry facilities, plutonium metallurgy, uranium chemistry, engineering design and drafting, electronics, and other support functions. When the CMR was built, it represented state-of-the-art instrumentation and safety controls for a modern chemistry laboratory (Reference P146). 
In 1959, Wing 9 was added to the CMR to provide heavily-shielded facilities (hot cells) for remote-handling operations. These capabilities were used to support post-irradiation examination of irradiated fuels from the LMFBR Program and other advanced-fuel evaluation efforts. Nuclear fuels were also developed and characterized to support the ROVER Space Propulsion Program (References C001 and P146).

The hot cells consist of 16 cells in two banks of eight cells each with a shielded service corridor for egress of radioactive materials. Each bank of hot cells contains 18 master-slave manipulators, 10 shielded viewing windows, and 13 hydraulic doors weighing 18 tons each. The hydraulic door system is composed of 26 hydraulic cylinders that open and close the 18 ton shielding doors. The hydraulic cylinders have $81 / 2$-inch diameter shafts and an operational travel of approximately 8 feet. The pressure is supplied by four pumps that are energized by a series of relays. The basement service area contains the support equipment such as hydraulic controls and solenoid switching valves.

The following is a list of equipment utilized corresponding to stages of examination of irradiated fuels and hot cell waste packaging and cleanout:

\section{Nondestructive Examination}

Periscopes, binoculars, alpha survey meters and beta-gamma survey meters, thermocouples, hand micrometer, optical profilometer, still cameras, and laser for sealing fuel pins (References C001, P008, P012, P014, P015, P016, P019, P025, P081, P142, U032, U033, U040, U067, and U149).

\section{Specimen and Sample Preparation}

High and slow speed saws, thermal couples, sodium distillation equipment, differential thermal analysis (DTA) furnace, grinding and polishing equipment, still cameras, vacuum potting device, and laboratory glassware and hardware, and ultrasonic cleaners (References C001, C018, P003, P004, P005, P010, P011, P020, P021, P023, P027, $\mathrm{P} 030, \mathrm{P} 034, \mathrm{P} 039, \mathrm{P} 053, \mathrm{P} 055, \mathrm{P} 107, \mathrm{P} 108, \mathrm{P} 157, \mathrm{P} 160, \mathrm{P} 221, \mathrm{P} 222, \mathrm{P} 226, \mathrm{U} 005$, U020, U033, U034, U042, U053, U063, U067, and U149).

\section{Testing and Examination}

Electron microscope, microprobe, ultrasonic cleaners, laboratory glassware/hardware, steam distillation equipment, induction furnace, and 1450 Curie cobalt source (References C018, P009, P013, P035, P053, P055, P158, P159, P160, P161, P162, P163, P164, P165, P166, P173, P175, P177, P181, P221, P222, U033, U034, U042, U063, U067, and U159). 


\section{Maintenance and Waste Management}

Metal working equipment such as drills, saws, soldering guns, grinders, hand tools, waste compactor, radiation meters, arc welding equipment, and hoisting equipment (References C001, C306, DR002, P039, P043, P059, P060, P061, P064, P065, P067, P068, P119, P120, U033, U034, U042, U053, U063, U067, and U155).

\subsubsection{Wing 9 - Hot Cell Mission}

The primary mission of the CMR has not changed significantly since it was constructed. These activities include analytical chemistry, physical and inorganic chemistry, and metallurgy operations using U-235 and U-238, Pu-238 and Pu-239, and smaller quantities of neptunium, $U-233$, curium, americium, and other TRU isotopes. With the addition of Wing 9 , remote-handling capabilities were used to support post-irradiation examination of irradiated fuels from the LMFBR Program, and other advanced-fuel evaluation efforts including development and characterization of nuclear fuels in support of the ROVER Space Propulsion Program (References C001 and P146).

In 1986, the cells transitioned to decommissioning operations as samples were processed. All of the waste described by this document was generated from cleanout of the hot cells during decommissioning operations conducted from 1986 to 1991 (References C001, C002, C010, and P133).

\subsubsection{Defense Waste Determination}

WIPP requires generator sites to use AK to document that TRU waste streams to be disposed of at WIPP meet the definition of TRU defense waste. TRU waste is eligible for disposal at the WIPP if it has been generated in whole or part by one of the atomic energy defense activities listed in Section 10101(3) of the Nuclear Waste Policy Act of 1982 (NWPA) (Reference 8). Based on the review of AK, there is sufficient evidence to demonstrate that TRU wastes generated by hot cell operations in the CMR are contaminated with materials from atomic energy defense activities associated with defense research and development activities. Additionally, Wing 9 of the CMR played an integral role supporting the underlying historical and ongoing defense missions associated with the U.S. Department of Energy (DOE) test and research reactor programs described below.

The U.S. has historically operated and continues to operate reactors used for the development of nuclear energy technology. Additionally, these reactors have been utilized to produce radioisotopes for medical, industrial, and military purposes; to generate neutron environments for scientific research; and to conduct irradiation experiments in support of the government's defense, space, fusion, and advanced reactor programs. Collectively referred to as test and research reactors, these facilities have been typically operated by private contractors for the DOE. Mixed oxide, carbide, and alloy fuels for, or tests in, the DOE breeder reactor research and testing program 
(formerly the U.S. Atomic Energy Commission [AEC] and Energy Research and Development Administration [ERDA] Fast Breeder Reactor Program) were manufactured with plutonium obtained primarily from DOE production reactors at the Hanford site and Savannah River Site (SRS). DOE test and research reactor facilities include the Experimental Breeder Reactor-II (EBR-II), Transient Reactor Test (TREAT) Facility, Zero Power Plutonium (or Physics) Reactor (ZPPR), and Advanced Test Reactor (ATR) operated by Argonne National Laboratory-West (ANL-W) in Idaho, and the Fast Flux Test Facility (FFTF) at the Hanford site. The LANL hot cells played a major role in the examination of fuel specimens generated by this program and the AK documentation verifies the ongoing receipt, examination, and management of mixed oxides, carbide, and alloy fuels in Wing 9 of the CMR (References 2, C001, C010, M001, M002, M003, M004, M005, M011, and P150).

In 1967 the AEC initiated the LMFBR for developing and demonstrating fast breeder reactor technology for safe, reliable, and economical energy production. Critical to this demonstration program was the design, development, and construction or modification of facilities capable of manufacturing, testing, and examining these reactor materials. The first challenge was the procurement and development of domestic commercial capabilities to manufacture mixed oxide fuel to support the plans for future commercial reactors. To this end, the AEC awarded contracts to Kerr-McGee and Nuclear Materials and Equipment Corporation (NUMEC), a division of Babcock and Wilcox, to manufacture mixed-oxide fuel pins for this program. Between 1968 and 1979, Kerr-McGee and NUMEC produced mixed plutonium-uranium fuels for the LMFBR Program (Reference 2).

The ANL-W EBR-II and Hanford FFTF reactors were the most important facilities in the LMFBR program. The FFTF was constructed to produce higher neutron flux and testing capabilities than produced by EBR-II. The FFTF's unique capability allowed for closedloop testing of a variety of fuels, control materials, and structural materials in a controlled fast neutron flux environment approximating that required for the development of fast breeder commercial power generation. Ongoing post-irradiation examination of LMFBR mixed fuel specimens originating from NUMEC, Kerr-McGee, FFTF, and EBR-II were conducted in the CMR hot cells (References 2, M001, M002, M003, M004, M005, and M011).

During its 10 years of operation (1982-1992), the FFTF supported a variety of experiments associated with industrial, nuclear energy (domestic and international), nuclear defense, and medical research and development. Several projects were identified having defense applications, including a series of tests to evaluate tritium production by the irradiation of lithium oxide targets. This joint venture with Canada and Japan assessed tritium production from these proposed breeder materials in a fusion facility. The Multiple Isotope Production project generated physics data on Pu-238 isotope production and also demonstrated the capability of the FFTF to produce more than 20 other isotopes for defense, medical, and industrial programs. In 1992, defense missions proposed for the FFTF included large-scale tritium production projects, 
continued defense isotope production, waste burn experiments, and defense nuclear waste transmutation (Reference 2).

The EBR-Il supported ongoing defense experiments conducted throughout the 30-year operating life of the reactor (1964-1994). In 1968-1969, the reactor was converted to a fast-reactor irradiation test facility. Test fuels and materials were placed in the core assemblies identical to those holding the driver fuel assemblies. In addition to supporting the LMFBR Program, numerous experiments were conducted for defense applications, including support of the Bettis Atomic Power Laboratory dedicated to supporting the Naval Nuclear Propulsion Program. Other defense program experiments conducted at EBR-II included radiation of thermionic elements and tritium production test materials. During its final year, experiments included a cooperative effort between LANL and Lawrence Livermore National Laboratory (LLNL) to demonstrate disposition of weapons plutonium in a fast reactor (Reference $\mathrm{P} 150$ ).

The EBR-II, TREAT, ZPPR, and FFTF reactors also supported the irradiation of experimental fuel pins as part of the SP-100 Fuel Pin Irradiation Testing program. This program, initiated in 1983, was jointly funded by NASA, DOE, and the Strategic Defense Initiative Organization (SDIO). The SDIO (better known as the "Star Wars" program) was established to pursue technology in the development of a viable and comprehensive ballistic missile defense program. The SP-100 program's objective was to verify and validate the design of a compact, fast-spectrum nuclear reactor fuel for a broad range of national defense-related space applications. LANL fabricated 86 high density uranium nitrite experimental fuel pins that were irradiated in the EBR-II and FFTF reactors.

Post-irradiation examinations of these pins were performed in Wing 9 of the CMR, Hot Fuels Examination Facility at ANL-W, and Pacific Northwest Laboratory in Richland, Washington. This type of experimentation demonstrates that even though the primary mission of the DOE test and research reactors was focused on the development of commercial energy technology, the reactors had an underlying defense mission and ongoing defense research and development experiments were conducted in these facilities supported by the DOE hot cell laboratories (References 2, P300, and M005).

Additionally, CMR logbooks verify the examination of Annular Core Pulse Reactor (ACPR) reactor fuel in the hot cells between 1978 and 1979 and Omega West Reactor (OWR) reactor fuel in the hot cells between 1968 and 1985. The ACPR reactor provided intense neutron bursts for radiation effects testing of materials and electronics and was operated by Sandia National Laboratories (Reference U046). The OWR was a thermal, heterogeneous, closed tank test and research reactor operated by LANL from 1956 through 1992. The 8-megawatt reactor irradiated samples, acted as a neutron source for external neutron beam experiments, and provided facilities for in-core irradiation of capsules, fission counting for weapons diagnostics, and neutron 
radiography. Specific weapons related research and development activities conducted in the OWR include (References P151, P156, U005, U009, U049, U055, and U077):

- Irradiation of samples for calibration of gamma spectral shapes for fission chamber calibration of debris samples recovered from underground weapons tests;

- Irradiation of warhead explosives to evolve less vulnerable explosive systems;

- Neutron radiography of weapons components, such as nitrogen valves, bellows, and high explosives to assist in systems design;

- $\quad$ Production of tracer radioisotopes for weapons testing; and

- $\quad$ Physical experiments associated with weapons design and diagnostics.

RH TRU CMR hot cell debris waste was generated and packaged during the cleanout campaign conducted from the late 1980 s to early 1990 s as part of decommissioning activities. Segregation of the waste based on the fuel type analyzed was not conducted, and defense and non-defense related wastes are commingled. Therefore, Waste Stream LA-MHD03.002 is eligible for disposal at WIPP as a commingled defense waste stream generated "in part" by the atomic energy defense activities described in this section.

\subsection{RH TRU Waste Management}

The elements of RH TRU waste management discussed in this section include waste identification, segregation, and characterization, as well as organizational and administrative controls that were in place to ensure proper management of RH TRU waste in the CMR.

Following the hot cell mission change in 1986, waste from decommissioning operations and cell cleanout was generated. Waste certification procedures were implemented in 1987 prescribing required waste packaging, documentation of waste contents, solidification of liquids and particulates, treatment of potential pyrophorics, and exclusion of explosives and compressed gases during packaging of waste from the hot cells (References P121 and P123).

Wastes generated from contaminated areas were classified as low level or TRU waste based on the generating location, operation, and measured radiation content. According to waste packaging procedures, TRU waste was classified as waste materials contaminated with long-lived TRU radionuclides to levels greater than 100 nanocuries per gram $(\mathrm{nCi} / \mathrm{g})$, including all wastes generated within hot cells equipped with alpha contaminated containment boxes, wastes contaminated with $U-233$ and its daughter products, and radium(Ra)-226 sources at levels greater than $100 \mathrm{nCi} / \mathrm{g}$ (References P121 and P123). 
Based on generator AK, TRU waste containing RCRA hazardous materials were segregated as mixed waste. When identified, hazardous constituents were noted in the waste logbook (Reference P123). In accordance with RCRA requirements, LANL reviews discrete containers and applies generator AK and any other available information to characterize the waste in each container. In order to meet the WIPP requirements; however, CCP takes a conservative overview of operations in the area where the waste was generated and applies all HWNs associated with those processes to the waste stream.

Particulates were immobilized, regardless of size, if the particulate content exceeded one weight percent (wt \%) of the waste matrix in the waste package. Particulates were immobilized with Portland or Gypsum cement (References P121 and P123). Sand used for glovebox paint stripping operations was not classified as particulate (Reference P121).

Liquid wastes were handled differently depending on the composition and radioactive content. Etchant solutions in batch volumes up to a few liters, containing less than 500 microcuries of TRU radionuclides, were disposed in the radioactive acid waste drain in Room (Reference P121). Higher content solutions (greater than 500 microcuries), including alcohols, Dowanol EB, etchant solutions, kerosene, or mineral oil were neutralized if corrosive, and solidified with Envirostone (Gypsum cement), Portland cement, or vermiculite (References P003, P039, P121, and P123). Liquid and particulate solidification may have been combined (References P121 and P123).

Waste handling requirements differed for $\mathrm{CH}$ and $\mathrm{RH}$ TRU wastes removed from the hot cells. Handling was based on radiation dose rates measured on waste removed from the cells. Waste with surface dose rates that would result, when packaged in a 55-gallon drum, in a surface dose rate greater than 200 millirem per hour ( $\mathrm{mR} / \mathrm{hr}$ ) were classified as $\mathrm{RH}$. RH TRU waste was segregated from $\mathrm{CH}$ wastes pending disposal and shipment to WIPP (References P121 and P123).

\subsubsection{Types and Quantity of TRU Waste Generated}

The RH TRU waste inventory described by this AK document consists of $16 \mathrm{RH}$ TRU canisters; each canister volume is 0.89 cubic meters $\left(\mathrm{m}^{3}\right)$. Twelve of the 16 canisters contain up to three 55-gallon drums, each containing up to 121.5 -gallon cans of waste. The remaining four canisters contain a total of 1255 -gallon drums. These drums contain large debris items and hardware too large for cans (Reference U076). The materials are assigned LANL waste content code 007, which corresponds to $\mathrm{CH}$ and $\mathrm{RH}$ solids from hot cell operations (Reference $\mathrm{P} 123$ ). The $\mathrm{CH}$ debris waste generated during operations in the CMR is included in waste stream LA-MHD03.001 described in CCP-AK-LANL-009 (Reference 20). Based on a review of the AK record, $\mathrm{CH}$ waste may have originated from Wing 9; however no hot cell waste could be isolated in the $\mathrm{CH}$ waste stream that would be comparable to the RH waste stream described in this report. 
Waste Stream LA-MHD03.002 meets the WIPP-WAP and the WCPIP waste stream definitions of waste material generated from a single process or from an activity that is similar in material, physical form, hazardous constituents, and radiological constituents. Due to the destructive nature of the examinations performed in the hot cell, in conjunction with the waste management practices associated with the decontamination and decommissioning (D\&D) operations that generated this waste stream, further delineation of this waste stream based on radiological contamination is not possible.

Waste Stream LA-MHD03.002 consists of Summary Category Group S5000 heterogeneous debris materials generated during packaging of waste materials and clean out of the hot cells used for fuel examination activities conducted in the Wing 9 of the CMR. This waste stream consists predominantly of organic and inorganic debris and contains lesser amounts (less than 50 percent in any canister) of homogeneous organic and inorganic materials. Small quantities of floor sweepings, solidified liquids (organic and inorganic matrix), and solidified particulates (solidified inorganic matrix) are packaged with the debris. The liquids and particulates were solidified with Portland cement, Envirostone (Gypsum cement), or vermiculite. Section 5.4 includes a detailed description of the physical form of the waste stream used to delineate this waste stream.

\subsubsection{Description of Waste Generating Processes}

All of the waste described in this document was generated from CMR Wing 9 hot cell cleanout and decommissioning activities conducted from 1986 to 1991 . The waste consists of cleaning wastes and materials, tools, and equipment contaminated with residues from historical operations conducted from the early 1970s until decommissioning was completed in 1991 (References P123, P144, and U076).

Wing 9 was added to the CMR in 1959 to provide heavily shielded facilities (hot cells) for remote-handling operations. A timeline describing Wing 9 operations is included in Table 1 (Reference P146).

Table 1. Wing 9 Hot Cell Operations Timeline

\begin{tabular}{|l|l|}
\hline 1959 & Wing 9 constructed \\
\hline $\begin{array}{l}1959 \text { to early } \\
1970 \text { s }\end{array}$ & $\begin{array}{l}\text { Metallurgical examination of fuel samples from the ROVER } \\
\text { project }\end{array}$ \\
\hline $\begin{array}{l}1960 \text { s to early } \\
1990\end{array}$ & $\begin{array}{l}\text { Metallurgical examination of fuel pins and capsules from EBR II, } \\
\text { TREAT, OWR and others }\end{array}$ \\
\hline 1986 & $\begin{array}{l}\text { Hot cell mission changed to D\&D. Fuel examination work began } \\
\text { to diminish as D\&D activities progressed }\end{array}$ \\
\hline 1986 to 1991 & Hot cell D\&D activities produced 16 Canisters of RH TRU waste. \\
\hline
\end{tabular}


The hot cells were utilized to support research and development operations by conducting post-irradiation examination of irradiated fuels. Fuel segments not used in the examinations were segregated and packaged for off-site shipment, and are not packaged with the waste (References C010 and P123). Several processes were conducted as part of the research and development activities:

- Nondestructive Examination (References C001, P008, P012, P014, P015, P016, $\mathrm{P} 019, \mathrm{P} 025, \mathrm{P} 081, \mathrm{P} 142, \mathrm{U} 032, \mathrm{U} 033, \mathrm{U} 040, \mathrm{U} 067$, and U149)

- Visual Inspection

- Temperature Measurement

- Dimensional Measurements

- Eddy Current Inspection

- Radiation Measurements

- Puncture Gas Sampling and Laser Sealing

- $\quad$ Specimen and Sample Preparation (References C001, C018, P003, P004, P005, P010, P011, P020, P021, P023, P027, P030, P034, P039, P053, P055, P107, P108, P157, P160, P221, P222, P226, U005, U020, U033, U034, U042, U053, U063, U067, and U149)

- Disassembly and Sectioning

- Sodium or Sodium Potassium Removal/Distillation

- Mounting, Potting, and Impregnation

- Grinding

- Polishing

- Etching

- Cleaning and Rinsing

- Solvent Extraction and Dissolution

- $\quad$ Testing and Examination (References C018, P009, P013, P035, P053, P055, P158, P159, P160, P161, P162, P163, P164, P165, P166, P173, P175, P177, $\mathrm{P} 181, \mathrm{P} 221, \mathrm{P} 222, \mathrm{U} 033, \mathrm{U} 034, \mathrm{U} 042, \mathrm{U} 063, \mathrm{U} 067$, and U159)

- Electron Microprobe Examination

- Clad Density Testing and Analysis

- Fission Gas Analysis

- Burn-up Analysis

- Isotopic and Chemical Composition Determination and Testing

- Microstructural Examination

- Sample Irradiation with cobalt-60 $\left({ }^{60} \mathrm{Co}\right)$

- Auto-radiography 
- Maintenance and Waste Management (References C001, P039, P043, P059, P060, P061, P064, P065, P067, P068, P119, P120, U033, U034, U042, U053, U063, U067, and U155)

- General Maintenance Activities

- Cell Decontamination and Painting

- Machining and Container Fabrication

- Liquid and Particulate Waste Solidification

- Waste Segregation and Packaging

From the 1960 s through the early 1990 s the operation of the Wing 9 hot cell consisted primarily of the metallurgical examination of post-irradiated fuel pin and capsule samples from several breeder reactor programs (References P144 and P146).

Shipping casks containing fuel pins and capsules (fuel elements) were transferred into the hot cell area and remotely unloaded (References P017, P031, and P142). Preliminary tests were conducted on capsules and pins after they were unloaded to establish an "as-received" condition, and to determine if any of the capsules or pins required special treatment because of abnormal contamination, radiation, temperature, or appearance. Preliminary examination included visual inspection using periscopes or binoculars to identify abnormalities such as scratches, dents, discoloration, excessive bow, loose spacer wires, etc (References P014 and U067). Bow measurements were performed to determine the amount of bow relative to a series of grid lines, and evaluation of swipe samples on capsules or fuel pins using alpha survey meters and beta-gamma survey meters were performed to indicate potentially breached pins. Additionally, a radiation meter was used for direct measurements of the radiation of each capsule or pin at one meter (References P016, U033, and U149). The temperature of each pin was measured using a thermocouple device, and dimensional measurements were also made using a hand micrometer or optical profilometer (References P015, P019, P025, P081, U033, and U149). Eddy current inspection was used to detect cracks and determine material thickness (References U032 and U040). Photographs, which were not developed in the hot cell, were taken to satisfy the specific request of the experimenter and to document abnormalities identified during the initial examination. The fuel elements were then marked, if required, for future examination according to the experimenter's examination plan (References P081, P142, and U033).

Gas sampling and void volume calculations of the capsule/cladding for fissionable gas products were also typically performed during the initial examination. Radiography (not performed in the hot cell) or drawings were used to determine where to puncture the capsule for gas sampling. A variety of techniques were used to reseal the fuel pins and capsules following gas sampling, including the use of shrinkable tubing and laser sealing (References C001, P008, P012, and U067).

Following initial examination, fuel elements were disassembled and sectioned in preparation for additional examinations and measurements, such as microstructural, microprobe, density, burn-up, chemical analysis, and other special examinations. 
Sectioning was performed in an inert atmosphere with low levels of oxygen and moisture. A sectioning diagram was prepared for each fuel element to specify where the cuts were to be made and the purpose for each section. A high-speed saw (30005000 revolutions per minute (RPM)) with a 0.020 to 0.035 inch blade was used to make the cuts. Lubricants were not used during the sectioning process. Each section was then marked on the opposite surface from that which was to be polished and placed in individually identified stainless steel containers (References P020, P108, U033, U042, U067, and U149).

Rod cladding or capsules were often configured with a wire wrap (one turn per several inches of fuel rod) which enhanced heat transfer from the rod. This cobalt wire was removed prior to sample preparation. A slow-speed diamond wheel saw (250 RPM) was used to remove the spiral wire (References C001 and P023).

Irradiated fuel capsules and pins were often received with thermal bonds of sodium, or sodium-potassium alloy. During the remote disassembly of capsules and pins, the sodium or sodium-potassium alloy thermal bonds were removed in a manner to protect the pin cladding from exposure to the air until the sodium or sodium-potassium alloy was removed. The sodium or sodium-potassium alloy was removed from the capsule to withdraw the fuel pin. Hot mineral oil was used to melt the bonded sodium until the capsule clad moved off the fuel pin. Dowanol EB was added to the cooled mineral oil to react with the sodium. The fuel pin was then placed in a Dowanol EB bath and then rinsed with ethanol or Freon TF. After rinsing, fuel pins were often placed in water to assure that all of the sodium was reacted and all of the sodium salts (such as sodium monoxide $\left(\mathrm{Na}_{2} \mathrm{O}\right)$ ) were dissolved. Sodium-potassium alloy was removed in a similar manner, except the liquid sodium-potassium alloy was collected in kerosene and a mixture of kerosene and Dowanol EB was used to initially react the sodium and potassium (References P003, P004, P107, U033, and U067). An alternate technique sectioned the capsule at a prescribed location and was then placed in a jacketed heater. The heater was brought to approximately 110 degrees Celsius for 20 minutes at which time the sodium had melted and the pin began to slide out. The pin was then placed in Dowanol EB bath and allowed to react until the pin was visibly free of sodium. The pin was removed and washed with ethanol or Freon TF (References P005 and U067). A distillation technique was also employed to remove $\mathrm{Na}$ bonds from the fuel element sections. Fuel-cladding specimens of $1 / 2$ - to $3 / 4$-inch lengths were placed in sample holders and transferred to the still. Temperatures on the order of 500 degrees Celsius and vacuum pressure at approximately $10^{-4}$ millimeters mercury $(\mathrm{mm} \mathrm{Hg})$ were obtained to remove $\mathrm{Na}$ from the fuel elements. Liquid nitrogen was used to cool the condenser (References C001, C018, and P021).

Various potting and mounting techniques were used to secure fuel samples for grinding and polishing. Vacuum potting was achieved by pouring Epon (an epoxy resin) into sample cups, and applying a vacuum in the vacuum potting device. The process was carefully monitored to avoid bubbling Epon out of the sample. After curing overnight, the hardened Epon samples were moved to the metallographic cell (Reference P021). High pressure potting and heating was also used to improve hardening and 
impregnation of the potting material with the fuel sample (References P027 and P034). Fiberlay P19, a cold mix, was introduced and used the last 5 years of sample examination activities (Reference C018).

The sample was then ground several times using successively finer grit sand paper. Kerosene was used as a lubricant during the grinding process. The grinding paper was changed frequently and regular cleaning with alcohol was performed throughout grinding and polishing (References C001, P030, U020, U053, and U063).

Polishing was performed to create the smooth surface necessary to observe the crystalline properties of the fuel. Polishing was first performed with a diamond paste $(6,3$, and 1 micrometer $[\mu \mathrm{m}]$ grit size), then with aluminum oxide powder (down to 0.03 $\mu \mathrm{m}$ grit size). An "as polished" photograph was taken of the samples (References C001, U020, U053, U063, and U149).

Depending on the experimenter's request, several techniques for etching were performed to enhance the delineation of the grain boundaries, followed by additional photographs. Samples were etched using acid etching, cathodic etching, or electrolytic etching. Electrolytic etching used a nine volt alkaline battery. Cathodic etching was used only to etch the stainless steel cladding (on samples where it was not removed). Chemicals utilized in the various etching techniques include acetic acid, chromic oxide, ethanol, glycerol, hydrochloric acid, hydrofiuoric acid, lactic acid, nitric acid, oxalic acid, and sulfuric acid (References C001, U020, U063, and U149). Picric acid was also identified as an etching agent, however, review of logbooks and interviews of site personnel indicate its use was a once-only experimental use (Reference C015).

Cladding and fuel sample cleaning and rinsing was performed throughout the preparation process using physical means (e.g., wiping) and ultrasonic baths. Chemicals typically used during the cleaning process include various types of acids, alcohols, butyl acetate, Dowanol EB, Freon TF, Vythene, and water (References C001, P003, P010, P020, P030, P039, U020, U033, U034, U042, U063, U067, and U149).

Samples of irradiated fuels, oxides, and cladding materials were frequently extracted or dissolved prior to analytical evaluations. Solvent extraction and dissolution were used in combination or as stand alone activities. Uranium contaminants were extracted and separated from samples using acetone, methyl isobutyl ketone, and 2-nitropropane in combination with various nitrates (References P222 and P226). In addition, samples were often dissolved in hydrochloric, hydrofluoric, nitric, perchloric, and sulfuric acid, or any combination of these acids. Sample solutions were separated from slow dissolving or insoluble sample residues which were further treated by dissolution with a combination of hydrochloric, hydrofluoric, and nitric acids and then heated. Some low solubility materials were dissolved using a sealed-reflux system. The resulting sample solution was collected into an appropriate container (References C001, P157, P160, P221, P222, U005, U034, and U042). 
Samples selected for electron microprobe examination included polished, unetched, and mildly etched metallographic specimens. Following polishing, the samples were ultrasonically cleaned to a surface contamination level of 500 counts per minute. The samples were painted with a carbon-coating or a silver stripe to assure electrical conductivity from the sample to the mount. The samples were then transferred to the microprobe for analysis. The microprobe analysis used high voltage to generate $x$-rays characteristic of the elements present within the sample (References P011 and P177).

Density determinations were conducted for irradiated cladding and fuel materials in the hot cells. Cladding density sample preparation included submersion and heating of the sample in hydrofluoric or nitric acid to ensure complete absence of fuel materials (References P158 and U042). To measure the density, sample materials were placed on a holding tool, weighed, immersed in a known volume of bromobenzene, and weighed again (Reference P013).

Other sample processing activities conducted in the hot cells included collection of gaseous fission products from irradiated fuels, distillation, induction and incineration of irradiated fuel and cladding isotopic and chemical composition determination and testing, microstructural examination, and sample solution drying. Gases from dissolution were carried out of the hot cells in a helium gas stream, through a purification system to remove acid fumes, and onto a silica gel trap (Reference P159). Following acid dissolution, some sample solutions were distilled, and the collected distillates transferred from the hot cell and analyzed (Reference P160). When required, fuel samples were fumed to dryness with sulfuric acid (Reference P163). For determination of oxygen, carbon, hydrogen, tritium, or metallic impurities in irradiated fuels or cladding materials, samples were placed in crucibles and heated to temperatures ranging from 700 to $2000{ }^{\circ} \mathrm{C}$ with air or oxygen in an induction furnace. Combustion gases were handled and treated to collect oxygen, carbon, hydrogen, or tritium for analysis outside of the hot cells. For some processes, gases were passed over hot copper oxide or hot copper oxide-lead chromate to ensure complete oxidation (References P161 and P162). For oxide fuels, pellets consisting of fuel mixed with graphite were created for reaction in the furnace. To identify metals in irradiated fuels, oxidized samples were packed into electrodes and excited with a $15 \mathrm{amp}$ direct current arc for 50 seconds, and the resulting emission spectrum recorded on spectrographic plates (References P009, P161, P162, P164, P165, P166, P173, P175, P181, P221, $\mathrm{P} 222$, U033, U034, U042, U063, U067, and U159).

A variety of materials including paints, plastics, elastomers, insulation, sewage bacteria, and electronic components were irradiated in the hot cells with a $1450 \mathrm{Ci} \mathrm{Co-60}$ source. After the sample materials were placed in the cell, the source, stored in floor hole Z-17 when not in use, was transferred to the corridor in a four-ton bottom-loading cask, and remotely positioned in the applicable cell. Following use, the source was returned to floor storage (Reference P035). 
Auto-radiography was conducted in the hot cells and consisted of placing specimens on film. The exposure to the film differed according to the activity of the sample and ranged from 20-25 seconds for alpha and 30 seconds to 3 minutes for beta-gamma measurements (References C018, U033, and U149).

Maintenance and waste management activities conducted in Wing 9 included modification of utilities to the cells and alpha boxes, such as plumbing, electrical fixtures and equipment, decontamination and painting of cell tables and equipment, installation of shielding including lead in the form of sheeting, bricks, shot, and wool, and general activities, such as filter replacement, cell window maintenance, cleaning, equipment testing and repair, and housekeeping. Maintenance activities also included replacement and repair of mercury vapor lamps and fluorescent and incandescent light fixtures and bulbs. Machining and container fabrication activities included soldering, welding, cutting, grinding, polishing, drilling, and tapping. Decontamination operations were conducted using Freon TF, household detergents and water. Paint used consisted of plasite and Steel Coat paint (two part epoxy based paints). Cleaning was conducted with alcohol. Waste management activities included container handling, loading, and welding (References C001, P043, P059, P060, P061, P064, P065, P067, P068, P119, P120, U033, U034, U042, U053, U063, U067, and U155).

The waste described in this document was generated from CMR Wing 9 hot cell cleanout and decommissioning activities conducted from 1986 to 1991 . The decommissioning activities included the removal of all spent reactor fuel from Wing 9, the packaging of equipment and excess waste, and the removal of highly contaminated alpha containment boxes. The spent fuel was packaged, placed in shipping containers, and then shipped in a shielded cask to the Hanford site for storage. Equipment and excess waste was removed from the hot cells and the contaminated alpha containment boxes. The equipment and other materials were contaminated through contact with fuel materials during processing, or removal and decontamination operations. The excess waste consisted of residue materials from process operations including samples in particulate state from cutting, grinding, and polishing operations, as well as solidified sample etchant solutions. The alpha containment boxes were remotely decontaminated. The boxes were then transported to the size reduction facility for reduction and packaging. No special chemicals or decontamination practices were introduced during the D\&D activities generating the waste stream. A commercial cleaner (e.g., Fantastic) was the only product identified, used to wipe down the surfaces of the alpha boxes during the preliminary decontamination of these areas. This is further supported by the container-specific documentation completed in accordance with LANL waste management practices requiring the generators to identify chemicals introduced during the D\&D operations (References C010, C307, P039, P123, and U053). 
Waste generated from decommissioning consists of residue materials from process operations including samples in particulate state from cutting, grinding, and polishing operations, as well as samples dissolved in etchant solutions. In addition, equipment and other materials contaminated through contact with sample materials during processing, or removal and decontamination operations are included in the waste stream (References P039 and P123). 